\title{
Sozialpolitik und Verfassung im ersten Jahrzehnt der Bundesrepublik Deutschland
}

Von

Dr. Hans F. Zacher

Professor an der Universität München

Direktor des Max-Planck-Instituts für ausländisches und internationales

Sozialrecht, München 
Als Habilitationsschrift auf Empfehlung der Juristischen Fakultät der Universität München gedruckt mit Unterstützung der Deutschen Forschungsgemeinschaft.

\section{Universitàts- Bibliothek Muncren}

\section{Zacher, Hans F.:}

Sozialpolitik und Verfassung im ersten Jahrzehnt der Bundesrepublik Deutschland/von Hans F. Zacher. Berlin: Schweitzer, 1980.

ISBN 3-8059-0484-3

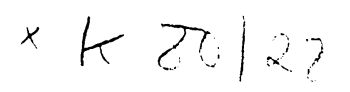

(C) 1980 by J. Schweitzer Verlag, Berlin.

Alle Rechte, insbesondere das Recht der Vervielfältigung und Verbreitung sowie der Übersetzung, vorbehalten. Kein Teil des Werkes darf in irgendeiner Form (durch Photcikopie, Mikrofilm oder ein anderes Verfahren) ohne schriftliche Genehmigung des Verlages reproduziert oder unter Verwendung elektronischer Systeme verarbeitet, vervie fältigt oder verbreitet werden. Printed in Germany.

Druck: Karl Gerike, Berlin; Bindearbeiten: Buchgewerbe GmbH Lüderitz und Baue-, Berlin. 
I.

Die Arbeit, die hier veröffentlicht wird, wurde 1961 abgeschlossen. Sie lag 1961/62 der Juristischen Fakultät der Universität München als Habilitationsschrift vor. Sie wurde daraufhin vom Verlag C.H. Beck zum Druck angenommen. Die Deutsche Forschungsgemeinschaft bewilligte den erforderlichen Zuschuß. Dann aber hatte ich den Ehrgeiz, sie an der einen oder anderen Stelle noch zu überarbeiten, insbesondere neues Material nachzutragen. Ich holte das Manuskript vom Verlag zurück. Am Anfang des Jahres 1963 bekam ich einen Ruf an die Universität des Saarlandes. Neue Aufgaben stellten sich ein. Die angezielte Verbesserung der Habilitationsschrift mußte das eine um das andere Mal neuen Prioritäten weichen. Zugleich stieg die Flut einschlägiger Literatur, Rechtsprechung und Gesetzgebung immer mehr an. Jeder Monat Verzug bedeutete, daß die Arbeit an immer mehr Stellen hätte ergänzt und verändert werden müssen, um als aktuell richtig und vollständig veröffentlicht werden zu können. Einige Jahre noch träumte ich den Traum, dies zu tun. Dann gab ich auf.

Im Laufe der Zeit aber wuchs das Bedürfnis, die Entwicklung der Bundesrepublik in geschichtlichen Phasen zu sehen. Das gilt auch für die Rechtsgeschichte - hier: für die Geschichte des Verfassungs- und des Sozialrechts. Je länger je weniger schien es statthaft, den Fluß der Rechtsentwicklung und Rechtserfahrung im Verlaufe der Bundesrepublik auf einer einzigen, ungeschichteten historischen Ebene zu sehen. Es wurde notwendig, Abschnitte voneinander abzuheben. Daraus erwuchs ein neues Interesse an Arbeiten, die sich - schon ursprünglich oder später - einer zurückliegenden Phase in der Entwicklung der Bundesrepublik konzentriert widmeten. Parallel dazu trat ein anderer Gesichtspunkt hervor. Unsere juristische und sozialwissenschaftliche Diskussion hat ein kurzes Gedächtnis. Auch (lort, wo sie nicht in historischen Phasen denkt, ja gerade dort, wo sie so tut, als wäre etwa alle verfassungsrechtliche Diskussion seit 1949 ohne die räumliche Tiefendimension der Geschichte auf das flächige Bild des gegenwärtig Relevanten aufzutıagen, beschränkt sie sich mehr oder minder auf "das zuletzt Gesagte" und verliert sie - von wenigen spektakulären Werken abgesehen - den vollen Diskussionsstand vorangegangener Epochen mehr und mehr aus dem Blick. Auch dies muß zu einer Nachfrage nach Arbeiten führen, welche die Diskussion zurückliegender historischer Phasen der Zeitgeschichte, der Zeitrechtsgeschichte und der Zeitverfassungsgeschichte reflektieren. Ich habe jeclenfalls bei meinen Arbeiten auf dem Feld 
der Begegnung von Verfassung, Sozialrecht und Sozialpolitik immer wieder festgestellt, daß der Befund, den meine Habilitationsschrift für den Zeitraum vom Aufbau des Verfassungsstailtes in den Ländern bis über den Zenit der "Adenauer-Zeit" hinaus aufzunehmen suchte, sowohl als Darstellung der Sach- und Rechtslage in dieser Phase wie auch als Medium, um die damalige Diskussion hierüber zu vergegenwärtigen, von nicht überholtem Interesse ist.

Das legte mir den Gedanken nahe, nunmehr den ursprünglicher. Text trotz seiner "Veralterung" ohne Überarbeitung vorzulegen. Der Versuch einer Überarbeitung war nicht nur unmöglich, er war in gewissem Sinne auch unzulässig geworden. Eine "Aktualisierung" des Werkes würde ja seine Fähigkeit, Zeugnis für die Gründer- und Aufbauphase der Bundesrepublik abzulegen, beeinträchtigen, wenn nicht aufheben. Daher also rührt mein Nut, ein zwischen 1958 und 1961 geschriebenes Werk versehen mit einer Einleitung, die der historischen Verortung dienen soll, und einem Sachregister, im übrigen aber gekürzt, jedoch nicht verändert, der Öffentlichkeit vorzulegen. Der Kürzung fiel vor allem zum Opfer, was spezifisch die Bayerische Verfassung betraf.

II.

Doch liegt mir daran, der dem Sachlichen vorbehaltenen Einleitung noch einige persönliche Bemerkungen voranzustellen: über die Umstände der Entstehung der Arbeit, vor allem aber über Menschen, denen ich in diesem Zusammenhang zu Dank verpflichtet bin. Eine zentrale Rolle spielt hier Hans Nawiasky ${ }^{1)}$. Bei ihm hatte ich 1952 promoviert. Im Anschluß daran regte er an, ich sollte mich habilitieren. Von ihm dazu eingeladen, schlug ich ihm Themen vor. Das liebste darunter wäre mir eine A rbeit über das Bundesverfassungsgericht gewesen, dessen erste Entscheidungen eben erst gezeigt hatten, welche Problematik seine Kompetenzen mit sich brachten. Doch Hans Nawiasky wehrte ab. Das Thema werde binnen kurzem überlaufen sein. (Und er sollte damit Recht behalten.) Er möchte mir eine andere Anregung geben. Er habe in den letzten Semestern in St. Gallen Seminare über "Die soziale Intervention des Staates" gehalten. Er halte das für eine zukunftsträchtige und von den Juristen gemeinhin vernachlässigte Problematik. Wir einigten uns auf das Thema

1) Siehe zu ihm: Hans Nawiasky - Ein Leben für Bundesstaat, Rechtsstaat und Demokratie, in: Festgabe für Theodor Maunz, 1971, S. $477 \mathrm{ff}$ 
"Das Verfassungsrecht der sozialen Intervention des Staates nach dem Grundgesetz und der Bayerischen Verfassung". Daß die Bayerische Verfassung in das Vorhaben mit aufgenommen wurde, mag heute schon unverständlich scheinen. Im Winter 1952/53, als dieses Gespräch mit Hans Nawiasky stattfand, schien es uns beiden notwendig, auch die Ebene des Landesverfassungsrechts zu repräsentieren. Das Grundgesetz war gut drei Jahre in Kraft. Die Erosion der Landesstaatlichkeit zeigte sich noch nicht mit ganzer Kraft und noch nicht in vollem A usmaß. Und eine Reihe von Landesverfassungen übertraf das Grundgesetz bei weitem an sozialer Programmatik. Für eine intensivere Erörterung die Bayerische Verfassung auszuwählen, empfahl sich nicht nur wegen ihrer weitreichenden, ja üppigen sozialen Programmatik 2). Hans Nawiasky hatte an ihr maßgeblich mitgewirkt. Und für mich war es die Verfassung meines Heimatlandes.

Die Verwirklichung des Planes sollte freilich lange auf sich warten lassen. Zunächst noch Referendar mit spärlichstem und sporadischem Unterhaltszuschuß war ich darauf angewiesen, in einer Anwaltskanzlei zu arbeiten. Nach dem Assessorexamen (1955) trat ich in die bayerische innere Verwaltung ein, von der ich alsbald als Hilfsarbeiter zum Bayerischen Verwaltungsgerichtshof überwechselte. Die Zeit, die mir neben der dienstlichen Arbeit blieb, reichte nicht aus, um mit einer so weiten, weder von der normativen, noch von der politisch-tatsächlichen Seite her zulänglich vorgeformten Thematik fertigzuwerden, zumal ich keine spezifischen Vorkenntnisse und Vorerfahrungen, in Sonderheit keine Forschungserfahrung dafür mitgebracht hatte. Erst während meiner Tätigkeit als Hilfsarbeiter am Bundesverfassungsgericht (1956-1959) fand ich zu Konzeptionen der Strukturierung, Schwerpunktbildung und Abgrenzung durch. Gegen Ende dieser Zeit (1958) sah ich mich gerüstet, "ans Schreiben" zu gehen. Vor meiner Rückkchr in die bayerische innere Verwaltung (1960) wollte ich das Angefangene vollenden. Die Deutsche Forschungsgemeinschaft bewilligte ein Stipendium für zehn Monate. Mehr wagte ich nicht zu beantraģen, um die Geduld meines Dienstherrn, den mein Urlaub mit einer - meiner - unbesetzten Stelle belastete, nicht zu ïberfordern. Aber diese zehn Monate reichten nicht aus, um dic Arbeit zu schreiben. So wurde sie

2) Siehe dazu später Hans F. Zacher, Bayern als Sozialstaat, BayVBl. n.F. 8.Jhg. (1962), S. 157 ff; ders., Zur sozialen Programmatik der Bayerischen Verfassung, in: Verfassung und Verfassungsrechtsprechung, Festschrift zum 25-jährigen Bestehen des Bayerischen Verfassungsgerichtshofs, 1972, S. 95 ff. Weitere Nachweise siehe dort. 
neben der Praxis wie begonnen, so auch fertiggestellt - im Früljahr 1961 noch einmal durch einen Sonderurlaub der bayerische:l inneren Verwaitung gefördert. Die Aufnahme neuen Materials mußte ich, um überhaupt einmal zum Schluß zu kommen, schon Ende 1960 im wesentlichen einstellen.

Im Sommer 1961 endlich lag die Arbeit fertig vor. Und eben in diesem Sommer 1961 starb Hans Nawiasky. Theodor Ma unz, obwohl damals zusätzlich mit dem Amt des Bayerischen Staatsministers für Unterricht und Kultus sowohl ausgezeichnet als auch belastet, übernahm die Rolle des Habilitationsvaters. Hans Spanner war Korreferent. Zu Beginn des Sommersemesters 1962 wurde ich habilitiert. Das weitere wurde oben schon gesagt.

III.

1. Somit ist offensichtlich, wem ich vor allem $z u$ danken habe: Hans $\mathrm{Nawiasky}$, der mir mit seiner Anregung die Hauptlinie meines wissenschaftlichen Weges schlechthin gewiesen hat. (Darüber, daß er mich die ganzen Jahre über eisern zwang, es bei der vollen Breite des Themas zu belassen, kann ich mich freilich allenfalls jetzt, wo die Gänze der Arbeit auch in der Veröffentlichung zur Geltung kommen kann, wirklich freuen.) Sodann habe ich Theodor Maunz zu danken, dessen Bereitwilligkeit, den verwaisten Habilitanden zu adoptieren, mir sehr viel geholfen hat. Auch habe ich der Deutschen Forschungsge$\mathrm{m}$ einschaft für ihr Stipendium und dafür zu danken, daß sie schon damals bereit gewesen wäre, den Druck zu fördern. Nicht vergessen möchte ich die bayerische innere Verwaltung, der ich mit meiner zweimaligen Bitte um Sonderurlaub ein jedenfalls damals noch unübliches Maß an Flexibilität zumutete. Ministerialdirigent Dr. Gotthard Brunner, späterer Präsident des Bayerischen Obersten Rechnungshofes, brachte sie auf. Die größte Last freilich hat meine Frau getragen. Das Vorhaben einer Habilitationsschrift über dieses überaus weite und ungeformte Thema zehrte an meiner Freizeit, fast seit wir uns kannten. Von 1958 bis 1961 endlich gab es keine Freizeit und keinen Urlaub mehr. Selbst die finanziellen Opfer waren groß. Und die erste Fassung des Werkes schrieb meine Frau auch selbst auf der Maschine. Wenn es je angebracht ist, seiner Frau ein Werk $\mathrm{zu}$ widmen, so ist es hier angebracht. Aber meine Frau mag derlei nicht. Und so will ich nur im Vorwort davon sprechen, das sie vielleicht gar nicht liest.

2. Nun gilt es aber auch noch, denen zu danken, die mir geholfen haben, das Werk doch endlich zu veröffentlichen. Da stehen an 
erster Stelle der Verleger, Dr. Arthur Sellie r, und die Deutsche Forschungsgemeinschaft. Daßihr Zuschuß nicht zum Druck, sondern nur zur Veröffentlichung im Typoskript reichte, habe ich zunächst - bei aller Freude und Dankbarkeit, den Zuschuß unter diesen Umständen überhaupt noch zu bekommen - bedauert. Mittlerweile bin ich froh darüber. Das typographisch bescheidene Auftreten der Arbeit mag diejenigen nachsichtiger stimmen, die $Z$ weifel haben, ob es richtig ist, eine so alte Arbeit gekürzt, aber sonst unverändert herauszubringen.

Sodann habe ich Herrn Rechtsreferendar Burkard Rappl zu danken, der mir bei der Kürzung der Arbeit, bei den entsprechenden technischen Umgestaltungen, bei den Korrekturen und bei der Beschaffung von Material für die Einleitung intensiv geholfen hat. Er hat das Sachregister erstellt. Auch meine Sekretärin, Frau Grita Schock, hat an der technischen Herstellung der hier veröffentlichten Fassung wesentlichen, opferreichen Anteil genommen.

Nicht vergessen sei aber auch Peter Krause - heute Professor in Trier. Als Referendar zählte er zur ersten Riege von Hilfskräften, die mir in Saarbrücken zur Seite stand. Da ich in meinen Saarbrücker Anfängen hoffte, den Druck alsbald bewerkstelligen zu können, beauftragte ich ihn, die Teile der Arbeit, die die Bayerische Verfassung betrafen, und die damals schon nicht mit abgedruckt werden sollten, zu kennzeichnen und bei der Gelegenheit auch nach "offensichtlichen Unrichtigkeiten" zu fahnden. Diese überaus sorgfältigen Vorarbeiten erleichterten es sehr, nunmehr das Werk auf den Weg zu bringen.

\section{IV.}

Ich bin mir des Risikos bewußt, eine Arbeit unverändert zu veröffentlichen, die ich vor nunmehr 18 Jahren, als ich 32 Jahre alt war, abgeschlossen habe, die ichnicht in akademischer Ambiance, sondern neben der Last täglicher praktischer A rbeit, wenn auch mit wissenschaftlichem Anspluch und Ziel, geschrieben habe, und deren Thema ich zurückblickend überhaupt für $z u$ weit halte, um von einem Autor allein in einem einzigen, wenn auch langwierigen A rbeitsgang erforscht und erörtert zu werden. Manchen Leser werden die Schwächen und Lücken stören, die mich schon damals abgehalten haben, las Werk zum Druck zu geben, und die mich zu dem aussichtsloser Versuch bestimmten, es zu verbessern und zugleich auf lem Stand der darüber verfließenden Zeit zu halten. Und mancher Leser wird - wie ich - noch weitere Schwächen und Lücken finclen. Vollends unbefriedigt muß der Leser bleiben, der in der Arbeit unmittelbar eine Darstellung des 
Gegenstands, wie sie jetzt und heute gegeben werden müßte, erwartet. Das gilt vor allem für den Anspruch, die Begegnung von Sozialpolitik und Verfassung so darzustellen, wie sie für das Jahr 1979 dargestellt werden müßte. Es gilt aber auch schon dafür, das Verhältnis von Sozialpolitik und Verfassung für die Zeit um 1960 vom Standort heutiger Erkenntnisse, Erfahrungen und Wertungen her zu beschreiben. Was allein ursprünglich angestrebt war und mit dieser Veröffentlichung möglich ist, das ist die Erörterung des Themas unmittelbar aus dem Erfahrungsund Erkenntnisstand der Zeit vor und um 1960. Ein Buch, das von heute her das Thema für damals behandeln wollte, wäre ebenso ein notwendig anderes, mit dem vorliegenden nicht identisches Werk wie ein Buch, welches das Thema heute aus der unmittelbaren Gegenwart für die unmittelbare Gegenwart darstellen wollte. Darum stellte sich auch die Frage einer aktualisierenden Überarbeitung nicht. Ich bitte alle Leser, dies zu beherzigen. Was an Kritik vom historischen Standort des Werkes selbst her möglich ist, lastet auf mir dann noch schwer genug.

München, im März 1979

Hans F. Zacher 
INHALTSVERZEICHNIS

Seite

VORWORT

V

INHAL TSVERZEICHNIS

XI

VERZEICHNIS UNÜBLICHER, IN DER ARBEIT

VERWENDETER ABKÜRZUNGEN

XXXVII

EINLEITUNG

XXXIX

I. Die Absicht dieser Einleitung

XXXIX

II. Das Thema der Arbeit und die Möglichkeiten ihrer historischen Verortung

XXXIX

1. Zum Thema der Arbeit

XXXIX

2. Zu den Schwierigkeiten, sozialpolitische Fintwicklungen strukturierend darzustellen

XLI

3. Der Gegenstand der Arbeit und die Möglichkeiten ihrer historischen Verortung

XLIV

4. Einige spezielle Aspekte

L

a) Vorbemerkung L

b) Die internationale Dimension

L

c) Die Entwicklung sozialpolitischer Rationalität

LIII

d) Die Entwicklung eines "Sozialrechts" LVIII

III. Ein Versuch, die Nachkriegszeit im Hinblick auf das thema historisch zu gliedern

LXVI

1. Uiberblick

LXVI

2. Zur ersten Periode (1945 - 1949)

LXVII

3. Zur zweiten Jeriole (1949-1957)

LXX

4. Zur dritten 1'eriode (1957-1966)

LXXVIII

5. Zur vierten Periorle (1966-1974)

LXXXIII

6. Zur fünften Periode (1974 bis zur Gegenwart

$\mathrm{XCV}$

7. Schlußbemerkung

CII 
SOZIALPOLITIK UND VERFASSUNG IM ERSTEN

JAHRZEHNT DER BUNDESREPUBLIK DEUTSCHLAND

A. DER GEGENSTAND DER UNTERSUCHUNG

I. Aufriß des Problems

II. Begriff und Bereich der sozialen Intervention des Staates

1. Der Begriff "sozial"

2. Der Staat als Träger der sozialen

Intervention

a) Bund und Länder als Interventionssubjekte

b) Die Abgrenzung anderer Interventionsträger

aa) Völkerrechtsgemeinschaft und internationale Organisationen 24

bb) Supranationale Interventionsträger 26

c) Innerstaatliche Interventionsträger

3. Zum Sachbereich der sozialen Intervention

a) Soziale und wirtschaftliche Intervention

aa) Zur Abgrenzung

bb) Exkurs: Die wirtschaftsverfassungsrechtliche Prämisse der sozialen Intervention

b) Soziale Intervention und Daseinsvorsorge

III. Das Verfassungsrecht als Gegenstand der Untersuchung und sein Verhältnis zur sozialen Intervention des Staates

B. DAS VERFASSUNGSRECH'T DER SOZLALEN INTERVENTION

1. ABSCHNITT: DIE BUNDESSTAATLICHE ORDNUNG

I. Die bundesstaatliche Aufgabenverteilung

1. Die Gesetzgebungszuständigkeit 
a) Die ausschließliche Gesetzgebungszuständigkeit des Bundes

b) Die konkurrierende Gesetzgebungszuständigkeit

aa) Übersicht

bb) Die Kompetenzen in bezug auf das

Recht der sozialen Sicherheit

1. Die Versorgung in der Kompetenzordnung

2. Die sozialversicherungsrechtliche Kompetenz

3. Die fürsorgerechtliche Kompetenz

c) Weitere Exemplifikation - die bundesrechtliche Ausfüllung der konkurrierenden Zuständigkeit

dd) Die bundesrechtliche Ausfüllung der konkurrierenden Zuständigkeit - Würdigung

c) Die Zuständigkeit des Bundes zum Erlaß von Rahmenvorschriften

d) Die ausschließliche Gesetzgebungszuständigkeit der Länder

2. Die Verwaltungskompetenzen

a) Die Bundesverwaltung

aa) Die bundeseigene Verwaltung mit eigenem Verwaltungsunterbau

bb) Die bundeseigene Verwaltung durch Bundesoberbehiorden

cc) Die Verwaltung durch bundesunmittelbare Körperschatten und Anstalten

dd) Die Rundesministerialverwaltung

aaa) Abgrenzung

1. Dif Rechtsetzungsaufgaben der Bundesregierung

2. Im besoncleren: Die normative Gestaltung der Arbeitsbedingungen

3. Die Leitung des Bundesrechtsvollzugs in den Ländern 
4. Die Leitung der Bundeseigenverwaltung

Seite

bbb) Der Bereich der Bundesministerialverwaltung

1. Allgemeines

2. Der überregionale Verwaltungsakt 102

3. Die nichtakzessorische Verwaltung 106

4. Die Fondsverwaltung

5. Die Koordination

b) Die Bundesauftragsverwaltung

c) Die landeseigene Verwaltung in Ausführung von Bundesgesetzen

d) Die bundesrechtliche Organisation der Landesverwaltung und gewisse organisatorische Besonderheiten der sozialen Verwaltung

aa) Das Problem

bb) Die Ausschüsse

cc) Rechtsfähige Verwaltungseinheiten

1. Problemübersicht

2. Rechtsfähige Verwaltungseinheiten grundsätzlich keine "Behörden" i. S. des Art. 84 Abs. 1, 85 Abs. 1 GG

3. Die Regelungskompetenz aus der Sachkompetenz

4. Organisationskompetenz für die Behörden rechtsfähiger Verwaltungseinheiten

5. Der sachlich beschränkte Vollzugsauftrag

6. Zur Exemplifikation der Problematik am Kommunalverfassungsrecht

7. Abschließencle Bemerkungen

(d) Die körperschaftliche Verbundverwaltung 160

e) Die reine Landesverwaltung 164

f) Zusammenschau 166

3. Die Rechtsprechungskompetenz 170

II. Die Verteilung der Mittel auf Bund und Länder, insbes. die bundesstaatliche Finanzverfassung 
Seite

1. Allgemeines

2. Die verteilung ler personellen und sachlichen Mittel

3. Die bundesstaatliche Finanzverfassung

a) Vorbemerkung

b) Das Finanzaufkommen und seine Gestaltung 180

aa) Vorbemerkung: der Kredit $\quad 180$

bb) Die Erwerbseinkünfte 181

c) Zweimal "Beiträge"

aaa) Beiträge im überkommenen finanzwissenschaftlichen Sinn

bbb) Die Organisations- und Sozialbeiträge

(d) Gebühren

ee) Die Steuern

ff) Die föderativen Sekundäreinnahmen der Länder - Zusammenfassung

c) Die Ausgabedisposition 193

a) Die Grundsatzregelung 193

bb) Die Sonderregelung des Art.120 GG 196

d) Der finanzielle Primat des Bundes 199

e) Zentralisation des Finanzwesens, Finanzausgleich unci somiale Intervention

III. Neitere Gesichtspunkir l(k) bundesstaatlichen Ordnung 208

IV. Zusammenfassende llärdigung

2. ABSCITNTYT: DTT STFT I TING DFR UNTFR- UND NTIPALIAATIICIEN VERBÄNDE 219

I. Allgemeines

1. Zur Bedeutung öfentlichtr. Verbandsautonomie

2. Verfassung und subsidiaritätsprinzip

II. Die Gemeinden und (iemrindeverbände

1. Die Gemeinden 
a) Die allgemeinen verfassungsrechtlichen Grundlagen

b) Die Gemeinden als Träger sozialer Intervention

aa) Grundsätzliches

bb) Die administrative Sachkompetenz der Gemeinden

cc) Die gemeindliche Finanzautonomie

2. Die Gemeindeverbände - Kreise und Bezirke

a) Die allgemeinen verfassungsrechtlichen Grundlagen

b) Die Gemeindeverbände als Träger sozialer Aufgaben

III. Die sonstigen Verbände

1. Zur allgemeinen Problematik

2. Personalverbandliche Ordnung und Grundgesetz

IV. Zwei besondere Fälle

1. Kirchen- und sonstige Religions- und Weltanschauungsgemeinschaften

a) Einige Aspekte ihres Verhältnisses zum Staatsganzen

b) Zum kirchlichen (religions- und weltanschauungsgemeinschaftlichen) Wirkungskreis Allgemeines

c) Kirchliche Caritas (Diakonie)

aa) Der kirchliche Vorbehaltsbereich

bb) Kirchlicher, außerkirchlicher und staatlicher Bereich in der Begegnung

d) Das kirchliche Dienstrecht

e) Die kirchlichen Werke und Einrichtungen

2. Die "soziale Selbstverwaltung"

a) "Soziale Selbstverwaltung" durch die Tarifvertragspartner

aa) Die Koalitionsfreiheit als verfassungsrechtlicher Ansatz 
Seite

bb) Die Tarifmacht als Kernsubstanz der "sozialen Autonomie"

aaa) Die Verfassungsgarantie

bbb) Zum Wesen der Tarifmacht

c) Der weitere Kreis der "sozialen

Selbstverwaltung"

aaa) Das Umfeld der Tarifmacht:

Arbeitskampf und Schlichtung

bbb) Der Ausstrahlungsbereich der "sozialen Selbstverwaltung"

dd) Die Rahmen-, Kontroll- und Subsidiärverantwortung des Staates

aaa) Allgemeines

bbb) Der subsidiäre Selbsteintritt des Staates

ccc) Rahmenordnung und Legalitätskontrolle

b) "Soziale Selbstverwaltung" im Betrieb

3. ABSCHNITT : DEMOKRATISCHES UND REPUBLIKANISCHES PRINZIP UND SOZIALE INTERVENTION DES STAATES

I. Das allgemeine Verhältnis zwischen demokratischer Staatsform und sozialer Politik

1. Egalitäre Demokratie und soziale Politik

a) Ideologisch-historische Verschwisterung im Egalitären

aa) Zur demokratischen Inklination des Sozialen

bb) Die ideelle soziale Inklination der Demokratie

b) Die Dynamik ler dromokratischen Macht und die soziale. Politik

aa) Die Distanz zwischen der Herrschaft der Mehrheit und einer ganzheitlich sozialen Politik

bb) Der positive Bezug der demokratischen Herrschaftsordnung zur sozialen Politik 
aaa) Vorbemerkung: Demokratische und nichtdemokratische Herrschaftsordnung im Vergleich

bbb) Die strukturelle soziale Inklination der Demokratie

2. Die "reale" Demokratie und die realen Entsprechungen der "formalen" Demokratie

a) "Reale" Demokratie, "Wirtschaftsdemokratie" usw.

b) Die "realen" Voraussetzungen der "formalen" Demokratie

3. Freiheitliche Demokratie und staatlicher Interventionismus

II. Die allgemeinen verfassungsrechtlichen $\mathrm{Grundlagen}$

III. Zu einigen Besonderheiten der konkreten demokratischen Ordnung

1. Vorbemerkung: Der demokratische Purismus

2. Legislative und Exekutivspitze

a) Der Grundzug: Parlament und Regierung Hauptfunktionäre der Demokratie

b) Parlament und Regierung

aa) Das parlamentarische Wahlrecht

bb) Das repräsentative Prinzip

cc) Die Stellung der Regierung

c) Ausgleichsfaktoren

aa) Vorbemerkung

bb) Der Staatspräsident

cc) Die zweite Kammer

dd) Die unmittelbare Demokratie

3. Demokratie und "Richterstaat"

a) Verfassungsrechtliche Grundlegung

b) Zur besonderen Funktion des Richters

c) Ihre demokratische Prämisse

d) Zur demokratischen Struktur der verschiedenen Gerichtszweige 
aa) Überblick

Seite

bb) Zur. Deutung

4. Demokratie, Bürokratie und Berufsbeamtentum

a) Zur verfassungsrechtlichen Grundlegung des Berufsbeamtentums

b) $\mathrm{Zu}$ seiner Funktion

5. Die Demokratie der Parteien und Verbände

a) Zum "Parteienstaat"

aa) Allgemeines

bb) Die Parteienfinanzierung

cc) Die Verpflichtung der Parteien auf die freiheitliche demokratische Grundordnung

b) Zum "Verbänclestaat"

aa) Wesen und allgemeine Wirkungsweise cler Verbände

bb) Die Vormachtstellung der organisierten Interessen

aaa) Allgemeines

bbb) Das organisierte soziale Interesse

cc) Die Regulier'ung der. "Verbändedemokratie":

aaa) Des verfassungsrechtliche Rahmen

bbb) Die Institutionalisierung des

$$
\text { Verbandseinflusses }
$$

cec) Die sicherung des Individuums

IV. Demokratie und selbstrelwaltung

1. Allgemeine's

2. Einige besondere liemerkungen

a) Demokratie und Iusschußwesen

b) Demokratie und recht!iche Selbstverwaltungseinheiten

c) Parteien und Verbünde in der Selbstverwaltung 
4. ABSCHNIT'T: DIE SOZIALE INTERVENTION IM

Seite RECHTSSTAAT

I. Allgemeines zu dem Verhältnis der sozialen Intervention zur rechtsstaatlichen Ordnung des Grundgesetzes

II. Die Gewaltentrennung und die mit ihr zusammenhängenden Prinzipien im Verhältnis zur sozialen Intervention

1. Wandlungen der Gewaltenteilung und soziale Intervention

2. Die soziale Intervention im "Gesetzesstaat"

a) Die allgemeine Tendenz zum Gesetzesstaat

b) Die Verklammerung von Gesetzgebung und Verwaltung

aa) Verwaltung - Rechtsstaat - Verwaltungsrecht

bb) Die rechtsstaatliche Notwendigkeit des Gesetzes

aaa) Der Vorbehalt des Gesetzes

1. Das Grundschema

2. Die positive verfassungsrechtliche Ordnung

3. Die "Lücke" im Gesetzesvorbehalt

4. Gesetzesfreie Leistungsverwaltung?

5. Sonderprobleme

a) Belastungen des Begünstigten

b) Begünstigungen, die Dritte belasten

c) Besondere Gewaltverhältnisse

d) Die Organisationsgewalt

6. Schlußbemerkung

bbb) Die rechtsstaatliche Pflicht der gesetzlichen Bindung der Verwaltung ergänzende Bindungen der gesetzesfreien Verwaltung

cc) Das rechtsstaatliche Gebot der Bestimmtheit der Verwaltungsbefugnisse 
dd) Die funktionelle Konkurrenz von Gesetzgebung und Verwaltung

Seite

474

c) Gesetzgebung und untergesetzliche Rechtsetzung

aa) Rechtsetzung durch Exekutivbehörden

bb) Die autonome Rechtsetzung

cc) Grenz- und Mischfälle zwischen

Satzung und Verordnung

dd) Das funktionelle Verhältnis zwischen

Rechtsverordnung und Satzung

ee) Die "soziale Autonomie"

d) Der Anteil der Gesetzgebung an der sozialen Intervention

3. Die soziale Intervention im "Justizstaat"

a) Bemerkungen zum Justizstaat

b) Die richterliche Primärkompetenz im Rahmen der sozialen Intervention

aa) Die Funktion - ihre soziale Bedeutung

bb) Die verfassungsrechtliche Garantie

cc) Die Ausweitung der sozialen Wirksamkeit des Richters

1. Soziale Staatsaufgabe und Rechtsprechung

2. Die spezifischen Erscheinungsformen richterlicher Sozialgestaltung

3. Das Verhältnis der Rechtsprechung $z u$ Gesetz(gebung) und verwaltungverfassungsstrukturelle Determinanten

dd) Staatliche und nichtstaatliche Rechtsprechung

c) Die gerichtlichen Kontrollkompetenzen

aa) Der gerichtliche Rechtsschutz gegenüber der Verwaltung

aaa) Die "Generalklausel" - Notwendigkeit und Bedeutung

bbb) Der Rechtsschutz gegenüber dem leistenclen Staat

1. Die verfahrens rechtliche Anpassung 
Seite

2. Das berechtigende Gesetz als Angelpunkt

3. Exkurs: Der rechtsstaatliche Zwang zur subjektiven Berechtigung

ccc) Weitere besondere Rechtsschutzprobleme

ddd) Zum Verhältnis von Verwaltung und kontrollierender Rechtsprechung

bb) Die richterliche Prüfung der Gesetze

aaa) Allgemeines

bbb) Der Rechtsschutz gegenüber dem untätigen Gesetzgeber

cc) Richterliche Kontrolle der Rechtsprechung 562

d) Die Verfassungsgerichtsbarkeit

e) Die verfassungsmäßige Konzeption der Struktur der sonstigen Gerichtsbarkeit

aa) Die fünf Säulen der (Nichtverfassungs-)

Gerichtsbarkeit

aaa) Die Grundlagen

bbb) Die besondere Sozialgerichtsbarkeit

ccc) Die Bedeutung der Verfassungsentscheidung für eine spezialisierte Gerichtsbarkeit

ddd) Das Verhältnis der Gerichtszweige zueinander

eee) Anhang: Zum Obersten Bundesgericht

bb) Sondergerichte - Sonderkammern(-senate) - Verfeinerung des Rechtsschutzes

cc) Die vertikale Gliederung - zum Instanzenzug

(d) Die Trennung von der Exekutive

f) Der Anteil der Rechtsprechung an der sozialen Intervention

4. Die soziale Intervention im "Verwaltungsstaat"

a) Die besondere Funktion der Verwaltung 
b) Verwaltung zwischen Gesetzgebung und Rechtsprechung

Seite

c) Zur Struktur der Verwaltung

5. Anhang: Das Verhältnis zwischen privatem und öfentlichem Recht im Lichte der Gewaltentrennung 614

a) Allgemeines

b) Verfahrensrechtliche Aspekte

c) Das materiellrechtliche Problem in der zwischenbürgerlichen Dimension

d) Das materielle Problem in der Staat-BürgerDimension

e) Wechselseitige Durchdringung und Angleichung von öfentlichem und privatem Recht

III. Die materiellen Prinzipien der Rechtsstaatlichkeit

1. Allgemeines

a) Zum Gegenstand

b) Der Grundsatz der verhältnismäßigkeit

c) Das Amtshaftungs - und Entschädigungs recht

2. Rechtsstaat und Rechtssicherheit

a) Das Postulat der Rechtssicherheit

b) Die Sicherheit des Normbestandes

aa) Zur Rückwirkung von Gesetzen

bb) Bestandskiatt von Cresetzen?

c) Die Bestandskrafi individueller Rechtsakte

aa) Allgemeines

bb) Der Widereut ussprünglich rechtswidr.iger $V$ e.r.wiltungsakte

aaa) Dor beginstigende Widerruf

bbb) Der lästigr Widerruf

d) Zur Bestandskl“cift : itulierter Leistungsansprüche 


\section{ABSCHNITT: DER SOZIALSTAAT}

Seite

I. Zum Wesen der grundgesetzlichen Sozialstaatsproklamation

II. Die grundsätzliche Exegese der grundgesetzlichen Sozialstaatsproklamation

1. Zum Inhalt der Sozialstaatserklärung

a) Die Trias der elementaren Deutungsmöglichkeiten

b) Die Auslegung im Sinne des historischkonkreten "sozial"-Begriffes

aa) Das Wort "sozial"

bb) Die Wortfügung vom sozialen Staat

cc) Der soziale Bundesstaat

dd) "Demokratisch und sozial"

ee) Der soziale Rechtsstaat

aaa) Sozialstaatsdeklaration und Rechtsstaatsprinzip

bbb) Sozialstaatsdeklaration und materiell-rechtsstaatliche Grundordnung

1. Sozialstaatsdeklaration und Grundrechte

2. Sozialstaatsdeklaration und Grundpflichten

3. Die Sozialstaatsdeklaration als Surrogat einer verfassungsrechtlichen Sachordnung

ff) Zusammenfassende Würdigung

gg) Historisch-subjektive Gesichtspunkte

hh) Das Ergebnis

c) Abgrenzung und Implikationen

aa) Der allgemeine Sozialgestaltungsauftrag

bb) Die allgemeine Gemeinschaftsverpflichtung der Individuen

cc) Die soziale Gerechtigkeit

dd) Das gemeine Wohl

ee) Daseinsvorsorge

d) Der undoktrinäre Minimalismus des Sozialstaatsprinzips 
2. Zur Geltungsweise des Sozialstaatsprinzips

a) Grundsätzliches zu den inhaltsbedingten Geltungsmöglichkeiten

aa) Geltungsproblematik und Geltungsanspruch 706

bb) Die Notwendigkeit zu differenzieren das Verbot unsozialen Handelns

b) Sozialstaatsprinzip und verfassungsgebundene Staatsfunktionen - insbes. Sozialstaatsprinzip und Gesetzgebung

aa) Die sozialstaatliche Bindung des Gesetzgebers

bb) Das Sozialstaatsprinzip als Legitimation

aaa) Der Leerlauf einer "echten" Legitimationswirkung

bbb) Die unechte, interpretatorische Legitimationswirkung

cc) Sozialstaatsprinzip und Gesetzesvollzug

aaa) Die Tragweite der sozialstaatlichen Bindung des Gesetzgebers

bbb) Sozialstaatsgerechte Gesetzesauslegung

c) Sozialstaatsprinzip und Verwaltung

d) Sozialstaatsprinzip und Rechtsprechung

e) Das Sozialstaatsprinzip als Quelle individueller Rechte und Pflichten im Staat-Bürger-Verhältnis?

aa) Das Fehlen einer unmittelbaren Verpflichtung des Bürgers

bb) Das Sozialstuatsprinzip als Anspruchsgrundlage gege $\cdot$ n den Staat?

f) Zur "Drittwirkung" des Sozialstaatsprinzips

3. Der "demokratische und soziale Bundesstaat" und der "republikanische, demokratische und soziale Rechtsstaat"

a) Der soziale Bundesstaat

aa) Sozialstaatsprinzip und bundesstaatliche Kompetenzordnung 
bb) Zur Tragweite des Art.28 Abs.3 GG

Seit

b) Die soziale Demokratie

aa) Affinität und wechselseitige Ergänzung von Sozialstaat und Demokratie

bb) Im besonderen zur "Wirtschaftsdemokratie"

c) Der soziale Rechtsstaat

aa) Allgemeines

bb) Einige besondere Probleme

aaa) Vorbemerkung

bbb) Sozialer Rechtsstaat und Subsidiaritätsprinzip

ccc) Rechtssicherheit im Sozialstaat

III. Die Schwerpunkte der sozialstaatlichen Sachordnung

1. Vorbemerkung

2. Sozialstaat und soziale Sicherheit

a) Allgemeines

b) Die allgemeine öfentliche Fürsorge als sozialstaatliches Minimum

766

c) Die Verwirklichung des Sozialstaates durch die gehobene soziale Sicherung

aa) Vorbemerkung

bb) Die Sozialversicherung

cc) Die Sonderversorgung

bbb) Die "unechte" Sonderversorgung

d) Die grundgesetzliche Sicherung des gegebenen Standes von Sozialversicherung und Sonderversorgung

3. Sozialstaat und Arbeit

a) Das sozialstaatliche Arbeitsrecht

aa) Allgemeines

bb) Einzelfolgerungen für das Arbeitsvertrags- und Arbeitsschutzrecht

cc) Folgerungen für das kollektive Arbeitsrecht 
Seite

aaa) Zum Betricbsvrrassungsrecht

bbb) Zur. "Sozialen Autonomie" der Tarifpartn $6 \cdot 1$ - lie Letztverantwortung des (Sozial)Staates

788

dd) Das sozialstaatliche Beamtenrecht

789

794

b) Das Recht auf Arbeit

c) Die Pflicht zur Arbeit

800

aa) Allgemeines

800

bb) Die Pflicht (Last) zur existenzerhaltenden Arbeit

aaa) Wesen und Frscheinungsformen

801

bbb) Das Verhältnis zu Art.12 GG

805

4. Sozialstat und Güterverteilung

a) Allgemeines

810

b) Allgemeine Vermögensstreuung

c) Die Verteilung der Produktionsmittel

813

d) Die Verteilung (les Bodens

e) Die Verteilung der Konsumgüter

f) Zum Nohnungsproblem

818

g) Anhang: Sozialstaatsprinzip und Vermögensschäden

5. Die allgemeinen nicht primäl sozialen staatlichen Leistungen

a) Die öfentliche Ciuter- mnl Leistungsversorgung

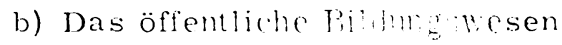

c) Das öffentliche (iesunthettswesen

6. Das sozialstactliche Verahrensrecht

a) Allgemeines

b) Das "Armenrechi"

c) Der Vollstreckingsscutz

7. Sozialstaat und biirgeriand (as liecht

a) Allgemeines 
b) Sozialstaat und Vertragsfreiheit 826

c) Sozialstaatsprinzip und Schadensersatzrecht 827

d) Das Problem der Unterhaltspflicht 828

8. Die (sozial-)staatliche Mittelbeschaffung 828

a) Sozialstaat und Abgabenrecht 828

aa) Zum Steuerrecht 828

bb) Das sonstige Abgabenrecht 832

b) Sozialstaat, Enteignung und Eigentumsbindung 832

c) Sozialstaat und persönliche Indienstnahme 835

9. Sozialstaat und Wirtschaftsordnung 835

a) Sozialstaatsprinzip und Wirtschaftsverfassung

b) Einzelprobleme 838

aa) Protektionistische Maßnahmen 838

bb) Das Problem der wirtschaftlichen Konzent ration

cc) Die Währungspolitik

6. ABSCHNITT: GRUNDRE.CHTSORDNUNG UND SOZIALE INTERVENTION

I. Allgemeine Fragen

1. Verfassungsmäßige Rechte und Grund- und Menschenrechte außerhalb der Verfassung

2. Grundrechte und Grundpflichten

a) Allgemeines - die programmatischen Grundpflichten

b) Zur Sozialpllichtigkeit

c) Grundrechte und Grundpflichten

d) Zur "einzigen eigentlichen rechtlichen Grundpflicht"

3. Ausgrenzende und bewahrende Grundrechte und sog. "soziale" Grundrechte

a) Allgemeines 
bb) Die auch "soziale" Funktion der Ausgrenzungen

Seite

cc) Die auch freiheitliche Funktion der "sozialen" Grundrechte

dd) Erscheinungsformen und Wirkungsweise der "sozialen" Verbürgungen
ee) Freiheit und Teilhabe - zu den Grenzen der Verfassungssynthese

f f) Ambivalente Verfassungsrechte

b) Ausgrenzende Grundrechte und sog. "soziale" Grundrechte

4. Einige Probleme der Grundrechtsgeltung

a) Allgemeine soziale Schranken der Grundrechte 861

aa) Grundrechte im Sozialstaat

bb) Sozialstaatsgerechte Grundrechtsauslegung

cc) Gesetzesvorbehalte

dd) Schutz der Menschenwürde - das gemeinsame Prinzip von Grundrechtsordnung und Sozialstaatlichkeit

b) Art.18 GG

c) Die Grundrechte im besonderen

Gewaltverhältnis

aa) Allgemeines

bb) Einige Einzelfragen

aaa) Grundrechte im offenen Anstaltsund im Körperschaftsverhältnis

bbb) Grundrechte im geschlossenen Anstaltsverhältnis

ccc) Die dienstrechtlichen Gewaltverhältnisse

d) Die Drittwirkung der Grundrechte und verwandte Probleme

aa) Zur sog. Drittwirkung der Grundrechte

aaa) Die Drittwirkung "ungeschriebenen" Rechts

bbb) Die ausdrücklich angeordnete Drittwirkung

bb) Die "Fiskalgeltung" der Grundrechte 
cc) Grundrechtsgeltung für Tarifverträge und Betriebsvereinbarungen

Seite aaa) Grundrechtsgeltung für Tarifvertragsrecht

bbb) Grundrechtsbindung für Betriebsvereinbarungen

II. Das Grundrecht der Gleichheit

1. Gleichheit und sozialer Rechtsstaat

2. Der allgemeine Gleichheitssatz

a) Der Gleichheitssatz als Willkürverbot

b) Zum speziellen Inhalt des Gleichheitssatzes

aa) Vorbemerkung

bb) Die soziale Bedeutung des Gleichheitssatzes

aaa) Gleichheit und sozialer Ausgleich

- Allgemeines

bbb) Gleichheit und sozialer Ausgleich

- Einzelfragen

cсc) Gleichheit der Teilhabe und der Belastung

cc) Opfergleichheit und Opferausgleich

aaa) Allgemeines

bbb) Einzelfragen

dd) Der Gleichheitssatz im Privatrecht

3. Die besonderen Gleichheitssätze (Art.2 und 3GG) 914

a) Allgemeines

b) Die Gleichheit von Mann und Frau

aa) Art. 3 Abs. 2 und 3 GG - Allgemeines

bb) Einzelfragen

aaa) Zum Stand der Entwicklung

bbb) Gleichberechtigung und soziale Sicherung

ccc) Gleichheit von Mann und Frau im A rbeitsrecht

1. Besonderer A rbeitsschutz für Frauen 
Seite

2. Iie Lohngleichheit

3. Zur Drittwirkung u. ä.

c) Das Verbot, nach der "Herkunft" zu differenzieren

4. Weitere besondere Gleichheitssätze

III. Die Verfassungsordnung des Eigentums

1. Eigentum und sozialer Rechtsstaat

2. Der gegenständliche Bereich des Eigentumsschutzes

a) Die Ausweitung des Eigentumsbegriffs

aa) Von der Sacheigentumsgarantie zur Sicherung vermögenswerter Berechtigungen einschließlich solcher öffentlichen Rechts

bb) Zum Eigentumsschutz öffentlichrechtlicher Berechtigungen im besonderen

b) Geschütztes und nicht geschütztes Eigentum?

3. Die Bindungen des Eigentums

a) Die soziale Bindung des Eigentums Allgemeines

b) Die sozialisierende Bindung des Eigentums

4. Die Entziehung des Eigentums

a) Übersicht

b) Die Enteignung

aa) Begriff und allgemeine soziale Bedeutung

bb) Die Entschäuligungspflicht

aaa) Dic llöhe der Entschädigung

1. Diє Rogelung des Grundgesetzes

a) Meinungsstand und Rahmeninterpretation

b) Die maßgebenden Elemente der Entschädigung

c) Die effektive Norm

2. Zur funktionalen Bedeutung dieser Regelung 
bbb) Zur Art und Weise der Entschädigung

ccc) Der Gestaltungsspielraum des Gesetzgebers

c) Die Umlegung

d) Die Sozialisierung

aa) Zur allgemeinen Bedeutung

bb) Inhalt und Grenzen der Sozialisierungse rmächtigung

cc) Insbes. die Sozialisie rungsentschädigung aaa) Zur Höhe

bbb) Zur funktionalen Bedeutung

e) Exkurs I: Die soziale Umschichtung

aa) Zum Begriff

bb) Soziale Umschichtung und Gleichheitssatz

cc) Soziale Umschichtung und Verfassungsgarantie des Eigentums

aa) Soziale Umschichtung im Rahmen der allgemeinen Eigentumsentziehungstypen der Verfassung

1. Übersicht

2. Soziale Umschichtung im Rahmen von Enteignung und Sozialisierung

bbb) Weitere Wege sozialer Umschichtung?

1. Der Anlaß der Frage

2. Soziale Umschichtung als Inhaltsbestimmung des Eigentums?

3. Die "Sozialentwährung"?

4. Die "soziale Umschichtung" als besonderer Eigentumsentziehungstyp

a) Zum Argument des Lastenausgleichs

b) Zum A rgument der Entflechtung

c) Zum Argument der Bodenreform 
dd) Schlußbemerkung

Seite

f) Exkurs II: Das Mitbestimmungsrecht im Schnittpunkt der Probleme

aa) Allgemeines

982

bb) Zur konkreten Grenzziehung

983

aaa) Zum Betriebsverfassungsrecht

984

bbb) Zum engeren Mitbestimmungsrecht

985

g) Der Eingriff in das Geldvermögen

h) Exkurs III: Die eigentumsinhaltsbestimmende Rechtsverkürzung

aa) Allgemeines

bb) Insbes. zur Verschlechterung sozialversicherungsrechtlicher Anwartschaften und Leistungen

5. Die Gewährleistung des Erbrechts

IV. Die verfassungsrechtliche Grundordnung der Ehe, der Familie, der Kindschaft und der Jugenderziehung und - förderung

1. Das Recht der Fhe und der Familie

a) Allgemeines

b) Einzelfragen

aa) Benachteiligungsverbot, Förderungsgebot und verwande Fragen

bb) Der Schutz von Ehe und Familie im familien- und eheinternen und im sonstigen zwischenbürgerlichen Bereich

c) Zum Zölibatsproblem

2. Elternrecht - Kinder- und Jugendschutz - Schule 1008

a) Eiternrecht

b) Kinder- und Jugendschutz

c) Schule und Bildung

3. Der Mutterschutz

4. Zur Stellung des unehelichen Kindes 
V. Die (sonstigen)F reiheitsgrundrechte

Seite

1. Vorbemerkung

1017

2. Das Recht auf Unverletzlichkeit der Wohnung

3. Glaubens-, Gewissens- und Bekenntnisfreiheit

1018

4. Die Meinungsfreiheit

1018

5. Die Freizügigkeit

1020

6. Die Berufsfreiheit

a) Freiheit des Berufs, des Arbeitsplatzes und der Ausbildungsstätte - negativer und positiver Status

b) Zur Freiheit der Berufswahl und -ausübung

aa) Freiheit und Schranken - Zum System

bb) Zur sozialen Problematik der Berufsfreiheit und ihrer Schranken

aaa) Allgemeines

bbb) Beschränkungen zum Schutz des Berufswilligen

ccc) Der Schutz des Berufsstandes

ddd) Die Sicherung sozialer Berufsfunktionen

eee) Die Abwehr sozialer Gefährdungen

$\mathrm{fff}$ ) Die soziale Gestaltung der Beschränkungen

c) Zur Freiheit der Wahl des Arbeitsplatzes

d) Die freie Wahl der Ausbildungsstätte

e) Arbeitszwang und Zwangsarbeit

f) Das Problem der Drittwirkung

7. Vereins - und Koalitionsfreiheit

a) Vorbemerkung

b) Zur Vereinsfreiheit

aa) Ihre positive soziale Funktion

bb) Die Grenze der Vereinsfreiheit

cc) Vereinsfreiheit und Vereinigungszwang

c) Zur Koalitionsfreiheit 
aa) Allgemeines

bb) Besondere A spekte der individualrechtlichen Abwehrfunktion

Seite

a) Allgemeines

d) Zum Kartellproblem

3. Die allgemeine Handlungsfreiheit

a) Grundsätzliches

aa) Zur Auslegung des Art. 2 Abs. 1 GG

1056

bb) Zusammenfassende Würdigung

1058

b) Freiheit und soziale Ordnung

1061

aa) Freiheit und Teilhabe

1061

bb) Die soziale Bindung der Freiheit

1062

cc) Einzelfragen

1064

aaa) Vorbemerkung

1064

bbb) Freiheit und soziale Sicherheit

1064

ccc) Freiheit und soziale Wirtschaft sordnung

1066

ddd) Die Freiheit in der Privatautonomie

9. Das Recht auf körperliche Freiheit, körperliche Unversehrtheit und Leben

a) Die körperliche Freiheit

aa) Allgemeines

1069

bb) Zur sozialen Problematik

1070

b) Die körperliche Unversehrtheit

1073

aa) Allgemeines

1073

bb) Zur sozialen Problematik

1073

aaa) Gesundheitspflegerische und

Heileingriffe

1073

1. Vorbemerkung

2. Der Schutz vor Gemeingefahren

1074

3. Der "soziale Heilzwang"

1075

4. Das Zwangsexperiment

1078

bbb) Geburtenkontrolle

ccc) Pflichten zum Einsatz der Gesundheit

ddd) Zur Drittwirkung 
c) Das Recht auf Leben

Sieite

d) Das Recht auf Leben und körperliche Unversehrtheit als indirektes Teilhaberecht

VI. Einige weitere Rechte

1. Garantie der Staatsangehörigkeit, Deutschenstatus und Auslieferungsverbot

2. Das Asylrecht

3. Das rechtliche Gehör

VII. Der Grundrechtssatz von der Menschenwürde

1. Vorbemerkung

1095

2. Grundsätzliches zur Deutung und Tragweite

a) Achtung und Schutz der Würde des Menschen

b) Das Verhältnis des Verfassungssatzes von der Menschenwürde zur gesamten Verfassungsordnung

c) Der Grundrechtssatz von der Menschenwürde als subjektives Recht

3. Einzelfragen

a) Schutz der Menschenwürde im Rahmen der sozialen Intervention

b) Zur "Drittwirkung" des Grundrechtssatzes von der Menschenwürde

c) Grundrechtsordnung und Subsidiaritätsprinzip

C. ABSCHLIESSENDE BEMERKUNGEN 


\section{VERZEICHNIS UNÜBLICHER, IN DER ARBEIT} VERWENDETER ABKÜRZUNGEN

Gitse-Schunck

Hu:ck, Lehrbuch des A reitsrechts, Bd. I

v. Iangoldt-Klein

Maunz-Dürig

Naviasky-Lechner

Naviasky-Leusser

Nijperdey, Lehrbuch de: Arbeitsrechts, $\mathrm{Bd}$ II

Renhardt, Verfassuigsschutz des Eirentums

Scleuner, Verfassuigsschutz des Eicentums
Friedrich Giese, Grundgesetz für die Bundesrepublik Deutschland, 5.Aufl., bearbeitet von Egon Schunck, Frankfurt a. M. 1960

Alfred Hueck und Hans Carl Nipperdey, Lehrbuch des Arbeitsrechts, 6.Aufl., Bd. I, Berlin/Frankfurt a. M. 1959

Helmut v. Mangoldt, Das Bonner Grundgesetz, 2.Auf1., bearbeitet von Friedrich Klein, Berlin/Frankfurt a. M. $1955 \mathrm{ff}$

Theodor Maunz und Günther Dürig, Grundgesetz, München/Berlin 1958 ff

Hans Nawiasky und Hans Lechner, Die Verfassung des Freistaates Bayern, Ergänzungsband zum Handkommentar, München 1953

Hans Nawiasky und Claus Leusser, Die Verfassung des Freistaates Bayern, Systematischer Überblick und Handkommentar, München/Berlin 1948

Alfred Hueck und Hans Carl Nipperdey, Lehrbuch des Arbeitsrechts, 6.Aufl., BI. II, Berlin/Frankfurt a. M. 1957

Ru(t)]f Reinhardt und Ulrich Scheuner, Verfassungsschutz des Eigentums, Tübingen 1954, S. $1-62$

das. S. $63-162$ 



\section{E I N L E I T U N G}

\section{Die Absicht dieser Einleitung}

Die A rbeit, die nachstehend veröffentlicht wird, ist um 1960 entstanden. Sie wird hier gekürzt, nicht aber verändert oder fortgeschrieben wiedergegeben 1 ).

Die Veröffentlichung soll einen Einblick geben, wie das Thema in den späten fünfziger Jahren verstanden und behandelt werden konnte. Damit dieser $Z$ weck erreicht wird, und vielleicht auch damit das Vorhaben vor Mißverständnissen bewahrt wird, ist es geboten, auszumachen, was der historische Ort der Entstehung und des Abschlusses der Untersuchung für ihr Thema und dessen Erörterung bedeutete. Die folgenden Zeilen wollen der Versuch solcher historischen Verortung sein.

Dabei ist nur daran gedacht, mit kurzen Strichen zu skizzieren, wie sich der Gegenstand der Untersuchung im Verlauf der Nachkriegsgeschichte der Bundesrepublik verändert hat. Die Relevanz, welche die damaligen Gegebenheiten und ihre Entwicklungsgeschichte zuvor und danach für die Arbeit als Ganzes, ihre Konzeption und ihren Inhalt im einzelnen gehabt haben, kann hier nicht erörtert werden. Das würde eine zu eingehende Untersuchung erfordern. In Sonderheit der Versuch, darzustellen, wie die Arbeit hätte aussehen müssen, wenn sie in Kenntnis der späteren Entwicklungen verfaßt worden wäre, würde nicht weniger bedeuten, als die ganze Untersuchung noch einmal zu schreiben.

II. Das Thema der Arbeit und die Möglichkeiten ihrer historischen Verortung

\section{Zum Thema der Arbeit}

Das originale Thema der Arbeit war "Das Verfassungsrecht der sozialen Intervention des Staates nach dem Grundgesetz und der bayerischen Verfassung". Für den Zweck dieser Veröffentlichung wurde hingegen das Thema "Sozialpolitik und Verfassung im ersten Jahrzehnt der Bundesrepublik Deutschland" gewählt.

Daß die bayerische Verfassung nicht mehr im Titel erscheint, entspricht der Überarbeitung des Textes, die im wesentlichen darin bestand, die Erörterungen, die spezifisch die bayerische Verfassung und - soweit es so etwas damals noch gab - die

1) S. dazu noch einmal das Vorwort oben S.V. 
bayerische Sozialpolitik betrafen, zu eliminieren. Und dies wiederum rechtfertigt sich daraus, daß Landesverfassungsrecht und soziale Intervention der Länder von 1960 bis heute außerordentlich an Bedeutung verloren haben.

Der "historisierende" Zusatz "im ersten Jahrzehnt der Bundesrepublik Deutschland" soll den historischen Ort der Arbeit im Titel evident machen. Freilich trifft diese Zeitangabe nicht ganz genau. Die Arbeit schließt nicht 1959, sondern 1960/61. Doch würde eine genauere Angabe im Titel nicht nur zu umständlich sein. Sie würde auch den falschen Anschein erwecken, als hätte ein bestimmtes Jahr des Abschlusses eine ganz besondere Bedeutung 2).

So bleibt zu erklären, warum die Worte "Das Verfassungsrecht der sozialen Intervention des Staates nach dem Grundgesetz" durch "Sozialpolitik und Verfassung" ersetzt wurden. Die Veränderung spart Worte, deren Einsparung notwendig ist, um Platz für den "historisierenden" Zusatz zu gewinnen. Sie setzt an die Stelle der spröden und vielleicht zu viele Fragen aufwerfenden Formel von der "sozialen Intervention des Staates" das Wort "Sozialpolitik", das die gebotenen Assoziationen des Lesers von heute wohl schneller und verläßlicher auslöst. Freilich sind die Begriffe "Sozialpolitik" und "Soziale Intervention" nicht identisch. Doch sind beide Begriffe offen und von gewisser Mehrdeutigkeit. Jedenfalls schien es möglich, den Zusatz "des Staates" wegzulassen, nachdem die Worte "soziale Intervention" durch "Sozialpolitik" ersetzt waren; denn der Staat ist als das beherrschende Subjekt von Sozialpolitik selbstverständlich geworden. Auch dort, wo Sozialpolitik von gesellschaftlichen Kräften (Verbänden, Unternehmen usw.) betrieben wird, erscheint er verantwortlich oder sonstwie in Bezug genommen. Ein Wort endlich zum Austausch von "Grundgesetz" gegen "Verfassung". Er soll hervortreten lassen, daß es um die "Gattung Verfassungsrecht" als Be-

2) Um dem noch genaueren Leser entgegenzukommen, sei ferner darauf hingewiesen, daß der Verfasser sich des Problems bewußt ist, das darin liegt, daß die Arbeit das Thema nicht über den Verlauf des "Ersten Jahrzehnts" oder - wie genauer zu sagen wäre - der Zeit zwischen 1949 und 1961 erörtert. Gemeint ist vielmehr die Darstellung der Verhältnisse, wie sie sich am Ende der angegebenen Periode darstellen, wie sie jedoch mit einer gewissen technischen, literarischen und psychologischen Notwendigkeit in den Jahren vorher entstanden, erfaßt und verstanden worden sein müssen, um in einer Arbeit solchen Umfanges reflektiert zu werden. 
zugsrahmen für die Sozialpolitik geht. Daß es sich bei der Verfassung der Bundesrepublik Deutschland um das Grundgesetz handelt, bedarf daneben keiner Hervorhebung im Titel 3 ).

Somit kann zusammengefaßt werden: Das Thema der nachstehend wiedergegebenen Arbeit ist,

- in welcher Weise die Verfassung in dem genaueren Sinn von formellem Verfassungsrecht, in dem das Grundgesetz die Verfassung der Bundesrepublik Deutschland ist,

- der Sozialpolitik des Staates, die unter den gegebenen wirtschaftlichen, politischen, rechtlichen und sonstigen gesellschaftlichen Verhältnissen primär den Charakter steuernder und korrigierender, verteilender und umverteilender, sichernder, ausgleichender und helfender Interventionen hat,

- Ziel und Gestalt gibt und Bedingungen setzt.

2. Zu den Schwierigkeiten, sozialpolitische Entwicklungen strukturierend darzustellen

Sozialpolitische Intervention des Staates entwickelt sich - wie wohl jede die gesellschaftlichen Verhältnisse gestaltende Innenpolitik - in einer eigentümlichen Dialektik zwischen der sozialen Situation, die sich als eine Herausforderung an die Politik darstellt und den - vor allem den normativen und institutionellen Bedingungen, unter denen die Antwort auf diese Herausforderung gesucht, gefunden und gegeben wird - letztlich also: unter denen interveniert wird. Wir haben somit eine Grundstruktur, die aus drei Elementen besteht:

SOZIALE SITUATION/ HERA USFORDERUNG

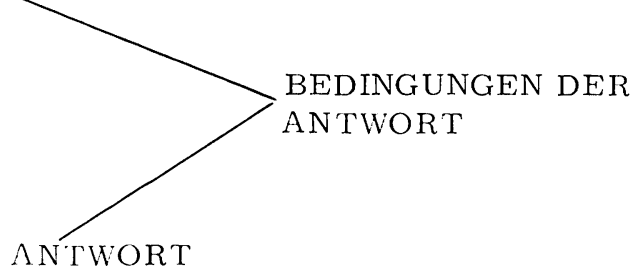

So klar dieses Grundschema zu sein scheint, so sehr muß von vornherein betont werden, daß diese Elemente und der Ablauf "Herausforderung - Bedingungen der Antwort - Antwort" immer nur sehr

3) Und die Vernachlässigung des Landesverfassungsrechts als der zweiten Schicht von Verfassungsrecht im Bundesstaat bedarf ebenso nicht besonderer, neuerlicher Rechtfertigung. 
künstlich isoliert werden können. In Wahrheit besteht

- ein Höchstmaß von Verwobenheit aller (scheinbar) isolierten "Situationen" mit einer nie erschöpfend feststellbaren Gesamtsituation, aller (scheinbar) isolierten Bedingungen der politischen Annahme einer gewissen Herausforderung und der Reaktion auf sie mit einer im ganzen nie erschöpfend feststellbaren Gesamtsituation und auch ein Zusammenhang jeder "Antwort" mit anderen "Antworten" (wenngleich in bezug auf die Antworten, weil sie sehr oft durch historisch begrenzte Handlungen, z. B. einen Gesetzgebungsakt, gegeben werden, die Hoffnung, sie isoliert wahrnehmen zu können und erörtern zu dürfen, eher berechtigt erscheint);

- ein Höchstmaß an Interdependenz zwischen der sozialen Situation und der ihr entsprechenden Herausforderung, den politisch-normativ-institutionellen Bedingungen der Antwort und der Antwort selbst (denn die soziale Situation verwandelt sich zur sozialen Herausforderung im Blick auf die mögliche Antwort und die gegebenen politischen Bedingungen; und die politischen Bedingungen entwickeln sich in Zusammenhang mit der sozialen Situation und den ihr entsprechenden Herausforderungen sowie in Richtung auf die Antworten, die gegeben oder vermieden werden sollen);

- ein Höchstmaß an Interdependenz der Veränderungen im Zeitverlauf, die sich - so selbstverständlich sie auch für soziale Situationen und politische Bedingungen ist - vor allem für die Rolle der Antworten ausmachen läßt. Jede Antwort verändert die soziale Situation und die entsprechenden Herausforderungen sowie die politischen Bedingungen weiterer Antworten auf gleiche oder andere soziale Herausforderungen.

Um Mißverständnissen $z u$ begegnen, muß auch festgestellt werden, daß dieser Prozeß nie einen eigentlichen Anfang, nie eine "Stunde Null", kennt. Jede soziale Situation ist auch Ausdruck bisheriger Politik (sowohl im Sinne von normativ-institutionellen Bedingungen der Reaktion als auch im Sinne von gegebenen Antworten). Jede Herausforderung wird aus der Erfahrung von Reaktionen der Politik und insbesondere aus der Erfahrung vordem gegebener oder verworfener Antworten formuliert. Die Geschichte der gegebenen oder vermiedenen oder verworfenen Antworten lebt immer unter den politischen Bedingungen künftiger Antworten fort. Das gilt nicht zuletzt in dem Sinne, daß merkwürdigerweise der Denkvorrat an Antworten, obwohl theoretisch unbegrenzt, praktisch immer begrenzt ist. Vorbilder spielen somit eine wesentliche Rolle. Das Arsenal der Antworten bestimmt so ebenso die 
Verwandlung sozialer Situationen in soziale Herausforderungen wie es die Möglichkeiten politischer Reaktionen mit begründet und mit begrenzt.

Eine ähnliche durchgehende Präsenz sowohl auf der Seite der sozialen Situationen und Herausforderungen als auch auf der Seite der politischen Bedingungen der Reaktion stellen wir bei einer Reihe weiterer Gestaltelemente fest. Drei seien hier genannt. Das erste sind die Wertmaßstäbe, die in einer Gesellschaft maßgebend oder doch möglich sind. Soziale Situationen werden zu einer sozialen Herausforderung in dem Maße, in dem sie, nach solchen Wertmaßstäben beurteilt, beseitigt oder korrigiert werden müssen. So begründen die gesellschaftlichen Wertmaßstäbe die Reaktionen des politischen Systems. Auf der anderen Seite ziehen sie ihnen auch eine Grenze ${ }^{4}$ ).

Das zweite "beiderseits" präsente Gestaltelement sind die sozialen Klassen, Schichten, Verbände, Aktionsgruppen usw. Diese sozialen Strukturen der Gesellschaft bestimmen weitgehend die soziale "Landschaft", in der soziale Situationen überhaupt wahrnehmbar und bewertbar erscheinen. Soziale Gruppen sind weitgehend die Bfzugsfelder sozialer Herausforderungen. Und ihre - direkte oder indirekte - soziale Mächtigkeit ist Bedingung der Antwort des politischen Systems par excellence. Als letztes Element seien die wirtschaftlichen Verhältnisse genannt. Zwischen dem Begriff "sozial" und "wirtschaftlich" besteht ein schwieriges Verhältnis von Nichtidentität und Nähe, das hier nicht näher untersucht werden kann. Gleichwohl darf davon ausgegangen werden, daß soziale Situationen weitgehend ökonomisch definiert werden können, daß soziale Herausforderungen weitgehend ökonomische Herausforderungen sind, daß die ökonomischen Möglichkeiten und Zielkonkurrenzen zu den wichtigsten Handlungsbedingungen des politischen Systems zählen, daß sozialpolitische Antworten weitgehend ökonomische Antworten sind und daß sie die ökonomische Situation verändern 5).

4) Auf das Problem der Divergenz zwischen den gesellschaftsimmanenten Normen und den Normen des politischen Systems braucht hier nicht weiter eingegangen werden.

5) S. zum vorigen demnächst Hans F. Zacher (Hrsg.), Bedingungen für die Entstehung und Entwicklung von Sozialversicherung, Schriftenreihe für Internationales und Vergleichendes Sozialrecht, Bd. 3, 1979; darin insbes. Peter A. Köhler, "Entstehung von Sozialversicherung" und Jens Alber "Die Entwicklung sozialer Sicherungssysteme im Lichte empirischer Analysen". Weitere Nachweise s.dort. 
So betrachtet ist jeder Versuch monokausaler Erklärung zum Irrtum verurteilt 6). Vielmehr erscheint es schon bedenklich und wenig aussichtsreich, auch nur ein Netz von wesentlichen Bedingungen sozialpolitischer Entwicklung selektieren zu wollen. Gleichwohl ist diese Selektion kausaler Konstellationen - praemissis praemittendis vollzogen und verwertet - der einzig mögliche Kompromiß zwischen dem Bedürfnis, die Entwicklung zu verstehen und aus ihr zu lernen, und der Unmöglichkeit, sie erschöpfend aufzunehmen und darzustellen.

3. Der Gegenstand der Arbeit und die Möglichkeiten ihrer historischen Verortung

Die nachfolgend abgedruckte Arbeit greift aus diesem Gefüge der Elemente sozialpolitischer Entwicklung eine sehr begrenzte Schicht heraus. Sie zielt nicht auf die Darstellung der sozialen Situation und der ihr entsprechenden Herausforderungen. Sie zielt nicht auf die Antworten, die gegeben wurden, angestrebt werden sollen oder vermieden werden sollen. Ihr Gegenstand sind auch nicht schlechthin die Bedingungen der Antwort. Die A rbeit beschäftigt sich mit einem ganz bestimmten Komplex von Bedingungen der sozialen Intervention des Staates: mit dem förmlichen Verfassungsrecht - hic et nunc: mit dem Grundgesetz.

Es war auch nicht die Absicht der Arbeit, dieses Verfassungsrecht aus der gegebenen sozialen Situation und den ihr entsprechenden sozialen Herausforderungen zu erklären und zu interpretieren. Vielmehr war es die Absicht, die normative Substanz in sich darzustellen. Ihre sozialpolitische Relevanz wurde generell anhand eines allgemeinen vorgegebenen sozialen Zwecks und Mandats des Staates aufgesucht: den ärmeren Schichten zu helfen und zu weit gespannte Wohlstandsdifferenzen abzubauen. Dies erschien zu der Zeit, als die A rbeit konzipiert und geschrieben wurde, als der allgemeinste Nenner dessen, was unter "sozial" und "sozialpolitisch" verstanden wurde und werden durfte (und es ist dieser allgemeinste Nenner des "Sozialen" und der "Sozialpolitik" bis heute geblieben). Im einzelnen freilich waren die historisch gegebenen oder zeitgenössisch diskutierten Antworten auf soziale Herausforderungen Exempel und Prüfstein der sozialpolitischen Relevanz der Verfassung. Da dies primär von einem verfassungsrechtlichen - allgemeiner: von einem juristischen - Standpunkt her unternommen wurde, standen dabei die durch das Recht gegebenen oder zu gebenden Antworten auf soziale Herausforderungen

6) S. dazu allgemein-historisch: Georg G. Issers, Neue Geschichtswissenschaft, dtv Wissenschaftliche Reihe, 1978. 
im Vordergrund. Vergleicht man dies mit der endlosen Fülle der sozialen Situationen und Herausforderungen, vor welche sich das politische System gestellt sieht, mit dem Netz der übrigen, nicht-verfassungsrechtlichen normativ-institutionell-politischen Bedingungen sozialer Intervention des Staates und mit der Summe der rechtsförmigen und nicht-rechtsförmigen Antworten des politischen Systems auf die sozialen Herausforderungen, so zeigt sich, welch "winziges" Segment aus dem Gesamtgefüge hier aufgegriffen wurde. Daß die A rbeit gleichwohl den zutage liegenden Umfang annehmen konnte, läßt andererseits darauf schließen, welch endlose Masse von Stoff insgesamt in Frage steht.

Die Absicht dieser Einleitung nun ist es, die historische Relativität eben jenes "winzigen" Ausschnittes aus dem Gesamtstoff sozialer Intervention des Staates darzutun. Genauer: sie will fragen, was am Gegenstand der A rbeit historischer Veränderung ausgesetzt war und ist, und auf welche Weise demzufolge die Arbeit mit der Zeit ihrer Entstehung zu identifizieren ist. Dieser Versuch muß davon ausgehen, daß jedes "Element" dieses Gesamtprozesses der sozialen Verhältnisse, der politischen Bedingungen, unter denen sie gestaltet werden und auf die reagiert wird, und der Antworten auf die gegebenen sozialen Probleme durch jedes andere "Element" dieses Gesamtprozesses bestimmt wird oder doch werden kann. Was die Verfassung für die soziale Intervention des Staates bedeutet, hängt also davon ab, welche politischen Kräfte die Verfassung tragen und erfüllen, welche sozialen Verhältnisse bestehen, unter welchen Wertvorstellungen sie $\mathrm{zu}$ welchen sozialen Herausforderungen erwachsen, und welche Antworten vorgegeben sind, erfunden und erstrebt oder perhorresziert werden. Die Geschichte der Rolle der Verfassung in der sozialen Intervention des Staates kann daher nur als die Geschichte aller dieser "Elemente" verstanden und dargestellt werden. Zugleich aber ist völlig klar, daß diese Darstellung aller "Elemente" und aller ihrer Interdependenzen die Möglichkeiten jedenfalls einer kurzen Skizze übersteigt. Somit muß ein Kompromiß gefunden, muß selektiert werden.

In diesem Sinne werden die parteipolitischen Kräfte, die sich in Bundestagswahlen, Bundestagsmehrheiten und Regierungskoalitionen im Bund manifestieren ${ }^{7)}$, zum Leitprinzip der historischen Skandierung erhoben. In ihnen reflektiert

7) S. umfassend hierzu (aber nur bis 1970) Bernhard Vogel, Dieter Nohlen, Rainer-Olaf Schultze, Wahlen in Deutschland, 1971. Für die späteren Wahlen etwa Statistisches Jahrbuch für die Bundesrepublik Deutschland, 1978, S. 81 ff. 
sich am deutlichsten, welche Kräfte die Verfassung erfüllen und benutzen und welche Antworten auf die sich wandelnden sozialen Herausforderungen gesucht und gegeben werden.

Andere politische Indikatoren dagegen müssen vernachlässigt werden. So schon die Wandlungen der politischen Parteien selbst, deren sozial- und verfassungspolitische Einstellungen sich mitunter stark verändert haben ${ }^{8)}$. So auch die politischen Verhältnisse in den Ländern, obwohl diese nicht nur über den Bundesrat auf die Bundespolitik und die Bundesverfassung einwirken, obwohl sie vielmehr - wie begrenzt auch immer - auch in sich imstande sind, alternative und komplementäre sozialpolitische Inhalte und Vollzugsstile $\mathrm{zu}$ entwickeln und $\mathrm{zu}$ realisieren ${ }^{9)}$. Vernachlässigt mußte ferner die politikbezogene Formation der Gesellschaft werden, die sich in Verbänden äußert 10). Ihre sozialpolitische Bedeutung - von den Gewerkschaften 11) und A rbeitgeberverbänden, den Kirchen und Wohlfahrtsverbänden 12) bis zu den Verbänden der Kriegsopfer, der Behinderten, der Vertriebenen - ist evident. Aber ebenso amorph ist ihre Entwicklung. Und ihre exakte und ausgewogene, auch empirisch verläßliche Erforschung ist ausgesprochen notleidend.

In diesem politischen Rahmen wird zuerst die Entwicklung des engsten Gegenstandes selbst, der Verfas sung, in ihrem juristischen Bestand nachgezeichnet. Der Text des Grundgesetzes wurde von 1949 bis heute vierunddreißigmal geändert 13). Nicht minder wichtig war die Entfaltung der Verfassung durch Rechtsprechung, Schrifttum und Staatspraxis ${ }^{14)}$. Die nachhaltigste

8) S. etwa Ossip K. Flechtheim (Hrsg.), Die Parteien der Bundesrepublik Deutschland, 1973 .

9) Das zeigt sich vor allem in den gesetzesarmen oder gar gesetzesfreien Bereichen der Sozialarbeit und der institutionellen Förderung.

10) S. etwa Heinz Josef Varein (Hrsg.), Interessenverbände in Deutschland, 1973; Herbert Schneider, Die Interessenverbände, Geschichte und Staat, Bd. 105, 4. Aufl. 1975. Beide mit eingehenden Schrifttumsverzeichnissen.

11) S. ergänzend Dieter Schuster, Die deutschen Gewerkschaften seit 1945, 2.Auf1., 1974; Hans F. Zacher, Staat und Gewerkschaften, 1977, m.w. Nachw.

12) S. dazu Rudolf Bauer, Wohlfahrtsverbände in der Bundesrepublik, 1978.

13) S. z.B. die Übersicht in Sartorius I, Verfassungs- und Verwaltungsgesetze der Bundesrepublik, Nr.1, S. 1 f.

14) S. dazu allgemein das umfassende Material bei Klaus Stern, 
Wirkung mußte der Rechtsprechung des Bundesverfassungsgerichts zukommen ${ }^{15)}$. Diese Entwicklung der Entfaltung und Interpretation der Verfassung kann freilich nur durch einige Wegmarken sichtbar gemacht werden.

Noch mehr bestand die Notwendigkeit, sich auf einige wenige Wegmarken zu konzentrieren, für die soziale Situation 16) und die ihr entsprechenden sozialen Herausforderungen. Vor allem die wirtschaftlichen Daten und Entwicklungen waren hier hilfreiche Anhaltspunkte - so wenig sie selbst ein umfassendes Bild der sozialen Lage geben können, ja so leicht sie in die Irre führen, wenn sie mit der Vielfalt gesellschaftlicher Wirklichkeit in eins gesetzt werden. Trotzdem konnte nicht versucht werden, andere Dimensionen wie etwa der demographischen, der technologischen oder auch der ideellen und sozialpsychischen Entwicklung so sehr sich die Gesellschaft gerade in dieser Hinsicht seit dem

Das Staatsrecht der Bundesrepublik Deutschland, Bd. 1, 1977. Speziell für den Bereich der Sozialpolitik s. für das Arbeitsrecht: Wolfgang Zöllner, A rbeitsrecht, 1977, S. 59 ff, 70 ff, m. eingeh. weiteren Nachweisen. S. für das Sozialrecht: Walter Bogs, Die Einwirkung verfassungsrechtlicher Normen auf das Recht der sozialen Sicherheit, Verhandlungen des 43. Deutschen Juristentages, Bd. II/G, 1960; Wilhelm Wertenbruch, Sozialverfassung - Sozialverwaltung, 1973; Helmar Bley, Die Relevanz verfassungsrechtlicher Grundentscheidungen im materiellen Sozialrecht, Die Sozialgerichtsbarkeit, 21.Jhg. (1974), S. 321 ff; Ernst Benda, Die verfassungsrechtliche Relevanz des Sozialrechts, Schriftenreihe des Deutschen Sozialgerichtsverbandes, B. XIV, 1975, S. 32 ff.

15) S. außer den Vorgenannten hierzu Theodor Maunz, Die allgemeinen Verfassungsprinzipien des Grundgesetzes und die neuere Rechtsprechung des Bundessozialgerichts zur Sozialversicherung, in: Maunz-Schraft, Die Sozialordnung der Gegenwart Bd.1/2 (1963) S. 7 ff; ders. Bundesverfassungsgericht und Sozialversicherung, ebenda Bd.6 (1967), S.31 ff; Walter Rudi Wand, Das Sozialrecht in der Rechtsprechung des Bundesverfassungsgerichts I, VSSR Bd. II (1974), S. 52 ff; Wolfgang Rüfner, desgl. II, ebenda S. 68 ff. Wolfgang Zöllner, Die Rechtsprechung des Bundesverfassungsgerichts zu Art.9 Abs. 3 GG, AöR Bd.98 (1973).

16) Zu den Fakten s, etwa Franz Neumann, Daten zu Wirtschaft Gesellschaft - Politik - Kultur der Bundesrepublik Deutschland $1950-1975,1976$. 
Ende des Zweiten Weltkrieges verändert hat - einzubeziehen 17).

Die Herausforderungen, die sich aus der sozialen Entwicklung ergeben, konnten im allgemeinen nur durch die Brille der Soz i a 1 politik gesehen werden, die versucht, auf die soziale Situation der Zeit $\mathrm{zu}$ reagieren oder gar die soziale Situation der jeweiligen Zukunft vorweg zu steuern 18 ). Und diese wiederum findet dort, wo es um die Rolle der Verfassung geht, ihren wichtigsten Ausdruck in der Sozialgesetzgebung 19 ).

Eine Selektion und Periodisierung, wie sie auf diese Weise unten vorgenommen wird, hat immer etwas Willkürliches, ja etwas "Gewaltsames" an sich. Beliebige andere Strukturen könnten kaum weniger berechtigt herausgegriffen werden. Der Verfasser bittet deshalb um Verständnis und Nachsicht, daß er gleichwohl versucht, Hilfsziele zu zeichnen, die es dem Leser ermöglichen, den historischen Ort der unten wiedergegebenen Arbeit so deutlich wahrzunehmen, daß er bei der Lektüre der Arbeit stets gegenwärtig bleiben kann.

17) S. Hans Günter, Sozialpolitik und postindustrielle Gesellschaft, Soziale Welt, 24. Jhg. (1973), S. 1 ff. S. zum cisideologischen Spektrum etwa Eike Ballerstedt und Wolfgang Glatzer, Soziologischer Almanach, 2.Auf1. 1975; Bernhard Schäfer, Sozialstruktur und Wandel der Bundesrepublik Deutschland, 1976; Wolfgang Zapf (Hrsg.), Lebensbedingungen in der Bundesrepublik: Sozialer Wandel und Wohlfahrtsentwicklung, 2.Auf1. 1978; "Wirtschaftlicher und sozialer Wandel in der Bundesrepublik Deutschland", Gutachten der Kommission für wirtschaftlichen und sozialen Wandel (maschinenschriftlich vervielfältigt), 1976.

18) S. zur Geschichte der Sozialpolitik seit 1945 etwa Gerhard Kleinhenz und Heinz Lampert, Zwei Jahrzehnte Sozialpolitik in der BRD. Eine kritische Analyse, ORDO Bd. XXII (1971), S. 103 ff; Reinhart Bartholomäi u.a. (Hrsg.), Sozialpolitik nach 1945 - Geschichte und Analysen. Festschrift für Ernst Schellenberg, 1977 (eine vorzügliche Sammlung weitgefächerter Einzelstudien); Willi Albers, Art. "Sozialpolitik VI: In der Bundesrepublik Deutschland", Handwörterbuch der Wirtschaftswissenschaften, Bd. 7 (1977), S. 110 f.

19) S. dazu am weitesten ausholend Michael Stolleis, Quellen zur Geschichte des Sozialrechts, 1976; ältere Nachweise s. dort. - Besonders eingehend erörtert ist die Geschichte der Sozialversicherung; Horst Peters, Die Geschichte der sozialen Versicherung, 2.Auf1. 1973. Für das Arbeitsrecht fehlen vergleichbare Darstellungen. S. dazu und zu dem vorhandenen Material: Wolfgang Zöllner, Arbeitsrecht 1977, S. 21 ff. 
Der Verfasser weiß vor allem, daß die Akzente, die er so setzen kann, höchst unvollständig sind. Wieviel müßte nicht eine "Sozialpolitik-Geschichte" der Nachkriegszeit noch einbeziehen: den vielfältigen Wandel von Größe, Zusammensetzung und Funktion der Familie, den Wechsel der Altersstruktur, die veränderte Einbeziehung der Frauen in das Erwerbsleben, die Minderung des Anteils der Erwerbstätigen an der Gesamtbevölkerung - die Ursachen und die Art und Weise dieser Prozesse -, die Zunahme des Anteils Unterhalts- und Sozialleistungsabhängiger in der Gesellschaft, die Verlagerung von der Landwirtschaft und vom produzierenden Gewerbe zum Dienstleistungsgewerbe, die Veränderung der Sozialleistungen nach Voraussetzungen, Art und Höhe, der Wandel des Verhältnisses der Verbände - der Kirchen, der Wohltätigkeitsverbände, der Gewerkschaften, der Arbeitgeberverbände usw. - zum Staat, zu ihren Mitgliedern, zu den anderen Verbänden, die Veränderung der Arbeitswelt, der Wohnverhältnisse, der Mobilität und vieles andere mehr. Aber hier ist nicht der Ort, über all dies zu berichten. Hier kann es nur darum gehen, ein Minimum von Anhaltspunkten zu ermitteln, um dem Leser die Szene, die ihm heute vertraut ist, von der Szene unterscheiden zu helfen, die der Verfasser zwischen 1958 und 1961 - bei der Abfassung der A rbeit - vor sich hatte.

Von hier ist auch noch einmal auf eine Eigenart der unten abgedruckten Arbeit selbst zu blicken. Sie ist von einem Juristen als eine juristische Arbeit geschrieben. Text und Interpretation des Grundgesetzes auf der einen Seite und rechtlich konstituierte oder doch faßbare soziale Intervention auf der anderen Seite sind deshalb ihr primärer Gegenstand. Der Stand der legislativen und der rechtsförmig-administrativen Interventionen des Sozialstaates und ihrer judikativen Interpretation und Kritik ist das wichtigste Beispiels- und Erfahrungsgut, anhand dessen die sozialpolitische Wirkung der Verfassung ermittelt und dargestellt wird. Alles übrige - politische Richtungen, Aktivitäten und Einfluß der Verbände, soziale Strukturen, Ideen und Forderungen und auch nicht rechtsförmige Antworten auf sie - reflektiert die Arbeit nur sporadisch. Am wenigsten spiegelt sich etwas von den konkreten politischen Kräften wider. Die Arbeit wollte die Verfassung als den Rahmen des politischen Handelns darstellen, nicht eben das politische Handeln selbst. Gleichwohl ist alles eine Funktion von allem. Weder die rechtsförmigen sozialpolitischen Interventionen noch die Wege der geschriebenen und ungeschriebenen Entwicklung des Verfassungsrechts können ohne die Interdependenz aller anderen Faktoren verstanden werden. Das historische Spezifikum auch dieser Arbeit ist daher komplex aus dem Zusammenwirken aller Faktoren gefügt. 
4. Einige spezielle Aspekte

\section{a) Vorbemerkung}

Um zu illustrieren, was die Jahre "um 1960" für das Thema und seine Bearbeitung bedeutet haben, wird unten versucht werden, die Zeit von 1945 bis zur Gegenwart in Perioden zu gliedern und deren Charakteristika, soweit sie für das Thema relevant sind und im gegebenen Rahmen Platz haben, aufzuzeigen. Ein anderer Weg könnte sein, einzelne Entwicklungen über die ganze Zeit hin durchzuzeichnen. Im allgemeinen scheint dieser Weg $z u$ weniger sinnfälligen Ergebnissen zu führen als derjenige der Bildung von Perioden und ihrer komplexen Beschreibung. Einige Linien seien gleichwohl hier vorweg angedeutet: die internationale Situation des Gemeinwesens, seiner Verfassung und der Sozialpolitik, die Methode sozialpolitischen Denkens und Redens und das juristische Zusammenwachsen weiter Teile des Sozialleistungsrechts zu einem "Sozialrecht".

Es handelt sich um Entwicklungen, deren spezifischer Stand "um 1960" die Arbeit in besonderer Weise negativ prägte; so nämlich, daß die Arbeit gerade hierin ihre eigene Relativität nicht sichtbar macht. Vielleicht müßte der Verfasser sich heute vorwerfen, nicht genügend sensibel reflektiert zu haben, welche Probleme hier offen waren. Doch gilt es hier nicht, die Schuldfrage zu erörtern, sondern allein, den historischen Ort der Arbeit $z u$ nennen. Und dafür jedenfalls ist es notwendig, einiges im Zusammenhang - über die sonst für die Darstellung gewählten Perioden hinaus - zu sagen.

\section{b) Die internationale Dimension}

Die Arbeit hat die Problematik, die ihren Gegenstand ausmacht, innerhalb der Bundesrepublik Deutschland und für diese gesehen. Diese Problematik unterliegt nun jedoch in hohem Maße internationaler Verflechtung. Und gerade diese hat sich seit 1945 in tiefgreifender Weise gewandelt.

Das beginnt mit dem Subjekt der Sozialpolitik, das hier im Vordergrund steht: dem Staat. Dem Grundgesetz, welches die Staatlichkeit auf Bund und Länder aufteilt, ging die Zeit voraus, in der die Besatzungsmächte Deutschland als Ganzes und in den Zonen regierten, in der sie allmählich autochthone Staatlichkeit in den Ländern aufkommen ließen und in zonalen, bizonalen und schließlich trizonalen Institutionen koordinierten 20$)$. Nachdem sie West-

20) S. dazu Friedrich Klein, Neues deutsches Verfassungsrecht, 1949; Walter Vogel, Westdeutschland 1945 bis 1950, Teil I 
deutschland zur Bundesrepublik zusammengeschlossen und diesem Staatswesen im Zusammenwirken mit deutschen politischen A utoritäten die Verfassung des Grundgesetzes gegeben hatten, bauten sie ihren eigenen Anteil an der deutschen Staatsgewalt nach und nach ab, bis er 1955 auf die Vorbehalte der "Bonner Verträge", insbesondere des Generalvertrages vom 23. Oktober 1954, beschränkt wurde 21).

Schon vorher aber hatte ein neuer, gegenläufiger Prozeß - ein Prozeß der "Entäußerung" deutscher Staatsgewalt - begonnen. Schon 1951/52 hat die Bundesrepublik die Europäische Gemeinschaft für Kohle und Stahl mitbegründet. 1957/58 folgten die Europäische Wirtschaftsgemeinschaft und die Europäische Atomgemeinschaft. Dadurch wurden neue, supranationale und also staatsähnliche, mit Bund und Ländern konkurrierende Subjekte sozialer Intervention geschaffen 22).

Und früher schon hatte ein anderer, internationaler Prozeß sozialpolitischer Ein- und Ausstrahlung eingesetzt: der Beitritt (oder Wiederbeitritt) $\mathrm{zu}$ internationalen Organisationen. Hervorzuheben ist hier vor allem der Beitritt zu dem Abkommen über die europäische wirtschaftliche Zusammenarbeit (OEEC) (1948/ 49) - mittlerweile abgelöst durch das Übereinkommen über die Organisation für wirtschaftliche Zusammenarbeit und Entwicklung (OECD) (1960/61) -, der Beitritt zum Europarat (1950), dessen sozialpolitische Aktivitäten von ganz besonderer Bedeutung sind 23$)$, der Beitritt zur Internationalen A rbeitsorganisation (1954), deren sozialpolitische Bedeutung evident ist 24$)$, und end-

\section{6, Teil II 1964.}

21) S. Ingo von Münch, Dokumente zum geteilten Deutschland, 1968, insbes. S. $226 \mathrm{ff}$.

22) S. zu den einschlägigen Vertragsbestimmungen: Hans F. Zacher, Internationales und europäisches Sozialrecht, 1976, S. 587 ff. Zur europäischen Sozialpolitik s. etwa Hans Peter Ipsen, Europäisches Gemeinschaftsrecht, 1972, S.931 ff; Albert Bleckmann, Europarecht, 2. Aufl., 1978, S. 388 ff (je mit eingehenden Nachw. ); zuletzt etwa Bengt Beutler, Roland Bieber, Jörn Pipkorn und Jochen Streil, Die Europäische Gemeinschaft - Rechtsordnung und Politik -, 1979, S.358 ff.

23) S. zu den einschlägigen Konventionen und Entschließungen Zacher, a.a.O. (Anm.22) S. $428 \mathrm{ff}$. - S. zu allem vorigen aus der frühen Zeit Johannes Schregle, Europäische Sozialpolitik. Erfolge und Möglichkeiten, 1954.

24) S. zu den einschlägigen Quellen Zacher, a.a.O. (Anm.22) S. $64 \mathrm{ff}$. 
lich der Beitritt zu den Vereinten Nationen (1973), dem der Beitritt oder die sonstige Mitarbeit in zahlreichen Sonderorganisationen der Vereinten Nationen vorausgegangen war ${ }^{25}$ ). Daneben entwickelte sich die internationale Zusammenarbeit auch außerhalb völkerrechtlicher Organisationen, vor allem das System der bilateralen sozialrechtlichen Verträge ${ }^{26)}$.

Eine andere Dimension internationaler Verflechtung eröffnet sich, wenn man an die betroffenen Gruppen und Sachprobleme denkt. So war nach 1945 und weit in die 50er Jahre hinein die Sozialpolitik damit beschäftigt, die ungeheure Zahl von "Gebietsfremden" einzubeziehen, die, Deutsche oder Nichtdeutsche, als Opfer des nationalsozialistischen Regimes, als Vertriebene, als Flüchtlinge und Asylsuchende usw. nach Westdeutschland gekommen waren. Später schufen die ausländischen Arbeitnehmer in der Bundesrepublik ganz neue sozialpolitische Probleme (und halfen auch wieder, solche zu lösen) 27), während der Strom deutscher Zuwanderer, ausländischer Flüchtlinge usw. - wenn auch mitunter abebbend - nie ganz versiegt.

So wie nun Sozialstaatlichkeit dem Subjekt nach im Verlauf der Nachkriegszeit sich immer mehr in supranationale und internationale Trägerschaft hinein erstreckte, so wuchs auch die sozialstaatliche Verantwortung immer klarer über die Bundesrepublik hinaus. Der Zusammenhang zwischen deutschen Sozialproblemen und deutscher Sozialpolitik einerseits und den Sozialproblemen

25) S. zur Situation vor dem Beitritt zur Organisation der Vereinten Nationen etwa Heinz Dröge, Fritz Münch und E1linor von Puttkamer, Die Bundesrepublik Deutschland und die Vereinten Nationen, 1966. Zur Situation nach dem Beitritt s. etwa: Ingo von Münch, Deutschland und die UNO, 1973.

26) S. zu den Anfängen des zwischenstaatlichen Sozialversicherungsrechts in der Nachkriegszeit Ernst Wickenhagen, Zwischenstaatliches Sozialversicherungsrecht, 1957. S. zum heutigen Stand: Heinz Plöger und Albrecht Wortmann, Deutsche Sozialversicherungsabkommen mit ausländischen Staaten. Zu den Fürsorgeabkommen s. etwa Anton Knopp unıl Otto Fichtner, Bundessozialhilfegesetz, 4.^uf1. 1979, S. $487 \mathrm{ff}$. - Hinsichtlich des Arbeitsrechts s. zum Vorigen Gerhard Schnorr, Das Arbeitsrecht als Gegenstand internationaler Rechtsetzung, 1960.

27) S. z.B. Tugrul Ansay und Volkmar Gessner (Hrsg.), Gastarbeiter in Gesellschaft und Recht, 1974; Helga und Horst Reimann (Hrsg.), Gastarbeiter,1974; Ursula Mehrländer, Soziale Aspekte der Ausländerbeschäftigung, 1976. 
und der Sozialpolitik in den Europäischen Gemeinschaften und ihren Mitgliedstaaten andererseits ist offensichtlich. Mitverantwortung für auswärtige soziale Verhältnisse erwächst ferner auch aus den anderen internationalen Organisationen und Kooperationssystemen. Eine völlig neue Wendung aber hat sich aus der wachsenden weltweiten Verantwortung der wirtschaftlich stärkeren und technologisch überlegenen Nationen für die schwächeren Nationen, der Inanspruchnahme der entwickelten Industrienationen für die Hilfe gegen die Armut in der Dritten Welt und aus dem Interesse der Industrienationen an der wirtschaftlichen Entwicklung der ärmeren Länder ergeben 28).

So streckt sich der Bogen der deutschen Sozialpolitik-Geschichte in der Zeit nach dem Zweiten Weltkrieg von den Jahren, in denen ein zerstörtes, darniederliegendes, von Flüchtlingsströmen überflutetes Deutschland von der Not- und später Entwicklungshilfe des Westens, vor allem der Vereinigten Staaten abhängig war bis hin zu einer Zeit, in der deutsche Prosperität und Sozialstaatlichkeit eine internationale Mitverantwortung für die sozialen Probleme auf der ganzen Erde - jedenfalls ihrer Armutszonen unübersehbar miteinschließen.

Eine wieder andere Beziehung $z$ wischen Nationalität und Internationalität wäre für den Austausch der Ideen und Denkmodelle zu registrieren. Was bedeutete britische oder skandinavische "Wohlfahrtsstaatlichkeit" in den Aufbaujahren der Bundesrepublik? Was bedeutete "Sozialismus" in den späten 60 er und frühen 70 er Jahren? Woher kam gerade in der Wohlstandsphase die neue Diskussion über die Armut? Wo nahmen Experten und Wissenschaftler ihre Leitbilder und Erfahrungen her? Und was bedeutete dies dann alles immer wieder für das Verhältnis von Sozialpolitik und Verfassung? Das kann hier alles nur gefragt werden.

\section{c) Die Entwicklung sozialpolitischer Rationalität}

In dem oben skizzierten Prozeß der interdependenten Abfolge von sozialer Situation und Herausforderung, von normativ-institutionell politischen Bedingungen der Reaktion und von Antworten auf die Herausforderung spielen objektive Information, rationale Diskussion, systematische Darstellung und wissenschaftliche Kreati-

28) S. dazuErster Entwicklungshilfebericht der Bundesregierung 1973 (Bundestagsdrucksache 7/1236), Zweiter Bericht zur Entwicklungspolitik 1975 (Bundestagsdrucksache 7/4293), Dritter Bericht zur Entwicklungspolitik 1977 (Bundestagsdrucksache 8/1185); Weltbank, Weltentwicklungsbericht 1978 . 
vität eine überaus bedeutsame, jedoch vielschichtige und schwer $\mathrm{zu}$ beschreibende Rolle. Sie dienen der Wahrnehmung der sozialen Verhältnisse, der Artikulation sozialer Herausforderungen, der Abk1ärung politischer Handlungsnotwendigkeiten und - möglichkeiten und der Entwicklung und kritischen Würdigung denkbarer Antworten auf gegebene soziale Herausforderungen. Dies gilt ganz allgemein. In der modernen, technologisch-wissenschaftlichen Gesellschaft ist die Notwendigkeit wissenschaftlicher Sozialpolitik im weitesten und vielfältigsten Sinne umso dringlicher, als Handlungsmöglichkeiten und Prioritäten der Politik von plausibler wissenschaftlicher Zuarbeit mehr als vordem abhängen können. Das solchermaßen interessante Verhältnis zwischen Sozialpolitik und Wissenschaft 29 ) hat sich in der Nachkriegszeit nicht unwesentlich gewandelt.

Zunächst zur Wissenschaft von der Sozialpolitik "für sich". 1956 verzeichnet die Bibliographie zu den Artikeln "Sozialpolitik" im Handwörterbuch der Sozialwissenschaften 30 ) noch ganz überwiegend Titel aus der Zeit von 1890 bis 1939. Was nach 1945 folgt, sind - soweit nicht Neuauflagen - grundsätzliche Studien über die Rolle der Sozialpolitik bei dem Neuaufbau des Gemeinwesens 31 ), überwiegend aber Einzelstudien, mit denen die Autoren versuchen, sich in der neuen sozialpolitischen Situation zurechtzufinden und anderen dabei zu helfen 32 ). Grundlegende Neu-

29) S. dazu Hans Achinger, Sozialpolitik und Wissenschaft, 1963; Gerhard Kleinhenz, Probleme wissenschaftlicher Beschäftigung mit der Sozialpolitik, 1970; Jürgen Krüger, Sozialpolitik ohne Wissenschaft? Zur Nachkriegsentwicklung der westdeutschen Sozialpolitik, Archiv für Wissenschaft und Praxis der sozialen Arbeit, 6.Jhg. (1975), S. 21 ff; Viola Gräfin von Bethusy-Huc, Das Sozialleistungssystem der Bundesrepublik Deutschland, 2.Aufl., 1976, S.278 ff.

30) Zusammengestellt von Gerhard Stavenhagen, Handwörterbuch der Sozialwissenschaften, Bd.9, 1956, S. 568.

31) Typisch insbes. Ludwig Heyde, Abriß der Sozialpolitik, 1.A ufl. 1920, 10.Aufl. 1953, jetzt 12. A ufl. 1966 (von Stephanie Münke und Peter Heyde). S. z. B. Paul Jostock, Grundzüge der Soziallehre und der Sozialreform, 1946; Ludwig Preller, Sozialpolitik. Kernfragen des Aufbaues, 1946 (2.Aufl. 1947); Walter Bogs (Hrsg.), Gegenwartsfragen sozialer Sicherheit, 1950.

32) Typisch für den pragmatischen Geist und die Erfahrung der Not, aus der heraus damals geschrieben wurde, ist etwa Horst Schieckels Vorwort zu seiner "Deutschen Sozialpolitik" 
arbeiten stehen freilich bevor. 1957 erscheint Erik Boettcher's vorzügliches Sammelwerk "Sozialpolitik und Sozialreform". 1958 bringt Hans Achinger seine "Sozialpolitik als Gesellschaftspolitik" heraus ${ }^{33)}$. 1961 erscheint von Elisabeth Liefmann-Keil die "Ökonomische Theorie der Sozialpolitik". 1962 bringt Ludwig Preller mit seiner "Sozialpolitik. Theoretische Ortung" sehr Grundsätzliches in die Diskussion ${ }^{34)}$. 1965 zieht Viola Gräfin von Bethusy-Huc die Bilanz der Diskussion um "Das Sozialleistungssystem der Bundesrepublik Deutschland" 35 ). Weitere bedeutsame, teils auch grundlegende und neue Arbeiten folgen ${ }^{36}$ ), ohne daß der Bedarf an ebenso umfassender und differenzierter wie verläßlicher wissenschaftlicher Handreichung bis heute voll befriedigt wäre ${ }^{37)}$.

(1955): "Das vorliegende Buch stellt den Versuch zur Samm1 ung und Sichtung einer Fülle von Geschehnissen dar, die nicht oder jedenfalls nicht in erster Linie aus Ideen und ideologischen Zielsetzungen geboren wurden, sondern aus der Zwangsläufigkeit der nackten Not der um ihre Lebensexistenz ringenden deutschen Menschen während der letzten 100 Jahre. Was in diesem Buche angesprochen und dargestellt wird, sind zwar nicht ausschließlich, vielleicht nicht einmal vorwiegend typisch deutsche Probleme. Aber sie sind doch in der Hauptsache aus dem deutschen Schicksal geboren und nur aus der deutschen Situation zu begreifen. Es ist wohl kein Zufall, daß der Begriff der "Sozialpolitik" bisher noch keine endgültige Klärung gefunden hat, und daß das Wort selbst sich kaum in eine andere Sprache übersetzen läßt. Dabei drückt es nichts Ideologisches oder gar Utopisches aus, sondern eine Summe von Realitäten... Sie ist nicht mehr wegzudenken aus unserem innerstaatlichen Leben und deshalb von außerordentlicher Bedeutung und einer ganz ungeheuren Dynamik. Sie in ihrem ganzen Ausmaß darzustellen, würde indessen den Rahmen dieses Buches bei weitem überschreiten. Worauf es mir ankam, war lediglich, die Aufgabe und das Wesen der Sozialpolitik herauszustellen und in Rück- und Vorschau ihren Weg und ihr Ziel in Deutschland aufzuzeigen."

33) 2.Aufl. 1971.

34) S. später seine Summe: Praxis und Probleme der Sozialpolitik, 2 Bde., 1970.

35) 2.Auf1. 1976.

36) S. dazu noch unten S. LXXX ff, S. XCIII ff.

37) S. etwa die Bibliographien bei Bernhard Külp und Wilfried Schreiber (Hrsg.), Soziale Sicherheit, 1971, S. $449 \mathrm{ff}$; von Bethusy-Huc, a.a.O. (Anm.29) (2.Aufl.) S. 306 ff; Heinz 
Einen ganz anderen "Konjunkturverlauf" nimmt dagegen die Politikberatung durch Sozialwissenschaftler ${ }^{38)}$. 1952 treten Gerhard Mackenroth 39) und Walter Auerbach 40) mit Reformplänen hervor. 1954 legt Walter Bogs seine "Grundfragen des Rechts der sozialen Sicherheit und seiner Reform" vor 41). 1955 erscheinen: aus der Feder von Hans Achinger, Joseph Höffner, Hans Muthesius und Ludwig Neundörfer die "Rothenfelser Denkschrift" über "Die Neuordnung der sozialen Leistungen", der "Schreiber-Plan" 42) und die "Kölner Denkschrift" der Professoren Walter Rohrbach, Erich Roehrbein und Carl Meyrich ${ }^{43)}$. 1957 erscheint auf Anregung des Vorstandes der SPD der "Sozialplan für Deutschland", für den vor allem Walter Auerbach und Ludwig Preller verantwortlich zeichnen 44). Den Reigen dieser Denkmäler wissenschaftlicher Beratung der Sozialpolitik schließt dann die Sozial-Enquête. Wie die Rothenfelser Denkschrift geht sie auf einen Auftrag der Bundesregierung zurück. 1964 bis 1966 arbeiten Hans Achinger, Walter Bogs, Helmut Meinhold und Wilfried Schreiber diesen Bericht über die "Soziale Sicherung in der Bundesrepublik Deutschland" aus ${ }^{45}$ ).

Später hingegen 1äßt die Bundesregierung Wissenschaftler nicht mehr "mit sich allein". In der Kommission über den wirtschaftlichen und sozialen Wandel, in der Sozialgesetzbuchkommission, der Arbeitsgesetzbuchkommission und der Kommission zur Ausarbeitung von Vorschlägen zur Gleichstellung von Mann

Lampert, Artikel "Sozialpolitik I: Staatliche" in: Handwörterbuch der Wirtschaftswissenschaft, Bd.7, 1977, S.60 ff (75 f) ; Willy Albers, Artikel "Sozialpolitik IV: In der Bundesrepublik Deutschland" ebenda S. $110 \mathrm{ff}$ (129 f).

38) S. dazu den eingehenden Bericht bei Gräfin Bethusy-Huc a.a.O. (Anm.29) (2.Auf1.) S. $58 \mathrm{ff}$.

39) Die Reform der Sozialpolitik durch einen deutschen Sozialplan, Schriften des Vereins für Sozialpolitik n.F. Bd. 4, 1952.

40) Modell eines Sozialplanes - eine Skizze, in: Die Krankenversicherung, 1952, S. 106 ff (abgedruckt auch in Walter Auesbach, Beiträge zur Sozialpolitik, 1971, S.23 ff).

41) Veröffentlicht 1955.

42) Wilfried Schreiber, Existenzsicherheit in der industriellen Gesellschaft, 1955.

43) Zum Problem der Realisierbarkeit der Vorschläge der Rothenfelser Denkschrift über "Die Neuordnung der sozialen Leistungen", 1955.

44) Sozialplan für Deutschland, Gutachten erstattet auf Anregung des SPD-Vorstandes von Auerbach, Bruch u.a., 1957.

45) 1966 - ohne Jahresangabe - erschienen. 
und Frau in der gesetzlichen Rentenversicherung - um nur einige wichtige Beispiele zu nennen - arbeiten Wissenschaftler, Praktiker und vor allem auch Vertreter von Interessenverbänden zusammen 46). Aber auch sonst ist das Element der Beratung der Sozialpolitik durch wissenschaftlichen Sachverstand später nie mehr so hervorgetreten wie von 1952 bis 1957 und in der Sozialenquête-Kommission.

Eine wieder andere Entwicklung hat die Information der Öffentlichkeit über die Sozialpolitik genommen. Berichte, Programme usw. der Regierung wurden im Lauf der Zeit immer mehr zu einem Instrument der Sozialpolitik. Wohl zum ersten Mal finden wir es in der Agrar-Sozialpolitik. Das Landwirtschaftsgesetz von 1955 führt die jährlichen "Grünen Berichte" und "Grünen Pläne" ein, um die soziale Stellung der Landwirtschaft permanent zu kontrollieren und zu fördern. Mit der Rentenreform 1957 werden der Sozialbeirat, sein jährliches Gutachten über die Fortentwicklung der Renten und der jährliche Rentenanpassungsbericht der Bundesregierung angeordnet 47 ). Die Ausbildung des wirtschaftspolitischen Instrumentariums des jährlichen Sachverständigengutachtens (1963) 48) und des Jahreswirtschaftsberichts der Bundesregierung (1967) 49) signalisiert den Durchbruch auch für die Sozialpolitik. 1969 erscheint das erste "Sozialbudget", 1970 der erste "Sozialbericht". Schon vorher, zur gleichen Zeit und danach entstand weit darüber hinaus eine breitgefächerte Vielfalt von Berichten, Plänen und Programmen, die alle dazu beit ragen sollten, die Auseinandersetzungen im Binnenbereich der Politik, in der Öffentlichkeit und zwischen Öffentlichkeit und Politik informierter und rationaler werden zu lassen 50 ).

46) S. zur Kommission über den wirtschaftlichen und sozialen Wandel deren Gutachten (1976) S. I ff; zur Sozialgesetzbuchkommission Hans F. Zacher, Materialien zum Sozialgesetzbuch, S.A 6 f, 69; zur Arbeitsgesetzbuchkommission "Entwurf eines Arbeitsgesetzbuches - Allgemeines A rbeitsvertragsrecht - 1977, S. 12 ff; und zur Kommission über die Gleichstellung von Mann und Frau in der gesetzlichen Rentenversicherung "Kommission eingesetzt" Bundesarbeitsblatt 1977, S. 487 f (488).

47) $\$ \$ 1272$ ff, RVO, $\$ \$ 49$ ff. AVG.

48) Gesetz über die Bildung eines Sachverständigenrates zur Begutachtung der gesamtwirtschaftlichen Entwicklung vom 14. August 1963 (BGB1. I S.685).

49) $₫ 2$ des Gesetzes zur Förderung der Stabilität und des Wachstums der Wirtschaft vom 8. Juni 1967 (BGB1. I S. 582).

50) Eine Übersicht $\mathrm{s}$. im Sachregister der Verhandlungen des 
Gerade auf diesem Weg aber erwies sich als Schwierigkeit, daß Meßbarkeit und Quantifizierung dem Ökonomischen vorbehalten sind - oder doch zu sein scheinen. Das Nichtökonomische ist auf verbale Umschreibung angewiesen. Das bedeutet, daß das Ökonomische weitaus sinnfälliger als das Nichtökonomische ausgedrückt und dargestellt werden kann. Es bedeutet dem voraus, daß das Nichtökonomische schon nicht so exakt aufgenommen und durchdacht werden kann wie das Ökonomische. Sowohl unter den Bedingungen gegenwärtiger Kommunikation als auch im Hinblick auf die wissenschaftlich-technologische Inklination dieser Gesellschaft bedeutet das sehr viel. Aber selbst innerhalb des Ökonomischen führt es zu Ungleichgewichten. So ist das Sozialbudget eine Aufwandsrechnung (eine Darstellung des finanziellen Input). Über die Sinnerfüllung dieses Aufwands (über den finalen Output) erfährt man nichts. Aus allen diesen Gründen trieb die Entwicklung zu dem Versuch, auch das Qualitative quantifizierbar zu machen. Die Bemühungen um "soziale Indikatoren" stellen somit ein wichtiges Element in der Rationalisierung von Sozialpolitik dar 51). Jedoch sind durchgreifende Hilfen der Sozialpolitik von dieser Seite her noch nicht zu sehen 52 ). Der Versuch der Bundesregierung, von einer Kommission über den wirtschaftlichen und sozialen Wandel in der Bundesrepublik Deutschland ein Entwicklungsgemälde zeichnen zu lassen, das Vergangenheit und Gegenwart in die Zukunft hinein fortschreibt, hat viele interessante Einzelheiten 53) hervorgebracht. Insgesamt freilich hat er die Hoffnungen auf politisch-praktische Orientierungs- oder gar Entscheidungshilfe kaum erfüllt.

\section{d) Die Entwicklung eines "Sozialrechts"}

Für den Gegenstand einer Arbeit über das Verfassungsrecht der sozialen Intervention mußte ferner von Bedeutung sein, in welchem Maße und auf welche Weise das "einfache" Recht, durch

7. Deutschen Bundestages, S. $327 \mathrm{ff}$.

51) S. dazu Wolfgang Zapf, Soziale Indikatoren - eine Zwischenbilanz, Allgemeines Statistisches Archiv, Bd. 60 (1976), S. 1 ff; Hans-Jürgen Krupp und Wolfgang Zapf, Sozialpolitik und Sozialberichterstattung, 1977.

52) Angesichts der großen verfassungspolitischen und - rechtlichen Problematik solcher sozialer Indikatoren ist es auch schwierig, den rechten Weg dafür zu finden. S. dazu Hans F. Zacher, Soziale Indikatoren als politisches und rechtliches Phänomen, VSSR Bd.II (1974), S.15 ff.

53) Vor allem die Auftragsstudien der Kommission. S. das Verzeichnis im Anhang des Gutachtens. 
welches das politische System auf die sozialen Herausforderungen reagiert, als eine Einheit gesehen und verstanden wird. Dafür ist zu betonen, daß zentraler Gegenstand der Untersuchung das formelle Verfassungsrecht der sozialen Intervention ist. Formelles Verfassungsrecht entfaltet seine intensivste Wirkung gegenüber einfachem Recht. Dieses kann - die niedrigere Norm an der höheren - am Verfassungsrecht gemessen werden. Verfassung als Maßgabe der Politik ist daher nie so spürbar wie in der Gesetzgebung. Heute nun ist es nicht schwer, anzunehmen, daß sozialpolitisch geprägte Gesetzgebung grundsätzlich unter dem Namen "Sozialrecht" zusammenzufassen ist 54). Auch wird mehr und mehr klar, daß und warum im juristischen "Alltag" gewisse Rechtsmaterien trotz ihrer sozialpolitischen Relevanz gleichwohl nicht unter den Begriff des "Sozialrechts" gezogen werden sollen: so das Arbeitsrecht, das Wohnungsrecht, das Finanz- und Steuerrecht, das Familienrecht usw. Vor dem Hintergrund des weiten "sozialpolitischen" Sozialrechtsbegriffs und seiner Offenheit, ja Unendlichkeit, wirkt es auch eher klärend als mißverständlich, wenn der Gesetzgeber parallel die Kodifikation von A rbeitsrecht und Sozialrecht in Angriff nimmt, um im "Sozialgesetzbuch" mitnichten alles "Sozialrecht", sondern nur einen Kernbereich von Sozialleistungen zusammenzufassen ${ }^{55)}$. Gerade in diesen Fragen von sozialrechtlicher Sachschau und Terminologie aber hat sich vom Ende des Zweiten Weltkriegs bis zur Gegenwart ein ungeheurer Wandel vollzogen. Er geht - wenn auch nicht in schlichter Identität oder Parallelität - einher mit einer wesentlichen Vertiefung der Bemühung um die Rechtsgebiete der sozialen Intervention, um sozialpolitisches Recht, um "Sozialrecht" überhaupt. Beides aber - das Erkennen immanenter Gemeinsamkeiten von "sozialpolitischem" Recht und die juristische, interpretatorische, dogmatische und rechtstheoretisch-verstehende Bemühung um dieses Recht - ist von großer und nicht exakt lokalisierbarer Bedeutung für die interdependente Abfolge von sozialer Herausforderung, Bedingungen der Antwort und Antwort. Denn Recht bestimmt die sozialen Verhältnisse mit, trägt dazu bei, daß soziale Herausforderungen erwachsen, gestaltet wesentliche Bedingungen des politischen Systems, das auf die sozialen Herausforderungen antwortet, und ist endlich selbst Hauptinstrument solcher Antwort.

54) S. Hans F. Zacher, Was ist Sozialrecht? in: Sozialrecht in Wissenschaft und Praxis, Festschrift für Horst Schieckel, 1978, S. $371 \mathrm{ff}$; s. auch dens., Sozialrecht, in: Rudolf WeberFas, Jurisprudenz, 1978, S.407 ff.

55) S. Hans F. Zacher, Materialien a.a.O. (Anm.46) S.A 5 f, $70 \mathrm{ff}, 72 \mathrm{ff}$. 
Unter allen in Betracht kommenden Rechtsgebieten traten nur das Arbeitsrecht und vielleicht auch das Finanz- und Steuerrecht mit anspruchsvoller juristischer Kultur in die Nachkriegszeit ein. Das Sozialversicherungsrecht, in den ersten Jahrzehnten des Jahrhunderts selbst dogmatisch wohl gepflegt, hatte schon während der Weimarer Zeit ständig an juristischem Niveau ver1oren 56). Die ständigen Veränderungen, denen es seit den frühen dreißiger Jahren ausgesetzt war, hatten seine juristische Kultur zum Erliegen gebracht - ein Mißstand, der erst mit Georg Wannagats "Lehrbuch des Sozialversicherungsrechts" (I. Bd. 1965) wenigstens hinsichtlich der Grundlagen überwunden werden konnte. Die übrigen "sozialpolitischen" Rechtsgebiete hatten kaum anspruchsvolle juristische Kultur mitgebracht und zu erwarten 57). Daran ändert die Reihe vorzüglicher Untersuchungen, die einzelnen Fragen gewidmet wurden, nichts Wesentliches 58 ).

Insofern mußte es als ein wichtiger Impuls erscheinen, daß übergreifende Begriffs- und Systemeinheiten eine gewisse Zentripetalwirkung entfalteten und die juristischen Energien konzentrierten. Ein erster Schritt hätte die Errichtung der Sozialgerichtsbarkeit (1953/54) sein können, die erstmals den Gesamtbereich der Sozialversicherung, die A rbeitsförderung, die Kriegsopferversorgung und eine Reihe weiterer Sozialrechtsbereiche freilich ohne die Sozialhilfe (damals noch Fürsorge) - zusammenfaßte. Jedoch reichte dieser Impuls offenbar nicht aus. Die innere Logik der Zuständigkeitsabgrenzung war zu gering. Und die

56) Auch die Apotheose juristischer Bemühung um das Sozialversicherungsrecht, die in Lutz Richters "Sozialversicherungsrecht" (1931) zu sehen ist, kann hieran nichts ändern. S. ihn auch zur älteren Literatur.

57) S. zum Vorigen etwa Hans F.Zacher, Die Lehre des Sozialrechts an den Universitäten in der Bundesrepublik Deutschland, 1968; dens., Die Sozialversicherung als Teil des öffentlichen Rechts, in: Sozialrecht und Sozialpolitik, Festschrift für Kurt Jantz, 1968, S. 29 ff; dens., Einige rechtstheoretische Aspekte der Entwicklung des cleutschen Sozialrechts, in: Perspectivas del derecho publico en la segundo midad del siglio XX, Madrid 1969, Bd.III, S.945 ff; dens., Grundfragen theoretischer und praktischer sozialrechtlicher A rbeit, VSSR Bd.IV (1976) S. 1 ff.

58) S. exemplarisch etwa die Festschriften für Johannes Krohn ("Beiträge zur Sozialversicherung", 1954), Friedrich Sitzler ("Sozialpolitik - Arbeits - und Sozialrecht", 1956) und Walter. Bogs ("Sozialreform und Sozialrecht", 1959). 
Entscheidungskompetenz der Gerichte zu sehr auf den Einzelfall gerichtet, um eine intensivere Bemühung in Richtung auf Systemzusammenhänge auszulösen 59).

Von größter Bedeutung erwies sich dagegen der für Deutschland neue Begriff der sozialen Sicherheit 60 ), dessen juristische Implantation vor allem Walter Bogs zu danken ist 61 ). Einen weiteren Schritt hat es bedeutet, daß die Unterteilung sozialer Sicherheit in Sozialversicherung, Versorgung und F'ürsorge, die an überkommenen Institutionen orientiert war, durch eine neue, entwicklungsoffene Dreiteilung in Vorsorge, soziale Entschädigung und sozialen Ausgleich ergänzt werden konnte 62 ). Das ermöglichte es unter anderem, bei der Konzeption des Sozialgesetzbuches über die Sozialversicherung hinaus nicht nur statt der rückwärts gewandten Kriegsopferversorgung ein zukunftsorientiertes soziales Entschädigungsrecht 63 ) sondern auch über das allgemeine

59) S. dazu Hans F.Zacher, Sozialgerichtsbarkeit und Sozialrecht, Zeitschrift für Sozialreform, 10.Jhg. (1965) S. $137 \mathrm{ff}$. = Die Sozialgerichtsbarkeit, 12.Jhg. (1965) S.69 ff; dens., Einige rechtstheoretische Aspekte usw. a.a.O. (Anm.57) S. $945 \mathrm{ff}$.

60) S. dazu den "Klassiker" Gerhard Weisser, "Soziale Sicherheit", in: Handwörterbuch der Sozialwissenschaften, Bd. 9 (1956) S. 396 ff (u. seine Bibliographie S. 412).

61) Seine Arbeiten zum Recht der sozialen Sicherheit sind zusammengestellt bei Hans F.Zacher, Gratulation für Walter Bogs, VSSR Bd. II (1974) S.98 ff (103). Hervorzuheben sind seine schon erwähnte grundlegende Arbeit über "Grundfragen des Rechts der sozialen Sicherheit und seiner Reform" (1955) und seine abschließende Bilanz in der Sozialenquête: "Die rechtliche Ordnung - Fiechtsprinzipien sozialer Sicherung" (Soziale Sicherung in der Bunclesrepublik Deutschland, Bericht der Sozialenquetê-Kommission, 1966, S.62 ff).

62) S. dazu Hans F. Zacher, Diskussionsbeitrag zu "Rechtsformen der sozialen Sicherung und allgemeines Verwaltungsrecht", VVDStRL Heft 28 (1970), S.223 ff (237 f); dens., Zur Rechtsdogmatik der sozialen Umverteilung, DÖV 23. Jhg. (1970), S. 3 ff (S.6 Anm.41); dens., Die Frage nach der Entwicklung eines sozialen Entschädigungsrechts, DÖV 25.Jhg. (1972), S. 461 ff (461 f).

63) S. dazu auch die Verhandlungen des 49. Deutschen Juristentages zu dem Thema "Empfiehlt es sich, die soziale Sicherung für den Fall von Personenschäden, für welche die Allgemeinheit eine gesteigerte Verantwortung trägt, neu zu regeln?", mit dem Gutachten von Wolfgang Rüfner (Verhandlungen usw. 
Ausgleichssystem der Sozialhilfe hinaus weitere Sozialleistungssysteme aufzunehmen, denen die Merkmale von Sozialversicherung und Versorgung oder auch sozialer Entschädigung fehlen also besondere Ausgleichssysteme wie die Ausbildungsförderung, den Familienlastenausgleich und das Wohngeld ${ }^{64)}$.

Durch das Sozialgesetzbuch erlangte aber auch die Kategorie des "Sozialleistungssystems" 65) juristisch-dogmatische Bedeutung; denn sie ist ein gemeinsamer Nønner für alle Teilbereiche des Sozialgesetzbuchs 66 ). Diese kodifikatorischen Bemühungen um das Sozialgesetzbuch haben zusammen mit der kurz zuvor einsetzenden Aufwertung des Sozialrechts im akademischen Unterricht 67 ) das wissenschaftliche Interesse für das Sozialrecht in bis dahin völlig unbekannter Weise stimuliert. Mehr als die zahlreichen Kommentare zum Sozialgesetzbuch selbst ${ }^{68)}$ manifestiert sich das in den übergreifenden systematischen Darstellungen des Sozialrechts, unter denen hier vor allem diejenigen von Helmar Bley 69), Wolfgang Rüfner 70) und Wilhelm Wertenbruch ${ }^{71)}$ genannt seien 72 ).

Zusammenfassend ist festzuhalten, daß sich das "sozialrechtliche Loch" im Rechtssystem und Rechtsbewußtsein mehr und mehr schließt. Zu Anfang der Entwicklung wurde Sozialpolitik durch eine Vielzahl von Rechtsgebieten realisiert, deren Zusammenhang und deren Unterschiede kaum gesehen wurden und unter denen die Rechtsbereiche, die Sozialleistungen regelten und die

Bd. I Teil E) und den Beratungen (a.a.O. Sitzungsbericht P) mit dem Referat von Hermann Heußner (daselbst, S.P 13 ff).

64) S. dazu im einzelnen Hans F.Zacher, Materialien a.a.O. (Anm.46) Teil A; Sozialgesetzbuch (Loseblatt) Teil A.

65) S. dazu etwa Gräfin von Bethusy-Huc a.a.O. (Anm.29).

66) S. Hans F.Zacher, Materialien a.a.O. (Anm.46) S.A $70 \mathrm{ff}$.

67) S. zuletzt dazu Bernd von Maydell, Untersuchung über die sozialrechtliche Ausbildung der Juristen an den Universitäten in der Bundesrepublik, insbes. im Wahlfachstudium, Schriftenreihe des Deutschen Sozialgerichtsverbandes Bd. XVI (1978) S. $110 \mathrm{ff}$.

68) S. dazu die Übersicht bei Zacher, Materialien a.a.O. (Anm. 46) Teil B.

69) Sozialrecht, 2.Auf1. 1977.

70) Einführung in das Sozialrecht, 1977.

71) Sozialverwaltungsrecht, in: Ingo v. Münch (Hrsg.), Besonderes Verwaltungsrecht, 5.Aufl., 1979, S.323 ff.

72) Weitere Hinweise zu diesem neu florierenden Schrifttum bei den Genannten. 
deshalb am intensivsten sozialrechtlich geprägt waren 73 ), dogmatisch am wenigsten ausgebildet waren. Heute bilden Kategorien wie "Sozialrecht", "soziale Sicherheit" und "Sozialleistungsrecht" wirkungsvolle Hilfen gedanklicher Zusammenfassung allen "sozialpolitischen" Rechts oder doch wichtiger, nicht stärker anders eingebundener Teile desselben. Und heute ist das Recht der sozialen Sicherheit, ist auch das Sozialleistungsrecht - als Summe und in seinen Teilen - dabei, die dogmatische Distanz zu anderen "sozialpolitischen" Rechtsbereichen und zum Recht schlechthin $\mathrm{zu}$ verringern ${ }^{74)}$.

Ein offenes, unbewältigtes Problem ist bis heute jedoch das Verhältnis von Sozialrecht und Soziala rbeit 75 ). Sozialarbeit in einem weiteren Sinne ist die helfende und kontrollierende 76) beratende, betreuende, erziehende, bewahrende, pflegende - personale Sorge für den Menschen, die durch gesellschaftliche oder vom Gemeinwesen bestellte Kräfte geleistet wird. Sie läßt sich nicht einmal in dem Maße rechtlich regeln, wie etwa ärztliche Dienstleistungen, die - durch Wissenschaft und "Kunstlehre", Recht, gesellschaftliche Regeln und Standesnormen vorgeformt von Sozialleistungsträgern (insbesondere der Kranken- und Unfallversicherungsträger) "gekauft" und so den Personen, die ihrer bedürfen, mit einiger Bestimmtheit vermittelt werden können. Sozialarbeit ist in einem Frontfeld der Entwicklung ein höchstpersönlicher Dienst, den nur der Mensch dem Menschen leisten kann. Wo Serien gleichartiger Defizite eine gleichartige

73) Während "sozialpolitische" Privatrechtsbereiche wie Arbeitsund Mietrecht immer auch, wenn nicht primär dem Leistungsaustausch dienen müssen, während das Familienrecht primär privater Selbstentfaltung dient, während das Steuerrecht primär auf Einkünfte des Staates für die verschiedensten $Z$ wecke abzielt, usw.

74) S. zu Vorstehendem ergänzend Hans F. Zacher, Sozialrechtswissenschaft und Sozialrecht, Die Sozialgerichtsbarkeit, 26. Jhg. (1979) S. $206 \mathrm{ff}$.

75) S. Kurt Wehlitz, Verwaltungshandeln und soziale Hilfen, in: Kurt Wehlitz, Referate und Aufsätze, Schriften des Deutschen Vereins für öffentliche und private Fürsorge, Schrift 251, 1972, S. 23 ff; Dieter Giese, Zur Kompatibilität von Gesetz und Sozialarbeit, in: Hans-Karl Otto und Siegfried Schneider (Hrsg.), Gesellschaftliche Perspektiven der Sozialarbeit, 3.Auf1. 1975, Bd. 1 S. 45 ff.

76) Über Ausmaß, Funktion und Bewertung des kontrollierenden Elements gehen die Meinungen freilich extrem weit auseinander. 
höchst unterschiedliche Ausgangspunkte und Ziele hatte 110). Verfassungsrechtlich fiel zudem ins Gewicht, laß die Juristen, die damals eine führende Stellung in der Interpretation des Grundgesetzes einnahmen, unter der Weimarer Verfassung aufgewachsen waren, deren Programmatik die meisten Länderverfassungen nach 1945 mehr oder weniger in Frinnerung gebracht oder auch variiert und angereichert haben. Verfassungsrecht wurde deshalb weithin nicht in dem Maße als von sozialer Programmatik entblößt gedacht, wie das heute weithin selbstverständlich ist. Erst in der nächsten Periode finden sich Verfassungsdoktrin und - praxis damit ab, daß - vereinfacht gesagt - der Rechtsstaat primär ein juristisches, der Sozialstaat primär ein politisches Phänomen ist.

Ein Moment sozialpolitischer Aktivierung der Verfassung jedoch ist noch zu erwähnen, das vielleicht nie mehr so hervorget reten ist wie in dieser Periode: die "Drittwirkung" der Grundrechte. Vor allem im Arbeitsrecht 111) glaubten Rechtsprechung und Literatur unmittelbar eine grundrechtsgerechte Ordnung herstellen zu sollen und zu können. Mit der Zeit gewann die Überzeugung Oberhand, daß Grundrechte ein Auftrag an clen Gesetzgeber sind, dessen Erfüllung ihm aber auch durch die Rechtsprechung nur. sehr begrenzt abgenommen werden kann 112 ). Aber es ist fraglich, ob es zu dieser Ausstrahlung der Grundrechte gekommen wäre, wenn nicht in jener Pionierphase so sehr "Frnst" mit ihnen gemacht worden wäre.

Was die wirtschaftliche und soziale situation anlangt, ist diese Periode die Zeit des "Wirtschaftswunders". Das Sozialprodukt steigt die ganze Zeit hindurch an. Die Wachstumsraten halten sich - obwohl sie auf 1957 hin zu einem Konjunkturtief absinken - im Durchschnitt der Periode auf einem später

110) S. dazu auch Hans F. Zacher, Was können wir über las Sozialstaatsprinzip wissen?, in: Hamburg-DeutschlandEuropa, Festschrift für Hans Peter Ipsen, 1977, S.207 ff (insbes. S. $231 \mathrm{ff}$ ).

111) S. die Hinweise bei Wolfgang Zöllner, Arbeitsrecht, 1977, S. 57 ff; Alfred Söllner, Arbeitsrecht, 6.Aufl., 1978, S. $39 \mathrm{f}$.

112) S. dazu etwa die Darstellungen bei Ernst II ollgang Böckenförde, Grundrechtstheorie und Grundrechtsinterpretation, NJW 27.Jhg. (1974) S. 1529 ff, insbes. S. 1532 ff; Hans Heinrich Rupp, Vom llandel der Grundrechte, AöR Bd. 101 (1976) S. $161 \mathrm{ff}$, insbes. S. $165 \mathrm{ff}$. 
nicht mehr erreichten Niveau 113). Die allgemeine Güterversorgung kann ganz weitgehend von Bewirtschaftung und Preisbindung freigestellt werden. Die Versorgung mit Wohnungen kommt zwar noch zu keinem befriedigenden Ergebnis. Jedoch sind die Zuwachsraten erstaunlich 114). Die größten Erfolge der Zeit liegen wohl in dem Abbau der Arbeitslosigkeit und in der Einkommens-/ Lebenshaltungskosten-Relation. Die Arbeitslosenquote sank von $11,0 \%$ im Jahr 1950 auf 3, $7 \%$ im Jahr 1957 115). Die Löhne stiegen nominell und real kontinuierlich an 116). Der Preisindex stieg noch von 1950 auf 1951, blieb aber bis 1955 annähernd konstant, um dann erst wieder zu steigen 117).

Die Wirtschaftspolitik konzentrierte sich auf die Festigung der marktwirtschaftlichen Ordnung, unterstütte aber gleichwohl interventionistisch den wirtschaftlichen Aufschwung - insbesondere im Hinblick auf den Wohnungsbau und die Vermehrung von Arbeitsplätzen. Wirtschafts- und Sozialpolitik wurden in enger Verbindung gesehen 118). Diese Ergänzung von Marktwirtschaft und Sozialpolitik findet sich vor allem im Arbeitsleben und im Wohnungswesen. Im A rbeitsleben traten den Möglichkeiten, die der wirtschaftliche Aufschwung einer freien Lohnentwicklung bot, zahlreiche gesetzgeberische Maßnahmen etwa in Richtung auf Mitbestimmung, Betriebsverfassung und Personalvertretung, Kündigungsschutz, Mindestarbeitsbedingungen, Heimarbeitsrecht usw. zur Seite. Auf dem Gebiet des Wohnungswesens finden wir ein kompliziertes Ineinander von Wohnungsbauförderung (siehe (as Erste Wohnungsbaugesetz von 1950), Entwicklung angemessener Wohnungsrechtsformen (siehe das Gesetz über das Wohnungseigentum und das Dauerwohnrecht 1951) und Abbau der Wohnraumbewirtschaftung sowie der Preisbindung.

113) S. Franz Neumann, Daten zu Wirtschaft-Gesellschaft-Politik-Kultur der Bundesrepublik Deutschland 1950-1975, 1976 , s. $345 \mathrm{ff}$.

114) S. Neumann, a.a.O. (Anm.113) \$. $273 \mathrm{ff}$.

115) 1952 sank sie mit 9,5\% erstmals unter die 10\%-Marke, 1956 mit 4, $4 \%$ erstmals unter die 5\%-Marke. S. Presseund Informationsamt der Bundesregierung, Gesellschaftiche Daten 1977, s. 123 .

116) Bei freilich extrem schwankenden jährlichen Zuwachsraten, s. Neumann, a.a.O. (Anm.113) s. 351 .

117) Im Jahr 1953 ergab sich das einzige Mal in der Geschichte der Bundesrepublik eine Minusrate im Anstieg des Preisindex für die Lebenshaltung. S. Neumann, a.a.O. (Anm. 113) S. $311 \mathrm{ff}$.

118) S. dazu etwa Kleinhenz-Lampert, a.a.O. (Anm.18) S. 106 ff. 
Ein weiteres zentrales Thema dieses Zeitabschnitts bleibt die Bewältigung der Kriegs- und Regimefolgen, die nunmehr bundeseinheitlich, weitgehend befreit von der Intervention der Besatzungsmächte und schon im Blick auf den ansteigenden Wohlstand Westdeutschlands angegangen werden konnte.

Zahlreiche gesetzliche und administrative Maßnahmen waren darüber hinaus notwendig, um die Institutionen und Organisationen der Sozialpolitik, die früher dem Reich zugeordnet waren, über die Länder und Zonen hinaus wieder auf den Bund hin zu orientieren. Im Hinblick auf den Normenbestand bedeutete dies: die Wiederherstellung der Rechtseinheit ${ }^{119)}$. Das veränderte freilich auch den bundesstaatlichen Rahmen der Sozialpolitik. Die sozialpolitischen Möglichkeiten der Länder wurden mehr und mehr zurückgedrängt. War es am Anfang der Periode noch denkbar, sich den "sozialen Bundesstaat" (Art.20 Abs.1 GG) als im Gleichgewicht zwischen dem "Sozialstaat Bund" und den "Sozialstaaten Länder" (s.a. A rt. 28 Abs. 1 Satz 1 GG) vorzustellen am Ende war das Ungleichgewicht nur zu deutlich.

Über all das hinaus aber wurde die Sozialreform - die "Große Sozialreform", die als eine grundlegende und für lange Zeit gültige Neuordnung der sozialen Leistungen gedacht war das Anliegen der Periode. Abgesehen von allen idealistischen und ideologischen Motiven und Ansprüchen bildeten den gemeinsamen Hintergrund dieser Bemühungen wohl vor allem drei Elemente: die historische Erfahrung, daß seit der Kodifikation der Reichsversicherungsordnung (1911) Sozialgesetzgebung fast nur noch als "Stückwerk" betrieben worden war; die Erfahrung des Zusammenbruchs und das Erlebnis der Möglichkeit und Notwendigkeit, "ganz neu" anzufangen; endlich und zunehmend das Bewußtsein der Prosperität, die eine allgemeine Prosperität nur sein konnte, wenn sie durch das Sozialleistungssystem auch denen zugute kam, die irgendwie gehindert waren, sich selbst einen vollen marktwirtschaftlichen Anteil zu erarbeiten oder sonstwie zu erwirtschaften. So erklärt sich, daß Politik und Wissenschaft sich in der Suche nach einem "Sozialplan" trafen ${ }^{120)}$. Und diese Periode umfaßte denn auch nicht nur viele bedeutsame Teilschritte, sondern endete 1957 mit einem der wohl bedeutendsten Jahre deutscher Sozialrechtsgeschichte.

119) S. dazu etwa Peters, a.a.O. (Anm.19) S.147 ff.

120) S. oben S. LVI ff; ferner Hans Günter Hockerts, Sozialpolitische Reformbestrebungen in der frühen Bundesrepublik 1953-1957, Vierteljahreshefte für Zeitgeschichte, 25. Jhg. (1977) S. $341 \mathrm{ff}$. 
Die A ufbauleistungen dieser Periode treten am eindrucksvollsten in der Geschichte ihrer Gesetzgebung zutage. Eine - notgedrungen willkürliche - Selektion der bedeutsameren sozialpolitischen Gesetze muß wohl die folgenden enthalten:

1950 Bundesversorgungsgesetz, Heimkehrergesetz, Kriegsgefangenen- Unterhalt sbeihilfegesetz, Erstes Wohnungsbaugesetz

1951 Heimarbeitsgesetz, Kündigungsschutzgesetz, Montan-Mitbestimmungsgesetz, Selbstverwaltungsgesetz (und damit Wiederherstellung der Selbstverwaltung der Sozialversicherung nach ihrer Abschaffung durch den Nationalsozialismus), Gesetz zur Regelung der Rechtsverhältnisse der unter Art.131 GG fallenden Personen

1952 Betriebsverfassungsgesetz, Lastenausgleichsgesetz und Feststellungsgesetz hierzu (unter Ablösung des Soforthilfegesetzes von 1949), Mindestarbeitsbedingungengesetz, Mutterschutzgesetz, Währungsausgleichsgesetz, Wohnungsbau-Prämiengesetz

1953 Altsparergesetz, A rbeitsgerichtsgesetz (und damit einheitlicher Neuaufbau der A rbeitsgerichtsbarkeit), Sozialgerichtsgesetz (und damit Trennung von Rechtsprechung und Verwaltung im Bereich der Sozialversicherungsaufsicht und - verwaltung sowie Zusammenfassung von Sozialversicherung und Kriegsopferversorgung in einer einheitlichen Gerichtsbarkeit), Bundesbeamtengesetz, Bundesentschädigungsgesetz (für die Entschädigung der Opfer des nationalsozialistischen Regimes), Bundesevakuiertengesetz, Bundesvertriebenengesetz, Schwerbeschädigtengesetz

1954 Gesetz über die Kindergeldkassen (und damit erstmalige, wenn auch in der Konstruktion mißglückte Einführung eines Kindergeldes in der Bundesrepublik), Kriegsgefangenenent schädigungsge set $z$

1955 Besatzungsschädengesetz, Gesetz über das Kassenarztrecht, Häftlingshilfegesetz, Personalvertretungsgesetz, Landwirtschaftsgesetz (das auch den Anfang einer langen Kette agrarsozialpolitischer Maßnahmen darstellt)

1956 Gesetz über die Krankenversicherung der Rentner

1957 Bundesbesoldungsgesetz, Jugendschutzgesetz, Erstes Lohnfortzahlungsgesetz, Seemannsgesetz, Soldatenversorgungsgesetz, Gesetz über eine Altershilfe für Landwirte, Neuregelung der Rentenversicherung der Arbeiter, der Angestellten und der knappschaftlichen Versicherung. 
deutung als richterliche Umsetzung demokratisch-rechtsstaatlicher Verfassungstexte im Lichte der zurückliegenden Erfahrungen und der aktuellen Gegebenheiten und Forderungen 85). Am Ende dieser Epoche steht die Arbeit am Grundgesetz, dessen Inkrafttreten und dessen Ins-Werk-Setzen den Anfang der nächsten Epoche biiden.

Was die soziale und wirtschaftliche Situation und ihre sozial- und wirtschaftspolitische Bewältigung anlangt, meinen Gerhard Kleinhenz und Heinz Lampert in ihrem Aufsatz "Zwei Jahrzehnte Sozialpolitik in der BRD" 86) treffend: "Es wäre nicht wirklichkeitsfremd, für die ersten Nachkriegsjahre nahezu jede wirtschaftspolitische Maßnahme zu interpretieren, da für fast die gesamte Bevölkerung des späteren Bundesgebietes die Lebenslage als sozial schwach beurteilt werden muß. Krieg und Kriegsfolgeerscheinungen hatten durch Verluste an Menschen, Gesundheit, Lebens- und A rbeitskraft, Heimat, Wohnung, Hausrat und Sachkapital besondere Notlagen für Individuen und Familien geschaffen... Diese und gleichartige Verluste in anderen europäischen Volkswirtschaften bestimmten zusammen mit dem Fehlen einer funktionsfähigen Geldordnung und anderer wirtschaftlicher und politischer Voraussetzungen auch die allgemeine wirtschaftliche Lage, die durch eine völlig unzureichende Versorgung der Bevölkerung mit den notwendigsten wirtschaftlichen Gütern und einen Mangel an Arbeitsplätzen gekennzeichnet war, der zu Massenarbeitslosigkeit führte". Es war die Zeit der "Verwaltung des Mangels", die Zeit, in der Forsthoffs juristische "Entdekkung" der Staatsaufgabe der "Daseinsvorsorge" eine der zentralen Botschaften der Rechts- und Staatslehre war, und in der man die Differenz eben dieser "Daseinsvorsorge" und der Sozialpolitik oft nicht mehr wahrnehmen, wenn überhaupt noch verstehen konnte. Ein weiteres Spezifikum bildete die Last der Regimefolgen, die nicht mit den Wirkungen von Krieg und Niederlage gekennzeichnet werden konnten und durften: die Wiedergutmachung des Unrechts rassischer, religiöser und politischer Verfolgung und die Hilfe für die Opfer.

freudig war. S. dazu Hans F. Zacher, Verfassungsentwicklung in Bayern 1946-1964, Jahrbuch des öffentlichen Rechts n. F. Bd. 15 (1966), S. 321 ff.

85) S. zu dieser Besprechung Otto Bachof und Dietrich Jesch, Die Rechtsprechung der Landesverfassungsgerichte der Bundesrepublik Deutschland, Jahrbuch des öfentlichen Rechts n. F. Bd. 6 (1957), S. 47 ff.

86) ORDO Bd.XII (1971), S. 102 ff (Zitat: S. 106). 
Die sozialpolitische Konzeption entzieht sich jeder kurzen Skizze, da sie nach Besatzungsmächten, Zonen und Ländern divergierte - innerhalb ein- und desselben Gebietes möglicherweise auch zwischen Besatzungsmacht und deutscher Regierung. Doch verdient der Versuch festgehalten zu werden, das verbliebene Eigentum nicht nur für die Bedürfnisse des Alltags (Wohnungsbeschlagnahme, Ablieferungspflichten usw.), sondern auch strukturell in Anspruch zu nehmen (Bodenreform, Entflechtung und nach der Währungsreform - auch Lastenausgleich) ${ }^{87}$ ). Sozialisierung wurde als möglich und sinnvoll ins Auge gefaßt und mitunter auch praktiziert 88). Die Systeme sozialer Sicherung und Hilfe waren nicht nur durch die Not der Zeit überfordert. Sie hatten nicht nur - insbesondere die Sozialversicherung - ihre reichseinheitliche Organisation und Finanzierung verloren, sie mußten auch damit fertig werden, daß die Besatzungsmächte die spezifischen Systeme der Sorge für die Kriegsopfer inhibierten, so daß die Kriegsopfer zunächst von den allgemeinen Systemen mitversorgt werden mußten ${ }^{89)}$. Im Arbeitsleben sorgten die Besatzungsmächte für die Zulassung von Gewerkschaften ${ }^{90)}$, denen auch die neuen Landesverfassungen (zusammen mit den Arbeitgeberverbänden) Raum gaben. Zugleich schufen die Besatzungsmächte ein wenig praktiziertes - Ausgleichs- und Schiedsverfahren in Arbeitsstreitigkeiten 91). Das Betriebsverfassungsrecht wurde wiederbelebt 92). Am Ende schaffte das Tarifvertragsgesetz für das vereinigte Wirtschaftsgebiet vom 9. April 1949 die bis heute maßgebliche Grundlage der Tarifautonomie. Landesgesetze hatten sich darüber hinaus vor allem mit Arbeitszeitfragen (Urlaub, Hauswirtschaftstag, Feiertagen usw.) befaßt.

87) Zur Geschichte des Lastenausgleichs s. z.B. Anlagenband zum Bericht der Sozialenquête-Kommission, o.J. (1966) S. $15 \mathrm{f}$.

88) S. zum frühen Meinungsstand noch Herbert Krüger, Sozialisierung, in: Bettermann-Nipperdey-Scheuner, Die Grundrechte, Bd. III, 1. Halbbd. 1958, S. 267 ff (zum Landesrecht insbes. S. 320 ff).

89) S. zur. Fntwicklung der sozialen Sicherung in dieser Zeit Horst Peters, Die Geschichte der sozialen Versicherung, 2. Auf1., 1973, S. $123 \mathrm{ff}$.

90) Kontrollratsdirektive $\mathrm{Nr} .31$ betreffend Grundsätze für die Errichtung von Gewerkschaftsverbänden vom 3. Juni 1946.

91) Kontrollratsgesetz Nr.35 betreffend Ausgleichs- und Schiedsverfahren in Arbeitsstreitigkeiten vom 20. August 1946.

92) Kontroll ratsgesetz Nr.22 vom 10. April 1946. Im Anschluß daran eine Reihe von Landesgesetzen. 
Noch vor Ende der Periode leitete die Währungsreform vom 20. Juni 1948 in Verbindung mit der Preisfreigabeanor (nnung vom 25. Juni 194893) den wirtschaftichen Aufschwung ein. Die Güterversorgung wurde primär wieder den Marktgesetzen anvertraut. Auf die Systeme sozialer Sicherung jedoch kamen nunmehr zusätzlich alle jene zu, die autonom-individuelle Vorsorge durch Sparen betrieben hatten. Dem Vertrauen in die Eigenvorsorge durch Sparen wurde danach - vor dem Hintergrund der Inflation von 1923 - der entscheidende Schlag versetzt, den spätere inflationäre Entwicklungen nicht vergessen ließen. Der Preisfreigabe folgte schließlich die Aufhebung des Lohnstops 94). Damit war nicht nur eine marktgerechte Entwicklung der Löhne, sondern auch eine freiere Entfaltung der Tarifautonomie ermöglicht.

Der wirtschaftliche Aufschwung ist freilich auch im in ter.nationalen Zusammenhang zu sehen. 1948 wurde der Marshallplan initiiert. Er verschaffte der deutschen Wirtschaft Sachwerte und beließ ihr den Gegenwert aus Rückzahlungspflichten usw. (der als ERP-Vermögen eine wichtige operative Reserve der Wirtschaftspolitik darstellte). Er führte Westdeutschland aber auch in die Kooperation des Europäischen Wirtschaftsrats und der Europäischen Zahlungsunion. Die harte wirtschaftliche Abgeschlossenheit Deutschlands nach außen und seine Abhängigkeit von fremder Hilfe, die von 1945 bis 1948 auf dem Wirtschaftsleben lastete, wichen so gegen Ende der Periode einer noch schmalen kooperativen Öffnung nach außen.

Alle diese Entwicklungen setzten freilich auch Daten für die Trennung zwischen den "Westzonen" und der "sowjetisch besetzten Zone", die mit der Gründung der beiden deutschen Staaten im Jahr 1949 zum Abschluß kommen sollte. Was dies für die Sozialpolitik und das politische System bedeutete, kann und braucht hier nicht ausgeführt zu werden.

\section{Zur zweiten Periode (1949-1957)}

Die zweite Phase ist die Zeit des Aufbaus der Bundesrepublik und in der Bundesrepublik. Es ist die Zeit des Frsten und des Zweiten Deutschen Bundestags (1949-1953 und 1953-1957). Und es ist zugleich die Zeit der beiden ersten Kabinette Adenauers 95).

93) Zur weiteren Entwicklung der Preisbindungen s. etwa Ernst Rudolf Huber, Wirtschaftsverwaltungsrecht, 2.Bd., 1954, S. $315 \mathrm{ff}$.

94) Gesetz zur Aufhebung des Lohnstops vom 3. November 1948.

95) Das zweite Kabinett Adenauer (1953-1957) wurde allerdings am 16. Oktober 1956 umgebildet. Bis dahin hatte es aus 
Das Grundgesetz enthielt keine sozialpolitische Konzeption, sondern nur die allgemeine Direktive des Sozialstaatsprinzips (Art.20 Abs.1, 28 Abs. 1 S.1). Im übrigen enthielt es Hinweise auf einzelne Materien, vor allem in den Gesetzgebungskatalogen (Art. 73 ff) 96). Sie waren ganz am überkommenen Rechtsbestand orientiert - ein Umstand, welcher innovierende Entwicklungen im System sozialer Sicherheit, im Sozialleistungssystem oder im noch weiteren Bereich des Sozialrechts legislatorisch und wissenschaftlich-dogmatisch nicht begünstigte. Damit war die leidige Auseinandersetzung "hie Rechtsstaat - hie Sozialstaat", die sich erst heute allmählich zu verlieren scheint, in der Verfassung angelegt 97 ). Unter den Verfassungsänderungen der Periode verdient vor allem die Einfügung des Art.120a in das Grundgesetz genannt zu werden, die dem Aufbau der Lastenausgleichsverwaltung Raum gab 98). Auch die Einfügung des Wehrrechts ist - wegen seiner dienst- und versorgungsrechtlichen Implikationen - nicht ohne soziale Relevanz 99). Den größten verfassungsändernden Aufwand aber verursachte die Finanzverfassung, die immer wieder geändert wurde 100). Diese intensive Diskussion um die Finanzverfassung hat offenkundig dazu beigetragen, daß die Finanzverfassung auch in der nachfolgend abgedruckten Arbeit - von heute aus gesehen - so überraschend intensiv behandelt wird. Der Verfasser sieht darin umso mehr eine Einseitigkeit der Arbeit, zu deren Entschuldigung er seine Zuflucht beim "Ge-

Ministern der CDU, CSU, FDP, BHE und DP bestanden. Danach bestand es aus Ministern der CDU, CSU, FVP (Freie Volkspartei) und DP.

96) Zu dieser Art "Sozialverfassungsrecht" im Grundgesetz s. Wilhelm Wertenbruch, Sozialverfassung, Sozialverwaltung, 1974, S. 1 ff. Zur Reflexion der sozialen Sicherheit im Grundgesetz s. auch Peters a.a.O. (Anm.19) S.143 ff.

97) S. dazu etwa den Sammelband Ernst Forsthoff (Hrsg.), Rechtsstaat1ichkeit und Sozialstaatlichkeit, 1968. Später etwa Walter Auerbach, Klärung um den sozialen Rechtsstaat, in: Alfred Christmann u.a. (Hrsg.), Sozialpolitik Ziele und Wege, 1974, S. $271 \mathrm{ff}$.

98) Gesetz zur Einführung eines Art.120a in das GG vom 14. August 1952 .

99) Gesetz zur Ergänzung des Grundgesetzes vom 19. März 1956. 100) Gesetz zur Änderung des Art. 107 des GG vom 20. April 1953, Zweites Gesetz zur Änderung des Art. 107 des GG vom 25. Dezember 1954, Finanzverfassungsgesetz vom 23. Dezember 1955 und Gesetz zur Änderung und Ergänzung des Art. 106 GG v. 24. Dezember 1956. 
schmack der Zeit" nehmen muß, als die "Steuerverfassung", die das Grundgesetz unter der Überschrift "Das Finanzwesen" regelt, gerade im Blick auf die Sozialpolitik niemals die ganze Finanzverfassung ist. Die Umverteilung über Beiträge und Sozialversicherungsleistungen, die das Grundgesetz nicht als Gegenstand der "Finanzverfassung" wahrnimmt, ist dies in Wahrheit - der Sache nach - sehr wohl 101).

Die Verfassungsinterpretation wird auf einen neuen Boden gestellt, indem 1951 das Bundesverfassungsgericht errichtet wird. Bis zum Ablauf der Periode füllt die Entscheidungspraxis des Gerichts jedoch erst sieben (!) der mittlerweile 48 Bände der Sammlung seiner Entscheidungen. Sozialpolitische Themen stehen nicht im Zentrum der ersten Juhre der Entscheidungspraxis, so sehr auch im einen oder anderen Falle damals sozialpolitisch Bedeutsames zu entscheiden war 102). Schon im

101) Vergleich: "Allgemeine Finanzverfassung" - "Sozialversicherungsfinanzen"

\begin{tabular}{l|r|r|r|r} 
Einnahmen Mrd. DM & \multicolumn{1}{c}{1960} & 1965 & 1970 & 1976 \\
\hline $\begin{array}{l}\text { Steuereinnahmen } \\
\text { Bund/Länder/Gemeinden }\end{array}$ & 68,7 & 106,1 & 154 & 268 \\
$\begin{array}{l}\text { Einnahmen Soz. Vers. } \\
\text { KV + UV + RV, ohne }\end{array}$ & & & & \\
Staatszuschüsse & 30,9 & 51,5 & 83,1 & 194,2 \\
\hline
\end{tabular}

\begin{tabular}{|c|c|c|c|c|}
\hline Ausgaben Mrd. DM & 1960 & 1965 & 1970 & 1974 \\
\hline $\begin{array}{l}\text { A usgaben der öff. Haushalte } \\
\text { (Bund, Länder, Gemeinden } \\
\text { GV, Lastenausgleichsfonds, } \\
\text { ERP-Sondervermögen) }\end{array}$ & 86,1 & 140,6 & 196,3 & 316,5 \\
\hline $\begin{array}{l}\text { A usgaben der Sozialver- } \\
\text { sicherung: KV + UV + RV }\end{array}$ & 29,4 & 49,2 & 77,4 & 196,4 \\
\hline
\end{tabular}

Quellen: Arbeits- und Sozialstatistik 1978, S. 105 ff. Statistisches Jahrbuch für die BRD 1978 und 1965.

102) Das Entscheidungsgut zu analysieren, ist hier nicht der Ort. Das Relevante ist in der unten abgedruckten Arbeit mitgeteilt. Die Übersicht, die Wolfgang Rüfner seinem Aufsatz über "Das Sozialrecht in der Rechtsprechung des Bundesverfassungsgerichts (II)" VSSR Bd.2 (1974), S.68 ff voranstellt, nennt aus den ersten 7 Bänden nur drei Entscheidungen. A1lerdings fehlt dort z. B. die (sehr umfangreiche) beamtenrechtliche und die (noch sporadische) arbeitsrechtliche Pra- 
ersten Band freilich findet sich eine zentrale Aussage zum Sozialstaatsprinzip: "Das Wesentliche zur Verwirklichung des Sozialstaats... kann nur der Gesetzgeber tun; er ist gewiß verfassungsrechtlich zu sozialer Aktivität, insbesondere dazu verpflichtet, sich um einen erträglichen Ausgleich der widerstreitenden Interessen um die Herstellung erträglicher Lebensbedingungen für alle zu bemühen, die durch die Folgen des Hitler-Regimes in Not geraten sind. Aber nur wenn der Gesetzgeber diese Pflicht willkürlich, d.h. ohne sachlichen Grund versäumte, könnte möglicherweise dem einzelnen hieraus ein mit der Verfassungsbeschwerde verfolgbarer Anspruch erwachsen" 103).

Jedoch fällt auf, daß sich die Staatsrechtswissenschaft der sozialpolitischen Einsilbigkeit des Grundgesetzes noch nicht ganz beugt. Symptomatisch ist der 1. Halbband des III. Bandes des Sammelwerkes "Die Grundrechte", der, herausgegeben von Karl A ugust Bettermann, Hans Carl Nipperdey und U1rich Scheuner, 1958 erscheint, unter dem Gesamttitel "Die Wirtschafts- und Arbeitsverfassung" sozialpolitische Themen vereinigt, für die das Grundgesetz keinen Anlaß abgibt, sie in ein Handbuch der Grundrechte aufzunehmen: so insbesondere die Artikel "Das A rbeitsrecht" von Wilhelm Herschel 104), "Das Mitbestimmungsrecht" von Horst Neumann-Duesberg 105), "Mutterschutz und Jugendschutz" von Johannes Denecke 106)' und "Die Sozialversicherung" von Hermann Dersch 107). Die Vereinigung der Deutschen Staatsrechtslehrer diskutiert 1951 "Enteignung und Sozialisierung" 108) und setzt mit ihrer Tagung zu "Begriff und Wesen des sozialen Rechtsstaates" 109) 1952 einen der Höhepunkte der Auseinandersetzung um den sozialen Rechtsstaat. In all dem zeigte sich, wie wenig Antwort das Sozialstaatsprinzip des Grundgesetzes auf wieviel sozialpolitische Frage war - die in sich je nach geschichtlicher Erfahrung, ideologischem und politischem Leitbild, primär verfassungsrechtlichen, politischen oder sozialen Anliegen usw.

xis des Bundesverfassungsgerichts (beachtlich insbes.

BVerf G 4, 96 zur Koalitionsfreiheit).

103) BVerfG 1, 97 (105).

104) a.a.O. S.325 ff.

105) a.a.O. S. $373 \mathrm{ff}$.

106) a.a.O. S. $475 \mathrm{ff}$.

107) a.a.O. S. $503 \mathrm{ff}$.

108) Mit Referaten von Hans Peter Ipsen und Helmut K.J. Ridder, in: VVDStRL, Heft 10, 1952.

109) Mit Referaten von Ernst Forsthoff und Otto Bachof, VVDStRL, Heft 12, 1954. 
höchst unterschiedliche Ausgangspunkte und Ziele hatle ${ }^{110)}$. Verfassungsrechtlich fiel zudem ins Gewicht, daß die Juristen, die damals eine führende Stellung in der Interpretation des Grundgesetzes einnahmen, unter der Weimarer Verfassung aufgewachsen waren, deren Programmatik die meisten Länderverfassungen nach 1945 mehr oder weniger in Erinnerung gebracht oder auch variiert und angereichert haben. Verfassungsrecht wurde deshalb weithin nicht in dem Maße als von sozialer Programmatik entblößt gedacht, wie das heute weithin selbstverständlich ist. Erst in der nächsten Periode finden sich Verfassungsloktrin und - praxis damit ab, daß - vereinfacht gesagt - der Rechtsstaat primär ein juristisches, der Sozialstaat primär ein politisches l'hänomen ist.

Ein Moment sozialpolitischer Aktivierung der Verfassung jedoch ist noch zu erwähnen, das vielleicht nie mehr so hervorgetreten ist wie in dieser Periode: die "Drittwirkung" der Grundrechte. Vor allem im Arbeitsrecht ${ }^{111)}$ glaubten Rechtsprechung und Literatur unmittelbar eine grundrechtsgerechte Ordnung herstellen $z u$ sollen und zu können. Mit der Zeit gewann die Überzeugung Oberhand, daß Grundrechte ein Auftrag an den Gesetzgeber sind, dessen Erfüllung ihm aber auch durch die Rechtsprechung nur sehr begrenzt abgenommen werden kann ${ }^{112)}$. A ber es ist fraglich, ob es zu dieser Ausstrahlung der Grundrechte gekommen wäre, wenn nicht in jener Pionierphase so sehr "Ernst" mit ihnen gemacht worden wäre.

Was die wirtschaftliche und soziale situation anlangt, ist diese Periode die Zeit des "Wirtschaftswunclers". Das Sozialprodukt steigt die ganze Zeit hindurch an. Die Wachstumsraten halten sich - obwohl sie auf 1957 hin zu einem Konjunkturtief absinken - im Durchschnitt der Periode auf einem später

110) S. dazu auch Hans F.Zacher, Was können wir über das Sozialstaatsprinzip wissen?, in: Hamburg-DeutschlandEuropa, Festschrift für Hans Peter Ipsen, 1977, S.207 ff (insbes. S. $231 \mathrm{ff}$ ).

111) S. die Hinweise bei llolfgang Zöllner, Arbeitsrecht, 1977, S. 57 ff; Alfred Söllner, Arbeitsrecht, 6. Aufl., 1978, S. $39 \mathrm{f}$.

112) S. dazu etwa die Darstellungen bei Ernst IIolfgang Böckenförde, Grundrechtstheorie und Grundrechtsinterpretation, NJW 27.Jhg. (1974) S. 1529 ff, insbes. S. 1532 ff; Hans Heinrich Rupp, Vom IIandel der Grundrechte, AöR $\mathrm{Bd} .101$ (1976) S. $161 \mathrm{ff}$, insbes. S. $165 \mathrm{ff}$. 
nicht mehr erreichten Niveau 113). Die allgemeine Güterversorgung kann ganz weitgehend von Bewirtschaftung und Preisbindung freigestellt werden. Die Versorgung mit Wohnungen kommt zwar noch zu keinem befriedigenden Ergebnis. Jedoch sind die Zuwachsraten erstaunlich 114). Die größten Erfolge der Zeit liegen wohl in dem Abbau der Arbeitslosigkeit und in der Einkommens-/ Lebenshaltungskosten-Relation. Die A rbeitslosenquote sank von $11,0 \%$ im Jahr 1950 auf 3, $7 \%$ im Jahr 1957 115). Die Löhne stiegen nominell und real kontinuierlich an 116). Der Preisindex stieg noch von 1950 auf 1951, blieb aber bis 1955 annähernd konstant, um dann erst wieder zu steigen ${ }^{117}$ ).

Die Wirtschaftspolitik konzentrierte sich auf die Festigung der marktwirtschaftlichen Ordnung, unterstützte aber gleichwohl interventionistisch den wirtschaftlichen Aufschwung - insbesondere im Hinblick auf den Wohnungsbau und die Vermehrung von Arbeitsplätzen. Wirtschafts- und Sozialpolitik wurden in enger Verbindung gesehen ${ }^{118)}$. Diese Ergänzung von Marktwirtschaft und Sozialpolitik findet sich vor allem im A rbeitsleben und im Wohnungswesen. Im Arbeitsleben traten den Möglichkeiten, die der wirtschaftliche Aufschwung einer freien Lohnentwicklung bot, zahlreiche gesetzgeberische Maßnahmen etwa in Richtung auf Mitbestimmung, Betriebsverfassung und Personalvertretung, Kündigungsschutz, Mindestarbeitsbedingungen, Heimarbeitsrecht usw. zur Seite. Auf dem Gebiet des Wohnungswesens finden wir ein kompliziertes Ineinander von Wohnungsbauförderung (siehe (las Erste Wohnungsbaugesetz von 1950), Entwicklung angemessener. Wohnungsrechtsformen (siehe das Gesetz über das Wohnungseigentum und das Dauerwohnrecht 1951) und Abbau der Wohnraumbewirtschaftung sowie der Preisbindung.

113) S. Franz Neumann, Daten zu Wirtschaft-Gesellschaft-Politik-Kultur der Bundes republik Deutschland 1950-1975, 1976 , S. 345 ff.

114) S. Neumann, a.a.O. (Anm.113) S.273 ff.

115) 1952 sank sie mit 9, 5\% erstmals unter die 10\%-Marke, 1956 mit 4, 4\% erstmals unter die $5 \%$-Marke. S. Presseund Informationsamt der Bundesregierung, Gesellschaftliche Daten 1977, s. 123 .

116) Bei freilich extrem schwankenden jährlichen Zuwachsraten, s. Neumann, a.a.O. (Anm.113) s.351.

117) Im Jahr 1953 ergab sich das einzige Mal in der Geschichte der Bundesrepublik eine Minusrate im Anstieg des Preisindex für die Lebenshaltung. S. Neumann, a.a.O. (Anm. 113) $\$ .311 \mathrm{ff}$.

118) S. dazu etwa Kleinhenz-Lampert, a.a.O. (Anm.18) S.106 ff. 
Ein weiteres zentrales Thema dieses Zeitabschnitts bleibt die Bewältigung der Kriegs- und Regimefolgen, die nunmehr bundeseinheitlich, weitgehend befreit von der Intervention der Besatzungsmächte und schon im Blick auf den ansteigenden Wohlstand Westdeutschlands angegangen werden konnte.

Zahlreiche gesetzliche und administrative Maßnahmen waren darüber hinaus notwendig, um die Institutionen und Organisationen der Sozialpolitik, die früher dem Reich zugeordnet waren, über die Länder und Zonen hinaus wieder auf den Bund hin zu orientieren. Im Hinblick auf den Normenbestand bedeutete dies: die Wiederherstellung der Rechtseinheit ${ }^{119)}$. Das veränderte freilich auch den bundesstaatlichen Rahmen der Sozialpolitik. Die sozialpolitischen Möglichkeiten der Länder wurden mehr und mehr zurückgedrängt. War es am Anfang der Periode noch denkbar, sich den "sozialen Bundesstaat" (Art.20 Abs.1 GG) als im Gleichgewicht zwischen dem "Sozialstaat Bund" und den "Sozialstaaten Länder" (s.a. A rt.28 Abs. 1 Satz 1 GG) vorzustellen am Ende war das Ungleichgewicht nur zu deutlich.

Über all das hinaus aber wurde die Sozialreform - die "Große Sozialreform", die als eine grundlegende und für lange Zeit gültige Neuordnung der sozialen Leistungen gedacht war das Anliegen der Periode. Abgesehen von allen idealistischen und ideologischen Motiven und Ansprüchen bildeten den gemeinsamen Hintergrund dieser Bemühungen wohl vor allem drei Elemente: die historische Erfahrung, daß seit der Kodifikation der Reichsversicherungsordnung (1911) Sozialgesetzgebung fast nur noch als "Stückwerk" betrieben worden war; die Erfahrung des Zusammenbruchs und das Erlebnis der Möglichkeit und Notwendigkeit, "ganz neu" anzufangen; endlich und zunehmend das Bewußtsein der Prosperität, die eine allgemeine Prosperität nur sein konnte, wenn sie durch das Sozialleistungssystem auch denen zugute kam, die irgendwie gehindert waren, sich selbst einen vollen marktwirtschaftlichen Anteil zu erarbeiten oder sonstwie zu erwirtschaften. So erklärt sich, daß Politik und Wissenschaft sich in der Suche nach einem "Sozialplan" trafen ${ }^{120)}$. Und diese Periode umfaßte denn auch nicht nur viele bedeutsame Teilschritte, sondern endete 1957 mit einem der wohl bedeutendsten Jahre deutscher Sozialrechtsgeschichte.

119) S. dazu etwa Peters, a.a.O. (Anm.19) S. $147 \mathrm{ff}$.

120) S. oben S. LVI ff; ferner Hans Günter Hockerts, Sozialpolitische Reformbestrebungen in der frühen Bundesrepublik 1953-1957, Vierteljahreshefte für Zeitgeschichte, 25. Jhg. (1977) S. $341 \mathrm{ff}$. 
Die Aufbauleistungen dieser Periode treten am eindrucksvollsten in der Geschichte ihrer Gesetzgebung zutage. Eine - notgedrungen willkürliche - Selektion der bedeutsameren sozialpolitischen Gesetze muß wohl die folgenden enthalten:

1950 Bundesversorgungsgesetz, Heimkehrergesetz, Kriegsgefangenen-Unterhalt sbeihilfegesetz, Erstes Wohnungsbaugesetz

1951 Heima rbeitsgesetz, Kündigungsschutzgesetz, Montan-Mitbestimmungsgesetz, Selbstverwaltungsgesetz (und damit Wiederherstellung der Selbstverwaltung der Sozialversicherung nach ihrer Abschaffung durch den Nationalsozialismus), Gesetz zur Regelung der Rechtsverhältnisse der unter Art.131 GG fallenden Personen

1952 Betriebsverfassungsgesetz, Lastenausgleichsgesetz und Feststellungsgesetz hierzu (unter Ablösung des Soforthilfegesetzes von 1949), Mindestarbeitsbedingungengesetz, Mutterschutzgesetz, Währungsausgleichsgesetz, Wohnungsbau-Prämiengesetz

1953 Altsparergesetz, A rbeitsgerichtsgesetz (und damit einheitlicher Neuaufbau der A rbeitsgerichtsbarkeit), Sozialgerichtsgesetz (und damit Trennung von Rechtsprechung und Verwaltung im Bereich der Sozialversicherungsauf sicht und -verwaltung sowie Zusammenfassung von Sozialversicherung und Kriegsopferversorgung in einer einheitlichen Gerichtsbarkeit), Bundesbeamtengesetz, Bundesentschädigungsgesetz (für die Entschädigung der Opfer des nationalsozialistischen Regimes), Bundesevakuiertengesetz, Bundesvertriebenengesetz, Schwerbeschädigtengesetz

1954 Gesetz über die Kindergeldkassen (und damit erstmalige, wenn auch in der Konstruktion mißglückte Einführung eines Kindergeldes in der Bundesrepublik), Kriegsgefangenenentschädigungsgeset $z$

1955 Besatzungsschädengesetz, Gesetz über das Kassenarztrecht, Häftlingshilfegesetz, Personalvertretungsgesetz, Landwirtschaftsgesetz (das auch den Anfang einer langen Kette agrarsozialpolitischer Maßnahmen darstellt)

1956 Gesetz über die Krankenversicherung der Rentner

1957 Bundesbesoldungsgesetz, Jugendschutzgesetz, Erstes Lohnfortzahlungsgesetz, Seemannsgesetz, Soldatenversorgungsgesetz, Gesetz über eine Altershilfe für Landwirte, Neuregelung der Rentenversicherung der Arbeiter, der Angestellten und der knappschaftlichen Versicherung. 
Dem ist hinzuzufügen, daß in dieser Periode die Bunclesrepublik in die internationale Gemeinschaft hineingeführt wurde. Sozialpolitisch bedeutsam war vor allem der Aufbau des supranationalen Europas, der Einbezug in den Europarat und in die Internationale A rbeitsorganisation 121). Abgesehen von der Mitarbeit in den Vereinten Nationen waren am Schluß dieser Periode alle rechtlichen Grundlagen für die internationale Kooperation der Bundesrepublik geschaffen.

\section{Zurdritten Periode (1957-1966)}

Diese Periode beginnt mit der Wahl des Dritten Deutschen Bundestages (1957-1961), in dem die CDU/CSU die absolute Mehrheit hat, umfaßt sodann den Vierten Deutschen Bundestag (19611965) und reicht hinein bis in die Anfänge des Fünften Bundestages (1965-1969). Dem Dritten Deutschen Bundestag entspricht das dritte Kabinett Adenauer (1957-1961), dem CDU, CSU und DP angehören. Nach der Wahl des Vierten Deutschen Bundestages kommt es zum vierten Kabinett Adenauer (1961/62), das 1962 vom fünften Kabinett Adenauer (1962/63) abgelöst wird, dem dann das erste Kabinett Erhard (1963-1965) folgt. Allen diesen Kabinetten gehören CDU, CSU und FDP an. Zu Beginn des Fünften Deutschen Bundestages wird das zweite Kabinett Erhard (1965/66) gebildet, dessen FDP-Mitglieder im Oktober 1966 ausscheiden. Am 1.Dezember 1966 wird ein Kabinett der Großen Koalition aus CDU, CSU und SPD gebildet, das von Bundeskanzler Kiesinger geleitet wird (1966-1969). Mit der Bildung dieses Kabinetts verändert sich die politische Landschaft in der Bundesrepublik bleibend. Daher wurde der Übergang vom zweiten Kabinett Frhard zum Kabinett Kiesinger zur historischen Grenzmarke gewäh1t, welche die dritte von der vierten Periode trennen soll.

Der Text des Grundgesetzes bleibt in dieser Zeit weitgehend unverändert 122). Sozialpolitisch interessant ist allenfalls die Änderung des Art. 120 Abs. 1 über die Kriegsfolgelasten durch das 14. Gesetz zur Änderung des Grundgesetzes vom 30. Juli 1965. Der zu Verfassungsänderungen notwendige breite Konsens der Aufbauphase ist offenbar geschwunden. Die dringendsten "Nachbesserungen" am Grundgesetz scheinen in der vorangegangenen Phase vorgenommen worden zu sein.

In der Auseinandersetzung zwischen Verfassung und Politik auch zwischen Verfassung und Sozialpolitik - beginnt nun die

121) S. dazu noch einmal oben S.L ff.

122) In die Epoche fallen nur vier verfassungsänderncle Gesetze. 
"Feinarbeit". Das heißt auch, daß Verfassung und Verfassungsgerichtsbarkeit stärker als kritische Instanzen gegenüber der Politik im allgemeinen und der Sozialpolitik im besonderen hervortreten als vorher; denn die hemmenden, begrenzenden, den Rechtsstaat konstituierenden und die Grundrechte ausformenden Verfassungssätze sind es ja, die präzise verfassungsrechtliche A rgumentation ermöglichen und anregen. Die zahlreichen Gesetze der Aufbauphase haben außerdem umfangreichen Stoff an "nachkonstitutionellen Gesetzen" für die verfassungsgerichtliche Nachprüfung geliefert. So steigt noch in den Bänden der Sammlung der Entscheidungen des Bundesverfassungsgerichts, die in diese Periode fallen und bei der unten wiedergegebenen Arbeit noch berücksichtigt werden konnten - das sind die Bände 7-12 - die Zahl der sozialpolitisch interessanten oder doch beachtlichen Entscheidungen rasch an 124). Und von nun an wird die So-

123) Die Entscheidungen in Band 11 und 12 konnten wegen der. Erscheinungsweise der Sammlung und des grundsätzlichen Abschlusses der Arbeit im Jahr 1960 nicht mehr voll ausgewertet werden. Jedoch hat sich der Verfasser bemüht, die ihm bekannt gewordenen Entscheidungen bis zum technischen Abschluß der A rbeit im Jahr 1961 einzubeziehen.

124) Die arbeitsrechtliche Zuständigkeit von Bund und I ändern wird geklärt (BVerfG 7, 342; 11, 89). Den Beamten wir.d ein verfassungsmäßiges Recht auf den angemessenen Lebensunterhalt zuerkannt (BVerfG 8, 1). Der formelle und materielle Spielraum der Leistungsverwaltung und ihrer rechtlichen Ordnung gegenüber der Verfassung wird ausgelotet (BVerfG 8, 155; 11, 50). Die Gleichbehandlung zwischen Fhen und eheähnlichen Gemeinschaften im Sozialrecht wird erstmals erörtert (BVerfG 9, 20). Indem das Bundesverfassungsgericht billigt, daß im Sozialgerichtsverfahren eine Anwaltsbeiordnung nicht stattfindet (BVerfG 9, 124),trägt es zur Entfremdung von Anwälten und Sozialrecht bei. Die Anwendung des Gleichheitssatzes auf das Sozialrecht findet ein Beispiel in der versorgungsrechtlichen Stellung der scheinehelichen Kinder (BVerfG 9, 201). Die Grenzen zwischen Personalvertretung und parlamentarischer Demokratie werden abgesteckt (BVerfG 9, 268). Die Frforlernis richterlicher Entscheidung (Art. 104 Abs. 2 GG) wird auch a die Unterbringung Entmündigter durch einen Vormund erstreckt (BVerfG 10, 302). Die Zwangsversicherung freier Berufe wird gebilligt (BVerfG 10, 354; 12, 319). Die Anfänge der deutschen Kinclergeldgesetzgebung - finanziert durch Arbeitgeberbeiträge, organisiert 
zialpolitik immer mehr zum täglichen Brot des Bundesverfassungsgerichts gehören ${ }^{125)}$.

Auch die Rechtswissenschaft rückt entschlossen in diese Auseinandersetzung ein. Einen Markstein in dieser Entwicklung bilden 1960 die Verhandlungen des 43. Deutschen Juristentages in München. Hier tagte zum ersten Mal im Rahmen des Deutschen Juristentages eine Sozialrechtliche Arbeitsgemeinschaft. Das Thema: "Die Einwirkung verfassungsrechtlicher Normen auf das Recht der sozialen Sicherheit" 126). Walter Bogs hielt das umfassende Referat, das eine einzigartige Summe der bis dahin sichtbaren Probleme im Bereich des Themas darstellt 127). Für das Ende des Abschnitts sei das monumentale Werk von Ernst Benda über "Industrielle Herrschaft und sozialer Staat" (1966) genannt 128).

Die wirtschaftliche und soziale Entwicklung ist dadurch gekennzeichnet, daß der Wohlstand selbstverständlich wird. Das heißt nicht, daß er es von Anfang an war. Aber am Ende ist er es - und das ist sehr bedeutsam für das Verständnis der folgenden Periode. Das Jahr 1957 steht im Zeichen einer ge-

unter Anlehnung an die Unfallversicherung - werden als Sozialversicherung qualifiziert (BVerfG 11, 105). Der Gleichheitssatz wird auf die Pfändungsgrenzen von Sozialleistungsansprüchen angewandt (BVerfG 11,283). Demokratisches Prinzip und Sozialversicherungs-Selbstverwaltung werden ein erstes Mal konfrontiert (BVerfG 11, 310). Die objektiven Zulassungsschranken für Kassenärzte werden für verfassungswidrig erklärt (BVerfG 11, 30; 12, 144). Auch Art. 14 GG gerät allmählich ins Blickfeld: zunächst für die Anwartschaft auf Sterbegeld aus der sozialen Krankenversicherung (BVerfG 11, 221), sodann gegenüber der Volkswagenwerk-Privatisierung (BVerfG 12, 354).

125) S. dazu noch einmal oben S.LXXIX Anm. 124; zur Bilanz dieser Jahre s. auch Hans F. Zacher, Soziale Gleichheit, AöR Bd. 93 (1968), S. $341 \mathrm{ff}$; dens., Das Sozialstaatsprinzip in der Rechtsprechung des Bundesverfassungsgerichts, Baverische Verwaltungsblätter n.F. 15. Jhg. (1969), S. 113 ff.

126) Verhandlungen des 43. Deutschen Juristentages $\mathrm{Bd}$. II/G: Sozialrechtliche Arbeitsgemeinschaft, 1962. - Die Verhandlungen sind so spät erschienen, daß sie in der unten wiedergegebenen Arbeit nicht mehr berücksichtigt werden konnten.

127) A.a.O. (Anm.126) S.G 5 ff.

128) Das zugleich eine umfassende Bilanz des bis dahin erschienenen Schrifttums enthält. 
wissen Rezession, die sich 1963 erneut einstellen wird, jedoch haben beide Abschwungphasen nicht die Bedeutung der Rezession von 1967 oder gar derjenigen von 1974/75. Das Bruttosozialprodukt wächst weiter 129). Die Lebenshaltungskosten wachsen stärker als in der vorigen Phase. Aber die Relation zu der Einkommensentwicklung bleibt ohne größere Spannung 130). Der wichtigste Indikator "sozialen Glücks" in dieser Zeit ist die Vollbeschäftigung. Die Arbeitslosenquote sinkt bis 1962 auf $0,7 \%$, beträgt $1963 / 640,8 \%$ und $1965 / 66$ wieder $0,7 \% 131)$.

Die Sozialpolitik ist nach den außerordentlichen Leistungen und auch Anstrengungen der Aufbauphase vor allem davon beansprucht, mit den geschaffenen Regelungen und Institutionen zu leben. Einige Reformen, die in der Aufbauphase liegengeblieben waren, wurden nachgeholt (Bundessozialhilfegesetz, Handwerkerversicherung, Unfallversicherungsreform). Im übrigen finden sich vor allem Ausführungsnormen, Korrekturen und Verbesserungen von sekundärer Bedeutung. Thematisch tritt nun die Vermögenspolitik verstärkt auf den Plan und die Bildungspolitik, die in der nächsten Periode so viel Aufmerksamkeit auf sich ziehen soll, erweist sich schon jetzt als unvermeidliche Ergänzung der traditionellen Sozialpolitik 132).

Eine Auswahl der wichtigsten sozialpolitischen Gesetze aus dieser Zeit möge auch für diesen Abschnitt verdeutlichen, worum man sich bemüht hat:

\section{Spar-Prämiengesetz}

1960 Handwerkerversicherungsgesetz, Jugendarbeitsschutzgesetz

1961 Bundessozialhilfegesetz, Jugendwohlfahrtsgesetz, Erstes Vermögensbildungsgesetz

1963 Bundesurlaubsgesetz, Unfallversicherungs-Neuregelungsgesetz, Gesetz über Wohnbeihilfe (und damit Einführung eines neuen $Z$ weiges des Sozialleistungssystems)

1964 Bundeskindergeldgesetz (Umwandlung dieses Zweiges des Familienlastenausgleichs von einer Sozialversicherung in ein Ausgleichssystem), Gesetz zur Förderung eines freiwilligen sozialen Jahres

129) S. dazu Neumann, a.a.O. (Anm.113) S. 345 ff.

130) Ebenda, S.316, 352 .

131) Sie beträgt 1958 (wie im Vorjahr) 3, 7\%, 1959 2,6\%, 1960 $1,3 \%$ und 1961 0,8\%. S. Gesellschaftliche Daten 1977, S.123.

132) S. dazu Kleinhenz - Lampert, a.a.O. (Anm.18) S. 123 ff, insbes. S. $140 \mathrm{ff}$. 
1965 Flüchtlingshilfegesetz, Zweites Vermögensbildungsgesetz, Neufassung des Wohnbeihilfegesetzes von 1963 (nunmehr: Wohngeldgesetz)

Methodisch tritt ein grundlegender Wandel der sozialpolitischen Diskussion ein. Die Flut der "Sozialpläne", die sich gegen Ende der vorigen Periode gezeigt hatten, verebbt 133). Erst clas erste Kabinett Erhard sieht noch einmal die Notwendigkeit, "das gegenwärtige Sozialrecht der Bundesrepublik Deutschland und dessen wirtschaftliche und soziologische Auswirkungen in überschaubarer Form darstellen zu lassen" 134). Es geht primär clarum, das Sozialleistungssystem sichtbar zu machen, nicht schlechthin Reformen vorzuschlagen. Auf der anderen Seite ist dies die Zeit, in der die sozialpolitische Wissenschaft wieder stärker mit Grundlagenarbeiten hervortritt 135 ).

Was die Entwicklung des Sozial rechts anlangt, zeichnet sich nicht nur Bemühung, sondern auch Erfolg ab. 1965 wurde als Parallele zu dem bereits traditionsreichen Deutschen Arbeitsgerichtsverband - der Deutsche Sozialgerichtsverband gegründet 136). Seine Tagungen und seine Schriftenreihe 137) haben viel dazu beigetragen, die Sozialrechtsdogmatik nicht nur zu pflegen, sondern ihr auch eine Art "berufsständische" Atmosphäre zu schaffen, in der sich kollegialer Austausch ebenso entwickeln kann wie Ermutigung 138).

133) S. noch einmal oben S.LXXVI.

134) Beschluß der Bundesregierung über die Durchführung einer Sozialenquête vom 29. April 1964, abgedr. in: Soziale Sicherung in der Bundesrepublik Deutschland. Bericht der. Sozialenquête-Kommission, o.J. (1966), S. $347 \mathrm{ff}$.

135) S. noch einmal oben S.LXXX.

136) S. zu den Gründungsverhandlungen: Die Sozialgerichtsbarkeit 12. Jhg. (1965), S.65 ff.

137) Diese Schriftenreihe enthält überwiegend die Referate und Verhandlungen der Tagungen, jedoch auch zusätzliche Einzelstudien. Zuletzt Bd.XVI"Auswirkungen von Inflation, Konjunktur und Unterbeschäftigung auf clas Sysiem der sozialen Sicherheit. Untersuchung über die sozialrechtliche Ausbildung der Juristen an den Universitäten cler Bundesrepublik, insbes. im Wahlfachstudium", 1978.

138) Immer wieder war übrigens gerade das Verhältnis zum Verfassungsrecht Thema von Referaten des Sozialgerichtsverbandes. Konzentriert in: "Die verfassungsrechtliche Relevanz des Sozialrecht s" Bd. IX der Schriftenreihe des Deutschen Sozialgerichtsverbandes 1975, mit dem Festvortrag 
Die internationale Öffnung der Bundesrepublik, clie in der vorigen Phase rechtlich eingeleitet worden war, erlebte in diesen Jahren - ähnlich wie die innere Gesetzgebung der Aufbauphase - die Verwirklichung. Im "Europa der Sechs" wird vor allem die Freizügigkeit und die soziale Sicherung der Wanderarbeitnehmer vorangetrieben ${ }^{139}$ ). Im Bereich des Europarates ragt die Schaffung der Europäischen Sozialcharta heraus. Sie wurde 1961 beschlossen und trat 1965 in Kraft ${ }^{140)}$. Die internationale Verflechtung der deutschen Sozialpolitik und des deutschen Sozialrechts bekamen in dieser Zeit jedoch zwei neue Akzente. Die Zahl der ausländischen Arbeitnehmer nahm von $0,6 \% 141)$ im Jahre 1957 auf 6, $1 \%$ im Jahre 1966 zu 142). Der andere Akzent ist die "Welt-Sozialpolitik". Zwar haben sich die gesamten Aufwendungen für die Entwicklungshilfe in dieser Periode nur wenig gesteigert 143). Jedoch hat sich erwiesen, daß die Bundesrepublik immer mehr in die entwicklungspolitische Verantwortung einbezogen ist 144).

\section{Zur vierten Periode (1966-1974)}

Politisch beginnt diese Periode nicht mit einer Bundestagswahl, sondern mit der Neugruppierung von Regierungsmehrheit und Opposition im Bundestag. Im Dezember 1966 tritt an die Stelle des CDU/CSU/FDP Kabinetts unter Ludwig Erhard die Große Koalition aus CDU/CSU und SPD unter dem Bundeskanzler Kurt Georg Kiesinger. Im September 1969 wird der Sechste Bundestag gewählt. An die Stelle der Großen Koalition tritt nunmehr das erste Kabinett Brandt der sozialliberalen Koalition. Im November 1972 muß der Bundestag aufgelöst werden, nachdem die sozialliberale

von Ernst Benda zu diesem Thema (a.a.O. (Anm.14) S. $32 \mathrm{ff})$.

139) S. zu den einschlägigen Quellen hinsichtlich der sozialen Sicherung der Wanderarbeitnehmer (ab 1958) Zacher, Internationales und Furopäisches Sozialrecht, S.664 ff, hinsichtlich der Freizügigkeit (ab 1961) ebenda S. $167 \mathrm{ff}$.

140) S. Zacher a.a.O. (Anm.22) S.128. Die Bundesrepublik war 1964 beigetreten.

141) Anteil der Ausländer an den abhängig Er.werbstätigen.

142) S. Neumann a.a.O. (Anm.113) S.34. S. zu den Anfängen der Reflexion aus der Zeit etwa Waller R.Schloesser u.a., Arbeitsplatz Europa, 1966.

143) S. z.B. Bericht zur Entwicklungspolitik der Bundesregierung (2. Bericht), Deutscher Bundestag Drucks. 7/4293.

144) S. aus der Zeit etwa Wolfgang Jahn, Art. "Entwicklungshilfe", in: Handwörterbuch der Sozialwissenschaften, 
Koalition bereits im Mai 1972 die Mehrheit im Bundestag verloren hatte. Der Siebte Bundestag wird gewählt, und Willy Brandt wird erneut Bundeskanzler. Im Mai 1974 - also nach neuerlich eineinhalb Jahren Amtszeit - tritt Willy Brandt jedoch zurück. Helmut Schmidt löst ihn als Bundeskanzler ab. Dies bildet die Zäsur zur fünften Periode.

Die Häufigkeit und Intensität, mit der in dieser Zeit das Grundgesetz geändert wurde, spiegelt einen wichtigen Charakterzug der Epoche. Die vorige Periode des späten Adenauer und des Kanzlers Erhard war durch einen gewissen Immobilismus gekennzeichnet. Der Konsens zwischen den beiden großen Parteien - CDU/CSU und SPD - war selten geworden. Verfassungsänderungen nun brauchten einen breiten Konsens. Die Regierungsmehrheit aber wollte weder viel Änderung, noch Konzessionen an den Konsens. Und die Opposition war interessiert, ihre Eigenart darzustellen. Damit stauten sich alle Vorhaben, die nur durch Verfassungsänderung bewirkt werden konnten. Die Bildung der Großen Koalition wirkt wie die Öffnung einer Schleuse. Zwölf Änderungen des Grundgesetzes fallen in diese Periode. Die spektakulärste Änderung stellt der Einbau der Notstandsverfassung dar 145). Von sozialer Relevanz sind am ehesten die Verfassungsänderungen, welche die Wirtschafts- und Finanzverfassung betreffen 146). Auch jetzt freilich ist es immer noch die "Steuerverfassung", die den Verfassungsgeber plagt. Die "Gesamtfinanzverfassung", welche die Finanzmassen der Sozialversicherung einschließen müßte, sieht der Verfassungsgeber immer noch nicht - und wohl nicht zum Schaden der Sozialpolitik. Diese Eigenart des Grundgesetzes ist an dieser Stelle nicht zuletzt deshalb in Erinnerung zu bringen, weil es das Jahr 1968 ist, von dem an die Sozialbeiträge höher steigen als die Steuerlasten 147). Die verfassungsrechtliche Anerkennung des "gesamtwirtschaftlichen Gleichgewichts" (Art. 104 Abs.3 S.1, Art.109 Abs.4, Art. 115 Abs. 1 S.2 GG) und des "wirtschaftlichen Wachstums" (Art.104a S.1)

Bd. 12 (1965), S. 560 ff und dessen Bibliographie.

145) 17. Gesetz zur Ergänzung des Grundgesetzes vom 14.Juni 1968.

146) 15. Gesetz zur Änderung des Grundgesetzes vom 8.Juni 1967; 20. Gesetz zur Änderung des Grundgesetzes vom 12. Mai 1969; 21. Gesetz zur Änderung des Grundgesetzes ( $F$ inanzreformgesetz) vom 12. Mai 1969. Dazu eine Änderung des Art. 120 GG durch das 24. Gesetz zur Änderung des Grundgesetzes vom 28. Juli 1969.

147) "Wachstum und Währung", Sachverständigenrat zur Begutachtung der gesamtwirtschaftlichen Entwicklung, Jahresgut- 
stammen ebenso aus dieser Zeit wie die Gemeinschaftsaufgaben der Verbesserung der regionalen Wirtschaftsstruktur und der Agrarstruktur (Art.91a Abs.1 GG). Auch der Gedanke wirtschaftlicher Planung findet Eingang in das Grundgesetz (Art.91a Abs.3, $91 \mathrm{~b}, 109$ Abs. 3 GG). Die Wirtschafts- und Finanzverfassung ist damit gegenüber dem Stand, welcher der unten wiedergegebenen Arbeit zugrunde lag, ganz wesentlich verändert. Die Darlegungen dieser Arbeit sind in kaum einem Gegenstande so "historisch" wie im Hinblick auf die Finanzverfassung. Zu vermerken ist ferner, daß der Bund in dieser Epoche seine sozialpolitischen Zuständigkeiten geringfügig ausweiten konnte: um die Regelung der Ausbildungsbeihilfen (Art. $74 \mathrm{Nr} .13$ ) und um die wirtschaftliche Sicherung der Krankenhäuser und die Regelung der Krankenhauspflegesätze (Art. 74 Nr.19a GG) 148).

In der Folgezeit verebbt der Strom der Verfassungsänderungen. Die sozialliberale Koalition hat dafür nicht die Mehrheit. Man richtet sich wieder auf schmäleren Konsens ein. Außerdem ist der Nachholbedarf der 60 er Jahre auch befriedigt. Während der beiden Kabinette Brandt zählen wir fünf Verfassungsänderungen. Sozialpolitisch relevant ist wohl nur die Stärkung und Neustrukturierung der Bundeskompetenzen auf dem Gebiet der Beamten- und Richterbesoldung ${ }^{149)}$.

In der Verfassungsinterpretation zeigt sich nicht minder ein neuer Aufbruch. Daß erstmals in der Geschichte der Bundesrepublik die Sozialdemokratische Partei zunächst an der Bundesregierung beteiligt war, sie später sogar dominierte, ist kaum mehr als ein Symbol für den weit gespannten und reich differenzierten Aufbruch "nach links", der sich in vielen Kreisen nunmehr vollzieht ${ }^{150)}$. Verfassungsrechtlich reicht das von der Wiederentdeckung des Sozialstaatsprinzips ${ }^{151)}$ und der Tendenz, Freiheitsrechte als Teilhaberechte zu verstehen ${ }^{152)}$, über viel-

achten 1978/79 (1978), S. 113 .

148) 22. Gesetz zur Änderung des Grundgesetzes vom 12. Mai 1969.

149) 28. Gesetz zur Änderung des Grundgesetzes vom 18. März 1971.

150) S. Peter Pulte, Die neue Linke, 1973.

151) S. insbes. Hans-Hermann Hartwich, Sozialstaatsprinzip und gesellschaftlicher Status quo, 1970; Karl Albrecht Schachtschneider, Das Sozialprinzip 1974.

152) S. dazu z.B. die Darstellungen bei Ernst Wolfgang Böckenförde a.a.O. (Anm.112) S. 1535 ff; Dietrich Wiegand, Sozialstaatsklausel und soziale Teilhaberechte, DVB1. 27.Jhg. (1974), S. 657 ff; Hans Heinrich Rupp, a.a.O. (Anm.112) S. $183 \mathrm{ff}$. 
fältige Versuche "linker", "sozialistischer" Uminterpretation des Grundgesetzes - in Sonderheit seines Demokratiebegriffs bis hin zur Negation von "Opas Grundgesetz". Als am Finde der Periode das Grundgesetz 25 Jahre alt wird, beklagt Hans Peter Ipsen die Gefährdung des Verfassungskonsenses 153). Doch durchaus auch im Spielraum verbleibenden Konsenses materialisiert sich der Geist der Zeit. 1971 befassen sich die Deutschen Staatsrechtslehrer mit dem Thema "Grundrechte im Leistungsstaat" 154). Und 1972 spricht das Bundesverfassungsgericht zum ersten Mal von einem Freiheitsrecht - dem Recht auf freie Wahl der Ausbildungsstätte (Art. 12 Abs. 1 S. 1 GG) - als einem Teilhaberecht 155). Im allgemeinen freilich bleibt es bei der Tendenz immer differenzierterer Anwendung der Verfassung auch im Bereich der Sozialpolitik 156).

Die wirtschaftliche Entwicklung in der Periode war reich an Veränderungen. Am Anfang stand die erste schwere Rezession in der Bundesrepublik 157), von der sich die Wirtschaft freilich rasch erholte. Die Arbeitslosenquote, die von 1966 auf 1967 von $0,7 \%$ auf $2,1 \%$ gesprungen war, sank bereits 1968 wieder auf $1,5 \%$ und blieb von 1969 bis 1971 bei $0,8 \% 158)$. Zugleich war zunächst der Preisantrieb gebrochen, der sich im Verlauf der vorigen Periode immer deutlicher gezeigt hatte. Die Inflation stellte sich freilich rasch wieder ein. Die Preissteigerungsrate wuchs von 1969 bis 1974 unaufhörlich - bis zu einer seit 1951 nicht mehr erreichten Höhe 159). Am Ende der Periode zeichnete sich erneut eine Rezession, die schärfste der bisherigen Geschichte der Bundesrepublik, ab. Im Herbst 1973 kam es zur sogenannten Erdölkrise. 1974 stagnierte das Bruttosozialprodukt. 1975 blieb es erstmals hinter dem des Vorjahres zurück 160). Die Arbeitslosenquote, die schon vorher wieder angestiegen war

153) Hans Peter Ipsen, Über das Grundgesetz - Nach 25 Jahren, DÖV, 27.Jhg. (1974), S. 289 ff. S. zum gleichen Anlaß als "Gegenstück" etwa Peter Römer, Das malträtierte Grundgesetz, Blätter für deüsche und internationale Politik, 1974, S. $443 \mathrm{ff}$.

154) Mit Referaten von Wolfgang Martens und Peter Häberle, VVDStRL, Heft 30 (1972), S. 193 ff.

155) BVerfG 33, 303 (330 f).

156) S. für das Sozialrecht oben S. LXXIX, insbes. Anm. 124.

157) S. z.B. Neumann a.a.O. (Anm.113) S. 350.

158) 1970 sank sie sogar auf $0,7 \%$.

159) S. z.B. "Wachstum und Währung" a.a.O. (Anm.147) s.48. 160) "Wachstum und Währung" a.a.O. (Anm.147) S.240 f. 
(1972: 1, 1\%; 1973: 1,2\%), sprang 1974 auf 2,6\% 161). Zugleich stieg der Preisindex, wie schon bemerkt, 1973/74 auf eine Rekor.dhöhe 162). Alles in allem: die Epoche begann mit einer Rezession, die schon 1968/69 spürbarer Erholung wich; der folgende mäßige Abstieg ging von 1973 an jedoch in einen krisenhaften Absturz über.

Die sozialpolitische Szene der Zeit war freilich weder von der Rezession am Anfang gekennzeichnet, noch konnte sie von der Krise am Ende wesentlich geprägt sein. Für sie war entscheidend, daß man sich in der vorigen Periode an den Wohlstand gewöhnt hatte. Ja, nicht nur das Bewußtsein, eine Wohlstandsgesellschaft 163) zu sein, auch die Rede von der Überflußgesellschaft war selbstverständlich geworden. Daß es etwas zum Verteilen gab, schien nicht mehr das Problem zu sein. Die Frage war nur mehr die des richtigen "Wie". Und der Aufschwung von 1968/1969 ließ es trotz der vorausgegangenen Rezession sinnlos erscheinen, diese sozioökonomische Unterstellung in Zweifel zu ziehen. Die Euphorie der. "Leistungsverbesserung" kam auf. Zugleich bordete die Sozialpolitik über ihr traditionelles Ufer. Sie verlor sich in dem weiten Feld der Gesellschaftspolitik. Der Kampf gegen Not und Ungleichheit veredelte sich zum Bemühen um mehr "Lebensqualität"164). Die lange Dauer der bürgerlichen Regierungsmehrheit und die gewisse Sterilität ihrer letzten Kabinette hatte die Frage nach Alternativen aufgestaut 165). Die Beteiligung der Sozialdemokratie an der Regierung, alsbald die Führung der Regierung durch die Sozialdemokratie schien manchem nun den verschiedensten Zielen, ja Utopien Raum zu geben. Ein vielgliedriger Fächer politischer Auffassung und Haltung öfnet sich weit über alles, was mit Sozialdemokratie gemeint ist und von ihr erwartet werden kann, hinaus nach links 166). Ein neues Demokratieverständnis, das sich auf Partizipation gründete 167), schien

161) "Wachstum und Währung" a.a.O. (Anm. 147) S. 234.

162) S. z.B. Neumann a.a.O. (Anm.113) S.316 f.

163) Nicht zufällig erscheint 1967 Christian von Ferbers "Sozialpolitik in der Wohlstandsgesellschaft"

164) S. etwa Friedrich Wilhelm von Dörge (Hrsg.), Qualität des Lebens, 1973 .

165) S. zu den Vorhaben der "inneren Reformen": Hans Werner Kettenbach, Der lange Marsch der Bundesrepublik, 1971.

166) Exemplarisch für die Kritik der "neuen Linken" am Sozialstaat: Wolfgang Müller-Christel Neusüß, Die Sozialstaatsillusion und der. Widerspruch von Lohnarbeit und Kapital, in: Problem des Klassenkampfes, Sonderheft 1, 1971. 
fältige Versuche "linker", "sozialistischer" Uminterpretation des Grundgesetzes - in Sonderheit seines Demokratiebegriffs bis hin zur Negation von "Opas Grundgesetz". Als am Ende der Periode das Grundgesetz 25 Jahre alt wird, beklagt Hans Peter Ipsen die Gefährdung des Verfassungskonsenses 153). Doch durchaus auch im Spielraum verbleibenden Konsenses materialisiert sich der Geist der Zeit. 1971 befassen sich die Deutschen Staatsrechtslehrer mit dem Thema "Grundrechte im Leistungsstaat" 154). Und 1972 spricht das Bundesverfassungsgericht zum ersten Mal von einem Freiheitsrecht - dem Recht auf freie Wahl der Ausbildungsstätte (Art. 12 Abs. 1 S. 1 GG) - als einem Teilhaberecht 155$)$. Im allgemeinen freilich bleibt es bei der Tendenz immer differenzierterer Anwendung der Verfassung auch im Bereich der Sozialpolitik 156).

Die wirtschaftliche Entwicklung in der Periode war reich an Veränderungen. Am Anfang stand die erste schwere Rezession in der Bundesrepublik 157), von der sich die Wirtschaft freilich rasch erholte. Die Arbeitslosenquote, die von 1966 auf 1967 von $0,7 \%$ auf $2,1 \%$ gesprungen war, sank bereits 1968 wieder auf 1,5\% und blieb von 1969 bis 1971 bei $0,8 \% 158$ ). Zugleich war zunächst der Preisantrieb gebrochen, der sich im Verlauf der vorigen Periode immer deutlicher gezeigt hatte. Die Inflation stellte sich freilich rasch wieder ein. Die Preissteigerungsrate wuchs von 1969 bis 1974 unaufhörlich - bis zu einer seit 1951 nicht mehr erreichten Höhe 159). Am Ende der Periode zeichnete sich erneut eine Rezession, die schärfste der bisherigen Geschichte der Bundesrepublik, ab. Im Herbst 1973 kam es zur sogenannten Erdölkrise. 1974 stagnierte das Bruttosozialprodukt. 1975 blieb es erstmals hinter dem des Vorjahres zurück 160). Die Arbeitslosenquote, die schon vorher wieder angestiegen war.

153) Hans Peter Ipsen, Über das Grundgesetz - Nach 25 Jahren, DÖV, 27.Jhg. (1974), S.289 ff. S. zum gleichen Anlaß als "Gegenstück" etwa Peter Römer, Das malträtierte Grundgesetz, Blätter für deüsche und internationale Politik, 1974 , S. $443 \mathrm{ff}$.

154) Mit Referaten von Wolfgang Martens und Peter Häberle, VVDStRL, Heft 30 (1972), S. $193 \mathrm{ff}$.

155) BVerfG 33, 303 (330 f).

156) S. für das Sozialrecht oben S. LXXIX, insbes. Anm. 124.

157) S. z.B. Neumann a.a.O. (Anm.113) S. 350.

158) 1970 sank sie sogar auf $0,7 \%$.

159) S. z.B. "Wachstum und Währung" a.a.O. (Anm.147) S.48. 160) "Wachstum und Währung" a.a.O. (Anm.147) S.240 f. 
(1972: 1, 1\%; 1973:1,2\%), sprang 1974 auf 2,6\% 161). Zugleich stieg der Preisindex, wie schon bemerkt, 1973/74 auf eine Rekordhöhe 162). Alles in allem: die Epoche begann mit einer Rezession, die schon 1968/69 spürbarer Erholung wich; der folgende mäßige Abstieg ging von 1973 an jedoch in einen krisenhaften Absturz über.

Die sozialpolitische Szene der Zeit war freilich weder von der Rezession am Anfang gekennzeichnet, noch konnte sie von der Krise am Ende wesentlich geprägt sein. Für sie war entscheidend, daß man sich in der vorigen Periode an den Wohlstand gewöhnt hatte. Ja, nicht nur das Bewußtsein, eine Wohlstandsgese11schaft 163) zu sein, auch die Rede von der Überflußgesellschaft war selbstverständlich geworden. Daß es etwas zum Verteilen gab, schien nicht mehr das Problem zu sein. Die Frage war nur mehr die des richtigen "Wie". Und der Aufschwung von 1968/1969 ließ es trotz der vorausgegangenen Rezession sinnlos erscheinen, diese sozioökonomische Unterstellung in Zweifel zu ziehen. Die Euphorie der "Leistungsverbesserung" kam auf. Zugleich bordete die Sozialpolitik über ihr traditionelles Ufer. Sie verlor sich in dem weiten Feld der Gesellschaftspolitik. Der Kampf gegen Not und Ungleichheit veredelte sich zum Bemühen um mehr "Lebensqualität" 164). Die lange Dauer der bürgerlichen Regierungsmehrheit und die gewisse Sterilität ihrer letzten Kabinette hatte (i) Frage nach Alternativen aufgestaut ${ }^{165)}$. Die Beteiligung der Sozialdemokratie an der Regierung, alsbald die Führung der Regierung durch die Sozialdemokratie schien manchem nun den verschiedensten Zielen, ja Utopien Raum zu geben. Ein vielgliedriger Fächer politischer Auffassung und Haltung öffnet sich weit über alles, was mit Sozialdemokratie gemeint ist und von ihr erwartet werden kann, hinaus nach links 166). Ein neues Demokratieverständnis, das sich auf Partizipation gründete 167), schien

161) "Wachstum und Währung" a.a.O. (Anm. 147) S. 234.

162) S. z.B. Neumann a.a.O. (Anm.113) S.316 f.

163) Nicht zufällig erscheint 1967 Christian von Ferbers "Sozialpolitik in der Wohlstandsgesellschaft".

164) S. etwa Friedrich Wilhelm von Dörge (Hrsg.), Qualität des Lebens, 1973.

165) S. zu den Vorhaben der "inneren Reformen": Hans Werner Kettenbach, Der lange Marsch der Bundesrepublik, 1971.

166) Exemplarisch für die Kritik der "neuen Linken" am Sozialstaat: Wolfgang Müller-Christel Neusüß, Die Sozialstaatsillusion und der. Widerspruch von Lohnarbeit und Kapital, in: Problem des Klassenkampfes, Sonderheft 1, 1971. 
Bildungspolitik zu einem wichtigen Komplement herkömmlicher Sozialpolitik erhoben wird 179). Daß die Studentenrevolte in das Aufbruchbild dieser Epoche gehört, konnte dies nur verstärken.

Auch eine noch so knappe Skizze der sozialpolitischen Szene der Zeit kann aber nicht darauf verzichten, darauf hinzuweisen, daß noch vor der Erdölkrise der Bericht des Club of Rome die Götterdämmerung des wirtschaftlichen Wachstums einleitete ${ }^{180)}$. Eine Epoche, die sich mit der Summe dessen, was in ihr gewollt wurde, übernommen hatte, atmete befreit auf, als ihr die Grenzen des Machbaren an die Wand geschrieben wurden 181).

Auch der Stil des Nachdenkens und Redens über Sozialpolitik ändert sich in dieser Epoche. Da ist zunächst die gewaltige Zunahme von Berichten zu nennen, welche die Bundesregierung oder einzelne Bundesministerien - teils durch das Gesetz verpflichtet, teils durch den Bundestag aufgefordert, teils auch aus eigener Initiative in regelmäßigen Perioden, in unregelmäßigen Abständen oder einmalig - erstatten 182). Seit 1968 erstellt die Bundesregierung ein Sozialbudget 183). Ab 1970 erscheint das Sozialbudget im Verbund (grundsätzlich) jährlicher Sozialberichte, in denen die Bundesregierung sozialpolitische Vorhaben und deren Verwirklichung darstellt. Doch ist dies nur ein Beispiel unter vielen. Zu nennen sind ferner Prognosen, Projektionen, Programme und Pläne als Instrumente politischer Integration, Diskussion und Willensbildung 184). Dem intensiven Bemühen um Informationen und Daten, der Ausweitung der sozialpolitischen Diskussion zu

179) S. dazu aus der Zeit: Bildungsbericht der Bundesregierung 1970.

180) Dennis L. Meadows, The Limits to Growth, New York 1972.

181) S. zusammenfassend zur Epoche Richard Löwenthal und Hans Peter Schwarz (Hrsg.), Die Zweite Republik, 1974.

182) Die erste dem Verfasser bekannte Übersicht über das Berichtswesen der Bundesregierung findet sich leider erst für die 7. Wahlperiode: Verhandlungen des Deutschen Bundestages, 7. Wahlperiode, Sachregister, S. 327 If.

183) S. dazu Hermann Berié, Das Sozialbudget: Grundlagen, Methoden und Verfahren, 1970.

184) S. allgemein für den Standpunkt der Bundesregiel'ung etwa Reimut Jochimsen, Planung im staatlichen Bereich, Bulletin des Presse- und Informationsamtes der Bundesregierung 1971, S. $1236 \mathrm{ff}$. S. ferner etwa die von Joseph $\mathrm{H}$. Kaiser herausgegebene Reihe "Planung" Bd. I 1975, Bd. II 1966, Bd. III 1968, Bd. IV 1970, Bd.V 1971. Speziell für den Sozialbereich s. Reinhard Bartholomei, Sozialplanung, in: 
einem gesellschaftspolitischen "Bemühen um mehr Lebensqualität" und insbesondere auch dem Überdruß an einer monetär orientierten Sozialpolitik entsprach es, über Statistiken und Budgetrechnungen hinaus zu "sozialen Indikatoren" vorzustoßen 185).

Im sozialpolitischen Schrifttum wird das Spektrum der Auseinandersetzungen vor allem dadurch erweitert, daß die soziologische Komponente verstärkt hervortritt ${ }^{186)}$. Franz Xaver Kaufmanns "Sicherheit als soziologisches und sozialpolitisches Problem - Untersuchungen zu einer Wertidee hochdifferenzierter Gesellschaften" (1970) schafft nachhaltige Ernüchterung über die Selbstgef älligkeit einer Politik sozialer Sicherung. Vermerkt seien endlich die zur Epoche gehörenden Bemühungen um wissenschaftliche Systemfindung der Sozialpolitik 187).

Legislatorisch brachte die Zeit zwei weitreichende kodifikatorische Projekte: das eines Arbeitsgesetzbuches 188) und das eines Sozialgesetzbuches ${ }^{189)}$. Beide Vorhaben wurden mit der

Alfred Christmann u.a. (Hrsg.),Sozialpolitik, Ziele u. Wege, 1974, S. $57 \mathrm{ff}$. Zahlreiche weitere Beispiele s. bei Hans F.Zacher, Bericht über das in der Bundesrepublik Deutschland geltende Wirtschaftsrecht, Kommission der Europäischen Gemeinschaften, Reihe Wettbewerb - Rechtsangleichung, Heft 20, 1973, S. $33 \mathrm{ff}, 39 \mathrm{ff}$.

185) Speziell zu diesem Zusammenhang: Wolfgang Zapf, Lebensqualität und soziale Indikatoren, Archiv für Wissenschaft und Praxis der sozialen Arbeit, 3. Jhg. (1972), S. $267 \mathrm{ff}$. S. zur Diskussion der Zeit insbes. im sozialpolitischen Zusammenhang Hans F.Zacher, Soziale Indikatoren als politisches und rechtliches Phänomen, VSSR Bd. II (1974) S. $15 \mathrm{ff}$.

186) Gleich am Anfang der Epoche: Christian von Ferber, Sozialpolitik in der Wohlstandsgesellschaft, 1967.

187) Horst Sanmann (Hrsg.), Leitbilder und Zielsysteme der Sozialpolitik, 1973.

188) S. dazu etwa "Kommission zur Erstellung eines Arbeitsgesetzbuches", Arbeit und Recht XVII.Jhg. (1970), S. 371. Thilo Ramm, Arbeitsgesetzbuch, Konstituierung der Sachverständigenkommission, Deutsche Richterzeitung 1971, S. $31 \mathrm{ff}$; ders., Sachverständigenkommission für ein Arbeitsgesetzbuch konstituiert, Recht der Arbeit (24.Jhg.) 1971, S. 49 ff; ders., Arbeitsgesetzbuch und politische Entscheidung, Zeitschrift für Rechtspolitik (5.Jhg. 1972), S. $13 \mathrm{ff}$.

189) Zum Sozialgesetzbuch s. Hans F.Zacher, Materialien 
Regierungserklärung des Bundeskanzlers Brandt 1969 eingeleitet und 1970 in Angriff genommen - bisher freilich mit sehr unterschiedlichem Ertrag ${ }^{190)}$.

Im übrigen ist aus der Gesetzgebung dieser Zeit hervorzuheben:

1967 Finanzänderungsgesetz, Gesetz zur Förderung der Stabilität und des Wachstums der Wirtschaft

1969 Arbeitsförderungsgesetz, Erstes Arbeitsrechtsbereinigungsgesetz, Berufsbildungsgesetz, Gesetz über die Fortzahlung des Arbeitsentgelts im Krankheitsfalle (Lohnfortzahlungsgesetz)

1970 Gesetz über den Wegfall des von Rentnern für ihre Krankenversicherung zu tragenden Beitrags, Bundesausbildungsförderungsgesetz,

3. Vermögensbildungsgesetz, Gesetz über vermögenswirksame Leistungen für Bundesbeamte, Berufssoldaten und Soldaten auf Zeit

1971 Vereinheitlichung und Neuregelung des Besoldungsrechts in Bund und Ländern, Unfallversicherung für Schüler und Studenten sowie Kinder in Kindergärten, Graduiertenförderungsgesetz, Gesetz über den Kündigungsschutz für Mietverhältnisse über Wohnraum, Gesetz über die Errichtung einer Stiftung "Hilfswerk für behinderte Kinder"

1972 Betriebsverfassungsgesetz, Gesetz zur Förderung sozialer Hilfsdienste, Gesetz zur wirtschaftlichen Sicherung der Krankenhäuser und zur Regelung der Krankenhauspflegesätze, Arbeitnehmerüberlassungsgesetz, Gesetz über die Krankenversicherung der Landwirte, Rentenreformgesetz (Einführung einer flexiblen Altersgrenze, Öffnung der Rentenversicherung für Selbständige und Hausfrauen, Rente nach Mindesteinkommen)

a.a.O. (Anm.46), insbes. Teil A; Peter Krause, Die Entwicklungsgeschichte des Sozialgesetzbuches, Blätter für Steuerrecht, Sozialversicherung und Arbeitsrecht, 32. Jhg. (1977), S. $65 \mathrm{ff}$.

190) S. zu den Ergebnissen der Arbeitsgesetzbuch-Kommission: Entwurf eines Arbeitsgesetzbuches - Allgemeines Arbeitsvertragsrecht - hrsg. v. Bundesminister f. Arbeit und Sozialordnung, 1977. S. zu den Ergebnissen der Sozialgesetzbuch-Kommission Zacher, a.a.O. (Anm.46). 
1973 Gesetz über die Mindestanforderungen an Unterkünfte für Arbeitnehmer, Gesetz über Betriebsärzte, Sicherheitsingenieure und andere Fachkräfte für Arbeitssicherheit, Gesetz zur Verbesserung von Leistungen in der gesetzlichen Krankenversicherung ( $z$. B. unbegrenzte Krankenhauspflege, Haushaltshilfe, Krankengeld und Sonderurlaub wegen Pflege eines erkrankten Kindes)

1974 Bundespersonalvertretungsgesetz, Gesetz zur Weiterentwicklung des Schwerbeschädigtenrechts.

Was die wissenschaftliche Pflege des Sozial rechts anlangt, vereinigten sich in dieser Zeit eine Reihe günstiger Umstände. Schon die vorherige Periode hatte den Grund für eine wieder qualifiziertere Pflege des Sozialrechts gelegt. Das zeigte sich in zwei Habilitationsschriften, die nunmehr erschienen: Wolfgang Gitter, Schadensausgleich im Arbeitsunfallrecht (1969) und Harald Bogs, Die Sozialversicherung im Staat der Gegenwart (1973). Ende der 60er Jahre wurden die Ausbildungs- und Prüfungsordnungen für Juristen umgestaltet und das Sozialrecht fand - im einzelnen auf sehr verschiedene Weise - unter den Wahlfächern Platz 191). Das stimulierte auch Verlage und Autoren, sich um Studienliteratur zu bemühen. Endlich gab das Kodifikationsvorhaben des Sozialgesetzbuchs kräftige Impulse. Eine Reihe von Autoren fand neues Interesse und Mut, sich diesem Gebiet zuzuwenden 192).

Eine Linie rechtspolitischer und rechtsdogmatischer Befassung mit dem Sozialrecht ist freilich besonders zu erwähnen. Im Zusammenhang mit dem Vorhaben, das Scheidungsrecht zu reformieren, erwies sich, daß die Gleichbehandlung von Mann und Frau im Sozialrecht und - viel allgemeiner noch - die Harmonisierung von Familienrecht und Sozialrecht nicht länger zurückgestellt werden können. Einmal mehr war es der Deutsche Juristentag, der den Auftakt gab. Er behandelte 1968 das Thema "Empfiehlt es sich, die gesetzlichen Vorschriften über die soziale Sicherung der nichtberufstätigen Frau während und nach der Ehe, insbesondere

191) S. dazu Rupert Scholz, Das Sozialrecht im neuen Ausbilclungs- und Prüfungsrecht, Zeitschrift für Sozialreform, 17. Jhg. (1971), S. $641 \mathrm{ff}$; s. dazu auch Bernd v. Maydell, Untersuchungen über die sozialrechtliche Ausbildung der Juristen an den Universitäten der Bundesrepublik, insbes. im Wahlfachstudium, Schriftenreihe des Deutschen Sozialgerichtsverbandes, Bd.XVI, 1978, S. $110 \mathrm{ff}$.

192) S. dazu oben S. LXII. 
im Falle der Scheidung zu ändern?" 193). Im weiteren Rahmen dieser Diskussionen 194) löste sich das Sozialrecht noch deutlicher als bisher aus einer Monogamie mit dem Arbeitsrecht, um sich seinem anderen genuinen privatrechtlichen "Partner", dem Familienrecht, zuzuwenden. Es verstand sich nicht länger nur als Kompensation von Überlastung und Insuffizienz im familiären Bedarfsdeckungs- und Umverteilungsverband. Der erste, wichtigste Abschluß dieser Entwicklung, die Scheidungsrechtsreform und der in sie einbezogene Versorgungsausgleich, gehören freilich der nächsten Periode an.

Abschließend wieder der Blick auf die internationalen $\mathrm{Zu}-$ s a m m e nhänge. Die prägenden außenpolitischen Ereignisse dieser Zeit liegen auf dem Gebiet der Ostpolitik und der sog. innerdeutschen Beziehungen. Ihre sozialpolitischen Implikationen sind verstreut ${ }^{195)}$ und können hier nicht analysiert werden. Die internationale Integration der Bundesrepublik fand ihren Höhepunkt mit dem Eintritt in die Organisation der Vereinten Nationen (1973). Bemerkenswert ist, daß der Anteil der Entwicklungshilfe-Leistungen am Bruttosozialprodukt in dieser Zeit zurückgegangen ist, um sich erst in der nächstfolgenden Periode wieder zu erhöhen ${ }^{196}$ ).

193) S. dazu das Gutachten von Herbert Langkeit, Verhandlungen des 47. Deutschen Juristentages 1968, Teil F.; ferner das Referat von Hans F.Zacher, Sitzungsbericht $O$ des 47. Deutschen Juristentages (1968), S.O 7 ff.

194) S. dazu umfassend und grundlegend Franz Ruland, Familiärer Unterhalt und Leistungen der sozialen Sicherheit, 1973.

195) Z.B. deutsch-polnisches Rentenabkommen, Problematik der Familienzusammenführung, der Aussiedlung usw.

196) Jahr Anteil der Gesamtlei- Anteil der öffentlichen Mittel stungen am Sozial- für Entwicklungshilfe am produkt in $\mathrm{v} . \mathrm{H}$.

Bruttosozialprodukt in $\mathrm{v} . \mathrm{H}$.

$\begin{array}{lll}1967 & 0,92 & 0,41 \\ 1968 & 1,23 & 0,41 \\ 1969 & 1,31 & 0,38 \\ 1970 & 0,80 & 0,32 \\ 1971 & 0,88 & 0,34 \\ 1972 & 0,67 & 0,31 \\ 1973 & 0,52 & 0,32 \\ 1974 & 0,83 & 0,37 \\ 1975 & 1,19 & 0,40 \\ 1976 & 1,19 & 0,31\end{array}$

Quelle: 3. Entwicklungshilfebericht der Bundesregierung BT-Drucks. 8/1185, S.147. 
Bemerkenswert entwickelt hat sich in dieser Zeit aber auch die (2uote ausländischer $\Lambda$ rbeitnehmer in der Bundesrepublik. Sie stieg von 6, 1\% im Jahr 1966 bis 11,9\% im Jahr 1973 197).

\section{Zurfünften Periode ( 1974 bis zur Gegenwart)}

Die fünfte der hier skizzierten Perioden begann mit der Bildung (les ersten Kabinetts Schmidt im Mai 1974. Der Bundestag wurde im Herbst 1976 neu gewäh1t. Daraufhin wurde erneut ein sozialliberales Kabinett unter. Helmut Schmidt gebildet. Die politische Konstellation war in dieser Zeit durch die knappe Mehrheit der Bundesregierung im Bundestag und - vereinfacht gesagt - die Mehrheit der. Opposition im Bundesrat gekennzeichnet. Das "Kopf-an-Kopf-Rennen" von Regierung und Opposition in der Bundespolitik lähmte vermittels der Machtposition im Bundesrat mitunter die Innenpolitik. Diese Situation, vor allem aber die mangelnde Bereitschaft zu einem übergreifenden Konsens drückt sich in der geringen Zahl verfas sungsändernder Geset$z \mathrm{e}$ aus. Insgesamt wurde die Verfassung in dieser Zeit nur dreimal geändert - jedesmal ohne sozialpolitische Relevanz.

Politische Ambiance ler Verfassung und Verfassungsinterpretation hatten schon zu Beginn der Periode wieder in den engeren Rahmen les Verfassungskonsenses, wie er sich von len späten 40er Jahren bis zur Mitte der 60er Jahre dargestellt hatte, zurückgefunden. Gewiß bliebe vieles von dem reichen Spektrum der unruhigen Jahre nach 1968 in der Diskussion 198) und relevant 199). Und gewiß auch haben Verfassungsrechtfertigung und -interpretation aus der Auseinandersetzung mit einem vordem ungeahnt reichen und breiten Spektrum von Meinungen über die Verfassung und ihren Inhalt gelernt 200). Jedoch ist das

197) $\begin{array}{ll}1966 & 6,1 \text { v.H. der Arbeitnehmer insgesamt } \\ 1967 & 4,7 \\ 1968 & 5,1 \\ 1969 & 7,2 \\ 1970 & 9,1 \\ 1971 & 10,3 \\ 1972 & 10,8 \\ 1973 & 11,9 \\ 1974 & 10,4\end{array}$

Quelle: Neumann, a.a.O. (Anm.113) S. 34.

198) S. etwa Udo Mayer - Gerhard Stuby (Hrsg.), Das lädierte Grundgesetz, 1977 .

199) S. z.B. Helmut Ridder, Die soziale Ordnung des Grundgesetzes, 1975 .

200) Umfassend reflektiert bei Peter Häberle, Verfassung als 
Band der Auseinandersetzungen wieder enger, sind die Widersprüche weniger und schwächer geworden 201). Das vielleicht eindrucksvollste Dokument der verfassungspolitischen Beruhigung ist der Schlußbericht der "Enquête-Kommission Verfassungsreform" von 1976 202). Diese Enquête-Kommission war erstmals durch Bundestagsbeschluß vom 8. Oktober 1970 eingesetzt worden. Nach Auflösung des Sechsten Deutschen Bundestages mußte sie durch den Siebten Deutschen Bundestag bestätigt werden. Dies geschah am 22. Februar 1973. Der Schlußbericht trägt das Datum vom 2. Dezember 1976. Er schlägt kaum wesentliche Änderungen am Grundgesetz vor, wenigstens keine von ersichtlicher sozialpolitischer Relevanz.

Die sozialpolitische Relevanz der Verfassung 203) äußerte sich vor allem auf zwei Gebieten: dem der Mitbestimmung und dem der Gleichberechtigung von Mann und Frau im Sozialrecht. In der Auseinandersetzung um die Mitbestimmung hatte im Dezember 1974 eine Anhörung verfassungsrechtlicher Sachverständiger 204)

offener Prozeß, 1979.

201) Zur Bewältigung der vielfältigen Probleme des Grundrechtsverständnisses s. insbes. Ernst Wolfgang Böckenförde, a.a.O. (Anm.112); Ernst Friesenhahn, Der Wandel des Grundrechtsverständnisses, Sitzungsbericht F/G zum 50. Deutschen Juristentag, 1974; Peter Badura, Das Prinzip der sozialen Grundrechte und seine Verwirklichung im Recht der Bundesrepublik Deutschland, Der Staat Bd. 14 (1975), S. 17 ff; Hans Heinrich Rupp, a.a.O. (Anm.112); Hans F. Zacher, Freiheits- und Sozialrechte im modernen Verfassungsstaat, in: Stanis-Edmund Szydzik (Hrsg.), Christliches Gesellschaftsdenken im Umbruch, 1977, S. 75 ff; Konrad Hesse, Bestand und Bedeutung der Grundrechte in der Bundesrepublik Deutschland, Europäische Grundrechte-Zeitschrift 5. Jhg. (1978), S. 427 ff. - Zum jüngsten Stand der Diskussion um die Interpretation von Grundrechten als Teilhaberechte s. Rüdiger Breuer, Grundrechte als Anspruchsnormen, in: Verwaltungsrecht zwischen Freiheit, Teilhabe und Bindung. Festschrift aus Anlaß des 25jährigen Bestehens des Bundesverwaltungsgerichts, 1978, S. 89 ff; Konrad Redeker, Zur Ausgleichsfunktion von Teilhaberechten zwischen Freiheit und Bindung, ebenda, S. $511 \mathrm{ff}$.

202) Deutscher Bundestag Drucks. 7/5924.

203) S. dazu aus der Zeit Ernst Benda, Die verfassungsrechtliche Relevanz des Sozialrechts, a.a.O. (Anm.14).

204) Deutscher Bundestag, 7. Wahlperiode, Ausschuß für Arbeit und Sozialordnung, Protokoll Nr.62 über die Sitzung vom 
dazu geführt, daß der Regierungsentwurf 205) wesentlich verändert wurde. Auch gegenüber dem schließlichen Gesetz (1976) wurden jedoch weiter verfassungsrechtliche Einwände erhoben 206). Das Bundesverfassungsgericht hat sie in einer seiner wohl bedeutsamsten Entscheidungen am 1. März 1979 zurückgewiesen. Hinsichtlich der sozialrechtlichen Gleichstellung von Männern und Frauen im Arbeits- und Sozialrecht ist zunächst wieder eine Initiative des Deutschen Juristentages zu nennen, der 1974 diese Problematik in einer besonderen Abteilung erörterte ${ }^{207)}$. 1975 forderte das Bundesverfassungsgericht 208) vom Gesetzgeber, die Witwen- und Witwerversorgung in der Rentenversicherung bis zum Ende der übernächsten Legislaturperiode (1984) an die Erfordernisse des Gleichheitssatzes anzupassen 209). 1976 wurde der Versorgungsausgleich eingeführt 210). Um die Gleichstellung der Ehegatten im Rentensystem vorzubereiten, wurde 1977 von der Bundesregierung eine Kommission eingesetzt 211), deren Ergebnisse für 1979 erwartet werden 212).

\section{Dezember 1974.}

205) Deutscher Bundestag Drucks. 7/2172.

206) S. statt aller anderen: Peter Badura, Fritz Rittner u. Bernd Rüthers, Mitbestimmungsgesetz $1976 \mathrm{u}$. Grundgesetz - Gemeinschaftsgutachten - 1977. S. für die Verfassungsmäßigkeit statt aller anderen: Friedrich Kübler, Walter Schmidt u. Spiros Simitis, Mitbestimmung als gesetzgebungspolitische Aufgabe, 1978.

207) Verhandlungen des 50. Deutschen Juristentages, Bd. I (Gutachten) 1974, Teil D, Bd. II (Sitzungsberichte) 1975 Teil L. S. zu den einschlägigen Verhandlungen des 47. Deutschen Juristentages noch einmal oben S. XCIII.

208) BVerfG 39, 169.

209) S. zu dieser Aufgabe Hans F.Zacher, Gleiche Sicherung für Mann und Frau. Zur sozialpolitischen Relevanz der Rentenversicherung, Deutsche Rentenversicherung 1977, S. $197 \mathrm{ff}$.

210) Erstes Gesetz zur Reform des Ehe- und Familienrechts v. 14. Juli 1976, BGB1. I, S. 1421; Gesetz zur Änderung beamtenversorgungsrechtlicher Vorschriften vom 14. Juni 1976, BGB1.I, S.1477. Zu seiner verfassungs rechtlichen Problematik s. z.B. Franz Ruland u. Burkhard Tiemann, Versorgungsausgleich und steuerliche Folgen der Ehescheidung, 1977, S. $255 \mathrm{ff}$.

211) Bericht BAB1. 1977, S.487 f.

212) Hier mittlerweile auch die "zuwartende" Haltung des Bundesverfassungsgerichts (BVerfG 48, 346) in der Frage der Höhe der Witwenrente. 
Wirtschaftlich begann die Periode mit dem schweren Einbruch, den die Erdölkrise 1973 sicher nicht allein verursacht, jedenfalls aber ausgelöst hat. Zum einzigen Mal in der bisherigen Wirtschaftsgeschichte der Bundesrepublik Deutschland ging das Sozialprodukt 1975 zurück, um sich freilich in den folgenden Jahren wieder zu mehren 213). Die Inflation hatte 1974 mit einem Preiszuwachs von $7,0 \% 214$ ) ihren Höhepunkt erreicht, um bis 1977 auf 3,9\% zu sinken 215). Für 1978 zeichnete sich ein weiterer Rückgang ab 216). Die Hauptsorge blieb die ganze Zeit über die Beschäftigungslage. Die Arbeitslosenquote stieg von 2, 6 v. H. (1974) auf 4, 8 v.H. (1975), um von da an nur ganz langsam zu sinken 217).

Damit war auch schon eine sozialpolitische Hauptaufgabe der Periode gestellt: die Beschäftigungspolitik. Eine andere war, die Folgen der "Leistungseuphorie", die sich um 1970 eingestellt hatte, mit den Möglichkeiten in Einklang zu bringen. Sowohl in der Renten- als auch in der Krankenversicherung mußten Maßnahmen ergriffen werden, um Mittelaufkommen und Leistungsaufwand aneinander heranzuführen.

War die Sozialpolitik dadurch in Atem gehalten 218) und zugleich durch die schwierigen Mehrheitsverhältnisse in Bundestag und Bundesrat behindert, so gelangen ihr jedoch - auch über die Krisenbewältigung hinaus - beachtliche Schritte. Insgesamt blieb obwohl die Rede von den auch sonst großen Reformen, die für die vorige Periode so kennzeichnend gewesen war, abebbte - erhebliche Bewegung ${ }^{219)}$. Ja, es schien sich gerade in dieser Phase herauszustellen, daß Sozialpolitik sich stets bewegen muß, sich immer nur verwandeln, nie erfüllen kann 220$)$. In der sozialpoli-

213) S. "Wachstum und Währung" a.a.O. (Anm. 147) S.240 f.

214) Preisindex für die Lebenshaltung aller privaten Haushalte.

215) S. Sozialbericht 1978, S.324.

216) S. "Wachstum und Währung" a.a.O. (Anm.147) S. $306 \mathrm{f}$.

217) 1976: 4, 7\%; 1977: 4,6\% "Wachstum und Währung" a.a.O. (Anm. 147) S. 234.

218) S. Gerhard Bäcker, Wilhelm Breuer und Gerhard Naegele, Sozialpolitik in der Krise, Gewerkschaftliche Monatshefte 26. Jhg. (1975), S. $781 \mathrm{ff}$.

219) S. zum Vorigen etwa Erich Standfest, Sozialpolitik zwischen Anpassungsproblemen und Strukturkrisen, Gewerkschaftliche Monatshefte 29.Jhg. (1978), S.159 ff.

220) S. hierzu Hans F. Zacher, Was können wir über das Sozialstaatsprinzip wissen?, in: Hamburg, Deutschland, Europa. Festschrift für Hans Peter Ipsen, 1977, S. 208 ff. (S.239 ff); 
tischen Literatur setzt sich das soziologische Interesse fort 221 ). Hinzu trat die politikwissenschaftliche Aufmerksamkeit 222). Nicht minder aber fällt in der Sache auf, daß im sozialwissenschaftlichen Schrifttum nunmehr auch die Kritik am kapitalistischen Wohlfahrtsstaat 223), der Sozialpolitik als soziale Kontrol$1 \mathrm{e}^{224)}$ und als Element systemerhaltender gesellschaftlicher Reproduktion 225) zu Buch und Aufsatz wird.

Die Verwirklichung von Vorhaben der vorigen Periode 226), die Bewältigung der ökonomischen Schwierigkeiten der Zeit, die Harmonisierung von Leistungszusagen und -möglichkeiten und endlich die Eigendynamik der Sozialpolitik führten gerade in dieser Zeit $\mathrm{zu}$ einer besonderen Fülle sozialpolitischer Gesetze. Somit ist es hier noch schwerer als in der vorigen Periode, wichtige Gesetzgebungsakte von unwichtigen zu unterscheiden. Festgehalten seien:

1974 Gesetz über Konkursausfallgeld, Gesetz zur Reform der Einkommensteuer, des Familienlastenausgleichs und der Sparförderung (Umstellung des Familienlastenausgleichs

ders., Der Sozialstaat als Prozeß, Zeitschrift für die gesamte Staatswissenschaft, Bd. 134 (1978), S. 15 ff; ders., Das Sozialrecht im Wandel von Wirtschaft und Gesellschaft, Wirtschaft u. Wissenschaft, 26. Jhg. Heft 3 (1978) S. $17 \mathrm{ff}$.

221) S. z.B. Bernhard Badura - Peter Gross, Sozialpolitische Perspektiven 1976; Christian von Ferber und Franz-Xaver Kaufmann (Hrsg.), Soziologie und Sozialpolitik, Kölner Zeitschrift für Soziologie und Sozialpsychologie, Sonderheft 19, 1977.

$222)$ S. z.B. Axel Murswieck (Hrsg.), Staatliche Politik im Sozialsektor, 1976.

223) S. z.B. Tim Guldimann, Die Grenzen des Wohlfahrtsstaates, 1976 .

224) S. z.B. Ulrich Rödel - Tim Guldimann, Sozialpolitik und soziale Kontrolle, in: Tim Guldimann u.a. (Hrsg.), Sozialpolitik als soziale Kontrolle. Starnberger Studien 2, 1978 , S. $11 \mathrm{ff}$.

225) S. z.B. Friedrich Barabas, Thomas Blanke, Christoph Sachße, U1rich Stascheit, Jahrbuch der Sozialarbeit 1976, 1975, S. $379 \mathrm{ff}$.

226) Auch insofern ist eine zusammenfassende Würdigung mit der vorigen Periode gerechtfertigt: S. Hans Hermann Hartwich, Sozialstaatspostulat und Reformpolitik, Politische Vierteljahresschrift XVIII.Jhg. (1977) S.137 ff. 
von einem gemischten Steuer- und Sozialleistungssystem auf ein reines Sozialleistungssystem), Siebentes Gesetz zur Änderung beamtenrechtlicher, besoldungsrechtlicher Vorschriften (Dienstrechtlicher Teil des Familienlastenausgleichs), Gesetz über Altenheime, Altenwohnheime, Pflegeheime (Heimgesetz), Gesetz über die Angleichung der Leistungen zur Rehabilitation, Gesetz zur Änderung des Heimarbeitergesetzes und anderer arbeitsrechtlicher Vorschriften (Heimarbeiteränderungsgesetz), Gesetz über die Agrarberichterstattung, Zweites Gesetz über den Kündigungsschutz für Mietverhältnisse über Wohnraum, Gesetz zur Verbesserung der Betrieblichen Altersversorgung

1975 Gesetz zum Schutze der Auswanderer, Gesetz über die Sozialversicherung Behinderter, Gesetz über die Krankenversicherung von Studenten, Allgemeiner Teil des Sozialgesetzbuches, Gesetz zur Verbesserung der Haushaltsstruktur und Gesetz zur Verbesserung der Haushaltsstruktur im Geltungsbereich des Arbeitsförderungs- und Bundesversorgungsgesetzes (mit gewissen Leistungseinschränkungen)

1976 Gesetz zur Förderung von Wohnungseigentum und Wohnbesitz im sozialen Wohnungsbau, Gesetz zum Schutz der arbeitenden Jugend, Gesetz über die Mitbestimmung der Arbeitnehmer (Mitbestimmungsgesetz), Gesetz über die Entschädigung für Opfer von Gewalttaten, Erstes Gesetz der Reform des Ehe- und Familienrechts und Gesetz zur Änderung beamtenversorgungsrechtlicher Vorschriften (Einf ührung des Versorgungsausgleichs), Gesetz über die Annahme als Kind und zur Änderung anderer Vorschriften (Adoptionsgesetz) und Gesetz über die Vermittlung der Annahme als Kind (Adoptionsvermittlungsgesetz), Gesetz über die Versorgung der Beamten und Richter in Bund und Ländern (Beamtenversorgungsgesetz), Gesetz zur Förderung des Angebots an Ausbildungsplätzen in der Berufsausbildung (Ausbildungsplatzförderungsgesetz), Gesetz zur Regelung des Rechts der Allgemeinen Geschäftsbedingungen, Gemeinsame Vorschriften für die Sozialversicherung im Sozialgeselzbuch, Gesetz zur Weiterentwicklung des Kassenarztrechts

1977 Gesetz zur Dämpfung der Ausgabenentwicklung und zur Strukturverbesserung in der gesetzlichen Krankenversicherung (Krankenversicherungskostendämpf ungsgesetz), Zwanzigstes Rentenanpassungsgesetz (zahlreiche Leistungsänderungen in der Sozialversicherung)

1978 Einundzwanzigstes Rentenanpassungsgesetz (insbes. Sistierung der Rentenformel). 
Auf dem Gebiet des Sozial rechts hielt der Prozeß dogmatischer Entwicklung an. Mit dem Erscheinen des Allgemeinen Teils des Sozialgesetzbuches und der gemeinsamen Vorschriften über die Sozialversicherung im Sozialgesetzbuch erwuchs auch eine reiche - unterschiedlich bedeutsame, in vielem aber doch sehr nützliche - Kommentarliteratur zum Sozialgesetzbuch 227). Der Rubikon zur angemessenen wissenschaftlichen Entwicklung des Sozialrechts scheint überschritten zu sein. Jedoch ist in dieser Periode auch ein neuer Zug sozial- und arbeitsrechtlicher Diskussion festzustellen, der notifiziert werden muß. Die ideologische Öffnung nach "links", die für die vorige Epoche so kennzeichnend war, schlägt sich allmählich auch in der Verbreiterung des Spektrums juristischer Literatur nieder 228).

Bemerkenswert intensiviert hat sich auch die internationale Entwicklung. Der Zusammenhang der deutschen wirtschaftlichen und sozialen Entwicklung mit der wirtschaftlichen Entwicklung in der Welt war noch nie so deutlich wie seit der Erdölkrise. Aber auch die Verantwortung der entwickelten Länder für die armen Länder in der Welt wurde noch nie so scharf und kämpferisch formuliert wie in dieser Periode 229).

227) S. ein Verzeichnis bei Hans F.Zacher, Materialien, a.a.O. (Anm.46) Teil B.

228) Besonder's betont im Arbeitsrecht, s. dazu Thilo Ramm, Die "Linke" und das Arbeitsrecht, JZ 33.Jhg. (1978), S. 184; Peter Derleder, Dialog oder Perhorreszierung? ebenda, S. 791 f; 'l'hilo Ramm, Bonjour Tristesse, ebenda, S. 792 f. - Für das Sozialrecht s. etwa U1rich Mückenberger, Thesen zur Funktion und Entwicklung des Sozialrechts, Kritische Justiz 9.Jhg. (1976) S.341 ff; Friedrich BarabasChristoph Sachße, Bundessozialhilfegesetz - Sozialstaatliche Versorgung oder Armenpolizei?, ebenda, S.359 ff.

229) S. dazu: Dritter Bericht zur Entwicklungspolitik der Bundesregierung, a.a.O. (Anm.196). Zur Entwicklung der Entwicklungshilferaten s. oben Anm.196. 
7. Schlußbemerkung

Zum Schluß sei noch einmal folgendes ins Bewußtsein gerufen. Die Arbeit ist aus der Erfahrung der ersten der beiden Perioden (1945-1949; 1949-1957) geschrieben. Sie ist selbst wohl in die dritte Periode (1957-1966) einzuordnen, in der bereits der Atem dazu da war, über das zurückliegende Aufbauwerk zu reflektieren. Sie steht jedoch am Anfang dieser dritten Periode. Und sie weiß noch nichts davon, daß dies fast ein Jahrzehnt der Beruhigung, ohne grundsätzlichen Neuaufbruch, ohne ausschweifende Diskussion sein soll. Sie weiß erst recht nichts davon, was diskutiert werden wird, wenn der "Wohlstands-Sozialismus" der späten sechziger und frühen siebziger Jahre auf vielfältigste Weise mehr oder minder alles in Frage stellt, was von den ersten Jahren der Bundesrepublik an selbstverständlich schien.

Der Diskussionsrahmen ist heute wieder enger geworden 230). Und so könnte man hoffen, daß der Leser von heute der Arbeit von 1960/61 wieder näher steht als ein Leser etwa von $1970 \mathrm{ihr}$ gestanden hätte. Gleichwohl liegt zwischen $1960 / 61$ und 1979 ein Strom internationaler und nationaler technologischer, ökonomischer, gesellschaftlicher, politischer und rechtlicher Veränderungen. Gleichwohl ist auch die Vielfalt der Ideen, die in den späten sechziger und den frühen siebziger Jahren umging, virulent. Vor allem aber gibt es immer weniger Leser, welche die Szene, vor der die Arbeit geschrieben wurde, selbst erfahren hatten, immer mehr aber solche, die nur die sechziger oder gar nur die siebziger Jahre selbst bewußt erlebt haben. Sie werden ganz besonders um die Offenheit und um die Mühe gebeten, den zeitlichen Ursprung dieser Arbeit zu akzeptieren wie er war.

230) S. z.B. Bruno Molitor, Sozialpolitik auf dem Prüfstand, 1976; Heinz Müller (Hrsg.), Fortentwicklung der sozialen Sicherung, 1978. 


\section{A. DER GEGENSTAND DER UNTERSUCHUNG}

\section{Aufriß des Problems}

Die sozialen Spannungen, die das politische Leben der Bundes republik in seinen Anfängen noch so sehr geprägt hatten, haben sich vermindert. 1 )

1) Aus der sozialwissenschaftlichen Literatur zur Diagnose s. z. B. Geiger, Die Klassengesellschaft im Schmelztigel, 1949; v. Wiese, Soziale Sicherheit und sozialer Aufstieg als Probleme unserer Zeit, Soziale Welt, 1.Jhg. (1949/50) Heft 3 S. 3 ff; ders., Gesellschaftliche Stände und Klassen, 1950, insbes. S. 68 ff; Seeling, Die sozialen Spannungen der Gegenwart ("Politische Bildung" Heft 18), 1951; Pfister, Der Wandel der Sozialstruktur in Westdeutschland und die Probleme der sozialen Sicherung, Deutsche Versicherungszeitschrift, V. Jhg. (1951), S. 266 ff; Moeller, Soziale Umschichtung, Kölner Zeitschrift für Soziologie und Sozialpsychologie, 5. Jhg. (1952/53), S. 21 ff; Zimmermann, Die Arbeiterfrage heute, Schmollers Jahrbuch für Gesetzgebung, Verwaltung und Volkswirtschaft, 74.Jhg. (1954) S.1 ff; Bolte, Ein Beitrag zur Problematik der sozialen Mobilität, Kölner Zeitschrift für Soziologie und Sozialpsychologie, 8. Jhg. (1956), S. 27 ff; Münke, Die Armut in der heutigen Gesellschaft, 1956; Janowitz, Soziale Schichtung und Mobilität in Westdeutschland, Kölner Zeitschrift für Soziologie und Sozialpsychologie, 10. Jhg. (1958), S. 1 ff; Pross, Die soziale Schichtung in der Bundesrepublik, Deutsche Rundschau, 84.Jhg. (1958) S.916 ff; Ortlieb, Unsere Konsumgesellschaft, in "Zur Ordnung von Wirtschaft und Gesellschaft" Hamburger Jahrbuch für Wirtschafts- und Gesellschaftspolitik, 4.Jhg. 1959 (Festausgabe für Eduard Heimann), S. 225 ff. Spezifisch zusammengestelltes Zahlenmaterial $\mathrm{s}$. in der vom Allensbacher Institut für Demoskopie herausgegebenen Schrift "Die soziale Wirklichkeit" (o.J.; ca.1955); ferner bei Bosch, Die Sozialstruktur in West- und Mitteldeutschland, 1958. Außer den zum nachfolgenden Text noch zu gebenden Nachweisen vgl. die allgemeinen Darstellungen zur Sozialpolitik sowie die - allerdings großenteils speziellere - Literatur zur sog. Sozialreform (zusammengestellt bei Richter, Die Sozialreform, Anhang V, insbes. Teil 1). Im Themenkreis der letzteren bewegen sich auch die sog. Sozialberichte der Bundesregierung (vg1. Sozialbericht 1958, Bundesarbeitsblatt S. $133^{x}$; Sozialbericht 1959, Bundesarbeitsblatt S. $1^{\mathrm{X}}$ ff; Sozialbericht 1960 , Bundesarbeitsblatt S. $609 \mathrm{ff}$ ). 
Die Masse der Menschen hat auskömmlich zu leben. Der allgemeine Lebensstandard steigt. Zwar ist die Spanne zwischen den Durchschnittseinkommen und den Spitzeneinkommen einer zahlenmäßig kleinen Oberschicht immer noch sehr groß. Zwar ist dem Großteil der Bevölkerung eine nennenswerte Vermögensbildung noch nicht möglich gewesen, während sich Riesenvermögen in der Hand einiger weniger ballen. Zwar sind die meisten Menschen auf ein Arbeitseinkommen - auf ihr eigenes oder das ihres familiären Garanten - angewiesen, während andere von of t hohen "arbeitslosen" oder wenigstens "arbeitsarmen" Kapitalnutzungen leben können. Zwar muß der höhere Lebensstandard, nicht selten auch schon der ausreichende Unterhalt der Familien vielfach damit erkauft werden, daß mehrere ihrer Mitglieder als Verdiener eingesetzt werden, während andere Familien von einem Arbeitseinkommen nicht schlechter leben. Aber wie groß die bestehenden Gegensätze auch sein mögen; im allgemeinen fehlt ihnen die Schärfe der schreienden Not.

Doch wäre nichts weniger richtig, als die soziale Frage oder auch nur die soziale Aufgabe des Staates für erledigt zu halten. Die soziale Befriedung ist, wie von vornherein einzuräumen war, nur eine relative. Die Wohlstandsdifferenzen sind nicht in einem Maße ausgeglichen, das schlechterdings als gerecht empfunden werden dürfte und würde. Die soziale Befriedung ist ungleich und unvollkommen. Immer noch gibt es bittere Not. Immer wieder zeichnen sich Gruppen ab, denen zu wenig geholfen wird. Nie wird die atypische Armut ganz erfaßt werden können. Die soziale Bef riedung ist weiter wenigstens dem Grade nach labil. Prosperität und Vollbeschäftigung haben Probleme gelöst, die bei einem Nachlassen der Konjunktur sofort und vielleicht mit noch größerer Gewalt wieder aufbrechen werden. Vor allem aber ist die soziale Befriedung weithin gar nicht die Frucht eines primären ökonomisch-sozialen Gesundungsprozesses sondern etwas Künstliches, Sekundäres. Die industrie-kapitalistische Wirtschaft und die ihr entsprechende moderne atomistische, einkommensbetonte Gesellschaft neigen wesensmäßig zur suzialen Desintegration. Der kapitalistischen Wirtschaft ist eine oligarchische Kapitalverteilung eigentümlich, ein permanenter Vorzug der Kapitalseigner bei der Verteilung des Sozialprodukts und die Persistenz ihres ökonomischen Vorsprungs über Generationen hin. 2) (Die vorhandenen Reste feudalistischer Wirtschaftsmacht folgen längst den gleichen Gesetzen.) Die Masse der Menschen ist auf das Arbeitseinkommen verwiesen: auf die Arbeit in abhängiger

2) Zur "persistierenden oligarchischen Kapitalverteilung" s. z. B. Rüstow, Ortsbestimmung der Gegenwart, Bd. I, 1950, S. $161 \mathrm{ff}$. 
Stellung; auf die subjektive Fähigkeit zu arbeiten; und auf die objektive Möglichkeit, ausreichend bezahlte Arbeitsgelegenheit zu finden. Die Arbeit ist Ware und bringt immer nur eine Kopfquote des Arbeits-Preises je Arbeitskraft ein. Je geringer diese Kopfquote ist, desto schwerer fällt die Mitsorge für andere, insbesondere für die Familie. Die "Risiken" der Arbeitslosigkeit, der Invalidität, der Krankheit, des Alters, des Kinder reichtums, der Witwenschaft und Waisenschaft, der Mutterschaft treten mit aller Schärfe hervor. Die Wirtschaft kann ihnen nicht aus sich heraus grundlegend abhelfen. Die Wirtschaft kann eigengesetzlich aber auch jene sozialen Differenzen nicht ausgleichen, die sich aus dem politischen Schicksal der Gemeinschaft ergeben: die Kriegsfolgen, die Folgen der Vertreibung, die Folgen nationalsozialistischer Verfolgung usw. Sie sind in weitem Umfang noch offen; und sie sind, wenn überhaupt, nur deshalb latent, weil die Gemeinschaft sich laufend bemüht, auszugleichen und zu helfen.

Der soziale Raum ist in Wahrheit auch hier und heute mit Spannungen - offenen und latenten, effektiven und potentiellen, psychisch und real virulenten sozialen Spannungen - erfüllt. Die Einsicht, daß sie ein Übel sind und so gut als möglich ausgeräumt werden sollen, ist heute fast allgemein. "Unsere heutige Welt ist sozial eingestellt und ist mit Recht stolz'darauf. ... Alles andere wird eher verziehen als unsoziales Verhalten. "3) Für diejenigen, die durch den sozialen Ausgleich begünstigt werden sollen, ist diese Haltung ein natürlicher Egoismus. 4) Ein egalitäres ${ }^{5)}$ Gerechtigkeitsdenken bestärkt nicht nur sie selbst darin sondern verleiht ihrem Begehren Durchschlagskraft, ja, läßt ganz allgemein und unabhängig von jedem Anstoß seitens der Bedürftigen soziale Bestrebungen aufkommen. Der moderne Glaube an die Vollendbarkeit der Geschichte steigert sie zum sozialen Chilias-

3) Liermann, Das kanonische Recht als Grundlage europäischen Rechtsdenkens, Zeitschrift für evangelisches Kirchenrecht, Bd. 6 (1957), S. $37 \mathrm{ff}$ (43). Sehr pointiert und kritisch herausgestellt bei Hayek, Was ist und was heißt "sozial"? in "Masse und Demokratie", 1957, S. 71 ff.

4) Sehr zugespitzt formuliert bei Schoeck, Das Problem des Neides in der Massendemokratie, in "Masse und Demokratie", 1957, S. $239 \mathrm{ff}$.

5) S. hierzu z.B. Rüstow, Ortsbestimmung der Gegenwart, Bd.I, S. 220 ff, Bd.III, 1957, S.90 ff. - Weitere Nachweise zum Verhältnis zwischen egalitärem und sozialem Denken s. u. B 1 (S. 45). 
mus.6) Das christliche Gebot der Nächstenliebe gibt ihnen die Weihe und Kraft religiöser Verpflichtung. ${ }^{7)}$ Auch eine humanitäre Profanethik hält mehr und mehr das "Soziale" für etwas Gutes schlechthin. ${ }^{8)}$ Daneben stehen handfeste, reale Motive. Der soziale Ausgleich soll gesellschaftliche Unruheherde beseitigen. Er soll die Gesellschaftsordnung und nicht zuletzt auch den ökonomischen Standard stabilisieren.9) Er soll lästigen Bettel und notbedingte Kriminalität vermeiden helfen. Die Angst davor, benei-

6) S. hierzu z.B. Freyer, Theorie des gegenwärtigen Zeitalters, 1958, insbes. S. $62 \mathrm{ff}, 206 \mathrm{ff}$.

7) Wolany, Vom Sozialstaat und sozialen Recht, in: Forum der Rechtsphilosophie, 1950, S.141 ff (153): "Nicht mit Unrecht wird gesagt, das Wort sozial sei der säkularisierte Ausdruck für Nächstenliebe". S.a. Mühlmann, Okzident und Orient gestern und heute, Zeitschrift für die gesamte Staatswissenschaft, Bd.113 (1957) S.133 ff (135): soziales Gewissen ist "säkularisierte Caritas". Eine rechtsgeschichtliche Parallele s. bei Liermann, Das kanonische Recht als Grundlage europäischen Rechtsdenkens, S. 43.

8) Vg1. Hayek, Was ist und was heißt "sozial"?

9) S. hierzu z.B. Gehlen, Bürokratisierung und Daseinssicherung, Universitas, 12.Jhg. (1957), S.43 ff (46); Mühlmann a.a.O. S.140 f; Hayek a.a.O., insbes. S. 74, 81. - Der Dualismus der Motive (Caritas einerseits, Spannungsausgleich andererseits) kommt auch deutlich zum Ausdruck in dem, was Weisser (Die Gesetzgebung über den Lastenausgleich, Finanzarchiv, n.F. Bd. $16(1955 / 56)$ S. 62 ff (76)) zu den Grundgedanken des Lastenausgleichsrechts schreibt: "Die Aufbringungsseite des Lastenausgleichsgesetzes bekennt sich zu einem Gedanken, dem wir in der Weltgeschichte immer wieder begegnen, wenn sich geschichtlich die Notwendigkeit zu tiefgreifenden sozialen Neuordnungen ergibt. In diesen Fällen ist es - man muß wohl sagen: in den Jahrtausenden - immer wieder zu tiefgreifenden Fingriffen in das Eigentumsrecht gekommen. Es wird autoritär dem einen genommen, damit dem anderen gegeben werden kann. Der Gesetzgeber ist überzeugt, daß hierzu eine moralische $\mathrm{Pf} 1 \mathrm{icht}$ besteht, und stellt überdies in den betreffenden besonderen geschichtlichen Situationen Erwägungen der Sta ts raison an, die davon ausgehen, daß bestimmte Grade der Not breiter Bevölkerungsgruppen den Bestand der Gesellschaftsordnung bedrohen." (Sperrungen vom Verfasser.) 
det, 10) bedroht oder beraubt zu werden, ja schließlich schon die Angst davor, Leid ansehen und mitleiden zu müssen, treibt $z u$ sozialen Konzessionen. Sie versprechen aber auch ökonomischen Vortei1:11) Konsumausweitung - ein Ziel, das vor allem die sog. expansive Lohnpolitik ${ }^{12}$ ) immer wieder herausstellt - und Erhaltung und Vermehrung der menschlichen Arbeitskraft. Die soziale Intervention schützt vor sozial-ökonomischer Erosion. Sie entspricht der sich mehr und mehr ausbreitenden Risikofeindlichkeit und dem modernen Sekuritätsbedürfnis. Die Mobilität der modernen Gesellschaft und ihre Kommunikationsmittel erlauben zudem einen weiträumigen Vergleich und die Orientierung der sozialen Bestrebungen an dem in größten Vergleichsräumen jeweils höchsten erreichten Stand. So heterogen die Motive und Antriebselemente der sozialen Strömung auch sein mögen, 13) sie vereinigen sich desungeachtet zu größter Wirkmächtigkeit.

Die sozialen Erwartungen konzentrieren sich auf den Staat.

10) Schoeck (Das Problem des Neides in der Massendemokratie) versteigt sich sogar zu der Gleichung: soziales Gewissen = "Angst vor Beneidetwerden". S. a. Hayek a.a.O. S.81.

11) Zum ökonomischen Motiv s. z.B. Colm, Volkswirtschaft1iche Theorie der Staatsausgaben, 1927, S.41; Kurt Schmidt, Möglichkeiten und Grenzen einer Finanzpolitik des sozialen Ausgleichs, ORDO, Bd.X, 1958, S.315 ff.

12) S. z. B. Erich Arndt, Art. "Lohn (II) Politik" im Handwörterbuch der Sozialwissenschaften, Lfg. 27, 1959, S. 16 ff (21).

13) Eine Übersicht s. bei Weisser, Art. "Soziale Sicherheit" im Handwörterbuch der Sozialwissenschaften, Bd.9, 1956, S. 396 ff (399 ff).

14) Zur Diagnose s. z.B. Forsthoff, Die Verwaltung als Leistungsträger, 1938; ders., Verfassungsprobleme des Sozialstaates, 1954; ders., Die Daseinsvorsorge der Kommunen, 1958; ders., Lehrbuch des Verwaltungsrechts, 7. Auf1., 1958, S. 56 ff; ders., Rechtsfragen der leistenden Verwaltung, 1959; Peters, Die Wandlungen der öffentlichen Verwaltung in der neuesten Zeit, 1954, S. 12 ff; Gehlen, Zur Problematik des Sozialstaates, Hessische Hochschulwochen für staatswissenschaftliche Fortbildung, Bd.11, 1956, S. 51 ff; ders., Bürokratisierung und Daseinssicherung (insbes. S. 46 f); Wilkens, Probleme des Wohlfahrtsstaats, in "Macht und Recht" Beiträge zur lutherischen Staatslehre der Gegenwart, 1956, S. $148 \mathrm{ff}$, insbes. S. $157 \mathrm{ff}$; Janssen, Probleme des Wohlfahrtsstaats, in "Verantwortung für den Menschen", Gedächtnisschrift für Heinrich Held, 1957, S. 125 ff; Krause, Der verteilende Staat, in "Beiträge zum Recht der Wasser- 
Er ist der potentiell mächtigste Träger des sozialen Ausgleichs. Ist er für ein soziales Anliegen gewonnen, so ist seiner Verwirklichung die präsumtiv größte Nachhaltigkeit gesichert. Er ist das geborene, notwendige Komplement und Korrektiv einer Wirtschaftsgesellschaft, die als solche, autonom sich selbst überlassen, nicht zureichend funktionieren kann. Er ist der vom Grundprinzip der Subsidiarität designierte Träger der als notwendig erkannten Abhilfen, die vom Individuum selbst und seinen engeren Gemeinschaften - der Familie, der Nachbarschaft, dem Berufsstand, der Gemeinde u.dgl. - nicht geleistet werden können; und er tritt als solcher in dem Maße stärker hervor, in dem die Dynamik immer zahlreicherer und immer bestimmenderer Lebenssachverhalte durch die moderne Technik und Industrialisierung, die weiträumige Kommunikation und die Eigengesetzlichkeit der extrem mobilen, atomistischen modernen Massengesellschaft der Disposition und Berechnung des Individuums und der kleinen Gemeinschaften mehr und mehr entgleiten. 15) Er ist Verursacher zahlreicher sozialer Fehlsituationen, so insbesondere der Kriegsfolgen, und somit primär verpflichtet, ihnen abzuhe1fen. Sein personell und territorial weit gespannter Zuständigkeitsbereich verspricht die Möglichkeit maximaler Egalität und korrespondiert somit mit dem egalitären Grundelement der modernen Sozialbewegung. Seine Distanz gegenüber den Individuen verbürgt die Anonymität und Unpersönlichkeit des sozialen Eingreifens: die nicht zu Bitte und Dank verpflichtende Unpersönlichkeit des Hilfe-Nehmens; die durch Unbestimmbarkeit des Begünstigten oder wenigstens die Übernahme der Hilfs- und Ausgleichspflicht in die Verantwortung der Gemeinschaft neutralisierte Unpersönlichkeit der Belastungen. Schließlich nimmt die staatliche Intervention die Last unmittelbaren und sozialen Helfens von den Schultern derjenigen, die sich, würde der Staat nicht eingreifen, dazu verpflichtet fühlten, die Beschwer staatlicher Umverteilung aber geringer achten als die individuellen Opferns und Gebens. 16)

Der Staat war auch von vorneherein "anfällig" für seinen sozialen Auftrag. Nicht nur, weil die soziale Fntwicklung seine subsi-

wirtschaft und zum Energierecht", Festschrift für Paul Giesecke, 1958, S. 1 ff; Frisch, Wohlfahrts- und Interessenstaat, Dokumente, 14.Jhg. (1958) S. 439 ff; Knoll, Lichtund Schattenseiten des Wohlfahrtsstaats, Politische Studien, 11. Jhg. (1960) S. $353 \mathrm{ff}$.

15) S. insbesondere Forsthoff und Peters a.a. O. vorige Anmerkung

16) Eine Parallele bietet die organisierte Caritas der Kirchen und der Wohltätigkeitsorganisationen. 
diäre Eingriffspflicht aktualisierte; nicht nur, weil er für allzu viele soziale Fehlentwicklungen unmittelbar verantwortlich zeichnet; und nicht nur, weil die sozialen Ideen mehr und mehr auch in die politisch maßgebende Schicht eindrangen. Je mehr die Statik der monarchisch-ständischen Ordnung und die ihr gemäße Gerechtigkeitskonzeption eines ständisch typisierten suum cuique der Dynamik der modernen Demokratie und der sie heraufführenden revolutionären Bewegtheit sowie der ihr entsprechenden egalitären Gerechtigkeitsauffassung wichen, desto mehr wurde die soziale Integration zur Existenzfrage des Staates. 17) Die Inbesitznahme des sozialen Problems durch die staatliche Politik entspricht nicht zuletzt aber auch dem Charakter der staatlichen Herrschaft als hochpotenzierter Machtausübung. 18) Versprechen und Durchführung einer sozialen Politik sind Mittel im Kampf um die politische Macht. Je mehr sich der Wunsch nach sozialer Intervention ausbreitete, desto mehr mußten die Herrschenden oder nach Herrschaft Strebenden sie einsetzen, um - sei es im Rahmen demokratischer Wahlen, sei es im Rahmen revolutionäre $r$ Alternativen - die Billigung der Herrschaft zu erlangen bzw. zu erhalten. Der "Sozialimperialismus", 19) den die Gegenwart in dem் konkurrierenden Bemühen von Ost und West um die sog. Entwicklungsländer beobachten kann, ist innenpolitisch längst eine vertraute Erscheinung. 20) Die soziale Intervention bereitet den Trägern staatlicher Macht aber eine noch weitergehende Versuchung. Sie wirkt staatsverfestigend. 21) Sie schafft Abhängigkeiten

17) Vg1. Hesse, Der Gleichheitsgrundsatz im Staatsrecht, AöR Bd. 77 (1951/52) S. $167 \mathrm{ff}(180 \mathrm{ff}$, insbes. S. 186) m.w. Nachw.; Ipsen, Gleichheit, in: Neumann-Nipperdey-Scheuner, Die Grundrechte, Bd. II, 1954, S. 111 ff (176).

18) Zum "Machtmotiv" s. Darmstaedter, Die Grenzen der Wirksamkeit des Rechtsstaats, 1930, S. 20, 26 ff; Forsthoff, Verfassungsprobleme des Sozialstaats, S. $10 \mathrm{ff}$; Weisser, Art. "Soziale Sicherheit" im Handwörterbuch der Sozialwissenschaften, S. 399 .

19) Vg1. Grabowsky, Der Sozialimperialismus als letzte Etappe des Imperialismus, 1939. Zum Zusammenhang der internationalen mit der nationalen Politik im Hinblick auf das Soziale s. neuerdings dens., Staatsverfestigung oder Staatsabbau? Zeitschrift für Politik, n. F. Jhg. 5 (1958) S. $97 \mathrm{ff}$ (S. 120: "Weniger die innere als die äußere Politik heischt den Wohlfahrtsstaat").

20) S. hierzu auch unten B 3 insbes. I 1 b (S. 319 ff).

21) Vgl. Forsthoff, Rechtsfragen der leistenden Verwaltung, S. 29: "Jeder moderne Staat ... erhält dadurch eine gewisse 
- schon allgemein durch die vielfältigen Ingerenzen, die sie im Gefolge hat; vor allem aber dadurch, daß die Gesellschaft - soweit sie vom Staat abgelöst gedacht werden kann - der Möglichkeit der sozialen Hilfe und $z$ wischenmenschlichen Mitsorge beraubt oder ihrer sozialen Verantwortung wenigstens entwöhnt wird und der Bedürftige daher fast ausschließlich auf die Hilfe des Staates angewiesen ist. Ihre potentielle Versagung macht ihn gefügig. 22)

Nimmt sich der Staat einmal der sozialen Frage an, setzt er damit zugleich die Ursache für ein immer weiter gehendes Verlangen. Die staatliche Hilfestellung lähmt nicht nur die gewissenhafte Eigenvorsorge und Eigeninitiative zur Vermeidung bzw. Behebung der auftretenden Notlagen. Sie zerstört auch die vor- und nebenstaatliche, zwischenmenschliche Solidarität. ${ }^{23)}$ Der einmal seitens des Staates aufgenommene soziale Ausgleich setzt die Bereitschaft, individuelles Mißgeschick zu tragen, radikal herab. Alle persönliche Beschwer soll auf die Gemeinschaft umgelegt werden. Jedes persönliche Risiko soll durch die Ausfallbürgschaft der Allgemeinheit von vorneherein entschärft werden. 24) Je weiter die soziale Entwicklung vorangetrieben wird, desto

Stabilität, daß er aus Gründen der Daseinsvorsorge, die er leistet, nicht ohne weiteres als Organisation vernichtet werden kann, ohne die Lebensgrundlagen des Volkes anzutasten." S. zum Problem auch Grabowsky, Staatsverfestigung oder Staatsabbau?

22) Zu dieser Entartung, die insbesondere für die bolschewistische und die faschistische Sozialpolitik kennzeichnend ist, s. nochmals Darmstaedter und Forsthoff a.a.O. (s. S. 7 zu Fußnote 18).Auf das Problem der Freiheitsgefährdung durch die soziale Intervention wird unten (B 4 (S.396 ff), 5 (S. 673 ff), 6 (S. $842 \mathrm{ff})$ )noch wiederholt zurückzukommen sein.

23) S. zu Vorstehendem schon Wilhelm von Humboldt, Ideen zu einem Versuch, die Grenzen der Wirksamkeit des Staates $\mathrm{zu}$ bestimmen (in der Ausgabe von Alexander v. BleichenRusswurm, 1923, S.31 ff, insbesondere S.36 f). S. ferner Gehlen, Bürokratisierung und Daseinssicherung, S.46 f; Knoll, Licht- und Schattenseiten des Wohlfahrtsstaates, insbesondere S. $360 \mathrm{ff}$. - Zur Gefahr einer Institutionalisierung der Nächstenliebe s.v. Jüchen, Die Krisis der Nächstenliebe in der heutigen Gesellschaft, Soziale Arbeit 9.Jhg. (1960) S. $145 \mathrm{ff}$.

24) S. Gehlen a.a.O.; s. Knoll a.a.O., insbesondere S. 355 f, 360 ff. 
weniger werden sodann die noch verbleibenden Unstimmigkeiten und Unvollkommenheiten ertragen. Immer sind die sozialen Forderungen dem sozialen Standard voraus. So wird die Sozialpolitik in ständiger Wechselwirkung mit ihren eigenen Schritten von dem Wollen der Beteiligten stets kräftig nach vorn gestoßen.

Die soziale Intervention des Staates setzte in der ersten Hälfte des 19. Jahrhunderts als Resultante frühindustrieller, frühkapitalistischer, monarchistisch, ständisch oder bürgerlich patriarchalischer, profanistischer, demokratischer und frühsozialistischer, ja auch nationalistischer und etatistischer Determinanten des politischen und wirtschaftlichen Lebens jener Zeit neu - mit Absichten und Mitteln, die sich von denen früherer Zeiträume nicht weniger unterschieden wie sie für die folgende Zeit bis zur Gegenwart bestimmend bleiben sollten 25) - ein. Der äußere Markstein dieses sozialpolitischen Aufbruches in den deutschen Landen darf in dem denkwürdigen preußischen Regulativ über die Beschäftigung jugendlicher Arbeiter in Fabriken vom 9. Mai 1839 (GS S. 156) gesehen werden. Seit jenen ersten Schritten entfaltete sich die staatliche Sozialpolitik, der aufgezeigten übermächtigen Gesetzmäßigkeit zufolge sich rasch ausbreitend und intensivierend, 26) zu einem tiefgestaffelten, vielfältig verschlungenen, verwirrenden System von Ordnungen und Maßnahmen zwischenbürgerlichen sozialen Ausgleiches, verteilender staatlicher Hilfe und umverteilender sozialer Korrektur.

Das Arbeitsrecht wuchs aus den arbeitsschutzrechtlichen Anfängen auf, bis es nunmehr die Interessen des abhängig erwerbstätigen Menschen umfassend schützt. 27) Ihm zur Seite trat die Sozialversicherung, die zunächst den bezeichnenden Namen einer "Arbeiterversicherung" trug. Der ursprünglich nur dem "Arbei-

25) Zur Entwicklung s. z.B. Zöllner, Entwicklungsphasen der Sozialpolitik, in "Sozialreform und Sozialrecht", Festschrift für Walter Bogs, 1959, S. 397 lf.

26) Gute, sachlich allerdings beschränkte Übersichten der Entwicklung bei Syrup-Neuloh, Hundert Jahre Staatliche Sozialpolitik 1839-1939, 1957; Erdmann, Die Entwicklung der deutschen Sozialgesetzgebung, 2. Aufl. 1957; s.a. Schneider, Das soziale Jahrhundert, 1950.

27) Zu den Wesenszügen der Entwicklung s. z.B. Hueck, Von der sozialen Fürsorge zur sozialen Gerechtigkeit, in "Probleme des modernen Sozialstaates in christlicher Sicht", 1955, S. 5 ff; Herschel, Vom Arbeitsschutz zum Arbeitsrecht, in "Hundert Jahre Deutsches Rechtsleben", Festschrift Deutscher Juristentag, Bd. I 1960, S. $135 \mathrm{ff}$. 
ter" zugedachte soziale Schutz mußte in angemessener Weise auch auf den "Angestellten" ausgedehnt werden. Damit begab sich die soziale Intervention in eine bürgerliche Schicht, und es war der Boden geschaffen, auf dem das Arbeits- und Sozialversicherungsrecht und das Beamtenrecht in Vergleichsbeziehung treten und sich fortan wechselseitig befruchten konnten. Abgerundet wurde die staatliche Sorge für den arbeitenden Menschen durch die Arbeitslosenversicherung und - fürsorge und die (mittelbar) staatliche Arbeitsvermittlung und Arbeitsplatzbeschaffung.

Aber die "soziale Frage" ist nicht identisch mit der "Arbeiterfrage", wie weit diese auch immer abgegrenzt werden mag. Sie war es von Anfang an nicht. 28) Und sie entfernte sich im Laufe der Entwicklung immer weiter davon, es zu sein. Die Arbeiterschaft integrierte sich dem sozialen Ganzen. 29) Andere soziale Anliegen traten neben die "Arbeiterfrage". 30) Andere Personengruppen erwiesen sich als der staatlichen Hilfe bedürftig; so vor allem diejenigen, die zugunsten der Gemeinschaft Opfer gebracht, in kausaler Verstrickung mit dem Schicksal der Gemeinschaft Verluste oder sonstwie von der staatlichen Gemeinschaft her Schäden erlitten hatten. Die Kriegsopferversorgung (einschließlich der Hilfe für die ehemaligen Kriegsgefangenen) erhielt, ebenso wie die Kriegssachschädenentschädigung, von hierher neue Impulse und Gestaltelemente. ${ }^{31)}$ Das soziale Verdikt gegen Armut und Not unterwarf das ganze allgemeine Problem des Sonderopferausgleiches neuen, stimulierenden Wertmaßstäben. ${ }^{32)}$ Die staatliche Hilfe für die Vertriebenen, die Sowjetzonenflüchtlinge, die Evakuierten, die Heimkehrer und die in Ostdeutschland politisch Verfolgten (die "Häftlinge" im Sinne des Häftlingshilfsgesetzes) darf - im einzelnen freilich in sehr unterschiedlicher Weise dem sozialen Denken zum Teil sogar kausal zugerechnet werden. ${ }^{33)}$ Selbst eine so sehr vom Rechtswert getragene staatliche

28) Vgl. Achinger, Sozialpolitik als Gesellschaftspolitik, 1958, S. $57 \mathrm{ff}$.

29) S.Höffner, Die Entwicklungen im Schicksal und Lebensgefühl der Arbeiterschaft und der Wandel der sozialpolitischen Leitbilder, in "Sozialreform und Sozialrecht", Festschrift für Walter Bogs, 1959, S. 139 ff.

30) S. a. Zimmermann, Die Arbeiterfrage heute.

31) Vgl. Braun, Motive sozialer Hilfeleistungen, 1955, S. 82 ff, 103 ff. - Auf das Problem der Rechtsnatur des Kriegsopferversorgungsanspruches ist unten sowohl unter dem Gesichtspunkt des Gleichheitsgrundsatzes wie auch des Eigentumsrechts intensiver einzugehen. S. dort auch die Nachweise.

32) S. hierzu die Nachweise unten S. 775 zu Fußn. 12 ff.

33) Vgl. Braun a.a.O. S.86 ff. 
Leistung wie die Entschädigung der Opfer nationalsozialistischer Verfolgung ist von sozialen Gestaltmomenten durchsetzt. ${ }^{34)}$ Das System staatlicher Hilfeleistungen dehnte sich ferner auch vom Ansatzpunkt kausal nicht gemeinschaftsbezogener, aber im Gemeininteresse unerträglicher und durch zumutbare Eigenvorsorge im allgemeinen nicht behebbarer Mangellagen her aus: im Rahmen des Mutterschutzes, der Jugendwohlfahrt und - förderung und der Familienhilfe. Wo abschätzbaren Risiken jedoch durch die zusammenwirkende Eigenvorsorge einer engeren Gemeinschaft gesteuert werden kann, ist die Möglichkeit staatlicher Hilfe durch die Einrichtung und Ausweitung der Sozialversicherung gegeben. Von ihr wurde - über den Kern der Arbeitnehmerversicherung hinaus - zum Zweck der sozialen Sicherung der Selbständigen wachsend Gebrauch gemacht. ${ }^{35)}$ Als ultima ratio der öffentlichen Hilfe entwickelte sich die Fürsorge von einem Instrument der Abwehr polizeiwidriger Mißstände zur differenzierten, vor allem auch um der Betroffenen selbst willen einsetzenden "Sozialhilfe". 36) So erwuchs aus den verschiedenen Zweigen der (beamten-, entschädigungs- und sonstwie ausgleichsrechtlichen) Sonderversorgung, der Sozialversicherung und der (gehobenen und allgemeinen) Fürsorge 37 ) ein System der "sozialen Sicherheit", 38) das im einzelnen mehr oder weniger reichlich, aber. insgesamt doch umfassend gegen die wirtschaftlichen Risiken der Erkrankung, der Invalidität, des Arbeitsunfalles, der Mutterschaft, des Kinderreichtums, des Alters, der Arbeitslosigkeit, des Verlustes des Ernährers usw. schützt. ${ }^{39)}$

34) Vgl. Braun a.a.O. S. 106 ff.

$35)$ S. hierzu z.B. Heyn, Die soziale Sicherung der Selbständigen, in "Beiträge zur Sozialversicherung", Festschrift für Johannes Krohn, 1954, S. 127 ff.

36) Zum Wesen der "Sozialhilfe" s. die Begründung des Entwurfs eines Bundessozialhilfegesetzes, Deutscher Bundestag, 3. Wahlperiode, Drucksache 1799, Abschnitt A (S.31 ff). Zur Entwicklung s.Knoll, Die sozialethischen und rechtlichen Wandlungen in der Beurteilung des Armenwesens, Zeitschrift für die gesamte Staatswissenschaft, Bd.111 (1955) S.418 ff.

37) Zum System s. z. B. Bogs, Grundfragen des Rechts der sozialen Sicherheit und seiner Reform, 1955.

38) Zu Begriff und Erscheinung s. Weisser, Art. "Soziale Sicherheit" im Handwörterbuch der Sozialwissenschaften, (w. Nachw. s. dort).

39) Zum Standards. außer den Vorgenannten die schon oben (S. 1 zu F'ußn.1) erwähnte Literatur zur Sozialreform. 
Der Sozialstaat beläßt es aber nicht bei Einkommenshillen (einschließlich der entsprechenden medizinischen Hilfen). Er ist auch gezwungen, objektbezogen die Güterverteilung zu korrigieren; denn die marktwirtschaltliche, preisgesteuerte Güterverteilung belastet mit jeder knappheitsbedingten Verteuerung den Ärmeren relativ stärker als den Reicheren. Der Staat kann am allgemeinsten und radikalsten helfen, indem er bewirtschaftet und die Preise bindet. Mittelbare Preisbeeinflussung durch währungs- und zollpolitische Maßnahmen, preissenkende Subventionen und fehlende Bedürfnisbefriedigungspotenz ausgleichende Beihilfen, Anreize zur Vermehrung des marktwirtschaftlichen Angebotes, privatrechtliche Beschränkungen der Verfügungsmacht und schließlich Bereitstellung der knappen - und zum Zwecke der Versorgung durch die öf fentliche Hand oder in ihrem Auftrag produzierten oder von ihr enteigneten - Güter zu sozial gestalteten Preisen helfen spezieller. In Zeiten - z. B. kriegsbedingt - gestörter marktwirtschaftlicher Güterverteilung tritt auf diese Weise das Preis- und Bewirtschaftungsrecht in eine zentrale soziale Funktion ein. Einzelne Korrekturen sind jedoch immer notwendig und finden laufend statt. Das wohl dauerhafteste Feld notwendiger Eingriffe ist das Wohnungswesen: Öffentlicher Wohnungsbau, Wohnungsbaulenkung und - förderung, Mietpreisbindung, Wohnraumbewirtschaftung, Mieterschutz, Mieterbeihilfen und auch Wohnungsaufsicht sind das wechselnd kombinierte Instrumentarium. Mit besonderer Liebe hat sich die Sozialpolitik immer auch der. Verteilung des (absolut) knappen Bodens gewidmet. Stichworte wie (ländliche) Bodenreform, Siedlungswesen, Heimstättenwerk, Förderung des Eigenheimbaues, aber auch Landpachtrecht u. dgl. umschreiben dieses Bemühen. Die öffentliche Energieund Verkehrsversorgung greift zwar über den Bereich des Sozialen hinaus. Gleichwohl darf ihre soziale Bedeutung nicht unterschätzt werden. Den sozialen Verhältnissen inadäquate Preise ("Tarife") und Unzuverlässigkeiten der Massenversorgung würden wieder gerade den sozial Schwächeren besonders hart treffen.

Eine eminent soziale Wirksamkeit entfaltet der Staat - unmittelbar und mittelbar - durch das Schulwesen. Die Einrichtung der unentgeltlichen, allgemeinen Pflichtvolksschule ist eine nicht mehr wegzudenkende Grundvoraussetzung der sozialen Integration. Die Berufsschule, ebenfalls unentgeltlich und pflichtmäßig, ergänzt sie in einer sozial sehr bedeutsamen Weise. Das Bildungsmonopol der wirtschaftlich Stärkeren konnte jedoch erst in dem Maße abgebaut werden, in dem ein System der Lehr- und Lernmittelfreiheit sowie der Unterhalts- und sonstigen Studienbeihilfen gleiche Chancen auch für das Studium an den höheren und Hochschulen sowie an den Fachschulen gewährte. Kaum übersehbar sind die Wirkungsweisen und positiven sozialen Folgen 
zahlreicher anderer öffentlicher Einrichtungen und Leistungen. Es darf noch das Beispiel der öffentlichen Gesundheitsfürsorge in all ihren Sparten hervorgehoben werden.

Im Prozeßrecht neutralisieren Gebühren- und Kostenfreiheit und Anwaltsbeiordnung (regelmäßig gewährt durch das sog. Armenrecht) die sozialen Unterschiede $z w i s c h e n$ den Rechtsschutzsuchenden; 40) wie auch sonst das Verfahrensrecht, insbesondere das engere Prozeßrecht, 41) einschließ1ich des Vollstreckungsrechts, 42) zunehmend in eine soziale Funktion hineingewachsen ist. Nicht vergessen werden darf das Privatrecht, das die Hauptlast des zwischenbürgerlichen Sozialausgleiches auf eine diesem in besonderem Maße adäquate Weise trägt. ${ }^{43)}$ Seine soziale Wirk-

40) S. z.B. Weidner, Ist der Ausschluß der Anwaltsbeiordnung in den unteren Instanzen der Sozialgerichtsbarkeit verfassungsmäßig ? JZ 14.Jhg. (1959) S.622 ff. Zur neueren Entwicklung der rechtspolitischen Situation s. Heimerich, Das überlebte Armenrecht, Der Betriebsberater, 15. Jhg. (1960) S. $1071 \mathrm{ff}$.

41) Zu seiner sozialen Funktion s. schon Grünberg, Der sozialpolitische Gehalt der österreichischen Civilprozeßgesetzgebung, 1900. Ferner Kisch, Die soziale Bedeutung des Zivilprozesses, Judicium 1.Jhg. (1928/29) S. 1 ff; Baur, Sozialer Ausgleich durch Richterspruch, JZ 12.Jhg. (1957) S. 193 ff. Weitere Nachweise noch verschiedentlich unten.

42) Die soziale Wirkung geht in eine doppelte Richtung: als Schuldner wird der "Arme" geschont $(\$ \$ 765 \mathrm{a}, 811,850 \mathrm{ff}$ ZPO; s.a. die vielfach anzutreffenden Pfändungsbeschränkungen für soziale Hilfsbezüge); als Gläubiger wird er bevorzugt ( $\$ 10$ Abs. $1 \mathrm{Nr} .2 \mathrm{ZVG}, \S 61 \mathrm{Nr} .1 \mathrm{KO}$ ).

43) Zu den Problemen s. z. B. Otto Gierke, Die soziale Aufgabe des Privatrechts, 1889; Menger, Das bürgerliche Recht und die besitzlosen Volksklassen, 1890 (5. Auf1. 1927); ders., Über die sozialen Aufgaben der Rechtswissenschaft, 1905; Ofner, Der soziale Charakter des AGBGB, Festschrift zur Jahrhundertfeier des Allgemeinen Bürgerlichen Gesetzbuches, Bd.I, 1911, S.441 ff; Renner, Die Rechtsinstitute des Privatrechts und ihre soziale Funktion, 2. Aufl. 1929;

Wieacker, Das Sozialmodell der klassischen Privatrechtsgesetzbücher und die Entwicklung der modernen Gesellschaft, 1953; ders., Das bürgerliche Recht im Wandel der Gesellschaftsordnungen, in "Hundert Jahre Deutsches Rechtsleben" Festschrift Deutscher Juristentag, Bd. II, 1960, S. 1 ff. 
samkeit erschöpft sich keineswegs etwa im Arbeitsrecht und im Miet- und Pachtrecht. Das ganze Schuldrecht - besonders ausgeprägt etwa im Recht der Massenleistungsverhältnisse, 44) in der Sonderbehandlung des Monopolisten und im Haftungsrecht - aber auch das Familienrecht - insbesondere das Unterhaltsrecht - und das Erbrecht sind Medien spezifisch sozialer Gestaltung. Ein weites Verständnis der dem Privatrecht eigenen Generalklauseln läßt die Maximen der sozialen Gerechtigkeit - oder was dafür gehalten wird - bis in die entlegensten Winkel der bürgerlichen Rechtsordnung sickern.

Wohl als das Herzstück der sozialen Intervention des Staates aber darf das öffentliche Finanzwesen bezeichnet werden. Ist der Sozialstaat wesentlich (auch) ein Staat der "Umverteilung" von Einkommen und Vermögen, 45 ) so ist er dabei in erster Linie ein Staat der Umverteilung über die öfentlichen Haushalte, ein Staat der sozial modifizierten und differenzierenden finanziellen Belastungen und Leistungen. Soziale Differenzen sind weitgehend mit Geld ausgleichbare Unterschiede der Bedürfnisbefriedigungspotenz. Ihrem Ausgleich im Rahmen vorhandener zwischenbürgerlicher Individualbeziehungen sind enge natürliche Grenzen gesteckt. Die persönlichen Bindungen und Reibungen, die er mit sich bringt, geben einer anonymen Umverteilung über die öffentliche Hand aber noch darüber hinaus den Vorzug. Auch eine direkte Sachgüterverschiebung muß die Ausnahme bleiben. Gleichheit und Dispositionsf reiheit der Belasteten und der Begünstigten werden prinzipiell am meisten geschont, wenn Geld weggenommen bzw. geleistet wird. Die Aversion des rechtsstaatlich-freiheitlichen Verfassungsrechts gegen Unberechenbarkeit, Ungleichheit, radikal umschichtende Enteignungen und endlich gegen eine totalplanende und - bewirtschaftende Wirtschaftspolitik gibt dem Ausdruck und schiebt auch ihrerseits die sozialen Ausgleichsvorgänge auf das Finanzwesen zu. ${ }^{46)}$ Daß sich das Gesetz der wach-

44) Zum speziellen Aspekt s. z. B. die Darstellung und Nachweise bei Simitis, Die faktischen Vertragsverhältnisse, 1957.

$45)$ S. z.B. Gehlen, Zur Problematik des Sozialstaates, a.a.O. S. 61 .

46) Zu dieser Wirkung des rechtsstaatlichen Verfassungsrechts, insbes. des Eigentumsschutzes, s. Forsthoff, Begriff und Wesen des sozialen Rechtsstaats, VVDStRL. H. 12, 1954, S. 8 ff (31 ff); ders., Eigentumsschutz öffentlichrechtlicher Rechtsstellungen, NJW 8.Jhg. (1955) S. 1249 ff (1250); ders., Diskussionsbeitrag zu "Die Finanzverfassung im Rahmen der Staatsverfassung", Veröffentlichungen der Vereinigung der Deutschen Staats rechtlehrer, Heft 14, 1956, S. 84 f; Hettlage, 
senden Staatsausgaben, seit Adolph Wagner es 1879 formulierte, so sehr bewahrheitet hat, ist nicht zuletzt eine Folge der sozialen Aufgabenstellung des Staates. 47) Riesigen Leistungen der öffentlichen Hand 48) stehen nicht weniger riesige Abgaben gegenüber. 49) Neben dem allgemeinen Staatshaushalt und den übrigen gebietskörperschaftlichen Haushalten stehen als Kristallisationszentren engerer Umverteilungs-"gemeinschaften" Hilfsfisci. Zu sozialen Zwecken eingerichtet - wie z. B. die Sozialversicherungsträger, in neuerer Zeit insbes. auch die Familienausgleichskassen - oder sonstwie gewissen sozialen Zusammenhängen in besonderem Maße homogen - wie einzelne berufsständische Einrichtungen - intensivieren sie den sozialen Ausgleich auf hervorragende Weise. ${ }^{50)}$ Bei all dem dienen die Abgaben, das gilt insbes. auch für die allgemeinen Steuern, nicht nur dazu, die Masse der Mittel zu beschaffen, die notwendig sind, um die sozialen Aufwendungen zu decken. Kraft der ihnen innewohnenden Möglichkeit gezielter Belastung und Entlastung (Verschonung) sind sie auch schon in der reinen Belastungssphäre ein vielgenutztes und letzt-

Die Finanzverfassung im Rahmen der Staatsverfassung, ebenda, S. 1 ff (S. 4 f, 94); Köttgen, Die gegenwärtige Lage der deutschen Verwaltung, DVB1. 72. Jhg. (1957) S.441 ff (443).

47) Zur dogmatischen und tatsächlichen Entwicklung s. Hansmeyer, Der Weg zum Wohlfahrtsstaat, 1957.

48) Bedauerlicherweise wird unter den Stichworten "Sozialausgaben", "-aufwendungen", "-haushalt" usw. immer nur der eklatant sozial gezielte Teil der sozial zweckhaften Leistungen der öffentlichen Hand ausgewiesen, wie insbes. die Sozialversicherungsleistungen, die Leistungen der Kriegsopferversorgung, des Lastenausgleiches u. ä., die Aufwendungen der allgemeinen Fürsorge u.dgl. mehr (Zahlen s. z. B. in "Die Sozialreform", Schriftenreihe des Instituts "Finanzen und Steuern", Heft 43, 1956, S. 41 fr; Fehrs, Die öffentlichen Sozialleistungen in der Bundes republik Deutschland einschließlich Berlin (West) von 1949 und 1958, Bundesarbeitsblatt 10. Jhg. (1959) S. $762 \mathrm{ff}$ ).

49) Einen interessanten Ausschnitt der spezifisch sozialen Leistungen s. bei Spiegelhalter, Die Struktur der betrieblichen Sozialaufwendungen, Der Arbeitgeber, 12.Jhg. (1960) S. 459 ff, $499 \mathrm{ff}, 565 \mathrm{ff}$. S. ferner. "Die Sozialreform". Im übrigen vergleiche man die allgemeinen Statistiken.

50) S. hierzu z.B. Jecht, Staatliche Wirtschaftspolitik und Einkommensverteilung, Schriften des Vereins für Sozialpolitik, n.F. Bd. 13 (1957) S. 126 ff; Schewe, Über den sozialen Ausgleich in der Rentenversicherung, in "Sozialreform und Sozialrecht", Festschrift für Walter Bogs, 1959, S.333 ff. 
1ich unentbehrliches Instrument des sozialen Ausgleichs. 51) Endlich wird die Finanzpolitik auch im Rahmen der Wirtschaftspolitik als ein Mittel der Distributionslenkung und der ökonomischen Sicherung gehandhabt.

Dieses hier nur in groben Strichen aufgezeigte soziale Engagement des Staates hat ein Maß erreicht, das die Frage, wo und wie und wie weit es noch getrieben werden kann und darf, - abseits von jeder prinzipiellen Abneigung gegen die sozial ausgleichende Einmischung des Staates - mit wachsender Eindringlichkeit stellt. Zwar ist der Staat weit davon entfernt, allen sozialen Nöten abhelfen zu können. Aber die offenen Probleme schrumpfen immer mehr auf jenen Kreis der Bedürfnisse zusammen, denen organisierte staatliche Hilfe in keinem Fall beikommen kann. ${ }^{52)}$ Schon nähert sich die Redistribution einem Plafond, an dem angekommen sie sich in begünstigender und belastender Wirkung aufheben müßte. ${ }^{53)}$ Dieser westdeutsche Gegenwartsstaat ist durch und

51) Zu den Möglichkeiten einer sozial gestaltenden Steuerpolitik $\mathrm{s}$. aus dem jüngeren Schrifttum vor allem Hicks, Steuerpolitik im Wohlfahrtsstaat, 1953, insbes. S. 30 ff; Schmölders, Finanzpolitik, 1956, S.113 ff (insbes. S. 116 f); Jecht, a.a.O. Staatliche Wirtschaftspolitik und Einkommensverteilung; Kurt Schmidt, Möglichkeiten und Grenzen einer Finanzpolitik des sozialen Ausgleichs, ORDO Bd.X (1958) S. 315 ff; ders., Zum Problem der Zweckkollision in der modernen Steuerpolitik, Finanzarchiv n.F. Bd. 19 (1959) S. 204 ff. Ein Kernproblem ist die vor allem im Einkommenssteuerrecht anzutreffende Progression der Besteuerung. Zur sehr lebhaften - Diskussion hierüber, die für den ganzen Problemkreis von Bedeutung ist, s. statt vieler anderer: Föhl, Das Steuerparadoxon, Finanzarchiv n.F. Bd. 17 (1956/ 57) S. 1 ff (weitere Nachweise s.dort insbes. S. 1 Fußn. 1 und 2); Kurt Schmidt, Zur ordnungspolitischen Problematik der Progressivbesteuerung, ORDO Bd.IX(1957) S. $217 \mathrm{ff}$; s.a. Koulis, Soziale Gestaltung der Besteuerung oder volkswirtschaftliche Steuerpolitik, 1948.

52) Vgl. Lord Beveridge, Voluntary Action, 1948 (Kapitel 7-12 dieses Werkes sind übersetzt unter dem Titel "Freies He1fen - Nöte, die auch der Sozialstaat noch kennt", Zeitschrift für Sozialreform 5. Jhg. (1959) S.306 ff).

53) Vg1. Tödt, Möglichkeiten und Probleme einer Änderung der. Einkommensverteilung, Bundesarbeitsblatt 10.Jhg. (1959) S. 773 ff; Claussen, Die Kosten des sozialen Fortschritts, Bundesarbeitsblatt 11. Jhg. (1960) S. $52 \mathrm{ff}$. 
durch Wohlfahrtsstaat: dem größten Glück der größten Zahl, dem größten Glück möglichst aller Bürger verpflichtet. Die soziale Aufgabe zeichnet sein Wesen wie wenig andere Bestimmungselemente.

Das ist die eine Hauptquelle der Bedeutung und Problematik der verfassungsrechtlichen Gestaltgabe der sozialen Intervention. Die andere, Spannung zeugende ist, daß dieser Staat wesentlich auch Verfas sungs ta t ist. In keiner Phase der deutschen Verlassungsgeschichte hat eine geschriebene Verfassung derart nachhaltig auf das ganze Staatsleben eingewirkt wie in der gegenwärtigen. Die "Verfassungsdämmerung", die in Zeiten des Totalitarismus und der Diktatur erahnt wurde, 54) strahlte auf zum "Verfassungstag". An die Stelle des government of man trat, soweit Verfassungs recht das irgend zu bewirken vermag, das government of law. Das Grundgesetz 55) regelt nicht nur die staatliche Organisation; es bestimmt das Staatsleben auch materie11. 56) Dieses Verlassungsrecht bindet Rechtsprechung, Verwaltung und Gesetzgebung (Art.20 Abs. 3, 1 Abs.3 GG). Der Befeh1 zur Befolgung der Verfassung 57) wurde in einer weit über das im konstitutionellen Rechtsstaat übliche Maß hinausgehenden Weise sanktioniert. ${ }^{58}$ )

So setzt das Verfassungsrecht dem staatlichen Handeln einschneidende Begrenzungen und schenkt ihm - wenngleich darin hinter dem Negativen, der Grenzziehung, zurückbleibend - bedeutsame Impulse. Auch und gerade ein so wesentlicher Sektor staatlicher Aktion, wie die soziale Intervention ihn darstellt, wird daher von

54) Kägi, Die Verfassung als rechtliche Grundordnung des Staates, 1945, S. $35 \mathrm{f}$.

55) Die Länderverfassungen sind darin nicht einheitlich. Dem Typ der Vollverfassung, wie ihn die Bayerische Verfassung verkörpert, entsprechen außerdem noch die Verfassungen von Hessen, Bremen, Rheinland-Pfalz, dem Saarland und Berlin. Dem gegenüber sind die Verfassungen von Hamburg, Niedersachsen und Schleswig-Holstein im wesentlichen auf das Organisatorische beschränkt. Einem Zwischentyp gehören die Verfassungen von Baden-Württemberg und NordrheinWestfalen an.

56) Zur spezifischen Bedeutung des materiellen Verfassungsrechts s. Kägi a.a.O. S. $94 \mathrm{ff}$.

57) Zum Befehl zur Befolgung der Verfassung im allgemeinen s. Nawiasky, Allgemeine Rechtslehre, 2. Aufl. 1948, S. 38 f; ders., Allgemeine Staatslehre, Teil 3, Staatsrechtslehre, 1956, S. 94 f, 97; Maunz, Deutsches Staatsrecht, 9. Aufl. 1959 , S. $88 \mathrm{f}$.

58) Einzelheiten s. u. B 4 (S.396 ff). 
der Verfassung her - begrenzend und leitend - vorgeformt. Konflikte konnten bei der Vitalität des Sozialen einerseits und der Ge1tungskraft des Verfassungsrechts andererseits nicht ausbleiben. Konflikte ergeben sich aber auch immer wieder zwischen Verfassungsnormen, die das soziale Handeln des Staates antreiben, und Verfassungsnormen, die gewissen Gesamtkonzeptionen, Einzelmaßnahmen oder Nuancen der Ausgestaltung der sozialen Intervention im Wege stehen. Hier einerseits die wirklichen Grenzen des Verfassungsrechts aufzuzeigen, an diesen aber gegenläufige politische Bestrebungen zum Stehen zu bringen, oder umgekehrt die vom Verfassungsrecht ausgehenden Anregungen und Weisungen aufzugreifen und zur Geltung zu bringen, ist deshalb eine zunehmend aktueller gewordene verfassungsrechtliche Aufgabe.

\section{Begriff und Bereich der sozialen Intervention des Staates}

\section{Der Begriff "sozial"1)}

Wenn die Hilfstätigkeit zugunsten des wirtschaftlich Schwächeren

1) Die Lehre von diesem Begrifl ist wenig ausgebildet (was z.B. auch Rogge, Flüchtlingsverwaltung, Flüchtlingsrecht und Sozialstaat, DVB1. Jhg. 71 (1956) S. 37 ff (40 ff) beklagt). Zu nennen wären: Stammler, Wirtschaft und Recht, 1896, S. $115 \mathrm{ff}$; Wasserrab, Socialwissenschaft und sociale Frage, 1900, insbes. S.26 ff; Silberschmidt, Das Reichsgericht und der Begriff des Sozialen, in "Die Reichsgerichtspraxis im deutschen Rechtsleben", Bd.II 1929, S.1 ff; Zimmermann, Das "Soziale" im geschichtlichen Sinn- und Begriffswandel, in Festgabe für L.v.Wiese, 1948, S. 173 ff; Geck, Erkenntnis und Heilung des Soziallebens, Soziale Welt Jhg. 1 (1949/50) S. 3 ff ( $5 \mathrm{f}$ ); Menger, Der Begriff des sozialen Rechtsstaates im Bonner Grundgesetz, (Recht und Staat, Heft 173) 1953, S.23 ff; Bülow, Art. "Sozial" in Bernsdorf-Bülow, Wörterbuch der Soziologie, 1955, S. 465 f; Rogge, a.a.O.; Hedemann, Was ist sozial? Der Arbeitgeber, 1956, S.198 ff; Hayek, Was ist und was heißt "sozial". Zu der nachstehend herausgestellten Begriffstrias - sozial = gesellschaftsbezogen; sozial = gesellschaftszugewandt und - eingeordnet; sozial = gesellschaftskritische Ablehnung der schlechten Lage der ärmeren Schichten - s.Geck a.a.O.; Menger a.a.O.; Bülow a.a.O.; "Der große Herder", 5. Aufl. Bd. 8, 1956, Sp. 845; Hayek a. a.O., bei dem jedoch teils die erste und dritte, teils auch die zweite und dritte Bedeutung ineinanderfließen; auch Wasserrab a.a.O., bei dem jedoch die zweite Bedeutung nicht hervortritt. Eingehende entsprechende Nachweise zum Begriff des "Sozialstaates" s.u. B 5 II 1 a. A. (S. 676 ff). 
als "sozial" bezeichnet wird, so wird dieses Wort nicht in seiner allgemeinsten Bedeutung, seiner Grundbedeutung gebraucht. Diese ergibt sich aus dem Sinngehalt des lateinischen Wortes "socialis"2), aus dem das französische Wort "social" wuchs, 3) das schließlich in den deutschen Sprachgebrauch überging. 4) Danach ist "sozial" die Bezeichnung für das auf die Gesellschaft (oder Gemeinschaft $)^{5)}$ Bezogene im Sinne einer wertfreien oder jedenfalls nicht notwendig werthaften Beziehung. In diesem Sinne trifft "sozial" freilich auch auf die "soziale" Intervention zu. Ihre Gesellschaftsbezogenheit liegt auf der Hand. Diese teilt sie aber mit vielen anderen Erscheinungen des öffentlichen Lebens.

Das Wort "sozial" ist hier vielmehr mit einer engeren Bedeutung gebraucht. Solche engeren Begriffsinhalte haben sich als Nie-

2) Über die inhaltliche Bedeutung und ethymologischen Beziehungen dieses Wortes und seiner engsten Familie s. ErnoutMeillet, Dictionnaire Ethymologique de la Langue Latine, 1939, S. 949; Walde-Hofmann, Lateinisches Ethymologisches Wörterbuch, 3. Auf1. Bd.II, 1954, S.551. Georges, Lateinisch-Deutsches Handwörterbuch, 8. Auf1. 1918, Bd. II Sp. 2701 teilt u. a. folgende Wortbedeutungen mit: socialis, $e=$ Die Gesellschaft betreffend, gesellschaftlich, gesellig; socialitas, atis = die Geselligkeit; socialiter $=$ kameradschaft lich; societas, atis = Jede Gesellschaft, Verbindung mit andern im Guten und Bösen, die Teilnahme, Gemeinschaft, das Bündnis, Complott, die Verbindung unter den Völkern einer Sprache, Nationalverbindung, die Verbindung durch Ehe und Blutsverwandtschaft; socio, avi, atum, are = vergesellschaften, vereinigen, verbinden; socius, a, um = teilnehmend, in Verbindung stehend, zugesellt; subst. = ein Gesellschafter, eine Gesellschafterin, ein Genosse, Kamerad, Compagnon, Teilnehmer(in).

3) Sachs-Villatte, Enzyklopädisches französisch-deutsches Wörterbuch, 34. Aufl. 1955, 1. Teil S.834, schreibt hierzu: social (1t. socialis kameradschaftlich, gesellig von socius, s. fr. sociable) 1.) gesellschaftlich, gesellig; être - in Gesellschaft lebendes Wesen; 2.) pol. sozial; Gesellschafts...

4) Vgl. Kluge-Götze, Ethymologisches Wörterbuch der dt.Sprache, 16. Auf1., 1953, S. 734 .

5) Auf den Unterschied dieser beiden Formen menschlichen $\mathrm{Zu}$ sammenlebens braucht hier nicht näher eingegangen zu werden. Soziale Beziehungen bestehen überall da, wo überhaupt Menschen zusammen leben, gleich in welcher spezifischen Form. 
derschlag von Werturteilen über Art und Inhalt der Beziehungen zur Gesellschaft ${ }^{6}$ ) in verwirrender Vielfalt ergeben. ${ }^{7)} \mathrm{Je}$ nachdem, ob die Beziehungen zur Gesellschaft den den Werturteilen zugrunde liegenden Postulaten entsprechen oder nicht, erscheinen bzw. erschienen sie als die "einzig richtigen" Beziehungen zur Gesellschaft, die allein den Namen "sozial" verdienen. ${ }^{8)}$

Auf diese Weise begriffsbildend hat im besonderen die Auffassung gewirkt, welche die Inkorporation des Individuums in die Gemeinschaft, seine Subordination unter die Gemeinschaft und demnach seine Pflicht zur Rücksichtnahme auf die Gesellschaft im Vordergrund sieht. Auf ihrem Boden erstand der Begriff des "Sozialen", der die an der sittlichen Forderung, das Wohl des gesellschaftlichen Ganzen (Gemeinwohl) zu fördern und sich ihm unterzuordnen, orientierte Beziehung eines Menschen zur Gesellschaft kennzeichnet, 9) ein Begriff, der zweifellos in seinem Gegenstück "asozial" populärer ist.

Am nachhaltigsten auf diese Weise begriffsbildend wirkte aber die Forderung, die üble Lage der wirtschaftlich schlechter gestellten Schichten der Gesellschaft kritisch zu sehen und verbessernd zu ändern. In ihrem Sinn bezeichnet das Wort "sozial" eine Einstellung und ein Verhalten gegenüber der Gesellschaft, das von der Mißbilligung zu weit gespannter Wohlstandsdifferenzen - Unterschiede der individuellen Abhängigkeitsverhältnisse 10) - und von dem Postulat der Hilfe für die ärmeren Schichten 11) be-

6) Zu diesem kritischen "sozial"-Begriff s. z.B. (in bezug auf die "soziale Idee") Schilling, Geschichte der sozialen Ideen, 1957, S. 14 f.

7) S. d. oben S. 18 zu Fußn.1 Zitierten.

8) Vgl. Fechner, Freiheit und $Z$ wang im sozialen Rechtsstaat, 1953, S. 18: "Der soziale Gedanke betrifft ... das richtige und notwendige Verhältnis der Glieder einer Gemeinschaft zum Ganzen."

9) Zu diesem Sprachgebrauch s, außer den S. 18 in Fußn. 1 a. E. Zitierten insbes. Sohm, Die sozialen Pflichten der Gebildeten, 4.-5. Auf1. 1897, S.6; Ziegler, Die geistigen und sozialen Strömungen des 19. Jahrhunderts, 1899, S.523; Zimmermann a.a.O. S. 190.

10) Vg1. Gehlen, Zur Problematik des Sozialstaats, S. 56: Die Moderne perhorresziert nicht nur den wirtschaftlichen Unterschied als solchen, sondern vor allem auch die persönliche Abhängigkeit.

11) Als "arm" dürfen nicht nur die dringendste Not Leidenden verstanden werden (wie in der früheren "Armenfrage" und 
stimmt ist. 12) Dieser "sozial"-Begriff umschließt "das der gesamten Sozialbewegung Gemeinsame". 13) Er gibt wieder, was "von jeher als die entscheidende politische Empfehlung sozialpolitischer Arbeit im ganzen empfunden"wurde 14) (wenngleich die Sozialpolitik als Gesellschaftspolitik weiter auszugreifen hat ${ }^{15)}$ ).

"Armenpflege"). Vielmehr sind die "relativ" Armen einzubegreifen (s. hierzu v. Wiese, Über die Armut, Kölner Zeitschrift für Soziologie und Sozialpsychologie 6. Jhg. (1953/54) S. $42 \mathrm{ff}$ ).

12) Zu diesem Begriff s. außer den oben S. 18 Fußn. 1 a.E. Zitierten insbes. Zimmermann a.a.O. passim; Rogge, Flüchtlingsverwaltung, Flüchtlingsrecht und Sozialstaat, S.40 ff; s. ferner Carl Schmitt, Nehmen/Teilen/Weiden, Gemeinschaft und Politik 1.Jhg. (1953) S. 18 ff (23 f) - der auf das Teilen und Umverteilen abstellt - . Zur Lebendigkeit dieses Begriffs im allgemeinen Sprachgebrauch, die sich in ungezählten Wortverbindungen erweist, vgl. auch Grimm, Deutsches Wörterbuch, Bd.X, 1905, 1.Abt. Sp. 1826; Duden, 14. Auf1. 1954, S.632.

13) Das sich unten (B 5 II 1 S. 676 ff) auch als die Substanz der Sozialstaatsproklamation erweisen wird (zum Zitat: Dürig, Verfassung und Verwaltung im Wohlfahrtsstaat, JZ 8. Jhg. (1953) S. 193 ff (196)).

14) Achinger, Sozialpolitik als Gesellschaftspolitik, S.56: "Die Bemühung um eine Minderung der Unterschiede ist von jeher als die entscheidende politische Empfehlung sozialpolitischer Arbeit im ganzen empfunden worden; eine Empfehlung für die verschiedensten Gruppen, für Fortschrittler und Reaktionäre: denn sie glättet die Wogen der Empörung und empfiehlt sich damit dem Besitzenden; sie schafft den Armen ihr Recht und öffnet ihnen den $W$ eg in eine bessere Zukunft. Sie verspricht den Mitlebenden oder wenigstens ihren Kindern einen besseren Anteil an den Gütern des Lebens. Meinungsverschiedenheiten hat es im letzten Jahrhundert nur darüber gegeben, wie weit der Ausgleich gehen solle. Insbes. blieb die Frage offen, ob dieser Ausgleich auch das Eigentum an den Produktionsmitteln erfassen soll."

15) Allerdings wird der Gegenstand der Sozialpolitik auch enger abgegrenzt. S. hierzu z. B. Günther, Sozialpolitik, 1922, S. $47 \mathrm{ff}, 466 \mathrm{ff}$, der insgesamt 13 Inhalte des Begriffs "Sozialpolitik" registriert. Aus neuerer Zeit s. z. B. Hoffmann, Über den Begriff und die Grenzen der Sozialpolitik, 1948 (ungedruckte Erlanger Dissertation). 
"Sozial" in diesem Sinne ist nicht identisch mit "sozialistisch". 16) "Sozialistische Forderungen" sind in der Regel aber auch "sozial", nur eben ohne jeden Anspruch auf Primat und Ausschließlichkeit. Welche konkreten Maßnahmen zu ergreifen sind, welche Einzelziele anzustreben sind, welches Maß an Wohlstandsdifferenz eine Korrektur erheischt und welches Maß an Ausgleich herbeizuführen ist, das läßt dieser Generalbegriff weitestgehend offen. Er umschließt, was oben als die soziale Intervention des Staates umschrieben wurde, so sehr diese sich im Laufe der Entwicklung gewandelt hat.

\section{Der Staat a $1 \mathrm{~s}$ Träger der sozialen Interven- tion}

\section{a) Bund und Länder als Interventionssubjekte}

Soziale Ziele zu verfolgen ist dem Staate nicht vorbehalten. Aber der Staat als der mächtigste und in seiner Zwecksetzung einzigartig universelle menschliche Verband 1 ) ist auch der potenteste Faktor willkürlicher Sozialgestaltung. Die allgemeine Staatengemeinschaft und die engeren völkerrechtlichen Gemeinschaften sind ebenso wie die unterstaatlichen - öffentlichen und privaten - Verbände und erst recht die Einzelpersonen in der Verfügungsgewalt über die sozialen Sachverhalte stärker beschränkt als der Staat.

Westdeutschland sieht in dieser Staatsfunktion die Bundesrepublik, genauer: den Bund und die Länder. 2)

16) Zum Begriff des Sozialismus s. statt aller anderen RammLandshut-Landauer-Seidel-Tillich-Weisser, Art. "Sozialismus" im Handwörterbuch der Sozialwissenschaften, Bd.9, 1956 , S. $486 \mathrm{ff}$.

1) Zu diesem im vorstehenden Zusammenhang entscheidenden Wesen des Staates s. f.v.a. Nawiasky, Allgemeine Staatslehre, Teil 1, Grundlegung, 1945.

2) "Die Bundesrepublik Deutschland - das sind verfassungsrechtlich der Bund und die Länder als ein Ganzes" (BVerfGE 6, $309(340))$. S. zu dieser Konzeption des grundgesetzlichen Bundesstaats Nawiasky, Grundgedanken des Grundgesetzes für die Bundes republik Deutschland, 1950, S. 35 ff; ders., Allgemeine Staatslehre, Teil 3, S. 144 ff; Maunz, Deutsches Staatsrecht, S. 156 f. Während die Staatsqualität des Bundes $\mathrm{bzw}$. der Bundes republik verfassungsdogmatisch außer Zweifel steht, wird diejenige der Länder unter dem Grundgesetz zwar weniger als unter der Weimarer Verfassung aber doch immer wieder angezweifelt (s. z. B. Kreutzer, Der Bund und 
Sie wird nicht wesentlich geschmälert durch die der Bundesrepublik in den sog. Pariser Verträgen ${ }^{3}$ ) auferlegten Beschränkungen in der Ausübung der staatlichen Gewalt. Freilich ist zweifelhaft, ob diese schwerwiegenden Einschränkungen der Bundesrepublik diejenige Unabhängigkeit lassen, die sie besitzen muß, um in jeder Hinsicht "Staat" zu sein. 4) Das kann hier aber dahingestellt bleiben. Die Bundesrepublik gestaltet die sozialen Verhältnisse in eigenständiger Willensbildung. Darin ist sie durch die Einschränkungen auf bes. Rechtsgebieten nur exzeptionell behindert. Die Möglichkeiten der notstandsweisen Rückübernahme der öffentlichen Gewalt durch die Besatzungsmächte 5) und einer gesamtdeutschen Lösung gegen den Willen der Bundes republik6) 1 iegen in einer ungewissen Zukunft und beengen das Wirken der Bundesrepublik aktuell überhaupt nicht. Die Bundesrepublik ist in ihrem Territorium diejenige Ordnungseinheit, die in der sozialen Wirklichkeit als Staat wirkt.

Noch weniger wird die effektive Staatlichkeit der Bundesrepublik beeinträchtigt durch die Annahme, das Deutsche Reich bestehe fort, über deren Richtigkeit hier nicht zu entscheiden ist. ${ }^{7)}$ Dem

die Länder in der Bundesrepublik Deutschland, in "Bund und Länder" hrsg. von Ossip K. Flechtheim, 1959 S. 1 ff; kritisch ferner Zinn, Der Bund und die Länder, AöR Bd. 75 (1949) S. $291 \mathrm{ff}(296 \mathrm{ff}))$. Im Allgemeinen wird die Staatsqualität der Länder in Staats rechtswissenschaft und -praxis bejaht ( $s$. statt aller anderen BVerfGE 1, 14 (34)). Eine bundesstaatstheoretische Vertiefung dieses Ausgangspunkts erscheint in diesem Rahmen unnötig.

3) S. Ges.betr. das Protokoll v. 23.10.1954 über die Beendigung des Besatzungsregimes in der Bundesrepublik Deutschland (BRD) v. 24.3.1955, BGB1. II S.213; Ges. betr. den Vertrag v. 23.10.1954 über den Aufenthalt ausländischer Streitkräfte in der BRI) v. 24.3.1955, BGB1. II S.253; Ges. betr. den Beitritt der BRD zum Brüsseler Vertrag und zum Nordatlantikpakt v. 24.3.1955, BGB1. II S.256; Bekanntmachung zum Protokoll v. 23.10.1954 über die Beendigung des Besatzungsregimes in der BRD v. 30.3.1955, BGBl. II S.301.

4) Zu Deutschlands Rechtslage nach den Pariser Verträgen s. Bishop, The Contractual Agreements with the Federal Republic of Germany, American Journal of International Law, Vol. 49 (1955) pp. 125 ff; Grewe, Souveränität der Bundesrepublik, AöR Bd.80 (1955/56) S.231 fl.

5) Art. 5 des Vertrages über die Beziehungen der. Bundesrepublik zu den drei Mächten.

6) Art. 7 ebenda

7) Zum Stand der Meinungen s. die zusammenfassenden Darstel- 
Deutschen Reiche - bestünde es allen widrigen Umständen zum Trotze noch - fehlte jedenfalls jegliche tatsächliche Wirkungsmöglichkeit.

\section{b) Die Abgrenzung anderer Interventionsträger}

aa) Völkerrechtsgemeinschaft und internationale Organisationen

Seit jeher ist die internationale Sozialpolitik 1) eines der fruchtbarsten Elemente des sozialen Fortschritts. Internationaler Vergleich und Erfahrungsaustausch haben die Entwicklung immer wieder vorangetrieben. Multilaterale und bilaterale Verträge haben nicht nur erreichte Standards überstaatlichen Garantien unterworfen und nachhinkende Staaten wegweisend oder verpflichtend angetrieben. Sie haben Menschen, die im Ausland leben, der sozialen Hilfen ihres Heimatlandes versichert oder ihnen diejenigen des Gastlandes verschafft, was sich gerade mit der zunehmenden Entfaltung der sozialen Sicherheit, 2) insbes. des Sozialversicherungsrechts, 3 ) als notwendig erwies, um die außerhalb

lungen bei v. Mangoldt-Klein, Das Bonner Grundgesetz, 1957 (im Folgenden abgekürzt: v. Mangoldt-Klein), S. 29 ff; Maunz a.a.O. S. $14 \mathrm{ff}$. Aus dem speziellen Schrifttum s. Scheuner, Die Funktionsnachfolge und das Problem der staatsrechtlichen Kontinuität, in "Vom Bonner Grundgesetz zur Gesamtdeutschen Fassung" Festschrift für Hans Nawiasky, 1956, S. $9 \mathrm{ff}$ insbes. S.23 ff; Wengler, Deutschland als Rechtsbegriff, ebd. S. 49 ff; Merk, Das Reich, Zeitschrift für die gesamte Staatswissenschaft Bd. 112 (1956) S. $291 \mathrm{ff}$; Vocke, Politische Gefahren der Theorien über Deutschlands Rechtslage, Europa-Archiv 12.Jhg. (1957) S. 10, 199 ff; Marschall v. Bieberstein, Zum Problem der völkerrechtlichen Anerkennung der beiden deutschen Regierungen, 1959; Schenk, Zur Rechtslage Deutschlands, AöR Bd.85 (1960) S.96 ff; Stein, Die Ausgangsposition der Diskussion über Deutschlands Rechtslage, DÖV 13. Jhg. (1960) S. $327 \mathrm{ff}$.

1) S. statt aller anderen Savelsberg, Art. "Sozialpolitik (V) Internationale Sozialpolitik" im Handwörterbuch der Sozialwissenschaften, Bd.9, 1956, S. $564 \mathrm{ff}$ und die dort (S.571 f) angegebene umfangreiche Literatur.

2) S. gerade hierzu auch das grundlegende ILO-Übereinkommen Nr. 102 über die Mindestnormen der sozialen Sicherheit v. 28. Juni 1952 (abgedruckt u.a. bei Richter, Sozialreform, Anh. I 1).

3) Eine Zusammenstellung der einschlägigen Abkommen der Bundesrepublik s. bei Eckert, Sozialversicherungsgesetze, Bd. "Allgemeines", S.24.112 off. 
ihres Heimatstaates lebenden und arbeitenden Menschen nicht zu "Sozial-Bürgern zweiter Klasse" absinken zu lassen. ${ }^{4)}$ Sie haben endlich Menschen, deren sich kein Heimatstaat annimmt, insbes. den Flüchtlingen, ${ }^{5)}$ einen internationalen Status und damit auch einen sozialen Mindeststatus eingeräumt. Geld-, Sach- und Dienstleistungen, von "reicheren" an "ärmere" Länder gegeben, haben vielfältig Not gelindert und soziale Aufbau- und Genesungsprozesse ermöglicht oder wenigstens gestützt. Gerade dieser $Z$ weig der internationalen Sozialpolitik, die unmittelbare Hilfsaktion, ist gegenwärtig, im Zeichen der Hilfe für die Entwicklungsländer, in seine bisher reichste Blüte eingetreten.

Bei all dem haben die internationalen Organisationen große Verdienste auf sich gehäuft. In erster Linie darf auf die traditionsreiche Internationale Arbeitsorganisation hingewiesen werden, 6) ferner auf die Weltgesundheitsorganisation. Vor allem aber sind die Vereinten Nationen zu nennen (denen z.B. auch die beiden vorgenannten Organisationen als Sonderorganisationen zugeordnet sind). Ihre Erklärung der Menschenrechte vom 10. Dezember 1948 ist nicht zuletzt auch ein Manifest des sozialen Wollens der ganzen Menschheit und eine - wenngleich nur deklamatorische - Legitimation aller öffentlichen Sozialarbeit. Zu nennen ist ihr Wirtschafts- und Sozialrat mit seinen zahlreichen Ausschüssen und Unterausschüssen, das Amt ihres Hohen Kommissars für die Flüchtlingsfragen, ihr Kinderhilfsfond (UNICEF) usw. Zu erinnern ist an den Europarat, der sich derzeit um eine

4) S. hierzu auch Dobbernack, Die grundsätzlichen Probleme der zwischenstaatlichen Abkommen über soziale Sicherheit, Bundesarbeitsblatt 1955, S. 12 ff.

5) Vg1. das Gesetz betreffend das Abkommen vom 28. Juli 1951 über die Rechtsstellung der Flüchtlinge vom 1. September 1953 (BGBl. II S. 559).

6) Über ihr Wirken s. z.B. "Dreißig Jahre Kampf für soziale Gerechtigkeit" 3. Auf1. 1951; eine Systematische Übersicht über die Übereinkommen und Empfehlungen findet sich in "The international Labour Code 1951", 1951. Einen Überblick über die für das Gebiet der Bundes republik wirksamen Abkommen s. in der Bekanntmachung über die Verbindlichkeiten aus den vom Deutschen Reich ratifizierten Übereinkommen der Internationalen Arbeitsorganisation v. 5. Juni 1952 (BGBl. II S.607). S. zu ihrem Tätigkeitsbereich auch Schnorr, Das Arbeitsrecht als Gegenstand internationaler Rechtssetzung, 1960. 
Europäische Sozialcharta bemüht. ${ }^{7)}$ Soziale Ziele hat sich auch die - freilich insoweit nicht sehr aktive - Westeuropäische Union gesteckt. 8) Doch sind damit nur einige der sozial wirksamen internationalen Organisationen genannt. Die Zahl der einschlägigen Regional- und Spezialorganisationen ist nur noch schwer zu überblicken.

So wichtig alle diese Erscheinungen auch sind, sie müssen hier außer Betracht bleiben. Sie folgen anderen Gesetzen als denen, die dem eigenen sozialen Wirken der Staaten vorgegeben sind. Zwar kommunizieren die Phänomene. Die internationalen Instanzen wirken antreibend, unterstützend und normierend auf das interne Verhalten der Staaten ein. Andererseits werden diese durch ihre eigene, wesensmäßige soziale Verpflichtung veranlaßt, auch nach außen entsprechend zu wirken. Soweit auf diese Weise (verfassungsgebundenes) Handeln jeweils des einzelnen Staates in Frage steht, ist den internationalen Bezügen der staatlichen Sozialpolitik im Folgenden auch Aufmerksamkeit zu schenken. Das eigenständige Wirken internationaler Gemeinschaften jedoch, mag die Bundes republik daran auch beteiligt sein, ist davon zu sondern. ${ }^{9}$ )

bb) Supranationale Interventionsträger

Soziale Dispositionen können auch von der Europäischen Gemeinschaft für Kohle und Stah1 (EGKS) und - mehr noch - von der

7) S. "Um eine 'Europäische Sozialcharta"", Zeitschrift für Sozialreform 3.Jhg. (1957) S. 18 f; Richter, Die Sozialreform, Anh. I, 2.

8) S. insbes. Art. II des sog. Brüsseler Vertrags v. 23. Oktober 1954 (BGB1. II S.283).

9) Dagegen müßten Einrichtungen und Organisationen, die innerhalb der Bundes republik zwischen den Ländern untereinander oder zwischen den Ländern und dem Bund geschaffen werden, in den Kreis der Betrachtung einbezogen werden, obwohl Beziehungen dieser Art häufig dem Völkerrecht zugeordnet werden. Sie stehen in erster Linie doch unter der gesamtstaatlichen Verfassungsordnung der Bundesrepublik. Auf dem sozialen Sektor treten nennenswerte Erscheinungen dieser Art aber nicht hervor (vgl. Schneider, Staatsverträge und Verwaltungsabkommen zwischen deutschen Bundesländern, DÖV 10.Jhg. (1957) S. 644 ff; Kölble, Verwaltungsabkommen zwischen Bund und Ländern, DÖV 13.Jhg. (1960) S. $650 \mathrm{ff})$, so daß das Problem vernachlässigt werden kann. 
Europäischen Wirtschaftsgemeinschaft (EWG) 1) ausgehen.2) Trotzdem haben sie und ihre soziale Intervention aus dem Kreis der Betrachtung auszuscheiden. Das wäre selbst dann geboten, wenn EGKS und EWG in irgend einer Weise als "Staaten" anzusehen wären. 3) Vom soziologischen Modell eines "normalen" Staa-

1) Die Europäische Atomgemeinschaft - die dritte der gegenwärtig bestehenden, supranationalen Gemeinschaften, an denen die Bundes republik beteiligt ist - hat ohnedies keine (im engeren Sinne) sozialen Aufgaben (Art.2 des Vertrages zur Gründung der Europäischen Atomgemeinschaft, BGB1. II 1957 S. 1014).

2) Zu den Möglichkeiten sozialer Intervention durch die EGKS vgl. die allgemeinen Darstellungen bei Armbruster-Engel, Handbuch der Montan-Union, 1953 ff; Jerusalem, Das Recht der Montan-Union, 1954, S. $191 \mathrm{ff}$; s. ferner Biskup, Die soziale Entwicklung in der Montan-Union, Zeitschrift für Sozialreform, Jhg. 3 (1957) S. 309 ff; Kreyssig, Die soziale Fundierung der Montanunion, Gewerkschaftliche Monatshefte 9. Jhg. (1958) S.217 ff. - Zu den weitergehenden Möglichkeiten der EWG s.: Knolle, Die Sozialpolitik der Europäischen Wirtschaftsgemeinschaft, Bundesarbeitsblatt, 1957, S. 488 ff; Niemann, Lohn- und Sozialpolitik in der westeuropäischen Integration, Mitteilungen des wirtschaftswissenschaftlichen Instituts der Gewerkschaften, 10. Jhg. (1957) S. 257 ff; Biskup, Die Sozialvorschriften des Vertrages über die Europäische Wirtschaftsgemeinschaft, Die Sozialversicherung, 12. Jhg. (1957) S. $341 \mathrm{ff}$; ders., Die Sozialbestimmungen des Vertrages zur Gründung der Europäischen Wirtschaftsgemeinschaft, Recht der Arbeit, 10.Jhg. (1957) S. 457 ff; Wiechec, Sozialpolitik in der Montan-Union, Recht der Arbeit 12. Jhg. (1959) S. $291 \mathrm{f}$; v. Borries, Die Verwaltungskommission der Europäischen Wirtschaftskommission für die soziale Sicherheit der Wanderarbeiter, Bundesarbeitsblatt 11. Jhg. (1960) S. 54 ff; Wohlfahrt-Everlin-Glaesner-Sprung, Die Europäische Wirtschaftsgemeinschalt, 1960, Vorbem. vor Art.117 und Erl. zu Art. $117 \mathrm{fr}$.

3) (1) EGKS: Dem st a a t s re cht wird die EGKS zugeordnet von Nawiasky, Allgemeine Staatslehre, 2. Teil, Bd.2, 1955, S. 207 f und Allgemeine Staatslehre 3, S. 144 (Bundesstaat!), Ophüls, Juristische Grundgedanken des Schuman-Plans, NJW, Jhg. 4 (1951) S. 289 if (289) (partieller Bundesstaat), und Schlochauer, Der übernationale Charakter der EGKS, JZ, Jhg. 6 (1951) S. 290 f (partieller Wirtschaftsstaat; dieser Autor neigt sich später allerdings mehr und mehr der völker- 
tes fehlt diesen Gemeinschaften so viel, daß sie gerade in bezug auf die soziale Wirksamkeit nicht ohne weiteres mit einem sol-

rechtlichen Erklärung zu: Europäische Fragen von völkerrechtlicher Bedeutung, Archiv des Völkerrechts, Bd.3 (1951/ $52)$ S. 146 ff (184 ff) Rechtsfragen der europäischen Ordnung, das. Bd. 5 (1955) S. 40 ff ( $57 \mathrm{ff}$ ); Die Frage der Rechtsnatur der EGKS, Festschrift für Hans Wehberg, 1956 S. $361 \mathrm{ff}$ (insbes. S. 372)).

v. der Heydte, Schuman-Plan und Völkerrecht, in Festgabe f. Rudolf v. Laun, 1953, S.111 ff $(115,118)$ bezeichnet die EGKS als staatsähnlich (partieller. Bundesstaat). Die überwiegende Zahl der Autoren zählt die EGKS allerdings zu den völkerrechtlichen - den staatlichen allerdings sehr angenäherten - Organisationsformen: Bilfinger, Vom politischen und nicht-politischen Recht in organisatorischen Kollektivverträgen, ZaöRuVR Bd. XIII (1950/51) S.615 ff. (623 f.); Hallstein, Der Schuman-Plan, 1951, S. 18; Jaenicke, Die EGKS, ZaöRuVR Bd.XIV (1951/52) S. 1 ff (44 und passim); ders., Die Wendung zum supranationalen Gedanken im Schuman-Plan, Recht, Staat, Wirtschaft, Bd.3 (1951) S.245 ff (255 f); Kraus, Betrachtungen über die rechtliche Struktur der EGKS, in Festgabe für Rudolf Smend, 1952, S.206 ff.; Much, Die Amtshaftung im Recht der EGKS, 1952, S. 17 f.; Armbruster-Engel a.a.O. A 10 S. 5 f; Rindschedler, Rechtsfragen der Europäischen Einigung, 1954, S.201 f; Jerusalem a.a.O. S. 13 f; Wehberg, Entwicklungsstufen der internationalen Organisation, Die Friedenswarte, Bd. 52 (1954) S. 193 ff (205-209); Mokre, Staatenverbindungen zwischen Staatsrecht und Völkerrecht, Österreichische Zeitschrift für öffentliches Recht n. F. Bd. VII (1956) S. 228 ff (unter Leugnung einer klaren Trennungsmöglichkeit); Münch, Die Abgrenzung des Rechtsbereichs der supranationalen Gemeinschaft gegenüber dem innerstaatlichen Recht, Berichte der Deutschen Gesellschaft für Völkerrecht, Heft 2, 1958, S. 73 ff (76 f); Frler, Das Grundgesetz und die öffentliche Gewalt internationaler Staatengemeinschaften, Veröffentlichungen der Vereinigung der Deutschen Staats rechtslehrer, Heft 18, 1960, S. 7 ff (15 ff). - Zum Problem s. ferner Sauer, Die völkerrechtliche Bedeutung der Montan-Union, Österreichische Zeitschrift für öffentliches Recht n.F. Bd.IV (1953) S. 1 ff; Ule, Der Gerichtshof der Montangemeinschaft als europäisches Verwaltungsgericht, DVB1. 67.Jhg. (1952) S.65 ff (65). Auch die fremdsprachige Literatur zu dieser Frage anzuführen, erscheint in diesem Rahmen unnötig. Auf sie ist auch weitgehend von den Zitierten verwiesen. 
chen gleich behandelt werden können. Ihre zeitliche und gegenständliche Beschränkung, ihre Abhängigkeit von den Mitgliedsstaaten in Existenz und Willensbildung, ihre extrem reduzierte Direktbeziehung zu den Einwohnern der Mitgliedsstaaten und die von den Verfassungsschemata der Mitgliedsstaaten, insbes. auch vom deutschen, grundlegend abweichenden Struktur- und Aktionsmodalitäten der Gemeinschaftsgewalten - das alles sind Umstände, die Unterscheidung weitaus näher legen als Gleichsetzung. ${ }^{4)}$

\section{c) Innerstaatliche Interventionsträger}

Ganz außer Betracht zu bleiben hat als solche auch die vielgestaltige private soziale Aktion und die Eigenordnung und -gestalt, die ihr von ihren jeweiligen Trägern - Einzelpersonen, privatrechtlichen Verbänden der verschiedensten Art und Stiftungen gegeben wird. Doch liegt ein integrierender Bestandteil der sozialen Gesamtordnung des Staates darin, in welchem Umfang er soziale Elemente dieser Art zuläßt und selbständig gewähren läßt, inwieweit und auf welche lleise er sie ermuntert, unterstützt, lenkt, kontrolliert oder hemmt, inwieweit er ihnen soziale Aufgaben, die auch der Staat wahrnehmen könnte, überläßt und endlich, inwieweit er sie an der Wahrnehmung der staatlichen Sozialarbeit beteiligt. Von der steuerlichen Begünstigung privater Spendentätigkeit und der staatlichen Förderung der sog. betrieblichen So-

(2) EWG: An Stimmen, die sie den Staaten zuzählten, fehlt es, soweit ich sehe, bisher. - Für Nicht-Staatlichkeit aber Supranationalität: Jaenicke, Der übernationale Charakter der EWG, Festschrift für. Makarov (= ZaöRuVR Bd.19), 1958, S. 153 ff. - Zum Urteil beschränkter Supranationalität gelangt Ullmann, Die Europäische Wirtschaftsgemeinschaft eine supranationale Organisation? Österreichische Juristenzeitung, 14.Jhg. (1959) S. $449 \mathrm{ff}$. Gegen Staatlichkeit auch Münch a.a.O.; Erler a.a.O.; Wohlfahrt-Everlin-GlaesnerSprung a.a.O. Art. 1 Anm.5.

4) Zu den verfassungsrechtlichen Problemen der "Übertragung" "deutscher Staatsgewalt" auf Einrichtungen dieser Art s. die Relerate von Erler und Thieme sowie die Diskussion der Vereinigung der Deutschen Staatsrechtslehrer über das Thema "Das Grundgesetz und die öfentliche Gewalt internationaler Staatengemeinschaften" (Veröffentlichungen der Vereinigung der Deutschen Staatsrechtslehrer, Heft 18, 1960, S. 7 ff). 
zialpolitik 1) bis zur Zusammenarbeit des Staates mit den Wohlfahrtsverbänden2) und Jugendorganisationen, zur "sozialen Autonomie" der Sozialpartner ${ }^{3)}$ und zur beständigen Einflußnahme der großen Verbände auf die gesetzgeberische, verwaltende und rechtsprechende Wirksamkeit des Staates 4$)$ reicht das Spektrum der Begegnung staatlicher und außerstaatlicher Mittel und Kräfte. Sie muß mit einen Gegenstand dieser Untersuchung bilden. Wenn dagegen die Eigenwirksamkeit privater Aktionsträger als solche ausgeschieden wird, so wird - das muß betont werden damit nicht verkannt, daß der Staat an sich außer Stande wäre, allein und unter Ausschluß aller privaten Konkurrenz quantitativ und qualitativ das zu leisten, was im freien Zusammenwirken des Staates mit der Vielfalt der privaten Kräfte geleistet werden kann. Allein, gerade darin zeigt sich, daß deren Wirken wesentlich außerhalb der Sphäre staatlicher Intervention liegt.

Anders als hinsichtlich der privatrechtlichen ist hinsichtlich der öffent 1 ich recht 1 i chen Interventionsträger grundsätzlich davon auszugehen, daß sie trotz dieser oder jener Form rechtlicher oder auch tatsächlicher Selbständigkeit Instrumente des Staates sind. Das, was sie an staatsunabhängiger sozialer Eigenwirksamkeit entfalten können, tritt an Bedeutung hinter ihrer zweckhaft instrumentalen Existenz regelmäßig weit zurück. Als Hauptbeispiel von sozialen Einrichtungen dieser Art dürfen die Sozialversicherungsträger genannt werden. Je mehr aber Selbstbestimmung und Aufgabenkreis zunehmen, desto deutlicher setzt sich die - jedenfalls mögliche - soziale Eigenwirksamkeit von der entsprechenden staatlichen Aussparung und Kontrolle sowie von der Erfüllung entsprechender staatlicher Aufträge ab. Insbes. bei den $\mathrm{Ge}$ meinden, den mit der größten Eigenständigkeit ausgestatteten unterstaatlichen Verbänden und zugleich hochbedeutsamen Interventionsträgern, bleibt trotz aller staatlichen Abgrenzung und Einmischung und trotz aller Abhängigkeit von sonstwie seitens des Staates zu setzenden Prämissen ein Spielraum eigenbestimmter Sozialarbeit. Wie die Gemeinden sich

1) S. hierzu z.B. Hax, Art. "Betriebliche Sozialordnung (III) Betriebliche Sozialpolitik" im Handwörterbuch der Sozialwissenschalten, Bd.2, 1959, S. 74 ff und die dort nachgewiesene Literatur. - Zur Größenordnung dieses wichtigen Elements des Soziallebens s. z. B. Spiegelhalter, Die Struktur der betrieblichen Sozialaufwendungen.

2) Zum Ausmaß ihres Wirkens s. z.B. "Die freie Wohlfahrtspflege" hrsg. v. Bundesminister des Innern, 1956

3) S. hierzu unten B 2 IV 2 (S. 287 ff).

4) S. hierzu unten B 3 III 5 b (S. 373 ff). 
in ihm bewegen, liegt - so sehr ihr Handeln dem sozialen Wirken des Staates ergänzend korrespondiert - außerhalb dessen, was hier als die soziale Intervention des Staates ins Auge zu fassen ist. 5)

Eine Sonderstellung nehmen die $\mathrm{Ki} \mathrm{rchen} \mathrm{ein.} \mathrm{Als} \mathrm{Träger} \mathrm{und}$ Prediger anspruchsvoller sozial-ethischer Postulate, als Organisationssubstrate einer traditionsreichen und blühenden Diakonie und nicht zuletzt auch als "Dienstherren" einer großen Schar von Geistlichen, Religiosen und Laien ist ihre überragende Bedeutung evident. Als Körperschaften des öffentlichen Rechts sui generis sind sie jedoch zwar gewisser Privilegien öfentlichrechtlicher Körperschaften teilhaftig, von staatlichem Auftrag und staatlicher Aufsicht jedoch völlig frei. Hat das eigenständige soziale Wirken der Kirchen in diesem Rahmen grundsätzlich außer Betracht zu bleiben, so hat sich die Aufmerksamkeit andererseits umso mehr auf das Problem zu konzentrieren, auf welche Weise ein Träger sozialer Aktivität vom Range der Kirchen als von Verfassungs wegen unabhängiger Verband in das soziale Gesamtgefüge eingelassen ist. M.a.W.: Das Problem der Position der Kirchen in der sozialen Intervention des Staates ist in erster Linie ein solches der Abgrenzung. ${ }^{6)}$

3. Zum Sachbereich der sozialen Intervention

a) Soziale und wirtschaftliche Intervention

a) Zur Abgrenzung 1 )

Die umfassende Gemeinsamkeit der sozialen Intervention mit der wirtschaftlichen Intervention ist offensichtlich. 2) Stellt die wirtschaftliche Intervention einen korrigierenden Eingriff des Staates

5) Des Näheren s. u. B 2 II (S. $225 \mathrm{ff}$ ).

6) Des Näheren s. u. B 2 IV 1 (S.252 ff).

1) S. z.B. Pütz, Theorie der allgemeinen Wirtschaftspolitik und Wirtschaftslenkung, 1948, S. 138 ff (145 f; Marbach, Zur Frage der wirtschaftlichen Staatsintervention, 1950, S. 30 ff, 87, 103; Hans Huber, Das Staatsrecht des Interventionismus, Zeitschrift für schweizerisches Recht, n.F. Bd. 71 (1951) S. 173 ff (181 f); Jecht, Staatliche Wirtschaftspolitik und Einkommensverteilung, S. $128 \mathrm{f} \mathrm{u}$. passim.

2) Zur Verbindung s. außer den Vorgenannten Seidel, Wirtschaftspolitik und soziale Ethik, Festschrift für Hans Ehard, 1957, S. 14 ff (15 ff); Wendt, Bemerkungen über das Verhältnis von Wirtschaftspolitik und Sozialpolitik, in "Sozialreform und Sozialrecht" Festschrift für Walter Bogs, 1959, S.365 ff. 
in den Ablauf der Wirtschaft dar, 3) so ist die soziale Intervention im großen und ganzen ebenfalls nichts anderes als eine Korrektur wirtschaftlicher oder wenigstens wirtschaftich bedingter oder relevanter Gegebenheiten. ${ }^{4)}$ Auch dort, wo die soziale Intervention ganz ohne die Absicht, einen ökonomischen Prozeß verändern zu wollen, über wirtschaftliche Güter disponiert, wirkt sie auf die ökonomischen Daten in einer Weise ein, die es schwierig macht, sie von der wirtschaftlichen Intervention abzulösen. ${ }^{5)}$ Erst dort, wo - etwa auf dem Sektor des Bildungs- und des Gesundheitswesens - nichtwirtschaftliche Ursachen oder Folgen wirtschaftlicher Schlechterstellung mit ausschließlich oder wenigstens primär nichtwirtschaftlichen Mitteln ausgeglichen werden, verdünnt sich der - freilich über die verteilungspolitische Funktion der staatlichen Mittelschöptung immer noch vorhandene - Konnex bis zur Grenze der Wahrnehmbarkeit. Andererseits ist auch die Wirtschaftspolitik nicht nur das, worin sie und die Sozialpolitik sich im Kern treffen, nämlich Verteilungspolitik. 6) Der Staat greift in die Wirtschaft auch ein, um den Markt zu ordnen, die freie Konkurrenz zu sichern, das Sozialprodukt zu maximieren, Autarkiebestrebungen zu fördern, fachlich-partielle oder regionale Schwierigkeiten zu überbrücken, die lästige Amplitude der Konjunkturschwankungen zu vermindern, aus Gründen internationaler Verpflichtung oder der Landesverteidigung u.a.m.7) Aber ein Staat, der sich der sozialen Integration verpfichtet

3) Zum Begriff der wirtschaftlichen Intervention s. z.B. F. R. Huber, Wirtschaftsverwaltungsrecht, 2. Auf1., Bd. I, 1953, S. $34 \mathrm{ff}$; Scheuner, Die staatliche Intervention im Bereich der Wirtschaft, Veröffentlichungen der Vereinigung der Deutschen Staatsrechtslehrer, Heft 11, 1954, S. 1 ff ( 7 ff); Küng, Art. "Interventionismus" im Handwörterbuch der Sozialwissenschaften, Bd.5, 1956, S.321 ff; s.a. deren Nachweise.

4) Achinger, Soziale Sicherheit, 1953, S.21: "Die moderne Sicherheitspolitik stellt, wirtschaftspolitisch gesehen, einen kontinuierlichen Interventionismus dar."

5) S. hierzu z.B. Marbach a.a.O. S. 30 f; Schüle, Die staatliche Intervention im Bereich der Wirtschaft, Verötfentlichungen der Vereinigung der Deutschen Staatsrechtslehrer, Helt 11, 1954, S. 75 ff (95); s.a. Jecht a.a.O. S. 129.

6) Vg1. Jecht a.a.O.; zur Distributionspolitik s. ferner Weisser, Art. "Distribution (II) Politik" im Handwörterbuch der Sozialwissenschaften Bd.2, 1959, S. $635 \mathrm{ff}$ und die dort verzeichnete Literatur.

7) S. hierzu z.B. die einschlägigen Ausführungen der oben S. 31 f zu Fußn. 1, 3 und 5 Zitierten. 
weiß, steht auch dabei unter deren Gesetz. 8) Die mehr oder weniger weitläufigen Zusammenhänge etwa zwischen der Marktordnung - man denke an die sozial intendierten Konzeptionen von der sozialistischen Lenkungswirtschaft bis zur. "sozialen Marktwirtschaft" -, der Maximierung des Sozialprodukts 9) und der Stützung der Prosperität auf der einen und den sozialen Verhältnissen und Erfordernissen auf der anderen Seite belegen das. "Es gibt überhaupt keine wirtschaftspolitischen Maßnahmen des Staates, die nicht verteilungspolitische Effekte haben oder jedenfalls haben könnten." 10)

So lassen sich wirtschaftliche und soziale Intervention im allgemeinen nur schwer voneinander sondern. Unterscheidungen können vorwiegend nur gradueller Natur sein. Danach ist auch im Folgenden zu verfahren. Je unmittelbarer, spezifischer, wesentlicher sich eine Erscheinung auf den sozialen Ausgleich und die soziale Hilfe für die ärmeren Schichten bezieht, desto mehr wird auch ihre verfassungsrechtliche Problematik im Zentrum der Untersuchung stehen müssen. Je entfernter, mittelbarer oder zufälliger dagegen dieser Zusammenhang ist, je geringer die wesensmäßige soziale Bindung und der spezifisch soziale Zweckgehalt einer wirtschaftspolitischen Erscheinung ist oder je mehr sie als Instrument der wirtschaftspolitischen Technik einem eventuellen sozial intendierten Einsatz neutral gegenübersteht, desto mehr ist sie an die Peripherie zu verweisen. Die wirtschaftliche mit der sozialen Intervention um ihrer gegenseitigen Durchdringung willen völlig gleich zu behandeln, verbietet schon die unerträgliche Stoffülle, die sich daraus ergeben würde. Die parallelen Untersuchungen zum Recht der wirtschaftlichen Intervention 11 ) beweisen das. Vor allem aber würde auf diese Weise das Typische der sozialen Intervention unterdrückt statt, wie geboten, hervorgekehrt.

8) S. die oben S. 31 zu Fußn. 2 Zitierten.

9) S. zu deren sozialer Bedeutung Gawronsky, Staatsgewalt und Volkswohlfahrt, 2. Aufl. 1950, S. 12 f.

10) Jecht a.a.O. S. 129.

11) Vgl. aus der Fülle des einschlägigen Schrifttums insbesondere Böhm, Die Ordnung der Wirtschaft als geschichtliche Aulgabe und rechtsschöpferische Leistung, 1937; ders., Wirtschaftsordnung und Staatsverfassung, 1950; Schüle, Verfassung und Wirtschaft, 1948; ders., Die staatliche Intervention im Bereich der Wirtschaft; Scupin, Die Rechtslage der Wirtschaft unter dem Bonner Grundgesetz, 1950; Raiser, Wirtschaftsverfassung als Rechtsproblem, in: Festschrift für Julius Gierke, 1950, S.181 ff; Nipperdey, Die Grund- 
bb) Exkurs: Die wirtschaftsverfassungsiechtliche Prämisse der sozialen Intervention

Die wirtschaftsverfassungsrechtliche 1) Grundfrage nach dem zulässigen oder gar gebotenen Wirtschaftssystem muß jedoch noch an dieser Stelle aufgegriffen werden. Das zunächst deshalb, weil schon die angenommene Symbiose von wirtschaftlicher und sozialer Intervention - wenn anders nicht die wirtschaftliche Intervention $\left.{ }^{2}\right)$ mit der staatlichen Gestaltgabe der. Wirtschaft schlechthin gleichgestellt werden soll - eine gewisse Antwort auf diese Grundfrage voraussetzt. Sodann aber auch deshalb, weil die Gesamtgestalt der sozialen Intervention davon abhängt, mit welchen grundsätzlichen wirtschaftlichen Gegebenheiten sie sich ausein-

prinzipien des Wirtschaftsverfassungsrechts, DRZ 5. Jhg. (1950) S. 193 ff; ders., dass., Recht Staat Wirtschaft, Bd.3 (1951) S. 223 ff; ders., Die soziale Marktwirtschaft in der Verfassung der Bundesrepublik, 1954 (= Wirtschaft und Wettbewerb 4. Jhg. (1954) S.211 ff); Herbert Krüger, Staatsverfassung und Wirtschaftsverfassung, DVB1. 66. Jhg. (1951) S. 361 ff; Hans Huber, Das Staatsrecht des Interventionismus; Strauss, Wirtschaftsverfassung und Staatsverfassung, 1952; E.R.Huber, Wirtschaftsverwaltungsrecht, 2. Auf1., 2 Bde., 1953/54; ders., Der Streit um das Wirtschaftsverfassungsrecht, DÖV 9.Jhg. (1956) S.97 ff, $135 \mathrm{ff}, 172 \mathrm{f}, 200 \mathrm{ff}$; Hamann, Rechtsstaat und Wirtschaftslenkung, 1953; ders., Deutsches Wirtschaftsverfassungsrecht, 1958; Scheuner, Die staatliche Intervention im Bereich der. Wirtschaft; Partsch, Die verfassungsmäßige Sicherung der. Wirtschaftsprinzipien, ORDO Bd.VI (1954) S. 19 ff; Ehlermann, Wirtschaftslenkung und Entschädigung, 1957; Voigt, Wirtschaftsverfassung und Wirtschaftsentwicklung in der Bundesrepublik Deutschland, in "Staat und Bürger" Festschrift für. Willibalt Apelt, 1958, S. 73 ff; Gygi, Interventionsrecht und Interventionsverwaltung, 1958; Ballerstedt, Wirtschaftsverfassungsrecht, in: Bettermann-Nipperdey-Scheuner, Die Cirundrechte, Bd. III, 1. Halbbd., 1958, S.1 ff; Rau, Wirtschaltslenkende Verwaltung, DVB1. 75.Jhg. (1960) S.339 ff. Alle weiteren Nachweise s. bei den Zitierten.

1) Zum Begriff des IIirtschaftsverfassungsrechts s. die Vorgenannten. Zusammenfassend s. etwa Ballerstedt a.a.O. S.3 ff; zum Grundsätzlichen s. a. Strickrodt, Die Idee der Wirtschaftsverfassung als Gestaltungs- und Interpretationsprinzip, JZ 12.Jhg. (1957) S.361 ff. Weitere Nachweise s. dort.

2) S. nochmals S. 32 zu Fußn. 3. 
anderzusetzen und in welchem wirtschaftsstrukturellen Medium sie sich zu bewegen hat. Es macht gerade für seine soziale Wirksamkeit einen tiefgreifenden Unterschied aus, ob der Staat als Träger einer Zentralverwaltungswirtschaft die Güterverteilung schon von der Produktion her bestimmt oder ob er sich als das Subjekt einer interventionistischen oder neutralistischen Wirtschaftspolitik der Eigengesetzlichkeit eines mehr oder weniger freien Marktes gegenübersieht. Und es macht nicht weniger einen tiefgreifenden Unterschied aus, ob der Staat sich der vielfältigen Mittel des wirtschaftlichen Interventionismus bedienen kann, um die marktgesetzlich bestimmten Wirtschaftsabläufe und - zustände einer sozialen Korrektur zu unterziehen, ob er, wie die "soziale Marktwirtschaft"3) das will, auf die sog. marktkonformen Mittel beschränkt ist, oder ob er endlich zur völligen (wenn auch vielleicht nur binnen-) wirtschaftspolitischen Abstinenz verurteilt ist - was letzteres bei dem innigen Zusammenhang $z$ wischen wirtschaftlicher und sozialer Intervention diese mehr oder weniger zum Erliegen brächte.

Das Grundgesetz ist jedoch weder Ausdruck noch Sanktion eines wirtschaftstheoretischen Modells. Es "garantiert weder die wirtschaftspolitische Neutralität der Regierungs- und Gesetzgebungsgewalt noch eine nur mit marktkonformen Mitteln zu steuernde 'soziale Marktwirtschaft'. Die 'wirtschaftspolitische Neutralität' des Grundgesetzes besteht lediglich darin, daß sich der Verfassungsgeber nicht ausdrücklich für ein bestimmtes Wirtschaftssystem entschieden hat. Dies ermöglicht dem Gesetzgeber die ihm jeweils sachgemäß erscheinende Wirtschaftspolitik zu verfolgen, solern er dabei das Grundgesetz beachtet. "4) Die Bundesrepublik

3) Zum Wirtschaftsverfassungs recht der "sozialen Marktwirtschaft" s. insbes. Nipperdey a.a.O. (S. 33 zu Fußn.11); $s$. ferner statt aller anderen Müller-Armack, Art. "Soziale Marktwirtschaft" im Handwörterbuch der Sozialwissenschaften, Bd.9, 1956, S. 390 ff und die dort nachgewiesene Literatur.

4) BVerfGE 4, $7(17$ l). Mit diesem Ausspruch hat das Bundesverfassungsgericht die zunächst so überhitzte Diskussion über das Wirtschaftsverfassungsrecht durchgreifend beruhigt. Er entspricht der gegenwärtig herrschenden - und zu Recht herrschenden - Meinung. Zum Meinungsstand und seiner Entwicklung s. etwa v. Mangoldt-Klein, Art.2 Anm. III 8; E. R. Huber, Der Streit um das Wirtschaftsverfassungsrecht; Ehlermann, Wirtschaftslenkung und Entschädigung, S. 14 ff; Hamann, Deutsches Wirtschaftsverfassungsrecht, S. $31 \mathrm{ff}$. S. ferner die oben S. 33 zu Fußn. 11 Zitierten. In Anbetracht der fast 
ist also nicht $z u$ wirtschaftspolitischer Neutralität und Passivität verpflichtet. Sie kann sich der "marktkonformen Mittel", wie sie die Vertreter der "sozialen Marktwirtschaft" empfehlen, ebenso bedienen wie der weitergehenden und direkteren Mittel cles Interventionismus. Lediglich dem Übergang zur Zentralverwaltungswirtschaft stellen sich unüberwindliche Barrieren entgegen. $Z$ war verbietet das Grundgesetz auch diese nicht als solche. Aber es enthält eine Reihe von Bestimmungen, die, ohne spezifisch gegen sie gerichtet zu sein, einer Zentralverwaltungswirtschaft im Wege stehen: die komplizierte und schwerfällige parlamentarisch-gewaltenteilige Staatsorganisation auf der einen, die grundrechtlichen Sicherungen der Individualsphäre - insbes. das Grundrecht der freien Wahl von Beruf und Arbeitsplatz (Art. 12 GG), das Grundrecht des Eigentums (Art.14 GG), das Grundrecht der im Kern unantastbaren freien Entfaltung der Persönlichkeit (Art.2 Abs.1, 19 Abs.2 GG) und endlich der verfassungsrechtliche Schutz der Würde der Persönlichkeit (Art. 1 Abs. 1 GG) - auf der anderen Seite. 5) Daß der Staat gehindert ist, zur Zwangsverwaltungswirtschaft zu greifen, 6 ) bedeutet, daß er seine soziale Intervention auf die verteilungswirksamen Eigengesetz-

überreichen literarischen Erörterung darf auf eine besondere Darstellung des Problems und seiner Lösung hier verzichtet werden.

5) Eine Zusammenstellung der Argumente s. bei Ehlermann, Wirtschaftslenkung und Entschädigung, S.23 ff. Grundlegend vor allem E. R. Huber, Der Streit um das Wirtschaftsverfassungsrecht. Übrigens legen auch die Argumente, die Nipperdey (a.a.O.; s.o. S. 33 zu Fußn.11) zusammengetragen hat, um dem Staat des Grundgesetzes den Weg des Interventionismus abzuschneiden, und die zu diesem Ende nicht überzeugen konnten, die Unmöglichkeit einer Zentralverwaltungswirtschaft treffend dar.

6) Eine wichtige Ergänzung findet dieses Verbot in der Erkenntnis, daß der Staat die freiwirtschaltliche Betätigung nicht durch Ausdehnung der Eigenwirtschaft der öffentlichen Hand austrocknen darf (s. insbes. Strickrodt, Die wirtschaftichen Staatsunternehmen in ihrer verfassungsrechtlichen und unternehmenswirtschaftlichen Bedeutung, 1954, insbes. S. 14 ff; Torz, Privatwirtschaftliche Betätigung der öffentlichen Hand und Grundgesetz, DÖV 11.Jhg. (1958) S. 205 ff. S. zum Problem auch Ballerstedt, Wirtschaftsverfassungsrecht, S.32 f - der die verfassungs rechtlichen Schranken vielleicht zu zurückhaltend beurteilt -; ferner Dürig in Maunz-Dürig, Grundgesetz, 1958 ff (im Folgenden zitiert mit: Maunz-Dürig), Art. 2 Abs. I Randn. 52, Art. 19 Abs. III Randn. $47 \mathrm{f}$ - der in 
lichkeiten des Marktes und die autonomen Dispositionen der Marktteilnehmer einzustellen hat. An ihre Stelle die staatlich gewillkürte und von der Wurzel an kommandierte Güterverteilung treten zu lassen, ist ihm verwehrt.

Andererseits ist der Staat aber nicht nur nicht gehindert, wirtschaftspolitisch einzugreifen. Er ist - vor allem, um sich als Sozialstaat zu verwirklichen 7) - sogar unausweichlich genötigt, die wirtschaftlichen Zustände und Abläufe zu beeinflussen. So hat sich die Wirtschaftspolitik auf dem breiten Feld zwischen der absolut unbeeinflußten freien Marktwirtschaft auf der einen und der Zwangsverwaltungswirtschaft auf der anderen Seite zu bewegen. Sie ist - ohne daß damit ein bestimmtes wirtschaftstheoretisches System rezipiert wird - auf eine "gemischte Wirtschaftsverfassung" festgelegt. ${ }^{8)}$ Doch interessiert diese Untergrenze des verfassungsrechtlich gebotenen Interventionismus zunächst nicht so sehr; denn daß interveniert, wenigstens spezifisch sozial interveniert werden soll und wird, liegt dem aufgeworfenen Problem schon voraus. Festzuhalten ist vielmehr, daß die soziale Intervention von Verfassungs wegen auch - und zwar auch im technischen Sinn - eine wirtschaftliche sein kann, jedoch nicht zur Zwangsverwaltungswirtschaft umschlagen darf und deshalb wesensmäßig immer auch Korrektur der marktwirtschaftlichen Verteilungsmängel zu sein hat.

\section{b) Soziale Intervention und Daseinsvorsorge}

Eng verwandt sind sich auch soziale Intervention und öffentliche Daseinsvorsorge. 1) Die Daseinsvorsorge ist der Inbegriff der

seiner extremen Forderung nach Einschränkung der eigenwirtschaftlichen Betätigung der öffentlichen Hand verfassungsdogmatisch zu weit geht -; s.a. Frentzel, Die gewerbliche Betätigung der öffentlichen Hand, 1958, S. 15 ff; Maunz, Die Gesetzmäßigkeit des Fernsehwerbens, Bayerische Verwaltungsblätter n. F'. 3. Jhg. (1957) S. 4 ff (4). Weitere Nachweise s. bei den Zitierten).

7) S. u. B 5 III (S. 762 fif) (insbes. 9 S. 835 ff).

8) S. hierzu statt aller früheren E.R. Huber, Der Streit um das Wirtschaftsverfassungsrecht; ferner Ehlermann, Wirtschaftslenkung und Entschädigung, S.23 ff; Hamann, Deutsches Wirtschaftsverfassungsrecht, $\mathrm{S} .31 \mathrm{ff}$; Dürig in Maunz-Dürig, Art. 2 Abs. I Randn. 44; insgesamt übereinstimmend Ballerstedt, II irtschaftsverfassungsrecht, insbes. S. $49 \mathrm{ff}$.

1) Grundlegend zum Begriff der Daseinsvorsorge Forsthoff, Die Verwaltung als Leistungsträger; ders., Rechtsfragen der lei- 
Bemühungen des Staates und seiner Unterverbände, insbes. der Kommunen, 2) den Menschen die Lebensgüter zu verschaffen, die sie brauchen, um ihre Existenz zu erhalten und darüber hinaus ein angemessenes Leben zu führen. Darin trifft sie sich mit der sozialen Intervention; und die Masse der sozialen Anliegen sind auch solche der Daseinsvorsorge. ${ }^{3)}$

Trotzdem lagern beide Erscheinungen in verschiedenen Dimensionen. Die öffentliche Daseinsvorsorge ist eine Reaktion auf die zunehmende Abhängigkeit des Menschen von "fremden" Leistungen: von der Bereitstellung einer Arbeitsgelegenheit, der Zahlung eines angemessenen Lohnes, der Produktion der notwendigen Güter, der Verteilung der Güter an jedermann, der ihrer bedarf, zu einem erträglichen Preis usw. 4) Fällt eine dieser Funktionen aus, so bedroht ihn das in seiner Existenz oder drückt ihn empfindlich unter den angemessenen Lebensstandard, weil er nicht in der Lage ist, das Fehlende aus eigener Kraft oder auch

stenden Verwaltung; s.a. dens. Lehrbuch des Verwaltungsrechts, S. $320 \mathrm{ff}, 355 \mathrm{ff} u$. passim. Im übrigen vgl. etwa Becker, Verwaltung und Verwaltungsrechtsprechung, VVDStRL. H. 14, 1956, S.96 ff (110). - In neuerer Zeit hat sich eine fruchtbare Begriffskritik erhoben. Vgl. Simitis, Die faktischen Vertragsverhältnisse, S. 463 ff; Fischerhof, Öfentliche Versorgung mit Wasser, Gas, Elektrizität und öffentliche Verwaltung, DÖV 10. Jhg. (1957) S. 305 ff (312 ff); ders., "Daseinsvorsorge" und wirtschaltliche Betätigung der Gemeinden, DÖV 13.Jhg. (1960) S. $41 \mathrm{ff}$ ( $\mathrm{m}$. bes. eingeh. Nachw.); Siebert, Faktische Vertragsverhältnisse, 1958, S. 12 f; Hamann, Deutsches Wirtschaftsverfassungsrecht, S. 68 ff; Maunz, Grundfragen des Energiewirtschaftsrechts, Verwaltungsarchiv, Bd. 50 (1959) S. $315 \mathrm{ff}$ (319 ff); Dürig in Maunz-Dürig, Art. 19 Abs. III Randn. 47 (insbes. S. 31, Fußn. 1); weitere Nachweise $s$. bei den Genannten.

2) Vgl. Forsthoff, Die Daseinsvorsorge der Kommunen, 1958; weiteres s. u. B 2 II (S. 225 ff).

3) Weitgehend wird im Schrifttum daher auch die Daseinsvorsorge als die wesensbestimmende Aufgabe des Sozialstaates angesehen (s. u. B 5 II 1 ff (insbes. S.679 Fußn. 5) S.676 ff).

4) S. Forsthoff, Die Verwaltung als Leistungsträger, S. 3 ff = Rechtsfragen der leistenden Verwaltung, S.24 ff. 
mit Hilfe seiner engeren, insbes. der familiären Gemeinschaft bereitzustellen. Auf dieses mit der Massierung der Menschen und ihrer Bedürfnisse, der hochdifferenzierten Arbeitsteilung, der Verflüchtigung des Konsumkapitals und der Technisierung der Produktions- und Verteilungsvorgänge riesenhaft angewachsene Risiko ihrer Glieder antwortet die staatliche (kommunale usw.) Gemeinschaft, indem sie auf diese oder jene Weise selbst dafür sorgt, daß die lebensnotwendigen Güter bereit stehen oder beschafft werden können. Diese Daseinsvorsorge ist von der ökonomischen Position der Bedürftigen grundsätzlich unabhängig. ${ }^{5)}$ Zwar ist sie als Einkommenshilfe für die Erwerbsunfähigen - 6) sei es als Sorge für ein ausreichendes (Arbeits-)Erwerbseinkommen, 7) sei es als zweckgebundene Einkommensergänzung (Beihilfen u. ä.) - eine Hilfe gerade für die Armen oder wenigstens Ärmeren. Zwar begünstigt auch die öffentliche (öffentlich gesteuerte) Darreichung lebensnotwendiger Güter in erster Linie die wirtschaftliche Unterschicht; denn sie träfe ein überhöhter Preis relativ härter als die wirtschaftlich besser Gestellten, und diese können sich leichter Ersatz beschaffen als jene. Zwar verhütet endlich die güterdarreichende Daseinsvorsorge den sozialen Abstieg derjenigen, die durch überhöhten Preis oder die völlige Unerreichbarkeit knapper Güter in ihrer gesamten Lebenshaltung bedroht würden. Aber die Daseinsvorsorge greift darüber hinaus weit aus in den Bereich von Bedürfnissen, die auch Angehörige der Mittel-, ja selbst der Oberschicht nicht mehr aus eigenem befriedigen können, weil sie entweder mit den Mitteln privater Marktwirtschaft überhaupt nicht befriedigt werden können oder nur zu einem allgemein untragbaren Preis. ${ }^{8)}$ Kriegsbewirtschaftung, Verkehrs- und Energieversorgung bieten Beispiele.

Demgegenüber ist die soziale Intervention in erster Linie die Antwort der staatlichen Gemeinschaft auf die vorhandenen Wohlstandsdifferenzen. Sie kümmert sich um die Daseinsvorsorge der Ärmeren, d.h. vor allem um die Daseinssorgen, die sie haben, weil sie die Ärmeren sind. Sie interessiert sich für die Daseinsvorsorge auch, soweit diese einer drohenden Pauperisierung ent-

5) Vgl. Forsthoff, Die Verwaltung als Leistungsträger, S. 5 Fußn. 6 = Rechtsfragen der leistenden Verwaltung, S. 26 Fußn.6

6) Vgl. Forsthoff, Rechtsfragen der leistenden Verwaltung, S. 18

7) Vgl. Forsthoff, Die Verwaltung als Leistungsträger, S. 7 = Rechtsfragen der leistenden Verwaltung, S. 27

8) Bei allgemeiner Knappheit tritt auch die subjektive Einschätzung des entsprechenden Mangels als "Armut" zurück (s. v. Wiese, Über die Armut, S.43 f, 47). 
gegenwirkt. Aber sie zielt nicht, wie die baseinsvorsorge, auf die Massengüterversorgung ab, weiter gefaßt: nicht auf die Befriedigung der Bedürfnisse einer sozial hicht diflerenzierten Allgemeinheit.

Die Daseinsvorsorge hebt sich insoler'n von der sozialen Intervention $a b$. Andererseits wird die Selbständigkeit der sozialen Intervention gegenüber der Daseinsvorsorge in dem typischen sozialen Bestreben nach Hebung der unteren Schichten und Verminderung der wirtschaftlich-sozialen Spannung sichtbar. Zwar wäre es vielleicht nicht richtig, die Daseinsvorsorge auf die elementaren Lebensgüter der biologischen Existenzerhaltung zu beschränken und eine sozial intendierte Besserung über dieses Minimim hinaus unter diesem Gesichtspunkt zu sondern. Es ist nur schwer möglich, "den Begriff der Daseinsvorsorge unter irgendwelchen quantitativen oder qualitativen Gesichtspunkten zu begrenzen. 1:9) Aber die Daseinsvorsorge ist kein dynamisches Prinzip. Sie will Mängel ausgleichen, die sich im Rahmen des status quo der Lebensverhältnisse einstellen, nicht aber diesen selbst wesentlich verschieben. 10) Die soziale Intervention aber will das wenigstens auch. 11)

9) Forsthoff, Rechtsfragen der leistenden Verwaltung, S. 12; s.a. Forsthoff, Lehrbuch des Verwaltungsrechts, S. 322 .

10) S. dens. Rechtsfragen der leistenden Verwaltung, S. $12 \mathrm{f}$.

11) Forsthoff (Rechtsfragen der leistenden Verwaltung, S.26, insbes. Fußn.6, und S. 37 f) will die "soziale Fürsorge... von der Daseinsvorsorge scharf geschieden wissen" (S.26 Fußn.6), weil "die staatliche Fürsorge in jeder Form... eine einseitig staatliche Aufgabe" sei (\$.37). Die Daseinsvorsorge sei dagegen zwar nicht erschöplend aber doch in dem "Teil, der besonders problematisch und einer dogmatischen Klärung vorzugsweise bedürftig" sei, durch "die Zweiseitigkeit des Leistungsverhältnisses und las Angewiesensein des einzelnen auf den Bestand des Leistungsverhältnisses" gekennzeichnet (S.38). Diese Abgrenzung überzeugt in sich schon nicht (zur Kritik s.a. Fischerhof, Öfentliche Versorgung mit Wasser, Gas, Elektrizität und öflentliche Verwaltung, S.312). Sie setzt einen l'eil der Daseinsvorsorge für das Ganze. Sie geht aber auch von einem sehr eigenartigen Begriff der "öffentlichen Fürsorge in jeder Form" aus. Keinesfalls kann diese dem gleichgesetzt werden, was hier unter sozialer Intervention verstanden wird. Die Abgrenzung Forsthoffs kann daher für den vorstehenden Zusammenhang nicht übernommen werden. 
III. Das Verlassungsrecht als Gegenstand der Untersuchung und sein Verhältnis zur sozialen Intervention

des Staates

Der eigentliche Gegenstand der Untersuchung ist jedoch nicht allgemein die soziale Intervention des States sondern ihre verfassungrechtliche Regelung - ihre Regelung durch jene oberste Rechtsschicht, die, noch über der Gesetzgebung stehend, den Anspruch einer normativen Grundordnung des ganzen Staatslebens erhebt. Gemeint ist also das durch den Vorrang vor den Gesetzen ausgezeichnete Verfassungsrecht im formellen Sinn 1) - konkret gesprochen: das Grundgesetz für die Bundesrepublik Deutschland.2) Dabei spielt es grundsätzlich keine Rolle, ob es sich um revisibles oder irrevisibles Verfassungs recht (i.S. des Art. 79 $\left({ }_{G}\right.$ ) handelt oder ob sonstwie höherrangiges oder niederrangiges Verfassungsrecht vorliegt. ${ }^{3)}$ Aufzusuchen ist die verfassungsrechtliche Grundordnung der sozialen Intervention, wie sie hic et nunc gilt und nicht auch der Spielraum ihrer denkbaren Veränderungen. Diese Grundordnung besteht aber nicht nur aus den Sätzen des geschriebenen Verfassungsrechts. Gewisse Grundsätze liegen ihm voraus und gelten, ohne in die Verfassungsurkunde aufgenommen zu sein, mit derselben bindenden Kraft. ${ }^{4}$ Sie erst integrieren das Gesamtbild.

Die Verfassung, wie sie hier verstanden wird, ist Teil der Rechtsordnung. Die soziale Intervention dagegen findet im Recht zwar weitgehend Grund, Mittel und Form, erschöpft sich aber nicht im Rechtlichen. Sie ist Teil des staatlichen Seins, das mehr und anderes umgreift als die staatliche Rechtsordnung. 5)

1) Zum Begriflichen s. etwa Carl Schmitt, Verfassungslehre, 1928 (Neudruck 1954 und 1957), S. 1 ff; Nawiasky, Allgemeine Staatslehre, Teil 3, S.93 ff; Maunz, Deutsches Staatsrecht, S. $35 \mathrm{ff}$.

2) Zum Grundgesetz als Verfassung s. v. Mangoldt-Klein, Uberschrift des Grundgesetzes, Anm. III (S.23 ff); Maunz a.a.O. S. 38 fl.

3) Finzelne Nachweise hielzu s. u. S. 663 ff.

4) S. Nawiasky, Positives und überpositives Recht, JZ 9. Jhg. (1954) S. 717 ff; H.J.Wolff, Rechtsgrundsätze und verfassungsgestaltende Grundentscheidungen als Rechtsquellen, in "lorschungen und Berichte aus dem öffentlichen Recht" Gedächtnisschrilt für. Walter Jellinek, 1955, S. 33 ff; Ridder, Vom Grund des Grundgesetzes, JZ 13. Jhg. (1958) S. 322 ff; s.a. BVerfit: 2, 380 (403).

5) Um dies festzustellen braucht nicht in die Auseinandersetzung 
Aber selbst von der staatlichen Rechtsordnung ist die Verfassung nur ein Teil. Regelungen der sozialen Intervention finden sich dagegen in der ganzen staatlichen Rechtsordnung. Ihre Masse liegt eindeutig außerhalb (unterhalb) des Verfassungsiechts. Die verfassungs rechtliche Ordnung bietet also nur einen sehr schmalen und sehr distanzierten Aspekt der sozialen Intervention.

Trotzdem durchdringt er in einzigartiger. Weise das Ganze der sozialen Intervention des Staates. "Das Wesen des Rechts liegt doch gerade darin, daß das Sollen in Sein umgesetzt" wird. 6) Die rechtlich-normative Ordnung ist, wie auch immer sie von der staatlichen Wirklichkeit geschieden werden mag, eine höchst wirksame Ursache für das jeweilige So-Sein der staatlichen Gemeinschaft. 7) Das gilt in ganz besonderer W'eise für das Verfas-

mit den verschiedenen Ansichten über das Verhältnis von Staat und Recht eingetreten zu werden (s. f.v.a. Georg Jellinek, Allgemeine Staatslehre, 3. Aufl. 1914 (3. Neudruck 1921) S. 162 ff, 332 ff; Kelsen, Allgemeine Staatslehre, 1925, S. $6 \mathrm{ff}, 47 \mathrm{ff}$; Schindler, Recht und Staat, in: Verhandlungen des Schweizerischen Juristentages 1931, S.83 ff; Heller, Staatslehre, 1934, S. 216 ff; 242 ff; Nawiasky, Allgemeine Staatslehre, Teil 1, S. 36 ff, 73 f, 127 f, 143 f). Auch wenn Recht und Staat zu identifizieren wären (Kelsen a.a.O. S.6 ff), könnte der Spielraum freier Gestaltung nicht übersehen werden, der den staatlichen Organen im Rahmen dieser Rechtsordnung verbleibt (ebd. S.236 fi). Nicht zu erörtern ist auch das Wesen des rechtsfreien Raumes (vgl. Fngisch, Der rechtsfreie Raum,ZStI, Bd. 108 (1952) S. 385 ff); denn wie auch immer dieses zu beurteilen ist: daß die normative Ordnung nicht alle Lebensbereiche erschöpfend durchdringen kann, steht außer Zweifel (s. Darstellung und Nachweis bei Engisch a.a.O.). Endlich ist aul die nicht völlig auszuräumende Gefahr bewußten oder unbewußten unrichtigen Rechtsvollzuges hinzuweisen.

6) Schindler, Recht Staat Völkergemeinschalt, Ausgewäh1te Schriften und Fragmente aus dem Nachlaß, 1948, S. 16; s.a. dens., Recht und Staat, S. 103; dens., Verfassungsrecht und soziale Struktur, 1. Auf1. 1932 (2. Aufl. 1944 war dem Verf. nicht greifbar), S.31 f. Weitere Nachweise s. etwa bei Simitis, Die faktischen Vertragsverhältnisse, $5.4 \mathrm{ff}$, insbes. $\mathrm{S} .31 \mathrm{ff}$ (beachtlich auch die eigenen Ausführungen dieses Autors a.a.O.).

7) S. z.B. Schindler, Verfassungsrecht und soziale Struktur, S. 63 . 
sungs recht. ${ }^{8)}$ Sein Standort in der Hierarchie der Normen befähigt es zur potentiell intensivsten Wirkungsweise. Es strahlt nicht nur unmittelbar auf das staatliche Sein aus. Es prägt auch alle unter ihm stehenden Ränge des staatlichen Rechts. Über diese wirkt es wiederum auf die Wirklichkeit ein. Wird also in dieser Untersuchung nicht das Gesamtbild der sozialen Intervention zu zeichnen sein, so wird die Betrachtung der normativen, formellen Verfassung doch wesentliche Züge dieses Gesamtbildes erkennen lassen.

8) Vgl. Smend, Verfassung und Verfassungsrecht, 1928, S. 75 ff; Hesse, Die verfassungsrechtliche Stellung der politischen Parteien im modernen Staat, VVDStRL. H. 17, 1959, S.10 ff (12 ff, 48 f); ders., Die normative Kraft der Verfassung, 1959, insbes. S. $7 \mathrm{ff}$. 



\section{B. DAS VERFASSUNGSRECHT DER SOZIALEN INTERVENTION}

\section{Abschnitt \\ Die bundesstaatliche Ordnung}

"Die Bundes republik Deutschland ist ein... sozialer Bundesstaat" (Art.20 Abs.1 GG). "Die verfassungsmäßige Ordnung in den Ländern muß den Grundsätzen des ... sozialen Rechtsstaates im Sinne dieses Grundgesetzes entsprechen" (Art.28 Abs.1 Satz 1 GG). Das bundesstaatliche Ganze, gegliedert in Bund und Länder, soll also ein sozial wirkendes Staatswesen sein. Dieses normative Bekenntnis wäre unwahr, wenn die staatlichen Aufgaben und Mittel nicht so verteilt wären, daß Bund und Länder die Möglichkeit sozialstaatlicher Selbstverwirklichung hätten.

Die Formel vom "sozialen Bundesstaat" 1) postuliert eine entsprechende Verteilung von Kompetenz und Potenz. Aber sie verteilt nicht selbst. Die Frage, wie die sozialen Wirkungsmöglichkeiten verteilt sind und wie umgekehrt das Gesamt der sozialen Intervention der Bundesrepublik von der Verteilung der sozial relevanten Zuständigkeiten und Mittel geprägt ist, hat sich an die spezifisch Aufgaben und Mittel zuweisende bundesstaatliche Grundordnung zu richten. Aufbauend auf der Kompetenzvermutung zugunsten der Länder (Art.30, 70 Abs. 1 GG) weist diese dem Bund ein weites Feld von Aufgaben und Befugnissen zu.

\section{Die bundesstaatliche Aufgabenverteilung}

1. Die Gesetzgebungszuständigkeit

a) Die ausschließliche Gesetzgebungszuständigkeit des Bundes

Der Katalog der ausschließlichen Gesetzgebungszuständigkeit des Bundes (Art.73 GG) weist diesem zwar keine ausgesprochenen Schwerpunktmaterien der sozialen Intervention $z u$, jedoch immerhin Regelungsgegenstände von großer sozialer Bedeutung.

Zu nennen ist das Wehrecht (Nr.1). Hinsichtlich der dienstlichen Stellung der Soldaten, der Wehrpflicht, der Soldatenversorgung, der Versorgung der Angehörigen, der Arbeitsplatz- und der sonstigen sozialen Sicherung der zum Wehrdienst eingezogenen Personen hat es auch soziale Wertvorstellungen zu verwirklichen. Nur für die (soziale Rücksichtnahme bei der) Regelung der Wehr-

1) S. unten Abschnitt 5 II 3 a (S. 737 ff) 
pflicht ${ }^{1)}$ ist dabei freilich Art. $73 \mathrm{Nr} .1$ GG die alleinige Grundlage der ausschließlichen Bundeskompetenz. Für die dienst- und versorgungs rechtlichen Regelungen konkurriert Art. $73 \mathrm{Nr} .1 \mathrm{mit}$ Art. 73 Nr. 8 GG. 2) Hinsichtlich der arbeits-, beamtendienstund sozialversicherungs rechtlichen Sicherung eingezogener Personen ${ }^{3)}$ grenzt die Kompetenznorm an die konkurrierende $\mathrm{Zu-}$ ständigkeit nach Art. $74 \mathrm{Nr} .12$ und Art. $75 \mathrm{Nr} .1 \mathrm{GG} 4)$ und ist die eigene Bedeutung des Art. $73 \mathrm{Nr} .1$ wohl sehr zurückhaltend zu beurteilen.

Sozial bedeutsam ist auch die Regelung der Freizügigkeit (Art. 73 Nr. 3 GG), die der Bundesgesetzgeber für Fälle einschränken kann, "in denen eine ausreichende Lebensgrundlage nicht vorhanden ist" (Art. 11 Abs.2 GG); somit also auch unter sozialen Aspekten. ${ }^{5)}$

1) Derzeit einschlägig $₫ 12$ Abs. 4 des Wehrpflichtgesetzes

2) Die beiden Kompetenznormen eindeutig zu scheiden, ist ohne Interesse. - Zu bemerken ist, daß hinsichtlich der Beschädigtenversorgung eine Konkurrenz mit Art. 72 Nr. 10 GG jedenfalls solange nicht in Frage kommt, als keine "Kriegs"Beschädigungen vorliegen.

3) S. das Eignungsübungsgesetz v. 20.Januar 1956 (BGBl.I S.13) i.d.F. des Änderungsgesetzes v. 20. Januar 1959 (BGB1. I S.25) und das Arbeitsplatzschutzgesetz v. 30. März 1957 (BGB1.I S. 293).

4) Vg1. Katzenstein, Rechtliche Erscheinungsformen der Machtverschiebungen zwischen Bund und Ländern seit 1949, DÖV 11. Jhg. (1958) S. 593 ff (594).

5) (1) Allerdings zielen Freizügigkeitsbeschränkungen wegen mangelnder Lebensgrundlage in der Regel vor allem darauf $a b$, daß "der Allgemeinheit daraus besondere Lasten entstehen würden"und dies vermieden werden soll (Art.11 Abs.2 $\mathrm{GG})$; s. die $\$ ₫ 4 \mathrm{ff}$ des Gesetzes über die Freizügigkeit vom 1. November 1867 (BGB1. S. 55; i.d.F. des Art. 37 EGBGB und der Verordnungen vom 13. Februar 1924, RGB1. I S. 100, und vom 5. Juni 1931, RGB1. I S. 279, 308) - die Fortgeltung dieser Bestimmungen im einzelnen zu erörtern ist hier nicht der Ort - und das Gesetz über die Notaufnahme von Deutschen in das Bundesgebiet vom 22. August 1950 (BGB1. I S. 367; i.d. F. des Gesetzes vom 27. Juli 1957, BGBl. I S. 1207).

(2) Ergänzend ist zu bemerken, daß "gerade das Freizügigkeits recht... seit jeher die Materie (ist), an der die selbstverständliche Möglichkeit des ausschließlich zuständigen Bundesgesetzgebers, seine Kompetenz teilweise auf den Landesgesetzgeber zu delegieren" (Art. 71 GG), "veranschaulicht 
Das Recht der Einw anderung (Art.73 Nr.3 GG) kann den Arbeitsmarkt, aber auch die Existenzbedingungen selbständig Erwerbstätiger beeinflussen. 6) Das Recht der A us w anderung (Art.73 Nr.3 GG) ist weitgehend ein Recht des sozialen Schutzes. 7)

Bedeutung für die wirtschaftlichen und über diese auch für die rein sozialen Zusammenhänge hat stets das Währungs-, Geldund Münzwesen (Art. $73 \mathrm{Nr} .4 \mathrm{GG}$ ).

Über soziale Gestaltungsmöglichkeiten verfügt der Bund schließlich im Rahmen seiner Kompetenz zur Regelung der $\mathrm{Rechtsverhältnisse} \mathrm{des} \mathrm{in} \mathrm{seinem} \mathrm{Dienst} \mathrm{und} \mathrm{im}$ Dienst der bundesunmittelbaren Körperschaften des öffentlichen Rechts stehenden Personenkreises (Art. $73 \mathrm{Nr} .8 \mathrm{GG}$ ). 8) Von den außerhalb des Art. 73 GG dem Bunde ausschließlich vorbehaltenen Materien interessiert hier vor allem ebenfalls eine dienstrechtliche, nämlich die des Art. 131 GG; denn die Situation der unter den besonderen Verhältnissen der unmittelbaren Nachkriegszeit ihres Dienstes verlustig gegangenen Bediensteten stellte kein geringes soziales Problem dar.

Im Rahmen des Steuerrechts ist der Sektor, den Art. 105 Abs. 1 GG der ausschließ1ichen Gesetzgebungszuständigkeit des Bundes unterwirft - es sind die Z $\mathrm{Z} l 1 \mathrm{e}$ und die Finanzmonopole - relativ klein.9) Allerdings muß die hohe Empfindlichkeit der

wird" (Dürig, Freizügigkeit, in: Neumann-Nipperdey-Scheuner, Die Grundrechte, Bd. II, 1954, S. 507 ff (526); vgl. \$3 Abs. 1 des Freizügigkeitsgesetzes; s.a. die weiteren Hinweise bei Dürig, a.a.O. Fußn.71).

6) Im wesentlichen ist der Schutz des inländischen Arbeitsmarktes aber zurückverlegt in die Sphäre des Arbeitsrechts, das die Beschäftigung von Ausländern im Inland von einer Genehmigung abhängig macht ( $\$ 43$ AVAVG).

7) Vg1. das Gesetz über das Auswanderungswesen vom 9. Juni 1897 (RGB1. S. 463; i.d.F. der Verordnungen vom 14. Februar 1924, RGB1. I S. 107, und vom 18. Juni 1926, RGB1. I S. 274) und die Verordnung gegen Mißstände im Auswanderungswesen vom 14. Februar 1924 (RGB1. I S. 107).

8) Grundlegend zur Diskussion um den Begriff des Dienstrechts Wacke, Zur Neugestaltung des Beamtenrechts, Bemerkungen zu den Unterschieden der drei deutschen Dienstrechte, AöR $\mathrm{Bd} .76$ (1950/51) S. $385 \mathrm{ff}$.

9) Seit durch Art. 106 Abs. $1 \mathrm{Nr} .7$ GG in der Fassung des Finanzverfassungsgesetzes vom 23. Dezember 1955 (BGB1. I S. 817) dem Bund das Recht zusteht, eine ihm allein zufließende Er- 
sozial relevanten Gegebenheiten für alle abgabenrechtlichen Veränderungen berücksichtigt werden. Die Zölle sind für das inländische Preisniveau und für die inländische Wirtschaft besonders bedeutsam. Sie und die Finanzmonopole spielen ferner als Einnahmeposten des Bundeshaushalts keine geringe Rolle.

\section{b) Die konkurrierende Gesetzgebungszuständigkeit}

aa) Übersicht

Die Schwerpunkte sozialer Intervention auf dem Gebiete der Gesetzgebung erfaßt vielmehr der Katalog der konkurrierenden Gesetzgebungszuständigkeit in Art. 74 GG: Die Angelegenheiten der Flüchtlinge und Vertriebenen (Nr.6), die öffentliche Fürsorge (Nr.7), die Kriegsschäden und die Wiedergutmachung ( $\mathrm{Nr} .8$ ), die Versorgung der Kriegsbe$\mathrm{schädigten}$ und die Fürsorge für die ehemaligen Kriegs gefangenen (Nr.10), das Recht der Wirtschaft (Nr.11) und der Verhütung des Mißbrauchs wirtschaftlicher Machtstellung ( $\mathrm{Nr} .16)$, das A r beitsrecht, einschließlich der Betriebsverfassung, des Arbeitsschutzes und der Arbeitsvermittlung sowie die Sozialversicherung einschließlich der Arbeitslosenversicherung ( $\mathrm{Nr} .12)$, die Ü berführung von Grund und Boden, von Naturschätzen und Produktionsmitteln in Ge meineigentum oder in andere Formen der Gemeinwirt schaft (Nr.15), das landwirtschaftliche $\mathrm{Pachtwesen,} \mathrm{das}$ Wohnungs wesen, das Si edlungs - und Heimstättenwesen (Nr.18). Vielfache Möglichkeiten sozialer Intervention bietet aber auch die Kompetenz zur Regelung des bürgerlichen Rechts und des gerichtlichen Veríahrens aller Gerichtszweige - mit Ausnahme der gemäß Art. 108 Abs. 5 GG notwendig durch Bundesgesetz zu regelnden Finanzgerichtsbarkeit - (Nr. 1), des

gänzungsabgabe der Einkommens- und Körperschaftssteuer zu erheben, müßte konsequenterweise dem Bund auch die ausschließliche Ciesetzgebung über diese Ergänzungsabgabe zustehen. Es ist undenkbar, daß die Länder diese Abgabe regeln. Aber da ohnedies die Grenzen zwischen ausschließlicher und konkurrierender Zuständigkeit auf dem Gebiete des Steuerrechts praktisch aufgehoben und durch die Sperrwirkung des Bundesrechts (Art. 72 Abs. 1 GG) effektiv auch der Bereich der nach Art. 105 Abs.2 GG konkurrierenden Steuergesetzgebung ausschließlich zur Disposition der Bundesgesetzgebung steht ( $\mathrm{s}$. hierzu unten $\mathrm{S} .75$ ), kommt diesem Versäumnis des Finanzverfassungsgesetzes kaum mehr das $z u$, was man eine akademische Bedeutung nennt. 
Vereinsrechts in bezug auf die korporative Organisation sozial relevanter Kräfte ( $\mathrm{Nr} .3$ ) und das stets für den Arbeitsmarkt bedeutsame Aulenthalts - und Niederlassungs rechts der Ausländer (Nr.4). Schließlich kann gerade auch die Kompetenz zur akzessorischen Regelung des Enteignungs rechts (Nr.14) in den Dienst der sozialen Intervention genommen werden. Auch das Strafrecht ( $\mathrm{Nr} .1$ ) ist schließlich ein Mittel sozialer Ordnung.

Diesem Katalog tritt zur Seite die umfassende konkurrierende Zuständigkeit auf dem Gebiet des Steuerrechts nach Art. 105 Abs. 2 GG, die Hauptinstrumente der sozialen Intervention wie die Steuern vom Einkommen, vom Vermögen, von Erbschaften und Schenkungen umfaßt (Nr.2). Aber auch die Verbrauchs - und Verkehrssteuern (Nr.1) - von denen das Grundgesetz nur die "mit örtlich bedingtem Wirkungskreis" 1) der Landesgesetzgebung vorbehält - sind wenigstens zum Teil von wesentlich sozialer Wirksamkeit oder zumindest Ausstrahlung auf die sozialen Belange. Schließlich können auch die Realsteuern (Nr.3) nicht als sozial-neutral außer acht gelassen werden.

bb) Die Kompetenzen in bezug auf das Recht der sozialen Sicherheit

1. Die Versorgung in der Kompetenzordnung. Der Katalog der konkurrierenden Gesetzgebungszuständigkeit spricht die zentralen Erscheinungsformen dessen an, was (im technischen Sinn) als "soziale Sicherheit" angesprochen wird: Fürsorge, (Sozial-)Versicher.ung und Versorgung. 1) Öffentliche Fürsorge und Sozialversicherung sind in Art. $74 \mathrm{Nr} .7$ und 12 GG ausdrücklich genannt. Die Versorgung ist u.a. mit dem wichtigen Zweig der Kriegsopferversorgung ausdrücklich der konkurrierenden Gesetzgebungskompetenz zugewiesen (Art. $74 \mathrm{Nr} .10 \mathrm{GG}$ ). Andere der konkurrierenden Gesetzgebungszuständigkeit unterliegende Materien implizieren versorgungsrechtliche Regelungen, so etwa "die Angelegenheiten der Flüchtlinge und Vertriebenen" (Art.74 Nr.6),

1) S. zu diesem unglücklichen Terminus des Grundgesetzes und seinem sachlichen Gehalt die mit reichlichen Nachweisen belegte Darstellung von Blendermann, Steuern mit örtlich bedingtem Wirkungskreis, 1957.

1) Zum System s. z.B. Rohrbeck, Der Begriff der Sozialversicherung und ihre Abgrenzung zur Versorgung und Fürsorge, in "Gegenwartsfragen sozialer Versicherung" hrsg. von Walter Bogs, 1950, S. 17 ff; Bogs, Gegenwartsfragen des Rechts der sozialen Sicherheit und seiner Reform, S. 15 ff; Weisser, Art. "Soziale Sicherheit" im Handwörterbuch der Sozialwissenschaften. 
"die Kriegsschäden und die Wiedergutmachung" (Art. 74 Nr.9), "die Fürsorge für die ehemaligen Kriegsgefangenen" (Art.74 $\mathrm{Nr} .10)$. Die dienstrechtlichen $Z$ weige der Sonderversorgung liegen außerhalb der konkurrierenden Gesetzgebungszuständigkeit teils im Bereich der ausschließlichen (Art. $73 \mathrm{Nr} .1$ und Nr. 8, Art. 131 GG), teils im Bereich der Rahmengesetzgebung des Bundes (Art. $75 \mathrm{Nr} .1 \mathrm{GG}$ ).

Eine Bundeskompetenz für die Einführung einer allgemeinen Staatsbürgerversorgung, 2) eines die ganze Bevölkerung einheitlich umfassenden Systems generell festgelegter Bezüge zur Beseitigung typischer sozialer Notlagen, fehlt jedoch. Allerdings hat der Bund die Möglichkeit, aus den zu seiner gesetzgeberischen Disposition stehenden Elementen ein Gesamtsystem der sozialen Sicherheit zu entwickeln, das einer allgemeinen Staatsbürgerversorgung effektiv sehr nahe käme. So könnte diese noch mehr als bisher durch eine entsprechend ausgedehnte und umgestaltete Sozialversicherung partiell substituiert werden. Die allgemeine Staatsbürgerversorgung schließt nicht, wie das für die Versorgung an sich kennzeichnend ist, die für die Sozialversicherung typische beitragsweise Mittelaufbringung durch die Beteiligten restlos aus. ${ }^{3)}$ Andererseits eignet der Sozialversicherung, indem sie aus allgemeinen Steuermitteln bezuschußt wird, 4) ihrerseits ein charakteristisches Element der Versorgung. 5) Von der Basis der Fürsorge her können den traditionellen, am Entschädigungsgedanken - genauer: am kausalen Bezug der auszugleichenden Nachteile und Notlagen zur staatlichen Gemeinschaft, orientierten $Z$ weigen der Sonderversorgung andere - unmittelbar. und prinzipiell ohne kausale Bedingung auf typische Notlagen abgestellte $Z$ weige einer Quasi-Sonderversorgung zur Seite gestellt werden. Der Gegensatz zwischen der berechtigenden Versorgung und der nicht subjektiv berechtigenden Fürsorge ist bereits seit

2) Zum Unterschied zwischen Sonderversorgung und allgemeiner Staatsbürgerversorgung s. Bogs, a.a.O. S. $19 \mathrm{ff}$.

3) S. z.B. Achinger, Sozialpolitik als Gesellschaftspolitik, S.119 ff; s.a. Bogs, a.a.O. S.21. - Zur Annäherung von Versicherung und Versorgung in einer das ganze Volk als Risikogemeinschaft umfassenden allgemeinen Volksversicherung, deren Beiträge sich von Steuern letztlich nicht mehr wesentlich unterscheiden s. z.B. Weisser, a.a.O. S.409; Weddigen, Art. "Sozialversicherung (I) Theorie" im Handwörterbuch der Sozialwissenschaften, Bd.9, 1956, S.594 ff (594f).

4) S. hierzu auch Art. 120 Abs. 1 GG.

5) Vg1. Bogs, a.a.O. S.24 ff (27f), $53 \mathrm{ff}$; Weddigen, a.a.O., insbes. S. $596 \mathrm{f}$. 
der Anerkennung des Rechtsanspruchs auf Fürsorge dahin. Im übrigen ist die Fürsorge, die der Versorgung dadurch eng verwandt ist, daß sie wie diese aus allgemeinen Steuermitteln gespeist wird, nicht ausschließlich auf individuelle, am konkreten Bedürnis ausgerichtete Hilfen beschränkt. ${ }^{6)}$ Die Differenzierung der Fürsorge nach typischen Mehrbedarfsmerkmalen, die sich auf die Dauer als unumgänglich erwies, ${ }^{7}$ ) hat zu einer Verfestigung und Generalisierung der entsprechend "gehobenen" Fürsorgeleistungen geführt, die ihnen allen Anschein der Versorgung gibt. Die (bisher landesrechtliche) Sonderregelung der Blindenhilfe "auf versorgungsrechtlicher Grundlage" versorgung (Sonderunterstützung, Wochen- und Stillgeld) nach dem Mutterschutzgesetz ${ }^{9)}$ sind extreme Beispiele dieser Entwicklung. Sie führt zu versorgungsähnlichen Fürsorgeleistungen in Falltypen, in denen die Verweisung auf die allgemeine Fürsorge sozial unzuträglich erscheint, eine sozialversicherungsrechtliche Sicherung jedoch - sei es mangels der Schätzbarkeit oder Zufälligkeit des auszugleichenden Fehlbedarfs, 10$)$ sei es, weil eine beitragsweise Mittelaufbringung unzumutbar erscheint nicht möglich ist.

Trotz dieser in den grundgesetzlichen Bundeskompetenzen enthaltenen Möglichkeiten, das System der sozialen Sicherheit zu entfalten und zu vervollständigen, ist es mehr als ein Unterschied im Akzent, daß der Bund auf diesen differenzierten Weg beschränkt ist und nicht direkt zu einer allgemeinen Staatsbürgerversorgung schreiten kann. Vor allem ist ihm die einheitliche und

6) Daß sich der Grundsatz der individuell-konkreten Hilfe im praktischen Vollzug des Fürsorgerechts nicht so verwirklichen läßt, wie er konzipiert ist, sei nur angemerkt und darf nicht grundsätzlich ins Gewicht fallen (vgl. hierzu Bogs, a.a.O. S. $36 \mathrm{ff})$.

7) Vg1. $\$ \$ 11 \mathrm{~b}$ ff der Reichsgrundsätze über Voraussetzung, Art und Maß der öffentlichen Fürsorge; s. nunmehr $\$ \$ 25$ ff des Entwurfs eines Bundessozialhilfegesetzes, Deutscher Bundestag, 3. Wahlperiode, Drucksache 1799.

8) Ebd. Begründung zu $\$ 64$ (S.49).

9) $\$ \$ 11,13,14$ des Mutterschutzgesetzes. - Zum Rechtscharakter dieser Leistungen s. BSGE 6, 213 (223); s.a. Rohrbeck, Der Begriff der Sozialversicherung und ihre Abgrenzung zu Versorgung und Fürsorge, S.26 f.

10) Zu dieser. Voraussetzung jeglicher Versicherung s. z.B. Braess, Art. "Versicherungswesen" im Handwörterbuch der Sozialwissenschaften, 32. Lfg. 1960, S.239 ff (239 f). 
beitragslose, unterschiedslos von der ganzen Staatsbürgergemeinschaft zu tragende und zu nutzende Staatsbürgerversorgung versagt. Das bedeutet effektiv, daß diese eindeutige Form der allgemeinen Staatsbürgerversorgung dem grundgesetzlichen Sozialordnungsbild fremd ist. Die Länder sind trotz ihrer allgemeinen Komplementärkompetenz (Art. 30, 70 Abs.1 GG) gehindert, ihrerseits eine allgemeine Staatsbürgerversorgung einzurichten. Die bundesrechtliche Regelung der konkurrierenden Veranstaltungen der Versorgung, Sozialversicherung und Fürsorge, hat das Terrain bereits besetzt (Art. 72 Abs.1, 125 GG). Die verbliebenen Lücken lassen nicht Raum für etwas, das den Namen Staatsbürgerversorgung verdienen würde. Mit einem nennenswerten Abbau des bundes rechtlichen Rechtsbestandes ist nicht zu rechnen. 11)

2. Die sozialversicherungsrechtliche Kompetenz. "Sozialversicherung" ist nicht gleich "soziale Sicherheit". Das gilt sowohl für den außerrechtlichen Allgemeinbegriff der Sozialversicherung (und der sozialen Sicherheit) 12) als auch für den speziellen Begriff des Art. 74 Nr. 12 GG. 13) Das Nebeneinander der sozialversicherungsrechtlichen mit der fürsorgerechtlichen und den verschiedenen sonderversorgungsrechtlichen Kompetenzen in Art. 74 GG (nebst Art. $73 \mathrm{Nr} .1$ und 8, $75 \mathrm{Nr} .1$ GG) ergibt diese Auslegung des Art. $74 \mathrm{Nr} .12 \mathrm{GG}$ zwingend. 14)

"Sozialversicherung" i.S. des Art. $74 \mathrm{Nr} .12$ GG ist vielmehr das Spezifische, das "sich der Sache nach als Sozialversicherung darstel1t". 15) Das bedeutet, daß sie in erster Linie Versicherung zu sein hat, d.h. gegenseitige Deckung eines zufälligen und schätzbaren (Geld-) Bedarfes zahlreicher gleichartig Bedrohter. 16)

11) S. a. unten S. 62 ff und S. 75 ff.

12) S. o. S. 49 zu Fußn. 1.

13) BVerfGE 11, 105 (111 f).

14) Die gegenteilige Behauptung war offenbar nur eine Zweckbehauptung, die man für nötig hielt, um die Kindergeldgesetzgebung des Bundes auf Art. $74 \mathrm{Nr} .12$ GC stützen zu können. S. hierzu BVerfGE a.a.O.; s. ferner unten zu Fußn. 20 ff.

15) BVerfGE 11, 105 (112).

16) Zu diesem Versicherungsbegriff s. z.B. Braess, Art. "Versicherungswesen" im Handwörterbuch der Sozialwissenschaften, S. 240. Zur Zuordenbarkeit der Sozialversicherung zu der Versicherung in diesem Sinne s. z. B. Rohrbeck, Der Begriff der Sozialversicherung und ihre Abgrenzung zur Versorgung und Fürsorge, insbes. S. 18 ff. Extrem für die allgemein-sachbegriffliche Untrennbarkeit von Sozial- und Indivi- 
Von daher ist sie gekennzeichnet durch die Bildung von Versicherungsgemeinschaften und die beitragsweise Mittelaufbringung. Als solidarische Selbsthilfe unterscheidet sie sich so von Fürsorge und Versorgung, die beide Fremdhilfe sind. 17) Aber sie ist nicht schlechthin Versicherung sondern Sozi a 1 versicherung: ein Mittel der Sozialpolitik, 18) ein Instrument des staatlichen Schutzes für wirtschaftlich bedrängte oder wenigstens gefährdete Volksschichten. 19) Um ihre soziale Wirksamkeit zu sichern, richtet sie der Staat nicht nur ein sondern zwingt er grundsätzlich auch alle von dem fraglichen Risiko in der gleichen, sozial als abhilfebedürftig erkannten Weise Bedrohten - möglicherweise unter Einschluß komplementär Beteiligter (wie das für die "Arbeiterversicherung" durch die Beteiligung der Arbeitgeber

dualversicherung Möller, Die Abgrenzung zwischen Sozialund Privatversicherung, in "Gegenwartsfragen sozialer Versicherung" hrsg. v. Walter Bogs, 1950, S.74 ff; Krohn, Zur Rechtsnatur der Sozialversicherung, in "Beiträge zur Versicherungswissenschaft", Festschrift für Walter Rohrbeck, 1955, S. $175 \mathrm{ff}$. Gegen die Unterordnung der Sozialversicherung unter den Begriff der Versicherung vor allem das ältere Schrifttum (s. die Nachweise bei Bogs, Grundfragen des Rechts der sozialen Sicherheit und seiner Reform, S. 23); s. nunmehr auch - jedoch zu allgemein und unpräzis - BVerfGE $11,105(112 \mathrm{ff})$.

17) S. o. S. 49 zu Fußn. 1 und S. 50 zu Fußn. 3.

18) Hierzu als allgemeines Begriffselement s. Bogs, a.a.O. S. 24 f. Zur Bedeutung des "sozialpolitischen Motivs" für die Zuordnung einer Einrichtung zur Sozialversicherung i.S. des Art. $74 \mathrm{Nr} .12 \mathrm{GG}$ s.a. Werner Weber, Die verfassungsrechtliche Problematik der Zwangsversorgungseinrichtungen der freien Berufe, in "Aktuelle Probleme der Versicherungswirtschaft vom Standpunkt der Versicherungswissenschaft betrachtet", hrsg. v. Walter Rohrbeck, 1954, S. $7 \mathrm{ff}$ (12 ff).

19) Sehr betont bei Scheuner, Berufständische Versorgungseinrichtungen und Grundgesetz, in "Aktuelle Probleme der Versicherungswirtschaft vom Standpunkt der Versicherungswissenschaft betrachtet", hrsg. v. Walter Rohrbeck, 1954, S.71ff (75 l). - Das Bundesverfassungsgericht kennzeichnet die Sozialversicherung, gerade auch im Hinblick auf Art. 74 Nr. 12 GG als "ein Stück staatlicher Fürsorge" (BVerfGE 11, 105 (114)), wie es auch schon in anderem Zusammenhang - den Begriff der Fürsorge dabei immer etwas sorglos gebrauchend - vom Sozialversicherungsrecht als "Recht der Fürsorge im weiteren Sinne" sprach (BVerfGE 9, 124 (133); s.a. BVerfGE 10, $141(166))$. 
charakteristisch geworden ist) 20) - in die Solidargemeinschaft. 21) Umgekehrt schließt er diese gegen den Beitritt von Versicherungsinteressenten $a b$, denen ein dem $Z$ weck und der Zusammensetzung der Solidargemeinschaft entsprechendes soziales Schutzbedürfnis fehit. 22) Als "sozial" hat sich die Sozialversicherung ferner dadurch zu bewähren, daß Staffelung und Relation der Beiträge und Leistungen zu einem sozialen Ausgleich innerhalb der Versicherungsgemeinschaft führen. ${ }^{23)}$ Aber diese Gestaltung allein genügt nicht immer, um die Sozialversicherung funktionsfähig zu machen und zu erhalten. Sie muß, wenn nötig, um ihren "Fürsorge"-Zweck erfüllen zu können, von der öffentlichen Hand aus allgemeinen Steuermitteln bezuschußt werden. ${ }^{24)}$ Bekommt die Sozialversicherung schon durch die soziale Umverteilung innerhalb der Versicherungsgemeinschaft einen versicherungsfremden, versorgungsähnlichen Charakterzug, so wird dieser durch die staatliche "Fremdhilfe" noch deutlicher. Das interne Spannungsverhältnis zwischen Versicherungs- und Versorgungsprinzip ist ein Wesensmerkmal der Sozialversicherung. 25) Die Sozialversicherung ist somit gekennzeichnet durch "die Verbindung von versicherungsmäßiger Selbsthilfe (durch Risikoausgleich) und von sozialem Ausgleich innerhalb der gesetzlich begrenzten Versicherungsgemeinschaft sowie zusätzliche Staatshil$\left.f^{\prime \prime}, 26\right)$ diese freilich nur im Prinzip. Den materiellen Elemen-

20) Vg1. allgemein Weddigen, Art. "Sozialversicherung (I) Theorie" im Handwörterbuch der Sozialwissenschaften, S. 594. Zur Zugehörigkeit dieses Elements zum (traditionell vorgezeichneten) Sozialversicherungsbegriff des Art. 74 Nr. 12 GG $\mathrm{s}$. BVerfGE 11, 105 (114). Die vom Bundesverfassungsgericht (a.a.O.) gutgeheißene Regelung der Kindergeldgesetzgebung des Bundes hat die Einseitigkeit von Belastung und Hilfe jedoch zu einem System geführt, das als "Sozialversicherung" kaum noch hingenommen werden kann. Das Bundessozialgericht hat das Problem deutlicher gesehen, aber dann doch "überspielt" (BSGE 6, 213 (227 f).

21) Vgl. BSGE 6, 213 (227); Bogs, a.a.O. S.26 f. S. a. Weddigen, a.a.O. S. $596 \mathrm{f}$.

22) Vg1. Bogs, a.a.O. S. 27.

23) Vgl. Bogs, a.a.O. S.24 ff.

24) S. O. S. 50 zu Fußn. 4 und 5

25) S. hierzu insbes. Weddigen, a.a.O. S. 595 und passim

26) Bogs, a.a.O. S.28; s. auch dens., Diskussionsbeitrag zu "Die Abgrenzung zwischen Sozial- und Privatversicherung" in "Gegenwartsfragen sozialer Versicherung" hrsg. v. Walter. Bogs, S. 89 f; dens., Zur Rechtsnatur der Versorgungsein- 
ten entspricht ein organisatorisches: die Trägerschaft öffentlichrechtlicher Körperschaften und Anstalten. 27) Sie allein kann der spezifischen Struktur und Aufgabe der Sozialversicherung gerecht werden und gehört (demgemäß) zur festen Tradition der deutschen Sozialversicherung.

Die Umschreibung des Begriffs der Sozialversicherung i.S. des Art. $74 \mathrm{Nr} .12 \mathrm{GG}$ ist in zweifacher Hinsicht von besonderer Bedeutung. Auf der einen Seite in Richtung auf die Individualversicherung. Art. $74 \mathrm{Nr} .11 \mathrm{GG}$ umfaßt nicht die Versicherung schlechthin sondern nur das "privatrechtliche Versicherungswesen" und zwar als Bestandteil des "Rechts der Wirtschaft". Versicherungen, die weder "privatrechtliche Versicherung" noch "Sozialversicherung" sind, unterliegen daher - von der Möglichkeit spezieller versicherungsrechtlicher Kompetenzen im Rahmen anderweit sachlich abgegrenzter Zuständigkeiten sei zunächst abgesehen - nicht der Gesetzgebungszuständigkeit des Bundes sondern nur derjenigen der Länder. 28) Auf der anderen Seite ist der Übergang zur Versorgung problematisch. Die konkurrierende Gesetzgebungskompetenz zur Regelung der Fürsorge und gewisser Zweige der Sonderversorgung kann Versorgungseinrichtungen nur beschränkt aufnehmen. Überschreiten sie den Rahmen der Sozialversicherung, so können sie daher der Kompetenz des Bundes entfallen.

Der sozialversicherung s rechtliche Bereich wird eindeutig verlassen, wenn das Versicherungselement völlig aufgegeben wird. Das wäre etwa dann der Fall, wenn von dem Prinzip der Versicherungsgemeinschaft und der Aufbringung (wenigstens eines Teiles) der Mittel durch Beiträge aus dieser Versicherungsgemeinschaft abgegangen würde. Auch eine allgemeine Volksversicherung, deren "Versicherungsgemeinschaft" die (ungeschiedene) "Volksgemeinschatt" wäre und deren Beiträge allgemeine

richtungen freier Berufe, in "Beiträge zur Sozialversicherung", Festschrift für Johannes Krohn, 1954, S. 35 ff (insbes. S. 50 f). Vgl. ferner Werner Weber, Die verfassungsrechtliche J'roblematik der Zwangsversorgungseinrichtungen der freien Berufe, S. 12 ff; Scheuner, Berufsständische Versorgungseinrichtungen und Grundgesetz, S. 75 f; Schneider, Die öffentlichrechtliche Alterssicherung freier Berufe und das Grundgesetz, 1959, S.48 ff.

27) Vg1. BVerfGE 11, 105 (113); Bogs, Diskussionsbeitrag zu "Die Abgrenzung zwischen Sozial- und Privatversicherung", a.a.O.; ders., Zur Rechtsnatur der Versorgungseinrichtungen freier Berufe, a.a.O.; Weber, a.a.O. S. 13.

28) Vg1. BVerfGE 10, 141 (162 f, $165 \mathrm{f})$. 
Steuern wären, 29) würde das Versicherungsprinzip in einem Maße negieren, daß es unmöglich erschiene, sie noch als "Sozialversicherung" zu bezeichnen. 30 )

Das Versicherungsprinzip darf auch dahin nicht restlos verlassen werden, daß nicht mehr ein zufälliger und schätzbarer Bedarf sondern ein sicherer oder unübersehbarer Bedarf umgelegt wird. Allerdings ist dieses Erfordernis locker zu handhaben. ${ }^{31}$ Der Arbeitslosenversicherung z.B. fehlt die langfristige Schätzbarkeit und in gewissem Sinne auch die Zufälligkeit weitgehend. 32) Trotzdem schlägt Art. $74 \mathrm{Nr} .12$ GG sie ausdrücklich zur Sozialversicherung. Aber völlig preisgegeben werden darf der Grundsatz der Zufälligkeit und Schätzbarkeit nicht. Die Zuordnung der bundes rechtlichen Kindergeldgesetzgebung zur "Sozialversicherung" 33) ist kein Gegenbeweis. Der Kinderaufzucht fehlt nicht die Schätzbarkeit. Ihr fehlt aber auch nicht völlig jede Zufälligkeit. Daß der Zufall in einem Maße zurückgedrängt ist, das die Privatversicherung nicht mehr akzeptieren würde, ist eine andere Frage. Sie macht beispielhaft deutlich, auf welche Weise die Sozialver'sicherung, als "Versicherung" über die Individualversicherung hinausgehen kann. ${ }^{34)}$

29) S. о. S. 50 zu Fußn. 3

30) S. o. S. 49 , insbes. a.E.

31) Vgl. BVerfGE 11, 105 (114); s. dazu a. BSGE 6, 213 (228), 238 (242).

32) Vgl. Weddigen, A tt. "Sozialversicherung (I) Theorie", in Handwörterbuch der Sozialwissenschaften, S. 603 .

33) BVerfGE i1, 105 (111 ff); BSGE 6, 213 (227 f), 238 (242); SG Karlsruhe, Urt.v. 14. Mai 1957, Ehe und Familie im privaten und öffentlichen Recht, 4.Jhg. (1956) S. 381; Friedrichs, Zur Verfassungsmäßigkeit der Kindergeldgesetzgebung, Betriebsberater, 13. Jhg. (1958) S. 1024 lf (1026); Rohwer-Kahlmann, Die soziale Fürsorge nach dem Bundesversorgungsgesetz - eine Versorgungsleistung, Die Sozialge richtsbarkeit 6. Jhg. (1959) S.341 if (342). - Gegen eine Kompetenz des Bundes zur Kindergeldgesetzgebung: Schnitzler, Zur Verfassungsmäßigkeit der. Kindergeldgesetzgebung, MI)R 10. Jhg. (1956) S. 712 ff (712 f); Ehlers, Zur Verfassungswidrigkeit des Kindergeldgesetzes, Der Betrieb 10. Jhg. (1957) S. 308; s.a. Sievers, Kindergeldgesetzgebung und Grundgesetz, NJW 10.Jhg. (1957) S. $441 \mathrm{ff}$.

34) S. a. BSGE, a.a.O. - Dagegen ist es unrichtig, mit RohwerKahlmann (a.a.O.) zu behaupten, die Sozialversicherung sei allgemein ein Instrument zur Bildung des Soziallohnes; das Kindergeld sei ein Mittel zum Zweck des Soziallohnes (dage- 
Schließlich muß die dem Versicherungsprinzip wesentliche Gegenseitigkeit gewahrt bleiben. Es geht nicht an, die Beiträge von Personen aufzubringen, die von dem "versicherten Risiko" nicht bedroht sind und die Leistungen einem Personenkreis zuzuführen, der die Mittel nicht aufgebracht hat. Die Solidargemeinschaft der Sozialversicherung ist nicht schlichte Umverteilungsgemeinschaft. Wenn die Arbeitnehmerversicherung die Beiträge grundsätzlich zum Teil, ausnahmsweise, nämlich im Falle gewisser Minimallöhne ${ }^{35)}$ und in der Unfallversicherung ${ }^{36)}$ auch ganz, vom Arbeitgeber erhebt, so ist das keine echte Abweichung vom Gegenseitigkeitsprinzip; denn der Sozialversicherungsbeitrag des Arbeitgebers ist versteckter Lohn für den Arbeitnehmer. Bei der Unfallversicherung kommt ferner das Eigeninteresse des Arbeit-

gen auch BSGE 6, 213 (226 f)); deshalb sei die Kindergeldgesetzgebung Sozialversicherungsrecht. Eine Soziallohnregelung muß sich im Rahmen des Arbeitsrechts halten. Eine umverteilende Regelung von der personellen Erstreckung der Kindergeldgesetzgebung des Bundes verläßt diesen. Sie kann nicht auf den Kompetenzbereich "Arbeitsrecht" des Art. 74 Nr.12 GG gestützt werden (BSGE 6, 213 (226 f); a. A. Friedrichs, a.a.O. S. hierzu auch Schnitzler, a.a.O. und Sievers, a.a.O. S.443). Es wird der Sache - bezeichnenderweise - auch nicht gerecht, die Kindergeldgesetzgebung ideell aufzuteilen und, soweit sie Arbeitnehmer betrifft, auf Art. 74 Nr.12 GG ("Arbeitsrecht"), soweit sie Selbständige betrifft, auf Art. $74 \mathrm{Nr} .11 \mathrm{GG}$ (gegen diese Kompetenzgrundlage auch BSGE 6, 213 (226)), soweit sie endlich Sozialversicherungsoder Versorgungsempfänger betrifft, auf Art. $74 \mathrm{Nr} .12$ ("Sozialversicherungsrecht") bzw. auf die jeweils für die Sonderversorgung gegebene Kompetenznorm zu stützen (so aber Schaefer, Kindergeldgesetzgebung und Grundgesetz, Ehe und Familie im privaten und öffentlichen Recht, 4. Jhg. (1957) S. 353 ff (354 f). S. hierzu auch Schnitzler und Sievers a.a.O.). Damit soll nicht geleugnet werden, daß die Gesamtschau aller dieser Kompetenznormen, zu denen noch die fürsorgerechtliche des Art. $74 \mathrm{Nr} .7$ GG hinzukommt (s. unten S. 61 zu Fußn. 55), wohl entscheidend dafür war, daß die Staatspraxis die Bundeskompetenz für die Kindergeldgesetzgebung - nicht ohne gequälte Argumente - letztlich doch anerkannte. - Unzulässig ist es nach dem Gesagten auch, die Kindergeldgesetzgebung des Bundes ohne nähere Unterscheidung schlechthin auf Art. $74 \mathrm{Nr} .12$ GG zu stützen.

35) $₫ 381$ Abs. 1 RVO, $₫ 1385$ Abs. 4 RVO. $\$ 117$ Abs. 4 AnVG. 36) $\$ \$ 731 \mathrm{ff}, 989 \mathrm{ff}, 1162 \mathrm{ff} \mathrm{RVO}$. 
gebers an der Freistellung von der eigenen zivilrechtlichen Haftung hinzu. ${ }^{37)}$ Das Verhältnis zwischen den Umlagen für die Familienausgleichskassen und den Kindergeldern ist dagegen nicht durchwegs unproblematisch ${ }^{38)}$ und stellt die Kindergeldgesetzgebung des Bundes einmal mehr an die Grenze dessen, was nach Art. $74 \mathrm{Nr} .12 \mathrm{GG}$ als Sozialversicherung bezeichnet werden kann. ${ }^{39)}$

Der sozial versicherungs rechtliche Charakter wird im Verhältnis zur Individualversicherung im allgemeinen 40 ) vor allem durch den sozialpolitischen Zweck und den internen sozialen Ausgleich sowie - gegebenenfalls - durch die staatliche Zuhilfe konstituiert; im Verhältnis zum privatrechtlichen Versicherungswesen i.S. des Art. $74 \mathrm{Nr} .11 \mathrm{GG}$ vor allem durch die zwingende Anordnung und Abgrenzung und die Trägerschaft einer öffentlichrechtlichen Verwaltungseinheit. Fehlt der zwingende öfentlichrechtliche Charakter, so bleibt die fragliche Einrichtung, mag sie sonst sozial gestaltet sein oder nicht, im Kompetenzbereich des Bundes (Art.74 Nr.11 GG). Eine zwingend öffentlich-rechtlich gestaltete Einrichtung, der die materiell soziale Ausgestaltung fehlt, fällt jedoch aus der Bundeskompetenz heraus. 41)

Unter diesem Gesichtspunkt ist auch der Streit darüber zu sehen, ob Sozialversicherung nur eine reine A rbeitnehmerversicherung sein kann oder auch dem sozialen Schutz Selbständiger dienen darf. Letzteres ist der Fall. 42) Art. $74 \mathrm{Nr} .12$ GG stellt

37) Vgl. BSGE 6, 213 (227); Krohn, Die Rechtsnatur der Sozialversicherung, S. 183 .

38) S. oben S. 54 zu Fußn. 20

39) S. oben S. 56 zu Fußn. 33 und 34.

40) Zu den Abgrenzungsschwierigkeiten s. nochmals Möller und Krohn, a.o. (S. 52 zu Fußn. 16).

41) S. nochmals S. 55 zu Fußn. 28

42) BVerfGE 11, 105 (112 f); Bogs, Zur Rechtsnatur der Versorgungseinrichtungen freier Berufe; Weber, Die verfassungsrechtliche Problematik der $Z$ wangsversorgungseinrichtungen freier Berufe, S.13; Scheuner, Berufsständische Versorgungseinrichtungen und Grundgesetz, S. 75 f; Schneider, Die öffentlichrechtliche Alterssicherung freier Berufe und das Grundgesetz, S. $49 \mathrm{ff}$. A.A. Gerber, Über die verfassungsrechtliche Zulässigkeit einer landesgesetzlich begründeten öffentlichen Versorgungsanstalt für Ärzte aller Art und Apotheker zur Sicherung ihres öffentlichrechtlich gebundenen Berufs, 1954, S. 24 f; Schmitt-Lermann, Die Verfassungsmäßigkeit der Pflichtmitgliedschaft bei der bayerischen Ärzteversorgung, 
die Sozialversicherung allerdings in einen auffälligen arbeitsrechtlichen Zusammenhang. Dieser zwingt jedoch nicht dazu, den kompetenz-rechtlichen Begriff der Sozialversicherung auf die Arbeitnehmerversicherung zu beschränken. Der äußere $\mathrm{Zu}$ sammenhang in Art. $74 \mathrm{Nr} .12 \mathrm{GG}$ ist vielmehr mit der historischen Entwicklung sowie damit, daß die Sozialversicherung auch heute noch in erster Linie Arbeitnehmerversicherung ist und nach der sozialen Struktur der Industriegesellschaft - immer auch bleiben muß, hinreichend erklärt. Dem vorrechtlichen Gesamtbild, das der grundgesetzlichen Kompetenzordnung zugrunde liegt, gehört jedoch bereits ein Gesamtkomplex "Sozialversicherung" an, der über die Arbeitnehmerversicherung hinausgreift zur sozialen Versicherung Selbständiger. ${ }^{43)}$ Er sollte durch das Grundgesetz nicht beschnitten werden. Hätte das Grundgesetz die sozialversicherungs rechtliche Kompetenz des Bundes auf die reine ("klassische") Arbeitnehmerversicherung zurückführen wollen, so hätte es in Anbetracht des perfekten Ausbaues der Arbeitnehmerversicherung auch die Stagnation der bundes rechtlichen Fortentwicklung der Sozialversicherung wollen müssen. Das kann nicht angenommen werden. 44) Das bedeutet, daß auch die Kindergeldgesetzgebung Sozialversicherung sein kann, obwohl sie über den Kreis der Arbeitnehmer hinausreicht. 45) Vor allem aber kann auch eine soziale Sicherungseinrichtung für freie Berufe, wenn sie sonst entsprechend gestaltet ist, Sozialversicherung i.S. des Art. $74 \mathrm{Nr} .12$ GG sein,

1954 (ungedruckt), S. 52 ff, insbes. S. 57 ff; Maunz, Rechtsgutachten über die Verfassungsmäßigkeit der Bayerischen Ärzteversorgung nach dem Grundgesetz, 1955 (ungedruckt) S. 2 ff; Hamann, Deutsches Wirtschaftsverfassungsrecht, S. 174; BayVerfGH VGHE n. F. 12 II 14 (17 f) - anders jedoch für den Begriff der Sozialversicherung i.S. des Art. 171 BayVerf: VGHE n.F. 4 II $219(239,242$ f, 245); 5 II 287 (292 ff) -; elastischer: Peters, Die verfassungsrechtliche Zulässigkeit berulsständischer Pflichtversorgungseinrichtungen für Ärzte, 1953, S.11 f; Adler, Zulässigkeit von Alterszwangsversorgungseinrichtungen freier Berufe nach dem Grundgesetz, Deutsche Versicherungszeitschrift, 7.Jhg. (1953) S. 200 if (204).

43) S. z.B. Bogs, Zur Rechtsnatur der Versorgungseinrichtungen freier Berufe, insbes. S. 51; Heyn, Die Versicherungspflicht der Selbständigen; ders., Die soziale Sicherung der Selbständigen; Schneider, a.a.O. S. 53.

44) Vgl. BVerfG 11, 105 (112 f); Schneider, a.a.O. S. 52 f. 45) BVerfGE 11, 105 (113). 
obwohl sie sich nicht auf Arbeitnehmer bezieht. ${ }^{46}$ )

Soweit eine entsprechende soziale Sicherung "ein notwendiger Bestandteil des rechtlichen Berufsbildes ist", 47) enthalten auch berufsrechtliche Kompetenzen die Befugnis zu sozialversicherungsmäßigen Regelungen. 48) Im Hinblick auf die generelle Kompetenznorm des Art. $74 \mathrm{Nr} .12 \mathrm{GG}$ kommt dem jedoch keine entscheidende Bedeutung zu.

3. Die fürsorgerechtliche Kompetenz. Das fürsorgerechtliche Element in der konkurrierenden Zuständigkeit zur Regelung der sozialen Sicherheit bringt Art. 74 Nr. 7 GG ein. Grundsätzlich ist damit die am konkret-indjviduellen Bedürfnis ausgerichtete Nothilfe gemeint. Für besondere Falltypen, bei denen der Zweck der "Fürsorge" durch die individuell festgesetzte, konkret zugemessene Minimalhilfe nicht in sozial befriedigendem Maß erreicht werden könnte, kann die Fürsorge auch zur generell bestimmten, über das absolute Minimum hinausgehenden Leistung gesteigert werden. In diesen Grenzformen berührt sich die Fürsorge mit der Versorgung. ${ }^{49)}$ Aber die fürsorgerechtliche Kompetenz gibt nicht schlechthin eine Grundlage für versorgungsrechtliche Regelungen ab. Fürsorge und Versorgung sind zu trennen. 50) Die versorgungsähnlichen Formen der Fürsorge müssen immer noch vom Prinzip der Fürsorge her - als dessen Adaption an besondere soziale Verhältnisse - erklärt werden können.

Es gibt auch keine Kommunikation zwischen Fürsorge (im engeren technischen Sinn der Terminologie zur sozialen Sicherheit 51))

46) S. die einschlägigen Nachweise oben S. 58 zu Fußn. 42. Für die Zugehörigkeit der sozialen Alterssicherung freier Berufe zur Sozialversicherung i.S. des Art. $74 \mathrm{Nr} .12$ GG s. ferner Ipsen, Rechtsfragen berufsständischer Zwangsversorgung, in "Aktuelle Probleme der Versicherungswirtschaft vom Standpunkt der Ver.sicherungswissenschaft betrachtet" hrsg. v. Walter Rohrbeck, 1954, S. $31 \mathrm{ff}(67 \mathrm{f})$.

47) BVerfGE 1, 264 (272).

48) So für das Schornsteinfegerrecht (als "Handwerksrecht" i. S. des Art. $74 \mathrm{Nr} .11 \mathrm{GG}$ ); BVerfGE 1, 264 (271 f); für das Recht der Rechtsanwälte und Notare (Art. 74 Nr. 1 GG): Schneider, Die öffentlichrechtliche Alterssicherung freier Berufe und das Grundgesetz, S. $47 \mathrm{f}$.

49) S. O. S. 49 .

50) S. O. S. 49 zu Fußn. 1 und Text und Anmerkungen oben S. 49 .

51) S. о. S. 49 zu Fußn. 1. 
und Sozialversicherung. Fürsorge ist Fremdhilfe aus allgemeinen Haushaltsmitteln. 52) Sozialversicherung ist wesentlich wenigstens auch - Selbsthilfe einer besonderen Solidargemeinschaft. Die Bundeszuständigkeit für die sozialversicherungsrechtlich gestaltete soziale Sicherung der freien Berufe aus der Fürsorgekompetenz (Art. $74 \mathrm{Nr} .7 \mathrm{GG}$ ) abzuleiten, 53) ist deshalb - nicht nur, wie gezeigt, unnötig 54) sondern auch - unmöglich. Es wäre aber auch unmöglich, die Kindergeldgesetzgebung (wenn sie nicht als "Sozialversicherung" qualifiziert werden könnte) als "allgemeine Fürsorge" zu rechtfertigen. 55) Es gehört nicht zum Wesen der Fürsorge, engere, auf einen bestimmten Bedarf abgestellte Umverteilungsgemeinschaften zu schaffen und mit den in diesen $Z$ wangsgemeinschaften aufgebrachten Mitteln sonst ungedeckten Notlagen abzuhelfen. Die dem bisherigen Recht eigenen Fürsorgeverbände beweisen nichts Gegenteiliges. sie sind nur Mittel, um den Fürsorgezweck zu verwirklichen, nicht Umlage- und Umverteilungsgemeinschaften. 56) Die Einr.ichtung von Beitragsgemeinschaften und intermediären Finanzgewalten außerhalb der Sachgebiete, denen diese wesensmäßig entsprechen, insbes. in Verfolg von Staatsaufgaben, die üblicherweise aus allgemeinen Steuermitteln erfüllt werden, würde auch die durch die steuerrechtliche Zuständigkeitsverteilung (Art. 105 GG) beherrschte abgabenrechtliche Grundkonzeption der bundesstaatlichen Mittelverteilung und - disposition verzerren. 57)

52) Gegen die Hereinnahme des Kriteriums der Mittelaufbringung in den verfassungsrechtlichen Fürsorgebegriff insbes. BSGE 6, 213 (223 ff), 238 (242)

$53)$ So Schneider, Die öfentlichrechtliche Alterssicherung freier. Berufe und das Grundgesetz, S. 56 .

54) S. a. Schneider, a.a.O.

55) I ür Art.74 Nr.7 GG als Kompetenzgrundlage BSGE 6, 213 (217 ff), 238 (241 f); BayLSG Urteil v. 18. November 1957, Breithaupts Sammlung, 47.Jhg. (1958) S.322; SG Hamburg, Urteil v. 1.Juni 1956, Die Sozialgerichtsbarkeit 3. Jhg. (1956) S.363; Friedrichs, Zur Verfassungsmäßigkeit der Kindergeldgesetzgebung, S. 1024 ff; wie hier dagegen Schnitzler, Zur Verfassungsmäßigkeit der Kindergeldgesetzgebung; Sievers, Kindergeldgesetzgebung und Grundgesetz. - S. hierzu auch oben S. 56 zu Fußn. 34 .

56) Vgl. $\$ \$ 1 \mathrm{fl}$ der Reichsverordnung über die Fürsorgepflicht, Der Entwurf eines Bundessozialhilfegesetzes (Deutscher Bundestag, 3. Wahlperiode, Drucksache 1799) verzichtet auf die Fürsorgeverbände, ohne das Wesen der Fürsorge zu verändern.

57) S. hierzu unten S. 186 und die dortigen Nacnweise. 
Art. $74 \mathrm{Nr} .7$ GG ist somit - ebenso wie Art. $74 \mathrm{Nr} .12$ GG keine kompetenzrechtliche Generalklausel für das Recht der sozialen Sicherheit. Dennoch ist die Vorschrift nicht auf die Fürsorge im engeren technischen Sinne beschränkt. 58) Sie greift jedoch nicht in den weiteren Raum der sozialen Sicherheit aus, 59) sondern in die Richtung der allgemeinen Wohlfahrtspfleg e.60) Nach der Entstehungsgeschichte 61) steht - exemplarisch - fest, daß der Ausdruck "öffentliche Fürsorge" auch für "die Mutter-, Säuglings-, Kinder- und Jugendfürsorge" steht.62) Die Kompetenznorm verläßt dabei, z. B. hinsichtlich des Schutzes der Jugend gegen sittliche Verwahrlosung, 63) sogar den engeren Bereich des Sozialen schlechthin. Nichtsdestoweniger ist sie eine hochbedeutsame Kompetenzgrundlage für die Regelung der sozialen Hilfe jenseits des sozialen Leistungswesens, das mit dem Begriff der sozialen Sicherheit umschrieben wird.

cc) Weitere Exemplifikation - die bundes rechtliche Ausfüllung der konkurrierenden Zuständigkeit

Die sozialen Gegenstände der konkurrierenden Zuständigkeit durchwegs im einzelnen zu erörtern, ist hier nicht möglich. Auf einige Schwerpunkte ist jedoch über das bisher Gesagte hinaus

58) Vgl. BSGE 6, 213 (217 ff), 238 (242): Schneider, Die öffentlichrechtliche Alterssicherung freier Berufe und das Grundgesetz, S. 56. Für weite Auslegung des Art. 74 Nr. 7 GG auch BSGE 6, 213 (219) - jedoch unter gänzlich unbehelflicher Berufung auf das Sozialstaatsprinzip - .

59) Unrichtig insofern BSGE und Schneider ebd.

60) S. a. BSGE 6, $213(218 \mathrm{f})$

61) Doemming-Füßlein-Matz, Die Entstehungsgeschichte der Artikel des Grundgesetzes, Jahrb. d. öffentlichen Rechts n. F. Bd. 1 (1951) S. 1 ff (S. 509 ff).

62) BSGE 6, 213 (221); Dennecke, Mutterschutz und Jugendschutz, in: Bettermann-Nipperdey-Scheuner, Die Grundrechte, Bd.III, 1. Halbband, 1958, S. $475 \mathrm{ff}(479)$. - Zum Mutterschutz s. BSGE 6, 213 (223). Zur Jugendwohlfahrt s. die Begründung zum Entwurf eines Gesetzes zur Änderung von Vorschriften des Reichsjugendwohlfahrtsgesetzes (Deutscher Bundestag, 1. Wahlperiode, Drucks. 3461 S.4; Muthesius, Reichsjugendwohlfahrtsgesetz, 1950, Allgemeine Vorbemerkungen V 2).

63) Zu den notwendigen Einschränkungen gegenüber der Tendenz, die Kompetenz der "öffentlichen Fürsorge" zu sehr in das Polizeirecht (Ordnungs recht) hinein auszudehnen s. Bettermann, Bundeskompetenz für Jugendschutz? AöR Bd.83 (1958) S. 91 ff (94 ff). 
hinzuweisen. Dabei ist Gelegenheit zu nehmen, das Verhältnis zwischen gesetzlichem Bundes- und Landesrecht zu sichten, wie es sich in der Verfassungswirklichkeit entwickelt hat. Vorweg zum Folgenden ist zu bemerken, daß sich die Kompetenznormen vielfach überschneiden und mit den "natürlichen" gesetzlichen Regelungseinheiten nicht immer decken. Für einzelne gesetzliche Regelungen oder Teile von ihnen kommen daher nicht selten mehrere Kompetenzgrundlagen in Betracht. Das kann hier nicht im einzelnen aufgegliedert werden. Die Betrachtungsweise kann auch insofern nur eine schwerpunktartige sein.

Auf dem Gebiet des bürgerlichen Rechts (Art. $74 \mathrm{Nr} .1$ $\mathrm{GG}$ ) ist für das Landes recht schon seit dem Inkrafttreten des Bürgerlichen Gesetzbuches kaum mehr Raum (Art.3, 55, 218 EGBGB). Die spätere Rechtsentwicklung hat allerdings einzelne Materien wieder aus der. Umarmung des bürgerlichrechtlichen Kodilikationsprinzips gelöst. So gehört insbes. die bürgerlichrechtliche Substanz des Arbeitsrechts der konkurrierenden Gesetzgebungszuständigkeit als "Arbeitsrecht" (Art. $74 \mathrm{Nr} .12$ GG) und nicht als bürgerliches Recht an. 1)

Auf dem Gebiet des gerichtlichen Verfahrens (Art. 74 $\mathrm{Nr} .1$ GG) sind die hier am meisten interessierenden Spezialgerichtsbarkeiten, die Arbeitsgerichtsbarkeit durch das Arbeitsgerichtsgesetz und die Sozialgerichtsbarkeit durch das Sozialgerichtsgesetz, bundesgesetzlich geregelt. In Ergänzung des Arbeitsgerichtsgesetzes hat kein, in Ergänzung des Sozialgerichtsgesetzes nur ausführendes Landesrecht von geringer Bedeutung Raum. Die Lage auf dem Gebiete des allgemeinen verwaltungsgerichtlichen Verfahrens, des Zivilprozesses, des Strafprozesses, der freiwilligen Gerichtsbarkeit und des Gerichtsverfassungsrechts ist ähnlich. Die Vorbehalte der einschlägigen bundesrechtlichen Regelungen zugunsten des Landesrechts betreffen keine hier interessierenden Materien. Der Vollständigkeit halber sei darauf hingewiesen, daß die durch Art.108 Abs.5 GG dem Bundesgesetzgeber vorbehaltene Regelung der Finanzgerichtsbarkeit der\%eit nur in den Teilstücken des Gesetzes über den Bundesfinanzhof vom 29. Juni 1950 (BGB1. S. 257) und des Gesetzes über Maßnahmen auf dem Gebiet der Finanzgerichtsbarkeit vom Oktober 1957 (BGBl. I S. 1746) erfolgt ist. Die im übrigen noch maß-

1) BVerfGE 7, $342(347$ f). - Ursprünglich hatte Art.95 EGBGB den Landesgesetzgeber ermächtigt, das Gesinderecht zu regeln. Diese Bestimmung war schon durch Nr.8 des Aufrufs des Rates der Volksbeauftragten vom 12. November 1918 (RGB1. S. 1303; i.V.m. $\$ 1$ des Übergangsgesetzes vom 4. März 1919, RGBl. S.285) gegenstandslos geworden. 
gebende landesrechtliche Grundlage ist aber durch Art. 108 Abs. 5 GG der Disposition des Landesgesetzgeber's bereits entzogen.

Im besonderen sind auch die Angelegenheiten der l'lücht 1 i n ge und Vertriebenen (Art. 74 Nr.6 GG) bundesiechtlich geregelt: durch das Lastenausgleichsgesetz (genauer: durch dessen Leistungsteil), das Währungsausgleichsgesetz, das Bundesvertriebenengesetz, das Flüchtlingsnotleistungsgesetz und zahlreiche ergänzende Gesetze. ${ }^{2}$ ) Das Landesrecht hat demgegenüber nur mehr geringe Bedeutung und besteht in der Regel nur in Ausführungsverordnungen. 3 )

Auf dem Gebiete der öffentlichen Fürsorge (Art. i4 Nr. 7) 4) ist durch die Verordnung über die Fürsorgepflicht und die Reichsgrundsätze über Voraussetzung, Art und Maß der öffentlichen Fürsorge bereits das Wichtigste geregelt. Wichtige Sonderregelungen enthaiten das Tuberkulosehilfsgesetz und das Körperbehindertengesetz. 5) Wenngleich die ergänzenden landesrechtlichen Fürsorgebestimmungen relativ umfänglich sind, so behandeln sie doch Fragen sekundärer Bedeutung. Das Reichsjugendwohlfahrtsge

2) (1) S. z.B. die Zusammenstellung in der Sammlung "Lastenausgleich", Textsammlung mit Verweisungen, C.B. Beck, München. - S. hierher auch das Heimkehrergesetz.

(2) Das Flüchtlings- und Vertriebenenrecht erstreckt sich typisch (ähnlich wie etwa das Wiedergutmachungsrecht, das Kriegsbeschädigtenrecht und das Recht der Kriegsgelangenen) auf zahlreiche spezielle Kompetenzbereiche. Hierauf kann, wie schon eingangs bemerkt, nicht näher eingetreten werden.

3) Auf Hinweise auf Landes verordnung srecht wird im Rahmen dieser Übersicht grundsätzlich verzichtet. Hier geht es um die Gesetzgebungszuständigkeit und das ist die Zuständigkeit zur formellen Gesetzgebung. Landesverordnungsrecht beruht, soweit es nicht auf landesgesetzliche Frmächtigungen zurückgeht oder Landesgesetze auslührt, in ler Regel auf bundesgesetzlicher Er.mächtigung (Art.80 Ahs. 1 Satz 1 GG), ist also nicht am Kompetenzraum der. Linder sondern dem des Bundes orientiert. Auf die quantitativ an der Kontaktstelle zwischen Bundes- und Landesrecht im Vordergrund stehenden Organisationsverordnungen wird unten - im Zusammenhang mit der Kompetenzaufteilung im Bereich der. Verwaltung - zurückzukommen sein.

4) S. oben S. 60 ff.

5) Eine Zusammenstellung der bisherigen gesetzlichen Crundlagen des Fürsorgerechts $s$. in der Begründung des Entwurfs eines Bundessozialhilfegesetzes, Deutscher Bundestag, 3. Wahlperiode, Drucks. 1799. 
setz ${ }^{6)}$ beschränkt die Landesgesetzgebung auf ein Minimum an eigener Regelung ( $\mathrm{s}$. $\$ \$ 9$ Abs. 1, 9a Abs. 2 und 3 Satz 2, 14 Abs. 3 Satz 3, 29 Abs. 4, 31, 42 Abs. 2, 65 Abs. 2, 70 Abs. 1 Satz 1, 71 Satz 1, 72 Abs. 3, 75 Satz 2 des Jugendwohlfahrtsgesetzes. Der Mutterschutz, der, soweit er nicht Arbeitsrecht ist, ebenfalls "Fürsorge" i.S. dieser Vorschrift ist, 6) ist über das engere Fürsorgerecht hinaus durch das Mutterschutzgesetz in einer die Länder präkludierenden Weise geregelt. 7)

Die sachlichen Kriegs s chäden (Art. 74 Nr.9 GG; wie sich aus Art. $74 \mathrm{Nr} .10$ ergibt, können hier nur Kriegs s a ch schäden gemeint sein) regelt ebenfalls das Lastenausgleichsgesetz neben das noch das Bundesevakuiertengesetz, das Allgemeine Kriegsfolgengesetz und $z$. T. auch das Heimkehrergesetz getreten sind. Daneben spielen landesrechtliche Ergänzungsı orschriften keine große Rolle.

Das Recht der Wi e dergutmachung (Art.74 Nr.9 GG) ist im wesentlichen im Bundesentschädigungsgesetz geregelt. Daneben ist für das materielle Landes recht nur Raum hinsichtlich der Anerkennung und Betreuung der Verfolgten ( $\$ 229$ BEG). Auch die Wiedergutmachung im öffentlichen Dienst ist bundesrechtlich geregelt (Gesetz zur Regelung des Wiedergutmachung für Angehörige des öffentlichen Dienstes). 8)

Das Recht der Kriegsbeschädigten und Kriegshinterbliebenen (Art. $74 \mathrm{Nr} .10 \mathrm{GG}$ ) ist maßgeblich im Bundesversorgungsgesetz und im Schwerbeschädigtengesetz 9 ) gere-

6) Hierzu als "Fürsorgerecht" s.o. S. 62 Fußn. 62 und 63.

7) Fine besondere Art von "Fürsorge" ist wohl auch die Häftlingshilfe nach dem Gesetz übes Hilfsmaßnahmen für Personen, die aus politischen Gründen in Gebieten außerhalb der Bundes republik Deutschland und Berlins (West) in Gewahrsam genommen wurden (Häftlingshilfegesetz - HHG). Das gleiche gilt hinsichtlich des Heimkehrerhilferechts (i.s. des Heimkehrergesetzes), soweit es nicht persönlich Kriegsgeschädigte und Kriegsgefangene (Art. $74 \mathrm{Nr} .10 \mathrm{GG}$ ) betrifft ( $\$ 1$ des Heimkehrergesetzes).

8) Der Adressatenkreis der Wiedergutmachung wird ferrer in zahlreichen einzelnen Vorschriften angesprochen.

9) Dieses ist nicht nur Kriegsbeschädigtenrecht sondern vor allem Arbeitsrecht und öffentliches Dienstrecht. Daneben ist es auch Wiedergutmachungsrecht ( $\$ 1$ Abs. 1 Buchst. c des Schwerbeschädigtengesetzes) sowie Sozialversicherungsund allgemeines Fürsorgerecht ( $\$ 1$ Abs. 1 Buchst.d und Abs. 2, $\$ 2$ a.a.O.). 
gelt. 10) Die Hilfe für die ehemaligen $\mathrm{Kriegsgef}$ ang enen ist im Heimkehrergesetz und im Kriegsgefangenenentschädigungsgesetz bundesgesetzlich geordnet.11) 12)

Auf dem Gebiete des Wirtschafts rechts (Art. $74 \mathrm{Nr} .11$ GG) auch nur einen Überblick über die denkbaren, sozial relevanten Regelungen zu geben, ist hier nicht möglich. Allgemein darf aber festgestellt werden, daß auf dem Gebiet des Wirtschafts rechts (ausschließlich alles dessen, was als bürgerliches Recht, Strafrecht, Arbeitsrecht, Sozialisierung usw. schon erwähnt wurde oder noch zu erwähnen ist) das Landesrecht allgemein eine sehr untergeordnete Rolle spielt. 13) Im besonderen ist darüber hinaus darauf hinzuweisen, daß es dem Landesgesetzgeber nicht möglich ist, auf die - sozial sehr interessante Preisgestaltung einzuwirken. Durch das Preisgesetz ${ }^{14)}$ und zahlreiche spezielle Preisklauseln bundesrechtlicher Provenienz ist der Landesgesetzgebung die Einwirkung auf das Preisrecht un-

10) Sowohl auf Art. $74 \mathrm{Nr} .9$ wie auch auf Art. $74 \mathrm{Nr} .10 \mathrm{GG}$ beruhen die Vorschriften über die Wiedergutmachung in der Kriegsopferversorgung (Bundesgesetz zur Wiedergutmachung nationalsozialistischen Unrechts in der Kriegsopferversorgung v. 25. Juni 1958 (BGB1. I S.412) und Bundesgesetz zur Wiedergutmachung nationalsozialistischen Unrechts in der Kriegsopferversorgung für Berechtigte im Ausland i.d.F. des Gesetzes v. 25. Juni 1958 (BGB1. I S.414).

11) Ergänzend $\mathrm{s}$. das Gesetz über die Unterhaltsbeihilfe für Angehörige von Kriegsgefangenen i.d.F. v. 30. April 1952 (BGB1. I S.262), dem in der Gegenwart keine nennenswerte Bedeutung mehr zukommen dürfte.

12) Auch die in Art. $74 \mathrm{Nr} .10$ GG genannten Materien werden typischerweise durch gewisse Regelungen erfaßt, die andere Kompetenzbereiche einbeziehen (s.o. S. 64 zu Fußn.2 (2), S. 65 zu Fußn. 8). Als Beispiel kann vor allem auch das Heimkehrergesetz dienen, das als lürsorge für die ehemaligen Kriegsgefangenen auf Art. $74 \mathrm{Nr} .10$ GG beruht, der Sache nach aber insbesondere auch Berufs-, Sozialversicherungsrecht $u$. ä. enthält.

13) Zur Illustration sei verwiesen auf die - hinsichtlich des Landes rechts freilich weit weniger als hinsichtlich des Bundesrechts vollständige - Zusammenstellung der wirtschaftsrechtlich einschlägigen Reichs - und Bundesgesetze und Landesgesetze bei Huber, Wirtschaftsverwaltungsrecht, Bd. II, S. $822 \mathrm{ff}$.

14) Zur Geltung s. BVerfGE 8, 274. 
möglich gemacht. 15) Die für die Preisbildung ebenfalls sehr wichtigen weitgehend (auch oder nur) dem Kompetenzbereich des Art. $74 \mathrm{Nr} .17$ GG ("Ein- und Ausfuhr land- und forstwirtschaftlicher Erzeugnisse") angehörenden Ein- und Ausfuhrbestimmungen sind wiederum Bundesrecht. 16)

Auch auf das umfangreiche Gebiet des A rbeits rechts (Art. $74 \mathrm{Nr} .12$ GG) 17) können hier nur Schlaglichter geworfen werden.

Das A rbeits vertrags recht ist grundlegend in den $\$ \$ 611$ ff $\mathrm{BGB}, \$ \$ 59 \mathrm{ff} \mathrm{HGB}, \mathbb{\$} 105 \mathrm{ff}$ GewO ausgebildet, als deren wichtigste Ergänzungen noch die vorläufige Landarbeitsordnung vom 24. Januar 1919, das Kündigungsschutzgesetz und das Gesetz über die Fristen für die Kündigung von Angestellten erwähnt werden sollen. Wesentlich ergänzt wird das Arbeitsvertragsrecht auch durch die Vorschriften über die obrigkeitliche Festsetzung von Arbeitsentgelten und sonstigen Vertragsbedingungen, wie sie das Bundes recht vor allem in dem Gesetz über die Festsetzung von Mindestarbeitsbedingungen und in $\$ 19$ des Heimarbeitsgesetzes enthält. 18) Neben diesen Bestimmungen ist der Raum für landesrechtliche Vorschriften gering. Lediglich im Urlaubsrecht hat sich - von einigen Randfragen abgesehen Landes recht zu entfalten vermocht. 19) Praktisch unbedeutenden

15) Wenn auch das formell-gesetzliche Preisrecht weitgehend nur in Ermächtigungen an die Exekutive besteht, so ist eben durch diese Ermächtigung die Kompetenz der Exekutive begründet und der Landes g e s e t z geber von einer eigenen Regelung ausgeschlossen. Das gilt auch, soweit die Ermächtigung sich an die Landesregierung richtet (von den politischparlamentarischen Beziehungen zwischen Landesparlament und Landes regierung ist hier abzusehen).

16) Vgl. zum Recht der Ein- und Ausfuhr die Darstellung bei Hubes, Wirtschaftsverwaltungsrecht, Bd.I 1953, S. $147 \mathrm{ff}$, $516 \mathrm{ff}, \mathrm{Bd}$. II S.281 li, $752 \mathrm{f}$.

17) S. hierzu oben $\$ .63$ zu Fußn. 1.

18) Weitere einschlägige Bestimmungen s. in "Arbeitsrecht" hrsg. v. Nipperdey (o.J.; Loseblattsammlung) Nr. $100 \mathrm{ff}$.

19) Zur urlaubsrechtlichen Kompetenz der Länder s. BVerfGE 7, 342; erläuternd insbes. Grossmann, Änderung der vorkonstitutionellen Urlaubsgesetze durch die Länder, Betriebsberater 15.Jhg. (1960) S. $867 \mathrm{fr}$. Gegen die Landeskompetenz zuletzt vor allem Bötticher, Gesetzgebungskompetenz der Länder auf dem Gebiet des Arbeitsvertragsrechts? Recht der Arbeit 11.Jhg. (1958) S.361 fr. Zum Stand der Rechtsentwicklung s. Hilger, Das Recht des Erholungsurlaubs in der Bundes republik Deutschland und in Westberlin, in 
Raum läßt ferner das Bundesgesetz zur Regelung der Lohnzahlung an Feiertagen, das selbst die Feiertage nicht festlegt, 20) vielmehr - vom Tag der deutschen Einheit abgesehen (Gesetz über den Tag der deutschen Einheit vom 4. August 1953, BGB1. I S. 778) - an die landes rechtlichen Bestimmungen anknüpft. 21) Reste landesrechtlichen Arbeitsvertragsrechts haben sich auf Grund des Vorbehaltes des Art.67 EGBGB im Bergrecht erhalten.

Auf dem Gebiet des Arbeits schutzes 22) als die wesentlichen Grundlagen für das Arbeitszeitrecht die $\$ \$$ 105 a ff GewO, die Arbeitszeitordnung und das Ladenschlußgesetz; für den Schutz der arbeitenden Frau das Mutterschutzgesetz und das Recht des Hausarbeitstages; 23) für den Jugendschutz das Jugendschutzgesetz; für den Heimarbeiterschutz das Heimarbeitsgesetz; für den allgemeinen Gefahrenschutz insbes. die $\$ \$ 618 \mathrm{f}$ $\mathrm{BGB}, \$ \$ 63 \mathrm{f}$ HGB, $\$ 120$ a GewO, zahlreiche Bestimmungen des die Unfallversicherung betreffenden Dritten Buches der Reichsversicherungsordnung; für die Gewerbeaufsicht insbes. $\$ 139 \mathrm{~b}$ GewO i.V.m. den dort in bezug genommenen Vorschriften und zahlreichen kompetenzzuweisenden Bestimmungen in speziellen Gesetzen (s. z.B. $\$ 19$ GastG, $\$ 27$ ArbZO, $\$ 26$ JSchG, $\$ 19$ MuSchG). Auch auf diesem Gebiet kann also der dem Landesrecht verbliebene Spielraum nicht mehr groß sein. Im wesentlichen handelt es sich um (die zahlreichen) Ausführungsbestimmungen rein organisatorischer Bedeutung (Zuständigkeitsbestimmungen).

"Deutsche Landesreferate zum 5. Internationalen Kongreß für Rechtsvergleichung in Brüssel", 1958, S. 163 ff (163 f).

20) Zur grundsätzlichen Landeskompetenz für die Bestimmung der Feiertage s.BayVerfGHE n.F. 6 II 78 (95, 99); Maunz, Deutsches Staatsrecht, S. 74.

21) Zur Befugnis der Länder, neben der bundesrechtlich angeordneten Lohnfortzahlung eine Zuschlagspflicht einzuführen, s. BVerfGE 2, $232(236 \mathrm{f})$.

22) Eine Zusammenstellung der einschlägigen Vorschriften s. in "Arbeitsrecht" (s.o. S. 67 zu Fußn. 18) Nr.350 fr.

23) Allgemeine bundesrechtliche Grundlage ist die Anordnung des Reichsarbeitsministers über Arbeitszeitverkürzung für Fraven und Schwerbeschädigte und minderleistungsfähige Personen v. 22. Oktober 1943 (RAB1. III S. 325; zur Fortge1tung s. Hueck, Lehrbuch des Arbeitsrechts, Bd.I S.655; "A rbeitsrecht" hrsg. v. Nipperdey, Nr.404 S.1 Fußn.2). Um ihretwillen gelten auch die - ausschließlich vorkonstitutionellen - Hausarbeitsgesetze der Länder (s. "Arbeitsrecht" Nr.410 ff) als Bundes recht fort. 
Sachliche Sonderregelungen sind nur ganz beschränkt möglich, z.B. im Bergrecht.

Auch das Betriebsverfassungsrecht 24) ist bundesrechtlich geregelt: $s$. das Betriebsverfassungsgesetz. Das Personalvertretungsgesetz ergänzt es, beruht aber auf Art. $73 \mathrm{Nr} .8$, $75 \mathrm{Nr} .1$ GG. Das Gesetz über die Mitbestimmung der Arbeitnehmer in den Aufsichtsräten und Vorständen der Unternehmen des Bergbaues und der Eisen und Stahl erzeugenden Industrie und das Cresetz zur Ergänzung des Gesetzes über die Mitbestimmung der Arbeitnehmer in den Aufsichtsräten und Vorständen des Bergbaus und der Eisen und Stahl erzeugenden Industrie ergänzen das Betriebsverfassungs recht nach der gesellschaftsrechtlichen Seite hin (Art. $74 \mathrm{Nr} .1$ und $11 \mathrm{GG}$ ). Das Landes recht hat - außerhalb der Ausfüllung des Bundesrahmengesetzes über die Personalvertretung im öffentlichen Dienst - keine Möglichkeit mehr, das Betriebsverfassungsrecht zu gestalten.

Das Tarif recht ist durch das Tarifvertragsgesetz ebenfalls so geregelt, daß dem Landesgesetzgeber nichts mehr zu tun bleibt. Dasselbe gilt für das heute sehr in den Hintergrund getretene Schlichtungs recht infolge der Regelung des Kontrollratsgesetzes Nr.35 betreffend Ausgleichs- und Schiedsverfahren in Arbeitsstreitigkeiten vom 20. August 1946 (ABl. des Kontrollrates S. 174). 25) Dagegen wäre für landesrechtliche Beschränkungen des Streikrechts, 25a) soweit sie sonst verfassungs rechtlich zulässig sind, noch Raum.

In der Sozialversicherung (Art. $74 \mathrm{Nr} .12 \mathrm{GG}$ ) spielt das Landesrecht ebenfalls nur eine sehr untergeordnete Rolle. Die Krankenversicherung (II. Buch der Reichsversicherungsordnung), die Unfallversicherung (III. Buch der Reichsversicherungsordnung), die Rentenversicherung der Arbeiter (IV. Buch der Reichsver.sicherungsordnung) und der Angestellten (Angestelltenversicherungsgesetz) sowie die knappschaftliche Versicherung (Knapp-

24) Die einschlägigen Vorschriften s. in "Arbeitsrecht", hrsg. v. Nipperdey, $\mathrm{Nr} .570 \mathrm{ff}$.

25) Das Kontrollratsgesetz Nr.35 gilt gem. Art. $74 \mathrm{Nr} .12,125$ Nr. 1 GG i.V.m. Art. 1 Abs. 1 Satz 3 und Abs. 2 des Vertrages zur Regelung aus Krieg und Besatzung entstandener Fragen vom 26. März 1952/23. Oktober 1954 (BGB1. 1955 II S. 405) und dem Schreiben der drei Außenminister an den Bundeskanzler vom 26. März 1952 (BGB1. 1955 II S. 508) als Bundes recht (um nicht zu sagen: "Quasibundesrecht") weiter. 25a) $\mathrm{Zu}$ dessen Zugehörigkeit zum Kompetenzbereich des Art. 74 $\mathrm{Nr} .12$ GG s. Hamann, Deutsches Wirtschaftsverfassungsrecht, S. 174 . 
schaftsgesetz) und die Altersversorgung des Handwerks (Gesetz über die Altersversorgung für das deutsche Handwerk; nunmehr Handwerkerversicherungsgesetz) waren schon reichsrechtlich und sind nunmehr bundes rechtlich geregelt. ${ }^{26)}$ Neuerdings sind hinzugekommen die - nur mit Hängen und Würgen noch als "Sozialversiche rungsrecht" $\mathrm{zu}$ deklarierende - Kindergeldgesetzgebung des Bundes 27) und die Altershilfe für Landwirte (Gesetz über eine Altershilfe für Landwirte). Neben den (reichs-bzw.) bundesrechtlichen Vorschriften 28) des "klassischen" Sozialversicherungsrechts kann das Landesrecht nur über relativ wenige und minder wichtige, ihm überlassene Fragen disponieren. Dagegen ist dem Landesgesetzgeber ein gewisser Spielraum in Richtung auf die soziale Sicherung selbständig Tätiger verblieben, die durch die vorhandenen bundesrechtlichen Regelungen noch keineswegs abschließend geregelt ist. 29) Bayern z. B. hat (je) eine Ärzte-, Apotheker- und Dentistenversorgung eingerichtet (Art.46 ff des Gesetzes über das öffentliche Versicherungswesen - VersG - vom 7. Dezember 1933, BayBS I S.242),

26) Die Einzelnachweise s, bei Eckert, Die Sozialversicherungsgesetze (o.J.; Loseblattsammlung).

27) S. oben S. $49 \mathrm{ff}$.

28) S. a. noch $\ 28$ der Verordnung über das Schornsteinfegerwesen.

29) Gelegentlich wird behauptet, die vorhandenen bundesrechtlichen Regelungen schlössen - i.S. eines Kodifikationsprinzips - die landes rechtliche Einrichtung einer Sozialversicherung auch dann aus, wenn ihr gegenständlicher und sachlicher Bereich vom Bundesrecht nicht erfaßt ist (vgl. Weber, Die verfassungsrechtliche Problematik der Zwangsversorgungseinrichtungen der freien Berufe, S. 12 ff; Ipsen, Rechtsf ragen berufsständischer Zwangsversorgung, S.69; Scheuner, Berufsständische Versorgungseinrichtungen und Grundgesetz, S. 78 f). Dem kann nicht beigetreten werden (vgl. Peters, Die verfassungsrechtliche Zulässigkeit berufsständischer Pflichtversorgungseinrichtungen für Ärzte, S. 12; Gerber, Über die verfassungsrechtliche Zulässigkeit einer. landesgesetzlich begründeten öffentlichen Versorgungsanstalt für Ärzte aller Art und Apotheker zur Sicherung ihres öffentlichrechtlich gebundenen Berufs, S. 25; Schmitt-Lermann, Die Verfassungsmäßigkeit der Pflichtmitgliedschaft bei der Bayer. Ärzteversorgung, S. 58 f; Maunz, Rechtsgutachten über die Verfassungsmäßigkeit der Bayerischen Ärzteversorgung nach dem Grundgesetz, S.6). - Im übrigen s. zur Zugehörigkeit der sozialen Sicherung freier Berufe zur Sozialversicherung i.S. des Art. 74 Nr. 12 GG oben S. 52. 
Art. $74 \mathrm{Nr} .12 \mathrm{GG}$ rechnet die Arbeitsvermittlung dem Arbeitsrecht, die Arbeitlosenversicherung der Sozialversicherung $z u$. Beide Materien sind bundesgesetzlich geregelt (Gesetz über Arbeitsvermittlung und Arbeitslosenversicherung).

Das Enteignungs recht ist der konkurrierenden Zuständigkeit zugeschlagen, soweit die Enteignung "auf den Sachgebieten der Art. 72 und 74 in Betracht kommt" (Art. 74 Nr. 14 GG). Die Kompetenz ist akzessorisch. Art. $74 \mathrm{Nr} .14 \mathrm{GG}$ erläutert nur authentisch die übrigen Kompetenznormen der konkurrierenden Zuständigkeit hinsichtlich ihrer enteignungsrechtlichen Implikation. Enteignungsrechtliche Vorschriften des Bundes, die hier interessieren, finden sich vor allem im Siedlungsrecht (Art.74 Nr. 14 und 18 GG; s. insbes. das Reichssiedlungsgesetz 30 )), im Flüchtlingsnotleistungsgesetz (Art. $74 \mathrm{Nr} .14$ und 6 GG) und im Fünften Teil des Bundesbaugesetzes (Art. $74 \mathrm{Nr} .14$ und $18 \mathrm{GG}$ ). Im übrigen richtet sich die Enteignung - auch zur Befriedigung des sozialen Sachbedarfes - weitgehend nach Landes recht.

Die Überführung von Grund und Boden, von Naturschätzen und Produktionsmitteln in $\mathrm{G}$ e meineigentu $\mathrm{m}$ oder in andere Formen der Gemeinwirtschaft (Art.74 Nr.15 GG) ist bis jetzt weder vom Bund noch von den Ländern ${ }^{31)}$ nachhaltig in Angriff genommen worden. Der berühmt gewordene hessische Versuch einer Sozialisierung ist heillos stecken geblieben. 32) Hier liegt eines der wenigen Gebiete des ganzen Katalogs der konkurrierenden Gesetzgebungszuständigkeit, das dem Zugriff der Länder rechtlich (!) noch nicht verschlossen ist. 33)

Dem Mißbrauch wirtschafticher Machtstel1ungen (Art. $74 \mathrm{Nr} .16 \mathrm{GG}$ ) steuert - neben zahlreichen, verstreuten Einzelvorschriften und insbes. den Generalklauseln des Privatrechts - das Gesetz gegen Wettbewerbsbeschränkungen, also wiederum Bundesrecht.

Der Förderung der 1 and-und forstwirtschaft1ichen Erzeugung (Art. $74 \mathrm{Nr} .17 \mathrm{GG}$ ), der im Hinblick auf die

30) Weitere einschlägige Gesetze s. unten zu Art. 74 Nr. 18 GG.

$31)$ S. hierzu auch Krüger, Sozialisierung, in: BettermannNipperdey-Scheuner, Die Grundrechte, Bd. III 1. Halbband, 1958, S. $267 \mathrm{ff}(320 \mathrm{ff})$.

32) S. zur Entwicklung in Hessen z.B. Ortlieb/Stavenhagen, Art. "Sozialisierung II 1", Handwörte rbuch der Sozialwissenschaften, Bd.9, 1956, S. $464 \mathrm{ff}$ (468 f) und deren Nachw. (s.a. S. 484, 486); Krüger, a.a.O. S. 322 ff (dort auch Literaturbericht).

33) Zu den Grenzen s. nochmals Krüger, a.a.O. (Fußn.31). 
Lage der Landbevölkerung eine erhebliche soziale Bedeutung zukommt, dient das Landwirtschaftsgesetz des Bundes, das allerdings nur wenig sachliche Regelung enthält. ${ }^{34)}$

Das 1 andwirtschaftliche Pachtwesen (Art. $74 \mathrm{Nr} .18$ ) ist durch das Landpachtgesetz bundesiechtlich geregelt.

Für das Wohnungswesen (Art. $74 \mathrm{Nr} .18 \mathrm{GG}$ ) sind - neben den einschlägigen Bestimmungen des bürgerlichen Rechts (Art. $74 \mathrm{Nr} .1 \mathrm{GG}$ ), dem z. $\Gamma$. auch die nachfolgend $\mathrm{zu}$ nennenden Gesetze angehören - maßgeblich das Erste und Zweite Wohnungsbaugesetz, das Bergarbeiterwohnbaugesetz, das Wohnraumbewirtschaftungsgesetz, das Erste Bundesmietengesetz, das Mieterschutzgesetz und das (jüngste) Ciesetz über den Abbau der Wohnungszwangswirtschaft und über ein soziales Miet - und Wohnrecht mit seinen Untergesetzen. Neben der Regelung einiger Rand- und Abwicklungsfragen ist dem Landesrecht gegenwärtig nur noch hinsichtlich der allgemeinen Wohnungsaufsicht (Beschaffenheit der Wohnungen usw.) ein Spielraum belassen.

Das Siedlungs - und He imstät tenwesen (Art. $74 \mathrm{Nr} .18$ GG) dürfte durch die bundes rechtlichen Regelungen des Reichssiedlungsgesetzes, des Reichsheimstättengesetzes, die siedlungsrechtlichen Vorschriften des Bundesvertriebenengesetzes, das Kapitel II des Vierten Teiles der Dritten Verordnung des Reichspräsidenten zur Sicherung von Wirtschaft und Finanzen und zur. Bekämpfung politischer Ausschreitungen vom 6. Oktober 1931 und die Kleingarten- und Kleinlandpachtordnung weitgehend erschöpft sein. Das Landes recht kann sich - abgesehen von der Förderung des Siedlungswesens im größeren Zusammenhang der. Bodenreform, auf den gleich noch zurückzukommen sein wird - daneben fast nur noch in der Anordnung zusätzlicher Finanzierungshilfen u. ä. bestätigen.

Das Bodenrecht (Art.74 Nr.18 GG) ist, da es vor allem auch das Recht der städtebaulichen Planung und Bodenordnung enthält, 35) für die sozialen Lebensverhältnisse der Bevölkerung von großer Bedeutung. Fs ist, insbesondere durch das Bundesbaugesetz, weitgehend lür den Bund in Anspruch genommen.

Ein besonderes Problem, das hier anhangsweise zu erörtern ist,

34) Zum Recht der Ein- und Ausfuhr, das auf verschiedene Weise auf die sozialen Verhältnisse zurückwirkt und nach Art. $74 \mathrm{Nr} .17$ GG ebenfalls zur konkurrierenden Gesetzgebung gehört, s. oben S. 67 zu Fußn. 16

35) Zur maßgeblichen Auslegung s. BVerfGF 3, 407 (insbes. S. $413 \mathrm{ff}, 424 \mathrm{ff})$. 
bietet die Kompetenz zur Regelung der ländlichen Boden re fo $1 . \mathrm{m}$. Wird darunter auch die Überführung von Grund und Boden in Gemeineigentum oder andere Formen der Gemeinwirtschaft (Art.15 GG) verstanden, so unterfällt sie insoweit der konkurrierenden Gesetzgebung (Art. 74 Nr.15 GG). Doch entspricht die Hereinnahme der Agrarsozialisierung nicht dem aus der Nachkriegsgesetzgebung zur Bodenreform in Westdeutschland entwikkelten Begriff. Der danach maßgebliche Begriff der Bodenreform meint speziell die Umgestaltung der Besitzverhältnisse am Boden zugunsten individueller (nicht-gemeinwirtschaftlicher) Rechtsträger. 36) Diese ist, soweit sie Eigentum entzieht, nur als Enteignung (i.S. des Art.14 GG) zulässig. 37) Aber Art. $74 \mathrm{Nr} .14 \mathrm{GG}^{38}$ ) bietet dennoch keine kompetenzrechtliche Lösung. Einerseits ist die enteignungs rechtliche Kompetenz dort selbst nur akzessorisch geregelt. Andererseits ist Bodenreform eben in keinem Fall nur Enteignung. Der Bund kann zur Regelung der "Bodenreform" demnach nur dann zuständig sein, wenn ihn eine außerhalb Art.74 $\mathrm{Nr}$. 14 und 15 GG liegende Kompetenznorm hierzu ermächtigt. Ins Auge fällt der Kompetenzkomplex des "Bodenrechts" (Art. $74 \mathrm{Nr}$. 18 GG). 39) Doch dieser Begriff ist enger auszulegen. ${ }^{35)}$ Ihn ungehemmt auch auf die Bodenverteilung zu beziehen, verbietet schon die entsprechende besondere Rahmenkompetenz (Art. 75 $\mathrm{Nr} .4$ GG).40) Andere in Art. 74 GG genannte Sachgebiete sind der Bodenreform zwar verwandt und nehmen sie bei entsprechender spezifischer Ausgestaltung auch auf: so das Siedlungswesen ( $\mathrm{Nr}$. 18), 41) einschließlich der Ansiedlung von Flüchtlingen, Vertrie-

36) S. statt aller anderen Ehrenforth, Das Recht der Siedlung und Bodenreform (o.J., Loseblattausgabe) "Einführung", Bd. I, S. 83a/84 m.W.Nachw. - Weitere Nachw. s. unten S. 980 .

37) Näheres s. unten S. 980.

38) Dalür, daß Art. $74 \mathrm{Nr} .14$ GG auch für die Enteignung im Rahmen der Bodenreform maßgeblich ist, $\mathrm{s}$. Nawiasky-Lechner, Erl. zu Art. 163 Abs.V.

39) Für Art. $74 \mathrm{Nr} .18$ GG (Unterfall: Bodenrecht) als Kompetenzgrundlage der Bodenreformgesetzgebung s. Huber, Wirtschaftsverwaltungsrecht, Bd. II S. 49; Ehrenforth, a.a.O. S.20.

40) Vg1. BVerfGE 3, 407 (414).

41) Für die Zuordnung zum Kompetenzbereich des Siedlungswesens: BVerwGF 1, 140 (141); für die (allgemeinere) Zuordnung zu Art. $74 \mathrm{Nr} .18$ GG s. Simon, Anm. zu Württ.-Bad. VGH Urt.v.28. Mai 1951, Recht der Landwirtschaft, 3. Jhg. (1951) S.243 f (243); Ehrenforth, a.a.O. S. 20. 
benen, Kriegssachgeschädigten und Kriegsopfern (Nr.6, 9, 10), und die Förderung der land- und forstwirtschaftlichen Erzeugung (Nr.17). Sie decken die Bodenreform jedoch nicht, soweit sie nur Neugestaltung der Eigentumsverhältnisse am Boden ist, ohne eine der besagten engeren $Z$ wecke zu verfolgen. In dieser Grund- und Generalfunktion ist die Bodenreform dem Bundesgesetzgeber nur als "Bodenverteilung" (Art. $75 \mathrm{Nr} .4 \mathrm{GG}$ ), also nur im Wege der Rahmengesetzgebung, zugängig. 42) Ob die westdeutsche Nachkriegsgesetzgebung zur Bodenreform 43) demnach unter Art. 74 GG subsumiert werden kann, ist eine diffizile Frage, die nicht für alle Länder einheitlich beantwortet werden kann. Sie kann hier nicht abschließend geprüft werden. Desgleichen muß die Frage der zoneneinheitlichen Geltung (Art.125 Nr.1 GG) hier offen bleiben. Fest steht jedoch, daß das vorkonstitutionelle Bodenreformrecht selbst dort, wo es, wie allenfalls in der amerikanischen Besatzungszone, ${ }^{44)}$ zoneneinheitlich ist, nur Bundesrecht geworden sein kann, soweit es den Tatbeständen des Art. 74 GG zuzuordnen ist. Als Bodenverteilungsrecht (Art. 75 Nr. 4 GG) wurde es nicht in Bundes recht transformiert. ${ }^{45)}$ Ungeachtet der - zu verneinenden - Frage, ob Art.125 GG für die Rahmengesetzgebung überhaupt gilt, scheitert eine Fortgeltung der Bodenreformgesetzgebung als Rahmenrecht schon daran, daß sie eine (jeweils) in sich vollständige, einer weiteren (landesrechtlichen) Ausfüllung nicht bedürftige Gesetzeseinheit darste11t. ${ }^{46)}$

Die Befugnis zur konkurrierenden Gesetzgebung auf den wichtigsten Gebieten des Steuerrechtes (Art.105 Abs.2 GG) hat der Bund bis auf geringfügige Reste erschöpft. 47 )

42) Zu Art. 75 Nr. 4 ("Bodenverteilung") GG als Kompetenzgrundlage einer eventuellen Bundes-Bodenreformgesetzgebung s. Kratzer, Ist das Gesetz zur Beschaffung von Siedlungsland und zur Bodenreform Bundes- oder Landesrecht? Recht der Landwirtschaft, 5. Jhg. (1953) S. 32 ff.

43) Zum Stand der Gesetzgebung s. Huber, Wirtschaftsverwaltungsrecht, Bd.II, S. $71 \mathrm{ff}$; Ehrenforth, a.a.O. S. $14 \mathrm{ff}$.

44) Für die Fortgeltung des Bodenreformrechts in der amerikanischen Besatzungszone als Bundesrecht auf der Grundlage der Art. 74, 125 GG: BVerwGE 1, 140 (141); Ehrenforth, a.a.O. S. $19 \mathrm{f}$.

45) Kratzer, a.a.O. S.33 f; a.A. Ehrenforth, a.a.O. S.19 f.

46) Vgl. BVerfGE 4, 115 (135), 219 (239); 7, 29 (41 f); 8, 186 (194 f).

47) Hettlage, Die Finanzverfassung im Rahmen der Staatsverfassung, Veröffentlichungen der Vereinigung der Deutschen Staats rechtslehrer, Heft 14 (1956) S.22: "Damit ist aus der 
dd) Die bundesrechtliche Ausfüllung der konkurrierenden Zuständigkeit - Würdigung

Die Bilanz, die hier gezogen werden mußte, verbietet es jedenfalls für den Bereich der sozialen Intervention, an der konkurrierenden Gesetzgebungszuständigkeit noch das primäre Gesetzgebungsrecht der Länder, das in Art.70, 72 GG konstituiert ist, als das Wesentliche anzusehen. Als das Primäre erwies sich vielmehr die Befugnis des Bundesgesetzgebers, durch eigene Aktion die Landesgesetzgebung auszusperren (Art.72 Abs.1 GG). 1) Hier tritt erstmals eine Erscheinung ins Blickfeld, die im Rahmen der Untersuchung der bundesstaatlichen Aufgabenverteilung noch wiederholt $z u$ beobachten sein wird: Wo immer die Verfassung dem Bundesgesetzgeber die Möglichkeit eröffnet hat, eine ursprünglich (auch oder allein) dem Lande zukommende Kompetenz an den Bund zu ziehen, führt das früher oder später zu mehr oder weniger vollständigen Präklusion der Länder.

Es sei hier noch nicht auf die Tendenzen und ihre Ursachen eingegangen, die allgemein und für den Bereich der sozialen Intervention im besonderen das stark unitarische Gesamtbild bewirkt haben, das die Aufgabenverteilung zwischen Bund und Ländern heute bietet. Vielmehr sei zunächst nur auf die besonderen Umstände hingewiesen, die im Rahmen der konkurrierenden Gesetzgebungszuständigkeit wirksam waren und sind.

Hierzu zählt in erster. Linie das "trojanische Pferd" des Katalogs der konkurrierenden Gesetzgebungskompetenz: Art. $125 \mathrm{GG}$. Ihm zufolge sperrt nicht allein künftige Bundesgesetzgebung den Bereich der konkurrierenden Gesetzgebungszuständigkeit für die Länder sondern auch die Tätigkeit früherer Gesetzgeber, insbes. des Reichsgesetzgeber's. Seine legislative Tätigkeit wird dem Bunde wie dessen eigene zugerechnet. 2) Bei dem traditionell

formell konkurrierenden Bedarfsgesetzgebung praktisch eine ausschließliche Bundeszuständigkeit ... geworden".

S. dens., Die Neuordnung der deutschen Finanzverlassung, Finanzarchiv n.F. Bd. 14 (1953/54) S. 405 ff (422 f);

Strickrodt, Die Finanzverfassung des Bundes als politisches Problem, 1951, \$. 15. - Im besonderen ist die Erleichterung der Bundesgesetzgebung durch Art. 105 Abs. 2, 2. Halbsatz GG zu berücksichtigen.

1) Werner Weber (Die Verfassung der Bundes republik in der Bewährung, 1957, S. 17) stellt mit Recht fest, daß "aus der konkurrierenden Gesetzgebungszuständigkeit des Bundes praktisch weithin eine ausschließliche Kompetenz" geworden ist.

2) BVerfGE 7, 18 (27): "...das Ziel der Bestimmung (scil. 
starken Anteil der Reichsgesetzgebung an der sozialen Gesetzgebung seit der Gründung des Kaiserreiches kam und kommt dieser Klausel gerade auf dem hier interessierenden Sektor eine eminente Bedeutung zu. Der Umlang ihrer Wirksamkeit wurde noch dadurch gesteigert, daß die Anwendung des Bedarfsvorbehaltes des Art. 72 Abs. 2 GG gerade auf die Transformation alten Reichsrechts (also auch des Reichsrechts aus der Zeit des Finheitsstaates!) unterblieb. ${ }^{3}$ )

Aber auch auf die Setzung neuen Bundesrechts blieb dieser oft übergangene und durch die Verfassungsrechtsprechung interpretatorisch entwertete Bedarfsvorbehalt ohne nennenswerten Finfluß. 4) 5) Doch selbst wenn Art. 72 Abs. 2 CG verfassungsrechtlich ernst genommen worden wäre, hätte die Vorschrift das Ausufern der Bundesgesetzgebung nicht aufgehalten. Ihre unüberlegte (Föderalismus vortäuschende) (iestaltung macht sie weitaus mehr zur Legitimation einer maximal ausgedehnten Bundesgesetzgebung als

Art. 125 GG; d.V.)..., dem Bund auf dem Gebiet der konkurrierenden Gesetzgebung die Rechtssetzung durch das Reich zuzurechnen, so daß ihr Gegenstand als vom Bund in Anspruch genommen gilt".

3) Die Auffassung des Bundesverfassungsgerichts (BVerfGE 1, 283 (293 ff); 2, 232 (236); 7, 18 (25), 330 (337). Zum Meinungsstand s. Maunz in Maunz-Dürig, Art. 72 Randn. 13 Fußn. 3) mag vielleicht nicht richtig sein. Sie hat jedoch die Praxis bestimmt, die heute - es handelt sich um Übergangsrecht! - wohl nicht mehr rückgängig zu machen ist.

4) Vg1. das Zeugnis aus der Praxis des Bundesrates: Katzenstein, Rechtliche Erscheinungsformen der Machtverschiebung zwischen Bund und Ländern seit 1949, S.596. - Das Rückgrat wurde der Bedarfsklausel - wie auch Katzenstein ebd. bekundet - dadurch gebrochen, daß das Bundesverfassungsgericht die Nachprüfung, ob lür ein Bundesgesetz auf dem Gebiete der konkurrierenden Gesetzgebungszuständigkeit die Vuraussetzungen des Art. 72 Abs. 2 GG vorlagen oder nicht, grundsätzlich ablehnt, indem es "der. Bedürfnisf'rage" den "Charakter" einer echten Ermessensentscheidung" des Bundesgesetzgeber's zuerkennt (BVerfGF 2, 213 (224 f); 4, $112(127 \mathrm{f}))$. Zu Kritik und Meinungsstand s. Maunz, a. a. O. Randn. 12, $14 \mathrm{f}$.

5) Für das Steuerrecht ist nach Art. 105 Abs. 2 GG die Voraussetzung des Art. 72 Abs. 2 GG ohnedies nur hinsichtlich derjenigen Steuern beachtlich, die nach Art.106 Abs. 2 Nr.1-6 und Abs. 6 Satz $1 \mathrm{GG}$ den Ländern zulließen aber nach Art. 105 Abs.2 GG zur konkurrierenden Gesetzgebung gehören. 
zu deren Hemmnis. 6) Das gilt ganz besonders für den sozialen Bereich. Die soziale Intervention betrifft ihrem Wesen nach die Lebensverhältnisse der Bürger; nach Art. 72 Abs. 2 Nr. 3 GG ergibt sich gerade aus dem Erfordernis der "Wahrung der Einheitlichkeit der Lebensverhältnisse über das Gebiet eines Landes hinaus" das Bedürfnis nach bundesgesetzlicher Regelung. 7) Die soziale Intervention stellt in fast allen Fällen einen Eingriff in das Wirtschaftsleben dar; nach der eben genannten Bestimmung ergibt sich ein Bedürfnis zu bundesgesetzlicher Regelung gerade aus dem Interesse an der Wahrung der Wirtschaftseinheit über das Gebiet eines Landes hinaus. In Anbetracht der relativ großen lokalen Mobilität der westdeutschen Nachkriegsgesellschaft und in Anbetracht der verfassungsrechtlichen Konzeption der Freizügigkeit (Art.11 GG), der Gleichheit der Bürger (Art.3 GG) insbes. auch der Gleichheit der staatsbürgerlichen Rechte und Pflichten jedes Deutschen in jedem Lande (Art.33 Abs. 1 GG) und der expansiven und egalitären Tendenz alles Sozialen stellt das Gebiet eines Landes nur beschränkt einen abgrenzbaren Raum durchgreifender sozialer Besserstellung dar; nach Art. 72 Abs. 2 Nr. 1 GG besteht das Bedürfnis nach bundesgesetzlicher Regelung dann, wenn "eine Angelegenheit durch die Gesetzgebung einzelner Länder nicht wirksam geregelt werden kann". 8) Die Verflochtenheit der wirtschaftlichen und sozialen Verhältnisse bewirkt zudem, daß das isolierte Vorgehen eines Landes rasch die Interessen eines anderen Landes oder der Gesamtheit beeinträchtigen würde (Art. 72 Abs. $2 \mathrm{Nr} .2$ GG).9) Art. 72 Abs.2 GG ist kein Widerstand gegen, sondern eine verfassungsrechtliche Rechtfertigung, ja Ermunterung für den Trend zur bundesgesetzlichen Regelung sozialer Angelegenheiten.

Dazu kommt, daß andere Regelungen des Grundgesetzes die Zuständigkeitsverteilung der Art.72, 74 GG von vorneherein korrumpieren. Von weit reichender Bedeutung ist in diesem Zusammenhang die Übernahme der Kriegsfolgelasten durch den Bund nach Maßgabe eines Bundesgesetzes (Art.120 Abs.1 GG); denn diese Bundesgesetzgebung kann nicht ohne Abstimmung auf die Regelung des entsprechenden Kriegsfolgenrechts (in einem weiten

6) Vgl. Maunz, a.a.O. Randn.20 ff, insbes.Randn.23; Scheuner, Die Aufgabe der Gesetzgebung in unserer Zeit, DÖV 13.Jhg. (1960) S. $601 \mathrm{ff}$ (605).

7) S.a. Scheuner, a.a.O.; s. ferner nochmals Maunz, a.a.O. Randn. 23.

8) Ein auf andere Weise sozial relevantes Beispiel für die Anwendung dieser Klausel s. bei Maunz, a.a.O. Randn. 21.

9) S. hierzu das Beispiel bei Maunz, a.a. O. Randn. 22. 
Sinne) erfolgen. 10) Das Recht der Sozialversicherung wird als "notwendiges" Bundesrecht in erheblichem Umfange geradezu "einzementiert" durch die Überbürdung der "Lasten der Sozialversicherung mit Einschluß der Arbeitslosenversicherung und der Arbeitslosenfürsorge" auf den Bund (Art.120 Abs.1 GG) und die Konstituierung "derjenigen sozialen Versicherungsträger...., deren Zuständigkeit sich über das Gebiet eines Landes hinaus erstreckt" als "bundesunmittelbare Körperschaften des öffentlichen Rechts" (Art.87 Abs.2 GG). 11) Der praktisch nicht tragbare Widerspruch dieser beiden Regelungen mit einer landesgesetzlichen Ordnung des einschlägigen Sozialversicherungs rechts ist evident. Hinzuweisen ist in diesem Zusammenhang schließlich noch auf Art. 119 GG, wonach die Bundes regierung mit Zustimmung des Bundesrates gesetzesgleiche Rechtsverordnungen auf dem Gebiete des Flüchtlingsrechts erlassen darf, - eine Bestimmung, die Art. 74 Nr.6 GG von vorneherein modifizierte.

\section{c) Die Zuständigkeit des Bundes zum Erlaß von Rahmenvor- schriften}

Eine Reihe sozial interessanter Materien findet sich auch in dem Kompetenzbereich, in dem der Bund sog. Rahmenvorschriften erlassen darf (Art.75 GG). Im Vordergrund steht das Recht des Bundes, Rahmenvorschriften über die Rechtsverhältnisse derim öffentlichen Dienst der Länder, Gemeinden und anderen Körperschaften des öffentlichen Rechts stehenden Personen zu erlassen (Art. 75 Nr.1 GG). 1) Diese - mit dem ausschließlichen Recht des Bundes zur Regelung der Rechtsverhältnisse seiner Beamten nach Art. 73 Nr. 8 GG korrespondierende - Zuständigkeit beinhaltet andererseits eine nicht unwichtige Einschränkung der allgemeinen konkurrierenden Zuständigkeit des Bundes auf dem Gebiet des Arbeitsrechts hinsichtlich

10) Zur kompetenzansaugenden Wirkung der Finanzverantwortung ("Wer zahlt, schaffe an") s. Fischer-Menshausen, Bemerkungen, DÖV 6.Jhg. (1953) S.229 f (230). Zur kompetenzverschiebenden Wirkung des Art. 120 GG s. ferner Dobbernack, Die Bedeutung des Grundgesetzes und des Besatzungsstatuts für die Sozialversicherung und die Kriegsopferversorgung, Die Sozialversicherung 4.Jhg. (1949) S. $146 \mathrm{ff}$.

11) Vg1. auch Art. 130 Abs. 3 GG

1) Die weitere, in Art. 98 Abs. 3 Satz 2 GG vorgesehene Kompetenz des Bundes, Rahmenvorschriften über die Rechtsverhältnisse der Richter in den Ländern zu erlassen, ergänzt diesen Zuständigkeitsbereich nach dem Dienstrecht der Richter hin. 
des nicht-beamtenrechtlichen Dienstrechts der Länder. 2) Der Bund hat von dieser Zuständigkeit vor allem durch das Personalvertretungsgesetz, das Rahmengesetz zur Vereinheitlichung des Beamtenrechts (Beamtenrechtsrahmengesetz) und das Bundesbesoldungsgesetz einen nachhaltigen Gebrauch gemacht. ${ }^{3)}$ Im übrigen hat der Bund bisher von den - sozial ebenfalls wichtigen Kompetenzen zur Regelung der Bodenverteilung 4) und der Raumordnung 5) (Art.75 Nr.4 GG) noch keinen eigenen Gebrauch gemacht.

Dem Gegenstande nach stellen diese Bundeszuständigkeiten zur Rahmengesetzgebung eine nicht unwesentliche Ergänzung der Befugnis des Bundes zur sozialen Gesetzgebung dar. Der Bund ist bei dieser Gesetzgebung allerdings wesentlich beschränkt. "Der Bund darf nur den Rahmen setzen. Rahmen aber bedeutet, daß das Bundesgesetz nicht für sich allein bestehen kann, sondern darauf angelegt sein muß, durch Landesgesetz ausgefüllt zu werden". Bundes rahmengesetze dürfen "ihre Zweckbestimmung, nur eine Grenze für landesgesetzliche Eigenregelung bilden, nicht überschreiten. Sie müssen dem Landesgesetzgeber Raum für Willensentscheidungen in der sachlichen Rechtsgestaltung übrig lassen". 6) Während im Bereich der ausschließlichen Gesetzgebungszuständigkeit des Bundes den Ländern die Gesetzgebungsbefugnis schon durch die Verfassung entzogen ist und sie ihnen im Bereich der konkurrierenden Gesetzgebungszuständigkeit durch den Bundesgesetzgeber entzogen werden kann, bleibt die Gesetzgebungszuständigkeit den Ländern im Bereich der Rahmengesetzgebung selbst dann erhalten, wenn der Bund von seiner Rahmenkompetenz Gebrauch gemacht hat. 7) Trotzdem kann kein Zweifel bestehen, daß den Ländern neben dem Rahmenrecht des Bundes nur untergeordnete Fragen zur Entscheidung übrig bleiben. Auch die Kompetenz des Bundes zum Erlaß von Rahmenvorschriften bedeutet also eine entscheidende Gewichtsverlagerung zum Bund hin.

2) Zum Begriff des Dienstrechts s. nochmals Wacke, Zur Neugestaltung des Beamtenrechts.

3) Zur Würdigung s. Katzenstein, Rechtliche Frscheinungsformen der Machtverschiebung $z$ wischen Bund und Ländern seit 1949, S. $596 \mathrm{f}$.

4) S. hierzu oben S. 73 zu Fußn. 40-46.

5) Raumordnung ist nicht schon begrifflich eine Maßnahme der sozialen Intervention (vgl. zum Begriff der Raumordnung:

BVerfGE 3, 407 (425 ff)). Sie kann aber soziale Belange mit verfolgen (s. z.B. Schnaas, Raumordnung und Arbeitsrecht, Bundesarbeitsblatt 11. Jhg. (1960) S. 464 ff).

6) BVerfGE 4, 115 (129 f).

7) Ebd., S. 129 - S. zur genaueren Umschreibung der Rahmenkompetenz ebd. S. $127 \mathrm{ff}$. 
d) Die ausschließliche Gesetzgebungszuständigkeit der Länder

Den Bereich, in den der Bundesgesetzgebung einzudringen verwehrt ist, umschreibt das Grundgesetz nicht ausdrücklich. Er kann nur im Wege der Subtraktion der dem Bunde eröffneten oder vorbehaltenen Materien von der Gesamtmasse aller möglichen Gesetzgebungsgegenstände, die im Grundsatz durch Art.70 Abs. 1 GG den Ländern zugewiesen ist, ermittelt werden. Er ist demnach im ganzen amorph. Welche Reserven an sozialem Wirkungsfeld für die Länder in diesem Kompetenzbereich noch stecken, kann deshalb abschließend nicht gesagt werden. Daß sie nicht groß sein können, liegt aber im Hinblick auf den Umfang des ausschließlichen und vor allem des konkurrierenden Gesetzgebungsbereiches des Bundes sowie der Zuständigkeit des Bundes zum Erlaß von Rahmenvorschriften auf der Hand.

Unter den Materien, die den Ländern vorbehalten sind, nimmt das $\mathrm{Schulrecht}$ eine hervorragende Stellung ein. Ihm hat das Grundgesetz schon eine soziale Note gegeben, indem es in Art. 7 Abs. 4 Satz 2 Privatschulen diskriminiert, die "eine Sonderung nach den Besitzverhältnissen der Eltern" fördern, und in Abs. 6 das. bestimmt, daß Vorschulen aufgehoben bleiben. Von weitaus breiterer sozialer Wirksamkeit als diese Klauseln des Grundgesetzes sind aber die dem Landesgesetzgeber überlassenen Bestimmungen über den Wirkungskreis, die Einrichtung und die Unterhaltung öffentlicher Schulen, über die Schulpflicht und vor allem über die Schulgeld- und Lernmittelfreiheit sowie die Gewährung von Ausbildungsbeihilfen. Hier wird der Grund für die Chancengleichheit der Ausbildung gelegt! Dem Landesgesetzgeber steht damit ein beachtlicher sozialer Wirkungskreis offen.

Unter den Gebieten, die dem Landesgesetzgeber vorbehalten sind, ist in diesem Zusammenhang auch noch das Kom muna recht zu nennen, für das das Grundgesetz nur die Grundsätze des Art. 28 Abs. 1 Satz 2 und 3 und Abs. 2 sowie des Art. 106 Abs. 6 GG verbindlich aufgestellt hat. Die Länder können so vor allem den sozialen Wirkungskreis der Gemeinden näher abgrenzen und die Modalitäten der sozialen Intervention durch die Ciemeinden festlegen.

Schließlich ist als eine Oase der Landesgesetzgebung noch die Gesetzgebung über die Steuern mit örtlich bedingtem Wirkungskreis zu nennen, die nach Art. 105 Abs.2 Nr.1 i. V.m. Art. 70 Abs. 1 GG den Ländern vorbehalten ist. 1) Als

1) Im übrigen ist anzunehmen, daß alle sonstigen Steuerarten unter eine der in Art. 105 Abs. 1 und 2 GG genannten Steuern bzw. Steuertypen fallen. Art.105 GG teilt also die Steuerge- 
Steuern mit örtlich bedingtem Wirkungskreis sind in Art. 105 Abs. 2 Nr. 1 GG beispielhaft aufgezählt die Grunderwerbsteuer, die Wertzuwachssteuer und die Feuerschutzsteuer. Ferner sind dazu zu rechnen die Vergnügungssteuer, die Wohnraumsteuer, die Jagdsteuer, die Schankerlaubnissteuer, die Getränkesteuer, die Totalisatorsteuer und - mit Einschränkung - die Speiseeissteuer. ${ }^{2)}$ Die Bedeutung der steuerrechtlichen Domäne der Landesgesetzgebung ist also an sich nicht übermäßig hoch zu veranschlagen. Eine Reihe der genannten Steuern fällt insbes. ihrem Gegenstand nach als Mittel der sozialen Intervention aus.

Abschließend ist zu sagen: Die kapitalen Fragen der sozialen Intervention sind durch die Zuständigkeitsverteilung des Grundgesetzes fast alle der Gesetzgebung des Bundes e röf n et und, soweit die Zuständigkeit eine konkurrierende ist, durch die Entwicklung des Gesetzesrechts den Lände rn auch bereits versperrt. Die soziale Gesetzgebung ist ganz überwiegend Sache des Bundes.

\section{Die Verwaltungskompetenzen}

Die Konzeption des Cirundgesetzes von der Aufteilung der Verwaltungsaufgaben ist durch das Bemühen ausgezeichnet, den Ländern,

setzgebung erschöpfend auf, ohne für die Deduktion einer über die "Steuern mit örtlich bedingtem Wirkungskreis" hinausgehenden (ausschließlichen) steuerrechtlichen Gesetzgebungszuständigkeit der Länder Raum zu lassen. In diesem Sinne Höpker-Aschoff, Das Finanz- und Steuersystem des Bonner Grundgesetzes, AöR Bd. 75 (19,49) S. 306 ff (321); Lorenz, Die Gesetzgebungskompetenz der Länder auf dem Gebiet der Verkehrs- und Verbrauchssteuern mit örtlich bedingtem Wirkungskreis, DC̈V 7.Jhg. (1954) S. 456 f (456); Hettlage, Die Neuordnung der deutschen Finanzverfassung, Finanzarchiv n.F. Bd. 14(1953/54) S. 405 ff (422); Meilicke, Der Steuererfindungsgeist von Bund und Ländern seit Inkrafttreten des Grundgesetzes - seine verfassungsrechtlichen Grenzen, in Festschrift für Ottmar Bühler, 1954, S.91 ff (108 f); Blendermann, Steuern mit örtlich bedingtem Wirkungskreis, S. $52 \mathrm{f}$; ebenso die Bundes regierung, Deutscher Bundestag, 2. Wahlperiode (1955) Drucksache 480 S. 109.

2) So die Aufstellung bei Blendermann, a.a.O. S.91. Seine reich belegte - Begründung s. ebd. S. $10 \mathrm{ff}$. S. a. seine Übersicht über den Stand der Meinungen S.6 ff, auf die hier ausdrücklich verwiesen wird. - Die Entscheidung BVerfGE 7, 244 steht trotz ihres irreführenden Leitsatzes Nr. 4 (ebd. S. 244) nicht im Widerspruch zu den Thesen Blendermanns und 
denen die Masse der Gesetzgebungskompetenzen (direkt oder indirekt, ganz oder zum Teil) entzogen wurde, die Masse der Verwaltungsaufgaben $z u$ erhalten. Ausgehend von der allgemeinen Kompetenzvermutung zugunsten der Länder (Art.30 GG) hat das Grundgesetz die Verwaltungsaufgaben nur exzeptionell und in sehr abgestuften Formen an den Bund gezogen. Gerade im sozialen Bereich hat die Verwaltungstätigkeit des Bundes trotzdem erstaunliche Ausmaße angenommen.

\section{a) Die Bundesverwaltung}

aa) Die bundeseigene Verwaltung mit eigenem Verwaltungsunterbau

Die extremste Form der Bundesverwaltung ist die Bundesverwaltung mit eigenem Verwaltungsunterbau. Unter den im Grundgeset'z vorgesehenen Fällen (Art. 87 Abs.1, 37 b, 108 GG) kann als sozial bedeutsam die Versorgung der Soldaten der Bundes we hr (Art. 87 b Abs. 1 Satz 3 GG) angesehen werden, die jedoch bisher in bundeseigener Verwaltung nur geführt wird, soweit sie sog. Dienstzeitversorgung ist. 1)

Erhebliche soziale Bedeutung kommt auch der bundeseigenen F'in a n z verwaltung zu. Nach dem Grundgesetz sollen Zölle, Finanzmonopole, die der konkurrierenden Gesetzgebung unterworfenen Verbrauchssteuern, die Beförderungssteuer und die Umsatzsteuer vom Bund in bundeseigener Verwaltung verwaltet werden (Art.108 Abs. 1 Satz 1); desgleichen können die einmaligen Vermögensabgaben und die Einkommens- und Körperschaftssteuer, soweit der Bund diese in Anspruch nimmt, in bundeseigene (oder in Bundesauftrags-)Verwaltung genommen werden (ebd. Abs. 1 Satz 4 und Abs.2). Voll realisiert ist dieses Programm jedoch bis heute nicht.

(1) Das Finanzverwaltungsgesetz (FVG) vom 6. September 1950 (BGB1. I S.448; i.d.F. der Gesetze vom 21. August 1951, BGB1. I S. 774 und vom 27. April 1955, BGB1. I S. 189) glaubte eine Kompromißlösung treffen zu dürfen, die sich trotz gewichtiger ver-

der mit ihm Übereinstimmenden (s. BVerfGE 7, $257 \mathrm{f}$ ).

1) $₫ 87 \mathrm{Abs} .1$ des Soldatenversorgungsgesetzes. Die Beschädigtenversorgung soll nach $₫ 88$ Abs. 1 des Soldatenversorgungsgesetzes durch die Länder im Auftrage des Bundes ausgeführt werden. Diese Lösung dürfte aber nach Art. $87 \mathrm{~b}$ GG schwerlich legitim sein. 
fassungs rechtlicher Bedenken 2) bis heute erhalten hat. Ihr Angelpunkt ist die Oberfinanzdirektion, eine "gemischte" Bundesund Landesbehörde, wohl die eigenartigste Behörde des gegenwärtigen deutschen Bundesstaats rechts. Ihr Leiter, der Oberfinanzpräsident, wird von Bund und Land gemeinsam berufen und ist Bundes - und Landesbeamter zugleich ( $\$ 5$ FVG). ${ }^{3)}$ Sie gliedert sich in eine Zoll- und Verbrauchsteuerabteilung und eine Bundesvermögens- und Bauabteilung, die beide mit Bundesbediensteten besetzt sind, sowie eine Besitz- und Verkehrsteuerabteilung, die mit Landesbediensteten besetzt ist ( $\$ 6 \mathrm{FVG}$ ). Der letzteren sind aber Verwaltungsangehörige des Bundes zugeteilt, die die Umsatz - und Beförderungssteuer verwalten ( $\$ 9$ Abs. 1 FVG). Die Oberfinanzdirektion ist Mittelbehörde ( $\$ \$ 1$ Abs. $1 \mathrm{Nr}$. 1, 2 Abs. $1 \mathrm{Nr} .1$ FVG). Unter ihr arbeiten die Hauptzollämter (und deren Hilfsstellen), die Bundesbehörden sind, und die Finanzämter, reine Landesbehörden ( $\$ \S 1$ Abs. 1 Nr.2, 2 Abs. 1 $\mathrm{Nr} .2$ FVG).

(a) Mit diesem Apparat nun wird die bundeseigene Verwaltung durchgeführt für die Zölle und Verbrauchssteuern, für die in der Unterinstanz die Hauptzollämter ( $\$ 13$ FVG) und in der Mittelinstanz die "bundeseigenen" Zoll- und Verbrauchssteuerabteilungen der Oberfinanzdirektionen zuständig sind ( $\$ 6$ Abs.2 FVG).

(b) Für die Umsatz- und Beförderungssteuer hat man jene ausweichende Lösung geschaffen, an der die verfassungs rechtlichen Bedenken 4) in erster Linie einsetzen: Die unterste "bun-

2) S. hierzu allgemein kritisch: Wacke, Das Gesetz über die Finanzverwaltung, Finanzarchiv n. F. Bd.12 (1950/51) S. $713 \mathrm{ff}$; Klein, Von der föderativen zur stärker unitarischen Gestaltung des Finanzwesens in der Bundesrepublik Deutschland, in: Festschrift für Giese, 1954, S. $61 \mathrm{ff}(83 \mathrm{f}$; s. aber auch Höpker-Aschoff, Das Finanzwesen der Bundesrepublik, Finanzarchiv n. F. Bd. 12 (1950/51) S. 725 ff (728): "Die Kundigen waren sich sofort darüber klar, daß man hier einen krummen Weg suchen müsse, um den Bestimmungen des Grundgesetzes und zugleich den praktischen Bedürfnissen zu genügen. Das Finanzverwaltungsgesetz hat ihn darin gefunden..."

3) Verfassungsrechtliche Bedenken zu der Institution des Oberfinanzpräsidenten in der Ausgestaltung des Finanzverwaltungsgesetzes $\mathrm{s}$. bei: Wacke, Das Gesetz über die Finanzverwaltung, S. $714 \mathrm{ff}$; Klein, a.a.O. S. $83 \mathrm{ff}$.

4) Gegen die Verfassungsmäßigkeit dieser Lösung: Wacke, Das Gesetz über die Finanzverwaltung, S. $717 \mathrm{ff}$; Klein, a.a.O. S. $86 \mathrm{ff}$. 
deseigene Instanz", die in bezug auf die Umsatz- und die Beförderungssteuer tätig wird, sind die Verwaltungsangehörigen des Bundes, die der Besitz- und Verkehrssteuerabteilung der Oberfinanzdirektionen zugewiesen sind ( $\$ 9$ Abs. 1 FVG). Praktisch als Unterinstanz fungieren jedoch die (landeseigenen) Finanzämter, deren "Hilfe" die Oberfinanzdirektionen "bei der Bearbeitung der Umsatzsteuer und der Beförderungssteuer" in Anspruch nehmen können.

(c) Durchaus legitim konnte dagegen das Finanzverwaltungsfür die auch vom Bund in Anspruch genommene Einkommens- und Körperschaftssteuer statt der bundeseigenen die Bundesauftragsverwaltung durch das Finanzamt und die Besitz- und Verkehrssteuerabteilung der Oberfinanzdirektion anordnen (Art. 108 Abs. 2 GG; $₫ \S 6$ Abs. 2, 21, 34 Nr. 4 FVG).

(2) Von der Verwaltung der Finanzmonopole sind die Länder gänzlich ausgeschlossen. Näher auf diese sehr eigenartigen Regelungen 5) einzugehen, ist hier überflüssig.

(3) Einmalige Vermögensabgaben sind - von den in Art. 120 a GG speziell geregelten Lastenausgleichsabgaben abgesehen - derzeit nicht zu verwalten.

Schließlich darf auch die soziale Bedeutung des Auswärtigen Dienstes (Art. 87 Abs. 1 Satz 1 s.a. Art. 32 Abs. 1 GG) nicht verkannt werden, der wertvolle Hilfe für den im Ausland befindlichen Deutschen - sei es im Einzelfall, 6) sei es durch Vorberei-

5) S. hierzu die Darstellung bei Huber, Wirtschaftsverwaltungsrecht I, S. 102, $512 \mathrm{ff}, 562 \mathrm{ff}$.

6) Vg1. das Gesetz betreffend die Organisation der Bundeskonsulate sowie die Amtsrechte und Pflichten der Bundeskonsuln vom 8. November 1867 (BGB1. S. 137; i.d.F. der Gesetze vom 14. Mai 1936, RGB1. I S. 447 und vom 16. Dezember 1950, BGB1. S. 784); sein $\$ 1$ bestimmt:

"Die Bundeskonsuln sind berufen,... die Beobachtung der Staatsverträge zu überwachen und den Angehörigen der Bundesstaaten, sowie anderer befreundeter Staaten in ihren Angelegenheiten Rat und Beistand $z u$ gewähren. Sie müssen hierbei nach den Bundesgesetzen... sich richten..."

$\S 26$ bestimmt ferner:

"Hilfsbedürftigen Bundesangehörigen haben die Bundeskonsuln die Mittel zur Milderung der augenblicklichen Not oder zur Rückkehr in die Heimat... zu gewähren". Hieraus und aus der Zahl der Amtshilfezuständigkeiten (vgl. insbes. $\$ \$ 16,17,19$ des Gesetzes) ergibt sich eine umfang- 
tung und Abschluß von Abkommen sozialen Inhalts - leisten kann.

Weitere Zweige bundeseigener Verwaltung mit bundeseigenen Mittel- und Unterbehörden können gem. Art. 87 Abs. 3 Satz 2 GG dann eingerichtet werden, wenn dem Bunde auf Gebieten, für die ihm die Gesetzgebung zusteht, neue Aufgaben erwachsen. Dabei wird allerdings ein dringender Bedarf vorausgesetzt; und das Gesetz, 7) durch das diese Verwaltung eingerichtet wird, bedarf der Zustimmung des Bundesrates und im Bundestage der absoluten Mehrheit. $\mathrm{Ob}$ in Anbetracht der schon beim Inkrafttreten des Grundgesetzes gegebenen Relation zwischen Aufgaben und Verwaltungseinrichtungen künftig von dieser Möglichkeit berechtigterweise viel Gebrauch gemacht werden kann, darf bezweifelt werden.

bb) Die bundeseigene Verwaltung durch Bundesoberbehörden

Im Bereich seiner Gesetzgebungszuständigkeit 1) hat der Bund dort, wo er eine bundeseigene Verwaltung mit eigenem Verwal-

reiche Kompetenz des konsularischen Dienstes auch im sozialen Bereich. S. nunmehr auch $₫ 112$ (insbes. Abs.6) des Entwurfs eines Bundessozialhilfegesetzes, Deutscher Bundestag, 3. Wahlperiode, Drucksache 1799.

7) Der Ansicht von Maunz (Deutsches Staats recht S. 199), Koellreutter (Deutsches Staats recht, 1953, S.234) und Giese (Das Grundgesetz für die Bundes republik Deutschland, Art. 87 Anm.10), es sei kein förmliches Gesetz notwendig sondern nur ein schlichter Beschluß, kann der Verf. sich nicht anschließen (wie hier: Kratzer, Zustimmungsgesetze, AöR Bd. 77 (1951/52) S. 266 ff (270); v. Mangoldt, Bonner Grundgesetz, Art.87 Anm.7; Hamann, Das Grundgesetz, 1957, Art. 87 Anm. C 8).

1) Umstritten ist hierbei vor allem, ob der Bund von seiner Kompetenz auch bereits Gebrauch gemacht haben muß (so Kratzer, Die Bundesoberbehörde, DÖV Jhg. 3 (1950) \$. 529 ff (531), der zusätzlich die Voraussetzungen des Art. 72 Abs.2 GG speziell für die Errichtung der Bundesoberbehörde erfüllt wissen will (S.530); Maunz, Deutsches Staatsrecht, S.205; im Ergebnis ebenso Schäfer, Die bundeseigene Verwaltung, DÖV 11.Jhg. (1958) S.241 ff (246)), oder ob es genügt, daß ihm das Gesetzgebungsrecht überhaupt zusteht (so v. Mangoldt, Bonner Grundgesetz, Art. 87 Anm.6; Pathe, Die Ausführung der Bundesgesetze, DVB1.66. Jhg. (1951) S.681 ff (682); Hamann, Das Grundgesetz, Art.87 Anm.6). Der Frage dürfte in Anbetracht der nahezu völligen Ausnutzung seiner Gesetzgebungskompetenz durch den Bund auf dem sozialen 
tungsunterbau nicht errichten muß, will oder kann, - neben der Befugnis, bundesunmittelbare Körperschaften und Anstalten des öffentlichen Rechts zu errichten, auf die gleich zurückzukommen sein wird - die Möglichkeit, selbständige Bundesoberbehörden zu errichten (Art. 87 Abs. 3 Satz 1 GG). Sie sind als Bundes - und als $\mathrm{O}$ be $\mathrm{r}$ behörden begrifflich auf die Wahrnehmung überregionaler Aufgaben beschränkt, deren zentrale Durchführung ohne Zuhilfenahme eines besonderen (bundeseigenen oder landeseigenen) Verwaltungsunterbaues möglich ist.2) Trotz der sich daraus ergebenden beschränkten Verwertbarkeit dieser Form bundeseigener Verwaltung hat sie - von der durch einfaches Bundesgesetz Gebrauch gemacht werden kann - im allgemeinen, wie im besonderen im sozialen Bereich große Bedeutung erlangt.

Auf dem Gebiet der Sozialversicherung führt das Bundesversicherungsamt die Aufsicht über die gem. Art. 87 Abs.2 GG bundesunmittelbaren Sozialversicherungsträger; ihm sind auch gewisse Zuständigkeiten des früheren Reichsversicherungsamtes übertragen ( $₫ \S 1,2$ des Bundesversicherungsamtsgesetzes). Die Aufsicht über die übrigen Versicherungsträger führen dagegen die obersten Landesbehörden. ${ }^{3)}$ Im sozialen Zusammenhang beachtlich sind ferner das Bundeskartellamt ( $\mathbb{S} 44 \mathrm{ff}, 48 \mathrm{ff}$ des Gesetzes gegen Wettbewerbsbeschränkungen) und das Bundesverwaltungsamt (Gesetz über die Errichtung des Bundesverwaltungsamtes v. 28. Dezember 1959, BGB1. I S. 829), das hier besonders wegen seiner Zuständigkeit für das Auswanderungswesen ( $\$ 2$ a.a.O.),gewisse versorgungsrechtliche Angele-

Sektor wenig Bedeutung mehr zukommen.

2) S. Kratzer, Die Bundesoberbehörde, S.531; Köttgen, Der Einfluß des Bundes auf die deutsche Verwaltung, Jahrbuch des öffentlichen Rechts, n.F. Bd. 3 (1954) S. 67 ff (74 f). Die Voraussetzungen der Errichtung von Bundesoberbehörden sind ebenso umstritten wie die Befugnisse und Gestalt, die ihnen gegeben werden dürfen. Die Problematik ist so vielgestaltig und ungeklärt, daß sie hier auch nicht angedeutet werden kann. Vgl. hierzu vor allem die Darstellungen von Kratzer, Die Bundesoberbehörde; v. Mangoldt, Das Bonner Grundgesetz, Art.87 Anm.6; Köttgen, a.a.O. S. $74 \mathrm{f}$ und passim; Katzenstein, Rechtliche Erscheinungsform der Machtverschiebung zwischen Bund und Ländern seit 1949 S. 600 f; Maunz, Deutsches Staatsrecht, S. 204 f.

3) Zur Kompetenzabgrenzung s. z.B. BSGE 1, 17; LSG BadenWürttemberg v. 11. Dezember 1959 - L IV bK 2299/56 Breithaupts Sammlung Bd.49 (1960) S. 870 . 
genheiten ( $\$ 3$ a.a.O.) und die Auslandsfürsorge 4 ) zu nennen ist. Eine vom Grundgesetz selbst (in dem nachträglich eingefügten Art.120 a GG) vorgesehene obere Bundesbehörde 5) besonderen Rechts ist das Bundesausgleichsamt für die Aufgaben der La stenausgleichs verwaltung, die in der Unter- und Mittelinstanz durch die - in Bundesauftragsverwaltung tätigen - Ausgleichsämter und Landesausgleichsämter der Länder wahrgenommen werden ( $\$ \$ 305$ ff LAG).

\section{cc) Die Verwaltung durch bundesunmittelbare Körperschaften und Anstalten 1)}

Weitaus mehr Bedeutung als die beiden bisher genannten Formen bundeseigener Verwaltung hat aber die Verwaltung durch unmittelbar dem Bunde unterstehende Körperschaften und Anstalten des öffentlichen Rechts erlangt. Auf diese Form der Bundesverwaltung hat für den sozialen Bereich das Grundgesetz bereits selbst verwiesen, indem es die sozialen Versicherungsträger, deren Zuständigkeitsbereich sich über das Gebiet eines Landes hinaus erstreckt, unmittelbar dem Bunde unterstellte (Art.87 Abs.2 GG). 2) Sie hat gerade im sozialen Bereich auch eine breite verfassungsrechtlich durch Art.130 GG aktivierte - historische Grundlage. Diese ist wiederum Ausdruck einer strukturell-sachgesetzlichen Tendenz zahlreicher sozialer Verwaltungsaufgaben zur anstaltlichen und körperschaftlichen Organisation und zur

4) Anordnung des Bundesministers des Innern über die Wahrnehmung von Zuständigkeiten auf dem Gebiete der Auslandsfürsorge durch das Bundesverwaltungsamt v.21. Januar 1960 (BAnz. Nr.23 v. 4. Febr. 1960).

5) Maunz, Deutsches Staats recht, S.205, will mit guten Gründen das Bundesausgleichsamt sogar "mehr dem Typus der obersten Bundesbehörden als dem der Bundesoberbehörden" zurechnen. Der Gesetzgeber ( $\$ 307 \mathrm{LAG}$ ) bezeichnet es als "selbständige Bundesoberbehörde".

1) Der weitverbreitete Ausdruck "bundesunmittelbare Selbstverwaltung", der zur Kennzeichnung dieser Art der Bundesverwaltung weithin verwandt wird, ist einseitig; denn Anstaltsverwaltung ist, wenn sie auch nicht notwendig rein bürokratische Verwaltung ist sondern Verwaltung unter Zuziehung der Beteiligten, nicht notwendig auch Selbstverwaltung im herkömmlichen Wortsinn. Vgl. Köttgen, Art. "Selbstverwaltung" im Handwörterbuch der Sozialwissenschaften, Bd.9, 1956 , S.220 ff (224).

2) Zu Auslegung und Tragweite des Art.87 Abs.2 GG s. inbes. BSGE 1, 17. 
Selbstverwaltung. 3 ) Die Verwaltung durch bundesunmittelbare Körperschaften und Anstalten bietet zudem ganz allgemein einen starken Anreiz, Verwaltungsaufgaben, deren Wahrnehmung durch eine bundeseigene Verwaltung mit eigenem Verwaltungsunterbau nicht statthaft, deren Erfüllung allein in der Instanz der Bundesoberbehörden und der Bundesministerien aber nicht möglich ist, an den Bund zu ziehen. Sie steht zur Disposition der einfachen Bundes gesetzgebung (Art. 87 Abs. 3 Satz 1 GG). Ist sie einmal eingerichtet, kann der Bund ihre Behördenorganisation und ihre allgemeinen Verwaltungsgrundsätze grundsätzlich ebenso bestimmen wie für die übrige bundeseigene Verwaltung (Art.86 GG). Im Cregensatz zu bundeseigener Verwaltung durch Bundesoberbehörden kann sie aber zudem mit eigenem - d.h. anstalts-oder körperschaftseigenem - Verwaltungsunterbau arbeiten. ${ }^{4)}$

3) Näheres s. unten 2. Abschnitt S.219 ff.

4) Das ist allerdings nicht unbestritten (wie hier: v. Mangoldt, Bonner Grundgesetz, Art.87 Anm.5; Peters, Verfassungsrechtliche Fragen eines Gesetzes über die Regelung der Beziehungen zwischen Ärzten, Zahnärzten und Krankenkassen (Kassenarztrecht), Gutachten 1953, Deutscher Bundestag, 1. Wahlpe riode, Drucksache Nr.3904, S. 3; Schneider, Körperschaftliche Verbundverwaltung, AöR Bd. 83 (1958) S. 1 ff (15), Hamann, Deutsches Wirtschaftsverfassungs recht, S.179).

Köttgen (in: Der Einwand der Mischverwaltung und das Grundgesetz, DÖV 8.Jhg. (1955) S. 485 ff (492) und Der Einfluß des Bundes auf die deutsche Verwaltung, S.75, 115 f) und Süsterhenn (Grundgesetz und Bundesnotenbank, in "Verfassung und Verwaltung", Festschrift für Laforet, 1952, S. 177 ff (183)) sind der Ansicht, ein Verwaltungsunterbau der rechtsfähigen Verwaltungseinheiten sei unzulässig. Satz 2 des Art. 87 Abs. 3 GG wirke auf dessen Satz 1 zurück. Bundeseigener Verwaltungsunterbau dürfe danach nur unter den in Satz 2 ebd. vorgesehenen Voraussetzungen eingerichtet werden. Dem kann nicht zugestimmt werden. Zunächst spricht aus der unbestrittenen Staatspraxis das Beispiel der im T'ext gleich noch zu erwähnenden Bundesanstalt für Arbeitsvermittlung und Arbeitslosenversicherung - das Köttgen in nicht überzeugender Weise als historisch bedingte Ausnahme zu rechtfertigen versucht - eine zu deutliche Sprache. Sodann aber ist es interpretatorisch unrichtig, Satz 2 a.a.O. in dieser Weise dem ganzen Satz 1, d.h. den Bundesoberbehörden wie auch den Körperschaften und Anstalten des Bundes zuzuordnen. Bundesoberbehörden können schon begrifflich keinen Verwaltungsunterbau haben. Ihre Ergänzung durch einen Unterbau 
Auf diese Weise besteht eine mittelbare, bundeseigene Verwaltung der Arbeitsvermittlung und Arbeitslosenversicherung im Rahmen der Bundesanstalt für Arbeitsvermittlung und Arbeitslosenversicherung mit eigenen Unterbehörden (Arbeitsämtern) und Mittelbehörden (Landesarbeitsämtern) (Gesetz über Arbeitsvermittlung und Arbeitslosenversicherung). Dieser "Arbeitsverwaltung" sind zahlreiche verwandte Aufgaben übertragen, so z.B. der Vollzug des Dritten Abschnittes "Kündigungsschutz bei Massenentlassungen" ( $\$ \$ 15 \mathrm{ff}$ ) des Kündigungsschutzgesetzes und im Zusammenwirken mit den Hauptfürsorgestellen - der Vollzug des Schwerbeschädigtengesetzes. Bundesunmittelbare Sozialversicherungsträger sind (außer der Bundesanstalt für Arbeitsvermittlung und Arbeitslosenversicherung) die Bundesversicherungsanstalt für Angestellte, in der Regel die Arbeiter-Ersatzkassen, die AngestelltenErsatzkassen, die Betriebskrankenkassen der Bundesbahn, der Post, der Verkehrsverwaltung und zahlreiche andere Betriebskrankenkassen, eine große Zahl der Träger der gewerblichen

bedarf der speziellen Legitimation. Körperschaften und Anstalten können in sich einen Verwaltungsunterbau, einen Behördenapparat haben. Sie haben aber selbst dann, wenn sie eine aufgegliederte Behördenorganisation besitzen, nicht "bundeseigene Mittel- und Unterbehörden", also einen bundeseigenen Verwaltungsunterbau, wie er in Art. 87 Abs. 1 Satz 1 GG konzipiert ist. Diese Behörden stehen unmittelbar im bürokratischen Aufbau der Verwaltungsorganisation des Bundes. Die Behörden der Körperschaften und Anstalten aber stehen primär in diesen Verwaltungseinheiten und werden über diese dem Bunde zugerechnet. Hinzuweisen ist auch darauf, daß Art.86 GG die bundeseigene Verwaltung neben der durch bundesunmittelbare Körperschaften oder Anstalten anführt, so daß das Ineinssetzen der Bundesverwaltung durch besondere Verwaltungseinheiten mit der unmittelbaren Bundesverwaltung einerseits durch Bundesoberbehörden andererseits durch bundeseigene Mittel- und Unterbehörden auch aus diesem Grunde unrichtig ist. - Eine ganz andere Frage, auf die noch zurückzukommen sein wird und in der Köttgen (Der Einwand der Mischverwaltung und das Grundgesetz, S.491; Der Einfluß des Bundes auf die deutsche .Verwaltung, S. 115f), der sie verneint, recht gegeben werden $m u ß$, ist die, ob landesunmittelbare (landesinkorporierte) Körperschaften und Anstalten einen Überbau in bundesunmittelbaren Körperschaften haben dürfen und diesen auf diese 1 ieise ein eigener Unterbau verschafft werden darf. 
Unfallversicherung, einige Träger der landwirtschaftlichen Unfallversicherung, die Arbeitsgemeinschaft der Knappschaften der Bundesrepublik Deutschland, sowie die Mehrzahl der bestehenden Knappschaften. 5) Hinzuzuzählen sind noch der Gesamtverband der Familienausgleichskassen ( $\$ 20$ des Kindergeldgesetzes) und der Gesamtverband der landwirtschaftlichen Alterskassen ( $\$ 16$ des Gesetzes über eine Altershilfe für Landwirte) sowie diejenigen Familienausgleichskassen und landwirtschaftlichen Alterskassen, die bundesunmittelbaren Berufsgenossenschaften angegliedert sind ( $\$ 16$ des Kindergeldgesetzes, $₫ 12$ des Gesetzes über eine Altershilfe für Landwirte). ${ }^{6)}$

Dieser Weg, die Verwaltung sozialer Angelegenheiten an sich $z u$ ziehen, steht dem Bunde über die schon erwähnten Beispiele hinaus grundsätzlich für alle diejenigen Aufgaben offen, hinsichtlich deren ihm die Gesetzgebungskompetenz gegeben ist (Art. 87 Abs. 3 Satz 1 GG). Dem sind freilich von der Sache her gewisse Grenzen gesetzt. Nicht jeder Verwaltungsaufgabe ist die Mediatisierung zuträglich, die mit ihrer Übertragung an eine Körperschaft oder eine rechtsfähige Anstalt mehr oder weniger immer in Kauf genommen werden muß. Jeder derartigen Anstalt oder Körperschaft - so wie der Bundesanstalt für Arbeitslosenversicherung und Arbeitsvermittlung - einen eigenen Verwaltungsunterbau zu geben, ist außerdem praktisch nicht tragbar. Bundesunmittelbare Körperschaften und Anstalten zu errichten, deren örtlicher Wirkungskreis nicht über ein Land hinausgeht, ist dem Buncle andererseits verwehrt. ${ }^{7)}$ Trotzdem ist gerade in dieser Verwaltungsform der Weg zu suchen, auf dem der Bund soziale

5) Nach Eckert, Sozialversicherungsgesetze, Art.87 GG Anm. 1 (32.56 f).

6) Ergänzend sei noch vermerkt, daß auch die für die Preisgestaltung nicht unbedeutenden Einfuhr- und Vorratsstellen als bundesunmittelbare Anstalten des öffentlichen Rechts organisiert sind. S. hierzu z. B. Huber, Wirtschaftsverwaltungsrecht $\mathrm{Bd}$. I S. $147 \mathrm{ff}$.

7) arg. Art.87 Abs.2 GG. - Peters (Verfassungsrechtliche Fragen des Entwurfs eines Gesetzes über die Regelung der Beziehungen zwischen Ärzten, Zahnärzten und Krankenkassen (Kassenarztrecht), 1953, S. 4 ff) und Scheuner (Berufsständische Versorgungseinrichtungen und Grundgesetz, S.93) scheinen zwar der Ansicht zu sein, der Grundsatz des Art. 87 Abs. 2 GG beziehe sich nur auf Sozialversicherungsträger. Art. 87 Abs.2 GG muß aber als Ausdruck eines allgemeinen Prinzips gelten. Die Staatspraxis hat sich an dieses Prinzip bisher gehalten. 
Aufgaben unter dem geringsten, verfassungsrechtlichen Widerstand an sich ziehen kann.

Im Zusammenhang mit der Bundesverwaltung durch bundesunmittelbare Körperschaften und Anstalten muß auch die auf der speziellen Verfassungsnorm des Art.88 GG beruhende Deutsche $B$ unde sbank erwähnt werden. Sie ist Träger der Währungspolitik ( $\$ 3$ des Gesetzes über die Deutsche Bundesbank vom 26. Juli 1957, BGB1. I S. 745) und somit auch ein die sozialen Verhältnisse entscheidend mitgestaltender Faktor.

Sie wurde als "bundesunmittelbare juristische Person des öffentlichen Rechts" errichtet ( $\$ 2$ ebd.), weicht aber nicht nur in diesem formalen Element von dem Schema der Träger mittelbarer Bundesverwaltung ab. Ihre leitenden Gremien "haben die Stellung von obersten Bundesbehörden" ( $\$ 29$ Abs.1 ebd.). Von Weisungen der Bundesregierung ist die Bundesbank freigestellt ( $\$ 12$ Satz 2 ebd.). Die Koordination der Tendenzen und Maßnahmen zwischen Bundesregierung und Bundesbank geschieht im Wege der Beratung ( $\$ 13$ ebd.). Sie ist - intensiver als es bei einer anderen bundesunmittelbaren Körperschaft oder Anstalt der Fall ist oder vielleicht sogar der Fall sein kann - in einem föderativen Sinne dezentralisiert. ${ }^{8)}$ In ihrem hohen Maß an Unabhängigkeit, dem Gewicht ihrer Aufgaben und ihrer strukturellen Eigenständigkeit ist die in Art. 88 GG institutionell garantierte Bundesbank schon fast mehr ein Verfassungsorgan 9) als ein Instrument der - unter Verantwortung und Autorität der Bundesregierung handelnden - Bundesverwaltung.

\section{dd) Die Bundesministerialverwaltung}

Auch der Bundesregierung - dem Kollegium oder seinem Haupt, dem Bundeskanzler, und seinen Gliedern, den Bundesministern, - ist, wenngleich nicht sehr präzis, eine besondere Art der bundeseigenen Verwaltung zugewiesen.

8) S. hierzu Wagenhöfer, Der Föderalismus und die Notenbankverfassung, Festschrift für Hans Ehard, 1957, S.97 ff, insbes. S. $111 \mathrm{ff}$.

9) Wagenhöfer, a.a.O. S.120: "Man könnte ... die Notenbank in die ... Exekutive ... eingliedern, indem man die Regierungsgewalt im weiteren Sinne begrifflich zwischen Bundespräsident, Bundesregierung und Bundesbank aufteilt". 
aaa) Abgrenzung

1. Die Rechtsetzungsaufgaben der Bundesregie rung. Als Verwaltungsaufgaben können hier nicht jene Zuständigkeiten gemeint sein, die die Bundesregierung in bezug auf die Gesetzgebung hat. 1) Inwieweit diese Kompetenzen materiell, begrifflich der Legislative zugerechnet werden dürfen oder inwieweit sie als Ausfluß der sog. Regierungsgewalt aus dem Komplex der Verwaltung ausgeschieden werden können, bedarf hier keiner Entscheidung. Unter dem Gesichtspunkt der Aufgabenverteilung $z$ wischen Bund und Ländern sind sie jedenfalls nicht im Zusammenhang mit den Verwaltungskompetenzen sondern mit den Gesetzgebungskompetenzen des Bundes zu sehen. Diese umgrenzen auch die der Legislative zugewandten Tätigkeiten der Bundesregierung. 2)

2. Im besonderen: Die normative Ciestaltung der A rbeitsbedingungen. Das gilt auch von einem besonderen, im gegebenen Zusammenhang hochaktuellen Kreis von Zuständigkeiten der Bundes regierung bzw. des Bundesministers für Arbeit: den Zuständigkeiten zur autoritativen Gestaltung der Arbeitsbedingungen.

(1) Im Vordergrund steht die Zuständigkeit des Bundesarbeitsministers, gem. $\$ 5$ TVG Tarifverträge für a $11 \mathrm{gemein-}$ ve rbindlich zu e rklären. Seine Befugnis ist an bestimmte, sachliche Voraussetzungen geknüpft ( $\$ 5$ Abs. 1 TVG). Zur

1) Dabei wird man unterscheiden können zwischen

(1) der Einwirkung auf die ordentliche legislative Tätigkeit von Bundestag und Bundesrat durch Initiative (Art. 76 Abs. 1 GG) und Konsultation (Art. 43 Abs.2, 53 G(i),

(2) der abgeleiteten, quasilegislatorischen Tätigkeit der Bundesregierung (die dabei vielfach an die Mitwirkung des Bundesrates gebunden ist) durch Rechtsetzung im Verordnungswege auf Grund gesetzlicher Ermächtigungen (Art.80 GG), (3) der außerordentlichen Legislativkompetenz der Bundes regierung (unter Mitwirkung des Bundesrates aber auch des Bundespräsidenten) im Falle des Gesetzgebungsnotstandes (Art.81 GG) und

(4) der Zuständigkeit zum Erlaß gesetzesgleicher Verordnungen nach Art. 119 GG.

2) Eine unmittelbare Einwirkung der Bundesregierung auf die Landesgesetzgebung (z. B. ein Einspruchsrecht gegen Landesgesetze nach dem Vorbild des Art.98 Abs. 2 des österreichischen Bundes-Verfassungsgesetzes oder nach dem - allerdings nur bedingt verwertbaren - Vorbild des Art. 12 Abs. 2 
Allgemeinverbịndlichkeitserklärung bedarf der Minister der Zustimmung eines aus je drei Vertretern der Spitzenverbände der Arbeitnehmer und der Arbeitgeber bestehenden Ausschusses (ebd.). Widerspricht die Oberste Arbeitsbehörde eines Landes der in Aussicht genommenen Erklärung, so bedarf der Bundesarbeitsminister ferner der Zustimmung des Kabinetts ( $\mathbb{S}$ Abs. 3 TVG). Für Einzelfälle kann der Bundesminister das Recht auf die Oberste Arbeitsbehörde eines Landes übertragen ( $\$ 5$ Abs. 6 TVG). "Mit der Allgemeinverbindlicherklärung erfassen die Rechtsnormen des Tarifvertrags in seinem Geltungsbereich auch die bisher nicht tarifgebundenen Arbeitgeber und Arbeitnehmer" ( $\$ 5$ Abs. 4 TVG). ${ }^{3)}$

(2) Eine dieser Regelung sachlich eng verwandte Sonderregelung findet sich in dem Seemannsgesetz vom 26. Juli 1957 (RGB1. II S.713). Danach können Tarifverträge Ausnahmen von gewissen Bestimmungen des Gesetzes vorsehen ( $\$ \$ 104 \mathrm{Abs} .2,140 \mathrm{Abs} .1$ ). Derartige Ausnahmebestimmungen in Tarifverträgen bedürfen der Genehmigung ( $\$ \$ 104$ Abs.3 Satz 1, 140 Abs.2 Satz 1 a.a.O.). Diese Genehmigung erteilt, wenn der Tarifvertrag mehrere Länder berührt, der Bundesminister für Arbeit im Einvernehmen mit dem Bundesminister für Verkehr ( $\$ 104$ Abs. 3 Satz 2 a.a.O.) bzw. im Einvernehmen mit den Bundesministern für Verkehr und Ernährung, Landwirtschaft und Forsten $(\$ 140$ Abs.2 Satz 2 a.a.O.); wenn nur ein Land betroffen wird, erteilen sie die entsprechenden Landesminister (ebd.). Genehmigte Ausnahmebestimmungen von den in den $\$ \$ 104$ Abs. 2 und 140 Abs. $1 \mathrm{Nr} .2$ des Seemannsgesetzes genannten Vorschriften sind allgemeinverbind1ich ( $\$ \$ 104$ Abs.3 Satz 3, 140 Abs. 2 Satz 3 a.a.O.).

(3) Die Festsetzung von Mindestarbeit sbedingunge n ist durch das Gesetz über die Festsetzung von Mindestarbeitsbe-

RV 1919) kennt das (irundgesetz nicht.

3) Die aus dem Recht des Vereinigten Wirtschaftsgebietes übernommene Regelung bestimmt an sich die Zuständigkeit des Direktor's der Verwaltung für Arbeit bzw. des Verwaltungsrates des Vereinigten Wirtschaftsgebietes. Nach der Fassung der Vorschrift sowie der herrschenden Übung des Gesetzgebers (s.u.(2) bis(5)) und (ler Verwaltung kann kein Zweifel bestehen, daß der Bundesarbeitsminister bzw. die Bundes regierung "die nunmehr sachlich zuständige Stelle" i.S. des Art. 129 Abs. 1 GG ist. - S. hierzu (im Ergebnis übereinstimmend, wenngleich in der Begründung nicht einleuchtend) Bettermann, Die Allgemeinverbindlicherklärung eines Tarifvertrags:

Rechtsschutz, Rechtskontrolle und Rechtsnatur, Recht der Arbeit, 12.Jhg. (1959) S.245 ff (253) mit weiteren Nachweisen. 
dingungen vom 11. Januar 1952 (BGB1.I S. 17) dem Bundesminister für Arbeit im Zusammenwirken mit einem Hauptausschuß und Fachausschüssen übertragen. Der Hauptausschuß besteht aus je fünf, die Fachausschüsse bestehen aus je drei bis fünf Vertretern der Arbeitgeber- und der Arbeitnehmerseite, die vom Bundesarbeitsminister berufen werden ( $\$ \$ 1$ Abs.1-3, 4 Abs. 1,5 Abs. 1, 6 a.a.O.). Der Bundesarbeitsminister oder von ihm bestellte Beauftragte führen den Vorsitz in den Ausschüssen $(\$ \S 2$ Abs.2, 5 Abs. 1 a.a.O.). Für die Festsetzung der Mindestarbeitsbedingungen bestehen enge, sachliche Voraussetzungen ( $\ 1$ a.a.O.). Für welche Wirtschaftszweige oder Beschäftigungsarten Mindestarbeitsbedingungen festzusetzen sind, bestimmt der Bundesarbeitsminister im Einvernehmen mit dem Hauptausschuß ( $\$ 3$ a.a.O.). Über die Mindestarbeitsbedingungen beschließt sodann der zuständige Fachausschuß ( $\$ 4$ Abs. 2 a.a.O.), in dem dem Beauftragten des Ministers der Stichentscheid zukommt ( $\$ 5$ Abs.2 a.a.O.). Sie bedürfen der Zustimmung des Bundesarbeitsministers ( $\$ 4$ Abs.3 Satz 1 a.a.O.), der sie - stimmt er zu als Rechtsverordnung erläßt und verkündet (Satz 2 und 3 ebd.). Die Befugnis, Fachausschüsse zu errichten und Mindestarbeitsbedingungen zu erlassen - nicht auch, die Errichtung eines Hauptausschusses und die Ausübung der im Einvernehmen mit dem Hauptausschuß auszuübenden Befugnisse! - kann der Bundesarbeitsminister auf die oberste Arbeitsbehörde eines Landes übertragen, wenn die Mindestarbeitsbedingungen nur dieses Land betreffen sollen ( $\$ 10$ a.a.O.).

(4) Eine sachlich nahestehende, wenngleich in den Zuständigkeitsbestimmungen stark abweichende Sonderregelung enthält $\S$ 92 a HGB für bestimmte Gruppen von $\mathrm{H}$ a ndels ve rtrete $\mathrm{rn}$, die im allgemeinen als sog. Einfirmenvertreter typisiert werden. Danach "kann der Bundesminister der Justiz (!) im Einvernehmen mit den Bundesministern für Wirtschaft und für Arbeit nach Anhörung von Verbänden der Handelsvertreter und der Unternehmer durch Rechtsverordnung, die nicht der Zustimmung des Bundes rates bedarf, die untere Grenze der vertraglichen Leistungen des Unternehmers festsetzen, um die notwendigen sozialen und wirtschaftlichen Bedürfnisse dieser Handelsvertreter oder einer bestimmten Gruppe von ihnen sicherzustellen. Die festgesetzten Leistungen können vertraglich nicht ausgeschlossen oder beschränkt werden" ( $\$ 92$ a Abs. 1 HGB). Für Versicherungsvertreter besteht diese Festsetzungsbefugnis in noch weiterem Umfang ( $\$ 92$ a Abs. 2 HGB).

(5) Eine eigenständige, mit der des Tarifvertragsgesetzes, noch mehr aber mit der des Gesetzes über die Festsetzung von Mindestarbeitsbedingungen verwandte Regelung ist die des 
H e i m a rbeits gesetzes. Nach diesem Gesetz bildet die zuständige Arbeitsbehörde Heimarbeitsausschüsse, die aus je drei Vertretern der Auftraggeber und der Beschäftigten und einem von der Arbeitsbehörde bestimmten Vorsitzenden bestehen, dem der Stichentscheid im Ausschuß zukommt ( $\$ 4)$. Der Ausschuß kann mit Zustimmung der Arbeitsbehörde gewisse Arbeitsbedingungen regeln ( $\$ 11$ a.a.O.) und Entgelte sowie sonstige Vertragsbedingungen mit bindender Wirkung für alle Beteiligten festsetzen ( $\$ \$$ 19-21 a.a.O.). Besondere Entgeltausschüsse können mit Zustimmung der Arbeitsbehörde ferner Mindestarbeitsbedingungen für fremde Hilfskräfte festsetzen ( $\$ 22$ a.a.O.). Die Aufgaben der Arbeitsbehörde im Sinne dieser Vorschriften stehen grundsätzlich den Obersten Arbeitsbehörden der Länder zu ( $\$ 3$ Abs. 1 a.a.O.). Dem Bundesarbeitsminister stehen sie dann zu, wenn eine Angelegenheit das gesamte Bundesgebiet betrifft, oder wenn sie jedenfalls das Gebiet mehrerer Länder betrifft, ohne daß diese sich auf eine einheitliche, zuständige Stelle einigen können (ebd.).

Wären diese umfassenden Zuständigkeiten der Bundes regierung und vor allem des Bundesministers für Arbeit Verwaltungszuständigkeiten 4) - genauer: Zuständigkeiten zum Erlaß von Verwaltungsakten -, so müßte es gerade für den sozialen Fragenkreis als höchst erstaunlich registriert werden, daß dem Bund in solchem Ausmaße ungeschriebene Verwaltungszuständigkeiten übertragen sind. Es handelt sich aber um keine Verwaltungssondern um Rechtsetzungszuständigkeiten. Das tritt im Gesetz selbst am klarsten hinsichtlich der Kompetenz zur Festsetzung der Mindestarbeitsbedingungen der Handelsvert reter hervor, 5) läßt sich aber auch für den Erlaß von Mindestarbeitsbedingungen 6$)$ und für die Festsetzung von Vertragsbedingungen und Ent-

4) Köttgen, Der Einfluß des Bundes auf die deutsche Verwaltung, S.76, führt die Festsetzung von Mindestarbeitsbedingungen und von Vertragsbedingungen für Heimarbeiter als Beispiele bundesministerieller Verwaltungskompetenz an. Köttgen hat sich mit dem Wesen dieser Befugnisse aber nicht auseinandergesetzt.

5) Daß es sich um eine Frmächtigung zum Erlaß von Rechtsverordnungen handelt, geht aus dem Gesetz ganz klar hervor ( $\$$ 92 a Abs. 1 Satz1, Abs. 2 Satz 2 HGB). Die festgesetzten Vertragsbedingungen haben normative Kraft ( $\$ 92$ a Abs. 1 Satz 2 HGB).

6) Die Mindestarbeitsbedingungen haben normativen Charakter ( $\$ 8$ des Gesetzes über die Festsetzung von Mindestarbeitsbedingungen i.V.m. $₫ \S 1$ Abs. 1,5 Abs. 4 TVG). Die Fest- 
gelten nach dem Heimarbeitergesetz 7) nicht bestreiten. Die Erklärung der Allgemeinverbindlichkeit von Tarifverträgen wird zwar verschieden beurteilt. ${ }^{8)}$ Überzeugen kann jedoch allein die normative Charakterisierung. ${ }^{9}$ ) Schließlich muß die Ausnahme-

setzung ist als Rechtsverordnung zu erlassen ( $\$ 4$ Abs. 3 Satz 2 a.a.O.). Diese ist vom Bundesminister für A rbeit zu verkünden (Satz 3 ebd.). - Wie hier Huber, Wirtschaftsverwaltungs recht, Bd. II S. $468 \mathrm{f}$.

7) Die Festsetzung von Entgelten und Bedingungen hat ebenfalls normativen Charakter ( $\$ 19$ Abs. 2 Satz 4 des Heimarbeitsgesetzes i.V.m. $\ 5$ Abs. 4 TVG). Sie ist "im Wortlaut" amtlich $\mathrm{zu}$ veröffentlichen (Satz 2 ebd.) und tritt grundsätzlich erst nach der Verkündung in Kraft (Satz 3 ebd.). S.a. $\$ 9$ des Heimarbeits gesetzes. - Wie hier: Huber, Wirtschaftsverwaltungsrecht, Bd. II S. 470; Hueck-Nipperdey, Lehrbuch des Arbeitsrechts, 6. Auf1. Bd. II 1957, S. 483 (Fußn. 39); Maus, Beteiligung von Ausschüssen an Verwaltung und Normsetzung im Arbeitsrecht, in "Sozialreform und Sozialrecht", Festschrift für Walter Bogs, 1959, S.169 ff (186); BVerwGE 6, 213.

8) Zum Streitstand s. die eingehenden Nachweise bei HueckNipperdey, Lehrbuch des Arbeitsrechts, Bd. II S.471 f (Fußn. 9). S.a. die nachstehend (Fußn.9) Zitierten und deren Nachweise.

9) (1) So zur Allgemeinverbindlicherklärung nach $₫ 5 T V G$ : Knolle, Arbeitsbedingungen der Frau und Grundrechte, Betriebsberater, 4.Jhg. (1949) S. $451 \mathrm{f}$ (451) - nur beiläufig -; Berger, Die Rechtsnatur der Allgemeinverbindlicherklärung, Betriebsberater, 11.Jhg. (1956) S. 533 ff; ders., Die Allgemeinverbindlicherklärung als Rechtsverordnung, DVB1. 71. Jhg. (1956) S. 858 ff; Hildegard Krüger, Die Rechtsnatur der Allgemeinverbindlicherklärung, RdA 10.Jhg. (1957) S. 46 ff; Lieb, Rechtsnatur und Mängel der Allgemeinverbindlicherklärung eines Tarifvertrages, RdA 10.Jhg. (1957) S. $260 \mathrm{ff}$; Bettermann, Die Allgemeinverbindlicherklärung eines Tarifvertrages, insbes. S. 253 ff; Bundesverwaltungsgericht BVerwGE 7, 82 .

(2) Aus dem älteren Schrifttum seien vor allem genannt:

(a) als Vertreter der sog. älteren Gesetzestheorie Jacobi, Grundlehren des Arbeitsrechts, 1927, S.99 ff; Kaskel, Arbeits recht, 3. Auf1. 1928, S. 45;

(b) als Vertreter der sog. beschränkten Gesetzestheorie Oertmann, Abänderung von für allgemein verbindlich erklärten Tarifverträgen, Gewerbe- und Kaufmannsgericht, 24. Jhg. 
genehmigung nach dem Seemannsgesetz ebenfalls als Rechtsetzungsakt qualifiziert werden, soweit - und nur soweit - die genehmigten Tarifbestimmungen durch sie allgemeinverbindlich werden. 10)

(1918/19) S.233 ff; Sinzheimer, Grundzüge des Arbeitsrechts, 1927, S. 272, und

(c) als Vertreter der sog. jüngeren Gesetzestheorie Molitor, Tarifvertragsordnung, 1930, $\$ 2$ TVO Anm.4, 5; Neumann, Tarifrecht, 1931, S. 117 f. - S.a. (ohne Stellungnahme zum Theorienstreit) Nawiasky, Rechtsfragen des wirtschaftlichen Neuaufbaues, 1935, S.76; ders., Die Allgemeinverbindlicherklärung des Gesamtarbeitsvertrages, Schweizer. Juristenzeitung, 37.Jhg. (1940/41) S.246 f; ders., Allgemeine Rechtslehre, S.81. Im Hinblick auf $₫ 5$ Abs. 5 Satz 3 TVG kann zwar heute die ältere Gesetzestheorie keinesfalls mehr aufrecht erhalten werden. Auch die beschränkte Gesetzestheorie ist heute unanwendbar. Damit hat der Gesetzgeber sich aber nicht etwa klar für die sog. Vertragstheorie, die den normativen Charakter der Allgemeinverbindlicherklärung leugnet, entschieden (wie z.B. Hueck-Nipperdey-Tophoven, Tarifvertragsgesetz, 3. Auf1. 1955, §5 Randnote 42, meinen). Wenn nach $₫ 5$ Abs. 5 Satz 3 TVG die Wirksamkeit der Allgemeinverbindlichkeit spätestens mit dem Ablauf des Tarifvertrages endigt, so ist das mit der jüngeren Gesetzestheorie nicht weniger vereinbar als mit der Vertragstheorie. Ein Argument gegen die Qualifikation der Allgemeinverbindlicherklärung als Rechtsetzungsakt ergibt sich daraus jedenfalls bestimmt nicht.

10) Der Genehmigung kommt an sich kein normativer Charakter $\mathrm{zu}$. Der genehmigte Tarifvertrag hat zwar - von seiner in den Fällen der $\$ \$ 104$ und 140 Abs. $1 \mathrm{Nr} .2$, Abs. 2 Satz 3 des Gesetzes hinzutretenden Allgemeinverbindlichkeit zunächst ganz abgesehen - als solcher normativen Charakter $(\$ \$ 1$ Abs. 1, 4 TVG). Die Genehmigung teilt ihn aber nicht. Auch der Genehmigung eines Rechtsetzungsaktes durch eine andere als die rechtsetzende Stelle (z.B. Genehmigung einer von der Regierung zu erlassenden Rechtsverordnung durch das Parlament, ein Haus oder einen Ausschuß des Parlaments) kommt nicht der Charakter eines Rechtsetzungsaktes zu (s.f.v.a.: BVerfGE 2, $237(255 \mathrm{f})$ mit eingehenden Nachweisen). Die Genehmigung ist Geltungsbedingung des Tarifvertrages, der ohne die Genehmigung nicht einmal die ihm als Tarifvertrag zukommende Geltungskraft ( $\$ \$ 3,4$ TVG) entfalten könnte. Sie ergeht gegenüber den sie nachsuchen- 
Die Befugnis des Bundesgesetzgebers, Rechtsetzungskompetenzen der Bundes regierung zu begründen, lejtet sich - wie schon grundsätziich bemerkt - nicht aus den Bestimmungen des Grundgesetzes über die Verwaltungszuständigkeiten sondern aus den Rechtsetzungskompetenzen des Bundesgesetzgebers selbst hier vor allem Art. $74 \mathrm{Nr} .12 \mathrm{GG}$ - ab. Er kann sie nach Maßgabe des Art.80 GG auf die Bundesregierung bzw. einzelne Bundesminister übertragen. Weder Art. $80 \mathrm{GG}$ noch ein anderer Verfassungssatz erlegt dem Bundesgesetzgeber aber eine Pflicht auf,

den Tarifpartnern. Anders aber steht es mit der ipso iure damit verbundenen Allgemeinverbindlichkeit. Diese Wirkung ist nicht die eigene Wirkung des Tarifvertrages, die durch die Genehmigung nur in Kraft gesetzt würde. Hier geht die Wirkung der Genehmigung über die dem Tarifvertrag eigene Wirkung nicht weniger hinaus als bei der Allgemeinverbindlicherklärung eines Tarifvertrages. Der hoheitliche Akt begründet die Verbindlichkeit des Tarifvertrages für diejenigen, die nicht tarifgebunden sind ( $\$ 3 \mathrm{TVG}$ ), von dem allgemeinverbindlichen Tarifvertrag aber erfaßt werden $(\$ 5$ Abs. 4 TVG, $\$ \$ 104$ Abs. 3 Satz 3, 140 Abs. 2 Satz 3 des Seemannsgesetzes). Die Allgemeinverbindlicherklärung ist auch hier gegenüber der nicht schon i.S. des $₫ 3$ TVG tarifgebundenen Rechtsetzung durch Rezeption des Tarifvertrages. Verdunkelt wird der Sachverhalt hier allerdings in besonderem Maße dadurch, daß der Gesetzgeber - in offensichtlicher Verkennung dieser Gegebenheiten - keine Veröffentlichungspflicht der Genehmigung vorgesehen hat (zur Notwendigkeit der Veröffentlichung s, allgemein Zöllner, Zur Publikation von Tarifvertrag und Betriebsvereinbarung, DVB1. 73.Jhg. (1958) $\mathrm{S} .124 \mathrm{ff})$. Doch ändert das weder die Rechtsnatur des Aktes noch die an seinen Erlaß zu stellenden verfassungs rechtlichen Anforderungen. (Für Charakterisierung der Genehmigung als Verwaltungsakt: Herschel, Allgemeinverbindlicherklärung von Tarifverträgen, in "Sozialreform und Sozialrecht", Festschrift für Walter Bogs, 1959, S. 125 ff (135)). Soweit allein die Genehmigung in Frage steht, ist die Kompetenz des Bundesministers (der Bundesministerien) nur verfassungsmäßig, soweit sie sich in den Grenzen hält, die dem Erlaß "überregionaler Verwaltungsakte" durch Bundesorgane außerhalb der im Grundgesetz ausdrücklich begründeten Verwaltungszuständigkeiten gesetzt sind (s.u. S. 102 ff). Das ist hinsichtlich der Regelung des Seemannsgesetzes $\mathrm{zu}$ bejahen. 
die Landes regierungen zu ermächtigen. Ob er das föderalistische Prinzip schont und länderfreundliche Regelungen wie in $₫ 3$ des Heimarbeitsgesetzes schafft, oder ob er der Bundesregierung den ganz entschiedenen Vorrang einräumt, wie in dem Gesetz über die Festsetzung von Mindestarbeitsbedingungen oder auch in $\$ 5$ TVG, oder ob er schließlich, wie in $₫ 92$ a HGB, die Landesregierungen völlig ausschließt, ist verfassungs rechtlich nicht vorweggenommen. 11)

Umgekehrt ist vielmehr nicht unproblematisch, wenn der Bundesgesetzgeber die Wahrnehmung dieser Rechtsetzungsaufgaben durch die Landesarbeitsminister usw. so definitiv anordnet, wie das in den einschlägigen Regelungen üblich ist. Art. 80 Abs. 1 Satz 1 GG erlaubt dem Bundesgesetzgeber nur, die Landesregierung zum Erlaß von Rechtsverordnungen zu ermächtigen, nicht auch unmittelbar einzelne Landesminister oder nachgeordnete Behörden. 12) Die Entscheidung darüber, welches Organ innerhalb des Landes zuständig sein soll, ist grundsätzlich der Disposition des Landes rechts bzw. der entsprechend e rmächtigten Landesregierung überlassen. 12) Dieser Grundsatz ist unzweifelhaft anzuwenden, wenn die fragliche Normsetzung in jeder Hinsicht einwandfrei dem allgemeinen Bild des Erlasses einer Rechtsverordnung entspricht, wie das hinsichtlich der Entgeltbestimmungen für Handelsvertreter ${ }^{13)}$ der Fall ist, wo sich der Gesetzgeber denn auch ganz an das Schema des Art. 80 GG gehalten hat. Aber gilt der Grundsatz des Art. 80 Abs. 1 Satz 1 GG auch dort unverändert, wo - wie bei der Allgemeinverbindlicherklärung sowie bei der Festsetzung der Mindest- und Heimarbeitsbedingungen - unter Beteiligung von Organen der "politischen Selbstverwaltung" Recht gesetzt wird, das gerade um seines Inhalts willen nicht (allein) den allgemeinen politischen Organen sondern spezifisch zusammengesetzten Sonderbehörden anvertraut wird? Schon daß die Rechtsetzungsgewalt eines Bundesministers an die Willensbildung eines solchen Ausschusses gekoppelt wird, stellt eine Ausnahme von Art. 80 Abs. 1 Satz 1 GG dar und weist so darauf hin, daß das Grundgesetz, wenn es nicht neben Art. 80 Abs. 1 Satz 1 GG kraft ungeschriebenen Rechts Platz für diese Erscheinung schafft, sie überhaupt unmöglich macht; denn ess ist prak-

11) Zu Unrecht vernachlässigt Bettermann (Die Allgemeinverbindlicherklärung eines Tarifvertrags, S.253) insoweit die Differenz zwischen Verwaltungs - und Rechtsprechungskompetenz.

12) BVerfGE 11, 77. - Weiteres und Nachweise s. bei Maunz in Maunz-Dürig, Art. 80 Randn. 8

13) S. oben S.95 zu Fußn. 5. 
tisch auch nicht denkbar, daß für den Landesbereich zwar derartige Ausschüsse vorgesehen werden, unmittelbar bundesgesetzlich aber nur unter Beteiligung der ganzen Landesregierung, während erst diese den zuständigen Landesminister an ihre Stelle rufen könnte. Der ganze Komplex drängt aus der exklusiven Aufzählung der Rechtsetzurgsadressaten in Art. 80 Abs. 1 Satz 1 GG heraus. Man wird - schon von der Tradition gerade dieser Nebenform der "sozialen Autonomie" 14) und somit vom vorrechtlichen Gesamtbild des Grundgesetzes her sowie um der Rücksichtnahme auf die verfassungsrechtlich gesicherte Position der beteiligten Träger der "sozialen Autonomie" willen - annehmen müssen, daß das Grundgesetz trotzdem Raum dafür gelassen hat. Später werden noch ähnliche Erscheinungen zu würdigen sein. So ist die (echte) Autonomie in Art.80 GG überhaupt nicht einbezogen. 15) Die nicht verbandlich-"demokratisch" strukturierte anstaltliche Rechtsetzung oder die Rechtsetzung durch die allein durch staatliche Einsetzung legitimierten Organe von Leitungs verbänden etwa kann dieses umfassende Privileg (insbes. die Befreiung von Art. 80 Abs. 1 Satz 2 GG) zwar nicht beanspruchen, ist aber gleichwohl nicht unzulässig, obwohl die Ermächtigungsinhaber nicht dem Adressatenkreis des Art. 80 Abs. 1 Satz 1 GG angehören. 16) Art. 80 Abs. 1 Satz 1 GG grenzt den Kreis möglicher Träger untergesetzlicher Rechtsetzungsbefugnisse also nicht erschöpfend ab. Wenn, wie im Falle der Allgemeinverbindlicherklärung und der Festsetzung von Mindest- und Heimarbeitsbedingungen, legitimerweise besondere Rechtsetzungsbehörden eingerichtet werden, so kann von Art. 80 Abs. 1 Satz 1 GG auch dadurch abgewichen werden, daß an dieser Rechtsetzung für den Landesbereich nicht "die Landes regierung" sondern ein durch die Art seiner sonstigen Geschäfte dazu besonders berufener Minister beteiligt wird. Doch wie dem im einzelnen immer auch sei: Jedenfalls folgen diese Erscheinungen ihrem Wesen gemäß den Grundsätzen über die Rechtsetzung, der Bundeskompetenzen hierzu und den Möglichkeiten und Grenzen des Bundesgesetzgebers, seine Gesetzgebungsmacht zu delegieren.

3. Die Leitung des Bundes rechtsvollzugs in den Ländern. Auszuscheiden sind auch die Zuständigkeiten der Bundes regierung im Rahmen der obersten Leitung und Beaufsichtigung der landeseigenen Ausführung von Bundesgesetzen (Art. 84 Abs.2-5 GG) und der Bundesauftragsverwaltung der Länder (Art.

14) S. unten Abschnitt 2 IV 2 (S. 287 ff).

15) S. unten Abschnitt 4 II 2 c (S.480 ff, insbes. S.487 ff).

16) S. unten Abschnitt 4 II 2 c, (S.480 ff, insbes. S. 489 ff). 
85 Abs.2-4 GG). Der Bund "verwaltet" dabei nicht selbst und unmittelbar. Er dirigiert und beaufsichtigt die Verwaltungstätigkeit der Länder und das von Verfassungs wegen unter erheblichen Beschränkungen. Es handelt sich in diesen Fällen exekutiver Bundeszuständigkeit um einen Appendix zu den Instituten der landeseigenen und der Bundesauftragsverwaltung.

4. Die Leitung der Bundeseigenverwaltung. Als eine besondere Art bundeseigener Verwaltung scheiden endlich auch die Kompetenzen aus, die der Bundesregierung als der Spitze der Bundesexekutive zustehen: also die Tätigkeit als oberste Bundesbehörde im Verhältnis zu den Unter-, Mittel- und Oberbehörden des Bundes und als aufsichts- und weisungsberechtigte Instanz gegenüber den Trägern mittelbarer Bundesverwaltung. 17) Hier ist die Kompetenz der Bundesregierung zwar Verwaltungskompetenz, jedoch nur Ausfluß des Rechts des Bundes, jeweils durch eigene Unter-, Mittel- oder Oberbehörden oder durch Körperschaften und Anstalten zu verwalten.

\section{bbb) Der Bereich der Bundesministerialverwaltung}

1. A 11 gemeines. Was hier in Frage steht, das sind vielmehr die Verwaltungskompetenzen, die dem Bunde gerade in der Weise zugeteilt sind, daß sie durch die Bundesregierung (als Kollegium oder durch die Bundesministerien) selbst und allein, ohne die $\mathrm{Zu}$ hilfenahme ausführender, unterstellter Bundesbehörden, bundesunmittelbarer rechtsfähiger Verwaltungsträger oder der Länder wahrgenommen werden dürfen oder müssen. Es handelt sich um Fälle zentraler, bundeseigener Verwaltung, die nicht von Bundeszentralstellen 1) oder - was der Ministerialverwaltung noch viel näher steht - von Bundesoberbehörden 2) sondern von Bundes-

17) S. hierzu auch BSGE 1, 17 (25 ff).

1) Vgl. Art. 87 Abs. 1 Satz 2 GG. Die grundgesetzlich zugelassenen Zentralstellen spielen im Zusammenhang der sozialen Intervention keine Rolle.

2) Mit der Verwaltung durch Bundesoberbehörden steht die Bundesministerialverwaltung in scharfer Konkurrenz. Eine Subsidiarität der Bundesministerialverwaltung im Verhältnis zur Verwaltung durch Bundesoberbehörden wird nicht anerkannt (vgl. Köttgen, Der Einfluß des Bundes auf die deutsche Verwaltung, S. 76). Vielmehr wird die Bundesministerialverwaltung als Mittel angesehen, die Errichtung zu vieler Bundesoberbehörden zu vermeiden (Füsslein, Der überregionale Verwaltungsakt, DVB1. 66. Jhg. (1951) S. 33 ff (36)). 
ministerien durchgeführt wird. Anders als die Verwaltung durch bundeseigene Behörden oder bundesunmittelbare Körperschaften und Anstalten ist diese Verwaltungsform im Grundgesetz nicht ausdrücklich zugelassen. ${ }^{3)}$ Nichtsdestoweniger hat sie sich in der Praxis einen Platz gesichert. 4) Das Schweigen des Grundgesetzes wird dahin gedeutet, daß der Verfassungsgeber, der Bundesregierung, Bundeskanzler und -minister als oberste Exekutivspitze vorsah, dieser Exekutivspitze ein gewisses Maß zentraler Verwaltungsaufgaben als selbstverständlich zurechnete. ${ }^{5)} \mathrm{Im}$ Prinzip kann eine ungeschriebene Ministerialverwaltungskompetenz des Bundes heute auch nicht mehr geleugnet werden. Fraglich ist - hier macht sich der Mangel positiver Fixierung durch das Grundgesetz entscheidend bemerkbar - jedoch der Bereich, in dem eine solche Ministerialverwaltung vorgesehen und aus geübt werden kann.

Unwesentlich ist dabei für den vorliegenden Zusammenhang die - unstreitig zulässige - eigene Sach- und Personalverwaltung der Bundesministerien. Es geht um die Verwaltungswirksamkeit nach außen.

2. Der überregionale Verwaltungsakt. Die klassische Kernsubstanz der Verwaltungstätigkeit der Bundesministerien bildet der überregionale Verwaltungsakt. ${ }^{6}$ ) Trotz weitgehender Zurückhaltung des Schrifttums 7) hat die Staatspraxis den

3) Das rechtfertigt es, diese Form der bundeseigenen Verwaltung erst hier zu erörtern. Systematisch richtiger erschiene es, sie als zweite Form der Bundeszentralverwaltung neben der durch Bundesoberbehörden gleich im Anschluß an diese zu erörtern. Jedoch war es angezeigt, zunächst die vom Grundgesetz selbst angebotenen Möglichkeiten aufzuzählen. Sie sind der ausdrückliche, positive Rahmen, in dem die ungeschriebene Zuständigkeit zur Bundesministerialverwaltung gesehen werden muß.

4) Vgl. Köttgen, Der Einfluß des Bundes auf die deutsche Verwaltung, S. $75 \mathrm{f}$.

5) Vg1. neben dem nachfolgend, insbes. zum überregionalen Verwaltungsakt noch zu nennenden Schrifttum die bei Eckert, Sozialversicherungsgesetze, in der Vorbem. vor Art. 83 GG (32.51) wiedergegebene Rechtsauffassung der Bundesregierung.

6) a.a.O. Köttgen, Der Einfluß des Bundes auf die deutsche Verwaltung, S. $75 \mathrm{f}$.

7) S. insbes. Wesse1, Die Verwaltung, DV 2.Jhg. (1949) S.327 ff (327 f); Kratzer, Die Ausführung von Bundesgesetzen als 
überregionalen Verwaltungsakt der Bundesministerien 8) zugelassen, wenn "ein bestimmter Sachverhalt wegen seiner überländermäßigen Bedeutung sinnvollerweise nur von obersten Bundesbehörden geregelt werden kann 9) oder wenn ein Anknüpfungspunkt im Inland überhaupt fehlt". 10) Auf der Grundlage dieses Prinzips

eigene Angelegenheit der Länder, Bayer. Staatsanzeiger, 5 . Jhg. (1950) Nr.13 S. 4 f (5); ders., Gemeinsamer Verwaltungsakt von Bund und Land, BayVB1. n. F. 4.Jhg. (1958) S. 74 ff (76); Hamann, Das Grundgesetz, Art. 83 Anm. C 2, Art. 87 Anm. A/B.

8) Der Begriff des überregionalen Verwaltungsaktes ist - wenngleich das nicht immer klar erkannt wird - überhaupt nur interessant in bezug auf die Verwaltungstätigkeit der Bundesministerien (obersten Bundesbehörden). Daß die Bundesoberbehörden oder Bundeszentralbehörden als grundgesetzlich legitimierte Verwaltungsbehörden echte gesetzesakzessorische Verwaltung betreiben und dabei auch Verwaltungsakte erlassen können, muß außer Zweifel gestellt werden; desgleichen, daß diese Akte regionale wie überregionale Bedeutung haben können. Nur für die Verwaltungstätigkeit der Bundesministerien bedarf es der "außergrundgesetzlichen" Legitimation aus dem Wesen des über regionalen Verwaltungsaktes. S. hierzu auch das oben S. 102 zu Fußn. 7 und unten zu Fußn. 10 zitierte Schriftum.

9) Vgl. BVerfGE 11,6 (17 f). Dieses Erfordernis ist sehr eng auszulegen; denn viele Verwaltungsakte haben Bedeutung über ein Land hinaus (z. B. Zulassung eines Kraftfahrzeuges), ohne daß dies die Übertragung der Zuständigkeit auf Bundesbehörden notwendig erscheinen ließe (vgl. Katzenstein, Rechtliche Erscheinungen der Machtverschiebung zwischen Bund und Ländern, S.602).

10) So der Rechtsausschuß des Bundesrates, Bundesrat Drucksache Nr.109/54; s.a. Katzenstein, a.a.O. S. 601 f; BVerfGE a.a.O.; ähnlich schon Füsslein, Der überregionale Verwaltungsakt insbes. S.35. Vg1. zusammenfassend ferner Weingart, Der überregionale Verwaltungsakt, Bayerische Verwaltungsblätter n. F. 6.Jhg. (1960) S.174 ff. - Eckert (Sozialversicherungsgesetze, Art.87 GG Anm.2 (32.55) gibt nach einer Niederschrift des Bundesjustizministeriums das Ergebnis einer "Besprechung der Bundes ressorts am 9.2.51" wieder. Danach

"wird als Voraussetzung für den Erlaß von Verwaltungsakten durch die Bundesministerien gem. Art. 87 Abs. 3 GG (sic! d. V.) verlangt : 
hat der überregionale Verwaltungsakt und damit die Verwaltungstätigkeit der Bundesministerien zwar im allgemeinen eine nicht unerhebliche Ausdehnung erfahren. 11) Gerade in der sozialen Verwaltung blieb der Kreis derartiger Kompetenzen jedoch klein. 12) Aber selbst bei größerer Ausnützung dieser ungeschriebenen Verwaltungskompetenz des Bundes ist auf diesem Wege - wenn nicht das oben angeführte Prinzip verlassen wird!kaum jemals ein wesentlicher Einbruch in die Verwaltungszustän-

1. Die Verwaltungsakte sind nur zulässig, wenn sie unerläßlich notwendig sind.

2. Sie sind nur zulässig, wenn sie über den Bereich eines Landes hinauswirken.

3. Gesetze, die den Erlaß solcher Verwaltungsakte vorsehen, bedürfen der Zustimmung des Bundesrates.

4. Art.72 GG muß entsprechende Anwendung finden. Im Einzelfalle ist stets zu prüfen, ob im Rahmen des Art. 72 GG ein Bedürfnis zur bundesgesetzlichen Regelung besteht. ..."

Hierin wird das Bemühen sichtbar, den Kreis der überregionalen Verwaltungsakte eng zu halten. Die zu 3 und 4 genannten Voraussetzungen sind allerdings nicht unbedenklich. Sie können aus der negativen Voraussetzung umschlagen zur positiven Legitimation. Als Antrieb zur Begründung zentraler Verwaltungszuständigkeiten würde Art.72 Abs.2 GG aber nicht weniger mißverstanden wie es unrichtig wäre, in der Zustimmung des Bundes rates zur Begründung überregionaler Verwaltungsakte - etwa über den Gedanken der Zustimmung der Länder und des volenti non fit iniuria - eine Rechtsgrundlage für die Begründung überregionaler Verwaltungsakte zu sehen (vg1. Kratzer, Gemeinsamer Verwaltungsakt von Bund und Land, insbes. S.76).

11) vg1. Katzenstein, Rechtliche Erscheinungsformen der Machtverschiebung zwischen Bund und Ländern, S. $601 \mathrm{f}$.

12) Zu nennen wäre z.B. die Ausnahmebewilligung durch den Bundesarbeitsminister nach $₫ 28$ a des Heimkehrergesetzes (eingefügt durch das Gesetz vom 17. August 1953, BGBl. I S.931); ferner die Erlaubnis von Preiskartellen in besonderen Fällen durch den Bundeswirtschaftsminister gem. $\$ \$ 8,44$ Abs. 1 $\mathrm{Nr} .2$ des Gesetzes gegen Wettbewerbsbeschränkungen. $\mathrm{Zu}$ nennen sind auch die schon erwähnten Genehmigungs zuständigkeiten nach $\$ \$ 104,140$ des Seemannsgesetzes, insofern sie nicht Normsetzung sind. - Ein, in der Allgemeinheit, mit der das Gesetz ihn vorsieht, offenbar unzulässiger Fall findet sich in $₫ 6$ Abs. 2 des Mitbestimmungsgesetzes. 
digkeit der Länder möglich. 13)

Das für den "überregionalen Verwaltungsakt" maßgebliche Kompetenzabgrenzungsprinzip gilt für die hoheitliche, ja für die dem materiellen Gesetz akzessorische Bundes(ministerial)verwaltung schlechthin. Der Gesetzgeber kann der Bundes regierung keinen Verwaltungsauftrag erteilen, der, iuxta constitutionis verbum Platz suchend, nicht durch die sachgesetzliche Unausweichlichkeit der Bundeskompetenz - somit also durch die Gründe, die auch den in der Verfassung nicht angesprochenen Fall des überregionalen Verwaltungsaktes legitimieren - gerechtfertigt ist.

13) Anhangsweise ist darauf hinzuweisen, daß eine Ausdehnung der Verwaltungskompetenzen der Bundesministerien auch nicht über eine dem überregionalen Verwaltungsakt eng verwandte Form möglich ist: über den gemeinsamen Verwa $1 \mathrm{tungsakt}$ von Bund und Land (vgl. Köttgen, Der Einwand der Mischverwaltung und das Grundgesetz, S. 488; Gerner, Die Frage der Mischverwaltung im Verhältnis zwischen Bund und Ländern, Bayerische Verwaltungsblätter n. F. 1.Jhg. (1955) S.193 ff (194). Füsslein, Mischverwaltung oder Mitverwaltung, DVB1. 71.Jhg. (1956) S. 1 ff (1);

Kratzer, Gemeinsamer Verwaltungsakt von Bund und Land). Füsslein (a.a.O. S.3) meint allerdings, es mache einen Unterschied, ob ein gemeinsamer Verwaltungsakt vorgesehen ist oder ob zugunsten des Bundes ein Vorbehalt der Zustimmung oder des Einvernehmens begründet wird. Jedoch ist es Formalismus, die Finmischung des Bundes in die Verwaltung der Länder auf diesem Umweg rechtfertigen zu wollen. Dagegen ist die Richtigkeit der Ansicht Köttgens (a.a.O. S.489), anstelle des Weisungsrechtes (Art.84 Abs. 5 GG) könnten auch Vorlagepflichten mit einem Einspruchsrecht (= Recht zur Weisung zu einem anderen Vorgehen) des Bundes begründet werden, nicht ganz von der Hand zu weisen (dagegen allerdings Füsslein, a.a.O.). Doch geht Köttgen (ebd.) zu weit, wenn er aus Art.84 Abs.5 GG auch die Möglichkeit ableiten will, Zustimmungsvorbehalte zugunsten des Bundes zu begründen. - Allgemein ist aber anerkannt, daß der Kontakt zwischen Bundes - und J andesverwaltung durch Anhörungsrechte (vielfach ausgedrückt als Pflicht, im Benehmen mit... zu handeln) hergestellt werden kann (vg1. Köttgen, a.a.O. S. 487; Gerner, a.a.O. S.195; Füsslein, a.a.O. S.1; Katzenstein, Rechtliche Erscheinungsformen der Machtverschiebung zwischen Bund und Ländern, S.602). Auf diesem Wege eröffnen sich gerade auch den Bundesministerien Wirkungsmöglichkeiten im exekutiven Bereich. 
3. Die nichtakzessorische Verwaltung. Grundsätzlich die gleichen Beschränkungen muß der Bund sich aber auch im Rahmen der nichtakzessorischen Verwaltung auferlegen.

"Nichtgesetzesakzessorische" Verwaltung darf weder als rechtsfreie noch schlechthin rechtsgrundlose Verwaltung gedacht werden. Sie ist vielmehr Verwaltung, die sich an einen allgemeinen, den Verwaltungsorganen erteilten verfassungsauftrag anlehnt, dessen exekutivische Wahrnehmung die Verfassung nicht durch einen Gesetzesvorbehalt mediatisiert hat. In diesen Grenzen ist gesetzesfreie Verwaltung auch unter der gegenwärtigen rechtsstaatlich-demokratisch-legalistischen Verfassungsordnung noch denkbar. 14) Obwohl die Verteilung der Verwaltungskompetenzen in den Art. $83 \mathrm{ff}, 108$ GG primär an der gesetzesakzessorischen Verwaltung orientiert ist, kann nicht angenommen werden, daß solchermaßen gesetzesfreie Verwaltung gem. Art.30 GG nur den Ländern möglich und dem Bund versagt ist. 15) Nur bedarf eine entsprechende Bundeskompetenz immer eines besonderen, die Vermutung des Art.30 GG überwindenden Nachweises. 16)

Hinsichtlich der bundeseigenen Vollverwaltung, die in der Verfassung immer für ganz bestimmte Sachgebiete begründet ist (Art. 87 ff, 108 GG), ist dieser Nachweis aus dem Sinn der Sachkompetenz zu führen.17) Die Bundesverwaltung durch Bundesoberbehörden und durch bundesunmittelbare Körperschaften und Anstalten ist zur Disposition des Gesetzgebers gestellt (Art.87 Abs. $3 \mathrm{GG}$ ) und somit immer eine gesetzesakzessorische - eine quasigesetzesfreie allenfalls, soweit das Gesetz sich auf eine allgemeine Zuständigkeitsbestimmung beschränkt oder gewisse Rand- und Komplementärfunktionen lediglich impliziert. ${ }^{17)}$ Spielraum und

14) S. u. Abschnitt 4 II 2 b, bb, aaa (S. 420 ff).

15) Vgl. Laforet, Verwaltung und Ausführung der Gesetze nach dem Bonner Grundgesetz, DÖV 2.Jhg. (1949) S.221 ff (221); Köttgen, Subventionen als Mittel der Verwaltung, DVBl. 68. Jhg. (1953) S. 485 ff (488 f); ders., Die Organisationsgewalt, VVDStRL. H. 16, 1958, S. 154 ff (170); Herrfahrdt, Bonner Kommentar, Art. 83 Anm. II 2; Schäfer, Die bundeseigene Verwaltung, S.242 f; Maunz, Deutsches Staatsrecht, S.200; s.ferner Koellreutter, Deutsches Staatsrecht, S.230; Köttgen, Der Einfluß des Bundes auf die Deutsche Verwaltung, S. 78 ff; Ipsen, Öffentliche Subventionierung Privater, 1956, S. 41 = DVB1. 71.Jhg. (1956) S. $461 \mathrm{ff}, 498 \mathrm{ff}, 602 \mathrm{ff}(500)$; Hamann, Das Grundgesetz, Art. 83 Anm. C 2; Denecke, Mutterschutz und Jugendschutz, S. 480 f.

16) S.d. oben zu Fußn. 15 Zitierten. 
Problem der nichtgesetzesakzessorischen Bundesverwaltung konzentrieren sich also im Bereich der Bundesministerialverwaltung. Die Bundesregierung ${ }^{18)}$ ist im Grundgesetz ohne fachlich umschriebenen Vollzugsauftrag institutionalisiert (Art.62 ff GG). Sie ist verfassungsunmittelbar; in ihrer Tätigkeit dem Gesetz zwar unterworfen (Art.20 Abs. 3 GG), jedoch um ihrer Leitungsfunktion willen nicht auf dessen Impulse verwiesen (Art.64, 65 GG u.a. Bestimmungen). Ihr Aufgabenkreis liegt zwar im Kern fest, ist in der Peripherie aber amorph und wird wesentlich iuxta legem gestaltet. Sie ist der geborene Träger der ungeschriebenen $\mathrm{Zu}$ ständigkeit des Bundes zu nicht-gesetzesakzessorischer Verwaltung, soweit jeweils ein notwendiger Konnex zu einer anderen Bundesbehörde fehlt.

Die Legitimation, deren diese ungeschriebene Kompetenz der Bundes regierung (als Bundeskompetenz) im Hinblick auf Art.30 GG bedarf, kann nur aus denselben Sachnotwendigkeiten entnommen werden, die auch den "überregionalen Verwaltungsakt" rechtfertigen: Die Erfüllung einer unausweichlichen Staatsaufgabe, deren Wahrnehmung das Grundgesetz zwar nicht ausdrücklich geregelt, aber auch nicht negiert hat, muß davon abhängen, daß sie vom Bund wahrgenommen wird, und Art.30 GGi.V.m. den übrigen Kompetenzverteilungsnormen darf nicht dahin zu verstehen sein, daß der Nachteil, der mit der Negation der Bundeskompetenz einträte, von der Verfassung in Kauf genommen wurde. Die Grenzen der Bundeskompetenz werden dabei gerade im Bereich der gesetzesfreien Verwaltung locker gezogen werden können. Liegen doch in ihm zahlreiche Einwirkungsmöglichkeiten "leichter Hand" (Konsultationen, Remonstrationen, Empfehlungen u.a.m.), von denen nicht angenommen werden kann, daß die Verfassung sie unter Vernachlässigung der gesamtstaatlichen Interessen, denen sie zu dienen vermögen, inhibieren wollte, nur um den Zuständigkeitsbereich der Länder abzusichern.

Als Beispiele möglicher gesetzesfreier Bundes(ministerial)verwaltung seien aus dem unüber'schaubaren Feld möglicher Betätigungsformen und -mittel herausgegriffen: Aufklärungsaktio-

17) Köttgen (Der Einfluß des Bundes auf die deutsche Verwaltung, S. 78) spricht von den "einen ausdrücklich legitimierten Verwaltungsauftrag komplettierenden Hilfszuständigkeiten".

18) In diesem Zusammenhang ist unter Bundesregierung grundsätzlich zu verstehen: entweder das Kabinett oder der Bundeskanzler oder ein Bundesminister oder mehrere Bundesminister gemeinsam oder ein oder mehrere Bundesminister zusammen mit dem Bundeskanzler. 
nen, 19) Empfehlungen an die Bevölkerung, 20) Aufrufe, Preisgespräche, nichtförmliche Schlichtungsverhandlungen, die Förderung der Bildung und Tätigkeit von Vereinen, die sich über das ganze Bundesgebiet erstrecken, 21) und Subventionen, soweit sie nach Gegenstand und $Z$ weck den Landesrahmen sprengen. 22)

4. Die Fondsverwaltung. Der Beispielsfall der Subventionen führt den Gedankengang auf die Problematik der sog. Fondsverwaltung, die als ein Unterfall der "gesetzesfreien" Verwaltung betrachtet werden muß, soweit sie nicht auch ein materielles Gesetz vollzieht sondern nur das formelle Haushaltsgesetz. 23) Die Fondsverwaltung 24 ) bildet wie nichts sonst einen Kanal unkontrollierten Überfließens der Bundesverwaltung in den verfassungsmäßigen Exekutivraum der Länder. 25)

Aber auch für die Fondsverwaltung können - soweit sie als Bun-

19) Ein Beispiel ist die vom Bundesminister für Wohnungsbau herausgegebene - allerdings bedauerlich verunglückte "Wohnfibel" (Das neue Miet- und Wohnrecht in der Bundesrepublik Deutschland, 1960).

20) Ein interessanter Fall derartiger Tätigkeit ist die Aufstellung der Richtlinien des Bundesarbeitsministers für die Regelung der Arbeitsbedingungen (ohne Löhne) von Hausgehilfen im Bundesgebiet vom 22. Mai 1952 (BAB1. S. 289). "Die Richtlinien sollen in Ergänzung der gesetzlichen Vorschriften... und unter Berücksichtigung der seitherigen Entwicklung als Grundlage für eine angemessene, den Interessen beider Teile Rechnung tragende Ausgestaltung des Arbeitsverhältnisses der Hausgehilfen dienen... Es wird empfohlen, bei Einzelheiten auf diese Richtlinien bezug zu nehmen und etwaige abweichende Vereinbarungen zu einzelnen Punkten (schriftlich) besonders festzulegen..." (Einleitung der Richtlinien).

21) Vg1. Denecke, Mutterschutz und Jugendschutz, S. 480 f; Köttgen, Der Einfluß des Bundes auf die deutsche Verwaltung, S. 79 .

22) S. Köttgen und Ipsen a.o. (S.106 zu Fußn. 15) a.O.

23) S. hierzu nochmals unten Abschnitt 4, II 2 b, bb, aaa (S. 420 ff).

24) S. insbes. Köttgen, Der Einfluß des Bundes auf die deutsche Verwaltung, S. $78 \mathrm{ff}$ und S. 120 ff (passim); s.a. Ipsen, Öffentliche Subventionierung Privater, S.40 f (+ DVBl. 1956, S. 500).

25) Die speziell finanzpolitischen und finanzverfassungs rechtlichen Aspekte werden unten (II) (S.175 ff) noch zu erörtern sein. 
desverwaltung iuxta verbum constitutionis gerechtfertigt werden muß26) - keine besonderen Regeln gelten. Der Umstand allein, daß er Geld hat, legitimiert den Bund nicht, es für jeden denkbaren Zweck auszugeben und durch die Bedingungen und Auflagen, unter denen er es ausgibt, diese von ihm beliebig ausgewählten Zwecke nachhaltigst zu verfolgen. ${ }^{27)}$ Soweit die Fondsverwaltung außerhalb der dem Bund ausdrücklich zugewiesenen Verwaltungsaufgaben (Art. 87 Abs.1 GG u.a.) und außerhalb des grundgesetzmäßig gesetzlich begründeten Wirkungskreises der Bundesoberbehörden und bundesunmittelbaren Körperschaften und Anstalten (Art.87 Abs.3 GG) stattfindet, kann auch sie gegenüber Art.30 GG nur insoweit legitimiert werden, als sie sachgesetzlichen Notwendigkeiten entspricht, deren Anerkennung dem Grundgesetz unterstellt werden darf. Daß sich der Bund ein formell-materielles Gesetz "erspart" und bei der Hergabe der Mittel die hoheitlichen Formen verläßt, kann ihn nicht von den Kompetenzschranken befreien, die das Grundgesetz aufgerichtet hat. 28)

Fin zulässiger "überregionaler Subventionsakt" wird z. B. die Ausgabe von Mitteln an Verbände (Zentralverbände, Bundesverbände) sein, deren Einzugs - und Wirksamkeitsbereich sich über das ganze Bundesgebiet erstreckt.29) Das gleiche gilt von der finanziellen Förderung anderer Unternehmungen, deren Belegenheit und Tätigkeitsbereich allein den Bund als adäquaten, funktionsgerechten Partner erscheinen läßt. Aber auch der Belegenheit nach lokale Angelegenheiten können in die notwendige Bundeszuständig-

26) Zu erinnern ist daran, daß Bundesverwaltung durch Bundesoberbehörden und bundesunmittelbare Körperschaften und Anstalten durch Gesetz gerechtfertigt werden müßte (Art.87 Abs. 3 GG), also auch insoweit, als sie Fondsverwaltung wäre.

27) Köttgen, Der Einfluß des Bundes auf die deutsche Verwaltung, S.79: "Die Bedeutung dieser Bundeszuschüsse beruht nicht zuletzt auf den Aullagen, unter denen in der Regel solche Zuschüsse nur gegeben werden..."

28) Vg1. BVerfGE 12, 205 (246 ff). S. hierzu ferner Evers, Verfassungsrechtliche Bindungen fiskalischer Regierungs- und Verwaltungstätigkeit, NJW 13. Jhg. (1960) S.2073 ff u.s. eingeh. Nachw. - Auf das Problem der Verfolgung der Exekutive auf der. "Flucht ins Privatrecht" durch das Verfassungs recht s.ferner noch unten Abschnitt 4 S. 396 ff (passim), insbes. II $5(\mathrm{~S} .614 \mathrm{ff})$.

29) Vgl. die Beispiele bei Köttgen, Der Einfluß des Bundes auf die deutsche Verwaltung, S.79 f. S. dort aber auch die Bedenken, die mit Riücksicht auf die föderativen Belange dennoch angemeldet werden müssen. 
keit fallen. Im übrigen hat der Bund sich aber darauf zu beschränken, die Mittel bereitzustellen und - soweit er das finanzverfassungsrechtlich kann oder muß - den Ländern zuzuweisen, denen die Verteilung nach außen zu überlassen ist (Art.30 GG). Ob diese Grundsätze bei dem - allgemein, wie im besonderen sozial bedeutendsten "gesetzesfreien" Zweig der Fondsverwaltung, dem Vollzug des Bundesjugendplans, ${ }^{30)}$ durchwegs gewahrt sind, ist äußerst zweifelhaft, kann hier jedoch nicht im einzelnen untersucht werden.

5. Die Koordination. Will der Bund Mittel bereitstellen und an die Länder (über die Länder) verteilen oder sie gemeinsarn mit den Ländern einsetzen, so setzt das - wenn es sich nicht um einen gesetzlich fixierten Bedarf handelt und wenn der Bedarf nicht so weit gestreut ist, daß die Mittel nach generellen Personal- oder Sachquoten pauschaliert verteilt werden können - voraus, daß der Bedarf konkret ermittelt, mit den vorhandenen Mitteln verglichen und, soweit diese hinter dem Bedarf zurückbleiben, nach dessen Dringlichkeit und nach der zu erwartenden Produktivität des Mitteleinsatzes gewürdigt und befriedigt wird. Bund und Länder müssen hierbei zusammenwirken. Dem Bund aber kommt - als zentralem Leistungsträger - eine gewisse Letztentscheidung zu. Jedenfalls obliegt ihm die Koordination.

Diese Koordinationskompetenz ${ }^{31}$ ) ist keine spezifische Erscheinung der gesetzesfreien oder gesetzesabhängigen Verwaltung. Sie ist auch nicht ausschließlich der Fondsverwaltung zuzurechnen (obwohl sie in dieser ihren Schwerpunkt hat); denn sie kann auch im Rahmen anderer gemeinsamer Aktionen Anerkennung heischen.

30) (1) Zum Bundesjugendplan s. die Richtlinien für den Bundes jugendplan v. 16. Dezember 1958 (GMB1. 1959, S.33). Ein Seitenstück hierzu ist die Studienförderung im Rahmen des sog. Honnefer Modellplanes.

(2) Im übrigen sind die bundesministeriellen, nicht einer ausdrücklichen grundgesetzlichen Bundeskompetenz entsprechenden Fondsverwaltungen meist gesetzlich geregelt oder wenigstens grundgelegt (s. die nachfolgend zitierten Regelungen für die Wohnungsbaumittel). In diesem Zusammenhang wenigstens erwähnt werden muß aber noch der Grüne Plan. Er findet im Landwirtschaftsgesetz $z$ war einen gesetzlichen Ansatz und auch gewisse formale und materielle Direktiven (von freilich sehr fraglichem Wert). Aber das Landwirtschaftsgesetz regelt nicht den Vollzug.

31) S. hierzu auch Köttgen, Der Einfluß des Bundes auf die deutsche Verwaltung, S.88 f. 
Sie distanziert sich von dem "überregionalen Verwaltungsakt" dadurch, daß sie in das Bund-Länder-Verhältnis eingelagert ist, in das, selbst wenn eine Letztentscheidung des Bundes getroffen wird, der terminus "Verwaltungsakt" nicht passen will. Sie liegt im Gemengefeld der bisher umschriebenen Erscheinungen bundesministerieller Verwaltungszuständigkeit, allein wegen ihrer spezifischen Funktion daraus hervorgehoben.

In den (bundes-)ministeriellen Bereich fällt sie schon mangels anderer Heimstatt. Sie wird dorthin aber auch durch das Prinzip des Art.84, 85 GG verwiesen, wonach den Ländern im Rahmen der Ausführung von Bundesgesetzen nur die Bundesregierung bzw. die obersten Bundesbehörden als dirigierende und aufsichtsführende Instanz entgegentreten. ${ }^{32)}$

Die Koordinationskompetenz darf nicht nur um der Einheitlichkeit des Vollzugs willen in Anspruch genommen werden. Die Uneinheitlichkeit des Gesetzesvollzugs, die nach Ausnutzung aller in Art. 84 Abs. 2-5 bzw. 85 Abs. 2-4 GG gegenüber der Landesverwaltung gegebenen Mittel der bundesseitigen Einflußnahme noch möglich ist, ist vom Grundgesetz in Kauf genommen. Der Bund darf im Rahmen der gesetzesfreien Verwaltung diese Prinzipien nicht umgehen.

Am ausgeprägtesten tritt diese Koordinationsfunktion im Wohnu ng s ba u wesen hervor. Dort obliegt es zunächst den zuständigen obersten Landesbehörden, jährliche Wohnungsbauprogramme aufzustellen ( $\$ 13$ Satz 1 1.WoBauG; $₫ 29$ Abs. 1 Satz 12 . WoBauG). Diese Landesprogramme stimmen sie sodann "unter Leitung des Bundesministers für den Wohnungsbau" so ab, daß sich für das Gebiet der Bundesrepublik ein Gesamtplan ergibt ( $\$ 13$ Satz 2 1. WoBauG; $\$ 29$ Abs. 1 Satz 2 2. WoBauG). An diesem Gesamtprogramm beteiligt sich der Bund durch Bereitstel-

32) Parallele - mehr formal als sachlich verschiedene - Funktionen kommen.der Bundes regierung (den zuständigen Bundesministern) im Falle des Normativprogramms zu, soweit dieses nicht durch Gesetz sondern Rechtsverordnung festzustellen ist (Art.80 GG. Beispiele: Umsiedlungsplan nach $₫ \$ 31$ Abs.2, 32 Abs. 1 des Bundesvertriebenengesetzes; Rückführungsplan nach $₫ 7$ des Bundesevakuiertengesetzes). Da Art. 80 Abs. 1 GG dem Bundesgesetzgeber zwar demokratisch-parlamentarische und rechtsstaatliche Beschränkungen auferlegt, jedoch keine föderativen, liegt hier die Gefahr der Umgehung der beschränkteren Verwaltungskompetenzen des Bundes über eine schwer faßbare und qualifizierbare Art von Maßnahmeverordnung. 
lung von Mitteln ( $\$ 14$ 1. WoBauG; $₫ 18$ 2. WoBauG), die der Bundesminister für den Wohnungsbau bewirtschaftet ( $₫ 15$ 1. WoBauG; $\$ 22$ 2. WoBauG). Er verteilt sie auf die Länder. Dabei hat er zunächst einen Verteilungsvorschlag und sucht die Zustimmung der obersten Landesbehörden zu erlangen ( $\$ 16$ Abs. 1 Satz 2 und 3 1. WoBauG; $₫ 19$ Abs. 1 Satz 2 und 3 2. WoBauG). Erhält er sie nicht, versucht er es mit einem Vermittlungsvorschlag (Satz 4 ebd.). Stimmen ihm die zuständigen Landesbehörden nicht binnen angemessener Frist $z u$, so entscheidet der Bundesminister für den Wohnungsbau "nach pflichtmäßigem Ermessen über die Verteilung der Mittel" (Satz 5 ebd.). 33) Erwähnenswert ist, daß der Bundesminister für den Wohnungsbau die Verteilung der Mittel auch mit Auflagen verknüpfen kann ( $\$ 16$ Abs. 3 Satz 1 1. WoBauG; $\$ 19$ Abs.3 Satz 1 2. WoBauG). Ähnlich sind die Zuständigkeiten nach dem Gesetz zur Förderung des Bergarbeiterwohnungsbaues $(\$ \$ 11,12,21)$.

\section{b) Die Bundesauftragsverwaltung}

Die dem Bund den intensivsten Einfluß gewährende Form der Ausführung von Bundesgesetzen $d u r c h$ die Länder ist die Bundesauftragsverwaltung (Art.85 GG). ${ }^{1}$ ) Die Fälle, in denen sie Platz greift bzw. Platz greifen kann, sind im Grundgesetz erschöpfend aufgezählt.2) Hier interessieren nur die Finanzverwaltung, die Lastenausgleichsverwaltung, die Unterhaltssicherung und die Beschädigtenversorgung der Bundeswehr.

(1) Auf dem Gebiet der Finanzverwaltung ${ }^{3)}$ steht im Vordergrund die Auftragsverwaltung (des Bundesanteiles an) der Einkommen- und Körperschaftssteuer. ${ }^{4)}$ Sie ist, obwohl Art. 108 Abs. 2 GG das verschleiert, im Grundgesetz definitiv angelegt. Die Inanspruchnahme eines Teiles der Einkommen- und Körperschaftssteuer zugunsten des Bundes, die in Art. 106 Abs.3 der ursprünglichen Fassung des Grundgesetzes in die Macht des Bun-

33) Zur Auslegung und Anwendung dieser Vorschriften s. BVerfGE 1, 299.

1) Vg1. allgemein Schäfer, Die Bundesauftragsverwaltung, DÖV 13. Jhg. (1960) S.641 ff. Zum Rechtscharakter s. insbes. S. $645 \mathrm{f}$ und die dort. Nachw.

2) Art. 87 b Abs.2, 87 c, 87 d, 89 Abs. 2 Satz 2, 90 Abs.2, 108 Abs. 1 Satz 4, Abs.2, Abs. 4 Satz 1, 120 a Abs. 1 Satz 1 GG.

3) S. hierzu die Darstellung oben S. 82 ff.

4) Dazu müßte, wenn sie je eingeführt würde, die Ergänzungsabgabe zur Einkommen- und Körperschaftssteuer i.S. des Art. 106 Abs. $1 \mathrm{Nr} .7$ GG kommen (so wohl zumindest nach Art. 108 Abs. 3 Satz 1, Abs. 4 Satz 1 und Abs. 1 und 2 GG). 
desgesetzgebers gestellt wurde und daher von Art.108 Abs.2 GG lediglich als möglich vorausgesetzt wird, ist durch Art. 108 Abs. 3 und 4 des Grundgesetzes in der Fassung des Finanzverfassungsgesetzes vom 23. Dezember 1955 verfassungs rechtlich bindend angeordnet. Da es technisch ein Ding der Unmöglichkeit ist, den Bundesanteil an diesen Steuern gem. Art.108 Abs.2, 1. Halbsatz GG in bundeseigener Verwaltung, den Landesanteil gem. Abs. 3 das. in landeseigener Verwaltung einzubringen, 5 ) bleibt nach den gegenwärtigen finanzverfassungs rechtlichen Bedingungen nur die Übergabe des Bundesanteils in die Auftragsverwaltung der Länder gem. Art. 108 Abs.2, 2. Halbsatz GG ( $\$ 34 \mathrm{Nr} .4$ FVG), so daß er von diesen zusammen mit dem Landesanteil verwaltet wird. (Das sachliche Übergreifen der intensiveren Bundesingerenz von der Auftragsverwaltung des Bundesanteils auf die landeseigene Verwaltung des Landesanteils ist, da die Anteile bei der Aufbringung noch nicht geschieden werden können, die notwendige weitere Folge.) Von nicht geringerer sozialer Relevanz als die Auftragsverwaltung der Einkommen- und Körperschaftsteuer ist die Auftragsverwaltung der Lastenausgleichsabgaben ( $\$ 204$ LAG i.V.m. Art. 108 Abs. 3 Satz 1, Abs. 4 Satz 1 und Art. 106 Abs. 1 Nr. 5 GG).6) Demgegenüber tritt die Auftragsverwaltung der Abgabe Notopfer Berlin ( $\$ 34 \mathrm{Nr} .3$ FVG i.V.m. Art. 108 Abs. 3 Satz 1, Abs. 4 Satz 1 und Art. 106 Abs. 1 Nr.6 GG) hier an Bedeutung zurück. 7)

5) Wacke, Das Finanzwesen der Bundesrepublik, 1950, S.49; Höpker-Aschoff, Das Finanz- und Steuersystem des Bonner Grundgesetzes, S.329; Hettlage, Die Neuordnung der deutschen Finanzverfassung, S. $425 \mathrm{f}$.

6) (1) Zunächst wäre wohl daran zu denken, die Lastenausgleichsabgaben als "einmalige Vermögensabgabe" i.S. des Art. 108 Abs. 1 Satz 1 und 4 GG anzusehen (so Hamann, Grundgesetz Art.108 Anm. C 6; Schäfer, Die Bundesauftragsverwaltung, S.644). Aber richtiger dürfte es sein, sie nicht als einmalige Vermögensabgabe sondern als eine Steuer vom Vermögen oder - im Sinne der Finanzverfassung des Grundgesetzes - als eine Steuer eigener Art anzusehen. Für die letztere Charakterisierung spricht eindeutig Art. 106 Abs. 1 und 2 GG, insbes. die Nr.5 des Abs.1. Danach sind die Lastenausgleichsabgaben keine "einmalige Vermögensabgabe". Sie rechnen somit zu den "übrigen Steuern" i.S. des Art. 108 Abs. 3 Satz 1 GG.

(2) $\$ 34 \mathrm{Nr} .1$ FVG hatte den Ländern die Soforthilfeabgabe in Auftragsverwaltung zugewiesen (wohl nach Art.108 Abs. 1 Satz 4 GG). Da das Soforthilfegesetz durch $₫ 373$ Nr. 1 LAG aufgehoben wurde, handelt es sich heute dabei nur mehr um 
Die umfassenden Ingerenzrechte des Bundes, die das Institut der Auftragsverwaltung an sich einschließt (Art. $85 \mathrm{GG}$ ), sind für die Finanzverwaltung - wie fast für jeden Verwaltungszweig, in dem es zur Anwendung kommt, - modifiziert. Insbes. kann der Bundesfinanzminister die Länder durch weisungsgebundene Bevollmächtigte überwachen lassen (Art. 108 Abs. 4 Satz 2, 2. Halbs. GG).

(2) Die Lastenausgleichsverwaltung (= Verwaltung der Ausgleichsleistungen), die durch den mit Gesetz vom 14. August 1958 (BGBl. I S. 445) eingefügten Art.120 a GG verfassungsrechtlich konzipiert ist, kombiniert das System der bundeseigenen Verwaltung (Bundesausgleichsamt als obere Bundesbehörde Bundesminister der Finanzen als aufsichtsführende Behörde; vg1. $\$ \$ 307,312$ L,AG) mit dem System der Bundesauftragsverwaltung (durch Ausgleichsämter und Landesausgleichsämter der Länder und der den Ländern inkorporierten Gemeinden und Gemeindeverbänden; vg1. $\$ \$ 305,306,308,311 \mathrm{LAG}$ ) auf eine besondere Weise. ${ }^{8)}$ Das für die Bundesauftragsverwaltung kennzeichnende, sich auf Rechts- und $Z$ weckmäßigkeitsfragen erstrekkende Aufsichts- und Weisungs recht der Bundes regierung und der obersten Bundesbehörden gegenüber den Landesbehörden (Art. 85 Abs. 3 und 4 GG) steht hinsichtlich der Landesausgleichsbehörden dem Präsidenten des Bundesausgleichsamtes zu (Art.120 a Abs. 1 GG i.V.m. $\$ \$ 312$ Abs.2, 319 Abs. 2 LAG). In Unterordnung unter die von der Bundesregierung mit Zustimmung des Bundesrates zu erlassenden allgemeinen Verwaltungsrichtlinien (Art. 85 Abs. 2 Satz 1 GG; $₫ 318$ LAG) steht dem Präsidenten des Bundesausgleichsamtes ebenfalls das Recht zum Erlaß allgemeiner Verwaltungsrichtlinien zu (Art. 120 a Abs. 1 GG i.V.m. $\$ 319$ Abs.2

LAG). Er verwaltet außerdem den Ausgleichsfonds( $\$ 319$ Abs. 1 LAG).9) Unter gewissen Anpassungen gilt diese Regelung über

eine Verwaltung "in Abwicklung".

7) Nach $\$ 34$ Nr.4 FVG gehört auch die Reichsfluchtsteue $r$ zur Finanz-Auftragsverwaltung. Die Bestimmungen über diese für den sozialen Bereich ohnedies unter keinem Gesichtspunkt bedeutsame Steuer sind längst aufgehoben (Gesetz zur Aufhebung überholter steuerrechtlicher Vorschriften vom 23. Juli 1953, BGB1. I S.689).

8) Zur Einrichtung bundeseigener Mittel- und Unterbehörden nach Art. 120 a Abs.2, 87 Abs. 3 Satz 2 GG vg1. Schäfer, Die Bundesauftragsverwaltung, S. 644 Fußn.29.

9) Somit ist die Lastenausgleichsverwaltung zwischen Bund und Ländern aufgeteilt. Die Lastenausgleichsverwaltung ist aber keine (unzulässige) Mischverwaltung. Das wäre sie, wenn - 
den engeren Bereich des Lastenausgleichsrechts hinaus auch für die Härteregelung nach dem Vierten Teil des Allgemeinen Kriegsfolgengesetzes ( $\$ \$ 76$ ff das.). 10)

(3) Nach Art. $87 \mathrm{~b}$ Abs. 1 Satz 3 GG kann die Beschädigtenversorgung der Bundeswehr der (bundeseigenen) Bundeswehrverwaltung übertragen werden. Davon wurde bisher nur für die Dienstzeitversorgung Gebrauch gemacht ( $\$ 87$ des Soldatenversorgungsgesetzes). Im übrigen wurde die Beschädigtenversorgung auf der Grundlage des Art. 87 b Abs.2 GG, wonach Bundesgesetze, die der Verteidigung dienen, ihren Vollzug in Bundesauft ragsverwaltung vorsehen können, den Ländern in Bundesauftragsverwaltung übertragen ( $\$ 88$ des Soldatenversorgungsgesetzes). Ebenso ist den Ländern der Vollzug des Unterhaltssicherungsgesetzes aufgrund Art. 87 b Abs. 2 GG in Auftragsverwaltung überlassen. 11)

\section{c) Die landeseigene Verwaltung in Ausführung von Bundesge- setzen}

Soweit die Bundesgesetze weder durch bundeseigene Verwaltung noch durch Landesbehörden in Bundesauftragsverwaltung ausge-

wozu Art. 120 a GG keine spezielle Handhabe bietet - ein Instanzenzug von den Lastenausgleichsbehörden der Länder zum Bundesausgleichsamt hergestellt worden wäre (zum Verbot des Instanzenzuges von Landes- zu Bundesbehörden s. Kratzer, Die Bundesoberbehörde, S. 534; Köttgen, Der Einfluß des Bundes auf die deutsche Verwaltung, S. 74 f, 77; ders., Der Einwand der Mischverwaltung und das Grundgesetz, S.488, 491; Gerner, Zur Frage der Mischverwaltung im Verhältnis zwischen Bund und Ländern, S. 194; Füsslein, Mischverwaltung oder Mitverwaltung, S. 1; Hamann, Das Grundgesetz, Art. 83 Anm. C 3). Das ist nicht der Fall (s. z.B. $\$ 312$ Abs.2, 319 Abs.2, 336, 338, 345 Abs. 2 und 3 LAG). Es handelt sich um einen (zulässigen) Fall "vertikaler", sachlicher Aufgabenteilung (vgl. Kratzer, Die Bundesoberbehörde, S.534; Köttgen, Der Einfluß des Bundes auf die deutsche Verwaltung, S.77). Die Aufsichts - und Weisungsrechte des Bundesausgleichsamtes sind nicht die einer überan untergeordnete Instanzen sondern die Befugnisse des Bundes gegenüber den Ländern im Rahmen der Auftragsverwaltung (Art. 85 Abs. 2-4, 120 a GG).

10) Die $\$ \$ 68$ ff des Allgemeinen Kriegsfolgengesetzes als Lastenausgleichsrecht i.S. des Art. 120 a GG anzusehen, dürfte nicht verfehlt sein (vgl. zum Begriff des Lastenausgleichs: Präambel und $\$ 1 \mathrm{LAG}$; s.a. die $\$ \$ 68$ Abs. 3 Satz 3, 71 Abs. 2, 73 Abs.2, 75 des Allgemeinen Kriegsfolgengesetzes). 
führt werden, führen die Länder sie als eigene Angelegenheit aus (Art.83 GG). Diese Verwaltungsform ist nach der Konzeption der Verfassung die Grundsatzform, in der Bundesgesetze ausgeführt werden sollen. Aber die Verfassung selbst hat diesen Grundsatz weitgehend ausgehöhlt. Die bisherige Untersuchung hat ergeben, daß die Verfassung selbst bereits zahlreiche Verwaltungsaufgaben und insbes. soziale Verwaltungsaufgaben dem Bunde unmittelbar oder über die Disposition des Bundesgesetzgebers zugeordnet hat. So sind die Länder - um noch einmal auf das Wichtigste hinzuweisen - aus sozialen Kernbereichen, wie die Arbeitsvermittlung und die Arbeitslosenversicherung sie darstellen, durch die bundesunmittelbare Anstaltsverwaltung eliminiert. Die staatlichen Verwaltungsaufgaben in bezug auf die Beaufsichtigung und Unterstützung der Sozialversicherungsträger sind ihnen in dem erheblichen Umfange aus der Hand genommen, in dem die Versicherungsträger bundesunmittelbar sind. Sie sind schließlich in der Lastenausgleichsverwaltung auf gewisse Aufgaben beschränkt und auch hier in Auftragsverwaltung des Bundes tätig. Trotzdem ist ihnen ein weites Feld sozialer Verwaltungsarbeit verblieben.

Der Versuch, die einschlägigen Verwaltungsaufgaben aufzuzählen, wäre mit unverhältnismäßigen Schwierigkeiten verbunden, wenn nicht gar zum Scheitern verurteilt. Die Landeszuständigkeit zum Vollzug von Bundes recht umfaßt als Grundsatz- und Komplementärkompetenz ein unüberschaubares Feld. Die einzelnen in Frage stehenden Gesetzeseinheiten werden zudem fast durchwegs nicht einheitlich vollzogen. Verwaltungsmäßiger Gesetzesvollzug ist vermengt mit primär gerichtlichem. Der Vollzug in landeseigener Verwaltung steht dicht neben dem Vollzug durch Bundesbehörden, Bundesanstalten und Bundeskörperschaften.

Im folgenden kann daher nur auf einige Gesetzeseinheiten hingewiesen werden, aus denen sich wesentliche, vor allem auch sozial bedeutsame Vollzugsaufgaben der landeseigenen Verwaltung ergeben. Selbst bei dieser schwerpunktartigen Aufzählung muß jede nähere Unterscheidung unterbleiben. Unter diesem Vorbehalt seien genannt:

(1) Aus dem Recht der F1ücht1inge und Vertriebenen das Bundesvertriebenengesetz, 1) das Flüchtlingsnotleistungsgesetz und (soweit hierher gehörig) das Heimkehrer- und Häftlingshilferecht; 1)

\section{1) S. hierzu auch Schäfer, Die Bundesauftragsverwaltung, S. $644 \mathrm{f}$.}

1) Für die mit dieser Fußnote gekennzeichneten Gesetze darf in besonderem Maße darauf hingewiesen werden, daß sie nur 
(2) aus dem Gebiet der öffentlichen Fürsorge das allgemeine Fürsorgerecht (Reichsverordnung über die Fürsorgepflicht), das Körperbeschädigtengesetz, 1) das Gesetz über die Tuberkulosehil$\mathrm{fe}^{1)}$ und das Jugendwohlfahrtsgesetz;

(3) aus dem K rieg s c häde n recht das Bundesevakuiertengesetz und (soweit hierher gehörig) das Heimkehrergesetz; 1 )

(4) aus dem Wiedergutmachungs recht das Bundesentschädigungsgesetz;

(5) aus dem Sachbereich der Sorge für die Kriegsbeschädigt e $n$ und - hinte rbliebenen das Bundesversorgungsgesetz und das Schwerbeschädigtengesetz; 1) 2)

(6) in der Fürsorge für die ehemaligen $\mathrm{Kri}$ egs gefangenen das Kriegsgefangenenentschädigungsgesetz und das Heimkehrergeset $z{ }^{1)}$

(7) aus dem Gebiet des Wirtschafts rechts neben vielem anderen das Preisgesetz und die auf seiner Grundlage ergangenen Rechtsverordnungen;

(8) aus dem Gebiet des A rbeits rechts vor allem das Arbeitsschutzrecht, das Schlichtungsrecht, das Recht der Mindestarbeitsbedingungen und das Heimarbeitsrecht. ${ }^{3}$ )

(9) aus dem Gebiet des Sozialversicherungs rechts die Reichsversicherungsordnung und die anderen (bundes rechtlichen) Sozialversicherungsgesetze durch organisatorische Gestaltung, Beaufsichtigung und Unterstützung der landesunmittelbaren (im Gegensatz zu den bundesunmittelbaren) Sozialversicherungsträger; 4 )

(10) aus dem Gebiet der Verhütung des Mißbrauches wirtschaftlicher $\mathrm{Machtstellungen}$ das Gesetz gegen Wettbe-

teils durch die Landesverwaltung (einschließlich der landesinkorporierten Körperschaften und Anstalten, insbes. der landesinkorporierten Sozialversicherungsträger)vollzogen werden. Daneben steht - im einzelnen aufs verschiedenste angeordnet - der Vollzug durch Bundesbehörden sowie durch Bundeskörperschaften und - anstalten, insbes. durch die Bundesanstalt für Arbeitsvermittlung und Arbeitslosenversicherung und die sonstigen bundesunmittelbaren Sozialversicherungsträger (Art. 87 Abs. 2 GG).

2) Um Mißverständnissen vorzubeugen, darf noch einmal daran erinnert werden, daß das Schwerbeschädigtengesetz auch dem Wiedergutmachungsrecht, dem Sozialversicherungsrecht und vor allem dem Arbeitsrecht zugehört.

3) S. hierzu insbes. $\mathbb{\$} 12$ ff des Gesetzes über die Festsetzung von Mindestarbeitsbedingungen und $\$ ₫ 23$ ff des Heimarbeitsgesetzes.

4) Zur Kompetenzabgrenzung s. nochmals oben S. 86 zu Fußn. 3. 
werbsbeschränkungen, soweit dessen Vollzug nicht dem Bundeskartellamt oder dem Bundeswirtschaftsminister obliegt ( $\$ 44$ Abs. 1 das.);

(11) aus dem Bereich des landwirtschaftlichen Pachtwesens das Landpachtgeset $z ; 5)$

12) aus dem Wohnungswesen das Erste und Zweite Wohnungsbaugesetz, 6) das Bundesmietengesetz, 5) das Wohnraumbewirtschaftungsgesetz sowie das Gesetz über den Abbau der Wohnungszwangswirtschaft und über ein soziales Miet- und Wohnrecht mit seinen (weiteren) Untergesetzen; ${ }^{5)}$ aus dem Si edlungsund Heimstättenwesen das Reichssiedlungsgesetz, das Reichsheimstättengesetz, das Kapitel II des Vierten Teiles der Dritten Verordnung des Reichspräsidenten zur Sicherung von Wirtschaft und Finanzen und zur Bekämpfung politischer Ausschreitungen vom 6. Oktober 1931, die Kleingarten- und Kleinlandpachtordnung; aus den zuletzt genannten Rechtsgebieten und dem Grundstückverkehrs- und Bodenrecht ferner das Bundes b a u gesetz.

Die Ausführung der Bundesgesetze als eigene Angelegenheit durch die Länder ist diesen aber nur unter erheblichen Vorbehalten zugunsten des Bundes - des Bundesgesetzgebers und der Bundesregierung - überlassen. Die Länder unterstehen der Rechtsaufsicht des Bundes, die primär von der Bundesregierung gehandhabt wird (Art. 84 Abs. 3 und 4 GG). Die Verwaltung ist an die allgemeinen Verwaltungsvorschriften gebunden, die die Bundesregierung mit Zustimmung des Bundesrates erlassen kann (Art. 84 Abs.2 GG). Durch Bundesgesetz, das der Zustimmung des Bundesrates bedarf, kann die Einrichtung der Behörden und das Verwaltungsverfahren 7 ) geregelt und kann darüber hinaus die Bundesregierung zu Einzelweisungen an die Landesverwaltung ermächtigt werden (Art. 84 Abs. 1 und 5 GG). Die Landesverwaltung ist also dort, wo sie Bundesgesetze ausführt,auch dann einer intensiven Einflußnahme des Bundes ausgesetzt, wenn sie nicht im Bundesauftrag tätig wird.

(I) Wohl am nachhaltigsten ausgenutzt wurde die Befugnis der Bundesregierung, mit Zustimmung des Bundesrates allgemeine

5) In diesen Gesetzen begegnen sich insbes. verwaltungsmäßiger und gerichtlicher Vollzug.

6) Soweit nicht die Planerstellung und Mittelverteilung durch den Bundesminister für den Wohnungsbau in Frage steht! (s.oben S. 110 )

7) Einschließlich des Rechts der Verwaltungsgebühren, deren Gestaltung selbst wieder von sozialer Bedeutung ist. 
Verwaltungsvorschriften zu erlassen. ${ }^{8)}$ Hier im einzelnen darauf einzugehen, ist jedoch nicht möglich.9)

(II) In zahlreichen Fällen hat der Bund auch von seiner Befugnis Gebrauch gemacht, durch Bundesgesetz mit Zustimmung des Bundesrates die Einrichtung und das Verfahren der Behörden zu regeln.

(1) Auf dem Gebiete der Flücht1ingsverwaltung bestimmt das Bundesvertriebenengesetz allgemein, daß die Länder verpflichtet sind, "zentrale Dienststellen" zu seiner Durchführung zu unterhalten $(\$ 21)$. Bei ihnen sind Beiräte einzurichten, deren Zusammensetzung die Länder regeln ( $\$ \$ 22,25$ BVFG). Einzelvorschriften über Zuständigkeiten und Verfahrensfragen enthält vor allem der Zweite Teil des Dritten Abschnittes dieses Gesetzes, der die Eingliederung der Vertriebenen und Flüchtlinge in die Landwirtschaft betrifft ( $\$ \$ 35 \mathrm{ff}$ ). Das ebenfalls hier einschlägige Flüchtlingsnotleistungsgesetz überläßt die Bestimmung der Anforderungsbehörden und der zur Entschädigungsfestsetzung zuständigen Behörden den Ländern, die dabei im Benehmen mit dem Bundesminister für Vertriebene vorzugehen haben $(\$ \$ 3$ Abs. 1, 29). Über das Verfahren enthält es eingehende Vorschriften $(\$ \S 21 \mathrm{ff})$. Erwähnt sollen gleich an dieser Stelle auch die Organisations- und Verfahrensbestimmungen des Häftlingshilfegesetzes sein $(\$ \S 9$ a ff das.).

8) Vg1. Katzenstein, Rechtliche Erscheinungsformen der Machtverschiebung zwischen Bund und Ländern seit 1949, S. 602 .

9) Auf einen besonderen Fall sei dennoch hingewiesen: Der Vollzug des Bundesversorgungsgesetzes ist nicht nur durch das Gesetz über das Verwaltungsverfahren der Kriegsopferversorgung und das Gesetz über die Einrichtung der Verwaltungsbehörden der Kriegsopferversorgung sondern vor allem auch durch die Verwaltungsvorschriften zur Durchführung des Gesetzes über die Versorgung der Opfer des Krieges i.d. F. v. 9. August 1956 (Beilage z. BAnz Nr. 157 bzw. BAnz Nr. 169) und i.d.F. vom 25. Oktober 1957 (BAnz Nr. 208), die Allgemeinen Verwaltungsvorschriften zur Durchführung des Gesetzes über das Verwaltungsverfahren der Kriegsopferversorgung vom 8. Februar 1956 (BAnz Nr.33) und die Verwaltungsvorschriften zur Durchführung des Gesetzes über die Errichtung der Verwaltungsbehörden der Kriegsopferversorgung vom 10. August 1951 (BAnz Nr. 155) so eingehend geregelt, daß sich die Landesverwaltung praktisch in einer kaum günstigeren Lage als der einer Auftragsverwaltung befindet (vg1. Köttgen, Der Einfluß des Bundes auf die deutsche Verwaltung, S. 86, 88). 
(2) Im Fürsorgerecht sind Behörden und Verfahren im Abschnitt "A. Träger der Fürsorge" der Verordnung über die Fürsorgepflicht sehr zurückhaltend umschrieben. Nur die Institutionen der Fürsorgeverbände und Aufsichtsbehörden $(\mathbb{S} 2,3,4)$ und der Einspruchsausschüsse $(\$ 3 a)$ als solche sind festgelegt, so daß dem Landes recht noch Wesentliches zu regeln bleibt. Das Gesetz über die Tuberkulosehilfe knüpft an die Einrichtung der Landesfürsorgeverbände an und überträgt ihnen den Vollzug ( $(7)$. Im übrigen enthält das Gesetz nur einige Vorschriften über das Verfahren ( $\$ \$ 25 \mathrm{ff})$, zu denen eine sehr merkwürdige Vorschrift über "Arbeitsgemeinschaften" der "an der Bekämpfung der Tuberkulose beteiligten Stellen" kommt ( $\$ 26)$. Das Körperbeschädigtengesetz regelt nur beschränkt auch Fragen der Behördeneinrichtungen und des Verwaltungsverfahrens ( $\$ \$ 4 \mathrm{ff}$ das.). Eingehende Vorschriften über Behörden und Verfahren weist das Jugendwohlfahrtsgesetz auf.

(3) Im Wiedergutmachungs recht soll zwar nach $₫ 184$ Abs. 1 Satz 1 des Bundesentschädigungsgesetzes den Ländern die Einrichtung der Behörden und die Regelung des Verfahrens überlassen bleiben. Trotzdem enthält das Gesetz aber eingehende Vorschriften auch über das Verwaltungsverfahren ( $\$ \$ 175 \mathrm{ff}, 185$ ff). Darüber hinaus bestimmt $₫ 229$ des Bundesentschädigungsgesetzes sogar, daß diese Verfahrensvorschriften auch für "Ansprüche nach den Vorschriften der Länder über die Anerkennung und Betreuung der Verfolgten" maßgeblich sein sollen. 10) Das Gesetz zur Regelung der Wiedergutmachung für Angehörige des öffentlichen Dienstes enthält Verfahrensvorschriften, die auch gelten, soweit das Gesetz von den Ländern durchzuführen ist ( $\$ \$ 24 \mathrm{ff})$.

(4) Sehr eingehend sind Behördeneinrichtung und Verfahren für das Versorgungs recht geregelt durch das Gesetz über die Errichtung der Verwaltungsbehörden der Kriegsopferversorgung

10) Die Gültigkeit der Vorschrift ist, soweit sie nicht das Verfahren vor den Entschädigungs ge richten betrifft (Art. $74 \mathrm{Nr}$. $1 \mathrm{GG}), \mathrm{zu}$ verneinen. Die Kompetenz des Bundes zur Regelung des Verwaltungsverfahrens der Länder besteht, wie sich aus Art. 84 Abs. 1 GG klar ergibt, nur im Falle der Ausführung von Bundesrecht durch die Länder (s.a. Köttgen, Der Einfluß des Bundes auf die deutsche Verwaltung, S.91). Die Anwendung der landesrechtlichen Anerkennungs - und Betreuungsbestimmungen stellt aber nicht etwa eine mittelbare Anwendung von Bundesrecht, des Bundesentschädigungsgesetzes, dar; denn dessen Entschädigungstatbestände sind von den landesrechtlichen Anerkennungsbestimmungen vollkommen gelöst ( $\$ 178 \mathrm{BEG}$ ). 
vom 12. März 1951 (BGB1. I S. 169) und das - weitaus umfänglichere - Gesetz über das Verwaltungsverfahren der Kriegsopferversorgung vom 2. Mai 1955 (BGB1. I S.202). Hier bleibt für die Länder kaum mehr Raum zu eigener organisatorischer Entfaltung. 11) Das auch, wenn auch nicht ausschließlich, in den Bereich der Kriegsopferversorgung gehörende Schwe rbesch ädigtengesetz wird teils durch die Bundesanstalt für Arbeitsvermittlung und Arbeitslosenversicherung, teils aber durch die ursprünglichen Hauptfürsorgestellen der Länder, teils im Zusammenwirken dieser mit der Bundesanstalt vollzogen. 12) Es enthält Vorschriften über die Einrichtung der Beschwerdeausschüsse bei der Hauptfürsorgestelle und über das Verfahren $(\$ \subseteq 27,30)$.

(5) Auf dem Gebiete der Fürsorge für die ehemaligen Kriegs g e fangenen enthält sich das Heimkehrergesetz einer Regelung von Behörden und Verfahren. Dagegen bringt das Kriegsgefangenenentschädigungsgesetz ( $\$ \$ 10 \mathrm{ff}, 35 \mathrm{ff}$ ) eingehende Vorschriften über das Verfahren und über die bei den - landesrechtlich für zuständig erklärten - Behörden zu bildenden, in erheblichem Umfange entscheidenden Ausschüsse.

(6) Das auf dem Gebiet des Wirtschafts rechts in diesem Zusammenhang exemplarisch genannte, von den Landesbehörden (mit) zu vollziehende Preisgesetz regelt weder die Einrichtung der Behörden noch ihr Verfahren näher. Das Gesetz gegen W e t t be we rbsbeschränkungen überläßt dem Landesrecht die Bestimmung der zuständigen obersten Landesbehörde, regelt aber ihre Zuständigkeiten und Befugnisse sowie ihr Verfahren als Kartellbehörde eingehend ( $\$ \$ 4 \mathrm{ff}$ ).

(7) Im A r beit s recht ist die bundesgesetzliche Regelung hinsichtlich des Arbeitsschutzrechtes sehr zurückhaltend. 13) Weitgehende Vorschriften über das Schlichtungsverfahren und über die zur Mitwirkung im Schlichtungsverfahren berufenen Ausschüsse enthält das Kontrollratsgesetz Nr. 35 betreffend Ausgleichs - und Schiedsverfahren in Arbeitsstreitigkeiten. 14) Die

11) s.o. S. $119^{\prime}$ zu Fußn.9

12) Darin liegt jedoch kein unzulässiger Fall von Mischverwaltung; denn es wird kein einvernehmliches Handeln sondern nur wechselseitiges Benehmen erfordert (vg1. $\$ \$ 22,25$ SchwBeschG; Köttgen, Der Einwand der Mischverwaltung und das Grundgesetz, S. 487).

13) Die zahlreichen, in vielen Gesetzen verstreuten Bestimmungen, die sich im wesentlichen nur auf Zuständigkeiten beziehen - die Behörden also schon voraussetzen - und kein besonderes Verfahren regeln, hier anzuführen, würde zu weit gehen; vg1. die oben S. 62 angeführten Gesetze. 
nach $₫ \mathbb{S} 4,5$ des Heimarbeitsgesetzes zu errichtenden Heimarbeitsausschüsse haben neben der Teilnahme an der Rechtsetzung ( $\$ \$ 10,11,18$ 1it.b, 19 des Heimarbeitsgesetzes) auch Aufgaben im rein administrativen Bereich ( $\$ \Phi 9$ Abs. 2,18 1it. a und b des Heimarbeitsgesetzes), so daß die Vorschriften über ihre Einrichtung auch hierher zu zählen sind.

(8) Für den Vollzug des Sozialversicherung s rechts ist die Einrichtung der Unterbehörden (Versicherungsämter) zwingend vorgeschrieben und relativ eingehend geregelt ( $\$ \$ 36$ ff RVO). Die Existenz oberster Landesbehörden wird vorausgesetzt und in den sozialversicherungs rechtlichen Zuständigkeitsbestimmungen relevant (vor allem $\$ \$ 3,6$ des Bundesversicherungsamtsgesetzes, $\$ 110 \mathrm{RVO})$. Ihre Zuständigkeiten können zum Teil auf andere Behörden, insbes. Mittelbehörden übertragen werden (ebd.). Das Verfahren der Versicherungsbehörden ist in der Reichsversicherungsordnung und in den Sondergesetzen der Sozialversicherung teils eingehend, teils punktuell geregelt.

(9) Das L a ndpachtgesetz besagt über Verfahren und Behörden nur ein Minimum ( $\$ 17)$.

(10) Hinsichtlich des Wohnungswesens regeln weder die beiden Bundeswohnungsbaugesetze noch das Wohnraumbewirtschaftungsgesetz, das Bundesmietengesetz, das Gesetz über Miet-und Lastenbeihilfen und das Gesetz über Bindungen für öffentlich geförderte Wohnungen die Einrichtung der Behörden. Sie ist den Ländern überlassen. 15) Über das Verfahren bestimmen die genannten Gesetze sporadisch Einzelheiten. Im Siedlungs recht sind ebenfalls nur Einzelheiten über Behörden und Verfahren geregelt (am eingehendsten wohl noch in der Kleingarten- und Kleinlandpachtordnung). Reichlich Organisations- und Verfahrensbestimmungen enthält das $\mathrm{Bund}$ e s b a uesetz.

(III) Demgegenüber hat der Bundesgesetzgeber von der Möglichkeit, der Bundesregierung die Befugnis zu Einzel weisungen zu erteilen, bisher nur in verschwindendem Umfange Gebrauch gemacht. In dem hier interessierenden Felde der sozialen Intervention des Staates wurden Einzelweisungen der Bundesregierung durch $₫ 3$ Abs.2 des Flüchtlingsnotleistungsgesetzes vorgesehen.

14) Zur Charakterisierung dieser Tätigkeit als Ausführung eines Bundesgesetzes s.o. S. 69 zu Fußn. 25.

15) Zur Ergänzung des Ersten Bundesmietengesetzes s. das Gesetz zur Ausführung des Ersten Bundesmietengesetzes vom 16. Oktober 1956 (BayBS II S.13). 
(IV) Schließlich sind die der Bundes regierung im Rahmen der Rechts a u f icht zustehenden Befugnisse bisher nicht aktuell geworden. 16)

Einen besonderen Platz nimmt die landeseigene Finanzverwaltung ein. In bezug auf sie gibt das Grundgesetz dem Bund erheblich vermehrte Einmischungsrechte.

Fr kann nicht nur - ähnlich wie nach Art.84 Abs.2 GG - den Aufbau der Landesbehörden und ihr Verfahren regeln; ein Bundesgesetz mit Zustimmung des Bundesrates kann auch - ähnlich der Befugnis der Bundesregierung im Rahmen der Auftragsverwaltung (Art. 85 Abs.2 Satz 2 GG) - die einheitliche Ausbildung der Beamten regeln (Art.108 Abs. 3 Satz 2 GG). Wie bei der Auftragsverwaltung (Art. 85 Abs. 2 Satz 2 GG) sind die Leiter der Mittelbehörden im Einvernehmen mit der Bundes regierung zu bestellen (Art. 108 Abs. 3 Satz 3 GG). 17) Im übrigen sind die Ingerenzrechte dieselben wie in Art. 84 GG (s.a. Art. 108 Abs. 6 GG). Den Ländern ist allerdings die Befugnis garantiert, die Verwaltung der den Gemeinden (Gemeindebehörden) zufließenden Steuern diesen zu übertragen (Art. 108 Abs. 3 Satz 4 GG).

Sachlich erstreckt sich die landeseigene Verwaltung bundesrechtlich geordneter Steuern gemäß Art. 108 Abs. 3 i.V.m. Art. 108 Abs. 1, 2 und 4, Art. 106 Abs. 2 und 107 GG auf die Steuern vom Vermögen, von Erbschaften und Schenkungen, auf die Verkehrssteuern mit Ausnahme der Beförderungssteuer und auf die Realsteuern. An sich müßte hierher auch die Verwaltung der Landesanteile an der Einkommen- und Körperschaftsteuer gerechnet werden (Art.108 Abs.2 GG). Aber eine getrennte Verwaltung von Bundesanteil und Landesanteil ist bis zum Endstadium der Verwaltung, der Bereitstellung der Einnahmen für die weitere Verwaltung und ihre Verrechnung, undenkbar. Somit kommt dieser Unterscheidung hier keine Bedeutung zu.

Auf die Vollziehung sozial intervenierender Gesetze - mit anderen Worten: auf die soziale Verwaltung - ist dieses verfassungsrecht1iche Institut der Ausführung der Bundesgesetze durch

16) Dieses völlige Zurücktreten der Bundesaufsicht ist nicht nur die Frucht der - sicher vorhandenen - Loyalität der Bundesländer und der - wohl auch vorhandenen - föderalistischen Rücksichtnahme des Bundes. Es ist auch das Ergebnis der intensiven Rechtskontrolle der Verwaltung durch die Gerichte. Sie hat die Bundesaufsicht, soweit sie auf die Rechtsaufsicht beschränkt ist, einer eigenen Funktion fast beraubt.

17) S. hierzu $₫ 5$ FVG. 
die Länder als "eigene Angelegenheit" in keiner Hinsicht besonders eingerichtet. Kein Zweig der sozialen Verwaltung ist den Ländern im Grundgesetz ausdrücklich als "eigene Angelegenheit" zugewiesen. Keine der Eingriffsmöglichkeiten des Bundes ist von vorneherein nur auf alle oder gewisse soziale Verwaltungsaufgaben anwendbar oder auf sie nicht anwendbar. Trotzdem kann einer genaueren Betrachtung die besondere Problematik und Stellung der Ausführung von Bundesgesetzen sozialen Gehalts durch die Länder als "eigene Angelegenheit" nicht verborgen bleiben, insbes. die Eigenart des Raumes, den sie einnimmt. Landeseigene Ausführung von Bundesgesetzen setzt begriffiich das Vorhandensein von Bundesgesetzen voraus. Sie setzt begrifflich ferner Bundesgesetze voraus, die des Verwaltungsvollzuges fähig sind. Diese beiden Voraussetzungen umgrenzen den aufzusuchenden Raum im äußersten. Er wird eingeengt dadurch, daß verschiedentilich bundesnähere Verwaltungsformen (bundeseigene, Bundesauftragsverwaltung) Platz greifen, denen gegenüber die landeseigene Verwaltung subsidiär ist (Art. 83 GG). Das Volumen der landeseigenen Verwaltung ist eine Funktion des - des verwaltungsmäßigen Vollzuges fähigen - Bundesrechts einerseits und des Bereiches der bundeseigenen und der Bundesauftragsverwaltung andererseits. Nun hat sich schon oben gezeigt, daß die beiden Größen der Bundesgesetzgebung und der Bundesverwaltung (einschließlich der Bundesauftragsverwaltung) in einer spezifischen Beziehung zum Komplex der sozialen Intervention des Staates stehen. Das ergibt eine - wenngleich weniger scharf konturierte - Beziehung auch zwischen sozialer Intervention und landeseigenem Vollzug der Bundesgesetze. Grundlegend ist einerseits das extreme Übergewicht des Bundes auf dem Gebiete der sozialen Gesetzgebung, das in der Verfassung teils definitiv, teils potentiell angelegt ist. Die Grenzen, in denen Verwaltungsvollzug sozialen Bundesrechts überhaupt denkbar ist, sind von dieser Seite also sehr weit gezogen. Grundlegend ist andererseits der starke Zug zur. bundeseigenen und auch bundesauftragsweisen sozialen Verwaltung, der wiederum in der Verfassung, hier aber ganz überwiegend potentiell (durch die bundesgesetzliche Disposition über die bundesunmittelbare "Selbstverwaltung" und die Bundesoberbehörden) und nur ausnahmsweise definitiv (Art.87 Abs.2, 108 Abs.1, 2 und 4, 120 a (GG!) angelegt ist. Die Grenzen,in denen landeseigener Vollzug sozial tendenziöser Bundesgesetze grundsätzlich möglich wäre, sind also stark zugunsten der bundeseigenen und der Bundesauftragsverwaltung eingebuchtet. Ist aber der Anteil der landeseigenen Verwaltung am Vollzug sozial tendenziöser Bundesgesetze relativ geringer als der Anteil der landeseigenen Verwaltung am Vollzug der. Bundesgesetze im allgemeinen ist und nach der Konzeption des Grundgesetzes sein soll -, so ist die 
Masse der dem landeseigenen Vollzug verbleibenden Verwaltungsaufgaben dennoch sehr groß. Die bundesgesetzesakzessorische Verwaltung ist eben insgesamt so voluminös, daß auch ein relativ geringerer Anteil der landeseigenen Verwaltung daran sich - absolut gesehen - noch in recht erheblichen Größenordnungen bewegt.

d) Die bundes rechtliche Organisation der Landesverwaltung und gewisse organisatorische Besonderheiten der sozialen Verwaltung

aa) Das Problem

An dieser Stelle ist nun noch auf einen Fragenkreis einzugehen, der die Bundesauftragsverwaltung und die Ausfühmung der Bundesgesetze in landeseigener Verwaltung in gleicher - oder wenigstens ähnlicher - Weise betrifft: auf die Befugnisse des Bundes, auf der Grundlage der Art. 84 Abs. 1 und 85 Abs. 1 GG den Vollzug von Bundes recht durch innerhalb der Landesverwaltung zu bildende Ausschüsse ${ }^{1}$ ) oder durch landesinkorporierte ${ }^{2}$ ) rechtsfähige

1) Die bisher recht spärliche Literatur zum Ausschußwesen hat erst jüngst eine starke Belebung erfahren. Für das Aus schußwesen in Deutschland s. inbes. Haas, Ausschüsse in der Verwaltung, Verwaltungsarchiv Bd. 49 (1958) S. 14 ff; Groeben, Mitwirkung von Ausschüssen in der staatlichen Verwaltung, A) Der norddeutsche Raum, das. S.231 ff; Thierfelder, dasselbe, B) Der süddeutsche Raum, das. S. 249 ff; Maus, Beteiligung von Ausschüssen an Verwaltung und Normsetzung im Arbeitsrecht. - Zur Systematik des Ausschußwesens s. insbes. Haas, a.a.O.

2) Das Grundgesetz gebraucht in Art.130 Abs. 3 GG den Begriff der "landesunmittelbaren" Körperschaft und Anstalt. Damit kann nichts anderes gemeint sein, als daß die genannten Körperschaften der staatlichen Gesamtheit Land (Gliedstaat) und nicht der staatlichen Gesamtheit Bund (Zentralstaat) eingegliedert sein sollen. Der Begriff ist in unüberlegter, sprachlicher Anlehnung an den Begriff der bundesunmittelbaren Körperschaft und Anstalt des öffentlichen Rechts geprägt, der in Art. $73 \mathrm{Nr} .8,86,87$ Abs. 2 und Abs. 3 Satz 1 GG gebraucht ist. Dieser bezeichnet, indem er sich gegen die $Z$ wischenschaltung der Länder zwischen Bund und Körperschaft bzw. Anstalt wendet, die Körperschaften und Anstalten, die dem Staatswesen Bund eingegliedert sind. Der Gegensatz dazu ist die Eingliederung in das Land; denn das ist die entscheidende Alternative der Körperschaft oder Anstalt des öffentlichen 
Verwaltungseinheiten 3) anzuordnen. Dieser Ausschnitt aus der insgesamt sehr umstrittenen Exegese der Art. 84 Abs.1, 85 Abs. $\left.1 G^{4}\right)$ ist zwar in seiner Bedeutung nicht auf den sozialen Bereich beschränkt. Weder verfassungs rechtlich noch etwa aus sachlogischen Gründen ist die Verwaltung durch Kollegialorgane, insbes. Ausschüsse unter Laienbeteiligung (sog. politische Selbst. verwaltung), 5) oder rechtsfähige Verwaltungseinheiten, insbes. Selbstverwaltungskörper (sog. rechtliche Selbstverwaltung), 5) außerhalb des sozialen Bereichs unmöglich. 6) Sie hat aber im wirtschaftlichen, und hier wiederum im sozialen Bereich einen

Rechts im Bundesstaat, daß sie nur entweder dem Zentralstaat oder den Giiedstaaten eingefügt sein kann (vg1. Forsthoff, Die öffentliche Körperschaft im Bundesstaat, 1931, S. 42 und passim). Der Begriff der landesunmittelbaren Körperschaft oder Anstalt ist - daran 1äßt die Durchsicht des Grundgesetzes unter diesem Gesichtspunkt keinen Zweifel - der 1ogisch notwendige Gegensatzbegriff zu dem der bundesunmittelbaren Körperschaft. Das Wort "landesunmittelbar" drückt das aber kaum aus. Es wird daher im Text weitgehend vermieden.

3) Zu diesem Begriff und den darunter zu verstehenden körperschaftlichen und anstaltlichen Einrichtungen s. insbes. Köttgen, Die rechtsfähige Verwaltungseinheit, 1939.

4) Vg1. hierzu allgemein: Rohwer-Kahlmann, Verfassungsrechtliche Schranken der Zustimmungsgesetze, AöR Bd. 79 (1953/ 54) S. 208 ff; Köttgen, Der Einfluß des Bundes auf die deutsche Verwaltung, S. 86 ff; Haas, Bundesgesetze über Organisation und Verfahren der Landesbehörden, AöR Bd. 80 (1955/56) S. $81 \mathrm{ff}$.

5) Zu dieser umstrittenen Terminologie s. z.B. Forsthoff, Lehr buch des Verwaltungsrechts, S.415 f mit eingeh. Nachweisen.

6) Die sog. politische Selbstverwaltung oder sonstige Kollegialverwaltung ist im Grundgesetz überhaupt nicht erwähnt (vgl. Baring, Die politische Selbstverwaltung und die Verwaltungsgerichtsbarkeit, DVB1. 70.Jhg. (1955) S.685ff, $721 \mathrm{ff}$ (689)). Die Verwaltung durch rechtsfähige Verwaltungseinheiten ist im Grundgesetz zwar erwähnt (außer Art.28 für die Gemeinden und Gemeindeverbände s. Art. 87 Abs. 2 und Abs. 3 Satz 1, Art. $73 \mathrm{Nr} .8,75 \mathrm{Nr} .1,130$ Abs. $3 \mathrm{GG}$ ), aber, wenngleich Art. 87 Abs. 2 GG mit der empirisch gegebenen Konzentration dieser Verwaltungsform auf dem sozialen Bereich korrespondiert, in keiner Weise auf den sozialen Bereich beschränkt (s. z. B. Köttgen, Art. "Selbstverwaltung" im Handwörterbuch der Sozialwissenschaften). 
Schwerpunkt gefunden. ${ }^{7)}$

Die Bestimmungsgründe dieser Erscheinung sind vielfältig und komplex und können hier im einzelnen nicht erörtert werden. 8) $\mathrm{Zu}$ den allgemeinsten Determinanten dürte das existentielle Interesse der Betroffenen an der "Richtigkeit" der zu treffenden Entscheidungen zu zählen sein. Dieses Interesse drängt nach Sicherungen gegen eine "weltfremde" und "knöcherne" Bürokratie, gegen einen von Parlament und Regierung möglicherweise "parteipolitisch" einseitig gesteuerten Verwaltungsapparat, gegen das die individuelle Verantwortlichkeit paralysierende Zurücktreten des Entscheidenden im anonymen Regiment der Funktionäre und gegen die Gefahr der Willkür des - nicht der Infrakontrolle kollegialer Organstrukturen unterworfenen - bürokratischen Entscheidungsträgers. Es postuliert daher die Entscheidung oder doch wenigstens Mitentscheidung durch Sachkundige, durch Träger gleichgerichteter Interessen, durch Mandatare der Interessengruppe oder wenigstens durch "unverbildete" Repräsentanten des sog. "gesunden Menschenverstandes", durch partei- und politikfremde Vertreter einer gedachten "Objektivität" und schließlich durch das Kollegium (das schon um der vorgenannten Postulate willen unentbehrlich erscheint). Eine andere, außerordentlich mächtige, mit der erstgenannten verflochtene Determinante entspringt der weitgehenden verbandlichen Organisation der sozialen Interessen. Die Interessenverbände, ihrer beschränkten Zielsetzung und Legitimation wegen von der unmittelbaren Teilnahme an der allgemeinpolitischen Entscheidung ausgeschlossen, sehen im Bereich der Verwaltung die von ihnen vertretenen Interessen in erheblichem Maße vor diesen spezifisch zugewandten, organisatorisch herausgelösten oder wenigstens herauslösbaren Entscheidungsträgern auf dem Spiel. Die Chance, unmittelbaren Einfluß hierauf zu gewinnen, wird ihnen mit Rücksicht auf das Bedürfnis, sich vor ihren Mandanten als Prokuratoren zu bewähren, zur

7) S. zum älteren Recht z.B. E.R. Huber, Rechtsformen der wirtschaftlichen Selbstverwaltung, Verwaltungsarchiv $\mathrm{Bd} .37$ (1932) S. $301 \mathrm{ff}$, insbes. S. $315 \mathrm{f}, 343 \mathrm{ff}$; zum gegenwärtigen Stand s. dens., Selbstverwaltung der Wirtschaft, 1958, S. $35 \mathrm{ff}, 62 \mathrm{f}$; s. ferner Scheuner, Wirtschaftliche und soziale Selbstverwaltung, DÖV 5.Jhg. (1952) S. 609 ff. Partsch, Verfassungsprinzipien und Verwaltungsinstitutionen, 1958, S.20; Forsthoff, a.a.O. S.416 ff; Maus, Beteiligung von Ausschüssen an Verwaltung und Normsetzung im Arbeitsrecht.

8) Einzelnes und Nachweise zum Folgenden s. insbes. unten Abschnitt 3 (vor allem Ziff. III) (S. $315 \mathrm{ff}$; insbes. S. 340 ff). 
Notwendigkeit. Die institutionelle Publizität ihrer Einflußnahme erlaubt ihnen zudem, das Wirken der (jeweils) konkurrierenden Verbände wenigstens teilweise zu kontrollieren (und - wenn die Umstände "günstig" sind - zurückzudrängen). Staatspolitisch entspricht dem die Erwartung, die Verbände, indem ihr Einfluß reguliert und publiziert wird, insoweit unter eine öffentliche Kontrolle zu bringen und in die Verantwortung für die zu fällenden Entscheidungen einzubeziehen. Gesteigerte Legitimität fördert diese Tendenzen in bezug auf die Arbeitgeberverbände und Gewerkschaften. Die Verfassung konzipiert sie als die - freiwillig gebildeten-eigenverantwortlichen Träger einer weitreichenden Mächtigkeit, die Wirtschafts- und Arbeitsbedingungen zu gestalten. 9) Es entspricht dieser Funktion, daß sie in die umliegenden Entscheidungsfelder eindringen, auch wenn diese an sich der staatlichen Gewalt vorbehalten bleiben. Als eine dritte wichtige Determinante sei noch das "genossenschaftliche" Prinzip genannt, das die deutsche Sozialpolitik vor allem in ihren sozialversicherungsrechtlichen Anfängen beherrscht hat, das aber auch später immer wieder verfolgt wurde und für gewisse Probleme (jedenfalls unter gewissen Voraussetzungen) auch heute noch den sachgesetzlich gebotenen Lösungsweg vorzeichnet. 10) Mit dem letztgenannten Element läuft vielfach die nicht selten zu beobachtende unausweichliche Notwendigkeit parallel, sozial zweckbestimmte Vermögensmassen gesondert zu sammeln und zu bewirtschaften. Vor allem die Entwicklung der Sozialversicherung bezeugt den Sachzwang, der auf die Organisation gewisser Zweige der sozialen Intervention von dem genossenschaftlichen Element und dem Element des $Z$ weckvermögens her ausgeht.

Diese Eigenart des sozialen Verwaltungssektors war schon einmal zu erwähnen, nämlich im Zusammenhang mit der Bundesverwaltung durch bundesunmittelbare Körperschaften und Anstalten. Dort hat sich gezeigt, daß das außerordentliche Ausmaß körperschaftlicher und anstaltlicher Sozialverwaltung im sozialen Sektor auch eine starke Ausdehnung dieser Art der Bundesverwaltung mit sich bringt. Dem ebenfalls großen Volumen der Verwaltung durch Ausschüsse u. ä. kann dagegen nach der Zuständigkeitsverteilung des Grundgesetzes eine derartige - in bezug auf die Verwaltungskompetenz der Länder - kompetenzabsorbierende Bedeutung nicht zukommen.

Unter dem Gesichtspunkt der Art. 84 Abs. 1, 85 Abs. 1 GG steht in bezug sowohl auf die Beteiligung von Ausschüssen wie von rechtsfähigen Verwaltungsträgern eine nachhaltige Ingerenz des

9) S. hierzu unten Abschnitt 2 IV 2 (S. 287 ff).

10) S. hierzu unten S. 755 . 
Bundes in die Verwaltungseinheit "Land" in Frage. Die Übertragung von Aufgaben an kollegiale Organe und an rechtsfähige Verwaltungseinheiten entfremdet die Erledigung dieser Verwaltungsaufgaben dem Willenszusammenhang, der durch die Hierarchie der staatlichen Verwaltung mit ihrer - von Grenzfällen abgesehen - unbeschränkten Weisungsgebundenheit und durch die parlamentarische Abhängigkeit ihrer ministeriellen Spitze gekennzeichnet ist. 11) Diese Entfremdung ist umso wirksamer je mehr in den Ausschüssen verwaltungsexterne Elemente maßgeblich mitwirken und die Exemtion der Ausschüsse sowie der rechtsfähigen Verwaltungseinheiten aus der Verwaltungshierarchie durch Reduktion der Aufsichts- und Weisungs rechte ausgebaut wird. Wenn und insoweit der Bund also imstande ist, derartige Sonderformen der Verwaltung zu dekretieren, kann er die Entscheidungseinheit "Land" in nicht unerheblichem Maße desintegrieren. 12)

Dabei steht heute nicht das Problem im Vordergrund, ob dem Bunde über die Körperschaften, Anstalten, Ausschüsse usw. ein stärkerer Einfluß auf die Verwaltungsarbeit eingeräumt werden kann, als er ihm nach Art.84 GG zukommt. (Im Rahmen des Art. 85 GG ist eine Intensivierung der Bundesingerenz ohnedies kaum denkbar.) Dolose oder aus Unklarheit geborene Praktiken, die auf diesem Umwege eine Vermehrung des Reichs- bzw. Bundeseinflusses auf die Landesverwaltung erstrebten, waren früher häufiger. 13) Das Problem der Mischverwaltung zeigt sich in diesem

11) S. z.B. Loening, Der ministerialf reie Raum in der Staatsverwaltung, DVB1. 6๕.Jhg. (1954) S.173 ff.

12) Vg1. Fursthoff, Die öffentliche Körperschaft im Bundesstaat, 1931 , S.28 ff.

13) (1) s. zur älteren Entwicklung: Forsthoff, a.a.O., insbes. S. $75 \mathrm{ff}, 82 \mathrm{ff}, 130 \mathrm{ff}$. - Die neuere Entwicklung, die auf detaillierterer Kompetenzaufteilung durch die Art. 83 ff GG basiert, geht grundsätzlich davon aus, daß öffentliche Körperschaften usw., deren Kompetenz sich auf ein Land beschränkt, in den Landesbereich fallen und zur Disposition der zuständigen Landesbehörden zu stellen sind, während Körperschaften usw., die über ein Land hinausreichen, der Bundesverwaltung zuzuordnen sind (s.a. Art. 87 Abs.2, Abs. 3 Satz 1 GG). Das Bundesversicherungsamtsgesetz hat das Sozialversicherungsrecht auf diesen Boden gestellt (s. insbes. $\$ \$ 1$ Abs. 1, 2, 3, $5,6,8 \mathrm{Nr} .1$ des Gesetzes). Auch in der übrigen ("außersozialen") Rechtsentwicklung unter dem Grundgesetz sind Verstöße gegen dieses Prinzip nicht zu beobachten. - Im überkommenen Recht finden sich noch einige Reichskompetenzen, die von der Verwaltungspraxis und vom Schrifttum als auf den 
engeren Sachzusammenhang derzeit im wesentlichen nur in Gestalt der öffentlich-rechtlichen Dachorganisationen, die über den landesinkorporierten Verbänden auf der sog. Bundesebene gebildet werden. Auf diesen Sonderfall wird zurückzukommen sein. 14) Grundsätzlich ist die Frage aber die, ob und inwieweit die Verwaltungsaufgaben den Ländern in Richtung auf ein Tertium, auf ein Niemandsland hin entzogen werden dürfen.

\section{bb) Die Ausschüsse}

Für das Ausschußwesen muß davon ausgegangen werden, daß die Frage der kollegialen Organisation von Behörden, einschließlich der Hereinnahme von Laien, eine Frage der Einrichtung der Behörden i.S. der Art. 84 Abs. 1, 85 Abs. 1 GG ist. 1) Dem stehen auch kaum Bedenken entgegen, soweit es sich um rein berat ende Ausschüsse handelt.

Bundesarbeitsminister übergegangen angesehen werden. Art. 129 Abs. 1 i.V.m. Art. 83 und 87 GG und i.V.m. dem Bundesversicherungsamtsgesetz ausgelegt, dürfte hier aber zu so wesentlichen Kor rekturen führen (s.hierzu auch BSGE 1, 17), daß auf eine Auseinandersetzung mit diesen altrechtlichen Kompetenzbeständen verzichtet werden kann.

(2) Der bundesstaat1iche Gedanke, um den es dabei geht, kommt trefflich in den Worten Forsthoffs (a.a.O. S.42) zum Ausdruck:

"Die Korporation des öffentlichen Rechts gehört in den bundesfreien gliedstaatlichen Bereich. Sie hat zum Zentralstaat und seiner Ordnung keine unmittelbare Beziehung. Das gilt natürlich nur für die gliedstaatliche öffentliche Körperschaft. Da auch der Zentralstaat Staat ist, hat auch er seinen eigenen organisatorischen Bereich und die freie Entscheidung über das Öffentliche. Auch er kann also öffentliche Korporationen ins Leben rufen,..." (Sperrung vom Verf.).

14) S. unten S. 160.

1) Vg1. Köttgen, Der Einfluß des Bundes auf die deutsche Verwaltung, S. 90; Huber, Wirtschaftsverwaltungs recht Bd. II S. 631,634 ; Haas, Bundesgesetze über Organisation und Verfahren der Landesbehörden, S.92; Hamann, Das Grundgesetz, Art. 84 Anm. C 3; s.a. die im Text angeführte Staatspraxis. A.A. Rohwer-Kahlmann, Verfassungs rechtliche Schranken der Zustimmungsgesetze, S.212 ff, 222 ff. Zur Natur des Ausschusses als "Behörde" s. Rasch, Die Behörde, Verwaltungsarchiv Bd.50(1959) S. 1 ff (S.14 f) mit weiteren Nachweisen. 
Hierher zählen die Beiräte der Flüchtlingsverwaltung ( $\$ 22$ Abs. 2 BVFG), die Fürsorgeausschüsse ( $\$ 3$ a der Verordnung über die Fürsorgepflicht) und, da sie im administrativen Bereich nicht verbindlich handeln können, auch die Heimarbeitsausschüsse $(\$ \S$ 9 Abs. 2, 11, 18, 19 des Heimarbeitsgesetzes).

Soweit - wie das in $\$ 18$ Abs. 3 BaulBeschG hinsichtlich der dort vorgesehenen kollegialen Enteignungsbehörden der Fall war - die We is ung sgebundenheit der Behörde ausdrücklich und unbeschränkt festgelegt ist, sind auch beschließende Ausschüsse unbedenklich. Der Willenszusammenhang innerhalb der Exekutive ist gewährleistet. 2)

Der Konflikt tritt erst zutage bei jenen nicht nur beratenden Ausschüssen, hinsichtlich derer die Weisungsgebundenheit $\mathrm{nicht}$ verbürgt ist und hinsichtlich derer, selbst wenn sie nicht von jeder Weisung und Aufsicht durch übergeordnete Behörden frei sein sollen, ihre Zusammensetzung und ihr Verfahrensmodus eine weitgehende $\mathrm{Reduktion}$ der hierarchischbürokratischen Einflußnahme mit sich bringen.

(1) Als solche dürfen hier aus dem Bereich der landeseigenen Verwaltung (Art.84 Abs.1 GG) genannt werden:

(a) Die Beschwer.deausschüsse bei den Hauptfürsorgestellen 3 ) für den Vollzug des Schwerbeschädigtengesetzes. Das Land entsendet in sie - ebenso wie die Bundesanstalt für Arbeitslosenvermittlung und Arbeitslosenversicherung - nur eines von sieben Mitgliedern ( $\$ 27$ Abs. 1). Die Hauptfürsorgestelle beruft außerdem zwei schwerkriegsbeschädigte Arbeitnehmer und zwei Arbeitgeber auf Vorschlag zuständiger Verbände, ferner eine sozial erfahrene Persönlichkeit ( $\$ 27$ Abs.2). Alle Mitglieder sind auf vier Jahre zu bestellen ( $\$ 27$ Abs. 4 Satz 1 ), was die Bedeutung dieses Berufungs rechts modifiziert. Der mit dem Stichentscheid ausgestattete Vorsitzende ( $\$ 29$ Abs. 2 Satz 3) kann nicht der Ver-

2) Hier kam nơch dazu, daß das Land bundesrechtlich nicht genötigt war, in den Ausschuß auch verwaltungsfremde Personen hereinzunehmen. Die Enteignungsbehörde kann also als reine Kollegialbehördf. im alten Sinne, für die der Terminus "Ausschuß" nur unter. Vorbehalt paßt, organisiert werden. Nunmehr überläßt $\$ 104$ Abs. 2 des Bundesbaugesetzes die Entscheidung über die Mitwirkung "ehrenamtlicher Beisitzer" dem Landesverordnungsgeber.

3) Einen Beschwerdeausschuß gibt es auch beim Landesarbeitsamt ( $\$ 28$ SchBesch $(i)$. Da dieser Ausschuß aber nicht in die Landesverwaltung eingeschaltet ist, hat er hier außer acht zu bleiben. 
treter der Hauptfürsorgestelle oder der Bundesanstalt sein $(\$ 29$ Abs.1). Der Ausschuß entscheidet mit Stimmenmehrheit ( $\$ 29$ Abs.2). Er ist zuständig zur Entscheidung über Beschwerden gegen Anordnungen der Hauptfürsorgestellen ( $\$ 26$ Abs. 1).

(b) Auch in erster Instanz in die Hände von Ausschüssen gelegt ist der Vollzug des Kriegsgefangenenents chädi gungs gesetzes, soweit er die Entschädigung betrifft. Der sog. Feststellungsausschuß, der über den Antrag auf Entschädigung in erster Instanz entscheidet, besteht aus dem Leiter der zum Vollzug des Gesetzes bestimmten Behörde oder Dienststelle oder dessen Stellvertreter als Vorsitzendem und zwei ehrenamtlichen, von den Wahlkörperschaften der Land- und Stadtkreise auf zwei Jahre gewählten Beisitzern, von denen einer ein ehemaliger Kriegsgefangener sein muß ( $\$ 12)$. Übel die Beschwerde entscheidet ein weiterer Ausschuß, der sich aus einem Behörden- oder Dienststellenleiter oder seinem Stellvertreter und zwei gewählten Beisitzern zusammensetzen muß $(\$ \S 18,19)$. - Im Verfahren wegen Gewährung von Beihilfen oder Darlehen sind in erster Instanz der Feststellungsausschuß und ein weiterer Ausschuß ( $\$ 39$ ) gutachtlich tätig ( $\$ \$ 40,42)$, während über die Beschwerde gegen die Ablehnung des Antrages durch den Dienststellenleiter ( $\$$ \&) der Beschwerdeausschuß entscheidet $(\$ 43)$.

(c) Hier zu nennen ist auch noch der Landes jug endwo h 1 fahrtsausschuß ( $\ \ 12$ ff des Jugendwohlfahrtsgesetzes), der als Teil des Landesjugendamtes auch bestimmend, nicht nur beratend, auf dessen Tätigkeit einwirkt (s. insbes. $\$ 14$ Abs. 2). Dagegen soll hier nicht näher auf den praktisch weitaus wichtigeren Fall der als leil der Jugendämter bei den Landkreisen und kreisfreien Städten zu bildenden Jugendwohlfahrtsausschüsse ( $\$ ₫ 9 \mathrm{ff}$ ) eingegangen werden, da diese Ausschüsse in erster Linie in den Problembereich der bundesrechtlichen Eingriffe in das Kommunalverfassungs recht auf der Grundlage des Art. 84 Abs. 1 GG gehören, der unten noch näher zu erörtern sein wird.

(2) Eine für einen umfangreichen Ausschnitt sozialer Verwaltung bedeutsame Einrichtung, die aber im Gegensatz zu den bisher genannten Ausschüssen in der Bundesauftragsverwaltung steht, sind die Ausgleichsausschüsse und Beschwerdeausschüsse der Lastenausgleichs verwaltung, die neben konsultativen auch zahlreiche Fntscheidungszuständigkeiten haben $(\$ \$ 309,310,335,336,345$ Abs.2, 347 LAG). Der Ausgleichsausschuß besteht aus dem Leiter der Behörde, bei der das Ausgleichsamt errichtet ist, oder dem Dienststellenleiter oder jeweils dem Vertreter als Vorsitzenden und zwei ehrenamtlichen Beisitzern ( $\ 309$ Abs. 2). Von den Beisitzern soll einer Geschädigter, insbes. - je nach dem geltend gemachten Schaden - Ver- 
triebener oder Kriegssachgeschädigter sein, der andere dagegen nicht Vertriebener oder Kriegssachgeschädigter sein ( $\$ 309$ Abs. 3). Die Beisitzer werden nach Anhörung der Geschädigtenverbände von den kommunalen Wahlkörperschaften der Kreisebene gewählt ( $\$ 309$ Abs.4). Die Beschwerdeausschüsse, die auch für mehrere Stadt - und (oder) Landkreise gemeinsam errichtet werden können, sind entsprechend zusammengesetzt ( $\$ 310) .4$ )

Wenngleich keinem der genannten Ausschüsse die sachliche Unabhängigkeit bundes rechtlich ausdrücklich garantiert ist, so wäre es doch widersinnig anzunehmen, sie seien der Weisungs- und Aufsichtsgewalt der hierarchisch gebundenen Verwaltung unbeschränkt unterworfen. Eine derartige Bindung würde schon im Rechtsbereich - soweit es sich nicht um offensichtliche Verirmugen sondern um $Z$ weifelsfragen, insbes. auch um die Handhabung der sog. unbestimmten Rechtsbegriffe handelt - vollends aber im Ermessensbereich die Absicht durchkreuzen, die der Gesetzgeber mit der "kunstvollen" Zusammensetzung der Ausschüsse verfolgt hat, nämlich die Absicht, Entşcheidungen herbeizuführen, die durch die maßgebliche Mitwirkung von Sachkundigen, Interessenvertretern oder schlechthin Bürgern sowohl einem größeren Vertrauen der Bevölkerung und der Beteiligten begegnen als auch objektiv ein höheres Maß an sachlicher Richtigkeit erreichen als die (allein) von der bürokratischen Verwaltung get ragenen Entscheidungen. 5) Die Weisungsgebundenheit müßte darüber hinaus das für die Ausschußtätigkeit maßgebliche Mehrheitsprinzip aufheben, was insbes. dort wunder nehmen müßte, wo - wie in $₫ 29$ Abs. 2 SchwerBeschG - das Mehrheitsprinzip ausdrücklich statuiert ist.6)

4) Für die Weisungsunabhängigkeit dieser Ausschüsse s. Haueisen, Zur rechtlichen Qualifikation des Rentenbescheides, NJW 11.Jhg. (1958) S. 441 ff (443) insbes. Fußn.28. - Nach $\$ 331$ Abs. 1 LAG entscheiden "die Ausgleichsbehörden und die bei ihnen gebildeten Ausschüsse... in freier Beweiswürdigung darüber, welche für die Entscheidung maßgeblichen Angaben als bewiesen oder glaubhaft gemacht anzusehen sind" Das bezieht sich aber offensichtlich nicht auf die Frage der Weisungs befugnis.

5) Zu dieser Bedeutung der Zusammensetzung s.a. Haueisen, a.a.O.

6) S. z.B. Groeben, Mitwirkung von Ausschüssen in der staatlichen Verwaltung, a.a.O. S.237:

"Soweit Entscheidungen getroffen werden können, ist festzuhalten, daß die Ausschüsse insofern weitgehend unabhängig und selbständig sind. Sie sind, allgemein gesehen, zwar an die Gesetze und meist auch an Verwaltungsanweisungen ge- 
Wie immer auch die Einschränkung der Weisungs- und Aufsichtsrechte gegenüber derartigen Ausschüssen beurteilt werden mag, 7) muß jedenfalls angenommen werden, daß die bürokratische Verwaltung im Rahmen der Ausschußkompetenz aus der Willensbildung im Ermessensbereich total, im Rechtsbereich in mehr oder weniger enge Grenzen verwiesen wäre.

Am vollkommensten sind die Ausschüsse aus der Landesexekutive - i.S. einer Entscheidungseinheit - dort ausgeklammert, wo ihnen strikt volle sachliche Unabhängigkeit gewährleistet ist. Für solche Ausschüsse gibt es - soweit der Verf. zu sehen vermag in dem Bereich der auf der Grundlage der Art. 84 Abs. 1, 85 Abs. $1 \mathrm{GG}$ geregelten sozialen Landesverwaltung derzeit allerdings kein Beispiel.

Die Frage, ob auch solche mehr oder weniger unabhängige, "ministerialfreie" 8) Ausschüsse auf Grund Art.84 Abs.1, 85 Abs. 1 GG dem Organismus der Landesverwaltung vom Bundesgesetzgeber oktroyiert werden können, würde einfach zu verneinen sein, wenn fest stünde, daß das Grundgesetz sachliche Unabhängigkeit überhaupt nur bei den Gerichten, nicht aber bei Verwaltungs behörden zuließe.9) Ein allgemeiner Satz dieses Inhaltes läßt sich aus dem Grundgesetz aber nicht entnehmen. 10) In Anbe-

bunden, nicht aber an Einzelweisungen der Fachressorts. Vor allem ist ihnen der Ermessensspielraum überlassen, soweit ein solcher bei Verwaltungsakten auszuschöpfen ist. Das liegt ja auch in der mit der Bildung der Ausschüsse verfolgten Absicht. Ausschüsse, die keine Möglichkeit einer Ermessensbetätigung haben oder gar in ihrer Entscheidung von der Weisung einer Behörde abhängig sind, scheinen gegen ihre Natur zu verstoßen".

Ebenso Werner, Weisungsfreie Verwaltungsbehörden, Jurist. B1ätter, 79. Jhg. (1957) S.229 ff (232).

7) S. insbes. Haas, Ausschüsse in der Verwaltung, S. $21 \mathrm{ff}$.

8) Zum Terminus $s$. Loening, Der ministerialfreie Raum in der Staatsverwaltung, S. 173 und passim.

9) Klar (unabhängige Verwaltungsbehörden grundsätzlich negierend) in dieser Hinsicht z. B. die Regelung der österr. Verfassung, die gerade hierin wieder die klare, doktrinäre Sicht ihres Schöpfers Kelsen verrät. - S. hierzu die interessanten Ausführungen von Werner, Weisungsfreie Verwaltungsbehörden; dens., Kollegiale Verwaltungsbehörden mit richterlichem Einschlag, Jurist. Blätter, 80.Jhg. (1958) S. 217 ff und dessen weit. Nachweise.

10) BVerfGE 9, 268 (279 ff); BVerwGE 7, 66 (73) - jedoch sehr 
tracht der deutschen Tradition, der unabhängige Gremien in der Verwaltung durchaus vertraut sind, 11) hätte es dazu wohl auch eines ausdrücklichen Verbotes der Verfassung bedurft. Aus der allgemeinen Bindung der vollziehenden Gewalt an "Gesetz und Recht" (Art.20 Abs.3 GG) ergibt es sich nicht; denn die Bindung auch der weisungs- und aufsichtsunabhängigen Ausschüsse an die Gesetze ist unbestritten und durch Art. 19 Abs. 4 GG in einem für den einfachen Gesetzgeber unaus räumbaren Minimum sanktioniert. Desgleichen ist nichts aus dem Grundsatz der Gewaltenteilung (Art.20 Abs.2 Satz 2 GG) 12) zu entnehmen; 13) denn unabhängige Exekutivbehörden sind vom Gesetzgeber und von den Gerichten nicht weniger distanziert als abhängige. Äußerste Grenzen steckt lediglich der für den Bund in Art.65 GG niedergelegte, für die Länder mittelbar aus Art. 28 Abs. 1 Satz 1 GG zu entnehmende

auf den Fall abgestellt; Huber, Wirtschaftsverwaltungs recht Bd. II S. 634; Bachof, Wehrpflichtgesetz und Rechtsschutz, 1957, S. 47 f; Friesenhahn, Parlament und Regierung im modernen Staat, Veröffentlichungen der Vereinigung der Deutschen Staats rechtslehrer, Heft 16, 1958, S. 9 ff (72); a. A. mit hier nicht interessierenden Modifikationen Loening, a.a.O.; zweifelnd Haueisen, Anm. zum Urt. des LSG Schleswig vom 15.Juli 1954, DÖV 8.Jhg. (1955) S.60 (s.diesen auch: Zur rechtlichen Qualifizierung des Rentenbescheides, S. 443, mit weit. Nachw. (Fußnote 33)); vermittelnd in Richtung auf die Unverzichtbarkeit der $R$ e chtskontrolle: Haas, Ausschüsse in der Verwaltung, insbes. S. $22 \mathrm{f}$.

11) Bachof, a.a.O. S. 48 .

12) Ob Art. 20 Abs. 2 Satz 2 GG unmittelbar für die Länder gilt, kann hier dahingestellt bleiben. Für die Länder ergibt sich das Gewaltenteilungsprinzip jedenfalls aus der Rechtsstaatsgarantie des Art. 28 Abs. 1 Satz 1 GG (s.f.v.a. v. Mangoldt-Klein Art. 28 Anm. III 2a i.V.m. Art. 20 Anm. VI 2 und V 5 b). Wenn Vogel (Das Bundesverfassungsgericht zum Bremer Personalvertretungsgesetz - Probleme der Gewaltenteilung, der Regierungsverantwortung und der hergebrachten Grundsätze des Berufsbeamtentums, MDR 13. Jhg. (1959) S. $894 \mathrm{ff}$, insbes. S. 895) dem Bundesverfassungsgericht (BVerfGE 9, 268) vorwirft, man tue dem Rechtsstaatsprinzip keinen Gefallen, wenn man ihm auch noch den Gedanken der Regierungsverantwortung einbaue, man müsse diesen vielmehr aus der Gewaltenteilung ableiten, so ist er zu fragen, ob denn die Gewaltenteilung außerhalb der Rechtsstaatlichkeit steht. Diesen Zusammenhang hat Vogel übersehen. Näheres hierzu s. unten Abschnitt 6 II (S. $890 \mathrm{ff}$ ).

13) Vg1. BVerfGE 9, $279 \mathrm{f}$. 
Grundsatz der Verantwortlichkeit der Regierung. 14) Doch ist dieser erst verletzt, wenn die Ausgliederung von Verwaltungsaufgaben auf unabhängige Behörden der Regierung die Erfüllung ihrer Aufgabe, die Gesamtpolitik zu leiten und zu verantworten, unmöglich macht. 15) Das ist eine Grenze, die die üblichen Fälle unabhängiger Ausschüsse usw. nicht trifft. 16) Das im Hinblick auf Art. 84, 85 GG aufgeworfene Problem wird durch sie nicht gegenstands10 .

Darum ist $\mathrm{zu}$ fragen: Welche Grenzen ergeben sich aus Art. 84, 85 GG selbst? Sie bestehen für die landeseigene Verwaltung (Art. 83, 84 GG) darin, daß dem Land die Möglichkeit erhalten bleiben muß, die Tätigkeit der Ausschüsse - eventuell mit genau vorbezeichneten Aufsichtsmitteln - wirksam dahin zu überwachen, daß diese das Recht, das das Land gem. Art.83 GG zu vollziehen und darüber hinaus nach Art.20 Abs.3, 31 GG zu beachten hat, und die allgemeinen Verwaltungsvorschriften, die der Bund nach Art. 84 Abs. 2 GG erlassen kann, einhalten. 17) Würden Ausschüsse

14) BVerfGE 9, $281 \mathrm{ff}$. - Loening, Der ministerialf reie Raum in der Staatsverwaltung, S. 176, liest aus Art.65 GG weitergehend ein umfassendes Verbot "ministerialfreier" Verwaltung heraus. -

15) BVerfGE 9, 282.

16) S. hierzu bereits die vom Bundesverfassungsgericht nicht beanstandete Regelung unabhängiger Ausschüsse in Personalangelegenheiten der öffentlichen Angestellten und Arbeiter

(BVerfGE 9, 284); ferner die Zulässigkeit einer unabhängigen Einigungsstelle, die nicht - wie beanstandet (ebd. S.282 f) für die Personalangelegenheiten der Beamten sondern nur für deren soziale Angelegenheiten zuständig ist (ebd. S.285). S.a. BVerwGE 7, 66 (73).

17) Vg1. Haas, Ausschüsse in der Verwaltung, S. $22 \mathrm{f}$. - Es mag wunder nehmen, daß sich die "Rechtskontrolle" auch auf die Einhaltung von "Verwaltungsvorschriften" erstrekken soll. Es soll hier nicht mit denen gerechtet werden, die zwischen Rechts - und Verwaltungsvorschriften andere Unterscheidungen aufwerfen als diejenigen des Adressatenkreises grundsätzlich gleicherweise generell-normativer Rechtsbefehle. Was im gegebenen Zusammenhang die Erstreckung der Kont rolle auf Gesetz (im materiellen Sinn) und Verwaltungsvorschrift veranlaßt, ist nichts anderes als der Umstand, daß gem. Art. 84 Abs. 3 Satz 1 GG das Land auch dafür verantwortlich ist, daß die Verwaltungsvorschriften (oder - wenn man will - Art. 84 Abs. 2 GG) beachtet werden. Daran kann kein berechtigter Zweifel bestehen, obwohl nach Art. 84 Abs. 3 Satz 1 
weitergehend "ministerialfrei" gestellt, so würde das Land dadurch der Möglichkeit beraubt, seiner Pflicht zu genügen, die Bundesgesetze "dem geltenden Rechte gemäß" auszuführen (Art. 84 Abs. 3 Satz 1 GG), für deren Erfüllung das Land als solches, nicht etwa die handelnde Behörde - hier also: Der Ausschuß -, einzustehen hat (ebd. Abs.4) 18). Auf die Erfüllung dieser grundgesetzlichen Pflicht der Länder kann der einfache Bundesgesetzgeber auch nicht verzichten. 19) Die Richtigkeit dieser Ansicht bestätigt sich in der Gegenprobe. Diese hat anzusetzen an dem Umstand, daß dem Bund nach Art. 84 Abs. 1 GG keine

und Abs. 4 GG die Länder ausdrücklich nur die Einhaltung des "Rechts" zu gewährleisten haben. "Dem geltenden Rechte gemäß" (Art. 84 Abs. 3 Satz 1 GG) wird im Hinblick auf Art. 84 Abs. 2 GG das Bundesrecht eben doch nur dann ausgeführt, wenn auch die Verwaltungsvorschriften beachtet werden. Etwas anders liegt die Problematik hinsichtlich der Einze 1we isungen nach Art. 84 Abs. 5 GG, die Haas (a.a.O. S.23) von vorneherein in den Vorbehalt zugunsten der Landesverwaltung gegenüber den Ausschüssen mit aufnehmen möchte. Diese Einzelweisungen bedürfen der speziellen gesetzlichen Legitimation. Nun würde aber ein Gesetz, das einerseits unabhängige Ausschüsse einrichten, andererseits aber gerade in bezug auf den Zuständigkeitsbereich dieser Ausschüsse Einzelweisungen der Bundes regierung an die Länder zulassen würde, sich selbst widersprechen. Über die Folgen dieses inneren Widerspruchs braucht hier nicht weiter gehandelt zu werden.

18) S. z.B. Bullinger, Der Anwendungsbereich der Bundesaufsicht, AöR Bd.83 (1957/58), S.279 ff (284ff).

19) Die Einrichtung unabhängiger Verwaltungsgremien als Verzicht des Parlaments auf seine Kontrollrechte gegenüber der Verwaltung zu erklären (so Haas, Verwaltungsstreit zwischen Behörden des gleichen Rechtsträgers, DöV 5.Jhg. (1952) S. $133 \mathrm{ff}$ (137); ders., Ausschüsse in der Verwaltung, S.22 f), ist darüber hinaus auch innerhalb desselben Staatsorganismus (Bund oder Land) verfehlt (s.a. Loening, Der ministerialfreie Raum in der Staatsverwaltung, S. 176). Dadurch würde nicht nur die grundsätzliche Unverzichtbarkeit verfassungsrechtlich begründeter Kompetenzen ignoriert. Dadurch würde auch der Gesetzgeber unzulässig mit dem Parlament gleichgestellt. Wenn auch in den Ländern (von Bayern wegen des Senats abgesehen) ein Unterschied zwischen Parlament und Gesetzgeber im allgemeinen nicht sichtbar wird, so gilt das doch nicht für den Bund, wo sich Bundestag und Bundesrat jeweils in parlamentarischer Kontrolle und Gesetzgebung in sehr verschiedenen Positionen befinden. 
anderen Organisationsbefugnisse zustehen als diejenigen, die ohne die bundesgesetzliche Regelung den Ländern selbst zustehen. 20) Würde also dem Bundesgesetzgeber das Recht eingeräumt, voll unabhängige Ausschüsse einzusetzen, so müßte dieses Recht - soweit eine bundesgesetzliche Regelung fehlt - auch den Ländern zugestanden werden. Die Länder würden mit einer derartigen Regelung sich aber selbst der Möglichkeit berauben, der Pflicht zur gesetzmäßigen Exekutive nachzukommen. Sobald ein Ausschuß - solchermaßen unkorrigierbar - dann Bundesrecht verletzt, müßte das Land gemäß Art. 84 Abs. 3 und 4 GG dafür einstehen, ohne sich auf sein Landesgesetz berufen zu können, 21) vielmehr gerade deshalb, weil es mit dieser Regelung die Rechtskontrolle preisgab. Die Vorschrift, durch die das Land die Ausschüsse dermaßen verselbständigte, würde - ungeachtet der Frage, ob auch in diesem Falle dadurch schon ihre Ungültigkeit bewirkt würde - gegen Art. 83, 84 Abs. 3 Satz 1 GG verstoßen.

Noch weiter gehen diese Beschränkungen im Rahmen der Bundesauftragsverwaltung (Art.85 GG). Hier muß der Bundesgesetzgeber die im Rahmen der Landesverwaltung zu bildenden Ausschüsse nicht nur der Rechtskontrolle durch das Land unterwerfen und auch nicht nur der Kontrolle über die Einhaltung der allgemeinen Verwaltungsvorschriften, die der Bund nach Art. 85 Abs. 2 Satz 1 GG erlassen kann. Hier muß der Bundesgesetzgeber darüber hinaus den Ländern die Befugnis belassen, die Ermessensausübung, auf die sich die Bundesaufsicht ebenfalls erstreckt (Art. 85 Abs. 4 GG), zu überprüfen. Sonst sind die Länder nicht in der Lage, ihrer Pflicht nachzukommen, den Vollzug der Weisungen der obersten Bundesbehörden sicherzustellen (Art.85 Abs. 3 GG). 22)

Es ist nicht Aufgabe dieser Untersuchung, über diese Grundlinien hinaus den Fragen unabhängiger Verwaltungsgremien weiter nachzugehen. Insbes. muß hier dahingestellt bleiben, wie diese Rechts- und Ermessenskontrolle geregelt werden kann und darf.23)

20) Dazu kommt freilich, daß der Landesgesetzgeber an Landesverfassung und Grundgesetz, der Bundesgesetzgeber nur an dieses gebunden ist. Das ist hier jedoch ohne Bedeutung.

21) S. Bullinger, Der Anwendungsbereich der Bundesaufsicht, S. $284 \mathrm{ff}$.

22) S. Haas, Ausschüsse in der Verwaltung, S.23. Diese Grundsätze sind insbes. für die Handhabung der Vorschriften über die Ausschüsse in der Lastenausgleichsverwaltung bedeutsam.

23) S. allgemein Haas, a.a.O. S. 21 ff. - Ein besonderes Problem bildet dabei der beliebte und allgemein als hinreichende 
Es ist auch nicht weiter zu erörtern, ob das geltende Gesetzesrecht diesen Erfordernissen immer genügt. 24) Grundsätzlich ist zu sagen, daß der Bundesgesetzgeber Ausschüsse im Rahmen der landeseigenen Verwaltung nur von der Ermessensaufsicht - ungeachtet der durch allgemeine Verwaltungsvorschriften eintretenden Ermessensbindung -, im Rahmen der Bundesauftragsverwaltung nur von der Aufsicht in dem Ermessensraum, den nicht Weisungen und Verwaltungsvorschriften des Bundes ausfüllen, freistellen darf. Damit steht eine relativ geringe Variationsbreite zur Disposition. Sie erklärt sich aber aus der Notwendigkeit, das Spannungsverhältnis zwischen Bund und Land, das bei der Ausführung von Bundesrecht durch die Länder auftritt, durch Ingerenzrechte des Bundes und korrespondierende Verantwortlichkeiten der Länder auszugleichen.

Zusammenzufassen ist: Der Ermessensraum (in bezug auf die Ausführung von Bundesgesetzen) kann jedenfalls der hierarchischbürokratischen - und so auch: mittelbar parlamentarischen - Willensbildung der Länder durch die Einrichtung unabhängiger Ausschüsse entzogen werden, die ohnedies sekundäre Rechtskontrolle nicht.

Rechtskontrolle anerkannte Ersatz verwaltungsinterner Aufsichtsmittel durch das $\mathrm{Recht}$ der (hierarchisch gebundenen) Verwaltung, gegen Ausschußentscheidungen die Gerichte anzurufen (vg1. hierzu BVerwGE 7, 66 (73); Loening, Der ministerialfreie Raum in der Staatsverwaltung, S.179; Baring, Die politische Selbstverwaltung und die Verwaltungsgerichtsbarkeit, DVB1. 70.Jhg. (1955) S. $684 \mathrm{ff}, 721 \mathrm{ff}$ (691); Haas, a.a.O. S. 28 f; Groeben, Mitwirkung von Ausschüssen in der staatlichen Verwaltung, S.238; Haueisen, Die rechtliche Qualifizierung des Rentenbescheids, S.443 f; s.a. deren Nachweise und Beispiele; s. ferner LSG Schleswig, Urteil v. 15. Juli 1954, DÖV 8. Jhg. (1955) S. 59). Dieses Institut ist als Ersatz für verwaltungsinterne Aufsichtsmittel aber nur bedingt tauglich, wohl vor allem nur dort, wo es einerseits (nur) um Rechtsfragen geht und wo andererseits subjektive Rechte in Frage stehen, hinsichtlich deren in jedem Falle die Gerichte das letzte Wort hätten (Art.19 Abs.4 GG). - Gegen die Zulassung des Insichprozesses gegen Ausschußentscheidungen praeter legem: Rasch, Die Behörde, S.29.

24) Zur Kritik - allerdings von seinem weitaus strengeren Standpunkt aus - s. vor allem Rohwer-Kahlmann, Verfassungs rechtliche Schranken der Zustimmungsgesetze, S. $210 \mathrm{ff}, 222 \mathrm{ff}$. 


\section{cc) Rechtsfähige Verwaltungseinheiten}

1. Problem übersicht. Differenzierter zu sehen sind die Probleme der Einrichtung iandesinkorporierter, rechtsfähiger Verwaltungseinheiten und ihrer Einbeziehung in den Vollzug des Bundesrechts gemäß Art. 84, 85 GG.

(I) Dabei ist zunächst zu unterscheiden $z$ wischen der Heranziehung schon vorhandener, nicht auf Bundesrecht beruhender rechtsfähiger Verwaltungseinheiten einerseits - auf die unter (II) zurückzukommen sein wird - und der Einrichtung besonderer Verwaltungseinheiten durch Bundesrecht zum Vollzug bestimmter, ebenfalls bundesrechtlicher Verwaltungsaufträge. 1)

(1) Alis derartige spezifische Verwaltungsträger sind zu nennen die Fürsorgeverbände, die aber bundesrechtlich (als solche überhaupt) nur konzipiert sind, während ihre Trägerschaft und die Weisungs- und Aufsichtsgewalt der landesrechtlichen Regelung unterstellt ist ( $\$ \$ 2,3$ der Fürsorgepflichtverordnung). 2)

(2) Das klassische Beispiel sind die Sozialversiche $r u n g s t r a ̈ g$ e $r$ einschließlich der jüngst hinzugekommenen $\mathrm{Fa}-$ milienausgleichskassen und landwirtschaftlichen Alterskassen. Sie sind den Ländern inkorporiert, soweit ihre Zuständigkeit nicht über das Gebiet eines Landes hinausreicht (Art. 87 Abs. 2 GG). Die Aufsicht über sie steht den Landesbehörden zu $(\$ \S 3,5$ des Bundesversicherungsamtsgesetzes; s.a. $\$ \$ 16,20$ des Kindergeldgesetzes und $\$ 12$ des Gesetzes über eine Altershilfe für Landwirte). Den Landesbehörden stehen auch zahlreiche Gestaltungs - und Mitwirkungsbefugnisse bei der Errichtung, Veränderung und Auflösung der Versicherungsträger zu. ${ }^{3)}$ Die Wahrnehmung der Versicherungsaufgaben ist aber den von den Beteiligten nach Maßgabe

1) S. zu der. Unterscheidung der Vollzugsaufträge an Gemeinden einerseits und an spezielle Institutionen andererseits Köttgen, Die Gemeinde und der Bundesgesetzgeber, 1957, S. 65 f, 88.

2) Der Entwurf eines Bundessozialhilfegesetzes (Deutscher Bundestag, 3. Wahlperiode, Drucksache 1799) verzichtet auf die Anordnung besonderer Fürsorgeverbände.

3) Der Hinweis auf den ursprünglichen Standort der Regelung

- für die Krankenversicherung vorwiegend die $\$ \$ 225-305$ RVO,

für die Unfallversicherung vorwiegend die

$\S \S 623$ - 648, 783 - 798,956 - 960 RVO,

für die Arbeiterrentenversicherung vorwiegend die

\$ 1326 - 1337 RVO -

nützt hier allerdings wenig; denn die Überleitung der alten, aus der hinsichtlich der Position der öffentlich-rechtlichen 
des Selbstverwaltungsgesetzes zu wählenden Organen anvertraut, deren Wahl die Länder nur überwachen können ( $\$ 11$ des Selbstverwaltungsgesetzes). Die Aufsicht beschränkt sich auf die Rechtsaufsicht ( $\$ 30$ Abs. 1 RVO).

(II) Die Heranziehung schon vorhandener Verwaltungsträger zum Vollzug des Bundesrechtes auf der Grundlage der Art. 84, 85 GG stellt sich vornehmlich als Vollzugsauftrag an die Ge mein den und Gemeindeverbände dar, mit deren Existenz der Bundesgesetzgeber gem. Art.28 Abs.2 GG rechtsnotwendig rechnen kann. 1) Diesem Fragenkreis fehlt zwar der spezifische Bezug zum Sozialen. Die Heranziehung der Gemeinden oder Gemeindeverbände zum Vollzug des Bundesrechts ist aber nicht nur auch im sozialen Bereich sehr weit verbreitet, sie kann - als Problem - auch schwerlich aus dem Gesamtzusammenhang der Her-

Körperschaften und Anstalten unklaren Konzeption des Kaiserreichs und des Weimarer Reichs (s.o. S. 129 Fußn. 13) oder aus dem Einheitsstaat von 1933 stammenden Kompetenznormen, die vielfach Reichsorgane und - behörden berechtigen, auf das neue Recht ist im Text dieser Bestimmungen noch nicht vollzogen. Bedenkt man aber, daß hinsichtlich der hier in Frage stehenden, i.S. des Art. 87 Abs. 2 GG 1andesunmittelbaren Sozialversicherungst räger.

a) die Kompetenzen schon immer in gewissem Umfange auf die Landes regierungen, die obersten Landesbehörden lauteten und diesen Stellen auch erhalten geblieben sind,

b) die den Oberversicherungsämtern zugewiesenen Zuständigkeiten nunmehr gem. $\$ 6$ des Bundesversicherungsamtsgesetzes auf die obersten oder andere Landesbehörden übergegangen sind ( $z u$ den entsprechenden Kompetenzbeschränkungen der Oberversicherungsämter s. LSG Baden-Württemberg, Urt.v. 11. Dezember 1959 - L IV b K 2299/56 - Breithaupts Sammlung Bd.49 (1960) S.870),

c) die den Versicherungsämtern zugewiesenen Zuständigkeiten diesen, also Landesbehörden, erhalten geblieben sind, d) die Kompetenzen des Reichsversicherungsamtes gem \$ $\$$ des Bundesversicherungsamtsgesetzes auf die obersten oder andere Landesbehörden übergegangen sind,

e) die Befugnisse des Reichsarbeitsminister's - insbes. auch die gem. dem Gesetz vom 14. Februar 1934 (RGB1. I S. 89) vom Reichsrat auf ihn übergegangenen - gem. Art. 129 Abs. 1 GG i. V.m. Art. 83 ff GG in nicht unerheblichem Umfang an die obersten Landesinstanzen fallen (vgl. BSGE 1, 17) oder vielleicht sogar gem. Art. 123 Abs.1 GG erlöschen müssen, so wird klar, daß der Tatbestand der Inkorporation in die 
einnahme rechtsfähiger Verwaltungseinheiten in die landeseigene Verwaltung gem. Art. 83 ff GG gelöst werden. Eine erschöpfende Typologie der Vollzugsaufträge an die Gemeinden und ihrer näheren Regelung zu geben, ist hier nicht möglich. Unklare, wandelbare und sich wandelnde Konzeptionen haben hier zu viel Unterschiede geschaffen. Es seien daher nur einige wenige, im sozialen Bereich besonders interessierende Formen herausgegriffen.

(1) Die das Organisationsrecht der Länder schonendste Form ist der fakultative Vol1zugsauftrag, die bloße bundesrechtliche "Erlaubnis" an die Länder, zur Erledigung einer bestimmten Verwaltungsaufgabe auch die Gemeinden oder Gemeindeverbände heranzuziehen, wie sie z.B. in $\$ 305$ Abs. 2 LAG und $\S 111$ Abs. $1 \mathrm{Nr} .3$ RAO enthalten ist, aber auch von $₫ 3$ Abs. 1 und 3 des F1üchtlingsnotleistungsgesetzes impliziert wird.

(2) Problematischer ist dagegen schon die definitive $\mathrm{Zu}$ we is ung bestimmter Verwaltungsaufgaben an die Gemeinden oder Gemeindeverbände, wie sie sich für den hier interessierenden Bereich insbes. in $\$ ₫ 8$ ff des Jugendwohlfahrtsgesetzes findet. Aber auch die Reichsversicherungsordnung hat den Gemeinden und Gemeindeverbänden zahlreiche Aufgaben zugewiesen ( $\mathrm{s}$. z.B. $\$ \$ 120,231,265,305,389 \mathrm{f}, 453 \mathrm{ff}, 466,967,1020 \mathrm{f}$ RVO).

(3) Diese Vollzugsaufträge werden verschiedentlich mit der Anordnung verbunden, daß sie als eigene (Selbstverwaltungs-) Angele ge nheit der Gemeinden zu betrachten sind (so $\$ 8$ Abs. 1 des Jugendwohlfahrtsgesetzes) oder als übertragene (Auftrags-) Ang e 1 e g e nhe it en (s. z.B. $\$ 3$ Abs. 3 Satz 1 des Flüchtlingsnotleistungsgesetzes; so wohl auch $₫ 305$ Abs. 2 LAG für den Fall, daß die Lastenausgleichsverwaltung auf Gemeinden oder Gemeindeverbände übertragen wird).

(4) Schließlich sehen derartige bundesrechtliche Regelungen vereinzelt auch noch Eingriffe in das kommunale Verfassungs recht vor (so indem $₫ 3$ Abs. 3 Satz 2 des Flüchtlingsnotleistungsgesetzes die Leistungsanforderung durch kollegiale Gemeindebehörden ausschließt; noch eingehender die bundesrechtliche Ausgestaltung der obligatorischen Jugendwohlfahrtsausschüsse bei den Trägern der Kreisjugendämter nach $₫ \S 9$ ff des Jugendwohlfahrtsgesetzes).

Landesorganisation und die Abtrennung vom Bunde nicht mehr $z$ weifelhaft sein kann. 
2. Rechtsfähige Verwaltungseinheiten grundsätz1 ich keine "Behörden" i.S. des Art.84 Abs. 1,85 Abs. 1 GG. Für die Würdigung der durch diese Praxis - und wohl auch durch die ihr zugrunde liegenden Notwendigkeiten - aufgeworfenen Fragen ist ein Umstand von besonderer Wichtigkeit, der weithin nicht oder nicht klar genug gesehen wird: Rechtsfähige Verwaltungseinheiten sind als solche keine Behörden; sie haben vielmehr Behörden. ${ }^{4)}$ Es mag rechtsfähige Verwaltungseinheiten geben, die der Sache nach nicht mehr als eine - finanztechnischer Gründe wegen mit der Rechtsfähigkeit ausgestattete staatliche Behörde sind (und auch nur durch eine einzige Behörde repräsentiert werden). 5) Derartige Abarten interessieren hier nicht. Ihre Willensbildung kann sich nicht wesentlich von der einer staatlichen Behörde unterscheiden. Sie sind vor allem keine Zellen der Selbstverwaltung (im rechtlichen Sinne), deren breite Ausdehnung eines der hier gegenständlichen Sonderprobleme des sozialen Bereichs in der Verwaltung ist. Die typischen Formen der rechtsfähigen Verwaltungseinheiten, die Anstalten und Körperschaften des öffentlichen Rechts, sind aber als solche keine Behörden. Ist dem so, so kann auch die Vollmacht, die die Art. 84 Abs. 1, 85 Abs. 1 GG dem Bunde erteilen, die Einrichtung der $\mathrm{B}$ ehö $\mathrm{rde} \mathrm{n}$ der Landesverwaltung zu regeln, grundsätzlich nicht auf die Einrichtung rechtsfähiger Verwaltungseinheiten als

4) Rasch, Die Behörde, S.20 und S.24 (Fußn. 143) mit weit. Nachw.; Buß, Sind juristische Personen des öffentlichen Rechts Behörden? DÖV 12. Jhg. (1959) S. 293 f; Gerth, Die juristischen Personen des öfentlichen Rechts, ihre Organe und ihre Behörden, DÖV 12.Jhg. (1959) S. 849 ff; Schäfer, Die Bundesauftragsverwaltung, S.647. - Für die Sozialversicherungsträger s. z. B. L. Richter, Sozialversicherungsrecht, 1931 , S. 189 f. - Grundlegend verkannt wird die Notwendigkeit dieser Unterscheidung bei Schneider, Körperschaftliche Verbundverwaltung, AöR 83.Bd. (1958/59) S. 1 ff; ders., Die öffentlich-rechtliche Alterssicherung freier Berufe und das Grundgesetz, 1960, S. 57 ff. Er glaubt, das wesentliche Argument dafür, daß der Bund die Einrichtung rechtsfähiger Verwaltungsträger innerhalb der Landesverwaltung aufgrund Art. 84 Abs. 1, 85 Abs. 1 GG anordnen kann, damit gewonnen zu haben, daß er dartut, der Begriff "Einrichtung" schließe auch den der "Errichtung" ein (a.a.O. S. $16 \mathrm{ff} \mathrm{bzw.} \mathrm{S.} 58 \mathrm{f}$ ).

5) Vg1. Köttgen, Die rechtsfähige Verwaltungseinheit, 1939, S. 72 ff und seine Beispiele. 
solcher bezogen werden. 6)

Einem anderen Verständnis des Wortes "Behöıden" steht auch die Parallelvorschrift zu Art. 84 Abs. 1, 85 Abs. 1 GG für die Bundesverwaltung, Art. 86 Satz 2 GG entgegen. Dort ist - Art. 86 Satz 1 und 2 GG zusammen gelesen - gesagt: "Führt der Bund die Gesetze durch bundeseigene Verwaltung oder durch bundesunmittelbare Körperschaften oder Anstalten des öffentlichen Rechts aus, so (regelt) die Bundesregierung, ... soweit das Gesetz nichts anderes bestimmt, die Einrichtung der Behörden". Es ist ganz ausgeschlossen, insbes. wenn auch noch Art. $87 \mathrm{GG}$ in die Interpretation einbezogen wird, hier etwas anderes anzunehmen, als daß der Grundgesetzgeber das Wort "Behörden" nicht für rechtsfähige Verwaltungsträger, wohl aber für ihre und des Staates unmittelbare Organe gebraucht hat.

3. Die Regelungskompetenz aus der Sachkompetenz. Damit ist nicht gesagt, daß das Grundsesetz überhaupt rechtsfähige Verwaltungseinheiten im Rahmen der Landesverwa1tung ausschließen wollte. Das Grundgesetz setzi landesinkorpo-

6) A.A. Köttgen, Kommunale Auftragsverwaltung und Grundgesetz, Die Selbstverwaltung, 5.Jhg. (1951) S.346 ff (247); ders., Der Einfluß des Bundes auf die deutsche Verwaltung, S. 90, 115; ders., Die Gemeinde und der Bundesgesetzgeber, 1957, S. 75 f; Schneider, Körperschaftliche Verbundverwaltung, insbes. S. $16 \mathrm{ff}$; ders., Die öfentlichrechtliche Alterssicherung freier Berufe und das Grundgesetz, S. 58 ff; Speziell die Gemeinden bezeichnen als Behöıden i. S. des Art. 84 Abs. 1 darüber hinaus Kessler, Der Bund und die Kommunalpolitik, DVB1. 68.Jhg. (1953), S. $1 \mathrm{ff}$ (4), und Forschbach, Grundsätzliche Erwägungen zum Flüchtlingsnotleistungsgesetz DVB1. 68. Jhg. (1953) S. 331 f (332). Bemerkenswert ist der Zirkelschluß, der Köttgen in diesem Punkt unterlaufen ist, wenn er (Kommunale Auftragsverwaltung und Grundgesetz, S. 347) ausführt, die Zuständigkeil des Bundes zur. Einbeziehung der rechtsfähigen, landesinkorporierten Verwaltungseinheit in den Vollzug des Bundesrechts auf der Grundlage des Art.84 Abs.1 GG ergebe sich schon daraus, daß die Gemeindebehörden doch immer als Behörden angesehen worden seien. Die Frage, die sich auf Grund der Art. 84 Abs. 1, 85 Abs. 1 GG stellt, ist also - wie Köttgen selbst dabei übersieht - in Wahrheit die, ob die Behörden der. rechtsfähigen Verwaltungseinheiten Behörden i.S. dieser Verfassungsbestimmungen sind, nicht die, ob die Verwaltungseinheiten selbst "Behörden" sind. 
rierte, rechtsfähige Verwaltungseinheiten vielmehr voraus (s. Art. $75 \mathrm{Nr} .1$ i.V.m. Art. $73 \mathrm{Nr} .8,87$ Abs.2, 130 Abs. 3 GG). Damit ist auch nicht gesagt, daß das Grundgesetz dem Bundesgesetzgeber verbietet, der Landesverwaltung von sich aus rechtsfähige Verwaltungseinheiten zum Vollzuge des Bundesrechts einzufügen. Art. 87 Abs. 2 GG würde dem klar widersprechen; 7) denn der. Grundgesetzgeber konnte unmöglich davon ausgegangen sein, daß alle nicht über den Bereich eines Landes hinaus zuständigen Sozialversicherungsträger auf Landes recht beruhten. Nur auf Art. 84 Abs.1, 85 Abs. 1 GG kann der Bundesgesetzgeber sich dabei nicht stützen.

Die Legitimation des Bundesgesetzgebers, die Einrichtung 1andesinkorporierter, rechtsfähiger Verwaltungseinheiten zu regeln, kann sich demnach grundsätzlich - d.h. von der Einrichtung der Schrumpfformen behördengleicher Verwaltungseinheiten abgesehen - nur aus der sachlichen Regelungskompetenz für das Gebiet ergeben, auf dem die Körperschaft oder Anstalt tätig werden soll. 8) Gerade für das Gebiet der Sozialversicherung das in diesem Zusammenhang nicht nur wegen seines sozialen Bezuges sondern auch deshalb prototypisch ist, weil Art. 87 Abs. $2 G G 9)$ speziell dafür den Beweis erbringt, daß landesinkorpo-

7) Zur Argumentation aus Art. 87 Abs.2 GG s.a. BVerfGE 11, 105 ( $123 \mathrm{f})$.

8) Haas, Bundesgesetze über Organisation und Verwaltung der Landesbehörden, S.98 f. S. a. Bettermann, Das Verwaltungsverfahren, Veröffentlichungen der Vereinigung der Deutschen Staatsrechtslehrer, Heft 17, 1959, S. 118 ff (157): "In der Tat schließen die Art. 73 ff GG auch organisationsrechtliche Kompetenzen in sich ein". - Schief gesehen ist der Zusammenhang dagegen bei Schneider (Die öffentlichrechtliche A1terssicherung der freien Berufe, S. $59 \mathrm{f}$ ), wenngleich gerade Glieder seiner Argumentation ihn zum Ergebnis des Textes hätten führen müssen.

9) Hinzuweisen ist übrigens auch auf Art. 120 Abs. 1 GG. Wenn dort gesagt ist "Ier Bund trägt ... die Zuschüsse zu den Lasten der Sozialversicherung...", so bedeutet das einerseits, daß nach den Vorstellungen des Grundgesetzgebers die Sozialversicherung (wenigstens grundsätzlich) von rechtsfähigen Verwaltungseinheiten und nicht unmittelbar vom Staat durchgeführt wird; denn würde die Sozialversicherung unmittelbar von der staatlichen Verwaltung durchgeführt, so wäre der Ausdruck "Zuschüsse" verfehlt. Andererseits liegt dieser Vorschrift die Vorstellung zugrunde, daß die Verwaltungseinheiten, die die Sozialversicherung 
rierte Verwaltungseinheiten auf bundesrechtlicher Grundlage möglich sein müssen - steht auch außer Zweifel, daß die Zuständigkeit des Bundes zur Gesetzgebung (Art. 74 Nr. 12 GG) die Befugnis beinhaltet, die Einrichtung landesinkorporierter, rechtsfähiger, öfentlichrechtlicher Versicherungsträger anzuordnen. 10) Und zwar ergibt das nicht nur das historische, von Art. $74 \mathrm{Nr} .12 \mathrm{GG}$ gewiß auch involvierte Erscheinungsbild der deutschen Sozialversicherung, die eine vom Staat unmittelbar durchgeführte Versicherung - von der sog. Eigenversicherung abgesehen, auf deren Besonderheiten hier, die Abweichung rechtfertigend, nicht eingegangen zu werden braucht - nicht kennt. Es ergibt sich auch nicht nur aus dem das deutsche Sozialversicherungs recht mit schwankender Gründlichkeit beherr-

durchführen, sowohl dem Bunde wie auch den Ländern inkorporiert sein können. Könnten sie nur dem Bunde inkorporiert sein, so wäre die ausdrückliche Festlegung der Kostentragungspflicht des Bundes überflüssig (Art. 109 GG).

10) (1) Vg1. Haas, Bundesgesetze über Organisation und Verfahren der Landesbehörden, S.98 f; ebenso, jedoch im weiteren Verlauf seiner Untersuchung nicht ganz konsequent, Peters, Verfassungsrechtliche Fragen des Entwurfs eines Gesetzes über die Regelung der Beziehungen zwischen Ärzten, Zahnärzten und Krankenkassen (Kassenarztrecht) S.2; vg1. ferner BVerfGE 11, 105 (123 f).

(2) So ging man - allerdings im besondern unter Berufung auf den Selbstverwaltungscharakter, auf dessen Bedeutung gleich noch zurückzukommen sein wird, - auch für die Regelung des Kassenarztrechtes durch das Gesetz über Änderungen von Vorschriften des $Z$ weiten Buches der Reichsversicherungsordnung und zur Ergänzung des Sozialgerichtsgesetzes (Gesetz über Kassenarztrecht - GKAR) vom 17. August 1955 (BGB1. I S. 513) überwiegend davon aus, daß die Zuständigkeit des Bundes zur Regelung der kassenärztlichen Selbstverwaltungsorganisation sich aus Art. $74 \mathrm{Nr} .12 \mathrm{GG}$ und nicht aus Art. 83 ff GG ergebe (vgl. den noch beim Ersten Bundestag eingebrachten, auch noch dem zum Gesetz führenden, im Zweiten Bundestag eingebrachten Initiativentwurf zugrunde1iegenden Regierungsentwurf, Deutscher Bundestag, 1. Wahlperiode Drucksache Nr.3904, Begr. S. 17 f; s.a. die Ste1lungnahme des Berichterstatters des Vermittlungsausschusses bei den abschließenden Beratungen des Bundesrates in dessen 144. Sitzung vom 8. Juli 1955, Verhandlungen des Bundesrates 1955, S. $196 \mathrm{f}$ ).

(3) Im besonderen zu den Familienausgleichskassen s. BVerfGE 11, 105 (112 ff, $123 \mathrm{ff}$ ). 
schenden Prinzip der Selbstverwaltung. Sondern es ergibt sich schon ganz einfach aus dem Versicherungsgedanken, der die Ausgrenzung von Risikogemeinschaften und Garantievermögen erfordert. Die rechtsfähige Verwaltungseinheit ist also der Gesamtregelung der Sozialversicherung als Medium sachlogisch vorgegeben. 11) Mutatis mutandis ähnlich verhält es sich hinsichtlich der Regelung gewisser ständischer Organisationen im Wege der Einrichtung von Korporationen öffentlichen Rechts; so ergibt sich die Zuständigkeit zur Errichtung von Rechtsanwaltskammern aus Art. $74 \mathrm{Nr} .1,12)$ die Zuständigkeit zur Errichtung von Industrie- und Handelskammern ${ }^{13)}$ und von Handwerkskammern, Innungen und Kreishandwerkschaften 14) aus Art. 74 Nr.11 GG. Umgekehrt ist dem Bund die Zuständigkeit zur Regelung der ärztlichen Berufsorganisation 15) oder der landwirtschaftlichen Selbst-

11) Vgl. BVerfGE 11, 105 (113). S. ferner oben S. 86 zu Fußn. 2 und die dortigen Nachw. Aus dem vorgrundgesetzlichen Schrifttum s, vor allem L. Richter, Sozialversicherungsrecht, 1931, S.10. - Zu den sachgegebenen und traditione1len Strukturprinzipien des deutschen Sozialversicherungsrechts s. umfassender Richter ebd. S. 9 ff. Zu den Motiven der Errichtung der Sozialversicherungsträger als rechtsfähige Verwaltungseinheiten s. darüber hinaus Köttgen, Die rechtsfähige Verwaltungseinheit, $\mathrm{S} .77 \mathrm{ff}$.

12) Vgl. Haas, Bundesgesetze über Organisation und Verfahren der Landesbehörden, S.99. - Auch die Regierungsentwürfe einer Bundes rechtsanwaltsordnung, die auch das Kammernwesen regeln soll (Deutscher Bundestag, 1. Wahlperiode, Drucks. 3650;2. Wahlperiode, Drucks. 1014) berufen sich nur auf Art. $74 \mathrm{Nr} .1 \mathrm{GG}$ als Kompetenzgrundlage.

13) (1) vgl. Haas, a.a.O.; Reuss, Die Organisation der Wirtschaft, in: Bettermann-Nipperdey-Scheuner, Die Grundrechte, Bd. III, 1. Halbbd. 1958, S.91 ff (98).

(2) So ist auch zu clem Initiativentwurf eines Gesetzes zur vorläufigen Regelung des Rechts der Industrie- und Handelskammern (Gesetz vom 18. Dezember 1956, BGB1. I S.920) in dem Ausschußbericht des Bundestages (Deutscher Bundestag, 2. Wahlperiode, Drucks. Nr.2380, Begr.S.2) ausgeführt, die Zuständigkeit des Bundes zum Erlaß des Gesetzes ergebe sich aus Art. $74 \mathrm{Nr} .11 \mathrm{GG}$, während die Zustimmung des Bundesrates deshalb notwendig sei, weil das Gesetz auch eine Bestimmung über das Verwaltungsverfahren enthält, nämlich hinsichtlich des Verfahrens der Beitragsbeitreibung (!)

14) Reuss, a.a.O.

15) So hat das Bundesverfassungsgericht daraus, daß nach Art. 
verwaltung 16) deshalb abzusprechen, weil eine entsprechende Sachkompetenz fehlt. 17) Dementsprechend wäre aber auch - um wieder zu dem hier im Vordergrund stehenden Sachgebiet zurückzukehren - dem Bund die Regelung der Einrichtung besonderer Fürsorgeverbände ${ }^{18)}$ als Instrumente der öffentlichen Fürsorge untersagt; denn irgend ein notwendiger sachlicher Zusammenhang zwischen der öffentlichen Fürsorge und außerhalb der staatlichen Verwaltung und der vorhandenen kommunalen Verbände zu denkenden sachlichen oder personalen Einheiten ist nicht erkennbar. 19)

Ergibt sich die Zuständigkeit des Bundes zur. Einrichtung rechts-

$74 \mathrm{Nr} .19$ GG der Bund nur zur Regelung des ärztlichen Zulassungswesens zuständig ist, geschlossen, daß ihm die Regelung der ärztlichen Berufsorganisation versagt sei (BVerfGE 4, 74 (83 ff), noch deutlicher in BVerfGE 7, 59(60)). 16) Vg1. Haas, a.a.O. S.99 und die das. S.97 (Fußn. 39) angegebenen weiteren Nachweise. S. ferner die Stellungnahme des Rechtsausschusses des Bundesrates zu dem Entwurf eines Gesetzes über die Selbstverwaltung der Landwirtschaft (Bundesratsdrucksache $\mathrm{Nr} .96 / 1 / 53$ und Verhandlungen des Bundesrates, 104. Sitzung vom 27. März 1953, Sitzungsber. S. $157 \mathrm{f}$ ).

17) Nichts anderes gilt von den von Schneider (Die öffentlichrechtliche Alterssicherung freier Berufe und das Grundgesetz, S. 59) als Beweis der Bundeszuständigkeit aus Art. 84 Abs. 1 GG angeführten Flurbereinigungs-Teilnehmergemeinschaften (Art. $74 \mathrm{Nr} .17$ u. $18 \mathrm{GG}$ ).

18) Die der Entwurf eines Bundessozialhilfegesetzes nun auch fallen 1äßt (s.o. S. 140 zu Fußn.2).

19) Ob sich daraus ein Bedenken gegen die gegenwärtige Regelung der $₫ \S 1$ ff der Fürsorgepflichtverordnung herleiten läßt, wie vereinzelt angenommen wird (Haas, a.a.O. S.99) kann aber nicht allein aus der aufgestellten These beantwortet werden. Die positivrechtliche Regelung dürfte vielmehr unbedenklich sein. Sie sagt nur, daß die Länder bestimmte Einheiten als Landes- oder Bezirksfürsorgeverbände zu erklären und die Stellen, die ihre Aufgaben und Befugnisse wahrnehmen, zu bezeichnen haben. Da für den Sachbereich "öffentliche Fürsorge" außer Zweifel steht, daß die Fürsorge einen bestimmten Verband als Träger haben muß und daß bestimmte Stellen für ihn handeln müssen, in den weiteren organisatorischen Details den Ländern jedoch nicht vorgegriffen wird, entspricht diese - der Sache nach gewiß äußerst zurückhaltende - bundes rechtliche Regelung nicht den aufgestellten Grundsätzen. 
fähiger Verwaltungseinheiten aus der Sachkompetenz und nicht aus Art.84, 85 GG, so entfällt damit auch der Zusammenhang zwischen der Bundeskompetenz und dem Verwaltungsvollzug von Bundesrecht, wie er für die Befugnisse aus Art. 84 Abs. 1 GG, 85 Abs. 1 GG besteht. Dem Bund ist es also nicht verwehrt, Selbstverwaltungskörperschaften einzurichten, deren Bundes rechtsvollzug sich in der Selbstverwirklichung, d.h. in der Selbstverwaltung erschöpft. Vorausgesetzt ist nur, daß die Selbstverwaltung in dieser reinen Form zum Gesetzgebungsbereich des Bundes gehört. 20)

Andererseits beschränkt sich die Bundeszuständigkeit nicht auf die Regelung der Einrichtung von Selbstverwaltungsverbänden. Wo sachlogische Zusammenhänge $z$ wischen dem vom Bunde zu regelnden Sachbereich und der (ganzen oder teilweisen) Durchführung der Regelung durch andere Verwaltungsträger bestehen, ist der Bund auch für die Einrichtung rechtsfähiger Verwaltungseinheiten zuständig, die nicht im engeren Sinne Selbstverwaltungsverbände sind. ${ }^{21}$ ).

20) So beanstandet Köttgen, Die Gemeinde und der Bundesgesetzgeber, S.88 (Fußn. 14), zu Unrecht, daß sich die in $\$ 1$ des Gesetzes zur vorläufigen Regelung des Rechts der Industrieund Handelskammern den Kammern gestellten Aufgaben nur schwerlich als Ausführung von Bundesgesetzen deuten ließen. Die Durchführung des Gesetzes realisiert eben im wesentlichen die Standesorganisation der Industrie und des Handels. Die Beanstandung Köttgens beweist, da die Bundeskompetenz zur Regelung des Industrie- und Handelskammerwesens vernünftigerweise nicht bestritten werden kann, nur einmal mehr, daß nicht Art. 84 Abs. 1, 85 Abs. 1 GG sondern der Sachkompetenzkatalog der Art. 73 ff GG der Sitz der Regelung ist.

21) (1) In das gegenteilige Extrem scheint vor allem Haas, Bundesgesetze über Organisation und Verfahren der Landesgesetze, S.98 f, verfallen zu sein, dessen Vorstellungen insoweit aber unk1ar bleiben. Fin Festhalten an organisatorischen Abgrenzungskriterien wie dem der Selbstverwaltung oder dem der körper'schaftlichen Struktur würde aber schon der Anknüpfung an die $\mathrm{S}$ a ch kompetenz widersprechen. Sie fordert, wenn sie schon zugrunde gelegt wird, den freien Lauf der Sachgesetzlichkeit. Abgesehen davon, würde die fragliche Beschränkung ganz eindeutig dem vorrechtlichen Gesamtbild widersprechen. Am drastischsten bezeugt dies der Beispielsfall der Sozialversicherungsträger. Der materiellen Bundeskompetenz des Art. 74 Nr.12 GG unterfallend, waren sie seit je (und sind sie noch) teils Anstalten, teils 
Neben diesen diversen Möglichkeiten des Bundes, auf Grund seiner Sachkompetenzen die Rechtsverhältnisse besonderer Verwaltungsträger zu regeln, die den Ländern inkorporiert sind, besteht die Befugnis des Bundes, auf der Grundlage des Art. 87 Abs. 3 Satz 1 GG bundesunmittelbare Verwaltungseinheiten zu schaffen. Die Akzente sind dabei - ganz abgesehen von den verschiedenen verfassungs rechtlichen Grenzen der Verwendbarkeit bundes - und landesinkorporierter Einheiten - verschieden gesetzt. Will der Bund eine bundesunmittelbare Körperschaft oder rechtsfähige Anstalt des öffentlichen Rechts errichten, so kann er dies, wenn der zu errichtende Verwaltungsträger auf einem Gebiet tätig werden soll, das der Gesetzgebungskompetenz des Bundes unterfällt (Art. 87 Abs. 3 Satz 1 GG). Will der Bund dagegen landesinkorporierte Verwaltungsträger anordnen, so steht

Körperschaften und war die dem Grundgesetz vorausliegende Entwicklung der Selbstverwaltung (einschließlich der Verbands - und Selbstverwaltungsbasis der Anstalten) keine einheitlich und eindeutig auf eine verbandliche und Selbstverwaltungsstruktur aller Sozialversicherungsträger zulaufende (Grundzüge s, bei Bogs, Entwicklungen und Rechtsformen der Selbstverwaltung in der Sozialversicherung, in "Gegenwartsfragen sozialer Versicherung", hrsg. v. Walter Bogs, 1950, S. 137 ff; Selpien, Die Selbstverwaltung in der Praxis der Versicherungsträger, ebd. S. 159 ff; s.a. die weiteren Beiträge und Diskussionsbeiträge ebd. S.169 ff). Näheres s. unten S. 244, insbes. Fußn. 10 (S. 245).

(2) In Frage kommt - neben der Verwaltung durch reine Selbstverwaltungskörperschaften - die Verwaltung durch Anstalten, denen zwar eine verbandliche Gestalt gegeben sein kann, die im engeren Sinne jedoch immer im Gegensatz zur Körperschaft stehen. Ihnen kann jeglicher Selbstverwaltungscharakter fehlen. Dennoch können sie die kompetenzgerechte Regelung darstellen. Zu denken ist auch an die sog. Le itungs - (Lenkungs-) ve rbände (zu ihnen s. z. B. Forsthoff, Lehrbuch des Verwaltungsrechts, S. 427 f, m.w. Nachweisen), denen ebenfalls der Selbstverwaltungscharakter fehlt. Dagegen wird die Einrichtung rechtsfähiger Behörden (s.o. S. 143 zu Fußn. 5 und den 'Text hierzu) wohl in keinem Falle aus der Sachkompetenz abgeleitet werden können. Fraglich ist aber auch, ob sie unter Art. 84 Abs.1, 85 Abs. 1 GG fällt. Das mag hier dahinstehen. Sollte der Bund außerstande sein, den Ländern Produkte dieses verwaltungssystematischen Wildwuchses einzupflanzen, so bräuchte das wohl niemand zu bedauern. 
ihm eine entsprechende, generelle Kompetenz hierzu nicht zu. Nicht einmal die Art. 84 Abs. 1, 85 Abs. 1 könnten, würden sie die Regelung der Einrichtung rechtsfähiger, landesinkorporierter Verwaltungseinheiten erlauben, als gleichwertige Kompetenzgrundlage angesehen werden; denn sie lassen die Regelung der Behördeneinrichtung durch den Bundesgesetzgeber nur im $\mathrm{Zu}$ sammenhang mit einem bestimmten Vollzugsauftrag 22) zu, was Art. 87 Abs. 3 Satz 1 GG auch dann nicht in gleicher Weise voraussetzt, wenn diese Kompetenz davon abhängig ist, daß der Bund auf dem fraglichen Sachgebiet nicht nur gesetzgeberisch tätig werden kann sondern auch schon gesetzgeberisch tätig geworden ist. 23) Muß der Bund aber nicht nur die Akzessorietät zu einem Vollzugsauftrag wahren sondern die Organisationskompetenz aus der Sachkompetenz deduzieren können, so ist die Grenze noch enger gezogen.

4. Organisationskompetenz für die Behörden rechtsfähiger Verwaltungseinheiten. Berechtigen somit die Art. 84 Abs.1, 85 Abs. 1 GG den Bund nicht, die Einrichtung rechtsfähiger Verwaltungseinheiten an sich zu regeln, so sind diese Verfassungsbestimmungen für die mittelbare Landesverwaltung doch nichts weniger als bedeutungslos. Sie beziehen sich nicht nur auf die Behörden der unmittelbaren Staatsverwaltung sondern auch auf die der rechtsfähigen Verwaltungsträger. Das ergibt sich aus dem allgemeinen Begriff der Behörde.24) Es ergibt sich ebenso aus dem in Art. 86 Satz 2 GG zum Ausdruck gekommenen Sprachgebrauch des Grundgesetzgebers. Wenn die Art. 84 Abs. 1, 85 Abs. 1 GG die Behörden der mittelbaren Staatsverwaltung nicht entsprechend dem Art. 86 GG besonders erwähnen, so hat das seinen Grund darin, daß für die Landesverwaltung eine ausdrückliche Erwähnung der mittelbaren Staatsverwaltung in den Art. 83 - 85 GG durchwegs fehlt. Die Art.83 - 85 GG sprechen die Länder in ihrer Gesamtheit an, in die auch die Verwaltung durch rechtsfähige Verwaltungseinheiten gehört. ${ }^{25}$ )

22) Zur strengen Akzessorietät der Befugnisse aus Art.84 Abs. 1, 85 Abs. 1 GG s. vor allem Köttgen, Kommunale Auftragsverwaltung und Grundgesetz, S. 347; ders., Die Einflußnahme des Bundes auf die deutsche Verwaltung, S.91; ders., Die Gemeinde und der Bundesgesetzgeber, S. 77; Rohwer-Kahlmann, Verfassungs rechtliche Schranken der Zustimmungsgesetze, S. $221 \mathrm{f}$.

23) S. oben S. 85 zu Fußn. 1.

24) S. nochmals oben S. 143 zu Fußn. 4. 
Indem sich die Art.84 Abs.1, 85 Abs. 1 GG auf die Behörden der rechtsfähigen Verwaltungseinheiten erstrecken, ergibt sich eine lückenlose Organisationskompetenz, wo dem Bunde auch die Sachkompetenz, einschließlich der Befugnis, die Einrichtung rechtsfähiger Verwaltungseinheiten zu regeln, zusteht. 26) Umgekehrt ist eine Divergenz der Organisationskompetenz dort ausgeschlossen, wo die Einrichtung rechtsfähiger Verwaltungseinheiten schon von der Sache her unmöglich ist. Die Differenz wird dort fühlbar, wo dem Bunde die entsprechende, die Einrichtung rechtsfähiger Verwaltungsträger einschließende Sachkompetenz fehlt. Hier dürfen die Bestimmungen des Bundes über die Behördeneinrichtung nicht zu einer Beeinträchtigung der Gestaltungsfreiheit der Länder führen. Wo die Länder entsprechende Verwaltungseinheiten nicht errichtet haben, dürfen sie nicht über Art. 84, 85 GG vom Bund dazu gezwungen werden. Wo der Bund die Existenz entsprechender Verwaltungseinheiten tats ächlich oder rechtsnotwendig voraussetzen kann, darf er nicht mehr in die Organisationskompetenz der Länder eingreifen als das jeweils der in Frage stehende Vollzugsauftrag erfordert. 27)

5. Der sachlich beschränkte Vollzugsauftrag. Noch nicht abschließend beantwortet ist damit die Frage, ob der Bundesgesetzgeber befugt ist, landesinkorporierten Verwaltungseinheiten, die als solche nicht zu seiner Disposition stehen, definitive Vollzugsaufträge zu erteilen. Sie muß bejaht werden, soweit es dem Wesen der Aufgabe und dem Wesen der Verwaltungseinheit entspricht, daß jene durch diese wahrgenommen wird. Im übrigen ist sie zu verneinen. Aus Art. 84 Abs. 1, 85 Abs. 1 GG 1äßt sich eine allgemeinere Bundeskompetenz nicht herleiten. Die rechtsfähige Verwaltungseinheit ist keine "Behörde". Auch wenn der Vollzugsauftrag als die Abbreviatur eines an die Behörden der fraglichen Verwaltungseinheit gerichteten Vollzugsauftrages verstanden wird, kann nicht übersehen werden, daß er den Aufgabenkreis der Verwaltungseinheit verändert. Schließlich versch1ägt auch die Erwägung nicht, daß der Bundesgesetz-

25) Grundlegend zur Eingliederung der besonderen Verwaltungseinheiten in die Staatsverwaltung Forsthoff, 1)ie öfentliche Körperschaft im Bundesstaat, insbes. S. $28 \mathrm{ff}$.

26) Dabei ist zu beachten, daß die Kompetenz aus Art. 84 Abs.1, 85 Abs. 1 GG immer eine konkurrierende ist, während die Sachkompetenz des Bundes eine ausschließliche, konkurrierende oder Rahmenkompetenz sein kann.

27) S. oben S. 151 zu Fußn.22. - Zu weitgehend Schneider, Die öfentlichrechtliche Alterssicherung freier Berufe und das Grundgesetz, S. 59 . 
geber, indem er die Einrichtung der Behörden regeln kann, diese so gestalten kann, daß sie nach Struktur und Stellung denen der parallel gedachten rechtsfähigen Verwaltungseinheiten weitestgehend gleichen. Immer können nur Behörden (als solche) und nicht Verwaltungseinheiten (als solche) geschaffen werden. Die Abgrenzung des Aufgabenkreises der rechtsfähigen Verwaltungseinheiten ist nicht eine Frage der organisatorischen Kompetenz - im speziellen Sinne der Art. 84 Abs. 1 und 85 Abs. 1 GG - sondern der Sachkompetenz.28) Liegt diese, wie eingangs unterstellt, hinsichtlich der Einrichtung gewisser Verwaltungseinheiten bei den Ländern, so muß der Bund in Ausübung seiner Organisationskompetenz daran anknüpfen, wie die Länder die Aufgaben verteilt haben; (ebenso wie die Länder die Aufgabenverteilung, die der Bund auf Grund seiner Sachkompetenz vornimmt, zu respektieren haben, soweit sie selbst noch über die Behördeneinrichtung bundesrechtlich eingerichteter Verwaltungs einheiten disponieren können). Diese Sachkompetenz ist im Prinzip unteilbar. Hinsichtlich der Aufgabenzuweisung ist sie es jedoch nicht notwendigerweise. Dem Bund können Sachregelungen zustehen, deren Vollzug wesensmäßig Verwaltungseinheiten zukommt, die hinsichtlich ihrer allgemeinen Gestaltung in die (ausschließliche) Landeskompetenz fallen. Sinnvoll ist das im allgemeinen jedoch nur dann, wenn die Kompetenzordnung davon ausgehen kann, daß die fraglichen Verwaltungseinheiten auch wirklich bestehen, wenn die Länder also entweder rechtlich oder tatsächlich gehindert sind, sie $\mathrm{nicht}$ $\mathrm{zu}$ errichten. 29)

Entsprechende Grundsätze müssen für den bundesgesetzlichen Ausschluß rechtsfähiger Verwaltungseinheiten vom Vollzug vom Bundesrecht gelten. ${ }^{30)}$

6. Zur Exemplifikation der Problematik am Kommunalverfassungsrecht. Die Probleme, die sich aus diesen Grundregeln im einzelnen ergeben, hier erschöpfend zu behandeln, ist weder möglich noch veranlaßt. Angedeutet müssen sie jedoch werden. Sie treten im besonderen hervor hinsichtich

28) In diesem Zusammenhang ist noch einmal auf die bedingte Parallele des Art. 86 GG zu verweisen. Art. 86 GG regelt die Behördeneinrichtung (auch für die besonderen Verwaltungseinheiten). Die Finrichtung der besonderen Verwaltungseinheiten ist dagegen in Art. 87 ff geregelt.

29) Zur praktischen Beschränkung des Problems auf das Kommunalrecht s. unten 6. Nachweise s. S. 154 zu Fußn. 33

30) Zum Kommunalrecht s. die Nachweise S. 155 Fußn. 34. 
der Gemeinden und Gemeindeverbände. ${ }^{31)}$ Ihre Existenz als landesinkorporierte, rechtsfähige Verwaltungseinheiten kann der Bund nach Art.28 Abs.2 GG voraussetzen. Ihre Rechtsverhältnisse kann er aber - von Art. $75 \mathrm{Nr} .1$ GG und noch allgemeineren Regelungszusammenhängen abgesehen - nicht regeln. Die Probleme des Spannungsverhältnisses zwischen Bundesgesetzgebung und Kommunalrecht sind daher prototypisch für die durch das Auseinanderklaffen der Kompetenz zur Einrichtung der Behörden der Landesverwaltung und zur Regelung der Rechtsverhältnisse der landesinkorporierten, rechtsfähigen Verwaltungseinheiten potentiell angelegten Konfliktslagen.

Das Problem der Zulässigkeit des sachlich beschränkten bundesgesetzlichen Vollzugsauftrages ${ }^{32}$ ) verengt sich von vorneherein auf die Gemeinden und Kreise. Sie sind die einzigen landesinkorporierten und - im Prinzip - der Landeskompetenz unterstehenden Verbände, deren Bestand bundesverfassungsrechtlich gesichert ist (Art.28 GG) und überdies wohl auch tatsächlich-politisch nicht in Frage gestellt werden kann, deren umfassender Wirkungskreis einer Ausgliederung besonderer Kompetenzzuweisungsfelder Raum läßt und die ihrem Wesen nach entsprechend verschiedenartige Aufgaben aufnehmen können. Für sie wird die bundesgesetzliche Zuweisung von Aufgaben daher in Betracht kommen. ${ }^{33)}$

31) Aus der umfangreichen Literatur zu dem Problemkreis seien hier insbes. genannt: Köttgen, Kommunale Auftragsverwaltung und Grundgesetz; ders., Die Gemeinde und der Bundesgesetzgeber; Bleek, Bundesebene, 1953; Kessler, Der Bund und die Kommunalpolitik, DVBl. 68.Jhg. (1953) S. 1 ff; Böhm, Rechtsprobleme der Gesetzgebungszuständigkeit des Bundes, DVB1. ebd. S.321 ff (insbes. S. 324); Forschbach, Grundsätzliche Erwägungen zum Flüchtlingsnotleistungsgesetz, DVB1. ebd. S.331 f; Rohwer-Kahlmann, Verfassungsrechtliche Schranken der Zustimmungsgesetze, insbes. S. $221 \mathrm{f}$; Haas, Bundesgesetze über Organisation und Verfahren der Landesbehörden, insbes. S.95 f; G. Küchenhoff, Bund und Gemeinde, BayVB1. n.F. 4.Jhg. (1958) S. 65 ff, 110 ff; von Hausen-von der Heide, Die rechtliche und funktionelle Bedeutung der Art. 84 und 85 GG, DÖV 11.Jhg. (1958) S. 753 ff; von Hausen, Nochmals: Die Zuständigkeit des Bundesgesetzgebers aus Art. 84 und 85 GG, DÖV 13.Jhg. (1960) S. 1 ff; ders., Zur Diskussion über die Bundeszuständigkeit aus Art. 84 und 85 GG, ebd. S. 441 ff; Schäfer, Die Bundesauftragsverwaltung, S. 647 .

32) S. oben S. 152.

33) Das Schrifttum hat sich leider mit den notwendigen Differen- 
Entsprechendes gilt für den bundesgesetzlichen Ausschluß der Gemeinden und Gemeindeverbände vom Vollzug des Bundesrechts. ${ }^{34)}$

Wie dargetan, kann der Bund, nachdem auch die Behörden besonderer Verwaltungsträger "Behörden" i.S. der Art.84 Abs. 1, 85 Abs. 1 GG sind, über die innere Zusammensetzung der am Vollzug beteiligten Behörden ohne Rücksicht darauf disponieren, ob die Aufgabe der unmittelbaren oder mittelbaren Staatsverwaltung übertragen ist. ${ }^{35)}$ Er kann daher dort, wo er einen Vollzugsauftrag unmittelbar an die Gemeinden oder Gemeindeverbände richten kann, in deren Verfassungsrecht eingreifen. Er kann ferner dort, wo er den Ländern die Disposition über die Zuweisung an die unmittelbare oder mittelbare Staatsverwaltung vorbehalten muß, die Übertragung an kommunale Behörden von ihrer besonderen Ausgestaltung abhängig machen. ${ }^{36)}$ Er muß sich dabei nur

zierungen noch nicht hinreichend befaßt. Einhellig wird angenommen, daß grundsätzlich (primär) die Länder darüber entscheiden, welche Vollzugsaufgaben den Gemeinden - die Kreise werden meist nicht erwähnt - zukommen (vgl. Haas, Bundesgesetze über Organisation und Verfahren der Landesbehörden, S.96; Köttgen, Die Gemeinde und der Bundesgesetzgeber, S.22, 72, 74, 78). Ganz überwiegend wird aber auch eine konkurrierende Zuständigkeit des Bundes angenommen, den Gemeinden - immer unter Anlehnung an eine entsprechende Sachkompetenz des Bundes, die ja auch sub specie der Art. 84 Abs. 1, 85 Abs. 1 GG nicht fehlen darf - gewisse Aufgaben zuzuweisen (Köttgen, Kommunale Auftragsverwaltung und Grundgesetz, S. 347 f; ders., Die Gemeinde und der Bundesgesetzgeber, S. 72 ff, 78; Kessler, Der Bund und die Kommunalpolitik, S.4; v. Hausen, Nochmals: Die Zuständigkeit des Bundesgesetzgebers aus Art. 84 und 85 GG; ders., Zur Diskussion über die Bundeszuständigkeit aus Art. 84 und 85 GG; s.a. den bei v. Hausen (Zur Diskussion usw. S. 441) wiedergegebenen Beschluß der Kommission des Rechtsausschusses des Bundes rats. A. A. Haas, a. a.O. S.95).

34) Für die Befugnis des Bundes, die Gemeinden vom Vollzug in gewissen Angelegenheiten auszuschließen: Köttgen, Die Gemeinde und der Bundesgesetzgeber, S. 76; Helmreich-Widtmann, a.a.O. - Dagegen: Haas, a.a.O. S.95 f.

35) S. oben S. 151.

36) Im Schrifttum wird die Befugnis des Bundes, in das Kommunalverfassungs recht - unter Wahrung der Akzessorietät zu bundes rechtlichen Vollzugsaufträgen - einzugreifen, teils bejaht (Kessler, Der Bund und die Kommunalpolitik, S.4; 
immer in den Grenzen der Akzessorietät zu dem Vollzugsauftrag halten, da ihm ein Mandat, die Organisation des besonderen Verwaltungsträgers $\mathrm{zu}$ regeln,im übrigen feh1t. ${ }^{37)}$

Ein besonders wichtiger aber auch schwieriger Schnittpunkt der gegenläufigen Kompetenzen des Bundes und der Länder ist der Sitz der Zuständigkeit, die Aufsichtsbefugnisse zu regeln, insbes. die Frage zu entscheiden, ob die Behörden des rechtsfähigen Verwaltungsträgers mit der hierarchisch-staatlichen Verwaltung durch deren Rechts-oder auch durch deren Ermessensaufsicht verbunden sein sollen. Daß die Entscheidung über das Maß an Unabhängigkeit, das selbständigen Verwaltungsträgers zukommen soll, grundsätzlich eine Frage ist, die der Gesamtregelung der Rechtsverhäitnisse eben des selbständigen Verwaltungsträgers als solchem angehört, dürfte außer $Z$ weifel stehen. ${ }^{38)}$ Anderer-

Forschbach, Grundsätzliche Erwägungen zum Flüchtlingsnotleistungsgesetz, S.332; Bleek, Aktuelle Fragen der Kommunalpolitik in der Bundesebene, S. $7 \mathrm{f}$; Köttgen, Die Gemeinde und der Bundesgesetzgeber, S. 89 ff; von Hausen-von der Heide, Die rechtliche und funktionelle Bedeutung der Art. 84 und 85 GG, insbes. S. 755; Schäfer, Zehn Jahre Grundgesetz, DVB1. 74.Jhg. (1959), S. $341 \mathrm{ff}$ (343); ders., Die Bundesauftragsverwaltung, S.647; von Hausen, Nochmals: Die Zuständigkeit des Bundesgesetzgebers aus Art. 84 und 85 GG; ders., Zur Diskussion über die Bundeszuständigkeit aus Art. 84 und $85 \mathrm{GG}$ ), teils jedoch verneint (Böhm, Rechtsprobleme der Gesetzgebungszuständigkeit des Bundes, S. 324; RohwerKahlmann, Verfassungs rechtliche Schranken der Zustimmungsgesetze, S.221; Maunz, Deutsches Staatsrecht, S. 174; $\mathrm{s}$. ferner die Mehrheit der zuständigen Kommission des Rechtsausschusses des Bundes rates, zit. bei von Hausen, Zur Diskussion usw., S.441).

37) S. nochmals insbes. Köttgen, a.a.O.

38) Am entschiedensten zum Ausdruck kommt das hinsichtlich jener Grenzfälle der Körperschaft bzw. Anstalt des öffentlichen Rechts, die einen dieser Namen führen, ohne der weithin als begrifflich eingeschlossenen Hypothek der Staatsaufsicht zu unterliegen, der Kirchen und der Rundfunkanstalten. Wer die Zuständigkeit zur Regelung des Rundfunkwesens hat, kann auch die Rundfunktanstalten, die heute wohl nach herrschender Ansicht (und vor allem nach der gefestigten Praxis der Nachkriegszeit) keiner Staatsaufsicht im herkömmlichen Sinn unterliegen müssen sondern in einer - durch die Rundfunkräte und Verwaltungsräte und durch Ernennungs rechte hergestellten - organischen Verbindung zum Gesamtstaats- 
seits aber gehört zur Regelung der Einrichtung der Behörden wie die Ausführungen über das Ausschußwesen gezeigt haben auch die Ordnung der Aufsichts- und Weisungs rechte, denen eine Behörde unterworfen sein soll. Da die "Behörden" i.S. der Art. 84 Abs. 1, 85 Abs. 1 GG alle Landesbehörden, also mittelbare und unmittelbare sind, gehört zu den aus diesem Bestimmungen flieBenden Regelungskompetenzen auch die zur Entscheidung über die Abhängigkeit der Behörden eines rechtsfähigen Verwaltungsträgers gegenüber den staatlichen Behörden. Auch hier ist jedoch, soll die Zuständigkeit zur Ordnung der Gesamtverhältnisse des Verwaltungsträgers nicht verletzt werden, die strenge Akzessorietät zum jeweiligen Verwaltungsauftrag zu wahren. Auch hier wird es sich ferner, da der Bund einen definitiven Vollzugsauftrag an die landesinkorporierten Verwaltungseinheiten nur in Ausnahmefällen erteilen kann, in der Regel nur um bedingende Auflagen handeln, die die Länder, wollen sie das ihnen nach Art. 83 ff GG zustehende Vollzugsgeschäft auf rechtsfähige Verwaltungseinheiten übertragen, einhalten müssen. ${ }^{39)}$ In diesem Rahmen dürfte es auch zulässig sein, daß der Bund Vollzugsaufträge an Gemeinden dem eigenen oder übertragenen Wirkungskreis zuweist. ${ }^{40)}$ Dabei darf nicht übersehen werden, daß gerade diese Unterschei-

wesen stehen können (wie sie übrigens ähnlich bei der Bundesnotenbank verwirklicht ist), mit der aufsichtslosen Selbständigkeit ausstatten. Das ergäbe sich - gerade das Beispiel des Rundfunkwesens dürfte das sehr plausibel verdeutlichen - dann aus der Sachkompetenz zur Regelung des Rundfunkwesens. Hier aus Art.84 Abs.1 GG heraus irgendwelche generelle Abweichungen zuzulassen, verbietet sich.

39) So meint Köttgen (Die Gemeinde und der Bundesgesetzgeber, S.76), der Bund könne die Aufgabenübertragung auf die Gemeinden davon abhängig machen, daß die Gemeinden sie in voller Weisungsgebundenheit zu erledigen haben.

40) Für die Zulässigkeit der Zuweisung eigener, d.h. im Ermessensbereich weisungsfreier Aufgaben (Selbstverwaltungsaufgaben) einerseits und übertragener, d.h. auch im Frmessensbereich weisungsgebundener Aufgaben andererseits: Köttgen, Kommunale Auftragsverwaltung und Grundgesetz, S.324; Kessler, Der Bund und die Kommunalpolitik, S.4; Böhm, Rechtsprobleme der Gesetzgebungszuständigkeit des Bundes, S. 324; Bleek, Aktuelle Fragen der Kommunalpolitik auf Bundesebene, S. 6 f; Schäfer, Die Bundesauftragsverwaltung, S.647; von Hausen, Nochmals: Die Zuständigkeit des Bundesgesetzgebers aus Art. 84 und 85 GG; ders., Zur Diskussion über die Bundeszuständigkeit aus Art. 84 und 85 GG. 
dung an die sachliche Struktur der betreffenden Verwaltungseinheit rührt. Die Befugnis aus Art. 84 Abs.1, 85 Abs. 1 GG wird also auf Grenzen stoßen, die sich sowohl aus der Sachkompetenz als auch - wie vor allem in bezug auf die Gemeinden und Gemeindeverbände (Art.28 GG) - aus den eigentlich sachregelnden Normen der Verfassung ergeben können. Spezifische Grenzen ergeben sich weiter gerade insofern aus Art.84 Abs.1, 85 Abs.1 GG selbst. Der Bund darf dem Land die Rechtsaufsicht über die Behörden der rechtsfähigen Verwaltungseinheiten nicht entziehen, damit das Land seinen sich aus Art.84 GG ergebenden Verpflichtungen gerecht werden kann. Er darf im Rahmen der Auftragsverwaltung den Ländern auch nicht die Möglichkeit nehmen, die Weisungen des Bundes voll, also auch im Ermessensraum, durchzusetzen. 41) Die Gründe dafür sind dieselben, wie die hinsichtlich der Ausschüsse ausgeführten. Es darf darauf verwiesen werden.

Eine wiederum gerade im sozialen Bereich besonders häufige Verbindungs- oder Übergangsform zwischen dem Vollzugsauftrag an landesinkorporierte Körperschaften und der Regelung der Behördeneinrichtung besteht schließlich darin, daß die Gemeinden oder Gemeindeverbände zum Vollzug von Bundesrecht in der Weise herangezogen werden, daß ihnen die Wahl von Beisitzern zu Ausschüssen der sozialen Verwaltung übertragen wird.

So die Wahl der Beisitzer zu den Ausgleichsausschüssen und zu den Beschwerdeausschüssen der Lastenausgleichsverwaltung ( $\$ \$$ 309 Abs.4, 310 Abs. 3 LAG) und zu den Ausschüssen zur Durchführung des Kriegsgefangenenentschädigungsgesetzes ( $\$ \$ 12$ Abs. 4, 19 Abs. 3 KgfEG); s.a. die Nomination der Vertreter der öffentlichen Körperschaften in den Gremien der Bundesanstalt für Arbeitsvermittlung und Arbeitslosenversicherung ( $\$ 12 \mathrm{Abs} .3$ und

A. A. Laforet (Verwaltung und Ausführung von Gesetzen nach dem Bonner Grundgesetz, S. 222), Wessel (Verwaltung, S. 327), Rohwer-Kahlmann (Verfassungsrechtliche Schranken der Zustimmungsgesetze, S.221 f) und Maunz (Deutsches Staatsrecht, S. 174); die Mehrheit der zuständigen Kommission des Rechtsausschusses des Bundesrates (s. von Hausen, Zur Diskussion usw., S.441).

41) Vgl. Schäfer, Die Bundesauftragsverwaltung, S.647. - Umgekehrt dürfen die Länder, wenn sie die Gemeinden in Auftragsangelegenheiten (Art.85 GG) am Vollzug beteiligen, sich nicht der Weisungsmöglichkeiten begeben, die sie haben müssen, um den Ermessensweisungen des Bundes nachkommen zu können. Eine Übertragung als "eigene Angelegenheit" - ohnedies fast eine contradictio in adiecto - wird daher schlechthin ausscheiden (vgl. Köttgen, Die Gemeinde und der Bundesgesetzgeber, S. $78 \mathrm{f}$ ). 
4 AVAVG).

Die Bundeskompetenz, dies anzuordnen, kann wohl als Regelung der Behördeneinrichtung gerechtfertigt werden. Die Ausschüsse, in die die Gemeinden wählen bzw. für die sie nominieren, sind Behörden, über deren Zusammensetzung der Bund nach Art. 84 Abs.1, 85 Abs.1 GG entscheiden kann. Eine über die Mitwirkung an der Bildung der Ausschüsse hinausgehende Beteiligung am Gesetzesvollzug ist nicht vorgesehen. Dieses unmittelbare mit der Behördeneinrichtung zusammenhängende Minimum auch in bezug auf die Gemeinden zu regeln, muß aus Art. 84 Abs.1, 85 Abs. 1 GG dem Bund zugestanden werden. Sonst ergäbe sich eine - sicher nicht im Sinne dieser Vorschriften liegende - unsystematische, sachliche Beschränkung der Art und Weise, in der der Bund die Einrichtung der Behörden regeln kann. Die Gemeinde und $\mathrm{Kreisvertretungen} \mathrm{sind} \mathrm{die} \mathrm{verfassungs} \mathrm{rechtlich} \mathrm{verbürgte}$ Unterstufe der Demokratie (Art. 28 Abs. 1 Satz 2 GG), auf die zurückzugreifen dem Bundesgesetzgeber nicht verwehrt werden kann.

7. Abschließende Bemerkungen. Zusammenfassend kann gesagt werden: Die Art.84, 85 GG geben dem Bund keine Möglichkeit, aus den Ländern rechtsfähige Verwaltungseinheiten auszugliedern und dadurch den Einfluß des Gesamtverbandes auf die Verwaltungserledigung zu mindern. Möglichkeiten in dieser Richtung ergeben sich für den Bund nur aus der Sachkompetenz. Da die Sachkompetenz des Bundes in sozialen Angelegenheiten äußerst umfangreich ist und wegen des wesensmäßigen Zusammenhanges zwischen den Veranstaltungen staatlicher, sozialer Intervention und dem technischen Mittel der rechtsfähigen Verwaltungseinheit in hohem Maße auch die Befugnis zur Einrichtung selbständiger Verwaltungseinheiten umfaßt, ist diese Kompetenzgrundlage allerdings in vielen Fällen gegeben. Andererseits ist aber in dieser Befugnis des Bundes nur bedingt ein Schwund der eigenen Organisationshoheit zu sehen; denn, da die Heranziehung rechtsfähiger Verwaltungseinheiten sachgegeben sein muß, wären in der Regel der Fälle die Länder - wollen sie nicht sachwidrig vorgehen - selbst gezwungen, rechtsfähige Verwaltungseinheiten einzurichten, soweit sie selbst die gleichen sachlichen oder organisatorischen Fragen zu regeln hätten. Der Schwund eigenstaatlicher Organisationshoheit ist weniger in dem "ob" der Einrichtung landesinkorporierter Verwaltungseinheiten zu sehen sondern in der entsprechenden Befugnis des Bundes, diese Verwaltungseinheiten in ihrer inneren Struktur und ihren Verbindungsfäden zum Staat und den übrigen innerstaatlichen Verbänden usw. zu definieren. Die Art. 84 Abs. 1 und 85 Abs. 1 GG geben anderer- 
seits dem Bund das Recht, über die Einrichtung nicht nur der unmittelbaren sondern auch der mittelbaren Landesbehörden zu verfügen. Insofern ist also die Bundeskompetenz durch die weitreichende Verwendung rechtsfähiger Verwaltungseinheiten und die teils ausschließlichen Gesetzgebungskompetenzen der Länder in bezug auf diese weder erweitert noch geschmälert.

\section{dd) Die körperschaftliche Verbundverwaltung}

Abschließend ist nun noch auf eine neue Erscheinungsform der Mischverwaltung auf dem Wege über die Verwaltung durch rechtsfähige Verwaltungseinheiten wenigstens hinzuweisen. Schon zu Anfang dieses Exkurses 1 ) war darauf aufmerksam gemacht worden, daß die Heranziehung von Körperschaften und Anstalten derzeit im allgemeinen nicht mehr Probleme der Mischverwaltung in jenem technischen Sinne, der ein administratives Zusammenwirken von Zentralstaat und Gliedstaaten ausdrückt, mit sich bringt. Während nun aber die kombinierte Einwirkung von Zentralstaat und Gliedstaaten auf ein- und dieselbe Verwaltungseinheit heute bedeutungslos geworden ist, hat sich eine neue Form der Mischverwaltung herausgebildet: die körperschaftliche Verbundverwaltung. ${ }^{2}$ Sie ist dadurch gekennzeichnet, daß eine Verwaltungsauf-

1) S. oben S. 125 .

2) (1) Die bisher eingehendste Untersuchung, die allerdings durch eine Reihe nicht zu billigender Prämissen beeinträchtigt ist, ist die schon zitierte Abhandlung "Körperschaftliche Verbundverwaltung" von Schneider (s. diesen nunmehr auch: Die öffentlichrechtliche Alterssicherung freier Berufe und das Grundgesetz, S.61 f). Von ihr ist auch der Terminus "körperschaftliche Verbundverwaltung" übernommen, der an sich zu eng ist, da er durch Gebrauch des Wortes "körperschaftlich" die entsprechende Form "anstaltlicher" Verwaltung auszuschließen scheint. Nun wäre allerdings eine anstaltliche Verbundverwaltung nicht weniger denkbar als eine körperschaftliche. Sie würde, indem sie z. B. nicht etwa auf besonderen, in Körperschaften zusammengefaßten Gemeinden aufbaut sondern unverbrämt nur auf Bund und Ländern als 'Träger der Sonderverwaltung, sogar eine reinere Form der Mischverwaltung darstellen als die "körperschaftliche". Aber gegenwärtig findet sich dieser Typ der Mischverwaltung nur im körperschaftlichen Rahmen verwirklicht.

(2) Zur körperschaftlichen Verbundverwaltung haben sich früher schon - im wesentlichen negativ - Köttgen ("Föderalismus und Dezentralisation in der. Bundes republik Deutschland" in Deutsche Landesreferate zum IV. Internat. Kongreß für 
gabe durch eine Vielheit landesinkorporierter Verwaltungseinheiten und eine bundesunmittelbare Verwaltungseinheit gemeinsam erledigt wird, wobei die letztere im Regelfalle als Dachverband über den landesinkorporierten Verwaltungseinheiten steht. Diese Verwaltungsform, bei der der Einfluß des Bundes auf die Verwaltungserledigung im Raum des Landes nicht über die verfassungsmäßig in Art. 84, 85 GG vorgesehenen Kanäle verläuft sondern zunächst über die Einflußnahme des Bundes auf die bundesunmittelbare Verwaltungseinheit und von dieser - ohne die (parlamentarische) Exekutivspitze der Länder zu durchlaufen - unmittelbar auf die landesinkorporierten Körperschaften $z u$, hat ihre mit Abstand umfassendste Anwendung bisher gerade im sozialen Bereich gefunden.

(1) Am ältesten und entwickeltsten ist die körperschaftliche Verbundverwaltung wohl im Bereich der Krankenversicherung, wo auf der Versicherungsseite neben den Krankenkassen und den landesinkorporierten Kassenverbänden die Bundesverbände der verschiedenen Arten von Krankenkassen bestehen (vgl. für den heutigen Rechtszustand: das Bundesgesetz über die Verbände vom 17. August 1955, BGB1. I S.524, und die $\$ \$ 406$ ff RVO), während auf der Ärzteseite neben den landesinkorporierten kassenärztlichen Vereinigungen auch die kassenärztlichen Bundesvereinigungen am Vollzug des Krankenversicherungs rechts teilnehmen (vgl. für den derzeitigen Rechtszustand: das Gesetz über Kassenarztrecht und die $\$ \$ 368$ ff $R V O)$.

(2) Auf dem Gebiete des Kindergeldrechts wurde neben den Familienausgleichskassen ( $\$ \$ 15 \mathrm{ff}$ ), die - je nach dem Zuständigkeitsbereich der Berufsgenossenschaft, der sie angeschlossen sind ( $\$ 16$, a.a.O.; Art.87 Abs.2 GG) - teils landesinkorporiert, teils bundesunmittelbar sind, der bundesunmittelbare Gesamtverband der Familienausgleichskassen eingerichtet ( $\$ \$ 19$ ff des Kindergeldgesetzes). ${ }^{3)}$

(3) Der bisher wohl jüngste Fall findet sich im Gesetz über eine Altershilfe für Landwirte. Die bei den landwirtschaftlichen

Rechtsvergleichung in Paris, 1955, S.298 (Anm.55a); Der Einwand der Mischverwaltung und das Grundgesetz, DÖV 8. Jhg. (1955) S. 485 ff (491)) und Gerner (Zur Frage der Mischverwaltung im Verhältnis zwischen Bund und Ländern, BayVB1. n. F. 1 (1955) S. 193 ff (195)) geäußert.

3) Zur Verfassungsmäßigkeit dieser Vorschriften s. BSGE 6, 213 (238), 238 (243); BayLSG Urt.v. 18. Nov.1957, Breithaupts Sammlung von Entscheidungen, 47.Jhg. (1958), S.322 (324); weitaus zurückhaltender dagegen BVerfGE 11, 105 (123 ff). 
Berufsgenossenschaften errichteten und daher wie sie entweder landesinkorporierten ode $r$ bundesunmittelbaren landwirtschaftlichen Aiterskassen ( $\$ \$ 11 \mathrm{f}$ ) sind in dem bundesunmittelbaren Gesamtverband der landwirtschaftlichen Alterskassen zusammengeschlossen ( $\$ \$ 16 \mathrm{ff}) .4$ )

Das Problem der körperschaftlichen Verbundverwaltung ist wie allgemein zutreffend erkannt wird - ein Spezialproblem der Mischverwaltung. Die Grundsätze über die Mischverwaltung erfordern eine saubere, sachliche Trennung der Verwaltungsaufgaben zwischen Bund und Ländern. Ein Komplex von Verwaltungsaufgaben darf nicht zur funktionell verzahnten, gemeinsamen Erledigung Bund und Ländern zugewiesen werden. ${ }^{5)}$ Das würde zur Vermengung der Verantwortlichkeiten führen und somit dem föderalistischen Gedanken, der Bund und Länder als selbständige, jeweils staatliche Entscheidungseinheiten postuliert, widersprechen. Ihm ist nicht dadurch genügt, daß die Länder und der Bund an der Erledigung möglichst vieler Verwaltungsaufgaben beteiligt werden. 5a) Auf den Bahnen der Mischverwaltung würde der Bundesstaat im - oberflächlich - kompliziert organisierten Einheitsstaat enden.

Eine sachliche Aufgabenteilung ist jedoch nicht ausgeschlossen. Daß diese nicht ins Miniaturformat gehen soll, ist zwar selbstverständlich, im Grunde aber nur eine rechtspolitische Forderung. Die Untergrenze des Ineinanders und Nebeneinanders von Bundes - und Landesverwaltung läßt sich nicht quantitativ bestimmen sondern nur qualitativ: danach, ob eine sachliche Aufteilung möglich ist. Wo immer noch das Urteil möglich bleibt, daß die eine Verwaltungsaufgabe der Bund, die andere die Länder wahrnehmen, ist bei aller sonstigen, sachlichen, systematischen oder

4) Zur Verfassungsmäßigkeit dieser Vorschriften s. insbes. Schneider, Körperschaftliche Verbundverwaltung, dessen Ausführungen die "ergänzte Aufsatzfassung eines Gutachtens über die Verfassungsmäßigkeit des Gesetzentwurfs über die Alterssicherung für Landwirte" darstellen.

5) S. hierzu die oben S. 86 zu Fußn.2, S. 105 zu Fußn. 13 und S. 114 zu Fußn.9 Zitierten.

5a) Die gegenteilige Grundtendenz durchzieht allerdings die Ausführungen Schneiders, Körperschaftliche Verbundverwaltung. - Es entspricht auch nur dem Minderwertigkeitskomplex der Länder und nicht der Idee des Bundesstaats, wenn die Länder damit beruhigt werden, daß nicht die Impermeabilität der Landesverwaltung sondern nur diejenige der Bundesverwaltung gestört wird (so aber Schneider, Die öffentlichrechtliche Alterssicherung freier Berufe und das Grundgesetz, S.61 f). 
nur irgendwie äußerlichen Zusammengehörigkeit der beiden in Frage stehenden Verwaltungsaufgaben ihre getrennte Wahrnehmung durch Bund und Länder zulässig. 6) Hieraus sind die notwendigen Schlüsse auch für die körperschaftliche Verbundverwaltung zu ziehen. 7) Auch sie darf nicht durch funktionelle Vermengung der Verwaltungserledigung durch Bundes- und Landesverwaltungsträger mittelbar zu einer Mischverwaltung führen. Eine sachliche Aufgabenteilung unter bundesunmittelbaren und landesinkorporierten, rechtsfähigen Verwaltungseinheiten ist aber nicht unzulässig. Wo aber dieselbe Verwaltungsaufgabe in funktioneller Verzahnung, insbesondere also in notwendigem Zusammenwirken oder in instanziellem Hintereinander von (mittelbaren) Landesund Bundesbehörden durch rechtsfähige Verwaltungseinheiten des Bundes und der Länder gemeinsam durchgeführt wird, dort würde die "Verbundverwaltung" die Verantwortlichkeiten verwischen. ${ }^{8)}$

Keine Bedenken bestehen jedoch dagegen, daß Bundeskörperschaften aus entsprechenden Landeskörperschaften hervorgehen. Diese Verflechtung allein stellt noch keine unzulässige Mischverwaltung dar.9) 10)

6) S. hierzu die immer noch gültigen, klassischen Ausführungen von Forsthoff in seinem Buch "Die öffentliche Körperschaft im Bundesstaat", insbes. S. $28 \mathrm{ff}, 122 \mathrm{ff}$.

7) Davon geht im Prinzip auch Schneider (Körperschaftliche Verbundverwaltung) aus, nur honoriert er sein Prinzip nicht im Detail.

8) Vg1. Köttgen, Der Einwand der Mischverwaltung und das Grundgesetz, S.491; Gerner, Zur Frage der Mischverwaltung im Verhältnis zwischen Bund und Ländern, S. 195 (unter nicht zutreffender Berufung auf Art. 87 Abs. 3 Satz 2 GG); Schneider, Körperschaftliche Verbundverwaltung, S. $10 \mathrm{ff}$, $24 \mathrm{f}$ und Die öffentlichrechtliche Alterssicherung usw., S. 61 (der allerdings die Grenzen zu weit zieht). - S.a. BSGE 6, 213 (238), 238 (243) (wo auf die Weisungsbefugnis der Bundeskörperschaft abgestellt ist); BVerfGE 11, 105 (123 ff) (wo rein "technische Koordinationsaufgaben" vom Verbot der Mischverwaltung ausgenommen werden).

9) Köttgen, a.a.O.; Gerner, a.a.O.; Schneider, a.a.O. und passim.

10) Schneider (Körperschaftliche Verbundverwaltung, S.11) behauptet unter Berufung auf Forsthoff (Die öffentliche Körperschaft im Bundesstaat, S. 76 f), ein Dachverband landesinkorporierter Körperschaften, der über das Territorium eines Landes hinausreiche, könne "überhaupt nur als Bundeskör- 


\section{e) Die reine Landesverwaltung}

Spielt sich der Vollzug des Bundesrechts teils im ausschließlichen Herrschaftsbereich des Bundes, teils zwar primär im Herrschaftsbereich der Länder, jedoch unter nachhaltiger Ingerenz des Bundes ab, so verbleibt den Ländern zur ausschließlichen eigenständigen Erledigung nur der Teil der gesetzesakzessorischen Verwaltung, der im Vollzug des Landesrechts besteht (A rt. 30,83 ff GG). 1) In diesem Bereich hat der Bund keine Einmischungsbefugnisse, soweit die Länder das Grundgesetz und das übrige Bundes recht nicht verletzen. ${ }^{2}$ ) Die Impermeabilität der Entscheidungseinheit Land, an sich ein Erfordernis der Bundesstaatlichkeit, 3) für den Vollzug des Bundesrechts aber vielfach durchbrochen, ${ }^{4}$ ) ist für diesen exekutiven Bereich noch ge-

perschaft konstituiert werden". Nun sagt zwar Forsthoff (a.a.O. S. 77), der einem einzelnen Land inkorporierte (rechtsfähige) Verband öffentlicher Körper'schaften dürfte nicht den Gliedkörperschaften vorgeordnet werden, die einem anderen Lande inkorporiert sind. Er negiert damit aber nicht die Möglichkeit, daß derartige Verbände durch zwischenstaatliche Übereinkünfte unter den Ländern geschaffen werden. Verbände landesinkorporierter Körperschaften müssen also nicht schon deshalb, weil ihre Zuständigkeit über den Bereich eines Landes hinausgeht, notwendig in den Raum des Bundes fallen. Das Grundgesetz hat in Art. 130 Abs. 3 dementsprechend auch ausdrücklich die "auf Staatsverträgen zwischen den Ländern beruhenden Körperschaften und Anstalten des öffentlichen Rechts" den landesunmittelbaren gleich und mit ihnen den bundesunmittelbaren Körperschaften und Anstalten gegenübergestellt. Hier ist also eine Rechtsform von Dachverbänden, die - weil sie zugegebenermaßen nicht einfach zu handhaben ist - bisher unausgenützt geblieben ist, die aber eine echte Alternative zum bundesunmittelbaren Dachverband darstellt.

1) Zum Vollzug von Landesrecht durch Bundesbehörden s. Zeidler, Ausführung von Landesgesetzen durch Bundesbehörden, DVB1.75.Jhg. (1960) S.573 ff.

2) Im Vordergrund stehen die in Art.93 Abs. $1 \mathrm{Nr} .2,3$ und 4 GG umschriebenen Klagemöglichkeiten des Bundes gegen die Länder zum Bundesverfassungsgericht. Der Bundeszwang (Art.37 GG) spielt nur eine sekundäre Rolle.

3) S. hierzu insbes. Forsthoff, Die öfentliche Körperschaft im Bundesstaat, S. $28 \mathrm{ff}, 91 \mathrm{ff}, 122 \mathrm{ff}$ und passim.

4) S. hierzu z.B. die grundsätzlichen Bemerkungen bei Köttgen, Der Einwand der Mischverwaltung und das Grundgesetz, S. 
wahrt. 5)

So schmal aber der legislative Bereich der Länder ist, so schmal ist auch der Bereich der reinen Landesverwaltung; zu nennen ist vor allem die Schulverwaltung. Die Kommunalverwaltung ist den Ländern durch bundes rechtliche Vollzugsaufträge schon nicht mehr unerheblich entfremdet. Im übrigen fallen darunter alle diejenigen Bereiche, in denen dem Bund zwar die Gesetzgebungszuständigkeit konkurrierend oder als Rahmenkompetenz zusteht, er aber noch nicht davon Gebrauch gemacht hat. Wie geringfügig diese Zone heute noch ist, braucht hier nicht noch einmal auseinandergesetzt $z u$ werden.

Besonders zu erwähnen ist noch die reine Landessteuerverwaltung. Zwar ist der sachliche Geltungsbereich des Art. 108 Abs. 3 und 6 GG nicht ausdrücklich auf den Vollzug von Bundesrecht beschränkt. So entsteht der Anschein, als erstreckten sich die dort dem Bunde eingeräumten Ingerenzrechte - hinsichtlich der Behörden und des Personals sowie der allgemeinen Verwaltungsvorschriften - auf a11e "übrigen Steuern" (Art.108 Abs. 3 Satz 1 GG), also auch auf die in Vollzug von Landes recht e rhobenen. ${ }^{6}$ ) Der vergleichende Blick auf Art. 83 ff GG läßt jedoch - orientiert auch an Art. 30 GG - keine andere Annahme zu, als daß sich diese Ingerenzrechte auf den Vollzug des Bundesrechts beschränken. 7) Die praktische Bedeutung dieses Reservates der Länder

487; dens., Der Einfluß des Bundes auf die deutsche Verwaltung, S. $71 \mathrm{ff}$.

5) Doch will das nicht allzuviel heißen, da "Impermeabilität" an sich wohl nicht "teilbar" ist.

6) So Nawiasky, Die Grundgedanken des Grundgesetzes, S. 52 f; Wacke, Das Finanzwesen der Bundesrepublik, S. 52 f; v. Mangoldt, Bonner Grundgesetz (1. Auf1.), Art. 108 Anm. 5 (für die Befugnisse aus Art. 108 Abs.3); Bettermann, Das Verwaltungsverfahren, S.157, 160 f (unter Annahme einer konkurrierenden Landeszuständigkeit der Länder im Bereich der "Landesfinanzverwaltung").

7) Das bestätigt vor allem die Gesetzgebungspraxis: vg1. $\$ 3$ AO i.d.F. des Gesetzes v.11. Juli 1953 (BGB1. I S. 511). Der Gesetzgeber wollte, indem er die Geltung des kardinalen Steuerverwaltungsgesetzes, die Reichsabgabenordnung auf die Steuern beschränkte, "die nach Art. 105 Abs. 1 und 2 des Grundgesetzes der Gesetzgebung des Bundes unterliegen", das Steuerverwaltungsrecht des Bundes bewußt den Grenzen der steuerrechtlichen Gesetzgebungskompetenz des Bundes anpassen (vgl. Begründung des Entwurfs eines Gesetzes zur 
ist freilich gering. In Frage kommt die reine Landesverwaltung nur für die "Steuern mit örtlich bedingtem Wirkungskreis" (A rt. 105 Abs. 2 Nr. 1 GG). Diese fließen zudem überwiegend den Gemeinden und Gemeindeverbänden $z u$, denen die Länder - unter Ausschluß jeder organisatorischen Bundesingerenz - auch die Verwaltung übertragen können (Art. 108 Abs. 3 Satz 4 GG).

\section{f) Zusammenschau}

Seit der Weimarer Zeit gehört es zu den beliebtesten "Wahrheiten" des deutschen Bundesstaatsrechts, daß die Gesetzgebung überwiegend beim Zentralstaat, die Verwaltung dagegen überwiegend bei den Gliedstaaten liege. Auch für das Grundgesetz ist das oft und oft behauptet worden. Allein der Schein trügt. Richtig ist zwar, daß der Anteil der Länder an der Masse der Verwaltungsaufgaben relativ größer ist als ihr Anteil an der Gesetzgebung und umgekehrt der Anteil des Bundes an der Gesetzgebung gröBer als sein Anteil an der Verwaltung. Aber der Gedanke, auf dem Verwaltungssektor wäre die auf dem Gebiete der Gesetzgebung herrschende Proportion ins Gegenteil verkehrt und dadurch das Ungleichgewicht zugunsten der Länder wieder ausbalanciert, wäre irrig. Die Verhältnisse im Sachbereich der sozialen Intervention, die zwar nicht pars pro toto gesetzt werden dürfen, deren ungeheure Bedeutung für das gegenwärtige Staatsleben ihnen jedoch Gewicht und Strahlkraft gibt, demonstrieren diese Situation treffend.

Änderung von Vorschriften der Reichsabgabenordnung, Verhandlungen des Deutschen Bundestages, 1. Wahlperiode 1949, Drucks. Nr.3926 S.4; Stellungnahme der Bundes regierung zu der Äußerung des Bundesrates, ebenda, S.10; Ausschußbericht Verhandlungen des Deutschen Bundestages, 1. Wahlperiode 1949, Drucksache Nr.4179 S.2; Berichterstatter Abg. Dr. Miessner in der 257. Sitzung des Bundestages, 1. Wahlperiode 1949, StenBer. Bd. XV S. 12467 B/C). - Das Schrifttum pflichtet dieser Auffassung ausdrücklich meist nur für die Verwaltungsvorschriften (Art. 108 Abs.6 GG) bei: v. Mangoldt, a.a.O. Art. 108 Anm. 8; Bühler, Bonner Kommentar, Art.18 Anm. II 6; Hamann, Das Grundgesetz, Art. $108 \mathrm{Anm}$. C 11. A. A. (speziell in bezug auf die Verwaltungsvorschriften): Klein, Von der föderativen zur stärker unitarischen Gestaltung des Finanzwesens der Bundesrepublik Deutschland, S. 120 f; Bettermann, a.a.O. S. 160 f Fußn.131 (unter Annahme einer konkurrierenden Zuständigkeit des Bundes und der Länder für den Bereich der "Landesfinanzverwaltung"). 
Entsprechend der geringfügigen sozial relevanten Gesetzgebungskompetenz der Länder ist der Raum der sozialen, reinen Landesverwaltung, in die der Bund sich nicht aufsichtlich einmischen kann, bescheiden. Die Masse der sozialen Verwaltungsarbeit besteht im - mehr oder weniger streng gesetzesakzessorischen Vollzug von Bundes recht. Sie liegt daher im Einflußbereich des Bundes, wenngleich die Intensität der bundesseitigen Befugnisse stark abgestuft ist. Dabei ist für den sozialen Bereich typisch, daß soziale Verwaltungsaufgaben nur in geringem Umfange $z u$ den grundgesetzlich notwendigen Zuständigkeitsbereichen bundeseigener staatlicher Verwaltung gehören. Das eigentümlichste Ausdehnungs gebiet der sozialen Bundesverwaltung ist die Verwaltung durch bundesunmittelbare Körperschaften und Anstalten.

Ist der Zuständigkeitsbereich der Länder von hier aus auch stark eingebuchtet, so liegt der Großteil des Vollzuges sozial relevanten Bundes rechts aber doch bei ihnen. In den Überschneidungsbereich, in dem der Bund legislativ, die Länder dagegen exekutiv tätig werden, dringt nun aber der Bund selbst - nicht nur, wie vorausgesetzt, legislativ, sondern auch - exekutiv ein. Intensiver geschieht das in dem - wiederum gerade im sozialen Sachgebiet nicht unerheblichen - Feld der Bundesauftragsverwaltung. Beschränkter, jedoch trotzdem noch von großer Wirksamkeit ist der Einfluß, den der Bund auf den landeseigenen Vollzug des Bundesrechts nehmen kann. Soweit die Länder nicht ihr eigenes Recht ausführen, ist so ihre Impermeabilität als exekutive Entscheidungseinheit zerstört. Der Bund kann rein exekutive Entscheidungen vorwegnehmen. Er kann sich in den Gesetzesvollzug durch die Länder darüber hinaus mittels seiner akzessorischen Kompetenz, ihre Verwaltungsverfahren und die Einrichtung ihrer Verwaltungsbehörden zu regeln, einschalten.

Die Verwaltung ist aber an sich schon eingekeilt zwischen der Gesetzgebung einerseits und der Rechtsprechung andererseits. Es wird noch an anderer Stelle ${ }^{1)}$ darauf zurückzukommen sein, wie sehr das verschiedentlich als Entdeckung gefeierte Schlagwort vom "Verwaltungsstaat" geeignet ist, die Situation des Lebens der staatlichen Gemeinschaft unserer Tage zu verzeichnen. Nicht nur das Volumen der Verwaltung, auch das Volumen der Gesetzgebung und das Volumen der Rechtsprechung ist gewachsen. Ein "Mehr an Staat" ist das Kennzeichen der Situation. Das "Mehr an Verwaltung" ist nur die Ausstrahlung dieser Entwicklung auf dem Verwaltungssektor. Dieses "Mehr an Verwaltung" besteht aber nicht in einem größeren Maß an Entscheidungsfrei-

1) S. unten Abschnitt 4 II 2 b, aa (S.418) und 4 (S. 603 ff). 
heit der Verwaltung, sondern - vornehmlich quantitativ zu verstehen - in einem "Mehr" an Aufgaben, ja an anbefohlener Aktivität. Die Entscheidungsfreiheit der Verwaltung ist in ständiger Schrumpfung begriffen. Vor allem von der Gesetzgebung her wird der Verwaltung immer mehr ihr Ermessensspielraum verkürzt. Aus verschiedenen Gründen, auf die hier zunächst nicht einzugehen ist, differenziert der Gesetzgeber seine an die Verwa1tung gerichteten Befehle in zunehmendem Maße. Das gilt im besonderen für die Gesetzgebung auf dem sozialen Gebiet. Sie regelt nicht Gnadenausteilung oder Barmherzigkeitsübung durch die Verwaltung, nicht Hilfe an Untertanen, sondern die R e cht e, die möglichst gleich allen sozial Schutzbedürftigen zustehen, die sich in jeweils der gleichen Lage befinden. Auf der anderen Seite unterliegt die Verwaltung einer erschöpfenden Rechtskontrolle durch die Gerichte. Zwischen einer Gesetzgebung, die sich extrem scheut, eine Entscheidung dem Ermessen der Verwaltung anheim zu geben, und der umfassenden Rechtskontrolle durch die Gerichte wird so die Verwaltung als selbständige Entscheidungsfunktion erstickt. Sie wird progressiv zum Automatismus eines subalternen Rechtsvollzuges herabgemindert. Das ist gerade hier von hervor ragender Wichtigkeit. In dem Raum, in dem sich legislative Bundeszuständigkeit und exekutive Landeszuständigkeit überschneiden, der also für die "Schwerpunktverlagerung" Legislative - Bund/Exekutive - Land entscheidend sein müßte, geht der zu vollziehende Gesetzesbefehl vom Bunde aus. Wo Bundesrecht $z u$ vollziehen ist, wird - regelmäßig - die Verwaltung in letzter. Instanz durch ein oberes Bundesgericht kont rolliert. Die Landesverwaltung ist also eng zwischen Bundeslegislative und Bundesjudikatur eingelagert. Nimmt man das Ausmaß der Bundesingerenz im rein exekutiven Raum des Bundesrechtsvollzugs durch die Länder hinzu, so kann man ermessen, wie wenig es noch bedeutet, wenn die Länder grundsätzlich das Bundesrecht vollziehen. 'l'rotzdem ist freilich dieses wenige im sinne des föderalistischen Pr.inzips noch nicht wertlos. 2)

Mit dem veränderten Verhältnis zwischen Gesetzgebung und Verwaltung hat die Assoziation Bund/Legislative - Länder/Exekutive einen anderen Sinn bekommen. Verleitet von der Möglichkeit, auf die in den Mittelpunkt des Staatslebens gerückten Verwaltungsagenden Einfluß zu nehmen, und gedrängt von dem Erfordernis, dem Verwaltungshandeln rechtsstaatliche Grenzen und Grundlagen zu geben, hat sich die Gesetzgebung in einem früher nicht gekannten Sinn zur. Herrin der Verwaltung aufgeworfen. Somit

2) S. hierzu z.B. Nawiasky, Die Grundgedanken des Grundgesetzes für die Bundes republik Deutschland, S. $63 \mathrm{f}$. 
wurde auch die legislative Vormachtstellung des Bundes im exekutiven Raum in ganz neuer Weise relevant. Die Weiche für die exekutive Kompetenzverteilung wird heute bereits im Raum der legislativen Kompetenzverteilung gestellt! Von hier aus wird die Verwaltungskompetenz der Länder ausgehöhlt und unterwandert. ${ }^{3}$ ) Nicht nur verdichtet sich als Reflex auf die größere Dichte der bundesgesetzlichen Regelung das Netz der über den Landesvollzug des Bundes rechts gezogenen Rechtsaufsicht des Bundes. Indem sich die Distanz zwischen Gesetz und Verwaltungserledigung vermindert hat, wurde der Landesvollzug enger an das Bundesgesetz und darüber hinaus an den Bund überhaupt herangezogen. Die durch die Gesetzgebungskompetenz gegebene Möglichkeit, das Verwaltungshandeln zu initiieren, zu dirigieren und $z u$ limitieren, drängt zur Vervollkommnung. Die funktionale Einheit von verwaltungs rechtlicher Gesetzgebung und gesetzesakzessorischer Verwaltung drängt auch zur kompetenzmäßigen Einheit und auf diesem Wege zur Einheit des tragenden politischen Willens. Das verursacht die Tendenz, auch die Verwaltungsagende in den Herrschaftsbereich des legislativ kompetenten Bundes zu ziehen, sei es nun durch Übernahme in die Bundesverwaltung, sei es durch umfangreiche Ingerenzrechte gegenüber den Ländern. 4)

Diese Tendenz mußte im sozialen Bereich schon wegen seines politischen Gewichts besonders wirksam werden. Der Boden dafür ist durch die umfassende Gesetzgebungskompetenz des Bundes bereitet worden. Dazu kommt die dem Sozialen wesensmäßig eigene egalitäre Tendenz, die länderweise Unterschiede nicht gerne hinnimmt und somit über die einheitliche Gesetzgebung hinaus auch den bundeseinheitlichen Vollzug als Ziel postuliert. Die von der Finanzverfassung ausgehenden - in speziellem $\mathrm{Zu}$ sammenhang noch zu erörternden - Ausstrahlungen, die für den

3) Kreutzer, Bund und Länder in der Bundes republik Deutschland, in "Bund und Länder", hrsg. von Flechtheim, 1959, S. 1 ff $(15 \mathrm{f})$.

4) Es ist das wohl kaum zu überschätzende Verdienst Köttgens, entgegen den überkommenen, bequemen Klischee-Vorstellungen auf diesen Strukturwandel hingewiesen zu haben. - S. zum Vorstehenden und ergänzend hierzu die folgenden Ausführungen Köttgens: Der Einfluß des Bundes auf die deutsche Verwaltung, S. $81 \mathrm{f}$; Sachverantwortung als verfassungsrechtlicher Maßstab des Finanzausgleichs, S.358 f; Gemeindliches Satzungsrecht und Grundgesetz, DVB1. 70. Jhg. (1955) S. $445 \mathrm{ff}$ (450); Der Einwand der Mischverwaltung und das Grundgesetz, S. 486 f; Die gegenwärtige Lage der deutschen Verwaltung, DVB1. 72. Jhg. (1957) S. $441 \mathrm{ff}$ (444). 
sozialen Bereich ihren besonderen Akzent durch Art.120 GG erhalten, haben desgleichen auf die Konzentration der Verwaltung oder wenigstens ihre Oberleitung beim Bund hingewirkt. 5)

\section{Die Rechtsprechungskompetenz}

Die unabhängigen Gerichte verhalten sich zu der Entscheidungseinheit Land oder Bund, in die sie eingebettet sind, zwar wesentlich anders als etwa die Gesetzgebung und die Verwaltung. Trotzdem ist es keineswegs unwichtig, welchem Gemeinwesen sie zugehören. Es ist umso bedeutsamer als der gestaltende Einfluß der. Gerichtsbarkeit heute größer ist denn je zuvor. 1)

Die Zuständigkeitsverteilung bezüglich der Rechtsprechung weist keine ursprüngliche Relation zur sozialen Intervention des Staates auf. Was sich an speziellen Zusammenhängen ergibt, beruht in dem Übergewicht des sozialen Bundes rechts im Verhältnis zum sozialen Landes recht, dem ein erhöhter Wirkungsgrad des Bundesgerichts in sozialen Angelegenheiten folgt.

In der Verfassungsgerichtsbarkeit 2) kommt dem Bundesverfassungs gericht das entschiedene Übergewicht zu. Die Landesverfassungsgerichte können nur innerhalb des Staatsgebildes Land - mit seinen räumlichen und sachlichen Zuständigkeitsgrenzen - wirken. Die Vorlagemöglichkeiten nach Art.100 GG zählen im Vergleich hierzu kaum. Das Bundesverfassungsgericht wirkt dagegen nicht nur im Bund, als Zentralstaat, sondern im Gesamtstaat. Es hat das Grundgesetz nicht nur gegenüber dem Bund sondern auch gegenüber den Ländern, also in Bund und Ländern und im Verhältnis zwischen Bund und Ländern durchzusetzen. Daraus ergibt sich auch die Relation der Kompetenzen im sozialen Bereich. Je mehr das Grundgesetz soziale oder sozial relevante Fragen geregelt hat, je mehr es ihre Regelung (mit Vorrang) dem Bund vorbehalten oder überlassen und je mehr es auf diese Weise soziale Fragen der ausschließlichen Erledigung innerhalb der Entscheidungseinheit Land entzogen hat, desto größer ist auch die Ingerenz des Bundesverfassungsgerichts und desto schmäler sind die Wirkungsmöglichkeiten der Landesverfassungsgerichte im Bereich der sozialen Intervention. Welcher Löwenanteil dem Bundesverfassungsgericht demnach zukommen muß, haben schon die bisherigen Darlegungen über die Verteilung der Gesetzgebungszuständigkeit ergeben.

5) S. unten II. (S. 175 ff) - Zur Bedeutung des Art. 120 GG s. insbes. unten II 3 c, bb. (S. 196 ).

1) S. hierzu unten Abschnitt 4 II 3 (S. 508 ff).

2) Näheres und Nachweise hierzu s. unten S.564. 
Anders verhält es sich hinsichtlich der sonstigen (nichtverfassungsgerichtlichen) Gerichtsbarkeit. Für sie ist die grundsätzliche Zuständigkeit der Landesgerichte garantiert (Art. 92 ff GG). Bundesgerichte können - von dem nicht errichteten Obersten Bundesgericht (Art.95 GG), den Dienst- und Dienststrafgerichten für die Bediensteten des Bundes und von den Wehrstrafgerichten, die hier nicht in Betracht kommen, abgesehen nur als obere Bundes gerichte eingerichtet werden (Art.92, 95, 96 $\mathrm{GG})$. Grundsätzlich müssen in gerichtlichen Verfahren in mindestens einer Instanz Landesgerichte entscheiden, ehe ein Bundesgericht (oberes Bundesgericht) angegangen werden kann. Nur ausnahmsweise können obere Bundesgerichte auch in erster (und letzter) Instanz zuständig sein. ${ }^{3)}$ Nicht einmal dafür besteht eine verfassungsmäßige Garantie, daß jede Sache bis an ein oberes Bundesgericht geführt werden kann. Das nicht errichtete Oberste Bundesgericht sollte in seinem Zuständigkeitsbereich wiederum durch den Aktionsradius der oberen Bundesgerichte begrenzt sein (Art. 96 Abs. 2 GG).

Damit ist der Landesgerichtsbarkeit ein unbestreitbares, quantitatives übergewicht schon durch die verfassungsrechtliche Konzeption des Aufbaues der Gerichtsbarkeit gesichert. Die Zahl der von den oberen Bundesgerichten zu entscheidenden Fälle ist schon deshalb geringer als diejenige der von den Landesgerichten zu entscheidenden, weil selbst dort, wo Rechtsmittel an eine Instanz führen, diese stets nur in einem Teil der Fälle ergriffen werden. Ein weiterer Grund ist der, daß sich grundsätzlich in jedem Instanzenzug die Zuständigkeitspyramide nach oben verjüngt und - rechtspolitisch gesehen - verjüngen muß: einerseits dadurch, daß Rechtsmittel gegen gewisse erst- oder zweitinstanzliche Entscheidungen überhaupt nicht zugelassen werden, andererseits dadurch, daß die oberen Gerichte in der Nachprüfung der angefochtenen Entscheidungen beschränkt sind. Diese Gründe für einen verdünnten Zufluß von Rechtsprechungsaufgaben zu den oberen Bundesgerichten werden dadurch potenziert, daß dort, wo ein mehr als zweistufiger (insbes. drei- oder vierstufiger) Gerichtsaufbau notwendig erscheint, alle Instanzen mit Ausnahme der letzten, Landesgerichte sein müssen. Zwei Vorinstanzen filtern mehr Sachen ab als eine. Wo - wie derzeit nur in der ordentlichen Gerichtsbarkeit - ein vierstufiger Aufbau gegeben ist, wird, da ein mehr als dreistufiger Instanzenzug nicht praktikabel ist, das bei der untersten Stufe ansetzende Verfahren

3) Zu den Grenzen der erstinstanzlichen Zuständigkeit oberer Bundesgerichte vgl. BVerfGE 8, 174. 
regelmäßig in einer landesgerichtlichen zweiten oder dritten Instanz enden. An ein oberes Bundesgericht kann es dann eventuell noch über gewisse Vorlagepflichten letztinstanzlicher Landesgerichte kommen.

Es braucht hier nicht im einzelnen dargelegt zu werden, von welch großer Bedeutung dieser Kompetenzbereich der Landesgerichtsbarkeit ist. Die unzähligen Fälle, die ihrer Natur nach oder. aus praktischen Gründen, insbesondere wegen der besonderen Situation der Parteien, endgültig oder jedenfalls in tatsächlicher Hinsicht abschließend vor den Landesgerichten entschieden oder wenigstens verhandelt und verglichen oder sonstwie erledigt werden, geben ihrer Eigenart Raum, sich zu entfalten.

Nicht übersehen werden darf auch die meinungsbildende Wirksamkeit, welche die Landesgerichtsbarkeit, in der Vorhand stehend, entfalten kann. Auch grundsätzliche Fragen hat sie - regelmäßig - zuerst zu entscheiden. An den erst- und obergerichtlichen Entscheidungen entzündet sich die Diskussion über jene zuerst. Die Höchstgerichte müssen sich, wenn sie an die Entscheidung herangehen, nicht selten bereits mit einer umfangreichen Judikatur der Landesgerichte auseinandersetzen.

Trotzdem ist das qualitative Übergewicht der oberen Bundesgerichte eindeutig. 4) Sie unterscheiden die grundsätzlichen Rechtsfragen. Das ist ihre legitime Funktion; und die Verfahrensgesetze sind so eingerichtet, daß grundsätzliche Rechtsfragen möglichst vollständig an die oberen Bundesgerichte herangebracht und Abweichungen unterer Gerichte von der Ansicht der oberen Bundesgerichte diesen zur Nachprüfung gestellt werden kömnen.

Bei dieser Situation kommt der Frage eine besondere Bedeutung $\mathrm{zu}$, ob die oberen Bundesgerichte auch zur letztinstanzlichen Auslegung des Landes rechts berufen sind bzw. durch Bundesgesetz berufen werden dürfen, oder ob diese den Landesgerichten vorbehalten ist. Diese Frage ist gerade in jüngster Zeit kontrovers geworden, 5) und vom Bundesverfassungsgericht zu-

4) S. Nawiasky, Grundgedanken des Grundgesetzes, S.48; Werner Weber, Die Verfassung der Bundestepublik in der. Bewährung, S. 17; Kreutzer, Bund und Länder in der Bundesrepublik Deutschland, in "Bund und Länder", hrsg. v. Flechtheim, S. 1 ff (S. 14 f).

5) Vg1. Haas, Landesrecht vor Bundesgerichten, I)VB1. 72. Jhg. (1957) \$. 368 ff, 567; Arndt, Landesrecht vor Bundesgerichten, I)VB1. 72.Jhg. (1957) S. 566 f; Forster, Revisibles Landesbeamtenrecht? BayVB1. n. F. 3.Jhg. (1957) 
gunsten der Bundeskompetenz entschieden worden. 6) Die Frage kann hier nicht näher geprüft werden. Soviel kann aber gesagt werden, daß es weder möglich noch geboten ist, die oberen Bundesgerichte von der Anwendung des Landesrechts überhaupt auszuschließen. Die Frage nach der Zulässigkeit der Anwe ndung von Landes recht durch die oberen Bundesgerichte rennt offene Türen ein; denn bei der Verwobenheit von Bundes- und Landesrecht, wie sie die bundesstaatliche Rechtsordnung im allgemeinen, unsere konkrete deutsche Rechtsordnung im besonderen auszeichnet, wäre ein Gericht, das entweder Bundes- oder Landesrecht in irgend einer Weise nicht anwenden könnte, von vorneherein partiell gelähmt. ${ }^{7}$ ) Die Frage, die allein einer ernsthaften I)iskussion bedarf, ist die, ob der Bundesgesetzgeber von sich aus den Instanzenzug auch in Angelegenheiten, bei denen landesrechtliche Rechtsfragen im Vordergrund stehen oder sogar ausschließlich entscheidend sind, zu den oberen Bundesgerichten hinaufführen darf. Der Landesgesetzgeber darf es (Art.99 GG). Dem Bundesgesetzgeber sollte es grundsätzlich verwehrt sein. Es würde - wie schon gesagt - zu weit führen, hier das Für und llider der Argumente abzuwägen. Die grundsätzlichen bundesstaatlichen Bedenken gegen die gegenteilige herrschende Lehre dürfen jedoch nicht verschwiegen werden.8) Daß der Bundesge-

S. $279 \mathrm{ff}$; Werthauer, Die Kompetenz der oberen Bundesgerichte zur Anwendung von Landesrecht, NJW 10.Jhg. (1957)

S. $1387 \mathrm{ff}$; Müller, Dürfen die oberen Bundesgerichte auch anderes als Bundesrecht anwenden? NJW 11.Jhg. (1958) S. 11; Bettermann, Grundgesetz und Revisibilität, JZ 13. Jhg. (1958) S. $235 \mathrm{ff}$; Zippelius, Beamten-Landesrecht vor Bundesgerichten, IDVB1. 74.Jhg. (1959) S.41 ff; s.a. deren weitere Nachweise.

6) BVerfGE 10, 285. S. dort ebenfalls weitere Nachweise.

7) Vgl. BVerfGE 6, 45 (51 f); s.a. BVerfGE 10, 285 (292 ff).

8) Das Problem stellt sich insbes. auf dem Gebiet der Verwaltungsgerichtsbarkeit (im weitesten Sinne als gerichtliche Kontrolle der Verwaltung). Soll in Bundesgerichten ein zweiter Arm der Bundesrechtsaufsicht entstehen, wie er in Art.84, 85 GG nur für die Ausführung von Bundesrecht durch die Länder, nirgends aber für die Ausführung von Landesrecht durch die Länder vorgesehen ist? Gewiß ist die bundesgericht1iche Kontrolle landesgerichtlicher Entscheidungen keine Bundesaufsicht i.S. der Art. 84, 85 GG (vg1. z.B. Schäfer, Bundesaufsicht und Bundeszwang, AöR Bd.78 (1952/53) S. 1 ff (13)). Aber praktisch kommt die Tätigkeit der oberen Bundesgerichte, soweit sie gegenüber den Ländern oder Landesgerichten 
setzgeber die ihm von besagter herrschender Ansicht zugeschriebene Befugnis, auf Grund des Art. 74 Nr. 1 GG auch die Revision wegen Verletzung des Landes rechts an die oberen Bundesgerichte zu führen, nicht voll aus geschöpft hat, ist im Hinblick auf die sonstige Kompetenzfreudigkeit des Bundes als eine - vielleicht unbewußte - Verbeugung vor den Erfordernissen der Bundesstaatlichkeit zu werten.

Insgesamt ergibt sich also für die Rechtsprechung ein merkwürdiges Ineinander und Nebeneinander von Bundesgerichtsbarkeit und Landesgerichtsbarkeit. Berücksichtigt man aber, daß den oberen Bundesgerichten die maßgebliche Auslegung des Bundesrechts obliegt und zu diesem Ende regelmäß3ig ihre Entscheidung über Rechtsfragen des Bundesrechts herbeigeführt werden kann, und berücksichtigt man weiter, welchen Raum das Bundesrecht im sozialen Bereich einnimmt, so kann daraus ersehen werden, welche sozialgestaltende Wirksamkeit von der Bundesgerichtsbarkeit $\mathrm{zu}$ der auch das Bundesverfassungsgericht zu zählen ist - ausgeht. Das quantitative Übergewicht der Landesgerichtsbarkeit darf aber in seiner Bedeutung gerade auch für die sozialen Fragen nicht unterschätzt werden. Für unabsehbar viele Fälle kommt es nicht darauf an, von welchem Geist die grundsätzlichen Entscheidungen der Bundesgerichte getragen sind sondern nur darauf, aus wel-

ausgeübt wird, einer Bundes(rechts)aufsicht sehr nahe (vg1. Baur, Die dritte Instanz im künftigen Zivilprozeß, Zeitschrift für zivilistische Praxis, 71.Bd. (1958) S.161 ff (177, 179); Bullinger, Der Anwendungsbereich der Bundesaufsicht, S. 306), wie auch die Ausübung der Reichs- (Bundes-)Verfassungsgerichtsbarkeit gegenüber den Ländern nicht zu Unrecht als "unparteiische Reichsaufsicht" ("unparteiische Bundesaufsicht") bezeichnet wird (vg1. Schäfer, a.a.O. S.20 m.weit. Nachw.). In diesem Zusammenhang ist auch auf die Bedenken hinzuweisen, die in der Weimarer Zeit gegenüber der Errichtung eines Reichsverwaltungsgerichts unter bundesstaatlichen Gesichtspunkten von Forsthoff (Die öffentliche Körperschaft im Bundesstaat, S.129) vorget ragen worden waren, wenngleich diese Gedankengänge auf die konkrete, grundgesetzliche Ordnung nur mutatis mutandis bezogen werden dürfen (s.a. Nawiasky, Grundprobleme der Reichsverfassung, Teil 1, Das Reich als Bundesstaat, 1928, S.96 ff). Der Parlamentarische Rat schlug diese Erwägungen nicht schlechterdings in den Wind. Die Gegner eines Bundesverwaltungsgerichts, die mit ihrer Forderung wohl auch zu weit gegangen waren, unterlagen jedoch (vgl. Doemming-Füsslein-Matz, Die Entstehungsgeschichte der Artikel des Grundgesetzes, S. 706 ff). 
chem Geist und Gesetzesverständnis das erst- oder zweitinstanzielle Landesgericht das Verfahren führt und entscheidet.

Abschließend ist auf die Kompetenznorm des Art. 74 Nr.1 GG hinzuweisen, die das gerichtliche Verfahren und die Gerichtsverfassung der konkurrierenden Gesetzgebung zuweist. Der Bund hat somit - wie schon bisher hervorgetreten - eine umfassende Vollmacht, die Verfassung und das Verfahren auch der Landesgerichte $z u$ regeln. 9 )

\section{Die Verteilung der Mittel auf Bund und Länder, insbes. die bundesstaatliche Finanzverfassung}

\section{Allgemeines}

Die Aufgaben der sozialen Intervention zu erfüllen, bedarf der jeweilige Träger der Aufgabe der notwendigen Mittel: des Personals, der sachlichen Verwaltungsmittel und der Finanzmittel. Die Grenzen innerhalb deren die sozialen Aufgaben erfüllt und gesucht werden können, bestimmen sich weitgehend nach dem Maß, in dem die entsprechenden Mittel aufgebracht werden können. Gewiß gibt es soziale Maßnahmen, die den Staat sachlich nicht belasten. Es sind dies die direkt $z$ wischenbürgerlichen Ausgleichsordnungen, wie etwa die soziale Gestaltung des Arbeitsvertrags- und des Mietund Pachtrechts. Aber selbst die soziale Regelung von Gegenständen der $z$ wischenbürgerlichen Sphäre, die nicht unmittelbar einen

9) Problematisch ist bis heute geblieben, ob der Bundesgesetzgeber auf Grund dieser Bestimmung auch in den Raum der Verfassungsautonomie der Länder eindringen und - wie in $\$$ 15 ArbGG geschehen - die Verwaltung und Dienstaufsicht für einen bestimmten Gerichtszweig einem bestimmten Regierungsressort übertragen darf (zu $₫ 15$ ArbGG s. Baur, Ist der Bundesgesetzgeber befugt, eine Vorschrift darüber zu treffen, daß Landesgerichte einem bestimmten Landesminister unterstellt werden? DRiZ 34.Jhg. (1956) S. 119 ff). Den Bedenken hat vor allem die Entscheidung BVerfGE 11, 77 $(85 \mathrm{f})$ neue Nahrung gegeben: "... ein Eingriff der Bundesgewalt in die Verfassungsordnung der Länder ist nur zulässig, soweit es das Grundgesetz ausdrücklich bestimmt oder zuläßt. Vor allem dort, wo das Grundgesetz die Grenze zwischen den Kompetenzen des Bundes und denen der Länder zieht, verzichtet es in der Regel darauf, die Verfassungsorgane der Länder zu bestimmen, die die Landeskompetenzen wahrzunehmen haben;...; es verweist ... auf das Landesverfassungsrecht; aus ihm ergibt sich, welches Organ die Zuständigkeit wahrzunehmen hat". 
staatlichen Aufwand zu verursachen scheint, kann je nach Art und Intensität doch einen staatlichen Mittelaufwand bedingen: die Verwaltungseinrichtungen zur Durchsetzung, desgleichen die notwendigen Gerichte, Ausgleichsleistungen an die Belasteten, Ergänzungsleistungen an die Begünstigten usw. Soziale Maßnahmen, die in keiner Weise staatliche Mittel bedingen, stellen - man kann wohl sagen - die Ausnahme dar. Im übrigen aber wird der Aktions radius der sozialen Intervention des Staates durch sein Potential an personellen, sachlichen und finanziellen Mitteln mehr oder weniger schroff determiniert.

Von dieser Gesetzmäßigkeit werden in erster Linie die Bereiche potentieller sozialer Intervention betroffen, hinsichtlich deren der budgetären Disposition nicht schon vorgegriffen ist. Wo eine verfassungsrechtliche - oder für die Länder auch: bundesgesetzliche - Verpflichtung zu einem gewissen Sozialaufwand besteht oder wo gewisse soziale Einrichtungen vorhanden sind, die schon aus psychologisch-politischen Gegebenheiten heraus nicht beliebig - meist sogar überhaupt nicht - reduziert werden können, da müssen eben staatliche Mittel eingesetzt werden. Die Fesseln, die der sozialen Intervention des Staates von der Mittelseite her angelegt sind, hindern daher vor allem den Vorstoß in sozialpolitisches Neuland - etwas einseitig ausgedrückt: den sozialen Fortschritt - und den weiteren Ausbau der vorhandenen Einrichtungen und Leistungen. Die Gemeinwesen können am weitesten voranschreiten, denen die Kette der Mittel, an der sie liegen, am längsten geschmiedet ist.

\section{Die Verteilung der personellen und sachli- chen Mittel}

Die Aufteilung der personellen Mittel - als solcher, die auch der finanziellen Mittel zur Unterhaltung des Personals - auf Bund und Länder hat im Grundgesetz keine grundsätzliche Regelung gefunden. Das Grundgesetz setzt Dienstkräfte des Bundes und der Länder als vorhanden voraus (vgl. Art. $73 \mathrm{Nr} .8,75 \mathrm{Nr} .1$ $G G$ ). Es läßt Dienstpflichten zu (Art. 2 und $3 G G$ ). Es kennt vereinzelte Kompetenznormen, die Dienstpflichten involvieren. ${ }^{1)}$ Es regelt den "Blutsanteil" der Länder an der Gesamtzahl der Bun-

1) Am deutlichsten ist das wohl in Art. $73 \mathrm{Nr} .1 \mathrm{GG}$ : Der Bund ist ausschließlich zuständig zur Gesetzgebung über die Verteidigung und den Schutz der Zivilbevölkerung, also auch die Dienstpflicht, d.h. nicht nur die im Grundgesetz ausdrücklich genannte Wehrpflicht sondern auch den zivilen Ersatzdienst und den sonstigen zivilen Dienst. 
desbediensteten (Art.36 GG) - was einigermaßen das Gegenteil einer Aufteilung des insgesamt vorhandenen Kräftepotentials auf Bund und Länder ist - . Aber mehr sagt es nicht. Unter den gegebenen Verhältnissen wird dieser Mangel nicht sehr fühlbar werden. Zumindest unter Verzicht auf wählerische Ausleseprinzipien werden bei konkur renzfähiger Entlohnung (Besoldung) alle Teile ihren Personalbedarf gleicherweise decken können. Der Frage nachzugehen, welche Wege das Grundgesetz eröffnet, um für den Fall eines akuten Personalmangels anteilig Bund und Länder aus dem vorhandenen Reservoir zu versorgen, würde hier zu weit führen. 2)

Die Aufteilung der s a chlichen - exklusive der finanziellen Mittel hat das Grundgesetz sporadisch in Angriff genommen. Bedeutsam ist vor allem die Überleitungsvorschrift hinsichtlich des ehemaligen Reichsvermögens: Art.134 GG. 3) Nach dieser - ausweislich ihres Absatzes 4 - immer noch der Ergänzung durch ein Bundesgesetz harrenden 4 ) Vorschrift wird das Vermögen des

2) Zu überlegen wäre in negativer Hinsicht, wo die Grenzen liegen, die den Bund hindern, durch attraktive Gestaltung seines Dienstes (Art. $73 \mathrm{Nr} .8 \mathrm{GG}$ ) und nachteilige Gestaltung des Landesdienstes (Art. 75 Nr.1 GG) den Zustrom unter Schaden für die Länder auf sich zu lenken. (Den Ländern einen solchen Weg in umgekehrter Richtung abzuschneiden, ist dem Bunde auf Grund der Kompetenz nach Art. 75 Nr.1 GG ohnedies jederzeit möglich). Hier dürfte der Grundsatz der Bundestreue, der auch zulasten des Bundes wirkt, eine Schranke bilden. In positiver Hinsicht wäre zu erwägen, ob der Bund auf Grund seiner Kompetenz nach Art. $73 \mathrm{Nr} .8,75 \mathrm{Nr} .1$ GG einen Verteilungsschlüssel oder ein Verteilungsverfahren einführen könnte oder ob derartiges durch Übereinkommen zwischen Bund und Ländern geschehen könnte. - Die letzte Möglichkeit, die Einführung einer l)ienstpflicht, ist nach Art. 12 Abs. 2 Satz 1 GG nur beschränkt gegeben. Wer in dem verbleibenden, materiellen Rahmen die Regelung einer allgemeinen Dienstpflicht - jenseits von Verteidigung und zivilem Bevölkerungsschutz - vornehmen könnte, sagen die Art. 73 ff nicht ausdrücklich. Sollten es die Länder sein (Art.30 GG)? Oder. wäre eine ausdehnende Auslegung der Bundeskompetenz aus Art. $73 \mathrm{Nr} .8,75 \mathrm{Nr} .1$ GG zulässig?

3) Die Zuweisung der ehemaligen Reichswasserstraßen, -autobahnen und -straßen an den Bund (Art. 89 Abs. 1, 90 Abs. 1 GG) interessiert hier nicht.

4) Zur Frage der unmittelbaren oder verbindlich-programmatischen Geltung der Vorschrift s. z.B. Holtkotten, Bonner 
Reichs grundsätzlich Bundesvermögen (Abs. 1). Für das Verwaltungsvermögen statuiert jedoch Abs. 2 Satz 1 a.a.O. eine wichtige Ausnahme:

Soweit es nach seiner ursprünglichen Zweckbestimmung überwiegend für Verwaltungsaufgaben bestimmt war, die nach diesem Grundgesetz nicht Verwaltungsaufgaben des Bundes sind, ist es unentgeltlich auf die nunmehr zuständigen Aufgabenträger und, soweit es nach seiner gegenwärtigen, nicht nur vorübergehenden Benutzung Verwaltungsaufgaben dient, die nach diesem Grundgesetz nunmehr von den Ländern zu erfüllen sind, auf die Länder zu übertragen.

Ohne daß hier in eine detaillierte Interpretation dieser Vorschrift eingetreten werden müßte, kann gesagt werden, daß damit im großen und ganzen das Verwaltungsvermögen des Reiches auf Bund und Länder aufgabengerecht verteilt ist.

Das "sonstige Vermögen", also das Finanzvermögen des Reiches, das grundsätzlich dem Bund zusteht (Art.134 Abs.1 GG) und, soweit es nicht nach Art. 134 Abs. 3 GG heimfällt, den Ländern übertragen werden kann - nicht muß - (Abs. 2 Satz 2 a.a.O.), dient nicht unmittelbar der Verwirklichung gewisser Staatsaufgaben. Seine Nutzungen können dafür eingesetzt werden; einzelne Vermögensstücke können in Verwaltungsvermögen umgewandelt werden. Aber diese Möglichkeit ist von vorwiegend finanziellem, haushaltichem Interesse.

Abgesehen von dem ehemaligen Reichsvermögen besitzt der Bund an sachlichen Mitteln im wesentlichen 5) das, was er seit 1949 erwerben konnte, und verfügen die Länder über das, was sie 1945 noch besaßen und seither erwerben konnten. 6) Damit wird bereits sichtbar, daß die Fortentwicklung des Bestandes an sachlichen Mitteln wiederum vom Finanzhaushalt abhängt. Das gilt umso mehr, als eine unmittelbare Beschaffung sachlicher Mittel durch den Stat ohne finanziellen Ausgleich infolge der Eigentumsgarantie des Art. 14 Abs. 3 Satz 2 und 3 GG heute unmöglich ist. ${ }^{7)}$ Auch die Regelung der Enteignungskompetenz (Art.

Kommentar, Art.134 Anm. II A 1 mit eingehenden Nachw.

5) S. a. Art. 133 GG: Rechtsnachfolge in das Vermögen des Vereinigten Wirtschaftsgebietes. - S. ferner die Beteiligung des Bundes am Vermögen ehemaliger Länder nach Art. $135 \mathrm{GG}$.

6) S. die Modifikation bei Veränderungen im Bestand der Länder - insbes. zum Problem der Preußen-Nachfolge - in Art. $135 \mathrm{GG}$.

7) Zu der dadurch eingetretenen Verlagerung aller Entzugs-, 
$74 \mathrm{Nr} .14 \mathrm{GG}$ ) ist daher von sekundärer Bedeutung. Immerhin ist daran zu beachten, daß die Zuständigkeit zur Enteignungsgesetzgebung der Kompetenz zur Gesetzgebung über den Gegenstand folgt, mit dem die Enteignung zusammenhängt, also nicht der Verwaltungskompetenz. 8) Was das für den sozialen Sektor bedeutet, bedarf im Hinblick auf das oben zur Gesetzgebungskompetenz Ausgeführte keiner weiteren Erörterung.

3. Die bundesstaat1iche Finanzverfassung 1)

a) Vorbemerkung

Schon der kurze Blick auf die Verteilung der persönlichen und (rein) sachlichen Mittel hat gezeigt, welche zentrale Bedeutung der Verteilung der finanziellen Mittel auf Bund und Länder zukommt. Die Finanzverfassung ist der wichtigste Sektor der bundesstaatlichen Mittelverteilung und ein Kernstück des Bundesstaatssystems überhaupt. Nicht weniger aber ist sie ein Kernstück des Rechts der sozialen Intervention. 2) Sowohl die Aufkommens- wie auch die Ausgabegestaltung ist von höchster Bedeutung für die soziale Aktion des Staates. Die Ausstrahlungen der Finanzverfassung auf den vorstehenden Sachzusammenhang - die bundesstaatliche Ordnung der sozialen Intervention des Staates - sind enorm und die Zusammenhänge, in die hineinzuleuchten ist, sind sehr komplex. Das erschwert die Darstellung, die daher mehr schwerpunkthaft als erschöpfend sein muß.

Umverteilungs - und Gewährungsvorgänge auf das Finanzwesen s. die oben S. 14 zu Fußn. 46 Zitierten.

8) Art. $74 \mathrm{Nr} .14 \mathrm{GG}$ steht damit in einer gewissen Parallele zu zu Art. 84 Abs.1, 85 Abs. 1 GG.

1) Mit dem Begriff der Finanzverfassung, von der hier nur ein Ausschnitt zu erörtern ist, hat sich insbes. Strickrodt immer wieder befaßt. Vgl. dessen folgende Abhandlungen: Die Finanzverfassung des Bundes als politisches System, 1951, insbes. S. 7 ff; Finanzverfassungsrecht - Idee und Gesta1tungsmöglichkeiten, Betriebsberater 8.Jhg. (1953) S. 805 ff; Finanzverfassung - Verwirklichungsmöglichkeiten im System, JZ 10. Jhg. (1955) S. 469 ff; Finanzverfassung als selbständiges Normensystem, ebd. S. 129 ff; Finanzverfassung als Real- und Rechtsstruktur der Wirtschafts - und Sozialordnung, o.J. (1956) insbes. S. 7 f. - Zum Begriff der Finanzverfassung $\mathrm{s}$. ferner Wacke, Die Finanzverfassung, DÖV 8. Jhg. (1955) S. 577 ff; Hettlage, Die Finanzverfassung im Rahmen der Staatsverfassung, S. 3 f; Schmölders, Finanzpolitik, 1955, S. 19 ff. - S.a. die Nachw. d. Zitierten. 
An dem Wendepunkt des Abschnittes "X. Das Finanzwesen", an dem das Grundgesetz von den Bestimmungen über die Aufteilung der Zufluß-, Gesetzgebungs-, Verwaltungs- und (beschränkt) auch Rechtsprechungshoheit über die Steuern auf Bund und Länder (Art. 105-108) zu den Vorschriften über das Haushaltswesen des Bundes (Art.110-115) übergeht, steht allerdings ein Satz, der, wäre er der Sache nach ebenso das Herzstück dieses Abschnittes wie der äußeren Stellung nach, größte Klarheit erhoffen ließe, nämlich Art. 109 GG:

Bund und Länder sind in ihrer Haushaltswirtschaft selbständig und voneinander unabhängig.

Diese Vorschrift trifft voll aber nur für die formell-budgetäre, nicht jedoch für die materielle Finanzgebarung zu. Mit Recht wurde sie als eine "fromme Verfassungslüge" 3) und als eine "halbe Wahrheit" 4) charakterisiert. 5) Die materielle Finanzgebarung ist durch zahlreiche Daten, die vom jeweiligen Partner - also für die Länder vom Bund, in viel geringerem Maße umgekehrt auch für den Bund von den Ländern - gesetzt werden, so beengt, daß von "selbständig und voneinander unabhängig" jedenfalls in bezug auf die Position der Länder nicht die Rede sein kann. 6)

b) Das Finanzaufkommen und seine Gestaltung

aa) Vorbemerkung: der Kredit

Gewisse Einnahmeposten bei Bund und Ländern unterliegen allerdings ausschließlich dem in Art.109 GG proklamierten Gesetz der Trennung. Dazu zählt in erster Linie die Kreditschöpfung der öffentlichen Hand. Sie hat für den Bund eine Regelung in Art. 115 GG gefunden, die - selbstverständlich - von der Unabhängigkeit der Kreditpolitik des Bundes von den Ländern 1) ausgeht. Für die

2) S. hierzu neben den oben S. 14 zu Fußn. 46 ff Angegebenen auch Kurt Schmidt, Wirtschaftsordnung und öfentliche Mittelverwendung, ORDO Bd. IX (1957) S.217 ff.

3) Hettlage, Finanzpolitik und Finanzrecht, DÖV 8.Jhg. (1955) S. $1 \mathrm{ff}, 33 \mathrm{ff}(5)$.

4) Bühler, Bonner Kommentar, Art. 109 Anm. II.

5) Zur Kritik s. ferner Strickrodt, Die Finanzverfassung des Bundes als politisches Problem, S. 14 f; Schneider, Fünf Jahre Grundgesetz, NJW 7.Jhg. (1954) S.937 ff (941).

6) S. hierzu auch die Schrift "Länderhaushalte 1952-1954" des Instituts "Finanzen und Steuern" (Heft 49 seiner Schriftenreihe, 1957). 
Länder fehlt eine Sondervorschrift. Hier greift, soweit eine Klarstellung neben Art.20 Abs.1, 28 Abs.1 GG noch notwendig ist, Art. 109 GG ein.

Aber diese Freiheit in bezug auf die Kreditschöpfung ist, so wichtig sie für die Finanzwirtschaft des Staates immer sein mag, lür das finanzielle Verhältnis von Bund und Ländern zueinander doch mehr von technischer, sekundärer Bedeutung. Der Kredit ist eine Schein-"Einnahme". Er stellt, wenn anders er irgend redlich sein soll, einen Vorgriff auf künftige "echte" Einnahmen dar, aus denen er zu verzinsen und zu tilgen ist.2) Die Freiheit der Kreditpolitik jeweils von Bund und Ländern ist somit letztlich eine Funktion der Freiheit in der Gestaltung der übrigen Staatsfinanzen. Diese bedingt und begrenzt jene. ${ }^{3)}$

bb) Die Erwerbseinkünfte

Frei von wechselseitiger Einflußnahme sind auch die Einnahmen aus wirtschaftlichen Unternehmungen des Bundes und der Länder. 1) 2) Hier handelt es sich um "echte" Einnahmen. Aber diese

1) Da Art. 115 Satz 1 GG für die Kreditaufnahme des Bundes eine gesetzliche Bewilligung voraussetzt, hat der Bundesrat das Äußerungsrecht nach Art. 76 Abs.2 GG und das Einspruchsrecht nach Art. 77 Abs.2-4 GG. Darin liegt tatsächlich-politisch natürlich eine Einflußmöglichkeit der Länder. Aber rechtlich handelt der Bundesrat dabei als ein Organ des Bundes.

2) S. f. v.a. Neumark, "Grundsätze und Arten der Haushaltsführung und Finanzbedarfsdeckung" im Handbuch der Finanzwissenschaft, Bd. I 1952, S.606 ff (649 ff) und dessen reiche Nachweise.

3) S. a. Art.106 Abs. 4 Satz 2 Nr.2 GG: "Im Rahmen der ordent1ichen Einnahmen haben der Bund und die Länder gleichmäßig Anspruch auf Deckung ihrer notwendigen Ausgaben".

1) Die rechtlichen Verhältnisse des wirtschaftlichen Vermögens der öffentlichen Hand in Bund und Ländern haben in der jüngsten Zeit manche Darstellung und kritische Würdigung gefunden (s.v. allem Strickrodt, Die wirtschaftlichen Staatsunternehmen in ihrer verfassungsrechtlichen und unternehmenswirtschaftlichen Bedeutung, 1954; Fischer, Bundeseigene Erwerbsunternehmen als Haushalts- und Rechtsproblem, Finanzarchiv n.F. Bd.15 (1954/55) S.419 ff; Duhmer, Das öffentliche Vermögen, 1955, insbes. S.39 ff; v. Eynern, Über den Einfluß des Bundes auf seine Unternehmen, in "Zur Ordnung 
Einnahmen spielen trotz des ungeheuren Volumens, das die wirtschaftliche Betätigung von Bund und Ländern heute erreicht hat, 3 ) im "steuerstaatlichen" Gesamthaushalt nur eine sehr bescheidene Rolle. 4) Das hat historische, ökonomische und aktuell-politische

von Wirtschaft und Gesellschaft", Hamburger Jahrbuch für Wirtschafts - und Gesellschaftspolitik, 4.Jhg. (1959) Festausgabe für Eduard Heimann, S. 113 ff, s.a. deren Nachweise). Ohne daß das Problem ausdrücklich angesprochen würde, erscheint dabei die gegenseitige Selbständigkeit von Bund und Ländern selbstverständlich.

2) In der Praxis bestehen freilich auch hier zahlreiche Überschneidungen, die sich aus der gemeinsamen Beteiligung des Bundes und einzelner Länder an derartigen Unternehmungen ergeben. Das führt zur gemeinsamen Verwaltung dieser Vermögenseinheiten durch Bund und Länder. Die in der vom Bundesministerium für wirtschaftlichen Besitz des Bundes herausgegebenen Schrift "der Bund als Unternehmer" (1958) wiedergegebene Zusammenstellung der Aufsichtsräte von Unternehmen, an denen der Bund beteiligt ist, zeigt diese Verflechtung sehr deutlich. Diese Erscheinung ist aber nicht staats- sondern gesellschafts rechtlicher Natur und gehört daher nicht in den vorliegenden Zusammenhang.

3) S. hierzu z.B. Duhmer, a.a.O. S. 48 ff und dessen Nachweise. Neuere Angaben bei Triesch, Schleichende Sozialisierung, Die politische Meinung 3.Jhg. (1958) Heft 26 S. 31 ff. - Für den Bund s. ferner die Anlage zum jährl. Bundeshaushaltsplan und die eben (Fußn.2) erwähnte Schrift "Der Bund als Unternehmer".

4) S. die Relationen, die sich bei einem Vergleich mit den Gesamteinnahmen ergeben (Statist. Jahrbuch f.d. Bundes republik Deutschland, 1958, S.366 f - Tabelle XIX A 1 Spalten 30 und 47):

Bund:

"Erwerbseinkünfte" Einnahmen insges.: Länd e $r$ (ohne Stadtstaaten): "Erwerbseinkünfte": Einnahmen insges.:

\begin{tabular}{|c|c|c|c|c|}
\hline 1953 & 1954 & $1955^{\circ}$ & 1956 & \\
\hline 143,2 & 300,0 & 232,2 & 546,0 & Mill. \\
\hline 23029,7 & 24071,3 & 26226,1 & 28231,9 & D.M \\
\hline 351,2 & $29:, 9$ & 493,8 & 360,5 , & Mill. \\
\hline
\end{tabular}


Gründe. Die erwerbswirtschaftliche Zurückhaltung der öffentlichen Hand entspricht aber auch dem aus der Grundrechtsordnung abzuleitenden grundsätzlichen Verfassungsbekenntnis zur freien Wirtschaft. 5) Verbietet sich von ihm her die Zwangsverwaltungswirtschaft, 5) so ist es auch unzulässig, die private Wirtschaft durch die erwerbswirtschaftliche Betätigung des Staates (und seiner Unterverbände) zu erdrücken. 6)

Unter der Verfassungsordnung des Grundgesetzes wären deshalb auch der - für die staatskapitalistische Wirtschafts- und Finanzverfassung der kommunistischen Länder kennzeichnenden - Verlagerung der öffentlichen Mittelschöpfung von der Steuer weg zur Erwerbswirtschaft der öfentlichen Hand und der mehr oder weniger verschleierten Umsatz- und Verbrauchsbesteuerung ihrer Produktion Grenzen gesetzt, die eine wesentliche Verschiebung des Finanzaufkommens nicht zuließen. Ebenso wäre es nicht möglich, die Verteilung allgemein und durchgreifend über die Preise und Löhne der staatlichen Unternehmen zu steuern - wie das wiederum für die kommunistischen Länder typisch ist - .

Dagegen ist nicht auch der unter dem Grundgesetz möglichen Staatserwerbswirtschaft die unmittelbare sozialpolitische Aktion verschlossen. Staatserwerbswirtschaft impliziert - unter sozialen Aspekten gesehen- die Alternative der maximalen Gewinnerzielung und der Verwendung der Einnahmen über den allgemeinen Haushalt auf der einen Seite und der sozial optimalen Gestaltung der Preise sowie der Löhne und Arbeitsbedingungen auf der anderen Seite; wobei niedrige Preise und hohe Löhne und Sozialleistungen wiederum regelmäßig in einem alternativen Verhältnis stehen. Von der sozialen Tarifgestaltung in den Unternehmen der Daseinsvorsorge 7) abgesehen, scheint sich die Staatserwerbswirt-

S. hierzu auch Köttgen, Die wirtschaftliche Betätigung der Gemeinden, in "Hundert Jahre Deutsches Rechtsleben", Festschrift Deutscher Juristentag, Bd.I, 1960, S. 577 ff (587): "Die Prognose einer Verdrängung des Steuerstaates durch den Unternehmerstaat hat sich im großen nicht bewahrheitet". S. dort auch weitere Nachweise.

5) S. o. S. 34 .

(i) S. S. 36 zu Fußn.6.

7) Die sozialpolitischen Möglichkeiten der Tarifpolitik im Bereich der Daseinsvorsorge hat vor allem Teutscher (Die öffentliche Wirtschaft, 1953: S.403; Die öfentlichen Unternehmen und ihre wirtschaftspolitischen Aufgaben, Zeitschrift für die gesamten Staatswissenschaften, Bd.109 (1953) S. 398 ff) hervorgehoben. 
schaft jedoch regelmäßig für die erstere Alternative - und damit auch gegen die Erfüllung ihrer innerwirtschaftlichen sozialen Führungsaufgabe - zu entscheiden. ${ }^{8)}$

$\mathrm{Zu}$ bemerken ist schließlich, daß die Erwerbswirtschaft von Bund und Ländern zwar von gegenseitiger Einflußnahme frei ist, nicht aber außerhalb der Kompetenzordnung steht. Jedenfalls soweit sie spezifisch staatliche Befugnis oder Aufgabe ist (Art. 30 GG) 9 ), ist sie dem Bunde nur möglich, wenn sie in seine Verwaltungskompetenzen fällt, 10) während die Länder die Vermutung dieser Befugnis für sich haben. Rein vermögensverwaltende Erwerbswirtschaft 11) wird dagegen - als nicht typisch staatlich - diesen Beschränkungen unterliegen.

8) Zum Versagen des Staates als Unternehmer im Bereich der betrieblichen Sozialpolitik (im engeren Sinne) s. Triesch, Schleichende Sozialisierung, S. 43 f. - Die Erscheinung hat mehrere Gründe. Einerseits lassen die Gesetzmäßigkeiten, denen ein Unternehmen, das am Markt auftreten, einkaufen und verkaufen und dabei bestehen soll, unterworfen ist, wenig Spielraum. Andererseits muß der Verdacht vermieden werden, als würden Steuergelder zu ruinöser Konkurrenz eingesetzt. Und schließlich wäre der Kreis der Begünstigten bei derartiger staatlicher Sozialpolitik häufig ein sehr zufälliger. Außerdem mögen auch noch weniger sachgemäße Gründe mitwirken, so z. B. das Motiv, daß erzielter hoher Gewinn für die mit der Leitung und Überwachung betrauten Beamten und Angestellten ein zuverlässigerer Ausweis gegenüber der Kontrolle durch Bürokratie (einschl. Rechnungshof) und Parlament ist als eine Sozialpolitik, deren Manifestationen sich allzuleicht "verlaufen" und über deren Berechtigung nach Art und Maß sich häufig streiten läßt. Die ständig durch bürokratische und parlamentarische Kontrolle bedrohten Verwalter öffentlicher Unternehmen werden mitunter selbst bei eigenem guten Willen auf die Bahn der Resignation gedrängt.

9) S. hierzu z.B. Maunz in Maunz-Dürig, Art. 30 Randn. 7 und 10 und die dort. Nachw.

10) S. hierzu oben S.45.

11) Zur insofern legitimierenden Wirkung der Art.134, 135 GG s. Hamann, Deutsches Wirtschaftsverfassungsrecht, S. $74 \mathrm{f}$. Doch ist die Möglichkeit vermögensverwaltender Erwerbswirtschaft nicht auf die Fälle übernommenen Vermögens beschränkt. 


\section{cc) Zweimal "Beiträge"}

Unter den hoheitlichen Einnahmen ${ }^{1)}$ des Staates sind vorweg die Beiträge zu erwähnen.

aаa) Beiträge im überkommenen finanzwissenschaftlichen Sinn

Beiträge, soweit sie im strengen, überkommenen Sinn des Begriffes als "Entgelte für mittelbare Vorteile, die jemandem aus der Herstellung und Unterhaltung öffentlicher Veranstaltungen erwachsen" 2), verstanden werden, kommen heute - obwohl dafür keine verfassungs rechtliche Notwendigkeit besteht 3 ) - nur noch im Kommunalrecht vor. 4 )

Die Kompetenz, sie zu regeln, folgt der Zuständigkeit zur rechtlichen Ordnung der Verwaltungsveranstaltung, auf die sich die Beitragspflicht bezieht. 5) Dagegen fließen sie wesensmäßig dem Träger dieser Verwaltungsveranstaltung zu.6) Da die Zuständigkeit, Verwaltungsagenden der Länder (einschließlich der Kommunen) zu regeln, beim Bunde liegen kann, ergibt sich die Möglichkeit bundesseitig angeordneter und bestimmter Beiträge, die in

1) (1) Nichthoheitliche Verwaltungseinnahmen wie z.B. die Veräußerung von Verwaltungsvermögen (z.B. Altpapier) stehen zweifellos der Gebietskörperschaft zu, in deren Bereich sie angefallen sind (vgl. Wacke, Das Finanzwesen der Bundes republik, S.44). Doch ist dieser Einnahmeposten hier so irrelevant, daß weiter darüber kein Wort zu verlieren ist.

(2) Unter den hoheitlichen Einnahmen können die Geldstrafen hier unberücksichtigt bleiben.

(3) Zu den hoheitlichen Einnahmen gehören auch die Ablieferungen der Sondervermögen und Anstalten (z. B. der Bundespost und Bundesbahn an den Bund). Sie bieten keine anderen Probleme als sie im Zusammenhang mit den wirtschaftlichen Unternehmen zu erörtern waren.

2) Gerloff, "Die Gebühren" in Handbuch der Finanzwissenschaft, 2. Aufl. Bd. II 1956 S.203 ff (204). - Zum Begriff des Beitrages s. ferner Büchner, "Beiträge", ebd. S.225 ff; Hettlage, Art. "Beiträge" im Handwörterbuch der Sozialwissenschaften, Bd.I 1956 S. 727 ff. S. a. BVerfGE 7, 244 (254 ff); 9, 291 (297 f).

3) S. die Erörterungen in BVerfGE 7, 244 (254 ff), welche diese Unterstellung voraussetzen.

4) S. z.B. Büchner, a.a.O. S.229 ff; Hettlage, a.a.O. S. 729 f.

5) Vgl. Hamann, Das Grundgesetz, Art. 105 Anm. A/B.

6) Vg1. Wacke, Das Finanzwesen der Bundesrepublik, S.44. 
die Kassen der Länder bzw. der Gemeinden und Gemeindeverbände fließen. Das Prinzip der getrennten Finanzgebarung (Art. 109 GG) wird dadurch effektiv durchbrochen.

Beiträge dieser Art gehören jedoch nicht zum spezifischen Instrumentarium der sozialen Intervention. 7) Für den Landeshaushalt im engeren Sinn verlieren sie an Bedeutung auch dadurch, daß sie regelmäßig in der kommunalen Ebene absorbiert werden.

\section{bbb) Die Organisations - und Sozialbeiträge}

Weitaus mehr Gewicht kommt einer anderen Abgabeform zu, die mit dem klassischen "Beitrag" den Namen teilt. 1) Sie unterscheidet sich von diesem einmal dadurch, daß sie das Prinzip des Vorteilsausgleiches nicht notwendig rein verwirklicht, ja regelmäßig modifiziert und mitunter völlig verläßt; ferner dadurch, daß sie unter einer Verwaltungsveranstaltung nicht (nur) eine bestimmte, konkrete sachliche Veranstaltung versteht, sondern auch Institutionen, Organisationen, verwaltungsmäßig lokalisierbare Vorgänge usw. Typisch für diese Abgabeform ist die Zuordnung zu einem "Hilfsfiskus", einer "intermediären Finanzgewalt", einer besonderen Verwaltungseinheit, deren speziellem Zweck der jeweilige Beitrag spezifisch dient. 2) Der personelle Einzugsbereich dieser intermediären Finanzgewalten stellt jeweils eine aus der allgemeinen staatlichen Gemeinschaft ausgegrenzte besondere Gemeinschaft dar, innerhalb deren die Beiträge steuergleich erhoben werden. Am deutlichsten ist dies im Falle der körperschaftlichen Organisation. Das Phänomen ist jedoch auch bei anstaltlicher Organisationsform denkbar. Die Hauptbeispiele sind der Sozialversicherungsbeitrag auf der einen und der berufsständische "Kammer". Beitrag auf der anderen Seite. ${ }^{1)}$

Die Zuständigkeit, diese Beiträge gesetzlich anzuordnen und zu regeln, ergibt sich aus der Zuständigkeit, den Bestand und die Wirksamkeit der als intermediäre Finanzgewalt agierenden Ver-

7) Wichtige Aspekte einer sozialen Gestaltung des Beitragswesens s. bei Barocka, Die Berücksichtigung sozialer Gesichtspunkte bei der Erhebung von Gebühren und Beiträgen für kommunale Abwasseranlagen, ihre Möglichkeiten, Problematik und Grenzen, DVB1. 75.Jhg. (1960) S. 825 ff.

1) Vg1. Büchner, a.a.O. S. 229 und 236 ff mit weiteren Nachweisen.

2) S. Büchner ebd. S.a. BVerfGE 11, 105 (110). - Zur (nicht notwendigen aber regelmäßig zu verzeichnenden) Umverteilungsfunktion dieser Verwaltungseinheiten s.a. die oben S. 15 zu Fußn. 50 Zitierten. 
waltungseinheit zu regeln. ${ }^{3)}$ Da diese Zuständigkeit weitgehend zumindest konkurrierend - beim Bunde liegt, während die hilfsfiskalischen Verwaltungseinheiten vielfach den Ländern inkorporiert sind, 4) ergibt sich insoweit die Möglichkeit einer Fremdbestimmtheit des Gesamtlandeshaushaltes.

Für den engeren Landeshaushalt ist diese aber nur dann von praktischer Bedeutung, wenn die Länder für ein Defizit einstehen müssen oder von den Hilfsfisci Ablieferungen erhalten. Für das letztere ist, soweit landesinkorporierte Verwaltungseinheiten bundes rechtlich geregelt sind, kein Beispiel ersichtlich. Dem ersteren beugt - für den sozialen Bereich - Art. 120 GG vor.

\section{dd) Gebühren}

Gebühren fließen zwar - wohl schon begriffsnotwendig - dem Gemeinwesen zu, das die Verwaltungsleistung oder Gerichtshandlung tätigt, die durch die Gebühr abgegolten wird. 1) Dieses Gemeinwesen verwaltet sie regelmäßig auch. Aber die den Ländern zustehenden Gebühreneinnahmen können normativ vom Bunde her fremdbestimmt sein. Die gesetzliche Regelung der Gebühren steht dem Gemeinwesen zu, das auch das Verfahren regelt, in dem die Leistung, mit der die Gebühr in bedingendem Zusammenhang steht, erbracht wird. Für die gerichtlichen Gebühren ist es seit jeher selbstverständlich, daß sie von dem Gesetzgeber gere-

3) Vgl. Hamann, Das Grundgesetz, Art. 105 A/B. - Für die Sozialversicherungsbeit räge wurde noch von keiner Seite bestritten, daß die Kompetenz aus Art. 74 Nr. 12 GG herzuleiten ist. Das Bundesverfassungsgericht (BVerfGE 11, 105 (110) hat die Ausnahme von der Kompetenzregelung der Art. $105 \mathrm{ff}$ GG selbst für den Kindergeldbeitrag anerkannt, bei dem die Vorteilsausgleichung keine nennenswerte Rolle mehr spielt. - Für die Kammerbeiträge s. die entsprechende Ansicht bei Klein, Kammerbeitrag und Finanzverfassung, DVB1. Jhg. 74 (1959) S. $315 \mathrm{ff}$. A. A. Vogel, dass. DVBl. 73. Jhg. (1958) S. 491, der die Kammerbeiträge als Steuern i. S. der Art. $105 \mathrm{ff}$ GG behandelt wissen will. Die Steuerähnlichkeit ist - wie im Text schon angesprochen - zuzugeben. Aber es ist doch offensichtlich, daß die Art. 105 ff GG diese Beiträge nicht als Steuern ansehen und das Grundgesetz sie dennoch nicht verbieten will. Also erübrigt nichts, als die Kompetenz bei der allgemeinen Sachkompetenz zu suchen. - Weitere Nachweise zum Problem s. bei Vogel und Klein je a.a.O.

4) S.O. I 1 (S. $45 \mathrm{ff})$.

1) Wacke, Das Finanzwesen der Bundes republik, S. 44. 
gelt werden, der das Gerichtsverfahren ordnet, in der Regel also vom Bundesgesetzgeber (Art. $74 \mathrm{Nr} .1$ GG).2) Aber für die Verwaltung kann nichts anderes gelten. Fül die bundeseigene Verwaltung regelt der Bund die Gebühren naturgemäß ausschließ1ich. Für die Bundesauftragsverwaltung und den landeseigenen Vollzug von Bundesrecht richtet sich die Kompetenz nach Art. 84 Abs. 1, 85 Abs. 1 GG). ${ }^{3)}$ Nur für die reine Landesverwaltung sind

2) (1) Für die ordentliche Gerichtsbarkeit vgl. das Gerichtskostengesetz vom 18. Juni 1878 (BGB1. S. 141) i.d. F. der Bekanntmachung vom 26.Juli 1957 (BGB1. I S.941), das Gesetz über die Kosten in Angelegenheiten der freiwilligen Gerichtsbarkeit vom 25. November 1935 (BGB1. I S. 1371) i.d. F. der Bekanntmachung vom 26. Juli 1957 (BGB1. I S.960) und das Gesetz über die Kosten der Gerichtsvollzieher vom 26. Juli 1957 (BGB1. I S. 861/887).

(2) Für das arbeitsgerichtliche Verfahren vg1. \$12 ArbGG

(3) Für das sozialgerichtliche Verfahren vgl. \$\$ $183 \mathrm{ff}$ SGG

(4) Für das finanzgerichtliche Verfahren vgl. $\$ 311 \mathrm{AO}$

(5) Das verwaltungsgerichtliche Verfahren kennt eine bundesrechtliche Gebührenregelung nur für das Verfahren vor dem Bundesverwaltungsgericht (vgl. $\$ 189$ VGO i.V.m. $\$ 73$ BVerwGG). Für das Verfahren vor den Verwaltungsgerichten und Oberverwaltungsgerichten/Verwaltungsgerichtshöfen ist das Gebührenrecht derzeit noch landes rechtlich geregelt ( $\$$ $189 \mathrm{VGO})$.

3) (1) S. hierzu Haussleiter, Gebührenvorschriften auf der Ermächtigungsgrundlage des Preisgesetzes, DöV 8. Jhg. (1955) S. 681 ff (684). (Harnann, Das Grundgesetz, Art. 105 Anm. A/ $B$, beschränkt sich darauf, die Gebührenkompetenz aus der Steuerkompetenz nach Art.105 GG auszuklammern).

(2) In der Praxis sind die Fälle bundesrechtlicher Regelung von Gebühren der Landesverwaltung allerdings selten. Zu nennen wären der wohl auch zum sozialen Bereich zu zählende Fall der Gebühren für die Ausstellung der Schiffsdienstbücher $(\$ 9$ des Gesetzes über Schiffsdienstbücher vom 12 . Februar 1951, BGB1. II s. 3, i. V.m. \$2 Satz 2 der VO zur Durchführung des Gesetzes usw. vom 22. Februar 1951, BGB1. II S. 26) und der hier an sich nicht interessierende Fall der Paßgebühren ( $\$ 13$ des Paßgesetzes vom 4. März 1952, BGBl. I S. 290, i.d.F. des Gesetzes vom 24. März 1956, BGB1. I S.435, i. V.m. der Paßgebührenordnung vom 12. Juli 1958, BGB1. I S.471). Die sonst interessanie Aufstellung von Gerloff "Die Gebühren" beweist für die bundesrechtliche Praxis wenig, da sie neben diesen Beispielen auch alte, reichsrechtliche oder auf dem Preisgesetz beruhende Regelungen anfüht. 
die Länder auch ausschließlich zur Regelung des Gebührenrechts zuständig. Da der Gebührenpolitik eine erhebliche soziale Bedeutung zukommt oder wenigstens zukommen kann, 4) ist diese $\mathrm{Zu}-$ ständigkeitsverteilung nicht nur unter dem budgetären sondern auch unter dem Aspekt der sozialen Gestaltung und Handhabung des Gebührenrechts von Bedeutung. 5)

\section{ee) Die Steuern}

Für unseren "Steuerstaat" von der allergrößten Tragweite sind die Verhältnisse auf dem Gebiete der Steuern. 1) Gerade in bezug auf sie ist aber der Grundsatz des Art. 109 GG auf das nachhaltigste ausgehöhlt.

Vorweg muß darauf hingewiesen werden, daß dies nicht für die Erträge der Finanzmonopole gilt. Sie, die das Grundgesetz stets mit den Steuern gewissermaßen "in einem Atemzuge" nennt, ${ }^{2)}$ stehen nach Zufluß, Gesetzgebung und Verwaltung ausschließlich dem Bunde zu (Art. 105 Abs. 1, 106 Abs.1 und 108 Abs. 1 GG).

Hinsichtlich der St e u e reinnahmen überschneiden sich jedoch die Einflußsphären des Bundes und der Länder ${ }^{3)}$ erheblich. 4) 5)

4) Vg1. Schmölders, Finanzpolitik S.193 ff; Gerloff, Die Gebühren, S. $209 \mathrm{f}$. - Man denke insbes. an das Problem des Armenrechts; s.a. oben S. 9 zu Fußn. 26.

5) S. hierzu auch Barocka, Die Berücksichtigung sozialer Gesichtspunkte bei der Erhebung von Gebühren und Beiträgen für kommunale Abwasseranlagen, ihre Möglichkeiten, Problematik und Grenzen.

1) Die Steuern allein machen durchschnittlich 60 v. H. der Gesamteinnahmesumme der Länderhaushalte aus, während der Rest sich auf Zuweisungen und Zuschüsse, Einnahmen der Vermögensbewegung, Einnahmen aus Wirtschaftsunternehmen, Gebühren, Geldstrafen usw. verteilt (s.hierzu z.B. "Länderhaushalte 1952-1954", S. 39 if).

2) Zur sachlichen Verwandtschaft der "Finanzmonopole" mit den Verbrauchssteuern vg1. Wacke, Das Finanzwesen der Bundes republik, S. 19; Schmölders, Allgemeine Steuerlehre, 3. Auf1. 1958, S. 50, 217.

3) Der verfassungs rechtlich institutionalisierte Steueranteil der Ge m e inden und Gemeindeverbände (Art. 106 Abs.6 GG) braucht hier noch nicht besonders erwähnt zu werden. Er gehört unter bundesstaatlichen Verteilungsaspekten zu den Einnahmequellen der Länder (Art.106 Abs.8 GG) - eine Annahme, die vornehmlich der landesinkorporierten Stellung 
Zwar ist die Zuflußhoheit hinsichtlich der einzelnen Steuern - abgesehen von der Einkommen- und Körperschaftsteuer - säuberlich auf Bund und Länder verteilt (Trennsystem vgl. Art. 106 Abs. 1 und 2 GG). Aber die Disposition des Bundesgesetzgebers über die Verteilung der Einkommen- und Körperschaftsteuer, die durch die verfassungsrechtlichen Grundsätze (Art.106 Abs. 3-5 GG) zwar eingegrenzt ist, bei dem verfassungspolitisch vorgegebenen $Z$ weck dieser Puffer-Steuermasse aber doch nur bedingtvorgezeichnet werden konnte, bringt schon in die Sphäre der Zuflußhoheit eine Dominante des Bundes, die vom Länderhaushalt her als bundesseitige Fremdbestimmtheit erscheinen muß.

Noch viel weiter reicht diese Fremdbestimmtheit im Bereich der legislativen Regelung der Steuern. Sowohl die ausschließlich den Ländern zufließenden Steuern wie auch die Einkommen- und Körperschaftsteuer - und somit auch der Länderanteil daran unterliegen der Gesetzgebung des Bundes (Art. 105 GG). Nur die unbedeutenden, zumeist ohnedies in die Kasse der Gemeinden und Gemeindeverbände fließenden "Steuern mit örtlich bedingtem Wirkungskreis" stehen den Ländern nach Zufluß und Gesetzgebung zu (Art. 106 Abs.2 Nr. 7 GG); ähnlich wie andererseits alle dem Bunde zufließenden Steuern auch seiner Gesetzgebungskompetenz unterliegen (Art.105, 106 Abs.1 GG). Diese umfassende Gesetzgebungs befugnis des Bundes relativiert wiederum die verfassungsrechtliche Regelung der Zuflußhoheit. ${ }^{6)}$

Im Verwaltungssektor muß der Bund zwar die Kompetenz der Länder zur Verwaltung eines Teiles auch der Steuern hinnehmen, die ihm zufließen (Art.108 Abs.1-3 GG). Da aber alle Steuern die dem Bunde zufließen, von den Ländern in Auftragsverwaltung zu nehmen sind (Art. 108 Abs. 1 Satz 4, Abs. 2 und Abs. 4 Satz 1 GG), ist der Bund durch die ihm gebotenen Ingerenzrechte (Art. 85, 108 Abs. 3, 4 und 6 GG) reich entschädigt. Die Länder unterliegen aber sogar hinsichtlich der Steuern, die ihnen zufließen, den durch Art. 108 Abs.3 GG gesteigerten Organisations-, Leistungs-

der Gemeinden und Gemeindeverbände entspricht (Art.28 GG).

4) Dabei sollen hier die außerhalb des Rechtlichen liegenden Interdependenzen der Ergiebigkeit verschiedener, in ein- und demselben Staatswesen erhobener Steuern nicht erörtert werden. Jedoch liegt hierin ein sehr wichtiger Zug des effektiven Gesamtbildes.

5) Zum Nachstehenden s. auch die das Finanzwesen betreffenden Ausführungen zur bundesstaatlichen Aufgabenverteilung (s.o. I (S. 45 ff)).

6) S. Fischer-Menshausen, Das Finanzverfassungsgesetz, DöV 9.Jhg. (1956) S.161 ff (164). 
und Aufsichts rechten des Bundes im Rahmen landeseigenen Vollzugs von Bundes recht (Art. 84, 108 Abs.6 GG). Hinsichtlich der Einkommen- und Körperschaftsteuer ist der Einfluß des Bundes auf die Verwaltung noch dadurch intensiviert, daß der - für die Außentätigkeit der Verwaltung untrennbare - Bundesanteil daran in Auftragsverwaltung geführt wird (Art. 108 Abs.2 GG) und die damit verbundenen Aufsichtsmaßnahmen des Bundes unmittelbar und unausweichlich auf die an sich landeseigene Verwaltung des Landesanteiles ausstrahlen. ${ }^{7)}$ Die Biersteuer wird vom Bund nicht nur gesetzlich ge regelt sondern auch verwaltet, obwohl sie den Ländern zufließt (Art. 105 Abs. 2 Nr. 1, 106 Abs. 2 Nr. 5, 108 Abs. 1 Satz 1 GG).

Die Rechtsprechung in Steuersachen liegt in letzter Instanz in den Händen eines oberen Bundesgerichts (Art.96 Abs.1 GG), so daß auch in dieser Hinsicht der maßgebliche Einfluß des Bundes gewährleistet ist. ${ }^{8)}$

Damit beherrscht der Bund vor allem die Steuergesetzgebung, aber in intensivster Weise auch den Vollzug der Steuergesetze. Während der Bund die Steuern, die ihm zufließen, im wesent1ichen nach jeder Richtung in der Hand behält, ist den Ländern nur im Hinblick auf die "Steuern mit örtlich bedingtem Wirkungskreis" durchgehende Gestaltungsfreiheit belassen. Die übrigen den Ländern zufließenden Steuern sind ganz entscheidend vom Bund her determiniert. Sie sind fremdbestimmte Größen im Haushalt der Länder. Der Bund beherrscht, indem er die Steuergesetzgebung und ihren Vollzug in der Hand hat, das Steuerrecht aber auch als ein zentrales Instrument des sozialen Ausgleiches,

7) Vgl. oben S.112 ff und S.115ff.

8) Daraus, daß die Regelung der Finanzgerichtsbarkeit dem Bunde ausschließlich übertragen ist (Art. 108 Abs. 5 GG), wurde anfänglich vielfach der Schluß gezogen, der Bund habe das Recht oder sogar die Pflicht, abweichend von der in Art. 92, 96 Abs. 1 GG zum Ausdruck gekommenen Konzeption, auch die unteren Gerichte der Finanzgerichtsbarkeit als Bundesgerichte einzurichten. (Fine Übersicht über den älteren Stand der Meinungen s. bei Wacke, Das Gesetz über die Finanzverwaltung, S.720 (Fußn.2)). Diese durch nichts als unitaristischen Eifer gerechtfertigte Annahme darf heute jedoch als überholt angesehen werden. Durch $₫ 1$ des Gesetzes über Maßnahmen auf dem Gebiet der Finanzgerichtsbarkeit vom 22. Oktober 1957 (BGB1. I S. 1746) wurden die Finanzgerichte als "Gerichte der Länder" ausdrücklich bestätigt, nachdem schon bis dahin die Staatspraxis diese Linie eingehalten hatte. - Zu den Einzelheiten S.o. S. 170 ff. 
das es nicht nur über seinen fiskalischen Zweck sondern auch und vor allem in seiner inneren Gestaltung und Handhabung ist.

ff) Die föderativen Sekundäreinnahmen der Länder - Zusammenfassung

Die dem Bunde zufließenden Mittel sind also fast ausschließlich eigenbestimmt, die den Ländern zukommenden Mittel dagegen ganz überwiegend vom Bunde her fremdbestimmt.

Die Einnahmen der Länder bestehen nun aber nicht nur aus dem bisher ins Auge gefaßten ursprünglichen Aufkommen. Ihnen flieBen auch Mittel aus der. Umverteilung des Aufkommens zu, so aus dem Bundesaufkommen die $F$ in anzzuweisungen (Art. 106 Abs. 5 Satz 2 GG), die Ausgleichsle istungen (Abs. 7 ebd.) und die Ergänzungszuweisungen im Rahmen des vertikalen Finanzausgleichs (Art. 107 Abs.2 Satz 3 GG), aus dem Länderaufkommen die Ausgleichszuweisungen aus dem horizontalen Finanzausgleich (Art. 107 Abs. 2 Satz 1 und 2 GG). Diese Umverteilung liegt - von den schon in der Verfassung hinreichend bestimmten Ausgleichsleistungen abgesehen - naturgemäß in der Hand des Bundes. Wenn dieser dabei auch den verfassungs rechtlichen Grundsätzen folgen muß, so erhöht sich durch diese Kompetenz doch einmal mehr seine finanzverfassungsrechtliche Potenz. 1)

Von einer Finanzautonomie der Länder kann demnach keine Rede sein. 2) Es kann zunächst auch unerörtert bleiben, ob das

1) Speziell für den horizontalen Finanzausgleich, also den Fall, in dem der Bund als Träger der Finanzhoheit nur auf die zurückgezogenste Weise eingeschaltet ist, sagt Wacke (Das Finanzwesen der Bundes republik, S.46), "daß ge rade diese Macht, starken Ländern Steuereinnahmen fortzunehmen und sie schwachen Ländern zuzuwenden, dem Bunde eine besondere Stärke gibt".

2) Äußerst scharf hebt das Braeutigam, WettbewerbsordnungSteuer reform-Nationalbudget, Finanzarchiv n. F. Bd. 16 (1955/56) S. 81 ff (117 ff) hervor: "Ist die steuerliche Gesetzgebungshoheit der Länder so weit eingeschränkt, daß sie praktisch ganz beim Bund liegt, so sind die Länder in ihrer Einnahmegestaltung nicht mehr autonom... und ist die ihnen verbliebene 'Ertragshoheit' an bestimmten Steuern oder Steuerquoten... nur noch eine juristische Konstruktion, die den ökonomischen Zusammenhängen keineswegs mehr gerecht wird und deren begriffsverwirrender Tragweite sich der Verfassungsgeber offenbar 
Grundgesetz selbst dem Bunde ausreichende Bindungen auferlegt, um den finanziellen Rückhalt für eigenständige Operationen der Länder zu erhalten. Fest steht jedenfalls, daß die den Ländern zukommende Finanzmasse im wesentlichen durch Verfassung und Bundes recht - einschließlich der weitgehenden Disposition der Bundesorgane über dessen Vollzug - prädisponiert ist. ${ }^{3}$ )

Der Bund beherrscht aber nicht nur das ihm zufließende Aufkommen. Er disponiert über das Volumen des gesamtstaatlichen Finanzaufkommens und teilt - in den von der Verfassung gesteckten Grenzen - sich und den Ländern den jeweiligen Anteil daran zu. ${ }^{4}$ )

\section{c) Die Ausgabedisposition}

\section{aa) Die Grundsatzregelung}

Auf der Ausgabeseite besteht ebenfalls ein - wenngleich weitaus weniger hervortretender - Vorrang des Bundes. Während die Länder dem Bunde keine Ausgaben anlasten können, hat der Bund die Möglichkeit, den Ländern durch Gesetze, die sie nach Art.83 ff GG zu vollziehen haben, Ausgabepflichten aufzubürden.

Die Tragweite der hierin eingeschlossenen bundesseitigen Prädisposition über die Ausgabeseite der Länderhaushalte wird mit einem Blick auf das Übergewicht des Bundes in der Gesetzgebung und die weitgehende Vollzugsverantwortung der Länder klar. Die

gar nicht bewußt geworden ist" (a.a.O. S.119). - Sperrung im Original. - Löwenstein (Verfassungsrecht und Verfassungs realität, AöR Bd. 77 (1951/52) S. 387 ff (414 ff)) hat gesagt: "Ein Staat mit einer Bundeseinkommensteuer ist eben kein echter Bundesstaat mehr". Diese vom Autor selbst als "überspitzt" bezeichnete Formulierung trifft gewiß nicht zu. Aber sie macht - im Kontrast - sichtbar, wie weit die Regelung des Grundgesetzes geht.

3) Den Interessen der Länder kommt allerdings ein System von Zustimmungsvorbehalten zugunsten des Bundes rates entgegen (Art. 105 Abs. 3, Art. 106 Abs. 4 Satz 1, Abs. 5 Satz 2, Art. 107 Abs. 1 Satz 2, Abs. 2 Satz 1, Art. 108 Abs. 3 Satz 2, Abs. 6 (GG). Aber der Bundess rat ist - wie schon wiederholt zu betonen Anlaß war - weder mit einem Land noch mit der Summe der Länder gleichzusetzen. Diese Zustimmungsvorbehalte heben den "bündischen" Charakter all der genannten finanzverfassungs rechtlichen Bundeskompetenzen nicht auf. Noch weniger bewirkt dies das im übrigen gegebene Einspruchsrecht des Bundes rates (Art. 77 GG).

4) Vgl. Fischer-Menshausen, Das Finanzverfassungsgesetz, S. 164,169 . 
für den sozialen Bereich spezifischen Proportionen sind bekannt und brauchen hier nicht nochmals gesondert hervorgehoben zu werden.

Wenn er den Ländern neue, zusätzliche Lasten auferlegt, muß er allerdings - jedenfalls nach der Neufassung des Art. 106 GG durch das Finanzverfassungsgesetz vom 23. Dezember 1955 - ihnen entsprechende Mittel zuweisen und zwar entweder durch Finanzzuweisung oder durch eine Änderung des Beteiligungsverhältnisses an der Einkommen- und Körperschaftsteuer (Art.106 Abs. 5 GG). Vor der Neufassung des Art.106 GG durch das Finanzverfassungsgesetz vom 23. Dezember 1955 war zwar für das damalige Recht und noch mehr im Hinblick auf die durch Art.107 GG geforderte und legitimierte Neuregelung streitig, ob die Ausgaben von dem Gemeinwesen zu tragen sind, das ihre Verausgabung gesetzlich anordnet, 1) oder von dem Gemeinwesen, das sie im Verwaltungs wege verausgabt. 2) Es war das Verdienst Köttgens, 3) klar auseinandergesetzt zu haben, daß eine eindeutige Zurechnung der "Sachverantwortung" nur dort möglich ist, wo Gesetzgebung und Verwaltung in einer Hand liegen. 4) Dort, wo Gesetzgebungs - und Verwaltungskompetenz sich spalten, kann die Ausgabelast nicht generell dem Bund oder den Ländern zugerechnet werden. 5) Der Gesetzgeber muß zusätzliche Ausgaben, die er dem Verwaltungsträger verursacht, durch zusätzliche Einnahmen ausgleichen. 6) Für Art. 106 Abs. 4 und 5 GG n. F. kann nun

1) So vor allem Ludwig, Finanzverantwortung und Deckungsverantwortung, Städtetag 6.Jhg. (1953) S. $141 \mathrm{ff}$; v.d. Heide, Zur Abgrenzung zwischen den Bundes-, den Länder- und den Kommunalfinanzen, DVB1. 68. Jhg. (1953) S. $289 \mathrm{ff}$.

2) So vor allem Fischer-Menshausen, Die Abgrenzung der Finanzverantwortung zwischen Bund und Ländern, DÖV 5. Jhg. (1952) S. 673 ff; ders., Die staatswirtschaftliche Bedeutung des neuen Finanzausgleichs, DÖV 8. Jhg. (1955) S. $261 \mathrm{ff}(263)$.

3) Köttgen, Sachverantwortung als verfassungs rechtlicher Maßstab des Finanzausgleichs, JÖV 6. Jhg. (1953) S. $398 \mathrm{ff}$. Zustimmend Hettlage, Die Finanzverfassung im Rahmen der Staatsverfassung, S.20; s.a. Hettlage, Die Neuregelung der deutschen Finanzverfassung, S.411 ff.

4) Köttgen, a.a.O. S.360.

5) Köttgen, a.a.O. S.362.

6) Köttgen, a.a.O. S.363 unter Heranziehung des $₫ 54$ des Reichsfinanzausgleichsgesetzes vom 27. April 1926 (BGBl.I S.203); übereinstimmend Hettlage, Die Neuordnung der deutschen Finanzverfassung, S.412 f. 
nicht mehr zweifelhaft sein, daß die dem Gesetzesvollzug zu verausgabenden Mittel von dem Gemeinwesen zu erbringen sind, welches das Gesetz vollzieht. ${ }^{\text {) }}$ Der Gesetzgeber muß aber, wenn er einem anderen Gemeinwesen auf diese Weise neue Lasten auferlegt, diesem auch zusätzliche Mittel verschaffen. Art.106 Abs. 5 GG spricht das für das Verhältnis Bund-Land eindeutig aus. Eine Ausgabenüberbürdung durch den Landesgesetzgeber auf den Bund kommt ohnedies nicht in Frage. ${ }^{8)}$

Die Klausel des Art. 106 Abs. 5 GG schwächt diese Relation nur bedingt $a b$; einerseits deshalb, weil sie zu ihrer Realisierung eines - freilich verfassungs rechtlich bindend vorgeschriebenen Bundesgesetzes bedarf, andererseits - und dies vor allem - des halb, weil sie auf dem vom Finanzverfassungsgesetz vom 23. Dezember 1955 angetroffenen status quo aufbaut, der schon ein hochentwickeltes Maß staatlicher Ausgabelasten in sich barg.

7) Vgl. Bühler, Bonner Kommentar, Art.106 GG n.F. Anm. 4a; Fischer-Menshausen, Das Finanzverfassungsgesetz, DÖV 9.Jhg. (1956) S.161 ff (167); Heim, Verwaltungskosten der Länder aus der Bundesauftragsverwaltung, DÖV 11. Jhg. (1958) S. $566 \mathrm{ff}$ - dieser auch zu dem besonders diffizilen Problem der Verwaltungskosten im Bereich der Auftragsverwaltung; weit. Nachw. s. dort.

8) Auch nicht im Rahmen des Art.120 GG. Die Kriegsfolgelasten übernimmt nach Abs. 1 ebd. der Bund nur nach Maßgabe eines Bundesgesetzes. Die Zuschüsse zu den Lasten der Sozialversicherung mit Einschluß der Arbeitslosenversicherung und der Arbeitslosenfürsorge sind bundesgesetzlich geregelt. - Oben (I 1 b, bb S. 49 ff) wurde allerdings die Ansicht vertreten, daß auch Altersversorgungen der freien Berufe zur "Sozialversicherung" i.S. des Art. 74 Nr.12 GG gehören und insoweit noch spielraum für landesgesetzliches Sozialversicherungs recht vorhanden sei. Damit erhebt sich die Frage, ob, wenn derartiges Landesrecht Zuschüsse vorsieht, diese vom Bund zu tragen sind. Das muß verneint werden. Ganz offensichtlich setzt Art.120 Abs.1 GG die Zuschüsse als bundesrechtlich geregelt voraus. Sonst wäre es nicht verständlich, daß die Vorschrift gerade die Zuschüsse von dem Vorbehalt der "näheren Bestimmung eines Bundesgesetzes" ausnimmt. S. hierzu auch $₫ 17$ des Ersten Gesetzes zur Überleitung von Lasten und Deckungsmitteln auf den Bund (Erstes Überleitungsgesetz) i.d.F. vom 28. April 1955 (BGB1. I S.193). - Im übrigen s, zum Problem auch Zeidler, Ausführung von Landesgesetzen durch Bundesbehörden, DVB1. 75. Jhg. (1960) S. 573 ff. 
bb) Die Sonderregelung des Art.120 GG

Dieses System ist nun aber gerade für den sozialen Bereich durch eine Vorschrift durchbrochen, der für den ganzen hier zu erörternden engeren Sachzusammenhang eine grundlegende Bedeutung zukommt: Art.120 GG. Danach trägt der Bund die Zuschüsse zu den Lasten der Sozialversicherung, zur Arbeitslosenversicherung und Arbeitslosenfürsorge. ${ }^{1)}$ Nach Maßgabe eines Bundesgesetzes ${ }^{2)}$ trägt er neben den Besatzungskosten ferner die inneren und äußeren Kriegsfolgelasten. Da die heute vorhandenen sozialen Gefällsituationen weithin kriegsbedingt sind, ist der Bund daher gehalten, in erheblichem Umfange soziale Aufwendungen zu übernehmen, die nach den allgemeinen Grundsätzen von den Ländern $\mathrm{zu}$ bestreiten wären.

Maßgeblich ist im wesentlichen das Erste Gesetz zur Überleitung von Lasten und Deckungsmitteln auf den Bund (Erstes Überleitungsgesetz), das derzeit in der Fassung vom 28. April 1955 (BGB1. I S.193) gilt. Danach werden z. B. vom Bund ganz oder überwiegend getragen :

(1) Die Fürsorgekosten für die Empfänger von Kriegsfolgenhilfe (Heimatvertriebene, Evakuierte, aus der Sowjetzone Zugewanderte, Ausländer und Staatenlose, Angehörige von Kriegsgefangenen, Vermißten und Heimkehrern, Kriegsbeschädigte, Kriegshinterbliebene) ( $\$ \$ 1$ Abs. $1 \mathrm{Nr} .3,7-13)$;

(2) Die Aufwendungen für die Umsiedlung Heimatvertriebener und für die Auswanderung von Kriegsfolgenhilfe-Empfängern ( $\$ 1$ Abs. 1 Nr.4, 14, 14a);

(3) Die Aufwendungen für verdrängte Angehörige des öffentlichen Dienstes und für ehemalige berufsmäßige Wehrmachtsangehörige ( $\$ 1$ Abs. $1 \mathrm{Nr} .7)$;

(4) Die Aufwendungen für Kriegsbeschädigte, Kriegshinterbliebene u. ä. ( $\$ 1$ Abs. 1 Nr.8).

Diese grundlegende Bedeutung dieser Anomalie ${ }^{3)}$ liegt einerseits darin, daß der Bund, wenn er als Gesetzgeber auf diesem Sektor Ausgaben anordnet, die im Bereich der Landesverwaltung

1) S.a. S. 195 zu Fußn.8.

2) Zum älteren Meinungsstand zur Gestaltungsf reiheit des Bundesgesetzgebers und ihren Grenzen s. die Darstellung bei Holtkotten, Bonner Kommentar, Art. 120 Anm. II insbes. 3 ; nunmehr aber BVerfGE 9, 305 (317 ff).

3) S. a. BVerfGE 9, 305 (329) mit weit. Nachw. 
$z u$ leisten sind, diese Lasten weitaus perfekter aus seiner "Tasche" zu zahlen hat, als dies die Klausel des Art. 106 Abs. 5 GG selbst bei neu übertragenen Ausgaben erzwingen könnte. ${ }^{4)}$ Andererseits können hier die Länder im Rahmen ihrer Verwaltungstätigkeit über Bundesmittel verfügen und somit - auf der Ausgabeseite die einzige, freilich geringfügige, Einbruchsstelle in der umgekehrten Richtung - den Bundeshaushalt beeinflussen.

So sehr dies auf den ersten Blick als eine eigenartige Aktionsfreiheit der Länder zulasten des Bundes erscheint, die hier und dort auch zu Unträglichkeiten geführt haben mag;5) im Endeffekt haben die Angst, die Länder könnten hier Bundesmittel "verwirtschaften", und die Dynamik des Grundsatzes "Wer zahlt, schafft $a n^{\prime \prime 6) ~ d a z u ~ g e f u ̈ h r t, ~ d a ß ~ d e r ~ B u n d ~ h i e r ~ m e h r ~ u n d ~ m e h r ~ a u c h ~ i n ~ d i e ~}$ Verwaltungsarbeit der Länder eingedrungen ist. Am weitesten vorgeprellt ist diese Entwicklung in der Sondervorschrift für den Lastenausgleich; Art. 120 a GG. Im übrigen mußte mit anderen Mitteln auszukommen gesucht werden. Dabei hat der Bund sich nicht mit dem die Idee der Impermeabilität der Landesverwaltung durchaus schonenden Mittel der Interessenquoten 7) und der Pau-

4) Vg1. insbes. BVerfGE 9, 305 (317 ff): "Art. 120 GG verbietet es, Bundesgesetze zu erlassen, nach denen die Länder Kriegsfolgelasten tragen" (318).

5) S. hierzu z.B. Holtkotten, a.a.O. Anm. II 3 b (S. 13 f) mit weit. Nachw.

6) Vg1. Fischer-Menshausen "Bemerkungen" DÖV 6.Jhg. (1953) S. 229 ff $(230)$.

7) (1) Interessenquoten werden - in Grenzen - allgemein für zulässig gehalten. - Vgl. Strickrodt, Die Finanzverfassung des Bundes als politisches Problem, S. 27 f; v. Mangoldt, Bonner Grundgesetz, Art.120 Anm.3; Holtkotten, Bonner Kommentar, Art. 120 Anm. II 3 c (S. 15); Hettlage, Die Neuordnung der deutschen Finanzverfassung, S. 449 f; Fischer-Menshausen, Die staatswirtschaftliche Bedeutung der neuen Finanzverfassung, S.264 f; Ilamann, Das Bonner Grundgesetz, Art. 120 Anm. C 1; Maunz, Deutsches Staatsrecht, S.245;

BVerfGE 9, 305 (330).

(2) In der Praxis hat die Bedeutung der Interessenquoten allerdings stark abgenommen. Nach $₫ 2$ des Ersten Überleitungsgesetzes vom 28. November 1950 (BGB1. S. 773) waren die Länder noch mit 10-25 v. H. an den Ausgaben beteiligt. In $₫ 1$ Abs. 1 der Neufassung des Gesetzes vom 21. August 1951 (BCBl. I S.779) wurde die Interessenquote sachlich und der Höhe nach eingeschränkt. Schließlich kam sie fast ganz in Wegfall ( $\$ 2$ Abs. $1 \mathrm{Nr} .1-3$ des Gesetzes zur Regelung 
schalierung ${ }^{8)}$ begnügt. Er hat das ihm gemäß Art. 84, 85 GG zur Verfügung stehende Instrumentarium der Verwaltungsingerenz auf das äußerste strapaziert, 9) insbes. indem er den Ländern die Anwendung der Haushaltsvorschriften des Bundes insoweit zur Pflicht machte 10) und sie "in Angelegenheiten von grundsätzlicher oder erheblicher finanzieller Bedeutung... hinsichtlicht der wirtschaftlichen Verwaltung der Bundesmittel an die

finanzieller Beziehungen zwischen Bund und Ländern (Viertes Überleitungsgesetz) vom 27. April 1955, BGB1. I S. 189). In der derzeit geltenden Fassung vom 28. April 1955 beteiligt es die Länder nur noch an der Kriegsfolgenhilfe für Sowjetzonenflüchtlinge mit $20 \mathrm{v} . \mathrm{H}$. ( $\$ 1$ Abs. $1 \mathrm{Nr} .3,2$. Halbsatz).

8) Vg1. $\$ 21$ a des Ersten Überleitungsgesetzes in der Fassung vom 28. Apri1 1955.

9) S. oben S. 112 und S. 115. - Zur kompetenzansaugenden Wirkung auch auf dem Gebiet der Verwaltung s. Dobbernack, Die Bedeutung des Grundgesetzes und des Besatzungsstatus für die Sozialversicherung und die Kriegsopferversorgung, S.148. - Köttgen (Der Einwand der Mischverwaltung und das Grundgesetz, S. 490 f; s.a. Der Einfluß des Bundes auf die deutsche Verwaltung, S.88) ist der Ansicht, daß es gar nicht um die Anwendung der Art. 84, 85 GG geht sondern dem Bund im Rahmen des Art.120 GG eine finanzwirtschaftliche Ingerenz sui generis möglich ist. Dem kann nicht gefolgt werden. Die Verfassung bietet dafür keinen Anhaltspunkt. Die von Köttgen angeführten Beispiele aus dem älteren Verfassungs recht besagen für die Rechtslage unter dem Grundgesetz nichts. Die Maßgabe eines Bundesgesetzes nach Art. 120 Abs. 1 GG kann nicht als eine Ermächtigung an den Gesetzgeber verstanden werden, im sachlichen Rahmen des Art. 120 GG die Kompetenzordnung des Grundgesetzes auszuhöhlen (wenn es auch in BVerfGE 9, 305 (330) im Hinblick auf die Formel des Art.120 GG von der "näheren Bestimmung eines Bundesgesetzes" heißt: "Der Bundesgesetzgeber kann auch Einzelheiten regeln, z.B. die Art und Weise, in der der Bund die Last trägt"). Die Bundesbefugnisse nach Art. 84, 85 GG sind auch so aus gebildet, daß mit ihrer Hilfe die sich aus Art.120 GG ergebenden Probleme durchaus gemeistert werden können. Hier eine vom Bundesgesetzgeber zu füllende Lücke zu vermuten, besteht also kein Anlaß.

10) $₫ 4$ Abs. 2 Nr. 1 des Ersten Überleitungsgesetzes i.d. F. vom 28. April 1955. 
Weisungen der obersten Bundesbehörden" band. 11) 12) Und er hat wohl den Bereich des Zulässigen bereits verlassen, indem er die Länder der Prüfungskompetenz des Bundesrechnungshofes unterwarf. 13) So ist im Bereich des Art.120 GG so etwas wie ein Verwaltungskondominium von Bund und Ländern entstanden. 14)

Anzunehmen, daß in diesem Rahmen der Bundeshaushalt einer spürbaren, vom Bund nicht beherrschbaren Einwirkung von der Länderseite her unterliegt, wäre demnach unrichtig. Umgekehrt aber entstehen auch in diesem Raume Daten, mit denen in den Länderhaushalten ge rechnet werden muß: die Interessenquoten, die Differenzen zwischen den Pauschalbeträgen und den effektiven Aufwendungen und die persönlichen und sächlichen Aufwendungen (Nicht-Zweckausgaben), die - von eng begrenzten Ausnahmen abgesehen - vom Bunde nicht übernommen werden. 15)

d) Der finanzielle Primat des Bundes

Während sich also die Einflußmöglichkeiten der Länder auf den

11) $₫ 4$ Abs. 2 Nr.2 des Ersten Überleitungsgesetzes i.d.F. vom 28. April 1955. - Ob dieses Weisungs recht verfassungsmäßig ist, erscheint zweifelhaft. Nach Art. 84 Abs. 5 Satz 1 GG können Weisungs rechte nur der Bundesregierung, nicht auch einzelnen obersten Bundesbehörden übertragen werden. Warum für die Mittelbewirtschaftung etwas anderes gelten soll, ist nicht einzusehen. (Für das Weisungs recht: FischerMenshausen, Die staatswirtschaftliche Bedeutung der neuen Finanzverfassung, S.264).

12) $₫ 4$ Abs.2 des Ersten Überleitungsgesetzes in der ursprünglichen Fassung enthielt einen Zustimmungsvorbehalt. Die Verfassungsmäßigkeit dieses Vorbehalts ist aus den zu $₫ 4$ Abs. $2 \mathrm{Nr} .2 \mathrm{n} . \mathrm{F}$. ausgeführten Gründen selbst dann zweifelhaft, wenn man mit Köttgen, Der Einwand der Mischverwaltung und das Grundgesetz, S. 489, an der Stelle des Weisungs rechts (Art. 84 Abs. 5 GG) auch einen Zustimmungsvorbehalt zuließe (s.hierzu auch oben S. 105 zu Fußn.13).

13) Vg1. $\$ 4$ Abs. 2 und 5 des Gesetzes über Errichtung und Aufgaben des Bundesrechnungshofes vom 27. November 1950 (BGBl.I S.765). Dieses Kontrollmittel widerspricht - soweit es den Ländern aufgezwungen wird und sich diese nicht freiwillig der Kontrolle des Bundes rechnungshofes unterwerfensowohl Art. 109 wie auch Art. 84 GG.

14) S. hierzu auch Köttgen, Der Einfluß des Bundes auf die deutsche Verwaltung, S. 80 (Länderverwaltung gerät in den "Stromkreis des Bundes"!) und S. 88.

15) Vgl. $₫ 1$ Abs. 3 des Ersten Überleitungsgesetzes. 
Haushalt des Bundes - von der Funktion des Bundesrates abgesehen - im Rahmen des Geringfügigen halten, ist die Haushaltsgebarung der Länder nur innerhalb einer großen Zahl von Fixpunkten frei, die vom Bunde gesetzt sind. 1) Damit liegt aber das Gesetz des Handelns in viel weiterem Umfange als es der Blick allein auf die Ausgabeseite vermuten ließe, beim Bunde. Der gewiß fragwürdige, aber doch auch heute noch gültige Wahrheit enthaltende Grundsatz der Haushaltsgestaltung "Die Ausgaben bestimmen die Einnahmen" gilt für die Länder nur mehr in jenem bescheidenen Umfange, in dem sie selbst ihre Einnahmen gestalten, also nach den von ihnen beabsichtigten Ausgaben ausrichten können.

Nun ließe sich freilich einwenden, daß die Freiheit des Bundes auch eine Freiheit in Armut, die Unf reiheit der Länder dagegen eine Gefangenschaft in "goldenen" Käfigen sein könne. Dieser Einwand kann restlos nur widerlegt werden, indem unter Beiziehung umfassenden, differenzierten statistischen Materials und erschöpfender Interpretation der Art. 105 ff GG in allen ihren bisherigen Entwicklungsphasen die gegebenen Verhältnisse und die künftigen Gestaltungsmöglichkeiten ausgemessen werden. Das wäre eine Aufgabe, die in diesem Rahmen nicht übernommen werden kann.

Die Tendenz der Akkumulation der Finanzmacht beim Bunde und der Austrocknung der Länder ist aber auch so als zwangsläufig offensichtlich. Das Grundgesetz der Finanzwirtschaft eines jeden gegliederten, insbesondere auch des bundesstaatlich geordneten Gemeinwesens, die Anziehungskraft des größeren Etats, 2) darf

1) S.Strickrodt, Die Finanzverfassung des Bundes als politisches Problem, S. $14 \mathrm{f}$ : "Kommt es... in den einzelnen Ländern zu den Haushaltsbeschlüssen, so sind die Grundlagen für die tatsächlichen Haushaltsansätze alsdann bereits anderwärts normiert" (S.15). - Zum Mangel einer "Finanzgestaltungskraft der Länder" s. v. Eynern, Der Finanzausgleich zwischen Bund, Länder'n und Gemeinden, in "Bund und Länder", hrsg. von Flechtheim, 1959, S.124 ff (132 f).

2) S. hierzu statt vieler anderer: Klein, Von der föderativen zur stärker unitarischen Gestaltung des Finanzwesens in der Bundesrepublik Deutschland, S. 72 ff. - Popitz, der meist als Urheber der These von der Anziehungskraft des größeren Etats genannt wird, hat sie allerdings - soweit ersichtlich in einem anderen Sinne gemeint, nämlich in dem, daß bei vergleichbaren Gemeinwesen - z.B. Gemeinden - in dem mit dem größeren Etat die Wachstumsrate des Etats höher liegt 
hier als bekannt vorausgesetzt werden. Es ist eine außerrechtlich rorgegebene, finanzpolitische Realität. Sie wird gesteigert durch die egalitäre Staatsauffassung, ${ }^{3)}$ die sich - durch die besonderen historischen Gegebenheiten des nationalsozialistischen Einheitsstaates, des Krieges und der Nachkriegszeit mit allen ihren Auswirkungen darin außerordentlich bestärkt 4) - nicht an die Ländergrenzen, die dieser so überaus mobilen Gesellschaft keine Freizügigkeitsbeschränkungen auferlegen, hält. Die moderne Wirtschaftsgesellschaft sucht die größtmögliche Wirtschaftseinheit. Alles drängt nach einheitlichen Finanzverhältnissen im größeren staatlichen Raum: in der ganzen Bundesrepublik. 5) "Die öffentliche Meinung nimmt schon geringfügige Leistungsund Belastungsunterschiede nicht mehr widerspruchslos hin".6) Dem Egalitätsbedürfnis könnte allerdings auch durch einen horizontalen Finanzausgleich weit entgegengekommen werden. ${ }^{7)}$ Dieser. Weg wird aber im Vergleich zur Zentralisierung des Finanzwesens als kompliziert und unvollkommen empfunden. Auf diese Weise mündet das Egalisierungsbestreben in die eine große zentralistische Konzentrationsbewegung zum Bundeshaushalt hin.

als in dem Gemeinwesen mit dem kleineren Etat (s.hierzu Popitz, Der künftige Finanzausgleich zwischen Reich, Ländern und Gemeinden, 1932, insbes. S. 262 ff; im dogmengeschichtlichen Zusammenhang mit weiterem Material erwähnt bei Hansmeyer, Der Weg zum Wohlfahrtsstaat, S.20 f). In der Folgezeit wurde dieses Gesetz aber auch für die Relation Zentralstaat-Gliedstaaten, also für das Verhältnis des Etats des "größer'en" Cremeinwesens gegenüber dem Etat des "kleineren" Gemeinwesens behauptet. Seine Gültigkeit ist so offenkundig, als daß für sie hier der Beweis geführt werden müßte.

3) S.hierzu noch unten IV (S. 210 ff), Abschn.3 I 1 (S.315 ff) und Abschn.6 II 1 ( $\$ .890$ ff).

4) S. näheres noch unten IV (S. 210 ff).

5) Vor allem Hettlage hat diesen Gesichtspunkt immer wieder. zutreffend herausgestellt: Die Neuordnung der Deutschen Finanzverfassung, S.409 ff, 458 und passim; Die Finanzverfassung im Rahmen der Staatsverfassung, S. 14 ff. - S.a. Maunz, Die l'inanzverfassung im Rahmen der Staatsverfassung, S. 53; v. Eynern, 1)er Finanzausgleich zwischen Bund, Ländern und Gemeinden, insbes. S. $132 \mathrm{f}$; s. ferner Hansmeyer, Der Weg zum Wohlfahrtsstaat, S. 81 ff mit weit. Nachw.

6) Hettlage, Die Finanzverfassung im Rahmen der Staatsverfassung, S. 19 .

7) S. unten $\$ .205$. 
Das sind die politischen Gegebenheiten. In welchem Maße sich ihnen die verfassungsrechtliche, föderalistische Ordnung äußerstenfalls entgegenstellen könnte, braucht hier nicht beurteilt zu werden. Aufs erste vermitteln die Klauseln des Art. 106 Abs. 4 und 5 GG sogar den Eindruck, als hätte das Grundgesetz darin ein $\ddot{A} u ß e r s t e s$ getan. Aber das Grundgesetz hat die Finanzen nicht selbst im Sinne eines Trennsystems ${ }^{8}$ ) fest verteilt sondern nur Grundsätze aufgestellt, nach denen sie durch den Bundesgesetzgeber zu verteilen sind, und dabei dem Bundesgesetzgeber durch Ermessensspielräume eingeräumt, in die - will anders es seine Aufgabe nicht verkennen - auch das Bundesverfassungsgericht, im Streitfalle angerufen, nicht eindringen dürfte. Indem es so - in Grenzen - den Bund selbst zum Richter im Finanzstreit zwischen sich und den Ländern machte, hat es die Schleusen zum Bunde hin aufgetan. Schon der allgemeine Sog und Druck zum Bundeshaushalt wird es ihm leichter als den Ländern werden lassen, Staatsaufgaben als die seinen erscheinen zu lassen (Art. 106 Abs. 4 Satz $2 \mathrm{Nr} .1 \mathrm{GG}$ ), die damit verbundenen Ausgaben als "notwendig" darzutun (ebenda Nr.2) und im "billigen Ausgleich" der Deckungsbedürfnisse (ebenda Nr.3) nicht zu knapp abzuschneiden. Hat ihn das Grundgesetz selbst nicht schon in Art. 120 und in Art. 106 Abs. 5 Satz 2 und 107 Abs. 2 Satz 3 mit der Aufgabe eines zentralen Finanzreservoirs bedacht? Dazu kommt noch die auf die Finanzverteilung - vornehmlich nach Art.106 Abs. 4 GG - zurückwirkende Befugnis des Bundes, über seinen Aufgabenkreis definitiv weitgehend selbst zu bestimmen. Dazu kommen ferner die vielfältigen Variations- und Kombinationsmöglichkeiten, die sich aus der umfassenden Kompetenz des Bundes zur Steuergesetzgebung im Verein mit seiner Zuständigkeit zur Aufkommensverteilung ergeben.

Die Individualität der Länder geht infolgedessen verloren, weil bei Entfaltung aller Besonderheiten die Mittel verweigert bleiben müssen. Wenn eine Aufgabe von den Ländern a $11 \mathrm{gem}$ e in als eine staatliche und als die ihre angenommen wird - von dem Fall einer bundeseinheitlichen, bundesgesetzlichen Regelung braucht gar nicht gesprochen zu werden (s.a. Art. 106 Abs. 5 GG) -, so wird sie als eine Länderaufgabe nach Art. 106 Abs. 4 Satz 2 Nr. 1 GG berücksichtigt werden müssen. Wenn sich ihre Aufwendungen dafür auf einem einheitlichen Niveau halten, dann werden

8) Zur Systematik der bundesstaatlichen Finanzordnung und ihrer Terminologie s. z. B. Müller, Zur Problematik des Finanzausgleiches zwischen Oberstaat und Gliedstaaten im Bundesstaat, AöR Bd. 83 (1958) S. 25 ff (S. 34 ff). 
sie in der Regel auch als notwendig anerkannt werden müssen (ebenda Nr.2). Schließlich wird der billige Ausgleich der Dekkungsbedürfnisse sie berücksichtigen müssen; die Einheitlichkeit der Lebensverhältnisse wird dabei ja gewahrt (ebenda $\mathrm{Nr} .3$ ). In diesem Falle werden Bundes regierung und Bundestag auch mit einer geschlossenen Mehrheitsfront im Bundesrat rechnen müssen. Wenn aber ein Land oder nur einige wenige Länder in dem ihnen durch Art. 30 GG gelassenen, im Detail nie auszuschöpfenden Rahmen eine Aufgabe in Angriff nehmen wollen, dann fehlt nicht nur der Rückhalt im Bundesrat. Dann fehlt auch die communis opinio, die das Deckungsbedürfnis im Rahmen des Art.106 Abs. 4 GG legitimieren könnte. Welche Bedeutung der Individualität der Länder, die die bundesstaatliche Gliederung erst sachlich relevant werden läßt, zukommt, bedarf keiner Hervorhebung. Die Einebnung der Deckungsbedürfnisse der Länder, die das Grundgesetz in Art. 106 Abs. 4 Satz 2 Nr.3, 2. Halbsatz GG verlangt, wo es die "Einheitlichkeit der Lebensverhältnisse im Bundesgebiet" zur Maxime des bundesstaatlichen Finanzausgleichs erhebt, vermindert im Ergebnis auch wieder den Spielraum der Länder insgesamt und vermehrt - reziprok - den des Bundes.

Die Auswirkungen der finanziellen Übermacht des Bundes sind zunächst die, daß es ihm erleichtert wird, von seinen verfassungsmäßigen Kompetenzen Gebrauch zu machen, sei es von seinen Gesetzgebungskompetenzen, sei es von den Verwaltungskompetenzen. Auch die Hürde des Art. 105 Abs. 5 GG, die sich gesetzlichen Anordnungen, die im Landesbereich zu vollziehen sind, entgegenzustellen scheint, kann er umso leichter überwinden, je mehr er die Finanzmasse im Ganzen beherrscht. Den Ländern wird dagegen durch diese Finanz-Heteronomie ihre Sachautonomie, wo immer eine Maßnahme Geld kostet, auch dort verkürzt, wo sie ihnen der Sache nach unbestritten zukommt.9)

Vermittels seiner akkumulierten Finanzmacht dringt der Bund aber auch mehr und mehr in den Landesbereich ein. 10) Auf die Entwicklung im Gefolge des Art. 120 GG wurde bereits hingewiesen. Daneben zeigen sich aber auch para-konstitutionelle Ten-

9) Schneider, Fünf Jahre Grundgesetz, S.941: "In dem Maße, in dem die Länder die finanzielle Beweglichkeit verlieren, büßen sie selbstverständlich auch an politischer Betätigungsfreiheit ein".

10) Vgl. Köttgen, Der Einfluß des Bundes auf die deutsche Verwaltung, S.80, $88 \mathrm{ff}$; ders., Sachverantwortung als verfassungs rechtlicher Maßstab des Finanzausgleichs, S. 35 a. 
denzen. "Der Bund macht einfach auf dem kalten Wege des Budgets jene öffentlichen Aufgaben, in denen er seine Politik machen will, zu Bundesaufgaben und sichert sich zu ihrer. Durchführung den entsprechenden Anteil am Kuchen des Finanzausgleichs. Er nimmt dann die so beanspruchten Aufgaben dadurch wahr, daß er. Gnaden in Form von Subventionen aller und weitester Art austeilt und damit Abhängigkeiten schafft, die ihm das Durchsetzen seiner Politik ermöglichen". 11) Dabei sind zwei Haupterscheinungsformen zu unterscheiden. Die eine besteht in den gezielten $\mathrm{Zu}-$ schüssen an die Länder, durch die - sei es nun mit oder ohne Auflagen - die Maßnahmen der Länder gelenkt und beeinflußt werden. 12) Die andere Hauptform ist durch das Stichwort "Fondsverwaltung" gekennzeichnet. 13) Dabei bedient sich der Bund nicht des Umweges über die Länder. Er zieht die Angelegenheit an sich. Indem er sie jedoch - abgesehen von der Ausgabeermächtigung im Haushaltsgesetz - nicht gesetzgeberisch regelt, sondern sich darauf "beschränkt", was er durch den Einsatz finanzieller Mittel - auf die verschiedenste Weise - erreichen kann, und indem er zudem diese Fondsverwaltung grundsätzlich in der Ministerialebene durchführt, für deren Verwaltungskompetenzen ausdrückliche, klare grundgesetzliche Regelungen fehlen, 14) dringt er dabei unauffällig, aber nicht unwesentlich über seinen eigenen Kompetenzbereich hinaus vor. Das Zuschußwesen wurde allerdings durch die Neuregelung des Finanzausgleichs im Wege des Finanzverfassungsgesetzes vom 23 . Dezember 1955 verfassungs rechtlich ausgeschlossen 15) und -

11) Gleissner, Bund und Länder in Österreich, Zeitschrift für Politik, n.F. 5.Jhg. (1958) S.230 ff (237). Diese für Österreich geschriebenen Sätze kennzeichnen - wie sich die Dinge gleichen! - auch die in der Bundesrepublik herrschenden Verhältnisse treffend. - S. zum folgenden auch Ehard, Das Verhältnis zwischen Bund und Ländern und der Bundes rat, Bayerische Verwaltungsblätter, n. F. 7.Jhg.(1961) S. 1 ff (2).

12) Köttgen, Der Einfluß des Bundes auf die deutsche Verwaltung, S.90, spricht in bezug auf die zweckgebundenen Zuschüsse des Bundes zu den Kosten der Landesverwaltung von einer "planmäßigen Mediatisierung der Länder auf diesem parakonstitutionellen Weg allein mit Hilfe der akkumulierten Finanzmacht des Bundes". - Kritisch auch Hettlage, Die Neuordnung der deutschen Finanzverfassung, S. 445 f, 450.

13) S. hierzu insbes. Köttgen, a.a.O. S. 79 ff, 89 f, 107. S. dazu schon oben S. 108.

14) S. oben I 2 a dd, bbb (S. 101 ff).

15) Vgl. Bühler, Bonner Kommentar, Art. 106 Anm. B III 4 a und Art. 107 n. F. Anm. B I. 
soweit zuschen ist - wohl auch tatsächlich eingedämmt. Die Fondsverwaltung, oft auch mit einem Zuschußwesen verkoppelt, floriert jedoch weiter und ist für viele Bundesministerien nachgerade "L.ebenszweck". 16) Dazu kommen die Komplexe, in denen sich Bundeskompetenz und Landeskompetenz in Gemengelage befinden und bei denen sich der finanzkräftige Bund, der zudem allein den untelsich nicht immer einigen und in ihrer Finanzkraft sehr ungleichen Ländern gegenüber steht, in stetigem Vordringen befindet. 17) Die Länder schließlich, durch die finanzielle Entlastung, die sie dadurch erfahren, bestochen, sind gerade hierin alles andere als die Wächter der föderalistischen Ordnung.

Das Resultat, das sich aus diesen Gegebenheiten für den Bereich des Sozialen ergibt, ist, daß die Finanzverfassung die Kompetenzverteilung überlagert, indem sie, soweit die Wahrnehmung der Kompetenzen notwendig mit der Disposition über geldliche Mittel verbunden ist, dem Bunde die Ausnützung seines Kompetenzraumes erleichtert, den Ländern dagegen erschwert. Da soziale Intervention in aller Regel mit der Verausgabung von Mitteln verbunden ist, muß sich diese Überlagerung der "Sach" - Verfassung - Wie sie hier einmal genannt sei - durch die Finanzverfassung gerade im sozialen Bereich intensiv auswirken. Art. 120 GG macht davon nicht etwa eine Ausnahme. Die Norm ist vie1mehr Ausdruck dieser Tendenz. Daß sie sich vornehmlich auf soziale Angelegenheiten bezieht oder auswirkt, ist die Besonderheit schlechthin, die die Finanzverfassung für den Bereich des Sozialen aufzuweisen hat. Sie ist auch eine Bestätigung dafür, daß gerade in dieser. Richtung die Energien besonders heftig ansetzen.

e) Zentralisation des Finanzwesens, Finanzausgleich und soziale Intervention

Das Zur.ücktreten der Länder und der länderweisen Unterschiede im Rahmen der Finanzverfassung ist aber nicht nur eine bedingende Gegebenheit, auf cler die soziale Aktion des Bundes aufbauen kann und mit der die Länder rechnen müssen. Die Restriktion der l'inanzatonomie der Länder und der Ausgleich ihrer Finanzkraft sind auch Mittel der sozialen Intervention. Zwar wirkt die finanzielle Finelonung der Länder in erster Linie allgemein

16) Vgl. die l)asstellung bei Köttgen, a.a. O., insbes. S. 107, 138, die aus dem Bundeshaushaltsplan auch für spätere Rechnungsjahre bestätigt werden kann.

17) S. hierzu auch die Ausführungen über die sog. Koordinationskompetenz oben I 2 a dd (S. 91 ff). 
finanz- und wirtschaftspolitisch. Sie können aus diesem komplexen Zusammenhang nicht als spezifische Instrumente der sozialen Intervention herausgelöst werden. Umgekehrt steht aber fest, daß gerade die sozialpolitischen Notwendigkeiten - insbesondere die sozialen Verhältnisse in den ärmeren Ländern - einer stärkeren Ausbildung der finanziellen Autonomie, Autarkie und somit Differenzierung der Länder entgegenwirken. 1)

Würden die Finanzkraftunterschiede nicht ausgeglichen und würden die finanziellen Verhältnisse einer länderweisen Sonderentwicklung überlassen, so würden die armen Länder immer noch ärmer und die reichen Länder dagegen immer noch reicher. Da die Steuerlast im umgekehrten Verhältnis zur Steuerkraft stünde, wären in den ärmeren Ländern die Steuern relativ höher, die öffentlichen Einrichtungen dagegen relativ weniger ausgebildet als in den reicheren Ländern. Dieses Gefälle würde eine Abwanderung der produktiven Elemente - Wirtschaftsunternehmen, arbeitsfähige Bevölkerung - von den ärmeren Ländern in die reicheren Länder auslösen; je größer das Gefälle um so stärker wäre die Wanderung. Die sehr mobile deutsche Nachkriegsbevölkerung könnte durch derartige Bedingungen verhältnismäßig leicht und weitgehend in Bewegung versetzt werden. Staats rechtliche, an die Ländergrenzen geknüpfte Hindernisse stünden der Wanderung nicht hemmend im Wege. Diese "soziale Erosion" würde in den ärmeren Ländern einen relativ hohen Anteil an nichtproduktiver, ja unterstützungsbedürftiger Bevölkerung zurücklassen. Dabei würden mit abnehmender Besiedelungsdichte die fixen öffent1ichen Lasten je Kopf der Bevölkerung zunehmen. Ein Pauperisierungsprozeß nähme seinen Weg, 2) der die ärmeren Länder immer mehr der Fähigkeit berauben würde, ihren Aufgaben ge-

1) S. hierzu und zum folgenden: Ritschl, Eine Neuregelung des Finanzausgleichs, Finanzarchiv n.F. Bd. 13 (1951/52) S. 369 ff, insbes. S. 370; Hettlage, Die Neuordnung der deutschen Finanzverfassung, Finanzarchiv n. F. Bd. 14 (1953/54), S. $405 \mathrm{ff}$, insbes. S. $408 \mathrm{ff}$ und passim; ders., Die Finanzverfassung im Rahmen der Staatsverfassung, VVDStRL. H. 14 (1956) S. $1 \mathrm{ff}$, insbes. S. $14 \mathrm{ff}$; Isenberg, Regionale Wohlstandsunterschiede, Finanzausgleich und Raumordnung, Finanzarchiv n.F. Bd. 17 (1956/57) S. 64 ff. - Eine gegenüber der herrschenden Lehre zurückhaltende, stärker differenzierende Darstellung und Würdigung der Probleme s. bei Littmann, Raumwirtschaftliche Auswirkungen der Finanzpolitik, Finanzarchiv n. F. Bd. 19 (1959) S. $367 \mathrm{ff}$.

2) S. hierzu insbes. Isenberg, a.a.O. S. $65 \mathrm{ff}, 75 \mathrm{ff}$ und passim. 
recht $z u$ werden. Die Folgen, die diese Entwicklung für die sozialen Verhältnisse und für die Fähigkeit der Länder, dieser Probleme Herr zu werden, haben müßte, liegen auf der Hand.

Von dieser Gesetzmäßigkeit geht in erster Linie ein starker Impuls in Richtung auf eine Zentralisation des Finanzwesens beim Bund aus. Aber solange die bundesstaatliche Gliederung als eine der Grundlagen des Staates ernst genommen werden soll, sind ihr Grenzen gesetzt. Die perfekte Konzentration des Finanzwesens beim Bund müßte praktisch zur Absorption der Länder durch den Bund führen. Darum muß ein Weg gefunden werden, der einen angemessenen Aktionsraum der Länder wahrt und trotzdem die unterschiedlichen finanziellen und wirtschaftlichen Gegebenheiten und ihre Auswirkungen ausgleicht oder wenigstens entschärft. Dieser Weg ist der Finanzausgleich. ${ }^{3)}$ Daß das Grundgesetz diesen Weg eröffnet hat, ist daher für das Funktionieren der bundesstaatlichen Ordnung als Rahmen der sozialen Intervention des Staates von erheblicher Bedeutung.

Der bundesstaatliche Finanzausgleich kann über den Bundeshaushalt als sog. vertikaler Finanzausgleich - oder, wie Hettlage das genannt hat, als "väterlicher" - durchgeführt werden. Er kann aber auch unter den Ländern abgewickelt werden, als horizontaler - oder, um wieder den bildhaften Ausdruck Hettlages 4) zu gebrauchen, als "brüderlicher". - Für die soziale Intervention als gesamt-(bundes-)staatliches Anliegen, als welches sie den bundesstaatlichen Finanzausgleich antreibt und durch ihn verfolgt wird, ist diese Alternative nicht von Bedeutung. Die Entscheidung $z$ wischen dem horizontalen und dem vertikalen Weg kann jedoch wieder auf die Finanzverteilung zwischen Bund und Ländern überhaupt zurückwirken. Der vertikale Ausgleich fördert die Finanzkonzentration beim Bunde, der horizontale wehrt dieser Tendenz. Darum ist es nicht unerheblich, daß das Grundgesetz in Art. 107 Abs.2 den horizontalen Ausgleich obligatorisch, den vertikalen Ausgleich - die "Finanzzuweisungen" - dagegen fakultativ vorschreibt.

3) Zum Finanzausgleich als ein Mittel der "Sicherung der Eigenständigkeit und Eigenverantwortlichkeit der Gebietskörperschaften" s. jüngst Müller, Zur Problematik des Finanzausgleichs zwischen Oberstaat und Gliedstaaten im Bundesstaat, S.34 ff und seine Nachweise; Isenberg, a.a.O. S.97 und passim; s.a. Köttgen, Sachverantwortung als verfassungs rechtlicher Maßstab des Finanzausgleichs, S.359.

4) Die Finanzverfassung im Rahmen der Staatsverfassung, S. 28 . 
III. Weitere Gesichtspunkte der bundesstatlichen Ordnung

Die bundesstaatliche Ordnung gewinnt Gestalt nicht nur aus der Verteilung der Aufgaben und der Mittel sondern auch aus der wechselseitigen Einflußnahme des Bundes auf die Glieder und der Glieder auf den Bund und aus der Vorsorge für den Streitfall zwischen Bund und Ländern. Diese Aspekte besagen für den Zusammenhang der sozialen Intervention jedoch über das schon bisher Ausgeführte nichts Spezielles.

Die wichtigsten Formen der Einflußnahme des Bundes a uf die Lände $r$ wurden bereits im Rahmen der Aufgabenund Mittelverteilung, insbes. in Erwähnung der immer wiederkehrenden Probleme der Verwaltungsingerenz des Bundes erörtert und in ihrer Bedeutung für die soziale Staatstätigkeit gewirdigt. Die Randformen der Einflußnahme des Bundes, insbes. der Bundeszwang haben keine dem sozialen Bereich gegenüber eigentümliche Ausprägung oder. Wirkung. Nur eines verdient noch hervorgehoben zu werden: die Bundesgarantie der Sozialstaatlichkeit der Länder, wie sie sich aus Art. 28 Abs. 1 Satz 1 und Abs. 3 GG ergibt. Hinter dem bescheidenen Raum, der einer sozialen Aktivität - oder eben ihrer Kehrseite : der sozialen Nicht-Aktivität der Länder verblieben ist, steht noch der Bund als Bürge der Sozialstaatlichkeit der Länder. ${ }^{1)}$

Die Einflußnahme der Länder auf den Bund konzentriert sich auf den Kompetenzbereich des Bundes rates. Die Kompetenzen des Bundes rates sind ein Regulativ gegenüber der Expansionstendenz des Bundes einerseits und gegenüber. einem Auseinanderfallen des Bundeswillens und des Länderwillens andererseits. Der Bundesrat ist an der Grenzzone zwischen Bund und Ländern als Grenzwache - sowohl mit ihrer sperrenden wie mit ihrer vermittelnd, kontrollierenden Funktion - postiert. (Ob der Grundgesetzgeber die wichtigsten Ubergangsstellen erkannt hat, erscheint verfassungspolitisch höchst fraglich, kann aber hier nicht weiter erörtert werden). 2) Insofern diese Crenze auch die Grenze zwischen der sozialen Intervention des Bundes und der Länder ist, wirken sich die Bundesratszuständigkeiten auch auf ihre Lage, Beobachtung und optimale Überbrückung aus.

1) S.hierzu unten S. $737 \mathrm{ff}$.

2) Die Zuständigkeiten des Bundesrates im einzelnen darzulegen, darf hier als unnötig angesehen werden. S. hierzu z. B. Schäfer, Der Bundesrat, 1955, S. 60 ff; Maunz-1)ürig, Art. 50 Randn. $2 \mathrm{ff}$. 
Besonders abgestellt ist dabei auf den Sachbereich der sozialen Intervention jedoch nirgends. Auf die Kernzonen der Bundesratskompetenzen wurde bereits im Zusammenhang mit der bunclesstaatlichen Teilung der Aufgaben und Mittel hingewiesen. In den schwächeren, mehr konsultativen Erscheinungsformen der Wirksamkeit des Bundesrates ist sein Kompetenzbereich ohnedies als sachlich umfassend angelegt (vgl. Art.50, 53, 77 GG). Aber auch von den zentralen Positionen definitiver Mitgestaltung des Bundeswillens durch den Bundesrat gehen diffuse Ausstrahlungen aus, wie sie vor allem durch die ungeahnten Auswirkungen illustriert werden, die der Zustimmungsvorbehalt des Art.84 Abs.1GG auf alle Gesetzgebungsmaterien gezeitigt hat, deren bundesgesetzliche Regelung in landeseigener Verwaltung vollzogen werden soll. ${ }^{3}$ )

Gerade in diesem Bereich des Verwaltungsvollzugs des Bundesrechts durch die Länder liegt überhaupt auch der für den Bereich der sozialen Intervention augenfälligste Schwerpunkt der Kompetenzen des Bundesrates, der dabei nicht nur über Art.84 Abs.1 und 5 und Art.85 Abs.1 GG auf die verfahrensrechtliche und - durch die praktischen Zusammenhänge über die Basis des Grundgesetzes hinausgreifend - materiellrechtliche Gesetzgebung des Bundes einwirkt sondern auch auf die bundesseitige Oberleitung des Vollzuges (Art. 84 Abs. 2 bis 3 GG). Wo die Länder im Vollzug des Bundesrechts ihren relativ breitesten Aktionsraum haben, verdichtet also auch noch eine umfassende Bundesratskompetenz ihren Einfluß auf den Inhalt der (gesamt-)staatlichen Tätigkeit. Umgekehrt ist dort, wo der Vollzug im Bundesbereich liegt, auch die Mitwirkung des Bundesrates in Gesetzgebung und Exekutive am dünnsten. Ausschaltung und Beteiligung der Länder im exekutiven Raum und Ausschaltung und Beteiligung der Länder an der Bildung des Bundeswillens via Bundesrat potenzieren sich also jeweils.

Sachlich ist die spezifische Ausstrahlung, die vom Bundesrat auf die soziale Aktivität des Bundes ausgeht, sehr beschränkt. Der Bunclesrat ist nicht derart zusammengesetzt, daß er zu den sozialen Fragen eine grundsätzlich andere Einstellung haben könnte als Bundestag und Bundessegierung. ${ }^{4)}$ Zwar besteht die

3) S. hierzu insbes. Kratzer, Zustimmungsgesetze, AöR Bd.77 (1951/52) S. 266 ff; Held, Der autonome Verwaltungsstil der Länler und das Bundesratsveto nach Art.84 Abs.1 GG, Aöl Bd.80 (1955/56) S. $50 \mathrm{ff}$; Haas, Bundesgesetze über Organisation und Verfahren der Landesbehörden, AöR Bd. 80 (1955/56) S. 81.

4) S.hierzu z.B. Drath, Die Gewaltenteilung im heutigen deutschen Staatsrecht, in "Faktoren der Machtbildung", Bd.2 der Schriften des Instituts für politische Wissenschaft, 1952, S. $99 \mathrm{ff}, \mathrm{S} .123 \mathrm{f} .-$ S. zu nachfolgendem auch unten Abschnitt 3 III 2 (S.341 ff), insbes. S. 350 . 
Möglichkeit und ist es die Regel, daß die politische Kräftegruppierung in den Ländern eine andere ist als die im Bunde. Somit werden sich nicht selten - auch in sozialen Angelegenheiten Meinungsverschiedenheiten zwischen Bundesrat und Bundestag und (oder) Bundesrat und Bundesregierung ergeben. Aber den Stellungnahmen, die sich auf diese Weise im Bundesrat zu sozialen Fragen herausbilden, eignet sich irgend ein Spezifikum, das durch den Ursprung dieses Willensbildungsprozesses in den Ländern bedingt wäre. Das Herrschaftssystem in den Ländern, das - über die Landtage und Landesregierungen - die politische Zusammensetzung auch des Bundesrates bestimmt, ist demjenigen, das die Machtverhältnisse in den unitarischen Bundesorganen ergibt, homogen. Zwischen den ersten und zweiten Kammern der Konstitutionen des 19. Jahrhunderts bestanden ebenso soziale Unterschiede wie zwischen dem Bundesrat und dem Reichstag der Kaiserzeit. Derartige Gegensätze fehlen zwischen Bundesrat und Bundestag gänzlich. Daß durch die in Art. 51 Abs. 2 GG vorgeschriebene Staffelung des Stimmengewichts der Länder den politischen Kräften kleinerer Länder im Bundesrat relativ größere Bedeutung zukommen kann als im Bundestag und den politischen Kräften größerer Länder geringere Bedeutung als im Bundestag - eine Annahme, die ohnedies die verschiedenen Amalgamierungsvorgänge in den Landtagen und im Bundesrat einerseits und im Bundestag andererseits außer acht 1 äßt -, könnte hier nur dann von Bedeutung sein, wenn die sozialpolitischen Tendenzen sich nach der Größe der Lände" unterscheiden würden. Das ist aber hic et nunc nicht der Fall.

Von einer gewissen Bedeutung könnte sein, daß über den Bundesrat nur Kräfte zum Zuge kommen, die in den Ländern in der Regierungsverantwortung stehen, während für den Bundestag eine derartige Beschränkung notwendigerweise nicht besteht.

Als eine dem Bundesrat eigentümliche Funktion könnte schließlich die Aufgabe erscheinen, den unitarischen Organen gegenüber die regionalen Besonderheiten stärker durchzusetzen. Aber dieser Aktionsrichtung steht das auch im Bundesrat geltende Mehrheitsprinzip entgegen. Sonderinteressen, die nicht einer Mehrheit von Ländern (wenigstens im Prinzip) gemeinsam sind, haben im Bundesrat ihren Patron nicht.

\section{Zusammenfassende Würdigung}

Die bundesstaatliche Gliederung wird im sozialen Bereich umfassend relevant. Die soziale Intervention ist nicht etwa eine Angelegenheit, die dem Bunde - geschweige denn den Ländern - allein zufiele. Aber der Bereich des Sozialen ist nicht ein Feld gleichgewichtiger Gewalt- und Gewichtsverteilung zwischen Bund und 
Ländern. Die "sozialpolitische Führung hat sich eindeutig beim Bunde konzentriert". 1) Er bestimmt Richtung und Volumen der gesamtbundesstaatlichen, sozialen Aktion entscheidend. Was die Länder an Wesentlichem eigenständig beitragen können, bleibt im Marginalen.

Am extremsten ist die Proportion hinsichtlich der Gesetzgebung. Damit sind aber auch schon die Weichen für die Verwaltung gestellt. Zwar ist absolut gesehen die Verwaltung - auch im sozialen Bereich - grundsätzlich und überwiegend Landessache. Aber soweit sie bundesgesetzakzessorisch ist, ist auch die Landesverwaltung einer intensiven bundesseitigen Beeinflussung unterworfen. Dazu kommt, daß die Vorrangstellung der Landesverwaltung im Gesetzesvollzug gerade im sozialen Bereich stark eingeschränkt ist, sei es durch die Bundesverwaltung, insbes. die Verwaltung durch bundesunmittelbare, rechtsfähige Verwaltungseinheiten, sei es durch die Bundesauftragsverwaltung mit ihrer gesteigerten Bundesingerenz. Auch in der Rechtsprechung ist durch das Übergewicht des Bundesrechts der maßgebliche Einfluß der oberen Bundesgerichte auf das ganze Rechtsleben gesichert, wozu der alle Rechtsgebiete durchdringende Einfluß des Bundesverfassungsgerichts tritt.

Was den Ländern an individuell gestaltbarem Bereich fehlt oder verloren gegangen ist, liegt beim Bunde. Was aber dem Bunde zugewachsen ist, ist auch dem Bundesrate als Einflußobjekt zugewachsen. Dadurch hat sich die politische Aktivität der Länder über das Medium des Bundes rates vom eigenen, individuellen Bereich zum Bundesbereich hin verlagert. Dieser Prozeß ist heute allenthalben, nicht nur im sozialen Bereich zu beobachten. 2) Er bringt aber - so sehr das auch verschleiert sein mag und so sehr die Länder aus einem unverkennbaren Minderwertigkeitskomplex dazu neigen, sich durch kollektive Einflußrechte für die (länderweise) individuelle Verfügungsmacht entschädigen zu lassen - den Ländern keinen Ersatz für ihre Eigenkompetenz. Die Stimme des Bundes rates ist nicht notwendig die Stimme aller Länder und

1) Werner Weber, Die Verfassung der Bundesrepublik in der Bewährung, S. 17 .

2) v.Lex, Die Entwicklung des Verhältnisses von Bund und Ländern in der Bundesrepublik, in "Verfassung und Verwaltung", Festschrift für Laforet, 1952, S. 51 ff (57); ders., Zehn Jahre Grundgesetz, BayVB1. n.F. 5.Jhg. (1959) S. 133 ff (135); Katzenstein, Rechtliche Erscheinungsformen der Machtverschiebung $z$ wischen Bund und Ländern seit 1949, insbes. S. $597 \mathrm{ff}, 603 \mathrm{f}$. 
nicht die Stimme einzelner Länder. Sie ist die Kuriatstimme der Länder, getragen von Ländermehrheiten. Der Wille des Bundesrates ist andererseits nicht der Bundeswille. Der Bundesrat ist nur eines der Organe, die gemeinsam unter wechselnder Gewichtsverteilung den Bundeswillen hervorbringen. Die Aufgabe des Bundesrates, die Mitgestaltung des Bundeswillens, zielt naturgemäß auf das Bundeseinheitliche, nicht das länderweise Verschiedene $a b$. Die Individualität der Länder zu wahren, ist weder der verfassungsrecht1ichen Konzeption noch den bisherigen Erfahrungen nach die Funktion des Bundesrates.

Wie aber kommt es zu dieser ungleich gewichtigen Verteilung der sozialpolitischen Potenz auf Bund und Länder? Welches sind die (im weiteren Sinne) sozialen Gesetzmäßigkeiten, die hinter den gesetzlichen Dispositionen stehen? Was sind die Ursachen dafür, daß alle Entscheidungen, die das Grundgesetz selbst offen gelassen hat, nach und nach zugunsten des Bundes fielen? Die einheitliche Tendenz durchschlagender Kräfte in dieser Richtung ist offensichtlich.

Da sind zunächst einmal die allgemeinen zentralistischen Kräfte. deren Mächtigkeit mit der Schwäche des föderalistischen Gedankens korrespondiert. Es ist jener Zentralismus, der sich als historisch-politische Heilslehre darauf berufen kann, daß der "Fortschritt" seit dem Erlöschen der letzten Reste des "finsteren Mittelalters" auf deutschem, staatsrechtlichem Boden, seit dem Untergang des Heiligen Römischen Reiches Deutscher Nation, konsequent über den Deutschen Bund, den Zollverein, die Ansätze von 1848/49, den Norddeutschen Bund, das Kaiserreich, das Reich von Weimar zum Reich von 1933 und somit zur immer stärkeren Unifizierung des deutschen, staatlichen Lebensraumes geführt hat. Er betrachtet die Re-Föderalisierung des Staatslebens durch die Entwicklung der Jahre nach 1945 und das Grundgesetz als einen Rückschritt, der sich nicht nur von sich aus verbietet, sondern im Zeitalter zunehmender Dichte der Verkehrsbeziehungen, im Zeitalter einer immer "kleiner" werdenden Welt, in der Epoche der europäischen Einigung auch spezifisch unzeitgemäß erscheint. Er hat ein leichtes Spiel gegen einen Föderalismus, der auf Ländern aufbauen muß, die zum Teil nach 1945 erst mehr oder minder zufällig geworden sind, und auf Landesbürgern, die - wie die Vertriebenen, Flüchtlinge usw. - zu einem großen Teil ohne überkommene persönliche Beziehung zu dem Lande sind, in dem sie leben. Dieser Föderalismus, auf sehr heterogenen geschichtlichen Wurzeln ruhend, durch Mißverständnisse, Anfechtungen, ideengeschichtliche Einflüsse und historische Niederlagen seit Jahrzehnten geschwächt, mit der egalitären Demokratie 
wesensmäßig verfeindet, 3) fristet heute seine politische Realität weithin nur mehr in dem verfälschenden politischen System des Parteienbundesstaates als der Verteidigungsbastion der jeweiligen Bundes-Minderheit. ${ }^{4)}$

Die unitarisch-zentralistische Richtung findet nun gerade im sozialen Aktionsfeld einen bereiten Boden. 5) Maunz 6) diagnostiziert mit Recht eine verbreitete Überzeugung, wonach "ein Bürger in einem größeren Staatsgebilde besser behütet und umsorgt sei als in einem kleineren". So bestärken sich der sozialstaatliche und der unitarische Trend gegenseitig. Dem Glauben an die

3) Zum Gegensatz zwischen Föderalismus und Demokratie s. Carl Schmitt, Verfassungslehre, S.388 ff; Kägi, Persönliche Freiheit, Demokratie und Föderalismus, in "Die Freiheit des Bürgers im schweizerischen Recht", Festgabe zur Hundertjahrfeier der Bundesverfassung, hrsg. v. den juristischen Fakultäten der schweizerischen Universitäten, 1948, S.53 ff (61 ff; s.a. S. 58); ders., Föderalismus und Freiheit, in "Erziehung zur Freiheit", 1959, S. 171 ff (184 ff). - Zum Gegensatz $z$ wischen moderner egalitärer Staatsordnung und territorialgegliederter Staatsgestaltung s.a. Scupin, Deutscher Bundesstaat und Gleichheitssatz, in: Festschrift für Karl Gottfried Hugelmann, Bd. II 1959, S. 579 ff (580) m.w. Nachw. - Zum Spannungsverhältnis zwischen dem gesamtstaatlichen Gleichheitsprinzip und dem Föderalismus s.a. Imboden, Der verwaltungsrechtliche Vertrag, Zeitschrift für schweizerisches Recht, n.F. Bd. 77 (1958) S. 1 a ff (81a).

4) Zur Diagnose des gegenwärtigen deutschen Föderalismus s. z.B. Jerusalem, Zentralismus und Föderalismus, in "Verfassung und Verwaltung", Festschrift für Wilhelm Laforet, 1952, S. 37 ff,insbes. S. 41 ff; Mommsen, Föderalismus und Unitarismus, 1954; Werner Weber, Spannungen und Kräfte im westdeutschen Verfassungssystem, insbes. S. $65 \mathrm{ff}$; v. d. Gablentz, Die Chancen des Föderalismus in der gegenwärtigen Gesellschaft, in "Bund und Länder", hrsg. v. Ossip K. Flechtheim, 1959, S. 142 ff; Kreutzer, Bund und Länder in der Bundesrepublik Deutschland, ebenda S. 1 ff; Loewenstein, Verfassungslehre, S.318 ff. Allgemeiner zur Situation des Föderalismus im modernen Staat s. a. Kägi, a.a.O. - Die zahlreichen schon angeführten und noch zu nennenden Nachweise zum Bund-Länder-Verhältnis sollen hier nicht noch einmal zusammengestellt werden.

5) j.a. Loewenstein, a.a.O.

6) Deutsches Staatsrecht, S.166. 
sozialpolitische Qualifikation des Zentralstaates steht zudem eine gewichtige historische Legitimation zur Seite: seit der kaiserlichen Botschaft vom Jahre 1881 war das Reich de $r$ Avantgardist des sozialen Fortschritts, neben dem die Länder nichts Bleibendes von größerer Bedeutung mehr hervorgebracht haben. Der soziale Standard hat, soweit er staatlicherseits determiniert war, schon lange vor dem nationalsozialistischen Einheitsstaat ein reichseinheitliches Gepräge getragen. Für die sozialen Spannungssituationen im Gefolge der Kriegs- und Nachkriegszeit mußte zudem die zentrale Vorsorge als das einzig Gemäße erscheinen. Ihnen fehlt ganz überwiegend jeder sachliche Anknüpfungspunkt an die Bundesländer. Allein mit der Politik des Einheitsstaates und dem Schicksal des Gesamtvolkes hängen sie zusammen. Eine unterschiedliche Behandlung dieser Probleme mußte auf die Dauer umso mehr unerträglich erscheinen, als für einen Großteil der Betroffenen, insbes. die Flüchtlinge und Vertriebenen auch ein personaler Anknüpfungszusammenhang mit den Bundesländern, in die sie die Stürme der Nachkriegszeit verweht haben, fehlt. Art.120 GG reflektiert diesen Tatbestand getreulich. Der Zentralstaat, der Bund, erscheint als der berufene Ordner und Wahrer sozialer Belange, die bundeseinheitliche Regelung als das gegebene Mittel sozialer Ordnung.

In dieselbe Richtung weist der Charakter der sozialen Intervention als eines der wichtigsten Elemente der Gestaltung der Lebensverhältnisse der staatlichen Gemeinschaft. Die Bundesrepublik wird als eine staatliche Gemeinschaft mit grundsätzlich einheitlichen Lebensverhältnissen verstanden. Die historischen Gegebenheiten weisen sie als solche aus. Das Grundgesetz selbst hat diesem Grundsatz gewissermaßen Verfassungsrang verliehen (Art. 72 Abs. 2 Nr. 3 und Art. 106 Abs. 4 Satz $2 \mathrm{Nr} .3$ ). Wesentliche Unterschiede in der sozialen Ordnung würden diese Einheitlichkeit stören.

Mit besonderer Kraft wirkt der soziale Ideenhintergrund der Egalität und der Gerechtigkeit. Zwischen dem Postulat einer gesamtstaatlichen Gleichheit und der föderalistischen Gliederung besteht ein Spannungsverhältnis, 7) das von vorneherein eine volle Entfaltung des bundesstaatlichen Fächers verhindert. Hinter der sozialen Intervention steht eine egalitäre Vorstellung. Sie erstreckt sich auf den jeweils größten Raum, in dem die Lebensverhältnisse vergleichbar und angleichbar sind, hält sich also nicht an die Ländergrenzen sondern bewegt sich - soweit sie nicht schon mit europäischen oder Weltmaßstäben operiert - im Raum des Bundes. Von der Verfassung selbst wird die Egalitätsidee als 
eine ungebrochen gesamtstaatliche rezipiert (Art.3, 33 Abs. 1 GG). Wenn auch nicht von Art.3,33 Abs. 1 GG unmittelbar, 8) so doch von der dahinter stehenden Idee her wird daher jede länderweise Differenzierung diskriminiert.

Die hinter der sozialen Intervention stehende Egalitätsvorstellung ist, wie jene selbst, Ausfluß von Postulaten materieller Gerechtigkeit. Die Gerechtigkeit aber kennt keine Grenzen.

Pascal 9) hat kritisiert: "Drei Breitengrade werfen die ganze Jurisprudenz über den Haufen; ein Meridian entscheidet über die Wahrheit. ... Eine schöne Gerechtigkeit, deren Grenze ein Fluß ist!" Freilich muß auch Gerechtigkeitsübung wesentliche Unterschiede in den Verhältnissen anerkennen und berücksichtigen, in die sie hineinwirkt - Unterschiede wie sie also etwa der Sozialarbeit in jeweils völlig fremden Staaten vorgegeben sind. Die Ländergrenzen aber, die innerhalb eines Territoriums mit im wesentlichen gleichen Lebensverhältnissen verlaufen, markieren nur selten solche Unterschiede. Echte Gerechtigkeitsübung muß ferner auch die Integrität eigenwertiger, überkommener Gemeinschaften respektieren. Die Länder von heute und ihre Einwohnerschaft stellen solche aber nur sehr bedingt dar.

Das alles verdichtet sich zu der vorherrschenden, kaum noch irgendwo zu überwindenden politischen Grundhaltung, die alle länderweisen - oder sonstwie regionalen - Unterschiede des sozialen Standards, insbes. der staatlichen Sozialleistungen, negiert, 10) eine bundeseinheitliche Regelung postuliert und damit direkt oder indirekt auf die Konzentration aller sozial relevanten Kompetenzen beim Bund und die Elimination der Länder als eigenständige Träger sozialpolitischer Entscheidung hinarbeitet. 11)

8) S. z.B. BVerfGE 10, 354 (371).

9) Pascal, Edition définitive des oeuvres complètes, éd. F. Strowski, no 319 = 1'ascal, Pensées et opuscules, éd. Brunschwicg, nO 294; Übersetzung nach Rüttenauer in: Pascal, Gedanken, eingeleitet von Guardini, erschienen im Verlag "Stuttgarter Hausbücherei" (o.J.).

10) Vg1. Fischer-Menshausen, Die staatswirtschaftliche Bedeutung des neuen Finanzausgleichs, S. 265; Hettlage, Die Finanzverfassung im Rahmen der Staatsverfassung, S. 18 ff; Maunz, ebd. S. 53; Hansmeyer, Der Weg zum Wohlfahrtsstaat, S. 81 ff mit weit. Nachw.; Kreutzer, Bund und Länder in der Bundesrepublik Deutschland, S. 13 ff; v. Eynern, Der Finanzausgleich zwischen Bund, Ländern und Gemeinden, insbes. S.132 f; s.a. die oben S. 213 zu Fußn. 4 Zitierten.

11) Vgl. Hettlage, Die Neuordnung der deutschen Finanzverfas- 
Hat sich doch sogar der Bundesrat schon genötigt gesehen, in sozialen Angelegenheiten Ländervorbehalte zu vernachlässigen, um einem bei der Vehemenz der in diesem Raum wirksamen Kräfte bedenklichen Konflikt auszuweichen. ${ }^{12)}$

Diese eigengesetzliche Position des Sozialen im bundesstaatlichen Kräfteparallelogramm wird mit begründet und gestützt durch die dichte Verflochtenheit mit der Wirtschafts- und Finanzpolitik. Die Bundes republik begreift sich ausdrücklich als Wirtschaftseinheit (Art. 72 Abs. 2 Nr.3 GG). Die wirtschaftlichen Gegebenheiten lassen kaum eine andere Wahl. Die grundgesetzlichen Befugnisse des Bundes auf dem Gebiet der Wirtschaftspolitik lassen für eine eigene Wirtschaftspolitik der Länder nur einen sehr beschränkten Raum.13)

Die sog. "regionale" Wirtschaftspolitik der Länder, die gelegentlich als deren wirtschaftspolitische Aufgabe bezeichnet wird, 14) ist in Wahrheit vor allem Bestandteil der Wirtschaftspolitik des Bundes. Er muß als der maßgebliche Träger der Wirtschaftspolitik bei der Gestaltung der wirtschaftlichen Verhältnisse in dem einheitlichen Wirtschafts raum, den die Bundesrepublik bildet, regionale Unterschiede berücksichtigen, muß sie ausgleichen und seine Maßnahmen ihnen anpassen, wenn die zwischen den "Regionen" bestehenden Gefälle- und Spannungslagen nicht zu Schäden am Gesamtkörper der "Wirtschaftseinheit" führen sollen.15) Gewiß können und müssen die Länder in dem schmalen Feld wirtschaftspolitischer Gestaltungsbefugnisse, das ihnen verblieben ist, für ihren Bereich ebenfalls "regionale" Wirtschaftspolitik betreiben. Aber so nützlich diese ergänzende Aktivität der

sung, insbes. S.413 f, $442 \mathrm{f}$ und passim; ders., Die Finanzverfassung im Rahmen der Staatsverfassung, S.14 ff.

12) Katzenstein, Rechtliche Erscheinungsformen der Machtverschiebung zwischen Bund und Ländern seit 1949, S.603.

13) Vg1. Ballerstedt, Wirtschaftsverfassungsrecht, in Bettermann-Nipperdey-Scheuner, Die (irundrechte, Bd. III, 1. Halbband 1958, S. $1 \mathrm{ff}$ (S.61 ff); Löwenstein, Verfassungsrecht und Verfassungsrealität, AöR Bd. 77 (1951/52) S.387 ff $(414,416)$; - wohl zu weitgehend - Krüger, Staatsverfassung und Wirtschaftsverfassung, DVB1. 66. Jhg. (1951) S.361 ff (367 f).

14) Vgl. Seidel, Wirtschaftspolitik und soziale Ethik, S.19 ff; ders., Die deutsche Bundesrepublik und der Föderalismus, BayVB1. n. F. 4.Jhg. (1958) S.193 ff (196).

15) Vgl. "Zur Frage regionaler Wirtschaftspolitik", Denkschrift des Institutes für Raumforschung Bonn, 1954. 
Länder auch sein mag; der Schwerpunkt auch der "regionalen" Wirtschaftspolitik liegt nicht weniger beim Bund als der Schwerpunkt der Wirtschaftspolitik überhaupt. Somit bleibt den Ländern, wenn sie auf die wirtschaftlichen Verhältnisse in ihrem Territorium über ihren bescheidenen Zuständigkeitsbereich hinaus einwirken wollen, nur der Weg, die Wirtschaftspolitik des Bundes auf die jeweils in ihrem Bereich anfallenden Probleme aufmerksam zu machen und auf deren Lösung zu drängen. Die mittelbare Wirksamkeit solcher landespolitischer Aktivität soll nicht in Abrede gestellt werden. 16) Aber die Entscheidung darüber, in welchem Maße den Anregungen der Länder gefolgt werden soll, liegt in seinem Zuständigkeitsbereich beim Bund, dem die Verantwortung dafür durch die Stellungnahme des Landes nicht abgenommen werden kann.

Die soziale Intervention ist fast immer von Einfluß auf die wirtschaftlichen Verhältnisse. Selbst wenn sie nicht unmittelbar darauf abzielt, verändert sie die wirtschaftlichen Daten. Wirtschaftspolitik und Sozialpolitik müssen daher koordiniert werden. Die Wirtschaftspolitik des Bundes könnte aber, läge die Sozialpolitik in größerem Maße bei den Ländern, durch diese empfindlich gestört werden. Die verfassungspolitische Dezision für die Konzentration der Wirtschaftspolitik beim Bund löst daher die Tendenz aus, auch die sozialpolitischen Kompetenzen auf den Bund zu vereinigen. 17)

Entsprechende Zusammenhänge bestehen - wie schon dargetan ${ }^{18)}$ -

16) Das und nichts anderes meint erstaunlicherweise auch Seidel, wenn er von regionaler Wirtschaftspolitik des Landes spricht. So führt er in "Wirtschaftspolitik und soziale Ethik", S. 20 aus :

"... im föderativen System ist die Zentrale gezwungen, die Einwendungen, Vorstellungen und Forderungen der Länder nicht nur wie die eines Oberpräsidenten hinzunehmen, sondern sie ist gezwungen, sich mit ihnen auseinanderzusetzen". In "Die deutsche Buncles republik und der Föderalismus", S. 196 sagt er:

"Gewiß werden die entscheidenden Wirtschaftsgesetze im Bundestag gemacht. Aber manches Gesetz würde anders ausfallen und die Durchführung der Gesetze anders aussehen, wenn es keine bayerische Staatsregierung, sondern nur eine Bonner wirtschaftliche Mittelinstanz in Bayern gäbe".

17) S. Kreutzer, Bund und Länder in der Bundesrepublik Deutschland, S. 13 .

18) S. oben II 3, (S. 179 ff, insbes. S. 199 und S.205 ). 
zwischen dem Finanzwesen einerseits und der sozialen Intervention (sowie der Wirtschaftspolitik) andererseits. Auch die Konzentration des Finanzwesens beim Bund führt dazu, daß die sozial interveniente Aktivität der Länder an kürzesten Ketten liegt.

Diese Verkümmerung des föderativen Ordnungsbildes in einem so wichtigen und umfangreichen Sachbereich wie dem der sozialen Intervention bleibt nicht isoliert. Sie strahlt auf die ganze bundesstaatliche Kompetenzordnung aus. Die Kompetenzordnung auf dem Gebiete des Wirtschafts - und des Finanzwesens wirkt nicht nur auf die Zuständigkeitsverteilung im sozialen Bereich ein. Sie ist umgekehrt auch von der zentralistischen sozialpolitischen Gestaltungsmacht und - aufgabe des Bundes mitbestimmt. Aber auch mit anderen Sachbereichen bestehen Interdependenzen. Vor allem aber bewirkt der Vorrang des Bundes, im Rahmen der sozialen Intervention, an der der größte Teil des Volkes - in welcher Weise auch immer - regen Anteil nimmt, einen ständigen Prestigegewinn des Zentralstaates und eine Abwertung der Gliedstaaten in der öffentlichen Meinung. Es ist nicht zuviel gesagt, daß von der Konzentration der Wirtschafts - und Sozialpolitik beim Bund her die föderative Gesamtordnung unterspült wird. 19)

Dabei ist nicht zu übersehen, wie wenig nicht nur der Staat an sich der föderalistischen Werte entbehren kann, sondern wie sehr gerade der Sozialstaat, dessen elementares Spannungsverhältnis zur Freiheit evident ist, des - Gewalten teilenden, 20) die Autonomie intensivierenden 21 ) - freiheitlichen Korrektivs des Föderalismus bedarf. 22) In der staats rechtlichen Diskussion um den "Sozialstaat" stand bisher immer die - vermeintliche - Antinomie von "Sozialstaat" und "Rechtsstaat" im Vordergrund. 23) Ob nicht die Antinomie zwischen "Sozialstaat" und "Bundesstaat" - wenngleich weniger auf verfassungs rechtlicher als auf verfassungspolitischer Ebene - dieselbe Beachtung verdiente? 24)

19) Loewenstein, Verfassungsrecht und Verfassungsrealität, S. 416; ders., Verfassungslehre, S.318 ff; Hartung, Deutsche Verfassungsgeschichte vom 15. Jahrhundert bis zur Gegenwart, 6. Aufl. 19, S. 372 f.

20) S. unten Abschnitt 2 I (S. 219 ff).

21) S. unten Abschnitt 3 (S. $315 \mathrm{ff}$ ), insbes. IV (S. $390 \mathrm{ff}$ ).

22) S. hierzu Kägi, Rechtsstaat-Sozialstaat, sozialer Rechtsstaat, "Die Schweiz", ein nationales Jahrbuch, 1945, S. 129 ff (144).

23) S. unten Abschnitt 5 (S. 673 ff), insbes. II 3 c (S. $744 \mathrm{ff})$.

24) S. unten Abschnitt 5 (S. $673 \mathrm{ff})$, insbes. II 3 a (S. $737 \mathrm{ff})$. 


\section{Abschnitt}

Die Stellung der unter- und nebenstaatlichen Verbände

\section{Allgemeines}

1. Zur Bedeutung öffentlicher Verbandsautonomie Der Föderalismus wird als ein spezieller Anwendungsfall des Subsidiaritätsprinzips 1) sowie des - der Montesquieu'schen horizontalen Gewaltenteilung zur Seite gestellten - Prinzips der vertikalen Gewaltenteilung 2) und dieses wieder als ein Geschwister des

1) (1) $\mathrm{Zu}$ dem vornehmlich von der katholischen Staatslehre entwickelten Subsidiaritätsprinzip im allgemeinen s. z. B.: Utz, Das Subsidiaritätsprinzip, 1953, mit Beiträgen von Utz (S. 7 ff: "Die geistesgeschichtlichen Grundlagen des Subsidiaritätsprinzips"; S. $101 \mathrm{ff}$ : "Die Subsidiarität als Aufbauprinzip der Ordnungen: Wirtschaft, Gesellschaft und Staat"), Hengstenberg (S.19 ff: "Philosophische Begründung des Subsidiaritätsprinzips"), van der Ven (S.45 ff: "Organisation, Ordnung und Gerechtigkeit") und Küchenhoff (S. $67 \mathrm{ff}$ : "Staatsverfassung und Subsidiarität"); Link, Das Subsidiaritätsprinzip 1955; Utz, Formen und Grenzen des Subsidiaritätsprinzips, 1956; Marcic, Vom Gesetzesstaat zum Richterstaat, 1957, S. $428 \mathrm{ff}$; Rauscher, Subsidiaritätsprinzip und berufsständische Ordnung in "Quadragesimo anno" 1958. - Ähnliche Gedankengänge auf "evangelischer Seite" s. bei Berggrav, Der Staat und der Mensch, 1946, S.181 ff, $186 \mathrm{ff}$; zur evangelisch orientierten Diskussion um dieses Prinzip s. ferner Cordes, Kann evangelische Ethik sich das Subsidiaritätsprinzip, wie es in der Enzyklika "Quadragesimo anno" gelehrt wird, zu eigen machen? Zeitschrift für evangelische Ethik (o. Jhg. 1959) S. 145 ff.

(2) Zum Föderalismus als Glied im subsidiären Staatsaufbau s.: Laforet, Föderalismus und Gesellschaftsordnung, o.J. (1947) S.29 ff; Stadler, Subsidiaritätsprinzip und Föderalismus, 1951; Link, a.a.O. S.V.; Süsterhenn, Dass Subsidiaritätsprinzip als Grundlage der vertikalen Gewaltenteilung, in "Vom Bonner Grundgesetz zur gesamtdeutschen Verfassung", Festschrift für Hans Nawiasky, 1956, S. $141 \mathrm{ff}$ (151 ff und passim); v. Nell-Breuning-Sacher, Zur christlichen Staatslehre, 2. Aufl. 1957, Sp. 166 ff (insbes. Sp. 168); Küchenhoff, Bund und Gemeinde, BayVBl n.F. 4.Jhg. (1958) S. 65 ff, 101 ff, insbes. S. $65 \mathrm{f}$; s.a. Hengstenberg, a.a.O. S. $28 \mathrm{f}, 39 \mathrm{ff}$; Küchenhoff, a.a.O., insbes. S.97; Marcic, a.a.O. S.430 f. 
Subsidiaritätsprinzips ${ }^{3)}$ bezeichnet. Beide, Subsidiaritätsprinzip und vertikale Gewaltenteilung, reichen aber wesentlich unter die Sphäre der bundesstaatlichen Machtaufteilung hinab: das Subsidiaritätsprinzip, ansetzend beim Individuum, über die Familie und über die gemeindlichen (gebietskörperschaftlichen) sowie die ständischen Einheiten zur Ebene des Staates aufsteigend; ${ }^{4)}$ die vertikale Gewaltenteilung erst über der privaten Sphäre, zuunterst bei den Gemeinden und ähnlichen primären Körperschaften. 5)

Hier, im Anschluß an die föderative Problematik, interessiert der unterstaatliche Objektbereich des Subsidiaritätsprinzips, auf den sich auch der Gedanke der vertikalen Gewaltenteilung richtet: die öffentlichen (und öffentlichrechtlichen) Gemeinschaften ihr Eigenrecht gegenüber dem Staat und gegeneinander. Auf die Subsidiaritätsrelation $z w i s c h e n$ dem Individuum und seinen privaten Gemeinschaften (insbes. der Familie) einerseits und dem Staat und den dazwischen stehenden publiken Gemeinschaften andererseits wird unter grundrechtlichen Aspekten zurückzukommen sein. 6) Die rein behördenorganisatorischen und anstaltli-

2) (1) Zum Gedanken der vertikalen Gewaltenteilung im allgemeinen s.Peters, Die Gewaltenteilung in moderner Sicht, 1954, S. 23 ff; Süsterhenn, a.a.O.; v.Lex, Die Grundlagen unserer föderativen Staatsordnung, in "Vom Grundgesetz zur gesamtdeutschen Verfassung", Festschrift für Hans Nawiasky 1956, S.237 ff (240); Kägi, Föderalismus und Freiheit, S. $181 \mathrm{f}$; Werner Weber, Die Teilung der Gewalten als Gegenwartsproblem, in: Festschrift für Carl Schmitt, 1959, S.253 ff (266 ff); Wolff, Verwaltungs recht I, 3. Aufl. 1959, S. 57 f; s.a. Bachof, Begriff und Wesen des sozialen Rechtsstaates, a.a.O. S. 49.

(2) Zur bundesstaatlichen Ordnung als Mittel vertikaler Gewaltenteilung s.Peters, a.a.O. S.24 f; Süsterhenn, a.a.O.; v. Lex, a.a.O.; Jahrreiß, Die Wesensverschiedenheit der Akte des Herrschens und das Problem der Gewaltenteilung, in "Vom Grundgesetz zur gesamtdeutschen Verfassung", Festschrift für Hans Nawiasky, 1956, S. 119 ff (123); Kägi, a.a.O.; Werner Weber, a.a.O. S.267; Wolff, a.a.O. S.58. - S.hier$\mathrm{zu}$ auch Loewenstein, Verfassungslehre, S.296 ff.

3) Vgl. Süsterhenn, a.a.O.

4) S. z.B. Hengstenberg, a.a.O. S.28 ff, 39 ff; Küchenhoff, a.a.O., insbes. S. 79 ff; Utz, Formen und Grenzen des Subsidiaritätsprinzips; Rauscher, a.a.O. S. $19 \mathrm{ff}, 56 \mathrm{ff}$.

5) S. die oben zu Fußn.2 (1) Zitierten.

6) S. unten Abschnitt 6 (S. 842 ff, insbes. S. 1107 ). 
chen, vom Subsidiaritätsprinzip nicht angesprochenen Mittel der vertikalen Gewaltenteilung 7) sind nicht von der elementaren Ordnungsbedeutung der autonomen, eigenberechtigten Gemeinschaften.

Die gestaffelte Verteilung der öfentlichen Aufgaben auf die zwischen dem Individuum und dem Staat stehenden Gemeinschaften bildet ein differenzierendes Gegengewicht gegen die Uniformität etatistischer Gleichheit und die Gleichmacherei. Sie bricht die erdrückende Gewalt zentraler Willensbildung - im konkreten Zusammenhang: die Diktatur der demokratischen Mehrheit des Staatsvolkes und seiner Repräsentanten. Damit wird nicht nur die freiheitliche, rechtsstaatliche Wirkung aller Funktions- und Gewaltenteilung erzielt. Die Autonomie individueller Gemeinschaften intensiviert auch die in der kollektiven beschlossene individuelle Selbstbestimmung. Sie erhöht zugleich, indem sie die Distanz zwischen kollektiver Entscheidung und Mitentscheidung des einzelnen vermindert, die Mit- und Selbstverantwortung und beflügelt, die Kenntnis der öfentlichen und privaten Gegebenheiten und Möglichkeiten fördernd, die Eigeninitiative. 8) Sie erlaubt eine Disziplinierung von Lebensbereichen, die der Staat unmittelbar nicht erreichen könnte.

Das öffentliche Mandat des kleineren Verbandes bedrängt aber auch das Individuum.9) Die kleinräumige Bindung hemmt den freizügigen Schritt. Der Zufall, nicht oder jedenfalls in geringerem Maße durch das Gesetz der großen Zahl gemildert, treibt sein Spiel spürbarer. Das Reservoir der Führungsauslese ist nicht selten noch beschränkter als die Aufgabe. Die schützende Isolierung des einzelnen in der Masse fehlt. Subjektive Urteile

7) S. hierzu Peters, a.a.O. S.25 f, 27 ff; Wolff, a.a.O. S. 57 f.

8) Zu Vorstehendem s. z.B. die oben S. 219 zu Fußn. 1 und 2 Zitierten; ferner unten S. 390 und S. 755 sowie die dort jeweils gegebenen Nachweise.

9) Vg1. Kägi, Persönliche Freiheit, Demokratie und Föderalismus, S. 59 ff; Bachof, Begriff und Wesen des sozialen Rechtsstaats, S.49; Werner Weber, Die verfassungsrechtliche Problematik der Zwangsversorgungseinrichtungen der freien Berufe, S. 12 ; s.a. Krüger, Das besondere Gewaltverhältnis, Veröffentlichungen der Vereinigung der Deutschen Staatsrechtslehrer, Heft 17, 1957, S. 109 ff (123); Werner Weber, Diskussionsbeitrag hierzu, ebenda S. 186 ff (187 f). Im besonderen zur freiheitsbedrängenden Wirksamkeit der Interessenverbände s. Gruner, Die Wirtschaftsverbände und die Demokratie, 1956, S.119. Zu den Koalitionen s.u. S. 303 zu Fußn. 7 und 8. 
und Vorurteile, Bindungen und Rücksichtnahmen hindern das objektiv Richtige, sich durchzusetzen. Der mediatisierte Bürger wird partiell aus der gesicherten und wohlkontrollierten Ordnung des Staatswesens herausgelöst. Die Organisation der kleineren Gemeinschaft ist vielfach weniger durchgeformt, labiler als die staatliche. Die Möglichkeit der Disziplinierung von Lebensbereichen, die dem Staat nicht oder wenigstens nicht ebenso adäquat zugängig wären wie seinen Unterverbänden, ist sub specie der Freiheit kein eindeutiger Vorteil. 10) Die differenzierende Durchbrechung der Egalität endlich züchtet bei denen, die sie begünstigt, den Gruppenegoismus. Die sie belastet, sehnen sich aus ihr heraus, um des Heils umfassender egalitärer Gerechtigkeit teilhaftig zu werden.

Die Spannung Staat-Verbände-Individuum wird in ihren positiven wie in ihren negativen Zügen im Bereich des Sozialen mit größter Schärfe sichtbar. Kommt es doch gerade gegenüber dem der Machtversuchung umfassender Sozialgestaltungskompetenz und vielfältiger sozialer Abhängigkeit ausgesetzten Staat darauf an, seine monolithische Konzent ration aufzulockern und dem Bürger Widerlager und Auswege zu geben. Ist es doch gerade im Sozialen besonders wichtig, durch die engeren Gemeinschaften Kräfte zu aktivieren, die der staatliche Gesamtverband nicht einzusetzen vermag. Kann die soziale Hilfe doch nur dann freiheitlich und menschenwürdig gestaltet werden, wenn es gelingt, soziale Fremd- und Eigenverantwortung und Initiative zu wecken und den Bürger aus dem Bannkreis des staatlichen Sozialgestaltungsmonopols heraus und in die überschaubare, vertraute, persönlich geprägte, möglicherweise sogar freiwillige Solidargemeinschaft zu führen. 11) Andererseits belasten alle die Schwächen des kleineren Verbands - von der persönlichen Reibung bis zur Labilität und vom beschränkten sachlichen und personellen Potential bis zur betonten Herrschaft des Zufalls - die sozial Betroffenen besonders schwer. ${ }^{12)}$ Vor allem aber ist jede differenzierende Gliederung, die im sozialen Bereich wirksam werden soll, dem sozial-egalitären Sog im Wege, der die kleinste gebietskörper-

10) Zu dem Dilemma zwischen der staatsabwehrenden und der individualitätsbedrängenden Wirkung der Selbstverwaltungseinheiten s. Darmstaedter, Die Grenzen der Wirksamkeit des Rechtsstaats, S. $228 \mathrm{ff}, 266 \mathrm{ff}$.

11) S. zu Vorstehendem nochmals die Nachweise unten S. 755. S. hierzu auch Kägi, Rechtsstaat-Sozialstaat-sozialer Rechtsstaat, S. 144.

12) S. hierzu die vorstehend S. 221 zu Fußn.9 Zitierten und unten S. 755 . 
schaftliche oder personalverbandliche Sonderung nicht weniger scharf negiert als den Föderalismus, an dem das Kräfteverhältnis bereits aufgezeigt wurde. Aus diesem Grund ist die verfassungs rechtliche Position dieser Verbände - ohne daß von vorneherein und allgemein gesagt werden könnte, ob ihre Stärkung oder ihre Schwächung das sozial "Bessere" ist - für das Gesamtbild der sozialen Intervention von hervorragender Bedeutung.

\section{Verfassung und Subsidiaritätsprinzip}

Gelegentlich wird behauptet, das Prinzip der Subsidiarität sei als solches - positives Verfassungsrecht. 1) "Entsprechend der soziologischen Stufenfolge (Person, Familie, Korporation, Gemeinde, Land)" sei im Grundgesetz (Art. 1, 6, 9, 28, 30, 79) "ein juristisches Vorrangprinzip festgelegt..., wonach der Staat erst die letzte Instanz ist, auf die zu 'rekurrieren' ist, falls alle anderen nicht ausreichen". 2) Dem kann nicht beigetreten werden. Dem Grundgesetz kann ein Prinzip der Subsidiarität, das mehr ist als die Summe der einzelnen Ausgrenzungen und Leithinweise zugunsten engerer Gemeinschaften und zugunsten der Individuen, nicht entnommen werden. ${ }^{3)}$ Gewiß sind alle die verschiedenen Ausgrenzungen, Garantien und Grundsatznormen zugunsten des Individuums, 4) der Ehe und der Familie, 5) der privaten Vereinigung, 6) der Gemeinden und Gemeindeverbände, 7) gewisser öffentlicher Personalverbände 8) und der Länder 9) Ausdruck eines vorrechtlichen (oder auch naturrechtlichen) Subsi-

1) Dürig, Verfassung und Verwaltung im Wohlfahrtsstaat, JZ 8. Jhg. (1953) S. 193 ff (198); v. Münch, Staatliche Wirtschaftshilfe und Subsidiaritätsprinzip, JZ 15.Jhg. (1960) $\mathrm{S} .303 \mathrm{ff}(304 \mathrm{f})$. Auf der Grundlage des von ihm auch sonst reichlich überanstrengten Sozialstaatsprinzips wird ein ähnlicher Organisationsgrundsatz behauptet von Klein, Christ und Kirche in der sozialen Welt, 1956, S. 125.

2) Dürig, a.a.O.

3) Kritisch hierzu auch Stern, Rechtsfragen der öffentlichen Subventionierung Privater, JZ 15. Jhg. (1960) S. 518 ff, 557 ff (523 Fußn. 40).

4) Zur Grundrechtsordnung s. unten Abschnitt 6 (S. 842 ff).

5) Zum Status von Fhe und Familie s. unten Abschn. 6 IV (S. $995 \mathrm{ff}$ ).

6) Zum Grundrecht der Vereinigungsfreiheit s. unten Abschnitt $6 \mathrm{~V} 7$ (S.1046 ff).

7) S. u. II $(\mathrm{S} .225 \mathrm{ff})$.

8) s. u. III (S. 242 ff).

9) ร. o. Abschn.1 (S. 45 ff). 
diaritätsdenkens. 10) Aber wo darüber hinaus könnte behauptet werden, der Staat oder die sonst jeweils "weitere" Gemeinschaft müsse sich der Aktivität enthalten, weil eine "engere" Gemeinschaft zuständig wäre? 11)

Selbst wenn das Subsidiaritätsprinzip positives Recht wäre, wäre diese Feststellung schon kaum jemals mit Sicherheit zu treffen. Das Subsidiaritätsprinzip ist in sich unbestimmt und bedarf der gestaltenden Anwendung je nach den konkreten Verhältnissen. 12) Im besonderen spaltet sich über den engsten personalen Gemeinschaften, Ehe und Familie, die Stufenleiter der Gemeinschaften in die kommunalen und die - vom subsidiaritätsdenken sehr betonten - berufsständischen Gemeinschaften, um sich erst unter dem Dach der höheren, staatlichen Einheit, die aber im Bundesstaat in Bund und Länder geteilt ist, wieder zu treffen. 13)

10) Vg1. Maunz, Deutsches Staats recht, S. 62 f.

11) Nicht selten dient das Subsidiaritätsprinzip dazu, die individuelle Freiheit zu umschreiben. So wird nicht etwa das Verhältnis zweier Gemeinschaften angesprochen, wenn von einer Subsidiaritäts relation zwischen dem Staat und "der. Wir.tschaft" die Rede ist (s. z.B. v. Münch, a.a.O.). "Die Wirtschaft" ist keine Gemeinschaft eigenen Rechts - das ihr aus dem ungeschriebenen Verfassungsgrundsatz der. Subsidiarität zufliegt! - sondern die Summe aller sich auf Grund ihrer individuellen (oder Vereinigungs-)Freiheit wirtschaftlich Betätigenden. (v. Münch, a.a.O. leitet auch (S.305) die Subsidiarität durchaus individualrechtlich ab). Aber wo bleibt hier. die Eigenbedeutung des postulierten Verfassungsprinzips der Subsidiarität? - Auch Sterns (a.a.O.) Subsidiaritätsprinzip als "das notwendige Korrelat eines mit universaler Kompetenz ausgestatteten Sozialstaats" läßt sich entweder zureichend aus dem Grundrechtsschutz usw. herleiten oder eben nicht aus der Verfassung entnehmen. - Zum Versuch, das Subsidiaritätsprinzip aus dem Sozialstaatsprinzip abzuleiten s. unten Abschnitt 5 II 3 c ( $\$$. 744 ff).

12) S. von den oben S. 219 zu Fußn. 1 Zitierten insbes. Van der. Ven, a.a.O. S. 53; Küchenhoff, a.a.O. S. 72; Utz, formen und Grenzen des Subsidiaritätsprinzips, S. 83 f; Süsterhenn, a.a.O. S. $148 \mathrm{f}$.

13) Die von Dürig (s.o. S. 223 zu Fußn. 1) unterstellte Stufenfolge Person-Familie-Korporation-Gemeinde-Land-Bund ist in dieser Eindeutigkeit einfach nicht denkbar. - S. zum Text: Hengstenberg, a.o. (S. 219 zu Fußn. 1) a.O. S. 28 f, 41 (unter romantisierender Gleichstellung von "Stand und Land" gegenüber dem Staat $=$ Bund); Küchenhoff, a.a. O. S. 80 . 
Auch sonst bietet die Rangfolge der weiteren und engeren Gemeinschaften Schwierigkeiten mannigfacher Art. 14) Hieraus fließi eine Menge von Zuordnungsproblemen, die erst durch positive Entscheidung und nicht schon aus dem Subsidiaritätsprinzip selbst gelöst werden können. Daher kann auch im Grundgesetz eine verbindliche subsidiaristische Ordnung nur gesehen werden, soweit es die notwendige Kompetenzzuweisung selbst trifft. Im übrigen verbleibt die Entscheidung dem nach der (sonstigen) Ordnung des Grundgesetzes zuständigen Regelungssubjekt, vornehmlich a1so dem Bundes- und Landesgesetzgeber. Demgemäß hat sich auch die nachfolgende Untersuchung darauf zu beschränken, der vom Grundgesetz geschaffenen, positiven Subsidiaritätsordnung nachzuspüren.

\section{Die Gemeinden und Gemeindeverbände}

Die allgemein bedeutsamsten unterstaatlichen Verbände sind die Gemeinden und Kreise. Sie und die sonstigen Gebietskörperschaften führen die in der Bund-Länder-Relation ansetzende Reihe ter ritorialverbandlicher Gliederung im unterstaatlichen Raum fort. 1) Mit betonter Eindeutigkeit bekennen sich die Verfassungen zur kommunalen, insbes. zur gemeindlichen Selbstverwaltung (Art.28 Abs. 1 und 2 GG).

\section{Die Gemeinden}

a) Die allgemeinen verfassungs rechtlichen Grundlagen

"Den Gemeinden muß das Recht gewährleistet sein, alle Angelegenheiten der örtlichen Gemeinschaft im Rahmen der Gesetze in

14) Hengstenberg, a.a.O. S. 37, 39; van der Ven, a.a.O. S. 49 ff; Rauscher, a.a.O. S. 58 f.

1) Dagegen ist es nicht richtig, einem weitverbreiteten Schlagwort folgend von "drei Ebenen" Bund-Länder-Gemeinden (Kommunen) zu sprechen. Dadurch würde die Grenze zwischen dem Staatlichen und dem Unterstaatlichen ignoriert. Ferner wird die Inkorporation der Gemeinden (Kommunen) in die Länder zugunsten einer angemaßten beschränkten Bundesunmittelbarkeit verunklart. Gegen das Schlagwort von den "drei Ebenen" insbes. Maunz, Bund und Gemeinden, Bayerische Verwaltungsblätter, n.F. 6.Jhg. (1960) S. 205 f; ders., Land und Gemeinden, ebenda S.303 f. Maunz erwidert insoweit insbes. Jobst, Die Eigenständigkeit der Gemeinde, ebenda, S. $201 \mathrm{ff}$; sowie dems., Bund, Länder und Gemeinden, ebenda, S. $301 \mathrm{ff}$ (weitere Nachweise s. bei Jobst). - Zur Subsidiaritätstrias Bund-Länder-Gemeinden s. Küchenhoff, Bund und Gemeinden. 
eigener Verantwortung zu regeln" (Art.28 Abs.2 Satz 1 GG). Damit ist den Gemeinden zunächst einmal eine ursprüngliche, d. h. verfassungsunmittelbare universelle Kompetenz eingeräumt, die örtlichen Belange wahrzunehmen. Diese kann vom Gesetzgeber - und nur von ihm - umschrieben und modifiziert werden. Aber bis zur gesetzlichen Schranke hat die Gemeinde die Vermutung der Aktionsfreiheit für sich. 2) Bei der Regelung der gemeindlichen Selbstverwaltung darf der Gesetzgeber deren Wesensgehalt zudem weder dadurch verletzen, daß er ihren Gegenstand ("Angelegenheiten der örtlichen Gemeinschaft") zu eng begrenzt noch dadurch, daß er die Entscheidungsf reiheit ("in eigener Verantwortung zu regeln") mehr als im Rahmen der herkömmlichen Ausnahmen durch staatliche Ingerenzen beschneidet. ${ }^{3)}$ Damit ist ein Stück öfentlicher. Gewalt aus der Kompetenz

2) S. z.B. Köttgen, Wesen und Rechtsform der Gemeinden und Gemeindeverbände, in Peters, Handbuch der kommunalen Wissenschaft und Praxis, Bd.I, 1956, S. 185 ff (214); Maunz in Maunz-Dürig, Art.28 Randn. $30 \mathrm{~m}$. eingeh. Nachweisen.

3) Am deutlichsten ist diese doppelte Abwehrichtung der Wesensgehalts-Grenze herausgestellt in BVerwGE 6, 19, insbes.S. 25 (dort auch zahlreiche Nachweise). - S. sonst zur Wahrung des Wesensgehaltes der Selbstverwaltung als der entscheidenden Grenzmarke für die Gestaltungsmacht des Gesetzgebers: BVerfGE 1, $167(175,178) ; 7,358$ (365); 8, 332 (359 f); v. Mangoldt-Klein, Art.28 Anm. IV 1 b, d und f; Maunz, a.a.O. Randn. 31 f; je mit umfassendem Nachweis des Schrifttums; Hamann, Das Grundgesetz, Art. 28 Anm. C 7, ebenfalls mit weiteren Nachweisen. - Köttgen, a.a.O. S.214,ist der Meinung, der Gesetzgeber habe "lediglich die Grenze des Verfassungsmißbrauchs zu respektieren". In der Praxis dürften die Ergebnisse dieser Theorie sich von denen der herrschenden Ansicht nicht wesentlich unterscheiden. Von einer beachtlichen Minderheit wird allerdings auch die Meinung vertreten, die Gestaltungsbefugnis des Gesetzgebers ("im Rahmen der Gesetze") beziehe sich nicht auf den gegenständlichen Kompetenzbereich sondern nur auf die Modalitäten der Selbstverwaltung: Arndt, Das Bundesverfassungsgericht, DVB1. 66. Jhg. (1951) S.297 ff (299); Bohley, Die Behandlung der Gemeinden im Grundgesetz und in der Bayer. Verfassung, Bay. Bürgermeister 2.Jhg. (1949) S. 265 f, 3. Jhg. (1950) S. 5 f (1949, S.265 f); Genzer, Was bedeutet Art. 28? Der Städtetag 3.Jhg. (1950) S. 314 ff (316 f); Neuhoff, Kommunale Selbstverwaltung und Bonner Grundgesetz, DÖV 5. Jhg. (1952) S. 259 ff; Weber, Staatsverwaltung und Selbst- 
des Staates ausgegrenzt. Weder der Bund noch die Länder können die "Angelegenheiten der örtlichen Gemeinschaft", 4) mit anderen Worten die "Aufgaben, die in der örtlichen Gemeinschaft wurzeln oder auf die örtliche Gemeinschaft einen spezifischen Bezug haben und von dieser örtlichen Gemeinschaft eigenverantwortlich und selbständig bewältigt werden können", 5) in ihrer Masse an sich ziehen. 6) Detaillierte Abgrenzungen jedoch fehlen im Grundgesetz. ${ }^{7}$

verwaltung in der Gegenwart, S. 39, 49 f; Ipsen, Gemeindliche Personalhoheit unter Selbstverwaltungsgarantie, DÖV 8. Jhg. (1955) S.650 ff (650); Becker, Die Selbstverwaltung als verfassungs rechtliche Grundlage der kommunalen Ordnung in Bund und Ländern, in: Peters, Handbuch der kommunalen Wissenschaft und Praxis, Bd.I, 1956, S. 113 ff. Diese Ansicht ist durch die Verfassungswirklichkeit, wie sie von der Rechtsprechung des Bundesverfassungsgerichts maßgeblich heraufgeführt wurde, überholt.

4) Am eingehendsten zu diesem Begriff bisher: Partsch, Angelegenheiten der örtlichen Gemeinschaft, Festschrift für Bilfinger, 1954, S.301 ff.

5) BVerfGE 8, $122(134)$.

6) S. die oben S. 226 zu Fußn. 3 Zitierten.

7) Da der Verfasssungsgeber keine detaillierten Sachgebiete herausstellen wollte, konnte er auch auf ein Schema der Aufgabenteilung verzichten, wie es sich in der deutschen (mitteleuropäischen) Bundesstaatstradition in Gestalt der Gewaltenteilung entwickelt hat. Das wirkt umgekehrt darauf zurück, daß die Verfassung auch die Frage im unklaren läßt, ob unter der Wahrnehmung der Aufgaben der örtlichen Gemeinschaft die Ausübung einer, zweier oder sogar dreier der klassischen drei Gewalten zu verstehen ist. Hierzu ist folgendes zu sagen:

(1) Eine verbal an den auch in Art.28 GG verwendeten Begriff der Selbst-"verwaltung" anknüpfende Auslegung will den eigenen Wirkungsbereich der Gemeinde auf die reinen Verw a $1 \mathrm{tung}$ s a ufgaben (in einem sicher sehr weiten Sinn) beschränkt sehen (vgl. Köttgen, Gemeindliches Satzungs recht und Grundgesetz, DVB1. 70.Jhg. (1955), S.445 ff; Schunck, Die Rechtsstellung der Gemeinden und Gemeindeverbände nach dem Bonner Grundgesetz, Recht im Amt 3.Jhg. (1956) S. 369 ff (370)).

(2) Dagegen nimmt die sowohl an den Wortlaut des Art.28 Abs. 2 Satz 1 GG ("regeln") wie auch an das historisch gewachsene Bild gemeindlicher Selbstverwaltung anknüpfende, zutreffende, herrschende Ansicht an, daß nicht nur die - 
b) Die Gemeinden als Träger sozialer Intervention

aa) Grundsätzliches

Der Sachbereich der. "Angelegenheiten der örtlichen Gemeinschaft" steht in keiner spezifischen Beziehung zur sozialen Intervention. Soziale Spannungslagen, "die in der örtlichen Gemeinschaft wurzeln oder auf die örtliche Gemeinschaft einen spezifischen Bezug haben und von dieser örtlichen Gemeinschaft eigenverantwortlich und selbständig bewältigt werden können", 1) sind keine typische Erscheinung höherer Größenordnung. Die zunehmende quantitative Ausbreitung der sozialen Intervention war im Gegenteil grundsätzlich ein Zuwachs an staatlicher Aktivität, der das Gewicht der. Gemeinden im öffentlichen Leben schmälerte. 2) Die zunehmende gesetzliche Reglementierung sozialer. Angelegenheiten war zugleich ein Teilstück des Prozesses der Finschränkung gemeindlicher. Entscheidungsf reiheit mit Mitteln

selbstverständlich darunter fallende - Verwaltung sondern auch die statutarische Rechtsetzung je nach dem Sachgebiet, das sie betrifft, in den Bereich der "Angelegenheiten der örtlichen Gemeinschaft" fallen kann (BVerwGE 6, 247, insbes. S.252. - Giese, Grundgesetz, Art. 28 Anm. II 4; Becker, Die Selbstverwaltung als verfassungs rechtliche Grundlage usw. S. 158; Ipsen, Gemeindliche Personalhoheit und Selbstverwaltungsgarantie; Hamann, Das Grundgesetz, Art.28 Anm. C 8; ders., Autonome Satzungen, 1958, S.21, 49, 67; v. Mangoldt-Klein, Das Bonner Grundgesetz, Art. 28 Anm. IV 1 c; Maunz, Grundgesetz, Art.28 Randn. 35). Dabei darf allerdings nicht verkannt werden, daß - genau so wie die Gesetzgebung mehr beim Bunde liegt und die Verwaltung mehr bei den Ländern - die generelle, normative Behandlung einer Frage eher den lokalen Rahmen verläßt als ihre administrative Erledigung (s.a. Küchenhoff, Bund und Gemeinde, insbes. S.67). Das spiegelt sich auch in der besonderen Betonung der. Gesetzmäßigkeit des Satzungsrechts bei BVerwG und Giese (a.a.O.).

(3) Von der Rechtsprechung als gemeindlicher Aufgabe ist dagegen nirgends die Rede. Die herkömmliche deutsche Gerichtsverfassung läßt dafür auch keinen Raum (vg1. Partsch, Angelegenheiten der örtlichen Gemeinschaft, S. 303). Zur Gemeindegerichtsbarkeit s. BVerfGE 10, 200 (214 f).

1) BVerfGE 8, $122(134)$.

2) Vgl. Partsch, Angelegenheiten der örtlichen Gemeinschaft, S. 310,312 f. 
der Legislative. 3) Die Tendenz geht auch hier - wie das analog schon hinsichtlich des Bund-Länder-Verhältnisses festzustellen war - nach "oben", zur Zentrale. Das Egalitätsdenken einer extrem beweglichen Bevölkerung - deren "Wurzellosigkeit" und "Vermassung" gerade auch im Wandel von der Bürgergemeinde zur Einwohnergemeinde zum Ausdruck kommt - wertet die Gemeindegrenzen nicht als sinnvolle Zäsuren des sozialen Standards. Das Mißverhältnis der sozialen Aufgaben zur Leistungsfähigkeit der Gemeinden und die wesensmäßige Unmöglichkeit einer lokal-punktuellen Korrektur der Masse aller wirtschaftlichen Gegebenheiten weisen ebenfalls die Richtung von der Gemeinde zur größeren, insbes. zur staatlichen Einheit.

Für die frontale - nicht nur gelegentliche, abseitige oder untergeordnete, der Sache nach sekundär-exekutivische - Inangriffnahme sozialer Angelegenheiten durch statutarische Rechtsetzung etwa im Sinne städtischer Armenordnungen des ausgehenden Mittelalters ist praktisch kein Raum mehr belassen. 4) Vielfäliger sind die Vel'waltungs aufgaben, die, soweit sie obrigkeitlicher Art sind, jedoch teils bei den größeren Gemeinden (Stadtkreisen, kreisfreien Städten) konzentriert, 5) teils lediglich zur auftragsweisen Erledigung überlassen, 6) teils schließlich beides sind. ${ }^{7)}$ Im Zentrum gemeindlicher Sozialarbeit stehen die

3) Vg1. Köttgen, Die Gemeinde und der Bundesgesetzgeber, S. $35,42,64 \mathrm{ff}, 70 \mathrm{ff}$.

4) Eine vermutlich obsolete Ausnahme: $₫ 466$ RVO.

5) So liegen die Aufgaben der Bezirksfürsorgeverbände regelmäßig bei den Landkreisen und kreisfreien Städten (vgl. Schräder, Kommunale Sozialpolitik, in: Peters, Handbuch der kommunalen Wissenschaft und Praxis, Bd. II, 1957, S.265 ff (271)). Über die Delegation an Gemeinden s. Thoma, Die of fentliche Fürsorge, in: Peters, a.a.O. S.283 ff $(301 \mathrm{f})$. Desgleichen ist die Förderung der Jugendwohlfahrt, soweit sie bei den Jugendämtern liegt, Aufgabe der Landkreise und kreisfreien Stälte ( $\$ 8$ Abs. 2 JWG); s.ferner Jans, Jugendhilfe, in: Peters, a.a. O. S.315 ff (322f).

6) So z.B. die in der Reichsversicherungsordnung vorgesehenen sozialversicherungs recht 1 ichen Zuständigkeiten der Ciemeinden ( $\$ \$ 120,265,967,1020$ RVO); s. ferner die Vorbehalte in $\$ 3$ Abs. 3 des Flüchtlingsnotleistungsgesetzes und in $₫ 305$ Abs. $2 \mathrm{~L} \wedge \mathrm{G}$. Dasselbe dürfte für die Übertragung von Aufgaben auf die Gemeinden im Rahmen der öffentlichen Fürsorge gelten (vgl. Thoma, Die öffentliche Fürsorge, S. $301 \mathrm{f})$.

7) So im allgemeinen die Durchführung des Lastenausgleiches 
sachleistenden Veranstaltungen, 8) vornehmlich solche daseinsvorsorgender Art.9) 10) Hierin liegt die klassische Komplementärfunktion der Gemeinden, in der sie der Staat nur beschränkt

durch die bei den Landkreisen und Stadtkreisen (kreisfreien Städten) gebildeten Ausgleichsämter ( $\$ 305$ LAG).

8) Bei den sachleistenden Veranstaltungen liegt, wie auch das Folgende noch belegen wird, ganz allgemein der Schwerpunkt der gemeindlichen Selbstverwaltung. Werner Weber (Staatsverwaltung und Selbstverwaltung in der Gegenwart, S.51 f) will die gemeindliche Sachverwaltung sogar mit den "Angelegenheiten der örtlichen Gemeinschaft" identifizieren; ähnlich auch Köttgen, Die wirtschaftiche Betätigung der Gemeinden, in "Hundert Jahre Deutsches Rechtsleben", Festschrift Deutscher Juristentag, Bd.I, 1960, S. 577 ff (616 f).

9) Zu der engen Verbindung zwischen gemeindlicher Selbstverwaltung und Daseinsvorsorge s. zunächst allgemein Hüttl, Kommunale Versorgungswirtschaft - Teil der Daseinsvorsorge im modernen Staat; Zeiss, Kommunales Wirtschafts recht und Wirtschaftspolitik, in: Peter's, Handbuch der kommunalen Wissenschaft und Praxis, Bd. III, 1958, S.611 ff (611 und passim); Brügelmann-Ludwig, Kommunale Versorgungswirtschaft, ebd., S.655 ff, insbes. \$.656 ff; Forsthoff, Die Daseinsvorsorge und die Kommunen, 1958; Köttgen, Die wirtschaftliche Betätigung der Gemeinden. - S.a. unten S.232.

10) Das Wirkungsfeld der gemeindlichen Sozialarbeit findet sich trefflich illustriert bei Schräder, Kommunale Sozialpolitik, S. $207 \mathrm{f}$ :

"Ein Gang durch die Gemeinde wird schnell zeigen, ob und inwieweit ihre Politik im weiteren Sinne sozial ausgerichtet ist. Eine solche soziale Ausrichtung besteht, wo z. B. bei der Stadtplanung und Raumgestaltung Sorge getragen wird, daß in der Nähe von dichtbesiedelten Wohngebieten, wo die minderbemittelten Bürger wohnen, Cirünanlagen und Kinderspielplätze geschaffen werden; wo der soziale Wohnungsbau eine besondere Beachtung findet und Mieten, Größe der Wohnungen und Räume auf die Bediirtnisse nicht nur der breiten Schichten, sondern auch der Minderbemittelten abgestellt sind; wo der Verkehr und die verkehrseinrichtungen auf die Bedürfnisse der Erwerbstätigen und derer, die kein eigenes Auto haben, besondere Rücksichten nimmt; wo die Tarife nicht nur für die Verkehrseinrichtungen, sondern auch für Gas, Strom, Wasser usw. in besinderer Weise auf die Verhältnisse der Minderbemittelten, der Kinderreichen usw. abgestellt sind. 
ersetzen kann. 11) Eine Reihe von Bedürfnissen kann nur durch lokale Sachveranstaltungen befriedigt und diese können nicht ebensogut zentral als lokal verwaltet werden. Trocknet der Staat die gemeindliche Selbstverwaltung ansonsten vor allem durch zentrale Reglementierung aus, so verschlägt dieses Medium dort nicht, wo konkrete Sacheinheiten zu gestalten und zweckvoll einzusetzen sind. 12) Die Unzahl der konkreten Initiativen, Entscheidungen und Maßnahmen, die notwendig ist, damit sie in einer den lokalen Möglichkeiten und Notwendigkeiten angepaßten Weise wirksam werden können, läßt sich durch eine zentrale Regelung nicht vorwegnehmen.

Unter den verschiedenen Autonomiebereichen 13) treten die Verfassungsautonomie ${ }^{14}$ ) und die Organautonomie der Gemeinden an

Die soziale Kommunalpolitik im weiteren Sinne wird sich insbesondere auch auf kulturellem Gebiet erweisen. Der Bau von Schulen wird in sozial orientierten Gemeinden in der Dringlichkeitsstufe anders rangieren als z. B. dort, wo es in erster Linie auf äußere Repräsentation, auf die Hebung von Industrie, Gewerbe, Verkehr und dergleichen ankommt. Es darf allerdings nicht übersehen werden, daß jede Gemeinde bestrebt sein muß, zunächst durch ihre Finanz-, Verkehrs- und Gewerbepolitik sicherzustellen, daß sie finanzkräftig genug wird, um überhaupt soziale Aufgaben erfüllen zu können. Die Betätigung sozialer Kommunalpolitik im weiteren Sinne wird sich ferner daran feststellen lassen, wie es den breiten Schichten, insbesondere auch den minderbemittelten Bürgern, ermöglicht wird, an den kulturellen Gütern und Veranstaltungen, an Theateraufführungen, musikalischen Darbietungen, Vorträgen, Ausstellungen und am Besuch von Museen teilzunehmen. Ein besonderer Gradmesser für den sozialen Geist der Gemeinde wird auch die Art des Ausbaus und der Ausgestaltung der Volksbüchereien sein".

11) Forsthoff, Die Daseinsvorsorge in den Kommunen, S.16, sagt: "daß diejenigen Aufgaben der Daseinsvorsorge, welche heute den Gemeinden... obliegen, auch unter dem Gesichtspunkt einer richtigen Ordnung der Daseinsvorsorge ihnen gebühren und daß die geschichtliche Entwicklung, die den gegenwärtigen Zustand hervorbrachte, vernünftig in dem Sinne war, daß sie eine grundsätzlich richtige Ordnung hervorgebracht hat".

12) S. a. Forsthoff, a.a.O. S.9.

13) S. hierzu z.B. Nawiasky, Grundbegriffe der Gemeindeautonomie, in: Die Gemeindeautonomie, 1946, S.21 ff.

14) Zur verfassungsrechtlichen Garantie der gemeindlichen Verfassungsautonomie durch Art.28 Abs.2 Satz 1 GG und Art. 11 
eigentümlicher sozialer und kommunaler Bedeutung am stärksten zurück. 15) Die gemeindliche Personalhoheit, eine der Kernsubstanzen der "Angelegenheiten der örtlichen Gemeinschaft", 16) umschließt in der sozialen Betreuung der Gemeindebediensteten eine der wichtigsten natürlichen Sozialaufgaben der Gemeinden. Die gemeindliche Finanzautonomie ${ }^{17)}$ liegt dem sozialen Aktionsraum der. Gemeinden bedingend voraus, dessen gesicherten Bestand die Grenzen der gemeindlichen Sachautonomie (administrativen Autonomie) mit umschreiben. 18)

\section{bb) Die administrative Sachkompetenz der Gemeinden}

Die geläufige, eminent daseinsvorsorgende Bedeutung der gemeindlichen Energiever'sorgungs- und Verkehrsbetriebe 1) hat im Verein mit der Konzentration der gemeindlichen Wirksamkeit auf die Sachveranstaltung 2) ein Bild der "Angelegenheiten der örtlichen Gemeinschaft" geprägt, das die - vor allem von kommunaler Seite gern mit der (gemeindlichen) Daseinsvorsorge schlechthin identifizierte - gemeindliche Versorgungswirtschaft und - dies verallgemeinernd - die wirtschaftliche Betätigung der Gemeinden als den Funktionskern der gemeindlichen Selbstverwaltung erscheinen 1äßt. 3) Der hieraus abgeleitete Anspruch der Gemeinden

Abs. 2 Satz 2 BayVerf s. z.B. BayVGH VGHE n. F. 8, 42 (56).

15) Zu den allgemeinen Zusammenhängen zwischen der demokratischen Struktur der Cemeinden und ihrer sozialen Wirksamkeit s.u. Abschnitt $3(\mathrm{~S} .315 \mathrm{ff})$, insbes. I $1(\mathrm{~S} .315 \mathrm{ff})$ und IV $1(\mathrm{~S} .390 \mathrm{ff})$ und $2 \mathrm{~b}(\mathrm{~S} .394 \mathrm{ff})$.

16) Vgl. BVerfGE 1, 167 (175 ff); 7, 358 (364 f); 8, 332 (359). S.ferner Henrichs, Die Rechtsprechung zur Verfassungsgarantie der kommunalen Selbstverwaltung in Deutschland, insbes. S. 735; Ipsen, Gemeindliche Personalhoheit unter Selbstverwaltungsgarantie; Schunck, Die Rechtsstellung der Gemeinden und Ciemeindeverbände nach dem Grundgesetz, s. 371; Görg, Kommunales Dienstrecht, in: Peters, Handbuch der kommunalen Wissenschaft und Praxis, Bd. II, 1957, S. 44 ff (54 ff); Maunz, in Maunz-Dürig, Art. 28 Randn. 32; je mit weiteren Nachweisen.

17) S. unten S. 236.

18) S. unten S. 232.

1) S. o. 5.230 zu Fußn.9.

2) S. o. $\$ .230$ zu Fußn. 8.

3) F ür die Zurechnung der Daseinsvorsorge und der wirtschaftlichen Betätigung der Gemeinden zu dem Funktionskern ihrer Selbstverwaltung: Köttgen, Die Gemeinde und der Bundesgesetzgeber, S.48; ders., Die wirtschaftliche Betätigung der 
auf die Wahrnehmung der Daseinsvorsorge 3 ) ist in Anbetracht der engen Verbindung zwischen Daseinsvorsorge und sozialer Hilfe ${ }^{4)}$ von äußerstel sozialer Prätention. Seine Substanz ist jedoch auf zweilache lleise relativiert und dadurch gemindert. Die "Daseinsvorsorge" ist ein deskriptiver Begriff, der sich weder dazu eignet, die Zuständigkeiten verschiedener Kompetenzträger voneinander abzugrenzen, noch ein Kriterium dafür abgibt, was der öffentlichen oder der privaten Sphäre angehören sol1. 5) Aufgaben der "Daseinsvorsorge" sind keineswegs an sich schon "Angelegenheiten der örtlichen Gemeinschaft".6) Die Prüfung, ob sie "in der örtlichen Gemeinschaft wurzeln oder auf die örtliche Gemeinschaft einen spezifischen Bezug haben und von dieser örtlichen Gemeinschaft eigenverantwortlich und selbständig bewältigt werden können", 7) wird durch ihre Charakterisierung als "Daseinsvorsorge" in keiner Weise präjudiziert. Die Grenze zwischen der staatlichen und der gemeindlichen Kompetenz steht in keiner funktionellen Beziehung zur "Daseinsvorsorge". Andererseits sind mögliche Aufgaben der "öffentlichen Daseinsvorsorge" - genauer": der. "Daseinsvorsorge" durch die öffentliche Verwaltung - noch nicht auch notwendige oder wesentliche Aufgaben der öffentlichen Verwaltung. Selbst dann, wenn fest steht, daß

Gemeinden, S.616 ff. Für die Zurechnung der gemeindlichen Daseinsvorsorge i.S. der gemeindlichen Energieversorgungs- und Verkehrsbetriebe zum Wesensgehalt der gemeindlichen Selbstverwaltung S.z.B. BayVerfGH VGHE NF 10 II 113 (122ff). - G e gen die Aufnahme der wirtschaftlichen Betätigung der Gemeinden und insbes. ihrer Versorgungsunternehmen in clen Schutzbereich der Wesensgehaltsgarantie des Selbstverwaltungsiechts (nach Art. 28 Abs.2 GG und Art. 11 Abs. 2, 83 Abs. 1 Bayverf): Fischerhof, Öfentliche Versorgung mit II asser, Gas, Elektrizität und öffentliche Verwaltung, DÖV 10.Jhg. (1957), S. 305 ff (314 f); ders., "Daseinsvorsorge" und wirtschaftliche Betätigung der Gemeinden, DÖV 13. Jhy . (1960) \$. 41 [f (44); Maunz, Grundfragen des Energiewirlschattsrechts, Verwaltungsarchiv, Bd.50(1959) S.315ff (328). Im besonderen gegen die Aufnahme der Energieversorgung in den unantastbaren Bereich der gemeindlichen Angelegenheiten: Friesenhahn, Grundgesetz und Fnergiewirtschaft, Flektrizitätswirtschaft, Bd. 56 (1957) Heft 1, S. 12 ff (17). S.a. I) ürig, in Maunz-1)ürig, Art. 19 Abs. III Randn. 47 (insbes. S. 31 Jußn. 1).

4) \$. ०. \$.37.

5) Zur Begriffskritiks. die oben S.37 zu Fußn. 1 Zitierten.

6) S. die Vorgenannten sowie die oben S.232 Fußn.3 a. E. Genamnten.

7) BVerfGE 8, $122(134)$. 
eine Agende der Daseinsvorsorge, würde sie als öffentliche Daseinsvorsorge betrieben, in den Bereich der Angelegenheiten der örtlichen Gemeinschaft fiele, bleibt es immer noch dem "Rahmen der Gesetze" 8) überlassen, die grundsätzliche Befugnis der Gemeinden, sie aufzunehmen, regulierend zu beschränken.9)

In diesem Sinne relativ erscheint auch das Mandat der Gemeinden zur Energie- und Verkehrsversorgung der Bevölkerung. 10) Nur soweit sie rein örtlicher Natur ist, kann der Staat sie den Gemeinden nicht abnehmen. 11) Nur soweit sie in öffentliche Verwaltung genommen werden muß, sollten anders die Angelegenheiten der örtlichen Gemeinschaft nicht Schaden leiden, 12) darf sie den Gemeinden nicht zugunsten der privaten Wirtschaft vorenthalten werden. 13) Entsprechend verhält es sich hinsichtlich der anderen sozial einschlägigen Materien, die dem gemeindlichen Selbstverwaltungs recht zugeschrieben werden. Dem Charakter einer Angelegenheit als "Daseinsvorsorge" oder dessen Negation kommt für die kommunalverfassungs rechtliche Qualifikation keine auch nur indizielle Bedeutung zu. Entscheidend ist die Zurechnung einer Angelegenheit zur örtlichen Gemeinschaft: zur örtli-

8) Art. 28 Abs. 2 Satz 1 GG.

9) S. hierzu Fröhler, Landesgesetzliche Beschränkungen der wirtschaftlichen Betätigung der öffentlichen Hand? Bayer. Verwaltungsbl. n.F. Jg. (1956) S. $135 \mathrm{ff}$ (139 f). S.a. die oben S.232 Fußn. 3 a.E. Zitierten, insbes. Fischerhof, a.a.O.; Dürig, a.a.O.

10) S. nochmals oben S. 232 zu Fußn. 1 und 3.

11) Die Zuständigkeit überörtlicher Aufgabenträger zur Verkehrsversorgung steht außer Frage. - Nicht so vorurteilsfrei wird gelegentlich die Sachlage auf dem Gebiet der Energieversorgung gesehen (s.hierzu auch nochmals die oben S. 232 Fußn. 3 Zitierten.

12) Die Gemeinden können sich wohl nur darauf berufen. Für den Staat selbst ergibt sich die Notwendigkeit der Übernahme einer Agende aus anderen Gründen, insbes, aus dem Sozialstaatsprinzip. Auf der anderen Seite geben diese Grundsätze aber auch das Maß ab für die gemeindliche Aufgabenstellung.

13) Das ist der entscheidende Gesichtspunkt im Streit um die Verfassungsmäßigkeit des Art. 75 der Bayerischen Gemeindeordnung (s.hierzu die oben S.232 zu Fußn. 3 Zitierten; ferner, für die Gültigkeit der Vorschrift eintretend, Ehrensberger, Verfassungs rechtliche Fragen im Grenzgebiet zwischen Kommunaler Selbstverwaltung und freier Wirtschaft, DÖV 9. Jhg. (1956) S. 129 ff). Fröhler hat diesen Gesichtspunkt verdienstvoll aber ungehört herausgearbeitet (s.o. S. Fußn. 3 und S. zu Fußn.9). 
chen Gemeinschaft als Gegensatz zu überörtlichen Gemeinschaften oder auch rein personellen, nicht örtlichen Gemeinschaften; und zur örtlichen Gemeinschaft als einer öffentlichen Gemeinschaft, einer Trägerin öffentlicher Verwaltung, im Gegensatz zum privaten, rein "gesellschaftlichen" Lebensbereich. Wohnungsbau, 14) Wohnungsaufsicht, 15) Ortsplanung, 16) Schulwesen, Erwachsenenbildung, öffentliche Fürsorge, Jugendfürsorge und Jugendpflege, 17) sonstige Wohlfahrtspflege, Gesundheitswesen usw. - das sind alles Angelegenheiten, die in gewissem Umfang und unter bestimmten Gesichtspunkten zum unentziehbaren Bestand gemeindlicher Selbstverwaltung gehören. Aber die Ausschließlichkeit der gemeindlichen Zuständigkeit ist (doppelt) relativ.

Wie schwach die Position der Gemeinden im speziellen, konkreten Konfliktsfall auch sein mag; eine Masse sozialer Aufgaben 18) steht ihnen doch unentziehbar zu, zumal neben den eben erwähnten auch die ins Auge zu fassen sind, die sich aus der gemeindlichen Personal-19) und Finanzhoheit 20) ergeben. 21)

14) Für die gemeindeutsche Rechtsauffassung ist bemerkenswert, daß das Erste und das Zweite Bundesbaugesetz je in $₫ 1$ Abs. 1 den sozialen Wohnungsbau kumulativ dem Bund, den Ländern, den Gemeinden und den Gemeindeverbänden zur Pflicht machen. - Die Konkurrenz zwischen der öfentlichen und der privaten Funktion ist hinsichtlich des Wohnungsbaues noch nicht problematisch geworden.

15) Die Wohnungsaufsicht stellt eine ihrer Natur nach öffentliche Aufgabe dar. Die Dimension öfentlich-privat ist insofern nicht kritisch.

16) Das Bundesbaugesetz (s.insbes. dessen Ersten bis Vierten Teil) hat die Symbiose zwischen grundsätzlicher Gemeindekompetenz und staatlicher Hilfs- und Aufsichtszuständigkeit sowie der Wirksamkeit anderer überörtlicher Gemeinschaften zutreffend herausgestellt. - Auch insofern handelt es sich um eine typisch iffentliche Aufgabe. Die Grenze zum privaten Bereich hin ist nicht umstritten.

17) S. hierzu umfassend Köttgen, Das umstrittene Mandat zur Jugendpflege, IÖOV 14.Jhg. (1961) S. 1 ff m.w. Nachw., der insbes. auch die Cirenze zur "freien" Jugendpflege hin erörtert.

18) S.a. nochmals oben S. 230 zu Fußn. 10.

19) S.o. S.232 zu Fußn. 16.

20) S.u. S. 236 .

21) In diesem Sinne erscheint es - abgesehen davon, daß auch die Gemeinden durch das verfassungs rechtliche Sozialstaatsprin- 


\section{cc) Die gemeindliche Finanzautonomie}

Nicht anders als die sozialgestaltende Bewegungsfreiheit des Bundes und der Länder hängt auch das soziale Aktionsvolumen der Gemeinden von ihrer finanziellen Ausstattung und Verfügungsmacht ab. 1) Das Grundgesetz läßt es an besonderen Garantien insofern jedoch fehlen. Zwar ist allein schon die Garantie der gemeindlichen Selbstverwaltung in Art.28 GG auch als die Garantie eines Minimums an eigenverantwortlicher Gestaltung der gemeindlichen Finanzverhältnisse und einer - im Rahmen dieser Finanzhoheit zu verwirklichenden - hin reichenden finanziellen Ausstattung zu verstehen. ${ }^{2)}$ Das Grundgesetz hat in seinem Art. 106, insbes. in dessen Abs.6, in der Fassung des Gesetzes zur Änderung und Ergänzung des Art. 106 GG vom 24. Dezember 1956 (BGB1.I S. 1077) diese Garantie in etwa auch konkretisiert. ${ }^{3)}$

zip gebunden sind - schon von der gemeindlichen Aufgabenstellung her nicht unrichtig, wenn Becker (Die gemeindeverfassungsrechtliche Entwicklung im Bundesgebiet, 1953, S.8) sagt: "Die soziale Gerechtigkeit, die im Mittelpunkt der gemeindlichen Selbstverantwortung steht, ist das regulative Prinzip" der Gemeindearbeit.

1) S. z.B. Partsch, Angelegenheiten der örtlichen Gemeinschaft, S. 310 ; Sattler, Gemeindliche Finanzverfassung. Bedeutung gemeindlicher Finanzhoheit für die Selbstverwaltung, in: Peters, Handbuch der kommunalen Wissenschaft und Praxis, Bd.III, 1958, S. 1 ff (insbes. S.4); Köttgen, Die wirtschaftliche Betätigung der Gemeinden, S. $587 \mathrm{f}$.

2) Vg1. Henrichs, Die Rechtsprechung zur Verfassungsgarantie der kommunalen Selbstverwaltung in Deutschland, S. 732; Heckt, Die gemeindliche Selbstverwaltung und die Finanzreform, DÖV 8.Jhg. (1955) S.265 ff (266); Schunck, Die Rechtsstellung der Gemeinden und Gemeindeverbände nach dem Grundgesetz, S. 371 f; Sattler, a.a.O. S.9 und passim.

3) (1) Aus der vorwiegend rechtspolitischen Diskussion um die finanzverfassungsrechtliche Stellung der Gemeinden aus der Zeit vor der Neuregelung von $1956 \mathrm{s.}$ z.B. Klein, Von der föderativen zur stärker unitarischen Gestaltung der Finanzverfassung in der Bundesrepublik Deutschland, Festschrift für Giese, 1953, S. $61 \mathrm{ff}$ (94 ff, $109 \mathrm{ff})$; Rietdorf, 1)ie Finanzverantwortung des Bundes gegenüber den Gemeinden, I)Ö 6.Jhg. (1953) S. $225 \mathrm{ff}$; Heun, Neuverteilung der Steuern Rückkehr zur verbundenen Steuerwiltschaft, DÖV 6. Jhg. (1953) S. 485 ff; ders., Die verbundene Steuerwirtschaft und ihre Gegner, DÖV 7.Jhg. (1954) S. $292 \mathrm{ff}$; Augustin, Die Frage der verbundenen Steuerwirtschaft zwischen Bund, Ländern 
Aber sowohl die Einnahmen- wie auch die Ausgabenseite der gemeindlichen Haushalte wird - von den tatsächlichen Gegebenheiten und den in der. IIIlensmacht der Gemeinden gelegenen Elementen einmal ganz abgesehen - in so erheblichem Umfange erst durch das Bundes- und vor allem durch das Landesrecht bestimmt, daß weder aus Art. 28 GG noch aus Art. 106 GG etwas über die Relation zwischen den für soziale Maßnahmen freien finanziellen Potenzen der Gemeinden und den gemeindlichen Kompetenzen zu sozialer Intervention gesagt werden kann. ${ }^{4)}$ Anzumerken ist in diesem Zusammenhang noch, daß die Verfassung den Gemeinden keine steuerrechtlichen Befugnisse gewährleistet, denen größere sozialgestalterische Bedeutung zukäme. Was den Gemeinden zugestanden ist, das ist - neben der hinreichenden Finanzausstattung im allgemeinen - der Zufluß der Realsteuern und eines landesgesetzlich zu bestimmenden Anteiles an der Einkommensteuer und der Körperschaftsteuer. (Art.106 Abs.6 GG). Die Verfassung gibt ihnen aber kein gesetzesfestes Recht auf einen Anteil an der normativen Gestaltung der ihnen zufließenden Steuern. 5) Und sie berechtigt zwar die Landesgesetzgebung, den Gemeinden die Verwaltung der ihnen zufließenden Steuern zu übertragen (Art. 108 Abs. 3 Satz $4 C_{i}(i)$, verpflichtet sie aber nicht hierzu. Die ihnen in der hierdurch grundgelegten Verfassungswirklichkeit zukommende Befugnis zur Rechtsetzung und Verwaltung im Steuerrecht ist als Instrument der sozialen Intervention nur von geringem Gewicht. 6) In eindeutiger Zuordnung zu den Gemeinden stehen die

und Gemeinden, IÖV 6. Jhg. (1953) S. 709 ff; Hettlage, Die Neuordnung der deutschen Finanzverfassung, Finanzarchiv Bd. 14 (1953/54) \$. $405 \mathrm{ff}$ (435 ff); Heckt, Die gemeindliche Selbstverwaltung und die Finanzreform.

(2) Darstellung und Würdigung der Auswirkungen des Gesetzes vom 24. lezember 1956 bei: Heckt, Die Neuordnung der verfassungsrechtlichen Grundlagen der gemeindlichen Selbstverwaltung, DÖ) 10.Jhg. (1957) S. 164 ff; Sattler, Gemeindliche Finanzverlassung, S. $11 \mathrm{ff}$; Hacker, Finanzausgleich in: Peters, a.a.O. (I3(l. III) S. 395 ff (410 ff). - Zur Verfassungswirklichkeit unter der Regelung des Art. 106 GG n. F. Patzig, Der kommunale Finanzausgleich im Zeichen des Steuerverbundes, 1)VP1. 74. Jhg. (1959) S. $1 \mathrm{ff}$.

4) Zur "relativen Sicherheit", die die Regelung des Art. 106 Abs. 6 GGin. $\%$ den Gemeinden (und Gemeindeverbänden) bietet, s.insbes. Sattler, a.a.O., Hacker, a.a.O.

5) Sattler, a.a.O. S. $10 \mathrm{f}$.

6) (1) Auf die Finkommensteuer und Körperschaftsteuer, an denen die Ciemeinden nach Art. 106 Abs. 6 Satz 4 GG zu beteili- 
Gebühren und Beiträge, die im Verwaltungsbereich der Gemeinden anfallen. 7) Doch kommt dem Gesetz auch insoweit konstitutiv gestaltgebende Bedeutung zu. ${ }^{8}$ )

gen sind, fehlt den Gemeinden jeder Einfluß. Dasselbe gilt für die übrigen Landessteuern, an denen die Gemeinden gemäß Satz 5 ebenda anteilig beteiligt werden (z. B. Kraftfahrzeugsteuer).

(2) Die den Gemeinden durch Art. 106 Abs. 6 Satz 1 GG zugesicherten Realsteuern unterliegen der Gesetzgebung des Bundes (Art. 105 Abs. 2 Nr.3 GG) und sind auch bundesgesetzlich geregelt (vg1. Grundsteuergesetz vom 1. Dezember 1951 i.d. F. der Bekanntmachung vom 10. August 1951 (BGB1. I S. 519 ber. S. 790); Gewerbesteuergesetz i.d.F. vom 18. November 1958 (BGB1. I S. 755)). Die Gemeinden können die Hebesätze bestimmen, haben dabei aber keine für die soziale Intervention beachtlichen Gestaltungsmöglichkeiten ( $\$ 21$ des Grundsteuergesetzes, $₫ ₫ 16$ ff des Gewerbesteuergesetzes). Die Verwaltung ist ihnen durch die Länder zum Teil überlassen (näheres s. hierzu bei Schifer, Die einzelnen Gemeindesteuern, in Peters, a.a.O. (Bd. III) S. 308 ff und zwar für die Grundsteuer S.328 ff, für die Gewerbesteuer S.315 ff).

(3) Im übrigen können die Länder den Gemeinden Steuern zuweisen, die ihnen (den Ländern) zufließen (Art. 106 Abs.6 Satz 5 GG). Sind diese bundesgesetzlich geregelt, so können die Länder den Gemeinden keine normative Gestaltungsmacht einräumen, sondern ihnen nur die Verwaltung übertragen (Art. 108 Abs. 3 Satz 4 GG). Soweit es sich um Steuern mit örtlich bedingtem Wirkungskreis handelt, die nach Art. 105 Abs. 2 Nr. 1 GG den Ländern zur ausschließlichen Gesetzgebung zustehen, können sie den Gemeinden auch die Regelung oder schlechthin die "Steuerfindung" überlassen (s.a. Sattler, a.a.O. S. $25 \mathrm{ff}$ ). Gerade diese Steuern sind aber ihrer Natur nach für den sozialen Ausgleich kaum je von Bedeutung. Sie können sozial gestaltet werden, nicht aber zur sozialen Umschichtung führen (s.o. S. 75).

7) S. hierzu auch (mutatis mutandis) die oben Abschnitt 1 II $3 \mathrm{~b}$, cc (S. 185 ff) und dd (S. 187 ff) angeführten Grundsätze.

8) Ein weiteres Problem: Muß den Gemeinden die wirtschaftliche Betätigung als Einnahmequelle zugestanden werden? Der Bayerische Verfassungsgerichtshof (VGHE n. F. 10 II 113 (123 f)) scheint - sub specie der Art.11 Abs.2, 83 Abs. 1 BayVerf - diese Frage zu bejahen, soweit die Einnahmen durch Versorgungs-und Verkehrsbetriebe erzielt werden, um die Verluste anderer Versorgungs- und Verkehrsbetriebe, 
Die verfassungs rechtlichen Determinanten der finanziellen Potenz der Gemeinden lassen demnach ein generelles Urteil über ihr soziales Aktionsvermögen nicht zu. Abschließend ist auf die soziale Tragweite des Umstandes aufmerksam zu machen, daß den Gemeinden in gewissem Umfange die Verwaltung und auch die generelle Ordnung von Abgaben überlassen werden muß oder wenigstens kann. Gesetzgebung und Verwaltung auf dem Gebiete des Abgabewesens schließen mehr oder weniger immer Möglichkeiten des sozialen Ausgleiches und der sozialen Rücksichtnahme in sich.9)

2. Die Gemeindeverbände - Kreise und Bezirke

a) Die allgemeinen verfassungs rechtlichen Grundlagen

Art. 28 Abs. 1 Satz 2 GG bringt mittelbar eine institutionelle Garantie der Gliederung des Bundesgebietes in Gemeinden und K reise zum Ausdruck. 1) Sie besagt freilich nur, daß diese Selbstverwaltungseinheiten da sein und - das ist die unmittelbare Aussage des Art.28 Abs. 1 Satz 2 GG - demokratisch legitimierte

deren daseinsvorsorgende Aufrechterhaltung notwendig ist, auszugleichen (s. hierzu schon oben S. 234 zu Fußn. 13; zur Garantie der wirtschaftlichen Betätigung der Gemeinden s.a. schon die oben S. 236 zu Fußn. 3 Zitierten). Schon der Standpunkt des Bayerischen Verfassungsgerichtshofes erscheint bedenklich. Die Annahme einer weitergehenden Garantie "rentierlicher" wirtschaftlicher Betätigung müßte als unrichtig angesehen werden. Es kommt darauf an, wie der Staat die Gemeinden insgesamt stellt. Nur wenn er ihnen andere Mittel, die Verluste aus notwendigen daseinsvorsorgenden Betrieben auszugleichen, versagt, wird man den Gemeinden zugestehen dürfen, daß sie wenigstens auf dem Wege rentierlicher wirtschaftlicher Betätigung ihren Aufgaben gerecht zu werden versuchen.

9) Im einzelnen darf hierzu verwiesen werden auf das oben A I (S. 14 ff zu Fußn. 46), B Abschnitt 1 I 1a (S. 45), b (S. 48 ), 2 a-e (S. 82 ff), 3 (S. 170 ) und II (S. 175 ff) Ausgeführte sowie die dortigen Nachweise. - Ergänzend ist zu bemerken: Für die soziale Gestaltung des Entgeltwesens macht es keinen Unterschied, ob öfentlichrechtliche Gebühren oder privatrechtliche vert ragliche Gegenleistungen verlangt werden.

1) Vgl. Weber, Staats- und Selbstverwaltung in der Gegenwart, S. 38 f; Becker, Die Selbstverwaltung als verfassungs rechtliche Grundlage der kommunalen Ordnung in Bund und Ländern, S. 113 ff (141). 
Repräsentativorgane haben müssen. Gegenstand und Inhalt des Selbstverwaltungsrechts der Kreise zu bestimmen, ist dem Gesetzgeber überlassen (Art. 28 Abs. 2 Satz 2 GG).

Die übrigen Gemeindeverbände spricht Art.28 Abs.2 GG mit an, indem auch ihnen die Selbstverwaltung "im Rahmen ihres gesetzlichen Aufgabenbereiches nach Maßgabe der Gesetze" zugebilligt wird. Das Grundgesetz garantiert ihnen jedoch weder Bestand noch Aufgabenkreis. 2) Von dieser Freiheit Gebrauch machend haben keineswegs alle deutschen Länder "höhere" Gemeindeverbände eingerichtet. 3 )

\section{b) Die Gemeindeverbände als Träger sozialer Aufgaben}

Das Grundgesetz hat, indem es auf die besagte Weise Kreise und höhere Gemeindeverbände institutionalisierte, nur Ansatzpunkte für die gesetzliche Begründung von Kompetenzräumen, nur verfassungsrechtliche Hüllen für mögliche kommunale Aufgabenträger über der Gemeindeebene geschaffen, nicht jedoch diese Kompetenzräume selbst konzipiert und nicht die Aufgabenträger eingerichtet. Aber damit ist doch verfassungsrechtlich der. Weg bereitet für die Sachgesetzlichkeiten, die gewisse Angelegenheiten der Kompetenz der Kreise oder höheren Gemeindeverbänden zuordnen. In diesem funktionellen Verhältnis stehen die verfassungsrechtlichen Grundnormen über die Kreise und höheren Gemeindeverbände auch zu deren sozialen Aufgabenkreis.

Auf soziale Kompetenzen üben die Gemeindeverbände nur einen verhältnismäßig geringen Sog aus. Gemeindeverbände sind in der Regel keine als wesentlich empfundenen Lebenseinheiten. Das egalitäre Gerechtigkeits - urd Opportunitätsdenken anerkennt die Grenzen von Gemeindeverbänden nicht als legitime Zäsuren des sozialen Standards. Die Leistungsfähigkeit der Gemeindeverbände ist zu wenig überschaubar. Die Zwischenstellung zwischen Gemeinde und Staat nimmt der Kompetenz der Gemeindeverbände fast durchwegs den Anspruch sachlogischer Notwendigkeit. Was "lokal" ist, wirdd den Gemeinden zugerechnet. Was aber "überörtlich" ist, drängt zur umfassendsten Entscheidungseinheit, dem Staat; dies umso mehr, als Gemeindeverbände mit Organisationseinheiten der staatlichen Verwaltung zu korrespondieren pflegen,

2) Vg1. Becker, a.a.O. S.143; s.a. Heigl, in: Mang, Verwaltungsrecht in Bayern, Bd.I, Nachtrag, 1952, S. 239.

3) Vgl. Naunin, Verfassungsrecht der regionalen Gemeindeverbände, in: Peters, Handbuch der kommunalen Wissenschaft und Praxis, Bd. I, 1956, S.470 ff. 
so daß auch der Stat zu der eventuell gebotenen Dezentralisation und regionalen Adaption imstande scheint. Kaum je Rechtsetzungsaufgaben, vornehmlich Verwaltungsaufgaben und auch hier soweit es um den eigenen Wirkungskreis geht - vor allem Sachveranstaltungen werden daher nach nicht immer einheitlichen und zwingenden Zweckmäßigkeitsgesichtspunkten den Gemeindeverbänden zugewiesen. 1)

Eine Besonderheit eigener. Struktur stellt jedoch die sog. K reis ebene dar. Sie vereinigt die kreisfreien Städte (Stadtkreise) mit den Landkreisen. Sie vermischt also Gemeinden und Gemeindeverbände - präziser: die größeren, leistungsfähigeren Gemeinden mit den Landkreisen als Substituten der kleineren, präsumtiv nicht hinreichend leistungsfähigen (nicht kreisfreien "Land" -) Gemeinden. Die Kreisebene ist die unterste Ebene gebietskörperschaftlichel selbstverwaltung hinsichtlich derjenigen Angelegenheiten, die den Wirkungskreis der kleineren Gemeinden überschreiten. Sie partizipiert noch am überzeugenden Kompetenzanspruch der örtlichen Gemeinschaft. Gerade auch soziale Aufgaben, deren generelle $̈$ berweisung an die Gemeinden nur an cler zu geringen Leistungsfähigkeit der kleineren (nicht kreisfreien) Gemeinden scheitert, konzentrieren sich bei den "Kreisen" (kreisfreien Städten/stadtkreisen und Landkreisen). 2)

Fiü die höheren Ciemeindeverbände fehlen entsprechend $z$ wingende Zuteilungskriterien weitestgehend. Die Frage, ob eine Angelewenheit, die den Rahmen der kreisfreien Großgemeinden und der Landkreise verlassen hat, doch nicht dem Staate selbst sondern einer zwischen ihm und den "Kreisen" eingeschobenen regionalen Einheit anvertraut "ierlen soll, kann nur selten aus unausweichlicher sachlogischer Notwendigkeit heraus beantwortet werden. Am ehesten scheint das noch hinsichtlich gewisser sachleistender Veranstaltungen der liall zu sein (insbes. Anstalten mit großräumigem Finzugsgebict Wie Heil- und Pflegeanstalten, Gehörlosen-

1) Zu den grundsätzlichon Erwägungen s. auch nochmals das oben S. 228 Ausgerïhrte und die dortigen Nachweise.

2) V@l. Schräder, Kommunale Sozialpolitik, S.266. - Zu den eigenen Kreisangelegenheiten auf dem Gebiet der Fürsorge und der Jugendwohlfahrt s, schon oben S. 229 zu Fußn. 5, zu den übertragenen Kreisangelegenheiten auf dem Gebiet des Lastenausgleichsicchts s. oben S. 229 zu Fußn. 7. Weitere einschlägige Aufgaben der Kreise s. bei Canter, Verfassungsrecht der Landkreise, in: Peters, Handbuch der kommunalen IIissenschaft und l'axis, Bd. I 1956, S.409 ff (417 ff, insbes. S. $425 \mathrm{f}$ ). 
und Blindenanstalten, besondere Unterrichtsanstalten u.a.m.). ${ }^{3)}$ Die höheren Gemeindeverbände sind demnach zwar nicht von umfassender aber doch von schwerpunktartig gewichtiger sozialer Wirksamkeit.

\section{Die sonstigen Verbände}

\section{Zur allgemeinen Problematik}

Den Kommunen entspricht wesensmäßig eine klare konzentrische Ordnung. Für die Personalverbände fehlt ein entsprechend eindeutiges Ordnungsbild von vorneherein. Die unter persönlichen Kriterien abgrenzbaren Kreise überschneiden sich. Ihre Aufgliederung und Ordnung bedarf der gestaltgebenden gesetzgeberischen Dezision in besonderem Maße.

Der Mannigfaltigkeit der denkbaren personalen Verbandsprinzipien entspricht die Vielfalt der Ordnungsvorstellungen von einer staatlicherseits respektierten Eigenwirksamkeit personaler Verbände. Die katholische Staatslehre will den Gebietskörperschaften berufsständische Korporationen zur Seite gestellt wissen, hinter denen der Staat subsidiär zurücktreten soll. 1) Daneben wird aber. gerade von kirchlicher Seite ein gewisser Vorrang auch der kirchlichen Gemeinschaft(en) behauptet. 2) Die Konkurrenz von Kirche und Staat besteht insbes. auch in bezug auf die kirchliche Liebestätigkeit, deren Bedeutung für die sozialen Probleme nicht zu leugnen ist. Schließlich nehmen aber auch nicht kirchliche Wohlfahrtsverbände die Anerkennung der Rücksichtnahme des Staates in Anspruch und Vorschriften wie $₫ 5$ der Fürsorgepflichtverordnung 3 ) und $₫ 6$ des Jugendwohlfahrtsgesetzes 4$)$ scheinen sie darin zu bestätigen. 5) Aus anderen Ursprüngen rührt wiederum der

3) Zu den einschlägigen Zuständigkeiten der Bezirke s. Naunin, Verfassungs recht der regionalen Gemeindeverbände, S. 472 ff. Im besonderen liegen die Aufgaben der Landesfürsorgeverbände ( $\$ 2$ der Verordnung über die lürsorgepflicht) weitgehend bei diesen Verbänden (Naunin, a.a.O., S.473).

1) S.o. S.219ff und S.223 ff und die dort (insbes. S. 219 Fußn. 1) gegebenen Nachweise

2) S. u. IV 1 (S. 252 ff).

3) S. nunmehr die $\$ \$ 10,87$ des Entwurfs eines Bundessozialhilfegesetzes (Deutscher Bundestag, 3. Wahlperiode, Drucks. 1799) und dessen Begründung S. 33, 35, 39, 56.

4) Zu dem noch weitergehenden Neuregelungsentwurf s. Köttgen, Das umstrittene Mandat zur Jugendpflege.

5) Köttgen, Art. "Selbstverwaltung" im Handwörterbuch der Sozialwissenschaften, Bd.9, 1956, S.220 ff (223), ist der Meinung, 
Autonomieanspruch der Gewerkschaften und Arbeitgeberverbände her, 6) dessen Verwirklichung das Wirtschaftsleben gerade in seinen sozialen Bezügen durchgreifend beherrscht. Schon diese vier Hinweise zeigen, wie diffus die Vorstellungen sind, die sich mit der hier aufgegriffenen Fragestellung verbinden. Sie reichen von der der konstitutiven Rechtsform nach noch privaten Vereinigung (Koalitionen, Wohlfahrtsverbände) bis zur öffentlichrechtlichen Körperschaft (Kirchen, berufsständische Organisationen ${ }^{7}$ ), von dem auf der Grundlage der Freiwilligkeit stehenden Verband (Koalitionen, Wohlfahrtsverbände) bis zur Zwangsorganisation (berufsständische $Z$ wangsorganisationen 7 )) und von vorwiegend innen-orientiert tätigen Verbänden (berufsständische Organisationen) bis zu rein extrovertierten Aktionseinheiten (Wohlfahrtsverbände).

Daneben wird von den verschiedensten Verbänden - neben der selbstbestimmten Eigenwirksamkeit oder auch ohne das - ein Einfluß auf fremde Entscheidungen und Maßnahmen, insbes. auf die staatliche Rechtsetzung, Verwaltung und Rechtsprechung,auf die Willensbildung der kommunalen Selbstverwaltungsträger und sonstigen öfentlichrechtlichen Körperschaften und Anstalten ausgeübt oder erstrebt. Was hierbei in den Formen der sog. politischen Selbstverwaltung aber weit darüber hinaus im Rahmen legitimer und illegitimer Einwirkung vor sich geht, 8) gehört als eigenständiges Phänomen aber nicht hierher. Verbände, die sich darauf beschränken, nehmen nicht öffentliche Aufgaben zur e i genverantwortlichen Frledigung für sich in Anspruch. Sie sind keine den Kommunen oder anderen Selbstverwaltungsträgern gleichzustellenden Glieder des Aufbaues der staatlichen Gemeinschaft, die in sich gewisse, praemissis praemittendis den staatlichen unmittelbar vergleichbare Leistungs-, Ausgleichs- und

die "Verbände der freien Wohlfahrtspflege und Jugendverbände würden zum mindesten einer entsprechenden Überprüfung bedürfen".

6) S. u. IV 2 (S.287 ff).

7) Zum Bild der berufsständischen Korporation s.f. v.a. v. Nell-Breuning, Art. "Ständischer Gesellschaftsaufbau" im Handwörterbuch der Sozialwissenschaften, Lfg. 15 (1957) S. 6 ff (9 f); spezieller (aus der jüngeren Literatur): Rauscher, Subsidiaritätsprinzip und berufsständische Ordnung in "Quadragesimo anno", S. 122 ff, 126 ff. - S.a. die Darstellung bei Nawiasky, Rechtsfragen des wirtschaftlichen Neuaufbaues, $\$ .27 \mathrm{ff}, 82 \mathrm{ff}$, die allerdings über das übliche Schema erheblich hinausgreift.

8) S. hierzu unten Abschnitt 3 (S.315 ff), insbes. III 5 b (S. 373 ff). 
Organisationsaufgaben erfüllen. ${ }^{9)}$ Sie bedienen sich der staatlichen (und sonstigen öfentlichen) Gewalt zur Durchsetzung ihrer. Kollektivinteressen. ${ }^{10)}$ Sie sind daher unter dem Gesichtspunkt der staatlichen Willensbildung zu erörtern, 8) jedoch nicht unter. der Subsidiarität der größeren Gemeinschaft gegenüber der kle:neren oder der vertikalen Gewaltenteilung. Dieselbe systematische Zuordnung gilt für die politischen Parteien, die als Aktionsgemeinschaften wesensmäßig nach außen, auf die Willensbildung des Volkes und seiner Repräsentativorgane hin orientiert sind (Art. 21 Abs. 1 Satz 1 GG). 11)

2. Personalverbandliche Ordnung und Grundgesetz

An einer - mit der Kernnorm der gebietskörperschaftlichen Ordnung des Art.28 GG vergleichbaren - prinzipiellen Regelung des Personalverbandswesens läßt es das Grundgesetz fehlen. 1) Daß Art.9 Abs. 1 GG die Vereinigungsfreiheit gewährleistet, besagt nichts. Diese Verfassungsnorm betrifft nur die Bildung privater Vereinigungen. 2) Sie beinhaltet keinen Anspruch gegen den Staat, diesen freigebildeten Vereinigungen öffentliche Aufgaben zu übertragen. ${ }^{3)}$ Auch daß das Grundgesetz die Existenz rechtsfähiger Ve rwaltungseinheiten voraussetzt (Art. $73 \mathrm{Nr} .8,75 \mathrm{Nr} .1,86,87$, $130 \mathrm{GG}$ ), besagt für die spezifische Fragestellung schlechthin nichts.

9) Hans Huber, Staat und Verbände, 1958, S.4 und 18: "Niemand kann sich vorstellen, daß die Verbände, so wie sie sind, solche Kommunen im Aufbau der Nation darzustellen vermöchten".

10) S. z.B. Messner, Die soziale Frage, S.616.

11) S. unten Abschnitt 3 III 5 a (S. $370 \mathrm{ff}$ ).

1) Vgl. Köttgen, Art. "Selbstverwaltung" im Handwörterbuch der Sozialwissenschaften, S.224; Reuss, Die Organisation der Wirtschaft, insbes. S.99 f; s. ferner Ballerstedt, Wirtschaftsverfassungs recht, S. 24 ff; Rietdorf, Zum staatsrechtlichen Lehrbegriff der "mittelbaren Staatsverwaltung", DÖV 12.Jhg. (1959) S.671 ff (672). Art.28 GG enthält die gefragte Regelung nicht!(Vg1. Maunz in Maunz-Dürig, Art. 28 Randn. 28).

2) BVerfGE 10, 89 (102), S. 354 (361 f); Huber, Wirtschaftsverwaltungsrecht, Bd.I, S. 198 f; Hamann, Das Grundgesetz, Art. 9 Anm. B 3; v. Mangoldt-Klein, Art. 9 Anm. III 6 a, 8, V 9; je m. weiteren Nachweisen.

3) Vg1. Wernicke, Bonner Kommentar, Art. 9 Anm. II $1 \mathrm{f}$; Köttgen, Das umstrittene Mandat zur Jugendpflege, S. 4. 
Nur einzelne, zudem extraordinäre, Verbandstypen spricht das Grundgesetz an: die - grundsätzlich außerhalb des öffentlichrecht1ichen Bereichs stehenden - Vereinigungen "zur Wahrung und Förderung der Arbeits - und Wirtschaftsbedingungen" (Art.9 Abs.3 GG)4) und die Religionsgesellschaften, die "ihre Angelegenheiten selbständig innerhalb der Schranken der für alle geltenden Gesetze" ordnen und verwalten (Art. 140 GG i. V.m. Art. 137 RV 1919). 5)

Eine gewisse Grundanlage zu verbandlichen Strukturen schafft das Grundgesetz schließlich auch, indem es den Sozialstaat im besonderen auf das Instrument der Sozialversicherung verweist (Art.74 Nr.12, 87 Abs.2 GG).6) Die Sozialversicherung tendiert, wie nicht zuletzt die deutsche Tradition beweist, zur Trägerschaft der besonderen Vel'waltungseinheit. 7) Wenn dabei auch der Notwendigkeit eines haftenden Vermögensstockes und seiner zweckgerechten Verwendung durch die anstaltliche ${ }^{8)}$ Organisationsform genügt werden könnte, so drängen die der Sozialversicherung wesensmäßig zugeordneten Elemente der Solidargemeinschaft und der genossenschaftlichen Selbsthilfe - kräftig gestützt durch das demokratisch-autonomistische Denken 9) - doch zur Körperschaft. ${ }^{7)}$ Verbandliche Konzeptionen durchsetzen die Organisation der Sozialversicherung daher regelmäßig auch dort, wo sie an sich eine anstaltliche ist. 10) so ist es - wenn zunächst

4) S. hierzu unten IV 2 (S. $287 \mathrm{ff})$.

5) S. hierzu unten IV 1 (S. $252 \mathrm{ff})$.

6) S. hierzu auch oben Abschnitt 1 I 1 b bb (S. 49 ff) und unten S. 762 ff.

7) S. hierzu auch oben \$. 125 .

8) Letztlich könnte sogar an die Form der Stiftung gedacht werden.

9) S. hierzu unten Abschnitt 3 IV (S. 390 ff).

10) Zum Ineinanderfließen der verbandlichen und anstaltlichen Flemente im Bereich der Sozialversicherungsträgers. z. B. IIerner II eber, Art. "Juristische Personen" im Handwörterbuch der Sozialwissenschaften, Bd.5, 1956, S.449 ff (450); ders., Art. "Körperschaften des öffentlichen Rechts" ebd., Bd.6, 1959, S.38 ff (39). Zur verbandlichen Struktur der anstaltlichen Versichelungsträger s.a. schon etwa die Darstel1 ung bei Richter, Sozialversicherungsrecht, S.92 ff; nunmehr $s$. das Selbstverwaltungsgesetz, das für "jeden Träger der Sozialversicher"ung grundsätzlich einheitliche Regeln schafft $(\$ 1)$. Auch im schrifttum zur. Selbstverwaltung in der Sozialversicherung tritt die Unterscheidung $z$ wischen anstaltlich oder korporativ konzipierten (oder auch nur deklarierten) 
wohl auch nur eine redaktionell-terminologische Schlamperei und normativ unverbindlich - wenigstens deskriptiv doch nicht abwegig, wenn Art. 87 Abs. 2 GG von den "sozialen Versicherungsträgern" nur als "Körperschaften" spricht.11) 12)

Versicherungsträgern bis zur Irrelevanz zurück (s. z. B. die - untereinander im übrigen sehr heterogenen und daher insoweit wohl besonders aufschlußreichen - Beiträge zu diesem Thema in "Gegenwartsfragen sozialer Versicherung" hrsg. v. Walter Bogs, 1950; Bogs, Entwicklung und Rechtsformen der Selbstverwaltung in der Sozialversicherung, a.a.O. S. 137 ff; Selpien, Die Selbstverwaltung in der Praxis der Versicherungsträger, a.a.O. S. 159 ff; Kühn, Besonderheiten der Selbstverwaltung in der Rentenversicherung, a. a. O. S. 169; Schrader, Besonderheiten der Selbstverwaltung in der Unfallversicherung, a.a.O. S.177 ff; Höfner, Besonderheiten der Selbstverwaltung in der Knappschaft, a.a.O. S.187 ff; ferner die Diskussionsbeiträge hierzu a.a.O. S. $194 \mathrm{ff}$. Zum Thema s. ferner etwa Bischoff, Staatsaufsicht und Selbstverwaltung in der Sozialversicherung, in "Sozialpolitik, Arbeits- und Sozialrecht", Festschrift für Friedrich Sitzler, 1956, S. 113 ff). - Als auf eine Grenzform sei auf die Bundesanstalt für Arbeitsvermittlung und Arbeitslosenversicherung hingewiesen. (Eine außerordentliche Fehlleistung des Gesetzgebers: "Die Bundesanstalt ist eine Körperschaft des öffentlichen Rechts" ( $\$ 2$ Abs. 1 Satz 1 AVAVG)). In ihren Organen sitzen nicht nur Vertreter der Arbeitnehmer und der Arbeitgeber sondern auch "Vertreter der öffentlichen Körperschaften" ( $\$ \$ 9$ Abs.1, 12 AVAVG). Hier kann eindeutig nur mehr von einer - verbandlich getragenen - politischen Selbstverwaltung im Rahmen der Anstalt gesprochen werden (zu dieser Rechtsfigur s. Köttgen, Art. "Selbstverwaltung" im Handwörterbuch der Sozialwissenschaften, S.224). - Eine andere Kuriosität sind die landwirtschaftlichen Alterskassen und (noch mehr) die Familienausgleichskassen. Sie sind zwar verbandlich gestaltet, aber ohne Rücksicht auf das Prinzip der Identität. Ein Verband (die Berufsgenossenschaft) verwaltet die Angelegenheiten eines Personenkreises, der nicht als das Substrat des herrschenden Verbandes angesehen werden kann. Hier wird das Verbandsprinzip - gedankenlos oder fraudulös - nur mehr abstrakt verwirklicht, nur mehr kopiert (zur Diagnose und Kritik s. Schewe, Körperschaften ohne Selbstverwaltung?).

11) Normativ betrachtet schließt der Ausdruck "Körperschaften" aber die "Anstalten" ein. Vgl. Herrfahrdt, Bonner Kommen- 
Aus diesen punktuellen Ansätzen kann kein - wie auch immer gedachtes - verbindliches korporatives System abgeleitet werden; 13) auch nicht in Zusammenschau mit der (föderativen und kommunalen) gebietskörperschaftlichen Stufenordnung; 14 ) auch nicht in Verbindung mit der Grundrechtsordnung 15) - weder etwa mit den Gemeinschaftsgrundrechten des Art. 6 16) und des Art. 9 GG 17) noch mit den Grundrechten der individuellen Freiheit, insbes. Art.2 Abs.1 GG 18) -; auch nicht in gemeinsamer Erwägung mit allgemeinen Grundsätzen wie denen von der Menschenwürde 19) und vom sozialen Rechtsstaat; ${ }^{20)}$ auch nicht endlich mit Rücksicht auf die grassierenden, selbst das Konkret-Spezielle nicht meisternden und nur für einen Teil der pluralistischen staatstragenden Gesellschaft verbindlichen Subsidiaritätsthesen. 21)

Insbes. kann nicht davon die Rede sein, das Grundgesetz schreibe einen sog. berufsständischen Aufbau vor.

Ferner gewährt das Grundgesetz den diversen freien Wohlfahrtsverbänden keinen verfassungs rechtlichen Sonderstatus. 22) Gewiß ist seine Gewährung durch die unterverfassungsrechtliche Ord-

tar, Art. 87 Anm. II 3; Giese, Grundgesetz, Art. 87 Anm. 7; Hamann, Grundgesetz, Art.87 Anm. C 5.

12) Doch handelt es sich bei all dem nur um eine verfassungsrechtlich angelegte Inklination zum besonderen Sozialversicherungsträger im allgemeinen und zum verbandlichen Versicherungsträger im besonderen. Eine präzise verfassungsrechtliche Verbindlichkeit besteht nicht. Die Annahme, die Sozialversicherungsträger hätten einen ursprünglichen, ihnen nicht vom Staate übertragenen Wirkungskreis (s. Bischoff, Staatsaufsicht und Selbstverwaltung in der Sozialversicherung, S. 115 und passim), kann keinesfalls in dem Sinne richtig sein, Claß den Versicherungsgemeinschaften ein solcher Wirkungskreis von Verfassungs wegen zukommt und nicht durch Gesetz entzogen werden dürfte.

13) S. nochmals die oben S. 244 zu Fußn. 1 Zitierten.

14) S. O. S. 223 und II (S. 225 ff).

15) Vgl. Köttgen, Das umstrittene Mandat zur Jugendpflege, S. 4 ff; s. ferner oben S. 223 und unten S. 1107.

16) S. O. I (S. 219 ff).

17) S. o. S. 244 zu Fußn. 3 und oben I (S. 219 ff).

18) Vgl. Köttgen, a.a.O. S.4; s. ferner unten Abschnitt 6 V 8 (S.1056 ff).

19) S. U. S.1107.

20) S. u. S. 755. 
nung 23) schon in der Verfassung tendenziell angelegt, ist es eine "rechtsstaatliche Selbstverständlichkeit", daß der "gesellschaftlichen Initiative keine spezifischen Grenzen gezogen werden", und beinhaltet "eine freiheitliche Grundordnung... in jedem Fall die Chance pluralistischer Entfaltung" nicht nur der Jugendarbeit sondern auch der sonstigen Wohlfahrtspflege. 24) Art.9 Abs. 1 GG stützt diesen Zug von der gesellschaftlich-kollektiven Seite her. ${ }^{25)}$ Art. 1 und 2 GG entsprechen ihm vom Individuum her, dessen Würde und Freiheit die Alternative $z$ wischen staatlicher und staatsfreier Hilfe und Förderung wünschenswert erscheinen lassen. 26) 27) Das Sozialstaatsprinzip wird gerade die soziale Aktivität freier Verbände besonders fördernswert erscheinen lassen und Privilegierungen - insbes. gegenüber Art. 3 GG rechtfertigen. 28) Endlich drängt nach solchen Privilegierungen auch die Nachbarschaft der (rein) freien Verbandsarbeit mit der IVirksamkeit der Kirchen, deren caritative Betätigung in ihrem verfassungsrechtlichen Sonderstatus mit garantiert ist. 29) Aber ein staatsorganisatorisches Prinzip, wonach der Staat gewisse soziale Aufgaben den jeweils bestehenden Wohlfahrtsverbänden überlassen müßte und mit Rücksicht darauf selbst nicht in Angriff nehmen dürfte oder bräuchte, ist nicht verbürgt. ${ }^{30}$ )

21) S.o. I (S. $219 \mathrm{ff})$.

22) Zum Problem s. schon oben S. 242 zu Fußn.3-5.

23) S.oben S. 242 zu Fußn. 3 f.

24) Köttgen, Das umstrittene Mandat zur Jugendpflege, S. 1, speziell zur Jugendpflege (im Gegensatz zu den "sich formal als hoheitliche Vollzugszuständigkeiten darstellenden Aufgaben der Jugendfürsorge", die er "zum Vorbehaltsgut der Verwaltung" rechnet): "Daß auf diesem Gebiet gesellschaftlicher Initiative keine spezifischen Grenzen gezogen werden können, ist eine rechtsstaatliche Selbstverständlichkeit. Eine freiheitliche Grundordnung beinhaltet in jedem Fall die Chance pluralistischer Entfaltung der Jugendarbeit".

25) Zu den Wirksamkeitsgrenzen s.o. S. 244 zu Fußn. 3.

26) S.u. Abschnitt 6 V (S.1017 ff) und VII (S. $1095 \mathrm{ff})$.

27) Dagegen, ein Recht auf freie Jugendpflege aus dem Elternrecht (Art.6 GG) abzuleiten, zutreffend Köttgen, a.a.O. S. 5 f. Weitere Nachweise s. dort.

28) Zur Auslegung des Sozialstaatsprinzips s.u. Abschnitt 6 II (S. $890 \mathrm{ff})$, insbes. S.919.

29) S. unten IV 1 (S. 252 ff).

30) (1) Der gegenteilige Standpunkt ist im Schrifttum - soweit ersichtlich - nicht eindeutig vertreten. Literaturstellen, die in diese Richtung gehen (z.B. Utz, Formen und Grenzen des 
Andererseits steht das Grundgesetz dem Einbau personaler Unterverbände in die staatliche Gemeinschaft auch nicht entgegen. ${ }^{31}$ ) Es verbietet im besonderen nicht die Ausklammerung sozialer Angelegenheiten aus dem staatlichen Zuständigkeitsbereich zugunsten engerer (auch per'sonal strukturierter) Einheiten. ${ }^{32}$ )

Subsidiaritätsprinzips, S. 82 f, 98 ff, 117 ff), können, soweit sie nicht ohnedies im Grunde nur die kirchlichen Verbände und Einrichtungen meinen (wie Franz Klein, Christ und Kirche in der sozialen Welt, S. 129 ff, 134 ff), durchaus dahin gedeutet werden, daß sie kein verfassungs rechtliches sondern ein rechtspolitisches Prinzip im Auge haben oder wenigstens nur die verfassungsmäßigen Individualrechte zugunsten dieses Prinzips anführen wollen. S. zum Thema eingehend Köttgen, Das umstrittene Mandat zur Jugendpflege, und die dortigen Nachweise.

(2) Im Landesverfassungs recht ist allerdings gelegentlich auch den Verbänden ler freien Wohlfahrtspflege eine privilegierte Stellung eingeräumt. So gewährleistet Art.6 Abs.3 der Verfassung des Landes Nordrhein-Westfalen "das Mitwirkungsrecht... der Verbände der freien Wohlfahrtspflege in den Angelegenheiten der Familienfürsorge und der Jugendfürsorge". Ähnliches bestimmt Art.26 der Verfassung des Landes Rheinland-Pfalz. Dagegen sieht Art. 13 Satz 3 der Verfassung des Landes Baden-Württemberg nur vor, daß die Aufgaben des Staates und der Gemeinden im Jugendschutz "auch durch die freie Wohlfahrtspflege wahrgenommen werden" können. Ein Privileg ganz anderer Art ist es, wenn nach Art. 35 der Bayerischen Verfassung die Wohltätigkeitsorganisationen fünf Vertreter in den Bayerischen Senat entsenden.

31) BSGE 6, 213 (225): Der "Girundsatz, daß die Allgemeinheit nur dann Träger von Maßnahmen sein soll, wenn diese Aufgabe nicht auch von einer kleineren Gemeinschaft ebenso gut erfüllt werden könnte..., kann nicht als abwegig (sic!) oder gar verfassungswidrig bezeichnet werden". BVerfGE 10, 89 (104):

"In einem Staat, der den ciedanken der Selbstverwaltung bejaht und in seiner Gesetzgebung weitgehend verwirklicht, kann die Wahl der Organisationsform einer Körperschaft nicht schon als solche verfassungswidrig sein".

32) Zur Exemplifikation s. nochmals oben S. 87 , S. 125 und S. 140 ff. Zur Sozialversicherung s.auch oben den Text. Erstaunlicherweise hat jedoch Ipsen (Rechtsfragen berufsständischer Zwangsversorgung, S. $51 \mathrm{ff}$ ) versucht, gerade vom Sozialstaatsprinzip her gegen die berufsständische $Z$ wangsversorgung zu argumentieren. Seine Ausführungen 
Vor allem verbietet das Grundgesetz nicht die für die Effektivität der körperschaftlichen Organisation so wesentliche Zwangsmitgliedschaft bei öffentiichen Körperschaften. Gewiß gelten die allgemeinen Sicherungen der individuellen Freiheiten und Rechte

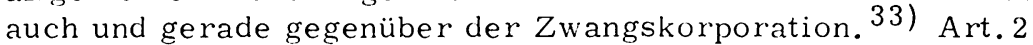
Abs. 1 GG - ebenso als grundsätzliche Garantie der individuellen Freiheit wie als Vorbehalt der verfassungsmäßigen Ordnung gegenüber dieser Freiheit - spielt eine zentrale Rolle. ${ }^{34)}$ Vorbehalt und Vorrang des Gesetzes müssen auch im Bereich der zwangskörperschaftlichen Selbstverwaltung gewahrt werden, 35$)$ desgleichen der richterliche Rechtsschutz. ${ }^{36)}$ Schließlich darf die private Vereinigungsfreiheit (Art.9 Abs.1 GG) nicht dadurch erstickt werden, daß ihr ein allumfassendes Netz von $Z$ wangsverbänden den Lebens raum entzieht. ${ }^{37)}$ Aber ein grundsätzliches Verbot der

vermögen jedoch nicht zu überzeugen. S. hierzu auch Schneider, Die öffentlichrechtliche Alterssicherung freier Berufe und das Grundgesetz, S. 31 .

33) Eine gute Übersicht über die Probleme s, bei Reuss, Die Organisation der Wirtschaft, S. $105 \mathrm{ff}$. S. ferner insbes. BVerfGE 10, 89 (102 ff), 354 (361 ff); ergänzend hierzu Rietdorf, Zum staatsrechtlichen Lehrbegriff der "mittelbaren Staatsverwaltung", DÖV 12.Jhg. (1959), S.671 ff; s.a. trotz des anspruchsvollen Titels wenig überzeugend - Linckelmann, dass., ebenda, S. $561 \mathrm{ff}, 831 \mathrm{ff}$.

34) S. z.B. BVerfGE 10, 89(102), 354(362 ff). - Davon geht zutreffend auch Gass (Zur verfassungs rechtlichen Problematik der saarländischen Arbeitskammer und der bremischen Arbeitnehmerkammern, DÖV 13.Jhg. (1960), S. 778 ff) aus. Daß er zu den von ihm entwickelten weittragenden - die genannten Einrichtungen negierenden - Folgerungen kommt, liegt an seiner unrichtigen Auslegung des Art.2 Abs. 1 GG.

35) S. hierzu unten S. 444 und S. 445.

36) Vgl. BVerfGE 10, 89 (109 f).

37) Zum Schutz der positiven Vereinigungs freiheit durch Beschränkung der öffentlichrechtlichen Zwangskorporierung s. insbes. Quidde, Grundrechtsschutz vor Zwangsmitgliedschaften, DÖV 11.Jhg. (1958) S. $521 \mathrm{ff}$, insbes. S. 524; Schneider, Die öffentlichrechtliche Alterssicherung freier Berufe und das Grundgesetz, S. $29 \mathrm{f}$. Auch bei Ipsen (Rechtsfragen berufsständischer Zwangsversorgung, S.40 ff) tritt diese Erwägung immer wieder zutage. - Allein auf dem Gedanken der positiven Vereinigungsfreiheit beruht wohl das Richtige - nämlich die Negation eines Interessenvertretungsmonopols öffentlichrechtlicher Zwangsverbindungen - in der These Redekers 
Zwangsmitgliedschaft enthält Art. 9 Abs. 1 GG insbes. schon deshalb nicht, weil diese Vorschrift sich nur auf private Verbände bezieht. 38 )

Das öffentlichrechtliche Verbandswesen, das sich auf dieser $\mathrm{Ba}-$ sis einer weitgehenden grundgesetzlichen Neutralität erhalten bzw. entwickelt hat, ist nicht überreich aber doch von Bedeutung, auch von sozialer. ${ }^{39)}$

(Kammerbegriff und Grundgesetz, DVB1. 63. Jhg. (1952) S. $201 \mathrm{ff}, 239 \mathrm{ff}$ ), berufsständische Kammern dürften nur "Disziplinierungs" -zwecken, nicht auch der Interessenwahrung dienen. (Gegen Redeker: Weber, Die Kammern der Heilberufe und das Grundgesetz, DÖV 5.Jhg. (1952) S. 705 ff, insbes. S. 709 f; dagegen nochmals Redeker, Gegenwartsfragen berufsständischer Selbstverwaltung, S.625 ff (628)).

38) S. nochmals die oben S. 244 zu Fußn. 2 Zitierten. Ergänzend $\mathrm{s}$. hierzu Füßlein, Vereins- und Versammlungsfreiheit, in: Neumann-Nipperdey-Scheuner, Die Grundrechte, Bd.II, 1954, S. 425 ff (431 f, 435), der die Zwangsverbände - jeder Art! vom Begriff der Vereinigung i.S. des Art. 9 Abs. 1 GG ausnimmt und deshalb das Problem der negativen Vereinigungsfreiheit gegenüber der öffentlichen Gewalt als gegenstandslos betrachtet (S. 435).

39) Außer den anstaltlich-verbandlichen Sozialversicherungsträgern und den ihnen appendizär zugeordneten Kassen (zahn)ärztlichen Vereinigungen interessieren auf dem sozialen Feld mehr oder weniger stark noch die berufsständischen Körperschaften, die zudem den Charakter des Personalverbandes am eindeutigsten verwirklichen:

(1) Von den bundesrechtlich geregelten Körperschaften haben vor allem die Körperschaften der $\mathrm{H}$ andwe $\mathrm{rks}$ organisation, die Handwerksk a mme rn, Innungen und die kraft Gesetzes bürgerlichrechtlichen Innungsverbände unter den verschiedensten Gesichtspunkten sozial bedeutsame Aufgaben $(\$ \$ 49$, 75,84 der Handwerksordnung). Desgleichen haben sich auch die Rechtsanwalts - und Notarkammern mit sozialen Fragen innerhalb des eigenen Berufsstandes zu befassen ( $\$ 89$ Abs. 2 Nr.3 der Rechtsanwaltsordnung vom 6 . August 1959, BGB1. I S. 565; $₫ 67$ Abs. 3 der Bundesnotarordnung v. 24. Februar 1961, BGB1. I S.98).

(2) Demgegenüber haben sich die Industrie- und $\mathrm{Han}$ d elskammern nicht mit sozialen Angelegenheiten zu beschäftigen (vgl. $₫ 1$ Abs. 5 des Gesetzes zur vorläufigen Regelung des Rechts der Industrie- und Handelskammern vom 18. Dezember 1956, BGB1. I S.920). 


\section{Zwei besondere Fälle}

1. Kirchen- und sonstige Religions- und Weltanschaungs gemeinschaften

a) Einige Aspekte ihres Verhä1tnisses zum Staatsganzen

Das verfassungs rechtlich garantierte Selbstbestimmungs recht 1 ) der Religions - und Weltanschauungsgemeinschaften - unter denen die Kirchen eine so hervorragende Stellung einnehmen, daß sie auch in diesem Zusammenhang eindeutig im Vordergrund gesehen werden müssen 2) - ist, in Beziehung gesetzt zu dem gängigen

(3) Unter den landes rechtlich geregelten Organisationen sind die $\ddot{A} r z t e-, Z$ ahnärzte - und Tie rärztekammern zu nennen, die soziale Angelegenheiten innerhalb des Standes (Altersversorgung u. ä.) zu erledigen haben. Zu den gemeindeutschen Grundzügen s. Lossen, Art. "Heilberufe" im Handwörterbuch der Sozialwissenschaften, Band 5, 1956, S.97 ff (99 f).

(4) Hinzuweisen ist endlich auf die verschiedenenorts vorhandenen Landwirtschaftskammern und auf die Arbeitskammern.

1) Zu der Kritik an der Verwendung der Begriffe Autonomie und Selbstverwaltung zur Charakterisierung des durch das geltende Verfassungs recht gewährleisteten Selbstbestimmungs rechts der Kirchen - einer Kritik, die dem allgemeinen Wortsinn der erwähnten Begriffe zugunsten fachterminologisch verengter Inhalte allzu verschlossen gegenüber steht - s. z. B. Hesse, Der Rechtsschutz durch staatliche Gerichte im kirchlichen Bereich, 1956, S. 78; Scheuner, Die staatskirchenrechtliche Tragweite des niedersächsischen Kirchenvertrags von Kloster Loccum, Zeitschrift für evangelisches Kirchenrecht, Bd. 6 (1957/58) S. 1 ff (9); Mikat, Kirchen und Religionsgemeinschaften, in: Bettermann-Nipperdey-Scheuner, Die Grundrechte, Bd.IV, 1. Halbband, 1960, S.111 ff (173).

2) Die Weimarer Verfassung (Art.137) unterschied (1.) zwischen Religionsgesellschaften und Weltanschauungsvereinigungen, (2.) zwischen Religionsgesellschaften (und Weltanschauungsvereinigungen) des öffentlichen und des privaten Rechts und (3.) zwischen den Religionsgesellschaften, die von ihr schon als Körperschaften des öffentlichen Rechts angetroffen wurden, und solchen, denen sie die Chance, diesen Status zu erlangen, erst einräumte. Den Begriff der $\mathrm{Ki} \mathrm{rche} \mathrm{kennt} \mathrm{sie}$ nicht. Art. $140 \mathrm{GG}$ - der "nicht das Ergebnis einer klar bewußten, grundsätzlichen staatskirchenpolitischen Entscheidung des Parlamentarischen Rats" ist, sondern "mehr unter die 
Vorstellungsbild eines korporativen Staatsaufbaues, eine Anomalie. Das Außerordentliche liegt weniger darin, daß sie im Hinblick

Verlegenheitsergebnisse verfassungsgebender Parlamentsarbeit" gehört (Smend) - scheint dieses System übernommen zu haben. "In Wahrheit vermitteln diese Distinktionen (scil. der Weimarer Verfassung; d.V.) keine echten Aufschlüsse. Kirchenpolitisch und damit auch staatskirchenrechtlich betrachtet, verläuft die Trennungslinie, die die Religionsgemeinschaften maßgeblich gruppiert, ... zwischen den beiden großen Kirchen auf der einen und allen anderen Religionsgemeinschaften auf der anderen Seite. Das ganze Problem des institutionellen Zusammenhangs von Staat und Kirche sowie der Teilhabe der Kirchen an der öfentlichen Ordnung erfüllt nur die Beziehungen zwischen dem Staat und den beiden großen Kirchen. Diese haben ... eine soziale Mächtigkeit und einen privilegierten hoheitlichen Status von außerordentlicher Dichte bewahrt, ... . Für alle sonstigen... Religionsgemeinschaften dagegen... ist der beherrschende Grundzug ihrer Beziehungen zum Staat der des Trennungssystems" (Weber, Art. "Staatskirchenrecht" im Handwörterbuch der Sozialwissenschaften, Bd.9, 1956, S. 753 ff (754)). Das neuere Landesverfassungsrecht, das den Fragen des Staatskirchenrechts nicht in der "verschämten" Weise des Grundgesetzes auszuweichen pflegte, hat in wirklichkeitsnaher Betrachtung daher auch der Kirchen (zumindest) wieder besonderer Erwähnung getan (vgl. Art. 4 ff BadwürttVerf; Art. 142 ff BayVerf; Art. 59 ff BremVerf; Art.48 ff Hess Verf; Art.19 ff NordrhWestfVerf; Art.41 ff RheinlPfVerf; Art. 35 ff SaarlVerf; s. ferner (inzwischen aufgehoben) Art. 34 BadVerf; Art. 29 WürttBadVerf). Auch die Wissenschaft hat sich um die Aktivierung der Differenz zwischen den Kirchen und den übrigen Religionsgemeinschaften bemüht (vgl. Heckel, Melanchthon und das heutige Staatskirchenrecht, "Um Recht und Gerechtigkeit", Festschrift für Erich Kaufmann, 1950, S.83 ff (84 f, 97); ders., Kirchengut und Staatsgewalt, "Rechtsprobleme in Staat und Kirche", Festschrift für Rudolf Smend, 1952, S. 103 ff insbes. S. $108 \mathrm{ff}$; Köttgen, Kirche im Spiegel deutscher Staatsverfassung der Nachkriegszeit, DVB1. 67.Jhg. (1952) S. 485 ff (488); Hesse, Schematische Parität der Religionsgesellschaften nach dem Bonner Grundgesetz? Zeitschrift für evangelisches Kirchenrecht, Bd.3 (1953/54) S. 188 ff; ders., Der Rechtsschutz durch staatliche Gerichte im kirchlichen Bereich, S. 79 ff; Werner Weber, Die Gegenwartslage des Staatskirchenrechts, Veröffentlichungen der. Vereinigung der deutschen Staats rechts- 
auf das Grundrecht der Glaubens-, Gewissens- und Bekenntnisfreiheit (Art. 4 GG) - jedenfalls sub specie des staatlichen Rechts ${ }^{3)}$ - keine Zwangsorganisationen sein können. ${ }^{4)}$ Das Besondere ist ihre Unabhängigkeit vom Staat. In einzigartiger Weise stehen ihm vor allem die Kirchen 5) koordiniert, 6) getrennt und doch positiv auf ihn hingeordnet 7 ) gegenüber. ${ }^{8}$ )

lehrer, Heft 11, 1954, S. 153 ff (171 f); Peters, dass. ebenda S. 177 ff (186 f); Scheuner, Kirche und Staat in der neueren deutschen Entwicklung, Zeitschrift für evangelisches Kirchenrecht, Bd.7 (1960) S.225 ff (270 f); Mikat, a.a.O. S. 166 ff). Die Bayerische Verfassung deutet die besondere Stellung durch die besondere Nennung im Verfassungstext an (s.hierzu auch Nawiasky-Leusser, Erl. vor Art.142 (S.222)). Daran kann die Verfassungsinterpretation unbedenklich im Sinne des Vorstehenden anknüpfen. Das Grundgesetz nimmt dagegen nur auf die Kirchenartikel der Weimarer Verfassung Bezug (Art. 140 GG). Doch sind diese nicht mit ihrem "Weimarer" sondern mit einem moderneren, zeitgenössischen Inhalt rezipiert worden (zur Notwendigkeit der Umdeutung s. z. B. Holtkotten, Bonner Kommentar, Art. 140 Anm. II 2 und 3; Scheuner, a.a.O. S.226 und passim; Mikat, a.a.O. S. $134 \mathrm{ff}$, insbes. S. 138; je m.w. Nachw.). Diesem liegt die Erkenntnis und Anerkennung der Sonderstellung der Kirchen voraus ( $s$. die oben Zitierten).

3) Zur staatskirchenrechtlichen Notwendigkeit, die Position der Kirche von der staatlichen Ordnung her zu bestimmen, s. Scheuner, Kirche und Staat in der neueren deutschen Entwicklung, S. 256 ff, insbes. S.258; w. Nachw. s.dort.

4) Zum grundrecht1ichen Schutz des freien Eintrittes und Austrittes aus den bestehenden Religionsgemeinschaften S. z.B. Hamann, a.a.O. Art. 4 Anm. B 2; v. Mangoldt-Klein, Art. 4 Anm. II 7 und III 2 ; s.a. Hamel, Glaubens- und Gewissensfreiheit, in: Bettermann-Nipperdey-Scheuner, Die Grundrechte, Bd.IV, 1. Halbband, 1960, S. $37 \mathrm{ff}$ (63). - Zu dem auf der mitgliedschaftsbegründenden Natur der Taufe beruhenden, abweichenden Selbstverständnis der katholischen Kirche und dessen Zurüicktreten im Staatskirchenrecht s. Peter's, Die Gegenwartslage des Staatskirchenrechts, S. 179 ff.

5) S. die oben S. 252 zu Fußn.2 Zitierten.

6) Zum Koordinationscharakter des Staat-Kirche-Verhältnisses s. z.B. Mikat, Kirchen- und Religionsgemeinschaften, S. 145 ff m. w. Nachw.

7) Jie Formel des "Systems der positiven Trennung von Staat und Kirche" s. insbes. bei Ridder, Art. "Kirche und Staat in 
Kirchen (Religions- und Weltanschauungsgemeinschaften) unterliegen keiner Staatsaufsicht. 9) Nur die weiten "Schranken des für alle geltenden Gesetzes" binden sie (Art.140 GG i.V.m. Art. 137 Abs. 3 Satz 1 RV 1919). Diese Schranken ergeben sich weder aus der Summe aller Gesetze noch aus der Summe aller für jedermann geltenden Gesetze sondern nur aus den Gesetzen, die "trotz grundsätzlicher Bejahung der kirchlichen Autonomie vom Standpunkt der Gesamtnation als sachlich notwendige Schranke der kirchlichen Freiheit anerkannt werden" müssen, m.a.W. aus den "für die Gesamtnation als politische, Kultur- und Rechtsgemeinschaft unentbehrliche(n) Gesetz(en)". 10) Kirchen, Religions-

Deutschland" im Staatslexikon, 6. Auf1. Bd.IV, 1959, Sp. 1028.

8) Als jüngste Gesamtdarstellungen dieses Problemkreises s. z. B. Scheuner, Kirche und Staat in der neueren deutschen Entwicklung, insbes. S.251 ff; Mikat, a.a.O., insbes. S. 134 ff; alle weiteren Nachweise s. bei diesen.

9) Im Gegensatz zu den Tendenzen der Weimarer Zeit heute ganz h.L.: Holtkotten, Bonner Kommentar, Art. 140 Anm. 5a; Peters, a.a.O. S. $187 \mathrm{ff}$; Hesse, Der Rechtsschutz durch staatliche Gerichte im kirchlichen Bereich, S. 77 f; Hamann, Das Grundgesetz, Art.140 Anm.C 7; Mikat, a.a.O. S.169 ff; w. Nachw. s. dort.

10) Heckel, Das staatskirchenrechtliche Schrifttum der Jahre 1930 und 1931, Verwaltungsarchiv Bd. 37 (1932) S. 280 ff (284); s.a. dens., Kirchliche Autonomie und staatliches Stiftungsrecht, 1932, S. 18 f. Im Gegensatz zur Weimarer Zeit (vgl. Anschütz, Die Verfassung des Deutschen Reiches, 14. Aufl. 1933, Art. 137 Anm.5) ist diese Auslegung der Klausel der "Schranken des für alle geltenden Gesetzes" heute - bei vielen Unterschieden im einzelnen - ganz h. L. Vgl. Kalisch, Grund- und Einzelfragen des kirchlichen Dienstrechts, Zeitschrift für evangelisches Kirchenrecht, Bd.2 (1952/53) S. 27 $f$ und passim; Hesse, Schematische Parität der Religionsgesellschaften nach dem Bonner Grundgesetz? S. 195; ders., Der Rechtsschutz durch staatliche Gerichte im kirchlichen Bereich, S. $72 \mathrm{ff}$; Scheven, Die Bedeutung des Art.19 Abs. IV GG für die Anfechtung kirchlicher Verwaltungsakte, Zeitschrift für evangelisches Kirchenrecht, Bd.4 (1955) S. $157 \mathrm{ff}$ (175); Müller, Der Loccumer evangelische Kirchenvertrag a1s Spiegel der staatskirchenrechtlichen Lage in Deutschland, DÖV 8.Jhg. (1955) \$. $421 \mathrm{ff}$ (424); Mikat, a.a.O. S. $175 \mathrm{ff}$; w. Nachw.s.dort (insbes, bei Mikat, a.a.O.). - Die anfänglich gelegentlich verneinte Fortgeltungsfrage (vgl. Holtkotten, Bonner Kommentar, Art.140 Anm. II 3) ist zu bejahen. 
und Weltanschauungsgemeinschaften werden vom Staat nicht errichtet sondern anerkannt (Art. $140 \mathrm{GG}$ i.V.m. Art. $137 \mathrm{RV}$ 1919), vorausgesetzt, nicht dekretiert. 11) "Ihr Wirkungskreis ist nicht ein Stück sondern ein Gegenstück des staatlichen Wirkungskreises". 12) Gemäß ihrem vom Staate rezipierten Selbstverständnis haben sie einen ursprünglichen, nicht vom Staate abgeleiteten, nur ihnen eigenen Auftrag. ${ }^{13)}$ Deshalb gibt es zwischen ihnen und dem Staat grundsätzlich auch kein Verhältnis der Subsidiarität. 14)

Die spezifische Geschiedenheit der Kirchen, Religions- und Weltanschauungsgemeinschaften vom Staat wird unter personalorganisatorischen und territorialen Aspekten durch deren überund außerstaatliche Verflochtenheit deutlich unterstrichen. 15)

11) S.a. oben S. 254 zu Fußn. 4.

12) Wasse, Die Werke und Einrichtungen der evangelischen Kirche, 1954, S. 52. (Die Arbeit Wasses ist unter demselben Titel gekürzt auch in der Zeitschrift für evangelisches Kirchenrecht, Bd.4(1955) S. 74 ff abgedruckt. Die folgenden Zitate beziehen sich auf die ausführlichere selbständige Schrift.)

13) Vg1. Köttgen, Kirche im Spiegel deutscher Staatsverfassungen der Nachkriegszeit, S. 486 f; Smend, Staat und Kirche nach dem Bonner Grundgesetz, Zeitschrift für evangelisches Kirchenrecht, 1.Jhg. (1951) S. 4 ff, insbes. S. 7 ff; Holtkotten, Bonner Kommentar, Art.140 Anm. II 3; Weber, Die Gegenwartslage des Staatskirchenrechts, S. 158 f, 168 ff, 174 f; Peters, ebenda S. 179 ff; Hamann, Das Grundgesetz, Art. 140 Anm.B 1; ferner die oben S. 255 zu Fußn.9 Zitierten und ihre weiteren Nachweise. Aus der speziellen Literatur zum Niedersächsischen Kirchenvertrag siehe Thieme, Der Vertrag von Kloster Loccum, DVB1. 70.Jhg. (1955), S.273 ff; Scheuner, Die staatskirchenrechtliche Tragweite des niedersächsischen Kirchenvertrags von Kloster Loccum, insbes. S. 8 ff, 22 .

14) Vgl. Hengstenberg, Philosophische Begründung des Subsidiaritätsprinzips, S. 31; Klein, Christ und Kirche in der sozialen Welt, S. $136 \mathrm{f}$.

15) Für die katholische Kirche war diese schon immer kennzeichnend. Für die evangelische Kirche ist weniger an die ökumenische, die Selbständigkeit der Mitgliedskirchen nicht wesentlich antastende Verbindung zu denken. Problematischer ist gegenwärtig die Zusammenfassung von Gliedkirchen aus der Bundes republik und der Ostzone in der Evangelischen Kirche in Deutschland, in der Evangelisch-Lutherischen Kirche Deutschlands und in der Evangelischen Kirche der Union ( $s$. 
Aber die "nationale" Kirche ist fast immer auch eine Sondergemeinschaft innerhalb der größeren "übernationalen" Kirche. 16) Andererseits bilden die Religions-(Weltanschauungs-)genossen, die in ein- und demselben Staate leben und zusammenwirken, auch eine auf diesen Staat bezogene Sondergemeinschaft. Als solche müssen sie vor allem hic et nunc dem Staatskirchenrecht erscheinen: indem ihnen, den Bürgern oder wenigstens Einwohnern des Staates, das Recht eingeräumt wird, "ihre" Angelegenheiten selbständig zu ordnen und zu verwalten, stellt sich ihre organisierte Gesamtheit (auch) als eine Ausgliederung aus dem Staatsganzen dar. 17) Diese negative ausgrenzende Relation zum Staat ist nicht ohne ihr positives Gegenstück, die Zuordnung und Hinwendung, denkbar.

Der personellen und territorialen Gemeinsamkeit entspricht die sachliche Berührung, der die Religions- und Weltanschauungsgemeinschaften regelmäßig nicht ausweichen wollen und vor allem die Kirchen als historisch gewordene Verbände von weltlicher Körperlichkeit und sozialer Mächtigkeit auch nicht ausweichen können. Ihr verpflichtend empfundener Sendungsauftrag zwingt sie, in die größere Gesamtheit, in der sie jeweils stehen, hineinzuwirken. Diese kirchenpolitisch zum Öffentlichkeitsanspruch sublimierte Tendenz wird auf der Basis eines - nicht zuletzt auf der weitgehenden Personalunion der Kirchen-"Völker" mit dem Staatsvolk beruhenden - entsprechenden staatsbeherrschenden Gemein-

hierzu z. B. Brunotte, Art. "Evangelische Kirche in Deutschland" im Evangelischen Kirchenlexikon, Bd.I, 1956, Sp. 1193 ff; ebenda Bd.III, 1959, Sp. 1554 ff; Wilkens, Art. "Vereinigte Evangelisch-Lutherische Kirche Deutschlands" ebenda, S. 1622 ff ( $1624 \mathrm{ff}))$.

16) Das erscheint am wenigsten selbstverständlich für die katholische Kirche. Cibt es zwischen den Diözesen und der Weltkirche eine erhebliche Einschiebung? Abgesehen von den Gemeinsamkeiten, die durch die äußere staatliche Ordnung und dic staatlich geprägte Einheit der Umwelt hervorgerufen werden, ist vor allem an die nationale Repräsentation der Kirche durch die sog. Fuldaer Bischofskonferenz (für Bayern auch die Bayerische Bischofskonferenz) und die Vertretung des deutschen Episkopats bei der Bundesregierung, an die Unterworfenheit unter die Kompetenz ein- und desselben Nuntius (can. $267 \$ 1 \mathrm{CIC}$ ) und an das Konkordats recht zu erinnern.

17) S. hierzu auch Peters, Die Gegenwartslage des Staatskirchenrechts, S. $178 \mathrm{ff}$. 
willens vom Staate anerkannt. 18) Das wird durch die Anerkennung der Religionsgemeinschaften als Körperschaften des öffentlichen Rechts (Art.140 GG i,V.m. Art.137 Abs.6 RV 1919) an das Licht des Verfassungs rechts gehoben, wenngleich dieser Öffentlichkeitsanspruch nur für die Kirchen zur vollen Entfaltung kommt. 19) Er äußert sich - grundsätzlich ohne schon unmittelbar konkrete Postulate positivrechtlichen Ranges herzugeben, vielmehr in erster Linie das Ineinander von Staat und Kirche gegenüber dem Trennungsprinzip legitimierend - in der institutionalisierten oder von der Kirche frei genommenen Anteilnahme derselben an staatlichen Entscheidungen. 20) Er kommt zum Ausdruck ferner in der Zusammenarbeit von Staat und Kirche in den Grenzfeldern gemeinsamen Interesses 21) und in der Überlassung (wenigstens potentiell) staatlicher Aufgaben an die Kirchen. 22) Er schlägt sich schließiich im positiven Schutz der Kirchen (und

18) S. hierzu Heckel, Melanchthon und das heutige deutsche Staatskirchenrecht, S. 100 f; ders., Kirchengut und Staatsgewalt, insbes. S. $107 \mathrm{ff}$; Smend, Staat und Kirche nach dem Bonner Grundgesetz, S. 7 ff; ders., Der Niedersächsische Kirchenvertrag und das heutige Staatskirchenrecht, JZ 11. Jhg. (1956) S. 50 ff ( 51 ff); Weber, Die Gegenwartslage des Staatskirchenrechts, insbes. S. $169 \mathrm{ff}$; Peters ebenda insbes. S. 183 ff; Müller, Der Loccumer Kirchenvertrag als Spiegel der staatskirchenrechtlichen Lage in der Bundesrepublik, S. 422 f, 427; Thieme, Der Vertrag von Kloster Loccum, S. 273 f; Scheuner, Die staatskirchenrechtliche Tragweite des Vertrages von Kloster Loccum, S. 8 ff, 22 ff; Hamann, Das Grundgesetz, Art. 140 Anm. C 4; Hesse, Der Rechtsschutz durch staatliche Gerichte im kirchlichen Bereich, S. 50 f, 55 , 61; Maunz, Sind Staat und Kirche auf dem rechten Weg? in "Die Katholiken vor der Politik", hrsg. v. Gustav E. Kafka, 1958, S. $67 \mathrm{ff}$ (69 ff); Scheuner, Kirche und Staat in der neueren deutschen Entwicklung, insbes. S.268 ff; Mikat, Kirchen und Religionsgemeinschaften, S. $142 \mathrm{ff} ; \mathrm{w}$. Nachw. und vor allem Näheres s. bei den Genannten.

19) S. die oben S. 252 zu Fußn. 2 Zitierten.

20) S. hierzu z.B. Werner Weber, Die Gegenwartslage des Staatskirchenrechts, S. 170 f; Peters, dass. S. 192 f.

21) S. hierzu im allgemeinen z.B. Mikat, Kirchen und Religionsgemeinschaften, S. 194 ff. - Spezielles s. unten S.266 ; s.a. Süsterhenn, Die kirchliche Liebestätigkeit im sozialen Rechtsstaat der Gegenwart, S.112, 117.

22) S. hierzu unten S. 266. 
Religions- und Weltanschauungsgemeinschaften) durch den Staat nieder.23) 24)

b) Zum kirchlichen (religions- und weltanschauungsgemeinschaftlichen) Wirkungskreis - Allgemeines

Kerngegenstand des kirchlichen Selbstbestimmungsrechts 1) und reinster Quell des kirchlichen Öffentlichkeitswirkens sind Lehre und Kultus. 2) Hier liegt in der historisch-konkreten Wirklichkeit auch der Urgrund der eminenten sozialen Bedeutung der Kirchen. Auch ungeachtet der in diesem Rahmen wohl außer Betracht zu lassenden Tröstungen, die der sozial Bedrängte durch Lehre und Kultus der Kirche zu erfahren vermag: die kirchliche Lehre der Gerechtigkeit und der Nächstenliebe trug und trägt - über den formulierten Anruf der kirchlichen an die staatliche Autorität ebenso wie über die ethische Verpflichtung des Gläubigen, über die Teilnahme an der Sozialgestaltung des Staates und anderer Träger ebenso wie über die kircheneigene Diakonie ${ }^{3)}$ und sonstige Sozialarbeit und über noch viele andere Medien - alle vergangene und gegenwärtige soziale Wirklichkeit und Gestaltung mit.

Alle anderen Gegenstände des kirchlichen Selbstbestimmungsrechts 1) nehmen ihre spezifisch soziale Bedeutung in erster Linie davon, daß sie dazu beitragen, die sozialen Maximen der Kirchen $z u$ verbreiten und $z u$ entfalten. Die unmittelbare Verwirklichung im Rahmen des kirchlichen Selbstbestimmungsbereichs konzentriert sich auf den engeren Bereich der organisierten Caritas.3) Im übrigen tritt sie mehr oder weniger zurück, ja muß sie vor dem primär spirituellen Zweck der kirchlichen Gemeinschaft zurücktreten. So sind etwa, obwohl die historischen und andauernden sozialen Verdienste des kirchlichen Schulwesens gar nicht übersehen werden können, sowohl die - durch Art. 7 Abs. 4 und 5 GG mitgarantierten - kirchlichen (Privat-)Schulen als auch die Mitträgerschaft der Kirchen am öffentlichen Religionsunterricht (Art. 7 Abs. $3 \mathrm{GG}$ ) 4) eindeutig vor allem unter dem geistigen Bildungszweck zu sehen. Desgleichen spielt der soziale Umvertei-

23) S. hierzu vor allem die Darstellung bei Mikat, a.a.O. S. $215 \mathrm{ff}$.

24) S. zum Vorstehenden nochmals die oben S. 258 zu Fußn. 18 Zitierten.

1) S. die Darstellung des kirchlichen Selbstbestimmungsrechts bei Mikat, a.a.O. S. $171 \mathrm{ff}$, insbes. S. $181 \mathrm{ff}$.

2) S. hierzu z.B. Mikat, a.a.O. S. 182.

3) S. unten c (S.260 ff).

4) S. hierzu Peters, Elternrecht, Erziehung, Bildung und Schu1e, in: Bettermann-Nipperdey-Scheuner, Die Grundrechte, 
lungszweck für das kirchliche Abgabewesen - sowohl das rein innerkirchliche 5) als auch die staatlich autorisierte Kirchenbesteuerung (Art.140 GG i.V.m. Art.137 Abs.6 RV 1919)6) - keine wesentliche Rolle. Die beschränkte Selbstbestimmung in bezug auf das kirchliche Dienstrecht ${ }^{7)}$ endlich beruht keineswegs auf dem Verlangen, den Kirchen ein maximal soziales (gerechtes und liebesgerechtes) Dienstrecht zu ermöglichen. Sie soll ihnen vielmehr schlechthin die Anpassung des Dienstrechts an ihre spezifische Struktur und Aufgabe ermöglichen; und der Konflikt zwischen einem "sozialeren" staatlichen Dienst recht und einem "weniger sozialen" kirchlichen Dienstrecht ist mitnichten undenkbar. ${ }^{7)}$

\section{c) Kirchliche Caritas (Diakonie)}

\section{aa) Der kirchliche Vorbehaltsbereich}

Caritative Hilfe ist eine der Kirche von Anfang an eigene Aufgabe. Nach dem christlichen Sittengesetz, das das Wesen der christlichen Kirchen mitbestimmt, ist es Sache der Christen, als einzelner wie als Gemeinschaft, nicht zuletzt also als organisierte Kirche, dem Armen zu helfen. In der Diakonie verwirklicht die Kirche wesentlich sich selbst. 1) Kirchliche Caritas gehört daher zu den Angelegenheiten, die die Kirche als die "ihren" selbstän-

5) S. Mikat, a.a.O. S.229 f.

6) S. hierzu Mikat, a.a.O. S.229 ff.

7) S. unten S. 274 .

1) Am umfassendsten in jüngster Zeit wohl dargetan von Franz Klein, Christ und Kirche in der sozialen Welt. Bei diesem $\mathrm{s}$. auch eingehende Nachweise. S. des weiteren auch Berg, Das Diakonat als Lebensfunktion der Kirche, in "Das diakonische Amt der Kirche", hrsg. v. Krimm, 1953, S. 477 ff; Karl-Friedrich Weber, Innere Mission und Wohlfahrtsstaat, in "Macht und Recht", Beiträge zur lutherischen Staatslehre der Gegenwart, 1956, S.173 ff (194): "Daß die Innere Mission, wie sie geschichtliche Gestalt gewonnen hat, eine unaufgebbare Aufgabe der Kirche erfüllt, dürfte deutlich geworden sein, denn das Tun der Inneren Mission ist Selbstbezeugung des innersten Wesens der Kirche". Oder Janssen, Probleme des Wohlfahrtsstaates, in "Verantwortung für den Menschen", Gedächtnisschrift für Heinrich Held, 1957, S.125 ff (135): "..., daß die Kirche auf ihre Liebesarbeit nicht verzichten darf. Sie würde in der Tat einen toten Glauben beweisen, wenn sie nicht sozial und karitativ wirksam würde". 
dig ordnen und verwalten kann. 2) Die von den Kirchen getragene Wohltätigkeit hat aber zudem - vor allem wohl wegen ihrer tatsächlich gegebenen historischen und gegenwärtigen Bedeutung, vielleicht auch aus der Erkenntnis, daß erst die christliche Liebe aller sozialen Arbeit die "Seele" gibt, und schließlich wegen der Wirkzusammenhänge zwischen geistiger (geistlicher) und materieller Hilfe - in besonderem Maße teil an dem Öffentlichkeitsanspruch der Kirchen. ${ }^{3)}$ Wie den Kirchen auf Grund ihres Öffentlichkeitscharakters ein "Anteil an der Verantwortung für das politische Gesamtschicksal" 4) zugesprochen wird, so werden sie in bezug auf ihre Wohltätigkeit als neben dem Staate "mitverantwortliche Träger der Daseinsvorsorge" 5) angesehen.

Das darf allerdings die Unterschiede $z$ wischen der kirchlichen Liebestätigkeit und staatlicher sozialer Intervention nicht ver-

2) Mikat, Kirchen und Religionsgemeinschaften, S.193; ferner Süsterhenn, Die kirchliche Liebestätigkeit im sozialen Rechtsstaat der Gegenwart, in "Die Katholiken vor der Politik", hrsg. v. Gustav E. Kafka, 1958, S. 105 ff, insbes. S.116; Franz Klein, Das Recht des sozial-caritativen Arbeitsbereichs, 1959, S. $41 \mathrm{ff}$, insbes. S. $44 \mathrm{ff}$.

3) Vgl. Weber, Die Gegenwartslage des Staatskirchenrechts, S. 166, 174; Peters, ebenda S.190; Klein, Christ und Kirche in der sozialen Welt, S. 133, 236 ff (Fußn. 316); Scheuner, Die staatskirchenrechtliche Tragweite des Kirchenvertrags von Kloster Loccum, S.23; Süsterhenn, a.a.O. S. 116 und passim; Franz Klein, a.a.O. S. $41 \mathrm{ff}$. Im Landesverfassungs recht wird gelegentlich ausdrücklich "die Wohlfahrtspflege der Kirchen... gewährleistet" (Art.6 BadWürttVerf; Art. 122 Abs. 1 ehem. WürttHohenzVerf; Art. 35 Abs.2 ehem. BadVerf; s.a. Art. 35 Abs. 3 SaarlVerf) oder es werden wenigstens ihre Wohltätigkeitseinrichtungen als gemeinnützig anerkannt (Art. 63 BremVerf; Art. 46 RheinlPfVerf; Art. 40 SaarlVerf; Art. 35 Abs. 1 ehem. BadVerf). Außerdem wird ihre Mitwirkung bei der Jugend- und Familienpflege garantiert (Art.6 Abs. 3 NordrhWestfVerf; Art.26 RheinlPfVerf).

4) Karl-Friedrich Weber, a.a.O. S. 174.

5) Köttgen, Kirche im Spiegel deutscher Staatsverfassungen der Nachkriegszeit, S.487; Mikat, Kirchen und Religionsgemeinschaften, S.141. - In einem ganz spezifischen Sinne meint das auch Janssen, Probleme des Wohlfahrtsstaates, S. 135: "Die Kirche muß also immer soviel an Aktivität behalten, daß sie jederzeit in der Lage ist, in kritischen Lagen eine dann unter Umständen ins Ungeheuere erweiterte Verantwortung zu übernehmen". 
gessen machen, die auch für die Grenzziehung zwischen dem unantastbar kirchlich-autonomen Bereich und den dem Staate zugänglichen Sachgebieten entscheidend sein müssen. Die kirchliche Diakonie ist gekennzeichnet durch die rein religiös-sittliche, rechtlich nicht konkretisierbare Pflicht zu helfen 6 ) auf der Seite der Gebenden und durch den gnadenhaften, einen rechtlichen Anspruch ausschließenden, rechtsfremden Charakter der Hilfe für den Nehmenden. 7) Die soziale Intervention des Staates ist dagegen gekennzeichnet durch das Medium der rechtlichen Normierung und die Möglichkeit zwangsweiser Durchsetzung des Rechts. 8) Die kirchliche Liebestätigkeit ist - mag sie gleichwohl weithin ausstrahlen - in ihrem Kern festgelegt auf die von der Kirche umschlossene Menschengemeinschaft und hat somit in bezug auf die staatliche Einheit, in der mehrere Religionsgemeinschaften und Religions(gemeinschafts)freunde zusammenleben,

6) S. Klein, Christ und Kirche in der sozialen Welt, insbes. $\mathrm{S} .41 \mathrm{ff} \mathrm{m}$. eingeh. Nachweisen; ders., Das Recht des sozialcaritativen Arbeitsbereichs, S. 56 ff, insbes. S. 57. - S. auch Buchrucker, Der Wohlfahrtsstaat als kirchliches Problem, Evangelisch-Lutherische Kirchenzeitung, 8.Jhg. (1954) S. 36 ff insbes. S. 38 .

7) S. insbes. Buchrucker, a.a.O.

8) (1) Vg1. Gerstenmaier, "Wichern zwei" in "Das diakonische Amt der Kirche", hrsg. v. Krimm, 1953, S. 499 ff insbes. S. $502 \mathrm{f}, 532 \mathrm{ff} ; \mathrm{s} . \mathrm{a}$. Klein, je a.a.O.

(2) Es liegt nahe, diese Gegenüberstellung noch einen Schritt weiter zu führen zur Antithese Gerechtigkeit-Liebe oder Gerechtigkeit-Barmherzigkeit und dabei als den vom Staat zu verwirklichenden Wert die Gerechtigkeit, als den von der Kirche zu realisierenden Wert die Liebe/ Barmherzigkeit anzusehen (Ansätze s, bei Wendland, Die dienende Kirche und das Diakonenamt, in "Das diakonische Amt der Kirche", hrsg. v. Krimm, 1953, S. 443 ff (467 f)). Doch fließen auf beiden Seiten und $z$ war im besonderen im Kontaktfeld von Staat und Kirche beide Elemente ineinander über. Dem Problem nachzugehen, wäre gewiß nicht unwichtig und möchte wohl auch fruchtbar sein. Es ist jedoch nicht möglich, hier diese mit speziellen theologischen und rechtsphilosophischen Diskussionen belastete Frage zu entwirren. Eine gemeingültige Grenzziehung könnte hiervon auch nicht erwartet werden. Dazu ist das Problem zu sehr mit der zerklüfteten Meinungswelt der Theologie verfilzt. - $\mathrm{Zu}$ dem Fragenkreis s. z. B. Klein, Christ und Kirche in der sozialen Welt, S. 19 ff und die dort (S.39, 152 ff) nachgewiesene Literatur. 
Teil-Charakter. Die staatliche Intervention erfaßt grundsätzlich die ganze staatliche Gemeinschaft. Daraus ergibt sich von vorneherein eine Abschichtung, die die Masse dessen, was hier als soziale Intervention ins Auge gefaßt ist, dem Staate zuweist. Soziale Maßnahmen, die sachgerecht nicht mit freiwillig aufgebrachten Mitteln sondern nur mit erzwingbaren (erzwungenen) Leistungen bewerkstelligt werden können, müssen vom Staate getroffen werden. Das gleiche gilt von Maßnahmen, die gegen den Willen des Hilfsbedürftigen durchgesetzt werden müssen. 9) Wo - sei es aus Gründen der Egalität, der Gerechtigkeit oder bloß der Effektivität der über die Massen des modernen Staates zu breitenden Ordnung - gnadenweise Hilfe von Fall zu Fall nicht erträglich ist sondern an ihre Stelle der präzise Anspruch treten muß, ist der Staat kompetent. Wo - wie z. B. im Bereich der Wirtschaft - konfessionalistische Grenzziehungen sachfremd wären, ist der Staat die adäquate Regelungseinheit und eine kirchliche Kompetenz aus geschlossen. Schließlich fehlt in der modernen Gesellschaft vielfach auch der personell-subjektive Anknüpfungspunkt an kirchliche Gemeinschaften. Einem nicht kirchlich "Organisierten" kann der Staat nicht zumuten, die Hilfe der Kirchen nachzusuchen, ja vielleicht nicht einmal, sie anzunehmen; 10) der Staat muß selbst helfen.

Es ist gewiß auch in bezug auf die demnach außerhalb ihres Selbstbestimmungsrechts liegenden Materien und Funktionen Sache der Kirchen, mahnend, beratend und stimulierend auf den Staat einzuwirken. 11) Aber eine eigenverantwortliche Erledigung durch sie scheidet aus. Ih re Sache ist es, aus religiösem Sinn $z u$ helfen, Opfer anzuregen und an den Bedürftigen heranzuführen. Hierin liegt ein Kern, den der Staat letztlich gar nicht absorbieren kann. "Was durch ihren" - der Kirche - "Dienst geschieht, kann der Staat, weil er die Liebe Christi nicht zu erfüllen vermag, nicht leisten". 12) Quantitativ aber verbleibt den Kirchen dort, wo die soziale Intervention des Staates dem denkbaren Maximum zustrebt, nur eine periphere soziale Wirksam-

9) Vgl. Gerstenmaier, a.a.O. S. 524; Klein, Christ und Kirche in der sozialen Welt, S. $133 \mathrm{f}$.

10) Klein, Das Recht des sozial-caritativen Arbeitsbereichs, S. $58 \mathrm{f}$.

11) Vgl. Gerstenmaier, a.a.O. S. 524. - S. ferner oben S.252 (a.E.) und S. 259 (a.A.).

12) Karl-Friedrich Weber, Innere Mission und Wohlfahrtsstaat, S.194; s.a. Klein, Christ und Kirche in der sozialen Welt, S. $138 \mathrm{f}$. 
keit. 13)

Gibt es nun aber überhaupt ein Feld, auf dem die soziale Aktivität des Staates durch die garantierte Existenz und Liebestätigkeit der Kirchen vom Recht begrenzt wird? Ist es nicht vielmehr so, daß der Staat dort, wo seine soziale Intervention der Diakonie begegnet, er ohnedies an der ihm eigengesetzlichen Grenze seiner Wirksamkeit angelangt ist, so daß er ungeachtet aller Rechtsschranken gar nicht in den Raum kirchlicher Caritas übertreten könnte, selbst wenn er wollte? Das Verhältnis Staat-Kirche ist für die soziale Intervention des Staates mehr als ein Stück "natürlicher Grenze" der Wirksamkeit dess Staates.

Dabei ist zunächst daran zu denken, "as rein innerkirchlich in der organisierten Caritas - die von der. Tendenz der Zeit zur "Masse" nicht ausgenommen ist und auch nicht ausgenommen werden kann - auch dann noch generell geregelt und administriert werden kann, ja muß, wenn das freiwillige und gnadenhafte Wesen der Liebestätigkeit nicht angetastet wird. Die innerkirchliche Organisation des christlichen Liebeswerkes arbeitet als eine Organisation von Menschen irdische Güter verwaltend, dabei zum Teil mit einem Instrumentarium, das dem staatlichen gleicht.

13) Zur Würdigung dieses für die Gegenwart signifikanten $\mathrm{Zu}$ standes S. z.B. Dibelius, Grenzen des Staates, 1949, insbes. S. 112 ff; Berggrav, Staat und Kirche in lutherischer Sicht, 1952; Grob, Staatliche Sozialfürsorge oder christliche Liebestätigkeit, Kirche in der Zeit, 8.Jhg. (1953) S. 173 ff; Gerstenmaier, a.a.O. insbes. $5.522 \mathrm{ff}$; Buchrucker, Der Wohlfahrtsstaat als kirchliches Problem; Wilkens, Probleme des Wohlfahrtsstaates, in "Macht und Recht", Beiträge zur lutherischen Staatslehre der Gegenwart, 1956, S. 148 ff; Karl Friedrich Weber, Innere Mission und Wohlfahrtsstaat; Klein, Christ und Kirche in der sozialen Welt, S. 123 ff; Janssen, Probleme des Wohlfahrtsstaates; Münchmeyer, Die Wandlung der Welt mit ihren Konsequenzen für die Diakonie, in "Diakonie der Kirche in einer veränclerten Welt", hrsg. v. Brennecke, 1956, S.93 ff. - Zul Cielahr der Institutionalisierung der Nächstenliebe in Staat und Kirches. Jüchen, Die Krisis der Nächstenliebe in der heutigen Gesellschaft, Soziale Arbeit, 9. Jhg. (1960) S. 145 ff (151 ff). Darauf, wie anders die Proportionen im Fallo eines sozial inaktiven Staates (z.B. im Mittelalter) oder eines allgemein funktionsgeschwächten Staates (z.B. Deuts(hland nach 1945) sein können, braucht hier nicht eingegangen zu werden (s.a. schon Janssen oben S. 261 zu Fußn. 5). 
Trotzdem und trotz der Rückwirkungen, die dieserart innerkirchliche Dispositionen auf die sozialen Maßnahmen des Staates haben können, ist der Staat von jeglicher Ingerenz oder gar Substitution ausgeschlossen. 14)

In einem Punkte ist die Autonomie aber noch weit über den Bereich der kirchlichen Liebestätigkeit hinaus von Bedeutung für die Reichweite der sozialen Intervention des Staates: im kirchlichen Dienstrecht. Der Dienst in der Kirche, sei es der Dienst des Geistlichen, des Kirchenbeamten, des kirchlichen Angestellten oder des Arbeiters, kann "nur vom Wesen der Kirche und ihrem Auftrag her recht verstanden werden". 15) "In dem aufgetragenen Zeugnis von der in Jesus Christus geoffenbarten Gnade Gottes liegt das den kirchlichen Dienst konstituierende und legitimierende Element". 16) Von hierher rechtfertigt es sich, das Dienstrecht als "ihre Angelegenheit" der Autonomie der Kirchen zu unterstellen. 17) Das gilt auch für den Dienst im Liebeswerk der Kirche. ${ }^{18)}$ So wesentlich dieses zur Kirche gehört, so wesentlich gehört der Dienst darin zum Dienst der Kirche. 19) Zudem erscheint hier, wo opfernde Hilfe notwendig ist, die Ausbildung

14) S. Klein, Das Recht des sozial-caritativen Arbeitsbereichs, S. $44 \mathrm{ff} ; \mathrm{s} . \mathrm{a}$. Süsterhenn, Die kirchliche Liebestätigkeit im sozialen Rechtsstaat der Gegenwart, S.116. Allgemein zur Verfassungs- und Organisationsautonomie der Kirche s. Mikat, Kirchen und Religionsgemeinschaften, S. 182 ff und seine Nachw.

15) Kalisch, Grund- und Einzelfragen des kirchlichen Dienstrechts, Zeitschrift für evangelisches Kirchenrecht, S. 30 f.

16) ebenda, S. 31 .

17) S. unten S. 274.

18) S. Kalisch, a.a.O. S.30; Klein, Christ und Kirche in der sozialen Welt, S.238 f (Anm.316) - wenngleich nicht unter Berufung auf die Selbstbestimmung sondern auf das von diesem Autor stets überanstrengte Sozialstaatsprinzip -; (stärker differenzierend) ders., Das Recht des sozial-caritativen Arbeitsbereichs, S.333 ff; Süsterhenn, Die kirchliche Liebestätigkeit im sozialen Rechtsstaat der Gegenwart, S. 116.

19) In bezeichnender Übereinstimmung sagen hierzu $₫ 1$ der "Richtlinien des Deutschen Caritasverbandes für Arbeitsverhältnisse in den Anstalten der Gesundheitsfürsorge" und die Einleitung der "Richtlinien für Arbeitsverträge in den Einrichtungen der offenen und halboffenen Fürsorge, die dem Central-Ausschuß für die Innere Mission der Deutschen Evangelischen Kirche angeschlossen sind":

"Die Caritas/Innere Mission ist eine Lebensäußerung 
eines adäquaten, nicht allein auf dem nackten do ut des beruhenden sondern - um im Bilde zu bleiben - auch das Kalkül des "Gotteslohnes" veranschlagenden, an der Notwendigkeit der Leistung und nicht ihres Entgelts orientierten und schließlich auf die Einigkeit im Geiste abgestellten Dienstrechts sogar besonders dringlich. 20)

bb) Kirchlicher, außerkirchlicher und staatlicher Bereich in der Begegnung

Handelt es sich bei Besagtem zunächst um den innerkirchlichen Bereich, so begegnet das caritative Wirken der Kirchen dem Staate aber auch immer wieder außerhalb. Hier gilt es, dem Öffentlichkeitsanspruch der Kirchen und ihres Liebeswerkes Rechnung zu tragen.

Was die Überschreitung des personellen Eigenbereichs durch die Kirche betrifft, so ist es gewiß unproblematisch, soweit sie darin besteht, daß die caritative Hilfe auch (jeweils) Kirchenfremden zugute kommt. Darin, daß die Kirchen ihre Hilfe nicht nur als infra-gemeindlich oder infra-kirchlich verstehen sondern sie stets nach außen offen halten, liegt ein wesentliches Element der christlichen Caritas. 1) Wer die kirchliche Liebestätigkeit sich frei entfalten lassen will, kann ihr diese Ausstrahlung nicht versagen. 2)

Schwieriger liegen die Verhältnisse dagegen, soweit die kirchliche Aktivität in genau der umgekehrten Richtung den engeren mitgliedschaftlichen Rahmen verläßt, indem sie an Außenstehende um Hilfe für die Bedürftigen herantritt. Es ist, wenn je ihr Öffentlichkeitscharakter ernst genommen werden soll, geradezu ein Beruf der Kirche, nicht müde zu werden in der Ermahnung alle r Menschen zur Caritas. Aber wenn sie mehr tut als "predigen",

der katholischen/Evangelischen Kirche. Alle in ihr tätigen Mitarbeiter dienen dem gemeinsamen Werk christlicher Nächstenliebe".

20) Vgl. Klein, Christ und Kirche in der sozialen Welt, S. $238 \mathrm{f}$ (Anm.316); Karl Friedrich Weber, Innere Mission und Wohlfahrtsstaat, S. $187 \mathrm{f}$. - Zur Eigenart dieses Dienstes s. z.B. auch Wendland, Die dienende Kirche und das Diakonieamt; zu seiner rechtlichen Regelung s. die Darstellung bei Klein, Das Recht des sozial-caritativen Arbeitsbereichs, S.333 ff.

1) S. z.B. Gerstenmaier, "Wichern zwei", S. 504.

2) S. aber oben S. 263 zu Fußn. 10 und den Text hierzu. 
wenn sie sachliche Veranstaltungen trifft, um die erzielten Liebesgaben zu sammeln oder gar, um den Spendeneifer auf sich zu konzentrieren, dann begibt sie sich, in Konkurrenz mit der (den) jeweils anderen Kirche(n) und den nicht-kirchlichen Wohltätigkeitsverbänden, ja letztlich mit allen gesellschaftlichen Einheiten, die auf diesem Wege die Mittel für eine von ihnen zum Ziele genommenen Wirksamkeit aufbringen wollen, in ein Gebiet, das der Staat um seiner Ordnungsfunktion willen nicht preisgeben kann. Und doch bewegt sie sich darin legitim. Da es unmöglich ist, ihre moralisch-mahnende und ihre sachliche caritative Tätigkeit voneinander gänzlich zu scheiden, entsteht ein Spannungsverhältnis, wie es sich im Streit um die Gestaltung des Sammlungsrechts (der freilich auf der anti-etatistischen Seite keineswegs nur von den Kirchen geführt wird) zeigt. Er läßt sich weder zugunsten einer extrem staats-"freundlichen" Auffassung noch zugunsten einer absoluten Sammlungs-Freiheit entscheiden. Das Spannungsverhältnis muß vielmehr permanent ausgestanden werden im Wege einer Regelung, die den Kirchen über den - ihnen in keinem Falle zu verwehrenden - Appell an die eigenen Mitglieder hinaus noch das Recht gewährleistet, an alle Bürger mit dem Aufruf heranzutreten, nicht nur zu helfen sondern ihr, der Kirche, "helfen zu helfen", und zwar bis eben zu jener Grenze, an der eine weitere Ausdehnung dieser Aktivität das staatliche Gemeinwesen schädigen würde. Ein staatliches Sammlungs recht, das nicht im Interesse eines staatlichen Sammlungsmonopols und nicht, um die Kirchen niederzuhalten, sondern lediglich im Interesse des unverzichtbaren Mindestmaßes an Ordnung, deren das Sammlungswesen bedarf, der Sammlungstätigkeit im allgemeinen und dabei der kirchlichen im besonderen Schranken setzt, wäre ein "für die Gesamtnation als politischer, Kulturund Rechtsgemeinschaft unentbehrliches Gesetz" und somit ein "für alle geltendes Gesetz" i.S. des Art.137 Abs.3 RV 1919, das auch die Kirchen bindet. 3 )

3) (1) Zum Begriff des "für alle geltenden Gesetzes"s. oben S. 263 zu Fußn. 10

(2) Zur Frage des Sam $\mathrm{mlungs}$ rechts im Ergebnis übereinstimmend Klein, Christ und Kirche in der sozialen Welt, S. 134: "Eine Beschränkung des Sammlungs rechts durch den Staat läßt sich letztlich nur dann rechtfertigen, wenn die Kirche von ihm in einer. Weise Gebrauch machen würde, die zu einer Gefährdung der öffentlichen Ruhe, Sicherheit und Ordnung führt". S. ferner dens., Das Recht des sozial-caritativen Arbeitsbereichs, S. 49 ff; Süsterhenn, Die kirchliche Liebestätigkeit im sozialen Rechtsstaat der Gegenwart, S. 116. 
Noch enger ineinander verzahnt sind Staat und Kirchen dort, wo sie in ihrer jeweiligen sozialen bzw. caritativen Wirksamkeit sachlich aufeinander treffen. Daß hier die Dispositionen nicht jedenfalls nicht immer und wahrscheinlich nicht einmal in der Regel - so getroffen werden können, daß jedem Konfessionszugehörigen "sein" Altersheim und "seine" Fürsorgerin und dem Konfessionslosen das staatliche (kommunale) Altersheim oder die staatliche (kommunale) Fürsorgerin zur Verfügung steht, ist evident. Selbst wenn anstatt der statischen Kompetenzverteilung der freie Wunsch und Wille des jeweils Betroffenen maßgebend wäre, der Makel einer geistigen Beengung des Bedürftigen also entfiele, wäre dieses System nicht tragbar. Wie aber soll verteilt werden? Nur kirchliche Anstalten, Organisationen, Bedienstete usw. gewähren zu lassen, ist nicht möglich, sei es mit Rücksicht auf die Bekenntnisfreiheit derer, die damit gezwungen wären, sich der Betreuung mehr oder minder radikal Andersdenkender zu überlassen, sei es wegen der ungeordneten Rivalität der kirchlichen Träger untereinander, sei es wegen der wesensmäßigen Freiwilligkeit und Unabhängigkeit des kirchlich-caritativen Tuns, das somit den Bedürfnissen der staatlichen Gemeinschaft, wie sie als Ganzes doch nur vom Staate repräsentiert wird, nur schwer eingeordnet werden kann - um nur die wichtigsten Gründe zu nennen.

(3) Zur Diskussion um das gegenwärtig noch praktizierte, jedoch vermutlich in nicht ferner Zukunft durch neue Sammlungsgesetze der Länder abgelöste Gesetz zur Regelung der öffentlichen Sammlungen und sammlungsähnlichen Veranstaltungen ( $\mathrm{S}$ a m m lungsges et z) vom 5. November 1934 (RGB1. I S. 1086; i.d.F. d. Verordnungen vom 26. September 1939, RGB1. I S. 1943 und vom 23. Oktober 1941, RGB1. I S. 654) s. die Vorgenannten, insbes. Klein, Christ und Kirche in der sozialen Welt, S.240 ff (Anm.321) mit eingehenden Nachweisen. - Das Gesetz, das den "Religionsgesellschaften des öffentlichen Rechts" Sammlungen gestattet, die "bei Gottesdiensten in Kirchen und in kirchlichen Versammlungsräumen" veranstaltet werden ( $\$ 15 \mathrm{Nr} .4$ ), jede sonstige kirchliche Sammlung jedoch dem allgemeinen, umfassenden System von Genehmigungsvorbehalten unterwirft ( $\$ \$ 1-7)$, erlaubt $z w a r, d a$ alles im Befinden der Genehmigungsbehörden steht, eine großzügige Handhabung und hat sich auf diese Weise bis heute halten können. Es ist "bei Licht besehen" aber nicht nur im Hinblick auf Art.140 GG i.V.m. Art. 137 RV 1919 sondern auch auf die allgemeinen Rechtsstaatsgrundsätze (Bindung der Verwaltung an das Gesetz!) und in gewissen Grenzen wohl auch auf Art. 2 Abs. 1 und 9 Abs. 1 GG ein Monstrum an Verfassungswidrigkeit. 
Eine ausschließlich staatliche Trägerschaft der an sich staatlich ebenso wie kirchlich denkbaren Einrichtungen und Dienste ist nicht weniger undenkbar. Sie widerspräche schon der Freiheit der kirchlichen Liebestätigkeit und ihrem Öffentlichkeitscharakter. Sie würde - extrem durchgeführt - die Bekenntnisfreiheit und mitunter sogar die allgemeine persönliche Freiheit derer beengen, die gerade bei einer (ihrer) Kirche Schutz und Hilfe suchen 4$)$ und schließlich die Wirksamkeit der geistig-seelischen Kräfte verleugnen, die nur von der Religion her gewahrt und gekräftigt werden können. 5) Es gibt auch keine einfache Regel der Subsidiarität zwischen staatlicher Wohlfahrtspflege und kirchlicher Liebestätigkeit - genau so wenig wie Staat und Kirche im Verhältnis der Subsidiarität stehen. ${ }^{6}$ ) Die Lösung liegt in der Partnerschaft, 7) im Nebeneinander und Miteinander. $\left.{ }^{8}\right)$ Auch hier also ein Spannungsverhältnis - und zwar ein noch weit schwieriger zu erfassendes und zu ertragendes als das zwischen kirchlichem Tun und staatlicher Ordnungsaufgabe -, das nicht durch Realteilung aufgehoben werden kann sondern in Permanenz auf der Suche nach dem in der sich wandelnden Situation jeweils Richtigen ausgetragen werden muß.9)

4) Vgl. zum spezifischen Zusammenhang K1ein, Christ und Kirche in der sozialen Welt, S. 127 ff mit Nachweisen und eingehender Deduktion aus Grundgesetz und Gesetzesrecht (s. S. 232 ff - Anm. 304 - 311); s.a. dens., Das Recht des sozialcaritativen Arbeitsbereichs, S. $58 \mathrm{f}$.

5) Vg1. Dibelius, Grenzen des Staates, S. 113 f; Utz, Formen und Grenzen des Subsidiaritätsprinzips, S. 117 ff; Klein, Christ und Kirche in der sozialen Welt, S. 128, $136 \mathrm{ff} \mathrm{m.w.}$ Nachw. aus dem Schrifttum des Fürsorge- und Jugendfürsorgewesens (insbes. S.233 ff - Anm.307-309).

6) S. oben S. 256 zu F'ußn.14. Vg1. ferner Köttgen, Das umstrittene Mandat zur Jugendpflege, S. 5. - A. A. scheinbar Peters, Die Gegenwartslage des Staatskirchenrechts, S. 190; Süsterhenn, Die kirchliche Liebestätigkeit im sozialen Rechtsstaat der Gegenwart, S.116 f; Mikat, Kirchen und Religionsgemeinschaften, s. 193. - Auch mit einer Formulierung wie der von Dibelius (a.a.O. S.116), daß der Staat nur dort sozial tätig sein soll, wo "andere" die Aufgaben nicht besser erfüllen, läßt sich praktisch wenig anfangen.

7) S. insbes. Klein, Christ und Kirche in der sozialen Welt, S. 135 ; s.a. dens., Das Recht des sozial-caritativen Arbeitsbereichs, $\mathrm{S.} 56 \mathrm{ff}$.

8) S. a. Süsterhenn, a.a.O. S. 117.

9) Zum Vorstehenden s.a. Wilkens, Probleme des Wohlfahrtsstaates, S. 152 . 
In der Praxis ist daraus jene "komplizierte Symbiose" zwischen öffentlicher Hilfsvollmacht und weltanschaulichem Hilfsträger entstanden, 10) die heute das Bild der Fürsorge für den bedürftigen Menschen außerhalb der großen staatlichen Institutionen wie Sozialversicherung, Arbeitslosenversicherung usw. prägt. Diese Symbiose ist keineswegs ausschließlich, jedoch signifikant durch ein spezifisches Strukturprinzip beherrscht. Es basiert einerseits auf der auf die Dauer größeren finanziellen und auch sonst materiellen Potenz des Staates - und der als ihm eingegliedert in diesem Zusammenhang zuzurechnenden kommunalen Körperschaften -, die sich aus der Abgabenhoheit ergibt und neben der die Quellen, aus denen die kirchliche Hilfstätigkeit gespeist wird, nicht aufkommen können.11) Es basiert andererseits auf der Tatsache, daß der Staat seinerseits auf die Dauer nicht in der Lage ist, mehr persönliche Dienstleistungen für soziale $Z$ wecke zu mobilisieren als "auf dem normalen Markt der Dienste... käuflich" sind. 12) Auf dem freien "Markt der Dienste" sind nun aber von vorneherein nicht so viele Kräfte zu "kaufen", als für den sozialen Einsatz benötigt werden. ${ }^{13)}$ Zudem verlangen gewisse

10) Achinger, Zur Neuordnung der sozialen Hilfe, S. 21.

11) Das versteht sich für das freiwillige Opfer und für Leistungen aus dem kirchlichen Vermögen von selbst. Aber hat die Kirche nicht in der Kirchensteuer ein der staatlichen Abgabe gleichwertiges Instrument? Nein! Zunächst einmal kann die Kirche den Staat nicht hindern, so viel an Steuern zu erheben, wie er für nötig hält. Da die staatliche Besteuerung im "Steuerstaat" eine Tendenz zur Grenze des als erträglich Angesehenen hin aufweist, bleibt für die Kirchensteuer als zusätzliche Belastung ohnedies nur mehr wenig Spielraum. Eine hohe Kirchenbesteuerung könnte auch die seelsorglichen Anliegen der Kirche gefährden. Schließlich aber würde die Kirche die Erfüllung der Liebespflicht des Christen einerseits und die Kirchensteuer andererseits verfälschen, wenn sie auf dem Wege über die erzwingbare Abgabe ihre Glieder zum caritativen Opfer anhalten würde. Wenn die Kirche (als Organisation) von dem ihr verbleibenden Überschuß gibt, ist das gut und recht. Aber ein Mittel zur "Einhebung" christlicher Liebe darf die Kirchensteuer nicht werden. S. zum Ganzen Klein, Christ und Kirche in der sozialen Welt, insbes. S. 79 ff, 142. (S. zum kirchlichen Abgabenwesen auch nochmals Mikat, Kirchen und Religionsgemeinschaften, S. $229 \mathrm{ff}$ ).

12) Achinger, a.a.O.

13) Achinger, a.a.O. - Eine praktische Frage, die hier nicht $z u$ erörtern ist, ist allerdings die, ob nicht gerade für die hier 
Tätigkeiten eben eine andere seelische Grundlage als die des Leistung-Geld-Austausches. 12) Darin, diese fehlenden Dienste aufzubieten, liegt die Stärke der kirchlich-caritativen Institutionen (wenngleich auch hier ein dem Schwund der religiösen Überzeugung parallel gehender Schwund der Anziehungskraft zu verzeichnen ist). 14) Indem dies ins Blickfeld gerückt wird, soll freilich keineswegs gesagt werden, daß eine Aufteilung hier Geld-hier Dienst etwa die sachimmanent vorgezeichnete Lösung des bestehenden Spannungsverhältnisses ist. Die eigenständige Aufgabenstellung von Staat und Kirche korrespondiert zwar zum Teil mit dieser Gegenüberstellung, jedoch eben nur zum Teil und die Grenzen decken sich nicht. Was vielmehr mit diesem Hinweis bewirkt werden soll, ist das Verständnis dafür, daß zu dem legitimen Spannungszustand zwischen behördlicher Wohlfahrtspflege und kirchlicher Liebestätigkeit auch der labile "Anspruch" auf Staatszuschüsse an die kirchlich-caritativen Einrichtungen auf angemessene (staatsbestimmte) Pflegesätze usw. gehört. 15) Vom Stand-

in Frage stehenden Leistungen beständig ein zu niedriger Kaufpreis - sprich: Lohn - geboten wird.

14) S. zum Vorstehenden auch Gerstenmaier, "Wichern zwei", S. 523 .

15) (1) S. hierzu z.B. Klein, Christ und Kirche in der sozialen Welt, S. 141 ff; ders., Das Recht des sozial-caritativen Arbeitsbereichs, S.67; Weber, Innere Mission und Wohlfahrtsstaat, S. 188 ff; Süsterhenn, Die kirchliche Liebestätigkeit im sozialen Rechtsstaat der Gegenwart, S. 116 f; s.a. Hesse, Der Rechtsschutz durch staatliche Gerichte im kirchlichen Bereich, S. $60 \mathrm{f}$.

(2) Eine gewisse Hemmung scheint Art.145 Abs.2 BayVerf zu bieten: "Neue freiwillige Leistungen des Staates, der politischen Gemeinden und Gemeindeverbände an eine Religionsgemeinschaft werden durch Zuschläge zu den Staatssteuern und Umlagen der Angehörigen dieser Religionsgemeinschaft aufgebracht". Diese Bestimmung, die einerseits in einer unausgegorenen Nachbarschaft zum Kirchensteuerrecht (Art. 143 Abs. 3 BayVerf) steht, andererseits mit der Religions- und Bekenntnisfreiheit (Art. 107 Abs. 1 und 6 BayVerf) nicht gerade harmoniert, stellt ein Überbleibsel aus dem trennungsfreudigen Verfassungsjahr 1919 dar. Sie entspricht $₫ 17$ Abs. 4 der Bayerischen Verfassungsurkunde vom 4. August 1919. Würde sie wörtlich genommen, so stünde sie, wenn vielleicht auch nicht wirklich jeder bisher nicht gezahlten Leistung an kirchliche Kassen (so aber Kratzer, Bayerische Verfassungsurkunde, 1925, $\$ 17$ Anm.8), so doch wenigstens jeder grundsätzlich neuartigen Leistung im Wege (Hoegner, S.175). 
punkt der verfassungs rechtlichen Konzeption 16) eines Eigenrechts des Staates auf soziale Intervention, eines Eigenrechts

Sie würde die bestehende Zusammenarbeit zwischen Kirche und Staat - von der caritativen Arbeit bis etwa zur Erhaltung der kirchlichen Kunstschätze -, die weitestgehend auf der staatlichen (Mit-)Finanzierung beruht, nicht zulassen. Die ganz vom Öffentlichkeitsanspruch der Kirchen beherrschte Staatspraxis hat sie demzufolge auch gänzlich vergessen. Sie läßt sich in das dargestellte staatskirchenrechtliche und kirchenpolitische System des Grundgesetzes und der Bayerischen Verfassung nur einfügen, indem sie ausschließlich auf Zuschüsse zu rein kirchlichen $Z$ wecken bezogen wird. Wo die Kirche legitimerweise über ihren engsten sachlichen Raum in eine breitere Öffentlichkeitsarbeit ausgreift, muß es dem Staate freistehen, das Gemeinwohl zu fördern, indem er die Wirksamkeit der Kirchen - auch finanziell - unterstuitzt ( $z$ u diesem Legitimationsgrund s, allgemein Klein, Das Recht des sozial-caritativen Arbeitsbereichs, S.67). Da auf diese Weise aber möglicherweise kirchliche Mittel indirekt für rein kirchliche $Z$ wecke freigestellt werden und andererseits der moderne Staat ohnedies kaum auf den Gedanken verfallen dürfte, von sich aus religionsgenossenschaftlich beschränkte Abgaben zu erheben, um rein kirchliche $Z$ wecke fördern zu können, kann Art. 145 Abs. 2 BayVerf als bedeutungslos betrachtet werden - eine Erscheinung, die nicht allzuselten eintritt, wenn jüngere Verfassungen Einzelvorschriften aus älteren Verfassungen kopieren. Das Ergebnis kann umso weniger erstaunen, als eine Vorschrift dieses Inhalts dem übrigen deutschen Verfassungs recht fremd ist (vgl. Art. 140 GG i.V.m. Art. 138 RV 1919; Art. 5, 7 BadWürttVerf; Art. 52 Hess Verf; Art. 21 NordrhlVestfVerf; Art. 45 Rhein1PfVerf).

(3) Das im Text und vorstehend Gesagte bejaht nicht die Frage nach der Pflicht des Staates zur Erstattung von Stolg e bühren bei geistlichen Verrichtungen für Fürsorgeempfänger (insbes. Beerdigungskosten) aus Mitteln der Fürsorge. Wenn auch die staatliche Praxis in unangebrachtem Entgegenkommen - und vielleicht auch im Hinblick auf das erschütternde Versagen von Geistlichen, das nicht zulasten des Fürsorgeempfängers gehen soll - heute dazu neigt, Beerdigungskosten für die kirchliche Beerdigung zu zahlen (vgl. Jehle, Fürsorge recht, 3. Aufl. $1958 \mathrm{~S} .155 \mathrm{f})$, so liegt darin doch nichts anderes als eine Subventionierung der Kirche in ihrem engsten Wirkungskreis als Kultgemeinschaft über den Fürsorge- 
der Kirche auf öffentliche caritative Betätigung und der Spezialität des jeweiligen Aufgabenkreises kann dazu nur gesagt werden: Wenn diese permanente Auseinandersetzung je dahin entschieden würde, daß die Kirche nur das leisten darf, wozu sie auch sachlich-finanziell imstande ist, oder daß der Staat sich ganz auf die Bereitstellung der sachlich-finanziellen Mittel beschränkt, wäre sie falsch entschieden. Dazwischen liegen viele Möglichkeiten der Kombination, die, wenn sie nur die verfassungs rechtliche Grundkonzeption und die sachlichen Gegebenheiten hinreichend berücksichtigen, durchaus legitim sind. Eines ist aber noch hervorzuheben; die Kirche muß als eigenständiger Träger (auch) der öfentlichen Wohlfahrtspflege angesehen werden. Werden ihr Geld und sonstige sachliche Mittel gegeben, so darf sie ihre Eigenständigkeit dadurch nicht einbüßen. Sie darf nicht in ein Lohndienstverhältnis zum Staat treten und sein verlängerter Arm werden. 17)

Wie wenig die Beziehungen Kirche-Staat auf diesem Gebiet einer grundsätzlichen, ein für allemal geltenden Regelung zugänglich sind, zeigen die Vorschriften des $₫ 5$ der Fürsorgepflichtverordnung 18) und des $₫ 6$ des Jugendwohlfahrtsgesetzes, 19) die die

haushalt! Vgl. demgegenüber Can. $1235 \S 2$ CIC: "Pauperes gratis... funerentur et sepeliantur...". Im Sinne der hier vertretenen Auffassung s. BVerwG Urt. v.6. Oktober 1959 BVerwG V C 316.58 - DVB1. 75.Jhg. (1960) S.246 = Bayerische Verwaltungsblätter n.F. 6.Jhg. (1960) S.52; BayVGHE 12, 69; weit. Nachw.s. dort.

(4) Eine gewisse Parallele zum Streit um Pflegesätze usw. liegt in dem an Art. 7 Abs. 4 und 5 GG anknüpfenden Streit um Staatszuschüsse für kirchliche Schulen (s. z. B. den Hinweis bei Werner Weber, Die Gegenwartslage des Staatskirchenrechts, S. 163).

16) Inwieweit andere Rechtsgründe als die hier zum engeren $\mathrm{Zu}$ sammenhang gehörcnden - z.B. die erstaunlicherweise immer noch nicht verbrauchte Berufung auf die Säkularisation Ansprüche rechtfertigen, steht hier nicht zur Diskussion. Zur Garantie staatlicher Leistungen an die Kirchen s. allgemein Mikat, Kirchen und Religionsgemeinschaften, S.224 ff.

17) S.Klein, a.a.O. S.132, 135; Weber, Innere Mission und Wohlfahrtsstaat, S. $175 \mathrm{f}, 190 \mathrm{f}$; Janssen, Probleme des Wohlfahrtsstaates, S. 135.

18) S. hierzu unter den speziellen Aspekten z.B. Franz Klein, Das Recht des sozial-caritativen Arbeitsbereichs, S.61. Zur Neuregelung s. die $\$ ₫ 10,87$ des Entwurfs eines Bundes- 
Kollision von behördlicher und "freier" und somit auch kirchlicher Fürsorge (Jugendfürsorge) regeln. Sie lassen der jeweils angemessenen Gestaltung freien Raurn. 20)

\section{d) Das kirchliche Dienstrecht}

In ganz anderer Weise als vermittels der caritativen Tätigkeit der Kirchen wird die soziale Intervention des Staates durch die kirchliche Autonomie auf dem Gebiete des kirchlichen Diens $\tau$ rechts beschränkt. Daß diese anerkannt ist, wurde grundsätzlich bereits bemerkt. 1) In der Tat genießen die Kirchen heute eine weitgehende Exemtion vom staatlichen Beamten- und Arbeitsrecht - von diesem freilich weitaus weniger als von jenem - und vom Sozialversicherungs recht. Dabei ist allerdings zu berücksichtigen, daß nur ein Teil dieser Exemtionen eine unmittelbare Ent-

sozialhilfegesetzes (Deutscher Bundestag, 3. Wahlperiode, Drucksache 1799) und die Begründung hierzu (a.a.O. S.33, $35,39,56)$.

19) S. a. $\$ \$ 6,11,62$ ff, 69 Abs. 1 JWG. Vg1. K1ein, a.a.O. S. 61 ff. - Zur Neuregelung s. die entsprechenden Bestimmungen in dem Entwurf eines Gesetzes zur Änderung und Ergänzung des Reichsjugendwohlfahrtsgesetzes (Deutscher Bundestag, 3. Wahlperiode, Drucksache 2226); s. hierzu auch Köttgen, Das umstrittene Mandat zur Jugendpflege.

20) Zur Zusammenarbeit von Staat und Kirche s.a. die Darstellung bei Klein, a.a.O. S. $56 \mathrm{ff}$, insbes. S. $59 \mathrm{ff}$.

1) S. oben S.265 fu Fußn. 15 bis 20 und den Text hierzu. Eine zusammenfassende, reich belegte Darstellung findet sich bei Kalisch, Grund- und Einzelfragen des kirchlichen Dienstrechts, insbes. S.28 ff. An jüngeren Darstellungen ist vor allem der Abschnitt "Das Dienstvertragsrecht der Mitarbeiter von öfentlichrechtlichen Trägern sozial-caritativer Arbeit" bei Klein, Das Recht des sozial-caritativen Arbeitsbereichs (S.333 ff; s. a.a.O. auch S.47) zu erwähnen, der zwar zwischen dem engeren Kirchendienst zu "geistlichen, d.h. seelsorglichen Zwecken" und dem sozial-caritativen Dienst unterscheidet ( $\mathrm{S} .333 \mathrm{f}$ ), aber auch für letzteren eine gewisse "rechtliche Besonderheit auf Grund seiner religiösen Grundlegung und auf Grund des im kirchlichen Raum geschaffenen sozialen Ordnungs rechts" in Anspruch nimmt (S.334 f). Mikat (Kirchen und Religionsgemeinschaften, S. 183 f, 187) e rwähnt das kirchliche Selbstbestimmungs recht in bezug auf den Status der Geistlichen und sonstigen "Amtsträger", ohne letzteren Begriff näher zu erläutern. 
sprechung zum autonomen Status der Kirchen darstellt und ihnen im übrigen Einschränkungen zugute kommen, die sich das staatliche Recht allgemein gegenüber öffentlichrechtlichen Dienstherren, gegenüber caritativen Organisationen, gegenüber Orden und ordensähnlichen Gemeinschaften oder auch gegenüber sog. Tendenzbetrieben auferlegt bzw. auferlegen muß.

(1) Es entspricht unmittelbarer eindeutig der Autonomie im Sinne des Art. 137 Abs. 3 RV 1919, daß der kirchliche Dienst aus dem staatlichen Beamtenrecht herausgenommen wird (vgl. $₫ 135$ des Beamtenrechts rahmengesetzes; einschließlich des Besoldungs rechts $(\$ 49$ des Bundesbesoldungsgesetzes 2$)))^{3)}$, also gerade auch der sozial wirksamsten beamtenrechtlichen Materien. ${ }^{4)}$ Auch das Betriebsverfassungsgesetz findet "auf Religionsgemeinschaften und ihre karitativen und erzieherischen Einrichtungen" schlechthin keine Anwendung ( $\$ 81$ Abs.2). Hier zu nennen ist auch die Herauslösung der (allein davon betroffenen) evangelischen Kirchen aus dem Geltungsbereich der ATO, TOA und TOB außerhalb der in $₫ 9$ TVG für die Beseitigung von Tarifordnungen vorgesehenen Wege. 5)

(2) Sind diese Ausnahmen direkt auf die Kirchen abgestellt, so bestehen daneben noch eine Reihe von Grundsätzen des Arbeitsund Sozialversicherungs rechts, die zwar nicht in spezifischer

2) Implicite auch Art. 35 des Bayerischen Besoldungsgesetzes.

3) S.a. Mikat, a.a.O. S.187 und Fußn.323. Die Rechtsprechung hatte das nach 1945 schon vor der gesetzlichen Neuregelung herausgestellt (s.insbes. Kalisch, Kirchengesetzlich angeordnete Kürzungen von Dienst- und Versorgungsbezügen, Zeitschr.f.evangelisches Kirchenrecht, Bd.1 (1951) S. 280 ff und seine Nachweise). Zur Entwicklung der staatlichen und kirchlichen Gesetzgebung s. Kümmel, Die Problematik des kirchlichen Dienstes im Beamten-, Besoldungs- und Tarifrecht des Staates, Recht im Amt, 3.Jhg. (1956) S.275 ff.

4) Auch das Gesetz zur Regelung der Rechtsverhältnisse der. unter Art. 131 des Grundgesetzes fallenden Personen erstreckt sich nicht auf die Kirchenbediensteten. S. hierzu BGHZ 18, 373 (375).

5) S. Bundesarbeitsgericht, Urt.v. 26.Juni 1956, AP $\$ 1$ TOA Nr.3. S.ferner Kalisch, Grund- und Einzelfragen des kirchlichen Dienstrechts, S. 59 ff mit weit. Nachweisen (Die entscheidenden Probleme sind allerdings weder hier noch dort herausgestellt.) S.a. Klein, Das Recht des sozial-caritativen Arbeitsbereichs, S.336. A. A. noch Kümmel, a.a.O. S.278 f ( $s$. auch dessen weitere Hinweise). 
Entsprechung zur Autonomie der Kirche stehen, ihr aber doch zugute kommen.

(a) Beschränkungen in der Anwendung des Arbeitsrechts auf den kirchlichen Bereich ergeben sich z.B. daraus, daß Ordens- und ähnliche Gemeinschaftsverhältnisse - aus denen heraus ein hervorragender Anteil aller kirchlichen Dienste geleistet werden nicht als Arbeitsverhältnisse im Sinne des Arbeitsrechts angesehen werden. 6) Sie sind zum Teil auch von der Unfallversicherung und Rentenversicherung unter der Voraussetzung befreit, daß den betreffenden Personen eine lebenslängliche Versorgung gewährleistet ist ( $\$ 541 \mathrm{Nr} .3, \S 1227$ Abs. 1 Nr. 5 i. V.m. $\$ 1231$ Abs. 3 RVO, \ $2 \mathrm{Nr} .7$ i.V.m. $\$ 8$ Abs. 3 AnVG), ohne diese Voraussetzung von der Kranken- und Rentenversicherung dann, "wenn sie sich aus überwiegend religiösen oder sittlichen Beweggründen mit Krankenpflege, Unterricht oder anderen gemeinnützigen 'Tätigkeiten beschäftigen" und neben dem freien Unterhalt keine oder nur eine geringe Vergütung erhalten $(\$ \S 172$ Abs. 1 Nr.6, $\$ 1227$ Abs. 1 Nr. 5 RVO, $₫ 2 \mathrm{Nr} .7$ AnVG). 7)

(b) Das Arbeitsrecht hält sich dagegen von Beschäftigungen, die nicht in erster Linie dem Erwerb dienen, auch dann schon zurück, wenn sie nicht im Rahmen einer besonderen Gemeinschaft ausgeübt werden. 8) Es überläßt ihre rechtliche Ordnung an sich dem privater Autonomie stärker zugänglichen allgemeinen bürgerlichen Recht.

(c) Schließlich ergeben sich Einschränkungen des Arbeitsrechts unter dem Gesichtspunkt des Tendenzbetriebes, den es zwar von seiner Geltung nicht ausnimmt, dessen besonderen Bedürfnissen es jedoch durch die Adaption arbeitsrechtlicher Normen entgegenkommt. So findet das Betriebsverfassungsgesetz "auf Betriebe,

6) Vgl. Schnorr von Carolsfeld, Arbeitsrecht, 2. Auf1. 1954, S. 4, 6; Nipperdey, Lehrbuch des Arbeitsrechts, Bd. II S. $188 \mathrm{f}$, 702; BAGE 2, 289 (Urt.v. 18.Febr. 1956 - ZAZR 294/54) mit Anm. v. Hersche1, AP $\$ 5$ ArbGG Nr.1. - S.a. $\$ 4$ Abs. 2 lit. b des Betriebsverfassungsgesetzes.

7) Diese engherzige Verklausulierung der Ausnahme gegenüber "Mitgliedern geistlicher Genossenschaften, Diakonissen, Schwestern vom Roten Kreuz, Schulschwestern und ähnlichen Personen", wie sie das Gesetz selbst aufzählt, grenzt ans Alberne. Befremdlich und unsystematisch ist in diesen Fällen auch die Nachversicherungspflicht für die Rentenversicherung im Falle des Austritts ( $\$ 1232$ Abs. 5 RVO, $₫ 9$ Abs. 5 AnVG). Kritisch hierzu auch Klein, Das Recht des sozial-caritativen Arbeitsbereichs, S. $340 \mathrm{f}$.

8) Vgl. Nipperdey, a.a.O. (s.o. Fußn.6). S. insbes. $₫ 4$ Abs. 2 1it.d des Betriebsverfassungsgesetzes. 
die ... konfessionellen, karitativen... und ähnlichen Bestimmungen dienen" in einigen Vorschriften keine, im übrigen "nur insoweit Anwendung, als nicht die Eigenart des Betriebes dem entgegensteht" ( $\$ 81$ Abs.1). Die Rechtsprechung hat ähnliche Rücksichten bei der Anwendung des Kündigungsschutzrechts genommen. 9) (d) Anzumerken ist schließlich noch, daß die Geistlichen und Kirchenbeamten im Hinblick auf ihre Versorgung wie die Beamten anderer Dienstherren von der Sozialversicherungspflicht freigestellt sind $(\$ \$ 169$ Abs. 1 Satz 2, 172 Abs. 1 Nr. 1 Satz 2, 1229 Abs. $1 \mathrm{Nr} .2$ und 3 RVO, $₫ 6$ Abs. 1 Nr. 2 und 3 AnVG; für die Unfallversicherung wohl nach $₫ 541 \mathrm{Nr} .1 \mathrm{RVO}) .10)$

Ist so die Verfassungswirklichkeit noch recht schwach auf die verfassungsmäßige Autonomie der Kirchen hin orientiert, so läßt sie doch die wesentlichen Grundsätze aufscheinen, die die Beziehung zwischen dem autonomen kirchlichen Dienstrecht und dem staatlichen Recht beherrschen müssen. Zunächst einmal ist offensichtlich bei weitem nicht alles, was den Dienst in der Kirche betrifft, deren Selbstbestimmung vorbehalten. Sodann ist ein Gefälle

9) (1) Zum Kündigungsschutz im kirchlichen Tendenzbetrieb s. insbes. die umstrittene Entscheidung BAGE 2, 279 (Urt.v. 31. Januar 1956 - 3 AZR 67/54) und hierzu die Anmerkungen von Frey und Neumann-Duesberg, AP $₫ 1$ KSchG Nr. 15; ferner Schneider, Gewissensf reiheit und Kündigungsschutz, Arbeit und Recht, Jhg.4 (1956) S.97 ff; Hessel, Weltanschauung des A rbeitgebers und Kündigungsschutz im Arbeitsverhältnis, Betriebsberater, 11.Jhg. (1956) S. 406 ff; Klein, dass., das. S. 755 ff; Küster "Nachwort" das. S. 757 ff (die Beiträge von Hessel, Klein und Küster sind abgedruckt auch in Arbeits- und Sozialrecht, 5.Jhg. (1956) S. $125 \mathrm{ff}, 243 \mathrm{f}, 244 \mathrm{ff}$ ); s. ferner Weber, Innere Mission und Wohlfahrtsstaat, S. $187 \mathrm{f}$; Klein, Christ und Kirche in der sozialen Welt, S.239 f (Anm.316); ders., Das Recht des sozial-caritativen Arbeitsbereichs, S. 336 .

(2) Ein nicht uninteressantes Problem der kirchlichen Autonomie im Verhältnis zum Kündigungsschutz, nämlich die Frage, ob die kirchenbehördliche Genehmigung einer Kündigung eine Genehmigung i.S.d. $₫ 3$ Satz $3 \mathrm{KSchG}$ sein kann, behandelt der Beschluß des LAG Kiel vom 16. Dezember 1953 AP $₫ 3$ KschG Nr.1 (m.abl. Anm.v. Herschel).

10) S. hierzu - im eigentlichen Anliegen allerdings überholt Wacke, Die Heranziehung von Kirchenbeamten und Geistlichen zur Sozialversicherung, AöR Bd.74 (1948) S.438 ff, und Anm. zu dem Beschluß des Thüring. LAG Erfurt v. 5. Okt. 1948 - S-R-Beschw - 6/48 - SB 1/48 - AöR Bd.75(1949) S. 116 ff. 
zu beobachten von der Autonomie der Kirchen in bezug auf die Kirchenbeamten zur beschränkten Gestaltungsfreiheit im Gebiete des Arbeitsrechts und von der Zurückhaltung des Staates gegenüber dem Dienst aus religiöser Hingabe zur stärkeren Ingerenz im Falle gewöhnlicher Erwerbstätigkeit im Dienst der Kirche. Wird diese Beobachtung der verfassungsrechtlichen Wurzel der kirchlichen Autonomie, Art. 137 Abs.3 RV 1919, gegenübergestellt, so ergibt sich Näheres.

Haben danach die Kirchen "ihre Angelegenheiten" zu ordnen und zu verwalten, so leuchtet ohne weiteres ein, daß das Dienstrecht umso mehr eigene ("ihre") Angelegenheit der Kirche ist, je mehr der betreffende Dienst inhaltlich von der Kirche geprägt ist; und daß es umso weniger in ihren Machtbereich fällt, je weniger die Eigenart des betreffenden Dienstes von der Kirche (als Dienstherr) her bestimmt wird. Die Spanne reicht vom Amt des Geistlichen 11) bis zum Kraftfahrer oder zur Hollerithkartenlocherin in kirchlichen Diensten. 12)

Zieht die Formel von "ihren Angelegenheiten" die eine Linie, so wird eine zweite Grenzlinie durch die "Schranken der für alle gel-

11) S. z.B. Mikat, Kirchen und Religionsgemeinschaften, S. 183 f, 187.

12) Kalisch (Grund- und Einzelfragen des kirchlichen Dienstrechts, S. 50) schreibt hierzu: "Dabei wird ihr Dienstrecht um so stärker von der Kirche autonom gestaltet und an das der Geistlichen angelehnt werden, je stärker die betreffenden Dienste an der Verkündigung unmittelbar beteiligt sind, wie das z. B. bei der Gruppe der Prediger, der Katecheten, den Kirchenmusikern und einem Teil der Diakone der Fall ist. Die Kirche wird sich anderseits auf eine geringere eigenständige Rechtsgestaltung beschränken, soweit ihr Dienst nur mittelbar dem Auftrag der Kirche dient, wie z.B. bei reinen Bürokräften oder den Arbeitern auf kirchlichen Gütern. Für sie tritt in entsprechend größerem Umfange das allgemeine weltliche Arbeitsrecht ein. Ganz außerhalb des kirchlichen Dienstrechts kann keiner der Mitarbeiter der Kirche stehen und sei es nur, daß die Kirche auch von ihren Arbeitern oder einem Kraftfahrer zumindest Zugehörigkeit zur Kirche und ein kirchenfreundliches Gesamtverhalten verlangen muß". - Vgl. auch Klein, Christ und Kirche in der sozialen Welt, S.238 ff (Anm.316); ders., Das Recht des sozial-caritativen Arbeitsbereichs, S.333 ff. - Dagegen scheint Mikat (a.a.O.) die kirchliche Selbstbestimmung nur für Geistliche und "Amtsträger" anerkennen zu wollen. 
tenden Gesetze" bestimmt. Das Recht zum Schutz des zum Erwerbszweck abhängig tätigen Menschen, wie es heute vornehmlich im Arbeits recht und im Sozialversicherungs recht sich findet, gehört in seiner wesentlichen Substanz gegenwärtig zu dem "für die Gesamtnation als politische, Kultur- und Rechtsgemeinschaft unentbehrlichen" Rechtsbestand, ist also weitgehend "für alle geltendes Gesetz" i.S. des Art.137 Abs. 3 Satz 1 RV 1919.13) Zu den demnach auch die Kirchen bindenden "elementaren Gesetzen unserer Sozialordnung" wird man insbes.das Verbot der Kinderarbeit, die den Jugend- und Mutterschutz bezweckenden Gesetze, das Verbot der Sonn- und Feiertagsarbeit (soweit nicht gerade durch die Eigenart des kirchlichen Dienstes gefordert...), die Arbeitszeit- und Arbeitsschutzvorschriften, 14) den Kündigungsschutz 15) rechnen müssen". 16) Ferner gehört hierher das Recht der Mindestarbeitsbedingungen, 17) dem in Anbetracht der Abneigung der Kirchen gegen Tarifverträge ${ }^{18)}$ sogar hier möglicher-

13) Vg1. Kalisch, a.a.O. S. 62 f; s.a. Klein, Christ und Kirche in der sozialen Welt, S.238 ff; ders., Das Recht des sozialcaritativen Arbeitsbereichs, S.336 f. S.a. nochmals die eingangs gegebene Zusammenstellung S. 275 unter(2) und die Anmerkungen hierzu. - Zur Auslegung der Klausel von den "Schranken der für alle geltenden Gesetze s.o. S. 255 zu Fußn. 10.

14) Hierzu meldet Klein (Christ und Kirche in der sozialen Welt, S.238 f) Bedenken an, die jedoch, da sie vor allem sich gegen die Anwendung des Arbeitsrechts auf Ordensgemeinschaften richten, weitgehend gegenstandslos sein dürften; modifizierend nunmehr ders. in: Das Recht des sozial-caritativen Arbeitsbereichs, S. 337 .

15) $\mathrm{Zu}$ den gebotenen Einschränkungen s.o. Text und S. $277 \mathrm{zu}$ Fußn.9. - Hierher zu zählen ist auch der besondere Kündigungsschutz für Schwerbeschädigte (vgl. Kalisch, a.a.O. S.62). Für Geltung der Kündigungsschutzbestimmungen im kirch1ichen Dienstrecht auch Klein, Das Recht des sozial-caritativen Arbeitsbereichs, S.336.

16) Kalisch, a.a.O. S.63.

17) Ein Parallelproblem bot die Anwendbarkeit des Gesetzes zur Aufhebung des Lohnstops vom 3. November 1948 (WiGBl. S.117) gegenüber ungünstigen Arbeitsbedingungen durch einen kirchlichen Arbeitgeber. Sie wurde- unter ausdrücklicher Bezugnahme auf Art. 137 Abs. 3 Satz 1 RV 1919 - bejaht (LAG Mannheim, Urt.v.17. Februar 1951 - Sa 105/50 - AP $1951 \mathrm{Nr} .244$ mit insoweit zust. Anm. von Herschel).

18) Vg1. Kalisch, a.a.O. S. 57 f. - S.a. oben S. 275 zu Fußn. 5 und den Text hierzu. 
weise eher praktische Bedeutung zukommen kann als anderswo. 19) Dabei ist immer das Schutzobjekt des staatlichen Arbeitsund Sozialversicherungs rechts vor dem Auge zu behalten: der Mensch, der, grundsätzlich darauf angewiesen, in abhängiger Stellung tätig ist, um seine Lebensbedürfnisse befriedigen zu können, und daher Bedrängnissen und Gefährdungen, letztlich existenzbedrohender Art ausgesetzt ist. Die Grenzen dieses Schutzzweckes ziehen in der Regel auch die positiv abgesteckten Grenzen des sachlichen und persönlichen Geltungsbereiches der einschlägigen Rechtsnormen. Wo dieser darüber hinausgreift, wird aber - so nicht ein anderer unabdingbar zu verfolgender $Z$ weck dies begründet - wenigstens der kirchlichen Autonomie freie Hand zugestanden werden müssen. So fallen die Rechtsverhältnisse in Ordens- und ähnlichen Gemeinschaften und in individueller Erfüllung religiöser Hingabe aus dem Schutzkreis spezifisch sozialer staatlicher Hilfe grundsätzlich heraus. 20) "Eine nach Lage des Falles allenfalls nur eingeschränkte Anwendbarkeit arbeitsrechtlicher Normen ergibt sich aus der Natur der Sache für den Personenkreis, der nicht mit Rücksicht auf das Produkt seiner Arbeitsleistungen, sondern aus Gründen der Heilung, der sittlichen Besserung oder Erziehung oder aus sonstigen Gründen caritativer oder religiöser Art beschäftigt wird. Das ist insbesondere bei zahlreichen in Anstalten ... beschäftigten Kranken, Süchtigen, Verwahrlosten, besserungsbedürftigen Jugendlichen und entlassenen Strafgefangenen der Fall". 21)

19) Hierher zu zählen wird - im Gegensatz zum Verwaltungsrechtsschutz im beamteten Kirchendienst - auch der bisher ganz unbestrittene Rechtsschutz durch die staatlichen Arbeitsgerichte sein.

20) S.o. im Text, insbes. S. 276 zu Fußn.6 und 8. Zur grundsätzlichen Herausnahme der Orden aus dem sozialen Schutzrecht s. insbes. auch Klein, Christ und Kirche in der sozialen Welt, S. 238 f; der's., Das Recht des sozial-caritativen Arbeitsbereiches, S.336 f und $340 \mathrm{f}$. - Ob die (S. 276 in Fußn. 7) erwähnte Nachversicherungs pf1 icht mit Art. 137 Abs. 3 Satz 1 RV 1919 i. V.m. Art. 140 GG vereinbar ist, ist sehr die Frage (s.a. Klein, a.zuletzt a.O. S.340 f). - Mit Recht weist aber Klein (ebenda $\$$. 337 ) darauf hin, daß soziale Schutzvorschriften auch dem Schutz Dritter dienen können Klein nennt den Schutz der Patienten durch Arbeitszeitvorschriften für das Pflegepersonal - und sich dann und insoweit auf die Orden erstrecken.

$21)$ Kalisch, a.a.O. S.62. - S.a. Karl-Friedrich Weber, Innere Mission und Wohlfahrtsstaat, S. 188. 
Ein klassisches Mittel der Kirche, ihre Dienstrecht ihren Bedürfnissen zu adaptieren, ist das kircheneigene Beamtenrecht. 22) Aber sie muß dabei auch wirklich beamtenrechtliche Sicherungen schaffen; denn einen reinen Nominal-Beamtenstatus bräuchte der Staat nicht - etwa durch die Herausnahme aus dem Arbeits - und Sozialversicherungs recht - zu respektieren. Insgesamt wird also der das Beamtenrecht beherrschende Alimentationsgrundsatz durchgeführt werden müssen. 23) Ein gewisser sozialer Mindeststandard ist also garantiert. Inwieweit darüber hinaus das kirchliche Beamtenrecht durch "für alle geltende Gesetze" gebunden ist, und inwieweit insbes. die für die staatliche Regelung des "öffentlichen Dienstes" $z u$ berücksichtigenden "hergebrachten Grundsätze des Berufsbeamtentums" (Art.33 Abs. 5 GG) solche darstellen, braucht hier nicht weiter verfolgt zu werden. 24) Vielfach wird die Vergleichbarkeit mit dem Berufsbeamtentum überhaupt fehlen (z. B. beim katholischen Geistlichen).

So greifen das aus der Beschränkung der Kirche auf "ihre Angelegenheiten" fließende Abgrenzungsprinzip und die Bindung an die "für alle geltenden Gesetze" ineinander. Dem Bedürfnis und dem

22) S. nochmals oben die Zusammenfassung S. 275 unter (1) u. dort auch Fußn.2.

23) Zur Anwendung des Grundsatzes der Erhaltung wohlerworbener Rechte (Art. 129 RV 1919) im Recht der Geistlichen und sonstigen Kirchenbeamten s. BGHZ 12, 321 (326); Kalisch, Kirchengesetzlich angeordnete Kürzung von Dienst- und Versorgungsbezügen m. eingeh. Nachw. - Zur evtl. Pflicht der Kirchen, eine den Gesetzen zu Art.131 GG ähnliche Regelung zu schaffen, s. BGHZ 18, 373 (375 f).

24) Ein umstrittenes, hier nicht näher zu erörterndes Problem, das auch mit der Qualifikation des Art. 19 Abs. 4 GG als "für alle geltendes Gesetz" zusammenhängt, ist die Frage des Rechts schutzes im kirchlichen Dienst. S. hierzu f.v.a. die Ausführungen von Kalisch, Grund-und Finzelfragen des kirchlichen Dienstrechts, S. 47 f; Scheuner, Die Nachprüfung kirchlicher Rechtshandlungen durch staatliche Gerichte, Zeitschrift f.evangelisches Kirchenrecht, Bd. 3 (1954) S. 352 ff; Scheven, Die Bedeutung des Art. 19 Abs.IV des Grundgesetzes für die Anfechtung kirchlicher Verwaltungsakte, Zeitschrift f. evangelisches Kirchenrecht, Bd.4 (1955) S. 157 ff (180 ff); Thieme, Die Zuständigkeit staatlicher Gerichte zur Entscheidung von Streitigkeiten zwischen den Kirchen und ihren Mitgliedern, AöR Bd. 80 (1955/56) S. 421 ff (439 ff); Hesse, Der Rechtsschutz durch staatliche Gerichte im kirchlichen Bereich, S. 142 ff; Mikat, Kirchen und Religionsgemeinschaften, S. $184 \mathrm{f}$. 
Recht der Kirche, den Dienst umso mehr eigenständig zu gestalten, je mehr er seinem Inhalt nach typisch kirchlich ist, entspricht auf der anderen Seite ein Zurückweichen staatlicher Ingerenz sowohl vor den Rechtsverhältnissen des Dienstes in religiöser Gemeinschaft und individueller religiöser Selbsthingabe wie auch vor der autonomen Regelung des Rechts der Geistlichen und (sonstigen) Kirchenbeamten. Der verbleibende, intensiverer Herrschaft staatlichen Rechts ausgesetzte, im privaten Anstellungsverhältnis zu Erwerbszwecken geleistete und auch bei maximaler Ausdehnung des kirchlichen Beamtenrechts aus begriffs- oder sachlogischen Gründen nicht in dieses einzubeziehende kirchliche Dienst wird in der Regel auch der inhaltiich kirchenfernere sein.

Die (bedingte) Aussperrung des Staates von der Regelung des kirchlichen Dienstrechts ist für die soziale Intervention nur von beschränkter Bedeutung. Wo die soziale Intervention am dringlichsten ist, im eigentlichen Anwendungsbereich des Arbeits- und Sozialversicherungs rechts, greift dieses im wesentlichen auch im kirchlichen Raum durch. Im kirchlichen Beamtenrecht ist durch die Alimentationspflicht des Dienstherrn das sozial Notwendige vorgekehrt. 25) Wo aber Dienst aus rein oder wenigstens vorwiegend religiösen Gründen, als religiöses Opfer, geleistet wird, insbes. also in religiöser Gemeinschaft, da wäre eine soziale Intervention des Staates verfehlter Perfektionismus. 26) Damit soll nicht beschönigt werden, daß es (auch) im rein kirchlichen Raum sozial unbefriedete Winkel gibt. Aber die soziale Intervention des Staates kann die feinen Verflechtungen von religiös Bedingtem und durch menschliche Unvollkommenheit Verursachtem, die derartige innerkirchliche soziale Mißstände kennzeichnet, nicht auflösen. Letztlich geriete sie in die Gefahr, nicht nur die Selbstbestimmung der Kirche sondern auch die Freiheit des Glaubens, des religiösen Bekenntnisses und der ungestörten Religionsausübung zu verletzen.

\section{e) Die kirchlichen Werke und Einrichtungen}

Die Masse kirchlicher Caritasarbeit wird nicht im Rahmen der allgemeinen kirchlichen Gemeinschaft und Organisation sondern in besonderen kirchlichen Werken und Einrichtungen 1)

25) Gute Hinweise auf die Regelung der Alimentation der katholischen Kleriker nach dem kanonischen Recht s. bei Klein, Christ und Kirche in der sozialen Welt, S.213 f (Anm.237).

26) Zu den sozialen Schutzvorschriften des kanonischen Rechts s.Klein, ebenda mit weit. Nachw. 
geleistet. Es braucht nur auf die Hauptträger kirchlichen caritativen Wirkens, den Caritasverband auf katholischer Seite und die Innere Mission bzw. die Hilfswerke auf Seiten der evangelischen Kirchen hingewiesen zu werden. 2)

Sind diese Werke und Einrichtungen nicht der Sonderstellung der Kirchen teilhaftig, so entfällt für sie ein ausgeprägter Sonderstatus jedenfalls sub specie constitutionis. Denn die Verfassung kennt eine notwendige Ausnahmeposition von Wohltätigkeitsvereinigungen $u . \ddot{a}$. nicht. 3) Auch die Berufung auf Art.4 GG könnte hieran nichts ändern. 4) Es geht nicht darum, ob einzelne das Recht haben aus religiöser Überzeugung "gute Werke" zu tun und sich dazu zusammenzuschließen. (Ersteres ist sicher und letzteres durch Art.9 Abs.1 GG zusätzlich garantiert.) Es geht auch nicht darum, ob Vereinigungen, Stiftungen und andere juristische Personen nicht wenigstens in dem Sinne sich auf Art. 4 GG berufen können, daß sie frei sind, Werke zu tun, wie sie den kirch1ich verkündeten moralischen Grundsätzen entsprechen (eine Frage der Anwendung des Art.19 Abs.3 GG, die bejaht werden muß ${ }^{5}$ )). Alles das unterstellt, kommt ihnen weder der kirchliche Öffentlichkeitsanspruch noch das verfassungs rechtlich garantierte Selbstbestimmungs recht der Kirchen zu. Kirchliche Werke sind nicht selbst Kirchen oder Religionsgemeinschaften, sondern schon begrifflich - auf eine (oder mehrere) bestehende Kirche(n) bzw. Religionsgemeinschaft(en) hingeordnet. Sie können für sich allein die den Kirchen durch die Verfassung eingeräumte Position nicht in Anspruch nehmen.6)

Die staatskirchenrechtlichen Normen, die das Zusammen und Nebeneinander von Staat und Kirche im sozialen Feld bestimmen,

1) Zum Terminus s. Wasse, Werke und Einrichtungen der evangelischen Kirche, S. 13 ff.

2) Zu den sonstigen Verbänden und Einrichtungen auf katholischer Seite vgl. Klein, Christ und Kirche in der sozialen Welt, S.107. Zu den einschlägigen evangelischen Veranstaltungen s. Wasse, a.a.O. insbes. S. $25 \mathrm{ff}, 77 \mathrm{ff}, 151 \mathrm{ff}$.

3) s.o. III (S. 242 ff).

4) Zur Anwendung des Art. 4 GG auf kirchliche Werke und Einrichtungen s. Wasse, a.a.O. S. $121 \mathrm{ff}$.

5) S. z.B. v. Mangoldt-Klein, Art.19 Anm. VI 3 b mit weit. Nachw.; s.a. Dürig in Maunz-Dürig, Art. 19 Abs. III Randn.53.

6) Vgl. Wasse, a.a.O. S. 119 ff; Köttgen, Bemerkungen über den rechtlichen Status der Werke und Einrichtungen der evangelischen Kirchen als Grundsatzfrage des kirchlichen und staatlichen Rechts, Zeitschrift f. evangelisches Kirchenrecht, Bd. 4 (1955) S. 144 ff (155). 
können auf die kirchlichen Werke und Einrichtungen unmittelbar nur insoweit angewendet werden als die Kirchen in ihnen und durch sie wirken. Nur soweit sie zweckhaft ausschließlich einer bestimmten Kirche zugeordnet und institutionell von ihr beherrscht werden, soweit also ihr ganzes Wesen der Kirche zuzurechnen ist und letztlich ein ihnen gewährter Status nichts anderes mehr als der Status "ihrer" Kirche selbst ist, können sie in deren verfassungs rechtliche Positionen hineingenommen werden. ${ }^{7)}$ Das gilt vor allem für alle rechtlich nicht verselbständigten, nur innerkirchlich organisatorisch abgesonderten Veranstaltungen. 8) Im hier interessierenden Rahmen sind dafür die Hilfswerke der Evangelischen Kirchen beispielhaft.9)

7) Unscharf spricht Weber (Die Gegenwartslage des Staatskirchenrechts, S. 171) von einer Erstreckung der kirchlichen Autonomie auf die kirchlichen "Trabantenorganisationen". Heckel (Kirchliche Autonomie und staatliches Stiftungsrecht, S.13) will die Autonomie "auf alle dem Verband eingegliederten Teilorganismen erstrecken"; und zwar meint er damit "nicht nur die genossenschaftlichen Unterverbände sondern auch die ihr eingegliederten religionsgesellschaftlichen Stiftungen". Klein (Das Recht des sozial-caritativen Arbeitsbereichs, S.48) sieht das entscheidende Kriterium darin, daß der besondere "Träger sozial-caritativer Arbeit, ... rechtlich im kirchenamtlichen Bereich grundgelegt" ist.

8) Vg1. Wasse, a.a.O. S.56 ff.

9) Vg1. Wasse, a.a.O. S.25 ff, 152. - Das gilt nicht mehr für das Werk "Innere Mission und Hilfswerk der Evangelischen Kirche in Deutschland" wie es durch Vertrag zwischen der Evangelischen Kirche in Deutschland und dem Central-Ausschuß der Inneren Mission vom 8. März 1957 (AB1. EKiD S. 74) begründet wurde. Dieses selbst nicht rechtsfähige Gebilde ist eine "Dachorganisation" über dem - einwandfrei innerkirchlichen - Hilfswerk der Evangelischen Kirche in Deutschland und dem Centralausschuß der Inneren Mission. Letzterer besitzt eigene Rechtspersönlichkeit und steht mit der Evangelischen Kirche in Deutschland nur in einer lockeren, institutionellen Bindung (s.hierzu Wasse, a.a.O. S. $9 \mathrm{f}, 12 \mathrm{f}, 96 \mathrm{f}, 112 \mathrm{f}, 154$ ). Wenn nun auch das gemeinsame Werk, das ja eine Verschmelzung vorbereiten soll, dem Auftrage nach intensiv in die Evangelische Kirche einbezogen wurde (vgl. $\ 1$ des Vertrages, $\mathbb{\$} 1$, 2 des Kirchengesetzes über den Zusammenschluß von Innerer Mission und Hilfswerk der Evangelischen Kirche in Deutschland vom 8. März 1957, ABl. EKiD S. 73) und deren Einfluß 
Auch rechtlich verselbständigte Einheiten können - als Erscheinungsformen kirchlicher Selbstorganisation 10) - am kirchlichen Status teilhaben, vorausgesetzt daß sie ausschließlich und verbindlich den $Z$ wecken der betreffenden Kirche zugeordnet sind, in ihrer Gebarung von der betreffenden Kirche beherrscht werden und, soweit sie Personengesamtheiten sind, ihre Mitglieder ausschließlich der betreffenden Kirche angehören. 11) Aber eine undifferenzierte Gleichstellung wird kaum je möglich sein. Insbes. stellt sich die Verwendung privatrechtlicher Organisationsformen 10$)$ der Übertragung von Modellvorstellungen entgegen, die an den öffentlichkörperschaftlichen Kirchen (und Religionsgemeinschaften) ausgebildet wurden. 12) Doch werden Öffentlichkeitsanspruch und Selbstbestimmungs recht kirchennaher Organisationen wie etwa der kirchlichen Genossenschaften (Orden u. dg1.), 13) des Landesverbandes der Inneren Mission der Evangelisch-Lutherischen Kirche in Bayern, 14) oder auch - wenngleich schon mit Vorsicht - des Werkes "Innere Mission und Hilfswerk der Evangelischen Kirche in Deutschland" 15) und des Deutschen

auch institutionell vorherrscht ( $\$ 7$ des Vertrages), so kann es doch die kirchen-externe Wurzel nicht verleugnen (s. z. B. $\mathbb{S} 2,7,16$ des Vertrages). Aber die in Aussicht genommene Verschmelzung wird wohl die Rückkehr zum rein kirchen-internen Typ bringen.

10) Soweit sich die Kirche für derartige Ausgründungen des staatlichen Rechts bedient, ist sie an dessen Vorschriften als an "für alle geltende Gesetze" gebunden. Aber die Entscheidung darüber, von den bestehenden Möglichkeiten Gebrauch zu machen, fällt in ihr Selbstbestimmungs recht (vgl. Köttgen, a.a.O. S. $154 \mathrm{f}$ ).

11) Vg1. - mit im einzelnen abweichenden Kriterien, im Ergebnis jedoch ähnlich - Wasse zur "ersten Grundform" der von ihm klassifizierten "kircheneigenen Rechtsträger", a.a.O. S. $79 \mathrm{ff}, 103,107 \mathrm{ff}, 115 \mathrm{f}, 120$.

12) Auch die Eigenschaft der öffentlichrechtlichen Korporation, die möglicherweise verliehen wird ( $s$. für die Orden Art. 2 Abs. 2 des Bayerischen Konkordates; w. Hinweise dafür s. bei Mikat, Kirchen und Religionsgemeinschaften, S.215), ist nicht identisch mit der verfassungskonzipierten der Art. 140 GG i.V.m. Art. 137 RV 1919 und Art. 143 BayVerf.

13) S. die vorstehende Fußn.

14) S. hierzu Wasse, a.a. O, S. 79 ff, 120, 152.

15) S. o. S. 284 zu Fußn.9. - Die zweckhafte Determination des Werkes ist eindeutig. Die institutionelle Bindung wird insgesamt als gerade noch ausreichend angesehen werden können ( $\$ \$ 7$ ff des oben zitierten Vertrages). 
Caritasverbandes e.V.16) im Lichte der verfassungs rechtlichen Stellung der Kirchen, denen sie jeweils zugeordnet sind, gewürdigt werden müssen.

Damit ist der Gesetzgebung und - soweit sie sonst dazu imstande ist - der Verwaltung nicht verwehrt, auch anderen, distanzierteren kirchlichen Verbänden und Veranstaltungen eine Sonderstellung einzuräumen. 17) Eine aus den staatskirchenrechtlichen Bestimmungen der Verfassung herzuleitende Notwendigkeit hierfür besteht nicht.

Welche spezifisch soziale Bedeutung einerseits der Teilhabe der kirchlichen Werke und Einrichtungen am Sonderstatus der Kirchen und andererseits der Befugnis der Kirchen, sich auf diese Weise organisatorisch zu entfalten und ihren besonderen Aufgaben anzupassen, 18) zukommt, bedarf schließlich keiner Hervorhebung.

16) Zur Darstellung des Zweckes und der Organisation s. Klein, Christ und Kirche in der sozialen Welt, S. 104. Klein selbst (Das Recht des sozial-caritativen Arbeitsbereichs, S. 48) versagt dem Deutschen Caritasverband den "kirchenamtlichen" Charakter (s.hierzu schon oben S. 284 zu Fußn. 7). Er will ihn aber an der Öffentlichkeitsfunktion der katholischen Kirche partizipieren lassen (ebd.) und räumt ihm eine der kirchlichen verwandte dienstrechtliche Autonomie ein (a.a.O. S.335).

17) S. hierzu z.B. Wasse, a.a.O. S. 120 f. Zahlreiche Hinweise auf den tatsächlichen Stand s. bei Klein, Das Recht des sozial-caritativen Arbeitsbereichs, passim. Zum Dienstrecht s.a. die Zusammenstellung oben S. 274.

18) S. hierzu nochmals oben S. 284 zu Fußn. 7 und S. 285 zu Fußn.10. Zur Zugehörigkeit der entsprechenden "Organisationsgewalt" zum kirchlichen Selbstbestimmungsrecht s.a. Hesse, Der Rechtsschutz durch staatliche Gerichte im kirchlichen Bereich, S.69; Mikat, Kirchen und Religionsgemeinschaften, S.182. - Wohl zu wenig präzis Süsterhenn (Die kirchliche Liebestätigkeit im sozialen Rechtsstaat der Gegenwart, S. 116), wenn er aus dem kirchlichen Selbstbestimmungsrecht die Betätigungsfreiheit für "alle kirchlichen Caritasorganisationen" herleiten will. 
2. Die "soziale Selbstverwaltung"

a) "Soziale Selbstverwaltung" durch die Tarifvertragspartner

aa) Die Koalitionsfreiheit als verfassungs rechtlicher Ansatz

Die äußere Aussage des Art. 9 Abs. 3 GG verbirgt dem ersten Blick die auf die Kompetenzordnung reflektierende Substanz der Norm. Aber Art. 9 Abs. 3 GG verdankt seinem historisch-polemischen Charakter nicht etwa eine inhaltsleere, formale Absonderung; die Norm ist vielmehr "aufgeladen" mit einem historisch mitgebrachten Sinngehalt, der das Fassungsvermögen ihres Wortlautes bis zum Bersten anfüllt.

Schon der Begriff der Koalition, der "Vereinigung zur Wahrung und Förderung der Arbeits- und Wirtschaftsbedingungen", ist dadurch in einer ganz besonderen, vom Wortlaut her überraschenden, jedoch auf historischer Basis von einer zutreffenden und durchgreifenden Rechtsüberzeugung getragenen Weise präzisiert. Darunter ist nur zu verstehen "eine freiwillige Vereinigung je von Arbeitnehmern oder Arbeitgebern zum Zwecke der Wahrnehmung der Interessen ihrer Mitglieder an der Gestaltung der Arbeits - und Wirtschaftsbedingungen gegenüber der 'anderen Seite" ". 1) Andere Vereinigungen zur Gestaltung des Wirtschaftslebens sind nicht eingeschlossen. ${ }^{2)}$ Das bedeutet für die Position der Koalitionen (der Koalitionsfreiheit) im weiteren Gefüge einer verbandlichen Gliederung des staatsumschlossenen Ganzen 3 ) etwas von vorneherein ganz Spezifisches: Koalitionen sind - jede für sich - primär berufen, nach außen zu wirken. Interne Ausgleichs - und Ordnungsaufgaben nehmen die Koalitionen (als solche) grundsätzlich nur in Unterordnung unter diesen Zweck wahr.

Koalitionen sind ferner an sich nicht Körperschaften des öffentlichen Rechts - wenngleich sie es sein können ${ }^{4)}$ - und somit nicht

1) S. Dietz, a.a.O. S.426.

2) Zu Art.9 Abs. 3 GG h.L. Vg1. Wernicke im Bonner Kommentar, Art.9 Anm. II 3 a und b; v. Mangoldt-Klein, Bonner Grundgesetz, Art.9 Anm.V 9; Dietz, a.a.O. S. 427 f; je mit weiteren Nachw. - A. A. Hamann, Das Grundgesetz, Art. 9 Anm. C 7; ders., Deutsches Wirtschaftsverfassungs recht, S. 105; Maunz, Staats recht, S. 126.

3) S. hierzu auch Brill, Gewaltenteilung im modernen Staat, Gewerkschaftliche Monatshefte, 7.Jhg. (1956) S. 385 ff (392 f), der in der "sozialen Selbstverwaltung" eine Form der vertikalen Gewaltenteilung erkennen zu können glaubt.

4) Vgl. Huber, Wirtschaftsverwaltungsrecht, Bd.II, S.373 ff; Dietz, a.a.O. S.438 f mit weiteren Nachweisen. 
schon ihrer äußeren Rechtsnatur nach 1 : ̈̈६er öffentlicher Aufgaben. ${ }^{5)}$ Sie dürfen keinen $Z$ wangscharikit. haben ${ }^{6)}$ und auch selbst nicht unbeschränkt dahin wirker, daß alle Arbeitgeber bzw. A rbeitnehmer sich in ihnen organisieren. $\left.{ }^{7}\right)$ Sie erfassen daher nicht notwendig den ganzen in Frage stohenden Personenkreis. Sie sind dem Sozialleben nicht als staatlich errichtetes Organisationselement eingepflanzt. Der Zugang zu ihnen und das Wirken in ihnen darf denen, die sich darin formieren wollen, nur nicht vorenthalten werden. So scheint festzustehen, daß die Koalitionen, wie sie sich bisher dargestellt haben, bestenfalls an der Peripherie des Bildausschnittes beheimatet sind, den dieser Abschnitt der Untersuchung anzuleuchten hat. ${ }^{8)}$

5) S. zu diesem Problem auch Ballersiedt, Wirtschaftsverfassungs recht, S. 85 .

6) Dietz, a.a.O. S.436 mit eingeh. Nachw.

7) Das gilt vor allem dann, wenn man mit der zutreffenden h.L. die negative Koalitionsfreiheit nicht nur gegenüber dem Staat sondern auch gegenüber den Verbänden als geschützt ansieht (s.f.v.a. v. Mansoldt-Klein, a.a.O. Art.9 Anm.V 11 und 12; Dietz, a.a.O. S. 453 ff; Nikisch, Arbeitsrecht, 2. Auf1. Bd.II, 1959, \$.28 ff; je mit weit. Nachw.) Aber auch von dem Boden der gegenteiligen Ansicht aus - vor allem schon im Interesse der positiven Koalitionsfreiheit können die Berufsverbände nicht beliebig jedes Mittel anwen. den, um eine maximale Expansion \%u erzielen (s.hierzu die Darlegungen von Nipperdey, Lehrluch des Arbeitsrechts, Bd.II, 1957, S. $114 \mathrm{ff}, 274 \mathrm{f}$; Dieiz, a.a.O. S. $449 \mathrm{ff}$, insbes. Fußn. 114; Galperin, Organisationszwang und Koalitionsfreiheit, in "Sozialreform und Sozialr"cht" Festschrift für Wa1ter Bogs, 1959, S. 87 ff, insbes. S.90 fí ebenfalls je mit weiteren Nachweisen).

8) Im besonderen - wenngleich da: hit. nicht wesentlich ist sind sie nicht das, was die berufsctindischen Organisationen i.S. der katholischen Soziallchle : ind (.. hicr uben S.242): sie sind keine Leistungsgemeinschalten, die den ArbeitgeberArbeitnehmer-Gegensatz in sich aufleh:nen und aufheben sollen; sie sind auch keine $Z$ wangskripurationen, die infolge $Z$ wangsmitgliedschaft jeweils allo in lage kommenden Personen erfassen und somit keine Zwinchenräume lassen, die unkontrolliert bleiben oder vom state (subsidiär) ausgefüllt werden müssen. - Dafür, daß die haholische soziallehre den Koalitionen neben den berufsständischen korporationen eine notwendige Funktion bemißt, s. z.H. Messner, Die soziale Frage, S. 576 . 
Entscheidend dafür, die Koalitionen dennoch in diesem Zusammenhang zu sehen, ist die spezifische öffentliche Funktion, die ihnen kraft ihrer von der Koalitionsfreiheit mit umschlossenen Tarifmacht zukommt.

bb) Die Tarifmacht als Kernsubstanz der "sozialen Autonomie"

\section{aaa) Die Verfassungsgarantie}

Das Grundgesetz erwähnt die Tarifmacht nicht ausdrücklich. Ihren ersten Ansatz findet sie in der in Art.9 Abs. $3 \mathrm{GG}$ angelegten dualistischen Zuordnung der Koalitionen der Arbeitgeberseite und der Arbeitnehmerseite zueinander. Bedeutet sie zunächst ein Aufeinander-Einwirken, so findet, auf diesen Lagern ruhend, das Gewölbe der Koalitionsfreiheit seinen Schlußstein doch im Zusammenwirken beider Seiten. Die umstrittenen "Arbeits - und Wirtschaftsbedingungen" in Gesamtvereinbarungen zu ordnen, ist das notwendige Ziel der Interessenwahrung, wenn diese nicht - was durch Art. 9 Abs. 3 GG nicht gedeckt ist - von vorneherein auf die Vernichtung des "Gegners" abzielt und somit ein Arrangement mit ihm erübrigt. "Die historische Entwicklung hat dazu geführt, $\mathrm{da}$ solche Vereinbarungen in Gestalt geschützter Tarifverträge mit Normativcharakter und Unabdingbarkeit abgeschlossen werden". 1) Darum liegt in "Art.9 Abs. 3 GG ein verfassungs rechtlich

1) BVerfGE 4, 96 (106). - Im Anschluß an die zitierte Entscheidung des Bundesverfassungsgerichts hat sich ein Streit entsponnen, ob der Gesetzgeber in der Lage sein soll, Voraussetzungen dafür aufzustellen, unter denen Koalitionen den Schutz des Art.9 Abs. 3 GG genießen oder Tarifmacht für sich in Anspruch nehmen können. Ähnlich wie das Bundesverfassungsgericht nimmt Nikisch (Anm. zur Entscheidung des Bundesverfassungsgerichts, JZ 10. Jhg. (1955) S. 205 ff (206); Arbeits recht, 2. Aufl. Bd. II, 1959, S. 58 ff) eine Gestaltungsfreiheit des Gesetzgebers dahin an, daß er die Tarifhoheit (und andere Rechte) nicht einheitlich allen Koalitionen zugestehen muß sondern daß er - um einen ungenauen Ausdruck zu gebrauchen - ungeeignete Verbände davon ausschließen kann. Andere, vor allem Schnorr (Bundesverfassungsgericht und kollektives Arbeits recht, Recht der Arbeit, 8. Jhg. (1955) S. 3 ff), Nipperdey, Lehrbuch des Arbeits rechts, Bd. II, S. 106 ff und Dietz, a.a.O. S.461 sind dagegen der Meinung, daß der Begriff der Koalition durch Art.9 Abs. 3 GG verfassungsrechtlich vorgegeben ist und die Tariffähigkeit allen Verbänden zusteht, die sonach Koalitionen sind. Eine gewisse Gestaltungsfreiheit wird man dem Gesetzgeber aber nicht ab- 
geschützter Kernbereich auch in der Richtung..., daß ein Tarifvertragssystem im Sinne des modernen Arbeitsrechts staatlicherseits überhaupt bereitzustellen ist und daß Parteien dieser Tarifverträge notwendig freigebildete Koalitionen sind". 1) Die funktionale Betätigungsgarantie zugunsten der Koalitionen ${ }^{2)}$ wird so überhöht zu dem den Koalitionen jeweils verschiedener Frontseiten gemeinsam zukommenden, ${ }^{3)}$ dem Art. 9 Abs. 3 GG immanenten Recht, vermittels der Tarifverträge unmittelbar verbindliches, objektives Recht für die Arbeitsverhältnisse zwischen den jeweiligen Verbandsmitgliedern zu schaffen. ${ }^{4)}$

sprechen können, schon um seiner Ordnungsaufgabe willen. Art. 9 Abs. 3 GG allein gibt weder ein ganzes Koalitionsrecht noch ein ganzes Tarifrecht ab. Der Gesetzgeber muß die Grundlinien der Verfassung konkretisieren und ergänzen. Dabei ist ein wenngleich geringer Spielraum unentbehrlich. Zur Deutung des Art.9 Abs. 3 GG i.S. einer grundsätzlichen Garantie der Tarifmacht s.a. Ballerstedt, Wirtschaftsverfassungs recht, S.86. - Nachweise zu der überholten Lehre Meissingers und des Bayerischen Landesarbeitsgerichts, wonach der Gesetzgeber die Koalitions- (und Tarif-)fähigkeit auf sog. Fachgewerkschaften beschränken dürfe (und im Tarifrecht auch beschränkt habe) $s$. bei den Zitierten.

2) Vgl. die viel zitierten Worte E. R. Hubers (Wirtschaftsverwa1tungsrecht, Bd.II, S.381 f): Die Koalitionsfreiheit ist "ein korporatives Daseins- und Betätigungs recht der Berufsverbände selbst... In diesem ... Bestandteil bedeutet die Koalitionsfreiheit ein Grundrecht der Koalitionen auf Existenz und 'Tätigkeit im Sinne einer 'institutionellen und funktionellen $\mathrm{Ga}$ rantie" ".

3) Huber (a.a.O. S.433) spricht von einem "Rechtsetzungsrecht zur gesamten Hand".

4) (1) Dafür, daß Art.9 Abs. 3 GG verfassungsrechtliche Grundlage auch für die Tarifmacht der Koalitionen ist, s. außer BVerfG a.a.O. vor allem Huber, Wirtschaftsverwaltungsrecht $\mathrm{Bd}$.II, S. $444 \mathrm{ff}$; Meissinger, Grundlagen und Grenzen der gewerkschaftlichen Machtmittel, Recht der Arbeit, 9. Jhg. (1956) S. 401 ff, insbes. S.403, 405; Ballerstedt, a.a.O. S. 86; Dietz, a.a.O. S.480; Nikisch, Arbeitsrecht Bd. II S. 54 ff, insbes. S. $55 \mathrm{f}$.

(2) Eine andere Meinung will dagegen die Rechte der Koalitionen nicht nur aus Art. 9 Abs. 3 GG, der bisweilen sogar in Vergessenheit gerät, sondern aus einer Synthese der freiheitlichen demokratischen Grundordnung (Art.2, 9, 18, 21 GG) und des Sozialstaatsprinzips (Art.20 Abs.1, 28 Abs.1 GG) herlei- 
Fällt es demnach in den "Kompetenzbereich" der Tarifpartner, "Rechtsnormen, die den Inhalt, den Abschluß und die Beendigung des Arbeitsverhältnisses sowie betriebliche und betriebsverfassungsrechtliche Fragen regeln", 5) zu erlassen, so ist der staatliche Gesetzgeber doch nicht davon ausgeschlossen; auch nicht etwa schlechterdings insoweit, als die Träger der "sozialen Autonomie" selbst tätig werden. Das Sozialstaatsprinzip 6) und die Kompetenznorm des Art. 74 Nr. 12 GG lassen den übergreifenden Regelungsauftrag des Staates, dem er durch ein weitverzweigtes System großenteils zwingender arbeits- und betriebsverfassungsrechtlicher Normen permanent nachkommt, unschwer erkennen. 7) Der staatliche Gesetzgeber darf nur nicht so weit gehen, daß er den Koalitionen in der konkreten Gestaltung der "Arbeits- und Wirtschaftsbedingungen" definitiv, nichts Wesentliches mehr übrig lassend, vorgreift. ${ }^{8)}$ Seine Regelung muß in erster Linie Grundordnung bleiben. ${ }^{9}$ ) Der historisch fixierte Sinngehalt des Art. 9 Abs. 3 GG wird dabei vor allem verlangen, daß den Koalitionen die konkrete Ausmarktung von Leistung und Gegenleistung im Arbeitsverhältnis - also von Lohn, Arbeitszeit usw. - zugänglich bleibt.

\section{bbb) Zum Wesen der Tarifmacht}

Mit dieser nicht den einzelnen Koalitionen sondern den in dyarchischer Zuordnung der Arbeitnehmer- und Arbeitgeberseite labil aus den jeweils kontrahierenden Koalitionen (und evtl. Unterneh-

ten (Schnorr, Bundesverfassungsgericht und kollektives Arbeitsrecht, S. 5 ff; und vor allem Nipperdey, Lehrbuch des A rbeitsrechts Bd.II, S.30 ff). Auf die freiheitliche, demokratische Grundordnung verweist, ergänzend zu Art.9 Abs. 3 GG auch Nikisch (Arbeitsrecht Bd.II S.54). Doch kommt diesen Gesichtspunkten nicht die gleiche, für die "soziale Selbstverwaltung" schlechthin fundamentale Bedeutung $z u$, die Art. 9 Abs. 3 GG beigelegt werden muß (s. hierzu auch noch unten Abschnitt 3 I 2 a (S.329) und IV (S.390 ff);

Abschnitt 5 II 3 b (S. $741 \mathrm{ff}$ ) und (S. 789).

5) $₫ 1$ Abs. 1 TVG.

6) S. unten S.789.

7) S.a. unten dd (S.302 ff).

8) S. S.289 zu Fußn. 1 und 2; insbes, auch Ballerstedt, a.a.O. S. 86 .

9) S. insbes. unten S. 310 . 
mern) gebildeten Tarifgemeinschaften 1) zustehenden Gestaltungsmacht ist das Wesen dessen angesprochen, was als "soziale Autonomie" und "soziale Selbstverwaltung" bezeichnet zu werden pflegt. 2) Durch sie werden die Koalitionen zu potentiellen Trägern einer eminent "öffentlichen" 3) Aufgabe, die der Staat aufgreifen

1) Bogs (Autonomie und verbandliche Selbstverwaltung im modernen Arbeits- und Sozialrecht, Recht der Arbeit, 9. Jhg. (1956) S. 1 ff (abgedruckt auch in "Hessische Hochschulwochen für staatswissenschaftliche Fortbildung" Bd.9, 1956, S. $334 \mathrm{ff}$ ) (5)) spricht insofern von der "Tarifgemeinschaft" als einer "zur autonomen Rechtsetzung fähigen Gemeinschaft" (s.a. oben S. 287 zu Fußn. 3). Ein Anklang an das Leistungsgemeinschaftlich-berufsständische ist nicht zu verkennen ( $\mathrm{s}$. o. S. 288 zu Fußn. 8). Nicht zu Unrecht mahnt aber Abendroth (Diskussionsbeitrag in "Gegenwartsprobleme sozialer Versicherung" hrsg. v. Walter Bogs, 1950, S. $201 \mathrm{ff}(203 \mathrm{f}$, 209)), "die Ideologie der Sozialpartnerschaft" sei "nicht nur abwegig sondern gefährlich". Arbeitgeber und Arbeitnehmer seien und blieben "soziale Gegenspieler".

2) Literarischer Protagonist des Begriffs und der Idee der sozialen Selbstverwaltung ist - mit Irrungen im Detail, doch unter Förderung der Grundgedanken - Meissinge r, s.dessen folgende Veröffentlichungen: Tarifhoheit in der sozialen Selbstverwaltung, Recht der Arbeit, 4.Jhg. (1951) S. 46 ff; Gewerkschaftsmonopol in der sozialen Selbstverwaltung? Betrieb, 4.Jhg. (1951) S. 445 ff; Reliefbild des Arbeitsrechts, 1952, S. 16 ff; Müller - M., Probleme des Koalitionsrechts in der sozialen Selbstverwaltung, 1953; Koalitionsrecht - ein Mittel zum Zweck der sozialen Selbstverwaltung, Arbeit und Recht, 2.Jhg. (1954) S. 65 ff; Soziale Selbstverwaltung im Fachprinzip, Arbeit und Recht, 3.Jhg. (1955) S. 1 ff; Grundlagen und Grenzen der gewerkschaftlichen Machtmittel; Die Gewerkschaften im staatsfreien Raum der sozialen Selbstverwaltung, Arbeit und Recht, 3. Jhg. (1955) S.339 ff. - An speziellen Erörterungen s. ferner Sitzler, Soziale Selbstverwaltung im demokratischen Staat, Sozialer Fortschritt, 1.Jhg. (1952) S. 73 ff; Bogs, Autonomie und verbandliche Selbstverwaltung im modernen Arbeits - und Sozialrecht; Erdmann, Die soziale Selbstverwaltung in ihrer rechts- und staatspolitischen Bedeutung, in "Sozialpolitik, Arbeits- und Sozialrecht", Festschrift für Friedrich Sitzler, 1956, S. 43 ff; Gesamtdarstellungen s. z.B. bei Nipperdey, Lehrbuch des Arbeitsrechts, Bd.II, S. 21 ff; Nikisch, Arbeitsrecht, Bd.II, S. 43 ff; je mit weit. Nachw.

3) Zum Öffentlichkeitscharakter s.z.B. Nikisch, a.a.O. 
muß, soweit die berechtigten Verbände sie nicht zureichend erfüllen. 4) Dem staatskomplementären Charakter dieser den Verbänden eröffneten Funktion entspricht es, daß ihr spezifisches Instrument, die tarifvertragliche Rechtsetzung, das im Rahmen der allgemeinen privaten Verbandsautonomie quantitativ Übliche und qualitativ Mögliche verläßt ${ }^{5)}$ und nach Geltungs- und sonstiger Wirkungsweise die Nachbarschaft staatlicher Gesetzgebung erreicht. 6)

S. 45 ff; Bogs, Zur Entwicklung und Rechtsform des Tarifvertrags, in: Festschrift für Julius Gierke, 1950, S. 39 ff, insbes. S. 52 ff; Herbert Krüger, Staatliche Gesetzgebung und nichtstaatliche Rechtsetzung, Recht der Arbeit, 10.Jhg. (1957) S. $201 \mathrm{ff}$ (203); Ballerstedt, Wirtschaftsverfassungsrecht, S.86; s.a. Kaskel-Dersch, Arbeitsrecht, 5. Aufl. 1957, S. 277; stärker differenzierend Erdmann, a.a.O. S. 44 f, 49; für einen Status der Koalitionen als "anerkannte öffentliche Verbände" Scheuner, Wirtschaftliche und soziale Selbstverwaltung, S.611. Zur Frage eines Status als (öffentlichrechtlich) "beliehene" Verbände s. noch unten S. 297 zu Fußn. 20. S. zum Öffentlichkeitscharakter auch die S. 292 zu Fußn.2 Zitierten. - Dürig (Maunz-Dürig, Art. 1 Abs.III, Randn.116) glaubt, allerdings im Hinblick auf die strenge Kategorie des öffentlichen $R$ echts, die Tarifverträge damit in die rein private Sphäre abschieben zu können, daß er sie als "do ut des"-Verträge bezeichnet. Der Maßstab des öffentlichen Rechts sei hier nicht angelegt (s.hierzu unten S. 297 zu Fußn. $20)$. Der Gedanke verdient auch unter dem allgemeineren Gesichtspunkt des Öffentlichen Beachtung. Ihm wäre zunächst entgegenzuhalten, daß der Gedanke des do ut des dem öffentlichen Leben nicht fremd ist (zur Problematik und Deutung s.a. Krüger, a.a.O. S.203 f). Aber dieses Motiv, aus dem heraus die 'Tarifmacht möglicherweise gehandhabt wird, darf die objektive Funktion nicht vergessen lassen. Das Bundesverfassungsgericht hat sie zutreffend umschrieben, indem es sagt, "daß einer der Zwecke des Tarifvertragssystems eine sinnvolle Ordnung des Arbeitslebens, insbes. der Lohngestaltung, unter Mitwirkung der Sozialpartner sein soll" (BVerfGE 4, 96 (107)). Somit liegt im Abschluß von Tarifverträgen die "gemeinsam von Arbeitgebern und Arbeitnehmern durchgeführte Erfüllung einer wirtschafts- und sozialpolitischen Aufgabe größten Ausmaßes" (Bogs, Zur Entwicklung und Rechtsform des Tarifvertrags, S. 55).

4) S. oben S. 287 und unten dd (S. $302 \mathrm{ff}$ ).

5) S. hierzu unten S.295 ff zu Fußn. 15-20. 
Dennoch - und zwar bezeichnenderweise - ist tarifvert raglich gesetztes Recht 7) nicht staatliches Recht. ${ }^{8)}$ Die "Staatsferne"19) gehört zum Wesen der "sozialen Autonomie". 10) Die Koalitionen stehen auch als Träger der Tarifmacht in keinem organisatorischen Zusammenhang mit dem Staat, der es erlauben würde, ihm ihren Willen zuzurechnen. Insbes, unterliegen sie nicht der Aufsicht des Staates. 11)

Tarifvertrags recht ist auch nicht autonomes Recht im Sinne herkömmlicher öffentlichrechtlicher Autonomie. 12) Die Gewerkschaf-

6) Vgl. insbes. Herbert Krüger, Staatliche Gesetzgebung und nichtstaatliche Rechtsetzung. S. ferner etwa Hans Huber, Staat und Verbände, S. $7 \mathrm{f}$ : "Rechtlich bedeutet er (scil. der Tarifvertrag) ... Erschließung einer neuen Rechtsquelle. Aus ihr fließt kraft staatlicher Ermächtigung, jedoch in der Staatsferne, ein selbständiges Recht. Der Tarifvertrag erscheint in seinem Zwielicht jedoch auch als ein Surrogat und zugleich als ein angriffiger Widersacher und Nebenbuhler des staatlichen Gesetzes".

7) Zusammenfassende Darstellung der Entwicklung und des Standes der Meinungen über die Rechtsnatur des Tarifvertragsrechts s. z. B. bei Huber, Wirtschaftsverwaltungsrecht, Bd. II S. $424 \mathrm{ff}$; Nipperdey, Lehrbuch des Arbeitsrechts, Bd. II, S. 424 ff (besonders reich belegt); Nikisch, Arbeitsrecht Bd. II, S. $213 \mathrm{ff}$.

8) Zur älteren, nie zu Bedeutung gelangten These, die Tarifverträge seien Rechtsverordnungen gleichzusetzen (Dechant) s. z. B. Klein, Verordnungsermächtigungen im Deutschen Verfassungs recht, in "Die Übertragung rechtsetzender Gewalt im Rechtsstaat", Wissenschaftliche Schriftenreihe des Instituts zur Förderung öffentlicher Angelegenheiten e.V., Bd. 12 (1952) S. 7 ff (112 f) mit weit. Nachweisen.

9) S. Huber a.o. (Fußn.6) a.O.

10) S. Huber ebd.; ferner die Nachweise oben S. 292 zu Fußn. 2.

11) "Ein vom Staat abhängiger oder von ihm kontrollierter Verband ist keine Koalition" (Dietz, a.a.O. S. $435 \mathrm{f}$ - Zitat S.436). Ist ein Berufsverband öffentlichrechtlich organisiert, so unterliegt er zwar der Staatsaufsicht. Diese muß aber auf reine Legalitätskontrolle beschränkt sein, den Verbänden "die Selbstverwaltung ihrer eigenen Angelegenheiten, insbes. die unabhängige Wahrung der Interessen ihrer Mitglieder überlassen" (Huber) und "sich jeden Eingriffs in das Leben des Verbandes enthalten" (Dietz) (vgl. Huber, a.a.O. S.374, s.a. S. 369; Dietz, a.a.O. S. 438 f).

12) S. hierzu und zum unmittelbar Folgenden: Peters, Die Sat- 
ten und Arbeitgeberverbände sind keine öffentlichrechtlichen Personenverbände. 13) Vor allem setzen vermittels der Tarifmacht nicht, wie es für die herkömmliche Autonomie typisch ist, verbandsinterne Autoritäten Recht für die Verbandsmitglieder, sondern die Verbände zusammen setzen Recht jeweils auch für Dritte, nämlich für alle Mitglieder jeweils auch der anderen kontrahierenden Verbände. Daran, daß von "Autonomie" und "Selbstverwaltung" - wenn überhaupt - nur im übertragenen Sinne die Rede sein kann, besteht kein Zweifel. 14)

Aber es hieße das Kind mit dem Bade ausschütten, wenn deshalb die Besonderheit, die die Tarifmacht auszeichnet und in die Nähe öffentlichrechtlicher Machtentfaltung rückt, übersehen würde: Die Fähigkeit der Tarifparteien, durch Vereinbarung Recht zu setzen, das nicht nur in jedem Verband verbandsintern gilt sondern auch für die Mitglieder der verschiedenen Verbände untereinander unmittelbar verbindlich ist. Diese Befugnis kann mit allgemeiner privater Verbandsautonomie nicht mehr erklärt werden. 15) Ist daher an der Delegationstheorie 16) an sich schon je-

zungsgewalt innerstaatlicher Verbände, in Handbuch des deutschen Staats rechts, Bd. II, 1932, S.204 ff (269); Bogs, Zur Entwicklung der Rechtsform des Tarifvertrags, insbes. S. 60; Klein, a.a.O. S. $111 \mathrm{f}$; ders., Rechtsgutachten über verfassungs rechtliche Fragen des Urteils des Bundesarbeitsgerichts vom 2. März 1955 - betreffend Lohngleichheit von Mann und Frau, 1955, S. 19 f; Huber, Wirtschaftsverwaltungs recht Bd.II, S. 428 f; Böckenförde, Der allgemeine Gleichheitssatz und die Aufgabe des Richters, 1957, S. 12; je mit Nachweisen aus dem älteren Schrifttum. S. ferner Dürig in Maunz-Dürig, Grundgesetz, Art. 1 Abs. 3 Randn. 115 ff.

13) S. oben S.287f zu Fußn. 4 und 5 und S. 289 zu Fußn. 1.

14) S. zur Begriffskritik: Scheuner, Wirtschaftliche und soziale Selbstverwaltung, S.611; Huber, Wirtschaftsverwaltungsrecht, Bd.II, S.379 ff; Erdmann, Die soziale Selbstverwaltung in ihrer rechts- und staatspolitischen Bedeutung, S.45; Nipperdey, Lehrbuch des Arbeitsrechts, Bd.II, S.21; Nikisch, Arbeitsrecht, Bd.II, S. $47 \mathrm{f}$.

15) (1) Zunächst zu diesem Punkt zwei Erwägungen: (a) Wenn die Normsetzungsbefugnis der Tarifparteien nichts anderes wäre als Ausfluß ihrer jeweiligen Verbandsautonomie, so hätten schon die Tarifverträge, die vor der ersten Sonderregelung durch die Verordnung über Tarifverträge, Arbeiter- und Angestelltenausschüsse und Schlichtung von Arbeitsstreitigkeiten vom 23. Dezember 1918 geschlossen wurden, dieselbe unmittelbare (oder gar unabdingbare) Wirkung auf die Einzelar- 
denfalls so viel richtig, daß die Rechtsetzungsmacht der Koalitionen einer Ermächtigung im staatlichen Recht bedarf, weil sich innerhalb der staatlichen Rechtsordnung keine andere Rechtset-

beitsverhältnisse haben müssen, die sie seither haben; denn was die Tarifpartner auf Grund der allgemeinen Verbandsautonomie vermochten, vermochten sie auch schon vor 1918 . Diese Wirkung der Tarifverträge fehlte aber damals (s.f.v. a. Sinzheimer, Der korporative Arbeitsnormenvertrag, Teil 2, 1908, S.21 ff, $31 \mathrm{ff}$; ders., Rechtsfragen des Arbeitstarifvertrags, 1913, S.21 ff; s.a. "Tarifvertragsrecht - Einigungswesen" Verhandlungen der Gesellschaft für soziale Reform, Schriften ders. Bd. 5, Heft 4/5 (1914) S. 18 ff u. passim; aus der Sicht nach Erlaß der. Tarifverordnung s. insbes. Hueck, Das Recht des Tarifvertrages, 1920, S.94 ff (mit eingeh. Nachw.); ders., Normenverträge, Jherings Jahrbücher, Bd. 73 (1923) S. 33 ff ( 85 ff); unrichtig Schnorr, Bundesverfassungsgericht und kollektives Arbeitsrecht, S. 8). Die unabdingbare und unmittelbare Geltung beruht also auf dem besonderen staatlichen Tarifvert rags recht.

(b) Die Überzeugungskraft der Verweisung auf die privatrechtliche Verbandsautonomie leidet auch darunter, daß gerade die Charakterisierung als öffentlichrechtliche Autonomie mit dem Hinweis darauf abgelehnt wird, das von den Verbänden gemeinsam mit Verbindlichkeit für die Mitglieder vertrag. lich gesetzte Recht sei nicht dem verbandsintern für die Mitglieder eines Verbandes gesetzten Recht gleichzustellen. Ist dieser Einwand nicht auch für die private Autonomie zu beachten? Die Stellung der privatrechtlichen Verbände ist hierin nicht anders als die der öffentlichrechtlichen. - Zum Text s. a. Scheuner, Ausländische Erfahrungen zum Problem der Übertragung rechtsetzender Gewalt in "Die Übertragung rechtsetzender Gewalt im Rechtsstaat" usw. S. 118 ff (145). (2) Zahlreiche weitere Argumente für die Überschreitung der privaten Verbandsautonomie durch die Tarifmacht $s$. bei Bogs, a.a.O. S. 52 ff; s.a. Laufke, Vertragsfreiheit und Grundgesetz, in "Das deutsche Privatrecht in der Mitte des 20. Jahrhunderts", Festschrift für Heinrich Lehmann, Bd.I, 1956, S. 145 ff (182 Fußn. 140 a. E.).

16) Führend vertreten wird sie vom Bundesarbeitsgericht (BAGE 1, 258 (264), 348 (352 ff); 4, 240 (251 f)). Sie liegt auch der Entscheidung des Bundesverfassungsgerichts (BVerfGE 4, 96) zugrunde (s. insbes. S. 108). Im Schrifttum s.insbes. Meissinger, Tarifhoheit in der sozialen Selbstverwaltung, S.49; ders., Gewerkschaftsmonopol in der sozialen Selbstverwaltung? S. 445; ders., Reliefbild des Arbeitsrechts, S. 17 f; 
zungsmacht als die des Staates von selbst versteht, 17) so muß ihr also darüber hinaus zugegeben werden, daß die den Tarifpartnern erteilte Ermächtigung 18) inhaltlich den üblichen Rahmen privater Verbandsautonomie verläßt.19) Ob das nun Anlaß gibt, in ihr eine Erscheinung des öffentlichen Rechts zu sehen, 20) ist eine

ders., Koalitionsrecht - ein Mittel zum Zweck der sozialen Selbstverwaltung, S.67; E.R. Huber, Wirtschaftsverwaltungsrecht, Bd.II, S. 427 ff; Hildegard Krüger, Anm.zu BAG Urt. v. 15. Januar 1955- 1 AZR 305/54, NJW 8. Jhg. (1955) S.684 ff (685); Laufke, a.a.O. S. 181 f; Herbert Krüger, Staatliche Gesetzgebung und nichtstaatliche Rechtsetzung, S. 202 f; Nipperdey, (insbes.in:) Lehrbuch des Arbeitsrechts, S.22, 141 ff, 262 f; Nikisch, Arbeitsrecht Bd.II, S. 43 ff, insbes. S. 46 f; s.a. Hans Huber, Staat und Verbände, S. 9 f. - Die Gegenmeinung wird vor allem vertreten von Klein, Verordnungsermächtigungen nach deutschem Verfassungsrecht, $\mathrm{S} .111 \mathrm{f}$, 117; ders., Rechtsgutachten über verfassungsrechtliche Fragen des Urteils des Bundesarbeitsgerichts vom 2. März 1955, S. 18 ff; Böckenförde, Der Allgemeine Gleichheitssatz und die Aufgabe des Richters, S. 12; Dürig in Maunz-Dürig, Grundgesetz, Art. 1 Abs. 3 Randn. 115 ff. S.hierzu auch Erdmann, Die soziale Selbstverwaltung in ihrer rechts- und staatspolitischen Bedeutung, S.44 f.

17) Vgl. die nüchterne Betrachtung des Problems unter diesem Gesichtspunkt bei Nawiasky, Rechtsfragen des wirtschaftlichen Neuaufbaus, S. 16 ff, 43 ff; s.a. Beitzke, Anmerkung z. BAG Urt. v. 15. Januar 1955 - 1 AZR 305/54 -, AP Art. 3 GG Nr. 4.

18) Diese Ermächtigung ist positivrechtlich primär im Tarifvertragsgesetz zu sehen (s. Herbert Krüger, a.a.O. S.203). Aber dieses stellt seinerseits nur einen Ausfluß der Verfassungsnorm des Art.9 Abs. 3 GG dar. Enthält diese nicht an sich schon ein Tarilvertrags recht im heutigen Sinne und ist der gesetzlichen Frgänzung bedürftig, so muß andererseits der Gesetzgeber das Tarifvertragsrecht gewähren und kann es nicht beseitigen ( $s$. BVerfGE 4, 96 (106 ff); s. ferner nochmals oben aa (S.287 ff) a. E.).

19) S. nochmals oben S. 295 zu Fußn. 15.

20) Huber (Beliehene Verbände, DVB1. 67.Jhg. (1952) S. 456 ff (458 f); Wirtschaftsverwaltungs recht Bd.II, S. $376 \mathrm{ff}$, insbes. S.379 ff) - der auch die öfentlichrechtliche Einordnung der Tarifverträge selbst relativ weit vorantreibt (Wirtschaftsverwaltungsrecht $\mathrm{Bd}$.II, S.431 ff) und die Tarifmacht als "öffentlichrechtliche Befugnis" und "subjektiv öffentliches Recht" 
Qualifikationsfrage von sekundärer Bedeutung. 21)

und zwar nicht als "bloßes Freiheitsrecht" sondern als "hoheitliches Gestaltungs recht", als "status aktivus" und "echte Tarifhoheit" qualifiziert (a.a.O. S.446) - und ihm folgend Nipperdey (Lehrbuch des Arbeitsrechts Bd.II, S. 143) halten die Koalitionen für "beliehene Verbände". Herbert Krüger (Die Stellung der Interessenverbände, NJW 9. Jhg. (1956) S. $1217 \mathrm{ff}$ (1219)) ist dagegen der Ansicht, daß die staatsähnliche Rechtsetzungsmacht mit der Rechtsfigur der Beleihung nicht hinreichend gedeutet werden kann. Dem wird beizutreten sein. Die Rechtsfigur des beliehenen Verbandes läßt ebenso wie die Überbetonung der "Delegation" der Tarifhoheit vom Staat auf die Koalitionen die causa ihrer Position, A rt. 9 Abs. 3 GG, zu sehr in den Hintergrund treten (s.hierzu a. Meissinger, Reliefbild des Arbeitsrechts, S. 17). - Scheuner (Wirtschaftliche und soziale Seibstverwaitung, S.611) der die Anwendung des Begriffes der Selbstverwaltung auf die hier als soziale Selbstverwaltung angesprochene Erscheinung ablehnt - will den Gewerkschaften und Arbeitgeberverbänden aber den Status anerkannter öffentlicher Verbände beilegen. - Dagegen zeichnet sich der Gedanke einer rein privatrechtlichen Deutung bei Dürig (a.a.O. Randn. 116) ab: Die Normen des Tarifvertrags seien keine "hoheitlichen Normen" sondern "Normen, deren Setzung durch $₫ 1$ TVG der Privatautonomie überlassen und den arbeitsrechtlichen Koalitionen wegen Art. 9 III letztlich auch belassen werden $\mathrm{mußt}$ ". Er sieht offensichtlich zwischen "übertragen" (delegieren) und "überlassen" einen wesentlichen Unterschied (insofern ähnlich Bogs, a.a.O. S.60). Für privatrechtliche Qualifikation auch Schmidt-Rimpler-GiesekeFriesenhahn-Knur, Die Lohngleichheit von Männern und Frauen, AöR Bd.76 (1950/51) S. 165 ff (177 f). - Zum Problem s. ferner Nawiasky, a.a.O.

21) Gerade die Diskussion um Folgerungen, die man an die Rechtsnatur der Tarifmacht knüpfte, hat die Erörterung des Problems selbst stark verzerrt. Nicht nur für die Grenzziehung öffentliches/privates Recht gilt das. Heute steht die Debatte vor allem unter dem Stern der Grundrechtsgeltung für Tarifverträge (Art.1 Abs. 3 GG), bei der man beliebt, je nachdem, welches Ergebnis für richtig gehalten wird, schon in der Konstruktion und Klassifizierung der Tarifmacht den entsprechenden Grund der Argumentation zu legen (s.insbes. das Bundesarbeitsgericht, Herbert Krüger, Hildegard Krüger, Nipperdey, Klein (Gutachten), Böckenförde, Dürig - wie oben S. 296 zu Fußn. 16 zitiert-). 


\section{cc) Der weitere Kreis der "sozialen Selbstverwaltung"}

aaa) Das Umfeld der Tarifmacht: Arbeitskampf und Schlichtung

Die Rechtsetzung durch Gesamtvereinbarung ist die Kernzone der sozialen Selbstverwaltung. Von hier aus breitet sie sich aus zu den Randfeldern, über die hin die Wege zur Gesamtvereinbarung führen und deren staatliche Okkupation schließlich die Freiheit des normativen Kollektivvertrages abwürgen müßte.

In erster Linie ist zu nennen das $\mathrm{Sch} 1 \mathrm{i} c \mathrm{ht} u \mathrm{ngs}$ we sen. Eine beliebige staatliche $Z$ wangsschlichtung würde die soziale Autonomie aushöhlen. Der Staat darf einen Schlichtungsanspruch nur dort für (allgemein oder fallweise) verbindlich erklären - und somit die Tarifhoheit der Koalitionen sistieren -, wo die "Sozialpartner" ihrer Aufgabe nicht gerecht werden, wo nämlich ihre Nichteinigung zu einem unmittelbaren und akuten Notstand führt, der die Lebensinteressen der Gesamtbevölkerung bedroht. 1) Schon bei der

1) (1) Zur Zugehörigkeit des Schlichtungswesens zur sozialen Selbstverwaltung s.z.B. Meissinger, Reliefbild des Arbeitsrechts, S. 29; Nipperdey, a.a.O. S. 22 f; Nikisch, Arbeitsrecht, Bd.II, S. 48; ders., Die Schlichtung von Arbeitsstreitigkeiten, in "Hundert Jahre deutsches Rechtsleben", Festschrift Deutscher Juristentag, Bd. II 1960, S. $317 \mathrm{ff}$, insbes. 340 f. Vgl. ferner Art. I Abs. 1 KRG Nr. 35. S. dagegen Huber, Wirtschaftsverwaltungs recht Bd. II, S. 463 .

(2) Dafür, daß die Zwangsschlichtung grundsätzlich unzulässig, im Falle eines Notstandes jedoch zulässig ist, s. Fechner, Sozialer Rechtsstaat und A rbeitsrecht, S. 163; Müller, Gedanken zur Systematik des Schlichtungsrechts, Die Dritte Gewalt, VI.Jhg. (1955) Heft 7/8, S. 8 ff (16 f). Nipperdey, a.a.O. S. 22 f, 32, 36, 535 ff; Nikisch, Arbeitsrecht, Bd. II, S. 57; Küchenhoff, Das Prinzip der staatlichen Subsidiarität im Arbeitsrecht, Recht der Arbeit, 12. Jhg. (1959) S. 201 ff (206). Für eine weitergehende Zulässigkeit s. Huber, a.a.O. S.454, 462; ähnlich Hessel, Staatliche Schlichtung? Arbeits- und Sozialrecht, 1953, S.268 f; Cornellsen, Über das Recht zur Schlichtung von Arbeitsstreitigkeiten, A rbeit und Recht, 3. Jhg. (1955) S. 41 ff, insbes. S. 44 f; Ziegler, Selbstverantwortliche Schlichtung in der Sackgasse, Sozialer Fortschritt 9. Jhg. (1960) S. $101 \mathrm{ff}$. Auch Nikisch scheint nunmehr (Die Schlichtung von Arbeitsstreitigkeiten, S.340 f) die verfassungsrechtlichen Grenzen der Zwangsschlichtung lockerer zu sehen, hat jedoch gegen die Ausdehnung des $Z$ wangs rechtspolitische Bedenken. - Weitergehend als die h. L. gegen die Zulässigkeit von Zwangsschlichtung Kunze, Verfassungswidriger Zwang 
Regelung des Schlichtungsverfahrens wird er - z.B. in bezug auf die Einlassungspflicht 2) - eine gewisse Zurückhaltung üben müssen, die die Selbstverantwortlichkeit der Koalitionen schont.

Der Kernzone der Tarifhoheit vorgelagert ist auch der Bereich des Arbeitskampfes, letztlich also des Streiks und der Aussperrung. ${ }^{3)}$ Anders als hinsichtlich des Schlichtungswesens, dessen Extrem, die verbindliche $Z$ wangsschlichtung, mit der obrigkeitlichen Satzung von Tarifordnungen der Sache nach in eins zusammenfällt, bedeutet eine gesetzliche Regelung des Arbeitskampfes und eine Beschränkung der Kampfmittel und ihres Gebrauches noch nicht eine Beschränkung der Tarifautonomie. Eine limitierende Ordnung des Arbeitskampfes, wie sie von der herrschenden Ansicht auch sonst für zulässig gehalten wird, 4) wäre daher auch unter dem hier leitenden Gesichtspunkt nicht zu beanstanden. Die Regelung wird aber darauf zu achten haben, daß sie den Koalitionen nicht die Möglichkeit nimmt, die "Arbeits- und Wirtschaftsbedingungen" $\mathrm{zu}$ wahren und zu fördern;5) insbes. wird sie nicht das der Idee der Tarifautonomie zugrunde liegende Gleichgewicht der beiden Seiten durch einseitig schwächende Maßnahmen zerstören dürfen. 6)

zur Schlichtung, Sozialer Fortschritt 9.Jhg. (1960) S.98 ff.

2) Nipperdey (a.a.O. S.537) will die Einlassungspflicht denselben strengen Voraussetzungen unterwerfen, denen der verbindliche Schiedsspruch unterliegt (ähnlich offenbar Müller, a.a.O. S. 17), Nikisch, Arbeitsrecht Bd.II, S. 57 f, will im Prinzip mit Recht die Einlassungspflicht nicht so eng begrenzt wissen; denn sie ist der erheblich weniger tiefgehende Eingriff (s.a. dens., Die Schlichtung von Arbeitsstreitigkeiten, S. $240 \mathrm{f})$.

3) Im engeren Sinne kann der Arbeitskampf allerdings nicht zur sozialen "Selbstverwaltung" gerechnet werden (vgl. Nikisch, a.a.O. S.49). Es steht hier aber der unleugbare funktionale Zusammenhang zwischen der Ellbogenfreiheit im Arbeitskampf und der Ausnutzung der Tarifmacht in Frage; (s.hier$\mathrm{zu}$ auch Meissinger, Koalitionsrecht - ein Mittel zur sozialen Selbstverwaltung, S.66 f).

4) Vgl. Wernicke im Bonner Kommentar, Art. 9 Anm. II 3 d; Hamann, Das Grundgesetz, Art.9 Anm. C 9; v. MangoldtKlein, Das Bonner Grundgesetz, Art. 9 Anm. VII; Dietz, Die Koalitionsfreiheit, S. 462 ff; bei diesen auch weitere Nachweise und Darstellung des Streitstandes.

5) S. z.B. Nipperdey, a.a.O. S. 37, 104 f, 615; Ballerstedt, Wirtschaftsverfassungs recht, S. $86 \mathrm{f}$.

6) Gegen die einseitige Behinderung der Aussperrung s. Nipperdey, a.a.O. S. 30, 619 . 
bbb) Der Ausstrahlungsbereich der "sozialen Selbstverwaltung"

Den Berufsverbänden kommen vielfältige Wirkungsmöglichkeiten $\mathrm{zu}$, die nicht auf den Abschluß von Gesamtvereinbarungen ausgerichtet sind. In der politischen Selbstverwaltung ist ihnen breiter Raum gewährt. Auch im Rahmen der sog. rechtlichen Selbstverwaltung üben sie als Träger von Wahlvorschlägen u.dgl. nachhaltigen Einfluß aus. In umfassender Weise wirken sie selbst und die von ihnen in die verschiedenen Gremien delegierten Vertrauensleute an Gesetzgebung, Verwaltung und Rechtsprechung mit. 1) Ein dichtes Netz teils voluminöser Kanäle führt so von den Koalitionen zu den Endpunkten staatlicher Willensbildung und zwar vor allem dort, wo soziale Anliegen in Frage stehen.

Die Postulationsfähigkeit vor den Arbeitsgerichten und Sozialgerichten ( $\$ 1$ ArbGG, $₫ 166$ SGG) ermöglicht es den Verbänden nicht nur, die Arbeits- und Wirtschaftsbedingungen ihrer Mitglieder auch durch die Vertretung vor Gericht zu wahren und $\mathrm{zu}$ fördern, sondern stellt auch eine weitere Quelle des Einflusses der Koalitionen auf diese Gerichtszweige, vor allem auf die Arbeitsgerichte dar.

Ein außerordentlich wichtiger Kompetenzbereich der Gewerkschaften liegt in den Positionen, die ihnen das Betriebsverfassungsgesetz, 2) das Personalvertretungsgesetz und das (engere) Mitbestimmungs recht eingeräumt haben.

Aber das alles ist hier schon nur mehr am Rande zu erwähnen. In Ausübung dieser Befugnisse wirkt jede Koalition bzw. jede Seite der Front der Koalitionen für sich. Auch dort, wo die Beteiligung paritätisch ausgewogen ist, ist dieser Wirkungsbereich und diese Wirkungs weise nicht gleichzustellen mit dem selbstverantwortlichen, gemeinsamen, exklusiven Zusammenwirken der beiderseitigen Koalitionen zur Erledigung der ihnen überlassenen Aufgaben. Es mag sein, daß ihnen ihre eigenverantwortlich gestaltende Anteilnahme am öffentlichen Leben eine besondere rechtspolitische Legitimation für die Zuteilung weiterer Einflußchancen und Wirkungsmöglichkeiten verleiht. Aber ein wesensmäßiger. Zusammenhang dieser Kompetenzen mit dem Recht auf soziale Selbstverwaltung in dem engeren, auf die Gestaltung der

1) Eine Zusammenstellung s. bei Nipperdey, a.a.O. S. $144 \mathrm{ff}$; eingehender, wenngleich speziell für die Organisationen der Arbeitnehmerseite: Drews, Die Gewerkschaften in der Verwaltungsordnung, 1958 .

2) S. z.B. Dietz, Das Monopol der Sozialpartner und die Betriebsvereinbarung, Recht der Arbeit 8. Jhg. (1955) S. $241 \mathrm{ff}$. 
"A rbeits- und Wirtschaftsbedingungen" durch Gesamtvereinbarungen hinauslaufenden Sinn besteht nicht. 3) Auch Art.9 Abs. 3 GG schließt eine Garantie dieser Position jedenfalls in ihrer gegenwärtigen Ausgestaltung nicht ein. ${ }^{4)}$ Beim Mitbestimmungsrecht wird allerdings zu berücksichtigen sein, daß Art. 9 Abs. 3 GG zwar das Mitbestimmungs recht nicht garantiert, daß die rechtliche Regelung aber auch nicht jeden Einfluß der Gewerkschaften ausschließen kann, ohne sie eines zur Wahrung und Förderung der Arbeits- und Wirtschaftsbedingungen unerläßlichen Mediums zu berauben. $\left.{ }^{5}\right)$

dd) Die Rahmen-, Kontroll- und Subsidiärverantwortung des Staates

aaa) Allgemeines

Die "soziale Selbstverwaltung" entspringt der Koalitionsfreiheit, also einem - wenigstens in erster Linie - gegen den Staat gerichteten Freiheits recht. Sie ist nicht mittelbare Staatsverwaltung sondern Komplementfunktion der "bloß subsidiären Rolle des Staates..., die erhebliche soziale Räume ganz der freien Gestaltung der mächtigen Gruppen überlassen" muß. 1) Sie steht nicht

3) Verschiedentlich wird allerdings das alles unterschiedslos zur sozialen Selbstverwaltung gerechnet (Schnorr, Bundesverfassungs gericht und kollektives Arbeitsrecht, S. $8 \mathrm{f}$;

Nipperdey, a.a.O. S.22 ff, 36 f). S. dagegen Nikisch, a.a.O. $\mathrm{S} .47 \mathrm{ff}$. Auch Meissinger (Reliefbild des Arbeitsrechts, S. 29 f) unterscheidet.

4) Vg1. Dietz, Die Koalitionen, S. 462; Nikisch, a.a.O. S.47 ff. Schnorr (a.a.O. S. 8 f) und Nipperdey (a.a.O. S.24) behaupten für die Postulationsfähigkeit allerdings das Gegenteil. Doch ist ein überzeugender Grund dafür schlechthin unerfindlich (s.a. Dietz, ebd.).

5) Schnorr (a.a.O.S.8 f) und Nipperdey (a.a.O. S.22, 36 f) $z$ ählen die Mitbestimmung unter gewerkschaftlicher Beteiligung nicht nur zur Gesamterscheinung der sozialen Selbstverwaltung sondern auch zu deren verfassungs rechtlich garantierte Substanz. Das ist insofern unrichtig, als bei der Mitbestimmung nicht von "Selbstverwaltung" die Rede sein kann (vgl. Nikisch, a.a.O. S.50 f). Im übrigen wird jedoch dem Ergebnis im Prinzip zuzustimmen sein, daß den Gewerkschaften hier auf dem Umweg über die Garantie der Mitbestimmung außerhalb des Art. 9 Abs. 3 GG eine verfassungsrechtliche Minimalposition eingeräumt ist.

1) Scheuner, Die staatliche Intervention im Bereich der Wirt- 
zur Disposition des Staates. Er kann nicht anordnen, daß und welche Koalitionen zu bestehen und welche Mitglieder ihnen anzugehören haben. ${ }^{2)}$ Er kann die Teilhaber der labil dyarchischen Autonomie $^{3)}$ nicht dazu zwingen, von ihren Befugnissen Gebrauch zu machen, und vor allem in keiner direkten Weise hindern, sich nicht zu einigen. Er kann schließlich ihr Wirken nicht aufsichtlich steuern. 4 )

Trotzdem ist der Staat aus der Verantwortung für die öffentlichen Belange, denen der "richtige" Gebrauch der "sozialen Selbstverwaltung" zu dienen hat, und die durch den Nichtgebrauch oder den - nicht etwa schon durch die Struktur der Tarifgemeinschaft ausgeschlossenen - "falschen" Gebrauch 5) vernachlässigt oder gefährdet werden, nicht entlassen.6) Verantwortung verbleibt ihm im besonderen für die Bereiche, für die sich Koalitionen überhaupt nicht gebildet haben. Verantwortung obliegt ihm - schon um der negativen Koalitionsfreiheit willen ${ }^{7)}$ - für die

schaft, S.38. S.a. die Wandlung Meissingers von dem Satz "Die soziale Selbstverwaltung ist ein Stück demokratischer Staatsverwaltung" (Tarifhoheit in der sozialen Selbstverwaltung, S. 46) zu seiner Untersuchung über die "Gewerkschaften im staatsfreien Raum (!) der sozialen Selbstverwaltung". S. a. nochmals oben S.291 und die dortigen Nachweise.

2) Zu den Möglichkeiten gesetzlicher Regulierung s. oben S. 289 zu Fußn. 1.

3) S.o. S. 292 zu Fußn. 1. Freilich sind letztlich alle Koalitionen der Arbeitnehmerseite zusammen mit allen Koalitionen der Arbeitgeberseite (abgesehen von den Einzelarbeitgebern im Rahmen des Firmentarifs) tariffähig. Aber das Minimum ist doch nur (abgesehen wieder vom Firmentarif auf der Arbeitgeberseite) eine Koalition auf jeder Seite. Wenn ein sinnvolles Zusammenwirken auch ein gewisses Mindestmaß an korrelativer Sachkompetenz voraussetzt, sind doch häufig mehrere Kombinationsmöglichkeiten gegeben. Zu den Möglichkeiten einer gesetzlichen Beschränkung S.o. S. 289 zu Fußn. 1.

4) S. о. S. 294 zu Fußn. 11.

5) Zum institutionell bedingten Fehlerrisiko s. etwa Herbert Krüger, Staatliche Gesetzgebung und nichtstaatliche Rechtsetzung, S. 203 f; Hans Huber, Staat und Verbände, S. 7 f, 9 f.

6) S.o. S.289. S.hierzu ferner Nikisch, Arbeitsrecht Bd.II S. 45 ff; Küchenhoff, Das Prinzip der staatlichen Subsidiarität im A rbeits recht.

7) Weidner (Ist der Ausschluß der Armenanwaltsbeiordnung in den unteren Instanzen der Sozialgerichtsbarkeit verfassungs- 
Nichtorganisierten, für die Minderheit oder Mehrheit von "Außenseitern", 8) denen er freilich nicht schuldet, sie auf den sozialen Stand zu heben, den sie im berufsverbandlichen Zusammenschluß erreichen könnten. Schließlich muß er sich für den Organisierten selbst verantwortlich wissen, der, durch die Übermacht seines sozialen Gegenspielers und des Verbandes seiner eigenen Frontseite in die Koalition getrieben und (oder) in ihr gehalten, nicht geringen Gefährdungen seiner Freiheit, 9) ja sogar nachteiligen Verfügungen über seinen sozialen Standard ausgesetzt ist.

Aber der Staat kann sich seiner Aufgabe weder dadurch entledigen, daß er die "Wahrung und Förderung der Arbeits- und Wirtschaftsbedingungen" unter Ausschluß der Koalitionen an sich zieht, 10) noch dadurch, daß er sie, ihre irregulare "Selbstverwaltung" zur mittelbaren Staatsverwaltung umwandelnd, in seinen Dienst stellt und seiner Aufsicht unterwirft. 11) Er muß den Koalitionen sowohl ihr Betätigungsfeld als auch ihre Staatsferne lassen.

mäßig? JZ 14.Jhg. (1959) S.622 ff (625)) weist zutreffend auf ein Parallelproblem hin: der Staat darf dem Bedürftigen den Armenanwalt nicht unter Hinweis darauf vorenthalten, daß jener sich der Hilfe eines Verbandsvertreters bedienen könne; denn damit wird der Bedürftige in dessen Verband getrieben.

8) Vgl. Leibholz, Die kritischen Punkte des Grundgesetzes, Deutsche Universitätszeitung, 12.Jhg. (1957) Heft 13/14, S. $18 \mathrm{ff}$ (21). Zum Problem s. ferner die oben S. $221 \mathrm{zu}$ Fußn. 9 Zitierten.

9) S.hierzu insbes. die Jahresversammlung der Gesellschaft für Sozialen Fortschritt e. V. in Bonn 1957 unter dem Thema "Freiheit und Bindung im kollektiven Arbeitsrecht" (Schriften der Gesellschaft für Sozialen Fortschritt e. V. Band 6, 1957): Dietz, Historische und arbeitsrechtliche Betrachtung (S. $13 \mathrm{ff}$ ); v. Nell-Breuning, Philosophische und gesellschaftskritische Betrachtung (S. $27 \mathrm{ff}$ ); Diskussion (S. 37 ff) mit Beiträgen u.a. von Nikisch (S.37 ff), Bohn (S.41 ff), Siebert (S. $47 \mathrm{ff}$ ), v. Bismarck (S. 52 f), Bührig (S. $53 \mathrm{ff}$ ), Lobeck (S. $56 \mathrm{ff}$ ), Preller (S. $59 \mathrm{ff}$ ). S. ferner Hans Huber, Staat und Verbände, S. 9 f; Briefs, Gewerkschaft und Freiheit, in "Erziehung zur Freiheit", 1959, S. $111 \mathrm{ff}$. S.a. die oben S. 221 zu Fußn.9 Zitierten.

10) S. nochmals oben S. $289 \mathrm{ff}$.

11) S. nochmals oben S.287ff und S.289 ff. 


\section{bbb) Der subsidiäre Selbsteintritt des Staates}

Ein dieser sehr freiheitlich konzipierten aber gerade deshalb so schwierigen Subsidiärrolle des Staates 1) adäquates Instrument ist der unmittelbare Selbsteintritt des Staates in Aufgaben, die von der "sozialen Selbstverwaltung" nicht erfüllt werden. Er findet sich exemplarisch verwirklicht in den Vorschriften über die Festsetzung von Mindestarbeitsbedingungen, im Heimarbeitsgesetz, in den Vorschriften über die Allgemeinverbindlicherklärung von Tarifverträgen und im Recht der Zwangsschlichtung.

(1) Die dem Gegenstand nach umfassendste und daher durch Voraussetzungen materieller und formeller Art am engsten eingezäunte Maßnahme ist die Festsetzung von Mindestarbeits bedingungen.2) Das Gesetz über die Festsetzung von Mindestarbeitsbedingungen erlaubt nur die Festlegung der "untersten Grenze der Entgelte und sonstigen Arbeitsbedingungen in einem Wirtschaftszweig oder einer Beschäftigungsart" ( $\$ 4$ Abs.4). Aber auch in Richtung auf dieses Minimum von Disposition darf der Staat von dem Grundsatz der "Regelung von Entgelten und sonstigen Arbeitsbedingungen... in freier Vereinbarung zwischen den Tarifvertragsparteien durch Tarifverträge" nicht beliebig abweichen ( $\$ 1$ Abs.1). Er darf Mindestarbeitsbedingungen nur für Wirtschaftszweige oder Beschäftigungsarten festsetzen, für die Koalitionen nicht bestehen oder in denen sie nur eine Minderheit der Arbeitnehmer oder Arbeitgeber umfassen ( $\$ 1$ Abs. 1 lit. a). Die Festsetzung muß "zur. Bef riedigung der notwendigen sozialen und wirtschaftlichen Bedürfnisse der Arbeitnehmer erforderlich" erscheinen (ebd. lit.b). Wenn für denselben Bereich ein Tarifvertrag kraft Allgemeinverbindlicherklärung gilt, hindert das die Festsetzung von Mindestarbeitsbedingungen (ebd. lit.c). Tarifverträge gehen ihnen im übrigen vor ( $\$ 8 \mathrm{Abs} .2)$. Aber nicht nur diese materiellen Bedingungen drängen das staatliche Eingreifen zurück. Es wird dem Staate durch die Beteiligung der Arbeitgeber- und der Arbeitnehmerorganisationen nicht nur auf dem IVege der. Anhörung ( $\$ 7)$ sondern auch über die entscheidend mitwirkenden Ausschüsse ( $\$ \$ 2-6)$ in einem Maße entfremdet, das den Gegensatz zwischen der sozialen Selbstverwaltung und der obrigkeitlichen Festsetzung der Arbeitsbedingungen fast etwas

1) Zur Anwendung des Prinzips der Subsidiarität auf diesen Sachzusammenhang s. insbes. Küchenhoff, Das Prinzip der staatlichen Subsidiarität im Arbeits recht.

2) Zur Stellung der Festsetzung von Mindestarbeitsbedingungen gegenüber der sozialen Selbstverwaltung s. z. B. Nipperdey, Lehrbuch des Arbeits rechts, Bd.II, S.38, Küchenhoff, a.a.O. S. $202 \mathrm{f}$. 
zurücktreten 1äßt. Doch ist der bestimmende Einfluß des Bundesministers für Arbeit und somit einer rein staatlich-politischen Instanz ganz eindeutig gegeben. ${ }^{3)}$ Er kann zwar nicht gegen den Willen der zuständigen Ausschüsse handeln, diese können sich aber auch nicht gegen seinen Willen durchsetzen, es sei denn dahin, daß eben nichts geschieht $(\$ \$ 3,4)$. Ist so äußerlich ein Gleichgewicht der Kräfte zwischen dem Minister und den Ausschüssen gegeben, so senkt sich die Waage durch die Stellung des Ministers in bezug auf die Ausschüsse selbst auf seine Seite. Der Hauptausschuß, der mit dem Bundesarbeitsminister die Wirtschaftszweige oder Beschäftigungsarten bestimmt, für die Mindestarbeitsbedingungen festgesetzt werden sollen ( $\$ 3$ Abs. 1 ), wird vom Bundesminister berufen. Er hat dabei "auf Grund von Vorschlägen der Gewerkschaften und" Arbeitgeberverbände zu verfahren, genießt aber eine gewisse Gestaltungsfreiheit zumindest dadurch, daß er den Ausschuß "unter billiger Berücksichtigung der Minderheiten" zusammenstellen muß ( $\$ 2$ Abs.3). Dadurch, daß die Berufung auf drei Jahre wirkt (ebd.), erlangen die Ausschußmitglieder zudem eine gewisse Unabhängigkeit gegenüber den Organisationen, die sie vorgeschlagen haben. Ihm selbst oder seinem Beauftragten steht schließ1ich der Vorsitz in diesem im übrigen paritätisch zusammengesetzten Ausschuß und somit das entscheidende Stimmgewicht zu. Auch die Fachausschüsse, die zusammen mit dem Minister über die Mindestarbeitsbedingungen $z u$ bestimmen haben, ( $(3 \mathrm{Abs} .2$ und 3$)$, werden vom Bundesarbeitsminister errichtet (ebd. Abs.1). Bei der Berufung der Beisitzer ist er, da das Fehlen ausreichender Koalitionen vorausgesetzt ist, von vorneherein freier gestellt ( $\$ 6 \mathrm{Abs} .1$ ). Den Vorsitzenden, dem der Stichentscheid zukommt, bestimmt ebenfalls er $(\$ 5)$.

(2) Im Gegenstande eng begrenzt, im übrigen sehr ähnlich, ist die Festsetzung von Entgelten und sonstigen Bedingungen für Heim a rbeit nach den $₫ \S 19,21,22$ des Heimarbeitsgesetzes. Auch sie setzt voraus, daß Koalitionen nicht bestehen oder nur eine Minderheit von Beteiligten umfassen ( $\$ 19$ Abs. 1). Auch hier wirken Ausschüsse, die Heimarbeitsausschüsse, bestimmend mit

3) An seine Stelle tritt hinsichtlich der Fachausschüsse und des Erlasses der Mindestarbeits bedingungen der zuständige Landesarbeitsminister, "wenn Mindestarbeitsbedingungen festgesetzt werden sollen, die nach Umfang, Auswirkung und Bedeutung nur ein Land betreffen" und der Bundesminister für. Arbeit die genannten Befugnisse deshalb auf ihn delegiert ( $\$ 10)$. 
$(\$ \$ 18$ 1it.c, 19).4) Sie setzen die Bedingungen fest, die jedoch der Zustimmung des Bundesministers für Arbeit bzw. des örtlich zuständigen Landesarbeitsministers bedürfen ( $₫ 19$ Abs. 2 i.V.m. $\S 3)$. Dieser beruft die Ausschüsse "aus den Kreisen der beteiligten Auftraggeber und Beschäftigten" ( $\$ 4$ Abs.2). Der von ihm bestimmte Ausschußvorsitzende hat den Stichentscheid ( $\$ 4$ Abs.2 und 3). Bei der Festsetzung von Mindestarbeitsbedingungen für "fremde Hilfskräfte" wirken entsprechend gebildete Entgeltsausschüsse mit $(\$ 22)$. Entsprechend dem begrenzteren Feld, auf dessen Verhältnisse die Regelung abgestellt ist, sind die materiellen Voraussetzungen für das staatliche Eingreifen im Heima rbeitsgesetz also nicht so eng gezogen wie in dem vorerwähnten Gesetz. Entsprechend der geringeren Koalitionsbildung und -tätigkeit in bezug auf die Heimarbeit ist der Einfluß der Koalitionen a priori beschränkt. Aber das Prinzip des staatlichen subsidiären Eingriffes ist bei beiden Regelungen dasselbe.

(3) Eine andere Funktion als die beiden bisher genannten Maßnahmen erfüllt die Allgemeinverbindlicherklärung von Tarifverträgen nach $₫ 4$ des Tarifvertragsgesetzes. Die Festsetzung von Heimarbeitsbedingungen oder Mindestarbeitsbedingungen setzt den völligen Ausfall einer wirksamen Tätigkeit der sozialen Selbstverwaltung voraus. Die Allgemeinverbindlicherklärung dagegen setzt voraus, daß die Sozialpartner zwar tätig geworden sind, nämlich einen Tarifvertrag abgeschlossen haben. Nicht die Untätigkeit der Koalitionen bewirkt das Eingreifen des Staates sondern ihre unvollständige, personelle Kompetenz. Verbleiben zu viele Nichtorganisierte außerhalb der getroffenen tarifvertraglichen Regelung, so können dadurch nachteilige Wirkungen auf das Arbeitsleben entstehen. Hier kann die Allgemeinverbindlicherklärung helfen. "Mit der Allgemeinverbindlicherklärung erfassen die Rechtsnormen des Tarifvertrages in seinem Geltungsbereich auch die bisher nicht tarifgebundenen Arbeitgeber und Arbeitnehmer" ( $\$ 5$ Abs. 4 TVG). Der allgemeinverbindlich zu erklärende Tarifvertrag muß einen erheblichen, personellen Geltungsbereich aufweisen: Mehr als die Hälfte der an sich in den sachlichen Geltungsbereich des Tarifvertrages fallenden Arbeitnehmer muß bei tarifgebundenen Arbeitgebern beschäftigt sein ( $\$ 5$ Abs. 1 Satz $1 \mathrm{Nr} .1$ TVG). Die Allgemeinverbindlicherklärung muß im öffentlichen Interesse geboten sein (ebd. Nr.2). Darüber

4) Maus (Mitwirkung von Ausschüssen an Verwaltung und Normsetzung im Arbeitsrecht, S. 177) nennt die Heimarbeitsausschüsse "Ausdruck einer vom Gesetzgeber anerkannten sozialen Selbstverwaltung", dehnt damit aber - wie der Zusammenhang ergibt - den Begriff aus. 
hinaus ist sie ohne weiteres zulässig, wenn sie "zur Behebung eines sozialen Notstandes erforderlich erscheint" ( $₫ 5$ Abs. 1 Satz 2 TVG). 5) Noch strenger als die sachlichen Voraussetzungen sind die formellen, die außerdem den Gewerkschaften und A rbeitgeberverbänden eine Stellung geben, wie sie sie nach den unter (1) und (2) genannten Vorschriften bei weitem nicht haben. Zwar liegt die Allgemeinverbindlicherklärung beim Bundesminister für Arbeit. 6) Dieser braucht aber die Zustimmung des Tarifausschusses, 7) der aus je drei Vertretern der Spitzenverbände der Gewerkschaften und A rbeitgeberverbände besteht ( $\$ 5$ Abs. 1 Satz 1 TVG). Der Bundesminister beruft den Ausschuß "auf Grund von Vorschlägen der Spitzenorganisationen" ( $\$ 1$ der Verordnung zur Durchführung des Tarifvertragsgesetzes.) Aber er hat darin keine Stimme und somit auch keinen Stichentscheid. A1lein schon eine "Seite" der Koalitionsfront kann seinen Entschluß zur Allgemeinverbindlicherklärung blockieren. Dazu kommt noch eine einschneidende Verfahrensvoraussetzung: Die Allgemeinverbindlicherklärung muß von (wenigstens) einer Tarifvertragspartei beantragt sein ( $\$ 5$ Abs. 1 TVG). Diese Regelung gibt Zeugnis von den sich überschneidenden Interessen, die das Instrument der Allgemeinverbindlicherklärung in einem als das "natürlichste" und "unnatürlichste", als ein die negative wie die positive Koalitionsfreiheit schonendes und angreifendes und endlich als ein den

5) Nach seinem klaren Wortlaut dispensiert das Gesetz für den Fall des sozialen Notstandes nicht nur von der quantitativen Voraussetzung des $₫ 5$ Abs. 1 Satz 1 Nr. 1 TVG sondern auch von dem Erfordernis des öffentlichen Interesses. Ist es aber denkbar, daß die Allgemeinverbindlicherklärung zwar "zur Behebung eines sozialen Notstandes erforderlich", nicht aber zugleich "im öffentlichen Interesse geboten erscheint"? Das muß verneint werden. In dieser Richtung ist die "Ausnahme" des $₫ 5$ Abs. 1 Satz 2 TVG daher gegenstandslos.

6) An die Stelle des Bundesministers für A rbeit kann einerseits der zuständige Landesarbeitsminister treten, wenn der Bundesminister die Befugnis zur Allgemeinverbindlicherklärung auf ihn delegiert ( $\$ 5$ Abs. 6 TVG). Dieser beruft dann auch einen eigenen (Landes-) Tarifausschuß ( $\$ 10$ Abs.2 der Durchführungsverordnung zum Tarifvertragsgesetz i.V.m. $\$ 1$ Abs. 1 TVG). Andererseits kann auch die Bundesregierung eingeschaltet werden, deren Zustimmung der Bundesminister für Arbeit einholen muß, wenn er die Allgemeinverbindlicherklärung entgegen dem Einspruch eines Landes erklären will ( $\$ 5$ Abs.3 TVG; s. a. Huber, Wirtschaftsverwaltungsrecht Bd. II, S. 449). 
Staat verdrängendes und engagierendes Mittel der sozialen Intervention erkennen lassen. ${ }^{8)}$

(4) Eine Zwangsschlichtung gibt es nach dem gegenwärtig geltenden Gesetzes recht im allgemeinen nicht.9) Sowohl eine Einlassungspflicht wie die Verbindlicherklärung von Schiedssprüchen ist lediglich im Lande Rheinland-Pfalz und im südbadischen Landesteil Baden-Württemberg (ehem. Land Baden) vorgesehen. Die erwähnten, landesgesetzlichen Bestimmungen lassen allerdings die subsidiäre Position, in der der Staat sich als Träger der Zwangsschlichtung befindet, nur undeutlich erkennen. 10) Die Einleitung des Schlichtungsverfahrens von Amts wegen, die auch die Einlassungspflicht zur Folge hat, ist unter der Voraussetzung für zulässig erklärt, daß der Streitigkeit "wesentliche öffentliche Bedeutung" zukommt ( $\$ 12$ Abs. 2 des badischen Landesgesetzes über das Schlichtungswesen bei A rbeitsstreitigkeiten vom 19. Oktober 1949, GVBl. 1950 S. $60 ; \S 10$ Abs. 3 des rhein1. pfälz. Landesgesetzes über das Ausgleichs- und Schiedsverfahren in A rbeitsstreitigkeiten vom 30. März 1949, GVBl. S.98). Das badische Gesetz läßt auch die Verbindlicherklärung eines Schiedsspruches allgemein dann zu, "wenn das öffentliche Interesse es erfordert" ( $\$ 18 \mathrm{Abs} .1$ ). Stärker differenziert dagegen das rheinl. -

7) Auch ihn charakterisiert Maus als Ausdruck der "sozialen Selbstverwaltung".

8) Ein Überblick über die Praxis bei Ringer, Zehn Jahre Allgemeinverbindlichkeit von Tarifverträgen, A rbeit und Recht 7. Jhg. (1959) S.289 f.

9) Einen Sonderfall stellen die Vorbehalte für die Streitigkeiten dar, die die Interessen der alliierten Besatzungsmächte berühren (Art. II Abs.2, X Abs.2 lit.b KRG Nr. 35; $\$ 15$ Abs. 1 lit. b des nachstehend im Text zit. bad. Landesgesetzes; $\mathbb{\$} \mathbb{1 0} \mathrm{Abs} .3,13 \mathrm{Abs} .1$ lit.b des nachstehend im Text zit. rheinl.-pfälz. Landesgesetzes). Für sie besteht Finlassungspflicht und die Möglichkeit der Verbindlicherklärung. Die Annahme, daß diese Vorbehalte "überholt" seien (Nipperdey, a.a.O. S. 539 Fußn.43), dürfte nicht richtig sein (vgl. Art. 5 des Vertrages über die Beziehungen zwischen der Bundes republik und den drei Mächten vom 26. Mai 1952 i. d.F. vom 23. Oktober 1954, BGBi. 1955 II S.301, 305). Praktische Bedeutung kommt ihnen außerhalb des in Art. 5 a.a.O. geregelten Notstandes aber nicht zu.

10) Zur Einordnung des staatlichen Schlichtungswesens in den Zusammenhang der Subsidiarität s. Küchenhoff, Das Prinzip der staatlichen Subsidiarität im Arbeitsrecht, S. 204. 
pfälz. Gesetz, nach dem die Verbindlicherklärung nur erfolgen darf, "wenn der Streitigkeit wesentliche öffentliche Bedeutung zukommt und der Inhalt des Schiedsspruches bei gerechter Abwägung der Interessen beider Teile der Billigkeit entspricht und seine Durchïührung aus wirtschaftlichen und sozialen Gründen erforderlich ist" ( $\$ 13$ Abs.3 Satz 1 ). Nach dem badischen Gesetz muß die Verbindlicherklärung von einem der betroffenen Sozialpartner beantragt sein ( $\$ 18$ Abs.2). Nach dem rheinl.-pfälzischen Gesetz ist das die Regel, von der abgewichen werden kann, wenn das öffentliche Interesse dies dringend erfordert ( $₫ 13$ Abs. 5). 11)

Der Staat ist aber nicht schon kraft Verfassungs rechts auf die genannten Maßnahmen oder gar ihre gegenwärtige, gesetzliche Regelung festgelegt und beschränkt. 12) Vor allem kann der Verfassung nichts für eine Garantie der Teilhabe der Berufsverbände an der staatlichen Willensbildung, wie sie gegenwärtig die aufgezeigte Regel ist, entnommen werden. Auch kommt dem in der Rechtsentwicklung zutage tretenden Grundzug, wonach der parlamentarische Gesetzgeber als Funktionär des Selbsteintritts zugunsten delegierter Autoritäten ganz zurücktritt, - ungeachtet seiner sachgesetzlichen Adäquanz - keine verfassungsrechtliche Verbindlichkeit zu. Eine Veränderung der wirtschaftlichen Verhältnisse oder der Struktur der Koalitionen u. ä. kann aber durchaus auch sub specie der sachlichen Voraussetzungen ein erweitertes Eingreifen des Staates bedingen. Es wird Sache des Gesetzgebers sein, hier durch den Ausbau der Ordnung staatlichen Eingreifens vorzubeugen und notfalls Abhilfe zu schaffen. Im besonderen harrt das Problem der Zwangsschlichtung noch der befriedigenden umfassenden Regelung. 13 )

\section{ccc) Rahmenordnung und Legalitätskont rolle}

Weitaus diffiziler als den Funktionsausfall der "sozialen Selbstverwaltung" auszugleichen, ist es, ihre positive Funktionserfüllung - ohne aufsichtliche Mittel - so zu lenken, daß weder das allgemeine noch das individuelle Wohl in einem Maße beeinträchtigt wird, das mit der (sozial-) staatlichen Verantwortung nicht mehr vereinbart werden konnte.

11) Zur verfassungskonformen Auslegung dieser Vorschriften Nipperdey, a.a.O. S. 539.

12) S. Meissinger, Die Gewerkschaften im staatsfreien Raum der sozialen Selbstverwaltung, S. 340.

13) S. oben S. 299 und die Nachweise dort Fußn. 1 und 2. 
Der einfachste und sicherste Weg für den Staat, sich dieser Verantwortung $z u$ entledigen, ist, daß er selbst $z$ wingende Ordnungen aufrichtet. "Je mehr $z$ wingende Normen der staatliche Gesetzgeber selbst gesetzt hat, um so weniger bleibt der nichtstaatlichen Rechtsetzung zu tun". 1) Die Summe der gesetzlichen und gesetzesermächtigten untergesetzlichen Regelungen der "Arbeits- und Wirtschaftsbedingungen" zeigt, mit welcher Selbstverständlichkeit von diesem Mittel Gebrauch gemacht wird und Gebrauch gemacht werden muß. "Im Grunde genommen steckt jedoch hierin keine prinzipielle Lösung des Problems. Denn es handelt sich ja nicht darum, die nichtstaatliche Rechtsetzung auszurotten oder wenigstens in Reservate zurückzudrängen". 2)

Ein weiterer Weg liegt in einer grundsätzlichen staatsgesetzlichen, auf die spezifische Aufgabe der Koalitionen Bedacht nehmende Regelung ihrer inneren Organisation und ihres Rechtsetzungsverfahrens. 3) Der Vorbehalt des Art.9 Abs.2 GG 4) und das Vorbild des Art.21 GG ergeben die Basis für eine Grundsatzgesetzgebung hinsichtlich der inneren Organisation. Der aus dem Schweigen der Verfassung über die Tarifmacht folgende Vorbehalt der gesetzlichen Regelung der tarifvertraglichen Rechtsetzung 5) erlaubt auch Vorschriften über das dabei einzuhaltende Verfahren. Freilich kann es sich nur um Minimalforderungen handeln. Zudem kann eine reine Organisations- und Verfahrensordnung keine endgültige Gewähr für die inhaltliche "Richtigkeit" des Verfahrensprodukts erbringen. Aber gewisse Abhilfen wären doch zu gewinnen. Daß der Gesetzgeber bisher davon keinen Gebrauch gemacht hat, mag bis zu einem gewissen Grad darauf zurückzuführen sein, daß die satzungsmäßige innerverbandliche und die vereinbarte $z$ wischenverbandliche Ordnung der vorhandenen Koalitionen im allgemeinen den Maximen entspricht, die der Gesetzgeber aufrichten wollte und könnte.

Fin letztes Mittel, die "soziale Selbstverwaltung" im (unerläßlichen) Zaum zu halten, ist eine materielle, das Tätigwerden der Koalitionen nicht ausschließende oder erübrigende aber auch

1) Herbert Krüger, Staatliche Gesetzgebung und nichtstaatliche Rechtsetzung, S. 204.

2) Krüger, Staatliche Gesetzgebung und nichtstaatliche Rechtsetzung, S.204.

3) Zum Rechtsetzungsverfahren s.Krüger, a.a.O. S.204f.

4) Zur Anwendbarkeit des Art. 9 Abs. 2 GG auf Koalitionen i.S. des Art. 9 Abs. 3 GG s. v. Mangoldt-Klein, Art. 9 Anm. VI 1; Dietz, Die Koalitionsfreiheit, S. 448; je mit weit. Nachw.

5) S. o. S. $289 \mathrm{ff}$, insbes. zu Fußn. 1. 
nicht nur ihr Verfahren vorzeichnende, die "soziale Selbstverwaltung" inhaltlich determinierende Grundsatzordnung. 6) Ihr Minimum liegt in den auch für das Tarifvertragsrecht verbindlichen Verfassungssätzen. 7) Die "Grundrechtsdrittwirkung" 8) schützt insbes. die individuelle Sphäre. Das sonstige Gesamtinteresse der staatlichen Gemeinschaft kann auf diese Weise dagegen nur wenig gefördert werden. 9) Allgemeine Verfassungssätze können die positive Gestaltung von "Arbeits- und Wirtschaftsbedingungen" nur sehr beschränkt vorwegnehmen. 10) Ob die rechtspolitisch relevanten Sachgesetzlichkeiten jemals ein Ausgreifen des (einfachen) Gesetzgebers in dieser Richtung zulassen, ist eine problemreiche Frage.

Die Sanktion dieser Bindungen ist durch die notwendige Abwesenheit staatlicher - d.h. in diesem Zusammenhang wohl exekutivischer - Aufsicht gekennzeichnet. Die Unterworfenheit der "sozialen Selbstverwaltung" unter die Verfassung und das (verfassungsmäßige) staatliche Gesetz11) äußert sich daher vor allem im Richterspruch, der dem verfassungs- oder gesetzwidrigen Tarifvertrag die Anwendung versagt. 12) Dieser richterlichen Legalitätskontrolle kommt somit eine für die "soziale Selbstverwaltung" elementare Bedeutung zu. Ihre gestaltgebende Funktion wird vor allem dort sichtbar, wo das gegenüber dem "autonomen" Recht der Tarifpartner anzuwendende und durchzusetzende staatliche Recht selbst erst der richterlichen Entfaltung bedarf. Gerade die Umsetzung der Verfassung in eine materielle Grund-

6) Vgl. Krüger, a.a.O. S.205.

7) S. insbes. Krüger, a.a.O. S.205 f.

8) S. hierzu unten S. 883.

9) Zur Geltung des Sozialstaatsprinzips für das Tarifvertragsrecht s.u. S. 789 a.E.

10) S.u. Abschnitt 4 I (S.396 ff) und II (S.406 ff) (passim), Abschnitt 6 I 3 (S. 848 ff).

11) Vgl. Nipperdey, Lehrbuch des A rbeitsrechts, Bd. II, S.273ff.

12) Eine selbständige Normenkontrolle gibt es gegenwärtig nicht. Die besondere Zulassung der Sprungrevision in Tarifstreitigkeiten ( $\$ \$ 2$ Abs. $1 \mathrm{Nr} .1,76$ Abs. 1 ArbGG) läßt aber deutlich werden, welche besondere Tragweite der Gesetzgeber der inzidenten Normenkontrolle des Tarifvertragsrechts beimißt (wenngleich die genannten Bestimmungen auch noch andere $Z$ wecke verfolgen). Der Einrichtung eines besonderen Normenkontrollverfahrens durch Gesetz - etwa im Rahmen der Arbeitsgerichtsbarkeit - stünden keine verfassungsrechtlichen Bedenken entgegen. 
ordnung der "sozialen Selbstverwaltung" hat dies immer wieder deutlich werden lassen.

b) "Soziale Selbstverwaltung" im Betrieb

Die Vergleichsbeziehung zwischen der betrieblichen Mitbestimmung und der "eigentlichen", von den Koalitionen getragenen "sozialen Selbstverwaltung" ergibt sich aus der Analogie zwischen Betriebsvereinbarung und Tarifvertrag. 1) Aber die Betriebsvereinbarung ist nicht in derselben Weise Kern der betrieblichen Mitbestimmung wie der Tarifvertrag Kern der "sozialen Selbstverwaltung". Mitunter tritt sie neben den zahlreichen sonstigen durch das Betriebsverfassungsrecht (i.w.S.) gewährleisteten Mitbestimmungs- und Mitwirkungs rechten sogar in den Hintergrund - ein Schicksal, das dem Tarifvertrag im Rahmen der "sozialen Selbstverwaltung" bei allem sonstigen Engagement der Koalitionen fremd ist. Vor allem aber unterscheiden sich die beiden Ebenen "sozialer Selbstverwaltung" dadurch, daß die Koalitionen primär zweckhaft auf die Gestaltung der "Arbeits- und Wirtschaftsbedingungen" ausgerichtet sind, während die betriebliche Mitbestimmung das primär aus anderen $\mathrm{Zwecken}$ begründete Betriebsverhältnis modifiziert. Die "soziale Selbstverwaltung" ist als Institution Ausfluß eines Freiheitsrechts. Die betriebliche Mitbestimmung ist soziales und freiheitliches Gestaltelement einer ihr vorgegebenen Institution, des Betriebs. 2) Schließlich entbehrt die betriebliche "soziale Selbstverwaltung" des grundsätzlichen und eindeutigen Öffentlichkeitscharakters der tarifvertraglichen. Staatliche und betriebliche Regelung der betrieblichen Arbeits- und Wirtschaftsbedingungen sind nicht in demselben Maße vertauschbar wie staatliche und tarifvertragliche Regelung der Arbeits- und Wirtschaftsbedingungen. Zur Abwesenheit

1) S. hierzu schon Hueck, Normenverträge, S.81 ff.

2) Siebert, Diskussionsbeitrag zu "Freiheit und Bindung im kollektiven A rbeitsrecht", Schriften der Gesellschaft für Sozialen Fortschritt e. V. Band 6, 1957, S. 47 ff (50): "Trotz der Gemeinsamkeit der kollektiv-normativen Gestaltungswirkung besteht u. a. der recht wesentliche Unterschied, daß man in den Betriebsverband schon durch die Begründung des Arbeitsverhältnisses schlechthin eintritt, während die Tarifunterworfenheit, abgesehen von der Allgemeinverbindlichkeitserklärung, erst durch einen zusätzlichen, verbandsrechtlichen Akt begründet wird, nämlich durch den Beitritt zu dem Arbeitgeber- und Arbeitnehmerverband. Insofern ist das Moment des Unterworfenseins bei der Betriebsvereinbarung vielleicht deutlicher als beim Tarifvertrag". 
organisatorischer Bindungen der betrieblichen Autonomie an die Staatsgewalt, die sie mit der "sozialen Selbstverwaltung" teilt, tritt also eine Minderung des staatskomplementären Charakters ihrer Funktion, der die soziale Selbstverwaltung in so hervorragendem Maße auszeichnet. 3 )

Das Grundgesetz garantiert die betriebliche Mitbestimmung nicht ausdrücklich. Die verbindliche Programmatik des "demokratischen und sozialen Rechtsstaats" (Art.20 Abs.1, 28 Abs. 1 Satz 1 GG) wird allerdings einen beliebigen Abbau des in langer Entwicklung erreichten status quo nicht zulassen. 4) Bestimmte Ausformungen sind damit jedoch nicht gewährleistet.

3) Dafür, daß der Betriebsrat keine Funktionen ausübt, die der Staatsverwaltung zuzurechnen sind, s. BayVerfGH VGHE n.F. 2 II 98 (101 f; s. aber auch das abweichende Votum das. S. 102 f). Näheres und Nachweise dazu, daß Betriebsrat und Belegschaft keine Ausgliederungen aus der staatlichen Gemeinschaft darstellen s. Nipperdey, Lehrbuch des A rbeitsrechts, Bd. II S. 689 ff. Brill (Gewaltenteilung im modernen Staat, S. 392 f) sieht dagegen auch im Betriebsräterecht ein Mittel der modernen Gewaltenteilung. - Zu dem sehr umstrittenen Fragenkreis der Zuordnung des Betriebsverfassungsrechts zum öffentlichen oder privaten Recht, der mit den im Text aufgezeigten Gesichtspunkten allein nicht aufzuklären ist und im Sinne der privatrechtlichen Theorie entschieden werden muß, $\mathrm{S}$. die zusammenfassenden Darstellungen bei Götz Hueck, Die Betriebsvereinbarung, 1952, S. 19 ff; Nipperdey, a.a.O. S. 682 ff; Helmut Frey, Die Rechtsnatur der Belegschaft und des Betriebsrats, Recht der Arbeit, 13. Jhg. (1960) S. 89 ff; sämt1. weit. Nachw.s. bei diesen.

4) S. hierzu unten Abschnitt 3 I 2 (S. $329 \mathrm{ff})$ und II (S. $338 \mathrm{ff})$ und Abschnitt 5 II 3 b (S. $741 \mathrm{ff})$, III 3 a cc (S. $788 \mathrm{ff})$. 


\section{Abschnitt}

Demokratisches und republikanisches Prinzip und soziale Intervention des Staates

I. Das allgemeine Verhältnis zwischen demokratischer Staatsform und sozialer Politik 1)

1. Egalitäre Demokratie und soziale Politik

a) Ideologisch-historische Verschwisterung im Egalitären

Die moderne, egalitäre Demokratie, die durch die maximal allgemeine und formalisiert (arithmetisch) gleiche Ausdehnung des Wahl- und Stimmrechts auf die Bürger gekennzeichnet ist, 2) steht mit der sozialen Funktion des Staates in intimer Wechselbeziehung. ${ }^{3)}$ Der Wunsch nach sozialem Einsatz der staatlichen Potenzen hat die egalitäre Demokratie mit heraufgeführt. Diese hat die in sie gesetzten Erwartungen zwar nicht immer erfüllt; jedoch ist ihr eine gewisse sozialfreundliche Tendenz nicht abzusprechen. Vor allem aber hat umgekehrt die Ausbildung der egalitären Demokratie die Forderung erweckt und bestärkt, der Ausbreitung der politischen Rechte auch eine Einebnung der ökonomischen Verhältnisse folgen zu lassen.

\section{aa) Zur demokratischen Inklination des Sozialen}

Die kausale Beziehung zwischen der Forderung nach sozialem Eingreifen des Staates und moderner demokratischer Staatsgestaltung findet ihren historischen Ausdruck vor allem in dem Kampf gewisser sozialrevolutionärer Bewegungen des 19. Jahrhunclerts um das allgemeine und gleiche Wahlrecht. 1) Im Ver-

1) Zur fundamentalen Bedeutung der demokratischen Staatsform für die soziale Intervention s. vorweg Forsthoff, Verfassungsprobleme des Sozialstaates, S.13 ff, insbes. S. 17 und 23.

2) S. hierzu z.B. Leibholz, Strukturprobleme der modernen Demokratie, S. $1 \mathrm{ff}, 13 \mathrm{ff}, 42 \mathrm{ff}, 136 \mathrm{f}, 147 \mathrm{ff}$.

3) S. außer den nachfolgend Zitierten: Nawiasky, Staatstypen der Gegenwart, 1934, S. 43 ff, 91 ff; ders., Allgemeine Staatslehre, Teil 2, Bd.II, S. $139 \mathrm{ff}$, Teil 4 S. $86 \mathrm{ff}$.

1) S. zu dieser Dreiecksassoziation (Demokratie-soziale Staatsintervention-allgemeine und gleiche Wahlen) die zeitgenössische Bemerkung bei L.v. Stein, Geschichte der sozialen Bewegung in Frankreich von 1789 bis auf unsere Tage, 3 Bde. 1850 (Neuausgabe 1921) Bd. 3 ("Das Königtum, die Republik und die Souveränität der französischen Gesellschaft seit der Februarrevolution 1848") S. $177 \mathrm{f}$. 
trauen auf die zahlenmäßige Stärke und die politische Einmütigkeit der bedrängten unteren Volksschichten rechneten vor allem die englischen Chartisten damit, daß die Gewährung des allgemeinen und gleichen Wahlrechts dem "vierten Stand" den entscheidenden und notwendig erscheinenden Einfluß auf die Staatswillensbildung bringen würde. ${ }^{2)}$ Desgleichen gehörte die allgemeine und gleiche Wahl seit jeher zu den Programmpunkten der deutschen Sozialdemokratie. 3) 4) Von hier führt eine gerade Linie zur modernen Demokratie. ${ }^{5)}$

2) S. hierzu z.B. Beer, Geschichte des Sozialismus in England, 1913, S. 221 ff, insbes. S.226, 271 ff; Rosenberg, Demokratie und Sozialismus, 1938, S. 51 ff. - Die Überzeugung der Chartisten, die sich von allen anderen zeitgenössischen sozialen Bewegungen wohl am stärksten durch ihre Konzentration auf die Forderung nach politischer Gleichberechtigung unterschieden und alle Hoffnung auf die Teilhabe aller an der demokratischen Macht setzten, ist ein schöner Beweis für die Kraft, die der demokratische Gedanke im damaligen England gehabt haben muß. (Der Unterschied zu den kontinentalen Parallelbewegungen kommt gerade bei Rosenberg, a. a. O. recht deutlich heraus).

3) S. das Berliner Programm des Allgemeinen Deutschen Arbeitervereins (1867), das Eisenacher Programm der Sozialdemokratischen Arbeiterpartei (1869), das Gothaer Programm der Sozialdemokratischen Arbeiterpartei (1875) und das Erfurter Programm der Sozialdemokratischen Partei (1891) (die einschlägigen Stellen der Programme s. z.B. bei Treue, Deutsche Parteiprogramme 1861-1956, S.58, 59, 67, 76; zur Erläuterung s.Kautsky, Das Erfurter Programm, 17. Aufl., 1922, S. $211 \mathrm{ff})$. - Zur Einstellung Lasalles, der im allgemeinen Wahlrecht das "formelle Mittel zur Durchsetzung des Prinzips des Arbeiterstandes als das herrschende Prinzip der Gesellschaft" sah, s. z.B. Ramm, Ferdinand Lasalle, 1953, S. 57 ff. - Es ist im übrigen natürlich nicht möglich, hier die Geschichte der Haltung der sozialistischen Bewegungen und Theoretiker im Deutschland des 19. und 20. Jahrhunderts zur Frage des Wahl rechts zu schreiben. Hingewiesen sei auf Smend, Maßstäbe des parlamentarischen Wahlrechts (1912), in "Staats rechtliche Abhandlungen", 1955, S. 19 ff, insbes. S. 23 ff, der die Frage in größere Zusammenhänge stellt, aber auch (S.32 f, Anm.13) weitere Nachweise zum besonderen Problem bringt.

4) Zu ähnlichen Bewegungen in Frankreich, s. z. B. Rusenberg, a. a. O. S. $44 \mathrm{ff}$. 
Damit soll nicht behauptet werden, die neuzeitliche soziale (inklusive: sozialistische) und die moderne demokratische Bewegung seien ein- und dieselbe Sache. Der Sieg der Demokratie ist nicht ausschließlich eine Frucht sozialer (oder sozialistischer) Tendenzen. 6) Umgekehrt wäre es verfehlt, die modernen sozialrevolutionären und - reformerischen Bewegungen schlechthin für demokratisch zu erklären. ${ }^{7)}$ Sozialer Ausgleich wurde immer auch ganz und gar undemokratischen Machtträgern zugetraut, so vor allem dem Monarchen 8 ) oder dem autoritären Staatschef. 9)

5) Vgl. Thoma, Über Wesen und Erscheinungsformen der modernen Demokratie, 1948, S. $11 \mathrm{ff}$.

6) Vgl. Thoma, a.a.O. S. 8 ff.

7) Über das Verhältnis der historischen sozialistischen Bewegung zur Demokratie s. (außer dem die Herrschaft des Proletariats als "Demokratie" einschließenden und daher nur der Sache, d.h. dem von ihm gebrachten Material, nicht auch der Darstellung, insbes. der Terminologie nach verwertbaren Buch von Rosenberg über "Demokratie und Sozialismus") unter sehr verschiedenen Aspekten z.B. Kelsen, Sozialismus und Staat, 1920, S.92 ff; Sombart, Der Proletarische Sozialismus, 10. Auf1. von "Sozialismus und soziale Bewegung", 1924, Bd. 1 S.386 f, Bd.2 S.247 ff; Thoma, a.a.O. S. $11 \mathrm{ff}, 24 \mathrm{ff}$; Schumpeter, Kapitalismus, Sozialismus und Demokratie, 2. Auf1. 1950, S. $373 \mathrm{ff}, 376 \mathrm{ff}$.

8) So insbes. der Gedanke des sozialen Königtums bei Lorenz von Stein, Das Königtum, Die Republik usw., insbes. S. $1 \mathrm{ff}$. Hier zu nennen ist auch der Gedanke des Volkskönigtums bei Lasalle (s. hierzu die kritische Darstellung von Ramm, Ferdinand Lasalle, S. $57 \mathrm{ff}$ ).

9) Daß der National sozialist Hitler den von ihm erweckten sozialen Erwartungen und anfänglich auch getätigten Fortschritten viel an politischem Erfolg zu verdanken hatte, steht - trotz gewisser zeitgeschichtlicher Bemühungen, die die demokratisch-politische Integrität der Weimarer Sozialdemokratie nicht von der politischen Fallibilität der Wähler, die die Sozialdemokratie als die "ihren" in Anspruch nimmt, unterscheiden können oder wollen und diese durch jene aufgehoben glauben - außer Zweifel. Auch Mussolini gerierte sich nicht ohne Erfolg als sozialer Heilsbringer. Hier zu nennen sind auch die autoritären Staaten von Franco-Spanien bis zum österreichischen "Stände"-Staat, die sich samt und sonders in besonderem Maße zur sozialen Befriedung berufen glaubten bzw. glauben. 
Nicht auf den Weg zur wahren Demokratie strebten und führten auch jene radikalen sozialistischen Kräfte, die nicht willens waren, die Macht im Staate in arithmetischer Gleichstellung der Individuen der von ihnen angeführten "unteren" Schichten mit denen der feudalen oder kapitalistischen Oberschicht und auch der bourgeoisen Mittelschicht zu teilen sondern die Macht allein für das "Proletariat" begehrten. 10) Unter Gleichsetzung von Volk = "Proletariat", "werktätige Massen" u.s. ä. belieben auch sie, das Prädikat "demokratisch" für sich in Anspruch zu nehmen. 11) Mit Demokratie, wie sie hier zu verstehen ist, kann dieses Herrschaftssystem jedoch nicht gleichgestellt werden. Wahr bleibt trotz aller gebotenen Einschränkungen, daß seit dem Aufkommen sozialer politischer Tendenzen in der neueren Geschichte stets ein kräftiger Strom sozialer Politik in die demokratische Richtung geflossen ist.

\section{bb) Die ideelle soziale Inklination der Demokratie}

Auf der anderen Seite neigte und neigt die der modernen Demokratie zugrunde liegende Idee der politischen (formalorganisatorischen) Gleichberechtigung immer dazu, sich in der Idee der ökonomischen (materiellen) Gleichberechtigung fortzusetzen. 1)

10) Die Geschichte diese $r$ "demokratischen" Bewegung ist trotz des sorglich erweckten Anscheines der Objektivität der - doppelt - rote Faden der Schrift von Rosenberg ("Demokratie und Sozialismus"). Zur Entwicklungslinie von Babeuf und Robespierre über Marx und Engels bis Lenin kann auf seine Darstellung verwiesen werden.

11) S. hierzu Max Adler, Politische und soziale Demokratie, 1926, S. 49 f (m.w. Nachw.); Rosenberg, a.a.O. insbes. S. $10 \mathrm{ff}, 15 \mathrm{ff}, 337 \mathrm{ff}$.

1) So schon Tocqueville, De la Démocratie en Amérique (Oeuvres complètes, Edition de J.-P. Mayer (Gallimard) $3^{\mathrm{e}}$ Edition, 1951, pp 203 e.s., und passim, Hasbach, Moderne Demokratie, 2. Auf1. 1921, S.349 ff; Kägi, Falsche und wahre Gleichheit im Staat der Gegenwart, Universitas 8. Jhg. (1953) S. 735 ff (737ff); Schoeck, Das Problem des Neids in der Massendemokratie; Rüstow, Ortsbestimmung der Gegenwart, Bd. I S. 209, 222 f; s.a. Bd. III S. 90 ff; Leibholz, Strukturprobleme der modernen Demokratie, S.87. - S. a. die treffende Formulierung von Fleiner (Schweizerisches Bundesstaatsrecht, 1923, S. 760): "Ist die Rechtsgleichheit ein Lebenselement der Demokratie, so ist sie aber auch ihre Klippe. Denn sie fördert jenen Fanatismus und Neid, der die Menschen auf allen Gebieten des Lebens gleichbehandeln will..." 
Eine umfassende Gleichheitsvorstellung muß die Trennung zwischen dem politischen und ökonomischen Bereich von vorneherein ausschließen. Wird die politische Gleichberechtigung als Nahziel erreicht, so muß danach die ökonomische Egalisierung umso dringlicher erscheinen. Aber auch ohne die Prämisse einer einheitlichen Gleichheitskonzeption kann der Stand der politischen Egalität, einmal erreicht, die Begierlichkeit wecken, nun auch die materielle Gleichstellung herbeizuführen. Die Teilhabe an der demokratischen Macht alarmiert alle dahin zielenden Kräfte - in breitester Front das Gerechtigkeits- und Hilfsbedürfnis, ja selbst den primitiven Neid der Massen, ${ }^{2)}$ der Egalität fordert und die jeweils verwirklichte, notwendigerweise immer nur unvollkommene Gleichstellung stets durch weitere Maßnahmen vervollkommnet wissen will. 3) Der Fortschritt von der heteronomen, autokratischen zur autonomen, demokratischen Ordnung erweckt oder bestärkt zudem den Glauben an die Gestaltbarkeit und Perfektibilität der gesellschaftlichen und staatlichen Ordnung. 4)

In dieser Umsetzung bildet die Idee der demokratischen Egalität einen kräftigen Anstoß zur sozialen Intervention des Staates. 5) Allerdings darf nicht verkannt werden, daß "sozial" und "egal" nicht ein- und dasselbe sind. Darauf, daß ferner die demokratische Machtgesetzlichkeit auch dazu locken kann, eine soziale Ungleichheit durch eine andere zu ersetzen, wird gleich zurückzukommen sein.

b) Die Dynamik der demokratischen Macht und die soziale Politik 1)

aa) Die Distanz zwischen der Herrschaft der Mehrheit und einer ganzheitlich sozialen Politik

Das egalitäre massendemokratische Herrschaftssystem ist nicht an sich schon Bürge einer umfassenden, gerechten Sozialordnung.

2) S. nochmals die S. 318 zu Fußn. 1 Zitierten. Besonders sei auf Rüstow, a.a.O. Bd. III S.90 ff hingewiesen.

3) S. vor allem Schoeck, a.a.O.

4) Vgl. Tocqueville, a.a.O. - Zum modernen Glauben an die willkürliche Vollendbarkeit von gedachten Entwicklungsprozessen s.ferner z.B. Freyer, Theorie des gegenwärtigen Zeitalters, S. $62 \mathrm{ff}, 206 \mathrm{ff}$.

5) Nawiasky (a.a.O. - s.o. S. 315 zu Fußn.3-) rechnet die materielle Vorsorge für das Wohl der Bürger daher sogar zur begrifflichen Essenz der egalitären Demokratie.

1) Zum Machtmotiv der sozialen Politik s. die Nachweise oben S. $7 \mathrm{f}$ zu Fußn. 18 bis 22 und den Text hierzu. 
Die demokratische Herrschaftsordnung $k$ an $n$ zu einem materiell sozialen Staatswillensinhalt führen, $m u ß$ das aber $n i c h t$ und wird sogar in der Regel bewirken, daß die Anliegen einzelner, 2 sozial bedürftiger Minderheitsgruppen unberücksichtigt bleiben.

Demokratie ist Herrschaft der Mehrheit. Alles, was in der sog. freiheitlichen Demokratie zugunsten der Minderheit geschieht, um ihr Los zu erleichtern, kann letztlich die Härte dieses Gesetzes nur weniger aktuell spürbar machen, nicht aber brechen. Eine Einstimmigkeits-Demokratie ist undenkbar; und qualifizierte Mehrheitserfordernisse können, so nützlich und wünschenswert sie in besonderen Fällen sind, zur unerträglichen Bevorzugung von Minderheiten gegenüber der Mehrheit führen. Entscheidet aber die Mehrheit, so besteht keine Garantie dafür, daß sie "sozial" entscheidet.

Die Zusammensetzung der Mehrheit aus Kräften, die von wahrhaft sozialem Wollen beherrscht sind, ist nur eine Möglichkeit unter vielen. Um das Problem schematisch zu umreißen: Besteht die herrschende Mehrheit in der wirtschaftlich schlechter gestellten "größeren Hälfte" des Volkes, so liegt darin keine Garantie, daß diese nichts als den sozialen Ausgleich will. Will sie die "Herr'schaft des Proletariats", die den "Bourgeois" in die Verelendung stürzt, um sich auf seine Kosten zu bereichern, so ist das nicht soziale Angleichung sondern die prinzipielle Aufrechterhaltung der sozialen Differenz mit vertauschten Rollen. Bildet sich dagegen die Mehrheit exklusiv aus der wirtschaftlich besser gestellten "größeren Hälfte" des Volkes, so wird der Wille zur sozialen Tat nur so weit reichen wie die innere Verpflichtung an Ideale der Nächstenliebe und der Gerechtigkeit, die Hoffnung auf wirtschaftlichen Nutzen der sozialen Besserung und die Angst vor dem Radikalismus des Proletariats. Bildet sich eine Mehrheit aus der "Mitte", so bleibt nicht nur eine Oberschicht sondern auch jener 'Teil der Unterschicht, der mit der Mittel-

2) Vgl. Herkner, Sozialrevolutionäre Bewegungen in der Demokratie, Jahrbuch für Gesetzgebung, Verwaltung und Volkswirtschaft, n.F. 33.Jhg. Heft 2 (1909) S. 241 ff; ders., Die A rbeiterfrage, 7.Auf1. 1921, S. $84 \mathrm{ff}$; Hasbach, Die moderne Demokratie, 2. Auf1. 1921 , S.333 ff; Forsthoff, Verfassungsprobleme des Sozialstaats, S. 13 ff. - Zu den Erfahrungen des historischen Sozialismus mit der Demokratie und seiner Auseinandersetzung mit ihnen s. Kelsen, Sozialismus und Staat, S.92 ff; Rosenberg, Demokratie und Sozialismus, S.207 ff und passim; Thoma, Über Wesen und Erscheinungsformen der Demokratie, S. $24 \mathrm{ff}$. 
schicht - aus welchen Gründen auch immer - nicht koalieren konnte, von der Macht ausgeschlossen. Dann ist, soweit die Interessen sich sondern lassen, nicht ohne weiteres anzunehmen, daß die an der demokratischen Herrschaft teil habenden Kräfte von "unten" sich auch der besonderen Interessen der Minderheitsgruppe(n) annehmen.

Diese Gesetzmäßigkeiten der Demokratie treten in der modernen mittelbaren Massendemokratie mit ihren spezifischen Strukturbedingungen besonders scharf hervor. Sie ist als ein Verfahren zu verstehen, durch das "einzelne die Entscheidungsbefugnis vermittels eines Konkurrenzkampfes um die Stimmen des Volkes erwerben". 3) Die Abgeordneten, die parlamentarischen Gruppen,

3) Vg1. Schumpeter, Kapitalismus, Sozialismus und Demokratie, S. $381 \mathrm{ff}, 427 \mathrm{ff}$ - Zitat S. 428 -. Zur Relation zwischen diesem $G$ rundgesetz der mittelbaren Demokratie und dem materiellen Gehalt s.insbes. S. 448: Es muß nicht sein, "daß der soziale Sinn eines Tätigkeits-Typs notwendig auch das treibende Motiv und folglich die Erklärung des letzteren darstellt. Wenn dies nicht der Fall ist, dann kann eine Theorie, die sich mit einer Analyse des sozialen Zieles oder des zu befriedigenden sozialen Bedürfnisses begnügt, nicht als hinreichende Begründung für die Tätigkeit, die diesem Ziel dient, akzeptiert werden. Zum Beispiel ist der Grund, warum es so etwas wie eine ökonomische Tätigkeit gibt, natürlich der, daß die Menschen sich nähren und kleiden usw. wollen. Die Mittel zur Befriedigung dieser Wünsche zu liefern, ist das soziale Ziel oder der soziale Sinn der Produktion. Trotzdem sind wir uns alle einig, daß diese These ein sehr wirklichkeitsfremder Ausgangspunkt für eine Theorie der wirtschaftlichen Tätigkeit in der kommerziellen Gesellschaft wäre und daß wir besser vorwärtskommen, wenn wir von 'Thesen über Profite ausgehen. In ähnlicher Weise ist der soziale Sinn oder die soziale Funktion der parlamentarischen Tätigkeit ohne Zweifel die, Gesetze und teilweise auch Verwaltungsmaßnahmen hervorzubringen. Aber um zu verstehen, wie die demokratische Politik diesem sozialen Ziele dient, müssen wir vom Konkurrenzkampf um Macht und Amt ausgehen und uns klar werden, daß die soziale Funktion, so wie die Dinge nun einmal liegen, nur nebenher erfüllt wird - im gleichen Sinne wie die Produktion eine Nebenerscheinung beim Erzielen von Profiten ist". S.hierzu auch Friedrich, Art. "Demokratie" im Handwörterbuch der Sozialwissenschaften, Bd.2 (1959) S. 560 ff (563). - Eine Exegese der Theorie Schumpeters s. bei Herder-Dorneich, Theorie der Bestimmungsgrün- 
die Regierungen usw. treiben daher eine Politik und eine Propaganda, die das Volk, die verschiedenen politischen und vorpolitischen Gruppen, von denen sie Stimmen erhoffen können, in ihren besonderen Interessen ansprechen. Mit einer objektiven Gemeinwohlpolitik, deren Maximen die Erkenntnisfähigkeit des Wählers übersteigen und deren Nutzen nicht in seiner Erlebnissphäre spürbar wird, kann der demokratische Politiker nicht hoffen, an die Macht zu kommen oder an der Macht zu bleiben. Also wird er - offen oder unter der Decke einer entsprechend formulierten Gemeinwohlpolitik - die partikulären Interessen nicht nur berücksichtigen sondern mitunter sogar anstacheln, ja verhätscheln, um sich die Wählermassen zu sichern, die, zwischen den Konkurrenten um die Macht als zwischen den Förderern und Feinden ihres Wohles unterscheidend, ihm die Macht verschaffen können. ${ }^{4)}$ Die

de finanzwirtschaftlicher Staatstätigkeit, 1957 (Freiburger Dissertation), insbes. S. $44 \mathrm{ff}$.

4) (1) Das Gesetz, daß der politische Wille der Wählerschaft durch die politische Führung erst artikuliert wird (s. vor a1lem Kaufmann, Die Problematik des Volkswillens in der Demokratie, 1931; Scheuner, Grundfragen des modernen Staates, Recht-Staat-Wirtschaft, Bd. III (1951) S. 126 ff (127 f)), wird in diesem Prozeß in einer zweifachen Weise wirksam. Auf der einen Seite kann die Regierung bzw. die Führung der Opposition gewiß einen erzieherischen Einfluß auf die Wähler ausüben, indem sie es versteht, Gesichtspunkten des Gesamtwohls zur Beachtung zu verhelfen. Auf der anderen Seite kann diese Artikulierung des politischen Wollens aber gerade auf die Geltendmachung partikulärer Interessen gehen, als deren Verfechter sich die Führung einer politischen Richtung dann produziert.

(2) Besonders deutlich zeigen sich die Wirkungen - und Nachteile! - dieser strukturellen Besonderheit demokratischer Politik in der Budgetgestaltung, bei der es keine Partei wagt, Sonclervorteile für einen Bevölkerungsteil abzuschlagen, der möglicherweise als Wählerquelle in Frage kommen kann; es sei denn, es handelt sich um Maßnahmen zulasten der eigenen Stammwählerschaft, die zu deren durch den eventuellen Zuwachs nicht ausgeglichenen Abwanderung führen könnten. S.hierzu Schmölders, Finanzpolitik, S. 84 f; Herder-Dorneich, Theorie der Bestimmungsgründe finanzwirtschaftlicher Staatstätigkeit, insbes. S. $81 \mathrm{ff}, 111 \mathrm{ff}$; Hettlage, Finanzpolitik und Finanzrecht, S. 3 f; Liefmann-Keil, Die Entwicklung der Theorie der Bewilligung öffentlicher Einnahmen und Ausgaben, Finanzarch.n.F. Bd. 19(1958/59) S.218 ff mit interes- 
partikulären Interessen des Anteils an der Gesamtwählermasse, den er als für ihn unter den gegebenen persönlichen und strukturellen Voraussetzungen erreichbar gewinnen, erhalten oder ausweiten will, müssen nicht auf einen sozialen Ausgleich gehen. In der Regel streben sie nur einen Sondervorteil an. 5)

Diese Relation zwischen Demokratie und sozialer Intervention erhält eine besondere Note noch dadurch, daß die Demokratie im Prinzip eine Konzentration der Politik auf die Interessen der mächtigeren Gruppen, d.h. - von den Machteinflüssen der plutokratischen Oberschicht einmal abgesehen - der zahlreichsten Gruppen mit sich bringt. Gewiß gibt es Ausnahmen, die mit der "Zünglein-an-der-Waage" - Funktion kleiner Parteien und Gruppen (dieser als innerparteilicher Gruppen oder als Wechselwähler) hinreichend gekennzeichnet sind. Aber als Regelerscheinung ist festzustellen, daß auf der Drehscheibe der demokratischen Politik die Interessen umso mehr von der zentripetalen Kraft des Konkurrenzkampfes um Macht und Amt zum Mittelpunkt hingezogen werden, je größer die Kopfzahl der Wähler ist, denen dieses Interesse gemeinsam und wesentlich ist, während sie umso mehr von der. Zentrifugalkraft machtpolitischer Irrelevanz an die $\mathrm{Pe}-$ ripherie des Geschehens gespült werden, je geringer diese Zahl ist. Daß diese Gesetzmäßigkeit für sich allein kein sachlicher Maßstab für die Auslese der vordringlich zu befriedigenden Interessen ist, ist evident.

bb) Der positive Bezug der demokratischen Herrschaftsordnung zur sozialen Politik

aaa) Vorbemerkung: Demokratische und nichtdemokratische Herrschaftsordnung im Vergleich

Schließlich erhebt sich nach alledem die Frage, ob eine Herrschaftsurdnung, in der immer ein 'Teil des Volkes (der Gesel1schaft) über den anderen herrscht, wie in der Demokratie die Mehrheit über die Minderheit, eine soziale Politik überhaupt erlaubt. Wird nicht immer der herrschende Teil die Macht dazu benutzen, auch den wirtschaftlichen Vorteil an sich zu ziehen, den Besitz zu erhalten, das als fehlend Empfundene sich zu verschaffen? Und das auf Kosten des anderen Teils. Wird nicht der beherrschte Teil die Macht erstreben, um mit ihr, sobald er sie in Händen hält, genau so zu verfahren? 1) In dieser strukturbeding-

santen weit. Nachw.

5) Vgl. Forsthoff, Verfassungsprobleme des Sozialstaates, S. 13 ff.

1) S. zum Problem vor allem L.v. Stein, Das Königtum, die Republik usw. S. $1 \mathrm{ff}, 128 \mathrm{ff}, 168 \mathrm{ff}$. 
ten Distanz zwischen Demokratie und sozialer Intervention finden diejenigen eine grundsätzliche Rechtfertigung, die im Hinblick auf die Notwendigkeiten der sozialen Intervention eine Herrschaftsordnung, die die Macht einem außergesellschaftlichen Subjekt, insbes. einem Monarchen - nicht allein im Sinne eines Erbmonarchen -, zuweist, der Demokratie vorziehen. $\left.{ }^{2}\right)$

Das Risiko einer außer- und übergesellschaftlichen Allein- oder Cliquenherrschaft, die Unabsetzbarkeit unfähiger oder böswilliger Machthaber wirkt sich aber im Bereich der sozialen Intervention nicht weniger aus als anderswo. Dazu kommt, daß die kardinale Prämisse, ein Monarch - oder eine andere ihm vergleichbare Herrschaft - stünde außerhalb und über der Gesellschaft, so daß seine Maßnahmen deshalb nicht den ungerechten Vorteil eines Teiles sondern stets das Wohl des ganzen Volkes zum Ziele hät-

2) (1) Vgl. v.Stein und Lasalle (s.o. S. 317 zu Fußn. 8); s.zum Problem ferner Herkner und Hasbach (s.o. S. 319 zu Fußn. 1) und Forsthoff, Verfassungsprobleme des Sozialstaates, S. $18 \mathrm{f}$. -

(2) Der systematischen Vollständigkeit halber sei vermerkt, daß, soweit ersichtlich, die Forderung nach einer A ris tok ratie im sozialen Interesse nicht erhoben wurde bzw. wird. Mit Recht nicht. Aristokratien und Oligarchien sind kaum jemals als die Herrschaft außer-und übergesellschafticher Kräfte anzusehen, vielmehr regelmäßig als die Herrschaft einer Minderheit über die Mehrheit. Je enger der Kreis der zur Macht Berufenen ist, desto mehr kann sie sich freilich der Position einer außer-und übergesellschaftlichen Monarchie nähern. Umgekehrt wird der Charakter der Herrschaft der Minderheit über die Mehrheit umso deutlicher, je größer der Kreis der "Aristokraten" ist. Schließlich kann sogar der Übergang zu gewissen Erscheinungsformen der Demokratie flüssig werden, die in Wahrheit schon fast als Massen-Oligarchien anzusehen sind, wie die Demokratie des Zensusund Mehrklassenwahl rechts. (Letztere könnte als ein $Z$ witter von Demokratie und Oligarchie bezeichnet werden.) Alle diese Systeme verfestigen die Herrschaft einer Minderheit über die Mehrheit. Sie scheiden unter dem Gesichtspunkt des Sozialen als ernsthafte Konkurrenten sowohl der Monarchie wie der "wahren", egalitären Demokratie von vorneherein aus. (Der liberal-patriarchalische Gedanke, daß der vermögende Bürger besser als der unvermögende selbst bestimmen könne, was diesem frommt, wirkte trotz vielleicht redlichen Ansatzes immer, wo er verwirklicht wurde, sich doch nicht anders aus denn als ein Schutz der Klasseninteres- 
ten, einen Idealfall, nicht jedoch den Regelfall kennzeichnet. ${ }^{3)}$ Wo sich der Monarch an eine mächtige Schicht, die seine Herrschaft trägt, anlehnt oder anlehnen muß, wird diese ihre Position kaum weniger zu ihren Gunsten zu nutzen wissen wie die demokratisch herrschende Mehrheit. Gewiß kann der Monarch mäBigend wirken. Wie weit er dabei gehen kann, hängt allerdings ganz von der konkreten Situation ab. Die Übergänge zwischen dem "wahrhaft" souveränen Monarchen und dem von einer Schicht unterjochten sind fließend. Daß diese Schicht des dadurch verschafften Vorteiles präsumtiv bedürftiger oder gar - unter irgendwelchen Wertungsmaßstäben - "würdiger" ist als die demokratische Mehrheit, wird kaum bewiesen werden können.

Damit soll nicht verkannt werden, daß die Herrschaft eines außer- und übergesellschaftlichen Machtträgers ihrer Natur nach einen höheren Grad an Vollkommenheit aller und gerade auch der sozialen Politik ermöglicht, als ein demokratisches Staatswesen, in dem der unmittelbare Durchgriff auf das als solches erkannte gemeine Beste durch die gebotenen vielfältigen Rücksichtnahmen erschwert wird. ${ }^{4)}$ Aber die in Frage stehenden Staatsformen gewährleisten nicht, daß dieses Maximum erreicht wird. Im besonderen die sozialen Zustände können unter ihnen auch negativ bis zu jenem Maximum gesteigert werden, das unter feudalen und monarchisch verbrämten plutokratischen Herrschaftssystemen aber auch unter der oligarchisch oder tyrannisch geführten "Diktatur des Proletariats" Geschichte geworden ist.

Soziale Differenzen kennt auch die Demokratie. Aber in ihr herrschen Gesetzmäßigkeiten, die - freilich diffus und indirekt - approximativ auf einen Zustand tendieren, wie er auch von einer prinzipiellen und umfassenden sozialen Intervention erstrebt wird. Dadurch - so wird sich zeigen - erweist sich die Demokratie auch hier als eine Staatsform des Mittelmaßes. Nicht zur Vollkommenheit geschaffen, bringt sie im großen und ganzen die Dinge aber doch auf einen positiven Weg.

sen eben jener vermögenden Bürger.)

3) Vg1. die eingehende Auseinandersetzung L.v. Steins mit diesem Problem (Die Monarchie, die Republik usw. passim insbes. S. 1 ff (vor allem S. 16 ff)), das er aber doch als das weniger gefährliche gegenüber der demokratischen Mehrheitsherrschaft betrachtet.

4) Vgl. Schumpeter, a.a.O. S.401 ff. 
bbb) Die strukturelle soziale Inklination der Demokratie

In der Demokratie ist jedenfalls gesichert, daß das (als solches verstandene) Wohl der Mehrheit den Zielpunkt der Politik bildet. Eine sozialer Hilfe bedürftige Unterschicht, deren Interessen vom Staate nicht berücksichtigt werden, kann im großen und ganzen und auf die Dauer nur eine Minderheit sein. Keine andere Staatsform bietet eine vergleichbare Garantie für das "größte Glück der größten Zahl". Freilich können sich auch in der Demokratie Abweichungen ergeben. Plutokratische Positionen und, davon abhängige oder eigenständige Bildungsvorsprünge können den Einf1uß von Minderheitsgruppen über ihre quantitative Legitimation hinaus wachsen, wirtschaftliche und Bildungs-Schwächen dagegen den Einfluß "unterer" Schichten unter das ihrem quantitativen Anteil Entsprechende sinken lassen. 1) Aber im Bereiche des allgemeinen und gleichen Wahlrechts kann keinerlei "qualitative" Vormacht auf die Dauer Bestand haben, die der gezählten Wählermehrheit nicht spürbare Zugeständnisse machen müßte. ${ }^{2)}$

In diesem Elementargesetz steckt - für sich gesehen - nur ein recht relativer und beschränkter Ansatz zur sozialen Intervention. Aber von ihm gehen weitere Konsequenzen aus. Die allgemeinste ist die Sogwirkung, die vom Wohlstand der Mehrheit ausgeht: Eine kleine Oberschicht kann ihren Reichtum weit besser konservieren als eine Mehrheit ihren Wohlstand.

Eine zweite Konsequenz ergibt sich aus dem Zwang zur Mehrheitsbildung. 3) Das Schreckgespenst einer Demokratie, die durch den Interessengegensatz zwischen Mehrheit und Minderheit nur zur Unterdrückung der Minderheit durch die Mehrheit, niemals aber zum Ausgleich befähigt erscheint, basiert auf der Vorstellung eines in zwei, in sich homogene, sich distanziert und feindlich als ökonomische Ober- und Unterschicht gegenüberstehende Teile gespaltenen Volkes. Es mag dahingestellt bleiben, ob eine solche Situation jemals rein gegeben war und unter welchen Voraussetzungen sie auftreten könnte. Auf die (westlichen) Massendemokratien der Gegenwart trifft dieses Schema jedenfalls nicht $z u$. In ihnen herrscht eine Pluralität der Gruppenbildungen und

1) S.hierzu auch unten 2. (S. $329 \mathrm{ff}$ ). - Zum Problem des Bildungsmonopols auch unten S. 339 zu Fußn. 7.

2) Der Fall einer nennenswerten Analphabetenschicht braucht hier nicht ins Auge gefaßt zu werden. Im übrigen s. zum demokratischen Problem des Bildungsmonopols unten S. 339 zu Fußn. 7 .

3) Vgl. hierzu und zum Folgenden: Michels, Soziologie des Parteiwesens in der modernen Demokratie, 2. Aufl. 1925 (Neu- 
Interessengegensätze. Die Übergänge zwischen den Eckpositionen des "ganz Armen" und des "ganz Reichen" sind fließend. Zusätzlich überspannen weltanschauliche und nationale regionale Gemeinsamkeiten die ökonomischen Zäsuren und schaffen Querlinien. Unter diesen Umständen kann eine homogene Minderheit denkbar sein, eine kompakte, homogene Mehrheit gibt es nicht. Die Mehrheit umfaßt stets Gruppen (und Individuen) von recht verschiedenen Standorten und Interessen. Die Massenparteien, die in sich eine Fülle von Interessengegensätzen aufnehmen und recht und schlecht vertuschen oder wirklich ausgleichen, und die Regierungskoalitionen, in denen diese Gegensätze erst in einer höheren parteiexternen Sphäre zum Austrag kommen, zeigen das. Eine Gruppe, die sich diesem Zwang zur Mehrheit nicht fügen kann, bleibt von der Macht der Mehrheit ausgeschlossen. ${ }^{\text {f }}$ Die am gravierendsten davon betroffene Gruppe ist die zahlenmäßig geringe wirtschaftliche Oberschicht, die sich das Bündnis mit "unten" mehr oder weniger teuer erkaufen muß. Ein umgekehrter Vorgang ist die sich für die unterste Schicht ergebende Notwendigkeit, ihrerseits die radikalen Ziele wenigstens zu riskieren und, der Zusammenarbeit mit "oben" zuliebe, auf eine gemäßigte Politik des sozialen Ausgleichs einzuschwenken. Aber wie die Konstellation auch sei - das Wesen der Demokratie, zu dem nicht zuletzt der Kompromiß gehört, pflegt sich im Zwang zum Ausgleich bemerkbar zu machen. In dem durch den Kreis der innerhalb der Mehrheit aktiven Interessen objektiv umgrenzten Rahmen kann dieser Ausgleich durchaus auch zu dem Effekt einer mehr oder weniger approximativ umfassenden sozialen Inte rvention führen.

Diese Erscheinung bleibt nicht auf sich beschränkt. Sie kann eine allgemeinere Tendenz zur sozialen Angleichung auslösen. Vor allem können die auf das Innenverhältnis der Mehrheit gezielten Maßnahmen meist gar nicht auf deren Potentaten, Wähler, Sympathisanten usw. beschränkt bleiben. Sie strahlen also unmittelbar auf einen großen 'Teil des Volksganzen aus.

Schließlich aber ist jede demokratische Mehrheit bestrebt, sich auszubreiten. Minderheiten wollen Mehrheiten werden. Mehrheiten wollen "überwiegende" Mehrheiten werden. Minderheitsparteien wollen Mehrheitsparteien werden. Kleinere Parteien wollen so kräftig werden, daß sie in der Koalition Einfluß haben. Mehrheitsparteien wollen zur "verfassungsändernden Mehrheit" auf-

druck 1957), S. $5 \mathrm{ff}, 17 \mathrm{ff}, 20 \mathrm{ff}$.

4) Der krankhafte Fall einer nicht nur vorübergehend negativen Mehrheit muß hier außer Betracht bleiben. 
steigen und sich so etablieren, daß sie nicht mehr aus dem Sattel geworfen werden können. In fast allen Fällen bedeutet das eine Ausbreitung des berücksichtigten Interessenfeldes. Selbst Interessenparteien, die unter dem Zeichen eines Einzelinteresses angetreten sind, bemühen sich, darüber hinaus auszugreifen. ${ }^{5)}$ Allen sitzt die Angst im Nacken, von der Herrschaft der Mehrheit ausgeschlossen zu werden. Und so werden immer mehr Interessen berücksichtigt - die stimmkräftigsten zuvörderst. So entsteht um diejenigen Interessen, die zunächst ad hoc ausgereicht hätten, eine Mehrheit zu einen, ein Vorhof von Interessen, die über dieses Minimum hinaus berücksichtigt werden. Damit wächst auch das Feld des sozialen Ausgleichs.

Hiermit soll nicht verkleinert werden, daß durch diese Gesetzmäßigkeiten in erster Linie partikulare Interessen einer gesonderten Berücksichtigung zugeführt werden. Aber diese einzelnen Maßnahmen ergänzen sich nicht nur gegenseitig. Sie fordern auch immer neue Interessen und dementsprechend neue Maßnahmen heraus. So kann schließlich ein Gesamtgefüge von Maßnahmen entstehen, das durchaus auch prinzipiellen Vorstellungen einer systematischen sozialen Intervention entspricht. ${ }^{6)}$

Die sozialtendenziöse Politik steht der interessenvariierenden Ausbreitung des politischen Einzugsgebietes zudem deshalb in besonderem Maße offen, weil sie von "oben" und "unten" erstrebt werden kann: von "unten" im unmittelbaren Eigeninteresse; von "oben" im mittelbaren Eigeninteresse (Abwehr von Neid, Unruhe, Radikalismus) oder im Fremdinteresse (Caritas, soziale Gerechtigkeit). Der jeweilige Standpunkt setzt natürlich dem übereinstimmenden Urteil über die Zweckmäßigkeit konkreter Maßnahmen Grenzen. Aber ein Zusammengehen im Grundsätzlichen ist weitgehend möglich. Daher kann gerade eine gemäßigte soziale Politik Klammer einer vom ökonomischen Äquator weit nach oben und unten ausholenden Mehrheit werden.

5) Michels, a.a.O. S. $17 \mathrm{ff}$.

6) Über die Tendenz zur Einkommensumverteilung über die öffentliche Hand und zur Einkommensnivellierung als Folgen eines allgemeinen und gleichen Wahlrechts (und über die immanenten Grenzen der Nivellierungstendenz) handelt besonders eindringlich Downs, An Economic Theory of Democracy, 1957; kurze inhaltliche Wiedergabe s. bei Liefmann-Keil, Zur Entwicklung der Theorie der Bewilligung öffentlicher Einnahmen und Ausgaben, S.228 ff (insbes. S.231 f). - S. zum Text auch BVerfGE 5, 85 (198). 
2. Die "reale" Demokratie und die realen Entsprechungen der "formalen" Demokratie

a) "Reale" Demokratie, "Wirtschaftsdemokratie" usw.

Eine andere Auffassung der Demokratie hält die materielle, wirtschaftliche Einebnung von vorneherein für einen wesentlichen Bestandteil derselben. Für sie bedeutet die Entscheidung für die Demokratie nicht nur (oder überhaupt nicht) eine Aussage über Subjekt und Prozeß der Staatswillensbildung sondern auch (oder nur) eine wirtschafts- und sozialpolitische Dezision, die durch die Zuteilung wirtschaftlicher Gestaltungsmacht an das Volk - die "Masse", das "Proletariat" usw. - im ökonomischen Bereich Verhältnisse erstrebt, die in Analogie zur politischen Demokratie stehen. 1) Das ist - bei unüberschaubaren Unterschieden im einzelnen - gemeint, wenn gegenüber der "formalen" organisatorischen Demokratie die - allein "wahre" 2) - "reale" 3) und "soziale" 4)

1) S. a. schon oben 1 a (S. $315 \mathrm{ff})$, insbes. S. 318 .

2) In diesem Sinne etwa spricht von einer "wahren" gegenüber der liberalen Demokratie Kofler, Liberalismus und Demokratie, Zeitschrift für Politik, n. F. 6. Jhg. (1959) S. 113 ff. Zum Selbstverständnis der sowjetischen Herrschaftsordnung als der "wahren" Demokratie s. die klassischen Ausführungen Stalins (Fragen des Leninismus, 1947 - übersetzt nach der 11. russischen Auflage von 1939 - S. 625 f, 633 f).

3) Zum Begriff der. "realen" Demokratie s. z.B. Dürig, Art. "Staatsformen" im Handwörterbuch der Sozialwissenschaften $\mathrm{Bd} .9 \mathrm{~S} .742 \mathrm{ff}(750)$. Zum Verhältnis der "realen" zur "formalen" Demokratie s. ferner insbes. Abendroth in: SultanAbendroth, Bürokratischer Verwaltungsstaat und soziale Demokratie, 1955, S. $59 \mathrm{ff}, 81 \mathrm{ff}$ (insbes. S. $91 \mathrm{ff}, 98 \mathrm{ff}$ ), $103 \mathrm{ff}$, $111 \mathrm{ff}$. - Zum Selbstverständnis des marxistisch-kommunistischen Staates als "reale" Demokratie s. ferner Stalin, a. a.O. und die unten S. 330 zu Fußn. 5 zur "Volksdemokratie" Zitierten.

4) Zur. "sozialen" Demokratie s. Adler, Politische und soziale Demokratie; Heller, Rechtsstaat oder Diktatur? 1930, S. 7, 11; Abendroth, a.a.O. - Polemisch dagegen Kelsen, Wesen und Wert der Demokratie, 2. Auf1. 1929, S. 93 ff. Sehr spitz polemisiert gegen diesen Begriff auch Hayek (Was ist und was heißt "sozial", S.78). Doch basiert seine Kritik auf einem einseitigen Verständnis des Wortes "sozial", das er nur mit der Bedeutung "der Gesellschaft eigenartig" oder "aus dem spezifisch gesellschaftlichen Prozeß hervorgehend" gelten lassen will (S.77 f). - Zum Begriff des "demokratischen und so- 
Demokratie, die in verfälschender Verdopplung so genannte "Volksdemokratie" 5) und - mit einem darüber hinausreichenden Begriff - die "Wirtschaftsdemokratie" 6) gefordert wird.

zialen Rechtsstaats" im Sinne des Grundgesetzes s. unten Abschnitt 5 II 3 (S. $736 \mathrm{ff}$ ), insbes. b ( $\mathrm{S} .741 \mathrm{ff}$ ).

5) Zum Begriff der Volksdemokratie, der den der "realen" Demokratie impliziert und zugleich die - in dem Pleonasmus der Formulierung, der durch die Überbetonung des Volkes den Abbau der effektiven Volksherrschaft kompensieren soll, reziprok zum Ausdruck gebrachte - Ablehnung der "formalen" Demokratie enthält,s. Maunz, Deutsches Staatsrecht, S. $311 \mathrm{ff}$; Fraenkel, Die Selbstbestimmung in der Demokratie und in der Volksdemokratie, Deutsche Rundschau, 86. Jhg. (1960) S. $778 \mathrm{ff}$. Zum Demokratiebegriff in der DDR s. ferner z.B. Polak, Die Entwicklung des volksdemokratischen Staates 1945-1948, Staat und Recht, 7.Jhg. (1958) S. 853 ff (857 ff). Kröger, Der Sozialismus siegt! ebenda S. $757 \mathrm{ff}$ (763 ff); Unger, Die Rolle der Wahlen in der DDR, ebenda S.953 ff (955 ff). - Wenn Nawiasky (Allgemeine Staatslehre, Teil 2 Bd. II S. 161) in der Volksdemokratie einen Staat sieht, in dem "die aktive Beteiligung am Staat möglichst Vieler im Vordergrund steht, die Freiheit des Einzelnen vom Staat aber. in der Hauptsache fehlt", so hat er damit lediglich einen denkbaren, der freiheitlichen Demokratie antithetisch gegenüberstehenden Idealtyp einer nicht-1iberalen Demokratie im Auge (s.a. Allgemeine Staatslehre, Teil 4 S.88). Die historisch konkret gegenwärtigen Volksdemokratien sind dagegen zwar sehr wohl durch die Abwesenheit persönlicher Freiheit, mitnichten aber durch eine maximale Ausbildung des status activus des Bürgers gekennzeichnet.

6) S. hierzu z.B. - bei jeweils sehr verschiedener Vorstellung von dem, was unter Wirtschaftsclemokratie zu verstehen ist -: Decker, Zum Begriff der Wirtschaftsdemokratie, Die Arbeit, 4. Jhg. (1927) S. $825 \mathrm{ff}$; die von Naphtali herausgegebene, von einer Autorengemeinschaft ausgearbeitete Schrift "Wirtschaftsdemokratie", 4. Aufl. 1929; Renner, Wege der Verwirklichung - Betrachtungen über die politische Demokratie, Wirtschaftsdemokratie und Sozialismus, 1929; Rauecker, Wirtschaftsdemokratie, 1929; Tatarin-Tarnheyden, Berufsverbände und Wirtschaftsdemokratie, 1930; ders., Recht der Berufsverbände und Wirtschaftsdemokratie, in Nipperdey, Die Grundrechte und Grundpflichten der Reichsverfassung, Bd. III 1930, S. 519 ff; Arndt, Das Problem der Wirtschaftsdemokratie, SJZ 1.Jhg. (1946) S. 137 ff; Böhm, Die Bedeutung 
Diese Transposition der Demokratie ins Ökonomische baut - abgesehen vom bloßen Fortdenken der politischen Gleichheit ins Ökonomische 7) - auf der für das plutokratische Trauma des Sozialismus kennzeichnenden Identifikation von politischer und wirtschaftlicher Macht ${ }^{8}$ ) auf, vor deren Hintergrund die rein politische ("formale") Demokratie als eine bloße Farce erscheint. Aber es geht nicht nur um die wirtschaftliche Nivellierung, nicht nur um die Angleichung des Einkommens- und Vermögensstandards als ökonomisch-materielles Pendant zum allgemeinen und gleichen Wahlrecht oder um einen wirtschaftlichen Ersatz für dieses. Neben der egalitären steckt dahinter - nicht immer, aber doch vielfach - die freiheitliche, autonomistische Komponente der Demokratie. ${ }^{9)}$ Will die Demokratie jedem (die gleiche) Freiheit gewähren, so erscheint doch im Ganzen der wirtschaftlich Abhängige weniger "frei" als der wirtschaftlich "Unabhängige". Die politische Freiheit selbst scheint durch die wirtschaftliche Ungleichheit und Unf reiheit gefährdet. Nicht nur politische Gleichheit und Freiheit sondern wirtschaftliche Gleichheit und durch sie gleiche ökonomische Freiheit wird also gefordert. ${ }^{10)}$.

der Wirtschaftsdemokratie für die politische Verfassung, ebenda S. $141 \mathrm{ff}$; ders., Das wirtschaftliche Mitbestimmungsrecht der Arbeiter im Betrieb, ORDO Bd.IV (1951) S. $21 \mathrm{ff}$ (42 ff, $95 \mathrm{ff}$ ); Kraus, Wirtschaftsdemokratie und Wirtschaftsaufbau, 1947; Krüger, Staatsverfassung und Wirtschaftsverfassung, S.364 ff; Huber, Wirtschaftsverwaltungsrecht, Bd. I S. 40 f, 261, Bd.II S. 478 f, 546, 571; Ortlieb, Der Kampf um Wirtschaftsdemokratie und Mitbestimmung, in "Wege zum sozialen Frieden", hrsg. von Ortlieb und Schelsky, 1954, S. $9 \mathrm{ff}$; Landshut, Mitbestimmung und Wirtschaftsdemokratie, ebenda S. $36 \mathrm{ff}$; (einzelne weitere Nachweise aus der Zeit bis 1954 s. bei Krone, Bibliographie zur Mitbestimmung, ebenda S.277 ff, insbes. S. $279 \mathrm{ff})$.

7) S.O. S. 318 .

8) Vgl. Sombart, Der proletarische Sozialismus, Bd.1 S. 359 f.

9) Zum Dualismus der egalitären und freiheitlichen Tendenz s. Krüger, Staatsverfassung und Wirtschaftsverfassung, S. 364 f; ders., Sozialisierung, S. 272 (m. eingeh. weiteren Nachweisen).

10) S. insbes. Abendroth, in: Sultan-Abendroth, Bürokratischer Verwaltungsstaat und soziale Demokratie, S. $103 \mathrm{ff}$ und passim; Krüger, Sozialisierung, S. 272 f; w. Nachw.s. dort. Vgl. ferner Leibholz, Die kritischen Punkte des Grundgesetzes, S. 20: "Aufgabe gerade des konsequentesten Demokratismus ist es, mit Hilfe eines radikalen Egalitarismus die Freiheit denen wieder zu bringen, die sie durch die Frei- 
So verwundert es nicht, daß im Vordergrund dieser Konzeptionen - soweit sie auf dem Substrat der freiheitlichen Demokratie und der Anerkennung des Privateigentums erwachsen sind - das betriebliche Mitbestimmungsrecht steht. 11) Es eignet sich nicht nur, die Dispositionsfreiheit des Kapitaleigentü mers zugunsten einer Mitberechtigung der Arbeitnehmer zu koupieren und damit die ökonomische Distanz zwischen "Kapital" und "A rbeit" zu vermindern. Der A rbeiter soll dadurch auch vom "Betriebsuntertan" zum demokratischen Betriebs-Bürger gehoben werden. 12) Das an den Anfängen stehende Wort von der "konstitutionellen Fabrik" 13) verdeutlicht den zugrundeliegenden Analogieschluß von den politischen auf die wirtschaftlichen Verhältnisse. 14) Von hier aus geht der Gedankengang zunächst zur

heit verloren haben. ... den Verlust der Freiheit mit Hilfe der Gleichheit zu kompensieren und hierdurch erst die Voraussetzungen dafür zu schaffen, daß die durch die Freiheit Depossedierten und damit ungleich Gewordenen wieder in den Besitz der Freiheit gelangen".

11) Zur betrieblichen Mitbestimmung (in jenem allgemeinsten Sinn, der auch die Befugnisse der herkömmlichen Betriebsräte einschließt) als Programmpunkt der Wirtschaftsdemokratie s. Naphtali, Wirtschaftsdemokratie, S.14 ff und passim; Renner, Wege zur Verwirklichung, S. 67 ff und passim; v. Schwenk, Demokratie und Mitbestimmung, Gewerkschaftliche Monatshefte, 2.Jhg. (1951) S. 541 ff; Böhm, Das wirtschaftliche Mitbestimmungsrecht der Arbeiter im Betrieb, insbes. S. $95 \mathrm{ff}$ (ausschließ1ich kritisch); Landshut, Mitbestimmung und Wirtschaftsdemokratie (desgl.); A bendroth, a.a.O. S.67, 91 f, 103 ff; Hamann, Deutsche Wirtschaftsverfassung, S. 53 f; Kofler, Liberalismus und Demokratie, S. 118 ff; Heinz Seidel, Mitbestimmungsziele, Mitbestimmungsmöglichkeiten, Mitbestimmungswirklichkeit, Gewerkschaftliche Monatshefte, 11.Jhg. (1960) S. $193 \mathrm{ff}$.

12) Vg1. Renner, a.a.O. S.24 ff, $40 \mathrm{f}$ und passim; Abendroth, a.a.O. S. $103 \mathrm{ff}$.

13) S. Freese, Das konstitutionelle System im Fabrikbet riebe, in "Die Verhandlungen des zehnten Evangelisch-sozialen Kongresses, abgehalten in Kiel am 25./26. Mai 1899", 1899, S. 56 ff; ders., Die konstitutionelle Fabrik, 1909.

14) Vg1. Partsch, Die verfassungsmäßige Sicherung von Wirtschaftsprinzipien, Ordo Bd. VI (1954) S. 19 ff (31 f): Der Gedanke der "Wirtschaftsdemokratie" geht "von der Vorstellung aus, daß im Wirtschaftsvorgange einer der Beteiligten die Rolle spielt, die dem souveränen Volk, von dem sich 
überbetrieblichen Mitbestimmung in Wirtschaftsräten usw., womit vor allem mittels der Parität von "Kapital" und "Arbeit" - letztere verkörpert durch die Arbeitnehmerschaft und ihrer gewerkschaftlichen Zusammenfassung - ebenfalls die Verfügungsmacht über das Kapital durch ihre Unterordnung unter eine von der A rbeitnehmerschaft gleichberechtigt mitgestaltete überbetriebliche Ordnung und Planung entwertet werden sol1. 15) Ähnlich soll die Arbeitnehmerschaft durch die Beteiligung der Gewerkschaften an der Verwaltung gemeinwirtschaft 1 i cher Unternehmenszusammenfassungen am Wirtschaftspotential beteiligt werden. 16) Überhaupt soll eine einflußreiche Stellung der Gewe rkschaften dem Arbeitnehmer eine kollektive Kompensation für seinen fehlenden Anteil am Kapital bieten 17) und zwar nicht nur in der betrieblichen und überbetrieblichen Mitbestimmung und im klassischen Terrain der "sozialen Selbstverwaltung" 18) sondern auch durch den Aufbau von $G$ enossenschaften 19) und gewerkschaftseigenen Unternehmungen 20) und die unmittelbare Einf $1 \mathrm{u} \beta \mathrm{n}$ ahm e auf die staatliche Verwaltung und auf Selbstverwaltungsorga-

jede staatliche Gewalt in der Demokratie herleitet, zukommt. Diese Vorstellung stimmt mit den tatsächlichen Verhältnissen nicht überein".

15) (1) Zur überbetrieblichen Mitbestimmung als einer Form der Wirtschaftsdemokratie s. Naphtali, a.a.O. S.151 f und passim; Tatarin-Tarnheyden, Berufsverbände und Wirtschaftsdemokratie, insbes. S. $10 \mathrm{ff}$; ders., Recht der Berufsverbände und Wirtschaftsdemokratie, insbes. S. $522 \mathrm{ff}$; Huber, a.a.O. Bd.I S. 41, Bd.II S. 478 f; s.a. Böhm, a.a.O. passim.

(2) Zur Aufhebung der "Kopfzahlgleichheit" zugunsten der "organischen" Gleichheit von Kapital und Arbeit als dem tragenden Prinzip der überbetrieblichen Mitbestimmung s. Tatarin-Tarnheyden, Berufsverbände und Wirtschaftsdemokratie, S. 12 f, 62 f mit weit. Nachweisen; s.a. dens., Recht der Berufsverbände und Wirtschaftsdemokratie, S. $523 \mathrm{f}$.

16) S. hierzu Naphtali, a.a.O. insbes. S. 14 ff, 35 ff; Huber, a.a.O. S. 41, 261 (Bd. I).

17) Vgl. Naphtali, a.a.O. durchgehend; Abendroth, a.a.O. insbes. S. $59 \mathrm{ff}, 71 \mathrm{ff}, 91 \mathrm{f}$.

18) Naphtali, a.a.O. S. 144 ff; Tatarin-Tarnheyden, Berufsverbände und Wirtschaftsdemokratie, S. 28 ff, $39 \mathrm{ff}$; ders., Recht der Berufsverbände und Wirtschaftsdemokratie, S. 543 ff; Meissinger, Reliefbild des Arbeitsrechts, S. $19 \mathrm{ff}$.

19) Renner, Wege zur Verwirklichung, S. $41 \mathrm{ff}, 46 \mathrm{ff}, 79 \mathrm{ff}$ und 
ne. ${ }^{21)}$ Schließlich steigert sich die "Realisierung" der Demokratie zur umfassenden Sozialis i erung 22 ) und endlich zur Konzentration des Kapitals beim sta te, der zum Adressaten aller Leistungen und zum Verteiler von Lohn und Versorgung wird. 23)

b) Die "realen" Voraussetzungen der. "formalen" Demokratie

Ungeachtet aller ideologischen, politisch-theoretischen und begrifflichen Vorf ragen und allen politischen Mißbrauches, der dem Gedankengut der "realen" Demokratie anhaftet, ist die Idee der "realen" Demokratie als Hinweis auf die notwendige wirtschaftlich-soziale Ambiance der "formalen" Demokratie ernst zu nehmen. Die Demokratie kann nur unter gewissen Bedingungen unverfälscht funktionieren, unter denen die eines Mindestmaßes an wirtschaftlich-sozialer Homogenität eine der bedeutsamsten ist. 1) Zerreißen extreme ökonomische Ungleichheiten

passim.

20) Naphtali, a.a.O. S.87 ff.

21) Naphtali, a.a.O. S. 144 ff. - Zum wirtschaftsdemokratischen Verständnis der Selbstverwaltung in der Sozialversicherung s. Oberwinster, Paritätische Selbstverwaltung in der Sozialversicherung, "Beiträge zur Sozialversicherung", Festschrift für Johannes Krohn, 1954, S. 185 ff.

22) Naphtali, a.a.O. S. 14 ff, 21 ff, 35 fi, 53 ff, 173 ff; Huber, Wirtschaftsverwaltungsrecht $\mathrm{Bd}$.I S. 40 f; Herbert Krüger, Sozialisierung, S.272 f.

23) Vgl. Naphtali, a.a.O. S. 7 ff und passim. Eine dem verschwisterte Konzeption der "Wirtschaftsdemokratie" hat A rndt in seiner schon erwähnten Abhandlung über "Das Problem der Wirtschaftsdemokratie" entworfen: Der Staat, der eine Demokratie sein soll, soll die Wirtschaft durch Vollplanung beherrschen. (Die Begriftsbilclung ist allerdings ungewöhnlich; denn primär handelt es sich um Planwirtschaft und Etatismus. Die Demokratie als Statsform ist cler Sache nach akzidentiell.)

1) S. z.B. Heller, Staatslehre, s. 137 f, $247 \mathrm{ff}$; Schumpeter, a.a.O. S. 460 ff; Krüger, Staatsverfassung und Wirtschaftsverfassung, S.365 f; Abendroth, in Sultan-Abendroth, Bürokratischer Verwaltungsstaat und soziale Demokratie, S. $60 \mathrm{f}$, $91 \mathrm{f}$; Ortlieb, Unsere Konsumgesellschaft, S.239 ff (insbes. S.239, 242); Ritschl, Wirtschaftsordnung und Rechtsstaat, in "Zur Ordnung von Wirtschaft und Gesellschaft", Hamburger Jahrbuch zur Wirtschafts- und Gesellschaftspolitik, 4.Jhg. (Festausgabe für Eduard Heimann), 1959, S.256 ff (266 ff). - 
das Volk in feinfliche Gruppen, so fehlt schließlich jenes Minimum an gemeinsimem Interesse an der Erhaltung des Bestehenden, das allein die Beachtung der demokratischen Spielregeln zu sichern vermag. 2) Unkontrollierte kapitalistische Machtpositionen können sich in den politischen Raum hineinfressen und die Wirksamkeit cler. Allgemeinheit und Gleichheit der Wahl durch Bildungsdistanzen (und demzufolge Informationsvorteile), durch Propagandaaufwand, durch Bestechung in allen ihren engeren und weiteren Erscheinungsformen und sonstige, die freie Entscheidung von Wählern und Gewählten beeinträchtigende wirtschaftliche Abhängigkeiten zum wirklich rein "Formalen" degradieren. ${ }^{3)}$ Der dauernd wirtschaftlich Geknechtete wird es andererseits schwer haben, politisch mit dem vollen Gewicht der. Verantwortung als "Freier" zu entscheiden. 4)

Die wirtschaftlichen Ungleichheiten, die das Programm der "realen" Demokratie bekämpft, können also zu Gefahren für die Demokratie werden. Indem die Institutionen der "Wirtschaftsdemokratie" diese Gefahrenherde beseitigen, verteidigen sie die "formale" Demokratie. ${ }^{5)}$ Doch gilt das letztlich von aller sozialen Politik.
3. Freiheitliche Demokratie und statlicher Interventionismus

In diesem Sinne kann auch der wegen seiner vermeintlichen Unvereinbarkeit mit (ler Demokratie viel geschmähte wirtschaftliche Interventionismus ${ }^{1)}$ ein Element positiv demokratischer Po-

S.a. Schüle, Demokratie als politische Form und als Lebensform, in "Rechtsprobleme in Staat und Kirche, Festgabe für Rudolf smend, 1952, S.321 ff.

2) S. die Vorgenannten, Schumpeter insbes. a.a.O. S.467 ff.

3) S. insbes. Decker, Zum Begriff der Wirtschaftsdemokratie; A rndt, Das Problem der. Wirtschaftsdemokratie, S. 167;

Kraus, Wirtschaftsdemokratie und Wirtschaftsaufbau, insbes. S. $11 \mathrm{ff}, 22 \mathrm{ff}, 33 \mathrm{ff}$.

4) S. hierzu nochmals Krüger, Staatsverfassung und Wirtschaftsverfassung, S. 365 .

5) S. nochmals oben S. 334 zu Fußn. 1, insbes. wohl Abendroth, a.a.O. S. $60 \mathrm{ff}, 71 \mathrm{f}, 91 \mathrm{f}, 104 \mathrm{ff}$.

1) Gegen die Vereinbarkeit von Demokratie und Wirtschaftsintervention: Böhm, Die Bedeutung der Wirtschaftsdemokratie für die politische Verfassung, S.145 f; ders., Wirtschaftsordnung und Staatsverfassung, 1950, S. 39 ff; Röpke, Die Gesellschaftskrisis der Gegenwart, 1948, S. 136 ff; s.a. Böhm, 
litik sein. Er ist nicht nur inhaltlich einer der Wege zur wirtschaftlichen Homogenisierung. Er demokratisiert die gesamte Machtstruktur. Er beschränkt die Macht der. "geborenen" Träger wirtschaftlicher Macht, der Eigentümer und privaten Eigentumsverwalter, und erstreckt in demselben Maße die kollektive

Das Mitbestimmungsrecht der Arbeiter im Betrieb, S. $57 \mathrm{ff}$. Die Gleichstellung von "reiner" Marktwirtschaft und Demokratie, wie sie Böhm (Wirtschaftsordnung und Staatsverfassung, S. 49 ff und passim; Das wirtschaftliche Mitbestimmungsrecht der A rbeitnehmer, passim) propagiert, beruht auf der Gleichstellung der Konsumenten mit den Wählern und der Produzenten (i.S. von Kapitaleignern) mit den Gewählten. So schreibt er (Wirtschaftsordnung und Staatsverfassung, S.51): "Marktgesetze sind also bei Lichte besehen nichts anderes als eine aufs Äußerste getriebene, technisch aufs Raffinierteste vervollkommnete tägliche und stündliche, plebiszitäre Demokratie, ein die ganze Nacht hindurch vom Morgen bis in die Nacht währendes Volksreferendum. ... Die Wettbewerbswirtschaft ist ... in sich selbst ein demokratischer Vorgang". Doch wäre es genau so verfehlt, diese Wirtschaftsform in der Demokratie des Grundgesetzes mitgarantiert zu sehen, wie es für die "wirtschaftsdemokratischen" Vorstellungen im oben erwähnten Sinne abgelehnt werden mußte. Diese Vergleiche verfremden und vereinfachen zu sehr, als daß sie tragen könnten. Der Unternehmer ist kein konstitutioneller Monarch, als der er in den wirtschaftsdemokratischen Vorstellungen der "konstitutionellen" Fabrik begriffen wurde. Die Arbeitnehmer eines Betriebes oder eines Wirtschaftszweiges sind nicht das Quasi-Staatsvolk, das sich in seinen Betriebsräten und Gewerkschaftsfunktionären Repräsentanten beruft. Aber auch die Verbraucher sind kein Staatsvolk, das einen Unternehmer oder seine Produkte "wählt". Jede dieser Gleichstellungen 1äßt zu viel "Übriges", das nicht als quantité négligeable abgetan werden darf, unberücksichtigt. - Zur Kritik s. z. B. l'artsch, Die verfassungsmäßige Sicherung von Wirtschaftsprinzipien, S. $31 \mathrm{ff}$. - Für die Vereinbarkeit von Demokratie und Wirtschaftsinterventionismus: Saitzew, Der Interventionismus, in Festgabe für Fritz Fleiner, 1937, S.321 ff (345); Schumpeter, Kapitalismus, Sozialismus und Demokratie, S. $351 \mathrm{f}$, $471 \mathrm{ff}$; Scheuner, Grundfragen des modernen Staates, S. 130; Krüger, Staatsverfassung und Wirtschaftsverfassung, insbes. S. 366; Friedrich, Art. "Demokratie" im Handwörterbuch der Sozialwissenschaften, S. $563 \mathrm{f}$. 
politische Macht der jeweiligen demokratischen Mehrheit in den Raum wirtschaftlicher Macht.2)

Umgekehrt korrespondiert die Demokratie positiv mit dem Interventionismus, indem sie - freilich nicht immer im wünschenswerten Maße - die Solidarität, ${ }^{3)}$ die Mitverantwortlichkeit des einzelnen am Ganzen ${ }^{4)}$ und, als Folge der bewußt werdenden kollektiven Autonomie, die Freiwilligkeit der Unterwerfung unter die Gesetze fördert. 4) Alles das ist dringendst nötig, um die Freiheitsbeschränkungen einer interventionistischen Politik erträglich halten zu können.

Aber die Gefahren des wirtschaftlichen und sozialen Interventionismus für die Demokratie dürfen nicht übersehen werden. ${ }^{5}$ ) Die Empfindlichkeit der Demokratie für zu weitgehende ökonomische Abhängigkeiten äußert sich auch im Verhältnis Staat-Bürger und Mehrheit-Minderheit. Wirtschaftliche und soziale Intervention schaffen wirtschaftliche existenzielle Abhängigkeiten des einzelnen vom Staat, der unter dem Kommando der Mehrheit steht. Das steigert auf der einen Seite den Sog zur Mehrheit und den Kampf um die Mehrheit; und gibt der jeweiligen Mehrheit größere Chancen, ihre Position zu perpetuieren und mit der

2) Das ist im Grunde auch die Konzeption Arndts (Das Problem der Wirtschaftsdemokratie; s.a. oben S. 334 zu Fußn.23).

3) S. Wieacker, Das bürgerliche Recht im Wandel der Gesellschaftsordnungen, in "Hundert Jahre Deutsches Rechtsleben", Festschrift Deutscher Juristentag, Bd. II, 1960, S. 1 ff (9): Der Anspruch auf menschenwürdiges Dasein richtet sich zunächst gegen den Staat. "Da aber in der Demokratie die Gesellschaft als solidarisch mit ihren Mitgliedern erscheint, bleibt die Forderung nicht aus, daß auch jeder einzelne das menschenwürdige Dasein eines jeden anderen zu verbürgen und sich zu diesem Ende Einschränkungen zu unterziehen habe" .

4) Vgl. Bachof, Begriff und Wesen des sozialen Rechtsstaates, S. $46 \mathrm{f}$; Fechner, Freiheit und $Z$ wang im sozialen Rechtsstaat, S. 22 f. - S. hierzu auch noch unten Abschnitt 5 II 3 b (S. 741 ff) und $c$ (S. 744 ff).

5) S. nochmals oben S.335 zu Fußn. 1. - Auf die Schwierigkeiten, die es der Demokratie - im Vergleich zu autoritären Systemen - in Anbetracht des Zwangs zu allzuvielen Rücksichtnahmen kostet, eine dirigistische oder Planungspolitik $z u$ treiben, soll hier nicht näher eingegangen werden ( $\mathrm{s}$.hierzu z. B. Schumpeter, Kapitalismus, Sozialismus und Demokratie, insbes. S. 474 ff; Böhm, Wirtschaftsordnung und Staatsverfassung, S.43). 
Minderheit die Demokratie zu ersticken. ${ }^{6)}$ Auf der anderen Seite schwindet, je mehr der Aktions- und Verantwortungsbereich des Individuums beschnitten und ihm Lebensvorsorge und - risiko abgenommen werden, die Widerstandskraft gegen die Usurpation der Macht gegenüber dem Träger dieser Vorsorge und Versorgung. 7) Die Demokratie, will sie eine freiheitliche bleiben, kann den Weg des Interventionismus und der "realen" Demokratie daher nicht unbegrenzt gehen.

Die Politik der "realen" Demokratie, der doktrinären "Wirtschaftsdemokratie" usw. ${ }^{8)}$ läuft - um dies noch anzumerken Gefahr, eine Ungleichheit durch eine andere zu ersetzen, nicht nur, soweit sie den staatlichen Eingriff erfordert. Auch den privaten Kapitalisten gegen das sozialistische Kollektiv des Betriebs, der Gewerkschaft, der Genossenschaft usw. auszutauschen, ist nicht immer die freiheitlichere Lösung. $\left.{ }^{9}\right)$

\section{Die allgemeinen verfassungs rechtlichen Grundlagen}

Die Demokratie des Grundgesetzes (Art.20, 28 Abs. 1 GG) ist eindeutig eine organisatorische ("formale"), keine nur "rea1e". 1) Die verfassungsrechtliche Ausgestaltung der staatlichen Herrschaftsorganisation 2) läßt darüber keinen $Z$ weifel.

Das allgemeine und gleiche Wahlrecht (Art.28 Abs. 1 Satz 2, 38 Abs. 1 Satz 1 GG) qualifiziert in Anbetracht der zentralen Machtstellung der aus diesen Wahlen hervorgehenden Volksvertretungen 3$)$ die Demokratie als e galitä $r$. Sie ist keine Klassendemokratie, weder im liberalen noch im sozialistischen Sinn. $\left.{ }^{4}\right)$

Die Verfassung determiniert die Volksherrschaft inhaltlich als sozial (Art.20 Abs.1, 28 Abs. 1 Satz 1 GG). Damit gebietet sie

6) S.a. Werner Weber, Spannungen und Kräfte im westdeutschen Verfassungssystem, S.148 f.

7) S. z.B. Knoll, Licht- und Schattenseiten des Wohlfahrtsstaates, S. 363 .

8) S. o. S. 329 .

9) S. z.B. Landshut, Mitbestimmung und Wirtschaftsdemokratie.

1) Zur Unterscheidung zwischen der Demokratie i.S. des Grundgesetzes und der "Volksdemokratie" s. Maunz, Deutsches Staatsrecht, S. 57, 170, $311 \mathrm{ff}$; s. a. BVerfGE 5, 85 (176 ff).

2) S. u. III (S.340 ff).

3) S. u. S. 340 .

4) S. BVerfGE 5, 85 (176 ff, insbes. 198). - Zum sozialist. Klassenstaat s.a. oben S. 318 zu Fußn. 11. 
nicht nur eine Politik, welche die "demokratiegerechte" Homogenität des Volkskörpers fördert. 5) Ihr Wille wird auch nicht verwirklicht werden können, ohne daß diese oder jene spezifisch "wirtschaftsdemokratische", nämlich kollektivierende Maßnahme ergriffen und Einrichtung geschaffen wird. 5) Aber die Verfassung hat weder mit dem demokratischen noch mit dem sozialen Prinzip irgend eines der vielen "wirtschafts" -, "real" - oder "sozial" - demokratischen Programme ${ }^{6)}$ rezipiert. Das Grundgesetz erwähnt unter den bekannten Forderungen ${ }^{6)}$ nur die Sozialisierung (Art.15 GG), und auch diese nur in ermächtigendem Sinn. Aus dem demokratischen Prinzip des Grundgesetzes auch noch die positive Übernahme bestimmter anderer "wirtschafts" -, "real" - oder "sozial"-demokratischer Programmpunkte zu folgern, wäre nicht gerechtfertigt. 7)

5) S. u. Abschnitt 5 (S.673 ff).

6) S. o. S. 329 .

7) Vg1. Krüger, Staatsverfassung und Wirtschaftsverfassung, S. 365 f; Hamann, Deutsches Wirtschaftsverfassungsrecht, S. 52 ff; Abendroth, in: Sultan-Abendroth, Bürokratischer Verwaltungsstaat und soziale Demokratie, S. 61 (eingeschränkt dagegen ebd. S.91 f, $98 \mathrm{ff}$; Neumann-Duesberg, Das Mitbestimmungsrecht, in: Neumann-Nipperdey-Scheuner, Die Grundrechte, Bd. III 1. Halbband 1959, S. $373 \mathrm{ff}(376 \mathrm{f}))$. - Als einziges, dem demokratischen Prinzip (als Organisationsprinzip) unverzichtbar verbundenes materielles Postulat wäre an ein "allen den gleichen Zugang und die gleichen Entwicklungsmöglichkeiten eröffnendes Erziehungssystem" zu denken (vgl. Maunz, Deutsches Staatsrecht, S. 56; im folgenden v. Mangoldt-Klein, Art.20 Anm.V). Ungleichheit der Bildung verfälscht das Funktionieren der Demokratie in ganz anderer, viel bedeutsamerer Weise als ökonomische Ungleichheit allein (s. z.B. Rüstow, Ortsbestimmung der Gegenwart, Bd.IS.165 ff). Der Bruch der Bildungsmonopole auch ein "wirtschaftsdemokratisches" Postulat (vgl. Naphtali, Wirtschaftsdemokratie, S. 155 ff) - ist der Demokratie integrierend verbunden (s. z.B. v. Waldkirch, Die freie Bildung des Volkswillens, in "Die Freiheit des Bürgers im schweizerischen Recht", Festgabe zur Hundertjahrfeier der Bundesverfassung, hrsg. von den Juristischen Fakultäten der schweizerischen Universitäten, 1948, S. $117 \mathrm{ff}(131 \mathrm{f}))$. Doch steht insofern jedenfalls Art. 7 GG als ein den Grundsatz der "sozialen Demokratie" wenigstens verdeutlichender Anhaltspunkt zur Verfügung, was für die übrigen "wirtschaftsdemokratischen" Postulate nicht zutrifft, wenn man nicht die "Be- 
Schließlich ist diese Demokratie eine freiheitliche (Art.1, 2, 4 ff, 18 Satz 1, 21 Abs. 2 Satz 1 GG). Sie ist der rechtsstaatlichen Ordnung unterworfen (Art.28 Abs. 1 Satz 1 GG). So gewiß die soziale Nivellierung der wirtschaftlichen "Befreiung" der schlechter Gestellten dient, so sind gerade von hier her der einseitigen ökonomischen "Realisierung" der Demokratie Grenzen gesteckt. ${ }^{8)}$

\section{III. $\mathrm{Zu}$ einigen Besonderheiten der konkreten demokratischen Ordnung}

\section{Vorbemerkung: Der demokratische Purismus}

Das Grundgesetz kennt keine anderen als demokratisch legitimierte Machtträger. "Alle Staatsgewalt geht vom Volke aus" (Art.20 Abs. 2 Satz 1 GG). 1) Ein Machtträger eigenen Rechts, wie es ein dynastischer Monarch sein könnte, ist weder als Gegenspieler der demokratischen Institutionen im Sinne der konstitutionellen Monarchie noch als eine periphere Ergänzung der primär demokratischen Herrschaftsordnung im Sinne der parlamentarischen Monarchie vorgesehen. Die Garantie des republikanischen Prinzips in Art. 20 Abs. 1 GG verbietet i. V.m. Art. 79 Abs. 3 GG sogar eine Verfassungsänderung in dieser Richtung. 2)

triebsverfassung" (Art. $74 \mathrm{Nr} .12 \mathrm{GG}$ ) insgesamt als etwas "Wirtschaftsdemokratisches" charakterisieren will.

8) S. o. S.335 und unten Abschnitt 4 (S.396 ff), Abschnitt 5 (S. $673 \mathrm{ff})$, insbes. II 3 c (S. $744 \mathrm{ff})$, Abschnitt 6 (S. $842 \mathrm{ff})$.

1) Zur Geltung dieses Prinzips auch für die Richter s.u. S. 352 a.A. insbes. Fußn. 1.

2) Die Exegese des Begriffs der Bundes republik (Art.20 Abs. 1 GG; ferner Selbstbezeichnung der Bundesrepublik in der Überschrift und der Präambel des Grundgesetzes) und der "Grundsätze des re publikanis chen... Rechtsstaates" (Art.28 Abs. 1 Satz 1 GG) knüpft vielfach an Machiavellis Unterscheidung Einherrschaft = Monarchie / Vielherrschaft = Republik (s.hierzu Nawiasky, Staatslehre, Teil 2 Bd. II $\mathrm{S} .123 \mathrm{ff}$, T'eil $4 \mathrm{~S} .25 \mathrm{ff}$ ) an (Giese, Grundgesetz für die Bundesrepublik Deutschland, Anm. II 3 zur Überschrift; Wernicke, Bonner Kommentar, A rt.20 Anm. II 1 a; v. MangoldtKlein, Art.20 Anm. IV). Gegen diese Auslegung ist einmal anzuführen, daß sie neben der grundgesetzlichen Proklamation der Demokratie - s. vor allem das Nebeneinander in A rt. 28 Abs.1 Satz 1 GG - bedeutungslos wäre (vgl. Hamann, Grundgesetz, Einf. I D 5 (S.40)). Zum anderen entspricht dieser Begriff der "Republik", zu dem unerläßlich der Komplementär- 
2. Legislative und Exekutivspitze

a) Der Grundzug: Parlament und Regierung - Hauptfunktionäre der Demokratie

Die demokratische Herrschaft verwirklicht sich wesentlich auf dem "Hauptstrang" Staatsvolk - Parlament - Regierung. Im Bund haben Bundesregierung und Bundestag zusammen mit dem Bundesrat alle politische Macht inne, die durch die Begriffe Legislative und Exekutive ausgedrückt wird, und teilen sie mit dem Bundespräsidenten nur ausnahmsweise und am Rande. 1)

begriff der "Monarchie" hinzuzudenken ist, nicht dem Verständnis der "Monarchie" in der politischen Vorstellungswelt der Gegenwart. Sie sieht in der Monarchie das Prinzip der dynastischen - also nicht durch Wahl erlangten - und lebenslänglichen - also nicht auf Zeit übertragenen - Stellung des Staatsoberhauptes, mag dessen "Herrschaft" mehr oder weniger formal oder real sein (vgl. Dürig, Art. "Staatsformen" im Handwörterbuch der Sozialwissenschaften, S.743 f; s.a. Nawiasky, Staatslehre, Teil 2 Bd.II S. 126; speziell zum Begriff der "Republik" i.S. des Grundgesetzes: Dürig in Maunz-Dürig, Art.20 Abs.1 Randn.1, Art.28 Randn.4). Republik als Absage an "Monarchie" in diesem Sinne ist nicht als Absage gegen die Einherrschaft sondern als Absage gegen das erbliche, lebenslängliche Staatsoberhaupt zu verstehen (vgl. Dürig, a.a.O.). Wird das "republikanische" Prinzip so interpretiert, so gewinnt es auch eine eigenständige Funktion neben dem demokratischen; denn auch der demokratische Staat könnte sich, ohne an seinem Charakter ernstlich Schaden zu nehmen, mit einem erblichen Staatsoberhaupt versehen. D a s verhindert das Bekenntnis des Grundgesetzes zur Republik. Alles übrige, was sonst im Begriff der Republik stecken könnte, kann das demokratische Prinzip allein auch leisten. Im Hinblick auf die seit 1918 zwar immer schwächer werdenden, jedoch nicht gänzlich erlahmten, romantisierenden Bestrebungen auf Wiedereinführung einer wenn auch noch so schwachen Monarchie entbehrt der Begriff auch nicht der ihm entsprechenden polemischen Situation.

1) Eine Darstellung der Einzelheiten kann und muß hier unterbleiben. Es darf auf die Ausführungen zu Bundestag, Bundesrat, Bundespräsident, Bundesregierung, Bundesgesetzgebung und Bundesverwaltung in den systematischen Darstellungen des Bundesstaatsrechts (s. z.B. Nawiasky, Grundgedanken des Grundgesetzes für die Bundesrepublik Deutschland, 
b) Parlament und Regierung

aa) Das parlamentarische Wahlrecht

Der für die soziale Determination der Politik entscheidende Grundsatz, die a $11 \mathrm{gemeine}$ und gleiche Wahl, wurde bereits festgehalten (Art. 28 Abs. 1 Satz 2, 38 Abs. 1 Satz 1 GG).

Daneben tritt die Alternative zwischen Mehrheits - und Verhältniswahl an Bedeutung zurück. Dem Verhältniswahlrecht wurde gelegentlich eine Affinität zur sozialen Politik zugesprochen. 1) Daran ist insofern etwas Wahres, als das Verhältniswahlrecht mit seiner fast vollkommenen Gleichwertigkeit des Stimmgewichts am weitesten jenen egalitären Vorstellungen nahekommt, die auch den sozialen Bestrebungen entscheidend mit zugrunde liegen. Es macht ferner die sozialen Kräfte in genau jenem Maße parlamentarisch sichtbar, in denen sie, in den einzelnen Parteien verkörpert, jm Volke vorhanden sind. Das Mehrheitswahlrecht kann dagegen, wie es auch sonst zu einer Inkongruenz von Stimmenverhältnis und Sitzezahl führen kann, auch von den sozialen Kräften ein falsches parlamentarisches Bild ergeben. Hier zeigt sich jedoch bereits, daß das Wahlsystem gegenüber dem sozialen Sachgehalt der Politik weitgehend neutral ist; denn das Mehrheitswahlrecht kann ebensogut zu einer "ungerechtfertigten" Mehrheit wie Minderheit der sozialen Elemente im Parlament führen. 2) Unterschiedlich sind Mehrheits- und Verhältniswahlrecht auch in ihrer Wirkung auf die politische Gruppenbildung. Das Mehrheitswahlrecht fördert die Tendenz zu wenigen, großen Parteien, das Verhältniswahlrecht führt nicht selten zur Zersplitterung. (Allerdings kommt es immer auf die konkreten politischen Zustände an.) Über das Mehrheitswahlrecht kann eine soziale politische Richtung, die nicht allein die Mehr-

S. $83 \mathrm{ff}, 93 \mathrm{ff}, 54 \mathrm{ff}, 117 \mathrm{ff}, 122$; Maunz, Deutsches Staatsrecht, S. $178 \mathrm{ff}, 273 \mathrm{ff}$ ) und in den Kommentaren zum Grundgesetz verwiesen werden.

1) Vg1. Nawiasky, Staatslehre, Teil 2 Bd.I S.239. - Zum Verhältniswahlrecht als Programmpunkt des Sozialismus s. Dankwart A. Rüstow, Eine Bemerkung zur Debatte über das Prinzip der Verhältniswahl, Zeitschr.f.d.ges. Staatswissenschaft Bd. 106 (1950) S. 324 ff (338 ff).

2) Dementsprechendes gilt für die Gefahren der "Wahlkreisgeometrie". Die historischen Erfahrungen lassen im allgemeinen die Situation zu einseitig erscheinen. Selbst die den historischen Praktiken zugrunde liegende Entsprechung von Besiedelungsdichte und Wohlstand kann sich ändern. 
heit einer entsprechenden Anzahl von Wahlkreisen für sich hat, nur innerhalb eines größeren Verbandes, innerhalb dessen sie möglicherweise zum Kompromiß gezwungen ist, zu Einfluß im Parlament gelangen. Im Rahmen des Verhältniswahlrechts kann sie zwar isoliert in das Parlament vorstoßen. Erlangt sie dabei nicht die Mehrheit der Sitze, so muß sie sich aber in der Sphäre des Parlaments zu einem Koalitionskompromiß herbeilassen oder sich als Oppositionspartei von der Macht zurückziehen. Daß das eine oder das andere System sozialen Tendenzen günstiger oder ungünstiger wäre, kann somit alles in allem nicht gesagt werden. 3)

Darum bedeutet es für die soziale Haltung der Demokratie nichts Grundsätzliches, daß das Grundgesetz die Alternative von Mehrheits- und Verhältniswahlrecht weder für den Bund noch für die Länder präjudiziert.

Schließlich ist noch auf die Unmitte 1 barkeit der Wahl hinzuweisen (Art. 28 Abs. 1 Satz 2, 38 Abs. 1 Satz 1 GG). ${ }^{4)}$ Sie darf - so groß ihre Bedeutung ganz abstrakt gesehen ist - in der historisch-konkreten Situation nicht überbewertet werden. Wahlmännerkollegien 5) sind im Parteienstaat regelmäßig nicht mehr als mechanische Vermittler des Wählerwillens. Dagegen mediatisieren die Parteien den Wählerwillen, indem sie kraft ihres Vorschlagsrechts die freie Auswahl des Wählers beschränken. Der bestimmende Einfluß der Parteien auf die demokratische Willensbildung hat das Problem der Unmittelbarkeit der Wahl überspielt. 6)

bb) Das repräsentative Prinzip

Die intensive Korrespondenz zwischen den (sozialen) Interessen

3) Eines könnte man vielleicht sagen: Das Verhältniswahlrecht erlaubt eine stärkere Herausbildung von Sonderinteressen, die bei der Koalitionsbildung nicht in dem Maße entschärft werden, wie bei ihrem Aufgehen in dem Interessenkonglomerat einer der Massenparteien, die das Mehrheitswahlrecht hervorzubringen pflegt.

4) Zur Auslegung s. etwa Maunz in Maunz-Dürig, Art.38 Randn. $43-46$.

5) Vgl. Maunz ebd. Randn. 43 a.A. mit Fußn. 3.

6) S. hierzu insbes. Rinck, Der Grundsatz der unmittelbaren Wahl im Parteienstaat, JZ 13.Jhg. (1958) S. 193 ff. Zu Einzelfragen des Verhältnisses des Parteieneinflusses auf die Unmittelbarkeit der Wahl s.a. Maunz, a.a.O. Randn.43-46 und dessen Nachweise. Zum Parteienstaat s. ferner unten 5 (S.370 ff). 
der Wähler und den Machtinteressen ler Gewählten und ihrer Gruppen, der Parteien, wird nicht daclurch unterbrochen, daß die Abgeordneten zu "Vertretern des ganzen Volkes" erklärt werden, die "an Aufträge und Weisungen nicht gebunden und nur ihrem Gewissen unterworfen" sind (Art. 38 Abs. 1 Satz 2 GG). 1) Diese Bestimmung kann "Aufträgen und Weisungen" die Kraft rechtlicher Verpflichtung vorenthalten. Aber sie kann durch nichts verhindern, daß der Abgeordnete sich tatsächlich-politisch nach dem Wollen seiner vergangenen und potentiellen künftigen Wähler seiner Person und seiner Partei und nach den Wünschen seiner Partei, die ihm seinen Sitz verschafft hat und wieder verschaffen oder vorenthalten kann, richtet und nach der Opportunität anstelle seines Gewissens entscheidet. Das plebiszitäre Element der modernen egalitären Demokratie ist mit einem einfachen Ge- und Verbot nicht beherrschbar. ${ }^{2}$ )

\section{cc) Die Stellung der Regierung}

Die Väter des Grundgesetzes waren bemüht, der Regierung, insbes. dem Bundeskanzler, eine vom Parlament möglichst unabhängige Stellung zu geben. Das Gefüge der parlamentarischen Kontrollen gegenüber der Regierung (Art. 43, 67, 68 GG) erlaubt es nicht, eine Regierung lediglich abzuberufen, sondern nur, einen Bundeskanzler durch einen anderen zu ersetzen. Man glaubte sogar, noch weiter gehen und die Regierung zum Gegenspieler des Parlaments machen zu können: In Art.113 GG wird für alle ausgabemehrenden oder einnahmemindernden Beschlüsse vom Bundestag und Bundesrat die Zustimmung der Regierung

1) Zur Auslegung des Art. 38 Abs. 1 Satz 2 d. z.B. Maunz in Maunz-Dürig, Art. 38 Randn.9 ff und seine eingeh. Nachw.

2) Zum Schwund der repräsentativen und dem Vordringen der plebiszitären Komponente im deutschen Parlamentarismus s. aus dem reichen Schrifttum etwa:

Leibholz, Der Parteienstaat des Bonner Grundgesetzes, Recht-Staat-Wirtschaft, Bd. III 1951, S.99 ff; clers., Strukturprobleme der modernen Demokratie, S. 21 f, 73 f, 78 ff; v. d. Heydte-Sacher1, Soziologie der deutschen Parteien, 1955, S. 193 ff; Kremer, Der Abgeordnete zwischen Entscheidungsfreiheit und Parteidisziplin, 1956; Fraenkel, Die repräsentative und plebiszitäre Komponente im demokratischen Verfassungsstaat, 1958; Landshut, Wandlungen der parlamentarischen Demokratie, in "Zur Ordnung von Wirtschaft und Gesellschaft", Hamburger Jahrbuch für Wirtschafts- und Gesellschaftspolitik, 4.Jhg. (Festausgabe für Eduard Heimann), 1959, S. $151 \mathrm{ff}$. 
verlangt. 1) Darin liegt an sich eine weitreichende Möglichkeit der Regierung, auf die Gesetzgebung einzuwirken, deren Bedeutung umso größer ist, als für den verteilenden und umverteilenden Staat der sozialen Intervention gerade die Disposition über die finanziellen Mittel von äußerster Wichtigkeit ist. Ist also die Regierung Hüterin der Objektivität ${ }^{2)}$ und Beschützerin der gerechtfertigten Interessen der Minderheiten gegenüber der Mehrheit des Bundestages (und des Bundesrates)?

Die Regelung des Grundgesetzes ist lebensfremd. Sie verkennt die dichte Funktionseinheit, die im parlamentarischen System zwischen Regierung und Parlamentseinheit besteht und bestehen muß. 3) Das Grundgesetz geht selbst davon aus, daß der Bundeskanzler der Exponent einer Parlamentseinheit ist (Art.63 GG), der das fortdauernde Vertrauen der Parlamentsmehrheit und deren gesetzgeberische und sonstige parlamentarische Unterstützung genießt. Ein Auseinanderfallen der politischen Richtung von Parlamentsmehrheit und Bundesregierung hält es für krankhaft und will es baldmöglichst beseitigt wissen (Art.67, 68, $81 \mathrm{GG}$ ). Die Frage, ob in der Bundesrepublik das System der völligen Trennung von Exekutive und Legislative im Sinne des amerikanischen Präsidialsystems oder eines ähnlichen Systems überhaupt lebensfähig wäre, ${ }^{4)}$ braucht hier nicht aufgeworfen zu werden. Das Grundgesetz hat diesen Weg nicht gewählt. Seine Regelung beruht auf der Annahme, daß es genüge, für den Ausnahmefall a u ch die Regierung ohne korrelative Parlamentsmehrheit zuzulassen. Als ob eine parlamentarische Regierung, die keine Mehrheit mehr hinter sich wei $\beta$ und nur wegen der Verfassungsnorm des Art.67 GG nicht expressis verbis gestürzt werden kann, der Sache nach in irgend einer Weise besser dastünde als eine gestürzte parlamentarische Regierung, die als geschäftsführende weiterarbeitet! 5)

1) S. hierzu insbes. Henrichs, Art.113 des Grundgesetzes, 1958.

2) S. Strickrodt, Die Finanzverfassung des Bundes als politisches Problem, S. 42 .

3) Vgl. die Darstellung bei Friesenhahn, Parlament und Regierung im modernen Staat, Veröffentlichungen der Vereinigung der Deutschen Staatsrechtslehrer, Heft 16, 1958, S. 9 ff, insbes. S. $33 \mathrm{ff}, 41 \mathrm{ff}$ mit eingeh. Nachw.;Landshut, Wandlungen der parlamentarischen Demokratie, S. $158 \mathrm{ff}$.

4) S. hierzu z.B. Loewenstein, Verfassungslehre, S. $109 \mathrm{ff}$.

5) Man sollte doch nicht - wie etwa Füßlein, Die Stabilität des Regierungssystems unter der Geltung des Grundgesetzes, Zeitschrift für Politik, n.F. Bd.6 (1959) S. 310 ff - glauben, daß die Stabilität der politischen Verhältnisse in der Bundes- 
Auszugehen ist vielmehr davon, daß die prinzipielle Aktionsgemeinschaft von Parlamentsmehrheit und Regierung für das fruchtbare Wirken beider Seiten unerläßlich ist. 6) Diese Aktionsgemein schaft läßt sich in der politischen Wirklichkeit nicht durchhalten ohne Übereinstimmung in den Grundsätzen, ja meist auch in den Details. Regierung und Parlamentsmehrheit bilden eine Zurechnungs- und Verantwortungseinheit im Kampf um die demokratische Macht. Der Wähler, der sich für eine politische Richtung entscheidet, entscheidet sich nicht für die eine Meinung im Parlament und die andere Meinung in der Regierung. Regierung und Parlamentsmehrheit müssen ihre politische Haltung also aufeinander abstimmen. Dieser Vorgang kann, je nach dem Grad von Heterogenität und Homogenität, nach Parteienvielheit cder Parteieneinheit der in Regierung und Mehrheit vereinten Kräfte recht unterschiedlich sein. Es ist deshalb noch nicht von vorneherein

republik von den Vorschriften über das konstruktive Mißtrauensvotum kommt! Sie kommt von einer - insofern glücklichen Partei- und Mehrheitskonstellation, die die Parteien und ihre Führer einerseits und die Wähler andererseits, nicht aber die paar gedruckten Worte des Art. 67 GG geschaffen haben. Nicht einmal die "moralische" Wirkung des Art. $67 \mathrm{GG}$ ist hoch zu veranschlagen. Eine Regierungsmehrheit, die zerfällt, wird davon nicht deshalb abgehalten, weil sie weiß, daß sie der Regierung nicht ausdrücklich das Mißtrauen bekunden darf. Wer aus dem Boot der Regierungspolitik ausspringen will, hat (meist gegenüber dem Wähler) seine Gründe. Vielleicht verficht er sie mit massiveren Waffen lieber. Hat er diese aber nicht zur Verfügung, so wird er eben zu einer Politik der Nadelstiche, zur legislativen und finanzpolitischen Belagerung der Regierung schreiten. Aber wenn er (dem Wähler) den Kampf gegen die Regierung zu schulden glaubt, so wird er ihn aufnehmen; denn der Wähler erwartet diesen Kampf mit eben den Mitteln, die gegeben sind. - Zur Kritik des "konstruktiven Mißtrauensvotums" s. Nawiasky, Grundgedanken des Grundgesetzes der Bundesrepublik Deutschland, S.99 ff; Glum, Kritische Bemerkungen zu Art. $63,67,68,81$ des Bonner Grundgesetzes. in "Um Recht und Gerechtigkeit", Festschrift für Erich Kaufmann, 1950, S. 47 ff; ders., Das parlamentarische Regierungssystem in Deutschland, Großbritannien und Frankreich, 1950, S. 298 ff; Friesenhahn, Parlament und Regierung im modernen Staat, insbes. S. $59 \mathrm{f}$ (mit eingeh. weit. Nachw.).

6) S. S. 345 zu Fußn. 3; s. ferner BVerfGE 6, 84 (94). 
ausgeschlossen, daß die Mitglieder der Regierung und die Mitglieder des Parlaments über ein- und dieselbe Frage verschiedener Meinung sind. Die verschiedene Stellung des Parlamentariers und des Ministers in bezug auf den Wähler und in bezug auf die politische Aufgabe können sich hier auswirken. Art.113 GG ist ein Zeugnis für diesen Tatbestand und zwar geboren aus der Erkenntnis, daß entgegen der ursprünglichen, kontrollierenden Aufgabe des liberalen (meist auch konstitutionellen) Parlaments heute der Parlamentarier infolge seiner größeren Nähe zum Wähler, zum Interessenverband, zur örtlichen Parteiorganisation usw. und seiner größeren Entfernung von der Gesamtverantwortung oft mehr als die Regierung dazu neigt, durch populäre Entschlüsse mehr dem Wahleffekt als dem Gemeinwohl Rechnung zu tragen. ${ }^{7)}$ Aber in wirklich wichtigen Fragen können Regierung und Regierungsmehrheit es sich nicht leisten, mit verschiedenen Konzeptionen aufzutreten. Solange daher die Einheit der Regierungsmehrheit tragfähig ist, amalgamieren die Meinungen im Kabinett und den Fraktionen zu einer einheitlichen Lösung. Gewiß kommt es gelegentlich dazu, daß die Ansichten von Regierung und - an sich - regierungstreuen Parlamentarieren auch in der Öffentlichkeit differieren. Aber dabei handelt es sich um Außenseiter, um Pannen, um "Disziplinlosigkeiten" usw. Am Ende wird alles wieder ins Lot gebracht.

Gegenüber dieser Interessen-, Zurechnungs- und Verantwortungseinheit muß auch Art.113 GG toter Buchstabe bleiben. 8) Selbst dann, wenn die Regierungsmehrheit im Parlament der Regierung "davongerannt" sein sollte, kann die Regierung den Wechsel, den "ihre" Parlamentarier damit den interessierten Wählern oder ihren Agenten, den Verbänden usw., ausgestellt haben, nicht zu Protest gehen lassen. Die praktischen Frfahrungen beweisen das. 9) Aber nicht einmal gegen Zufallsmehrheiten ist Art. 113 GG eine wirksame Waffe; denn wenn es der Opposition oder auch nur irgendwelchen Außenseitern gelingt, einen Mehrheitsbeschluß zustande zu bringen, durch den ein Interesse honoriert

7) Vgl. z.B. Schmölders, Finanzpolitik, S. 84 f; Hettlage, Die Finanzverfassung im Rahmen der Staatsverfassung, S. 12; Maunz, dass., S.39 f; s.hierzu auch die Nachweise oben S. 322 zu Fußn. 4 (2) und S. 328 zu l'ußn.6 und den Text hier$\mathrm{zu}$.

8) Vgl. Strickrodt, Die Finanzverfassung des Bundes als politisches Problem; Hettlage, Finanzpolitik und Finanz recht, S. 3 f, 5, 33; ders., Die Finanzverfassung im Rahmen der Staatsverfassung, S. 12 .

9) Vgl. Hettlage, a.a.O. - Zur Würdigung s.a. Maunz, a.a.O. S. 40 . 
wird, das auch die Regierung zu vertreten behauptet, so wird die Regierung es sich eher neun- als einmal überlegen, ob sie sich durch Versagen der Zustimmung als ein "Feind" dieses Interesses bloßstellen soll. 10) Diese Überlegung schwächt die Wirksamkeit des Art. 113 GG noch dann, wenn die Regierung schon in die Minderheit geraten ist und, gestützt auf Art.67 GG, den Kampf gegen eine negative Mehrheit führt. Selbst dann kann es eine tödliche Verlegenheit für sie sein, einem Mehrheitsbeschluß des Parlaments die Zustimmung versagen zu müssen.

Erweist sich somit, daß Art. 113 GG ebenso wie Art. 67 GG als Waffe der Regierung gegen das Parlament praktisch bedeutungslos sind, so ist dasselbe schließ1ich auch von Art. $81 \mathrm{GG}$ zu sagen; denn der dort vorgesehene Gesetzgebungsnotstand ist aus einem übertriebenen Sicherungsbedürfnis heraus überkompliziert und steril gestaltet.

Entgegen dem ersten Anschein des Grundgesetzes beherrscht also nicht das Gegenüber von Regierung und Parlament sondern die Aktions- und Verantwortungseinheit von Bundesregierung und Bundestagsmehrheit die Machtverhältnisse im Bunde.

\section{c) Ausgleichsfaktoren}

\section{aа) Vorbemerkung}

Die machtdynamische, interessenpolitische Wechselbeziehung zwischen dem Volk und seiner demokratischen Repräsentation entfaltet sich am reinsten dann, wenn die Führung auf einen einheitlichen Organismus und der Willenszusammenhang zwischen dem Volk und ihr auf einen einzigen Kanal der repräsentativen Legitimation beschränkt ist. Die Konzentration der demokratischen Herrschaft auf den "Strang" Volk - Parlament - Regierung ist somit eine ideale Basis für die Verwirklichung der Machtgesetzlichkeiten der modernen Massendemokratie mit allen ihren sozialen Triebkräften und Einseitigkeiten.

Wird dagegen der Führungsorganismus aufgespalten und der Willensbildungskontakt entsprechend gesondert, so liegt darin die Möglichkeit, andere Interessen als die parlamentarisch-parteipolitisch artikulierten egalitär-mehrheitlichen an die Macht heranzuführen. Das bedeutet immer Reibung, Hemmung sowohl dieser wie jener Interessen, Zwang zum Kompromiß und somit nicht nur $z u$ einer breiteren Willensbasis sondern auch zur Harmonisierung nicht unvereinbarer Interessen, aber möglicherweise schließlich auch Kampf. Gemessen am typischen Bild der sozialen Verhal-

10) Henrichs, a.a.O. S. 51 . 
tensweise der egalitär-massendemokratischen, "einschienig" repräsentativen Staats - und Regierungsform 1) bewirkt die Hereinnahme zusätzlicher Organe und Willensbildungskanäle regelmäßig eine Verminderung des Drucks auf die Minderheit, möglicherweise auch eine positive Förderung der Minderheit und schließlich aber nicht zuletzt die Rücksicht auf ein numerischelektoral nicht zu ermittelndes Gemeininteresse, 2) mag diese vielleicht auch nur objektiv aus dem Zwang zum Kompromiß resultieren.

Die Minderheit, deren Lage so möglicherweise gebessert wird, kann - im Bild der sozialen Schichtung gesprochen - eine Minderheit "unten" oder "oben" sein. Im ersteren Falle wirkt das Korrektiv direkt sozial. Im letzteren Fall kann es der Erhaltung sozial ungerechtfertigter Positionen dienen. Es kann aber auch einer sozial "ungesunden" Nivellierung oder erst recht einer revolutionären Umwälzung des wirtschaftlichen Besitzstandes entgegenwirken. Auch dann wirkt es in sozialem Sinn. Obwohl es immer auf die einzelne Regelung ankommt und ein generelles Urteil unmöglich ist, kann daher gesagt werden, daß in der Differenzierung der demokratischen Herrschaft die Chance einer "Verbesserung" ihrer sozialen Gehalte liegt.

\section{bb) Der Staatspräsident}

Eine der bedeutsamsten Möglichkeiten, die parlamentarische Herrschaft zu moderieren, ist es, dem Parlament eine volksgewählte Exekutivspitze - mit oder ohne Einwirkungsbefugnis auf die Gesetzgebung - gegenüberzustellen. Die Mehrheit der Wähler, die hinter dem Präsidenten steht, kann sich von der Mehrheit der Wähler, die hinter der Mehrheit des Parlaments steht, tiefgreifend unterscheiden. Es ist etwas anderes, ob sich die Stimmen in Gruppen getrennt auf Abgeordnete und Parteien einigen - die sich möglicherweise ihrerseits erst im Parlament zu einer Mehrheit zusammenfinden - oder ob die Stimmen sich auf eine einzige Person vereinigen. ${ }^{1)}$

1) S. O. I 1 b (S. 319 ff).

2) Vgl. (auch zum Folgenden) Forsthoff, Verfassungsprobleme des Sozialstaates, S. $18 \mathrm{ff}$.

1) Vgl. L.v.Stein, Die Monarchie, die Republik usw. S. 172 f, 181 (Zitat S.172 f): "...Präsidentur ... vereinigt in sich zwei Momente, durch die sie den klarsten und einfachsten Ausdruck dieser Souveränität bildet. Sie ist zuerst vom Volke gewählt, und mithin, indem der Wille des ganzen Volkes dem Präsidenten die Vertretung der Staatspersönlichkeit 
Der Bundespräsident des Grundgesetzes erfüllt diese Funktion nicht. Seine demokratische Legitimation ist, wenn auch nicht allein auf den Bundestag gestützt, so doch insgesamt vom parlamentarischen Betrieb nicht gelöst und bewußt kompliziert und schwach gehalten. Seine Kompetenzen sind, von einigen exzeptionellen Fällen abgesehen, ohne politischen Tiefgang. ${ }^{2}$ )

\section{cc) Die zweite Kammer}

Eine der wirksamsten und variabelsten Ausgleichsmöglichkeiten liegt darin, dem Volkshaus des Parlaments - nach heutigem Sprachgebrauch der ersten, nach früherem Sprachgebrauch der zweiten Kammer - eine zweite Kammer hinzuzufügen. 1) Die "ersten Kammern", Herrenhäuser u.dgl. der konstitutionellen Verfassungsepoche haben hinlänglich bewiesen, welche "sozialen" Einflüsse von Einrichtungen dieser Art so oder so ausgeübt werden können.

Das Grundgesetz kennt eine eigentliche zweite Kammer nicht. Doch nimmt der Bundesrat weitgehend die Funktionen einer solchen ein. Als föderatives Organ 2 ) ist er jedoch von vorneherein

durch den Akt der selbständigen Wahl überträgt, ist eben diese Wahl die allgemeinste... abstrakteste Betätigung des allgemeinsten Prinzips der Republik, welche die Souveränität des ganzen Volkes enthält. ... Sie enthält aber zweitens die Gesamtheit der höchsten staatlichen Vertretung in einer Person. ... Sie stellt aber zugleich mit dem unverantwortlichen Präsidenten die Staatsgewalt über die Macht der besitzenden und der nichtbesitzenden Klassen..." S. zu dieser Problematik ferner etwa die Beiträge von Carl Schmitt, Verfassungslehre, S. 350 ff; Forsthoff, Verfassungsprobleme des Sozialstaates, S. $18 \mathrm{f}$; Fraenkel, Die repräsentative und die plebiszitäre Komponente im republikanischen Verfassungsstaat, 1958, S. $48 \mathrm{ff}$.

2) Zur Darstellung s. etwa Nawiasky-Grundgedanken des Grundgesetzes der Bundesrepublik Deutschland, S. 106 ff; Maunz, Deutsches Staatsrecht, S.298 ff; ders., in Maunz-Dürig, Art. 54 Randn. 1 ff. - Zur Würdigung s.ferner Weber, Die Verfassung der Bundesrepublik in der Bewährung, S. 37; dens., Spannungen und Kräfte im westdeutschen Verfassungssystem, S. $30 \mathrm{ff}, 38,161 \mathrm{f}$.

1) Zu den Möglichkeiten und Problemen einer zweiten Kammer s. aus neuerer Zeit etwa Schwarz-Liebermann v. Wahlendorf, Struktur und Funktion der sog. zweiten Kammer, 1958; Loewenstein, Verfassungslehre, S. $181 \mathrm{ff}$.

2) S. hierzu und zum Folgenden auch schon oben S. $208 \mathrm{ff}$. 
weniger dazu bestimmt, gewisse soziale Interessen zu beobachten als die Interessen der Länder selbst. Seine Kompetenzen sind ganz danach ausgestaltet. ${ }^{3)}$ Seiner effektiven parteipolitischen Zusammensetzung nach kann er allerdings, da der Prozeß seiner demokratischen Legitimation sich nicht nur in der länderweisen Sonderung abspielt sondern vor allem - wie es zwar nicht im Grundgesetz vorgeschrieben, in der Praxis aber doch die ausnahmslose Regel ist - den sehr eigentümlich wirksamen Vorgang der Mehrheitsbildung, in der Regel also der Koalitionsbildung, in den Landesparlamenten zu durchlaufen hat und da schließlich das "Stimmgewicht" der Länder im Bundestag und Bundesrat ein verschiedenes ist, von derjenigen des Bundestages abweichen. Die Zusammensetzung des Bundesrates ausschließlich aus Personen, die als Kabinettsmitglieder in Amt und Pflicht stehen, bedingt auch individualpsychische Unterschiede gegenüber einer Kammer aus reinen Parlamentariern. Das kann sich auch auf die Entscheidung in sozialen Belangen auswirken. Aber im großen und ganzen ist der Bundesrat "aus dem gleichen Holz geschnitzt" wie der Bundestag, nämlich aus den Exponenten derjenigen politischen Parteien, die sich im Gesamtkonzert der Politik in der Bundesrepublik durchzusetzen vermögen. Sie umklammern die Willensbildung im Bundestag und Bundesrat. ${ }^{4)}$ Trotzdem ist dem Bundesrat Aufgabe und Möglichkeit moderierend zu wirken, auch in den Angelegenheiten der sozialen Intervention nicht abzusprechen.

Die Bedeutung des Bundesrates wird andererseits gegenüber einer eigentlichen zweiten Kammer dadurch erheblich erhöht, daß er nicht nur an der Gesetzgebung sondern auch nachhaltig an der Verwaltung des Bundes teilnimmt. ${ }^{3)}$

\section{dd) Die unmittelbare Demokratie}

Ein gewisser Ausgleich der Einseitigkeit der mittelbaren Demokratie im allgemeinen und ihrer monistisch-parlamentarischen Erscheinungsform im besonderen kann schließlich durch die Kop-

3) S. den Katalog bei Schäfer, Der Bundesrat, 1955, S.60 ff; Maunz in Maunz-Dürig, Art. 50 Randn. 4 ff.

4) Zur Illustration: Lt. Süddeutsche Zeitung v.28./29.11.1959 (Nr.285 S.2) erklärte der Bundeskanzler und CDU-Parteiführer Adenauer offenbar über den "Ungehorsam" des Bundesrates gegenüber der Bundesregierung erstaunt, "ein CDU-Politiker müsse aber mit gleichen Augen sehen, einerlei ob er in der Bundesregierung sitze oder im Bundesrat". 
pelung von mittelbarer und unmittelbarer Demokratie 1) erzielt werden. Parlamentarische Wahl- und konkrete Sachentscheidungsmehrheit können differieren. Der die Partikularinteressen über die Summe der beteiligten Individualinteressen hinaus aktivierende Konkurrenzkampf um Macht und Amt wirkt sich auf die Referendumsstimme schwächer aus als auf die Wählerstimme. Nicht zuletzt in sozialen Angelegenheiten ist auch die erzieherische Wirkung des Referendums von Bedeutung. Der als Wähler gern fordernde und die Sorge um das Richtige und Erreichbare dem Mandatar überlassende Bürger unterliegt als Abstimmender der mäßigenden Last unmittelbarer Mitverantwortung. Andererseits kann die aus den politischen Führungskonzeptionen der um die demokratische Macht ringenden Elite herausgelöste konkrete Abstimmungsentscheidung des Bürgers auch radikaler, einseitiger und kurzsichtiger sein als es seine Wählerentscheidung zu sein vermöchte. Die Gefahr der Radikalität wird erhöht dadurch, daß das Volk als "Souverän" sich selbst nur ungern an ein übergeordnetes Gesetz, die Verfassung also, gebunden weiß. 2) Gerade der sozialpolitische Effekt der unmittelbaren im Verhältnis zur mittelbaren Demokratie ist daher schwer abzuschätzen. Auf die konkrete Ausgestaltung sowohl der mittelbaren wie auch der unmittelbaren Demokratie und des Verhältnisses beider zueinander würde viel ankommen.

Das Grundgesetz negiert jedoch die unmittelbare Demokratie. ${ }^{3)}$

3. Demokratie und "Richterstaat"

a) Verfassungsrechtliche Grundlegung

Auch die Träger der dritten, der rechtsprechenden Gewalt bedürfen der demokratischen Legitimation (Art.20 Abs.2 GG). Das Grundgesetz hat mit seinen Vorschriften über die Wahl der Richter des Bundesverfassungsgerichts (Art.94 Abs. 1 Satz 2) und

1) S. hierzu aus neuerer Zeit etwa Werner Weber, Mittelbare und unmittelbare Demokratie, in: Festschrift für Karl Gottfried Hugelmann, Bd. II 1959, S. 765 ff.

2) S. hierzu z.B. Kägi, Zur Entwicklung des schweizerischen Rechtsstaates seit 1848, Zeitschrift für schweizerisches Recht, n.F. Bd. 71 (1952) S. 173 fi (205 ff).

3) Art. 20 Abs. 2 Satz 2 GG ist hinsichtlich der "Abstimmungen" eine Farce. Die Volksabstimmung nach Art.29 und 118 GG ist ohne allgemeine Bedeutung. Zur Frage s. z. B. Maunz in Maunz-Dürig, Art.20 Randn. 51 ff und seine Nachweise. 
der Richter des Obersten Bundesgerichts sowie der oberen Bundesgerichte (Art.95 Abs.3, 96 Abs.2; s.a. Art.98 Abs.4) eindeutig bekundet, daß es ihm damit ernst ist. 1) Ein Modus der Richterernennung, der sie von der Wurzel der demokratischen Willensbildung im Volke abtrennt, etwa eine permanente Kooptation, ist keinesfalls zulässig. ${ }^{2)}$

Was den Richter jedoch von den übrigen (demokratischen) Organen unterscheidet, ist seine relative Demokratieferne. Die Verfassung gibt für diesen Charakter des Richteramtes allerdings nur wenige Anhaltspunkte: der Ausschluß einer sachlichen Kontrolle der Amtsführung durch nichtrichterliche ("demokrati-

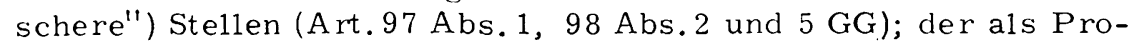
totyp herausgestellte Berufsrichter auf Lebenszeit; die durch die Zusammensetzung der Richterwahlausschüsse gekennzeichnete

1) A.A. Thieme, "Alle Staatsgewalt geht vom Volke aus", JZ 10. Jhg. (1955) S. $657 \mathrm{f}$, der meint, in bezug auf die richterliche Gewalt, vor allem auf die Verfassungsgerichtsbarkeit (!) sei der Grundsatz des Art.20 Abs. 2 Satz 1 GG durchbrochen. Diese Ansicht ist nicht richtig (s. Dürig, Art. "Staatsformen" im Handwörterbuch der Sozialwissenschaften, S. 749 f; s.a. Marcic, Vom Gesetzesstaat zum Richterstaat, S. 340 ff; s. ferner die unten Fußn.2 Zitierten). Dagegen scheint Menger (Das Gesetz als Norm und Maßnahme, VVDStRL. H. 15, 1957, S.9 ff (27)) mehr der Ansicht Thiemes zuzuneigen, wenn er schreibt: "Während alle anderen Staatsorgane ihren Auftrag lediglich auf die Volkssouveränität zurückführen, finden die Rechtsprechungsorgane die Legitimation ihres 'Tuns in der 'Souveränität des Rechts' ". Ferner dürfte es in diese Richtung zielen, wenn Werner Weber (Die Verfassung der Bundesrepublik in der Bewährung, S. 42; spannungen und Kräfte im westdeutschen Verfassungssystem, $\mathrm{S} .113 \mathrm{f}$ ) den gegenwärtig praktizierten Kreationsverfahren die Fähigkeit abspricht, den Richter demokratisch zu legitimieren.

2) Zur Diskussion um dieses einige Zeit sehr umstrittene Thema darf auf die Verhandlungen des 40. Deutschen Juristentages (1953) und zwar seiner öffentlichrechtlichen Abteilung über das Thema "Empfiehlt es sich, die vollständige Selbstverwaltung der Gerichte im Rahmen des Grundgesetzes gesetzlich einzuführen?" verwiesen werden (s. Ridder (Gutachten) das. Bd.1 S.91 ff (S. 109, 118, 124 f); Ipsen (Referat) Bd. 2 S. C 5 ff (S.C $15 \mathrm{f}$ ); Arndt (Korreferat) ebenda S. C $41 \mathrm{ff}$ (S. C 42 ff) und die Beschlüsse S. C 140; reiche weitere Nachweise $s$, bei den Zitierten). 
starke Brechung der demokratischen Legitimation und möglichste Versachlichung der Berufung des Richters, die dem Durchzug der aktuellen demokratischen Dynamik zum richterlichen Amt entgegenwirkt (Art.95 Abs.3, 96 Abs. 2, 98 Abs. 4 GG); ja selbst noch beim Bundesverfassungsgericht die Brechung der demokratischen Legitimation durch die Wahl je der Hälfte der Richter durch Bundesrat und Bundestag (Art.94 Abs.1 GG); und schließlich überhaupt die organisatorische Sonderung der Rechtsprechung von Legislative und Exekutive (Art. 20 Abs. 2 Satz 2 GG) und ihre definitive Übertragung auf "die Richter" (Art.92 GG).

Es ist nicht leicht, aus diesen wenigen Ansätzen, die gleichwohl eine Fülle traditioneller Vorstellungen und Postulate implizieren, das gültige verfassungsrechtliche Bild des Richters, der Gerichte und der Rechtsprechung zu deduzieren. ${ }^{3)}$ Doch ergeben sich immerhin einige Grundprinzipien, die hier wesentlich sind. So ist das Richteramt von dem Verständnis der demokratischen Magistratur als eines Mandates auf Zeit ausgenommen. Art.97 Abs. 2 Satz 2 GG erlaubt ausdrücklich die Berufung von Richtern auf Lebenszeit und in der Praxis ist der Berufsrichter auf Lebenszeit ( $d_{i}$ h. bis zur Erreichung der gesetzlichen Altersgrenze) die Regel. $\left.{ }^{4}\right)$ Das Richteramt ist von jeder politischen Kontrolle außer der Entscheidung über die Wiederwahl des auf Zeit gewäh1ten Richters und der Entscheidung über die Beförderung des Berufsrichters freigestellt (Art.97,98 Abs.2 und 5 GG). ${ }^{5}$ ) Diese

3) S, vor allem den groß angelegten und materialreichen Versuch von Bettermann, Die Unabhängigkeit der Gerichte und der gesetzlichen Richter, in Bettermann-Nipperdey-Scheuner, Die Grundrechte, Bd. III, 2. Halbbd. 1959, S.523 ff.

4) Vgl. Bettermann, a.a.O. S. 590 und 598 (insbes. Fußn. 326).

5) (1) $\mathrm{Zu}$ den verschiedenen richterlichen Verantwortlichkeiten s. Bettermann, a.a.O. S. $575 \mathrm{ff}$.

(2) Ridder (a.a.O. S. $116 \mathrm{f}$ ) und ihm folgend Arndt (a.a.O. S. C 57) halten ein Surrogat für weitergehende demokratische Kontrollen über die Rechtsprechung bereit: die öffentliche Meinung, die die Rechtsprechung beobachtet und lenkt. Von einer weiteren Erörterung dieses Gesichtspunktes kann im vorliegenden, auf das Organisatorische abstellenden Zusammenhang abgesehen werden. Bemerkt sei nur, daß die Meinungsfreiheit zwar für das Funktionieren der Demokratie unerläßlich ist, daß die öffentliche Meinung ohne entsprechende organisatorische Sanktionen allein die demokratische Willensbildung nicht zu tragen und durchzusetzen vermag. Das Dunkelfeld zwischen Impotenz und Revolution wäre zu groß. 
Kontrolle kann durch Anstellung auf Lebenszeit 6) und durch lange Wahlperioden der Zeitrichter ${ }^{7)}$ stark beschnitten werden. ${ }^{8}$ ) Sieht man von der nicht die richterliche Tätigkeit selbst betreffenden Dienstaufsicht 9 ) durch den parlamentarisch verantwortli-

6) Sie ist vor allem für den hauptamtlichen Berufsrichter von Bedeutung. Er, der sich mit seiner Existenz auf das Amt einstellt, wäre, sofern er auf Wiederwahl bzw. Neuberufung angewiesen wäre, von dieser Ungewißheit aufs stärkste betroffen. Dem Laienrichter ist das Richteramt dagegen meist mehr Bürde. Für ihn stellt jedenfalls die Nicht-Wiederberufung in der Regel keine Belastung dar. Für ihn ist die Berufung auf Zeit das Gegebene. Diese entspricht auch seiner Funktion, Träger lebendigen Kontakts zum "Volk", zu den betroffenen Kreisen oder zu interessierten Gruppen zu sein. Hier muß sich nachge rade das demokratische Prinzip auf Zeit wieder durchsetzen. Dieses Prinzip verschafft sich aber auch dort Geltung, wo es zwar nicht um das Laienelement im üblichen Sinne geht, wo aber der lebendige Kontakt mit den aktuellen politischen Kräften nicht auf die fallweise Nachwahl von Nachfolgern für durch Tod, Alter, Krankheit usw. ausscheidende Lebenszeit-Richter beschränkt bleiben darf. Das Nebeneinander rechtsgelehrter Lebenszeit- und Zeitrichter im Bundesverfassungsgericht ( $\$ 4 \mathrm{BVerfG}$ ) ist Ausdruck dieses Bedürfnisses.

7) Die Amtszeit des Zeitrichters findet ihre obere Grenze in dem Bedürfnis, durch ihn die Verbindung der Gerichte mit dem "Volk" institutionell zu verwirklichen. Die Untergrenze ergibt sich daraus, daß die Wiederwahl nicht zu einer Kontrolle der laufenden Geschäftsführung wird und so durch die kurze Amtsperiode mittelbar der Grundsatz der sachlichen Unabhängigkeit (Art.97 Abs. $1 \mathrm{GG}$ ) verletzt wird. Die Bedeutung des Richteramtes nach außen und für seinen Inhaber ist dabei mit entscheidend, So ist es unschädlich, wenn ehrenamtliche Beisitzer, Schöffen usw. nur auf 2, 3 oder 4 Jahre bestellt werden. Dagegen werden die (stets hauptamtlichen) Zeitrichter des Bundesverfassungsgerichts auf 8 Jahre gewählt ( $\$ 4$ BVerfGG).

8) Umgekehrt darf die Unabhängigkeit der Gerichte nicht durch die Bestellung von Richtern auf unbestimmte Zeit, die also dann der Kontrolle des für die Abberufung zuständigen Organs ausgesetzt wären, aufgeweicht werden. Die Schärfe, mit der die Rechtsprechung die Verwendung von Hilfsrichtern, Richtern auf Probe usw. bekämpft hat, findet hierin ihre Rechtfertigung. S. zum Problem Bettermann, a.a.O. S. 590 ff $u$. seine Nachweise. 
chen Ressortminister 10) ab, so konzentriert sich die demokratische Legitimation des Richteramtes auf den Akt der Kreation. Diese wiederum kann durch differenzierte Gestaltung des Kreationsorgans, wie sie vor allem in den Richterwahlausschüssen des Grundgesetzes vorgezeichnet ist, im Sinne einer Reduktion massiver Wahrnehmung aktueller Gruppeninteressen und zugunsten stärkster Rücksichtnahme auf die objektiven Erfordernisse des Amtes moderiert werden. 11)

Diese objektiven Erfordernisse des Amtes werden an sich, solange nicht die politischen Sitten so verwildert und die politischen Differenzen so tiefgreifend sind, daß - ohne Rücksicht auf Nutzen und Schaden des Ganzen - jede Position im Staat recht ist, um die Macht einer der um sie konkurrierenden Gruppen zu vermehren, einer unmittelbar parteipolitischen Prägung der Richterberufung entgegenstehen. Umgekehrt wird - ebenfalls solange die Zustände gesund sind - die Pflichtstellung des Richteramtes, $m$. a. W. sein Ethos, den Richter hindern, die Ausübung seines Amtes in dem Maße auf die Wiederwahl (bzw. die Beförderung) einzuste1len, wie etwa der Parlamentarier oder der Minister. ${ }^{12}$ ) $\mathrm{Ja}$, in

9) Vgl. Dinslage, Richterliche Unabhängigkeit und Dienstaufsicht, Deutsche Richterzeitung, 38.Jhg. (1960) S.201 ff.

10) Zu dieser Dienstaufsicht als einer demokratischen Einrichtung s. BSGE 2, 201 (207).

11) S. die Darstellung des Rechts der. Richterberufung und - beförderung bei Bettermann, a.a.O. S.605 ff.

12) S. Peter Schneider, Zur Problematik der Gewaltenteilung im Rechtsstaat der Gegenwart, AöR Bd.82 (1957) S. 1 ff (25). Es steht außer Zweifel, daß die Pflichtstellung des Richters - die Unterordnung unter Gesetz und Recht (Art.20 Abs. 3 GG) und die Negation jeder anderen Bindung (Art.97 Abs.1 GG) in der Regel dem rechtsgelehrten Berufsrichter am klarsten bewußt wird. Der Laienrichter kann sie schon im Hinblick auf seine beschränkte Fähigkeit, die jeweils gegebenen Entscheidungsmöglichkeiten klar zu überblicken, nur bedingt realisieren. Darum ist es auch für den hier gegebenen Zusammenhang nicht unwichtig, daß durch Ait.97 Abs.2 GG nicht nur die Rechtsverhältnisse des Berufsrichters geregelt werden sondern dieser auch als unentbehrlicher Grundtyp des Richters verbindlich herausgestellt wird (vgl. Bettermann, a.a.O. S. $640 \mathrm{f}$. m.w. Nachw.). Dieser wird in der Regel auch rechtsgelehrt sein; doch hat das Grundgesetz diese Frage nicht ausdrücklich angeschnitten (s.hierzu Bettermann, a.a.O. S.639f). Zum rechtsgelehrten Richter als dem Grundtyp des rechtsstaat. lichen Richters s. Jahrreiß, Demokratischer Rechtsstaat und 
dem richterlichen Ethos liegt gerade der Vertrauensfaktor, der dem Richter an Autorität aufwiegt, was ihm die relativ geringe demokratische Legitimation nicht einbringt.

\section{b) Zur besonderen Funktion des Richters}

In der Demokratie des Richters in seiner Zurückgezogenheit aus dem demokratischen Blutkreislauf, liegt einer der wichtigsten Gründe für den starken Macht- und Ansehenszuwachs, den die Gerichte im modernen demokratischen Staat erfahren haben. 1) Die Demokratie spürt selbst unbehaglich ihre Einseitigkeit, ihre Anfälligkeit für die aktuelle Dynamik der politischen Kräfte. Fast hoffnungslos in sich selbst relativiert sucht sie einen archimedischen Punkt, aber in Wahrheit keinen absoluten. Mit einem außergesellschaftlichen Machtträger nimmt sie es nicht auf. Sie will nicht einmal einen Ansatz hierzu - keinen Präsidenten, dessen Herrschaft im Caesarismus enden könnte. Sie will überhaupt nicht, daß dieser "archimedische Punkt" eine politisch gestaltende, mit ihrem plebiszitärparlamentarischen Sein konkurrierende Ausstrahlung hat. Dazu ist sie sich selbst zu wichtig. Sie will ein Korrektiv, aber sie will eines, das gebändigt ist durch seine Einbezogenheit in die Demokratie und durch ihm selbst wesensmäßig vorgegebene Schranken gegenüber dem ungehemmten Angreifen ins Politische. So richtet sich ihr Blick auf den Richter. Demokratiefern und doch demokratisch konstituiert, der Sachlichkeit und Gerechtigkeit verpflichtet und dem (demokratischen) Gesetz untertan, unabhängigs und gebunden zugleich, erscheint er als der deus ex machina der demokratischen Verlegenheit. Ob er es so sehr ist, wie manche glauben, ist eine offene Frage. Ihr braucht hier nicht nachgegangen zu werden. Daß eine Komplementärfunktion der Richter gegenüber den politisch gestaltenden Gewalten immer gegeben ist, und in der Demokratie in ganz spezifischer Weise, ist nicht zu leugnen. 2)

Rechtsprechung, Recht Staat Wirtschaft Bd.2 (1950) S. 203 ff (21:3 if).

13) Werner Weber (s. oben S. 353 zu Fußn. 1) sieht darin überhaupt die Quelle der richterlichen Legitimität. S.a. Menger, a.a.O. (oben S. 353 zu Fußn. 1).

1) S. zur Gesamtproblematik Marcic, Vom Gesetzesstaat zum Richterstaat. Vgl. ferner unten Abschnitt 4 II 3 (S. 508 ff).

2) S. zu Vorstehenden (mit gewissen Vorbehalten) auch Weber, Das Richtertum in der deutschen Verfassungsordnung, in Festschrift für Hans Niedermeyer, 1953, S.261 ff; dens., Die Verfassung der. Bundes republik in der Bewährung, S. $41 \mathrm{ff}$; Spannungen und Kräfte im westdeutschen Verfassungssystem, 
Das gilt auch und gerade für das Feld der sozialen Intervention. Hier hat der Richter an sich schon eine feste Position. Soziale Intervention ist Ausgleich. Der Richterspruch ist ein Instrument des Ausgleichs, das im Bereich des privaten Rechts durch kein anderes ersetzt werden kann. In der Demokratie aber kommt da$z u, d a ß$ der unabhängige Richter die Interessen, die vor ihm streiten, nicht nach ihrem Stimmgewicht, nach ihrer demokratischen "Durchschlagskraft" abschätzen soll und wird. Er hat sie nach ihrem inneren Wert, nach einer tiefer und weiträumiger gesehenen Legitimität zu wägen. Die demokratischen Gesetzmäßigkeiten der Progression der politischen Bedeutung der Interessen mit ihrem zunehmenden Stimmgewicht und der Degression ihrer Berücksichtigung mit dem abnehmenden Stimmgewicht sind vor dem Richter aufgehoben. Die Interessen der Mehrheit und der Minderheit unterscheiden sich vor ihm nicht qualitativ. Soweit seine Macht reicht, kann er also der Bruchstückhaftigkeit und Einseitigkeit, die der sozialen Intervention in der Demokratie anhaftet, entgegenwirken. Freilich auch nur in seinem Kompetenzbereich! Wo ihn Gesetzgebung und Exekutive in ihrem jeweiligen legitimen Funktionsbereich präjudizieren, ist er gebunden. Immerhin: Die Verfassungsgerichtsbarkeit ist grundsätzlich durch nichts als durch die Verfassung präjudiziert. Doch auch die sonstige Gerichtsbarkeit hat einen weiten Raum. Einerseits kann ihn die Gesetzgebung gar nicht erschöpfend präjudizieren. Generalklauseln (unbestimmte Rechtsbegriffe) und Ermessensspielräume, ja sogar Lücken des Gesetzes sind unvermeidlich. Zum anderen entspricht es dem demokratischen Trend zum richterlichen Korrektiv, ihm zu vertrauen und Spielraum zu lassen. Nicht immer ist weise Selbsterkenntnis und -beschränkung der Grund dafür. Verantwortung, die vor den Wählern nicht getragen werden soll, wird auf den Richter abgeschoben. Unfähigkeit der maßgeblichen politischen Kräfte zum politischen Kompromiß schließt bisweilen die generelle, gesetzgeberische Lösung aus, während der Richter über sie entscheiden muß und so in die Vorhand vor den Gesetzgeber kommt. 3 )

\section{c) Ihre demokratische Prämisse}

Diese wohltuende Funktion des Richtertums wird von ihm nur dann voll ausgefüllt, wenn es nicht selbst Repräsentant eines bestimmten Interesses ist. Ist die "Aristokratie der Robe" nicht

\section{S. 112 ff, 159; ferner Forsthoff, Lehrbuch des Verwaltungs- rechts, S. 7 .}

3) S. zum Ganzen unten Abschnitt 4 II 3 (S.508 ff). Dort auch eingehende Nachweise. 
die Herrschaft eines (i.w.S.) sozial offenen, nur durch die individuelle Innehabung des Amtes gekennzeichneten Personenkreises sondern die Herrschaft einer durch vorgegebene, familiäre oder auch nur ökonomische Gemeinsamkeiten verbundene Gruppe, so ist sie zumindest potentiell eine Klassenherrschaft 1 ) (und zwar von Haus aus die Herrschaft einer Minderheit über eine Mehrheit). Zwar ist es nicht ausgeschlossen, daß eine Richterkaste, ein hohes Ethos entwickelnd, über der Gesellschaft steht. A ber die Gefahr ihrer sozialen Lokalisierung ist groß. Sie kann auf die Dauer - auch und gerade im Rahmen des grundsätzlich gleichen Zugangs aller zu den öffentlichen Ämtern (Art.33 Abs. $2 \mathrm{GG}$ ) - nur vermieden werden, wenn die für eine sachgerechte Wahrnehmung der richterlichen Pflichten erforderliche Bildung und Ausbildung nicht bei gewissen Schichten monopolisiert sondern breiten Schichten umfassend eröffnet ist. Die zentrale Stellung des Bildungsproblems im Gefüge der Demokratie zeigt sich einmal mehr. 2) Aber eine breite Streuung der Bildung - wiewohl sie fast immer die Streuung auch in der Zusammensetzung der Richterschaft fördern wird - kann allein die Konzentration der Richterschaft auf e ine Schicht nicht hindern. Dagegen schützt wo nicht ein weiser und wahrhaft gesellschaftsunabhängiger Monarch regiert - noch am ehesten die demokratische Berufung des Richters.

Damit ist an das Dilemma gerührt, vor das die Frage nach der richterlichen Gestaltung des Rechtes der Richterberufung stellt. Auf der einen Seite braucht der Richter die demokratische Legitimation. Sie ist nicht nur die im demokratischen Staat einzig glaubwürdige. Sie ist auch die Gewähr für eine breite Streuung der im Richtertum lebendigen Interessen. ${ }^{3)}$ Andererseits nimmt

1) In diesem Sinne glaubte Heller (Rechtsstaat oder Diktatur?, S. 8 ff) das Aufkommen der richterlichen Prüfung von Gesetzen und insbes. die Rechtsprechung zum Verbot gesetzgeberischer Willkür als Abwehr gegen den egalitär-demokratischen Ansturm der unteren Klassen gegen das Bürgertum werten zu sollen.

2) S. oben S. 329 und S. 338 .

3) S. hierzu Draht, Die Gewaltenteilung im heutigen deutschen Staatsrecht, S. $111 \mathrm{ff}$. - Dabei ist natürlich nicht gesagt, daß jeder einzelne Richter alle Interessen gleich schätzt und würdigt. Auch er ist von seinem subjektiven, persönlichen Standpunkt abhängig. Aber eine in sich "gemischte" Richterschaft wird sich nicht nur durch eine gewisse Standeshomogenisierung abschleifen. Sie kann sich innerhalb der Instanzenzüge, in dem Spannungsverhältnis von Präjudiz und Einzelentschei- 
die Fähigkeit des Richters zur Ergänzung der politischen Gewalten in dem Maße ab, in dem auch se in Amt in den Strudel massendemokratischer Dynamik gezogen wird. ${ }^{4)}$ Das Grundgesetz deutet, indem es die demokratische Basis der richterlichen Gewalt unverrückbar festlegt, die aktuellen Einflüsse der Demokratie dagegen zurückdrängt, die Notwendigkeit der ausgewogenen Mittellösung an.

d) Zur demokratischen Struktur der verschiedenen Gerichtszweige

aa) Überblick

Der Grad der Demokratisierung der Gerichte - wie er sich in den Relationen Lebenszeit - und Zeitrichter, Berufs- und Laienrichter, rechtsgelehrter und nicht rechtsgelehrter Richter ${ }^{1)}$ und in der Dichte der demokratischen Legitimation ausdrückt ist hinsichtlich der einzelnen Gerichtszweige und innerhalb derselben teils von Verfassungs teils von Gesetzes wegen sehr verschieden.

Eine besondere Stellung nehmen die Verfassungsgerichte ein. Die kraft der parlamentarischen Wahl der Richter ${ }^{2)}$ demokratisch Erstgeborenen unter den Gerichten bevorzugen den rechtsgelehrten Richter ${ }^{3)}$ und verbinden das lebenszeit- mit dem zeitrichterlichen Element. ${ }^{4)}$ Der Bund entscheidet sich zudem aus-

dung und vor allem innerhalb der Kollegien ergänzen und ausgleichen. Die Kollegialgerichte als "präsumptiv bessere Gerichte" gegenüber dem Einzelrichter erhalten hiervon einen neuen Akzent.

4) Zur Gefahr der "sozialen Gebundenheit der Gerichte" s. Bettermann, a.a.O. S. 525 f, 528, 611 .

1) S. nochmals oben S. 352 ff. Vg1. ferner nochmals Bettermann, a.a.O. S. 589 .

2) Vg1. Art.94 Abs. 1 Satz 2 GG, $\$ \$ 4$ ff BVerfGG. (Zu beachten ist, daß ein Teil der Bundesverfassungsrichter Bundesrichter sein müssen, deren demokratische Berufung durch den Richterwahlausschuß (Art.95 Abs.3,96 Abs.2 GG) ihrer Wahl zum Bundesverfassungsrichter vorausgegangen sein muß).

3) Ausnahmslos beim Bundesverfassungsgericht: $\$ 3$ BVerfGG (verfassungs rechtlich angelegt schon in der notwendigen Mitgliedschaft von Bundesrichtern (Am.94 Abs. 1 Satz 1 GG)).

4) Im Bundesverfassungsgericht verkörpern die Richter der oberen Bundesgerichte das lebenszeitrichterliche Element. Die übrigen Mitglieder werden auf acht Jahre gewählt ( $\$ 4$ BVerfGG). 
schließlich für den Berufsrichter. ${ }^{5)}$

Das beherrschende Element der Nichtverfassungsgerichtsbarkeit ist eindeutig der auf Lebenszeit bestellte, rechtsgelehrte $\mathrm{Be}-$ rufsrichter. ${ }^{6}$ Seine demokratische Legitimation leitet er grundsätzlich von der des ernennenden Ressortministers ab. ${ }^{7)}$ Für die Richter der oberen Bundesgerichte sieht das Grundgesetz die Berufung durch Richterwahlausschüsse vor. ${ }^{8)}$

Daneben kennen alle Gerichtszweige den auf Zeit bestellten Laienbeisitzer. Aber seine Mitwirkung ist grundsätzlich auf die untere(n) Instanz(en) beschränkt. Die ordentliche Gerichtsbarkeit verzichtet - vor allem in Zivilsachen - sogar weitgehend auf ihn.

Auffällig und höchst eigentümlich häufen sich die "Demokratisierungs" -Elemente in der A rbeits- und Sozialgerichtsbarkeit. Ehrenamtliche, auf Zeit bestellte Beisitzer sind in allen Instanzen und grundsätzlich an allen Verfahren beteiligt: bei den Arbeits-, Landesarbeits- und Sozialgerichten im Verhältnis 2 Laienrichter: 1 Berufsrichter; bei den Landessozialgerichten, dem Bundesarbeits- und dem Bundessozialgericht im Verhältnis 2 Laienbeisitzer: 3 Berufsrichter. ${ }^{9)}$ Bei den Arbeits- und Sozialgerichten finden sich im Gegensatz zu den anderen Gerichtszweigen regulär Richter auf Zeit. ${ }^{10)}$ Nur bei den Arbeits- und Sozialgerichten (erster Instanz) gibt es ferner den nicht-rechtsgelehrten Berufsrichter. 11) Allein für die Berufung der Berufsrichter (Vorsitzen-

5) $₫ 3$ Abs.4 BVerfGG (zu den Bundesrichtern s.a. nochmal Art. 94 Abs. 1 Satz 1 GG).

6) Vgl die eingehende Darstellung bei Bettermann, a.a.O. S. $598 \mathrm{f}, 640 \mathrm{f}$.

7) In nuce gilt das auch für die Richterwahlausschüsse (Art.95 Abs. 3, 96 Abs. 2, 98 Abs. 4 GG).

8) Art.95 Abs.3, 96 Abs.2 GG; s.a. das Richterwahlgesetz vom 25. August 1950 (BGG1. S.368).

9) Vgl. $\$ \$ 16,35,41 \mathrm{Ar} \cdot \mathrm{bGG}, \$ \$ 3,12,33,40 \mathrm{SGG}$. - S. hierzu Roehrbein, $\mathrm{Zu}$ der Mitwirkung von Laien in der Sozialgerichtsbarkeit, "Beiträge zur Sozialversicherung", Festschrift für Johannes Krohn, 1954, S.231 ff.

10) $\$ 18$ Abs. 4 ArbGG; s.a. $\ 210$ SGG. Zur Verfassungsmäßigkeit des $\$ 210$ SGG s. BSGE 5, 289. - Im übrigen s. zur Verwendung des Zeitrichters als Hilfsrichter und zur Regelung für andere Gerichtszweige: Bettermann, a.a.O. S. 589 f, 598 ff, $635 \mathrm{f}$ und die dortigen Nachweise.

11) S. $\$ 18$ Abs. 3 ArbGG. - Zur Würdigung s. z.B. Oehmann, Nicht rechtsgelehrter Berufsrichter, "Sozialpolitik, A rbeitsund Sozialrecht", Festschrift f.Friedrich Sitzler, 1956, S. 355 ff. 
den) der Arbeits-, Landesarbeits- und Sozialgerichte ist neben der Entscheidung des zuständigen Ressortministers und neben der Mitwirkung eines - eventuell landesgesetzlich eingerichteten - Richterwahlausschusses (Art.98 Abs.4 GG) 12) die Konsultation von Verbänden vorgesehen. In der A rbeitsgerichtsbarkeit wirken die Koalitionen bei der Berufung von A rbeitsgerichtsvorsitzenden über einen von ihnen paritätisch beschickten Ausschuß. 13) Bei der Berufung der Kammervorsitzenden des Landesarbeitsgerichts sind sie unmittelbar anzuhören. ${ }^{14)}$ Die Berufung der Vorsitzenden der Sozialgerichte erfolgt nach Beratung mit einem Ausschuß, der aus Vertretern der Versicherten, der Arbeitgeber, der Versorgungsberechtigten, der mit der Kriegsopferversorgung vertrauten Personen sowie der Sozialgerichtsbarkeit besteht. 15) Diese Verbände haben schließlich einen entscheidenden Einfluß auch auf die Berufung der ehrenamtlichen (Laien-)Beisitzer. 16)

\section{bb) Zur Deutung}

Die Verschiedenheit der Regelungen kann auch nicht annähernd als die dem Aufgabenkreis des jeweiligen Gerichtstyps angemessene demokratische Gestaltung allein erklärt werden. Historische Entwicklungslinien und - schichten und Meinungsverschiedenheiten des Ressorts ${ }^{1)}$ haben Unterschiede mit sich gebracht, die

12) Zur Einrichtung der Richterwahlausschüsse in Bund und Ländern s.Bettermann, a.a.O. S.606 ff. - Bei den Arbeitsgerichten kommt noch die Beteiligung der Landesjustizverwaltung dazu ( $₫ 18$ Abs. 1 ArbGG).

13) $₫ 18$ Abs. 1 und 2 A rbGG

14) $₫ 36$ Abs. 1 A rbGG

15) $₫ 11 \mathrm{SGG}$

16) Vg1. $\$ \$ 20,37,43$ ArbGG, $\$ \$ 13,14,35,45$ SGG. - Diese Regelung unterscheidet sich von dem Recht der Bestellung ehrenamtlicher Beisitzer in anderen Gerichtszweigen vorwiegend durch das Hervortreten der Verbandsmacht. Eine Einwirkung von Kräften außerhalb der Gerichtsverwaltung - von lokalen Volksvertretungen, berufsständischen Vertretungskörperschaften, Verbänden usw. - auf die Bestellung der ehrenamtlichen Beisitzer ist seit jeher und in fast allen Verfahren vorgesehen (vgl. Bettermann, a.a.O. S.613 ff; nachzutragen ist die Regelung der $\$ \$ 26$ ff VerwGO).

1) Gerade in der reichhaltigen und grundlegenden Nachkriegsgesetzgebung des Bundes zum gerichtlichen Verfahrens recht hat es sich oft bis ins rein Zufällige und Lächerliche unterscheidend ausgewirkt, daß für verschiedene Gesetze nicht nur ver- 
außer jedem Verhältnis zum Problem der Demokratisierung stehen. Zudem steht das Laienelement vielfach fern jeder Demokratisierung ausschließlich unter dem Zeichen des Sachverstandes. Aber doch äußern sich auch Sachgesetzlichkeiten des Verhältnisses der Demokratie zur Rechtsprechung.

Offenkundig sind die Zusammenhänge hinsichtlich der Verfassungsgerichtsbarkeit. Ohne gesteigerte demokratische Legitimation wurde sie $z$ wischen den demokratisch hochpotenzierten Entscheidungsbetroffenen zerrieben. Ohne ein gewisses Mindestmaß an Homogenität mit den aktuellen politischen Kräften könnte sie sich nicht am Grat zwischen Recht und Politik, zwischen Rechtsfindung und Rechtsergänzung halten. Ohne das rechtsgelehrte und berufsrichterliche Element wäre ihre juridische Selbstverpflichtung an das Recht und ihre Standfestigkeit gegenüber den politischen Gewalten zu gering und die schwierige Rechtsprechungsaufgabe nicht zulänglich zu bewältigen.

Mutatis mutandis gelten diese Gesichtspunkte auch für die gesteigerte demokratische Legitimation der Richter der oberen Bundesgerichte und für den eindeutigen Vorrang des rechtsgelehrten Lebenszeit- und Berufsrichters bei diesen. Vor allem ist auf die judikative Führungsaufgabe, auf die föderative Homogenitätsfunktion und auf die Schutzfunktion zugunsten des Bundes dieser Gerichte hinzuweisen.

In der allgemeinen und besonderen Verwaltungsgerichtsbarkeit wirkt heute noch ein Moment, das für die historischen demokratisch determinierten Anfänge des einen Zweiges der deutschen verwaltungsgerichtlichen Tradition, des sog. preußischen, kennzeichnend war: die Verwaltungsgerichte sollen der bürokratischen Verwaltung als Einrichtungen der politischen Selbstverwaltung, d. h. also unter Beteiligung verwaltungsfremder Bürger, gegenübertreten. Dieser Gedanke hat mit der Ausbildung der Selbstverwaltung auf weiten Gebieten der Verwaltung und mit der Trennung der Verwaltungsgerichtsbarkeit von der Verwaltung viel an Konsequenz eingebüßt. 2) Allenfalls als eine Mindestreserve an politischer. "Selbstverwaltung" und bürgerlicher Verwaltungskontrolle kann das Laienelement in der allgemeinen Verwaltungsgerichtsbarkeit, der Finanzgerichtsbarkeit und der Sozialgerichtsbarkeit noch verstanden werden.

schiedene Ministerialbürokratien sondern auch verschiedene Bundestags- und Bundesratsausschüsse bemüht wurden.

2) Zum Problemkreis s. Baring, Die politische Selbstverwaltung und die Verwaltungsgerichtsbarkeit. 
Gerade in der Sozialgerichtsbarkeit ist die doppelte Demokratisierung durch das Laienelement und durch die Beteiligung der Verbände an der Richterauswahl viel mehr eine Fortsetzung der Selbstverwaltung "vor" der Rechtsprechung in die Rechtsprechung hinein. 3)

In Parallele hierzu steht die Arbeitsgerichtsbarkeit. Von der übrigen Gerichtsbarkeit zunächst aus Gründen der sachnahen Gestaltung gesondert, verkörpert ihr Laienelement den typischen Interessengegensatz der arbeitsrechtlichen Streitigkeit. Nunmehr setzt sich über dieses Laienelement und die sonstigen Einflußkanäle der Arbeitgeberverbände und Gewerkschaften auf die Ar beitsgerichtsbarkeit 4 ) die "soziale Selbstverwaltung" des Arbeitslebens durch die Koalitionen in der Arbeitsgerichtsbarkeit fort. 5)

Mehr als alles andere zeigt sich aber in der eigenartigen demokratischen Struktur der Arbeits- und Sozialgerichtsbarkeit der hohe Grad der "Verbändedemokratie", der das Sozialleben beherrscht.6)

Im Gesamtbild zeichnet sich aber noch eine andere Linie ab: Nirgends wo die gerichtliche Kontrolle der staatlichen Daseinsvorsorge und sozialen Hilfe in Frage steht, scheint auf eine aktuelle Demokratisierung der Gerichte, insbes. durch das Laienelement verzichtet werden zu können. ${ }^{7)}$ Stand am Anfang der Fnt-

3) Das gilt besonders hinsichtlich der Sozialversicherung: Dieselben Verbände, die als Wahlvorschlagsberechtigte die Selbstverwaltung in den Sozialversicherungsträgern bestimmend beeinflussen ( $\$ 4$ des Selbstverwaltungsgesetzes) und einen erheblichen Einfluß auf die Verwaltung der Bundesanstalt für Arbeitsvermittlung und Arbeitslosenversicherung ausüben ( $\$ S 9$ ff $A V A V G$ )wirken bestimmend auf die Richterauswahl ein (s.o. S. 362 zu Fußn. 12 ff). Zur Beisitzerproblematik in der Sozialgerichtsbarkeit s.a. unten S.584 zu Fußn. 13.

4) S. O. S. 360 a. E. und oben S. 301 .

5) Werner Weber (Die Einheit der rechtsprechenden Gewalt, Zeitschrift für Sozialreform, 3.Jhg. (1957) S. 109 ff (111 f); Spannungen und Kräfte im westdeutschen Verfassungssystem, $\mathrm{S} .126 \mathrm{f}$ ): "In der Arbeitsgerichtsbarkeit" ist "eine komplette eigene Gerichtsbarkeit entstanden..., in der sich der Staat und die Sozialpartner zur Ausübung einer Art kondominaler Gerichtshoheit vereinigt haben" .

6) S. unten $5 \mathrm{~b}$ (S. $373 \mathrm{ff})$.

7) S. Ipsen, Empfiehlt es sich, die vollständige Selbstverwaltung 
wicklung die Demokratisierung der Strafgerichtsbarkeit - m.a. W. des strafenden Eingriffs des Staates in die bürgerliche Existenz - und der damals nur gegen den eingreifenden Staat gewendeten Verwaltungsgerichtsbarkeit, so muß nunmehr gerade auch in bezug auf die gerichtliche Kontrolle der staatlichen Gewährungen dem Mißtrauen gegen den "lebensf remden", "staatsabhängigen", gesellschaftlich klassifizierten Berufsrichter begegnet werden. Damit steht die Rechtspolitik vor einem Dilemma. Sie kann diesen Gesichtspunkt nicht vernachlässigen. Gefährdet sie aber ernstlich die relative Demokratieferne des Richters, so büßt er seine soziale Ausgleichs- und Ergänzungsfunktion ein.

4. Demokratie, Bürokratie und Berufsbeamtent u m 1)

a) Zur verfassungs rechtlichen Grundlegung des Berufsbeamtentums

Ähnlich dem Richtertum bilden auch Bürokratie und Beamtentum 1) eines der Widerlager der Demokratie, die von dem permanenten Wandel der herrschenden Kräftekonstellation nicht völlig absorbiert werden. ${ }^{2}$ ) Sie haben etwas Bleibendes schon von der Sache her. Das Reservoir an hinreichend qualifizierten oder gar eingearbeiteten Fachkräften ist in keinem Staate so groß, daß die personelle Zusammensetzung des öffentlichen Dienstes jeweils

der Gerichte im Rahmen des Grundgesetzes gesetzlich einzuführen? S. C 16: "Daß der Richter demokratischer Legitimation bedarf, entspricht auch seiner Aufgabe im sozialen Rechtsstaat, durch Rechtsschutzverantwortung für jeden einzelnen ein wesentliches Element dieser Daseinsvorsorge bereitzustellen". S. auch Forsthoff, Lehrbuch des Verwaltungsrechts, S. $472 \mathrm{f}$.

1) Zur Unterscheidung von Bürokratie und Berufsbeamtentum s. z.B. Neesse, Staatsdienst und Staatsschicksal, 1955, S. 14 ff.

2) (1) Vgl. Werner W'eber, Die Verfassung der Bundesrepublik in der Bewährung, S.41 ff, der in der Trias von massendemokratischen Gruppenpotenzen, Richtertum und Beamtentum "die Flemente" sieht, "aus denen sich das Verfassungsgefüge aufbaut" (S.45).

(2) Die scharfe Trennung von Richtertum und Beamtentum ist andererseits eine Frucht des Grundgesetzes (s. Art. 33 Abs. 4 und 5, Art.60, Art.98 Abs.3, Art.132 GG). Zur Bedeutung dieser Spaltung im Corps der berufsmäßigen staatlichen Amtsträge $r$ in Exekutive und Judikative als einer Verfeinerung der Gewaltenteilung s.Draht, Die Gewaltenteilung im heutigen deutschen Staatsrecht, S. 111. 
genau der politischen Struktur der Exekutivspitze angepaßt werden könnte. 3 )

Eine zureichende Gegenwirkung gegen die Universalität demokratischer Einseitigkeit ist aber nur von einer Beamtenschaft $z u$ erwarten, die ein gewisses Mindestmaß an rechtlicher Sicherurg genießt, kraft deren sie sich außerhalb der Parteien Zank und Hader gestellt weiß. ${ }^{4)}$ Das Grundgesetz hat in Art. 33 Abs. 4 und 5 dem Berufsbeamtentum denn auch verfassungsmäßige Festigkeit gegeben. 5) Damit ist gewährleistet, daß das Schwergewicht der Verwaltungstätigkeit unter der Sphäre des Kabinetts bei Personen liegt, die in einem Beamtenverhältnis auf Lebenszeit stehen. Schon dadurch, daß das Beamtenkorps in dieser Weise auf Dauer angelegt ist, scheiclet seine Verpflichtung auf die jeweils herrschende politische Kräftegruppe aus. Nur der Staat als gedachte Einheit kann dieses Beamtenverhältnis tragen. Nur auf ihn kann sich die Treuepflicht des Beamten beziehen. 6) Auf dieser Basis vermag sich das Beamtentum zu einer Vergegenwärti-

3) S. zu Vorstehendem insbes, auch Hans Huber, Demokratie und Bürokratie, Schweizerische Monatshefte, 37.Jhg. (1957) S. $130 \mathrm{ff}$ (132 ff).

4) S. z.B. Heyland, Das Berufsbeamtentum im neuen, demokratischen, deutschen Staat, 1949, S.85 ff.

5) Zum Inhalt des Art. 33 Abs. 4 und 5 GG s. die Verhandlungen der Öffentlichrechtlichen Abteilung des 39. Deutschen Juristentages 1951 mit dem Thema "Inwieweit läßt Art. 33 Abs. 5 des Grundgesetzes eine Reform des Beamtenrechts zu?" mit dem Referat von Grewe (a.a.O. S. D 3 ff), dem Korreferat von Fischbach (a.a.O. S. D $33 \mathrm{ff}$ ) und einer Bibliographie (S. D $163 \mathrm{f}$ ). - S.ferner die zusammenfassenden Darstellungen bei Jess, Bonner Kommentar, Art.33 Anm. II 5-7; Hamann, Das Grundgesetz, Art. 33 Anm. C 4-8; v. MangoldtKlein, Art.33 Anm. VII; Otto, Der Beamte als Träger der Staatsgewalt, Zeitschrift für Beamtenrecht 4. Jhg. (1956) S. $233 \mathrm{ff}$.

6) Darin steckt eine der Wurzeln des Satzes von der Bindung des Beamten an die Gesamtheit und der Absage des Beamten an partikuläre Bindungen, wie sie zu den hergebrachten Grundsätzen des Berufsbeamtentums gehört: Art.96 BayVerf; Art. 130 Abs. 1 RV 1919; Art. 77 Abs. 2 BadWürttVerf; Art. 56 HessVerf; Art. 80 NordrhWestfVerf; Art. 127 Abs. 1 RhPfVerf; Jess, a.a.O. Anm. II $7 \mathrm{i}$; Hamann, a.a.O. Anm. C 7 g; weitere Nachweise s.bei den Zitierten. - S. hierzu auch v. Münch, Die Einflußnahme der politischen Parteien auf Beamtenernennungen und Beförderungen, Zeitschrift für Beamtenrecht, 8. Jhg. 
gung der staatlichen Ganzheit zu erheben, wie der demokratische Staat sie sonst nur noch in Symbolen - einschließlich des Staatsoberhaupts - und wohl auch im Richtertum kennt. 7)

Die Position des Berufsbeamtentums könnte auch bei grundsätzlicher institutioneller Beibehaltung des Beamten auf Lebenszeit durch gezielte Handhabung des Einstellungs- und Beförderungsrechts seitens der jeweiligen Exekutivspitze (bzw. der sie tragenden parlamentarischen Mehrheit) geschwächt werden. 8) Doch hat die Verfassung die eigenständige Wirkmächtigkeit des Berufsbeamtentums insofern durch die Vorschrift mit geschützt, wonach jeder "nach seiner Eignung, Befähigung und fachlichen Leistung gleichen Zugang $z u$ jedem öffentlichen Amte" hat (Art. 33 Abs. 2 GG). 9 )

Diese Bestimmung ist vor allem aber Ausdruck einer Maxime, die für das Berufsbeamtentum als ergänzender Faktor der Demokratie entscheidend ist: Die Offenheit des Zuganges aller Volksschichten zum Beamtentum. Sie setzt, um realisiert zu werden, eine breite Streuung der Bildung voraus, die für die Berufsaufgaben des Beamten erforderlich ist. Aber dabei handelt es sich nur einmal mehr um das allgemein erforderliche Substrat der Demokratie, ohne das diese nicht unverfälscht ausgelebt werden kann. Dieses Substrat vorausgesetzt, leitet der in Art. 33 Abs. 2 GG ausgesprochene Grundsatz den Zustrom aus allen

(1960) S. $245 \mathrm{ff}$.

7) S. vor allem Herbert Krüger, "Der Staat sind wir", Der Beamtenbund, 1.Jhg. (1950) S. 4 ff; Gerber, Die grundsätzliche Bedeutung der beamtenrechtlichen Regelungen des Bonner Grundgesetzes, DVB1. 66. Jhg. (1951) S. $489 \mathrm{ff}$ (mit eingeh. Nachw. ); Fischbach, Inwieweit läßt Art. 33 Abs. 5 GG eine Reform des Beamtenrechts zu? S. D $45 \mathrm{f}$; Weber, Staatsverfassung und Selbstverwaltung, S. $87 \mathrm{ff}$, insbes. S. 98 mit weit. Nachweisen.

Ablehnend: Werner Weber, Spannungen und Kräfte im westdeutschen Verfassungssystem, S.20, 30, $159 \mathrm{ff}$.

Kritisch: Grewe, Inwieweit läßt Art. 33 Abs. 5 GG eine Reform des Beamtenrechts zu? S. D $7 \mathrm{f}$; einschränkend: Mestern, Geschichte - Staat - öffentlicher Dienst, in Neues Beamtentum, hrsg. vom Institut zur Förderung öffentlicher Angelegenheiten e.V. 1951 S.27 ff (30 ff); s.hierzu auch Bank, Zur Gesamtverantwortung der Beamtenschaft, DÖV 11. Jhg. (1958) S. $331 \mathrm{f}$.

8) S. Heyland, Das Berufsbeamtentum im neuen, demokratischen deutschen Staat, S. $94 \mathrm{ff}, 106 \mathrm{f}$ und passim.

9) Zu Problem und Rechtslage s. v. Münch, a.a.O. 
Volksschichten in das Beamtentum und verhindert sowohl seine ständische Abkapselung als auch eine klassenmäßige Einseitigkeit. ${ }^{10)}$ Allerdings verbleibt ein Spielraum. Die rechtliche Durchsetzbarkeit dieser Norm ist infolge der Undurchsichtigkeit der personalpolitischen Gegebenheiten gering. Aber noch etwas wirkt - in Parallele wieder zur Richterschaft - der Einseitigkeit in der Zusammensetzung des Beamtenkorps entgegen: das Erfordernis der demokratischen Legitimation (Art.20 Abs.2 GG). 11) Die reguläre Fluktuation der demokratischen Mehrheitsverhältnisse bewirkt auf die Dauer einen gewissen Ausgleich möglicher Einseitigkeiten der Personalpolitik.

\section{b) $\mathrm{Zu}$ seiner Funktion}

Auch das Berufsbeamtentum stellt also einen Faktor des Ausgleiches gegenüber den partikularistischen Einseitigkeiten der modernen Demokratie dar. Über die substanzielle Bedeutung dieser Position braucht nach dem über das Richtertum Ausgeführte nicht erneut gehandelt zu werden. In der Wirkungsweise bestehen jedoch erhebliche Unterschiede zwischen Beamtentum und Gerichtsbarkeit. Auf der einen Seite ist das Beamtentum in der gestaltenden Vorhand. 1) Sein Raum ist die Exekutive und Exekutive ist positive Aktivität. Noch deutlicher wird die gestaltende Position des Beamtentums dort, wo sie über den eigentlichen Bereich der Exekutive hinüberreicht in den Raum der Gesetzgebung. (Es ist bekannt, wie wenig der parlamentarische Gesetzgeber ohne die fachlich-technische Hilfe der Exekutive auskommen kann und welch weittragende Einwirkungsmöglichkeiten der Ministerialbürokratie auf die Gesetzgebung darin liegen.) Andererseits ist das Beamtentum nicht etwa eine eigene "Gewalt" wie die Gerichtsbarkeit. ${ }^{2)}$ Es ist der qualitativ beherrschende Teil des "Menschen-

10) Wenn Werner Weber (Die Verfassung der Bundesrepublik in (er Bewährung, S.44 f) die "demokratische Integrität" des Beamtentums, d.h. den in ihm verkörperten Aufstieg breiter Volksteile in einwandfreier Auslese zur Teilhabe am Staat, hervorhebt, so ist das richtig, aber doch nicht selbstverständlich. Nicht das Berufsbeamtentum an sich ist demokratisch sondern nur eben ein demokratisch gestaltetes.

11) Für die unmittelbaren Staatsbeamtell ist die Ernennung und Beförderung durch die parlamentarisch-demokratisch verantwortliche Exekutivspitze oder unter deren Verantwortung obligatorisch (Art. 28 Abs. 1, 58, 60 Abs. 1 und 3 GG; BVerfGE $9,268(281 \mathrm{ff}))$.

1) Vgl. Forsthoff, Verfassungsprobleme des Sozialstaats, S. 21. 2) Für seine Qualifikation als "Gewalt": Thieme, Der Beamte 
materials" der Exekutive. Geleitet wird diese aber von der unmittelbar demokratisch und parlamentarisch determinierten ministeriellen Spitze. Es ist nicht Sache des Berufsbeamtentums, sich dieser als politische Willenseinheit entgegenzustellen. ${ }^{3)}$ Es hat das demokratische Mandat der jeweils herrschenden parlamentarisch-demokratischen Kräftekonstellation zu respektieren. ${ }^{4)}$ Nur in dem untergeordneten Zusammenspiel damit, nur in dem Raum, der ihm innerhalb der Bindung an Gesetz und dienstliche Weisung verbleibt, kann es seine eigenen Werte zur Darstellung bringen.

Die ausgleichende, den Staat vervollkommnende Wirkung eines intakten, sachlich denkenden Berufsbeamtentums ist dennoch außerordentlich groß. 5) Das gilt auch und ganz besonders im Terrain der sozialen Intervention. ${ }^{6}$ ) Was hier die Verwaltung zu leisten hat, wird noch zu erörtern sein. 7) Aber daß es sehr viel, ja dem Bürger gegenüber das allermeiste ist, ist notorisch. Zwar ist die Entscheidungsfreiheit durch das Gesetz stark beengt. Aber immer wieder bleiben der Verwaltung eigene Wirkungsmöglichkeiten.

Schließlich ist schon allein der technische Ablauf des reinen Gesetzesvollzuges eine Existenzfrage der sozialen Intervention; und

im sozialen Rechtsstaat, Zeitschrift für Beamtenrecht, 8. Jhg. (1960) S. 169 ff (174 ff). - Die Behauptung des Textes sagt übrigens nichts gegen den Hinweis Werner Webers (Die Verfassung der Bundesrepublik in der Bewährung, S. 43 f), "wie sehr gerade die Massendemokratie zur Bewahrung einer realen Gewaltenteilungs ... eines unabhängigen Beamtentums bedarf".

3) Zum "politischen Dualismus zwischen Kabinett und Berufsbeamtentum" s. Heyland, Das Beruf sbeamtentum im neuen demokratischen deutschen Staat, S. 80 ff; s. a. Hans Huber, Demokratie und Bürokratie, S. 135.

4) Vgl. Leibholz, Der Parteienstaat des Bunner Grundgesetzes und das Beamtentum, Der Beamtenbund, Sonderausgabe zum Delegiertentag 1951, \$. 6 ff; ders., Strukturprobleme der modernen Demokratie, S.111 f.

5) S. insbes. Kern, Die Verfassungsfunktion des Berufsbeamtentums, DÖV 4.Jhg. (1951) S.432 f; Forsthoff, Verfassungsrechtliche Prolegomena zu Art. 33 Abs. 5 GG, DÖV 4.Jhg. (1951) S. $460 \mathrm{ff}$.

6) Vgl. Forsthoff, Verfassungsprobleme des Sozialstaats, S. 19 ff; s.a. Weber, Staatsverwaltung und Selbstverwaltung in der Gegenwart, S.94.

7) S. unten Abschnitt 4 II 2 b aa (S. 418 ) und 4 (S.603 ff). 
er wird durch ein zuverlässiges, geschultes, objektives Beamtentum nach wie vor am perfektesten gewährleistet. 8) Aber noch mehr wirkt sich die eigenständige Stellung des Beamtentums darin aus, daß dieses die soziale Intervention ohne Ansehen der politischen Position des Betroffenen vollzieht - es mag dabei um Ermessensspielräume oder auch nur um die Modalitäten des gebundenen Vollzugs gehen. Das gibt sowohl dem Anhänger der politischen Minderheit als auch dem politischen Außenseiter die Beruhigung, nicht schlechter gestellt zu werden. Der Hilfsbedürftige, der sich an eine Behörde wendet, muß nicht befürchten, sein Begehren werde nach seiner politischen Einstellung (oder Einschätzung) beurteilt. Der Belastete, der von einer Maßnahme sozialen Ausgleichs betroffen ist, wird desgleichen nicht der Allgemeinheit der Belastung mißtrauen müssen. Dem Anliegen der sozialen Intervention und ihrem ungestörten Vollzug kann kaum ein größerer Dienst geschehen als dieser.

5. Die Demokratie der Parteien und Verbände

a) Zum "Parteienstaat"

\section{aa) Allgemeines}

Die "Volksherrschaft" verwirklicht sich in der modernen Massendemokratie vor allem in zwei Grundformationen: durch die mehr im Vordergrund des im engeren Sinne politischen, verfassungsinstitutionellen Geschehens stehenden Parteien und den mehr im gesellschaftlichen Hintergrund, jedoch nicht minder machtvoll wirkenden Verbänden. 1)

Die oben 2) umrissene Wirkungsweise der modernen egalitären Demokratie ist in erster Linie die spezifische Wirkungsweise der politischen Parteien. ${ }^{3)}$ Sie sind die berufenen Mittler zwischen

8) S. unten S.614 zu Fußn.6. - Zu den Rückwirkungen der sozialstaatlichen Aufgabenstellung auf das Beamtentum s. z. B. Partsch, Verfassungsprinzipien und Verwaltungsinstitutionen, S. 29 f; Thieme, Der Beamte im sozialen Rechtsstaat, S. $169 \mathrm{ff}$.

1) S. allgemein hierzu Loewenstein, Verfassungslehre, S. $369 \mathrm{ff}$.

2) S. oben I 1 b (S. 319 ff); s.a. III 2 (S. 341 ff).

3) Aus der Fülle der Literatur sei neben den Bemerkungen zu Art. $21 \mathrm{GG}$ in den Erläute rungswerken zum Grundge setz genannt: Die Verhandlungen des 38. Deutschen Juristentags 1950 über das Thema "Verfassungsrechtliche Stellung und innere Ordnung der Parteien; Ausführung und Anwendung der Art. 21 und 38 Abs. 1 Satz 2 des Grundgesetzes" mit dem Re- 
dem Volk und der Staatswillensbildung (Art.21 Abs. 1 Satz 1 GG). ${ }^{4)}$ Sie aktivieren die im Volk virulenten Interessen. Durch sie reflektieren sich die Interessen schließlich in Mehrheiten und Minderheiten. Über sie vollzieht sich die Progression der Durchschlagskraft stimmreicher Interessen und die Degression des Gewichts stimmarmer Interessen. Partikularität und Gruppenegoismus sind in ihnen ebenso angelegt wie die im Kampf um die Mehrheit unerläßliche Erstreckung auf möglichst viele Interessen. Das braucht hier nicht alles wiederholt $z u$ werden.

Hier ist nur noch die Frage aufzuwerfen, inwieweit sich die Normierung des Bestandes und des Verhaltens der Parteien, wie sie in Art.21 GG enthalten bzw. vorgesehen ist, auf die soziale Intervention auswirken kann. 5)

\section{bb) Die Parteienfinanzierung}

Das zentrale soziale Problem ist die Finanzierung der Parteien,

ferat von Leibholz (S. C $2 \mathrm{ff}$ ) und dem Korreferat von Reif (S. C $30 \mathrm{ff}$ ); die Verhandlungen der Vereinigung der Deutschen Staatsrechtslehrer in Wien 1958 über das Thema "Die verfassungsrechtliche Stellung der politischen Parteien im modernen Staat" (VVDStL. H. 17 (1959)) mit den Referaten von Hesse (S.10 ff) und Kafka (S. 53 ff); ferner Leibholz, Der Parteienstaat des Bonner Grundgesetzes; ders., Strukturprobleme der modernen Demokratie, insbes. S. $71 \mathrm{ff}, 78 \mathrm{ff}$; v. d. Heydte, Die Freiheit der Parteien, in Neumann-NipperdeyScheuner, Die Grundrechte, Bd. II, 1954, S. $457 \mathrm{ff}$; v.d. HeydteSacherl, Soziologie der deutschen Parteien; alle weitere Literaturs. bei clen Zitierten.

4) Art.21 GG gilt unmittelbar auch für die Länder (BVerfGE 1, $208(227))$.

5) Außer auf das nachfolgend Angeführte ist noch hinzuweisen auf Art. 21 Abs. 1 Satz 2 GG. Die Vorschrift garantiert die Freiheit der Parteigründung und sorgt somit für die Permanenz der demokratischen Fluktuation der Gruppenbildung. Abs. 1 Satz 3 des Art. 21 GG erfordert ferner die innere demokratische Ordnung. Die Vorschrift beseitigt heterogene Störungsherde der Demokratie und schwächt vor allem die Bevormundung des Wählers durch die Parteileitungen im Rahmen der Wahlen (insbes. der Wahlen mit festen Listen, s.o. S. 342 ) ab (s.hierzu z.B. Peters, die Kandidatenaufstellung für freie demokratische Wahlen, in "Vom Bonner Grundgesetz zur gesamtdeutschen Verfassung", Festschrift für Hans Nawiasky, 1956, S.341 (f). 
die in Art. 21 Abs. 1 Satz 4 GG angesprochen und von einem künftigen Parteiengesetz des Bundes zu ordnen ist (Abs. 3 ebd.). 1) Die Finanzierung der Parteien ist heute das Einfallstor plutokratischer Einflüsse auf das öffentliche Leben. Nicht Bestechung verschafft dem Kapital politische Macht, auch nicht die (Finanzierung der) Wahl des Kapitalinhabers. Die politischen Parteien werden durch die Gewährung geldlicher Hilfe den Interessen der Geldgeber verpflichtet; und den verpflichteten Parteien wird durch die geldliche Hilfe vermittels ihrer Auswirkungen auf den Wahlkampf ein Machtgewinn verschafft, der somit wieder den Geldgebern zugute kommt. 2) Daß von hierher der Hilfe für die ärmeren Schichten Gefahren drohen kömnen, ist offensichtlich. Die aufklärende Wirkung einer öffentlichen Rechnungslegung, wie sie in Art. 21 Abs. 1 Satz 4 GG vorgesehen ist, könnte dem Übel steuern. 3) Die Spende schlechthin zu verbieten, erscheint dagegen nicht möglich. Wichtig ist aber, daß nicht die finanzielle Förderung der dem Kapital näher stehenden Parteien auch noch begünstigt wird. Diese letzte Bemerkung erschiene überflüssig, wenn nicht gewisse, inzwischen vom Bundesverfassungsgericht aufgehobene Steuervergünstigungen für Spenden an politische Parteien tatsächlich diesen Effekt gehabt hätten. ${ }^{4)} \mathrm{Zu}$ weit getrieben können solche Systemwidrigkeiten zu einer Verfälschung der egalitären Demokratie führen, die sich möglicherweise zum Nachteil der sozialen Belange auswirkt.

cc) Die Verpflichtung der Parteien auf die freiheitliche demokratische Grundordnung

Art. 21 Abs. 2 Satz 1 GG verpflichtet die Parteien zwar auf die "freiheitliche demokratische Grundordnung", nicht aber auf die

1) Zur Finanzierung der Parteien s. insbes. "Rechtliche Ordnung des Parteiwesens", Bericht der vom Bundesminister des Inneren eingesetzten Parteienrechtskommission, 2 . Auf1. 1958, S. 74 ff; Grundmann, Die Finanzierung der Politischen Parteien, Zeitschr.f.d. gesamte Staatswissenschaft, Bd. 115 (1959), S. 113 ff; Maunz in Maunz-Dürig, Art. 21 Randn. 82 ff; weitere Nachweise s. dort.

2) Vgl. v.d.Heydte-Sacherl, a.a.O. S. $166 \mathrm{ff}$.

3) Vgl. "Rechtliche Ordnung des Parteienwesens", S.180 f. Kritisch zu dieser Möglichkeit: v. l. Heydte in v.d. HeydteSacherl, a.a.O. S. 172 f. - S. zum Problem auch Maunz in Maunz-Dürig, Art. 21 Randn. 78 ff mit eingeh. Nachw.

4) Vgl. BVerfGE 8, 51; Grundmann, a.a.O. S. $127 \mathrm{ff}$. 
sozialstaatliche Grundordnung. 1) Allerdings wird kaum eine Partei mit Erfolg direkt gegen die sozialstaatliche Grundordnung angehen können, ohne auch die freiheitliche demokratische Grundordnung anzugreifen. Art. 79 Abs. 3 GG schützt das Sozialstaatsprinzip in Art.20 GG. Es kann nur auf revolutionärem Wege beseitigt werden - d. h. auf einem Weg, der in aller Regel eine Zerstörung der freiheitlichen (lemokratischen Grundordnung einschließt. ${ }^{2)}$ Aber unmittelbares Schutzgut des Art.21 Abs.2 GG ist die Sozialstaatlichkeit nicht.

Aber das Risiko der Demokratie besteht nicht so sehr darin, daß eine politische Bewegung die Freiheit gegen den sozialen Standard ausspielt, als darin, daß die Massen ihre Freiheit gegen ein besseres Leben eintauschen (wollen). Andererseits hat, solange die freiheitliche demokratische Ordnung besteht, die soziale Vorwärtsentwicklung jene natürliche Chance, die der Interdependenz zwischen der modernen egalitären Massendemokratie und dem Sozialen entspricht. ${ }^{3)}$ Ist aber die freiheitliche demokratische Grundordnung zerstört, so finden sich nicht nur keine wirksamen Garantien mehr für die sozialen Verfassungspostulate. Selbst wenn sie erfüllt würden, keimte von hierher nicht so sicher eine freiheitlich-demokratische Ordnung. ${ }^{4)}$

b) Zum "Verbändestaat"

aa) Wesen und allgemeine Wirkungsweise der Verbände

Den Parteien kommt kein Monopol der politischen Formation des Volkes zu. 1) Sie teilen sich in die Funktion der politischen Aktivierung, Sichtbarmachung und Durchsetzung der Gruppeninteressen mit den Verbänden. 2) Diese konkurrieren mit ihnen

1) Zum Begriff der "freiheitlichen demokratischen Grundordnung" s. v. Mangoldt-Klein, Art.21 Anm. VII 2 i.V.m. Art. 18 Anm. III 4 b; Maunz in Maunz-Dürig, Art. 21 Randn. 114; je m.w. Nachw.

2) Für den analogen Zusammenhang hinsichtlich der in den Begriff der freiheitlich-demokratischen Grundordnung ebenfalls nicht eingeschlossenen bundesstaatlichen Ordnung s. Maunz, a.a.O. Randn. 115 u.s. Nachw.

3) S. o. I 1 (S. 315 ff). Zum besonderen Zusammenhang zwischen der freiheitlichen demokratischen Grundordnung i.S. des Art.21 GG und der Sozialstaatlichkeit s. BVerfGE 5, 85 (198, 336, 379 und passim).

4) S. a. oben I $2(\mathrm{~S} .329 \mathrm{ff})$ und $3(\mathrm{~S} .335 \mathrm{ff})$.

1) Vgl. v.d.Heydte in v.d.Heydte-Sacherl, a.a.O. S.57 f;

Maunz in Maunz-Dürig, Art.21 Randn. 36. 
allerdings nicht um die Gesamtverantwortung im Staate. Sie beschränken sich darauf, partikulare soziale oder wirtschaftliche Interessen ${ }^{3)}$ wahrzunehmen. ${ }^{4)}$ Soweit Wahlen zweckhaft auf die

2) Aus dem Schrifttum, das sie ais Hauptfrage behandelt, seien genannt: "Der Staat der Gegenwart und die wirtschaftlichen und außerwirtschaftlichen Interessengruppen", Rundtafelgesprāch auf dem XI. Deutschen Soziologentag 1952, Kölner Zeitschrift für Soziologie, n.F. 5. Jhg. (1952/53) S. 204 ff, mit einem Referat von Sternberger (S.204 ff, 229) und Diskussionsbeiträgen u.a. von Bergsträsser (S.214 ff), Abendroth (S.217 ff), Kossitsch (S.222 f); Eschenburg, Herrschaft der Verbände? (2.Auf1. von "Staatsautorität und Gruppenegoismus") 1955; Breitling, Die Verbände in der Bundesrepublik, 1955; Hans Huber, Die Umwälzungen im Staatsgefüge durch die Verbände, ORDO Bd. VII (1955) S. 189 ff; ders., Staat und Verbände, 1957; Krüger, Die Stellung der Interessenverbände in der Verfassungswirklichkeit, NJW 9. Jhg. (1956) S. 1217 ff; Kaiser, Die Repräsentation organisierter Interessen, 1956; ders., Die Dialektik der Repräsentation, in Festschrift für Carl Schmitt, 1959, S. 71 ff; Scheuner, Stellung und Einfluß der Verbände im heutigen Staat, Der Güterverkehr, 5.Jhg. (1956) S. 289 ff; "Legitime Interessenvertretung in der modernen Gesellschaft", Tagung der evangelischen Akademie Loccum, 1956, mit Referaten u.a. von Scheuner (S. 3 ff: Moderne Strukturfragen des demokratischen Staates), H.Krüger (S.12 ff: Die Verbände in der westdeutschen Politik) und Friedrich (S. 19 ff: Recht und Grenzen der Interessenvertretung); Gruner, Die Wirtschaftsverbände in der Demokratie, 1956; "Der Staat und die Verbände", hrsg. von Beutler-Stein-Wagner, 1957, mit Referaten von Scheuner (S. $10 \mathrm{ff}, 47 \mathrm{f}$ ) und Werner Weber (S. $19 \mathrm{ff}, 48 \mathrm{ff}$ ) und Diskussionsbeiträgen u. a. von Eschenburg ( $\mathrm{S} .30 \mathrm{ff}$ ), Herbert Krüger ( $\mathrm{S}$. $35 \mathrm{ff}, 51 \mathrm{f}$ ), Hans Huber (S.43 ff), Coing (S. $46 \mathrm{f}$ ), Kaiser (S. $50 \mathrm{f})$; Borriś, Staat und Verbände, in: Hessische Hochschulwochen für staatswissenschaftliche Fortbildung, Bd. 20 (1958), S. 134 ff; Briefs, Die Verbände - eine Gefahr für die Demokratie, Zeitwende - Die neue Furche, XXX. Jhg. (1959)S. 505 ff.

3) Ob auch die Wahrnehmung immaterieller, insbes. auch religiöser Interessen hierher gehört, ist eine in der einschlägigen Literatur umstrittene Frage. Das braucht hier nicht weiter verfolgt $z u$ werden.

4) S. z.B. "Rechtliche Ordnung des Parteiwesens", S. 80 f: "Das Wesen der Verbände liegt im Unterschied zu dem der Parteien darin, daß sie nur partikulare, soziale oder wirt- 
Teilnahme an der Gesamtverantwortung im Staate ausgerichtet sind, nehmen sie selbst daran nicht teil. 5) Sie unterliegen somit auch nicht dem Zwang zur.Erhaltung und Expansion der Wählerschaft und dem damit verbundenen $Z$ wang zur Ausbreitung der Propaganda und der politischen Tutel auf möglichst viele Interessen. Sie können es sich sogar leisten, auf den Gemeinwohl-Anstrich zu verzichten, der für politische Parteien als nahezu unentbehrlich gilt. ${ }^{6}$ ) Ihr Wesen liegt in der unverfälschten Wahrnehmung des speziellen Interesses. Die Zahl der Interessenten ist der Sache nach vorgegeben; und eine Werbung unter ihnen steht grundsätzlich nur im Sinne der Erweckung des Interesses, seines Bewußt-werden-Lassens, seiner Aktivierung in Frage. Das spezielle Interesse tritt also vermittels des Verbandes klar und gesondert zutage, nicht in der Legierung, die es sich in den politischen Parteien, soweit sie nicht reine Interessenparteien sind, regelmäßig gefallen lassen muß.

Da die Verbände nicht nach der institutionalisierten Macht und Gesamtverantwortung im Staate streben, verfolgen sie die ihnen eigenen Interessen im allgemeinen durch Einflußnahme auf die Träger politischer Entscheidungsmacht: auf die Parteien, 7) die Abgeordneten, ${ }^{8)}$ das Parlament als Ganzes, 9) die Regie-

schaftliche - gelegentlich auch immaterielle - Inte ressen wahrnehmen, ohne nach der Übernahme der Gesamtverantwortung im Staate zu streben".

5) Maunz in Maunz-Dürig, Art.21 Randn.24. - Zu dem Zusammenhang zwischen dem Streben der politischen Parteien nach der Gesamtverantwortung und ihrer Teilnahme an den Wahlen s. z. B. v.d. Heydte in v.d. Heydte-Sacherl, a.a.O. S. 5 ff.

6) Vgl. v.d.Heydte-Sacherl, a.a.O.S. 5 ff, 8 ff; weit. Nachw. s. dort. - S.a. oben S. 326.

7) S. hierzu insbes. "Der Staat der Gegenwart und die wirtschaftlichen und außerwirtschaftlichen Interessengruppen", insbes. das Referat Sternberger und der Diskussionsbeitrag Kossitsch; v.d.Heydte-Sacherl, a.a.O. S. 57 ff, 166 ff, 173 ff, $175 \mathrm{ff}$; Breitling, a.a.O. S.98 ff und passim; Kaiser, Die Repräsentation organisierter Interessen, S. $247 \mathrm{ff}$; Gruner, a. A. O. S. 39; s.a. Maunz, a.a.O. (Randn.24).

8) S. z.B. Sternberger in "Der Staat der Gegenwart und die wirtschaftlichen und außerwirtschaftlichen Interessengruppen", S.205; Breitling, a.a.O. S.93 ff und passim; s.a. Maunz, a.a.O. - Nicht zu vergessen ist dabei, daß es zu den wesentlichen Instrumenten der verbandlichen Einflußnahme auf die Parteien und ihre Fraktionen gehört, ihre Funktionäre über die Parteilisten in die Parlamente zu entsenden (s.d. oben 
rung ${ }^{10)}$ und nicht zuletzt die Bürokratie. 11) 12) Nur dann,

Fußn. 7 Zitierten). Gehlen (zur Problematik des Sozialstaats, S. 53) sieht gerade darin die sachgerechte Institutionalisierung des Verbandseinflusses auf die politischen Gesamtentscheidungen.

9) Vg1. Sternberger, a.a.O. S.205 f; Kaiser, a.a.O. S.255 ff; s.a. Breitling, a.a.O. S. 83, $93 \mathrm{ff}$. - Gegenüber dem Parlament als Ganzem geschieht die Einflußnahme vorwiegend durch Druckmittel, heute insbes. den politischen Streik (vgl. Sternberger, a.a.O. S.206, Kaiser, a.a.O. S.258 ff).

10) Vgl. Kaiser, a.a.O. S.267 ff.

11) Kaiser, a.a.O. S.267 ff; Landshut, Wandlungen der parlamentarischen Demokratie, S.161; s.a. Breitling, a.a.O. S. 91. Die notorisch intensive "Zusammenarbeit" von Ministerialbürokratie und Verbänden ist ein Phänomen besonderer Art. Wie kommt es, daß gerade die Beamtenschaft und vor allem eben die höhere Ministerialbürokratie in solchem Maße den Verbänden "aufgeschlossen" gegenübersteht, obwohl Wahlhilfe usw. hier keine Rulle spielt. Die Gründe sind vielfältig. Einerseits wissen die Verbände um die beherrschende Rolle der Ministerialbürokratie im Gesetzgebungsverfahren und beim Erlaß von Rechtsverordnungen. Sie wissen, daß das Parlament aus technischen Gründen vielfach nicht imstande ist, gegen die Entwürfe der Ministerialbürokratie, die ihm das Kabinett vorlegt, anzugehen. Sie setzen daher ihren Einfluß aufs intensivste bereits an der Stelle an, an der die ersten und oft wichtigsten Entscheidungen fallen, nämlich bei der Ministerialbürokratie. Diese ist somit in besonderem Maße dem konzentrierten Beschuß der Interessenverbände ausgesetzt. Die Ministerialbürokratie sieht andererseits in der Zusammenarbeit mit den Verbänden einen nicht geringen Vorteil. Zunächst einmal macht sie sich - oft recht unkontrolliert - den Sachverstand der Verbände zunutze. Sie wiegt sich in dem Gefühl, selbst zusammen mit den Verbänden die mehr oder minder unfehlbare Summe des einschlägigen Sachverstandes zu verkörpern, dem gegenüber der "Dilettantismus" des Parlaments ohne Gewicht ist. Die traclitionelle Abneigung der Bürokratie gegen Parteipolitik und Parlament steht im Hintergrund. Die Ministerialbürokratie vergewissert sich der Zustimmung der. Verbände darüber hinaus aber auch deshalb gern, weil sie deren E.influß auf das Parlament ihren Entwürfen zugute kommen lassen will. Schließlich liegt dem Sachverhalt, insbesondere soweit Rechtsverordnungen in Frage stehen, aber auch noch das Ge- 
wenn der Wirkungskreis eines Amtes oder einer Behörde sich unmittelbar auf den Interessenbereich gewisser Verbände konzentriert, erstreben und erwirken diese eine direktere Teilhabe an der Entscheidungsmacht. Diese äußert sich rechtlich meist in einem Mitspracherecht der Verbände bei der Bestellung der Amtsträger. Beispielhaft dafür sind der Einfluß der "zuständigen" Verbände auf die Arbeits- und Sozialgerichtsbarkeit, 13) ihr Vorschlagsrecht für die Bestellung von Mitgliedern einschlägiger Beiräte, Ausschüsse und ähnlicher Organe ${ }^{14)}$ sowie ihre Stellung

füh1 dafür zugrunde, daß staatliche Maßnahmen einer möglichst umfassenden demokratischen Legitimation bedürfen. Diese holt sich die Ministerialbürokratie nicht ungern bei den Verbänden - jedenfalls viel lieber als bei dem Parlament oder bei den Parteien.

12) S. zu Vorstehendem auch Nawiasky, Staatslehre, Teil 2.Bd. I S. 131 f; "Rechtliche Ordnung des Parteiwesens" S. 81. Ein zusätzliches Problem bildet dort, wo der unmittelbaren Demokratie größere Bedeutung zukommt, der Einfluß der Verbände auf die Entscheidung des Stimmbürgers. S.hierzu Hans Huber, Die Umwälzungen im Staatsgefüge durch die Verbände, S. 190; ders., Staat und Verbände, S.25. - Verwandt damit ist das allgemeinere, auch und gerade im parlamentarischen Staat aktuelle Problem der Interessenwahrung gegenüber der öffentlichen Meinung (vgl. Kaiser, a.a.O. S. 211 ff und passim). - Maunz (Maunz-Dürig, Art.21 Randn.24 S. 13 Fußn. 1) spricht von einer legitimen "Mitwirkung bei der außerparlamentarischen Meinungs- und Willensbildung".

13) S. o. S.360. - S. hierzu auch Kaiser, Die Repräsentation organisierter Interessen, S. $294 \mathrm{ff}$.

14) Meist wird den Verbänden ein Vorschlags recht eingeräumt, über das die berufende staatliche oder kommunale Stelle mehr oder weniger frei entscheidet: so zum Beirat bei dem Bundesvert riebenenminister ( $\$ \$ 23,24$ BVFG), zum Sozialbeirat der Bundesregierung ( $\$ 52$ AnVG, $₫ 1275$ RVO), zum ständigen Beirat beim Bundesausgleichsamt ( $\$ 314$ LAG), zu den Heimarbeitsausschüssen und den Entgeltausschüssen nach dem Heimarbeitsgesetz $(\$ \$ 4,5,22$ Abs. 3 des Heimarbeitsgesetzes), zu den 'larifausschüssen ( $\$ 5$ Abs. 1 TVG, $\$ 1$ DVO TVG), zum Hauptausschuß und zu den Fachausschüssen nach $₫ 2$ des Gesetzes über die Festsetzung von Mindestarbeitsbedingungen, zu den Schiedsausschüssen nach Art. VI und VII KRG Nr. 35, zu len Beschwerdeausschüssen bei der Hauptfürsorgestelle und beim Landesarbeitsamt ( $\$ \$ 27,28$ des Schwerbeschädigtengesetzes), zu den Einspruchs- und 
als Wahlverbände im Rahmen der nicht-gebietskörperschaftlichen, insbes. der sozialversicherungsrechtlichen Selbstverwaltung. 15) An anderer Stelle - insbes. z.B. bei der Auswahl der "zuständigen" Ressortminister 16) - wirdd der Anspruch auf

Beschwerdeausschüssen in Fürsorgesachen $(\$ 3$ a Abs. 3 der Fürsorgepflichtverordnung; künftig Anhörung von Verbandsvertretern, s. $\$ 107$ des Entwurfs eines Bundessozialhilfegesetzes, Deutscher Bundestag, 3. Wahlperiode, Drucks. 1799), zum Jugendamt und zum Landesjugendamt ( $\$ \$ 9$ a, 14 JWG) (s. zum Vorstehenden zum Teil auch Maus, Beteiligung von Ausschüssen an Verwaltung und Normsetzung im A rbeitsrecht, S. $171 \mathrm{ff})$. Genannt sei hier auch die Bestellung der Organe der Bundesanstalt für Arbeitsvermittlung und Arbeitslosenversicherung ( $\$ \$ 12,13$ AVAVG). - Gelegentlich ist auch nur die Anhörung "zuständiger" Verbände vorgesehen: so hinsichtlich der Wahl der Beisitzer der Ausgleichsausschüsse und der Beschwerdeausschüsse nach $\mathbb{\$} \$$ 309, 310 LAG, $\$ \$ 12$ Abs. 4, 19 Abs. 3 KgfEG; ähnlich eine subsidiäre Regelung hinsichtlich der Heimarbeitsausschüsse und der Entgeltsausschüsse nach dem Heimarbeitsgesetz (s.o.).

15) $₫ 4$ des Selbstverwaltungsgesetzes gibt den "zuständigen" Verbänden den Rang von geborenen Wählervereinigungen, die den sonstigen Wählergemeinschaften gegenüber bevorrechtigt sind. - Zur Bestellung der Organe der Bundesanstalt für Arbeitsvermittlung und Arbeitslosenversicherung s.o. S. 377 zu Fußn. 14. Zur Verbändedemokratie der Sozialversicherungsträger s. IBischoff, Staatsaufsicht und Selbstverwaltung in der Sozialversicherung, in "Sozialpolitik, A rbeits- und Sozialrecht", F'estschrift für Friedrich Sitzler, 1956, S. 113 ff (126 ff),zu den praktischen Erfahrungen, die die Vormacht der Verbände noch stärker hervortreten lassen als das Gesetz selbst,s.a. Aye, Die Bedeutung der Selbstverwaltung für die Weiterentwicklung der gesetzlichen Krankenversicherung, in: "Beiträge zur Sozialversicherung", Festschrift für Johannes Krohn, 1954, S.21 ff (27 f). - Die Siellung der Verbände in ler Selbstverwaltung der Sozialversicherungsträger zeigt auch den wahren verbände-demokratischen Hintergrund der Vertreter der. Versicherten und der Arbeitgeber im Sozialbeirat gem. \$\$ $1274 \mathrm{f} \mathrm{RVO,} \$ \$ 51 \mathrm{f}$ AnVG, der durch das unmittelbare Vorschlagsrecht des Verbandes Deutscher Rentenversicherungsträger, der Bundesversicherungsanstalt für. Angestellte und der. Arbeitsgemeinschaft der Knappschaften verdeckt wird.

16) Vgl. Kaiser, a.a.O. S. $274 \mathrm{f}$. 
Mitbestimmung seitens der Verbände geltend gemacht, noch jedoch ohne Anerkennung zu finden.

Das verbandlich protegierte Interesse ist schon um dieser Protektion willen regelmäßig von größter Durchschlagskraft. Das nicht "organisierte" Interesse tritt an Bedeutung zurück oder gerät in Vergessenheit. Darin liegt die erste Stufe der durch die Verbände bewirkten "Vorordnung der Interessen" und "Vorformung des politischen Willens", 17) daß sie nämlich durch ihre bloße Existenz eine politische Wertigkeit der von ihnen repräsentierten Interessen konstituieren und daß umgekehrt das Fehlen verbandlicher Repräsentation sich in einem Mangel an politischer Wertigkeit des nicht "organisierten" Interesses äußert. 18) Die nächste Stufe besteht darin, daß die innerhalb einer Interessengruppe bestehenden Gegensätze oder Unklarheiten ausgeräumt werden, so daß nach außen klare politische Ziele in eindeutiger Rangfolge verkündet und verfolgt werden können, die demgemäß von unmittelbaren Trägern der Staatswillensbildung als die "offiziellen" Interessen der Trägergruppe aufgefaßt werden dürfen.19) So sind die Interessenverbände die Zungen des Volkes, mit denen es seine verschiedenen Interessen artikuliert, formuliert und vertritt.20)

17) Vgl. Scheuner, Stellung und Einfluß der Verbände im heutigen Staat, insbes. S.291, 293; ders., Moderne Strukturfragen des demokratischen Staates, S. 7; ders., in: "Der Staat und die Verbände", S. 12 ff; Krüger, Die Stellung der Interessenverbände in der Verfassungswirklichkeit, S. $1218 \mathrm{f}$; ders., Die Verbände in der westdeutschen Politik, S. $14 \mathrm{f}$.

18) S. Hans Huber, Staat und Verbände, S. 20 ff.

19) Vgl. Krüger, Die Stellung der Interessenverbände, S. 1218 f; ders., Die Verbände in der westdeutschen Politik, S. $14 \mathrm{f}$; Scheuner, Stellung und Einfluß der Interessenverbände im heutigen Staat, S.291; ders., in "Der Staat und die Verbände" S.13. - Nicht nur in der Relation organisierte - nichtorganisierte sondern auch verbandsintern werden also Minderheitsinteressen (oder auch Interessen eines sonstwie schwächeren Teiles) unterdrückt. - S. dazu auch noch unten S. $388 \mathrm{ff}$.

20) Vgl. Peters, Art. "Demokratie" im Staatslexikon, 6. Aufl. Bd.2 (1958) Sp. $560 \mathrm{ff}$ (582 f): "Durch die Interessenverbände werden die oft stark divergierenden Wünsche, Forderungen usw. der in der Demokratie theoretisch die Mitträgerschaft der Souveränität bildenden Einzelpersonen aufgenommen, in brauchbare Form gebracht und damit zugleich von den eigentlich politischen, d.h. das Gemeinwohl vorstellenden Kräften und Tendenzen isoliert, gesetzestechnisch vorbereitet, ver- 
bb) Die Vormachtstellung der organisierten Interessen

\section{aaa) Allgemeines}

Die Chancen der demokratischen Durchsetzbarkeit der verschiedenen einzelnen von den insgesamt vorhandenen Interessen sind auf diese Weise danach abgestuft, ob sie "organisiert" sind oder nicht. Im Hintergrund dessen steht die strukturelle Unterscheidung zwischen den "organisierbaren" Interessen und den nicht "organisierbaren", welch letztere denn auch den Bodensatz des demokratischen Interessenmarktes bilden.

Unter den "organisierten" Interessen wäre an sich wiederum zu unterscheiden zwischen den kräftiger und straffer und den schwächer "organisierten" Interessen. Das dieser Unterscheidung anhaftende Zufällige weicht aber nur dort dem Prinzipiellen, wo ihr clas Verhältnis von wesensmäßiger Tendenz zur Organisation und von wesensmäßigem Widerstand gegen Artikulierung, Vereinheitlichung, Über- und Unterordnung usw. zugrunde liegt.

Wichtiger ist eine andere Unterscheidung, nämlich die nach der Bedeutung des repräsentierten Interesses und seiner Organisation für den demokratischen Kampf um Wähler, Macht und Amt. Die Triebfeder der Parteien, Abgeordneten und Regierungen, sich der "organisierten" Interessen und ihrer Organisationen anzunehmen, liegt ganz vor allem in der Nützlichkeit der Zusammenarbeit von Partei etc. einerseits und Verband andererseits für diesen Kampf. Die Rücksichtnahme auf ein Interesse wird also umso größer sein, je mehr Stimmen der repräsentierende Verband "verkaufen" kann oder je mehr seine sachlichen Mittel (Geld, Sachleistungen, Dienstleistungen usw.) als Wahlhilfe zu Buch schlagen. 1) U. U. kann allerdings das Gewicht einer Gruppe auch mehr in den Nachteilen ihrer akuten Gegnerschaft als in den Vorteilen ihrer - vielleicht gar nicht möglichen - Kooperation liegen. 2) Jedenfalls: die Progression des politischen Erfolges eines

waltungsbrauchbar formuliert und damit zu eindeutigen Programmsätzen von Interessengruppen gemacht".

S. hierzu ferner Friedrich, Recht und Grenzen der Interessenvertretung, insbes. S.20; Kaiser, Die Repräsentation organisierter Interessen, S.336 ff; ders., Die Dialektik der Repräsentation; "Rechtliche Ordnung des Parteiwesens", S. 79. $\mathrm{Zu}$ den negativen Aspekten der Monopolisierung und Mediatisierung s. Hans Huber, Staat und Verbände, S. 26.

1) S. die oben S. 375 zu Fußn. 7 Zitierten.

2) S. z.B. den Fall des politischen Streiks. 
Interesses mit der Zunahme der "interessierten" Stimmen wird durch die Relation von Verbandseinfluß und Verbands-Stimmen bestärkt; aber sie wird auch überlagert durch die die Rücksichtnahme auf das repräsentierte Interesse fördernde oder gar erzwingende Effizienz der dem Verband zu Gebote stehenden wahllenkenden Mittel.

\section{bbb) Das organisierte soziale Interesse}

Die soziale und wirtschaftliche Intervention des massendemokratischen Staates provoziert die Organisation der Interessen. 1) Der einzelne ist auf die intensive Wahrnehmung seiner Belange gegenüber dem planenden, umverteilenden, sozialgestaltenden Staat dringendst angewiesen. Damit geraten die wirtschaftlichen und sozialen Interessen in ganz besonderem Maße in den Sog der Eigengesetzlichkeit der massendemokratischen Interessenorganisation.

Die Frage nach der Organisierbarkeit eines sozialen Interesses gewinnt daher besonderes Gewicht. Gerade einzelne soziale Interessen sind aber nicht oder nur schwach organisierbar. Insbes. eignet sich Armut als solche schon nicht zur Organisation. Die Not der Fabrikarbeiter im früh- und hochkapitalistischen Zeitalter und ihre mehr und mehr ausklingende soziale Schlechterstellung im Spätkapitalismus 1 ieß und läßt sich organisiert zur Geltung bringen. Die große Zahl, die maximale Homogenität der individuellen Situation, der deutlich sichtbare gemeinsame Gegner und die Schlüsselposition der organisierten Arbeiterschaft im Produktionsprozeß ergaben ideale Voraussetzungen. Ähnlich positiv war die Organisierbarkeit der Flüchtlinge usw. vor der mit der Eingliederung rapide einsetzenden Dispersion der individuellen Schicksale und der mit dem wirtschaftlichen Aufstieg zunehmenden Relevanz des Fehlens einer gemeinsamen positiven Funktion. Das "organisierbare" Interesse der Kriegsgeschädigten usw. genießt ebenfalls günstige Voraussetzungen: Homogenität der Situation, eindeutiger Adressat (die Nation, der die Opfer gebracht

1) Vg1. Scheuner, Stellung und Einfluß der Interessenverbände im heutigen Staat, S. $290 \mathrm{f}$; ders., "Der Staat und die Verbände", S. 11; Krüger, Die Stellung der Interessenverbände in der Verfassungswirklichkeit, S. 1219; Weber, in "Der Staat und die Verbände",S.21; "Rechtliche Ordnung des Parteiwesens", S.81 f; Weber, Spannungen und Kräfte im westdeutschen Verfassungssystem, S. 145 f; s. zu diesem Aspekt auch Briefs, Die Verbände - eine Gefahr für die Demokratie, insbes. S. $506 \mathrm{ff}$. 
wurden) und im Rahmen der Wiederauf rüstung sogar eine substitutive positive Funktion. Die Liste der "organisierbaren" sozialen Gruppeninteressen könnte noch und noch vermehrt werden. Aber Armut schlechthin ist kein organisierbares Interesse: viel $\mathrm{zl}$ heterogen und differenziert in Erscheinungsform, Grund und Abhil femöglichkeit und bar jeder positiven Gemeinsamkeit. ${ }^{2)}$ Bettler lassen sich noch organisieren, Arme nicht. Ein ähnliches Problem bietet der Konsument. Auch die Verbraucherinteressen sind nur schwer organisierbar. ${ }^{3)}$ Die Folgen sind bekannt. Wenn heute die "soziale Frage" keine "Arbeiterfrage" mehr ist, 4) so ist das nicht zuletzt eine Auswirkung dieser Gesetzmäßigkeiten. Noch klarer aber tritt der Sachverhalt in dem Umstand zutage, daß die Rentenreform erst in Angriff genommen wurde, lange nachdem die Betriebsverfassung neu geregelt und die Mitbestimmung in der Montanindustrie gesetzlich festgelegt war. Und wenn als letzte aller sozialen Kernmaterien nunmehr das Fürsorgerecht, das Recht der "Ärmsten der Armen", der nicht "gruppenmäßig" Armen, einer Reform unterzogen wird, so ist auch das - ohne, daß dieser Gesichtspunkt Ausschließlichkeit beanspruchen dürfte - von indizieller Bedeutung.

Die gleichen Unterschiede wie auf der Seite der Begehrenden des sozialen Ausgleichs finden sich auf der Seite der passiv Betroffenen. Im besonderen fällt es finanziell-kapitalistischen Interessentengruppen relativ am leichtesten, fehlendes Stimmgewicht auf andere Weise auszugleichen - ein Umstand, der für die sozialen Belange unschwer von Einfluß sein kann.

Die Wirkung der Verbände ist also vor allem eine typisierende. Das typische soziale Interesse, das Gruppen gemeinsam ist, hat schon im parteidemokratischen Spiel der Kräfte einen Vorsprung. Durch die Verbandsbildung und -tätigkeit wird aus dem Vorsprung fast ein Monopol der politischen Berücksichtigung. Das atypische, rein individuelle bzw. der sog. kleinen Gruppe eignende Interesse wird im Mechanismus der Verbändedemokratie zerrieben. Das wahre Mosaikbild der sozialen Interessen wird vergröbert. Die $Z$ wischentöne, Nebenlinien usw. entfallen. Die Großflächen und Hauptkonturen breiten sich über alles aus. Steigert

2) Die Vertreter der Fürsorgeempfänger in den Fürsorgeausschüssen sind, recht überlegt, ein Kuriosum.

3) S. z.B. Kaiser, Die Repräsentation organisierter Interessen, S. 164 ff; Forsthoff, Rechtsfragen der leistenden Verwaltung, S. $20 \mathrm{f}$.

4) Zur Bedeutung dieses Faktums für den engeren Zusammenhang s. v.d. Heydte-Sacherl, a.a.O. S. 248 ff. 
diese Tendenz der Verbändedemokratie im wesentlichen nur eine Neigung, die in der Parteiendemokratie schon angelegt ist, so überlagert eine andere Tendenz mehr das Kräftespiel der Parteiendemokratie: Die Abstufungen in der "Organisierbarkeit" der Interessen und die Eigenfunktion der Verbände als politische Kampfeinheiten, die zu einer Disproportionalität von VerbandsInteressen-Gewicht und Interessen-Stimm-Gewicht führt. Hier kann das Mosaikbild der wahren sozialen Interessenpositionen durch das Verbändewesen verzerrt werden.

\section{cc) Die Regulierung der "Verbändedemokratie"}

aаa) Der verfassungs rechtliche Rahmen

Das Grundgesetz ignoriert die Verbände.1) Es institutionalisiert ihren Einfluß nicht - weder in der Weise, daß es ihn allgemein garantiert, wie etwa die Mitwirkung des Volkes garantiert ist (A rt.21 Abs. 1 Satz $1 \mathrm{GG}$ ), noch in der Weise, daß den Verbänden gewisse Einflußkanäle verfassungsmäßig zugesichert würden. Das Grundgesetz schließt den Einfluß der Verbände aber auch nicht aus. Es erlaubt die Verbandsbildung (Art.9 GG). A rt.21 Abs. 1 Satz 1 GG gibt den Parteien kein Monopol der Mit-Wirkung an der politischen Willensbildung des Volkes, das eine zusätzliche Mit-Wirkung der Interessenverbände ausschlösse. 2) So läßt das Grundgesetz die Verbände stillschweigend gewähren, 3 ) ohne ihnen über Art.9 GG hinaus einen verfassungs rechtlich gesicherten Status zu geben. ${ }^{4)}$ Soweit die Aktivität der Verbände einer Reglementierung überhaupt zugänglich ist, kann sie vom Gesetzgeber, im jeweiligen Kompetenzbereich auch von der Exekutive, den Parlamenten im Rahmen ihrer Autonomie usw. geregelt werden. Die unterverfassungsrechtliche Regelung der "Verbändedemokratie" hat jedoch die von der Verfassung gesteckten Grenzen zu respektieren, als die sich hierbei besonders die Vereinigungsfreiheit (Art.9 GG) und die definitive Ordnung der Staatswillensbildung bezüglich der Struktur und Zuständigkeit

1) Fraenkel, Die repräsentative und die plebiszitäre Komponente im demokratischen Verfassungsstaat, S. 57 f: "Der Parteienprüderie unter der Weimarer Verfassung entspricht eine Interessenverbandsprüderie unter dem Bonner Grundgesetz".

2) Vgl.Maunz in Maunz-Dürig, Art.21 Randn.36 mit S.16 Fußn. 7; eingeh.w. Nachw. s. dort.

3) S. z.B. Werner Weber in "Der Staat und die Verbände", S. $19 \mathrm{ff}$.

4) Den Versuch einer Umschreibung s. bei Hamann, Deutsches Wirtschaftsverfassungsrecht, S. $59 \mathrm{ff}$. 
der staatlichen Organe und der Vorrangstellung der Parteien (Art. $21 \mathrm{GG}$ ) bemerkbar machen.

\section{bbb) Die Institutionalisierung des Verbandseinflusses}

Die Möglichkeit, den Verbandseinfluß zu institutionalisieren und dadurch unter eine gewisse Kontrolle zu bringen, ist demnach durchaus gegeben.

In der Sphäre der obersten Verfassungsorgane des Bundes wirkt sich das Schweigen des Grundgesetzes jedoch als negative Sperre aus. So wird man annehmen müssen, daß die Einrichtung einer Verbändekammer (eines Bundeswirtschaftsrates) zur obligatorischen - wenngleich auch nur konsultativen - Mitwirkung am Gesetzgebungsverfahren nicht ohne verfassungsänderndes Gesetz möglich wäre. 1) Auch Institutionen wie Vernehmlassungsverfahren, 2) Hearings, 3) Ausschüsse und Beiräte 4) 5) können

1) S. Neumann-Duesberg, Mitbestimmung, S. 377; a. A. Hamann, Das Grundgesetz, Einf. I A 6 S.13.

2) Dabei wird der Rat der Verbände zu Gesetzes- und Verordnungsentwürfen nicht über eine von den Verbänden beschickte Versammlung sondern unmittelbar durch Anhörung der Verbände eingeholt (s. zu diesem vor allem in der Schweiz ausgebildeten Verfahren z.B. Gruner, Die Wirtschaftsverbände in der Demokratie, S. $107 \mathrm{ff}$ ). - Fine verbindliche Vorschrift dieser Art für das Gesetzgebungsverfahren dürfte im Hinblick auf die abschließende Regelung des Gesetzgebungsverfahrens durch das Grundgesetz nur durch verfassungsänderndes Gesetz getroffen werden können. Dagegen gibt es zahlreiche Ermächtigungen, die den Erlaß von Rechtsverordnungen an die Anhörung von Sachverständigen knüpfen. Es dürfte zulässig sein, der Bundesregierung insofern auch die Anhörung von Verbänden vorzuschreiben. S. hierzu Brenner, Zum Mitwirkungsrecht der Verbände und Vereinigungen bei der Gesetzgebung des Bundes und beim Frlaß von Verordnungen, Betriebsberater, 15. Jhg. (1960) S.373 ff.

3) Öffentliche Hearings werden von den zuständigen Parlamentsausschüssen veranstaltet. Sie verschaffen sich dabei durch Anhörung geeigneter Repräsentanten Kenntnis von der Meinung, die Sachverständige und Interessenverbände über einen Entscheidungsgegenstand haben. Diese Einführung dieser vor allem in den USA üblichen parlamentarischen Veranstaltung in der Bundes republik dürfte der parlamentarischen Autonomie unterliegen.

4) Dabei ist vor allem an Ausschüsse und Beiräte zu denken, die 
nicht unbegrenzt ohne verfassungsänderndes Gesetz vorgeschrieben werden.

der Bundesregierung bzw. einzelnen Bundesministern beigegeben sind (s. schon oben S. 377 zu Fußn. 14). Derartige Beiräte sind unbedenklich, soweit sie die Bundes regierung s e lbst sich - im Rahmen der haushaltsrechtlich bereitstehenden Mittel - zu ihrer Unterstützung attachiert. Eine Selbstbindung scheidet dabei aus. Schwieriger ist das Problem, wenn der Gesetzgeber der Bundesregie$r$ ung derartige Ausschüsse a ufdrängt. Diese Fälle sind gerade im sozialen Bereich häufig, soweit es sich um Ausschüsse handelt, die beim $\operatorname{Erla}$ von Rechtsverordnungen mitwirken sollen: die Mitwirkung des Tarifausschusses bei der Allgemeinverbindlicherklärung eines Tarifvertrages, die Mitwirkung des Hauptausschusses und der Fachausschüsse beim Erlaß von Mindestarbeitsbedingungen und die Mitwirkung der Heimarbeitsausschüsse bei der Regelung der Heimarbeitsbedingungen. Man wird diese Einrichtung für zulässig halten müssen (s.a. unten S. $392 \mathrm{ff}$ ). Aber auch sonst ist der Bundesgesetzgeber in bezug auf die Einrichtung von Ausschüssen für Geschäfte, die an sich der Bundes regierung zufallen, nicht engherzig verfahren. Von dem bedenklichsten Fall, dem Gesetz über den Personalgutachterausschuß für die Streitkräfte vom 23. Juli 1955 (BGB1. I S. 451; i.d.F. d. Gesetze vom 6. November 1956, BGB1. I S.843, und vom 1. April 1958, BGB1. I S. 205), kann hier abgesehen werden. Eine im vorliegenden Zusammenhang zentrale, einschlägige Institution ist der Sozialbeirat gem. $\$ 1274$ RVO, $₫ 51$ AnVG, in dem die Verbände aber nur sehr mittelbar zur Geltung kommen (s. $\$ 1275$ RVO, $\$ 52$ AnVG). Er ist Gutachter der Bundesregierung und mittelbar auch des Bundestages ( $\$ 1273$ RVO, $₫ 50$ AnVG) und übt somit nur eine rein konsultative Funktion aus (zu seiner Charakterisierung s. z. B. Bog's, Zur Konstitutionierung des Sozialbeirats, Die Sozialgerichtsbarkeit, 5.Jhg. (1958), S. 141 ff (144): ".. ein kraft Gesetzes ohne zeitliche Begrenzung konstituiertes Organ, das die Willensbildung von Regierung, Bundestag und Bundesrat durch Klärung der ... maßgebenden sozialpolitischen Verhältnisse gutachtlich vorzubereiten hat. Er gehört als gesetzlich berufener Berater der Regierung zur Exekutive, als Berater des Gesetzgebers aber zum Bereich der gesetzgebenden Gewalt; ... nicht entscheidendes, aber die Willensbildung des Gesetzgebers vorbereitendes Organ...") Am Rande hier zu erwähnen sind die Personalräte und Bundespersonalausschüsse nach dem Bundespersonalvertretungs- 
Die Frage, ob Einrichtungen, die den Einfluß der Verbände auf die staatliche Willensbildung institutionell verfestigen, verfassungspolitisch zweckmäßig sind und insbes. den Nachteilen der Verbändedemokratie abhelfen, kann hier nicht in. ihrer vollen Tiefe aufgeworfen werden. ${ }^{6)}$ Fest steht, daß sie den Einfluß der Verbände jedenfalls intensivieren, wenn die Verbände nicht gleichzeitig veranlaßt werden können, auf ihre sonstigen außerrechtlichen Einflußwege zu verzichten. Daß dies gelingt, ist frag-

gesetz.

5) Weitere Formen s. bei Kaiser, Die Repräsentation organisierter Interessen, S. $270 \mathrm{ff}, 275 \mathrm{ff}$.

6) Aus der jüngeren Literatur s. z.B.:

(1) Zur Frage eines Bundeswirtschaftsrates die positiven Stellungnahmen von Forsthoff (Die Wirtschaftsverfassung im Rahmen der Staatsverfassung, in "Ratgeber von Parlament und Regierung", hrsg. vom Institut zur Förderung öffentlicher Angelegenheiten e.V., 1951, S. 127 ff; Zur Problematik eines Bundeswirtschaftsrates, DÖV 5.Jhg. (1952) S. $714 \mathrm{ff}$ ), Herbert Krüger (Der Bundeswirtschafts rat in verfassungspolitischer Sicht, DÖV 5.Jhg. (1952) S. 545 ff; "Der Staat und die Verbände", S.51 f) und die negativen Stellungnahmen von Breitling (Die Verbände in der Bundes republik, S. 78 ff, 92 f), Kaiser (Die Repräsentation organisierter Interessen, S.352 ff), Scheuner (Stellung und Einfluß der Interessenverbände im heutigen Staat, S.293 f; "Der Staat und die Verbände", S.24 f);

(2) zur Problematik der Beiräte usw. Weisser, Die Problematik des Sachverständigen Rates in politischen Angelegenheiten und die Funktion der wissenschaftlichen Beiräte bei den Bundesministerien, in "Ratgeber von Parlament und Regierung", S. 30 ff; Kaiser, a.a.O. S. 270 ff, 275 ff, $283 \mathrm{ff}$; (3) zur Problematik des Hearing Sternberger in "Der Staat der Gegenwart und die wirtschaftlichen und außerwirtschaftlichen Interessengruppen", S.213 f; Reif, Das Parlament im demokratischen Staat, S. 213;

(4) zum Vernehmlassungsverfahren und verwandten Methoden Nawiasky, Staatslehre, Teil 2 Bd. II S. 22 f; Gruner, Die Wirtschaftsverbände in der Demokratie, S. 107 ff; Hans Huber, Staat und Verbände, S. $19 \mathrm{ff}$; s. a. Brenner, Zum Mitwirkungsrecht der Verbände und Vereinigungen bei der Gesetzgebung des Bundes und beim Erlaß von Verordnungen; (5) $\mathrm{Zu}$ weiteren Formen Kaiser, a.a.O. S.270 ff, $275 \mathrm{ff}$. S. zum Problem ferner Friesenhahn, Parlament und Regierung im modernen Staat, S.29, 67. 
lich. Die Dynamik der. Interessen flutet an den statischen Institutionen vorüber. Ist es aber nicht möglich, die Aktivität der Verbände unter Austrocknung der kaum übersehbaren "unterirdischen" Leitungen in den Kanal der organischen, offiziellen Einflußnahme umzuleiten, so wirkt dieser als ein zusätzliches, das Gewicht vermehrendes Medium verbandlicher Einflußnahme auf die Willensbildung des Staates. Die politischen Instanzen, die diese Institutionen gestalten, haben allerdings die Möglichkeit, dahin zu wirken, daß die organisierten Interessen mit einem sachlich ge rechtfertigten Stimmgewicht vertreten sind. Das kann die Verzerrung im Gewicht der Interessen, die der verschiedenen politischen Mächtigkeit der Verbände entspringt, korrigieren. Aber dabei ist zu berücksichtigen, daß die maßgeblichen politischen Potenzen auch bei der Entscheidung über das Stimmgewicht der Verbände in Wirtschaftsräten, Beiräten usw. dem Einfluß der Verbände unterworfen sind. Die ohnedies unter ihrer Statik leidende Institutionalisierung verbandlichen Einflusses kann auf diese Weise zur Perpetuierung und Steigerung einer zur Zeit ihrer rechtlichen Gestaltung gegebenen Einflußposition werden.

$\mathrm{Zu}$ bedenken ist schließlich, daß die "Verbändedemokratie" ebensowenig wie die "Parteiendemokratie" ohne das Widerlager der außerhalb des dynamischen Feldes der Konkurrenz der partikularen Kräfte stehenden, den "objektiven" Staat als Einheit unmittelbar zur Geltung bringenden Einrichtungen auskommen kann. ${ }^{7)}$ Als solche Gegenkräfte haben sich die Bürokratie (die Beamtenschaft) ${ }^{8}$ ) und die Gerichte erwiesen. Der institutionalisierte Verbandseinfluß schmälert auf diese oder jene Weise immer ihre Funktionsmächtigkeit - und zwar mehr als der nicht institutionalisierte, dem gegenüber sie sich gerade auf ihre legale Ausschließlichkeit berufen können. Will der Staat nicht den festen Boden unter den Füßen verlieren, so sind dem institutionalisierten Verbandseinfluß auch von dieser Seite her Grenzen

7) Vg1. Forsthoff, Verfassungsprobleme des Sozialstaates, $\mathrm{S} .17 \mathrm{ff}$; Weber in "Der Staat und die Verbände", S. $25 \mathrm{f}$; ders., Spannungen und Kräfte im westdeutschen Verfassungssystem, S. 157 ff. S.a. Messner, Die soziale Frage, S. 616 .

8) Zur Bedeutung der Bürokratie bzw. des Beamtentums in diesem besonderen Zusammenhang s. Forsthoff, a.a.O.; Weber, Staatsverwaltung und Selbstverwaltung in der Gegenwart, S. $97 \mathrm{f}$; ders., Spannungen und Kräfte im westdeutschen Verfassungssystem, S. $159 \mathrm{ff}$. 
zu setzen.9)

Das alles schließt aber nicht aus, daß die rechte Institution am rechten Platz in der rechten Zusammensetzung und mit den rechten Kompetenzen wohltätig wirken, d. h. den Verbandseinfluß veröffentlichen, binden und überschaubar machen, dem Staat wertvolle ergänzende Kräfte und breiteres Vertrauen zuführen und alles in allem beruhigend, verfestigend und harmonisierend wirken kann.

\section{ccc) Die Sicherung des Individuums}

Der einzelne ist auf die verbandliche Wahrnehmung seiner Interessen angewiesen. Daraus entspringt die Macht der Verbände.

9) Hingewiesen sei insbes. nochmals auf den zumindest bis zur Grenze getriebenen Einfluß der Verbände auf die Arbeitsund Sozialgerichte (s.hierzu und zur prinzipiellen Verbandsfreiheit der Justiz: Kaiser, Die Repräsentation organisierter Interessen, S. $292 \mathrm{ff}$; Weber, Spannungen und Kräfte im westdeutschen Verfassungssystem, S. 126 f, 143). - Die Teilhabe der Verbände an der Rechtsprechung bewirkt vor allem, daß die generalisierende, typisierende Interessenbetrachtung in die Rechtsprechung dieser Gerichtszweige Eingang findet. Ist der Effekt der paritätischen Beisitzerbesetzung im Prinzip der, daß die Meinungen der Beisitzer als präsumtiv gegensätzlich sich aufheben und die eigentliche Entscheidungsaufgabe dem Vorsitzenden bzw. dem berufsrichterlichen Kern der Gerichte zufällt, so kann er doch ausnahmsweise auch der sein, daß die Beisitzer sich in der Befürwortung des generellen, typischen Interesses gegenüber einem atypischen, individuellen Interesse treffen. Soweit sie in der Überzahl sind, können sie dann der "Herrschaft der Verbände" unmittelbar zum Durchbruch verhelfen. Da der Einfluß der Verbände - wie beschrieben - auch in den berufsrichterlichen Kern dieser beiden Gerichtszweige hineinreicht, ist aber ein Widerstand von dort nicht einmal immej zu erwarten. Darin ist eine entscheidende Funktionsschwäche der gegenwärtigen Arbeitsund Sozialgerichtsbarkeit $\mathrm{zu}$ sehen, wenn auch zugegeben wird, daß diesen Gerichtszweigen durch die Beteiligung der Verbände bei der Masse der Betroffenen ein gewisser Vertrauensvorsprung erkauft wurde. Die verzerrende Wirkung, die der Interessen repräsentation durch die Verbände weitgehend zukommt, kann dagegen durch die kontrollierende Einflußnahme der Gerichtsverwaltung usw. auf die Auswahl der Beisitzer und durch das berufsrichterliche Element eingedämmt werden. 
Sie bedrängt das Individuum - sowohl den, der sich dem Verband unterworfen hat, als auch den, der dieser Unterwerfung zu entgehen sucht. 1) Die Institutionalisierung des Verbandseinflusses, die in der rechtlichen Selbstverwaltung, in der politischen Selbstverwaltung und in den Gerichten nicht mehr "den Bürger" sondern den organisierten Bürger, das organisierte Interesse, den Verband sichtbar macht, 2) fügt dieser tatsächlichen Machtstellung einen Anteil an der staatlichen Gewalt hinzu. Dieser Anteil ist in einer freiheitlichen Demokratie ohne demokratische Legitimation nicht sinnvoll. Die notwendige Legitimation kann im allgemeinen aus der freigewählten Mitgliedschaft der Organisierten entnommen werden. Die Machtstellung der Verbände läßt die rechtliche Freiwilligkeit tatsächlich jedoch fragwürdig werden.

Aus dieser Situation ergeben sich für den auf die Freiheit und Gleichheit seiner Bürger und auf die Demokratie verpflichteten Staat eine Reihe von Notwendigkeiten für die Ordnung der Verbände und ihres Einflusses auf die öffentliche Gewalt.

Zunächst darf e $r$ den Nichtorganisierten nicht schlechter stellen als den Organisierten. ${ }^{3)} \mathrm{Er}$ würde sonst wenigstens die negative Vereinsfreiheit und die Gleichheit aller vor dem Gesetz verletzen. Möglicherweise, insbes. wenn er die Angehörigen bestimmter Verbände bevorzugen und die anderer Verbände vernachlässigen würde, würde er auch die positive Vereinsfreiheit verletzen. 4 )

Sodann muß er den verfassungsrechtlichen Grundwert der Freiheit auch gegenüber der privaten Verbandsmacht verwirklichen und zwar umso dringlicher, je größer sie kraft der tatsächlichen Verhältnisse oder kraft der Beteiligung an der öffentlichen Gewalt ist. Er verwirklicht dies im allgemeinen durch die - unmittelbare ${ }^{5)}$ oder mittelbare - Durchsetzung der Grundrechte im

1) Zur freiheitsbedrängenden Wirkung der Verbände s. die Nachweise oben S. 221 zu Fußn. 9 und S. 300 zu Fußn. 6.

2) $S$. außer oben aa ( $S .373$ ) und bb (S. 380 ff) auch Jacobi, Grundlehren des Arbeitsrechts, S. 19; Maus, Beteiligung von Ausschüssen an der Verwaltung und Normsetzung im A rbeitsrecht, S. 171 (ff).

3) S. Leibholz, Die kritischen Punkte des Grundgesetzes, S. 21.

4) S. hierzu die Ausführurgen zur Koalitionsfreiheit oben Abschnitt 2 IV 2 a dd (S. 302 ff), insbes. S. 304 zu Fußn.9.

5) Es ist nicht ausgeschlossen, daß Verbände im Sinne dieses Abschnittes Körperschäten des öffentlichen Rechts sind. 
Verband-Bürger-Verhältnis. 6) Darüber hinaus kann es angebracht sein, die Bindung der Verbände an die (freiheitliche) verfassungsmäßige Ordnung (Art.9 Abs.2 GG) durch besondere gesetzliche Regelungen zu realisieren. ${ }^{7)}$

Wenn er die Verbände an der staatlichen Gewalt beteiligt, muß er schließlich auch ein adäquates Maß an demokratischer Legitimation erfordern. Die Mitgliedschaft wird, wie schon bemerkt, allein als solche nur bedingt genügen. Wenn Organe mit Hilfe von Verbänden konstituiert werden, wird im allgemeinen auch eine demokratische Verbandsstruktur zu fordern sein. Die Parallelität der Verbände und Parteien in der Mitwirkung an der Willensbildung des Volkes verlangt - je reiner sie zutage tritt, umso dringlicher -, daß die Verbände nicht geringeren Anforderungen unterworfen werden als die Parteien nach Art. 21 Abs. 1 Satz 2 GG. ${ }^{8)}$ Schließlich weist gerade auch Art.21 Abs. 2 GG darauf hin, daß die Verfassungsgebundenheit der Verbände (Art. 9 Abs. 2 GG) umso ernster zu nehmen ist, je mehr der Verband als Mitträger der Willensbildung des Volkes Anerkennung finden soll. Auch damit wird letztlich die Position des einzelnen im Verband und gegenüber dem Verband gestärkt. 9)

\section{Demokratie und Selbstverwaltung}

\section{A $11 \mathrm{gemeines}$}

Fast allgemein gilt es als eine Steigerung der Demokratie, wenn unterhalb der zentralen demokratischen Organe möglichst viele Kompetenzen partiellen demokratischen Entscheidungsträgern seien es nun Organe der sog. politischen Selbstverwaltung (Ausschüsse usw.) oder demokratisch st rukturierte Selbstverwaltungskörperschaften - vorbehalten sind. Diese Einschätzung hat eine traditionelle Wurzel in der Antithese des 19. Jahrhunderts, in der die zentrale Verwaltung (zunächst auch noch die Gesetzgebung) eine Sache des Monarchen, die Selbstverwaltung dagegen Vorposten der Demokratie war. Mit der Beseitigung der Monarchie und der totalen Demokratisierung der zentralen Gewalten ist diese Antithese entfallen. ${ }^{1)}$ An ihre Stelle ist eine intrademo-

6) S. das zu den Koalitionen Ausgeführte oben S. 310 .

7) S. S. 310 .

8) S. S. 310 insbes. S. 311 zu Fußn. 4

9) S. zu Vorstehendem auch Forsthoff, Rechtsfragen der leistenden Verwaltung, S. 20 .

1) Vgl. Köttgen, Art. "Selbstverwaltung" im Handwörterbuch der Sozialwissenschaften. 
kratische Antithese getreten. Jede partielle Demokratie geht auf Kosten der zentralen Demokratie. Jede Herrschaft von "Teilvölkern" verkürzt die Herrschaft des Gesamtvolkes. 2) Umgekehrt wird die Idee der Demokratie als der Identität von Regierenden und Regierten ${ }^{3}$ ) beeinträchtigt, wenn das Gesamtvolk immer auch über Angelegenheiten entscheidet, die nur eine Gruppe angehen. ${ }^{4}$ Die Ausgrenzung und Selbstbestimmung engerer Gemeinschaften verdichtet den Einfluß des einzelnen auf diejenigen Angelegenheiten, die ihn angehen, und fördert so den automistischen Zweck der Demokratie. ${ }^{5)}$ Schließlich kann die Distanz $z$ wischen einem zentraldemokratisch-legitimierten Organ und der Wurzel der zentraldemokratischen Willensbildung so groß sein, daß der Volkswille durch die Beteiligung "volksnäherer", partielldemokratisch bestimmter Faktoren stärker zur Geltung gebracht werden kann als allein durch die zentraldemokratische Legitimation. Es ist daher richtig, wenn - trotz des Wegfalles der ursprünglich prodemokratischen Frontstellung der Selbstverwaltung - die politische und rechtliche Selbstverwaltung auch heute noch zum Vorstellungsbild der Demokratie ${ }^{6)}$ und zwar auch der Demokratie im Sinne des Grundgesetzes ${ }^{7)}$ gezählt wird.

Damit soll aber nicht gesagt sein, daß die Verfassung über die demokratische Selbstverwaltung in den Gemeinden und Gemeindeverbänden (Art.28 Abs. 1 und 2 GG) und über die Einrichtungen der Selbstverwaltung der Wirtschaft hinaus einen bestimmten

2) S. z.B. Kelsen, Wesen und Wert der Demokratie, S.69 ff.

3) Vgl. Carl Schmitt, Verfassungslehre, S. $204 \mathrm{ff}, 234 \mathrm{ff}$.

4) S. z.B. Peters, Entwicklungstendenzen der Demokratie in Deutschland seit 1949, in "Demokratie und Rechtsstaat", Festgabe für Zaccaria Giacometti, 1953, S.229 ff (243).

5) Hierauf beruht auch der erzieherische, Verantwortung, Wertgefühl und Vertrauen schaffende Effekt des Aufbaues der Demokratie von unten nach oben.

6) Vg1. Peters, a.a.O.

7) S. Peters, Verfassungsrechtliche Fragen des Entwurfs eines Gesetzes über die Regelung der Beziehungen zwischen Ärzten, Zahnärzten und Krankenkassen (Kassenarztrecht) S.2 und passim; v. Mangoldt-Klein, Art.20 Anm.V 1; Maunz, Deutsches Staatsrecht, S. 56; ders. in Maunz-Dürig, Art. 20 Randn.42. Für die demokratische Selbstverwaltung in der Sozialversicherung s. Maunz-Schraft, Das Selbstverwaltungsrecht der Sozialversicherung, Vorwort S. 1. 
Standard an rechtlicher oder politischer Selbstverwaltung garantiert. 8) Institutionen partieller Demokratie kann wohl - weil und soweit sie zum Gesamtbild der verfassungsmäßigen Demokratie gehören - der Gesetzgeber oder sonst zuständige Träger der Organisationsgewalt 9) schaffen. 10) Aber er muß sie nicht schaffen, 10) und er darf sie nicht in einem Maße schaffen, daß "der Pluralismus des demokratischen Prozesses die Funktionsfähigkeit sowohl der Teilbereiche wie vor allem des Gesamtverbandes aufhebt oder in unerträglichem Maße herabsetzt". 11) Sie dürfen den zentraldemokratischen Prozeß nicht aufheben sondern müssen ihm die übergeordnete, beherrschende Stellung, die ihm nach der Grundkonzeption der Verfassung zukommt, belassen.

2. Einige besondere Bemerkungen

a) Demokratie und Ausschußwesen

Nach diesen Grundsätzen darf es der Regierung nicht durch die Einrichtung weisungsunabhängiger Ausschüsse unmöglich gemacht werden, die Gesamtpolitik verantwortlich zu bestimmen. 1)

Dieser Gesichtspunkt würde an sich noch nichts gegen die bestimmende Beteiligung weisungsunabhängiger Ausschüsse an der delegierten Rechtsetzung der Exekutive besagen, wie sie für die Festsetzung der Mindestarbeitsbedingungen, die Festsetzung von Heimarbeitsbedingungen und Entgelten nach dem Heimarbeitsgesetz und für die Allgemeinverbindlicherklärung von 'Tarifverträ-

8) So wollen wohl auch die zu Fußn. 7 Zitierten nicht verstanden sein. - Wie hier zur politischen Selbstverwaltung: Baring, Die politische Selbstverwaltung und die Verwaltungsgerichtsbarkeit, S. 689 .

9) Auch die Verwaltung selbst kann sich im Rahmen der gesetzlichen Organisationsbestimmungen und im Rahmen der Mittel demokratische Accessoires schaffen. So beruhen z. B. die verschiedenen Beiräte bei den Bundesministerien, die aber sachverständige, keine demokratische Funktion haben, auf Verwaltungsanordnung. Aber diese Beiräte können in keinem Fall die Entscheidungsmacht der zentraldemokratisch fundierten Exekutive beeinträchtigen.

10) S. schon oben Abschnitt 2 I (S.219 ff) und II (S.225 ff).

11) Krüger, Staatsverfassung und Wirtschaftsverfassung, S.366 f (Zitat S.367).

1) BVerfGE 9, 268 (281 ff). Alles weitere s. oben S. $134 \mathrm{zu}$ Fußn. 9 ff und die dortigen Nachweise. 
gen vorgesehen ist. 2) Inwieweit die Exekutive Rechtsetzungsbefugnisse ausüben kann, hängt vom Gesetzgeber ab (Art.80 Abs. 1 GG); und wenn die Regierung glaubt, durch die Mitwirkungsbefugnis von Ausschüssen an der Rechtsetzung an der für richtig gehaltenen Politik gehindert zu sein, so kann sie sich ihrer Verantwortung dadurch entledigen, daß sie, nicht anders als wenn sie gar nicht ermächtigt worden wäre, kraft ihres Initiativrechts an den Gesetzgeber herantritt und diesen, der sich durch die Ermächtigung seines eigenen Gesetzgebungsrechts nicht begeben hat und kann, auffordert, das Notwendige vorzusehen. Art. 80 Abs. 1 Satz 1 GG bestimmt den Kreis der möglichen Adressaten von Verordnungsermächtigungen jedoch abschließend. ${ }^{3)}$ Organe der politischen Selbstverwaltung zählen nicht dazu. Die Autonomie verbandlicher Selbstverwaltungseinheiten fällt $z$ war aus dem Anwendungsbereich des Art. 80 GG heraus. 4) Aber die Rechtsetzung durch Ausschüsse kann nicht in derselben Weise ausgenommen werden. 5) Entscheidend für den demokratischen und rechtsstaatlichen Vorzug der verbandlichen Autonomie ist die der staatlichen Demokratie parallele Identität von "Regierenden" und "Regierten". Diese ist im Falle der Rechtsetzung durch Ausschüsse nicht gewährleistet. Für die aufgezeigten Fälle der Festsetzung von A rbeitsbedingungen ist sogar kennzeichnend, daß Verbandsvertreter mitwirken, um Recht für die "Außenseiter" zu setzen. ${ }^{6)}$ Deshalb wird die Beteiligung von Ausschüssen an der Rechtsetzung so gestaltet werden müssen, daß die Rechtsetzung verantwortlich bei einem Bundesminister bzw. bei der Bundesregierung oder der Landesregierung liegt. Andernfalls kann die Ermächtigung nicht mit Art. 80 Abs. 1 Satz 1 GG vereinbart werden. ${ }^{7)}$ Die Unmöglichkeit, durch Bundesgesetz unmittelbar auch

2) Zur Darstellung s. oben S. 92 und S.305.

3) Vgl. Maunz in Maunz-Dürig, Art. 80 Randn. 6 m.w. Nachw.

4) S. unten S. 487 .

5) S. unten S. 489.

6) S. oben S. 305 .

7) Dabei wird es eher erträglich sein, daß der Bundesminister nicht gegen den Ausschuß handeln kann, als daß der Ausschuß gegen den Bundesminister handeln kann. Dies muß als gänzlich ausgeschlossen gelten. Der erstere Fall erscheint dagegen möglicherweise noch tragbar, insbes. mit Rücksicht auf den erwähnten möglichen Appell an den Gesetzgeber. Eine schon einmal außer Verantwortung des Ministers erlassene Verordnung kann dagegen auch der Gesetzgeber nur wieder aufheben, nicht aber ungeschehen machen. 
einzelne Landesminister zu ermächtigen, ${ }^{8)}$ wie das bisher gerade für die Gremien zur Festsetzung von A rbeitsbedingungen im Landesbereich üblich war, ${ }^{9}$ ) wird allerdings an die Gesetzgebungskunst des Bundesgesetzgebers und an das Zusammenwirken zwischen Bundes- und Landesrechtsetzung hohe Anforderungen stellen, wenn praktikable Lösungen gefunden werden sollen.

\section{b) Demokratie und rechtliche Selbstverwaltungseinheiten}

Nach dem demokratischen Grundprinzip der Verfassung darf der Gesetzgeber nicht Selbstverwaltungsverbände ausgrenzen, ohne sie demokratisch zu verfassen. 1) In sich herrschaftlich strukturierte Verbände würden die demokratisch determinierte Homogenität des Gesamtstaatswesens stören. 2) Autoritäre Lenkungsverbände 3 ) oder nichtverbandlich strukturierte Anstalten 4 ) sind als Erscheinungen der Selbstorganisation des Staates denkbar. Ihre Befugnisse können sich aber nicht unter Berufung auf ihre "Autonomie": oder "Selbstverwaltung" von denen anderer - unmittelbarer - staatlicher Behörden unterscheiden. ${ }^{5)}$ Das gleiche muß für die Befugnisse von Verbänden gelten, die über den Kreis derjenigen hinausgreifen, die im Verband wahl- und stimmberechtigt sind. 6 )

8) BVerfGE 11, 77. Weiteres s. bei Maunz in Maunz-Dürig, Art. 80 Randn. 8 und dort. Nachw.

9) S. insbes, oben S.92.

1) Vgl. Matz, Grundgesetz 2. Auf1. 1954, Erl. zu Art.20; v. Mangoldt-Klein, Art. 20 Anm. V 3.

2) Krüger, a.a.O. S. 365 f: Argument Art.28 Abs. 1 Satz 2 und Art. 21 Abs. 1 Satz 2 GG.

3) S. hierzu Forsthoff, Lehrbuch des Verwaltungsrechts, S. $427 \mathrm{f} \mathrm{m}$. w. Nachw.

4) Anstaltliche Verwaltung ist entweder demokratisiert oder keine Form der Selbstverwaltung mehr (vgl. Nawiasky, Staatslehre Teil 2 Bd.I S.276; Köttgen, Art. "Selbstverwaltung" im Handwörterbuch der sozialwissenschaften, S.223 f).

5) Entscheidend geht es vor allem um die Qualifikationsdifferenz: ist die übertragene Rechtsetzungsgewalt Rechtsverordnungsgewalt unter Bindung an Art. 80 Abs. 1 Satz 2 GG oder autonome Satzungsgewalt? S. hierzu eingehend unten Abschnitt 4 II 2 c (S. 480 ff).

6) S. unten S.489. - Zu den Problemen der Familienausgleichskassen und landwirtschaftlichen Alterskassen s. Schewe, Körperschaften ohne Selbstverwaltung? - Zu weiteren Strukturproblemen der demokratischen Gestalt der Selbstverwaltungsträger s. oben S. 244. Zum Zusammenhang zwischen 
c) Parteien und Verbände in der Selbstverwaltung

Anzumerken ist schließlich, daß gerade innerhalb der Selbstverwaltung von einem Monopol der Parteien keine Rede sein kann. 1) Den nach fachlichen Gesichtspunkten gestalteten Organen der politischen Selbstverwaltung und der Nichtgebietskörperschaften stehen die Verbände weitaus näher. Sie sind daher - vom gebietskörperschaftlichen Bereich abgesehen - zu einer Art "Parteien der Selbstverwaltung" geworden, freilich ohne spezifischen Status. ${ }^{2)}$ Im übrigen darf hierzu auf das oben ${ }^{3)}$ Ausgeführte bezug genommen werden.

Autonomie und demokratischer Struktur der Sozialversicherungsträger s. insbes. Bogs, Selbstverwaltung in der Sozialversicherung, S.155 f; s.dazu auch Abendroth, Diskussionsbeitrag zu "Gegenwartsfragen sozialer Versicherung", S.201 ff.

1) Die Frage ist schon, ob es bei der Selbstverwaltung um die "politische Willensbildung des Volkes" geht. - S. zum Text Maunz in Maunz-Dürig, Art.21 Randn. 20 u. 36 u. die dort. Nachw.

2) S. Maunz, a.a.O. Randn. 20.

3) S. o. III 5 b (S. 373 ff), insbes, aa (S. 373 ) und cc (S.383). 


\section{Abschnitt}

Die soziale Intervention im Rechtsstaat

I. Allgemeines zu dem Verhältnis der sozialen Intervention zur rechtsstaatlichen Ordrung des Grundgesetzes

Die Demokratie ist die Elementarstruktur der verfassungsmäßigen Herrschaftsordnung. Dem rechtsstaatlichen Prinzip 1) entnimmt sie ihre Feinstruktur, welche die Herrschaft der demokratischen Mächte differenziert, modifiziert und moderiert. 2) Indem die Untersuchung sich dem Verhältnis der sozialen Intervention zu dieser rechtsstaatlichen Ordnung ${ }^{3)}$ zuwendet, stößt

1) Außer der nachfolgend zitierten Literatur seien hierzu vorweg erwähnt: Thoma, Rechtsstaatsidee und Verwaltungsrechtswissenschaft, Jahrbuch d. öffentl. Rechts Bd. IV (1910) S. 196 ff; Carl Schmitt, Verfassungslehre, S. 123 ff; Darmstaedter, Die Grenzen der Wirksamkeit des Rechtsstaats, 1930 (immer noch die umfassendste Monographie zum deutschen Rechtsstaat); Klein, Bonner Grundgesetz und Rechtsstaat, Zeitschrift für die gesamte Staatswissenschaft Bd.106 (1950), S. 390 ff; Friesenhahn, Die rechtsstaatlichen Grundlagen des Verwaltungsrechts, Recht-Staat-Wirtschaft Bd. II (1950) S. 239 ff; Hans Huber, Niedergang des Rechts und Krise des Rechtsstaats, in "Demokratie und Rechtsstaat", Festschrift für Zaccaria Giacometti, 1953, S. 59 ff; Menger, Der Begriff des sozialen Rechtsstaats im Bonner Grundgesetz, insbes. S. 4 ff; Forsthoff, Begriff und Wesen des sozialen Rechtsstaats, Veröffentlichungen der Vereinigung der deutschen Staatsrechtslehrer, Heft 12, 1954, S. 8 ff; Bachof, dass. ebd. S. $37 \mathrm{ff}$; Nawiasky, Staatslehre, Teil 3, S. $121 \mathrm{ff}$; Scheuner, Begriff und Entwicklung des Rechtsstaats, in "Macht und Recht", Beiträge zur lutherischen Staatslehre der Gegenwart, 1956, S. 76 ff; ders., Die neuere Entwicklung des Rechtsstaats in Deutschland, in "Hundert Jahre Deutsches Rechtsleben", Festschrift Deutscher Juristentag, Bd. II, 1960, S.229 ff.

2) Zum Verhältnis von Rechtsstaat und Demokratie s. insbes. Kägi, Rechtsstaat und Demokratie, in "Demokratie und Rechtsstaat", Festschrift für Zaccaria Giacometti, 1953, S. 107 ff; Bäumlin, Die rechtsstaatliche Demokratie 1954. Zur Abhängigkeit des Rechtsstaates von der Demokraties. insbes. Scheuner, Die neuere Entwicklung des Rechtsstaats in Deutschland, S.229.

3) Gumplowitz, Rechtsstaat und Socialismus, (1881), ist auch 
sie auf einen Gegenstand von augenfälliger thematischer Aktualität. Sie tritt hervor in dem Begriff des "sozialen Rechtsstaates", den das Grundgesetz in Art.28 Abs. 1 Satz 1 gebraucht und der wie kaum eine andere Wortfügung des Grundgesetzes breiteste Popularität genießt, zugleich aber Gegenstand einer heftigen Interpretationskontroverse ist. Auf der einen Seite wird er als Ausdruck positiver Harmonisierung sozialer und rechtsstaatlicher Konzeptionen, auf der anderen Seite jedoch als der Niederschlag eines Kompromisses gedeutet, der nichts als den trügerischen Anschein erweckt, als seien an sich unvereinbare soziale und rechtsstaatliche Grundsätze in Einklang gebracht worden. ${ }^{4)}$ Aber auch über diese Diskussion hinaus ist unter den Hauptgrundsätzen des gegenwärtigen Verfassungsrechts derjenige der Rechtsstaatlichkeit wohl der, dem nächst dem Sozialstaatsprinzip und in Verbindung mit diesem die entscheidende Weichenstellung für die soziale Intervention zugeschrieben wird.

Die Diskussion über die Deutung des Begriffes des "sozialen Rechtsstaats" hat ihre eine Wurzel in der Unsicherheit, die in bezug auf das Begriffselement "sozial" herrscht. Sie und noch mehr die allgemeinere Kontroverse über das Verhältnis des Rechtsstaates zur sozialen Intervention fußen aber vornehmlich auch auf den vielfältigen und erheblichen Differenzen, denen das Verständnis des Rechtsstaates unterliegt. ${ }^{5)}$ Die Fruchtbarkeit des bisher geführten Gespräches hat nicht wenig darunter gelitten, daß die Unterschiedlichkeit der Prämissen nicht hinlänglich offengelegt wurde.

Unvereinbar mit dem verfassungs rechtlichen Bekenntnis zum Rechtsstaat ist die soziale Intervention nur dann, wenn jener im Sinne der ä 1 teren, materiellen Rechtsstat slehre verstanden wird, die den Staat auf den Rechtszweck beschränkt und dabei insbesondere den Wohlfahrtszweck des Staates eliminier.t. 6) Von ihr führt kein Weg zu einer umfassenden sozialen

abgesehen von der Notwendigkeit, zwischen "sozial" und "sozialistisch" zu unterscheiden, für das Thema nur mehr sehr beschränkt von aktuellem Interesse.

4) Zur Kontroverse s.u. Abschnitt 5 II 3 c (S. 744 ff).

5) S.a. die Fragen, die Scheuner (Die neuere Entwicklung des Rechtsstaates in Deutschland, S.234) stellt.

6) S. z.B. die Darstellung dieser für den deutschen Raum vor allem von Kant und Wilhelm v. Humboldt grundgelegten Lehre bei Darmstaedter, Die Grenzen der Wirksamkeit des Rechtsstaates, S. 1 ff; kürzer gefaßt bei Menger, a.a.O. S. 7 ff, bei diesem (S.11) auch der Begriff des materiellen Rechtsstaats. 


\section{Intervention. 7)}

Wird der Rechtsstaat dagegen so verstanden, wie ihn die Lehre vom formellen (bürgerlichen) Rechtsstat begreift, 8) so besteht dieser absolute Gegensatz zwischen ihm und einer sozialen Determination der staatlichen Politik nicht. Allerdings stehen sich auch dieser Typ des Rechtsstaates und der Typ des sozial intervenierenden Staates "fremd" gegenüber. Die Institutionen des formellen Rechtsstaats zielen auf die Hemmung der Staatsgewalt durch Gewaltenteilung, Bindung der Verwaltung an das Gesetz, grundrechtlichen Schutz des Bürgers und umfassenden Rechtsschutz. 8) Sie bremsen jede staatliche Aktivität. Die Friktion mit einem politischen Wollen, das, wie das Soziale auf eine ganz außerordentliche Fülle staatlichen Handelns geht, ist jedoch besonders heftig. ${ }^{9)}$ Die Institutionen des Rechtsstaats riegeln die Individualsphäre gegen staatliche Eingriffe ab. Der sozial intervenierende Staat muß aber, um zu verteilen, vor allem umverteilen; d.h. er muß die Umverteilungsmasse durch belastende Maßnahmen schöpfen. Er muß sich dabei den rechtsstaatlichen Beschränkungen unterwerfen. Die durchdringende gesetzliche

Peters (Rechtsstaat und Rechtssicherheit, Recht-Staat-Wirtschaft Bd. III (1951) S.66 ff (66)) nennt diesen den "politischen Begriff des Rechtsstaats". S.a. Scheuner, a.a.O. S.283f.

7) Es ist das Bemühen der Schrift Darmstaedters (a.a.O.), die Möglichkeiten und Grenzen aufzuzeigen, die auch vom Boden der älteren, materiellen Rechtsstaatskonzeption für die Bewältigung der unausweichlichen sozialgestaltenden Aufgaben des modernen Staates bestehen. Jedoch zeigt gerade seine imponierend exakte Arbeit, daß die äußersten Grenzen im Hinblick auf das moderne Staatsverständnis gekünstelt und untragbar eng erscheinen und die Möglichkeiten, die seine anpassende Interpretation des Prinzips zu eröffnen vermag, nicht befriedigen (s. insbes. S. $52 \mathrm{ff}, 155 \mathrm{ff}, 201 \mathrm{ff}, 252 \mathrm{ff}$ ).

8) Vgl. insbes. die Darstellung des bürgerlichen Rechtsstaates bei Carl Schmitt, Verfassungslehre, S. 123 ff; weiter ausgreifend Scheuner, a.a.O. S.239 ff (insbes. aber S.244 ff); s.a. Friesenhahn, Die rechtsstaatlichen Grundlagen des Verwaltungsrechts; Menger, a.a.O. S. $11 \mathrm{ff}$.

9) S. a. Kägi, Zur Entwicklung des schweizerischen Rechtsstaats seit 1848, Zeitschrift für schweizerisches Recht, n.F. Bd.71 (1952) S. 173 ff (222 f); Bleibtreu, Demokratie, soziales Prinzip und Rechtsstaat, S. 106. 
Regulierung der sozialen Intervention als Reflex auf das Verbot des gesetzlosen Eingriffes und der fast monopolartige Vorrang der Steuer bei der Schöpfung der Umverteilungsmasse 10) als Reflex vor allem auf den rechtsstaatlichen Eigentumsschutz geben Zeugnis davon, wie die soziale Intervention dadurch beengt wird. Die soziale Intervention dringt ferner nicht nur in eine nur schwer sowohl abstrakt tatbestandlich wie rechtlich präzis faßbare und generalisierbare Vielfalt von Lebensverhältnissen ein, und ist zugleich von einem Pathos sozialer Gerechtigkeit getragen, das glaubt, jeden einzelnen Fall einer individuell angemessenen und gerechten Lösung zuführen zu sollen und zu können. ${ }^{11)}$ Die rechtsstaatlich notwendige Bindung der vollziehenden Gewalt an das Gesetz wird dadurch sehr erschwert. ${ }^{12)}$ Schließlich tendiert die Leistungsseite der sozialen Intervention danach, sich der rechtlichen Bindung überhaupt zu entziehen. Die Institutionen des Rechtsstaats eignen sich nur sehr beschränkt dazu, staatliche Aktivität zu erzwingen. Sie wurden in Abwehr des (vermeintlich?) über-aktiven Staates entwickelt und sind stumpfe Waffen gegenüber dem untätigen Staat. Ganz abgesehen davon, daß Handeln an sich immer nur auf Umwegen erzwungen, 13) dagegen auf direktem Wege verhindert werden kann. Der leistende Staat entzieht sich den rechtsstaatlichen Bindungen aber auch deshalb, weil diese wesentlich gegen den belastenden Staat gerichtet sind. Der gebende Staat erschien, als die Postulate formeller Rechtsstaatlichkeit entwickelt wurden, ebenso unwahrscheinlich wie ungefährlich. So ließen sie dem Staat insbes. die Legitimation gesetzesfrei zu handeln, soweit er nicht eingreift und belastet, sondern nu r gibt. Damit entstand um den leistenden Staat ein Hof

10) S. die oben S. 14 zu Fußn. 46 Zitierten.

11) Zur allgemeinen Tendenz s. Engisch, Die Idee der Konkretisierung in Recht und Rechtswissenschaft unserer Zeit, 1953, S. 178 ff, insbes. S. 214 ff, mit eingeh. Nachweis; Geiger, Grundrechte und Rechtsprechung, 1959, S.25.

12) Vgl. Gygi, Verwaltungsrecht und Privatrecht, 1956, S.11 f.

13) Man vergleiche die Schwierigkeiten, die das Zivilprozeßrecht hat, wenn Handlungen erzwungen werden sollen: $\$ \$ 887$, $888 \mathrm{ZPO}$. Die Ersatzvornahme ist nur bei vertretbaren Handlungen denkbar. Darüber hinaus stehen einer Ersatzvornahme innerhalb des staatlichen Organismus die schwerwiegenden Bedenken entgegen, die in der Drohung einer nachhaltigen Gewichtsverschiebung begründet sind. Schließlich muß dem Gedanken der Ersatzvornahme gerade in diesem $\mathrm{Zu}$ sammenhang die Unmöglichkeit des regressus in infinitum regulierend entgegengehalten werden. 
gelockerter Bindungen. So zeigt der Rechtsstaat der sozialen Intervention einen Januskopf: auf (ler einen Seite Hemmung, Beschränkung, Regulierung; auf der anderen Seite Distanz und Apathie. In dieser dem gebenden, leistenden, verteilenden Staat zugewandten "Hälfte" zeichnen sich die Züge der Schwäche des Rechtsstaates gegenüber der sozialen Intervention ab, auf welche die nachfolgende Untersuchung immer wieder stoßen wird. Wenn dadurch aber auch die homogene Konkordanz von Rechtsstaatlichkeit und Sozialstaatlichkeit in Frage gestellt wird, so beinhaltet sie doch keine prinzipielle Aversion des Rechtsstaates gegen die soziale Aktivität des Staates. Aber selbst die durch Hemmung und Mäßigung gekennzeichnete "Hälfte" ist nicht das Signum einer speziellen Sozialfeindlichkeit des Rechtsstaates. Der sozial intervenierende Staat muß sich nur der rechtsstaatsgemäßen Wege und Mittel bedienen. Der Prozeß der sozialen Intervention wird dadurch entscheidend modifiziert, ihr. Effekt im ganzen und allgemeinen aber kaum gemindert. 14) Die "Vorsprungszeit sozialer Notstände" vor den staatlichen Abhilfen 15) wird dadurch nicht erst begründet, wenngleich sicher vergrößert.

Die heute herrschende jünge re materielle Rechtsst a at slehre 16) begnügt sich aber nicht mehr mit den Postulaten des formellen Rechtsstaats. Sie fordert darüber hinaus, daß

14) S. vorläufig Ballerstedt, Wirtschaftsverfassungsrecht, S. 52 . Weitere Nachweise s. unten Abschnitt 5 II 3 c: (S. 744 ff).

15) Gehlen, Zur Problematik des Sozialstaates, S. 57.

16) S. vor allem Ruck, Freiheit und Rechtsstaat, in "Die Freiheit des Bürgers im schweizerischen Recht", Festgabe zur Hundertjahrfeier der Bundesverfassung, 1948, S. 75 ff (76 f, 84); Scheuner, Grundfragen des modernen Staats, S. $151 \mathrm{f}$ (m. Fußn.84); ders., Die neuere Fritwicklung des Rechtsstaats in Deutschland, S. $247 \mathrm{fl}$; Huber, Niedergang des Rechts und Krise des Rechtsstaats; Nawiasky, Allgemeine Staatslehre, Teil $3 \mathrm{~S} .130 \mathrm{f}$; s. ferner Klein, Bonner Grundgesetz und Rechtsstaat, S.395; Peter's, Rechtsstaat und Rechtssicherheit, S.67; Maunz-Dürig, Art.20 Randn. 58 ff. Ein materielles Element war clem formellen Rechtsstaatsbegriff von Ursprung an beigegeben. Jedoch man hat nach der extrem positivistischen Infallibilitätserklärung des (einfachen) Gesetzgebers mit dem materiellen Vorbehalt zu dessen Lasten nichts mehr anzufangen gewußt (s. hierzu Scheuner, Grundfragen des modernen Staats, a.a.O.; ders., Die neutre Entwicklung des Rechtsstaats in Deutschland, S.239 ff; Menger, Der Begriff des sozialen Rechtsstaats im Bonner Grundgesetz, S.12; je mit weit. Nachw.). 
die gesamte Staatstätigkeit an eine materielle Grundordnung gebunden wird. Ist der Rechtsstaat von dieser Konzeption bestimmt, 17) so kommt es für sein Verhältnis zur sozialen Intervention entscheidend auf den Inhalt dieser Grundordnung an. Ist sie sozialen Tendenzen feindlich, so bietet sie der sozialen Intervention mit der Schärfe Widerstand, mit der der Sanktionsmechanismus des Rechtsstaats immer dem Handeln viel mehr als dem Nicht-Handeln entgegenzutreten imstande ist. Geht die Grundordnung dagegen selbst in die Richtung der sozialen Intervention, so wird diese durch die materielle Substanz der Verfassung angetrieben und bestärkt. Das Gefüge rechtsstaatlicher Rechtsdurchsetzung wird zum Realisationsfaktor der verfassungsrechtlich normierten sozialpolitischen Maximen. 18) Allerdings ist es wesensmäßig unmöglich, verfassungsmäßigen Aktionsprogrammen und Zukunftsverheißungen - sozialen und anderen - die gleiche Effizienz zu verleihen wie negativen Ausgrenzungen und Besitzstandsverbürgungen. 19). Negative Ausgrenzungen sind gegen die staatliche Aktion gerichtet. Sie sind Ausnahmen von der Handlungsfreiheit des Staates. Soweit sie nicht reichen, kann der Staat sich entfalten. Aktionsprogramme dagegen präokkupieren, wenn sie verbindlich sein sollen, die staatliche Tat. Und das in dem Immobilitätsgrad der Verfassung. Sie nehmen entweder dem Staat die Freiheit der situationsgebundenen Entfaltung - und müssen schließ-

17) Mit Vorstehendem soll nicht eine abschließende Systematik der Rechtsstaatslehre gegeben sein. Die Ansichten vom "wahren" Rechtsstaat sind - um eine oft gebrauchte Wendung zu wiederholen - so zahlreich wie die Vielfalt der Begriffe "Staat" und "Recht" das bedingt. Es ging hier nur darum, ohne feinere Unterscheidung im einzelnen die drei Haupttypen herauszustellen, die für den konkreten Zusammenhang von Bedeutung sind. - Im übrigen s. die S. 396 zu Fußn. 1 Zitierten.

18) Eingehende Nachweise, insbes. zur rechtsstaatlichen Verwirklichung des Sozialstaats s.u. Abschnitt 5 II 3 c: (S. 744 ff). Das Bild eines Rechtsstaates dieser. Art hat wohl Thieme vor. Augen, wenn er (Der Beamte im sozialen Rechtsstaat, Zeitschrift für Beamtenrecht, 8. Jhg. (1960) S. 169 ff (170)) konstatiert, der Rechtsstaat sei immer auch Sozialstaat, weil er Rechte und somit Teilhabe gewähre.

19) S. hierzu und zum Folgenden: Forsthoff, Begriff und Wesen des sozialen Rechtsstaates, S. $10 \mathrm{ff}$. - Weitere Nachweise zum Problem s. - unter dem besonderen Gesichtspunkt des Verhältnisses der ausgrenzenden zu den sog. "sozialen" Grundrechten - unten Abschnitt 6 I 3 a (S. 848 ff). 
lich der unerträglichen Spannung zwischen dem Verfassungsprojekt und der Wirklichkeit weichen - oder sie sind von vorneherein von schwacher Verbindlichkeit. Aber sie disponieren nicht nur über die Tat, sie bedürfen ihrer auch. Die negative Ausgrenzung negiert die Aktion. Der positive Wille der Verfassung wird durch die Aktion realisiert. Nicht nur durch abhängigen Vollzug - seiner bedarf auch das Verbot. Das Verfassungsprogramm bedarf der ergänzenden Gestaltung. Die Verfassung kann die in Aussicht genommenen Institutionen, Leistungen usw. nicht selbst im Detail und somit also nicht definitiv und praktikabel ordnen. Dazu muß sie zu knapp und zu schwer abänderbar sein. Soziale Teilhabe bedarf in besonderem Maße einer flexiblen und differenzierenden Regelung; denn sie steht stets unter dem Vorbehalt nicht nur des im Einzelfall Angemessenen und Notwendigen, sondern auch des überhaupt Möglichen. 20) Würde die Verfassung sich in Regelungen erschöpfen, die definitiv getroffen werden können, so würde sie wieder ins Statische und Negative umschlagen 21) und ihre Stoßkraft für die Zukunft einbüßen. Sie muß sich also auf den Ansatz beschränken, den ein anderer Wille - in der rechtsstaatlichen Regel der des einfachen Gesetzgebers - zu vollenden hat. Dessen Gestaltungsakte sind aber nicht unmittelbar erzwingbar. ${ }^{22)}$ Nicht einmal eine hinreichende mittelbare Sanktion ist dem Staatsrecht möglich. ${ }^{23)}$ Was eben vom Rechtsstaat allgemein festgestellt wurde, daß er nämlich das staatliche LeistenMüssen so wenig in den Griff bekommt, gilt für die Sphäre des Verfassungs rechts wegen seiner Starre und Kürze und wegen der Notwendigkeit, seinem primären Adressaten, dem Gesetzgeber, Gestaltungsfreiheit zu belassen, ${ }^{24)}$ ganz besonders. Wie sollte

20) Mit etwas anderer Gewichtsverteilung sagt Forsthoff a.a.O. S. 20: "... haben Teilhaberechte keinen im vorhinein normierbaren, konstanten Umfang. Sie bedürfen der Graduierung und Differenzierung, denn sie haben einen vernünftigen Sinn nur im Rahmen des im Einzelfalle Angemessenen, Notwendigen und Möglichen".

21) Forsthoff, a.a.O. S. 19: "Auch soziale auf Teilhabe gerichtete Normierungen sind dem rechtsstaatlichen Gesetz zugänglich, soweit sie auf Ausgrenzungen beruhen,..."

22) S. Thieme, Liberalismus und Grundgesetz, Zeitschrift für die gesamte Staatswissenschaft, Bd. 113 (1957) S. 285 f (298). $\mathrm{S}$. hierzu noch unten S. 564, Abschnitt 5 II 2 b (S. 714 ff) und Abschnitt 6 I 3 a (S. 848 ff); dort auch weitere Nachweise.

23) S. O. S. 399 zu Fußn. 13.

24) S. hierzu insbes. Carl Schmitt, Rechtsstaatlicher Verfassungsvollzug, in Carl Schmitt, Verfassungsrechtliche Schrif- 
aber sonst in dieser obersten Sphäre des Rechts die soziale Intervention gesichert werden? Es bleibt - neben den erwähnten beschränkten Möglichkeiten, Aktionen zu befehlen - noch die Möglichkeit, Aktionen zu erlauben. 25) Soweit dabei die Verfassung an die Stelle des Gesetzes tritt und der Verwaltung oder auch den Gerichten einzelne, ganz bestimmte Vollzugsaufträge erteilt, verhält sich dieses Vorgehen zu den Elementen des formellen Rechtsstaates neutral. Entsprechende Detailregelungen sind in der Verfassung jedoch auch in dieser Weise nur ganz begrenzt möglich. Weiter kann die Verfassung nur gehen, indem sie den formellen Rechtsstaat abbaut. Sie kann zu Generalermächtigungen an die Verwaltung (oder auch die Rechtsprechung) schreiten. Dann hebt sie die Gesetzmäßigkeit der Verwaltung auf oder schränkt sie wenigstens empfindlich ein. Sie kann den Gesetzgeber (oder auch Verwaltung und Rechtsprechung) $\mathrm{zu}$ sozialen $Z$ wecken von den grundrechtlichen und ähnlichen Bindungen freistellen. Auch damit mindert sie die Rechtsstaatlichkeit. Diese Richtung materiell-verfassungs rechtlicher Verankerung der sozialen Intervention führt also früher oder später über die Grenzen des Rechtsstaates hinaus. Aus all dem ergibt sich "eine außerordentliche Konsistenz des Rechtsstaates gegenüber den Versuchen, ihn mit sozialen Gehalten zu erfüllen". 26) Trotzdem ist daran festzuhalten, daß der materielle Rechtsstaat jüngerer Auffassung sozial indifferent, antisozial oder prosozial sein kann. Nur kann er jenes mit größerer Intensität als dieses.

Das Grundgesetz hat nicht einen Rechtsstaat im Sinne der älteren, materiellen Rechtsstaatslehre verfaßt. 27) Der Staat war zur Zeit des Erlasses des Grundgesetzes schon viel zu intensiv in den sozialen und wirtschaftlichen Verhältnissen engagiert und es war viel zu selbstverständlich, daß dies - ungeachtet des erwarteten Rückganges planwirtschaftlicher Maßnahmen - auf lange Sicht so bleiben würde und müßte, als daß die vielberufenen Väter des

ten, 1958, S. 452 ff; s. zu den Gefahren unmittelbaren Verfassungsvollzugs durch die Verwaltung (und Rechtsprechung) auch Dürig, Verfassung und Verwaltung im Wohlfahrtsstaat, S. 195 .

25) Im Befehl ist natürlich das Dürfen immer mitenthalten. Hier. ist das bloße Dürfen gemeint.

26) Forsthoff, Begriff und Wesen des sozialen Rechtsstaats, S. 12.

27) In Hamanns Vorstellung vom Rechtsstaat finden sich offenbar in ihrem Verhä1tnis zum Staat des Grundgesetzes nicht ganz bewältigte Reste der Kant-Humboldt'schen Rechtsstaatsidee (s. Hamann, Das Grundgesetz, Einführung I D 1, insbes. g; der's., Deutsches Wirtschaftsverfassungsrecht, S. $38 \mathrm{ff}$, insbes. S. 41 und 45). 
Grundgesetzes daran hätten denken können, zu einem überlebten Staatsentwurf aus dem 18./19. Jahrhundert zurückzukehren. Es wäre abwegig, die Erwähnung des "Rechtsstaates" in Art.28 Abs. 1 Satz 1 GG als einen Rekurs auf diese Staatsvorstellung zu deuten. In Anbetracht der tatsächlich-politischen Gegebenheiten und auch der Entwicklung des Rechtsstaatsverständnisses - m.a. W.: des vorrechtlichen Gesamtbildes -, die dem Erlaß des Grundgesetzes vorausliegen, wäre eine solche Auslegung ganz unmöglich. Das Grundgesetz hat durch die Beifügung des Wortes "sozial" zudem ein ausdrückliches Gegengewicht gegen ein derartiges Mißverständnis geschaffen. Nicht zu übersehen ist auch, daß die $\mathrm{Zu}-$ ständigkeitsbestimmungen des Grundgesetzes (insbes. Art. 73-75) Agenden aufführen, deren staatliche Wahrnehmung den Bekenner klassischer Rechtsstaatlichkeit 28) erschaudern lassen muß.

Der vorherrschende Eindruck der grundgesetzlichen Ordnung ist demgegenüber der des formellen Rechtsstaates. 29) Das Grundgesetz konstituiert einen im Prinzip gewaltenteiligen Staat (A rt. 20 Abs. 2 und 3), verordnet die Gesetzmäßigkeit der Verwaltung (Art.20 Abs.3), ist um eine unabhängige Gerichtsbarkeit von umfassender Zuständigkeit (Art.92 ff) und lückenlosen Rechtsschutz besorgt (Art.19 Abs.4) und umgibt den Bürger mit weitreichender grundrechtlicher Sicherung (Art. 1-19, 101-103). Das Grundgesetz läßt es aber nicht dabei bewenden. Mit der Bindung des Gesetzgebers nicht nur an die Grundrechte (Art. 1 Abs.3), sondern an die ganze verfassungsmäßige Ordnung (Art.20 Abs.3) stößt es zur (modernen) materiellen Rechtsstaatlichkeit durch. Das ist um so deutlicher, als die verfassungsmäßige Ordnung eben nicht nur die staatliche Organisation (im weitesten Sinne) und nicht nur die Grundrechte einschließ1ich des Grundrechtssatzes von der Menschenwürde (Art. 1 Abs. 1), sondern auch das Prinzip der Sozialstaatlichkeit (Art.20 Abs. 1, 28 Abs. 1 Satz 1) umschließt. 30) Die

28) Sie stehen auch in offenbarem Gegensatz zu den Grenzen staatlicher Tätigkeit, die selbst ein so fortschrittlicher Vertreter dieser Lehre wie Darmstaedter (Die Grenzen der Wirksamkeit des Rechtsstaates, insbes. S. $155 \mathrm{ff}, 200 \mathrm{ff}, 252 \mathrm{ff}$ ) glaubt ziehen zu müssen.

29) Zum Folgenden s. ergänzend Maunz, Deutsches Staatsrecht, S. 57 ff; v. Mangoldt-Klein, Art. 20 Anm. VI und V 5 b; Scheuner, Die neuere Entwicklung des Rechtsstaats in Deutschland, S. $247 \mathrm{ff}$.

30) S. zu Vorstehendem insbes. Menger, Der soziale Rechtsstaat im Bonner Grundgesetz, S. 17 f; Hamel, Die Bedeutung der Grundrechte im sozialen Rechtsstaat, 1957, S.27 f. 
Bindung der vollziehenden Gewalt an "Gesetz und Recht" (Art.20 Abs. 3) ist zumindest ebenfalls als eine Absage an unkritische Legalität zugunsten der. Bindung an eine dem einfachen formellen Gesetz überlegene Normenschicht zu sehen. 31) Das Grundgesetz überhöht zudem die Prinzipien der Art. 1 und 20, inclem es sie (ler' Disposition des Verfassungsgebers entzieht (Art. 79 Abs.3). Indem Art. 28 Abs. 1 Satz 1 GG von dem "Rechtsstaat im Sinne dieses Grundgesetzes" spricht, dokumentiert die Verfassung ferner, daß über die positiven Detailregelungen hinaus die "verfassungsmäßige Ordnung" als eine rechtsstaatliche verstanden werden und gelten sol1. 32) Rechtsstaatliche Maximen wie die Rechtssicherheit, die Verhältnismäßigkeit von Zweck und Mittel, die Meßbarkeit aller staatlichen Befugnisse usw. ${ }^{33)}$ sind also geltendes Verfassungsrecht, auch wenn und soweit sie nicht schriftlich niedergelegt sind. Den Ländern ist durch Art. 28 Abs. 1 Satz 1 GG endlich aufgegeben, für ihren Bereich eine rechtsstaatliche Verfassungsordnung aufzurichten und zu erhalten, auch soweit das Grundgesetz sie nicht schon - wie z. B. hinsichtlich der Grundrechte - unmittelbar an seine positiven, rechtsstaatlichen Verfassungssätze bindet. Insgesamt ist also für den gesamtstaatli(hen Bereich der Bundes republik eine rechtsstaatliche Verfassungsordnung nicht nur im formellen, sondern auch im neueren materiellen Sinne gewährleistet.

Daran, daß diese durch Grundgesetz aufgerichtete rechtsstaatliche Ordnung einer sozialen Intervention schlechthin entgegen wäre, braucht im Ernst nicht gedacht zu werden. Das Sozialstaatsprinzip stützt im Gegenteil die soziale Intervention und regt sie an. Die materiell-rechtsstaatliche Substanz ist im ganzen sozial pusitiv. Dennoch oder vielleicht gerade deshalb bleibt problematisch, wie sie sich mit der furmellen Rechtsstaatlichkeit verbindet und wie sich die rechtsstaatliche Ordnung insgesamt zur tatsächlich-politischen Erscheinung der sozialen Intervention verhält.

31) Zur Auslegung s.u.

32) Vgl. Klein, Bonner Grundgesetz und Rechtsstaat, S.390: "Durch die llorte 'im Sinne dieses Grundgesetzes' bringt die westdeutsche Verfassungsurkunde implicite zum Ausdruck, daß auch die verfassungsmäßige Ordnung im Bunde selbst die Grundsätze des republikanischen, demokratischen und sozialen Rechtsstaates befolgt und verwirklicht". S. ferner Maunz, Deutsches Staatsrecht, S. 57; v. MangoldtKlein, Art. 20 Anm.VI, Einl., Ziff. 1 und 2.

33) Nachweise werden zum folgenden Text gegeben. 
II. Die Gewaltentrennung und die mit ihr zusammenhängenden Prinzipien im Verhältnis zur sozialen

Intervention

1. Wandlungen der Gewaltenteilung und soziale Intervention

$\mathrm{Zu}$ den Grundsäulen moderner, freiheitlicher Staatsordnung und bürgerlich-liberaler Rechtsstaatlichkeit gehört seit je die Aufgliederung der staatlichen Gewalt in Gesetzgebung, vollziehende Gewalt und Rechtsprechung, die Aufteilung dieser drei Funktionen auf verschiedene Organe und die persönliche T'rennung der Inhaberschaft. 1) Das Schema geht bekanntlich auf Montesquieu zurück. 2) Ihm liegt die Vorstellung dreier Machtsubjekt-Einheiten zugrunde: Monarch, Aristokratie und Bürgertum (Volk). Auf ihnen sollte die Gewaltentrennung aufbauen. Adel und Volk sollten, indem sie je eine Kammer des aus Gründen der. Balance in sich geteilten Legislativkörpers stellten, die Gesetzgebung innehaben. Dem Monarchen sollte die vollziehende Gewalt vorbehalten bleiben. Die Rechtsprechung - nicht eigentlich als "Gewalt" betrachtet - wurde mit keiner der politischen Einheiten verbunden. 3) Diese Vorstellung entsprach im großen und ganzen den Verhältnissen zur Zeit Montesquieus und in etwa auch noch der Zeit, in der sich der formelle, bürgerlich-liberale Rechtsstaat

1) S. f.v.a. Carl Schmitt, Verfassungslehre, S. $125 \mathrm{ff}, 182 \mathrm{ff}$, $200 \mathrm{ff}$.

2) Zur Entwicklungsgeschichte s. z.B. Carl Schmitt, a.a.O. S. $182 \mathrm{ff}$; s. neuerdings auch Eınst-Wolfgang Böckenförde, Gesetz und gesetzgebende Gewalt, 1958, S.20 ff.

3) Zur Konzeption Montesquieus s. die jüngsten Darstellungen bei Böckenförde, a.a.O. S. 29 ff, und Krauss, Die Gewaltengliederung bei Montesquieu, Festschrift für Carl Schmitt, 1959, S. 103 ff; ferner Imboden, Montesquieu und die Lehre der Gewaltentrennung, 1958. - S. zu dem genannten Essentiale des ursprünglichen Verständnisses der Gewaltenteilung auch: Küster, Das Gewaltenproblem im modernen staat, AöR Bd. 75 (1949) S. 397 ff (410 f); v.d. Hevdte, Montesquieu - vom Geist der Gesetze, 1950, S. 69 ff; Forsthoff in der. Einleitung zu Montesquieu, Vom Geiste der Gesetze, 1951, Bd.1 S.XXX f; Draht, Die Gewaltenteilung im heutigen deutschen Staatsrecht, in "Faktoren der Machtbildung", 1952, S.99 ff (103 und passim); Menger, Das Gesetz als Norm und Maßnahme, S. 25 ff; Werner. Weber, Spannungen und Kräfte im westdeutschen Verfassungssystem, S. 26 f, 45; ders., Die l'eilung der Gewalten als Gegenwartsproblem, Festschrift für Carl Schmitt, 1959, S.25. ff (25) ff). 
durchsetzte. ${ }^{4)}$ In dem Maße jedoch, in dem die Macht der Dynastien und die Stellung der Aristokratie von den aufkommenden massendemokratischen Kräften unterspült und schließlich beseitigt wurden, schwand das reale Substrat der Gewaltenteilung originaler Provenienz dahin. 5) Der Verfassungswandel von 1918, unleugbar auch der von 1933, und schließlich die Neuordnung in den Jahren 1945-1949 machten es immer wieder offenbar. Oben 6 ) wurde bereits darauf hingewiesen, daß die Verfassungsordnung des Grundgesetzes letztlich nur e ine Basis der politischen Willensbildung kennt: das Volk, das in Parteien (und Verbänden) gruppiert im dynamischen Wechselspiel mit der politischen Führungsschicht die Handhabung alle r "Gewalten" mehr oder weniger intensiv, unmittelbar oder mittelbar determiniert. Der Gedanke an eine, mit der Bindung an bestimmte soziale Gruppen zusammenhängende materielle Prädisposition der verschiedenen "Gewalten" zu den sozialen Problemen scheidet daher gänzlich aus. Was infolge der verschiedenen Tätigkeitsbereiche, Kreationsverfahren usw. an typischen Unterschieden verbleibt, ist vergleichsweise geringfügig.

Diese Entwicklung hat die Hemmungs- und Kontrollfunktion des Gewaltenteilungssystems gelähmt. Das gilt vor allem für das Verhältnis des parlamentarischen Legislativkörpers zur parlamentsgewählten und -abhängigen Regierung, ${ }^{7)}$ weniger für das Verhältnis der Legislative und Exekutive zur Rechtsprechung, die als "uneigentliche", nicht auf eine gesellschaftlich-politische Machtgruppe gestützte Gewalt im wesentlichen immer von ihrer Macht-Ferne und Unabhängigkeit charakterisiert war und mit dem Wandel der gesellschaftlichen Struktur kein ihr eigenes spezifisches Substrat zu verlieren hatte. ${ }^{8)}$ Fine Neubesinnung auf

4) S. Weber, Die Teilung der Gewalten als Gegenwartsproblem, a.a.O.

5) Zu diesem Wandel s. insbes. Küster, a.a.O.; v.d. Heydte, a.a.O.; Draht, a.a.O. S.99 ff, $135 \mathrm{ff}$; Menger,a.a.O. S.26; Werner Weber, Spannungen und Kräfte im westdeutschen Verfassungssystem, S. 27 und passim; ders., Die Teilung der Gewalten als Gegenwartsproblem, S.254 ff und passim.

6) Abschn. 3 III (S. 340 ff).

7) Vgl. Draht, a.a.O. S.119 ff, 127 ff; Peters, Die Gewaltenteilung in moderner Sicht, 1954, S.10 ff; Werner Weber, Die Teilung der Gewalten als Gegenwartsproblem, S.260 ff (s. a. S. 271 f). - S. ferner O. S. 344 und d. dort. Nachw.

8) Vgl. Werner Weber, ebd., S.259 f, 264, 271; s.a. Draht, a.a.O. S. $107 \mathrm{ff}$. - S. ferner o. Abschn. 3 III 3 (S.352 ff) und d. dort. Nachw. 
den freiheitssichernden Zweck der Gewaltenteilung und auf Mittel zur Ergänzung der funktionsschwach gewordenen horizontalen Gewaltenteilung ist daher notwendig geworden. ${ }^{9)}$ Auf diesem Boden wuchs die Deutung von Föderalismus und Selbstverwaltung als eines Komplementärsystems vertikaler Gewaltenteilung. 10) Man glaubte auch, das Balancesystem des Kräftespiels der Parteien und politisch mächtigen Gruppen als diejenige Erscheinung sehen zu dürfen, die nunmehr in Wahrheit eine Gewaltenteilung verwirklicht. 11) Aber die überkommene Dreiteilung der Gewalten 12 ) ist nicht aufgegeben. Sie konnte nicht aufgegeben werden

9) S. außer den S.406f in Fußn.3-7 Zitierten: Ballerstedt, Rechtsstaat und Wirtschaftslenkung, AöR Bd.74 (1948) S. 129 ff (155 f); Ernst v. Hippel, Gewaltenteilung im modernen Staat, o.J. (1949). - Eine Bibliographie zum Problem der Gewaltenteilung für die Zeit von 1949 bis 1955 findet sich übrigens bei Jahrreiß, Die Wesensverschiedenheit der Akte des Herrschens und das Problem der Gewaltenteilung, in "Vom Bonner Grundgesetz zur gesamtdeutschen Verfassung", Festschrift für Hans Nawiasky, 1956, S. 119 ff (119 f, Fußn. 1).

10) S. o. S. 219 , insbes. S. 220 zu Fußn. 2.

11) Vg1. Werner Weber, Spannungen und Kräfte im westdeutschen Verfassungssystem, S.28; ders., Die Teilung der Gewalten als Gegenwartsproblem, S.265 ff; Menger, Das Gesetz als Norm und Maßnahme, S. $27 \mathrm{f}$.

12) Auf die Versuche, die Zahl der Gewalten zu vermehren $z$. B. um eine aus der gesetzgebenden herausentwickelte verfassungsgebende Gewalt (vgl. z. B. Wolff, Verwaltungsrecht I, S. 54), um eine von der Exekutive abgegrenzte Regierungsgewalt (s. zu diesem Problem Scheuner, Der Bereich der Regierung im Rechtsstaat, in "Rechtsprobleme in Staat und Kirche", Festschrift für Rudolf Smend, 1952, S.253 ff) oder um eine besondere auswärtige Gewalt (s.hierzu Grewe und Menzel, Die auswärtige Gewalt der Bundesrepublik, Veröf fentlichungen der Vereinigung der deutschen Staatsrechtslehrer, Heft 12, 1954, S. 129 ff (130 ff) bzw. S. 179 ff (183 ff))oder sie zu vermindern - z. B. auf normsetzende und Finzelfall-entscheidende Gewalt (Jahrreiß, a.a.O.) - braucht hier nicht eingegangen zu werden (s.hierzu mit weiteren Beispielen Maunz-Dürig, Art.20 Randn. 77). Sie spielen für die hier in Frage stehenden Zusammenhänge keine entscheidende $R$ sl1e. - Der neuartige Versuch Loewensteins (Verfassungsletre, S. $39 \mathrm{ff})$, zwischen den Funktionen der politischen Grundentscheidung, ihrer Ausführung und der politischen Kontrolle zu unterscheiden, liegt mit der hier gemeinten, für den Rechts- 
ohne Verzicht auf die dem Rechtsstaat wesentliche maximale Bin(lung der staatlichen Macht an das Recht. 13) Der Rechtsstaat bedarf des formellen, von einem besonderen Legislativorgan 14) erlassenen Gesetzes zur normativen Bindung von Verwaltung und Rechtsprechung. 15) Er bedarf der Absonder ung der vollziehenden

staat wesentlichen Trichotomie der Funktionen in interessanter Überschneidung. Die von ihm herausgestellten GesetzmäBigkeiten werden auch hier immer wieder von Bedeutung sein. Aber von der Verfassung und von rechtsstaatlicher Sicht her ist doch die überkommene Dreiteilung die gegebene Basis der Erörterung.

13) Zur rechtsstaatlichen Maxime der normativen Bindung und reziprok - der Meßbarkeit der staatlichen Machtbetätigung s. Friedrich Julius Stahl, Die Philosophie des Rechts, 3. Auf1. Bd. II, Rechts- und Staatslehre auf der. Grundlage christlicher Weltanschauung, Zweite Abteilung, 1856, S. 137 (Der Rechtsstaat "soll die Bahnen und Grenzen seiner Wirksamkeit wie die freie Sphäre seiner Bürger in der Weise des Rechts genau bestimmen und unverbrüchlich sichern".); referierend über weitere, hierzu zeitgenössische Äußerung: Darmstaedter, Die Grenzen der Wirksamkeit des Rechtsstaats, S. 62 ff; Georg Meyer, Lehrbuch des Deutschen Staatsrechts, 1.Auf1. 1878, S.22 (Rechtsstaat ist ein Staat, "in dem die Befugnisse der Verwaltung gesetzlich fest umgrenzt sind und nur in Übereinstimmung mit den Gesetzen ausgeübt werden können".); Carl Schmitt, Verfassungslehre, S. 131; Thoma, Abschnitt "Der Vorbehalt der Legislative und das Prinzip der Gesetzmäßigkeit von Verwaltung und Rechtsprechung" im Handbuch des Deutschen Staatsrechts, Bd. II 1932, S. 221 ff (233: Der. Staat ist "Rechtsstaat in dem Maße, in dem seine Rechtsordnung die Bahnen und Grenzen der öffentlichen Gewalt normalisiert".). Zur Gesamtentwicklung s.nochmals Scheuner, Die neuere Entwicklung des Rechtsstaats in Deutschland.

14) bzw. "von besonderen Legislativorganen". - Zum demokratischen Rechtsstaat gehört, daß die Gesetze grundsätzlich wenn nicht vom Volk selbst so doch von einem Organ mit intensivster und breitester demokratischer Legitimation erlassen werden. Das Gesetz wird auf diese Weise zum Garanten der Autonomie des demokratischen Volkes und der approximativen Identität von Herrschern und Beherrschten (s. hierzu z. B. Nawiasky, Allgemeine Staatslehre, Teil 3, S. 122 ff).

15) S. zur rechtsstaatlichen Funktion des formellen Gesetzes die schon zitierte Monographie von Böckenförde über "Gesetz und gesetzgebende Gewalt". 
und der rechtsprechenden Gewalt von der gesetzgebenden, da die normative Fremdbindung in mamnigfacher Weise nachhaltiger wirkt als sie selbst eine ehrlich beabsichtigte Selbstbindung eines gewaltenvereinigenden Organs. Eine gesondere rechtsprechende Gewalt ist zur Durchsetzung des Rechts gegenüber dem Staat schlechterdings unerläßlich. 16) So hat auch das Grundgesetz eine gewaltenteilige Staatsordinung aufgerichtet - keineswegs von extremer Reinheit aber im Prinzip doch eindeutig. 17) Und sie ist also nicht funktionslos. 18) Nur muß sie nüchtern vor dem Hintergrund des demokratischen Monismus gesehen werden. Welche Bedeutung ihm für die sozial relevanten Inhalte des Staatswillens zukommt, wurde in den wesentlichen Zügen bereits im vorigen Abschnitt unter dem Gesichtspunkt der Relation Demokratie - soziale Intervention angedeutet.

Ein anderer Wandlungsprozeß in lem Funktionszusammenhang der gewaltenteiligen Herrschaftsordnung ist bedingt durch die $\mathrm{Zu}-$ nahme der Staatstätigkeit, die eingetreten ist seit der Staat aus seiner liberalistischen Reserve herausgetreten ist, sozial und wirtschaftlich interveniert, und in wachsendem Umfang auch schlechthin daseinsvorsorgend in die gesellschaftlichen und ökonomischen Gegebenheiten und Abläufe eingreift. Der Anteil des engeren Bereiches der sozialen Intervention an dieser Entwicklung ${ }^{19)}$ ist nicht quantitativ oder qualitativ typisierend ausscheid-

16) So z.B. Werner Weber, Die l'eilung der Gewalten als Gegenwartsproblem, S. 259 f, 264.

17) Die Grundsätze des grundgesetzlichen Gewaltenteilungssystems und die von der Verfassung selbst getroffenen Ausnahmen sind dargestellt bei 1)raht, Die Gewaltenteilung im heutigen deutschen Staatsrecht, und bei Peters, Die Gewaltentrennung in moderner. Sicht, insbes. S. $10 \mathrm{ff}$; s. a. V. Mangoldt-Klein, Art. 20 Anm. () b; Maunz-Dürig, Art. 20 Randn. $74 \mathrm{ff}$.

18) s. Werner Weber, a.a.O. S. 263 ff; s.a. Rumpf, Verwaltung und Verwaltungsrechtsprechmis, VVDStL. H. 14, 1956, S. 136 ff (145). Vgl. vor alle'n aber Peter Schneicler, Zur Problematik der Gewaltentoiluns im Rechtsstaat der Gegenwart, AöR Bd.82 (1957) S. 1 ll, insbes. S. 12 ff, 21 ff.

19) Sie wurde im Schrifttum beruits eingehend beschrieben und bedarf daher einer breiten Darstellung hier nicht. Nachw. und Hinw. finden sich bereits ). S. 1 ff unter A II 3 (S. 31 ff) und B 1 I 2 (S. 81 ff). N(rit. Nachw. ferner in den Anmerkungen zum folg. Text. 
bar. Fr ist aber jedenfalls so erheblich, daß sie zwar nicht allein aber doch auch dem Phänomen der sozialen Intervention als signifikant zugerechnet werden kann. Ihre Wege sind verschlungen und ihre Schwerpunkte nicht immer evident. Sie hat, je nachdem die Fxpansion der staatlichen Aktivität mehr auf dem Sektor der Rechtsetzung, der Verwaltung oder der Rechtsprechung hervorgetreten ist, zum Teil auch im Verein mit der zeitbedingten Verdichtung oder auch dem vorübergehenden Schwund der rechtsstaatlichen Postulate, viel zu dem Zustandekommen der Schlagworte vom "Verwaltungsstaat", "Gesetzgebungsstaat", "Justizstaat" usw. 20) beigetragen. In Wahrheit liegt weder allein ein Mehr an Verwaltung noch im besonderen ein Mehr an Gesetzgebung oder Rechtsprechung, sondern ein Mehr an "Staat" schlechthin vor. Ausgegangen ist die Entwicklung allerdings in erster Linie von einer gewaltigen Zunahme an Verwaltungsaufgaben. Zwar ließ sich ein Teil der neu aufkommenden Staatsaufgaben noch zweckgerecht mit dem liberaler Rechtsstaatlichkeit gemäßeren Mittel normativer Ordnung der intragesellschaftlichen Beziehungen 21) bewältigen. 22) Aber soweit seitens des Staates Leistungen dargereicht werden mußten, soweit Verteilung und Umverteilung über den Staat - und die ihm inkorporierten Verwaltungseinheiten - oder wenigstens unter seiner nicht nur generell normierenden sonder'n individuell dirigierenden Leistung und Aufsicht erfolgen mußten, soweit mußte die Verwaltung tätig werden. Dadurch wurde der Gesetzgeber über den Erlaß unmittelbar sozialgestaltender, normativer Ordnungen hinaus aktiviert. Soweit das Verwaltungshandeln nicht ohnedies den Legislativakt voraussetzt, steht es wenigstens in der. Macht des Gesetzgebers, kraft des Vorranges les Gesetzes und der Gesetzesgebundenheit der Verwaltung das Verwaltungshandeln zu initiieren und zu regulieren. Dieser Aufgabe, das Notwendige, und dieser Versuchung, ein Übriges zu tun, könnte und kann sich der Gesetzgeber nicht entziehen. so schwoll nicht nur das Verwaltungs- sondern auch das Gesetzgebungsvolumen an. Damit stieg auch die Zahl potentieller

20) Zu diesen Begriffen s. Ule, Über das Verhältnis von Verwaltungsstaat und Rechtsstaat, in "Staats- und verwaltungswissenschaftliche Beiträge", 1957, S. $127 \mathrm{ff}$.

21) Vgl. Darmstaedter, Grenzen der Wirksamkeit des Rechtsstaates, \$. 155 ff und passim (s.insbes. S. $252 \mathrm{ff}$ ). - S. hier$z u$ auch Bettermann, Grundfragen des Preisrechts für Mieten und Pachten, 1952, S. 120 f; Bachof, Begriff und Wesen des sozialen Rechtsstaats, S. $65 \mathrm{f}$.

22) Trpisch sind bis heute große Teile des Arbeitsrechts geblieben. 
Rechtsstreitigkeiten. Sie vermehrten den Wirkungskreis der Rechtsprechung. Darüber hinaus wurde die Zuständigkeit der Gerichte erweitert. Die Eigengesetzlichkeit rechtsstaatlichen Sanktionsdenkens, die besondere Vertrauensposition der "Dritten Gewalt" und nicht zuletzt das mit der zunehmenden Existenzabhängigkeit der Bürger des verteilenden Staates wachsende Rechtsschutzinteresse haben dazu beigetragen. In stetiger Wechselbeziehung haben so Gesetzgebung und Verwaltung und Rechtsprechung sich um das mehr und mehr präzisierte, verfeinerte und verschränkte Gerüst rechtsstaatlicher Gewaltent rennung herum ausgebreitet. 23) Das Verhältnis der Gewalten zueinander und die innere Struktur der einzelnen Funktionen wurden durch diesen Expansionsprozeß vielfach betroffen und problematisch. 24)

2. Die soziale Intervention im "Gesetzesstaat"

a) Die allgemeine Tendenz zum Gesetzesstaat

Das westdeutsche Staatswesen ist augenfällig "Gesetzgebungsstaat" und "Gesetzesstaat" - jedenfalls in einem quantitativen Sinn. 1) "Motorisierte Gesetzgeber" (Carl Schmitt) - der Gesetz-

23) Peter Schneider, Zur Problematik der Gewaltenteilung im Rechtsstaat der Gegenwart, S.12: "So stehen wir. denn vor der Tatsache, daß im ganzen die Reichweite staatlicher Aktivität größer geworden, daß sich diese Entwicklung jedoch nicht im Bereiche einer Gewalt lokalisieren läßt, sondern Legislative, Exekutive und Rechtsprechung gleichmäßig erfaßt..." Vgl. ferner Kaufmann, Crundrechte und Wohlfahrtsstaat, Recht Staat Wirtschaft, Bd. IV (1953) S. 77 ff (83); Giese, Staatsrechtliche Gedanken zur Verwaltungsreform, DÖV 9.Jhg. (1956) S. 357 ff (358f).

24) Alle Nachweise zu Vorstehendem s. zum nachfolgenden Text.

1) (1) Leider fehlt für den Begriff des "Gesetzesstaates" eine so eingehende Begriffssystematik, wie sie Ule für den Verwaltungsstaat entwickelt hat (Ule, Über das Verhältnis von Verwaltungsstaat und Rechtsstaat). Doch lassen sich - in Anlehnung an Ule - wohl folgende speziellere Begriffe herausstellen:

(a) ein schlicht quantitativer, durch den das rein äußere Übergewicht der Gesetze vor den übrigen Staatstätigkeiten hervorgehoben werden soll;

(b) ein funktioneller Begriff des Gesetzgebungsstaates, der auf die Ausbreitung der Gesetzgebung (Rechtsetzung) als der vorherrschenden Staatstätigkeit abhebt, neben der die rechtsprechende und vollziehende Gewalt an eigenständiger Bedeu- 
geber des Bundes diejenigen der kompetenzarmen Länder freilich fast über Sichtweite zurücklassend - produzieren eine Überfülle von Gesetzen, die sie rasch und immer wieder novellieren, erteilen Verordnungsermächtigungen und finden sich sodann durch noch zahlreichere und nicht weniger aktive verordnungsgebende Instanzen in der Rechtsetzung aufs eifrigste unterstützt. Die Gesetzgebung verläßt ihren Kernbereich: das Schaffen dauernder Ordnungen, um kurzfristige, sachlich konkrete Maßnahmen zu ergreifen bzw. anzuordnen. 2) Das "überanstrengte" Recht ver-

tung (qualitativ) verlieren;

(c) ein organisatorischer Begriff des Gesetzgebungsstaates, der auf die Vorherrschaft der gesetzgebenden Organe und zwar über den funktionellen Bereich der Gesetzgebung hinaus abstellt (grundlegend Carl Schmitt, Legalität und Legitimität, 1932). Für diesen Begriff dürfte der T'erminus "Gesetzesstaat" als Synonym abzulehnen sein.

(2) Im Schrifttum tritt die nähere Unterscheidung nicht immer hervor. Bei Ule (a.a.O. S.138 ff) geht die Diagnose vorwiegend auf einen Gesetzgebungsstaat im organisatorischen Sinn (allerdings in der besonderen Legierung des Gesetzgebungs - und Rechtsprechungsstaates); ähnlich Wernicke, Bonner Kommentar, Art. 20 Erl. II 2 g; Gross, "Betrachtungen", DVB1. 70.Jhg. (1955) S.389 f (390). Überwiegend wird von Gesetzes-bzw. Gesetzgebungsstaat dagegen in einem quantitativ-funktionellen Sinn gesprochen (vgl. z. B. Scheuner, Der Begriff der Regierung im Rechtsstaat, S.277 (s.a. S.274);

Dürig, Verfassung und Verwaltung im Wohlfahrtsstaat, S. 194 f; Giese, Staatsrechtliche Gedanken zur Verwaltungsreform, S. 358; Lerche, Grundrechtsbegrenzungen "durch Gesetz" im Wandel des Verfassungsbildes, DVB1. 73. Jhg. (1958) S. 524 ff (526)) .

2) Zum Problem der Maßnahmegesetze s. vor allem Forsthoff, Über Maßnahme-Gesetze in "Forschungen und Berichte aus dem öffentlichen Recht", Gedächtnisschrift für Walter Jellinek, 1955, S.221 ff; Haußleiter, Maßnahmerecht und Dauerrecht auf dem Gebiet der wirtschaftspolitischen Verordnungsund Gesetzgebung, DÖV 9. Jhg. (1956) S. 143 ff; Ballerstedt, Über wirtschaftliche Maßnahmegesetze, Festschrift für Walter Schmitt-Rimpler, 1957, S.369 ff; Menger und Wehrhahn, Das Gesetz als Nor'm und Maßnahme, Veröffentlichungen der Vereinigung der Deutschen Staatsrechtslehrer, Heft 15, 1957, S. 3 ff bzw. S. 35 ff; Zeidler, Bundesverfassungsgericht und "Maßnahmegesetz", JZ 15.Jhg. (1960) S. 391 ff; Maunz-Dürig, Art. 20 Randn. 99 fr; Scheuner, Die Aufgabe der Gesetzgebung in unserer Zeit, \$. 602 ?. 
liert seine Standfestigkeit, seinen "konservativen Charakter" und wird zum rasch reflektierenden "Situationsspiegel". 3)

Diese Entwicklung ist im Wesen eines demokratischen, gewaltenteiligen, föderativen Rechtsstaates angelegt, der seine Aufgabe in einer umfassenden sozialgestaltenden Wirksamkeit sieht. Das diesem Staat anlastende Aufgabenpensum kommt immer wieder und von vielen Seiten auf den Gesetzgeber zu. ${ }^{4)}$ Das gilt sowohl insoweit, als die staatliche Tätigkeit primär in der rechtlichen Ordnung liegt, wie das vor allem hinsichtlich der Gestaltung zwischenbürgerlicher (privatrechtlicher) Beziehungen der Fall ist, als auch insoweit, als der Staat zwar primär zu sachlichen Veranstaltungen, konkreten Maßnahmen usw., die an sich Aufgabe der Verwaltung sind, aufgerufen ist, diese aber der allgemeinen Regelung durch den Gesetzgeber bedürfen oder doch zugänglich sind.

Die Rechtsprechung kann den Gesetzgeber nur sehr begrenzt entlasten. 5) Sie kann ihm vorarbeiten, indem sie aus allgemeinen Grundsätzen sachgerechte Maßstäbe zur Lösung bestimmter vom Gesetzgeber noch nicht aufgegriffener Fragen ermittelt. Stimmen diese mit der in den zuständigen Legislativorganen vertretenen allgemeinen Ansicht überein und gewinnen sie hinreichende Bestimmtheit und Beständigkeit, so kann das aus der Rechtsprechung hervorgehende Gewohnheitsrecht (Juristenrecht) den Gesetzgeber sogar auf Dauer einer ausdrücklichen Regelung enthe-

3) Vgl. Hans Huber, Niedergang des Rechts und Krise des Rechtsstaates, insbes. S. 79 ff ("6. Die Überanstrengung des Rechts"),S.82: "... wenn es gesellschaftlichen Wechsel und wechselnde Bedürfnisse nur noch registrierend in sich aufnimmt, ist es kein Recht mehr, sondern nur noch ein Situationsspiegel. Der konservative Charakter des Rechts und die Dynamik der wechselnden Massenbedürfnisse in der Gegenwart vertragen sich gegenseitig nicht, aber die Dynamik und auch die Unentbehrlichkeit des Rechts als Reglementierungsmittel sind stärker, und so verliert eben das Recht sein stützencles Rückgrat. Es wird selber kompaßloser Voluntarismus einer fließenden gesellschaftlichen Wirklichkeit".

4) Jahrreiß, Größe und Not der Gesetzgebung, in "Mensch und Staat", S. $19 \mathrm{ff}$ (S. 20 f, $51 \mathrm{ff}$ und passim);s.a. Scheuner, Diskussionsbeitrag zu "Das Gesetz als Norm und Maßnahme", VVDStRL. H. 15, 1957, S. 69 ff (75); ders., Die Aufgabe der Gesetzgebung in unserer Zeit, insbes. S. $605 \mathrm{ff}$.

5) S. hierzu noch unten $3(\mathrm{~S} .508 \mathrm{ff})$, insbes. b (S.512 ff). 
ben. ${ }^{6)}$ Je weniger nun aber eine ganz bestimmte Lösung aus allgemeinen Rechtsgrundsätzen abgeleitet werden kann und je mehr politischen Gestaltungswillens es bedarf, um sie zu statuieren, desto mehr verschließt sich dieser Weg. Er ist an sich von vorneherein sekundärer Natur. Rechts an wendung ist die Aufgabe der Gerichte. Die Unterworfenheit der Rechtsprechung unter das Gesetz (Art.20 Abs.3, 97 Abs. 1 GG bürdet dem Gesetzgeber Kompetenz und Verantwortung auf.

Die Verwaltung ergeht sich von Haus aus nicht in der Rechtsfindunğ. Sie kommt dem Gesetzgeber auch nicht spezifisch dadurch entgegen, daß sie - wie die Rechtsprechung - eine neue recht$1 \mathrm{i} c \mathrm{~h}$ e Spannungslage erkennt und zu deuten und zu bewältigen versucht. Sie sieht vielmehr die tatsächlichen und praktischen Erfordernisse im Vordergrund und versucht im Ranmen ihres allgemeinen Auftrages und inrer allgemeinen Zuständigkeitsordnung des Problems Herr zu werden. So stößt sie den Gesetzgeber vielleicht auf neue Aufgaben, die er selbst noch nicht gesehen hat oder aufgreifen wollte. ${ }^{7)}$ Aber wie weit kommt sie ohne die Normierung durch den Gesetzgeber und wie weit kann der Gesetzgeber sie sich selbst überlassen? Umfassende Gesetzesvorbehalte ${ }^{8)}$ erheben das Gesetz weitestgehend zur Voraussetzung jedes Tätigwerdens der Verwaltung. Aber selbst in dem Bereich der Verwaltung, der keinem Gesetzesvorbehalt unterliegt, kann der Gesetzgeber normierend eingreifen und bindet er die Verwaltung dadurch (Art.20 Abs.3 GG). Aus dieser universellen Kompetenz erwächst schließlich auch eine universelle Letztverantwortung des Gesetzgebers.

Seine Befugnis, die anderen beiden Gewalten durch die generelle normative Ordnung zu binden und mit dem Mittel der Gesetzgebung zu dirigieren, auszunutzen, wird der Gesetzgeber - über die naturgemäße Tendenz einer jeden Zuständigkeit, ausgefüllt $z u$ werden, hinaus - durch strukturelle Bedingungen der Verfassungsordnung entscheidend angetrieben.

Stimulierend wirkt vor allem die breite demokratische Reflexion

6) Interessant ist, daß die Rechtsordnung die Gerichte in dieser Funktion ausdrücklich bestätigt und bestärkt. S. die Zuständigkeit der (Vereinigten) Großen Senate der oberen Bundesgerichte zur Rechtsfortbildung: $\$ 137$ GVG, $\$ 11$ Abs. 4 VGO, $₫ 43 \mathrm{SGG}, \$ 45 \mathrm{Abs} .2 \mathrm{ArbGG}$. Zu den Problemen des Richterrechts s.ferner unten 3 (S. 508 ff), insbes. S. 525

7) Vgl. Becker, Verwaltung und Verwaltungs rechtsprechung, S. 103 .

8) S. u. b bb (S. 420 ff). 
der parlamentarischen Gesetzgebungsorgane. ${ }^{9)}$ Sie sind das klassische Feld des Kampfes um den Stimmzettel, der nicht zuletzt mit mehr oder weniger einseitigen "Gefälligkeitsgesetzen" geführt wird. In hervorragender Weise setzen gerade die sozialen Materien mit ihren breiten und doch differenzierten Interessentenschichten diesen demokratischen "Mechanismus" in Gang. 10) Auf der anderen Seite hebt die Schicksalsgemeinschaft der Regierung mit "ihrer" Parlamentsmehrheit den Gegensatz zwischen Gesetzgebungsorgan und Exekutivspitze weitgehend auf und mindert vor allem auch die Bereitschaft der Regierung, sich der legislativen Einmischung zu erwehren.

Die Parlamente können mit Hilfe der Gesetzgebung aber nicht nur auf die der Regierung unterstehende Exekutive in einer jedes andere Mittel parlamentarischer Kontrolle an nachhaltiger Wirksamkeit hinter sich lassenden Weise eingreifen. 11) Sie können damit auch die Schranken vertikaler Gewaltenteilung überspringen; und weitgehend kann die Brücke vom weiteren zum engeren Gemeinwesen nu $r$ mittels der gesetzgebenden Gewalt des ersteren geschlagen werden. Der Bundesgesetzgeber bindet die Landesverwaltung und-gerichte (Art.20 Abs.3, 83 ff, 97 Abs. 1 GG) und drängt im Bereich der konkurrierenden und Rahmengesetzgebung auch den Landesgesetzgeber zurück (Art. 72, 74, 75 GG). Während dem Bunde - genauer: der Bundesverwaltung eine verbindliche Einwirkung auf die Verwaltungen der Länder außerhalb des Vollzugs von Bundesgesetzen versagt ist, bindet er durch den Erlaß von Bundesgesetzen nicht nur die Verwaltungen an diese Gesetze, sondern er gewinnt auch Leitungs- und Aufsichtsbefugnisse über die Landesverwaltung (Art.84, 85 GG). Auf dem Gebiete der Rechtsprechung korrespondiert mit der bundesgesetzlichen Regelung der Zuwachs unbestrittener Letztzuständigkeit der oberen Bundesgerichte. 12) Die Bundesgesetzgebung ist also die schneidigste Waffe des Bundes im Machtkampf mit den Ländern. Parallel verlaufen die 'Tendenzen hinsichtlich der kommunalen Selbstverwaltung, in die prinzipiell nur das (Bundes- oder Landes-) Gesetz eingreifen kann (Art.28 Abs.2 GG). 13)

9) Vgl. Landshut, Wandlungen der parlamentarischen Demokratie, S. $159 \mathrm{f}$.

10) S. nochmals oben Abschnitt 3 (S. $315 \mathrm{ff}$ ).

11) S. hierzu Scheuner, Die Aufgabe ler Gesetzgebung in unserer Zeit, S. 607.

12) S. zu der Tragweite der Art.96, 99 GG oben S.170, insbes. Fußn. $5 \mathrm{ff}$. 
$\mathrm{Ja}$, auch dort, wo der Gesetzgeber von sich aus selbständige Verwaltungseinheiten eingerichtet hat, kann er Anlaß haben, sich in diesem Sinne des Gesetzes als eines Instrumentes der Verwaltungsführung zu bedienen. Hat das ausgliedernde Gemeinwesen Bund oder Land - dem ausgegliederten Verwaltungsträger Selbstver'waltung unter Reduktion der staatlichen Ingerenz auf die Rechtsauf sicht gewährt, so ergibt sich ein Dilemma sobald einerseits die Verwaltungsübung der Selbstverwaltungsorgane mißbilligt wird, während andererseits die Prinzipien der Selbstverwaltung und der reinen Gesetzmäßigkeitskontrolle nicht revoziert werden sollen. Hier bietet sich, sofern nur der Gegenstand der Meinungsverschiedenheit der gesetzgeberischen Behandlung zugängig ist, ebenfalls das Gesetz als ein Mittel an, die Verwaltungseinheiten an der Kandare zu halten. Erhöhte Bedeutung kommt diesen Zusammenhängen gerade im Rahmen der sozialen Intervention $z u$, die so sehr zur möglichst allgemeinen, umfassenden, einheitlichen Regelung und zum Ausschluß partikularer, insbes. länderweiser Besonderheiten tendiert.

Damit wird der Blick auf das Egalitätsdenken als auf einen weiteren Grund der immer stärkeren Ausdehnung des Gesetzes gelenkt. Zwar binclet der Gleichheitsgrundsatz Verwaltung und Rechtsprechung nicht weniger als die Gesetzgebung (Art.3, 1 Abs. 3, 20 Abs. 3 GG). Jedoch kann daraus nicht der Grundsatz abgeleitet werden, die zuständigen, wenngleich möglicherweise jeweils verschiedenen Behörden und Gerichte müssen die ihnen belassenen Erkenntnis-, Beurteilungs- und Ermessensspielräume in bezug auf gleichliegende Fälle in durchwegs ganz der gleichen Weise ausfüllen. ${ }^{14)}$ Nur dann werden Abweichungen unmittelbar durch den Gleichheitssatz unterbunden, wenn sie willkürlich sind bzw. auf sachfremden Erwägungen beruhen. 15)

Die Toleranzzone ist breit. 16) Die Kontrolle ist durch die mangelnde Publizität der Einzelentscheidungen erschwert. Es kann somit zu recht unterschiedlichen Praktiken kommen. Ihnen kann nur mit Hilfe eingehender gesetzlicher Regelung entgegenget reten

13) S. zu Vorstehendem Scheuner, a.a.O.

14) BVerfGE 1, 83 (85), 352 (345); Ipsen, Gleichheit, S. 148, 150.

15) S. unten B 6 III $1(\mathrm{~S} .934$ f) und 2 (S. 935 ff); zu der interessanten Frage des Verhältnisses des Gleichheitsgrundsatzes zur Gesetzmäßigkeit der. Verwaltung s. Ipsen, a.a.O. S. 147 ff, $164 \mathrm{ff}$ mit weit. Nachw.

16) S. Menger, Rechtssatz, Verwaltung und Verwaltungsgerichtsbarkeit, DÖV 8.Jhg. (1955) S. 587 ff (592). 
werden. Perfektionistisches Egalitätsdenken drängt aber auf eine maximale Reduktion des Differenzialkalküls durch den Gesetzgeber und gibt auf diese Weise einen Grund mehr für die Expansion der Gesetzgebung ab. 17) Die innige Verbindung egalitärer und sozialer. Postulate verknüpft auch diese Stimulanz der Gesetzgebung in besonderem Maße mit der sozialen Intervention.

\section{b) Die Verklammerung von Gesetzgebung und Verwaltung}

\section{aa) Verwaltung - Rechtsstaat - Verwaltungsrecht}

Schon bisher ist deutlich geworden, daß das Wachstum der Legislativtätigkeit in entscheidendem Zusammenhang mit der Expansion der Verwaltung steht. Die große Masse der dem Staat im Rahmen der sozialen (und wirtschaftlichen) Intervention gestellten Aufgaben bedarf der verwaltungsmäßigen Wahrnehmung. Der soziale Ausgleich durch entsprechende Gestaltung der zwischenbürgerlichen Rechtsverhältnisse ohne Hilfeleistung durch bzw. Umverteilung über den Staat, d.h. also allein durch Legislative und Judikative kann nur in einem relativ kleinen Bereich wirksam werden. 1) Im übrigen bedarf es der Veranstaltungen, Eingriffe und Leistungen der Verwaltung. Der Umfang, in dem die Verwaltung im daseinsvorsorgenden, wirtschaftlich und sozial intervenierenden Staat tätig werden muß, hat ihm das Prädikat eines "Verwaltungssta ates" eingetragen, das zwar in

17) Scheuner, Diskussionsbeitrag zu "Verwaltung und Verwaltungs rechtsprechung", Veröffentlichungen der Vereinigung der Deutschen Staatsrechtslehrer, Heft 14, 1956, S. $181 \mathrm{ff}$ (184): "... daß die Verwaltung in einem wachsenden Maße gesetzesgebundene Anwendung des Rechts werden muß, weil die Gleichheitsforderung nur durch detaillierte Gesetzesmaßstäbe erfüllt werden kann". - S.a. ders., Diskussionsbeitrag zu "Das Gesetz als Norm und Maßnahme", S.74; ders., Die Aufgabe der Gesetzgebung in unserer Zeit, S. $605 \mathrm{ff}$.

1) Z.B. im Arbeitsrecht, im Mietrecht und in anderen leilgebieten des bürgerlichen Rechts. - Die Inanspruchnahme des Richters zur konkret-individuellen Gestaltung von Rechtsverhältnissen, die der Natur der Sache nach auch der Ver'waltung aufgetragen werden könnte (Beispiel: freiwillige Gerichtsbarkeit, Beschlußsachen im arbeitsgerichtlichen Verfahren), bezeichnet ein Grenzfeld, in dem sich lerwaltung und Rechtsprechung im materiell-funktionellen und im formell-organisatorischen Sinne begegnen (s. unten 3 (S. $508 \mathrm{ff}))$. 
einem anderen Sinne begrifflich entwickelt, mit der schlichten Bedeutung quantitativen Übergewichts der Verwaltung jedoch populär geworden ist. ${ }^{2)}$ Die Verwaltungstätigkeit ist im Rechts-

2) (I) Zum Begriff des "Verwaltungsstaates" s. Ule, Über das Verhältnis von Verwaltungsstaat und Rechtsstaat. Im Hinblick auf seine eingehende Darstellung und seine Belege kann es hier mit einer kurzen Zusammenfassung sein Bewenden haben. Die verschiedenen Begriffe sind:

(1) Der Verwaltungsstaat als Korrespondenzbegriff zum Justizstaat und zwar

(a) als Verwaltungsstaat, in dem die auswechselbaren $\mathrm{Zu}$ ständigkeiten zulasten der Gerichtsbarkeit überwiegend der Verwaltung zugewiesen sind, oder

(b) als Verwaltungsstaat, in dem die Verwaltung nicht der Kontrolle durch die allgemeinen Justizgerichte sondern durch besondere Verwaltungsgerichte unterliegt.

(2) Der Verwaltungsstaat, der über das Verhältnis Verwaltung - Justiz hinaus insbes. auch in der Relation Verwaltung - Gesetzgebung durch ein Übergewicht der Verwaltung gekennzeichnet ist. Das kann

(a) allgemein in einem quantitativen Vorherrschen der Verwaltung in einem undifferenzierten, materiellen und organisatorisch-formellen Sinn gemeint sein. Es kann aber auch näher dahin präzisiert sein, daß

(b) die Verwaltung als Funktion sich im Verwaltungsstaat in gesteigertem Maße ausbreitet, so daß schließlich nicht nur die Gerichte sondern auch die gesetzgebenden Organe ( $\mathrm{s}$. Maßnahmegesetze!) Tätigkeiten ausführen, die im funktionellen Sinne "eigentlich" Verwaltung sind.

(c) Endlich - und das ist die klarste und tiefste, auch folgenschwerste Begriffsbildung - wird unter Verwaltungsstaat im organisatorischen Sinn ein Staat verstanden, "in dem sich die Staatsgewalt bei Verwaltungsbehörden konzentriert oder doch jedenfalls mit ihrem Schwergewicht auf Verwaltungsbehörden verlagert" (Ule, a.a.O. S.138).

(II) Wenn die Bundesrepublik als "Verwaltungsstaat" bezeichnet wird, so spielen die unter 1 (S.406 ff) genannten Begriffe keine Rolle. In aller Regel ist, wenngleich bei sehr verschiedenen Vorstellungen, im einzelnen von einem Verwaltungsstaat im organisatorischen Sinn die Rede (vgl. Peters, Lehrbuch der Verwaltung, 1949, S. V und S. 131; ders., Der Kampf um den Verwaltungsstaat, in "Verfassung und Verwaltung", Festschrift für Wilhelm Laforet, 1952, S. 19 ff; ders., Die Gewaltentrennung in moderner Sicht, S. 7 - je unter dem Gesichts- 
staat an das Gesetz gebunden (Art.20 Abs. 3 GG) und an das Gesetz zu binden. ${ }^{3)}$ Der Rechtsstaat ist ein Staat des Verwaltungsrechts. 4) Der "Verwaltungsstaat" im quantitativen Sinn muß, wenn er nicht zum Verwaltungsstaat im organisatorischen Sinn einer verfassungs rechtlichen Vormachtstellung der Verwaltung umschlagen soll, 5) zum Staat der Verwaltungsgesetze werden. ${ }^{6}$ )

\section{bb) Die rechtsstaatliche Notwendigkeit des Gesetzes}

\section{aaa) Der Vorbehalt des Gesetzes}

Die Ausdehnung der Legislative ist, wie gesagt, vor allem auch die unausweichliche Konsequenz jener rechtsstaatlichen Prinzipien, die eine gesetzliche Ermächtigung und darüber hinaus eine

punkt einer Diskrepanz der Verfassungsordnung gegenüber den politischen Tendenzen und Realitäten; Hans Schneider, Gerichtsfreie Hoheitsakte, 1951 , S. 30 Anm. 40; Koellreutter, Grundf ragen des Verwaltungsrechts, S. 13 f, 24, 43; Leibholz, Die kritischen Punkte des Grundgesetzes, S. 19; Werner Weber, Spannungen und Kräfte im westdeutschen Verfassungssystem, S.35, 14, 6 ff). Bei allen aber schwingt der Gesichtspunkt der quantitativen Dominanz der Verwaltungsaufgaben mehr oder weniger deutlich mit. Dort, wo das Stichwort "Verwaltungsstaat" nur beiläufig gebraucht ist, ist es dagegen meist offensichtlich, daß dieser Gesichtspunkt im Vordergrund steht (s. z.B. Köttgen, Der Einfluß des Bundes auf die deutsche Verwaltung, S.72; Scheuner, Diskussionsbeitrag zu "Das Gesetz als Norm und Maßnahme" VVDStRL. H. 15, 1957, S. 66 ff (75)). S. hierzu auch Köttgen (Subventionen als Mittel der Verwaltung, DVB1. 68. Jhg. (1953) S.485 ff (485)), der von einem Übergang von dem organisatorischen Verwaltungsstaat der Zeit zwischen 1933 und 1945 zu einem mehr quantitativen spricht.

3) S. hierzu oben S. 409 zu Fußn. 13.

4) Roessler, Das soziale Verwaltungsrecht, Bd. I, 1872, S. VII: "... der Rechtsstaat aber ist der. Staat des Verwaltungsrechts".

5) S. Ule, Über das Verhältnis von Verwaltungsstaat und Rechtsstaat, insbes. S. $162 \mathrm{ff}$. Besonders eingehend setzt sich Darmstaedter (Die Grenzen der Wirksamkeit des Rechtsstaates, S. 52 f, 172 ff, 190 ff, 201 ff) mit der Kausalität Wohlfahrtsstaat - Verwaltungsstaat (im organisatorischen Sinn) auseinander.

6) S. Scheuner, Diskussionsbeitrag zu "Das Gesetz als Norm und Maßnahme", S. 75. 
eingehende gesetzliche Ordnung des Verwaltungshandelns zu dessen Voraussetzung machen. Je kürzer diese rechtsstaatlichen Normen die Verwaltung an die Kette des Gesetzes legen, desto weiter treiben sie dieses in den gegenständlichen Bereich der Verwaltung hinein, und desto häufiger erfordern sie den Erlaß und die Novellierung einschlägiger Gesetze.

1. Das Grundschema. Nach der rechtsstaatlichen Tradition besagt der Vorbehalt des Gesetzes, 1) die Verwaltung bedürfe in allen Fällen, in denen sie in "Freiheit oder Eigentum" des Bürger's eingreift, und darüber hinaus in den (sonst) in der Verfassung ausdrücklich vorgesehenen besonderen Fällen der gesetzlichen Legitimation als Voraussetzung der Zulässigkeit ihres Handelns. Dabei bedeutet die Formel von dem Eingriff in Freiheit und Figentum, die längst nur mehr Name einer bewußten Sache ist, nichts anderes, als daß jede "Begründung abstrakter oder konkreter Verpflichtungen durch Forderung eines Tuns, Duldens oder Unterlassens einschließlich der Entziehung oder Beschränkung von Rechten" unter den sog. Allgemeinvorbehalt des Gesetzes fällt. 2) Die ganze Eingriffsverwaltung ${ }^{3)}$ soll der gesetzlichen

1) Mit dem Vorbehalt des Gesetzes wird ein beziehungsreiches Thema des deutschen Staats- und Verwaltungsrechts angesprochen (heute noch grundlegend: Thoma, Der Vorbehalt der Legislative und die Gesetzmäßigkeit von Verwaltung und Rechtsprechung). Ursprünglich lag die Spannung des Problems vorwiegend in der Polarität zwischen der formellen Gesetzgebung durch Parlament und Krone und dem eigenständigen Verordnungs recht der letzteren, der Exekutive. Dieser or'ganisatorische Dualismus - durch den Wegfall der "Krone" des einen, durch die demokratische Exekutivspitze nicht ebenbürtig ersetzten Elementes beraubt - hat sich mehr und mehr aufgelöst. Das prinzipielle Rechtsetzungsmonopol der Legislativorgane ist unbestritten. An seine Stelle ist das Problem der materiellen Abgrenzung und des funktionellen Nebeneinander und Miteinander von Gesetzgebung und Verwaltung in den Vordergrund getreten. Seine Spannung liegt zwischen der potentiell gesetzesfreien und der notwendig gesetzes gebundenen Verwaltung. S. zu Vorstehendem z. B. Thoma, a.a.O. S. 222 ff; Scheuner, Der Bereich der Regierung im Rechtsstaat, S.263 ff; s.a. Böckenförde, Gesetz und gesetzgebende Ciewalt, insbes. \$. $221 \mathrm{ff}, 309 \mathrm{ff}, 320 \mathrm{ff}$.

2) (1) Wolff, Verwaltungsrecht I, S.125. - Weit. Nachw. s.u. zum Text.

(2) In der Ausdehnung der Formel von "Freiheit und Eigentum" zum umfassenden Allgemeinvorbehalt liegt eine Parallelent- 
Grundlage bedürfen. Im übrigen aber soll die Verwaltung, soweit nicht spezielle Gesetzesvorbehalte der Verfassung entgegenstehen, auf eine gesetzliche Grundlage ihres Vorgehens nicht angewiesen, den gesetzten Regelungen freilich stets unterworfen sein.

Die demnach grundsätzlich mögliche gesetzesfreie Verwaltung kann nicht unter Berufung darauf negiert werden, daß alle rechtlich anzuerkennenden Kompetenzen des Staates ohnehin der Begründung im Recht bedürften. Recht und Gesetz 4 ) sind hier auseinanderzuhalten. Das Gesetz ist - entsprechend seiner Funktion im gewaltenteiligen Staat - primär im förmlichen Sinne zu verstehen. Es entnimmt seine Autorität der Verfassung. Diese regelt aber nicht nur die Gesetzgebung, sondern konstituiert auch die Verwaltung und beauftragt sie mit dem Vollzug der Gesetze.5) Sie kann darüber hinaus der Verwaltung unmittelbar Aufgaben zuweisen. 6) Ist das geschehen, so leiten sich die entsprechenden

wicklung zu der Ausweitung des Eigentums- bzw. Enteignungsbegriffes und zu der Expansion des grundrechtlichen Freiheitsschutzes bis zu dem nach der herrschenden Auslegung des Art. 2 Abs. 1 GG heute erzielten gegenständlichen Maximum. Obwohl der gemeindeutsche Gesetzesvorbehalt schon ursprünglich umfassender war als die Formel von "Freiheit und Eigentum" annehmen ließ und auch nicht nur auf den verfassungs rechtlich positivierten Schutz dieser beiden Rechtsgüter zurückging (vgl. Böckenförde, Gesetz und gesetzgebende Gewalt, S.320), ist die innere Konsequenz dieser gleichlaufenden Entwicklung doch von Interesse.

3) Zur Abgrenzung der Eingriffs- von der Leistungsverwaltung s. z.B. Becker, Verwaltung und Verwaltungsrechtsprechung, insbes. S. $105 \mathrm{ff}$, m. eingeh. Nachw.; Bachof, Diskussionsbeitrag hierzu, S. $174 \mathrm{ff}$; Loschelder, Die Wahrung der öffentlichen Sicherheit und Ordnung in ihrem Verhältnis zur Leistungsverwaltung, DVB1. 72. Jhg. (1957) S. 819 ff; Klüber, dass., ebd. S. 827 ff; Rupp, Die Beseitigungs- und Unterlassungsklage gegen 'Träger hoheitlicher Gewalt, DVB1. 73. Jhg. (1958) S. 113 ff; s.a. Lerche, Grundrechtsbegrenzungen "durch Gesetz" im Wandel des Verfassungsbildes, DVB1. 73. Jhg. (1958) S. 524 ff (528); Werner, Verwaltungsrecht als konkretisiertes Verfassungsrecht, DVB1. 74.Jhg. (1959), S.530; Maunz-Dürig, Art. 20 Randn. $131 \mathrm{ff}$.

4) nicht im spezifischen Sinn des Art.20 Abs. 3 GG.

5) Vgl. Nawiasky, Allgemeine Staatslehre, Teil 3, S. $106 \mathrm{ff}$.

6) ebd. 
Befugnisse nicht weniger aus dem Recht ab als die über das Medium les Gesetzes vermittelten. Ob es geschehen ist, ist eine Frage des positiven Verfassungsrechts. ") Es ist aber nicht so, daß in clem als Rechtsgebilde richtig verstandenen Staat die Verwaltung immer nur förmliche, unter der Verfassung rangierende Gesetze zu vollziehen hätte. ${ }^{8)}$

7) Vgl. Kelsen, Hauptprobleme der Staatsrechtslehre, 2. Auf1. 1923 , S. $501 \mathrm{f}$.

8) (1) Dieses Mißverständnis wurde nicht zuletzt durch die reine Rechtslehre heraufbeschworen, die nicht nur die Verwaltung als Normvollzug verstanden (s, vor allem Kelsen a.a.O. S. $491 \mathrm{ff}$; dens., Allgemeine Staatslehre, S.236 ff) sondern sich auch (mißverständlich?) dahin ausgedrückt hat, daß Verwaltung "nur als Individualisierung oder Konkretisierung von Gesetzen begriffen werden" könne (Kelsen, Allgemeine Staatslehre, S. 109 f, der wohl das Wort "Gesetz" in diesem Zusammenhang ebenfalls nicht wörtlich verstanden wissen will). Als dann die österreichische Bundesverfassung den Satz aufgenommen hatte "Die gesamte staatliche Verwaltung darf nur auf Grund der Gesetze ausgeübt werden" (Art.18 Abs.1), nahm die Überzeugung von der ausschließlich gesetzesvollziehenden Funktion der Verwaltung verschiedentlich axiomatischen Charakter an (s.u. (2)). In Wahrheit ist die rechtslogische Substanz des Art. 18 österr. BV jedoch nur die, daß die Verfassung über den Umfang der Verwaltungsbefugnisse disponieren kann. Die spezielle Regelung ist positive Disposition der verfassungsgebenden Gewalt, nicht etwa logisch vorgegeben (deutlich bei Antoniolli, Allgemeines Verwaltungsrecht, 1954, s. 18). Auch die österreichische Verfassung kommt nicht ohne verfassungsunmittelbare Ermächtigungen an die Verwaltung aus, zählt sie allerdings erschöpfend auf ( $\mathrm{s}$. Adamovich, Handbuch des österreichischen Verwaltungsrechts, 5. Auf1. Bd.I, 1954, S. 13). Soll also die logische Möglichkeit der verfassungsunmittelbaren Verwaltungskompetenz allein davon abhängen, ob sie generell - in Form einer ausdrücklichen oder implizierten Cieneralklausel oder wie man es sonst nennen möchte - oder enumerativ erteilt ist? Diese Frage stellen, heißt sie verneinen (zum Ergebnis s. nochmals Kelsen, Hauptprobleme der Staats rechtslehre, S.501 f).

(2) Ein illustratives Beispiel für die aufgezeigten rechtstheoretischen Erkenntnismöglichkeiten und Mißverständnisse geben die Beratungen der Vereinigung der Deutschen Staatsrechtslehrer über "Die Organisationsgewalt" ab (Veröffent1ichungen dieser Vereinigung, Heft 17, 1958, S. 154 ff). Dabei ist freilich nicht zu verkennen, daß Organisationsgewalt und 
2. Die positive verfassungsrechtliche Ordnung. Das Grundgesetz hat sich gegen eine universelle Gesetzesabhängigkeit der Verwaltung entschieden. Es institutionalisiert die Verwaltung selbständig als eine der drei Gewalten (Art.20 Abs.2 GG).9) Es bindet sie zwar universell an das Gesetz (Art. 20 Abs. 3 GG), sagt aber nirgends, daß nur auf Grund Gesetzes "verwaltet" werden dürfte. 10) Seine Gesetzesvorbehalte 11) tragen

gesetzesfreie Verwaltung nicht ein- und dasselbe sind. Aber die Verwandtschaft der Probleme ist offensichtlich. Allein Ipsen in seinem Diskussionsbeitrag ( $S .257 \mathrm{ff}$ (257 f), ging so ins Extrem, hierzu auszuführen: "Nach meiner Auffassung besteht das Wesen der Organisationsgewalt ... darin, daß sie eben keine Rechtsgrundlage besitzt, sondern fließt aus der inneren Aufgabe, der Mission der Verwaltung, sich überhaupt zu betätigen. ... die Innehabung der Organisationsgewalt durch die Verwaltung wird nicht durch die Norm begründet sondern nur begrenzt und beschränkt" Dagegen bewegte sich die ganze übrige Diskussion durchaus auf der Grundlage der Erkenntnis, daß die Organisationsgewalt der Verwaltung einer Begründung im Recht bedarf ( $\mathrm{s}$. z.B. Köttgen, Schlußwort, S.269 f, 272). Dabei unterlief es aber Vertretern der österreichischen Staatsrechtswissenschaft, daß sie den Inhalt des Art. 18 der österreichischen Bundesverfassung als rechtslogische Erkenntnis - und nicht nur als positivrechtliche Norm - ansahen (vgl. Ermacora, Mitbericht, S. 191 ff (220); Pfeifer, Diskussionsbeitrag, S. 229 ff (260)).

9) Allerdings spricht das Grundgesetz dabei von "vollziehender. Gewalt". Das ist jedoch kein Argument für eine rein gesetzesvollziehende Funktion der Verwaltung. Schon Montesquieu sprach in "De 1'esprit des lois" (XI. Buch, Kap.6) von der. "puissance exécutrice" und meinte damit - wie seine Exemplifikation beweist - keineswegs einen bloßen Vollzug der Gesetze. Auch in der Folgezeit war mit "Fxekutive" bzw. "vollziehender Gewalt" keine Beschränkung dieser Art verbunden. Gerade im konstitutionellen Staat war sie mitnichten auf die Funktion des bloßen Vollzugs der formellen Gesetze verwiesen.

10) Eine Vorschrift vom Inhalt des Art. 18 der österreichischen Bundesverfassung (s.o. S. 423 zu Fußn.8) fehlt. Zu dem Lnterschied zwischen Art.20 Abs. 2 und 3 GG und Art. 18 österr. BV s. Ermacora, Die Organisationsgewalt, \$. $220 \mathrm{ff}$. U.a. bemerkt er mit Bezug auf die letztgenannte Vorschrift: "Beachten Sie den gleichartigen Art.20 Abs. 3 GG, so müssen Sie erkennen, daß sich hierbei im Vergleich mit der österr. BV Geister und Rechtsordnungen scheiden" (S.220). 
partiellen, nicht universellen Charakter. Die Grundrechtsordnung (Art. 1-19, 101-104 GG) konkretisiert in etwa den überkommenen Allgemeinvorbehalt. Die übrigen Vorbehalte betreffen abgesehen von den eine Sonderstellung einnehmenden haushaltsrechtlichen Vorschriften (Art.110 ff GG) - nur Detailfragen. 12) Auch der VIII. Abschnitt des Grundgesetzes beweist nichts Gegenteiliges. Zwar sind dort die Verwaltungsaufgaben primär unter

11) Ihnen fehlt vielfach auch die spezifische Frontrichtung gegen das selbständige Handeln der Verwaltung. Zum System s. Ermacora, Der verfassungsrechtliche Gesetzesvorbehalt, DÖV 13.Jhg. (1960) S.561 ff.

12) (1) S. BVerfGE 8, 155 (167). - Eine Übersicht der Gesetzesvorbehalte s. bei Maunz, Deutsches Staatsrecht, S. 79; näheres $z u$ den Gesetzesvorbehalten der Grundrechtsordnung s. z.B. bei Lerche, Grundrechtsbegrenzungen "durch Gesetz" im Wandel des Verfassungsbildes.

(2) Eine zentrale Position kommt Art. 2 Abs. 1 GG zu. Diese umfassende Freiheitsgarantie ist durch den Text der Verfassung unter den Vorbehalt der "verfassungsmäßigen Ordnung" gestellt. Das Bundesverfassungsgericht hat, indem es (BVerf GE 6, 32 (37 ff)) unter der. "verfassungsmäßigen Ordnung" jedes formell und materiell verfassungsmäßige Gesetz versteht, diesen Vorbehalt, soweit er sich gegen freiheitsbeschränkende Eingriffe der Verwaltung wendet, mit gesteigerter Deutlichkeit unter das Leitbild des überkommenen Gesetzesvorbehaltes gestellt (s.a. Lerche, a.a.O. S. 528). Aber auch wenn die Auslegung des Bundesverfassungsgerichts unzutreffend wäre, d.h. wenn die "verfassungsmäßige Ordnung" i.S. des Art. 2 Abs. 1 GG nicht nur die Summe der gesamten übri gen Verfassungsordnung, sondern eine Auswahl besonders wichtiger und daher dem Wert der. "freien Entfaltung der Persönlichkeit" vorzuziehender. Nerte bzw. der sie realisierenden oder schützenden Verfassungsgrundsätze darstellen würde, wäre die Position der Vorschrift im Hinblick auf das Problem der Gesetzmäßigkeit der Verwaltung wohl keine andere. Daß die Verwaltung deshalb in die freie Fntfaltung der Persönlichkeit ohne gesetzliche Grundlage eingreifen clürfte, ist nicht anzunehmen, weil es zu sehr dem verbindlichen, traditionellen Rechtsstaatskonzept widersprechen würde. Fs kann also nur darum gehen, daß die Gesetzgebung ihrerseits die Freiheit der Persönlichkeitsentfaltung nicht weiter einschränken darf, als dies aus der verfassungsmäßigen Or.dnung (in dem ermittelten spezifischen Sinn) heraus geboten und gerechtfertigt ist. 
dem Gesichtspunkt der Gesetzesakzessorietät auf Bund und Länder verteilt. Aber der Schluß von dem Nebeneinander der "Auslührung der Bundesgesetze" und der "Bundesverwaltung" auf ein grundgesetzliches Bekenntnis zur Zulässigkeit gesetzesfreier Verwaltung besitzt zumindest so viel Tragfähigkeit, daß er die gegenteilige Vermutung ausräumt. 13)

Für die Länder dürfte sich daraus zwar kein Zwang ergeben, ihrerseits durch die Landesverfassung ebenfalls einen gesetzesfreien Raum der Verwaltung zuzulassen. Sie können im Rahmen des Art. 28 Abs. 1 Satz 1 GG die Landesverwaltung durchaus auf den Gesetzesvollzug beschränken. 14)

Bleibt somit Raum für gesetzesfreie Verwaltung, so ist diese doch weder hier noch dort rechtsfreie Verwaltung. 15) Sie ist nicht irgend eine von außen in den Staat einbrechende Gewalt sondern diejenige Funktionseinheit, die die Verfassung 16) als die vollziehende konstituiert hat. 17) Sie ist von ihrem Ursprung her eingespannt in das Recht und zwar in eine ganz konkrete positive Ordnung. Sie hat das Recht einzuhalten (Art.20 Abs. 3 GG) und zwar nicht nur die geschriebenen Gesetze und die Verfassung, sondern auch die der Rechtsordnung ungeschrieben zugehörenden Rechtssätze. 18) Sie hat die verfassungsgestaltenden Grundent-

13) S. oben S. 106.

14) Dagegen dürften die Länder im Hinblick auf Art. 28 Abs. 2 GG den Gemeinden wohl nicht vorschreiben können, sie dürften nur Bundes- oder Landesgesetze vollziehen. - Zu Art.28 GG als Garantie gesetzesfreier Verwaltung s. Köttgen, Die Organisationsgewalt, S. 170 .

15) S. vor allem Becker, Verwaltung und Verwaltungsrechtsprechung, S. $101 \mathrm{ff}$ mit weit. Nachw.; s.a. Spanner, Diskussionsbeitrag zu "Die Organisationsgewalt", VVDStRL. H. 16, 1958, S.255 ff (256): "Eine staatliche Verwaltung in einem völlig rechtsfreien Raum gibt es nicht".

16) Für den Bund ist unmittelbar Art. 20 Abs.2 i.V. vor allem mit den Vorschriften des V., VIII. und X. Abschnittes maßgebend. In den Ländern beruht die Legitimation der exekutiven Gewalt auf dem jeweiligen Landesverfassungsrecht. Art. 28 Abs. 1 und Art. 20 Abs. 3 GG stehen jedoch gewährleistend dahinter.

17) S. die oben S. 422 ff zu Fußn.5-8 und oben zu Fußn. 15 und die zum nachfolgenden Text Zitierten.

18) S.Becker, Verwaltung und Verwaltungsrechtsprechung, S. 101 ff und seine Nachw. - Zu den letzterwähnten Sätzen ungeschriebenen Rechts s. vor allem Nawiasky, Positives und 
scheidungen 19) nicht nur zu respektieren, sondern zu realisieren. ${ }^{20)}$ Sie hat sich im Rahmen der vorgegebenen Zuständigkeitsordnung zu halten, 21) nicht nur indem sich Organsubjekt und Organe in ihrem Aufgabenkreis halten und Übergriffe oder auch nur Friktionen an der Grenze vermeiden 22 ) sondern auch, indem sie positiv das in der Kompetenzordnung projektierte dynamische $\mathrm{Zu}$ sammenwirken ausleben. ${ }^{23)}$ Und wo all das noch nichts sagen sollte, gilt doch, daß die Verwaltung zu sein hat nach dem Bilde einer Verwaltung, das der Verfassung zugrunde liegt. Die Grundzüge und Detailregelungen der Verfassung lassen es deutlich werden. Das vorrechtliche Gesamtbild, dem ja durchaus eine Vorstellung von dem zugehört, was eine Verwaltung zu sein hat, prä-

überpositives Recht, und Wolff, Rechtsgrundsätze und verfassungsgestaltende Grundentscheidungen als Rechtsquellen, in "Forschungen und Berichte aus dem öffentlichen Recht", Gedächtnisschrift für Walter Jellinek, 1955, S.33 ff.

19) S. Wolff, a.a.O. S. $47 \mathrm{ff}$.

20) Becker, a.a.O. S. $101 \mathrm{ff}$, insbes. S. 104.

21) Der Zuständigkeitsordnung kommt für die rechtliche Gestaltwerdung gesetzesfreier Verwaltung kardinale Bedeutung zu (s. z.B. Becker, a.a.O. S. 102; Spanner, Diskussionsbeitrag zu "Die Organisationsgewalt", S.256; Pfeifer desgl. S.259 f; Wolff, Verwaltungsrecht I, S.122 f). Im einzelnen kommen vor allem in Frage die Kompetenzabgrenzung zwischen Bund und Ländern (vgl. oben Abschnitt 1 I 2 (S. 81 ff)) und zwischen Staat und Gemeinden (Art. 28 Abs. 2 GG; s. Köttgen, Die Organisationsgewalt, S. 170 f), die Vorschriften über Zusammenwirken und Zuständigkeitsabgrenzung der obersten Staatsorgane - für die Verwaltung des Bundes also insbes. der Bundesregierung, des Bundespräsidenten, des Bundes rates und schließlich des Bundestages (S. Abschnitt III - X des Grundgesetzes) - und ihrer Glieder - z.B. die Geschäftsverteilung innerhalb der Bundesregierung, wie sie durch die Art.62, 64, $65,69,95,96,112 \mathrm{GG}$, einzelne gesetzliche Zuständigkeitsvorschriften, die Ernennungsakte (unter Bestimmung der Geschäftsbereiche) und die Geschäftsordnung umschrieben ist sowie alle sonstigen Zuständigkeitsbestimmungen des Verfassungs-, Gesetzes- und Gewohnheitsrechts (s. Becker, a.a.O. S. 102).

22) S. Wolff, a.a.O. S. 122 f.

23) Dazu gehört z.B. auch die Einfügung des Verwaltungshandelns in die politischen Grundentscheidungen, soweit sie von kompetenten Organen erkennbar getroffen wurden (vgl. Wolff, a.a.O. S.123). 
zisiert es. Wenn gesagt wird, Verwaltung müsse letztlich "Verwirklichung des Gemeinwohls in Gerechtigkeit" sein, 24) so ist das auf diese Weise in dem verfassungsrechtlichen Urgrund der Verwaltung enthalten.

Das bedeutet nicht, daß die gesetzesireie Verwaltung darauf beschränkt ist, Zwecke zu verfolgen, die in der Verfassung als Staats- und Verwaltungszweck normativ anerkannt sind. 25) Die wenigen Generalklauseln, die das Grundgesetz bei fast völligem Fehlen spezieller Regelungen enthä1t - doch wohl nur der Schutz der Menschenwürde (Art. 1 Abs. 1 Satz 2 GG) und die Sozialstaatserklärung (Art.20 Abs. 1, 28 Abs. 1 Satz 1 GG) -, sind nicht imstande, alles einzufangen, was nach dem das Grundgesetz tragenden Staatsbild Sache des Staates und seiner vollziehenden Gewalt ist. 26)

3. Die "Lücke" im Gesetzesvorbeha1t. Die aufgezeigte Rechtsbindung genügt aber nicht, um das rechtsstaatliche Unbehagen zu unterdrücken, das die sog. gesetzesfreie Verwaltung auslöst. Das Gesetz ist das einzige Ordnungsinstrument, das eine allseits verbindliche, verläßliche, eingehende, allgemeine und dauerhafte Regelung eines Ordnungsobjektes, insbes. auch eines im Sachbereich der Verwaltung gelegenen, ermöglicht. Die Verfassung ist in der Regel unvollständig, knapp und allgemein. So-

24) Becker, a.a.O. S. 102; s.a. seine weiteren Nachweise.

25) A.A. Hamann, besonders deutlich in: Wirtschaftswerbung in Rundfunk und Fernsehen, NJW 10.Jhg. (1957) S. 1422 ff; s.a. sein "Grundgesetz" Einf. I D 1 c und I D 7 c.

26) Die gegenteilige Auffassung führt zu einer entsetzlichen Presserei. Meist wird das Sozialstaatsprinzip mißbraucht. Die Dinge werden auf den Kopf gestellt, wenn man nicht zugeben will, daß der Staat mehr sein darf und soll als der Staat der. in der. Verfassung enumerativ aufgezählten Zwecke. Damit soll nicht gesagt werden, daß sich ein Staat in seiner Verfassung nicht derartige Beschränkungen auferlegen können sollte. Das ist aber nur dann anzunehmen, wenn die Aufzählung wirklich erschöpfend ist und nicht nur. Schwerpunkte herausgreift, wie das beim Grundgesetz offensichtlich der Fall ist. Ein Wort Kelsens beleuchtet die Hintergründe des Problems:" Wohl hat der Staat Zwecke, aber sie sind nur Zwecke von Menschen; der Staat ist nicht Subjekt dieser Zwecke sondern Objekt derselben. ... Ist Verwaltung die Erfüllung staatlicher Aufgaben, dann ist es nicht der Staat, der verwaltet, sondern der verwaltet wir d" (Hauptprobleme der Staatsrechtslehre, S. 495). 
weit ihr überhaupt Positives entnommen werden kann, ist das Differenzialkalkül ihres Vollzuges außerordentlich groß. Damit soll nicht gesagt sein, die Verfassung sei wesensmäßig außerstande, der Verwaltung hinreichend bestimmte Befugnisse und Aufträge zu erteilen. Sie kann das sehr wohl, aber nur selten und ausnahmsweise. Die allgemeinen Grundsätze der Verfassung können das Gesetz nicht ersetzen. So etwa ist auch das Sozialstaatsprinzip (Art.20 Abs.1, 28 Abs. 1 Satz 1 GG). nicht bestimmt genug, um als rechtsstaatsgemäße Legitimation sozialstaatsgerechten Verwaltungshandelns zu dienen, wo an sich eine gesetzliche Grundlage gefordert werden muß.2\%) Es kann das Handeln der Verwaltung nicht so bestimmen und begrenzen, wie das notwendig ist, um das Eindringen der Verwaltung in die Individualsphäre erträglich erscheinen zu lassen. Den Maßnahmen der Verwaltung fehlt grundsätzlich die Allgemeinheit und somit schon in nuce jegliche Berechenbarkeit.28) Aber selbst wo es

27) S. hierzu auch Stern, Rechtsfragen der öffentlichen Subventionierung Privater, S. 523 f. Allerdings stellt Stern die notwendigen Fragen wohl nicht in der richtigen Reihenfolge.

Sie müssen gestellt werden, wie folgt:

1. Wie weit reicht der allgemeine Gesetzesvorbehalt?

2. Ist das Sozialstaatsprinzip ein Gesetz in clessen Sinn?

3. Schiebt das Sozialstaatsprinzip, wenn es selbst kein rechtsstaatlich bestimmtes Gesetz ist, in seinem Sachbereich den Gesetzesvorbehalt beiseite?

Die dritte Frage wird unten (Abschnitt 5 II (S. 676 ff)) verneint werden. Die zweite Frage ist, obwohl die Interpretation des Sozialstaatsprinzips (unten a.a.O.) erst noch zu erfolgen hat, im Text bereits verneint worden. Die erste Frage darf nicht vom Sozialstaatsprinzip her beantwortet werden. Insgesamt ist zu sagen: Soweit der Gesetzesvorbehalt reicht, stellt das Sozialstaatsprinzip keine entsprechende Handlungsermächtigung dar. Dagegen gehört es zu der Substanz des "Rechts", das, hinter dem Gesetz stehend, die "gesetzesfreie" Verwaltung dirigiert und legitimiert.

28) Das gilt auch lür den verwaltungsrechtlichen Vertrag. Nach Abschluß sichert er den Beteiligten zwar vort refflich. Vor Abschluß ist der Betroffene aber, wenn ihm cler gesetzliche Rückhalt fehlt, der Übermacht des potentiellen Vertragspartners Staat ausgeliefert. S. zu dieser speziellen Relation Gesetzmäßigkeit des. Verwaltung - Vertragsfreiheit im öffentlichen Recht: Forsthoff, Anm. zu Bundesverwaltungsgericht, Urt.v. 24.Okt. 1956 - BVerwG V C 236/54 - DVB1. 72.Jhg. (1957) S. $724 \mathrm{ff}$. 
sich um Planungen handelt, sind diese außerhalb des Weisungsverhältnisses der planenden Behörde zu den ihr untergebenen unverbindlich und somit unzuverlässig. Die Maximen des Rechtsstaats, wonach der Staat den Bindungen des Rechts zu unterwerfen ist und die Beziehungen des Bürgers zum Staat grundsätzlich solche des Rechts sein sollen, 29) können daher im allgemeinen nur durch das Gesetz realisiert werden. ${ }^{30)}$

Nun ist allerdings das, was nach den ausdrücklichen Regelungen des positiven Verfassungsrechts nicht unter irgend einen Gesetzesvorbehalt fällt, gar nicht so viel. Zwar kommt den besonderen, über den Allgemeinvorbehalt hinausreichenden Vorbehalten des Grundgesetzes ${ }^{31}$ ) jedenfalls für den hier interessierenden Sachzusammenhang nur jeweils sehr begrenzte Bedeutung $z u$. Selbst die organisatorischen Vorbehalte des VIII. Abschnittes und des Art. 108 des Grundgesetzes betreffen primär das BundLänder-Verhältnis und gestalten erst sekundär, wenngleich sehr nachhaltig und nicht ohne auch insoweit gut ins Bild zu passen, das Verhältnis zwischen Legislative und Exekutive. Aber umfassend unterliegen nicht nur alle Staatseinnahmen sondern auch alle Staatsausgaben - und somit fast die gesamte Leistungsverwaltung, d.h. also das Pendant der unter den Allgemeinvorbehalt fallenden Eingriffsverwaltung ${ }^{32}$ ) - dem Vorbehalt des Haushaltsgesetzes (Art.110 GG) und des kreditbewilligenden Gesetzes (Art. 115 GG). ${ }^{33)}$

29) S. hierzu z.B. BVerwGE 1, 159 (161), 321 (326 f).

30) Kritisch hierzu Jahrreiß, Größe und Not der Gesetzgebung, S. $58 \mathrm{ff}, 67$.

31) S. oben S. 425 zu Fußn. 11.

32) S. oben S. 422 zu Fußn. 3.

33) Art.110 und 115 GG gelten nicht unmittelbar für die Länder (Art.109 GG). Doch dürfte im Hinblick auf die Tradition der repräsentativen Demokratie in Deutschland der durch Art. 28 Abs. 1 GG den Ländern vorbehaltene Spielraum abweichender Gestaltung nicht groß sein. Die Verabschiedung des Haushalts durch Gesetz kann nahezu als gemeindeutsches Verfassungsrecht angesehen werden. Daß Hamburg den Haushaltsplan nicht durch Gesetz, sondern durch Beschluß der Bürgerschaft feststellen läßt (Art.66 HambVerf), dürfte in Anbetracht der Identität des Beschlußorgans mit dem gesetzgebenden Organ (Art. 48 Abs.2, 66 Abs. 2 Satz 1 HambVerf) und der weitgehenden Übereinstimmung des Verfahrens (Art.49, 66 HambVerf) nicht von tiefgreifender Bedeutung sein. S. zu Vorstehendem auch Menger, "Cresetz als Norm und Maßnahme", S. 14 f; Scheuner, Diskussionsbeitrag hierzu, S. 75. 
Die haushaltsgesetzliche Legitimation kann jedoch die dem Al1gemeinvorbehalt entsprechende (formell- und) materiellgesetzliche Regelung in ihrer rechtsstaatlichen Schutzfunktion nicht ersetzen. ${ }^{34)}$ Das Haushaltsgesetz ermächtigt zwar die Verwaltung, die vorgesehenen Ausgaben zu tätigen, 35 ) begründet aber keine Rechte Dritter 36 ) und ist zu einer näheren und dauernden Regelung nicht nur nicht gehalten, sondern - in Grenzen - sogar außerstande. ${ }^{37)}$ Das Haushaltsrecht schließt also die Lücke, die der Allgemeinvorbehalt in bezug auf die reine Leistungsverwaltung läßt, - unter rechtsstaatlichen Aspekten - nur unzulänglich. Der auf die Leistungen der öffentlichen Hand Angewiesene bleibt einer schwer kontrollierbaren Verwaltungskompetenz ausgesetzt. Die soziale Intervention, die so sehr auch Leistungsverwaltung ist, bewegt sich hier in einem Bereich gelockerter Rechtsstaatlichkeit. ${ }^{38)}$

4. Gesetzesfreie Leistungsverwaltung? Darf und muß das hingenommen werden? Trifft die traditionelle Auffassung vom Allgemeinvorbehalt des Gesetzes überhaupt noch zu? Ist nicht jede Verwaltungstätigkeit vom Gesetz abhängig? ${ }^{39)}$ Kann

34) S. Bachof, Begriff und Wesen des sozialen Rechtsstaats, S. 63; Stern, Rechtsfragen der öffentlichen Subventionierung Privater, S. $521 \mathrm{f}$ (mit eingeh. Nachw.); a. A. mit unzureichenden Gründen BVerwGE 6, 282 (287).

35) Ipsen, Öffentliche Subventionierung Privater, S. 39 f (= DVB1. 1956 S. 500), will entgegen der ganz herrschenden Meinung in einem Haushaltsansatz nicht einmal eine Vollzugsermächtigung an die Verwaltung sehen. Aber was hätte dann das Haushaltsgesetz überhaupt noch für einen Sinn?

36) Vgl. $\$ 24$ RHO. - Die Frage, ob im Verhältnis zwischen Parlament und Regierung eine Pflicht der letzteren zum Vollzug des Haushalts oder einzelner Ansätze besteht, wird dadurch nicht präjudiziert. S. hierzu Stern, a.a.O. S. 522 u.s. Nachw.

37) S. das sog. "Bepackungsverbot" des Art. 110 Abs. 2 und 3 GG.

38) S. z.B. Bachof, Begriff und Wesen des sozialen Rechtsstaats, S. 57, 63; ders., Anmerkung zu BVerwG Urt.v.27. Juni 1955III C 25/54 - JZ 11. Jhg. (1956) S. 35 f; Stern, a.a.O. S. $521 \mathrm{ff}$.

39) Zum Meinungsstand s. Roos, Der Grundsatz der gesetzmäßigen Verwaltung und seine Bedeutung für die Anwendung des Verwaltungsrechts, in "Rechtsquellenprobleme im schweizerischen Recht", Festgabe der rechts- und staatswissenschaftlichen Fakultät der Universität Bern für den Schweizerischen Juristenverein, 1955, S. 117 ff (126 ff - für Deutschland s. S. 127 f); Stern, a.a.O. S. 521 ff, insbes. S. 523 Fußn. 48 (nachzutragen zu den einen umfassenden Gesetzesvorbehalt befür- 
nicht nur so "das Gesetz als Garantie rechtsstaatlicher Verwaltung" voll wirksam werden? 40)

Daß diese Fragen zunehmend gestellt werden, 41) ist nicht nur eine Folge gesteigerter Lebendigkeit der rechtsstaatlichen Postulate sondern noch mehr die Folge der Umwandlung der Staatsaufgaben und -wirksamkeit. Die Beschränkung des Gesetzesvorbehaltes auf Eingriffe in Freiheit und Eigentum "ist historisch auf die Staatsauffassung des liberalen Bürgertums zurückzuführen. Seither hat sich eine Hinwendung zu einer egalitär-sozialstaatlichen Denkweise und damit eine wesentliche Veränderung der Auffassungen über die Stellung des einzelnen zu der im Staat verkörperten Gesamtheit vollzogen. Diese Wandlung könnte auch die Grenzen des Gesetzesvorbehalts verschoben und diesen Vorbehalt auf neue Bereiche ausgedehnt haben". ${ }^{42)}$ Der im traditionellen Allgemeinvorbehalt konkretisierte Rechtsschutz des Bürgers ist an einem Staatsbild orientiert, in dem der Bürger zuvörderst die Position des Unbeteiligten einnahm 43). Im Staat der Gegenwart dagegen will er an seiner Daseinsvorsorge teilhaben und von der staatlicherseits betriebenen Umverteilung begünstigt werden. Er ist auf die Effektivität dieser Teilhabeposition in erheblichem Maße auch angewiesen. Aber er will sie nicht einfach vertauschen gegen die "alte Freiheit". Die gesicherte Individualsphäre soll bleiben. Freiheit und Teilhabe stehen so in einem vielfachen Spannungsverhältnis nebeneinander. ${ }^{44)}$ Und

wortenden Stimmen: Hamann, Deutsches Wirtschaftsverfassungs recht, S.41).

40) Imboden, Das Gesetz als Garantie rechtsstaatlicher Verwa1tung, 1954, S. $18 \mathrm{ff}, 41 \mathrm{f}$.

41) S. außer den vorstehend Zitierten insbes. Köttgen, Subventionen als Mittel der Verwaltung, DVB1. 68.Jhg. (1953) S. $485 \mathrm{ff}(487 \mathrm{f})$; ders., Die Organisationsgewalt, S. 174; Herbert Krüger, Die Auflage als Instrument der Wirtschaftsverwaltung, DVB1. 70.Jhg. (1955) S.380 ff, $450 \mathrm{ff}, 518 \mathrm{ff}$ (451); Menger, Rechtssatz, Verwaltung und Verwaltungsgerichtsbarkeit; Ipsen, Öfentliche Subventionierung Privater, S.33 ff (= DVB1. 1956, S. 499 f, insbes. Fußn.64); Maunz-Dürig, Art.20 Randn. $131 \mathrm{ff}$.

42) BVerfGE 8, 155 (167).

$43)$ S. neuerdings Kern, Aspekte des Verwaltungsrechts im Industriezeitalter, Festschrift für Carl Schmitt, 1959, S. $81 \mathrm{ff}$ (87).

44) Forsthoff, Begriff und Wesen des sozialen Rechtsstaates, S. 19: "Freiheit und Teilhabe sind die Kardinalbegriffe, die heute das Verhältnis des Einzelnen zum Staate bestimmen". S.a. Werner, Verwaltungsrecht als konkretisiertes Verfassungs recht, S. 530 . 
nicht nur das. Die Teilhabe selbst soll freiheitlich strukturiert sein. Sie soll gesichert, berechenbar, voraussehbar, durchsetzbar sein. Sie soll ein Maximum an eigener Disposition und Lebensgestaltung belassen. Ist es nicht so, dann hat der auf die staatliche Obsorge Angewiesene letztlich gar keine Freiheit mehr. 45) Die "Freiheit in der Teilhabe" 46) - dieses Wort macht zugleich den unauflöslichen Rest an Antinomie, der in dem Sachverhalt steckt, bewußt - ist die notwendige Ergänzung der "alten", "negativen" Freiheit. 47) Nur wenn er auch das bewirkt, macht der Rechtsstaat wirklich, wie er soll, "die Staatssouveränität für das Selbstbewußtsein des Menschen der Neuzeit überhaupt erträglich". 48) Ergänzend muß ein besonderer Aspekt verdeutlicht werden: die Konkurrenzsituation des Bürgers. Staatliche Unterstützung für die einen belastet die anderen, die mit ihnen in wirtschaftlicher Konkurrenz stehen. Das zeigt sich vor allem im Subventionswesen. ${ }^{49)}$ Der leistende, sozialgestaltende

45) Vgl. Hesse, Der Gleichheitsgrundsatz im Staats recht, AöR $\mathrm{Bd} .77$ (1951/52) S. 167 ff (220).

46) Flume, Steuerwesen und Rechtsordnung, in "Rechtsprobleme in Staat und Kirche", Festschrift für Rudolf Smend, 1952, S. 59 ff (96, insbes. Fußn. 78).

47) S. a. Bachof, Begriff und Wesen dess sozialen Rechtsstaates, S. 58; Jahrreiß, Größe und Not der Gesetzgebung, S. 58 ff; Bleibtreu, Demokratie, soziales Prinzip und Rechtsstaat, S. 108 .

48) Ballerstedt, Rechtsstaat und Wirtschaftslenkung, AöR Bd. 74 (1948) S. 130 ff (136), bestimmt den "materiellen Rechtswert .... dessen Schutz der moderne Rechtsstaatsgedanke dient", wie lolgt: "er schirmt den Privatrechtsbereich gegen den Inhaber des Rechtsschöpfungs- und Gewaltmonopols ab. Die Idee des Rechtsstaats macht so die Staatssouveränität für das Selbstbewußtsein des Menschen der Neuzeit überhaupt erst e rträglich. Geschichtlich irreführend ist es, diese Grundposition des modernen Rechtsstaatsgedankens als Schutz der. bürgerlichen Freiheitssphäre zu bezeichnen. Es handelt sich nicht um die Grenze zwischen Freiheit und Gebundenheit, sonder'n um die Grenze zwischen der öffentlichen Gewaltunterworfenheit des Untertanen und seiner privaten Selbstverantwortung". - S. zum Vorstehenden auch Werner Weber, Staatsund Selbstverwaltung in der Gegenwart, S.28; Simitis, Die faktischen Vertragsverhältnisse, S. 521 f; Stern, Rechtsfragen der öfentlichen Subventionierung Privater, insbes. S. $524 \mathrm{f}$.

49) Vgl. Stern, Rechtsfragen der öffentlichen Subventionierung Privater, S. 524 f. S.a. Maunz-Dürig, A rt. 20 Randn. 135 ff. 
Eingriff des Staates in die wirtschaftlichen Konkurrenzverhältnisse begründet so ein relatives Interesse an der gesicherten Teilhabe - relativ, weil es erst durch die Teilhabegewährung an einen vergleichbaren Adressaten geweckt wird, relativ aber auch, weil es zunächst nur alternativ besteht zum Interesse an der Abwehr der Begünstigung des Konkurrenten. An seiner Vitalität besteht dennoch nicht der geringste Zweifel.

Alle diese Gesichtspunkte lassen es unerläßlich erscheinen, über die ausdrücklichen Anordnungen der Verfassung hinausgreifend kritisch zu prüfen, ob sich nicht aus dem generellen, intensiven Verfassungsbekenntnis zur Rechtsstaatlichkeit einerseits und der gewandelten Aufgabe und Wirkungsweise des Staates andererseits ein neues Verhä1tnis zwischen Gesetz und Leistungsverwaltung ergibt.

Die ideale Lösung des Problems scheint es zu sein, den Allgemeinvorbehalt des Gesetzes auf die Leistungsverwaltung auszudehnen und damit die Individualsphäre gegen jede gesetzesfreie Einwirkung der Exekutive abzuschirmen. Der Gedanke erweckt die bildhafte Vorstellung als würde dadurch die Halbkugel des gegen die Eingriffsverwaltung gewendeten Schutzes zu einer Vollkugel umfassender Absicherung vervollständigt. Man ist versucht, darin die adäquate Adaption des Gesetzesvorbehaltes an die inhaltliche Wandlung des Staat-Bürger-Verhältnisses zu sehen. Die deutsche Tradition des grundsätzlich nicht-universellen Gesetzesvorbehalts würde geschont und dem Bekenntnis der Verfassung zu ihr entsprochen. Ja das Grundgesetz scheint mit seiner betonten Gewährleistung der Persönlichkeits- und Individualsphäre durch die Grundrechte diese Perfektion des Allgemeinvorbehaltes geradezu zu fordern. Auf einen Gesetzesvorbehalt für staatliches Handeln, das die Individualsphäre nicht tangiert, kann andererseits sowohl unter allgemein rechtsstaatlichen wie unter positiv verfassungs rechtlichen Aspekten unbedenklich verzichtet werden.

Aber dieser Lösungsversuch muß scheitern. Der Rechtsschutz des Bürgers gegen den daseinsvorsorgenden, leistungsgewährend sozialgestaltenden Staat kann nicht unmittelbar aus dem Vorbild des Rechtsschutzes gegenüber der eingreifenden Verwaltung heraus entwickelt werden. ${ }^{50)}$ Die Interessenlage im Rahmen der

50) (1) Herbert Krüger, Die Auflage als Instrument der Wirtschaftsverwaltung, S. 381 .

(2) Ein im weiteren Zusammenhang hierher gehörender Versuch, dem neuen Verständnis des Staates und seines Verhältnisses zum Bürger durch Umgestaltung der Relation Exekutive - Legislative gerecht zu werden, wurde von Menger 
Leistungsverwaltung unterscheidet sich in einer gerade für die Abgrenzung zwischen Individual- und Staatssphäre wesentlichen

(Rechtssatz, Verwaltung und Verwaltungsgerichtsbarkeit, insbes. S. 588) unternommen. Menger will im Gesetz nicht mehr so sehr die Schranke des Dürfens für Staat und Verwaltung als die Schranke des Müssens, d.h. des Leistenmüssens des Staates sehen. Mengers These beleuchtet treffend die rechtspolitische Situation. Sie kennzeichnet auch wirklichkeitsnah den Tausch der Parteirolle zwischen Verwaltung und Bürger in der Berufung auf das Gesetz, der durch den Wechsel von der Eingriffs- zur Leistungsverwaltung bedingt ist. Aber sie bringt keine Lösung des positiv verfassungs rechtlichen Problems, das durch den der Funktionsweise der Eingriffsverwaltung zugeordneten traditionellen Vorbehalt des Gesetzes und sein Mißverhältnis zur Leistungsverwaltung hervorgerufen wird. (Hierzu eignet sich Mengers These auch schon wegen ihres einseitigen Ausgangspunktes - Gesetz = Grenze des Dürfens - nicht.) S. auch noch den folgenden Text.

(3) An Menger erinnert es, wenn das Bundesverwaltungsgericht (BVerwGE 7, 180 (185)) ausführt: "Ebenso wie die eingreifende Verwaltung einer gesetzlichen Ermächtigung bedarf, um in die Rechtssphäre des Bürgers eingreifen zu dürfen, kann die gewährende Verwaltung nur durch Gesetz verpflichtet werden, in einem bestimmten Sinne Leistungen, sei es im öffentlichen Interesse, sei es im Interesse des Bürgers, zu erbringen". Mengers These ist dabei durch die Unterstellung ergänzt, daß die Verwaltung ohne Gesetz überhaupt nicht leisten $\mathrm{mu}$. (Menger scheint eher das Gegenteil zu meinen, was eben seine Theorie in den Bereich des Rechtspolitischen verweist.) Daß mit dieser Umkehrung des Allgemeinvorbehalts das offene Problem nicht gelöst werden kann, ergibt sich auch daraus, daß das Bundesverwaltungsgericht es für möglich und angebracht hält, daneben ausdrücklich offen zu lassen, "ob die Verwaltung im gewährenden Bereich ohne gesetzlichen Auftrag überhaupt tätig werden darf". (4) Eine ähnliche Spiegelung des Allgemeinvorbehalts in den Bereich der Leistungsverwaltung könnte darin gesehen werden, daß ebenso wie die Verwaltung nicht eingreifen darf, wo das Gesetz es nicht erlaubt, sie leisten muß, wo das Gesetz es gebietet. Die Unvollständigkeit der These, deren Substanz sich schon aus dem Grundsatz der Gesetzmäßigkeit der Verwaltung ergibt, ist offensichtlich.

(5) Schließlich sei noch hingewiesen auf die Fehldeutung des Staat-Bürger-Verhältnisses in bezug auf staatliche Leistun- 
Weise von derjenigen, die in bezug auf die eingreifende Verwaltung besteht. Hier will der Bürger Lasten, Einschränkungen und dergleichen vermeiden. Der Allgemeinvorbehalt verhilft ihm da$\mathrm{zu}$, wenigstens nur das dulden oder leisten zu müssen, was das Gesetz rechtfertigt. Gegenüber der Leistungsverwaltung kann der Gesetzesvorbehalt nicht in dieser Weise funktionieren. "Es liegt auf der Hand, daß es nicht auf die Möglichkeit ankommen kann, Wohltaten abzuwehren". 51) Sind dem Bürger die angebotenen Vergünstigungen lästig, so mag er sie ablehnen. ${ }^{52)}$ Sollen ihm Wohltaten, die als lästig empfunden werden (können), rechtlich aufgezwungen werden, so würde das bei zweckgerechter Auslegung des Aligemeinvorbehalts zwanglos unter diesen subsumiert werden können. Entscheidend für das Verhältnis des Bürgers zur leistenden Hand des Staates ist also etwas ganz anderes als die Abwehr, nämlich das, "daß man notfalls eine Vergünstigung erzwingen kann und zwar nicht nur eine Vergünstigung überhaupt sondern vor allem eine Vergünstigung zu vorteilhaften Bedingungen". 53) Dazu ist das Gesetz erforderlich. Soweit die Verfassung nicht selbst einen bestimmten Anspruch eingeräumt hat, kann nur das Gesetz dem der Leistung Bedürfenden die notwendige, gerichtlich durchsetzbare Rechtsposition verleihen. Aber der Gesetzesvorbehalt schafft das anspruchbegründende Gesetz nicht. Es ist Tatbestand seiner Anwendung, sonst nichts. Der Gesetzesvorbehalt kann mittelbar auf die gesetzliche Regelung hinwirken; denn soweit ein Handeln der Verwaltung, das unumgänglich erscheint, unter dem Vorbehalt des Gesetzes steht, wird der Gesetzgeber früher oder später dazu kommen, ihm die erforderliche Grundlage zu geben. Aber auch dieses Ordnungsprinzip, das im 19. Jahrhundert nach und nach zur legislativen Durchdringung der

gen, die dem Urteil des OVG Lüneburg vom 22. Juni 1955 V OVG A 40/54 - DVB1. Jhg. 71 (1956) S.24 zugrunde liegt. Danach ist das Gesetz für die eingreifende Verwaltung die Obergrenze ihres Dürfens, für die leistende Verwaltung dagegen die Untergrenze ihres Müssens (insbes. S.25 a.a.O.). Dabei wird der Primat des Grundsatzes der Gesetzmäßigkeit der Verwaltung - im Sinne der Bindung der Verwaltung. an das Gesetz - übersehen (vgl. Ule in der Anmerkung zu dieser Entscheidung, a.a.O. S.25 ff (26 f)).

51) Krüger, a.a.O.

52) Ein zusätzliches rechtliches Prinzip, das den Bürger vor dem Ansinnen von Leistungen schützt, die er doch ablehnen . würde bzw. müßte, erscheint weder notwendig noch angebracht.

53) Krüger, a.a.O.; s.a. Menger, Rechtssatz, Verwaltung und Verwaltungsgerichtsbarkeit, S. 592 . 
gesamten Eingriffsverwaltung geführt hat, kann nicht auf den Bereich der gewährenden Verwaltung übertragen werden. Auf die belastende Verwaltung angewendet bedingt der Allgemeinvorbehalt kein Risiko des Bürger's. Je weniger der Staat ihn durch ein Tätigwerden des Gesetzgebers überwindet, desto unverkürzter bleiben ihm "Freiheit und Eigentum". (Daß die daraus entspringende Schwäche des Staates und die nicht weniger ungehinderte Nutzung von "Freiheit und Figentum" der anderen auf jeden Bürger zurückwirkt, ist eine sekundäre Erscheinung und hier außer Betracht zu lassen.) Dem Staat ist seinerseits kein unvermeidbares Risiko aufgebürdet; denn er kann seiner Verwaltung durch die notwendige Gesetzgebung die erforderliche Legitimation verschaffen. Staatlicherseits ist die Lage in bezug auf die gewährende Verwaltung - die Geltung des Allgemeinvorbehalts auch für sie unterstellt - nicht anders. Aber der Bürger trägt das Risiko, daß der Gesetzgeber nicht tätig wird und die Leistung, die die Verwaltung, wäre sie gesetzesfrei, zu bringen bereit wäre, nicht anordnet. Er braucht und will aber die Leistung. Er will a $\mathrm{c}$ h den Rechtsanspruch. Aber er will nicht auf eine Leistung, die er - sub specie der tatsächlichen verwaltungsmäßigen Bedingungen - an sich haben könnte, verzichten, nur weil eine gesetzliche Regelung aussteht. Sein Interesse verlangt "Handlungsfähigkeit und Handlungsf reiheit für die Verwaltung, damit sie in die Lage versetzt wird, Wohltaten zu erweisen". 54)

Darin muß das letztlich Entscheidende gesehen werden. Denkbar wäre auch das Gegenteil: Die Askese, der Verzicht auf die ungesetzliche Leistung, um des Reflexes willen, daß diejenigen Leistungen, die der Staat - aus sachlicher Überzeugung oder wegen des auf ihn bzw. die maßgeblichen Funktionäre ausgeübten Druckes - glaubt erbringen zu müssen, lückenlos auf der Grundlage eines Gesetzes erbracht werden müssen. Aber diese Askese gehört nicht zu den Grundanschauungen der staatlichen Gemeinschaft. Sie gehört nicht zum Bild des konkreten, bundesrepublikanischen Rechtsstaates. Dazu ist der Hang nach der staatlichen Hilfe zu groß. Dazu ist auch die Rechtsstaatstradition zu sehr nach der Eingriffsseite hin orientiert.

Gewiß bleibt damit das ebenso legitime wie vitale Interesse daran unbefriedigt, daß nicht eine gesetzesfreie Leistungsverwaltung, nur unvollkommen kontrollierbar, in Konkurrenzsitua-

54) Krüger, a.a.O.; S. dort auch den treffenden Satz: "Daß man hier Verwaltung will und doch auch wieder nicht will, das macht die eigenartige Dialektik des Verhältnisses von Staat und Bürger in der gewährenden Verwaltung aus". 
tionen Mitbewerber ungleich bevorzugt und damit die ausgeschlossenen Mitbewerber über das Minus an staatlicher Leistung hinaus durch die nachteilige Veränderung der Konkurrenzsituation beschwert. Aber dieses Interesse, so sehr es zur gesetzlichen Regelung des Leistungswesens drängt, ist nicht grundsätzlich und allgemein genug, um die aufgezeigten Gesichtspunkte zu verdrängen. Zudem ist es im Grunde, soweit es sich von dem allgemeinen Interesse an einer gesicherten Teilhabe unterscheidet, selbst an der Negation beschwerender Eingriffe ausgerichtet. Nicht die Vorenthaltung als solche wird insofern als das Belastende empfunden sondern die (mittelbare) Belastung, die als Folge der Begünstigung des Konkurrenten auftritt. Der ihm gemäße Weg seiner Befriedigung ist also der einer entsprechenden Ausschöpfung des Eingriffsbegriffes (eventuell unter. Zuhilfenahme von Rechtsfiguren wie das Recht am eingerichteten und ausgeübten Gewerbebetrieb), nicht aber die generelle Unterstellung der Leistungsverwaltung - oder auch nicht spezifisch ausgewählter Teilbereiche, wie etwa aller "Subventionen" 55) - unter den Gesetzesvorbehalt. 56 )

Der Rechtsschutz des Bürgers gegenüber dem leistenden Staat kann also nicht dadurch dem Standard des Rechtsschutzes gegenüber der eingreifenden Verwaltung angeglichen werden, daß auch für den leistenden Staat das Gesetz zur Voraussetzung des Verwaltungshandelns erhoben wird. Die radikale Entsprechung könnte vielmehr - wenn auf die "gesetzesfreie" Leistung nicht verzichtet werden soll - nur darin liegen, daß das Gesetz die Leistungspflicht der Verwaltung begrenzt. Soweit das Gesetz die an den Staat gestellten Ansprüche nicht reguliert, begrenzt oder ausschließt, hätte dann die Verwaltung entsprechend den gestellten Anforderungen zu leisten. Nur (lann würde die Risikoverteilung zwischen Staat und Bürger derjenigen entsprechen, die der gegen den belastenden Eingriff gerichtete Allgemeinvorbehalt bewirkt. Die Konsequenz wäre ein Chaos. Eine reale Möglichkeit lieg: in dem "Allgemeinvorbehalt" des Ciesetzes als der Grenze des

55) Anders Stern, Rechtsfragen der öffentlichen Subventionierung Privater, S.521 ff, insbes. \$. 524 f; Maunz-Dürig, Art.20 Randn. 137.

56) Maunz-Dürig (Art.20 Randn. 135) verlangen eine materiellgesetzliche Grundlage auch für alle begünstigenden Verualtungsakte, "deren Auswirkung sich nicht in einer bloßen Frhöhung der Aktivposten des Begünstigten erschöpft sondern diesem in einer gegebenen Konkurrenzlage gegenüber Dritten in besonderer Weise den Rücken stärkt". Diese Grenze st noch viel zu allgemein. 
Leisten-Müssens nicht. ${ }^{57)}$ Das positive Verfassungsrecht ist weit davon entfernt, diese Lösung rezipiert zu haben. Es ist eine andere Frage, ob das positive Verfassungsrecht einzelne Ansprüche gewährt und sie unter den Vorbehalt des Gesetzes stellt. Selbst wenn es verfassungsmäßige Einzelrechte dieser Art gäbe, könnte das das allgemeine Problem nicht lösen.

Eine Angleichung des legalistischen Rechtsschutzes gegenüber der Leistungsverwaltung an den gegenüber der Eingriffsverwaltung könnte auch darin gesehen werden, daß den Interessenten ein Anspruch auf gesetzliche Regelung der an sie zu erbringenden Leistungen eingeräumt würde. Aber die Problematik der Konkretisierung und Durchsetzung eines solchen Anspruches und seines Einbaues in das Verfassungsgefüge ist so groß, daß darin keine ernstliche Möglichkeit liegt. Soweit Ansprüche dieses Inhalts überhaupt möglich sind, nehmen sie eine extrem exzeptionelle, punktuelle Position ein.

So bleibt nichts anderes, als der Verwaltung - auf der Grundlage des Haushaltsgesetzes - die Freiheit des Leistens zu belassen; während es dem Gesetzgeber aufgegeben bleibt, auch das Leistungswesen ordnend zu durchdringen, ohne daß sein Tätigwerden Voraussetzung des Verwaltungshandelns ist. Es hat sich einmal mehr gezeigt, daß das Verhältnis des Bürgers zum leistenden Staat anderen immanenten Gesetzmäßigkeiten folgt als sein Verhältnis zum eingreifenden, belastenden, beschränkenden Staat. 58) Der dichte legalistische Schutz des Allgemeinvorbehalts muß auf dieses beschränkt bleiben. ${ }^{59)}$ Eine ebenso umfas-

57) S. hierzu oben S. 434 zu Fußn. 50 (2).

58) Vgl. Forsthoff, Begriff und Wesen des sozialen Rechtsstaates, S. 14 .

59) Obwohl das oftmals in Frage gestellt und vereinzelt auch das Gegenteil behauptet wurde (s.o. S.431f zu Fußn.38-42), ist das auch unter der Herrschaft des Grundgesetzes ganz allgemein herrschende J,chre geblieben. S. z.B. Friesenhahn, Die rechtsstaatlichen Grundlagen des Verwaltungs rechts, S.245 f; Scheuner, Cirundfragen des modernen Staates, S. $152 \mathrm{f}$; Wintrich, Über Figenart und Methode verfassungsgerichtlicher Rechtsprechung, in "Verfassung und Verwaltung", Festschrift für. Wilhelm Laforet, 1952, S.227 ff (242 f); Bachof, Begriff und Wesen des sozialen Rechtsstaates, S. 55, 63; Ule, Zur Anwenclung unbestimmter Rechtsbegriffe im Verwaltungsrecht, in "Forschungen und Berichte aus dem öffentlichen Recht", Gedächtnisschrift für Walter Jellinek, 1955, S. 309 ff (328); ders., Über das Verhältnis von Verwal- 
sende Garantie rechtlicher Ordnung des Kontaktes zwischen Verwaltung und Individualsphäre kann fïr den Bereich der leistenden Verwaltung nicht gegeben werden.

5. Sonderprobleme. Einige - im Vergleich zu gewissen Praktiken: zusätzliche - rechtsstaatliche Hilfe wird allerdings noch eine wachsame Interpretation des Allgemeinvorbehalts bzw. des mit ihm korrespondierenden Eingriffsbegriffes 60 ) bringen können.

a) Belastungen des Begünstigten. Diese Interpretation hat ihre Aufmerksamkeit im besonderen den mit staatlichen Leistungen verbundenen Belastungen zuzuwenden, also vor allem den Auflagen 61) und Bedingungen 62) und den verschiedenen Formen der Koppelung 63) von Vergünstigung und Beschwer-

tungsstaat und Rechtsstaat, S. 156; Krüger, Rechtsstaatliche Gesetzgebungstechnik, DÖV 9. Jhg. (1955) S. 550 ff (554); Haas, Systeme der öffentlich-rechtlichen Entschädigungspflicht, 1955, S. 51; Jesch, Unbestimmter Rechtsbegriff und Ermessen in rechtstheoretischer und verfassungsrechtilicher Sicht, AöR 82.Bd. (1957) S. 163 ff (240, 246 f); Becker, Verwaltung und Verwaltungsrechtsprechung, S. 100 f; Rumpf, Der ideologische Gehalt des Bonner Grundgesetzes, S. 28 f;

Schlochauer, Öffentliches Recht, 1957, S.16, 161; Wolff, Verwaltungsrecht I, S. 124 f; Forsthoff, Lehrbuch des Verwaltungsrechts, S. 14, 115. Aus der Rechtsprechung s. VerfGH Rhein1Pf AS 2, 246 (268); HessVGH Urt.v. 19.Juli 1957 - OS I 86/55 - Recht der internationalen Wirtschaft, 2. Jhg. (1957) S. 223 (inhaltlich wiedergegeben).

Zur Verwaltungspraxis s. Köttgen, Der Einfluß des Bundes auf die deutsche Verwaltung, S. 78 ff; Becker, Verwaltung und Verwaltungsrechtsprechung, S. 103 .

60) Zur Abgrenzung s. die oben S.422 zu Fußn. 3 Zitierten. Zur. gebotenen Ausweitung der Kategorie des Fingriffs s. insbes. auch Lerche, Grundrechtsbegrenzungen "durch Gesetz" im Wandel des Verfassungsbildes, S. 528 .

61) S.insbes. Darstellung und Nachweise bei Herbert Krüger, Die Auflage als Instrument der Wirtschaftsverwaltung.

62) S. hierzu auch die Zürcher Dissertation von Hans Rudolf Huber, Verwaltungsrechtliche Auflagen und Bedingungen und ihr Zusammenhang mit dem Hauptinhalt von günstigen Verwaltungsakten, 1955.

63) S. insbes. Darstellung und Nachweise bei Forsthoff, Lehrbuch des Verwaltungsrechts, S.67, 87, 266 f. 444 f. - S.a. die Darstellung und Exemplifikation bei Krause, Der verteilende Staat, S. $15 \mathrm{ff}$. Willigmann, Koppelung mehrerer Ver- 
nis. 64) Hat der Empfänger der Leistung einen gesetzlichen Anspruch darauf, so kann ihn allerdings die Verwaltung von vorneherein nur in dem gesetzlich zugelassenen Umfang belasten. ${ }^{65}$ ) Allein dort, wo die Verwaltung aus freien Stücken tätig wird, ist es ihr nicht verwehrt, die Bedingungen, unter denen sie tätig wird, selbst zu gestalten.66) Das führt nicht selten dazu, daß der Vorbehalt des Gesetzes, der den Bürger vor ungesetzlichen Eingriffen schützen soll, umgangen wird.67) Die Verwaltung macht ihre Leistung davon abhängig, daß der Bürger Belastungen

waltungsobliegenheiten, DVB1. 75. Jhg. (1960) S. $753 \mathrm{ff}$.

64) Nicht hierher gehören Ausgleichs- und Umlageregelungen, durch die innerhalb eines bestimmten Kreises von Betroffenen zum Zwecke der Einebnung gegebener Vor- oder Nachteile die einen zu Leistungen verpflichtet, die anderen $z u$ Leistungen berechtigt werden (Beispiel: die Ausgleichskassen; zum Typ s. z.B. Hamann, Rechtsstaat und Wirtschaftslenkung, 1953, S. 131 f; Götz, Wirtschaftsverwaltungs rechtliche Ausgleichsabgaben, AöR Bd. 85 (1960) S.200 ff). Die im Rahmen dieser Systeme erhobenen Abgaben sind jedenfalls selbständige Belastungen, die einer gesetzlichen Grundlage bedürfen. Es ist keine Frage, daß eine verwaltungsmäßige Regelung, die Abgaben und Leistungen als eine Gesamtheit anordnet, insgesamt der gesetzlichen Grundlage bedarf (vgl. BVerwGE 6, 282; Witten, Subventionen in der Rechtsprechung, DVB1. 73.Jhg. (1958) S. $699 \mathrm{f}$ ).

65) Vgl. Krüger, a.a.O. S.451 mit weit. Nachw.

66) Vgl. Krüger ebd. mit weit. Nachw. - Hier zeigt sich wieder die Schwäche des Rechtsstaates gegenüber der sozialen Intervention. Begünstigende Verwaltungsakte, die die Handlungsf reiheit des Bürgers, einschließlich des freien Gebrauchs seines Eigentums betreffen, stehen vor dem grundrechtlichen Hintergrund prinzipieller Freiheit. Die Verwaltung folgt, indem sie in den Grenzen der regulierenden $\mathrm{Ge}-$ setze clie Freiheit gewährt, stets einer Pflicht (s.hierzu z. B. Strickrodt, Zum "begünstigenden" Verwaltungsakt in "Staat und Bürger", Festschrift für Willibalt Apelt, 1958, S.231 ff; Maunz-Dürig, Art. 20 Randn. 132 - mit weit. Nachw. -; BayVGHE n. F. 10.3 (7)). Dagegen gibt es keinen entsprechenden, verfassungsmäßigen Anspruch auf Leistung. Die Verwaltung ist bei der Gewährung von Leistungen daher in ganz anderer Weise frei als in der Feststellung, daß der Gebrauch der Freiheit zugelassen ist bzw. wird.

67) Zur Unzulässigkeit dieser Umgehung s. Hans Rudolf Huber, a.a.O. S. 80 . 
auf sich nimmt oder Eingriffe duldet, zu denen ihn das Gesetz nicht - jedenfalls nicht in diesem Zusammenhang und nicht unter der Sanktion der Versagung gerade dieser Leistungen - ver pflichtet. Je weniger der Betroffene in der Lage ist, auf die begehrte Leistung zu verzichten, umso mehr ist er - tatsächlich gezwungen, die verlangten Voraussetzungen zu erfüllen, die Auflagen hinzunehmen usw. Die leistende Behörde verschafft sich so ein Feld ungesetzlicher Eingriffsverwaltung.

Dem muß von zwei Seiten her begegnet werden. Einerseits muß erkannt werden, daß die Leistung nur diejenigen Belastungen mitzurechtfertigen, rechtlich zu absorbieren, imstande ist, die ihr $z$ weckhaft untergeordnet sind. Das sind Auflagen, Bedingungen usw., die dazu dienen, die sinngerechte Verwertung und volle Wirksamkeit der Leistung zu sichern, oder auch - soweit dadurch nicht der Charakter der individuellen Begünstigungen aufgehoben wird - dazu, die Verwaltung zur Leistung zu befähigen. 68 In diesem Rahmen Leistungen mit Belastungen zu koppeln, ist unbedenklich. Aber alle weiteren Eingriffe und Belastungen bedürfen der Legitimation. Diese kann aber auch in der Einwilligung ("Unterwerfung") des Betroffenen liegen.

Das ist nun die andere Seite, von der her das Problem anzugehen ist: die Grenze der legitimierenden Wirkung der Unterwerfung. Es ist nicht schlechthin unzulässig, wenn eine Behörde ihren Aufgaben dadurch gerecht zu werden versucht, daß sie auf freiwillige Unterordnung hinarbeitet. Aber sie darf eine Unterwerfung nicht erzwingen, auch nicht indirekt, indem sie die Unterwerfung als "Kaufpreis" für eine Leistung nimmt, auf die ihr "Partner" gar nicht verzichten kann. Eine erzwungene Einwilligung, auf die der Grundsatz volenti non fit iniuria bestenfalls der Form, nicht aber der Sache nach zutrifft, rechtfertigt keinen

68) Vgl. Krüger, a.a.O. S. 451; Forsthoff, a.a.O. S. 198, 444. Für das schweizerische Recht siehe Hans Rudolf Huber, a.a.O. S. $75 \mathrm{ff}$ (insbes. S.78 ff), \$.90 ff. - Die These des Bundesverwaltungsgerichts (BVerwGE 6, 282; Urt. v. 19. Dez. 1958 - VII C 204/52 - DÖV 12.Jhg. (1959) S. 706 (708)), Begünstigungen (dort: Subventionen) bedürften nur dann der Begründung im Gesetz, wenn zwischen Belastungen und Vergünstigungen ein untrennbarer Zusammenhang bestünde, reicht daher zur Lösung des Problems nicht aus (s.a. oben S. $441 \mathrm{zu} \mathrm{Fußn.64).} \mathrm{Gewisse} \mathrm{Belastungen} \mathrm{sind} \mathrm{der} \mathrm{Leistung}$ nach Inhalt und $Z$ weck zugeordnet und untergeordnet. 
Eingriff in die Individualsphäre. ${ }^{69)}$ Immer ist im Auge zu behalten, daß die Verwaltung - auch und gerade gesetzesfrei, auch und gerade leistend - immer nur handeln kann, um ihre verfassungsmäßige, rechtmäßige Funktion zu realisieren. Dazu gehört es, daß ihr belastendes, eingreifendes Handeln der gesetzlichen Grundlage bedarf. Der mittelbare Zwang zur Unterwerfung umgeht diesen Grundsatz und stört das Bild der verfassungsmäßigen Verwaltung. Es wird sicher im einzelnen schwer festzustellen sein, wo die Grenze zwischen zulässiger Veranlassung und unzulässigem Druck, zwischen Freiwilligkeit und Zwang liegt. Aber der Grundsatz ist klar und muß zu einer spürbaren Aktualisierung des Gesetzesvorbehalts gegenüber der leistenden Verwaltung führen. Das Stichwort, daß die Behörden nur handeln dürfen, um ihre rechtmäßige Funktion zu realisieren, weist aber auch noch auf etwas anderes hin: Die Behörde darf mit ihren Auflagen usw. nicht den Bereich ihrer Kompetenz verlassen. ${ }^{70)}$ Sie darf dem Betroffenen keine "Gegenleistungen" abnötigen, deren Zweck weder zur Leistung der Verwaltung noch sonst zum Zuständigkeitsbereich der Behörde in einem Zusammenhang steht. ${ }^{71)}$.

69) Vg1. Forsthoff, a.a.O. S.199; Wolff, Verwaltungsrecht I, S. $247 \mathrm{f}$.

70) Dieser Gesichtspunkt steht bei Forsthoff (a.a.O., insbes. S. 87, 444) einseitig im Vordergrund.

71) (1) Die einzelnen, verwaltungsrechtlichen Detailprobleme, die sich aus dem Vollzug dieser Prinzipien ergeben, sind hier nicht zu erörtern. Wichtig wird es sein, durch sachgemäße Anwendung der Grundsätze über die Nichtigkeit und Teilnichtigkeit der in Frage stehenden Rechtsgeschäfte und rechtsgeschäftlichen Staatsakte den richtigen Ausgleich zu finden zwischen dem Interesse der Verwaltung, eine Leistung nur unter den gestellten Bedingungen zu vergeben, und dem Interesse des einzelnen, die Leistung ohne die unzulässigen Bedingungen zu erlangen. Im Hinblick auf das Gesagte wird diesem Interesse im allgemeinen der Vorzug zu geben sein. (2) Außerhalb des Problemkreises der akzessorischen oder gekoppelten Belastung steht es, ob Aktionen der Leistungsverwaltung deshalb dem Gesetzesvorbehalt zu unterstellen sind, weil sie "jedenfalls dann den Charakter der Begünstigung (verlieren), wenn der Vorteil versagt wird", "die potentielle Belastung für den einzelnen" Bedürftigen "stets latent vorhanden" sei und "jederzeit aktuell werden" könne (Stern, Rechtsfragen der öffentlichen Subventionierung Privater, S. 524). Diese Argumente betreffen das allgemeine Problem, ob die Leistungsverwaltung überhaupt aus dem Vorbehalt des 
b) Begünstigungen, die Dritte belasten. Ganzunproblematisch ist, daß eine gesetzlich nicht begründete Belastung nicht damit gerechtfertigt werden karn, daß zugleich ein anderer begünstigt wird oder daß sie dazu dient, einen anderen $z u$ begünstigen. Dementsprechend unterstehen Akte, die zugleich den einen begünstigen, während sie einen anderen rechtlich belasten, - jedenfalls hinsichtlich ihres belastenden Teiles und, soweit die Begünstigung davon nicht getrennt werden kann, zur Gänze - dem Vorbehalt des Gesetzes. 72) Von hierher können sich, wie angedeutet, neue Gesichtspunkte auch für die Gesetzesbedürftigkeit begünstigender Akte ergeben. 73) Aber ist es - wenn die potentiell gesetzesfreie Leistungsverwaltung nicht im Prinzip in Frage gestelit werden soll - nicht möglich, einen Leistungsakt allgemein allein schon dann als Eingriffsakt zu qualifizieren, wenn er sich auch nur mittelbar und nur rein tatsächlich nachteilig auf Dritte auswirkt oder vielleicht auch nur auswirken kann. ${ }^{74}$ ) Die öffentliche Subventionierung Privater etwa unterliegt nicht schon deshalb schlechthin dem Gesetzesvorbehalt, weil sie die Konkurrenzverhältnisse auch und gerade derjenigen, denen Subventionen nicht zukommen, beeinflussen kann. $\left.{ }^{75}\right)$

Gesetzes ausgespart bleiben darf oder nicht (so sind sie auch - jedenfalls primär - von Stern (a.a.O.) gemeint). Es wäre unmöglich, Akte der Leistungsverwaltung direkt deshalb als auch nach dem traditionellen Gesetzesvorbehalt gesetzesbedürftige Eingriffsakte zu qualifizieren, weil die Leistung, die sie beinhalten, auch hätte versagt werden können. Deshalb ist es auch unrichtig, wenn Obermayer (Das Bundesverfassungsgericht und der Vorbehalt des Gesetzes, DVB1. 74. Jhg. (1959) S. 354 ff (356))die - allerdings ohnedies gesetzlich geregelten - Leistungen des Lastenausgleichs deshalb der Eingriffsverwaltung zurechnet, weil das Sozialstaatsprinzip den Staat zum Lastenausgleich verpflichte und die Versagung der Leistungen daher als Belastung rechtlich relevant wäre. (Seine weitere Argumentation, der Lastenausgleich sei der Eingriffsverwaltung auch deshalb zuzurechnen, weil er Schäden ausgleicht, die ursprünglich durch Eingriffe entstanden seien, verkennt darüber hinaus den Lastenausgleich schon rein positivrechtlich-tatbestandlich.)

72) S.o. S. 441 zu Fußn. 64 und S. 442 zu Fußn.68. S. ferner etwa Maunz-Dürig, Art.20 Randn. 133-135.

73) S.o. S. 438 zu Fußn. 55 und 56.

74) Vgl. aber Maunz-Dürig, a.a.O. Randn. 135.

75) Anders aber Stern, Rechtsfragen der öffentlichen Subventionierung Privater, insbes. S. 524 f; Maunz-Dürig, a.a.O. Randn. 135 und 137 . 
c) Besondere Gewaltverhältnisse. Auch die Belastungen, die in den besonderen Gewaltverhältnissen 76) liegen, sind unter diesen Gesichtspunkten kritisch zu prüfen. Vor allem das durch die Nutzung öfentlicher Anstalten begründete besondere Gewaltverhältnis 77) ist ein Schlupfwinkel ungesetzlicher Belastungen. ${ }^{78)}$ Soweit dem besonderen Gewaltverhältnis aber belastende Folgen zugeschrieben werden, die weder durch ihre Zuordnung zu dem Vorteil gerechtfertigt sind, den der Anstaltsnutzer zieht, noch durch eine wirkliche freiwillige Unterwerfung, 79) bedarf es der gesetzlichen Grundlage. ${ }^{80)}$ Einen dritten Rechts-

76) Grundlegend für das richtige Verständnis des besonderen Gewaltverhältnisses Nawiasky, Forderungs- und Gewaltve rhältnis, in Festschrift für Ernst Zitelmann, 1913; ferner Freudenberger, Beiträge zur Lehre vom besonderen Gewaltverhältnis im öffentlichen Recht, Annalen des Deutschen Reichs, 64.Jhg. (1931) S. 163 ff. - Aus neuerer Zeit s. Thieme, Die besonderen Gewaltverhältnisse, DÖV 9. Jhg. (1956) S. 521 ff; und vor allem die Beratungen der Vereinigung der Deutschen Staatsrechtslehrer, Heft 15, 1957, über "das besondere Gewaltverhältnis", mit dem Referat von Herbert Krüger (S.109 ff) und dem Korreferat von Ule (S.133 ff). Leisner, Die schutzwürdigen Rechte im besonderen Gewaltverhältnis, DVB1. 75.Jhg. (1960) S.617 ff.

77) $\mathrm{Zu}$ den Besonderheiten dieses "besonderen Gewaltverhältnisses", die im allgemeinen viel zu wenig ernst genommen werden, s. z.B. Werner Weber, Diskussionsbeitrag zu "Das besondere Gewaltverhältnis", VVDStRL. H.15, 1957, S.186 ff; Forsthoff, a.a.O. S. 118 .

78) Vgl. Forsthoff, a.a.O. S. 118 f, 444 f; s.a. S. 122.

79) Auch mittelbarer $Z$ wang und tatsächlicher Druck können je nach Intensität die F'reiwilligkeit der Unterwerfung ausschließen. Vgl. Bachof, Verwaltungsakt und innerdienstliche Ileisung, S.301; ders., Begriff und Wesen des sozialen Rechtsstaats, S. 59; Thieme, a.a.O. S.522. - Auch Forsthoff (Lehrbuch des Verwaltungsrechts, S.434) spricht von "vielfach gewagter Überdehnung des Satzes volenti non fit iniuria". - Freudenberger, Beiträge zur Lehre vom besonderen Gewaltverhältnis im öffentlichen Recht, S. 191 (insbes. l'ußn.2) und S.193, weist darauf hin, daß der das Gewaltverhältnis begründende Unterwerfungswille vom Recht gebilligt sein muß. Noch weitergehend gegen die Einwilligung als Legitimation: Leisner, a.a.O. S.618 ff.

80) Zutreffend schreibt Becker im Art. "Anstalten des öffentlichen Rechts" im Handwörterbuch der Sozialwissenschaften, 
grund iuxta legem kann es nicht geben. 81) Es ist unter rechtsstaatlichen Aspekten einfach unerträglich, wenn immer noch und immer wieder behauptet wird, für das besondere Gewaltverhältnis hätte der Vorbehalt des Gesetzes keine Gültigkeit. Er hat Gültigkeit, wenngleich eine modifizierte: 82$)$ Er bezieht sich

Bd. 1 1956, S. 208 ff (209): "An Stelle mangelnder gesetzlicher Regelung zu Eingriffen in Freiheit und Eigentum bedient sich die öffentliche Anstalt des besonderen Gewaltverhältnisses, das der Benutzer freiwillig anerkennt, wenn er sich in den Wirkungsbereich der öffentlichen Anstalt begibt. Diese Konstruktion reicht bei Monopolbetrieben (z.B. Versorgungsbetrieben) und $Z$ wangsanstalten (z.B. Fürsorgeerziehung, Heilanstalten) nicht aus, da diese auf gesetzliche Grundbestimmungen nicht verzichten können" . - Im Text wird allerdings nicht das Monopol als entscheidend angesehen sondern der Grad der Abhängigkeit von der Leistung des Monopolisten. (Handelt es sich um ein rechtliches Monopol, dann bedarf dieses selbst der rechtlichen Grundlage.)

81) Als einer von vielen unterscheidet z.B. Forsthoff (a.a.O. $\mathrm{S} .116 \mathrm{f}) \mathrm{zwischen}$ dem besonderen Gewaltverhältnis (1) auf Grund Gesetzes, (2) auf Grund Unterwerfung und (3) kraft Eintritts in den Bereich einer öfentlichen Anstalt (wo angeblich "weder Gesetz noch individuelle Willenskundgebung die Einbeziehung in das besondere Gewaltverhältnis decken" . S. a. Thieme, Die besonderen Gewaltverhältnisse, S. 524). Aber der Eintritt in die Anstaltsnutzung ist doch auch eine Willensbekundung. (Wer ohne seinen Willen in den rein äußerlichen Anstaltsbereich kommt, unterliegt doch nicht der Anstaltsgewalt als solcher.) Nur ist der Eintritt in das Anstaltsnutzungsverhältnis im Gegensatz etwa zum Eintritt in das Beamtenverhältnis vielfach ein viel weniger bewußt erteiltes Blankett. Aber als eine Blankettunterwerfung muß er doch auch verstanden werden. Alles übrige heißt doch nur, das besondere Gewaltverhältnis aus sich selbst allein zu rechtfertigen. Das kann gegenüber der Verfassung nicht durchdringen.

82) S. Freudenberger, a.a.O. S. 172 f, 174 f, 190 ff; Leisner, a.a.O. S. $618 \mathrm{ff}$. S. hierzu ferner Bachof, Der Rechtsschutz im öffentlichen Recht: gelöste und ungelöste Probleme, DÖV 6.Jhg. (1953) S. 417 ff (422); Thieme, a. a.O. S. 522; Obermayer, Verwaltungsakt und innerdienstlicher Rechtsakt, 1956, S. 121 f; Spanner, Organisationsgewalt und Organisationsrecht; Scheuner, Die neuere Entwicklung des Rechtsstaats in Deutschland, S. 257 f; BayVerfGH VGHE n. F. 4 II 30 (37). - Zur Ausbildung des besonderen Gewaltverhält- 
nicht notwendig auf die einzelnen im Gewaltverhältnis liegenden Verwaltungsbefugnisse sondern wesentlich auf das besondere $\mathrm{Ge}$ waltverhältnis als Ganzes. ${ }^{83)}$ Dem muß für den Bereich der sozialen Intervention besondere Aufmerksamkeit geschenkt werden. Eine große Fülle besonderer Gewaltverhältnisse ist in ihm und, in ihn hineinragend, um ihn herum angesiedelt. Allerdings ist die Unsicherheit, inwieweit es sich im einzelnen Falle noch um ein besonderes Gewaltverhältnis handelt, groß. Doch ist das nur die erfreuliche Folge der rechtstheoretischen Entzauberung des besonderen Gewaltverhältnisses, die die Beziehung zwischen diesem und dem allgemeinen Gewaltverhältnis als einen konträren, nicht kontradiktorischen, in graduellen Abstufungen überbrückten Gegensatz bloßgestellt 84 ) und der begriffsjuristischen Abkapselung und Selbstrechtfertigung des besonderen Gewaltverhältnisses ein Ende gemacht hat. Welchen Wert hätte es z.B. im Hinblick auf die exakte Durchnormierung des Rechts der Rentenversicherung, des lückenlosen Rechtsschutzes aller Beteiligten usw. noch, das Verhältnis des Rentenversicherten zur Versicherungsanstalt (i.S. des Vierten Buches der Reichsversicherungsordnung und des Angestelltenversicherungsgesetzes) als ein besonderes Gewaltverhältnis zu identifizieren? ${ }^{85}$ ) Nur wo der Betroffene einem komplexen Bündel undetaillierter, unausgeschiedener Machtbefugnisse des "Gewalthabers" ausgesetzt ist bzw. sein soll, ist es sinnvoll, von einem besonderen Gewaltverhältnis zu sprechen. ${ }^{86)}$ Gerade für diese Fälle ist es auch

nisses unter dem universellen Gesetzesvorbehalt des österreichischen Verfassungsrechts (Art. 18 österr.BVG) s. Ermacora, Das besondere Gewaltverhältnis in der österreichischen Rechtsordnung, DÖV 9.Jhg. (1956) S. 529 ff.

83) Vgl. Freudenberger, a.a.O.; Leisner, a.a.O.

84) Vgl. Nawiasky, Forderungs- und Gewaltverhältnisse, S. 30 ff; ders., Allgemeine Rechtslehre, S.245; Freudenberger, a.a.O. S. $166 \mathrm{ff}$; Thieme, a.a.O. S. 522 .

85) So noch - in wohl zu traditionalistischer. Anlehnung an das Wort Versicherungsanstalt - Forsthoff, Lehrbuch des Verwaltungsrechts, S. 122. Ähnlich könnte man fragen, ob auch das Verhältnis zwischen dem gegen A rbeitslosigkeit Versicherten oder gar dem Empfänger von Arbeitslosenhilfe und der Bundesanstalt für Arbeitsvermittlung und Arbeitslosenversicherung als besonderes Gewaltverhältnis klassifiziert werden kann. - Zutreffend lehnt Thieme (a.a.O. S. 522) die Qualifikation als besonderes Gewaltverhältnis ab; s.a. Leisner, a.a.O. S. 620 .

86) Leisner (a.a.O. S.620) sucht das Wesentliche unter dem 
wichtig, das Erfordernis der gesetzlichen Grundlage klarzustellen. Dieses Erfordernis besteht ganz eindeutig hinsichtlich derjenigen Gewaltverhältnisse, die von vorneherein durch Machtausübung gegen den Willen und gegen das Individualinteresse des Betroffenen gekennzeichnet sind. Sie spielen im Sozialbereich unmittelbar keine Rolle. 87) Das Gesetz ist aber auch dort notwendig, wo zwar der Gesamtcharakter des besonderen Gewaltverhältnisses von einer Leistung an den Betroffenen beherrscht wird, diesem die Leistung jedoch aufgezwungen wird. Fälle dieser Art sind von erheblicher Bedeutung für den sozialen Bereich. Hierher können die Schutzaufsicht ( $\$ \$ 56$ ff JWG), die Fürsorgeerziehung ( $\$ \$ 62$ if JWG), und die verschiedenen Schulpflichtverhältnisse (Volksschulpflicht ${ }^{88}$ ), Berufsschulpilicht ${ }^{89}$ )) ge rechnet werden. 90) Hierher können ferner die verschiedenen Fälle der zwangsweisen Unterbringung und Behandlung geisteskranker, geistesschwacher, rauschgift- und alkoholsüchtiger 91) sowie

Begriff der Unvorhersehbarkeit zusammenzufassen. - Ein einschlägiges Beispiel aus der neueren Rechtsprechung bietet BSGE 11, 1 ( $5 \mathrm{ff}$, insbes. 7), wonach die Mitgliedschaft bei der kassenärztlichen Vereinigung ein besoncleres Gewaltverhältnis mit sich bringt.

87) Der Extremfall ist das durch die Freiheitsstrafe begründete Gewaltverhältnis. Es steht mit dem sozialen Recht nur in sanktionärem Zusammenhang.

88) Zu den gesetzlichen Bestimmungen s. die Zusammenstellung in "Verfassungs- und Verwaltungsgesetze", begründet von Carl Sartorius, Nr. 47.

89) Außer der vorstehend genannten Zusammenstellung s. die spezielle Zusammenstellung bei Nipperdey "A rbeitsrecht Sammlung der wichtigsten... a rbeits rechtlichen Vorschriften", 6.Auf1. Nr.421.

90) Die Wirkungsrichtung des $Z$ wanges kann sich bei diesen schließlich Minderjährige betreffenden Gewaltverhältnissen gegen den betroffenen Minderjährigen selbst oder gegen den Inhaber der elterlichen Gewalt oder gegen beide richten. Unter dem sozialen Aspekt ist die Richtung gegen den Inhaber der elterlichen Gewalt fast noch wichtiger als diejenige des Schutzes des betroffenen Minderjährigen gegen sich selbst. Er soll davor geschützt werden, daß die, von denen er abhängt, ihn verkommen lassen, ausbeuten usw. In diesem Sinne ist auch die Drittwirkung beachtlich, die besonders die Berufsschulpflicht gegenüber dem Arbeitgeber des berufsschulpflichtigen Minderjährigen zeitigt.

91) Eine Zusammenstellung der einschlägigen Gesetze s. bei Maunz-Dürig, Art. 104 Randn. 18; s.a. $\$ \$ 42$ b und c StGB. 
geschlechtskranker 92) Personen in geeigneten Anstalten gerechnet werden, wobei allerdings das nackte öffentliche Interesse an der Beseitigung des Übels vielfach dem sozialen Hilfs- und Ausgleichszweck vorgeht. Im besonderen dient die geschlossene Fürsorge sozialen $Z$ wecken, die das geltende Recht als Zwangsmaßnahme allerdings nur in sehr begrenztem Umfang kennt.93) Soweit durch die genannten Maßnahmen die Freiheit der Betroffenen beschränkt wird, ergibt sich über das Erfordernis des Gesetzes hinaus aus Art.104 GG das Erfordernis des Richterspruchs. 94) Nicht weniger deutlich ist das Erfordernis des Gesetzes, wenn zwar nicht eine Leistung aufgenötigt wird, jedoch ein Rechtsverhältnis, innerhalb dessen durch Leistung des Betroffenen diesem auch eine - das Ziel des Ganzen bildende - Gegenleistung der öffentlichen Hand gesichert werden soll. 95) Diese Sozialversicherungsverhältnisse, in denen der Leistungsberechtigte auch leistungspflichtig ist, gehörten, wären sie besondere Gewaltverhä1tnisse, 96) hierher. In diesem Zusammenhang ist auch der Benutzungszwang zu erwähnen, wie er für öffentliche Versorgungsbetriebe vielfach vorgesehen ist. 97) Aber auch alle diejenigen besonderen Gewaltverhältnisse (insbes. Anstaltsnutzungsverhältnisse), in die der "Gewaltunterworfene" rechtlich freiwillig eintritt,

92) $\$ 18$ des Gesetzes zur Bekämpfung der Geschlechtskrankheiten vom 23. Juli 1953 (BGB1. I S. 700).

93) Aktue11 $₫ 20$ FürsPf1VO. - $\$ 11$ Abs. 1 Satz 3 der Reichsgrundsätze über Voraussetzungen, Art und Maß der öffent1ichen Fürsorge bestimmt darüber hinaus ausdrücklich, daß die fürsorgeweise Unterbringung in einer Anstalt oder einer fremden Familie zwangsweise nur auf $\mathrm{Grund}$ besonderer Gesetze geschehen darf.

94) Zur Erstreckung dieses Erfordernisses auf Freiheitsbeschränkungen auf der Grundlage privatrechtlicher Herrschafts- und Fürsorgeverhältnisse s. nunmehr die grundlegende (und überaus begrüßenswerte) Entscheidung BVerfGE 10,302 .

95) Hier ist rechtstechnisch die Belastung das Primäre. Sie ist auch zweckhaft der Leistung nicht unter- sondern korrespondierend zugeordnet.

96) S.o. S. 447 zu Fußn. 85. - Früher wurde überwiegend ein besonderes Gewaltverhältnis angenommen (vgl. Jacobi, Grundlehren des Arbeitsrechts, S. 440 ff; Richter, Sozialversicherungsrecht, S. 57, 85, 95). Richter (a.a.O. S. 57) wies immerhin schon einschränkend darauf hin, daß "mit dieser Rechtsfigur... nicht die ganze Sozialversicherung erklärt werden" kann. 
bedürfen der gesetzlichen Grundlage, wenn die Machtbefugnisse des "Gewalthabers" weiter gehen sollen als durch den Zweck der Leistungen bedingt ist, die durch den Eintritt in das Gewaltverhältnis angestrebt werden. Etwas anderes kann nur gelten, wenn der Eintritt nicht nur rechtlich, sondern auch tatsächlich im freien Belieben des Betroffenen steht. Für die Grenzen der Anstaltsfürsorge, 98) der Krankenhauspflege und dergleichen 99)

97) Dem kommt für die soziale Intervention wenig Bedeutung zu.

98) Gemeint ist hier die "freiwillige", d.h. nicht gegen den Willen des Betroffenen ausgeübte Anstaltsfürsorge i.S. des $₫ 11$ Abs. 1 der Reichsgrundsätze. Sie hat in $\$ 6$ FürsPflVO eine das Anstaltsproblem nicht ausdrücklich ansprechende, mittelbare quasigesetzliche Grundlage. Diese bezieht sich auf die Leistung und räumt keine über die Leistung und das ihr an Machtbefugnissen zweckhaft Untergeordnete hinausgehenden Machtbefugnisse ein. (Das gilt auch von den einschlägigen landesrechtlichen Vorschriften, soweit sie nur die Pflicht zur Anstaltsfürsorge konstituieren; s. z. B. Art. 4 BayFürsorgegesetz.) - Von Unterwerfung kann bei demjenigen, der speziell der Anstaltspflege bedürftig ist und somit gar keine Wahl hat, nicht die Rede sein. Weitergehende Gewaltbefugnisse auf ein Gewaltverhältnis kraft Unterwerfung zu stützen, ist also ganz unmöglich. Nur bei demjenigen, der auch tatsächlich die Wahl hat, Anstaltsfürsorge oder Geld- und Sachfürsorge in Anspruch zu nehmen (s. $\$ 11$ Abs. 1 der Reichsgrundsätze), könnte von einem Gewaltverhältnis kraft Unterwerfung die Rede sein, wenn er sich entschließt, in das Anstaltsverhältnis einzutreten. - Zu der Möglichkeit, den Fürsorgebedürftigen mittelbar zum Eintritt in die Anstaltsfürsorge zu zwingen durch ganze oder teilweise Vorenthaltung der Mittel aus der offenen Fürsorge s. BayVGHE 4, 225 (227).

99) (1) Vgl. $\$ 184$ RVO (s.a. $\$ 559$ g, i RVO). Die Wahl zwischen Krankenpflege und Krankengeld einerseits und Krankenhauspflege (+ Hausgeld) andererseits hat grundsätzlich nur der Versicherte mit eigenem Hausstand. Der Versicherte ohne eigenen Hausstand unterliegt einem mittelbaren Zwang zum Eintritt in die Krankenanstalt insofern, als ihm Leistungen der Krankenkasse eben nur in Form der Krankenhauspflege gewährt werden müssen. Doch kann natürlich auch bei dem Versicherten, der rechtlich die Wahl hat, diese tatsächlich ausgeschlossen sein. Inwieweit es sich bei dem Verhältnis des Patienten zum Krankenhaus um ein besonderes Gewaltverhältnis handeln kann, wird unter mehreren Gesichtspunkten verschieden zu beurteilen sein. Dieser ver- 
und der Benutzungsverhältnisse öfentlicher Versorgungsunternehmen 100) ist das von erheblicher Bedeutung. Die gesetzesfreie Verwaltung ist also auf Gewaltverhältnisse beschränkt, die nur Leistungszwecken dienen - und in den Machtbefugnissen auf diese beschränkt sind - oder wirklich nach freiem Belieben eingegangen werden. 101) Abschließend sei bemerkt, daß für die dienstrechtlichen Gewaltverhältnisse der Beamten, Richter und Soldaten die gesetzliche Grundlage unerläßlich ist, auch wenn das Dienstverhältnis freiwillig eingegangen ist. 102)

d) Die Organisationsgewalt. Schließlich ist noch das Problem der sog. Organisationsgewalt ${ }^{103)}$ anzuschneiden, d.h.

waltungsrechtlichen Frage hier weiter nachzugehen, ist nicht veranlaßt (s.a. die Nachw. u. (4)). Ein besonderes Gewaltverhältnis ist nicht schlechthin auszuschließen. Man denke nur an die Behandlung in Krankenanstalten oder Genesungsheimen, die vom Versicherungsträger (Krankenkasse, Berufsgenossenschaft) selbst betrieben werden ( $\mathrm{s}$. Thieme, Die besonderen Gewaltverhältnisse, S. 522).

(2) Im Rahmen der Rentenversicherung sind ebenfalls vergleichbare Anstaltsverhältnisse möglich: $\$ \$ 84,86$ AnVG, \$ 1305, 1307 RVO.

(3) Zur Kriegsopferversorgung s. $\$ \$ 11 \mathrm{ff}$ BVG.

(4) Zum Status des Krankenhauspatienten s. z. B. BGHZ 1, 383 und BGH Urteil v. 10. Juli 1954 - VI ZR 45/54 - NJW 9. Jhg. (1956), S. 1106 für den in das Krankenhaus eingewiesenen Kassenpatienten; BGHZ 4, 138 für den in das städt. Krankenhaus eingewiesenen Fürsorgeempfänger; BGHZ 9, 145 und Wolff, Anm. zu dieser Entscheidung, JZ 8. Jhg. (1953) S. 552 ff, für den Patienten der Universitätsklinik; vgl. ferner Siebert, Privatrecht im Bereich öfentlicher Verwaltung, in Festschrift für Hans Niedermeyer, 1953, S. $215 \mathrm{ff}$ (222 ff); s.a. die jeweils gegebenen weit. Nachw.

100) Ist ihre gesetzliche Grundlage auf die Leistung beschränkt, so können nicht aus dem "besonderen Gewaltverhältnis" der Anstaltsnutzung Machtbefugnisse hergeleitet werden, die nicht mehr durch den Zweck, die Effektivität der Leistung zu sichern, gerechtfertigt sind.

101) s.a. Werner, Diskussionsbeitrag zu "Die Organisationsgewalt", VVDStRL. H. 17, 1958, S.240 ff (244).

102) Für die Dienstpflichten ist die Notwendigkeit des Gesetzes ganz klar (s.a. Art.2 Abs.2, 12 Abs.2, 19 Abs. 1 GG). Für das öfentliche Dienstverhältnis kraft "Unterwerfung" ergibt es sich aus Art. 33 Abs. 4 und 5, 98 Abs. 1 und 3 GG.

103) S. insbes. die schon mehrfach erwähnten Verhandlungen 
die Frage, inwieweit die Exekutive das Recht hat, sich selbst zu organisieren 104) und inwieweit auch die Organisation der Verwaltung dem (förmlichen) Gesetz vorbehalten ist. Die Organisationsgewalt ist einer der standhaftesten Überreste des konstitutionellen Verfassungsrechts. Im Streit um sie ringt, auch nachdem das Rechtsetzungsmonopol des demokratisch-parlamentarischen Gesetzgebers längst anerkannt ist, vermittels der Traditionsgebundenheit des Rechtssatzbegriffes immer noch ein Stück eigener Rechtssetzungskompetenz der Exekutive mit der Zuständigkeit des förmlichen Gesetzgebers. Obwohl der bestimmende Zusammenhang der organisatorischen Vorschriften mit dem materiellen Recht und die dementsprechende Rechtssatzqualität genereller, insbes. zuständigkeitsbegründender Organisationsakte zunehmend erkannt wird, 105) wird deshalb immer wieder behauptet, der Gesetzgeber könne - ja solle sich sogar 106) - der gesetz-

der Vereinigung der Deutschen Staatsrechtslehrer über "Die Organisationsgewalt", vor allem den Bericht von Köttgen und den Mitbericht von Ermacora. Weitere Nachw.s. dort.

104) Das ist der engere und gebräuchlichere Begriff der Organisationsgewalt (vgl. Köttgen, a.a.O. S.154). Ein weiterer Begriff schließt auch die organisatorische Befugnis des Gesetzgebers ein (vgl. Ermacora, a.a.O. S.231 f; s.a. Obermayer, Verwaltungsakt und innerdienstlicher Rechtsakt, S. $117 \mathrm{f})$.

105) Die Ausgangspositionen und Ergebnisse sind freilich weit aufgefächert. Aus der Fülle des Schrifttums s. Kelsen, Hauptprobleme der Staats rechtslehre, S. 245 ff; ders., A11gemeine Staatslehre, S.237; Nawiasky, Bayerisches Verfassungsrecht, 1923, S.343, 441; ders., Allgemeine Rechtslehre, S. $111 \mathrm{ff}$ und passim; Richter, Die Organisationsgewalt, 1926; Obermayer, Verwaltungsakt und innerdienstlicher Rechtsakt, S.117 f, 119 f; Menger, Das Gesetz als Norm und Maßnahme, S. 15 ff; Spanner, Organisationsgewalt und Organisationsrecht, DÖV 10.Jhg. (1957) S. 640 ff; Forsthoff, Lehrbuch des Verwaltungsrechts, S. 385 f; Jesch, Zulässigkeit gesetzesvertretender Verwaltungsverordnungen, S. $84 \mathrm{ff}$. - Eine Zusammenstellung weiteren Schrifttums und der Rechtsprechung zu spezielleren Fragen s. bei Schack, Rechtsverordnungen im formellen Sinn? DÖV 11. Jhg. (1958) S. 273 ff; Nachweise vornehmlich aus der Staatspraxis s. bei Hamann, Die Bindung der staatlichen Organisationsgewalt an die Gesetzgebung, NJW 9.Jhg. (1956) S. $1 \mathrm{ff}$. 106) S. z.B. Peters, Diskussionsbeitrag zu "Die Organisationsgewalt", VVDStRL. H. 17, 1958, S.247 ff. 
lichen Regelung der Verwaltungsorganisation enthalten. 107) Aber selbst demjenigen, der hierin strengere Auffassungen vertritt, erscheint es fast selbstverständlich, daß im verwaltungsinternen Hintergrund fast immer ein Rest von Selbstorganisation der Exekutive bleibt, obwohl den diesbezüglichen Anordnungen nach allgemeinen Kriterien zum Rechtssatz kaum etwas fehlt. 108)

Die Problematik wird für das geltende Bundesverfassungsrecht auch nicht - soweit das überhaupt möglich wäre - durch einen generellen institutionellen Vorbehalt 109) überholt, der die Verwaltungsorganisation gewissermaßen um ihrer selbst willen und nicht wegen ihres Normcharakters oder wegen engen Zusammenhanges mit dem materiellen Verwaltungsrecht an den förmlichen Gesetzgeber zöge. Die positive verfassungsrechtliche Ordnung des Grundgesetzes ist unzulänglich. Für die gesetzesakzessorische Bundesverwaltung unterhalb der Ministerialebene und außerhalb der originären bundeseigenen Verwaltung (Art.87 Abs.1 GG) beinhalten die Art. 87 Abs.3, 108 Abs. 1 GG weitreichende institutionelle Vorbehalte. Zusammen mit den nur für die organisatorische Ingerenz des Bundes in die Verwaltung der Länder verbindlichen Vorbehalten der Art. 84 Abs. 1, 85 Abs. 1 und 108 Abs. 3 GG bestimmen sie insgesamt die Verlagerung der Verwaltungsorganisation auf den (Bundes-) Gesetzgeber auf das spürbarste. Sie erschöpfen das Thema jedoch bei weitem nicht. Ein universeller institutioneller Vorbehalt ist offensichtlich nicht gewollt.

Die prinzipielle Unsicherheit ist daher groß. Der Tendenz nach läßt sich sagen, daß an sich alles, was nach allgemeinen, nicht gerade am Traditionsbegriff konstitutioneller Organisationsgewalt orientierten Kategorien als genereller Rechtssatz zu gelten hat, auch dem (förmlichen) Gesetz zu überlassen ist. Der Wandel vom konstitutionellen Dualismus zum demokratisch-parlamentarischen Monismus der Rechtsetzung fordert diese Konsequenz gebieterisch. Die verwaltungseigene Organisationsgewalt ist auf ihren Kernbereich, die Direktions- und Dispositionsbefugnis über die der Verwaltung zugeordnete Kombination persönlicher und sächlicher. Mittel 110) zu verweisen. Ein Grenzfeld eng damit verstrickter organisatorischer Anordnungen wird in gewissen, hier

107) S. zusammenfassend Köttgen, a.a.O.

108) Zu dieser. "Verlustliste des Rechtsstaats" s. Köttgen, a.a.O. S. $165 \mathrm{ff}, 176 \mathrm{ff}$; s.a. Obermayer, a.a.O. S.119 f; Spanner, a.a.O. S.642; Ermacora, a.a.O. S. 228 ff; Forsthoff, a.a.O. S.381, 386. - Ablehnend Richter, Die Organisationsgewalt, \$. $11 \mathrm{ff}$.

109) Vg1. Köttgen, a.a.O.S.161 ff.

110) S. Köttgen, a.a.O. S.270. 
nicht näher zu verfolgenden Grenzen allerdings auch dann der verwaltungseigenen Organisationsgewalt zugeschlagen werden können, wenn diese Anordnungen "an sich" allgemeine Rechtssätze darstellen. 111) Soweit demnach die organisatorischen Anordnungen durch Gesetz zu treffen sind, wirkt sich der (materiel1e) Allgemeinvorbehalt des Gesetzes dahin aus, daß die Verwaltung auch die organisatorischen Prämissen der (materiellen) Eingriffsbefugnisse ihrer Behörden und Funktionäre nicht sine lege bzw. extra legem selbst schaffen kann. 112) Umgekehrt kann die Verwaltung aber auch nicht Rechte und Pflichten der Bürger, die im leistenden Gesetzesvollzug in Frage stehen, durch allgemeinverbindliche organisatorische Anordnungen gestalten. 113) Obwohl die Organisation der gesetzesfreien Verwaltung an sich keiner gesetzlichen Regelung bedarf, 114) kann sich so aus dem funktionalen Zusammenhang mit der materiellen gesetzlichen Regelung ein reflektorischer Vorbehalt des Gesetzes auch für die Organisation ergeben. 115) Die Bedeutung dessen für die soziale Intervention ist offensichtlich. 116)

Besser als das Grundgesetz haben die Landesverfassungen für die parlamentarisch-demokratische und rechtsstaatliche Absicherung der Organisationsgewalt gesorgt. 117)

111) S. die oben S. 453 zu Fußn. 108 Zitierten, insbes. Obermayer, Spanner, Köttgen, Forsthoff, a.a.O.

112) Zum Stand der Diskussion und Praxis s. Köttgen, a.a.O. S. $175 \mathrm{ff}$; neuerdings s.Jesch, Zulässigkeit gesetzesvertretender Verwaltungsverordnungen? S. $84 \mathrm{ff}$.

113) Vgl. Bachof, Diskussionsbeit rag zu "Die Organisationsgewalt", S.264 ff (265); s.a. Richter, Die Organisationsgewalt, insbes. S.11 f; Obermayer, a.a.O. S.120; Weber, Diskussionsbeitrag zu "Die Organisationsgewalt", S. 244.

114) Vg1. Darstellung und Nachweise bei Köttgen, a.a.O. S. $170 \mathrm{ff}, 174 \mathrm{f}$.

115) Das hat das Bundesverfassungsgericht in BVerfGE 8, 155 entscheidend verkannt. Auch Köttgen (a.a.O. S. 174) wird dem nicht gerecht. Der Sache nach wie hier: Jesch, a.a.O., insbes. S.85 ff, 93; s.hierzu a. Obermayer, Das Bundesverfassungsgericht und der Vorbehalt des Gesetzes.

116) Zu den Gefahren des gesetzlosen organisatorischen Aufbaues einer Leistungsverwaltung $\mathrm{s}$. Scupin, Diskussionsbeitrag zu "Die Organisationsgewalt", VVDStRL. H.17, 1958, S.261 ff. Scupin exemplifiziert aufschlußreich mit dem "Honnefer Modell".

117) Vg1. Köttgen, a.a.O. S.163; s.a. BVerfGE 8, 155 (166). 
Hervorzuheben ist, daß die Übertragung von Verwaltungsaufgaben auf rechtsfähige Verwaltungseinheiten oder weisungsunabhängige Ausschüsse des Gesetzes bzw. der gesetzlichen Grundlage bedalf. 118) Das gilt im besonderen auch dann, wenn durch die

118) Die Errichtung einer Anstalt oder Körperschaft bedarf nach Art. 87 Abs. 3 GG jedenfalls dann des Gesetzes, wenn eine bundesunmittelbare Anstalt oder Körperschaft ins Leben gerufen wird. Nach gemeindeutschem Verfassungsrecht ist dasselbe im Grundsatz auch für die Errichtung sonstiger rechtsfähiger Verwaltungseinheiten anzunehmen (vg1. E. R. Huber, Wirtschaftsverwaltungsrecht, Bd. I, S. 64; Hamann, Die Bindung der staatlichen Organisationsgewalt an die Gesetzgebung, S. 3; Spanner, Organisationsgewalt und Organisationsrecht, S.643; Köttgen, Die Organisationsgewalt, S. 172 mit weit. Nachw.; Forsthoff, Lehrbuch des Verwaltungs rechts, S. 432, 442). Nun ist allerdings nicht allgemein auszuschließen, daß das Landesverfassungs recht (ungeschriebene) organisatorische Vorbehaltsrechte der Exekutive hinsichtlich der Verleihung des "Öffentlichkeits"-Status für Körperschaften kennt. Doch ist davon auszugehen, daß es sich dabei nur um eine Verleihung der mit diesem Status verbundenen Privilegien handelt ( $\mathrm{s}$. Forsthoff, a.a.O. S.385), nicht um die Übertragung staatlicher Aufgaben und die Ausstattung mit Hoheitsrechten (vgl. Richter, Die Organisationsgewalt, S.9; Forsthoff, a.a.O. S. 380,384 f, 432, 442 ). Auf die Frage, ob die Hoheitsrechte durch freiwilligen Beitritt bzw. Unterwerfung ausgelöst werden, kann es dabei nicht ankommen (vg1. Krüger, Das besondere Gewaltverhältnis, S.119; a. A. wohl Werner Weber, Art. "Körperschaften des öffentlichen Rechts" im Handwörterbuch der Sozialwissenschaften, Bd. 6 (1959) S. 38 ff (40), der auf die Zwangsmitgliedschaft abstellt; auch der BayVerfGH (VGHE n. F. 4 II 30 (37), 150 (161) erwähnt ausdrücklich die unf reiwillige Begründung). Die Verleihung von Hoheits rechten muß immer durch Gesetz bzw. auf Grund Ciesetzes erfolgen (s. insbes. Richter und Forsthoff, a.a.O.). Die Notwendigkeit des Gesetzes bzw. der gesetzlichen Grundlage für die Übertragung staatlicher Aufgaben auf selbständige Verwaltungseinheiten folgt auch schon daraus, daß das Gesetz (bei Ausgründungen von Gemeinden u. ä.: die Satzung) die einzige Brücke von ihnen zum Muttergemeinwesen ist, durch die dessen Weisungsbefugnis festgelegt bzw. ersetzt werden muß (s. hierzu Bachof, Verwaltungsakt und innerdienstliche Weisung, in 
Frrichtung rechtsfähiger Anstalten oder Körperschaften besondere Gewaltverhältnisse begründet bzw. institutionalisiert wer(len sollen. 119)

6. Schlußbemerkung. Der absolute Vorbehalt des Gesetzes, in dessen sachlichen Geltungsbereich die Verwaltung nicht tätig werden darf, ohne durch das Gesetz dazu berechtigt zu sein, erschöpft den Entfaltungsraum der Exekutive somit nicht, wenngleich er ihn weitgehend, von den verschiedenen Ansatzpunkten der Eingriffsverwaltung (als Allgemeinvorbehalt), der Organisation (institutioneller Vorbehalt) und der Einnahme- und Ausgabewirtschaft (Vorbehalt des Haushaltsgesetzes) her eindringend, okkupiert. In seiner vollen Tragweite ist er auf die sog. Eingriffsverwaltung beschränkt. Die (weitergehenclen) institutionellen organisatorischen Vorbehalte sind, jedenfalls soweit das Grundgesetz in Frage steht, gegenständlich begrenzt. Funktion und Inhalt des Haushaltsgesetzes sind äußerst einseitig. Die Notwendigkeit, jegliche eingreifende Verwaltung durch das Gesetz zu legitimieren, bedingt allerdings infolge der vielfältigen Verflochtenheit eingreifender und nicht eingreifender Verwaltung ein tiefes Eindringen des Gesetzes auch in die letztere.

In ungeheurem Umfang muß der Gesetzgeber also schon kraft der angeführten Vorbehalte die soziale Intervention des Staates gestalten, weil ohne sein Tätigwerden die Verwaltung nicht intervenieren clarf. Aber trotzdem bleibt Raum, in dem die Verwaltung auch ohne die Voraussetzung des Gesetzes, insbes. des materiellen Gesetzes, tätig werden kann. Diese Lücke des Rechtsstaates darf nicht vernachlässigt werden. Aber sie kann perfekt nur geschlossen werden um den Preis eines höheren Risikos der Lückenhaftigkeit der staatlichen Hilfe, die bei der Erstreckung des Allgemeinvorbehaltes auch auf die Leistungsverwaltung in Kauf genommen werden müßte. Wie gesagt, bedeutet das, daß sie nicht auf diese Weise und somit nicht perfekt geschlossen werden kann.

"Verfassung und Verwaltung", Festschrift für Wilhelm Laforet, 1952 , S.285 ff (313 f); ders., Diskussionsbeitrag zu "Die Organisationsgewalt", S.265; Köttgen, a.a.O. S. 185; Bettermann, Verwaltungsverfahren, S. 154). Das ist auch entscheidend für die Notwendigkeit des Gesetzes bei der Errichtung weisungsfreier Ausschüsse (s. die zuletzt Zitierten).

119) S. BayVerfGH VGHE n.F. 4 II 30 (37). - Das muß wiederum Anlaß sein, dem besonderen Gewaltverhältnis der Nutzung nicht-rechtsfähiger Anstalten besonders kritisch gegenüberzustehen. 
bbb) Die rechtsstaatliche Pflicht der gesetzlichen Bindung der Verwaltung - ergänzende Bindungen der gesetzesfreien Verwaltung

Als Ausgleich bleibt die rechtsstaatliche Maxime, den Staat möglichst umfassend an das (Gesetzes-) Recht zu binden.

Der Gesetzgeber muß möglichst auch die potentiell gesetzesfreie Verwaltung, jedenfalls soweit sie die Individualsphäre berührt, nor'mativ durchdringen. Der "Alleingang" der Exekutive bringt, wenn sich eine Angelegenheit der bindenden individuellen Abklärung - z. B. durch unwiderrufliche einmalige Zusagen, Vertrag usw. - entzieht, Abhängigkeit und Unsicherheit der Betroffenen und die Gefahr unangemessener Ungleichheit mit sich. Die Individualsphäre der Beteiligten ist infolge der grundsätzlichen Bereitschaft des Staates zur Intervention und der mit ihr - bedingend und bedingt - zusammenhängenden Totalorientierung der individuellen Bedürfnisse auf die staatliche Intervention hin mit eben dieser allzu intensiv verknüpft. Die gesetzliche Regelung gibt der sozialen Intervention dagegen Berechenbarkeit und $\mathrm{Zu}-$ verlässigkeit und grenzt Eigen- und Gemeinsphäre eindeutig ab. Sie ist der Garant der dem rechtsstaatlichen Ordnungsbild entsprechenden "Freiheit in der Teilhabe". 1)

Die Ausdehnung der gesetzlichen Ordnung ist übrigens nicht nur ein Mittel, um allgemein das Handeln der Verwaltung berechenbar zu machen und die Betroffenen aus der Position des Almosen empfangenden Objekts in die Position des berechtigten Subjekts zu überführen; sie ist auch das wirksamste Mittel um hintanzuhalten, daß der Rechtsschutz der Betroffenen durch die vielerörterte "Flucht" der Verwaltung ins Privatrecht oder in gewisse schwer definierbare Mischformen vermindert wird. 2) Desglei-

1) S. nochmals die Nachweise oben S. 431 zu Fußn. 38 ff.

2) s. zu diesen Erscheinungen f.v.a. E.R. Huber, Wirtschaftsverwaltungsrecht, Bd.I S. 53 ff, 518 ff; Siebert, Privatrecht im Bereich der öffentlichen Verwaltung, in Festschrift für Hans Niedermayer, 1953, S.215 ff (mit eingehenden Nachw.); Forsthoff, Begriff und Wesen des sozialen Rechtsstaats, S. 13 f und passim; ders., Lehrbuch des Verwaltungsrechts, S. 68 ff, 355 ff, 436 ff, 448 ff und passim (mit weit. Nachw.); Bachof, Begriff und Wesen des sozialen Rechtsstaats, insbes. S. $55 \mathrm{ff}$; Herbert Krüger, Die Auflage als Instrument der Wirtschaftsverwaltung, insbes. S.383 ff; Wolff, Verwaltungsrecht I, S.78 ff, $82 \mathrm{ff}$. Evers, Verfassungsrechtliche Bindungen fiskalischer Regierungs- und Verwaltungstätigkeit, NJW 13. Jhg. (1960) S. 2073 ff. - Näheres hierzu s. unten 5 (S. $614 \mathrm{ff}$ ). 
chen kann letztlich nur eine durchgängige gesetzliche Regelung der Gefahr wirksam begegnen, daß die Verwaltung ihre tatsächliche oder rechtliche Monopolstellung und die Abhängigkeit der Bedürftigen ausnutzt, um sich - im Wege der Koppelung, der Auflage, unter dem Vorwand der Anstaltsgewalt usw. 3) Machtvorteile $z u$ verschaffen, die ihr nicht zukommen. ${ }^{4)}$

Es ist deshalb über alle sonstigen Notwendigkeiten einer gesetzlichen Regelung auch der begünstigenden Verwaltungstätigkeit die sich aus der bundesstaatlichen Ordnung, der sonstigen verfassungsmäßigen und gesetzlichen Verwaltungsgliederung, dem Ineinandergreifen von Leistungs- und Eingriffsverwaltung, der Berührung rnit bestehenden gesetzlichen Regelungen usw. zahlreich ergeben - hinaus ein Stück rechtsstaatlicher Entelechie, daß die allermeisten Materien leistender Verwaltung eine gesetzliche Ordnung gefunden haben. Bei den relativ seltenen staatlichen Leistungen, die ohne eine (materiell-) gesetzliche Reglementierung erbracht werden, fehlt es nicht selten an der Allgemeinheit bzw. Typisierbarkeit der Regelung ${ }^{5)}$ oder an einer intensiven Berührung mit der Individualsphäre. ${ }^{6)}$ Gewisse Ausnahmefälle - wie z.B. die Übernahme von Patenschaften in kinderreichen Familien durch das Staatsoberhaupt - tragen eine andere

3) S. oben aaa 5 (S. $440 \mathrm{ff}$ ).

4) Damit wird natürlich das Problem auf den Gesetzgeber zurückverschoben. Inwieweit er unangemessene Regelungen treffen kann, bestimmt sich nach der Verfassung. Und hierfür ist Forsthoff (insbes. Lehrbuch des Verwaltungsrechts S. 67 Fußn. 5) zuzugeben, daß die geltenden deutschen Verfassungen diese Frage nicht erkannt und demzufolge auch nicht gelöst haben (s.a. Ipsen, Das Grundgesetz in seiner Vorläufigkeit, Recht-Staat-Wirtschaft, Bd.II 1950 S. 182 ff (189)).

5) Das Paradebeispiel ist die Hilfe in Katastrophenfällen. Für sie ließe sich äußerstenfalls ein Rahmengesetz schaffen, das für den Rechtsschutz der Betroffenen kaum viel bedeuten könnte. Stern (Rechtsfragen der öffentlichen Subventionierung Privater, S. 524) glaubt sie als Gnadenakt nicht dem "Rechtswert unterstellt". Das befriedigt nicht.

6) Ein Beispiel ist der Bundesjugendplan, dessen Mittel, soweit sie nicht dem Vollzug von Gesetzen dienen, meist an Organisationen oder für bestimmte kollektive Unternehmungen und Einrichtungen vergeben werden (vgl. die Richtlinien für den Bundesjugendplan v. 16. Dezember 1958 (G.MB1. 1959, S. 33)). 
Rechtfertigung in sich. ${ }^{7)}$ Bedenkliches - wie z. B. der Vollzug des Honnefer Modellplans - ist selten. ${ }^{8)}$

Ist an der Pflicht des Gesetzgebers, regelnd in die Leistungsverwaltung einzudringen, nicht $z u$ zweifeln, so ist es um ihre Durchsetzbarkeit umso schlechter bestellt. Das Handelnmüssen des Gesetzgebers ist nicht erzwingbar. Selbst eine bloße verfassungsgerichtliche Feststellung verfassungswidrigen Nichthandelns 9) könnte kaum gerechtfertigt werden; denn die besagte Pflicht des Gesetzgebers ist nur relativ - als die Pflicht, möglichst umfassend zu normieren - zu verstehen. Ein bestimmter Regelungsgegenstand ist nicht bezeichnet. Nur dort, wo der Gesetzgeber etwas tut, was dem aufgestellten Grundsatz widerspricht, ist er zu "fassen". Bestenfalls könnte also der Abbau rechtsstaatsmäßiger, gesetzlicher Normierungen effektiv verhindert werden - und auch das nur in Grenzfällen, die wohl nur im Rahmen eines weitergehenden Umbaues des Verfassungsgefüges denkbar sind.

Für den Auf- und Ausbau der gesetzlichen Regelung wirkt der besagte Grundsatz nur rechtspolitisch. Hier liegt der Schwerpunkt der Gefährdung. Mit dem Ausbau der gesetzlichen Ordnung konkurriert die sukzessive Ausweitung des Aktionsfeldes der Verwaltung. Solange der Gesetzgeber dieser nicht folgt, ist sie auf sich selbst gestellt und der Betroffene auf ihre ihn nicht im strengen Sinne berechtigenden Planungen angewiesen. ${ }^{10)}$ Wird der Verwaltung freie Aktivität im Prinzip zugestanden, so ist kaum noch

7) Gedacht ist an Ehrengaben des Staatsoberhaupts, die wie z.B. die Übernahme der Ehrenpatenschaft oder die Gewährung von Ehrengaben an verdiente aber verarmte Persönlichkeiten nicht selten - zumindest auch - sozialen Zwecken dienen. $\mathrm{Zu}$ ihrer Legitimation wird man wohl auf die Rechtsfigur der Prärogative zurückgreifen müssen. Hier handelt es sich um "Gnade" (s. \$.458 zu Fußn. 5).

8) Dagegen, daß die Studienförderung heute fast ausschließlich im Verwaltungswege betrieben und geordnet wird, sind schärfste Bedenken anzumelden. Die Frage, welcher Ausbildungsgang gewährleistet und wieviel öffentliche Hilfe erwartet werden kann, ist von einschneidendster individueller Bedeutung.

9) S. hierzu unten S. $557 \mathrm{ff}$.

10) Natürlich kann sich die Verwaltung auch vertraglich binden. Aber dieses auch sonst sehr begrenzt verwendbare Mittel eignet sich nicht für die Massenerledigung und scheidet somit für die meisten Angelegenheiten aus. 
irgendwo der Grad der Entwicklung auszumachen, der nicht überschritten werden darf.11) Selbst dort, wo das mit haushaltsgesetzlicher Unterstützung gepaarte materiellrechtliche Stillhalten des Gesetzgebers und die selbständige Fintwicklung der Verwaltung zu einem bewußten Zusammenspiel ausarten, durch das zwar (zunächst) für die Erledigung einer gewissen Staatsaufgabe gesorgt, dem Staate jedoch die verbindliche gesetzliche Regelung erspart werden soll, 12) könnten die fraglichen Verwaltungsmaß-

11) Die von Stern (Rechtsfragen der öffentlichen Subventionierung Privater, S. 524) versuchte Gegenüberstellung von "Gnadenakten" und Maßnahmen, die "dem Rechtswert unterstellt" sind, ist ein Spiel mit Unbekannten, zumal wenn der Begriff der "Gnade" schon so weit gesteckt wird wie bei Stern (s. oben S.458 zu Fußn.5).

12) Die Frage, wann überhaupt das Vorgehen der Exekutive in Konkurrenz mit dem Gesetz tritt, wann ein Aktionsplan der Verwaltung mit dem (fehlenden) Gesetz vergleichbar und somit das Manko an gesetzlicher Regelung von der Aktivität der Verwaltung her tatbestandlich faßbar wird, ist außerordentlich beziehungs reich. Die notwendige Klärung kann in diesem Zusammenhang nicht geleistet werclen. Hingewiesen sei nur auf einen Gesichtspunkt, nämlich daß der Vergleich notwendig an andere Kriterien anknüpfen muß, als sie für die Kennzeichnung von Gesetz und Verwaltungshandeln an sich maßgebend sind. Nur das Durchstoßen zur funktionellen Substanz von Gesetzgebung und Verwaltung kann das Mißverhältnis offenbar werden lassen. Ein Ansatz liegt vielleicht in der These Böckenfördes, wonach "die Begründung und Ausformung statusbezogener Rechtsverhältnisse, die Festlegung institutioneller Ordnungen für die verschiedenen Lebensbereiche" die eigentliche Aufgabe der Gesetzgebung ist (Böckenförde, Gesetz und gesetzgebende Gewalt, S.341; s.a. dessen Nachweise aus den Lehren Steins, Stahls und Gneists, S.152 ff, $164 \mathrm{ff}, 173 \mathrm{ff}$ ). Ist eine Maßnahme (Maßnahmengesamtheit) der Verwaltung von solcher subjektiver und zeitlicher Ausdehnung, daß sie mit Rücksicht auf ihre sachliche Figenart nicht ohne Grundlegung in wenigstens gedachten Rechtspositionen und wenigstens gedachten institutionellen Ordnungen projektiert und durchgeführt werden kann, dann ist der "Alleingang" der Verwaltung funktionswidrig. Die "natürliche" A rbeitsteilung $z$ wischen ihr und der Gesetzgebung ist gestört. Die Unverbindlichkeit der (gedachten) Rechtspositionen und (gedachten) institutionellen Ordnungen ist sachwidrig. Hier etwa dürfte der Stein des rechtsstaatlichen Anstoßes 
nahmen nicht unmittelbax als verboten angesehen werden.

Je schwächer die direkte Sanktion der gesetzgeberischen Pflicht zur Bindung der Exekutive ist, desto wichtiger erscheinen die mittelbaren Abhilfen und Rechtsgewährleistungen, die dem Verwaltungshandeln, durch das der Staat sich des einer gesetzlichen Regelung zugänglichen Gegenstandes in einer die gesetzliche Regelung substituierenden Weise annimmt, 13) positiv nachstoßen. Dabei geht es darum, den Staat zum Schutze des Betroffenen an seinem Verwaltungshandeln so festzuhalten, wie wenn er die, durch dieses substituierte, gesetzliche Regelung schon getroffen hätte. 14) In der Breitendimension wird beim Gleichheitsgrundsatz anzusetzen und dem Vorgehen der Verwaltung Allgemeinheit

liegen. Hierin erweist sich dann auch erneut die besondere Bedeutung des aufgezeigten Grundsatzes für den Sachzusammenhang der sozialen Intervention. Sie ist im wesentlichen typisiert generell und nicht individuell, existentiell und nicht akzidentiell, prinzipiell notwendig und nicht fall- und gnadenweise Ausnahme. Sie ist nur vor clem Hintergrund institutioneller Ordnungen und unter Anknüpfung an Staaten zweckvoll und sachgerecht durchführbar. Der Anwendungsbereich situationsgebundener Einzelmaßnahmen ist relativ beschränkt. Auch dann, wenn die Verwaltung "autonom" eine soziale Spannungslage generell aufgreift und interveniert, kommt sie nicht ohne - wenigstens gedachte - Ordnungsbilder aus. Indem aber sie und nicht der Gesetzgeber sie entwickelt und effektuiert,bleiben sie im Unverbindlichen. Daraus resultiert für eine jeweils typisierbare Vielzahl von Betroffenen eine tiefgreifende Unsicherheit ihrer Lebensverhältnisse.

13) S. nochmals S. 460 zu Fußn. 12.

14) Vg1. Forsthoff, Lehrbuch des Verwaltungsrechts, S. $10 \mathrm{f}$ (insbes. S. 11). - S. hierzu und zum Folgenden Ballerstedt, Wirtschaftsverfassungsrecht, S.34: "Der rechtsleere Raum, in dem die Staatsintervention sich bewegt, wird einmal dadurch geschaffen, daß der Grundsatz der Gesetzmäßigkeit cler Verwaltung bei gewährenden Verwaltungsakten, also gegenüber der Verwaltung als Leistungsträger, zur Gewährleistung der Rechtsstaatlichkeit des Verwaltungshanclelns nicht mehr ausreicht. Verfeinerung des Ermessensbegriffs, unermüdliche Konkretisierungsbemühungen um den Gleichheitsgrundsatz, Forderung der Planungsbeständigkeit (Ipsen: "Plangewährleistung") sind Richtpunkte, auf die eine Fortbildung des Wirtschaftsverfassungsrechts zustreben sollte". 
zu verschaffen sein. ${ }^{15)}$ In der Tiefendimension wird die individuelle Position durch die Aktualisierung der Grundsätze über den Widerruf der Verwaltungsakte, 16) über die Verbindlichkeit verwaltungsbehördlicher Zusicherungen 17) und über die Gewährleistung behördlicher Pläne, ${ }^{18)}$ die vor dem Hintergrund der allgemeinen Prinzipien von Treu und Glauben und der zur materiellen Substanz des Rechtsstaates gehörenden Rechtssicherheit 19) $\mathrm{zu}$ sehen sind, zu festigen sein. Am einfachsten sind die Konsequenzen dort zu ziehen, wo die Verwaltung der äußeren Gestaltung nach in Formen tätig wird, die denen der Gesetzgebung nahe kommen, wo sie also z.B. in publizierten Verwaltungsordnungen selbst die Grundsätze aufstellt, die sie vollzieht. Zumindest geben diese der Anwendung des Gleichheitsgrundsatzes eine zuverlässige Grundlage, die durch bloße Freizeichnungsklauseln nicht

15) Zu diesem Zusammenhang s. insbes. Hesse, Der Gleichheitsgrundsatz im Staatsrecht, S.220; Ipsen, Gleichheit, S. $147 \mathrm{ff}$, 164 ; s.a. Hildegard Krüger, Der Gleichbehandlungssatz als Rechtsgrundlage öffentlich-rechtlicher Gruppenrechte, DVBl. 70.Jhg. (1955) S. 178 ff, 208 ff; Werner, Verwaltungsrecht als konkretisiertes Verfassungsrecht, S. 530 f; Forsthoff, a.a.O. S. 71; BGH Urt.v. 30.April 1959 - III ZR 24/58 DVB1. Jhg. 75 (1960) S. 141.

16) S. hierzu z.B. Forsthoff, a.a.O. S. 242 f.

17) S. hierzu z.B. Wolff, Verwaltungsrecht I S.129, 195 und seine Nachweise.

18) Zur "Plangewährleistung" s. Ipsen, Diskussionsbeitrag zu "Die staatliche Intervention im Bereich der Wirtschaft", VVDStRL. H. 11 (1954) S. 129 ff (129); Herbert Krüger, desg1. ebd. S. $137 \mathrm{ff}(139)$. S.a. Ipsen, Staatliche Wirtschafts-Intervention, Staatsverfassung und Wirtschaftsordnung, JZ 7. Jhg. (1952) S. 759 ff (761); Haas, System öffentlichrechtlicher Entschädigungspflichten, S. 47; Lerche, Grundrechtsbeschränkungen "durch Gesetz" im Wandel des Verfassungsbildes, S. 529 Fußn. 53; Scheuner, Die neuere Entwicklung des Rechtsstaats in Deutschland, S.253. Kritisch Ehlermann, Wirtschafts lenkung und Entschädigung, 1957, S.67 ff (mit weit. Nachw.). Zurückhaltend auch Hamann, Rechtsstaat und Wirtschaftslenkung, S. 126.

19) Zum Gebot der Rechtssicherheit als einer Emanation der Rechtsstaatlichkeit s. vor allem BVerfGE 2, 380 (403 ff); 3, 4 (11), 225 (237), 248 (253); 7, 89 (92). - Zu der engen Verbindung der Anwendung von Treu und Glauben im öffentlichen Recht mit dem rechtsstaatlichen Grundsatz der Rechtssicherheit s. z.B. BFHE 67, 355 (361 f). - Näheres s. unten III 2 (S. $637 \mathrm{ff})$. 
aus der Welt geschafft werden kann. ${ }^{20)}$ Sicher kann dadurch nicht der Zustand voll hergestellt werden, der bestünde, wenn der Gesetzgeber tätig geworden wäre. Das darf auch gar nicht erstrebt werden, um nicht einer stillschwiegenden Kompetenzverschiebung Vorschub zu leisten. Aber ein wirksamer Schutz gegen die Umgehung des rechtsstaatlichen Gebotes der gesetzlichen Regelung des Verwaltungshandelns kann aus diesen Gesichtspunkten heraus wohl entwickelt werden.

c) Das rechtsstaatliche Gebot der Bestimmtheit der Verwaltungsbefugnisse

Obwohl die Verfassung - von der verwandten Bestimmung des Art. 80 Abs. 1 Satz 2 GG abgesehen - darüber nichts sagt, ist heute allgemein anerkannt, daß es nicht genügt, wenn belastende Ver-

20) Die Rechtsprechung hat der Verwaltung immer wieder den "Streich" gespielt, daß sie Bestimmungen, die als Verwaltungsvorschriften erlassen waren, als verbindliche und auch gegen die Verwaltung wirksame Rechtsnormen qualifiziert hat: RGZ 40, 68 und 48, 85 (betreffend die Grundsätze für die Besetzung der Subaltern- und Unterbeamtenstellen bei den Reichs- und Staatsbehörden mit Militäranwärtern); BGHZ 10, 295; BayObLGZ 1955, 281; BayVGHE n.F. 9, 47 (betreffend Beihilfegrundsätze; weitere Nachweise s. in den zitierten Entscheidungen); BGHZ 25, 231; Bad. - Württ. Landessozialgericht, Entsch.v. 27. Mai 1960 - L 2 U a 1881/58 - Breithaupt 49. Jhg. (1960) S. 790; (Richtlinien über Zuschläge zur Unfallfürsorge für Strafgefangene); BGH Urt.v.16. Juni 1958 - III ZR 68/57 - ZBR Jhg. 6 (1958) S. 345 (Richt1inien über die Gewährung von Ministerialzulagen). Eine ähnliche Forderung erhebt Forsthoff (Lehrbuch des Verwaltungsrechts S. $10 \mathrm{f}$ ) hinsichtlich der Richtlinien der Landesregierung von Württemberg-Baden über die Rechtsverhältnisse der 1945 aus dem Dienst geschiedenen Beamten. Allerdings handelte es sich in allen diesen Fällen - jedenfalls der Argumentation nach darum, daß vorhandene Rechtsverhältnisse geändert oder gestaltbare Rechte gestaltet wurden. Das ist nicht ganz der Fall, in dem die Verwaltung von sich aus und ohne Anlehnung an vorgegebene Rechtsverhältnisse Leistungen gewährt. Doch zeigen die genannten Entscheidungen, die hier nicht näher analysiert werden sollen, immerhin in dieselbe Richtung, in der auch die im Text vorgeschlagene Lösung liegt. Zum Problem für den besonderen Fall der Subventionen s.a. Stern, Rechtsfragen der öffentlichen Subventionierung Privater, S. 360 . 
waltungsmaßnahmen überhaupt eine Grundlage im Gesetz haben. Die Befugnis hierzu muß vielmehr durch das "Gesetz nach Inhalt, Gegenstand, Zweck und Ausmaß hinreichend bestimmt und begrenzt" sein, "so daß die Eingriffe meßbar und in gewissem Umfang für den Staatsbürger voraussehbar und berechenbar werden". 1) Dieser zutreffend aus dem allgemeinen Prinzip der Rechtsstaatlichkeit und den besonderen Prinzipien der Gewaltenteilung, der Gesetzmäßigkeit der Verwaltung und des Erfordernisses gerichtlichen Rechtsschutzes deduzierte Grundsatz bewirkt in seinem Geltungsbereich eine besondere Dichte der gesetzlichen Regelung. Der Gesetzgeber ist mit den betroffenen Verwaltungsgegenständen subjektiv und objektiv auf das einläßlichste befaßt.

Dieser Grundsatz gilt nicht für das Haushaltsgesetz;2) und er gilt nicht für die (rein) institutionellen Vorbehalte, durch die staatsorganisatorische Anordnungen ohne Rücksicht auf ihren Charakter als allgemeinverbindliche Norm und vor allem ohne Rücksicht auf ihren bedingenden Zusammenhang mit materiellen Regelungen, die ihrerseits dem Vorbehalt des Gesetzes unterliegen, dem Gesetzgeber reserviert werden. Er ist dem rechtsstaatlichen Gesetzesvorbehalt zugeordnet, der die Herrschaft der Gesetze über den Bürger sichern soll.

Da es für die leistende Verwaltung einen absoluten Vorbehalt des Gesetzes nicht gibt, liegt es nahe zu sagen, daß für sie auch das rechtsstaatliche Konkretisierungsgebot nicht gelten kann. ${ }^{3)}$

1) BVerfGE 8, 274 (325 f - Zitat S.325 -) m. eingeh. Nachw.; s.a. die vorzüglich belegte Darstellung bei Jesch, Unbestimmter Rechtsbegriff und Ermessen in rechtstheoretischer und verfassungsrechtlicher Sicht, S.237 ff; ferner Woeckel, Rechtsstaatliche Anforderungen zum Erlaß von Hoheitsakten, Bayerische Verwaltungsblätter, n. F. 5. Jhg. (1959) S. 365 ff und seine Nachw.

2) Seine Funktion ist durch Art.110 Abs. 1 und 2 GG in einer ganz anderen Weise umschrieben (s.hierzu z. B. Bühler, Bonner Kommentar, Art.110 Erl. II 2 und 3; s.a. die Detailregelungen der Reichshaushaltsordnung).

3) Ule, Anm. zu OVG Hamburg, Urt.v. 1. November 1950 OVG Bf 327/50 - DVB1. Jhg.66 (1951) S. 52 ff (53); Wint rich, Uiber Eigenart und Methode verfassungsgerichtlicher Rechtsprechung, S.234; Herbert Krüger, Rechtsstaatliche Gesetzgebungstechnik, S. 554; s.a. Württ. - Bad. VGH, Urt.v.

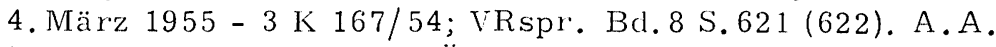
(für Subventionen) Ipsen, Öffentliche Subventionierung Priva- 
In Anbetracht der nur relativen Pflicht des Gesetzgebers, auch die Leistungsverwaltung zu ordnen, läßt sich argumentieren, es sei schon ein Schritt zur Realisierung des Rechtsstaates, wenn der Gesetzgeber überhaupt ein Minimum an Ordnung schafft; der verbleibende Spielraum der Verwaltung könne ebensowenig beanstandet werden, wie es hätte rechtlich beanstandet werden können, wenn der Gesetzgeber untätig geblieben wäre. Aber es ist nicht dasselbe, ob der Gesetzgeber schweigt und der gesetzesfreien Betätigung Raum läßt oder ob er der Verwaltung einen eigenen Vollzugsauftrag erteilt. Einerseits schafft er ihr dadurch eine festere Basis. Das Gesetz setzt sich gegen gegenständlich konkurrierencle gesetzliche Regelungen durch. Die gesetzesfreie Verwaltung hat dagegen alle irgendwie hereinragenden gesetzlichen Bindungen voll zu respektieren. Andererseits ist die gesetzesfreie Verwaltung von besonderen, direkt auf das Objekt ihrer Aktivität bezogenen Bindungen regelmäßig frei. Hat dagegen der Gesetzgeber eingegriffen, so unterliegt die Verwaltung jedenfalls einem Minimum an Reglementierung auch und gerade in Hinsicht auf den speziellen Gegenstand. Der Gesetzgeber tritt in die Sachverantwortung ein. Soll er auf halbem Wege stehen bleiben und sich darauf beschränken dürfen, die Verwaltung zu weiterem Vorgehen nach ihrem weitgespannten Ermessen zu ermächtigen?

Die sich aufdrängende antithetische Fragestellung lenkt bereits darauf hin, daß die Lösung nicht im Extrem sondern nur in der Mitte - in einer allerdings sehr schwierig zu fixierenden Mitte liegen kann. Der Gesetzgeber (larf keine Regelung schaffen, die dem rechtsstaatlichen Bild der rechtsgebundenen Verwaltung widerspricht. Das wäre aber cler Fall, wenn der Verwaltung durch Gesetz die Befriedigung gewisser individueller Bedürfnisse übertragen, wemn clie Verwaltung dadurch gegenüber jedermann zur Erfüllung dieser Aufgaben legitimiert und vielleicht auch von weitergehenclen Forderung freigestellt und wenn der Bürger von Gesetzes wegen su auf die Hilfe der Verwaltung verwiesen würde, auf daß schließlich die Entscheidung über das Ob und Wie der Befriedigung des Bedürfnisses von der Verwaltung zu treffen wäre. Je tiefer diese Entscheidung in die Individualsphäre der Betroffenen einschneidet, je mehr sie darauf angewiesen und davon abhängig sind, umso deutlicher wird, daß die liegelung dem rechtsstaatlichen Prinzip zuwider ist. Zwar liegt eine direkte Entsprechung zu cinem Gesetz, das in ähnlicher Weise zu Fingriffen ermächtigen würde, nicht vor. Dieses ist die

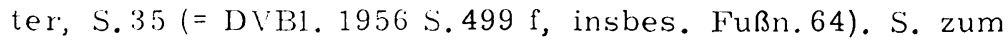
Problem auch Stern, Rechtsfragen der öffentlichen Subventionierung Privater, $\$ .525,559 \mathrm{f}$. 
Alternative $z u$ einem nur zu begrenzten Eingriffen ermächtigenden Gesetz oder zu keinem Gesetz, d.h. zu dem mit insoweit unangetasteter Individualsphäre korrespondierenden völligen Fehlen einschlägiger Verwaltungsbefugnisse. Das - um es einmal kurz zu nennen: - leistungsermächtigende Gesetz dagegen ist die $A_{\perp} 1-$ te rnative zu einem die Leistungen der Verwaltung angemessen regulierenden Gesetz oder zu keinem Gesetz, was hier eben doch ein Angewiesensein auf die (gesetzesfreie) Verwaltung bedeuten kann. Aber es vernachlässigt, die Verwaltung mehr berechtigend als verpflichtend und den Bürger mehr ausliefernd als beschützend, doch die Pflicht zur Bindung der Verwaltung an das Recht. Die dem Problem eigentümliche Spannungslage zwingt daher, von dem strengen Bestimmtheitserfordernis der Eingriffsermächtigung abzusehen, jedoch gewisse weiter gespannte aber doch noch spürbar hindernde Schranken auch für gesetzliche "Leistungsermächtigungen" zu fordern. ${ }^{4)}$

4) (1) Ähnlich Jesch, Unbestimmter Rechtsbegriff und Ermessen in rechtstheoretischer und verfassungsrechtlicher Sicht, S.246 ff; Hamann, Deutsches Wirtschaftsverfassungsrecht, S.47; Stern, a.a.O. S. 525; Werner, Verwaltungsrecht als konkretisiertes Verfassungsrecht, S. 531.

(2) Es ist eine gewisse Versuchung, das Problem unter Berufung auf Art.80 Abs. 1 Satz 2 GG lösen zu wollen. Der clort für Rechtsetzungsermächtigungen niedergelegte Grundsatz ist eine andere - durch die Aufnahme in die Verfassung ausgezeichnete - Emanation desselben rechtsstaatlichen Grundprinzips, dem auch das Gebot der Bestimmtheit der Befugnis zu konkreten Verwaltungsakten entnommen ist. A rt. 80 Abs.1 GG unterscheidet nicht danach, welchen Gegenstand die Ermächtigung hat. (Die das Kriegsgefangenenentschädigungsgesetz betreffende Entscheidung BVerfGE 5, 71 trägt keine Bedenken, die Vorschrift auch dort anzuwenden, wo es um die Regelung staatlicher Leistungen geht). So könnte man fragen, ob es dann nicht selbstver ständlich ist, daß das Bestimmtheitsgebot uneingeschränkt auch für die Leistungsverwaltung gilt. Aber das Argument trägt nicht. Art. $80 \mathrm{GG}$ betrifft die gesetzliche Regelung der Rechtsetzung durch Fxekutivbehörden. Das hier fragliche Bestimmtheitsgebot betrifft die gesetzliche Regelung der Verwaltung durch Exekutivbehörden. Dort stehen sich verschiedene Organe (Legislative - Exekutive) in Ausübung derselben Funktion gegenüber. Hier sind es zwei Funktionen (Rechtsetzung - Verwaltung), die nicht unbedingt von verschiedenen Organen (Legislative - Exekutive) ausgeübt werden müssen; denn soweit die Regelung des 
In diesem weiteren Rahmen ist unbedenklich auch Raum für eine elastische Gestaltung, die für die leistende Verwaltung ganz unerläßlich ist. Zwar wird das Bild der sozialen Leistungen vordergründig beherrscht von den fixen Barleistungen, die von der Verwaltung unter Feststellung der Anspruchsvoraussetzungen nur zu errechnen sind: den langfristigen Rentenleistungen der Kriegsopferversorgung, der Sozialversicherung 5 ) und des Lastenaus-

Verwaltungshandelns gemäß Art.80 GG der Exekutivspitze überlassen ist, ist auch diese - als Rechtsetzungssubjekt dem Bestimmtheitsgebot unterworfen. Die Verwaltungsfunktion der Verwaltungsbehörden steht noch neben der Rechtsetzungsfunktion, die diesen Behörden aus Art.80 GG i.V. $m$. den ermächtigenden Gesetzen erwächst (s.hierzu z.B. Bundesverwaltungsgericht, Urt.v. 9. Oktober 1957 - VII B 56/57 - DVB1. Jhg. 73 (1958) S. 172; BFHE 67, 355, insbes. S. 358; s.a. Jesch, Zulässigkeit gesetzesvertretender Verwaltungsverordnungen? S. 82 ff). Die mißglückte Entscheidung BVerfGE 8, 155 hat die darin liegende Problematik zwar nicht bewältigt aber umso stärker bewußt werden lassen. Diese Entscheidung deutet, wenngleich in sehr unbefriedigender Weise übrigens ebenfalls auf die im Text vorgeschlagene Mittellösung des Problems hin. Dort ist zunächst ausgeführt, der Gesetzgeber könne hinsicht1ich der Organisation der Leistungsverwaltung, die keinem Gesetzesvorbehalt unterliege (S. $165 \mathrm{ff}$ ), Bestimmungen schaffen, die hinter den abweichenden Verwaltungsvorschriften an Geltungskraft zurückträten (S. 169). Sodann führt das Gericht aus: "Damit ist allerdings nicht gesagt, daß die Verwendung dieser Formen unbeschränkt möglich ist. Die Grenze liegt dort, wo der Gesetzgeber Vorschriften von solcher Bedeutung und in solchem Umfang für subsidiär erklärt, daß sich dadurch innerhalb des Staatsgefüges eine Gewichtsverschiebung zwischen gesetzgebender Gewalt und Verwaltung ergibt". Münzt man die recht abwegigen Ausführungen über die Möglichkeit von im Verhältnis zu Verwaltungsvorschriften subsidiären Gesetzesvorschriften auf das allgemeine Problem der gesetzlichen Bestimmung von Verwaltungsbefugnissen bei Fehlen eines (absoluten) Gesetzesvorbehalts (s.a. die etwas krausen Bezugnahmen a.a. O. S. 171), so stellt sich die zitierte Formel der Tendenz nach als Ausdruck einer vermittelnden Lösung dar. (Die Formel ist allerdings in sich zu unscharf und wird in den aufgestellten Kriterien dem Problem nicht gerecht.)

5) Diese Versicherungsleistungen gehören nur bedingt zur Leistungsverwaltung. Sie sind regelmäßig mit durch den Beitrag 
gleichsrechts; den Kindergeldern; den vorübergehenden Geldleistungen wie Krankengeld, 5) Unterhaltsgeld bei Unfall, Stillgeld, A rbeitslosengeld ${ }^{5)}$ u.a.m.; und den einmaligen Zahlungen wie vor allem den Sterbegeldern der Sozialversicherung und den Entschädigungszahlungen des Lastenausgleichsrechts, des Kriegsgefangenenentschädigungsrechts, des Heimkehrerrechts, des Wiedergutmachungsrechts usw. Aber diese normative Endgültigkeit der sozialen Leistungen ist, so sehr das Bedürfnis nach maximaler Egalität, Sicherheit und Berechenbarkeit der Leistungen, Indifferenz der Leistungen gegenüber den individuellen Verhältnissen und freier. Verfügbarkeit nach dieser Gestaltungsform drängt, nur unter sehr engen Voraussetzungen möglich. Notwendig ist in erster Linie, daß die Bedürfnisse durch Geldieistungen befriedigt werden können. ${ }^{6)}$ Die Leistungen müssen ferner zur

des Empfängers gedeckt. Aus dieser Gesamtheit von Leistung und Gegenleistung können sie nicht gelöst werden.

6) Die festen Geldleistungen sind in vielfältigem Sinne Entsprechungen des Steueraufkommens. Erstens, hängt die Konzentration der Schöpfung der Umverteilungsmasse auf das Steuerwesen (nebst den unbedeutenden anderen festen, hoheitlichen Abgaben wie Gebühren usw.) mit der Konzentration der Leistungen auf Geldzahlungen eng zusammen. Der Staat kann in Anbetracht seiner rechtsstaatlichen, vor allem der eigentumsrechtlichen Bindung in so großem Umfange, wie er Leistungen benötigt, überhaupt nur Geldmittel durch die Erhebung von Steuern aufbringen. Umgekehrt wird auch die Geldleistung als die die persönliche Sphäre am meisten schonende Art staatlicher Hilfe angesehen und empfunden. Es erscheint also - wie immer wieder zu bemerken veranlaßt ist als der reibungsärmste Umverteilungsvorgang, Geldabgaben einzuheben und Geldzahlungen zu leisten. Zweitens, erlaubt die maximale Teil-, Vertret- und 'Tauschbarkeit des Geldes die weitestgehende Allgemeinheit, Gleichheit und Festigkeit der Regelung von Leistungen des Staates und an den Staat. Wenn Maunz (Die Finanzverfassung im Rahmen der Staatsverfassung, S.58) sagt, es sei "heute eine Selbstverständlichkeit", daß "keine Steuer anders als auf Grund eines förmlichen Gesetzes erhoben werden kann unter Ausschluß des freien Ermessens der Finanzverwaltung" (!), so findet das ein Gegenstück darin, daß der Staat auch bei seinen eigenen Geldleistungen das Ermessen der Verwaltung extrem ausschaltet und ausschalten kann. 
unkontrollierten, nicht speziellen Zwecken verpflichteten Verwendung durch den Adressaten erbracht werden. Sie müssen einen besonderen Grund haben, der den Verzicht auf den Vorbehalt der konkreten Notwendigkeit und Möglichkeit als angemessen oder sogar notwendig erscheinen läßt. Und schließlich muß die Gesamtsumme in einer Größenordnung bleiben, die auch wirklich in jedem Fall aufgebracht werden kann. 7) Die Vielfalt der notwendigen sozialen Leistungen findet darin kein erschöpfendes Unterkommen. Schon bezüglich der grundsätzlich fixen Geldleistungen läßt es sich nicht vermeiden, der Verwaltung einen Spielraum zu geben, der allein eine sachgerechte Erledigung jedes einzelnen Falles erlaubt. Unbestimmte Rechtsbegriffe müssen in großer Zahl helfen. Gelegentlich läßt es sich aber auch nicht umgehen, die Leistung ${ }^{8)}$ oder einzelne, ihre Höhe bestimmende Elemente derselben 9) dem Ermessen der zuständigen Behörde zu überlas-

7) Nach dem in der Bundesrepublik gegenwärtig herrschenden System sozialer Sicherheit ist der Hauptanwendungsbereich der fixen Geldzahlungen in der Sozialversicherung und in der sogenannten Sonderversorgung zu suchen. Aber der Text soll keine Option gegen ein System allgemeiner Staatsbürgerversorgung zum Ausdruck bringen. Auch und gerade eine allgemeine Versorgung kann sich nicht auf Geldleistungen beschränken sondern muß unmittelbar persönliche Leistungen und sachliche Veranstaltungen gewähren. Auch ein allgemeines Versorgungssystem kommt nicht darum herum, an der Peripherie einen "Polster" von Fürsorgeleistungen (unter Prüfung der Bedürftigkeit) vorzusehen. Auch ein System allgemeiner Versorgung kann nicht auf die Zweckbindung gewisser Leistungen verzichten (im Gegenteil wird der ethische Rigorismus eines totalen Versorgungssystems gerade die Gebundenheit der Leistungen bedingen). Und schließlich wird auch ein umfassendes System der Versorgung nicht um die Rücksicht auf das volkswirtschaftlich Mögliche herumkommen; denn "in jeder wirtschaftsgeschichtlichen Situation" gibt es "ein Maß, das schlechterdings nicht über'schritten werden kann, weil das Sozialprodukt auch bei noch so starken Verteilungskor rekturen für die sozialpolitisch zu Schützenden mehr nicht hergibt" (Weisser, Art. "Soziale Sicherheit" im Handwörterbuch der Sozialwissenschaften, S. 401).

8) Z.B. $\$ 64$ des Bundesversorgungsgesetzes; $\$ 590$ RVO; Abschn. I Nr. 4 und Abschn. I, Nr. 1 des Erlasses des Reichsarbeitsminister's über Verbesserungen in der gesetzlichen K rankenversicherung vom 2. Nov. 1943 (RA rbB1. II S.485). 9) S. z.B. $\$ \$ 566,594$ Abs. 3 RVO. - Zu einem zentralen Pro- 
sen, weil nur auf diese Weise eine alle Umstände des einzelnen Falles berücksichtigende Lösung gewährleistet werden kann. Doch sind diese Irregularitäten nicht so wesentlich. Grundsätzlich braucht die Verwaltung einen freien Gestaltungsraum dort, wo sie nur Fürsorge zu betreiben, d.h. der keiner anderen Hilfe teilhaftigen individuellen Not in dem konkret erforderlichen und ausreichenden Maß abzuhelfen hat. 10) Zur konkreten Harmonisierung von Soll und Haben muß sie hinsichtlich derjenigen Leistungen berechtigt sein, die sowohl über das absolute Minimum als auch über das auf Dauer Fixierte hinausgehen. 11) Aber noch mehr Die Verwaltung muß hinausgreifen über die reine Geldleistung zur Gewährung sachlicher und persönlicher Leistungen und hinausgreifen über die generelle Versorgung des Bedürftigen zu seiner dem $Z$ wecke nach spezialisierten Unterstützung. Sie muß dabei mit den sehr unterschiedlichen sachlichen und persönlichen Voraussetzungen fertig werden. Sie ist vielfach auf die Mitwirkung der Betroffenen angewiesen oder muß, da ihn die mangelnde Verfügungsmacht über die Hilfsmittel ohnedies schon einengt, wenigstens auf seine Wünsche Rücksicht nehmen. Das läßt sich nicht im Detail reglementieren. Die Vielfalt der Gegebenheiten, ihrer Variationen, Kombinationen und Permutationen ist unüberschaubar. Vor allem aber: Es geht nicht ohne die gestalterische Initiative der Verwaltungsbehörden, die das Gesetz - ebensowenig wie die Verfassung die Gestaltungsfunktion des Gesetzgebers - letztlich nicht durchschlagskräftig zu erzwingen vermag. Es ist unmöglich, hier ein System dieser spezifischen Verhältnisse und ihrer gesetzgeberischen Bewältigung zu entwickeln. Zur Exemplifikation sei nur verwiesen auf den Spielraum, den die Regelung der Hilfe im Krankheitsfalle lassen muß, um den Spannungen zwischen dem sachlich, personell und finanziell Möglichen, der Bereitschaft und den Wünschen des Betroffenen und dem Zweck der Hilfe gerecht zu werden; ${ }^{2}$ ) auf die Befugnis, im Rahmen der per-

blem s. jüngst Schultze-Lock, Minderung der Erwerbsfähigkeit - ein Ermessenstatbestand? NJW 13.Jhg. (1960) \$.365 ff.

10) S. z.B. $\$ 6$ der Fürsorgepflichtverordnung, $\$ \$ 6,10$ ff der. Reichsgrundsätze über Voraussetzungen, Art und Maß der öffentlichen Fürsorge. - S.a. $\$ \$ 17,18$ des Gesetzes über die Tuberkulosehilfe.

11) S. insbes. $\$ \$ 253,298,300-302,323$ LAG; $\$ 73$ des Allgemeinen Kriegsfolgengesetzes; $\$ \$ 3,13$ ff des Ersten Wohnungsbaugesetzes; $\mathbb{S} 6$, 18 ff des Zweiten Wohnungsbaugesetzes.

12) S. vor allem die Bestimmungen über die Heilbehandlung der Versorgungsberechtigten ( $\$ \$ 10 \mathrm{ff} B V G$ ), die Leistungen der Krankenversicherung ( $\$ \$ 179 \mathrm{ff} R \mathrm{RO}$ ) und die einschlägigen 
sönlichen Fortkommenshilfe, z.B. durch Ausbildungs- und Berufsförderung, zwischen den objektiven Gegebenheiten, der subjektiven Eignung und dem Wollen und Trachten des Betroffenen zu vermitteln; 13) auf die Problematik wirtschaftlicher Hilfsmaßnahmen, die dem danach strebenden Bedürftigen den Aufbau einer selbständigen Existenz ermöglichen sollen und subjektive Eignung, objektive Voraussetzungen und Notwendigkeiten und die Dreiecksrelation zu anderen Vorhaben und den verfügbaren Mitteln zu berücksichtigen haben; ${ }^{14)}$ auf die sehr ähnliche Situation bei der Arbeitsplatzbeschaffung durch Förderung privater Unternehmen, 15) die mit der Aufbauhilfe Hand in Hand gehen kann; 16) auf die Entscheidung über die Förderungswürdigkeit nicht-staatlicher sozialer Einrichtungen; 17) auf die vielfältigen Probleme des Siedlungswesens und der Wohnungsbauförderung, die, zwischen behördlicher und privater Initiative variierend, amtliche Wirksamkeit und öfentliche Mittel, private Mittel, privates Erwerbsstreben und privates Wohninteresse in mannigfachen Kombinationen jedoch mit möglichst breitem Effekt und unter optimaler Verwendung der öffentlichen Mittel vor einen Wagen zu spannen haben; 18) und vor allem auf die sachlichen Veranstaltungen der öffentlichen Hand - vom Krankenhaus ${ }^{19)}$ bis zum Kinder- und Altersheim, 20)

Bestimmungen über die Unfallversicherung (insbes. $\$ \$ 58 \mathrm{ff}$ RVO). S. auch die einschlägigen Vorschriften des Gesetzes über die Tuberkulosehilfe und des Körperbehindertengesetzes.

13) S. z.B. $\$ \$ 26$ f des Bundesversorgungsgesetzes; $\$ \$ 7$ Abs. 3 und 4,14 des Körperbehindertengesetzes; $\$ \$ 3,13$ ff des Gesetzes über die Tuberkulosehilfe; $\$ 302$ LAG (i.V.m. der Weisung über die Ausbildungsbeihilfe i.d. F. v. 28. März 1958, MtB1. BAA S. 103); $\$ \$ 131,133$ AVAVG; $\$ \$ 10 \mathrm{f}$ des Heimkehrergesetzes; $\mathbb{\$} 28$ f des Kriegsgefangenenentschädigungsgesetzes.

14) S. z.B. $\$ \$ 253$ ff LAG; $\$ \$ 35 \mathrm{ff}, 72 \mathrm{ff} B V F G ; \$ \$ 28 \mathrm{f}$ des Kriegsgefangenenent schädigungsgesetzes; s.a. $\$ \$ 11$ Abs.2 $\mathrm{Nr} .1,31$ der Reichsgrundsätze über Voraussetzungen, Art und Maß der öffentlichen Fürsorge.

15) S. vor allem $\$ 132$ AVAVG.

16) S. $\$ 259$ LAG, $\$ 79$ BVFG.

17) S. z.B. \$134 AVAVG.

18) S. außer den beiden Wohnungsbaugesetzen und dem Bergarbeiterwohnungsbaugesetz vor allem $\$ \$ 298$ ff LAG, $\$ 85$ AnVG, $\$ 1306$ RVO, $\$ 143$ AVAVG.

19) Außer clen einschlägigen Vorschriften des Kommunalrechts s. zur E.richtung von Heilanstalten durch die Träger der Krankenversicherung $\$ 346$ Abs. 2 Nr.2, durch die Träger 
vom Umschulungslehrgang bis zum (arbeitsbeschaffenden 21 ) oder regional wohlstandspolitischen 22)) Straßenbau -, die ohne umfassende, immer nur unter Würdigung aller konkreten Umstände zu treffende Initiative der zuständigen Verwaltungsbehörden nicht denkbar sind. 23)

Näheres Zusehen offenbart eine innere Gesetzmäßigkeit, welche die Unterschiede in der Präzision der legalistischen Sicherung der Leistungsverwaltung reguliert und präzisiert. Sie kann auf drei Elemente zurückgeführt werden. Das erste kann in der Notwendigkeit einer elastischen Regelung gesehen werden, die durch den $Z$ wang bedingt ist, die auftretenden Bedürfnisse mit den vor-

der Unfallversicherung $\$ 736$ Abs. 1, durch die Versorgungsverwaltung $₫ 2$ des Ges.ü.d. Errichtung d. Verwaltungsbehörde der Kriegsopferversorgung.

20) Außer den einschlägigen kommunalrechtlichen Vorschriften s. $\$ 86$ AnVG und $\$ 1307$ RVO.

21) Vgl. $\$ \$ 138,140$ ff AVAVG.

22) Als Grundlage kommt vor allem das Landwirtschaftsgesetz in Frage.

23) Die umfassendste Ermächtigung - gegen die rechtsstaatliche Bedenken nicht unterdrückt werden können - stellt das Landwirtschaftsgesetz dar. Es hat zwar keinen rein sozialen Charakter, ist aber im Hinblick auf die Bedeutung für die oft recht arme Landbevölkerung und die ländlichen Dienstnehmer auch hier zu erwähnen. Eine sehr weite Generalklausel, die in der Nachbarschaft beschränkter Sonderregelungen rechtsstaatlich nicht verdächtig ist sondern nur deutlich die normative Unerschöpflichkeit der fraglichen Sachverhalte zum Ausdruck bringt, ist in $\$ 138$ AVAVG enthalten. Danach ist die Bundesanstalt befugt, mit Zustimmung des Bundesministers für Arbeit zuzulassen, daß "weitere Maßnahmen gefördert werden, wenn sie zur. Verhütung und Beendigung der Arbeitslosigkeit zweckdienlich und geeignet sind, die Ausgaben für das Arbeitslosengeld zu senken". Ähnliche, auf den Zweck des Trägers beschränkte, sonst aber ganz allgemeine, weite Generalaufträge finden sich in $\$ 84$ AnVG und $\$ 1305$ RVO. Danach können die Träger der Rentenversicherung bzw. die Bundesanstalt für. Angestellte "Mittel der Versicherung aufwenden, um allgemeine Maßnahmen oder Einzelmaßnahmen zur Erhaltung und Frlangung der Erwerbsfähigkeit der Versicherten und ihrer Angehörigen oder zur Hebung der gesundheitlichen Verhältnisse der versicherten Bevölkerung zu fördern oder durchzuführen. 
handenen Mitteln zu befriedigen. Diese Notwendigkeit wirkt sich weniger einschneidend aus, soweit es sich um Bedürfnisse han(lelt, die mit den vorhandenen Geldmitteln befriedigt werden können. Dagegen muß die Verwaltung zu recht mannigfaltigen Arrangements greifen, um die sonst notwendigen sachlichen und persönlichen Mittel, soweit vorhanden, mit der Vielfalt der Bedürfnisse zur Deckung zu bringen. Das zweite Element ist in der Rücksichtnahme auf die personale Individualität des Falles zu sehen. Diese Rücksichtnahme ist eine sachlich notwendige, soweit die Hilfe der öffentlichen Hand eine spezifische Initiative oder Mitwirkungsbereitschaft voraussetzt, durch die die staatliche Leistung erst fruchtbar werden kann oder überhaupt erst ihren konkreten $Z$ weck erhält. ${ }^{24)}$ Das ist in aller Regel der Fall clort, wo die Hilfe sich nicht auf einen Mangel im Kreis der Elementarbedürfnisse bezieht, die zu befriedigen präsumtiv jedermann willens ist. Wirtschaftliche Aufbauhilfe, Berufsförderung, Förderung des Figenheimbaus und dergleichen sind nur sinnvoll, wenn in concreto der auf das Förderungsziel gerichtete Wille des Betroffenen vorhanden ist. Die Rücksichtnahme auf den Betroffenen kann aber auch eine gewillkürte sein, die dem Hilfsbedürftigen so viel Entscheidungsfreiheit als möglich lassen will. Sie hat so einen spezifisch rechtsstaatlichen, freiheitlichen Gehalt. Beide Fälle erfordern eine konkrete Adaption sowohl der einzelnen Maßnahme im Verhältnis zum einzelnen Fall wie auch des Gesamt der (möglichen) Maßnahmen zum Gesamt der sich auf diese Weise ergebenden Bedürfnisse. Sie kann nur durch eine entsprechende Gestaltungsfreiheit der Vollzugsbehörde ermöglicht werden. Am wichtigsten, der Idee des Rechtsstaats am engsten verbunden und am schwersten faßbar ist das dritte Element: Die Lockerung der legalistischen Strenge nach den Abstufungen der Intensität, mit der die Leistungen in die Individualsphäre gestaltend eindringen. Elementarleistungen, auf die der Betroffene zur angemessenen Eirhaltung seiner Existenz angewiesen ist, kennzeichnen den Endpunkt. Sie müssen die größte Festigkeit aufweisen. Unsicherheit und Angewiesensein auf die konkrete Dezision (ler. Vollzugsorgane sind hier am schwersten erträglich. Wo die Abhängigkeit am größten ist, muß sie am meisten durch die Herrschaft der Gesetze gemildert werden. Das ist so bei der Eingriffsverwaltung, die durch die Unterworfenheit des Bürgers unter die Macht des Staates gekennzeichnet ist. Und es ist so, wo umgekehrt die Macht des Staates sich darin manifestiert, daß er not-

24) Zur partiellen Fxemplifikation s. Scharmann, Die Mitwirkung des Behinderten bei der Durchführung von Rehabilitationsmaßnahmen, in "Sozialreform und Sozialrecht", Festschrift für llalter Bogs, 1959, S. $317 \mathrm{ff}$. 
wendige Hilfe gewähren oder versagen kann. Diese Relation wird umso lockerer, je mehr sich das Manko des Bedürftigen über das Elementare erhebt. Wer vom Staat die ihm fehlenden Mittel will, um sich einen Betrieb einzurichten - den er zur adäquaten Ausnutzung seiner Fähigkeiten im selbständigen Erwerb braucht, den er aber aus eigener Kraft nicht einrichten kann - oder ein Eigenheim zu bauen - das ihm als notwendige Wohnstätte dienen soll, das er aber ohne fremde Mittel nicht erstellen kann - ist in der Regel nicht mehr existenziell von dem Ja oder Nein des Staates abhängig. Noch weniger ist es derjenige, der sich überhaupt nur die Mittel zunutze machen will, die der Staat zugunsten sich sozial auswirkender Veranstaltungen auswirft (z. B. Arbeitsplatzdarlehen), weil er an sich - sei es aus Eigennutz, sei es aus altruistischen Motiven - in dieser Richtung tätig sein will. Hier wird nur mehr die Partnerschaft der öffentlichen Hand gesucht, deren Interessen zum Teil parallel mit denjenigen des Petenten verlaufen. Schließlich hört der Kontakt mit der Individualsphäre überhaupt auf, nämlich bei denjenigen rein sachlichen Maßnahmen der öffentlichen Hand, die erst mittelbar wieder in die Individualsphäre hineinwirken, z.B. bei dem regional wohlstandspolitischen Bau von Straßen oder bei der Errichtung einer Heilanstalt. Hier endet auch das Erfordernis legalistischer Bestimmung des Verwaltungshandelns (über das Haushaltsgesetz hinaus). Es wird erst wieder aktuell, sobald durch sekundäre Maßnahmen die "objektiven" staatlichen Veranstaltungen an die Einzelperson herangeführt werden.

dd) Die funktionelle Konkurrenz von Gesetzgebung und Verwaltung

Die Funktionen von Gesetzgebung und Verwaltung sind in gewissen Grenzen vertauschbar. 1) Hält sich der Gesetzgeber zurück, so kann die Verwaltung, freilich unter ganz anderen Wirksamkeitsbedingungen, denselben Effekt erzielen, den der Gesetzgeber mit einer weitergehenden Regelung unmittelbar oder im Zusammenspiel mit der Verwaltung hätte herbeiführen können. Wie weit er. vordringt, ist - im Verhältnis zur Verwaltung - prinzipiell der. Entscheidung des Gesetzgebers überlassen. Fr bestimmt dadurch nicht nur die Konzeption des Zusammenspiels zwischen Gesetzgebung und Verwaltung. Er kann auch seinen Willen in sehr erheblichem Maße an die Stelle desjenigen der. Fxekutive treten lassen. 2)

Die Erwägungen über den Vorbehalt des Gesetzes und die rechts-

1) S. hierzu schon oben S.425 zu Fußn. 12.

2) S. zu Vorstehendem Wolff, Verwaltungsrecht I, S.61. 
staatliche Pflicht zur gesetzlichen Bindung der Verwaltung haben schon gezeigt, daß dem Rückzug des Gesetzgebers aus der Verantwortung für die Verwaltung verfassungsrechtliche Grenzen gesteckt sind. Das Grundgesetz zieht den Gesetzgeber aber noch weiter nach vorne, indem es selbst gewisse Grundrechtseinschränkungen (ausschließlich oder neben denjenigen "auf Grund eines Gesetzes") nur "durch Gesetz" zuläßt (Art.8 Abs.2, 11 Abs. 2, 14 Abs. 3 Satz 2, 15 Satz 1 GG; s.a. Art. 12 Abs. 1 Satz $2 \mathrm{GG})$. Das bedeutet nun nicht, daß von Verfassungs wegen die Verwaltung insoweit gänzlich ausgeschlossen und das Gesetz selbst schon alles Spezielle und Konkrete enthalten sollte oder gar müßte - auch dort nicht, wo die Grundrechtseinschränkung ausschließlich "durch Gesetz" erfolgen kann. Aber es verlangt (loch einen höchsten Steigerungsgrad der Detailintensität der Regelung. ${ }^{3)}$ Für den vorliegenden Zusammenhang ist das besonders für die Sozialisierung von Bedeutung, die nach Art. 15 Satz 1 GG nur. "durch Gesetz" erfolgen kann. ${ }^{4}$ "

Treibt so selbst die Verfassung den Gesetzgeber an die Front funktionellen Verwaltungshandelns, so hält sie ihn andererseits auch wieder davor zurück, die Kompetenzen der Verwaltung zu absorbieren. Zwar haben die den "Maßnahmegesetzen" gewidmeten Untersuchungen ${ }^{5)}$ ergeben, daß es nicht möglich ist, allgemein einen Funktionsbereich der Verwaltung abzugrenzen, in den der Gesetzgeber bzw. das Gesetz nicht eindringen dürfte. 6)

3) $\mathrm{Zu}$ Vor'stehendem sei in toto verwiesen auf Lerche, Grundrechtsbeschränkungen "durch Gesetz" im Wandel des Verfassungsbildes.

4) S. hierzu Herbert Krüger, Sozialisierung, in BettermannNipperdey-Scheuner, Die Grundrechte, Bd.III, 1.Halbband, 1958, S.267 ff (312): "Das Gesetz muß vollständig sein. Es darf sich auch dann nicht auf eine Ermächtigung an die Exekutive beschränken, wenn es sich dabei nicht in Widerspruch $z u$ anderen Bestimmungen des GG, z. B. Art.80, setzen würde. Das Gesetz muß vielmehr alles enthalten, was zur Bewirkung der Vergesellschaftung erforderlich ist,..."

5) $S$. die oben $\$ .474$ zu Fußn.2 Zitierten.

6) Forsthoff, Über Maßnahme-Gesetze, S.228; ders., Lehrbuch des Verwaltungsrechts, S.9; Menger, Das Gesetz als Norm und Maßnahme, insbes. S.24 ff; Wehrhahn, desgl.; die Diskussionsbeiträge zu "Das Gesetz als Norm und Maßnahme", a.a.O. und zwar insbes. Klein (S.66 ff), Scheuner (S.69 ff), Merk (S.76 ff), Hans Schneider (S.89 ff); Ballerstedt, Über wirtschaftliche Maßnahmegesetze; ders., Wirtschaftsverfassungsrecht, S. 34 ff; BVerfGE 4, 7 (18 f); 10, 89 (107f); 
Eine engere Interpretation der Zuständigkeit des Gesetzgeber.s ${ }^{7)}$ würde die Möglichkeit voraussetzen, einen sachlichen Begriff cles Gesetzes verbindlich zu setzen. Diese Möglichkeit scheitert an dem Fehlen einer dahingehenden Rechtsüberzeugung ebenso 8) wie an den Notwendigkeiten des vom Grundgesetz verfaßten gesellschaftsaktiven Verteilerstaates. ${ }^{9)}$ Aber die Schranke des Art. 19 Abs. 1 Satz $1 \mathrm{GG}$, die für alle die Grundrechte einschränkend tangierenden Gesetze Allgemeinheit 10) vorschreibt, schafft Distanz zwischen Norm und Einzelfall und somit ein funktionelles Reservat der Verwaltung beim Vollzug belastender Gesetze. 11) Allgemeiner, nicht auf den Geltungsbereich des Art. 19 Abs. 1 Satz 1 GG beschränkt, ergibt sich sachlich dasselbe aus dem Gleichheitssatz. 12) 13) Das notwendig gleichheitliche (allgemeine) Gesetz bedarf der vollziehenden Konkretisierung durch die Exekutive

Maunz-Dürig, Art.20 Randn.110. - S.a. Hans Schneider, Über Einzelfallgesetze, Festschrift für Carl Schmitt, 1959, S. $159 \mathrm{ff}$.

7) Die verfassungsrechtliche Normierung der Gesetzgebungszuständigkeit (Art. $77 \mathrm{GG}$ ) wird zutreffend als Angelpunkt hervorgehoben von Forsthoff, Über Maßnahme-Gesetze, S.227, und Menger, Das Gesetz als Norm und Maßnahme, S.24.

8) Außer den S.475 zu Fußn.6 Zitierten s. hierzu Böckenförde, Gesetz und gesetzgebende Gewalt, insbes. S.330 ff.

9) S. Forsthoff, Über Maßnahme-Gesetze, insbes. S.228; Ballerstedt, Über wirtschaftliche Maßnahmegesetze; ders., Wirtschaftsverfassungsrecht, a.a.O.; Böckenförde, a.a.O., insbes. S. 334, 342; Maunz-Dürig, Art. 20 Randn.96.

10) Zu den Erfordernissen, die Art. 19 Abs. 1 Satz 1 GG an die Gesetze stellt, s. die zusammenfassende Darstellung bei v. Mangoldt-Klein, Art. 19 Anm. III, und Dürig in MaunzDürig, Art. 19 Abs. I Randn.

11) Zur Bedeutung des Art. 19 Abs. 1 Satz 1 in diesem Zusammenhang s. Menger, Das Gesetz als Norm und Maßnahme, S.29 f; K1ein, Diskussionsbeitrag hierzu; Hans Schneider, Ïber Finzelfallgesetze, S. $170 \mathrm{f}$.

12) Vg1. Hans Schneider ebd. S. $171 \mathrm{ff}$; Zeidler, Bundesverfassungsgericht und "Maßnahmegesetz", insbes. S. 393; MaunzDürig, Art.20 Randn. 112; s.a. Münch, Diskussionsbeitrag zu "Das Gesetz als Norm und Maßnahme" VVDStRL. H. 15, 1957, S. $87 \mathrm{ff}(88)$.

13) Zu weiteren Schranken der Maßnahmegesetze bzw. Individualgesetze und Zeitgesetze s. z.B. Forsthoff, Über MaßnahmeGesetze, S.228 ff; Menger, a.a.O. S.29 ff; Wehrhahn, Das Gesetz als Norm und Maßnahme, S. 54 ff; Schneider, a.a.O. 
In die rechtspolitische bzw. Soziologische Diskussion über das Phänomen des Maßnahmegesetzes ist hier nicht einzutreten. Grobe Fälle dessen, was so genannt wird, gibt es im Rahmen der sozialen Intervention kaum. Die Paradebeispiele von Maßnahmegesetzen (z.B. das jährliche Getreidepreisgesetz) liegen meist auf rein wirtschaftlichem Gebiet. Ob das gern als Maßnahmegesetz bezeichnete Investitionshilfegesetz 14 ) in den engeren Rahmen der sozialen Intervention gehört, mag man ebenso bezweifeln, wie es andererseits von fragwürdigem Nutzen ist, etwa das Gesetz zur Regelung der Rechtsverhältnisse der unter Art. 131 des Grundgesetzes fallenden Personen, ${ }^{15)}$ das Wohnungsrecht, 16) das Wohnungsbaurecht ${ }^{17)}$ oder alles Kriegsfolgerecht 18) - also wohl nicht nur aktuelle Maßnahmen wie das Soforthilfegesetz 19) sonder'n auch das Lastenausgleichsrecht, das Recht der Flüchtlinge und Vertriebenen usw. - als Maßnahmegesetz zu deklarieren.

Für das Nebeneinander von Verwaltung und Gesetzgebung ist schließlich noch eine (auch aber nicht allein) der sozialen Intervention eigentümliche Sachgesetzlichkeit zu beachten. Sie liegt in der unmittelbaren Beziehung der zu ergreifenden Maßnahme bzw. der zu treffenden Regelungen zu normativ nicht oder jedenfalls nicht in gleicher Weise beherrschbaren Sachverhalten. Der Staat kann nicht abstrakt verteilen und umverteilen, vorsorgen und gewähren, geben und nehmen. Er kann es sinnvoll nur unter hautenger Anpassung an die sachlichen, insbesondere die wirtschaftlichen Gegebenheiten. Diese sind sehr vielfältig; nicht weniger sind es die Methoden ihrer Feststellung und die Urteile über das aus ihnen zu Folgernde. Daraus resultiert das Übergewicht der konkreten, definitiven Entscheidungen gegenüber abstrakten Vorentscheidungen. Beschränkt sich der Gesetzgeber auf diese, so bleibt seine Regelung schwach und unverbindlich. (Meist ist diese Beschränkung ohnedies unmöglich, weil eine Eini-

S. $171 \mathrm{ff}$; Maunz-Dïrig, Art. 20 Randn.93 ff, insbes. Randn. 106 if.

14) Das Bundesverfassungsger.icht (BVerfGE 4, 7) hat keinen Anlaß genommen, das Investitionshilfegesetz unter diesem Gesichtspunkt besonders zu würdigen ( $\mathrm{s}$. hierzu Forsthoff, Über Maßnahme-Gesetze, S.228; s.a. BVerfGE 10, 89 (107 f)). $\mathrm{Zu}$ dem beliebtesten Beispiel eines Maßnahmegesetzes, der lex Platow, s. nunmehr BVerfGE 10, 234 und Zeidler, a.a.O. 15) So z.B. Wehrhahn, a.a.O. S. 35.

16) Vgl. Ule, Diskussionsbeitrag zu "Das Gesetz als Norm und Naßnahme", a.a.O. S. $100 \mathrm{ff}(101 \mathrm{f})$.

17) Vgl. Merk, Diskussionsbeitrag zu "Das Gesetz als Norm und Maßnahme", S. 77. 
gung über die abstrakten - m.a.W. theoretischen - Grundlagen einer Entscheidung häufig viel schwieriger ist als ein Kompromiß über das praktische Ergebnis. Wird eine Einigung im Grundsätzlichen dennoch versucht, so kommt es - gewollt oder ungewollt - vielfach zu nichtssagenden Formelkompromissen.) Will er aber weiter vordringen, so muß er seine Dispositionen bis ganz nach vorne an die Front des Details des Konkreten und auch für den Einzelfall Endgültigen erstrecken. ${ }^{20)}$ Die Verwaltung

18) Vg1. Menger, a.a.O. S.22.

19) Vgl. Merk, a.a.O.

20) S. z.B. Werner, Verwaltungsrecht als konkretisiertes Verfassungsrecht, S.231. - Ein Beispiel bietet das Gegenüber des Gesetzes über die Errichtung der Verwaltungsbehörden der Kriegsopferversorgung und der Verwaltungsvorschriften zur Durchführung dieses Gesetzes. Das Gesetz beschränkt sich auf einige Grundzüge. In $\ 1$ bestimmt es, daß Versorgungsämter und Landesversorgungsämter zu errichten sind. In $₫ 2$ ist vorgesehen, daß "nach Maßgabe des Bedürfnisses und der Zweckmäßigkeit" von den Ländern orthopädische Ver'sorgungsstellen, versorgungsärztliche Unter'suchungsstellen, Versorgungskuranstalten, Versorgungsheilstätten, Versorgungskrankenhäuser, Beschaffungsämter, Prüfämter und Krankenbuchlager zu errichten sind. Von diesen Grundsätzen bis zur konkreten Gestaltung ist ein weiter Weg. Der Vollzug kann hier zu diesem, dort zu jenem Ergebnis führen. In den Verwaltungsvorschriften zur. Durchführung des Gesetzes hat man diese Freiheit der Länderverwaltungen zum Teil widerrufen. Der darin unternommene Versuch, den Vollzug generell $\mathrm{zu}$ ordnen und $\mathrm{zu}$ vereinheitlichen, jedenfalls hinsichtlich der Einrichtung der Versorgungsämter, hat zu einer nicht zu überbietenden Kleinkıämerei geführt. Die Regelung ist technisch aber so gehalten, daß sie auch Inhalt eines Gesetzes sein könnte. Sie bietet daher ein Beispiel für das andere Extrem, dem eine gemäßigte Mittellösung offenbar nicht vorgelagert werden kann. Fin weiteres Beispiel ist die Formulierung einer Landwirtschaftspolitik des Bundes in $\$ 1$ des Landwirtschaftsgesetzes, das es jedoch gar nicht unternimmt, damit der Verwaltung schon definitiv liompetenzen zu übertragen. Die Formel des $₫ 1$ soll - von der dirigierenden Bedeutung für die künftige Bundesgesetzgebung abgesehen - wohl vor allem den Zweck haben, der Aufklärungs-, Berichts- und Vorschlagspflicht der Bundesregierung ( $\$ \$ 2,4,5,6$ a.a.O.) die Marschrichtung anzugeben. Aber nicht einmal diese bescheidene Aufgabe dürfte sie erfüllen können. 
wird dadurch zum entscheidungslosen Apparat.21) Die Funktion der laufenden, konkreten Anpassung an die korrespondierenden Sachgegebenheiten kann aber nicht entbehrt werden. Sie muß daher vom Gesetzgeber wahrgenommen werden. ${ }^{22)}$ Die insofern typische Regelung der permanenten Rentenanpassung durch Gesetz ( $\$ \$ 1272$ ff $R V O$, $\$ \$ 49$ ff AnVG) ist ein Eingeständnis dieser Notwendigkeit. 23) Auf der anderen Seite zeigt sich die Unmöglichkeit einer abstrakten und gleichwohl präzisen und durchsetzbaren Regelung in den weiten Ermessensspielräumen, durch

21) Die "Technisierung der Verwaltung" ist die rationale Konsequenz dieser Entwicklung. S. hierzu die Darstellung bei Karl Zeidler, Über die Technisierung der Verwaltung, 1959. Dort (S.11, 27) finden sich auch sehr interessante Bemerkungen über die Wechselbeziehungen zwischen der Technisierbarkeit der Verwaltung und der aufgezeigten Entwicklung der Gesetzgebung.

22) S. hierzu z.B. Scheuner, Diskussionsbeitrag zu "Das Gesetz als Norm und Maßnahme", S. 73 ff; Forsthoff, Lehrbuch des Verwaltungsrechts, S. 58 f, 119; Wolff, Verwaltungs recht I, S. 61 .

23) Die Regelung, die gewiß nicht die schlechteste unter ihresgleichen ist, offenbart die Schwierigkeiten einer abstrakten Entscheidung. Sie basiert auf der "allgemeinen Bemessungsgrundlage", d.i. das "durchschnittliche Bruttojahresarbeitsentgelt aller Versicherten" im Mittel der letzten drei Jahre ( $\$ 1255$ Abs. 2 RVO, $\ 32$ Abs. 2 AnVG). $\ 1272$ Abs. 1 RVO bzw. $\$ 49$ Abs. 1 AnVG bestimmt, daß bei "Veränderungen der allgemeinen Bemessungsgrundlage... die Renten... angepaßt" werden. "Die Anpassung hat der Fntwicklung der wirtschaftlichen Leistungsfähigkeit und der Produktivität sowie den Veränderungen des Volkseinkommens je Frwerbstätigen Rechnung zu tragen" ( $\$ 1272$ Abs. 2 RVO, $\$ 49$ Abs.2 AnVG). Ist das nicht eine liormel, deren Vollzug der Verwaltung überlassen werden könnte? Das ist schon deshalb ganz ausgeschlossen, weil im Hinblick auf die Notwendigkeit von Bundeszuschüssen auf Einheitlichkeit nicht verzichtet werden kann. Das Beispiel weist auch sonst eine andere Frontrichtung, nämlich die des Gesetzes zur. Verordnung auf. Aber clavon einmal abgesehen, zeigt die bisherige Entwicklung, daß diese allgemeine Formulierung unmöglich hinreichen würde, um die Rentenanpassung zuverlässig zu steuern. Nicht einmal der sog. Sozialbeirat konnte sich immer über das gebotene Maß an Anpassung einig werden. Das läßt sich letztlich nur. willensmäßig entscheiden. Fs ist deshalb 
die die Gestaltungsfunktion der Verwaltung belassen bzw., wenn man so will, zugeschoben wird. ${ }^{24)}$ Nicht zuletzt ist auch der Anwendungsbereich der besonderen Gewaltverhältnisse kraft Anstaltsnutzung zum großen Teil eine Frucht dieses Dilemmas. ${ }^{25}$ ) Der Gesetzgeber wird den vielfältig differierenden Erfordernissen der Verwaltung dadurch gerecht, daß er ganze Sach- und Rechtskomplexe der Verwaltung zur "autonomen" Gestaltung überläßt (und tut dabei gelegentlich des Guten zuviel).

\section{c) Gesetzgebung und untergesetzliche Rechtsetzung}

aa) Rechtsetzung durch Exekutivbehörden

Die "Überanstrengung" des Gesetzgeber's und des Gesetzes verlangt nach Abhilfe. Die dem demokratisch-parlamentarischen, gewaltenteiligen Verfassungsstaat eigentümliche Monopolisierung der. Rechtsetzung beim parlamentarischen Gesetzgeber läßt sich rein nicht durchhalten. Zu den klassischen Aushilfen zählt es, die Exekutive ${ }^{1)} \mathrm{zu}$ er.mächtigen, im Verordnungswege Recht $\mathrm{zu}$

nur konsequent, daß diese Entscheidung dem Gesetzgeber vorbehalten blieb.

24) Dazu s.o. S. 463.

25) S. hierzu auch Krüger, Das besondere Gewaltverhältnis, S. 129; Weber, Diskussionsbeitrag hierzu, S. $191 \mathrm{f}$.

1) Die Ermächtigung an die Justiz (Gerichte oder Organe der Gerichtsverwaltung) spielt keine vergleichbare Rolle. Die Zuständigkeit des Obersten Gerichtshofes der sog. DDR zum Erlaß von Richtlinien - deren Rechtssatzqualität nicht eindeutig feststeht - entspricht östlichem Vorbild und ist dem deutschen Recht sonst fremd (vgl. hierzu Jacobi, Die Richtlinien des Obersten Gerichtshofes der DDR in "Staat und Bürger", Festschrift für Willibalt A pelt, 1958, S. 203 ff). Die (verfassungs-) gerichtliche Normenkontrolle hat zwar in negativer Richtung quasilegislativen Effekt, desgleichen in positiver oder negativer Richtung die Entscheidung des Bunclesverfassungsgerichts über die Zugehörigkeit eines Rechtssatzes zu den allgemeinen Regeln des Völkerrechts (Art.25, 100 Abs. 2 GG), über die Fortgeltung von Recht als Bundesoder Landesrecht (Art.126 GG) u.a.m. Aber freie Gestaltung der Rechtsordnung, wie sie für die Rechtsetzung wesentlich ist, liegt in dieser richterlichen - wenn vielleicht auch noch so schwanken - Rechtsanwendung nicht (s.a. u. S. 481 zu Fußn.2 f). Es entspricht nicht dem Bild der geltenden Verfassung, daß die Gerichte in typischer Weise Recht setzen. Mit Recht ist daher Art. 80 GG (wie auch Art. 129 GG) 
setzen. ${ }^{2)}$ Dieser Weg scheint sich für den sozial intervenierenden Staat 3) wie für den modernen Verteilungsstaat überhaupt 4 ) ganz besonders zu empfehlen. Die Verwaltung ist jedenfalls der äußeren Wirksamkeit nach der Hauptträger der staatlichen Aktion. Die Vereinigung von Rechtsetzung und Durchführung in ihrer Hand scheint ihre Wirkungsmöglichkeiten und somit die Wirkungsmöglichkeiten des Staates zu steigern. 5) Aber der Rechtsstaat kann diesen Weg nicht unbedenklich und unbedingt beschrei-

nur der Rechtsetzung durch die Exekutive zugewandt. Damit soll nicht gesagt sein, daß die Gerichte bzw. die Organe der Gerichtsverwaltung in keinem Falle in vergleichbarer Weise Recht setzen können. Aber sie können das nur in einem engen Bereich, der nicht nur sachlich sondern auch organisch zur Justiz gehört, z.B. durch den Erlaß von Geschäftsordnungen, die Regelung der Geschäftsverteilung und dergl. (soweit darin Rechtsetzung zu erblicken ist. - S. hierzu Darstellung und Nachweis bei Bettermann, Die Unabhängigkeit der Gerichte und der gesetzliche Richter, S. 549 ff).

2) Eine umfassende Darstellung der Problematik findet sich in "Die Übertragung rechtsetzender Gewalt im Rechtsstaat", Schriftenreihe des Instituts zur Förderung öfentlicher Angelegenheiten e. V. Bd. 12, 1952, mit einem Vorbericht von Klein (S. $7 \mathrm{ff}:$ "Verordnungsermächtigungen nach deutschem Verfassungsrecht"), Berichten von Klein (S.79 ff "Die Übertragung rechtsetzender Gewalt nach deutschem Verfassungsrecht") und Scheuner (S.118 ff: "Ausländische Erfahrungen zum Problem der Übertragung rechtsetzender Gewalt"), einer eingehenden Diskussion (S.167 ff) und einer Reihe von Finzelberichten über die Rechtslage im Ausland (S.221 ff).

3) Vgl. Leibholz, Die kritischen Punkte des Grundgesetzes, Deutsche Universitätszeitung 12.Jhg. (1957) Heft 13/14 S. 18 ff (19); kritisch Herschel, Rationalisierung des Rechts, insbes. des Arbeitsrechts, in "Sozialpolitik, Arbeits- und Sozialrecht" Festschrift für Friedrich sitzler, 1956, S.287 ff (292 ff).

4) S. hierzu außer den in Fußn.2 Genannten: Krause, Wirtschaftslenkung und Ermächtigungsstil, in "Beiträge zum A rbeits-, Hanclels- und Wirtschaftsrecht", Festschrift für Alfred Hueck, 1959, S.413 ff.

5) Das ist das Ziel des "Kampfes um den Verwaltungsstaat", soweit er auf der Basis der Anerkennung des demokratischen Rechtsstaates geführt wird (Nachweise s.o. S.419 zu Fußn. 2). 
ten. Er löst die Sicherungen auf, die in der Trennung der Rechtsetzung und Verwaltung nach Funktion und Organen liegen. 6)

Das Grundgesetz hat die Rechtsetzung des Bundes beim parlamentarischen Gesetzgeber konzentriert (Art. 77 ff GG). Die Exekutivorgane verfügen, von dem Sonderfall des Art.119 GG abgesehen, über kein eigenes, gesetzesunabhängiges Gesetzgebungsrecht. 7) Rechtsetzungsbefugnisse der Verwaltung bedürfen der Ermächtigung durch das Gesetz, das "Inhalt, Zweck und Ausmaß der erteilten Ermächtigung" bestimmen muß (Art. 80 Abs. 1 GG). Das ist eine sehr gesetzesstaatliche, gewaltenteilungsstrenge und in diesem Sinne rechtsstaatliche Lösung. Sie schränkt die Rechtsetzung im Verordnungswege spürbar ein, ${ }^{8)}$ auch soweit es sich

6) Sind Rechtsetzung und Verwaltung in der Hand eines Machtsubjektes vereinigt, so verliert auch die Kontrollfunktion einer unabhängig gebliebenen Rechtsprechung an Durchschlags kraft. Die antirechtsstaatliche Entwicklung nach 1933, die erst spät auch die Unabhängigkeit des Richters als solche antastete, beweist das. Allein schon die Vereinigung von Gesetz gebung und Verwaltung in der Regierung (später: der Person) Hitlers genügte, um die Justiz in enge Schranken zu verweisen.

7) Zu dem Sonderfall der sog. Organisationsgewalt s.o. S.451 ff und die dortigen Nachweise. Der Gesetzgebungsnotstand (A rt. $81 \mathrm{GG}$ ) gibt allerdings drei Exekutivorganen (Bundesregierung, Bundesrat und Bundespräsident) zusammen ein außerordentliches Gesetzgebungsrecht. Doch kann diese (impotente) Institution hier unberücksichtigt bleiben.

8) Zur Auslegung s. außer Klein, a.a.O. (Fußn.2) vor allem Bernhard Wolff, Die Ermächtigung zum Erlaß von Rechtsverordnungen, AöR Bd.78 (1952/53) \$. 194 ff. Weitere Nachweise und vor allem eine Zusammenstellung der maßgeblichen relativ strengen Entscheidungspraxis finden sich bei Winke1mann, Die Rechtsprechung des Bundesverfassungsgerichts zu A rt. 80 Grundgesetz, NJW 12.Jhg. (1959) S.961 ff; Maunz in Maunz-Dürig, Art.80 Randn.9, 10, 13. (Hierzu ist nachzutragen, daß las Bundesverfassungsgericht, nachdem es sich mit der $\$ 2$ des Preisgesetzes betreffenden Entscheidung BVerfGE 8, 274 eine unverständliche Inkonsequenz geleistet hat (vgl. Winkelmann, a.a.O. S.962 ff), wieder auf seine strengere Linie eingeschwenkt ist: BVerfGE 10,251 (255 ff). Diese dürfte damit als die endgültige anerkannt sein). Kritik an der ihrer Ansicht nach zu engen Rechtsprechung des Bundesverfassungsgerichts üben z. B. Friesenhahn, Parlament und Regierung im modernen Staat, S.39 (Fußn. 74); Wolff, Verwaltungs- 
nicht um belastende, "eingreifende" Gesetze sondern um gewährende, leistungsbegründende Gesetze handelt. ${ }^{9}$ )

Für die Ermächtigung der Landesexekutive durch Landesgesetz ${ }^{10)}$ gilt A rt. 80 GG nicht unmittelbar. 11) Das Landesverfassungsrecht hat also die Möglichkeit, auch zu anderen Lösungen als der in Art. 80 Abs. $1 \mathrm{GG}$ vorgezeichneten zu greifen, etwa zu sachlich begrenztem, verfassungsunmittelbarem Verordnungsrecht ${ }^{12)}$ oder zu Ermächtigungen, deren - im Vergleich zu Art.

recht I S. 98 .

9) S. hierzu oben S. zu Fußn. 50 (2).

10) Für die Ermächtigung der Landesexekutive durch Bundesgesetz gilt Art.80 GG (nach dem eindeutigen Wortlaut der Vorschrift) unmittelbar. $Z$ u den sich daraus ergebenden Problemen s. z.B. Zippelius, Verordnungen der Landesregierungen auf $G$ rund bundesgesetzlicher Ermächtigungen; Maunz in Maunz-Dürig, Art.80 Randn. 8, 20, 21. Einen jüngeren Fall aus der Praxis s. in BFHE 67, 107 (111).

11) Vgl. (einmütige Stellungnahme der) A rbeitsgruppe I in "Übertragung rechtsetzender Gewalt im Rechtsstaat" S. 189 und Nr. 7 Abs. 1 der Ergebnisse der Arbeitstagung ebd. S.218; Nawiasky-Lechner, Erl. 1 zu Art. 55 Nr.2 Satz 2 und 3; Bachof, Die Verleihung des Professorentitels, DöV 6. Jhg. (1953) S. 497 ff (499); Bernhard Wolff, Die Ermächtigung zum Erlaß von Rechtsverordnungen, S. 213 f; BVerwGE 6, 247 (249); A. A. Titzck, Zur Frage der Verfassungsmäßigkeit der polizeilichen Generalermächtigung zum Erlaß von Rechtsverordnungen, DÖV 8.Jhg. (1955) S. 453 ff (454); Hamann, Grundgesetz, Art.80 Anm.B; Maunz, Deutsches Staatsrecht, S. 194; ders., in Maunz-Dürig, Art. 80 Randn. 19 (unter vermittelnder Heranziehung des Art.28 Abs. 1 Satz 1 GG) mit weiteren Nachweisen.

12) Zu denken wäre an sachlich begrenzte, gesetzesunabhängige Ermächtigungen nach dem Vorbild des Art. 119 GC. Doch findet sich dafür - soweit zu sehen - im gegenwärtigen Landesverfassungsrecht kein Beispiel (Zusammenstellungen aus der Verfassungspraxis der deutschen Länder s. bei Klein, Verordnungsermächtigungen nach deutschem Verfassungsrecht, S. 73 ff, und Hamann, Autonome Satzungen und Verfassungsrecht, 1958, S. 69 ff). Andererseits könnte an die verfassungsunmittelbare Ermächtigung gedacht werden, daß bloße Ausführungs- oder Durchführungsverordnungen (s. hierzu z.B. Klein, a.a.O. S. 42 ff; Wolff, Verwaltungsrecht I, S. 100) auch ohne ausdrückliche gesetzliche Ermächtigung seitens der zuständigen obersten Exekutivbehörde (Regierung, Mini- 
80 Abs. 1 Satz 2 GG geringere - Bestimmtheit durch eine scharfe Kontrolle seitens der Legislativorgane ausgeglichen wird. 13) Doch darf dadurch die wesentliche Struktur des demokratischen, (gewaltenteiligen) Rechtsstaates im Sinne des Grundgesetzes (Art. 28 Abs. 1 Satz 1 GG), zu dessen verbindlichem Gesamtbild auch Art. 80 GG gehört, nicht angetastet werden. 14)

Der Exekutive können also Rechtsetzungsbefugnisse nur clurch Ermächtigungen übertragen werden, die inhaltlich präzis bestimmt und begrenzt sind. ${ }^{15)}$ Das ist von entscheidender Bedeutung auch und gerade dafür, in welcher. Weise und in welchem Umfang sich der Gesetzgeber der Aufgabe, las Recht der sozialen Intervention zu setzen, zugunsten der Verwaltung entschlagen kann. Dieses Delegationssystem läßt eine Ermächtigung der Sache nach überhaupt nur dann zu, wenn "Inhait, Zweck und Aus$m a \beta^{\prime \prime}$ der vom Veror'dnungsgeber' zu treffenden Regelung 16) vom Gesetzgeber vorfor nuliert werden können. Ist eine funktionelle Teilung in gesetzlichen Grundsatz und verordnungsrechtliche Komplementärregelung nicht möglich, so scheitert in concreto daran die Übertragbarkeit der Rechtsetzungsbefugnis. Der Gesetzgeber kommt nicht umhin, den Regelungsgegenstand, der sich einer funktionell geteilten Ordnung entzieht, selbst er'schöp-

sterium) erlassen werden. Man wird nicht fehlgehen, Art. 61 Abs. 2 BadWürttVerf, Art. 55 Nr. 1 BayVerf, Art. 124 BremVerf, Art. 107 HessVerf und Art.110 RheinlPfVerf in diesem Sinne zu verstehen (vgl. Klein, a.a.O. S. $76 \mathrm{f}$ - mit weit. Beisp. aus clem Verfassungsrecht verflossener Bundesländer -; Wolff, a.a.O.). Gegen die Zulässigkeit landesverfassungsrechtlicher, verfassungsunmittelbarer Verordnungser.mächtigungen wohl Maunz (vgl. Maunz-Dürig, Art. 80 Randn. 3, 14, 19).

13) Inwieweit das Landesverfassungsrecht im allgemeinen dieser Möglichkeit positiv gegenübersteht, ist, soweit zu sehen, nirgends ausdrücklich festgestellt (vgl. die Zusammenstellungen bei Klein, a.a.O. und Hamann, a.a.O.). Doch dürften die meisten der vor dem Grundgesetz erlassenen Verfassungen Raum für dergleichen Variationen lassen.

14) S. zu dieser Argumentation Bernhard Wolff, Die Ermächtigung zum Frlaß von Rechtsverordnungen nach dem Grundgesetz, S.214 f; s.a. Haueisen, Öffentlichrechtliche Vorfragen im Zivilprozeß, NJW 6.Jhg. (1953) S. 121 ff (122 Fußn.8); Maunz in Maunz-Dürig, Art.80 Randn. 19.

15) Die Nor'm wendet sich auch gegen clas üppige vorkonstitutionelle Ermächtigungswesen: Art.129 Abs. 3 GG.

16) Daß es sich bei lem "Zweck... der erteilten Ermächtigung" 
fend zu regeln. 17) Das Recht der sozialen Intervention bringt wie eben in verwandtem Zusammenhang dargetan 18) - einer grundsätzlichen und doch wirksamen Primärregelung verschiedentlich schwer überwindbare oder gar unüberwindbare Hindernisse entgegen. Sie $z$ wingen den Gesetzgeber selbst bis an die Front des Details vorzustoßen. Die Entlastung des Gesetzgebers durch den Verordnungsgeber ist in einer Weise geregelt, die gerade im Sachbereich der sozialen Intervention ihr grundsätzliches

i.S. des Art.80 GG um den vom Verordnungsgeber zu verfolgenden Zweck handelt, stellt Wolff (Die Ermächtigung zum Erlaß von Rechtsverordnungen nach dem Grundgesetz, S. 197) zutreffend klar. Daß "Inhalt... und Ausmaß der erteilten Ermächtigung" mit dem möglichen Inhalt und Ausmaß des Verordnungsrechts korrespondieren, steht schon nach dem Text der Verfassung fest. S. hierzu im übrigen die von Winkelmann, Die Rechtsprechung des Bundesverfassungsgericht zu Art. 80 des Grundgesetzes (s.o. S.482 zu lußn.8) S.962, zusammengestellten Grundsätze der Rechtsprechung des Bundesverfassungsgerichts.

17) Gewiß kann den praktischen Bedürfnissen auf gewissen Rechtsgebieten durch eine entsprechend lockere Handhabung des Art. 80 Abs. 1 Satz 2 GG entgegengekommen werden. Vor allem für das Steuerrecht wird immer wieder die Notwendigkeit hervorgehoben, durch weiträumige Ermächtigungen eine lokkere, elastische Regelung seitens des - im Vergleich zum Gesetzgeber wesentlich unkomplizierter arbeitenden - Verordnungsgebers zu ermöglichen (vgl. Klein, Grenzen gesetzlicher. Ermächtigungen zum Erlaß steuerlicher Rechtsverordnungen, 1951, S.25; BVerfGE 7, 282 (301); BFHE 60, 294(296); 64, 225 $(227 \mathrm{f})$, ähnlich für das Recht der Wirtschaftslenkung im allgemeinen (vgl. Krause, Wirtschaftslenkung und Frmächtigungsstil, insbes. S. $433 \mathrm{ff}$ ) und für clas Preisrecht im besonderen (BVerfGE 8, 274(310 f)). (Für das Steuerrecht geht es freilich oft nur darum, an liebgewordenen r'raktiken, die dem formellen Gesetzgeber genaue steuerrechtliche Kenntnisse ersparen und der Ministerialbürokratie ihre aus einer Art Geheimwissenschalt entspringende Machtstellung erhalten sollen, festzuhalten. Häufig wandeln sich die verordnungsrechtlichen Regelungen nicht öfter als die gesetzesrechtlichen. Fin Beweis clafür, daß es gar nicht so sehr um die Abgrenzung zwischen Bleibendem und Wandelbarem geht, wie immer behauptet wird.) Die leichte Anwendung des Art. 80 Abs. 1 Satz 2 GG hat aber jedenfalls ihre Grenzen dort, wo sie zu einer Aufhebung der Vorbestimmtheit des Verordnungsrechts im Gesetzesrecht führen würde. 
Ziel nicht immer erreicht. Ermächtigungen, die auf eine engere prinzipielle Vorformulierung des gesetzgeberischen Konzepts und Vorausbestimmung der verordnungsrechtlichen Regelung verzichten, läßt das Grundgesetz aber nicht $z u$, auch nicht etwa in der Weise, daß die - unterstelltermaßen entfallende - inhalt1iche Bestimmtheit durch eine aktuelle Kontrolle der Verordnungspraxis seitens des Gesetzgebers kompensiert werden könnte. 19) Trotzdem darf die Ausbreitung des Verordnungswesens (auch) im Recht der sozialen Intervention nicht unterschätzt werden. 20) Unter nicht unerheblicher Erweiterung des Machteinflusses der obersten Exekutivorgane wird dadurch der Gesetzgeber zahlrei-

18) s.o. S. $463 \mathrm{ff}$.

19) (1) Zu den einschlägigen Kontrollmöglichkeiten s. z. B. K lein, Die Übertragung rechtsetzender. Gewalt nach deutschem Verfassungsrecht, S.91 ff; Scheuner, Ausländische Erfahrungen zum Problem der Übertragung rechtsetzender Gewalt, S. 152 ff, 164 f. - Zur Notwendigkeit, sich wieder mehr auf Wege dieser Art zu besinnen s.a. Friesenhahn, Parlament und Regierung im modernen Staat, S. 39 f (insbes. Fußn. 74).

(2) Die wichtigste Erscheinung unter den Kompromißmöglichkeiten zwischen formeller Gesetzgebung und rein exekutiver Verordnung ist die sog. Zustimmungsverordnung. Das Grundgesetz schließt sie - obwohl Art.80 Abs.1 GG sie nicht erwähnt - nicht aus (s.Klein, a.a.O. S. 95 ff; BVerfGE 8, 274 (318 ff) m.w. Nachw.), privilegiert sie aber - eben indem Art.80 Abs. 1 GG sie nicht erwähnt - gegenüber dem Konkretisierungsgebot des Art. 80 Abs. 1 Satz 2 GG nicht (BVerfGE, a.a.O.). Der Zustimmungsvorbehalt verschärft somit ausschließlich die Kontrolle gegenüber dem Verordnungsgeber zulasten des (sie ausübenden) Gesetzgebers, ohne ihn entsprechend durch die Möglichkeit inhaltlicher Lockerung der Ermächtigungen zu entlasten.

20) Ein "berüchtigtes" Gebiet umfassender Verordnungspraxis ist das Steuerrecht (vgl. Z. B. dic Zusammenstellung bei Wacke, Staatsrecht1iche Früfung ler. Zusatzsteuer, 1957, S. $63 \mathrm{ff}$, insbes. S. 66). (Hinzuweisen ist gerade in diesem Zusammenhang u.a. auf die soziale Bedeutung der zahlreichen Härteklauseln in steuerrechtlichen Verordnungsermächtigungen, die dem Verordnungsgeber auch eine spezifisch soziale Aufgabe übertragen.) Teils für die Aufbringungs-, teils für die Leistungsseite der sozialen Intervention von größter Bedeutung ist das Verordnungsrecht zur Ergänzung des Lastenausgleichsrechts, das quantitativ ein Vielfaches des gesetzlichen Lastenausgleichsiechts ausmacht. Am Rande zu 
cher Regelungsaufgaben - insbos. in bezug auf Details, verfahrenstechnische Fragen, zeitliche Anpassungen und dergleichen - enthoben.

\section{bb) Die autonome Rechtsetzung}

Andere Grundsätze gelten für die Rechtsetzung im Rahmen verbandlicher Autonomie. 1) Das Recht der Gemeinden, "alle Angelegenheiten der örtlichen Gemeinschaft im Rahmen der Gesetze in eigener Verantwortung zu regeln" (Art. 28 Abs. 2 Satz 1 GG) umschließt eine Rechtsetzungsmacht, 2) die einer gesetzlichen Präzisierung zwar zugänglich ist, ihrer aber nicht bedarf. 3) 4)

erinnern ist die umfangreiche Ergänzung des Gesetzes zur Regelung der Rechtsverhältnisse der unter Art. 131 des Grundgesetzes fallenden Personen durch ein - ebenfalls ein Mehrfaches des Gesetzesrechts betragendes - eingehendes Verordnungsrecht. Auf anderen Rechtsgebieten von sozialer Bedeutung tritt das Verordnungsrecht dagegen fast ganz zurück, so in dem noch auf den gesetzesstaatlichen Fundamenten der Kaiserzeit ruhenden Sozialversicherungsrecht und auch im Arbeitsrecht, soweit es Privatrecht und somit traditionell (und sachbedingt) Gesetzesrecht ist. - Im übrigen darf der Blick nicht getrübt werden durch den gegenwärtigen Umfang des Verordnungsrechts, das noch vielfach aus vorkonstitutioneller Zeit stammt und auf Ermächtigungen zurückgeht, die heute dem Verordmungsgeber nicht mehr zur Seite stehen und auch nicht mehr zur Seite gestellt werden können (s.o. S.484 zu Fußn.15). Soweit das alte Verordnungsrecht demnach heute nur mehr der Disposition des Gesetzgebers offen steht und derjenigen des Verordnungsgebers erst durch erneute, Art. 80 Abs. 1 Satz 2 GG angepaßte Verordnungsermächtigungen unterstellt werden könnte, handelt es sich der Sache nach heute um (quasi-Gesetzesrecht. Die allmähliche gesetzliche Neurrhung ier einschlägigen Rechtsgebiete wiıd hier nach und nach! 11 andr.l und verfassungskonforme Verhältnisse schafferl.

1) Zum Begrills. \%.B. Peter:, Die Satzungsgewalt innerstaatlicher Verbände; Klein, Die Übertragung rechtsetzender Gewalt nach deutschem Verfassungsrecht, S. 109. - S.a. die Schrift von llarnann, Autonome Satzungen und Verfassungsrecht, die im cinzelnon aber viel Bedenkliches enthält.

2) S.o. S. 231 Jußn. 13.

3) BVerwGE 5, 247 (248 ff, insbes. S.252 f).

4) Noch weiter geht die autunome Rechtsetzungsgewalt der Kirchen, die nur durch dic. "Schranken des für alle geltenden Ge- 
A ber auch dort, wo die autonome Satzungsgewalt nicht unmittelbar auf die Verfassung zurückgeht sondern im Gesetz zu begründen bzw. begründet ist, ${ }^{5)}$ braucht dieses gesetzliche Fundament nicht nach Maßgabe des Art.80 Abs. 1 Satz 2 GG gestaltet zu sein. ${ }^{6)}$ Art. 80 GG spricht nur von Rechtsverordnungen. Diese können nicht - pars pro toto - der untergesetzlichen Rechtsetzung schlechthin gleichgestellt werden. Dazu ist der Sprachgebrauch zu eincleutig. 7) Auch schließt der in Art. 80 Abs. 1 Satz 1 GG genannte, exklusive Kreis von Ermächtigungsadressaten die traditionellen Subjekte autonomer, statuarischer Rechtsetzungsgewalt nicht ein. 8) Andererseits darf daraus nicht geschlossen werden, das Verfassungsrecht lasse autonome Rechtsetzung - vielleicht abgesehen von derjenigen der Gemeinden - überhaupt nicht mehr zu. 9) Das Giundgesetz kennt und erwähnt die Gemeinden und Gemeindeverbände, die sonstigen Körperschaften und die Anstalten des öffentlichen Rechts, 10$)$ denen nach deutschem Herkommen die autonome Rechtsetzung zukommt. ${ }^{11)}$ Es ist nicht anzunehmen, daß diese Gebilde unter der neuen Verfassungsordnung nur ohne diese Befugnis sollten existieren können. 12) Aus all dem rechtfertigt sich die Annahme, daß die autonome Rechtsetzung zulässig ist, aber nicht den strengen Grundsätzen des Art. 80 Abs. 1 Satz 2 GG sondern ihren eigenen, wesensmäßigen, überkommenen

setzes" begrenzt wird (Art. 137 Abs.3 Satz 1 RV 1919 i. V.m. Art. 140 GG). Diese Erscheinung steht dem vorstehenden Zusammenhang allerdings fremd gegenüber und soll hier nicht weiter verfolgt werden.

5) Das gilt auch für die Gemeindeverbände (Art.28 Abs. 2 Satz 2 GG).

6) BVerfGF 10, 20 (49 ff) - implicite -; BVerwGF 6, 247 (249 ff); llolff, Besprechung von "Hamann, Autonome Satzung und Verfassungsrecht", NJII 11.Jhg. (1958) S.2010; Maunz in Maunz-Dürig, Art. 80 Randn. 31 und 34 .

7) S. Peters, a.a.O. (S.487 Fußn. 1); Klein, Verordnungsermächtigungen nach deutschem Verfassungsrecht, S.28 f; ders. a.a.O. (Fußn. 1). Zum interpretatorischen Gewicht der überkommenen Begriffe s.a. Hamann, a.a.O. S.62 ff.

8) S.a. Hamann, a.a.O. S.64.

9) Maunz in Maunz-Dürig, Art.80 Randn. 31 lf, insbes. Randn. 33; ander's unrichtigerweise Hamann, a.a.O. S.68 f, $76 \mathrm{ff}$.

10) Vgl. Art.28,73 Nr.8,75 Nr.1, 87, $130 \mathrm{GG}$.

11) Zu den Vorbehalten, die hinsichtlich des autonomen Satzungsrechts der. Anstalten zu machen sind, s.u. im Text.

12) Diese absur.de Konsequenz nimmt Hamann, a.a.O. (Fußn.31) allerdings in Kauf; wie hier Maunz ebl., insbes. Randn. 33 . 
Regeln folgt, 13) denen fleilich (ine rechtsstaatliche Bindung der verbandsgewalt gleichwohi zuggenört. ${ }^{14)}$ In Anbetracht der weiten Verbreitung verbandlicher Selbutverwaltung im Bereich der sozialen Intervention kommt dies. 1 Form untergesetzlicher Rechtsetzung grundsätzlich große Bedeutung $z u$, nicht weniger auch wegen ihrer Freiheit von den rechtsstaatlichen Fesseln der Rechtsverordnungsermächtigung. Nicht nur für das Verhältnis zwischen dem Gesetz und dieser. Form der untergesetzlichen Rechtsetzung ist sie von Bedeutung sondern auch für das Gewicht der Autonomie selbst.

\section{cc) Grenz- und IIschfä1le zwischen Satzung und Verordnung}

Zwischen den beiden qualitativ eindeutigen Eckfällen, der Rechtsverordnung und der autonomen Verbandssatzung, liegt eine Reihe von Mischtypen unterstaatlicher Rechtsetzung, die in dieser oder jener Weise Elemente von beidcn Seiten enthalten. Sie häufen sich gerade im Raum der sozialen Intervention. Für sie muß jeweils besonders geklärt werden, wie sie zum Gesetz stehen.

Um Rechtsveroldnungen i.S. cies Art. 80 Abs. 1 GG handelt es sich bei Vorschriften, die von der staatlichen Exekutive unter definitiver Mitwirkung von Oranen der politischen Selbstverwaltung erlassen welden ( $\mathrm{z}$.B. die Allgemeinverbindlicherklärung von Tarifverträgen, der Erlaß von Mindestarbeitsbedingungen und dic Regelung der Jeimarbeitsbedingungen. 1) 2) Die Mitwirkung von Organen der politischen solbstverwaltung kann insbes. die Anwendung des Art. 80 Abs. 1 satz 2 GG nicht erübrigen. Sie bietet weder die organische Legitination noch die sachliche und persönliche Begrenzung, die in dor Verbandsautonomie beschlossen liegt und die Fxemtion von den Beschränkungen des Art. 80 Abs. 1

13) Vgl. außer (len S. $44:$ in 1.ußn.6 Zitierten die bei Eckert, Sozialversicherungsgesetac, IBand "Allgemeines" in Art. 80 GG An!n. 2 wiedergeneben sulachtliche Äußerung des Bundesministeriun ler lu: lom 9. Oktober 1951; (Bericht (ler) Arbeitsgruper. I in "1). ( bertragung rechtsetzender Gewalt im Rechtsstaat", S. 191; Nr.9 der Ergebnisse der A rbeitstagung das. S. 218.

14) S. hierzu Liverf(cl: 10, $89102 \mathrm{f}, 108 \mathrm{f})$; s.a. Maunz in Maunz-Dürig, Alt.80 lamm, 34 a. E. (anders aber das. im übrigen).

1) Zu diesen Regelungen s.1. \$.92 ff und $\mathrm{S.} 305 \mathrm{ff}$.

2) Zur Qualifikation a1: Rechtsverordnung s. schon oben S.92 ff, insbes. Fußn. 6 ff. 


\section{GG innerlich rechtfertigt. 3 )}

Rechtsverordnungen sind auch diejenigen Vorschriften, die zwar in bezug auf selbständige Einheiten und unter Begrenzung auf deren sachlichen und persönlichen Wirkungskreis,jedoch nicht von deren eigenen Organen sondern von staatlichen Stellen erlassen werden. Der Hauptfall sind die sog. oktroyierten Satzungen, ${ }^{4}$ deren Name nicht darüber hinwegtäuschen darf, daß sie in Wahrheit staatliches Recht sind. 5)

Wo liegt aber der Unterschied zwischen Vorschriften dieser Art und solchen, die zwar von den Organen rechtsfähiger Verwaltungs-

3) (1) Zum Erfordernis der Anwendung des Art. 80 Abs. 1 Satz 2 GG auf die Allgemeinverbindlicherklärung von Tarifverträgen s. Bettermann, Die Allgemeinverbindlicherklärung eines Tarifvertrages, S. 252 f, dessen Rechtfertigung der gegenwärtigen Regelung ( $\$ 5$ TVG) zwar im Ergebnis, nicht aber in der Begründung beigetreten werden kann. Sehr unglücklich begründet die negative Stellungnahme von Auffahrt, Anfechtbarkeit und Rechtsnatur der Allgemeinverbindlicherklärung von Tarifverträgen, Bundesarbeitsblatt $1957 \mathrm{~S} .756 \mathrm{ff}$.

(2) Zur Anwendung des Art. 80 Abs. 1 Satz 2 GG ist noch folgendes zu bemerken: Wie oben im Text ausgeführt, kann von diesem Erfordernis nicht einmal der Zustimmungsvorbehalt zugunsten der gesetzgebenden Organe befreien. Um wieviel weniger kann es ein entsprechender Vorbehalt zugunsten von Organen der politischen Selbstverwaltung. Fis kann deshalb auch nicht gebilligt werden, wenn Bettermann (a.a.O. S.253) bezüglich $\$ 5$ TVG in der "Notwendigkeit, daß eine Tarifvertragspartei die AVE beantragt, daß die in Abs. II genannten Personen, Behörden und Verbände gehört werden und daß der Tarifausschuß zustimmt", eine gegenüber Art. 80 Abs. 1 Satz 2 GG entscheidend ins Gewicht fallende Beschränkung der Frmächtigung sieht. Allerdings soll nicht in Abrede gestellt werden, daß in Grenzfällen derartige Schranken zugunsten der Zulässigkeit einer Ermächtigung wirken können. Primär muß aber die sachliche Beschränkung, die Bestimmung von Zweck, Inhalt und Ausmaß der Ermächtigung festgestellt und gewürdigt werden. Insoweit kann lediglich dem Antragserfordernis eine das Ausmaß beschränkende Bedeutung beigemessen werden - aber auch das nur in Ergänzung materiellsubstanzieller Maßstäbe.

4) S. Z.B. Wolff, Verwaltungsrecht I, S. 103.

5) BVerfGF 10, 20 (49 ff); Hamann, Autonome Satzung und Verfassungsrecht, S.27 f. - Nurz. T. ebenso llolff, a.a.O. 
einheiten erlassen werden, jrioch von Organen, die nicht auf einen außerstaatlichen (imerverbandlichen, inneranstaltlichen) Legitimationsvorgang zurückgehen sondern auf staatliche Einsetzung? Damit ist eine Fülle divergierender Erscheinungsformen und eine Problematik angesprochen, die nicht nur von größter allgemeiner und, in bezug auf die soziale Intervention, spezieller Bedeutung sondern auch in erstaunlichem \Iaß ungeklärt ist. Zweifellos sind weder die Satzungen herrschaftlich strukturierter Verbände ${ }^{6)}$ noch eigene Vorschriften nichtverbandlicher Anstalten oder Stiftungen Rechtsverordnungen im überkommenen Sinn, 7) somit auch nicht im Sinn des Art.80 GG. ${ }^{8)}$ Das bezeugt zudem der Kreis der in Art. 80 Abs. 1 Satz 1 GG genannten Ermächtigungsadressaten in Gegenüberstellung mit der Unmöglichkeit der Annahme, das Grundgesetz schließe derartige Formen untergesetzlicher Rechtsetzung aus. 9) Aber doch ist die Exemtion der autoritären Verbandsgewalt, der Anstaltsgewalt usw. vom rechtsstaatlichen Konkretisierungsverbot nicht innerlich gerechtfertigt. Was die verbandliche Autonomie gegenüber der Verbandsmacht der staatlichen Exekutive im liahmen der rechtsstaatlichen und demokratischen Verfassungsordnung entscheidend abhebt, ist die Parallelität des Identitätspr'inzips, 10) das im Rahmen der gesamtstaatlichen Gemeinschaft durch das vom demokratisch-parlamentarischen Gesetzgeber erlassene Gesetz, in der engeren Gemeinschaft durch die von der innerverbandlich demokratisch legitimierten Verbandsautorität erlassene Satzung verwirklicht wird. 11)

6) Zum Typ (Hauptbeispiel: die sog. Leitungsverbände) s. z.B. Forsthoff, Lehrbuch des lerwaltungsrechts, S. $427 \mathrm{f}$, und seine eingehenden Nachweise; ferner Schewe, Körperschaften ohne Selbstverwaltung? 1)ie Sozialgerichtsbarkeit 7. Jhg. (1960) $\$ .97 \mathrm{ff}$, insbes. S.99 f.

7) Außer den oben S. $48: \because: F u ß n .1$ und $S .488$ zu Fußn. 7 Zitierten s. zur Systematik, zu der im einzelnen hier nicht Stellung genommen sei, z.b. Forsthoff, a.a.O. S. $119 \mathrm{ff}, 129 \mathrm{ff}$ und $110 \mathrm{ffl}$, a.a.(). $\because .9 \%$

8) Vgl. Hamann, Autonone Satzung und Verfassungsrecht, S.63 ff.

9) S. nochmals oben S.43i 1 .

10) S. hierzu auch ob(n Alschnitt 3 IV (S. $390 \mathrm{ff}$, insbes. S. 390 ).

11) Vgl. BVerwGF: 6, 247 (2.j1); Maunz in Maunz-Dürig, Art. 80 Randn.31 (= Anm. III 1 引); zum Problem s.a. Imboden, Gemeindeautonomie und Per.tstsstaat, in "Demokratie und Rechtsstaat", Festschrift für Zaccharia Giacometti, 1953, S. $89 \mathrm{fr}$; vgl. ferner Harnarn, Autonome Satzung und Rechtsverordnung, S.39 f. - Ain deutlichsten tritt das in der Entsprechung der Galantif les kommunalen Demokratie (Art. 
Die Intensivierung des individuellen Finflusses im engeren Verband läßt es "verschmerzen", daß die durch verbandsautonome Satzung zu treffende Regelung nicht durch den allgemeinen Gesetzgeber selbst getroffen oder doch wenigstens in der durch Art. 80 Abs. 1 Satz 2 GG bezeichneten Weise konstituiert wird. Die größere Distanz zwischen dem allgemeinen Verordnungsgeber und dem Betroffenen verlangt dagegen die Konkretisierung der Verordnungsermächtigung im Sinne des Art. 80 Abs. 1 Satz 2 GG. Das ist noch mehr notwendig, wenn die verordnungsgebende Stelle nicht die (dem Gesetzgeber am nächsten stehende) Exekutivspitze sondern eine von ihr abgesetzte - wenngleich von ihr eingesetzte und vielleicht von ihr abhängige - anstaltliche oder korporationsleitende Stelle ist. Die Identität ist noch schwächer, die Distanz noch @rößer. Die formalen und rechtstechnischen Gemeinsamkeiten $z$ wischen einer innerverbandlich getragenen Rechtsetzung und einer ausschließlich auf staatliche Autorität zurückführenden Rechtsetzung durch (nicht innerverbandlich legitimierte) anstaltliche oder körper'schaftliche Organe ver'mögen eine Gleichbehandlung des jeweiligen Verhältnisses zum allgemeinen Gesetz nicht in einer. Weise zu begründen, die gegenüber der Grundstruktur der rechtsstaatlichen Demokratie Glaubwürdigkeit beanspruchen könnte. Das gilt insbes. von der gemeinsamen Funktion, eine den konkreten Verhältnissen möglichst gemäße, sachnahe Regelung zu ermöglichen und zu fördern, 12) sowie von der hier wie dort vorgegebenen Begrenzung durch den persönlichen und sachlichen Wirkungskreis der Körperschaft, Anstalt usw. 13) Diese das Satzungsrecht wesensmäßig begrenzenden Elemente können es in einer len durch Art.80 Abs. 1 Satz 2 GG zum Ausdruck gebrachten rechtsstaatlichen Erfordernissen entsprechenden lleise begrenzen. Aber es wäre Begriffsjurisprudenz - und zwar über ihr Wesen hinaus unlogische Begriffsjurisprudenz -, darin schon von vorneherein und immer eine rechtsstaatsgemäße Beschränkung zu sehen. ${ }^{14)}$ Die Begründung von nichtverbandlichen Anstalten, Leitungsverbänden u. (Igl. Wäre sonst ein billiger

28 Abs. 1 Satz 2 GG) zur Garantie des gemeindlichen Satzungsrechts (ebd. Abs. 2 Satz 1) hervor.

12) S. Z.B. BV VerwgE, a.a.O. S.251 f; Klein, Die Übertragung rechtsetzender. Gewalt nach deutschem Verfassungsrecht, S. 111 .

13) Vgl. Maunz in Maunz-Dürig, Art. 80 Randn. 34 a. E.

14) In diesem Sinne vermutlich unrichtig die oben ( $\$ .489 \mathrm{zu}$ Fußn. 13) zitierte gutachtliche Äußerung des Bundesministeriums für. Justiz. 
Umweg, um das verfassungsmäßige Verhältnis von Gesetz und Verwaltung zu umgehen. 15)

Die anstaltliche und korporative Rechtsetzung ist somit, wenn ihr nicht eine entsprechende verbandliche, demokratische Legitimation zugrunde liest, dem kionkretisierungsgebot des Art. 80 Abs. 1 Satz 2 GG nicht weniges unterworfen als die Rechtsetzung im Verordnungswege. Daß anstaltliche und korporative Rechtsetzung nicht Rechtsverordnungen i.S. des Art.80 GG hervorbringt und Art. 80 GG im übrigen - d.h. außer ihres Absatz 1 Satz 2 - darauf nicht angewendet werden kann, steht dem nicht entgegen. Art. 80 Abs. 1 Satz 2 GG bringt ein allgemeines rechtsstaatliches Prinzip zum Ausdruck. 16) Die ausdehnende Auslegung und die Anwendung dieser. Vorschrift auf die vorgenannten Fälle ist im Hinblick auf Art.20,28 GG nicht nur gerechtfertigt sondern geboten. ${ }^{17)}$

Im sozialen Recht der Gegenwart spielen - wenn man von den auf recht merkwürdige lleise (ien Berufsgenossenschaften angehängten Familienausgleichskassen und landwirtschaftlichen A1terskassen absieht 18) - nicht verbandlich strukturierte Korporationen keine Rolle. ${ }^{19)}$ (imgekehrt ist die verbandliche Verfassung

15) Diese Unterscheidung ist auch Anlaß, um mit der gebotenen Ehrlichkeit einzugestehen, (aß die sog. Leitungsverbände im demokratischen Staat ' 'on den genossenschaftlichen Verbänden wesentlich unterschicden werden müssen. Der Leitungsverband ist $110 \mathrm{r}$ oine lorm der (mittelbaren) staatlichen Verwaltung. 1)er Aushluck "Verband" sagt hier nichts anderes als daR ricl. "Ilkungskreis der "verbandsleitenden" Behörde sich aul tinen feston Personenkreis bezieht. Die erzwungene Begrindung cines Personenverbandes unter autor.itärer Leitung wïrde an: *nsten dem demokratischen Prinzip widersprechen.

16) Vgl. Maunz in Manm,-Dir.s. Art. 80 Randn. 19 mit weit. Nachw.; s.a. die when an Konkretisierungspflicht in bezug auf die Verwaltung befugisse (S.463 ff) gegebenen Nachweise.

17) Hamann, Autonono Satzung und Verfassungsrecht, S.55 ff, 62 ff, will, soweit sic nich iberhaupt unzulässig ist, untergesetzliche Rechuram in:ner nur in den Grenzen des Art.80 Abs. 1 Sat\% 2 Cir zulassen. Die ablehnende Haltung von Maunz (ebd. Randn. 34) hetrifft die hier gemeinte Art von "Autonomic" "ohl nir h: (s.a. seine Randn. 31 und 34).

18) S. hierzu Schewe, Köre $\mathrm{c}$ (haften ohne Selbstverwaltung?

19) Forsthoff's (Lehrtuch (if: \rwaltungsrechts, S.428) Prog- 
weit in den Bereich der Anstalten hinein ausgedehnt. Als wichtigste Träger verbandlicher Satzungsrechte kommen außer den Gemeinden und Gemeindeverbänden (Art.28 GG) 20) noch die 'Träger der Sozialversicherung in Frage, gleichviel ob sie als Anstalten oder als Körperschaften bezeichnet sind. 21) Auch die kassen-(zahn-)ärztlichen Vereinigungen sind Träger verbandlicher Autonomie. 22) Dasselbe gilt von den verschiedenen Berufsorganisationen. 23) Dagegen spielt anstaltliche Verwaltung, die nicht auf verbandlicher Grundlage beruht, eine erhebliche Rolle. Das wichtigste Beispiel ist die Bundesanstalt für Arbeitsvermittlung und Arbeitslosenversicherung. Obwohl sie laut $₫ 2$ Abs. 1 Satz 1 $\Lambda$ VAVG eine Körperschaft des öffentlichen Rechts ist, ist sie in Wahrheit nicht verbandlich strukturiert. Nicht nur die "Dreischienigkeit" der Zusammensetzung ihrer Organe, die zu einem - wenngleich minderberechtigten - Drittel aus Vertretern der "öffentlichen Körperschaften" bestehen ( $\$ \Phi 9$ ff AVAVG), steht dem entgegen. Auch die Bestellung der "Vertreter der Arbeitnehmer" und der "Vertreter der Arbeitgeber" fußt nicht auf der korporativen Mitgliedschaft sondern endet bei den einschlägigen Verbänden, die vorschlagsberechtigt sind. Diese Verbände können aber nicht als das korporative Substrat der Bundesanstalt angesehen werden. Soweit die Organe der Bundesanstalt ermächtigt werden, Rechtsvorschriften zu setzen, ${ }^{24)}$ muß diese Ermäch-

nose, die herrschaftlichen, nicht genossenschaftlichen Leitungsverbände seien im Vordringen, ist nicht nur auf dem sozialen Sektor überholt. Die Wiederaufrichtung der Demokratie hat hier einen entschiedenen Wandel geschaffen.

20) Näheres s.o. B 2 II (S. 225 ff).

21) Näheres s.o. S.242 ff.

22) Zur Kompetenz s. $₫ 368$ m RVO; s.a. BSGE 11, 1 (5 ff).

23) S. hierzu oben S. $242 \mathrm{ff}$.

24) Eine Zusammenstellung der Zuständigkeiten der Organe der Bundesanstalt findet sich bei Eckert, Sozialversicherungsgesetze, Bd. "Allgemeines", Hauptabschn.4, Selbstverwaltungsrecht, S.41.24 ff. Es ist hier nicht der Ort, im einzelnen nachzuprüfen, ob es sich bei den Vorschriften, die die Organe in eigener Zuständigkeit erlassen können, um Rechtsvorschriften handelt oder um Verwaltungsvorschriften, für die Art. 80 GG nicht gilt. Bezeichnend ist übrigens, daß hinsichtlich der weitaus überwiegenden Fälle, bei denen eindeutig Rechtsvorschriften in Frage stehen, der Erlaß von Rechtsverordnungen durch die Bundesregierung bzw. den Bundesminister für Arbeit nach Anhörung der zuständigen Organe der. Bundesanstalt vorgesehen ist. 
tigung daher Art. 80 Abs. 1 Satz: GG genügen. 25)

Aus dem Gesagten ergibt sich auch, daß es abwegig wäre, etwa für den Bereich nichtrechtsfähiger staatlicher Anstalten eine dem in Art. 80 Abs. 1 Satz 2 GG ausgesprochenen rechtsstaatlichen Gebot nicht unterstehende Rechtsetzungsgewalt zu konstatieren.

Das Wesen des Anstaltsverhältnisses kann, wie schon hinsichtlich der rechtsfähigen Anstalt gesagt, eine hinreichende Begrenzung enthalten, muß das aber nicht. Wo das nicht der Fall ist, muß der Gesetzgeber zusätzlich begrenzen. Eine kühne Konstruktion wäre es, eine Ausnahme für Anstaltsverhältnisse anzunehmen, die - rechtlich und tatsächlich - völlig frei eingegangen werden. Im Eintritt und im Verbleiben könnte eventuell eine Akklamation für das Wirken der Anstaltsleitung gesehen werden, der dadurch gleichsam die Legitimation einer quasi-verbandlichen Autorität zukäme. In diesel Konstruktion könnte die alte Lehre von der freien "internen" Gestaltung der Anstaltsverhältnisse eine neue, der rechtsstaatlichen und demokratischen Verfassungsordnung gemäße Heimat und Begrenzung finden. Doch würde es zu weit führen, diese Theorien hier zu vertiefen.

Mit den Anstaltsverhältnissen sind die besonderen Gewaltverhältnisse schlechthin angesprochen. Für sie alle gilt, daß es nicht eine allgemeine Befugnis der Verwaltung gibt, ihr Recht in eigener Zuständigkeit zu rege $1 n .{ }^{26)}$ Inwieweit es sich bei den einschlägigen Vorschriften um Rechtsvorschriften oder Verwaltungsvorschriften handelt, muß hier unerörtert bleiben. ${ }^{27)}$ So-

25) Wie schon oben im lext angedeutet, kann es bei der Ermittlung der Gronzen einer spezifischen Ermächtigung eine wesentliche Ililfe sein, wem - sie geboten - die allgemeinen Wirkungsgrenzen der in frage stehenden Verwaltungseinheit mit einbezogen werden.

26) s. oben b, bb, aaa (s.420 (f). - Zur Notwendigkeit der gesetzlichen Ermächlighn zum Erlaß der von ihm so genannten "Sonderveroldnunger" d.s. abstrakte Anordnungen zur Regelung sog. besondere. (irwaltverhältnisse) s.a. Wolff, Verwaltungsiecht I, S. J02.

27) Grundlegend fïr die jüngr... Diskussion Herbert Krüger, Rechtsveror(nnung urd Verwaltungsanweisung, in "Rechtsprobleme in Staat und kirche", Festgabe für Rudolf Smend, 1952, S.211 ff; Bacho!, Yrwaltungsakt und innerdienstliche Weisung; s. forner (Je) ner, Verwaltungsakt und innerdienstlicher Rechtsakt, s.inbes. S. $114 \mathrm{ff}$; Wolff, a.a.O. S. 101 f; Dürig in Maunz-J)ürig, Art. 19 Abs. IV Randn. 30. 
weit es um Rechtsvorschriften geht, muß Art. 80 Abs. 1 Satz 2 GG beachtet werden. ${ }^{28)}$ Nur für die Ausgestaltung des besonderen Gewaltverhältnisses durch autonomes Recht gilt die besagte Ausnahme. 29)

Art. 80 Abs. 1 Satz 1 GG verbietet nicht, Körperschaften und verbandlich strukturierten Anstalten die Befugnis zu erteilen, Recht mit Wirkung auch für und gegen Personen zu setzen, die dem zugrunde liegenden Verband nicht angehören. Auch hierbei handelt es sich noch um Satzungs- und nicht um Verordnungsrecht. 30) Allerdings wird man insoweit nicht auf das Be-

28) Zur Anwendung des Art. 80 GG auf die Regelung besonderer Gewaltverhältnisse $s$. Herbert Krüger, Das besondere Gewaltverhältnis, S. 119 und S. 131 (Leitsatz II 9); dagegen Merk, Diskussionsbeitrag zu "Das Besondere Gewaltverhältnis" VVDStRL. H. 15, 1957, S. 192 ff (196).

29) Eine andere Frage ist, inwieweit Art.80 Abs. 1 Satz 1 GG eingehalten werden muß. Soweit es sich um anstaltliches oder körperschaftliches Recht handelt, ist die Ausnahme schon nach dem Gesagten klar. Wie ist es aber bei der Regelung besonderer Gewaltverhältnisse durch Rechtsetzung (unmittelbar) staatlicher Stellen? Die Frage ist nicht sehr vordringlich, da auf untergeordnete Behörden die Befugnis jedenfalls im Wege der Subdelegation übergehen kann (Art. 80 Abs. 1 Satz 1 und 4 GG). Trotzdem ist auf die Möglichkeit folgender Argumentation aufmerksam zu machen: Art.80 GG geht von einem traditionalistischen Begriff der Rechtsveror.dnung aus. Der Regelung der besonderen Gewaltverhältnisse wurde der Charakter von Rechtssätzen zur Zeit des Inkrafttretens des Grundgesetzes noch in geringerem Maße zuerkannt als heute (s. die oben Fußn.28 Zitierten und ihre Nachweise). Was damals noch nicht Rechtssatz war, heute aber richtig als Rechtssatz erkannt wird, kann vielleicht nicht als Rechtsverordnung im überkommenen Sinn angesehen werden (s. den Begriff "Sonderver.or'lnung" von Wolff, a.a.O.) und somit auch nicht als Rechtsverordnung im Sinne von Art. 80 Abs. 1 Satz 1 GG. Dann könnte insofern noch die von Art.80 GG rezipierte "alte" Ordnung Anwendung finden. (Wolff, a.a.O. S. 102 glaubt eine entsprechende Ausnahme für das Verhältnis der Sonderveror'dnungen zu Art. 19 Abs. 1 GG machen zu müssen).

30) (1) Meist werden Rechtsetzungsakte dieser. Art als Satzungen und dgl. bezeichnet: Fleiner, Institutionen des deutschen Verwaltungsrechts, 8. Auf1. 1928, S.80 m. eingeh. Nachw. über die ältere Diskussion; Forsthoff, Lehrbuch des Verwaltungs- 
stimmtheitserfordernis des Art. 80 Abs. 1 Satz 2 GG verzichten können; ${ }^{31)}$ denn der verbandliche Zusammenhang zwischen Rechtsunterworfenem und rechtsetzender Autorität, der die autonome Satzung aus dem reinen Legislativ-Exekutivverhältnis, das Art. 80 Abs. 1 Satz 2 GG reguliert, heraustreten 1äßt, fehlt hier gerade. ${ }^{32)}$ Auch wird, wenn ein Verstoß gegen das demokratische Prinzip vermieden werien soll, ein enger Zusammenhang mit dem persönlich-verbandlichen Substrat des Verbandes oder (und) mit dem sachlichen IIikungsbereich desselben gegeben

rechts, S. 130, 420; llolff, Verwaltungsrecht I, S.103. Dagegen spricht Peter's, Die Satzungsgewalt innerstaatlicher Verbände, S.266, für diesen l’all von einer Rechtsverordnung. Nach For'sthoff (a.a.O.) soll erst für diesen Fall die Bezeichnung Satzung gerechtlertigt sein, die er der rein innerverbandlichen Rechtsetzung versagt. Dagegen mit Recht Wolff (a.a.O.).

(2) Zum Verhältnis zu Art.80 GG wie hier: Klein, Die Übertragung rechtsetzender. (rewalt nach deutschem Verfassungsrecht, S.111, 11T, und lellinek, Diskussionsbeitrag zu "Die Ubertragung rechtsetzoncler Gewalt im Rechtsstaat" in dem gleichnamigen Band, s. 167 ff (168) und wohl auch Scheuner, Ausländische Erfahrungen zum Problem der Übertragung rechtsetzender Gewali, $\therefore .144 \mathrm{f}$. Klein stellt an anderer Stelle (Verordnungsermächtisungen nach deutschem Verfassungsrecht, S.36; Die Clbertlayung rechtsetzender Gewalt nach deutschem Verfassungs recht, S. 89) allerdings ausdrücklich fest, Verordnungsermühlitigungen zugunsten von Anstalten und Körperschaften scien im Hinblick auf den exklusiven Adressatenkreis des A1. 30 Abs. 1 Satz 1 GG nicht mehr bzw. nur mehr im llege der subilelegation (ebd. Satz 4) zulässig. Soll es danach neben de personell ausgreifenden Satzung noch eine andere Al: der liechtsetzung durch besondere Verwaltungseinheiten : com, die sich davon durch mehr als den Namen "Rechtswluh hiw " unterscheidet? Im gleichen sinne ist die Feststellung (1) A rix.itsgruppe I "Die Übertragung rechtsetzender (iemalt in lirechtsstaat" S.191) und die Nr.9 der Ergebnisse der Alleitstilgung (ebd. S.218) nicht ganz

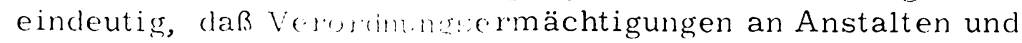
Körperschaften nur noc: :n Wlege der Subdelegation nach Art. 80 Abs. 1 Satz 1 un: 4 rici r.leilt werden könnten.

31) $\mathrm{Zu}$ dem Frfordernis (ne besonderen gesetzlichen Grundlage s. Forsthoff und inll jo a.a.O.

32) Eine Ausnahme machen missen wird man hinsichtlich der Gemeinden und der sonstigr: Gebietskörperschaften. Es gehört zu ihrem llesen, daR sin n. cht nur ihre Einwohner beherr- 
sein müssen. 33) Dagegen dürften für den gelegentlich ebenfalls hervorgehobenen Fall eines Ausgreifens der autonomen Satzungsgewalt über ihren allgemeinen sachlichen Wirkungsbereich hinaus

schen sondern alles, was in ihrem Gebiet belegen ist. (Vgl. Becker, Die Selbstverwaltung als verfassungs rechtliche Grundlage der kommunalen Ordnung in Bund und Ländern, S. $124 \mathrm{f}, 159 \mathrm{f}$.) Die verfassungsrechtliche Basis (Art.28 GG) impliziert diese Divergenz zwischen dem Kreis der Herrschaftssubjekte und-objekte, die schon primär in der Divergenz zwischen personellem Verband und Territorialherrschaft im Bereich des Staatlichen besteht und die demokratische Struktur des Staates nicht beeinträchtigt. (Eine andere Frage ist, inwieweit dadurch ein Sog zur Herabsetzung der Beschränkungen des Bürger rechtserwerbs usw. ausgelöst wird.) Das verkennt Hamann, der (Autonome Satzung und Verfassungsrecht, S.29 f) das "echte" autonome Satzungsrecht der Gemeinden auf den personellen Verband beschränken möchte. (Andererseits hat auch Forsthoff Unrecht, wenn er - a.a.O. S.130 - bei dieser Außenwirkung das gemeindliche Satzungs recht erst beginnen läßt. S.a. Wolff, a.a.O. S. 103.)- Übrigens läßt sich eine Divergenz zwischen dem Kreis der herrschaftslegitimierenden Subjekte und dem Kreis der Herrschaftsunterworfenen auch sonst, in reinen Personalverbänden, nicht vermeiden. Man denke an die Beschränkung der Herrschaftsteilhabe auf die Erwachsenen, Mündigen, Ehrbaren usw. Man denke bei den reinen Personenverbänden an die neu Eingetretenen, die im Hinblick auf ihr bei künftigen Wahlen usw. zu aktualisierendes Mitwirkungsrecht gewissermaßen auf Vorschuß unterworfen werden. Derartige Unreinheiten der Identität an den Grenzzonen der Herrschaft sind unwesentlich.

33) Es darf nicht zur Her.rschaft der Verbandsmitglieder über außerhalb des Verbandes stehende Personen kommen. Vielleicht ist auch Klein (s.o. S. 496 zu Fußn.30) dahin zu verstehen, wenn er zwar eine erweiterte Autonomie, nicht aber. den Erlaß von Rechtsverordnungen durch Anstalten und Körperschaften zulassen will. ( $\mathrm{Zu}$ den personellen Grenzzonen s. auch oben (S. $497 \mathrm{zu}$ Fußn.32.) Hinsichtlich eines Übergreifens aus Gründen sachlichen Zusammenhanges wird daran zu denken sein, ob die autonome Autorität hierzu ihrer Entstehung und Zusammensetzung und evtl. auch des staatlichen Einflusses auf ihr Tun nach als Mandatur der Gesamtgemeinschaft etwa in dem Sinne legitimiert ist, in dem ein nicht korporatives sondern nur sachverständiges, anstaltsleitendes 
keine Besonderheiten gelten. 34) Der sachliche weist keine dem persönlichen IIrkungsbereich vergleichbare legitimierende Beziehung zur Rechtsetzungsbefugnis auf. ${ }^{35)}$ Im übrigen sind die

Kuratorium auch bei nicht oder nur beschränkt staatlicher Provenienz zur. Rechtsetzung legitimiert sein kann. Doch ist das nur eine der möglichen Erwägungen. Den hier zusammenfließenden Prinzipien und den sich aus ihrem Zusammentreffen ergebenden Konflikten hier erschöpfend nachzugehen, ist im vorstehenden Rahmen nicht möglich und nicht nötig. Anzumerken ist nur, daß die gegenwärtige Praxis keine Fälle kennt, die zu Bedenken Anlaß geben könnten (s.u. S. 500 zu Fußn. 36).

34) Nicht ganz eindeutig Klein an den S. 496 in Fußn.30 genannten Orten.

35) (1) Zur Maßgeblichkeit des personalen Kriteriums (allerdings in einem anderen sinne) s, auch Hamann, Autonome Satzung und Verfassungsiecht, S. 30, 38 f. In der Regel wird demgemäß auch nur das personale Ausgreifen hervorgehoben (s. die S.49T zu Fußn.32 Zitierten).

(2) Zur Möglichkeit einer. Unterscheidung nach sachlichen Kriterien ist zu bedenken, daß der Wirkungskreis rechtsfähiger Verwaltungseinheiten grundsätzlich doch erst durch das Gesetz bestimmt wird. Es ist - soweit der Gesetzgeber keinen verfassungsrechtlichen Bindungen unterliegt - lediglich eine rechtspolitische Betrachtungsweise und Gestaltungsfrage, zwischen eigenen und übertragenen Angelegenheiten zu unterscheiden. Aus diesen rechtspolitischen Kategorien können keine Anhaltspunkte für lie Anwendung des Art. 80 Abs. 1 GG gewonnen werden. Fine vorgegebene rechtliche Unterscheidung ist nur dort besründet, wo die Verfassung ein Recht auf lechtsetzung gew äht, wie eben Art.28 Abs.2 Satz 1 GG fïr die Ciemeinten. Auf dieser Grundlage ist auch die Unterscheidum! zwischen Verordnung und Satzung möglich, die an lids sublehile Recht auf Rechtsetzungsgewalt anknüpft (vgl. Wollf, V(r.waltungsrecht I, S. 102 f). Aber diese Unterscheiduny in in Wahrheit auf das rechtsetzende Subjekt und somit auf lir. Unterscheidung zwischen der Rechtsetzung staatlicher Pehoirden und der Rechtsetzung selbständiger Verwaltungseinheiten (Körperschaften, Anstalten usw.) zurück. Sie baut laiaul anf, daß staatliche Behörden keine Rechte gegenüber dem sia: haben, rechtsfähige Verwaltungseinheiten (insbes. rechushlige Körperschaften und Anstalten) dagegen sehr. wohl und iisen die Rechtsetzung als Recht, jenen dagegen $n u r$ als Zuständigkeit eingeräumt ist (vgl. Na- 
beiden Fälle seltener als es die vergleichsweise lebhafte wissenschaftliche Erörterung annehmen 1äßt. 36)

wiasky, Allgemeine Rechtslehre, S. $73 \mathrm{ff}$; ders., Allgemeine Staatslehre, T'eil 3, S. $110 \mathrm{ff}$ ). Aber auch die übertragene Rechtsetzung der rechtsfähigen Körperschaft usw. ist in diesem Sinne eine Rechtsetzung eigenen Rechts. Nur ist sie durch bloßes Gesetz, die verfassungsmäßig verliehene dagegen nur durch Verfassungsgesetz entziehbar. (Von den verschiedenen Gestaltungsmöglichkeiten der Delegation sei hier ganz abgesehen.) Soll nun aber wirklich im Hinblick auf Art. $80 \mathrm{GG}$ danach unterschieden werden, ob die Rechtsetzungsmacht eines autonomen Verbandes usw. einen verfassungsrechtlichen Kern hat oder nicht? Das würde unmittelbar zu folgender Alternative führen: Entweder läßt man immer nur die verfassungsmäßige Substanz als Satzungsrecht und alles andere nur als Verordnungsrecht i.S. des Art. 80 GG gelten oder man unterscheidet überhaupt nur dort nach diesem Kriterium, wo die Verfassung selbst den Ansatzpunkt geschaffen hat. Eines ist so unmöglich wie das andere. Vor allem würde das letztere dazu führen, daß ausschließlich die Gemeinden einer Einschränkung hinsichtlich ihres "übertragenen" Wirkungskreises unterliegen; denn für andere Bereiche schafft die Verfassung keine Garantien einer Rechtsetzungsgewalt. Man wird daher von einer Unterscheidung nach sachlichen Gesichtspunkten nicht nur aus den im lext dargelegten Gründen absehen müssen.

36) (1) Beispiele s. bei Forsthoff, Lehrbuch des Verwaltungsrechts, S. 130, 420, und Hamann, a.a.O. S. 35 f, 38 f.

(2) Ein gern genanntes Beispiel ist $\$ 848$ a Abs. 1 RVO. Danach erlassen die Berufsgenossenschaften Unfallverhütungsvorschriften nicht nur für die Mitglieder (d.h. die Unternehmer - $\$ 649$ RVO -) sondern auch für die Versicherten (das sind die für die Unternehmer tätigen oder sonstwie versicherten Personen - $\$ \$ 537 \mathrm{ff}, 633 \mathrm{f}$ RVO). Aber liegt hier wirklich ein personelles Ausgreifen der autonomen Rechtsetzung vor? Die "Versicherten" besetzen - von einer. Sonderregelung für. die landwirtschaftliche Unfallversicherung abgesehen - zusammen mit den "Mitgliedern" die Organe der Berufsgenossenschaften paritätisch $(\$ 2$ des Selbstverwaltungsgesetzes; s.a. $\$ 4$ a.a.O.). Nur die Beitragspflicht obliegt einseitig den Mitgliedern. Entscheidend kommt es aber doch auf die Stellung in der verbandlichen Willensbildung an. - Auch ein anderes Beispiel, die Regelung der Gesellen- und Meisterprüfungen durch die Handwerkskammern $(\$ \$ 38,45$ der Handwerksordnung) bedarf im Hinblick auf die Teilnahme der Ge- 
(d) Das funktionelle Verhälnis $z$ wischen Rechtsverordnung und Satzung

Grundsätzlich alle untergesetzliche Rechtsetzung bedarf also einer gesetzlichen Frmächtigung, die den Bestimmtheitserfordernissen des Art. 80 Abs. 1 Satz 2 GG genügt. Nur die verbandliche Rechtsetzung ist von seiner (unmittelbaren oder analogen) Anwendung ausgenommen. Sie verlangt also dem Gesetzgeber eine geringere Präzision der grundlegenden Regelung ab als die sonstige untergesetzliche Rechtsetzung. Verbandliche Autonomie ist aber im Vergleich zur übrigen untergesetzlichen Regelung, insbes. der durch Rechtsverordnung, nur unter verhältnismäßig engen rechtlichen und tatsächlichen Voraussetzungen möglich. Ihr (potentiell) lockeres Verhältnis zum Gesetz zeigt daher nicht etwa einen Weg auf, vermittels clessen sich der Gesetzgeber in eben dem Umfang, in dem $e r$ zu Rechtsverordnungen ermächtigen kann, sich auch von del fessel des Art. 80 Abs. 1 Satz 2 GG befreien kann. Der Anwendungsbereich der Rechtsverordnung ist aber gerade auch insufern weiter, als sie - die gebotene gesetzliche Grundlage vorausgesetzt - unter Wahrung der gegebenen verfassungsrechtlichen schranken in den Bereich der Autonomie eindringen und das Statut verdrängen kann, wie das Gesetz selbst. Die Autonomie ist dagegen auf ihren Raum und ein schmales Umfeld beschränlt, aus dem sie auch der Gesetzgeber nicht beliebig herausführen kann. Die untergesetzliche Rechtsetzung durch nichtverbandliche Verwaltungseinheiten teilt mit der Rechtsverordnung das Frfordernis des Art. 80 Abs. 1 Satz 2 GG

sellen an der Willenshildurs der Handwerkskammer $(\$ \$ 86$, 91 f der Handwerksor(numg) einer Revision, die allerdings um die Feststellung eine. bleibenden Divergenz zwischen verbandlichem substl'at und Wirkungskreis der Rechtsetzung nicht herumkiommen wirk.

(3) Ganz anclets gearlet ist (las ebenfalls hier einschlägige Beispiel, das Hamamn (a.a.(). S.39) bringt: Die Befugnis der Gemeinden, aul (rmmel der $\$ \$ 119$ a, 120 GewO gewisse sozialpolitische Vurschriftri zu erlassen. Auch bei diesem Beispiel steht (las l'rohlom finer potentiell rein gebietsmäBig begründeten Herschat iber die Betroffenen und somit - im weiteren Zusammanhang - ein Überschreiten der durch den personellen V(rband rogenen Wirksamkeitsgrenzen in Frage (s.o. S. 496 zu Furn.32). Mehr im Vordergrund aber steht hier doch las lulasen des "eigenen" Wirkungskreises des autonomen Vertances (s.a. o. S. 499 zu Fußn. 34 und 35$)$. 
und unterliegt zudem den ihr wesensgemäßen organisatorischen Voraussetzungen. Ihre legislative Konkurrenzbasis ist daher wohl als noch schmäler zu bezeichnen.

Von einer beliebigen Vertauschbarkeit der verschiedenen Formen untergesetzlicher Rechtsetzung 1) kann weder im allgemeinen noch im besonderen gesprochen werden. Im Bereich der sozialen Intervention sind die Relationen einerseits durch die vielfache Verwendung rechtsfähiger Verwaltungseinheiten, insbes. der Körperschaften und Anstalten des öffentlichen Rechts, gekennzeichnet. Sie geben an sich eine Grundlage ab für eine relativ weitgehende Anwendung der Satzung. Andererseits aber ist die Satzung von Natur aus partikulare Ordnung. Sie steht dadurch im Gegensatz zur expansiven Egalität, die dem sozialen Trend eignet, ja ein gut Teil seines Elans ausmacht. 2) Sie leidet auch darunter, eine Ordnung unteren Ranges zu sein. Das nimmt ihr die Endgültigkeit ihrer Entscheidungen und setzt sie der Gefahr aus, daß sich benachteiligt fühlende Beteiligte an die übergeordnete Legislativinstanz, in der Regel also an den Gesetzgeber, rekurrieren, dessen Kräfte sich, im Bangen um die Gunst der Beteiligten, der Entscheidung meist auch nicht versagen. Insgesamt ist daher der Raum, den die Satzungsgewalt einnimmt, ver-

1) Sie wird mit unzulänglicher Begründung von Ilamann, a.a.O. S. 42 ff behauptet. An Hamanns Untersuchung ist sicher so viel richtig, daß die Abgrenzungen neu durchdacht werden müssen. Die traditionellen Begriffe sind bisher nicht hinlänglich mit der demokratischen, rechtsstaatlichen, horizontal und vertikal gewaltenteiligen Struktur unseres Staatswesens in Einklang gebracht worden und entsprechen daher. nicht mehr den sich aus dem Zwang zur Bewältigung des positiven Rechts ergebenden Bedürfnissen. Auch die vorstehende Untersuchung mußte sich mit einigen Andeutungen begnügen. Aber Hamann kann mit seiner Einheitstheorie nicht für. sich in Anspruch nehmen, das Problem gelöst zu haben. Auch die schließlichen Folgerungen seiner. Untersuchung (generelle Unzulässigkeit von Satzungsermächtigungen durch Bundesgesetz) sprechen drastisch gegen die Richtigkeit seiner Argumentation.

2) Es darf auf das oben im Zusammenhang mit der. Gesetzgebungszuständigkeit des Bundes, mit dem allgemeinen BundLänderverhältnis und mit der vertikalen Gewaltenteilung Ausgeführte verwiesen werden (s.o. Abschnitt 1 I 1 (S.45 If, insbes. S. $75 \mathrm{ff}), 2 \mathrm{f}$ (S.166 ff), II 3 e (S.205ff), IV (S.210 ff ), Abschnitt 2 II $1 \mathrm{~b}(\mathrm{~S} .228 \mathrm{ff}), 2 \mathrm{~b}(\mathrm{~S} .240)$ und III $(\mathrm{S} .242 \mathrm{ff})$. 
gleichsweise gering 3) - vergleichsweise, d.h. einerseits in Anbetracht der weiten Verbreitung entsprechender Organisationsformen im sozialen Bereich, andererseits im Verhältnis zu den vorhandenen gesetzlichen und verordnungsrechtlichen Regelungen. Diese letzteren haben zudem - das fixiert ihre Konkurrenzsituation gegenüber der Satzung ganz entscheidend - mit dem Gesetz nicht nur die Allgemeinheit gemein. Sie teilen mit ihm rechtspolitisch gesehen - und darauf kommt es in diesem Zusammenhang an - auch die Endgültigkeit, jedenfalls wenn sie von der dem ermächtigenden Gesetzgeber zugeordneten Exekutivspitze erlassen werden. Die funktionale Einheit $z$ wischen Regierung und Parlament bewirkt, daß jedenfalls grundsätzliche Entscheidungen seitens des Verordnungsgebers aus denselben Rücksichten getroffen werden, aus denen auch der Gesetzgeber handeln würde. ${ }^{4)}$ Die Satzung ist daher gegenüber Gesetz und Verordnung auf untergeordnete Fragen abgedrängt.

\section{ee) Die "soziale Autonomie"}

Ehe die Untersuchung diesen Problemkreis verläßt, muß aber noch auf die untergesetzliche Rechtsquelle hingewiesen werden, der im Bereich normativer Ordnung der abhängigen Arbeit die beherrschende Rolle zugefallen ist: auf den Tarifvertrag. Für ihn gilt Art. $80 \mathrm{GG}$ nicht. 1) Er ist nicht, mangels der organisatori-

3) Eine Exemplifizierung ist leider, so aufschlußreich und wichtig ein Inventarverzeichnis dor Satzungsermächtigungen und ihres Gebrauches wäre, nicht möglich. Es würde nicht nur die Sammlung und Sichtung aller einschlägigen gesetzlichen Bestimmungen voraussetzell. Fs könnte auch nicht an den Fragen der Gültigkeit volbeigehen und vor allem nicht an den verschiedenen Qualifikationsproblemen (insbes. den Fragen: Rechts- oder Verwaltungsvirschrift? Rechts- oder Sonderverordnung? usw.). Jie besaglen Klassifikationen hätten wieder Rückbezug auf die f'lagen der Gültigkeit usw. Diese Arbeit kann hier nicht geleistret nesclen.

4) Diese funktionseinheit wird im bundescleutschen Staats recht zudem überspannt durch die Wirkungsweise des Bundesrates, der dem Bundestag als Mitgesetzgeber, der Bundesregierung (und den einzelnen Bundesministern) als Mitverordnungsgeber zur. Seite steht (vgl. Art.76 ff, 80 Abs.2 GG).

1) Klein, Verordhungsemmichtigungen nach deutschem Verfassungsrecht, S. 111 f; Mavinz in Maunz-Dürig, Art.80 Randn. 33. - A.A. offensichtlich Zijllner, Zur Publikation von Tarifvertrag und Betriebsvereinbarung, DVB1. 73.Jhg. (1958) s. $124 \mathrm{ff}$ (126, insbes. Furn.29). 
schen Verbindung auch nicht mittelbar, staatliches Recht und schon gar nicht Rechtsverordnung. ${ }^{2}$ ) Wären die Koalitionen allerdings $Z$ wangsverbände, so könnte sich de $*$ ihre Rechtsetzung legitimierende und respektierende Staat von der aller Ermächtigung auferlegten rechtsstaatlichen Bindung nicht freizeichnen. ${ }^{3)}$ So aber gehört sowohl die Freiheitlichkeit, die freie Unterwerfung unter den Koalitionswillen, wie auch die umfassende Tarifmacht zum verfassungsrechtlichen Bild der Tarifautonomie. ${ }^{4)}$ Wo diese Voraussetzung nicht wirksam wird, wie insbesondere dort, wo die tarifarische Rechtsetzung auch gegenüber Außenstehenden wirkt ( $\mathrm{s}$. insbes. $₫ 3$ Abs. 2 TVG), wird bereits jetzt nicht um die Anwendung der rechtsstaatlichen Ermächtigungsschranke herumzukommen sein. ${ }^{5}$ ) Die rechtsstaatliche Position derartiger Ermächtigungen unterscheidet sich nicht wesentlich von der jener Ermächtigungen, die öfentlich-rechtlichen Verbandspersönlichkeiten über ihren persönlichen Verbandsbereich hinaus erteilt werden und ebenfalls den strengen Grundsätzen des Art. 80 Abs. 1 Satz 2 GG zu unterwerfen sind. 6) Vollends dann, wenn der Staat durch seine Allgemeinverbindlicherklärung eingreift und seine Autorität hinter die Nor'm - mit ihrer erweiterten Geltungskraft - stellt, greifen die Regeln des Art.80 Abs. 1 Satz 2 GG ein. 7)

2) S. hierzu nochmals oben S.291 ff.

3) Die umstrittene negative Koalitionsfreiheit sollte viel mehr als bisher auch unter dem rechtsstaatlichen Aspekt gesehen werden. - Ob die Rechtsetzungsgewalt den weiteren rechtsstaatlichen Beschränkungen echter autonomer Verbandsrechtsetzung oder den engeren Voraussetzungen des A rt. 80 Abs. 1 Satz 2 GG zu unterwerfen wäre, käme auf die Entwicklung im einzelnen an. $\mathrm{Zu}$ bemerken ist jedenfalls, daß die dyarchische Struktur der Tarifautonomie eine völlige Gleichstellung mit rein verbandlicher Autonomie (wie auch oben B 2 IV 2 S. 287 schon hervorgehoben) nicht gerade unterstützt. - Mit den weiteren Grenzen verbandsautonomer Rechtsetzung ist der gegenwärtige Stand der. Tarifautonomie sicher zu vereinbaren. Wäre sie dagegen an Art. 80 Abs. 1 Satz 2 GG zu messen, so stünde es wohl schlecht um sie.

4) S. oben B $2 \operatorname{IV} 2(\mathrm{~S} .287 \mathrm{ff})$.

5) Vgl. Zöllner, a.a.O. S.126. - Gegen Zöllner ist jedoch einzuwenden, daß die gegenwärtige Regelung, soweit sie eine Drittwirkung erlaubt - und gerade darauf kommt es an! wohl hinreichend begrenzt ist.

6) S. oben S.489ff, insbes. S. 496 zu Fußn.30 ff.

7) S. oben S.489ff, insbes. S. 489 zu Fußn. 1 ff. 
Aus ähnlichen Grünlen, wiø sie für den 'Tarifvertrag gelten, muß die Anwendung ler rechtstatlichen Grundsätze über das Ermächtigungswesen auch in li(\%ug auf die Betriebsvereinbarung abgelehnt werden. ${ }^{8)}$

Mit der grundsätzlichen Herausnahme der sozial-autonomen Rechtsetzung aus dem Anwendungsbereich des Art. 80 GG und dem damit verbundenen Zuricklieten ihrer gesetzlichen Reglementierung tritt aber umso beleutsamer ein anderer Gesichtspunkt hervor; die unmittelbare rechtsstaatliche Bindung der sozial-autonomen Rechtsetzung selbst. Sie hat als Funktion den für die Rechtsetzung geltenden "ordre public" einzuhalten. Der Rechtsstaat darf eine andere Rochtsetzungsmacht als eine strukturell rechtsstaatliche nicht institutionalisieren und respektieren. Elementare Grundsätze rochtsstaatlicher Rechtsetzung wie die Notwendigkeit der. Publikation als Geltungsvoraussetzung jeden Rechts 9) oder die Beschränkungen rückwirkender Belastungsgesetze 10) gelten auch fail die sozial-autonome Rechtsetzung.

(d) Der Anteil der Gesetzgebung an der sozialen Intervention

Vielgesetzgeberei und Degeneration der Gesetzgebung sind vielbeklagte Übel des Rechtslebens unserer Zeit. 1) Der Verfall der Gesetzgebungskunst ist nicht $z u$ ïbersehen. 2) Aber es liegt nicht daran, daß die Gesetrgebung "an sich" heruntergekommen wäre. Der Verfall der Geselzgebung isi - von den Leistungsgrenzen, die einer Gesetzgebung durch demoklatische, in allgemeinen Wahlen

8) Vgl. Maunz in Maumz-Dïris, Art.80 Randn. 33 a.E.

9) Zum rechtsstaatlicheri Cimmsatz s. z. B. BVerfGE 7, 330 (337f) und die doltigen Nirhwoise. - Zur Anwendung auf die sozial-autonome liechtsulfungs. die verdienstliche, wenngleich im Detail nich hr.hus us überzeugende Arbeit von Zöllner, Zur l'ublikation wn larifvertrag und Betriebsvereinbarung.

10) Zu den allgemeinch (immutsitzen s. unten III 2 (S.637 ff). $\mathrm{Zu}$ ihrer Anwendung auf he sozial-autonome Rechtsetzung s. vor allem Wielemam!, \%eit!irhe Grenzen kollektiver Gestaltungsmacht, liecht de. abeit, 12.Jhg. (1959) S. 454 ff und seine Nachweise.

1) S. nochmals die Nachneist when S. 412; zur Würdearmut der gegenwärtigen Cifsetzr(b)ungspraxis s. z. B. Reif, Das Parlament im demok!ntischen Staat, Zeitschrift für Politik, n. F. Jhg.6 (1959) i. 204 f: (207).

2) S. z.B. Marcic, Vom Gisetzesstaat zum Richterstatt, S.235ff. 
berufene Parlamente a priori gesetzt sind, abgesehen - im wesentlichen eine Folge der Vielgesetzgeberei und diese selbst eine Folge der objektiven, funktionellen Situation des Gesetzgebers. ${ }^{3)}$ Individuelle Disziplinlosigkeit und inadäquate Einstellung zur Aufgabe spielen im Vergleich dazu keine nennenswerte Rolle.

Seine funktionelle Suprematie im Staatsgefüge stellt den Gesetzgeber in einen übermächtigen Sog der Verantwortung, des Machtkampfes und des Drängens von außen. Seine Suprematie gegenüber unterstaatlichen Einheiten weist ihm diese Schlüsselposition auch im Ringen $z$ wischen dem Staat und unterstaatlichen Einheiten $z u$ - und das in einem Staatswesen, in dem unterstaatliche Einheiten öfentlichrechtlicher (und somit statischer) Natur mehr und mehr mit zentrifugaler Wucht an die Wand gedrückt werden. Der Bundesgesetzgeber spielt dieselbe Rolle im stets labilen Ausgleich zwischen Bund und Ländern. Damit ist auch schon wieder auf die Bedeutung des Gesetzgebers als dem vornehmsten Sachwalter der Egalität hingewiesen, die weit über die organisatorischen Zusammenhänge hinaus von den durchdringendsten Wirkungen ist.

Die funktionelle Suprematie ist dem gewaltenteiligen Rechtsstaat wesentlich. Das Gesetz ist der Garant der Allgemeinheit und Berechenbarkeit des staatlichen Handelns und somit der sich in diesen $G$ renzen bewegenden individuellen Freiheit. Der Gesetzgeber $m u ß$ sich deshalb der staatlichen Aufgaben annehmen, selbst wenn sie zunächst von der Verwaltung oder auch der Rechtsprechung aufgegriffen und von dieser Seite auch zu verwirklichen sind. Daß der gewaltenteilige Rechtsstaat den Gesetzgeber aus dieser Verantwortung nicht entläßt, ist eine der zentralen Weichenstellungen der Verfassungsordnung.

Die soziale Intervention muß demnach den Gesetzgeber intensiv beschäftigen. Sie stellt einen Riesenanteil an dem allgemeinen Aufgabenzuwachs des Staates, der auch ein Aufgabenzuwachs des Gesetzgebers sein muß, dar. Sie ist von eindeutiger machtpolitischer Relevanz. Zugleich sind ihre Angelegenheiten auch von groBem menschlichem Gewicht und müssen die damit verstrickten Interessen schon um deswillen beachtet werden. Macht und Ver-

3) Zur. Diagnose s. z.B. Hans Huber, Niedergang und Krise des Rechts des Rechtsstaats; Jahrreiß, Größe und Not der Gesetzgebung; Scheuner, Die Aufgabe der Gesetzgebung in unserer Zeit; s.a. die oben S.412 gegebenen weiteren Nachweise; ferner Kern, Aspekte des Verwaltungsrechts im Industriezeitalter, insbes. S. 100. 
antwortung des Gesetzgebers müssen ihn deshalb gerade zur sozialen Aktion anspornen. Allgemeinheit und Gleichheit gehören zu den Grundelementen des sozialen Strebens der Gegenwart. So fordert es wiederum gerade den Gesetzgeber heraus. Schließlich umgibt die soziale Intervention - im Geben und im Nehmen, im Geben freilich mit größerer Vollständigkeit - gestaltend die individuelle Sphäre. Der Gesetzgeber ist somit genötigt, umfassend und intensiv das Handeln des Staates ermächtigend oder beschränkend rechtlich zu binden. Der Ruf nach sozialer Sicherheit - diese nicht im engeren technischen Sinn verstanden - läuft rechtsstaatlich, rechtstechnisch gesehen, letztlich nicht allein, aber doch notwendig auch auf einen Ruf nach dem Gesetzgeber hinaus. ${ }^{4)}$

4) Sehr eindrucksvoll schildert Jahrreiß (Größe und Not der Gesetzgebung) die Situation. Daraus folgende Sentenzen: "... standen am Anfang der. Entwicklung Entschlüsse, die um des Menschen willen, aus Sorge um ihn höchst zweckmäßig oder gar einfach unvermeidlich waren. Und heute darf der Staat, gerade wenn er dem Menschen dienen soll, die Gesetzgebungstechnik kaum einen lag ruhen lassen". (S.20 f) "Damit die Freiheit des Bürgers gegen willkürliche staatliche Einzelentscheidung gesichert werde, ist der moderne VolksGesetzes-Staat geschaffen worden, läuft die moderne Gesetzesmaschine. ... wenn der Staat immer mehr Aufgaben an sich zieht oder an sich zichen muß, ...muß er immer häufiger und immer kräftiger in die Sphäre des Bürgers eingreifen und dazu muß dann das Volk die nötigen Gesetze billigen oder beschließen. Immer gewaltiger wird die Gesetzgebungsmaschine. ... Der Befehlshaber Staat rückt dem Bürger immer näher auf den Leib. Ind der Bürger bäumt sich nicht auf. Es ist vielmehr als riffe er: Du, Staat, rücke mir noch näher auf den Leib... und sichere mich dadurch in einem wenn auch bescheidenen stück Freiheit gegen die Gefahren der Natur und gegen den I)rurk in Menschengestalt, ... . Große und immer gröroe, aber allerdings gleiche und berechenbare Unfreiheit genouber dem eigenen Staat als Garantie von etwas freiheit gegenüber jenen ungleich und unberechenbar drohenden (ifwalten! Das ist das Erstrebte und das ist der Preis. 1)(. Sorial-Liberal-Staat muß die Gesetzgebungsmaschine stark laufen lassen". (S.58 f). - "Solange diese Angst und dieses Sekuritäts-Streben den Vorrang vor. allen anderen Motiven haben, solange wird es schwer sein, über das hier aufgezeigte \aß der Selbstdisziplin des Gesetzgebers hinaus auch nur schrittweise die äußere Größe der Gesetzgebung unserer Zeit zu mindern und den Weg zu fin- 
Dabei stellt die soziale Intervention in einem für sie typischen, hohen Maße legislative Aufgaben, die auch bei optimaler gesetzgebungstechnischer Behandlung entweder überhaupt nicht bzw. nur in unverbindlichen Grundzügen oder ganz und gar, bis in die Einzelheiten hinein, vom Gesetzgeber gelöst werden müssen. Gerade deshalb ist auch eine Arbeitsteilung $z$ wischen förmlicher Gesetzgebung und untergesetzlicher Rechtsetzung in der Region des Sozialen vielfach nicht möglich. Die rechtsstaatliche Ordnung des Grundgesetzes verstattet dem förmlichen Gesetzgeber aber auch sonst nicht, sich von den grundsätzlichen Entscheidungen zugunsten seiner Delegatare zu entlasten. Nur auf cliese oder jene Weise eng begrenzte Fragen kann er abgeben. Der weitere Spielraum in bezug auf die Autonomie verbandiicher Selbstverwaltungskörper kann sich nicht auswirken. Der Gesetzgeber, clessen Tätigkeit das Grundgesetz regelt, ist der Gesetzgeber eines Staatswesens, in dem öffentlichrechtlich gebundenen unterstaatlichen Verbänden kaum je eine grundsätzlich entscheidende Rolle zukommen kann; und am wenigsten bestehen die Voraussetzungen dafür in der nach umfassender, allgemeiner und endgültiger Entscheidung drängenden, von universeller Spannung erfül1ten Problem region des Sozialen.

Schließlich hat der Gesetzgeber zwar eine umfassende und in vielfältiger. Weise intensiv gestellte Aufgabe; deren Erfüllung findet ihre Grenzen aber an seinem Unvermögen, die gesollten suzialen Sachverhalte zu bewerkstelligen. Was das Recht nicht vermag, kann auch (ler Gesetzgeber nicht bewirken. Handeln, real bewirken, Tatsachen setzen - das kann (von Staats wegen) nur die Exekutive. Die soziale Intervention weist besonders intensive Bezüge zum Tatsächlichen auf. Das staatliche Geben setzt ein Haben und Können voraus, das der Gesetzgeber vielfach zwar grundlegend vorbereiten, jedoch oft nicht bewirken kann. Darin liegt eine tiefgreifende Aktionsschwäche, ja gerade$z u$ ein Aktionsausfall des Gesetzgebers in bezug auf die soziale Intervention und umgekehrt eines der vielfältigen Symptome der rechtsstaatlichen Schwäche des Suzialen.

3. Die soziale Intervention im "Justizstaat"

a) Bemerkungen zum Justizstaat

Die Rechtsstaatlichkeit steht und fällt mit der Einrichtung eines ausreichenden gerichtlichen Rechtsschutzes. Die gegenseitige kontrolle des Gesetzgeber's und der Verwaltung gibt keine Gewähr

den zurück zur wahren, inneren Größe der Gesetzgebung". (S.61). 
(ler Verfassungsmäßigkeit de' (iesetzgebung und der Verfassungsund Gesetzmäßigkeit der Verwaltung. Nur die "Dritte Gewalt" der von Gesetzgeber und Exekutive unabhängigen Richter kann das Funktionensystem in der elforderlichen Weise ergänzen. 1)

Über diese Kontrollfunktion (jer Gerichte darf aber nicht vergessen werden, daß vol aller funktionsgerechten Differenzierung des Staatsorganismus schon die richterliche Aufgabe des Staates da war: die Aufgabe der Streitentscheidung, die der Staat übernehmen muß, sobald er die chaotische Selbsthilfe unterbindet eine Aufgabe, die mit der Gerechtigkeitsdetermination des Staates eng verknüpft ist. Das Strafen ist ihm ebenfalls von Anfang an zugeordnet. Die kausale Konstellation von Rechtsfriede, Gerechtigkeit und staatlicher Richterfunktion erklärt das.

Die Sachgesetzlichkeiten dieses elementaren Richtens haben ganz unabhängig von dem Kontrolldenken der bürgerlichen Rechtsstaatslehre zur - im einzelnen nach Modus und Grad äußerst unterschiedlichen - organisatorischen und personellen Verselbständigung der Gerichtsbarkeit geführt. Die Gewaltenteilungslehre des 18. Jahrhunderts versteht sie noch in diesem Sinne. Die Rechtsstaatslehre des 19. Jahrhunderts nimmt dieser Absonderung ihren negativen Charakter und fügt ihr den agressiven Zweck einer Kontrolle der Fxekutive hinzu. Im 20. Jahrhundert endlich erstarkt - mit zunehmender Differenzierung und Vervollkommnung des rechtsstaatlichen Systems - der Gedanke des Verlassungsschutzes und ler kontrolle des Gesetzgebers durch die (ierichte. ${ }^{2)}$ Im Verlaufe dieser. Entwicklung konnte sich das Spannungsverhältnis zwischen den reziproken Kausalrelationen Orga-

1) Die Frage "(puis custodiet custodes?" bleibt zwar auch und gerade dort offen, wu umiassende gerichtliche Kontrollkompetenzen begrundet werden. Doch begänne mit ihr ein regressus ad infinitum; sie soll daher auf sich beruhen. Begrenzte Zugestänchisse - wie z. B. die Instanzenzüge oder die Überwachum: der Nichtrerfassungsgerichte durch die Verfassungsgerichte - rrisen die Möglichkeiten, dem berechtigten Kern les finge gorecht zu werden, und die damit verbundenen Risiken in sleicher Weise auf. Im Prinzip liegt die Hoffnung des Rechtsstates jedenfalls bei der Kontrolle der Gesetzgebung und V'erwaltung durch die Gerichte.

2) Zu den viel ältelen $\|$ u $z$ eln der Verfassungsgerichtsbarkeit s. z. B. Fingelhal.tt, Das richterliche Prüfungsrecht im modernen lerrassungsstaat, Jahrbuch des öfentlichen Rechts, "I. F. Bd.8 (1959) S.102 ff. 
nisation - Aufgabenstellung und Aufgabenstellung - Organisation, das vom Ursprung einer abgesonderten Gerichtsbarkeit an bestand, nicht auflösen. Es mußte sich verschärfen.

Dieses Verhältnis war zudem schon vor dem Hinzutreten der rechtsstaatlichen Komplikationen und ist noch heute damit belastet, daß die Gerichte bzw. die Richter immer wieder über die Streitentscheidung, das Strafen und die negative Kontrolle hinaus mit Aufgaben unstreitiger Rechtspflege und positiver Gestaltung betraut wurden. Dazu hatten mit verschiedenem Gewicht sowoh1 die amtsbedingte Sach - und Rechtskunde wie auch ihre Unabhängigkeit, ihr Unbeteiligt-Sein und das ihnen gerade deshalb entgegengebrachte Vertrauen Anlaß gegeben. Damit traten sie in ganz anderer Weise als im Rahmen rechtsstaatlicher Kontrolle in Konkurrenz mit der Exekutive. ${ }^{3)}$

So entzieht sich die universelle Wesensbestimmung von Gerichtsbarkeit und Rechtsprechung heute dem Zugriff einschichtiger Definition und öfnet sich nur mehr differenzierter und differenzierender Betrachtung. 4) Dasselbe gilt für die Position der Gerichtsbarkeit (als organisatorische Einheit) und der Rechtsprechung (als Funktion) im Staatsgefüge. Schließlich wirken sich die auseinanderstrebenden, zusammenlaufenden und sich überschneidenden Entwicklungs- und Gestaltungslinien auch auf das Verständnis dessen aus, was als "Justizstaat" angesprochen wird.

Das Verständnis des Begriffes "Justizstaat" differiert in zwei Hauptpunkten. Erstens kann mit "Justiz" entweder nur die (vorrechtsstaatliche) Substanz der Rechtsprechung - Strafgerichtsbarkeit, streitige Gerichtsbarkeit, freiwillige Gerichtsbarkeit -

3) S. f.v.a. Bettermann, Die freiwillige Gerichtsbarkeit im Spannungsfeld zwischen Verwaltung und Rechtspflege, in Festschrift für Friedrich Lent, 1957, S. 17 ff. - Weitere Nachw. s.u. (S. $512 \mathrm{ff})$.

4) Aus der (vielfach recht diffusen und desorientierten) jüngeren Diskussion über den Begriff der Rechtsprechung seien zunächst folgende Darstellungen hervorgehoben: Friesenhahn, Über Begriff und Arten der Rechtsprechung, in lestschrift für Richard Thoma, 1950, S. 21 ff; Menger, System des verwaltungsgerichtlichen Rechtsschutzes, 1954, S. 19 ff; Bettermann, Verwaltungsakt und Richterspruch, in "lorschungen und Berichte aus dem öffentlichen Recht", Gedächtnisschrift für Walter Jellinek, 1955, S.361 ff; Jahrreiß, Verfassungsrechtsprechung und Verfassungsgericht, in: Mensch und Staat, 1957, S. $137 \mathrm{ff}$ (insbes. S. $150 \mathrm{ff}$ ). 
und ihr organisatorisches Subjekt, die auch vom Grundgesetz 5 ) noch so genannte "ordentliche" Gerichtsbarkeit gemeint sein, 6) oder alle Rechtsprechung, insbesondere also auch die besondere Verwaltungs-(und Verfassungs-)gerichtsbarkeit. Zweitens kann sich die mit dem Wort "Justizstaat" ausgedrückte Prävalenz der Gerichte auf eine Ausbreitung ihrer Primärkompetenz zulasten der Verwaltung oder die Ausdehnung ihrer Kontrollkompetenz gegenüber den anderen Gewalten beziehen. ${ }^{7)}$

Wenn vom Staat des Grundgesetzes als von einem "Justizstaat" die Rede ist, so kann das nur in dem Sinne eines Nebeneinander mehrerer Gerichtszweige, einer prinzipiellen Gleichwertigkeit der "ordentlichen" Gerichtsbarkeit mit den übrigen Gerichtszweigen gemeint sein (vgl. Art.92 ff, insbes. Art.96, Abs.1GG).8) Zwar konzediert auch der Grundgesetzgeber noch, daß er sich auf Präsenz und Integrität der "ordentlichen" Gerichtsbarkeit in besonderem Maße verläßt. ${ }^{9)}$ Aber diese Justizstaatlichkeit älterer Provenienz ist nicht das, was das Gesamtgefüge kennzeichnet. 10) Die Kehrseite ist, daß auch die organisatorischen und

5) Art. 14 Abs. 3 Satz 4, Art. 19 Abs. 4 Satz 2, Art. 34 Satz 4 GG.

6) Das korrespondiert mit dem Begriff der Justiz, der die bei den Justizministerien ressortierenden Gerichte umfaßt (s. $z$. B. Menger, System des verwaltungsgerichtlichen Rechtsschutzes, S. 52 ff mit eingeh. Nachw.).

7) S. zu Vorstehendem insbes. Ule, Über das Verhältnis von Verwaltungsstaat und Rechtsstaat, insbes. S. $127 \mathrm{ff}$ und seine Nachweise. - Die Kombination des engeren Justizbegriffs mit der Expansion der Sekundärkompetenz kennzeichnet den Justizstaatsbegrilf des rrühen bürgerlichen Liberalismus, wie er in Bärs "Rechtsstat" (1864) seine klassische Darstellung und seinen Abgesang fand. Gegenüber der konkurrierenden Ausbreitung verwaltungs - und verfassungsgerichtlicher Kont rollinstitutionen ist dieser Justizstaatsbegriff indifferent. Nur das Justizgericht, las "ordentliche" Gericht oder - wie man heute sagen miißt. -. las. "Einheitsgericht", erscheint ihm als der funktionsigerechte Kont rollträger. (Damit soll nicht das alte Mißverständuis übernommen werden, als sei Bär selbst ein unbedingte. Anhänger des Einheitsgerichts gewesen.)

8) s. z.B. Hamann, Das (irundgesetz, Art.92 Anm.A/3.

9) s. oben Fußn.5.

10) Als Rest altel Justizstaatlichkeit betrachtet diese Zuständigkeiten Koellreutter, Deutsches Staatsrecht, S.244; Klein, Bonner Grundgesetz und liechtsstaat, S.407, entscheidet sich für ein "sowohl - als auch". 
persönlichen Garantien einer unabhängigen Gerichtsbarkeit für alle Zweige dieselben sind (Art.97f, $101 \mathrm{GG}$ ). Was die Stellung der "Richter." 11) der "rechtsprechenden Gewalt", 12) der "Rechtsprechung", 13) der "Gerichte" 14) und der Gesamtheit der verschiedenen "Gérichtsbarkeiten" 15) betrifft, so ist sie in erster Linie durch die umfassende Kontrolle der beiden übrigen Gewalten gekennzeichnet (Art. 19 Abs. 4, 93, 100 GG). Die Konkurrenz der Primärzuständigkeit, die niemals so im Feuer der Prinzipien stand wie die Kontrollfunktion der Gerichte, hat keine gleicherweise betonte Regelung gefunden. Das Grundgesetz sagt nur: "Die rechtsprechende Gewalt ist den Richtern anvertraut" (Art.92, 1. Halbs.). Darin spiegelt sich, wie unpolemisch der Verfassungsgeber darüber gedacht hat. Mochte ihm eine gewisse Kernsubstanz als selbstverständlich erscheinen, so hatte die Gestaltung der Grenzzonen durch die anderen Orts gewährleistete gerichtliche Letztzuständigkeit an Gewicht verloren.

b) Die richterliche Primärkompetenz im Rahmen der sozialen Intervention

aa) Die F'unktion - ihre soziale Bedeutung

Aus diesen Gestaltproblemen des grundgesetzlichen "Justizstaates" ergeben sich die wesentlichen Gesichtspunkte, von denen her das Verhältnis zwischen Rechtsprechung und sozialer Intervention zu sehen ist. Zunächst sei der Blick auf das Feld gerichtet, auf dem clie Gerichte originär, nicht erst im Anschluß an die Maßnahmen anderer Staatsorgane und zu deren Überwachung tätig werden. Hier gestalten sie selbst und ausschließlich, nur dem allgemeinen Gesetz unterworfen, die konkrete und individuelle soziale Wirklichkeit.

In dieser Funktion sind die Gerichte in erster Linie zu sehen als die Gestalter und Bewirker des sozialen Ausgleichs, der nicht über den Staat (oder die sonstige öffentliche Hand) sondern unmittelbar zwischen Bürger und Bürger, zwischen den privaten Rechtssubjekten, und zwar von Rechts wegen erfolgt. Der bürgerliche Rechtsstreit - nicht in dem engeren Sinne des Zivilprozesses sondern auch derjenige vor den Gerichten der freiwilligen

11) Art.92, 97, 98 GG und dessen ganzer IX. Abschnitt.

12) Art. 92 GG.

13) Art. 1 Abs.3, 20 Abs. 2 GG und die Überschrift seines IX. Abschnittes.

14) Art. 14 Abs. 3 Satz 4 GG und dessen ganzer IX. Abschnitt.

15) Art. 96 Abs. 1, 108 Abs. 5 GG. 
(ierichtsbarkeit 1) und vor allem auch vor den Arbeitsgerichten ${ }^{2}$ ) - ist das Element, in dem sich diese Wirksamkeit der Gerichte vollzieht. Zweckhaft soziale liechtssätze und Teilrechtsordnungen - allen anderen voran das A rbeitsrecht - erfahren durch die Gerichte die autoritative Umsetzung in Einzelfallrecht. Differenzen (auch) sozialen Gehaltes, deren spezielle Regelung nicht tendenzmäßig sozial gestaltet ist, können von den Gerichten unter Rückgriff auf allgemeinere Grundsätze in einer Weise verbeschieden werden, die auch der sozialen Spannungslage gerecht wird. So liegt es in der. Hand der. Gerichte, die Privatrechtsordnung als eine soziale Ordnung zu aktualisieren und zu integrieren.

Die streitentscheidende Primärzuständigkeit der Gerichte beschränkt sich nicht auf privatrechtliche Streitigkeiten und Streitigkeiten unter Privatrechtssubjekten. Auch öfentlichrechtliche Streitigkeiten tommen vor sic.3) Doch sie sind als selbständiger Typ im unterkonstitutionellen kaum nicht von gleicher Bedeutung für die soziale Intervention wie der (zwischen-)bürgerliche Rechtsstreit. Vor allem öffentlichrechtliche Streitigkeiten zwischen öffentlichrechtlichen Subjekten gehören zwar unlöslich zum Gesamtbild eines auf mehrere 'l'äger verteilten Interventionssystems. Es braucht nur an die Erstattungsstreitigkeiten zwischen verschiedenen sozialversicherungsträgern, Fürsorgeverbänden usw. erinnert zu werden. Aber auch sie stehen doch im Hintergrund, im Bereich des Technischen.

Die andere Stammfunktion der Crerichte, das Strafen, tritt an sozialer Bedeutung ${ }^{4)}$ neben der. St reitentscheidung deutlich zu-

1) Vgl. zusammenfassend Hahscheid, Zum Streitverfahren der Freiwilligen Gerichisbarkeit, JZ 9. Jhg. (1954) S. 689 ff.

2) Jedenfalls die U1teilssachon bezeichnet das Arbeitsgerichtsgesetz selbst als "bürgerliche Rechtsstreitigkeiten" ( $\$ 2$ Abs. $1 \mathrm{Nr} \cdot 1-3)$.

3) Der Prototyp siml lie J'al leistreitigkeiten vor den Verwaltungsgerichten. Fir den suzialen Bereich besonders wichtig ist der sozialgerichtliche l'arteistreit (\$51 SGG i.V.m. \$\$ 54 Abs. 5, $55 \mathrm{~N}^{\prime} \mathrm{.} .1$ und $2 \mathrm{G}(\mathrm{i})$. S. a. die Zuständigkeit des Bundesverwaltungsgerichts und des Bundessozialgerichts für nicht-verfassungsrechtiche, öfentlich-rechtliche Bund-Länderstreitigkeiten ( $50 \mathrm{Abs.1} \mathrm{Nr} .1 \mathrm{VGO}, \$ 39$ Abs.2 SGG). Auf den Verfassungstreit ist unten noch zurückzukommen.

4) S. hierzu auch Wiirtenberger, Strafrichter und soziale Gerechtigkeit, in "Stellung und Aufgabe des Richters im modernen Strafrecht", Nélanges Oscar Adolf Germann, 1959, S. $35 \mathrm{ff}$. 
rück. Als Sanktion sozial wichtiger Normen ist die Strafe unentbehrlich. Die Straízumessung selbst kann soziale Gerechtigkeit verwirklichen und sonstwie sozialen Notwendigkeiten Rechnung tragen. Aber beides ist nicht zentral.

Nach deutschem Herkommen entscheiden die Gerichte nicht nur über Rechtsstreitigkeiten und üben sie nicht nur Strafgewalt aus. Sie haben auch die Aufgabe, "einseitig", d. h. von einem kontradiktorischen Streitverhältnis unabhängig und außerhalb des Kriminalstrafwesens Rechtsfrieden zu stiften, Rechtsverhältnisse zu klären, pflegende und fürsorgende Anordnungen zu treffen und sonstwie positiv Rechts- und Lebensverhältnisse zu gestalten. Das Recht der freiwilligen Gerichtsbarkeit 5$)$ und seine jüngere Schwester, das Recht des arbeitsgerichtlichen Beschlußverfahrens, ${ }^{6}$ sind die Sammelbecken dieser Zuständigkeiten. Darunter befanden sich seit jeher Materien von eindeutiger sozialer Relevanz. 7) Die soziale Gezieltheit des arbeitsgerichtlichen Beschlußverfahrens ist offensichtlich. Aber auch das Recht der.

5) Zu seinem riesigen Erstreckungsbereich s. die Zusammenstellung bei Schlegelberger, Gesetz über die Angelegenheiten der Freiwilligen Gerichtsbarkeit, 7.Auf1. 1956, $\$ 1$ Randn. 20.

6) (1) Vgl. $\$ 2$ Abs. $1 \mathrm{Nr} .4$, Abs. 2 und 3 ArbGG. Ein öffentlichrechtliches Seitenstück dazu bilden die gerichtlichen Zuständigkeiten im Personalvertretungsrecht $(\$ \$ 76,93$ des Bundespersonalvertretungsgesetzes). Zur Verwandtschaft des Beschlußverfahrens mit dem Verfahren der freiwilligen Gerichtsbarkeit s. Maus, Handbuch des Arbeitsrechts, X A 2, $\$ 80$ A rbGG Randn.1 (S.204); s. a. Schnor von Carolsfeld, A rbeitsrecht, S.495; Götz Hueck in Hueck-Nipperdey, Lehrbuch des A rbeitsrechts, Bd. I S. 807.

(2) Dem Gegenstand nach sehr verwandt ist dem arbeitsgerichtlichen Beschlußverfahren die gerichtliche Entscheidung im Rahmen der (Nicht-) Wahl des "Elften Mannes" bzw. des "Fünfzehnten Vannes" nach $\$ 8$ des Mitbestimmungsgesetzes bzw. $\$ 5$ des Mitbestimmungsergänzungsgesetzes. Doch ist diese Entscheiclung nicht dem Arbeitsgericht sondern einem "ordentlichen", dem Oberlandesgericht, übertragen.

7) Es würde zu weit führen, hier in die Frörterung darüber einzutreten, in welchem Maße schon die "klassischen" Gegenstände freiwilliger Ger.ichtsbarkeit wenigstens unter anderem und wenigstens abstrakt suzial becleutsam sind. Vor allem das Vormundschaftswesen - das viel deutlicher sozial getönte Jugendwohlfahrtsrecht ist seine moderne Frweiterung - diente doch immer schon dem "Schwächeren". 
freiwilligen Gerichtsbarkeit schließt Kompetenzen ein, die unmittelbar und konkret sozialen Zwecken dienen, 7) wie das z.B. bei der richterlichen Anordnung der Schutzaufsicht und Fürsorgeerziehung ( $\$ \$ 57,65 \mathrm{ff} J \| G$ ) der Fall ist. ${ }^{8)}$

\section{bb) Die verfassungsrechtliche Garantie}

Dieser den Gerichten positiv zugewiesene Aufgabenkreis umschließt einen verfassungsmäßigen Kompetenzkern, der den Gerichten nicht entzogen werden darf. 1) Er ist nicht in der durch A rt. 19 Abs. 4 GG garantierten Letztentscheidungskompetenz zu sehen. Art. 92 GG hätte keinen selbständigen Sinn, stieße die Vorschrift nicht darüber hinaus zu einem materiellen Begriff

Darin steckt viel suziales Wertgut. Oder wie ist es mit den Formvolschriften, denen $z u$ genügen die gerichtliche Beurkundung usw. vorgenommen wird? Dienen sie nicht auch dazu, den "Schwächeren" vor Überrumpelung zu schützen?

8) (1) Eng damit verwandt sind die Unterbringungsanordnungen für süchtige, kranke und fürsorgebedürftige Personen. Soweit sie außerhalb des Strafverfahrensrechts und aufgrund Bundesrechts ergehen, ist für sie das Verfahren der freiwilligen Gerichtsbarkeit vorgesehen $(\$ \$ 1-3$ des Gesetzes über das gerichtliche verfahren bei Freiheitsentziehung vom 29. Juli 1956 (BGBl. I S.599)). Unter den materiellen Unterbringungsgründen ist besonder's $\$ 20$ der Fürsorgepflichtverordnung zu erwähnen. Zu den weiteren Rechtsgründen und zu den landesrechtlichen Regelungen s. die Zusammenstellung bei Maunz-Dürig, Art. 104 Randn. 17 f. - Darin, daß das Gericht auch von Amts wegen handeln kann, dürfte die Anordmung der schutzaufsicht und der Fürsorgeerziehung wohl einmalig dasteheri. Hier macht sich bemerkbar, daß diese $\mathrm{Zu}-$ ständigkeit vom Vormundschaftsrecht, dessen Vollzug nur dem Richter zusteht, herkornmt. Dagegen kommen die anderen Unterbringungsanor dhungen vom Polizeirecht und vom gerichtlichen schutz gesch willkürliche Festnahmen her (Art. 104 Abs. 2 GG).

(2) Das Verfahren der freiwilligen Gerichtsbarkeit ist wohl auch anzuwenden auf dir Fntscheidung des Oberlandesgerichts im Rahmen des Mitbestimmungsrechts (s.o. S. 514 zu Fußn. $6(2))$.

1) Zu dem Satz "Nur Richter dürfen Recht sprechen" s. z.B. Bettermann, Der Schut\% der Grundrechte in der ordentlichen Gerichtsbarkeit, in: Bettermann-Nipperdey-Scheuner, Die Grundrechte, Bd.III, 2.llalbbd., 1959, S. 779 ff (876) mit eingeh. Nachw. ( FuRn. 545). 
der. "Rechtsprechung" vor. 2) Die Konturen sind allerdings in Anbetracht der allgemeinen begrifflichen Unklarheit ${ }^{3)}$ und der prinzipiellen Unreinheit des vorrechtlichen Gesamtbilds 4 ) unscharf. Aber im wesentlichen ist klar, daß dazu die Ausübung grundsätzlich der Kriminalstrafgewalt, 5) die Streitentscheidung ${ }^{6)}$ ) und gewisse weitere traditionell ${ }^{8)}$ durch die Gerichte

2) Vgl. Ule, Anm. zu BVerwG Urteil v. 19. Februar 1957 - II C 72.57 - JZ 13.Jhg. (1958) S. 628 ff (628); Menger, Anm. zu BGH Urteil v.21.April 1959 - 1 StR 504/58 - JZ 15. Jhg. (1960) S.168 ff (168); ders., Höchstrichterliche Rechtsprechung zum Verwaltungsrecht, Verwaltungsarchiv, Bd. 51 (1960) S. 54 ff $(67 \mathrm{f})$. - Menger dreht sich allerdings im Kreise. Einerseits erkennt er zutreffend die Notwendigkeit einer. substanziellen Bestimmung dessen, was "Rechtsprechung" ist (s. dazu auch Bachof, Diskussionsbeitrag zu "Ver'waltungsrecht und Verwaltungsrechtsprechung", S. 178 f); andererseits will er seinen funktionalen, durch die Letztentscheidung geprägten Rechtsprechungsbegriff (s.hierzu Menger, Höchstrichterliche Rechtsprechung zum Verwaltungsrecht, Verwaltungsarchiv, Bd. 50 (1959) S.193 ff und seine dortigen Nachw. über seine früheren Stellungnahmen) sub specie des A rt. 92 GG retten. Seine Zuflucht nimmt er deshalb zu dem Kriterium, Rechtsprechung sei, was auf Verbindlichkeit und Rechtskraft abziele (a.a.O., Verwaltungsarchiv Bd.51 S.67, JZ Jhg. 15 S. 168). Das überzeugt nicht.

3) S. die oben S. 513 zu Fußn. 4 Zitierten.

4) Zur Notwendigkeit der Hereinnahme des vorrechtlichen Gesamtbilcles gerade für die Auslegung des Art.92 GG s. Bettermann, Verwaltungsakt und Richterspruch, S.570; Bachof, a.a.O. S.178 f.

5) S. f.v.a. BVerfGE 8, $197(207 \mathrm{f})$ und die Darstellung des Problems bei Bettermann, Der Schutz der Grundrechte in der ordentlichen Gerichtsbarkeit, S.873 ff. - Aber nicht, wie Rumpf (Verwaltung und Verwaltungsrechtsprechung, S. 151 f), der Wahrheit ein Prokrustesbett bereitend, meint, weil das Strafverfahren ein Streitverfahren, ist sondern weil das Strafen traditionell und zwar ganz elementar zu dem gehört, was des Richters Sache ist.

6) S. vor allem Friesenhahn, Über Begriff und Arten der Rechtsprechung, S.26 ff, $30 \mathrm{ff}$; Bettermann, Verwaltungsakt und Richterspruch, S. 370; Rumpf, Verwaltung und Verwaltungsrechtsprechung, S. $151 \mathrm{ff}$; Ule, Anm.zu BVerwG Urteil v. 19. Februar 1957, S.628 f; s.a. deren Nachweise.

7) S.a. Holtkotten, Bonner Kommentar, Art.92 Anm. II $1 \mathrm{~b}$ und 
ausgeübte rechtspflegende frunktionen ${ }^{9)}$ gehören.

Doch sind, wie gesagt, die (irenzen flüssig. 10) So wie es zulässig erscheint, die Strafgewall in eng zu umgrenzenden Ausnahmefällen den Verwaltungsbehörden zur (von den Gerichten voll kontrollierten) Ausübung zu übertıgen, 11) so ist auch der streitentscheidende Verwaltungsakt 12) nach wie vor nicht unzulässig. 13)

d und seine Nachweise.

8) S. o. S.512 zu Fußn.12.

9) S. hierzu vor allem Bettermann, Die freiwillige Gerichtsbarkeit im Spannungsfeld zwischen Verwaltung und Rechtsprechung, in Festschrift für Friedrich Lent, 1957, S. $17 \mathrm{ff}$; Habscheid, Die Zivilrechtspflege im Spannungsfeld verfassungsrechtlicher Grunclsätze, JZ 1958, S. 321 ff (326); s.a. Bachof, Diskussionsbeitrag zu "Verwaltung und Verwaltungsrechtsprechung", \$. $\$ 18 \mathrm{f}$.

10) Vgl. Lerche, Ordentlicher Rechtsweg und Verwaltungsrechtsweg, 1953, S. 110 .

11) Das Problem der Ausübung staatlicher Strafgewalt durch Verwaltungsbehörden wird seit langem im Zusammenhang mit der Steuer'strafgewalt der Finanzämter diskutiert. Der Streit hat einen volläufigen Abschluß durch die Entscheidung des Bundesgerichtshofes gefunden: BGH St 13, 102 (Urteil v. 21. Apri1 1959 - 1 Sth 504/58 - mit Anm. von Arndt, NJW 12. Jhg. (1959) \$. 1230 f, und ron Menger, JZ 15.Jhg. (1960) S. $168 \mathrm{ff}$ ) auf dessen Darstellung und Nachweise (desgl. die der zitierten Anmerkung(n) Bezug genommen werden darf.

12) S. hierzu z.B. Schüle, Der st reitentscheidende Verwaltungsakt, in "Staats- und verwaltungswissenschaftliche Beiträge", 1957, S. $277 \mathrm{ff}$; Wolff, lelwaltungsrecht I, S. 69 f, 242; je mit weiteren Nachweisen und Beispielen. - Wichtig ist jedoch, daß der entschiedenc itreit nicht zwischen der entscheidenden Behörde (hohirilenhierarchie) und dem Betroffenen bestanden hat; (imm liir den streitentscheidenclen Richterspruch ist dif Drittollung des Richters wesentlich. Nur die Drittstellung der Brhir) macht den streitentscheidenden Verwaltungsakt lamit vergleichbar (s. Ule, Anm. zu BVerwG Urteil v.19. Honar 1957, S.629 und seine Nachw.).

13) Friesenhahn, Iber Jerrifi und Arten der Rechtsprechung, S.31; Lerche, (O)denticher. Rechtsweg und Verwaltungsrechtsweg, S.110; Hamam, Das Grundgesetz, Einf. I D 7 b (S.54) (a.A. ebcl. Art.92 Anm. C 1); Maunz, Deutsches Staatsrecht, \$.210. - ^.A. Settermann, Verwaltungsakt und

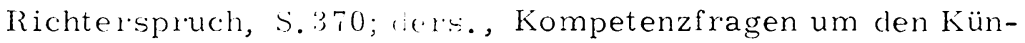
digungsschutz im Kleingatenrecht, NJW 10.Jhg. (1957) 
Allerdings muß es sich auch hier um historisch oder sachlich begründete Ausnahmen handeln; denn im Prinzip und auch in der tatsächlichen Regel müssen Rechtsstreitigkeiten vom Richter entschieden werden. Seit dem Wegfall der streitentscheidenden Aufgaben der Versicherungsbehörden auf dem Gebiet des Sozialversicherungsrechts und ihrem Übergang auf die Sozialgerichte 14) spielt der streitentscheidende Verwaltungsakt im Rahmen des sozialen Rechts ohnedies die zurückgezogene Rolle, die ihm gebührt. Vor allem ist er auf Streitigkeiten des öffentlichen Rechts beschränkt, wo er an sich kaum Bedenken begegnen kann. 15) Die

S. 1497 ff; Ule, a.a.O. BVerwGE 2, 208 (210 f) (Wenn das Bundesverwaltungsgericht in BVerwGE 1, 4 (10); 7, 66 (73) "streitentscheidende" Verwaltungsakte als solche unbeanstandet läßt, so will das in diesem Zusammenhang nichts besagen, weil jeweils die Drittstellung der entscheidenden Behörde fehlt.). - Ein nicht überzeugender Abgrenzungsversuch bei Schüle, a.a.O. S.294.

14) Vgl. $\$ 214$ SGG. Eine Zusammenstellung einschlägiger Bestimmungen der Reichsversicherungsordnung a. F. findet sich bei Eckert, Sozialversicherungsgesetze, Bd.2, S. VII, $181 \mathrm{ff}$. Diese Kompetenz wäre - gerichtliche Kontrolle der Streitentscheidung vorausgesetzt - übrigens kaum sehr bedenklich gewesen, da es sich (nach heutiger Auffassung) dabei nur um die Entscheidung öffentlichrechtlicher. Streitigkeiten handelte.

15) (1) Im öffentlichen Recht ist er heute noch durchaus üblich. S. die von den oben S. 517 zu Fußn. 12 Zitierten genannten Beispiele.

(2) Für den Bereich der sozialen Intervention interessiert vor allem der Verwaltungsentscheid über die Höhe von Enteignungsentschädigungen u. ä. Ansprüche, der - auch - streitentscheidend ist, wenn der zu entschädigende Eingriff nicht den durch die entscheidende Behörde repräsentierten Staat sonder'n einen Dritten begünstigte, den die Entschädigungspflicht trifft. Verwaltungs(vor)entscheidungen über die Höhe der Entschädigung sind zulässig (s. hierzu BVerfGE 8, 240 und Anm. zu dieser Entscheidung von Zacher in BayVB1. n. F. 4.Jhg. (1959) S. 120 f (121); je mit eingeh. Nachweisen). Die Frage der Zulässigkeit stellt sich hier aber schon gar nicht mehr eindeutig in bezug auf Art. 92 GG; denn es wäre fraglich, ob diese Vorschrift solche Streitigkeiten in die Kompetenz der Gerichte zöge, wenn nicht Art. 14 Abs. 3 Satz 4, 19 Abs. 4, 34 Satz 3 GG wären.

(3) Für zahlreiche Fälle öffentlichrechtlicher Streitigkeiten 
Entscheidung über Privatrechtsstreitigkeiten durch Verwaltungsakt ist selten. 16) Allerdings kommt es einer Streitentscheidung verschiedentlich sehr nahe, wenn die Kündigung eines Rechtsverhältnisses der behördlichen Zustimmung unterliegt. 17) Das ist gerade im sozialen Bereich sehr häufig (so im A rbeitsrecht ${ }^{18}$ ) und im Kleingartenpachtrecht ${ }^{19)}$ ). Doch könnte von einer Streit-

gelten, wie im erwähnten Fall, verfassungsrechtliche Sondervorschriften, neben denen Art.92 GG an selbständiger Bedeutung verliert:

Für Bund-Länderstreitigkeiten: Art.93 Abs. 1 Nr. 3 und 4 GG; für Verfassungsstreitigkeiten im Bunde: Art.93 Abs. 1 Nr. 1 GG;

für Verfassungsstreitigkeiten in den Ländern: Art.28 Abs. 1 Satz 1 GG i.V.m. Art.93 Abs. 1 Nr. 4 und A rt. 99 GG; für Entschädigungsstreitigkeiten: Art. 14 Abs. 3 Satz 4, 15 Satz 2 GG (zur Auslegung s.oben (2));

für Amtshaftungsklagen: Art. 34 Satz 3 GG.

16) Das einzige Beispiel aus dem Bereich des sozialen Rechts ist das Schiedsverfahren nach $\$ \$ 28$ ff des Gesetzes über Arbeitnehmererfindungen vom 25. Juli 1959. Doch ist der dem gerichtlichen Verfahren nur beschränkt obligatorisch vorgeschaltete ( $\$ 37$ a.a.O.), von einer quasi-richterlichen Behörde $(\$ 30$ a.a.O.) zu erlassende, nicht unbedingt verbindliche Einigungsvorschlag ( $\$ 34$ a.a.O.) nicht ein gerade klassisches Beispiel für einen streitentscheidenden Verwaltungsakt. - Die wenigen anderen Fälle (Vorbescheide in Wild- und Jagdschadenssachon ( $\$ 35$ des Bundesjagdgesetzes) und in St randungssachen ( $\$ \$ 33,38$ der Strandungsordnung)) sind nicht einschlägig.

17) Zur Systematik derartiger. Vorbehaltes. Bettermann, Kompetenzfragen um den kindigungsschutz im Kleingartenrecht, S. $1497 \mathrm{f}$.

18) Unter totaler verwaltungshehördlicher Kontrolle steht die Kündigung Schwanrror is 9 des Mutterschutzgesetzes). Sehr weit geht auch der Vorbchalt für die Kündigung Schwerbeschädigter ( $\$ \$ 14$ ff des lichwerbeschädigtengesetzes). Nicht hierher gehört die Zustimmung des Landesarbeitsamtes zu Massenentlassungen nach $\mathbb{\$} 15$ ff des Kündigungsschutzgesetzes. Hier fehlt das individuelle Streitverhältnis. Zusammenfassend zu den einschlägigen Erscheinungen des Arbeitsrechts: Siebert, Finige fragen zur Wirkung des Verwaltungsaktes im A rbeitsverhältıis, in Festschrift für Karl Gottfried Hugelmann, Bd. II, 1959, \$.605 ff.

19) Vgl. $\$ 1$ der Kleingartenschutzverordnung vom 15. Dezember 
entscheidung nur dann gesprochen werclen, wenn nicht nur die behördliche Billigung Voraussetzung der zulässigen Kündigung wäre 20 ) sondern die erteilte Zustimmung die Rechtmäßigkeit der Kündigung schlechthin außer. Streit stellen würde. Das ist in der Regel nicht der Fall. 21)

\section{c) Die Ausweitung der sozialen Wirksamkeit des Richters}

1. Soziale statsaufgabe und Rechtsprechung. Das soziale Engagement des Staates und des Rechts hat auch den Richter in die soziale Aufgabenstellung verstrickt, was zuweilen auch so zugegangen ist, daß zuerst der Richter die Notwendigkeit des Ausgleichs erkannt und in seinem Funktionsbereich danach gehandelt hat. Die soziale Aufgabenstellung hat das Wesen des richterlichen Tuns tiefgreifend gewandelt und den Wirkungsbereich des Richters ausgeweitet. 1) Die strafrichterliche Tätigkeit tr.itt auch hier wieder zurück. Am deutlichsten ist der Wandel in der streitentscheidenden Wirkungsweise zutage getreten und in der darüber hinausgreifenden, nichtstreitigen Rechtspflege.

Ein auf die Streitentscheidung gestütztes System gesellschaftli-

1944 (RGB1. I S. 347). - S. hierzu Bettermann, a.a.O.

20) Auch bei versagter Zustimmung bleibt ein Streit darüber möglich, ob die Zustimmung überhaupt notwendig war.

21) Für die Zustimmungsvorbehalte nach dem Mutterschutzgesetz und dem Schwerbeschädigtengesetz dürfte das unbestritten sein. Das Gegenteil behauptet Bettermann (a.a.O., insbes. S. 1438; s.a. dens. Anm. zu BGH Urteil v. 4. Juni 1958 - V ZR 276/56 - NJW 12.Jhg. (1959) S. 43 f; und Ule, Anm. zu BVerwG Urteil v. 19. Februar 1957, S.629) für das Kleingartenpachtrecht. Mit Recht nimmt dagegen die herrschende Lehre eine dermaßen umfassende Wirkung der Zustimmung nicht an (vgl. BVerwGE. 4, 317, 332; BGH Urteil v. 4. Juni 1958, a.a.O.; weit. Nachweise s. bei Herzer. Die Anfechtbarkeit behördlicher Kündigungszustimmungen, DVB1. 72 . Jhg. (1957) S. $410 \mathrm{ff}$; s. hierzu a. BGHZ 32, 1 (5)).

1) Vgl. Baur, Sozialer Ausgleich durch Richterspruch; Brox, Richterliche Gestaltung privater Rechtsverhältnisse, JR 1960 S. 321 ff. - Gelegentlich auch Einschlägiges bei Marcic, Vom Gesetzesstaat zum Richterstaat. - Zu den weiteren Zusanmenhängen s.insbes. Kisch, Die soziale Bedeutung des Zivilprozesses, Judicium 1.Jhg. (1938/29) S. 1 ff; zu den entsprechenden Wandlungen des streitigen Erkenntnisverfahrens s. de Boor, Die Auflockerung des Zivilprozesses, S. 139 . 
cher Ordnung lebt von dem Vertrauen, die Summe der durch das Gesetz gerechtfertigten, zunächst durch den Streitgegner behinderten, durch den Richterspruch jedoch von diesem Hemmnis befreiten Einzelwillen werde in einer Art prästabilierter Harmonie das "Richtige", das Optimum, realisieren. Die Parteien determinieren den Streit. Ne eat iudex ex officio. Ne eat iudex ultra petita partium. Verhandlungsmaxime und Dispositionsmaxime sichern die Autonomie der Parteien. Dahinter steht der anthropologische Optimismus der Aufklärung und des Liberalismus, die Vorstellung von der natürlichen Gleichheit der Menschen. Das Ordnungsinstrument der Streitentscheidung ist umso leistungsfähiger, je mehr die Gesellschaft diesen Vorstellungen und Bindungen entspricht. Gegenüber einer staatsabhängigen, unmündigen Gesellschaft genügt - von der Maxime einer vom Staate zu verantwortenden, bestmöglichen Ordnung des Sozialgeschehens her gewürdigt - die Streitentscheidung nicht. Ist der Parteiwille desorientiert und defekt, sind die Sireitsteile heterogen und einander inadäquat, so stellt der Streit Alternativen, die weder mit dem einen noch mit dem anderen Alm zum "Richtigen" weisen. Dann muß der Richter der. Zweipoligkeit des Streites das Tertium des "Richtigen", des Optimum, hinzufügen.

2. Die spezifischen Frscheinungsformen richterlicher Sozialgestaltung. Im leichtesten Grad stört der Richter die Autonomie der Streitenden, indem er ex officio in die Prozeßführung eingreift. In (lahin gehenden Reformen des Zivilprozeßrechts (vgl. $\$ \$ 139,272$ b, $141 \mathrm{ZPO}$ ) und in der Abwanderung zum Verfahren der freiwilligen Gerichtsbarkeit, das dem Richter weitaus mehr V'erfahrensherrschaft gewährt, sind daher auch die ersten Anzeichen fir. die aufziehende Wandlung des richterlichen Berufs zu sehen. 2) Doch diese Korrektur kann allein nicht genügen. Der streit braucht substantielle Meliorationen.

F.r braucht sie umso mehr, als nicht nur der Parteiwille desorientiert erscheint sondern der. Funktionalismus des Streits von der Basis seiner Entscheidung, vom Gesetz her gestört ist. Der notwendige Formalismus staner gesetzlicher Regelungen, die Vielfalt des Lebens, soinf rindringliche, umfassende rechtliche Ordnung und das verfeinestr. limpfinden für die Unabdingbarkeit der Maxime, daß in jeckm Fall nateriell Gerechtigkeit geübt und erzielt werden mu? - diess frkpunkte kennzeichnen ein entschei-

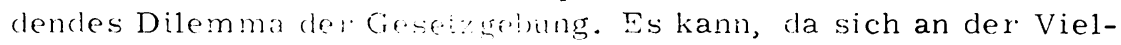

2) Vgl. Baur, Freiwillige (ierichtsbarkeit, Bd. I, 1955, S. 15 ff; ders., Sozialer Ausgleich durch Richterspruch, S. 193; weit. Nachw. s. dort. 
falt und der Individualität der. Sachverhalte nichts ändern läßt, da von einer intensiven Ordnung aller Lebensbereiche nicht mehr abgesehen werden kann und, da das Postulat lücken]oser individueller Gerechtigkeit unaufgebbar erscheint, nur zulasten der Definitivität des Gesetzes gelöst werden. ${ }^{3)}$ Die Streitentscheidung ist nicht mehr allein die Gegenüberstellung der Parteistandpunkte, des Sachverhaltes und des Gesetzes. Der Richter muß etwas hinzufügen: Die Konkretisierung des Gesetzes. Gewiß ist die Individualisierung der Norm immer spezifisch seine Leistung.

Aber die richterliche Aufgabe in einem Recht der Generalklauseln, unbestimmten Rechtsbegriffe und Ermessensvorbehalte unterscheidet sich von der. Individualisierung präziser Rechtssätze nicht nur quantitativ. Selbst dort, wo der Richter dieser Aufgabe streitentscheidend obliegt, zeigt sich das. Erst der Richter, nicht das allgemeine Gesetz sagt den Parteien endgültig, was sie mit Recht tun oder fordern dürfen. ${ }^{4)}$ Auf diese Weise nun tritt der Richterspruch gestaltend zum Parteiwillen hinzu. Der rechtlich beachtliche Parteiwille ist nicht nur nach "hinten", nach dem zur Zeit seiner Formung schon vorhandenen Gesetz, sondern auch nach "vorne", nach dem im Verhältnis zu ihm immer erst künftigen Richterspruch, orientiert. Auf der anderen Seite kann gerade die positive Aufgabe des Richter's, nämlich die Beteiligten zum "Richtigen" hinzuführen und sie darauf festzulegen, Gestaltungsfreiheit nicht entbehren. "Die Herausstellung einer positiven Ordnung" ist, "wie alles Schöpferische, kompliziert" 5) und kann daher in der Regel nicht durch generelle Anordnungen vorweggenommen werden. 6)

Das Problem des weiten gesetzlichen Spielraumes der richterlichen Entscheidung ist jedoch nicht notwendig mit der Tendenz zur Positivität der richterlichen Entscheidung gegenüber der partei-

3) S. z.B. Max Ernst Mayer, Rechtsphilosophie, 2. Auf1. 1926, S. 84 f. S.a. Gygi, Verwaltungsrecht und Privatrecht, S. 11 f; Geiger, Grundrechte und Rechtsprechung, S.25.

4) S. die schon klassisch gewordene Charakterisierung der Generalklausel "als ein Stück offengelassener. Gesetzgebung" durch Hedemann (Die Flucht in die Generalklausel, 1935, S. 58).

5) Bötticher, Regelungsstreitigkeiten, in Festschrift für Friedrich Lent, 1957, S. 89 ff (99).

6) Für den Bereich des Erb- und Familienrechts s. die ausdrücklich auf den "sozialen Rechtsstaat" gestützte Forderung richterlicher Freiheit bei Müller-Freienfels (Kernfragen des Gleichberechtigungsgesetzes, JZ 12. Jhg. (1957) S.685 (687, $691))$. 
autonom gesetzten Streitalternative verbunden. Auch dort, wo der. Richter nichts als Ja oder. Nein zu der ihm vorgegebenen Alternative zu sagen hat, ist er in größtem Ausmaß nicht instand gesetzt, die Entscheidung ohne den Zusatz eigener Wertung zu gewinnen.

Damit soll nicht gesagt sein, daß es keine schlichte Streitentscheidung mehr gibt. Auch heute noch verläuft ein großer Teil der Rechtsprechung in den festen Bahnen der Anwendung eindeutiger und definitiver Bestimmungen auf das Streitverhältnis. Aber rund herum ist ler Boden aufgeweicht von Generalklauseln, unbestimmten Rechtsbegriffen, von Vorbehalten des billigen Ermessens und was der@leichen mehr ist.

Die aufgezeigte Entwicklung ist im Bereich des Sozialen besonders weit vorangeschritten. Sammeln sich hier doch alle Ursachen. Die soziale Intervention des Staates insgesamt ist eine Antwort auf die Herausforderung, die in der Fehlentwicklung der autonom gesetzten Gesellschaft la@. Auch im Streitverhältnis zeigt sich dieses Ungenügen. Die soziale Intervention ist andererseits das Feld, auf dem sich die sensibelsten Gerechtigkeitsvorstellungen mit der umfassenden Forderung nach intensivster Regelung vielfältigster Lebensbeziehungen zu einem schier unüberwindlichen Hindernis zugleich genereller und eindeutig definitiver vereinigen.

(1) Vor irgendwelchen Detailvorschriften müssen die kardinalen Generalklauseln genannt werden, die heute das ganze Recht durchsetzen: "Treu und Glauben", ausgegangen von $₫ 242$ BGB, und die "guten sitten", ausgegangen von $₫ 138$ BGB. Was die Rechtsprechung mit Hilfe lieser beiden Elemente an sozialem Ausgleich gemeistert (aber auch sich angemaßt) hat, ist notorisch.

(2) Gewissermaßen als oinc Inkarnation der sozialen Intervention wirkt die Regelung des Kïndigungsschutzes. Danach darf die Kündigung nicht "sorial ungerechtfertigt" sein ( $\$ 1$ Abs. 1 kSchG) und muR sie "wriale (irsichtspunkte" ausreichend be rücksichtigen (ebd. Abs..3). Durrh cine Legaldefinition (ebd. Abs.2) und nähere Umschreibung (ebx. Abs.3) sind dem Richter allerdings einige genauese Anhaltwpunkte gegeben. Nicht weniger bezeichnend für die Aus loichwald gabe des Richters ist seine Befugnis, das nicht rechtsuirksan gekündigte Arbeitsverhältnis (auf entsprechenden Antras) t:ot\%dem aufzulösen, wenn es "unzumutbar" geworden ist bzu. den Botriebszwecken zuwiderläuft ( $\$ 7$

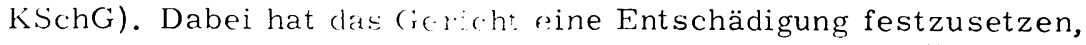
die gewisse untereinande: :nkrrnmensurable Momente "angemessen" berücksichtigt ( $\$ 9$ Hsch(i). Hier zeichnet sich ab, wie der 
Richter letztlich die sich vielfältig widersprechenden Interessen entwirren soll.

(3) Immer auch von sozialem Gewicht ist der miet - und pachtrechtliche Bestandsschutz. Das Mieterschutzgesetz und das Geschäftsraummietengesetz legen ihn weitgehend in die Hand der Gerichte, vielfach nur unter Angabe recht weitherziger Maßstäbe (vg1. $\$ \$ 2,4,22,23$ MSchG, $\mathbb{\$} 8$ ff des Geschäfts raummietengesetzes; s.a. $\$ 556$ a BGB). Noch weiter gehen die Befugnisse der Gerichte als Mieteinigungsämter. ( $\$ \$ 37 \mathrm{ff}$ MSchG), die ohne gesetzlich festgelegte Voraussetzungen verschiedene, inhaltlich festgelegte gestaltende E.ingriffe in die Miet-

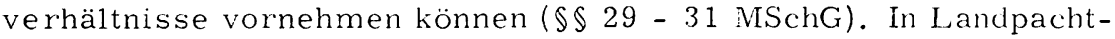
verträge können die Landwirtschaftsgerichte in erheblichem MaBe auf der Grundlage teils wenig präziser Regelungen eingreifen ( $\$ \$ 7,8$ des Landpachtgesetzes). Besonders weit im Sinne der Gestaltung prellen die Vorschriften über die richterliche Regelung der Auseinandersetzung der aufgelösten Miet- und Pachtverhältnisse vor (vgl. $\$ \$ 4$ Abs.3-6, 5a, 6 MSchG; insbes. aber die Globalermächtigung des $\$ 11$ des Landpachtgesetzes).

(4) Mit am deutlichsten tritt die veränderte Wirkungsweise des Richters im "Vertragshilfeverfahren" hervor. 7) das nach Lage des Falles von erheblicher sozialer Bedeutung sein kann (s. hierzu $\mathbb{S} 1 \mathrm{ff}$ des Vertragshilfegesetzes; $\mathbb{\$} \$ 83 \mathrm{ff}$ des Bundesvertriebenengesetzes).

(5) Nicht zu unterschätzen ist die soziale Bedeutung des V ollstreckungs schutzes, in dessen Rahmen der Richter "einen Ausgleich zwischen dem berechtigten Durchsetzungsinteresse des Gläubigers und dem Selbsterhaltungsinteresse des Schuldners versuchen sol1". 8) $\$ 765$ a ZPO ist die zentrale Norm und treffender Ausdruck dafür, wie weitgehend das Gesetz die Entscheidung dem Justizium des Richters überläßt. ${ }^{9)}$

(6) Hinzuweisen ist auch nochmals auf die oben 10) schon er-

7) S. hierzu auch Bötticher, Regelungsstreitigkeiten, insbes. S.92 ff, und seine weiteren Nachweise.

8) Baur, Besprechung von "Jonas-Pohle, Zwangsvollstreckungsnotrecht, 16. Auf1." JZ 10.Jhg. (1955) S.64; ders., Sozialer Ausgleich durch Richterspruch, S. 195.

9) Die Aufgabe des Richters darf freilich nicht einseitig im Schuldnerschutz gesehen werden. Nicht selten ist der Gläubiger schutzbedürftig und - würdig, der Schuldner dagegen nicht.

10) S. oben S.514, insbes. Fußn. 6. 
wähnten gerichtlichen Zustänligkeiten im Rahmen des Mit bestimmungsrechts und des Betriebsverfassungsrechts. Die Bewegungsfreiheit der gerichtlichen Entscheidung ist hier ebenfalls sehr groß.

3. Das Verhältnis der Rechtsprechung zu Gesetz ( gebung) und verwaltungsverfassungsstrukturelle Determinanten. Diese Frscheinung verdient das besondere verfassungsrechtliche Interesse vor allem wegen der sich in ihr abzeichnenden Entwicklung des Verhältnisses der rechtsprechenden Gewalt zur gesetzgebenden und vollziehenden. Die richterliche Gewalt drängt sich auf dem Feld der beiden anderen Gewalten vor. Die Gesetzgebung läßt ih. Raum, indem ihre generelle Regelung der gerichtlichen Fallentscheidung - und mittelbar damit auch dem gerichtlichen Fallrecht ${ }^{11)}$ - gebundene Freiheit läßt; und sie verschafft ih. Raum, indem sie gerichtliche Kompetenzen begründet, wo auch verwaltungsbehördliche Zuständigkeiten denkbar wären. Es ist sicher nicht r.ichtig, von der freiwilligen Gerichtsbarkeit schlechthin (der. Sache nach) als von "Verwaltung" zu sprechen ${ }^{12}$ ) oder das arbeitsgerichtliche Beschlußverfahren gar als "Verwaltungsrechtspflege" zu bezeichnen. ${ }^{13)}$ Aber ebenso

11) S. Baur, Sozialer Ausgleich durch Richterspruch, S. 194 Fußn. 10 .

12) So aber. Sauer, Allgemeine Prozeßlehre, 1951, S. 42.

13) Schnorr von Carolsfeld, Arbeitsrecht, S.495, spricht von einer. "Art Verwaltungsiechtspflege auf Betriebsebene". Rohlfing-Rehwolle, Albeitsgerichtsgesetz, $\$ 80$ Anm.1, nennt das Beschlußverfahren cin "Verfahren sozialer Verwaltung .... welches zur Zuständigkeit der Arbeitsgerichte gehört". Schließlich glaubt Kaskel-Dersch, A rbeitsrecht, S.308, das Beschlußverfahren als "eine Art A rbeitsverwaltungsgerichtsbarkeit" ansprechen zu sillen. - Diese Bezeichnung wäre auch dann sachwidrig und terminologisch bedenklich, wenn die betriebsvelfassungsıechtlichen Streitigkeiten öfentlichrechtlicher Natur wärrol (wie vor allem Dietz (Dietz-Nikisch, A rbeitsgerichtsgesetz, 1954, Vorbem. 5, 6, 7 vor $\$ 80$ und Dietz, Betriebsverfassums recht, 3. Aufl. 1960, $\$ 1$ Randn. $15 \mathrm{ff}$ ) das annimmt; s. a. ceine Nachweise). Gänzlich ungerechtfertigt ist sie abe', wrnn mit der zutreffenden herrschenden Lehre dicse Arsicht abzulehnen ist (s. zusammenfassend Nipperdey, Lehrbuch des A rbeitsrechts, Bd. II, S.689 ff, und jünsst Helmut Frey, Die Rechtsnatur der Belegschaft und des Betritits sats, Recht der Arbeit, 13. Jhg. (1960) \$. 89 ff). 
steht umgekehrt außer Zweifel, daß in bezug auf eine ganze Reihe gerichtlicher Agenden in der Kompetenzträgerschaft eine Konkurrenz mit der Verwaltung besteht. ${ }^{14)}$ So erscheint es durchaus nicht notwendig, daß schon die Anordnung der Schutzaufsicht und der Fürsorgeerziehung im Wege richterlicher Anordnung ergeht. 15) Würde das Jugendamt sie erlassen und der Richter nur kontrollierend dahinter stehen, wäre das mit A rt.92 GG durchaus zu vereinbaren. Oder - um ein anderes Beispiel hinzuzufügen - die Bestellung eines Wahlvorstandes für die Betriebsratswahlen ( $\$ 2$ Abs. 1 Nr. 4 lit.c ArbGG i.V.m. $\$ \$ 15$ Abs.2, 82 Abs. 1 lit.c BetrVG) könnte ebensogut auch einer Verwaltungsbehörde übertragen sein. ${ }^{16)}$ Die Einwirkung etwa des Mieteinigungs-

14) S. vor allem Bettermann, Die freiwillige Gerichtsbarkeit im Spannungsfeld zwischen Verwaltung und Rechtsprechung.

15) Vgl. Bettermann, a.a.O. S.29 f. - Verfassungsrechtlich notwendig ist die richterliche Anordnung nur, soweit die Fürsorgeerziehung einen Entzug der Freiheit mit sich bringt (Art. 104 Abs. 2 GG).

16) (1) In der Tat wurde früher angenommen, es handle sich dabei um Verwaltungstätigkeit; s. hierzu z. B. Dietz-Nikisch, A rbeitsgerichtsgesetz, Vorbem. vol $\$ 80$ Randn. 17; Dietz, Betriebsverfassungsgesetz, $₫ 82$ Randn. 7; je mit weit. Nachw. (2) Darüber hinaus ist allgemein ein Vergleich der gerichtlichen Zuständigkeiten im Betriebsverfassungsrecht ( $\$ \$ 2 \mathrm{Abs}$. $1 \mathrm{Nr} .4$ und 5, Abs. 2 und 3 ArbGG i.V.m. $\$ 82$ BetrVG) mit den entsprechenden Zuständigkeiten der Verwaltungsgerichte in Personalvertretungssachen interessant ( $\$ 76$ des Bundespersonalvertretungsgesetzes; Art. 76 des bayerischen Personalvertretungsgesetzes). Im Gegenüber von Betriebsverfassungsrecht und Personalvertretungsrecht zeigt sich die prinzipielle Konkurrenz gerichtlicher und verwaltungsbehördlicher Zuständigkeit in Angelegenheiten dieser Art. Vieles, was im Rahmen des Betriebsverfassungsrechts die Arbeitsgerichte zu entscheiden haben, entscheiden im Personalvertretungs recht die Dienstbehörden. Das hängt auch mit der im Verhältnis zum privatrechtlichen Dienstherrn ganz anderen Stellung des öffentlichrechtlichen Dienstherrn im Gesamt des Betriebsverfassungs- bzw. Personalvertretungs rechts zusammen. Trotzdem zeigt es, wie weit verwaltungsbehördliche Kompetenzen die gerichtlichen ersetzen können; denn die verschiedenen personalvertretungsrechtlichen Entscheidungsbefugnisse der Dienstbehörden konnten ihnen zum Teil nur deshalb übertragen werden, weil diese nicht nur dienstherrliche Funktionen ausüben sondern eben an sich Verwaltungsbehörden sind. 
amts auf Mietverträge ( $\$ \$ 29-31 \mathrm{MSchG)}$ oder des Landwirtschaftsgerichts auf Landpachtverträge $(\$ \Phi 7 \mathrm{f}$ der Landpachtordnung) sieht privatrechtsgestaltenden Verwaltungsakten, 17) wie sie auch das soziale Recht kennt, ${ }^{18)}$ jedenfalls zum Verwechseln ähnlich. Und vor allem überall dort, wo die Gerichte Rechtsverhältnisse positiv herauszubilden und $z u$ fixieren haben, erhebt sich die Frage, ob dazu nicht "eigentlich" die Verwaltung berufen ist.

Die verfassungsrechtliche Plattform dieser Expansion der Judikative ist Art.92 GG. Es gehört zu den zentralen Weichenstellungen des Gefüges der grundgesetzlichen Gewaltenteilung, daß Art.92 GG die dritte Gewalt gegen Eingriffe in ihren Funktionsbereich, die "Rechtsprechung", abschirmt, daß die Impermeabilität der anderen Gewalten gegenüber der Rechtsprechung aber nicht in gleicher lleise gesichert ist. 19) Allerdings ist weder tatsächlich noch von der Verfassung her daran zu denken, daß mit irgendwelchen im Range unter der Verfassung stehenden Mitteln alle Zuständigkeiten bei den Gerichten vereinigt werden könnten. Das Grundgesetz hat auch die beiden anderen Gewalten institutionalisiert. Aber es hat ihnen keine vergleichsweise so feste Umfriedung ihres Funktionsbereiches zuteil werden lassen, wie sie Art.92 GG - als Generalklausel neben den zah1reichen Sondervorschriften, die gerichtlichen Zuständigkeiten garantierend - für die Gerichte enthält.

Die Relationen Rechtsprechung-Gesetzgebung und Rechtsprechung - Verwaltung, die sich im Rahmen der Expansion des richterlichen Funktionsbereichs ergeben, sind durchaus ungleich. Ein Ausgreifen der rechtsprechenden Gewalt in den Wirkungsbereich des Gesetzgebers mit seinen Nitteln ist nicht möglich. Vor allem gibt es eine delegierte kechtsetzung durch Gerichte grundsätzlich nicht. 20) Der Vorgang kann vielmehr nur der sein, daß das Gesetz

17) Zum privatrechtsgestaltenden Verwaltungsakt s. Huber, Wirtschaftsverwaltungsrecht, Bd.I S. $72 \mathrm{ff}, 78 \mathrm{ff}$; Forsthoff, Lehrbuch des Verwaltungs rechts, S. $64 \mathrm{f}$.

18) Extrem der Zwangsurbeitsvertrag nach $\ 19$ des Schwerbeschädigtengesetzes. S. irn übrigen zum Arbeitsrecht nochmals Siebert, Finige Fragen zur Wirkung der Verwaltungsakte im Arbeitsverhälnis. Zu erinnern ist auch an die verschiedenen rechtsgestaltenden Verfügungen im Rahmen der Wohnraumbewirtschaftung.

19) Vgl. Draht, Lie Ciewaltenteilung im heutigen Staatsrecht, S. 107 ff; Baur, Freiwillige Gerichtsbarkeit, Bd. I, S.9; ders., Sozialer Ausgleich durch Richterspruch, S. 193. 
die richterliche Fallentscheidung nur wenig oder gar nicht prädisponiert und somit der Richter in seiner eigenen, der rechtsprechenden Funktion den Gesetzgeber ergänzt und ersetzt. Indem daraus Richterrecht erwächst, entsteht dann allerdings etwas, was in seiner Wirkungsweise dem gesetzten Recht sehr ähnlich ist. 21)

Im Verhältnis zur Verwaltung kann sich die gerichtliche Zuständigkeit dagegen in wesensgleicher Weise ausbreiten. Zwar wird es fast ausnahmslos untunlich sein, wenn die Gerichte auch rein tatsächliche Veranstaltungen treffen, und bleiben diese in der Praxis meist auch der Verwaltung (im organisatorischen Sinn) vorbehalten. Aber alle verbindliche Regelung von Einzelfällen, aller individuelle Rechtsbefehl und Rechtsvollzug ist dem Richter grundsätzlich nicht weniger möglich als der Exekutivbehörde. Der Gesetzgeber hat weitgehend freie Hand. Die Verfassung hindert nicht, daß er selbst sich vor der rechtsprechenden Gewalt zurückzieht und ihr in mehr oder weniger großem Umfang, nur eben nicht schlechthin, die Verantwortung für die Rechtsfindung im Einzelfall oder auch für die Rechtsbildung bezüglich der einschlägigen typischen Sachverhalte und Interessenlagen überläßt. ${ }^{22)}$

20) S. oben S. 489 zu Fußn. 2.

21) Zum Richterrecht s. aus neuerer Zeit z.B. Meier-Hayoz, Der Richter als Gesetzgeber, 1951; Liver, Der Begriff der. Rechtsquelle, in "Rechtsquellenprobleme im Schweizerischen Recht", Festgabe der Rechts- und Wirtschaftswissenschaftlichen Fakultät der Universität Bern für den Schweizerischen Juristenverein, Jahresversammlung 1955, S. 1 ff (36 ff);

Esser, Grundsatz und Norm in der richterlichen Fortbildung des Privatrechts, 1956; w. Nachw. s. dort. - Zur Bedeutung des Richterrechts für den vorstehenden Zusammenhang $\mathbf{s}$. Baur, Sozialer Ausgleich durch Richterspruch, S. 194 insbes. Fußn. 10.

22) Vgl. BGHZ 11, 34 (50 ff); BVerfGF: 3, $225(243 \mathrm{f}, 247 \mathrm{f})$; stärker differenzierend BSGE 2, 164 (168 ff). - Zu dem Dilemma der gewaltenteiligen Verfassungsordnung, in Anbetracht der Unvollkommenheit aller Gesetzgebung entweder das Risiko der Justizverweigerung zu billigen oder dem Richter notfalls rechtschöpferische Befugnisse zuzugestehen, s. z. B. Raclbruch, Rechtswissenschaft als Rechtsschöpfung, Archiv für Sozialwissenschaft und Sozialpolitik, XXII. Band (1906) S.355 ff, insbes. S.358 ff: "Die Gewaltenteilungslehre, das Rechtsverweigerungsverbot und die Unvollkommenheit der Gesetze vertragen sich nicht miteinander, eines clieser drei Stücke muß weichen" (S.359). "Rechtsprechung und Rechtswissen- 
Sie hindert auch nicht, daß er den Richter für zuständig erklärt, dort, wo es sich nicht um "Rechtsprechung" im Sinne des Art.92 GG handelt und er also auch die Zuständigkeit der Verwaltung begründen könnte. ${ }^{23)}$

Mit dem Hinweis auf das elastische Verhältnis zwischen Gesetzgebung und Rechtsprechung ist aber auch schon eine weitere Weichenstellung angedeutet, die den Zufluß sozialer Aufgaben des Staates zu einem verhältnismäßig so großen Teil in die Kanäle der dritten Gewalt leitet. Während es als ganz unproblematisch hingenommen wird, wenn der Gesetzgeber der Rechtsprechung Spielraum läßt, herr'scht gegenüber Gestaltungsspielräumen der Verwaltung größtes rechtsstaatliches Mißtrauen. ${ }^{24)}$ Freilich gilt dieses Mißtrauen in erster Linie der eingreifenden Verwaltung. A ber der. Richter greift in aller Regel ein. Und selbst dem Strafrichter, dem Typ des eingreifenden Richters, für den die gesetzliche Bindung zweifellos am wichtigsten ist, stehen Zumessungsspielräume zur Verfügung, die für eine Verwaltungsbehörde ganz undenkbar wären. Für den Streitrichter ist anerkannt, daß er dort, wo eine positive Regelung fehlt, den Streit nicht mit einem "non liquet" unentschieden lassen kann sondern daß er als hypothetischer quasi-Gesetzgeber aus der "sonstigen" Rechtsordnung die Normen zu entwickeln hat, nach denen er entscheidet. ${ }^{25}$ ) $\mathrm{Um}$ wieviel mehr muß ihm jeder gesetzliche Strohhalm als stützende Grundlage seiner Fntscheidung recht und billig sein, wenn er nur einen solchen findet. Die elementare rechtsfriedenstiftende Funktion des Richters und die moderne Vertrauensposition des Richters unserer staatlichen Gegenwart ${ }^{26)}$ bewirken vereint, daß der Richter von der gesetzesstaatlichen Kandare, an die die Verwaltung mit so großem lifer. gelegt wird, verschont bleibt. ${ }^{25)}$

Dabei soll nicht verkanm werdell, daß der Spielraum des Rich-

schaft sind trotz der Gewalienteilungslehre immer rechtsschöpferisch geblieben und werden es immer bleiben, und nur darin unterschridel irh der heutige vom ehemaligen und hoffentlich auch vom zukiunftigen Juristen, daß er verbirgt, was jene offen zugestehen" (S.364). Diese Voraussage Radbruchs kann als erfiillt be\%.ichnet werden.

23) S. vor allem Bettrimam, I)ie freiwillige Gerichtsbarkeit im Spannungsfeld zwischen Verwaltung und Rechtsprechung; s.a. Baur, a.o. (S. 52 T l.ußn. 19) a.O.; Ule, Anm. zu BVerwG Urteil v. 19. Frb:uar 1957, S.629.

24) S. oben S. 46:3.

25) S. hierzu auch Ra(l\}) uch a.o. ( S. 528 Fußn.22) a.O.

26) S. oben Abschniti :3 III :3 (.5.352 ff, insbes. S.357). 
ters vorwiegend ein Spielraum der Rechtsfindung, der Spielraum der Verwaltung vorwiegend ein Spielraum zweckgerechter Dezision ist. Das ist hier nicht entscheidend. Es soll auch nicht näher auf die - durch die Diskussion um den unbestimmten Rechtsbegriff 27) in den letzten Jahren so intensiv geförderten - Unterschei dungen zwischen Ermessen, Beurteilungsspielraum u.a.m. eingegangen werden. Sie sind berechtigt. Aber sie dürfen nicht dazu führen, daß verkannt wird, daß Ermessensübung und Rechtsfindung Subjektivität einfließen lassen. Schon bei jeder Auslegung waltet auch Subjektivität, 28 ) wieviel mehr waltet sie dort, wo der Richter allgemeine Grundsätze und unbestimmte Rechtsbegriffe zu konkretisieren, billiges Ermessen - das in seiner Hand als das Ergebnis eines Rechtsfindungsprozesses angeseher wird! 29) - zu üben oder lückenausfüllend zugestandenermaßen hypothetische Rechtsregeln aufzustellen hat. ${ }^{30)}$ Der Weg zwischen dem Gesetz und der konkreten Ordnung eines individuellen Sachverhalts durch den Richter oder die Verwaltungsbehörde, den das Recht auf den Schultern des Rechtsanwenders zurückzulegen hat, kann viel weiter sein zwischen einer scheinbar erschöpfenden gesetzlichen Generalklausel und ihrer richterlichen Handhabung 31 ) als $z w i s c h e n$ einer präzisen, einen gewissen Spielraum an Verwaltungsermessen aussparenden gesetzlichen Regelung und dem Verwaltungsakt, der auf ihr beruht. ${ }^{32}$ ) Nur die organisatorische Po-

27) Nachweise s.u. S. 552 zu Fußn.6.

28) Vg1. Sax, Das strafrechtliche Analogieverbot, 1953, S. 63 ff, 75 ff und seine Nachweise.

29) Vgl. Bettermann, Verwaltungsakt und Richterspruch, S.365 ff und seine Nachweise.

30) S. hierzu auch Lerche, Art. "Frmessen" im ev. Staatslexikon, 6.Aufl. 1959, Sp. 12 ff (15).

$31)$ S. hierzu z.B. Hedemann, Die Flucht in die Generalklauseln, 1933, insbes. S. $67 \mathrm{fr}$.

32) Die Ernüchterung über das Verhältnis des Richters zum Gesetz, über das Subjektive und Voluntative seines Tuns, hat zwar schon mit Bülow (Gesetz und Richteramt, 1885) eingesetzt. Die sog. Freirechtsschule hat dann die Thesen - Ungesundes und Mißverhältnisse zur Norm erhöhend - übersteigert (als literarischen Schlußstein s. etwa Hermann Isay, Rechtsnorm und Entscheidung, 1929). Aber Bülow und denen, die auf ihm aufbauend das Problem durchdachten (zur Entwicklung s. die Darstellung bei Engisch, Die Idee der Konkretisierung in Recht und Rechtswissenschaft unserer Zeit, 1953, S. $178 \mathrm{ff}$ ), kommt das Verdienst zu, gezeigt zu haben, wie persönlich, individuell, subjektiv die richterliche Entscheidung 
sition des entscheidenden Subjektes ist hier und dort eine andere. Die Ver'waltungsbehörcle kann angewiesen werden, diese oder jene Zweckgesichtspunkte $z u$ berücksichtigen (aber auch diese oder jene Auslegung zu wählen). Der Richter entscheidet selbst wenn nicht das Instanzgericht, also wieder ein Gericht, für ihn nicht nur über die engere Auslegung des Gesetzes sondern auch (larüber, welche Zweckmäßigkeitserwägungen er (natürlich "objektiviert") in seine Rechtsfindung einbauen will.

Nun wurde oben bereits hervorgehoben, wie sehr die soziale Intervention den Gesetzgeber in die Verlegenheit bringt, die allgemeinen Regeln anpassungsfähig zu gestalten, um individuell sachgerechte Entscheiclungen zu ermöglichen. Überträgt er diese variierende Handhabung der Exekutive, macht er sich allzu leicht rechtsstaatlich verdächtig. So liegt die Zuflucht zur richterlichen Kompetenz nahe.

Noch eine dritte Weichenstellung ist zu erwähnen: die Garantie der richterlichen Letztentscheidung (Art. 19 Abs. 4 GG). Das letzte Wort haben doch die Richter! Davor mag nicht nur der Gesetzgeber sondern auch die Verwaltung resignieren. Und es liegt nahe, "es" den Richter. "gleich selber machen zu lassen". Nur dort, wo der Rechtsvollzug aktuell politisch beherrschbar bleiben soll, muß der Gesetzgeber von der Sache her nach wie vor zur exekutiven Kompetenz greifen. 33 )

Gerade dieses Moment fehlt aber in der Regel. Die Konkretisiel'ungsspielräume, die eine an die Postulate umfassender, in a1len Verästelungen inclivicluell gerechter Sozialgestaltung gebundene Gesetzgebung lassen muR (oller glaubt, lassen zu müssen), dienen meist gar nicht cla $\%$, einer aktuell effektuierten und dirigierbaren Vollzugspolitik Platz zu schaffen. Sie sind der Tendenz nach dazu bestimmi, lem Gesetzesanwender die Ermittlung des im Einzelfall sachğmäßen unc Gerechten zu ermöglichen. Ja, es widerspräche ihnen sogar, wenn sie aus anderem als objekti-

und wie fiktiv es ist, in ihrn nur den "Mund des Gesetzes" (Montesquieu) zu sehen.

33) Bettermann, Die lreiwillige Gerichtsbarkeit im Spannungsfeld zwischen Verwalture und Rechtsprechung, S.39, weist allerdings auf die Mijglichkeit hin, in Fällen, in denen Richter Verwaltungsaufwaben durchführen, sie der richterlichen Unabhängigkeit zu b(-1auben. Es bestehen Bedenken, ob Bettermann damit Rocht hat. Jedenfalls würde damit, wie er selbst erwähnt, elneut lie "gerichtliche" Zuständigkeit gegen die Fntscheidung des abhängig handelnden Richters e röffnet (Art. 19 Abs. 4 i. V.rn. Art.97 GG). 
vem, sach- und gerechtigkeitsbezogenem Geist vollzogen würden. Das Lebensverhältnis, das den Gegenstand der Regelung bildet, soll nicht, jedenfalls nicht in erster Linie irgendwelchen Verwaltungserfordernissen entsprechend zugerichtet werden. Vor allem anderen soll es um seiner selbst, um seiner inneren Spannungen willen geklärt, gestaltet und befriedet werden. 34 ) "Der verfassungsrechtlich garantierte Ausschluß jeglicher Einflußnahme auf die Person des Richters und seinen Spruch ... prädestiniert den Richter für diese Aufgabe. ... Die um den Richter gelegte Zone der Neutralität soll eine dem konkreten Lebensverhältnis sachgerechte, unbeeinflußte Lösung ermöglichen". 35)

Damit eng zusammen hängt es, daß die neue, positiv gestaltende richterliche Funktion in so vieler Hinsicht aus der richterlichen Streitentscheidung heraus erwachsen ist und daß sie dieselben Gegenstände betrifft, die traditionsgemäß vor allem der richterlichen Beurteilung unterliegen. 36)

Das Streben nach der richterlichen Neutralität wird als Ursache des Trends zum sozialen Ausgleich durch Richterspruch für gewisse Rechtsgebiete durch eine andere allerdings nahezu überholt. Sie liegt in dem Streben beteiligter gesellschaftlicher Mächte, Angelegenheiten deshalb in die Hand der Gerichte zu legen, weil es ihnen gelungen ist oder weil sie zugleich fordern, daß sie Einfluß auf die (zuständigen) Gerichte haben. Die Gerichte fungieren dann als eine Art politischer Selbstverwaltung, nur eben ohne weitere Kontrollen (i.S. des Art. 19 Abs. 4 GG) hinter sich zu haben und ohne irgend einen persönlichen oder sachlichen Mandats-

34) S. z. B. Bötticher, Regelungsstreitigkeiten, S.98.

35) Baur, Sozialer Ausgleich durch Richterspruch, S. 196. Das Originalzitat lautet: "Nicht so sehr der präsumtive Gerechtigkeitsgehalt der zu treffenden Maßnahme prädestiniert den Richter für diese Aufgabe als vielmehr der verfassungsrechtlich garantierte Ausschluß jeglicher Einflußnahme auf die Person des Richters und seinen Spruch. Die um den Richter. gelegte Zone der Neutralität soll eine dem konkreten Lebensverhältnis sachgerechte, unbeeinflußte Lösung ermöglichen". Die Umstellung im Text ist vor allem deshalb erfolgt, weil es nicht ganz richtig erscheint, den Gerechtigkeitsgehalt und die Neutralität und Objektivität des Richters gegenüberzustellen. Die Elimination aktueller $Z$ weckhaftigkeit, wie sie für die Verwaltung typisch ist, weist doch auf die Bahn der Gerechtigkeit.

36) S. a. Baur, a.a.O. S. 195. 
der Entscheidung für den Richter nicht übersehen werden, die einen Weg beschreitet, der nicht allein in der Lage ist, die Notwendigkeiten der sozialen Intervention mit dem Ideal des Rechtsstaats zu versöhnen, das aber auch dazu beiträgt, so viel Rechtsstaat wie möglich mit so viel sozialer Intervention wie notwendig zu verschmelzen. 40 )

\section{dd) Staatliche und nichtstaatliche Rechtsprechung}

Befaßte sich die bisherige Erörterung mit der Stellung der richterlichen Primärkompetenz und ihrer verfassungsrechtlichen Grundlage im System der Gewaltenteilung, so ist nun noch auf ein besonderes Problem hinzuweisen, das gerade für die soziale Rechtsgestaltung von nicht geringer Bedeutung ist: auf das Verhältnis der staatlichen Gerichtsbarkeit zu nichtstaatlichen Entscheidungsträgern. Auf der einen Seite steht die Gefährdung des individuellen Rechtsschutzes durch die Einrichtung "privater" im Sozialbereich praktisch gleichzusetzen mit: verbandlicher Schiedsgerichte, auf der anderen Seite die mögliche, meist verdeckte Aushöhlung richterlicher Streitentscheidungskompetenz durch staats-fremde Schiedsstellen, Einigungsstellen und dergleichen. Art.92 GG stellt sich beiden Gefahren entgegen. Die Rechtsprechung ist dem Bund und den Ländern, somit also dem Staate, vorbehalten. 1) Die Qualifikation eines Spruchkörpers als staatliches Gericht setzt einen organisatorischen Mindestzusammenhang mit dem Staat voraus. Gerichte müssen - wenn auch äußerstenfalls nur mittelbar ${ }^{2}$ ) - dem Staat als Organe zugerechnet werden können. Das ist weder hinsichtlich der privaten Schiedsgerichte noch hinsichtlich der hier in Frage stehenden nichtstaatlichen Schieds- und Einigungsstellen ${ }^{3)}$ der Fall. 4)

40) Vgl. auch Baur, a.a.O. S. 195. - S. ferner Marcic, Vom Gesetzesstaat zum Richterstaat, insbes. S. 416 und an zahlreichen Stellen sonst (allerdings immer getragen von der für diesen Autor kennzeichnenden Richtergläubigkeit).

1) Vgl. Bettermann, Die Unabhängigkeit der Gerichte und (ler. gesetzliche Richter, S. 629 ff; BVerfGE 10, 200 (214).

2) BVerfGE 10, 200 (214 f).

3) (1) Zu denken ist hier vor allem an die Einigungsstellen i.s. des $\$ 50$ des Betriebsverfassungsgesetzes. In Frage kommen weiter tarifvertraglich begründete Schiedsstellen, denen neben den Schlichtungsstellen i. S. des $\$ 50$ Abs. 5 BetrVG und neben den Schiedsgerichten - wohl nur Zuständigkeiter: in Gesamtregelungsstreitigkeiten (S. Art. I Abs. 1 des Kontrollratsgesetzes $\mathrm{Nr} .35$ ) zukommen. 
Sie dürfen somit nicht in den curch Art.92 GG garantierten Zuständigkeitsbereich ler. Gerichte eindringen. Sie müssen sich in dem ihnen eigenen, seinem Wesen nach neben der Rechtsprechung der staatlichen Gerichte liegenclen Wirkungskreis halten. Die Rechtsprechung der Schiedsgerichte muß in jener Komplementärsphäre zur staatlichen Gerichtsbarkeit bleiben, in die Rechtsstreitigkeiten gelangen, weil die Beteiligten in ihrem eigenen Interesse auf die Inanspruchnahme staatlicher Gerichte, die ihnen gegen ihren Willen nicht versagt werden dürfte, verzichtet haben und vom öffentlichen Interesse aus gesehen - verzichten durften. 5) Das bedeutet, daß Schiedsgerichte nicht den Weg zum staatlichen Gericht versperren dürfen, wenn sie nicht auf dem freien Willen der Beteiligten beruhen. Die Gefahr "unfreiwilliger" Schiedsgerichtsbarkeit besteht im besonderen im Bereich der "sozialen

(2) Die Schiedsausschüsse nach Art. I Abs.2 und II des Kontrollratsgesetzes $\mathbb{N}_{1.35}$ müssen als Behörden dem Staat zugerechnet werden. Iber ihre Qualifikation als staatliches Gericht braucht nichts gesagt zu werden, da ihnen nur Gesamtregelungs- und nicht kechtsstreitigkeiten zur zudem nicht autoritativen Fintscheichung zufallen (s. zu dieser Sonderung auch den folgenden Text). Fine sehr interessante Konstruktion findet sich in $\$ 368$ h und i RVO hinsichtlich der Schiedsämter für die kassenärztliche Versorgung zur Entscheidung der Gesamtregelungsstreitigkeiten zwischen der Kassenärztlichen Vereinigun@ und den Verbänden der Krankenkassen. Die beiderseitigen St reitsteile sind Körperschaften des öffentlichen Rechts (v@l. Ș 368 k Abs. 3, 414 Abs. 4 RVO). Die Schiedsämter unterliegen dor. Staatsaufsicht ( $\$ 368$ i Abs. 6 RVO). Ihr Verlahren wirc durch staatliche Verordnung geregelt (ebcl. Abs. i). i sel! (lie extrem zwischenverbandliche Struktur und ihre Funklins ( $\$ 368 \mathrm{~h}$, $\$ 368$ i Abs. 1-4 RVO) zu einel Gleichstellun: mit nichtstaatlichen zwischenverbandlichen stellen zur linsheicuns: von Gesamtregelungsstreitigkeiten reizt, muissen dikse schiedsämter doch als (mittelbare) Staatsbehörlon fudi iziert werden. - Ganz in den Zusammenhang les Verwallun fingespannt sind auch die Einigungsstellen nach $\$ 6: 3$ los bu: spersonalvertretungsgesetzes.

4) S.a. Bettermann, Jis mahïngigkeit der Gerichte und der gesetzliche likinter, \$. $62 ! 3$.

5) Zur legitimen Iloraunahmo (ler Schiedsgerichtsbarkeit aus der statlichen (ivelus sorkit unter diesen Gesichtspunkten s. Menger, Anm. zu PGll, Urt. v. 21. April 1959 - 1 StR $504 / 58$ - (JZ 15..1he. (1560) S. 168). S.a. Dürig in MaunzDüris, Art. 19 Abs. I! Rasdr. 55 (mit weit. Nachw. zum Problem sub specie (les A:t.19 Abs. 4 GG). 
Selbstverwaltung", da die Koalitionen versucht sein könnten, Schiedsgerichte einzusetzen, den vexbandsangehörigen Personen aufzunötigen und so die Rechtsprechung auf Kosten cler staatlichen Gerichtsbarkeit an sich zu ziehen. Die gegenwärtige Regelung der Schiedsgerichtsbarkeit in Arbeitssachen ( $\$ \$ 101 \mathrm{ff}$ A rbGG) trägt, indem sie die normativ-tarifvertraglich begründete Schiedsgerichtsbarkeit sehr beschränkt, sowohl der Garantie staatlicher Gerichtszuständigkeit wie auch ihren spezifischen kollektivrechtlichen Gefährdungen Rechnung. 6)

6) (1) Tarifverträge können die Schiedsgerichtszuständigkeit nur für einen sehr engen Kreis von Sonderfällen begründen, näm1ich nur, soweit der persönliche Geltungsbereich des jeweiligen Tarifvertrages überwiegend Bühnenkünstler, Filmschaffende, Artisten oder Kapitäne und gewisse andere Seeleute umfaßt ( $\$ 101$ Abs. 2 Satz 1 ArbGG). Der Tarifvertrag kann die Zuständigkeit nur für tarifgebundene Personen begründen (ebd. Satz 2). Andere Personen können sich der Zuständigkeit des Schiedsgerichts durch Vereinbarung oder Vertrag unterwerfen, wenn sich ihr Arbeitsverhältnis ebenfalls nach dem Tarifvertrag richtet (ebd. Satz 3). Die Einrede des Schiedsvertrags ist an sehr enge Voraussetzungen gebunden ( $\$ 102$ A rbGG). Die Aufhebungsklage zum Arbeitsgericht kann nicht nur auf gewisse kapitale Verstöße (wie nach Abs. 1 Nr. 1 und 3 A rbGG), auf die Verletzung jeder Rechtsnorm gestützt werden (ebd. Nr.2). Damit ist die tarifvertraglich begründete Schiedsgerichtsbarkeit nur mehr als eine Vorinstanz für gewisse "ausgefallene" A rbeitsstreitigkeiten ausgestaltet, die einer ihrer Eigenart gemäßen Sonderbehandlung bedürftig sind Schon aus dem Grund, daß wegen der Verletzung einer jeden Rechtsnorm das Arbeitsgericht angerufen werclen kann, darf diese sachlich beschränkt zulässige Schiedsgerichtsbarkeit als unbedenklich angesehen werden. Nicht anders wie der streitentscheidende Verwaltungsakt als "Vorbescheid" für begrenzte Sachgebiete auch unter cler. Herrschaft des Art.92 GG zugelassen werden kann (s.o. S. 515), kann auch der schiedsgerichtliche "Vorbescheid" unbedenklich zugelassen wer.den, wenn seine Einrichtung seinem Anwendungsgebiet gemäß ist. Die Zulassung der Schiedsabrede für Rechtsstreitigkeiten der Tarifvertragsparteien untereinander ( $\$ 101 \mathrm{Abs.} 1 \mathrm{ArbGG}$ ), die zudem in derselben Weise der Aufhebungsklage unterliegt, ist, da die Abrede von den Beteiligten autonom in ihrem e:genen Interesse getroffen werden kann, von vorneherein kaum Bedenken ausgesetzt.

(2) Die in weiterem Kompetenzkreis zulässige Schiedsge- 
Rechtsprechung durch "private" Instanzen ist also nur in dem engen Rahmen zulïssig, in tem die Schiedsgerichtsbarkeit zugelassen werden kann. Dagegen unterliegen Schiedsstellen u. ä. von Art.92 GG her keinen Beschrii:kungen, soweit sie nicht zur Entscheidung von Rechtsstreitigkeiten sondern von sog. Regelungsstreitigkeiten, 7) nicht zum "lichten" sondern zum "Schlichten"8)

richtsbarkeit der ZPO ist an die Voraussetzungen der Individualität und Autonomie der Abrede und Parität der Beteiligten geknüpft ( $\$ 1025-1026 \mathrm{ZPO}$ ) und insoweit kein sozial bedenkliches Einfallstor verbandlicher Heteronomie. Von einem Verstoß gegen Art.92 GG kann nicht die Rede sein.

(3) Im öffentlichen Recht spielen Schiedsgerichte gelegentlich eine Rolle für Streitigkeiten unter öfentlichrechtlichen Personen, gewissermaßen kraft Abrogation der verwaltungsgerichtlichen Parteistreitigkeit. Wie diese selbst steht auch die öffentlichrechtliche Schiedsgerichtsbarkeit nicht im Vordergrund rechtsstaatlicher Staatsgestaltung. Es darf jedoch darauf hingewiesen weiclen, daß sie in einem Bereich sozialer Intervention eine besonders große Bedeutung erlangt hat: im Fürsorgewesen ( $\therefore$. Teil III der Fürsorgerechtsvereinbarung vom 18. September 1947 i.d. F. vom 3. Mai 1949; s. nun aber $\$ 187 \mathrm{Abs.} 1 \mathrm{VG}())$. Im Rahmen der Sozialgerichtsbarkeit gab es früher Schiedsgerichte zur Entscheidung von Vermögensauseinandersetzungsstreitigkeiten bei der Teilung von Berufsgenossenschaften ( $\$ 646$ RVO), wie ja die Erledigung von Auseinandersetzungsstreitigkeiten ein Hauptteil der öffentlichrechtlichen schiedsuerichtsbarkeit ausmacht (insbes. im Gemeinclerecht; s. $18 \%$ Abs. 1 VGO). Ob im sachlichen Geltungsbereich des S. i i l gerichtsgesetzes Schiedsgerichte heute noch möglich sind, ist umstritten (bejahend: Miesbach-Ankenbrark, Sablgerichtsgesetz, $₫ 202$ Anm.3; Mellwitz, Sozialgerinticesetz, 1956, \$2 Randn. 5; unter Beschränkung aul Parttistreiliskeiten: Hastler, Aufbau und Verfahren der sorialuctindalkeit, 1953 (ff), \$202 SGG Anm.3; Hofmann-Schroeter, Swinlsrrichtsgesetz, 2. Aufl. 1957, \$202 Anm.2. Verncinend: $110+11$ 1. a.a. O. $\$ 59$ Randn. 1; PetersSautter-Wolf, Kommenta: zur Sozialgerichtsbarkeit, Anm. zu $\$ 8$ und $\$ 59$ (das. mi! lie it. Nachw.)).

7) S. hierzu insbes. B̈̈ttirhor, Regelungsstreitigkeiten. - Der Begriff wird hier in lorrinstimmung mit Bötticher als Oberbegriff für Gesamt- unc lirzelregelungsstreitigkeiten gebraucht.

8) Zur Gegenüberstellung _. 2. B. die Formulierung bei Jacobi, Art. "Arbeitsstreitigkei:en (II) Schlichtung" im Handwörter- 
berufen sind. Das ist am deutlichsten, wo es sich um Gesamtregelungsstreitigkeiten handelt. Die Vorbereitung und äußerstenfalls die Festsetzung genereller Normen ist keine richterliche Aufgabe. Aber auch die positive Gestaltung einzelner Verhältnisse 7), zwar auf dem Boden nicht aber nach Maßgabe des Rechts sondern allein unter Abwägung der Interessen und unter Berücksichtigung der Zweckmäßigkeit, ist keine eigentliche und, nach Art.92 GG, keine notwendige richterliche Aufgabe. Erscheint in Regelungsstreitigkeiten eine Ordnungsinstanz erforderlich, so kann zwar der Richter als solche berufen werden, nicht weniger aber - je nach Lage der Sache - die Verwaltung oder eben eine vom Gesetz eingerichtete oder wenigstens zugelassene außerstaatiiche "Stelle" (Schieds-, Einigungs-, Schlichtungsstelle)

buch der Sozialwissenschaften, Bd.I 1956, S.361 ff (361): "(1) Rechtsstreitigkeiten, bei denen ein Wille um das Recht kämpft, das ihm ein anderer Wille streitig macht; hier ist eine Entscheidung nach Maßgabe der geltenden Rechtsordnung durch Rechtsspruch möglich;

(2) Regelungsstreitigkeiten, bei denen eine den Interessen der Parteien entsprechende rechtliche Regelung durch Willenseinigung erstrebt wird, dieser Erfolg aber daran scheitert, daß die Willenseinigung nicht gelingt; hier ist keine Entscheidung durch Rechtsspruch nach Maßgabe der geltenden Rechtsordnung möglich sondern nur Hilfe zur Willenseinigung unter billiger Abwägung der beiderseitigen Interessen und Berücksichtigung der Zweckmäßigkeit, äußerstenfalls ein $Z$ wangsausgleich der widerstrebenden Interessen" $^{\prime \prime}$.

9) (1) Die "Stellen"-Lösung verkörpern die (gesetzlichen oder tariflichen) betrieblichen Einigungs- und Schlichtungsstellen und die tariflichen überbetrieblichen Schlichtungsstellen (s.o. S. 534 zu Fußn.3 (1)). Dagegen sind die staatlichen Schlichtung sausschüsse, so sehr sie im Gegenstand den tariflichen gleichen, und so sehr sie durch ihre Zusammensetzung diesen angenähert sind, Beispiele der "Verwaltungs" - Lösung (s.o. S. 535 zu Fußn.3 (2)).

(2) Auch die Schiedsämter für die kassenärztliche Versorgung (s.o. S. 535 zu Fußn. 3 (2)) können als Beispiele für die "Verwaltung s"-Lösung bezeichnet werden. Doch liegen hier die Dinge doch ganz anders als sie etwa bei Schiedsausschüssen liegen, selbst wenn diese - wie die Schiedsämter - verbindlich entscheiden können. Die Gesamtregelungsstreitigkeiten, die sie entscheiden, bestehen zwischen öffentlichrechtlichen Verbänden. Die Privatpersonen, die darüber hinaus betroffen 
Nur darf durch die Einrichtung dieser Stellen der Durchgriff zur Rechtsentscheidung der staatlichen Gerichtsbarkeit nicht verbaut werden. 10) Rechtsstreitigkeiten, die einer Regelungsstreitigkeit inmitte liegen, dürfen durch die Kompetenz solcher Stellen der staatlich-gerichtlichen jedenfalls dann nicht entzogen werden, wenn diese Stellen nicht insofern als Schiedsgerichte qualifiziert und tätig werden können. ${ }^{11)}$ Eine weitergehende Zuständigkeit nichtstaatlicher Stellen zur Entscheidung auch von Rechtsstreitigkeiten würde nicht gegen Art.92 GG verstoßen. 12) Ihre Betrauung mit Regelungsstreitigkeiten ist dagegen vielfach der staatlichen und sei es auch der richterlichen - Einmischung in die fraglichen Rechts- und Sachverhältnisse vorzuziehen.

werden, die Kassenärzte, stehen zu dem einen dieser Verbände in einem öffentlichrechtlichen Rechtsverhältnis. Es handelt sich also in erster Linie um eine Frage der Verwaltungsorganisation. Ähnlich verwickelt liegen die Dinge hinsichtlich der Einigungsstellen nach dem Personalvertretungsgesetz. Hierzu muß grundsätzlich bemerkt werden, daß gegen verwaltungsorganisatorische Lösungen dieser Art unter dem Gesichtspunkt des Art.92 GG keine Bedenken geltend gemacht werden können.

10) S. hierzu insbes. Bötticher, Die Zuständigkeit der Einigungsstelle des $₫ 70$ Abs. 2 BetrVG in rechtsstaatlicher Sicht, in "Beiträge zum Arbeits-, Handels- und Wirtschaftsrecht", Festschrift für Alfred Hueck, 1959, S. 149 ff. Bötticher berührt damit den kritischen Punkt im Rahmen des geltenden Betriebsverfassungslechts. D)as geltende Schlichtungsrecht bietet dagegen keinen $\Lambda n l a ß z u$ Abgrenzungserörterungen.

11) "Gewaltenteilungs"-I'robleme dürften nicht schon dadurch auftauchen, daß ein- und (iieselbe Stelle sowohl mit Regelungs- als auch (im möglichen Rahmen der Schiedsgerichtsbarkeit) mit Rechtsstreitiskeiten befaßt wird.

12) Hier taucht ein interessanter Dreiecksbezug RechtsprechungVerwaltung-private Stellen auf. Drei konkurrierende potentielle Gestaltungsträger, von denen zwei (Verwaltung und private Stelle) grundsätzlich nicht zur endgültigen Entscheidung von Rechtsstreitigkeiten zugelassen werden können. Der Rückgriff auf die staatliche Gerichtsbarkeit gegen die Mißachtung bestehenden Rechts durch die Schiedsentscheidung erinnert zudem an $t \in n$ Gerichtsschutz gegen Verwaltungsakte. 
c) Die gerichtlichen Kontrollkompetenzen

aa) Der gerichtliche Rechtsschutz gegenüber der Verwaltung aaa) Die "Generalklausel" - Notwendigkeit und Bedeutung

Die gerichtliche Primärkompetenz kann und soll die Zuständigkeit der Verwaltung nicht aufsaugen. Das ist von der Sache und der Verfassung her vorgezeichnet und läßt sich nur in den Randzonen, deren Problematik eben angedeutet wurde, in Frage stellen und verschieben. Die Verwaltung muß an das Gesetz gebunden sein. Deshalb muß der sozial intervenierende Staat, der von der Aufgabe her vorwiegend "Verwaltungsstaat" ist, auch "Gesetzesstaat" sein und zwar ein "Staat des Verwaltungsrechts". 1) Die Rechtsbinclung braucht eine Sanktion. So intensiv die vielfältigen nichtgerichtlichen Kontrolien der. Verwaltung wirken, 2) eine gerichtliche Kontrolle machen sie nicht entbehrlich. Der sozial intervenierende Rechtsstaat muß also schließlich auch "Justizstaat" im Sinne globalen und dichten gerichtlichen Rechtsschutzes gegenüber der staatlichen Exekutive sein; man könnte sagen, ein "Staat der Verwaltungsrechtsprechung", wenn der. funktionale Sinn dieses Wortes nicht durch seinen gerichtsorganisatorischen so sehr verdunkelt wäre.

Im Grundgesetz sind die Konsequenzen mit Ernst gezogen: Art.

1) S.o. S. $412 \mathrm{ff}$ und $\mathrm{S} .418 \mathrm{ff}$.

2) S. die Zusammenstellung dieser Kontrollen bei Becker, Verwaltung und Verwaltungs rechtsprechung, S. $117 \mathrm{f}$; s. ferner "Die Leistungen der öffentlichen Verwaltung und ihre Kontrollen", Referate des 20. Staatswissenschaftlichen Fortbildungskursus der Hochschule für Verwaltungswissenschaften Speyer, Beilage zur Staatszeitung für Rheinland-Pfalz Nr.27, 29 und 31 vom 3., 17. und 31. Juli 1955. Im einzelnen handelt es sich um folgende Beiträge: Ringelmann, Die Leistungen der öffentlichen Verwaltung und ihre Kontrollen: Die Leistungen des Bundes und der Länder im Spiegel ihrer Haushaltspläne; Gramsch, Die Leistungen der Gemeinden und Gemeindeverbände in der Gegenwart; Dahlgrün, Die Leistungen der öffentlichen Verwaltung und ihre Kontrollen: Das staatliche Kontrollsystem, insbes. die Finanz- und Wirtschaftskontrolle; Frber, Die Personalkontrolle; Hölzl, Die Rechts- und Zweckmäßigkeitskontrolle der öffentlichen Verwaltung; ders., Die Leistungen der öffentlichen Verwaltung und ihre Kontrollen: Die Rechts- und Zweckmäßigkeitskontrolle der öffentlichen Verwaltung; Fetzer, Selbstkontrolle der öffentlichen Verwaltung durch Aufsicht. 
19 Abs.4 GG sichert umfassenden 3 ) gerichtlichen Rechtsschutz gegenüber der Verwaltung. Auch andernorts (Art. 14 Abs. 3 Satz 4, 15 Satz 2, 34 Satz 3 GG) garantiert das GG gelegentlich gerichtlichen Rechtsschutz. 4) Doch kommt diesen Vorschriften gegenüber der universellen Klausel des Art.19 Abs. 4 GG nur noch die Bedeutung eines Kompetenzreservates zugunsten der "ordentlichen" Gerichte zu.

Art. 19 Abs. 4 GG, der "königliche Artikel" (Jellinek 5)), schützt nicht schlechthin das Recht gegen Verletzungen und Durchbrechungen. Er schützt den Bürger in seinen Rechten. Der Bürger, das Individuum, ist dadurch nicht nur an den Schalthebel des Sanktionsmechanismus gestellt sondern überhaupt ins Zentrum des Rechtsstaates gerückt. Aber es wäre verfehlt, den Individualismus dieser Rechtsschutzform ${ }^{6}$ ) zu beklagen. Gegenüber einem Staat, der intensivst und in den verschiedensten Richtungen und Modalitäten laufend in das Leben seiner Bürger eingreift, ist nicht nur die ebenso umfassende gesetzliche Bindung der vollziehenden Gewalt sondern auch die universelle Rechtsschutzgarantie notwendig. 7) In erheblichem limfang fällt die Wirkung der auf individuelle Initiative hin ausgelösten Rechtskontrolle zudem auch mit einer "objektiven" Überprülung der Gesetzmäßigkeit der Verwaltung zusammen. 8) Institutionen einer selbständigen, d.h. vom

3) Zum sachlichen Geltungsbereich s. die derzeit wohl eingehendste und informativste Darstellung bei Dürig in MaunzDürig, Art. 19 Abs. 4 Ranin. 17-37.

4) Auf die verfassungsgerichtlichen Zuständigkeiten wird vornehmlich im nächstfolgenten Abschnitt einzugehen sein.

5) Eine Zusammenstellung der positiv würdigenden Prädikate, die dieser Vorschrift aus berufenem Munde beigelegt wurden, s. bei Dürig in Maum-I)ürig, Art. 19 Abs. IV Randn. 1.

6) S. Klein, Bonner Grundecsetz und Rechtsstaat, S.406 ff; Koellreutter, Giundfragen ies Verwaltungsrechts, S. 14.

7) S. z.B. Kägi, Rechtssciut: - Sozialstaat - sozialer Rechtsstaat, Die Sichweiz - ein nationales Jahrbuch, 1945, S. 129 ff (144); Werner, Allsemeno Verwaltungsgerichtsbarkeit und Sozialgerichtsbarkeit, WIII 7.Jhg. (1954) S. 1625 ff (1627); Becker, Stand und Aufgitbr der. Verwaltungswissenschaft, S. 18; Marcic, Vom Geseticsstatat zum Richterstaat, S.113, 295, 416 und passim; I.eibholz, Die kritischen Punkte des Grundgesetzes, S.19; Rouss, Zur Neuordnung des Revisionsrechts, insbes. im vervaltur:gsgerichtlichen Verfahren, DÖV 12.Jhg. (1959) S.10 if (12).

8) S. z.B. Becker, Verwitung und Verwaltungsrechtsprechung, S. 129 f; Rumpf desgl. S. 139 f; Bachof, Diskussionsbeitrag 
Individualinteresse ebenso wie von der Verwaltungsspitze unabhängigen richterlichen Gesetzmäßigkeitskontrolle könnten dagegen den individuellen Rechtsschutz nicht ersetzen und würden wohl auch eine "objektive" Kontrolle nicht in dem gleichen Maße herbeiführen wie die private Initiative.

\section{Zentral verwirklicht das Anliegen des Art. 19 Abs. 4 GG} durch die verwaltungsgerichtliche Generalklausel ( $\$ \$ 40,42$ VGO). Ihr Geltungsbereich wird eingeschränkt durch die Zuständigkeit der besonderen Verwaltungsgerichte und der ordentlichen Gerichte. Für die im vorstehenden Zusammenhang naturgemäß besonders wichtigen Sozialgerichte beinhaltet $₫ 51$ SGG eine partielle Generalklausel. In Steuersachen entscheiden grundsätzlich die Finanzgerichte. Die noch von traditionellen Vorstellungen getragene Reichsabgabenordnung (s.insbes. deren $\$ \$ 229,261$, 305) sah eine erschöpfende Rechtsschutzkompetenz der Finanzoder anderer Gerichte nicht vor. Sie wurde von den Gerichten unter fast einhelliger Zustimmung des Schrifttums aus Art. 19 Abs. 4 GG i.V.m. Art.96 GG heraus entwickelt.9) Als besondere Verwaltungsgerichte müssen auch die Dienststrafgerichte angesehen werden (vg1. Art.96 Abs.3 GG). Unter den Zuständigkeiten der ordentlichen Gerichte (s. $\$ 13$ GVG) müssen im Zusammenhang mit dem gerichtlichen Rechtsschutz gegenüber sozial intervenierender Verwaltung vor allem die schon in der Verfassung eingeräumten Kompetenzen im Rahmen des Entschädigungsrechts (Art. 14 Abs. 3 Satz 4, 15 Satz 2 GG) erwähnt werden. 10) Die subsidiäre Zuständigkeit der ordentlichen Gerichte, die in Art. 19 Abs. 4 GG angeordnet ist, ist dagegen kaum von praktischer Bedeutung. 11) Im Hintergrund allen gerichtlichen Rechts-

hierzu, S. 177; Forsthoff, Lehrbuch des Verwaltungsrechts, S. $461 \mathrm{f}$; Menger, Der Schutz der Grundrechte in der Verwaltungsgerichtsbarkeit in Bettermann-Nipperdey-Scheuner, Die Grundrechte, Bd. III, 2. Halbbd. 1959, S. $717 \mathrm{ff}$ (727 ff).

9) S. hierzu Darstellung und Nachweise bei Dürig in MaunzDürig, Art.19 Abs. IV Randn. 58 ff, insbes. Randn. 61.

10) Zur Zuständigkeit der ordentlichen Gerichte s. insbes. Bettermann, Der Schutz der Grundrechte in der ordentlichen Gerichtsbarkeit in Bettermann-Nipperdey-Scheuner, Die Grundrechte, Bd.III, 2. Halbbd. 1959, S. 779 ff (insbes. S. $818 \mathrm{ff}$ ). Eine weiter gefaßte Zusammenstellung zum großen Teil einschlägiger Zuständigkeiten der ordentlichen Gerichte s. bei Wieczorek, ZPO, $\$ 13$ GVG Anm. F IV, G - M.

11) S. die hier nicht einschlägigen Beispielsfälle bei Dürig a.a.O. Randn.64. - Bettermann (a.a.O. S.824 ff) zieht die Grenzli- 
schutzes steht der verfassungsgerichtliche Grundrechtsschutz. Die Verfassungsbeschwerde (Art.93 Abs.2 GG i.V.m. $\$ \$ 90$ ff BVerfGG) erlaubt die Anrufung des Bundesverfassungsgerichts grundsätzlich erst nach Anrufung der zuständigen Nicht-Verfassungsgerichte ( $\$ 90$ Abs. 2 BVerfGG), wenngleich dem Bundesverfassungsgericht eine Art Evokationsrecht eingeräumt ist ( $\$ 90$ Abs. 2 Satz 2 BVerfGG).

\section{bbb) Der Rechtsschutz gegenüber dem leistenden Staat}

1. Die verfahrensrechtliche Anpassung. Die umfassende Kontrollzuständigkeit der Gerichte gegenüber einer Verwaltung, die auf die vielfältigste Weise in die rechtlich geschützte Individualsphäre der Bürger eindringt, kann auf die Tätigkeit der Gerichte und ihr Verfahrensrecht nicht ohne Rückwirkung bleiben. Eine Verwaltungsgerichtsbarkeit, die einer vorwiegend eingreifenden Verwaltung zur Seite gestellt ist, kann sich mit der negativen Kontrolle und einer kassatorischen Entscheidung begnügen. Eine Verwaltungsgerichtsbarkeit, die gegenüber einer (auch) leistenden Verwaltung (auch) das Recht auf Teilhabe an diesen Leistungen zu schützen hat - und nur damit können die Verwaltungsgerichte einen abgerundeten Rechtsschutz gerade des sozialen Status des Bürgers bewirken -, muß dagegen auch positiv Leistungspflichten der Verwaltung statuieren können. Sie muß auch die Teilhaberechte des Bürgers zu "titulieren" imstande sein. Die Vornahmeklage ( $\$ 42$ Abs. 1 VGO; $₫ 54$ Abs. 1 SGG), die Leistungsklage ( $\$ 40$ Abs. 1 VGO; $\$ 54$ Abs. 4 und 5 SGG) und die Feststellungsklage ( $\$ 43$ VGO; $\$ 55$ SGG) sind Rechtsschutzformen, die diesen Bedürfnissen entsprechen. 1)

2. Das berechtigende Gesetz als Angelpunkt. Doch sind die Folgeprobleme der Universalität des Rechtsschutzes gegenüber einer Verwaltung vom 'xpansiv gewandelter Wirksam-

nien weniger eng.

1) S. zu diesen froblernen lluber, Wirtschaftsverwaltungsrecht, Bd. II S. 606 ff (instues. S. $613 \mathrm{ff}$ ) und S.639 ff; Werner, Al1gemeine Verwaltungserichtsbarkeit und Sozialgerichtsbarkeit, S. $1625 \mathrm{ff}$ (1626 ff); Krïger, Die Auflage als Instrument der Wirtschaftsverwaltung, insbes. S.381; Menger, Rechtssatz, Verwaltung und Verwaltungsgerichtsbarkeit; Becker, Verwaltung und lervaliungs rechtsprechung, insbes. S.113 f, 128 f; Rupp, Die Beseitigungs- und Unterlassungsklage gegen Träger hoheitliche! (if walt; w. Nachweise s. bei den Zitierten. 
keit 2) von sekundärer, technischer Bedeutung. Im Bunde mit einer verständnisvollen und hinlänglich einfallsreichen Richterschaft braucht der Betroffene nicht zu fürchten, wegen formaler Schwierigkeiten um seinen Rechtsschutz gebracht zu werden. Die Gefahr für den Bürger liegt vielmehr darin, daß es der Gesetzgeber an einer hinlänglichen rechtlichen Bindung der Exekutive fehlen 1äßt. 3) Läßt der Gesetzgeber im Rahmen einer Eingriffsoder Leistungsermächtigung zugunsten der Verwaltung dieser zu viel Spielraum, so findet der Richter das in Frage stehende Interesse des Betroffenen nicht zum Rechtsatz verdichtet.

Wenn es nicht wenigstens durch einen allgemeinen, das spezielle Recht ergänzenden Grundsatz (z. B. den Gleichheitsgrundsatz, den Grundsatz von Treu und Glauben) geschützt wird, kann der Richter ihm nicht Rechnung tragen. Fehlt schließlich einer Verwaltungsleistung die gesetzliche Regelung überhaupt, so kann auch der Richter nicht mehr an Rechtsschutz hergeben, als die einschlägigen allgemeinen Rechtsgrundsätze ihm an Maßstab bieten. Hier wird das Problem der rechtsstaatlichen Bindung der Verwaltung durch das Gesetz relevant. ${ }^{4)}$

3. Exkurs: Der rechtsstaatliche Zwang zur subjektiven Berechtigung. Aber noch ein anderes Problem kommt hier zum Durchbruch, das damit eng verwandt ist: Kann der Gesetzgeber zwar das Verhalten der Verwaltung (objektiv) rechtlich regeln, dem Bürger, dem das sonach geregelte Verhalten zugute kommen soll, jedoch ein Recht auf dementsprechendes Handeln der Verwaltung versagen? Art. 19 Abs. 4 GG scheint darauf unmittelbar keine Antwort zu geben. Die Vorschrift knüpft an die Rechte des Bürgers an, setzt sie voraus. Für das Verhältnis des Bürger's zur Eingriffsverwaltung fällt diese Konstruktion mit einem globalen Rechtsschutzanspruch des Bürgers zusammen; denn auf dem Boden seines Rechts auf Freiheit von ungesetzlichen Eingriffen ${ }^{5)}$ kann er jeden exekutivischen Eingriff der gerichtlichen Überprüfung auf seine Gesetzmäßigkeit zuführen. Er

2) Vgl. Becker, Verwaltung und Verwaltungsrechtsprechung, S. 123 .

3) Vgl. Menger, Rechtssatz, Verwaltung und Verwaltungsgerichtsbarkeit, S. 592 .

4) S. o. (S.420 ff und S.463ff).

5) Näheres und Nachweise s. oben (S. $420 \mathrm{ff}$ ). - Im besonderen $\mathrm{Zu}$ sammenhang mit Art. 19 Abs. 4 GG s. hierzu Wernicke im Bonner Kommentar, Art. 19 Anm. II 4 d mit eingeh. Nachw.; Dürig in Maunz-Dürig, Art. 19 Abs. IV Randn. 36 . 
hat aber nicht gleicherweise ein allgemeines Recht auf staatliche Leistungen, kraft dessen er schon jede Versagung beantragter Leistungen einer Uberprüfung daraufhin zuführen könnte, ob die Negation seines Begehrens auch durch das Gesetz gedeckt ist. ${ }^{6}$ ) Erst das Gesetz kann ihm in der Regel Ansprüche gewähren. Es gibt Ausnahmen von diesem Grundsatz, indem allgemeine Grundsätze - z.B. der Gleichheitsgrundsatz oder das Recht der Entschädigung wegen enteignungsgleichen Eingriffes - dem einzelnen als Reaktion auf ein gewisses Verhalten der Verwaltung einen Anspruch auf ein entsprechendes Folgeverhalten gewähren. Desgleichen gibt es Ausnahmen, wenn dem einzelnen unmittelbar durch die Verfassung gewisse Rechte eingeräumt sind, die der Gesetzgeber modifizieren, nicht aber ausschließen kann. Im übrigen aber ist der Bürger darauf angewiesen, daß das Gesetz ihm Ansprüche gegen die Verwaltung einräumt.

Verhielte sich die Verfassung dem gegenüber indifferent, so ließe sie es in der. Hand des Gesetzgebers, in welchem Umfang er der Verwaltung Leistungen oder sonstige Begünstigungen im Interesse einzelner vorschriebe, diesen aber die Möglichkeit vorenthielte, das gesetzlich gebotene Verhalten der zuständigen Exekutivorgane auch durch die Entscheidung des Gerichts zu erzwingen. Art. 19 Abs. 4 GG würde in dieses Verfassungsbild nicht passen. In der Tat könnte Art. 19 Abs. 4 GG nicht als ein "königlicher Artikel" (W.Jellinek), ein "Schlußstein" im "Gewölbe des Rechtsstaates" ('Thoma), die "Krönung des Rechtsstaates" (Ebers) ${ }^{7)}$ genannt werden, wäre er nicht als "verfassungsgestaltende Grundentscheidung" 1 ) und als "Grundsatznorm für die gesamte Rechtsordnung" z) zu bezeichnen, wenn sein sachlicher Geltungsbereich auf diese 11 eise der Disposition des einfachen Gesetzgebers überlassen wäre. Art. 19 Abs.4 GG gewinnt seine volle ihm zukommencle Bedeutung vor dem Hintergrund eines Rechtsstaates, in clem es lem Ge'setzgeber verboten ist, das die Individualsphäre des Buirge's berührende Verhalten der Verwaltung im Wege nur objektirrechtlicher Regelung zu ordnen. Die Rechtsfigur des bloken licuhishllexes hat, soweit es sich um gezielte begünstigende finwiliungen auf die Individualsphäre handelt, gegenüber Art.19 Abs.4 CG keinen Bestand. Die objektivrechtlich angeordnete Bersinstisung gibt immer auch ein Recht

6) S.a. hierzu oben (S. 420 if).

7) S. oben S. 422 zu Firn.j.

8) Dürig, a.a.O. Ranch. ..

9) v. Mangoldt-K1cin, Ar. 19 Anm. II 3 c. 
i.S. des Art. 19 Abs. 4 GG. 10) Nur mittelbare, zufä1lig-tatsächlich begünstigende Rechtsreflexe lösen keine subjektiven Rechte

10) (1) Grundlegend zum Vorstehenden Bachof, Der Rechtsschutz im öffentlichen Recht: Gelöste und ungelöste Probleme, DÖV 6. Jhg. (1955) S.417 ff (421); ders., Begriff und Wesen des sozialen Rechtsstaates, S. 72 ff; ders., Reflexwirkungen und subjektive Rechte im öffentlichen Recht, in "Forschungen und Berichte aus dem öffentlichen Recht", Gedächtnisschrift für Walter Jellinek, 1955, S. $287 \mathrm{ff}$, insbes. S. $303 \mathrm{ff}$. (Bachof (ebd. S.305 ff) will gewisse Ausnahmen anerkennen. Unter ihnen ist hier allein diejenige von Bedeutung, welche die Rechte juristischer Personen des öffentlichen Rechts betrifft (S.306 f). Dem Vorbehalt, daß über die Rechtsverhältnisse rechtsfähiger Verwaltungseinheiten u. ä. Erscheinungen der Gesetzgeber, der sie schafft, freier disponieren kann als über die Rechte natürlicher Personen und der in ganz anderer Zweckhaftigkeit stehenden juristischen Personen des privaten Rechts, wird zuzustimmen sein.) - Im Ergebnis im großen und ganzen übereinstimmend Menger, System des verwaltungsgerichtlichen Rechtsschutzes, S. 118; v. MangoldtKlein, A rt. 19 Anm. VII 3 (insbes. lit. b); Dürig, a.a.O. Randn. 33 ff (insbes. Anm.V 1 e); Bettermann, Der Schutz der Grundrechte in der ordentlichen Gerichtsbarkeit, S. 785 . Eingehende Nachweise über die Diskussion und den Streitstand s. bei den Zitierten. - Die terminologische Frage, ob man sagen soll, Art.19 Abs. 4 GG schütze zwar nur "Rechte", nunmehr seien unter Rechten aber auch "rechtlich geschützte Interessen" oder ähnliches zu verstehen, oder ob man sagen soll, Art.19 Abs.4 GG schütze subjektiv öffentliches Recht und rechtlich geschützte Interessen unter dem gemeinsamen Namen "Rechte", ist von zu vernachlässigender Bedeutung (s. hierzu auch Dürig, a.a.O. Randn. 34 - Anm. V 1 c mit weiteren Nachweisen).

(2) Eine gängige Meinung begnügt sich damit, die subjektive Berechtigung objektiv Begünstigter als Auslegungsregel zu proklamieren (s. z. B. Huber, Wirtschaftsverwaltungsrecht Bd.I S.684 f; Hamann, Deutsches Wirtschaftsverwaltungsrecht, S. 44; Forsthoff, Lehrbuch des Verwaltungsrechts, S. 172; BVerwGE 1, 321 (326 f)). Damit wird das Problem aber nicht gelöst. Auch die Frage der Umwandlung bloßer Rechtsreflexe vorkonstitutioneller Provenienz in klagbare Rechte (s. z.B. Forsthoff, a.a.O. S. 174; Dürig, a.a.O. Randn. 36 - Anm.V 2 a dd; je mit weiteren Nachw.) wird besser unter dem Aspekt der verfassungskonformen Auslegung 
i.S. dieser Verfassungsnorm aus. 11) Die kardinale Bedeutung dieses universellen Rechtsschutzanspruches für das Recht der sozialen Intervention ist evident. ${ }^{12)}$ Erst dadurch rückt der Bürger in eine vollwertige Subjektstellung ein, in der sich für ihn die

als mit Hilfe dieser "Vermutung" für das subjektive öffentliche Recht gelöst.

11) Zur Grenzziehung s. f.v.a. Dürig, a.a.O. Randn. 33-37 mit reichen Nachweisungen.

12) (1) Der klassische Fall, in dem dieses Prinzip erstmals mit breiter Wirkung zum Tragen kam, ist die Anerkennung des Anspruches auf Fürsorgeunterstützung in der Nachkriegszeit (BVerwGE 1, 159; weitere Nachweise s. z. B. bei Forsthoff, a.a.O. S.174, Fußn. 3; Dürig, a.a.O. Art.1 Abs. I Randn. 44, Art. 2 Abs. II Randn. 26 - Anm. III 2 a Fußn. 1 ; s. nunmehr $\$ 4$ des Entwurfs eines Bundessozialhilfegesetzes, Deutscher Bundestag, 3. Wahlperiode, Drucks. Nr.1799 sowie die amtliche Begründung dieses Entwurfs, insbes. S. 32 f). Der parallel laufende Streit um den Rechtsanspruch auf Tuberkulosehilfe (s. den Bericht bei Menger, Höchstrichterliche Rechtsprechung zum Verwaltungsrecht, Verwaltungsarchiv Bd. 48 (1957) S. 168 ff; nachzutragen OVG Münster, Urteil v. 16. Juli 1957 - VII A 226/56 - JZ 13.Jhg. (1958) S. 511 mit Anmerkung der Redaktion) ist durch das Gesetz über die Tuberkulosehilfe vom 23. Juli 1959 ( $\$ 1)$ im Sinne eines Rechtsanspruches entschieden. Eine analoge Entwicklung vom nur objektiven zum auch subjektiven Recht hat sich gelegent1ich der Umdeutung von Ver'waltungsvorschriften im untergesetzlichen Recht vollzogen; s. die oben S. 463 zu Fußn.20 angeführte Rechtsprechung : :ur Anwendung der Beihilfegrundsätze, der Richtlinien über ¿uschläge zur Unfallfürsorge für Strafgefangene und gewisser Versorgungsvorschriften. - Zu den Ansprüchen auf (Fürsorge-) Maßnahmen nach $₫ 26$ und auf Erziehungsbeihilten niach $₫ 27$ des Bundesversorgungsgesetzes rgl. BVerw(iE 3, 288; BVerwG Urt. v. 19. Dezember 1956 - BVerwG V 178.54 - Sammel- und Nachschlagwerk der Rechtsprechung des Bundesverwaltungsgerichts Nr.4367 \$26 JVG Vr. 1; BayVGH VGHE n.F. 8, 154. (2) Hinsichtlich der Lastenausgleichsleistungen "ohne Rechtsanspruch" ( $\$ \$ 231,233 \mathrm{~L}\}$ ( ) $)$ operiert das Bundesverwaltungsgericht vorwiegend mit dem Recht auf fehlerfreie Ermessenshandhabung (außer BVerwGE 2, 163 s, die im Sammel- und Nachschlagwerk der Rechtsprechung des Bundesverwaltungsgerichts zu 4273, $\$ 233 \mathrm{Nr} .2, \$ 254, \$ \S 301-302$ LAG nachgewiesene Judikatur). 
legislative Erfüllung der rechtsstaatlichen Maxime der gesetzlichen Bindung der Exekutive als Beherrschbarkeit, als nicht nur in Erwartung loyalen Verhaltens und wegen der Wirksamkeit der im Staatsapparat eingesetzten Infrakontrollen zu erhoffende sondern auch durchsetzbare Beherrschbarkeit des Verhaltens der staatlichen Organe realisiert. Er wird dadurch nicht zum Popularkläger, der ohne weiteres die Einschaltung des objektiven Rechts, was und wen immer es angeht, erzwingen kann. Nur seine Individualsphäre kann er beherrschen und zwar nicht mehr nur - was kaum jemand bezweifelt - in Abwehr aller Angriffe sondern auch in Verfolgung und Verwirklichung der Daten, die der Staat seiner Individualsphäre dadurch eingefügt hat, daß er durch allgemeine Vorschrift Leistungen an ihn angeordnet hat.

Diese aus der Emanation des Art. 19 Abs. 4 GG induzierende Auslegung des Rechtsstaatsprinzips steht im Einklang damit, daß auch der Rechtsschutz durch Amtshaftungsansprüche (Art. 34 GG i. V.m. $\$ 839$ BGB) - die alte ultima ratio des Rechtsstaates nicht etwa nur ausdrücklich eingeräumte subjektive Rechtspositionen absichert. Vielmehr geht die herrschende Praxis bezüglich des Tatbestandselements der "einem Dritten gegenüber obliegenden Amtspflicht" ( $z$ Recht) davon aus, daß jedermann einen Anspruch hat, daß sich die Amtsträger des Staates ihm gegenüb e $r$ (objektiv) rechtmäßig verhalten müssen. 14) Es wäre ein Rudiment des Satzes "Dulde und liquidiere", wenn die Spur des direkt gegen die Ausübung hoheitlicher Gewalt gerichteten Rechtsschutzes (Art.19 Abs.4 GG) schmäler gelegt wäre als die des Restitutionsanspruchs.

13) S. hierzu auch das "Rechtsstellungs"-Denken bei Hans J. Wolff, Der Abwendungsanspruch aus öffentlichen Reflexrechten, insbesondere im Fürsorgerecht, Festschrift zur Feier des 25jährigen Bestehens der Westfälischen Verwaltungsakademie in Münster und der Verwaltungs- und Wirtschaftsakademie Industriebezirk Sitz Bochum, 1950, S. $119 \mathrm{ff}$. Seinem differenzierenden Ergebnis (insbes. S. 127 ff, 135 f) kann indes nicht beigetreten werden.

14) S. hierzu z.B. Reinhardt, Empfiehlt es sich, die verschiedenen Pflichten des Staates zur Entschädigungsleistung aus der Wahrnehmung von Hoheitsrechten nach Grund, Inhalt und Geltendmachung gesetzlich neu zu regeln? Verhandlungen des 41 . Deutschen Juristentages, Bd. I, 1.Halbbd., 1955, S.237 ff (248 ff).

15) S.a. Bettermann, a.a.O. S. 842, der aber vom Art. 19 Abs. 4 GG auf die Legitimität der Praxis des Amtshaftungsrechts schließt. 
Indem der Staat gehindert wird, Rechtspositionen, die zweckhaft die Individualsphäre gestalten, durch ihre Etikettierung als nur objektives Recht der Rechtsschutzgarantie des Art. 19 Abs. 4 GG zu entziehen, wird er nicht zugleich auch gehindert, den zuständigen Behörden einen Ermessensspielraum zu gewähren. Grundlage des Rechtsschutzanspruches des Art. 19 Abs. 4 GG kann auch ein Anspruch auf rechtmäßige Ausübung des Ermessens sein. 16) Fine andere Frage ist, wie weit der Ermessensrahmen gezogen werden darf, ohne daß sich die rechtliche Bindung der Verwaltung überhaupt verflüchtigt. 17)

\section{(cc) Weitere besondere Rechtsschutzprobleme}

Anzumerken ist, daß auch die Rechtsfigur des besonderen Ge wa 1 t verhä1tnisses 1) von der Rechtsschutzklausel des Art. 19 Abs. 4 GG clurchdrungen wird. Die Aufgabe der Gerichte ist hier von besonderer Bedeutung, weil es ihnen in langsamem Vorantasten vom einzelnen Fall her eher möglich ist als dem Gesetzgeber, die Grundsätze aufzuspüren, die sich aus der recht1ichen Grundlage des Gewaltverhältnisses, in die ja ihr Zweck eingeschmolzen ist, für die Rechte und Pflichten der Behörden und cler Beteiligten ergeben. 2)

Die Verwaltung kann sich der gerichtlichen Kontrolle übrigens nicht dadurch entziehen, daß sie die "Flucht ins Privatrecht" 3 ) ergreift. Soweit sie privatrechtlich tätig wird, unterliegen ihre privatıechtlichen Rechtsbeziehungen der Jurisdiktion der ordentlichen oder gegebenenfalls der Arbeitsgerichte ( $\$ 13$ GVG, $\$ \$ 2,3$ A rbG(i). Fs ist in Hinblick auf Art.92, 1. Halbs. $\mathrm{GG}$ und Art. 19 Abs. $3 \mathrm{GG}$ auch clem Gesetzgeber nicht möglich, (lie ge richtliche Streitentscheidung auszuschließen. ${ }^{4)}$ Die Annah-

16) S. f.v.a. Dürig, a.a.(). Kandn. 36 .

17) S. oben S. $463 \mathrm{ff}$.

1) Zu seiner sozialen becleutunss $\mathrm{s}$. oben $2 \mathrm{~b})$ bb aaa $(\mathrm{S} .420 \mathrm{ff})$.

2) Zum Rechtsschulı in besulderen Gewaltverhältnis s. vor allem Ule, Das besonder. (ic.waltverhältnis. - Zum Verhältnis cles Art. 19 Abs. 4 (i(i zum besonderen Gewaltverhältnis s. insbes. die reich belegte Darstellung von Dürig, a.a.O. Art. 19 Abs. IV Rándn. 25.

3) S. dazu oben S. 45T fuRn. 2 ff.

4) Es darf angenommen? werlen, daß die Klausel des $\$ 4$ EGZPO, wonach "für biileserliche lifehtsstreitigkeiten, für welche nach dem Gegenstanc! ode: der Art des Anspmuchs der Rechtsweg zulässig ist", lkr Rechtsweg (durch die Landesgesetzgebung) nicht "aus lem Grunde" ausgeschlossen werden darf, 
me der Rechtsschutz des Bürgers sei zuverlässiger, wenn sich sein Verhältnis zum Staat in den Bahnen des Privatrechts abspie$1 \mathrm{e},{ }^{5)}$ ist an sich unbegründet. Es kommt immer auf die materiellrechtliche Regelung an. Das materielle Privatrecht nun allerdings ist den besonderen Interessenlagen bei der Begegnung zwischen Staat und Individuum nicht wie das öffentliche Recht auf den Leib geschrieben und bietet so der Verwaltung unter Umständen fragwürdige "Vorteile".

ddd) Zum Verhältnis von Verwaltung und kontrollierender Rechtsprechung

Die Rechtsprechung greift also tief in das Verwaltungsgeschehen ein. Soweit die Beziehungen zwischen Verwaltung und Bürger vom Recht beherrscht sind, wird die Verwaltung ihrerseits von der Rechtsprechung "beherrscht" - und das in der Potenz; denn die Rechtsprechung entscheidet selbst darüber, wie weit die rechtliche Bindung der Verwaltung reicht. Nur ein erneuter Gesetzesbefehl, eine ausdrückliche und eindeutige Änderung des Gesetzes, kann - effektiv - die Rechtsprechung von einer zu Unrecht angemaßten Rechtsbindung der Verwaltung und daraus folgenden Kontrollkompetenz zurückziehen. Die Verwaltung selbst kann über Rechtsfragen, die irgendwie auch die Individualsphäre berühren, nicht mehr endgültig entscheiden. Wenn auch die Anrufung der Gerichte von der Initiative der Betroffenen abhängt, 1) so führt diese doch zu einer sehr weitgehenden judikativen Erörterung aller einschlägigen Rechtsfragen. Die rechtsstaatlich notwendige "Verrechtlichung" der Verwaltung trägt das ihre dazu bei, um den Einfluß der Judikatur auf den Verwaltungsablauf zu intensivieren.

"weil als Partei der Fiskus, eine Gemeinde oder eine andere öfentliche Korporation beteiligt ist", heute der Sache nach Bestandteil des Verfassungsrechts ist. Die Streitentscheidungskompetenz der Gerichte, die ihnen Art. 92 GG garantiert, kann umso weniger gerade für diese Streitigkeiten eine Ausnahme erieiden als Art. 19 Abs. 4 GG gerade gegenüber dem Staat den Rechtsschutz aufs nachhaltigste entwickelt. Zur Anwendung des Art. 19 Abs. 4 GG auf die Verwaltung mit privatrechtlichen Mitteln s. Dürig, a.a.O. Randn. 19 mit weit. Nachw.

5) Krüger, Die Auflage als Instrument der Wirtschaftsverwaltung, S.385, schiebt die verfahrensrechtliche und die materiellrechtliche Sphäre nicht ganz glücklich ineinander.

1) Damit soll nicht verkannt werden, daß auch in anderen Verfahren als in denen, die der Bürger gegen den Staat anstrengt, z. B. in Strafverfahren, immer wieder wichtige Rechtsfragen zum Ausdruck kommen. 
Was dadurch die Gerichte an Einfluß und die Betroffenen an Rechtsschutz gewinnen, büßt nicht nur die Verwaltung an Macht ein. Es geht auch auf Kosten der Eigenverantwortlichkeit der Verwaltung für die Rechtmäßigkeit ihres Handelns. Ein "Prozeß ständiger Rechtsentleerung" der Verwaltung geht vor sich, der "das Rechtselement auf die Verwaltungsgerichte hin verlagert".2) Nicht nur, daß das Bemühen der Behörden nachläßt - ja: nachlassen muß -, das selbst als objektiv richtig erkannte Recht anzuwenden, und die Versuchung wächst, entweder - re iudicata nach den (vielleicht als falsch mißbilligten) Präjudizien zu schielen oder, wenn das Rennen noch offen ist, die bequemste, $z$ weckmäßigste usw. Lösung zu wählen, um sie den Gerichten, denen die Verantwortung für die Rechtmäßigkeit obliegt, zur Diskussion zu stellen und zu insinuieren. Die Gewichtsverlagerung zur Rechtsprechung hin hat auch die Folge, daß der Verwaltungsvollzug immer nur vorläufig, d. h. vorbehaltlich einer abweichenden $\mathrm{Ge}-$ richtspraxis, dirigiert und ausgerichtet werden kann. Das bedingt Unsicherheit und Schwankungen. Aber das alles kann im wesentlichen nicht ohne Schmälerung des Rechtsschutzes geändert werden. 3)

Die Verfassung garantiert nur R e chts schutz. Die Befugnis der Gerichte, auch das Ermessen über die Prüfung seiner rechtmäßigen Ausübung hinaus zu "kont rollieren", d.h. an Stelle der Verwaltungsbehörde selbst auszuüben, ist die Ausnahme. Die Verfassung sieht sie nicht ausdrücklich vor. Genau so wenig, wie

2) Forsthoff, Diskussionsbeitrag zu "Verwaltung und Verwaltungs rechtsprechung", S. 187 f (188).

3) Zu den Problemen s. z.I. Platz, Die gerichtliche Kontrolle der Leistungsverwaltung, DÖV 12. Jhg. (1959) S. 340 ff. Sein Vorschlag, der Verwaltung die Möglichkeit zu geben, rasch höchstrichterliche Entscheidungen herbeizuführen, verdient nur bedingt Beifall. Die Einschränkung gilt vor allem einer evtl. Gutachtenserstattung nach dem Vorbild des $\$ 63$ AO, $₫ 6$ Abs. 1 des Ciesetzes über den Bundesfinanzhof (s. hierzu allgemein Wacke, Die Erstattung von Gutachten durch den Bundesfinanzhof, AöR Bd. 83 (1958) S. 309 ff). Entscheidungen, die übereilt he rbeigeführt und getroffen werden, ermangeln der Reife. Der Wert, den die umfassende Erörterung einer Rechtsfrage durch möglichst viele (Unter-) Gerichte und möglichst viele Joteiligte in möglichst vielen Verfahren unter Erprobung der. Ansichten an ebenso vielen konkreten Fällen für das Reifen des Problems hat, darf nicht unterschätzt werden. 
ein Ausgreifen der Primärkompetenz in den Bereich der Verwaltung hinein, steht sie aber einer derartigen Intensivierung des gerichtlichen Rechtsschutzes schlechthin entgegen. ${ }^{4)}$ Doch ist diese Konstruktionsmöglichkeit für den sozialen Rechtsbereich ohne Bedeutung geblieben. Vielmehr wirken die Ermessensspielräume, die der Verwaltung verbleiben müssen, 5) als nachhaltiger Entscheidungs- und Verantwortungsvorbehalt der Exekutive. Anders ist die Situation hinsichtlich der unbestimmten Rechtsbegriffe. 6) Sie sind im sozialen (Verwaltungs-) Recht besonders weit verbreitet. Sie fungieren - wenngleich oft nur in der Illusion eines gleichermaßen rechtsstaatlich wie sozial orientierten, perfektionistischen Wunschdenkens - als Brücke zwischen der für unertbehrlich gehaltenen strikten generellen gesetzlichen Bindung der Staatsgewalt und der nicht weniger als unabdingbar betrachteten sozialen Einzelfallgerechtigkeit. Daneben kommen sie oft auch nur dem Gesetzgeber zuhilfe, der ohne sie nicht imstande wäre, die Vielfalt der Lebensverhältnisse in angemessen knappen gesetzlichen Formulierungen einzufangen. Auch darin genügen sie einem Bedürfnis, das im sozialen Bereich in besonderem Maße heimisch ist. Und nun auch hier wieder der gleiche Kurzschluß, der auch im Zusammenhang mit der Ausbreitung der richterlichen Primärkompetenz schon festgestellt werden mußte: Indem die Auslegung und Anwendung des unbestimmten Rechtsbegriffes cler richterlichen Kontrolle unterworfen wird, glaubt man, wie weit immer auch die Distanz zwischen präziser Normsubstanz und konkreter Fallentscheidung anzusetzen ist, mehr für den Rechtsstaat getan und weniger gegen ihn riskiert $\mathrm{zu}$ haben als bei der Gewährung auch noch so schmal bemessenen Ermessens. ${ }^{7)}$ Auch hier soll die Zuständigkeit des Richters ersetzen, was der Gesetzgeber an rechtlicher Prädisposition der Einzelentscheidung nicht zu leisten vermag. Erfreulicherweise hat nach dem Ausschwingen des Pendels zum Extrem einer völligen

4) S. z.B. Bettermann, Die freiwillige Gerichtsbarkeit im Spannungsfeld zwischen Verwaltung und Rechtsprechung, S. $35 \mathrm{f}$

5) S. hierzu nochmals oben b) cc (S. $520 \mathrm{ff})$.

6) Zum Problemkreis s. statt aller Älteren hierzu Jesch, Unbestimmter Rechtsbegriff und Ermessen in rechtstheoretischer und verfassungsrechtlicher Sicht. - Ergänzend s. z.B. Wolff, Verwaltungsrecht I, S. 132 ff; Ehmke, "Ermessen" und "unbestimmter Rechtsbegriff" im Verwaltungsrecht, 1960; alle weiteren Nachweise s. bei den Genannten.

7) Hedemann (Die Flucht in die Generalklausel, S.41) hat freilich schon 1935 die Entwicklung vom Ermessen zu den doch eben mit gewissem Gehalt gefüllten Generalklauseln beobachtet. 
richterlichen Usurpation der unbestimmten Rechtsbegriffe - und ihres Mißbrauches, der so manchen Ermessensspielraum ausgetrocknet hat, - nun eine Rückkehr zur Gleichgewichtslage einer gemäßigten, differenzierend urteilenden Betrachtungsweise eingesetzt. Nur dort, wo das Gesetz eine eindeutige Entscheidung hergibt, greift auch die gerichtliche Kontrolle Platz. Hat das Gesetz einen Beurteilungsspielraum gelassen, so hat ihn der Richter als einen Vorbehalt zugunsten der Jntscheidung der Verwaltung zu respektieren. ${ }^{8}$ ) Trotzdem bleibt die richterliche Ausfüllung unbestimmter Rechtsbegriffe eines der deutlichsten Symptome dafür, in welchem Ausmaß das Verwaltungsgeschehen von der Rechtsprechung her beherrscht wird.

bb) Die richterliche Prüfung der Gesetze

\section{aaa) Allgemeines}

Das geltende Verfassungsrecht überträgt den Gerichten nicht nur den Rechtsschutz gegenüber der. Verwaltung sondern auch die Prüfung der Verfassungsmäßigkeit der Gesetze und der Verfassungs- und Gesetzmäßigkeit der Verordnungen. Dabei dominiert die Zuständigkeit der. Verfassungsgerichte. Nach dem Grundgesetz können nur sie über die Gültigkeit eines förmlichen Gesetzes als Hauptfrage befinden. 1) Nur sie können die Verfassungsmäßig-

8) S. vor allem Bachof, Beurteilungsspielraum, Ermessen und unbestimmter Rechtsbegriff im Verwaltungsrecht, JZ 10. Jhg. (1955) S.97 ff; ders., Anm. zu BVerwG Urt. v.11.Oktober 1956 - I C 179/54 - I)VB1. 72.Jhg. (1957) S. 788 ff; Ule, Zur Anwendung unbestimmter Rechtsbegriffe im Verwaltungsrecht, in "Forschungen und Berichte aus dem öffent1ichen Recht", Gedächlnisschrift für Walter Jellinek, 1955, S. 309 ff; Jesch, a.a. (). S..165 ff; Forsthoff, Lehrbuch des Verwaltungsrechts, S. 66 f?; Wolff, a.a.O., insbes. S. $133 \mathrm{ff}$; weitere Nachweise s. bei cien Zitierten.

1) Art.93 Abs. $1 \mathrm{Nr} .2,100 \mathrm{GG}$. - Über die Gültigkeit von Bundesverordnungslecht kimnen auch Nicht-Verfassungsgerichte entscheider (BVorfGF: 1, 184). Doch gibt es derzeit keine Möglichkeit, daß übes limalesverordnungs recht durch NichtVerfassungsgerichte al: Hauptfrage entschieden würde, während das Bundesverascunssgericht nach Art.93 Abs. 1 Nr. 3 GG i.V.m. $\$ \$ 76$ if (abstrkte Normenkontrolle) BVerfGG auch über die Giiltigkeit con Verordnungsrecht als Hauptfrage befinden kann. Fü ic prüfung der Übereinstimmung von Landesverordnungsiecti mit dem Landesverfassungs recht kann das Landes(verfas sungs)recht die Zuständigkeit der Lan- 
keit nachkonstitutioneller, förmlicher Gesetze verneinen. ${ }^{2)}$ Das Bundesverfassungsgericht 1 äßt die Landesverfassungsgerichte an Kompetenz weit hinter sich; denn diese sind auf die Kontrolle innerhalb der Hierarchie des Landesrechts beschränkt. 3) Die NichtVerfassungsgerichte sind grundsätzlich auf die Inzidentprüfung der Gültigkeit von Rechtsvorschriften beschränkt, die - wie schon bemerkt - nicht zur endgültigen Verneinung der Gültigkeit nachkonstitutionellen förmlichen Gesetzesrechts führen darf (Art. 100 Abs. 1 GG).2)

Der individuelle Rechtsschutz wird durch die verfassungsrechtliche Regelung der abstrakten und konkreten Normenkontrolle (A rt. 93 Abs. $1 \mathrm{Nr} .2,100 \mathrm{Abs} .1 \mathrm{GG}$ ) etwas in den Hintergrund gedrängt. Nichtsdestoweniger besteht er auch gegenüber dem Gesetzgeber. Art. 19 Abs. 4 GG schützt auch gegen Rechtsverletzungen durch Rechtsetzungsakte. ${ }^{4)}$ Das Gesetz über das Bundesverfassungsgericht hat zudem auf der Grundlage des Art.93 Abs. 2 GG die Verfassungsbeschwerde gegen Gesetze und untergesetzliche Rechtsetzungsakte zugelassen ( $\$ 90 \mathrm{ff}$ BVerfGG). ${ }^{5)}$ Aller-

desverfassungsgerichte entsprechend Art. 100 Abs. 1 GG begründen (BVerfGE 1, 184 (210); 4, 179 (188)). Für die Prüfung untergesetzlichen Landesrechts ist ferner in $\$ 47$ VGO ein besonderes Normenkontrollverfahren vor den Oberverwaltungsgerichten (Verwaltungsgerichtshöfen) vorgesehen.

2) Zur Beschränkung der Zuständigkeit des Bundesverfassungsgerichts nach Art.100 Abs.1 GG auf nachkonstitutionelles, förmliches Gesetzes recht s. BVerfGE 1, 184; 2, 124; 4, 331.

3) Vgl. Art.93 Abs. 1 Nr.2, 100 Abs. 1 GG. - S.a. S. $553 \mathrm{zu}$ Fußn.1.

4) Vgl. Dürig in Maunz-Dürig Art.19 Abs.IV Randn.18 (Anm. III $1 \mathrm{~d}$ aa) und seine Nachweise.

5) (1) Arg. $\$ \$ 93$ Abs. 2 und 3, 95 Abs. 3 BVerfGG. - S.hierzu auch Karl Zeidler, Nachprüfung von Gesetzen im Rahmen der Verfassungsbeschwerde gem. $\$ \$ 90$ ff BVerfGG, DÖV 8. Jhg. (1955) S.335 ff.

(2) Das Nebeneinander der Verfassungsbeschwerde und der Klage nach Art. 19 Abs. 4 GG bereitet mannigfache Schwierigkeiten. Zunächst sind die Voraussetzungen nicht dieselben. A rt. 19 Abs. 4 GG schützt "alle" Rechte. Die Verfassungsbe-

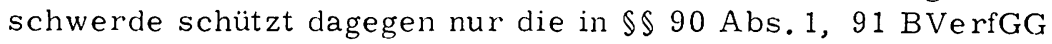
erschöpfend aufgezählten verfassungsmäßigen Rechte. Soweit sich die Voraussetzungen decken, ergibt sich die Frage nach dem Verhältnis der beiden Subsidiaritätsklauseln (A rt. 19 Abs. 4 Satz 2 GG, $₫ 90$ Abs. 2 Satz 1 BVerfGG) zueinander. Verweist Art.19 Abs.4 GG auf den "Rechtsweg" der Verfas- 
dings muß sowohl für den Rechtsschutz nach Art.19 Abs. 4 GG 6 ) wie auch für die Verfassungsbeschwerde ${ }^{7)}$ gefordert werden, daß der Rechtsschutzsuchende "selbst, gegenwärtig und unmittelbar durch das Gesetz" betroffen ist. Andernfalls kann sich der Betroffene nur gegen Vollzugsakte zur Wehr setzen, die ihm gegenüber auf Grund der rechtswidrigen Norm ergehen. Dabei wird ihm aber im Rahmen des richterlichen Prüfungsrechts gerichtlicher Rechtsschutz doch auch wieder gegenüber dem Gesetzgeber zuteil. ${ }^{8)}$

Die umfassende Kontrollkompetenz begründet eine erhebliche Mitverantwortung der (zuständigen) Gerichte für die Gesamtgestalt der Rechtsetzung. Sie bestimmen - nur dem Gesetzes- bzw. Verfassungsbefehl unterworfen - die rechtlichen Gestaltungsgren-

sungsbeschwerde oder umgekehrt $₫ 90$ Abs. 2 Satz 1 BVerfGG auf den "Rechtsweg" vor dem ordentlichen Gericht auf Grund des Art. 19 Abs. 4 GG? Mit Wernicke (Bonner Kommentar Art. 19 Anm. II 4 f) und Dürig (a.a.O. Randn. 54) sowie dem Bayerischen Verfassungsgerichtshof (Entsch. vom 16. September 1949 - Vf 26-VI-49 -, mitgeteilt bei Roemer, Die Rechtsprechung des Bayerischen Verfassungsgerichtshofs, SJZ 5. Jhg. (1950) Sp. 569 ff (473)) ist anzunehmen, daß auch die Möglichkeit, die Verfassungsgerichte anzurufen, ein Rechtsweg i.S. des Art. 19 Abs. 4 GG ist (zur Gegenmeinung s. BVerfGE 1, 333 (344 f) und v. Mangoldt-Klein, Art. 19 Anm. VII 5 b; s.a. die Angaben bei Dürig, a.a.O.). Trotzdem die Verfassungsbeschwerde am Rechtsweg des Art.19 Abs.4 GG scheitern zu lassen (so aber Dürig, a.a.O.; Bettermann, Der Schutz der Grundrechte in der ordentlichen Gerichtsbarkeit, S. 823), ist jedenfalls dann nicht vertretbar, wenn das ordentliche Gericht durch Art. 100 Abs. 1 GG gehindert wäre, die Rechtsverletzung festzustellen (s. hierzu auch Hesse, Der Rechtsschutz durch staatliche Gerichte im kirchlichen Bereich, S.90; Bettermann, a.a.O. S.789 f, 823). - Die von Dürig, a.a.O. Randn. 18 (Anm. III $1 \mathrm{~d} \mathrm{cc}$ ), angenommene Möglichkeit einer schlichten Feststellung der Rechtsverletzung ohne Feststellung der Verfassunझswidrigkeit des Gesetzes würde eine Umgehung des Art. 100 Abs.1 ( $\mathrm{G}$ G bedeuten. S. hierzu auch Strauss, Die rechtsprechende Gewalt im Bonner Grundgesetz SJZ 4.Jhg. (1949) Sp. 52.3 ff (527 unter 2).

6) Dürig, a.a.O. (Anm. III $1 \mathrm{~d} \mathrm{bb})$.

7) BVerfGE 1, $97(101 f), 208(237) ; 3,19(23), 383(392) ; 4,7$ (11); 5, 77 (81).

8) Zur Verfassungsbeschwerde im Anschluß an das gerichtliche Verfahren s. BVerfGF 9, 338. 
zen der Rechtsetzung. Das Gewicht liegt dabei durchaus bei der verfassungsgerichtlichen Prüfung der Vereinbarkeit förmlichen Gesetzesrechts mit der Verfassung. Die Bedeutung der verfassungsgerichtlichen Normenkontrolle beruht dabei vor allem auch in der Schwierigkeit, das knappe Konzentrat verfassungsrechtlicher Normensubstanz auf die Fülle der gesetzgeberischen Probleme hin zu konkretisieren. Dem Erkenntnisvermögen und den Wertvorstellungen der entscheidenden Richter kommt bei der interpretatorischen Entfaltung des Verfassungsgehaltes größte Bedeutung zu. ${ }^{9)}$ Es darf aber nicht zu einer sachlichen Hypertrophie der verfassungsgerichtlichen Normenkontrolle kommen. Die Verfassungsrechtsprechung darf nicht aus dem (vermeintlichen) Auftrag heraus handeln, von den Grunddispositionen der Verfassung her, diese interpretatorisch auffächernd und konkretisierend, die ganze unterverfassungsmäßige Rechtsordnung gestalten zu sollen. Sie muß den gestalterischen Primat des Gesetzgebers, der ihm nicht nur von der verfassungsgegründeten Funktion sondern auch von der demokratischen Autorität her zukommt, respektieren. Thre Aufgabe ist es nur, die Schranken aufzuzeigen, die der gesetzgebenden Gewalt durch die Verfassung gezo-

9) Zu diesen besonderen Problemen der Verfassungsrechtsprechung s. inbes. Kaufmann, Die Grenzen der Verfassungsgerichtsbarkeit, Veröffentlichungen der Vereinigung der Deutschen Staatsrechtslehrer, Heft 9, 1952, S.1 ff (12 ff). Wintrich, Über Eigenart und Methode verfassungsgerichtlicher Rechtsprechung, insbes. $5.228 \mathrm{ff}, 246 \mathrm{ff}$; ders., Aufgaben, Wesen, Grenzen der Verfassungsgerichtsbarkeit, in "Vom Grundgesetz zur gesamtdeutschen Verfassung", Festschrift für Hans Nawiasky, 1956, S. 191 ff; ders., Die Verfassungsgerichtsbarkeit im Gesamtgefüge der Verfassung, Bayerische Verwaltungsblätter, n.F. 2.Jhg. (1956) S.97 ff, 132 ff, insbes. S. 133 f; Scheuner, Probleme und Verantwortungen der Verfassungsgerichtsbarkeit in der Bundesrepublik, DVB1. 67.Jhg. (1952) S. 293 ff, insbes. S.295 ff; Hans Huber, Probleme des ungeschriebenen Verfassungsrechts in "Rechtsquellenprobleme im Schweizerischen Recht", Festgabe der rechts- und wirtschaftswissenschaftlichen Fakultät der Universität Bern für den Schweizerischen Juristenverein, Jahresversammlung 1955 (Band 91 bis 96 der Zeitschr. des Berni schen Juristenvereins), 1955, S.95 ff (107 ff); Forsthoff, Die Umbildung des Verfassungsgesetzes, in Festschrift für Carl Schmitt, 1959, S.35 ff (dieser besonders kritisch zur bisherigen Entwicklung der Verfassungs rechtsprechung in der Bundesrepublik). 
gen sind. 10)

bbb) Der Rechtsschutz gegenüber dem untätigen Gesetzgeber

Damit ist an eine Grenze gerührt, an die die gerichtliche Kontrolle der rechtsetzenden Gewalt immer wieder stößt. Mehr als die gerichtliche Kontrolle der Verwaltung ist sie auf das Negative beschränkt, darf sie nur sagen, was nicht hätte geschehen dürfen, und nicht, was hätte geschehen müssen. 1) Die richterliche Normprüfung ist so nahezu reiner Ausdruck des abwehrenden, freiheits- nicht teilhabesichernden Charakters rechtsstaatlicher Garantien. Während es wenig Schwierigkeiten bereitet hat, den verwaltungsgerichtlichen Rechtsschutz dem Rechtsschutzbedürfnis des (nicht mehr nur oder vorwiegend von staatlichen Eingriffen bedrohten sondern auch) auf staatliche Leistungen angewiesenen Bürgers anzupassen, ist eine analoge Um-

10) (1) S. z.B. Scheuner, Der. Bereich der Regierung, S. 281 f; Bachof, Begriff und Wesen des sozialen Rechtsstaats, S. 52 ff.

(2) Hierher gehört auch das Problem des terminologisch recht unglücklich so genannten gesetzgeberischen Ermessens. S. hierzu z. B. Forsthoff, Über Maßnahmegesetze, S.234 ff; Maunz, Deutsches Staatsrecht, S.230. Mit eingehenden Nachweisen über die Rechtsprechung des Bundesverfassungsgerichts ferner Llamann, Die Ermessensfreiheit der Gesetzgebung, NJW 8.Jhg. (1955) S.969 ff (dessen extreme, gesetzgebungsfeindliche Ansicht die Grenzen des Vertretbaren verläßt); Spanner, Bundesverfassungsgericht und freies Ermessen, Baverische V'erwaltungsblätter n. F. 4.Jhg. (1958) S. 1 ff (4); Maunz-Dürig, Aıt. 20 Randn. 117 ff.

(3) Eine starke Versuchung fiir die Verfassungsgerichte, selbst Gesetzgeber zu spielen, stellt offensichtlich das - im Prinzip zu billigencle, ja sogar sehr nützliche, dem Mißbrauch jedoch offensichtlich sehr leicht zugängliche - Instrument der verfassungskonformen Aus]cgrung dar. S. hierzu Bender, Inhalt und Grenzell des Giebuls der verfassungskonformen Auslegung, MDR 13.thg. (1959) S.441 ff; Herzog, Neue Wege der Normenkuntrollc. liaverische Verwaltungsblätter, n.F. 5. Jhg. (1959) S.276 f; je mit eingeh. Nachw.

1) S. z.B. Wintrich, Aufgaben, Wesen, Grenzen der Verfassungsgerichtsbarkeit, S.204 init weit. Nachw.; Menger, Der Schutz der Grundrechte in ler Verwaltungsgerichtsbarkeit, S. 740; Bergmann, Zwischenbilanz der verwaltungsgerichtlichen abstrakten Normenkontrolle, Verwaltungsarchiv $\mathrm{Bd} .51$ (1960) \$. 36 ff (57 f) mit weit. Nachw. 
stellung der Normenkontrolle nicht möglich. Es gibt keine Vornahme- oder Leistungsklage gegen der Gesetzgeber. ${ }^{2)}$ Lediglich die (nicht vollstreckbare) Feststellung ist möglich, daß der Gesetzgeber eine Regelung der Verfassung zuwider unterlassen hat. 3) Wie sollte eine Vornahmeklage gegenüber dem Gesetzgeber auch vollstreckt werden können? ${ }^{4)}$

Doch diese Frage greift nicht auf den Grund des Problems. Die unüberwindliche Schwierigkeit besteht darin, daß Verfassung und Gesetz gleicherweise allgemeine Normen enthalten. Gesetz und Verwaltungsakt bzw. Richterspruch stehen sich anders gegenüber als die allgemeine Norm und ihre Verwirklichung im konkreten Einzelfall. Das Gesetz kann das, was im einzelnen Fall zu geschehen hat, durch Gestaltung des Tatbestandes und Ordnung der Rechtsfolgen so endgültig bestimmen, daß aus ihm entnommen

2) Vgl. BVerfGE 1, 97; Württ. -Bad. VGH Urt. v.18. Juli 1952 3 K 39/52 - DÖV 6. Jhg. (1953) S.639 (640); HessStGH Besch1. v. 29. Oktober 1954 - PSt 183 - (zit. bei Lesser, Rechtsprechung des Hessischen Staatsgerichtshofes, JZ 11.Jhg. (1956) S. 157 ff (157)); Dürig in Maunz-Dürig, A rt. 1 Abs. III, Randn. 95 Fußn. 5, Art. 19 Abs. IV Randn. 18 (Anm. III $1 \mathrm{~d}$ dd); Maunz ebd. Randn. 119 Fußn. 7; Lechner-Wintrich, Die Verfassungsgerichtsbarkeit in Bettermann-Nipperdey-Scheuner, Die Grundrechte, Bd. III, 2. Halbbd. 1959, S. 643 ff (685).

3) (1) BVerfGE 6, 257 (263 ff); 8, 1 (9 f), 28 (35); BayVerfGH VGHE n. F. 11 II 203 (213); Lechner-Wintrich, a.a.O.

(2) S. zu Vorstehendem auch Wessel, Die Rechtsprechung des Bundesverfassungsgerichts zur Verfassungsbeschwerde, DVB1. 67. Jhg. (1952) S. 161 ff (164); Lechner, Bundesverfassungsgerichtsgesetz, 1954, $₫ 90$ Abs. 1 Anm.2; ders., Das Gesetz zur Änderung des Gesetzes über das Bundesverfassungsgericht, 1957, \$90 Anm.2a; ders., Zur Zulässigkeit der Verfassungsbeschwerde gegen Unterlassungen des Gesetzgebers, NJW.8.Jhg. (1955) S. 1817 ff; Ipsen, Die Verfassungsbeschwerde in der Praxis, 1959, S. $11 \mathrm{ff}$.

4) S. a. oben S. 396 ff, insbes. zu Fußn. 22. Das Bundesverfassungsgericht hat zwar gem. $₫ 35$ BVerfGG die Vollstreckung seiner Entscheidungen selbst zu regeln. Das kann aber nicht etwa bedeuten, daß es eine Regelung, die der Gesetzgeber treffen muß, an seiner Stelle treffen oder ein anderes Staatsorgan zur Ersatzvornahme ermächtigen kann. Die allgemeine Regelungsgrundlage des Art.94 Abs.2 GG könnte den einfachen Bundesgesetzgeber nicht berechtigen, in $₫ 35$ BVerfGG eine Regelung zu treffen, die das verfassungsmäßige Kompetenzsystem aus den Grundfesten heben könnte. 
werden kann, wozu die vollziehende Behörde verpflichtet ist. Würde dagegen die Verfassung einen Gegenstand gesetzlicher Regelung mit solcher Präzision vorzeichnen, daß schon aus ihr genau entnommen werden könnte, wie der Gesetzgeber zu verfügen hat (und daß er gar nicht anders verfügen kann), so hätte die Verfassung eben diesen Gegenstand selbst schon geregelt. Verwaltung und Rechtsprechung bräuchten keine Bedenken tragen, diese Regelung zu verwirklichen. Hätte die Verfassung trotz der eigenen hinreichenden Regelung die zusätzliche Dezision dem Gesetzgeber vorbehalten, so würde das nur bedeuten, daß der Gesetzgeber - und niemand sonst - über das Inkrafttreten der Regelung zu disponieren hat. Läßt die Verfassung dagegen sachlich Raum für die. gesetzgeberische Gestaltung, hat sie also die Regelung noch nicht erschöpfend vorgezeichnet, so ist es nach der Natur der Sache unmöglich, aus der Verfassung heraus zu entwickeln, wie die zu treffende Regelung positiv aussehen muß. Dieses Verhältnis ist nicht anders zwischen dem Gesetz und der untergesetzlichen Rechtsetzung.

Regelungsaufträge $m$ üssen auf diese Weise ohne durchgreifende Sanktion bleiben. Darin zeigt sich eindringlich, in welchem Maß sich die Leistungsseite der sozialen Intervention des Staates der rechtsstaatlichen Bindung entzieht. Der Rechtsschutz gegenüber dem eingreifenden Gesetzgeber ist gewährleistet. Der Rechtsschutz gegenüber dem Gesetzgeber, der Leistungen (genere11) anordnen soll, bleibt im Deklamatorischen stecken. 5)

5) (1) BVerfGE 6, 257 (266): Die Entscheidung des Bundesverfassungsgerichts, die die Verfassungswidrigkeit einer gesetzgeberischen Unterlassung (nur) feststellt, "bleibt deshalb gleichwohl nicht eine rein theoretische Deklaration. Von jeher hat man auch bei F'eststellungsklagen im Zivilprozeßverfahren gegen den Staat das Feststellungsinteresse in besonders weitgehendem Maße bejaht in der Erkenntnis, daß der Staat sich einer von seinen Gerichten festgestellten Rechtspflicht nicht entziehen werde (...). Im verfassungsgerichtlichen Verfahren, das ohmehin wegen der beschränkten Vollstreckungsmöglichkeiten lie loyale Zusammenarbeit der verschiedenen staatlichen Gewalten geradezu voraussetzt, darf angenommen werden, daß diese 'moralische' Wirkung auf den Gesetzgeber dem Spruch des höchsten und gerade zur Auslegung der Verfassung berufenen Gerichts in erhöhtem Maße zukommen wird". Zur rechtlichen Ineffizienz der Feststellung s. insbes. BVerfGF 8, 28 (35), S.a. Maunz, a.a.O. (2) Einen gewissen Anreiz kann es dem Gesetzgeber bieten, wenn das Verfassungsgelicht ihn hindert, eine Teilregelung, 
Aber von wem, unter welchen Voraussetzungen und in welchem Verfahren kann dieser coupierte Rechtsschutz überhaupt in Anspruch genommen werden? Das allgemeine Instrument wäre die Klage aus Art. 19 Abs. 4 GG. Sie ist auch gegen den Gesetzgeber gegeben, wenn dieser in individuelle Rechte eingreift. 6) Aber wann wird jemand durch ein Unterlassen des Gesetzgebers in seinen Rechten verletzt? 7) Das ist die entscheidende Frage auch für die Verfassungsbeschwerde zum Bundesverfassungsgericht, die der Klage nach Art.19 Abs. 4 GG vorgeht, soweit eine Verletzung der Grundrechte des Grundgesetzes und der sonstigen in $\$ 90$ Abs. 1 BVerfGG genannten verfassungsmäßigen Rechte gerügt wird. ${ }^{8)}$ Fest steht, daß kein potentieller Petent einen dirckten Anspruch gegen den Gesetzgeber auf dessen Tätigwerden an sich hat. Immer kann es nur ein Recht auf das vom Gesetzgeber auf Grund des Verfassungsbefehls zu Gewährende geben. Nur der, dem die gesetzgeberische Unterlassung vorenthält, was die Verfassung ihm gewährt wissen will, kann durch diese Unterlassung in seinen Rechten verletzt sein. Fin allgemeiner, unbestimmter oder nicht hinreichend verbindlich gemeinter ${ }^{9)}$ Rege-

die der Gesetzgeber gerne treffen möchte (bzw. schon getroffen hat), zu treffen, solange er nicht die damit verbundene Regelung, die er (auch) treffen müßte aber nicht treffen will, erläßt (s. dazu z.B. BVerfGE 6, 257 (266)). Unternimmt es der Gesetzgeber trotzdem, unter Verletzung des Gleichheitssatzes nur eine Teilregelung zu treffen (vgl. Ipsen, Gleichheit, S.160 f), so liegt eine sog. "relative Unterlassung" vor (s. die oben S. $558 \mathrm{zu} \mathrm{Fußn.3} \mathrm{(2)} \mathrm{Zitierten).}$

6) S. nochmals oben S.554 zu Fußn. 4 und den Text hierzu.

7) S. a. Bettermann, Der Schutz der Grundrechte in der ordentlichen Gerichtsbarkeit, S. 797.

8) S. nochmals oben $\$ .554$ zu Fußn. 5 und den 'Text hierzu.

9) Diese Unverbindlichkeit kann auch darin zum Ausdruck kommen, daß den dem Regelungsauftrag entsprechenden Chancen der potentiell Begünstigten der Charakter des Rechts bzw. der rechtlichen Anwartschaft abgesprochen wird. Die Verfassung selbst kann - ohne ihre rechtsstaatlichen Maximen preiszugeben freilich nur in Grenzen - sich selbst von dem in Art. 19 Abs. 4 GG manifestierten allgemeinen Rechtsschutzprinzip, das, wie dargetan, auf objektiven Sachverhalten aufbaut, dispensieren und somit objektivrechtlichen Sätzen, die die Individualsphäre in einer Weise gestalten, daß sie vom Gesetzgeber getroffen als "Rechte" (i.S. des Art. 19 Abs. 4 GG) anzusehen wären, diesen Charakter vorenthalten. 
lungsauftrag, von dem nicht feststeht, daß die zu treffende Regelung auch den Kläger begünstigen muß und wird, kann diesen nicht legitimieren. Ein solcher Regelungsauftrag gestaltet noch nicht seine Individualsphäre. Fr stellt keine rechtliche Beziehung zwischen dem Unterlassen des Gesetzgebers und dem Rechtskreis des Klägers her. F.s gibt Regelungsaufträge, die mit einem Recht der zu Begünstigenden Hand in Iland gehen. Art. 33 Abs. 5 GG i. V. $\mathrm{m}$. dem Alimentationsanspruch der Beamten ${ }^{10)}$ ist ein Beispiel dafür. Aber der Raum, in dem sie Platz greifen können, ist sehr schmal. Ist die Verfassung in ihrer Regelung hinreichend bestimmt und definitiv, d.h. ohne einen Vorbehalt zugunsten der Frmessensentscheidung des Gesetzgebers, so kann sie unmittelbar vollzogen werden und die Notwendigkeit, gegen den Gesetzgeber vorzugehen, entfällt. Ist die verfassungsrechtliche Regelung dagegen zu unbestimmt, so scheitert hieran die Legitimation des Klägers. 11)

Allerdings kann eine besondere Konstellation auch hier noch zu einer anspruchsähnlichen Position führen. Vor allem der Gleichheitsgrundsatz erweist hierbei seine (auch) teilhabeverschaffende Wirkung. 12) Erfüllt der Gesetzgeber einen ihm erteilten, verbindlich gemeinten Regelungsauftrag unter willkürlicher Differenzierung nur teilweise, so gewinnt vermittels des Gleichheitsgrundsatzes der Kreis der willkürlich Ausgeschlossenen mit einem Mal auch sub specie des Regelungsauftrages Profil. Das wegen Verletzung des Gleichheitsgrundsatzes angegangene Verfassungsgericht steht vor der. Alternative, die Gleichheit durch Beseitigung der getroffenen loilregelung herzustellen oder dem Gesetzgeber eine sachlich zu rechtfertigende Erweiterung bzw. Neuabgrenzung des betroffenen Porsonenkreises aufzugeben. Vor allem die Achtung vor de?n Rerselungsauftrag kann letzteres - d. h. die feststellung des Verbokes - als die verfassungsadäquate Lösung erscheinen lassen. 1:3) Doch unterscheidet sich dieses l'roblem der relativen (Interlassung des Gesetzgebers 14) in

10) S. BVerfGE 8, $1(11$ :f), 23, (35). - BVerfGE 8, 210 (216), Dürig (Maunz-I) üris, A.t. 1 Abs. II Randn.95 Fußn. 5) und Maunz (ebd. Art.20 Randr. 119) halten auch Art.6 Abs. 5 GG für einen in dieser. Wrise hrchsetzbaren Regelungsauftrag (s. hierzu noch unten S.1013 lf).

11) S. a. Maunz, a.a.().

12) S. zum Folgenden Ipsen, Gleichheit, S. 160.

13) S. BVerfGE 6, 25: (263 f1); 8, 1 (9 f); BayVerfGH VGHE n. F. 11 II 203 (213).

14) S. die oben S.5.5 a Fußn. 3 (2) und S.559 zu Fußn. 5 (2) Zitierten. 
Struktur und Auswirkungen deutlich von dem hier wesentlicheren der absoluten Unterlassung.

In welchem Umfang das Grundgesetz Regelungsaufträge enthält, aus denen heraus individuelle Rechte auf ein 'Tätigwerden des $\mathrm{Ge}-$ setzgebers abgeleitet werden könnten, ist hier nicht im einzelnen zu untersuchen. 15) Fest scheint zu stehen, daß das Grundgesetz außerhalb des Geltungsbereiches des $₫ 90$ Abs. 1 BVerfGG solche Rechte nicht zu gewähren beabsichtigt. Für den wichtigsten und umfassendsten Regelungsauftrag, das Sozialstaatsprinzip,wird das unten 16) noch darzutun sein. Somit dürfte die ungute Alternative, daß die gerichtliche Feststellung der Verfassungswidrigkeit eines gesetzgeberischen Unterlassens nicht durch das mit der Verfassungsbeschwerde angegangene Bundesverfassungsgericht sondern durch ein ordentliches Gericht auf der Grundlage des Art.19 Abs. 4 GG getroffen würde, vermieden sein.

\section{cc) Richterliche Kontrolle der Rechtsprechung}

Anzumerken ist schließlich, daß ein individueller Rechtsschutz durch Gerichte gegen Akte der Gerichte im Grundgesetz, insbes. auch in Art. 19 Abs. 4 GG, nicht verbürgt ist. 1) Das Gesetz über das Bundesverfassungsgericht hat allerdings auf der Grundlage des Art.93 Abs. 2 GG die Verfassungsbeschwerde ( $\$ \$ 90$ ff BVerf GG) auch gegen gerichtliche Entscheidungen zugelassen. 2) Die Grundrechte des Grundgesetzes und die sonstigen in den $\$ \$ 90$ Abs. 1, 91 BVerfGG genannten Rechte sind daher auch gegen Verletzungen durch Gerichtsentscheidungen geschützt. ${ }^{3)}$ Desgleichen können Landesverfassungsgerichte die Einhaltung der Grund-

15) S. hierzu S. 561 zu Fußn. 10; ferner unten Abschnitt 6 I 3 (S. $848 \mathrm{ff}$ ).

16) S. unten Abschnitt 5 II 2 b und c (S. $714 \mathrm{ff})$.

1) Art. 19 Abs. 4 GG versteht unter "öffentlicher Gewalt" nicht auch die Rechtsprechung (vgl. v. Mangoldt-Klein, Art.19 Anm. VII 2 c; Dürig in Maunz-Dürig, Art. 19 Abs. IV Randn. 17 (Anm. III $1 \mathrm{c}$ ); je mit eingeh. Nachw.).

2) Arg. $\$ \$ 90$ Abs. 2, 93 Abs. 1, 95 Abs. 2 BVerfGG.

3) Das Bundesverfassungsgericht wird dadurch immer der versuchung nahe gebracht, als Superrevisionsinstanz zu agieren. Die Fragen der Gesetzmäßigkeit und der Verfassungsmäßigkeit der angefochtenen gerichtlichen Entscheidungen sind häufig eng ineinander verflochten (vor allem seit Art. 2 Abs. 1 GG vom Bundesverfassungsgericht selbst primär als ein Grundrecht auf Freiheit von ungesetzlichen Beschränkungen und Belastungen gehandhabt wird (BVerfGE 6, 32 (36 ff); 7, 111 (115); 
rechte der Landesverfassung durch die sonstigen Gerichte des Landes kontrollieren ( $\$ 90$ Abs. 3 BVerfGG). ${ }^{4}$ )

Anders als der individuelle Rechtsschutz gegen gerichtliche Entscheidungen ist die objektive Kontrolle der Richter auf die Verfassungsmäßigkeit ihres Verhaltens im Grundgesetz selbst verankert. Sie steht dem Bundesverfassungsgericht zu. 5) Das Bundesverfassungsgericht ist also der oberste Hüter der Verfassung auch gegenüber der rechtsprechenden Gewalt. Bei ihm allerdings wird die Frage "Quis custodiet custodes?" nicht mehr weiter gefragt. ${ }^{6)}$

9, $3(11))$ - jedoch auch im Zusammenhang etwa mit dem Gleichheitsgrundsatz u.a.m.). Man kann nicht sagen, daß das Bundesverfassungsgericht der Versuchung, zu weit vorzudringen, immer widerstanden hat. Im Grundsatz hat es sich jedoch mit Glück bemüht, die Balance zwischen einem wirksamen $G$ rundrechtsschutz und der notwendigen Reserve gegenüber einer allgemeinen Gesetzmäßigkeitskontrolle zu halten (vgl. BVerfGE 1, 4 (5), 5 (6 f), 9, 82 (85), 418 (420, 428 f); 2, 121 (122), 336 (339); 3, 213 (219 f); 4, 1 (6 f), 52 (58); 5, $13(20) ; 6,7(10) ; 19(20), 32(43) ; 7,55(56))$. Für den bayerischen Verfassungsgerichtshof kann das gleiche gesagt werden (vgl. VGHE n. F. 1 II 101 (106); 2 II 9 (13 f); 3 II 11 (14); 5 II 273 (277); 7 II 1 (3 f), 66 (67 f)).

4) Soweit die Landesgerichte - wie in der Regel - auf Grund Bundesrechts tätig werden, ist die Kontrolle allerdings nur beschränkt möglich. Vgl. BayVerfGH VGHE n.F. 7 II 66 (68 f); 11 II 11 (22 f), 90 (94 f); 12 II 165 (165 f). S. schon früher VGHE n.F. 1 II 101 (108): 2 II 9 (13 f). Für eine noch engere Kompetenzabgrenzung s. z. I3. Roemer, Zur Rechtsprechung des Bayer. Verfassungsperichtshofes, SJZ 4. Jhg. (1949) Sp. $184 \mathrm{ff}(188)$ und 5. Jhe. (1950) Sp. 569 ff (572 f).

5) Art.98 Abs.2 und 5) ( $\mathrm{G}$. 'u heachten ist vor allem, daß dem Bundesverfassungsperich: labei auch der Schutz der verfassungsmäßigen Ordnung des L andes übertragen ist (ebd. Abs. 2 Satz 1). Vor allem ist $\cdots$ r: Interesse, daß das Anklagerecht gegenüber Bundesrichtern dem Bundestag zusteht (ebd.), der durch die vorgeschriebeno Z weidrittelmajorität allerdings stark gehemmt ist (s.hirzuz.B. Werner Weber, Spannungen und Kräfte im wrestcetschen Verfassungssystem, S.99 f). Die Länder werden im l:ahmen des Art.98 Abs. 5 Satz 1 GG nicht umhin können, eben:alls eine qualifizierte Mehrheit für die Anklage vorzuschreibon (s.a. die Nachw. bei Weber, a. a. O. S. 100).

6) Das Bundesverfassungsforicht hat sich von absolut ungeeig- 
Immer wieder ist das Augenmerk auf die Verfassungsgerichtsbarkeit gelenkt. Sie ist nicht als eine bestimmte rechtsprechende Funktion angesprochen, sondern rein pragmatisch als der $\mathrm{Zu}$ ständigkeitskreis, der nach der Verfassung den besonderen Verfassungsgerichten vorbehalten ist bzw. (durch den Gesetzgeber) übertragen werden kann. 1) Diese Zuständigkeiten aber, so vielfältig sie im einzelnen sind, haben doch ein Zentrum: Die Verfassungsunmittelbarkeit - die Verfassungsunmittelbarkeit des Gerichts selbst, das vor allem auf Grund der Verfassung zu entscheiden hat; die Verfassungsunmittelbarkeit der wichtigsten Staatsfunktionen, über deren rechtmäßige Ausübung es zu richten hat; und die Verfassungsunmittelbarkeit der Verfahrensbeteiliglen in den meisten der wichtigeren Verfahrensarten. 2) Die Verfassungsgerichte bestimmen letztlich, was als Verfassungs recht gilt. Nur der Verfassungsgeber selbst kann sie bindend eines anderen belehren. 3 )

Entsprechend der bundesstaatlichen Struktur des Gesamtstaatswesens und dem Nebeneinander von Bundes- und Landesverfassungsrecht bestehen in der Bundesrepublik auch Bundes- und Landesverfassungsgerichtsbarkeit nebeneinander. Die Landesverfassungsgerichtsbarkeit ist auf den innerstaatlichen Bereich der Länder beschränkt und wirkt kaum darüber hinaus in die zentralstaatliche oder gesamt-bundesstaatliche Sphäre ein. ${ }^{4)}$ Die

neten oder illegitimen Elementen selbst zu reinigen: $₫ 105$ BVerfGG.

1) Diesen Begriff der Verfassungsgerichtsbarkeit s.a. bei Maunz, Deutsches Staatsrecht, S.219; Friesenhahn, Art. "Verfassungsgerichtsbarkeit" im Handwörterbuch der Sozialwissenschaften, 29. Lieferung (1960), S. 82 ff (83).

2) S. zu diesem Grundgedanken etwa Jahrreiß, Verfassungsrechtsprechung und Verfassungsgericht (in Mensch und Staat) S. $137 \mathrm{ff}, 16 \mathrm{ff}$.

3) S. hierzu auch oben c bb (S.553 ff).

4) S. auch die vorsichtige Einschränkung des Art.100 Abs. 3 GG. - Im übrigen s. zur Verfassungsgerichtsbarkeit in den Ländern den umfassenden Bericht von Bachof-Jesch, Die Rechtsprechung der Landesverfassungsgerichte in der Bundesrepublik Deutschland, Jahrbuch des öffentlichen Rechts, n. F. Bd.6 (1957) S. 47 ff. Zum Verhältnis von Bundes- und Landesverfassungsgerichtsbarkeit s. insbes, auch Geiger, Die Bundesverfassungsgerichtsbarkeit in ihrem Verhältnis zur Landesverfassungsgerichtsbarkeit und ihre Einwirkung 
Verfassungsgerichtsbarkeit des Bundes dagegen greift über das zentralstaatliche Verfassungsleben hinaus, erstreckt sich auf das Bund-Länderverhältnis und im Vollzug des Grundgesetzes als (auch) gesamtstaatlicher Verfassung unmittelbar in das Verassungsleben der Länder hinein. Das Bundesverfassungsgericht ist letztentscheidender 'l'räger der Interpretation und der rechtliahen Entfaltung der grundgesetzlichen Ordnung. Es ist nicht nöig, hier über das oben schon Erwähnte hinaus darüber zu berichen, in welchen Verfahrensarten, unter welchen Beteiligten usw. sich das vollzieht. 5) Doch ist es, obwohl eine Generalklausel der verfassungsgerichtlichen Zuständigkeit fehlt, ${ }^{6}$ ) wohl nicht zu kühn, zu behaupten, daß alles, was als rechtlich verbindlicher Gehalt des Grundgesetzes in Anspruch genommen wird, auf irgend eine Weise zur Entscheidung des Bundesverfassungsgerichts gelangen kann.

Die Verfassungsgerichte sind so auch hochpotenzierte Mittler zwischen dem unmittelbar oder mittelbar sozial gezielten oder sozial relevanten abstrakt-rechtlichen Gehalt der Verfassung(en) and der Verfassungswirklichkeit. Was jenseits von aller rein akademischen, interpretatorischen Spekulation in der Realität des Verfassungsvollzugs als verfassungsmäßige Ordnung der sozialen Intervention anerkannt werden muß, hängt entscheidend davon ab, was das Bunclesverfassungsgericht und der Landesver-

auf die Verfassungsordnung der Länder, in "Verfassung und Verwaltung", Festschrift für Wilhelm Laforet 1952, S. $251 \mathrm{ff}$.

j) S. die Gesamidarstellung der bundesverfassungsgerichtlichen Zuständigkeit bei Lechner-Wintrich, Die Verfassungsgerichtsbarkeit, in Bettermann-Nipperdey-Scheuner, Die Grundrechte, Bd. III, 2. Halhbd. 1959, S.643 ff; Maunz, Deutsches Staatsrecht, \$.216 ff; s. ferner die speziellere Darstellung von Maunz, Die Bedellung des Bundesverfassungsgerichts für clas Arbeits- und sozialrecht, Recht der Arbeit 4. Jhg. (1950) S. $161 \mathrm{ff}$. - Zur Entscheidungspraxis des Bundesverfassungsgerichts $\therefore$. dif Berichte: Federer, Die Rechtsprechung des Bumber verfassungsgerichts zum Grundgesetz für die Bunclesrepublik Deutischland, Jahrbuch des öffentlichen Rechts, n.l. Bd.:3 (19.34) S.15 ff; Bernhard Wolff, Die Rechtsprechung des Bundesverfassungsgerichts von 1954 1957, Jahrbuch des öffentlichen Rechts, n.F. Bd. 7 (1958) S.108 ff. - Fingehende bibliographische Nachweise s. bei den Genannten.

i) Vg1. Art.93 GG i.V.m. \$ 13 BVerfGG. - S. a. Zacher, Ratifizierungsgesetz und Normenkontrolle, DVBl. 70.Jhg. (1955) S. $649 \mathrm{ff}, 696 \mathrm{f}(649)$. 
fassungsgerichtshof als solche erkennen und durchsetzen. ${ }^{7)}$

Die sozialgestalterischen Schwächen der Verfassung 8$)$ sind allerdings auch die Schwächen der Verfassungsgerichtsbarkeit. Die Grenzen des verfassungsgerichtlichen Auftrags sind dabei nicht immer evident. Auch dort, wo die Verfassung rechtlich verbindlich sein will, ist sie, um knapp und elastisch zu sein oder auch aus Gründen des politischen Kompromisses oder der psychologischen Schlagkraft juristisch unbrauchbarer Formeln wegen, oft vage und schwer verständlich. ${ }^{9}$ ) Hieraus ergeben sich ganz wesentlich die spezifische Macht und Verantwortung der Verfassungsgerichte 10) - auch für die soziale Ordnung.

e) Die verfassungsmäßige Konzeption der Struktur der sonstigen Gerichtsbarkeit

aa) Die fünf Säulen der (Nichtverfassungs-)Gerichtsbarkeit

\section{aaa) Die Grundlagen}

So bedeutsam die Verfassungsgerichtsbarkeit ist - den Rechtsalltag der richterlichen sozialen Intervention und des richterlichen Rechtsschutzes gegenüber der sozialen Intervention des Staates beherrschen die "sonstigen" Gerichte. Für ihre Struktur ist - abgesehen von den allgemeinen Vorschriften über die Unabhängigkeit des Richters (Art.97 f GG) ${ }^{1}$ ) und über die bundesstaatliche Aufteilung der rechtsprechenden Gewalt (Art.92, 95, 96, 98, 99 GG) ${ }^{2}$

7) Geiger, Einige Probleme der Bundesverfassungsgerichtsbarkeit, DÖV 5.Jhg. (1952) S.481 ff (482): "Die Entwicklung unserer Verfassung (...), der letztlich entscheidende Einfluß auf das Wollen und Können der übrigen Verfassungsorgane und die Begrenzung ihrer Zuständigkeiten und Macht liegt in der Hand des Bundesverfassungsgerichts". - S. hierzu auch die erfreulich offene Deduktion bei Jahrreiß, Verfassungsrechtsprechung und Verfassungsgericht, S. 155: "Die berühmte Frage: 'Wer hat zu entscheiden?' ... birgt in sich auch dies: 'Wer soll verbindlich irren dürfen?"

8) S. oben S.396 und II $3 \mathrm{c} \mathrm{bb}$ (S.553 ff).

9) S. zu Vorstehendem auch Wintrich, Aufgaben, Wesen, Grenzen der Verfassungsgerichtsbarkeit, S.209; ders., Die Verfassungsgerichtsbarkeit im Gesamtgefüge der Verfassung, S. $133 \mathrm{f}$.

10) S. auch oben c bb (S. 553 ff), insbes. S. $556 \mathrm{f} \mathrm{zu} \mathrm{Fußn.9}$ und 10.

1) S. a. unten III $2(\mathrm{~S} .637 \mathrm{ff})$.

2) S. oben S. $170 \mathrm{ff}$. 
vor allem die fünfgliedrige Anlage wesentlich, die in der Aufzählung der oberen Bundesgerichte in Art.96 Abs. 1 GG vorgezeichnet ist. Diese verfassungsrechtliche Fünfgliederung ist eine Originalität des Grundgesetzes. Art. 96 Abs. 1 GG wurde nicht von Anfang an klar im Sinne einer Fünfteilung interpretiert. Vielfach wurde angenommen, es seien nur vier obere Bundesgerichte zu errichten, darunter eines für die Arbeits- und Sozialgerichtsbarkeit. 3) Diese allzusehr am Wortlaut haftende Auffassung wurde von der Staatspraxis, die fünf obere Bundesgerichte - unter ihnen getrennt das Bundesarbeits- und das Bundessozialge-

3) (1) Kern, Die Rechtsprechung, DÖV 2.Jhg. (1949) S. $330 \mathrm{ff}$ (331); Zinn, Die Rechtsprechung, DÖV 2.Jhg. (1949) S.278 ff (280); ders., Die Rechtspflege im Bonner Grundgesetz, Verhandlungen des 37. Deutschen Juristentags, 1950, S. 46 ff $(65 \mathrm{f})$; Bachof, Verwaltungsgerichtsbarkeit und Justiz unter besonderer Berücksichtigung des Bonner Grundgesetzes, SJZ 5.Jhg. (1950) Sp. $161 \mathrm{ff}, 488 \mathrm{ff}$ (162); ders., Gedanken über die künftige Stellung der Verwaltungsgerichtsbarkeit, DRZ 5.Jhg. (1950) S. 169 ff (169); Holtkotten, Bonner Kommentar, Art.96 Anm. II A 1a; Giese, Grundgesetz (bis zur 3. Auf1.1953) Art.96 Anm.4; Koellreutter, Deutsches Staatsrecht, S. 244; v. Mangoldt, Das Bonner Grundgesetz (1.Aufl.) Art.96 Anm.3. - A.A. Maunz, Die oberste sozialrechtliche Gerichtsbarkeit nach dem Bonner Grundgesetz, Versicherungswissenschaft/Versicherungspraxis/Versicherungsmedizin, 4.Jhg. (1950) S.113 ff (insbes. S. 115 ff); Teutsch, Das künftige obere Bundesgericht für die Sozialgerichtsbarkeit, Recht der Arbeit, 3. Jhg. (1950) S.254 ff (256 f); ders., Die Sozialgerichtsbarkeit und die allgemeine Verwaltungsgerichtsbarkeit DÖV 3.Jhg. (1950) S. 168 ff (170); Miesbach, Gestaltung der Gerichtsbarkeit für Arbeitsrecht, Sozialversicherung und Kriegsopferversorgung, Deutsche Versicherungszeitschr. 5.Jhg. (1951) S.228 ff (228); ders., Das Bundessozialgericht, Bayerjche Verwaltungsblätter, n.F. 5. Jhg. (1959) S.233 ff, 272 ff (233); Scheuner, Die Selbständigkeit und Einheit der Rechtspflege, DÖV 6.Jhg. (1953) S. 517 ff (521); Giese, Grundgesetz (4.Auf1. 1955) Art.96 Anm.5; Dersch-Volkmar, A rbeits,gerichtsgesetz, 6. Auf1. 1955, $₫ 40$ Anm. 3 .

(2) v. Brünneck, Die Verwaltungsgerichtsbarkeit im Verhältnis zur Arbeitsverwaltung und Sozialversicherung, Betriebsberater, 4.Jhg. (1949) s.619 f (620) hielt es für möglich, die Sozialgerichtsbarkeit cier Arbeits- oder der allgemeinen Verwaltungsgerichtsbarkeit zuzuschlagen. 
richt - schuf, desavouiert. 4) Obwohl es verfassungsrechtlich nicht notwendig gewesen wäre, unter diesen fünf oberen Bundesgerichten fünf selbständige Gerichtszweige aufzubauen, 5) war rechtspolitisch gesehen - mit dem Bekenntnis zur Fünfgliederung der letztinstanzlich entscheidenden Bundesgerichtsbarkeit auch die Losung für eine entsprechende Entwicklung der Landesgerichtsbarkeit ausgegeben. Auf diese Weise geht das selbständige Nebeneinander der ordentlichen (allgemeinen) Verwaltungs-, Finanz-, Sozial- und Arbeitsgerichtsbarkeit auf die Verfassung zurück. 6)

bbb) Die besondere Sozialgerichtsbarkeit

Die Aufgabe der (besonderen) Sozialgerichtsbarkeit, die hier schon ihres Namens wegen im Vordergrund des Interesses steht, konnte von vorneherein nicht darin bestehen, alle Rechtsprechungs- und Rechtsschutzaufgaben von sozialer Bedeutung wahrzunehmen. 1) Obwohl der Gesetzgeber bei der Abgrenzung der Zuständigkeitsbereiche nur an gewisse evidente Mindestprogramme

4) Desavouiert jedenfalls im Hinblick auf die h. M., die in der Aufzählung des Art.96 Abs.1 GG das Maximum der oberen Bundesgerichte sieht, die der Gesetzgeber errichten darf: Kern, a.a.O. S.331; Zinn, Die Rechtsprechung, S.280; ders. Die Rechtspflege nach dem Bonner Grundgesetz, S. 66; Holtkotten, a.a.O. Anm. II A 1 a und 2; v. Mangoldt, a.a.O. Anm. 3; Giese, Grundgesetz (5.Auf1.) Art.96 Anm. 5; Hamann, Grundgesetz, Art.96 Anm.A/B. - A.A. Maunz, Deutsches Staatsrecht, S. 214.

5) Vg1. Hellmuth Loening, Die Verwaltungsgerichtsbarkeit im Bonner Grundgesetz, DÖV 2. Jhg. (1949) S.324 ff (324);

Bachof, Gedanken über die künftige Stellung der Verwaltungsgerichtsbarkeit, S. 169; Holtkotten, Bonner Kommentar, Art. 96 Anm. II A 4; Scheuner, a.a.O. S. 521 ; Hamann, Vereinheitlichung der Gerichtsbarkeit, DVB1. 70.Jhg. (1955) S.205 ff (206); ders., Grundgesetz Art.96 Anm. A/B. - Für die Finanzgerichtsbarkeit s. aber Art. 108 Abs. 5 GG. Allgemein für die Notwendigkeit eines entsprechend den oberen Bundesgerichten gegliederten Unterbaues: Schewe, Ist eine Vereinheitlichung der Gerichtsbarkeiten verfassungsrechtlich zulässig? Zeitschrift für Sozialreform 3. Jhg. (1957) S. $241 \mathrm{f}$.

6) S. a. Baur, Empfiehlt es sich, die verschiedenen $Z$ weige der Rechtsprechung ganz oder teilweise zusammenzufassen? Verhandlungen des 42. Deutschen Juristentages, Bd. I, 2. Teil, 1957, S. 28.

1) S. Sellmann, Die Zuständigkeitsabgrenzung zwischen den all- 
yebunden ist, weitgehend freie Hand hat, ${ }^{2)}$ war an eine derartise, an einem einzigen, noch dazu begrifflich so unsicheren Krierium orientierte Zuständigkeitsverteilung nicht zu denken. Sie ätte ein Konglomerat heterogener Funktionen in die Hände der jozialgerichte gelegt. Sie wäre vor allem auch nicht mit dem Neseneinander von Arbeits- und Sozialgerichtsbarkeit zu vereinbaen gewesen. Von der ordentlichen Gerichtsbarkeit hätte sie nur zinen Torso übrig gelassen. Trotzdem wäre eine überzeugende tbgrenzung weder zur ordentlichen noch zur allgemeinen Verwalungs- oder zur Finanzgerichtsbarkeit möglich gewesen.

Es mußte also einen engeren, "handfesteren" Begriff der Sozialge richtsbarkeit geben. Für die Arbeitsgerichtsbarkeit gab is einen analogen Anhaltspunkt in der Geschichte dieses Gerichtszweiges. ${ }^{3)}$ Für die Sozialgerichtsbarkeit deuteten die traditionelen Zeichen prima facie auf eine organisatorische Verselbständisung der rechtsprechenden Versicherungsbehörden. In der Tradiion des Reichsversicherungsamtes war von vorneherein die überzeugendste Stütze für die Gestaltgabe des oberen Bundesgerichts ler Sozialgerichtsbarkeit zu sehen. ${ }^{4)}$ Doch dürfte nicht Sozialge-ichtsbarkeit $=$ Sozialversicherungsgerichtsbarkeit ${ }^{5}$ ) gesetzt

gemeinen Verwaltungsgerichten und den Sozialgerichten, DVB1. 71.Jhg. (1956) S. 118 ff, 154 ff (119) mit weit. Nachw. ?) Vgl. Teutsch, a.a.O. S. $255 \mathrm{f}$; Holtkotten, Bonner Kommentar, Art.96 Anm. II A 1 b; Koellreutter, a.a.O. S.244; Hamann, a.a.O.; BVerwGE 1, 21 (24f); 6, 86 (92 f); s.a. v. Brünneck, a.a.O. S. 620 .

3) Zur Geschichte der Arbeitsgerichtsbarkeit s. z.B. Götz Hueck in Hueck-Nipperdey, Lehrbuch des A rbeitsrechts, Bd. I, S. 809 ff.

t) Vgl. Maunz, Die oberste sozialrechtliche Gerichtsbarkeit nach dem Bonner Grundgesetz; Teutsch, a.a.O.; s.a. Schewe, Zur Abgrenzung der Verwaltungs- und Sozialgerichtsbarkeit, Die Sozialgerichtsbarkeit, 1.Jhg. (1954) S. 133 ff (133); ders., Ist eine Vereinheitlichung der Gerichtsbarkeiten verfassungsrechtlich zulässig? S.242. Zum Traditionszusammenhang s. z. B. auch Joseph Schneider, Die Entwicklung des Rechtsschutzes in der Sozialversicherung, in "Sozialpolitik, Arbeits- und Sozialrecht", Festschrift für Friedrich Sitzler, 1956 , S. $329 \mathrm{ff}$.

"Sozialversicherung" in diesem Sinne schließt, das muß außer Zweifel gesetzt werden, die A rbeitslosenversicherung ein. Auch sie gehörte - in einem besonderen Spruchverfahren - zur Zuständigkeit der früheren Versicherungsbehörden $(\$ \$ 30 \mathrm{f}$ A VA VG v. 16. Juli 1927 (RGBl. I S. 187). 
werden. Für eine einheitliche Arbeits- und Sozialgerichtsbarkeit wäre diese Beschränkung erträglich - wohl sogar notwendig gewesen. Als gemeinsamer Nenner wäre der Schutz des abhängig erwerbstätigen Menschen anzusehen gewesen, dessen sozialer Sicherheit die Sozialversicherung auch heute noch im wesentlichen dient.6) Aber eine selbständige Sozi a 1 gerichtsbarkeit mußte auf eine breitere Spur gesetzt werden. Schon die subjektive Vorstellung des Grundgesetzgebers fügte der Zuständigkeit für das Sozialversicherungsrecht noch diejenige für das Versorgungswesen hinzu, so die Sozialgerichtsbarkeit auch als Nachfolgeinstitution der ohnedies mit den Oberversicherungsämtern und dem Reichsversicherungsamt organisatorisch verbunden gewesenen Versorgungsgerichtsbarkeit ${ }^{7)}$ denkend. ${ }^{8)}$ Doch die Interpretation des Art.96 Abs. 1 GG kann nicht bei dem historischen Anknüpfungspunkt der Versicherungsbehörden und der Versorgungsgerichte stehen bleiben sondern muß das der allgemeinen Fassung des Verfassungswortlauts gemäße allgemeine Prinzip aufsuchen.9)

6) Weidner (Zur Rechtsprechung des Bundessozialgerichts, S. $699 \mathrm{ff})$ geht bei seiner positiven Bewertung eines einheitlichen oberen Bundesgerichts für A rbeits- und Sozialgerichtsbarkeit von dieser Konzeption aus. Allerdings verdunkelt er selbst die Zusammenhänge, indem er die "soziale" (im Gegensatz zur "arbeitsrechtlichen") Seite gelegentlich über das Sozialversicherungs recht (einschließlich Arbeitslosenversicherung) hinaus ausdehnt. Aber seine Argumentation fußt auf der Beschränkung auf das Arbeits- und Sozialversicherungsrecht. Auch seine Beispielsfälle für die schädliche Wirkung der Existenz je eines Bundesarbeits- und Bundessozialgerichts (a.a.O. S. 701) beziehen sich nur auf diese beiden Rechtsgebiete. - Im Sinne Weidners auch Dersch, Wechselwirkungen zwischen Sozialversicherung und Arbeitsrecht in der neueren Entwicklung, in "Gegenwartsfragen sozialer Versicherung", Schriften der Hochschule für Arbeit, Politik und Wirtschaft, Wilhelmshafen-Rüstersiel, 1950, S.33 ff, insbes. S. 65 .

7) S. hierzu z.B. Peters-Sautter-Wolff, Kommentar zur Sozialge richtsbarkeit, $₫ 1$ SGG Anm. 1.

8) Vgl. Doemming-Füsslein-Matz, Die Entstehungsgeschichte der Artikel des Grundgesetzes, S. 707; s.a. Schewe, a.a.O. (S.569 zu Fußn.4).

9) Vgl. Schewe, a.a.O. (durchgehend). Gegen zu weite Ausdehnung über den subjektiv-historischen Kern hinaus: Sellmann, Zur Zuständigkeitsverteilung $z$ wischen den allgemeinen Verwaltungsgerichten und den Sozialgerichten, S. 119. 
Unqualifizierbar ist der Vorschlag, das Zuständigkeitsprinzip er Sozialgerichtsbarkeit im Dienst an "dem höheren Ziele soialer Gerechtigkeit" zu sehen. 10) Dieser aus sozialrichterliher Nabelschau erwachsene Gedanke verkennt, in welchem Maße s Sache aller Gerichtszweige ist, "soziale Gerechtigkeit" zu ben. 11)

Nicht weniger unbegründet ist es, den maßgeblichen Grundsatz ozialgerichtlicher Kompetenz darin zu finden, daß sich im soialgerichtlichen Verfahren "die Parteien in einem Verhältnis geenüberstehen, das man schlechthin als Geben und Nehmen im inne eines Austausches von Leistung und Gegenleistung betrachen muß". 12) Als ob nicht der ordentliche Richter derjenige wäre, er geradezu klassischerweise über Streitigkeiten um "Austausch on Leistung und Gegenleistung" zu entscheiden hätte! Aber was ollen auch Leistung und Gegenleistung sein? Als Leistung wird er Sozialversicherungsbeitrag ebenso gedacht wie das Opfer an eben und Gesundheit (sei es, daß dieses in der Unfallversicheung oder in der Kriegsopferversorgung relevant wird); als Geenleistung gelten Rente, Heilfürsorge usw. Welch traurige und nüberlegte Vorstellung eines "Austausches von Leistung und Geenleistung" ! Und selbst wenn man einschränkend hinzufügen woll, daß dieser "Austausch" immer über die öffentliche Hand vor ich gehen soll, kann darin kein brauchbares Abgrenzungsprinzip esehen werden. Auch der Streit um den Lastenausgleich, um Entignungs- oder Aufopferungsentschädigung, auch der Gebührentreit usw. ist nicht weniger ein Streit um "Leistung und Gegeneistung", dem zudem nicht selten ein deutlicher Bezug zu "soialer Gerechtigkeit" zukommt. Sollte für all das der Sozialrichr zuständig sein? So kann die Verfassung nicht interpretiert erden.

0) So Grömig, Die Zulässighkeit der Klage nach $₫ 54$ SGG, NJW 7.Jhg. (1954) s.1183 ff (insbes. S.1185).

1) Gegen Grömig (s. auch das Folgende) auch Werner, Allgemeine Verwaltungsgerichtsbarkeit und Sozialgerichtsbarkeit; Sellmann, Verwaltungsgerichtsbarkeit und Sozialgerichtsbarkeit, NJW 10.Jhg. (1957) \$. $1091 \mathrm{ff}$. - Zur sozialen Aufgabe aller, nicht nur der Sozialge richte s. ferner Hedemann, Was ist sozial? Der A rbeitgeler 1956, S. 198 ff (200).

2) Grömig, a.a.(). instes. S.1183. - Auf der gleichen Grundlage will Richter (Neuf Rf.chtsformen für das Leistungsverwaltungsrechi, NJW 11.Jhg. (1958) S.1518 ff (1518)) den Begriff der "Leistungsvervaltung" aufbauen. 
Mehr besticht aufs erste der Vorschlag, die Sozialgerichtsbarkeit als verwaltungsgerichtliche Entsprechung zur Leistungsverwaltung anzusehen. ${ }^{13)}$ Ist die Sozialgerichtsbarkeit nicht sogar d a s Pendant der anderen Sonder-Verwaltungsgerichtsbarkeit, der Finanzgerichtsbarkeit? Wird im Zuständigkeitsbereich der Finanzgerichtsbarkeit nicht das Geld eingenommen, das in der von der Sozialgerichtsbarkeit kontrollierten Sozialverwaltung aus gegeben wird? Jedoch auch die Versuchung dieser wohltuend sym metrischen Konstruktion muß zurückgewiesen werden. Sie vernachlässigt zu sehr das Nebeneinander der Sozial- und der allgemeinen Verwaltungsgerichtsbarkeit (ebenso wie dieser und der $F$ nanzgerichtsbarkeit). Die allgemeine Verwaltungsgerichtsbarkeit ist immer der Leistungs- und der Eingriffsverwaltung zugeord net. Nie ist alle Leistungsverwaltung "sozial", so daß der auf sic bezügliche Gerichtsschutz in der Sozialgerichtsbarkeit aufgehen könnte; nie ist aller Eingriff ein steuerlicher, so daß er nur der Judikatur der Finanzgerichte unterliegen könnte (deren steuerrechtliche Position durch Name und systematische Einordnung A rt. 108 Abs. 5 GG - außer Frage steht). Aber es ist schon nicht richtig anzunehmen, Sozialgerichtsbarkeit wäre ein Korrelat reiner Leistungsverwaltung. Ihr Kernbereich, die Sozialversicherung, kennt auch Eingriff und Zwang. Der Pflichtbeitrag, der nicht weniger zur sozialgerichtlichen Zuständigkeit gehören muß wie die Versicherungsleistung, ist Ausdruck des gesetzlichen Zwangs zur solidarischen Selbst- bzw. Fremdvorsorge der Versicherten und ihrer A rbeitnehmer. Nur der Zuschuß zur Sozialve sicherung, nur der Aufwand der Kriegsopferversorgung usw. kon men aus dem allgemeinen "Topf", der durch den steuerlichen Ein griff, der im Zuständigkeitsraum des sonderverwaltungsgerichtli chen Pendants der Sozialgerichtsbarkeit, der Finanzgerichtsbarkeit, belegen ist, gespeist wird. Die Umverteilung über die Hilfs fisci der Versicherungsträger usw. liegt dagegen im Zuständigkeitsbereich der Sozialgerichtsbarkeit.

Sicherer als diese Erwägungen führen Name und historisches Substrat der "Sozialgerichtsbarkeit" (i.S. des Art.96 GG) selbst auf den gemeinsamen Nenner des Gesetzeswortlautes und der gesetzgeberischen Vorstellung zu. 14) "Sozial"/Versicherung"/"Ver

13) Vgl. Ule, Empfiehlt es sich, die verschiedenen Zweige der Rechtsprechung ganz oder teilweise zusammenzufassen? Verhandlungen des 42. Deutschen Juristentages (1957), 1958, S. E 3 ff (E $34 \mathrm{f})$.

14) S. a. Schewe, Zur Abgrenzung von Verwaltungs- und Sozialgerichtsbarkeit, ders., Ist eine Vereinheitlichung der Gerichtsbarkeiten verfassungsrechtlich zulässig? S. 242 . 
sorgung" - die Ebene, auf dos sich diese Begriffe treffen, ist die "soziale Sicherheit" im techischen Sinn. 15) Hier in erster Linie liegt das Ausdehnungsfeld ler Sozialgerichtsbarkeit. 16) Eine weitere Stufe der Verallgemeinerung führt an ihre äußersten Grenzen: Sozialgerichtsbarkeit ist individueller Rechtsschutz gegen Vorenthaltungen (unmittelbar) sozial zweckhafter Maßnahmen des Staates (einschließlich der ihm inkorporierten Verwaltungsträger) und die Entscheidung sonstiger damit zusammenhängender (öffentlichrechtlicher) Streitigkeiten.17) Das ist der um die Sozialversicherung als Mittelpunkt zu schlagende Kreis von Angelegenheiten, in dem ohne strenge verfassungsrechtliche Bindung der Gesetzgeber die Zuständigkeit der Sozialgerichtsbarkeit gestalten kann.

Das Sozialgerichtsgesetz hat die Angelegenheiten der Sozialversicherung einschließlich der. Arbeitslosenversicherung ganz den Sozialgerichten zugewiesen (\$ 51 Abs. 1 und Abs. 2 Satz 1

15) S. hierzu nochmals Weisser, Art. "Soziale Sicherheit" im Handwörterbuch der Suzialwissenschaften.

16) In etwa im Ergebnis übereinstimmend Miesbach (Die Gestaltung der Gerichtsbarkeit für. A rbeitsrecht, Sozialversicherung und Kriegsopferversorgung, S.228), Kraegeloh, Begriff und Gegenstand der Sozialgerichtsbarkeit, Der Betrieb, 5. Jhg. (1952) S. $534 \mathrm{f}$ und Schewe (a.a.O.), wenn sie den möglichen Zuständigkeitsbereich der Sozialgerichte mit Sozialversicherung, (Kriegsopfer-) Versorgung und Fürsorge umschreiben. Miesbach stïtit sich dabei auf das interessante, in Fortsetzung der Relationen Reichsversicherungsamt - Zuständigkeit des Bundessozialgerichts für Sozialversicherung und Reichsversorgungsgericht - Zuständigkeit des Bundessozialgerichts für die Kriegsipferversorgung auch nicht inkonsequente, im Ilinblick auf die besondere Funktion und Bedeutung des ehemaligen Bundersamts für das Heimatwesen jedoch nicht gleicherweise ïhr.'.ngende Argument, das Bundessozialgericht könne als Iritte ehemalige Sondergerichtsbarkeit auf sozialem lielle auch dic fürsorgerechtliche Gerichtsbarkeit des früheren Bundessarrts für das Heimatwesen absorbieren. Hier wird der Anknïpfungspunkt der ehemaligen sozialen Sondergerichtsbarkeiten in ler Bedeutung wohl übertrieben gesehen.

17) In diesem Sinne auch liohwer-Kahlmann, Einheit der rechtsprechenden Gewalt oder rigenständige Sozialgerichtsbarkeit, Zeitschrift für sozialveforn, 3.Jhg. (1957) S.163 ff (163). 
SGG). 18) Darüber hinaus hat es auch den weiteren Kreis der sozialen Sicherheit in ihren Zuständigkeitsbereich einbezogen. Angelegenheiten der öffentlichen Fürsorge klammert es allerdings ängstlich aus (s. $₫ 51$ Abs. 2 Satz 2 SGG). Nur die infolge des Bedürftigkeitsvorbehaltes ihr sehr nahe kommende Arbeitslosenhilfe ( $\$ 144$ ff AVAVG) fällt als eine sonstige Angelegenheit der Bundesanstalt für Arbeitsvermittlung und Arbeitslosenversicherung in den Zuständigkeitskreis der Sozialgerichtsbarkeit ( $\$ 51$ Abs. 1 SGG). Deutlicher als in bezug auf die Arbeitslosenhilfe, breitet die Sozialgerichtsbarkeit sich mit der Zuständigkeit für die Krieg.

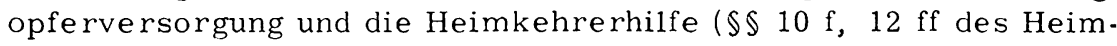
kehrergesetzes) in den Bereich staatlicher (Sonder)Versorgung hinein aus ( $\$ 51$ Abs. 1 SGG). 19) Ähnliches gilt für die Zuständigkeit in Sachen des Kindergeldgesetzes ( $\$ 51$ Abs. 3 SGG i.V.m. $\$ 28$ des Kindergeldgesetzes). 20) Dagegen liegt der Rechtsschutz in bezug auf die "übrigen Aufgaben der Bundesanstalt für Arbeitsvermittlung und Arbeitslosenversicherung" ( $\$ 51$ Abs. 1 SGG) 21) zum Teil außerhalb des engeren Bereichs der sozialen Sicherheit im weiteren Bereich der sozialen Intervention. 22)

Damit ist zwar das Minimum denkbarer sozialgerichtlicher Zuständigkeit 23) überschritten. Das Maximum ist jedoch längst nicht erreicht. So ist es nach Anerkennung eines Anspruches auf öffentliche Fürsorge nicht mehr verständlich, warum das Fürsorgerecht von der Sozialgerichtsbarkeit so peinlich ferngehalten

18) Die Zuständigkeit für Angelegenheiten des Gesetzes über die Unfallfürsorge für Gefangene ( $\$ 205$ SGG) ist als ein Anhängsel zur (sozialversicherungsrechtlichen) Zuständigkeit für Angelegenheiten der Unfallfürsorge zu betrachten.

19) Die Heimkehrerhilfe fällt über die Klausel "der übrigen Aufgaben der Bundesanstalt für Arbeitsvermittlung und Arbeitslosenversicherung" unter die Zuständigkeit der Sozialgerichte

20) Dabei mag auch der organisatorische Zusammenhang des Voll zugs des Kindergeldgesetzes mit der (sozialen) Unfallversicherung motivierend gewirkt haben.

21) Zu diesen Zuständigkeiten s. z.B. Peters-Sautter-Wolff, Kommentar zur Sozialgerichtsbarkeit, $\$ 51 \mathrm{Anm} .10 \mathrm{~d}$.

22) Zu den sonstigen Zuständigkeiten der Sozialgerichte - s. den Vorbehalt des $₫ 51$ Abs. 3 SGG - vgl. die Zusammenstellung ebd. Anm. 11.

23) Nach Schewe (Zur Abgrenzung von Verwaltungs- und Sozialgerichtsbarkeit, S. 135 f) und Sellmann (Zur Zuständigkeitsabgrenzung zwischen den allgemeinen Verwaltungsgerichten und den Sozialgerichten, S. 119): Sozialversicherungs- und Kriegsopferversorgungsangelegenheiten. 
wird. 24) Die Kriegsopferversorgung weist, als Anknüpfungsounkt, weiter auf das Lastenausgleichs- und das Vertriebenenrecht - oder wenigstens auf die darin vorgesehenen versorgungsähnlichen Leistungen - hin.

ccc) Die Bedeutung der Verfassungsentscheidung für eine spezialisierte Gerichtsbarkeit

Indem die Verfassung eine eigene Arbeits- und Sozialgerichtsbarreit erlaubt, ja sogar angeregt hat, hat sie der Bedeutung der sozialen Aufgaben des Richters einen sinnfälligen Ausdruck gegeben. Er ist allerdings insofern irreführend, als er den Eindruck erwecken kann, die sozial bedeutsamen oder wenigstens die zweckhaft sozialen Zuständigkeiten der rechtsprechenden Gewalt seien in diesen beiclen Gerichtszweigen konzentriert, wenn nicht gar erschöpfend vereinigt. Von der Basis der Erkenntnis aus, daß das nicht der Fall sein kann, und daß also ein erheblicher, insgesamt mindestens ebenbürtiger Anteil der sozialbezüglichen Funktion der Rechtsprechung bei den übrigen Gerichtszweigen liegt, zeigt sich das Ausmaß dieser Wirksamkeit des Richters erst ganz.

Wichtige $\mathrm{r}$ als diese optische Dokumentation ist die sachliche Bedeutung der Eigenständigkeit einer eigenen Arbeitsgerichtsbarkeit und einer besonderen Sozialgerichtsbarkeit neben der ordentlichen Gerichtsbarkeit, der allgemeinen Verwaltungsgerichtsbarkeit und der Finanzgerichtsbarkeit. Die letzten Jahre haben eine umfassende Diskussion über Wert und Unwert der Trennung verschiedener Gerichtszweige und ihrer Unterstellung unter die Aufsicht jeweils verschiedener Ressortminister gebracht. ${ }^{1)}$ Sie soll

24) Zur Zulässigkeit der Hereimnahme der Fürsorge in den Zuständigkeitsbereich der Sozialgerichte s. Miesbach, Kraegeloh und Schewe, a.o. (S.57: zu Fußn. 16) a.O.

1) Die Diskussion aus der Zeit vor dem 42. Deutschen Juristentag in Düsseldurf, 1957, Ker als Höhepunkt des Meinungsstreites angesehen werden kann, findet sich in dem Gutachten von Baur, Empfiehlt es sich, die verschiedenen Zweige der Rechtsprechung ganz oder teilweise zusammenzufassen? S. ferner die Referate zu diesem Thema von Ule (Verhandlungen des 42. Deutschen Juristentages, 1958, S. E 3 ff) und Herbert Arndt (ebd. S. F. 4\% ff) sowie die Debatte (ebd. S. E $65 \mathrm{ff}$ ). Auf diese ( $u e l l e n$ muß zum älteren Streitstand verwiesen werden. Für die Zeit nach dem 42. Deutschen Juristentag s. vor allem llerner Weber, Die Einheit der rechtsprechenden Gewalt, Zeitschrift für Sozialreform, 3.Jhg. (1957) 
hier nicht e rneut aufgerollt werden. Sicher ist, daß das System des - rein ohnedies nicht durchführbaren - Einheitsgerichts und des einheitlichen Gerichtsministeriums genau so Licht und Schatten aufweist wie das getrennter Gerichtszweige und Aufsichtsressorts. Sonderung gibt die Möglichkeit größter Anpassung an die Eigenart der Materie, auf die sich die Zuständigkeit erstreckt: Anpassung bei der Auswahl der Richter und Spezialistentum des nur in dieser Sparte tätigen Richters, angemessene spezifische Gestaltung der Gerichtsorganisation und des Verfahrens. Die organisatorische Verselbständigung gibt den Richtern einer besonderen Gericht sbarkeit auch vermehrt das Selbstbewußtsein und die Kraft, die Eigentümlichkeit des ihnen anvertrauten Lebensund Rechtsbereiches zu durchdenken und die ihr angemessenen spezifischen Rechtsgrundsätze zu entwickeln. Andererseits liegt das Risiko der übertriebenen Spezialisierung nahe. Der Richterspezialist gerät in die Gefahr unbewußter oder resignierter Beschränktheit, die schließlich seine Leistungsfähigkeit auch auf dem Spezialgebiet beeinträchtigen wird. Die übermäßige Verfolgung des Speziellen führt zur Zersplitterung. Die Gesamtzusammenhänge des materiellen und des Verfahrensrechts drohen vom Gesetzgeber und vom Richter vernachlässigt zu werden. Der speziellere Gerichtsapparat ist endlich einem stärkeren Einflußstreben der politischen Kräfte ausgesetzt, die gerade an seine $r$ Rechtsprechung interessiert sind. In einer einheitlichen oder wenigstens umfassenderen Gerichtsbarkeit laufen dagegen zu viele Interessen zusammen und wird eine gezielte Einflußnahme auf die jeweils zuständigen Unterabteilungen durch deren Vielfalt gehemmt. Wer die Verhältnisse kennt, kann nicht leugnen, daß an dem Wort von der "Hausgerichtsbarkeit" ein wahrer Kern ist. Nicht weniger ist der Zusammenhang zwischen dem Einfluß der

S. 109 ff; ders., Zur. Problematik des Rechtsprechungsministeriums, DVB1. 72.Jhg. (1957) S. $737 \mathrm{ff}$; ders., Spannungen und Kräfte im westdeutschen Verfassungssystem, S. 116 ff; Galperin, Die Vereinheitlichung der Gerichtsbarkeit und die Gerichte für Arbeitssachen, Zeitschrift für Sozialreform, 3.Jhg. (1957) S. 133 ff; Laube, Die Vereinheitlichung der Gerichtsbarkeit und die Gerichte der Sozialgerichtsbarkeit, das. S. 161 f; Rohwer-Kahlmann, Einheit der rechtsprechenden Gewalt oder einheitliche Sozialgerichtsbarkeit?; Hermann Reuss, Die Dritte Gewalt - Einheit oder Differenzierung in der Organisation der Rechtspflege, JR Jhg. 1957 S. 321 ff; Friederichs, Ressortvereinheitlichung - Allzuständiges Gericht, NJW 10. Jhg. (1957) S. 1344 ff. Weitere Nachweise s. bei den Zitierten und auch zum folgenden Text. 
Verbände und der organisatorischen Absonderung der die jeweils "organisierten" Interessen abhandelnden Gerichtsbarkeiten notorisch. 2)

Die Verselbständigung der Arbeitsgerichtsbarkeit und der Sozialgerichtsbarkeit unter der Herrschaft des Grundgesetzes hat die Vor- und Nachteile einer extremen Spezialisierung bereits deutlich werden lassen. ${ }^{3)}$ Der. Rechtsschutz ist durch den Einsatz spezialisierter Richter rationalisiert und somit verbessert. Gerichtsorganisation und Verfahren konnten ungehemmt den besonderen Bedürfnissen angeglichen werden. ${ }^{4)}$ Das Selbstbewußtsein der neuen oberen Bundesgerichte hat sie eine Rechtsprechung entfalten lassen, die an Eigenständigkeit nichts zu wünschen übrig 1äßt. Erkauft wurde das mit einer schlimmen Zerklüftung des Rechts der Gerichtsorganisation und des gerichtlichen Verfahrens der verschiedenen Gerichtszweige. ${ }^{5)}$ Den an der Arbeits- und Sozialge richtsbarkeit interessierten Verbänden wurde intensivster Einfluß zugestanden. ${ }^{6)}$ Den Ressortministern blieb - wenigstens

2) S. a. oben S. 532 zu FuRn. 36 und 37.

3) Positiv würdigend insbes. Molitor, A rbeitsrecht und Gerichtszuständigkeit, in "Sozialpolitik und Sozialrecht", Festschrift für Friedrich Sitzler, 1956, S. 303 ff; Reuss, Zwei Jahre Sozialgerichtsbarkeit, Betriebsberater, 11.Jhg. (1956) S. 660 ff; Galperin, Die Vereinheitlichung der Gerichtsbarkeit und die Gerichte für Arbeitssachen; ders., Die Arbeitsgerichtsbarkeit als besondere Gerichtsbarkeit, Die Betriebsverfassung, Jhg.4(1957) \$. 81 ff; Laube, Die Vereinheitlichung der Gerichtsbarkeit und die Gerichte der Sozialgerichtsbarkeit; Rohwer-Kahlmann, Einheit der rechtsprechenden Gewalt oder eigenständige Sozialgerichtsbarkeit; Gerhard Müller, Die Selbständigkeit der einz'lnen Gerichtszweige, insbes. der A rbeits- und Sozialgerichtsbarkeit, Die Betriebsverfassung, 3.Jhg. (1956) \$. 199 t. Negativ (insbes. die selbständige Sozialgerichtsbarkeit) wür(igend insbes. Friederichs, Zwei Jahre Sozialge richtsbarkot, Betriebsberater, 11. Jhg. (1956) S. 276 ff, 662 f. S. die Genannten und ihre Nachweise auch zum Folgenden.

4) Damit soll nicht gesagt werden, daß die getroffenen Sonderregelungen immer notwendig oder sonstwie gerechtfertigt waren.

5) S. hierzu z.B. Lengler, Die Einheit der rechtsprechenden Gewalt als prozeßrechtliches Problem, JZ 12.Jhg. (1957) S. 79 ff; Bettermann, Notwendigkeit, Möglichkeiten und Grenzen einer Angleichung der deutschen Verfahrensordnungen, Zeitschrift für Zivilprozeß, Bd.70 (1957) S. $161 \mathrm{ff}$.

6) s. oben Abschnitt 3 , III 3 d (S.360 ff). 
potentiell - die Dienstaufsicht und maßgebliche Teilnahme an der Richterwahl 7) erhalten, ${ }^{8)}$ obwohl sie die Politik, insbes. die Ge-

7) Zur Frage des Zusammenhangs zwischen Sachressort und Zuständigkeit zur Gerichtsverwaltung und Richterwahl s. Gerhard Müller, Kritische Gedanken zur Forderung nach der Einheit der Rechtspflege, S. $315 \mathrm{f}$.

8) (1) Damit ist in erster Linie gemeint, daß durch die Trennung der Gerichtszweige überhaupt erst einmal die Voraussetzung für eine getrennte Dienstaufsicht usw. geschaffen ist. Natürlich können auch getrennte Gerichtszweige einem einheitlichen "Rechtsprechungsministerium" oder dergleichen unter stellt werden. Aber es ist umgekehrt undenkbar, daß eine einheitliche Gerichtsbarkeit ( $\mathrm{zu}$ realen Teilen) verschiedenen Ministerien untersteht.

(2) Im Bund ist der zuständige Minister der Bundesminister für A rbeit und Sozialordnung ( $\$ 38$ Abs. 3 SGG; $₫ 40$ Abs. 2 A rbGG). Ihm steht auch die Mitwirkung bei der Richterwahl gem. Art. 95 Abs. 3, 96 Abs. 2 Satz 1 GG i.V.m. dem Richterwahlgesetz zu (zur indirekten Mitwirkung des Gesamtkabinetts s. $\$ 15$ Abs. 2 lit. b der Geschäftsordnung der Bundesregierung). (Dabei ist beachtlich, daß nach bisheriger Übung der Richterwahlausschuß nicht mitwirkt, wenn ein Bundesrichter zum Senatspräsidenten (oder Präsidenten) eines oberen Bundesgerichts befördert wird. In diesem Falle folgt der Vorgang ausschließlich den Regeln der Art. 60 Abs. 1 und 3, 58 GG.).

(3) Hinsichtlich der Arbeitsgerichte und Landesarbeitsgerichte bestimmt das Arbeitsgerichtsgesetz ( $\$ \$ 14 \mathrm{ff}, 33 \mathrm{ff}, \mathrm{s}$. insbes. $\$ \$ 15,34)$, daß die Dienstaufsicht, Richterernennung usw. bei der obersten Arbeitsbehörde des Landes liegt, die regelmäßig des Einvernehmens der Landesjustizverwaltung bedarf. Über die Verfassungsmäßigkeit dieser Vorschrift herrscht Streit (vgl. Baur, Ist der Bundesgesetzgeber befugt, eine Vorschrift darüber zu treffen, daß Landesgerichte einem bestimmten Landesminister unterstellt werden? Deutsche Richterzeitung, 34.Jhg. (1956) S. 119 ff).

(4) Das Sozialgerichtsgesetz hat hinsichtlich der Sozialgerichte und Landessozialgerichte nicht in gleicher Weise verbindlich definiert sondern der Landesregierung die Bestimmung der zuständigen Behörde überlassen ( $\$ \$ 7 \mathrm{ff}, 28$ ff SGG). Regelmäßig sind - kraft Landesrechts - die Landesarbeits- bzw. - sozialminister zuständig. Eine Zusammenstellung des einschlägigen Landesrechts s. z. B. bei Peters-Sautter-Wolff, Kommentar zur Sozialgerichtsbarkeit, Bd.II. 
setzgebungspolitik, in den fraglichen Rechtsgebieten maßgeblich bestimmen und ihnen die Leitung bzw. Aufsicht über die von den Sozialgerichten kontrollierte Verwaltung zusteht, $\left.{ }^{9}\right)$ so daß die Versuchung, die Rechtsprechung entsprechend zu lenken, als solche nicht ausgeschlossen werden kann.

Die Problematik findet eine Parallele in der Finanzgerichtsbarkeit. Nur ist dort ein vergleichbarer Einfluß organisierter Interessen weder begehrt noch eingeräumt worden und vielleicht auch gar nicht denkbar.

Die ordentliche Gerichtsbarkeit und die allgemeine Verwaltungsgerichtsbarkeit sind vor extremen Einseitigkeiten bewahrt. Die allgemeine Verwaltungsgerichtsbarkeit ist zwar, wenn sie nicht

9) Es ist eine zu begriffliche Operation, zuerst den Terminus "Hausgerichtsbarkeit" auf die Fälle zu spezialisieren, in denen ein Gerichtszweig ausschließlich oder doch überwiegend über Verwaltungsakte zu befinden hat, die von eben dem Minister bzw. der ihm nachgeordneten Verwaltung erlassen wurden, der auch für die "Verwaltung" des fraglichen Gerichtszweiges zuständig ist, um dann der Arbeitsgerichtsbarkeit den Charakter der "Hausgerichtsbarkeit" zur Gänze, der Sozialgerichtsbarkeit jedenfalls hinsichtlich der verwaltungsgerichtlichen Kontrolle der rechtsfähigen Verwaltungseinheiten abzusprechen (vgl. Süsterhenn, Einheitliches Gerichtsministerium? DVB1. 71.Jhg. (1956) S. $737 \mathrm{ff}$ (742 f); U1e, Empfiehlt es sich, die verschiedenen Zweige der Rechtsprechung ganz oder teilweise zusammenzufassen? S. E 8 f; ähnlich für die Arbeitsgerichtsbarkeit Herrschel, Rationalisierung des Rechts, insbes. des Arbeitsrechts, in "Sozialpolitik", A rbeitsund Sozialrecht", Festschrift für Friedrich Sitzler, 1956, S. $287 \mathrm{ff}(289)$ ). Die lahingehende Auffassung unterschätzt, vorausgesetzt, daß sie mit der Nichtanwendung des Epitheton "Hausgerichtsbarkeit" jeden Verdacht auch entfernter Einflußnahme negielen will, sowhl die Gesamtverantwortung als auch die eigengesetzliche Dynamik der Regierungsressorts. Hinsichtlich der Sozialversicherung wird zudem die Aufsichtsverantwortung für den Gesetzesvollzug durch die Sozialversicherungsträger vernachlässigt (zu diesen Zusammenhängen realistischer: BSGF: 2, $201(207 \mathrm{f})$; s. hierzu auch Weidner, Zur Rechtsprechung des Eundessozialgerichts, S. 764). - Damit soll nicht vertuscht werden, daß der Konflikt am stärksten ist, wo über Klagen unmittelbar gegen den aufsichtsführenden Minister bzw. die seiner uneingeschränkten Verantwortung unterliegende $V \in$ rwaltung zu entscheiden ist. 
einem reinen Rechtsprechungs-(Justiz-) Ministerium unterstellt ist, in einem gewissen Maß immer "Hausgerichtsbarkeit" des aufsichtsführenden Ministers. ${ }^{10)}$ Doch verläuft sich der geringe Einfluß, den der für die Verwaltungsgerichtsbarkeit zuständige Minister auf sie nehmen kann, im Volumen ihrer reich differenzierten Aufgabenbereiche. Bei der ordentlichen Gerichtsbarkeit tritt dieses Problem ohnedies in den Hintergrund. 11) Der Einfluß organisierter Interessen ist hier wie dort die Ausnahme. Das Laienelement - stark zurückgedrängt - repräsentiert in der Regel den Sachverstand oder, noch allgemeiner, Volksmeinung und "gesunden Menschenverstand". Der Richter ist grundsätzlich als durch den ganzen Aufgabenbereich hindurch austauschbar gedacht. Trotzdem kann man nichts weniger sagen, als daß diese beiden Gerichtszweige ihre Aufgabe nicht gemeistert hätten. Der Rechtsschutz ist gewiß nicht weniger perfekt, die Rechtsfortbildung wird nicht weniger sachkundig und energisch angepackt als bei den Sondergerichten.

Das läßt nun aber nicht den Schlußzu, die Rechtsprechung wäre bei einem Einheitsgericht am besten aufgehoben. Den Richter, der die Aufgabengebiete aller fünf Gerichtszweige gleich gut beherrscht, so daß er ohne wesentlichen Zeitverlust für die Neueinarbeitung zwischen allen verschiedenen Zuständigkeitsparteien des Einheitsgerichts ausgetauscht werden könnte, gibt es als Durchschnittstyp nicht. Der ordentliche Richter, der wohl die viel fältigsten Aufgaben zu bewältigen hat, wäre dessen nicht mächtig, wenn er zudem noch das spezielle Wissen des Verwaltungsrichters, des Sozialrichters, des Finanzrichters und des Arbeitsrichters haben müßte. Eine Einheitsgerichtsbarkeit müßte den Universalrichter entweder fingieren und damit die Qualität der Rechtsprechung absinken lassen oder doch wieder gewisse Schranken aufrichten. In diesem Fall würde aber auch wieder der Ressorteinfluß bei der Auswahl der Berufsrichter (Nachwuchs aus den verschiedenen Verwaltungszweigen) wirksam werden. Sind einmal Schranken aufgerichtet, so würden sich auf die Brennpunkte des organisierten Interesses abermals die Augen der Verbände richten. Sie würden sich Sonderkammern und dergleichen aus dem

10) Aber auch ein Rechtsprechungsministerium würde hinsichtlich der sog. Justizverwaltung wohl der Kontrolle der "eigenen" Gerichte unterliegen, wie gegenwärtig die Justizministerien der kontrolle der ordentlichen Gerichte ( $\$ \$ 23$ ff EGGVG). Desgleichen kann auch die Übertragung der Dienstaufsicht auf den Ministerpräsidenten die Kollision nicht völlig ausschlieBen.

11) S. aber das zu Fußn. 10 Bemerkte. 
Block heraus"keilen". Eine gewisse Sonderung ist auch im Verfahrensrecht unerläßlich. Die ordentliche Gerichtsbarkeit, die in sich neben den drei kardinalen Verfahrenstypen, dem Zivilprozeß, dem Strafprozeß und der freiwilligen Gerichtsbarkeit noch viele Sonderverfahren ( $z$. B. das Verfahren in Landwirtschaftssachen, in Kartellsachen, das Verfahren der Mieteinigungsämter usw.) aufgenommen hat, 12) ist der Beweis dafür, daß der materielle Zuständigkeitsbereich nicht beliebig ausgedehnt werden kann, ohne daß auch verschiedene, jeweils geeignete Verfahrensarten geschaffen werden.

ddd) Das Verhältnis der Gerichtszweige zueinander

Das reine Einheitsgericht mit einheitlichen Spruchkörpern und durchgehend einheitlichen Verfahren hat in Wahrheit keine Chance. Die Gestaltungsmöglichkeiten liegen realiter nur in der stärkeren oder schwächeren Trennung verschiedener Gerichtszweige. We1che Möglichkeiten für eine Regelung nach der Maxime "so vielfältig wie nötig, so einheitlich wie möglich" bestehen, ist eine vorwiegend rechtspolitische Frage, die hier nicht weiter erörtert werden soll. 1) Die Verfassung hat die hier wesentlichen Zäsuren der - wie auch immer gestalteten - Gliederung jedenfalls damit gesetzt, daß sie als die entscheidenden Positionen die ordentliche, Verwaltungs-, Finanz-, Arbeits- und Sozialgerichtsbarkeit einander gegenübergestellt hat. 2)

12) Vgl. Bettermann, Notwendigkeit, Möglichkeiten und Grenzen einer Angleichung der deutschen Verfahrensordnungen, S. $180 \mathrm{f}$.

1) S. dazu die oben $\mathrm{S} .575$ zu Fußn. 1 Zitierten.

2) Nach h. M. umfaßt diese Aufzählung des Art.96 Abs.1 GG das Maximum an oberen Bundesgerichten (s.oben S.568 zu Fußn. 4). Verschiedentlich wird aber angenommen, der Gesetzgeber habe die Möglichlicit, die Zahl der oberen Bundesgerichte zu vermindern bzu. sio sämtlich oder zum Teil irgendwie zu vereinigen: Strauss, Inire rechtsprechende Gewalt im Bonner Grunclgesetz, Sp. 530; Jlerbert Arndt, Die ungeteilte Rechtsprechung, Deutsche Richterzeitung, 28. Jhg. (1950) S. 229 f (231); Holtkotten, a. a.O. Anm. II A 3; Koellreutter, Deutsches Staatsrecht, S.244; Hamann, a.a.O.; A.A. Schewe, Ist eine Vereinheitlichung les Gerichtsbarkeiten verfassungsrechtlich zulässig? \$.241 f. - Zur Frage des getrennten Unterbaues s.oben S. 568 zu Fußn.6. A. A. Bachof, Gedanken über die künftige Stellung der Verwaltungsgerichtsbarkeit, S. 169; Schewa, a.a.O. Zur Disposition des Gesetzgebers über die Zuständigkeitsabgrenzung s.o. S. 569 zu Fußn. 2. 
Das Nebeneinander der ordentlichen und der Verwaltungsgerichtsbarkeit ist nicht problematisch: Dort im Prinzip die gerichtliche Primärkompetenz, ${ }^{3)}$ hier die gerichtliche Kontroile der Verwaltung und die Streitentscheidung im Innenraum der öffentlichrechtlichen Beziehungen. ${ }^{4)}$ Dasselbe gilt für das Verhältnis der ordentlichen Gerichtsbarkeit zur besonderen Verwaltungsgerichtsbarkeit. ${ }^{4)}$ Als solche stellt sich eindeutig die Finanzgerichtsbarkeit dar. Aber auch die Sozialgerichtsbarkeit muß nach ihrer oben umrissenen systematischen Basis im wesentlichen, nach der positivrechtlichen Ordnung ausschließlich - als eine solche angesehen werden. ${ }^{5)}$ Umgekehrt ist das Gegenüber der Arbeitsgerichtsbarkeit als einer Ausgeburt der (ordentlichen) Zivilgerichtsbarkeit 6 ) zur Verwaltungs- und Finanzgerichtsbarkeit unproblematisch. Die Separation der Finanzgerichtsbarkeit von der allgemeinen Verwaltungsgerichtsbarkeit ist durch die Schwierigkeiten des Steuerrechts, die nur vom langerfahrenen Spezialisten befriedigend bewältigt werden können, gerechtfertigt. Kritisch sind dagegen drei Grenzen: ordentliche Gerichtsbarkeit A rbeitsgerichtsbarkeit; allgemeine Verwaltungsgerichtsbarkeit Sozialgerichtsbarkeit; Arbeitsgerichtsbarkeit - Sozialgerichtsbarkeit. 7 )

Eine eigene Arbeitsgerichtsbarkeit ist - wie das Verhältnis zur ordentlichen Gerichtsbarkeit auch immer gestaltet werden mag unumgänglich. Schon ihre geschichtliche Wurzel 8) überzeugt da-

3) Die "justizstaatlichen" und justiz-verwaltungs-gerichtlichen Sekundärkompetenzen der ordentlichen Gerichtsbarkeit sollen damit nicht geleugnet werden. Derartige Überschneidungen sind nicht entscheidend.

4) S. hierzu auch Werner Weber, Spannungen und Kräfte im westdeutschen Verfassungssystem, S. $136 \mathrm{f}$.

5) S. die Legaldefinition des $₫ 1$ SGG. Vgl. ferner Schoen, Das Sozialgericht, ein besonderes Verwaltungsgericht, DÖV 7.Jhg. (1954) S. 597 ff; Werner, Allgemeine Verwaltungsgerichtsbarkeit und Sozialgerichtsbarkeit, insbes. S. 1625; Sellmann, Verwaltungsgerichtsbarkeit und Sozialgerichtsbarkeit.

6) Zur Parallelität streitiger Zivilprozeß-arbeitsgerichtliches Urteilsverfahren und Verfahren der freiwilligen Gerichtsbarkeit - Beschlußverfahren s.o. S.512 ff insbes. S.513 zu Fußn. 2 und S.514 zu Fußn.6 (1). Zur Unrichtigkeit der Annah me, beim Beschlußverfahren handle es sich um Verwaltungsgerichtsbarkeit oder etwas ähnliches s.oben S. $525 \mathrm{zu} \mathrm{Fußn.} 13$

7) S. hierzu schon oben S. 568.

8) S. oben S. 569 zu Fußn.3. 
von, obwohl die Motive der älteren Entwicklung der gegenwärtigen Situation nicht mehr gerecht werden. Auch der ordentliche Prozeß ist nunmehr vereinfacht und beschleunigt und jedermann zugänglich. Was für das Arbeitsgerichtsverfahren an weiteren Besonderheiten für notwendig gehalten wird, könnte ohne Schwierigkeiten auch in einem Sonderverfahren der ordentlichen Gerichtsbarkeit untergebracht werden. Der ordentliche Richter ist nicht (mehr?) der - präsumtiv - weltfremde Nurjurist, vor dem sich der einfache Arbeiter verloren glauben müßte. Der aktuelle Grund liegt schließlich auch nicht so sehr im Ruf nach dem Rechtsspezialisten, wenn auch das Arbeitsrecht sich eigenständig und umfangreich entwickelt hat, so daß seine Absenz der ordentlichen Gerichtsbarkeit eine nicht zu unterschätzende Entlastung ist, während die Routine des Arbeitsrichters die Leistungsfähigkeit des arbeitsgerichtlichen Rechtsschutzes hebt. 9) Als entscheidend muß der die Tätigkeit der Arbeitsgerichtsbarkeit durchziehende Interessengegensatz gelten, der sowohl die Arbeitnehmer wie auch die Arbeitgeberseite befürchten läßt, eine "Fehleinstellung" des entscheidenden Richters zu ihr würde sich nachhaltig jeweils zu ihrem Nachteil auswirken. Daher die doppelseitige Einflußnahme auf die Richterbank. 10) Man muß Zweifel haben, $o b$ das gegenwärtige Arbeitsgerichtsgesetz bei seiner Rücksichtnahme auf das Einflußstreben der "organisierten Interessen" nicht $\mathrm{zu}$ weit gegangen ist. Aber auf eine irgendwie gestaltete, intensive Kont rolle der Arbeitsgerichtsbarkeit durch die beteiligten gesellschaftlichen Kräfte wird keinesfalls verzichtet werden können. Das müßte auch dort, wo die Verbindung zwischen der ordentlichen und der A rbeitsgerichtsbarkeit enger gestaltet würde, einen Graben zwischen beiden aufreißen. Die Hervorhebung der - jedenfalls in der Spitze - selbständigen Arbeitsgerichtsbarkeit in Art.96 Abs.1 GG hat somit nur. Unvermeidliches legitimiert. ${ }^{11)}$

9) Vgl. Molitor, Arbeitsrecht und Gerichtszuständigkeit; Galperin, Die Vereinheitlichung aller Gerichtsbarkeiten und die Gerichte in Arbeitscarhell, insbes. S.134. Soweit von einer besoncle ren Rechtsfinclungsmethode die Rede ist (Galperin, a.a.O.; s.a. Rohwer-Kahlmann, Einheit der rechtsprechenden Gewalt oder eigenständige Sozialgerichtsbarkeit? S. 165 f), liegt allerdings eine ibertreibung vor.

10) Zur Regelung s. oben S. 360.

11) Vgl. Galperin, a.a.O. insbes. S. $135 \mathrm{f}$. Es ist bezeichnend, daß Art.96 Abs. 1 GG in seiner gegenwärtigen Fassung gerade darauf zurückgeht, daß die Gewerkschaften eine eigene A rbeitsgerichtsbarkeit gefordert haben (zur Vorrangstellung des Bundesarbeitsgerichtes im Rahmen der Entstehungsgeschichte des Art.96 Abs. 1 GG s.a. Doemming-Füsslein- 
Weit weniger eindeutig stehen die Zeichen hinsichtlich der Abgrenzung der Sozialgerichtsbarkeit von der allgemeinen Verwaltungsgerichtsbarkeit. Das gegenseitige Verhäitnis kann auch abgesehen von der öffentlichrechtlichen Belegenheit hier und der privatrechtlichen Belegenheit dort nicht mit dem zwischen ordentlicher und Arbeitsgerichtsbarkeit verglichen werden. Vor allem fehlt der Sozialgerichtsbarkeit ein durchgehender Interessengegensatz, der mit dem Arbeitgeber-Arbeitnehmer-Gegensatz der Arbeitsgerichtsbarkeit verglichen werden könnte. Im Regelfall der Sozialversicherungsstreitigkeit besteht noch mittelbar, bedingt durch die Beteiligung der Arbeitgeber an der Mittelaufbringung, ein solcher Gegensatz zwischen dem Arbeitgeber und dem Arbeitnehmer (Versicherten). Aber so wie die Sozialversicherung längst nicht mehr nur die Versicherung abhängig Erwerbstätiger ist, so reicht auch die Sozialversicherungsstreitigkeit darüber hinaus. 12) Wird Versorgung (oder Fürsorge) durch den Staat gewährt, so entfällt ein entsprechender Interessengegensatz überhaupt; es sei denn, man greift auf den Gegensatz Leistungsempfänger-Steuerzahler zurück. 13) Darau

Matz, Die Entstehungsgeschichte der Artikel des Grundgesetzes, S. $707 \mathrm{ff}$ ). - S. hierzu auch Werner Weber, Spannungen und Kräfte im westdeutschen Verfassungssystem, S. $126 \mathrm{f}$; ders., Die Einheit der rechtsprechenden Gewalt, S. $111 \mathrm{f}$. Seine These, daß man sich, weil es so ist, gerade mit der Absonderung der Arbeitsgerichtsbarkeit nicht abfinden sollte, überschätzt die Macht des Staates und unterschätzt den legitimen Kern der "organisierten Interessen".

12) S. hierzu auch Molitor, Arbeitsrecht und Gerichtszuständigkeit, S. 304 .

13) Die Problematik spiegelt sich in der Regelung der Beisitzerfrage in der Sozialgerichtsbarkeit. Für die Kammern für Angelegenheiten der Sozialversicherung und für Angelegenheiten der A rbeitslosenversicherung (einschließlich der übrigen Aufgaben der Bundesanstalt) wird ein durchgehender Interessengegensatz Arbeitgeber - Versicherter (Arbeitnehmer) fingiert bzw. sein Fehlen in einer nicht unerheblichen Zahl von Fällen negiert. Die Beisitzer stammen je zur Hälfte aus "dem Kreis der Versicherten und der Arbeitgeber" ( $\$ \$ 12$ Abs.2, 14 Abs. $2,33,40,46$ sGG). Für die Kammern für Angelegenheiten des Kassenarztrechts wird ein Vis-à-vis der Kassenärzte und der Krankenkassen konstruiert ( $\$ \$ 12$ Abs. 3 Satz 1, 14 Abs. 3 , 33, 40, 46 SGG). Dagegen schon: "In Angelegenheiten der Kassenärzte (Kassenzahnärzte) wirken als Sozialrichter nur Kassenärzte (Kassenzahnärzte) mit" ( $\$ 12$ Abs. 3 Satz 2 SGG). 
allein, daß überhaupt ein unmittelbarer Interessenteneinfluß durch die Gestellung von Beisitzern für notwendig gehalten wird, kann $z$ wingend nichts geschlossen werden; denn auch die allgemeine Verwaltungsgerichtsbarkeit entscheidet in Materien, in denen dies naheliegen würde, ohne daß der Gesetzgeber immer Sonderregelungen dieser Art getroffen hätte. 14) Während außerdem der Kompetenzbereich der Arbeitsgerichtsbarkeit von dem der ordentlichen Gerichtsbarkeit schon von der Sache her scharf abgegrenzt ist und die positive Detailabgrenzung durch den Gesetzgeber vorwiegend nur klärende Bedeutung hat, ist diese für die Sozialgerichtsbarkeit in tieferem Sinne konstitutiv. Der Übergang zum

Hier also eine Art Standesgerichtsbarkeit! Wieder anders die Regelung für die Kriegsopferversorgungskammern. Die Beisitzer stammen je zur Hälfte "aus dem Kreis der mit der Kriegsopferversorgung vertrauten Personen und der Versorgungsberechtigten" ( $\$ \$ 12$ Abs.3, 33, 40 SGG). Die Beisitzer "aus dem Kreis der mit der Kriegsopferversorgung vertrauten Personen" werden von den Landesversorgungsämtern ( $\$$ 14 Abs. 4 SGG) bzw. den ubersten Verwaltungsbehörden der Länder ( $\$ 46$ Abs. 3 SGG) benannt. Als Gegenüber der Versorgungsempfänger bzw. der auf Versorgung Anspruch erhebenden Personen sind sie ein höchst eigenartiges Phänomen. Jedenfalls drückt sich in ihnen die Erkenntnis aus, daß ein Interessengegensatz gewisser Gruppen gegen andere Gruppen nicht besteht. Nur weil man die Vertreter der Versorgungsberechtigten nicht beide Beisitzerposten einnehmen lassen wollte, den anderen Beisitzerposten auch nicht durch einen Berufsrichterposten ersetzen oder ihn entfallen lassen wollte, mußte man zu dieser l, ïsung greifen - m.a.W.: um der lieben Symmetrie willen. Denn was an Sachverstand dadurch dem Gericht zugetïhrt werlen kann, ist in Anbetracht der Entscheidungsmöglichkeiten und - gegenstände nicht nennenswert. - Im Schriftum hillt man sich über dieses Problem meist mit Ungenanispifit hinweg (s.f.v.a. Rohwer-Kahlmann, Einheit der rechtsplechonden Gewalt oder eigenständige Sozialgerichtsbarkeit, s. $16, j)$.

14) Fin etwa mit der Kriegsopferversorgung vergleichbarer Fall könnte im Lastenausqleichurecht gesehen werden. Im Verwaltungsverfahren sind dementsprechend auch die "beteiligten Kreise" durch Ausschußbrisitzer vertreten. Allerdings wird der Verwaltungsgerichtsharkeit etwas erspart, wenn ihnen für unvermeidlich gehaltene - Sonderkammern mit "interessierten" Beisitzern nicht eingefügt werden. Die Fachkammer’n und Fachsenate in l'ersonalvertretungssachen und die Flurbe- 
Kompetenzbereich der allgemeinen Verwaltungsgerichtsbarkeit ist vom Prinzip her schwer festzulegen, sobald der engere Raum der Sozialversicherung verlassen wird. 15) Auch die Notwendigkeit einer von der für die allgemeine Verwaltungsgerichtsbarkeit geltenden, abweichenden gerichtsorganisatorischen und (oder) verfahrensrechtlichen Sonder regelung kann nicht für alle den Sozialgerichten übertragenen Angelegenheiten gleich zutreffend behauptet werden. Der Ruf nach dem Spezialisten 16) ist zwar insofern überzeugend, als nicht erwartet werden darf, der Verwaltungsrichter könne sich ohne Einbuße an der Qualität der Rechtsprechung auch noch des ganzen Zuständigkeitsbereichs der Sozialgerichtsbarkeit bemächtigen. ${ }^{17)}$ Da aber eine mit der des

reinigungssenate wirken schon störend genug.

15) Werner (Allgemeine Verwaltungsgerichtsbarkeit und Sozialgerichtsbarkeit, S. 1625) bezeichnet die Sozialgerichtsbarkeit als "eine aus nüchternen $Z$ weckmäßigkeitsgründen abgespaltene Sondergerichtsbarkeit". - Zu dem untauglichen prinzipiel len Abgrenzungsversuch Grömigs s. oben S. 568 . - Zu den denjenigen der Sozialgerichtsbarkeit verwandten Aufgaben der Verwaltungsgerichtsbarkeit s. z. B. Werner, a.a.O.; Sellmann, Verwaltungsgerichtsbarkeit und Sozialgerichtsbarkeit, insbes. S. $1092 \mathrm{f}$ (der allerdings seinerseits die Sozialgerichtsbarkeit zu einseitig als Sozialversicherungsgerichtsbarkeit sieht). Des weiteren s. oben c bb (S. $553 \mathrm{ff})$ und die dortigen Nachweise. - Für einheitliche, den Sachbereich der jetzigen Sozialgerichtsbarkeit mit umfassende Verwaltungsgerichtsbarkeit $v$. Brünneck, Die Verwaltungsgerichtsbarkeit im Verhältnis zur Arbeitsverwaltung und Sozialversicherung, S. 620 .

16) S. z.B. Laube, Die Vereinheitlichung aller Gerichtsbarkeiten und die Gerichte der Sozialgerichtsbarkeit; Rohwer-Kahlmann, Einheit der rechtsprechenden. Gewalt oder eigenständige Sozialgerichte, insbes. S. $164 \mathrm{ff}$.

17) Man muß bedénken, daß die Zah1 der Richter (desgleichen der Kammern bzw. Senate) in der Sozialgerichtsbarkeit heute durchwegs die Zahl der Richter (Kammern, Senate) in der allgemeinen Verwaltungsgerichtsbarkeit übersteigt. Wäre die Sozialgerichtsbarkeit mit der allgemeinen Verwaltungsgerichtsbarkeit vereinigt, so würde die Inanspruchnahme der Richter durch die "sozialgerichtlichen" Angelegenheiten ihre Verfügbarkeit für die jetzt "verwaltungsgerichtlichen" Angelegenheiten vermindern. - S. zu Vorstehendem auch Teutsch, Die Sozialgerichtsbarkeit und die allgemeine Verwaltungsgerichtsbarkeit, S. 170 . 
(privatrechtlichen) Arbeitsrechts vergleichbare systematische Einheit im Zuständigkeitsbereich der Sozialgerichte, sobald er über die Sozialversicherung hinauswächst, fehlt, ist daraus keine genaue Orientierung für seine Ausdehnung zu gewinnen.

Im Hinblick auf die gemeinsame Basis der Arbeitsgerichtsbarkeit und der Sozialgerichtsbarkeit in Angelegenheiten der Sozialversicherung, des Schutzes des abhängig erwerbstätigen Menschen, muß somit die Frage gestellt werden, ob die Viererposition ordentliche Gerichtsbarkeit - A rbeitsgerichtsbarkeit - Sozialgerichtsbarkeit - allgemeine Verwaltungsgerichtsbarkeit wirklich glücklich ist. Fine einheitliche Arbeits- und Sozialgerichtsbarkeit - letzteres im Sinne einer Sozialversicherungsgerichtsbarkeit - hätte eine stärkere Eigengesetzlichkeit gegenüber den beiden allgemeinen Gerichtsbarkeiten für sich. Sie wäre zwar in sich gespalten in die privatrechtliche Arbeitsgerichtsbarkeit und in die öffentlichrechtliche Sozial(versicherung)gerichtsbarkeit, aber doch durch den gemeinsamen Boden, den Rechtskreis der abhängigen A rbeit, kräftig zusammengehalten. 18) Aber soll die Kriegsopferversorgung dann von den allgemeinen Verwaltungsgerichten übernommen werden? Das würde binnen kurzem $\mathrm{zu}$ einer eigenen Versorgungsgerichtsbarkeit im Verband der Verwaltungsgerichte führen. Die Eigenarten dieses Rechts- und (vor allem) Sachgebietes sind zu groß. Sie gerade weisen wieder auf das Gemeinsame der Sozialversicherungs- und Versorgungsangelegenheiten hin: die Probleme der Erwerbsunfähigkeit oder Erwerbsminderung infolge Körperverletzung oder sonstiger Gesundheitsschädigung, die Probleme des Wegfalls des Unterhaltsverpflichteten, die Probleme der Krankheitsheilung usw. Die Kriegsopferversorgung wäre "heimatlus" und würde nach eigenständiger Versorgungsgerichtsbarkeit verlangen, wenn nicht ein Zusammengehen mit der Rechtsprechung in Angelegenheiten der Sozialversicherung im Rahmen einer weiteren Sozialgerichtsbarkeit eine befriedigende Lösung erliauben würde. Daß der - gewiß undoktrinäre - Versuch einer selbständigen Sozialgerichtsbarkeit

18) S. hierzu insbes. Weidner, 'Zur Rechtsprechung des Bundessozialgerichts, S. 698 ff, mit zahlreichen Nachweisen; s.a. Molitor, Die Vereinheitlichung des A rbeitsrechts, NJW 2. Jhg. (1949) S.699 ff (700); Dersch, Wechselwirkungen zwischen Sozialversicherung und Arbeitsrecht in der neueren Entwicklung; ablehnend $v$. B rünneck, Die Verwaltungsgerichtsbarkeit im Verhältnis zur A rbeitsverwaltung und Sozialversicherung, S.620; Miesbach, Gestaltung der Gerichtsbarkeit für Arbeitsrecht, Sozialversicherung und Kriegsopferversorgung, S. $228 \mathrm{f}$. 
gemacht wurde, verdient unter diesem Gesichtswinkel Anerkennung. 19)

Eine solchermaßen konzipierte Sozialgerichtsbarkeit büßt ihre Homogenität mit der Arbeitsgerichtsbarkeit ein. Die Zäsur zwischen beiden muß schärfer gesetzt werden. 20) Die Friktionen, die sich aus der organisatorischen Trennung der Arbeits- von der Sozialge richtsbarkeit ergeben, sind trotz der vorhandenen Berührungspunkte nicht schwerwiegend. 21)

So schält sich die Sozialgerichtsbarkeit - als das jüngste Kind in der Familie der deutschen Gerichtsverfassung, wenn man von kleineren Sonderverfahren usw. absieht, - als das labilste Geschöpf in der grundgesetzlichen Konzeption der Gliederung der Gerichtsbarkeit heraus. Trotzdem muß in ihr ein hoffnungsvoller Anfang und zugleich schon die wesentliche Verwirklichung eines Gerichtszweiges gesehen werden, der bei einer den besonderen Eigentümlichkeiten maximal angemessenen organisatorischen und verfahrensrecht1ichen Gestaltung gewisse öffentlichrechtliche Materien von sozialer Bedeutung aufnehmen kann.

Insgesamt ist der Rechtsschutz in sozialen Belangen durch die vom Grundgesetz konzipierte Fünfteilung der Gerichtsbarkeit entscheidend und intensiv sachbezogen geprägt. 22)

19) Das verkennt Weidner (a.a.O.) bei seiner Kritik, die Sozialversicherungsgerichtsbarkeit und Sozialgerichtsbarkeit gleichsetzt.

20) Im Rechtspflegeausschuß des Parlamentarischen Rates hielt man allerdings die Konstruktion eines Bundesarbeitsgerichts, das zugleich oberes Bundesgericht auf dem Gebiet der Sozialversicherung und der Versorgung sein sollte, für möglich (vgl. Doemmig-Füsslein-Matz, Die Fntstehungsgeschichte der Artikel des Grundgesetzes, S. 707).

21) Die von Weidner, a.a.O. S.701 (1) gegebenen Beispiele von Entscheidungen, die den Mangel eines gemeinsamen Bundesa rbeits- und - sozialgerichts "bereits fühlbar." hätten werden lassen, belegen das nicht (s.a. Molitor, Arbeitsrecht und Gerichtszuständigkeit, S.311 ff). Mißglückte Entscheidungen, die, auf dem einen Rechtsgebiet getroffen, dem anderen nicht gerecht werden, gibt es nicht nur bei Sondergerichten. Auch innerhalb einer umfassenden Gerichtsbarkeit kommen solche Gewaltlösungen oder Unachtsamkeiten immer wieder vor.

22) S. a. Laube, Die Vereinheitlichung aller Gerichtsbarkeiten und die Gerichte der Sozialgerichtsbarkeit, S. 161; RohwerKahlmann, Einheit der rechtsprechenden Gewalt oder eigenständige Sozialgerichtsbarkeit, S.163. - Daß durch die Glie- 
eee) Anhang: Zum Obersten Bundesgericht

Ein Wort noch zum Obersten Bundesgericht (Art.95 GG). Es soll die fünf oberen Bundesgerichto iberdachen. Nur der "Einheitlichkeit der Rechtsprechung der oberen Bundesgerichte" sollen seine Entscheidungen dienen (Art.95 Abs.2 Satz $1 \mathrm{GG}$ ). Die eigenständige Entwicklung der verschiedenen Rechtsmaterien durch die verschiedenen Gerichtszweige würde es nicht beeinflussen. Die soeben aufgeworfene Problematik wird durch Art.95 GG also nicht berührt. Das Oberste Bundesgericht ist nicht das Surrogat einer Einheitsgerichtsbarkeit. Seine Errichtung wäre sicher weder allgemein 1) noch für die suzialen Belange 2) von großer Bedeutung.

\section{bb) Sondergerichte - Sonderkammern(-senate) - Verfeinerung des Rechtsschutzes}

Das Grundgesetz legt keineswegs die ganze Gerichtsverfassung auf die in Art. 96 Abs. 1 GG formulierte Fünfteilung fest. Durch Gesetz können Gerichte für besondere Sachgebiete errichtet werden (arg. Art. 101 Abs. 2 G(i). Das Grundgesetz hat selbst Vorbilder geschaffen: Die Dienststrafgerichte und Wehrdienstgerichte als durchgehend selbständige Sondergerichtsbarkeit des Bundes (Art.96 Abs. $3 \mathrm{GG}$ ) und die in letzter Instanz in das obere Bundesgericht der ordentlichen Gerichtsbarkeit, den Bundesgerichtshof, einmündende Wehsstrafgerichtsbarkeit (Art.96 a GG). $\mathrm{Ob}$ die Zahl der Bundesgerichte darüber hinaus vermehrt werden darf, mag allerdings zweifelhaft erscheinen (Art.92 GG). 1) Gegen die Errichtung besondere: I, andesgerichte bestehen jedoch keine verfassungs rechtlichen Bedenken. Außer den Dienststrafgerichten (Disziplinargerichen), die in Anbetracht der sozialen

derung unmittelbal auch der von Werner Weber (Die Einheit der rechteprechenden Gewalt, S.113; s.a. ders., Spannungen und Kiäfle im westdeutschen Verfassungssystem, S. $137 \mathrm{f}$ ) herauscestellt folheitliche Zweck (..."daß mit der unterschiedslosen \%usanmmonfassung der Gerichtsbarkeiten auch die Unter'scheidum zwischen der Einbeziehung des Menschen in die wohlfahrtistatliche Macht- und Sozialapparatur und der Anerkennung cine: eigenverantwortlichen Individualsphäre aufgegeben wir!".) (rreicht wird, ist dagegen zu verneinen.

1) S. z.B. Prost, Verzicht auf das Oberste Bundesgericht? NJW 10.Jhg. (1957) s.4! "f und seine Nachweise.

2) S. Molitor, Arbeitslechit und Gerichtszuständigkeit, S.315.

1) Verneinend Bettermann, I)ie Unabhängigkeit der Gerichte 
Lage des Beamten auch hier interessieren, sind jedoch Sondergerichtsbarkeiten von sozialer Bedeutung nicht entstanden. 2)

Viel mehr geht die Seuche um, innerhalb der fünf Gerichtszweige für gewisse Angelegenheiten besondere Spruchkörper zu bilden. Die Verfassung verbietet das nicht. ${ }^{3)}$ Auf diese Weise sind besondere Spruchkörper von mehr oder weniger großer Bedeutung auch für den sozialen Bereich entstanden. 4)

(1) Innerhalb der Sozialgerichte sind von vorneherein verschiedene Kammern bzw. Senate für Angelegenheiten der Sozialversicherung, der Arbeitslosenversicherung einschließlich der übrigen Aufgaben der Bundesanstalt, für die Kriegsopferversorgung und für Kassenarztrecht zu errichten ( $\$ \$ 10 \mathrm{Abs} .1$ und 2, 31, 40 SGG) Besondere Kammern bzw. Senate für die Angelegenheiten der Knappschaftsversicherung einschließlich der Unfallversicherung können gebildet werden $(\$ \S 10$ Abs. 1 Satz 2, 31 A Abs. 1 Satz 2, 40 SGG), desgleichen für die einzelnen $Z$ weige der Sozialversicherung ( $\$ \$ 12$ Abs.2, 33 Satz 2, 40 SGG). Die Sozialgerichtsbarkeit ist also so weit als möglich "verfachlicht".

(2) In der Arbeitsgerichtsbarkeit können Fachkammern gebildet werden ( $\$ 17$ Abs.2, 23 Abs. 3 Satz 2 ArbGG).

(3) In der allgemeinen Verwaltungsgerichtsbarkeit bestehen die Fachkammern bzw. Fachsenate für Personalvertretungssachen ( $\$ 77$ des Personalvertretungsgesetzes). Ferner sollen "die Sachgebiete der allgemeinen öffentlichen Fürsorge, der Tuberkulosehilfe und der sozialen Fürsorge für Kriegsopfer... in einer Kammer zusammengefaßt werden" ( $\$ 188$ Satz 1 VGO).

(4) Im Rahmen der ordentlichen Gerichtsbarkeit berühren die Baulandkammern bzw. - senate ( $\$ ₫ 157 \mathrm{ff}$ des Bundesbaugesetzes) und die Landwirtschaftsgerichte ( $\$ \$ 2 \mathrm{ff}$ des Gesetzes über das gerichtliche Verfahren in Landwirtschaftssachen)das hiesige Interesse.

und der gesetzliche Richter, S. 574. - S. hierzu ferner oben S. 568 zu Fußn. 4 und S. 581 zu Fußn. 2.

2) Zu Vorstehendem s. zusammenfassend Knoll, Die besonderen Gerichte, DÖV 7.Jhg. (1954) S. 232 ff, 263 ff; Bettermann, a.a.O. S. $572 \mathrm{ff}$.

3) S. z.B. BVerfGE 4, 387 (401 ff).

4) Übersichten über die Gesamtentwicklung s. bei Bettermann, Die Notwendigkeit, Möglichkeiten und Grenzen einer Angleichung der deutschen Verfahrensordnungen, S. 178 ff; Baur, Empfiehlt es sich, die verschiedenen $Z$ weige der Rechtsprechung ganz oder teilweise zusammenzufassen? S. 29. 
Auch diese besonderen Eritscheidungsgremien und Instanzenzüge haben die Vorteile der. Spezialisierung und die Nachteile der Sonderung, diese allerdings gemildert durch den organisatorischen Zusammenhang mit dem gesamten Gerichtszweig.

Fünf Hauptgerichtszweige, daneben Sondergerichte, darin besondere Spruchkörper - das ist das horizontale Gliederungsgefüge der Gerichtsbarkeit, das durch die Verfassung teils inauguriert, teils jedenfalls zugelassen wurde. So hat auch die soziale Intervention durch die Gerichte und der gerichtliche Rechtsschutz gegenüber der (sonstigen) sozialen Intervention des Staates ein reichgegliedertes Subjekt. Dadurch, daß zwei besondere Gerichtszweige speziell für die sozialen Angelegenheiten zuständig sind, während auch alle übrigen Gerichtszweige soziale Aufgaben haben, füllt die soziale Intervention mit besonderer Intensität die ganze Breite des Gefüges aus. Über und hinter all dem steht dann noch die Verfassungsgerichtsbarkeit.

Im großen und ganzen wird der Rechtsschutz dadurch wohl verbessert. Nicht selten wäre weniger Spezialisierung aber auch von Vorteil. Die Schwierigkeit, in die sich dadurch "der Bürger vor der Vielzahl der Gerichte" 5$)$ gestellt sieht, ist nicht unerheblich. Er muß den zuständigen Richter finden. Es wäre schlecht bestellt um den Rechtsschutz in sozialen Angelegenheiten, der immer auch mit dem "kleinen Mann", mit dem unbeholfenen Armen rechnen muß, wenn das damit verbundene Risiko, den falschen Richter gewählt zu haben, dem rechtsschutzsuchenden Bürger angelastet würde. Hier müssen alle Mittel aufgewendet werden - von der Rechtsbehelfsbelehrung über die Beratungspflicht der Richter bis zur Verweisung von Spruchkörper zu Spruchkörper und von Gerichtszweig zu Gerichtszweig6) - damit dem Bürger sein Recht wird und er nicht an technischen Schwierigkeiten verzweifeln $\operatorname{muß.7)}$

\section{cc) Die vertikale Gliederung - zum Instanzenzug}

Hinsichtlich der Gectaltung do: Instanzenzuges läßt das Grundgesetz dem Gesetzgeber freif Hand. Das Verfahren vor dem Bundesverfassungsgericht kon\%ipiort es allerdings selbst als einin-

5) Pohle, Der Bürger vor der Vielzahl der Gerichte, in "Staat und Bürger", Festschrift für Willibalt Apelt, 1958, S. 171 ff; s. diesen und seine Nachweise auch zum Folgenden.

6) S. hierzu $₫ 52 \mathrm{SGG}, \S 41 \mathrm{VGO}, \S 17 \mathrm{GVG}$ n. F.

7) Zur Bedeutung der Verweisungsmöglichkeit vom Gesichtspunkt des Art. 19 Abs. 4 GG s.Dürig, in Maunz-Dürig, Art. 19 Abs. IV Randn. 41. 
stanzig. Im übrigen steht es deutlich auf dem Standpunkt, daß die oberen Bundesgerichte grundsätzlich als letzte Instanz über einer (oder mehreren) landesgerichtiichen Instanz wirken sollen. 1) Aber der Gesetzgeber kann das Verfahren ebenso gut auf eine Instanz vor einem Landesgericht, ausnahmsweise auch auf eine Instanz vor einem oberen Bundesgericht 2) beschränken. ${ }^{3)}$

Diese Gestaltungsfreiheit des Gesetzgebers erlaubt ihm, den besonderen Bedürfnissen der Sachlage entgegenzukommen. Wie er dabei verfährt und welche rechtspolitischen Maximen ihn dabei bestimmen sollten, ist hier nicht zu erörtern. Der Problematik fehlt im allgemeinen der besondere Bezug zum Recht der sozialen Intervention. ${ }^{4)}$

Besondere Gestaltungsprobleme, die dem Recht der sozialen Intervention nicht ausschließlich aber doch wie nur wenigen anderen Rechtsgebieten eigentümlich sind, ergeben sich aber daraus, daß sich das Recht der sozialen Intervention an breiteste Schichten richtet und in seinen generell-tatsächlichen wie auch in seinen rechtlichen Grundlagen einem laufenden Wandel unterworfen ist. Der Zahl der Betroffenen entspricht die große Zahl der möglichen Kläger. Veränderungen bewirken das Auftreten neuer

1) Vgl. BVerfGE 8, 174 (177). (Ein dort nicht erwähntes Argument ist Art.99 GG.) - Ule (Besprechung von: Otto Bachof, Wehrpflichtgesetz und Rechtsschutz, DVB1. 72.Jhg. (1957) S. 326) hält eine zu weitgehende Beschränkung der Revision für einen Verstoß gegen Art.96 Abs.1 GG. Dem kann, wenn es sich - wie bei Ule - nur um ein Sonderrechtsgebiet handelt, nicht zugestimmt werden (s.a. BVerwGE 7,66 (75)).

2) BVerfGE 8, 174 (176 ff). - Bei anderen Bundesgerichten (Art.96 Abs.3, 96 a GG) richtet sich dagegen die Zulässigkeit der Beschränkung auf eine Instanz nach der allgemeinen Regel (s. nächste Fußn.).

3) BVerfGE 4, 74 (94 f), 205 (210 ff), 387 (411f); 6, 7 (12); 8, 174 (181 f); 9, 223 (230); BVerwGE 1, 60, 63; 3, 145 (147); 7, 66 (74f); BSGE 4, 24 (25f). - Weitere Nachweise s. bei v. Mangoldt-Klein, Art. 19 Anm. VII 5 c, Art. 20 Anm.VI 2; Dürig in Maunz-Dürig, Art. 19 Abs. IV Randn. 46. - Neuerdings meint Weidner (Die Rechtsprechung des Bundessozialgerichts, S.762) wieder, seines Erachtens "könnte eine weitere (auch rechtshistorische und rechtsvergleichende) Erforschung des Prinzips der Rechtsstaatlichkeit hier u.U. noch gewisse Korrekturen erbringen".

4) Zur Darstellung des Rechtszustandes s.o. S. 170 . 
Rechtsfragen. Beide Frscheinungen kumuliert bringen die voluninösen Klagewellen hervor, deren wohl größte aus dem Neuaufbau des Versorgungswesens nach dem Krieg hervorgegangen sein lürfte. Daraus entspringt in gleicher Weise das Bedürfnis nach rascher höchstrichterlicher Klärung der offenen Rechtsfragen wie die Notwendigkeit, die Rechtsmittel zu beschränken, so daß die Hauptlast den zahlreichen Untergerichten überlassen bleibt. Dies ist notwendig, um den Zugang zu den (Mittel- und) Oberinstanzen für die Rechtsfälle von grundsätzlicher Bedeutung und zu deren alsbaldiger. Entscheidung freizuhalten. Es ist auch notwendig, um die Prozeßdauer zu verkürzen und die Unsicherheit der individuellen Rechtslage zeitlich möglichst einzuschränken. Jie möglichst rasche endgülige höchstrichterliche Rechtsklärung st dagegen notwendig, damit Irechtsvollzugsunterschiede hintangehalten werden. Auch und gerade wo der Rechtsvollzug der Verwaltung obliegt, besteht dieses Bedürfnis. Verwaltungsordnungen iönnen zwar den Vollzug vorläufig vereinheitlichen. Sie binden jedoch die Gerichte grundsätzlich nicht. ${ }^{5)}$ Die Verwaltung muß jich der Rechtsprechung anpassen. ${ }^{6)}$ Daraus ergeben sich mögicherweise unerträgliche Schwankungen der Verwaltungspraxis der die für die Verwaltung recht unerfreuliche Notwendigkeit, die schon erledigten Fälle nochmals aufzurollen, was, da die bexünstigenden Verwaltungsakte l'egelmäßig von stärkerer Bestandsrraft sind als die nachteiligen, nicht selten zu einer unerwarteten Belastung des Haushalts führt. $\left.{ }^{7}\right)$ Die meist gebrauchten Mittel, im sowohl dem einen wie dem anderen Erfordernis Rechnung zu ragen, sind die Verdünnung der Rechtsmittelkanäle, teils unter Ausschaltung der mittleren Instanz und unmittelbarer Rechtsmitelzuständigkeit des oberen Bundesgerichts, und die gezielte Aus;chaltung derjenigen liechtsmittel, die nicht der obergerichtlithen Klärung offener Rechtsfragen von allgemeiner Bedeutung dienen. Daß die verschiedenen $\vee$ ariationen dieser die Einzelfallrerechtigkeit zurückstcllenden Ciestaltung des Instanzenzuges im jozialen Bereich ein geralezu sihwerpunktartiger Vorzug gegesen wird - insbes. in cler suzialuerichtsbarkeit, im verwaltungs-

Fine Zwischenstelluns nohmen die Ermessensrichtlinien ein, die notwendigerveise der Nachprüfung durch die Gerichte entzogen sind, soweit sir sich im Rahmen des Verwaltungser-

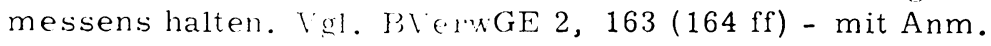
Bachof JZ 11. Jhg. (1956; S. 35 ff; BFHE 67, 355 (358 ff).

j) Zur Bedeutung der höchstrichterlichen Rechtsprechung für die Verwaltung s. z. P. SFIf 67,355 (364 ff) mit eingeh. Nachw.

7) S. zu Vorstehende'm Irlatz, Die gerichtliche Kontrolle der Leistungsverwaltum. 
gerichtlichen Verfahren in Lastenausgleichs- und Kriegsgefangenenent schädigungssachen usw. -, wurde bereits dargestellt. 8)

Das Bedürfnis, gerade grundsätzliche Fragen an die oberen Gerichte heranzubringen, hat dazu geführt, daß vielfach dem iudex a quo unüberprüíbar die Zulassung eines Rechtsmittels anheimgegeben wurde (vgl. $\$ \$ 64$ Abs. 1, 69 Abs. 3, 72 Abs. 1 A rbGG $\S \S 150 \mathrm{Nr} .1,162 \mathrm{Nr} .1 \mathrm{SGG}$; $286 \mathrm{AO}$; $\$ 546 \mathrm{ZPO})$. Er soll gleich sam aus der Masse des ihm vorliegenden Materials die klärungsbedürftigen Fälle "herauspicken". Diese Regelung, die den Richter, dessen Entscheidung überprüft werden soll, auch darüber entscheiden 1äßt, ob sie überprüft werden darf, ist rechtsstaat1ich sicherlich unschön. Sie ist aber nicht schlechtweg verfassungswidrig. Art. 19 Abs. 4 GG garantiert nicht den Rechtsschutz durch Richter gegen Richter. 9) Art. 101 Abs. 1 Satz 2 GG (ebenso $\$ 80$ Abs. 1 Satz 2 VGO) verlangt zwar, daß der "gesetzliche Richte $r^{\prime \prime}$ durch die generelle Norm vorbestimmt ist. 10) Dem ist aber auch genügt, wenn der über die Zulassung entscheidende iudex a quo durch die gesetzliche Normierung der Voraussetzungen der Rechtsmittelzulassung bzw. der Zulassungspflicht hinreichend gebunden ist. 11) Die Gefahr eines Mißbrauchs - d.h. in diesem Falle: einer willkürlichen Außerachtlassung der gesetzlichen Bestimmungen - genügt nicht, um die Regelung von vorneherein als verfassungswidrig erscheinen zu lassen. 12) Nur dann, wenn eine

8) S. oben S. 170

9) S. oben S. 562 . - Zur Verfassungsmäßigkeit der einschlägigen Bestimmungen unter diesem Gesichtspunkt s. BSGE 5, 150 (153). - Kritisch hierzu Weidner, Zur Rechtsprechung des Bundessozialgerichts, S. $761 \mathrm{f}$.

10) BVerfGE 6, 45 (50 f); 9, 223 (226).

11) Bettermann, Die Unabhängigkeit der Gerichte und der gesetzliche Richter, S. $570 \mathrm{f}$.

12) (1) In bezug auf Art. 101 Abs. 1 Satz 2 GG vgl. hierzu: BVerfGE 9, 223 (230); BSGE 5, 1 (2 f). Allgemein zu diesem Grundsatz: BVerfGE 1, 144 (149); BayVerfGH, VGHEn.F. 8 II 1 (6). - Nach der positiven gesetzlichen Ordnung könnte eine willkürliche, den Betroffenen dem gesetzlich vorgesehenen Instanz richter "entziehende" Nichtzulassung auch mit der Verfassungsbeschwerde angefochten werden ( $\$ 90 \mathrm{Abs} .1$ BVerfGG; s.a. BVerfGE 9, 223 (230)); auch BSGE 5, 1 (3) enthält für diesen Fall einen Vorbehalt.

(2) Weidner (Zur Rechtsprechung des Bundessozialgerichts, S. 765) will nun aber argumentieren, es gehöre "zu den Elementarprinzipien der Rechtsstaatlichkeit,.... daß ein Richter von der Ausübung des Richteramtes in den Sachen ausgeschlos 
sesetzliche Vorherbestimmung der Zulassung fehlen würde, müße ein Verstoß gegen Art.101 Abs. 1 Satz 2 GG angenommen werlen; es sei denn, daß eine verfassungskonforme, ergänzende Inerpretation des fraglichen Verfahrensgesetzes möglich ist. 13)

\section{1d) Die Trennung von der Exekutive}

'Die Staatsgewalt ... wird ... durch besondere Organe der Gejetzgebung, der vollziehenden Gewalt und der Rechtsprechung ausseübt" (Art.20 Abs.2 GG). "Die rechtsprechende Gewalt ist den zichtern anvertraut; sie wird durch ... die in diesem Grundgejetz vorgesehenen Bundesgerichte und durch die Gerichte der änder ausgeübt" (Art.92 GG). Richter und (Verwaltungs-)Beamte

sen ist, an denen er in einem früheren Rechtszug mitgewirkt hat". Entscheide der iudex a quo über die Zulassung des Rechtsmittels, so sei dieser Grundsatz verletzt. Diese Argumentation setzt zunächst einmal die Entscheidung über die Zulassung des Rechtsmittels an sich mit der vom iudex ad quem zu treffenden Entscheidung über die Zulässigkeit des (konkret eingelegten) Rechtsmittels in eins. Schon das ist das braucht hier nicht expliziert zu werden - sehr fragwürdig. Aber dies dahingestellt: Jedenfalls ist die Prämisse von der verfassungsrechtlichen Notwendigkeit eines mit einem anderen Richter besetzten Instanzgerichts falsch. Dieser Grundsatz kann nur unter der Voraussetzung gelten, daß die Instanz als solche verfassungsmäßig garantiert ist. Ist sie das nicht, so könnte es z. B. auch nicht verfassungswidrig sein, an Stelle eines liechtsmittels den Einspruch zum iudex a quo zu gewähren und mit dessen erneuter Entscheidung das Verfahren endguiltig abzuschließen. Wo bliebe dann der von Weidner ins Feld gefühte Grundsatz? - Was daran richtig ist, das ist, daß (lie abstrakte Mißbrauchsgefahr sich im Hinblick auf dic Interossensituation des iudex a quo erhöht. Aber das loch nicht in einem Maße, das die Regelung schlechterdings verfassungswidrig erscheinen ließe.

3) Vgl. Bettermann, a.a.(). \$.571. - Die weitverbreitete Ansicht, die Zulassung ler Rechtsmittel im arbeitsgerichtlichen Verfahren ( $\$$ (\$4 Abs. 1, 69 Abs.3, 72 Abs. 1, 74 Abs. 3, 77 Satz 1 ArbGG) involviere einen Ermessensspielraum des Untergerichts (eine zusammenfassende Übersicht über Rechtsprechung und Litratur s. z. B. bei Auffahrt, Die Zulässigkeit der Revision nach der Rechtsprechung des Bundesarbeitsgerichts, NJW 10.Jhg. (1957) S.484 ff (485 f)), bedarf demnach der Überpriifung. 
sind deutlich unterschieden und nicht mehr vertauschbar (Art.33 Abs. 4 und 5, 60 Abs. 1, 73 Nr. 8, 75 Nr. 1, 98 Abs. 1 und 3, 132 Abs. 1 Satz 1 GG). Das G rundgesetz konstituiert eine rechtsprechende (dritte) Gewalt, die nicht nur der Funktion sondern auch der Organisation und der Inhaberschaft nach von der staatlichen Exekutive sauber zu trennen ist. 1) Dem kommt in erster Linie Bedeutung für den Rechtsschutz gegenüber dem Staat zu. Nur ein von der Verwaltung institutionell gelöstes Gericht kann als unbeteiligter Dritter den Streit zwischen dem Bürger und der Verwaltung entscheiden. 2)

Dieser Grundsatz weist einen besonderen Zusammenhang mit der sozialen Intervention aus einem historischen Grunde auf. Die Versicherungsbehörden nach der Reichsversicherungsordnung haben im Spruch- und Beschlußverfahren auch endgültig streitentscheidend Recht gesprochen (vgl. $\$ \$ 35,1636$ ff RVO a.F.). Diese Verbindung von Rechtsprechung und Verwaltung in ein- und derselben Behördenhierarchie konnte unter dem Grundgesetz nich aufrecht erhalten werden. ${ }^{3)}$ Ganz unmöglich wäre es gewesen, Behörden Rechtsschutz gegen ihre eigenen Verwaltungsakte gewäh ren zu lassen. In Anbetracht der intensiven Verflochtenheit der Verwaltungstätigkeit der Versicherungsbehörden mit den Aufgaben und der Tätigkeit der Versicherungsträger ${ }^{4)}$ konnte es aber. auch kaum noch gebilligt werden, daß die staatlichen Versicherungsbehörden Rechtsschutz gegenüber den Akten der Versicherungsträger gewährten. Eine innere Aufspaltung der Versicherungsbehörden in richterliche und nichtrichterliche "Teile" hätte jede Personalunion und auch sonst jede Einflußmöglichkeit der

1) S. zusammenfassend Bettermann, Die Unabhängigkeit der Gerichte und der gesetzliche Richter, S.637 ff.

2) Grundlegend wohl Friesenhahn, Über Begriff und Arten der Rechtsprechung, S. $32 \mathrm{ff}$. - S. ferner BVerfGE 4, 331 (346ff); 10, 200 (216 ff); BVerwGE 1, 4 (9 f); 2, 95 (96 f).

3) Für die (modifizierte) Aufrechterhaltung der Verbindung z.B. Maunz, Die oberste sozialrechtliche Gerichtsbarkeit rach dem Bonner Grundgesetz; Teutsch, Das künftige obere Bundesgericht für die Sozialgerichtsbarkeit, S.255 f; ders., Die Sozial. gerichtsbarkeit und die allgemeine Verwaltungsgerichtsbarkeit, S. $171 \mathrm{f}$; Miesbach, Gestaltung der Gerichtsbarkeit für A rbeitsrecht, Sozialversicherung und Kriegsopferversorgung, S. 229 f; ders., Das Bundessozialgericht, S. 233 .

4) Zu den Bedenken gegen die Verbindung der Aufsicht ibier die Sozialversicherungsträger mit der Aufsicht über die Srozialgerichte im Sozialressort s. BSGE 2, 201 (206 ff); Weidner, Zur Rechtsprechung des Bundessozialgerichts, S. 764. 
Verwaltungs-"Abteilung" auf die Gerichts-"Abteilung" ausschlie3en müssen. Um eine den verfassungsrechtlichen Postulaten geügende Absonderung zu erreichen, wäre somit eine so weitgehende interne Trennung notwendig geworden, daß es nicht mehr lohnte, um der zu rettenden Gemeinsamkeiten (z. B. Name, räumliche Unterbringung, Sachverwaltung u. ä.) willen den Verdacht einer geringeren Unabhängigkeit der Rechtsprechung in Kauf zu iehmen. Das Sozialgerichtsgesetz und das Bundesversicherungsamtsgesetz haben daher die einzige der grundgesetzlichen Ordnung voll gerecht werdende Konsequenz gezogen. Die Rechtsprechungsaufgaben liegen in der Hand der Sozialgerichte, die Verwaltungsaufgaben bei den besonderen Versicherungsbehörden, 5) bzw. den sonstigen zuständigen Verwaltungsbehörden (insbes. dem Bundesminister für Arbeit und Sozialordnung und den zuständigen Landesministerien). Vielfach war befürchtet worden, die Güte sowohl der Rechtsprechung wie auch der Verwaltung werde darunter leiden.6) Die bisherige Entwicklung dürfte diese wohl vorwiegend einem gewissen Beharrungsvermögen entsprechenden Prognosen nicht bestätigt haben. ${ }^{7)}$

In bezug auf die Finanzgerichtsbarkeit war analog die Herauslösung der Finanzgerichte aus den Oberfinanzdirektionen notwendig geworden (vgl. $\$ \$ 47$ ff RAO a. F. gegenüber $\$ \$ 1,2$ des Gesetzes über Maßnahmen auf dem Gebiet der Finanzgerichtsbarkeit). ${ }^{8)}$

Der Anteil der Rechtsprechung an der sozialen Intervention

Nicht weniger als Gesetzgebung und Verwaltung ist die Rechtsprechung eine zentrale Wirkungsweise des sozial intervenierenden jtaates - zumal des sozial intervenierenden Rechtsstaates. Alles

5) Bundesgesetzlich vorgesehen sind nur mehr die Versicherungsämter ( $\$ \$ 36$ ff $R V O)$ und das Bundesversicherungsamt ( $\$ 1$ des Bundesversicherungsamtsgesetzes). Kraft Gesetzes den Oberversicherungsämtern zustehende Verwaltungsaufgaben werden durch dic zu:tinndige oberste Landesbehörde wahrgenommen, soweit das Landesrecht nicht neue Sonderbehörden (z.B. Oberversicherungsämter neuer Ordnung schafft.)

S. die oben S. 596 zu Fußn.3 Zitierten.

$\mathrm{Zu}$ den besonderen Aufaaber der (verwaltungsunabhängigen) Sozialgerichtsbarkeit s. z. B. Jerosch, Die rechtsstaatliche Funktion der Rechtsprechung im Sozialrecht, Die Sozialgerichtsbarkeit, 5.Jhg. (1958) S. 73 ff; ders., Zur Frage, worin sich Verwaltung und Rechtsprechung im Sozialrecht unterscheiden, ebenda s.212 if.

8) Zu den Beschwerdeausschüssen nach dem Soforthilfegesetz s. BVerfGE 4, 331; BVerwGE 1, 4. 
soziale Geschehen, das vom Recht her bestimmbar ist, beherrscht sie. Ihr Wahrspruch setzt die Rechtsordnung durch und verleiht ihr Leben. Letztentscheidend über die Rechtrnäßigkeit des Tuns des Staates und der ihm eingegliederten Verbände und sonstigen Rechtsträger und selbst rechtsvollziehend trägt die Rechtsprechung die Verantwortung dafür, wie das Recht verwirklicht wird. 1)

Ihre größte Eigenständigkeit und Ursprünglichkeit hat sie sich auch im Rahmen der sozialen Intervention dort bewahrt, wo (zwischen-)bürgerliche Rechtsbeziehungen in Frage stehen. In ihnen konkretisiert sie das Recht von erster und letzter Hand. Die soziale Tragweite dieser Funktion erhellt aus der Ebenbürtigkeit, mit der der direkte Kanal "von Mensch zu Mensch", von Privatrechtssubjekt zu Privatrechtssubjekt als Weg des sozialen Ausgleiches neben der (Um-)Verteilung über den Staat steht. Das System des sozialen Ausgleichs und der sozialen Entspannung muß, sich integrierend, die zwischenbürgerlichen Beziehungen einschließen. Ob sie dem Recht entsprechen, wird im Streit relevant. Die Entscheidung des Streits ist beim Richter monopolisiert. Genügt die bloße, einen der Streitsteile in seinem Anspruch bestätigende Streitentscheidung nicht, so kann er, wenn die Rechtsordnung ihn dazu ermächtigt, die Rechtsbeziehungen auch positiv gestalten. Der - von materiellen Begriffsvorstellungen her in gewissen Grenzen gerechtfertigte - Einwand, daß es sich dabei um Verwaltung handle, greift dagegen nicht durch; denn die Verfassung hat zwar dem Richter die Substanz seiner streitentscheidenden Kompetenz gesichert, seinem (gesetzlich prädisponierten) Ausgriff in den Bereich der Verwaltung (und Gesetzgebung) jedoch elastische, weit zurückliegende Grenzen gesteckt.

Die andere kardinale Funktion der Rechtsprechung im sozial intervenierenden Rechtsstaat ist die rechtliche Kontrolle der Verwaltung. Sie garantiert die Bindung der Exekutive an das Recht und sichert damit - soweit das Recht, insbes. das positive Gesetz den nötigen Rückhalt gibt - die Freiheit des Individuums vom Staat und seine 'Teilhabe an den staatlichen Leistungen. Kont rollierend wacht die Rechtsprechung also auch an dem anderen Kanal des sozialen Ausgleichs, der (Um-) Verteilung über den Staat.

Neben der Anwendung des Rechts und der Sanktion seiner Einhaltung steht die Durchsetzung des jeweils höherrangigen Rechts gegenüber den Akten der Rechtsetzung. Vor allem in der Normenkontrolle gegenüber (förmlichen) Gesetzen entfaltet die Rechtspre-

1) Zum Phänomen s.aus neuerer Zeit z. B. die reich belegte Dar stellung von Engisch, Die Idee der Konkretisierung in Recht und Rechtswissenschaft unserer Zeit, 1953, S. 178 ff. 
zhung auch die verfassungsrechtliche Ordnung des Sozialen.

Indem die "dritte" Gewalt die Rechtsbindung des Staates realisiert, trägt sie dazu bei, daß durch diese Rechtsbindung das tiee Eindringen des Staates in die Individualsphäre, das sich im direkten Eingriff ebenso manifestiert wie in der einem Angewiesenjein entsprechenden Leistung, voraussehbar, berechenbar und so zut als möglich beherrschbar wird. Aber nicht nur dadurch wirkt sie - das Gesetz verwirklichend und ergänzend 2 ) - auf die menschliche Ertragbarkeit der intensiven Verstrickung des Individuums m Kollektiv, in den Beziehungen zum Mit-Individuum und zur organisierten Gemeinschaft hin. Indem der Richter vielfach dort, wo die Norm die individuellen Verhältnisse nicht mehr beherrschen kann und das Gewicht der Gestaltgabe zum großen oder gröBeren Teil bei der Konkretisierung, bei einer auf der allgemeinen Norm zwar aufbauenden, jedoch positiv über das von ihr Decerminierte hinausstoßenden individuell gesetzten Regelung liegt, an Stelle der Verwaltungsbehörde als Subjekt der konkreten Anordnung einspringt, gibt er die beruhigende Gewähr, daß nicht der dirigierbare Staatsapparat in die Individualsphäre einbricht sondern er, der Richter, zwar auch Staatsfunktionär aber doch durch seine Unabhängigkeit selbst als Individuum, als Mensch hervorgehoben und zudem als ein von seinem Beruf her dem Recht und der Gerechtigkeit zugewandter Mensch, ordnend und ausgleichend disponiert. Das lertrauen in den Richter läßt es auch dort viel leichter erträglich erscheinen, daß er an Stelle der Exekutive das Recht indivilualisiert, wo, ohne daß es um positive Gestaltung konkreter Rechts- und Lebensverhältnisse geht, eine um der Wahrung der Einzelfallgerechtigkeit gegenüber der Vielfalt der Sachlagen willen alligemein gehaltene Norm in Richtung auf die Einzelfallgerechtickeit, auf die individuelle Angemessenheit und (normgewollte) Zweckmäßigkeit hin konkretisiert werden muß. Da die Spannung zwischen einer sensiblen Gerechtigkeit und der erforderten Regelung viellältigster Lebensverhältnisse gerade im sozialen Bereich besunders groß ist, ist speziell hierin der Gesetzgeher immer wirder darauf verwiesen (und versucht), auf das Medium w.r. ri(chterlichen Konkretisierung zurückzugreifen.

Die Verfassung hat (ler rechteprechenden Gewalt diesen (fast zu) festen Stand gegeben, ler ciner gegenüber Gesetzgebung und Exekutive mißtrauischen und vertrossenen, jedoch gegenüber dem Richter teils gläubig vertiau(nden, teils wenigstens gutwilligen 
und duldsamen Staatsauffassung entspricht. Die Garantien der Un abhängigkeit (Art.97 GG) und organisatorischen Selbständigkeit (Art. 20 Abs. 2, 92 GG) der Gerichte sowie die Hervorhebung des Richters (Art.92, 1. Halbsatz, 98 Abs. 1 und 3, 60 Abs. 1 GG) unter gleichzeitiger Sicherung seiner Verfassungstreue (Art. 98 Abs. 2 und 5 GG) und seiner demokratischen Legitimation (Art.94 Abs. 1 Satz 2, 95 Abs. 3, 96 Abs. 2, 98 Abs. 4 GG) schaffen und stärken die Vertrauensbasis der rechtsprechenden Gewalt. Die geradezu einseitige Kompetenzabsicherung zugunsten der Gerichte (insbes. Art. 19 Abs.4, 92, 93, $100 \mathrm{GG)}$ ) ergibt von Verfassungs wegen eine umfassende Rechtsgarantie und die Grundlage ihres weiteren gesetzlichen Ausbaues. Die sachgerechte Gliederung der Gerichte (Art.92-96a, 101 Abs. 2 GG) vermag die Effizienz ihrer Tätigkeit zu steigern. Im besonderen tritt die Verselbständigung einer besonderen Sozialgerichtsbarkeit neben der A rbeitsgerichtsbarkeit hervor - ein Zeichen für das Gewicht der Rechtsprechung in sozialen Angelegenheiten und zugleich für den Willen des Grundgesetzes, gerade ihr besondere Aufmerksamkeit $\mathrm{zu}$ schenken.

Doch bei aller konstitutionellen Bemühung um sie kann auch diese "rechtsprechende Gewalt" nicht über ihren Schatten springen. Der Richter kann nur Recht "sprechen". Er kann nur sagen, was in diesem oder jenem Fall Recht ist bzw. Recht wird. 3) Er kann nicht wie der Gesetzgeber Recht setzen. Entwickelt er allgemeine Sätze ungeschriebenen Rechts, um sie seiner Entscheidung zugrunde zu legen, so setzt er sie doch nicht verbindlich. ${ }^{4}$ Selbst wenn seiner Entscheidung allgemeine Verbindlichkeit zukommt wie den Entscheidungen der Verfassungsgerichte nach $\$ 31$ Abs. 1 BVerfGG, $₫ 21$ BayVerfGHG -, so doch eben seiner Entscheidung und nicht etwa von ihm gesetztem Recht. 5) Immer ist dem Richter

3) Vgl. Baur, Sozialer Ausgleich durch Richterspruch, S. 195 : "... bemüht sich der Richter in Ausübung der ihm neuerdings übertragenen Ausgleichsfunktionen um die Ordnung, Gestaltung eines in seinem Bestand angegriffenen, gefährdeten Lebensverhältnisses. Man kann... überspitzt vielleicht so formulieren: In diesem neuen Bereich hat der Richter nicht darüber zu entscheiden, wer Recht hat, sondern wie Recht w ird - Recht wird in einem Lebensverhältnis, das nicht lediglich in seiner gegenwärtigen Situation analysiert, sondern in seiner künftigen Entwicklung gesichert werden soll".

4) Zum Richterrecht s. nochmals oben S. 528 zu Fußn. 20, 21.

5) Die These von der bindenden Wirkung auch der (tragenden) Gründe der Entscheidungen des Bundesverfassungsgerichts ist verfehlt (vgl. BGHZ (Großer Zivilsenat) 13, 265 (271 ff); 
heteronom gesetztes Recht vorgegeben, das er nicht gestalten sondern nur in seiner Verbindlichkeit, bestenfalls verdeutlichen kann. 6) Genau so wenig, wie sie den Gesetzgeber direkt ersetzen kann und darf, darf die rechtsprechende Gewalt ihren Platz im Gewaltenteilungssystem dahingehend verlassen, daß sie den Gesetzgeber in einer Weise für verpflichtet erklärt, eine bestimmte Regelung zu erlassen, daß ihr Ausspruch im Wege der (ideellen) Vollstreckung an die Stelle der gesetzlichen Regelung selbst treten kann. Sie kann auch die Verwaltung durch ihren Ausspruch nur hindern, durch ihr Tun das Recht zu verletzen; sie kann ihr befehlen, das zu tun, was das Recht ihr eindeutig zu tun gebietet; aber sie kann nicht bewirken, was der Verwaltung an freier Gestaltung aufgetragen ist und diese zu tun unterläßt. Wo das übergeordnete

BGHSt 5, 231 (237); BDHE 1, 55 (56 f); Willms, Was bindet nach $₫ 31$ Abs. 1 BVerfGG? JZ 9.Jhg. (1954) S. 424 ff; Jesch, Zur Bindung der Entscheidungen des Bundesverfassungsgerichts über Verfassungsbeschwerden, ebenda S. 528 ff (529 f); Kadenbach, Zur bindenden Wirkung der Entscheidungen des Bundesverfassungsgerichts, AöR Bd.80 (1955/56) S.385 ff, insbes. S. 402 ff; weitere Nachweise über Rechtsprechung und Schrifttum s. bei den Zitierten).

6) Das ist für den insoweit interessantesten Bereich der Verfassungsgerichtsbarkeit am eindeutigsten, wo das Gericht bloß über Gültigkeit oder Ungültigkeit einer Norm entscheiden kann (vgl. Art.93 Abs. 1 Nr.2, 100 Abs. 1 GG i.V.m. $\$ 13$ Nr. 6 und $11, \S 31$ Abs. 2 BVerf(r) oder wo es nur um den Rang einer Norm geht (Art.126 GG i.V.m. $\$ 13 \mathrm{Nr} .14, \$ 31$ Abs.2 BVerfGG). Hinsichtlich der Normenkontrolle wirft die sog. verfassungskonforme Auslegung allerdings neue Probleme in Richtung auf eine Konkurrenz. der Verfassungs rechtsprechung mit der Gesetzgebung auf (s.o. S. 557 zu Fußn. 10 (3)). Weiter geht der Auftrag des Bundesverfassungsgerichts hinsichtlich der Feststellung "ob eine Regel des Völkerrechts Bestandteil des Bundesrechts ist $[n, 1,1)$ sie unmittelbar Rechte und Pflichten für den einzelnen er\%urt" (Art.100 Abs.2 GG i.V.m. $\$ 13$ Nr.12, \31 Abs. 2 BVerf( $\left(\begin{array}{l}(y) \\ x\end{array}\right)$. Hierbei hat das Bundesverfassungsgericht die Norm $\bullet r$ st aus dem Völkerrecht an das "Licht" des innerstaatlichen Rechts zu heben. Abstrakt betrachtet ist freilich auch das nur ein Akt der Erkenntnis. Aber der Spielraum des Irrtums ist hier größer und somit auch das eigenständige Gewicht der Fntscheidung. Ähnlich verhält es sich mit der verbindlichen Auslegung des Grundgesetzes im Organstreit (Art.93 Abs. 1 Nr. 1 GG i.V.m. $₫ 13$ Nr.5, $₫ 31$ Abs.2 BVerfGG). 
Recht ein positives Tun des Gesetzgebers oder der Verwaltung nicht normierend vorwegnimmt, kann es auch der Richter nicht bewirken. Im Bereich der sozialen Intervention, wo es so viel auf das Handeln, das Leisten, das positive Gestalten ankommt, ist das die spürbarste Einschränkung der richterlichen Aktionsmächtigkeit .

Ein anderer Gesichtspunkt muß abschließend noch hervorgehoben werden. Wo der Richter tätig wird, wird er das in der Regel nicht von Amts wegen. Das Einschreiten ohne Klage, Antrag usw. ist die Ausnahme. ${ }^{\text {) }}$ Das bedeutet, daß dort, wo die Rechtsverwirklichung dem Richter anvertraut ist, und soweit das der Fall ist, das Recht nur dann verwirklicht wird, wenn die Beteiligten - genauer: die vom Recht Begünstigten, die Berechtigten - den "Kampf ums Recht" aufzunehmen bereit sind. 8) Der Rechtsschutz des Bürgers durch die Gerichte - sei es gegen den Staat, sei es gegen Private - läßt die Alternative offen, daß dem Bürger sein Recht wird, wenn er sich zu ihm bekennt und es geltend macht, daß es ihm aber nicht wird, wenn er dazu zu unwissend, zu feig, zu träge oder aber auch zu zurückhaltend ist. Darin steckt Freiheit, wird die Personwürde sichtbar. Darin steckt aber auch der Keim einer Ungleichheit. Die formale Waffengleichheit wird zur sachlichen Ungleichheit, wenn die Fähigkeit zu kämpfen nicht die gleiche ist. Nur allzuoft ist der sozial Schwächere auch der a priori schlechter gerüstete Kämpfer ums Recht. 9) So wirkt das System des gerichtlichen Rechtsschutzes sich nur allzuleicht unsozial aus. Zwar ist der im Armenrecht risikolos streitende, mittellose Querulant eine bekannte Plage des Rechtslebens. Aber der ernster zu nehmende Fall ist doch der unbeholfene, unwissende Arme, der sein Recht weder erkennen noch sachgemäß geltend machen kann. Ihm helfen auch Armenrecht, Gebührenfreiheit und ähnliche Erleichterungen nicht immer; 10) wenn auch die zen-

7) Vgl. Bettermann, Verwaltungsakt und Richterspruch, S.371 f; ders., Die freiwillige Gerichtsbarkeit im Spannungsfeld zwischen Verwaltung und Rechtsprechung, S. 25.

8) S. zur Notwendigkeit des Ringens um das Recht für die Verwirklichung (und Fortentwicklung) die berühmte Schrift Rudolf v. Jherings, Der Kampf ums Recht, 1. Aufl. 1872.

9) S. Richter, Neue Rechtsformen für das Leistungsverwaltungsrecht, insbes. S. 1518 .

10) Aber auch ein System staatlicher Bevormundung aller Bürger könnte derlei Unterschiede nicht voll ausgleichen. Immer wird z. B. die Behörde auf die Darlegung persönlicher Verhältnisse durch den Betroffenen angewiesen sein. Wer dazu nicht fähig ist, muß Nachteile in Kauf nehmen. 
rale Position des gerichtlichen Rechtsschutzes erneut darauf inweist, wie wichtig es ist, daß durch diese Hilfen, insbes. das Irmenrecht die Waffengleichheit wenigstens so gut wie möglich ergestellt wird. Bis in diesen Winkel verschlägt sich also der Viderspruch von Freiheit und staatlicher Fürsorge.

Die soziale Intervention im "Verwa1tungsst a a $"$ "

\section{Die besondere Funktion der Verwaltung}

Die kapitale Bedeutung der Verwaltung für die soziale Intervenion war gleichsam die "Selbstverständlichkeit", von der diese Jntersuchung des Zusammenwirkens der drei "Gewalten" in der ozialen Intervention ausgegangen ist. 1) Indem die Funktion von Gesetzgebung und Rechtsprechung erörtert wurde, ergab sich, vie weitgehend die Verwaltung von der Gesetzgebung und Rechtprechung eingeengt, wie tiefgehend sie davon durchdrungen ist. is würde zu endlosen Wiederholungen führen, hier nochmals die Nirksamkeitsbedingungen der Verwaltung in extenso auszubreien.

Das ist fast wie eine Bestätigung des negativen Verwaltungsberiffes, 2) wonach, grob gesagt, Verwaltung das an staatlicher Nirksamkeit ist, was nicht Gesetzgebung und Rechtsprechung ist. Doch lenkt nur eine oberflächliche Optik auf diesen Gedanken. Der ür die Bundesrepublik festzustellende - man kann wohl sagen: naximale - Grad der legislativ - und judikativseitigen Bestimmtheit der Verwaltung ist nicht eine notwendige Konsequenz ihres Nesens. In erster Linie ist sie Ausdruck der Rechtsstaatskonzepion, die im Grundgesetz und auf Grund des Grundgesetzes speciell für die Bundesrepublik entwickelt wurde. Allerdings hängt serade der Gehalt dieses Gewaltenteilungssystems mit der Unestimmtheit, der Schwer-Frfaßbarkeit des "tertium" zusamnen, das als vollziehende Ciewalt bezeichnet wird.

Dem tiefer dringenden Blick beweist das beobachtete Verhältnis ler Gesetzgebung und Rechtsprechung zur Verwaltung, daß das Nesen der Verwaltung einen Kern hat, der sie - mag er zu ihrer rschöpfenden Definition auch nicht hinreichen - positiv charak-

S. oben S. 412 und S. 418.

Eine Zusammenstellung über den Begriff der Verwaltung s. bei Winkler, Zum Verwaltungsbegriff, Österreichische Zeitschrift für öffentliches Recht, n. F. BD. IX (1958/59) S.66 ff; Wolff, Verwaltungsrecht I, S. 7 ff. 
terisiert, einen Kern, in den Gesetzgebung und Rechtsprechung befehlend und lenkend eindringen, den sie aber nicht absorbieren können: Verwaltung ist tätige Leistung des Staates. ${ }^{3)}$ Soziale Gü terverteilung durch den Staat und Umverteilung über den Staat is tätige Leistung des Staates. Sie ist also unerläßlich (wenigstens auch) Aufgabe der Verwaltung. Die Verwaltung zahlt Gelder aus, erbringt Sachleistungen, stellt persönliche Dienste bereit. Sie plant, fördert oder bewirkt wirtschaftliche Hilfsmaßnahmen, bildungsfördernde Veranstaltungen usw. Aber sie schafft auch die Voraussetzungen dafür, daß die staatlichen Leistungen erbracht werden können. Sie verwaltet die Finanzen und sächlichen Mittel, sie unterhält das Personal. Sie baut Heime, errichtet personelle und sachliche "Apparate". Sie erwirtschaftet Mittel aus dem Staatsvermögen. Sie treibt Steuern und sonstige Abgaben ein. Dis Skala der Tätigkeiten reicht vom gesetzlich genau präzisierten und richterlich genau fixierbaren Tun bis zu jenen Aktionskomple xen, die vielleicht im Ganzen, jedoch niemals in der Masse der Details, aus denen allein sich das Ganze fügen kann, vom Gesetz prädisponiert werden können, und schließlich bis zu jenen Maßnahmen, die nur die freie, der Notwendigkeit und der Gelegenhei adäquate Initiative auf Grund eines generellen Auftrags hervorbringen kann. Versagt die Verwaltung - auch und gerade wenn nur aus Mißgeschick -, so kann der Staat die Leistungen nicht erbringen, die die Gesetze anordnen und die Urteile gebieten. Die rechtliche Ordnung der staatlichen Leistungen (jetzt nicht nur im Sinne von Begünstigungen, dies aber dem Zusammenhang nack doch vorwiegend) setzt gewisse Sachverhalte als gegeben oder wenigstens als gesollt und demzufolge wenigstens als angenomme nermaßen gegeben voraus. Entfallen diese Prämissen, weil die Verwaltung - aus welchen Gründen auch immer - sie nicht herstellt, so bleiben das leistungsgebietende Urteil oder Gesetz tote Buchstabe. 4)

Das gipfelt in dem Bereich der obersten Verwaltungsleitung, der im ganzen vielfach gar nicht mehr zur Verwaltung gezählt wird:

3) Grundlegend Erich Kaufmann, Art. "Verwaltung, Verwaltungsrecht" in Stengel-Fleischmann, Wörterbuch des Staatsund Verwaltungsrechts, 2.Aufl. Bd.III 1914, S.688 ff (688).

4) Zum Aufgabenstand der Verwaltung s. nochmals die Nachweise oben S.418 und S.421 und S.424. - Darüber hinaus s. zu Vorstehendem Becker, Die Leistungsaufgaben der öffentlichen Verwaltung nach den Zwecken, Mitteln und Formen des Verwaltungshandelns, DVB1. 75.Jhg. (1960) S. $297 \mathrm{ff}$. 
im Bereich der Regierung. 5) Sie trägt vor allen anderen die Verantwortung für das Schicksal des Staates. Von ihrer Politik hängt es entscheidend $a b$, ob ler Staat zu sozialen Leistungen fähig ist, oleibt oder wird. Am deutlichsten wird das sichtbar in bezug auf die sog. auswärtige Gewalt. Sie, die am wenigsten durch Gesetze gelenkt werden kann, setzt entscheidende Prämissen für das Staatswohl und für die Fähigkeit des Staates zum sozialen Ausgleich. Im Bereich der Regierung berührt sich die Sachverantwortung der Exekutive aber auch wieder mit der des Gesetzgebers; denn die Gesetzgebung ist ein wesentliches Instrument der jtaatsführung.

An die spezifische Stellung und Funktion der Regierung knüpft zuch ein anderes Wesensmerkmal der Verwaltung, das, neben ihrer Unersetzlichkeit als Leistungsträger für ihren Einsatz kennzeichnend ist: ihre aktuelle und zentrale Beherrschbarkeit durch die Regierung und über die parlamentarischen Legislativorgane, 6) vor allem soweit es sich um die unmittelbar staatliche Verwal:ung handelt, Beherrschbarkeit auch durch den engeren Kreis der Beteiligten, soweit es sich um Selbstverwaltung handelt. Einheitlichkeit des Rechtsvollzugs, aus Geschlossenheit sich ergebende jchlagkraft und Homogenität mit den maßgeblichen politischen Poenzen sind die Vorzüge, die die Verwaltung insoweit unverwechselbar kennzeichnen. ${ }^{7)}$ Sie markieren vor allem die Grenze der

j) S. vor allem Scheuner, Der Bereich der Regierung; Nawiasky, Allgemeine Staatslehre, Teil 2 Bd.II, S. 15 ff, Teil 3, S. 78 f; Wolff, Verwaltungsrecht I, S. 62 ff.

3) Vg1. zu dieser Koppelung Merk, Kann der Bundestag der Bundesregierung Weisungen erteilen? Zeitschrift für die gesamte Staatswissenschaft, Bd.114 (1958) S.705 ff.

(1) Der für das österreichische Verwaltungsrecht kennzeichnende formale Verwaltungsbegriff baut auf der Weisungsabhängigkeit auf (vgl. Winkler, Zum Verwaltungsbegriff). Das wäre für das deutsche Verwaltungsrecht allerdings nicht angebracht; denn weisungsunabhängige und trotzdem nicht der rechtsprechenden Crewalt zugehörende Vollzugsorgane sind ihm - wie schon wiederholt erwähnt - durchaus nicht fremd oder verwehrt (s.a. Wolff, Verwaltungsrecht I, S.8). Doch handelt es sich bei der auf Weisungs- und Kontroll rechten basierenden willensmäßigen Einheit der Verwaltung immerhin um etwas Typisches (vgl. Wolff, a.a.O. S.12).

(2) Sehr wichtig ist in diesem Zusammenhang die über die parlamentarische Abhängigkeit der Regierung hergestellte kontinuierliche Homogenität zwischen der parlamentarischen Legislative und der Exckutive. Sie unterliegt allerdings zahl- 
Vertauschbarkeit von Verwaltung und rechtsprechender Gewalt. ${ }^{8}$ Das Phänomen ist allerdings keine Eigentümlichkeit der sozialen Intervention. Es tritt in ihr vergleichsweise nicht einmal besonders hervor. Aber die besagte Eigenart der Exekutive gibt auch für sie mit das Maß der Expansion der Verwaltung an.

\section{b) Verwaltung zwischen Gesetzgebung und Rechtsprechung}

Diese Dirigierbarkeit überspringt jedoch nicht die Grenzen des Gesetzes, das die Verwaltung auf das nachhaltigste bindet und von Verfassungs wegen - binden soll. Man kann "heute nicht meh im Ernst behaupten, daß die Verwaltung gegenüber der Gesetzgebung eine eigene Orientierung besitzt". 1) Auf der anderen Seite steht als Wächter darüber, daß die gesetzliche Bindung - allgemeiner: die Rechtsbindung - auch eingehalten wird, die rechtsprechende Gewalt. "So wird der Ermessensbereich der Verwaltung von zwei Seiten, von der Gesetzgebung und von der Justiz her, eingeengt". 2) Wo und soweit eine in die Sache eindringende

reichen Brechungen, von dem Auseinanderfallen der parlamentarischen Kontrollmächtigkeit und der Zuständigkeit zur Gesetzgebung (die sich insbes. bei Bundestag und Bundesrat, dessen verfassungsmäßige Mitwirkung bei der Führung der Exekutive eingerechnet, nicht decken) bis zur Zäsur, die wei sungsunabhängige Ausschüsse, autonome Verbände usw. von dem willensmäßigen Zusammenhang mit der Exekutivspitze die dem maßgeblichen Gesetzgeber homogen ist (bzw. sein so ablöst. Am bedeutsamsten sind für die Bundesrepublik die Zäsuren, die das bundesstaatliche Verteilungssystem - gröBere Gesetzgebungsmacht beim Bund, breitere Exekutivzuständigkeit bei den Ländern - mit sich bringt. Ihnen versucht das System der verschiedenen Direktions- und Weisungsrechte der Bundesregierung (und des Bundesrates) zu begegnen (s. oben B 1 I 2 c-e (S. 115 ff)).

8) S. oben 3 b (S. $512 \mathrm{ff})$ und $\mathrm{f}(\mathrm{S} .597 \mathrm{ff})$.

1) Scheuner, Diskussionsbeitrag zu "Verwaltung und Verwa1tungsrechtsprechung" S. 182 ff (Zitat S. 183). - S.a. Kern, Aspekte des Verwaltungsrechts im Industriezeitalter, S. 100: "So wird der moderne Staat zu einem Gemeinwesen, das durch ein System gelenkter Sozialabläufe gekennzeichnet ist. Dieser soziale Rechtsstaat wird von der Verwaltung vollzogen. Er wird von einer Maßnahme orientierten Gesetzgebungsmaschinerie normativ gesteuert". (Sperrungen nicht aus dem Original).

2) Forsthoff, Diskussionsbeitrag zu "Verwaltung und Verwaltungsrechtsprechung" S. 187 f (Zitat S.187) - Zu der Sentenz 
Normierung möglich ist, ist die Verwaltung entscheidungsarm gevorden. 3) Nur dort, wo die Normierbarkeit der Vorgänge wegen hrer inneren Vielgestaltigkeit und Komplexität und wegen der Unibersehbarkeit der bedingenden Umstände nachläßt, breitet sich regelmäßig, graduell und gegenständlich sehr unterschiedlich, Ermessen aus. Und dort, wo das Gesetz nicht Bedingung sondern ur mögliche und (gegenüber dem Gesetzgeber zu sagen:) gesolle Grenze des Verwaltungshandelns ist, im Bereich der reinen Leistungsverwaltung, finden sich - aus sehr verschiedenen Gründen, vielfach solchen gesetzgeberischen Versagens oder wägenden Zuwartens oder politischer Opportunität - Räume nicht im engeren Sinne gesetzesakzessorischer und somit gesetzes gebundeier Verwaltung.

Soziale Verwaltung 4 ) schließt die ganze Spannweite ein. Das be-

Forsthoffs ist eine Erklärung angebracht: "Die Justiz" schränkt das Ermessen der Verwaltung nicht ein. Sie garantiert vielmehr die Verwirklichung der Ermessenseinschränkung, die der Gesetzgeber verfügt hat. Das (i.V.m. der Vollmacht des Richters, die Reichweite der gesetzlichen Bindung interpretatorisch zu ermitteln) scheint Forsthoff zu meinen.

3) Die treffenden und subtilen Beobachtungen Köttgens hierzu s. an den oben S.160 zu Fußn.2 genannten Stellen.

4) Wenn hier von sozialer Verwaltung die Rede ist, so soll damit nicht auf den älteren Begriff der sozialen Verwaltung zurückgegriffen werden, der "sozial" im allgemeinsten Sinne, d.h. also als "gesellschaftszugewandt, gesellschaftsbezogen" versteht (s. z.B. Roesler, Das soziale Verwaltungsrecht, 2 Bde. 1872/73). Es soll auch nicht auf den Sozialverwaltungsbegriff zurückgekommen werden, der mehr oder weniger zufällig einige notorisch "soziale" Verwaltungszweige zusammenfaßte oder auch nur die Sozialversicherung als Sozialverwaltung hervorhebt (s. z. B. die völlig unbehelflichen Abgrenzungsversuche bei Schwankhart, Besonderheiten der Sozialverwaltung im Verhältnis zur Allgemeinen Verwaltung, Bayerische Verwaltungsblätter, n.F. 3.Jhg. (1957) S. $111 \mathrm{ff}, 149 \mathrm{ff}(111))$. Fin Beispiel bietet die unbrauchbare Abgrenzung des wirtschaftswissenschaftlichen Studienfaches "Sozialverwaltung" nach der nationalsozialistischen Studienordnung (s. Brauweiler, Sozialverwaltung, 1936). Er umfaßt: A rbeitsverwaltung (einschließlich Arbeitsgerichtsbarkeit!), Sozialversicherung, Fürsorge (einschließlich Versorgung und Versorgungsgerichtsbarkeit) und Siedlungswerk (s. Brauweiler, a.a.O. S. $68 \mathrm{ff}, 139 \mathrm{ff}$ ). Hier ist "sozial" vielmehr in 
deutet aber auch, daß sie in ihrer Struktur diese Spannung aushalten muß. Auf weiten Strecken ist sie mehr oder weniger mechanischer Rechtsvollzug - ein Terrain, das einerseits als die technisierte Verwaltung, 5 ) andererseits (sei es, daß dort die Technisierung zwar möglich aber noch nicht durchgeführt ist, sei es, daß auf unmittelbare menschliche Leistung nicht ganz verzich tet werden kann) als die Verwaltung der mittleren Beamten 6 ) nach außen tritt. Wo das Gesetz die Bindung lockert und schließlich Freiheit läßt, ist aber die persönliche Initiative, die individuelle, sachgerechte Entscheidung, die überlegene Planung vonnöten. Hier ist der qualifizierte Beamte, der Jurist und der nichtjuristische Fachmann unentbehrlich. In diesem Bereich kann sich auch die Selbstverwaltung - die politische und die rechtliche Selbstverwaltung - entfalten, während sie als Subjekt rein mechanischen Rechtsvollzuges oft zum bloßen Dekor herabsinkt.

In dem der Verwaltung durch Gesetzgebung und Rechtsprechung gesteckten Rahmen der Entfaltung ist auch die Tragweite der für die zentrale Steuerung so wichtigen Verwaltungsvorschriften zu sehen. Soweit die Verwaltung engeren rechtlichen Bindungen unterliegt, ist die Leistungsbefugnis der Exekutivspitze ${ }^{7)}$ zwar geeignet, durch Interpretation und Klarstellung der Möglichkeiten und Pflichten der Verwaltung den Vollzug in Gang zu setzen. Dabei wird eine zentrale Regelung besonders geeignet sein, die zu nehmenden Rücksichten optimal zu wahren und den Vollzug einheitlich zu gestalten. Sie unterliegt aber dem Vorbehalt anderweiter gerichtlicher Entscheidung. Sobald die maßgeblichen (Ober-)Gerichte eine entgegengesetzte grundsätzliche Rechtsprechung entwickeln, muß sich die Verwaltung - einerseits aus Re-

einem engeren aber allgemeinen Sinn zu verstehen. "Soziale Verwaltung" soll demnach, funktionell erfaßt, alle sozial interessierende Tätigkeit der Verwaltung (im organisatorischen Sinne) sein.

5) Vgl. insbes. Karl Zeidler, Über die Technisierung der Verwaltung.

6) S. z.B. Forsthoff, Diskussionsbeitrag zu "Verwaltung und Verwaltungsrechtsprechung", S. 188.

7) Im Zusammenhang mit der bundesstaatlichen Aufteilung der Verwaltungsbefugnisse ist dieses Direktionsrecht ausdrücklich geregelt (s.o. B 1 I 2 c (S.115 ff) und d (S.125 ff)). Im übrigen ergibt sich, soweit eine ausdrückliche Regelung fehlt, die Befugnis zum Erlaß von Verwaltungsvorschriften ohne wei teres aus der Kompetenz zur Leitung eines Geschäftsbereiches (vgl. BVerwGE Urt. v. 9.Oktober 1957 - BVerwG VII B 56/57 - DVB1. 73.Jhg. (1958) S. 172). 
spekt vor der Letztentscheidungsmacht der Gerichte, andererseits ganz einfach, um eine wiederholte gerichtliche Korrektur und letztlich Amtshaftungsansprüche zu vermeiden (Art.34 GG) uber die jeweils einzeln entschiedenen Fälle hinaus fügen. ${ }^{8)}$ Nur soweit der Verwaltung eigener Gestaltungsraum zur Verfügung steht, ist ihren Verwaltungsrichtlinien gegenüber der Durchgriff auf das Gesetz und eine gerichtliche Ingerenz an sich nicht möglich. In den Bereichen leistender Verwaltung, die eine strikte gesetzliche Regelung nicht gefunden haben, ist diese Art verwaltungsmäßiger Regelung denn auch zu erheblicher Bedeutung gelangt (s. vor allem die Weisungen des Lastenausgleichsrechts ${ }^{9}$ )).

8) Ein schwieriges Problem! Einerseits hat unter den obwaltenden Strukturbedingungen des Verhältnisses Verwaltung-Rechtsprechung nicht nur der Bürger die Aufgabe, durch den

"Kampf ums Recht" sich sein Recht zu verschaffen und zur objektiven Verwirklichung des Rechts beizutragen (s.o. S. 597 ). Auch der Verwaltung, als dem Streitgegner des Bürgers, obliegt dieselbe Funktion. Rechtsprechung ist nicht weniger Menschenwerk als alle andere Staatsfunktion. Die zweckgerechte Streitführung durch die Beteiligten kann der Richtigkeit der Rechtsprechungsprodukte nur förderlich sein. Glaubt die Verwaltung, eine Rechtsprechung sei falsch, so hat sie so etwas wie eine Pflicht, die Rechtsprechung von dem (vermeintlich) falschen Weg wieder abzubringen. Es ist noch kein Zeichen von Illoyalität, wenn die Exekutive nicht auf jede obergerichtliche (geschweige denn untergerichtliche) Entscheidung hin schon einschwenkt. Aber wo ist die Grenze zu jenem unzulässigen Selbstwiderspruch des Staates, der durch das Verharren der Verwaltung auf einem von der Rechtsprechung sichtlich endgültig mißbilligten Rechtsstandpunkt hervorgerufen wird? - Zum I'roblem der Bedeutung höchstrichterlicher Entscheidungen für die Verwaltung s.f.v. a. BFHE 67, 355 (362 ff) und Jesch (Anmerkung hierzu (= Urteil v. 14. August 1958, I 39/57 L) JZ. 15. Jhg. (1960) S. 282 ff) je mit weiteren Nachweiser.

9) (1) Zur Eigenschaft der. Weisungen des Präsidenten des Bundesausgleichsamts als (für die Verwaltungsbehörden) verbind1iche Ermessensrichtlinien vgl. BVerwGE 2, 163 mit Anmerkung Bachof JZ Jhg. 11 (1956) S. 35 f; BVerwG Urt.v. 22. September 1955 - BVerwG III C 49.54 - Sammel- und Nachschlagwerk der Rechtsprechung des Bundesverwaltungsgerichts 4273 $(=\$ 362 \mathrm{Nr} .2 \mathrm{LAG})$. Das will aber keineswegs sagen, daß "Weisungen" immer Frmessensrichtlinien sind (s. den in BVerfGE 8, 155 entschiedenen Fall und hierzu nochmals 
Doch relativiert die stets notwendige Prüfung, ob die rechtlichen Grenzen des Ermessens nicht nur allgemein durch die in Frage stehenden Richtlinien sondern gerade auch durch ihre Anwendung auf den jeweils zur Entscheidung stehenden einzelnen Fall gewahrt sind, 10) ihre selbständige Wirkung. Nur die Befugnis zum Erlaß von Rechtsverordnungen verschafft der Exekutive (bzw. ihrer Leitung) gefestigtere Gestaltungsmöglichkeiten. Doch greift sie damit materiell bereits in die Gesetzgebung hinüber.

Aber ist die vollziehende Gewalt nicht durch Art.20 Abs. 3 GG auf einen festeren Grund gestellt? Nicht nur an das Gesetz, auch an das Recht schlechthin 11) ist sie gebunden. Gibt ihr das nicht eine Legitimation, auch dem Gesetz, das gegen das Recht verstößt, gegenüberzutreten? Nicht anders als die rechtsprechende Gewalt ist die vollziehende an "Gesetz und Recht" gebunden. Gibt ihr das nicht weiter auch eine Legitimation, sich gegen den Richter zu stellen, der gegen "Gesetz und Recht" verstößt? Unter Berufung auf den materiellen Gehalt der Verfassung und womöglich auch überpositives Recht ${ }^{12)}$ könnte dann die Ver-

Jesch, Zulässigkeit gesetzesvertretender Verwaltungsverord. nungen? S. $81 \mathrm{ff}$ ).

(2) Zu den Erlaßrichtlinien nach $₫ 131$ Abs. 2 AO s.BFHE 67, 355 (358 ff) und Anmerkung hierzu von Jesch (a.a.O.) je mit weiteren Nachweisen.

10) Das ist in BFHE 67, 355 (358 f) zwar richtig gehandhabt aber reichlich unklar zum Ausdruck gebracht.

11) $\mathrm{Zu}$ "Gesetz und Recht" i.S. des Art.20 Abs.3 GG, dem noch immer nicht befriedigend geklärten $Z$ willingsbegriff s. vor allem Wernicke, Bonner Kommentar, Art.20 Anm. II 3 e; Darmstaedter, Der Begriff "Recht" in Art. 20 Abs. 3 des Grundgesetzes, NJW 10.Jhg. (1957) S. 769 ff; Buchsbaum, nochma1s: Der Begriff "Recht" in Art.20 Abs. 3 GG, NJW 10.Jhg. (1957) S. 1181; Maunz, Deutsches Staatsrecht, S.58; Forsthoff, Die Bindung an Gesetz und Recht (Art.20 Abs. 3 GG), DÖV 12.Jhg. (1959) S. 41 ff; Maunz-Dürig, Art.20 Randn. 72; Schnorr, Die Rechtsidee im Grundgesetz, AöR Bd. 85 (1960) S. 121 ff. - Weitere Nachweise s. bei v. Mangoldt-Klein, Art.20 Anm. VI $4 \mathrm{f}$, wo sich allerdings keine befriedigende Klärung findet. Auch Jahrreiß, Gesetz und Recht - Recht und Gesetz, NJW 3.Jhg. (1950) S.3 ff, löst das in Art. 20 Abs. 3 GG steckende Rechtsquellen- und Gewaltentrennung sproblem nicht.

12) Zur Hereinnahme überpositiven Rechts in das positive Recht 
waltung die Bindung an Gesetz und Richterspruch abschütteln. Gewiß wäre sie so auch unbehindert imstande, den Verfassungsgehalt zu verwirklichen, wo Gesetzgeber und Gerichte ihn vernachlässigen. Das könnte im ersten Anlauf durchaus auch den sozial tendenziösen Verfassungssätzen, ja vielleicht auch der "sozialen Gerechtigkeit" 13) schlechthin zugute kommen. Aber der Preis wäre kein geringerer als der Tausch der wohltemperierten Ordnung gegen den diktatorischen Verwaltungsstaat oder das Chaos. Und doch wird immer wieder die These vom eigenen, auf A rt.20 Abs. 3 GG fußenden Recht der Exekutive gegen Gesetz und Gesetzgeber aufgestellt. ${ }^{14)}$ Provoziert wird sie dadurch, daß die verfassungsgerichtliche Feststellung der Nichtigkeit eines Gesetzes ex tunc wirkt. 15) Die Verwaltungsbehörde, die sich bis zur Normenkontrollentscheidung, die das Gesetz für nichtig erklärt, daran gehalten hat und halten mußte, erfährt also hintennach, daß sie ein ungültiges Gesetz angewandt hat. Das ist in der Tat mißlich. Dieser ex-nunc-Einschlag der verfassungsgerichtlichen Entscheidung 16) beeinträchtigt die gute Ordnung jedoch viel weniger

über die "Rechts"-Klausel des Art.20 Abs. 3 GG s. außer den S. 610 zu Fußn. 11 Zitierten, BVerfGE 3, 225 (233) und Nawiasky (Positives und überpositives Recht) noch unten S. 663.

13) Vg1. S.610 zu Fußn. 12 und S.663.

14) S. vor allem Hamann, Aussetzung der Vollziehung von Steuerbescheiden bei verfassungsrechtlich zweifelhaften Steuergesetzen, NJW 12.Jhg. (1959) S. 1465 ff (1469); Michel, Normenkontrolle durch die vollziehende Gewalt, NJW 13.Jhg. (1960) S. $841 \mathrm{ff}$ (der sich vor allem auch - ganz unbehelflich! - auf $\$ 76 \mathrm{Nr} .2$ BVerfGG beruft); zurückhaltender A rndt, Vollstreckbarkeit verfassungswidriger (Steuer-)gesetze, Betriebsberater, 14. Jhy. (1959) S. 533 ff (534 f); ders., Die Nichtigkeit verfassungswidriger Gesetze, DÖV 12.Jhg. (1959) S. 81 ff. - A.A. vor allem liönitz, Nochmals: Die Aussetzung der Vollziehung von Steuerbescheiden bei verfassungsrechtlich zweifelhaften steue: gesetzen, NJW 13.Jhg. (1960) S.226 ff (227 ff); Götz, Der. Wirkungsgrad verfassungswidriger Gesetze, NJW 13.Jhg. (1960) S.1177 ff. - Vermittelnd MaunzDürig, Art.20 Randn. 66.

15) BVerfGE 1, 14 (37); Bay VerfGH VGHE n. F. 1 II 64 (80).

16) Friesenhahn, Art. "Verfassungsgerichtsbarkeit" im Handwörterbuch der Sozialwissenschaften, S. 86 f, läßt die Mittelstellung des deutschen Systems zwischen einem reinen ex-tuncund einem reinen ex-nunc-System deutlich hervortreten:

"Nach deutscher Therrie und dem deutschen positiven Recht sind verfassungswidrige Gesetze von Anfang an nichtig, so 
als die Befugnis der Verwaltung, sich aus eigenem Recht über das für verfassungswidrig gehaltene Gesetz hinwegzusetzen, sie beeinträchtigen würcle. 17)

ciaß das Gericht nur eine deklaratorische Feststeliung irifit, während $z$. B. nach österreichischem Recht verfassungswidrige Gesetze durch das Verfassungsgericht pro futuro aufgehoben werden. Die Wirkung der Nichtigkeit ist aber insofern abgemildert, als Behörden und Gerichte das Gesetz erst nach Nichtigerklärung durch das Verfassungsgericht außer Anwendung lassen dürfen".

17) (1) $\mathrm{Zu}$ dem Fragenkomplex s. außer den S. 611 zu Fußn. 14 Zitierten und ihren Nachweisen noch Sigloch, Vorläufige Geltung verfassungswidriger Gesetze? JZ 13. Jhg. (1958) S. 80 ff; Schaar, Die Aussetzung der. Vollziehung von Steuerbescheiden bei verfassungsrechtlich $z$ weifelhaften Steuergesetzen, NJW 13. Jhg. (1960) S. 852 f; s.a. deren weitere Nachweise. Insbes. darf nochmals auf die, manche Härten vermeidende, vermittelnde Lösung bei Maunz-Dürig (s.o. S.611 zu Fußn. 14) verwiesen werden. Dabei ist jedoch darauf aufmerksam zu machen, daß das bayerische Verfassungsrecht einen Normenkontrollantrag der Exekutivspitze, wie ihn Art.93 Abs. 1 Nr.2 GG vorsieht, nicht kennt. Im eigenen Raum des bayerischen Landesverfassungsrechts können daher die von MaunzDürig an die Legitimation des Art.93 Abs. 1 Nr.2 GG geknüpften Abhilfen nicht Platz greifen.

(2) Die Unerbittlichkeit mancher Sprecher der gegenteiligen Ansicht scheint auch darauf zu beruhen, daß sie sich in gut deutschem Perfektionismus eine Lösung wie die österreichische (vgl. Ermacora, Der Verfassungsgerichtshof, 1956, S. $206 \mathrm{ff}, 260 \mathrm{ff}$ ) oder die italienische (vgl. Art.30 der Norme sulla Costituzione e sul funzionamento della Corte costituzionale, 1.11.marzo 1953, n.87), wonach die verfassungsgericht liche Nichtigerklärung (Aufhebung) einer Norm grundsätzlich nur für die Zukunft wirkt, nicht vorstellen können (oder wollen). Eine logische Notwendigkeit für das deutsche System besteht jedoch keineswegs (zum Grundsätzlichen s. Kelsen, Wesen und Entwicklung der Staatsgerichtsbarkeit, VVDStRL. H. 5, 1929, S. 30 ff (70 ff); Spanner, Die richterliche Prüfung von Gesetzen und Verordnungen, 1951, S. $74 \mathrm{ff})$. Die herrschende Praxis und Lehre entspricht allerdings dem geltenden Verfassungsrecht (s.a. Zacher, Ratifizierungsgesetz und Normenkontrolle, S. $650 \mathrm{f}$ und die dort gegebenen Nachweise). Es wäre aber de lege (constitutione) ferenda zu überlegen, ob nicht das ex-nunc-System eingeführt werden sollte. Viele 


\section{c) Zur Struktur der Verwaltung}

Die grundgesetzliche Konzeption von der Gestalt der Exekutive beruht auf Art.20 Abs.2 GG, d.h. auf dem Verfassungsgebot der "besonderen Organe... der vollziehenden Gewalt". Das zweite Grundelement ist die nicht ausnahmslos aber doch grundsätzlich notwendige Beherrschbarkeit der Verwaltung von der Exekutivspitze her. Für den Bund kommt es in Art.65 GG, für die Län(ler in der Klausel vom demokratischen Rechtsstaat (Art.28 Abs. 1 Satz 1 GG), 1) für das Bund-Länder-Verhältnis - die Verantwortung für den gesamtstaatlichen Vollzug des Bundesrechts auf die Exekutivspitze des Bundes zuführend - in den Leitungs-, Weisungs- und Aufsichtsbefugnissen der obersten Bundesorgane gegenüber den Ländern (qua Verwaltungssubjekte) zum Ausdruck. 2) Im übrigen ist das grundgesetzliche Bild der vollziehenden $\mathrm{Ge}$ walt wesentlich bestimmt von der bundesstaatlichen Gliederung $(\text { Art. } 83 \text { ff, } 108 \mathrm{GG})^{3)}$ und den Grundsätzen über die Selbstverwaltung und die mittelbare Staatsverwaltung (Art.28, 87 Abs. 2 und $3,130 \mathrm{GG}) .4$ ) Besondere Verwaltungszweige von spezifisch sozialer Bedeutung hebt das Grundgesetz nur gelegentlich hervor: die Lastenausgleichsverwaltung (Art.120 a GG), die Bundesfinanzverwaltung (Art. 87 Abs. 1 Satz 1, 108 GG), die Beschädigtenversorgung der Bundeswehr (Art. 87 b Abs. 1 Satz 2 GG) und die sozialen Versicherungsträger (Art. 87 Abs.2, 120 Abs. 1, 130 GG).

Schwierigkeiten, die im Gefolge des ex-tunc-Systems auftreten, können ohne diese grundsätzliche Änderung wohl kaum auch nicht durch eine bessere Regelung als $₫ 79$ BVerfGG sie getroffen hat - ausgeräumt werden.

(3) Zuzugeben ist freilich, laß die Dinge, so wie sie jetzt liegen, im argen liegen. Die lange Dauer der Verfahren vor dem Bundesverfassungsgericht, die Scheu des Bundesverfassungsgerichts von der. Möglichkeit einstweiliger Anordnungen ( $\$ 32$ BVerfGG) einen hinreichenden Gebrauch zu machen, das Fehlen angemessener : geselzlicher Lösungen dafür, wie die Gerichte, denon gegenüber der Bürger gegen den Vollzug des verfassungswidrigen Gestt\%es seine Zuflucht genommen hat, diesen Vollzug mit Rücksicht auf ihre (!) Vorlage nach Art. 100 Abs. 1 GG sollen aussetzen können usw. - das sind Umstände, die den Ruf rach einem selbständigen Handeln der vollziehenden Gewalt zwar nicht rechtfertigen aber doch verständlich erscheinen litssen.

1) S. nochmals BVerfGF: 9, 268 (281 f). - Im übrigen s.o. S.85.

2) S. hierzu oben B 1 I 2 c bis e (S.115 ff).

3) S. o. Abschnitt 1 I 2 (S.81 ff).

4) S. o. S.164, Abschritt 2 (S.219 ff) und Abschnitt 3 IV (S.390 ff). 
Der unterverfassungsgesetzlichen Ordnung bleibt erheblicher Spielraum für eine den jeweiligen Notwendigkeiten gerecht werdende Ausgestaltung der Verwaltungsorganisation.

Zum Schluß noch eine Bemerkung zur personellen Substanz der Verwaltung. Je freier, selbständiger, eigenverantwortlicher die Verwaltung ist, je weniger die Bindungen des Gesetzes (und dann zumeist auch des sonstigen Rechts) ihr Handeln inhaltlich bestimmen, je geringer demzufolge auch die Einmischung seitens der Rechtsprechung ist, desto mehr hängt das Funktionieren der Verwaltung, die Rechtlichkeit und Richtigkeit ihres Tuns, von ihrer strukturellen Qualifikation - von der Qualifikation des jeweils aktuell Zuständigen, von der Qualifikation der leitenden Amtsträger und von der Qualifikation der verwaltungsinternen Kontrollen 5) - ab. Aber auch im Hintergrund des untergeordneten Rechts vollzugs steht die Notwendigkeit präziser Organisation, die Personalverwaltung, die Klärung der grundsätzlichen Frage, die schwierige Subsumtion, die den Funktionären des Vollzugsmechanismus nicht zugemutet werden kann, - steht also eine Fülle von Aufgaben, für die es nicht weniger auf die optimale Struktur des Leistungs- und Aufsichtsapparates ankommt. Das hier im einzelnen auszubreiten, ist nicht nötig. Zu erinnern ist aber nochmals daran, daß das Grundgesetz, indem es in Art.33, Abs.2, 4 und 5 GG die - wenn auch elastische - Basis für die Entwicklung eines integren Berufsbeamtentums gelegt hat, eine tragende Säule nicht nur für den Rechtsstaat sondern auch und gerade für die soziale Intervention des Rechtsstaates aufgerichtet hat. ${ }^{6}$

5. Anhang: Das Verhältnis zwischen privatem un öffentlichem Recht im Lichte der Gewaltentrennung

\section{a) Allgemeines}

Mit dem bisher Ausgeführten konnte die Problematik des Zusammenwirkens der drei "Gewalten" im Rahmen der sozialen Intervention nicht erschöpft werden. Auf einen Fragenkreis muß jedoch

5) S. die Nachweise oben S. 540 zu Fußn.2.

6) Zu dieser Bedeutung des Berufsbeamtentums s. Peters, Rechtsstaat und Rechtssicherheit, S. 75; Die Verfassungsfunktion des Berufsbeamtentums; ders., Die Institution des Berufsbeamtentums im kontinentaleuropäischen Staat, S.41 ff, $47 \mathrm{ff}$; Forsthoff, Verfassungsrechtliche Prolegomena zu Art. 33 Abs. 5 GG, insbes. S. 462; Werner Weber, Staatsverwaltung und Selbstverwaltung in der Gegenwart, S.94 ff (mit weiteren Nachweisen). 
noch besonders hingewiesen werden, weil er nicht nur intensive Bezüge zur sozialen Intervention aufweist sondern auch in dem Problemgemenge der Gewaltenteilung und des ihr entsprechenden, rechtsstaatlichen Staat-Bürger-Verhältnisses angesiedelt ist: Der Fragenkreis der Trennung von öffentlichem und privatem Recht. Nicht diese Zweiteilung als solche soll in Frage gestellt werden - auch nicht zugunsten der Konstruktion eines sog. Sozialrechts, 1) die jedenfalls dem positiven deutschen Recht

1) Grundlegend für die Lehre eines zwischen öffentlichem und privatem Recht stehenden Sozialrechts waren die Arbeiten Otto Gierkes (Die Genossenschaftstheorie und die deutsche Rechtsprechung, 1887, S. 155 ff; Deutsches Privatrecht, Bd.I 1895, S.26 f), der allerdings - so sehr seine Theorie das Gegenüber von öffentlichem und privatem Recht (durchaus sachgerecht) relativierte - selbst die Unterscheidung in $\mathrm{z}$ we i Rechtsteile nicht in Frage stellen wollte. Vielmehr nahm er an, daß das Sozialrecht von der Grenze zwischen privatem und öffentlichem Recht "durchschnitten" wird (Privatrecht, a.a.O. S.27). Gierke mißverstehend wurde später dann von einzelnen Autoren das Sozialrecht oder wurden jedenfalls gewisse sozialrechtlich charakterisierte Rechtsfiguren als Sonderrecht, als Tertium, zwischen öffentliches und privates Recht eingeschoben (vgl. Nussbaum, Das neue deutsche Wirtschaftsrecht, 1920, S.65; Sinzheimer, Grundzüge des Arbeitsrechts, 2.Auf1. 1927, S.3; ders., Über einige Grundfragen des A rbeitstarifrechts, in "Die Reichsgerichtspraxis im deutschen Rechtsleben", Festgabe der juristischen Fakultäten zum fünfzigjährigen Bestehen des Reichsgerichts, Bd. IV 1929, S. 1 ff (14 ff); Walter Wolff, Zur Frage eines eigenständigen Sozialrechts, Gewerkschaftliche Monatshefte, 1.Jhg. (1950) S. 566 ff; unter rechtssystematischen, nicht positivrechtlichen Gesichtspunkten inklinierend auch Siebert, Privatrecht im Bereich der öffentlichen Verwaltung, S.216, $246 \mathrm{f}$; und noch deutlicher Lchm:nnn, Allgemeiner Teil des bürgerlichen Gesetzbuches, 10. Auf1. 1957, S.2 f; ein aus dem Vorbild des "Sozialrechts" entwickeltes "Gemeinschaftsrecht" postuliert Rhode, Arbeitsrecht, Sozialrecht, Gemeinschaftsrecht, 1944, insbes. S. $74 \mathrm{ff}$ ). Kritisch zur Lehre vom Sozialrecht als einem neben privatein und öffentlichem Recht eigenständigen dritten Rechtsgebiet z. F. Jacobi, Grundlehren des Arbeitsrechts, S. 377 ff (insbes. S.383 ff); Molitor, Über öffentliches Recht und Privatrecht, 1949, S. 15 ff; E. R. Huber, Wirtschaftsverwaltungsrecht, Bd.I, S. 72; Simitis, Die faktischen Vertragsverhältnisse, $1957, \mathrm{~S} .515 \mathrm{ff}, 550 \mathrm{ff}$; insbes. in bezug auf 
nicht entspricht. 2) "Tertium non datur". 3) Auch soll den Abgrenzungsproblemen nicht nachgegangen werden. 4) Vielmehr gilt es, vor dem Hintergrund dieser Gegebenheiten zu erörtern, was sich aus der Anwendung des privaten bzw. öffentlichen Rechts für das Gewicht der verschiedenen Staats-"Gewalten" und für die Rechtsstellung des Bürgers zum Staat ergibt.

Wenn behauptet wird, das private Recht sei im Vergleich zum öffentlichen das dem Rechtsstaat gemäßere, freiheitlichere Ordnungs- und Gestaltungsinstrument, 5) so beruht das auf sehr un-

das Arbeitsrecht (als "Sozialrecht"): Nikisch, A rbeitsrecht, Bd.I, S. 42 f; Kaskel-Dersch, A rbeitsrecht, S. 2 ff; Hueck, Lehrbuch des A rbeitsrechts, Bd.I S.6; s.a. Rhode, a.a.O. S. 27 ff. - Zur Lehre vom Sozialrecht s. ferner Wilacker, Privatrechtsgeschichte der Neuzeit, 1952, S.319 ff. Zur komplexen Gemengelage des öffentlichen und privaten Rechts auf dem Sachgebiet des Sozialrechts s. außer den Vorgenannten auch Henrich, Das österreichische Sozialrecht in der Kritik seiner Anwendung, Österreichische Juristenzeitung 11. Jhg. (1956) S. 4 ff, $29 \mathrm{ff}$.

2) S. z.B. Siebert, a.a.O. S.246 f; Lehmann, a.a.O. S.3.

3) Stern, Zur Problematik des energiewirtschaftlichen Konzessionsvertrages, AöR Bd.84 (1959) S. 137 ff, 273 ff (313); s. dort auch weitere einschlägige Hinweise.

4) S.f.v.a. Nawiasky, Allgemeine Rechtslehre, S.273 ff; ders., Allgemeine Staatslehre, Teil 3, S. $161 \mathrm{ff}$; Molitor, Über öffentliches Recht und Privatrecht; Wolff, Der Unterschied zwischen öffentlichem und privatem Recht, AöR Bd.76 (1950/51) S. 205 ff; ders., Verwaltungsrecht I, S. 78 ff; Siebert, Privatrecht im Bereich öffentlicher Verwaltung.

5) S. vor allem Darmstaedter, Grenzen der Wirksamkeit des Rechtsstaates, S. 155 ff und passim (insbes. S.252 ff); ferner Bettermann, Grundfragen des Preisrechts für Mieten und Pachten, S. 120 f; Bachof, Begriff und Wesen des sozialen Rechtsstaates, S. 65 f; Köttgen, Kodifikation des Privatrechts und arbeitsrechtliche Zuständigkeiten der Landesgesetzgebung, Betriebsberater, 11.Jhg. (1956) S.441 ff. (441f) - dieser insbes. auch zur rechtsstaatlichen Notwendigkeit der Trennung $z$ wischen öffentlichem und privatem Recht; Maunz, Grundfragen des Energiewirtschaftsrechts, Verwaltungsarchiv Bd.50 (1959) S. 315 ff (321); im spezifischen Zusammenhang der "Grundrechtsdrittwirkung" auch Dürig (insbes. Grundrechte und Zivilrechtsprechung, in "Vom Bonner Grundgesetz zur gesamtdeutschen Verfassung", Festschrift für Hans Nawiasky, 1956, S. 157 ff (164 und passim); Maunz-Dürig, Art. 1 Abs. III 
terschiedlichen Vorstellungen vom Wesen und von den Grenzen der beiden Rechtsteile und meist auch auf dem In-eins-Setzen gewisser typischer Techniken les einen oder des anderen mit dem Ganzen. Vor allem aber beruht es vielfach auf den Vorstellungen der älteren materiellen Rechtsstaatslehre, wonach der Staat sich aus den Angelegenheiten der "Gesellschaft" so weit als möglich herauszuhalten hat. ${ }^{6)}$ Darauf ist hier nicht näher einzugehen.

\section{b) Verfahrensrechtliche Aspekte}

Unter den im Rahmen der modernen Rechtsstaatsauffassung mög1ichen Erwägungen zugunsten des Privatrechts kann von vorneherein diejenige nicht als berechtigt anerkannt werden, die einer privatrechtlichen Ordnung wegen des besseren verfahrensrechtlichen Schutzes privater. Rechtsverhältnisse den Vorzug gibt. Soweit dieses Vorurteil gegen das öffentliche Recht noch grassiert, handelt es sich um ein Relikt aus der Zeit vor der Herstellung (ler Gleichwertigkeit der verschiedenen Gerichtszweige und der Einführung der Generalklausel. Heute ist dieses Argument gegenstandslos. 1) Fragwürdig ist allerdings auch die Richtigkeit der gegenteiligen Erwägung, das öffentliche Recht sei für die Regelung der Beziehungen der Verwaltung zum Bürger deshalb vorzuziehen, weil es generell die spezifischen Rechtsnormen entwickelt, die dem Bürger den größeren Schutz gewähren. ${ }^{2)}$ Das mag für bestimmte, besonders herausgebildete Verfahrensarten zutreffen. Im allgemeinen liegt der. Vorzug der Formen des öfentlichen Rechts aber doch in der verstärkten Rücksichtnahme auf das öffentliche Interesse und ihrer Anpassung an die Erfordernisse verwaltungstechnischer Praktikabilität. Diese mag auch der Klarheit der Staat-Bürger-Beziehungen zugute kommen. Und fest steht, daß - das kann gelegentlich den Ausschlag zugunsten der materiell öffentlichrechtlichen liegelung geben - der auf den typischen Verfahrensformen der Verwaltung (insbes. dem Verwaltungsakt) aufbauende Verwaltungs'echisschutz dem weniger formalen privatrechtlichen Handeln nicht ohne Präzisionsverluste angeschlossen werden kann. Die ent scheidenden Fragen sind jedoch nicht die

Randn. 128 f).

6) Das gilt insbes. fii. Inrmstaedter, a.a.O. - Vornehmlich in diesem Sinne auch Hallstein, Wiederherstellung des Privatrechts, SJZ 1.Jhg. (1946) S. 1 ff.

1) $\mathrm{Zu}$ den Bemühungen, den Verwaltungsrechtsschutz den Anforderungen der Leisturgsverwaltung anzupassen s. oben $3 \mathrm{c}$ aa (S. $540 \mathrm{ff})$.

2) S. z.B. Krüger, Die Auflage als Instrument der Wirtschaftsverwaltung, s. 335 . 
des Prozeß- sondern des materiellen Rechts. ${ }^{3}$ )

c) Das materiellrechtliche Problem in der zwischenbürgerlichen Dimension

Materiellrechtlich ist zwischen der Gestaltung zwischenbürgerlicher Rechtsverhältnisse und des Staat-Bürger-Verhältnisses zu unterscheiden. 1) Für das zwischenbürgerliche Verhältnis ist die Regelung unmittelbar durch Gesetz oder im Rahmen des Gesetzes durch die autonome Übereinkunft der Beteiligten, und somit also die prinzipiell privatrechtliche Lösung, im allgemeinen "rechtsstaatlicher" als der gestaltende Eingriff der Verwaltung, d.h. der typisch öffentlichrechtliche Weg. ${ }^{2}$ ) In diesem Gegenüber liegt der berechtigte Kern des rechtsstaatlichen Vorzugs des Privatrechts. Doch darf dieses nicht zum rechtsstaatlichen Fetisch werden. Es ist rechtsstaatlich, weil es, freiheitlich, den Beteiligten ihren autonomen Willen läßt und durch nichts anderes begrenzt als durch das Gesetz. Wenn aber mit diesen Mitteln nicht mehr auszukommen ist und der Staat sich tiefer und dichter in die Verhältnisse einmischen muß, wenn vor allem die Privatautonomie eingeschränkt oder beseitigt und durch konkrete Entscheidungen der öffentlichen Gewalt ersetzt oder korrigiert werden muß, dann ist es nicht auch an sich schon rechtsstaatlich, wenn dies irgendwie im Rahmen des Privatrechts geschieht. "Die Frage, ob eine Norm dem privaten oder dem öfentlichen Recht zuzurechnen ist, hat... mit dem Gedanken der Rechtsstaatlichkeit unmittelbar nichts zu tun". 3 )

Rechtsstaatlich $\mathrm{zu}$ fordern ist, daß die heteronome Einmischung des Staates in die privaten Verhältnisse an das Recht gebunden ist. Die Ausschaltung der Exekutive, die mit der "Privatisierung" meist irgendwie gemeint ist, ist - sub specie des Rechtsstaats nur als Mittel zu diesem Zweck positiv zu bewerten. Dabei ist jedoch zu bedenken: Was an Ordnungsaufgaben die Exekutive nicht leisten darf und das Gesetz (in klarer, definitiver Aussage) oder die echte Parteiautonomie nicht leisten können, muß anderen Entscheidungssubjekten, insbesondere aber der rechtsprechenden Gewalt, überlassen werden. Die Gefahren der Richterwill-

3) Vgl. Menger, Rechtssatz, Verwaltung und Verwaltungsgerichtsbarkeit, insbes. S. 592 .

1) Vgl. Bachof, Begriff und Wesen des sozialen Rechtsstaats, S. $65 \mathrm{f}$.

2) S. die oben S.616 zu Fußn. 5 Zitierten.

3) BayVerfGH VGHE n.F. 6 II 1 (9). 
sür 4) sowie der Willkür und des Machtmißbrauchs gesetzlich eingesetzter kollektiver Autoritäten - mit denen vor allem das collektive Arbeitsrecht operiert - dürfen nicht zu gering beweret werden. Sie sind mit einer exekutivfeindlichen, vermeintlich um des Rechtsstaates willen ihre Zuflucht zum Privatrecht nehmenden Tendenz nur zu leicht verbunden. Doch soll, indem vor Übertreibungen gewarnt wird, nicht der grundsätzliche Vorzug der mit dem Privatrecht verbundenen richterlichen Primärkompetenz vor derjenigen der staatlichen Verwaltung, des dem Recht and der Gerechtigkeit verpflichteten Richters vor dem politisch zentral beherrschbaren Exekutivapparat in Abrede gestellt werden. 5$)$

Immer kommt es auf die Sache, die rechtliche Sicherung der Individualsphäre an. Das bloße Abgrenzungs- und Zuordnungsproblem ist rechtsstaatlich grundsätzlich irrelevant. 6) Die Frage etwa, ob die sog. Massenleistungsverhältnisse unter Privaten deren Bedeutung für die öffentliche Daseinsvorsorge ${ }^{7)}$ und somit auch für den Sozialbereich notorisch ist -, die durch eine weitgenende Eindämmung von individueller Autonomie und individuellem Konsens gekennzeichnet sind, 8) dem öffentlichen Recht angehö-

4) Daß die privatgestaltende Tätigkeit der Verwaltungsbehörde dem öffentlichen Recht zugerechnet, dagegen die des Richters viel weniger als Fremdkörper im Privatrecht empfunden wird, hängt mit lem prinzipiellen Hintereinander des materiellen und des formellen Privatrechts (d.h. des Zivilprozeßrechts und des Rechts (ler freiwilligen Gerichtsbarkeit) zusammen, das auch sonst zu dessen Zurechnung zu einer größeren Einheit des Privatrechts geführt hat (s. hierzu Nawiasky, Allgemeine Rechtslehre, S.267 f, 276 ff).

5) Vg1. Werner Weber, Spannungen und Kräfte im westdeutschen Verfassungssystem, $\$ .136 \mathrm{ff}$. S.a. nochmals oben $3 \mathrm{~b}$ (S. $512 \mathrm{ff})$.

6) S. oben S.618 zu Fußn.3 - Für das Betriebsverfassungsrecht s. z. B. Nipperdey, Lehrbuch des A rbeitsrechts, Bd. II S. 693. S. den programmatischen Titel der Schrift Bärmanns "Typisierte Zivilrechtsordnung ler Daseinsvorsorge", 1948. (Aus der Schrift s.zum Folgenden insbes. S. 7 ff, $84 \mathrm{ff}$ ). Vgl. hierzu und zum Folgenden: Simitis, Die faktischen Vertragsverhältnisse, S.463 ff; Siebert, Faktische Vertragsverhältnisse, S.12 ff; sämtliche weiteren Nachweise s. bei diesen. - Im besonderen ist noch auf Krause, Allgemeine Geschäftsbedingungen und das Prinzip des sozialen Rechtsstaats, Betriebsberater, 10.Jhg. (1955) S. 265 ff, hinzuweisen. 
ren, 9) ist eine Frage der Systematik und der Nomenklatur, solange nicht etwa durch die öffentlichrechtliche Konstruktion weitergehende Befugnisse der Verwaltungsbehörden und eine Schwächung der Einzelposition gerade gegenüber dem Staat legitimiert werden sollen. Die stärkere öffentliche Pflichtbindung (Kontrahierungszwang, Tarife, statutarische Bestimmungen usw.), in die der daseinsvorsorgende (Privat-) Unternehmer genommen wer. den muß, und die Reduktion der Entscheidungsmöglichkeiten des "Konsumenten" auf die Annahme oder Ablehnung der Leistung unter den durch diese - die ökonomischen Gesetzmäßigkeiten von Angebot und Nachfrage sowie die freie Unternehmerdisposition überlagernde - Pflichtbindung determinierten Leistungsbedingungen, die die Abhängigkeit des "daseinsversorgten" Leistungsempfängers von Leistung und Leistungsträger sinnfällig zum Ausdruck bringen, mögen an das öffentliche Recht erinnern. ${ }^{10)} \mathrm{Je}$ nach den Abgrenzungskriterien, die für die Scheidung in öffentliches und privates Recht gelten sollen, können diese Elemente auch zur öffentlichrechtlichen Qualifikation der daraus entstehenden, vom öffentlichen Interesse und vom staatlichen Eingriff her bestimmten Rechtsbeziehungen führen. 11) Unter dem rechtsstaat-

9) Für die Forderung der "Publizierung" grundlegend George A. Loening, "Faktische Verträge" oder öffentliches Recht? Zeitschrift der Akademie für Deutsches Recht, 9.Jhg. (1942)

S. $289 \mathrm{ff}$. - Zum Problem s. ferner insbes. Siebert, Privatrecht im Bereich öfentlicher Verwaltung, $S .229 \mathrm{ff}$, insbes. S. 233 f; Simitis, a.a.O. \$. 509 f, 511 ff; Maunz, Grundfragen des Energiewirtschaftsrechts, S. 321 f; je mit weit. Nachweisen.

10) Vgl. Gygi, Verwaltungsrecht und Privatrecht, S.20: "Bei den Leistungsverhältnissen der Verkehrs- und Versorgungsbetriebe (Daseinsvorsorge) besteht auf Grund einer faktischen oder rechtlichen Normalsituation eine Rechtslage, die praktisch dem Über- und Unterordnungsverhältnis der Staatsgewalt entspricht". - Bei Simitis, a.a.O. s.insbes. S. $472 \mathrm{f}$, 531. - S.a. den Versuch Krauses (a.a.O. S.268 f), die Regulierung privater Rechtsverhältnisse durch allgemeine Geschäftsbedingungen an "das Interessenausgleichsschema" des Gesetzes zu binden.

11) S. hierzu aber Scheuner, Die Selbständigkeit und Einheit der Rechtspflege, S. 519: "Die Grenzlinie zwischen öffentlichem und privatem Recht ist im Laufe der Entwicklung Veränderungen der. Anschauungen ausgesetzt, und es scheint, als ob... der Höhepunkt einer Zurechnung der Materien zum öffentlichen Recht bereits überschritten ist, die Entwicklung in 
lichen Aspekt aber muß entscheidend sein, ob ihre Ordnung mit generell-normativen oder mit konkret-anordnenden, typisch verwaltungsmäßigen Mitteln bewirkt wird.

\section{d) Das materielle Problem in der Staat-Bürger-Dimension}

Auch für das Staat-Bürger-Verhältnis ist mit der Fragestellung 'öffentliches oder privates Recht?" noch nicht schlechterdings etwas über den "rechtsstaatlicheren" Weg gesagt. 1) Entscheidend ist, welche Rechtsformen dem Bürger die größere Sicherheit geben, die Beherrschbarkeit des Ineinander seiner Individualsphäre und des staatlichen Wirkungsbereiches erhöhen und die stärkere Rechtsbindung der öffentlichen Hand bewirken. Dabei steht im Vordergrund die Alternative: einseitige Gestaltungsmacht der Verwaltung und Unterwerfung bzw. Unterworfen-Sein

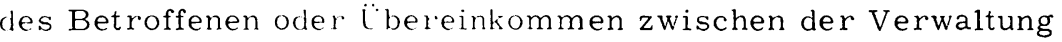
und ihrem privaten Partner; grob vereinfacht: Verwaltungsakt oder Vertrag. Ihre Gleichsetzung mit der Alternative zwischen privatem und öfentlichem Recht vernachlässigt $z$ war auf dessen Seite den öfentlichrechtlichen Vertrag und auf seiten des Privatrechts dessen nicht-vertragsrechtliche Substanz. Der öfentlichrechtliche Vertrag ist je(loch nur beschränkt zulässig und steht qualitativ und quantitativ am Rande des öffentlichen Rechts. ${ }^{2)}$ Die nicht-vertragsrechtlichen Teile des Privatrechts ferner spielen ihrer Natur nach und ganz besonders für das Staat-Bürger-Verhältnis nur eine begrenzte und meist - wie z. B. die Übereignungsgeschäfte - auch eine sekundäre Rolle. Das Feld der freien Gestaltung liegt im Bereich ler Vertragsautonomie. Das Auswei-

dem Maße, in lom das Zivilrecht sich sozialrechtlichen Gesichtspunkten öffnet, eher $r$ ückläufig werden kann" (Sperrung nicht im Original). S. diesen Leitgedanken auch zum Folgenden.

1) Mit Recht sagt Bachol" (Begriff und Wesen des sozialen Rechtsstaats, S.65 i), daß nichts damit gewonnen wäre, wenn der Staat sich grumlsälzlich auf den Boden des Privatrechts stellte.

2) Zum öffentlichrechtlichen Vertrag s. aus jüngerer Zeit insbes. Imboden, Der Verwaltungsrechtliche Vertrag, Zeitschr. für schweizerischos liecht, n.F. Bd. 77 (1958) S. 1 a ff; Stern, Zur Grundlegung oiner Lehre des öffentlichrechtlichen Vertrages, Verwaltungsarchiv Bd.49 (1958) S. 106 ff; Salzwedel, Die Crrenzen der Zulässigkeit des öffentlichrecht1ichen Vertrages, 1958; Apelt, Der verwaltungsrechtliche Vertrag, AöR Bd. 84 (1959) \$.249 ff. 
chen der Verwaltung ins Privatrecht 3 ) reflektiert regelmäßig darauf.

Ist nun - um die speziellere Frage zu stellen - die vertragsautonomistische Regelung unter rechtsstaatlichen Aspekten der einseitig hoheitlichen vorzuziehen oder nicht? Würde man die Machteinbuße des Staates und den damit verbundenen Schwund der öffentlichen Ordnung nicht als Verlust für die Rechtsstaatlichkeit ansehen müssen, so müßte die Frage zunächst jedenfalls für die Eingriffsverwaltung bejaht werden. Doch stellt sie sich für den Eingriff in Wahrheit nicht. Sobald die Verwaltung auf den Konsens des Betroffenen angewiesen ist, kann sie nicht mehr bloß "eingrei fen $^{\prime \prime}$. Die Bedeutung freier Übereinkünfte, die den $Z$ weck haben, dem Staat Eingriffsmöglichkeiten zu verschaffen, ist gering. In der Regel werden sie vor dem Hintergrund der subsidiären Befugnis des Staates zum einseitigen $Z$ wang getroffen. Soweit sie dazu dienen, den Eingriff den individuellen Wünschen des Betroffenen so gut als möglich anzupassen, sind sie nach rechtsstaatlichen Wertungsmaßstäben positiv zu beurteilen. Soweit sie den Zweck haben, die Eingriffsbefugnis der Verwaltung über die vorhandenen gesetzlichen Grundlagen hinaus auszudehnen oder der Verwaltung den Rückgriff auf unschönen $Z$ wang oder $z$ weifelhafte Rechtsgrundlagen zu ersparen, liegt die Gefahr ungesetzlicher, unzulässiger Ausnutzung der staatlichen Macht nahe. 4) Inwieweit Verträge dieser Art statthaben können, muß daher vorwiegend vom Prinzip der Gesetzmäßigkeit der Eingriffsverwaltung her beurteilt werden. 5)

Das Schwergewicht des Problems liegt bei der Leistungsverwa1tung und zwar - da hinsichtlich des Massenleistungsverhältnisses, wie erwähnt, die Vertragsautonomie auch im Privatrecht ausgetrocknet ist - beim individuellen Leistungsverhältnis. ${ }^{6)}$ Ist seine

3) Vg1. Haas, Verwaltungsprivatrecht im System der Verwaltungshandlungen und der fiskalische Bereich, DVB1. 75. Jhg. (1960) S. 303 ff. S. ferner die Nachweise oben S. 457 zu Fußn. 2 und unten S. 625 zu Fußn. 16.

4) Einige Illustrationen hierzu bei Gygi, Verwaltungsrecht und Privatrecht, S. 55 f (insbes. Fußn.4).

5) S. hierzu oben S.440 ff und o. S. $621 \mathrm{zu} \mathrm{Fußn.2.}$

6) (1) Die praktisch wohl wichtigsten Fälle liegen im Bereich des Subventionsrechts. S. hierzu Ipsen, Öffentliche Subventionierung Privater, insbes. S. $33 \mathrm{ff}, 59 \mathrm{ff}$; Siebert, Privatrecht im Bereich öffentlicher Verwaltung, S. 235 ff; Flessa, Schuldverhältnisse des Staates auf Grund Verwaltungsakts, DVB1. 72.Jhg. (1957) S. 118 ff; Stern, Rechtsfragen der öf- 
vertragsrechtliche oder seine einseitig hoheitsrechtliche Gestaltung dem Rechtsstaat gemäßer? Die Frage setzt voraus und eine richtige Antwort muß voraussetzen, daß eine spezielle Regelung feh1t. Wäre sie vorhanden, so würde sie nicht nur - in der Regel jedenfalls - den Weg vorschreiben. Sie würde auch diejenige Ordnung sein, die nach der Vorstellung des Gesetzgebers der besonderen Interessenlage am besten entspricht; und diese Adäquanz ist auch unter dem rechtsstaatlichen Gesichtspunkt das wichtigste Moment. Fehlt eine speziellere Regelung, so ist die Wahl des Mediums rechtsstaatlich nicht allgemein und grundsätzlich relevant. Für das öffentlichte Recht, ${ }^{7}$ d.h. für die allgemeinen Grundsätze des öffentlichen Rechts spricht, daß diese dem StaatBürger-Verhältnis auf den Leib geschnitten sind. Der freiheitliche Zug des (privatrechtlichen) vertragsrechtlichen Instrumentariums ${ }^{8)}$ täuscht und enttäuscht infolge der tatsächlichen Machtstellung des Staates nur allzu leicht, so daß die Vorzüge der obrigkeitlichen Ordnung wieder zutage treten. Was die allgemeinen, den Ermessensgebrauch 9 ) einschränkenden und bestimmenden Rechtsgrundsätze an Sicherung des Betroffenen beinhalten, kann ihm seine formale Gleichberechtigung als Verhandlungsund Vertragspartner der Verwaltung nicht ohne weiteres gewähren, solange er - wie es für die Leistungsverwaltung typisch ist - mehr oder Höherwertiges von der Verwaltung will, als er ihr synallagmatisch zu geben bereit ist. 10) Die nur formale Individualität des Vertragsschlusses erbringt ihm regelmäßig nicht einmal die Rücksichtnahme auf besondere Wünsche. Der Sache

öfentlichen Subventionierung Privater; je mit eingeh. Nachweisen.

(2) Zur Gegenüberstellung der individuellen und der Massenleistungsverhältnisse in diesem Zusammenhang s. Siebert, a.a.O. S.229 ff, $235 \mathrm{ff}$ (inshes. 235).

7) S. Bachof, Begrift und Wesen des sozialen Rechtsstaats, S. $65 \mathrm{f}$.

8) S. Siebert, a.d.(O) i. 24 i.

9) Gygi (Verwaltungsrecht und Privatrecht, S. 17) setzt der Vertragsautonomie dif Notwendigkeit strikter gesetzlicher Bindung der Verwaltung entgegen. Dieses Postulat kann vom rechtsstaatlichen Standpunkt aus nur unterstrichen werden. Aber darum geht es hier nicht, denn strikte Regelung kann im allgemeinen nur die Sonderregelung sein. Ihr Fall muß aber um der Klarheit der Zusammenhänge willen hier eliminiert bleiben.

10) Vg1. Krüger, Die Auflage als Instrument der Wirtschaftsverwaltung, S. 385; Forsthoff, Anmerkung zu BVerwG Urt.v. 24. Oktober 1956 - BVerwG V C 236/54-DVB1.72. Jhg. (1957) S.724 ff. 
nach herrscht Einseitigkeit wie im öffentlichen Recht - nur ohne die dieser Einseitigkeit entsprechenden typischen Bindungen des allgemeinen Verwaltungsrechts. Die Freiheit des Vertragsschlusses wird es in der Regel der Verwaltung auch erlauben, die Abwicklung des Leistungsverhältnisses in einer Art und Weise zu regeln, die den privatrechtlichen Schutz des Kontrahenten bis auf jenes geringe Maß abbaut, welches das öffentliche Recht im öffentlichen Interesse an Erfüllungs- und Bestandssicherung gewährt. 11) Aber das Privatrecht ist in seiner Weise dennoch auch imstande, einen der besonderen Interessenlage des Staat-BürgerVerhältnisses entsprechenden Schutz des Bürgers herzugeben. Zwar geht es formal und ging es zur Zeit der positiven Grundlegung seiner jetzigen Substanz wohl auch real von der Gleichheit der Rechtsbeteiligten aus. 12) Immer mehr hat es sich jedoch bemüht, den im privaten Bereich bestehenden wirtschaftlichen Machtungleichheiten - die denjenigen zwischen Staat und Untertan mehr oder weniger vergleichbar sind13) - Rechnung zu tragen. Soweit nicht Sonderregelungen geschaffen werden, hat man aus den Generalklauseln der $\$ \$ 138,157,242,826$ BGB und verwandten Sonderrechtsbestimmungen heraus dem Übermächtigen (insbes. dem sog. Monopolisten) Bindungen auferlegt, 14) die

11) S. hierzu auch Siebert, Privatrecht im Bereich öffentlicher Verwaltung, S.239.

12) S. z.B. Simitis, Die faktischen Vertragsverhältnisse, S.90 ff mit weiteren Nachweisen.

13) S. hierzu z.B. Gygi, Verwaltungsrecht und Privatrecht, S. 12 ff, insbes. S. 13 .

14) Zu den einschlägigen Rechtsgrundsätzen vgl. Soergel, BGB, 8.Auf1. 1952, $\$ 826$ Anm. B 10; RGR Komm. z. BGB, 10.Auf1. 1953, $₫ 138 \mathrm{Anm} .1 \mathrm{~A} \mathrm{~b}(\mathrm{~S} .275 \mathrm{f})$ und $\mathrm{f}(\mathrm{S} .280 \mathrm{f})$; Huber, Wirtschaftsverwaltungsrecht Bd.I, S. $427 \mathrm{f}$; Coing in Staudinger, BGB, 11. Auf1., Bd.I, 1957, Vorbem. vor $₫ 145$ Randn. 18 ff; Ermann, BGB, 2.Aufl. 1958, $₫ 138$ Anm. 11 t, $₫ 826$ Anm. 6 c dd; Bartholomeyczik in Müller-Henneberg und Schwarz, Gesetz gegen Wettbewerbsbeschränkungen - Gemeinschaftskommentar - 1958, Vorbem. 7 ff vor $\$ \$ 22-24$; Palandt, BGB, 18. Aufl. 1959, $\$ 138$ Anm. 5 a bb, $\$ \$ 826$ Anm. 8 j und u ee; umfassende Exemplifizierung bei Soergel-Siebert, BGB, 9. Aufl. Bd. I 1959, $\$ 138$ Randn. 52 ff (Hefermeh1). - S. nunmehr $\$ \$$ 22-27 des Gesetzes gegen Wettbewerbsbeschränkungen. - Zu dem für die Abwehr von Vorenthaltungen zentralen Kontrahierungszwang s. vor allem Coing, a.a.O. Randn. 9 (m. eingeh. Nachw.), ferner RGR Komm.z. BGB, Vorbem. 4 vor $₫ 145$; Ermann, a.a.O. Vorbem. 3 vor $\$ 145$; Palandt, 
im Effekt sehr weitgehend denen gleichen, die das öffentliche Recht dem Staate auferlegt. Der privatrechtlich handelnde Staat, dessen Mächtigkeit einzig dasteht, ist ihnen, wo er aus seiner spezifischen Position heraus handelt, ohne Zweifel unterworfen. 15). Noch einen Schritt weiter ist das Privatrecht in jüngster Zeit gegangen. Es entläßt den Staat, soweit er sich seiner als Mittel der öffentlichen Verwaltung bedient, 16) nicht aus den Bindungen, die das (öffentliche) Recht speziell ihm auferlegt. 17) Am

a.a.O. Vorbem. 3 vor $\$ 145$; Soergel-Siebert, a.a.O. vor $\$$ 145 Randn. 7 ff (Hefermehl); zur neuesten Diskussion hierzu Raiser, Vertragsfreiheit heute, JZ 13. Jhg. (1958) S. 1 ff (8).

15) S. nunmehr auch die Grundsatzbestimmung des $\$ 98$ des Gesetzes gegen Wettbewerbsbeschränkungen (i.V.m. dessen $\$ \S 22 \mathrm{ff})$.

16) (1) Zur Unterscheidung zwischen dem Privatrecht als Mittel der öfentlichen Verwaltung und dem Privatrecht als das notwendige Medium der rein fiskalischen Betätigung (privatrechtliche Hilfsgeschäfte, erwerbswirtschaftliche Staatstätigkeit) s. Siebert, Privatrecht im Bereich öfentlicher Verwaltung, insbes. S. $218 \mathrm{ff}$; Bachof, Begriff und Wesen des sozialen Rechtsstaats, S.61 f; Dürig, Grundrechte und Zivilrechtsprechung, $\mathrm{S} .184 \mathrm{ff}$; ders. in Maunz-Dürig, Art. $1 \mathrm{Abs}$. III, Randn. $134 \mathrm{ff}$; Wolff, Verwaltungsrecht I, S. 82 ff, insbes. S. 84 f. - Weitere Nachw. s. insbes. bei Dürig, a.a.O. und Raiser, Anmerkung zu BGH Urt. v. 10. Dezember 1958 - V ZR 70/57 - (BGHZ 29, 76 - s.a. diese Entscheidung) JZ 14. Jhg. (1959) S. $407 \mathrm{f}$.

(2) Damit ist das in begriflicher und systemtheoretischer Hinsicht immer dringencier werdende Problem angesprochen, ob es eine den Bereich des öffentlichen Rechts (nicht ausfüllende, jedoch) zum Privitı eht hin überschreitende öffentliche Verwaltung gibi. lgi. hierzu außer den (1) Zitierten z. B. Forsthoff, Lehrbuch les lerwaltungsrechts, S. 323, 356 ff. Eine interessante, Mrnnglich sehr kritisch zu würdigende Konzeption öffentlichr.r. Verwaltung aufgrund öffentlichen (und privaten) Rechts (ur.h Private mit den Mitteln des Privatrechts s. bei Friesenhain, Grundgesetz und Energiewirtschaft, Elektrizitätswirtschaft, j6..Jhg. (1957) Heft 1, S. 12 ff (13 f, $22 \mathrm{f})$.

17) S. Forsthoff, Lehrbuch des Verwaltungsrechts, S. 88, 113, 181 Anm. 3; Wolff, a.a.(). S. 84; Evers, Verfassungsrechtliche Bindungen fiskilischel Regierungs- und Verwaltungstätigkeit, NJW 13.Jhg. (1960) S.2073 ff mit eingeh. weit. Nachw. 
stärksten tritt das hinsichtlich der Grundrechtsbindung 18) und darunter am umfassendsten hinsichtlich des Gleichheitsgrundsatzes hervor. Beherrscht dessen Willkürverbot das Recht der Ermessensübung, 19) so nunmehr auch die Wertung des Verha1tens der Verwaltung unter den privatrechtlichen Rubriken der guten Sitten und von Treu und Glauben. 20) Damit schließt sich der Kreis. 21) Die Alternative "öffentliches oder privates Recht?" ist, weil die Einschränkung der Vertragsfreiheit des mächtigeren Partners durch das Privatrecht die korrespondierende Alternative "Verwaltungsakt oder Vertrag?" abgeschliffen hat, im Prinzip kein entscheidendes rechtsstaatliches Problem mehr. 22) Das Rechtsstaatsprinzip hat aber auch nur die Alternative gelassen: Entweder schränkt das Privatrecht den Staat, der sich seiner zum Zwecke öfentlicher Verwaltung bedient, so ein, wie es dem rechtsstaatlichen Postulat rechtlicher Bindung der staatlichen Gewalt entspricht, oder die Verwaltung verliert das ihr bei Fehlen einer Sonderregelung bislang zuerkannte - und nach Gesagtem auch weiter zuzuerkennende - Recht, zwischen den allgemeinen Formen des öffentlichen und privaten Rechts zu wählen.23)

18) S. die zu Fußn.16 gegebenen Nach- und Hinweise. - S.ferner unten S. $880 \mathrm{ff}$.

19) Vg1. Ipsen, Gleichheit, S. 147.

20) $\mathrm{Zu}$ den Generalklauseln als den Einfallstoren der Grundrechtsbindung ins Privatrecht s. unten 6 I 4 d (S. 876 ff) und die dortigen Nachweise.

21) Das Privatrecht enthält damit a u ch sein Sonderrecht für die öffentliche Verwaltung. Das beeinträchtigt seine Privatrechtsnatur nicht (vgl. Wolff, a.a.O. S. $83 \mathrm{ff}$; s.a. Haas, a.a.O. (oben S.622 zu Fußn.3). Es nimmt dem Privatrecht aber die Anfälligkeit für den Formenmißbrauch durch die Verwaltung. Die spezifische Anpassung des Rechts an die Interessenlage zwischen Staat und Bürger ist es ja, was erforderlich ist, nicht eine bestimmte Rubrizierung. Vgl. Wolff, a.a.O. S.85: "Würde sich die gesamte öffentliche Verwaltung in privatrechtlichen Formen abspielen, dann bedürfte es eines besonderen Verwaltungsrechts fast gar nicht".

22) Das Ergebnis liegt der Tendenz nach in der von Gygi (Verwaltungsrecht und Privatrecht, S. 17) gewiesenen Richtung, die Parteiautonomie durch gesetzliche Bindung der Verwaltung zu ersetzen (s.o. S.623 zu Fußn.9).

23) Vgl. Forsthoff, Lehrbuch des Verwaltungsrechts, S. 15, 113, 356 f; Wolff, Verwaltungsrecht I, S.82, 86 f, insbes. S.87; Dürig in Maunz-Dürig, Art. 1 Abs. III Randn.136 ("... zu verhindern, daß ein bloßes Changieren in den Rechtsformen 
Die Warnung vor der Flucht der Verwaltung ins Privatrecht 24 ) ist damit freilich, jedenfalls in bezug auf die Praxis des Rechtslebens, nicht gegenstandslos geworden. Die interessengerechte Regelung des öffentlichen Rechts ist, wenngleich in stetiger Entwicklung so doch unter den entscheidenden Aspekten gesicherter Bestand. Die Adaption der privatrechtlichen Regeln an die Besonderheiten des Staat-Bürger-Verhältnisses ist dagegen noch weithin mit "Reibungsverlusten" an Rechtsschutz und Rechtssicherheit verbunden, die der Verwaltung gelegentlich - und, geht sie darauf aus, wird sie gerade diese Gelegenheiten auszunutzen suchen - einen effektiven "Rechts" - Vorteil verschaffen können. 25) Die nachhaltigste Sicherung bedeutet wohl hier wie dort die spezielle Regelung. 26) Auf die Verdienste, die sich die sog. Stufentheorie 27 ) durch die Verbindung von privatem und öfent-

ein Changieren in der Rechtsmoral bewirkt".); Evers, a.a.O. - Zum Wahlrecht s. außerdem Siebert, Privatrecht im Bereich öffentlicher Verwaltung, S.216 ff, 246; Flessa, Schuldverhältnisse des Staates aufgrund Verwaltungsakts, S. 120.

24) S. die Nachweise oben S. 457 zu Fußn.2

25) S. a. Scheuner, Diskussionsbeitrag zu "Verwaltung und Verwaltungsrechtsprechung", S.185: "... daß die Verwaltung aus dieser Bindung ausweicht in die Zone des Privatrechts, wo die gesetzgeberische und verwaltungsgerichtliche Aufsicht sie nicht in gleicher Schärfe erfassen kann". - Auch in diesem Zusammenhang zu sehen ist ferner die Gefahr des Ausweichens der Verwaltung in undefinierbare Mischformen (vgl. Forsthoff, Begriff und Wesen des sozialen Rechtsstaats, S. 14; Scheuner, a.a.O.).

26) Nicht hier zu erörtern ist, ob eine Sonderregelung der Verwaltungstätigkeit gegenüber dem Bürger überhaupt noch dem privaten Recht zugerechnet werden kann (s.a. S.626 zu Fußn. 21). Vielleicht entspricht es der Erkenntnis der Grenzen, die der Rechtsgestaltung hier unter systematischen Aspekten gesetzt sind, daß scheuner (a.a.O.) auch davon spricht, daß die Verwaltung im Bereich des Privatrechts auch durch "die gesetzgeberische... Aufsicht... nicht in gleicher Schärfe" erfaßt werden kann.

7) Vgl.z.B. Krüger, I)ie Auflage als Instrument der Wirtschaftsverwaltung, S.385; Ipsen, Öffentliche Subventionierung Privater, S. 61 ff; Flessa, Schuldverhältnisse des Staates auf Grund Verwaltungsakts (der Autor selbst allerdings ablehnend); Dürig in Maunz-Dürig, Art. 1 Abs. III Randn. $137 \mathrm{f}$; je mit weit. Nachw.; s.a. Stern, Rechtsfragen der öffentlichen Subventionierung Privater, S.560 ff. 
lichem Recht zur optimalen Bewältigung der Probleme staatlicher Leistungsgewährungen erworben hat, sei ausdrücklich hingewiesen.

Die Parallelität privater wirtschaftlicher Machtpositionen mit derjenigen des Staates hat viel für die sachliche Annäherung des privaten und öffentlichen Rechts geleistet.

Das wird besonders deutlich hinsichtlich der Massenleistungsverhältnisse. Diese gleichen sich, ob der Staat (die Gemeinde usw.) oder ein Privater als Leistungsträger auftritt, über die Entsprechung der Mächtigkeit des privaten und des öffentlichen Leistungsträgers ${ }^{29}$ ) hinaus in eben der Massenhaftigkeit, deren Sachgesetzlichkeit zu ganz bestimmten, hier wie dort übereinstimmenden Ausformungen drängt. Das Spannungsverhältnis zwischen Macht und Abhängigkeit und die praktischen Bedürfnisse der Erledigung einer extrem großen Zahl gleichartiger Geschäfte haben im privaten Recht, wie schon erwähnt, ${ }^{30}$ ) zur Reduktion der Individualität und Konsensualität der Rechtsverhältnisse geführt. Das private Recht zeichnet sich in diesem Bereich nicht mehr durch die Herr. schaft der Vertragsautonomie aus. Einseitige - nicht selten vom Staat generell oder konkret gelenkte - Gestaltung der Leistungsbe dingungen auf der Seite des Leistungsträgers und die Alternative der Leistungsannahme zu diesen Bedingungen oder des Verzichts auf die Leistungen beherrschen das Bild, das somit dem öffentlichen Recht sehr verwandt erscheint. ${ }^{31}$ )' Umgekehrt mußte dieses, um dem ihm fremden Leistungswesen sachgerecht Herr zu werden (z.B. hinsichtlich der Haftungsfragen), Anleihen im privaten Recht aufnehmen. ${ }^{32)}$ Alles in allem wurden die privatrechtlichen und öffentlichrechtlichen Regeln für das Massenleistungsverhältnis so weitgehend angeglichen, daß es unter rechtsstaatlichen Gesichtspunkten nicht als relevant erscheint, ob die Verwaltung als Leistungsträger sich für den öffentlichrechtlichen oder den privatrechtlichen Weg ent scheidet. ${ }^{33)}$

28) Vg1. Gygi, Verwaltungsrecht und Privatrecht, insbes. S. 13 ff (mit eingeh. Nachw.). - Am Phänomen des Kontrahierungszwanges exemplifizierend hierzu von Interesse auch Hedemann, Der Kontrahierungszwang - Erinnerung und Ausblick, in Festschrift für Hans Carl Nipperdey, 1955, S. $251 \mathrm{ff}$.

29) Vg1. Gygi, a.a.O. S. 20.

30) S. oben S.619 zu Fußn. 8 und den Text hierzu.

31 ) S. oben S. 620 zu Fußn. 9 ff und den Text hierzu.

32) Vg1. Gygi, a.a.O. S.19 f; Forsthoff, Lehrbuch des Verwaltungsrechts, S. 357; je mit weiteren Nachweisen.

33) (1) Vg1. Gygi, a.a.O. S. 12 ff; Simitis, Die faktischen Ver- 
Über all dem darf nicht versessen werden, daß die Alternative zwischen dem privaten und dem öfentlichen Recht in bezug auf die Leistungsverwaltung zunächst nur das "Wie" des Leistens setrifft. Die Frage, ob die Verwaltung an sich - d.h. nicht nur 1s Folge einmal aufgenommener Darbietungen - leisten muß, jeantwortet sich danach, ob eine Rechtspflicht hierzu besteht. Jas ist zunächst keine Frage der Zuordnung zum öffentlichen der privaten Recht. Wo eine Rechtspflicht begründet ist, durchAringen sich allerdings die Regelungen des "Ob" und "Wie" aufs nnigste. Aber weder die allgemeinen Regeln des öfentlichen loch die des privaten Rechts können ohne einen speziellen rechtichen Leistungsgrund dem Bürger die Garantie zuverlässigen Leistens verschaffen, die die gesetzlich begründete Leistungsflicht gewährt. 34)

Wechselseitige Durchdringung und Angleichung von öffentlichem und privatem Recht

Is wäre reizvoll, von diesen Ansatzpunkten her aus dem Zustand

tragsverhältnisse, S. 00 i ff (insbes. s. z.B. S. 506, 509 f, 511 ff, 516 f, 531); Forsthoff, Lehrbuch des Verwaltungsrechts, S. 356 ff (insbes. \$. 357 : "..., daß im Rahmen der Daseinsvorsorge die Formen des öffentlichen und des privaten Rechts in gewissem Umfange vertauschbar sind. ... im allgemeinen ist es für die Abwicklung dieser öffentlichen Aufgabe ziemlich irrelevant geworlen, ob die eine oder andere Rechtsform gewählt "ird".); je mit weiteren Nachweisen. (2) Der Text setzt volatis, daß Massenleistungsverhältnisse nicht an sich schon - 1. h. auch wenn Private als Leistungsträger auftreten - öfentlichrechtlich sind (s.hierzu oben S.620 zu Fußn.9 uni (ien Text hierzu). Er setzt ferner voraus, daß die Verwaltung nicht immer dann schon öfentlichrechtlich handelt, wemm -ite "I)aseinsvorsorge" übt; denn Daseinsvorsorge ist kein b!auchbares Kriterium, um die öfentlichrechtliche IBetätigung de:s Staates von der privatrechtlichen zu unterscheideri (v/s]. Vaunz, Die Gesetzmäßigkeit des Fernsehwerbens, Batrorische Verwaltungsblätter, n.F. 3.Jhg. (1957) S. 4 ff (5 f); dirs., (irundfragen des Energiewirtschaftsrechts, S.319 ff; v. Gimm, Das Verwaltungshandeln und der Rechtsweg, NJII 10.Thg. (1957) S. 1055 ff; Forsthoff, Lehrbuch des Verwaltungsifents, S.323, 357 f; ferner Simitis, a.a.O. S.463 ff (passim));s.hierzu auch oben S.625 zu Fußn. 16. A.A. Rupp, Dir Bnse tigungs- und Unterlassungsklage gegen 'Träger hoheitlirle:: Gewalt, S. 115.

34) S. oben S. $457 \mathrm{ff}$. 
des Privatrechts und dem Verhältnis zwischen dem privaten und dem öfentlichen Recht auf Stand und Mittel der Sozialaktivität und -verantwortung des Staates zu schließen. Doch würde das zu weit führen. Immerhin muß darauf hingewiesen werden, in welchem Maße die Umgestaltung des Privatrechts, dessen gegenwärtiger Zustand sich so grundlegend von dem ursprünglichen Gefüge von individualistischer Privatautonomie, ius dispositivum, ius strictum und richterlicher Streitentscheidungs- und Rechtspflegekompetenz unterscheidet, symptomatisch ist für die - im allgemeineren und im spezielleren Sinn - soziale Verstrickung des Staates. Die individualistische Privatautonomie war nicht nur der Massenhaftigkeit der modernen Lebens- und Rechtsvorgänge nicht mehr gewachsen. 1) Ihre Basis, die formale Gleichheit, überließ auch den wirtschaftlich (oder sonstwie in bezug auf den geschäftsgegenständlichen Tausch- und Interessenwert) Schwäche ren in einem Maß der Gewalt des Mächtigeren, das nicht nur im Hinblick auf das wachsende soziale Gerechtigkeitsempfinden sondern auch wegen der zunehmenden Bedeutung wirtschaftlicher Machtgefälle unerträglich wurde. ${ }^{2)}$ Die Privatautonomie mußte eingeschränkt werden. Dem Weg zum umfassenden ius strictum waren durch die Fülle und Differenziertheit enge Grenzen gesetzt, sollte es weder zum Popanz vermeintlicher Vollkommenheit noch zur Schnürbrust noch zur Vollmacht unberechenbarer richterlicher Rechtsentwicklung werden. Das Instrumentarium mußte daher erweitert werden.

Soweit die Rechtsverhältnisse typisierbar waren, konnten zwischen Privatautonomie und dem unabdingbaren allgemeinen Gesetz Teilrechtsordnungen eingeschoben werden. Im Bereich der Sach- und unpersönlichen Dienstleistungen, die den individuell Mächtigeren auf der Anbieterseite einer nicht organisierten und schwer organisierbaren Nachfrage-(Konsumenten-) seite gegenüber zu sehen pflegen, bildeten sich die durch Kontrahierungszwang und Diskriminierungsverbot ergänzten bzw. sanktionierten, durch die allgemeinen Regeln der guten Sitten und von Treu und Glauben oder (und) durch spezielle Bestimmungen oder auch konkrete obrigkeitliche Einwirkung inhaltlich bestimmten allgemeinen Leistungsbedingungen (Geschäftsbedingungen, Tarife usw.

1) Zum Konflikt des allgemeinen Privatrechts mit der Massenhaftigkeit der modernen Rechtsvorgänge s. z. B. Bärmann, Typisierte Zivilrechtsordnung der Daseinsvorsorge; Siebert, Faktische Vertragsverhältnisse, S.12 ff (insbes. S. 14) und die dort gegebenen Nachweise.

2) Vgl. nochmals Gygi, a.a.O. S. 12 ff, Simitis, a.a.O. S. 37 ff, $463 \mathrm{ff}, 533 \mathrm{ff}$. 
heraus. Im Bereich der persönlichen Dienstleistungsverhältnisse (d.h. also des Arbeitsrechts i.w.S.), die prinzipiell den Schwächeren auf der zwar aus einer Masse von Individuen gefügten, durch die Gemeinsamkeit des Leistungsangebotes bzw. der Leistung jedoch relativ leicht organisierbaren Anbieterseite sehen, entwickelte sich dagegen der Ausgleich durch das Kollektiv, das das Gleichgewicht der Interessenträger und somit auch die Basis für eine kollektive, ebenfalls individualitätsfeindliche Vertragsfreiheit aber jedenfalls kollektiv-autonome, partikuläre Rechtsgestaltung herstellen konnte. Betriebsverfassung und Tarifvertragsrecht sind die Hauptfälle dieser Entwicklung. ${ }^{3)}$

Konnte hier der obrigkeitliche Eingriff (durch Rechtsetzung oder Verwaltungsakt) im allgemeinen im Hintergrund bleiben, so war das hinsichtlich der individuellen, nicht typisierbaren Rechtsverhältnisse nicht in demselben Maße möglich. Wo hier die Privatautonomie nicht sich selbst überlassen bleiben konnte, ohne daß eine definitive gesetzliche Regelung angemessen gewesen wäre, war nur zu wählen zwischen der individuellen Rechtsgestaltung durch den Richter oder dem korrigierenden Eingriff der Verwaltung. Gerade dieser, der sich - man mag über die Grenzen (vor allem mit rechtspolitischen Argumenten) streiten bei dem gegenwärtigen Umfang des sozialen Engagements des Staates weder in bezug auf die individuellen noch auch in bezug auf die typisierten Rechtsbeziehungen vermeiden läßt, ist symptomatisch für die Situation. ${ }^{4)}$

Bedeutet diese "Publizierung des bürgerlichen Rechts" 5) mehr ein Eindringen des öffentlichen Rechts mit seinen ihm eigenen Institutionen in den Raum des Privatrechts, so bringt die als Ausgleich der dem Staat-Bürger-Verhältnis ähnelnden intragesellschaftlichen einerseits massenhaften, andererseits durch Machtspannungen gekennzeichneten Rechtsbeziehungen aufgekommene "Entindividualisierung" 6) und "Sozialisierung" 7) des Pri-

3) Zu den Besonderheiten dioser neuen Rechtsform s.a. die oben S. 615 zu F'ußn. 1 zu dem Stichwort "Sozialrecht" angeführte Literatur.

4) S. hierzu oben S. 519f zu Fußn. 17-21 und S. 527 zu Fußn. 17 und auch Gygi, Verwaltungsrecht und Privatrecht, S. 7 ff.

5) Der Ausdruck stammt von Hedemann, Einführung in die Rechtswissenschaft, 2. Auf1. 1927, S.229, der damit jedoch nicht speziell den hoheitlichen Eingriff in privatrechtliche Rechtsverhältnisse meint sondern das ganze hier umschriebene Phänomen der Vermengung und Angleichung von öffentlichem und privatem Recht. 
vatrechts dessen materiell-gestaltliche Angleichung an das öffentliche Recht mit sich.

Doch ist dies nur die eine Seite des schon aufgezeigten Prozesses der Annäherung der beiden Rechtsteile und der Aufweichung ihrer Grenzen. Auf der anderen Seite steht das sich immer noch steigernde Hervortreten der wirtschaftlichen, daseinsvorsorgenden, leistenden und leistungsverantwortlichen Komponente der komplexen Machtposition des Staates. ${ }^{8)}$ Diese Leistungsaktivität findet ihren deutlichen Reflex vor allem darin, daß die weitgehende Austauschbarkeit des öffentlichrechtlichen und privatrechtlichen Instrumentariums der öffentlichen Verwaltung überhaupt möglich wurde. Die Eingriffsverwaltung kann ihrem Wesen nach nicht mit den Mitteln des Privatrechts auskommen.

Zweifellos gibt es noch reines öffentliches und privates Recht. Zweifellos gibt es hier und dort Kernzonen, die weder durch gegenseitige Durchdringung noch durch Strukturveränderung desintegriert werden. Aber ungeachtet dessen ist ein tiefgreifendes Ineinander von privatem und öfentlichem Recht und ein Zerfließen der Grenzlinien zwischen den beiden Rechtsteilen bezeichnend für die Aufgabenstellung des Staates, seiner Rechtsordnung und seiner Verwaltung, in der Gegenwart - nicht zuletzt auch für die soziale Funktion von Staat und Recht. $\left.{ }^{9}\right)$

III. Die materiellen Prinzipien der Rechtsstaatlichkeit

1. A 11 ge meines

a) Zum Gegenstand

Der Rechtsstaat des Grundgesetzes ist Rechtsstaat auch im materiellen Sinn. 1) Die Bindung der Verwaltung und Rechtsprechung an das Gesetz und der umfassende Schutz der individuellen Sphäre

6) S. z.B. Hallstein, Von der Sozialisierung des Privatrect.ts, Zeitschrift für die gesamte Staatswissenschaft, Bd. 102 (1942) S. 530 ff (531 und passim). S.a. Simitis, Die faktischen Vertragsverhältnisse, S. 523, $550 \mathrm{ff}$ und passim.

7) S. den eben zitierten Aufsatz von Hallstein.

8) S. nochmals Simitis, S. $463 \mathrm{ff}$ (insbes. z.B. S. $516 \mathrm{f}$ ).

9) Vgl. nochmals Siebert, Privatrecht im Bereich öffentlicher Verwaltung, S.216 ff und passim; ferner die sonstigen oben S. $615 \mathrm{zu}$ Fußn. 1 Zitierten.

1) S. zum Folgenden nochmals oben S.396 ff, insbes. S. $400 \mathrm{zu}$ Fußn. 16 ff und den Text hierzu. 
durch Gesetzesvorbehalt und Rechtsprechung, die sich im Widerspiel der drei "Gewalten" ver'wirklichen, genügen allein nicht. Materielle Rechtsstaatlichkeit - in dem hier in Frage stehenden jüngeren Sinn - verlangt die inhaltliche Bestimmung der ganzen Staatstätigkeit von einer obersten Rechtsschicht her, die an Geltungskraft auch dem Gesetz überlegen ist. Darin liegt die rechtsstaatliche Aufgabe des materiellen Verfassungsrechts. Das Grundgesetz entledigt sich ihrer - abgesehen von den die Staatstätigkeit inhaltlich bestimmenden Elementen der bundesstaatlichen, demokratischen und autonomistischen Grundordnung durch die Grundrechte (Art.1-19 GG), seine weiteren Rechtsgarantien (Art.33,101-104 GG) und die Statuierung des Soz i a 1 st a t s prinzips (Art.20 Abs. 1, 28 Abs. 1 Satz 1 GG). Auf diese Bestimmungen wird eingehend zurückzukommen sein.

Zwischen der ausdrücklichen, materiellen Sachordnung der Verfassung und den Normen über die organisatorische Ausformung und Gewährleistung des Rechtsstaates, wie sie in dem voraufgehenden Abschnitt erörtert wurden, liegt aber noch eine dritte Normgruppe, die dem Rechtsstaat - jedenfalls dem Rechtsstaat im Sinne des Grundgesetzes - nicht minder wesentlich ist. Sie ist insofern materielles Verfassungsrecht, als sie nicht die Staatsorganisation regelt. Von der durch Grundrechte, institutionelle Garantien, materielle Staatszielbestimmungen usw. gegebenen Sachordnung hebt sie sich aber dadurch ab, daß sie nicht bestimmte Sachfragen aufgreift, sondern allgemeine Grundsätze des staatlichen Lebens gibt. Es sind das die Grundsätze des Amtshaftungs- und Entschäcigungsrechts, der Grundsatz der Verhältnismäßigkeit, der Rechtssicherheit und - am weitesten ausholend - das Postulat der Grechtigkeit. Die damit angesprochenen Rechtsprinzipien sind sämtlich auch Gestaltelemente der sozialen Intervention des Staates, nicht alle freilich in gleich eigenständig bestimmender Weise und spezifischer Ausprägung.

\section{b) Der Grundsatz der Verhälinismäßigkeit}

DerGrundsatz der Verhä $1 \mathrm{th}$ ismäßigke it von Zweck und Mitte1, 1) erst in jüngerer Zeit aus der Enge seines polizeirechtlichen Ursprungs an (las Licht des allgemeinen Verwaltungsrechts gehoben, ${ }^{2)}$ gilt heute als ungeschriebener Bestandteil des Ver-

1) vgl. Rupprecht, Der Grundsatz der Verhältnismäßigkeit, 1955.

2) S.a. Dürig, Verfassung und Verwaltung im Wohlfahrtsstaat, S. 199 . 
fassungsrechts. ${ }^{3)}$ Seine rechtsstaatliche Aufgabe ${ }^{4)}$ erschöpft sich nicht mehr darin, die Bindung der Verwaltung an das Gesetz zu präzisieren. Er reguliert auch das Verhältnis des Gesetzes zur Verfassung, insbes. als das maßgebliche Prinzip gesetzlicher Grundrechtseinschränkung. 5) Das Verbot des Übermaßes gelangt dabei insofern zu allgemeinster Bedeutung, als die Grundfreiheit des Art. 2 Abs. 1 GG grundsätzlich dem einschränkenden gesetzgeberischen Zugriff ausgeliefert ist. ${ }^{6)}$ Indem es noch in der Sphäre freien gesetzgeberischen Ermessens den Gesetzgeber an den - wie vorauszusetzen: legitimerweise - von ihm verfolgten $Z$ weck bindet, rundet es, den gesetzesstaatlichen Schutz der Individualsphäre durch das Relevant-werdenlassen der Infrarelation von Gesetzeszweck und Gesetzeswirkung überhöhend, das Gefüge rechtsstaatlicher Sicherungen der individuellen Entfaltung bedeutsam ab. Es ist leicht einzusehen, daß ein Grundsatz von dieser Tragweite auch für die soziale Intervention, nämlich für den belastenden Ausgleichs- bzw. Umverteilungsakt, bestimmend ist. Das Gesetz ist an die Kette der Notwendigkeit seiner Mittel gelegt, die freilich nicht individuell gesehen werden darf. Aber das Verbot des Übermaßes ist immer nur in der Normspannung greifbar, welche die Dimension des Maßes angibt, d.h. nur im Rahmen des Grundrechts, das sich dem Eingriff widersetzt, ihn reguliert, erlaubt usw. oder des Grundsatzes (z.B. des Sozialstaatsprinzips), der ihn legitimiert. Es verflüchtigt sich nachgerade in den speziellen Ausprä-

3) Vg1. Lerche, Verbot des Übermaßes und Gerichtsschutz, Bayerische Verwaltungsblätter, n.F. 3.Jhg. (1957) S. 322 f; ders., Zum Apothekenurteil des Bundesverfassungsgerichts, Bayerische Verwaltungsblätter, n.F. 4.Jhg. (1958) S.231 ff; ders., Übermaßverbot und Verfassungsrecht (noch ungedruckt). Aus der (nicht klar orientierten und nicht grundsätzlich begründeten)Rechtsprechung des Bundesverfassungsgerichts s. BVerfGE 1, 167 (178); 3, 383 (399); 7, 377 (407); 8, $274(310,328) ; 9,338(346)$.

4) Zur Rechtsstaatlichkeit als Wurzel des Prinzips s. BayVGHE 9 II 158 (177).

5) S. Lerche, a.a.O., die zitierte Rechtsprechung des Bundesverfassungsgerichts (außer BVerfGE 8, 274).

6) Jedenfalls nach der hier nicht nur als maßgebend sondern auch als zutreffend zugrunde gelegten Auslegung des Art.2 Abs. 1 GG in BVerfGE 6, 32. - Zur Bedeutung des Grundsatzes der Verhältnismäßigkeit im Rahmen des Art. 2 Abs. 1 GG s. Dürig in Maunz-Dürig, Art. 2 Abs. I Randn. 63. 
gungen, die es darin findet. 7) Darum ist es - bei aller Anerkennung, die das Prinzip als solches für die soziale Intervention verdient - nicht tunlich, dieser wie wenige andere Verfassungsgrundsätze gefährlichen und bedenklichen Waffe des normkontrollierenden Richters gegen den Gesetzgeber ${ }^{8)}$ im gegebenen Zusammenhang eine weitergehende gesonderte Betrachtung zu widmen.

\section{c) Das Amtshaftungs- und Entschädigungsrecht}

Nicht näher einzutreten ist hier auch auf das Recht der Amtshaftung und Entschädigung. 1) Hinsichtlich der rechtsstaatlichen Bedeutung dieses (auch unter anderen Gesichtspunkten heterogenen) Normenkomplexes ist allerdings zu differenzieren. Der Ausgleich rechtswidrig zugefügter Nachteile, für den Fall der Amtspflichtverletzung verfassungsrechtlich garantiert durch die in Art.34 GG vorgesehene Staatshaftung, ist die - rechtsstaatlich konsequente - Sanktion der Bindung des Staates an das Recht. ${ }^{2)}$ Sie ist für den Sachbereich der sozialen Intervention, bei der es so weitgehend auch unmittelbar um materielle, restitutiv ersetzbare Werte geht, von umfassender Bedeutung, ohne bei undifferenzierter Totalsicht einen speziellen Bezug zum Sozialbereich aufzuweisen. Das gilt jedoch nicht für die innerhalb des Rechts des Ausgleiches rechtswidrig von hoher Hand (bzw. von staatlichen Organen) zugefügten Schadens zu beobachtende Strömung von der klassischen Amtshaftung für schuldhaft rechts-bzw. pflichtwidriges Handeln zur allgemeinen Entschädigungspflicht für schuldhafte und schuldlose rechtswidrige Eingriffe. ${ }^{3)}$ Diese Entwicklung steht mit dem hier zu erörternden

7) Vgl. Lerche, Zum Apotheken-Urteil des Bundesverfassungsgerichts, S.232.

8) Vgl. Lerche ebd. S.234 f.

1) Gesamtdarstellungen s. z.B. bei Forsthoff, Lehrbuch des Verwaltungsrechts, S.276 ff; Wolff, Verwaltungsrecht I, S. $316 \mathrm{ff}$.

2) Zu der noch auf die ersten Ansätze ("Dulde und liquidiere") zurückgehenden rechtsstaatlichen Funktion der Amts- und Staatshaftung s. z. B. Jellinek, Verwaltungsrecht, S. $310 \mathrm{ff}$; Darmstaedter, Die Grenzen der Wirksamkeit des Rechtsstaats, S. 226 f; Friesenhahn, Die rechtsstaatlichen Grundlagen der Verwaltung, S.278; Scheuner, Grundfragen des modernen Staates, S.153; Huber, Wirtschaftsverwaltungsrecht, Bd. II S. 667; Haas, Systeme öffentlichrechtlicher Entschädigungspflichten, S. 15, 54 ff. - S. hierzu auch oben S. 544 .

3) Zur Entwicklung s. die Darstellungen von Schack, Empfiehlt es sich, die verschiedenen Pflichten des Staates zur Entschä- 
Phänomen in einem doppelten Zusammenhang. Auf der einen Seite ist sie mit hervorgerufen durch die nicht zuletzt auch durch die soziale Aufgabenstellung des Staates verursachte Ausweitung des staatlichen Macht- und Aktionsvolumens. Sie steigert(e) das Gesamtrisiko fehlerhaften Verhaltens der Staatsorgane, das mit den Grundsätzen der Verschuldenshaftung allein nicht ohne Unbilligkeiten aufgefangen werden kann sondern erst erträglich wird, indem eine das Verschuldenserfordernis vernachlässigende "Gefährdungshaftung" ergänzend hinzutritt. Auf der anderen Seite ist es das gleiche verfeinerte Gerechtigkeitsempfinden, das gleiche Bewußtsein um das Vermögen des (in der modernen Massengesellschaft lebenden) Individuums, "Schicksals"-Risiken zu übernehmen, und die Unfähigkeit der kleineren Gemeinschaften, sie aufzufangen, das gleiche Prinzip der Verantwortlichkeit des Staates für das Einzelschicksal, das sowoh1 zum sozialen Ausgleich wie auch dazu drängt, daß die Gemeinschaft die Risiken irregulärer Belastung übernimmt, die von ihr (ihren Organen) im Rahmen eines Fehlerkalküls, das mit dem Ingangsetzen und -halten des Organisationsgetriebes trotz seiner rechtlichen Bindung und gerade in Relation zu ihr von vorneherein in Rechnung gestellt werden muß, 4) verursacht werden.

Daß die dahingehende - fast durchwegs juristen- bzw. richterrechtliche - Rechtsentwicklung ihren heutigen Stand erreichen konnte, hängt zweifellos mit dem (hier und da schon übertreibenden) Erstarken der Rechtsstaatlichkeit in der Gegenwart zusammen. 5) Allein der konkrete dogmatische Ansatz ist ein grundrechtlicher: Gleichheitsgrundsatz, Grundrecht der körperlichen Integrität und Eigentumsgrundrecht. Daher soll Näheres dazu unten, im Rahmen der Grundrechtsordnung gesagt werden. 6) Das

digungsleistung aus der Wahrnehmung von Hoheitsrechten nach Grund, Inhalt und Geltendmachung gesetzlich neu zu regeln? Verhandlungen des 41. Deutschen Juristentages, Bd. I, 1. Halbbd., 1955, S. 5 ff (8 ff); Reinhardt, dass. ebd. S. $237 \mathrm{ff}$ (248 ff, $256 \mathrm{ff}$ ); Forsthoff, Lehrbuch des Verwaltungsrechts, S. $309 \mathrm{ff}, 336 \mathrm{ff}$.

4) Zum Vorstehenden s. vor allem Forsthoff, a.a.O. (insbes. S.317). Zur Tendenz zur Gefährdungshaftung s. allgemein Esser, Die Zweispurigkeit unseres Haftpflichtrechts, JZ 8. Jhg. (1953) S. 129 ff; für das Amtshaftungsrecht Reinhardt, a.a.O. S. 256 ff; neuere Gesichtspunkte zum spezielleren $\mathrm{Zu}-$ sammenhang s. bei Zeidler, Die Technisierung der Verwaltung, S. $7 \mathrm{ff}$.

5) Auf den Einfluß des Sozialstaatsprinzips wird unten (Abschnitt 5 III 2 c, cc (S. 771 ff)) zurückzukommen sein. 
gleiche gilt für die Entschädigung wegen rechtmäßiger Eingriffe, deren vielfältige soziale Bedeutung evident ist. Auch der Ausgleich von rechtmäßig auferlegten Sonderopfern ist zwar dem Rechtsstaatsprinzip verbunden, 7) aber doch nicht anders als es rechtsstaatlich ist, daß und wie die Grundrechte der Gleichheit, des Eigentums - soweit es die Frage rechtmäßiger Eigentumsentziehung regelt - und der körperlichen Integrität soweit es eine gesetzliche und somit auch allgemeine, gleichheitliche Eingriffsordnung fordert - selbst die Verteilung zwischen Individuallast und Gemeinlast ordnen.

2. Rechtsstaat und Rechtssicherheit

a) Das Postulat der Rechtssicherheit

$\mathrm{Zu}$ den materiellen Generalprinzipien und Grundwerten des Rechtsstaats gehört die Rechtssicherheit. Sie ist von großer sozialer Tragweite. "Sicherheit" ist auch ein wesentliches Ziel sozialer Intervention: "soziale Sicherheit". 1) Rechtssicherheit bedeutet Berechenbarkeit und Vorhersehbarkeit der staatlichen Verhaltensweise. Sie erlaubt dem Bürger, sich auf die rechtlichen Daten in seiner und um seine Individualsphäre einzurichten. Sie erhöht seine Dispositionsmöglichkeiten - seine Freiheit, ${ }^{2}$ ) auch die Freiheit der Teilhabe.

6) S. unten Abschnitt 6 II 2 b cc (S.904 ff) und III (S.934 ff) passim.

7) Vg1. Friesenhahn, Die rechtsstaatlichen Grundlagen der Verwaltung, S. 279 f; Scheuner, Grundfragen des modernen Staates, S. 153 f.

1) Zum Zusammenhang zwischen Rechtssicherheit und "sozialer Sicherheit" (in einem untechnischen, weitausgreifenden Sinn) s. z.B. Werner, Allgemeine Verwaltungsgerichtsbarkeit und Sozialgerichtsbarkeit, S. 1627 (insbes. Fußn. 18); Thieme, Umfang und Grenzen des verfassungsrechtlich gewährleisteten Bestandsschutzes drr saarländischen Kriegsopferversorgung, Zeitschrift für. Sozialreform, 5. Jhg. (1959) S. $149 \mathrm{ff}$, 243 ff (245); fernes. Weidner, Zur Rechtsprechung des Bundessozialgerichts, S. 763 .

2) Der freiheitssichernde Effekt der Rechtssicherheit wird besonders deutlich im Zusammenhang mit dem nachfolgend zu erörternden Rückwirkungsproblem. S. schon den klassischen Grundsatz: nulla poena sine lege. In jüngerer Zeit wurde das wieder deutlich in den Versuchen, die Rückwirkungsproblematik vom Freiheitsgrundrecht her zu lösen (s.unten S.638 zu Fußn.1). 
Rechtssicherheit ist in erster Linie ein Resultat der Rechtsgebundenheit des Staates und insofern Ziel und Produkt der rechtsstaatlichen Staatsorganisation. ${ }^{3)}$ Doch erschöpft sich darin weder der wünschbare noch der positive Bestand an Rechtssicherheit. Die Rechtssicherheit stellt um der Rechtsstaatlichkeit der Bundesrepublik willen auch einen selbständigen, materiellen Verfassungsgrundsatz dar. ${ }^{4)}$

\section{b) Die Sicherheit des Normbestandes}

aa) Zur Rückwirkung von Gesetzen.

Mit dem Postulat der Rechtssicherheit ist die unumschränkte Befugnis des Gesetzgebers, rü ckwirkende Gesetze zu erlassen, unvereinbar. 1) Der Bürger muß auf den Bestand der Ge-

3) In diesem Sinne versteht vor allem Peters (Rechtsstaat und Rechtssicherheit) das Verhältnis von Rechtsstaat und Rechtssicherheit.

4) Außer den nachstehend noch zu Zitierenden s. insbes. BVerfGE 2, 380 (403 ff); 3, 4 (11), 225 (237), 248 (253); 7 , 89 (92).

1) Das Rechtsstatsprinzip - insonderheit als dessen Emanation, das Rechtssicherheitsprinzip - ist sedes materiae der al1gemeinen Rückwirkungsproblematik (s. statt aller anderen: BVerfGE 7, 89 (92); 8, 274 (304); BayVerfGH VGHE n.F. 3 II 129 (137); 5 II 1 (12), 243 (262 ff)).

A.rt.2 Abs. 1 GG ist als Ansatzpunkt für eine generelle Lösung des Rückwirkungsproblems nicht brauchbar (s.insbes. Klein, Von der Zulässigkeit zur Unzulässigkeit rückwirkender Steuergesetze, Steuer und Wirtschaft, Jhg. XXXI (1954) Sp. 1 ff (Sp. 21 ff); Deiting, Freie Entfaltung der Persönlichkeit, Rechtssicherheit und Rückwirkung von Steuergesetzen, Steuer und Wirtschaft, Jhg. XXXII (1955) Sp. $21 \mathrm{ff}$; Forsthoff, Lehrbuch des Verwaltungsrechts, S. 141 f; Maunz, Deutsches Staatsrecht, S.96; nicht ganz eindeutig MaunzDürig, Art.20 Randn. 47). Die Versuche, das Rückwirkungsproblem mit Hilfe von Art. 2 Abs. 1 GG zu meistern (s.f.v.a. Meyer-Cording, Die Rückwirkung von Gesetzen, JZ 7. Jhg. (1952) S. $161 \mathrm{ff}$ (164 ff); s.a. Dürig in Maunz-Dürig, Art.2 Abs. I Randn. 47), bauen meist auch auf einer anderen Auslegung dieses allgemeinen Freiheitsgrundrechtes auf als sie durch BVerfGE 6, 32 gegeben wurde. Jedenfalls vor deren Hintergrund, wonach Art. 2 Abs. 1 GG im allgemeinen nur als grundrechtlicher Gesetzesvorbehalt wirksam wird, kann die- 
setze vertrauen und sich in seinen Dispositionen darauf einrichten können. ${ }^{2)}$ Sein Vertrauen wird betrogen, wenn der Gesetzgeber an zurückliegende Tatbestände andere und zwar ungünstigere Rechtsfolgen knüpft als diejenigen, auf welche sich der Betroffene bei seinen auf den Tatbestand bezogenen Dispositionen hatte einrichten müssen und dürfen. Daher mißbilligt der Rechtsstaat das rückwirkende Gesetz. ${ }^{3)}$ Für den - jedenfalls nach traditionel-

se Vorschrift keine prinzipielle Lösung mehr bieten (s.a. schon früher: BVerfGE 2, $237(265$ f)). Bis ein rückwirkendes Gesetz wegen seiner Rückwirkung in den unantastbaren Wesensgehalt der persönlichen Freiheit (Art. 2 Abs. 1, 19 Abs. 2 GG), m.a.W. in den "letzten unantastbaren Bereich menschlicher Freiheit" (BVerfGE 6, 41) eindringt, ist es, wenn die Wahrheit nicht gepreßt werden soll, weit (Dürig, a.a.O. nimmt diesen Verstoß offensichtlich für sog. Überraschungsgesetze an). Diese Wesensgehaltsschranke weist keine spezifische Frontstellung gegen rückwirkende Gesetze auf. Damit soll der freiheitssichernde $Z$ weck des Rückwirkungsverbots, der auch oben schon hervorgehoben wurde, nicht verkannt werden. Aber nicht nur Grundrechte, auch objektive Verfassungsgrundsätze können die Freiheit sichern. Abgesehen davon schaltet Art.2 Abs. 1 GG in der Auslegung des Bundesverfassungsgerichts die objektiven Verfassungsgrundsätze, sobald sie bzw. ihre Auswirkungen die Freiheitssphäre tangieren, über die Klausel der verfassungsmäßigen Ordnung in mittelbare Bestandteile des allgemeinen Freiheitsgrundrechts um (s. zu dieser gegenseitigen Durchdringung von Grundrecht und Rückwirkungsverbot auch Dürig, a.a.O.), was nicht zuletzt für die Abwehr rückwirkender Gesetze (bzw. ihres Vollzugs) mithilfe der Verfassungsbeschwerde von Bedeutung ist (vgl. $\$ 90$ Abs. 1 BVerfGG). Weniger als Art.2 Abs. 1 GG wird der Gleichheitsgrundsatz als Grundlage eines Rückwirkungsregulativs herangezogen (vgl. vor allem Vogel, Zur Frage der Rückwirkung von Steuergesetzen, NJW 13.Jhg. (1960) S. 1182 ff (1183). Hierzu ist zu sagen: Rückwirkende Gesetze können - und können das vielleicht sogar besonder's leicht - gegen den Gleichheitsgrundsatz verstoßen, wenn sie zu mißbilligter Ungleichheit führen (vgl. Ipsen, Gleichheit, S. 167 mit weit. Nachw.; s.a. BVerfGE 7, 129 (152)). Doch ist auch hier eine grundsätzliche Frontstellung gegen rückwirkende Gesetze nicht gegeben.

2) S. z.B. BVerfGE 1, 264 (280), 7, 89 (92 f); 8, 274 (304);

s.a. Hamann, Das Grundgesetz, Einf. I D 1 a und d.

3) S. die radikale Ablehnung bei Benjamin Constant (moniteur 
ler Auffassung - gravierendsten Eingriff, die Strafe, schließt Art. 103 Abs. 2 GG die retroaktive Belastung ganz aus. ${ }^{4}$ ) Im übrigen - eine analoge Anwendung des Art. 103 Abs. 2 GG auf alle Belastungsgesetze ist unzulässig 5) - ist darauf abzustellen, inwieweit die bisherige Regelung durch schützenswertes Vertrauen in sie so verfestigt wurde, daß der Staat sich "daran festhalten lassen muß"'.

Wann das der Fall ist, ist nicht immer leicht zu sagen. Die Rechtsüberzeugung 6 ) ist noch nicht präzis entwickelt. ${ }^{7}$ Es liegt

v. 1.Juni 1928, S. 758 - zitiert nach Neumann, Zum Begriff der politischen Freiheit, Zeitschrift für die gesamte Staatswissenschaft, Bd. 109 (1953) S.25 ff (31)): "Retroaktivität ist das größte Verbrechen, welches das Recht begehen kann; sie ist das Zerreißen des Sozialvertrages, sie ist die Vernichtung derjenigen Bedingungen, kraft welcher die Gesellschaft Gehorsam vom Individuum verlangen kann. ... Retroaktivität raubt dem Gesetz seinen Charakter. Das retroaktive Gesetz ist kein Gesetz".

4) Zu Art. 103 Abs. 2 GG als Rückwirkungsverbot s. z.B. Dürig in Maunz-Dürig, Art. 103 Randn. 109.

5) Vgl. Dürig, a.a.O.; BVerfGE 7, 89 (95); für Analogie Vogel, Zur Frage der Rückwirkung von Steuergesetzen, S. 1183 f.

6) Dürig in Maunz-Dürig, Art.2 Abs.I Randn. 47 Fußn.2, glaubt: "Kaum etwas stößt im Volk (mit Recht) auf so große Verständnislosigkeit wie rückwirkende Belastungsgesetze". Ob er damit Recht hat, scheint mir nicht ganz außer Zweifel zu sein. Doch kommt es auf die Anschauung des breiten Volkes allein weder positiv noch negativ entscheidend an.

7) Die Rückwirkungsdiskussion in Rechtsprechung und Schrifttum hat um 1949/50 jäh eingesetzt, um sich seither in einem Maß auszudehnen, das kaum mehr überschaubar ist. Eine Zusammenfassung der älteren, grundlegenden Diskussion s. etwa bei Meyer-Cording, Die Rückwirkung von Gesetzen, und bei Klein, Von der Zulässigkeit zur Unzulässigkeit rückwirkender Steuergesetze. Aus der Zeit seit der von Klein gegebenen Zusammenfassung dürfen erwähnt werden: Coing, Grundsätzliches zur Rückwirkung von Gesetzen, Betriebsberater, 9.Jhg. (1954) S. 137 ff; Deiting, Freie Entfaltung der Persönlichkeit, Rechtssicherheit und Rückwirkung von Steuergesetzen; Paulick, Grundgesetz und Besteuerung, Steuerberatungsjahrbuch 1957/58, S. $85 \mathrm{ff}$ (111 ff); Claus Arndt, Zur Gültigkeit rückwirkender Gesetze, DVBl. 73. Jhg. (1958) S. $120 \mathrm{ff}$. Weitere Nachweise s. bei den Genannten. 
außerhalb der Aufgaben dieser Arbeit, die Rückwirkungsproblematik einer umfassenden Klärung zuzuführen. Doch darf hervorgehoben werden, daß das Rückwirkungsverbot als Vertrauensschutz verstanden werden muß. Das bedeutet einmal, daß der Bürger in den Bestand der älteren, ihm günstigeren Rechts im Zeitpunkt seiner Dispositionen mußte vertrauen dürfen. ${ }^{8)}$ War die Rechtslage unklar, 9) widersprach ihr ein Rechtsschein 10) oder mußte konkret mit einer Änderung gerechnet werden, 11) so

8) Vg1. BayVerfGH n. F. 5 II 243 (264 f).

9) S. z.B. BVerfGE 3, 58 (150); BSGE 3, 77 (83). - S.a. den sehr interessanten Fall des nicht zu Beginn der Geltungsperiode erlassenen periodischen Gesetzes (vgl. BVerwGE 3, 45).

10) Das ist vor allem bei dem immer wieder kritisch werdenden Fall gegeben, daß ein verfassungswidriges Gesetz (eine ungültige Rechtsverordnung usw.) diejenige Rechtslage bereits herzustellen suchte, die nach Klärung der Gültigkeitsfrage unter Vermeidung des gemachten Fehlers durch ein rückwirkendes, im übrigen gültiges Gesetz erneut hergestellt werden soll. Diese Möglichkeit darf nicht schlechthin ausgeschlossen werden, wenngleich es, wie im Text noch darzutun, immer auf die Gesamtabwägung ankommen muß. Vgl.

BVerfGE 7, 89 (93 f); BVerwGE 5, 122 (125).

11) Vg1. BVerfGE ebd. Ferner s. z.B. BVerwGE 5, 99 (101 f). Die Anforderungen werden hier streng zu halten sein. Grundsätzlich kann der Gesetzgeber dem Vertrauen in den bisherigen Rechtszustand seinen Gegenstand nur dadurch entziehen, daß er das Recht änclert. Der Bürger wird konkrete Gesetzgebungsbeschlüsse (vor Abschluß des Gesetzgebungsverfahrens) dahin respektieren müssen, daß er mit einer alsbaldigen Rechtsänderung rechnet (s. z. B. BVerfGE 1, 264 (280); 8, 274 (304 f)). Doch kann sich der Gesetzgeber nicht einfach vom Rückwirkungsverbot "freizeichnen", indem er gesetzgeberische Maßnahmen in Aussicht stellt. Inwieweit im übrigen d.h. ohne konkrete Gesetzgebungsbeschlüsse - irgendwelche Ankündigungen, Programme, oder einfach die Unklarheit der Rechtslage, ahnen lassen, daß auf den Boden des gegenwärtigen Rechts nicht mehr gebaut werden darf und inwieweit der Bürger diese Umstände beachten muß, wird sehr auf die Umstände des Falles ankommen (Beispiele - außer den in dieser Fußnote schon zitierten Entscheidungen: BVerfGE 2, 237 (266); 7, 89 (92 ff);BSGE 3, 77 (82); 9, 128 (130 f); BayVerf GH VGHE n.F. 5 II 1 (12 f); VerfGH Rheinland-Pfalz AS 3, 1 (16)). Die zu Fußn. 9 und 10 genannten Fälle gehören als Unterfälle wohl auch hierher. Im Verhältnis zwischen 
wird das Vertrauen in sie geringer wiegen; wenngleich der Staat, der für eine klare Rechtsordnung zu sorgen hat, 12) sich keinesfalls unbeschränkt auf dergleichen Irregularitäten berufen darf. Das Rückwirkungsverbot als Vertrauensschutz bedeutet weiter, daß das Vertrauen des Bürgers dadurch relevant geworden sein muß, daß er sich auf die Rechtslage, in die er vertraute, einließ. 13) Das Rückwirkungsverbot kann daher auch dort gelockert

dem nationalsozialistischen und dem Nachkriegsrecht hat sich auch noch eine andere Konstellation ergeben: Hinsichtlich der unsittlichen Normen des nationalsozialistischen Reiches konnte nicht darauf vertraut werden, daß sie den Zusammenbruch des Regimes überdauern (vg1. Meyer-Cording, Die Rückwirkung von Gesetzen, S. 162, $165 \mathrm{f}$ und seine Nachweise). Daß dieses Spannungsverhältnis zwischen gesetzlichem Unrecht und Recht innerhalb der fortdauernden rechtsstaatlich-demokratischen Ordnung entstehen und die rückwirkende Änderung des Rechts legitimieren könnte, ist nicht anzunehmen.

12) Zum rechtsstaatlichen Gebot der Rechtsklarheit s. z.B. BVerfGE 5, 25 (31); BayVerfGH VGHE n. F. 4 II 90 (103 ff).

13) Vg1. Wolff, Verwaltungsrecht I, S. 109: "Zulässig ist ferner die Rückwirkung von Rechtssätzen, die... Rechtsfolgen an vergangene Sachverhalte anknüpften, die der Einwirkung des Verpflichteten oder Berechtigten entzogen waren". Das ist so eng aber wohl nicht richtig. Auch das Vertrauen darauf, daß zurückliegende (beherrschbare oder nicht beherrschbare) Tatbestände diese oder jene Folgen gehabt oder nicht gehabt haben, kann für spätere, außerhalb des Anknüpfungssachverhaltes liegende Dispositionen beachtlich geworden sein. Gerade das Beispiel des Lastenausgleichs, das Wolff dem zitierten Satz anfügt, läßt das deutlich werden. Selbst wenn der Vermögensbestand zum Stichtag (21.Juni 1948) der Einwirkung des Verpflichteten entzogen gewesen wäre was nur bedingt der Fall war -, so wäre es doch für das spätere Verhalten (Veräußerungen, Geschäftsaktionen usw.) von erheblicher Bedeutung gewesen, zu wissen, welche Folgen an den Besitzstand zum Währungsstichtag geknüpft werden. Das kann nicht generell außer Betracht bleiben. Darum ist es gerade für den Lastenausgleich auch von Bedeutung, daß mit ihm schon seit der Währungsreform gerechnet werden mußte, wie sich nicht nur zwingend aus den Umständen ergab, sondern auch schon aus der ausdrücklichen Erwähnung in der Präambel des Währungsgesetzes (s. später Gesetz zur Sicherung von Forderungen für den Lastenausgleich v. 2. Sep- 
werden, wo es sich um geringfügige Änderungen handelt, von denen im allgemeinen angenommen werden darf, daß sie für die Dispositionen der Betroffenen keine entscheidende Rolle gespielt haben bzw. hätten. 14) Darüber hinaus wird dem Gesetzgeber zugebilligt werden müssen, daß auch für ihn durch spätere Ereignisse so wesentliche Voraussetzungen seiner vormaligen Anordnungen entfallen können, daß es ihm erlaubt sein muß, notfalls auch rückwirkende Änderungen zu treffen. Auch die Vertrauensbindung zwischen Gesetzgeber und Gesetzesunterworfenem steht unter der clausula rebus sic stantibus. Der Vertrauensschutz darf nicht dazu führen, daß das Recht seinen Ordnungs- und Gerechtigkeitszweck ${ }^{15)}$ nicht mehr erfüllen kann. Insgesamt wird es immer auf die billige und gerechte Relation zwischen der sachlichen Bedeutung der rückwirkenden Rechtsänderung, dem Grad ihrer Voraussehbarkeit, dem Einfluß des bisherigen Rechtszustandes auf die Dispositionen der Betroffenen und den sachlichen Notwendigkeiten, die zur rückwirkenden Rechtsänderung zwingen, ankommen. 16)

tember 1948, WiGB1. S.87; und dann noch das Soforthilfegesetz vom 8. August 1949, WiGB1. S.205) (vgl. auch BVerfGE 2, 237 (266)). - Zum Text s. ferner VerfGH Rheinland-Pfalz AS $3,1(17)$.

14) Das dürfte der systematische Ort des Elementes der Geringfügigkeit sein, das seit BVerfGE 7, 89 die Diskussion um die Rückwirkung von Steuergesetzen mitbestimmt (s.a.O., S.93: "Ein Abgabengesetz überschreitet durch seine Rückwirkung die rechtsstaatlichen Grenzen jedenfalls dann nicht, wenn die finanzielle Belastung voraussehbar, durch sachliche Erwägungen gerechtfertigt und im einzelnen unbedeute nd ist". - Sperrung nicht im Original). S.a. VerfGH Rheinland-Pfalz AS 3, 1 (17), wo der Zusammenhang zwischen Vertrauensschutz, Dispositionsmotivation und Rückwirkungsverbot sehr deutlich hervortritt.

15) Zum Widerstreit zwischen Rechtssicherheit und Gerechtigkeit im Rahmen des Rechtsstaatsprinzips s. vor allem BVerfGE 3, 225 (237 f), 248 (253); 7, 129 (152), 192 (196 f); $8,1(10)$.

16) Das Bundesverfassungsgericht hat insofern mit seiner Trias Voraussehbarkeit / sachliche Rechtfertigung / Geringfügigkeit (s.o. Fußn.14) schon das Richtige getroffen, wenn damit gesagt werden soll, daß bei Vorliegen aller drei Merkmale keinesfalls ein Verstoß gegen das Rückwirkungsverbot vorliegt. Dagegen ist es unzulässig, (mit Dürig in Maunz-Dürig, Art.2 Abs.I Randn. 47 Fußn.2) zu fordern, daß 
Für die soziale Intervention hat das grundsätzliche Verbot rückwirkender Belastungsgesetze Bedeutung vor allem als Regulativ der Aufbringungsseite. Daß steuerliche Lasten grundsätzlich nicht rückwirkend auferlegt werden dürfen, 17) wird allerdings das Gesicht der sozialen Intervention nicht ent scheidend prägen. Sachnäher ist die Anwendung des Rückwirkungsverbotes auf spezifisch soziale Abgaben (Sozialversicherungsbeiträge usw.). 18)19) Aber auch im Rahmen unmittelbaren sozialen Ausgleiches muß das Rückwirkungsverbot zur Anwendung gebracht werden, etwa bei der rückwirkenden Erhöhung von Löhnen. 20) Für die Leistungsseite bedeutet die rechtsstaatliche Beschränkung rückwirkender Belastungsgesetze insbes., daß der Gesetzgeber auch dort, wo er mit der Herabsetzung zugesicherter oder erbrachter sozialer Leistungen noch nicht an die Grenze verfassungsrechtli-

nur unter diesen Voraussetzungen - d.h. insbes. nur im Falle der Voraussehbarkeit und der Geringfügigkeit - eine Rückwirkung angeordnet werden dürfte. Die Elemente können sich kompensieren (z. B. unvorhergesehen aber geringfügig und zwingend geboten; oder schwerwiegend aber voraussehbar und zwingend geboten). Am schärfsten wird dann $\mathrm{zu}$ messen sein, wenn eine nicht vorauszusehende, nicht geringfügige Belastung allein aus Gründen sachlicher Notwendigkeit rückwirkend angeordnet werden soll. Doch wird auch dieser Fall nicht schlechthin ausgeschlossen werden dürfen.

17) S. hierzu die Nachweise oben S. 640 zu Fußn. 7; Vogel, Zur Frage der Rückwirkung von Steuergesetzen.

18) Die Bedeutung des Sozialversicherungsbeitrages für die zurückliegenden Dispositionen des betroffenen Arbeitnehmers kann nicht unter dem Gesichtspunkt gewürdigt werden, ob der Arbeitnehmer die fragliche Arbeit auch zu dem niedrigeren Nettolohn angenommen hätte. Das hätte er in der Regel getan. Das entscheidende Licht fällt auf dieses Problem von einer anderen Seite: der $\Lambda$ rbeitnehmer hätte für den fraglichen Zeitraum seinen Verbrauch auf den niedrigeren Nettolohn eingestellt. Daß er das nicht getan hat, kann er nicht mehı rückwirkend korrigieren.

19) Einen Fall rückwirkender Gebührenerhöhung, der, weil er die rückwirkende Beseitigung der Schulgeldfreiheit betraf, gesteigertes soziales Interesse verdient, hat der Bayerische Verfassungsgerichtshof (VGHE n.F. 5 II 243 (262 f)) richtig zuungunsten des rückwirkenden Gesetzes entschieden.

20) S. BayVerfGHE n.F. 6 II 78 (100f). - Zum Problemkreis s.a. Wiedemann, Zeitliche Grenzen kollektiver Gestaltungsmacht, Recht der Arbeit 12. Jhg. (1959) S. $454 \mathrm{ff}$. 
chen Figentumsschutzes stoßen würde, 21) Leistungen, die in der Vergangenheit getätigt wurden oder für zurückliegende Zeitabschnitte zu erbringen wären, nicht ohne weiteres herabsetzen darf (auf daß sie, soweit geleistet, als rechtsgrundlos zurückgefordert werden könnten). ${ }^{22)}$

\section{bb) Bestandskraft von Gesetzen?}

Mit dem Ausbau des Systems der sozialen Sicherheit und der zunehmenden Konsolidierung seiner wirtschaftlichen Grundlagen wird an dem Spannungsverhältnis $z$ wischen der Rechtssicherheit und der Dispositionsmacht des Gesetzgebers mehr und mehr ein anderer Aspekt hervortreten: Die Bestandssicherung für die $\mathrm{Zukunft}$. Inwieweit kann sich der Bürger darauf verlassen, daß soziale Leistungen, insbesondere Renten, die der Gesetzgeber - nicht nur auf Zeit - angeordnet hat, auch in Zukunft gewährt werden? Zum Teil wird dieses Problem durch den verfassungsrechtlichen Eigentumsschutz abgefangen, den auch öffentlichrechtliche Leistungsansprüche genießen, wenn der Begünstigte sie sich durch eigene Opfer oder (und) Leistungen ange"eignet" hat. 1) Einem generellen Abbau und einem schrankenlosen Absinken der sozialen Leistungen würde prinzipiell auch das Sozialstaatsprinzip entgegenstehen. ${ }^{2)}$ Aber ein lückenloser Schutz gegen die Finstellung oder wesentliche Verminderung der sozialen Leistungen findet sich weder hier noch dort. Vor allem gewisse Versorgungsleistungen, die weder durch Eigenleistung ange-"eignet" sind noch an der Untergrenze des sozialstaatlichen Minimums liegen, sind vom Figentumsrecht nicht, vom Sozialstaats-

21) Keinesfalls darf die rückwirkende Neuordnung eigentumsbegründender Tatbestände zu einer Umgehung des verfassungsrechtlichen Eigentumsschutzes (Art.14, insbes. Abs. 3 GG) führen. - Im übıigen aber lürfte der Grundsatz, daß die Rückwirkung ihre Grenze am erworbenen Recht findet (s. z.B. Forsthoff, Lehrbuch les Verwaltungsrechts, S. $139 \mathrm{f}$ mit weit. Nachw.), heute keine selbständige Geltung mehr beanspruchen können. Fr wird einerseits im allgemeinen Rückwirkungsverbot, andererseits im Figentumsschutz seine gerechte Auflösung finclen.

22) Beispiele aus (ler Rentenversicherung: BSGE 9, 128 (130 f); Kirchner, Verfassungsrechtliche Probleme der Rückwirkung der Neuregelungsgesetze, Die Sozialgerichtsbarkeit, 6. Jhg. (1959) S. $251 \mathrm{ff}$.

1) Auf das Eigentumsproblem wird unten S. 934 zurückzukommen sein.

2) S. unten Abschnitt 5 II 1 (S.676 ff) und 2 a (S.706 ff). 
prinzip nur relativ und mittelbar geschützt. Aber auch und gerade sie können die Funktion haben, dem Begünstigten die Eigenvorsorge zu ersparen. Disponieren die Betroffenen im berechtigten Vertrauen auf die in Aussicht gestellte Leistung, so muß das Rechtssicherheitsprinzip einer Abänderung hemmend entgegengestellt werden. Können die Betroffenen ihre Dispositionen den Veränderungen nicht mehr ausreichend anpassen, so darf die ausgesetzte Leistung ihnen gegenüber nicht mehr in einer die erwartungsgemäße Funktion verleugnenden Weise verändert, verkürzt oder aufgehoben werden. 3 )

Wie schon im Rahmen der Rückwirkungsproblematik ausgeführt, richtet sich der Schutz, den das Rechtssicherheitsprinzip gewährt, nach der Gesamtabwägung mehrerer Elemente: der Vertrauenserwartung, die das bestehende Recht erweckt (hier: gerade auch hinsichtlich seines Fortbestandes in der Zukunft), dem Gewicht der vertrauensgerechten Dispositionen der Betroffenen und dem sachlichen Zwang der Gründe, die den Gesetzgeber zur Änderung der bestehenden Regelung veranlassen. ${ }^{4)}$ Die dieser Abwägung innewohnende Elastizität ist gerade für zukunftsbestimmende Regelungen unerläßlich. Ein Weniger an Schutz der Betroffenen wäre andererseits mit dem Rechtsstaat nicht vereinbar.

3) Die dadurch bewirkte Sperre entspricht nicht dem grundrechtlichen Eigentumsschutz. Wenngleich sie - soweit es sich nach Sachlage um potentielles Eigentumsrecht handelt - einen Punkt markiert, an dem Rechtssicherheitsprinzip und Eigentumsrecht sich schneiden und bloße Erwartungen in eigentumsähnliche Anwartschaftsrechte umgewandelt werden können. Es kommt darauf an, ob die entscheidende Eigenleistung des Betroffenen, die das Eigentumsrecht begründet, mit dem Dispositionsakt in eins fällt, der das Vertrauen in den Rechtsbestand relevant werden läßt. (Eine Parallele bietet das Inswerksetzen des an sich widerruflichen Verwaltungsaktes, das einen Schnittpunkt zwischen freier Widerruflichkeit und begrenzter und entschädigungspflichtiger Widerruflichkeit darstellt. - S. z.B. Dürig, Der Staat und die vermögenswerten öffentlichrechtlichen Berechtigungen seiner Bürger, in "Staat und Bürger", Festschrift für Willibalt A pelt, 1958, S. 13 ff (S.46)). Hier liegt auch eine der fallweise verschiedenen, möglichen Lösungen des Anwartschaftsproblems, das nicht nur mit Hilfe "zivilrechtlicher Parallelen" (ebd. S.55 Fußn.116) angegangen werden darf.

4) S. zu dem letzteren Element auch BayVerfGH VGHE n.F. 5 II 196 (201); Dürig, a.a.O. S. 30 . 
c) Die Bestandskraft individueller Rechtsakte

aa) Allgemeines

Das andere Hauptproblem der Rechtssicherheit ist die Bestandskraft individueller Akte. 1) In bezug auf gerichtliche Entscheidungen - deren Gewährleistung zu den Hauptanliegen der Rechtssicherheit gehört 2) - ist den Erfordernissen der Rechtssicherheit durch die bestehenden gesetzlichen Regelungen offensichtlich genügt. Dagegen harrt das Problem der Bestandskraft der Verwaltungsakte noch weitgehend der Klärung. 3) Sie kann - so wenig die involvierten Fragen etwa rein verfassungsrechtlicher Natur sind und so wenig die Problemlösung allein aus dem Verfassungsrecht entnommen werden darf 4) - nicht ohne Rücksicht auf das Prinzip der Rechtssicherheit gewonnen werden.

Das volle rechtsstaatliche Gewicht der Frage wird allerdings erst in bezug auf den Widerruf ${ }^{5)}$ des ursprünglich mangelhaften Verwaltungsaktes spürbar. Für den ordnungsgemäßen Gesetzesvollzug wirkt das Rechtssicherheitsprinzip als ergänzendes Regulativ. Der Anpassung des (ursprünglich rechtmäßigen) Verwaltungsaktes an die Veränderungen der Sach- und Rechtslage widersetzt es sich grundsätzlich nicht, schafft andererseits aber doch Spielraum für Regelungen, die eine laufende Anpassung hemmen und auf den Fall wesentlicher Veränderungen reduzieren. ${ }^{6)}$ Hin-

1) Zum Zusammenhang zwischen Bestandskraft der Verwaltungsakte und Rechtsstaatlichkeit s. z.B. Friesenhahn, Die rechtsstaatlichen Grundlagen der Verwaltung, S. 254.

2) S. z.B. BVerfGE 7, 89 (94): "Das Prinzip der Rechtssicherheit ... wendet sich primär gegen die erneute Aufrollung der entschiedenen Sache vor den Gerichten". S. vor allem auch BVerfGE 2, 380 (403 ff).

3) Zusammenfassende Darstellungen s. z.B. bei Forsthoff, Lehrbuch des Verwaltungsrechts, S. 321 ff; Wolff, Verwaltungsrecht I, S. $269 \mathrm{ff}, 274 \mathrm{ff}$.

4) S. z.B. die Übersicht zur Interessenlage bei Wolff, a.a.O. S. 278 .

5) Die Terminologie liegt bekanntlich völlig im argen. Hier soll unter Widerruf nicht nur die Beseitigung ex nunc sondern auch die Beseitigung ex tunc verstanden werden. - Die Abänderung eines Verwaltungsaktes folgt weitgehend denselben Regeln wie der Widerruf. Unter dem verfassungsrechtlichen Gesichtspunkt der Rechtssicherheit kann im allgemeinen eine besondere Hervorhebung unterbleiben.

6) S. z.B. $\ 62$ BVG; $\$ 288$ LAG; $\$ 608$ RVO. - S. hierzu auch Haueisen, Verwaltungsakte mit Dauerwirkung, NJW 11.Jhg. (1958) 
sichtlich der rechtmäßigen Ermessensübung wird dem Rechtssicherheitsinteresse durch eine zwischen dem Schutz des Vertrauens in den begünstigenden (insbes. den "ins Werk gesetzten") Verwaltungsakt und dem öffentlichen Interesse an einer nicht nur im Ermessensrahmen gehaltenen sondern auch optimal zweckmäßigen Entscheidung abwägende, beschränkte Selbstbindung der Behörde hinreichend Rechnung getragen und ohne grundsätzliche Schwierigkeiten zu tragen sein. ${ }^{7)}$ Nur vor einer von ihm den Ursachen nach nicht zu vertretenden, für ihn nicht voraussehbaren oder auch (im Falle der Voraussehbarkeit) dem Risiko nach nicht beherrschbaren oder zumutbaren Rückwirkung wird der Betroffene bewahrt werden müssen. ${ }^{8)}$

\section{bb) Der Widerruf ursprünglich rechtswidriger Verwaltungsakte}

Das alles hält sich im Rahmen rechtsstaatlichen Gesetzesvollzugs. Im Problemkreis des Widerrufs fehlerhafter Verwaltungsakte ${ }^{1)}$ dagegen tritt das Prinzip der Rechtssicher-

\section{S. 1065 ff (1066).}

7) S. hierzu nochmals die oben S. 647 zu Fußn. 3 Zitierten.

8) Insofern gilt für die Zeit zwischen der maßgeblichen Änderung und der späteren Aufhebung oder Abänderung des Verwaltungsaktes im wesentlichen das, was unten zum evtl. rückwirkenden Widerruf ursprünglich rechtswidriger Verwaltungsakte zu sagen ist.

1) S. insbes. die Darstellungen bei Schütz, Der Widerruf gesetzwidriger begünstigender Verwaltungsakte, DÖV 11.Jhg. (1958) S. 449 ff; Haueisen, Betrachtungen über die Rücknahme fehlerhafter Verwaltungsakte, DVB1. 74.Jhg. (1959) S. 228 ff; Schäfer, Der Widerruf begünstigender Verwaltungsakte, 1960; Erning, Der Grundsatz der Rechtsstaatlichkeit und die Widerrufbarkeit des begünstigenden mangelhaften Verwaltungsaktes, DVB1. 75.Jhg. (1960) S. 188 ff; ders., Der Widerruf begünstigender mangelhafter Verwaltungsakte mit Doppelwirkung, ebd. S.467 ff; Wirth, Ein neuer Gedanke zur Rücknahme rechtswidriger begünstigender Verwaltungsakte, DÖV 13.Jhg. (1960) S. 173 f; Menger, Höchstrichterliche Rechtsprechung zum Verwaltungsrecht, Verwaltungsarchiv Bd.51 (1960) S. 149 ff (155 ff); Schur, Zur Bindung an fehlerhafte begünstigende Verwaltungsakte im Sozialversicherungs- und Versorgungsrecht, Zentralblatt für Sozialversicherung und Versorgung, 14.Jhg. (1960) S.113 ff; Reinhardt, Widerruf und Rücknahme unanfechtbar gewordener Verwaltungsakte, Bayerische Verwaltungsblätter, n.F. 6. Jhg. (1960)S.240 ff. Weitere Nachweise $s$. bei diesen. Die Genannten und ihre 
heit in Widerstreit zum Grundsatz der Gesetzmäßigkeit. Verlangt dieser die Herstellung des gesetzmäßigen Zustandes und somit den Widerruf des fehlerhaften Verwaltungsaktes, ${ }^{2}$ ) so verlangt demgegenüber der Grundsatz der Rechtssicherheit möglichst Beständigkeit für jeden Verwaltungsakt.

aaa) Der begünstigende Widerruf

Dieses Problem hat allerdings zwei wesentlich verschiedene Seiten. Der begünstigende Wider ruf beseitigt eine (rechtswidrige) Beschwer. Diese kann in einer absolut oder der Höhe nach zu Unrecht auferlegten Last oder darin bestehen, daß eine Leistung oder sonstige Vergünstigung ganz oder zum Teil vorenthalten wurde. In die Fortdauer dieser Beschwer setzt der Betroffene ${ }^{1)}$ kein relevantes Vertrauen. ${ }^{2)}$ Der begünstigende Widerruf wird somit grundsätzlich nicht durch Gesichtspunkte des Vertrauensschutzes gehindert. Problematisch ist hier nicht der. Widerruf gegen den Willen des Betroffenen. Problematisch ist die Frage, ob der Belastete ein unbeschränktes Recht auf Wahrung der. Gesetzmäßigkeit hat. Das ist nicht im Lichte des Vertrauensschutzes zu sehen. Hier greift der Schutz des Rechtsfriedens ein. Auch der Rechtsfriede ist ein rechtsstaatlicher Wert und ein Essentiale der Rechtssicherheit. ${ }^{3)}$ Die förmliche Feststellung individueller. Rechtsverhältnisse dient dem Rechtsfriedenszweck. Das gilt vor allem für gerichtliche Entscheidun-

Nachweise s. auch zum Folgenden.

2) S. insbes. Forsthoff, Lehrbuch des Verwaltungsrechts. S. 239 ff.

1) Denkbar ist, daß ein mittelbar Beteiligter auf den Bestand des - den anderen - belastenden Verwaltungsaktes vertraut. Doch wird dem jedenfalls hei rein tatsächlicher Auswirkung keine Bedeutung brigemessen werden dürfen. Anders kann (iie Rechtslage sein, wenn dem Interesse durch (verfahrens-) rechtliche sicherungen rochtliche Relevanz gegeben wurde; s. zu diesem Problomlirci: insbes. Frning, Der Widerruf begünstigender mangelhafter Verwaltungsakte mit Doppelwirkung.

2) S. z.B. Wolff, Verwaltungsrecht I, S. 279 f, 284.

3) S. z.B. BVerfG: 2, 380 (403): "Das Rechtsstaatsprinzip enthä1t als wesentlichen Bestandteil die Gewährleistung der Rechtssicherheit; diese verlangt nicht nur einen geregelten Ablauf des Rechtsfindungsverfahrens, sondern auch einen Abschluß, dessen liechtsbeständigkeit gesichert ist. ... Rechtsfriede und Rechtssicherheit sind von so zentraler Bedeutung für die Rechtsstaatlichkeit, daß um ihretwillen die Möglichkeit einer im Einzelfall vielleicht unrichtigen Entscheidung in Kauf genommen werden muß. 
gen, jedoch auch für Verwaltungsakte. Je justizförmiger das Verfahren ist, das zu ihnen führt, je mehr Garantien für eine umfassende und endgültige Klärung es enthält und je mehr die Klärung und Festlegung der individuellen Rechtslage isoliert hervortritt, desto klarer wird dieser Zweck ersichtlich. Er kann angemessene Beschränkungen der Anfechtung rechtfertigen. ${ }^{4)}$ Wie weit diese Beschränkungen im besonderen Zusammenhang gehen können, wird vom Gesetzgeber bzw. von der lückenausfüllenden richterlichen Rechtsfindung je nach der spezifischen Interessenlage $z u$ beurteilen sein. Der prinzipielle Gegensatz Gesetzmäßigkeit - Rechtssicherheit läßt zwischen der permanenten Überprüfbarkeit auf der einen Seite 5) und der befristeten, nur

4) S.a. Forsthoff, Lehrbuch des Verwaltungsrechts, S.236 f; Haueisen, Betrachtungen über die Rücknahme fehlerhafter Verwaltungsakte.

5) (1) Eine unbefristete Überprüfungsmöglichkeit ergibt sich in den atypischen Fällen, in denen entweder ein befristetes Rechtsmittel nicht vorgesehen ist oder die Rechtsmittelfrist infolge Unterbleiben der vorgeschriebenen Rechtsmittelbelehrung nicht in Gang gesetzt ist. Doch handelt es sich dabei, wie gesagt, um irregulare Fälle.

(2) Bedeutsamer sind diejenigen Bestimmungen, die eine immer erneute Überprüfung auch formell rechtskräftiger Verwaltungsakte zulassen. Gerade im Recht der sozialen Rentenleistunge $n$ ist das relativ häufig vorgesehen. In der Unfallversicherung $\mathrm{k}$ an $\mathrm{n}$ die Leistung neu festgesetzt werden, wenn eine erneute Überprüfung ergibt, daß die Leistung $z u$ Unrecht ganz oder teilweise abgelehnt, entzogen oder eingestellt worden ist ( $\$ 619$ RVO; so früher auch $₫ 1304 \mathrm{RVO}$ für die Invalidenversicherung. - Zur Auslegung des Wortes "kann" s. Lauterbach, Unfallversicherung, 2. Aufl. 1959, $\$ 619$ Anm. 1 und seine weiteren Nachweise. Sie geht in Richtung auf das "muß" der gleich zu erwähnenden neueren Regelungen). In der Rentenversicherung $m u \beta$ die Rente unter diesen Voraussetzungen neu festgesetzt werden ( $\$ 79 \mathrm{AnVG}$, $\$ 1300$ RVO n.F.; zur Auslegung s. Beck, $\ 1300$ RVO: Die Pflicht zur Neufeststellung, Zeitschrift für Sozialreform, 4.Jhg. (1958) S. $534 \mathrm{ff}$ ). Ein Anspruch auf diese Prüfung besteht bei gewissen schwerwiegenden Gründen ( $\$ 1744$ RVO). In diesem Sinne hat auch das - erfreulich eingehende - Gesetz über das Verwaltungsverfahren der Kriegsopferversorgung das Problem geregelt: Die Versorgungsverwaltung $\mathrm{k}$ a n n eine Zugunstenänderung immer vornehmen ( $\$ 40 \mathrm{Abs}$. 1); sie muß sie vornehmen, wenn durch eine grundsätzliche Entscheidung des Bundessozialgerichts eine Änderung der 
gewichtige, nachträglich auftretende (Wiederaufnahme-) Gründe nicht präkludierenden Anfechtung ${ }^{6)}$ die verschiedensten Möglichkeiten zu. Nur muß die Gestaltung im konkreten Zusammenhang dem Spannungsverhältnis zwischen Rechtssicherheit (Rechtsfriede) und Gesetzmäßigkeit (vielleicht auch "Gerechtigkeit" zu nennen) gemäß sein.

Diese Problematik ist gerade für das soziale Leistungswesen von erheblicher Bedeutung. Je weiter die positive Abänderung zugelassen ist, desto geringer ist die Gefahr, daß ein Betroffener zu Unrecht und auf Dauer von den ihm zustehenden Leistungen ausgeschlossen wird. ${ }^{7)}$

zugrunde gelegten Rechtsauffassung eingetreten ist (ebd. Abs.2); und sie hat in bestimmten Fällen in einer Art Wiederaufnahmeverfahren erneut zu entscheiden ( $\$ \$ 42 \mathrm{ff})$. Ähnlich erachtet es auch die Lastenausgleichsverwaltung außerhalb des gesetzlich vorgeschriebenen Wiederaufnahmeverfahrens ( $\$ 342$ LAG) als in ihrem Ermessen liegend, eine $\mathrm{Zu}$ gunstenänderung vorzunehmen (vgl. Abschn. 9 Abs. 3 und 5 des Rundschreibens betreffend die Aufhebung und Änderung von Bescheiden vom 12. September 1956, MtB1. BAA S.491); kritisch hierzu (für weitergehende Abänderungs $\mathrm{p} f \mathrm{licht}$ ) BVerwGE 10, 12 insbes. S. 14 f; dazu, da $\$ 342$ LAG keine ausschließliche Regelung darstellt, s.a. Harmening, Lastenausgleich, $\$ 342$ LAG Randn. 5 und seine Nachw.; KühneWolff, Die Gesetzgebung über den Lastenausgleich, $₫ 342$ LAG Anm. 1, vgl. schließlich auch $₫ 185$ Abs. 5 AVAVG.

6) BVerfGE 2, 380 (403): Mit dem Rechtssicherheitsprinzip ist "die rückwirkende Beseitigung eines Rechtsspruchs aus den hergebrachten Wiederaufnahınegründen vereinbar". S. hier$z u$ die in den vorigen Fußn. erwähnten Wiederaufnahmeverfahren. - Wenn an der zitierten Stelle des Bundesverfassungsgerichts erklärt wird, es sei mit dem Rechtsstaatsprinzip "unvereinbar..., einen in aller Form abgeschlossenen Fall nachträglich aus solchen (iründen zu erneuter Entscheidung zu stellen, die nach althergebrachter und unbestrittener Rechtsüberzeugung zur Begründung eines Wiederaufnahmeverfahrens nicht geeignet sind", so kann das nicht auf eine Zugunstenänderung eines Verwaltungsbescheides bezogen werden. Der Ausspruch hat eine Zugunstenänderung eines in einem gerichtsähnlichen Verfahren ergangenen begünstigenden Bescheides zum Anlaß.

7) S. nochmals die dahingehenden, S.650 in Fußn. 5 (2) erwähnten Beispiele. - Daneben darf das Problem der zu Unrecht auferlegten Last gewiß nicht vernachlässigt werden. Jedoch 


\section{bbb) Der lästige Widerruf}

Schlägt im Falle des begünstigenden Widerrufs der Rechtssicherheitsgedanke zuungunsten, der Gesetzmäßigkeitsgedanke dagegen zugunsten des Betroffenen aus, so ist es hinsichtlich des lästigen, eine (rechtswidrige) Vergünstigung beseitigenden Widerrufs genau umgekehrt. Dabei kann es darum gehen, daß nicht oder zu niedrig erhobene Belastungen nachgeholt, aber auch darum, daß ganz oder teilweise zu Unrecht gewährte Leistungen einbehalten oder zurückgefordert werclen. Gerade im letzteren Zusammenhang aber wird Rechtssicherheit wieder zu sozialer Sicherheit. 1) Wie der leistungsgewährende, begünstigende Verwaltungsakt im Vordergrund sozialer Verwaltungstätigkeit steht, 2) so ist das Problem des Widerrufs begünstigender Verwaltungsakte eines der wichtigsten verwaltungsrechtlichen Probleme des modernen, sozialaktiven Rechtsstaates. Die reine Durchführung des Gesetzmäßigkeitsprinzips hätte gerade im Sozialbereich die weittragendsten Folgen. Die Empfänger sozialer Leistungen können sich - jedermann weiß, wie verworren die Rechtslage zu sein pflegt - meist keine andere Bestätigung über die Rechtmäßigkeit des ihnen Gewährten verschaffen als den bewilligenden Bescheid. Sollen sie sich nicht guten Glaubens darauf verlassen dürfen, daß ihnen das Angewiesene auch wirklich zusteht? Soll der - gutgläubige - Empfänger in fortwährender Ungewißheit darüber verharren müssen, ob die Bewilligung einer Korrektur unterzogen, Gewährtes zurückgefordert und künftig zu Leistendes vorenthalten bleibt? Der Zweck der sozialen Leistungen darf nicht durch einen legalistischen Amoklauf vereitelt werden. An die Stelle der Sicherheit darf nicht Angst treten - insbesondere auch nicht Angst für den, dem zu Recht geleistet wird, ohne daß er jemals wirklich endgültige Gewißheit darüber erlangen könnte!

Gerade darum ist es so bedeutsam, daß die Härten der Gesetzmäßigkeit durch das Rechtssicherheitsprinzip spürbar gemildert werden. Während der begünstigende Widerruf des belastenden Aktes nur dem Rechtswert des Rechtsfriedens unterzuordnen ist, greift hier, darüber hinaus, auch wieder der Gedanke des Ver-

steht außer Zweifel, daß die Sicherheit der Leistungsgewährung weit mehr im Vordergrund des sozialen Interesses steht.

1) S. oben S.637 zu Fußn. 1.

2) S. hier'zu Haueisen, Zur rechtlichen Qualifikation des Rentenbescheids, NJW 11.Jhg. (1958) S.441 ff; ders., Verwaltungsakte mit Dauerwirkung. 
trauensschutzes durch. ${ }^{3)}$ Fs braucht nicht im einzelnen entwikkelt zu werden, unter welchen Umständen demnach ein Widerruf und wann er ex nunc oder ex tunc zulässig ist. Jedenfalls muß außer Zweifel stehen, daß der Grundsatz der Gesetzmäßigkeit - von eventuellen besonderen Erwägungen abgesehen - durch den Widerruf des gesetzwidrigen Verwaltungsaktes zu verwirklichen ist, wo ihm Hemmungen vom Rechtssicherheitsgedanken her nicht entgegentreten. Die zur Lösung des Problems so beliebt gewordene Formel vom überwiegenden öffentlichen Interesse, das den Widerruf rechtfertigen müsse, 4) verfehlt diese rechtsstaatliche Grundposition. ${ }^{5)}$ Die auf ihr basierende Kasuistik übersieht häufig auch das Nebeneinander von Vertrauensschutzund Rechtsfriedensgedanken. Während es für den Vertrauensschutz darauf ankommt, ob und in welchem Maße der Leistungsempfänger vertrauen durfte und im Vertrauen auf das ihm Bewilligte disponiert hat, und der Widerruf unter diesem Gesichtspunkt nur aber auch gerade insoweit eingeschränkt ist, als das Vertrauen durch die entsprechenden Dispositionen des Begünstigten relevant geworden ist, baut der Rechtsfriedensgedanke auf den Grundlagen, der Form und dem Inhalt des ergangenen Aktes auf, um, je mehr diesem Endgültigkeit zukommen sollte und zugerechnet werden durfte, ${ }^{6)}$ nur noch gewichtigen Gründen zu

3) N.a.W. Wolff, Verwaltungsrecht I, S.280: "Bei der lästigen Beseitigung mangelhafter Verwaltungsakte steht das Verbot der Gesetzwidrigkeit mit dem Prinzip der Rechtssicherheit sowie mit dem Grundsatz des Vertrauensschutzes in Widerstreit".

4) S. statt aller anderen nochmals Haueisen, Erning und Menger (oben S.648 zu FuRn. 1) und deren Nachweise.

5) Die Formel ist auch schon wegen ihrer Verwaschenheit schärfstens abzulehmen. Sie ist keine rechtsstaatliche Lösung dieses höchst rechtsstaatlichen Problems. In Wahrheit wird unter ihr nur eine umfassende Kasuistik gesammelt, deren Systematisierung noch nicht recht gelungen zu sein scheint. Interessanterweise bemerkt auch einer der Verfechter dieser Sammelformel (IVolff, Verwaltungsrecht I, S.284):"Auch das dringendste öfentliche Interesse reicht allein nicht zur. Beseitigung einer Rechtsstellung aus...". Gegen diese Formel vom Standpunkt der partiellen, sozialrechtlichen positiven Normierungen her argumentierend Schur, Zur Bindung an fehlerhafte begünstigende Verwaltungsakte im Sozialversicherungs- und Versorgungsrecht.

6) Zur Bedeutung des Verfahrens, in dem der Akt ergangen ist, für die Widerrufbarkeit s. die oben S. 650 zu Fußn. 4 Zitierten. 
weichen, die in ihm noch nicht berücksichtigt werden konnten (Wiederaufnahmegründe) oder die Zurechenbarkeit des Aktes an die erlassende Behörde bzw. den Adressaten in Frage stellen (Nichtigkeitsgründe). Dem Vertrauensschutz kann insbesondere auch durch die ex-nunc-Aufhebung Rechnung getragen werden. Als letzte Bremse gegen die legalistische Enttäuschung des staats bürgerlichen Vertrauens kann schließlich eine sachgerechte $\mathrm{Ab}$ wicklungsregelung wirksam werden. ${ }^{7)}$

7) (1) Das ist der "neue Gedanke" Wirths (Ein neuer Gedanke zur Rücknahme rechtswidriger begünstigender Verwaltungsakte), dem auch Dürig in seiner Vorbemerkung (ebd. S. 173) zuzustimmen scheint. So neu ist dieser Gedanke - auch von dem von Wirth und Dürig a.a.O. zitierten Vorbild des württembergischen Rechts abgesehen - allerdings nicht. Das Sozialversicherungsrecht hat das Problem seit jeher vorwiegend auf dieses Geleise geschoben, indem es die Rückforderung überzahlter Beträge in das Ermessen des Sozialversicherungsträgers stellt ( $\$ \$ 620,1301 \mathrm{RVO}, \$ 80 \mathrm{AVG})$. Im Verein mit dem sozialversicherungsrechtlichen Grundsatz, daß Überzahlungen, die der Versicherungsträger zu vertreten hat und vom Empfänger gutgläubig empfangen wurden, nicht zurückgefordert werden dürfen (vgl. Reichsversicherungsamt, Grundsätzliche Entscheidung Nr.5294 (AN 1939 II S.246); weitere Nachw. s. bei Eckert "Sozialversicherungsgesetze" $\$ 1305$ RVO a.F. Anm. 1; $\$ 1301$ RVO n.F. Anm. 1; $\$ 80$ AVG Anm.3),ergibt sich daraus ein einigermaßen brauchbarer Schutz des Betroffenen, während an sich die pauschale Ermessensregelung der genannten Bestimmungen als ein rechtsstaatlicher Mißstand anachronistisch wirkt. Auch im Recht der Kriegsopferversorgung ( $\$ 47 \mathrm{Abs} .3$ und 4 des Gesetzes über das Verwaltungsverfahren der Kriegsopferversorgung), der Arbeitslosenversicherung ( $\$ 185$ Abs. 1 und 2 AVAVG) und des Lastenausgleichsrechts, bei dem allerdings die Besonderheit einer Aufrechnungsmöglichkeit überzahlter Leistungen zulasten der Hauptentschädigung hinzukommt ( $\$ \$ 342,343$ Abs. 4 i.V.m. $\$ \$ 290,350$ a LAG), finden sich Hinweise auf diesen Lösungsweg. - Keine brauchbare Lösung ist dagegen die Entreicherungseinrede ( $\$ 818$ Abs. 3 BGB). Sie führt, wenn sie ernst genommen werden soll, zum Konsumzwang und zwar zum "Luxus"-Konsumzwang, da nach allgemeinen Grundsätzen sowohl der Verbrauch für den notwendigen Lebensunterhalt einerseits wie auch die Sparrücklage eine fortbestehende Bereicherung darstellt. Das wird der Interessenlage im Falle sozialer Leistungen regelmäßig nicht gerecht (s.a. die Regelung in $₫ 47$ Abs. 1 Satz 2, Abs. 3 und 4 
Die vorhandenen ausdrücklichen gesetzlichen Regelungen entsprechen den dargelegten Gesichtspunkten im allgemeinen. ${ }^{8)}$

des Gesetzes über das Verwaltungsverfahren der Kriegsopferversorgung, $₫ 185 \mathrm{Abs} .1$ und 4 AVAVG). Es ist interessant, daß das Bundesverwaltungsgericht diesem Mißstand für das Bundesbeamtenrecht dadurch das Wasser abgräbt, daß es den Widerruf des die fraglichen Bezüge bewilligenden Aktes nur für die Zukunft zuläßt (BVerwGE 8, 261 (insbes. 270); s. hierzu auch das vorausgegangene Urteil des Bayerischen Verfassungsgerichtshofes v. 11. Februar $1957 \mathrm{Nr} .84$ III 57, Bayerische Verwaltungsblätter n.F. 3.Jhg. (1957) S. 163; gestrig formalistisch und fiskalisch die Kritik hieran von Wagner, Vertrauensschutz bei feststellenden Verwaltungsakten, MDR, 14. Jhg. (1960) S. 546 ff). Übrigens kann der Vertrauensschutz im Abwicklungsstadium nicht nur hinsichtlich der Rückforderung sondern auch hinsichtlich weiterer Leistungen von Bedeutung werden, bezüglich deren sich der Betroffene schon engagiert hat (s.Abschn. 3 Abs. 2 des Rundschreibens betreffend Aufhebung und Änderung von Bescheiden).

(2) Etwas ganz anderes ist es ferner, den Betroffenen auf den Schadenersatz wegen Amtshaftung zu verweisen (so aber Forsthoff, Lehrbuch des Verwaltungsrechts, S.240), bei dem nicht nur alle Lasten des Prozesses (Behauptung, Beweis, Kosten usw.) auf die Seite des Betroffenen gelegt sind sondern auch die Haftungsbremse des Verschuldens eingebaut ist. Die Verwaltung darf sich nicht von ihrem Akt lossagen, um dann zuzuwarten, wie der Betroffene der Schwierigkeiten des Schadensersatzprozesses Herr wird.

8) (1) Für den Zuständigkeitsbereich der Sozialgerichte statuiert $₫ 77$ SGG markant die (doppelseitige) Bindungswirkung der formell rechtskräftigen Bescheide (s.a. $\$ 24$ des Gesetzes über das Verwaltungsverfahren der Kriegsopferversorgung). Die absolute Gellung dieses Grundsatzes wäre allerdings unerträglich. Deshalb stellt ihn $₫ 77$ SGG selbst unter den Vorbehalt anderer gesetzlicher Regelung. Solche Regelungen finden sich für die Zugunsten- und Zuungunstenänderung mangelhafter Bescheide in $\$ 1744$ RVO und $\$ \$ 42 \mathrm{ff}$ des Gesetzes über das Verwaltungsverfahren der Kriegsopferversorgung, speziell für die Zuungunstenänderung in $₫ 41$ des Gesetzes über das Verwaltungsverfahren der Kriegsopferversorgung und $\$ 185$ AVAVG (s. hierzu BSGE 3, 106 (109)) und schließlich für die Zugunstenänderung in $\$ \$ 619,1300$ (n.F.) RVO, $₫ 79$ AnVG, $₫ 40$ des Gesetzes über das Verwaltungs- 
Dagegen, daß auf diese Weise Unbilligkeiten und Härten vermieden werden, kann nicht mit Erfolg vom Grundsatz der Gesetz-

verfahren der Kriegsopferversorgung und wohl auch $₫ 185$ Abs. 5 AVAVG. Aus diesen positiven Regeiungen - sowie den hier nicht anzuführenden Vorschriften über die Anpassung (ursprünglich) rechtsmäßiger Verwaltungsakte an die geänderte Sach- und Rechtslage - Analogieschlüsse zu ziehen, ist durchaus zulässig (vgl. den - auch sonst zur Tragweite des $\S 77$ SGG lesenswerten - Versuch von Volkmann, Ausnahmen von der bindenden Wirkung der Verwaltungsakte nach $\S 77$ SGG, Die Sozialgerichtsbarkeit, 7. Jhg. (1960) S. $100 \mathrm{ff}$ ). Dagegen müssen gegen den Versuch, die notwendige Auflokkerung aus den Vor'schriften über die Berichtigung offenbarer Unrichtigkeiten ( $\$ 138$ SGG) zu entnehmen (vgl. Stötzner, Der fehlerhafte begünstigende Verwaltungsakt in der gesetzlichen Rentenversicherung, Die Sozialversicherung, 15.Jhg. (1960) S.96 ff), Bedenken erhoben werden. Endlich ist die Annahme, $₫ 77$ SGG habe auch alle ungeschriebenen Rechtsgrundsätze weiter gelten lassen (s. insbes. BSGE 7, 51 (53)), ja alle genannten einschlägigen gesetzlichen (Sonder)Regelungen würden überwölbt (und entwertet!) von dem allgemeinen Grundsatz der ex-nunc-Widerruflichkeit unrichtiger bewilligender Verwaltungsakte (Haueisen, Betrachtungen über die Rücknahme fehlerhafter Verwaltungsakte, S.239 f), zumindest ein grobes Mißverstehen des Gesetzes, das auf dem Boden des Unwillens gegen die rechtsstaatliche Absicherung des sozialen Leistungsrechts und der Unfähigkeit, mit den vorhandenen Mitteln (zu denen, neben den genannten Regelungen, auch die Wiederaufnahmeregelung der $\$ \$ 179 \mathrm{ff}$ SGG i.V.m. $\$ \$ 578$ ff ZPO zu rechnen ist) auszukommen, erwächst (dagegen auch Schur, Die Bindung an fehlerhafte begünstigende Verwaltungsakte im Sozialversicherungs- und Versorgungsrecht). S. zum Vorstehenden auch Depprich, Die Bindungswirkung von Bescheiden, Die Sozialgerichtsbarkeit, 7. Jhg. (1960) S. 6 ff.

(2) F'ür das Lastenausgleichsrecht fehlt eine er'schöpfende gesetzliche Regelung (s. $\$ 37$ a Abs. 2 des Feststellungsgesetzes, $\$ 335$ a Abs. 2 LAG; die Bedeutung des $\$ 342$ LAG ist (lemgegenüber beschränkt, - S. a. oben S. 650 zu Fußn. 5 a. E. und die dort. Nachw.). In dem schon zitierten Rundschreiben des Präsiclenten des Bundesausgleichsamtes vom 12. September 1956 (MtB1. BAA S. 491) betreffend Aufhebung und Änderung von Bescheiden ist eine Zusammenstellung der maßgeblichen Grundsätze unternommen, die im großen und 
mäßigkeit der Verwaltung her polemisiert werden. Zunächst einmal sind der Gesetzmäßigkeit der Verwaltung beim Setzen (!) der fraglichen begünstigenden Akte keine Grenzen gesteckt. Vielmehr wird die Aufmerksamkeit der Verwaltung dadurch - in Verbindung mit den einschlägigen innerdienstlichen Sanktionen (Regreßpflicht, Disziplinargewalt, Beurteilung) - geradezu angestachelt. Vor allem aber regiert das Prinzip der Gesetzmäßigkeit der Verwaltung nicht allein. Die Verwaltung ist an Gesetz und Recht gebunden (Art.20 Abs. 3 GG). Wenigstens zum "Recht" gehört die Verfassung - geschriebenes und ungeschriebenes Verfassungsrecht - und somit auch das Prinzip der Rechtssicherheit. Damit wird nicht einer Aufweichung des Gesetzmäßigkeitsprinzips das Wort geredet. Die Frage, um die es hier geht, liegt ihrer Natur nach schon am Rande der Reichweite dieses Prinzips: die Liquidation einer - wenigstens objektiv - schon vollzogenen Entfernung

ganzen zu billigen ist (zur rechtlichen Unverbindlichkeit dieser Richtlinien und zur Kritik an ihnen s.a. BVerwGE 10, 12 (13 ff); s. ferner BVerwGE 10, 64 (68)). Im Lastenausgleichsrecht findet sich eine Besonderheit, an der hier nicht vorübergegangen werden kann: der vorläufige Bescheid $(\$ 37$ a des Feststellungsgesetzes, $\$ 335$ a LAG; $\$ 2$ der 1. LeistungsDV-LA). Dieser vorläufige Bescheid kann keinen Vertrauensschutz genießen (s.a. Abschn.2 Abs. 2 lit. e des zitierten Rundschreibens). Damit ist aber nicht das Tor aufgestoßen für eine allgemeine Freizeichnung der Verwaltung. Rechtsstaatlichkeit - Rechtssicherheit - Rechtsfriede "verlangt nicht nur einen geregelten Ablauf des Rechtsfindungsverfahrens sondern auch einen Abschluß, dessen Rechtsbeständigkeit gesichert ist" (BVerfGE 2, 403). Die Regelung des Lastenausgleichs zeigt genau die Grenze zwischen der vertretbaren, ja wünschenswerten Lockerung und dem Unzulässigen duf: sie verlangt ein Interesse des Betroffenen an dem Bescheid noch zu einem Zeitpunkt, zu dem er endgültig nicht erlassen werden kann, und schreibt den endgültigen Bescheid vor, sobald er möglich ist. Daß gewisse Leistungen unter dem allgemeinen "Vorbehalt der Kürzung" - und zwar nicht nur der gesetzlichen Kürzung sondern auch der individuell berichtigenden Verminderung - gezahlt werden, wie das vom Bundessozialgericht (BSGE 4, 281 (284 f)) für das Recht der Kriegsopferversorgung behauptet wird, ist rechtsstaatlich höchst bedenklich. (Der vom Bundessozialgericht aufgestellte Grundsatz ist mit dem geltenden Recht der Kriegsopferversorgung nicht vereinbar. Warum dann solche vorrechtsstaatlichen Fossilien?) 
der Verwaltung vom Gesetz. Sie muß durch die Synthese von Gesetzmäßigkeit und Rechtssicherheit reguliert werden, die jener gibt, was ihr gebührt, ohne diese zu verletzen. ${ }^{9)}$

Ein Fall aus der Reihe der denkbaren Konstellationen muß noch besonders erwähnt werden, weil er - analog dem Problem der Zukunftsbeständigkeit der gesetzlichen Regelung sozialer Leistungen, auf die oben schon hingewiesen wurde - von wachsender Bedeutung zu sein scheint, einer Bedeutung, die ihr die gegenwärtig sehr zugespitzte Diskussion 10) freilich weit mehr unter dem Einfluß des Gefühls als aus sachlichen Erwägungen zuerkennt: der Widerruf unberechtigter Rentenbewilligungen für die Zukunft. Um den Gefühlswert, der hinter seiner Erörterung steht, zu erklären, ist der - jedenfalls literarisch - häufigste Beispielsfall anzuführen: einem alten Rentner (einer alten Rentnerin), der (die) jahre-, vielleicht jahrzehntelang eine ausdrücklich bewilligte Rente bezogen hat, wird diese, mit einem Mal als ursprünglich und fortdauernd unberechtigt erkannt, durch Widerruf des Rentenbescheides entzogen. Wenn in diesem Fall der Betroffene im Vertrauen auf die Rentenbewilligung disponiert, insbes. mögliche (!) und notwendige Eigenvorsorge unterlassen hat, 11) dann muß der Gesichtspunkt des Vertrauensschutzes durchgreifen. 12) Wenn andererseits der Mangel der Bewilligung

9) S. hierzu z.B. nochmals Menger, Höchstrichterliche Rechtsprechung zum Verwaltungsrecht, Verwaltungsarchiv Bd.51 S. 158 .

10) Zusammenfassend s. Bernhardt, Der Rentner und seine Menschenwürde, Zeitschrift für Sozialreform, 5.Jhg. (1959) S. $540 \mathrm{ff}$, dessen Abgleiten auf die Grundrechtssphäre, insbes. auf Art. 1 GG ein krasses Beispiel für den immer noch anhaltenden "Ausverkauf der Grundrechte" ist. S. später noch Rohwer-Kahlmann, Die Einwirkung verfassungsrechtlicher Normen auf das Recht der sozialen Sicherheit, NJW 13. Jhg. (1960) S. 1641 ff; alle weiteren Nachweise s. bei diesem. Dazu insbes. BSGE 9, 199 (206): Es verstößt nicht gegen die Menschenwürde, eine gesetzlich ungerechtfertigte (und, wie man hinzufügen muß, nicht an sich schon durch Art. 1 Abs. 1 GG erforderte) Position aufgeben zu müssen!

11) Dispositionen für die Zukunft (z.B. Wohnungsfrage) sind meist nicht in der Weise irrevisibel, daß ihnen nicht angemessener mit einer konkret gezielten Abfindung (Schadensersatz) Rechnung getragen werden könnte.

12) In dieser Richtung etwa BSGE 9, 199 (205): "Die Durchführung der Berichtigung könnte... dann ausnahmsweise unzulässig sein, wenn der Klägerin durch die Entziehung ein über 
dem Betroffenen zuzurechnen ist, so daß er sich - nach den Umständen des Falles - auch nicht im Hinblick auf die Rechtsfrieden schaffende Wirkung des Bewilligungsbescheides auf dessen Fortdauer verlassen durfte, ist ein schützenswertes Vertrauen nicht vorhanden. Der heikle und umstrittene Problemfall ist der des gutgläubigen, durch das rechtsirrige Handeln der Behörde in den Glauben seiner Bezugsberechtigung versetzte Rentner, dessen Vertrauen gleichwohl nicht durch seine Dispositionen relevant werden konnte, sei es, daß ihm - z.B. weil die Rente schon nach Eintritt der Erwerbsunfähigkeit bewilligt wurde - Eigenvorsorge auch im Falle der Kenntnis seiner Nicht-Berechtigung nicht möglich gewesen wäre, sei es, daß ihm die Rente selbst keinen Spielraum für besondere, auf sie gründende Zukunftsdispositionen gelassen hat. 13) Hier ist der Schutz des Betroffenen auf den Rechtsfriedensgedanken reduziert. Nur noch das Interesse, "seine Ruhe zu haben", das Interesse am Fortbestand des einmal hergestellten Rechtszustandes kann hier unter dem Rechtssicherheitsaspekt relevant werden. 14) Dieses Vertrauen wird umso mehr Schutz verdienen, je mehr Endgültigkeit der Bescheid für sich in Anspruch nahm. Der förmlich erteilte Bescheid, der nach formeller Rechtskraft schon nach dem für seinen Erlaß maßgeblichen Recht nur noch aus schwerwiegenden (Wiederaufnahme-)Gründen beseitigt werden kann, 15) bezieht diesen Schutz schon vom Gesetz - hinter dem der Gedanke des Rechtsfriedens legitimierend steht -. Das Gesetz begründet die gesteigerte Friedensfunktion und erhält sie auch. Ist das einschlägige Verfahrensrecht weniger förmlich gestaltet und die Widerrufsgrenze weniger präzis gezogen, so wird als Minimum an Rechtsfrieden wohl

den Wegfall der Rente selbst hinausgehender Nachteil erwachsen würde, dessen schwere für die Klägerin unzumutbar wäre und in keinem Verhältnis zu dem öffentlichen Interesse stünde". (Doch muß auch hier die Formel vom öffentlichen Interesse als nicht sachgerecht zurückgewiesen werden.) Entsprechende Vorbchalte s.a. in BVerwGE 5, 312 (314) und Bundesverwaltungsgericht Urt.v. 29. Mai 1958 - BVerwG II C 211/57 - DVB1. 73. Jhg. (1958) S.652 (654).

13) S. oben S. 658 zu Fußn. 10.

14) Nur am Rande sei bemerkt, daß von "Ersitzung" als "Erwerbstitel" für den Leistungsanspruch keine Rede sein kann (s. zur Ersitzung im öfentlichen Recht der Gegenwart z. B. Forsthoff, Lehrbuch des Verwaltungsrechts, S. 178; Wolff, Verwaltungsrecht I, S.183).

15) S. hierzu nochmals oben S.655 zu Fußn.8 (1) genannte Vorschriften. 
die Selbstbindung der Behörde an ihre Rechtsauffassung ${ }^{16)}$ und Sachbeurteilung auf der Grundlage der ausschließlich von ihr und nicht auch von dem Betroffenen beherrschbaren Sachverhaltsfeststellung 17) beachtet werden müssen. Eine bloße Meinungs-

16) Das wird ganz deutlich bei der Beschränkung der Reformation auf Wiederaufnahmegründe (s. insbes. \$ 1744 RVO. vgl. o. S. 655 zu Fußn.8 (1)). Nicht unbedenklich sind diejenigen Regelungen, die den Widerruf wegen Rechtsmangels zwar grundsätzlich ausschließen, wohl aber dann zulassen, wenn die Unrichtigkeit im Zeitpunkt des Erlasses "außer Zweifel" steht $(\$ 41$ Abs. 1 Satz 1 des Gesetzes über das Verwaltungsverfahren der Kriegsopferversorgung; Abschn. 3 Abs. 1 des Rundschreibens betreffend Aufhebung und Änderung von Bescheiden). Soll dieses Risiko wirklich der Betroffene tragen müssen? Müßte nicht darauf abgestellt werden, ob die Unrichtigkeit auch nach außen, insbes. für den Betroffenen selbst erkennbar war? Der Grundgedanke ist ein ähnlicher wie im Falle gewisser Nichtigkeits- bzw. Wiederaufnahmegründe (z.B. $\$ 42$ Abs. $1 \mathrm{Nr} .1$ und 7 des Gesetzes über das Verwaltungsverfahren der Kriegsopferversorgung): zu große Distanz vom legitimen Handeln der Behörde, Zweifel in die Zurechenbarkeit des Aktes zu Staat und Recht. Zu erinnern ist auch an die Problematik um Nichtigkeit oder Anfechtbarkeit des gesetzlosen Verwaltungsaktes. Auch hier der Gedanke um die Distanz zwischen legitimer (eigentlicher) und effektiver, illegitimer (uneigentlicher) Handlungsweise der Behörde. Diesem Gesichtspunkt kann die Bedeutung gegenüber dem Schutz des Rechtsfriedens nicht abgesprochen werden. Allein: Ist mit der zweifelsfreien Unrichtigkeit - die ja mit den Augen der Aufsichtsbehörden, der Richter usw., nicht mit den Augen des Bürgers gesehen wird! - das richtige Kriterium gefunden? Diese Bestimmungen müssen so eng angewandt werden als möglich. (Für die Rückforderung stellen $\ 47$ Abs. 2 des Gesetzes über das Verwaltungsverfahren der Kriegsopferversorgung und $\$ 49$ Abs. 2 Satz 2 des Soldatenversorgungsgesetzes auf das Kennenmüssen ab.)

17) Auch dieser Gesichtspunkt kommt vor allem im Wiederaufnahmerecht zum Ausdruck. Neben der objektiv oder durch Einwirkung Dritter verminderten Beherrschbarkeit der Sache durch die Behörde, die den Regelfall des Wiederaufnahmeverfahrens bildet, müßte mehr auch an die Mitwirkungsmöglichkeiten und die Mit-Beherrschung des Sachverhalts bzw. der Sachverhaltsermittlung durch den Betroffenen gedacht werden, die bisher, von engen Ausnahmen abgesehen 
inderung der Behörde - auch wenn diese unter dem Eindruck löchstrichterlicher Entscheidungen erfolgt - würde jedenfalls segen die Rechtsfriedensfunktion des Bescheides und somit gesen den Grundsatz der Rechtssicherheit verstoßen. 18) Ergibt ;ich die Rechtswidrigkeit der Bewilligung jedoch aus anderen, ; chwerer wiegenden Gründen, so wird, wo eine besondere Regeung fehlt und nicht der Gesichtspunkt des Vertrauensschutzes veitere Einschränkungen gebietet, der Gesetzmäßigkeit der Vervaltung durch den Widerruf des Bewilligungsbescheides Rechnung setragen werden müssen. ${ }^{19)}$

( $\$ 1744$ Abs. 1 Nr. 3 und 4 RVO; $\$ 42$ Abs. 1 Nr. 6 des Gesetzes über das Verwaltungsverfahren der Kriegsopferversorgung), nur eine Rolle für die ex-nunc/ex-tunc-Problematik bzw. für die Rückforderung überzahlter Leistungen gespielt hat (s. $\$ 47$ Abs. 3 des Gesetzes über das Verwaltungsverfahren der Kriegsopferversorgung; $₫ 185$ Abs. 2 AVAVG; Abschn. 1 Abs. 1, Abschn. 3, Abschn. 4 Abs. 3 des Rundschreibens betreffend Aufhebung und Änderung von Bescheiden).

18) Die labilste Regelung bringt $₫ 185$ Abs. 1 AVAVG. Da diese Leistungen ihrer Natur nach befristet und eng zweckgebunden sind und Härten der Rückwirkung durch Einschränkungen derselben (Abs.2, a.a.O.) vermieden werden müssen, stößt sie nicht auf grundsätzliche Bedenken. Für das Recht langfristiger (lebenszeitlicher) Renten wäre diese Unsicherheit dagegen nicht erträglich und könnte sie wohl auch vom Gesetzgeber nicht angeordnet werden (s. hierzu nochmals das Problem des Vorbehaltsbescheides oben S.656 zu Fußn.8 (2)). Ganz anders ist die Sachlage dann, wenn ein begünstigender Bescheid in einen objektiven $Z$ weckzusammenhang eingespannt ist, in dem jede Irregularität als unerträglich anzusehen ist (z. B. bei gewissen Polizeierlaubnissen). Hier wird ein Widerruf möglich sein, möglicherweise freilich nur unter Entschädigung. Dieses Problem gehört nicht hierher und braucht daher nicht weiter erörtert zu werden. Nur zur Vermeidung von Mißverständnissen mußte hervorgehoben werden, da $\beta$ die Rechtslage in anderen $Z$ weckzusammenhängen als dem der Bewilligung sozialer Leistungen ein anderer sein kann.

19) Als Beispielsfälle s. die oben S. 658 zu Fußn. 12 zitierten Entscheidungen. - Der Rechtsstaat darf nicht in "Gefühlsduselei" ersticken. Es ist wirklich nicht unmenschlich, dem Rentner, dem solchermaßen legitim die ungerechtfertigte Rente entzogen wird, entgegenzuhalten, daß er schon viel zu viel gehabt hat, wenn er die Rente bisher bezog! Wenn ihm das nicht mehr abverlangt wird - und hier wird Großzügigkeit gewiß am Platze sein (s.a. oben S. 654 zu Fußn. 7) -,ist das Kulanz genug. 


\section{d) Zur Bestandskraft titulierter Leistungsansprüche}

Schließlich noch ein besonderes rechtsstaatliches Problem, das im Bereich des sozialen Leistungswesens immer wieder aktuell wird: die Bestandskraft titulierter Leistungsansprüche gegenüber dem (jüngeren) Gesetz. Dabei geht es nicht um den Fall, daß das Gesetz sich gegen die formelle Rechtskraft der fraglichen endgültigen Entscheidungen wendet. Ein Gesetz, das darauf abzielt, daß abgeschlossene Verfahren zuungunsten des Betroffenen wieder aufgerollt werden, verstößt gegen den Grundsatz der

Rechtsstaatlichkeit. 1) Problematisch erscheint nur der Fall, daß das jüngere Gesetz die materiellen Grundlagen ändert, auf denen der zuerkannte Dauerleistungsanspruch beruht (z. B. durch Reform der Kriegsopferversorgung, der Rentenversicherung usw.), und zwar in einer Weise, die den Betroffenen schlechter stellt. Der Gesetzgeber wäre dann jedenfalls legitimiert, die förmlich und rechtskräftig - insbesondere durch gerichtliche Entscheidung aber auch durch förmliche Verwaltungsverfahren 2) - zuerkannten Rechtsansprüche von der (ungünstigeren) Neuordnung auszunehmen. 3) Aber er ist dazu nicht verpflichtet. 4) Er kann, wenn er darin die gerechtere Lösung sehen darf, 5) einer einheitlichen

1) BVerfGE 2, 380 insbes. 403 ff; BayVerfGH VGHE n.F. 3 II 129 (137); 5 II 1 (12). Thieme, Umfang und Grenzen des verfassungsrechtlich gewährleisteten Bestandsschutzes der saar. ländischen Kriegsopferrenten, S.243 ff. - Etwas anderes gilt dann, wenn ein Rechtsbruch wie derjenige $z$ wischen der Zeit des "Dritten Reiches" und dem neu aufgebauten Rechtsleben nach 1945 zu liquidieren ist. Hier kann - sub specie der neuen Rechtsauffassung - der Unrechtsgehalt der alten, endgültigen Entscheidung so groß sein, daß ihm das Hemmnis der Rechtssicherheit weichen muß. - Etwas anderes gilt auch dann, wenn der Bescheid in "Not- und Übergangszeiten" ergangen ist und aus diesem Grunde seine Endgültigkeit nur eine vorläufige sein konnte (BSG Urt.v. 30. Januar 1957 - 1 RA 52/55 - Sozialrecht, Berliner SVAVG $\$ 56$ A a 1).

2) Zu den Grenzen der Gleichstellung s. z.B. Thieme, a.a.O. S. $247 \mathrm{ff}$. - In BVerfGE 2, 380 handelt es sich dagegen um einen extremen Fall gerichtsförmiger Verwaltungsentscheidung.

3) Vg1. BVerfGE 3, 4 (11). - Genau so ist er umgekehrt legitimiert, dem ungünstigeren "titulierten" Rechtsbestand den Vorzug vor dem günstigeren Neurecht zu geben (BVerfGE 7, 194, insbes. S. 196).

4) A.A. BVerfGE 3, 4 (11); Thieme, a.a.O.

5) S. die Ausführungen in BVerfGE 7, 196 über die "freie" (?) 
Neuordnung den Vorzug geben. 6) Dafür wird - vor allem, wenn unter "tituliert" nur die gerichtlich zuerkannte Leistung verstanden werden soll - meist der Charakter des Zufälligen sprechen, der der Unterscheidung zwischen "titulierten" und "nicht titulieren" Ansprüchen der Entstehung nach anzuhaften pflegt.

Daß der Gesetzgeber dabei durch den Gleichheitsgrundsatz gebunden ist, steht auf einem anderen Blatt. Art. 3 GG beinhaltet aber keine grundsätzliche gezielte Beschränkung. 7) Auch aus Art. 14 GG können sich Beschränkungen ergeben. Doch richtet sich die Antwort auf die Frage, ob der bewilligte Anspruch "Eigentum" i. S. der Verfassung ist, 8 ) in erster Linie nach Art und Inhalt des Anspruches, nicht nach seiner formalen Erstarkung in einem förmlichen "Titel". Vielmehr ist, wenn es sich um Eigentum handelt, die Behandlung der "titulierten" Berechtigung mit eine Frage der - notwendig ebenfalls rechtsstaatlich zu haltenden 9) - Regelung von Inhalt und Ausmaß (Art.14 Abs.1 GG) oder der Entziehung (ebd. Abs.3) des Eigentums; während, wenn es sich nicht um "Eigentum" handelt, dieses zusätzliche Regulativ entfällt.

3. Rechtsstaat - Gerechtigkeitsstaat

Der Rechtsstaat ist Gerechtigkeitsstaat. 1) Er ist es jedenfalls dann,

Wahl des Gesetzgebers zwischen dem Vorrang der Gerechtigkeit und der Rechtssicherheit.

6) S. die Neuordnung der Kriegsopferversorgung durch das Bundesversorgungsgesetz ( $\$ 86$ Abs. 1 BVG), die das Bundessozialgericht im Ergebnis mit Recht, wenn auch mit höchst unzulänglichen Gründen (s.a. u. Fußn. 10), nicht beanstandet hat: Vgl. BSGE 1, $210(215) ; 2,113,263 ; 3,251$; 421 ; s.a. BSGE 9, 199 (kritisch hierzu Weidner, Zur Rechtsprechung des Bundessozialgerichts, S. 704 f, 761, 763 mit weiteren Nachweisen).

7) S. nochmals BVerfGE 3, 4 (11).

8) S. zu diesem Problem unten Abschn. 6 III 2 a (S.935 ff).

9) Vg1. hierzu BayVerfGH VGHE n. F. 1 II 81 (90 ff).

10) Das ist der entscheidende Gesichtspunkt, den das Bundessosozialgericht in bezug auf die Neuordnung des Versorgungswesens durch das Bundesversorgungsgesetz (s.o. Fußn.6) übersehen hat. Seine Argumentation, das Versorgungsrecht kenne keine Rechtskraft (!), liegt dagegen neben der Sache.

1) Kägi, Rechtsstaat - Sozialstaat - sozialer Rechtsstaat, "Die Schweiz" - ein nationales Jahrbuch - 1945, S. $129 \mathrm{ff}$ (134ff); (stärker differenzierend ders., Zur Entwicklung des schweizerischen Rechtsstaats seit 1848, S. $178 \mathrm{f}$ ); Klein, Bonner Grundgesetz und Rechtsstaat, S. 395; ders., in v. Mangoldt- 
wenn er sich nicht auf eine formale, organisatorische, letztlich auch nicht viel mehr als auf die Gesetzmäßigkeit von Verwaltung und Rechtsprechung hinauslaufende Sicherung der Rechtsgebundenheit des Staates beschränkt sondern zu einer materiellen Grundordnung des ganzen Staatswesens, zur materiellen Rechtsstaatlichkeit 2) durchstößt. Der Rechtsstaat des Grundgesetzes tut das. 2) Der Verfassungsgeber war "bemüht, im Grundgesetz die Idee der Gerechtigkeit zu verwirklichen". 3) Die Grundrechte dienen ihr ebenso wie die Proklamation des sozialen (Rechts-) Staats. 4)

Aber die Gerechtigkeit ${ }^{5}$ ) hat noch tiefer Fuß gefaßt: Die Verfassung soll gerecht sein und der Ungerechtigkeit wehren; das ist das vorrechtliche Gesamtbild, 6) aus dem heraus das Grundgesetz

Klein, Art.20 Anm. VI 1; Peters, Rechtsstaat und Rechtssicherheit, S.67; Paulick, Die verfassungsrechtlichen Bindungen des Gesetzgebers beim Erlaß von Steuergesetzen, Zeitschrift für die gesamte Staatswissenschaft, Bd. 109 (1953) S. $483 \mathrm{ff}$ (500); Bachof, Begriff und Wesen des sozialen Rechts staates, S. 39; Nawiasky, Allgemeine Staatslehre, Teil 3, S. $130 \mathrm{f}$; Hamel, Die Bedeutung der Grundrechte im sozialen Rechtsstaat, S.28; Krüger, Sozialisierung, S.283; Hartz, Sittlichkeit, Rechtssicherheit und Gewaltenteilung als Elemente des Rechtsstaats, Steuerberater-Jahrbuch 1958/59, S. $31 \mathrm{ff}$ (42 ff, $59 \mathrm{f}$ ); Leibholz, Die Gleichheit vor dem Gesetz, 2.Aufl. 1959, S.219; BVerfGE 3, 248 (253); 7, 89 (92), 194 (196); BayVerfGH VGHE n.F. 4 II 51 (58 f). - Kritisch Scheuner, Die neuere Entwicklung des Rechtsstaats in Deutschland, S. $248 \mathrm{f}$.

2) S. oben S.396ff.

3) BVerfGE 3, 233.

4) Vgl. Menger, Das Gesetz als Norm und Maßnahme, S. 107:

"Dem Grundgesetz liegt eine - sicherlich nicht leicht greifbare - Gerechtigkeitsvorstellung zugrunde, die sich etwa aus dem Grundrechtskatalog und dem Bekenntnis zum sozialen Rechtsstaat erschließen 1 äßt" . - Scheuner, Die neuere Entwicklung des Rechtsstaats in Deutschland, S. 249 (und ff). Für die Verwirklichung der Gerechtigkeit durch die Art.1-3 GG: Schnorr, Die Rechtsidee im Grundgesetz, insbes. S. $134 \mathrm{ff}$.

5) In diesem Zusammenhang besonders wichtig hierzu Hans J. Wolff, Rechtsgrundsätze und verfassungsgestaltende Grundentscheidungen als Rechtsquellen, in "Forschung und Berichte aus dem öffentlichen Recht", Gedächtnisschrift für Walter Jellinek, 1955, S. $33 \mathrm{ff}$, insbes, S. $37 \mathrm{ff}$.

6) S. hierzu nochmals Nawiasky, Allgemeine Rechtslehre, S. $137 \mathrm{ff}$ 
auszulegen ist. Es hat den Girundsatz der Gerechtigkeit in sich aufgenommen. Er gehört zur. "verfassungsmäßigen Ordnung" und st "Recht" im Sinne des Art.20 Abs. 3 GG. 7) Damit ist keine Geähr gegeben, daß als (positivierte) Gerechtigkeit immer auch "wahre" Gerechtigkeit geübt wird. Aber die Konfliktsproblemaik, die ein Gegensatz zwischen überpositivem und positivem Recht erstehen läßt, ist - wie immer man sie beurteilen mag ndem das Grundgesetz diese naturrechtliche Kernsubstanz in seine oberste, unabänderliche Normschicht (Art. 79 Abs. 3 GG) aufgenommen hat, auf ein Minimum zurückgedrängt, das jedenalls im Rahmen dieser Untersuchung vernachlässigt werden sann. 8) Die verfassungsrechtliche Tragweite des nackten Ge-

7) S. hierzu vor allem Nawiasky, Positives und überpositives Recht, JZ 9.Jhg. (1954) S. 717 ff, der den "Vorbehalt des Widerspruchs gegen oberste Grundsätze der Gerechtigkeit als Bestandteil des positiven Rechts diesem zugehörig" erklärt und vorschlägt, "den Satz seinem rechtlichen Standort nach den Staatsfundamentalnormen zuzuweisen" (S. 719). Im System des Grundgesetzes bedeutet das, ihn in Art. 20 Abs. 3 GG anzusiedeln. Zur Anknüpfung der Gerechtigkeitsprüfung an Art. 20 Abs. 3 GG im Rahmen der Bindung der Verwaltung und des Richters an das "Recht" s.a. Forsthoff, Die Bindung an Gesetz und Recht (Art.20 Abs. 3 GG), DÖV 12. Jhg. (1959) S. 41 ff (insbes. S. 43); Maunz, Deutsches Staatsrecht, S. 58. Es ist nicht richtig, die Ansprüche des "Rechts" höher zu schrauben als die der "verfassungsmäßigen Ordnung" (s. Evers, Der Richter und das unsittliche Gesetz, 1956, S. 107 f). Nur wenn der Plafond (les "Rechts" - sei es der "Himmel" des Naturrechts, sei es das in das positive Verfassungsrecht rezipierte Naturrecht als Bestandteil der obersten Normschicht - und der "verfassungsmäßigen Ordnung" gleich hoch hängt, harmonieren die beiden Bindungsgrundsätze des Art. 20 Abs. 3 GG miteinander. So kann auch die Gerechtigkeit nicht nur Bestandteil (fre (Vorwaltung und Rechtsprechung bindenden) "Rechts" sondern muß sie auch Bestandteil der (den Gesetzgeber bindenilen) "verfassungsmäßigen Ordnung" sein.

8) Nach BVerfGE 3, 225 (instes. S.231 ff) stellt sich die Rechtslage so dar, daß die Entscheidung über die Vereinbarkeit von Recht mit den Grundsätzen der Gerechtigkeit in derselben Weise beim Bundesverfassungsgericht monopolisiert ist wie die Übereinstimmung von liecht mit dem Grundgesetz (Art. 100 Abs. 1 GG). Das bedeutet, daß die Verwaltung grundsätzlich keine Möglichkeit hat, sich gegen ungerechte Gesetze 
rechtigkeitsprinzips darf jedoch nicht überschätzt werden. "Was ist Gerechtigkeit?" 9) Mit einer formalen Gerechtigkeitslehre ist

- genauer: nur ungerechte, sonst keiner Verfassungswidrigkeit zu bezichtigende Gesetze - zur Wehr zu setzen (s.obı S. 610 ; s.a. Forsthoff, a.a.O. S. 42 f). Die Nicht-Verfassungsgerichte haben, soweit sie einen Verstoß annehmen wol len, die Möglichkeit, die Entscheidung des Bundesverfassungsgerichts einzuholen (Art. 100 Abs. 1 GG). Die "Ungerechtigkeit" eines (formellen, nachkonstitutionellen) Gesetzes festzustellen, ist dagegen nur dem Bundesverfassungsgericht erlaubt. Das im Text als quantité négligeable vernach lässigte "Fehlerkalkül" liegt also darin, daß das Bundesverfassungsgericht möglicherweise einen Verstoß dort nicht annimmt, wo er vorliegt. Dann ist niemand, auch kein sonstiges Gericht mehr imstande, aus dem Gerechtigkeitsverstoß die Konsequenzen zu ziehen. Dieser Standpunkt des Bundesverfassungsgerichts (s. eingangs) darf aber nicht ungewürdigt bleiben. Während das Gericht nämlich vorgibt, nach den Sternen des Naturrechts zu greifen, handhabt es den Grundsatz der Gerechtigkeit in Wahrheit (und mit Recht) als nichts anderes denn als einen Bestandteil der verfassungsmäßigen Ordnung, der obersten und unveränderlichen Rechtsschicht der Verfassung. Nur für das Verfassungsrecht selbst kann nämlich die Verwerfungskompetenz nach Art. 100 Abs. 1 GG monopolisiert sein. Würde das Bundesverfassungsgericht in Wahrheit annehmen, unmittelbar Naturrecht zu realisieren, so könnte es sein Prüfungsmonopol nur unter der Voraussetzung aufrechterhalten, daß es, infallibel, die Grenzen und Gebote des geltenden überpositiven Rechts nie verkennt! Wie will es denn sein Entscheidungsmonopol mit der unbedingten Geltung des Naturrechts unter der Voraussetzung vereinbaren, daß es irren und das Naturrecht verkennen und unverwirklicht lassen könnte? Es wäre doch ein Gipfel von Absurdität und Anmaßung, wollte das Gericht annehmen, daß das Naturrecht zwar keinem Gesetz und keiner Verfassung, wohl aber dem (auf nichts anderes als auf den Boden einer Verfassung gegründeten) Spruch eines Verfassungsgerichts weicht! Nur innerhalb des Verfassungsrechts kann das Entscheidungsmonopol des Bundesverfassungsgerichts sinnvoll sein. Man sollte nicht den Anschein erwecken, als ob das Bundesverfassungsgericht unmittelbar Naturrecht anwendete (Zur naturrechtlichen Resignation des Bundesverfassungsgerichts s. BVerfGE 10, 59 (81)). - S. zum Vorstehenden auch Dürig in Maunz-Dürig, Art. 1 Abs. II Randn. 83, wo vor allem 
ier nichts getan. Die Handhabung der "Gerechtigkeit" als Rechtsrinzip muß das konkrete Urteil, die Unterscheidung zwischen em hic et nunc Gerechten und Ungerechten oder jedenfalls zwichen dem vielleicht noch Gerechten und dem sicher nicht mehr rerechten erlauben. Dieses Urtéil setzt religiöse oder (und) etaphysische oder (und) anthropologische Prämissen voraus, on denen durchwegs behauptet werden kann, sie seien der Ienschheit oder auch nur der fraglichen Rechtsgemeinschaft geheinsam. Es bedarf der Ergänzung durch materiale Wertentcheidungen, 10) die zeit-, orts- und volksbedingt sind. Wo ist er Grund, von dem her die Frage "Was ist Gerechtigkeit?" bentwortet werden kann und darf? Wenn "Gerechtigkeit" als Maßtab menschlichen Handelns mit der heteronomen Autorität des Rechts gehandhabt werden soll, so kann dieser Grund nur der 3asisstock gemeinsamer Gerechtigkeitsvorstellungen der tragenen Rechtsgemeinschaft sein. ${ }^{11)}$ Nur so darf das Gerechtigkeitsostulat als Bestandteil der verfassungsmäßigen Ordnung - herbergekommen aus dem ihr vorausliegenden vorrechtlichen $\mathrm{Ge}-$ amtbild - verstanden werden.

Diese vom Verfassungsgeber positivierte Gerechtigkeitsvortellung hat ihren wichtigsten Niederschlag in der Verfassung elbst bereits gefunden. 12) Wer sich gegenüber dem unter dieser

der Grundsatz der Menschenwürde (Art. 1 Abs. 1 GG) als Umschaltnorm zwischen überpositivem und positivem Recht herangezogen wird.

9) S. die mutige Schrift Kelsens, "Was ist Gerechtigkeit?" (1953). - Aus der Fülle der Gerechtigkeitsliteratur s. Brunner, Gerechtigkeit, 1943; del Vecchio, Die Gerechtigkeit, 2. (deutsche) Aufl.1950; Sauer, Gerechtigkeit, 1959. S.a. die neuere Zusammenfassung bei Geiger, Art. "Gerechtigkeit" im Staatslexikon, 6. Aufl. Bd. III 1959, S. 779 ff. Alle weiteren Nachweise s. bei den Zitierten.

0) S. z.B. die entsprechende Einschränkung seiner Gerechtigkeitstheorie durch Hans J. Wolff, Über die Gerechtigkeit als principium iuris, in Festschrift für Wilhelm Sauer, 1949, S. 103 ff (113).

1) Zum consensus omnium als Geltungsgrund naturrechtlicher Postulate s. z.B. auch Würtenberger, Das Naturrecht und die Pholosophie der Gegenwart, JZ 10. Jhg. (1955) S. 1 ff (2). - Speziell zur sozialen Gerechtigkeit s. in diesem Sinne llendt, Bemerkungen über das Verhältnis von Wirtschaftspolitik und Sozialpolitik, in "Sozialreform und Sozialrecht", Festschrift für Walter Bogs, S. 365 ff (368 f).

2) S. oben S. 664 zu Fußn. 4. 
Verfassung stehenden und sich im Rahmen der (sonstigen) Rechtsordnung haltenden Staatshandeln auf das Postulat der Gerechtigkeit berufen will, ist den "Beweis" dafür schuldig, daß nicht diese Verfassung und nicht die von der Rechtsgemeinschaft getragene (sonstige) Rechtsordnung die maßgebliche Gerechtigkeitsvorstellung eben dieser Rechtsgemeinschaft verwirklichen sondern im Gegenteil dagegen verstoßen. Diese "Beweislast" bedeutet - zu Recht - "Beweisnot". 13) Soll wirklich ein Gesetz, das die Menschenwürde achtet, den Gleichheitsgrundsatz 14) verwirklicht, die verfassungsmäßigen Freiheitsrechte unangetastet 1äßt, das Eigentumsrecht in den Grenzen der Verfassung respektiert, sozial (sozialstaatlich) ist, den (sonstigen) materiellen, immanenten Substanzen der Rechtsstaatlichkeit und schließlich allem sonstigen Verfassungsrecht entspricht - soll dieses Gesetz wirklich irgendwie "ungerecht" sein können? ${ }^{15)}$ Soll der Richterspruch oder der Verwaltungsakt, der sich - wirklich im Rahmen dieser Verfassungs- und gesetzlichen Ordnung hält, schlechterdings ungerecht sein können, ohne daß diese "Ungerechtigkeit" schon durch die richtige Gesetzesauslegung, die richtige Ermessenshandhabung, m.a.W.: durch die engen Maßstäbe des Verfassungs- und unterverfassungsmäßigen Rechts abgefangen würde? ${ }^{15)}$

13) Vg1. Dürig in Maunz-Dürig, Art. 1 Abs. III Randn. 133: "Es ist klar, daß unsere Verfassungen die jüngsten umfassenden Plebiszite über die Wertauffassungen der Rechtsgemeinschaft darstellen". (Der Ausdruck "Plebiszite" ist allerdings problematisch).

14) Zum Gleichheitssatz als verfassungsrechtlichem Ausdruck der Gerechtigkeit s. unten Abschnitt 6 II (S. 890 ff).

15) S. BayVerfGH VGHE n.F. 11 II 127 (137). - S.a. MaunzDürig, Art. 20 Randn. 72; Schnorr, Die Rechtsidee im Grundgesetz, insbes. S. $134 \mathrm{ff}$ (der das "Recht" schon in Art. 1-3 GG ausgedrückt sieht). Forsthoff, Die Bindung an Gesetz und Recht, S. 43: "Mit dem Ergehen von Gesetzen, die der gesetzgeberischen Intention nach Unrecht sind und deren Unrechtsgehalt nicht schon aus anderen Verfassungsnormen erweislich ist, sondern aus Art.20 Abs. 3 GG deduziert werden muß, ist unter der gegenwärtigen Verfassungsordnung ernsthaft nicht zu rechnen". Forsthoff (ebd.) hält es aber für möglich, daß kleine "handgreifliche Ungerechtigkeiten... unterlaufen". Aber sie zu korrigieren ist doch eine Frage der Auslegung. Sie mit Hilfe des nicht interpretierend hinter das Gesetz gestellten sondern ihm als "Recht" gegen das "Gesetz" gestellten Gerechtigkeitsprinzips auszumerzen, heißt mi: Kanonen auf Spatzen schießen, zumal, wenn - wie Forsthoff 
Da diese Fragen kaum je bejaht werden können, hat sich die Diskussion um die Geltungskraft des Gerechtigkeitsmaßstabes auf das Problem der "verfassungswidrigen" Verfassungsnorm verengt. 16) Gerade an diesem Fall zeigt sich aber die Schwierigkeit, den gemeinsamen Überzeugungsfundes extra constitutionem festzustellen, 17) im Extrem. Wer könnte im Namen der verfassungsmäßigen Ordnung, die der originäre Verfassungsgeber unter das Gebot der Gerechtigkeit gestellt hat, nicht nur legitimiert 18) sondern auch tatsächlich in der Lage sein, gegen diesen Verfassungsgeber 19) den Vorwurf zu erheben und zu belegen, er habe die Gerechtigkeitsmaximen der von ihm staatsrechtlich konstituierten Rechtsgemeinschaft verkannt? Oder auch: Wie könnte dieser Vorwurf gegenüber dem verfassungsändernden Gesetzgeber - der Zweidrittelmehrheit in Bundestag und Bundesrat (Art. 79 Abs. 2 GG) - gerechtfertigt werden? Mit Recht sagt das Bundesverfassungsgericht, daß die theoretische Möglichkeit verfassungswidriger Verfassungsgesetze einer praktischen Unmöglichkeit gleich kommt. 20) Wenn es sich dennoch den Ausgleich eines "unerträglichen Widerspruches" $z$ wischen dem positiven Gesetz und der Gerechtigkeit zu deren Gunsten 21 ) und die Wahrung der "letz-

unterstellt - wirklich kein Verfassungsverstoß (auch nicht gegen Art. $3 \mathrm{GG}$ ) vorliegt.

16) Vgl. vor allem Bachof, Verfassungswidrige Verfassungsnormen, 1951; Maunz, Starke und schwache Normen in der Verfassung; Apelt, Verfassung und richterliches Prüfungsrecht, JZ 9. Jhg. (1954) S. 401 ff; Nawiasky, Positives und überpositives Recht; Marti, Naturrecht und Verfassungsrecht, in "Rechtsquellenprobleme im schweizerischen Recht", Festgabe der rechts- und wirtschaftswissenschaftichen Fakultät der Universität Bern für den Schweizerischen Juristenverein, 1955, S. 74 ff. Weitere Nachweise s. bei den Zitierten.

17) Vg1. Kägi, Rechtsstaat und Demokratie, S. 134: "Es fehlt unserer Zeit weithin jener feste Consensus über die Grundwerte des Rechtes, ohne die rechtsstaatliche Ordnung nicht möglich ist".

18) Zum Legitimationsproblem s. insbes. Nawiasky-Lechner, S. 25 f; Nawiasky, VGHF. n.F. 11 II 150.

19) Der ursprüngliche Verfassungsgeber war die Mehrheit des parlamentarischen Rates und die Mehrheit in zwei Dritteln der Länderparlamente (Art. 144 GG).

20) BVerfGE 3, 233; s.a. BayVerfGH VGHE n.F. 11 II 134.

21) BVerfGE 3, $232 \mathrm{f}$. 
ten Grenzen der Gerechtigkeit" 22) vorbehält, 23) so sichert es sich eine Korrekturchance wohl nur noch für den Fall, daß ihm Evidenz und öffentliche Meinung die Beweisführung ersparen.

Kann schon das Verbot der Ungerechtigkeit kaum selbständige Bedeutung erlangen, so gilt das um so mehr für das positive Gebot der Gerechtigkeit. ${ }^{24)}$ Wann läßt sich schon sagen, was genau getan werden muß, damit der einzig (!) gerechte Zustand hergestellt wird?

Soll der Grundsatz der Gerechtigkeit aber nicht doch Legitimation sein? Legitimation für den Gesetzgeber? Er bedarf ihrer nur dort, wo er auf Schranken stößt. Den verfassungsrechtlichen Schranken aber ist die Gerechtigkeitsorientierung immanent. Doch selbst wenn der Gesetzgeber einer rechtlichen Legitimation für jeden seiner Rechtsbefehle bedürfte und die Gerechtigkeit eine solche Legitimation wäre, könnte sie ihm nur streitig gemacht werden, wo er ungerecht handelt. 25)

Auch für die Verwaltung bleibt die Bedeutung der grundgesetzlich positivierten "Gerechtigkeit" gering. Der Vorbehalt des Gesetzes weicht dem allgemeinen Gerechtigkeitsauftrag nicht. ${ }^{26)}$

22) BVerfGE 3, 233.

23) Wenn der Bayerische Verfassungsgerichtshof glaubt, eine weitergehende Kontrolle ausüben zu sollen, so trügt der Anschein seiner These (vielleicht auch den Gerichtshof selbst). Er meint in Wahrheit immer nur die Anwendung höherrangigen aber ausdrücklich positivierten (Verfassungs-) Rechts. Vor der Anwendung anderer "oberster Gerechtigkeitswerte" scheut er ganz offenbar nicht weniger, eher noch mehr zurück als das Bundesverfassungsgericht (VGHE n.F. 11 II 137).

24) Dafür, daß sich viel eher sagen läßt, was ungerecht, als was gerecht ist, s. z.B. Wolff, Rechtsgrundsätze und verfassunggestaltende Grundentscheidungen als Rechtsquellen, S. 46.

25) Das etwa könnte der Sinn der Ansicht sein, daß die Bindung an "Gesetz und Recht" einen "Rechtsgrund" des Gesetzes verlangt (vgl. Maunz, Deutsches Staatsrecht, S. 58). Doch kann dieses Erfordernis nur im Rahmen der verfassungsmäßigen Ordnung, d.h. nur auf die Weise geltend gemacht werden, daß in den verfassungsmäßig vorgesehenen Verfahren die Geltung des Gesetzes zur Prüfung gestellt wird.

26) Vgl. Forsthoff, Lehrbuch des Verwaltungsrechts, S.271; Maunz, a.a.O. 
Die Bindung an das Gesetz wird durch ihn ebenfalls nicht aufgenoben. Dem ungerechten Gesetz, das die Verwaltung zwingen würde, ungerecht zu verfahren, könnte sie sich von Verfassungs wegen nicht anders widersetzen als jedem anderen verfassungswidrigen Gesetz. 27) Lediglich das Handeln der Verwaltung, das weder unter dem Vorbehalt des Gesetzes steht noch durch das Gesetz oder die Verfassung näher gebunden ist und das weder inem Gesetz noch der Verfassung widerspricht, an dem Grundsatz der Gerechtigkeit zu messen, daran dürfte das Interesse hicht groß sein.

Bleibt schließlich der Richter, dessen wesensgemäßer Auftrag die Gerechtigkeit ist. Sie ergänzt ihm die gesetzte Ordnung. Aber gegen sie aus dem Auftrag der Gerechtigkeit vorzugehen, ist ihm nur gegen das ungerechte Gesetz und nur im Rahmen der Verfassung erlaubt. ${ }^{27)}$ Also ist auch insofern die unmittelbare Bedeutung des Gerechtigkeitsgrundsatzes - was seine höchstrangige Positivierung durch die Verfassung betriff - nicht groß.

Trotz all dem ist es wichtig zu wissen, daß die Gerechtigkeit zu den obersten Geboten der Verfassung gehört - auch und gerade für die soziale Intervention; denn auch soziale Gerechtigkeit

27) S. hierzu nochmals oben S.665 zu Fußn. 7, 8. Dafür, daß "Recht" i.S. des Art.20 Abs. 3 GG nicht die Verweisung auf das Naturrecht sondern auf die Gesamtheit des außergesetzlichen positiven Rechts bedeutet s.a. Ipsen, Grundgesetz und richterliche Prüfungszuständigkeit, DV 2.Jhg. (1949) S.486 ff (490); Werniche, Bonner Kommentar, Art.20 Anm. II 3 c; Evers, Des Richter und das unsittliche Gesetz, S.105 ff mit eingeh. weit. Nachweisen; Schlochauer, Öffentliches Recht, s.16 f; im Virgebnis offensichtlich wie hier auch Maunz, Deutsches Staatsrecht, S.58. - Auch Forsthoff (Die Bindung an Gesetz und Recht, S. 42 ff) kommt - indem er eine Möglichkeit (ler Verwaltung, sich gegen das Gesetz auf das Recht zu belufen, praktisch verneint, dagegen dem Gericht eine Prüfungsmöglichkeit gegenüber "handfesten Ungerechtigkeiten" zugesteht -, wenn man das bejahte richterliche Prüfungsrecht in die Bahnen des Art.100 GG lenkt, der vertretenen Auffassung nahe. 
ist Gerechtigkeit und soziale Intervention ist (auch) soziale Gerechtigkeit. 28 )

28) S. hierzu zunächst du Pasquier, La notion de justice sociale et son influence sur le droit suisse, Zeitschrift für schweizerisches Recht, n.F. Bd.71 (1952) S. 69 ff; Höffner, Die soziale Gerechtigkeit und die überlieferte abendländische Gerechtigkeitslehre; kritisch zur Differenzierung zwischen Gerechtigkeit und sozialer Gerechtigkeit v. d. Heydte, Diskussionsbeitrag zu "Die Tragweite der Generalklausel in Art. 19 Abs. 4 des Bonner Grundgesetzes", Veröffentlichungen der Vereinigung der Deutschen Staatsrechtslehrer, Heft 8, 1950, S. 162 f. - Im besonderen zur Abfolge Rechtsstaat - Gerechtigkeitsstaat - Staat sozialer Gerechtigkeit s. Bachof, Begriff und Wesen des sozialen Rechtsstaates, S. 39 f, 44. 


\section{Abschnitt}

Der. Sozialstaat

I. Zum Wesen der grundgesetzlichen Sozialstaatsproklamation

Kein Wort des Grundgesetzes muß für sich allein so viel sagen wie das Wort "sozial". Alle anderen Verfassungsgrundsätze - etwa der der Demokratie, der Rechtsstaatlichkeit, der Bundesstaatlichkeit - sind durch Einzelvorschriften der Verfassung ergänzt und erläutert. Die Sozialstaatlichkeit dagegen hat ihren verbalen verfassungsrechtlichen Niederschlag fast ausschließlich in den Formeln vom "demokratischen und sozialen Bundesstaat" (Art.20 Abs.1 GG) und vom "republikanischen, demokratischen und sozialen Rechtsstaat" (Art.28 Abs. 1 Satz 1 GG) gefunden. Was die Kompetenznormen und die Grundrechte an zusätzlichen inhalts- oder formbezogenen Richtpunkten geben, ist vergleichsweise äußerst wenig.

Das Mißverhältnis zwischen der äußeren Normsubstanz und ihrem - positiven, noch mehr ihrem potentiellen - Aussageobjekt ist symptomatisch für die Schwierigkeit normativer, insbes. verfassungsrechtlicher. Vorwegnahme positiver sozialer Gestaltungsaufgaben. M.a.W.: Es ist symptomatisch für die soziale Schwäche materieller Rechtsstaatlichkeit. Sie läßt eine (eingehendere) verfassungsgesetzliche Regelung allzuleicht zum unverbindlichen Programm herabsinken, das die ganze Verfassung in den Verruf bringt, ein bloßes "Blatt Papier" zu sein. Resignation vor diesem Risiko kann ebenso zur kurzen Formel vom "sozialen Staat" raten wie Ehrlichkeit, die davor zurückschreckt, durch detaillierte Normierungen Erwartungen zu wecken, die nicht durch entsprechende Sanktionen davor bewahrt werden können, enttäuscht zu werden.

Doch damit allein ist die Kürze der grundgesetzlichen Einlassung auf das soziale Thema nicht zu erklären. Eine eingehendere Regelung hätte nicht nur in T'eilfragen unmittelbar vollziehbares und durchsetzbares Recht schaffen können. Sie hätte mit verläßlicher Effektivität auch die Gestaltungsvollmacht des Gesetzgebers eingrenzen und so, wenn schon nicht gestalterisches Wirken erzwingen, ihm doch wenigstens feste Bahnen vorzeichnen können.1) Fine detaillierte verfassungsrechtliche Regelung hätte vielleicht auch als "ehrlicher" gewertet werden dürfen. Die Formel vom sozialen Staat ruft ihrerseits trotz und gerade wegen ihrer Kürze

1) S. hierzu z.B. Nawiasky, Allgemeine Rechtslehre, S.38 f; dens., Allgemeine Staatslehre, Teil 3, S. $105 \mathrm{f}$. 
eine Masse vielfältiger Hoffnungen hervor, deren unkontrollierbares Aufkommen durch die Konkretheit einer näheren Regelung gemäßigt werden könnte.

Der äußere Minimalismus der grundgesetzlichen Sozialstaatsproklamation hat denn in der Tat auch noch andere Gründe als die eingangs genannten. Der Grundgesetzgeber sah sich gar nicht in der Lage, ein abgeschlossenes Sozialprogramm zu entwickeln und verbindlich zu setzen. Diese sozialgestalterische Impotenz beruhte einerseits auf der Unsicherheit, Unausgeglichenheit und Spannungsfülle der außen- und innenpolitischen, ökonomischen und sozialen Zustände im Westdeutschland der Zeit von 1948/49. Weder sie noch die damals möglichen Entwicklungsprognosen gáben eine verläßliche Grundlage für ein auf Dauer angelegtes, ${ }^{2}$ ) sachgerechtes Sozialstaatsprogramm ab. ${ }^{3)}$ Hätte also ein in sich sozialpolitisch geschlossener Grundgesetzgeber schon äußerste Zurückhaltung walten lassen müssen, so war dies dem konkreten Verfassungsgeber umso mehr auferlegt, als die seinen Willen tragenden politischen Kräfte durch vielfältige Differenzen an der positiven Ausbildung einer substanziellen, abgerundeten Konzeption gehindert waren. 4) Klar war, daß der Staat nicht in die Rolle sozialer Indifferenz zurückfallen durfte. Die sozialpolitischen Grundpostulate und Errungenschaften der ersten Hälfte des 20. Jahrhunderts waren im großen und ganzen unbestritten. Über die Mittel und Wege der Fortführung und Steigerung, über das Zielmodell und den erstrebenswerten Grad der Steigerung herrschten jedoch Meinungsverschiedenheiten, ja sogar scharfe Gegensätze. Den Fundus an Gemeinsamem auszumitteln und in extenso zu po-

2) Ipsen (Über das Grundgesetz, 1950, S. 14 ff = Das Grundgesetz in seiner Vorläufigkeit, Recht Staat Wirtschaft, Bd.II (1950) S. 182 ff (186 ff)) beanstandet allerdings, das Grundgesetz habe gerade die aktuellen sozialen Aufgaben, wie z. B. das Flüchtlingsproblem, nicht genügend gesehen und angepackt. Diese Kritik hat in dem Maße an Gewicht verloren, in dem Grundgesetz und Bundesrepublik aufgehört haben, Provisorien zu sein. Jedenfalls zurückschauend wird man auch zweifeln müssen, ob die Kritik Ipsens überhaupt auch nur vom Blickpunkt der "Vorläufigkeit" aus begründet erscheint.

3) Vg1. v. Mangoldt, Das Bonner Grundgesetz, (1. Aufl.) Art. 20 Anm. VII.

4) S. hierzu insbes. Abendroth, Zum Begriff des demokratischen und sozialen Rechtsstaats im Grundgesetz der Bundesrepublik Deutschland (zitiert nach dem Abdruck in SultanA bendroth, Bürokratischer Verfassungsstaat und soziale Demokratie), S.95, $98 \mathrm{ff}$. 
sitivieren, war sowohl im Hinblick auf die Eigenart der Materie, wie auch auf die innere und äußere Situation des parlamentari;chen Rates schlechterdings unmöglich.

In dieser Lage bot sich der Ausweg der allgemeinen Formel an, lie das Gemeinsame in die Verfassung hineinholen konnte, ohne da $\beta$ dies durch die Notwendigkeit detaillierter Festlegungen erschwert und durch Dezisionen über die bestehenden Differenzen verhindert worden wäre. Das Bekenntnis zum Sozialstaat ist Geheralklausel und dilatorischer Formelkompromiß5) in einem: Generalklausel als Niederschlag des übereinstimmenden Normwillens der verfassungsgestaltenden politischen Kräfte, dilatorischer Formelkompromiß ${ }^{6)}$ als Nichtentscheidung über die vielältig offenen Meinungsverschiedenheiten in bezug auf die Gestaltgabe des Sozialstaates. Sphinxhaft, schweigsam, mehrdeutig und deutungsträchtig, Entscheidung und Nichtentscheidung verschmelzend, allgemein, umfassend gewollt und doch nicht erschöpfend, von zentralem Anspruch, ohne die Kraft indessen, ihm ganz zu genügen, wurde die Wendung vom sozialen Staat zur ebenso oft übersehenen wie überschätzten verfassungsrechtlichen Basis sozialstaatlicher Verfassungswirklichkeit.

Sich vielschichtig überlagernde, heterogene Elemente vereinigend, von unausgleichbaren Spannungen erfüllt, setzt die Sozialstaatserk1ärung die Interpretation mannigfachen Gefahren des Irrtums aus, ja stellt sie sie letztlich vor eine kaum lösbare Aufgabe. ${ }^{7)}$ Auf der einen Seite droht die Skylla der Unterbewertung des vorhandenen Normwillens, die die objektive Mehrdeutigkeit überschätzt und die subjektive Nichtentscheidung zum Auslegungsprogramm der ganzen Norm erhebt; ${ }^{8)}$ auf der anderen Seite die

5) Im Sinne Carl Schmitts (Verfassungslehre, S. $31 \mathrm{f}, 118$ ).

6) Zur Wertung des Prinzips (les sozialen (Rechts-)Staats als Formelkompromiß s.z.B. Abendroth a.o. (S.674 zu Fußn.4) a.O.; Hettlage, Finanzverfassung im Rahmen der Staatsverfassung, S.95; Pähler, Verein und Sozialstruktur, Archif für Rechts- und Sozialphilosophie, Bd.XLII (1956) S. $197 \mathrm{ff}$ (222).

7) Es erscheint nicht unberechtigt, wenn Herrschel (Rationalisierung des Rechts, insbes. des Arbeitsrechts, in "Sozialversicherung, Sozialrecht und $\Lambda$ 'beitsrecht", Festschrift für Friedrich Sitzler, 1956, S.287ff (299)) meint, das Grundgesetz habe durch seine mißverständliche Formel vom sozialen Rechtsstaat die Entwicklung des Sozialrechts nachgerade kompliziert.

8) Vor allem Grewe (Das bundesstaatliche System des Grundgesetzes, DRZ 4.Jhg. (1949) S. 49 ff (351); Der Begriff des "sozialen Staates" in der deutschen Verfassungsentwicklung, Der Arbeitgeber, 1950/51 Nr.24/1 S.39 ff $(39,42))$ kapituliert vor den Interpretationsschwierigkeiten in dieser Richtung. S.a. Paulick, Der Grundsatz der Gleichmäßigkeit der Besteuerung - 
Charybdis einer Übersteigerung der Aussagekraft, die das Element der Nichtentscheidung vernachlässigt und die - infolge der objektiven Mehrdeutigkeit und der subjektiven Nichteinigung und Nichtentscheidung - fehlende Normsubstanz bewußt oder unbewußt durch eigene Konstruktionen und eigenes Wunschdenken des Interpreten ersetzt. ${ }^{9)}$ Dazwischen durchzusteuern, den bindenden Normkern zu erkennen, ohne dessen strukturelle Labilität und gewollte Elastizität zu übersehen, jedoch darüber hinaus zu respektieren, daß objektive Mehrdeutigkeit und subjektive Divergenz einer eindeutigen Normaussage entgegenwirken und somit das Substrat der Normgeltung zersetzen, ist die diffizile Notwendigkeit, vor der die Auslegung der Formel vom "sozialen Staat" steht.

II. Die grundsätzliche Exegese der grundgesetzlichen Sozialstaatsproklamation

\section{Zum Inhalt der Sozialstaatserklärung}

a) Die Trias der elementaren Deutungsmöglichkeiten

$\mathrm{Zu}$ Anfang dieser Untersuchung 1) wurden drei Grundinhalte des allgemeinen Verständnisses des Wortes "sozial" herausgestellt: "sozial" im allgemeinsten und neutralsten Sinn als "gesellschaftlich", "gemeinschaftlich", "gesellschaftseigen", "gesellschaftsbezogen"; "sozial" in einem engeren, wertenden Sinn als - auf die Mitglieder der Gesellschaft bezogen - "gesellschaftsgebunden", "gemeinschaft sverpflichtet", "gesellschaftszugewandt"; "sozial" schließlich im Sinne der (Summe der) historisch-konkreten politischen Sozialbewegung(en), d.h. "sozial" als Kennzeichen einer kritischen Haltung gegenüber den bestehenden innergesellschaftlichen Wohlstandsdifferenzen, als das Epitheton eines der üblen Lage schlechter gestellter Schichten abhelfenden Handelns. Die Diskussion um den Begriff des "sozialen Staates" hat sich bisher mit verbalen Argumenten nicht überbelastet. Trotzdem gruppiert sich die Auslegung des grundgesetzlichen Sozialstaatsbegriffs durch Modifikationen und Kombinationen reich variiert, im groBen und ganzen aber sehr deutlich - um diese drei Grundgehalte des Wortes "sozial".

Geradezu als selbstverständlich erschien und erscheint es nicht nur dem Nichtjuristen sondern auch einer breiten rechtswissenschaftlichen Allgemeinheit, den "sozialen Staat" im Sinne des historisch-konkreten politischen Sozialbegriffes zu begreifen - als

sein Inhalt und seine Grenzen, in "Probleme des Finanz- und Steuerrechts", Festschrift für Ottmar Bühler, 1954, S. $121 \mathrm{ff}$ (161: "Unbestimmtheit und Unbestimmbarkeit des Sozialstaatsbegriff s").

9) Einzelne Nachweise s. unten zu verschiedenen extremen Interpretationsergebnissen.

1) S. oben S. 18 . 
den Helfer der Schwächeren, 2) der die Teilhabe an den wirtschaftlichen Gütern nach "den Grundsätzen der Gerechtig-

2) Vgl. Nawiasky, Grundgedanken des Grundgesetzes für die Bundesrepublik Deutschland, S.66 (s. dens. a. Allgemeine Staatslehre, Teil 3, S. $51 \mathrm{f})$; Wolany, Vom Sozialstaat und sozialen Recht, S.149 (und passim); Maunz, Der deutsche Standpunkt zu den Empfehlungen des Europarates zur Schaffung einer Europäischen Sozialversicherungsordnung, Deutsche Versicherungszeitschrift, V.Jhg. (1951) S.272 ff (273); ders., Deutsches Staatsrecht, S. 60 f; Bettermann, Grundfragen des Preisrechts, S. 119; Dürig, Verfassung und Verwaltung im Wohlfahrtsstaat, S.196; ders., Besprechung zu "Menger, Der Begriff des sozialen Rechtsstaates im Bonner Grundgesetz", AöR Bd. 79 (1953/54) S.254 ff (255 ff); Bachof, Begriff und Wesen des sozialen Rechtsstaats, S. 102 ff; Diskussionsbeitrag hierzu, VVDStRL. H.12, 1954, S.99 ff (102 f); Pfeifer, dass. ebenda, S. 111 ff (112 f); Peters, Ist es verfassungsrechtlich zulässig, daß der Staat durch bestimmte Arbeitsschutzvor'schriften auch Personen erfaßt, die keine oder nur solche Arbeitnehmer beschäftigen, welche infolge der Art oder Organisation des Betriebes insoweit nicht schutzbedürftig sind, Bundesarbeitsblatt 1954, S.205 ff, 241 ff (208, 242); Fechner, Sozialer Rechtsstaat und A rbeitsrecht, \$. 162 und passim; Berger, Bedeutung und Tragweite des Grundsatzes vom sozialen Rechtsstaat, Die Betriebsverfassung, 2. Jhg. (1955) Nr. 8 S. 4 ff (6 und passim); Claus Arndt, Die Bundesrepublik Deutschland als sozialer Rechtsstaat, Die neue Gesellschaft, 3.Jhg. (1956) S.326 ff (330); Klein, Christ und Kirche in der sozialen Welt, S. 124 f; Thieme, Liberalismus und Grundgesetz, S.296; Rohwer-Kahlmann, Sozialıecht und Grundgesetz, Soziale Sicherheit, 6. Jhg. (1957) \$.358 ff (359); Dietz, Rechtsgutachtliche Äußerung zu der Fragge, ob Art. 3 Abs. 2 und 3 des Grundgesetzes für die Bumlesrepublik Deutschland der Berücksichtigung einer ger ingeren Wertigkeit von Frauenarbeit gegenüber der Männerarbeit sowie einer typisch geringeren sozialen Belastung der Frau gegenüber dem Mann bei der. Aufstellung einer Norm für den Lohn entgegensteht, 1957, S. 25; Hamann, Deutsches Wirtschaftsverfassungsrecht, S. 47; Leibholz, Die kritischen Punkte des Grundgesetzes, S. 19 f; ders., Strukturprobleme der modernen Demokratie, S. 87; Dersch, Der Verfassungsgrundsatz der Sozialstaatlichkeit und Rechtsstaatlichkeit in der Praxis der Sozialversicherung, in "Sozialreform und Sozialrecht", Festschrift für Walter Bogs, 1959, S. 59 ff (63 f); Wolff, Verwaltungsrecht I, S. 43 f; 
keit $^{3)}$ mit dem Ziele der Gewährleistung eines menschenwürdi-

Fuss, Gleichheitssatz und Richtermacht, JZ 14.Jhg. (1959) S.329 ff (335); Thieme, Der Beamte im sozialen Rechtsstaat, S. 170; Schneider, Die öffentlichrechtliche Alterssicherung freier Berufe und das Grundgesetz, S.23 (ff); BVerwG 7, 180 (182); KG Urteil vom 18. Februar 1955 - 1 Ss 584/54 (376/54), JZ 10. Jhg. (1955) S. 545 (546); Amtliche Begründung des Entwurfs eines Bundessozialhilfegesetzes, Deutscher Bundestag, 3. Wahlperiode, Drucksache 1799, S. 32. - Ohne ausdrückliche Erwähnung liegt diese Auffassung der Masse der Äußerungen zugrunde, die sich mit Einzelfragen unter dem Blickpunkt des Sozialstaatsprinzips befassen, ohne diesen (insoweit) grundsätzlich zu interpretieren. Nachweise folgen zum weiteren Text.

3) Zur Deutung des Sozialstaatsprinzips als Gerechtigkeitspostulat vgl. Maunz, a.a.O.; Dürig, Besprechung zu "Menger, Der Begriff des sozialen Rechtsstaats im Bonner Grundgesetz", S. 255 f; Peters, Ist es verfassungsrechtlich zulässig, daß der Staat durch bestimmte Arbeitsschutzvorschriften usw., S. 242; Abendroth, Zum Begriff des demokratischen und sozialen Rechtsstaats im Grundgesetz der Bundesrepublik Deutschland, S. 84 f, 90 f; Bachof, a.a.O. S. 39 ff, 80; Pfeifer, a.a.O.; Fechner, a.a.O., insbes. S. 162; Claus Arndt, a.a.O. S.330 (zurückhaltend); Rohwer-Kahlmann, a.a.O. S. 361; v. Mangoldt-Klein, Art.20 Anm. VII 3; Schloch. auer, Öfentliches Recht, S. 14; Leibholz, Die kritischen Punkte des Grundgesetzes, S. 19 f; ders., Strukturprobleme der modernen Demokratie, S. 87; 131; Dersch, a.a.O. S.64; Reinhold, Innere und äußere Freiheit im Wohlfahrtsstaat, Zeitschrift für Sozialreform, 5. Jhg. (1959) S. 529 ff (534), a.a.O. S.64; BVerfGE 5, 85 (198); BVerwGE 7, 180 (182). Eine extreme Deutung, die den Sozialstaat nur als Gerechtigkeitsstaat und zwar ohne soziale Materialisierung der Gerechtigkeit verstehen will, findet sich bei Menger, Der Begriff des sozialen Rechtsstaats im Bonner Grundgesetz, S. 24 ff (ähnlich vor allem Hamel, Die Bedeutung der Grundrechte im sozialen Rechtsstaat, S.28; wohl auch Peters, Kombination verschiedener Verfassungsgrundsätze als Mittel der Verfassungsauslegung, in Festschrift für Karl A rnold, 1955, S. 117 ff (124)). Zur Kritik s. die vorstehend Zitierten (insbes. Dürig, v. Mangoldt-Klein); s. ferner Ipsen, Besprechung zu Menger, Der Begriff des sozialen Rechtsstaats im Bonner Grundgesetz, DVB1. 72.Jhg. (1957) S.219. - Zum Begriff der sozialen Gerechtigkeit s. nochmals die Zusam- 
gen 4) Daseins 5) für alle" 6) zu ordnen sucht. 7)

menfassung bei Höffner, Die soziale Gerechtigkeit und die überlieferte abendländische Gerechtigkeitslehre. Zu dem sozial substanziierten Gerechtigkeitsbegriff, wie er etwa der Gleichung Sozialstaat $=$ sozialer Gerechtigkeitsstaat im Sinne der vorstehenden Nachweise zugrunde liegt, s. die Darstellung bei Du Pasquier, La notion de justice sociale et son influence sur le droit suisse.

4) Zur Menschenwürde als Telos der Sozialstaatlichkeit s. v. Mangoldt, Das Bonner Grundgesetz (1.Aufl.) Art.20 Anm.2b; Bachof, Begriff und Wesen des sozialen Rechtsstaats, S.42; Berger, Bedeutung und Tragweite des Grundsatzes vom sozialen Rechtsstaat, S. 6 ff (durchgehend); Klein, Christ und Kirche in der sozialen Welt, S. 124 f; Hamann, Das Grundgesetz, Einführung I D 2 (S.33); Leibholz, Die kritischen Punkte des Grundgesetzes, S.20; Schlochauer, Öffentliches Recht, S. 14; Ballerstedt, Wirtschaftsverfassungsrecht, S. 53 ff (ohne ausdrücklichen Anruf der Menschenwürde, jedoch der Sache nach sehr eindringlich). Reinhold, Innere und äußere Freiheit im Wohlfahrtsstaat, S. 536. - Abendroth (Zum Begriff des demokratischen und sozialen Rechtsstaates im Grundgesetz der Bundesrepublik Deutschland, S.93) glaubt, den sozialstaatlichen Sukkurs dem menschenwürdigen Dasein weniger des einzelnen als ganzer Gruppen reservieren zu sollen - eine Einschränkung, die im Ergebnis (insbes. unter praktischen Aspekten) in etwa gerechtfertigt sein mag, sich jedoch gerade unter Heranziehung des Begriffs der Menschenwürde schlecht begründen läßt.

5) (1) Zum Sozialstaat als Garant eines menschenwürdigen Daseins s. außer clen vorstehend Genannten auch Wernicke, Bonner Kommentar, Art.20 Anm. II 1 d; Fuss, Gleichheitssatz und Richtermacht, S.335 Fußn. 52.

(2) Der Sozialstaat a1s Garant des Existenzminimums wird z. B. erwähnt bei Dürig, Verfassung und Verwaltung im Wohlfahrtsstaat, S.196 ff; Paulick, Die verfassungsrechtlichen Bindungen des Gesetzgebers beim Erlaß von Steuergesetzen, S. 491 ff; Abendroth, a.a.O. S.93 (für die Existenzsicherung von Gruppen); Maunz, Die Finanzverfassung im Rahmen der Staatsverfassung, S.59; Wolff, Verwaltungsrecht I, S. 43 f; s.a. Leibholz, Die kritischen Punkte des Grundgesetzes, S.20, und ders., Strukturprobleme der modernen Demokratie, S.87 (der von der Gewährleistung eines sozialen Mindeststandards spricht); Wintrich, Die Bedeutung der "Menschenwürde" für die Anwendung des Rechts, Bayerische Verwa1- 
Verfeinertem juridischem Sinn hat diese schlichte Transposition sozial-politischer Postulate in das Verfassungsrecht vielfach nicht genügt. In einer durch fast heillose Unsicherheit über die

tungsblätter, n.F. 3.Jhg. (1957) S.137 ff (S.139: Sozialstaatsprinzip und Menschenwürde zusammen ergeben Anspruch auf Gewährleistung des Existenzminimums).

(3) Einen anderen Akzent hat es, wenn vom Sozialstaat als dem Staat der Daseinsvorsorge gesprochen wird (zu der Unterscheidung $z$ wischen sozialer Intervention und Daseinsvorsorge s. nochmals oben S. 37 ). Soweit damit weder gemeint ist, daß der Staat in Konsequenz seines sozial ausgleichenden Eingriffs zum Staat der Daseinsvorsorge wird und (oder) die Hilfe für die schwächeren Schichten dort Daseinsvorsorge ist, wo es um deren Existenzminimum geht, ist etwas anderes gemeint, als das, was im Text angedeutet sein soll. Im Schriftum wird nicht immer genau unterschieden. Im Sinne der Daseinsvorsorge als Ausfluß der Sozialstaatlichkeit s. z. B. Ipsen, Anmerkung zu BVerfG Urteil v. 19. Dezember 1951 - 1 BvR 220/51 - DÖV 5.Jhg. (1952) S. 217 f (218); Bachof, Begriff und Wesen des sozialen Rechtsstaats, insbes. S.40; Forsthoff, Verfassungsprobleme des Sozialstaats, S.8; Hamann, a.a.O.; Huber, Der Streit um das Wirtschaftsverfassungsrecht, S.202; Laufke, Vertragsfreiheit und Grundgesetz, S. 185 f; Thieme, Liberalismus und Grundgesetz, S. 295 f; s.a. Bleibtreu, Demokratie, soziales Prinzip und Rechtsstaat, S. 103.

6) Vg1. Art.151 Abs. 1 Satz 1 RV 1919: "Die Ordnung des Wirtschaftslebens muß den Grundsätzen der Gerechtigkeit mit dem Ziele der Gewährleistung eines menschenwürdigen Daseins für alle entsprechen". - Zur Verwandtschaft der gr'undgesetzlichen Sozialstaatsproklamation mit Art.151 RV 1919 s. Huber, Wirtschaftsverwaltungsrecht Bd.I, S. 36 f; Forsthoff, Begriff und Wesen des sozialen Rechtsstaats, S.27; Nipperdey, Die soziale Marktwirtschaft in der Verfassung der Bundesrepublik, S. 18. - Schon in der Weimarer Zeit wurde der Staat des Art. 151 RV 1919 als sozialer Rechtsstaat und Sozialstaat bezeichnet (s. z.B. Piloty-Schneider, Grundriß des Verwaltungsrechts, 4./5. Auf1. 1930, S.2).

7) S. zu Vorstehendem auch Scheuner, Grundfragen des modernen Staates, S. 154; Wernicke, Bonner Kommentar, Art. 20 Anm. II 1 a; Huber, Der Streit um das Wirtschaftsverfassungsrecht, S. $201 \mathrm{ff}$; Nipperdev, Lehrbuch des Arbeitsrechts, Bd.II, S.33; BVerfGE 1, 97 (105). 
"Grenzen des Staates" gekennzeichneten (verfassungs-)politischen Ambiance erschien es schon wichtig genug oder auch noch wichtiger, den Sozialstaatsbegriff - ihm den allgemeinsten Sozialbegriff unterlegend - als eine Negation gesellschaftlicher Autonomie und eine Bestätigung des allgemeinen Sozialgestaltungsauftrages des Staates zu deuten. $\left.{ }^{8}\right)$

Einen geradezu sensationellen Beifall hat schließlich die Sozialstaatsthese erhalten, die sich an den wertenden engeren Sozialbegriff anschließt. Sie hebt statt der nehmenden Teilhabe des einzelnen an der Gemeinschaft seine gebende Verstrickung in sie, statt der Berechtigung und Begünstigung des Individuums seine Belastung zu ihren und ihrer (anderen) Glieder Gunsten hervor. ${ }^{9}$ )

8) Aus dem in sich sehr differenzierten Schrifttum s. Ipsen, Enteignung und Sozialisierung, VVDStRL. H. 10, 1952, S. 74 ff (insbes. S. 74 f); Bachof, Begriff und Wesen des sozialen Rechtsstaats, S. 39 f, 80; Dürig, Art. 2 GG und die Generalermächtigung zu allgemeinpolizeilichen Maßnahmen, AöR Bd. 79 (1953) S. 57 ff (83 f); ders., Anmerkung zu BVerfG Urt. v. 16.Januar 1957 - 1 BVR 253/56 - JZ 12.Jhg. (1957) S. 169 ff (172); ders., in Maunz-Dürig, Art.2 Abs.I Randn. 24 f, 45; Abendroth, Zum Begriff des demokratischen und sozialen Rechtsstaats im Grundgesetz der Bundesrepublik Deutschland, S. $84 \mathrm{ff}, 90 \mathrm{f}$; Claus Arndt, Die Bundesrepublik Deutschland als sozialer Rechtsstaat, S. 333; Hamann, Das Grundgesetz, Art.12 Anm. C 5 b; Bleibtreu, Demokratie, soziales Prinzip und Rechtsstaat, S. 102 f; Lerche, Zum Apothekenurteil des Bundesverfassungsgerichts, Bayerische Verwaltungsblätter, n. F. 4.Jhg. (1958) S.231 ff (S.253 Fußn.17); Krause, Der verteilencle Staat, S.13; ders., Wirtschaftslenkung und Ermächtigungsstil, S. 432; Ballerstedt, Wirtschaftsverfassungsrecht, S. j] if; I3runo Molitor, Sozialpolitik im sozialen Rechtsstaat, Hessische Hochschulwochen für staatswissenschaftiche Forthildung, Bd.21, 1959, S.98 ff (102 ff); Stern, Rechtsfragen der offentlichen subventionierung Privater, S. 522 ff; Barockit, Die Berücksichtigung sozialer Gesichtspunkte bei der Trhebung von Gebühren und Beiträgen für kommunale Abwasseranlagen usw., S. 825 .

9) Vgl. - mit erheblichen Unterschieden im einzelnen - Wolany, Vom Sozialstaat und sozialen Recht, S. 145 ff, 153 ff, 164; Bettermann, Grundlragen des Preisrechts, S. 119 ff; Menger, Der Begriff des sozialen Rechtsstaats im Bonner Grundgesetz, S. $24 \mathrm{ff}$; Fechner, f'leiheit und Zwang im sozialen Rechtsstaat, 1953, \$.8 ff (insbes. S. 14) - grundlegend für fast die ganze spätere Diskussion -; ders., Sozialer Rechts- 
Sie setzt der gefährlichen Einseitigkeit eines nur passiv-nehmenden wohlfahrtsstaatlichen Staatsbewußtseins die notwendige Erkenntnis entgegen, daß staatliche Hilfe nicht von irgendwoher son. dern aus der staatlichen Gemeinschaft geschöpft wird und sozialer Ausgleich nicht bloß Begünstigung der einen sondern auch Belastung der anderen Glieder der staatlichen Gemeinschaft bedeutet, ja daß schon die passiv-nehmende Verknüpfung des Einze1schicksals mit der Gemeinschaft die Individuum-GemeinschaftsRelation ganz allgemein bejaht und aktiviert.

Diese drei Deutungen, einander gegenübergestellt, weisen einen für die Interpretation der Sozialstaatserklärung entscheidenden Zusammenhang auf: Sie geben dann, aber auch nur dann ein abgeschlossenes Gefüge, wenn der soziale Staat primär und wesentlich im Sinne des historischen Sozialbegriffes als der Staat des Ausgleichs, der Hilfe für die Schwächeren, der gerechten Sorge für ihr menschenwürdiges Dasein verstanden wird. Dieser Staat

staat und Arbeitsrecht, S. 162 f; Dürig, Verfassung und Verwaltung im Wohlfahrtsstaat, S. 197; ders., Grundfragen der öffentlichrechtlichen Entschädigung, JZ 10.Jhg. (1955) S. 521 ff (525); ders., Grundrechte und Zivilrechtsprechung, S. 167 Fußn.18; s.a. dens., in Maunz-Dürig, Art. 1 Abs. I Randn. 52; Scheuner, Die staatliche Intervention im Bereich der Wirtschaft, S.59; Bachof, Begriff und Wesen des sozialen Rechtsstaats, S.46; Krüger, Diskussionsbeitrag hierzu, Veröffentlichungen der Vereinigung der Deutschen Staatsrechtslehrer, Heft 12, 1954, S. 109 ff (111); Koellreutter, Grundfra. gen des Verwaltungsrechts, S.13; Peters, Kombination verschiedener Verfassungsgrundsätze als Mittel der Verfassungs auslegung, S. 124; Huber, Der Streit um das Wirtschaftsverfassungsrecht, S.202; Claus A rndt, Die Bundesrepublik Deutschland als sozialer Rechtsstaat, S. $331 \mathrm{f}$; Gerber, Die Sozialstaatsklausel des Grundgesetzes, AöR Bd. 81 (1956) S. 1 ff (38 ff, 42, 53); Nipperdey, Lehrbuch des Arbeitsrechts, Bd.II, S. 691 Fußn. 50; Wintrich, Die Bedeutung der Menschen würde für die Anwendung des Rechts, S. 140; Ballerstedt, Wirtschaftsverfassungsrecht, S. 55 ff; Rumpf, Der ideologische Gehalt des Bonner Grundgesetzes, S. 33 f; Maunz, Deutsches Staatsrecht, S.97; Schneider, Die öffentlichrechtliche Alterssicherung der freien Berufe und das Grundgesetz, S. 23 f; BVerfGE 4, 219 (234 f); VGH Freiburg, Urteil v. 12. September 1955 - 49/53 - JZ 11.Jhg. (1956) S. 18 (25); Bayerisches Landessozialgericht, Urteil v. 7. Oktober 1955 Kr 82/55 - BayAMB1. 1956 B S. 59 (61). 
muß - sonst kann er das nicht leisten - auch im allgemeineren Sinn ein sozialgestaltender, gesellschaftszugewandter Staat sein. 10) Er kommt aber auch nicht aus, ohne die Gemeinschaftsgebunclenheit und -bezogenheit aller Bürger - derjenigen, denen geholfen werden soll, und auch und gerade der anderen - zu aktivieren; denn nur auf dieser Grundlage kann er seiner engeren "sozialen" Aufgabe gerecht werden. 11) Wird der Sozialstaat dagegen wesentlich als der (im allgemeinen Sinn) gesellschaftsgestaltende und gesellschaftszugewandte Staat verstanden, so schließt er die beiden anderen Elemente nur potentiell, nicht notwendig ein. Gesteigerte Gesellschaftsingerenz des Staates ist nur bedingt mit einer gesteigerten Gemeinschaftsbindung der Individuen gekoppelt. Vor allem aber die im engeren Sinne soziale Zielbestimmung der gesellschaftsgestaltenden Staatswirksamkeit ist in diesem allgemeinsten Sozialstaatsbegriff als die speziellere in der allgemeineren Kategorie nicht notwendig mitenthalten. Wird der Sozialstaat schließlich primär im Sinne der Gemeinschaftsbindung der Bürger begriffen, so liegt darin zwar eine gewisse Inklination sowohl zum Sozialstaat im allgemeinsten wie auch zum sozialen Staat im engeren, historisch-konkreten Sinn. Aber keiner von beiden ist darin eingeschlossen. Der Sozialstaatsbegriff stößt also nur dann entscheidend in Richtung auf den sozialen Wohlstandsausgleich und die soziale Hilfe für die schwächeren Glieder der Gesellschaft vor, wenn er unmittelbar und in erster. Linie auf der Grundlage des historisch-konkreten, politischen, landläufigen Sozialbegriffes verstanden wird. Der allgemeinere, neutrale Sozial- und Sozialstaatsbegriff gibt diese "soziale" Stoßkraft ebenso preis wie ein wesentlich auf der Gemeinschaftsverpflichtetheit der Bürger aufbauender Sozial- und Sozialstaatsbegriff, während der engere, historisch-konkrete Sozial- und Sozialstaatsbegriff zwar mittelbar aber zwingend auch auf diese staatswesensbestimmenden Elemente zuführt.

Diese Grundposition leterminiert die Interpretation des Sozialstaatsbegriffes in höchst bedeutsamer Weise. Jede Auslegung, die vom historisch-konkloten, politischen Sozialbegriff abgehen und sich einem allgemeineren Sozialbegriff zuwenden will, muß sich die Frage vorlegen, ob gerade der darin liegende Verzicht auf die definitive Hereinnahme der engeren konkreten Sozial-

10) S. z.B. Dürig, Verfassung und Verwaltung im Wohlfahrtsstaat, S. 196; Wolff, Verwaltungsrecht I, S. 44; in diesem Sinne wohl auch Bachof, Begriff und Wesen des sozialen Rechtsstaats, \$. 39 f, 80; Bruno Molitor, Sozialpolitik im sozialen Rechtsstaat, S. $102 \mathrm{ff}$.

11) S. z.B. Schneider, a.a.O. S. $23 \mathrm{f}$. 
staatsbestimmung in die Verfassung erträglich erscheint.

b) Die Auslegung im Sinne des historisch-konkreten "sozial" Begriffes

a) Das Wort "sozial"

Schon eine allein am Sinn des Wortes "sozial"1) orientierte Interpretation zeigt, in welcher Richtung die Antwort liegt. Der Sozialstaatsbegriff ist auch als Verfassungsbegriff ein politischer Begriff. Der historisch-konkrete politische Gebrauch des Wortes "sozial" steht ihm somit von vorneherein am nächsten. Die ausschließliche Unterstellung der allgemeineren, abstrakten Sozialbegriffe wirkt vergleichsweise fremd und gekünstelt. Das gilt nicht nur für die Gleichstellung sozial = gesellschaftlich sondern auch und ganz besonders für die Verwendung der Vokabel "sozial" zur Bezeichnung der Gemeinschaftsgebundenheit und der. Einordnung des einzelnen in das gesellschaftliche Ganze. ${ }^{2}$ )

Selbst soweit das Wort "sozial" mehrdeutig verwendet wird, wird es weitgehend und zwar integrierend wenigstens a $\mathrm{uch}$ im historisch-konkreten politischen Sinn verstanden. Auch ein weitherziger Sprachgebrauch kann daher nicht ohne weiteres als Beweis für eine Wortauslegung herangezogen werden, der von mehreren möglichen Sinngehalten gerade diesen historisch-konkreten eliminieren würde.

Am Rande darf erwähnt werden, daß das Grundgesetz selbst das Wort "sozial" in den Wortzusammensetzungen "Sozialversicherung" (Art. 74 Nr.12, 87 Abs.2, 120 Abs. 1 GG) und "Sozialgerichtsbarkeit" (Art.96 Abs.1 GG) in einem eindeutig historischkonkret geprägten, mit dem herkömmlichen Wortverständnis des Wortes "sozial" parallel laufenden Sinn verwendet.

\section{1) S. oben S. 18 .}

2) Dersch (Der Verfassungsgrundsatz der Sozialstaatichkeit und der Rechtsstaatlichkeit in der Praxis der Sozialversicherung, $\mathrm{S} .63 \mathrm{f}$ ) konstatiert, es widerspreche dem herrschenden Sprachgebrauch, "sozial" als soziale Gebunclenheit zu verstehen. S.a. v. Mangoldt-Klein, Art. 20 Anm. VII 3. Auch Jerusalem (Besprechung zu "Fechner, Freiheit und Zwang im sozialen Rechtsstaat", NJW 7.Jhg. (1954) S.263) und ihm folgend Hamann (Das Grundgesetz, Einführung I D 2 (S. 32)) stellen fest, das "Soziale" bestehe nicht in der Einordnung in den Staat. Das trifft in dieser Allgemeinheit nicht zu. Richtig ist jedoch, daß dieser Wortsinn dem allgemeinen Sprachgebrauch nicht sehr nahe liegt. Wie schon einmal erwähnt, ist mehr seine Kehrseite ("asozial") geläufig. 
bb) Die Wortfügung vom sozialen Staat

Als Bestandteil der Formeln vom "demokratischen und sozialen Bundesstaat" und vom "republikanischen, demokratischen und sozialen Rechtsstaat" bezieht sich das Wort "sozial" adjektivisch in erster Linie auf das Substantiv "Staat". Diese Wortverbindung drängt erneut in die eingeschlagene Richtung. Den "sozialen Staat" als den Staat des helfenden, sozialen Ausgleichs zu ver'stehen, liegt weitaus näher, als hinter dieser Wendung nur den - ohne nähere Bestimmung - gesellschaftsingerenten Staat zu sehen oder nur den Staat, der die Gemeinschaftsbindung seiner. Bürger aktiviert.

Es ist sicher nur um ein weniges zu viel gesagt, den allgemeineren, lediglich die Sozialgestaltungskompetenz des Staates bejahenden Sozialstaatsbegriff als einen Pleonasmus zu bezeichnen. 1) Die Frage, ob der Staat befugt sein soll, in die gesellschaftlichen Verhältnisse einzugreifen, stellt sich - jedenfalls bis zur Grenze grundsätzlicher Verneinung - gegenwärtiger Verfassungsgestaltung im Ernst nicht und stellte sich ihr in Anbetracht der Zeitumstände auch 1948/49 nicht, obwohl das Grundgesetz in einer Zeit geschaffen wurde, in der als Reaktion auf den überwundenen totalen Staat die Virulenz alt-rechtsstaatlicher Ideen 2) hier und dort zutage trat. Jedenfalls war sie von weitaus geringerer Aktualität als das Problem der sozialen Hilfestellung des Staates für ein Staatsvolk, das in seiner Masse krasse Not litt, und blieb sie dem allgemeinen Bewußtsein fremd. Gegenwärtiges Staatsverständnis hält sich nicht bei der Entscheidung auf, ob der Staat das gesellschaftliche Geschehen bestimmend regulieren oder es sich autonom selbst überlassen soll. Es befaßt sich unmittelbar mit Inhalt und Modalität der Sozialgestaltung. Aber selbst wenn der Grunlgesetzgeber eine gesonderte Klarstellung jenes allgemeinen "ob" für nötig gehalten hätte, hätte er wohl kaum zur. Wendung vom "sozialen Staat" gegriffen, die doch im politischen sprachgebrauch einen viel spezielleren Sinn hat.

Noch weniger als für dicso allgemeinste Sozialstaatsdeklaration spricht die konkrete Staatshezogenheit des Wortes "sozial" für eine ausschließliche Deutung im Sinne betonter Gemeinschaftsgebundenheit der Individuen. Das (irundgesetz spricht vom "sozialen Staat", nicht von einem - wie es mutatis mutandis korrekterweise heißen müßte - "Staat sozialer Bürger". Das Grundgesetz ist die Verfassung eines Staates, der einem totalitären Staatswe-

1) So Menger, Der Begriff des sozialen Rechtsstaats im Bonner Grundgesetz, 5. 24 .

2) S. oben S. 396. 
sen nachfolgte und von Geburt an mit der Liquidation des totalitären Zuviel an "Gemeinschafts" - Verpflichtung des "Volksgenossen" befaßt war. Wie wäre es verständlich, wenn gerade diese Verfassung einseitig wieder die Verpflichtung und Bindung des Individuums konstatiert hätte, ohne wenigstens eine Gegenpflicht des Staates zu begründen? Wo anders aber hätte diese Gegenpflicht ihren Ausdruck gefunden als in der Sozialstaatsproklamation?

\section{cc) Der soziale Bundesstaat}

Das Grundgesetz spricht allerdings an keiner Stelle isoliert vom "sozialen Staat" sondern nur vom "sozialen Bundesstaat" (Art.20 Abs. $1 \mathrm{GG}$ ) und vom "sozialen Rechtsstaat" (Art.28 Abs. 1 Satz 1 GG). Doch besagt das nichts Gegenteiliges.

Der "soziale Bundesstaat" hat keine spezifische kombinatorische Bedeutung. 1) Dieser vom Grundgesetz verfaßte Bundesstaat soll eben - als Staat - sozial sein. Zwar wäre es nicht ausgeschlossen, die Bundesstaatlichkeit als Manifestation einer umfassenden "föderativen", in Gliederung und Subsidiarität beruhenden Soziallehre zu verstehen und im "sozialen Bundesstaat" den normativen Ansatzpunkt für ihre weitergehende, staats- und gesellschaftsgestaltende Verwirklichung zu sehen. ${ }^{2)}$ Aber die sprachliche Form entspricht diesem Sinngehalt nicht. Vor allem auch der parallelen Kombination des "sozialen Rechtsstaates" könnte diese Deutung nicht gerecht werden. Der "soziale Rechtsstaat" wurde aber in Art. 28 Abs. 1 Satz 1 GG nicht nur äußerlichtextlich gleichberechtigt in das Grundgesetz aufgenommen. Schon der parlamentarische Rat hat vielmehr im Rahmen des Entwurfes des jetzigen Art.20 GG ${ }^{3)}$ die Formeln "sozialer Rechtsstaat", 4)

1) S. Scheuner, Grundfragen des modernen Staates, S. 154; Schüle, Diskussionsbeitrag zu "Begriff und Wesen des sozialen Rechtsstaats", S. 106; v. Mangoldt-Klein, Art. 20 Anm. VII 1; Schlochauer, Öffentliches Recht, S. 14; Maunz, Deutsches Staatsrecht, S. 60.

2) Sehr weitgehend in dieser Richtung Fechner, Sozialer Rechtsstaat und A rbeitsrecht, S.163. - S. hierzu auch v. Mangoldt-Klein und Maunz je a.a.O.

3) Vgl. Doemming-Füsslein-Matz, Entstehungsgeschichte der Artikel des Grundgesetzes, S. 195 ff.

4) ebenda, S. 195 f. - Im Rahmen des Entwurfs des Art. 28 Abs. $1 \mathrm{GG}$ wurde von vorneherein ausschließlich die Formulierung des "sozialen Rechtsstaates" verwendet (s. ebenda S. $244 \mathrm{ff})$. 
"soziale Republik", 5) "soziale Bundesrepublik" 6) und "sozialer Bundesstaat" 7) ohne nähere Begründung ausgetauscht und somit offenbar für vertauschbar gehalten. Dieser Umstand hält auch schon wieder davon ab, der Formel vom "sozialen Bundesstaat" um jeden Preis einen spezifischen kombinatorischen Gehalt entlocken zu wollen.

Aber gibt nicht die Detailgestaltung der bundesstaatlichen Ordnung durch das Grundgesetz wenigstens einen Hinweis darauf, in welchem Sinne dieser Bundes-Staat ein sozialer Staat sein soll? Die grundgesetzliche Aufgaben- und Mittelverteilung, die oben schon dargelegt wurde, ${ }^{8}$ ) steht ganz eindeutig auf dem Boden eines umfassenden Sozialgestaltungsauftrages des Staates, in dessen Rahmen sie jedoch nicht zuletzt ein vielfältiges Tätigwerden des Staates in Richtung sozialer Hilfe und sozialen Ausgleichs in Rechnung stellt. 9) Schließlich enthält sie aber auch eine Reihe von Agenden, die nur dann oder nur dadurch angepackt werden können, wenn bzw. daß der einzelne zugunsten der Gemeinschaft in Anspruch genommen wird.

Trotzdem steht die bundesstaatliche Ordnung der Interpretation der Sozialstaatserklärung nicht indifferent gegenüber. Schon dadurch, daß sie Elemente der drei als wesentlich aufgewiesenen Sozialstaatsdeutungen verbindet, führt sie auf jene Interpretation hin, die die Sozialverpflichtung des Staates im Sinne der historisch-konkreten Sozialbewegung als primär ansieht und rückschließend den allgemeinen Sozialgestaltungsauftrag ebenso einbezieht wie die Gemeinverpflichtung des Individuums. Noch deutlicher wird die Affinität der bundesstaatlichen Aufgaben- und Mittelverteilung zu diesem Sozialstaatsbegriff durch einen anderen Gedankengang. Wird nämlich die bundesstaatliche Ordnung, soweit sie gegenständlich konkretisiert ist, als eine Aufzählung möglicher Betätigungsobjekte des Bundes und - wenigstens teilweise auch - der Länder verstanden, so genießt dieser Aufzählung gegenüber die Sozialstaatserklärung dann die größte Effektivität, wenn sie im Sinne des historisch-konkreten Sozialbegriffes verstanden wird. Der allgemeine Sozialgestaltungsauftrag des Staates läßt sich aus den aufgezählten Agenden erschließen. Wenn die Zuständigkeitskataloge für die Gesetzgebung und die sonstigen bundesstaatlichen Aufteilungsnormen auch nicht den $Z$ weck haben, das

5) ebenda, S. $196 \mathrm{ff}$.

6) ebenda, S.199.

7) ebenda, S. $200 \mathrm{f}$.

8) S. oben Abschn. 1 (S. $45 \mathrm{ff}$ ).

9) S. insbes. Abschnitt 1 I 1 (S. 45 ff). 
entsprechende staatliche Tätigwerden an sich als ein staatliches zu legitimieren und zu regulieren, 10) sondern vielmehr die Zuständigkeit für den Fall des 'Tätigwerdens bestimmen, so sind sie doch ein Beweis dafür, welche Tätigkeiten der Verfassungsgeber für möglich gehalten hat. Ausschließlich - oder neben der Bedeutung als allgemeiner. Sozialgestaltungsauftrag - als betonte Gemeinverpflichtung des Individuums verstanden, würde die Sozialstaatsklausel ebenfalls nur etwas sagen, was die Kompetenzordnung als Inhalt oder Prämisse staatlichen Tätigwerdens schon voraussetzt (und sich im übrigen vor allem in dem Gegenüber staatlicher Gesetzgebungsmacht und grundrechtlicher Ausgrenzungen manifestiert). Auch eine Pflicht der zuständigen Kompetenzträger, den Sozialgestaltungsauftrag des Staates - der ja viel zu allgemein ist, um als mehr als eine Funktionsbestimmung gewertet werden zu dürfen - zu realisieren oder die Gemeinverpflichtung des Individuums za aktivieren, kann einer so verstandenen Sozialstaatserkklärung nicht entnommen werden, so daß auch nicht dergestalt ein Zusammenhang mit der Kompetenzordnung besteht, daß die in ihr genannten, entsprechenden Möglichkeiten staatlicher Betätigung wirklich genutzt werden. Im Gegensatz dazu hebt sich die im Sinne des historisch-konkreten Sozialbegriffes verstandene Sozialstaatserklärung in doppelter Hinsicht ergänzend von der bundesstaatlichen Kompetenzordnung ab: Sie sagt, indem sie den Staat dazu anhält, sozial helfend und ausgleichend tätig zu werden, mehr aus als eine notwendige Prämisse der Kompetenzordnung; und sie effektuiert wenigstens die Kompetenznormen tendenziell, die sich mit Fragen der sozialen Intervention befassen.

dd) "Demokratisch und sozial"

Eine bedeutsame innere Verbindung besteht zwischen den Epitheta "demokratisch" und "sozial", die in Art. 20 Abs. 1 und 28 Abs. 1 Satz 1 GG dem Bundes- bzw. Rechtsstaat beigelegt sind. Ist doch die Idee des Wohlstandsdifferenzen ausgleichenden, für eine gerechte Teilhabe auch der. Schwächeren sorgenden Sozialstaats in ihrem ökonomischen Bereich eine gewisse Entsprechung zur demokratischen Idee der gleichheitlichen Teilhabe aller an der Macht. 1) Doch korrespondiert auch eine betonte Aktivierung der

10) Auf systematische Entgleisungen wie diejenige des Art.73 Nr. 1 GG ist hier nicht einzugehen.

1) S. insbes. Abendroth, Diskussionsbeitrag zu "Begriff und IVesen des sozialen Rechtsstaats", S. 85, 87 f, 90; ders., Zum Begriff des demokratischen und sozialen Rechtsstaates im Grundgesetz für die Bundesrepublik Deutschland, S.91, 
Gemeinschaftsstellung und - bezogenheit des Individuums, das in der Demokratie das Schicksal der staatlichen Gemeinschaft verantwortlich mitträgt, mit der demokratischen Herrschaftsstruktur. ${ }^{2)}$ Nur die dritte der möglichen Deutungen, der bloße allgemeine Sozialgestaltungsauftrag, findet dagegen hier keinen besonderen Anhaltspunkt.

\section{ee) Der soziale Rechtsstaat}

\section{aaa) Sozialstaatsdeklaration und Rechtsstaatsprinzip}

Die kompliziertesten, hier wohl bedeutsamsten Verbindungen und Antipositionen spricht jedoch die Formulierung vom "sozialen Rechtsstaat" (Art.28 Abs. 1 Satz 1 GG) 1) an.

Sie enthielte eine unauflösliche Antinomie, wenn der "Rechtsstaat" im Sinne der älteren materiellen Rechtsstaatslehre 2) auf den Rechtszweck beschränkt sein, das Adjektiv "sozial" demgegenüber den allgemeinen staatlichen Sozialgestaltungsauftrag oder die Pflicht des Staates zu sozialem Ausgleich und sozialer Hilfe zum Ausdruck bringen soll. Das "Soziale" im Sinn gesteigerter Gemeinschaftsbindung stünde neben dem "Rechtsstaat" dieser Art zumindest reichlich fremd da. Doch handelt es sich, wie dargetan, 2) bei der Bundesrepublik nicht um einen materiellen Rechtsstaat älterer Provenienz sondern um einen formellmateriellen Rechtsstaat im Sinne der jüngeren Lehre. Dieser ist für ein (allgemein) sozialgestaltendes Wirken des Staates durchaus offen; hebt er sich doch von der älteren materiellen Rechtsstaatsauffassung gerade dadurch $a b$, daß er deren Beschränkung des Staates auf den - in seiner inneren Unklarheit und notwendi-

$93 \mathrm{f}, 98$. - Aus dem vorgrundgesetzlichen Schrifttum s.

Heller, Rechtsstaat oder Diktatur? insbes. S. 7, 11. - S. ferner oben Abschnitt 3 ( $\$ .315 \mathrm{ff})$, insbes. I 1 a $(\mathrm{S} .315 \mathrm{ff})$ und 2 (S.329 ff).

2) Vg1. Fechner, Freiheit und Zwang im sozialen Rechtsstaat, S. 22 f; Bachof, Begriff und llesen des sozialen Rechtsstaats, S. $46 \mathrm{ff}$.

1) Dazu, daß in den Entwüıf $€ \cdot n$ zu dem jetzigen Art.28 Abs.1GG nie eine andere Formulierung des sozialen Staates in Frage stand, während zu Anfang der einschlägigen Beratungen des parlamentarischen Rates der "soziale Rechtsstaat" auch in den Vorläuferbestimmungen des Art.20 Abs.1 GG zu finden war, s. nochmals Doemming-Füsslein-Matz, Die Fntstehungsgeschichte der. Artikel des Grundgesetzes, S. 195 ff, $250 \mathrm{ff}$.

2) S. oben S.396 ff. 
gerweise meist gequälten Ausdehnung hier nicht zu würdigenden "Rechtszweck" nicht teilt.

Sollte aber nicht gerade das durch die Sozialstaatserklärung klargestellt werden? Dagegen spricht zu vieles. Zunächst ist noch einmal 3) daran zu erinnern, daß schon das Wort "Sozialstaat" in diesem Sinne ganz ungewöhnlich gebraucht wäre - jedenfalls, wenn es nur die Negation der Beschränkung auf den Rechtszweck und damit korrespondierend die Bejahung des allgemeinen Sozialgestaltungsauftrages zum Ausdruck bringen soll. Vor allem war die Negation der älteren materiellen Rechtsstaatslehre nicht eine der polemischen Positionen des Grundgesetzes. Zwar war, indem nach 1945 rechtsstaatliche Hoffnungen aufkeimten, nicht immer dasselbe gemeint. Auch die Erwähnung des Rechtsstaates im Grundgesetz mag Leser gefunden - und vielleicht sogar Mit-"Autoren" im parlamentarischen Rat gehabt - haben, die darin über die Machtbeschränkung des Staates hinaus auch eine $Z$ weckbeschränkung des Staates sahen. Aber diese altrechtsstzatlichen Reminiszenzen waren doch nie von einer Kraft, die eine ausdrückliche und nur diesem $Z$ weck dienende deklamatorische Zurückweisung in der Verfassung nötig oder auch nur verständlich hätte werden lassen.

Viel mehr wartet der moderne Rechtsstaat darauf, mit materiellen Gehalten normativ erfüllt zu werden, 4 ) und zwar gerade auch hinsichtlich seiner sozialgestaltenden Wirksamkeit. Die Substanziierung der (rechtsstaatlichen) Sozialgestaltung als "sozial" im engeren historisch-konk reten Sinn würde diesem Ergänzungsbedürfnis des rechtsstaatlichen Systems sehr wohl entsprechen. In der engeren, durch die Gleichung Rechtsstaat = Gerechtigkeitsstaat 5 lokalisierten Sphäre zeigt sich das ebenfalls. Das allgemeine Gerechtigkeitsprinzip bedarf der "Materialisierung", der Verankerung in der hic et nunc bewußten Wertordnung und in der konkreten Sachwelt. Die Sozialstaatserklärung ist - wird sie im engeren historisch-konkreten Sinn verstanden - geeignet, hierzu beizutragen.6) Der allgemeine Sozialgestaltungsauftrag kann in dieser Richtung so gut wie nichts leisten.

Anders steht es hinsichtlich der interpretatorischen Konkurrenz der Sozialstaatserklärung qua historisch-konkret verstandene So-
3) S. oben S. 685 .
4) S. oben S. $396 \mathrm{ff}$.
5) S. oben S. 663 .
6) S. außer dem oben Abschnitt 4 II 3 (S.508 ff) Ausgeführten und den dortigen Nachweisen noch Dürig, Verfassung und Verwaltung im Wohlfahrtsstaat, S. 196. 
zialverpflichtung des Staates und der Sozialstaatserklärung qua Konstituierung der Gemeinschaftsgebundenheit des Individuums. Diese kann an sich schon zur "Materialisierung" der Gerechtigkeit beitragen, wenn sie in dieser Richtung auch weitaus kräftiger zu wirken vermag, soweit sie als ein Reflex der Sozialverpflichtung der Gemeinschaft verstanden und somit ihrerseits substanziiert wird. Im weiteren Zusammenhang des modern-rechtsstaatlichen Verfassungssystems kann sie zwar keine zentrale Stellung einnehmen. Das Schema der Verteilung zwischen verfassungsgeschützter Eigensphäre und gesetzgeberischer Legitimation, den Bürger (im übrigen) in Anspruch zu nehmen, involviert an sich die Pflicht des einzelnen, außerhalb seiner verfassungsrechtlich geschützten Eigensphäre den ihm auf Grund Gesetzes oder durch Gesetz auferlegten Pflichten und Belastungen zu entsprechen. ${ }^{7)}$ Aber immerhin trifft die Betonung der Gemeinschaftsverpflichtung auf einen sehr empfindlichen Nerv gewisser überspitzter Rechtsstaatsvorstellungen, die das Individuelle dem Gemeinschaftlichen über Gebühr vorziehen. Hierüber ein Wort zu verlieren, das vor allem die Auslegung der grundrechtlichen Grenznormen über die Verteilung $z$ wischen Individual- und Gemeinsphäre beeinflussen könnte, hätte der Grundgesetzgeber durchaus Anlaß nehmen können. Im engeren Zusammenhang der Sozialverpflichtung des Staates und als Reflex auf diese besagt die Sozialstaatserklärung das nicht mit derselben Allgemeinheit obschon für einen sehr wichtigen und weit ausgreifenden Sektor und mit größerer Bestimmtheit.

bbb) Sozialstaatsdeklaration und materiell-rechtsstaatliche Grundordnung

1. Sozialstaatsdeklaration und Grundrechte. Die materielle Substanz moderner Rechtsstaatlichkeit ist vor allem in den Grundrechten zu sehen. Die Frage, inwieweit die Grundrechtsordnung des Grundgesetzes Anlaß gibt, die eine oder andere Auslegung der Sozialstaatsklausel zu bevorzugen, steht also in unmittelbarem Zusammenhang mit dem Gesamtbegriff des "sozialen Rechtsstaats".

Sie führt zuerst auf die Suche nach den grundrechtlichen Substanzen, die eine evidente Affinität zum allgemeinen Sozialgestaltungsauftrag des Staates (vg1. Art. 7, 13 Abs. 3 GG), zum sozialen Ausgleich und zur Hilfeleistung für die Schwächeren durch den Staat (vg1. Art. 3 insbes. Abs. 3 GG) oder zu beiden haben (Art. 1 Abs. 1,

7) Zum Befeh1 zur Befolgung der Verfassung s. oben S. $17 \mathrm{zu}$ Fußn. 57. 
6, 7 Abs. 6, 11 Abs. 2, 14, $15 \mathrm{GG}$ ), aber auch solchen, die eine besondere Gemeinschaftsbindung hervortreten lassen (Art.2 Abs. 1, 14 Abs. 2, 15 GG). Sie vertragen sich mit jeder Sozialstaatsinterpretation, ohne eine $z u$ bestätigen. Wenn sie nach einem allgemeinen Prinzip drängen, so noch am ehesten nach dem allgemeinen Sozialgestaltungsauftrag des Staates. Aber das bedeutet - um es noch einmal zu wiederholen - nicht, daß die Sozialstaatserklärung ausschließlich oder auch nur primär in diesem Sinne zu deuten ist. Das enger verstandene Sozialstaatsprinzip kann vielmehr als - zweifellos stärkerer - Beweis für die verfassungsimmanente Existenz des allgemeinen Sozialgestaltungsauftrages diesen grundrechtlichen Argumentationsbasen parallel geschaltet werden. Im übrigen - d.h. in Richtung auf den histo$r$ isch-konkreten Sozialstaatsbegriff und auf den Sozialstaatsbegriff als Ausdruck gesteigerter Gemeinschaftsbindung - drängen die vorhandenen grundrechtlichen Ansätze nicht zwingend danach, als Emanationen oder Korrelate des einen oder anderen Sozialstaatsprinzips verstanden zu werden.

Weiter führen kann nur der Blick auf die Fragen, die das Grundgesetz nicht oder nicht eindeutig entscheidet. Ist das Sozialstaatsprinzip in dem einen oder anderen Sinn als Komplement der Grundrechtsordnung notwendig? Auch hier drängt sich, als der nächstliegende, der Gedanke an den allgemeinen Sozialgestaltungsauftrag auf. Ist er nicht überhaupt schon deshalb mit den Grundrechten mitgedacht, weil der umfassende, ausgrenzende Grundrechtsschutz, wie ihn clas Grundgesetz gewährt, überhaupt nur einem Staat gegenüber notwendig erscheint, der sich nicht auf den besagten Rechtszweck beschränkt? Oder eine konkretere Frage: Bedarf es nicht der Anerkennung des allgemeinen Sozialgestaltungsauftrages als Bestandteil der "verfassungsmäßigen Ordnung", damit die für Gemeinschaft und Individuum notwendige Gestaltungsmacht des Staates nicht von Art. 2 Abs. 1 GG her erstickt wird? Es ist eine Frage der Auslegung des Art. 2 Abs. 1 $\mathrm{GG}$, ob nicht jedes sonst verfassungsmäßige Gesetz auch ohne cinen besonderen "Auftrag" Bestandteil der verfassungsmäßigen Ordnung ist - eine Frage, auf die zurückzukommen sein wird, auf die es hier aber nicht ankommt. Selbst wenn sie zu bejahen wäre, würde das noch nicht besagen, daß dieser allgemeine Sozialgestaltungsauftrag die Sozialstaatserklärung konsumiert, ohne für deren speziellere Deutung Raum zu lassen. Dieser allgemeine Sozialgestaltungsauftrag ist eben unausweichliche, verfassungsimmanente Prämisse der ganzen Verfassungsordnung - soll sie als Staatsgrundordnung ernst genommen werden dürfen und leistungsfähig sein; mag man sie äußerlich-verbal in der Sozialstaatserklärung mit ansiedeln oder nicht. Die Frage muß viel- 
mehr lauten, ob die Sozialstaatserklärung als Grundsatz der sozialen Hilfe oder als Grundsatz der Gemeinschaftsbindung - in seinen beiden engeren Bedeutungen also - von der Grundrechtsordnung her erforderlich oder verzichtbar erscheint. Diese Frage kann nicht von der Grundrechtsordnung her sondern endgültig nur von außen beantwortet werden. In dem einen und (oder) dem anderen Sinn könnte das Sozialstaatsprinzip als ein die Grundrechtsordnung überlagerndes und ihren individualistischen Charakter über die in ihr enthaltenen, ausdrücklichen Vorbehalte hinaus immanente Schranken zwingend sichtbar werden lassendes, moderierendes Auslegungsprinzip seine Bedeutung haben.

2. Sozialstaatsdeklaration und Grundpflichten. Die Grundrechte lenken die Aufmerksamkeit auf ihr (scheinbares) Gegenstück: die Grundpflichten. Das Grundgesetz statuiert besondere Grundpflichten, wie sie z.B. die Weimarer Verfassung in ihren Art. 132 - 134 enthielt, nicht. 1) Ist nun nicht im Sozialstaatsprinzip dergestalt ihr Surrogat zu sehen, daß es als soziale Inpflichtnahme der Individuen zu deuten ist? ${ }^{2)}$

Grundpflichten können als eigenständig wirksame Verfassungsrechtssätze nur sein entweder einzelne, konkrete Pflichten (echte Grundpflichten) oder verfassungsrechtliche Regulative für die durch Gesetz zu begründenden Pflichten (unechte Grundpflichten). ${ }^{3)}$ Sie können ferner bestimmte, durch Gesetz zu begründende Pflichten hervorheben und so der gesetzlichen Regelung gegenüber den rechtsstaatlichen Abwehrrechten interpretatorisch Bahn brechen. 4) Schließlich aber kann ein allgemeiner Pflichtstellungsgrundsatz aufgestellt werden, der,abgesehen davon, daß er die Pflicht des einzelnen dokumentiert, den Gesetzen und gesetzmäßigen Individualbefehlen zu folgen, ganz allgemein die immanente Gemeinschaftsbindung der gewährten Rechte klarstellt. Immer gilt, daß Grundpflichten "nur dann Pflichten im positiv-recht1ichen Sinn sein (können), wenn sie begrenzt sind. Prinzipiell unbegrenzte Pflichten würden cler Ilee des bürgerlichen Rechtsstaates

1) S. hierzu z.B. v. Mangoldt-Klein, Vorbem.B XI (S.110 ff); Maunz, Deutsches Staatsrecht, S. $87 \mathrm{ff}$.

2) S. hierzu auch nochmals Fechner, Freiheit und Zwang im sozialen Rechtsstaat, S. $14 \mathrm{ff}$.

3) Typisch Art. 134 RV 1919: "Alle Staatsbürger ohne Unterschied tragen im Verhältnis ihrer Mittel zu allen öffentlichen Lasten nach Maßgabe der Gesetze bei".

4) S. z.B. die Pflicht zur Übernahme von Ehrenämtern und zur persönlichen Dienstleistung "nach Maßgabe der Gesetze" (Art.132, 133 RV 1919). 
widersprechen" 5 )

Eine echte Grundpflicht ergibt die Sozialstaatsdeklaration unter keiner Auslegung. Sie ist zu allgemein und unbestimmt. 6) Ausschließlich als allgemeiner Sozialgestaltungsauftrag des Staates gedeutet, umschließt sie zwar den Hinweis darauf, daß auch die diesen Sozialgestaltungsauftrag gestaltenden sonstigen Verfassungssätze und die in seiner Erfüllung ergehenden Gesetze und anderen unterverfassungsrechtlichen Staatsakte, soweit sie der Verfassung entsprechen, zu befolgen sind. Doch fügt sie damit der jeder Verfassung immanenten "einzigen eigentlichen rechtlichen Grundpflicht", der Pflicht zur Befolgung der Verfassung und der Gesetze, 7) nichts hinzu. Als allgemeines Prinzip der gesteigerten Gemeinschaftsbindung stellt sie dagegen immerhin zusätzlich die Gemeinschaftsbindung der gewährten individuellen Rechte klar. Gemäß dem historisch-konkreten Sozialbegriff gedeutet ergibt die Sozialstaatsdeklaration schließlich jene spezielle Soziabilitätsverpflichtung des einzelnen, die der staatlichen Hilfs- und Ausgleichspflicht notwendigerweise entspricht. Sie vermag als interpretatorisch bedeutsamer Schrittmacher der in Erfüllung der Sozialstaatlichkeit begründeten bzw. zu begründenden Pflichten gegenüber den Abwehrrechten des einzelnen aber auch als Regulativ für die Gestaltung der seitens des Staates zu begründenden Pflichten zu wirken. Während sie in dieser Auslegung spezieller und effektiver ist, ist sie als allgemeines Prinzip der gesteigerten Gemeinschaftsbindung universell.

Als allgemeiner Sozialgestaltungsauftrag kann die Sozialstaatsdeklaration die einer ausdrücklichen Grundpflichtsordnung entbehrende Verfassung also nicht komplettieren. Ob sie dagegen a1s allgemeiner Ausdruck einer gesteigerten Gemeinschaftsverpflichtung der Individuen oder als - historisch-konkret gemeinte "soziale" Soziabilitätspflicht zu verstehen ist, kann vom Mangel einer Grundpflicht und dem Bedürfnis, ihm abzuhelfen, her nicht entschieden werden, wenngleich die Zusammenhänge dieses näher legen als jenes. Die Notwendigkeit eines allgemeinen Prinzips gesteigerter Sozialbindung besteht nicht. ${ }^{8)}$ Dagegen kann

5) Carl Schmitt, Verfassungslehre, S. 174.

6) S.a. unten 2 c-e (S. 726 bis S. 734 ).

7) Thoma, Die juristische Bedeutung der grundrechtlichen Sätze der deutschen Reichsverfassung im allgemeinen, in: Nipperdey, Grundrechte und Grundpflichten der Reichsverfassung, Bd.I, 1929, S. 1 ff $(2,29)$. S. zu dieser Pflicht auch oben S. 17 zu Fußn. 57.

8) S.a. oben S. 690 und S.692. 
ein spezieller historisch-konkret verstandener Sozialauftrag des Staates nicht ohne eine entsprechende spezielle Soziabilitätspflicht - wie sie in diesem Maße auch aus einem allgemeinen Prinzip gesteigerter Gemeinverpflichtung nicht entnommen werden kann - verwirklicht werden.

\section{Die Sozialstaatsdeklaration als Surrogat} einer verfassungsrechtlichen Sachordnung. Die materielle Rechtsstaatsordnung kann das Verhalten des Staates, insbes. seine Gesetzgebung, nicht nur, wie vorwiegend durch die Grundrechte, ausgrenzend beschränken sondern auch - und zwar nicht nur durch die Vorwegnahme gewisser Grundpflichten, auf deren Inanspruchnahme der Staat durch ihre Existenz verwiesen wird - positiv lenken. Die Möglichkeiten einer rechtsstaatlichen Verfassung in dieser Richtung sind beschränkt, 9) aber bestehen. Die Weimarer Verfassung ${ }^{10)}$ und zahlreiche Länderverfassungen zeigen, wie weitgehend die materielle Grundordnung ausgebaut werden kann. (Auf den Grad der Effektivität darf es hier zunächst nicht ankommen.) Die entsprechenden Ansätze im Grundgesetz (s. z.B. Art.6 und 7) sind jedoch bescheiden. Das materielle Hauptgrundrecht des Art. 1 Abs. 1 GG, dem durch dessen Satz 2 eine noch zu erörternde positive Richtung gegeben ist, unterscheidet sich von ausgebauten materiellen Grundordnungen durch das Fehlen konkreter Gestaltgabe. Darin, die materielle Rechtsstaatsordnung in dieser Hinsicht zu ergänzen, liegt die Hauptaufgabe der Sozialstaatsdeklaration. 11) Dieser Aufgabe kann

9) S. oben Abschn. 4 I (S. 396 ff) und unten Abschn. 6 I 3 (S. 848 ff).

10) S. insbes. deren Zweiten Hauptteil und hierin wiederum den $Z$ weiten, Vierten und Fünften Abschnitt.

11) S. nochmals oben S.673 . Zur Surrogatsfunktion des Sozia1staatsprinzips im Verhältnis zu sog. sozialen Grundrechten und dgl. (insbesondere zu den entsprechenden Grundsätzen der Weimarer Verfassung) s. Ipsen, Fnteignung und Sozialisierung, S.75; v. Mangoldt, Das Bonner Grundgesetz (1.Auf1.) Art. 20 Anm. 2 b (mit dem interessanten Hinweis, daß der Ausbau einer sozialen Grundrechtsordnung durch die Aktualisierung der Grundrechte - Art. 1 Abs. 3 GG - unmöglich geworden ist); Berger, Bedeutung und Tragweite des Grundsatzes vom sozialen Rechtsstaat, S.6; Werner, Sozialstaatliche Tendenzen in der Rechtsprechung, S.85; Leibholz, Strukturprobleme der modernen Demokratie, S. 87; Mellwitz, Die Interpretation der Sozialstaatserklärung in der höchstrichterlichen Rechtsprechung, S.249. Kritisch zu diesem Verhältnis 
sie nur gerecht werden, wenn sie mit dem Sinn des Sozialbegriffes der historisch-konkreten, politischen Sozialbewegung erfüllt wird. Mit der allgemeinen Soziabilitätspflicht der Individuen ist für die positive materielle Prädisposition des staatlichen Handelns nichts gewonnen, ebensowenig mit dem Bekenntnis zur allgemeinen Sozialgestaltungskompetenz des Staates. Nur eine konkrete, gegenständliche Orientierung des Sozialstaatsbegriffs kann ihn überhaupt befähigen, in diese Lücke - unvollkommen genug aushelfend einzuspringen.

\section{ff) Zusammenfassende Würdigung}

Die objektiven Auslegungselemente erschließen den Begriff des "sozialen Staates" somit eindeutig als die Konstituierung des sozial helfenden, sozial ausgleichenden Staates - das Wort "sozial" als im Sinne der historisch-konkreten Sozialbewegung zu verstehend.

Unter keinem Gesichtspunkt erwies es sich als richtig, die Sozialstaatserklärung ausschließlich als das Bekenntnis zu dem allgemeinen Sozialgestaltungsauftrag des Staates zu interpretieren. Zwar ist dieser allgemeine Sozialgestaltungsauftrag erteilt. Aber er ist "selbstverständlich". Er zählt zu den immanenten Prinzipien der Verfassung. Neben den zah1reichen anderen Hinweisen auf seine Existenz, die die Verfassung enthä1t, leistet die Sozia1staatserklärung in bezug auf den allgemeinen Sozialgestaltungsauftrag genug, wenn sie ihn, selbst als Aussage über den engeren, historisch-konkreten Sozialauftrag des Staates verstanden, ebenfalls bestätigt - mag man nun gerade in diesem Sozialauftrag den stärksten Anhaltspunkt für die Existenz des (auch) von ihm notwendig vorausgesetzten allgemeinen Sozialgestaltungsauftrags sehen; mag man die verbale Affinität der Formel vom "sozialen Staat" zu dem Grundsatz staatlicher Zuständigkeit zur Gestaltung und Ordnung der gesellschaftlichen Verhältnisse für bedeutsam genug halten, um auch ihn in Art. 20 Abs. 1, 28 Abs. 1 Satz 1 GG zu lokalisieren; und mag man so schließlich das Bekenntnis zur gesellschaftsordnenden und-leitenden Funktion des Staates in die Sozialstaatserklärung mit hineinlesen oder diese doch nur als einen Beweis mehr für ihre verfassungsrechtliche Unterstellung und Anerkennung werten.

(weil Sozialstaatserklärung soziale Grundrechte nicht ersetzen kann): Ipsen, Über das Grundgesetz, S. 14 = Das Grundgesetz in seiner Vorläufigkeit, S. 186; Abendroth, Zum Begriff des demokratischen und sozialen Rechtsstaats in dem Zusammenhang zwischen Art. 151 RV 1919 und dem Sozia:staatsprinzip;s. die Nachweise schon oben S.680 zu Fußn.6. 
Deutlicher tritt eine gewisse Parallelität hinsichtlich der historisch-konkreten Interpretation der Sozialstaatserklärung und ihrer. Deutung als Grundsatz der Gemeinschaftsverpflichtetheit der Gemeinschaftsglieder hervor. Nicht als ob diese Deutung irgendwo so in den Vordergrund träte, daß sie jene zu verdrängen imstande wäre. Vielmehr tritt nur die Frage auf, ob beide Grundsätze in der Sozialstaatserklärung kumulativ enthalten sind oder ob jener der Sozialverpflichtung des Staates vorherrscht und nur das an Sozialverpflichtung der Individuen impliziert, was er notwendig voraussetzt. Die Frage ist im letzteren Sinn zu beantworten. Zwar scheint in der Wort- und Sachverbindung des "sozialen Rechtsstaates" für den Sozialstaatsgrundsatz als Prinzip der individuellen Gemeinverpflichtung Raum zu sein, der nach Ausfüllung verlangt. Aber dieses Argument allein trägt nicht eine Auslegung, die im Verbalen, in dem weiteren Sinnzusammenhang des "sozialen Staates" und in den benachbarten Sinnzusammenhängen des "sozialen Bundesstaates und der "sozialen Demokratie" teils keine Grundlage, teils sogar. Widerspruch findet. Dabei ist zu berücksichtigen, daß die Sozialstaatserklärung als antiindividualistisches, gemeinschaftsrealisierendes Auslegungsprinzip der verfassungsmäßigen Individualrechte nicht unentbehrlich ist. Eine des Wertes der Gemeinschaft für das und gegenüber dem Individuum bewußte Grundhaltung der Verfassung findet sich schon in den Grundrechten selbst angedeutet und kann bei der Auslegung der Grundrechte auch ohne einen ausdrücklichen weiteren Niederschlag in der Verfassung zur Geltung gebracht werden. Im übrigen ist der antiindividualistische "Rückstoß" der staatsverpflichtenden Sozialstaatsdeutung ein gewichtiger Hinweis auf diese Grundposition der Verfassung. Wenn der antiindividualistische "Rückstoß" der historisch-konkret verstandenen Sozialstaatserklärung gerade in dieser Sachrichtung besonders kräftig wirkt, so entspricht das durchaus der Bedeutung des besonderen sozialen Anliegens für die so verfaßte Rechtsgemeinschaft.

\section{gg) Historisch-subjektive Gesichtspunkte}

Zum Schluß noch einen Blick auf die historisch-subjektive Interpretationsbasis. Die Verhandlungen des Parlamentarischen Rates weisen keinerlei Diskussionen über das Staats-Attribut "sozial" auf. 1) Dieses Schweigen ist höchst beredt. Die Formeln vom sozialen Staat - die Grundgesetz gewordenen vom "sozialen Bundesstaat" und vom "sozialen Rechtsstaat" und die Entwurf gebliebe-

1) S. nochmals Doemming-Füsslein-Matz, Die Entstehungsgeschichte der Artikel des Grundgesetzes, S. 195 ff, 244 ff (insbes. S.250 ff). 
nen von der "sozialen Republik" und der "sozialen Bundesrepublik" 2) - erschienen jedenfalls insoweit als unproblematisch als es sich um das Adjektiv "sozial" handelte. Der Wortverwendung muß also ein gängiges, übliches Wortverständnis zugrunde gelegen haben. Diesem lag es ganz ohne $Z$ weifel fern, von einem "sozialen Staat" zu sprechen, um damit - ohne weitere inhaltliche Bestimmung - einen "Staat sozialverpflichteter Bürger" zu bezeichnen. Es wäre äußerstenfalls noch tragbar, darin ein Bekenntnis zum allgemeinen Sozialgestaltungsauftrag des Staates zu sehen, obwohl auch das dem allgemeinen Wortverständnis fern liegt. Dieses entspricht jedenfalls im politischen Sprachgebrauch ganz eindeutig dem gegenüber den bestehenden Sozialverhältnissen kritischen, auf ihre Korrektur im Sinne des Wohlstandsausgleichs und der sozialen Hilfe drängenden Sozialbegriff. Nur in diesem Sinne konnte das Wort "sozial" so unkompliziert und unproblematisch gebraucht werden, wie dies durch den Parlamentarischen Rat geschehen ist.

Dem kann nicht entgegengehalten werden, daß das Wort "sozial" doch in den kombinatorischen Formeln des "demokratischen und sozialen Bundesstaates" und des "republikanischen, sozialen und demokratischen Rechtsstaates" verwendet wurde, gewissermaBen also in Kunstformeln, für die das allgemeine Wortverständnis von vorneherein nicht ohne weiteres maßgeblich sein dürfte. Gerade die spezifischen, in Art. 20 Abs. 1 und 28 Abs. 1 Satz 1 GG aufgegangenen Formeln der "sozialen Demokratie" 3) und des "sozialen Rechtsstaates" 4) haben eine Tradition, die durchaus in der Richtung der politischen Sozialbewegung 1iegt. 5)

\section{hh) Das Ergebnis}

Zusammenfassend darf also festgestellt werden: Der "soziale Staat" im Sinne der Art.20 Abs. 1, 28 Abs. 1 Satz 1 GG ist ein

2) S. nochmals die Nachweise oben S.686f zu Fußn.4-7.

3) Aus vorgrundgesetzlicher Zeit s. insbes. Adler, Politische und soziale Demokratie; Heller, Rechtsstaat oder Diktatur, insbes. S. 7 und 11.

4) Aus vorgrundgesetzlicher Zeit s. insbes. Heller, a.a.O., insbes. S.9 f, 18; Kägi, Rechtsstaat-Sozialstaat-sozialer Rechtsstaat, S. $143 \mathrm{ff}$ (wo allerdings stark auch die "soziale" Gemeinschaftsbindung der Individuen hervorgehoben ist).

5) Daß es für den "sozialen Bundesstaat" an einem entsprechenden Vorgang fehlt, ist mangels eigener Bedeutung dieser Wortfügung unerheblich. 
taat, der den Intentionen der historischen Sozialbewegung gemäß en bestehenden gesellschaftlichen, insbes. den für die persönlihe Bedürfnisbefriedigung wesentlichen ökonomischen Verhältnisen kritisch und verantwortlich gegenübersteht und sie durch Ausleich und Verhinderung von Wohlstandsdifferenzen, einschließich der Milderung damit zusammenhängender Abhängigkeitsverältnisse und Sicherung einer gerechten Teilhabe an den Gütern er Gemeinschaft und eines menschenwürdigen Daseins für alle nd somit im besonderen für die schwächeren Schichten, korriiert. 1)

\section{Abgrenzung und Implikationen}

a) Der allgemeine Sozialgestaltungsauftrag

er in diesem Sinne "soziale" Auftrag des Staates steht vor dem lintergrund eines gegenständlich grundsätzlich unbeschränkten ozialgestaltungsauftrags des Staates. Dieser ist nur kompetenzejahendes Prinzip. 1) Jener ist für den engeren "sozialen" Sach-

Nachweise s. unten S.704f zu Fußn. $2-7$.

Einen interessanten Versuch, darüber hinauszukommen, macht Bruno Molitor (Sozialpolitik im sozialen Rechtsstaat, S. 102 f), wenn er ausführt, "daß Parlamentsbeschlüssen, die... zu erkennen geben, daß die Zuständigkeit und Möglichkeit einer Gesellschaftsgestaltung durch den Staat negiert wird, ausgeschlossen sind" und zwar, wie er offenbar meint, von Verfassungs wegen ausgeschlossen sind. Wie dieser Verfassungssatz sanktioniert werden kann, ist allerdings sehr fraglich. Im allgemeinen wird ein Beschluß dieser Art doch dahin gehen, daß der Staat nichts tut. Die Sanktion müßte also darin bestehen, daß der Staat etwas zu tun angehalten wird. Der Grundsatz der Sozialgestaltungskompetenz gibt aber noch keine Lösung dafür, was positiv geschehen soll. Also kann er nicht in dieser Weise sanktioniert werden. Sollte es ausnahmsweise so sein, daß ein staatliches Tun - in der Regel wohl ein Gesetzgebungsakt - unterschiedlich danach ausfällt, ob es auf dem Willen cler Sozialgestaltung beruht oder nicht, könnte das Molitor'sche Prinzip zwar an sich eingreifen, indem der auf der Negation der Sozialgestaltung beruhende Akt für verfassungswidrig erklärt wird. Aber wer soll dem handelnden Organ nachweisen, daß es von der irrigen Meinung ausgegangen ist, es dürfe nicht sozialgestaltend tätig werden, und nicht einfach - was in seiner Kompetenz liegt - sozialgestaltendes Tätigwerden für inopportun gehalten hat? Ist es überhaupt jemals angebracht, die Frage der Verfassungsmä- 
und Zweckbereich dessen Verdichtung zu - unten noch näher zu bestimmenden - rechtlichen Verhaltenspflichten des Staates (und, durch ihn vermittelt, der ihm Unterworfenen).

Beide sind auseinanderzuhalten. Wer den Staat als Träger der Sozialgestaltung seiner angenornmenen Beschränkung auf den "Rechtszweck" wegen auf den verfassungsnormativen "Sozial(staats)zweck" beschränken will, 2) wird diesem alle Sozialgestaltung des Staates zuschlagen müssen, ohne die die moderne Gesellschaft nicht auskommt, die aber mit dem altliberalen

"Rechtszweck" nichts zu tun hat. "3) Dadurch wird die Sozialstaats proklamation zum allgemeinen Sozialgestaltungsauftrag hin ausge weitet, verwässert, aufgelöst. 4) Die Stoßkraft ihrer historischkonkreten Substanz geht darüber verloren.

Bigkeit eines Staatsaktes, insbes. eines Gesetzes, von einem subjektiven Moment dieser Art abhängig zu machen? Alles Fragen, die Molitors These letztlich paralysieren.

2) So aber Hamann, Die Ermessensfreiheit des Gesetzgebers, S.972; s.a. dens., Deutsches Wirtschaftsverfassungsrecht, S. 75 .

3) Die Kategorien Rechtszweck und Sozialzweck (Wohlfahrtszweck usw.) sind primär außerrechtlicher Natur. Damit, daß die Sozialstaatserklärung Bestandteil der Verfassung und ihre Verwirklichung somit Rechtsbefolgung ist, braucht sie noch nicht dem Rechtszweck zugeordnet zu werden.

4) Der Beispiele, zu welcher Verwirrung Unklarheit in diesem Punkte führt, sind leider allzu viele, als daß sie hier angeführt werden könnten. Einige Nachweise werden unten im speziellen Zusammenhang zu bringen sein. Ein extremes Beispiel sei jedoch schon hier hervorgehoben. Hamann (Das Grundgesetz, Art. 12 Anm.C 5 b) meint, nachdem er Maßnah. men gegen den Handel mit Betäubungsmitteln als durch das Sozialstaatsprinzip gegenüber Art. 12 GG gedeckt erklärt, es sei aber 'zu beachten, daß die Begriffe 'Gefahrenabwehr' (...) und Sozialstaatlichkeit nicht unbesehen einander gleichgestellt werden dürfen; nicht jede polizeiliche Maßnahme ist notwendigerweise sozialstaatsbedingt". Kaum zu überbietende Vermischung der Positionen! Wenn dieser selbe Autor (Wirtschaftswerbung in Rundfunk und Fernsehen, NJW 10. Jhg (1957) S. 1422 (1424)) schließlich die Frage, ob eine Rundfunkanstalt Werbefunk betreiben darf,im wesentlichen nach dem Maße des Sozialstaatsprinzips beantworten will, so zeigt sich, wohin eine Konzeption führt, die den Staat auf die Verfolgung des Rechtszwecks (alias die Verwirklichung der Rechtsstaatlichkeit) und des Sozialzwecks (alias die Verwirklichung un- 
b) Die allgemeine Gemeinschaftsverpflichtung der Individuen

Der im aufgezeigten Sinn "soziale" Staat ist ein gemeinschaftsbeonter Staat. Diese Gemeinschaftsbindung wird durch die rechtsstaatliche, insbes. die Grundrechtsordnung in freiheitlich-individualistischer Richtung gemäßigt. Aber sie gehört zum Wesen des ;Ozialverpflichteten Staates. 1) Er ist als gebender und helfender jtaat ein Staat der Gemeinschaftsbezogenheit des seiner Hilfe bedürftigen, seine Hilfe annehmenden und sich ihrer gemeinschaftssedingten Fremdgesetzlichkeit notwendigerweise unterordnenden Individuums und ein Staat der permanenten Ingerenz in individuelle Bereiche. Aber als Subjekt der Umverteilung und des Ausgleichs muß er auch belasten, beschränken und wegnehmen und greift er so wieder permanent in die Individualsphäre ein. Eine intensive Verstrickung der gemeinschaftlich verbundenen Individuen untereinander und mit der Gemeinschaft als Ganzem ist die Folge. Dieser Staat kann nicht vom unbedingten Vorrecht der Individualposition sondern nur vom Gleichgewicht der individuellen und gemeinschaftlichen "Ansprüche" her als funktionierend gedacht werden.

Aber auch hier ist wieder zu trennen zwischen einem allgemeinen Prinzip individueller Sozialpflicht und der besonderen, durch den engeren Sozialauftrag des Staates ausgelösten Unterworfenheit unter den gebotenen Ausgleich, die Einfügung in das Gesamtsystem der Hilfe und der Umverteilung. Die verfassungsrechtliche Betonung der Sozialpflicht der staatlichen Gemeinschaft darf nicht dadurch beeinträchtigt werden, daß diese besondere Gemeinschaftsverpflichtung ihrer Glieder in einer allgemeinen Soziabilitätspflicht, ja schließlich einer allgemeinen nationalen Pflichtstellung aufgeht. ${ }^{2)}$

differenzierter Sozialstaatlichkeit) beschränken will.

1) S. nochmals oben S.681 die in Fußn.9 Zitierten. - Aus dem vorgrundgesetzlichen Schrifttum s. insbes. Kägi, Rechtsstaat - Sozialstaat - sozialer Rechtsstaat, S. $142 \mathrm{ff}$.

2) Ein in dieser Richtung nicht mehr zu überbietendes Mißverständnis der Sozialstaatserklärung unterläuft Rumpf (Der ideologisiche Gehalt des Bonner Grundgesetzes, S. 34), wenn er ausführt: "Die nationale Interpretation des Sozialstaatsgedankens ... findet heute einen klaren Anhaltspunkt im Text selbst: die Ausstattung des Bundes mit der Kompetenz zur Gesetzgebung über die Wehrpflicht bedeutete auch für den sozialphilosophischen Gehalt des GG und damit für das in der Bundesrepublik bestehende Verhältnis von Individuum und Gemeinschaft eine Wende". (Sperrung nicht im Original). Dieser Satz zeigt deutlich, daß mit 


\section{cc) Die soziale Gerechtigkeit}

Dieser so verstandene soziale Staat ist ein Staat sozialer Gerechtigkeit. ${ }^{1)}$

Aber es wäre verfehlt, zu sagen, er sei ein Staat nur der Gerechtigkeit ohne die spezifische Tendenz zu Ausgleich und Hilfe, ohne - wenn man will - den wohlfahrtsstaatlichen Akzent. 2) Dieses Sozialstaatsverständnis ginge am historisch-konkreten Substrat der Sozialstaatsidee vorbei. Mit dem Argument, das Grund gesetz habe eine wohlfahrtsstaatliche Ordnung - wie sie etwa der Zweite Hauptabschnitt der Weimarer Verfassung konzipiert hatte - nicht aufgerichtet, ${ }^{3)}$ 1äßt sich die Elimination des historischkonkreten Kerns aus dem Sozial staatsbegriff nicht rechtfertigen. Diese sozialpolitische Substanz wurde gerade über den Sozialstaatsbegriff in das Grundgesetz hineingerettet. Die Sozialstaatserklärung ist Surrogat einer eingehenden sozialen Verfassungsordnung 4) und weder polemischer Gegensatz hierzu noch beziehungslose Neuerung. Die Behauptung, das Wesentliche am sozialen Staat sei die Soziabilitätspflicht seiner Bürger, diese sei gleichzusetzen der Pflicht zu gegenseitiger Gerechtigkeitsübung und werde überwölbt durch die entsprechende Gerechtigkeitsübung auch seitens der staatlichen Gemeinschaft, geht am vitalsten Gehalt der Sozialstaatserklärung, an der verfassungsrechtlichen Antwort auf den Ruf nach sozialer Hilfe und Gerechtigkeit, zugunsten einer artifiziellen, blutleeren Konstruktion vorbei. ${ }^{5)}$

Eine andere Einschränkung muß gegenüber der Gleichung Sozial-

der Verselbständigung des gemeinschaftsbetonenden Gehalts des Sozialstaatsprinzips ein Weg beschritten wird, der nicht nur mit dem Wortverständnis (s. hierzu die Nachweise oben S. 684 zu Fußn. 2) sondern auch mit dem möglichen Ausdruckswollen des Verfassunggebers nicht mehr in Einklang gebracht werden kann (z. Einseitigkeit der Fechner'schen These vom Sozialstaat als gemeinschaftsbetontem Staat s.a. Bachof, Besprechung zu "Fechner, Freiheit und Zwang im sozialen Rechtsstaat", DVB1. 69. Jhg. (1954) S. 378 f (379)).

1) S. nochmals die Nachweise oben S.678 zu Fußn. 3.

2) Vg1. Menger, Der Begriff des sozialen Rechtsstaats im Bonner Grundgesetz, S.24 ff.

3) Menger, a.a.O. S.20 ff.

4) S. oben S. 673 ff und oben S. 695 f, insbes. S.695 zu Fußn.9.

5) S. nochmals die oben S. 678 zu Fußn. 3 Zitierten, insbes. Dürig und v. Mangoldt-Klein, a.a.O. 
staat $=$ Gerechtigkeitsstaat ebenfalls noch gemacht werden. Es ist zumindest eine Frage, ob der Sozialstaat sich darin erschöpft, soziale Gerechtigkeit zu üben. Es ist nicht auszuschließen, daß es Fragen gibt, deren Beantwortung in dem Rahmen, in dem sie offen sind, von einer nicht überspannten Gerechtigkeitslehre her als gerechtigkeitsindifferent bezeichnet werden muß, während sie vom Sozialstaatsprinzip her noch gesteuert wird. Auch in dieser Hinsicht darf dessen positive Substanz nicht im allgemeinen Prinzip ertränkt werden.

\section{dd) Das gemeine Wohl}

Der soziale Staat im Sinne des Grundgesetzes kann mit Fug auch als Gemeinwohlstaat angesprochen werden. Aber auch das ist eine allgemeinere Charakterisierung als die des "Sozialstaates" selbst. Dieser substanziiert erst das "Gemeinwoh1". 1)

\section{ee) Daseinsvorsorge}

Schließlich ist auch richtig, daß der Sozialstaat ein Staat der Daseinsvorsorge 1) und der Verteilung ${ }^{2)}$ ist. Er verteilt und verteilt um. Er sorgt für die Schwächeren, um auch ihnen ein menschenw ürdiges Dasein zu gewährleisten, ${ }^{3)}$ und treibt damit Daseinsvorsorge. Indem er seine - im engeren Sinne - soziale Funktion wahrnimmt, wird er infolge der gegebenen Interdependenzen in eine Gesamtverantwortung für Daseinsvorsorge und Güterverteilung verwickelt. $\left.{ }^{4}\right)$

Doch hieße es das Wesen des Sozialstaats verkennen, ihn mit dem Staat der Daseinsvorsorge und der Verteilung synonym zu lesen; wie es noch mehr das ihm zugrunde liegende soziale Prinzip verkennen hieße, wenn es mit dem der Daseinsvorsorge und der Verteilung in eins gesetzt würde. ${ }^{5)}$ Daseinsvorsorge kann dem weiteren Kreis des allgemeinen staatlichen Sozialgestaltungsauftrages zuzurechnen - andere $Z$ wecke haben als den sozia-

1) S. hierzu Wolany, Vom Sozialstaat und sozialen Recht, S. 146; Franz Klein, Christ und Kirche in der sozialen Welt, S.123 f, 230 (Fußn.292).

1) S. die oben S.680 zu Fußn. 5 (3) Zitierten.

2) Vgl. Forsthoff, Verfassungsprobleme des Sozialstaats, S. 8; Krause, Der verteilende Staat, S. 13.

3) S. oben S. 679 zu Fußn. 4 und $5(1,2)$.

4) Vgl. Leibholz, Strukturprobleme der modernen Demokratie, S. 87.

5) S. hierzu und zum Folgenden oben S. 37. 
1en. ${ }^{6)}$ Sie wird diesen häufig mitverfolgen. Vor allem wird sie aber immer auch vom Sozialstaatsprinzip inhaltlich mitgestaltet und regiert sein. ${ }^{7)}$ Aber sie muß sich nicht darin erschöpfen, die Sozialstaatlichkeit zu verwirklichen; genau so wenig wie sich umgekehrt die Sozialstaatlichkeit in Vorsorge und Verteilung erschöpfen soll. ${ }^{8)}$

d) Der undoktrinäre Minimalismus des Sozialstaatsprinzips

Die interpretatorische Entfaltung des grundgesetzlichen Sozialbegriffes darf nicht übertrieben werden. Die Auslegung hat sich vielmehr immer des inneren und äußeren Minimalismus bewußt zu bleiben, der die Sozialstaatsklausel des Grundgesetzes kennzeichnet. 1) Sie ist "eine Entscheidung für das der gesamten Sozialbewegung Gemeinsame". 2) Sie ist keine Entscheidung für den Sozialismus, ${ }^{3)}$ geschweige denn für seine kommunistischen

6) Hamann (Deutsches Wirtschaftverfassungsrecht, S. 75; s. auch nochmals die oben S. 700 zu Fußn. 2 und $S .700$ zu Fußn. 4 gegebenen Nachweise) ist - ausgehend davon, daß der Staat des Grundgesetzes auf den Rechts(staats)zweck und den Sozial(staats)zweck beschränkt ist - der Meinung, das Sozialstaatsprinzip umschreibe den zulässigen Kreis staatlicher Daseinsvorsorge. Wie er dabei den Sozial(staats)zweck zerdehnt, zeigt sich darin, daß er - von diesem Ausgangspunkt her! - die Daseinsvorsorge nur (!) zur Bewältigung gemeinschaftsbedingter Leistungen, zur Bändigung der Technik und zur Bereitstellung lebenswichtiger, von der privaten Wirtschaft nicht erbrachter Leistungen zulassen will (Deutsches Wirtschaftsverfassungsrecht, S. 68 f). Zur Kritik dieser Auffassung s. schon oben S.700 zu Fußn. 4 und den Text hierzu.

7) S. hierzu Wolany, Vom Sozialstaat und sozialen Recht, S.160; Huber, Wirtschaftsverwaltungsrecht Bd.II, S.272; Krause, Der verteilende Staat, insbes. S. 13.

8) Vgl. Menger, Der Begriff des sozialen Rechtsstaates im Bonner Grundgesetz, S.28 ff (allerdings von seinem hier nicht akzeptierten Standpunkt Sozialstaat = Gerechtigkeitsstaat ausgehend); Ballerstedt, Wirtschaftsverfassungsrecht, $\mathrm{S} .53 \mathrm{f}$ und $54 \mathrm{ff}$, passim (sehr eindringlich).

1) S. oben S.673 ff.

2) Dürig, Verfassung und Verwaltung im Wohlfahrtsstaat, S.196, wo er auch schreibt, "daß'sozial" nicht ... im Sinne einer bestimmten Sozialtheorie zu lesen ist".

3) Vgl. Wolany, Vom Sozialstaat und sozialen Recht, S. 144 ;; Dürig, a.a.O.; Berger, Bedeutung und Tragweite des Grund- 
und bolschewistischen Steigerungsformen. Sie ist aber ebensowenig eine Entscheidung für die katholische oder - was es zur Zeit der Grundgesetzgebung noch gar nicht so sehr gab - evangelische Soziallehre.

Die Schwierigkeiten aus den heterogenen Sozialvorstellungen der das Grundgesetz tragenden politischen Kräfte, das Gemeinsame zu destillieren, wurden schon angedeutet. ${ }^{4}$ ) Sie schwächen die Effektivität der Sozialstaatserklärung. Aber dieser Effektivität darf nicht um den Preis einer inhaltlichen Verfälschung aufgeholfen werden. Keine sozial profilierte politische Richtung von irgend einem Einfluß wollte, indem sie - sei es durch ihre Vertreter im Parlamentarischen Rat, sei es durch die Mitwirkung an der landesparlamentarischen Zustimmung zum Grundgesetz, sei es schließlich durch die politische Mitarbeit unter der grundgesetzlichen Ordnung - das Grundgesetz einschließlich seiner nirgendwo ersichtlich in Frage gestellten Sozialstaatsformel bejahte, sich dem Diktat eines fremden Sozialideals unterwerfen. Keine soziale Richtung darf für sich buchen, mittels des Sozialstaatsbegriffes als des hölzernen Pferdes zur Überraschung der überlisteten Bewohner des grundgesetzlichen Troja gerade ihre Sozialmaximen in dieses hineinverbracht $z u$ haben.

Gewarnt werden muß schließlich aber nicht nur vor einer ideologischen Überanstrengung des Sozialstaatsprinzips und seiner Indienstnahme für gewisse komplette Sozialkonzeptionen. Gewarnt werden muß auch vor dem - meist damit Hand in Hand gehenden aber auch sonst beliebten - Detailausverkauf des Sozialstaatsprinzips, der ganz gewisse Einzelpostulate aus ihm ableitet. 5) Der Sozialstaatsgrundsatz ist von höchster Immobilität. Er ist nicht

satzes vom sozialen Rechtsstaat, S. 7; Gerber, Die Sozialstaatsklausel des Grundgesetzes, S. 31 f; Hamann, Das Grundgesetz, Einführung I D 2 (S.32); Klein, Christ und Kirche in der sozialen Welt, S.123 (und ff); Giese-Schunck, Grundgesetz, Art. 20 Anm. II 4. - Wolany (a.a.O. S. 153) hebt mit Recht hervor, daß der Sozialstaat kein Staat radikaler, rächender Umverteilung ist, der die Reichen verarmen läßt, um die Armen reich zu machen.

4) S. oben S. 673 ff.- S.hierzu auch Dürig, a.a.O.: "Gemeinsam ist der Sozialbewegung, die als Gegenbewegung in die Neuzeit eintrat, nach wie vor nur ihre Frontstellung. Diese ist aber so eindeutig, daß vom Negativen her auch positiv der Mindestinhalt dessen, was der Begriff 'sozial' bedeutet, bestimmbar ist".

5) Auf Einzelheiten ist unter III (S. 762 ff) zurückzukommen. 
nur einfacher Verfassungssatz. Er ist über Art. 20 Abs. 1, 79 Abs. 3 GG auch der Verfassungsrevision entzogen. Was aus ihm im einzelnen gefolgert wird, muß ebenso "ewigen" Bestand haben können wie das Prinzip selbst. Die Möglichkeit, das Sozialstaatsprinzip "in die Zeit hinein" $\mathrm{zu}$ konkretisieren, soll dadurch nicht beschnitten werden. Allein, dabei wird Vorsicht zu walten haben. Von dem Anspruch auf Detaillösungen aus dem Sozialstaatsgrundsatz muß auch schon deshalb zurückhaltend Gebrauch gemacht werden, weil das Sozialstaatsprinzip zwar in gewissem Sinne das Surrogat einer eingehenden verfassungsrechtlichen Sozialordnung ist, aber selbst eine solche eben nicht sein soll und sein kann. Dieser Unterschied zwischen der Weimarer Verfassung und dem Grundgesetz bzw. zwischen den stärker ausgebauten Länderverfassungen und dem Grundgesetz muß respektiert werden.

2. Zur Geltungsweise des Sozialstatsprinzips 1 )

a) Grundsätzliches zu den inhaltsbedingten Geltungsmöglichkeiten

aa) Geltungsproblematik und Geltungsanspruch

So unbestimmt das Sozialstaatsprinzip inhaltlich im einzelnen auch sein mag, fest steht, daß es im wesentlichen positiv orien-

1) Eine Frage, die hier nicht näher behandelt werden soll, ist die der überpositiven Geltung des Sozialstaatsprinzips, die vor allem von Hamann behauptet wird. (Die Ermessensfreiheit der Gesetzgebung, S.972; Das Grundgesetz, Einführung I D 2 (S. 32) und Art. 20 Anm. C 3). Die von ihm (Die Ermessensfreiheit der Gesetzgebung, S.972 Fußn.36) - unter erstaunlichem Verzicht nicht nur auf eine Darlegung und Würdigung der ganzen überreichen Tradition des christlichen Abendlandes sondern auch auf die Auswertung der, da von der christlichen Religion unabhängigen, vielleicht für ein "Natur" Rechts-Postulat noch aufschlußreicheren Haltung des vorchristlichen Altertums (s. hierzu statt vieler anderer Bolkestein, Wohltätigkeit und Armenpflege im vorchristlichen Altertum, 1939) - als Beleg vorgewiesene Stelle aus einem jüdischen Gesetz des Jahres 1241 reichte zu deren Nachweis gewiß nicht aus. Hamann sollte auch bedenken, ob gerade er, der das Sozialstaatsprinzip ungeheuer ausdehnt (s.o. S.700 zu Fußn. 4 und S. 704 zu Fußn.6), gut daran tut, diesen Grundsatz als überpositives Recht auszugeben. Doch dies beiseite. Wahr ist, daß das Sozialstaatsprinzip weitgehend überpositives Recht positiviert. Es ist nur daran zu denken, 
tiert ist. Der Sozialstaat hat die Pflicht, sozial zu sein. Ihrer entledigt er sich nicht schon dadurch, daß er sich unsozialer Handlungen enthält und die Maßnahmen, die er ergreift, nicht unsozial gestaltet. Er muß auch unsoziale Verhältnisse, die mit oder ohne sein Zutun entstanden und seinem korrigierenden Eingriff zugängig sind, bereinigen. ${ }^{2)}$

Damit häuft sich in der Geltungsproblematik des Sozialstaatsprinzips die Schwierigkeit der Inhaltsbestimmung mit den schon wiederholt angesprochenen Schwierigkeiten, die Verwirklichung positiv verordnender Verfassungsnormen durch die konkrete unterverfassungsrechtliche Ordnung verfassungsrechtlich zu sichern. 3)

Diese Schwierigkeiten haben von Anfang an die Erkenntnis von der Aktualität und Positivität des Sozialstaatsprinzips beeinträchtigt. Zwar wird ihm nur selten jegliche Rechtswirksamkeit abgesprochen. ${ }^{4)}$ Aber allein und unmittelbar aus ihm hervorge-

daß es der Verwirklichung der Gerechtigkeit und der Menschenwürde dient. Inwieweit diesem überpositiven Hintergrund ohne verfassungsrechtlichen Niederschlag Positivität zukommen könnte oder nicht, ist eine Frage zweiter Ordnung ( $\mathrm{s}$. zu ihr schon oben S.663 ), die, nachdem das Sozialstaatsprinzip Verfassungsinhalt höchster Geltungskraft ist (Art. 20 Abs. 1 i.V.m. Art. 79 Abs. 3 GG), im Rahmen dieser Untersuchung nicht beantwortet $z u$ werden braucht.

2) Mit Recht betont Hamann (Das Grundgesetz, Einführung I D 2 (S.32)), daß die Sozialstaatlichkeit auch der sozialen Indifferenz kontradiktorisch gुegenübersteht. - Zur sozialen Aktivierung des Gleichheitssatzes durch das Sozialstaatsprinzip s. unten Abschnitt 6 II 2 b, bb (S.898 ff) und die dortigen Nachweise.

3) S. nochmals oben \$. 396 ff und unten Abschnitt 6 I 3 (S. $848 \mathrm{ff}$ ).

4) Grewe (s.o. S. 675 zu Fußn.8) geht dabei von der inhalt1ichen Unbestimmtheit aus. Radikal in dieser Richtung auch der "frühe" Ipsen (Üb૯r das Grundgesetz, S. 14 ff = Das Grundgesetz in seiner Vorläufigkeit, S. $186 \mathrm{ff}$ ). Abendroth (Diskussionsbeitrag zu "Pegriff und Wesen des sozialen Rechtsstaats", S. 85 f, 90; Zum Begriff des demokratischen und sozialen Rechtsstáts im Grundgesetz für die Bundesrepublik Deutschland, S. 82) erkennt dem Sozialstaatsprinzip, obwohl er seine rechtsnormative Geltung ablehnt, wenigstens Bedeutung für die Auslegung des Grundgesetzes und programmatisch bindenden Charakter zu (dies a. zuletzt a.O. S. 83 f), Forsthoff (Begriff und llesen des Sozialen Rechtsstaates, 
hende Rechtswirkungen werden doch mit Ernst bestritten. 5) Insbes. wird ihm die Fähigkeit abgesprochen, sich gegenüber altem, von ihm vorgefundenem Recht durchzusetzen. 6)

Eine Auslegung jedoch, die auf diese Weise resigniert die ganze Sozialstaatsklausel "abschreibt", schöpft die in ihr liegenden normativen Wirkungsmöglichkeiten nicht aus. Sie vernachlässigt die Überlegung, daß jeder Verfassungsnorm grundsätzlich die Auslegung zu geben ist, die ihre größte Effektivität sichert. Sie vernachlässigt den ganz in diese Richtung gehenden Geltungswillen des Grundgesetzes, das bloße Deklamation grundsätzlich nicht kennt. Sie übersieht vor allem auch, daß das Attribut "so-

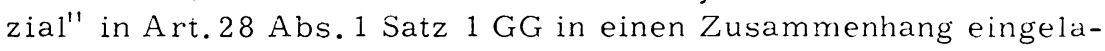
gert ist, dem es nur als positiv geltender Normbestandteil gerecht werden kann. ${ }^{7)}$

Sje kann auch nicht darauf gestützt werden, daß nach Art. 20 Abs. 1 GG die Bundesrepublik (bereits) ein sozialer Stat ist.

S. $25 \mathrm{ff}, 33 \mathrm{ff}, 127 \mathrm{f})$ wendet sich zwar entschieden gegen eine normative Geltung, erkennt aber doch gewisse Ausstrahlungen (insbes. Auslegungsgrundsatz und programmatische Bindung) an; ähnlich wohl Böckenförde, Der allgemeine Gleichheitssatz und die Aufgabe des Richters, S.60 (i.V.m. seinen Ausführungen zum Gegensatz Rechtssatz - Rechtsgrundsatz, ebd. S. 1).

5) Vg1. Müller, Die Rechtsprechung des Bundesarbeitsgerichts, Betriebsberater 10.Jhg. (1955) S. 577 ff (579); ders., Der

Gedanke des sozialen Staats in der bisherigen Rechtsprechung des Bundesarbeitsgerichts; Hueck, Der Sozialstaatsgedanke in der Rechtsprechung des Bundesarbeitsgerichts, in "Staat und Bürger", Festschrift für Willibalt Apelt, 1958, S. 57 ff (71 f); BSGE 1, 134 (144).

6) Wolff, Der Abwendungsanspruch aus öffentlichen Reflexrechten insbes. im Fürsorgerecht, S. 134; Paulick, Der Grundsatz der Gleichmäßigkeit der Besteuerung - sein Inhalt und seine Grenzen, S. 161; v. Mangoldt-Klein, Art. 20 Anm. VII 2 a. Dagegen insbes. Rohwer-Kahlmann, Sozialrecht und Grundgesetz, S. 359 f. - Etwas anderes ist es dagegen, wenn Molitor (Anmerkung zu Bundesarbeitsgericht, Urteil v.21.Oktober 1954 - 2 AZR 40/53 - Arbeitsrechtsblattei, Mutterschutz Entscheidung 4) Zweifel hegt, ob jedes Gesetz immer wieder. daraufhin geprüft werden soll, ob es "den neueren sozialen Anschauungen" entspricht. Das berührt nicht die Geltungskraft sondern den Inhalt des Sozialstaatsprinzips.

7) Vgl. Wolany, Vom Sozialstaat und sozialen Recht, S. 142; 
Schon um der Parallelität mit Art.28 Abs. 1 Satz 1 GG willen darf diese Ist-Form nicht so verstanden werden, als ob das Grundgesetz den von ihm verfaßten Staat so wie es ihn, auf dem Vorhandenen aufbauend, einrichtete, als einen "sozialen" beurteilte, ohne ihn als einen solchen verbindlich setzen zu wollen. Die Sozialstaatserklärung ist nicht unverbindlicher Hinweis auf einen an sich vorhandenen Zustand. ${ }^{8)}$ Sie ist das Konzentrat des normativen sozialen Wollens der Verfassung. ${ }^{9)}$ Sie ist aktuelles Recht. 10) Nur fragt sich eben, in welchem Sinne und inwieweit.

bb) Die Notwendigkeit zu differenzieren - das Verbot unsozialen Handelns

Für die Interpretation besteht nur die Möglichkeit zu differenzieren, um dadurch der Sozialstaatserklärung eine maximale Effektivität zu verleihen. 1) Ebensowenig wie die Norm wegen der aufgezeigten Geltungsschwierigkeiten zur Gänze brach liegen bleiben darf, ist es möglich, sie durchgehend gleicher Geltungskraft zuzuführen.

Laufke, Vertragsfreiheit und Grundgesetz, S. $184 \mathrm{f}$.

8) S.a. Forsthoff, Begriff und Wesen des sozialen Rechtsstaats, S. 26 .

9) S. nochmals oben S.673 ff und II 1 (S.676 ff). S. ferner Laufke, a.a.O. S. $158,184 \mathrm{f}$.

10) Außer den nachfolgend in spezielleren Zusammenhängen noch zu gebenden Nachweisen s. für die Aktualität des Sozialstaatsgrundsatzes: Wolany, Vom Sozialstaat und sozialen Recht, S. 142; Hamamn, Rechtsstaat und Wirtschaftslenkung, S.58; ders., Das (rrundgesetz, Einführung I D 2 (S. 31) und Art. 20 Anm. ( 3; ders., Deutsches Wirtschaftsverfassungsrecht, S. 46; F. R.Huber, Wirtschaftsverwa1tungsrecht Bd.I, S. 36; (lers., Der Streit um das Wirtschaftsverfassungsiecht, \$.200 f; Werner, Allgemeine Verwaltungsgerichtsbarkeit und sozialgerichtsbarkeit, S. 1627; Scheuner, Berufsständische Versorgungseinrichtungen und Grundgesetz, S. 101 f; Nipperdey, Diskussionsbeitrag zu "Begriff und Wesen des sozialen Rechtsstaats", VVDStRL. H. 12, 1954, \$. 92 ff (9: f, 37 f); Schüle, dass. ebenda S. $106 \mathrm{ff}$ (107); v.d.Hevite, dass. ebenda S. $108 \mathrm{ff}$ (109); Ipsen, dass. ebenda S. 117 ff (119); Laufke, a.a.O. S. 158, $184 \mathrm{ff}$; Mellwitz, Die Interpretation der Sozialstaatserklärung in der höchstrichterlichen Rechtsprechung, S. 249.

1) S. a. den Hinweis bei Jerche, Zum Apothekenurteil des Bunclesverfassungsgerichts, S. 233 Fußn. 17. 
Das Gesamtfeld von Sachaussage und Geltungsanspruch der Sozialstaatserklärung wird von zwei Dimensionen bestimmt, deren eine von der inhaltlich eindeutig bestimmbaren Normsubstanz zur vagen Grenze des Formelkompromisses, deren andere vom Negativen, vom Verbot, zum Positiven, zum Befehl, zu verwirklichen und zu gestalten, verläuft. Dürften diese beiden Dimensionen als die Achsen eines Koordinatensystems übereinander gelegt werden, so würden sie zwischen dem "eindeutig"-Schenkel der einen und dem "negativ"-Schenkel der anderen Achse ein Feld präzis bestimmbaren und sanktionierbaren Norminhalts ausschneiden. Nun vermag dieses Bild logisch nichts zu leisten; denn die beiden Dimensionen stehen in enger Wechselbeziehung und dürfen nicht als voneinander unabhängig, "senkrecht" zueinander verlaufend gedacht werden. Aber der Gedanke, daß nämlich jedenfalls das Verbot eindeutig unsozialen Handelns bindendes Recht ist, bleibt richtig. ${ }^{2)}$

Nur darf er nicht isoliert und darf er nicht als das allein Wesentliche herausgestellt werden. Die beiden aufgezeigten Dimensionen vereinigen in sich eine durchgreifende Spannung zwischen Statik und Dynamik. Die Verwirklichung des Sozialstaates in der Zeit, unter den sich stets wandelnden Umständen und Beteiligten, ist ein dynamischer Vorgang. Dynamik ist das Wesensgesetz der Sozialstaatlichkeit. Das Verbot eindeutig unsozialen Handelns aber ist in erster Linie statisch ausgerichtet. Das bedeutet nicht nur, daß es die Sozialstaatsdeutung nicht bei ihm bewenden lassen kann. Das bedeutet auch, daß es sich der Evolution des Sozialstaates nicht hemmend entgegenstellen darf. ${ }^{3)}$

Das wirkt auf den Inhalt dieses Verbotes zurück. Der kritische Punkt liegt im Element des (eindeutig) "Unsozialen". "Unsozial" ist zunächst das primär Unsoziale: die Verkehrung "sozialer" Zustände in "unsoziale" oder die Verschlimmerung "unsozialer"

2) Im Sinne dieses Gedankens Nipperdey, Diskussionsbeitrag zu "Begriff und Wesen des sozialen Rechtsstaats", S.97 f; Merk, dass. VVDStRL. H.12, 1954, S.99 ff (101); Schüle, dass. ebenda S.117 ff (118 f); Laufke, a.a.O. S.158, $184 \mathrm{f}$; Thieme, Liberalismus und Grundgesetz, S. 296 f; Rumpf, Der ideologische Gehalt des Bonner Grundgesetzes, S. 29; s.a. Huber, Der Streit um das Wirtschaftsverfassungsrecht, S. 202; Hamann, Das Grundgesetz, Einführung I D 2 (S. 32).

3) S. a. Schneider, Die öffentlich-rechtliche Alterssicherung freier Berufe und das Grundgesetz, S.27. 
Zustände. "Unsozial" ist aber auch das sekundär Unsoziale: der A bbau der sozialen Einrichtung, Maßnahmen und Hilfen, ein Minus an "Sozialem". Auf diesem Phänomen liegt im Gegenwartsstaat, der die Grundentwicklung zum Sozialstaat hinter sich hat, das Hauptgewicht. Daß die Front der Sozialstaats-Norm (auch) gegen einen wesentlichen Abbau des erreichten sozialen Standards gerichtet ist, steht außer Zweifel. ${ }^{4)}$

Aber gerade hier droht die Gefahr einseitiger Statik. Der soziale Standard kann am leichtesten in einzelnen Einrichtungen, Leistungen und Hilfen oder in konkreten, überschaubaren sozialen Systemen erfaßt werden. Demnach tendiert der Schutz des sozialen Standards dazu, als Einrichtungsgarantie verstanden und mißverstanden zu werden. 5) Einzelne konkrete Ausbildungen des Sozialstaates werden verabsolutiert und für sakrosankt erklärt.

Diese Ausrichtung der Sozialstaatserklärung hat ihr Richtiges. Gewisser sozialer Einrichtungen kann der Staat unter keinen Umständen entbehren. Auch ist der Sozialstaat, wie er sich in der Verfassungswirklichkeit herausgebildet hat nicht rein zufällig sondern weitgehend einer inneren Gesetzmäßigkeit folgend das geworden, was er ist. Schließlich hatte der Verfassungsgeber eine gewisse sozialstaatliche Entwicklung vor Augen gehabt und kann angenommen werden, daß diese für seinen normativen Willen nicht unerheblich war.

Als Grundsatz ist das Umdenken des Sozialstaatsprinzips in eine Bestandsgarantie jedoch gefährlich. Soziale Maßnahmen sind mehr oder weniger unselbständige Glieder eines Gesamtgefüges. Sie stehen in Interdependenz mit einer Fülle von Daten, sozialpolitisch gewillkürten und anderen. Ihre Wirksamkeit hängt von

4) Vgl. Fechner, Sozialer Rechtsstaat und A rbeitsrecht, S. 166 ff; Fechner-Maier, Die Rechtswirksamkeit der arbeitsrechtlichen Bestimmungen des sog. Truppenvertrages, S.92; Berger, Bedeutung und Tragweite des Grundsatzes vom sozialen Rechtsstaat, S. 7; Huber, 1)r. Streit um das Wirtschaftsverfassungs recht, S.202; Liufke, a.a.O. S.158, 185; Thieme, Liberalismus und Grundgeset 2, S. 297 ff; Lerche, Zum Apothekenurteil des Bundesverfassungsgerichts, S. 233 Fußn. 17; Molitor, Sozialpolitik im sozialen Rechtsstaat, S.103. Forsthoff (Begriff und Wesen des sozialen Rechtsstaats, S.25 ff, $35 \mathrm{f}$ ) übt mit der Begründung Kritik an dieser Auffassung, daß der "sozial"-Begriff zu wenig präzis sei, um eine brauchbare Garantienorm abzugeben.

5) S. die zu Fußn. 4 Zitierten. Die Nachweise zu Einzelfragen werden unten (III ( $\$ .762$ ff)) gegeben. 
einer Reihe von Entsprechungen und Beziehungen ab. Wandeln sich die Umstände, kann ihre Anpassung notwendig sein. Umgekehrt kann möglicherweise ihr Effekt nur oder schon durch die Änderung korrespondierender Umstände gesteigert oder erhalten werden. Vor allem aber kann sein, daß ein "sozialer" Zustand oder ein zwar insgesamt gleich "sozialer" aber sonstwie erwünschter Zustand nur durch einen Wechsel im System, durch die Veränderung einer größeren Reihe zusammenhängender Maßnahmen und Daten hergestellt werden kann. Schließlich darf nicht übersehen werden, daß im Falle einer nicht beherrschbaren Verschlechterung der außerrechtlichen Bestimmungselemente das Absinken des sozialen Standards nur durch großräumige Umstellungen im System aufgefangen werden kann. Die optimale Fortentwicklung der sozialstaatlichen Wirklichkeit setzt hierin eine gewisse Dispositionsfreiheit voraus. Die ganzheitliche Evolution kommt nicht ohne Schwankungen und Verschiebungen, mitunter auch nicht ohne (anderweit auf lange Sicht zu kompensierende) Lücke im Kosmos der Einzelelemente aus. ${ }^{6)}$ Extrem institutionelles Sozialstaatsdenken wird sich Schritten, die solche Wege gehen, widersetzen. ${ }^{7)}$ Es verhindert damit möglicherweise so-

6) Die Entwicklung in der Bundesrepublik von ihrem Entstehen bis heute bietet ein gutes Beispiel für die Schwierigkeiten und Erfolgschancen eines ganzheitlichen Evolutionsprozesses. Ohne daß damit alle einzelnen Sachgebiete beurteilt werden sollen, kann gesagt werden, daß der soziale Zustand in der Bundesrepublik heute eindeutig besser ist als im Jahre 1949. Zwar ist diese Verbesserung in erheblichem Umfange darauf zurückzuführen, daß das "klassische" Instrumentarium der Rentenleistungen usw. ausgebaut wurde. Aber der breite "Wohlstand für alle" kommt nicht daher. Er wurde über eine strukturelle Änderung der ökonomischen Bedingungen erreicht, in deren Verlauf nicht selten auf ursprünglich als unerläßlich geltende, ausschließlich oder wenigstens auch sozial zweckhafte Maßnahmen (insbes. der Bewirtschaftung und (ler Preisbindung sowie Subventionen) verzichtet wurde.

7) Zeitungsmeldungen zufolge (vg1. Süddeutsche Zeitung Nr. 139 v. 10. Juni 1960, S.2) hat der Vorsitzende des sozialpolitischen Ausschusses des Bundestags, Prof. Schellenberg (SPD) beanstandet, die Sozialausgaben des Bundes (und der gesamten öffentlichen Hand) seien zwar absolut gestiegen, relativ d.h. im Anteil am Haushaltsvolumen - jedoch gesunken. Das ist - abgesehen von den Bedenken, die gegen die Heranziehung der relativen Werte sprechen - ein eindrucksvolles Beispiel für übersteigertes institutionelles Sozialstaatsdenken. 
ziale Meliorations- und Gesundungsprozesse und grundlegende, langfristige Sozialreformen. Die geschützten Institutionen bringt es in die Gefahr der Wirksamkeitsminderung. Sub specie des Sozialstaatsprinzips kann es also, so hoffnungsvoll es dieses auf den ersten Blick zu realisieren scheint, in die Irre führen. Nicht auf die einmal ergriffenen Maßnahmen kommt es an sondern auf einen auf die Dauer gesehen optimalen sozialen Gesamtzustand 8 ) - der freilich, um es noch einmal zu wiederholen, gewisse elementare Einrichtungen, Maßnahmen, Leistungen, Hilfen oder wie es sonst zu nennen wäre, immer wird aufweisen müssen, wenn er genügen soll.

Die Kontur des zunächst einigermaßen bestimmt erscheinenden Verbotes unsozialen Handelns wird von hierher aufgeweicht. Ob eine Maßnahme als Glied einer größeren sozialpolitischen Entwicklung zu sehen ist und als "unsozial" zu qualifizieren, wird weitaus schwerer zu entscheiden sein als der "unsoziale" Charakter einer einzelnen Maßnahme festgestellt werden kann. Immer nur gegenüber einem einzelnen Gesetz oder einem sonstigen konklet faßbaren Staatshandeln kann jedoch eine verfassungsrechtliche Sanktion durchgreifen. Fine Gesamtentwicklung als solche oder eine gedankliche Konzeption ist einem rechtlichen Verdikt im allgemeinen nicht ausgesetzt. ${ }^{9)}$ Aber auch die Durchsetzung

Als ob nur die Umverteilung - und zwar nur die Umverteilung, die sich in den öffentlichen Haushalten unter der Rubrik "Sozialausgaben" niederschlägt - soziale Wirkungen zeitigen und nur eine maximale Steigerung dieser Umverteilung eine positive Evolution des sozialen Standards manifestieren würde!

8) Vgl. Huber, Der Streit um das Wirtschaftsverfassungsrecht, S. 202; eindringlich, wenngleich mit anderem Akzent und sehr überspitzt: Ballerstedi, IIirtschaftsverfassungsrecht, S.55.

9) Etwas anderes könnie (rein theoretisch) dann gelten, wenn das Grundgesetz die Ministeranklage kennen würde. Ein Kabinett, das eine unsoziale Gesamtpolitik treibt, könnte - abgesehen von der. Impralutikahilität der Ministeranklage im allgemeinen - auf diesem Wige davon abgehalten werden. Obwohl auch hier kaum noch irgend etwas geltend gemacht werden könnte, was sich nicht auch in Einzelmaßnahmen niederschlüge. Vor allem aber sind die wichtigsten Schritte immer vom Willen des Parlaments abhängig, das doch der regelmäBige Träger des Anklagerechts ist. (Vom Problem der politischen Verantwortlichlieit sei hier abgesehen.) Die Präsidentenanklage kann in lieser Richtung mangels einschlägiger Zuständigkeiten des Bundespräsidenten kaum je von Bedeutung werden. 
der Sozialstaatlichkeit gegenüber einem "unsozialen" Gesamtplan durch die Vernichtung und Verhütung seiner konkreten Ausbildungen bereitet Schwierigkeiten. Nicht nur die Zurechnungsschwierigkeiten sind damit gemeint. Eine wesentliche Einschränkung ergibt sich auch daraus, daß eine einzelne Maßnahme nicht schon allein wegen ihrer Zugehörigkeit zu einem "unsozialen" Gesamtplan interdiziert werden kann, wenn sie selbst nicht als "unsozial" zu beurteilen ist. Einzelmaßnahmen, die integrierende Glieder einer größeren sozialpolitischen Entwicklung sind, werden - soweit sie nicht der konkrete Zusammenhang mit anderen "unsozialen" Einzelmaßnahmen erfaßt - nur dann als sozialstaatswidrig angesehen werden dürfen, wenn nicht nur diese Gesamtentwicklung sondern auch sie selbst einwandfrei als "unsozial" erkannt werden können. 10) Das schwächt die Verbotswirkung des Sozialstaatsprinzips. Aber der Preis muß gezahlt werden. Die sozialstaatliche Bewahrung darf diese sozialstaatliche Entwicklung nicht hindern. Gehört es - worauf noch näher einzugehen sein wird - zu den Aufgaben der Sozialstaatserklärung, die Reibungsflächen zu glätten, die das Verfassungsrecht am Wege der sozialen Aktion des Staates aufrichtet, so muß das innere Gefüge des Sozialstaatsprinzips erst recht im Sinne der sozialen Fortentwicklung gestaltet sein.

b) Sozialstaatsprinzip und verfassungsgebundene Staatsfunktionen - insbes. Sozialstaatsprinzip und Gesetzgebung

\section{ad) Die sozialstaatliche Bindung des Gesetzgebers}

Trotz dieser Elastizität, ja inneren Labilität, ist das V e rbot des unsozialen (Staats-) Handelns als das fundamentale Element der Geltung des Sozialstaatsprinzips anzusehen. Das drückt sich in erster Linie darin aus, daß die Bindung des Gesetzgebers an das Sozialstaatsprinzip 1) sich - soweit es um eine

10) Vgl. Fechner-Maier, Die Rechtswirksamkeit der arbeitsrechtlichen Bestimmungen des sog. Truppenvertrages, S.92.

1) Zur Verpflichtung des Gesetzgebers durch das Sozialstaatsprinzip im allgemeinen s. Friesenhahn, Die politischen Grundlagen des Bonner Grundgesetzes, S. 178; E. R. Huber, Wirtschaftsverwaltungsrecht Bd.I, S. 36; Fechner, Sozialer Rechtsstaat und Arbeitsrecht, S. 161; Berger, Bedeutungen und Tragweite des Grundsatzes vom sozialen Rechtsstaat, S. 9; Herschel, Arbeitsschutz im sozialen Rechtsstaat, S. 574; v. Mangoldt-Klein, Art. 20 Anm. VII 2 b; Schlochauer, Öffentliches Recht, S. 14; Rohwer-Kahlmann, Sozialrecht und Grundgesetz, S. 359 f; Hueck, Der Sozialstaatsgedanke in der Recht- 
exakte, durch die verfassungsgerichtliche Normenkontrolle sanktionierte Bindung geht - ausschließlich über dieses Verbot realisiert. 2)

Zwar ist das Sozialstaatsprinzip auch ein verpflichtender A u f trag an den Gesetzgeber, sozial tätig zu werden. ${ }^{3)}$ Aber worin liegt die Sanktion dieses Auftrages? Soweit dem Sozialstaatsprinzip eine Regelung mit der für ihre unmittelbare Anwendung notwendigen Bestimmtheit entnommen werden könnte, bedürfte deren Geltung nicht mehr der notwendigen Vermittlung durch den Gesetzgeber. Wo aber eine durch das Sozialstaatsprinzip nur im Grundsatz angelegte Regelung in der Weise unvollkommen ist, daß ihre vollzugsreife Bestimmtheit oder sonstwie ihre Geltung erst der legislativen Ergänzung bedarf, oder wo eine gesetzliche Regelung durch das Sozialstaatsprinzip überhaupt erst

sprechung des Bundesarbeitsgerichts, S. 71 f und passim; Dersch, Der Verfassungsgrundsatz der Sozialstaatlichkeit und der Rechtsstaatlichkeit in der Praxis der Sozialversicherung, S. 60; Barocka, Die Berücksichtigung sozialer Gesichtspunkte bei der Erhebung von Gebühren und Beiträgen usw., S. 825; BVerfGE 6, 32 (41); Bayerisches Landessozialgericht Urt. v. 7. Oktober 1955 - Kr 82/55 - BayAMB1. 1956 B S. 59 (61).

2) S. nochmals die oben S. 711 zu Fußn. 4 Zitierten. Aus den S.714 zu Fußn.1 Genannten s. insbes. Herschel, a.a.O. Hueck, a.a.O., meint allerdings, ein Verstoß führe nicht zur Nichtigkeit des Gesetzes. Dem kann jedenfalls insoweit nicht beigetreten werden, als es sich um eindeutig unsoziale Gesetze handelt. In sich widerspruchsvoll und der Konsequenzen offensichtlich nicht ganz bewußt bestreitet der Bundesfinanzhof (Urt. v.28.8.59 - VI 111/58 U - NJW Jhg. 13 (1960) S. 71 (72)) die Befugnis der Steuergerichte, "steuergesetzliche Bestimmungen, die kein Grundrecht verletzen, etwa wegen Verletzung der Sozialstaatsklauseln der Art. 20 und 28 GG für nichtig zu erklälen". Dansit wird - abgesehen davon, daß der Bundesfinanzhof $z$ wischen dem Prüfungsrecht der Steuergerichte und dem des Bundesverfassungsgerichts einen inhaltlichen und nicht so sehr den durch das sog. negative Verwerfungsmonopol des Bundesverfassungsgerichts (Art. 100 Abs. 1 GG) gekennzeichneten Unterschied macht - die Aktualität des Sozialstaatsprinzips überhaupt negiert. Ein Beispiel mehr für die schon notorische Unlust des Bundesfinanzhofes, das Grundgesetz gegenüber dem Gesetzgeber zu realisieren!

3) BVerfGE 1,97 (105): "Das Wesentliche zur Verwirklichung des Sozialstaates aber kann nur der Gesetzgeber tun; er ist 
gefordert ist, ist die gesetzgeberische Willensbildung durch keinen Richterspruch (oder einen sonstigen Surrogatsakt) zu ersetzen. ${ }^{4)}$ Insoweit fehlt dem Sozialstaatsprinzip also die durchgreifende Sanktion. Viel wirksamer ist es daher auch in dieser Richtung noch dadurch, daß es das positive Ausgreifen des Gesetzgebers, das bei drängenden Problemen meist unausbleiblich ist, durch das Verbot unsozialer Regelung gleichsam einschient. Auf dem Weg, den das Sozialstaatsprinzip dem Gesetzgeber an sich positiv abfordert, zwingt es ihn letztlich am wirksamsten dadurch, daß es den vom Gesetzgeber selbst in Gang gebrachten und gehaltenen Wagen der Gesetzgebung durch Verbotsschilder und Abweisblenden davon abhält, nicht ihn sondern eine andere Route zu steuern.

\section{bb) Das Sozialstaatsprinzip als Legitimation}

\section{aaa) Der Leerlauf einer "echten" Legitimationswirkung}

Verschiedentlich wird dem Sozialstaatsprinzip auch eine andere als die fordernde und die verbietende Bedeutung zugemessen, die legitimierende. ${ }^{1)}$ Ist nicht das Sozialstaatsprinzip überhaupt erst die Grundlage, die das soziale Wirken des Staates und seines (rechtsstaatlich notwendigen) Schrittmachers, des Gesetzgebers, erlaubt und rechtfertigt?

Die Frage ist nur vor dem Hintergrund der Annahme berechtigt, der Staat sei auf die in der. Verfassung angegebenen Zwecke beschränkt. 2) Der Gesetzgeber ist aber in der Wahl der zu verfol-

gewiß verfassungsrechtlich zu sozialer Aktivität... verpflichtet". - S.ferner z.B. Maunz, Der Deutsche Standpunkt zu den Empfehlungen des Europarates zur Schaffung einer Europäischen Sozialversicherungsordnung, S. 273; Wernicke, Bonner Kommentar, Art.20 Anm. II 1 d; Ipsen, Anmerkung zu BVerfG Urt. v. 19. Dezember 1951 - 1 BvR 220/51 - S. 218; Bachof, Begriff und Wesen des sozialen Rechtsstaats, S.43; Merk, Diskussionsbeitrag hierzu, S.101; Herschel, Arbeitsschutz im sozialen Rechtsstaat, S. 574 und passim; Leibholz, Die kritischen Punkte des Grundgesetzes, S. 19; ders., Strukturprobleme der modernen Demokratie, S. 88, $130 \mathrm{f}$.

4) S. hierzu unten e (S. $729 \mathrm{ff})$.

1) Vgl. Bachof, Begriff und Wesen des sozialen Rechtsstaats, S.43; Schlochauer, Öfentliches Recht, S.14; Laufke, Vertragsfreiheit und Grundgesetz, S. 185; Lerche, Zum Apothekenurteil des Bundesverfassungsgerichts, S.233 Fußn. 17.

2) In diesem Sinne wird die legitimierende Bedeutung von $\mathrm{Ha}$ mann angenommen (s.hierzu schon oben S.700 zu Fußn.2 
genden Zwecke und der zu regelnden Gegenstände grundsätzlich frei und nur exzeptionell, wenngleich sehr nachhaltig durch die Verfassung beschränkt. ${ }^{3}$ ) Nicht einmal für diejenigen Gesetze, die in die persönliche Sphäre eingreifen, gilt etwas anderes. Zur "verfassungsmäßigen Ordnung" i.S. des Art. 2 Abs. 1 GG gehören alle Gesetze, die der Verfassung nicht widersprechen, nicht nur solche, die durch sie positiv gerechtfertigt sind. ${ }^{4)}$ Aber selbst dann, wenn - allgemein oder wenigstens im Anwendungsbereich des Art. 2 Abs. 1 GG - die Gesetze einer besonderen Rechtfertigung bedürften, könnte der Staat nicht exklusiv auf den Sozialstaatsgrundsatz in dem hier gemeinten engeren Sinne und den ihm als Rechtsstaat eignenden Rechtszweck beschränkt werden. ${ }^{5)}$ Wenn überhaupt ein allgemeines Prinzip die über die Rechtsbewahrung und die Staatserhaltung (nach außen) hinausgehenden, kaum überschaubaren Aufgaben des modernen Staates aufzunehmen imstande ist, so ist es der allgemeine Sozialgestaltungsauftrag des Staates. 6) Würde die Last der Legitimation, die auf diesem - an sich nur klarstellenden, den gegebenen Zustand deuten-

und S.700 zu Fußn. 4 und S.T04 zu Fußn.6).

3) Vgl. Scheuner, Der Bereich der Regierung, S.281 f.

4) BVerfGE 6, 32 .

5) In diesem Sinne Hamann, Die Ermessensfreiheit der Gesetzgebung, S.972; s.a. dens., Das Grundgesetz, Einführung I D $1 \mathrm{c}$ und $\mathrm{g}$, und Deutsches Wirtschaftsverfassungsrecht, S. 75 .

6) S. hierzu nochmals oben $\mathrm{S.681}$ zu Fußn. 8 und S.699f. - Das gilt insbes. auch, soweit es für notwendig gehalten wird, die dem Regulativ des Art.2 Abs. 1 GG untergeordneten Zwecke durch ein besonderes Sachauftrags- oder Kompetenzprinzip als Bestandteile der "verfissungsmäßigen Ordnung" auszuweisen. Dürig (Anm. zu BVerfG Urt. v. 16. Januar 1957 1 BvR 253/56 - S.172; Maunz-Dürig, Art. 2 Abs. 1 Randn. $24 \mathrm{f}$ und 45) sieht das - nachiem er sich der (in besagter Anmerkung kritisierten) Fntscheidung BVerfGE 6, 32 glaubt nicht anschließen zu können - der Sache nach richtig. Leider verwischt dabei gerade er, der in "Verfassung und Verwaltung im Wohlfahrtsstaat" (. .196 ) noch so gut zwischen dem Sozialstaatsprinzip als de . Positivierung des "der gesamten Sozialbewegung Gemeinsamen" und der aus ihm zu schließenden allgemeineren "Zuständigkeit des Staates..., die Sozialordnung und damit auch die Wirtschatsordnung zu schaffen und gestaltend (nicht nur streitschlichtend) in sie einzugreifen", zu unterscheiden wußte und diesen Unterschied auch jetzt (Anmerkung usw. a.a.O.; Maunz-Dirig, a.a.O. Randn.24) nicht 
den, vom perfektionistischen Bedürfnis, der staatlichen Ordnung einen Zweck- und Kompetenzplafond zu geben, her jedoch nicht selten mißverstandenen - kompetenzbejahenden Prinzip ruht, dem Sozialstaatsprinzip (im wesentlichen engeren Sinn) überbürdet, so würde entweder die Funktionsfähigkeit des Staates beeinträchtigt oder ginge das zum undifferenzierten Sozialgestaltungsauftrag ausgeweitete Sozialstaatsprinzip seiner spezifischen Stoßrichtung verlustig. ${ }^{7)}$

Für eine allgemeine konstitutive Legitimationsfunktion des Sozialstaatsprinzips ist also kein Raum. Worin kann aber dann die ihm zugeschriebene Legitimationswirkung bestehen? Die Verwal-

unterschlägt, mit den Vokabeln "Sozialauftrag", "Sozialentscheidung", "Sozialgestaltungsauftrag" u.a.m. die Begriffe und Phänomene. Was er aber unter diesen Namen als Rechtfertigungsgrund für Freiheitseinschränkungen im Namen der "verfassungsmäßigen Ordnung" (Art.2 Abs.1 GG) ausdeutet, ist ganz einwandfrei nichts anderes als das, was hier als der allgemeine Sozialgestaltungsauftrag bezeichnet wird. (Nur ein Beispiel: Der "soziale Ausgleich zwischen den Wirtschaftsträgern von Schiene und Straße" wird gegenüber Art. 2 Abs. 1 GG aus dem Sozialgestaltungsauftrag gerechtfertigt (Maunz-Dürig, a.a.O. Randn.45)). Ist es aber dann, wenn diese Konstruktion ohnedies schon "hart in die Nähe einer generellen Gemeinwohlklause1" gelangt (Anm. a.a.O.; Maunz-Dürig, a.a.O. Randn.24) und wenn die Entscheidung über das zur Sozialgestaltung Notwendige grundsätzlich in die letztlich erst durch die Wesensgehaltsschranke des Art. 19 Abs. 2 GG begrenzte Macht des (demokratischen) Gesetzgebers gelegt wird (Maunz-Dürig, a.a.O. Randn.25), nicht ehrlicher - so wie das Bundesverfassungsgericht (BVerfGE $6,32)$-, die prinzipielle Befugnis, im (sonstigen) Rahmen der Verfassung die allgemeine Handlungsfreiheit $z u$ beschränken, zuzugeben? Ist es nicht ein sogar gefährlicher Anschein eines - von der Verfassung als solches nicht konstituierten - staatsbegrenzenden Prinzips, der gelegentlich auch dort zu einer Machtbeschränkung des Staates führen kann, wo diese aus der Verfassung nicht zu rechtfertigen ist?

7) S. nochmals oben S. 676 und S.699, ferner die vorstehende Fußn. 6. 
tung kann, soweit Gesetz und Gesetzesvorbehalt dafür Platz lassen, das Sozialstaatsprinzip unmittelbar, "gesetzesfrei" vollziehen - ist insoweit durch das Sozialstaatsprinzip legitimiert. Allein das ist eine sekundäre Erscheinung. Auf sie wird noch zurückzukommen sein. ${ }^{8)}$ Hier steht immer noch in Frage, inwieweit der Staat, der demokratische und soziale Rechtsstaat, wie er in höchster Machtvollkommenheit durch den Gesetzgeber repräsentiert wird, vom Sozialstaatsprinzip eine Rechtfertigung seines Handelns beziehen kann.

bbb) Die unechte, interpretatorische Legitimationswirkung

Was auf diese Frage hin ins Blickfeld rückt, kann kaum mehr mit rechtsbegrifflichem Fug als eine Legitimation bezeichnet werden, ist nur mehr mittelbar und unselbständig wirksame Legitimation, ist mehr ein verfassungsrechtliches Wegbereiten und Platzmachen für die soziale Aktivität des Staates. Gemeint ist die interpretatorische Ausstrahlung des Sozialstaatsprinzips in die Ebene der Verfassung. 1) Sie führt zu einer sozial staatsgerechten Aus-

8) S. unten S. 762.

1) In der allgemeinen Verlegenheit um Inhalt und Tragweite des Sozialstaatsgrundsatzes wurde dessen Bedeutung für die Auslegung der Verfassung und der Gesetze, m.a.W. seine unselbständig mittelbare Wirksamkeit, besonders gern als Aktualisierungsmöglichkeit dieses sphinxhaft unzugänglichen Verfassungswortes hervorgehoben: Vgl. Wolff, Der Abwendungsanspruch aus öffentlichen Reflexrechten, insbes. im Fürsorgerecht, S. 134; Klein, Bonner Grundgesetz und Rechtsstaat, S.400; Friesenhahn, Die politischen Grundlagen des Bonner Grundgesetzes, S.178; Scheuner, Grundfragen des modernen Staates, S.154; ders., Die institutionellen Garantien des Grundgesetzes, Recht Staat Wirtschaft Bd. IV (1953) S. 88 ff (96); ders. in Reinhardt-Scheuner, Verfassungsschutz des Eigentums, S.77; Ipsen, Anmerkung zu BVerfG Urt. v. 19. Dezember 1952 - 1 PvR 220/51 - S.218; Wernicke, Bonner Kommentar, Art.20 Anm. II 1 d; Hamann, Rechtsstaat und Wirtschaftslenkung, S. 56; ders., Das Grundgesetz, Einführung I D 2 (S.31) und Art.20 Anm.C 3; Forsthoff, Begriff und Wesen des sozialen Rechtsstaats, S. $27 \mathrm{ff}$; Bachof, dass. S.43; Nipperdey, Diskussionsbeitrag hierzu, S.93 f; Abendroth, desg1. S. 85 f, 90; ders., Zum Begriff des demokratischen und sozialen Rechtsstaates im Grundgesetz für die Bundesrepublik Deutschland, S. 83; Berger, Bedeutung und Tragweite des Grundsatzes vom sozialen Rechtsstaat, S.9; Müller, Die Rechtsprechung des Bundesarbeitsgerichts, S. 579; 
legung der verfassungsrechtlichen Schranken der staatlichen Wirksamkeit, insbes. also der Grundrechte. ${ }^{2)}$ Nicht als ob diese jedem sozialstaatsoedingten Vorhaben nachgeben würden. ${ }^{3)}$

ders., Der Gedanke des sozialen Staats in der bisherigen Rechtsprechung des Bundesarbeitsgerichts, S. 524 f; Gerber, Die Sozialstaatsklausel des Grundgesetzes, S.29, 53 und passim; Laufke, Vertragsfreiheit und Grundgesetz, S. 185; v. Mangoldt-Klein, Art.20 Anm. VII 2 b; Thieme Liberalismus und Grundgesetz, S. 296 f; Leibholz, Die kritischen Punkte des Grundgesetzes, S. 19; Schlochauer, Öffentliches Recht, S. 14; Hueck, Der Sozialstaatsgedanke in der Rechtsprechung des Bundesarbeitsgerichts, S. 72 und passim; Dersch, Der Verfassungsgrundsatz der Sozialstaatlichkeit und der Rechtsstaatlichkeit in der Praxis der Sozialversicherung, S.60; BVerfGE 1, 97 (105); BSGE 1, 134 (144); BAGE 1, 51 (56 f) (zur weiteren Rechtsprechung des Bundesarbeitsgerichts s. Hueck und Müller, a.a.O. ); OVG Lüneburg OVGE 4, 224 (225). - Zwischen der interpretatorischen Ausstrahlung in der Verfassungsebene - m.a. W.: im inneren Gefüge der Verfassung - und der interpretatorischen Auswirkung auf das Recht im Range unter der Verfassung besteht ein erheblicher Unterschied. Auf die letztere Wirkung ist hier nicht abgestellt; vielmehr ist auf sie noch unten zurückzukommen. Hier ist die Frage der intrakonstitutionellen interpretatorischen Auswirkung gemeint (s. hierzu aus der Zahl der Genannten ganz besonders Abendroth und Gerber je a.a.O.).

2) S. insbes. Friesenhahn, a.a.O.; Scheuner, a.a.O., der.s., Die staatliche Intervention im Bereich der Wirtschaft, S.20f; ders., Berufsständische Versorgungseinrichtungen und Grundgesetz, S. 101 f; ders., Grundrechtsinterpretation und Wirtschaftsordnung, DÖV 9.Jhg. (1956) S. 65 ff (69); E.R. Huber, Wirtschaftsverwaltungsrecht, Bd.I S.30; Dürig, Verfassung und Verwaltung im Wohlfahrtsstaat, S. 197; Knoll, Eingriffe in das Figentum im Zuge der. Umgestaltung gesellschaftlicher Verhältnisse, AöR Bd. 79 (1953/54) S.455 ff und Bd. 81 (1956) S. 157 ff (Bd. 79 S. 480 f); Forsthoff, a.a.O. S.28; Abendroth, Zum Begriff des demokratischen und sozialen Rechtsstaats im Grundgesetz der Bundesrepublik Deutschland, S. 86 f; Ipsen, Rechtsfragen berufsständischer Zwangsversorgung, S.61; Berger, a.a.O. S. 8; Gerber, a.a.O., insbes. S. $38 \mathrm{ff}$; v. Mangoldt-Klein, S.61, 97; Bruno Molitor, Sozialpolitik im sozialen Rechtsstaat, S. $103 \mathrm{f}$.

3) Vgl. Bettermann, Grundfragen des Preisrechts für Mietenund Pachten, S. 119 f; Hamann, Rechtsstaat und Wirtschafts- 
Auch nicht so, als ob das Sozialstaatsprinzip einen grundsätzlichen Vorrang beanspruchen könnte. 4) Die präzisere Ausprägung der ihm gegenübertretenden besonderen Verfassungsrechtssätze sichert vielmehr diesen den Vorteil a priori größeren interpretatorischen Gewichts. Aber soweit diese ihre konkrete, positive Ausprägung (im übrigen) eine soziale und eine sozial indifferente oder gar unsoziale oder eine soziale und eine sozialere Auslegung zuläßt, fordert die innere Einheit der Verfassung, ${ }^{5)}$ daß bei dieser Alternative die sozialere, bei jener Alternative die so-

lenkung, S.27; ders., Das Grundgesetz, Einführung I D 2 (S.31 f); Forsthoff, Begriff und Wesen des sozialen Rechtsstaats, insbes. S. 25 f; Böhmert, Diskussionsbeitrag hierzu, Veröffentlichungen der Vereinigung der Deutschen Staatsrechtslehrer, Heft 12, 1954, S.116; Scheuner, Berufsständische Versorgungseinrichtungen und Grundgesetz, S. 102; Maunz, Rechtsgutachten über die Verfassungsmäßigkeit der Bayerischen Ärzteversorgung nach dem Grundgesetz, S.24 f; Ballerstedt, Wirtschaftsverfassungsrecht, S. $52 \mathrm{f}$; Dürig in Maunz-Dürig, Art.2 Abs.I Randn.87; Mellwitz, Die Interpretation der Sozialstaatserklärung in der höchstrichterlichen Rechtsprechung, S. 249.

4) Hamann (Das Grundgesetz, Einführung I D 2 (S. $31 \mathrm{f}$ ) weist in diesem Zusammenhang darauf hin, das Sozialstaatsprinzip sei überpositives Recht und deshalb höheren Ranges als die Grundrechte. Zur Frage des überpositiven Geltungsgrundes des Sozialstaatsprinzips dar'f auf das oben Fußn. 1 S. 706 Ausgeführte bezug genommen werden. Aber dessen ungeachtet ist es abwegig, den überpositiven Geltungsgrund des Sozialstaatsprinzips ausgerechnet gegen die Grundrechte ausspielen zu wollen, für die wahrlich der überpositive Geltungsgrund zu einem guton T'eil mindestens so nahe liegt wie für das Sozialstaatsprinzip. Hier wird wieder einmal vor naturrechtlichen Bäumen der positivrechtliche Wald nicht mehr gesehen. Alt. 79 Abs.3 ( $\mathrm{FG}$ gibt den Art. 1 und $20 \mathrm{GG}$, nicht aber allen Grundrechten höhere Geltungskraft. Das Sozialstaatsprinzip hat also 'T'il an einer höheren Bestandskraft als die Grundrechte (in ihrer grundgesetzlichen, positivrechtlichen Ausgestaltung). Doch würde die ursprüngliche Einheit der Verfassung vernachlässigt und Art. 79 Abs. 3 GG mißverstanden, wenn der durch diese Vorschrift gesicherten konstitutionellen Substanz ein allgemeiner interpretatorischer Vorrang eingeräumt würde.

5) S. hierzu nochmals Peters, Kombination verschiedener Verfassungsgrundsätze als Mittel der Verfassungsauslegung, S. $123 \mathrm{f}$. 
ziale Auslegung gewählt wird.

Das bedeutet vor allem, daß den indiviciualistisch ausgerichteten, grundrechtlichen Sicherungen herkömmlicher bürgerlicher Rechtsstaatlichkeit - soweit als nach dem objektiven Gehalt der Verfassung möglich - diese individualistische Einseitigkeit genommen wird. 6) Hier liegt der entscheidende Ansatz für die intrakonstitutionelle Verwirklichung der im Sozialstaatsprinzip implizierten Gemeinschaftsbindung und darüber hinaus für die Versöhnung der im Grundgesetz nicht immer organisch vereinigten Substanzen traditioneller bürgerlicher und moderner, spezifisch sozialer Rechtsstaatlichkeit. 7) Um diesen Ansatz zu entfalten, ist allerdings notwendig, daß die Erkenntnis der interpretatorischen Strahlkraft des Sozialstaatsprinzips mehr als bisher über das grundsätzliche Lippenbekenntnis hinaus in die Tat konkreter Anwendung umgesetzt wird.

Die dem sozialstaatlichen Auslegungsargument entsprechende affirmative, deklaratorische Legitimationswirkung kann umschrieben werden wie folgt: Entspricht ein gesetzgeberisches Vorhaben positiv dem Grundsatz der Sozialstaatlichkeit, so spricht eine gewisse "Vermutung" dafür, daß verfassungsrechtliche Hindernisse nicht bestehen. Die "Vermutung" ist dabei im ganz und gar untechnischen Sinn zu verstehen. Es geht darum, daß das fragliche Vorhaben diejenigen Resistenzschwächen für sich in Anspruch nehmen kann, die infolge des Verfassungsprinzips der Sozialstaatlichkeit grundsätzlich die ganze Verfassung gegenüber sozialstaatlichen Maßnahmen aufweist. ${ }^{8)}$

6) S. die oben S.720 zu Fußn.2 Zitierten. Zur Auslegung der Grundrechte insbes. auch unter diesem Aspekt s. den folgenden 6. Abschnitt (S.842 ff).

7) S. hierzu unten $3 \mathrm{c}(\mathrm{S} .744 \mathrm{ff})$.

8) Als extrem offen liegendes Beispiel darf hervorgehoben werden, daß etwa für ein freiheitsbeschränkendes Gesetz, das dem Sozialstaatsprinzip positiv entspricht (d.h. nicht nur nicht sozialstaatswidrig ist), die Frage nach der allgemeinen Tragweite der Klausel von der verfassungsmäßigen Ordnung (Art.2 Abs.1 GG) unerheblich ist. Jedenfalls das Sozialstaatsprinzip gehört zur verfassungsmäßigen Ordnung (vgl. Hamann, Rechtsstaat und Wirtschaftslenkung, S.66; ders., Deutsches Wirtschaftsverfassungsrecht, S. 89; Peters, Kombination verschiedener Verfassungsgrundsätze als Mittel der Verfassungsauslegung, S. 123; ders., Ist es verfassungsrechtlich zulässig, daß der Staat durch bestimmte Arbeitsschutzvorschriften auch Personen erfaßt, die keine oder nur solche Arbeitnehmer 
cc) Sozialstaatsprinzip und Gesetzesvollzug

aaa) Die Tragweite der sozialstaatlichen Bindung des Gesetzgebers

Von allergrößter Bedeutung ist in einem Gesetzesstaat wie dem des Grundgesetzes, was das Sozialstaatsprinzip für den Gesetzgeber bedeutet. Die Bindung der Verwaltung 1) und der Rechtsprechung 2 ) an das Sozialstaatsprinzip ist dagegen von sekundärer Bedeutung. In der Masse ihrer Geschäfte vollziehen diese beiden "Gewalten" die Gesetze. Je mehr diese den Sozialstaat

beschäftigen, welche infolge der Art oder Organisation des Betriebes insoweit nicht schutzbedürftig sind? S.208; Bachof, Begriff und Wesen des sozialen Rechtsstaats, S.42; Nipperdey, Diskussionsbeitrag hierzu, S.94 f, 98; Claus A rndt, Die Bundesrepublik Deutschland als Rechtsstaat, S. 331; Gerber, Die Sozialstaatsklausel des Grundgesetzes, S. 42 f; BVerwGE 3, 303 (304); mit umgekehrten Vorzeichen auch BVerfGE 6, 32 (41); s.a. nochmals oben S. 717 zu Fußn. 6.) Maunz (Rechtsgutachten über die Verfassungsmäßigkeit der Bayerischen Ärzteversorgung nach dem Grundgesetz, S.25) sieht eine gewisse Auswirkung der Sozialstaatserklärung darin, daß sie einem "grundgesetzlich bedenkenfreien Vorhaben die Gutheißung des Verfassunggebers auf $f^{\prime \prime}$-drücken kann. Dabei geht er mit Recht dennoch davon aus, daß der Sozialstaatsgrundsatz nicht von sonstigen grundgesetzlichen Schranken befreit.

1) S. unten S.726 ff. - Zur Verwaltung als Adressat der Sozialstaatsnorm im allgemeinen s. z. B. v. Mangoldt, Das Bonner Grundgesetz (1.Aufl.) Art.20 Anm.2 b; v. Mangoldt-Klein, Art. 20 Anm. VII 2 b; Huber, Wirtschaftsverwaltungsrecht $\mathrm{Bd}$. I, S.36; Forsthoff, Begriff und Wesen des sozialen Rechtsstaats, S.27 f; Fechner, Sozialer Rechtsstaat und A rbeitsrecht, S. 161; Herschel, Arbeitsschutz im sozialen Rechtsstaat, S. $572 \mathrm{f}$.

2) S. unten S.728f . - Zur Rechlsprechung als Adressat des Sozialstaatsprinzips s. allgemein E. R. Huber, Wirtschaftsverwaltungs recht Bd.I S.36; Fechner, Sozialer Rechtsstaat und A rbeitsrecht, S. 161, 166 und passim; Berger, Bedeutung und Tragweite des Grundsatzes vom sozialen Rechtsstaat, S.9; Hamann, Das Grundgeset\%, Finführung I D 2 (S.31); v. Mangoldt-Klein, Art.20 Anm. VII 2 b; Hueck, Der Sozialstaatsgedanke in der Rechtsprechung des Bundesarbeitsgerichts, S. 71; Bayer. Landessozialgericht, Urt.v. 7. Oktober 1955 - Kr 82/55 - BayAMB1. 1956 B S. 59 (61). 
verwirklichen, verwirklichen ihn Rechtsprechung und Verwaltung durch ihren Vollzug. Selbst indem sie Verfassung und die sonst arizuwendenden Gesetze unter dem gebietenden Aspekt der Sozialstaatlichkeit auslegen, 3 ) erfüllen sie nicht etwa einen eigenen, spezifisch sozialstaatlichen Auftrag sondern ihre allgemeine gesetzesvollziehende Funktion, wenngleich die soziale Bindung der gesetzesanwendenden Gewalten - einmal bewußt geworden - die interpretatorische Aufmerksamkeit schärfen kann.

\section{bbb) Sozialstaatsgerechte Gesetzesauslegung}

Die besagte sozialstaatliche Auslegungsmaxime erlaubt eine beliebte Methode zur Aktualisierung des Sozialstaatsprinzips, die man auf anderem Wege nicht wagt, nicht für möglich oder nicht für ausreichend hält. 1) Sie darf aber nicht überschätzt und nicht mißbraucht werden. Es ist in erster Linie Sache des Gesetzgebers, den Sozialstaat positiv zu entwickeln. 2) Die rechtlichen Möglichkeiten, ihn auf diesen Weg zu zwingen, sind - wie oben 3 ) dargetan - begrenzt. Dem Bedürfnis, das lückenhafte SanktionsInstrumentarium zu ergänzen, darf nicht auf dem Wege der Auslegung Rechnung getragen werden. Sie hat das Gesetz zu deuten und steht insofern unter ihm. Nur wenn das Gesetz eine "sozialstaatlichere" und eine "weniger sozialstaatliche" Auslegung zuläßt, kann sich der Interpretationsbehelf der präsumtiven Sozia1staatlichkeit der Gesetze Zugang und Geltung verschaffen. Dabei wird immer die Gesamtheit der Interpretationselemente zu würdigen sein. Der Widerstand gegen das Eindringen des sozialstaatlichen Interpretationszieles wird mit der Eindeutigkeit der übrigen Auslegungselemente zunehmen. Andererseits wird die Kraft des sozialstaatlichen Interpretationsarguments in dem Maße wachsen, in dem der aus dem sozialstaatlichen Gewicht der offenstehenden Interpretationsalternative(n) entstehende "Druck" zunimmt. Er wird sein Maximum dort erreichen, wo zwischen einer sozialstaatsgerechten und einer eindeutig sozialstaats- und somit verfassungswidrigen Auslegung zu wählen ist. Aber auch hier setzt die sog. verfassungskonforme Auslegung noch ein Minimum an Aufnahmefähigkeit für den sozialstaatlichen Gesetzesinhalt voraus. Ultima ratio im Falle des eindeutigen Widerspruchs ist nicht die gewaltsame, (in bezug auf den Interpreten) usurpatorische Sinn-

3) Zur Auslegung unter Heranziehung des Sozialstaatsprinzips

s. nochmals oben S. 719 zu Fußn. 1 .

1) S. oben S.719 zu Fußn. 1 .

2) S. nochmals oben S.714 und die dort. Nachweise.

3) S. oben S. 714 . 
verkehrung des Gesetzes sondern der verfassungsgerichtliche Anspruch seiner Verfassungswidrigkeit. 4) Die Interpretation bzw. der Interpret ist nicht befugt, dem Gesetz einen bestimmten sozialen Gehalt gleichsam gegen seinen Willen zu oktroyieren. ${ }^{5)}$

Das sozialstaatliche Interpretationsargument ist aber auch nicht einfach als eine Günstigkeitsklausel zugunsten "der Schwächeren" zu handhaben. 6) - Damit würden die Gestaltungsaufgaben des Gesetzgebers ignoriert, ja negiert. A1s Günstigkeitsklausel dürfte das sozialstaatliche Interpretationsargument nur dann angewendet werden, wenn für den Gesetzgeber selbst die Maxime gälte, daß er die im Rahmen seiner umfassenden Ordnungsaufgaben zu treffenden Entscheidungen immer dann sub specie des Sozialstaats "richtig" fällte, wenn er die für die jeweils "Schwächeren" günstigere bzw. günstigste Regelung wählte. Diese Maxime wäre schlechterdings stupid. Sie würde die Struktur und Kompliziertheit der inneren Zusammenhänge im Gefüge des Rechts bzw. in der Sach- und Interessenkonstellation der von der staatlichen Ordnungsaufgabe umschlossenen Lebensverhältnisse sträflich verkennen. Weil die Dinge so einfach nicht liegen, darum ist ja das Sozialstaatsprinzip im wesentlichen kein fertiges Rezept sondern "nur" Grundsatzauftrag. Das sozialstaatliche Interpretationsargument muß sich der gesetzgeberischen Sach- und Wertungskonzeption einfügen. Nur so kann es ordnungsgerecht fruchtbar werden.

Gelegent1ich wird behauptet, das Sozialstaatsprinzip habe nicht die Kraft, einen Wandel in der Auslegung vorkonstitutionellen Rechts zum "Sozialeren" hin zu bewirken. 7) Das ist nicht richtig - jedenfalls nicht in dieser. Allgemeinheit. Entscheidend ist,

4) Zum Problem der verfassungskonformen Auslegung s. oben S. 557 zu F'ußn. 10 (3).

5) Vg1. Bayer. Landessozialgericht, Urteil vom 11. März 1957 Ar 927/56 - Breithaupts Simmlung, 46.Jhg. (1957) - S.958 (959 f).

6) S. hierzu die trotz ihres anderen positivrechtlichen Zusammenhangs auch hier interessierenden, trefflichen Ausführungen von Henrich, Das öster reichische Sozialrecht in der Kritik seiner Anwendung, Oster reichische Juristenzeitung, 11. Jhg. (1956) S. 4 fr, 29 ff (S. 7 f).

7) Vgl. Klein, Bonner Grundgesetz und Rechtsstaat, S.400 f; Held, Fürsorgepflicht und Fürsorgeanspruch nach geltendem Verfassungs- und Verwaltungsrecht, DöV 4.Jhg. (1951) S. 8 ff; Patzig, Klagbarer Rechtsanspruch der öffentlichen Fürsorge, NJW 4.Jhg. (1951) S. 62 f (63). 
ob das Sozialstaatsprinzip selbst einen Wandel gegenüber dem normativen Zustand gebracht hat, unter dem das fragliche Altrecht entstanden ist bzw. unter dem sich die bisher maßgebliche Auslegung entwickelt hat. Liegt ein wesentlicher Wandel vor und ist dieser für die auszulegende Regelung bedeutsam, so rechtfertigt, ja gebietet er auch die Anpassung der Interpretation. 8) Daß das Sozialstaatsprinzip einen grundsätzlichen Unterschied gegenüber dem Rechtszustand früherer Epochen bedeutet, die ein so umfassendes, Aktualität beanspruchendes Verfassungsprinzip nicht kannten, ist dieser Wandel nicht selten anzunehmen. Aber auch in diesem Zusammenhang setzt die sozialstaatsgerechte Interpretation voraus, daß die auszulegende Norm dafür hinreichend offen ist.

\section{c) Sozialstaatsprinzip und Verwaltung}

Verwirklicht auch die Verwaltung den Sozialstaat vornehmlich durch den Vollzug des sozialstaatlichen Gesetzesrechts, so ist sie darauf doch nicht beschränkt. Läßt ihr das Gesetz einen Ermessensspielraum, so hat sie diesen, soweit die zu treffende Entscheidung sozial relevant ist, dem Sozialstaat so gemäß wie möglich auszufüllen. 1) Je mehr die Verwaltung sich durch eigene Entscheidung entfalten kann, desto größer wird diese Bedeutung des Sozialstaatsprinzips.

So steht das Sozialstaatsprinzip als unmittelbar wirkendes Regulativ vor allem hinter der sozial so wichtigen Leistungsverwaltung, die ja auch materiell "gesetzesfrei" sein kann. 2) Sanktio-

8) S. f.v.a. Nawiasky, Allgemeine Rechtslehre, S. 130 f, 138.

1) Vgl. Klein, Bonner Grundgesetz und Rechtsstaat, S. 400; Forsthoff, Begriff und Wesen des sozialen Rechtsstaats, S. 28 f; Fechner, Sozialer Rechtsstaat und Arbeitsrecht, S. 161; Thieme, Liberalismus und Grundgesetz, S. 297; Leibholz, Die kritischen Punkte des Grundgesetzes, S. 19; Bayer. Landessozialgericht, Urteil vom 7. Oktober 1955 - Kr 82/55 BayAMB1. 1956 B S. 59 (61); Barocka, Die Berücksichtigung sozialer Gesichtspunkte bei der Erhebung von Gebühren und Beiträgen usw. S. 825. Zur verwaltungsgericht1ichen Ermessenskontrolle unter diesem Aspekt $\mathrm{s}$. ferner auch v. MangoldtKlein, Art. 20 Anm. VII 2 b.

2) Vgl. Bachof, Begriff und Wesen des sozialen Rechtsstaats, S. 63; dagegen - für die Subventionierung Privater - Stern, Rechtsfragen der öffentlichen Subventionierung Privater, S. 523 ff (aber doch nur, indem er die Subventionierung an sich dem Gesetzesvorbehalt unterstellt, den das Sozialstaats- 
niert (insbes. durch die gerichtliche Verwaltungskontrolle) wird es freilich auch hier grundsätzlich nur als das Verbot unsozialen Staatshandelns werden können. Dennoch ist es gerade in bezug auf die "gesetzesfreie" Verwaltung nicht ohne rechtserhebliche Bedeutung auch für die positive Verwirklichung des Sozialstaates. Hier wirkt das Sozialstaatsprinzip als Legitimation. Soweit die Verwaltung "gesetzesfrei" tätig werden darf, ist sie nicht der Notwendigkeit einer rechtlichen Grundlage enthoben. Nur kann diese auch in ihrem allgemeinen Auftrag, wie die Verfassung ihn umreißt, gefunden werden. ${ }^{3)}$ Entspricht ein - potentiell "gesetzesfreies" - Tun der Verwaltung positiv dem Sozialstaatsgrundsatz, so steht seine Zugehörigkeit zu diesem Auftrag außer Zweifel. ${ }^{4}$ ) Die Bindung der Verwaltung an das Gesetz und den Vorbehalt des Gesetzes 5) sprengt das Sozialstaatsprinzip dagegen nicht. ${ }^{6)}$ Das Grundgesetz hat den sozialen Rechtsstaat konstituiert, also ein optimales "Sowohl - als auch" gewollt. 7) Das inhaltlich weit ausgedehnte, nicht aufgegliederte und präzisierte Sozialstaatsprinzip wäre als eine aktuell verpflichtende Norm, kraft deren der Bürger von der Verwaltung konkret und ohne die Vermittlung des Gesetzes in Anspruch genommen werden könnte, rechtsstaatlich untragbar. ${ }^{8)}$ Das von dem Verfassungsbekenntnis zum sozialen Staat implizierte soziale Pflichtprinzip9) wirkt mittelbar, indem

prinzip nicht durchbricht; s. Fußn. 54). - Zur gesetzesfreien Verwaltung s. oben Abschnitt 4 II $2 \mathrm{~b}$ bb aaa (S.420 ff).

3) S. zu diesen Problemen oben S. 424.

4) Vgl. Bachof, a.a.O. S.43, 63; s.a. Barocka, a.a.O.

5) S. oben Abschnitt 4 II 2 b, bb aaa (S. $420 \mathrm{ff}$ ).

6) Vgl. Herschel, Arbeitsschutz im sozialen Rechtsstaat, S.578; s.a. Bachof, a.a.O. - Zu "vorsichtig" Stern, wenn er (a.a.O. S.523) meint, das Sozialstaatsprinzip eigne sich als Ermächtigung für Eingriffsakte "nur begrenzt".

Nicht ganz eindeutig Barocka, a.a.O.

7) S. unten $3 \mathrm{c}(\mathrm{S} .744 \mathrm{ff})$.

8) S. nochmals oben S. 693 ; s.a. Forsthoff, Begriff und Wesen des sozialen Rechtsstaats, S.27. Damit wird nicht verkannt, daß das Sozialstaatsprinzip in Art.20 und 28 GG gleichrangig neben dem Rechtsstaatsprinzip steht. Sicher hätte der Verfassunggeber die Möglichkeit, ein so allgemeines, unmittelbar aktuelles Pflichtprinzip zu konstituieren, gehabt. Aber er hätte dann den bürgerlich-rechtsstaatlichen Gesamtcharakter des Grundgesetzes aufgehoben. Gerade dieser sollte aber gewahrt werden.

9) S. oben S.676, insbes. \$.681 die zu Fußn.9 Zitierten und S. 701 . 
es die Interpretation der Verfassung und der Gesetze beeinflußt und hier auf eine Anerkennung der bürgerlichen Pflichtstellung und auf die Modifizierung der individualistischen Abwehrrechte drängt. 10)

\section{d) Sozialstaatsprinzip und Rechtsprechung}

Auch die Rechtsprechung realisiert die Sozialstaatlichkeit zunächst durch die Anwendung des Gesetzesrechts. Die sozialstaatsgerechte Auslegung des bestehenden Gesetzesrechts gewinnt bei ihr, die die Auslegung und Anwendung des Rechts umfassend und letztverantwortlich kontrolliert, allerdings eine so hervorragende Bedeutung, daß sie schon fast einem eigenen sozialstaatlichen Mandat gleichkommt.

In ein solches tritt die Rechtsprechung denn auch ein, wern sie, wozu sie berufen ist, das Recht im Rahmen der Fallentscheidung fortbildet und ergänzt. 1) Nicht minder deutlich läßt die gericht-

10) S. oben S. 719 und die dortigen Nachweise.

1) (1) Aus der Zahl der oben S.723 zu Fußn.2 Genannten s. hierzu insbes. Fechner, a.a.O.; Berger, a.a.O.; Hamann, a.a. O.; Hueck, a.a.O. S.71. Fechner (a.a.O. S.168) bemerkt, der Richter könne sich beim Ausbau des Sozialstaates nicht so weit vorwagen wie der Gesetzgeber. Das ist richtig. Dem Richter sind nicht nur Tatsachen und Interessen vorgegeben sondern auch bindende Rechtssätze, die, wenn sie ihm auch die konkrete Fallentscheidung nicht vorgeben, ihn loch bei der Auffindung der (gedachten) Rechtssätze, aufgrund deren er die (echte oder unechte) Lücke, auf die er auftrifft, schließt, beengen. Der Gesetzgeber ist, wenn er eine neue oder besondere Regelung trifft, an das übrige Gesetzesrecht nur gewissermaßen logisch, nicht aber rechtlich gebunden. Der Richter kann die vorhandenen Grundsätze und Nachbarrechtssätze, die das zu lösende Problem durchziehen bzw. berühren, schon aus rechtlichen Gründen nicht ignorieren. (2) Der Aufgabe, das Recht sozialstaatlich auszulegen, zu exgänzen und fortzubilden, hat sich insbes. das Bundesarbeitsgericht mit großem (gelegentlich zu großem) Eifer angenommen. Siehe hierzu die kritischen Berichte von Müller (Der. Gedanke des sozialen Staates in der bisherigen Rechtsprechung des Bundesarbeitsgerichts) und Hueck (Der Sozialstaatsgedanke in der Rechtsprechung des Bundesarbeitsgerichts). Hinweise auch auf die Rechtsprechung anderer Gerichte enthalten die Darstellungen von Werner (Sozialstaatliche Tendenzen in der Rechtsprechung) und Mellwitz (Die Interpretation der Sozial- 
liche Zuständigkeit, die Rechtmäßigkeit der Verwaltung und die Verfassungsmäßigkeit der. Gesetzgebung zu überprüfen, den unmittelbaren Vollzug des Sozialstaatsprinzips durch die rechtsprechende Gewalt werden. ${ }^{2)}$ Gerade die Durchsetzung des Sozialstaatsprinzips gegenüber (lem Gesetzgeber 3 ) 1äßt - so beschränkt die Möglichkeiten, das Sozialstaatsprinzip dabei über das Verbot des eincleutig Unsozialen hinaus zu realisieren,auch sind - die hohe Verantwortung der Gerichte, insbes. des Bundesverfassungsgerichts, für die Sozialstaatlichkeit deutlich werden.

e) Das Sozialstaatsprinzip als Quelle individueller Rechte und Pflichten im Staat-Bürger-Verhältnis?

aa) Das Fehlen einer unmittelbaren Verpflichtung des Bürgers

Das Sozialstaatsprinzip verpflichtet den Bürger dem Staat gegenüber nicht unmittelbar. 1) Nur der Gesetzgeber (bzw. das in diesem Sinn auszulegende Gesetz) kann die Sozialpflichtigkeit der In(lividuen, 2) indem er sie konkretisiert, auch aktualisieren. Die Verwaltung kann sich nicht unmittelbar auf sie berufen. ${ }^{3)}$ Der Richter hat, da er die vom Sozialstaatsprinzip nicht angetasteten Gesetzesvorbehalte respektieren muß, kaum je Gelegenheit, die soziale Pflichtstellung im Rahmen quasilegislativer Rechtsfindung zur Geltung zu bringen.

staatserklärung in der höchstrichterlichen Rechtsprechung). Verschiedene weitere Hinweise s. unten III (S. 762 ff).

2) Insbes. die Bedeutung der verwaltungsgerichtlichen Kontrolle wird hervorgehoben lurch Klein, Bonner Grundgesetz und Rechtsstaat, S. 400; v. Mangoldt-Klein, Art. 20 Anm. VII 2 b; Barocka, a.a.O. S.825. - Es liegt in dem - hier nicht erneut zu umschreibenden - Wesen ihrer Zuständigkeit, daß vor allem die Sozialgerichtsbarkeit in der vordersten Front verwaltungsgerichtlicher Verwirklichung des Sozialstaates steht (s. hierzu insbes. Winer, Allgemeine Verwaltungsgerichtsbarkeit und Sozialguri('htsbarkeit).

3) Zur Weigerung des Bundesfinanzhofes, das Sozialstaatsprinzip im Rahmen der allen Gerichten nach Art. 100 Abs. 1 GG (unter Vorbehalt der negativen Entscheidung zugunsten des Bundesverfassungsgerichts) zustehenden Prüfung der Verfassungsmäßigkeit der. Gesetze zur Geltung zu bringen, s. nochmals oben S.715 zu Fußn.2.

1) Forsthoff, Begriff und Wesen des sozialen Rechtsstaates, S.27. - S.a. oben S. 693 .

2) S. oben S.676 und S.701.

3) S. oben S. 726 . 
bb) Das Sozialstaatsprinzip als Anspruchsgrundlage gegen den Staat?

Näher - zunächst schon wegen des primär gebenden, verteilenden, helfenden Charakters des Sozialstaates - liegt der Gedanke, aus dem Sozialstaatsprinzip individuelle Rechte herzuleiten. 1) Nicht nur das Rechtsstaatsprinzip 2) sondern auch das der Menschenwürde dienende Sozialstaatsprinzip drängt danach, den (begünstigten) Betroffenen aus der bloßen Objektstellung herauszuheben und in eine Subjektstellung, eine subjektive Rechtsstellung, einen status positivus socialis einzuweisen. ${ }^{3)}$ Erschiene es nicht folgerichtig, das Sozialstaatsprinzip selbst als ein berechtigendes Prinzip, als einen Inbegriff von Berechtigungen, zu verste-

1) Das Sozialstaatsprinzip als Quelle subjektiver Rechte bejaht vor allem Hamann, Das Grundgesetz, Einführung I D 2 (S.31) und Deutsches Wirtschaftsverfassungsrecht, S.46. Ge ge n das Sozialstaatsprinzip als selbständige und unmittelbare Quelle subjektiver Rechte: Forsthoff, Begriff und Wesen des sozialen Rechtsstaats, S.27; Scheuner, Berufsständische Versorgungseinrichtungen und Grundgesetz, S.102; ders., Die Abgrenzung der Enteignung, DÖV 7.Jhg. (1954) S. 587 ff (591); Ipsen, Rechtsfragen der berufsständischen $Z$ wangsversorgung, S. $51 \mathrm{f}$; Leibholz, Strukturprobleme der modernen Demokratie, S. 87 f, 130 f; Hueck, Der Sozialstaatsgedanke in der Rechtsprechung des Bundesarbeitsgerichts, S. 72; Stern, Rechtsfragen der öfentlichen Subventionierung Privater, S. 557 f; OVG Lüneburg OVGE 4, 224 (225). Scheuner meint an anderer Stelle (Verfassungsschutz des Eigentums, S. 77), das Sozialstaatsprinzip sei "nur ausnahmsweise die Quelle individueller Rechtspositionen". Fechner (Sozialer Rechtsstaat und A rbeitsrecht, S. 161, 166) hält dafür, das Sozialstaatsprinzip könne "in Grenzen" als Anspruchsgrundlage dienen. Schließlich meint Schlochauer (öffentliches Recht, S.14 f), der soziale Rechtsstaat gebe im Gegensatz zum Wohlfahrtsstaat einen "Anspruch auf soziale Gerechtigkeit". Damit sind aber wohl mehr Idee und Tendenz gemeint als aktuelles Recht.

2) S. oben S. $544 \mathrm{ff}$.

3) Dürig, Verfassung und Verwaltung im Wohlfahrtsstaat, S. 197 f; Bachof, Reflexwirkungen und subjektive Rechte im öffentlichen Recht, S.302; ders., Begriff und Wesen des sozialen Rechtsstaats, S. 74; Stern, a.a.O. S. 557; s.a. Claus Arndt, Die Bundesrepublik Deutschland als sozialer Rechtsstaat, S.333; OVG Hamburg, Urteil v. 22. Januar 1951 - Bf. II 366/50 - DVB1. 66.Jhg. (1951) S.311 (312). 
hen? Das Sozialstaatsprinzip hat sich durch seine undifferenzierte Universalität und mangelnde Präzision diese Geltungsmöglichkeit jedoch selbst abgesprochen. ${ }^{1)}$ Es fehlt ihm das Minimum an Bestimmtheit, das erforderlich wäre, um über den Staat angesonnene Ansprüche allein auf Grund des Sozialstaatsprinzips (positiv) zu entscheiden. ${ }^{4)}$

Diese Bestimmtheit erreicht das Sozialstaatsprinzip - für sich allein, ohne anspruchsvermittelnde zusätzliche Norm - erst an der Grenze des Minimums, an der zwischen Gewährung und Nichtgewährung des absolut Existenznotwendigen zu entscheiden ist. Der Anspruch auf das Existenzminimum 5) kann aber - abgesehen einmal von Art. 1 Abs. $1 \mathrm{GG}^{6}$ ) - über eine sozialstaatsgerechte Auslegung des Art. 2 Abs. $2 \mathrm{GG}^{7}$ ) und über das Verbot, das geltende Fürsorgerecht einschließlich seiner subjektiven Berechtigung in unsozialer Weise abzubauen, nicht weniger überzeugend gewonnen werden. ${ }^{8)}$

Alle darüber hinausgehenden Ansprüche werden konkret faßbar erst im Netz der gegebenen Rechtsordnung. Soweit sie die individuelle Sphäre rechtlich gestaltet und schützt, schützt sie auch gegen sozialstaatswidrige Eingriffe. Auch insoweit würde eine - hintergründige - subjektive Berechtigung aus dem Sozialstaatsprinzip jedenfalls nicht relevant.

Gerade die entscheidende Frage aber, ob dann, wenn die geltende Rechtsordnung, um sozialstaatsgemäß zu sein, einer Ergänzung bedarf, 9) das Sozialstaatsprinzip einen Anspruch auf diese

4) Zur Notwendigkeit, auch das staatliche Leisten-Müssen gesetzlich zu beschränken s. Menger, Rechtssatz, Verwaltung und Verwaltungsgerichtsbarkeit, insbes. S. 588 .

5) Vg1. Dürig, Verfassung und Verwaltung im Wohlfahrtsstaat, S. 197 .

6) S. hierzu unten S.766ff, insbes. S. $766 \mathrm{f} \mathrm{zu} \mathrm{Fußn.} 4$ und 6 (2) und S. 1105 insbes. zu Fußn. 15 ff.

7) S. hierzu unten $S .766 \mathrm{ff}$, insbes. S. $766 \mathrm{f} \mathrm{zu} \mathrm{Fußn.} 5$ und 6 (2) und Abschnitt 6 V 9 d (S.1083 ff).

8) S. hierzu unten $\mathrm{S.766}$ und $\mathrm{S.} 1083$.

9) Gemeint sind damit nicht die kleinen - echten oder unechten Lücken, die sich durch einen sozialstaatsgerechten Weiterbau der positiv vorhandenen Regelungen eindeutig schließen lassen. Daß sie nicht zum Nachteil der Betroffenen ausschlagen dürfen, ist noch unter dem Gesichtspunkt der rechtsstaatlich gebotenen - auch und gerade in dieser Beziehung in hervorragendem Maße den Gerichten anvertrauten - Wahrung des gegebenen Rechts zu sehen. Was hier gemeint ist, sind 
Ergänzung gibt, muß verneint werden. Der Anspruch muß an der Gestaltungskompetenz des Gesetzgebers - daran, daß das Sozialstaatsprinzip auf den Gesetzgeber verweist, ohne ihn ins Positive hinein greifbar zu präjudizieren 10) - scheitern. 11)

Die gesetzgeberische Gestaltungskompetenz hindert die volle Sanktion eines jeden Anspruchs auf positive Erfüllung eines verfassungsrechtlichen Regelungsauftrages. Grundsätzlich wird zur approximativen Durchsetzung subjektiv berechtigender Regelungsaufträge aber wenigstens die gerichtliche Feststellung für zulässig gehalten, die Untätigkeit des Gesetzgebers widerspreche der Verfassung. Auf diese Feststellung kann klagen, wer durch die Untätigkeit des Gesetzgebers in seinen Rechten verletzt ist. Das setzt, von dem Willen der Verfassung zur subjektiven Berechtigung abgesehen, voraus, daß der Regelungsauftrag auf die Individualsphäre des Anspruchsstellers bezogen ist und sie, die gesetzliche Regelung bindend steuernd, mittelbar und zunächst latent aber bestimmend gestaltet. 12) Das Sozialstaatsprinzip gestaltet allein und für sich die Individualsphäre jedoch nicht. In dem Geltungsbereich des Verbots unsozialen Handelns ergeben sich aus ihm zwar zwingende Folgerungen, auch für die Gestalt der individuellen Rechtssphäre. Insoweit korrespondiert es aber durchwegs mit verdeutlichenden und vollziehenden Regelungen mit den Regelungen, die den vorhandenen sozialen Standard bestimmen, vom dem das Verbot unsozialen Handelns im Prinzip ausgeht. 13) In bezug auf den weiteren Auf- und Ausbau des Sozialstaates - der allein hier in Frage steht - bleibt es jedoch zu sehr im Unbestimmten, als daß sich aus ihm schon ableiten ließe, welche Stellung dem einzelnen kraft des Sozialstaatsprinzips zukommen, d.h. durch den Gesetzgeber verschafft werden muß. 14) Das Sozialstaatsprinzip dirigiert einseitig das ordnende Verhalten des Staates - ist nur objektives Recht.

die offenen Gestaltprobleme, die nicht mehr mit rein rechtlicher - wenn auch noch so weit gespannter - Argumentation sonclern nur durch den rechtspolitisch wertenden und gestaltenden, vom Sozialstaatsprinzip gesteuerten aber nicht vorweggenommenen gesetzgeberischen Entschluß gelöst werden können.

10) S.o. S. 706 .

11) Gegen einen Anspruch gegen den Gesetzgeber insbes. auch Herschel, Arbeitsschutz im sozialen Rechtsstaat, S. 575.

12) S. zum Vorstehenden insges. oben S. 557.

13) S. o. S. 709.

14) S. nochmals oben S. 714 . 
Dem entspricht, daß der, der sich durch die gesetzgeberische Nichterfüllung des sozialstaatlichen Regelungsauftrages beeinträchtigt glaubt, sich nicht an das Bundesverfassungsgericht wenden kann. 15) Daß das Grundgesetz die Feststellung einer sozialstaatswidrigen gesetzgeberischen Unterlassung den in Art. 19 Abs. 4 GG für den Fall der Verletzung von Rechten für zuständig erklärten (Nichtverfassungsgerichten, insbes. den) ordentlichen Gerichten anvertrauen wollte, 16) verneint sich wohl von selbst.

Eine sog. relative Unterlassung, d.h. eine Verletzung des Gleichheitssatzes durch eine personell differenzierende teilweise Nichtregelung einer im übrigen geregelten Materie, die nicht zur Ungültigkeit der getroffenen Teilregelung sondern in Anbetracht ihrer Unverzichtbarkeit zur Feststellung der Verfassungswidrigkeit der Unterlassung führt, 17) kann wegen der Unbestimmt-

15) Die Verfassungsbeschwerde ist in der Verfassung selbst nicht vorgesehen. In ihrer gesetzlichen Ausgestaltung dient sie nur der Geltendmachung enumerativ aufgezählter verfassungsmäßiger Rechte, unter die das Sozialstaatsprinzip nicht fällt ( $\$ 90$ Abs. 1 BVerfGG). Das ist wichtig für die richtige Deutung von BVerfGE 1, 97 (165). Dort ist ausgeführt, wenn der Gesetzgeber seine dem Verfassungsbekenntnis zum Sozialstaat entsprechende Pflicht zu "sozialer Aktivität" und zur Bemühung "um einen erträglichen Ausgleich der widerstreitenden Interessen und um Herstellung erträglicher Lebensbedingungen für alle..., die durch die Folgen des Hitlerregimes in Not geraten sind, ... willkürlich, d.h. ohne sachlichen Grund versäumte, könnte möglicherweise dem einze1nen hieraus ein mit der Verfassungsbeschwerde verfolgbarer Anspruch erwachsen". Dieser Anspruch muß einem Grundrecht entnommen werden können, nicht unmittelbar dem Sozialstaatsprinzip. Sonst hätte das Bundesverfassungsgericht nicht an die Verfassungsbeschwerde denken dürfen. Dem entspricht es auch, daß das Gericht vorweg bemerkt: "Wenn auch die Wendung vom 'suzialen Bundesstaat' nicht in den Grundrechten... steht, so enthält sie doch ein Bekenntnis zum Sozialstaat, das bei der Auslegung des Grundgesetzes... von entscheidender Bedeutungs sein kann". Das Bundesverfassungsgericht sieht also das Sozialstaatsprinzip nicht als Anspruchsgrundlage sondern als ein Auslegungselement, das mittelbar zu sozialen Leistungsansprüchen auf der Grundlage der vorhandenen Grundrechte führen kann.

16) S. oben S. 540 und S. 557.

17) S. oben S. 557 . 
heit des Sozialstaatsprinzips nur ausnahmsweise vorliegen.

Der Versuchung, das Sozialstaatsprinzip wenigstens vorläufig $\mathrm{zu}$ aktualisieren und den in ihm ruhenden Gesetzgebungsauftrag mittelbar zu sanktionieren, indem ihm - letztlich durch Richterspruch - einzelne konkrete Folgerungen entnommen werden, 19) darf aus den gleichen Gründen nicht nachgegeben werden. Schon oben wurde zwar darauf hingewiesen, daß in Grenzfällen, in denen die Alternativen einfach und eindeutig sind und somit schon das Verbot unsozialen Handelns zu einer klaren Lösung führt, eine unmittelbare Anwendung des Sozialstaatsprinzips durchaus möglich ist. Entsprechendes gilt, wo das Sozialstaatsprinzip wenigstens im Zusammenhang mit dem übrigen Recht zwingende und eindeutige Schlüsse zuläßt. Wo dieser relativ schmale Streifen entlang der Untergrenze der Sozialstaatlichkeit und der Kontaktzone zwischen dem Sozialstaatsprinzip und dem sonstigen Recht verlassen wird, ist die Verwirklichung des Sozialstaates nur mehr im Rahmen rechtspolitischer Dispositionen möglich, die zu treffen Sache des Gesetzgebers, nicht des Richters ist. Der Gesetzgeber hat die Pflicht, diese Aufgabe zu erfüllen, auch und gerade, indem er feste Rechtspositionen gegenüber dem Staat schafft. 20) Aber das Sozialstaatsprinzip gibt sie nicht unmittelbar her. 21) Die Fiktion subjektiver Berechtigungen auch in diesem Raum würde letztlich nicht nur die sozialstaatliche Pflichtstellung der Verwaltung - ganz und gar ungeregelt - ungemein erweitern sondern vor allem den sozialstaatlichen Auftrag der Gerichte in den Raum der Gesetzgebung hinein ausdehnen. Damit würde nicht nur die Zuständigkeit in einem Maße verschoben, das mit dem Grundsatz vom sozialen Rechtsstaat nicht gewollt gewesen sein kann. Damit würde auch die Notwendigkeit einer allgemeinen und verläßlichen Ordnung vernachlässigt, die, dem sozialen Rechtsstaat wesentlich, durch richterliche Fallentscheidung keineswegs genau so gut verwirklicht werden kann wie durch das Tätigwerden des Gesetzgebers. 22)

18) S.a. Ipsen, Gleichheit, S. 160.

19) In diesem Sinne Hamann, Das Grundgesetz, Einführung I D 2 (S. 31, 33) und Art. 20 Anm.C 3 (s.a. oben S.729 zu Fußn.1).

20) S. oben S. 729 zu Fußn. 3.

21) S. oben S. 729 zu Fußn. 1.

22) Vgl. Bachof, Begriff und Wesen des sozialen Rechtsstaats, S.43. - S. zu Vorstehendem insbes. auch Leibholz, Strukturprobleme der modernen Demokratie, $\mathrm{S} .87 \mathrm{f}, 130 \mathrm{f}$. 


\section{f) Zur "Drittwirkung" des Sozialstaatsprinzips}

Eine unmittelbare und selbständige Drittwirkung des Sozialstaatsprinzips ist nicht anzuerkennen. 1) Der eigentliche Adressat des Sozialstaatsprinzips ist der Staat. ${ }^{2)}$ Schon als Pflichtprinzip zulasten der Individuen und zugunsten des Staates kann das Sozialstaatsprinzip nicht unmittelbare Geltung beanspruchen. Wenn nun auch die Sozialpflichtigkeit der Individuen sich nicht in der Sozialpflichtigkeit gegenüber dem Staat erschöpft sondern auch ein "soziales" Verhalten der Bürger untereinander postuliert, ${ }^{3)}$ so doch ebenfalls nicht als unmittelbar aktuelles Recht.

Der Staat als Rechtsordnungssubjekt hat aber die zwischenbürgerlichen Beziehungen "sozial" zu regeln. Das wirkt sich über den direkten gesetzgeberischen Vollzug dieses Auftrages hinaus durch eine entsprechende Auslegung und Anwendung der einschlägigen Normen aus. 4) Insbes. der wertende Vollzug der Generalklauseln gibt die Möglichkeit zu einer legitimen Konkretisierung der Sozialpflichtigkeit. ${ }^{5)}$

Verschiedentlich wird auch die Drittwirkung der Grundrechte ${ }^{6}$ ) der "Drittwirkung" des Sozialstaatsprinzips als Mittel oder Folge zugeschrieben. 7) Daran ist etwas Richtiges. Zwischen den Grundrechten und dem Sozialstaatsprinzip bestehen Parallelen. Beide

1) A.A. Hamel, Die Bedeutung der Grundrechte im sozialen Rechtsstaat, S.36 f; s.a. Merk unten S. 736 zu Fußn. 10.

2) S. außer oben 1 ( $\mathrm{S} .676 \mathrm{ff}$ ) für den speziellen Zusammenhang Ballerstedt, Wirtschaftsverfassungsrecht, S. 56 .

3) S. von den oben S. 681 zu Fußn.9 Genannten insbes. Wolany, Vom Sozialstaat und sozialen Recht, S.155, 164; Fechner, sozialer Rechtsstaat und Arbeitsrecht, S. 162 f; E.R. Huber, Der Streit um das Wirtschaftsverfassungsrecht, S. $201 \mathrm{f}$; Ballerstedt, Wirtschaftsverfassungsrecht, S. 57.

4) Vgl. Fechner, a.a.O. S.166.

5) Vg1. Ballerstedt, a.a.O.

6) S. unten Abschnitt 614 d (s.8.376 ff).

7) Nipperdey, Diskussionsbeitrag zu "Begriff und Wesen des sozialen Rechtsstaats", \$.96 f; ders., Die Würde des Menschen, in: Neumann-Nipperdey-Scheuner, Die Grundrechte, Bd.II 1954, S. 1 ff (20); Hildegard Krüger, Ein Jahr Bundesarbeitsgericht, Recht der Arbeit, 8.Jhg. (1955) S. 244 ff (250 f);

Werner, Sozialstaatliche Tendenzen in der Rechtsprechung, S. 93; Ballerstedt, a.a.O. S. 59; BAGE 1, 185 (193); 4, 274 (276). In anderem Sinne zieht BVerfGE 6, 55 (72) das Sozialstaatsprinzip als Argument für die umfassende Geltung des Art. 6 Abs. 1 GG heran. 
haben mit dem Konflikt zwischen "Stärkeren" und "Schwächeren" zu tun. Die Grundrechtsordnung bringt die Konfliktslösung für das Staat-Bürger-Verhältnis nicht ohne damit Wertrangordnungen erkennen zu lassen, die darüber hinaus Beachtung verdienen. Insofern liegen in der Grundrechtsordnung Ansatzpunkte für die Konkretisierung des Sozialstaatsprinzips und ebenso im Sozialstaatsprinzip Antriebskräfte, die auf eine umfassende Realisierung der in der Grundrechtsordnung herausgestellten Rechtswerte hindrängen. Aber weder die Grundrechte ${ }^{8)}$ noch das Sozialstaatsprinzip haben den $Z$ weck und sind imstande, die zwischenbürgerlichen Beziehungen unmittelbar zu regeln. Sozialstaatsprinzip und Grundrechte - auch in ihrer eben aufgezeigten Verschränkung - wirken, abgesehen von der positiven Ausmünzung ihres grundsätzlichen Rechtsgehaltes durch den Gesetzgeber, auf die zwischenbürgerlichen Rechtsbeziehungen über die Auslegung des Privatrechts und über den wertenden Vollzug seiner Generalklauseln, 9) die eine umfassende, ja fast lückenlose Er.schließung des Privatrechts für diese Wertungselemente erlauben, 10) ein.

3. Der "demokratische und soziale Bundesstaat" und der "republikanische, demokratische und soziale Rechtsstaat"

Oben 1) wurde zur Auslegung der Formel vom "sozialen Staat" auf die Wort- und Sachverbindungen Bezug genommen, in die sie durch Art. 20 Abs. 1 und 28 Abs. 1 Satz 1 GG gestellt ist. Nunmehr ist umgekehrt zu fragen, welche besondere Bedeutung diesen Wort- und Sachverbindungen unter Berücksichtigung der gewonnenen Interpretation zukommt.

8) Abgesehen von gewissen Ausnahmen, auf die unten im 6.Abschnitt (S. $842 \mathrm{ff}$ ) zurückzukommen ist.

9) Zur Verwirklichung des Verfassungsrechts, insbes. der Grundrechte im Privatrecht über die wertausfüllungsbedürftigen Normen, insbes. die Generalklauseln des Privatrechts, s. unten Abschn.6 I 4 d (S.876 ff) und die dortigen Nachweise.

10) Wenn Merk (Diskussionsbeitrag zu "Begriff und Wesen des sozialen Rechtsstaats", S. 101) ausführt, "eine Handlung ... eines einzelnen, die schlechthin nicht mehr als sozial angesehen werden kann", sei als Verstoß gegen Art.20,28 GG anzusehen, "gegen den im Wege Rechtens vorgegangen werden kann", so kann diese Behauptung im Rahmen des Privatrechts woh1 lückenlos dadurch realisiert werden, daß die gegebenen Generalklauseln (insbes. $\$ 826$ BGB!) in diesern Sinne gehandhabt werden.

1) S. oben $1 \mathrm{~b} \mathrm{cc}$ - ee (S.686 bis S.696). 
a) Der soziale Bundesstaat

aa) Sozialstaatsprinzip und bundesstaatliche Kompetenzordnung Die Wendung vom "sozialen Bundesstaat" hat keine eigene kombinatorische Bedeutung. 1) Fraglich kann insofern nur sein, welche sachliche Tragweite das Nebeneinander von Sozialstaatsprinzip und bundesstaatlicher Ordnung hat.

Dabei ist davon auszugehen, daß das Grundgesetz nicht etwa nur den Bund oder nur die Länder zu "sozialen Staaten" erklärt hat. Art. 20 Abs. 1 und 28 Abs. 1 Satz 1 GG lassen - zusammen gelesen - keinen Zweifel, daß das Gesamtstaatswesen, der Bund und die Länder ohne Unterscheidung im Wesen "soziale Staaten" sein sollen.

Wie im übrigen Mittel und Kompetenzen zur Verwirklichung des Sozialstaates unter Bund und Ländern aufgeteilt sind, wurde oben ${ }^{2)}$ bereits dargetan. Hinzuweisen ist hier nur auf eines. Nachdem Bund und Länder "Sozialstaaten" sind bzw. zu sein haben, ist das Sozialstaatsbekenntnis grundsätzlich kein tauglicher Behelf zur Auslegung der bundesstaatlichen Kompetenzordnung. Wer z.B. annimmt, es entspreche der "sozialstaatlichen Norm", den Begriff der Fürsorge (Art. $74 \mathrm{Nr} .7 \mathrm{GG}$ ) weit auszulegen, 3 ) verkennt, daß die Interpretation dieses Begriffes nicht darüber entscheidet, in welchem Maße der Staat überhaupt die "Fürsorge" ordnen darf, sondern darüber, inwieweit der Bund und inwieweit die Länder sie ordnen dürfen. Da die Alternative die der Kompetenz hier wie dort eines "sozialen Staates" ist, kann für ihre Entscheidung von der Sozialstaatsdeklaration her nichts gewonnen werden.

bb) Zur Tragweite des Art.28 Abs. 3 GG

Ein besonderes Problem bietet Art.28 Abs. 3 GG. Danach gewährleistet der Bund (u.a.), daß (lie verfassungsmäßige Ordnung der Länder gemäß Art. 28 Abs. 1 GG "den Grundsätzen des... sozialen Rechtsstaates" entspricht. Kann von hierher der Bund über das in der übrigen bundesstaatlichen Kompetenzordnung umschriebene Maß hinaus die sozialstaatliche Selbstverwirklichung der Länder dirigieren und das Suzialstaatsprinzip für die Länder verbindlich konkretisieren?1) Die praktische Bedeutung der Fra-

1) S. oben S.686 zu Fußn. 1.

2) S. oben 1. Abschnitt (S. 45 ff).

3) BSGE 6, 213 (219).

1) Maunz (Deutsches Staatsrecht, S. 198 f) meint: "Der Begriff des sozialen Rechtsstaates vollends eröffnet so unüberseh- 
ge leidet schon darunter, daß die sozialen Wirkungsmöglichkeiten der Länder im Vergleich zu denen des Bundes verhältnismäBig gering sind. Doch würde das noch nicht die grundsätzliche Bedeutung mindern. Diese wird jedoch dadurch beeinträchtigt, daß sich die Gewährleistung nur auf die "verfassungsmäßige Ordnung der Länder" bezieht, also auf die normative Ordnung und zwar die grundsätzliche normative Ordnung der Staatsorganisation, des Staats-Bürger-Verhältnisses und der materiellen, insbes. der legislativen Staatswirksamkeit. ${ }^{2)}$ Gerade die Möglichkeiten einer sozialen Intervention der Länder durch Rechtsetzzung sind jedoch relativ gering. Dennoch bleibt Raum für die Gewährleistung der Sozialstaatlichkeit der Länder und somit das grundsätzliche Problem, auf welche Weise der Bund eingreifen kann.

Art. 28 Abs. 3 GG verpflichtet den Bund, weist ihm aber keine Kompetenzen zu. Um die Gewährleistung zu realisieren, muß er sich der anderweit geregelten Anrufung des Bundesverfassungsgerichts (Art.93 GG) und des Bundeszwangs (Art.37 GG) bedienen. 3) Mit der Anrufung des Bundesverfassungsgerichts kann der. Bund - genauer: die Bundesregierung - erreichen, daß ein Landesgesetz als gegen das Sozialstaatsprinzip verstoßend für nichtig erklärt wird, also eine verfassungsgerichtliche Kontrolle der Landesgesetzgebung auslösen, die in jedem anderen Normenkontrollverfahren, soweit es sich auf ein Landesgesetz bezieht, nicht weniger bewirkt werden kann. 4) Darüber hinaus kann der Bund, indem er rügt, das Land habe die Pflicht zur Sozialstaatlichkeit verletzt (Art.93 Abs.1 Nr.3 GG), 5) auch die Feststellung herbei-

bare Auslegungen, daß der Bund, wenn er es für richtig hielte und die politische Kraft dazu besäße, nicht nur die Homogenität sondern die Konformität der Länder in bezug auf innere Struktur, Gesetzesvollzug und sonstige Verwaltung herbeiführen könnte. Der Bund gewährleistet ja die Übereinstimmung der Landesverfassungen mit jenem Verfassungsrahmen und mit den im GG aufgestellten Grundrechten".

2) Zum Begriff der "verfassungsmäßigen Ordnung der Länder" i.S. des Art.28 Abs. 3 GG s. v. Mangoldt-Klein, Art. 28 Anm. V 1; Maunz in Maunz-Dürig, Art. 28 Randn. 45. - Zum Ausschluß des Sachbereichs des Vollzugs des Bundesrechts (i.S. des Art. 84 GG) s. darüber hinaus v. Mangoldt-Klein, a.a.O. Anm.V 2 a; Maunz, a.a.O. Randn. 47.

3) Vgl. v.Mangoldt-Klein, a.a.O. Anm.V 2 a; Maunz, a.a.O. Randn. 42. Weitere Nachweise s. dort.

4) Vgl. v. Mangoldt-Klein, a.a.O. Anm.V 3 m. weit. Nachw.

5) Vgl. v.Mangoldt-Klein, a.a.O. Anm.V 2 a. 
führen, daß eine gewisse Unterlassung der verfassungsmäßigen Ordnung des Landes gegen das Sozialstaatsprinzip verstößt. Der Bund kann damit den zwingenden, rein rechtlichen Gehalt des Sozialstaatsprinzips, seiner Verletzung negativ wehrend, gegenüber der verfassungsmäßigen Ordnung der Länder zur Geltung bringen - aber auch nicht mehr. Inwieweit das Instrument des Bundeszwangs in dieser Funktion mit dem Verfassungsstreitverfahren konkurriert, 6) soll hier nicht weiter geprüft werden. Durch die Letztentscheidungskompetenz des Bundesverfassungsgerichts, die auch hinter dem Bundeszwang steht (Art.93 Abs.1 $\mathrm{Nr} .3$ GG), liefe der Bundeszwang insoweit jedenfalls immer wieder auf die besagten bundesverfassungsgerichtlichen Entscheidungstypen hinaus. Wichtig ist vielmehr, daß mit dem Bundeszwang tatsächlich dem Bund eine Einflußnahme ermöglicht ist, die ihn zur positiven Verwirklichung der Sozialstaatlichkeit in den Ländern vorstoßen läßt.

Das ist an sich kein spezifisches Problem der Gewährleistung mehr. Art. 28 Abs. 3 GG verpflichtet nur den Bund, von den ihm eingeräumten Möglichkeiten im Sinne der Gewährleistung Gebrauch zu machen. 7) Art.37 GG ist nicht an den sachlichen Geltungsbereich des Art. 28 Abs. 3 GG gebunden. ${ }^{8)}$ Für den sozialstaatlichen Effekt des Bundeszwangs ist aber davon auszugehen, daß wiederum die auch durch $A$ rt. 28 Abs. 3 GG gesicherte Homogenitätsklausel des Art. 28 Abs. 1 GG die maßgebliche Bundespflicht i.S. des Art. 37 Abs. 1 GG statuiert. ${ }^{9}$ ) Verletzt das Land die Pflicht zu einer verfassungsmäßigen Ordnung nach "den Grundsätzen des... sozialen Rechtsstaats im Sinne dieses Grundgesetzes", so löst das das Recht des Bundes aus, "die notwendigen Maßnahmen ( $z u)$ treffen, um das Land... zur Erfüllung seiner Pflichten anzuhalten".

Wie der verfassungsgerichtliche Entscheid setzt also auch der Bundeszwang beim Negativen, bei der Pflichtverletzung an. Aber das Bundesverfassungsgericht kann eine Unterlassung grundsätzlich nur feststellen und als verfassungswidrig beanstanden. Die Pflichterfüllung kann es nicht vorwegnehmen, weil die Verwirklichung des Sozialstaatsprinzips im allgemeinen über die rechtliche Erkenntnis des sozialstaatlich Fr.rforderten hinaus ein politisches Wollen voraussetzt, das ihm nicht zusteht. Auch im Wege der

6) Vgl. v. Mangollt-Klein, Art.37 Anm. IV 2

7) Vgl. v.Mangoldt-Klein, Art.28 Anm.V 2; Maunz, a.a.O. Randn. 43.

8) Vg1. v. Mangoldt-Klein, Art.37 Anm. III.

9) Vgl. v. Mangoldt-Klein, a.a.O. Anm. III 2 a m.weit. Nachw. 
Vollstreckung ( $\$ 35$ BVerfGG) hat es keine Möglichkeit, die unerläßliche politische Willensbildung der kompetenten (Landes-) Organe in Gang zu setzen. Anders der Bund als politische Zentralgewalt - repräsentiert durch Bundesregierung und Bundesrat. Seine Machtbefugnisse sind zweckhaft auf die Erfü11ung (ler nicht erfüllten Bundespflicht des sich verfehlenden Landes abgestellt. Der Bund kann versuchen, mittelbar durch geeignete Maßnahmen ${ }^{10)}$ dahin zu wirken, daß das Land seine Pflicht doch noch erfüllt, d.h. im vorstehenden Zusammenhang, sich doch noch zu der ausstehenden, sozialstaatsverwirklichenden Willensbildung bereit findet. Er kann äußerstenfalls aber zur (möglicherweise - das ist hier von besonderer Wichtigkeit - auch legislativen) Ersatzvornahme greifen. 10) Der Bund hat sich dabei nicht nur hinsichtlich der Art sondern auch hinsichtlich des Inhalts der zu ergreifenden Maßnahmen in den Grenzen des "Notwendigen" zu halten. 11) Er wird also seinen unmittelbaren Druck oder seine Ersatzvornahme nur soweit treiben dürfen, als es notwendig ist, den sozialstaatswidrigen Zustand zu beseitigen. Außerdem ist es sein Auftrag nicht, eine volle sozialstaatliche Wirklichkeit herzustellen. Er hat nur die Bundespflicht zu einer den Grundsätzen des sozialen Rechtsstaates entsprechenden verfassungsmäßigen Ordnung (!) des Landes durchzusetzen. Der Bund ist also im erstrebten oder ersatzweise vorgenommenen - Ausbau der landesrechtlichen Sozialstaatlichkeit auf einen viel engeren Raum beschränkt als das in der Fülle seiner eigenen Zuständigkeiten handelnde Land selbst. Aber es ist immerhin von höchster. Bedeutung, daß der Bund - d.h. die Bundesregierung mit Zustimmung des Bundesrates - die Möglichkeit hat, die Verwirklichung des aus dem Sozialstaatsprinzip als unerläßlich nachweisbaren Minimums an sozialer verfassungsmäßiger Ordnung in den Ländern positiv durchzusetzen.

Wie Art.20 Abs. 1 i.V.m. Art. 79 Abs. 3 GG das Sozialstaatsprinzip in die oberste Schicht des Bundesverfassungsrechts eingereiht hat, so hat es Art. 28 Abs. 1 Satz 1 GG in das Kernstück der födlerativen Grundordnung hineingenommen. Die bündische Gewährleistung und Durchsetzung ist eine Folge dieser Anerkennung der Sozialstaatlichkeit als Zentralwert der gesamtstaatlichen Rechtsol'dnung. 12)

\footnotetext{
10) Vgl. v. Mangoldt-Klein, a.a.O. Anm. IV 5 b und die dort. Nachweise.

11) Art.37 Abs. 1 GG: "... die notwendigen Maßnahmen... um das Land... zur Erfüllung seiner Pflichten anzuhalten". Zur Erläuterung s. v. Mangoldt-Klein, a.a.O. Anm. IV 5 c.

12) Den Ländern steht eine umgekehrte Garantiefunktion der Su-
} 


\section{b) Die soziale Demokratie}

aa) Affinität und wechselseitige Ergänzung von Sozialstaat und Demokratie

Sowohl in Art. 20 Abs. 1 wie auch in Art. 28 Abs. 1 Satz 1 GG sind die Epitheta "demokratisch" und "sozial" gleicherweise dem Staate zugeordnet. Dem Nebeneinander der Begriffe entspricht eine enge Verbindung ihrer Gegenstände.

Demokratie und Republik auf der einen, Sozialstaat auf der anderen Seite - dieses Gegenüber erinnert daran, daß es republikanische und demokratische Autoritäten sind, die den Sozialstaat zu entfalten haben. Die politische Entscheidungsgewalt wird innegehalten von den Exponenten politischer Aktionsgruppen, die in der Regel immer nur einen Teil der virulenten Interessen repräsentieren, deren Kampf um die politische Macht auf die Dauer aber doch auf einen umfassenden Interessenausgleich tendiert. 1) Diese Demokratie des Grundgesetzes, die Demokratie des allgemeinen und gleichen, freien und geheimen Wahlrechts ist kein Klassenstaat. 2 ) Sie ist dem Sozialstaat wesensverwandt. Auch er ist auf Ausgleich gerichtet. Auch er ist kein Klassenstaat - weder "von oben" noch "von unten", d.h. also auch nicht ein Klassen-

zialstaatlichkeit des Bundes nicht zu. Was dem Bund aber an Einfluß auf die Länder gewährt ist, ist - wenngleich auf ganz anderer Ebene - in gewissem Maße durch die vielfältigen politischen Einflußnahmerechie des Bundesrates kompensiert. Eine entscheidende Akzentuierung liegt freilich darin, daß die Sozialstaatlichkeit eine Bundespflicht der Länder, nicht auch eine (die Länder irggendwie berechtigende) Bundespflicht des Bundes selbst ist. IIährend z. B. der Bund - von Art. 37 GG einmal ganz abgesehen - die Verletzung der Pflicht zur sozialstaatlichen Velfissungsordnung gem. Art. 28 Abs. 1 und 3, 93 Abs. 1 Nr.3 GG und dirüber hinaus die bestehenden Landesgesetze auch nach Alt.93 Abs. $1 \mathrm{Nr} .2 \mathrm{GG}$ vor das Bundesverfassungsgerich bringen kann, sind die Länder darauf beschränkt, das bestehencle Bundesrecht gem. Art.93 Abs. 1 Nr.2 GG auf seine Sozialstiatlichkeit überprüfen zu lassen. Der Extremfall, daß der Bund sich seiner sozialstaatlichen Aufgabe grundsätzlich entzieht und es in einem die Bundestreue verletzenden Maß den Ländern allein überläßt, die Sozialstaatlichkeit der Bunclesrepublik zu verwirklichen, ist indiskutabel.

1) S. oben Abschnitt 3, insbes. I 1 (S. $315 \mathrm{ff})$, und III (S. $340 \mathrm{ff}$ ).

2) Vgl. nochmals die schon dort zitierten eindrucksvollen Ausführungen in BVerfGE 5, 85 (198). 
staat der (zunächst) ärmeren Schichten.

Aber die Demokratie ist für sich noch keine Garantie gegen einen Klassenstaat. Demokratie ist Herrschaft der Mehrheit. Radikale, in sich geschlossene Mehrheiten können versuchen, ihre Herrschaft zur Ausbeutung der Minderheit zu nutzen. Die Verfassung versucht dem zu wehren; durch gewisse Grundrechte aber auch durch das Sozialstaatsprinzip. Um im Modell zu denken: daß das Sozialstaatsprinzip der Benachteiligung der Minderheit der schlechter Gestellten durch die Mehrheit der besser Gestellten widerstrebt, ist evident; als Prinzip des Ausgleichs und der Hilfe deckt es aber auch nicht einen bloßen Rollentausch, bei welchem die Mehrheit der schlechter Gestellten durch Expropriation der Minderheit der besser Gestellten diese zu ihren Gunsten aus ihrer ökonomischen Position zu verdrängen sucht, ja widersetzt es sich der planmäßigen Pauperisierung der Minderheit. 3)

Die moderne Demokratie des allgemeinen und gleichen Wahlrechts der Massen ist egalitär. Von ihr geht ein Zug zur universellen Egalisierung aus, insbes. auch eine Tendenz zur Einebnung der ökonomischen Verhältnisse. 4) Darin geht sie weiter als das Sozialstaatsprinzip. Dieses ist, soweit es als Rechtssatz Geltung beanspruchen kann, nicht rigoros egalitär. Absolute Einebnung gehört nicht zu dem gemeinsamen Bestand an Postulaten der historischen Sozialbewegung. Diese ist nicht ohne das Streben nach sozialer Gerechtigkeit zu denken;5) und soziale Gerechtigkeit enthält immer auch einen Kern des suum cuique tribuere. In der aufgezeigten Differenz liegt aber kein grundsätzlicher Widerspruch zwischen Demokratie und Sozialstaat. Regelmäßig wirkt die egalitäre Tendenz, durch die Beharrung der bestehenden Verhältnisse "entschärft" und auf Nahziele beschränkt, als wohltätiger Impuls der Sozialstaatlichkeit. Aber auch eine weitergehende Entwicklung zur massendemokratischen Egalität läge noch durchaus im Bereich der Eventualitäten, die das Sozialstaatsprinzip als Formelkompromiß dem Entscheid der maßgeblichen Mehrheit überläßt. Man wird nicht behaupten können, eine egalitäre Angleichung der Bedürfnisbefriedigungskompetenz sei von den verschiedenen Kräften und Richtungen der historischen Sozialbewegung geschlossen negiert worden. Gewiß gibt es eine Grenze. Ungerechte Egalität, die der Würde des Menschen nicht

3) Vgl. Wolany, Vom Sozialstaat und sozialen Recht, S. 153, $155 \mathrm{f}$.

4) S. auch hierzu oben Abschnitt 3 I 1 (S. $315 \mathrm{ff}$ ).

5) S. oben S.678 zu Fußn. 3 . 
mehr gemäß ist (Art.1 Abs.1 GG) und wesentlich Ungleiches gleich behandelt (Art. 3 GG), kann auch sub specie des Sozialstaatsprinzips nicht hingenommen werden. Aber dabei handelt es sich auch vom Standpunkt der - im Kern ja politischen - Demokratie aus um eine radikalisierte Entartungserscheinung, deren Realität unter den gegebenen politischen, wirtschaftlichen und verfassungsrechtlichen Verhältnissen nicht näher in Betracht gezogen werden muß.

Daß der Sozialstaat seinerseits die Entwicklung einer der politischen Demokratie adäquaten, gesunden ökonomischen und sozialpsychischen Substruktion unterstützt, sei am Rande noch einmal in Erinnerung gebracht. $\left.{ }^{6}\right)$

\section{bb) Im besonderen zur "Wirtschaftsdemokratie"}

Mit gesteigerter Affinität begegnen sich Sozialstaat und Demokratie im Raum dessen, was mit der "Wirtschaftsdemokratie" gemeint ist. 1) Der egalitäre und der autonomistische Grundzug der Demokratie treffen, einander bekräftigend, auf die sozialstaatlichen Tendenzen nach Abbau der Wohlstandsdifferenzen, nach Mäßigung der Abhängigkeitsverhältnisse und genossenschaftlicher Hilfe und Mitverantwortung.

Oben 2) ist bereits dargelegt worden, daß trotz dieser Inklination der Demokratie zu gewissen sozialpolitischen Gestaltungsformen ihre definitive Ableitung aus den Grundelementen der Demokratie allein nicht möglich ist, schon gar nicht aber aus der rein politisch konzipierten Demokratie des Grundgesetzes. Wirtschaftsdemokratie - oder wie man es sonst nennen mag - ist ein Fortoder Andersdenken der politischen Demokratie, nicht etwa nur eine Konkretisierung ihrer Idee. Trotzdem hat die Auslegung des Sozialstaatsprinzips nie zu vergessen, daß dieses in eine demokratische Verfassung eingebettet und schon äußerlich in die engste Verbindung mit dem Bekenntnis zur Demokratie gebracht ist. 3) Sozial wirksame Institutionen der "Wirtschaftsdemokratie" 4) werden unter diesem Gesichtspunkt in bezug auf ihre Ver-

6) S. oben S. $334 \mathrm{f}$.

1) S. oben S. $329 \mathrm{ff}$.

2) S. oben S. $338 \mathrm{ff}$.

3) Zur Auslegung des Sozialstaatsprinzips unter dem demokratischen Aspekt s. vor allem Abendroth, Diskussionsbeitrag $\mathrm{zu}$ "Begriff und Wesen des sozialen Rechtsstaats", S. 85, $87 \mathrm{f}$, 90; ders., Zum Begriff des demokratischen und sozialen Rechtsstaats im Grundgesetz der Bundesrepublik Deutschland, passim. 
ankerung im Sozialstaatsprinzip - praemissis praemittendis - interpretatorisch bestätigt werden können. $\left.{ }^{3}\right)$

Nicht richtig ist es aber, dem Sozialstaatsprinzip von der Demokratie her das Postulat einer Machtgleichheit von Kapital und Arbeit und in deren Verfolg einer Stärkung der Gewerkschaften aufzupfropfen. Die Aufhebung der "Kopfzahlgleichheit" zugunsten der "organischen" Gleichheit von Kapital und Arbeit 6) kann nicht aus einem politischen Prinzip gefolgert werden, das gerade auf dem Kopfzahldenken des allgemeinen und gleichen Wahlrechts beruht. Wenn ein Ausgleich der "Kopfzahlgleichheit" aus sozialen Gründen erforderlich erscheint, so ist das aus dem Sozialstaatsprinzip abzuleiten und dringt von hierher in die Demokratie ein. ${ }^{7}$ ) Allerdings läßt das Grundgesetz keinen $Z$ weifel daran, daß die politische Gesamtordnung vom "Kopfzahl"-Prinzip beherrscht werden soll. $\left.{ }^{8}\right)$

\section{c) Der soziale Rechtsstaat}

\section{aa) Allgemeines}

Das Grundgesetz versteht sich als die Verfassung eines sozialen

4) S. oben Abschnitt S. 329, insbes. S.332 zu Fußn. $11 \mathrm{ff}$.

5) Einzelheiten s. unten III (S.762 ff).

6) S. hierzu oben S.333 zu Fußn. 15 (2) und den Text hierzu.

7) Zumindest unscharf insofern Abendroth, Zum Begriff des demokratischen und sozialen Rechtsstaats im Grundgesetz der Bundesrepublik Deutschland, S.90, der die Gleichstellung nicht nur der Individuen sondern auch der sozialen Gruppen unter Berufung auf die innere Verbindung von Demokratie und Sozialstaatlichkeit fordert. Im übrigen scheint $A$ bendroths Ansicht dahin zu gehen, daß eine soziale Demokratie zwischen der "organischen" und der "Kopfzahlgleichheit" zu changieren hat, je nachdem, welches system jeweils len "unteren" Schichten hilfreicher ist. So wendet er sich etwa scharf gegen die "organische" Gleichheit der" Sozialpartner. in der Selbstverwaltung von Sozialversicherungsträgern und tritt insoweit für die "Kopfzahlgleichheit" ein (Abendroth, Diskussionsbeitrag "Gegenwartsfragen sozialer Versicherung", S.204; s. hierzu auch Bogs, Selbstverwaltung in der Sozialversicherung, S. $152 \mathrm{ff}$, insbes. S. $156 \mathrm{ff}$ und $\$ .205 \mathrm{f}$ (Diskussionserwiderung)).

8) S. oben Abschnitt 3 II (S.338 ff) und III 2 (S. $341 \mathrm{ff}$ ). - Fin politisches Verfassungselement, wie es Art.165 RV 1919 enthielt, kann den organisatorischen Bestimmungen des Grund- 
Rechtsstaates. Es könnte sonst nicht von den "Grundsätzen des ... sozialen Rechtsstaates im Sinne dieses Grundgesetzes" sprechen (Art.28 Abs.1 Satz 1 GG). Den Rechtsstaat entwickelt es in seinen organisatorischen und grundrechtlichen Vorschriften eingehend und mit betontem Geltungsanspruch. Den Sozialstaat erwähnt es noch einmal in Art.20 Abs.1 GG, auffallenderweise ohne dort auch das Bekenntnis zum Rechtsstaat anzubringen, den es gestaltet, nicht proklamiert. Im übrigen spricht es hier und dort - vor allem im Rahmen der bundesstaatlichen Kompetenzordnung - sozialstaatliche Materien an, baut es den Sozialstaat aber nicht eigentlich aus, jedenfalls nicht in einer Weise, die mit der verfassungsrechtlichen Ordnung des Rechtsstaats in Vergleich gebracht werden dürfte. ${ }^{1)}$ Darin liegt der positivrechtliche Grund der Schwierigkeit des grundgesetzlichen Begriffs des "sozialen Rechtsstaats" und des grundgesetzlichen Gegenüber von Rechtsstaat und Sozialstaat. Die verschiedensten Sozialstaats- und Rechtsstaatskonzeptionen, aus einem heterogenen Untergrund divergierender Staatstheorien und sozialpolitischer Ordnungsbilder erwachsen, durch das Grundgesetz gerade hinsichtlich der Sozialstaatlichkeit sich weitgehend selbst überlassen, häufig in den entscheidenden Gemeinsamkeiten und Differenzen nicht hinreichend abgeklärt, führten zu einer verwirrenden Vielfalt von Deutungen und Wertungen des "sozialen Rechtsstaats" - von der Feststellung des Widerspruchs bis zur Ineinssetzung des Rechts- und Sozialstaates. Nur die Synthese, das unvoreingenommene Ineinanderfügen der rechtsstaatlichen und der sozialstaatlichen Substanzen der Verfassung kann ihr jedoch gerecht wer(len. 1a)

Das Ineinssetzen von Rechtsstaat und Sozialstaat 2) verein-

1) S. vor allem (lie frühe (und viel zitierte) Kritik bei Ipsen, Über das Grundgesetz, \$. $14 \mathrm{ff}=$ Das Grundgesetz in seiner Vorläufigkeit, S. 186 If; Klein, Bonner Grundgesetz und Rechtsstaat, S. $399 \mathrm{ff}$. Aus späterer Zeit s. z.B. Forsthoff, Begriff und Wesen des sozialen Rechtsstaats, S. $14 \mathrm{f}$ und passim; Rumpf, Der ideologische Gehalt des Bonner Grundgesetzes, S.29 f. - S.a. die oben S.546 zu Fußn. 10 Zitierten.

1a) S.a. Barocka, Die Berücksichtigung sozialer Gesichtspunkte bei der Erhebung von Gebühren und Beiträgen usw., S.825.

2) Reichlich euphemistisch Marcic, Vom Gesetzesstaat zum Richterstaat, S.409 f: "Fis waltet kein Widerspruch zwischen dem Rechtlichen und dem Sozialen; rechtlich ist sozial, so- 
facht die Zusammenhänge im Übermaß. Es ist logisch überhaupt nur denkbar auf dem Boden der doppelten Gleichstellung: Rechtsstaat $=$ Gerechtigkeitsstaat und Sozialstaat $=$ Staat der sozialen Gerechtigkeit. 3) Mit der Bezeichnung als Gerechtigkeitsstaat ist aber weder das Spezifische des Rechtsstaats noch das Spezifische des Sozialstaats auch nur annähernd präzisiert. Gerade in den Methoden und "Nahzielen" des Rechtsstaates und in der konkreten gegenständlichen Ausrichtung des Sozialstaats liegen die Differenzpunkte.

Bei der Feststellung des Widerspruchs 4 ) kann nicht stehen geblieben werden. Er drängt nach Auflösung, schon um der Einheit des Rechts und der Einheit der Verfassungsordnung willen. Diese Auflösung könnte nicht in einem Zurücktreten des Geltungsanspruchs der Rechtsstaatlichkeit oder der Sozialstaatlichkeit gefunden werden. Ein Zurücktreten des Rechtsstaatsprinzips wäre von vorneherein ausgeschlossen. ${ }^{5)}$ Es ist das stärker ausgebildete. Die im Grundgesetz getroffenen rechtsstaatlichen Regelungen können nicht als unter einem allgemeinen sozialstaatlichen Vorbehalt stehend angesehen werden. Das Grundgesetz steht unter dem deutlichen Zeichen eines sachlichen Primats der Rechtsstaat 1 ichkeit. 6 ) Aber dennoch würde nichts erlau-

zial ist rechtlich. Der soziale Rechtsstaat und der rechtliche Sozialstaat, das sind im Wesen Synonyma, bloß in den Akzenten kommen Nuancen zum Vorschein" (a.a.O.S.409).

3) Vg1. Paulick, Die verfassungsrechtlichen Bindungen des Gesetzgebers beim Erlaß von Steuergesetzen, S.487; Hamann, Das Grundgesetz, Einführung I D 2 (S.33); Rohwer-Kah1mann, Sozialrecht und Grundgesetz, S.359. Aus dem vorkonstitutionellen Schrifttum ist insbes. zu erwähnen: Kägi, Rechtsstaat - Sozialstaat - sozialer Rechtsstaat, S.145. Offenbar lag ein ähnlicher Gedanke - etwa: (bürgerlicher) Rechtsstaat $=$ Gerechtigkeit für die Oberschicht; sozialer Rechtsstaat $=$ Gerechtigkeit (auch) für das breite Volk schon der Begriffsbildung bei Heller (Rechtsstaat oder Diktatur, insbes. S.9 f, 18) zugrunde.

4) S. insbes. Klein, Bonner Grundgesetz und Rechtsstaat, S. $399 \mathrm{ff}$.

5) S. die oben S.720 zu Fußn. 3 Zitierten.

6) S. o. S.745 zu Fußn. 1, insbes. Forsthoff und Rumpf, a.a.O. - Wenn Scheuner (Diskussionsbeitrag zu "Enteignung und Sozialisierung", Veröffentlichungen der Vereinigung der Deutschen Staatsrechtslehrer, Heft 10, 1952, S. 153 ff (154), meint, bei der notwendigen Versöhnung zwischen (freiheitlichem) Rechtsstaat und (gleichheitlichem) Sozialstaat müsse "der 
ben, den Geltungsanspruch des Sozialstaatsprinzips zu leugnen. 7) Doch versetzt das Grundgesetz gar nicht in das Dilemma eines unauflösbaren Widerspruchs. Nur wenn die Rechtsstaatlichkeit des Grundgesetzes im älteren materiellen Sinn als Beschränkung des Staates auf die Rechtsbewahrung verstanden werden müßte, wäre ihr Gegensatz zum Sozialstaatsprinzip unüberwindlich. Die Rechtsstaatlichkeit des Grundgesetzes ist jedoch als eine formelle und zugleich im neueren Sinn materielle entwickelt. ${ }^{8)}$ In ihr ist Platz für das Sozialstaatsprinzip. Es ist Bestandteil der - für den materiellen Rechtsstaat jüngerer Prägung kennzeichnenden - obersten Schicht materiellen Rechts, von der her die Wirksamkeit des Staates inhaltlich bestimmt wird. ${ }^{9}$ )

In diesem Rahmen, als oberstes materielles, normatives Bestimmungselement des Staates, durchgesetzt mittels des Mechanismus formaler Rechtsstaatlichke it ${ }^{10)}$ aber auch darauf beschränkt und durch die rechts staatlichen Schranken staatlicher Wirksamkeit um grenzt, hat das Sozialstaatsprinzip seine Geltung zu entfalten. Das ist de $r$ Kompromiß, in dem das Grundgesetz Sozialstaat und Rechtsstaat einander gegenübergestellt hat, sprachlich adäquat aus jedrückt in der Formel vom "sozialen Rechtsstaat".

Maximale Sozialstaatlichkeit müßte der sozialen Entwicklung freie Bahn schaffen. Im "sozialen Rechtsstaat" heiligt dagegen kein sozialer Zweck irgend ein Mitte 1 , das dem Rechtsstaat nicht gemä $\beta$ ist. Der Rechtsstaat ist ein System von Hemmungen, nicht von Antrieben. 11) Der "soziale" Rechtsstaat ist es nicht mindex; nur daß er mit seinen Hemmnissen gleichsam eine soziale Schiene legt, auf der die staatliche Aktivität geführt und auf die sie auch konzentriert wird. Der Rechtsstaat beschränkt die Exekutive darin, aus eigener Vollmacht und eigenem Antrieb zu hande1n. Die Rechtsprechung ist wesensmäßig ebenfalls beschränkt. Im "sozialen Rechtsstaat" gibt es davon nicht etwa eine grundsätzliche Ausnahme für soziale Maßnahmen.

Akzent heute mehr auf der Gleichheit und dem sozialen Bestreben (liegen) als auf dem liberalen Gedanken", so meint er damit offenbar weniger das positive Verfassungsrecht als seinen politischen und ideellen Hintergrund.

7) S. o. S. $706 \mathrm{ff}$.

8) S. O. S.396 ff.

9) S. o. $1 \mathrm{~b}$, ee, bbb (S.691 ff).

10) Scheuner (Diskussionsbeitrag zu "Verwaltung und Verwaltungsrechtsprechung", S. 184) spricht vom Rechtsstaat als dem "Vehikel" materialer sozialer Gerechtigkeit. 
"Das Wesentliche zur Verwirklichung des Sozialstaates ... kann nur der Gesetzgeber tun". 12) Der aber kann nicht alles tun, was zur maximalen Verwirklichung des Sozialstaates getan werden müßte. Der "total genormte Wohlfahrtsstaat" ist eine Utopie. 13) Der Rechtsstaat riegelt die Individualsphäre ab, sichert Freiheit und Unbeteiligtsein durch Schutz gegen Eingriffe und Belastungen. Der Sozialstaat muß in die Individualsphäre eindringen und zwar nicht nur begünstigend sondern auch beschränkend und belastend. Auch der "soziale Rechtsstaat" ist dafür auf die Modalitäten angewiesen, die der Rechtsstaat allgemein zuläßt. Der Sozialstaat muß umwandeln. Der "soziale Rechtsstaat" ist auch darin vornehmlich "Rechtsstaat", daß er vor" allem das Bestehende schützt. Der sachliche Gehalt dieser Hemmungen der sozialen Aktivität durch die rechtsstaatlichen Bindungen darf nicht unterschätzt werden. ${ }^{14)}$ In einer Zeit des wachsenden Sozialprodukts und der vollwertigen Geldwirtschaft sind sie nicht so sehr spürbar. Die dem Sozialstaat immer wesentliche Umverteilung kann nehmend durch die an rechtsstaatlichen Widerständen relativ arme Abgabenerhebung, 15) gebend durch einfach normierbare und normgerecht $\mathrm{zu}$ vollziehende, die individuelle Freiheit maximal schonende Geldleistungen 16) erfolgen. Bei (konstantem oder) sinkendem Sozialprodukt und Nachîassen der Tauschfunktion des Ge1des wird eine unmittelbare Sachumverteilung - sei es durch Übertragung der Verfügungsmacht, sei es durch Finräumung von Konsum- oder Nutzungsbeteiligungen usw. - notwendig, der erheblich schärfere rechtsstaatliche Widerstände entgegengebracht werden. Aber nicht nur hinsichtlich der Umverteilung sondern

11) Zum Folgenden s.o. S.396ff und die dort. Nachw.

12) BVerfGE 1, 97 (105).

13) Vgl. Rumpf, Der ideologische Gehalt des Grundgesetzes, S. $28 \mathrm{f}$.

14) $\mathrm{Zu}$ "optimistisch" wohl Abendroth, Zum Begriff des demokratischen und sozialen Rechtsstats im Grundgesetz der. Bundesrepublik Deutschland, S. 100 .

15) S. hierzu die oben S. 14 zu Fußn. 46 Zitierten. S. insbes. (wie auch dort zitiert) Forsthoff (Begriff und Wesen des sozialen Rechtsstaats, S.32), dessen These, "die rechtsstaatliche Verfassung (stehe) also dem Sozialstaat nicht im Wege" gerade unter der Voraussetzung steht, daß die Umschichtung nicht durch unmittelbare Entziehung oder Entwertung rechtsstaatlich geschützter Positionen sondern auf dem Wege über die Besteuerung erfolgt.

16) S. O. S.463, insbes. S. $468 \mathrm{zu} \mathrm{Fußn.6}$ und den Text hierzu. 
ganz allgemein wird jede Anspannung der derzeit so sehr gelokkerten sozialen Situation vor allem auch die rechtsstaatlichen Bremsen bis zum Glühen heißlaufen lassen.

Der Rechtsstaat trägt und verwirklicht die Sozialst a a $1 \mathrm{ichkeit} \mathrm{-} \mathrm{soweit} \mathrm{sie} \mathrm{normiert} \mathrm{und} \mathrm{normierbar} \mathrm{ist.}$ Aber wie wenig vermag die eine sozialstaatliche Verfassungsnorm! Wie wenig vermag sie vor allem über den Gesetzgeber, der allein "das Wesentliche zur Verwirklichung des Sozialstaates" tun kann. Und wie wenig beherrscht schließlich auch das Gesetz selbst die Tatsachen, um die es sich bemüht. Der Rechtsstaat sichert auch die Teilhabe an den Leistungen des Sozialstaats. Aber wieviel schwächer ist er doch darin als in der Sicherung des Unbeteiligtseins. ${ }^{17)}$

Der Rechtsstaat, der als "sozialer Rechtsstaat" die sozialstaatliche Grundnorm in sich aufgenommen hat, kommt seinerseits nicht unberührt davon. Sozialstaatliche Aktivität trifft auf die "weichen" Stellen des Rechtsstaats. Darauf etwa, das Individuum durch einen universellen Gesetzesvorbehalt vor den Gefährdungen des begünstigenden und leistenden "Einbruches" in die Individualsphäre zu schützen, ist er nicht eingerichtet. Die sozialstaatliche Intention hindert ihn zusätzlich, den offenen Ring des Gesetzesvorbehalts um des utopischen Zieles eines "total genormten Wohlfahrtsstaates"13) willen unter $\mathrm{Zu}$ rücksetzung der sozialen Aktionsfähigkeit zu schließen. 18) Die sozialstaatliche Notwendigkeit massenhafter Eingriffe in unüberschaubar viele individuelle Lebensverhältnisse und das schon in (ler Natur des modernen Rechtsstaats als "Gerechtigkeitsstaat" liegende, durch das sozialstaatliche Streben nach "sozialer Gerechtigkeit" aber noch gesteigerte Bedürfnis nach einer trotzdem fallweise, individuell "gerechten" Entscheidung bedrängen die rechtsstaatliche Idee der Gesetzmäßigkeit und Meßbarkeit der staatlichen Befugnisse. Die legislative Aufgabe kann vielfach nur unter Vernachlässigung ler Prizision der allgemeinen Norm gelöst werden. Die richterlich $z$ u handhabende Generalklausel kennzeichnet den Fluchtweg ics "suzialen Rechtsstaates". 19) Der Rechtsstaat, der sich als "so\%ialer Rechtsstaat" zum staatlichen Sozialgestaltungsauftrag und zur sozialen Aufgabe im engeren historisch-konkreten Sinn bekannt hat, kann sich keine einseitige

17) S.a. oben Abschnitt 4 I (S.396 ff) und II (S. 406 ff) (insbes. S.431).

18) S. oben Abschnitt 4 II 2 b, bb, aaa (S.420 ff).

19) S. oben Abschnitt 4 I (S.396 ff) und II $3 \mathrm{~b}$, aa (S.512 ff) und cc (S. $520 \mathrm{ff})$. 
Sicherung der Freiheit, der ungestörten Individualität, des Unbeteiligtseins an den allgemeinen Angelegenheiten leisten. Die darin liegende Wandlung des Rechtsstaats ist vorwiegend ideologischer Natur. Sie äußert sich positivrechtlich nicht in einer Beseitigung oder interpretatorischen Auflösung des individuellen Rechtsschutzes sondern in einer der sozialen Bindung angemessenen Gestaltung bzw. Auslegung der einschlägigen Normen, insbes. also der Grundrechte. Aber hier wie dort bringt die Aktualisierung der Rechtsstaatlichkeit als eines Prinzips nicht nur der negativen Abwehr sondern des Ausgleichs zwischen Freiheit und Bindung und als eines Regulativs des gebenden und nehmenden Austausches zwischen Individuum und staatlicher Gemeinschaft, die mit der verfassungsrechtlich anerkannten Übernahme der sozialen Staatsaufgabe verbunden ist, das überkommene Rechtsstaatsverständnis in Verlegenheiten.

Während die entscheidende Konzession des Rechtsstaats an den Sozialstaat im "sozialen Rechtsstaat" in einer immanenten Bindung der rechtsstaatlichen Freiheits- und Abwehrrechte an die soziale Gemeinschaftsaufgabe besteht, ${ }^{20)}$ ist - dies vorausgesetzt - die Unterwerfung des Sozialstaats unter den Rechtsstaat eine vollkommene. 21) Der "soziale Rechtsstaat" ist Sozialstaat in den Formen und Grenzen des Rechtsstaats. ${ }^{22)}$ Darin prägt sich nicht zuletzt die Eigenart der verfassungsrechtlichen Normierung der Sozialstaatlichkeit, wie sie das Grundgesetz enthält, aus. Die ungegliederte, tatbestandlich nicht präzis aufzuschließende, umfassende, voluminöse Sozialstaatsklausel kann von

20) Vg1. Bettermann, Grundfragen des Preisrechts für Mieten und Pachten, S. 119 f; E.R. Huber, Wirtschaftsverwaltungsrecht Bd.I, S.46; Scheuner, Die staatliche Intervention im Bereich der Wirtschaft, S. 20 f; Berger, Bedeutung und Tragweite des Grundsatzes vom sozialen Rechtsstaat, S. 7 f; Gerber, Die Sozialstaatsklausel des Grundgesetzes, insbes. S. 41 f; Nipperdey, Lehrbuch des Arbeitsrechts Bd. II S. 34 f; Maunz, Grundfragen des Energiewirtschaftsrechts, S. $321 \mathrm{f}$; Vertragsfreiheit heute, S. 5 ff. S.a. A bendroth, Diskussionsbeitrag zu "Begriff und Wesen des sozialen Rechtsstaates", insbes. S.87 ff; Peters, Kombination verschiedener Verfassungsgrundsätze als Mittel der Verfassungsauslegung, S.124.Zur entsprechenden Auslegung der Grundrechte s. die oben S. 720 zu Fußn. 3 Zitierten; s.a. den folgenden 6.Abschnitt (S. $842 \mathrm{ff})$.

21) S. die oben S. 720 zu Fußn. 3 Zitierten.

22) S. a. Bruno Molitor, Sozialpolitik im sozialen Rechtsstaat, S. 102 . 
rechtsstaatlichen Beschränkungen nicht ausnehmen und ihnen gegenüber nicht legitimieren. Würde sie das, so würde sie den Rechtsstaat auflösen. 23) Das Grundgesetz hätte durch engere Bestimmungen, die mit dem Wesen des Rechtsstaats vereinbar gewesen wären und ihn nicht grundsätzlich in Frage gestellt hätten, für bestimmte soziale Gegenstände und Aktionsrichtungen verfassungsrechtlich Raum für die soziale Entwicklung schaffen können. Es hätte auch, wenngleich von vorneherein mit geringer Effektivitätschance, die rechtsstaatliche Ordnung mit besonderen Teilhaberechten sozial anreichern können. Die Möglichkeiten dafür wären begrenzt gewesen, ${ }^{24)}$ hätten, optimal genutzt, die "Sozialität" der Verfassung im Verhältnis zur und in Verbindung mit der Rechtsstaatlichkeit aber doch weiter vorantreiben können als das durch die Verwendung des Wortes "sozial" in Art. 20 und $28 \mathrm{GG}$ allein geschehen konnte. ${ }^{25}$ )

23) Mit Recht nimmt Forsthoff (Begriff und Wesen des sozialen Rechtsstaats, S.27 Fußn.29) an, daß das Adjektiv "sozial" nicht ausreicht, um staatliche Befugnisse rechtsstaatsgemäß zu umschreiben. Zu weit geht er allerdings, wenn er sagt, es sei "für die juristische Begriffsbildung unbrauchbar". Forsthoff (ebd. S. $25 \mathrm{f}$ ) meint ferner zutreffend, das - wie zu unterstellen: rechtlich umfassend aktuelle - Sozialstaatsprinzip, polemisch auf eine angemessenere, gerechtere Güterordnung gerichtet, wäre "ein Mittel zu unübersehbaren Diskriminierungen und Verwirkungen. Das wäre aber die Vernichtung des Rechtsstaats". Aber er geht auch hier wieder einen (kleinen) Schritt zu weit, wenn er sagt, die Entscheidung für das polemisch verstandene soziale Element im sozialen Rechtsstaat würde dazu führen, "daß das Grundgesetz seine Gewährleistungsfunktion nur im Rahmen dessen ausübt, was von der jeweiligen Mehrheit und Regierung als sozial verstanden wird".

24) Zur "außerordentlichen Konsistenz des Rechtsstaats gegenüber den Versuchen, ihn mit sozialen Gehalten zu erfüllen" (Forsthoff) s.o. \$. 396 und die dortigen Nachweise.

25) Werner (Sozialstaatliche Tendenzen in der Rechtsprechung, S. 85) und Berger (Bedeutung und Tragweite des Grundsatzes vom sozialen Rechtsstaat, S.10) meinen, das Sozialstaatsprinzip ersetze der Sache nach soziale "Grundrechte" wie die der Weimarer Verfassung vollauf. Ipsen (Über das Grundgesetz, S. 14 = Das Grundgesetz in seiner Vorläufigkeit, $\mathrm{S}$. 186) und Abendroth (Zum Begriff des demokratischen und sozialen Rechtsstaats in dem Grundgesetz der Bundesrepublik Deutschland, S.85) sind dagegen der Meinung, das Grundge- 
Hemmt und beschneidet der Rechts sta t den Sozialstaat, so ve rede $1 \mathrm{t}$ er ihn doch auch. Beschränkt er die staatliche Aktivität, so modifiziert er sie doch so, daß sie, wo sie Platz greift, wohltätiger wirkt als ohne die rechtsstaatliche Mäßigung. Nur als Rechtsstaat kann der Sozialstaat so aufgebaut werden, daß den Beteiligten eine beherrschbare Individualsphäre, Freiheit und Sicherheit der Teilhabe, soweit am Platze auch Freiheit des Unbeteiligtseins und letztlich eine Subjektposition erhalten bleibt bzw. verschafft wird. 26) Erst vom Rechtsstaat her wird die sozialstaatliche Forderung nach dem status positivus socialis sinnvoll und

setz bleibe in dieser Hinsicht hinter der Weimarer Verfassung zurück (weitere Nachweise zu dieser Frage s.o. S. 695 zu Fußn.9). Nun ist aber die Alternative nicht diejenige: Sozialstaatsprinzip oder soziale "Grundrechte"; und erst recht nicht die: Sozialstaatsprinzip oder soziale "Grundrechte" der Weimarer Veriassung. Daß eine Generalklausel umfassender ist als Detailregelungen, dürfte ebensowenig zu bezweifeln sein wie daß Detailvorschriften eine intensivere Geltung beanspruchen können. Dabei kommt es wieder auf die Präzision dieser Bestimmungen an. Optimalen Effekt kann nur eine Kombination von Generalklausel(n) und präzisen Einzelregelungen erzielen. In der Weimarer Verfassung fehlte nicht nur eine Generalklausel vom Umfang des Sozialstaatsprinzips und war der Geltungswille, der hinter den Einzelvorschriften stand, schwach. Eine Steigerung, die die grundgesetzliche und die Weimarer Regelung hinter sich läßt, ließe sich sehr wohl denken. - Im übrigen s. zu den "sozialen Grundrechten" unten Abschnitt 6 I 3 (S. $848 \mathrm{ff}$ ).

26) Außer dem oben Abschnitt 4 (S.396 ff) zur sozialen Funktion der rechtsstaatlichen Regeln Ausgeführten sei zum Wechselspiel der Sicherung von Freiheit und Teilhabe im "sozialen Rechtsstaat" verwiesen auf Fechner, Freiheit und Zwang im sozialen Rechtsstaat, S.16 ff; ferner auf die oben S.750 zu Fußn.20 Zitierten. - Zum sozialen Rechtsstaat als dem Versuch, möglichst viel Freiheit und Sicherheit m:t maximaler Erfüllung der an den Staat gerichteten sozialen Funktionserwartung zu verbinden, s. außer den Genannten Kägi, Rechtsstaat - Sozialstaat - sozialer Rechtsstaat, insbes. S. 142 ff; ders., Die Entwicklung des schweizerischen Rechtsstaats seit 1848, S. 221 ff; s. ferner Köttgen, Gemeinde und Bundesgesetzgeber, S. 33; Rumpf, Der ideologische Gehalt des Bonner Grundgesetzes, S.28. 
dieser Status aktue11. 27) Nur als "sozialer Rechtsstaat" kann der Sozialstaat die Menschenwürde verwirklichen, wie er es soll. Nur um den Preis der rechtsstaatlichen Hemmungen, nur als "sozialer Rechtsstaat" kann sich der Sozialstaat des Abgleitens in den Totalstaat - wenn man so will: in den totalen Wohlfahrtsoder Versorgungsstaat 29) - erwehren. 30)

27) Zur Ableitung der Forderung der Verrechtlichung der Position des Bedürftigen aus dem Wesen des sozialen Rechtsstaats s. (außer den oben S.730 zu Fußn. 3 Zitierten) BVerwGE 1, 159 (161 f); BGHZ 25 (234 f); Schlochauer, Öffentliches Recht, S.14. Zur. "Subjektivierung" objektiver Rechtspositionen über die extrem rechtsstaatliche Norm des Art. 19 Abs. 4 GG s.o. S. 544.

28) Positivrechtlich darl auf Art. 1 Abs. 1 GG hingewiesen werden. Zur Verknüpfung des Sozialstaats mit dem Staatsziel der Verwirklichung der Menschenwürde s. die oben S.746 zu Fußn. 4 Zitierten. Im besonderen tragend für die Vereinigung von Sozialstaat und Rechtsstaat im "sozialen Rechtsstaat" bei Berger, Bedeutung und Tragweite des Grundsatzes vom sozialen Rechtsstaat, S. $7 \mathrm{f}$.

29) Die Terminologie betreffend "Wohlfahrtsstaat" und "Versorgungssta a t" ist nicht einheitlich. "In beiden Fällen handelt es sich um Schlagworte, die von den Gegnern der Sozialpolitik in die Diskussion geworfen sind. Wir sollten nicht so sehr über diese irreführenden Schlagworte, sondern über die Sache selbst diskutieren" (Lepinski, Diskussionsbeitrag zu "Die Sozialpolitik und die Freiheit des Men-

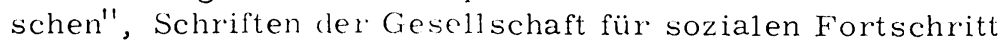
e.V., Bd.9, 1959, S.62 ff (63)). In "der Sache selbst" muß entscheidend sein, ob les. Staat die individuelle Entfaltung unterdrückt oder ihr Jaum läßt, ob er totalitär ist oder freiheitlich. Vom "Ilohlfahirstaat" glauben z. B. Gerber (Die Sozialstaatsklausel (les (irundgesetzes, S. 42) und Wolff (Verwaltungsrecht I, $\therefore .44$ l) (ron Sozialstaat bzw. den sozialen Rechtsstaat abheben zu können. Dürig (Grundfragen des öffentlichrechtlichen lintschädigungssystems) sieht das Gegenstück zum (freiheitlichen) sozialen Rechtsstaat dagegen im "Versorgungsstaat". Abendroth (Zum Begriff des demokratischen und sozialen liechtsstats im Grundgesetz der Bundesrepublik Deutschlanı, \$.99) hält dafür, es gebe einen "Wohlfahrtsstaat", zu dem hin der. Sozialstaat ohne wesentliche Beeinträchtigung der Rechtsstaatlichkeit fortentwickelt werden könnte. Weitgehend wird jedoch der "Wohlfahrtsstaat" mehr oder weniger als synunym für den Sozialstaat gebraucht. So 
Aber nicht nur "veredelt" die Rechtsstaatlichkeit den Sozialstaat. Dem Rechtsstaat ist seinerseits das sozialsta at liche Verfassungselement - verfassungspolitisch betrachtet unentbehrlich. 31) Sein formaler Legalismus läuft auf den Willen des (einfachen) Gesetzgebers als das maßgebliche Entscheidungssubjekt der sozialen Ordnung hinaus, in der Demokratie also auf den Dezisionismus der Mehrheit. Seine liberale, individualistische Einseitigkeit in der materiellen Substanz überläßt die soziale Entwicklung dem freien Spiel der Kräfte. Eine übergreifende Ordnung fehlt. Die Gerechtigkeitsdetermination des Rechtsstaates ist wegen ihrer inhaltlichen Unbestimmtheit selbst dann als solche unzureichend, wenn ihr normative Geltung zugeschrieben wird. Hier der Gesetzgebung und dem Freiheitsgebrauch Direktiven zu geben, ist die wichtige Aufgabe des Sozialstaatsprinzips. ${ }^{32)}$ Indem der Sozialstaat die ökonomischen Ungleichheiten und Abhängigkeitsverhältnisse mildert, unterbaut er schließlich auch die Freiheitlichkeit des Rechtsstaats, 33) die nur rechtlich-normativ fundiert, nicht voll ausschwingen kann, sondern erst dann, wenn die außerrechtliche Ambiance sie begünstigt. 34)

\section{bb) Einige besondere Probleme}

aaa) Vorbemerkung

Die verfassungsrechtliche Deutung des sinnträchtigen, neuarti-

meint (w.v.a.) Claus Arndt (Die Bundesrepublik Deutschland als sozialer Rechtsstaat, S. 333), der Wohlfahrtsstaat sei ein zwingendes Gestaltungsziel der sozialstaatlichen Gesetzgebung. Dürig (Art.2 des Grundgesetzes und die Generalermächtigung zu allgemeinpolizeilichen Maßnahmen, S. 83) bezeichnet den Sozialstaat als einen "sozialgestaltenden Wohlfahrtsstaat".

30) Vg1. Kägi, a.a.O., insbes. Zur Entwicklung des schweizerischen Rechtsstaates seit 1848, S.222; Fechner, Freiheit und Zwang im Sozialen Rechtsstaat, S. 9 f; Dürig, a.a.O.; Gerber, a.a.O.

31) S. nochmals oben S.751 zu Fußn. 25.

32) Besonders deutlich bei Herbert Krüger, Diskussionsbeitrag $\mathrm{zu}$ "Begriff und Wesen des sozialen Rechtsstaates", VVDStRL. H. 12, 1954, S. 109 ff (110 f).

33) S.a. Hesse, Der Gleichheitsgrundsatz im Staatsrecht, S. 185; Hamel, Die Bedeutung der Grundrechte im sozialen Rechtsstaat, S. $19 \mathrm{ff}$.

34) Zu dieser Bedeutung der sozial-rechtsstaatlichen Synthese s. Olbersdorf, Sozialer Rechtsstaat und Arbeitsrecht, S. 135 und $135 \mathrm{ff}$, passim. 
gen Begriffes des "sozialen Rechtsstaates" hat fast noch mehr als die des Sozialstaatsprinzips allein mit der Versuchung zu kämpfen, bestimmte sozialtheoretische Ordnungsvorstellungen oder einzelne, besonders wichtig erscheinende sozialpolitische Postulate "hineinzulesen" und auf diese Weise apokryph zu positivieren. Eine besondere Gefahrenquelle spekulativer Überentfaltung des "sozialen Rechtsstaats" scheint es zu sein, die individualistisch-freiheitliche Substanz seines rechtsstaatlichen Elements zu verselbständigen und ohne Rücksicht auf ihre positive grundgesetzliche Ausgestaltung gegen die Sozialstaatlichkeit auszuspielen. Das Grundgesetz hat aber die Rechtsstaatlichkeit anders als die Sozialstaatlichkeit - grundsätzlich positiv ins einzelne gehend entwickelt. Den freiheitlichen Ausgrenzungen hat es eine abschließende Regelung zuteil werden lassen. An ihr findet der Sozialstaat seine Grenzen, nicht an einem irgendwie erdachten Freiheitsprinzip. 1)

\section{bbb) Sozialer Rechtsstaat und Subsidiaritätsprinzip}

Nicht selten wird dem Wesen des sozialen Rechtsstaats - oder auch des mehr oder weniger in seiner rechtsstaatlichen Legierung gesehenen und daher als freiheitlich verstandenen Sozia1staates - das Subsidiaritätsprinzip zugeordnet. 1) Soweit das mit

1) Das Grundgesetz spricht zwar gelegentlich von einer freiheitlichen demokratischen Grundordnung (Art. 18 Satz 1, 21 Abs. 2 Satz 1, 91 Abs. 1 GG). Aber damit meint es nicht einen von der positiven Detailgestaltung individueller und kollektiver Freiheit durch die Verfassung unabhängigen Verfassungssatz der "Freiheitlichkeit" sondern vielmehr die hinter der verfassungsrechtlichen Gesamtordnung stehende wesentliche Substanz, gewissermaßen clen freiheitlichen Extrakt des Grundgesetzes. Vgl. hierzu z.B. v. Mangoldt-Klein, Art. 18 Anm. III 4 b; Maunz in Maunz-Dürig, Art. 21 Randn. 114; s.a. BVerfGE 2, 1 (12 f). Zum Verhältnis der freiheitlichen und demokratischen (irundor lnung zur Entwicklung des Sozialstaates s. insbes. BVerfGE 5, 85 (197 ff).

1) Vgl. Wolany, Vom Sozialstaat und sozialen Recht, S.153 ff, 157 f, $160 \mathrm{ff}$; Fechner, Freiheit und Zwang im sozialen Rechtsstaat, S. $16 \mathrm{ff}, 22 \mathrm{f}$; ders., Sozialer Rechtsstaat und Arbeitsrecht, S. 162 f; Bachof, Begriff und Wesen des sozialen Rechtsstaats, S. 46; Olbersdorf, Sozialer Rechtsstaat und Arbeitsrecht, S. 135, 139 f; Gerber, Die Sozialstaatsklausel des Grundgesetzes, S.42; Klein, Christ und Kirche in der sozialen Welt, S. $125 \mathrm{ff}, 316 \mathrm{ff}$; Nipperdey, Lehrbuch des Arbeitsrechts, S. 22,32 ff, 142 f, 263 (insbes. S. 35); ders., Die 
dem Anspruch eines selbständigen Verfassungsgebotes geschieht, 2) zu Unrecht. Das allgemeine Subsidliaritätsprinzip ist viel zu unpräzis und leistungsschwach, um als Rechtssatz ernstlich in Betracht zu kommen. ${ }^{3)}$ Als Sammelbezeichnung für die Summe der verfassungsrechtlichen Regelungen individueller und kollektiver Freiheit wäre es kein eigenständiges Prinzip (und darüber hinaus terminologisch recht unglücklich). Als Hintergrundprinzip der einschlägigen Rechtsregelungen würde es diese über ihre zwingende Aussage hinaus fortführen und somit den Boden des positiven Rechts verlassen. ${ }^{4)}$ Als Resultante aus einem allgemeinen Prinzip rechtsstaatlicher "Freiheitlichkeit" und sozialstaatlichen Einmischungsstrebens kann es ebenfalls nicht zur Geltungskraft positiven Verfassungsrechts aufsteigen, weil es diese "Freiheitlichkeit" - wie sie dem als eigenständiges Verfassungsprinzip vorauszusetzen wäre - als geltendes Recht nicht gibt.

Trotzdem ist der Hinweis auf das Subsidiaritätsprinzip vom "sozialen Rechtsstaat" her nicht verfehlt. Als Deutungsschema, das die unterverfassungs rechtliche Gestaltung des Sozialstaats den Weg der geringsten Reibung an den Begrenzungsflächen der Freiheit zu führen vermag, lenkt es auf rechtspolitische Gesamtkonzeptionen hin, die sich den verfassungsrechtlichen Erfordernissen optimal einfügen. ${ }^{5)}$ Aber diese dürfen nicht verfassungsrecht1ich verselbständigt werclen.

Die Erkenntnis etwa der multilateralen Interdependenz zwischen einer weiträumigen individuellen Freiheit, einer gesteigerten Selbstverantwortung und zwischenbürgerlichen Gemeinverpflichtetheit und der Möglichkeit und Notwendigkeit eines "Verhaltens" unmittelbarer sozialstaatlicher Aktivität ist von so großer

Rolle des Staates bei der Regelung des Arbeitsverhältnisses, Recht der Arbeit, 11.Jhg. (1958) S. 321 ff (323); Ballerstedt, Wirtschaftsverfassungsrecht, S. 55; Menger, Die Bestimmung der öffentlichen Verwaltung nach Zwecken, Mitteln und Formen des Verwaltungshandelns, S.299; Gass, Zur verfassungsrechtlichen Problematik der saarländischen Arbeitskammer und der bremischen A rbeitnehmerkammer.

2) In diesem Sinne extrem Klein, a.a.O.

3) S. oben S.223 ff.

4) S. oben Abschnitt 2 (S.219 ff), insbes. S. 223 und unten Abschnitt 6 (S. $842 \mathrm{ff}$ ).

5) Zumindest auch in diesem Sinne sind die meisten der oben S.755 zu Fußn. 1 Zitierten zu verstehen. 
Wichtigkeit für eine optimale Synthese von Rechtsstaat und Sozialstaat in der Verfassungswirklichkeit, daß die daraus folgende Maxime, Freiheit und individuelle Verantwortung zu heben und den unmittelbaren Eingriff des Staates zurückzudrängen, fast als ein "Grundgesetz" sozialer Rechtsstaatlichkeit bezeichnet werden kann. 6) Aber diese Maxime darf verfassungsrechtlich nicht absolut gesetzt werden. Entsprechen die ökonomischen, sozialpsychischen oder auch die anthropologischen Voraussetzungen dieser Konzeption nicht (voll), so kann ein Vordringen der unmittelbaren sozialstaatlichen Aktion bis an die vom positiven Verfassungsrecht, insbes. also von der Grundrechtsordnung gezogenen Grenzen notwendig werden. ${ }^{\text {) }}$ Hier liegt die Grenze - dort das Optimum. Nur die Verletzung der Grenze, nicht auch die mangelnde Erkenntnis oder Verwirklichung des Optimum bewirkt die verfassungsrechtliche Verantwortlichkeit und Sanktion.

Ist das Subsidiaritätsproblem in der Individuum-Staat-Beziehung durch die grundrechtliche Ordnung nach verfassungsrechtlicher Struktur und Lösung ziemlich eindeutig vorgezeichnet, so gilt das Gegenteil für die subsidiäre Verantwortlichkeit bzw. die Autonomie der zwischen Individuum und Staat stehenden Ve rbände. ${ }^{8}$ ) Die Familie bildet ein Sonderproblem und ist in Art.6 GG auch besonders angesprochen. Schwierigkeiten bestehen vor allem hinsichtlich der überpersönlichen Kollektiveinheiten. Die entscheidungs- und effektnahe Mitarbeit des einzelnen in einem kleineren oder mittleren Verband bildet und stärkt in ihm zwar mehr als die Massendemokratie des Staates das bürgerliche Pflichtbewußtsein und die Fähigkeit, Verantwortung zu tragen. 9) Die Autonomie der kleineren (ihrerseits "demokratischen") Gemeinschaft hebt die individuelle Selbstbestimmung. Aber die Heteronomie der Mehrheit macht sich hierin oft schärfer bemerkbar als in der größeren Gemeinschaft. Die Kontrolle der Rechtmäßigkeit ist in der kleineren Gemeinschaft nicht unerheblich erschwert, der "Kampf ums Recht" im engeren Kreis durch oft unüberwindliche Friktionen behindert. Der Vorzug der "Freiheitlichkeit" der kleineren Einheit entspricht olt nicht den Erwartungen einer gern zu

6) S. auch hierzu nochmals die oben S. 755 zu Fußn. 1 Zitierten (mit Ausnahme wohl von Klein, a.a.O.).

7) Auch über den rechtsstaatlichen Grundsatz der Verhältnismäßigkeit (s.o. S.633) ist keine umfassende Nachprüfung der freiheitlichen "Richtigkeit" einer sozialpolitischen Konzeption zu bewirken. Als selbständiges Prinzip gibt es kein Kriterium der Zulässigkeit konkreter Zwecksetzung ab sondern läßt es das jeweilige $Z$ weck-Mittel-Verhältnis relevant werden. 
euphemistischen Theorie. 10) Trotzdem wird man alles in allem sagen können, daß die Staffelung der Träger sozialer Aufgaben zwischen Individuum und Staat ein Instrument ist, das - vorsichtig und der jeweiligen konkreten Situation gemäß gehandhabt seinerseits auf eine optimale Verwirklichung des "sozialen Rechtsstaates" hinführen kann. 11) Aber es wäre verfehlt, behaupten zu wollen, der "soziale Rechtsstaat" oder gar schon der "soziale Staat" ergäben eine irgendwie präzisierbare Aussage über den verfassungsmäßigen "vertikalen" Aufbau des Staates, und zwar im Sinne eines dem Subsidiaritätsprinzip entsprechenden Aufbaues von unten nach oben, im Sinne der körperschaftlichen Selbstverwaltung, im Sinne des Lebensrechts der Familie usw. 12) Das Grundgesetz enthält präzise Ausgrenzungen für die Familie (Art.6), die Vereinigungen (Art.9 Abs.1 und 2), die Koaiitionen (Art. 9 Abs. 3), die Gemeinden (Art.28 Abs. 1 Satz 2 und Abs.2) und die Kirchen (Art.140 GG i.V.m. Art.136 ff RV 1919). Das sind die Strukturprinzipien, die die Verfassung unter diesem Aspekt dem Sozialstaat vorgibt! Die Verfassungsnorm des "sozialen Rechtsstaats" fügt ihnen Entscheidendes nicht hin$\mathrm{zu}$.

Es ist ein eindrucksvolles Beispiel für die virulente Lust, das Sozialstaatsprinzip mit ideologisch bedingten Postulaten zu überfrachten, wenn in einem durchaus ernst zu nehmenden Werk über die soziale Arbeit der Kirchen deren Autonomie und die Freiheit ihrer Caritasarbeit verfassungsrechtlich aus dem Sozialstaatsprinzip heraus entwickelt werden, während der staatskirchenrechtlichen Verfassungsartikel kaum Erwähnung getan wird. 13)

8) S. insbes. hierzu oben Abschnitt 2 (S. 219 ff), insbes. S. 223.

9) S. insbes. Fechner, Freiheit und Zwang im sozialen Rechtsstaat, S. 22 f.

10) S. zu Vorstehendem oben S. 222 zu Fußn. $10 \mathrm{f}$ und den Text hierzu, S. 300 zu Fußn. 5 und 6 und den Text hierzu.

11) Vgl. Wolany, Vom Sozialstaat und sozialen Recht, S. 157 f, $160 \mathrm{ff}$; Fechner, Freiheit und Zwang im sozialen Rechtsstaat, S. 22 f; ders., Sozialer Rechtsstaat und Arbeitsrecht, S. 162 f; Franz Klein, Christ und Kirche in der sozialen Welt, S. 125 ff (136 ff).

12) In diesem Sinne die in der vorstehenden Fußnote Zitierten. Während aber Wolany und Fechner (je a.a.O.) zweifeln, ob sie wirklich positivrechtliche Prinzipien behaupten wollen, steht dies für Franz Klein, a.a.O., fest.

13) Franz Klein, a.a.O. S. $125 \mathrm{ff}$ (insbes. S. $129 \mathrm{ff}$ ) und S. $236 \mathrm{ff}$ (und die Anm. hierzu S. $316 \mathrm{ff}$ ). - In entsprechendem doch weniger prätentiösem Sinne Wolany, a.a.O. - S. zu den positiv- 
Genau so wenig wie dies ist es gerechtfertigt, ein von Art.9 Abs. 1 GG unabhängiges Eigenrecht privater Wohlfahrtsverbände aus dem Sozialstaatsgrundsatz abzuleiten. 14) Gewiß ist es ein Weg und cum grano salis auch ein sehr freiheitlicher Weg - der Sozialstaatlichkeit, private Wohlfahrtsverbände umfassend wirken $\mathrm{zu}$ lassen und sie zu unterstützen. Aber irgend ein Verfassungsgebot in dieser Richtung läßt sich auch aus einer verbindenden Interpretation der Vereinigungsfreiheit mit dem Sozialstaatsprinzip nicht ableiten. 15$)$

Auch in bezug auf das kollektive Arbeitsrecht wurde - allerdings unter stärkerer Einbeziehung der positiven Normierung des Rechtsstaats - der Versuch unternommen, aus dem "sozialen Rechtsstaat" ganze Systeme als die verfassungsrechtlich allein möglichen zu deduzieren. ${ }^{16)}$ Die allgemeine Kombination von Rechtsstaatlichkeit und Sozialstaatlichkeit dürfte jedoch gerade für die Tarifautonomie nicht von durchgreifender Bedeutung sein: Der entscheidende Ansatz liegt in Art.9 Abs. 3 GG. 17) Für die Frage der Mitbestimmung besticht es freilich sehr, die Sozial-

rechtlichen Problemen oben Abschnitt 2 IV 1 (S. 252 ff).

14) Franz Klein, a.a.O. S. $125 \mathrm{f}$ und (für die kirchliche Caritas) S. $236 \mathrm{ff}$ (316 ff).

15) Zu den Wohlfahrtsverbänden $s$, auch oben Abschnitt 2 I (S. $219 \mathrm{ff}$ ) und III (S. $242 \mathrm{ff})$.

16) Es ist die typische, von ihm insbes. auch hinsichtlich seiner wirtschaftsverfassungsrechtlichen Thesen ("Die soziale Marktwirtschaft in der Verfassung der Bundesrepublik') geübte Methode Nipperdeys, in einer Zusammenschau die irgendwie einschlägigen Verfassungsnormen zu vermengen, um aus diesem Mischungsprodukt (keineswegs immer zwingende) Folgerungen abzuleiten, die sich in einzelnen Verfassungsnormen nicht ausgedrückt finden. In dieser Weise entwickelt er sein A rbeitsverfassungsrecht insbes. im Lehrbuch des Arbeitsrechts $\mathrm{Bd}$. II S. $32 \mathrm{ff}$ und passim (weitgehend übereinstimmend schon früher Schnor*, Jundesverfassungsgericht und kollektives Arbeitsrecht). Die Berechtigung einer kombinatorischen Auslegungsmethode soll keineswegs bestritten werden (s. insbes. Peters, Die Kombination verschiedener Verfassungsgrundsätze als Mittel der. Verfassungsauslegung). Nur geht die Methode Nipperdeys einen sehr weiten Weg, mit dessen Länge und Unübersichtlichkeit die Gelegenheit zum Einfließen subjektiver Vorstellungen cles Interpreten unverhältnismäßig zunimmt. - Eine in dieser Richtung weitgehend übereinstimmende Deutung des "sozialen Rechtsstaats" findet sich auch bei Fechner, Sozialer Rechtsstaat und Arbeitsrecht. 
staatlichkeit - ähnlich wie vom demokratischen Autonomiegedanken - auch vom freiheitlichen Grundgedanken des Rechtsstaais und von dem ihm gemäßen Postulat der Erziehung zur Selbst- und zwischenbürgerlichen Mitverantwortung unterstützt zu sehen.

\section{ccc) Rechtssicherheit im Sozialstaat}

Stand bisher der freiheitliche Aspekt des "sozialen Rechtsstaats" im Vordergrund, so muß nun noch auf die Problematik hingewiesen werden, die von der Rechtssicherheit als einem Element der. Rechtsstaatlichkeit in den "sozialen Rechtsstaat" hineingetragen wird.

Daß Rechtssicherheit auch "soziale Sicherheit" sein kann, wurde oben 1 ) bereits hervorgehoben. Abwegig ist es aber, den Rechtsstaat darin vom sozialstaatlichen Element her noch "rechtsstaatlicher" machen zu wollen, als er es von Hause aus ist. Der Sozialstaat gewährt Hilfe und Ausgleich. Der Rechtsstaat unterstützt ihn darin, indem er die Rechtsposition der Betroffenen und Begünstigten festigt. Insofern gehen Rechtsstaat und Sozialstaat Hand in Hand, ${ }^{2}$ wie sich beide Elemente auch sonst in dem Verlangen nach rechtlicher Absicherung der individuellen Position bestärken. ${ }^{3)}$ Der soziale Rechtsstaat nimmt in diesem Rahmen des Bestandsschutzes auch den unvermeidlichen Fortbestand formaler, materiell nicht gerechtfertigter Rechtspositionen in Kauf. 4) Aber der Sozialstaat würde mißverstanden, wenn ihm unterstellt würde, er fordere die Belassung jeder, auch einer rechtswidrig begünstigenden Position, wenn sie nur immer einem sozial Bedürftigen zukommt. ${ }^{5}$ ) Was der Sozialstaat zu gewähren hat, wird grundsätzlich durch die allgemeinen Gesetze bestimmt. Die Grenze, die das - dem Sozialstaatsprinzip nicht

17) S. oben Abschnitt 2 IV 2 (S.287 ff).

18) Vg1. Schnorr, a.a.O., insbes. S. 5 ff; Nipperdey, a.a.O. Zum edukativen Moment s.a. Fechner, Freiheit und Zwang im sozialen Rechtsstaat, S. 22 f. - S. hierzu noch unten III ( $762 \mathrm{ff}$

1) Abschnitt 4 III 2 ( $\$ .637 \mathrm{ff})$.

2) Vgl. BGHZ 25, 231 (234 f), wonach die freie Widerruflichkeit der Leistungen der Gefangenenfürsorge verfassungswidrig wäre.

3) S. die oben S. 730 zu Fußn. 3 Zitierten und S. 751 zu Fußn. 25.

4) Vgl. LSG Nordrhein-Westfalen, Urteil v.16.April 1957 - LS I KV 138/56 - Die Sozialgerichtsbarkeit 5. Jhg. (1958) S. 226 (in bezug auf $₫ 77$ SGG).

5) Anders LSG Bremen, Urteil v. 20. Februar 1957 - LV 161/55

- Betriebsberater 12.Jhg. (1957) S. 543. 
widersprechende - Gesetz festlegt, konkretisiert für den Betroffenen seinen sozialstaatlichen "Anspruch". Gewährt ihm der "Zufa11" einer Gesetzesüberschreitung durch die vollziehenden Organe ein Mehr, so ist das kein Grund $z u$ behaupten, gerade die auf diese Weise erlangte ausnahmsweise Vorzugsposition liege im Sinne der Sozialstaatlichkeit. Der Sozialstaat würde, wenn er solche "Zufälle" über das rechtsstaatlich Gebotene hinaus honorieren würde, möglicherweise seine Verwirklichung als Ganzes beeinträchtigen. ${ }^{6}$ Es entspricht der Gemeinverpflichtung des Sozialstaats-Bürgers und der gesteigerten Gemeinverpflichtung clesjenigen, der vom Sozialstaat nimmt oder nehmen möchte, daß er seinen Anteil so beansprucht, wie es der allgemeinen sozialstaatlichen Ordnung entspricht und nicht so, wie ihn eine Irregularität, die weder in seiner individuellen Situation begründet noch sonst adäquat gerechtfertigt ist, stellt. ${ }^{7}$ )

Desgleichen widerspricht es nicht dem "Sozialen" im sozialen Rechtsstaat, wenn individuelle Gewährungen - wie es rechtsstaatlich zulässig ist - dem Gesetz gemäß einschlägigen Änderungen der Verhältnisse oder einer Änderung des Gesetzes selbst angepaßt werden. Auch und gerade dieses selbst wird nicht durch das Sozialstaatsprinzip fixiert. Die nachteilige Änderung einer leistungsgewährenden Regelung wird durch das Sozialstaatsprinzip nicht grundsätzlich verhindert. ${ }^{8)}$ Allerdings ist die sozialstaatliche Bedeutung einer Gesetzesänderung eine grundsätzlich andere als die der Änderung einer individuellen Rechtsposition. Der Sozialstaat findet sich im wesentlichen in seinen Gesetzen verwirklicht. Sie manifestieren auch den Standard, der in seinem - durch die überkommenen, im verfassungsrechtlichen Bekenntnis zum sozialen Staat positivierten Vorstellungen mitbestimmten - Wesensgehalt dur.ch das Sozialstaatsprinzip gegen "unsoziale" Abänderungen gesichert ist.9) Aber entscheidend ist der Eingriff in diesen sozialen Standard, nicht etwa der Fortbestand einer einmal gewährten Leistung an sich. Der Sozialstaatsgrundsatz ist als solcher kein Bestandsschutzprinzip, sondern nur inhaltlich an einem gewissen hestand orientiert. Andererseits wird aber der rechtsstaatliche Bestandsschutz sehr weitgehend auch im Interesse des Sozialstaats liegen. Wo z.B. der rechts-

6) S.a. BVerfGE 9, $20(35)$.

7) Vgl. BVerfGE 7, 129 (152); BSGE 9, 196 (204 f). S.a. oben Abschnitt 4 III 2 ( $\$ .637 \mathrm{ff}$ ).

8) Grundsätzlich anders Thieme, Umfang und Grenzen des verfassungsrechtlich gewährleisteten Bestandsschutzes der saarländischen Kriegsopferversorgung.

9) S. oben S. $709 \mathrm{ff}$. 
staatliche Vertrauensschutz eingreift, weil das Fehlen einer Eigenvorsorge, die nach bisherigem Recht unterbleiben konnte, nach neuerem Recht zu Verarmung führen muß, 10) wird auch das Sozialstaatsprinzip gegen diese Änderung ins Feld geführt werden müssen. 11)

\section{Die Schwerpunkte der sozialstaatlichen Sachordnung}

1. Vorbemerkung

Der Sozialstaat ist ein Staat des Ausgleichs. In erster Linie ist er um die "Schwächeren" in der staatlichen Gemeinschaft bemüht, sucht er ihnen zu helfen, ihre Lage zu bessern, ihre Bedürfnisbefriedigungspotenz zu heben. Der Abbau des Wohlstands der wirtschaftlichen Oberschicht und die Drosselung ihres Anteiles an der Einkommensverteilung ist keine primäre Sorge des Sozialstaates. Die gemeinsame Tendenz der historischen Sozialbewegung ist diejenige von "unten" nach "oben". Aber das Wirtschaftsvermögen und die rein produktiven Einnahmen des Staates selbst reichen für die Aufschüttung des "unten" bestehenden Mankos an Bedürfnisbefriedigungspotenz nicht aus. Die Rückwirkungen der sozialen Hilfe auf die wirtschaftliche Oberschicht bleiben demnach nicht aus. Ihr Anteil am Volkseinkommen muß - am schmerzlosesten geschieht es bei wachsendem Sozialprodukt gekürzt und notfalls - dieser Eingriff wirkt am drastischsten ihr Anteil am Volksvermögen beschnitten werden.

Die allgemeinste Formel für diesen Ausgleich schiene es zu sein, den "Reichsten" am meisten zu nehmen und den "Ärmsten" am meisten zu geben und Wegnahme und Zugabe von diesen beiden Endpunkten zu einer Mittellinie hin bis Null abnehmen zu lassen. Aber diese Allgemeinformel des sozialen Ausgleichs würde den Tatsachen nicht gerecht: Reichtum ist nicht gleich Reichtum; Armut ist nicht gleich Armut; und Wohlstandsdifferenz ist nicht gleich Wohlstandsdifferenz. Produktivvermögen ist von anderer ökonomischer Bedeutung als Konsumvermögen. Einkommen aus persönlicher Arbeitsleistung ist etwas anderes als reine Kapitalnutzung. "Armut" kann in Vermögenslosigkeit oder (und) in fehlendem Erwerbseinkommen bestehen. Sie kann in persönlichen, allgemein ökonomischen oder gemeinschaftsbedingten Umständen

10) S. oben S. $645 \mathrm{f}$.

11) S. zu den vorstehend angesprochenen Problemen auch Weidner, Zur Rechtsprechung des Bundessozialgerichts, S. 762 f. - Zur rein rechtsstaatlichen Beurteilung dieser Probleme s. nochmals oben Abschnitt 4 III 2 (S. 637 ff); s. ferner die dortigen Nachweise. 
gegründet sein. Die Wohlstandsdifferenz kann in einem allgemeinen Unterschied des für den Konsum verfügbaren Vermögens, in der Verfügungsmacht über Produktivvermögen auf der einen und ihrem Fehlen auf der anderen Seite, in dem Vorhandensein eines bestimmten Bedürfnisobjekts hier und seiner Unerreichbarkeit dort, in einem geringeren persönlichen Bedarf hier und einem unausweichlichen höheren Bedarf dort gesehen werden. Dies alles sind nur einige der denkbaren Kategorien. Aber sie zeigen deutlich, wie unmöglich eine totale und generelle Nivellierung wäre. Der Sozialstaat muß daher immer an konkreten Wohlstandsobjekten, Bedürfnissen und Spannungslagen ansetzen.

Gegenstand und Instrumentarium der sozialen Intervention, demgemäß nach Problematik und Lösungsmöglichkeiten reich facettiert, sind infolge der zwischen den einzelnen Sach- und Methodenfragen bestehenden vielfältigen und dichten Zusammenhänge kaum überschaubar und sehr komplex. 1) Eine umfassende Systematisierung, an der es derzeit leider fehlt, wäre zu umfangreich, als daß sie hier, im Rahmen einer Untersuchung, die vom Normativen ausgeht, ${ }^{2)}$ in Angriff genommen werden dürfte. Das Sozialstaatsprinzip als Rechtsgrundsatz ist gegenständlich universell. Keine Wohlstandsdifferenz, keine soziale Notlage ist ausgenommen. Jedes Mittel, das zur Lösung sozialer Probleme dienen kann, ist recht. Das Sozialstaatsprinzip ist gegenüber der Frage nach Objekt und Mittel deshalb nicht etwa indifferent. Aber es ist - so wie es die Verfassung fixiert hat - durch und durch allgemeines Prinzip.

Allerdings ist die Sozialstaatserklärung des Grundgesetzes an einem bestimmten vorrechtlichen Gesamtbild orientiert. ${ }^{3)}$ Daraus ist zu schließen, daß ihm gewisse soziale Einrichtungen, die $\mathrm{zu}$ dessen unbestrittenem Funclus gehören, besonders "am Herzen liegen". 4) Doch darf nicht übersehen werden, daß das Grundgesetz die Möglichkeit, ganz bestimmte Einrichtungen zu garantieren, gerade nicht ergriffen sondern seine Zuflucht zur Generalklausel (und zum Formelkompromiß) genommen hat. Auch die historische Kernsubstanz der Sozialpolitik im deutschen Raum ist daher - obwohl sie den elementaren Ansatzpunkt abgibt, um von der amorphen Abstraktion des Sozialstaatsprinzips die konkrete Gestalt des Sozialstaats abzulösen - in erster Linie als Glied des

1) Zur Exemplifizierung darf auf die Ausführungen oben S.1ff und auf die Beispiele zu den Abschnitten B 1-4 (S.

S.672 hingewiesen werden.

2) S. oben S. $41 \mathrm{ff}$.

3) S. oben II 1 (S.676 ff) u. 2a (S.706 ff).

4) S. oben S. 
größeren Gesamtgefüges der sozialen Intervention und des sozialen Standards zu sehen. So ist es auch nicht möglich, einen engeren Kreis sozialstaatlicher Maßnahmen und Einrichtungen als durch das Sozialstaatsprinzip präzis fixiert herauszustellen.

Der nachstehende Versuch, durch die Erörterung einiger besonderer Fragen die allgemeinen Erwägungen über den Inhalt des Sozialstaatsprinzips, wie sie bisher angestellt wurden, sowoh1 $z u$ verdeutlichen als auch fruchtbar zu machen, kann daher nicht auf ein abgeschlossenes System gestützt werden. Trotzdem scheint es nicht schwer zu fallen, aus der Fülle der sozialen Probleme und Methoden, sie zu lösen, diejenigen herauszugreifen, die im Zentrum des sozialstaatlichen Blickfeldes stehen und am diringendsten einer Wertung vom verfassungsrechtlichen Prinzip her zu bedürfen scheinen.

2. Sozialstaat und soziale Sicherheit

\section{a) Allgemeines}

Sozialstaatlichkeit äußert sich am aktuellsten immer in der gewährenden Hilfe für die wirtschaftlich Schwächeren. ${ }^{1)}$ Es mag sein, daß "die Überbetonung des Sozialen in diesem engen Sinne einen der Krankheitskeime unserer Gesellschaftsordnung" darstellt.2) Und sicher geht es dem sozialen Rechtsstaat im Sinne des Grundgesetzes zutiefst um die "Verwirklichung des Rechts zu einer der Würde und der Freiheit des Menschen gemäßen Sinnerfüllung seines Daseins in der Gemeinschaft". 3) Wird die Wirtschaftsverfassung "der Würde und Freiheit des Menschen jeweils in der artverschiedenen Weise, die seiner Teilhabe an der Wirtschaftsgemeinschaft als Unternehmer, Arbeitnehmer oder Verbraucher", gerecht, 4) so daß schon die "erste Einkommensverteilung" den sozialen Spannungen entgegenwirkt, so wird der größte sozialstaatliche Effekt unter größter Schonung der Freiheit erreicht.

Aber der Sozialstaat kann der unmittelbaren Güterzuteilung deshalb nicht entraten. Auch die "vollkommenste" und "sozialste" Wirtschaftsverfassung (und Wirtschaftsverfassungs-Wirklichkeit) kann grundsätzlich nur demjenigen Einkommen zukommen lassen, der Kapital oder Arbeitskraft einzusetzen hat. Wird ihr scheinbar mehr abverlangt, so handelt es sich doch um

\footnotetext{
1) S. nochmals Thieme, Der Beamte im sozialen Rechtsstaat, S. $170 \mathrm{f}$.

2) Ballerstedt, Wirtschaftsverfassungsrecht, S. 55.

3) ebd., S. 54 .

4) ebd., S. 60 .
} 
nichts anderes als um eine kaschierte Umverteilung. Wer aber weder (hinreichend) Kapital noch (volle) Arbeitskraft einzusetzen hat oder - man vergleiche das Problem der kinderreichen Familie - mit dem Nutzwert e in er Arbeitskraft den Konsum mehrerer decken muß, muß so bei der "ersten Einkommensverteilung" leer ausgehen oder jedenfalls unzureichend versorgt werden. Erlaubt die Wirtschaftsordnung die volle Ausnützung des vorhandenen Kapitals und der vorhandenen Arbeitskräfte nicht - was von der staatlichen Wirtschaftspolitik nicht in jedem Fall verhindert werden kann -, so weitet sich der Kreis derjenigen, die von der "ersten Einkommensverteilung" nicht oder nur unzulänglich erreicht werden.

Der Eigenvorsorge sind enge Grenzen gesteckt. Die Familie ist nicht nur wegen ihres oft recht romantisch diagnostizierten menschlich-geistigen "Verfalls" sondern wegen harter ökonomischer Gesetzmäßigkeiten, leren eine eben angedeutet wurde, weitgehend nicht in cler Lage, lie von der. "ersten Einkommensverteilung" Unversorgten zu absorbieren. Private Wohltätigkeit kann lindernd aber nicht durchgreifend wirken. So bleibt letztlich nur noch die Hilfe des Staates und seiner Unterverbände, um die fehlenden Einkommen auszugleichen. Dieser Notwendigkeit entspricht das System der sozialen Sicherheit, das in den drei Grundformen der Versicherung, der Versorgung und der Fürsorge gegen die Risiken der Erkrankung, der alters- oder der unfallbedingten Invalidität, cler Mutterschaft, des Kinderreichtums, der Arbeitslosigkeit und des Todes, insbes. des Ablebens unter Hinterlassung unterhaltsberechtigter Personen, durch die Bereitstellung von Barleistungen oder (und) Sachleistungen, insbes. medizinische Hilfe, schützt. 5)

5) (1) S.f.v.a. Weisse1, Art. "Soziale Sicherheit" im Handwörterbuch der Sozialwissenschiften. Zum System und weitere Nachweise s. oben Abschnitt 1 I 1 b, bb (S. 49 ff).

(2) Schmitt-Lermann (Dio Verfassungsmäßigkeit der Pflichtmitgliedschaft bei der Bayruischen Arzteversorgung, S. 28 ff) legt dar, das vorrechtiche Gesamtbild des grundgesetzlichen Sozialstaatsbegriffes sei durch ein Gemisch aus Eigenund Familienhilfe, caritativer Hilfe, Fürsorge, Versicherung und Versorgung gek'nnzeichnet gewesen. Er folgert daraus die größtmögliche Ciestaltungsfreiheit des Gesetzgebers. Dem ist im Cirundsatz zuzustimmen. Jedoch ist stärker (als dies bei schmitt-Lermann hervortritt) zu unterscheiden zwischen den außerstaatlichen Hilfen (Eigen- und Familienhilfe einschließlich der privaten Versicherung, Wohlfahrtsverbände u. ä.) und dem System der staatlichen 
b) Die allgemeine öffentliche Fürsorge als sozialstaatliches Minimum

Der soziale Staat muß den Bedürftigen jedenfalls das gewähren, was die allgemeine $F$ ür sorge beinhaltet: 1 ) die individuelle, auf die konkrete Notlage abgestellte, die Prüfung der Bedürftigkeit voraussetzende Hilfe aus allgemeinen, nicht speziellen Beiträgen und dg1. entstammenden Mitteln. 2) Die Fürsorge ist das Minimum, das der soziale Staat dem Notleidenden ${ }^{3)}$ schon um seiner Menschenwürde ${ }^{4}$ ) und seines Rechts auf Leben ${ }^{5)}$ willen

Hilfen (Fürsorge, Versicherung und Versorgung). Nur das letztere ist vom Staat voll beherrschbar. Die außerstaatliche Hilfe kann der Staat zwar ordnen, anspornen usw. Aber ihr Funktionieren ist doch an eine Fülle von Prämissen gebunden, die der Staat nicht willkürlich verändern kann. Die Verantwortung des Sozialstaates liegt - so wünschenswert es ist, wenn er die außerstaatlichen Hilfen aktiviert - also letztlich in einem funktionsfähigen System unmittelbarer Hilfe der öffentlichen Hand.

1) Zur Garantie der öffentlichen Fürsorge durch das Sozialstaatsprinzip s. außer den nachfolgend Fußn.4-6)

Zitierten insbes. E.R. Huber, Der Streit um das Wirtschaftsverfassungsrecht, S.202; Thieme, Liberalismus und Grundgesetz, S. 298 f; Leibholz, Die kritischen Punkte des Grundgesetzes, S. 19.

2) S. oben S. $49 \mathrm{ff}$ und S. $60 \mathrm{ff}$.

3) Fürsorge wird - man vergleiche auch den Zusammenhang mit den "Jedermann"-Rechten aus Art. 1 Abs. 1 und 2 Abs. 2 GG wohl jedermann, nicht nur dem "Deutschen" zugestanden werden müssen. - Für die Hilfe gegenüber dem asylsuchenden Ausländer als Ausfluß der Sozialstaatlichkeit s. Klein, Christ und Kirche in der sozialen Welt, S. 126, 231 (Fußn.300).

4) Wintrich (Die Bedeutung der Menschenwürde für die Anwendung des Rechts, Bayerische Verwaltungsblätter, n. F. 3.Jhg. (1957) S. 137 ff (139)) leitet den Anspruch auf Fürsorge aus der Berührung des Sozialstaatsprinzips mit dem Grundrechtssatz von der Menschenwürde ab. Ähnlich - nur weniger dezidiert im Sinne eines Anspruchs - auch BSGE 9, 199 (205); s.a. Dürig in Maunz-Dürig, Art. 1 Abs. I Randn. 43; Nipperdey s. unten S.767 zu Fußn.6 a.E.

5) Art.2 Abs. 2 GG wurde nicht selten neben dem Sozialstaatsprinzip zur Gewinnung des Anspruchs auf Fürsorge herangezogen; s. die eingehenden Nachweise bei Dürig in MaunzDürig, Art. 2 Abs. II Randn.27 (Fußn.1). Zur Auslegung des Art. 2 Abs. 2 GG s. unten S. 842 und S. $1083 \mathrm{ff}$. 
schuldet.6) Sie steht hinter dem engeren System der "sozialen Sicherheit" und hilft auch noch dort, wo dessen speziellere Gewäh.rungen versagen. A ber sie greift auch darüber hinaus. Sie ist die letzte Zuflucht der atypischen Armut und bewährt gerade

6) (1) Zur Gewährung des Existenzminimums als Pflicht des Sozialstaats s.a. oben S. 679 zu Fußn. 5. Zur Ableitung eines Minimalanspruchs aus dem Sozialstaatsprinzip s. schon oben II 2 e (S. 729 ff). Hinsichtlich der subjektiven Berechtigung aus dem gesetzlichen Fürsorgeanspruch s. oben S. 547 zu Fußn. 12 .

(2) In Rechtsprechung und Schrifttum wird allein aus dem Sozialstaatsprinzip nur selten ein Anspruch auf Fürsorge oder die Garantie eines solchen hergeleitet (in diesem Sinne: Ipsen, Anm. zu BVerfG Urt. v. 19. Dezember 1952 - 1 BvR 220/51 - S.218; Dürig, Besprechung zu Menger "Der Begriff des sozialen Rechtsstaates im Bonner Grundgesetz", S. 257; ders., in Maunz-Dürig, Art.2 Abs. II Randn.27 (Fußn.1); Jellinek, Diskussionsbeitrag zu "Begriff und Wesen des sozialen Rechtsstaats", S. 118). Ansonsten wird dem Sozialstaatsprinzip der Charakter einer unmittelbaren Rechtsgrundlage versagt (v. Mangoldt-Klein, Art. 20 Anm. VII $2 \mathrm{c}$ ). In bezug auf das überkommene Fürsorgerecht wurde ihm die Kraft abgesprochen, dessen veränderte Auslegung im Sinne eines Anspruches zu erzwingen (Wolff, Der Abwendungsanspruch aus öffentlichen Reflexrechten insbes. im Fürsorgerecht, S. 134; Klein, Bonner Grundgesetz und Rechtsstaat, S. 401; Held, Fürsorgepflicht und Fürsorgeanspruch nach dem geltenden Verfassungs- und Verwaltungsrecht, DÖV 4.Jhg. (1951) S. 8 ff (S. 10); Patzig, Klagbarer Rechtsanspruch auf öffentliche Fürsorge, NJW 4.Jhg. (1951) S.62 f (63); Merk, Diskussionsbeitrag zu "liegriff und Wesen des sozialen Rechtsstaats", S.101 f). Inzwischen ist der Anspruch auf Fürsorge allgemein anerkannt, wird aber meist auf rechtsstaatliche und sozialstaatliche Erwägungen gestützt (s. vor allem BVerwGE 1, 159 (161 f); BayVGH VGHE n.F. 2, 14 (18 ff); Bauer, Aktuelle Kernfragen der Verwaltungsrechtspflege, DÖV 1.Jhg. (1943) S.28 f; Bachof, Begriff und Wesen des sozialen Rechtsstaits, \$. 51 f; s.a. Forsthoff, dass. S. 29; Werner, Sozialstaatiche Tendenzen in der Rechtsprechung, S.95 ff (97)). S.a. nochmals S. 766 zu Fußn. 4 und 5. Die dort erwähnten Ansichten verbindet Nipperdey (Die Würde des Menschen, S. 6 f), indem er den Fürsorgeanspruch aus einer Zusammenschau des Prinzips des sozialen Rechtsstaats, des Grundrechtssatzes von der Menschenwürde (Art. 1 Abs.1 GG) und des Rechts auf Leben (Art.2 Abs. 2 GG) ableitet. 
darin den Sozialstaat auf das bedeutsamste. 7) Ja sie greift freilich gegebenenfalls unter äußerster Beschränkung - selbst dann noch ein, wenn der Bedürftige aus eigenem Verschulden in Not geraten ist oder verbleibt. ${ }^{8)}$ Sie dient endlich wohl auch heute noch 9) über den $Z$ weck des Sozialen hinaus der allgemeinen öffentlichen Gefahrenabwehr. 10)

c) Die Verwirklichung des Sozialstaates durch die gehobene Soziale Sicherung

aa) Vorbemerkung

So wenig die Fürsorge ausschließlich im Zusammenhang der sog. sozialen Sicherheit gesehen werden darf, so wenig darf diese auf das Institut der Fürsorge beschränkt bleiben. Die allgemeine öffentliche Fürsorge kann nur der Boden im Gefüge der sozialen Sicherheit sein, auf den der fällt, dessen Notlage nicht schon durch das Netz der spezielleren Hilfen abgefangen ist. 1) Bedürftigkeitsprüfung und Beschränkung auf das Minimum sind für die Fürsorge als allgemeines Instrument unterster Existenzerhaltung unverzichtbar. Für denjenigen, der ohne sein Verschulden gehindert ist, durch seine A rbeitskraft einen ausreichenden Anteil an der ersten Einkommensverteilung zu erlangen, sind diese Eigentümlichkeiten der Fürsorge grundsätzlich nicht zumutbar; und auch im objektiven öffentlichen Interesse ist es untunlich, ihn darauf zurückzuwerfen. Der Sozialstaat muß grundsätzlich lückenlos wird er es nie können! - einen angemessenen, genereli festgelegten Ausgleich des fehlenden Einkommens bzw. der dem Einkommen inadäquaten Belastung gewähren. Dem vorrechtlichen Gesamtbild des grundgesetzlichen Sozialstaates gehört ein

7) Werner, a.a.O. S.97.

8) S. $\ 20$ der Reichsfürsorgepflichtverordnung; $\$ 13$ der Reichsgrundsätze; $₫ 23$ des Entwurfs eines Bundessozialhilfegesetzes, Deutscher Bundestag, 3. Wahlperiode, Drucksache 1799.

9) Zur Entwicklung s. Knoll, Die sozialethischen und rechtlichen Wandlungen in der Bewertung des Armenwesens, Zeitschr. für die gesamte Staatswissenschaft, Bd.111 (1955) S. $418 \mathrm{ff}$. Siehe hierzu auch du Pasquier, La notion de justice sociale et son influence sur le droit suisse, pp. 83 e.s.

10) $\mathrm{Zu}$ den quasi-Ver-sorgungszweigen s. unten S. 777.

1) Die amtliche Begründung des Entwurfs eines Bundessozialhilfegesetzes (Deutscher Bundestag, 3. Wahlperiode, Drucksache 1799)bezeichnet die öffentliche Fürsorge als "Ausfallbürge für die Fälle sozialer Notlage" (S.31, s.a. S.37). 
hoch entwickeltes System aus Sozialversicherung und Sonderversorgung an, 2) das diesem Zwcck dient. Es wurde unter der Herrschaft des Grundgesetzes - insbes. durch Einführung des Kindergeldes und durch den Aufbau gewisser durch die Nachkriegssituation Westdeutschlands bedingter Zweige von Sonderversorgung 3) - wesentlich erweitert. 2) Der Bestand und die Ausdehnung dieses Systems gehobener sozialer Sicherung ist ein nicht zu übersehender Beweis dafür, daß sie im Prinzip zur Substanz der Sozialstaatlichkeit des Grundgesetzes gehört.

\section{bb) Die Sozialversicherung}

Das klassische Instrument sozialer Sicherung im deutschen Raum ist seit den ruhmvollen Anfängen durch die Gesetzgebung des Kaiserreichs die Sozialversicherung. 1) Sie gewährt - bei im einze1nen sehr verschiedener Gestaltung - Schutz gegenüber allen Risiken, die dem Erwerbstätigen aus dem Verlust oder der Minderung seiner Arbeitskraft und dem abhängig Beschäftigten aus der Arbeitslosigkeit erwachsen. Subjektiv kann ihr Schutz beliebig weit erstreckt werden, wenngleich praktische Gründe gegen eine unbeschränkte Ausdehnung in die höheren Einkommensschichten spre-

2) Eine Übersicht s. z.B. bei Bogs, Grundfragen des Rechts der sozialen Sicherheit und seiner Reform. S. dort insbes. die im Detail bereits überholte, im Ganzen aber sehr informative Übersicht auf der beiliegenden graphischen Darste1lung. Zum internationalen Hintergrund vgl. außer Art. 25 der Allgemeinen Erklärung der. Menschenrechte der Vereinten Nationen vom 10. Dezember 1948 insbes. das Übereinkommen Nr. 102 der Internationalen Arbeitsorganisation über die Mindestnormen der sozialen Sicherheit vom 28. Juni 1952 (abgedrucktz. B. bei Richtel, Die Sozialreform, Anhang I, 1) und den Code européen de Sécurité sociale des Europarates (abgedruckt ebendir Anhang I 2). - Im übrigen s. oben Abschnitt 1 I 1 b, bb (\$.+4 If).

3) Außer der überkommenten und nur neu geregelten Kriegsopferversorgung insbes. die Leistungen des Lastenausgleichsrechts, der Heimkehrerhilfє, der Häftlingshilfe, die Versorgung nach Art.131 GG und - obwohl von ganz eigener Bedeutung - die Entschäligunğ der (Opfer nationalsozialistischer. Verfolgung.

1) Zum Begriff der Suzialversicherung s. schon oben S. 52 ff. Überblick und Schrifttum s. bei Weddingen, Art. "Sozialversicherung (I) Theorie" und savelsberg, Art. "Sozialversicherung (II) Entwicklung und heutiger Stand" im Handwörterbuch der Sozialwissenschaften, Bd.9, 1956, S. 594 ff, 604 ff. Ein- 
chen. Ihrer historischen Entwicklung nach blieb sie zunächst fast ganz auf die abhängig Erwerbstätigen der unteren Einkommensschichten beschränkt ("A rbeiterversicherung"), während sie später mehr und mehr auch auf die abhängig Erwerbstätigen der mittleren Einkommensschichten und auf besonders anfällige Gruppen von selbständig 'Tätigen (Handwerk, Landwirtschaft u.a. m.) ausgedehnt wurde. 2) In der Tat ist bei den höheren Einkommensgruppen das Bedürfnis nicht so dringend. Eigenvorsorge ist eher möglich. Gewisse selbständige Erwerbstätigkeiten sind daneben meist mit einer Kapitalnutzung verbunden, die nicht nur zu einem den laufenden Bedarf überschreitenden Einkommen führt, sondern auch das Risiko der Arbeitsunfähigkeit weniger scharf auftreten 1äßt. ${ }^{3)}$

Die Sozialversicherung verwirklicht den Sozialstaat geradezu ideal.4) Ein leistungsfähiges Instrument sozialer Sicherheit und

gehendes Material bei Brackmann, Handbuch der Sozialversicherung.

2) Vg1. für die Altersversorgung: das Gesetz über die Altershilfe für Landwirte, das Gesetz über die Altersversorgung für das deutsche Handwerk, $\ 2$ Nr.3-6 AnVG, $₫ 1227$ Abs. 1 Nr. 3 und 4 RVO, $\ 28$ der Verordnung über das Schornsteinfegerwesen, ferner die schon erwähnten Versorgungseinrichtungen des bayerischen Rechts für die Ärzte, Zahnärzte, A potheker und Drogisten; für die Unfallversicherung: $\$ \$ 537$ Nr.6-9, 538, 539 RVO; für die Krankenversicherung: $₫ 166$ RVO. - Allgemein s. hierzu Heyn, Die soziale Sicherung der Selbständigen, in "Beiträge zur Sozialversicherung", Festschrift für Johannes Krohn, 1954, S. 127 ff. - S. ferner oben S. 52 ff, insbes. S.58 ff zu Fußn. 42-46.

3) Dafür, daß die Sozialversicherung freier Berufe u.a. selbständig Erwerbstätiger dennoch i.S. des Sozialstaatsprinzips liegt (liegen kann) s. BVerfGE 10, 354 (370 f); Schneider, Die öffentlichrechtliche Alterssicherung freier Berufe und das Grundgesetz, S. 23 ff; früher schon Schmitt-Lermann, Die Verfassungsmäßigkeit der Pflichtmitgliedschaft bei der Bayerischen Ärzteversorgung, S. 47 f; Maunz, Rechtsgutachten über die Verfassungsmäßigkeit der Bayerischen Ärzteversorgung nach dem Grundgesetz, S.13. - Ausweichend Weber, Die verfassungsrechtliche Problematik der Zwangsversorgungseinrichtung der freien Berufe, S.21; Ipsen, Rechtsfragen berufsständischer Zwangsversorgung, S. 50 ff; Scheuner, Berufsständische Versorgungseinrichtungen und das Grundgesetz, S. $101 \mathrm{f}$.

4) Vgl. Forsthoff, Begriff und Wesen des sozialen Rechtsstaats, 
sozialer Umverteilung führt sie an die Mitverantwortung am Sozialstaat heran und zeigt sie durch genossenschaftliche Struktur und Beitragspflicht konkret, daß Hilfe der Gemeinschaft eine Kehrseite immer auch in der Gebundenheit und in der Leistung an die Gemeinschaft hat.

\section{c) Die Sonderversorgung}

aaa) Die "echte" Sonderversorgung

Mit der Sozialversicherung konkurriert die Versorgung. 1) Sie ist denkbar als Sonderversorgung und als allgemeine Staatsbürgerversorgung. Die letztere deckt die von der "sozialen Sicherheit" anvisierten Risiken für alle Staatsbürger in gleicher Weise.

Das gegenwärtige deutsche System kennt nur die Sonderversorgung. Sie gewährt Leistungen zum Ausgleich bestimmter Schäden, die wiederum aus einer ganz bestimmten Ursache erwachsen sind; es ist gerade diese Ursache, die den Staat dazu veranlaßt, Leistungen zu gewähren. 2) Grundsätzlich handelt es sich um Schäden, die im Gemeininteresse oder jedenfalls im Zusammenhang mit dem Gesamtschicksal der staatlichen Gemeinschaft erwachsen sind und wegen dieses Bezuges von der Gemeinschaft ausgeglichen werden sollen. Der Sonderversorgung kommt es in erster Linie auf den auf spezifische Weise verursachten Schaden an. Die individuelle oder typische Notlage, die damit verbunden ist, spielt erst für die Gestaltung der Entschädigung eine Rolle. Die Sonderversorgung kann somit nicht ausschließlich als ein Bestandteil des Systems der sozialen Sicherheit angesehen werden, wirkt aber doch in ihrem Simn, indem die Entschädigung entweder den Schadenserfolg voll ausgleicht und somit die typische Notlage "überholt" oder sich, außerstande einen vollen Ausgleich zu bewirken, auf die Beseitigung der durch das Schadensereignis verursachten Notlage gleichsam als Mindestprogramm beschränkt.

(1) Das klassische Beispirl riner Sonderversorgung in diesem Sinne ist die Kriegsopferversorgung, wie sie sich seit

S. 9, 26; v.Altrock, Der Standort der Sozialversicherung im Rechtsgefüge, in "Sozialreform und Sozialrecht", Festschrift für Walter Bogs, 1959, S. 15 ff (31); Dersch, Der Verfassungsgrundsatz der Sozialstaatlichkeit und Rechtsstaatlichkeit in der Praxis der Sozialversicherung, S. $60 \mathrm{ff}$.

1) Vg1. oben S.49 ff.

2) Bogs, Grundfragen des Rechts der sozialen Sicherheit und seiner Reform, S.20 f. S. das. auch zum Folgenden. 
dem Militärpensionsgesetz von 1871 entwickelt hat und nun in dem Bundesversorgungsgesetz - ergänzt durch das Gesetz über die Unterhaltsbeihilfe für die Angehörigen von Kriegsgefangenen - geregelt findet. 3) Ihre Entsprechung für die Friedenszeit findet sie in der Beschädigtenversorgung der Bundeswehr. Hier zu erwähnen ist auch noch die Sicherung des Unterhalts der Angehörigen Wehrpflichtiger nach dem Unterhaltssicherheitsgesetz, gewissermaßen eine Sonderversorgung auf Zeit. 4)

(2) Ein neuer Zweig der Sonderversorgung ist heute kaum von geringerer Bedeutung: der Lastenausgleich - im Gegensatz zur Kriegsopferversorgung als dem Ausgleich der persönlichen Kriegsschäden- die Regelung der sachlichen Kriegs- und Kriegsfolgeschäden. Diese Figenschaft als Vermögensschadensregelung distanziert den Lastenausgleich zunächst von der "sozialen Sicherheit" im üblichen Sinn; knüpft diese doch an die Behinderung an, sich durch Einsatz der Arbeitskraft ein angemessenes Auskommen zu verschaffen. Hinreichend einträgliches Kapitalvermögen kann die soziale Sicherung seitens des Staates erübrigen; nicht aber ist umgekehrt das Fehlen von Kapitalvermögen eines der Risiken, auf das die "soziale Sicherheit" speziell abgestellt ist. Das Gesamtvolumen der Lastenausgleichsleistungen (vgl. \$\$ $228 \mathrm{ff}$ LAG) geht denn über das, was der sozialen Sicherheit zugerechnet werden kann, weit hinaus. Aber dieses Gesamtvolumen kann zunächst nicht voll realisiert werden. Daher mußten vorläufige Hilfen eingerichtet werden. Diese gehen in Richtung der sozialen Sicherheit: so vor allem die Kriegsschadenrente ( $\$ 261$ LAG), die dem Erwerbsunfähigen das Einkommen aus dem untergegangenen Vermögen (insbes. zu denken als die untergegangene Eigenvorsorge) ersetzen soll, und die Ausbildungsbeihilfe (\$ 302 LAG) 5 ) usw. Ergänzt wird dieses System nunmehr

3) Eine Darstellung der Grundzüge s. z.B. bei Schieckel, Art. "Kriegsopferversorgung" im Handwörterbuch der Sozialwissenschaften, Bd.6, 1959, S.376 ff.

4) Diese Regelung erscheint so selbstverständlich, daß ihr sczialer Charakter schon fast verdunkelt ist. Deshalb ist es nützlich, darauf hinzuweisen, in welchem Maße der Lohnausgleich während des Wehrdienstes z.B. in der Schweiz noch ein - man kann sogar sagen: offenes - soziales Problem ist (s. z.B. du Pasquier, La notion de justice sociale et son influence sur le droit suisse, p. 81 e.s.; s. zum Thema auch Nawiasky, Die Rechtsverhältnisse bei der Entschädigung fir $r$ den Einkommensausfall der aktivdiensttuenden Wehrmänne:, Schweizerisches Zentralblatt für Staats- und Gemeindeverwaltung, 41.Jhg. (1940) S. $441 \mathrm{ff})$. 
noch durch die Härtebeihilfe (insbes. die Unterhalts- und Ausbildungsbeihilfe) nach dem Allgemeinen Kriegsfolgenschlußgesetz $(\$ \$ 68 \mathrm{ff}$ - insbes. $\$ 73-\mathrm{AKG}) .5)$

(3) Als Sonderversorgung können auch die Ausbildungsbeihilfe, die Arbeitslosenhilfe und die nicht durch Beitragsleistungen des Heimkehrers "gedeckten" Sozialversicherungsleistungen nach dem Heimkehrergesetz ( $\$ \$ 10,12 \mathrm{ff})$ bezeichnet werden.

(4) Die Leistungen nach dem Bundesversorgungsgesetz, dem Unterhaltsbeihilfegesetz und clem Heimkehrergesetz gewährt das $\mathrm{H}$ äft 1 ingshilfegesetz auch den ehemaligen Häftlingen aus der sowjetischen Besatzungszone, Ostberlin und den sog. Vertreibungsgebieten bzw. ihren Angehörigen oder ihren Hinterbliebenen.

(5) Hier anzuführen sind ferner die unterhaltssichernden Leistungen nach dem Bundesent schädigungsgesetz.

(6) Das Bundesvertriebenengesetz (insbes. sein Dritter Abschnitt "Eingliederung der Vertriebenen und Flüchtlinge" - $\$ \$$ 26 bis 81 -), das Bundesevakuiertengesetz ( $\$ \$ 10$ ff), das Heimkehrergesetz ( $\$ \$ 7 \mathrm{ff}$ ), las Kriegsgefangenenentschädigungsgesetz ( $\$ \$ 28 \mathrm{ff}$ ), das Lastenausgleichsgesetz ( $\$ \$ 253 \mathrm{ff}, 302 \mathrm{f}$ ), das Allgemeine Kriegsfolgenschlußgesetz ( $\$ 73$ Abs. $1 \mathrm{Nr} .4$ ), das Schwerbeschädigtengesetz und - hier zu nennen, obwohl von einer historisch bedingten, sachlich unhaltbaren Betrachtungsweise immer noch als Fürsorge von der Versorgung säuberlich geschieden - die $\mathbb{S} \$ 26$ f des Bundesversorgungsgesetzes enthalten darüber hinaus ein umfangreiches und reich variiertes Instrumentarium der Existenzaufbauhilfe, dessen Maßnahmen, obwohl es sich meist nicht um feste, im voraus generell bestimmte Leistungen

5) Damit soll nicht verkannt werden, daß diese Leistungen vom Gesetz "ohne Rechtsanspruch" eingeräumt und nicht abschlieBend bestimmt wurden (vgl. $\$ \$ 233,253$ (ff), 302 LAG; $\$ \$ 88$ Abs. 2, $73 \mathrm{AKG}$ ). Die Versorgung (i.S. der"sozialen Sicherheit") geht aber wesentlich auf generell bestimmte Leistungen, auf die ein Rechtsanspruch besteht. Dazu ist zu sagen, daß Irregularitäten im Sinne einer Abweichung zum Unbestimmten hin auch im Rahmen von Versorgungssystemen denkbar sind. Anclererseits ist das Fehlen eines gesetzlich eingeräumten Rechts im Hinblick auf Art. 19 Abs.4 GG nicht sehr bedeutsam (s. oben $A$ bschnitt 4 II 3 c, aa ( $\$ .540 \mathrm{ff}$ )). Außerdem sind die genannten Leistungen durch die einschlägigen Durchführungsbestimmungen zum Lastenausgleichsgesetz und zum Allgemeinen Kriegsfolgenschlußgesetz. weitgehend präzisiert. 
handelt und der reine Entschädigungscharakter mitunter sehr im Vordergrund steht, nach Inhalt, Zweck und Wirkung von der Fürsorge wie auch von der Sozialversicherung deutlich geschieden und als sinnvolle Ergänzung auch der sozialen Sicherung durch Versorgung zuzurechnen sind.

(7) Das öffentliche Dienstrecht - durch Art.33 Abs. 4 und 5 GG in der Verfassung selbst spezieller geregelt 6) - nimmt dem Eingreifen der allgemeinen Einrichtungen der sozialen Sicherheit den Anlaß, indem es die Beamten und Soldaten durch die Alters-, Invaliditäts-, Unfall- und Hinterbliebenenversorgung und durch die Beihilfe in Krankheitsfällen vor den entsprechenden Risiken schützt. ${ }^{\text {) }}$ Als selbständige Sonderversorgung tritt dagegen die - mit der Sozialversicherung gekoppelte - Nachversicherung ehemals versorgungsberechtigter Personen hervor ( $\$ 1232$ RVO; $₫ 9$ AnVG). Einen gegenwärtig besonders wichtigen und umfangreichen $Z$ weig der Sonderversorgung stellt die Regelung nach Art.131 GG dar. ${ }^{8}$ )

(8) Im Sozialversicherungsrecht ist auch die Versorgung von Personen "versteckt", die, ohne im öffentlichen Dienst zu stehen, im Interesse der Öffentlichkeit einen Unfall erlitten haben ( $(537 \mathrm{Nr} .3-5$ RVO).9)

(9) Einen abartigen Fall betrifft die Unfallfürsorge für Gefangene. ${ }^{10)}$

6) Zum Sozialstaatsprinzip im öffentlichen Dienstrecht s. unten S. $794 \mathrm{ff}$.

7) Zum Versorgungsrecht s.a. oben S. 771 (1).

8) Zum Zusammenhang mit dem Sozialstaatsprinzip s. insbes. BVerfGE 3, 58 (134): "So ist mit Recht das G 131 als soziale Tat gewertet worden; die Bundesrepublik hat sich hier ihrer Verfassung gemäß (Art.20,28 GG) - als sozialer Rechtsstaat bewährt".

9) In diesem Zusammenhang darf auf die weitgehende versorgungsrechtliche Selbstentfremdung der Sozialversicherung im allgemeinen hingewiesen werden. Ist ihr ein versorgungsrechtliches Element durch den internen Sozialausgleich und vor allem durch den Zuschuß aus allgemeinen Finanzmitteln von vorneherein eigen, so geht doch die besondere Vergünstigung für gewisse Personenkreise hinsichtlich der Anwartschaft u. ä. Fragen darüber hinaus (s. z. B. $\$ \$ 21$ ff des Heimkehrergesetzes; s. schon oben S. 773 (3)). Vgl. z. B. Bogs, Grundfrage Rechts der sozialen Sicherheit und seiner Reform, S. $57 \mathrm{ff}$.

10) Zum Zusammenhang mit dem Sozialstaatsprinzip s. BGHZ 25, 231 (233 ff); LSG Bad. - Württ. Entsch.v.27. Mai 1960 - L 2 Ka 
Auch in der Sonderversorgung verwirklicht sich der Sozialstaat. Im besonderen ist es eine seiner vornehmsten Aufgaben, gerade denjenigen zu erträglichen Lebensbedingungen zu verhelfen, die der Gemeinschaft - wollend oder nicht - Opfer gebracht oder eine der Gemeinschaft auferlegte Last in hervorragender Weise zu tragen haben und dadurch in eine Notlage geraten sind. 11) Gerade der Ausgleich der persönlichen und sachlichen Kriegsschäden und Kriegsfolgeschäden ist daher ein sozialstaatliches Anliegen. 12) Allerdings zielt das Sozialstaatsprinzip dabei wesentlich auf die Beseitigung und Vermeidung von Notlagen und den Ausgleich von Wohlstandsnachteilen im Vergleich zur Allgemeinheit ab. 13) Der Sozialstaat ist nicht schlechthin Lastengemeinschaft. 14) Er widersteht nur dem Absinken in den Bereich der Wohlstandsmängel. Er kann darum auch nicht Grundlage eines allgemeinen, wesentlich auf den Saldoausgleich gerichteten Entschädigungsanspruches (Aufopferungsanspruches) sein. 15) Ein

1881/58 - Breithaupts Sammlung 49. Jhg. (1960) S. 790 (791).

11) BVerfGE 1, 97 (105): "... der Gesetzgeber ... ist gewiß zu sozialer Aktivität, insbes. dazu verpflichtet, sich...um die Herstellung erträglicher Lebensverhältnisse für alle die zu bemühen, die durch die Folgen des Hitlerregimes in Not geraten sind". Die Spezialisierung auf die "Folgen des Hitlerregimes" darf die allgemeine Basis dieses Anspruches nicht verdunkeln. Besser formuliert findet sich die Sentenz bei Werner, Sozialstaatliche Tendenzen in der Rechtsprechung, S.92. S. hierzu auch Ipsen in der Anmerkung zu dem zitierten Urteil des Bundesverfassungsgerichts (Urt.v. 19. Dezember 1951 - 1 BvR 220/51 - Anm. S. 218).

12) Vgl. außer den vorstehend Zitierten Forsthoff, Begriff und Wesen des sozialen Rechtsstaats, S. 26; Dürig, Der Staat und die vermögenswerten Berechtigungen seiner Bürger, S. 52 f. Speziell für die Vertriebenen- und Flüchtlingshilfe s. ferner Hamann, Das Grundgesetz, Einf. I D 2 (S.33); Rogge, Flüchtlingsverwaltung, Flïchtlingsrecht und Sozialstaat; BVerwGE 7, 180 (182 f). Speziell für den Lastenausgleich einschließlich des Ausgleichs der Demontageschäden s. außerdem Hamann, Deutsches Wirtschaftsverfassungsrecht, S.47. Für den Lastenausgleich s.a. Obermayer, Das Bundesverfassungsgericht und der Vorbehalt des Gesetzes, DVB1. 74. Jhg. (1959) S. 354 ff (356).

13) S. BVerfG und Werner je a.a.O.

14) Unrichtig Hamann, Deutsches Wirtschaftsverfassungsrecht, S. 47, $68 \mathrm{f}$; wohl auch Obermayer, a.a.O.

15) Anders Wintrich, Uber Eigenart und Methode der verfassungs- 
solcher ergibt sich in gewissen Grenzen aus dem Gleichheitssatz und dem Grundrecht des Eigentums. 16) Das Sozialstaatsprinzip steht ihm nicht entgegen, auch nicht wo er nur "Reichtumsdifferenzen" ausgleicht. Aber es ergänzt und modifiziert ihn. Es fügt inm insbes. die Sorge für die Schwächeren hinzu - für diejenigen, die schon dazu gehören und diejenigen, die infolge des Schadens, den sie genommen haben, $z u$ ihnen zu stoßen drohen. 17) Soweit der rechtsstaatlich-eigentumsrechtliche Entschädigungsanspruch reicht, bestimmt das Sozialstaatsprinzip mehr über das Wie als über das Ob der Leistung. Wie weit sich dieser Anspruch erstreckt, wird noch zu erörtern sein.16) Aber wie dem auch sei: er darf nicht vergessen lassen, daß auch dem Sozialstaatsprinzip selbst ein gleichlaufendes Element eignet: Der. Sozialstaat darf am allerwenigsten diejenigen der Verarmung anheimfallen lassen, die der Gemeinschaft geopfert orler sonstwie für die Gemeinschaft Lasten zu tragen haben und dadurch in wirtschaftliche Bedrängnis geraten sind. Der Sozialstaat ist nicht blind für die Ursachen einer Notlage. Auch er muß Unterschiede, die "für eine am Gerechtigkeitsgedanken orientierte Betrachtungsweise ... in dem jeweils in Betracht kommenclen Zusammenhang ... bedeutsam sind", honorieren. 18) So kann und muß

gerichtlichen Rechtsprechung, S. 243 Fußn. 40; Greiner, Wiederherstellung des klassischen Enteignungsbegriffes, DÖV 7. Jhg. (1954) S. 583 ff (586 insbes. Fußn. 36); s.a. Scheuner, Grundfragen des modernen Staates, S. 153 f; Schack, Empfiehlt es sich, die verschiedenen Pflichten des Staates zur Entschädigungsleistung aus der Wahrnehmung von Hoheitsrechten nach Grund, Inhalt und Geltendmachung gesetzlich neu zu regeln? S.23 Anm.81. Kritisch (zu Wintrich und Greiner) Scheuner, Die Abgrenzung der Enteignung, S. 591.

16) S. dazu unten Abschnitt 6 II 2 b cc (S. 904 ff).

17) In diesem Sinne vor allem die Ausdehnung des Figentumsschutzes auf Sozialversicherungsansprüche unter Berufung auf das Sozialstaatsprinzip durch BSGE 9, 127 (128 ff). Insufern ist auch zu billigen, daß der Bundesgerichtshof unter Berufung auf den "sozialen Rechtsstaat" den Aufopferungsanspruch zunächst auf Körperverletzung (Impfschäden) ausgedehnt hat (BGHZ 9, 83 (89)), um ihm später auch noch Ansprüche der Hinterbliebenen zu entnehmen (BGHZ 18, 286 (290 f); zustimmend in der Anmerkung zu diesem Urteil ( $\mathrm{v}$. 17. Oktober 1955 - III ZR 84/54 -) Sieg, JZ 11.Jhg. (1956) S. $178 \mathrm{f})$. Zur Ausdehnung des Schutzes der "Rechte" auf "vermögenswerte Interessen" als Notwendigkeit des "sozialen Rechtsstaats" s. Bachof, Begriff und Wesen des sozialen 
er zwischen verschuldeter und unverschuldeter Not unterscheiden. So kann und muß gerade er als gemeinschaftsbetonter Staat zwischen gemeinschaftsbedingter und nicht gemeinschaftsbedingter Not differenzieren. Das entspricht sowohl dem insofern wohl eindeutigen common sense wie auch einer weit zurückreichenden, dem vorrechtlichen Gesamtbild des Grundgesetzes zugrunde gelegenen Entwicklung des sozialen Leistungswesens.

Dazu kommt - das gegenwärtige System der sozialen Sicherheit vorausgesetzt - immer auch noch die Entsprechung zur Sozialversicherung. Hinsicht1ich des individuellen Risikos ist eine Versicherung zumutbar; hinsichtlich der aus dem Willen und dem Schicksal der Gemeinschaft herrührenden Risiken ist eine Versicherung unter Heranziehung des (möglichen) Betroffenen jedenfalls nicht zumutbar. Teils ist sie auch nicht möglich, weil es an jeder Schätzbarkeit des Risikos fehlt. Teils ist sie nicht sinnvoll, weil es an jeder engeren Risikogemeinschaft als der des Staatsvolkes fehlt. Den Betroffenen können angemessene Lebensverhältnisse also nur über die Versorgung verschafft werden.

Insgesamt ist freilich diese Art der Sonderversorgung vom rechtsstaatlichen Entschädigungsdenken kaum weniger bestimmt als vom Sozialen. Auch in der Ausgestaltung der verschiedenen einschlägigen Zweige der. Sonderversorgung und ihrer einzelnen Leistungen sind soziale Ililfe, sozialer Ausgleich und Entschädigung fast immer untrennbar verknüpft. 19) Es darf wohl gesagt werden, daß die Sonderversorgung zum Ausgleich kausal gemeinschaftsbezogener Schäden mehr als manche andere soziale Institution eine Äußerung des. "sozialen Rechtsstaats" ist.

bbb) Die "unechte" Sonclerversorgung

F'ür den Sozialstaat besonder's wichtig sind jene - wie die der "echten" Sonderversorgung - generell festgesetzten grundsätzlich ohne konkrete Bedürftigkeitsprüfung und über das Maß des absoluten Existenzminimums hinaus gewährten Leistungen aus allgemeinen Steuermitteln, (lie - ander's als die der "echten" Sonderversorgung - zur Abhilfe typischer Notlagen ohne (notwendigen) kausalen Gemeinschaftsbezug getätigt werden. ${ }^{1)}$ So wesentlich die Frrüllung des sozialstatlichen Auftrages an sich ist, 2) so bedeut-

Rechtsstaats.

18) Vgl. BVerfGE 1, 264 (276).

19) S. die Darstellung bei Braun. Motive sozialer Hilfeleistung.

1) S. hierzu schon oben Abschnitt 1 I 1 b, bb (S. 49 ff) insbes. S. 49 und S. 60 ff.

2) S. oben S. $768 \mathrm{f}$. 
sam ist diese Art der Versorgung. Not beschränkt sich nicht auf gemeinschaftsbedingte oder sonstwie in eine besondere Verantwortung der Gemeinschaft fallende Übel. Die Sozialversicherung ist wesensmäßig nur beschränkt imstande abzuhelfen. Die allgemeine Fürsorge schließlich kann nur das Minimum gewähren, das dem sozialen "Anspruch" des unverschuldet in Not Geratenen grundsätzlich nicht gerecht wird. Hinter dem wichtigsten Beispiel, der (Zusatz-)Versorgung im Falle der Mutterschaft, steht allerdings nicht nur das Sozialstaatsprinzip sondern vor allem die Spezialnorm des Art. 6 Abs.4 GG. 3) Dagegen stellt sich etwa die Versorgung der Zivilblinden 4) - sub specie der Verfassung vorwiegend als ein Ausfluß der Sozialstaatlichkeit dar.

Die grundgesetzliche Sicherung des gegebenen Standes von Sozialversicherung und Sonderversorgung

Das Grundgesetz geht offensichtlich von der sozialen Sicherung durch Fürsorge, Sozialversicherung und Sonderversorgung aus.1) Inwieweit ist dieses System aber durch das Sozialstaatsprinzip garantiert? Daß die Fürsorge als Minimum der sozialen Sicherheit "eisern" garantiert ist, bedarf keiner neuerlichen Erwähnung. Es geht um die "oberen Stockwerke" der sozialen Sicherheit, um Sozialversicherung und Sonderversorgung.

Ein ersatzloser, die Substanz verletzender A b ba $u$ ist weder hinsichtlich der einen noch hinsichtlich der anderen Institution zulässig. Die Sozialversicherung ist integrierencler Bestandteil des vorrechtlichen Gesamtbildes des grundgesetzlichen Sozialstaates ${ }^{2)}$ und vom Grundgesetz selbst gleichsam als selbstverständlich unterstellt. Sie ist im Prinzip garantiert, ${ }^{3)}$ freilich

3) Es ist erstaunlich, daß daneben das Sozialstaatsprinzip als Verfassungsgebot (auch) des Mutterschutzes noch so hervorgehoben wird wie in BAGE 2, 32 (34 f); s.a. Hueck, Der Sozialstaatsgedanke in der Rechtsprechung des Bundesarbeitsgerichts, S.62. Hamann, Das Grundgesetz, Art. 6 Anm. C 7, sieht Art. 6 Abs. 4 GG "als eine notwendige Folge der Sozialstaatserklärung" an. - Im übrigen s. hierzu oben S.51 zu Fußn. 9 .

4) S. hierzu oben S. 51 zu Fußn. 8

1) S. oben Abschnitt 1 I 1 b, bb (S. 49 ff).

2) Zu den aufschlußreichen einschlägigen Bestimmungen des Landesverfassungsrechts und der Weimarer Verfassung s. Dersch, Die Sozialversicherung, in: Bettermann-NipperdeyScheuner, Die Grundrechte Bd.III, 1. Halbbd. S. 503 ff (insbes. S. $503 \mathrm{ff}, 517 \mathrm{ff}$ ). 
keineswegs in einem Detail der Gestaltung oder Erstreckung. ${ }^{4)}$ Desgleichen kann aus den schon erwähnten Gründen auf die Sond e rversorgung nicht verzichtet werden, soweit sie "soziale Sicherheit" gegenüber kausal gemeinschaftsbezogenen Notlagen gewährt. Darüber hinaus wird sie schon aus sozialstaatlichen Gründen nicht überall entbehrt werden können, weil die Alternative Sozialversicherung oder Fürsorge nicht immer eine sozial gerechte und erträgliche Lösung beinhaltet. Doch wird hinsichtlich der Sonderversorgung das Problem der sozialstaatlichen Garantie zum Teil durch andere Rechtsgründe - insbes. Opferausgleich, Eigentumsrecht, öffentliches Dienstrecht, Mutterschutz u. a. - verdeckt. Jedenfalls wäre eine wesentliche Verminderung der sozialen Sicherheit durch eine wesentliche Reduktion der Sozialversicherung und der Sonderversorgung oder auch nur einer der beiden Einrichtungen sozialstaatswidrig. Daß dabei das Kriterium der wesentlichen Verminderung immer auch in Beziehung zur absoluten Grenze der Leistungsfähigkeit des Staates gesehen werden muß, muß dabei in Rechnung gestellt werden.

Eine andere Frage ist die nach der Vertauschbarkeit der Sozialversicherung und der Versorgung. Der A usdehnung der Sozialversicherung in den Bereich der Versorgung hinein sind natürliche Grenzen gesteckt, die eine wesentliche Verschiebung in dieser Richtung ausgeschlossen erscheinen lassen. 5)

Das gilt nicht umgekehrt auch für die Übernahme sozialversicherungsrechtlich gedeckter oder potentiell zu deckender Risiken in die soziale Sicherung durch Versorgung. Dem Sozialstaatsprinzip kommt es entscheidend darauf an, daß die soziale Sicherheit durch den Wechsel von der Sozialversicherung zur Versorgung nicht beeinträchtigt wird; ${ }^{6)}$ das muß nicht der Fall sein. Zwar verwirklicht die Sozialversicherung durch die Elemente der Versicherungsgemeinschaft und der Eigenbeteiligung den Sozialstaat "idealer" als die - über ihr notwendiges

3) Fechner, Sozialer Rechtsstaat und Arbeitsrecht, S. 167; Fechner-Maier, Die Rechtswirksamkeit der arbeitsrechtlichen Bestimmungen des sog. Truppenvertrages, S.92; Berger, Bedeutung und Tragweite des Grundsatzes vom sozialen Rechtsstaat, S. 6; E. R.Huber, Der Streit um das Wirtschaftsverfassungsrecht, S.202 (mit der auch hier für richtig gehaltenen Einschränkung auf die Garantie gegen ersatzlosen Wegfall). S.a. die oben S. 770 zu Fußn. 4 Zitierten.

4) S. insbes. Berger, a.a.O.; ferner (ohne ausdrückliche Bezugnahme auf das Sozialstaatsprinzip) Dersch, a.a.O. S. 516.

5) S. oben S. $52 \mathrm{ff}$. 
Eigenfeld hinaus erstreckte - Versorgung. Aber auch die Schönfärberei von der sozialversicherungsrechtlichen Solidarität, von dem Selbstgefühl der Eigenvorsorge und was dergleichen mehr ist, kann nicht ernst genommen werden. Die Bedeutung der Selbstverwaltung ist gering. Der Kreis der Beteiligten ist regelmäßig viel zu groß, um eine glaubwürdige Solidarität aufkommen zu lassen. Der Zwangscharakter der Mitgliedschaft und der Beitragszahlung coupiert das Pathos der "Eigenvorsorge" empfindlich. Die Erkenntnis, daß der Beitrag der Rentenversicherung nicht so sehr zur Vorsorge für den Leistenden als zur Deckung des aktuellen Rentenbedarfes dient, ist allgemein verbreitet. Der wahre Kern der sozialversicherungsrechtlichen Solidarität und Selbsthilfe ist nicht so bedeutsam, daß der Sozialstaat seinetwegen an der Sozialversicherung festhalten müßte. Auch die grundgesetzliche Unterstellung der Sozialversicherung als vorhanden ist nicht als absolute institutionelle Garantie zu verstehen. Auch auf sie hat das Grundgesetz zugunsten des elastischeren, dynamischen, allgemeinen Sozialstaatsprinzips verzichtet. Von der Sache her sind einem Wechsel von der Sozialversicherung zur Versorgung jedoch enge Bahnen vorgegeben. Der Gleichheitssatz reguliert diesen Vorgang entscheidend mit. Wird ein Risiko allein aus allgemeinen Steuermitteln gedeckt, so muß die Deckung allen in der gleichen sozialen Lage befindlichen Personen zugute kommen. Das Kriterium der Beitragsbelastung für die Bestimmung des Kreises der Leistungsberechtigten entfä1lt. Der Übergang von der Sozialversicherung zur Versorgung kann nicht einfach darin bestehen, daß die Beitragspflicht gestrichen und der Kreis der "Versicherten" in den Kreis der Versorgungsempfänger umbenannt wird. Der Sprung von der Sozialversicherung zur beitragslosen "Sozialversicherung" ist nicht möglich. Es gibt nur einen Sprung von der Krankenversicherung zur allgemeinen Krankenversorgung, von der Rentenversicherung zur allgemeinen Alters- und Invalidenversorgung der Staatsbürger usw. Es gibt schließlich nicht die Alternative Sozialversicherung und Sonderversorgung(en) o de $r$ nur Sonderversorgung(en), sondern nur die Alternative Sozialversicherung und Sonderversorgung(en) o de $r$ allgemeine Staatsbürgerversorgung. In der allgemeinen Staatsbürgerversorgung zerfließen die Grenzen zwischen Sozialversicherung und Versorgung ohnedies. 7) Zusammenfassend ist somit festzuhalten, daß der Übergang einzelner Risiken von der Sozialversicherung zur Sonderversorgung keinen grundsätzlichen sozialstaatlichen Bedenken begegnet. Der prinzipielle Abbau der Sozialversicherung kann zulässigerweise nur im Rahmen eines
6) S. Huber, a.a.O.
7) S. oben S. 50 zu Fußn. 3. 
Umbaues der sozialen Sicherheit zur allgemeinen Staatsbürgerversorgung geschehen.

Den Weg in der a $11 \mathrm{gem}$ einen $\mathrm{Sta}$ a $\mathrm{s}$ bürgerver sor gung enden zu lassen, besteht vom Sozialstaatsprinzip her kein Hindernis. ${ }^{8)}$ Daß dabei die Freiheit der persönlichen Entfaltung in ihrem unantastbaren Wesenskern gewahrt werden muß (Art.2 Abs. 1, 19 Abs. 2 GG), steht außer Frage. ${ }^{9}$ ) Desgleichen steht außer Frage, daß es schwer ist, eine allgemeine Staatsbürgerversorgung so zu gestalten, daß die Freiheit hinreichend gewahrt bleibt. Im Grenzfall muß die soziale Sicherheit hinter der Freiheit zurücktreten. ${ }^{10)}$ Der soziale Rechtsstaat kann kein total planender und zuteilender Versorgungsstaat sein. 11) Aber das sind Probleme des Maßes und der Gestaltung. Daß die Institution einer allgemeinen Staatsbürgerversorgung mit dem Sozialstaat unvereinbar sei, kann nicht bewiesen werden. Etwas anderes ist, daß die allgemeine Staatsbürgerversorgung dem grundgesetzlichen Sozialordnungsbild deshalb fremd ist, weil nach dem Stand der Rechtsentwicklung und nach der bundesstaatlichen Kompetenzverteilung weder der Bund noch die Länder imstande sind, eine allgemeine Staatsbürgerversorgung - und nicht nur eine Reihe verschiedener, in Summe einer allgemeinen Staatsbürgerversorgung nahe kommender sozialer Hilfen - einzuführen. 12)

8) In diesem Sinne wohl Abendroth, Zum Begriff des demokratischen und sozialen Rechtsstaats im Grundgesetz der Bundesrepublik Deutschland, S.98 f; Claus Arndt, Die Bundesrepublik Deutschland als sozialer Rechtsstaat, S. 333 .

9) Wolany, Vom Sozialstaat und sozialen Recht, S. 150 f: "Um den einzelnen eine Teilhabe an den Gütern der Gemeinschaft zu ermöglichen, muß auch eine 'Verteilung des Sozialprodukts' in entsprechender "lleise vorgenommen werden. Aber. selbst bei diesem (nichi gan': zutreffend) gewöhnlich als 'Versorgung' bezeichneten Vorgang geht es nicht etwa um eine Sicherung im sozialistischen Sinne, sondern um die Ermöglichung der. Teilhabe an sucialen Genuß. Insofern als der Bedürftige über die Zuwenlungen frei verfügen kann, nicht auf eine staatliche 'Krippe' angewiesen ist, bleibt der Sozialstaat auch bei seinon cliesbezüglichen Maßnahmen in seiner Zwischenstellung zwischen Sozialismus und Liberalismus".

10) Vg1. Dürig, Grundfragen des öffentlichrechtlichen Entschädigungssystems, \$. \$. 52 .

11) S. Wolff, Verwaltungsrecht I, S.44. S. ferner oben S.744 ff.

12) S. oben Abschnitt 1 I 1 b bb (S. 49 ff), insbes. S. 49. 
3. Sozialstaat und Arbeit

a) Das sozialstaatliche Arbeitsrecht

\section{aa) Allgemeines}

Das andere augenfällige "Dauerkerngebiet der Sozialstaatlichkeit"1) - neben der "sozialen Sicherheit" - ist das Arbeitsrecht. 2) In Auseinandersetzung mit der Problematik der abhängigen Arbeit hat sich ein guter Teil des gemeinsamen Ideengutes der politischen Sozialbewegung herausgebildet, das durch das grundgesetzliche Bekenntnis zum sozialen Rechtsstaat in das Verfassungsrecht hineingeholt wurde; und vom Sozialstaatsprinzip her strahlt es fortwirkend aus auf die Gestaltung des Arbeitsrechts. 3)

Die arbeitsrechtliche Rollenverteilung wird weitgehend von der Vermögensschichtung her gesteuert. Der Typ des Arbeitnehmers ist dadurch gekennzeichnet, daß er auf das Arbeitseinkommen zur Erhaltung seiner Existenz angewiesen ist. Der wichtigste Typ des A rbeitgebers ist dadurch gekennzeichnet, daß er über das Kapital verfügt, das er mit der Arbeit produktiv verbindet. Der soziale Gedanke steht dieser ungleichen Vermögensverteilung kritisch gegenüber. Aber das ist für die soziale Gestaltung des Arbeitsrechts nicht entscheidend. Nicht nur kann der kapitalistische Arbeitgebertyp keine Ausschließlichkeit beanspruchen. Der soziale Staat kann vielmehr selbst dann die abhängige Arbeit nicht negieren, wenn er eine durchgreifende Vermögensumschichtung und eine breite Vermögensstreuung herbeiführen wollte. Nicht nur für eine eventuelle "Übergangszeit" sondern auf Dauer müßte er dennoch mit der abhängigen Arbeit rechnen. Das hat anthropologi-

1) Werner, Sozialstaatliche Tendenzen in der Rechtsprechung, S. 93 .

2) Außer Werner, a.a.O. s. Schüle, Die staatliche Intervention im Bereich der Wirtschaft, S. 108; Forsthoff, Begriff und Wesen des sozialen Rechtsstaats, S.9; Hamann, Das Grundgesetz, Einführung I D 2 (S. 31). Umfassend Fechner, Sozialer Rechtsstaat und Arbeitsrecht; Berger, Bedeutung und Tragweite des Grundsatzes vom sozialen Rechtsstaat, insbes. S. 10; Olbersdorf, Sozialer Rechtsstaat und A rbeitsrecht; Thieme, Der Beamte im sozialen Rechtsstaat, S.170. S. ferner die Rechtsprechungsberichte: Müller, Der Gedanke des sozialen Staats in der bisherigen Rechtsprechung des Bundesarbeitsgerichts; Hueck, Der Sozialstaatsgedanke in der Rechtsprechung des Bundesarbeitsgerichts.

3) S. zu dieser Wechselwirkung vor allem Fechner, a.a.O. 
sche Gründe, vor allem aber wirtschaftliche und technische: die Unvermeidlichkeit des Groß- und Mittelbetriebes und die entsprechende Unvermeidlichkeit der Konzentration des Kapitals. Eine künstliche Vermögensstreuung könnte äußerstenfalls das Kapital in kleine Anteile zersplittern. Das würde jedoch die abhängige A rbeit nicht erübrigen. Der Inhaber eines Anteilssplitters würde durch sein "arbeitsloses Einkommen" nicht des Zwangs zur Existenzerhaltung durch Arbeit enthoben. Sollte er diese dann auch in einem Betrieb verrichten, zu dessen Kleinanteilseignern er gehört, hebt sein Einfluß auf die Betriebsleitung seine Abhängigkeit als A rbeitnehmer nicht grundsätzlich auf. Das sozialstaatliche A rbeitsrecht darf daher die abhängige Arbeit nicht negieren. 4) Es muß sich auf ihren Boden stellen und sie, wie sie ist, sozial zu gestalten suchen. ${ }^{5)}$

Der Arbeitnehmer ist im Normalfall auf sein Einkommen aus abhängiger Erwerbstätigkeit angewiesen. Er muß sich zum Zwekke der Nutzung seiner Arbeitskraft der Leitung eines Arbeitgebers unterordnen und sich den sachlichen und persönlichen Gegebenheiten seines Betriebs einfügen. Der Arbeitgeber erwartet die größtmögliche Leistung und leistet den geringstmöglichen Lohn. Um Unterbeschäftigung zu vermeiden und stets die geeigneten Arbeitskräfte zur Verfügung zu haben, drängt er nach größtmöglicher Disponibilität des Arbeitsverhältnisses. Damit ist das Schutzinteresse des tendenziell schwächeren Arbeitnehmers gegenüber dem tendenziell stärkeren Arbeitgeber umrissen, das dem Sozialstaatsprinzip angelegen ist. Der soziale Staat muß die Arbeitskraft schützen, 6) die Abhängigkeit mildern, 7) die Leistungsanforderungen begrenzen, den Lohn kontrollieren und den A rbeitsplatz sichern. Damit soll nicht etwa der Satz aufgestellt werden: sozial ist, was dem Arbeitnehmer nützt. Die Sozialstaatlichkeit ist - wie schon einmal betont 8 ) - nicht etwa ein primitives Günstigkeitsplinzip. Fs geht nicht einseitig um die Interessen der Arbeitnehmer sonclern um einen Interessenausgleich, aber eben um einen Ausgleich, der nicht von der Schwäche der Arbeitnehmerposition diktiert ist sondern diese im Ge-

4) Vg1. Kaskel-Dersch, Arbeitsrecht, S. 1; s.a. E.R.Huber, Der Streit um das Wirtschaftsverfassungsrecht, S.202 f.

5) S. insbes. Olbersdorf, Sozialer Rechtsstaat und Arbeitsrecht, S. $136 \mathrm{f}$.

6) Zum verfassungsrechtlichen Schutz der Arbeitskraft s.a. Herschel, Das Arbeitsrecht, S.339 ff.

7) Zur modernen Abneigung gegen jedwede Abhängigkeit s. nochmals Gehlen, Zur Problematik des Sozialstaats, S. 56.

8) S. oben S. 724 . 
genteil so gut als möglich mit ausgleicht.

Für clas Verhältnis zwischen dem Sozialstaatsprinzip und der Regelung des Arbeitsverhältnisses ist immer im Auge zu behalten, daß das Sozialstaatsprinzip nicht selbst - auch nicht in einzelnen Folgerungen - Arbeitsrecht ist sondern die Gestaltung des Arbeitsrechts objektiv betrifft. Als Maxime der arbeitsrecht1ichen Gesetzgebung muß es jedoch für deren verständige - auch ergänzende - Auslegung, Anwendung und Fortbildung herangezogen werden.

bb) Einzelfolgerungen für das Arbeitsvertrags- und Arbeitsschutzrecht

Im einzelnen fordert das Sozialstaatsprinzip vor allem einen gerechten, angemessenen Lohn, 1) sodann die Abwehr der der Arbeitskraft drohenden Gefahren durch das Arbeitsschutzrecht (im engeren Sinn), 2) insbes. auch die zeitliche Begrenzung der zulässigen Leistungsanforderungen durch das Arbeitszeitrecht 3) und das Recht der Arbeitsruhe und der Lohnfortzahlung an Feiertagen. 4) Der Frauen-, 5) Mutter-6) und Jugendschutz, 7) der

1) Zur Unmöglichkeit einer allgemeinen rechtlichen Festlegung s. z.B. Herschel, a.a.O. S.345 ff und seine Nachweise.

2) Grundlegend Herschel, Arbeitsschutz im sozialen Rechtsstaat. - Für eine Garantie des Arbeitsschutzes durch das Sozialstaatsprinzip s. ferner: Berger, Bedeutung und Tragweite des Grundsatzes vom sozialen Rechtsstaat, S. 7, 9; Fechner, Sozialer Rechtsstaat und Arbeitsrecht, S. 167; E. R. Huber, Der Streil um das Wirtschaftsverfassungsrecht, S. 202; Thieme, Liberalismus und Grundgesetz, S.298 f. Zur sozialstaatlichen Affinität des Arbeitsschutzes s.a. Forsthoff, Begriff und Wesen des sozialen Rechtsstaats, S. 26 .

3) Besonders aktuell war der inzwischen abgeklungene Streit um das Nachtbackverbot. Für die Rechtfertigung dieses Verbots aus dem Sozialstaatsprinzip s. Peters, Ist es verfassungsrechtlich zulässig, daß der Staat durch bestimmte Arbeitsschutzvorschriften auch Personen erfaßt, die keine oder nur solche Arbeitnehmer beschäftigen, welche infolge der Art oder Organisation des Betriebes insoweit nicht schutzbedürftig sind? Sonderdruck S.6; OLG Braunschweig, Urteil vom 1. Oktober 1954 - Ss 139/54 - NJW 8.Jhg. (1955) S. 276; KG Urteil vom 18. Februar 1955 -; Ss 584/54 (376/54) - JZ 10. Jhg. (1955) S. 545.

4) Eine Einrichtungsgarantie für den "Sonntag und die staatlich 
zum Teil eine speziellere verfassungsrechtliche Grundlage in Art. 6 GG findet, ist ebenfalls ein sozialstaatliches Anliegen. Einem Zurücktreten des Arbeitsschutzes hinter seinen jetzigen Standard wird sich das Sozialstaatsprinzip - freilich mit der ihm. eigenen Elastizität - widersetzen. Auch der unabdingbare Anspruch auf angemessenen (bezahlten) Urlaub findet im Sozialstaatsprinzip seinen verfassungsrechtlichen Rückhalt. 8) Ein wichtiges Element des sozialstaatlichen Arbeitsrechts ist der Bestandsschutz des Arbeitsverhältnisses. 9) Eine zentrale Funktion für den sozialen Ausgleich im Arbeitsverhältnis kommt der Fürsorgepflicht des Arbeitgebers zu. Gleichsam als Generalklausel hilft sie den Sozialstaatsgrundsatz auch dort verwirklichen, wo eine ausdrückliche Regelung fehlt. 10) Im Recht der Arbeitneh-

anerkannten Feiertage... als Tage der Arbeitsruhe" findet sich schon in Art. 140 GG i.V.m. Art. 139 RV 1919. Für die verfassungsrechtliche Regelung der Arbeitsruhe und der Lohnfortzahlung an Feiertagen außerhalb des Grundgesetzes s. Herschel, Das Arbeitsrecht. S. $353 \mathrm{ff}$.

5) Zur Verbindung von Hausarbeitstag und Sozialstaatsprinzip s. BAGE 1, 51 (56 f), 60, 63; Urt. v. 25. März 1960 - 1 AZR $551 / 58$ - Sozial- und arbeitsrechtliche Entscheidungen 1960, S. 125 (Nr.54); Galperin, Anm. zu BAG Urteil vom 14. Juli 1954 - 1 AZR 105/54 - (BAGE 1, 51), JZ 9.Jhg. (1954) S. 571 f (571); Herschel, Arbeitsschutz im sozialen Rechtsstaat, S. $574 \mathrm{f}$; zweifelnd Bulla, Anm. zu BAG Urteilen vom 14. Juli 1954 - 1 AZR 105-89-138/54 - AP Art. 3 GG Nr. 1-3. - Zur Frage der Lohngleichheit $s$. noch unten S. 793 zu Fußn. 21 (2).

6) Zum Mutterschutz als sozialstaatlichem Postulat s. schon oben S. 778 zu Fußn. 3 und den Text hierzu. Zu Art.6 GG s. unten S. 1012 .

7) Zum Jugendschutz nach Art.6 GG s. unten Abschnitt 6 IV 2 (S. $1008 \mathrm{ff}$ ).

8) Olbersdorf, Soziale1. Rechtsstaat und A rbeitsrecht, S. 134; Hueck, Der Sozialstiatsgedanke in der Rechtsprechung des Bundesarbeitsgerichts, S. 63 f; BAGE 2, 342 (347); 3, 23 (24); BAG Urteil vom 20.April 1956-1AZR 448/54-AP\$611 Urlaubsrecht $\mathrm{Nr} .7$.

9) Vg1. Olbersdorf, a.a.O. S. 137; Fechner-Maier, Die Rechtswirksamkeit der arbeitslechtlichen Bestimmungen des sog. Truppenvertrages, S.92; Nipperdey, Lehrbuch des Arbeitsrechts, B(l.II, S. 120, 638; ders., Der Arbeitskampf als unerlaubte Handlung, S.93; Thieme, Liberalismus und Grundgesetz, S.298 f; Hueck, a.a.O. S.68; BAGE 1, 128 (133 f), 136 (136); BAG Urteil vom 26. November 1955 - 2 AZR 516/ 
mererfindung muß die Persönlichkeit des Arbeitnehmererfinders den gebührenden Schutz finden. 11) Die betrieblichen Sozialeinrichtungen sind zu fördern, dürfen aber ihrerseits nicht zu einer übersteigerten Abhängigkeit des Arbeitnehmers vom Arbeitgeber und seinem Betrieb führen. 12) 13)

Allerdings muß immer wieder vor übertriebenen Einzelfolgerungen gewarnt werden. Einen Urlaubsanspruch - obwohl er, wie nicht denkbar, weder aus einer ausdrücklichen gesetzlichen Regelung noch aus den sozialstaatsgerecht ausgelegten einschlä-

54 - AP $\$ 1 \mathrm{KschG} \mathrm{Nr.14;} \mathrm{LSG} \mathrm{Bremen,} \mathrm{Urteil} \mathrm{vom} \mathrm{25.} \mathrm{Mai}$ 1956 - Av 7/55 - DVB1. 72.Jhg. (1957) S. 208 (208ff). Weitere Nachweise s. zum folgenden Text.

10) Das Sozialstaatsprinzip ist der bindende verfassungsrecht1iche Grund der Fürsorgepflicht. Nicht aber tritt das Sozialstaatsprinzip an die Stelle des Fürsorgeprinzips. In dieserm Sinne Siebert, Einige Entwicklungslinien im neueren Individualarbeitsrecht, Recht der Arbeit, 11.Jhg. (1958) S.366 ff (368); Hueck, Lehrbuch des Arbeitsrechts, Bd. I, S. 359 Fußn.6. Weitere Nachweise s. unten S.787 zu Fußn. 15.

11) Olbersdorf, a.a.O. S. 139.

12) S. hierzu Olbersdorf, a.a.O.; Lemke, Pensionskassen und sozialer Rechtsstaat, Recht der Arbeit, 10. Jhg. (1957) S. $256 \mathrm{ff}$, insbes. S. $257 \mathrm{f}$.

13) Berger (Bedeutung und Tragweite des Grundsatzes vom sozialen Rechtsstaat, S.8) und Olbersdorf (a.a.O. S. 137) meinen, nur ein personenrechtliches Verständnis des Arbeitsverhältnisses entspreche dem Sozialstaat. Diese These ist billigenswert. Vor begriffsjuristischen Folgerungen muß jedoch dringend gewarnt werden. - Berger (a.a.O. S. 10) glaubt ferner im Fall des Verstoßes eines Vertrages gegen eine Schutzbestimmung gebe es keine Teilnichtigkeit (mit oder ohne die Folge der Totalnichtigkeit - $\$ \$ 134,139$ BGB-) mehr. Vielmehr verlange der Sozialstaatsgrundsatz, den Vertrag durch die verletzte Schutzbestimmung zu ergänzen. Die These kann in ihrer Allgemeinheit nicht gebilligt werden. Das Sozialstaatsprinzip hat $₫ 139$ BGB nicht geändert. Nur die im Rahmen des $\$ 139$ BGB i. V.m. $\$ \$ 133,157$ BGB zu treffende Abwägung wird vom Sozialstaatsprinzip beeinflußt. Von größerer Bedeutung dürfte die These Bergers für die fakttischen Arbeitsverhältnisse sein. Doch ist das nicht eine Frage des - unmittelbar angewandten - Sozialstaatsprinzips sondern eine Frage des Rechts der faktischen Arbeitsverhältnisse und der sozialstaatlichen Schutznormen. 
gigen Generalklauseln und (unterverfassungsrechtlichen) allgemeinen Rechtsgrundsätzen, noch aus dem (in der opinio necessitatis durch das grundgesetzliche Bekenntnis zum sozialen Staat bestärkte) Gewohnheitsrecht noch schließlich aus dem einschlägigen Individual- oder Kollektivvertragsrecht abgeleitet werden kann - unmittelbar aus dem Sozialstaatsprinzip abzuleiten, geht nicht an. ${ }^{14)}$ Desgleichen wird das Sozialstaatsprinzip unvertretbar überanstrengt, wenn aus ihm das Verbot befristeter Verträge (Kettenverträge) über das $\mathrm{Ma} \beta$ hinaus entnommen wird, das sich aus den einschlägigen gesetzlichen Bestimmungen und aus den allgemeinen - sozialstaatsgerecht gehandhabten - Grundsätzen, insbes. der Fürsorgepflicht des Arbeitgebers ergibt. 15) Damit würde nicht nur die inhaltliche Unbestimmtheit des Sozialstaatsprinzips - zugunsten apokrypher richterlicher Rechtsschöpfung - verkannt. Damit würde ihm auch eine "Drittwirkung" zuerkannt, die ihm nicht zukommt. 16) Gesetzgeber und Gesetz würden an Hand eines sozialpolitischen Maßstabs kritisiert, der der des entscheidenden Richters nicht der des Sozialstaatsprinzips ist. 17)

14) S. - wie oben S. 785 \%u Fußn. 8 zitiert - Hueck, a.a.O. (insbes. S.64) gegen gewisse Übertreibungen des BAG, a.a.O.

15) Das Bundesarbeitsgericht und Nipperdey (je a.o. (S.785 zu Fußn.9) a.O.) glauben, die Zulässigkeit befristeter Arbeitsverhältnisse, insbes. der sog. Kettenverträge, sei vom Sozialstaatsprinzip her unmittelbar eingeschränkt. Zustimmend: Trieschmann, Zur Zulässigkeit von Kettenverträgen im A rbeitsrecht, Der Betrieb, 5. Jhg. (1955) S. 336 ff (337); Hildegard Krüger, Die Rechtsprechung des Bundesarbeitsgerichts zum Kündigungsschutzgesetz, NJW 8.Jhg. (1955) S. 1049 ff (1050); Werner, Sozialstaatliche Tendenzen in der Rechtsprechung, $\$ .92 \mathrm{f}$. Mit Recht nehmen demgegenüber Hueck (Anm. zu BAG Urteil vom 21. Oktober 1954 - 2 AZR 25/53 - (BAGE 1, 128) AP $\$ 1$ KSchG Nr.7; Der Sozialstaatsgedanke in der Rechtsprechung des Bundesarbeitsgerichts, S. 68 f; Lehrbuch des Arbertsrechts, Bd.I, S.484 Fußn. 37), Nikisch (Kündigungssschutz bei sogenannten Kettenverträgen und bei befristeten $A$ ibeitsverträgen, Betriebsberater 10 . Jhg. (1955) S. 197 ff (193)) und Siebert (a.o. (S. 786 Fußn. 10) a.O.) nach wie vor an, das Problem der Zeit- und Kettenverträge müsse über die Fürsorgepflicht des Arbeitgebers als der einschlägigen, das Sozialstaatsprinzip vollziehenden und aus seinem Geist zu handhabenden Arbeitsrechtsnorm gelöst werclen.

16) S. oben S. $735 \mathrm{f}$.

17) Überspannt auch die Folgerung des LSG Bremen (Urteil vom 
c) Folgerungen für das kollektive Arbeitsrecht

\section{aaa) Zum Betriebsverfassungsrecht}

Umfassend im Sinne des sozialen Ausgleichs wirkt das betriebliche Mitbestimmungsrecht. 1) Es tritt vermittelnd in die Machtspannung zwischen der Arbeitgeber- (Unternehmer-) und der Arbeitnehmerseite, die als "vorarbeitsrechtliche" durch die wirtschaftliche, eigentumsrechtliche Position, als arbeitsrechtliche durch die Leitungsbefugnis der Arbeitgeber gekennzeichnet ist. ${ }^{2}$ ) Ihre - in bezug auf die Arbeitnehmerschaft als Kollektiv - autonomistische und in der Abwehr unternehmerischer Autokratie auch freiheitliche, alles in allem aber zutiefst soziale Tendenz läßt die Mitbestimmung als ein spezifisches Institut des "demokratischen und sozialen Rechtsstaats" erscheinen. "3) Ihre sozialpolitische Tradition ist lang und ihre Rolle immer eine wesentliche gewesen. Sie muß zum garantierten Standard deutscher Sozialstaatlichkeit gerechnet werden, allerdings nur im Prinzip und keineswegs in irgendwelchen Details der gegenwärtigen Regelung. ${ }^{4)}$ Bei einer

25. Mai 1956 - Av 7/55 - DVB1. 72. Jhg. (1957) S. 208), wonach die Anrechnung der Kündigungsabfindung nach $₫ 113 \mathrm{Abs}$. $1 \mathrm{Nr} .2$ AVAVG a.F. sozialstaatswidrig sein soll. Dagegen s. BSGE 1, 134 (144) - 1eider ohne nähere Begründung - und BSGE 1, 144; 2, 164 - überhaupt ohne Bezugnahme auf das Sozialstaatsprinzip.

1) Zu den verfassungsrechtlichen Grundlagen des Mitbestimmungsrechts s. Neumann-Duesberg, Das Mitbestimmungsrecht, insbes. S.374 ff.

2) Vgl. Wolany, Vom Sozialstaat und sozialen Recht, S. 159 f; A bendroth, Zum Begriff des demokratischen und sozialen Rechtsstaats im Grundgesetz der Bundesrepublik Deutschland, S. 91; Olbersdorf, Sozialer Rechtsstaat und Arbeitsrecht, S. 136 ff, insbes. S. 138; Berger, Bedeutung und Tragweite des Grundsatzes vom sozialen Rechtsstaat, S.9.

3) Außer den vorstehend Zitierten s. Neumann-Duesberg, a.a.O. S. $375 \mathrm{ff}$. S. ferner oben S. 743 sowie S. $755 \mathrm{ff}$.

4) Im Sinne einer sozialstaatlichen Garantie der betrieblichen Mitbestimmung s. Fechner, Sozialer Rechtsstaat und Arbeitsrecht, S.167 (nur für die soziale, nicht auch für die wirtschaftliche Mitbestimmung); Fechner-Maier, Die Rechtsgü1tigkeit der arbeitsrechtlichen Bestimmungen des sog. Truppenvertrags, S.92; E.R.Huber, Der Streit um das Wirtschaftsverfassungsrecht, S.202 (s. diesen auch schon Wirtschaftsverwaltungsrecht, Bd. II, S.477); Nipperdey, Lehrbuch des Arbeitsrechts, Bd.II, S.32 ff, insbes. S.693 (s. diesen auch 
eventuellen Fortentwicklung des Mitbestimmungsrechts wird darauf $z u$ achten sein, daß den Arbeitnehmern weder durch eine rein kapitalistische Beteiligung noch durch eine Gewinnbeleiligung an sich schon ein ausreichendes Äquivalent für die Teilnahme an der betrieblichen Willensbildung geboten wird, wie sie im Mitbestimmungsrecht nach dem gegenwärtig erreichten Stand beschlossen liegt.

bbb) Zur "Sozialen Autonomie" der Tarifpartner - die Letztverantwortung des (Sozial)Staates

Die Bedeutung der. Gewerkschaften für den Stand der Löhne und der sonstigen Arbeitsbedingungen ist - sowohl im Vergleich mit einem unorganisierten Arbeitsmarkt wie im Vergleich mit einer. staatlichen Ordnung aller Arbeitsbedingungen - evident. Die Arbeitgeberverbände sind als Kontraktpartner und auch darüber. hinaus zur Disziplinierung der anderen "Markt" - Seite unentbehrlich. Obwohl die Freiheit und die Gestaltungskompetenz der Koalitionen demnach im Simne des Sozialstaates liegen, 1) stellt sich die Frage ihrer Garantie ${ }^{2)}$ unter diesem Aspekt nicht. Sie

S. 538 zur sozialstaatlichen Bedeutung des Einigungsverfahrens); wohl auch Dietz, Betriebsverfassungsgesetz, S.49; hinneigend auch Maunz, Deutsches Staatsrecht, S.61. S. ferner die oben S. 788 zu Fußn. 2 Zitierten. Gegen die Ableitung des Mitbestimmungsrechts aus dem "sozialen Rechtsstaat" Forsthoff, Begriff und Wesen des sozialen Rechtsstaats, S. 27 .

1) S. Forsthoff, Begriff und llesen des sozialen Rechtsstaats, S.26. Auf einem - seiner Sozialstaatskonzeption entsprechenden - besonderen lley kommt Fechner (Sozialer Rechtsstaat und Arbeitsrecht, \$. 162 f) zu einem Kontakt zwischen Sozialstaatlichkeit und "sozialer. Selbstverwaltung", inclem er nämlich den sozialstiatsgemäßen Charakter aller Selbstverwaltung hervorhebt (s. schon oben S. $755 \mathrm{ff}$ ).

2) Im sinne einer Garantic les Koalitionsfreiheit und der Tarifmacht der Koalitionen: ()lbej:sdorf, Sozialer Rechtsstaat und A rbeitsrecht, S. 139 f; Fechner, a.a.O. S. 165 ff; FechnerMaier, Die Rechisgüligkoit ler arbeitsrechtlichen Bestimmungen des sogenamnten l'ruppenvertrags, S.92; Berger, Bedeutung und Tragweite des Grundsatzes vom sozialen Rechtsstaat, S. $7 \mathrm{ff}$. - Nipjereley (Lehrbuch des Arbeitsrechts, S. 53 f) meint sogar, die Koalitionsfreiheit sei mit der Sozialstaatlichkeit so verbunden, laß Art.9 Abs. 3 GG über Art. 20 Abs. 1 GG durch Art. 79 Abs. 3 GG in die irrevisible oberste Schicht des Verfassungsrechts aufgenommen sei. 
ist in Art. 9 Abs. $3 \mathrm{GG}$ spezieller begründet. 3 ) Allerdings wird dem Sozialstaatsprinzip für die Auslegung der "Koalitionsfreiheit" eine entscheidende Bedeutung zukommen. ${ }^{4)}$ Die Gewerkschaften können ihren sozialen Auftrag nur erfüllen, wenn sie und dementsprechend auch ihre Gegner - in der Wahl des Kampfmittels grundsätzlich frei sind 5$)$ und sie letztlich ebenso zur. entscheidenden Waffe des Streiks ${ }^{6}$ ) wie ihre Gegner zur Waffe der Aussperrung greifen dürfen. Nicht zuletzt entsprechen die Beschränkungen des "schlichtenden" staatlichen Eingriffes in die Tarifhoheit der Koalitionen deren sozialstaatlicher Funktion.7) Auch ist nicht etwa nur der Tarifvertrag als solcher in seiner

3) S. oben Abschnitt 2 IV 2 a (S. 287 ff). - Schnorr (Bundesverfassungsgericht und kollektives A rbeitsrecht, S. 5 ff), Nipperdey (Lehrbuch des Arbeitsrechts, Bd. II, S. 22 f, 32 ff und passim) und Nikisch (A rbeitsrecht, Bd.II, S.208) sehen die verfassungsrechtliche Begründung der tarifrechtlichen Weiterungen der Koalitionsfreiheit in der kombinierten Aussage des Grundgesetzes über die Koalitionsfreiheit (Art.9 Abs. 3), die Entfaltung der persönlichen Freiheit (Art. 2 Abs. 1), die Bindung an die freiheitliche demokratische Grundordnung (Art. 18 Satz 1, 21 Abs. 2 Satz 1) und den demokratischen und sozialen Rechtsstaat (Art. 20 Abs. 1, 28, Abs. 1 Satz 1).

4) S. außer den in Fußn. 3 Zitierten BVerfGE 4, 96 (102).

5) In Zusammenschau mehrerer Verfassungsprinzipien (s. oben S. 754 zu Fußn. 32): BAGE 1, 291 (308f); s.a. Nipperdey, Lehrbuch des Arbeitsrechts, Bd. II S. 105. Kritisch Hueck, Der Sozialstaatsgedanke in der Rechtsprechung des Bundesarbeitsgerichts, S. 71 .

6) Zum Schutz des Streikrechts durch das Sozialstaatsprinzip: Abendroth, Zum Begriff des demokratischen und sozialen Rechtsstaats im Grundgesetz der Bundesrepublik Deutschland, S. 74; Olbersdorf, Sozialer Rechtsstaat und Arbeitsrecht, S. 140; Berger, Bedeutung und Tragweite des Grundsatzes vom sozialen Rechtsstaat, S. 7; Fechner, Sozialer Rechtsstaat und Arbeitsrecht, S. 167; Schnorr, Bundesverfassungsgericht und kollektives Arbeitsrecht, S. 7; Nipperdey, Lehrbuch des Arbeitsrechts, Bd. II, S. 105, 615. Im übrigen s. hierzu oben S. $299 \mathrm{f}$.

7) S. Olbersdorf, a.a.O. S. 140; Nipperdey, Lehrbuch des Arbeitsrechts, Bd.II, S.23, 32 f, 535; Kunze, Verfassungswidriger Zwang zur Schlichtung, S. 100 (der aber im sozialstaatlichen Schutz der Schlichtungsfreiheit entschieden zu weit geht). Im übrigen s. hierzu oben S. $299 \mathrm{f}$. 
herkömmlichen Gestalt garantiert ${ }^{8)}$ sondern im Prinzip auch die Unabdingbarkeit seiner Normen, ohne die er seinen sozialen Schutzzweck nicht erfüllen kann. ${ }^{9)}$ Allerdings muß gerade auch in diesem Zusammenhang vor einer Überforderung des Verfassungsrechts gewarnt werden. ${ }^{10)}$

Der Akzent der Sozialstaatlichkeit liegt aber auf der sozialen Verantwortung des Staates. Die "soziale Selbstverwaltung" ist sub specie des Sozialstaats nicht Selbstzweck sondern Mittel zum sozialstaatlichen $Z$ weck, gerechte Arbeitsbedingungen sicherzustellen. Sie funktioniert in Verfolgung dieses Zweckes nicht so zuverlässig, daß allein schon ihre Einrichtung den Staat von seiner Verantwortung für eine gerechte Teilhabe der Arbeitnehmer an der Einkommensverteilung ${ }^{11)}$ befreien würde. Darüber hinaus kann er die "soziale Selbstverwaltung" von vorne-

8) S. die oben S. 789 zu Fußn. 1 und 3 Zitierten und S.287 und S. 289 und den Text hierzu.

9) Vgl. Fechner-Maier, Die Rechtsgültigkeit der arbeitsrechtlichen Bestimmungen des sog. Truppenvertrags, S.92; Nipperdey, Lehrbuch des Arbeitsrechts, Bd. II S.22, 263.

10) Mit Recht weist Siebert (Einige Grundgedanken des gegenwärtigen A rbeitsrechts, Recht der Arbeit 9.Jhg. (1956) S. 12 ff (16)) darauf hin, daß das Prinzip des sozialen Rechtsstaats besonders auch als Regulativ des kollektiven Arbeitsrechts nicht überfordert werden darf. So weist z. B. auch Hueck (Die Tariffähigkeit des deutschen Bühnenvereins, Recht der Arbeit 9.Jhg. (1956) S. 45 ff (50 f)) die Annahme zurück, das Sozialstaatspı-inzip zwinge die Berufsverbände dazu, Tarifverträge abzuschließen und sanktioniere diese Pflicht durch den Verlust der Tariffähigkeit. - Eine der typischen Übersteigerungen ist es, wenn Nipperdey (Lehrbuch des Arbeitsrechts, Bd. II, S. 142) behauptet, die Mitwirkung der Koalitionen im Rahmen der politischen Selbstverwaltung sei durch den "sozialen Rechtsstaat" garantiert. Das läßt sich nicht beweiscn. - Dalüber hinaus muß noch einmal darauf hingewiesen werden, in welchem Maße Schnorr und Nipperdey (je a.o. (S.790 zu fußn.3) a.O.) durch die Zusammenschau mehrerer Verfassungsprinzipien, unter denen sich auch das des. "sozialen liechtsstaats" befindet, über das Ziel hinausschießend glauben, das geltende kollektive Arbeitsrecht verfassungsilechtlich "betonieren" zu sollen bzw. zu können.

11) Vgl. Ipsen, Anmerkung zu BVerfG Urteil vom 19. Dezember 1951 - 1 BvR 220/51 - \$.218; Olbersdorf, Sozialer Rechtsstaat und Arbeitsrecht, S. 140 . 
herein nicht "einrichten" wie eine Behörde. Der wesentlich freiheitliche Charakter der Koalitionen erlaubt ihm nur, ihre Tätigkeit zu regulieren. 12) Wenn und soweit sich Koalitionen nicht bilden, wenn und soweit sie entweder aus übereinstimmendem Wollen oder wegen streitiger Nichteinigung nicht ordnend tätig werden, bleibt bzw. wird die soziale Verantwortung des Staates aktuell. Die Festsetzung von Mindestarbeitsbedingungen, 13) die Allgemeinverbindlicherklärung von Tarifverträgen, 14) die staatliche Schlichtung und letztlich die Zwangsschlichtung 15) sind die gegebenen Mittel, die dem Staat unter IVahrung seiner Subsidiarität gegenüber der "sozialen Selbstverwaltung" 16) erlauben, seiner Verantwortung für sozial gerechte Arbeitsbedingungen zu genügen. 17) Letztlich darf der Staat aber auch nicht davor zurückscheuen, in die "soziale Selbstverwaltung" einzugreifen und sich über den Willen der Koalition hinwegzusetzen, wern ihre Zuständigkeit und Wirksamkeit zu einem sozialstaatswidrigen Zustand führt. 18) Er muß dabei die Koalitionsfreiheit und desgleichen die mittelbar verfassungsrechtlich garantierte Tarif-

12) S. oben Abschnitt 2 IV 2a, dd (S.302 ff), insbes. S. 302.

13) Zur Festsetzung der Mindestarbeitsbedingungen als Ausdruck der Sozialstaatlichkeit s. Fechner, Sozialer Rechtsstaat und Arbeitsrecht, S. 163; Olbersdorf, a.a.O.; Nipperdey, Lehrbuch des Arbeitsrechts, Bd.II, S. 35.

14) Zur Allgemeinverbindlicherklärung als Ausdruck der Sozialstaatlichkeit s. Olbersdorf, a.a.O.; Nipperdey, a.a.O. S. 487. - Eine interessante Verbindung stellt Kirchner (Wann erscheint die Allgemeinverbindlicherklärung von Tariverträgen im öffentlichen Interesse geboten? Arbeit und Rechi VII. Jhg. (1959) S.295 ff (295 f)) her, wenn er für das öffentliche Interesse an der Allgemeinverbindlicherklärung das Maß an Sozialstaatswidrigkeit des ohne sie bestehenden Zustandes bezeichnet.

15) Zum Sozialstaatsprinzip als Grundlage der Zwangsschlichtung s. Hessel, Staatliche Zwangsschlichtung? S.268 f; Cornelssen, Über das Recht zur Schlichtung von Gesamtstreitigkeiten, S.44 f; Heimann, Die rechtliche Möglichkeit eires staatlichen Eingriffs in die Tarifautonomie der Sozialpcrtner, Recht der Arbeit 9. Jhg. (1956) S.409 f.

16) Zur Subsidiarität des Staates s. Olbersdorf, a.a.O.; Heimann, a.a.O.; Nipperdey, a.a.O. S. 35.

17) S. zu Vorstehendem nochmals oben Abschnitt 2 IV 2 a, dd (S. 302 ff), insbes. S.305 ff und die dortigen Nachweise.

18) Vgl. Heimann, a.a.O. - S.a. oben S. 310. 
hoheit - so wie sie garantiert ist: als Prinzip - voll wahren. Der unmittelbare staatliche Eingriff, der grundsätzlich nur dadurch erfolgen kann, daß der Gesetzgeber die Rechtsetzung (wieder) an Stelle der Koalitionen ausübt, wird die Ausnahme und auf die Her'stellung eines sozialstaatsgerechten Zustandes beschränkt bleiben müssen. ${ }^{19)}$

Dagegen ist die richterliche Korrektur des im Rahmen der "sozialen Autonomie" gesetzten Rechts in der Weise, daß eine Tarifnorm als unmittelbar sozialstaatswidrig außer Anwendung gelassen wird, nicht möglich. Der Staat ist Adressat und Subjekt der Sozialstaatlichkeit. ${ }^{20)}$ In seiner sozialstaatlichen Rechtsordnung haben die Koalition sich zu halten. Aber er hat selbst diese seine sozialstaatliche Rechtsordnung zu entwickeln. Eine sozialstaatsgerechte Auslegung und Anwendung des geltenden Rechts wird kaum jemals eine Lücke lassen, die einen unmittelbaren Rückgriff auf den Verfassungsgrundsatz der Sozialstaatlichkeit zur Vermeidung "unsozialer" Tarifnormen als wünschenswert er'scheinen ließe.21)

19) Vgl. Heimann, a.a.O.

20) S. hierzu auch oben S. $735 \mathrm{f}$.

21) (1) Wenn z.B. das Bundesarbeitsgericht (Urteil vom 20.April 1956 - 1 AZR 448/54 - AP $\$ 611$ BGB Urlaubsrecht Nr.7) die Unabdingbarkeit des Urlaubsanspruchs auch gegenüber Tarifverträgen behauptet, so weist Hueck (Der Sozialstaatsgedanke in der Rechtsprechung des Bundesarbeitsgerichts, S. 64) demgegenüber mit Recht darauf hin, daß das Sozialstaatsprinzip besser zur Bestätigung entsprechenden Gewohnheitsrechts herangezogen worden wäre.

(2) Ein anderes Beispiel: Unter dem isolierten Gesichtspunkt des Gleichheitsgrundsatzes könnte es bedenklich erscheinen, den Frauen trotz größeren sozialen Schutzes und dementsprechend geringerer Leistung denselben Lohn zuzubilligen. Dies liegt jedoch im Sinne des Sozialstaatsprinzips, (las seine Vergünstigungen nicht durch die Lohneinbuße aufgehoben wissen will (BACiI: 1, 258 (265 f); Gaul, Die Bedeutung der Frauenlohnurteile les Bundesarbeitsgerichts für die Tarifpraxis und das IL()- l̈bereinkommen 100, Recht der Arbeit, 8.Jhg. (1955), \$.361 ff (362); Berger, Bedeutung und Tragweite des Grundsatzes vom sozialen Rechtsstaat, S.9; Hamann, Das Grundgeselz, Art. 3 Anm. C 4; Nipperdey, Lehrbuch des Arbeitsrechts, Bd.II, S.276; Hueck, Der Sozialstaatsgedanke in der Rechtsprechung des Bundesarbeitsgerichts, S.61; s.a. Beitzke, Anm. zu BAG, a.a.O. (= Urteil vom 15. Janual 1955-1 AZR 305/54 -) AP Art. 3 GG Nr. 4 
dd) Das sozialstaatliche Beamtenrecht

Anhangsweise muß auf das Beamten recht hingewiesen werden. Es ist Recht der abhängigen Arbeit und hat somit wie das A rbeitsrecht eine soziale Schutzaufgabe. Die Geltung des Sozialstaatsprinzips auch für das Beamtenrecht kann nicht in $Z$ weifel gezogen werden. Daß es in erster Linie auf die Interessen des öffentlichen Dienstes abzustellen ist, 1 ) ist in Wahrheit kein Gegenargument. Das Sozialstaatsprinzip ist - um dies noch einmal zu sagen - kein primitives Günstigkeitsprinzip. Es nimmt den Gegeninteressen nicht von vorneherein ihre Berechtigung. Es fordert nur einen Interessenausgleich, der dem "Schwächeren" das Seine nicht nach dem Maß seiner Schwäche sondern nach dem Maß seines Schutzbedürfnisses gibt. Daß das öffentliche Interesse als Gegeninteresse von besonderer Kraft ist, steht außer Frage. Ein sozialstaatsgerechtes Beamtenrecht braucht daher kein Beamtenrecht zu sein, das das Bild des überkommenen Beamtenverhältnisses zerstört, insbes. nicht ein "arbeitsrechtliches" Beamtenrecht. Das Grundgesetz hätte den Weg dazu auch schon durch Art. 33 Abs. 4 und 5 verbaut. Aber es ist nicht so, als ob diese Sonderregelung ein "Schutzwall" gegen eine - mit dem fal-

(Blatt 8 Rücks.); zurückhaltend Molitor, Anm. zu BAG, a.a. $O$. A rbeitsrechtsblattei, Gleichbehandlung im Arbeitsverhältnis, Entsch.6). Zumindest schafft das Sozialstaatsprinzip Raum für eine Gleichbehandlung im Lohn trotz unterschiedlicher Leistung (Dietz, Rechtsgutachtliche Äußerung zu der Frage, ob Art. 3 Abs. 2 und 3 des Grundgesetzes für die Bundesrepublik Deutschland der Berücksichtigung einer geringeren Wertigkeit von Frauenarbeit gegenüber der Männerarbeit sowie einer typisch geringeren sozialen Behandlung der Frau gegenüber dem Mann bei der Aufstellung einer Norm für den Lohn entgegensteht, S. $24 \mathrm{ff}$; s.a. Galperin, Gleicher Lohn für Männer und Frauen, JZ 11. Jhg. (1956) S. $105 \mathrm{f}(108 \mathrm{f})$ ). $\mathrm{Um}$ diesen $\mathrm{G}$ rundsätzen die in Anspruch genommene Geltung für das Tarifrecht zu verschaffen, bedarf es keiner unmittelbaren Geltung des Sozialstaatsprinzips gegenüber der "sozialen Selbstverwaltung" sondern nur einer entsprechenden, sozialstaatsgerechten Auslegung des Gleichheitsgrundsatzes (insbes. des Art. 3 Abs.2 GG). Zur mittelbaren Geltung des Art. 3 GG für das Tarifvertragsrecht s. unten Abschnitt 6 I $4 \mathrm{c}$ (S. $865 \mathrm{ff})$ und II 3 (S.914 ff).

1) In Polemik gegen das Sozialstaatsprinzip als Strukturprinzip des Beamtenrechts s. Wacke, Das Personalvertretungsgesetz und seine Kommentare, JZ 12.Jhg. (1957) S.289 ff (291 f). 
schen Pathos, dem die Beamtenrechtspolitik heute so sehr ausgesetzt ist, gelegentlich als "drohend" beklagte - "soziale" Gestaltung des Beamtenrechts wäre. 2)

Im Gegenteil, die "hergebrachten Grundsätze des Berufsbeamtentums" (Art.33 Abs.5) haben das "öffentlich-rechtliche Dienstund Treueverhältnis" (ebd. Abs.4) des Beamten schon bisher so gestaltet, daß der Beamte der sozialen Sicherung nicht entbehrte. Der Dienstherr hat eine Fürsorge- und Schutzpflicht gegenüber dem Beamten. 3) Der Beamte hat ein "Recht auf Gewährleistung einer seiner sozialen Lebensstellung entsprechenden Sicherung, auf Aufrechterhaltung seiner Eigenschaft als Beamter, auf angemessenen Lebensunterhalt und Versorgung auf Lebenszeit". 4) Schon durch die verfassungsrechtliche Rezeption der überkommenen Grundsätze sind für das Beamtenrecht somit die wichtigsten Anliegen erledigt, denen das Sozialstaatsprinzip hinsichtlich des A rbeitsrechts unmittelbar zu begegnen hat. Das Sozialstaatsprinzip bestärkt jedoch den darin enthaltenen sozialen Schutzgedanken und trägt ihn, wo er durch die "hergebrachten Grundsätze" noch nicht entwickelt, für ihn aber dennoch Raum gelassen ist. ${ }^{5)}$

2) In diesem Sinne jedoch - freilich ohne besagtes Pathos Wacke, a.a.O. S.291. Erstaunlicherweise scheint er geneigt zu sein, alles was mit "Sozialrecht", "sozialem Rechtsstaat" und dg1. zu tun hat, mit "Arbeitsrecht" $z u$ identifizieren und dem Beamtenrecht gegenüberzustellen. Mit Beifall zitiert er eine Äußerung von Fitting-Heyer (Personalvertretungsgesetz, 1955, S. 296): "Personalvertretungsrecht ist primär nicht Sozialrecht sondern Verwaltungsrecht..." Was soll das für eine Alternative sein!

3) S. f.v.a. v. Mangoldt-Klein, Art.33 Anm. VII 3 d 2.

4) Ebenda, Anm. VII 3 d 5.

5) Aus der Kasuistik: In BVerwGE 1, 57 (59) wird die Frage geprüf, ob die Rechtsstellung eines Widerrufsbeamten gegen das Sozialstaatsprinzip verstößt. Sie wird unter dem Hinweis verneint, daß eine mißbräuchliche Entlassung nach der einschlägigen beamtenrechtlichen Regelung ausgeschlossen ist. Hier begegnet der Bestandsschutzgedanke wieder, der hinsichtlich des A rbeitsrechts aus lem Sozialstaatsprinzip abgeleitet wurde. Doch ist fraglich, ob es hier wirklich entscheidend auf das Sozialstaatsprinzip ankam. Die Möglichkeit einer mißbräuchlichen Ausübung (ler Staatsgewalt verstößt in erster Linie und ohne Rücksicht auf die soziale Belegenheit des Gegenstands gegen die Rechtsstaatlichkeit! - Stumpf (Besoldungsneuregelung und Verfassungs recht, Recht im Amt 7.Jhg. (1960), S. $161 \mathrm{f})$ glaubt, sich für (len Anspruch der Beamten auf ange- 
Am stärksten wirkt sich das Sozialstaatsprinzip im Beamtenrecht wohl hinsichtlich der irregulären Wege der Versorgung aus, die von den hergebrachten Grundsätzen des Berufsbeamtentums nicht hinreichend vorgebildet sind, jedoch nicht ohne eine empfindliche Lücke im System des sozialen Schutzes des Beamten entbehrt werden können. Zu nennen sind etwa die Versorgung nach Art. 131 GG, - mit Einschränkung auch - die Wiedergutmachung im öffentlichen Dienst, die Nachversicherung ausgeschiedener Versorgungsberechtigter und der Unterhaltsbeitrag im Dienst strafrecht. 6 )

Den überkommenen Grundsätzen des öfentlichen Dienstrechts eher fremd als zugehörig ist auch das Personalvertretungsrecht, soweit es dabei auch um die Vertretung der Beamten geht - von der einheitlichen Vertretung der öffentlichen Bediensteten als solcher ganz abgesehen. Doch dürfte auf eine quasi-betriebsverfassungsrechtliche Repräsentation auch der Beamten nach dem Stand der Entwicklung nicht mehr schlechtweg verzichtet werden können. ${ }^{7)}$

So steht zwar Art. 33 Abs. 4 und 5 GG als lex specialis vor dem Sozialstaatsprinzip. ${ }^{8)}$ Das Sozialstaatsprinzip ist jedoch dadurch

messene Besoldungserhöhung nicht nur auf Art.35 GG sondern auch unmittelbar auf das Sozialstaatsprinzip berufen zu sollen.

6) S. Werner, Sozialstaatliche Tendenzen in der Rechtsprechung, S.94, dem insbes. der Hinweis auf die soziale Bedeutung des Unterhaltsbeitrags im Dienststrafrecht zu danken ist (a.a.O. S.94 f, Fußn.20). S. im übrigen oben S. $771 \mathrm{ff}$.

7) Dietz (Personalvertretungsgesetz, S.29) sagt mit Recht, Betriebsverfassungsgesetz und Personalvertretungsgesetz seien beide Elemente der Entwicklung der Bundesrepublik zum sozialen Rechtsstaat. Dagegen Wacke, a.a.O. S.291, der jedoch von einer gewissen Gleichstellung Arbeitsrecht $=$ sozialer Rechtsstaat ausgeht und in Anbetracht der Gegensätzlichkeit von Arbeitsrecht und Beamtenrecht glaubt, diese Bezeichnung ablehnen und die Eigenständigkeit des öffentlichen Dienstrechts gegenüber der Sozialstaatlichkeit betonen zu sollen (!). S.a. schon oben S. 795 zu Fußn. 2.

8) Nicht recht verständlich ist es, wenn Wacke (a.a.O. S.291 f) gerade "die Art. 73 Ziff. 8 und 75 Ziff. 1 GG (sowie Art. 33 V)" als "leges speciales gegenüber dem allgemeinen Gedanken des sozialen Bundesstaates und Rechtsstaates" diesem gegenüberstellt. Diese Kompetenznormen, die Wacke als konstituierende Flemente eines öffentlichen Dienstrechts (unter Einschluß 
vom Beamtenrecht nicht ausgeschaltet. Es greift durch die Auslegung und durch die Lücken les Art. 33 Abs. 3 und 5 GG auf das Beamtenrecht durch. 9) 10)

\section{b) Das Recht auf Arbeit}

Die Existenzerhaltung durch Einsatz der Arbeitskraft ist ein Grundphänomen des sozialen Lebens. Das System der sozialen Sicherheit knüpft entscheidend daran an. Das Arbeitsrecht greift einen wesentlichen, ja den für die breiten Massen allein interessanten Ausschnitt, den Einkommenserwerb durch abhängige Arbeit auf. Der objektiven Notwendigkeit der Arbeit, noch mehr aber dem subjektiven Zwang, die eigene Existenz durch Arbeit $z u$ erhalten, entspricht die Idee des "Rechts auf Arbeit".

- Ihr Name trügt. Ein allgemeiner subjektiver Anspruch gegen den Staat auf Verschaffung einer auskömmlichen Arbeitsgelegenheit ist nicht denkbar. Er würde eine Verfügungsmacht des Staates über die entscheidenden ökonomischen Daten voraussetzen, wie sie nicht einmal ein voll planender Staat haben kann. ${ }^{1)}$ Selbst

der Beamten, Angestellten und A rbeiter) betrachtet - womit er die Bedeutung des Zuständigkeitskatalogs überbewertet -, sind Ausgestaltungen (auch) des Sozialstaates,aber nicht leges speciales in dem Sinne, daß sie den besonderen Gegenstand a nders regeln als die lex generalis (das Sozialstaatsprinzip) den allgemeineren, ihn mitumspannenden Gegenstand.

9) Ob sich das Sozialstaatsprinzip durchgesetzt hätte, wenn die hergebrachten Grundsätze des Berufsbeamtentums eindeutig "unsoziale" Auswirkungen gehabt hätten, ist eine Frage, die wegen des höheren Ranges des Sozialstaatsprinzips (Art.20 Abs. 1 i.V.m. Art. 79 Abs. 3 GG) und der allgemeinen Fassung des Art. 33 Abs. 3 und 4 GG wohl bejaht werden müßte.

10) Zur "Sozialstaatsbindung" (les Staates als Arbeitgeber s. BVerfGE 3, 377 (381): "..., daß eine Behörde als Arbeitgeber ihre Interessen nicht mit der gleichen Schärfe verfolgen würcle wie es im privaten A rbeitsverhältnis vorkommt. Dies gilt umso mehr, nachlem clas GG die Sozialstaatlichkeit zu den tragenden Prinzipien unseres Staates erklärt hat".

1) Dürig (Grundfragen des öffrntlichrechtlichen Entschädigungssystems, S. 525) sprich: lavon, daß nur der unfreiheitliche Staat seinen Bürger gegen alle Lebenseventualitäten absichern könnte. "Schulfall: Vollbeschäftigung einerseits, aber erreichbar nur durch A rbeitseinsatz- und Arbeitslenkungsgesetzes... andererseits". Diesem bestechenden (und auch anderswo gelegentlich anzutreffenrlen) Visavis ist entgegenzutreten 
wenn die Verfassungen ihn ausdrücklich gewähren, wollen und dürfen sie nicht wörtlich verstanden werden. ${ }^{2)}$ Im wesentlichen geht es immer nur um einen - vielleicht verbindlich gemeinten, aber selbst dann nicht unmittelbar durchsetzbaren - Auftrag an die zuständigen Organe, für die Maximierung der Arbeitsgelegenheiten tätig zu sein. Diesen Auftrag impliziert aber auch das Sozialstaatsprinzip. 3) Nur über einen ausreichenden Bestand an Arbeitsplätzen kann auf die Dauer ein menschenwürdiges Dasein und eine gerechte Teilhabe aller an den vorhandenen Gütern gewährleistet werden. Dieser sozialstaatliche Auftrag geht jedoch auf ein positives, gestaltendes Tun und kann somit gegenüber den letztkompetenten Instanzen nicht von Rechts wegen durchgesetzt werden. Nur soweit es sich abwehrend gegen Maßnahmen wendet, die dem "Recht auf Arbeit" entgegenwirken, ist eine unmittelbare Sanktion des Sozialstaatsprinzips denkbar. Aber eine einzelne Maßnahme wird kaum jemals eindeutig interdiziert werden können. Die wirtschaftlichen Zusammenhänge sind zu komplex. Die isolierte Wertung einzelner Maßnahmen wäre bedenklich. Die einzubeziehenden größeren Entwicklungen sind zu schwer abzusehen.

Eine unmittelbare rechtliche Wirkung wird dem sozialstaatlichen "Recht auf Arbeit" daher letztlich nur dort abgerungen werden können, wo Einrichtungen in Frage stehen, die ihrem Wesen nach und auf Dauer seiner Verwirklichung dienen, insbes. also die Arbeitsvermitt1ung. 4) Damit soll nicht gesagt sein, daß die gegenwärtige Form der Arbeitsvermittlung 5) in irgend

(richtig gesehen bei Hueck, Freiheit und Zwang im Arbeitsrecht, S. 191 f). Die Vollbeschäftigung wird doch nicht durch Zwang zur Arbeit gewährleistet! Mehr recht hätte Dürig, wenn er so verstanden werden dürfte, als könnte die Vollbeschäftigung nur von einem Staat gesichert werden, der voll plant und zwar nicht nur durch Gewährung von Arbeitsgelegenheit sondern dann auch durch Verplanung und letztlich durch zwangsweisen Arbeitseinsatz. Aber auch dadurch läßt sich "Vollbeschäftigung" nicht unbeschränkt erreichen.

2) Vgl. Hersche1, Das Arbeitsrecht, S.328 ff und seine Nachweise.

3) Vgl. Olbersdorf, Sozialer Rechtsstaat und Arbeitsrecht, S. $138 \mathrm{f}$; s.a. v. Münch, Staatliche Wirtschaftshilfe und Subsidiaritätsprinzip, JZ 15. Jhg. (1960) S. 303 ff (303).

4) Vgl. Olbersdorf, a.a.O.

5) Vgl. den Zweiten Abschnitt ( $\$ \$ 35 \mathrm{ff}$ ) des Gesetzes über die Arbeitsvermittlung und die Arbeitslosenversicherung. 
einer Weise garantiert ist. Nur wird der Staat auf die Vorsorge für eine ausreichende Arbeitsvermittlung unter keinen Umständen - auch nicht in Zeiten der Vollbeschäftigung - verzichten dürfen. Er wird darauf wegen der inneren Verknüpfung zwischen einer wohlfunktionierenden Arbeitsvermittlung und der Arbeitslosenunterstützung gar nicht verzichten können. Gerade die A r beitslosenunterstützung ist aber eine eminent sozialstaatliche Einrichtung. 6) Der Gedanke des "Rechts auf Arbeit" und der Gedanke der "sozialen Sicherheit" treffen sich in ihr. Als Instrument der "sozialen Sicherheit" entschädigt sie für die Nichterfüllung des "Rechts auf Arbeit" und sanktioniert sie dieses, wenngleich nur mittelbar und sehr bedingt. Aber auch und gerade hinsichtlich der Arbeitslosenunterstützung ist damit nicht ihre gegenwärtige Gestaltung, die der Arbeitslosenversicherung, garantiert. 7)

Nicht zuletzt im Zusammenhang des "Rechts auf Arbeit" ist die Pflicht des Staates zu sehen, denjenigen, die aus behebbarer persönlicher Behinderung nicht bzw. nicht mehr am A rbeitsprozeß teilnehmen können, zur Beseitigung dieser Behinderung aus eigener Kraft jedoch nicht imstande sind, dazu zu verhelfen, daß sie in den Arbeitsprozeß eingegliedert bzw. wieder eingegliedert werden können. Habilitation, Rehabilitation und Eingliederung sind unaufgebbare Grundsätze des Sozialstaats. $\left.{ }^{8}\right)$ Nicht nur ist diese Art der Obsorge auf die Dauer die "rentabe1-

6) Ipsen, Anmerkung zu BVerfG Urteil vom 19. Dezember 1951 - 1 BvR 220/51 - S.218 ff; Olbersdorf, a.a.O.

7) Arbeitslosigkeit ist ein Grenzfall eines versicherbaren Risikos (s. hierzu schon oben S. 56 zu Fußn. 32 und den Text hierzu). In Krisensituationen kippt sie mehr oder weniger in eine Versorgung um. Gerade hier wäre - das ist auch zu den obigen Überlegungen über einen Wechsel von der Sozialversicherung zur Versorgung nachzutragen - eines der Grenzfelder gegeben, in denen am ehesten an die Aufgabe des sozialversicherungsrechllchen Prinzips gedacht werden könnte (s. oben S.778ff).

8) S. vor allem die bekannte stelle aus den amtlichen Erläuterungen zu $₫ 1$ der Reichsgrundsätze über Voraussetzung, Art und Maß der öffentlichen Fürsorge: "Das Ziel jeder Fürsorge muß sein, sich überflüssig zu machen, d.h. den Hilfsbedürftigen in seinem Willen und in seiner Kraft so zu stärken, daß er sich durch eigenes Können, Mühen und Schaffen selbst behaupten, insbes. für seine unterhaltsberechtigte Familie selbst sorgen kann". 
ste". Sie liegt in erster Linie im Interesse der Betroffenen selbst, deren menschenwürdiges Dasein am nachhaltigsten dadurch gefördert wird, daß sie in die Lage versetzt werden, sich statt des abgeleiteten Einkommens aus staatlicher Hand originäres Einkommen aus eigener Kraft zu verschaffen. Am eindeutigsten dürfte die Beseitigung körperlicher Mängel einschließlich eventuell notwendiger Umschulungen als sozialstaatlich unentbehrlich zu identifizieren sein. ${ }^{9}$ ) Schwieriger sind sub specie der sozialstaatlichen Verfassungsnorm - abgesehen also etwa vom Gedanken des Opferausgleichs - die Maßnahmen gesteigerter Eingliederungsfürsorge, wie sie vor allem in der beruflichen Weiterbildung 10) und in der Verschaffung und Sicherung von Arbeitsplätzen 11) zu sehen sind, zu beurteilen. Eine allgemeine Regel ohne Rücksicht auf die jeweils gegebenen Gesamtumstände wird sich insofern auch für den Abbau vorhandener Einrichtungen nicht aufstellen lassen.

Abschließend ist auch nochmals auf den im Zusammenhang mit dem Arbeitsrecht bereits erwähnten Schutz des Bestandes der A rbeitsverhältnisse (insbes. den Kündigungsschutz) hinzuweisen. Er ist gewissermaßen die "Abrundung" des erfüllten Rechts auf Arbeit.

\section{c) Die Pflicht zur Arbeit}

\section{aa) Allgemeines}

Das natürliche Gegenstück des "Rechts auf Arbeit" wäre die "Pflicht zur Arbeit". Sie besteht selbstverständlich innerhalb eines Arbeitsverhältnisses. Das ist hier jedoch nicht gemeint. Würde sich das "Recht auf Arbeit" gegen die Gemeinschaft richten, so müßte auch die Pflicht zur Arbeit eine öffentliche sein. 1)

Das Grundgesetz lehnt eine allgemeine Arbeitspflicht nachdrücklich ab (Art.12 GG). Es spart nur die "herkömmliche, allgemeine, für alle gleiche, öffentliche Dienstleistungspflicht" (Art.12 Abs.2 Satz 1)2) und die Zwangsarbeit "bei gerichtlich angeord-

9) S. vor allem $₫ 2$ des Körperbehindertengesetzes; $₫ 3$ des Tuberkulosehilfegesetzes; $₫ 26$ des Bundesversorgungsgesetzes.

10) S. z.B. $\$ 10$ des Heimkehrergesetzes.

11) Die zentrale Regelung ist das Schwerbeschädigtengesetz.

1) $\mathrm{Zu}$ den Versuchen einer verfassungsrechtlichen Fixierung der Pflicht zur Arbeit s. Hersche1, Das Arbeitsrecht, S. 332 ff.

2) Die weiteren Ausnahmen des Art. 12 Abs. 2 Satz 2 und 3 und Abs. 3 GG sind der Sache nach als Unterfälle des Abs. 2 Satz 1 anzusehen. 
neter Freiheitsentziehung" aus (ebd. Abs.4) und weist damit zugleich darauf hin, wie weit das Problem der Arbeitspflicht über den Sachzusammenhang der sozialen Intervention hinausgreift. Fest steht danach jedenfalls, (laß eine Arbeitsordnung, die auf einem planenden Arbeitseinsatz beruht, unmöglich ist. Die erwähnten Ausnahmen - auf die im grundrechtlichen Zusammenhang zurückzukommen sein wirl $\left.{ }^{3}\right)$ - haben nicht nur formal sondern auch der Sache nach exzeptionellen Charakter.

\section{bb) Die Pflicht (Last) zur existenzerhaltenden Arbeit}

aaa) Wesen und Erscheinungsformen

Gibt es auch keine allgemeine pflicht zur Arbeit, so gibt es doch eine Pflicht, den eigenen Unterhalt und den Unterhalt derjenigen, für die man von Rechts wegen zu sorgen hat, 1) durch eigene Arbeit $z u$ beschaffen. ${ }^{2)}$ Sie ist die schlechthin primitive Folgerung aus der Gemeinverpflichtung des Individuums als der Kehrseite der sozialstaatlichen Hilfspflicht. ${ }^{3)}$

3) S. unten Abschnitt 6 (S.842 ff).

1) Die Abgrenzung der Unterhaltspflicht ist ebenfalls ein Problem, das verfassungsrechtliche Beachtung verdient. Sie darf nicht willkürlich vorgenommen werden (Art. $3 \mathrm{GG}$ ) und darf nicht dazu mißbraucht werden, den "Sozialstaat" zu entlasten. Das geltende deutsche Unterhaltsrecht aktiviert jedoch die Familie in den Grenzen des Zumutbaren und entspricht so Art. 6 GG. Der (larin verwirklichte Subsidiaritätsgedanke ist dem llesen des sozialen Rechtsstaates wohl vertraut (s. oben $\mathrm{S} .755 \mathrm{ff}$ ).

2) $\$ 16$ Abs. 1 des Entwurfes rines Bundessozialhilfegesetzes (Deutscher Bundestag, 3. IIahlperiode, Drucksache 1799) und die Amtliche Begründung hierzu (s.diese auch S.33). S.a. Nipperdey, Die Würde des Nenschen, s. 7: "Jeder muß in erster Linie für sich und die Seinen selbst aufkommen und ist nicht berechtigt, die lerantwortung dafür nach seinem Belieben auf die öfentliche. Iancl abzuwälzen".

3) Vgl. Bachof, Freiheit des Berufs, in: Bettermann-Nipperdey, Scheuner, Die Grundrechte, Bd. III, 1.Halbbd. 1958, S. 155 ff $(257,263)$. S. dic Amtl. Begründung des Entwurfes eines Bundessozialhilfogeselzes, S.32 f. - Die gemeinte Pflicht bedarf der gesetzlichen Festlegung (s. den nachfolgenden Text nebst Anmerkungen). Die Gemeinverpflichtung ergibt unmittelbar keine Rechtspflichten. Sie schafft - wie oben ausgeführt (s. oben II 1 ( $\mathrm{S} .676 \mathrm{ff}$ ) und $2 \mathrm{c}$ (S.726ff), e (S.729ff), f (S.735f ) und im folgenden Text wieder zu erwäh- 
Sie äußert sich in $z$ wei Hauptricht ungen: einerseits in der Pflicht, die Arbeitskraft nicht schlechthin ungenützt $z u$ lassen, 4) sie nicht in unsittlichem Tun zu vergeuden 5) und sich nicht sonst durch einen unverantwortlichen Lebenswandel 6) in die Notwendigkeit öffentlicher Hilfe zu versetzen; andererseits in der Pflicht, im Falle der Hilfsbedürftigkeit, die Hilfe der Allgemeinheit so gut als möglich durch eigene A rbeit zu erübrigen ${ }^{7}$ ) oder zu entschädigen. ${ }^{8)}$

nen sein wird - nur den verfassungsrechtlichen Raum für die gesetzliche Begründung der Pflicht, insbes. gegenüber den Individualgrundrechten (hier: Art.12 GG); s. unten S.

4) $\$ 361 \mathrm{Nr} .5 \mathrm{StGB}$ : "wer sich dem... Müßiggang dergestalt hingibt..." S.a. $\$ 16$ Abs. 1 des Entwurfs eines Bundessozialhilfegesetzes.

5) $\$ 20$ der Fürsorgepflichtverordnung: "Wer infolge seines sittlichen Verschuldens ... der öffentiichen Fürsorge... anheimfällt...."

6) $\$ 20$ der Fürsorgepflichtverordnung; $\$ 361$ Nr. 5 StGB: "Spie1, Trunk oder Müßiggang".

7) $\$ 19$ der Fürsorgepflichtverordnung; $\$ \$ 5,7$ der Reichsgrundsätze über Voraussetzungen, Art und Maß der öffentlichen Fürsorge; $\$ 361 \mathrm{Nr} .7 \mathrm{StGB}$. S. nunmehr auch $\$ \$ 1 \mathrm{Abs}$. 2, 11 Abs. 1, 16 Abs. 2 und 3, 17, 18, 23, 24 des Entwurfes eines Bundessozialhilfegesetzes. - In einer höheren Fbene reflektiert sich diese Pflicht im Recht der Arbeitslosenversicherung ( $\$ \$ 75 \mathrm{ff}$, insbes. $\$ \$ 78 \mathrm{ff} A V A V G)$, obwohl hier versicherungsmäßige Erwägungen (Arbeitsunwille statt Arbeitslosigkeit: nicht das versicherte Risiko des zufälligen Nachteils!) im Vordergrund stehen und zum selben Ergebnis führen. S. zur Anwendung dieser Bestimmungen BSGF 3, 298; 4, 1. Die Kritik, die Weidner (Zur Rechtsprechung des Bundessozialgerichts, $S .759 \mathrm{f}$ ) an diesen Entscheidungen übt, geht zu weit. Sein Schluß, das AVAVG unterwerfe unterschiedslos alle Arbeitsverhältnisse der obligatorischen Versicherung und kenne "schon aus diesem Grunde kein Verbot willkürlicher Gefahrerhöhung" (S.759), ist unverständlich. - Zum Zusammenhang des Arbeitslosenversicherungsrechts mit dem Fürsorgerecht s. $\$ \$ 7$ Abs. 4, 13 Abs. 1 der Reichsgrundsätze.

8) Außer den vorstehend zitierten Regelungen s. $\$ 20$ cler Fürsorgepflichtverordnung. Auch der. Arbeitszwang ( $\$ 362$ StGB) oler die Unterbringung im Arbeitshaus ( $\$ 42$ d StGB) als Folge einer Verurteilung nach $\$ 361 \mathrm{Nr} .5$ oder 7 StGB dienen u.a. - freilich nur u.a.! - diesem Zweck. 
Diese Pflicht kann in erster. Linie dadurch geltend gemacht werden, daß die Hilfe durch die Verschaffung einer Arbeitsgelegenheit gewährt wird.9) Aber die Versagung der staatlichen Fürsorge gegenüber dem, der eine vorhandene Arbeitsgelegenheit nicht nützt, ist als ausschließliche Sanktion der besagten Pflichten nicht tragbar. Sie kann an sich nur gegenüber dem in Frage kommen, der in dem Zeitpunkt der Hilfsbedürftigkeit noch arbeitsfähig ist. Daß dem, im Zeitpunkt der Bedürftigkeit Arbeitsunfähigen, der sich oder (und) die Seinen schuldhaft in die Notlage versetzt hat, die Fürsorge deshalb versagt wird, ist undenkbar. 10) Der Betreffende kann nicht nur nicht über die Existenz der gegen ihn Unterhaltsberechtigten verfügen; 11) er kann auch nicht auf seine eigene Menschenwürde und nicht auf sein Leben verzichten. 12) Der Staat kann ihn für sein Verhalten zur Verantwortung ziehen. 13) Aber er kann ihm die Fürsorge nicht versagen.

Aber auch im Falle des noch arbeitsfähigen Hilfsbedürftigen kann er die Fürsorge nicht schlechthin immer dann ausschließen, wenn der Betroffene nicht $z u$ arbeiten bereit ist. Er kann das nicht, wenn es um die Hilfe für selbst nicht arbeitsfähige Unterhaltsberechtigte des arbeitsunwilligen Betroffenen geht. 14) Er

9) $\$ \$ 19,20$ der Fürsorgepflichtverordnung. $\$ 7$ der Reichsgrundsätze. Besonders eingehend $\$ \$ 16$ Abs.2, 17, 18 des Entwurfs eines Bundessozialhilfegesetzes.

10) Die Kürzung auf das absolute Minimum bzw. die Beschränkung auf geschlossene Fürsorge ist dagegen möglich ( $\$ 13$ der Reichsgrundsätze nebst den amtlichen Erläuterungen hierzu; $\$ 23$ Abs. 2 des Entwurfes eines Bundessozialhilfegesetzes nebst der Amtlichen Begründung hierzu). Auch sonst ist eine Sonderbehandlung der schuldhaft Bedürftigen möglich und zulässig (wie z.B. die Beschränkung der Kostenersatzpflicht $u$.a. auf diesen Personenkreis durch $₫ 85$ des Entwurfs eines Bunclessozialhilfegesetzes).

11) S. hierzu auch die Schonklauseln in $\$ 13$ Abs. 3 der Reichsgrundsätze und in $\$ 2: 3$ Abs. 3 des Entwurfes eines Bundessozialhilfegesetzes.

12) Vgl. Dürig in Maunz-Dürig, Art. 1 Abs.I Randn.22, Art.2 Abs. II Randn. 12 .

13) Durch Bestrafung ( $\$ 361 \mathrm{Nr} .5$ StGB), durch qualifizierte Heranziehung zur. Arbeitspflicht ( $\$ 20$ der Fürsorgepflichtverordnung) durch Reduzierung der Fürsorgeleistung (s. oben Fußn.10) usw.

14) Vg1. $\$ 23$ Abs. 1 und 3 des Entwurfes eines Bundessozialhilfegesetzes und die Amtliche Begründung hierzu. 
kann das aber auch nicht immer, wenn es um die Hilfe allein für den arbeitsunwilligen Betroffenen geht. 15) Der Sozialstaat kann ihn nicht "verkommen", nicht in menschenunw ürdiges Elend absinken lassen. Indem der Bedürftige die ihm angetragene Arbeit ablehnt, kann er nicht mit Wirkung für den Staat und gegen sich selbst auf seine Menschenwürde und sein Recht auf Leben verzichten. 16) Der Staat, der Sozialstaat sein will und die Menschenwürde und das Leben schützt, kann die begehrte und zur Wahrung der Schutzgüter der Art. 1 Abs. 1 und 2 Abs. 2 GG uner1 äßliche Fürsorge auch dann nicht einfach versagen, wenn die Bedürftigkeit aktuell verschuldet ist. 17) Aber er kann den Bedürftigen auch nicht aus der Gegenpflicht zur Arbeit entlassen. Er würde ihn sonst den Arbeitswilligen gegenüber bevorzugen und die Arbeitsverweigerungen honorieren. Es gibt nur eine Lösung, die der zwingenden rechtlichen und tatsächlichen Situation gerecht wird: der Staat muß helfen und zugleich die abgelehnte Gegenleistung an die Gemeinschaft erzwingen. Er kann dem Betroffenen eine Arbeit anweisen 18) und ihn letztlich in geschlossener Unterbringung zur Arbeit heranziehen (und erziehen). 19) Aber er kann

15) Vg1. die Amtliche Begründung zu $\$ 23$, a.a.O.

16) S. oben S.803 zu Fußn. 12. - Es kann zwar Fälle geben, in denen der Bedürftige Fürsorge und Arbeit unter Umständen aus Beweggründen ablehnt, die seiner Menschenwürde gerecht werden, und darin eine weder gegen die verfassungsmäßige Ordnung noch gegen die Rechte Dritter oder das Sittengesetz verstoßende Entfaltung seiner Persönlichkeit zu sehen ist (s. a. Dürig, Grundrechte und Zivilrechtsprechung, S.163). Das hat auch der Sozialstaat zu respektieren (Art. 1 Abs. 1, 2 Abs. $1 \mathrm{GG}$ ). Und er kann es respektieren, nicht nur, weil die Öffentlichkeit in ganz anderer Weise berührt wird als durch den Regelfall; sondern vor allem deshalb, weil die staatliche Hilfe ernstlich abgelehnt wird. Im Regelfall aber wird nur die Arbeit, nicht aber die Hilfe abgelehnt - und wenn schon um der Arbeit willen zunächst auch die Hilfe, so doch nicht auf die Dauer und unter Umständen, die die Hilfe wirklich entbehrlich machen würden.

17) Zum Problem der Verminderung der Fürsorge auf das Minimum s. dagegen oben S.803 zu Fußn. 10.

18) $\$ 361 \mathrm{Nr} .7 \mathrm{StGB}$ beinhaltet eine strafrechtliche, nicht so deutlich $₫ 20$ der Fürsorgepflichtverordnung auch eine verwaltungsrechtliche Sanktion. Künftig klarer: $₫ 24$ Abs. 1 Satz 2 des Entwurfes eines Bundessozialhilfegesetzes.

19) $\$ 20$ der Fürsorgepflichtverordnung; s. nun auch $\$ 24$ des Entwurfes eines Bundessozialhilfegesetzes; ferner $\$ 361 \mathrm{Nr} .7$ i. V. m. $\$ \$ 362,42$ d StGB. 
ihn nicht einfach ausspeien in die Gosse der Verelendung.

Für diesen Anspruch auf Fürsorge ist es freilich gleichgültig, ob er vom Gesetz als subjektive Berechtigung anerkannt wird oder nicht. 20) Er würde so, wie er existiert, in dieser Koppelung von Hilfe und Beschwer, doch nicht geltend gemacht. Und keiner, der den relevanten Tatbestand - Hilfsbedürftigkeit nach angetragener und abgelehnter Arbeitsgelegenheit - erfüllt, könnte ihn geltend machen; denn schon durch das Arbeitsangebot ist der Bedürftige klaglos gestellt. 21) Entscheidend ist, daß der Staat seine Aufgabe, in dieser Weise zu helfen, erkennt und annimmt.22)

\section{bbb) Das Verhältnis zu Art. 12 GG}

Art. 12 GG widersetzt sich dieser Arbeitspflicht nicht. Zunächst ist schon allgemein festzuhalten: Die Gegenpflicht der Arbeitsleistung ist Bestandteil der Sozialpflichtigkeit des Individuums und somit der wohl wichtigsten immanenten Schranke aller Individualgrundrechte. 1) Die Arbeitsweigerung, das Sich-Verkommen-Las-

20) $§ 23$ Abs. 1 des Entwurfes eines Bundessozialhilfegesetzes:

"Wer sich weigert, zumutbare Arbeit zu leisten, hat keinen Anspruch auf Hilfe zum Lebensunterhalt". S. hierzu auch die Amtliche Begründung des Entwurfes zu $\$ 23$ und $\$$. 33 .

21) S. auch die einschlägige Anspruchsvoraussetzung des Fürsorgeanspruchs: $\$ \$ 5,7$ der Reichsgrundsätze, $\$ \$ 1$ Abs. 2,2 Abs.1, 11 Abs. 1 des Entwurfs eines Bundessozialhilfegesetzes. - Vorsichtiger als $\$ 23$ Abs. 1 des genannten Entwurfes sagt die Amtliche Begründung des Entwurfes (S.33): Der Betroffene "kann sich daher" auf seinen Rechtsanspruch nur dann berufen, wenn er auch die ihm nach dem Gesetz obliegenden Pflichten erfül1t". - Dagegen ist mit der Fiktion Dürigs (Maunz-Dürig, Art. 1 Abs. I Randn. 64 Fußn. 2) "Wer zumutbare Arbeit ablehnt, erklärt sich selbst für nicht fürsorgebedürftig" in Wahrheit nichts anzufangen. Wie sollte es darauf ankommen, daß man sich "als fürsorgebedürftig erklärt" oder. nicht? Es kommt ja auch positiv nicht auf die bloße Erklärung des Petenten sondern auf die Bedürftigkeit an.

22) Wie die in den vorstehenden Anmerkungen genannten Bestimmungen des geltenden Fürsorge- und Strafrechts und des projektierten künftigen Fürsorgerechts erkennen lassen, sind die notwendigen normativen Fürsorgen getroffen.

1) Vg1. Bachof, Die Freiheit des Berufs, S.257. - Es ist auffallend, daß gerade Dürig, der so gerne auf die Notwendigkeit des "sozialbereiten Bürgers" hinweist (Grundfragen des öf- 
sen des Bedürftigen ist ein Verstoß gegen das - zudem gesetzlich positivierte (positivierbare) ${ }^{2}$ ) - Sittengesetz und trifft somit ebenfalls auf eine immanente Schranke aller Grundrechte. ${ }^{3)}$ Die Verweigerung der tätigen Fürsorge für die Unterhaltsberechtigten verletzt schließlich auch noch die Rechte Dritter und stößt somit an eine weitere immanente Schranke der Grundrechte. ${ }^{4)}$ So erhebt sich von vorneherein die Frage, ob die soziale Arbeitspflicht als Gegenleistung für die öffentliche Hilfe überhaupt am Maß des Art. 12 Abs. 1 und 2 GG gemessen werden darf und ihre Zulässigkeit in dieses Grundrecht nicht schon ungeschrieben "hineingedacht" ist. 5)

fentlichrechtlichen Entschädigungssystems, S. 525; MaunzDürig, Art. 1 Abs. I Randn. 52), so sehr die Freiheit des Nichtstuns für den verteidigt, der der öffentlichen Hilfe bedarf (Maunz-Dürig, Art. 1 Abs. I Randn.64). Er baut dabei offenbar zu sehr auf die Tragfähigkeit der Alternative "Fürsorge + Arbeit oder keine Arbeit und keine Fürsorge".

2) Insbes. $\$ 361 \mathrm{Nr} .5$ und 7 StGB.

3) Vgl. Dürig in Maunz-Dürig, Art.2 Abs. I Randn. 74.

4) Vgl. Dürig, ebd. Randn.73. - Das - d.h. den Rechts- und Sittenverstoß, der in der Vernachlässigung der Unterhaltspflicht liegt - allein will Dürig (a.a.O., Art. 1 Abs. I Randn. 64) als Grund zur Herausnahme der Arbeitspflicht aus Art. 12 GG gelten lassen. Er übersieht dabei nicht nur die immanente Schranke der Sozialpflichtigkeit (s.o. S. zu Fußn. 1) sondern den Verstoß gegen das Sittengesetz, der schon darin liegt, daß jemand sich selbst verkommen läßt und nur, um nicht arbeiten zu müssen, sich in einen menschenunwürdigen Zustand versetzt. - Zur Gültigkeit des $₫ 20$ der Fürsorgepflichtverordnung unter dem speziellen Aspekt der Vernachlässigung der Unterhaltspflicht s.a. Bachof, Die Freiheit des Berufs, S. 263 .

5) Allerdings gilt das nicht für den Schutz gegen die " $Z$ wangsarbeit", die nach $₫ 20$ der Fürsorgepflichtverordnung (und künftig nach $\$ 24$ des Entwurfs eines Bundessozialhilfegesetzes) zulässig sein soll. Art. 12 Abs. 4 GG enthält einen Vorbehalt zugunsten einer Gerichtsentscheidung. Dieser Vorbehalt kann nicht durch "Mißbrauch" des Grundrechts erübrigt werden. Das verkennt Dürig, a.a.O. Art. 1 Abs. I Randn. 64. Während er gegen den, der es nur ablehnt, zu seinem eigenen Unterhalt $\mathrm{zu}$ arbeiten, keinerlei Zwang zur Arbeit zulassen will und in $\ 20$, 1. Alternative der Fürsorgepflichtverordnung einen Verstoß gegen Art. 12 Abs. 2 und 4 GG erblickt, hält er $₫ 20,2$. Alternative a.a.O. für zulässig, weil sich der, 
Doch selbst dann, wenn Art.12 GG grundsätzlich anzuwenden wäre, wäre die zwangsweise Geltendmachung der Arbeitspflicht zulässig.

Die allgemeinere Pflicht, nicht sittenwidrig auf die Hilfe der Allgemeinheit "zuzusteuern", berührt Art.12 GG ohnedies nur am Rande. Sie zwingt nicht zu einem bestimmten Beruf und einer bestimmten Arbeit sondern allenfalls dazu, überhaupt etwas zu tun, während Art.12 GG auch die Freiheit des Nichtstuns schützt. ${ }^{6)}$ Aber Art. 12 GG gibt kein Recht darauf - entgegen der sozialen Pflichtstellung des Bürgers, entgegen den guten Sitten und möglicherweise auch noch entgegen den Rechten Dritter 7) - jegliche Erwerbstätigkeit abzulehnen, um schließlich der Allgemeinheit zur Last zu fallen. 8)

Näher an das Verbot der Arbeitspflicht (Art.12 Abs. 2 Satz 1 GG) scheint die Anweisung einer bestimmten Arbeit 9 ) heranzukommen. Aber zunächst ist hierzu zu bemerken, daß eine strenge Pflicht, die angewiesene Arbeit auszuüben, nicht besteht. Kann der Betroffene sich selbst Arbeit verschaffen, so daß er zu seinem Unterhalt auf die behördlich nachgewiesene Beschäftigung nicht mehr angewiesen ist, und ergreift er diese Möglichkeit, so kann er sich der "Last", die angewiesene Arbeit zu leisten, legitim entziehen. 10) Im übrigen sollte man keine Anstände nehmen, die fragliche Pflicht als eine "herkömmliche, allgemeine, für alle gleiche Dienstleistungspflicht" i.S. des Art. 12 Abs. 2 Satz 1 GG anzusehen. An ihrer Herkömmlichkeit kann kein $Z$ weifel bestehen. 11) Die "Beschränkung auf eine 'allgemeine, für alle gleiche' öffentliche Dienstleistungspflicht ... stellt sich als ein Anwendungsfall des Gleichheitssatzes (Art.3) dar". 12) Allgemeinheit

der seine Unterhaltspflicht verletzt, außerhalb des Schutzes des Art. 12 Abs. 22 GG gestellt hat. Was ist dann aber zum Verhältnis des $₫ 20,2$. Alternative a.a.O. zu Art. 12 Abs. 4 GG zu sagen? Ist immer dann, wenn materiell ein $Z$ wang zur A rbeit ausgeübt werden larf, auch schon $Z$ wangsarbeit und das ohne Gerichtsentscheidung zulässig? Diese Konsequenz ist unannehmbar.

6) S. Bachof, a.a.O. $\$ .195 \mathrm{~m}$.weiteren Nachweisen.

7) S. oben S. $805 \mathrm{f}$ zu furn. 18.

8) S. Bachof, a.a.O. S. 257, s.a. S.263.

9) S. oben S.804 zu Fußn. 18.

10) S. Bachof, a.a.O. S. 257 Fußn. 386.

11) S. nochmals $₫ 361 \mathrm{Nr} .7 \mathrm{StGB}, \S 20$ der Fürsorgepflichtverordnung, $\$ 7$ der Reichsgrundsätze.

12) Bachof, a.a.O. S.261. 
und Gleichheit sind nicht formal zu betrachten. Sie fordern nur eine gleiche Belastung aller in der besagten Weise Betroffenen. 13) Diese Gleichmäßigkeit ist ohnedies geboten. Die Anweisung einer Arbeit ist also auch unter diesem Gesichtspunkt zulässig. Dabei ist immer wieder zu bedenken, welche grundlegenden Argumente für die Zulässigkeit dieser Arbeitspflicht sprechen. Wenn der Verfassungsgrundsatz der Sozialpflichtigkeit des Bürgers gegenüber dem Sozialstaat seine Funktion, die Individualrechte als immanentes Prinzip den Erfordernissen des Sozialstaates anzupassen, erfüllen soll, so muß er sich hier bewähren. 14)

Die "geschlossene" Arbeitspflicht 15) unterliegt sowohl nach Art. 12 Abs. 4 GG wie auch nach Art. 104 GG dem Vorbehalt der gesetzesgegründeten, richterlichen Entscheidung. 16) Aber diese formale Voraussetzung allein kann nicht genügen. Sonst wären der Umgehung des Art. 12 Abs. 1 und 2 GG Tür und Tor geöffnet. Der A rbeitszwang kann vielmehr nur unter tatbestandlichen Voraussetzungen angeordnet werden, die dem Wesensgehalt des Art. 12 GG Rechnung tragen (Art.19 Abs.2 GG). 17) Grundsätzlich wird das der Fall sein, wenn an sich eine Freiheitsbeschränkung angeordnet ist und eine gelenkte Arbeitsverwendung des in seiner Freiheit Beschränkten geboten erscheint. Der Strafvollzug ist also der klassische Anwendungsfall des Art. 12 Abs. 4 GG. 18) Aber seine Anwendung ist nicht auf den Strafvollzug beschränkt. 19) Kann einem Mißbrauch der in Art. 12 Abs. 1 und 2 GG niedergelegten Rechte nicht anders als ciurch $Z$ wangsarbeit unter gerichtlich angeordneter Freiheitsentziehung gesteuert werden, so kann die-

13) S.a. v. Mangoldt-Klein, Art. 12 Anm. VII 2 c.

14) Zur Gültigkeit des $\$ 361 \mathrm{Nr} .7 \mathrm{StGB}$ s. nochmals Bachof, a.a.O. S.257, insbes. Fußn. 386 und S.263. A.A. Dürig in Maunz-Dürig, Art. 1 Abs. I Randn. 64 Fußn. 2.

15) $\$ 20$ der Fürsorgepflichtverordnung; $\$ 24$ des Entwurfes eines Bundessozialhilfegesetzes. S.a. $\$ 361 \mathrm{Nr} .5$ und 7 i. V.m. $\$ \$ 362,42$ d StGB.

16) Zu Art. 12 Abs. 4 s. v. Mangoldt-Klein, Art. 12 Anm.VII 4. Dem Erfordernis ist für $§ 20$ der Fürsorgepflichtverordnung nun durch das Freiheitsentziehungsgesetz genügt.

17) S. Bachof, Die Freiheit des Berufs, S. 262.

18) Damit sind jedenfalls $\$ 361 \mathrm{Nr} .5$ und $7 \mathrm{i} . \mathrm{V} . \mathrm{m} . \$ \$ 362,42 \mathrm{~d}$ StGB gedeckt.

19) S. Karl Heinz Klein, Vorschriften über die Fürsorgeunterbringung zur Arbeit, DÖV 9.Jhg. (1956) S. 488 f; Bachof, a.a.O. S. 262 f (insbes. S.263 Fußn.416); a.A. Dürig in Maunz-Dürig, Art. 1 Abs. I Randn. 64. 
se im Gesetz vorgesehen und vom Richter ausgesprochen werclen. $\$ 20$ der Fürsorgepflichtveror(lnung entspricht dem. "Wer obwohl arbeitsfähig infolge seines sittlichen Verschuldens der öffent1ichen Fürsorge selbst anheimfällt oder einen Unterhaltsberechtigten anheimfallen läßt" und "Arbeit beharrlich ablehnt oder sich der Unterhaltspflicht beharrlich entzieht" handelt so sehr seiner Sozialpflicht, dem Sittengesetz und möglicherweise den Rechten Dritter zuwider, daß die Einschränkung seiner Freiheit geboten erscheint. 20) Wer sich darüber hinaus durch sein Verhalten straffällig gemacht hat, hat nicht weniger seine Arbeitskraft der Gemeinschaft zur Verfügung zu stellen. ${ }^{21)}$ Schließlich ist mit die-

20) (1) Für die Gültigkeit der Vorschrift s. Klein, a.a.O.; Bachof, a.a.O. - Dürig, a.a.O., hält sie nur für gültig, soweit die Verletzung der Unterhaltspflicht in Frage steht. Dazu schon oben S.805 fu Fußn. 1 und 4. Hier sei noch darauf hingewiesen, daß der Tatbestand des $\$ 20$ der Fürsorgepflichtverordnung gerade hinsichtlich der Vernachlässigung der Unterhaltspflicht Bedenken aufkommen läßt. Nimmt man nämlich von den beiden Alternativen jeweils den die Unterhaltspflicht betreffenden Tatbestand, so ergibt sich zunächst kein Zusammenhang mit der Verwendung bzw. Nichtverwendung der Arbeitskraft. $\$ 20$ der Fürsorgepflichtverordnung ist trotzdem auch insoweit verfassungsmäßig. Das Tatbestandsmerkmal "obwohl arbeitsfähig" weist darauf hin, daß auch das Entziehen aus der Unterhaltspflicht in Zusammenhang mit dem Einsatz der Arbeitskraft oder mit der Verwendung des Arbeitserlöses stehen muß. Allerdings wird hier eine vorsichtige (verfassungskonforme) Auslegung am Platz sein. (2) $\$ 24$ des schon mehrfach erwähnten Entwurfes eines Bundessozialhilfegesetzes läßt den sittlichen Vorwurf verbal weniger scharf hervortreten. Der Sache nach besteht jedoch kein Unterschied, der zu einer im Ergebnis anderen Beurteilung zwingen würde.

21) $\$ \$ 361 \mathrm{Nr} .5$ und 7,362 , 42 ( $\operatorname{StGB}$ (s. schon oben $\mathrm{S} .808 \mathrm{zu}$ Fußn. 18). Mit Recht weist Bachof (a.a.O. S.263 Fußn.416) darauf hin, der Stanlpunkt Dürigs zu $\$ 20$ der Fürsorgepflichtverordnung miisse auch eine Überprüfung dieser. Bestimmung - insbes. des von Dürig nicht erwähnten $\$ 361 \mathrm{Nr}$. $5 \mathrm{StGB}$ - nach sich ziehen. $\$ 361 \mathrm{Nr} .5$ StGB enthält keinen A rbeitszwang, der gegen $A r t .12 \mathrm{GG}$ verstoßen könnte und unterscheidet sich dachrch wesentlich von der von Dürig verworfenen Bestimmung les $\$ 361 \mathrm{Nr} .7 \mathrm{StGB}$. Sollte es aber zulässig sein, daß über $\$ \S 361 \mathrm{Nr} .5,362,42$ d StGB eine strafweise Arbeitspflicht auch über den verhängt wirdd, der 
ser wie mit jener Maßnahme auch die Erwartung verbunden, daß der Betroffene auf den Weg eines sinnvollen Gebrauchs seiner Freiheit geführt werden kann.22) 23) 24)

\section{Sozialstaat und Güterverteilung}

\section{a) Allgemeines}

Die soziale Intervention beruht auf zwei Basisnormen: Existenzerhaltung durch Arbeit und ein den Bedürfnissen entsprechendes laufendes Einkommen - zwei Normen, die in der Masse der Fälle dieselbe Wirkung haben. Insoweit wird die soziale Intervention vom Gedanken einer Bedürfnisbefriedigung durch laufende Beschaffung der erforderlichen Güter mittels eines laufenden Einkommens beherrscht. Die Masse der vorhandenen Konsum- und Produktionsgüter und Kapitalien wird in ihrer jeweils gegenwärtigen Verteilung dadurch grundsätzlich nicht in Frage gestellt. Sie bleibt vom Prozeß des laufenden Einkommenserwerbs durch A rbeit, der umverteilenden Einkommensverschaffung und der Bedürfnisbefriedigung vermittels dieser Einkommen nicht unberührt. Eine Streuung ist die regelmäßige Folge. Aber die Dispositions-

nur sich selbst durch "Spiel, Trunk oder Müßiggang" der Fürsorge anheimfallen ließ, so wäre es widersinnig, wenn über ihn, der "infolge seines sittlichen Verschuldens der öffentlichen Fürsorge anheimfällt", nicht auch die mildere, rein verwaltungsrechtliche Maßnahme des $\$ 20$ der Fürsorgepflichtverordnung verhängt werden könnte. $\$ 20$ der Fürsorgepflichtverordnung ist eine dem sozialen Rechtsstaat durchaus adäquate Norm.

22) S. $₫ 24$ Abs. 3 des Entwurfes eines Bundessozialhilfegesetzes.

23) Gegenüber Art. 4 der Europäischen Menschenrechtskonvention ist $\$ 20$ der Fürsorgepflichtverordnung demnach in vollem Umfang gedeckt und zwar hinsichtlich der Unterhaltspflicht gegenüber Dritten nach Art. 5 Abs. 1 b i.V.m. Art. 4 Abs. 3 a (vgl. Dürig, a.a.O.; Bachof, a.a.O. S.263), hinsichtlich der Pflicht zum Selbstunterhalt nach Art. 4 Abs. 3 d (Bachof, a.a.O.); s.a. Klein, Vorschriften über die Fürsorgeunterbringung zur Arbeit, S. 489. - Für $\$ 24$ des Entwurfes eines Bundessozialhilfegesetzes ist eine andere Beurteilung nicht veranlaßt.

24) S. zu Vorstehendem insgesamt auch das Urteil des Arbeitsgerichts Ulm v. 25. Juni 1954 - Ca 311/54 - AP Art.12 GG $\mathrm{Nr} .2$ mit zustimmender Anmerkung von Wertenbruch, in der die Heranziehung von Insassen eines Flüchtlingslagers zu Arbeiten im Lager für zulässig erklärt wird. 
macht über die vorhandenen Güter ist trotzdem eine Quelle der übermacht und des wirtschaftlichen Vorteils ihrer Inhaber gegenüber denjenigen, die auf ein laufendes, an ihrer Arbeitskraft bzw. ihren Bedürfnissen orientiertes Einkommen angewiesen sind.

Der Sozialstaat kommt daher nicht ohne zusätzliche, auf die Güterverteilung direkt Einfluß nehmende Abhilfen aus. 1) Die Spannungen, die es auszugleichen gilt, sind aber vielfältig und wechseln mit den Umständen, die Mittel, sie auszugleichen verschiedentlich, insbes. im Rahmen eines Systemwechsels vertauschbar. Die sozialstaatliche Obsorge für das Wohl der Bürger überschreitet zudem vielfach den Rahmen des elementar Notwendigen. Von einer sozialstaatlichen Verfassungsverbürgung kann deshalb kaum jemals die Rede sein.

\section{b) Allgemeine Vermögensstreuung}

Vorweg zu erwähnen ist ein Bestreben, das sich noch nicht wesentlich von einer Politik der Zuteilung eines angemessenen laufenden Einkommens unterscheidet oder jedenfalls unterscheiden muß: die allgemeine, breite Vermögensbildung, insbes. über die "erste Einkommensverteilung". 1) Sie liegt im Sinne des Sozialstaates, weil sie die wirtschaftliche Abhängigkeit und Einfluß1osigkeit sowie die Anfälligkeit für besondere Belastungen und Behinderungen im Einkommenserwerb durch Arbeit mildern kann und eine freiere Konsumdisposition und elastischere Anpassung des Konsumaufwands an die Marktnotwendigkeiten ermöglicht. 2)

1) Ipsen, Enteignung und Sozialisierung, S. 75 : "In bezug auf die Eigentumsverfassung" bedeutet "Gestaltung der Sozialordnung' die Neu- und Anders-Gestaltung der Eigentumsherrschaft bis hin zu seiner Neu-Verteilung".

1) S. hierzu etwa Hein Müller, Wirtschaftliche Fragen der Bildung breitgestreuten Figentums, ORDO Bd.X (1958) S. 291 ff; v. Loesch, Zur Vermögensbildung der Arbeitnehmer, Schmoller's Jahrbuch für. Giesetzgebung, Verwaltung und Volkswirtschaft, 80. Jhg. (1960) S.433 ff.

2) Hier ist an die Theorie v. Thünens (Der isolierte Staat in Beziehung auf Landwirtschaft und Nationalökonomie, Bd. II, Der naturgemäße Arbeitslohn und dessen Verhältnis zum $Z$ insfuß und zur Landrente, Zwei Abteilungen, 1850/63) vom gerechten Lohn zu erinnern. v. Thünen geht aus von dem Lohn, der sich in einer Modellwirtschaft ergeben würde, in der der Boden ein freies Gut, alle Mitglieder der Volkswirtschaft Arbeiter wären und Kapitalbildung nur durch Sparen 
Vermögensbildung bei den bisher vermögenslosen bzw. vermögensschwachen Schichten setzt ein entsprechend über dem Existenzminimum liegendes Einkommen voraus. Der Staat muß daher, wenn er die Vermögensbildung will, vor allem für dieses Einkommen sorgen.

Die Vermögensbildung setzt weiter den Entschluß zum (vorläufigen) Konsumverzicht voraus. ${ }^{3)}$ Der Staat kann ihn fördern, indem er Anreize für das Sparen selbst bietet (z. B. Steuervorteile, Prämien). Er kann ihn - und zugleich weitere sozial-oder wirtschaftspolitische Ziele - aber auch fördern, indem er attraktive und geeignete Gelegenheiten für die Investition des Ersparten bereitstellt bzw. anregt. Die Ausgabe von Volksaktien und die staatliche Förderung des Eigenheimbaues sind derzeit wohl die aktuellsten Beispiele dafür. Selbst einem Zwangssparen, soweit es nicht die betroffenen Bevölkerungskreise unverhältnismäßig, "unsozial" belastet, stünden keine grundsätzlichen verfassungsrechtlichen Bedenken entgegen. ${ }^{4}$ ) In der Tat ist gerade die So-

aus dem Arbeitseinkommen erfolgen könnte. Jedes Mitglied der Volkswirtschaft hätte dann ein doppeltes Interesse: Als Arbeiter wünschte es den Lohn möglichst hoch", als Bezieher von Zins aus den gesparten Beträgen wünschte es den Zins möglichst hoch, also den Lohn möglichst niedrig. Unter dem Einfluß dieser beiden widerstreitenden Interessen würde sich der Lohn so einspielen, daß die Rente eines Arbeiters, die er aus seinem vom Lohn zu ersparenden Betrag ziehen kann, maximal ist. Diese ebenso ästhetische wie unbrauchbare Theorie hat ihr Bestechendes bis heute nicht verloren. "Gewiß macht keine Noblesse der Gesinnung eine falsche Formel richtig und gewiß sind allein schon die Voraussetzungen, unter denen Thünens Formel gilt, so willkürlich und so wirklichkeitsfremd, daß sie, selbst, wenn die Ableitung mathematisch fehlerfrei wäre, nicht viel Aussagewert besäße. Aber sollte nicht in einer Zeit, in der in praxi Lohnerhöhungen meist wegen gestiegener Produktivität verlangt und gewährt werden, die Aufgabe, die Thünen sich stellte, als bleibende Aufgabe zu verstehen sein?" (Salin, Art. "v. Thünen" im Handwörterbuch der Sozialwissenschaften, Bd. 10, 1959, S. 386 ff (388)).

3) S. zur sozialen Bedeutung des Sparens z. B. Zorn, Vom Sparen in unserer Gesellschaft, 1959, der allerdings die volkswirtschaftlichen Auswirkungen des Sparens zu eindeutig positiv einschätzt.

4) Zum Verhältnis der Bindung von Geld(vermögen) und Eigentumsgrundrecht s. unten S.987ff. 
zialversicherung in einem gewissen Sinn als ein System des $Z$ wangssparens anzusehen. Die Wirkungen der verschiedenen Wege zur Förderung der Vermögensbildung sind für die einzelnen Vermögensträger selbst - die z.B. mit dem Erwerb einer Aktie ein Risiko eingehen, das ihren wirtschaftlichen Horizont übersteigt - und auch und vor allem für die gesamte Volkswirtschaft jedoch von so zweifelhafter Bedeutung, insbes. so von den jeweiligen wirtschaftlichen Gesamtumständen abhängig, daß ein eindeutiges rechtliches Urteil schon kaum jemals im einzelnen Fall und noch weniger generell gefällt werden kann.

\section{c) Die Verteilung der Produktionsmittel}

Eines der ältesten sozialen Ärgernisse stellt die Konzentration der Verfügungsmacht über Rohstoffe und produzierte Produktionsmittel in den Händen einer wirtschaftlichen Oberschicht dar. Die Bedeutung, die der Disposition über die Wirtschaftsmittel, die Bedingungen ihres Einsatzes und ihre Nutzung sowie dem Zufluß dieser Nutzungen selbst zutiommt, läßt es ganz allgemein als sozial wünschenswert erscheinen, möglichst vielen Teilhabe an der Verfügungsmacht über die Produktionsmittel zu verschaffen.

Die reibungsärmste, in ihrer. Ilirkungsweise aber auch am wenigsten regulierbare, ist die kapitalistische Beteiligung möglichst vieler über die Vermögensbillung, speziell durch den Erwerb von Anteilen, insbes. von Aktien.

Unmittelbar, nicht marktwirtschaftlich verändert die Soziali sierung die Eigentumsherrschaft. 1) Das Grundgesetz bekennt sich in Arl. $15 \mathrm{GG}$ zur Möglichkeit der Sozialisierung. Es liegt nahe, das Sozialstaatsprinzip - durch Art.15 GG gerade auf dieses Mittel sozialer Neugestaltung hingewiesen - als den verfassungsrechtlichen Impuls anzusehen, der dazu zwingt, die soziale Besserstellung der von der Boherrschung und Nutzung der fraglichen Wirtschaftsgüter bishel ausgeschlossenen Personenkreise auf diesem Wege voranzulreiben. 2$)^{\text {So }}$ Surde bereits davon gesprochen, Art.15 GG schafle "mindestens reflexartig einen'status socialis positivus' zugunston der.jenigen Gruppen...., deren Teilhabe an der vergesellschafteten Eigentumsordnung der Pro-

1) Zur Unterscheiclung zwischen ler Verstaatlichung und der Uberführung in "andere formen der Gemeinwirtschaft", der in diesem Zusammenhang größte Becleutung zukommt, s. Herbert Krüger, Sozialisierung, S.291 ff.

2) Vgl. Ipsen, Enteignung und sozialisierung, S. 102, 122; s. dens. auch in der Anmerkung zu BVerfG, Urteil v. 19.Dezember 1951 - 1 BvR 220/51 - S.218. 
duktivgüter in Frage steht und in der bisherigen Ordnung fehlt ${ }^{\prime \prime}$. 3) In Wahrheit kann aus dem Sozialstaatsprinzip jedoch keine verfassungsrechtliche Notwendigkeit der Sozialisierung entnommen werden. 4) Wenn Art. 15 GG das spezielle Problem der Sozialisierung aufgreift, so hätte es an dieser Vorschrift gelegen, nicht nur die Möglichkeit hierzu einzuräumen und die Modalitäten zu ordnen sondern auch die Pflicht zur Sozialisierung nach "Grund und Höhe" festzulegen. Art. 15 GG in seiner gegenwärtigen Fassung ist ein Argument gegen einen Zwang zur Sozialisierung. Das Sozialstaatsprinzip selbst ist viel zu allgemein, als daß es etwas über die der Anordnung der Sozialisierung notwendig vorausliegenden Entscheidungen über ihr gegenständliches Ausmaß, ihre Formen und ihre Intensität aussagen könnte.

Damit soll nicht geleugnet werden, daß die Sozialisierung als Interventions mög 1 i chke it dem Sozialstaat wesentlich ist. 5) Als Instrument zur Sanierung zerrütteter Wirtschaftszweige 6) und somit zur Erhaltung der in Frage gestellten Arbeitsplätze und - einkommen, als Mittel eventuell notwendiger Wirtschaftsplanung, 7) vor allem aber zur Abwehr der Ballung und des Mißbrauchs wirtschaftlicher Macht 8 ) und zur strukturellen Verände-

3) Ipsen, Enteignung und Sozialisierung, S. 103, 122; s.a. Scheuner, Verfassungsschutz des Eigentums, S. 139. Dagegen Ipsen und Scheuner wohl zu begrifflich wertend - v. MangoldtKlein, Art. 15 Anm. II 3.

4) S. Wolany, Vom Sozialstaat und sozialen Recht, S. 142; Flume, Diskussionsbeitrag zu "Enteignung und Sozialisierung", VVDStRL. H. 10, 1952, S. 156 f (157); v. Mangoldt, Das Bonner Grundgesetz (1. Aufl.) Art. 20 Anm.2 b; Wernicke, Bonner Kommentar, Art.20 Anm. II 1 d; Forsthoff, Begriff und Wesen des sozialen Rechtsstaats, S. 27; E.R. Huber, Wirtschaftsverwaltungsrecht, Bd. II S. 155; Berger, Bedeutung und Tragweite des Grundsatzes vom sozialen Rechtsstaat, S. 7; Gebauer, Eigentumspolitische Probleme unserer Wirtschaftsverfassung, in "Vom Bonner Grundgesetz zur gesamtdeutschen Verfassung", Festschrift für Hans Nawiasky, 1956, S. 317 ff (321).

5) Herbert Krüger, Sozialisierung, S.276: "Vergesellschaftung kann auch in einem liberalen Staats- und Wirtschaftssystem die ultima ratio der Staatsintervention sein".

6) Vgl. Krüger, a.a.O.S.276 f, 285 mit eingehenden Nachweisen.

7) Vgl. Krüger, a.a.O. S.277 f mit eingehenden Nachw.; s.a. Rittig, Art. "Sozialisierung (I) Theorie" im Handwörterbuch der Sozialwissenschaften, Bd.9 (1956) S. 455 ff (458 f). - 
rung der Einkommensverteilung - insbes. unter Abbau der konzentrierten, ungleich verteilten "arbeitslosen" (Originär-)Einkommen 9) - kann sie unter Umständen, in geeigneter Weise und geeignetem Umfang durchgeführt, nicht nur zweckmäßig sondern vielleicht sogar geboten erscheinen. Insofern, nämlich gerade deshalb, weil Art.15 GG die Möglichkeit der Sozialisierung - als Möglichkeit - begründet und offen läßt, ist es richtig, darin einen Ausdruck der Sozialstaatlichkeit zu sehen. 10) Und es ist zumindest eine Frage, ob Art.15 GG nicht im Hinblick auf den höheren Verfassungsrang des Sozialstaatsprinzips (A rt.20 Abs. 1 i.V.m. Art. 79 Abs. 3 GG) einer Verfassungsrevision nur beschränkt zugängig ist. 11) 12)

Eine der Sozialisierung verwandte Form der beschränkten Teilhabe wenigstens der Arbeitnehmer eines bestimmten Unternehmens ${ }^{13)}$ wenigstens an der Disposition über die sachlichen Produktionsmittel, insbes. über ihre produktive Verbindung mit der A rbeit, ist die betriebliche $M$ it bestim $m$ ung. Über ihre prinzipielle sozialstaatliche Unerläßlichkeit wurde schon gesprochen. 14)

Damit soll nichts über den Umfang zulässiger Wirtschaftsplanung ausgesprochen werden. Daß Planungsmaßnahmen notwendig werden können, muß grundsätzlich außer Frage stehen. S. im übrigen hierzu unten.

8) Vg1. Krüger, a.a.O. S. 278 f mit Nachweisen; s.a. Rittig, a.a.O. S. 457 f. - Gegen die Sozialisierung zum Zwecke der Brechung privater Monopolmacht, v. Mangoldt-Klein, Art. 15 Anm. IV 2 mit weit. Nachw.

9) Vgl. Rittig, a.a.O.S.456 f.

10) Vgl. E.R. Huber, Wirtschaftsverwaltungsrecht, Bd.I S.663, Bd.II S. 13; Krüger, a.a.O. S.282 f; Maunz, Deutsches Staats recht, S. 139.

11) Für Unabänderlichkeit: Ipsen, Enteignung und Sozialisierung, S. 103; Abendroth, Zum Begriff des demokratischen und sozialen Rechtsstaats im Grundgesetz der Bundlesrepublik Deutschland, S.87. Gegen Unabänderlichkeit: E.R. Huber, Wirtschaftsverwaltungsrecht, Bd. II S. 155.

12) $\mathrm{Zu}$ den besonderen Aspekten des Art.15 GG s. unten Abschnitt 6 III 4 d (\$.963 ff).

13) Ipsen (a.a.O. S.103) sieht gerade sie auch hinsichtlich des status socialis positivus der. "Sozialisierungsberechtigten" im Vordergrund.

14) S. oben S. 788. Zu den besonderen Aspekten, die sich hierzu aus Art. 14, 15 GG ergeben, s. unten Abschnitt 6 III $4 \mathrm{f}$ (S.982 ff). 
Besondere Probleme bietet das Produktionsmittel Boder, das als solches am stärksten auf dem landwirtschaft 1 i chen Sektor hervortritt. Ländliche Bodenreform, 1) 1ändliche Siedlung und Landpachtrecht sind die hauptsächlichen Einrichtungen sozialstaatlicher Abhilfe ungerechter Bodenverteilung oder ungerechter Ausnützung der Eigentumsherrschaft über den landwirtschaftlich genutzten Boden. 2) Die mangelnde Aktualität der Bodenreform, die sich in Westdeutschland praktisch erwiesen hat, wirft jedoch ein bezeichnendes Licht auch auf ihre sozialstaatliche Position. Es ist keineswegs so, als müsse der Sozialstaat Bodenreform um jeden Preis betreiben. Abgesehen davon wird die Bodenreform ihrem Wesen nach gegenstandslos, wenn jener Zustand erreicht ist, den sie erstrebt. Eine Strukturveränderung, die erneut ein bodenreformatorisches Eingreifen notwendig macht, ist nur auf lange Sicht denkbar. Dagegen wird die ländliche Siedlung grundsätzlich stets gepflegt werden müssen. Allerdings sind auch hier das notwendige Ausmaß und die notwendigen Mittel viel zu unbestimmt, als daß vom Verfassungsrecht her auch nur von einer Garantie gesprochen werden könnte. Anders dürfte die Situation hinsichtlich des Landpachtrechts sein. Infolge seiner Besonderheiten wird schon im Interesse des Verpächters, besonder's aber im Interesse des Pächter's, des grundsätzlich "schwächeren" Teils, ein besonderes, angemessenes Landpachtrecht als eine auch sozialstaatliche Notwendigkeit angesehen werden müssen.

Auch die Verteilung des Produktionsmittels "städt is che $r^{\text {" }}$ (d.h. nicht iandwirtschaftlich genutzter Boden) und umbauter Raum steckt voll sozialer Problematik. Ist sie doch die Grundlage für die Verteilung von Produktionsstätten und Arbeitsplätzen und für die Herstellung des Konsumgutes "Wohnung", für die Lebensbedingungen der städtischen Bevölkerung, insbes. der "ärmeren" Schichten. Der Sozialstaat wird deshalb die Kontrolle darüber" nicht aufgeben dürfen. 3 )

1) S. hierzu oben S. 73 zu Fußn.36 ff und unten Abschniti 6 III (S. $934 \mathrm{ff})$.

2) S.a. Knoll, Eingriffe in das Eigentum im Zuge der Umgestaltung gesellschaftlicher Verhältnisse, AöR Bd.81 S.416.

3) Zum sozialstaatlichen Bezug des "Baurechts" s. Forsthoff, Begriff und Wesen des sozialen Rechtsstaats, S.9; Werner, Die Zuständigkeit des Bundes für ein Bundesbaugesetz, DVBl. 69.Jhg. (1954) S. 481 ff (481 f); Stamm, Zur Verwirklichung des sozialstaatlichen Prinzips, JZ 10.Jhg. (1955) S. 149 ff 


\section{e) Die Verteilung der Konsumgüter}

Das Problem der Teilhabe an den Produktionsmitteln wirkt vielfältig zurück auf die Teilhabe an den Konsumgütern. Doch hat die Versorgung der Bevölkerung mit Konsumgütern über den Markt darüber hinaus ihre eigene soziale Problematik, die in der Relation Preis-Einkommen liegt. "Überteuerungen" notwendiger Güter, die vor allem als Folge ihrer absoluten oder relativen Knappheit oder der Kostenstruktur ihrer Produktion (einschließlich der Verteilung) eintreten können, läßt sie für die ökonomisch schwächeren Schichten unerreichbar oder nur unter anderweitem, empfindlichem Konsumverzicht erreichbar werden. Diese Störung in der Konsumgüterverteilung bedarf der sozialstaatlichen Abhilfe.

Ist das zwar gewiß, so läßt sich auch hier nicht sagen, mit welchen Mitteln. Kreditpolitik, Investitionsförderung, Ein- und Ausfuhrregelung usw. können "marktkonform" sowohl die Knappheit wie auch die Kostenstruktur beeinflussen. Mitunter kann es geboten sein, Preise, die auf der Kostengrenze aufsitzen, durch Subventionen von der Anbieterseite her zu drücken oder durch gezielte Beihilfen die Nachfragepotenz der ansonsten von der Nachfrage ausgeschlossenen Bevölkerungskreise wieder herzustellen. Andererseits kann u. U. durch Preisvorschriften wirksamer eingegriffen werden. Als ultima ratio muß sich der Sozialstaat ein mehr oder weniger ausgedehntes System von Preis-1) und Bewirtschaftung svorschriften 2 ) vorbehalten. Er kann in die Notwendigkeit versetzt sein, zum umfassenden Verteilerstaat zu werden. ${ }^{3)}$ Damit soll nicht gesagt werden, die Bewirtschaftung sei ihrem Wesen nach ein sozialstaatliches Anliegen. Sie kann reine Daseinsvorsorge sein. ${ }^{4)}$ Aber sie ist potentiell ein unentbehrliches Mittel auch der sozialen Intervention.

(149), der jedoch das Sozialstaatsprinzip einseitig als Gemeinschaftsbindung des Figentums zur Rechtfertigung baurechtlicher Beschränkungen ausschlachtet.

1) Zum sozialstaatlichen Bezug des Preisrechts s. außer Bettermann (Grundfragen des Preisrechts für Mieten und Pachten, S. $119 \mathrm{ff}$ ) Bachof, Begriff und Wesen des sozialen Rechtsstaats, S. 48; BVerfGl: 8, 274 (329).

2) Zum sozialstaatlichen Bezug des Bewirtschaftungsrechts s. z.B. E.R. Huber, Wirtschaftsverwaltungsrecht, Bd. II S.272. S.a. Krause, Der verteilende Staat, S.13, der dabei das Sozialstaatsprinzip mehr als Regulativ des Bewirtschaftungsrechts sieht und zwar im Sinne seines gemeinschaftsbetonenden Gehalts.

3) S. hierzu schon oben $\$ .679$ zu Fußn. 5.

4) Die Grenzen sind freilich schwer zu ziehen. Wenn z.B. 


\section{f) Zum Wohnungsproblem}

Die anhaltendsten Auswirkungen hat die doppelte Knappheit des Bodens und des umbauten Raumes, wie sie für die Bundesrepublik immer noch kennzeichnend ist, auf dem Gebiet des Wohnung swe sens. Hier liegt eines der dringendsten sozialstaatlichen Probleme. 1)

Der Sozialstaat kann versuchen, durch Förderung des Wohnungsbaues das Angebot zu vermehren und durch Förderung des Eigenheimbaues die Bedürfnisträger vom fremden Angebot und der Unterwerfung unter die Bedingungen mietweiser Überlassung unabhängig zu stellen. 2) Er wird den Folgen der Marktüberlegenheit der Wohnungseigentümer durch die soziale Gestaltung des Mietvertragsrechts, 3) insbes. des mietrechtlichen Bestandsschutzes, 4) und durch die Wohnungsaufsicht vorbeugen müssen. Und er wird einer gesteigerten Mangellage nur durch Bewirtschaftung und Preisbindung Herr werden können. 5) Aber

Wolany (Vom Sozialstaat und sozialen Recht, S. 160) meint, der Sozialstaat habe im Notfall knappe Güter nicht nur den "Armen" sondern auch den "Reichen" zuzuteilen, so ist das insofern nicht falsch, als der Sozialstaat jedenfalls den "Reichen" durch die Bewirtschaftung nicht "verarmen" lassen darf (s. gerade auch hierzu Wolany, a.a.O. S.153). Aber wenn ein Gut so knapp ist, daß es, bliebe seine Verteilung auch weiterhin dem Markt überlassen, auch dem "Reichen" nicht mehr zugängig wäre - sei es, weil es wirklich so selten geworden ist, sei es, weil der Markt, gewaltsam oder nicht, zusammenbrechen würde -, so ist das wohl schon ein Fall, in dem der Staat als allgemein daseinsvorsorgende - nicht mehr (nur) als helfende und ausgleichende, für das Dasein der allgemein gefährdeteren Unterschicht sorgende - Ordnungsmacht einschreiten muß.

1) Vg1. Thieme, Der Beamte im sozialen Rechtsstaat, S. 170.

2) S. schon das Schlagwort vom "sozialen Wohnungsbau". S. hierzu ferner BVerwGE 1, 308 (310); Forsthoff, Begriff und Wesen des sozialen Rechtsstaats, S.26; Berger, Bedeutung und Tragweite des Grundsatzes vom sozialen Rechtsstaat, S.6.

3) S.a. Forsthoff, a.a.O. S.9.

4) Zur sozialstaatlichen Grundlage des Mieterschutzes s. z.B. Seka, Bedeutung und Umfang des Mieterschutzes, Zeitschrift für Miet- und Raumrecht, 8. Jhg. (1955), S.225 ff (225) m. w. Nachw.

5) Vgl. Berger, a.a.O.; Werner, Sozialstaatliche Tendenzen in der Rechtsprechung, S.90 ff. Zur Preisbildung und Bewirtschaftung s. ferner oben S. 817. 
es kommt immer auf die Umstände und die Marktentwicklung an. Der Versuch, nicht nur die Wohnraumbewirtschaftung und Preisbindung sondern auch den mietrechtlichen Bestandsschutz abzubauen und das soziale Wohnungsproblem durch die Förderung des Wohnungsbaues, die Gewährung von Mietbeihilfen und letzten Endes die Obdachlosenfürsorge allein zu bewältigen, wie er gegenwärtig vom Bund unternommen wird, ${ }^{6}$ ) ist nach den Erfahrungen der letzten Jahrzehnte zwar sozialstaatlich suspekt. Er wird jedoch nicht a priori als verfassungswidrig bezeichnet werden dürfen. 7)

\section{g) Anhang: Sozialstaatsprinzip und Vermögensschäden}

Schließlich ist auch noch auf den Ausgleich eingetretener Vermögensschäden hinzuweisen. Schon oben - im Zusammenhang mit den Problemen der Sonderversorgung 1) - wurde klargestellt, da $\beta$ es eine Pflicht des Sozialstaates ist, für einen "erträglichen" Unterhalt dessen zu sorgen, der auf die Nutzungen bzw. den Verzehr seines Vermögens angewiesen, dieses infolge eines irgendwie von der staatlichen Gemeinschaft "zu vertretenden" Umstandes einbüßte. Vermögenseinbuße ist aber nicht nur dort sozial relevant, wo sie zum Verlust der Unterhaltsbasis geführt hat. Auch dann, wenn der Unterhalt als solcher durch ein Arbeitseinkommen sichergestellt werden kann, kann ein Vermögensverlust zu einer unverhältnismäßigen Belastung des Betroffenen geführt haben, die ihn in die Kategorie der wirtschaftlich "Schwächeren" eingereiht hat. Auch hier ist es die Pflicht des Sozialstaats, helfend einzugreifen. Allerdings verlangt der Sozialstaat nicht einen reinen Saldoausgleich. Es geht um die Befreiung aus sozialen Mangelsituationen.2)

6) Vgl. Pergande, Vom Mieterschutz zum sozialen Mietrecht, Deutsche Richterzeitung, 37.Jhg. (1959) S.229 ff. - Als erste Stufe zur Verwirklichung les sog. "Lücke-Planes" s. das Gesetz über den Abbau der Wohnungszwangswirtschaft und über ein soziales Miet- und Wohnrecht v.23. Juni 1960 (BGB1. I S. 389) (Sperrung v. Verf.).

7) Allerdings ist es Schönfärberei, von dem neuen Wohnungsrecht als einem spezifisch "sozialen" zu sprechen. Wenn es vielleicht auch nicht "unsozial" im Sinne des sozialen Verfassungsbekenntnisses ist, so muß es noch nicht als positiv sozial anzusprechen sein. Das Wort "sozial" im Sprachgebrauch des Gesetzgeber's (s.Fußn.6) ist ein Mittel politischer Propaganda, das für die verfassungsrechtliche Subsumtion nichts besagt.

1) S. o. S. $771 \mathrm{ff}$.

2) S. zu Vorstehendem nochmals oben S.771ff und die dortigen Nachweise. 
5. Die allgemeinen nicht primär sozialen staat1 ichen Leistungen

a) Die öffentliche Güter- und Leistungsversorgung

Im vorhergegangenen Abschnitt wurde deutlich, daß der Staat u. U. seinen sozialen Aufgaben nur gerecht werden kann, indem er die Versorgung der Bevölkerung mit einem gewissen Gut oder einer gewissen Leistung entweder selbst übernimmt oder jedenfalls durchgehend lenkt und gewährleistet. 1) Von nicht geringerer sozialstaatlicher Bedeutung ist jedoch, daß der Staat und die ihm inkorporierten Körperschaften und Anstalten dann, wenn sie die Versorgung nicht primär oder jedenfalls nicht im Sinne einer conditio sine qua non aus sozialen Gründen - unmittelbar oder mittelbar - übernommen haben, die sozialen Belange berücksichtigen.

Ist z.B. eine - partielle oder allgemeine - Bewirtschaft ung aus Gründen der allgemeinen Daseinsvorsorge oder schlicht aus Gründen der öffentlichen Ordnung aufgenommen, so hat ihr die Sozialstaatlichkeit Maß zu geben. Der Verteilerstaat hat darauf zu achten, daß die knappen Güter gerade auch die "ärmeren" Schichten angemessen erreichen.

Hat die öfentliche Hand die Versorgung der Öffentlichkeit mit gewissen Gütern und Leistungen unmittelbar übernommen, wie das insbes. hinsichtlich der Energieversorgung oder der Verkehrsleistungen der Fall ist, so muß sie dabei das Sozialstaatsprinzip respektieren. 2) Die Möglichkeiten hierzu sind freilich wiederum so vielfältig, daß eine eindeutige Aussage über den verfassungsmäßig gebotenen Zustand kaum je möglich ist. Um die Entgelte sozial angemessen zu gestalten, können sie durch scharfe Kalkulation und eventuell auch unter Inanspruchnahme allgemeiner Haushaltsmittel allgemein niedrig gehalten oder sozial gestaffelt werden. Werden sie nach rein wirtschaftlichen Gesichtspunkten gebildet, so kann einer eventuellen sozial schädlichen "Überteuerung" immer noch durch Beihilfen aus allgemeinen Haushaltsmitteln gesteuert werden. Ein eindeutig "unsozialer." Zustand wird sich nur negativ feststellen lassen.

1) S.a. Thieme, Der Beamte im sozialen Rechtsstaat, S. $170 \mathrm{f}$.

2) Zur Bindung der öffentlichen Hand an das öffentliche Recht und die verfassungsmäßigen Begrenzungen der Verwaltung, auch lann, wenn Verwaltungsziele in Formen des Privatrechts verfolgt werden, s. oben S. $621 \mathrm{ff}$. 


\section{b) Das öffentliche Bildungswesen}

Gleiche Bildungschancen für alle! Das ist eine Parole, die wie kaum eine andere zum gemeinsamen Gedankengut der sozialen Bewegung gehört. Über die sachliche Berechtigung dieses Postulats ist sub specie der Gleichheit und der sozialen Gerechtigkeit kein Streit möglich. 1) Der. Staat ist durch das Sozialstaatsprinzip gehalten, ein System von Bildungs- und Förderungseinrichtungen zu schaffen und zu erhalten, das gleiche Bildungschancen ohne Rücksicht auf den wirtschaftlichen Rückhalt des Betreffenden gewährleistet. ${ }^{2)}$ Somit ergänzt das Sozialstaatsprinzip auch den "Schulartikel" des Grundgesetzes, der die soziale Problematik nur in der rein negativen Wendung gegen die "Sonderung der Schüler nach den Besitzverhältnissen der E1tern" in Privatschulen (!) (Art. 7 Abs. 4 Satz 3 GG) ${ }^{3}$ ) und gegen die Vorschulen (Art. 7 Abs. 6 GG) 4 ) berührt. Ein subjektiv-öffentliches Recht auf Bildung 5) vermag freilich auch das Sozialstaatsprinzip nicht zu begründen. ${ }^{6)}$

Im übrigen sind die Möglichkeiten einer sozialstaatsgerechten Gestaltung des Bildungswesens - allgemeine oder ausnahmsweise Schulgeld- und Lernmittelfreiheit, Ausbildungsbeihilfen, Stipendien, Heime usw. - so vielfältig, daß nicht nachgewiesen werden kann, die Verfassung fordere eine gewisse Regelung positiv. ${ }^{7)}$

c) Das öffentliche Gesundheitswesen 1)

Soll das Bildungswesen die geistige Leistungsfähigkeit aller so weitgehend entfalten, als dies möglich ist, so soll das Gesund-

1) Zum sozialstaatlichen Bezug des Schul- und Bildungswesens s. Forsthoff, Begriff und Wesen des sozialen Rechtsstaats, S.26; Berger, Bedeutung und Tragweite des Grundsatzes vom sozialen Rechtsstaat, S. 6 .

2) Vgl. Ipsen, Anmerkung zu BVerfG Urt. v. 19. Dezember 1951 - 1 BvR 220/51 - S.218.

3) Zur Auslegung s. Peters, Fiternrecht, Erziehung, Bildung und Schule, S. 436 .

4) Zur Auslegung s. ebd., \$. $442 \mathrm{f}$.

5) S. hierzu Peters, a.a.O. S.400 f.

6) Vgl. oben S. $730 \mathrm{ff}$.

7) Vg1. Merk, Diskussionsbeitrag zu "Begriff und Wesen des sozialen Rechtsistaats", S. 101.

1) Werner (Anmerkung zu OVG Berlin, Urteil v. 2. Juni 1954 OVG I B 159/53 - S.564) sieht zu allgemein im Gesundheitswesen eine Konkretisierung des Sozialstaatsprinzips; s.a. 
heitswesen die körperliche Leistungsfähigkeit erhalten und wiederverschaffen ${ }^{2}$ ) und körperliche Leiden heilen und lindern. Das System der sozialen Sicherheit schließt seit je die medizinische Fürsorge ein. Das Arbeitsschutzrecht - das soweit es staatliche Leistungen vorsieht, in diesen Rahmen gehört - bemüht sich ebenfalls um die Erhaltung der körperlichen Leistungsfähigkeit. Mehr und mehr wurde aber auch der soziale Charakter der allgemeinen Gesundheitsfürsorge erkannt. Das Körperbehindertengesetz und das Tuberkulosehilfegesetz sind deutliche Zeichen dieser Entwicklung. Mütterberatung, Schulgesundheitspflege usw. gehen in dieselbe Richtung. Das sozialstaatlich Wesentliche daran ist: Die notwendige Gesundheitsfürsorge darf an der Mittellosigkeit des Bedürftigen nicht scheitern. Insofern wird hinter den erreichten Gesamtstand der öfentlichen Gesundheitspflege nicht mehr zurückgegangen werden dürfen.

\section{Das sozialstaatliche Verfahrensrecht}

\section{a) Allgemeines}

Gelegentlich wird behauptet, das Sozialstaatsprinzip erfordere allgemein eine laxe Handhabung der Verfahrensformalitäten gegenüber einem sozial bedürftigen Prozeßbeteiligten. 1) Das trifft nicht zu. Das Sozialstaatsprinzip ist, wie schon wiederholt bemerkt, nicht als bloßes Günstigkeitsprinzip zu handhaben.

Dagegen müssen die Möglichkeiten, die das Verfahrensrecht gibt - z. B. Wiedereinsetzung, Aufklärungs- und Belehrungsrechte und -pflichten ${ }^{2)}$-, voll ausgeschöpft werden, damit die durch seine soziale Position bedingten Behinderungen eines $\mathrm{Be}-$ troffenen in der verfahrensrechtlichen Wahrnehmung seiner Angelegenheiten ihm nicht zum Schaden gereichen. ${ }^{3)}$

BayVerfG VGHE n.F. 8 II 1 (8); Dürig, in Maunz-Dürig, Art. 2 Abs. II Randn. 39.

2) S. hierzu nochmals das oben S. 797 im Zusammenhang mit dem Recht auf Arbeit über die Pflicht des Staates zur Herstellung der Arbeitsfähigkeit Ausgeführte.

1) Vgl. Dersch, Der Verfassungsgrundsatz der Sozialstaatlichkeit und der Rechtsstaatlichkeit in der Sozialversicherung, S. 65 .

2) Zur sozial- und rechtsstaatlich bedingten, gesteigerten Pflicht der Verwaltung, den sozial Bedürftigen zu helfen, ihre Rechte zu wahren und durchzusetzen, s. BGH Urt.v. 26. September 1957 - III ZR 65/56 - NJW 10.Jhg. (1957) S. 1873; BVerwGE 10, 12 (15); Geiger, Grundrechte und Rechtsprechung, S. $29 \mathrm{f}$. 


\section{b) Das "Armenrecht"}

Eine inadäquate Benachteiligung darf dem sozial schlechter Gestellten auch nicht daraus erwachsen, daß der gerichtliche Rechtsschutz regelmäßig, der verwaltungsrechtliche Rechtsschutz nicht selten nur gegen Gebühr und in gewissem Umfang auch gegen Vorauslage der zu erwartenden Kosten gewährt wird. Die mit der Gewährung des Armenrechts verbundene vorläufige bedingte Kosten- und Gebührenfreiheit ist daher das unerläßliche soziale Gegenstück zu dieser Gebühren- und Kostenlast. 1)

Soweit Anwaltszwang besteht, muß das Armenrecht auch die Bestellung eines postulationsfähigen Prozeßvertreters für die "arme" Partei einschließen. Es würde dem "Verfassungsgrundsatz" des demokratischen und sozialen Rechtsstaats "widersprechen, wenn eine Partei lediglich durch Armut daran gehindert werden könnte, ihre Rechte vor Gericht geltend zu machen". 2) "Bemittelten und Unbemittelten" muß "im gesamten Ablauf des Verfahrens Gelegenheit gegeben" sein, "gleichermaßen alles für die Entscheidung des jeweiligen gerichtlichen Verfahrens Erhebliche vorzutragen". 3) Das kann u. U. die Beiordnung eines geeigneten Vertreters 4) für die "arme", zur vollwertigen Wahrnehmung ihrer Rech-

3) S. das maßvolle Rundschreiben des Reichsversicherungsamts v. 30.Juli 1941 - 1 1603/41 - 613 (RAB1. II S. 311) i.d.F. v. 7. Mai 1942 - 11603 - (RAB1. II S. 313), in dem "die Versicherungsträger ... auf das Erfordernis einer sozialen Rechtsanwendung besonders hingewiesen" werden.

1) (1) BVerfGE 1, 109 (111); 2, 336 (insbes. 340) - allerdings nur unter Berufung auf den Gleichheitsgrundsatz - ; 9, 124 (131); Ipsen, Diskussionsbeitrag zu "Begriff und Wesen des sozialen Rechtsstaats", S. 121; Berger, Bedeutung und Tragweite des Grundsatzes vom sozialen Rechtsstaat, S.6;

Tschisgale, Das Armenrecht im Verfahren vor der Sozialgerichtsbarkeit, NJW 10.Jhg. (1957), S.164 ff (164); Weidner, Ist der Ausschluß ler Armenanwaltsordnung in den unteren Instanzen der Sozialgerichtsbarkeit verfassungsmäßig? JZ 14. Jhg. (1959) \$. $622 \mathrm{f}$.

(2) Dagegen ist es abwegig, die Gebührenpflicht auch dann noch für sozialstaatswidrig zu halten, wenn ihre soziale Beschwer durch die Möglichkeit des Armenrechts ausgeräumt ist. Vgl. BVerf(iF 10, 264 (268 ff); s.a. BVerwG Urt.v. 6. Oktober 1959 - V C 414/57 - DÖV 12. Jhg. (1959), S.907.

2) BVerfGE 1, 111 .

3) BVerfGE 9, 131.

4) S. die berechtigten Bedenken gegen die Beiordnung von Ju- 
te nicht fähige Partei auch dann notwendig machen, wenn ein Anwaltszwang nicht besteht. 5) Wenn das Sozialgerichtsverfahren, das grundsätzlich keine Kosten- und Gebührenpflicht und in den unteren Instanzen auch keine Anwaltspflicht kennt, deshalb auch die Bestellung eines Armenanwalts nur für das Verfahren vor dem Bundessozialgericht zuläßt, 6) so ist das deshalb nicht unbedenklich in Anbetracht der Besonderheiten des sozialgerichtlichen Verfahrens, wie es gegenwärtig geregelt ist, jedoch noch hinzunehmen. ${ }^{7)}$

Daß die Gewährung des Armenrechts grundsätzlich von einer vorsichtigen, summarischen, in dubio pro petente zu endigenden Prüfung der Erfolgsaussichten der fraglichen Rechtsverteidigung abhängig gemacht wird, 8) ist nicht zu beanstanden. Wenn der Staat seine Hilfe gewährt, braucht er sie nicht blind zu gewähren. 9)

Die zunächst durch das Sozialgerichtsgesetz für das sozialgerichtliche Verfahren, 10) nunmehr durch die Verwaltungsgerichtsordnung für das verwaltungsgerichtliche Verfahren in Angelegenheiten der allgemeinen Fürsorge, der Tuberkulosehilfe und der sozialen Fürsorge für Kriegsopfer ${ }^{11)}$ eingeführte allgemeine Kostenbefreiung bedeutet einen gewissen Fortschritt. Eine sozialstaatliche Garantie dafür kann jedoch nicht angenommen werden.

Ein weiterer, sozialstaatlich wichtiger Aspekt des Verfahrensrechts ist der des Vollstreckungsschutzes. 1) Der Schuldner darf

stizbeamten bei Hiendl, Der Justizbeamte als Armenvertreter nach $\$ 116$ ZPO, NJW 13. Jhg. (1960), S. $1749 \mathrm{f}$.

5) Vg1. Tschischgale und Weidner je a.a.O.

6) $\$ \$ 183,167$ Abs. 1, 202 SGG. Zum interpretatorischen Streitstand s. BVerfGE 9, 127; Weidner, a.a.O. S.622.

7) BVerfGE 9, 124. A.A. Tschischgale und Weidner je a.a.O.Weidners Bedenken gegen die Begründung des Bundesverfassungsgerichts ist weitgehend zuzustimmen.

8) S. die Grundsatznorm des $\$ 114 \mathrm{ZPO}$.

9) BVerfGE 2, 336 (341); 9, 124 (131); 10, 264 (268 ff, insbes. 270 f); BayVerfGHE n.F. 3 II 65 (66f).

10) $\$ 183 \mathrm{SGG}$.

11) $\$ 188 \mathrm{VwGO}$.

1) Vgl. Maercks, Symbolische Urteilsvollstreckung, NJW 8.Jhg. (1955) S. $820 \mathrm{ff}$ (820); Berger, Bedeutung und Tragweite des Grundsatzes vom sozialen Rechtsstaat, S. 6. 
durch die Vollstreckung nicht um sein Existenzminimum gebracht werden. 2) Auch darüber hinaus wird dem Gläubiger ein Zuwarten oder eine Modifikation der Vollstreckung zugemutet werden können, wenn die Vollstreckung gerade in dem beabsichtigten Zeitpunkt und gerade in der beantragten Art und Weise den Schuldner in eine zum Recht des Gläubigers außer Verhältnis stehende soziale Notlage bringen würde. 3) Allerdings kann dem Gläubiger nicht auf Dauer die Last auferlegt werden, von der Durchsetzung seiner - wie nach dem Abschluß des Erkenntnisverfahrens zu unterstellen - materiell gerechtfertigten Ansprüche abzusehen, nur damit auf diese Weise der Allgemeinheit die Last der Armenfürsorge für den Schuldner erspart bleibt. Das wäre eine allzu zufällige soziale Garantie- und Opferposition des Gläubigers.

Die andere soziale Seite des Vollstreckungsrechts ist die bevorzugte Befriedigung von Lohnforderungen z. B. im Konkurs-4) und im Zwangsversteigerungsverfahren. 5) Das Problem darf unter dem sozialstaatlichen Aspekt nicht vernachlässigt werden.

7. Sozialstat und bürgerliches Recht

\section{a) Allgemeines}

Schon bisher wurde offenbar, welche soziale Aufgabe der Ordnung der zwischenbürgerlichen Rechtsbeziehungen für die Verwirklichung des Sozialstaats zukommt. 1) Das Miet- und Pachtrecht wurde bereits erwähnt, desgleichen der große Komplex der privat-

2) Vgl. $\$ \$ 811,850$ ZPO. - Dürig (Der Grundrechtssatz von der Menschenwürde, AöR B(l.81 (1956) S. 117 ff (133); MaunzDürig, Art. 1 Abs. I Ran(n. 44) hält dieses Existenzminimum gegenüber dem Vollstreckungsrecht schon durch den Grundsatz der Menschenwürle für gesichert und zwar unverzichtbar (!).

3) Vgl. die Generalklausel des $\$ 765$ a ZPO, die zwar nicht auf die Erfordernisse des Sozialstaatsprinzips zugeschnitten ist, diesen aber genügt. Fin besonderes, meist auch soziales Problem ist der Vollstreckungsschutz gegenüber Räumungstiteln (vgl. $\$ 721 \mathrm{ZPO}, \$ 5$ a MSchG, $\$ \$ 30$ f des Wohnraumbewirtschaftungsgesetzes).

4) Vg1. $\$ 61 \mathrm{Nr} .1 \mathrm{KO}$.

5) Vg1. $\$ 10$ Abs. $1 \mathrm{Nr} .2$ ZVG.

1) Zur sozialen Bedeutung des bürgerlichen Rechts s. nochmals die oben S. 13 zu Fußn. 43 f Zitierten; s.a. oben S.618 und S. 629 . 
rechtlichen Normen des Arbeitsrechts, der aus der Kodifikation des bürgerlichen Rechts ausgebrochen ist und sich zu einem durch die verfassungsrechtliche Kompetenzordnung in seiner Eigenständigkeit bestätigten, besonderen Rechtsgebiet entwickelt hat. 2) Ist es die Aufgabe des Sozialstaates, die wirtschaftlichen Spannungen auszugleichen und wirtschaftliche Machtstellungen zu entschärfen, ${ }^{3)}$ so ist diese Aufgabe nicht vollkommen erfüllt, wenn nicht auch das bürgerliche Recht von ihr durchdrungen ist. ${ }^{4}$ )

Das geltende bürgerliche Recht entspricht dem sozialstaatlichen Postulat - von den schon erwähnten besonderen Rechtsgebieten und zahlreich verstreuten Einzelbestimmungen abgesehen - weniger durch ausdrückliche Regelungen als durch seine Generalklauseln (insbes. $\$ \$ 133,138,157,242,836$ BGB, $\$ 1$ UWG). Sie haben sich als das wichtigste Einfallstor der sozialen Gerechtigkeit in die bürgerliche Rechtsordnung erwiesen. Und sie sind in der Gegenwart die Umschaltestellen, in denen die "Drittwirkung" der Grundrechte und des Sozialstaatsprinzips realisiert wird. ${ }^{5}$ ) Sie erlauben die sozialstaatlich notwendigen Einschränkungen der Rechtsausübung und der Vertragsfreiheit. 6)

\section{b) Sozialstaat und Vertragsfreiheit}

Die Vertragsfreiheit, Angelpunkt der bürgerlichen Rechtsordnung, durch die Grundrechte (insbes. Art. 2 Abs. 1 GG) aufgerichtet ${ }^{1)}$ und durch das Sozialstaatsprinzip nicht grundsätzlich aufgehoben, 2) darf der soziale Staat nicht nur einschränken; ${ }^{3)}$

2) S. oben S.62 ff, insbes. S. 63 zu Fußn. 1 und S. 67 zu Fußn. $17 \mathrm{ff}$.

3) Vg1. Krause, Allgemeine Geschäftsbedingungen und das Prinzip des sozialen Rechtsstaats, S. 268 f; Olbersdorf, Sozialer Rechtsstaat und Arbeitsrecht, S. 135; Laufke, Vertragsfreiheit und Grundgesetz, S. 185 f.

4) S. insbes. Herschel, Arbeitsschutz im sozialen Rechtsstaat, S. 579 ff; s.a. Hamann, Das Grundgesetz, Einführung I D 2 (S. 31).

5) S. insbes. oben S. 735 ; s.a. oben S.618 und unten Abschn:tt 6 I 4 d (S.876 ff).

6) Werner (Sozialstaatliche Tendenzen in der Rechtsprechung, S. $101 \mathrm{f}$ ) weist zu Recht auf die Aufwertungsrechtsprechung als Vorläufer sozialstaatlichen Ausgleichs hin. Sie wurde bekanntlich aus $₫ 242$ BGB heraus entwickelt.

1) S. f.v.a. Dürig in Maunz-Dürig, Art. 2 Abs. I Randn. 53 ff.

2) S. insbes. Raiser, Vertragsfreiheit heute, JZ 13.Jhg. (1958)

S. 1 ff (4ff); s.a. Wieacker, Besprechung zu "Spiros Simitis, Die faktischen Vertragsverhältnisse", JZ 14.Jhg. (1959) s. ¿82 f. 
er $m u ß$ sie einschränken, wenn anders sie zur unsozialen Ausnutzung wirtschaftlicher Machtpositionen führen würde. 4) 5) Welche Einschränkungen demnach im einzelnen notwendig sind, hängt sehr von den Umständen ab. Das gilt insbes. von den preis- und bewirtschaftungsrechtlichen und den sonstigen der Wirtschaftslenkung dienenden Einschränkungen. Als am wichtigsten haben sie sich im Arbeitsrecht erwiesen. Auch das Mietrecht und das Pachtrecht können nicht darauf verzichten. Unerläßlich sind auch die Einschränkungen der Vertragsfreiheit der Monopolisten ("marktbeherrschenden Unternehmen"). 6)

\section{c) Sozialstaatsprinzip und Schadensersatzrecht}

Verlust der Gesundheit und Arbeitskraft und Verlust des Unterhalt gewährenden Vermögens sind die sozialen Risiken. Das Recht muß Vorsorge treffen, daß sie möglichst umfassend gedeckt sind. Es hat auch den privaten Schädiger heranzuziehen. Problematisch ist dabei vor allem die Abgrenzung zwischen Verschuldens-, Gefährdungs- und Verursachungshaftung, der Schutz des potentiellen Schädigers vor seinem Haftungsrisiko, das ihn ruinieren kann, und insofern auch der Ausgleich der Interessen zwischen Schädiger und Geschädigtem. Das Recht der Pflichtversicherung wird hier in seiner sozialen Tragweite deutlich. Nicht

3) S. z.B. Dürig, a.a.O. Randn. $60 \mathrm{ff}$ mit eingeh. Nachw. (Dürig geht a.a.O. aber von der hier nicht geteilten Annahme einer "Beweispflichtigkeit" des Staates für die Zugehörigkeit einer Einschränkung zu seinem Sozialauftrag, den er nicht eindeutig im engeren Sinne der Sozialstaatlichkeit versteht, aus.) S.a. BVerfGE 8, 274 (329); BVerwGE 1, 321 (324).

4) S. Krause, Allgemeine Geschäftsbedingungen und das Prinzip des sozialen Rechtsstaats, S. 268 f; Geiger, Grundrechtliche Schranken für eine Kartellgesetzgebung, 1955, S.9 f; Laufke, Vertragsfreiheit und Grundgesetz, S. 185 f; s. insbes. Raiser, a.a.O., insbes. S. 6 ff mit weit. Nachw. Vgl. im übrigen nochmals Dürig, a.a.O., insbes. Randn. $58 \mathrm{ff}$.

5) Eine strafrechtliche Parallele erwähnt Nipperdey (Diskussionsbeitrag zu "Begriff und Wesen des sozialen Rechtsstaats", S.98). Er weist auf die Unentbehrlichkeit der Strafbestimmungen gegen den Wucher hin.

6) S. nunmehr insbes. $\$ \$ 22,25$ ff des Gesetzes gegen Wettbewerbsbeschränkungen. Vgl. nochmals die oben zu Fußn. 3 Zitierten. Eine andere Frage ist die Kartellfrage; s. hierzu noch unten 9 ( $\mathrm{S} .835 \mathrm{ff}$ ). 
zuletzt soziale Bedeutung haben die Billigkeitsklauseln der $\$ \mathbb{\$}$ 829, 847 BGB. 1) Eine weniger "soziale" Gestaltung des deliktischen Schadensersatzrechts könnte eine Grenze erreichen, an der das Sozialstaatsprinzip Halt gebietet.

\section{d) Das Problem der Unterhaltspflicht}

Der Sozialstaat, der mit der Existenz und Funktionsfähigkeit der Familie ausgesprochen rechnet (Art.6 GG), wird - schon um die Familie als Lebensgemeinschaft zu respektieren - die Familie als den engsten sozialen Garantieverband betrachten. Das heißt aber nicht, er könne sich dadurch seiner Verantwortung entwinden. Der unterhaltsberechtigte Bedürftige muß, wenn er von "seinem" Unterhaltsverpflichteten einen ausreichenden Unterhalt nicht erlangen kann, vom Staat versorgt werden und zwar, von einem eventuellen Rückgriff auf den Verpflichteten abgesehen, nicht anders als einer, der von vorneherein auf sich allein gestellt war. Das ist die öffentlichrecht1iche Seite. Das eigentlich bürgerlichrechtliche Problem ist das der Ausgestaltung des Unterhaltsanspruches. Es ist ein soziales insofern als der Berechtigte ebenso angemessen versorgt und vor Not bewahrt werden soll wie der Garant nicht zugunsten der gegen ihn Berechtigten um seinen eigenen Unterhalt gebracht werden darf. 1) Feste Regeln lassen sich vom Sozialstaatsprinzip her jedoch nicht gewinnen. Vor allem kann die Hilfsbeziehung des Staates zu dem Garantieverband, dem einzelnen Garanten und dem Bedürftigen sehr verschieden gestaltet werden; und das wirkt sub specie des Sozialstaatsprinzips auch auf die familieninternen Beziehungen zurück.

8. Die (sozial-) staatliche Mittelbeschaffung

a) Sozialstaat und Abgabenrecht

\section{aa) Zum Steuerrecht}

Das allgemeinste Mittel, den Sozialstaat umfassend zu verwirklichen, ist das Steuerrecht. 1) Zwar ist es keineswegs nur Um-

1) Zu $₫ 829$ BGB s. Hedemann, Was ist sozial? Der Arbeitgeber, Jhg. 1956, S. 198 ff (200); zu $₫ 847$ BGB s. BGHZ 18, 149 (162).

1) Dürig (Der Grundrechtssatz von der Menschenwürde, S. 133; Maunz-Dürig Art. 1 Abs. I Randn.44) entnimmt eine entsprechende Beschränkung aus Art. 1 Abs. 1 GG.

1) Zur engen Verbindung von Sozialstaatsprinzip und Steuerrecht s. Bachof, Begriff und Wesen des sozialen Rechtsstaats, S. 48 . 
verteilungsinstrument sondern dient allgemein der Aufbringung der Gemeinlasten. Aber es dringt umfassender und tiefer in den Raum der individuellen Einkommen und Vermögen ein als irgend ein anderes Investitionsinstrument - von den unter dem Grundgesetz nicht in Betracht zu ziehenden Systemen eigentumsfeindlicher Vollplanung abgesehen. Es enthält darüber hinaus eine kaum überschaubare Vielfalt an Möglichkeiten, einzelne soziale Belange gezielt zu fördern. Die Steuer dringt in die Privatsphäre aber auch am schonendsten ein, weil sie die Auswahl der zur Deckung des Abgabesolls zu treffenden Erwerbsmaßnahmen und Konsumbeschränkungen oder Vermögensminderungen dem Pflichtigen überläßt. Sie erspart vor allem - wenigstens im allgemeinen - den Konflikt mit dem Eigentumsschutz, 2) ist zuverlässig an allgemeinen Maßstäben zu orientieren und erfreut den rechtsstaatlichen "Geschmack" so durch etwas, was man "rechtștaatliche Appetitlichkeit" nennen könnte. 3) Sie spiegelt sich auch auf der Ausgabeseite. Nicht nur läßt das Steueraufkommen dem Staat die größtmögliche Dispositionsfreiheit, insbes. - wenigstens unter normalen wirtschaftlichen Verhältnissen - die Wahl zwischen Geld- und Sachleistungen. Es erlaubt ihm gerade die Geldleistungen, die ihrerseits die Dispositionsfreiheit des Empfängers mehr schonen als unmittelbare Sachleistungen. Der Sozialstaat kann daher schon als freiheitlicher Rechtsstaat nicht auf das steuerrechtliche Instrumentarium verzichten.

Das sozialstaatliche Steuersystem muß das höhere Einkommen und das größere Vermögen wenigstens proportional stärker belasten als das niedrigere. $\left.{ }^{4}\right)$ Darüber, wie dieses System im einzelnen zu gestalten ist, sagt das Sozialstaatsprinzip nichts aus. 5) Doch dürfte eine Umstellung auf eine reine Verbrauchs-

2) S. hierzu unten S. $987 \mathrm{fr}$.

3) S. hierzu schon oben $s .14$ zu Fußn. 46 ff und den Text hier$\mathrm{zu}$.

4) Paulick (Grundgesetz und Besteuerung, S.92) glaubt aus dem Sozialstaatsprinzip 1.V.m. dem Gleichheitsgrundsatz entnehmen zu können, laß auch unter dem Grundgesetz der Sache nach gilt, was Art. 134 RV 1919 ausdrücklich vorgeschrieben hat: "Alle statsbürger ohne Unterschied tragen im Verhältnis ihrer Mittel zu allen öffentlichen Lasten nach Maßgabe der Gesetze bei". - An dieser Wirkung des Sozialstaatsprinzips zweifelnd jedoch ders., Der Grundsatz der Gleichmäßigkeit der Besteuerung, S. 161.

5) Zur sozialen Problematik des Steuersystems s. nochmals die oben S. 16 zu Fußn. 51 Zitierten. 
besteuerung ausgeschlossen sein. ${ }^{6)}$ Vor allem dürfte auf eine Einkommensbesteuerung nicht verzichtet werden können. Die Einkommensteuer ist an Gerechtigkeitswert und sozialpolitischer Bedeutung jeder anderen Steuer überlegen.

Eine andere Frage ist, ob die Progression des Einkommensteuertarifs sozialstaatlich notwendig ist. 7) An sich stellt sie das allgemeinste Mittel dar, um schon durch die Lastenverteilung den "Reichen" (die Differenz zwischen Proportional- und Progressivtarif) zu nehmen und ganz allgemein allen "Armen" (die Differenz zwischen dem Proportional- und dem Degressivtarif) $\mathrm{zu}$ geben. Insofern erscheint sie a priori als ein unverzichtbares Instrument sozialen Ausgleichs. Daß es wiederum nur diejenigen erfaßt, die überhaupt über ein Einkommen verfügen, würde jedenfalls dann noch nicht gegen die sozialstaatliche Notwendigkeit der Progression zu Buch schlagen, wenn zu den Einkommensbeziehern auch die Empfänger abgeleiteter Einkommen hinzugerechnet würden. Aber es kann ohnedies nicht übersehen werden, daß der Schein des unmittelbaren Redistributiveffektes der einkommensteuerlichen Progression durch die Wirklichkeit jedenfalls nicht voll bestätigt wird. ${ }^{8)}$ Über die Fort- und Rückwälzung der Einkommensteuerlast wird der Redistributiveffekt zumindest abgeschwächt bzw. in schwer überschaubaren, vom Recht kaum

6) S. zu Art. 134 RV 1919 Bühler, "Art. 134. Gleichheit der Lastenverteilung" in Nipperdey, Die Grundrechte und Grundpflichten der Reichsverfassung, Bd.2, 1930, S.313 ff (316); Anschütz, Die Verfassung des Deutschen Reiches, Art. 134 Abs. 2 Fußn. 1.

7) Maunz (Die Finanzverfassung im Rahmen der Staatsverfassung, S. 59) hält eine "soziale Ausgestaltung der Steuer durch angemessene Progression" für notwendig. S.a. Berger, Bedeutung und Tragweite des Grundsatzes vom sozialen Rechtsstaat, S.6. Bühler (a.a.O. S. 314) glaubte, die Notwendigkeit der Progression schon aus Art. 134 RV 1919 entnehmen zu sollen. In BVerfGE 6, 55 (70) spricht das Bundesverfassungsgericht davon, seit dem ersten Weltkrieg habe "sich der Gedanke durchgesetzt", "daß bei den direkten Steuern die Steuergerechtigkeit eine steilere progressive Staffelung des Steuertarifs erfordere", während vordem "die Progression des Tarifs sehr bescheiden gewesen" sei. Diese Äußerung läßt aber keine definitive Ansicht des Bundesverfassungsgerichts über die verfassungsrechtlich notwendige Gestaltung des Steuersystems erkennen.

8) S. die oben S. 16 zu Fußn. 51 Zitierten. 
beherrschbaren Bahnen fortgetragen. 8) Er wird aber auch durch die herkömmliche Gestaltung der Einkommensteuer selbst gemildert. Je höher die Untergrenze der Einkommensbesteuerung liegt und je größer die speziell den kleinen Einkommensbeziehern zustehenden sonstigen Vergünstigungen sind, desto mehr werden die kleinen Einkommensbezieher nicht durch die direkte Degression sondern durch die Einkommensteuerfreiheit und die indirekte Degression entlastet. Andererseits wirken sich die steuerlichen Freibeträge durch die Progression in den höheren Einkommensstufen stärker aus als in den unteren. Dazu kommt der $\mathrm{Zu}$ sammenhang mit dem Gesamtsteuersystem, dessen Verbrauchssteuern den Redistributiveffekt der Einkommensteuer insgesamt verwässern. Wird schließlich die Ausgabeseite des Staatshaushalts noch in Zusammenhang mit der Einnahmeseite gebracht und beobachtet, in welchem Maße die Umverteilung über die öffentliche Hand die Belastungen der unteren Einkommensschichten wieder ausgleicht, so verdichtet sich der Eindruck, daß der Progression kein übertriebener Eigenwert beigemessen werden darf. Es kommt immer auf die Gestaltung der Einkommensteuer, auf die Gestaltung des Gesamtsteuersystems und auf den Ausbau des Systems der öffentlichen Leistungen an.

Damit verliert allerdings das Sozialstaatsprinzip an steuerpolitischem Gewicht. Wo sich eine Benachteiligung der sozial schwächeren Schichten durch eine bestimmte Steuer ergibt, die nicht anderweit korrekt ausgeglichen ist, kann dieser Regelung jedoch das Verfassungsverbot des eindeutig "unsozialen Handelns unschwer entgegengehalten werden". 9)

Der Sozialstaat muß schließlich - wie schon die Problematik der einkommensteuerlichen Progression zeigt - nicht nur darauf bedacht sein, gerecht und ausreichend zu "nehmen" sondern auch gerecht und a usreichend zu belassen. Weder durch übermäßige Progression noch durch zu geringes Nachlassen der Steuerbelastung nach unten (larf er den Besteuerten in seiner Existenz gefährden. 10)

9) Der Verstoß muß dabei keineswegs so extrem sein wie in dem von Schüle (Diskussionsbeitrag zu "Begriff und Wesen des sozialen Rechtsstaats" S. 107) gebrachten Beispiel, wonach Einkommensteuer nur noch bei schlecht Verdienenden erhoben wird.

10) Vgl. Paulick, Die verfassungsrechtlichen Bindungen des Gesetzgebers beim Erlaß von Steuergesetzen, S. 491 ff; ders., Der Grundsatz der Gleichmäßigkeit der Besteuerung - sein Inhalt und seine Grenzen, S. 152 f; s.a. Maunz, a.a.O. S. 59. 
bb) Das sonstige Abgabenrecht 1 )

Aus dem Bereich des übrigen Abgabenrechts ist die Gestaltung des $G$ e büh ren rechts von besonderer sozialer Bedeutung. Von seiner Gestaltung hängt es $a b$, ob und in welchem Maße die Minderbemittelten von den gebührenpflichtigen Leistungen ausgeschlossen sind. ${ }^{2}$ )

Das Recht der B e it $r$ äge im herkömmlichen Sinn ist ob der arteigenen reinen Objektivität des Beitragsgrundes und der Beitragsbemessung sozialen Erwägungen weniger zugängig. Jedoch müssen die bestehenden Möglichkeiten auch hier ausgeschöpft werden. ${ }^{3)}$

Dagegen gehört die soziale Staffelung zum Wesen der Sozialversicherungs beiträge. ${ }^{4)}$ Sie unterliegt wohl auch der "labilen Garantie", deren die Sozialversicherung unter dem Sozialstaatsprinzip selbst teilhaftig ist. $\left.{ }^{5}\right)$

Für Kammerbeiträge und ähnliche Verbandssteuern wird nach Zweck des Verbandes, Grund der Mitgliedschaft, Differenziertheit der Mitgliedschaft - insbes. sub specie des Verbandszwecks - und Verwendungszweck der aufgebrachten Mittel das sozialstaatlich Notwendige von Fall zu Fall verschieden zu beurteilen sein.

b) Sozialstaat, Enteignung und Eigentumsbindung

Das rein monetäre Ausgleichsinstrumentarium reicht für eine

Dürig (in Maunz-Dürig Art. 1 Abs. I Randn.44) leitet die Pflicht der "Finanzgewalt" zur Erhaltung des Existenzminimums aus der Grundrechtsordnung ab. - Zur sozialstaatlichen Pflicht zur Herstellung bzw. Erhaltung des Existenzminimums s. oben S.679 zu Fußn.5. - Zum Problem s.a. Haas, System öffentlichrechtlicher Entschädigungspflichten, S.27: "die geforderte Leistung ist in ein ... richtiges Verhältnis $\mathrm{zu}$ den Mitteln des Pflichtigen zu bringen; und die Last des Normadressaten muß sich im ... richtigen Verhältnis zu den Lasten der übrigen Bürger halten".

1) S. zum Folgenden die eingehenden Darlegungen von Barocka, Die Berücksichtigung sozialer Gesichtspunkte bei der Erhebung von Gebühren und Beiträgen usw., S. 826 ff.

2) S. hierzu schon oben 5 (S.820 ff) und S. 823 .

3) S. insbes. Barocka, a.a.O.

4) S. oben S.52 ff und in diesem Abschnitt oben S.769ff und S. $778 \mathrm{f}$

5) S. oben S. $778 \mathrm{ff}$. 
voll ausgelebte soziale Intervention nicht aus. Es ist dem Sozialstaat weder möglich noch entspricht es seinem Wesen, alle Güterverschiebungen und Eigentumsbeschränkungen zu "erkaufen". Das maßgebliche Regulativ für die soziale Inanspruchnahme des Eigentums beinhalten die Art. 14, 15 GG. Auf deren Bedeutung und somit auf den Kern des Problems wird unten zurückzukommen sein. 1) Doch seien drei Punkte hervorgehoben, die für das Verhältnis zwischen Sozialstaatlichkeit und Eigentumsrecht charakterisierend sind.

Zunächst ist darauf hinzuweisen, daß der Sozialstaat nicht direkt $\mathrm{zu}$ bestim $\mathrm{m}$ ten Enteignungsmaßnahmen oder auch Eigentumsbeschränkungen verpflichtet ist. ${ }^{2)}$ Er hat seine sozialen Pflichten zu erfüllen und dabei, soweit notwendig, auch in das Eigentum einzugreifen. ${ }^{3)}$ Aber der Verfassungsgrundsatz der Sozialstaatlichkeit hat nicht unmittelbar ein gewisses Eigentum beseitigt oder dessen Beseitigung oder Umgestaltung bindend vorgeschrieben. ${ }^{4)}$

Zweitens muß klargestellt werden, daß es weder für das zulässige Maß der Belastungen und Beschränkungen des Eigentums noch für die Höhe einer Enteignungs- oder Sozialisierungsentschädigung gleichgültig sein kann, ob eine bestimmte Belastung oder ein bestimmter Eingriff in das Eigentum sozialstaatlich geboten ist oder nicht. 5) Die Bürgerpflicht zum sozialen Verhalten ist nicht eine allgemeine Cremeinverpflichtung der Gemeinschaftsglieder sondern eine Pflicht, sich speziell der Verwirklichung des Sozialstaates zu fügen. ${ }^{6}$ ) Nur so ist sie das entscheidende Pendant zum sozialen "Anspruch" der Bürger gegen den Staat. Nur so stellt sie eine spürbare Unterstützung der sozialstaatlichen Selbstverwirklichung gegenüber dem Widerstand, der ihr von seiten der individuellen Rechtspositionen her entgegengegebracht wird, dar. Es wäre eine Fortsetzung des Mißverständ-

1) S. unten Abschnitt 6 III (S.934 ff).

2) S. oben S.814 zu Fußn. 4

3) S. oben $4(\mathrm{~S} .810 \mathrm{ff})$.

4) Vgl. Ipsen, Fnteignung und Sozialisierung, S. 120: "Das Grundgesetz ist - außer in Art. 139 - indifferent gegenüber vorgängigen sozialen Umwälzungen und Kriegsfolgen. Es enthält insoweit weder unmittelbare positive Gestaltungen noch (negativ) Ablösungen erworbener Rechte". - S. hierzu auch unten Abschnitt 6 III 2 (S.935 ff) a.E.

5) S. vor allem Knoll, Eingriffe in das Eigentum im Zuge der Umgestaltung gesellschaftlicher Verhältnisse, insbes. AöR Bd. 79 S. $460 \mathrm{ff}, 475 \mathrm{ff}, \mathrm{Bd} .81 \mathrm{~S} .386 \mathrm{ff}$.

6) S. oben II $1 \mathrm{~b}(\mathrm{~S} .684 \mathrm{ff})$ und $\mathrm{c}$ bb $(\mathrm{S} .701)$. 
nisses, die aus dem Verfassungsbekenntnis zum sozialen Staat $z u$ entnehmende Sozialpflicht der Bürger als eine allgemeine ("nationale") Gemeinverpflichtung zu begreifen, wenn dem Eigentum die gleiche Resistenz gegenüber sozialen Umschichtungen wie gegenüber anderen Maßnahmen zugeschrieben würde. Entscheidend ist, daß sich die Belastung oder Wegnahme des Eigentums schon nach Objekt und Subjekt als eine soziale Maßnahme ausweist und rechtfertigt. Allein die Zweckbestimmung eines Eingriffes von einem sozialen Mangel her gibt ihm noch keinen sozialen Vorzug gegenüber dem angegriffenen Eigentum. Das Eigentum selbst muß - und das ist wohl immer nur in Würdigung des gesamten Eigentums seines Subjekts möglich - sozial "mißbilligt" und "anfällig" sein. 7) Ess muß jenem Überfluß angehören, den der Sozialstaat abbauen muß, um die sozialen Mangelsituationen zu beheben. Wer sonstwie Opfer bringen muß, um die Verwirklichung des Sozialstaats zu ermöglichen, der ist voll zu entschädigen. Der Sozialstaat ist eine Sache der Gemeinschaft, nicht eine Sache der zufällig in seinem Wege stehenden Einzelpersonen. 8) Der Grundsatz der Lastengleichheit 9) führt auch hier auf den richtigen Weg. 10)

Schließlich ist noch darauf hinzuweisen, daß die Enteignung nicht zu einem Rollentausch führen darf, wie er für die "Herrschaft des Proletariats" typisch ist. "Eine Bodenreform z. B. in der Form, daß nunmehr der bisherige Grundbesitzer betteln gehen müßte, ist im Sozialstaat nicht möglich, weil er kein rächender Verteilerstaat ist, sondern nur ein sorgender Aufbaustaat". 11) Den Belasteten muß eine erträgliche, angemessene Lebenshaltung und, wenn es wirklich notwendig sein sollte, bis zu dieser Grenze zu gehen, das Existenzminimum erhalten bleiben. 12)

7) S. vor allem Knoll, a.a.O. Bd. 79 S. $480 \mathrm{ff}$, Bd. 81, S. $415 \mathrm{ff}$. Vgl. ferner v. Mangoldt, Diskussionsbeitrag zu Enteignung und Sozialisierung, VVDStRL. H. 10, 1952, S. 150 ff (152).

8) Vg1. Maunz, Das Verhältnis des Baulandentschädigungsgesetzes zum Grundgesetz, 1955, S. 15 f; s.a. Ipsen, Enteignung und Sozialisierung, S. $90 \mathrm{f}$.

9) Vgl. Ipsen, Gleichheit, S. 195 f; Haas, System öffentlichrechtlicher Entschädigungspflichten, S. 22 ff.

10) S. zum Zusammenhang von Sozialstaat, Eigentumsschutz und Gleichheitssatz auch Werner, Sozialstaatliche Tendenzen in der Rechtsprechung, S.100; Knoll, a.a.O. Bd.81 S. $399 \mathrm{ff}$.

11) Wolany, Vom Sozialstaat und sozialen Recht, S. 153.

12) S. Oben S.831 zu Fußn. 10. 
Wenn das nicht durch die Belassung der fraglichen Güter bewirkt werden kann, so muß es eben durch die Entschädigung sichergestellt werden. 13)

c) Sozialstaat und persönliche Indienstnahme

Für die pflichtweise Indienstnahme privater Subjekte durch den Staat muß ebenfalls der Grundsatz der Lastengleichheit die entscheidende Richtschnur bilden. 1) Das gilt vor allem auch für die Entschädigungsfrage. Die öffentliche Indienstnahme darf nicht zur Verarmung der Betroffenen führen. Keinesfalls darf das Existenzminimum unterschritten werden. In der Gegenwart sind das Unterhaltssicherungsgesetz (betreffend den Unterhalt der Angehörigen eingezogener Wehrpflichtiger) und die Sonderversorgung für Kriegsopfer, Soldaten der Bundeswehr und sonstwie zwangsweise in den Dienst der Öffentlichkeit genommener Personen 2) aktuelle Beispiele für das Bemühen des Staates, hierin den Anforderungen sozialer Gerechtigkeit zu entsprechen. 3)

\section{Sozialstaat und Wirtschaftsordnung 1)}

a) Sozialstaatsprinzip und Wirtschaftsverfassung

Das soziale Problem ist zu allererst ein ökonomisches. Der soziale Staat hat sich daher in erster Linie in der Gestaltung der Wirtschaftsordnung zu verwirklichen. Er kann sich nicht auf Umverteilungsvorgänge, auf soziale Hilfen und auf den sozialen Schutz im Rahmen bestimmter zwischenbürgerlicher Beziehungen zurückziehen. Das würde zu einer Überbelastung des Staates als sozialem Leistungsträger führen und dabei doch erhebliche Lücken im System des sozialen Schutzes lassen. Je unbefriedi-

13) S. zu Vorstehendem insbes. auch Scheuner, Verfassungsschutz des Eigentums, S.136; Knoll, a.a.O. Bd.81 S.408ff.

1) Vgl. Ipsen, Gleichheit, \$. $195 \mathrm{f}$; insbes. aber dens., Die gesetzliche Indienstnahme Privater, in "Um Recht und Gerechtigkeit", Festschrilt lïr. Erich Kaufmann, 1950, S. $141 \mathrm{ff}$, insbes. S. $154 \mathrm{ff}$; Haas, System öffentlichrechtlicher Entschädigungspflichten, S. 20 \%, 22 f.

2) S. oben S. $771 \mathrm{ff}$.

3) S. im übrigen nochmals oben 3 c (S. 800 ff) ("Pflicht zur Arbeit").

1) Zu diesem Abschnitt clarf vorweg noch einmal auf das oben S.31 ff Ausgeführte Bezug genommen werden, insbes. auch auf die Beschränkungen, die sich diese Untersuchung hinsichtlich der "internen" Problematik der staatlichen Ordnung der Wirtschaft auferlegen muß. 
gender der allgemeine wirtschaftliche Zustand ist, desto mehr breitet sich die Abhängigkeit vom Staate aus. So unerläßlich die "soziale Sicherheit" ist, die Basis eines befriedigenden sozialen Zustandes muß die Möglichkeit eines jeden sein, seinen Bedarf angemessen durch seine Teilnahme am Wirtschaftsleben zu decken. ${ }^{2)}$ Nur auf dieser Grundlage kann der soziale Staat seiner Aufgabe dauerhaft und umfassend gerecht werden. "Die Ordnung des Wirtschaftslebens muß den Grundsätzen der Gerechtigkeit mit dem Ziele der Gewährleistung eines menschenwürdigen Daseins entsprechen". Diese Maxime des Art.151 RV 1919 breitet aus, was das Grundgesetz in seinem Bekenntnis zum sozialen Staat impliziert. 3 )

Der Staat, der diesen Auftrag hat, kann $\mathrm{nicht}$ wirtschaftspolitisch neutral sein. ${ }^{4)}$ Er muß kontrollieren und gestalten.

Die Mittel, die er verwendet, sind ihm nicht vorgeschrieben, "sofern er dabei (nur) das Grundgesetz beachtet". 5) "Das Grundgesetz" beschränkt ihn durch die Grundrechte, durch die sonstige rechtsstaatliche, die demokratische und die föderative Ordnung und eben durch das Sozialstaatsprinzip, das aber gerade auch hier nicht als ein Rezeptbuch für einzelne Programme mißbraucht werden darf.6) Er wird deshalb von einer zentralgeplanten $Z$ wangswirtschaft absehen müssen. Sie würde allzuleicht die Menschenwürde gefährden (Art.1 Abs.1 GG) und steht damit schon mit dem Sozialstaatsprinzip selbst in einem gewissen - freilich nicht sehr deutlichen-Gegensatz. 7) Vor allem aber verstößt sie gegen die freiheitliche Grundrechtsordnung. Dadurch ist der Staat aber nicht auf ein System staatlich unbeeinflußter, liberaler Marktwirtschaft festgelegt. Zwar schließt

2) Vg1. vor allem Ballerstedt, Wirtschaftsverfassungsrecht, S. 50 f, insbes. S. 54 und S. 60 .

3) S. nochmals die oben S.678ff zu Fußn. 3 bis 6 (insbes. die Fußn.6) Zitierten. - Zum Sozialstaatsprinzip als einem Leitgrundsatz der Wirtschaftsverfassung s. außer Ballerstedt, a.a.O. und den nachfolgend noch zu Zitierenden: Hamann, Deutsches Wirtschaftsverfassungsrecht, S. 14 und 16; Voigt, Wirtschaftsverfassungsrecht und Wirtschaftsentwicklung in der Bundesrepublik Deutschland, in "Staat und Bürger", Festschrift für Willibalt Apelt, 1958, S.73 ff, insbes. S. 78 f.

4) Vg1. Ballerstedt, a.a.O. S.60.

5) BVerfGE 4, 7 (18).

6) S. hierzu und zum Folgenden oben S. 34 und die dortigen Nachweise.

7) Zurückhaltend Hamann (Rechtsstaat und Wirtschaftslenkung, S.28). 
keine Bestimmung des Grundgesetzes eine liberale Marktwirtschaft ausdrücklich aus. Auch das Sozialstaatsprinzip ist nicht a priori gegen die Marktwirtschaft gerichtet. Ihm geht es immer nur um die Sache, um die Vermeidung sozialer Mißstände und die Erreichung eines sozialen Optimum. Es ist aber eine Binsenwahrheit, daß der soziale Staat, würde er die Wirtschaft wirklich dem liberalen Modell gemäß sich selbst überlassen, alsbald Grund hätte, korrigierend einzugreifen. Der soziale Staat kann sich nicht aus der Ordnung der Wirtschaft zurückziehen. Zwischen Zwangswirtschaft und reiner Marktwirtschaft hat er - die Grundrechte, die Rechtsstaatlichkeit, Demokratie und Bundesstaatlichkeit nicht weniger achtend als seinen sozialen Auftrag seine Bahn zu nehmen. ${ }^{8}$ )

Eine nähere Festlegung ist der Verfassung nicht zu entnehmen. Insbes. ist der soziale Staat des Grundgesetzes nicht auf die wirtschaftspolitischen Postulate der sog. "sozialen Marktwirtschaft" 9) festgelegt. 10) Der Satz "Das Sozialstaatsprinzip fordert ... die staatliche Durchsetzung der Marktwirtschaft" 11) ist schlechterdings durch nichts beweisbar. Die von der Theorie der "sozialen Marktwirtschaft" allein zugelassenen "marktkonformen" Mittel 12) sind durch nichts als das unter der Herrschaft des Grundgesetzes ausschließlich zulässige Instru-

8) Für die gemischte Wirtschaftsverfassung s. die oben S.37 zu Fußn. 8 Zitierten.

9) Vgl. zusammenfassend und mit den wesentlichen Nachweisen Müller-Armack, Art. "Soziale Marktwirtschaft" im Handwörterbuch der Sozialwissenschaften, Bd.9, 1956, S.390 ff.

10) Für die "soziale Marktwirtschaft" als das verfassungsrechtlich zwingend gebotene Wirtschaftssystem ist vor allem Nipperdey eingetreten (vgl. die oben S. 33 zu Fußn. 11 zitierten Werke dieses Autors). Dagegen s. außer BVerfGE 4, 7 (17f) und den oben S. 37 zu F'ußn. 8 Zitierten: v. Mangoldt-Klein, Art.2 Anm. III 8; Ballersterlt, Wirtschaftsverfassungsrecht, S.60. Weitere eingehende Nachweise s. bei den Zitierten.

11) Nipperdey, Die soziale Marktwirtschaft in der Verfassung der Bundesrepublik, S. 18.

12) Müller-Armack, a.a.(). \$.391: "Der Begriff 'marktkonform' mag in Grenzfällen unbestimmt sein, dürfte jedoch in der praktischen Wirtschaftspolitik zur Kennzeichnung von Verfahren genügen, bei denen auf die Funktion des Marktes Rücksicht genommen wirl". Zur marktkonformen und -inkonformen Intervention s. neuerdings Rau, Wirtschaftslenkende Verwaltung, S.341 ff. 
mentarium staatlicher Wirtschaftspolitik ausgewiesen. 13) Der Staat des Grundgesetzes kann grundsätzlich auch mit anderen, "marktinkonformen" Mitteln lenkend intervenieren und er muß es, wenn er eine soziale Notwendigkeit dafür erkennt. 14)

\section{b) Einzelprobleme}

Auf die Ziele, die der sozialstaatlichen Wirtschaftspolitik angelegen sein müssen, ist hier nicht noch einmal einzugehen. Die wesentlichen Mittel wurden bereits im Verlauf der bisherigen Erörterungen benannt, so daß auch auf deren Aufzählung - die systematisch und vollständig zu geben hier ohnedies nicht der Ort sein kann 1) - verzichtet werden kann.2) Nur auf einige besondere Probleme soll noch hingewiesen werden, die im Rahmen der sozialstaatlichen Wirtschaftsordnung nicht übergangen werden dürfen.

\section{aa) Protektionistische Maßnahmen}

Eines dieser Probleme ist die Stützung einzelner Wi rt schaftszweige, wie sie z. B. hinsichtlich der Landwirtschaft, dem Handwerk und der sonstigen "mittelständischen" Wirtschaft geleistet bzw. gewünscht wird. Sie interessiert im Zusammenhang mit dem Sozialstaatsprinzip überhaupt nur, soweit es dabei um die Befreiung der Beteiligten aus sozialen Notlagen und die Hebung ihres Lebensstandards auf ein angemessenes Niveau oder wenigstens um die Schaffung oder Erhaltung benötigter Arbeitsplätze geht. Insofern kann die Stützung dem Sozialstaatsprinzip entsprechen. 1) Aber ob und in welcher Weise sie geboten ist,

13) S. f.v.a. Dürig, Besprechung zu "Menger, Der Begriff des sozialen Rechtsstaats im Bonner Grundgesetz", S. 257; Ballerstedt, a.a.O.

14) Vgl. Ipsen, Anm. zu BVerfG Urt. v. 19. Dezember 1951 - 1 BvR 220/51 - S.218; E.R.Huber, Wirtschaftsverwaltungsrecht, Bd. I S. 35, Bd. II S. 204, 220; ders., Der Streit um das Wirtschaftsverfassungsrecht; Ballerstedt, a.a.O. und passim.

1) Aus der Rechtsprechung wäre noch zu erwähnen: BVerwGE 3, 303 (304): Die Versicherungsaufsicht liegt im Sinne des Sozialstaatsprinzips, weil sie den Mißbrauch der Machtstellung der Versicherer verhindert.

2) Vg1. allgemein Hamann, Rechtsstaat und Wirtschaftslenkung; Scheuner und Schüle, Die Intervention des Staates in der Wirtschaft.

1) Für die Sozialstaatlichkeit der Hilfe für Landwirtschaft und Handwerk s. Hamann, Deutsches Wirtschaftsverwaltungsrecht, 
wird von der Verfassung her kaum jemals eindeutig zu bestimmen sein. Ob ein Wirtschaftszweig zur "Gesunderhaltung" der Wirtschaft oder vielleicht des ganzen Volkskörpers notwendig erscheint oder ob er "aufgelassen" werden oder sich "gesund schrumpfen" soll, ist eine wirtschaftspolitische (und) gesellschaftsgestaltende Entscheidung, die im Verfassungsbekenntnis zum sozialen Staat nicht angesprochen ist. Fällt sie negativ aus, so kann es notwendig sein, daß der Sozialstaat Auslauf- oder (und) Übergangshilfe gewährt. Aber wie im einzelnen vorgegangen wird, ist durch das Sozialstaatsprinzip nicht präjudiziert.

Ähnlich verhält es sich hinsichtlich der regionalen Wirt$\mathrm{schaftshilfe.} \mathrm{Ihre} \mathrm{überragende} \mathrm{soziale} \mathrm{Bedeutung} \mathrm{erhellte}$ bereits oben im Zusammenhang mit dem bundesstaatlichen Finanzausgleich. 2) Aber auch hier ist das Sozialstaatsprinzip mehr "Ermächtigung" als Verpflichtung. Der Sozialstaat kann strukturell zu helfen suchen. Aber die Raumplanung kann sich auch gegen die Stützung und für die soziale Erosion entscheiden. Das kann im Ganzen für die soziale Entwicklung besser sein. Sie wird dann übergangsweise helfen müssen, das Gebiet sozial zu "evakuieren" und den verbleibenden Rest angemessen zu versorgen. ${ }^{3)}$ A ber auch hier liegt ein Komplex von Entscheidungen vor, die vom Verfassungsgrundsatz der Sozialstaatlichkeit nur schwach dirigiert werden.

bb) Das Problem der wirtschaftlichen Konzentration

Das Sozialstaatsprinzip gibt auch keine starren Regeln für die Lösung der Wettbewerbs- und Kartellproblematik her. 1) Sicher ist,

S.47; für die sozialstaatliche Notwendigkeit einer Förderung des Handwerks s. insbes. Gerber, Die Sozialstaatsklause1 des Grundgesetzes, S. 44 ff, insbes. S. 44 und S. 49 ff.

2) S. O. S. 205 .

3) Anders liegen die Verhültnisse dann, wenn aus besonderen Gründen die Abwanderung und wirtschaftliche Normalisierung nicht möglich ist. Dann muß die Gemeinschaft in angemessener Weise helfen. In (liesem Sinne ist es an sich richtig, wenn Hamann (Deutsches Wirtschaftsverfassungsrecht, S.47) die Berlinhilfe der Bundesrepublik als eine sozialstaatliche Notwendigkeit bezeichnet. Das setzt allerdings voraus, daß Berlin wirklich ein Land der Bundesrepublik ist, was hier nicht entschieden werden soll. Überdies darf diese juristische Erkenntnis nicht vergessen lassen, daß die politischen Motive andere - oder wenigstens: vorwiegend andere - sind als sozialstaatliche. 
daß es nicht angeht, Kartelle unter Berufung auf das Sozialstaatsprinzip schlechtweg zu verbieten. ${ }^{2)}$ Kartelle können - z.B. als Krisenkartelle - sozial nützlich ${ }^{3}$ ) oder - z. B. als Rationalisierungskartelle - wenigstens sozial indifferent sein. ${ }^{4)}$ Andererseits können Kartelle - z.B. Preiskartelle - in der Tat sozial schädliche Wirkungen entfalten und kann es sozialstaatlich notwendig sein, diesen Wirkungen durch geeignete Maßnahmen, äußerstenfalls durch ein Verbot oder die Auflösung des Kartells bzw. der Kartelle dieser Art zu begegnen. 5) Der Sozialstaat muß dem Mißbrauch der wirtschaftlichen Macht entgegentreten, ${ }^{6}$ ) nicht aber irgendwelchen bestimmten Wirtschafts- und Wettbewerbsformen als solchen.

Das gilt auch für andere Formen wirtschaftlicher Konzentration ${ }^{7)}$ und die Monopole. ${ }^{8)}$

\section{cc) Die Währungspolitik}

Zum Schluß noch ein Wort zur Währungspolitik. Die Sicherung der Stabilität der Währung ist ein kardinales soziales Problem. Eine soziale Politik wird daher auf sie größten Wert legen. Aber sie kann eine stabile Währung nicht garantieren. Die Währungs-

1) Hamann (Deutsches Wirtschaftsverfassungsrecht, S. 108) meint allerdings, die Frage des Kartellverbots sei primär eine der Anwendung des Sozialstaatsprinzips.

2) S. Forsthoff, Begriff und Wesen des sozialen Rechtsstaats, S. 27 mit Fußn. 30 .

3) Vg1. Hamann, a.a.O. S.110 f. - Isay (Soziale Marktwirtschait und Kartellgesetzgebung, Wirtschaft und Wettbewerb, 10. Jhg. (1954) S. 557 ff (560)) sieht - ohne allerdings das Sozialstaatsprinzip zu erwähnen - im Kartell ein adäquates Lenkungsinstrument der sozialen Marktwirtschaft.

4) Vgl. Hamann, a.a.O. S.110.

5) Vgl. Hamann, a.a.O. S.108 ff.

6) S. Krause, Allgemeine Geschäftsbedingungen und das Prinzi p des sozialen Rechtsstaats, S.268; Olbersdorf, Sozialer Rechtsstaat und Arbeitsrecht, S.135; Hamann, a.a.O. S. $108 \mathrm{ff}$.

7) Zur Rechtfertigung der Entflechtung aus dem Sozialstaatsprinzip s. Ridder, Enteignung und Sozialisierung, S. 144. Zur eigentumsrechtlichen Problematik s.a. noch unten Abschnitt 6 III 4 e (S.969 ff).

8) Zur möglichen Sozialstaatswidrigkeit eines gesetzlichen Monopols s. BVerfGE 9, 73 (82). 
politik ist eingebettet in eine Fülle nicht beherrschbarer oder wenigstens schwer überschaubarer Daten und Gesetzmäßigkeiten. Die währungspolitischen Entscheidungen sind daher rechtlich auch vom Sozialstaatsprinzip her kaum jemals meßbar. 1)

1) S. zum Vorstehenden Hettlage, Die Finanzverfassung im Rahmen der Staatsverfassung, S. 8 f. - Die wohl unüberwindlichen Schwierigkeiten, die sich einer wirksamen Normierung der Währungspolitik entgegenstellen, zeigt trotz des Optimismus des Verfassers am eindrucksvollsten der dahingehende Vorschlag Strickrodts (Verfassungsgarantierte Währung, Zeitschrift für das gesamte Kreditwesen, 5. Jhg. (1952) S. 533 ff; Finanzverfassung als selbständiges Normensystem, S. 130 f, 135; Finanzverfassungsrecht, Idee und Gestaltungsmöglichkeiten; Finanzverfassung, Verwirklichungsmöglichkeiten im System, S. 473 ff; Finanzverfassung als Real- und Rechtsstruktur der Wirtschafts- und Sozialordnung, S. 9 ff). 


\section{Abschnitt}

Grundrechtsordnung und soziale Intervention

\section{Allgemeine Fragen}

1. Verfassungsmäßige Rechte und Grund- und Menschenrechte außerhalb der Verfassung

Die Grundrechtsordnung des Bundes- und Landesverfassungsrechts ist im Rechtsraum der Bundesrepublik nicht (mehr) die allein maßgebliche. Neben ihr gilt eine dritte Grundrechtsschicht: Das Recht der von den Mitgliedern des Europarates am 4. November 1950 geschlossenen Konvention $\mathrm{zum} \mathrm{Schut-}$ ze der Menschenrechte und Grundfreiheiten Das Recht der Konvention ist indessen nicht Verfassungsrecht. 1) Es hat auch nicht den besonderen Rang, den Art. 25 GG den "allgemeinen Regeln des Völkerrechts" einräumt. 2) Es teilt "landesrechtlich" den gesetzesrechtlichen Rang des Zustimmungsgesetzes. ${ }^{3)}$ Allerdings sichert ihm der völkerrechtliche Hintergrund auf seine Weise nachhaltigere Beachtung als sie dem innerstaatlich abänderbaren Verfassungs- und Gesetzesrecht zusteht. Doch weist gerade dieser letzte Geltungsgrund über das staatliche Recht hinaus. Der Inhalt des Konventionsrechts wird vom Völkerrecht her bestimmt. Nicht zuletzt das in der Konvention selbst niedergelegte Sanktionssystem ${ }^{4)}$ gewährleistet, daß diese kausa-

1) Insbes. nicht über Art. 1 Abs. 2 GG, wie Dürig (Maunz-Dürig, Art. 1 Abs. II Randn. 58) gegenüber Echterhölter (Die Europäische Menschenrechtskonvention im Rahmen der verfassungsmäßigen Ordnung, JZ 10.Jhg. (1955) S.689 ff (691 f), mit Recht feststellt (weitere Nachweise s. bei den Zitierten).

2) Vgl. Echterhölter, a.a.O. S.690 f; v. Mangoldt-Klein, Art. 25 Anm. III 3 c; Dürig, a.a.O. Randn. 57; je m. eingeh. Nachw.

3) Gesetz über die Konvention zum Schutze der Menschenrechte und Grundfreiheiten vom 7. August 1952 (BGB1 II S. 685; ber. S. 953); Gesetz über das Zusatzprotokoll vom 20. März 1952 zur Konvention zum Schutze der Menschenrechte und Grundfreiheiten vom 20. Dezember 1956 (BGB1 II S. 1879). - Zur Geltungsfrage s. Dürig, a.a.O. Randn. 59 und seine Nachweise; ferner Herzog, Das Verhältnis der Europäischen Menschenrechtskonvention zu späteren deutschen Gesetzen, DÖV 12. Jhg. (1959) S. $44 \mathrm{ff}$.

4) S. f.v.a. Golsong, Das Rechtsschutzsystem der Europäischen Menschenrechtskonvention, 1958. - Gegen die Gleichstellung der "Menschenrechte" mit verfassungsmäßigen 
1e Beziehung in Permanenz fortwirkt. Eine rein innerstaatliche Betrachtungsweise würde dieser "dritten Grundrechtsordnung" im deutschen Rechtsraum nicht gerecht. Daher muß das Recht der Konvention außer Betracht bleiben. Diese Untersuchung kann die Hürde zum Völkerrecht hin nicht überspringen, ohne entweder unerträglich auszuufern oder die methodischen Besonderheiten, die eine sachgerechte Würdigung des "europäischen" Konventionsrechts unerläßlich voraussetzt, zu vernachlässigen.

Schwer wiegt dieser Verzicht nicht. Der deutsche verfassungsrechtliche Grundrechtsschutz geht in aller Regel weiter als derjenige der Konvention. ${ }^{5)}$ Die wenigen anderen Fälle sind zumeist nicht von Bedeutung für die Ordnung der sozialen Intervention. 6) Ist es im übrigen doch auch ein Kennzeichen der Konvention, daß sie sich auf die ausgrenzenden Grundrechte konzentriert. Selbst die einzige Bestimmung, die ausdrücklich ein Thema aufnimmt, das ansonsten in den "sozialen" Grundrechten der Verfassungen behandelt zu werden pflegt, 7) ist negativ gefaßt: "Das Recht auf Bildung darf niemandem verwehrt werden" (Art. 2 Abs. 1 des Zusatzprotokolls zur Konvention). ${ }^{8)}$

Rechten und die Nachprüfung eines "Menschenrechts"-Verstoßes auf Verfassungsbeschwerde hin s. statt aller anderen: BVerfGE 4, 110 (111 f) 6, 389 (440) 10, 271 (274); BayVerfGH VGHE n.F. 8 II 74; Herzog, Nochmals: Verfassungsbeschwerde gegen Verletzungen der Menschenrechtskonvention? DÖV 13.Jhg. (1960) S. 775 ff. Die Gegenmeinung - die sowohl die spezifische Aufgabe der Verfassungsgerichte als auch die durchgreifende Wirksamkeit des völkerrechtlichen Hintergrundes der "Menschenrechte" verkennt - wird insbes. von Guradze (Kann die Verfassungsbeschwerde auf eine Verletzung der Konvention zum Schutze der Menschenrechte gestützt werden? DÖV 13.Jhg. (1960) S.286 ff) vertreten. Weitere Nachweise s. bei den Genannten.

5) Vg1. Dürig, a.a.O. Randn. $60 \mathrm{ff}$.

6) Zu den besonderen $\Lambda$ speliten des Verbotes der Zwangs- und Pflichtarbeit (Art. 4 Abs. 2 der Konvention) s. schon oben Abschnitt 5 III 3 c (S. 800 ff). Berührungspunkte ergeben sich aus dem Recht auf Eheschließung (Art.12 der Konvention) hinsichtlich der dienstrechtlichen Heiratsbeschränkung und aus dem Rechtsschutzanspruch (Art.6 Abs.1, 14 der Konvention) hinsichtlich des Armenrechts. Darauf wird zurückzukommen sein.

7) S. unten 3 (S. $848 \mathrm{ff})$.

8) Den Versuch einer Gegenüberstellung der sozial relevanten Bestimmungen der Konvention mit den entsprechenden Nor- 
In ganz anderen Dimensionen lagert die Allgemeine Erk1 ärung der Menschenrechte, welche die Generalversammlung der Vereinten Nationen am 10. Dezember 1948 abgegeben hatte. Wie hätte sich der Block der marxistisch-leninistischen Länder dazu verstehen können, eine Erklärung allein von Freiheiten zu billigen? Aber auch der sog. Westen mußte in jener Weltstunde um die Krise der freiheitlichen Grundrechte an ihrer "soziologischen Grenze" 9) wissen. 10) Wie eine Zauberformel, welche die polemische Alternative zwischen der "Freiheit des Hungernden" und der "Sattheit des Sklaven" synthetisch aussöhnen soll, klingt es, wenn in der Präambel die Absicht kundgetan wird, "den sozialen Fortschritt und bessere Lebensbedingungen bei größerer Freiheit zu fördern". Neben Garantien der Freiheit des Eigentums und der Gleichheit enthält die Erklärung dann auch in den Art. 22-26 ein wohlformuliertes soziales Grundprogramm. ${ }^{11)}$ Jedoch auch dieses muß hier außer Betracht bleiben, und zwar nicht nur wegen seiner übernationalen Provenienz sondern wegen seines Mangels an rechtlicher - völkerrechtlicher und staatsrechtlicher - Verbindlichkeit.12)

So scheint als letzte - durch Art. 1 Abs. 2 GG 13) nahegelegte Frage die nach dem $\mathrm{Naturrecht}$ als der Quelle von Menschenrechten zu stellen zu sein. Allein sie erübrigt sich, ohne daß eine Diskussion über die Positivität von Naturrecht vonnöten wäre. Die verfassungsrechtliche Ordnung läßt keine naturrechtlichen Wünsche offen. ${ }^{14)}$

men des internationalen und des innerstaatlichen Rechts unternimmt Trieschmann, Soziale Menschenrechte - Internationale Normen und deutsches Arbeitsrecht, Bundesarbeitsblatt 1956, S. $452 \mathrm{ff}$.

9) S. Fechner, Die soziologische Grenze der Grundrechte, 1954.

10) S.a. Hamel, Die Bedeutung der Grundrechte im sozialen Rechtsstaat, S.27, der sich nicht zu Unrecht auf Roosevelts Proklamation (auch) der Freiheit von Not bezieht.

11) S. hierzu z.B. Kaufmann, Grundrechte und Wohlfahrtsstaat, Recht Staat Wirtschaft, Bd.IV (1953) S. $77 \mathrm{ff}$ (84 f); Trieschmann, a.a.O. (s. S. 843 zu Fußn. 8).

12) S. f.v.a. Echterhölter, Die Europäische Menschenrechtskonvention im Rahmen der verfassungsmäßigen Ordnung, S. 690; v. Mangoldt-Klein, Art. 25 III 3 c; Dürig, MaunzDürig, Art. 1 Abs. II Randn. 56; je m. eingeh. Nachw.

13) Zur Bedeutung der Norm s. insbes. Dürig, a.a.O. Randn. $73 \mathrm{ff}$.

14) S. die Darstellung bei Dürig, a.a.O. Randn. 84 ff. Zum Ganzen s. ferner oben S.663ff. - A.A. z.B. Hamel, a.a.O. S.22: 
2. Grundrechte und Grundpfichten

a) Allgemeines - die programmatischen Grundpflichten

Seit die Autoren der Weimarer Verfassung in "volkspädagogischem" Eifer es unternommen haben, den "Bürger des Deutschen Reiches durch seine Verfassungsurkunde nicht nur über seine Rechte, sondern mit ebenso nachdrücklichem Ernste auch über seine wichtigsten vaterländischen Pflichten" zu unterrichten, 1) ist es üblich geworden, Grundrechte und Grundpflichten 2) als verfassungssystematisches $Z$ willingspaar zu verbinden. Von diesem Denkschema her ist mit der Frage zu rechnen, warum hier nur von Grundrechten und nicht auch von Grundpflichten gesprochen werden soll. Die Antwort ist: weil das Grundgesetz keine aktuellen Grundpflichten von selbständiger Bedeutung enthält.

Grundpflichten stellen den rechtsstaatlichen Verfassunggeber vor ein Dilemma. Prinzipiell unbeschränkt - wie andererseits die Grundfreiheiten - können Grundpflichten nicht statuiert werden, ohne Freiheitlichkeit und Rechtsstaatlichkeit zu beeinträchtigen. So bleibt nur die Alternative: entweder werden die Grundpflichten in rechtsstaatlicher Weise bestimmt und begrenzt, oder es wird nur ihre gesetzliche Begründung programmatisch angekündigt und - möglicherweise - reguliert. 3) Die definitive "verfassungsgesetzliche Pflicht" muß wegen der Starre und Kürze der Verfassung die Ausnahme bleiben. ${ }^{4)}$ In der Regel sind Grundpflichten daher nur wegbereitende Ankündigungen entsprechender gesetzlicher Verpflichtungen. Das Grundgesetz kennt ausdrücklich niedergelegte Grundpflichten nicht. Ihre bloße Programmatik mag dem auf Aktualität bedachten 5) Grundgesetzgeber zuwider gewesen sein.6)

"Das Bonner Grundgesetz enthält weniger Grundrechte als die Weimarer Verfassung. Um so mehr wird hier die Frage nach den ungeschriebenen Menschenrechten von praktischer Bedeutung"'. Dem kann, wie gesagt, nicht zugestimmt werden.

1) Thoma, Die juristische Bedeutung der grundrechtlichen Sätze der deutschen Reichsverfassung im allgemeinen, S. 28.

2) S. die Überschrift des Zweiten Hauptteils der Weimarer Reichsverfassung "Grundrechte und Grundpflichten der Deutschen".

3) S. zu Vorstehendem Carl Schmitt, Verfassungslehre, S. $174 \mathrm{f}$; ders., Inhalt und Bedeutung des Zweiten Hauptteils der Reichsverfassung, S.597. S. hierzu und zum Nachfolgenden auch schon oben S. 693 .

4) Schmitt, Verfassungslehre, S. 174. 


\section{b)}

Das Grundgesetz hat sich damit dem Mißverständnis ausgesetzt, es habe mit dem Sozialstaatsprinzip eine allgemeine Soziabilitätspflicht begründen wollen. 1) Diese Deutung der Sozialstaatsproklamation hat sich als unrichtig erwiesen. 2) Eine andere Frage ist, ob das Grundgesetz, indem es eine allgemeine Soziabilitätspflicht "verschweigt", einer extrem individualistischen Interpretation, insbes. der Grundrechte, Raum geben wollte. Die Umstände sprechen dagegen. ${ }^{3)}$ Doch kann das hier auf sich beruhen. Für diesen Zusammenhang genügt es zu wissen, daß den Bürger des Sozialstaats eine gesteigerte Sozialpflichtigkeit im engeren Sinn des Wortes "sozial" trifft, welcher der grundgesetzlichen Sozialstaatsproklamation zugrunde liegt. ${ }^{4)}$ Diese Implikation des Sozialstaatsprinzips ist di e "Grundpflicht" des Grundgesetzes.

\section{C) Grundrechte und Grundpflichten}

Grundpflichten der vorbezeichneten Art und insbes. die sozialstaatliche Gemeinschaftsbindung des Individuums haben vor al$1 \mathrm{em}$ die interpretatorische Funktion, der Begründung entsprechender Pflichten durch das Gesetz legitimierend den Weg in die individualistischen Abwehrpositionen der Verfassung zu bahnen. 1) Sie sind so den Grundrechten zugeordnet. Sie sind so aber auch den Vorbehalten verwandt, welche die Ausübung bestimmter Grundrechte in einem bestimmten Sinn zur Pflicht machen und den Gesetzgeber einladen, die Grundrechtsausübung entsprechend $z u$ begrenzen. Pflichten dieser Art finden sich im Verband des Eigentumsrechts (Art.14 Abs.2 GG). Weniger von direkt sozialer Bedeutung ist die mit dem Recht der Eltern auf Erziehung ihrer Kinder gepaarte Pflicht (Art. 6 Abs.2 GG). Diese Bestim-

5) S. Art. 1 Abs. 3 GG.

6) S. v. Mangoldt, Das Bonner Grundgesetz (1.Aufl.), S. 39. v. Mangoldt-Klein (S.111 f) und Maunz (Deutsches Staatsrecht, S. 87) wollen diese Rechtfertigung deshalb nicht gelten lassen, weil das Grundgesetz trotzdem nicht um programmatische Bestimmungen herumgekommen ist. Als ob die Seltenheit dieser Ausnahmen nicht die Regel bestätigen würde!

1) S. o. S. $676 \mathrm{ff}$.

2) S. o. Abschnitt 5 II 1 b (S.684 ff) und c bb (S. 701).

3) Man vergleiche insbes. Art. 2 Abs. 1 und 14 Abs. 1 und 2 GG. S. f.v.a. v. Mangoldt-K1ein, S. 101.

4) S. o. Abschnitt 5 II 1 (S.676 ff).

1) S. oben Abschnitt 5 II 1 (S.676 ff) (insbes. S.693 ff und S. 701) und 2 (S.706 ff) (insbes. S.716 ff und S.729). 
mungen haben zwar meist auch den Zweck, die genannten Pflichten auch als solche und zwar - wie man gerne sagt - als "sittliche" anzuerkennen. Rechtlich äußern sie eine aktuelle Wirkung jedoch erst in den gesetzlichen Regulierungen der Pflicht und des Rechts.

Auf diese Weise berühren sie sich eng mit jenen Grundrechtsbestimmungen, die eine Pflicht ausdrücklich zwar nicht anerkennen und ihre Begründung auch nicht fordern, sie einem gewissen Grundrecht gegenüber jedoch zulassen. Das Grundgesetz regelt so die persönliche Dienstpflicht (Art.12 Abs.2-4GG; s.a. Art. 4 Abs. 3 GG).

So erweist sich schließlich, daß die "Grundpflichten" - abgesehen von der "moralischen" Wirkung, die sie vielleicht haben, und dem politischen Integrationswert, der ihnen beigemessen werden darf - verfassungsrechtlich nichts anderes sind als die "Hinterseite" der Grundrechtsordnung.

d) Zur "einzigen eigentlichen rechtlichen Grundpflicht"

Zum Schluß noch ein Wort zur "einzigen eigentlichen rechtlichen Grundpflicht" einer jeden Verfassung, der Pflicht zum Gehorsam gegenüber der Verfassung und den Gesetzen. 1) Im Grundgesetz fehlt eine entsprechende Vorschrift. Sie ist nichtsdestoweniger auch für die grundgesetzliche Verfassungsordnung selbstverständlich. 2)

1) Thoma, Die juristische Bedeutung der grundrechtlichen Sätze der deutschen Reichsverfassung im allgemeinen, S. 2, 29. $\mathrm{S}$. zu dieser Grundpflicht ferner Nawiasky, Allgemeine Rechtslehre, S. 38 f; Allgemeine Staatslehre, Teil III, S.94 f, 97.

2) S. Maunz, Deutsches Staatsrecht, S.88. S. ferner die vorstehend Zitierten und Nawiasky-Leusser, Erl. zu Art.117, wo auch für diese Bestimmung festgestellt wird, sie enthalte insoweit eine "Rechtspflicht, die allerdings selbstverständlich ist, weil sie sich unmittelbar aus dem Sinn der obersten Rechtsnormen ergibt". - Des näheren s. zur Interpretation des Grundgesetzes unter diesem Gesichtspunkt v. MangoldtKlein, S. $111 \mathrm{ff}$, und die dortigen Nachweise. 
3. Ausgrenzende und bew und sog. "soziale" Gruiirechte

a) Allgemeines

\section{aa) Zur Unterscheidung}

Wenn in diesem Zusammenhang das ihema "Grundrechte" angeschnitten wird, so drängt sich vor ailem die Unterscheidung der Grundrechte 1) auf zwischen den "suzialen" - früher gern auch "sozialistisch" genannten - Grundrechten, den "Sozialrechten", 2) den Teilhaberechten, den verfassungsmäßigen Verbürgungen staatlicher oder staatlich garantierter. Leistungen auf der einen und den "liberalen", den ausgrenzenden und abwehrenden, den Staat beschränkenden Grundrechten, len Freiheits- und Gleichheitsverbürgungen auf der anderen soite. 3 )

\section{bb) Die auch "soziale" Funktion de!' Iusgrenzungen}

Die soziale Relevanz dieser Unterscheidung ist augenfäilig. Aber sie darf nicht dazu führen, das soziale Gewicht des materiellen Verfassungsrechts einseitig bei den "sozialen Verfassungsrechten" zu suchen. Den Ausgrenzungen und Abwehrrechten wohnt nicht minder eine soziale Prägekrati inne als den sog. "sozialen"

1) Eine an Intensität, Aktualität und Nachweisen gegenwärtig wohl nirgends überbotene Übersicht zu den verschiedenen Klassifizierungen der Grundreclite s. in dem Abschnitt "I. Die Grundrechte. Vorbemerkungen" bei v. Mangoldt-Klein, S. $51 \mathrm{ff}$.

2) Gelegentlich wird auch von den sog. Gruppengrundrechten (z.B. der Familie, der Koalitionen) als "sozialen" Grundrechten gesprochen (s. hierzu z.B. v. Mangoldt-Klein, S. 105 f). Das ist hier nicht gemeint.

3) S. hierzu vor allem Carl Schmitt, Verfassungslehre, S.169f; ders., Inhalt und Bedeutung des zweiten Hauptteils der Reichsverfassung, S. 594 f; Hans Huber, Soziale Verfassungsrechte? in "Die Freiheit des Burgers im schweizerischen Recht", Festgabe der Juristischen Fakultäten der schweizerischen Universitäten zur Hundertjahrfeier der Bundesverfassung, 1948, S. $149 \mathrm{ff}$; Scheuner, Die institutionellen Garantien des Grundgesetzes, S. $96 \mathrm{ff}$; Forsthoff, Begriff und Wesen des sozialen Rechtsstaats, S. 18 ff, 35; v. Mangoldt-Klein, S. $71 \mathrm{ff}$; Leibholz, Strukturprobleme der modernen Demokratie, S. 87 f, $130 \mathrm{f}$; weitere Nachw. s. bei den Zitierten, insbes. bei v. Mangoldt-Klein, a.à.O. 
Grundrechten. 1) Das gilt nicht nur im allgemeinen Sinne des "Sozialen"; also nicht etwa nur in der Weise, daß die Freiheitsrechte eine freiheitliche Gestaltung der Wirtschaftsverfassung bedingen, die ganz notwendig unterschiedliche Bedürfnisbefriedigungspotenzen schafft, oder in der Weise, daß das Grundrecht des Eigentums vorhandene Vermögensdifferenzen konserviert usw. Es gilt auch im spezielleren und positiven Sinn.

"Soziale" Rechte können vielleicht die Teilhabe sichern. Sie können damit vielleicht auch die vielbesagte "Freiheit in der Teilhabe" (Flume) sichern, aber doch nicht die "Freiheit von der Teilhabe", von dem Angewiesen-Sein auf die Teilhabe am Gemeinen. Sie aber ist das Widerlager der "Freiheit in der Teilhabe", die von der Macht des Angewiesen-Seins auf die Teilhabe aufgesogen wird, wenn jene Alternative aufgehört hat zu existieren. ${ }^{2}$ ) Und sie ist in gewissem Grad auch Prämisse der Teilhabe derjenigen, die ihrer notwendig bedürfen. ${ }^{3)}$

Ausgrenzungen und Abwehrrechte gewähren - in anderer Weise als die "sozialen" Grundrechte - selbst Teilhabe, jedenfalls eine Chance der Teilhabe: nicht am Güterfluß der staatlichen Umverteilung und Zuteilung, sondern eigenständig und unmittelbar an der an sich vorhandenen Gütermasse. ${ }^{4)}$ Ein führender Vertreter des zeitgenössischen Liberalismus ${ }^{5)}$ sagt, es sei "verfehlt, anzunehmen, daß 'Klasseninteressen' die Unternehmer antreiben, für

1) S. außer den Vorgenannten auch Spanner, Die Rolle der Verfassung im gegenwärtigen politischen und sozialen Leben, S. $14 \mathrm{f}$.

2) S. hierzu Kaufmann, Grundrechte und Wohlfahrtsstaat, S. 81; Hamel, Die Bedeutung der Grundrechte im sozialen Rechtsstaat, 1957, S.23 ff.

3) Vgl. Rohrbeck, Die freiwillige Altersversorgung als Bestandteil der sozialen Sicherheit, Deutsche Versicherungszeitschrift, 8.Jhg. (1954) S.4 ff (4): "Denn nur eine wurzelfeste Wirtschaft kann aus ihrem Einkommen Mittel abspalten, die ausgleichenden sozialen $Z$ wecken dienen können. Eine solche Wurzelfestigkeit wird aber lediglich durch Selbsthilfe, auch bei Erstrebung der eigenen Sicherheit im Wirtschaftsleben erreicht. Wenn jeder in der Stunde der Not lediglich auf Staat oder Gemeinde angewiesen wäre, würden bald die öffentlichen Mittel erschöpft sein und den einzelnen die ganze Schwere des Schicksals treffen".

4) S.a. Hamel, a.a.O.

5 v.Mises, Art. "Liberalismus (II)" im Handwörterbuch der Sozialwissenschaften, Pd.6, 1959, S.596 ff (599). 
unbeschränkte Wirtschaftsfreiheit einzutreten. Wer für Wirtschaftsfreiheit eintritt, will vielmehr jenen heute armen und unbekannten Männern Bahn schaffen, die in kommenden Jahren diejenigen, die heute reiche Unternehmer sind, entweder verdrängen oder zur höchsten Anspannung ihrer Kräfte zwingen werden". Dieser potentielle Rollentausch ist nicht gerade das, was hier unter "sozial" verstanden wird; und die behauptete Gesetzmäßigkeit entspricht nicht so der Wirklichkeit, wie sie sich den Anschein gibt. Aber sie ruft doch die eminent soziale Bedeutung der beruflichen Aufstiegschancen in Erinnerung, die etwa mit der Berufsund Gewerbefreiheit verbunden sind. 6) Ein anderes Beispiel ist das klassische "soziale" Freiheitsrecht, das Koalitionsrecht. 7) Nicht minder deutlich wird der Zusammenhang im Eigentumsrecht. "Die beiden großen Sehnsüchte des heutigen Menschen, die von jedermann neben einander erhofft werden... sind 'Freiheit' und 'Sicherheit'. A uf ökonomischem Gebiet versöhnen sich Freiheit und Sicherheit im 'Eigentum'. Eigentum ist 'freiheitsdurchwirkte ökonomische Sicherheit', oder umgekehrt 'ökonomisch gesicherte Freiheit" ". ${ }^{8)}$ In ganz anderer Weise wirkt der Gleichheitsgrundsatz in der "sozialen" Richtung. Der Idee nach brisanter als Freiheits- und Eigentumsrechte. Aber der verfassungsrechtliche Befund stößt hier schon auf die Grenze zu den ambivalenten - ausgrenzenden und teilhabeverschaffenden - Rechten, die in diesem Zusammenhang noch nicht gemeint sind. 9)

\section{cc) Die auch freiheitliche Funktion der "sozialen" Grundrechte}

Können ausgrenzende Rechte somit auf ihre Weise auch Teilhabe gewähren, so garantieren andererseits "auch die Grundrechte, die nur Ansprüche auf Leistungen bestimmen, ... Funktionen der Freiheit: denn die Ansprüche gehen auf Beseitigung der sozialen Umstände, die die Ausübung solcher Funktionen verhin-

6) Es ist das Verdienst Werners (Anm. zu OVG Berlin, Urt. v. 2. Juni 1954 - OVG I B 159/53 - S. 564; Sozialstaatliche Tendenzen in der Rechtsprechung, S.99), die Interpretation des Art. 12, die ansonsten nur darauf bedacht ist, über die Beschränkungen nachzudenken, die der Berufs- und Gewerbefreiheit im sozialen Interesse auferlegt werden sollen, können und dürfen, auf diesen positiven Ausblick verwiesen zu haben.

7) S. hierzu auch Forsthoff, Begriff und Wesen des sozialen Rechtsstaats, S. 19.

8) Dürig, Der Staat und die vermögenswerten öffentlichrechtlichen Berechtigungen seiner Bürger, S. 52 .

9) S. unten $S$. 
dern". 1) Die Gewährleistung der Freiheit wehrt Hemmungen ab, die sich der Entfaltung einer Potenz in den Weg stellen könnten. Sie ist eine Chance, von der nur derjenige Gebrauch machen kann, der in entsprechender Weise potent ist. Die ausgrenzenden "Grundrechte brauchen offenbar ein Mindestmaß wirtschaftlichen Wohlstandes, um verwirklicht werden zu können". 2) Aber nicht nur das: es gibt Situationen, "wo infolge sozialer und wirtschaftlicher Notlagen die Grundrechte aufhören, dem Menschen etwas zu bedeuten". 3) Hier hat der Staat in erster Linie die ökonomischen Grundlagen aufzubessern, damit die Werte nicht verloren gehen, denen die ausgrenzenden Grundrechte dienen. 4 ) "Soziale" Grundrechte können den Zweck haben, dieses Eingreifen sicherzustellen.

dd) Erscheinungsformen und Wirkungsweise der "sozialen" Verbürgungen

Teilhabe- und Freiheitsrechte ergänzen sich also, sind aufeinander zugeordnet. Aber sie sind dabei einander nicht adäquat. Wirkungsgrad und Wirkungsweise unterscheiden sie grundlegend. 1) Ausgrenzungsrechte finden in der Verfassung eine wirksame und andererseits auch unentbehrliche höchste Gewährleistung. Sie lassen sich, sofern der Mechanismus der Rechtsfindung und und des Rechtsvollzugs überhaupt funktioniert, auch und gerade a1s verfassungsmäßige Rechte zuverlässig durchsetzen. Teilhaberechte setzen ein Objekt der Teilhabe voraus. Dieses ist vom Recht her nur bedingt beherrschbar und zwar doppelt bedingt vom knappen und starren Verfassungsrecht. Abwehrrechte können - eventuell unter dem nötigen Vorbehalt gesetzlicher Be-

1) Hamel, Die Bedeutung der Grundrechte im sozialen Rechtsstaat, S.19. S.a. S.23 u. passim.

2) Fechner, Die soziologische (irenze der Grundrechte, 1954, S. 16 ff (Zitat: S. 18).

3) ebd., S.21.

4) Diese Zusammenhängc Wurien bisher schon wiederholt in Erörterung der Wechsclbrzüge von Demokratie und sozialer Intervention und Rechtsstuiat und sozialer Intervention angesprochen. - Aus dem sichriftium s. nochmals Kaufmann, Grundrechte und Wohlfahrtsstaat, S. 81; Hesse, Der Gleichheitsgrundsatz im Staatsrecht, S.185; Hamel, Die Bedeutung der Grundrechte im sozialen Rechtsstaat, S.23 ff.

1) S. hierzu und zum Folgenrlen die oben S. 848 zu Fußn. 3 Zitierten sowie oben $\$ .396$ ff und die dortigen Nachweise. S. ferner Dürig, Art. 1 Abs. III Randn. 93 und $94 \mathrm{~m}$. eingeh. Nachw.; s.a. Geiger, Grundrechte und Rechtsprechung, S.28 ff. 
schränkung - schon grundsätzlich unbeschränkt als aktuelles Recht gewährt werden. Leistungsrechte können nicht ebenso schon als Allgemeinsätze effektiv sein. Das Reservoir der Freiheit ist a priori unbegrenzt. Das Reservoir der vom Staat zu verteilenden Güter ist a priori begrenzt. ${ }^{2}$ ) Die Summe der zu schaffenden Güter ist nicht verläßlich absehbar. Der Gebrauch gewährter Freiheit kann grundsätzlich dem einzelnen überlassen bleiben. Die an den Staat zu stellenden Ansprüche können nicht unbegrenzt, auch nicht vorläufig unbegrenzt gewährt werden. Teilhaberechte können in der Verfassung grundsätzlich nicht unbedingt, nicht endgültig, nicht unmittelbar vollziehbar errichtet werden. Allenfalls eine flexible gesetzliche oder verordnungsrechtliche Rechtsetzung kann sie effektiv gewähren. Meist bedarf es auch noch der insoweit normativ nur sehr unvollkommen lenkbaren Bemühungen der Verwaltung, um die Voraussetzungen ihrer Erfüllung zu schaffen. Verfassungsmäßige Teilhaberechte bewirken aber nicht - bei weitem nicht - so unmittelbar und sicher die soziologischen Voraussetzungen der Abwehrrechte, wie diese den notwendigen rechtsstaatlichen Überbau der Teilhabe herstellen.

A usnahmsweise sind Teilhaberechte auch unmittelbar vollziehbare. 3) Es sind dies vor allem die "unechten" Te i l habe rechte.4) Von diesen sind die einen in Wahrheit Ausgrenzungen, wie etwa die Schulgeldfreiheit. 5) Die Leistung ist in diesem Falle der Unterricht. Die Schulgeld- "Freiheit" ist, wie schon der Name sagt, nur die Abwehr eines Gebührenverlangens für diesen Unterricht. Die andere Gruppe "unechter" Teilhaberechte gewährt Leistungen, die nicht vom Staate zu erbringen sind. Es sind Vorschriften über den zwischenbürgerlichen Sozialausgleich (z.B. das Recht auf Urlaub, auf Vergütung des

2) Es kann sich nur um knappe Güter handeln. An der Verteilung von Gütern, die in keiner Weise knapp sind, durch den Staat besteht niemals ein Interesse.

3) Positiv zur Möglichkeit von Teilhaberechten insbes. Abendroth, Diskussionsbeitrag zu "Begriff und Wesen des sozialen Rechtsstaats", S.88. Positiver als dieser Text und seine eigenen Nachweise auch v. Mangoldt-Klein, S. 71 ff.

4) Das Adjektiv "unecht" bezieht sich hier nicht auf das "Recht" sondern auf die "Teilhabe". Zum Begriff des "unechten Grundrechts" s. unten S. 854 zu Fußn.8.

5) Z.B. s. Forsthoff, Begriff und Wesen des sozialen Rechtsstaats, S. 19 f; Dürig in Maunz-Dürig, Art. 1 Abs. III Randn. 93 Fußn. 3. 
feiertäglichen Lohnausfalles usw. ). 6)

Aber auch "echte" verfassungsmäßige Leistungsrecht e sind denkbar, wenn sie in einem Rahmen bleiben, der die Gesamtleistungsfähigkeit des Staates normalerweise nicht berühren kann, z.B. Minimalleistungen wie die öffentliche Fürsorge oder exzeptionelle Versorgungsleistungen.

Jedoch die Erfüllung der großen Leistungsaufgaben des Staates kann durch die Verfassung nur in der Weise vorgestaltet werden, daß den kompetenten Staatsorganen - aus rechtsstaatlichen Gründen in erster Linie also dem Gesetzgeber - Ma $\beta$ rege $1 \mathrm{n}$ über das zugunsten der "Berechtigten" Veranlaßte erteilt werden. Die Sanktion ist dabei noch einigermaßen komplett, wenn an einen vorhandenen Standard angeknüpft werden kann, der erhalten bleiben soll. "Soziale" Rechte können so mit Ein richtungsgarantien kombiniert sein und den Maßnahmen, Gesetzgebungsakten usw. vernichtend entgegentreten, die der Garantie zuwider die vorhandenen Einrichtungen abbauen. Auch verbindliche Programme können eine negative Wirkung dieser Art äußern, wenn die in Erfüllung des Verfassungsauftrages getroffenen Regelungen und Veranstaltungen wieder beseitigt oder in einer dem verbindlichen Wollen des Programmes widersprechenden Weise vermindert werden sollen. Das Subjekt des "sozialen" Grundrechts kann in diesen Fällen das Verhaltén seines staatlichen "Anspruchsgegners" einigermaßen beherrschen und so seine Position realisieren. Dies aber doch wieder nur, weil es sich der Sache nach um Abwehrrechte - um die Negation eines Minus gegenüber dem vorhandenen und gewährleisteten Stand der Teilhabe - handelt. Die Schwelle zu Abwehr und Ausgrenzung ist immer auch die Schwelle zur Effektivität. Daß es um Leistungen und 'Teilhabe geht, mindert die Stabilität solcher Positionen dann freilich immel noch hinreichend.

Wo aber eine Teilhabe noch nicht "eingerichtet" ist, wo Leistungen neu vorgesehen und gewahrt werden sollen, wo Positives nicht nur beizubehilten :indirn zu schaffen, zu formen, zu leisten ist, da verliert sich die Jitalität der "Berechtigung". Das zeigt sich schon bei verbindlichen Programmen. Nur wenn sie sowohl hinsichtlich des vificsungsbefehls an sich wie auch hinsichtlich der Legitimation lej Berechtigten hinreichend konkretisierbar sind, ist eine Sanktion durch eine ihrer Natur nach

6) Vgl. Hans Huber, Soziale Veıfassungsrechte? S. 158; weitere Nachweise s. bei v. Mangoldt-Klein, S. 74 f. Die von v. Mangoldt-Klein (S.75) aufgewor:ene terminologische Frage zu erörtern, ist nicht veranlaßs. 
nicht vollstreckbare gerichtliche Feststellung der Verfassungswidrigkeit der entsprechenden gesetzgeberischen Unterlassung überhaupt denkbar. ${ }^{7)}$ In allen übrigen Fällen ist an eine Durchsetzung des "Rechts" nicht mehr zu denken: nicht bei verbindlichen aber wegen ihrer Unbestimmtheit nicht auf ein persönliches Recht hin konkretisierbaren Programmen; nicht bei unverbindlichen Programmen; nicht bei Grundsatzregelungen, die gewisse Entscheidungen nur für den Fall vorwegnehmen, daß der Gesetzgeber eine einschlägige Regelung zu treffen unternimmt, ohne ihn zu dieser Regelung an sich veranlassen zu wollen.

Hier verflüchtigen sich subjektive Rechts-Qualität und RechtsSubjektivität. Und hier ist auch die Grenzzone zu den "une chten" Grundrechten. ${ }^{8)}$ Diese regeln Fragen des gesellschaft-

7) S. oben S. $557 \mathrm{ff}$.

8) Maunz (Deutsches Staatsrecht, S. 82) nennt so die "Gesamtregelungen des gesellschaftlichen Lebens". Er versteht darunter das im Text Gemeinte. Der Begriff der "Gesamtregelungen des gesellschaftlichen Lebens" wird hie $r$ je-. doch in einem weiteren Sinne gebraucht. Darin, daß die rein objektiven Programme usw., soweit sie sich als "soziale Grundrechte" gerieren oder sonstwie als solche bezeichnet werden, keine "echten" sondern allenfalls nur "unechte" Grundrechte sein können, stimmen mit Maunz auch Carl Schmitt (Verfassungslehre, S.163 ff), Hans Huber (Soziale Verfassungsrechte) und wohl auch Ule (Die Grundrechte, DV 2.Jhg. (1949) S.333 ff) überein. Doch grenzen vor allem Schmitt und Huber die "echten" Grundrechte noch enger ein, indem sie nur die ausgrenzenden darunter verstehen. Denkbar wäre es schließlich, unter "echten" Grundrechten nur (aktuelle) subjektiv-öffentliche Rechte zu verstehen (s. v. Mangoldt-Klein, S.110; s.a. Ule, a.a.O.). Dieser Begriff könnte wieder weiter sein als der Schmitts und Hubers, indem er nämlich auch leistungsgewährende Grundrechte einbezieht, soweit sie nur aktuelle subjektiv-öffentliche Rechte gewähren, und wohl enger als der von Maunz, der auch nicht aktuelle aber subjektbezogene Programme einzubeziehen scheint. Der Verfasser würde diese Begriffsbildung vorziehen. Doch ist kein Anlaß, diese begriffliche Frage hier zu vertiefen. Die Bedenken v. Mangoldt-Kleins (S. 110), von "echten" und "unechten" Grundrechten zu sprechen, sei unklar und daher nicht billigenswert, sind im allgemeinen begründet. Doch dürfte nach dem gegenwärtigen Stand der Le:1re von den Grundrechten, insbes. was den Gegensatz von ojjektivem und subjektivem Recht betrifft (vgl. v. Mangoldt- 
lichen Lebens ohne den Anschein oder die Absicht einer $s u b-$ jektiven Berechtigung rein objektivrecht1ich.9) Da sie in der Regel aber Interessengegensätze entscheiden, begünstigen sie freilich immer irgendwie einen Kreis von Interessenten, während sie einen anderen benachteiligen.

Die Effektivität der "sozialen" Verfassungsverbürgungen ist im allgemeinen also gering. Das schadet auch ihrem Integrationswert. 10) Der papierene Verfassungstext zählt in dieser nüchternen Zeit wenig, wenn ihn die Verfassungswirklichkeit nicht verifiziert. Mittels "sozialer" Grundrechte kann die Verfassung die Verfassungswirklichkeit aber meist nicht mehr beeinflussen als einer sich am eigenen Schopfe aus dem Sumpfe zu ziehen imstande ist.

\section{ee) Freiheit und Teilhabe - zu den Grenzen der Verfassungs- synthese}

Soziale Politik und freiheitliche, bewahrende Staats- und Sozialgestaltung stehen sich in starker Spannung gegenüber. Ein System des durch keine staatliche Kontrolle gestörten liberalen catch-as-catch-can vermeidet diese Friktionen ebenso wie ein System der Hilfe und Sicherheit, das auf dem Auslöschen der persönlichen Freiheit und eines persönlichen Besitzstandes basiert. 1) Das Nebeneinander von "sozialen" und "liberalen"

Klein, S. 80 ff und die dortigen Nachweise), und vor allem nach der jüngeren verfassungspolitischen Entwicklung zur möglichsten Aktualität der eingeräumten Rechte, keine Unklarheit dann aufkommen, wenn man von bloß objektivrechtlichen Grundsätzen, von Programmen ohne fixierbaren Subjektsbezug usw. als von "unechten" Grundrechten spricht, wenn schon äußere Zusammenhänge dazu zwingen, überhaupt von "Grundrechten" zu sprechen.

9) Gemeint sind hier nicht lie Grundsatznormen im weiteren Sinn, die als objektivrechtliche Rechtssätze auch in den Grundrechten und im orgunisutorischen Verfassungsrecht enthalten sein können (s. z.B. v. Mangoldt-Klein, S. 86 ff und seine Nachweise), sondern nur diejenigen Verfassungssätze, die nur oder wenigstens pr·irnär objektive Sachregelungen enthalten.

10) Vgl. zum Integrationswert Smend, Die Verfassung des Deutschen Reiches, 1929, S.XXIV f; ders., Verfassung und Verfassungsrecht (zitiert nach "Staatsrechtliche Abhandlungen") S. $260 \mathrm{ff}$.

1) Damit soll nicht verschwirgen werden, daß sich auch gegen 
Verfassungsrechten in einer Verfassung spiegelt die aufgezeigte Spannung wieder. 2) Es ist ein Versuch ihrer Auflösung und Balance.

Aber infolge der verschiedenen Funktionsweise und Wertigkeit der beiden Rechts-Typen ist es ausgeschlossen, den Spannungsausgleich - auch nur in den Grenzen, in denen er der Sache nach überhaupt möglich ist - schon in der Verfassung herbeizuführen. ${ }^{3)}$ Eine Verfassung, die gleicherweise das sozial Notwendige bewirkt und die Freiheit maximal wahrt, ist schon um deswillen undenkbar, weil sie das sozial Notwendige nicht selbst und unmittelbar bewirken kann.

Trügerisch wäre es, den Ausgleich innerhalb der Verfassung durch den Vorrang der "sozialen" Verfassungsrechte herbeiführen zu wollen, m.a.W. den ausgrenzenden Grundrechten die Zähne auszubrechen, mit denen sie sich gegen den sozial intendierten Eingriff wehren könnten. Das würde die von ihnen ausgehenden Hemmungen des sozialen Ausgleiches - wenn nicht die Hemmungen schlechthin - beseitigen. Aber es wäre keine Synthese. Die Spannung würde ausschließlich zugunsten des Sozialen und zuungunsten der Abwehrpositionen aufgelöst. Und wiederum: Der "soziale" Sollzustand wäre auch damit noch nicht bewirkt. Nur einzelne in rechtsstaatlicher Weise als unmittelbar vollziehbare Normen gestaltete "soziale" Grundrechte können Ausnahmen gegenüber den Abwehrrechten schaffen. Die weiteren "sozialen" Verbürgungen können nur mittelbar, über den Inhalt - genauer: die Auslegung - der Ausgrenzungsrechte auf ihr Ziel hinwirken. Nur so ist eine Synthese von Teilhabe und Freiheit im Gegenüber ausgrenzender und gewährender Verfassungsrechte möglich. ${ }^{4)}$

eine rein liberale Politik vom sozialen Verlangen und gegen einen unfreiheitlichen Sozialismus vom Drang nach Freiheit und Entfaltung her Widerstände ergeben. Doch geht es hier nur um die innere Spannung der verbindenden Systeme.

2) Vgl. v. Mangoldt-Klein, S. 72 ff und seine Nachweise; Leibholz, Strukturprobleme der modernen Demokratie, S. 88, 130.

3) Das ist der.Grundtenor Forsthoffs in "Begriff und Wesen des sozialen Rechtsstaats". Die Synthese ist jedoch nicht so ausnahmslos unmöglich, wie Forsthoff behauptet.

4) Vorstehendes betrifft einen Teilaspekt des Verhältnisses von Sozialstaatlichkeit und Rechtsstaatlichkeit. Für alles weitere darf daher auf die Abschnitte 4 (S. 396 ff) und 5 (S.673 ff), insbes. auf $\mathrm{S} .744 \mathrm{ff}$ verwiesen werden. 


\section{ff) Ambivalente Verfassungsrechte}

In der neueren Entwicklung der Grundrechte hat sich die Erkenntnis von der Ungleichartigkeit der positiven und der negativen, der "sozialen" und der "liberalen" Gr'undrechte mehr und mehr durchgesetzt und zu einer gewissen Konzentration auf diese geführt. Zugleich hat sich aber gezeigt, daß ausgrenzende Grundrechte im Staat der Daseinsvorsorge, des sozialen Ausgleiches und der permanenten leistenden Ingerenz in die individuelle Sphäre gewissermaßen in eine "soziale" Funktion einrücken. Damit soll nicht noch einmal auf ihre oben 1) schon erörterte Bedeutung für die "Freiheit von der Teilhabe", für die staatsfreie Verfügungsmacht eines jeden über seine persönlichen Fähigkeiten und Kräfte und sein Vermögen zum Zwecke seiner eigenen sozialen Befriedigung zurückgekommen werden. Es geht hier um die Teilhabe am Allgemeinen. Auf die wenigstens mittelbar teilhabeverschaffende Wirkung des Gleichheitsgrundsatzes wurde bereits aufmerksam gemacht. ${ }^{2}$ Indem er den Staat an willkürlichen Benachteiligungen hindert, stellt er ihn vor die Alternative, seine Leistung allen zu gewähren, denen sie eine, vom gewählten Ansatzpunkt ausgehend, gerechte Abgrenzung gewähren müßte oder sie auch den zunächst Bevorzugten zu entziehen. Ist diese Wirkung eine relative, so ist die teilhabeverschaffende Funktion eines anderen Grundrechts absolut. Art.2 Abs.2 GG gewährt ein Recht auf Leben. Wie im gegebenen Zusammenhang nochmals wird erörtert werden müssen, 3) wird dieses Grundrecht nicht nur dahin verstanden, daß es dem Staat den Eingriff in das menschliche Leben verbietet sondern auch lahin, daß der Staat - genauer: der Sozialstaat - verpflichtet ist, das Existenznotwendige zu gewähren, das der Bedürftige sich nicht selbst verschaffen kann und kein anderer zu gewähren hat oder gewährt. Auch dem grundrechtlichen Kardinalsatz von ler Menschenwürde (Art. 1 Abs. 1 GG) wird diese absolute Ambivalenz zugeschrieben werden müssen. ${ }^{4)}$

Diese Entwicklung ist signifikint. Sie weist darauf hin, daß die verfassungsmäßige Grundurdnun! , ler subjektiven Rechtsstellung des Bürgers in einem Staat (k.) Daseinsvorsorge und des sozialen Ausgleichs nicht auf (las Negative beschränkt bleiben kann. 5)
1) S. oben S.848 ff.
2) S. oben S.849 a.F.; s. ferner unten S. 903.
3) S. unten S.1083 ff.
4) S. unten S.1103 ff.
5) S. a. Abendroth, Diskussiorsbeitrag zu "Begriff und Wesen des sozialen Rechtsstaats", S.87; ferner Bachof, Begriff und 
Selbst wo die Verfassung sich auf eine ausgrenzende Ordnung konzentriert, wird sie aus dieser Position herausgeholt. Die soziale Abhängigkeit des Bürgers vom Staat beinhaltet staatliche Macht. Ungleiche Vorenthaltungen des leistenden Staates sind nicht anders ein Machtmißbrauch als ungleiche Belastungen. Oder um noch weiter zu gehen: Der Staat, der die daseinsvorsorgende Verantwortung für seine Bürger übernommen hat - was er nicht ohne weittragende sozialstrukturelle Folgen tut -, greift in das Leben seiner Bürger nicht nur dadurch ein, daß er sie, aktiv handelnd, tötet sondern auch dadurch, daß er ihnen vorenthält, was sie zum Leben brauchen und ohne seine Hilfe nicht verschaffen können. Nicht anders ist es hinsichtlich der staatlichen Verpflichtung auf ein menschenwürdiges Dasein seiner Bürger. Das erklärt nicht nur, daß eine rein negative Grundrechtsordnung nicht ausreicht, um den einzelnen zu sichern. Es erklärt auch, warum einerseits die Ausbildung spezifisch "sozialer", positiver Grundrechte unfruchtbar geblieben ist, während sich aus dem Negativen ein Ansatz positiven, "sozialen" Grundrechtsschutzes entwickelt.

Die soziale Intervention des Staates ist als solche, als etwas Positives, grundrechtlich im allgemeinen nicht faßbar. Die Verfassung kann sie objektivrechtlich inaugurieren, wobei sie von vorneherein Wesentliches den politischen Kräften überlassen muß. Sie kann deren Wirken zu steuern suchen. Aber sie muß scheitern, wenn sie es unternehmen wollte, die sozialen Veranstaltungen des Staates durch subjektive Berechtigungen der Herrschaft der Individuen zu unterstellen. Eine fruchtbare individuelle Rechtsposition läßt sich von der Verfassung erst wieder unter der Voraus setz ung sozialer Veranstaltungen und Leistungen herstellen. Von der Norm der Teilhabe her wird die Ausnahme der Vorenthaltung und der Benachteiligung mit derselben Allgemeinheit faßbar wie Belastung und Eingriff von der Norm der Freiheit und des Unbeteiligtseins her.

Die Norm der Teilhabe besteht aus einer absoluten Minimalsubstanz und einem nicht von vorneherein feststehenden und nicht gleichbleibenden Mehr. Das Minimum ist die Sorge um die Erhaltung der biologischen Existenz der Bürger und des für ihr menschenwürdiges Dasein Unerläßlichen. Über dieses Minimum läßt sich nicht diskutieren, ohne daß das Wesen des Staates als eines dem Menschen dienenden Sozialstaates in Frage gestellt wird. Dieses Minimum kennt kein eigentliches Insolvenzrisiko. Der

Wesen des sozialen Rechtsstaats, S. 42; Hamel, Die Bedeutung der Grundrechte im sozialen Rechtsstaat, S.23 ff. 
Staat, der es nicht mehr erfüllen kann, ist funktionsunfähig geworden oder befindet sich wenigstens in einer Krise auf Leben und Tod, in einem Notstand, in dem keine Verfassung mehr voll eingehalten werden kann und will. Der Absolutheit dieser Minimalnorm entspricht ein - nicht im technischen Sinn unseres bürgerlichen Rechts - absolutes Recht auf Teilhabe nach Maßgabe dieser Norm und auf Abwehr des Ausschlusses hiervon. Der Niederschlag dessen ist die besagte positive "soziale" Geltungsrichtung des Rechts auf Leben und des Verfassungssatzes von der Menschenwürde. Über dieses sozialstaatliche Fixum erhebt sich eine Fülle von Maßnahmen gesteigerter sozialer Obsorge. Ihr A usmaß bestimmt jeweils die Norm der möglichen Teilhabe. Sie ist relativ. Dem entspricht ein ebenso relatives Recht auf Teilhabe an dem jeweils an sich Gewährten und auf Abwehr des Ausschlusses von der Teilhabe. Das Willkürverbot des Gleichheitsgrundsatzes bringt dieses Recht auf die allgemeine Formel - auch insofern als es als Sanktion auch den Entzug der Teilhabe der willkürlich Bevorzugten offen läßt und somit nicht unter Gefährdung der Effektivität des Rechts unbedingt auch dann zur Gewährung einer Teilhabe zwingen will, wenn diese aus Gründen mangelnder Leistungsfähigkeit nicht mehr geboten werden kann.

\section{b) Ausgrenzende Grundrechte und sog. "soziale" Grundrechte}

"Soziale" Grundrechte und weitergehende "Gesamtregelungen des gesellschaftlichen Lebens" wurden in das deutsche Verfassungsleben im wesentlichen durch die Weimarer Verfassung eingeführt. 1) Die in den ersten Jahren nach 1945 erlassenen Landesverfassungen glaubten, von diesem Vorbild nicht abweichen zu sollen. Das Grundgesetz zeichnet sich demgegenüber durch fast völlige Abstinenz aus. Teils mit Rücksicht auf die unsichere Sachlage, 2) teils mit Rücksicht auf die damals noch in ganz anderem Maße als heute offene Zuständligkeit der Länder, ${ }^{3)}$ teils schließlich wohl aus in Art. 1 Abs. 3 GG manifestiertem Willen, dem Verfassungsrecht eine für "soziale" Grundrechte und Programme undenkbare unmittelbare Geltung zu geben, ${ }^{4)}$ glaubte man, auf eine gesellschaftsgestaltende P'rogrammatik verzichten zu sollen. 5)

1) S. den Zweiten Hauptteil "Grundrechte und Grundpflichten der Deutschen".

2) Vg1. v. Mangoldt, Das Bonner Grundgesetz (1.Aufl.) S. 35.

3) Vgl. v. Mangoldt-Klein, S.90; Maunz, Deutsches Staatsrecht, S. 82 .

4) S. oben S. 846 zu Fußn. 6

5) S. a. v. Mangoldt-K1ein, S.101. - Koellreutter (Deutsches Staatsrecht, S. 52) glaubi vor allem das Fehlen einer klaren 
Wenn einzelne der üblichen verfassungsrechtlichen Gesamtordnungen des sozialen und wirtschaftlichen Lebens herausgegriffen und einer mehr oder weniger umfassenden Regelung unterworfen wurden - s. Art. 6, 7, 9, 12, 14,15GG ${ }^{6)}$-, so war jeweils auch diese möglichst aktuell, d.h. also vorwiegend ausgrenzend gehalten. Im übrigen floß der Strom des sozialen Verfassungswollens in die soziale Generalnorm: in das Sozialstaatsprinzip, das man - mit Rücksicht auf den uneinheitlichen und undisziplinierten Gebrauch des Terminus "soziales Grundrecht" trotz seines objektivrechtlichen Charakters - wohl als das "soziale Hauptgrundrecht" bezeichnen könnte. ${ }^{7)}$

Dagegen wurde ein System ausgrenzender und abwehrender Verfassungsrechte geschaffen, deren Geltungskraft insbes. infoige ihrer Gesetzesfestigkeit (Art.1 Abs.3 GG) grundlegend über das vordem Traditionelle hinausgeht. Sie sind vollwertige subjektivöfentliche Rechte. Teils sind sie ferner verbunden mit Einrichtungsgarantien. Teils enthalten sie verfassungsrechtliche Leitprinzipien. In jedem Falle zeichnen sie dem staatlichen und sozialen Leben unausweichliche Wege vor und setzen sie ihm Daten von tiefgreifender und umfassender Bedeutung. Sie sichern Individuen und Gruppen den staatsfreien Lebensraum, der ihre Chance zur "Freiheit von der 'Teilhabe" umschließt. Sie beziehen die objektiven rechtsstaatlichen Bindungen der Staatsgewalt in die individuelle Sphäre ein und geben so auch einen entscheidenden Ansatz zur "Freiheit in der Teilhabe". Andererseits bilden sie die Abwehrlinie gegenüber dem nehmenden und verpflichtenden Eingriff der sozialen Intervention in den Bereich der Individuen und der berechtigten Gruppen. Gewisse, als ambivalent bezeichnete Grundrechte bergen schließlich auch ein Minimum an echtem "sozialem" Grundrechtsschutz. ${ }^{8)}$

A uf diese engere Grundrechtsordnung wird sich die nachfolgende Darstellung im wesentlichen zu beschränken haben. Sie bildet und gestaltet den Raum subjektiver Berechtigung, mit dem die Verfassung den Menschen bzw. den Bürger 9) umgibt. Die objek-

und einheitlichen Konzeption "innerhalb der politischen Machtfaktoren" verantwortlich machen zu sollen.

6) S. hierzu z.B. v. Mangoldt-Klein, S.90; Maunz, Deutsches Staatsrecht, S. 82 .

7) Surrogatsfunktion des Sozialstaatsprinzips im Verhältnis zu "sozialen Grundrechten" und einzelnen sozialen Grundsätzen s. oben S. $673 \mathrm{ff}$ und S. 695 .

8) S. oben S. $857 \mathrm{ff}$.

9) Zur Unterscheidung zwischen Menschen- und Bürgerrechten im geltenden Verfassungsrecht s. z.B. v. Mangoldt-Klein, 
tivrechtliche Grundsatzgesetzgebung und - gelegentlich bis zur Unverbindlichkeit absinkende - Programmatik auch sog. "sozialer Grundrechte" wird, wie stark immer sie das soziale Verhalten des Staates bestimmen mag, erst durch sie in die Subjektposition des Bürgers reflektiert.

4. Einige Probleme der Grundrechtsgeltung

a) Allgemeine soziale Schranken der Grundrechte

\section{aa) Grundrechte im Sozialstaat}

Der Sozialstaat bedingt die gebende und nehmende Anteilnahme des einzelnen am Allgemeinen und seine gesteigerte Einordnung in das größere Ganze der staatlichen Gemeinschaft. Er muß auf die gesellschaftlichen Verhältnisse Einfluß nehmen, die Entwicklung kontrollieren und den Besitzstand korrigieren. Er verkürzt die Individualität und die staatsfreie Eigenwirksamkeit der kleineren Gemeinschaften. Die Grundrechte sichern das Unbeteiligtsein des Individuums, drängen die Einflußnahme des Staates auf das persönliche Verhalten, auf die kleinere Gruppe, auf die gesellschaftlichen Verhältnisse und ihre Entwicklung zurück und schützen den status quo gegen obrigkeitlich dekretierte Veränderungen. Darin liegt die vielberufene Spannung zwischen Grundrechten und Sozialstaatsprinzip; und darin liegt auch ein gut Teil des nicht weniger vielberufenen "inner.en Widerspruchs" der Formel vom sozialen Rechtssaat.

Das Grundgesetz hat Sozialstaat und ausgrenzende Grundrechtsordnung nebeneinandergestellt und fordert die Synthese. Diese Synthese ist im Grunde schon angelegt in der fruchtbaren Positivität, mit der sich Sozialstaatlichkeit und ausgrenzende Grundrechtsordnung gegenüberstehen, stützen und ergänzen. 1) Sie ist möglich vor allem auch dadurch, daß der Sozialstaat sich weitgehend auf Wegen vollziehen kann, die "um die Grundrechte herum" führen. 2) Die Synthese des sozialen Rechtsstaates setzt aber voraus, daß die Grundrechte dem Sozialstaat nicht jedes Eindringen in den individuellen Bereich, nicht jede Finflußnahme auf die gesellschaftlichen Verhältnisse, nicht jede Besitzstandskorrektur verwehren. Sie beinhaltet eine gewisse Offenheit des Grundrechtsschutzes gegenüber dem Sozialstaat, ein apriorisches

S.97ff; Maunz, Deutsches Staatsrecht, S. $80 \mathrm{f}$.

1) S. o. Abschnitt 5 II $3 \mathrm{c}$ aa (S. $744 \mathrm{ff}$ ) und Abschnitt 6 I 3 a (S. $848 \mathrm{ff}$ ) (insbes. S. 848 und S. 850) und die dortigen Nachweise.

2) S. insbes. oben Abschnitt 4 I (S. 396 ff) und II 2 (S. 412 ff) (passim), Abschnitt 5 II 3 c (S. 744 ff) und die dortigen Nachweise. 
Hineindenken der Grundrechte in die sozialstaatliche Ordnung. Grundrechte im Sozialstaat sollen a $\mathrm{ch}$ dem einzelnen einen gesicherten, abgesonderten Rechtskreis verschaffen und ein staatsfreies Wirken kleinerer Gemeinschaften ermöglichen. Aber sie sollen das von vorneherein in einem Gemeinwesen, in dem es nicht nur darum geht, dem Sichausleben jeglicher Individualität Raum zu geben und das Unbeteiligtsein an der staatlichen Gemeinschaft zu schützen.

\section{bb) Sozialstaatsgerechte Grundrechtsauslegung}

Das hieraus fließende Erfordernis einer sozialstaatsgerechten A uslegung der Grundrechte ${ }^{1)}$ ist ihre erste und allgemeinste soziale Schranke. Aber die sozialstaatliche Aktion ist von den grundrechtlichen Beschränkungen nicht etwa entbunden. ${ }^{2)}$ Dem sozialstaatlichen Verfassungselement darf auch nicht sonstwie ein Vorrang vor den Grundrechten zugestanden werden. ${ }^{3)}$ Die präzisere Formulierung der Grundrechte sichert ihrem Wertgehalt dabei zudem einen so beträchtlichen Vorsprung, daß das sozialstaatliche Interpretationsargument nur selten eine ausschlaggebende Bedeutung erlangen und somit einen sozialen Einbruch in die grundrechtliche Abwehrposition erzielen kann.

Zwar kann eine detailliertere verfassungsrechtliche soziale Grundordnung, hier und da auch einen intensiveren interpretatorischen Einfluß gewinnen. Soweit aber die Verfassung nicht selbst soziale Vorbehalte in die Grundrechte hinein treibt oder durch aktuelle Anordnungen Ausnahmen schafft, ist auch die interpretatorische Bedeutung speziellerer Sozialprogramme nicht entscheidend größer als die des allgemeinen Sozialstaatsprinzips. Meist lassen auch sie verschiedene Wege der Verwirklichung zu, so daß aus ihnen nicht $z$ wingend entnommen werden kann, der Wille der Verfassung gehe auf diese oder jene ganz bestimmte Grundrechtsbeschränkung.

\section{cc) Gesetzesvorbehalte}

Tiefer kann der Sozialstaat in das grundrechtsgeschützte Feld nur eindringen, wenn die Grundrechte unter dem Vorbehalt gesetzlicher Einschränkung ${ }^{1)}$ stehen. Gesetzesvorbehalte erheben die

1) S. o. :S.720 zu Fußn.2 (s.a. Fußn. 1 das.)

2) ebd., S. 720 zu Fußn.3.

3) ebd., S. 721 zu Fußn. 4.

1) S. hierzu nochmals Lerche, Grundrechtsbegrenzungen "durch Gesetz" im Wandel des Verfassungsbildes. 
oberste in Permanenz fungierende demokratische Instanz, den Gesetzgeber, zum Schiedsrichter über den Bestand der ihnen unterstellten Grundrechte gegenüber den Bedürfnissen des Gemeinwe sens. 2)

Die einzelnen Gesetzesvorbehalte des Grundgesetzes 3 ) tragen keinen spezifisch sozialen Charakter. Das gilt auch für Art.2 Abs. 1 GG, wenngleich zu den von der verfassungsmäßigen Ordnung getragenen Gesetzen, die im Rahmen dieses Grundrechts die persönliche Freiheit beschränken, schon deshalb, weil das Sozialstaatsprinzip den Gesetzgeber dazu anhält, vornehmlich solche sozialer Aufgabenstellung gehören. ${ }^{4)}$ Es gilt ferner auch für den Regelungsauftrag und -vorbehalt des Art. 14 Abs. 1 und 3 GG, wenngleich das "Wohl der Allgemeinheit", dem das Eigentum zu dienen hat, in hervorragender Weise vom Sozialstaatsprinzip her determiniert ist. 5) Es gilt schließ1ich auch für die Ermächtigung zur Sozialisierung (Art. 15 Satz 1 GG); denn diese ist nicht nur zu (im engeren "sozialstaatlichen" Sinne) sozialen Zwecken denkbar oder erlaubt.6)

dd) Schutz der Menschenwürde - das gemeinsame Prinzip von Grundrechtsordnung und Sozialstaatlichkeit

Jede Einschränkung eines Grundrechts, auf welche Weise ihre Zulässigkeit auch immer begründet ist, hat den We sen s ge ha $1 \mathrm{t}$ des Grundrechts unberührt zu lassen (Art. 19 Abs.2 GG). Das neben der "historisch-soziologisch-politischen Inhaltsbestimmung" der Grundrechte wesentliche Regulativ für die Bestimmung dieses Wesensgehaltes ist der Kardinalsatz von der Menschenwürde (Art.1 Abs.1 GG). 1) 2) Der Sozialstaat dient der Ent-

2) S. zu diesen Zusammenhängen etwa Dürig in Maunz-Dürig, Art. 2 Abs. I Randn. 25 und seine Nachw.; s.a. BVerfGE 5, 85 (198).

3) Ohne nähere Unterscheidung seien genannt: Art.2, 4 Abs.3, 5 Abs. 2, 6 Abs. 3, 8 Abs. 2, 10, 11 Abs. 2, 12, 13 Abs. 2 und 3, 14 Abs. 1 und 3, 15, 16 Abs. 1, 104 und schließlich Art. 17 a GG.

4) S. o. S. 722 zu Fußn. 8. - S. ferner unten V 8 b, bb (S.1062 ff) u. cc (S.1064 ff).

5) S. unten S.945fr.

6) S. u. III 3 a (S.945 ff) und 4 d (S.963 ff).

1) Eine gewisse Koppel zwischen Art.1 Abs. 1 GG und Art. 19 Abs. 2 GG stellt Art. 1 Abs. 2 GG dar. S. die nachfolgend Zitierten.

2) Vg1. Dürig, Der Grundrechtssatz von der Menschenwürde, AöR, Bd.81 (1956) S. 117 ff (insbes. S. 133 ff); ders. in Maunz- 
faltung und dem Schutz der Menschenwürde. ${ }^{3)}$ Wie die Grundrechte, so ist auch das Sozialstaatsprinzip diesem Zentralwert der Menschenwürde mit ganz bestimmten materialen Inhalten zugeordnet. Diese sind es, hier wie dort, die sich widerstreiten können. Aber keine der beiden Schutzordnungen kann preisgegeben werden, ohne daß der Kern bloß gelegt und verletzt würde.

Die eigenartige Dialektik von Grundrechtsordnung und Sozialstaatsordnung, die den angespannten Gegensatz ebenso beinha1tet wie die wechselseitige Stützung und Ergänzung, findet in dem Grundsatz von der Achtung und dem Schutz der Menschenwürde in stetem Fortgang Ursprung und Auflösung. Der wesentliche Bezug der Grundrechte und der Sozialstaatlichkeit auf die Würde des Menschen bestätigt, daß die Spannung zwischen den beiden Elementen nicht dadurch aufgelöst werden darf, daß eines das andere aufzehrt. Er gibt aber auch die Hoffnung, daß sich das Wesentliche des Sozialstaats und das Wesentliche der Grundrechtsordnung letztlich gleichermaßen und nebeneinander verwirklichen lassen.

\section{b) Art. $18 \mathrm{GG}$}

Aber das Spannungsverhältnis bleibt. Es bleibt vor allem dort, wo grundgesetzliche Grundrechte keiner gesetzlichen Einschränkung weichen. Auch der Wesensgehalt der Grundrechte, auf den im Rahmen gewisser Gesetzesvorbehalte vorgestoßen werden kann, ist nicht nur ein Synonym für den Zentralwert der Menschenwürde, genau so wenig wie das Sozialstaatsprinzip. Somit bleibt die Möglichkeit, daß Grundrechte gegen den Sozialstaat ausgespielt werden. Daher richtet sich der Blick auf Art.18 GG. Aber an dieser Vorschrift erweist sich, daß der Staat des Grundgesetzes zwar eine "militante Demokratie" ist, nicht dagegen ebenso ein "militanter Sozialstaat".

Wer die in Art. 18 GG genannten Grundrechte "zum Kampfe gegen die freiheitliche demokratische Grundordnung 1) mißbraucht", verwirkt sie. Wer seine Grundrechte dagegen zum Kampf gegen die sozialstaatliche Grundordnung mißbraucht, verwirkt sie nicht.2)

Dürig, Art. 1 Abs. II Randn. 81; Wintrich, Zur Bedeutung der Menschenwürde für die Anwendung des Rechts, S. 140.

3) S. о. S. 679 zu Fußn. 4.

1) Zum Begriff s. z.B. v. Mangoldt-Klein, Art. 18 Anm. III 4 b.

2) S. die entsprechenden Zusammenhänge auch schon hinsichtlich der Verpflichtung der Parteien auf die freiheitliche demokratische Grundordnung (s.o. S. 372 ). S. auch die dortigen 
Allerdings wird er diesen Kampf nicht mit Erfolg führen können, ohne auch die freiheitliche demokratische Grundordnung anzugreifen. Art. 79 Abs. 3 GG schützt auch das Sozialstaatsprinzip in Art. 20 GG. Es kann nur auf revolutionärem Wege beseitigt werden, auf einem Weg also, der jedenfalls in aller Regel eine Zerstörung der freiheitlichen demokratischen Grundordnung einschließen wird. Aber unmittelbares Schutzgut des Art.18 GG ist die Sozialstaatlichkeit nicht.

Das kann nicht einfach damit abgetan werden, daß auch die Rechte, deren Mißbrauch abgewehrt werden soll, zum großen Teil Freiheits- und jedenfalls keine "sozialen" Rechte sind. Die soziale Bedeutung auch der ausgrenzenden Grundrechte ist bekannt. ${ }^{3)}$ Im übrigen braucht nur darauf hingewiesen zu werden, daß sich auch das Grundrecht des Eigentums unter den in Art.18 GG aufgezählten Rechten befindet, um die Tragweite des Problems zu illustrieren. Der Grund der sozialstaatsabgewandten Schutzrichtung des Art. 18 GG ist wohl der, daß die größere Gefahr nicht von einer Seite kommt, welche die Sozialstaatlichkeit angreift, sondern von einer Seite, welche die Freiheit zerstören will. 4 )

c) Die Grundrechte im besonderen Gewaltverhältnis

aa) Allgemeines

Die soziale Intervention des Staates steht in nicht unerheblichem Umfang in teils gegenständlicher, teils instrumentaler Beziehung zu besonderen Gewaltverhältnissen. ${ }^{1)}$ Daher sind für sie gerade auch die Grundrechtsbeschränkungen von Interesse, die mit den besonderen Gewaltverhältnissen verbunden sind. ${ }^{2)}$

Eine einheitliche Lösung für alle besonderen Gewaltverhältnisse gibt es nicht. ${ }^{3)}$ Der Begriff des besonderen Gewaltverhältnisses umschließt zu unterschiedliche Erscheinungen, als daß ein einheitliches Verhältnis zwischen diesen und den Grundrechten möglich

Nachweise.

3) S. oben S. $848 \mathrm{ff}$ und S. $857 \mathrm{ff}$.

4) Das Nähere und Nachweise hierzu s.a. S. 372.

1) S. o. S. $445 \mathrm{ff}$.

2) S. statt aller anderen v. Mangoldt-Klein, S.133 ff und seine Nachweise; ferner Hildegard Krüger, Die Grundrechte im besonderen Gewaltverhältnis, Zeitschrift für Beamtenrecht, 4.Jhg. (1956) S. 309 ff; v. Münch, Die Grundrechte der Strafgefangenen, JZ 13. Jhg. (1958) S. $73 \mathrm{ff}$.

3) S.a. v. Mangoldt-Klein, S.137; Krüger, a.a.O. S. 312. 
wäre. Insbesondere kann ein solches nicht aus der "Unterwerfung" und dem ihr entsprechenden "Grundrecht sausübungsverzicht" abgeleitet werden. Schon für die Rechtfertigung des besonderen Gewaltverhältnisses gegenüber dem Vorbehalt des Gesetzes ist das Argument der "Unterwerfung" weit weniger brauchbar als gemeinhin angenommen wird. 4) Auch für den "Grundrechtsausübungsverzicht" wird immer mit großer Vorsicht zu fragen sein, ob er wirklich freiwillig abgegeben wurde und alles das umfaßt, was in Entfaltung des eingegangenen Gewaltverhältnisses aus ihm herausgelesen wird. Aber selbst wo eine wirklich freiwillige, im vollen Umfang des "Grundrechtsausübungsverzichts" tragfähige Unterwerfung vorliegt bzw. von der grundrechtseinschränkenden Regelung eines besonderen Gewaltverhältnisses vorausgesetzt wird, sind Vorbehalte anzubringen. Der Staat, der die Grundrechte gewährt und durch seine Verfassung an sie gebunden ist, kann nicht ohne weiteres Einrichtungen schaffen, die nur Personen begünstigen oder sonstwie erfassen, die auf ihre Grundrechte verzichten. Er darf nicht auf die untere Grenze des Interesses der Betroffenen an ihren Grundrechten 5) spekulieren, um diese vorteilhaft "zurückzukaufen".6)

Nicht ein einheitliches Prinzip steht also in Frage sondern die differenzierte Erscheinung, daß gewisse Grundrechte sich

4) S. O. S. $445 \mathrm{ff}$.

5) Vg1. Fechner, Die soziologische Grenze der Grundrechte, S. 12 ff, insbes. S. 21.

6) Die zutreffende Unterscheidung, daß die Grundrechtsbeschränkung durch besondere Gewaltverhältnisse nicht die Grundrechtsfähigkeit sondern die Grundrechtsausübung betreffe (Dürig, Maunz-Dürig, Art. 19 Abs. III Randn. 18; ganz h. M.) und ein Verzicht nicht ein Grundrechts- sondern ein Grundrechtsausübungsverzicht sei (v. Mangoldt-Klein, S. 136; desgl. ganz h. M.), läuft leicht Gefahr, in Formalismus zu entarten. Wenn es richtig ist - und es ist richtig! -, daß Grundrechte deshalb unverzichtbar sind, weil die Verzichtbarkeit ihren Bestand gefährden würde (vgl. Koellreutter, Deutsches Staatsrecht, S. 52; Maunz, Deutsches Staatsrecht, S.113), so muß doch auch dem Verzicht auf die Ausübung gegenüber größte Vorsicht geübt werden. Unterscheiden sich Ausübungsverzicht und Rechtsverzicht praktisch nicht erheblich, so muß dem auch hinsichtlich der Folgen Rechnung getragen werden. Auf die Sache kommt es an! S. hierzu auch Lerche, Grundrechte der Soldaten, in: Bettermann-Nipperdey-Scheuner, Die Grundrechte, Bd.IV, 1. Halbbd. 1960, S. 447 ff (489). 
ge wissen besonderen Gewaltverhältnissen bis zu jeweils verschiedenen inhärenten Grenzen (Gewährleistungsschranken) ${ }^{7)}$ öffnen. Sie können einem besonderen Gewaltverhältnis Raum auch in ein Grundrecht hineinbrechen, das einen Gesetzesvorbehalt nicht enthält. Sie können es tiefer in den sachlichen Geltungsbereich eines Grundrechts eindringen lassen als der angebrachte Gesetzesvorbehalt eine gesetzliche Beschränkung erlauben würde. Sie übergehen etwa die formelle Kontrollnorm des Art. 19 Abs. 1 Satz 2 GG. 8) Im besonderen aber stehen die inhärenten Grenzen eines Grundrechts anders zur Wesensgehaltssperre der Grundrechte (Art. 19 Abs. 2 GG) als die grundrechtlich vorbehaltenen gesetzlichen Beschränkungen; denn sie entspringen selbst dem Wesen des Grundrechts und bestimmen sein Wesen mit. $\left.{ }^{9}\right)$

Soweit allerdings ein Grundrecht unter dem Vorbehalt des Gesetzes steht oder sich von vorneherein auf eine gesetzlich geregelte Rechtssubstanz bezieht - wie es vornehmlich bei den mit Einrichtungsgarantien gekoppelten Grundrechten der Fall zu sein pflegt - tritt die Eigenständigkeit inhärenter Schranken, die sich

7) Dafür, daß es um ein Problem der Gewährleistungsschranken geht, s. insbes. v. Mangoldt-Klein, S.135. Prinzipiell anderer Meinung Leissner, Die schutzwürdigen Rechte im besonderen Gewaltverhältnis. Er glaubt, ausschließlich auf den Gesetzesvorbehalt abstellen zu können (s.a. seine Nachweise S.624 F'ußn. 41).

8) V.Mangoldt-Klein (S. 138) und Wolff (Verwaltungsrecht I, S. 102) halten Art.19 Abs. 1 GG auf Grundrechtseinschränkungen durch besondere Gewaltverhältnisse ohne nähere Unterscheidung für unanwendbar. Dem kann nicht zugestimmt werden. Keinesfalls kann es eine Ausnahme von Art. 19 Abs. 1 Satz 1 GG geben (Art. 3 GG!). Art. 19 Abs. 1 Satz 2 GG gilt nur ciann nicht, wenn eine inhärente Grundrechtsschranke in Frage steht (s.a. Röhl, Die Nennung des eingeschränkten Grundrechts nach Art. 19 Abs. I Satz 2 des Grundgesetzes, Ä̈R Bd. 81 (1956/57) S. 195 ff, insbes. S. 207).

9) Vgl. v. Mangoldt-Klein, S.136 (wo er die Anwendung des Art. 19 Abs. 2 GG auf Grundrechtseinschränkungen krafi besorderen Gewaltverhältnisses ablehnt) und Art. 19 Anm. V 1 a (wo er die interpretatorische Bedeutung des Art. 19 Abs.2 GG für die Auffindung der Gewährleistungsschranken erörtert). S. ferner Lerche, Grundrechte der Soldaten, S.461 f. Gegen die Ausschaltung des Art. 19 Abs. 2 GG für Grundrechtseinschränkungen kraft besonderen Gewaltverhältnisses Wolff, Verwaltungsrecht I, S.102, 148. 
sachlich in demselben Grundrechtsumhof bewegen, nur bedingt hervor. Allenfalls in jenen seltenen Fällen, in denen eine gesetzliche Einschränkung auf Grund des grundrechtlichen Vorbehaltes der Vorschrift des - entgegen seiner allgemeinen Fassung nur exzeptionell anwendbaren - Art. 19 Abs. 1 Satz 2 GG 10) unterläge, während eine inhärente Schranke dieser Vorschrift den Gegenstand entzieht, allenfalls ferner dort, wo eine Grundrechtseinschränkung nur "durch Gesetz" und nicht "auf Grund Gesetzes" vorgenommen werden kann, 11) während einer inhärenten Schranke diese Differenzierung grundsätzlich fremd ist, kann sich ein Unterschied auch in diesem Bereich zeigen. Im übrigen vereinigt die gesetzliche Regelung eines Gewaltverhältnisses die Ausfüllung der "Vorbehaltsschranken" und der "Gewährleistungsschranken" 12) in sich. 13) Letztlich müssen auch die Grundsätze über die Möglichkeit gesetzesfreier besonderer Gewaltverhältnisse ${ }^{14}$ ) von hier her (mit)bestimmt werden und gerechtfertigt werden können.

Wie die Gewährleistungsschranken verlaufen, 15) bestimmt sich in erster Linie nach Struktur, Zweck und Funktion der einzelnen Grundrechte. Im Hinblick auf die besonderen Gewaltverhältnisse werden vor allem grundrechtsimmanente Prämissen wirksam, die das Grundrecht nur dann eingreifen lassen, wenn der Grundrechtsträger überhaupt imstande ist, von der gewährten Freiheit Gebrauch zu machen, d.h. wenn seine Handlungsfreiheit nicht anderweit legitimerweise so beschränkt ist, daß er sich nicht grundrechtsentfaltend betätigen kann. Ob ein Grundrecht diese Freiheit voraussetzt oder selbst noch gewährt, ${ }^{16)}$ wird in erster.

10) Zu dem beschränkten Anwendungsbereich des Art. 19 Abs. 1 Satz 2 GG s. Röh1, a.a.O., insbes. S. $203 \mathrm{ff}$.

11) Vg1. Lerche, Grundrechtsbegrenzungen "durch Gesetz" im Wandel des Verfassungsbildes.

12) S. zu diesen Begriffen (auch schon zum Vorstehenden) v. Mangoldt-Klein, S. $120 \mathrm{ff}$.

13) Zum Verhältnis der "technischen Behelfe von Gesetzesvorbehalten und deren Grenzen, wie im allgemeinen Gewaltverhältnis gebräuchlich", zu den substantiellen Veränderungen des "Grundrechtsbereiches durch die Zuordnungen zur Statusentscheidung" s.a. Lerche, Grundrechte der Soldaten, S.461 f.

14) S. oben S. $445 \mathrm{ff}$.

15) S. zum Folgenden allgemein v. Mangoldt-Klein, S. 123 ff, $133 \mathrm{ff}$.

16) S. zu diesem Problem auch Lerche, Grundrechte der Soldaten, S. $488 \mathrm{ff}$, der, am Einzelproblem operierend, die Alter- 
Linie aus seiner eigenen Gestaltung zu ermitteln sein. Auch das Gesamtsystem der grundrechtlichen Gewährleistungen, das eine gewisse Funktionsaufteilung unter den verschiedenen Grundrechten einschließt, gibt entscheidende Hinweise auf die Problemlösung. Die Grundrechtsinterpretation wird sich vor allem aber auch mit den Verfassungsnormen auseinanderzusetzen haben, die Gewaltverhältnisse als zulässig voraussetzen oder weitergehend institutionalisieren, 17) denen ihrerseits bestimmte Grundrechtsbeschränkungen wesentlich sind. Schließlich wird das vorrechtliche Gesamtbild - oder anders gesehen: der überkommene Bestand an besonderen Gewaltverhältnissen - interpretatorisch zu würdigen sein. Allerdings ist gerade bei der Auswertung der beiden letzterwähnten Gesichtspunkte Vorsicht am Platze. Sie dürfen nicht zur Stagnation führen. Auch neuen Typen besonderer Gewaltverhältnisse können die vorhandenen immanenten Schranken Raum geben. 18) Andererseits darf nicht von dem Zweck eines Gewaltverhältnisses auf die Zulässigkeit aller ihm gemäBen Grundrechtsbeschränkungen geschlossen werden. Der Grundsatz, im besonderen Gewaltverhältnis dürften "die Grundrechte der betroffenen Personen nur solchen Einschränkungen unterworfen werden, die der $Z$ weck des Gewaltverhältnisses zwingend erfordert", 19) muß als ein Ausdruck des gerade in diesem Zusammenhang außerordentlich wichtigen Verhältnismäßigkeitsprinzips mit seinem "nur" voll ernst genommen und darf nicht in eine Legitimation aller durch den Zweck des Gewaltverhältnisses erforderten Beschränkungen verkehrt werden. Die besonderen Gewaltverhältnisse waren - verfassungssystematisch betrachtet nicht vor den Grundrechten sondern frühestens $\mathrm{mit}$ ihnen da. Ihre verfassungsgerechte Gestalt ist von den Grundrechten von vorneherein mitgeformt. ${ }^{20)}$ Zudem sind die Grundrechte in der geltenden Verfassungsordnung stärker als sie in den Verfassungsepochen waren, in denen sich die gegebenen Gewaltverhältnisse herausgebildet haben. Die besonderen Gewaltverhältnisse müssen

native als Prinzip nicht sichtbar werden läßt. S. bei ihm auch weitere Nachweise.

17) S. die Übersicht bei v. Mangoldt-Klein, S. 137; Krüger, Die Grundrechte irn besonderen Gewaltverhältnis, S.310; vgl. ferner Lerche, a.a.O. S. $460 \mathrm{f}, 488 \mathrm{ff}$.

18) A.A. Krüger, a.a.O. S.311 f.

19) BayVerfGH VGHE n.F. 11 II 203 (212).

20) Vgl. Krüger, a.a.O. S.311 f; Bachof, Diskussionsbeitrag zu "Die besonderen Gewaltverhältnisse", Veröffentlichungen der Vereinigung der Deutschen Staatsrechtslehrer, Heft 15, 1957, S. 203 ff (205 f); ders., Freiheit des Berufs, S. 175 f; 
mit dieser entscheidenden Veränderung der Verfassungssubstanz in Einklang gebracht werden. 21) Vom Gewaltverhältnis her wird bei all dem in die Waagschale geworfen werden müssen, ob es auf freiwilliger "Unterwerfung" oder auf $Z$ wang beruht. Ein Grundrecht öfnet sich leichter und weitergehend einem Gewaltverhältnis, dessen Grundrechtsbeschränkungen einem freiwilligen Verzicht entsprechen, als einem besonderen Gewaltverhältnis, dessen Pflichtensubstanz ausschließlich aus dem Machtgehalt des allgemeinen Gewaltverhältnisses entnommen ist.

Hieran wird eine wichtige Unterscheidung geknüpft werden dürfen. Grundrechtsbeschränkungen aus einem unfreiwillig begründeten Gewaltverhältnis sind als solche nur dann durch entsprechende inhärente Grenzen gedeckt, wenn sie als die zwangsläufige Folge eines Gewaltverhältnisses auftreten, das seinerseits in dem durch die Grundrechtsordnung allgemein dem Gesetz überlassenen Raum vom Gesetz aus dem allgemeinen Gewaltverhältnis herausgehoben wurde. Die primäre Freiheitsbeschränkung, die das Gewaltverhältnis konstituiert, muß den allgemeinen Grundsätzen - pars pro toto: den grundrechtlichen Gesetzesvorbehalten entsprechen. Die sekundären Freiheitsbeschränkungen, die aus dem Gewaltverhältnis entspringen, könne n dieser Eigenschaft wegen privilegiert sein. ${ }^{22}$ ) Nur dann, wenn ein Gewaltverhältnis durch (wirklich!) freiwillige Unterwerfung begründet wurde, kann auch schon die primäre Statusminderung über die Vorbehaltsschranken hinausgreifen.

Endlich ist festzuhalten, daß nicht alle Grundrechte einer Einschränkung zugängig sind. 23) Eine Einschränkung etwa des Gleichheitsgrundsatzes oder der Glaubens- und Gewissensfreiheit wird in keinem Falle gerechtfertigt werden können. 24 )

Lerche, Grundrechte der Soldaten, S. 461.

21) S. auch Maunz, Deutsches Staatsrecht, S. 114: "Je rechtsstaatlicher eine Rechtsordnung ist, desto stärker wird die bedenkliche Lehre vom Anstaltsverhältnis, das Grundrechte durchbrechen kann, zurückgedrängt werden müssen".

22) Sachlich weitgehend übereinstimmend Leissner, Die schutzwürdigen Rechte im besonderen Gewaltverhältnis, S.62. S. ferner nochmals oben S. 868 zu Fußn. 15 und 16 und den Text hierzu.

23) Vgl. Maunz, Deutsches Staatsrecht, S. 114.

24) S. Forsthoff, Lehrbuch des Verwaltungsrechts, S.117. S. für den extremsten Fall des besonderen Gewaltverhältnisses, den Freiheitsstrafvollzug: v. Münch, Die Grundrechte des Strafgefangenen, S.74. - Das Problem der Bekenntnisfreiheit 
bb) Einige Einzelfragen

aaa) Grundrechte im offenen Anstalts- und im Körperschaftsverhältnis

Offene Anstaltsverhältnisse beinhalten in der Regel nur Beschränkungen der allgemeinen Handlungsfreiheit und eventuell auch Bindungen des Eigentumsgebrauchs; d. h. also nur Beschränkungen von Grundrechten, die entweder dem Gesetz bis auf einen auch für das besondere Gewaltverhältnis unantastbaren Wesenskern zugängig sind - so die allgemeine Handlungsfreiheit: Art. 2 Abs. 1 GG oder von vorneherein sich auf eine vom Gesetzgeber bzw. von der unterverfassungsmäßigen Rechtsordnung nach Maßgabe des verfassungsrechtlichen Leitbildes erst auszugestaltende Rechtssubstanz beziehen - so das Eigentumsrecht: Art.14 GG . Ob die Regelung der fraglichen Gewaltverhältnisse inhärente Grenzen realisiert oder sich auf dem Boden des allgemeinen Gesetzesvorbehalts bzw. gesetzgeberischen Gestaltungsauftrags bewegt, wird daher nicht sichtbar. 1) Soweit offene Anstaltsverhältnisse - z.B. indem die Meinungsäußerung für die Zeit der Anstaltsnutzung an eine Hausordnung gebunden wird - das Grundrecht der freien Meinungsäußerung (Art.5 GG) berühren, behindern sie diese kaum jemals mehr, als es im Rahmen der "allgemeinen Gesetze" (Art. 5 Abs.2 GG) liegt. 2) Das Problem der grundrechtsimmanenten Schranken kraft besonderen Gewaltverhältnisses kommt hinsichtlich offener Anstaltsverhältnisse daher regelmäßig nicht zum Tragen.

Entsprechendes gilt grundsätzlich für körperschaftliche Gewaltverhältnisse.

bbb) Grundrechte im geschlossenen Anstaltsverhältnis

Intensiver greifen geschlossene Anstaltsverhältnisse in die Grundrechte ein. 1) Sie werden durch Beschränkungen der allgemeinen

als innerkirchliches Grundrecht und der Kirchenzugehörigkeit als besonderes Gewaltverhältnis braucht hier nicht vertieft zu werden.

1) Auch nicht in bezug auf Art. 19 Abs. 1 Satz 2 GG. Vgl. Röhl, Die Nennung des eingeschränkten Grundrechts nach Art. 19 Abs. 1 Satz 2 des Grundgesetzes, S. $203 \mathrm{ff}$.

2) Art. 19 Abs. 1 Satz 2 GG findet auch auf die "allgemeinen Gesetze" i.S. des Art.5 Abs.2 GG keine Anwendung (Röhl, a.a.O. S.207).

1) Das einschneidendste Verhältnis dieser Art, der Freiheitsstrafvollzug, spielt für diese Untersuchung keine primäre 
Handlungsfreiheit, insbes. - aber nicht nur - der räumlichen Bewegungsfreiheit, begründet. Die verfassungsmäßigen Grenzen dafür sind weit gezogen (Art.2, 104 GG). ${ }^{2}$ ) Sie bedingen darüber hinaus aber nicht nur akzessorische weitere Beschränkungen der allgemeinen Handlungsfreiheit oder auch der körperlichen Bewegungsfreiheit 3 ) und sekundäre Beschränkungen anderer, der gesetzlichen Regelung in dem erforderlichen weiten Umfang von vorneherein zugängiger Rechte, insbes. des Eigentumsrechts (Art.14GG) 4) und der Berufsausübung (Art. 12 Abs. 1 Satz 2 GG).5) Sie schränken möglicherweise auch Rechte ein, die der Gesetzgeber sonst nicht in dieser Weise beengen kann: so die Freiheit der Religionsausübung (Art. 4 Abs. 2 GG); ${ }^{6}$ ) die Freiheit

Rolle. Doch ergeben sich zahlreiche Vergleichspunkte. S. daher zum Folgenden insbes. auch v. Münch, Die Grundrechte des Strafgefangenen. - Ein anderer Vergleichskomplex ist derjenige der Dienstverhältnisse mit gesteigerter Kommunikation der Bediensteten (Soldaten, Ersatzdienstpflichtige, kasernierte Polizisten u. ä.). S. daher zum Nachstehenden auch die einschlägigen Hinweise unten S. $874 \mathrm{f}$.

2) Eine "Unterwerfung" in die Beschränkung der körperlichen Bewegungsfreiheit wird nur dann legitimativ anerkannt werden können, wenn der Widerruf in angemessener Weise offen gehalten ist (vgl. Dürig, Maunz-Dürig, Art. 104 Randn.9).

3) Einer Intensivierung des Freiheitsentzugs - z.B. durch Hausoder Zimmerarrest - müssen enge Grenzen gesteckt werden. Die Garantien des Art.104 GG dürfen nicht umgangen werden. Eine "Unterwerfung" muß sich gegebenenfalls ausdrücklich darauf beziehen und darf nicht widerrufen sein. (Daß die "Unterwerfung" möglicherweise nur im Ganzen widerrufen werden kann, ist eine andere Frage.) Bei zwangsweiser Unterbringung wird auch der gesteigerte Freiheitsentzug nur zulässig sein, wenn er durch den Richterspruch (mit-) gedeckt ist (s.a. Dürig, a.a.O. Randn. 8).

4) A.A. Krüger, Die Grundrechte im besonderen Gewaltverhältnis, S. 311.

5) Vg1. Krüger, a.a.O.

6) Vgl. Krüger, a.a.O. S.311. Zur sekundären Einschränkbarkeit dieses Grundrechts, das - jedenfalls im Grundgesetz einen ausdrücklichen Gesetzesvorbehalt nicht aufweist s.a. v. Mangoldt-Klein, Art. 4 Anm. IV 4. - v. Münch (Die Grunclrechte des Strafgefangenen, S. 74) meint: "A.rt. 4 GG erschöpft sich nicht in einem bloßen Abwehrrecht, sondern gibt einen positiven Anspruch des Gefangenen gegen den Staat auf die Möglichkeit ausreichender seelsorgerischer Betreuung". 
der. Meinungsäußerung und - verbreitung über die "allgemeinen Gesetze" hinaus und die Freiheit der wissenschaftlichen und künstlerischen Betätigung (Art. $5 \mathrm{GG}$ ); 7 ) die Versammlungsfreiheit auch für Versammlungen, die nicht unter freiem Himmel stattfinden (Art. $8 \mathrm{GG}$ ); ${ }^{8}$ ) die Freizügigkeit über ihren Gesetzesvorbehalt hinaus (Art.11 GG);9) und die Berufswahl (Art.12 GG), die nicht realisiert werden kann. 10) 11)

Diese Beschränkungen können als wesentliche Implikationen des fraglichen Gewaltverhältnisses und zwangsläufige Folgen seiner Begründung zulässig sein, wenn ihnen Gewährleistungsschranken des berührten Grundrechts entsprechen. Die Notwendigkeit der Grundrechtseinschränkung für die Entfaltung eines bestimmten Gewaltverhältnisses führt diesen Nachweis noch nicht. Allgemein darf hierzu aber bemerkt werden, daß die geschlossenen

Da der Gefangene die Anstalt nicht verlassen kann, ist die Strafvollzugsbehörde verpflichtet, einen Seelsorger zu bestellen". Wäre das richtig, so müßte für die Insassen anderer Anstalten - mutatis mutandis und praemissis praemittendis - Entsprechendes gelten. Aber Art. 4 GG ist kein Leistungsrecht. Die Anstaltsseelsorge hat ihren verfassungsrechtlichen Platz an anderer Stelle, die v. Münch erstaunlicherweise nicht nennt, nämlich im Recht der Religion und der Religionsgemeinschaften (vg1. Art.140 GG i.V.m. Art. 141 RV 1919) und in den Kirchenverträgen (vg1. Art.28 des Reichskonkordats). Indem Art.4 GG ein Recht darauf gibt, von der Teilnahme an der Anstaltsseelsorge so wenig als möglich ausgeschlossen zu werden, ist der objektive Sollzustand dem von v. Münch gefolgerten im Ergebnis ähnlich (s. hierzu in anderem Zusammenhang auch Lerche, Grundrechte (ler Soldaten, S.495).

7) Zur Einschränkbarkeit im besonderen Gewaltverhältnis s. v. Mangoldt-Klein, Art. $5 \mathrm{Anm}$. IX 1 e und Anm. X 6 e.

8) S. hierzu v. Mangoldt-Klein, Art. 8 Anm. IV 2 c u. s. Nachw.; Krüger, a.a.(). S. 311 .

9) S. hierzu v. Mangoldt-Klein, Art.11 Anm. IV 1; Krüger, a.a.O. S. 311 .

10) Vgl. v. Mangoldt-Klein, $\Lambda$ rt. 12 Anm.V 2 d; Krüger, a.a.O. S. 311; Bachof, Freiheit des Berufs, S.176 f.

11) Zum Verhältniss der "Unterbringung" zum Recht auf körperliche Integrität vg1. Dürig, Maunz-Dürig, Art.2 Randn. 51; BayVerfGH VGHE n.F. 10 II 101 (105 ff). - Zu dem schwierigen Problem des Grundrechts auf ungestörte Wohnung im Rahmen geschlossener Unterbringung s. - in anderem Zusammenhang - Lerche, Grundrechte der Soldaten, S.493 f. 
Anstaltsverhältnisse sozialen Charakters nicht nur dem vorrechtlichen Gesamtbild entsprechen 12) sondern auch durch das Sozialstaatsprinzip weitgehend gefördert und gestützt werden. Gewiß liegt es im Sinne des "sozialen Rechtsstaats" Freiheit und soziale Hilfe gleichermaßen maximal zu realisieren. Gewiß relativiert das Sozialstaatsprinzip nicht einfach die Grundrechte. Aber es liegt auch im Sinne des "sozialen Rechtsstaats", daß die Freiheit nicht auf Kosten des Sozialstaates übersteigert wird. Das Sozialstaatsprinzip verlangt, daß derjenige, der soziale Hilfe empfängt, sich auch den Freiheitsbeschränkungen fügt, ohne die diese Hilfe nicht gewährt werden kann.

\section{ccc) Die dienstrechtlichen Gewaltverhältnisse}

Die dienstrechtlichen Gewaltverhältnisse beinhalten, abgesehen von den Beschränkungen der allgemeinen Handlungsf reiheit, vor allem Beschränkungen der Freizügigkeit, 1) der freien Meinungsäußerung und -verbreitung, 2) der wissenschaftlichen und künstlerischen Betätigung ${ }^{3)}$ und der freien Berufswahl und -ausübung. ${ }^{4}$ ) Das Koalitionsrecht der öffentlichrechtlichen Bediensteten ist um seine streikrechtliche Implikation verkürzt. ${ }^{5)}$

Diese Grundrechtsschranken finden sich intensiviert und vermehrt, soweit sich der Dienst in gesteigerter Kommunikation vollzieht, wie das bei Soldaten, Ersatzdienstpflichtigen und kasernierten Polizisten der Fall ist. ${ }^{6)}$ Hinzu kommen vor allem Beschränkungen der Grundrechte der freien Wohnung 7) und des Eigentums, ${ }^{8}$ ) der freien Religionsausübung, ${ }^{9)}$ sowie - jedenfalls

12) Zur Exemplifikation s. nochmals oben S. $445 \mathrm{ff}$.

1) Vg1. v. Mangoldt-Klein, Art. 11 Anm. IV 1; Lerche, Grundrechte der Soldaten, $S .487 \mathrm{ff}$ m. eingeh. w. Nachw.

2) Vg1. v. Mangoldt-Klein, Art. 5 Anm. IX 1 e; Lerche, a.a.O. $\mathrm{S} .467 \mathrm{ff} \mathrm{m}$. eingeh. w. Nachw.

3) Vgl. v. Mangoldt-Klein, Art. 5 Anm.X 6 e; Lerche, a.a.O. S. $495 \mathrm{f}$.

4) Vg1. v. Mangoldt-Klein, Art. $12 \mathrm{Anm} . \mathrm{V} 2$ d; Bachof, Freiheit des Berufs, S. 175 f; Lerche, a.a.O. S. $487 \mathrm{ff} \mathrm{m}$. eingeh. Nachw.

5) S. z.B. v. Mangoldt-Klein, Art. 9 Anm. VII 1 und 2 a.E. Zum Fehlen des Art.9 GG in Art. 17 a Abs. 1 GG s. Lerche, a.a.O. S. $470 \mathrm{f}$.

6) S. schon oben S. 871 zu Fußn. 1 a. E. - Zu den Problemen s. vor allem Lerche, a.a.O. und seine Nachweise. Zu den Steigerungen in der Beschränkung der schon vorgenannten Grundrechte s. Lerche a. S.871 Fulßn. 1 bis 5 gen. Ort. 
im Rahmen des Wehr- und Ersatzdienstes (Art. 17 a Abs. 1 GG) der Versammlungsfreiheit 10) und des Petitionsrechts, soweit es das Recht gewährt, Bitten und Beschwerden in Gemeinschaft mit anderen vorzubringen.

Die damit angesprochenen Gewährleistungsschranken der Grundrechte ergeben sich aus der verfassungsrechtlichen Anerkennung des beamtenrechtlichen Status (Art. 33 Abs. 4 und 5 GG) ${ }^{11}$ ) und des Status des Soldaten und des Ersatzdienstverpflichteten (Art. 73 Nr.1, Art.12 GG). 12) Inwieweit in bezug auf die letzteren durch Art. 17 a Abs. 1 GG Gewährleistungsschranken klargestellt oder - tiefergehende? - Gesetzesvorbehalte geschaffen wurden, kann hier dahinstehen. ${ }^{13)}$

7) Vg1. Lerche, a.a.O. S.492 f.

8) Gemeint sind damit Beschränkungen des Eigentumsgebrauches (vgl. Lerche ebd.). - Wenig glücklich erscheint es dagegen, darin, daß der Bayerische Verfassungsgerichtshof (VGHE n.F. 5 II 165 (195)) und das Bundesverfassungsgericht (BVerfGE 3, 58 (153)) den Anspruch auf die beamtenrecht1ichen Bezüge nicht als "Eigentum" i.S. des Art. 14 GG bzw. des Art. 103 BayVerf sondern als ein in Art. 33 Abs. 5 GG bzw. Art.95 GG spezieller geregeltes Recht ansehen, eine Stellungnahme zum Verhältnis zwischen "Eigentum" und "besonderem Gewaltverhältnis" $\mathrm{zu}$ vermuten (s. Mercker, Die Rechtsprechung des Bundesverfassungsgerichts, Bundesanzeiger 1954 Nr.24 S. 8 ff (9); v. Mangoldt-Klein, S. 136; Bachof-Jesch, Die Rechtsprechung der Landesverfassungsgerichte in der Bundesrepublik Deutschland, S. 71). Dieses Verhältnis von lex generalis und lex specialis kann mit den inhärenten Grundrechtsschranken für die in einem besonderen Gewaltverhältnis Stehenden nur bedingt verglichen werden. Dieses Problem hat zur besonderen Grundrechtsposition der "kasernierten" Bediensteten keinen speziellen Bezug. Nur die Erwähnung der Beschränkung seines Eigentumgsgebrauchs war zum Anlaß zu nehmen, an das Problem zu erinnern.

9) Vgl. Lerche, a.a.O. S.494 u.s.Nachw. - S.a. oben S.872 $\mathrm{zu} \mathrm{Fußn.6}$

10) Vgl. Lerche, a.a.O. S.470. - Allgemeiner v. Mangoldt-Klein, Art. 8 Anm.IV 2 c.

11) $\mathrm{Zu}$ den Grundrechtsbeschränkungen im Beamtenverhältnis s. Krüger, Die Grundrechte im besonderen Gewaltverhältnis, S. 312 .

12) Alles Nähere und Nachweise s. bei Lerche, a.a.O.

13) S. hierzu Lerche, a.a.O., insbes. S. $460 \mathrm{f}, 473 \mathrm{ff}$. 
d) Die Drittwirkung der Grundrechte und verwandte Probleme

\section{aa) Zur sog. Drittwirkung der Grundrechte}

aaa) Die Drittwirkung "ungeschriebenen" Rechts 1)

"Eine in jeder Beziehung der neuesten Entwicklung Rechnung tragende Verfassung muß sich darüber klar sein, daß die Individualperson nicht nur der im Staat verkörperten Macht der Gemeinschaft sondern auch der wirtschaftlichen Macht einzelner oder gesellschaftlicher Gebilde mannigfacher Art gegenübersteht und daß es daher ein ernstes Anliegen an das Staatsgrundgesetz ist, auch gegen Machtmißbrauch von dieser Seite Schutz zu gewähren". 2) Die angesprochene Staatsaufgabe ist in erster Linie die der sozialstaatlichen Modifikation der wirtschaftlichen Gefällsituationen. ${ }^{3)}$ Aber das Spezifische ist, daß der Staat nicht genuy tut, wenn er allen Anteil an den wirtschaftlichen Gütern verschafft. Alle müssen auch Anteil am Grundwert der Freiheit haben. Niemand soll seine Teilhabe an den materiellen Gütern durch Preisgabe seiner individuellen Sphäre und unangemessene Fremdabhängigkeit erkaufen müssen. Niemandens Teilhabe soll von willkürlichem Ausschluß und willkürlicher Minderung bedroht sein. 4)

Damit ist dem Staat in bezug auf die zwischenbürgerliche Or.d-

1) Dank der vorzüglichen Darstellung von Dürig (Grundrechte und Zivilrechtsprechung; Maunz-Dürig, Art. $1 \wedge$ bs. III Randn. $102,125 \mathrm{f}, 127 \mathrm{ff}$ ) wäre es reiner Überfluß, Problematik und Meinungsstand hier erneut auszubreiten. Auf clie genannten Untersuchungen und ihre Nachweisungen darf für das Folgende mit Nachdruck und statt aller anderen Nachweise bezug genommen werden. Nachzutragen ist: Flume, Rechtsgeschäft und Privatautonomie, in "Hundert Jahre Deutsches Rechtsleben", Festschrift Deutscher Juristentag, Bd. I 1960, S.135 ff $(140 \mathrm{f})$, dessen Ansicht im wesentlichen mit Dürig (a.a.O.) und dem Folgenden übereinstimmt. - Nicht mehr eingearbeitet konnte Leissner, Grundrechte und Privatrecht, 1960, werden.

2) Nawiasky-Leusser, Erl. vor Art.98 (S. 178).

3) ebd., S.178 f. - S. ferner oben Abschnitt 5 (S.673 ff).

4) Es handelt sich um einen weiteren Aspekt der wechsel seitigen Ergänzung von Freiheit und Teilhabe, wie er schon oben im Zusammenhang mit den Problemkreisen der Demokratie (s.o. Abschnitt 3 (S.315 ff), insbes. I 2 (S.329 ff) und 3 (S.335 ff)), der Rechtsstaatlichkeit (s.o. Abschnitt 4 (S.396 ff), insbes. S.431ff), der Sozialstaatlichkeit (s.o. Abschnitt 
nung eine Rechtsgestaltungsaufgabe gestellt, wie sie in bezug auf das Staat-Bürger-Verhältnis in erster Linie durch die Grundrechte bewältigt wurde. So liegt es nahe, ja erscheint es als ein sozialstaatliches Postulat, 5) dem aufgezeigten "ernsten Anliegen an das Staatsgrundgesetz" dadurch Rechnung zu tragen, daß die Geltung der Grundrechte auf die zwischenbürgerlichen Rechtsbeziehungen erstreckt wird.

Ein bestechend einfaches Konzept will den Grundrechten unmittelbare Drittwirkung zulegen - aus ihnen statt staatsgerichtete Rechte Rechte gegen jedermann, aus subjektiv-öffentlichen Rechten absolute Rechte machen. Jedoch fehlen dafür die Voraussetzungen, und die Konsequenzen wären (deshalb) absurd. Die Grundrechte sind Abwehrrechte des Menschen gegen den Staat, des einzelnen gegen das Kollektiv, des Schwachen gegen den Mächtigen. Sie sind Glieder einer "einseitig" strukturierten Ordnung. Sie setzen Macht, Befugnisse und Kompetenzen voraus und stellen ihnen Exemtionen entgegen. Das Privatrecht ist wesentlich eine Ordnung der "Gegenseitigkeiten", die Regelung der Beziehungen unter Gleichen. Wie sollen die vom Grundrecht vorausgesetzten Rollen im privaten Bereich besetzt werden? Soll Freiheit gegen Freiheit gestellt werden und sich aufheben? Wird aber die Bindung in den Vordergrund gestellt: ist es sinnvoll, Gleichen gegenüber Gleichen dieselben Bindungen aufzuerlegen, die dem überlegen Mächtigen auferlegt werden müssen, damit die Macht für den Schwächeren erträglich bleibt? Ist der Übermächtige gebunden, so findet das seinen Ausgleich darin, daß er jenseits dieser Bindungen nach seinem Willen disponieren kann. Der Gleiche unter Gleichen aber unterliegt dem Gesetz des Konsenses, ohne den er nichts über den anderen vermag. Ihm auch noch die Bindungen eines Übermächtigen aufzuerlegen, erdrückt jedes private Belieben. Es gäbe kein Privatrecht mehr, das diesen Namen führen dürfte. Ein ̈̈bermaß an Freiheit - Freiheit gegen Freiheit gesetzt - zerstört die Ordnung und führt das Recht des Stärkeren herauf. Ein Übermaß an $Z$ wang zur Freiheit und Ordnung der Freiheit - Bindung gegen Bindung gesetzt - zehrt die Freiheit auf. Das Wesen der Grundrechtsordnung als Schutz der Persönlichkeitswerte ist selbst das stärkste Argument gegen die gewaltsame ijber rlehnung ihrer Geltung.

5 (S. $673 \mathrm{ff}$ ), insbes. S.744 ff) und der Grundrechtsordnung im Staat-Bürger-Verhältnis (s.o. 3 a (S. 848 ff)) zutage getreten ist.

5) S. oben S.735, insbes. Fußn. 7 und den Text hierzu. 
Die allgemeineren Kategorien, denen der grundrechtliche Schutz zugehört, sind der Schutz des Schwächeren gegen den Stärkeren und die verschiedenen Rechtsgüter, denen dieser Schutz zuteil wird. Die der Verallgemeinerung und der Übertragung in das Privatrecht fähige Quintessenz ist demnach der Schutz des in den Rechtsguitern der Grundrechte Bedrohten gegen den - auf irgend eine Weise und sei es auch in engster Begrenzung - stärkeren Angreifer. Die Akzente sind verschieden verteilt. In der einen Dimension verdichtet sich die Eindeutigkeit des privatrechtlichen Schutzgebotes mit der zunehmenden verfassungsrechtlichen Bestimmtheit des Rechtsgutes und der Festigkeit seiner verfassungsrechtlichen Absicherung; auf der anderen Seite wächst diese Eindeutigkeit mit der Annäherung der Machtproportion zwischen dem stärkeren und schwächeren Privaten an das den Grundrechten ursprünglich wesensgemäße Verhältnis Staat-Bürger. ${ }^{6)}$ A ber fast immer handelt auch der Angreifer in Entfaltung eines grundrechtlich geschützten Rechtsgutes, in dessen Besitz er geschmälert wird, wenn das Recht sich auf die Seite des Bedrohten stellt. Hier zeigt sich das volle Gewicht der Fremdheit der Grundrechte im Privatrecht, in einer Ordnung der "Gegenseitigkeiten". Der Staat tritt dem Grundrechtsinhaber nicht mit vergleichbaren Gegenrechten gegenüber, wohl aber der andere Grundrechtsinhaber. Sein Gegenrecht wird nicht schon dadurch aufgehoben, daß er irgendwie der Stärkere ist. Die freie Entfaltung der Persönlichkeit ist auch die Entfaltung der stärkeren Persönlichkeit; Eigentum ist auch das des "reicheren" Eigentümers. Wenn der Staat sich voll und ganz den Grundrechten fügt, so entspricht das dem rechtsstaatlichen Verteilungssystem, das ihm die rechtsstaatlich moderierte Macht, dem Bürger die ausgrenzenden Abwehrrechte gewährt. ${ }^{\text {) }}$ Wenn der Staat von dem einen Bürger aber verlangt, er solle sich in die Grundrechte des anderen fügen, ohne sich auf seine eigenen Grundrechte zu berufen, gerät er in einen Selbstwiderspruch; denn er hat diese Grundrechte nicht weniger garantiert als jene. Eine sorgfältige Abwägung Rechtsgut um Rechtsgut, Geltungsanspruch um Geltungsanspruch, Machtposition um Machtposition muß einsetzen, wenn nicht Grundrecht durch Grundrecht aufgehoben werden soll. Nur sie kann einen "Selbstmord" der Grundrechtsordnung durch ihre Erstreckung in die privatrechtlichen Beziehungen hinein aufhalten. Die Vielfalt der Ergebnisse ist kaum überschaubar, eine zwingende Lösung privatrechtlicher Konflikte von der Grundrechtsordnung her in der Tat selten.

6) S. insbes. auch Ballerstedt, Wirtschaftsverfassungsrecht, S. 59 .

7) Vgl. Carl Schmitt, Verfassungslehre, S. 126. 
Das Medium, dem die Aufgabe zufällt, die in die Verfassung aufgenommenen elementaren Rechtsgüter auch unter Privaten zu realisieren, ist das Privatrecht selbst. Nur eine der Materie nachgehende Sachordnung kann verläßlich und praktikabel zum Ziele führen. Nun ist aber eine erschöpfende Regelung aller von der Grundrechtsordnung her - wenn auch noch so mittelbar - zu würdigenden privatrechtlichen Konflikte undenkbar. Worin ist die Lösung der einer ausdrücklichen Regelung nicht teilhaftigen Konflikte zu suchen? Eine direkte Anwendung grundrechtlicher Normen auf zwischenbürgerliche Beziehungen kann es grundsätzlich nicht geben. Erst im Schmelztiegel einer dem Gegenüber zweier Grundrechtsträger Rechnung tragenden Auswertung und Abwägung der Grundrechtsgehalte und ihrer Auseinandersetzung mit den privatrechtlichen Daten und Zusammenhängen kann die auf die (privaten) zwischenbürgerlichen Beziehungen anwendbare Norm gewonnen werden. Diesen Schmelztiegel hält wieder das Privatrecht selbst bereit: die wertausfüllungsfähigen und wertausfüllungsbedürftigen Normativbegriffe und Generalklauseln ( $\mathrm{s}$. insbes. $\$ \$ 133,138,157,242,826 \mathrm{BGB}, \$ 1 \mathrm{WG})$ und alle die anderen privatrechtsfremden Prämissen of fenen Normen ( $\mathrm{z}$. B. $\$ 823$ Abs. 1 BGB) des Privatrechts. ${ }^{8}$ ) Sie gewährleisten einen umfassenden Schutz sonst nicht näher privatrechtlich geregelter Rechtspositionen, also auch der in den Grundrechten grundgelegten. Sie sichern andererseits die restlose Homogenisierung der grundrechtlichen Substanz mit dem Privatrecht.

Auf diese Weise setzen sich die Grundrechte auch im Privatrecht durch und hat das Privatrecht in seinen Grundsatz- und in den einschlägigen Detailnormen einen zwingenden grundrechtlichen Hintergrund. Darüber darf aber nicht vergessen werden, daß sich der Staat als Träger der Privatrechtsordnung und der dieser Privatrechtsordnung unterworfene Bürger in einem von den Grundrechten unmittelbar, frontal betroffenen Staat-BürgerVerhältnis gegenüberstehen. So ergibt sich für die Privatrechtsordnung schließlich eine zwieschichtige Grundrechtsbindung: die ursprüngliche, direkte des Staat-Bürger-Verhältnisses; und die mittelbare, adaptierend abwandelnde der zwischenbürgerlichen Dimension. 9)

8) Vgl. Dürig, Grundrechte und Zivilrechtsprechung, S. 177; Maunz-Dürig, Art. 1 Abs. III Randn. 132; Bachof, Freiheit des Berufs, S. 173 f; je mit weit. Nachw.; Wolff, Verwaltungsrecht I, S.152; Maunz, Deutsches Staatsrecht, S. 87.

9) Für den Gleichheitssatz s. zu dieser Unterscheidung Götz Hueck, Der Grundsatz der gleichmäßigen Behandlung im Privatrecht, 1958, S. 81. 
bbb) Die ausdrücklich angeordnete Drittwirkung

Das leitende Prinzip der Grundrechtsdrittwirkung ist die Notwendigkeit, Angriffe auf die grundrechtsgeschützten Rechtsgüter auch dann abzuwehren, wenn sie zwar nicht von der staatlichen Gewalt ausgehen, aber doch von Subjekten, die - in einem sehr weiten Sinne - wie der Staat (versucht und) imstande sind, sie zu verletzen. Machtdifferenzen außerhalb des öffentlichrechtlichen Gewaltverhältnisses sind im allgemeinen ökonomischer Natur.

Diese besondere soziale Funktion bestätigen auch die wenigen Fälle echter, d.h. verfassungsgesetzlich als solche angeordneler unmittelbarer Drittwirkung. Das Grundgesetz kennt sie nur in Art. 9 Abs. 3 Satz 2 hinsichtlich der Koalitionsfreiheit also hinsichtlich eines Grundrechts von klassischer sozialer Funktion. 1)

\section{bb) Die "Fiskalgeltung": der Grundrechte}

Der aufgezeigte Weg, die Grundrechte über die Normen des Privatrechts zu verwirklichen, erlaubt auch, die Grundrechte gegenüber dem privatrechtlich handelnden Staat zur Geltung zu bringen.

Die Grundrechtsbindung des mit privatrechtlichen Mitteln öffentliche Verwaltung treibenden Staates hat eine vollkommene zu sein. 1) Das Verfassungsrecht, das durch die Grundrechte alle dem Staat wesenseigenen Machtäußerungen binden will, hat nur die Möglichkeit, entweder das Ausweichen der Verwaltung in die privatrechtlichen Formen zu unterbinden oder ihm dorthin nachzufolgen; und es hat diese Möglichkeit der - in ihrer Nützlichkeit außer Zweifel stehenden - privatrechtlichen Form, weil es über das Privatrecht eine ausreichende Grundrechtsbindung bewirken kann. ${ }^{2}$ ) Können sich die Grundrechte im Privat-

1) Zur Bedeutung der Drittwirkungsklausel s. z.B. v. MangoldtKlein, Art.9 Anm.V 12; Dietz, Die Koalitionsfreiheit, $\mathrm{S} .425 \mathrm{f}, 447,449 \mathrm{ir}$.

1) S. hierzu und zum Folgenden schon oben S. $621 \mathrm{ff}$, insbes. S. 625 zu Fußn. 16 und 17 und die Nachweise der dort Zitierten.

2) S.o. S.876 ff und oben S.621ff. - Wenn Dürig (Maunz-Dürig, Art. 1 Abs. III Randn. 138 a.E.) meint, die Abwehrmittel des Privatrechts genügten den verfassungsrechtlichen Anforderungen spätestens seit dem Inkraftreten der $\mathbb{S} \$ 25$ ff des Gesetzes gegen Wettbewerbsbeschränkungen, so ist der darin liegende $Z$ weifel, ob sie vorher genügt hätten, nicht ganz be- 
recht im allgemeinen deshalb nicht unverändert durchsetzen, weil im Privatrecht immer auch der Gegner Grundrechtsträger ist, und die abwägende Auflösung des Konflikts die Grundrechte notwendigerweise "beschnei(len" muß, um Rechte und Gegenrechte in einer dem Sinn der Grundrechtsordnung gerecht werdenden Relation widerspruchsfrei ineinanderzufügen, so rechtfertigt sich die totale Grundrechtsbindung des Staates - dem insofern immer auch die Träger mittelbarer Staatsverwaltung gleichzustellen sind - im Privatrecht umgekehrt gerade auch daraus, daß der Staat selbst nicht Grundrechtssubjekt ist. 3 )

Das ist der Staat auch nicht, soweit er rein fiskalisch im Rahmen privatrechtlicher Hilfsgeschäfte der öffentlichen Verwaltung oder erwerbswirtschaftlich - tätig wird. 4) Doch wird insofern die Grundrechtsbindung bis zu jener Norm abgeschwächt, die für die privaten Beziehungen von Grundrechtsträgern untereinander maßgeblich ist. 5) Der Fiskus ist Privatrechtssubjekt und allgemein wie ein solches zu behandeln. Diese Maxime gehört dem vorrechtlichen Gesamtbild der geltenden Verfassungsordnung als eine historisch tief wurzelnde und ihre innere Rechtfertigung erprobte Erscheinung an. Es besteht kein Anhaltspunkt dafür, daß die geltende Grundrechtsordnung hieran prinzipiell etwas ändern wollte. Zwar kann sich der Fiskus nicht unmittelbar gegenüber der hoheitlichen Gewalt auf Grundrechte berufen. 6) Ist er aber im Rahmen des Privatrechts wie ein Privatrechtssubjekt $\mathrm{zu}$ behandeln, so ist die mittelbare Auswirkung der Grundrechte auf das Privatrecht für den Fiskus keine grundsätzlich

rechtigt. Die richterrechtlichen Grundsätze über die Abwehr des Monopolmißbrauchs (s.o. S. 624 zu Fußn. 14) haben schon vordem einen - soweit es hier interessiert - entsprechenden Schutz gewährt. Damit soll nicht verkannt werden, daß die $\$ \$ 22 \mathrm{ff}$. a.a.O. technische und sanktionäre Verbesserungen und insbes. vielleicht auch größere Klarheit gebracht haben. Was die Klarstellung der Rechtslage betrifft, so kommt aber wohl $₫ 98$ des Gesetzes gegen Wettbewerbsbeschränkungen das größere Verdienst zu. - Was die vollkommene Durchsetzung der. Grundrechte im Privatrecht anbelangt, kommt cler M ög$1 \mathrm{ichkeit}$ des verfassungsgericht1ichen Schutzes eine besondere Bedeutung $\mathrm{zu}$ (vgl. Bachof, Freiheit des Berufs, S. 175 mit Fußn. 74). Da dieser. Schutz durch die verfassungsgerichtliche Überprüfung der zivilgerichtlichen Rechtsprechung gewährleistet werden kann (vgl. Dürig, MaunzDürig, Art. 1 Abs. III Randn. $125 \mathrm{f}$ und seine Nachweise), spielt auch insofern die "Flucht ins Privatrecht" keine grundrechtsmindernde Rolle. 
andere a.1s für die übrigen Privatrechtssubjekte. ${ }^{7)}$

Die mittelbare Drittwirkung erlaubt jedoch eine sehr weitgehende Anpassung. Der Fiskus weist als Privatrechtssubjekt eine Reihe von Besonderheiten auf, die in diesem Rahmen zu beachten sind: das Sonderrecht, das ihn als Privatrechtssubjekt umgibt; $\left.{ }^{8}\right)$ die tatsächliche Machtposition, die - ist der Fiskus doch das alter ego des Hoheitssubjekts Staat - mit der keines anderen Privatrechtssubjekts verglichen werden kann, 9) und schließlich die Pflichtstellung des Grundrechtsadressaten, dessen alter ego der Fiskus ist und dessen Verhalten auch als Fiskus nicht zum schreienden Selbstwiderspruch gegenüber der Grundrechtsbindung des Staates als Hoheitsträger führen darf. 10) Daß sich aus a]1 dem eine - im Vergleich zu den "schlichten" Privatrechtssubjekten - gesteigerte Grundrechtsbindung des Fiskus ergibt, liegt auf der Hand. 11)

3) Vg1. Dürig, Maunz-Dürig, Art. 19 Abs. III Randn. 30 f.

4) S. ebd. Randn. $42 \mathrm{fm}$. w. Nachw.

5) Vg1. Dürig, a.a.O.Art. 1 Abs. III Randn. 134 f und seine Nachw.

6) Zu den zu treffenden Differenzierungen s. statt anderer Dürig, Maunz-Dürig, Art. 19 Abs. III Randn. 29 ff, 37 ff, 42 ff.

7) Anderes gilt, sobald die unmittelbare Berufung auf die Grundrechte einsetzt, wie hinsichtlich der verfassungsgericht1ichen Überprüfung grundrechtsanwendender oder -nichtanwendender Zivilurteile (s.o. S. 880 zu Fußn. 2 a.E.). Der Fiskus ist von ihr ausgeschlossen, soweit er von der Grundrechtsberechtigung ausgeschlossen ist.

8) S. z.B. Wolff, Verwaltungsrecht I, S. $83 \mathrm{f}$.

9) Vg1. Bachof, Freiheit des Berufs, S.175 Fußn.73. - Diese Machtstellung des Fiskus kommt immer wieder zum Vorschein in den Erörterungen über die Stellung des Fiskus im Wettbewerbsrecht. Ja, es ist nachgerade die spezifische Fragestellung dieses Problemkreises, wie der Wettbewerb mit der öffentlichen Hand gegenüber den wettbewerbsfremden Einflüssen der originären Machtposition des Fiskus abgeschirmt werden kann (s. f.v.a. Sigloch, Die Unternehmen der öffentlichen Hand, 1929, S. 186 ff; Gütebier, Der unlautere Wettbewerb der öffentlichen Hand, 1934, S. 49 ff; Baumbach-Hefermehl, Wettbewerbs- und Warenzeichenrecht, 7. Aufl. 1956, S. 22 (Randn. 40)).

10) Vgl. Dürig, Maunz-Dürig, Art. 1 Abs. III Randn. 135.

11) S. ebd.; Bachof, Freiheit des Berufs, S. 174 f. Dagegen geht Löw (Fiskalgeltung der Grundrechte? DÖV 10. Jhg. (1957) S. $879 \mathrm{ff}$ ), indem er eine umfassende, unmittelbare Grundrechtsbindung des Fiskus behauptet, zu weit. 
cc) Grundrechtsgeltung für Tarifverträge und Betriebsvereinbarungen

Nur der normative Gehalt der Tarifverträge und Betriebsvereinbarungen weist besondere Probleme der Grundrechtsgeltung auf. Die obligatorische Substanz, soweit sie davon geschieden werden kann, folgt dagegen den allgemeinen Regeln für die Grundrechtsgeltung unter Privaten. 1)

\section{aaa) Grundrechtsgeltung für Tarifvertragsrecht}

Für die unmittelbare Grundrechtsbindung des Tarifvertragsrechts 1) spricht, daß die Grundrechte die "Gesetzgebung" (Art. 1 Abs. 3 GG) binden und das Tarifvertragsgesetz durch das Grundrecht der Koalitionsfreiheit dazu gezwungen wird, "ein Tarifvertragssystem im Sinne des modernen Arbeitsrechts ... bereitzustellen" 2) - die Tarifvertragsparteien ausdrücklich ermächtigt, "Rechtsnormen" zu setzen ( $\$ 1$ TVG). Der Versuch, die tarifliche Rechtsetzung als innerverbandliche Autonomie privater Verbände abzutun, scheitert nicht nur an Gegenstand und Tragweite der tariflichen Rechtsetzung sondern vor allem auch daran, daß sie sich ihrem Wesen nach nicht im Innern jeweils eines Verbandes hält sondern ein Gesamtakt mehrerer Verbände ist und selbst noch über deren personellen Bereich hinausgreift. 3$)$ Begriffliche Deduktionen aus der Abgrenzung "öffentlichrechtlich" - "privatrechtlich", dem Begriff der "Autonomie" und der "Delegation" verschlagen demgegenüber nicht; genau so wie es andererseits naiv wirkt, die tarifvertragliche Rechtsetzung mit der gemeindlichen Autonomie zu vergleichen und daraus ihre unmittelbare Grundrechtsbindung zu bestätigen. ${ }^{4)}$ Auch daraus, daß das Tarifvertragsrecht außerhalb jedes institutionellen Zusammenhanges mit der staatlichen Organisation und Willensbildung steht und somit nicht als staatliches Recht angesehen werden kann, 5) während

1) Zur privatrechtlichen Natur der innerbetrieblich-betriebsverfassungsrechtlichen Beziehungen s. schon oben Abschnitt S. 314 zu Fußn. 3 a.E. und $S .525$ zu Fußn. 13 a.E.

1) Zum Streitgegenstand s. außer den folgenden Nachweisen: Nipperdey, Lehrbuch des A rbeitsrechts, Bd.II S.276; Dürig, in Maunz-Dürig, Art. 1 Abs. III Randn. 115 Fußn. 1.

2) BVerfGE 4, 96 (106).

3) S. oben S. $291 \mathrm{ff}$.

4) S. zum Ganzen oben S.291ff und die dortigen Nachweise. Der Vergleich mit der gemeindlichen Autonomie findet sich insbes. in BAGE 1, 258 (263).

5) S. oben S.291 ff. 
sich die Grundrechte gerade an und gegen den Staat wenden und auch Art. 1 Abs. 3 GG spezifisch staatliche Funktionen nennt, 6) ist keine endgültige Klarheit zu gewinnen. Eine außerordentliche Erscheinung kann außerordentliche Maßstäbe verlangen. Das Tarifvertragsrecht ist seinem Gegenstand nach integrierender Bestandteil der rechtlichen Lebensordnung der staatlichen Gemeinschaft. Seine Regelungsaufgabe fiele in die unmittelbare staatliche Verantwortung, wenn die "soziale Autonomie" nicht davorträte. ${ }^{7)}$ Sie zwängt sich auf diesen Platz nicht halblegitim von außen her. Die Verfassung selbst gewährleistet ihn. ${ }^{8)}$ Die Gesetzgebung rechnet mit der Ergänzung des staatlichen Rechts durch die Tarifverträge. 9) Die staatliche Rechtsordnung verschafft der tariflichen Rechtsetzung Geltung, setzt sie durch. Sie begreift sich selbst erst vollständig unter Einschluß des tariflichen Rechts. Daher läge es durchaus nahe, dem Verfassunggeber zu unterstellen, er habe diese Rechtsquelle zu der "Gesetzgebung" hinzugedacht, die er unmittelbar durch seine Grundrechte binden wollte. Schließlich ist nicht ohne weiteres anzunehmen, die Normen, welche diese außerordentliche, jedes Maß sonstiger privater Autonomie verlassende Rechtsetzungsmacht im Rahmen der staatlichen Rechtsordnung legitimieren, 10) hätten gewollt, diese "Rechtsnormen" schuldeten den Grundrechten weniger Achtung als selbst das Gesetz. 11)

Entscheidend fällt jedoch folgender Gesichtspunkt ins Gewicht. Der unbedingten und unmittelbaren Geltung der Grundrechte im Privatrechtsverkehr mußte entgegengehalten werden, daß sich stets (grundrechtlich angelegte) Rechte und (grundrechtlich ange-

6) S. Klein, Rechtsgutachten über verfassungsrechtliche Fragen des Urteils des Bundesarbeitsgerichts v. 2. März 1955 - betreffend Lohngleichheit von Mann und Frau, S. 18 ff; Dürig, a.a.O. Randn. $100 \mathrm{f}$, dessen extrem formale Abgrenzung ( $\mathrm{s}$. insbes. Randn. 101 a. E.) jedoch nicht überzeugt.

7) S. oben Abschnitt 2 IV $2 \mathrm{a} b b, b b b(S .291$ ff) (insbes. a.A.) und dd (S. $302 \mathrm{ff}$ ).

8) S. oben Abschnitt 2 IV 2 a aa (S.287 ff) und bb (S.289 ff).

9) S. insbes. oben Abschnitt 2 IV 2 a dd (S.302 ff).

10) S. oben Abschnitt 2 IV 2 a aa (S.287 ff) (a.E.), bb (S.289 ff) (s. insbes. S. 297 zu Fußn. 18).

11) Vg1. Krüger, Staatliche Gesetzgebung und innerstaatliche Rechtsetzung, S. 205 f. Diesen Gesicht spunkt vernachlässigt Dürig (Maunz-Dürig, Art. 1 Abs. III Randn. 116 ( $\mathrm{S}$. 59 u. 60)), wenn er gegen eine Argumentation aus $₫ 1$ Abs. 1 TVG ("enthält Rechtsnormen") polemisiert. 
legte) Gegenrechte begegnen und sie sich dadurch privatrechtlichen Spielraum schaffend aufheben, abflachen, abschwächen. Im Verhältnis zwischen den Koalitionen als den Subjekten des Tarifrechts und den einzelnen Tarifnormadressaten findet sich ein solches Verhältnis von Recht und Gegenrecht zunächst nicht. Das eigene Recht der Koalitionen, tarifvertraglich Recht zu setzen, ist kein Gegen(grund)recht in diesem Sinn. Es ist gegen den Staat gerichtet; wie etwa auch das verfassungsmäßige Recht der Gemeinden, statutarisches Recht zu setzen, das die Gemeinden keineswegs von der Beachtung der Grundrechte gegenüber den durch ihre Normen Verpflichteten entbindet. Das "Gegenrecht", das sich dem Grundrecht des einzelnen - in ganz anderer Weise als im sonstigen Privatrechtsverkehr - von der Rechtsetzung der Koalitionen her entgegenstellt, ist vielmehr das Recht der Koalitionsmitglieder selbst, "zur Wahrung und Förderung der A rbeitsund Wirtschaftsbedingungen Vereinigungen zu bilden" und durch diese Vereinigungen ihre Angelegenheiten auch normativ selbst zu regeln, d.h. unabhängig vom Staat $z$ u regeln, potentiell anders zu regeln, als der Staat sie regeln würde, und letzten Endes auch potentiell anders, als der Staat sie regeln könnte. Die Koalitionsfreiheit ist ein Freiheitsrecht, ein Recht auf Freiheit vom Staate zur Bildung ordnungstragender Gemeinschaften: ein Recht schließlich auch, sich von den Bedingungen zu dispensieren, unter denen der Staat die "Arbeits- und Wirtschaftsbedingungen" zu regeln hat. Der einzelne, der von diesem Recht Gebrauch macht und sich einer Koalition anschließt, öffnet dadurch seine Grundrechtsposition der von dieser Seite kommenden Einschränkungen. Daß die Grundlage den "sozialen Autonomie" ein Freiheitsrecht ist, gibt den Ausschlag dafür, die tarifvertragliche Rechtsetzung nicht als eine unmittelbar grundrechtsgebundene Gesetzgebung anzuerkennen. ${ }^{12)}$ (Die Tragweite auch der negativen Koalitionsfreiheit wird in diesem Zusammenhang erneut sichtbar!)

12) Das wird auch in BAGE 1, 258 (269) nicht richtig gesehen. Im Frgebnis die (unmittelbare) Bindung ebenfalls ablehnend: Knolle, Arbeitsbedingungen der Frau und "Grundrechte"? Betriebsberater, 4.Jhg. (1949) S. 451 f; Klein, Rechtsgutachten über verfassungsrechtliche Fragen des Urteils des Bundesarbeitsgerichts v. 2.3.1955 - betreffend Lohngleichheit von Mann und Frau, S. 10 ff; Maunz, Rechtsgutachten zur Frage, ob Tarifverträge dem Grundsatz der Lohngleichheit von Mann und Frau unterworfen sind, 1956; v. Mangoldt-Klein, S. 67; Böckenförde, Der Allgemeine Gleichheitssatz und die Aufgabe des Richters, S.12; Dürig, in Maunz-Dürig, Art. 1 Abs. II Randn. 116. 
Der Satz freilich, "die Frage der Grundrechtsbindung der Tarifvertragsnormen" sei "gleichbedeutend mit der Frage der Grundrechtswirkung im Privatrecht überhaupt", 13) läßt noch wenig von den Schwierigkeiten ahnen, die sich für eine sachgerechte Umsetzung der Grundrechtsgehalte in einschlägige Privatrechtsnormen ergeben. ${ }^{14)}$ Geht die Rechnung, der einzelne genieße den vollen Grundrechtsschutz, weil er einem Kollektiv gegenüberstehe, nicht auf, weil der Normativgehalt der Tarifverträge nicht nur in der vertikalen Dimension Koalition - Koalitionsmitglied sondern auch in den horizontalen Dimensionen Koalition - Koalition und Mitglieder - Mitglieder belegen ist, so geht auch die umgekehrte Rechnung nicht auf, die etwa lauten könnte: der einzelne genieße, wenn seine Wirtschafts- und A rbeitsbedingungen durch Gesamtvereinbarung geregelt werden, nicht mehr (privatrechtlichen) Grundrechtsschutz als im Falle ihrer einzelvertraglichen Regelung. Der einzelne läuft, sobald er sich einer Koalition "unterwirft", Gefahr, von ihr - d.h. von ihrer willensbildenden Mehrheit und der sie repräsentierenden Führungsschicht, der aus irgendwelchen Gründen gewisse grundrechtlich geschützte Positionen bedeutungslos und "verkäuflich" sind - in seinen Grundrechten geschmälert zu werden. Die Freiwilligkeit der Koalitionszugehörigkeit gleicht diese Gefährdung nicht aus; denn sie ist nur eine rechtliche, während die tatsächliche Alternative $z$ wischen der Zugehörigkeit und der Nichtzugehörigkeit zu einer bestimmten Koalition häufig nicht besteht. Die Relation Arbeitgeber - Arbeitnehmer mit der ihr eigentümlichen sozialen Machtspannung dominiert andererseits in den durch Gesamtvereinbarung geregelten Arbeits- und Wirtschaftsverhältnissen nicht mehr. Nicht selten wird sie sogar durch die Machtposition der A rbeitnehmerkoalitionen in ihr Gegenteil verkehrt. Für die privatrechtliche Realisierung des Grundrechtsschutzes gegenüber den Tarifvertragsnormen sind insgesamt drei Machtspannungen als Gefährdungselemente im Auge zu behalten: erstens, diejenige $z$ wischen der Arbeitgeberkoalition und ihren Mitgliedern; zweitens, diejenige $z$ wischen der Arbeitnehmerkoalition und ihren Mitgliedern; drittens, diejenige zwischen den beteiligten Koalitionen. Nur eine Grundrechtsbeschränkung, die nicht durch die Ausnützung auch nur einer dieser Machtpositionen illegitim wird, kann von Bestand sein. 15) Im wesentlichen kann es sich also nur

13) Dürig, a.a.O. a.E.

14) Auch Dürig schiebt in dem vorzitierten Satz ein: "trotz allen sozialrechtlichen Einschlags im kollektiven Arbeitsrecht".

15) Götz Hueck, Der Grundsatz der gleichmäßigen Behandlung im Privatrecht, S. 105 f (Fußn.20) und S. 134, sieht dagegen 
um die Einschränkung grundrechtlicher Positionen handeln, von denen angenommen werden darf, daß sie bei verständiger Würdigung der eigenen und gegenseitigen Interessen auch von tatsächlich gleichgestellten Einzelvertragspartnern hingenommen würden. In die hypothetischen Überlegungen dieser Einzelvertragspartner ist einzurechnen, daß die Tarifgebundenheit weiter reicht (reichen kann) als die individuelle Vertragsbindung ( $\$ 4 \mathrm{Abs.} 3$ TVG). Darüber hinaus muß stets beachtet werden, daß die Grundrechte als Individualrechte immer eher einer individuell-autonomen Nichtausübung weichen als einer vom unmittelbaren Individualwillen des Grundrechtsträgers losgelösten kollektiv-autonomen Disposition, und daß die Grundrechtsbeschränkung zulasten einer großen Schicht von Tarifgebundenen eher dem grundrechtlichen ordre public widerspricht als eine einzelvertragliche Abmachung. Das alles wird dazu führen, daß tarifvertragliche Rechtsnormen, die sich über Grundrechte hinwegsetzen dürfen, eine schwerlich denkbare Ausnahme bleiben müssen.

Das Problem stellt sich je Grundrecht sehr verschieden. Soweit Grundrechte - von ihrem Wesenskern abgesehen, an den auch die Tarifverträge wohl immer gebunden sind - einer allgemeinen gesetzlichen Einschränkung zugängig sind oder überhaupt vom Gesetz erst ihre konkrete Gestalt erhalten, stellt sich in erster Linie die Frage, inwieweit das Gesetz einer (besonderen/abweichenden) tarifvertraglichen Regelung Raum gelassen hat und - in der verfassungsrechtlichen Ebene - wie weit es dafür Raum lassen muß bzw. darf. (Hieraus können sich schwierige interpretatorische Verschränkungen ergeben.16)) Die ernsteren Probleme stellen sich dort, wo Grundrechte einer gesetzlichen Einschränkung nicht oder nur beschränkt zugängig sind. Kann sich hier der Tarifvertrag Grenzverletzungen erlauben? Sicher nicht etwa hinsichtlich des allgemeinen Gleichheitssatzes als Willkürverbot; viel-

$\mathrm{zu}$ sehr das Innenverhältnis zwischen den Koalitionen und ihren Mitgliedern im Vordergrund. Darauf darf nicht allein abgestellt werden (s.a. Huecks weiteren Hinweis a.a.O. S. 167).

16) In diesem Spannungsfeld liegt etwa das Verbot einer (tarifvertraglichen) allgemeinen Organisations- oder Absperrklausel durch Art. 12 Abs. 1 Satz 2 GG (vgl. Scheuner, Grundrechtsinterpretation und Wirtschaftsordnung, S. 68; Nipperdey, Lehrbuch des Arbeitsrechts, Bd.II, S. 122 f, 275 Fußn. 10; Bachof, Die Freiheit des Berufs, S. 174). - Ein anderes Problem bestünde z. B. in dem Verhältnis der tarifvertraglichen Zulassung von Leibesvisitationen zu Art. 2 Abs. 2 GG. 
leicht aber hinsichtlich der Gleichheit von Mann und Frau, soweit sie formalisierend weiter geht als das allgemeine Willkürverbot. 17) Auch an begrenzte Freizügigkeitsbeschränkungen wäre, soweit sie mit dem Rechtsetzungsauftrag der Koalitionen zu tun haben, zu denken. Kaum wird man dagegen eine Beschränkung der freien Meinungsäußerung über den Rahmen der "allgemeinen Gesetze", zu denen freilich auch tarifvertragliche Bestimmungen gehören können, hinaus zulassen dürfen.

Tarifnormen müssen sich voll und ganz an die Grundrechte ha1ten, soweit sie ausnahmsweise Recht auch mit Wirkung gegen Personen schaffen, die den beteiligten Koalitionen nicht angehören. 18)

Völlige Grundrechtsgebundenheit ist für die Allgemeinverbindlicherklärung von Tarifverträgen anzunehmen. 19) Sie ist ein Akt staatlicher Rechtsetzung (Art. 1 Abs. 3 GG). 20)

17) S. hierzu noch unten II (S. $890 \mathrm{ff})$. Es ist doch der von allem Gleichberechtigungsübereifer verkannte Pferdefuß der Gleichberechtigung von Mann und Frau im Arbeitsrecht, daß die Frauen es mit Arbeitslosigkeit zu büßen haben, wenn sie in Zeiten rückgängiger Beschäftigung nicht den ihrer geringeren A rbeitskraft und ihrer größeren sozialen Schonung entsprechenden niedrigeren Lohn nehmen dürfen. Es ist erstaunlich, wie wenig Gedanken sich der Gleichberechtigungsradikalismus darüber macht. Soll, wenn einmal eine Beschäftigungskrise eintritt - vor der die Verfassung keinen Schutz bieten kann! -, vielleicht eine Frauenquote eingeführt werden, entsprechend der Schwerbeschädigtenquote oder (im öffentlichen Dienstrecht) der 131 er-Quote? Sollen die Arbeitnehmerkoalitionen, die solche Frauenquoten überhaupt nur sehr beschränkt vereinbaren könnten, im übrigen ihre weiblichen Mitglieder arbeitslos werden lassen und keine Zugeständnisse machen oder sollen sie Zugeständnisse machen dürfen. Gerade das letztere ist die Lösung, die der Konzeption der tariflichen Rechtsetzung als dem Ausfluß eines Freiheitsrechts entspricht. S. hierzu z.B. Molitor, Die arbeitsrechtliche Bedeutung des Art. 3 des Bonner Grundgesetzes, Archiv für civilistische Praxis, Bd. 151 (1950/51) S. 385 ff (409 ff).

18) Etwa nach $₫ 3 \mathrm{Abs} .2$ TVG. S. weiteres zu derartigen Erstrekkungen bei Bogs, Die Entwicklung der Rechtsform des Tarifvertrags, S. $52 \mathrm{ff}$.

19) S. Romberg, Allgemeinverbindlicherklärung von Tarifverträgen und Grundgesetz, AöR Bd. 77 (1951) S. 110 f; Dürig, in Maunz-Dürig, Art. 1 Abs. III Randn. 17; Maunz, Deutsches Staatsrecht, S. 105. A.A. Schmidt-Rimpler-Giesecke-Frie- 
bbb) Grundrechtsbindung für Betriebsvereinbarungen

Auch die Betriebsvereinbarung steht nicht unter einer unmitte1baren Grundrechtsbin(lung. 1) Sie setzt nicht staatliches Recht. Sie gründet nicht unmittelbar in der Verfassung. ${ }^{2}$ ) Sie nimmt nicht den außerordentlichen Rang unter den Rechtsquellen ein, den der Tarifvertrag inne hat, so daß auch vom vorrechtlichen Gesamtbild her die Versuchung, sie unter die "Gesetzgebung" zu zählen, vermieden ist. Andererseits fehlt ihr aber der spezifische freiheitliche Charakter des Tarifvertrages. 3 ) Es gibt keine Entscheidung für oder gegen die Zugehörigkeit zum Trägerverband der Betriebsvereinbarung, die mit der Entscheidung über die Zugehörigkeit zur Koalition zu vergleichen wäre. In jedem Betrieb, der nach dem Gesetz einen Betriebsrat haben muß, steht jeder Arbeitnehmer immer auch unter der Betriebsvereinbarung. Dieser Zwangscharakter muß sich auch auf die Grundrechtsbindung auswirken.

Das Privatrecht kann zulassen, daß sich der Arbeitnehmer, indem er in das Arbeitsverhältnis eintritt, gewisser grundrechtlich geschützter Positionen begibt. Hat es doch die Freiheitssphäre des Arbeitnehmers mit der Freiheits- und Eigentumssphäre des A rbeitgebers in Einklang zu bringen. Wenn dieses Arbeitsverhältnis nicht nur vom Direktionsrecht des Arbeitgebers sondern auch von dem den Betriebsrat tragenden betrieblichen Kollektiv bestimmt wird, so kann das - trotz des autonomistischen Charakters der Betriebsverfassung - eine weitergehende Beschränkung der grundrechtlichen Sphäre nicht rechtfertigen. Die antikollek-

senhahn-Knur, Die Lohngleichheit von Männern und Frauen, S. 181; Hueck, Die Bedeutung des Art. 3 des Bonner Grundgesetzes für die Lohn- und Arbeitsbedingungen der Frauen, S. $31 \mathrm{ff}$; Klein, Rechtsgutachten über verfassungsrechtliche Fragen des Urteils des Bundesarbeitsgerichts vom 2. März 1955 - betreffend Lohngleichheit von Mann und Frau, S. 22.

20) S. oben S. 96 zu Fußn. 8 und 9.

1) Vgl. Maunz, Deutsches Staatsrecht, S. 105, der die Grundrechtsbindung aber offensichtlich weitergehend ablehnt, als sie hier abgelehnt wird; gegen Grundrechtsbindung ferner Hueck, Die Bedeutung des Art. 3 des Bonner Grundgesetzes für die Lohn- und Arbeitsbedingungen der Frauen, S. 34 .

2) S. hierzu oben S. $313 \mathrm{f}$.

3) s. ebd. S.313, insbes. Fußn.2. - Nicht zutreffend gewürdigt bei Klein, Rechtsgutachten über verfassungsrechtliche Fragen des Urteils des Bundesarbeitsgerichts v. 2. März 1955 betreffend Lohngleichheit von Mann und Frau, S. 22 f. 
tivistische Richtung der Grundrechte, ihre Funktion als Abwehr des Machtmißbrauchs der Mehrheit und der Führungsschicht des Kollektivs muß zur Vorsicht mahnen.

Die Kompetenzen, die das Betriebsverfassungsrecht der Betriebsvereinbarung zuschreibt ( $\$ ₫ 56$ ff BetrVG), geben als solche jedoch zu keinen Bedenken Anlaß. Wenn darüber hinaus $₫ 51$ Satz 1 Betr. VG Arbeitgeber und Betriebsrat - die Träger der Rechtsetzung durch Betriebsvereinbarung - darauf verpflichtet, "darüber zu wachen, daß alle im Betrieb tätigen Personen nach den Grundsätzen von Recht und Billigkeit behandelt werden, insbesondere daß jede unterschiedliche Behandlung von Personen wegen ihrer Abstammung, Religion, Nationalität, Herkunft, politischen oder gewerkschaftlichen Betätigung oder Einstellung oder wegen ihres Geschlechts unterbleibt", so dürfte damit eine Grenze umschrieben sein, die es kaum jemals nötig machen wird, zur Wahrung der Grundrechte auf allgemeinere Normen zurückzugreifen. ${ }^{4)}$

\section{Das Grundrecht der Gleichheit}

\section{Gleichheit und sozialer Rechtsstat}

Kein anderes Grundrecht entspricht dem sozialen Staat so elementar wie das der Gleichheit. Keines kommt ihm an sozialer Trieb- und Sprengkraft nahe. "Soziale" Grundrechte 1) können im wesentlichen nichts anderes sein als gegenständlich beschränkte Rechte auf die Herstellung fehlender materieller Gleichheit. 2) Aber wie wenig kompensieren sie ihre Beschränktheit durch größere Durchsetzungskraft. Wie sehr büßen sie mit der Universalität an Elan ein. Wie viel schwerer tragen sie infolge ihrer Konkretheit und Überschaubarkeit an dem Risiko ausbleibender Realisierung. Die Freiheitsrechte andererseits haben zwar ihre soziale Funktion; ${ }^{3)}$ genau so wie der soziale Ausgleich und die Gleichheit ihre freiheitliche Funktion haben. ${ }^{4)}$ Aber Gleichheit

4) Zur Bedeutung dieser Vorschrift für die Gleichbehandlung im Privatrecht vgl. Götz Hueck, Der Grundsatz der gleichmäßigen Behandlung im Privatrecht, S.58 (Fußn.1) und 106 (Fußn. 20).

1) S. O. I 3 (S. $848 \mathrm{ff})$.

2) S. a. v. Mangoldt-Klein, Art. 3 Anm. II 4 b a.E.

3) S. o. S. $848 \mathrm{ff}$ und S. $850 \mathrm{f}$; s.a. oben Abschnitt 5 II 3 c (S. $744 \mathrm{ff}$ ).

4) S. o. S.338ff, S. $744 \mathrm{ff}$ und $S .850 \mathrm{f}$ und $\mathrm{S} .855 \mathrm{f}$ sowie die dortigen Nachweise. Für die freiheitliche Funktion der Gleichheit s. z. B. Hesse, Der Gleichheitsgrundsatz im Staatsrecht, S. 184 ff (insbes. 185). 
und Freiheit ${ }^{5)}$ stehen wie Sozialstaatlichkeit und Freiheit in einer fruchtbaren aber auch verzehrenden, moderierend abschwächenden Spannung. Die soziale Wirksamkeit der Freiheitsrechte ist notwendig eine individualistische, ja diffuse. So wichtig sie für das sozialstaatliche Ziel eines menschenwürdigen Daseins aller ist; die Gleichheit ist dem Sozialstaat enger verbunden. Sie ist der soziale cantus firmus der Grundrechtsordnung.

Gleichheit ist Gerechtigkeit. ${ }^{6}$ ) Sozialer Ausgleich ist Ausgleich einer Ungleichheit. 7) Gerechtigkeit ist soziale Gerechtigkeit. ${ }^{8)}$ Diesem fundamentalen Zusammenhang entströmte die Kraft, mit der Gleichheitsdenken und soziale Idee sich seit dem Untergang der altständischen Ordnungen um die Wende vom 18. zum 19. Jahrhundert vorangetrieben, aufge schaukelt und zum gemeinsamen Sieg im modernen egalitären, sozialen Massenstaat geführt haben. Gleichheitserkenntnis und soziale Spannung lagen dem Sturz der absoluten Monarchie und der von ihr privilegierten Herrenstände voraus. Der Abbau der wirtschaftlichen und politischen Privilegien war der erste Schritt zur Gleichheit und sozialen Entspannung. Die im 19. Jahrhundert beherrschende Gleichheit der Rechtsanwendung verdeckte für lange Zeit fast das Widerspiel der unvollkommeneren politischen (demokratischen) und wirtschaftlich-sozialen "Gleichheiten", die, wechselvoll ringend, allmählich vordrangen, 9) bis um die Wende vom 19. zum 20. Jahrhundert der Erfolg der egalitären und sozialen Ideen auf weiten Feldern heran-

5) S. f.v.a. Dahrendorf, Reflexionen über Freiheit und Gleichheit, in "Zur Ordnung von Wirtschaft und Gesellschaft" Hamburger Jahrbuch für Wirtschafts- und Gesellschaftspolitik, 4.Jhg. (1959), Festausgabe für Eduard Heimann, S. 56 ff.

6) Vg1. z.B. Götz Hueck, Der Grundsatz der gleichmäßigen Behandlung im Privatrecht, S.2: Der Gleichheitssatz "gehört als hervorragendes, wenn nicht sogar wichtigstes Element der Gerechtigkeit zu den ersten Grundprinzipien des Rechts überhaupt". S. dort (Fußn.4) auch einige Nachweise zum Thema Gleichheit und Gerechtigkeit. S. hierzu ferner Nef, Gleichheit und Gerechtigkeit, 1941. Sehr bemüht um eine Differenzierung: Böckenförde, Der allgemeine Gleichheitssatz und die Aufgabe des Richters, S. $47 \mathrm{ff}, 70 \mathrm{ff}$, ebenfalls mit weiteren Nachweisen.

7) Vg1. Hesse, Gleichheitsgrundsatz im Staatsrecht, S. 179 ff; s. diesen auch zum Folgenden.

8) S. hierzu schon oben S.663ff und die oben S. 414 zu Fußn. 3 Zitierten.

9) S. hierzu schon oben Abschnitt 3 I 1 a (S. 315 ff). 
reifte. Die Entwicklung mündet im republikanischen, demokratischen und sozialen Rechtsstaat: im Staat der monistischen Demokratie des allgemeinen, gleichen Wahlrechts, im Staat der materiellen, sozialen Gleichheit, im Staat des alle gleich verpflichtenden und berechtigenden Gesetzes, im Staat der Gerechtigkeit. Die Gleichheit dieses Staates ist eine sehr differenzierte Erscheinung, der trotzdem die Einheit nicht abgesprochen werden kann. Die formal-numerische Gleichheit des allgemeinen Wahlrechts und die relativierte Gleichheit gleichmäßiger Gesetzesanwendung ist ebenso "Gleichheit" wie das "suum cuique" inhaltlich schwächster Positivität einer universellen materiellen Gerechtigkeit.

Diese ist der Generalnenner. Im Bewußtsein moderner materieller Rechtsstaatlichkeit immer mehr zutage getreten, 10) bildet ihre, durch die Ausdeutung des allgemeinen Gleichheitsgrundrechts als ein gerechtigkeitsorientiertes Willkürverbot 11) am aktuellsten und umfassendsten realisierte 12 ) verfassungsrechtliche "Positivierung" 13) den Schlußstein der angedeuteten Entwicklung. Als sich die Gleichheit auf der einen Seite als totale, egalitäre Massendemokratie durchgesetzt hatte und das Risiko schonungsloser Majorisierung nackt zutage trat, und als auf der anderen Seite der Staat nicht zuletzt infolge seiner Bemühungen um die ökonomisch-soziale Gleichheit nicht nur in eine umfassende Daseinsverantwortung sondern auch in eine ungeahnte daseinsbedingende und-gestaltende Mächtigkeit eingetreten war, mußte ein Korrektiv dieser Mach der Mehrheit unentbehrlich erscheinen. Der Kampf der Weimarer Zeit um den richterlichen Schutz der Verfassung, im besonderen auch um die Aktualisierung der Grundrechte, ist wesentlich ein Ausdruck der Suche nach Abhilfe gegen das legislativ-parlamentarische Übergewicht. Die Um-

10) S. O. S. $663 \mathrm{ff}$.

11) S. u. 2 (S. $893 \mathrm{ff})$.

12) Leibholz, Die Gleichheit vor dem Gesetz, S. 219: "Nichts anderes nun als die Bindung des Gesetzgebers an die Gerechtigkeit und zwar eine konkrete, nicht näher allgemein rational zu formalisierende Gerechtigkeit, die in einer Gemeinschaft jeweils in Gestalt eines bestimmten Ideals lebendig ist, gewährleistet letzten Endes das verfassungsmäßige Gebot des hier zur Erörterung stehenden Gleichheitssatzes. In der Tat gilt dieses allgemeine Prinzip, das nicht mit Unrecht als ein immanentes Prinzip der Rechtsordnung... bezeichnet worden ist, im Sinne eines rechtlichen Imperativs in jedem Rechtsstaat".

13) S. o. S. $663 \mathrm{ff}$. 
wandlung des Grundrechts der Gleichheit aller vor dem Gesetz in ein auch und gerade gegen den Gesetzgeber gerichtetes, richterlich durchsetzbares, gerechtigkeitsorientiertes Willkürverbot ist der letzte und weitestgehende Schritt zur rechtsstaatlichen Mäßigung der legislativen Machtvollkommenheit der egalitär-demokratischen Mehrheit und ihrer parlamentarischen Repräsentanz 14) außerhalb des Bekenntnisses zu dem allgemeinen richterlichen Auftrag, den Rechtsstaat als Gerechtigkeitsstaat $\mathrm{zu}$ bewähren. ${ }^{15)}$

\section{Der allgemeine Gleichheitssatz}

a) Der Gleichheitssatz als Willkürverbot

Die Staatsrechtslehre der Weimarer Zeit hatte dazu angesetzt, dem Gleichheitsstatus neue Inhalte zu geben. 1) Die ihr gewährte Zeit reichte jedoch nicht zur Reife. Die Verfassungspraxis der Nachkriegszeit 2) hat - der Richtermacht mehr zugeneigt als je-

14) S. zu den vorstehend angedeuteten Zusammenhängen auch Ipsen, Gleichheit, S. 116.

15) S. hierzu oben S. $663 \mathrm{ff}$.

1) Alles Weitere s. bei Leibholz, Die Gleichheit vor dem Gesetz, 1.Auf1. 1925 (nunmehr: 2. Aufl. 1959); Aldag, Die Gleichheit vor dem Gesetz in der Reichsverfassung, 1925; "Die Gleichheit vor dem Gesetz im Sinne des Art. 109 der Reichsverfassung" Veröffentlichungen der Vereinigung der Deutschen Staatsrechtslehrer, Heft 3, 1927, mit den Referaten von Kaufmann (S.2 ff) und Nawiasky (S.25 ff); Rümelin, Die Gleichheit vor dem Gesetz, 1928; Mainzer, Gleichheit vor dem Gesetz, Gerechtigkeit und Recht, 1929; Anschütz, Die Verfassung des Deutschen Reiches (14. Aufl. 1933), die Erläuterungen zu Art. 109.

2) Zur maßgeblichen verfassungsgerichtlichen Rechtsprechung s. Federer, Die Rechtsprechung des Bundesverfassungsgerichts zum Grundgesetz, S. 28 ff; Bernhard Wolff, Die Rechtsprechung des Bundesverfassungsgerichts von 1954-1957, S. 116 ff; Bachof-Jesch, Die Rechtsprechung der Landesverfassungsgerichte, S. 77 ff; Hamann, Die Rechtsprechung des Bundesverfassungsgerichts über den Gleichheitssatz, NJW 10.Jhg. (1957) S. 2 ff; Böckenförde, Der Allgemeine Gleichheitssatz und die Aufgabe des Richters, S. 61 ff; Fuss, Gleichheitssatz und Richtermacht, insbes. S.332; Geiger, Grundrechte und Rechtsprechung, S.34 ff; Leibholz, Die Gleichheit vor dem Gesetz, S. 1 ff. - Für das Schrifttum und die weitere Rechtsprechung s. Wernicke, Bonner Kommen- 
de Epoche vorher ${ }^{3)}$ - nicht gezögert, diese Entwicklung zu vollenden. Sie deutet den allgemeinen Gleichheitssatz (Art. 3 Abs. 1 GG) als ein gerechtigkeitsorientiertes 4 ) Willkürverbot, 5) ein Gebot sachgerechter Differenzierung, ${ }^{5)}$ das auch den Gesetzgeber bindet. 6)

Dank seiner universellen Geltung und seiner extremen inhaltlichen Unbestimmtheit verleiht dieses Willkürverbot den Richtern, die es letztentscheidend anzuwenden haben, außerordentliche Macht. Es wäre Unfug, sie mit der Behauptung kaschieren zu wollen, das Willkürverbot sei ein Rechtsprinzip (das es freilich zu sein hat). Aber es geht auch nicht an, mit dem Argument der inhaltlichen Unbestimmtheit gegen die Auslegung des allgemeinen Gleichheitssatzes als Willkürverbot zu polemisieren, ohne zu berücksichtigen, daß diese Koppel richterlicher Kontrolle und gesetzgeberischer Gestaltungsmacht auch aus anderen als unmittelbar "grundrechtlichen" Gründen gewollt und notwendig sein kann. Auch der bestgeführte Angriff gegen die Identifikation Gleichheitssatz $=$ Willkürverbot muß vergeblich bleiben, wenn er allein aus der Interpretation des Art. 3 GG hervorgeht und die verfassungsstrukturellen Zusammenhänge, die das Problem "Gleichheitssatz und Richtermacht" 7) überhaupt erst heraufgeführt haben, ungewürdigt läßt. Die Interpretation des Gleichheitssatzes als Willkürverbot hätte sich nicht durchsetzen können, wenn sie nicht grundlegenden Vorstellungsbildern von Staat und Recht, Politik und Recht, Parlamentsmacht und Richtermacht, Mehrheitsdemokratie und Aristokratie der Robe entsprochen hätte. Sie wird, wenn jemals, erst abdanken, wenn diese Grundlagen sich ver-

tar, Erl. zu Art. 3; Ipsen, Gleichheit; v. Mangoldt-Klein, Art. 3; Hamann, Das Grundgesetz, Erl.zu Art. 3; Böckenförde, a.a.O. S. 43 ff; Maunz, Deutsches Staatsrecht, S. 105 ff; Leibholz, a.a.O. S. $1 \mathrm{ff}, 238 \mathrm{ff}$. - Im besonderen zum bayerischen Verfassungsrecht s. Nawiasky-Leusser, S.64 und Erl.zu Art.118; Nawiasky-Lechner, Erl.zu Art.118; Hoegner, S. $150 \mathrm{f}$.

3) S. oben Abschnitt 3 III 3 (S.352 ff) und Abschnitt 4 II 3 (S. 508 ff).

4) S. z.B. BVerfGE 1, $264(276) ; 3,58(135 \mathrm{f})$.

5) Seit BVerfGE 1, 14 (52), 208 (247), 264 (276 f) ständige Rechtsprechung (s. die oben S. 893 zu Fußn. 2 zitierten Berichte).

6) Seit BVerfGE 1, $14(52)$ bzw. VGHE n.F. 1 II $64(78 \mathrm{f})$ ständige Rechtsprechung (s. oben S. 893 zu Fußn.2). Eine spezielle Untersuchung stammt von Geiger, Der Gleichheitssatz und der Gesetzgeber, in "Staats- und verwaltungsrechtliche Beiträge", 1957, S. $167 \mathrm{ff}$. 
schieben. Dann mag vielleicht eine andere staatsrechtliche Lehrmeinung die Gleise gelegt haben; um ihrer allein aus dem Grundrecht der Gleichheit geschöpften juristischen Überzeugungskraft willen kann und wird der Zug der Verfassungspraxis sie nicht befahren. 8)

Als Willkürverbot besagt der allgemeine Gleichheitssatz, daß "weder wesentlich Gleiches willkürlich ungleich noch wesentlich Ungleiches willkürlich gleich" behandelt werden darf. 9) Er "ist verletzt, wenn sich ein vernünftiger, sich aus der Natur der Sache ergebender oder sonstwie sachlich einleuchtender Grund für die gesetzliche Differenzierung oder Gleichbehandlung nicht finden läßt". 10) Er "bedeutet für den Gesetzgeber die allgemeine Weisung bei steter Orientierung am Gerechtigkeitsgedanken, 'Gleiches gleich, Ungleiches seiner Eigenart entsprechend verschieden' zu behandeln". 11) Das Verfassungsgericht kann aber "nur die Überschreitung gewisser äußerster Grenzen beanstanden; es kann dem Gesetzgeber erst dann entgegentreten, wenn für eine von ihm angeordnete Differenzierung $\mathrm{zwischen}$ verschiedenen Personengruppen sachlich einleuchtende Gründe schlechterdings nicht mehr erkennbar sind, so daß ihre Aufrechterhaltung einen Verstoß gegen das allgemeine Gerechtigkeitsempfinden darstellen würde". 12) Umgekehrt liegt eine Verletzung des Gleichheitssatzes "nicht schon darin, daß der Gesetzgeber bei der Regelung eines bestimmten Lebensgebietes nicht alle tatsächlichen Verschiedenheiten der Lebensverhältnisse im einzelnen berücksichtigt. Entscheidend ist vielmehr, ob für eine am Gerechtigkeitsgedanken orientierte Betrachtungsweise die tatsächlichen Ungleichheiten in dem jeweils in Betracht kommenden Zusammenhang so bedeutsam sind, daß der Gesetzgeber sie bei seiner Regelung beachten muß". 13) Diese für die Anwendung des Gleich-

7) s. Fuss, Gleichheitssatz und Richtermacht.

8) Es ist hier nicht der Ort, die Zusammenhänge so eingehend darzulegen, wie es allein den an die Erörterung dieser für das ganze Verfassungsgefüge wesentlichen Frage zu stellenden interpretatorisch-systematischen Ansprüchen genügen könnte. Die vorstehenden Hinweise können nur kurz andeuten, warum es für angebracht gehalten wird, sich für die gegenwärtige Verfassungslage auf den Standpunkt der Gleichung Gleichheitssatz $=$ Willkürverbot zu stellen.

9) BVerfGE 4, 144 (155).

10) BVerfGE 1, 14 (52).

11) BVerfGE 3, 58 (135).

12) BVerfGE 3, $58(135 \mathrm{f})$.

13) BVerfGE 1, 264 (274). 
heitssatzes auf die Gesetzgebung ausgesprochenen Grundsätze ${ }^{14)}$ gelten entsprechend auch für Verwaltung 15 ) und Rechtsprechung. 16) Der Gleichheitssatz steht so umfassend auch für das rechtsstaatliche Gerechtigkeitspostulat. ${ }^{17)}$

\section{b) Zum speziellen Inhalt des Gleichheitssatzes}

\section{aa) Vorbemerkung}

Kraft seiner Universalität prägt der Gleichheitssatz die ganze Rechtsordnung. Er steckt dabei Grenzen, gibt grundsätzlich aber keine Lösungen vor. "Welche Elemente der zu ordnenden Lebensverhältnisse maßgebend dafür sind, sie im Recht als gleich oder ungleich zu behandeln, entscheidet grundsätzlich der Gesetzge-

14) Die vorstehend wiedergegebenen Zitate beinhalten nur einige zentrale Sätze aus der Judikatur (s. hierzu Ipsen, Gleichheit, S. 153: "Die in dem Bemühen, eine angenommene Gleichheitsbindung des Gesetzgebers zu präzisieren, hervorragendsten neueren Gerichtsentscheidungen können... schwerlich anders denn als Umschreibungen der Willkürverbots-Deutung angesehen werden. Sie sind im Grunde geronnene Theorie"). Es ist hier weder möglich noch notwendig, weitergehend ein umfassendes Bild der Einzelinterpretation des Gleichheitssatzes zu geben. Für alle weiteren Nachweise und Darstellungen s. o. S.893 zu Fußn.2 und S. 894 zu Fußn. 5.

15) Vgl. Ipsen, Gleichheit, S.146 ff.

16) S. ebd. - Grundlegend BVerfGE 4, 1 (7): "Ein... Verstoß liegt bei gerichtlichen Urteilen unter dem Gesichtspunkt des Willkürverbots des Art. 3 Abs. 1 GG nicht schon dann vor, wenn die Rechtsanwendung oder das eingeschlagene Verfahren Fehler enthalten. Hinzukommen muß vielmehr, daß diese bei verständiger Würdigung der das Grundgesetz beherrschenden Gedanken nicht mehr verständlich sind und sich daher der Schluß aufdrängt, daß sie a uf sachfrem den Erwägungen beruhen". (Sperrung nicht im Original).

17) S. o. S.890 ff und die dortigen Nachweise. S.a. Bachof-Jesch, Die Rechtsprechung der Landesverfassungsgerichte in der Bundesrepublik Deutschland, S.79: "Die Verknüpfung zwischen Gerechtigkeitsidee und Gleichheitssatz hat die Folge, daß die Verletzung des Gleichheitsgebotes fast immer zugleich einen Verstoß gegen das Rechtsstaatsprinzip beinhaltet". Inwieweit dem rechtsstaatlichen Gerechtigkeitspostulat jemals selbständige Bedeutung zukommen kann, darf hier dahingestellt bleiben (s.o. S.663ff). 
ber". 1) Die "Gleichbehandlungsgrundsätze" der verschiedenen Teilrechtsgebiete drücken daher in erster Linie die Gleichheitswertungen des Gesetzgebers bzw. der den Gesetzgeber substituierenden richterlichen Rechtsfindung aus. Selbst die Aufgabe, die negativen Wirkungsmöglichkeiten des Gleichheitssatzes systematisch zu sichten, kann immer nur approximativ gelöst werden. 2) "Wir können nicht etwa im Sinne des alten Naturrechts ein festes System von konkreten Verbotsnormen aus dem Willkürbegriff herleiten, die eine eindeutige Anwendung auf alle nur möglichen Lebensverhältnisse gestatten. Dieses Schicksal teilt der Willkürbegriff mit dem der materialen Gerechtigkeit, deren radikale, absolute Verneinung er enthält".3) Von dem Versuch, alle sozial irgendwie interessierenden Wirkungsmöglichkeiten des Gleichheitssatzes zu registrieren, muß daher Abstand genommen werclen. ${ }^{4)}$

1) BVerfGE 6, 273 (280); s.a. Ipsen, Gleichheit, S. 157. "... so besteht eine spezifische Ambivalenz des Gleichheitssatzes. Auf der einen Seite gestattet Art. 3 GG ... die rechtliche Differenzierung des faktisch Ungleichartigen, soweit nämlich diese Ungleichartigkeit einen gerechtfertigten Anlaß für die unterschiedliche Behandlung von Tatbeständen bietet. Das dem Gleichheitssatz innewohnende Prinzip, daß 'Ungleiches ungleich' zu behandeln ist, kann zu einer außerordentlichen Mannigfaltigkeit der Rechtsgestaltung, zu einer reich nuancierten Kasuistik und, vor allem im Wirtschaftslenkungsrecht, zu einer vielfältig gestuften und schattierten Skala von Interventionen führen. Auf der anderen Seite gründet sich auf Art. 3 GG weithin die recht1 iche Nive11ierung des faktisch Ungleichartigen, soweit nämlich diese Ungleichartigkeit als sachlich nicht gerechtfertigt, als vernunftwidriges Relikt überwundener oder $z u$ überwindender Entwicklungsstufen oder als Spiegelung sozialer Vorurteile, Anmaßungen oder Ressentiments gilt. Auch im Wirtschaftsbereich kann der Gleichheitssatz sowohl benutzt werden, um tatsächliche Ungleichartigkeiten durch entsprechende Ungleichbehandlung rechtlich $\mathrm{zu}$ konservieren als auch dazu, um tatsächliche Ungleichartigkeiten zu beseitigen, durch Ausgleichsmaßnahmen zu mildern oder rechtlich zu ignorieren" (E.R. Huber, Der Streit um das Wirtschaftsverfassungsrecht, S.175; s.a. Barocka, Die Berücksichtigung sozialer Gesichtspunkte bei der Erhebung von Gebühren und Beiträgen usw. S. 825).

2) Am weitesten vorgedrungen: Ipsen, Gleichheit.

3) Leibholz, Die Gleichheit vor dem Gesetz, S. 249. 
bb) Die soziale Bedeutung des Gleichheitssatzes

aaa) Gleichheit und sozialer Ausgleich - Allgemeines

Dagegen kann an der grundsätzlichen Frage, welchen Einfluß die sozialstaatliche Aufgabenstellung auf den Inhalt des Gleichheits-

4) (1) Zur Information darf allgemein nochmals auf die oben S. 893 zu Fußn. 2 zitierten Darstellungen verwiesen werden. Besondere Darstellungen für einzelne Sachgebiete finden sich gerade für das öffentliche Recht, den unmittelbaren Einwirkungsbereich des Gleichheitsgrundrechts, verhältnismäßig selten. Für das Sozialversicherungs - und Versorgungsrecht darf hingewiesen werden auf: Frey, Gleichheitserwägungen im Privatrecht und im Sozialversicherungs recht, A rbeit und Recht, Jhg. 7 (1959) S. 362 ff; ferner auf den Rechtsprechungsbericht von Weidner, Zur Rechtsprechung des Bundessozialgerichts, S. $707 \mathrm{ff}$; einen früheren Bericht s. ferner schon bei Bogs, Verfassungsrechtliche Entscheidungen des Bundessozialgerichts, S. 346 ff; weitere Probleme s. bei v.Altrock, Der Standort der Sozialversicherung im Rechtsgefüge, S.32, 34 ff; Dersch, Der Verfassungsgrundsatz der Sozialstaatlichkeit und Rechtsstaatlichkeit in der Praxis der Sozialversicherung, S. 68 und 70; Schmidt, Das Grundgesetz und das Sozialrecht, S.283 f. Weitere Nachweise s. bei den Zitierten. Für das Steuerrecht s. Paulick, Grundgesetz und Besteuerung, Steuerberater-Jahrbuch 1957/58, S. 85 ff; Grimm, Besteuerung und Grundgesetz, 1959, S. 7 ff. In das Privatrecht wirkt die Gleichheit nur mit jener $Z$ weispurigkeit und Mittelbarkeit hinein, die der Grundrechtswirkung für das Privatrecht allgemein eigen ist (s. oben S.876 ff a.E.; für Art. 3 im besonderen s. Götz Hueck, Der Grundsatz der gleichmäßigen Behandlung im Privatrecht, S.95 ff; BAGE 3, 31 (35), 180). Das scheint in besonderem Maße zu grundsätzlichen Erörterungen und Darstellungen herausgefordert zu haben. Für das Privat $\mathrm{recht}$ und insbes. das A rbeitsrecht s. statt aller älteren: Hueck, a.a.O.; Frey, a.a.O.; ders., Der Begriffsinhalt des Grundsatzes der Gleichbehandlung im Arbeitsrecht, A rbeit und Recht, 8.Jhg. (1960) S. 37 ff; ders., Argumente gegen die Gleichbehandlung im Arbeitsrecht als Rechtsprinzip, ebd. S.97 ff; ders., Allgemeine Regeln bei der Anwendung des Grundsatzes der Gleichbehandlung im Arbeitsrecht, ebd. S. 168 ff; ders., Zivilrechtliche Institute und Fürsorgedenken als versuchte Dogmatisierung des Gleichbehandlungsgrundsatzes im Arbeitsrecht; ebd. S.231 ff; ders., Die kon- 
satzes ausübt, nicht vorübergegangen werden. Die Freiheit des Gesetzgebers, grundsätzlich selbst die Elemente zu bestimmen, die für die Gleich- oder Ungleichbehandlung maßgebend sein sollen, "erfährt... eine Einschränkung durch die in der Verfassung selbst enthaltenen Grundentscheidungen". 1) Hierzu zählt die Sozialstaatlichkeit. 2) "Es kann nicht zweifelhaft sein, daß hier der entscheidende Ansatzpunkt für eine neue Phase der Radikalität des Gleichheitssatzes" ${ }^{\prime \prime}$ liegt. ${ }^{3)}$ Verpflichtet der Gleichheitssatz die öffentliche Gewalt, Ungleiches seiner Verschiedenheit gemäß ungleich zu behandeln, so bedeutet das, vom sozialstaatlichen Blickpunkt gesehen, daß der sozial Schwächere dem sozial Stärkeren gegenüber insoweit begünstigt werden darf, als dies zum $Z$ weck des sozialen Ausgleichs angebracht und soweit begünstigt werden muß, als es zum $Z$ wecke des sozialen Ausgleichs notwendig ist. 4) "Unterschiede, die sich aus der Natur der Sache

krete Ordnung im Betrieb und die Übung im Betrieb als versuchte Dogmatisierung des Gleichbehandlungsgrundsatzes im A rbeitsrecht, ebd. S. $302 \mathrm{ff}$.

(2) Keiner besonderen Erwähnung sollte es bedürfen, daß der Gleichheitsgrundsatz für alle Rechtsgebiete die gleiche Geltung beansprucht. Der "Grundsatz" etwa, "daß der Gleichheitsgrundsatz gerade in der Sozialversicherung niemals ungebührlich strapaziert werden darf' (v. Altrock, a.a.O. S.32), ist entweder nichtssagend - der Gleichheitsgrundsatz darf nirgends "ungebührlich" strapaziert werden!oder irreführend - als ob das Sozialversicherungsrecht ein dem Gleichheitspostulat gegenüber irgendwie relevant auszuzugrenzendes Sondergebiet wäre! (gegen v. Altrock und eine ihm leider oft recht nahekommende Entscheidungspraxis des Bundessozialgerichts: treffend Weidner, a.a.O. S. $707 \mathrm{f}$ (insbes. Fußn.69); eine erstaunliche Zurückhaltung gegenüber der Verwirklichung des allgemeinen Gleichheitssatzes im "Sozialrecht" s.auch bei Bogs (a.a.O. S.348)).

1) BVerfGE 6, 55 (71), 273 (280).

2) Zur Auslegung des Art.3 GG im Lichte des Sozialstaatsprinzips s. außer den nachfolgend Zitierten: Herschel, Arbeitsschutz im sozialen Rechtsstaat, S. 574; Hamann, Die Rechtsprechung des Bundesverfassungsgerichts über den Gleichheitsgrundsatz, S.3; Schlochauer, Öffentliches Recht, S.14; sehr interessante Aspekte bei Krause, Der verteilende Staat, S. $11 \mathrm{ff}$.

3) Ipsen, Gleichheit, S.174.

4) Vg1. BVerfGE 3, 58 (153). S. ferner - ohne Berücksichtigung eines positivrechtlichen Sozialstaatsauftrages - Kauf- 
in Verbindung mit dem verfassungsmäßigen, auf sozialen Ausgleich gerichteten Auftrag an den Gesetzgeber... ergeben, verletzen den Gleichheitsgrundsatz niemals". 5) "Man darf sogar. sagen, daß unter dem Gebot des sozialen Ausgleichs die wahre Gleichheit vor dem Gesetz erst gegeben ist, wenn sozial berücksichtigenswürdige Ungleichheiten aufgespürt und abgefangen worden sind".

Wo die Grenzen liegen, ist allerdings schwer zu bestimmen. Das inhaltlich minimale Willkürverbot wird durch das ebenfalls aussageschwache Sozialstaatsprinzip zwar qualitativ wesentlich, aber quantitativ geringfügig angereichert. Das Sozialstaatsprinzip ist nicht so utopisch und radikal egalitär, daß es dem Staat die restlose Beseitigurig aller sozialen Unterschiede abverlangt. Der Gleichheitssatz ist seinerseits wesentlich Abwehrrecht. Er. verbietet dem Staat, willkürlich Ungleichheiten zu schaffen oder vorhandene Ungleichheiten zu vertiefen und zu konservieren.

Aber er treibt ihn nicht - sanktioniert - verpflichtend an, aktiv und initiativ alle Ungleichheit in Gleichheit zu verwandeln. ${ }^{7}$ )

\section{bbb) Gleichheit und sozialer Ausgleich - Einzelfragen}

Le istungsansprüche gegen den Staat allein und mit der Begründung auf den Gleichheitssatz zu stützen, daß eine an sich und

mann, Die Gleichheit vor dem Gesetz, S.18; v.Caemmerer, Die Gleichberechtigung der Geschlechter im Beamtenrecht, AöR Bd. 76 (1950/51) S. 144 ff (152 f).

5) v.Altrock, a.a.O. S.32; s.ferner Hamann, Rechtsstaat und Wirtschaftslenkung, S. $55 \mathrm{f}$.

6) v.Altrock, a.a.O.S.34; s. ferner Ipsen, Gleichheit, S.173; Peters, Ist es verfassungsrechtlich zulässig, daß der Staat durch bestimmte Arbeitsschutzvorschriften auch Personen erfaßt, die keine oder nur solche Arbeitnehmer beschäftigen, welche infolge der Art oder Organisation des Betriebs insoweit nicht schutzbedürftig sind, S.242; Abendroth, Zum Begriff des demokratischen und sozialen Rechtsstaats im Grunclgesetz der Bundesrepublik Deutschland, S.88, 90 f, 98.

7) S.a. Fuss, Gleichheitssatz und Richterspruch, S.335 (Fußn. 52). S. aber BVerfGE 3, 58 (158): "Zwar darf sich der Gesetzgeber grundsätzlich nicht damit begnügen, vorgefundene tatsächliche Unterschiede ohne weiteres hinzunehmen; sind sie mit den Erfordernissen der Gerechtigkeit unvereinbar, so muß er sie beseitigen". Zustimmend hierzu Hamann, Das Grundgesetz, Art. 3 Anm.C 3 . 
ohne das Zutun des Staates vorhandene Ungleichheit anders nicht auszugleichen ist, wird demnach nicht möglich sein. Dagegen konstituiert der Gleichheitssatz Leistungsansprüche, wo "ungleich" Hilfe versagt wird, die in "gleichen" Fällen gewährt wurde 1) oder die belastende Ungleichheit - insbes. als "Sonderopfer" - in die gesteigerte Verantwortung der Gemeinschaft fällt. 2)

Bei Leistungen, die der Staat allgemein erbringt, die er aber, indem er Gebühren verlangt, oder durch andere Voraussetzungen in Beziehung zur Bedürfnisbefriedigungspotenz desjenigen setzt, der die Leistung in Anspruch nehmen will, sind verschiedene Konstellationen denkbar. Einerseits ist zu fragen, inwieweit dem Minderbemittelten eine Einschränkung hinsichtlich der Inanspruchnahme öffentlicher Leistungen zugemutet werden kann. 3) Auf der anderen Seite ist abzuwägen, inwieweit die Belastung durch allgemeine Lebenshaltungshilfen oder besondere Beihilfen ausgeglichen wird bzw. ausgeglichen werden kann. Doch kann der Gleichheitssatz, wenn beide Aushilfen nichts verschlagen, den Staat auch dazu nötigen, die Leistung ohne die Gebühr oder die sonst verlangte Voraussetzung zu gewähren.

Die Zusammenhänge werden deutlich etwa am Beispiel des A rmenrechts. 4) Soweit für gerichtliche Verfahren Gebühren- und Gerichtskostenpflicht sowie Anwaltszwang vorgeschrieben ist, belastet die Rechtsverfolgung den Minderbemittelten unverhältnismäßig, wenn er nicht gar von ihr ausgeschlossen ist. Das Institut, hier abzuhelfen, ist das Armenrecht. Da der Gleichheitssatz in Verbindung mit dem Sozialstaatsprinzip "eine weitgehende Angleichung der Situation von Bemittelten und Unbemittelten im Bereich des Rechtsschutzes" gebietet, 5) darf es für keine Verfahrensart ausgeschlossen werden, für die an der Gebühren- und Gerichtskostenpflicht bzw. am Anwaltszwang festgehalten wird.6) Einen Verzicht auf staatlichen Rechtsschutz

1) s. u. s. $903 \mathrm{f}$.

2) S. u. cc (S. $904 \mathrm{ff})$.

3) S. o. S.823 Furn. 1

4) S. hierzu schon oben $\mathrm{S} .823 \mathrm{f}$.

5) BVerfGE: 9, 124 (131); 10, 264 (270 f).

6) Die Nachweise für das Sozialstaatsprinzip s. schon oben S.823 f. Speziell für den Gleichheitssatz s. BVerfGE 2, 336 (340); 9, 124 (131); 10, 264 (268 ff); Pfeiffer, Bewilligung des Ar'menrechts im Klageerzwingungsverfahren nach $₫ 172$ StPO, NJW 6.Jhg. (1953) S.571 f (571); Weidner, Ist der Ausschluß der Armenanwaltsbeiordnung in den unteren In- 
kann der soziale Rechtsstaat seinen armen Bürgern nicht ansinnen. Allerdings darf er - und soll er wohl auch, um die Rechtsgleichheit $z w i s c h e n$ denen, die ihre Prozeßkosten selbst $z u$ bezahlen haben, und denen, die auf Kosten der Allgemeinheit prozessieren, auch in der umgekehrten Richtung nicht zu vernachlässigen - die Bewilligung des Armenrechts von einer Vorprüfung der Erfolgsaussichten abhängig machen. 7) Eine andere Frage ist, inwieweit der Staat verpflichtet sein soll, einer "armen" Partei außerhalb des Anwaltszwanges einen Anwalt allein schon deshalb beizuordnen, weil ihr "reicher" Gegner sich eine sachkundige Prozeßvertretung leisten kann. Hier wird große Zurückhaltung am Platze sein. Das Prozeßrecht kann auch aus einer "dummen" Partei keine "gescheite" machen; dieser Unterschied ist aber sicher von Bedeutung für den Ausgang eines Prozesses und andererseits viel mehr schicksals- und viel weniger gemeinschaftsbedingt,als ökonomisch-soziale Differenzen zu sein pflegen. Das Verfahrensrecht wird daher um der Gerechtigkeit willen allgemein gut daran tun, das Verfahren nicht zu sehr von der Prozeßführung der Parteien abhängen zu lassen. Dadurch kann der Mangel einer geeigneten Prozeßvertretung ausgeglichen werden. 8)

Ein anderes Beispiel, das die Wirkungsmöglichkeit des Gleichheitssatzes illustriert, ist das Bildungswesen. $y$ ) Der Sozialstaat kann seinem jungen Bürger nicht einen elementaren Bildungsverzicht zumuten. Er kann dem Problem durch absolute Schulgeldfreiheit abzuhelfen suchen. Aber er muß das nicht; eine entsprechend gestaffelte Schulgeldpflicht wird den sozialstaatlich-gleichheitlichen Ansprüchen nicht weniger ge-

stanzen der Sozialgerichtsbarkeit verfassungsmäßig? - Für die Herleitung des Anspruchs auf Gewährung des Armenrechts aus Art. 3 Abs. 3 GG ("Herkunft") s. Ipsen, Diskussionsbeitrag zu "Begriff und Wesen des sozialen Rechtsstaats", S.121; ders., Gleichheit, S.156 Fußn. 155; v. Mangoldt-Klein, Art. 3 Anm.V 2 a (S.210 f); Fuss, Gleichheitssatz und Richtermacht, S.334. - Eine wichtige Sonderfrage erörtert Hiendl, Der Justizbeamte als Armenvertreter nach $\$ 116 \mathrm{ZPO}$.

7) BVerfGE 2, 336 (341); 9, 124 (131); BayVerfGH VGHE n.F. 3 II 65 (66 f).

8) Vgl. BVerfGE 9, 124. Weidner, a.a.O. verneint - im Gegensatz zum Bundesverfassungsgericht, a.a.O. -, daß dem für das sozialgerichtliche Verfahren genügt ist. S. hierzu oben S. $823 \mathrm{f}$.

9) S. zum Folgenden oben S. 821. 
recht. Doch die Schulgeldfreiheit genügt nicht. Hinzukommen muß im notwendigen Umfang die Lernmittelf reiheit und schließlich die Unterhaltshilfe. Aber was fordert hierbei die "Gleichheit"?

Auch die (reinen) B elastungen, die der Staat seinen Untertanen auferlegt, sind am sozial erfüllten Gleichheitssatz auszurichten 10) Der Grundsatz der Gleichmäßigkeit der B e s t e u e rung 11) muß den sozialen Ausgleich einschließen. 12) Entsprechendes gilt für die Entziehung und Bindung des Eigent ums (außerhalb des steuerlichen Zugriffs). 13)

\section{ccc) Gleichheit der Teilhabe und der Belastung}

Die soziale Bedeutung des Gleichheitssatzes erschöpft sich nicht darin, daß er gebietet, sozial Ungleiches entsprechend seiner mißbilligten Ungleichheit in der Weise verschieden zu behandeln, daß das wesentlich Gleiche freigelegt wird. Er wirkt auch dadurch sozial, daß er gebietet, sozial Gleiches ohne willkürliche Differenzierung gleich zu behandeln. Der Staat muß Hilfe, die er gewährt, allen gewähren, die sich in der gleichen Lage befinden. Er muß soziale Lasten ebenso gleichmäßig verteilen. 1) Und er muß Ausgleichsmaßnahmen, die er trifft, belastend und begünstigend auf alle erstrecken, deren Verhältnisse gleich liegen mit den Verhältnissen derjenigen, bei denen der Ausgleich zunächst ansetzt. 2)

Das Grundrecht der Gleichheit bestätigt sich so über die ideelle Wirkung des Gleichheitsdenkens hinaus bis tief in das Techni-

10) S. oben Abschnitt 5 III 8 (S. 828 ff).

11) Zu seiner Ableitung aus dem Gleichheitssatz s. z. B. Klein, Der Beschluß des Bundesverfassungsgerichts zur Ehegattenbesteuerung in verfassungs rechtlicher Sicht, DöV 10. Jhg. (1957) S. 567 ff (574) und seine Nachweise (Fußn.44); eine differenzierte vergleichende Darstellung des allgemeinen Gleichheitssatzes und des besonderen Grundsatzes der Gleichmäßigkeit der Besteuerung, wie ihn etwa Art. 134 RV 1919 niedergelegt hatte,s. bei Paulick, Der Grundsatz der Gleichmäßigkeit der Besteuerung, S. $141 \mathrm{ff}, 154 \mathrm{ff}$.

12) S. oben Abschnitt 5 III 8 a (S. 828 ff). A.A. - jedenfalls, soweit das Sozialstaatsprinzip nicht zusätzlich zuhilfe genommen wird - Paulick, a.a.O. S. 154 ff, 161.

13) S. oben S. $823 \mathrm{ff}$ und unten III (S. $934 \mathrm{ff}$ ).

1) S. Ipsen, Gleichheit, S. 130 f, 195 f; Haas, System der öffentlichrechtlichen Entschädigungspflichten, S. $22 \mathrm{ff}$.

2) S. a. Ipsen, ebd. S.173 f. 
sche des Rechts hinein als das soziale Hauptgrundrecht. ${ }^{3)}$ Es wirkt teilhabeverschaffend und sichernd jedenfalls insofern, als es den Staat hindert, willkürliche Ausnahmen von seinen sozialen Leistungen zu machen oder Leistungen, die er allgemein gewährt, sozial Bedürftigen unter Nichtachtung ihrer besonderen Situation willkürlich vorzuenthalten. ${ }^{4)}$ Diese Wirkung wird zwar. weitgehend durch den Grundsatz der Gesetzmäßigkeit der Verwaltung - der gleichmäßigen Anwendung des nur als verfassungsmäßiges und somit auch gleichheitsgerechtes gültigen Gesetzes konsumiert. Aber im Rahmen der gesetzesfreien Verwaltung ${ }^{5}$ ) und im Rahmen der relativen gesetzgeberischen Unterlassung 6 ) bleibt doch auch Raum für den selbständigen Ausgriff ins (bedingt) Positive. Der Gleichheitssatz kann als das Grundrecht bezeichnet werden, dem in erster Linie die Aufgabe zufällt, die positive Seite des Sozialstaatsprinzips einer rechtlichen Subjektivität zuzuführen. 7) Darüber hinaus ist es dem Gesetzgeber immer ein verpflichtender Ansporn, Maßnahmen, die er zugunsten eines engeren Kreises von Betroffenen treffen will, - um sie überhaupt treffen zu dürfen - auf den weiteren Kreis aller gleichgelagerten Fälle zu erstrecken. ${ }^{8)}$

\section{cc) Opfergleichheit und Opferausgleich}

\section{aaa) Allgemeines}

Unter den besonderen Ausprägungen des Gleichheitssatzes, die nicht spezifisch auf den sozialen Bereich beschränkt sind, ist

3) S. - auch zum Folgenden - Hesse, Der Gleichheitsgrundsatz im Staatsrecht, S.219 f. Mit den begrifflichen Ausführungen Kleins (Rechtsgutachten über verfassungsrechtliche Fragen des Urteils des Bundesarbeitsgerichts vom 2. März 1955 - betreffend Lohngleichheit von Mann und Frau, S. 16 f), die Gleichheitssätze seien keine positiven Statusrechte und erst recht keine sozialen Grundrechte oder Sozialrechte, weil sie eben "überkommene" Grundrechte seien, ist gegen das Phänomen nichts auszurichten, wenn man nicht begrifflichen Unterscheidungen zuliebe den vollen Gehalt des Gleichheitssatzes verkürzen will.

4) S. schon oben S. $857 \mathrm{ff}$.

5) S. oben S.462 zu Fußn. 15 und den Text hierzu.

6) S. oben S. $557 \mathrm{ff}$.

7) S. Ipsen, Gleichheit, S. $175 \mathrm{f}$.

8) S. zu Vorstehendem auch Küchenhoff, Gleichheit und Ungleichheit im Verfassungsrecht, insbes. S.283 f: Gleichheit = "Gleichheit im Rechteminimum". 
eine hervorzuheben, der gerade für das Soziale zentrale Bedeutung zukommt: die Opfergleichheit. 1) Nicht nur - wie schon wiederholt erwähnt - die sozialen Lasten sondern alle dem einzelnen (oder auch der jeweils kleineren Gemeinschaft) von der (größeren) staatlichen Gemeinschaft aufzuerlegenden Lasten sind gleich $z u$ verteilen. Sind Belastungen - wie in der Regel die geldlichen angemessen teilbar, so dürfen sie schon nur in diesen Grenzen auferlegt werden. Sind Belastungen nicht in dieser Weise aufteilbar - wie die Weggabe bestimmter Vermögensobjekte oder Schäden an der Gesundheit - so ist die "besondere", über das alle "gleich" treffende Maß hinausgehende Belastung dem Gleichheitsgrundsatz gegenüber nur durch die Kompensation Mehr an Belastung - d.h. nur bei angemessener Entschädigung - gerechtfertigt.

Dieser Grundsatz des Opferausgleiches regiert den Enteignungsbegriff 2) und schützt so das individuelle Vermögen vor ungleichen Belastungen. Er steht aber auch hinter dem sog. Aufopferungsanspruch, der überall dort zum Opferausgleich führt, wo außerhalb des Bereichs verfassungsrechtlich zugelassener Enteignung ein "ungleiches" Sonderopfer nach einem die Gleichheit restituierenden Ausgleich verlangt - vor allem also hinsichtlich der Schäden an Leben, Körper und Gesundheit 3 ) -, ohne daß ein besonderes gleichheitsgerechtes Gesetz diesen Ausgleich angeordnet hätte. Die einst ungeahnte Ausdehnung des Enteignungsbegriffs und die Erstreckung des ergänzenden Aufopferungsgrundsatzes räumlich vom relativ kleinen Geltungsgebiet des $\$ 74$ EinlALI über das ganze Reichs- bzw. Bundesgebiet und sachlich in (len Körperschadensausgleich hinein 4$)$ kann überzeugend nur durch den $Z$ wang eines übergeordneten Prinzips erklärt

1) S. außer den oben S. 903 zu Fußn. 1 Zitierten insbes. Dürig, Zurück zum klassischen Enteignungsbegriff! JZ 9. Jhg. (1954) S. 4 ff ( 5 f, 12); ders., Grundfragen des öfentlichrechtlichen Entschädigungssystems, S. 522; ders., Der Staat und die vermögenswerten öffentlichrechtlichen Berechtigungen seiner Bürger, S. $28 \mathrm{f}$.

2) S. unten III 3 a (S.945 ff) (und $4(\mathrm{S.951}$ ff) passim).

3) Zum sachlichen Geltungsbereich der aufopferungsrechtlichen Rechtsgrundsätze s. Schack, Der für den Aufopferungsanspruch neben der Enteignungsentschädigung verbleibende Raum, JZ 11.Jhg. (1956) S.425 ff.

4) Der Anwendungsbereich des Aufopferungsanspruches hat sich dahinein geradezu verlagert. Vgl. Schack, a.a.O.; ferner Wolff, Verwaltungsrecht I, S.323 f; Forsthoff, Lehrbuch des Verwaltungsrechts, S.310 ff; alle weiteren Nachw. s. dort. 
werden, das zum Opferausgleich nötigt 5) - letztlich also nur durch den Geltungsanspruch des Gleichheitssatzes. ${ }^{6)}$ Alle anderen Konstruktionsversuche 7 ) verhüllen oder umschreiben das nur. Wenn heute dem Aufopferungsrecht Verfassungskraft beigelegt wird ohne daß dem Gesetzgeber das Recht bestritten würde, das Aufopferungsrecht auszugestalten -, und wenn es für Bundesrecht gehalten wird - das gleichwohl dem Landesgesetzgeber das Recht zur Regelung nicht nimmt -, wenn das Aufopferungsrecht schließlich also Bundesverfassungsrecht sein soll, das unmittelbar nur gilt, soweit es an einer spezielleren, angemessenen Regelung feh1t, 8) so rechtfertigt sich auch das im Kern aus der Herkunft des Opferausgleiches vom Gleichheitssatz.9)

Da der Sozialstaat gerade denjenigen zu helfen hat, die um der Gemeinschaft willen Opfer gebracht haben, 10$)$ treffen sich Sozialstaatlichkeit und Gleichheitssatz im Opferausgleich. Im Normalfall des Opferausgleiches wird das sozialstaatliche Element - abgesehen von der Notwendigkeit sozialstaatlicher Auslegung des Gleichheitssatzes - vom allgemeineren, bestimmteren und subjektiv berechtigenden Gleichheitssatz verdeckt. Die volle soziale

5) S.a. Wolff-Raiser, Sachenrecht, 10.Auf1., S. 187 m.Fußn.43.

6) Während der Zeit, in der die Verfassung beiseite geschoben war, muß an dessen Stelle eine der Rechtsordnung fundamental zugrunde liegende materielle Gerechtigkeitsvorstellung der Rechtsgemeinschaft gedacht werden.

7) $\mathrm{Zu}$ den verschiedenen Rechtfertigungsversuchen s. die $\mathrm{Zu}-$ sammenstellung bei Schack, Empfiehlt es sich, die verschiedenen Pflichten des Staates zur Entschädigungsleistung aus der Wahrnehmung von Hoheitsrechten nach Grund, Inhalt und Geltendmachung gesetzlich neu zu regeln? S. $18 \mathrm{ff}, 34 \mathrm{ff}$.

8) Zum Meinungsstand s. z.B. Schack, a.a.O. S. $37 \mathrm{f}$; Wolff, a.a.O. S. 320 f. S. zum Vorstehenden auch Haas, System der öffentlichrechtlichen Entschädigungspflichten, S.29 Fußn. 35 .

9) Der Gleichheitssatz gebietet mit dem vollen Gewicht einer bundesverfassungsrechtlichen Norm den Opferausgleich, der durch das unterverfassungsmäßige Recht zu ordnen ist, d.h. also in erster Linie durch den Gesetzgeber. Soweit der Gesetzgeber keine besondere Regelung getroffen hat, ist das inzwischen hinreichend allgemeine Enteignungs- und Aufopferungsrecht anzuwenden, das deshalb, auch ungeachtet des verfassungsrechtlichen Eigentumsschutzes und seiner Grenzen, nicht ersatzlos entfallen darf sondern nur durch eine dem Gleichheitsgebot entsprechende gesetzliche Regelung abgelöst werden kann.

10) S. o. S. $771 \mathrm{ff}$. 
Tragweite des Opferproblems entfaltet sich aber vor allem in den Fällen breit gestreuter Schädigungen, denen gegenüber das allgemeine Aufopferungsrecht versagt und der gleichheitsgrundrechtliche Opferausgleich "ins Schwimmen" gerät. Das sind in erster Linie die Folgen nationaler Katastrophen - im konkreten geschichtlichen Zusammenhang vor allem die Kriegs- und Kriegsfolgeschäden. In diesen Randzonen des grundrechtlich determinierten Opferausgleichs gewinnt das Sozialstaatsprinzip an Bedeutung.

Dem (gleichheitsgrundrechtlichen) Opferausgleichssatz erwächst seine Bestimmtheit in zwei Dimensionen: in derjenigen, die von der allgemeinen Last zum besonderen Opfer, vom generell Gleichen zum exzeptionell Ungleichen führt; und in derjenigen, die von der schicksalhaft, "vom Leben", auferlegten Last zu dem dem einzelnen von der Gemeinschaft im Interesse der Gemeinschaft auferlegten Opfer führt. Gewinnt der Opferausgleich sub specie des Gleichheitssatzes zunächst dadurch Profil, daß eine ungleiche Belastung nicht angeordnet werden darf, wenn nicht für ihren Ausgleich Sorge getragen ist, 11) so kann seine Notwendigkeit nach Grund und Ausmaß hinsichtlich eines schon erbrachten Opfers mit Bestimmtheit nur dann aus dem Gleichheitssatz abgeleitet werden, wenn gesagt werden kann, welchen Ausgleich die Gemeinschaft von vorneherein hätte aussetzen müssen, um die Einforderung des Opfers gegenüber dem Gleichheitssatz zu legitimieren. ${ }^{12}$ Verbietet andererseits der Gleichheitssatz mit hinreichender Eindeutigkeit dem Staat nur, Ungleichheiten zu schaffen, nicht aber ebenso allgemein, vorhandene Ungleichheiten zu belassen, 13) so resultiert daraus das Erfordernis des kausalfinalen Gemeinschaftsbezuges als Voraussetzung der grundrecht-

11) S. die oben S. 903 zu Fußn. 1 und oben S.905 zu Fußn. 1 Zitierten. Zu der Erwägung, daß auch die Junktim-Klausel des Art. 14 Abs. 3 Satz 3 GG Ausdruck dieses allgemeinen Prinzips ist, s. insbes. Haas, System der öffentlichrechtlichen Entschädigungspflichten, S. 30; vgl. ferner Ipsen, Gleichheit, S. 131.

12) Deshalb gibt es keine grundrechtliche Notwendigkeit zu einem "Opferausgleich" wegen reiner Naturkatastrophen (vg1. Scheuner, Verfassungsschutz des Eigentums, S. 107; s.a. Dürig, Der Staat und die vermögenswerten öffentlichrechtlichen Berechtigungen seiner Bürger, S.52, dem jedoch nicht zugestimmt werden kann, wenn er den "'Zufall' (z.B. einer Naturkatastrophe)" und das "'Schicksal" (z.B. eines Bombenteppichs)" gleichstellt).

13) S. oben S.898 ff a.E. 
lichen Notwendigkeit des Ausgleiches schon eingetretener Belastungen.

In beiden Dimensionen - teils mehr in dieser, teils mehr in jener - verflüchtigen sich die Schäden, die einzelne im Rahmen der nationalen Katastrophe des Krieges und der unmittelbaren Nachkriegszustände erlitten haben. "Wenn... über eine Rechtsgemeinschaft - wie über die unsere - infolge totaler Kriege totale Katastrophen hereinbrechen, in denen gewissermaßen die Hingabe von Freiheit, Leben, Gesundheit und Eigentum zum 'Normalfall' wird, also gerade den Charakter des im Begriff 'Opfer' schon enthaltenen Exzeptionellen verliert, dann wird es sehr schwer $z u$ bestimmen, $o b$ die ... causa des besonderen Opfers des Menschen überhaupt eingreift, ob also nach Art. 3 ein das 'ungleiche' Opfer kompensierender Anspruch überhaupt entstanden ist". 14) Andererseits fällt es aber auch schwer, den kausalfinalen Gemeinschaftsbezug festzustellen. Welche Einbußen sind von der Gemeinschaft noch beherrschbar und zu verantworten gewesen und welche einfach Schicksal? 15) Diese vielfältigen und undurchsichtigen Verhältnisse können nur mehr durch die generalisierende Regelung des Gesetzes, nicht mehr in unmittelbarer Anwendung der Verfassung auf den einzelnen Fall bewältigt werden. Der Gleichheitssatz setzt dem Gesetz nur mehr eine Untergrenze. Unter ihr darf es nicht bleiben, wenn die Pflicht des Gesetzgebers, diejenigen Ungleichheiten, die "mit den Erfordernissen der Gerechtigkeit unvereinbar" sind, zu beseitigen,16) erfüllt

14) Dürig, a.a.O.S.29, s.a. S. 51 f. Ähnliche Überlegungen hinsichtlich der Enteignungsentschädigung s. bei Knoll, Eingriffe in das Eigentum im Zuge der Umgestaltung gesellschaft1icher Verhältnisse, AöR Bd.81 S.407 f.

15) S. Scheuner, Verfassungsschutz des Eigentums, S. $107 \mathrm{f}$; Dürig, a.a.O. S. $51 \mathrm{f}$.

16) BVerfGE 3, 58 (158). - Allzusehr ist übersehen worden, daß das Bundesverfassungsgericht in seiner ersten einschlägigen Fntscheidung (BVerfGE 1, 97 (105)) ausgeführt hat: "Der Gesetzgeber... ist gewiß verfassungsrechtlich... dazu verpflichtet, sich um einen erträglichen Ausgleich der widerstreitenden Interessen und um die Herstellung erträglicher Lebensbedingungen für alle die zu bemühen, die durch die Folgen des Hitlerregimes in Not geraten sind. Aber nur wenn der Gesetzgeber diese Pflicht willürlich, d.h. ohne sachlichen Grund versäumte, könnte möslicherweise dem einzelnen hieraus ein mit der Verfassunssbeschwerde verfolgbar $\in$. Anspruch erwachsen". Das Bundesverfassungsgericht gebraucht also die Worte ("willkürlich, d.h. ohne sachlichen 
werden soll. Hier greift nun aber das Sozialstaatsprinzip ein, dem es nicht so sehr auf die kausal-finale Gemeinschaftsbezogenheit ankommt als auf die soziale Mangellage. 17) So vermengen sich im Umfeld des engeren Opferausgleiches die gleichheitsgrundrechtliche und die sozialstaatliche causa der ausgleichenden Hilfe der staatlichen Gemeinschaft. Je mehr die Konturen des gleichheitswidrigen, grundrechtsnotwendig auszugleichenden Sonderopfers schwinden, desto mehr kommt es auf die initiative Leistungsfähigkeit der Sozialstaatlichkeit an. 18) 19)

Grund"), die es sonst gebraucht, um das gleichheitsgrundrechtliche Willkürverbot zu umschreiben. Ferner spricht es von einem mit der Verfassungsbeschwerde verfolgbaren Anspruch. Es muß also an die Verletzung eines Grundrechtes gedacht haben (vgl. $\$ 90$ BVerfGG). Das Grundrecht kann nur das der Gleichheit sein.

17) S. O. S. $771 \mathrm{ff}$.

18) Dürig (Der Staat und die vermögenswerten öffentlichrechtlichen Berechtigungen seiner Bürger, S. $52 \mathrm{f}$ ) will den ganzen, jenseits des engeren Aufopferungsrechts liegenden Komplex der Kriegs- und Katastrophenfolgen in den Bereich des sozialstaatlichen Auftrages verweisen, obwohl er an anderer Stelle (s.o. S.908 zu Fußn. 14) in Übereinstimmung mit der hier vertretenen Auffassung nur davon spricht, daß der Anwendung des Gleichheitssatzes Schwierigkeiten entgegenstünden, und nicht etwa davon, seine Anwendung sei ausgeschlossen. Richtiger ist es, von einer Gemengelage der rechtsstaatlichen (gleichheitsgrundrechtlichen) Entschädigungsproblematik und der sozialstaatlichen Hilfs- und Ausgleichsproblematik zu sprechen. Das kommt überdies auch bei Dürig selbst zum Ausdruck, wenn er den Ansprüchen auf den Ausgleich von Kriegs- und Kriegsfolgeschäden (S.51 f) unmittelbar folgend (S.53) die Gruppe derjenigen Ansprüche eindeutig gegenüberstellt, "denen als Erwerbscausa sowohl Leistung als auch besoncleres Opfer fehlen".

19) Ein besonderes Problem hinsichtlich der opferausgleichenden Liquidation der Kriegsfolgen bildet die Frage der staatsrechtlichen Kontinuität über das Jahr 1945 bzw. 1949 hinaus. Da die Bundesrepublik die volle Identität mit dem Deutschen Reich in Anspruch nimmt, muß sie sich im innerstaatlichen Bereich auch daran festhalten lassen, ohne daß es auf die objektive Richtigkeit der Lehre von der Identität ankäme (zur - in der Argumentation widersprüchlichen - Rechtsprechung des Bundesverfassungsgerichts s. Dürig, a.a.O. $\$ .51 \mathrm{f}$ Fußn. 106). 


\section{bbb) Einzelfragen}

Typisch in der Gemengelage von Opferausgleich und sozial determiniertem Ausgleich steht das Lastenausgleichsrecht. 1) In sich, was die Natur der auszugleichenden Schäden betrifft, heterogen (vgl. $\$ \$ 1,12$ ff LAG), unterscheidet es nach außen nicht $z w i s c h e n$ dem besonderen, im Interesse der Gemeinschaft auferlegten Opfer und dem individuellen, aber in unlösbarem Zusammenhang mit dem Schicksal der Gemeinschaft stehenden und deshalb nach Ausgleich rufenden Schaden.

Sehr auf dieser Seite steht z.B. der Ausgleich der Vertreibungsschäden ( $\$ 12$ LAG). Zwar fehlt - trotz der Masse der Vertreibungsfälle - nicht die greifbare Exzeptionalität. Aber der kausalfinale Gemeinschaftsbezug ist nicht für alle erfaßten Tatbestände einheitlich und für nicht wenige unter ihnen muß er verneint werden. Ähnlich liegt es hinsichtlich des sonstigen Vertriebenenrechts (i.S. des Bundesvertriebenengesetzes). 2)

Dagegen scheidet hinsichtlich der Häftlingshilfe (i.S. des Häftlingshilfegesetzes) wohl das Sonderopfer in bezug auf die bundesrepublikanische Rechtsgemeinschaft aus (vgl. $\$ \$ 1$ ff des Häftlingshilfegesetzes). ${ }^{3)}$

Näher am echten Opferausgleich stehen dagegen der Kriegss a chschadenausgleich ( $\$ 13$ LAG) und vor allem der Ausgleich der kriegsbedingten $\mathrm{Schäden}$ an Körper und Gesundheit und am Leben Unterhaltsverpflichteter (i.S. des Bundesversorgungsgesetzes). 4) Das Sonderopfer ist grundsätzlich

1) Vgl. Nahm, Sozialaufgaben in der öffentlichen Verwaltung, in "Probleme der Sozialordnung", Referate des 21. Staatswissenschaftlichen Fortbildungskurses der Hochschule für Verwaltungswissenschaften, Speyer, Beilage zur Staatszeitung für Rheinland-Pfalz, Nr. 1 v. 15. Januar 1956; s.a. BVerfGE 11, 64 (70 f). Scheuner (Verfassungsschutz des Eigentums, S. $107 \mathrm{f}$ ) will es ganz aus dem Opferausgleich ausgeklammert wissen; s.a. Dürig, a.a.O. S.52. RohwerKahlmann (Die Krise des Eigentums, Zeitschrift für Sozialreform, 2.Jhg. (1956) S.239 ff, 308 ff (311, Fußn.60)) will dagegen die Lastenausgleichsansprüche allgemein als Opferausgleichsansprüche qualifizieren.

2) S. a. Dürig ebd.

3) S. a. Dürig ebd.

4) Eine nicht immer systematisch korrekt argumentierende Ansicht sieht in der Kriegsopferversorgung einen reinen (rechtsstaatlich notwendigen) Opferausgleich: Rohwer-Kahlmann, 
eindeutig. ${ }^{5)}$ Der kausal-finale Zusammenhang kann, nachdem die eigene Rechtsgemeinschaft den Krieg durchgeführt hat, nicht damit in Zweifel gezogen werden, daß der Feind die Opfer "gewählt" hat. 6) Abgesehen von der Abwegigkeit dieses Einwandes betrifft der Kriegsschadenausgleich nicht nur Fälle, in denen der Feind der Schädiger war ( $\$ 13$ LAG, $\$ \$ 1$ ff BVG).

Die $\mathrm{Kri}$ egsgefangenenentschädigung und die Unterstützung der Angehörigen Kriegsgefangener gleicht exzeptionelle Opfer aus. Aber der kausal-finale Gemeinschaftsbezug dieses Opfers erscheint dort gelockert, wo der Betroffene über den Zeitraum hinaus festgehalten wurde, der von der eigenen Rechtsgemeinschaft irgendwie beherrschbar war. ${ }^{7)}$

Die Problematik der Kriegsgefangenenentschädigung und des Vertriebenenrechts vereinigen sich in der $\mathrm{Heimkehrerhilfe}$ (s. das Heimkehrergesetz). 8 )

Sehr flach nur hebt sich aus dem Gesamt der Schäden und Lasten der Nachteil ab, den das Bundesevakuie rtengesetz auszugleichen sucht. 9)

Die Krise des Eigentums, S.242 f, 310 f (Fußn.60); ders., Die Rechtsnatur des Versorgungsanspruchs, in "Sozialreform und Sozialrecht", Festschrift für Walter Bogs, 1959, S. 303 ff; ders., Die Sozialfürsorge nach dem Bundesversorgungsgesetz - eine Versorgungsleistung, S.434; Steding, Verwirrung über das Wesen der Kriegsopferversorgung, Zeitschrift für Sozialreform, 5. Jhg. (1959), S. 89 ff, insbes. S. 92 ff; Grömig, Die sittliche Rechtfertigung für eine Schadensersatzrente nach dem Bundesversorgungsgesetz, ebd. S.188 ff, $265 \mathrm{ff}$; Thieme, Umfang und Grenzen des verfassungsrechtlich gewährleisteten Bestandsschutzes der saarländischen Kriegsopferrenten, S.169 f. Zum Gedanken des Opferausgleiches als Grundlage der Kriegsopferversorgung s. ferner Bogs, Grundfragen des Rechts der sozialen Sicherheit und seiner Reform, S. 29 f. - Gegen die Qualifikation als Aufopferung (Opferausgleich): BGHZ 20, 61 (64 f); Schwankhart, Zweifelsfragen aus dem Sozialversicherungsrecht, S.240; Dürig, a.a.O. S. 52 .

5) S. die vorstehend in diesem Sinne Zitierten. Dürig (a.a.O. S.29) vereinfacht die Probleme etwas zu sehr, wenn er davon spricht, daß in der totalen Katastrophe des totalen Krieges "gewissermaßen die Hingabe von Freiheit, Leben, Gesundheit und Eigentum zum 'Normalfall' wird."

6) A.A. Dürig, a.a.O. S. $51 \mathrm{f}$.

7) S. hierzu auch Dürig, a.a.O. S. 52 . 
Vor allem der kausal-finale Gemeinschaftsbezug ist bei den B esatzungsschäden problematisch (soweit der Schaden nicht deutschen Stellen zugerechnet werden kann). 10)

Würde die Sonde tiefer geführt, so würde sich zeigen, wie fast jede dieser Regelungen ein Mosaik der verschiedensten Lebenssachverhalte überdeckt. Keiner dieser Komplexe kann zur Gänze eincleutig zum gleichheitsgrundrechtlichen, rechtsstaatlich notwendigen Sonderopferausgleich gezählt werden. Der Gleichheitsgrundsatz kann nur den Rahmen geben, innerhalb dessen sich der Ausgleich zu vollziehen hat. Unmittelbares Regulativ dieses A usgleiches kann er im allgemeinen auch dort nicht sein, wo, wie vor allem bezüglich der Kriegsopferversorgung und des Kriegssachschadenrechts, typischer Sachverhalt und Gleichheitsgebot weithin profiliertere Folgerungen ergeben als hinsichtlich der Masse der Kriegsfolgeschäden; denn auch in diesem Terrain ist die komplexe Verbindung mit weniger deutlichen Sonderopfern und weniger deutlich kausal-final gemeinschaftsbezogenen Nachteilen nicht aufgehoben. ${ }^{\text {i1) }}$

\section{dd) Der Gleichheitssatz im Privatrecht}

Im besonderen soziale Bedeutung entfaltet der Gleichheitssatz auch insofern, als er das Privatrecht nötigt, der willkürlichen Ausübung privater Macht Grenzen zu stecken. ${ }^{1)}$ Der Gleichheitssatz gilt im Privatrecht nicht schlechthin so, wie er im Staatsrecht "dasteht". Privates Belieben um der "Gleichheit" willen zu ersticken, wäre eine Sünde wider die Freiheit. Aber der Sozialstaat, der sich zur Gleichheit der Menschen bekennt, darf nicht hinnehmen, daß Bürger um ihrer ökonomischen Unterlegen-

8) S. hierzu auch Dürig, a.a.O. S.52.

9) S. hierzu auch Dürig, a.a.O. S.52 f.

10) Das Besatzungsschädenrecht zählt zu den umstrittensten Elscheinungen in diesem Zusammenhang. Für die Problematik darf verwiesen werden auf BGHZ 11, 43; BVerwGE 4, 6; BVerwG Urt. v.28. Mai 1958 - BVerwG V C 216/54 - NJW 12. Jhy. (1959) S. 306 ff; schack, Anm. hierzu ebd.; alle weiteren Nachw. s. dort.

11) Insofern ist der Opferausgleichstheorie (s.o. S. $910 \mathrm{zu}$ Fußn.4) entgegenzutreten.

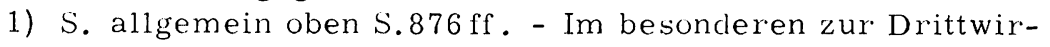
kung des Gleichheitssatzes s. statt aller anderen: Böckenförde, Der allgemeine Gleichheitssatz und die Aufgabe des Richters, S. 18 ff; Götz Hueck, Der Grundsatz der gleichmäßigen Behandlung im Privatrecht, S.95 ff; weitere Nachw. s. bei diesen. 
heit willen zum Opfer ungerechtfertigter Privatwillkür werden.

Wie er im einzelnen Gleichheit schafft, 2) steht grundsätzlich im Ermessen des Gesetzgebers. Er muß nur die Grenzen beachten, die der Gleichheitssatz als allgemeines, übergeordnetes Rechtsprinzip ihm steckt. Soweit der Gesetzgeber ausdrückliche Regelungen nicht getroffen hat, 3 ) ist es Aufgabe der Rechtsprechung, aus den einschlägigen Generalklauseln des Privatrechts die entsprechenden Grundsätze zu entwickeln. Der Grundsatz der Gleichbehandlung der Arbeitnehmer 4 ) oder die - nunmehr in $\$ \$ 25 \mathrm{ff}$, insbes. $\$ 26$ Abs. 2 des Gesetzes gegen Wettbewerbsbeschränkungen positivierten und stärker in das öffentliche Recht hinübergezogenen - Grundsätze über den zulässigen Gebrauch wirtschaftlicher Machtstellungen ${ }^{5)}$ sind Beispiele für sozial interessierende privatrechtliche Spiegelungen des gleichheitsgrundrechtlichen Willkürverbotes.

Bei allen diesen Frscheinungen darf nicht aus dem Auge verloren werden, daß es sich um Umsetzungen des Gleichheitsgrundsatzes handelt. Wenn das Bundesarbeitsgericht den "Grundsatz der Gleichbehandlung des Arbeitnehmers" dahin faßt, "daß damit lediglich die sachfremde und willkürlich differenzierende Behandlung der Arbeitnehmer verboten ist, es aber gestattet ist, Ungleiches nach Maßgabe der vorhandenen Verschiedenheit ungleich zu behandeln", 6) also mit Formulierungen arbeitet, wie sie für die Umschreibung des Willkürverbotes des Gleichheitsgrundrechts gängig sind, so darf nicht das Mißverständnis aufkommen, hier und dort sei dasselbe gesagt. ${ }^{7}$ ) Was für den Staat als Grundrechtsadressat "sachfremd und willkürlich" ist, ist es nicht von vorneherein auch für den Arbeitgeber und umgekehrt. ${ }^{8)}$

2) S. oben S. 898 zu Fußn.4 (1) a.E.

3) Zur Rangordnung der besonderen und allgemeineren Rechtssätze s. BAGE 3, 31, 180.

4) S. außer den oben S.898 zu Fußn.4 (1) a.E. gegebenen Nachweisen noch Frey, Der Grundsatz der Gleichbehandlung im Arbeitsrecht, 1954 .

5) S. oben S.624, insbes. Fußn. 14.

6) BAGE 7,147 (148) mit Nachweisen aus der älteren kechtsprechung.

7) Das Bundesarbeitsgericht verlangt diese Unterscheidung auch selbst (BAGE 3, 180).

8) Die "Flucht in die Generalklausel" bringt es mit sich, daß allenthalben auch in der Gesetzgebung äußerlich übereinstimmende Formulierungen gebraucht werden; s. z.B. $\$ 26$ Abs. 2 und 27 Abs. 1 des Gesetzes gegen Wettbewerbsbeschränkun- 
Entsprechendes gilt für die Anwendung des Gleichheitssatzes im Betriebsverfassungsrecht (s.a. $₫ 51$ BetrVG) und die Geltung des Gleichheitsgrundsatzes im Tarifvertragsrecht.9) Was für den Staat "sachfremd und willkürlich" wäre, ist es nicht notwendig auch für die Träger der betrieblichen und tarifvertraglichen Rechtsetzung. 10)

3. Die besonderen Gleichheitssätze (Art. 2 und 3 GG)

\section{a) Allgemeines}

"Niemand darf wegen seines Geschlechtes, seiner Abstammung, seiner Rasse, seiner Sprache, seiner Heimat und Herkunft, seines Glaubens, seiner religiösen 1) oder politischen Anschauung benachteiligt oder bevorzugt werden". Mit dieser Vorschrift des Art. 3 Abs. 3 GG wird, ebenso wie durch den die Gleichheit der Geschlechter schon vorwegnehmenden Art. 3 Abs. 2 GG, der allgemeine Gleichheitsgrundsatz des Grundgesetzes konkretisiert und formalisiert. 2) "Die Freiheit des Gesetzgebers, innerhalb gewisser äußerster Grenzen der Gerechtigkeit die Vergleichspaare zu bestimmen, an denen er die Lösung seiner jeweiligen gesetzgeberischen Aufgabe orientiert, wird ihm in den Fällen des Art. 3 Abs. 2 und 3 GG genommen. Hier ist es ihm untersagt, bestimmte Verschiedenheiten der Menschen durch Verschiedenheit der rechtlichen Ordnung zu berücksichtigen, weil der Verfassungs-

gen. Das ist ein Beispiel mehr für die kaum noch übersehbare richterliche Aufgabe, aus dem verschwommenen, gesetzten Recht erst "etwas zu machen", für den Übergang der Dezision vom Gesetz auf den Richter.

9) Für die Geltung des allgemeinen Gleichheitssatzes - dessen Anwendung auf das Tarifvertragsrecht an Problematik weit hinter der Anwendung der besonderen Gleichheitssätze, insbes. der Gleichheit von Mann und Frau zurückbleibt - für das Tarifvertragsrecht s. Hamann, Das Grundgesetz, Vorbem. S. 62 und Art. 3 Anm.C 4; Laufke, Vertragsfreiheit und Grundgesetz, S. $181 \mathrm{f}$. Gegen die Geltung s. Maunz, Rechtsgutachten zur Frage, ob Tarifverträge dem Grundsatz der Lohngleichheit von Mann und Frau unterworfen sind. S. hierzu auch Götz Hueck, Der Grundsatz der gleichmäßigen Behandlung im Privatrecht, S. 58 f, 105.

10) S. hierzu oben S. $883 \mathrm{ff}$.

1) S. auch Art.33 Abs. 3 GG und Art. 140 GG i.V.m. Art. $136 \mathrm{RV}$ 1919; vgl. Ipsen, Gleichheit, S. 146.

2) Vgl. Leibholz, Die Gleichheit vor dem Gesetz, S.6. 
geber diese Verschiedenheiten, gemessen an der weitgehenden Gleichheit aller Menschen, als unerheblich für die künftige, von ihm gewollte Rechtsordnung ansah". 3) "Differenzierungen, die auf anderen Unterschiedlichkeiten der Lebensumstände beruhen, bleiben von dem Differenzierungsverbot (allerdings) unberührt"'.4) Es muß ein "kausaler" 5) - oder wie richtiger zu sagen wäre: ein "finaler" 6) - "Zusammenhang zwischen einem der aufgeführten Grüncle und der Benachteiligung oder Bevorzugung gegeben sein", 5) damit das absolute Differenzierungsverbot dieses "besonderen Gleichheitssatzes" 7) eingreift. So gilt er zwar relativ, 8) stellt er aber doch eine wirksame Mindestsicherung der durch die verbotenen Unterscheidungen Gefährdeten dar. ${ }^{9}$ )

Für den sozialen Bereich ist dieser Schutz von nicht geringer Bedeutung. Keine rassische, religiöse ${ }^{10)}$ oder sprachliche Minderheit darf von den sozialen Hilfen und Sicherungen ausgeschlossen werden. Keiner solchen Gruppe dürfen diskriminierende Bedingungen gestellt werden. Keiner solchen Gruppe dürfen besondere soziale Lasten auferlegt werden. Keine abstammungsmäßige, rassische, sprachliche, religiöse ${ }^{10)}$ oder politische Gruppe darf sich - als solche! - einen sozialen Vorteil verschaffen. Die Gefahr der Umgehung - der "vorgeschobenen Motive" 11) - ist a1lerdings groß. Im Ernstfall wird das Bundesverfassungsgericht Gespür und Mut nötig haben, um der Wahrheit die Ehre zu geben.

Nicht selten sind den Angehörigen einer der durch Art. 3 Abs. 3 GG ausgewiesenen Gruppen soziale Besonderheiten gemeinsam, die ein staatliches Eingreifen notwendig machen. Das ist nicht unzulässig. Es kommt nur darauf an, daß der fragliche soziale Sachverhalt als solcher Grund und Gegenstand der Maßnahme ist und nicht eines der in Art. 3 Abs. 3 GG bezeichneten Differential-

3) BVerfGE 10, 59 (73); vorher schon BVerfGE 3, 225 (240); 6, 55 (71); s. ferner Ipsen, Gleichheit, S. 155 f, $180 \mathrm{f}$.

4) BVerfGE 3, 225 (241); 5, 9 (12); 6, 389 (422 f); Fuss, Gleichheitssatz und Richtermacht, S. $335 \mathrm{f}$.

5) BVerfGE 2, 266 (286); v. Mangoldt-Klein, Art. 3 Anm.V 3 c mit weit. Nachw.

6) Fuss, a.a.O. S.336.

7) Fuss, a.a.O. S. 335.

8) S. Fuss, a.a.O. S.335 f. - Mit anderem Akzent auch v. Mangoldt-Klein, Art. 3 Anm.V 1; Leibholz, a.a.O. S. 6 f.

9) Vgl. Ipsen, Gleichheit, S. 145; v. Mangoldt-Klein, a.a.O.

10) S. nochmals oben S. 914 zu Fußn. 1.

11) Fuss, a.a.O. S. 336 mit Fußn. 59. 
momente. ${ }^{12)}$ In aller Regel werden sich dann auch die Grenzlinien der begünstigenden oder belastenden Maßnahme nicht mit clen verbotenen Differentialmomenten decken. So wäre es etwa absurd, die Entschädigungsgesetzgebung, soweit sie den Juden zugute kommt, oder auch den sog. Israelvertrag, als einen Verstoß gegen das Verbot rassischer Bevorzligung aufzufassen. Werden die Entschädigungen doch nicht wegen der Rassezugehörigkeit sondern wegen der erlittenen Schäden und Unbill geleistet. Entsprechendes gilt hinsichtlich der Hilfe für die Vertriebenen, Heimatvertriebenen und Sowjetzonenflüchtlinge, für einen Personenkreis also, der primär nach seiner. "Heimat", d. h. nach seiner durch Geburt oder Ansässigkeit begründeten örtlichen Herkunft, 13) abgegrenzt ist (s. $\$ \$ 1$ ff des Bundesvertriebenengesetzes). Sie werden nicht ihrer "Heimat" wegen begünstigt sondern wegen ihrer Vertreibung bzw. ihrer Flucht. 14) Umgekehrt stellt eine Regelung, die versucht, eine bestimmte einzigartige Zuwanderungsbewegung - wie z. B. die Flucht aus der Ostzone - unter Kontrolle zu bringen, keine unzulässige Diskriminierung der zuwandernden Personen nach ihrer. Heimat dar. 15)

Für die Ausstrahlung des Art. 3 Abs. 3 GG in das Privatrecht gelten keine Besonderheiten. 16) Daß die dezidierten Diskriminierungsverbote in ihrer vollen Tragweite ernst genommen wer-

12) S. o. S. 915 zu Fußn. 3 und 4.

13) S. z.B. Ipsen, Gleichheit, S. 146; v. Mangoldt-Klein, Art. 3 Anm. V 2 a (S. 210).

14) Noch weniger problematisch ist das hinsichtlich der durch das Bundesevakuiertengesetz begünstigten Personen (s. $\$ 1$ a.a.O.).

15) Vg1. BVerfGE 2, 266 (286); Dürig, Freizügigkeit, S. 531 f. Einen weiteren Beispielsfall für eine zulässige Unterscheidung nach der "Heimat" (Gesetz zu Art.131 GG) s. BVerfGE 3,58 (158 f). Für das Sozialversicherungsrecht s. die - allerdings erstaunlich unbelarften - Bemerkungen bei Fickert, Sozialversicherungsgesetze, Bd. "Allgemeines", Art. 3 GG Anm. 3 .

16) Zum Allgemeinen s. oben I $4 \mathrm{~d}(\mathrm{~S} .876 \mathrm{ff})$. - Zur Geltung des Art. 3 Abs. 3 GG im Privatrecht s. im besonderen: Dürig, Grundrechte und Zivilrechtsprechung, S. 169 f; Götz Hueck, Der Grundsatz der gleichmäßigen Behandlung im Privatrecht, S. 100 ff, 198, und deren Beispiele und Nachweise. Weitere Nachweise zur Gleichbehandlung der Geschlechter (der Gleichbehandlung von Mann und Frau) s. unten (S.917 ff). 
den müssen, bedarf keiner Betonung. 17) Die privatrechtliche Positivierung in $\$ 51$ des Betriebsverfassungsgesetzes hebt das treffend hervor. 18)

b) Die Gleichheit von Mann und Frau

aa) Art. 3 Abs. 2 und 3 GG - Allgemeines

Unter den "besonderen Gleichheitssätzen" des Art. 3 GG sollte derjenige der Gleichberechtigung von Mann und Frau (Abs.2), in Art. 3 Abs. 3 ausgedrückt als das Verbot der Benachteiligung oder Bevorzugung wegen des Geschlechts, die quantitativ und qualitativ am schwersten wiegenden Folgen haben. Dabei ist unzweifelhaft, daß"den Staatsgewalten... keine unfruchtbare und gar nicht realisierbare Gleichmacherei abverlangt" wird, 1) "daß man nicht entgegen den natürlichen Gegebenheiten eine Gleichheit von Mann und Frau fingieren wollte", 2) daß "Gleichberechtigung stets... auf Gleichwertigkeit aufbaut, die die Andersartigkeit anerkennt", 3) (aß "keine Umschichtung der Gesellschaftsordnung beabsichtigt war" 4) daß "das Differenzierungsverbot des Art. 3 Abs. 2 GG ebenso wie das des Abs. 3 " den "aufgeführten faktischen Verschiedenheiten" nur die "rechtliche, nicht aber auch... (die) gesellschaftliche, soziologische, psychologische oder sonstige Wirkung" nehmen sollte. "5) Aber die Gleichberechtigung der Geschlechter ist doch mit einem Nachdruck ausgesprochen (Art. 3 Abs. 2 und 3, 117 Abs. 1 GG), der dazu zwingt, es maximal zur Geltung zu bringen.

Der allgemeine, gegenüber den Differenzierungsverboten des Art. 3 Abs. 3 GG angebrachte Vorbehalt von "Differenzierungen, die auf anderen Unterschiedlichkeiten der Personen oder auf Unterschiedlichkeiten der Lebensumstände beruhen", 6) würde, gegenüber der Gleichberechtigung von Mann und Frau undifferenziert angewandt, deren Bedeutung radikal beschränken. Der Un-

17) Einen Beispielsfall s. bei Arbeitsgericht Rosenheim, Urt. v. 25.Juli 1957 - I 80/57 Tr. XI 180 - Arbeitsrecht in Stichworten, Bd. 19 \$.97 (Nr.263).

18) $\$$. auch $\$ \$ 56,91$ des Bundespersonalvertretungsgesetzes; Art. 56 des Bayer. Personalvertretungsgesetzes.

1) Fuss, Gleichheitssatz und Richtermacht, S. 335.

2) Beitzke, Gleichheit von Mann und Frau, S. 206.

3) BVerfGE 3, 225 (241).

4) Beitzke, a.a.O. S. 207.

5) BVerfGE a.a.O.; s. hierzu auch v. Mangoldt-Klein, Art. 3 Anm. IV 6.

6) S. oben S. 915 zu Fußn. 4. 
terschied der Geschlechter prägt die "Personen" und ihre "Lebensumstände" allgemeiner und unmittelbarer als andere Differentialmomente. Di.e Gleichheit der Geschlechter ist aber nicht nur in der Verfassung zu deutlich betont, um auf diese Weise ausgehöhlt werden zu dürfen. Sie entzieht sich der unbedingten Anwendung des für die Differenzierungsverbote des Art. 3 Abs. 3 GG entwickelten Vorbehaltes schon dadurch, daß sie in der Verfassung nicht nur durch ein solches Differenzierungsverbot geschützt sondern auch und in erster Linie positiv angeordnet ist (Art. 3 Abs. 2 GG). Allgemeine Unterschiede $z$ wischen Mann und Frau dürfen demnach "nur dann zu verschiedener Behandlung im Recht führen..., wenn sie das zu ordnende Lebensverhältnis so entscheidend prägen, daß etwa vergleichbare Elemente daneben vollkommen zurücktreten und die verschiedene rechtliche Regelung also mit den Begriffen 'Benachteiligen' und 'Bevorzugen' nicht mehr sinnvoll zu erfassen ist". ") Der Grundsatz der Gleichheit von Mann und Frau wirft also schwierige Wertungsfragen auf. Wenn gesagt wurde, es müsse "bestimmt werden, wo nach dem Gesamtzusammenhang unseres heutigen Sozialgefüges Unterschiede noch gerechtfertigt sind, und wo nicht", 8) so trifft diese Formulierung, so "unrechtlich" sie wirkt, gerade wegen ihrer Offenheit gegenüber dem jeweils zu ermittelnden "Gesamtzusammenhang" der rechtlichen mit den außerrechtlichen Elementen, das Problem an seiner ernstesten Seite.

\section{bb) Einzelfragen}

\section{aaa) Zurn Stand der Entwicklung}

Die frühere gesellschaftliche und rechtliche Deklassierung der Frau war in ihrer ganzen Breite zwar auch,aber nicht schlechthin, sondern nur bedingt und im einzelnen auf sehr unterschiedliche Weise ein - im Sinne dieser Untersuchung - soziales Problem. Sie ist als solches verstärkt hervorgetreten, als die Frau aus der Familie und aus der sie erschöpfenden, spezifischen Aufgabenstellung in der Familie herauswuchs, in einer Zeit also, in der - Hand in Hand damit - auch die Gleichberechtigungsentwicklung einsetzte. Diese hat einen großen Teil der einstmals offenen Gleichberechtigungsprobleme bereits vor der Verfassungsneuordnung nach 1945 erledigt. 1) Die politische Gleichberechtigung der Frau - in der Demokratie die unerläßliche Voraussetzung ihrer dauerhaften sozialen Gleichstellung - war und ist so kein Problem

7) BVerfGE 10, 59 (74), im Anschluß an BVerfGE 6, 389 (422 f).

8) Beitzke, Gleichheit von Mann und Frau, S.207.

1) S. hierzu Beitzke, a.a.O. S. $199 \mathrm{ff}, 213 \mathrm{ff}$. 
mehr, ${ }^{2)}$ desgleichen nicht der grundsätzlich gleiche Zugang zum Berufsleben ${ }^{3)}$ und ihre prinzipielle Gleichstellung im bürgerlichen Recht. ${ }^{4)}$ Offen geblieben war noch die familienrechtliche Gleichstellung der Frau mit ihren vielfältigen Auswirkungen ein sozial nur mittelbar bedeutsamer Fragenkreis, 5) der inzwischen durch das Gleichberechtigungsgesetz vom 18. Juni 1957 (BGB1. I S.609) neu geregelt wurde. 6) Einige Gleichberechtigungsprobleme von erheblicher sozialer Tragweite harren dagegen noch heute der vollständigen Klärung.

\section{bbb) Gleichberechtigung und soziale Sicherung}

Als der - trotz verschiedentlicher Novellierung - noch am wenigsten befriedigend geregelte Komplex muß die unterschiedliche Versorgung der Angehörigen im Beamtenrecht, Sozialversicherungsrecht und im Recht der Kriegsopferversorgung bezeichnet werden. 1) Dabei geht es vor allem um das Problem der Witwen(Witwer-)rente bzw. -versorgung ${ }^{2}$ ) und der Waisenrente bzw.

2) S. z.B. Beitzke, a.a.O. S.215.

3) Vg1. Beitzke, a.a.O.S.217 f; s. hierzu auch BVerfGE 6,55 (82).

4) Vgl. Beitzke, a.a.O. S.216 f.

5) Zur Ausgangslage vor dem Gleichberechtigungsgesetz s. etwa Beitzke, a.a.O. S. 226 ff.

6) Was nach diesem Gesetz und nach dessen zentraler Korrektur durch die Entscheidung BVerfGE 10, 59 ernstlich - von den Äußerungen nimmersatter Radikaler abgesehen - offen blieb, sind Randfragen ohne soziale Tragweite.

1) Vgl. Scheffler, Ehe und Familie, in: Bettermann-NipperdeyScheuner, Die Grundrechte, Bd.IV, 1.Halbbd., 1960, S.245 ff $(315 \mathrm{f})$.

2) (1) Für die Rentenversicherung $\mathrm{s}$. $\$ \$ 1256-1257 \mathrm{RVO}$ a.F., deren Ungültigkeit durch BSGE 5, 17 (22 f) anerkannt wurde; übereinstimmend Hildegard Krüger, Witwerrente und Waisengeld nach dem Tod der sozialversicherten (versorgungsberechtigten) Ehefrau und Mutter, MDR 11.Jhg. (1957) S. 68 ff; dies., Die Rechtsprechung des Bundessozialgerichts zu den Witwerrenten, NJW 10.Jhg. (1957) S. 1209 ff (1211 f); Dersch, Die Sozialversicherung, S.508; Weidner, Zur Rechtsprechung des Bundessozialgerichts, S. 709 f. Zweifelhaft erscheint auch die Gültigkeit der $\$ \$ 1264-1266$ RVO n. F. (vgl. Weidner, a.a.O.; a.A. BSGE 5, 17 (24 f); Dersch, a.a.O. S. 508 f). - Zur Parallele im Angestelltenversicherungsrecht s. $\$ \$ 41 \mathrm{ff} A \mathrm{nVG}$ und die Vorgenannten. 
- versorgung. 3) Als Seitenprobleme erweisen sich die - durch die $\$ \S 205 \mathrm{ff}$ RVO verfassungskonform auslegbar geregelte - Familienhilfe des Krankenversicherungsrechts 4) und die ungleich geregelte Beihilfe für die Ehegatten von Beamten und Beamtinnen. 5) 6) 7)

(2) Für die Unfallversicherung s. $\$ \$ 588$ f RVO (gegen die Gültigkeit Krüger, Witwerrente und Waisengeld usw. wohl auch Dersch, a.a.O. S. 509).

(3) Für die Kriegsopferversorgung s. $\$ \$ 40-43$ des Bundesversorgungsgesetzes. Zur Gültigkeit der aiten Fassung s. BSGE 5, 26 (32); 9, 36; dagegen Krüger, Witwerrente und Waisengeld usw.; dies., Die Rechtsprechung des Bundessozialgerichts usw.; Weidner, a.a.O. S. 710 .

(4) Für die beam te n rechtliche Hinterbliebenenversorgung s. $\ \$ 123 \mathrm{ff}$, insbes. $\$ 132$ des Bundesbeamtengesetzes, $\S \S 71 \mathrm{ff}$, insbes. $\$ 78$ des Beamtenrechtsrahmengesetzes. Kritisch hierzu Krüger, Witwerrente und Waisengeld usw. Einen Problemfall aus dem privatrechtlichen öffentlichen Dienst s. in BAG Urt. v. 28. November 1958 - 1 AZR 307/58 - AP Art. 3 GG Nr. 39.

3) (1) Für die Rentenversicherung s. $\$ 1258$ RVOa.F.; § 1267 RVO n.F.; $\$ 44$ AnVG. Kritisch hierzu Krüger, Witwerrente und Waisengeld usw., S.70; Dersch, a.a.O. S. 509. (2) Für die Unfal1versicherung s. $\$ \$ 591$ ff RVO; kritisch hierzu Dersch, a.a.O. S. 509.

(3) Für die Kriegsopferversorgung s. $\$ 45$ des Bundesversorgungsgesetzes. Zur Gültigkeit s. BSGE 5, 26 (33 f); dagegen Krüger, Witwerrente und Waisengeld usw., S. 70; dies., Die Rechtsprechung des Bundessozialgerichts usw., S. $1209 \mathrm{ff}$; Weidner, a.a.O. S. 210.

4) Vgl. BSGE 10, 28; 12, 38.

5) Vgl. nunmehr Nr.2 Abs. 1 Ziff. 1a der Beihilfevolschriften v. 17. März 1959 (BAnz Nr. 54). Zum früheren Beihilferecht s. BayVerfGH VGHE n.F. 11 II 203.

6) Zum arbeitsrechtlichen Parallelproblem s. BAG Urt. v. 28. März 1958 - 1 AZR 336/57 - AP Art.3 GG Nr.28; Urt. v. 28. November 1958 - 1 AZR 307/58 - ebd. Nr.39.

7) Den Ansatz einer möglichen Ungleichbehandlung von Mann und Frau im Sozialversicherungsrecht stellt auch $\$ 150$ Abs. 1 RVO dar: "Der Ortslohn wird für Männer und Frauen... besonders festgesetzt" . Doch handelt es sich hierbei im wesentlichen um einen Reflex des Problems der Lohngleichheit. S. hierzu auch BSGE 8, 164 (167 f). 
Daß clieser Rechtsbereich gleichheitsgrundrechtlich noch nicht befrieclet ist, liegt an zwei hartnäckig bewahrten Vorurteilen des Gesetzgebers, 8) die ihn veranlassen, die Frauen dadurch $z u$ benachteiligen, daß sie ihren Männern und Kindern nicht die gleiche Garantie der Versorgung bieten können, die ein Mann seiner Frau bzw. seinen Kindern zu bieten imstande ist, und andererseits die selbst versorgungsbedürftigen Ehemänner verstorbener, beschädigter oder erkrankter Ehefrauen schlechter zu stellen als die versorgungsbedürftigen Ehefrauen verstorbener, beschädigter oder erkrankter Ehemänner. Der Gesetzgeber sieht erstens in der Verdienerrolle des Mannes und Vaters und in der Hausfrauenrolle der Frau und Mutter eine gleichsam verbindliche Regel. Daraus folgert er die Befugnis, eine abweichende Rollenverteilung durch die Schlechterstellung der Beteiligten zu ahnden,wenn nicht $\mathrm{zu}$ ignorieren. Zweitens hält er nur den Ausfall des (Bar-) Verdieners und nicht auch den Ausfall des realversorgenden, Dienste leistenden Funktionärs der "Hausfrauen"-Rolle für ein sozial abzusicherndes Risiko. 9) Beides widerspricht der Verfassung.

Gewiß darf der Gesetzgeber von einem Normalbild der Ehe bzw. Familie ausgehen, in dem der Mann (Vater) der Verdiener, die Frau (Mutter) die Hausfrau ist. 10) Aber er muß das Recht der Frau respektieren, erwerbswirtschaftlich nicht anders tätig $z u$ sein als der Mann, und das Recht der Ehegatten, die Rollen entsprechend anders zu verteilen. 11) Er darf dieses Recht nicht dadurch zunichte machen, daß er den Regelfall universell fingiert oder auch nur unter unangemessener Erschwernis der Geltendmachung des Gegenteils vermutet. Er darf es auch nicht dadurch beschneiden, daß er die Frau als Verdiener zwar zur Kenntnis nimmt, sie jedoch schlechter stellt als den Mann als Verdiener. Schlechter gestellt wird die Frau aber nicht nur dann, wenn ihre eigene soziale Sicherung geringer ist als die des Mannes; schlechter gestellt wird sie auch dann, wenn ihre Angehörigen (ihr Ehegatte, ihre Kinder) weniger gesichert sind als die Angehörigen verdienender Männer. 12)

8) Das Bundessozialgericht (s.o. S. $919 \mathrm{f} \mathrm{zu} \mathrm{Fußn.2} \mathrm{und} 3 \mathrm{u}$. unten Fußn.9 und 10) teilt sie weitgehend.

9) So auch BSGE 5, 17 (20), 26 (30 f); 9, 36 (39 f).

10) Vgl. $\$ \$ 1356$ ff r.F. BGB; BVerfGE 10, 59 (75); BSGE 5, 17 (21), 26 (30 f); 9,36 (40 ff).

11) BVerfGE 6, 55 (80 ff); Scheffler, Ehe und Familie, S. 290 und passim.

12) Unverständlich ist, wenn das Bundessozialgericht (BSGE 5, 26 (33 f)) zur Rechtfertigung der Waisenversorgung nach $₫ 45$ 
In unzulässiger Weise benachteiligt wird die Frau aber auch, wenn der Wert ihrer - im Rahmen der "Norm" liegenden - Hausfrauenfunktion negiert wird. Das im bürgerlichen Recht entwickelte ${ }^{13)}$ Normbild der Ehe bezieht seine Legitimation gegenüber der Gleichheit von Mann und Frau gerade daraus, daß es der Frau eine andersartige aber gleichwertige Rolle zuweist als dem Mann. 14) "Die Frau erfüllt ihre Verpflichtung, durch A rbeit zum Unterhalt der Familie beizutragen, in der Regel durch die Führung des Haushalts". 15) Was der Mann, dem die (haushaltsführende) Frau und was die Kinder, denen die (haushaltsführende) Mutter stirbt, verlieren, kann deshalb kein rechtliches "Nichts" sein. 16) Die Annahme, es wäre ein tatsächliches "Nichts", endlich wäre nichts weniger als absurd.

Schließlich ist $z u$ bedenken, daß gleiche Sozialversicherungsbeiträge für Mann und Frau eingefordert werden, daß von dem Beamten und der Beamtin die gleichen Dienstleistungen erbracht werden, daß die verunfallte oder kriegsbeschädigte Frau in gleicher Weise beeinträchtigt sein kann wie ein Mann usw. 17)

Anhangsweise sei noch auf ein Sonderproblem des Beamtenrechts hingewiesen: die $\mathrm{A} b \mathrm{f}$ indung der verheirateten Beamt in.18) Diese - ausnahmsweise - die Frauen begünstigende Ein-

Abs. 5 Satz 1 BVG ausführt, die Versorgung der Kinder werde nicht nach deren Geschlecht unterschiedlich geregelt, die Unterschiede im Geschlecht des die Versorgung veranlassenden Elternteils aber mit keinem Wort erwähnt! Sollte hier ein Gesetz um jeden Preis gehalten werden?

13) S. o. S.921 zu Fußn. 10.

14) BVerfGE 3, 225 (241 f); 10, 59 (75).

15) $₫ 1360$ Satz 2 n. F. BGB.

16) Es wäre nicht - wie das Bundessozialgericht (BSGE 9, 36 (39 f)) meint - eine "Ausdehnung" des $\$ 1360$ n.F. BGB sondern nur der schuldige Respekt vor dieser Vorschrift und dem hinter ihr stehenden Willen der Verfassung, wenn der reale Wert der Hausfrauenarbeit sozialrechtlich anerkannt würde.

17) $Z u$ den vorstehenden Gesichtspunkten s. nochmals Scheffler, Ehe und Familie, S. 315 f. Insbes. zum Beamtenrecht s. Beitzke, Gleichheit von Mann und Frau, S. 220 m. w. Nachw. (Fußn. 137); hinsichtlich der Sozialversicherung und der Kriegsopferversorgung s. Krüger, Weidner und Dersch je o. (S.919f Fußn.2 und 3) a.O.

18) Vgl. $₫ 152$ des Bundesbeamtengesetzes, $₫ 63 \mathrm{Nr} .5$ des Beamtenrechtsrahmengesetzes. 
seitigkeit bedarf ebenfalls des Ausgleiches. 19) 20)

\section{ccc) Gleichheit von Mann und Frau im Arbeitsrecht}

Die Diskussion um die Gleichberechtigung von Mann und Frau im A rbeitsrecht 1 ) hat sich, nachdem die Frage der besonderen Kündigungsgründe für Frauen befriedet war, 2) auf den Arbeitsschutz und die Lohngleichheit konzentriert. ${ }^{3)}$

1. Besonderer Arbeitsschutz für Frauen. Aus der Problematik des besonderen Arbeitsschutzes der Frau ist vorweg der Mutte rschutz auszuklammern. Er gründet auch in Art. 6 Abs. 4 GG. 4) Eine Auslegung des Art. 3 Abs. 2 und 3 GG, welche die Zulässigkeit des Mutterschutzes bestreiten wollte,

19) S. Beitzke, a.a.O. S. 220 und seine Nachweise.

20) Im übrigen ist das $\mathrm{B}$ e a $\mathrm{m}$ ten $\mathrm{recht}$, nachdem die besonderen Bestimmungen über die Entlassung verheirateter Beamtinnen beseitigt sind (zum Problem s. noch Jellinek-v. Caemmerer-Grewe, Zur Gleichberechtigung der Geschlechter im Beamtenrecht, Drei Stellungnahmen, AöR Bd. 76 (1950/51) S. $137 \mathrm{ff}(138 \mathrm{ff}, 144 \mathrm{ff}, 161 \mathrm{ff})$; Beitzke, a.a.O. S. 218 ff; Scheffler, a.a.O. S.317 ff), von geschlechtergleichheitlichem Konfliktsstoff befreit (eine Übersicht über die Probleme s. bei Jellinek-v. Caemmerer-Grewe, a.a.O.; Beitzke, a.a.O.).

1) Zur Gesamtproblematik s. z.B. Beitzke, Die Gleichberechtigung von Mann und Frau im Arbeitsrecht, Recht der Arbeit, 6.Jhg. (1953) S. $280 \mathrm{ff}$; ders., Die Gleichheit von Mann und Frau, S.221 ff; je m.w. Nachw.

2) Unmittelbar nach der verfassungsrechtlichen Neuordnung hat die Benachteiligung der Frau bei der Kündigung eine große Rolle gespielt (s. etwa die Nachweise im NJW-Fundheft "Arbeitsrecht" Bd.1 (1945-53), 1954, S.231 f). Ähnlich wie im Beamtenrecht die Frage der besonderen Entlassungsgründe für Frauen wurde dieses Problem jedoch bald abgeklärt. S. hierzu etwa Molitor, Die arbeitsrechtliche Bedeutung des Art. 3 des Bonner Grundgesetzes, S. 412 ff; Beitzke, Die Gleichberechtigung von Mann und Frau im Arbeitsrecht, S. 283.

3) Weitere Sonderprobleme s. bei Beitzke, a.a.O. (Fußn.1) und Molitor, a.o. (Fußn.2) a.O. S. ferner schon oben S.919 zu Fußn. 2 a.E. und S. 920 zu Fußn.6. - Zur beamtenrechtlichen, häfuig parallelen Problematik s. oben Fußn. 20.

4) Zum Zusammenhang mit dem Sozialstaatsprinzip s. oben Abschnitt 5 III 2 c cc bbb (S. $777 \mathrm{f})$ und 3 a (S. $782 \mathrm{ff}$ ). 
käme darüber nicht hinweg. Doch wäre sie auch ohne das unrichtig. Ein dem Gegenstand des Mutterschutzes vergleichbarer Lebenssachverhalt fehlt bei den Männern. Daß der Mutterschutz nur Frauen betrifft, ist 'mit den Begriffen 'Benachteiligen' und 'Bevorzugen' nicht mehr sinnvoll zu erfassen". 5) Der Mutterschutz knüpft zudem an die besondere Eigenschaft "Mutter" an, also an eine Unterscheidung der Person und der Lebensumstände, die mit dem ausgeschlossenen Unterscheidungsmerkmal "Frau" nicht zusammenfällt. 6) Er bezweckt 7) nicht den Schutz der "Frau" sondern der "Mutter". 8)

Arbeitsschutzrechtliche Vorschriften, welche die Frauen $\mathrm{schlechthin} \mathrm{betreffen,} \mathrm{sind} \mathrm{gegenüber} \mathrm{dem} \mathrm{Gleichberech-}$ tigungsprinzip noch nicht damit zu rechtfertigen, daß sie "Gemeingut aller Kulturstaaten" sind 9) - so sehr auch das vorrechtliche Gesamtbild in diese interpretatorische Richtung drängt. Art. 3 Abs. 2 und 3 GG nimmt dem Gesetzgeber "die Freiheit..., an funktionale oder biologische Unterschiede als an ungleiche Elemente der Lebensverhältnisse anzuknüpfen und demgemäß Mann und Frau verschieden zu behandeln"; 10) es sei denn, daß sie "das zu ordnende Lebensverhältnis so entscheidend prägen, daß etwa vergleichbare Elemente daneben vollkommen zurücktreten". 11) Ob dies der Fall ist, kann weder für besondere A $r$ beitszeitbeschränkungen 12) noch für Beschäftigungsverbote oder - beschränkungen 13) allgemein gesagt werden. Jedoch können diese wie jene gerechtfertigt sein, soweit sie biologischen oder funktionalen Unterschieden Rechnung tragen, die das Verhältnis der Frau bzw. des Mannes zur Arbeit entscheidend und wesentlich verschieden prägen. ${ }^{14)}$ Dabei wird

5) S. O. S.918 zu Fußn.7.

6) S. o. S.915 zu Fußn. 4.

7) S. 0. S. 915 zu Fußn. 5 und 6.

8) Vgl. BVerfGE 6, 389 (422); 10, 59 (74), wo jeweils "Bestimmungen zum Schutze der Frau als Mutter" als unbedenklich erklärt werden; ferner Beitzke, Die Gleichheit von Mann und Frau, S. 221.

9) Beitzke, a.a.O.

10) BVerfGE 10, 59 (73).

11) ebd., S. 74.

12) S. insbes. $\$ \$ 17$ ff der Arbeitszeitordnung (s. hierzu auch Fußn. 14).

13) S. $\$ 16$ der Arbeitszeitordnung; $₫ 92$ des Seemannsgesetzes.

14) Das Bundesverfassungsgericht (BVerfGE 5, 9 (12)) hat die $\$ \$ 17$ Abs. 2 Satz 2 und 19 der Arbeitszeitordnung für gültig erklärt. Für die Zulässigkeit des Verbotes von Untertage- 
es auf eine angemessene Relation zwischen der Bedeutung der Sonderregelung, insbes. der Differenz im Vergleich zum allgemeinen - d.h. in diesem Falle: zu dem für Männer geltenden Recht, dem Ausmaß der zugrunde liegenden tatsächlichen Unterschiede und dem mit der unerläßlichen Generalisierung notwendig verbundenen Kalkül der Einbeziehung von Personen, bei denen die wesentlichen besonderen Verhältnisse nicht vorliegen, ankommen.

Teils dem Schutz der Frau schlechthin, teils speziell dem Schutz der haushaltsführenden Frau, der Ehefrau, Mutter usw. dient der Hausarbeitstag. 15) Soweit er den Schutz der Frau in ihrer familiären Stellung bezweckt, also Frauen zugute kommt, 16) die eine Familie - Mann und (oder) Kind(er) - zu versorgen haben, ist die Regelung nicht nur zusätzlich durch Art. 6 GG legitimiert; 17) sie knüpft auch an engere Kriterien als an das allgemeine Merkmal "Frau" an. Soweit der Hausarbeitstag aber, wie es derzeit die Regel ist, 18) zwar nur Frauen, diesen aber unter Bedingungen gewährt wird, die auch bei Männern vorliegen können, 19) müssen Vorbehalte angebracht werden, die allein mit dem Gesichtspunkt zulässiger Typisierung nicht ausgeräumt wer-

bergbau und Nachtarbeit s. Beitzke, Gleichheit von Mann und Frau, S. 221 .

15) Vgl. Anordnung des Reichsarbeitsministeriums über Arbeitszeitverkürzung für Frauen, Schwerbeschädigte und minderleistungsfähige Personen vom 22. Oktober 1943 (RAB1. III S. 325 ) - zu deren Fortgeltung s. Hueck, Lehrbuch des Arbeitsrechts, Bd.I S. 655 -; Bremisches Gesetz über den Hausarbeitstag vom 29. Juni 1948 (GB1. S.95); Hamburgisches Gesetz über den Hausarbeitstag vom 17. Februar 1949 (GVBl. S. 15); Niedersächsisches Gesetz betr. hauswirtschaftliche Freizeit für Frauen vom 9. Mai 1949 (GVB1. S. 104). - Näheres zum Recht des Hausarbeitstages s. bei Hueck, a.a.O. S. $655 \mathrm{ff} ; \mathrm{s.a}$. seine Nachweise.

16) Als bezah1ter ist der Hausarbeitstag auch ein besoncleres Problem der Lohngleichheit. S. dazu auch den folgenden Text.

17) Zur verfassungsrechtlichen Zulässigkeit des besonderen Schutzes der Stellung der Frau in der Familie s. BVerfGE 6, 389 (422); 10, 59 (74). Zum besonderen Problem s. ferner Scheffler (Ehe und Familie, S. $308 \mathrm{f}$ ), die diesen Schutz aber zu sehr auf den Mutterschutz beschränkt.

18) S. oben Fußn. 15.

19) Vgl. Arbeitsgericht Iserlohn, Urteil v.13. Mai 1958 - 1 Ca $272 / 58$ - Arbeitsrecht in Stichworten, Bd.20, S. 167 (Nr.435). 
den können. ${ }^{20)}$

2. Die Lohngleichheit. ${ }^{21)}$ Art. 3 Abs. 2 und 3 GG gebietet, daß die Frau jedenfalls dann nicht geringer entlohnt werden darf als der Mann, wenn sie in der gleichen Tätigkeit eine gleiche Leistung erbringt. 22) Leistet die Frau in gleicher (vergleichbarer)

20) Zum ä1teren Streitstand s. Beitzke, Gleichheit von Mann und Frau, S.221. - Das Bundesarbeitsgericht hat sich, indem es - ohne überzeugen zu können - einerseits typisierte, andererseits die teilweise unleugbare Bevorzugung der Frau als solcher durch Berufung auf das Sozialstaatsprinzip rechtfertigen zu können glaubte, vor die geltenden Regelungen gestellt (BAGE 1, 51 (56 f), 60, 63; zustimmend Galperin, Anm. zu BAG Urt. v. 14.Juli 1954 - 1 AZR 105/54 - (=BAGE 1, 51); Herschel, A rbeitsschutz im sozialen Rechtsstaat, $S$. 574 f; Hueck, Lehrbuch des Arbeitsrechts, Bd.I, S. 655 ff; zweifelnd Bulla, Anmerkung zu BAG Urt. v. 14. Juli 1954 - 1 AZR 105 bzw. 89 bzw. 138/54 - (= BAGE 1, 51, 60,63) AP Art. 3 GG Nr. 1-3 (B1. 4 Rücks.). Die neuere Rechtsprechung des Bundesarbeitsgerichts ist dagegen zurückhaltender (vgl. BAG Urt. v.25. März 1960 - 1 AZR 551/58 - Sammlung arbeitsrechtlicher Entscheidungen, 1960, S. 125 (Nr.54) mit Anm. von Gangloff; ferner Urteil v. 25. März 1960 - 1 AZR $556 / 58$ und $420 / 58$ - ebenda S. 128 (Nr.55) und S. 130 (Nr.56) mit Anmerkung von Dietz (S.131 ff). In diesem Sinne auch Scheffler, a.a.O.

21) Aus dem umfangreichen Schrifttum s. z.B. Nipperdey, Gleicher Lohn der Frau für gleiche Leistung, 1951, S. 4 ff; ders., Lehrbuch des Arbeitsrechts, Bd.II, S.275 ff; Hueck, Die Bedeutung des Art. 3 GG für die Lohn- und Arbeitsbedingungen der Frauen; ders., Lehrbuch des Arbeitsrechts, Bd. I, S. 259 f, 654; Herschel, Gleichberechtigung der Frau und Lohngleichheit, Betriebsberater, 10.Jhg. (1955) S. 290 ff; Galperin, Gleicher Lohn für Männer und Frauen, JZ 11. Jhg. (1956) S. 105 ff; Nikisch, Arbeitsrecht, Bd. I, S. 302 ff; Dietz, Rechtsgutachtliche Äußerung zu der Frage, ob Art. 3 Abs. 2 und 3 des Grundgesetzes für die Bundesrepublik Deutschland einer geringeren Wertigkeit der Frauenarbeit gegenüber der Männerarbeit sowie einer typisch geringeren sozialen Belastung der Frau gegenüber dem Mann bei der Aufstellung einer Norm für den Lohn entgegensteht; alle weiteren Nachw. s. dort.

22) Vgl. Beitzke, Gleichheit von Mann und Frau, S.223 f; Galperin, a.a.O. S. 107; Hueck, Lehrbuch des Arbeitsrechts, Bd. I, S. 654 . 
'Tätigkeit Geringeres als der Mann, so kann sie auch geringer entlohnt werden.23) Aber diese geringere Leistung darf nicht vermutet werden. 24) Sie muß objektiv, ohne Rücksicht auf das Geschlecht des Arbeitnehmers festgestellt werden. 25) Daher sind nur solche Lohndifferenzierungen zulässig, die auch bei Männern vorgenommen werden können, wenn und soweit es sich um Arbeiten handelt, die in gleicher Weise für Männer und Frauen vorgesehen sind. 26) Wo, wie beim Akkord, der Lohn unmittelbar an die Leistung anknüpft, hat eine Differenzierung $z u$ unterbleiben. 27)

Neben der geringeren Leistungsfähigkeit der Frau beeinträchtigt den wirtschaftlichen Wert der Frauenarbeit vor allem der besondere soziale Schutz der Frau. 28) Dieser besondere Schutz der Frau kann nur zulässig sein, soweit Unterschiede zwischen den Geschlechtern bestehen, die das zu ordnende Lebensverhältnis so entscheidend prägen, daß die übrigen Vergleichselemente dahinter zurücktreten. 29) Demgemäß wird es in der Regel auch zulässig sein, diesen Unterschieden Rechnung tragend das Prinzip des gleichen Lohns für gleiche Leistung zu durchbrechen und den Frauenlohn nicht entsprechend der wirtschaftlichen Wertminderung der Frauenarbeit abzusenken. ${ }^{30)}$ Jedoch muß der besondere

23) Vgl. Beitzke, a.a.O.; Galperin, a.a.O. S. $107 \mathrm{f}$.

24) BAGE 1, 258 (269), 348 (356); 2, 125 (128 f), 133, 240 (247 ff); BAG Urt. v. 2. März 1955 - 1 AZR 246/54 - AP Art. 3 GG Nr. 6. A.A. Klein, Rechtsgutachten über verfassungsrechtliche Fragen des Urteils des Bundesarbeitsgerichts v. 2. März 1955 - betreffend Lohngleichheit von Mann und Frau, S. 34 ff; für Zulässigkeit der Typisierung: Dietz, Rechtsgutachtliche Äußerung usw., S. $20 \mathrm{ff}$.

25) Vgl. Nikisch, Arbeitsrecht Bd.I, S. 305 f, 308 f; Nipperdey, Lehrbuch des Arbeitsrechts, Bd.II S. $277 \mathrm{f} \mathrm{m}$. w. Nachw.

26) Zu den Gestaltungsmöglichkeiten s. Gaul, Die Bedeutung der Frauenlohnurteile des Bundesarbeitsgerichts für die Tarifpartner und das ILO-Übereinkommen 100, S. $364 \mathrm{ff}$; ders., Der Frauenlohn in den Tarifverträgen.

27) Vgl. BAGE 1, 258 (268), 240 (246); Hueck, Die Bedeutung des Art. 3 GG für die Lohn- und A rbeitsbedingungen der Frauen, S. 37; a.A. Dietz, a.a.O. S. $44 \mathrm{f}$.

28) Zu den für den wirtschaftlichen Wert der Frauenarbeit bestimmenden Umständen s. z.B. Dietz, Rechtsgutachtliche Äußerung usw., S. $33 \mathrm{ff}$.

29) S. 0. S.914ff und S. 917 sowie vorstehend zu S. $890 \mathrm{ff}$.

30) S. hierzu schon oben $\mathrm{S} .784 \mathrm{ff}$ und S. 793 zu Fußn. 21. Vgl. ferner v. Caemmerer, Zur Gleichberechtigung der Geschlechter im Beamtenrecht, S. 152 f; Nikisch, Arbeitsrecht Bd. I, S. 307 f; 
soziale Schutz der Frau bei der Lohngestaltung nicht in jedem Falle ignoriert werden. ${ }^{31)}$ Zwar wird die Frau trotz des bestehenden Arbeitsschutzes etwa für die Zeit, in der sie tätig ist, den ihrer Leistung entsprechenden Zeitlohn erhalten und sich nicht schon deshalb einen Lohnabschlag gefallen lassen müssen, weil in irgend einer Weise (vielleicht in unbestimmter Zukunft) der ihr zukommende soziale Schutz den wirtschaftlichen Wert ihrer A rbeit mindern könnte. ${ }^{32)}$ Aber es ist nicht durchwegs geboten, der Frau auch den freien Hausarbeitstag zu vergüten, 339 die vermehrten Pausen mitzubezahlen oder gar den Überstunden- oder Nachtzuschlag zu bezahlen, den sie sich wegen der bestehenden A rbeitszeitbeschränkungen für Frauen nicht verdienen kann.

Nicht eine Faus.tregel kann hier helfen sondern nur die Abwägung aller Umstände. Frauenlohn und soziale Sonderstellung der Frau müssen in eine gesunde Relation gebracht werden. ${ }^{34)}$

Die gleichen Grundsätze wie für den Lohn (im engeren Sinne) haben für Sozialleistungen wie Gratifikationen, Ruhegelder usw. $\mathrm{zu}$ gelten. ${ }^{35}$ )

Werden im Hinblick auf die Unterhaltsverpflichtungen der Arbeitnehmer Sozialzulagen gewährt, so müssen sie für Männer und Frauen prinzipiell gleich sein. ${ }^{36)}$ Doch wird, da der Verfassungssatz von der Gleichheit von Mann und Frau das Regelbild der Familie, das den Mann und Vater als Verdiener ("Ernährer"), die Frau und Mutter als Hausfrau kennt, nicht zerstört hat, 37) typi-

Nipperdey, Lehrbuch des Arbeitsrechts, Bd. II, S.276; Dietz, a.a.O. S. $20 \mathrm{ff}$ (insbes. S. $24 \mathrm{ff}$ ). A.A. Beitzke, Gleichheit von Mann und Frau, S.224; Klein, Rechtsgutachten über verfassungsrechtliche Fragen usw., S. 34 ff, insbes. S. 38.

31) S.o. S. 793 zu Fußn. 21; s. insbes. Dietz, a.a.O. A.A. BAGE 1, 258 (265 f), 348 (356); Nikisch, a.a.O.; Nipperdey, a.a.O.

32) A.A. Klein, a.a.O. S.34 ff; wohl auch Dietz, a.a.O. S.20 ff. 33) S. o. S. $890 f f$ a.E.

34) Vg1. Herschel in einem Vortrag, berichtet in Betriebsberater, 5.Jhg. (1950) S.92 f (93); ders., Gleichberechtigung der Frau und Lohngleichheit, S. 290 f (291); Hueck, Die Bedeutung des Art. 3 GG für die Lohn- und Arbeitsbedingungen der

Frauen, S.38. In dieser Richtung auch Dietz, a.a.O., insbes. S. $20 \mathrm{ff}$.

35) S. Beitzke, a.a.O. S.224 m.w. Nachw.

36) Vgl. Beitzke, a.a.O. S.224; Nipperdey, Lehrbuch des Arbeitsrechts, Bd.II, S.278; je m.w.Nachw.

37) S. o. S. 921 zu Fußn. 10. 
siert werclen dürfen. ${ }^{38)}$ Aber diese 'Typik muß elastisch sein. sie muß (ler autonomen Abweichung der Frau bzw. der Ehegatten von der Regel Raum lassen und Rechnung tragen. ${ }^{39)}$

Alles in allem erscheinen besonders Frauenlöhne nicht schlechthin unzulässig. Sie müssen nur in Struktur und Elementen den a ufgezeigten Grundsätzen folgen. D.h. sie müssen konkreter Ausdruck der Leistung der Frau im Vergleich zur konkreten Leistung und Entlohnung des Mannes sein; sie dürfen den besonderen sozialen Schutz der Frau nur in Anschlag bringen, soweit er die Leistung konkret hinter der verglichenen Leistung des Mannes zurückbleiben läßt; und sie dürfen die mögliche Ernährerund Verdienerrolle auch der Frau nicht ignorieren. Ob es danach noch praktisch erscheint, besondere Frauentarife aufzustellen, ist eine andere Frage, die in der Regel zu verneinen sein wird (soweit nicht die A rbeit an sich nur von Frauen verrichtet wird). Dem wirtschaftlichen Minderwert der Frauenarbeit 40$)$ kann in diesen Grenzen angemessen Rechnung getragen werden. 41) Daß ihm Rechnung getragen wird, liegt nicht zuletzt im Interesse der Frauen selbst; denn die erzwungene Überbewertung ihrer Arbeit müßte ihren Arbeitsplatz gefährden. 42)

3. Zur Drittwirkung u. ä. Der Gleichbehandlungssatz binclet unmittelbar nur den Staat, wenn dieser - durch Gesetz, auf Grund des Gesetzes über die Festsetzung von Mindestarbeitsbedingungen, des Heimarbeitergesetzes usw. oder im Wege der

38) Vg1. Dietz, Rechtsgutachtliche Äußerung usw., S.47 ff; s.a. Molitor, Die arbeitsrechtliche Bedeutung des Art. 3 des Bonner Grundgesetzes. S. ferner oben S.921 zu Fußn.10. Für die Zulässigkeit einer Sozialzulage für Familienernährer s. BAGE 1, 258 (268).

39) S. die parallelen Zusammenhänge oben S.919 ff und die Nachw. hierzu.

40) S. nochmals Dietz, a.a.O. S. $17 \mathrm{ff}, 33 \mathrm{ff}$.

41) Daß der wirtschaftliche Minderwert nicht pauschal in Anschlag gebracht werden darf, ist dem Bundesarbeitsgericht (BAGE 1, $348(354 \mathrm{f})$ ) zuzugeben. Der komplexe Begriff des "wirtschaftlichen Minderwertes" ist ein allzu gefügiges Instrument, um die Gleichberechtigung zu sabotieren. A.A. insbes. Dietz, a.a.O. S.20 ff mit weit. Nachw.

42) S. z.B. Molitor, Die arbeitsrechtliche Bedeutung des Art. 3 des Bonner Grundgesetzes, S. 409 ff; Klein, Rechtsgutachten über verfassungsrechtliche Fragen usw., S.41; Scheffler, Ehe und Familie, S. 309 Fußn. 286. 
Allgemeinverbindlicherklärung von Tarifverträgen 43) - Arbeitsbedingungen und Löhne festsetzt. 44) Eine unmittelbare Drittwirkung entfaltet Art. 3 Abs. 2 und 3 GG nicht. ${ }^{45)}$ Erst in Abwehr mißbräuchlicher kollektiver oder individueller Machtausübung entfaltet er als allgemeiner Rechtsgrundsatz privatrechtliche Valenz. 46) Daß ihm ob seiner entschlossenen Betonung, die das Grundgesetz ihm zuteil werden ließ, dabei größte Bedeutung zukommen muß, ist offenbar. $₫ 51$ des Betriebsverfassungsgesetzes 47) entspricht dieser verfassungsrechtlichen Basis, wenn im besonderen auch die Gleichbehandlung der Geschlechter zur Pflicht des Arbeitgebers und des Betriebsrates gemacht wird.

Damit ist auch die Frage der bindenden Wirkung des Grundsatzes gegenüber Betriebsvereinbarungen geklärt. ${ }^{48)}$ Für

43) A.A. Hueck, Die Bedeutung des Art.3 GG für die Lohn- und Arbeitsbedingungen der Frauen, S.31 ff; Klein, Rechtsgutachten über verfassungsrechtliche Fragen usw., S.22. S. hierzu schon oben S. $883 \mathrm{ff}$.

44) Gebunden ist auch der staatliche Schlichter, jedenfalls soweit er einen verbindlichen Schiedsspruch fällen kann (für die Bindung a 11 e $r$ Schlichter: Beitzke, Die Gleichheit von Mann und Frau, S.225; gegen die Bindung selbst des staatlichen Schlichters: Hueck, a.a.O. S. 33 f). Für staatliche Schlichter, die nur Empfehlungen geben können, spielt die Bindungsfrage keine entscheidende Rolle. Für sie ließe sich vertreten, daß sie mit ihren Empfehlungen so weit gehen können wie die Tarifparteien, an die sich ihre Empfehlungen richten. Aber der Einsatz der staatlichen Autorität wird doch im Vordergrund stehen müssen. Anders ist die Situation bei Schlichtern, die voll im Rahmen der "sozialen Autonomie" tätig werden. Sie sind nicht stärker gebunden als die Tarifparteien, die sie eingesetzt haben und $z$ wischen denen $\mathrm{zu}$ schlicnten ist.

45) S. Beitzke, a.a.O. S. 210 ff, 224 f; v. Mangoldt-Klein, Art. 3 Anm. IV 9; Klein, Rechtsgutachten über verfassungsrecht1iche Fragen usw., S. 10 ff; Galperin, Gleicher Lohn für Männer und Frauen, S. 106 f. - Im übrigen s. hierzu oben S. $883 \mathrm{ff}$.

46) S. oben I 4 d (S.876 ff).

47) S.a. $\$ \$ 56,91$ des Bundespersonalvertretungsgesetzes.

48) Vgl. Nikisch, Arbeitsrecht, Bd.I, S.426; Nipperdey, Lehrbuch des Arbeitsrechts, Bd. II, S.820. Für die Bindung der Betriebsvereinbarung an den Gleichheitssatz s. z.B. Beitzke, a.a.O. S.225; Galperin, a.a.O. S.106; Hueck, Lehrbuch des A rbeitsrechts, Bd.I, S.260 (anders noch Hueck, Die Bedeutung des Art. 3 GG für die Lohn- und Arbeitsbedingungen 
Tarifverträge wird der Spielraum, in dem sich eine unterschiedliche Behandlung von Arbeitnehmern und Arbeitnehmerinnen, die weiter geht als das Gesetz sie vorsehen könnte, weder als ein Mißbrauch der innergewerkschaftlichen Macht 49) noch als ein Mißbrauch der "sozialen Autonomie" der zusammenwirkenden Berufsverbände darstellt, nicht groß sein. ${ }^{50)}$

\section{c) Das Verbot, nach der "Herkunft" zu differenzieren}

Im Schrifttum hat noch ein anderes der in Art. 3 Abs. 3 GG aufgezählten Merkmale soziale - und zwar, so wie sie ihm zugemessen wurde: zentrale soziale - Bedeutung erlangt, nämlich das der "Herkunft". Ausgehend davon, daß das Willkürverbot des allgemeinen Gleichheitssatzes hinsichtlich der sozialen Gleichstellung nicht allzuviel zu leisten vermag, glaubt man, "daß die Sozialstaatsklausel Veranlassung geben sollte, den Bégriff 'Herkunft' in einem sozialen Sinne zu verstehen, im Sinne einer Deutung des sozialen Standortes desjenigen, der in dieser Weise charakterisiert werden kann". 1) Er soll vom Sozialstaatsgrundsatz her "eine Sinndeutung als Gebot zu ökonomischer Egalisierung empfangen", 2) zu einem "speziellen Benachteiligungsverbot für

der Frauen, S. 34). - Einen Beispielsfall s. in BAG Urteil v. 28. März 1958 - 1 AZR 336/58 - AP Art. 3 GG Nr. 28.

49) S. Götz Hueck, Der Grundsatz der gleichmäßigen Behandlung im Privatrecht, S. 105 (Fußn. 20).

50) Für die Bindung der Tarifverträge: BAGE 1, 258 (262 ff), 348 (353 f); 2, 125 (128), 133 (140), 240 (250 ff); BAG Urteil v. 2. März 1955 - 1 AZR 246/54 - AP Art. 3 GG Nr.6; Gaul, Die Bedeutung der Frauenlohnurteile des Bundesarbeitsgerichts usw., insbes. S. $360 \mathrm{f}$; ders., Frauenlohn in Tarifverträgen; Nikisch, Arbeitsrecht, Bd. I, S.304 f; Galperin, a.a.O. S. 105 ff; Hueck, Lehrbuch des Arbeitsrechts, Bd.I, S. 260; Nipperdey, Lehrbuch des Arbeitsrechts, Bd. II S. 275 f; Hamann, Das Grundgesetz, Art. 3 Anm. C 4; weit. Nachw.s. insbes. bei Galperin und Nipperdey je a.a.O. Gegen die Bindung: Ipsen, Gleichheit, S. 144; Maunz, Rechtsgutachten zur Frage, ob Tarifverträge dem Grundsatz der Lohngleichheit von Mann und Frau unterworfen sind; Klein, Rechtsgutachten über verfassungsrechtliche Fragen usw., S. $10 \mathrm{ff}$. Zum älteren Streitstand s. Beitzke, Gleichheit von Mann und Frau, S. 224 f. - Näheres zur hier vertretenen Problemlösung s. oben S. $883 \mathrm{ff}$.

1) Ipsen, Diskussionsbeitrag zu "Begriff und Wesen des sozialen Rechtsstaats", S.119 ff (Zitat S.120).

2) Ipsen, Gleichheit, S. 173 f (Zitat S. 173). 
Minderbemittelte" 3) werden.

Nun ist zwar. "Herkunft" i.S. des Art. 3 Abs. 3 GG nicht im 1okalen sondern im "ständisch-sozialen Sinn" zu verstehen. 4) Aber dem Wort "Herkunft" wird unerträgliche Gewalt angetan, wenn es als Bezeichnung für den jeweiligen "ständisch-sozialen" Standort gedeutet wird. "Herkunft" steht im Vorstellungsbild des "Her-kommens", einer - wie auch immer gearteten - Ortsveränderung also. "Dem Wort 'Herkunft' ist, ähnlich wie dem verwandten, gelegentlich sogar synonym gebrauchten Wort 'Abstammung’, das Element des Überkommenen eigentümlich, das zwar in die Gegenwart hineinwirkt, aber von der gegenwärtigen Lage des Menschen unabhängig ist, ja häufig gerade als Ausdruck eines gewissen Spannungsverhältnisses zwischen der gegenwärtigen sozialen Lage und derjenigen gebraucht wird, in die der Mensch hineingeboren ist. 'Herkunft' meint also die von den Vorfahren hergeleitete soziale Verwurzelung, nicht die in den eigenen Lebensumständen begründete Zugehörigkeit $\mathrm{zu}$ einer bestimmten sozialen Schicht". 5)

Aber wie sollte ein Verbot der Bevorzugung und Benachteiligung eines Menschen wegen seines jeweiligen sozialen Standortes auch sozial wirken können? Hieße das denn nicht, daß das Recht den sozialen Standort eines Menschen grundsätzlich nicht als Besonderheit zur Kenntnis nehmen und der Inhaber des ungünstigeren sozialen Standortes keine Hilfe, der des günstigeren sozialen Standortes keine ausgleichende Belastung erfahren dürfte? Würde andererseits aus Art. 3 Abs. 3 GG nur das Verbot herausdesti1liert, niemand wegen seines ungünstigen sozialen Standortes zu benachteiligen und niemand wegen seines günstigen sozialen Standortes zu bevorzugen, so bliebe ein interpretatorisch unverdaulicher Rest zurück. Dagegen paßt das Verbot der Unterscheidung nach der sozialen Herkunft im Sinne eines Verbotes einer Unterscheidung nach der sozialen Verwurzelung organisch in das Bild des gleichheitlichen Sozialstaates: nicht deshalb wird jemanlem geholfen, weil er aus einer bestimmten Schicht kommt, sondern nur (leshalb, weil er sich in einer Situation sozialer Bedürftigkeit befindet; nicht deshalb wird jemandem nicht geholfen, weil er aus einer bestimmten Schicht kommt, sondern nur deshalb,

3) Fuss, Gleichheitssatz und Richtermacht, S.334 (s. bei diesem aber auch die Einschränkungen, S. 335 Fußn. 52, S. 336 Fußn. 56).

4) Vgl. BVerfGE 5, 17 (22); 9, 124 (128 f); Ipsen, Gleichheit, S. 146; v. Mangoldt-Klein, Art. 3 Anm.V 2 a (S. 210).

5) BVerfGE 9, 124 (129). 
weil er seiner gegenwärtigen Situation nach der Hilfe nicht bedarf; nicht deshalb endlich wird jemand belastet, weil er einer bestimmten Schicht angehört, ${ }^{6}$ ) sondern deshalb, weil er sich in einer Situation befindet, in der er einen sozialen Ausgleich leisten kann. So verstanden bestätigt der Tatbestand der "Herkunft" in Art. 3 Abs. 3 GG, daß der soziale Staat kein Klassenstaat ist, 7) weder im Sinne einer Herrschaft des Proletariats noch im Sinne der Herrschaft der Bourgeoisie. So vermag das Verbot der Unterscheidung nach der Herkunft "zur Ausgestaltung des Sozialstaatsprinzips zu wirken". ${ }^{8)}$

\section{Weitere besondere Gleichheitssätze}

Das geltende Verfassungsrecht statuiert außer den vorstehend erwähnten personalbestimmten "Gleichheiten" auch noch gegenständlich bestimmte "Gleichheiten", so die Gleichheit der Wahl (Art. 28 Abs. 1 Satz 2, 38 Abs. 1 GG) und den gleichen Zugang zu den öffentlichen Ämtern (Art.33 Abs. 2 und 3 GG). Ein weiterer besonderer Gleichheitssatz ist der der gleichen staatsbürgerlichen Rechte und Pflichten eines jeden Deutschen in jedem Lande (Art. 33 Abs.1 GG). Diese besonderen "Gleichheiten" haben auch ihre soziale Funktion. Die letztgenannte bundesstaatliche Gleichheit hat Teil an der sozial einebnenden Wirkung des föderativen Systems.1) Die Wahlgleichheit macht die Demokratie zur egalitären mit ihren spezifischen sozialen Wirkungen. 2) Der gleiche Zugang aller $\mathrm{zu}$ den öffentlichen Ämtern öffnet nicht nur den Zugang zu ihnen nach "unten" und gibt so individuelle Aufstiegschancen. Er macht die öffentlichen Ämter erst zu substanziell egalitär-demokratischen. Er verhindert - soweit das Recht das verhindern kann -, daß gewisse Ämter zum Besitzstand einzelner sozialer Klassen werden, erhält sie sozial "offen". 3) Wahlgleichheit und gleicher Zugang zu den öffentlichen Ämtern runden so die "Gleichheit vor dem Gesetz" staatsorganisatorisch integrierend ab. ${ }^{4}$ )
6)
S. z. B. Scheuner, Verfassungsschutz des Eigentums, S.73, $111 \mathrm{f}, 137$.
7) S. zu diesem Zusammenhang Scheuner, Die staatliche Inter- vention im Bereich der Wirtschaft, S.21 f. S.a. Fuss, Gleichheitssatz und Richtermacht, S.335 Fußn. 52.
8) Ipsen, Gleichheit, S. 146; zustimmend v. Mangoldt-Klein, Art. 3 Anm.V 2 a (S.210). Zu dem Zusammenhang, in dem das Zitat steht, s. oben S. 931 zu Fußn. 1 und 2.
1) S. oben Abschnitt 1 (S. $45 \mathrm{ff})$, insbes. S. $210 \mathrm{ff}$.
2) S. oben Abschnitt 3 I 1 (S. $315 \mathrm{ff}$ ) und II (S. $338 \mathrm{ff}$ ).
3) S. oben Abschnitt 3 III 3 (S.352 ff) und 4 (S. 365 ff).
4) S. zu Vorstehendem auch Küchenhoff, Gleichheit und Un- gleichheit im Verfassungs recht. 
III. Die Verfassungsordnung des Eigentums

\section{Eigentum und sozialer Rechtsstaat}

Wirtschaftliche Freiheit ohne individuelles Eigentum ist nicht denkbar. Genau so wenig ist soziale Sicherheit in Freiheit ohne individuelles Eigentum möglich. 1) Freiheit und soziale Sicherheit versöhnen sich im Eigentum. 2) Das Verfassungsbekenntnis zum Eigentum ist das substantiell bedeutsamste Element der Freiheitlichkeit des durch die Verfassung ausgerufenen Sozialstaates. Es ist - ohne daß damit etwas über die Menschenrechtsqualität des Eigentumsrechts gesagt sein soll ${ }^{3)}$ und ohne daß andererseits die Möglichkeit einer menschenwürdigen Gesellschaftsordnung unter Verzicht auf das Eigentum, wie sie der politischen Utopie immer geläufig war, der geschichtlichen Wirklichkeit aber nur in Ausnahmefällen, insbes. in Fällen religiös oder sonstwie weltanschaulich-ethisch homogener Gemeinschaften, angehört, in Abrede gestellt werden soll - eine wesentliche Voraussetzung dafür, daß dieser Sozialstaat sich als das darstellt und verwirklicht, was er sein soll: als ein Staat der Sorge um das menschenwürdige Dasein.

Allein, das soziale Gesicht des Eigentums ist ein doppeltes. "Am Schnittpunkt von individueller Entfaltung und gesellschaftlicher Organisation" kann es "ebenso Elemente eines Integrationswie eines Konfliktfaktors zeitigen". ${ }^{4)}$ Das Eigentum gewährt Freiheit der Disposition, wirtschaftliche Macht, soziale Sicherheit, soziales Prestige und einen von der Arbeit unabhängigen Anteil am Sozialprodukt. Aber es gibt alles das nur demjenigen, der Eigentum hat, und nur in dem Maße, in dem er es hat. Ungleiche Verteilung des Eigentums bedingt soziale Spannung und Desintegration, ja bedroht schließlich in ökonomische Machtspannung umgesetzt sogar die Freiheit. 5) Individuelles Eigentum ist aber wesentlich ungleich verteiltes Eigentum. Dekretierte Gleichheit der Eigentumsverteilung würde seine freiheitliche Funktion para-

1) S. o. I 3 a (S. 848 ff), insbes. S. $848 \mathrm{ff}$.

2) Dürig, Der Staat und die vermögenswerten öffentlichrechtlichen Berechtigungen seiner Bürger, S. 56, s.a. S. $30 \mathrm{ff}$.

3) Vgl. Dürig, Das Eigentum als Menschenrecht, Zeitschrift für die gesamte Staatswissenschaft, Bd.109 (1953) S. 326 ff.

4) Bruno Molitor, Art. "Eigentum (I) Soziologie des Eigentums" im Handwörterbuch der Sozialwissenschaften, 28. Lfg. 1960, S. $33 \mathrm{ff}(34)$. S. diesen auch sonst zum Vor- und Nachstehenden.

5) S. z.B. Ritsch1, Wirtschaftsordnung und Rechtsstaat, S. 266 ff. 
1ysieren. Individuelles Eigentum und soziale Integration - darin liegt eine gewaltige Spannung. Es ist die typische Spannung der sozialstaatlichen Verfassung, die sich zum Eigentum bekennt. Es ist die Spannung, die der Sozialstaat um seiner Freiheitlichkeit willen aushalten muß; und die er bewältigen muß, wenn er nicht scheitern soll.

Die Verfassung nimmt diese Spannung auf, indem sie das Eigentum individualbezogen, als Grundrecht, institutionell gewährleistet (Art. 14 Abs. 1 Satz 1 GG), es aber sogleich auch unter die verpflichtende Gemeinschaftsbindung stellt (A rt.14 Abs.2 GG). 6) Sie gibt ihrer Bewältigung Raum, indem sie es dem Gesetzgeber überläßt, das Eigentum - unter Wahrung seines Wesensgehalts (Art. 19 Abs.2 GG) - nach Inhalt und Schranken zu definieren (Art. 14 Abs. 1 Satz 2 GG) und in den von der Verfassung gezogenen das Eigentumsrecht profilierenden 7) - Grenzen über seinen Entzug zu disponieren (Art.14 Abs. 3, 15 GG). ${ }^{8}$ )

2. Der gegenständliche Bereich des Eigentumsschutzes

a) Die Ausweitung des Eigentumsbegriffs

aa) Von der Sacheigentumsgarantie zur Sicherung vermögenswerter Berechtigungen einschließlich solcher öffentlichen Rechts

Die Eigentumsgarantie war ursprünglich Sacheigentumsgarantie. Dem Namen nach ist sie es wohl noch heute. Diese Gleichsetzung des Grundrechts, das "die Freiheit im güterweltlichen Lebensbereich" so absichern soll, 1) daß damit "die entscheidende Grundlage und das ordnende Element für eine möglichst unabhängige

6) Nach Werner Weber (Eigentum und Enteignung, S. 333) weist "das Grundgesetz (Art. 14 Abs. 1 Satz 2 und Abs.2) aus sozialstaatlicher Verantwortung mit Nachdruck darauf hin, daß das Eigentum nicht als beliebiges und unbegrenztes Herrschaftsrecht zu verstehen, daß es vielmehr wandlungsfähig und Gemeinschaftsbindungen ('Pflichtbindungen') unterworfen ist".

7) Vgl. Werner Weber, a.a.O. S.357; v. Mangoldt-Klein, Art. 14 Anm. II 6 c; Zacher, a.a.O. S.111.

8) Zur grundsätzlichen Deutung s.a. Haas, System der öffentlichrechtlichen Entschädigungspflicht, S. 8.

1) Dürig, Der Staat und die vermögenswerten öffentlichrechtlichen Berechtigungen seiner Bürger, S. 30 .

2) Werner Weber, Eigentum und Enteignung, S.353. 
Lebensgestaltung" gewährleistet sind, 2) geht auf eine Zeit zurück, in der - im langfristigen Umschlag vom Feudalismus zum Industriekapitalismus - eine freie Lebensgestaltung nur für den als möglich und auch angemessen erachtet wurde, der sich dafür durch ererbtes oder erworbenes Sacheigentum legitimierte. Nur er war voller "Bürger". Mit dem sich entfaltenden Kapitalismus "verflüchtigte" sich die Funktion des Eigentums. 3) Das Sacheigentum an clen Produktionsmitteln löste sich auf in ein Geflecht von Beteiligungen und Obligationen. Die harte Dynamik des neuen Systems ließ die Bedeutung der objektiven Chancen und subjektiven Fähigkeiten, vorhandenes Sachvermögen einzusetzen und auszuwerten, in den Vordergrund treten. Manager und Techniker stellten das gesellschaftliche Monopol der Produktiveigentümer und den bürgerlichen Ausweisschein des Konsumkapitals in elementarer Weise in Frage. Zur gleichen Zeit brach sich der soziale Anspruch von unten Bahn. Die Lebensgrundlage der beruflichen Leistungsfähigkeit, ja der Arbeitskraft überhaupt, wurde derjenigen des Sacheigentums sozial ebenbürtig. Das Leitbild der Eigentümergesellschaft zerbrach.

Aber auch clas Leitbild der autonomen Gesellschaft zerbrach. Der Staat - kaum hatte er dem Bestimmungselement der persönlichen Leistungsfähigkeit durch die Gewerbefreiheit und den Abbau ständischer Vorrechte im Bereich der staatlichen Funktionen Raum gegeben - sah sich genötigt, kontrollierend in die Verwertung von Kapital und Arbeitskraft einzugreifen. Die Kehrseite dieses Systems von Vorbehalten, die Erlaubnisse und Berechtigungen, bildeten ein weiteres Element der Lebensgrundlage des modernen Staatsbürgers. ${ }^{4)}$ Schließlich trat zur kontrollierenden in rasch wachsendem Maße die (zwangs-) vorsorgende, ausgleichende und umverteilende Wirksamkeit des Staats, die Basis der individuellen Fxistenz unausweichlich mitprägend. 5)

"Die wirtschaftliche Lebensgrundlage der meisten Menschen und der Wirtschaftsablauf beruhen" nunmehr. "auf schuldrechtlichen, dinglichen, arbeitsrechtlichen und verwaltungsrechtlichen Bezie-

3) S. Schumpeter, Kapitalismus, Sozialismus und Demokratie, S. $228 \mathrm{ff}, 256 \mathrm{ff}$; s.a. Bruno Molitor, Art. "Eigentum (I) Soziologie des Eigentums" im Handwörterbuch der Sozialwissenschaften, S. $35 \mathrm{ff}$.

4) S. Forsthoff, Eigentumsschutz öfentlichrechtlicher Rechtsstellungen, S. 1250; Dürig, a.a.O. S.35 f.

5) Rohwer-Kahlmann, Die Krise des Eigentums, S. 239 f; Dürig, a.a.O. S.36. Speziell für die Sozialversicherung s. RohwerKahlmann, a.a.O. S. 309 f; BSGE 9, 127 (128). - S. zu Vorstehendem auch Molitor, a.a.O. S. $37 \mathrm{f}$. 
hungen und Rechtsstellungen, die mit dem Sach-eigentum weithin nur noch in einem lockeren Zusammenhang stehen".6) Es ist gewiß ein schönes sozialpolitisches Ziel, das (Sach-)Eigentum "breit zu streuen". 7) Aber es darf nicht darüber hinwegtäuschen, daß sich auch dann, wenn es erreicht wäre - wenn jedermann sein Eigenheim, seinen Wagen usw. hätte ${ }^{8)}$-, die funktionale Situation des "Eigentums" nicht grundsätzlich ändern würde. ${ }^{9)}$

Der Ausweitung der Eigentumsfunktion bzw. der Auflockerung, Differenzierung und Komplikation der Vermögenssituationen parallel, aber nicht nur ihr, sondern auch der zunehmenden Kontrolle und Gestaltung der gesellschaftlichen, insbes. der wirtschaftlichen Verhältnisse durch den Staat entsprechend, 10) intensivierte und weitete sich gegenständlich auch der Angriff der staatlichen Gemeinschaft auf das individuelle Vermögen. 11) Damit,"daß die vermögenswerten Objektivationen menschlicher Freiheit nur noch zum geringen Teil in Gestalt von Sacheigentum erfolgen", muß "das Sacheigentum auch aufhören, das alleinige Zugriffsobjekt zu sein". 12) Für die öffentlichrechtlichen Positionen des einzelnen liegt die "Gefährdung" durch den Staat in ihrer Natur. ${ }^{13}$ Aber auch im privatrechtlichen Bereich kann der Staat nicht mehr mit "okkasionellen Eigentumsverlagerungen zu Gunsten bestimmter öffentlicher Unternehmungen" 12) auskommen. Er greift "nach dem ganzen Vermögen des Bürgers". 14)

6) Weber, a.a.O. S. 353 .

7) S. oben S. $810 \mathrm{f}$.

8) Zu den eigentumspolitischen Hemmnissen und Auswirkungen s. z.B. Molitor, a.a.O. S. $37 \mathrm{f}$.

9) S. a. Dürig, a.a.O. S. 36 Fußn. 53.

10) Speziell zu diesem Zusammenhang s. z.B. Scheuner, Verfassungsschutz des Eigentums, S.88.

11) Eine illustrative Zusammenstellung der Vielfalt der Eingriffe s. z. B. bei Haas, System der öffentlichrechtlichen Fintschädigungspflichten, S. $16 \mathrm{f}$.

12) Dürig, a.a.O. S. 35 .

13) BVerfGE 2, 380 (401): "Der Staat greift nicht erst neuerdings auch nach den vermögenswerten subjektiven Rechten des öffentlichen Rechts, sondern nimmt von jeher für sich in Anspruch, solche Rechte, die er selbst geschaffen hat, im Rahmen der Gesetze oder durch Gesetz wieder zu entziehen". Gegen die Behauptung des Bundesverfassungsgerichts, das Risiko dieses Zugriffs habe sich nicht erhöht, mit Recht Thieme, Umfang und Grenzen des verfassungsrechtlich gewährleisteten Bestandsschutzes der saarländischen Kriegsopferrenten, S. $161 \mathrm{f}$. 
"Wenn also die Eigentumsgarantie auch in der heutigen Lage einen minimalen Bestand freiheitlicher Lebensgestaltung für alle Bürger sichern soll, so muß sie neben dem Sacheigentum auch die sonstigen Vermögenspositionen einbeziehen, mit deren Hilfe die Individuen ihre wirtschaftliche Existenz aus eigener Kraft behaupten". 15) Das bedeutet zunächst: Ausdehnung des Eigentumsschutzes auf alle vermögenswerten privaten Rechte, wie sie sich schon unter der Weimarer Verfassung vollzogen hat, 16) und wie sie unter dem Grundgesetz 17) mit Recht beibehalten wurde. Das bedeutet aber auch: Einbeziehung derjenigen vermögenswerten Positionen öfentlichen Rechts, die funktional an die Stelle des Sacheigentums bzw. des privaten Vermögens getreten sind.18) 19)

bb) Zum Eigentumsschutz öffentlichrechtlicher Berechtigungen im besonderen

Die Frage, wann eine öffentlichrechtliche Rechtsposition "derjenigen des Eigentümers so nahe kommt, daß Art.14 GG Anwendung finden muß", 1) wird in der Praxis noch mit großer Unsicherheit erörtert. ${ }^{2)}$ Im Grundsätzlichen ist das Problem jedoch

14) BGHZ 6, 270 (278).

15) Weber, a.a.O. S.353; s. ferner Scheuner, a.a.O. S.87 ff (s. diesen auch zum Voraufgegangenen); s. insbes. auch Forsthoff, Rohwer-Kahlmann und Dürig, wie vorstehend (S.936 zu Fußn. 4 und 5) zitiert.

16) S. z.B. die Darstellung bei Weber, a.a.O. S.339 ff.

17) Seit BGHZ 6, 270 allgemeine Meinung (s. z. B. v. MangoldtKlein, Art.14 Anm. III 1 b).

18) Seufert, Bayerisches Enteignungsrecht, S.19. Gegen das Argument des Funktionswandels für die Einbeziehung öffentlichrechtlicher Rechtspositionen in das Eigentum s. BVerfGE 2, 380 (401).

19) Eine Parallelentwicklung außerhalb des Bereichs (unmittelbarer) Vermögensschäden stellt der Aufopferungsanspruch wegen Schäden am Leben und an der Gesundheit dar ( $s$. hier$\mathrm{zu}$ schon oben II $2 \mathrm{~b} \mathrm{cc}$ (S. $904 \mathrm{ff})$.

1) BVerfGE 4, 219 (241). - In BVerfGE 11, 221 (226) führt das Bundesverfassungsgericht aus, für "öffentlichrechtliche Vermögenspositionen" könne "der Schutz des Art.14 GG nicht schlechthin sondern nur dann in Anspruch genommen werden..., wenn sie die konstituierenden Merkmale des Eigentumsbegriffes tragen". Als ob das nicht bei jeder Vermögensposition so wäre!

2) S. zum Stand der Meinungen Dürig, Der Staat und die vermö- 
geklärt. 3) "Eigentum" kann nur sein, was seinem Träger auf andere Weise als nur kraft staatlicher Zuweisung zugerechnet werden kann. Für diese Zurechnung ergeben sich zwei Grundtatbestände: der Einsatz von Kapital und (oder) Arbeit, der die Inhaberschaft einer öfentlichrechtlichen Berechtigung und ihren Vermögenswert zu persönlichem "Eigentum" macht; und das persönliche, besondere Opfer, das die staatliche Gemeinschaft angenommen bzw. erzwungen hat und ausgleichen muß, wobei die Entschädigungsberechtigung zu "Eigentum" wird. Vermögenswerte Rechte, die nicht durch eigenverantwortliche Leistung oder durch besonderes Opfer individuell zurechenbar geworden sind sondern einseitig gewährt wurden - was nicht ausschließt, ja in der Regel voraussetzt, daß individuelle Tatbestandselemente, wie etwa die Bedürftigkeit, die Zuweisung begründeten -, sind dagegen kein "Eigentum". Das gilt im besonderen für Ansprüche, "die der Staat seinen Bürgern in Erfüllung seiner Fürsorgepflicht durch Gesetz einräumt". 4)

Damit scheiden von vorneherein aus die Ansprüche auf allgemeine öffentliche Fürsorge, Tuberkulosefürsorge, ZivilblindenPflegegeld, 5) Subventionen, Stipendien, Prämien und dg1.6)

Auf der anderen Seite stehen dem einzelnen etwa die ge we r b1 ichen Berechtigungen als "Eigentum" zu, die er sich durch Kapital und (oder) persönliche Leistung "zugeeignet" hat. 7) Von besonderer sozialer Bedeutung ist die Eigentumsqualität des

genswerten öffentlichrechtlichen Berechtigungen seiner Bürger, insbes. Abschnitt I; Thieme, Umfang und Grenzen des verfassungsrechtlich gewährleisteten Bestandsschutzes der saarländischen Kriegsopferrenten, S. $158 \mathrm{ff}$.

3) Das ist das große Verdienst Dürigs (s. seine vorerwähnte Abhandlung und seine Anmerkung zu BSG Urt. v. 19. März 19576 RKa 5/55 - JZ 13. Jhg. (1958) S. 22 ff; alle weiteren Nachweise s. dort).

4) BVerfGE 2, 381 (402); 3, 11; 11, 64 (70); weit. Nachw.s. bei 'Thieme, a.a.O. S.166 f.

5) Zur Rechtsnatur s. Schwankhart, Zweifelsfragen aus dem Sozialversicherungsrecht, S. $239 \mathrm{f}$ mit weit. Nachw.

6) S. zu diesen Eeispielen Dürig, a.a.O. S. 53; Wolff, Verwaltungsrecht I, S. $327 \mathrm{f}$.

7) Im einzelnen ist freilich gerade hier noch vieles umstritten; s. Forsthoff, Eigentumsschutz öffentlich-rechtlicher Rechtsstellungen; Dürig, a.a.O. S. 41 ff und seine Nachweisungen. Zum Eigentum an der Kassenpraxis s. außer Dürig, a.a.O., insbes. BSGE 5, 40, 246 (249). 
- durch Beiträge "erworbenen" - Sozialversicherungsan spruches. 8) Dazu kommen die "echten", eindeutigen Opfera usgleichsentschädigungen, wie z. B. Fnteignungsentschädigungen und Aufopferungsansprüche. 9)

8) (1) Ganz h.M.: s.Dürig, a.a.O. S.43 f und seine Nachweise (Fußn. 76); Rohwer-Kahlmann, Die Einwirkung verfassungsrechtlicher. Normen auf das Recht der sozialen Sicherheit, S. 1643 ff, ebenfalls mit weit. Nachw. (S.1645 Fußn.36); s. nunmehr auch BSGE 9, 127 (128); ferner. Weidner, Zur Rechtsprechung des Bundessozialgerichts, S. 761. Die frühere Rechtsprechung des Bundessozialgerichts (BSGE 3, 77; SozR SVAG $₫ 56$ Aal) war zurückhaltend. Offen gelassen ist die Frage in BVerfGE 11, 221 (226), aber doch mit starker Neigung zur eigentumsrechtlichen Lösung. Ablehnend v. Altrock, Der Standort der Sozialversicherung im Rechtsgefüge, S.32 ff. (2) Ule (Rentenkürzungen als Enteignung, Zeitschrift für Sozialreform, 2.Jhg. (1956) S. $138 \mathrm{ff}$, $180 \mathrm{ff}$ (182)) glaubt, zwischen dem durch Beiträge gedeckten und dem nicht gedeckten Anteil der Versicherungsleistung unterscheiden und nur jenen als "Eigentum" qualifizieren zu sollen. Das läßt sich aber nicht trennen (s.a. Dürig, a.a.O. S.43 mit Fußn. 77; Weidner, a.a.O.). Die Sozialversicherung enthält wesensmäßig ein Element der Versorgung ( $\mathrm{s}$. oben $\Lambda$ bschnitt 1 I 1 b, bb (S. 49 ff) und Abschnitt 5 III 2 c (S. 768 ff). Das ändert aber nichts daran, daß der, der nicht durch Beiträge (eigene und (oder) Arbeitgeberbeiträge) an der Versicherung beteiligt ist, die Anwartschaft nicht e rwe rben kann. Hier liegt der individuelle Eigentums-Zurechnungsgrund. Daher hat auch v. Altrock (a.a.O. S.33) nicht recht, wenn er die Sozialversicherungsleistungen mit der Begründung aus dem Schutz des Art.14 GG herausnimmt, "daß der Versicherte mit solchen Beiträgen immer nur Anwartschaften innerhalb des vom Staat bereitgestellten, dem sozialen Ausgleich unterworfenen Fürsorgesystems öffentlichrechtlicher Natur erwirbt" (s. dagegen auch Weidner, a.a.O.; s. dazu ferner a.noch unten $4 \mathrm{~h}$ (S. 991 ff)).

(3) Einen besonderen (von Dürig a.a.O. Fußn. 77 nicht ganz zutreffend gewürdigten) Fall stellt aber die Unfallversorgung des Lebensretters nach $\$ 537 \mathrm{Nr} .5$ a RVO dar. Der Lebensretter hat zwar keine Beiträge gezahlt. Fr hat - jeclenfalls grundsätzlich - auch nicht der Gemeinschaft geopfert. Er hat $z$ war sein Leben eingesetzt, aber eben doch nicht, um die Anspruchsberechtigung zu erlangen. Ein eigenartiger Grenzfall, für den der Eigentumscharakter wohl abgelehnt werden muß. 
Dazwischen aber liegen jene Leistungen, die zwar an besondere Belastungen einzelner im Rahmen des Gesamtschicksals anknüpfen, bei denen aber die individuelle Zurechenbarkeit der staatlicherseits gewährten Ausgleichsleistungen darunter leidet, daß die "Ungleichheit" der Belastung im Rahmen der allgemeinen Katastrophe nicht mehr eindeutig oder (und) die Verantwortlichkeit der staatlichen Gemeinschaft für den Ausgleich durch die Schwäche oder das Fehlen des kausal-finalen Gemeinschaftsbezuges der Schädigung in Frage gestellt ist. In dieser Gemengelage von allgemeinem, insbes. sozial determiniertem Ausgleich und rechtsstaatlich notwendiger Entschädigung befinden sich: die Kriegsopferversorgung, 10) die - auch und gerade als Regelungskomplex - einem "echten" Sonderopferausgleich noch am nächsten kommt; ähnlich, wenngleich schon einen Schritt näher an der sozialen Hilfe, die Unterstützung der Angehörigen K rieg sgefangene $r$ und die Kriegsgefangenenentschädigung; 11) in sich heterogen der Lastenausgleich 12) - als Kriegsschadenausgleich sehr dem "echten" Sonderopferausgleich nahekommend; als Vertreibungsschadenausgleich nicht nur Ausgleich von der Gemeinschaft auferlegter Sonderopfer sondern auch sonstwie mit dem Gesamtschicksal verbundener und notwendig in seinem Rah-

9) S. hierzu Dürig, a.a.O. S.48 ff; Beispiele und Nachweise s. dort.

10) Zur Qualifikation als Opferausgleich s.o. S.910 ff. Für die Qualifikation als Figentum insbes. Rohwer-Kahlmann, Die Krise des Eigentums, S.242 f, 310 f; ders., Die Rechtsnatur des Versorgungsanspruchs nach dem Bundesversorgungsgesetz, insbes. S. 315; ders., Der Einfluß verfassungsrechtlicher Normen auf das Recht der sozialen Sicherheit, S. 1645; Seufert, Bayerisches Fnteignungsrecht, S.19; Thieme, Umfang und Grenzen des verfassungsrechtlich gewährleisteten Bestandsschutzes der saarländischen Kriegsopferrenten, S. 157 ff, insbes. S. 167 ff. Dagegen Ule, Rentenkürzungen als Enteignung? S. 182; Dürig, a.a.O. S.52. Zur Rechtsprechung des Bundessozialgerichts s. Weidner, a.a.O. S. 761 .

11) Zur (Qualifikation als Opferausgleich s. oben S.910 ff. Gegen die (Qualifikation als Eigentum Dürig, a.a.O. S. 52 .

12) Zur (Qualifikation als Opferausgleich s. oben S. $910 \mathrm{ff}$. Gegen die Qualifikation als Eigentum BVerfGE 11, 64 (70 f); Ule, a.a.O. S.182; Dürig, a.a.O. S. 52; dahingestellt in BVerwGE 3, 297 (299). Für die Qualifikation als Eigentum Rohwer-Kahlmann, Die Krise des Eigentums, S.310 f (Fußn.60). 
men zu sehender besonderer Belastungen; als Sparerschädenausgleich sozialer Korrektur der Währungsreform (ähnlich der Begünstigung der Altsparer durch das Altsparergesetz) -; wie der Vertreibungsschadenausgleich des Lastenausgleichs in sich uneinheitlich das (sonstige) Vertriebenenrecht ${ }^{13}$ ) (das allerdings nur in geringem Umfang unmittelbar vermögenswerte Rechte gewährt); analog einerseits der Kriegsgefangenenhilfe, andererseits dem Vertriebenenrecht die Heimkehrerhilfe;14) soweit als "echter" Sonderopferausgleich anzusehen, ist "Eigentum" dagegen der Anspruch auf die Entschädigung von Besatz ungs schäden;15) sehr ein Anliegen des "nationalen" Prestiges und der sozialen Hilfe die Häftlingshilfe nach dem Häftlingshilfegesetz;16) ein Akt der "Liquidation" des Deutschen Reiches, mit dem identisch zu sein die Bundesrepublik für sich in Anspruch nimmt, und zugleich auch soziale Hilfe sind die Leistungen nach dem Kriegsfolgenschlußgesetz (s.a. Art.135 a GG); sehr problematisch endlich und in sich auch ihrem Wesen nach nicht einheitlich die Entschädigung nationalsozialistischer Verfolgung. ${ }^{17}$ Wo liegt die Grenze des "Eigentums"? Die vorliegenden Urteile neigen zu sehr zum Pauschalen und schließen sich zu eng an die vom Gesetzgeber gewählten Regelungseinheiten an, ohne den darunter verborgenen Differentialmomenten der geregelten Lebenssachverhalte und ihrer Erheblichkeit für das verfassungsrechtliche Problem, das die gesetzgeberische Gestaltung nur bedingt beeinflussen kann, nachzugehen. Das Problem kann im Rahmen dieser Untersuchung nicht weiter verfolgt werden. Aber fest steht, daß nicht alle der vorgenannten Ansprüche "der Dynamik staatlicher Sozialgestaltung" überlassen werden dürfen, die auch das Sozialstaatsprinzip nicht hindert, "bei veränderten sozialen Verhältnissen ohne Rücksicht auf die Statik 'wohler'worbener Rechte' wieder frei $z u$ disponieren". 18) Andererseits muß für

13) Zur Qualifikation als Sonderopferausgleich s.o. S.910 ff . Gegen die Anerkennung als "Eigentum" Dürig, a.a.O. S. 52 .

14) Zur Qualifikation als Sonderopferausgleich s.o. S.910ff. Gegen die Anerkennung als "Eigentum" Dürig, a.a.O. S. 52.

15) Die Qualifikation als "Eigentum" steht und fällt mit der Qualifikation als "Sonderopferausgleich"; s. hierzu oben S.912 zu Fußn. 10.

16) Zur Qualifikation a1s Sonderopferausgleich s.o. S.910ff . Gegen die Anerkennung als Eigentum Dürig, a.a.O. S. 52 .

17) S. hierzu Dürig, a.a.O. S. $50 \mathrm{f}$ und seine Nachweise.

18) S. Dürig, a.a.O. S. 30 und S. 52; s.a. Wolff, Verwaltungsrecht I, S.327. - Zur entsprechenden Interpretation des Sozialstaatsprinzips s. oben Abschnitt 5 II 2 a (S. 706 ff) und 
die Masse der fraglichen Ansprüche diese Freiheit bestehen. Das Kriterium, das auf die Spur der goldenen Mitte führt ist noch nicht gefunden. 19) 20)

Auszuklammern sind aus dem verfassungsrechtlichen Eigentumsschutz die Besoldungs- und Versorgungsansprüche der $B$ eamten. Sie finden ihre verfassungsmäßige Garantie in den beamtenrechtlichen Grundsatznormen (Art. 33 Abs. 5 GG). 21)

\section{b) Geschütztes und nicht geschütztes Eigentum?}

Der dargestellten, notwendigen Ausweitung des Eigentumsbegriffes stehen Bemühungen gegenüber, den verfassungsrechtlichen Eigentumsschutz - auf ganz andere Weise - auch einzuengen. Dabei wird das Eigentum in zwei Klassen eingeteilt. 1) Die eine bildet das "aggressive" 2) "Monopol- und Ma chteigent um",3)

e (S. 729 ff). Dabei darf nicht übersehen werden, daß das Sozialstaatsprinzip an sich zur Verrechtlichung von Gewährungen drängt. Diese Verrechtlichung kann, soweit es sich um Vermögenspositionen handelt, über das gesetzliche subjektive Recht hinaus nur in Richtung auf den verfassungsrechtlichen Eigentumsschutz gesteigert werden (s. Dürig, a.a.O. $\mathrm{S} .30 \mathrm{ff}$ ). Wenn daher das Bundessozialgericht (BSGE 9, 127 (128 ff)) die Sozialversicherungsrente grundsätzlich als Eigentum behandeln will, weil somit das wichtigste Vermögen, das sich der Bürger im Sozialstaat erwirbt, unter Mißachtung des Sozialstaatsprinzips ungeschützt bliebe, so ist dem Argument zuzustimmen.

19) Dürig (a.a.O. S. 51 ff) beruhigt sich etwas zu leicht, indem er zwar die meisten der vorgenannten Ansprüche als eine Sondergruppe zwischen den "erworbenen" und den "Fürsorge" Ansprüchen herausstellt, jedoch glaubt, sie hinsichtlich der Eigentumsfrage ganz zu den letzteren schlagen zu sollen.

20) Zum Problem der Rentenkürzung s. unten $4 \mathrm{~h}$ (S.991 ff).

21) S. BayVerfGH VGHE n.F. 5 II 166 (195); BVerfGE 3, 58 (153). Weiteres s. bei Dürig, a.a.O. S. $33 \mathrm{f}$.

1) S. zum nachfolgenden Raiser, Diskussionsbeitrag zu "Enteignung und Sozialisierung", VVDStRL. H.10, 1952, S. 158 f; dens., Zur Eigentumsgarantie des Grundgesetzes, AöR Bd. 78 (1952/53), S. 118 f; Knoll, Eingriffe in das Eigentum im Zuge der Umgestaltung gesellschaftlicher Verhältnisse, AöR Bd. 79 S. $480 \mathrm{ff}$.

2) Raiser, Diskussionsbeitrag... S. 159.

3) Knoll, a.a.O. S. 490 . 
das "insbesondere als materielle Grundlage eines Unternehmens dem Eigentümer $\mathrm{zu}$ wirtschaftlicher und soziales. Macht verhilft und damit öffentliche Interessen berührt", 4) das sich nicht einordnen läßt "in den demokratischen Staat, der keine übermäßige Machtzusammenballung dulden darf, und in den sozialen Staat, mit dessen Erfordernissen eine ungebundene wirtschaftliche Macht über andere Glieder der Rechtsgemeinschaft ebenso unvereinbar ist, wie deren Ausschluß von der Möglichkeit der Teilhabe an der wichtigsten Grundlage des Lebens ${ }^{11}$. 5) Die andere Klasse könnte vielleicht als die des Privateigentums bezeichnet werden: das ist das "politisch ungefährliche, ja höchst erwünschte Eigentum in der Hand des einfachen Bürgers, dessen Unabhängigkeit damit gesichert wird", 6) "das aus individual- wie sozial-ethischen Gründen anerkannt, gewertet und als für die Erhaltung der Menschenwürde und eines gesunden Volksaufbaues unentbehrlich angesehen wird" 7), das "sozial nützliche oder wenigstens unschädliche Eigentum", das allein "Dienst am Wohle der Allgemeinheit" sein kann, das "Gebrauchs-, Verbrauchs- und Arbeitseigentum", aber "auch größeres Eigentum, Sparkapital usw.", soweit es nur nicht "Monopol- und Machteigentum" ist. ") Dieses Privateigentum soll das "Eigentum" sein, das allein den vollen verfassungsrechtlichen Schutz genießt. Dem mißbilligten "Machteigentum" dagegen wird nur ein abgeschwächter Schutz 9) - wenn überhaupt noch einer - zuerkannt. Seine soziale Inpflichtnahme wird bis zur entschädigungslosen Entziehung erstreckt. 10) Die Abtrennung des Eigentums, "dem der besondere Grundrechtsschutz zu versagen ist", vom "echten" Eigentum wird als zulässige Bestimmung von Inhalt und Schranken des Eigentums gewertet. ${ }^{11)}$

Diese Folgerungen sind jedoch ungerechtfertigt. ${ }^{12)}$ Die verfas-

4) Raiser, Zur Eigentumsgarantie.... S. 119.

5) Knoll, a.a.O. S. 490.

6) Raiser, Diskussionsbeitrag... S. 159.

7) Knoll, a.a.O. S. 480.

8) Knoll, a.a.O. S. 490.

9) S. Raiser, a.a.O. (S.159 bzw. S.119).

10) Raiser ebd.

11) Knoll, a.a.O., insbes. S.491. Eine ähnliche Theorie für die Rechtfertigung der Bodenreform s. bei Sellschopp, Die Frage der Entschädigung in der Bodenreform, DöV 5.Jhg. (1952) S. 242 ff; ders., Enteignung und Entschädigung in der Bodenreform, Zeitschrift für das gesamte Siedlungswesen, 1. Jhg. (1952) S. $46 \mathrm{ff}$.

12) Gegen die Vorgenannten s. insbes. Werner Weber, Diskus- 
sungsrechtliche Neuordnung hat nicht einfach einen Teil vordem zweifelsfrei vorhandenen Eigentums "gekappt" und ins verfassungsrechtliche Nichts fallen lassen. 13) Art.15 GG beweist, daß auch das produktive Eigentum, das doch im wesentlichen das diskriminierte "Machteigentum" ist, geschützt sein soll. Inwieweit den Besonderheiten dieses "Machteigentums" durch die Bestimmung seines Inhaltes und seiner Schranken und durch die Regelung der Entschädigung im Falle seiner Entziehung Rechnung getragen werden kann und zu tragen ist, ist eine andere Frage. Sie muß auf dem Boden seiner verfassungsrechtlichen Eigentumsqua1 ität beantwortet werden.

3. Die Bindungen des Eigentums

a) Die soziale Bindung des Eigentums - Allgemeines

Die entscheidende sozial eigentumsordnende Aufgabe des Gesetzgebers ist, das Eigentum zu binden. Der Wesenskern des Eigentums ist ihm - unantastbar - durch die Verfassung vorgegeben.

Der Inhalt der einzelnen Eigentumsrechtstypen bestimmt sich, soweit er ohne die Schranken des Eigentums gedacht werden kann, mehr nach der Natur der Sache als nach anderen Rücksichten. Die Entziehung des Eigentums ${ }^{1}$ ) ist - von der Entziehung des Geldeigentums abgesehen - der Ausnahmefall, nicht der eigentumsrechtliche "Alltag". Auf der Eigentumsbegrenzung und - bindung ruht somit die Hauptlast der Einordnung des Eigentums in das soziale Leben. 2) Über die Eigentumsbindung ist die Masse der Spannungen auszugleichen, die im Gefolge der ungleichen Verteilung der Güter auftreten. In der Regel die Eigentumsbindung - und nur in meist pathologischen Ausnahmefällen die Entziehung des Eigentums - ist dazu berufen, das Eigentum als Faktor der Freiheit in das System des sozialen Ausgleichs einzubeziehen.

Die Verfassung weist den Gesetzgeber auf diese Aufgabe von zwei Seiten her hin: durch die allgemeine Ge mein schafts verpflichtung des Eigentums (Art.14 Abs. 2 GG); sodann aber auch flurch das Sozialstaatsprinzip. Das Sozialsta t sprinzi p - las, um das in Frinnerung zu rufen, nicht als bloße Gemeinschaftsverpflichtung des einzelnen mißverstanden werden

sionsbeitrag zu "Enteignung und Sozialisierung", VVDStRL. H. 10, 1952, S. 164 ff (164 f); Scheuner, Verfassungsschutz des Eigentums, S. 112; v. Mangoldt-Klein, Art. 14 Anm. III 3 b.

13) Das ist die Folgerung bei Knoll, a.a.O. S. $490 \mathrm{ff}$.

1) S.u. $4(\mathrm{~S} .951 \mathrm{ff})$.

2) S. zu Vorstehendem auch Werner Weber, Eigentum und Enteignung, S. 357 . 
darf - gibt dem gesetzgeberischen Auftrag, Inhalt und Schranken des Eigentums zu regeln (Art. 14 Abs. 1 Satz 2 GG) bzw. eine dem Gemeinwohl dienende Eigentumsordnung zu schaffen, einen ganz bestimmten materiellen Gehalt. ${ }^{3}$ )

Auf das Ganze der verfassungsrechtlichen Eigentumsordnung geblickt, könnte gesagt werden, die Gemeinschaftsbindung des Eigentums schließe die Möglichkeit seiner Entziehung ein.4) Im engeren Rahmen der eigentumsgrundrechtlichen Systematik, insbes. der verfassungsrechtlichen Eigentumsbindungsklauseln, stehen Bindung und Entziehung jedoch in Gegensatz. Die Grenze ist von zwei Ausgangspunkten her zu ziehen. Der eine, absolute, ist der der Eigentumsinstitutsgarantie. Sie gebietet dem Gesetzgeber, ein Recht zu belassen, "das den Namen Eigentum verdient, bei dem also Beschränkungen des Herrschaftsbeliebens Ausnahmen sind". 5) Eine "Bindung", unter der einem Recht der Ausschließlichkeits- und Dispositionscharakter in einem mit der Institutsgarantie unvereinbarem Maß verloren geht, kann nicht mehr als bloße Eigentumsbindung im hier gemeinten engeren Sinn angesehen werden. So ist es richtig zu sa-

3) S. zu dieser Beziehung des Sozialstaatsprinzips zur Gemeinschaftsverpflichtung des Eigentums Ipsen, Enteignung und Sozialisierung, S. 85; Abendroth, Zum Begriff des demokratischen und sozialen Rechtsstaats in dem Grundgesetz der Bundesrepublik Deutschland, S. 87 (allerdings den eigenständigen Sinn der Eigentumsrechts-Klauseln zu sehr vernachlässigend); s.a. Scheuner, Verfassungsschutz des Eigentums, S.71, 76 ff. Wenn gesagt wird, Art.14 Abs. 2 GG konkretisiere das Sozialstaatsprinzip (E.R.Huber, Wirtschaftsverwaltungsrecht Bd. I S.663, Bd. II S. 13), so gilt das jedenfalls insofern, als Art.14 Abs. 2 GG dem Sozialstaatsprinzip einwandfreien Zugang zur Eigentumsgestaltung schafft. Zu sagen, der Gemeinwohlvorbehalt des Eigentumsgrundrechts sei lex specialis gegenüber dem Sozialstaatsprinzip und das Eigentumsgrundrecht dürfe daher nicht vom Sozialstaatsprinzip her ausgelegt werden (Forsthoff, Begriff und Wesen des sozialen Rechtsstaats, S. 28), ist dagegen nicht richtig. Gemeinwohl und Sozialstaatlichkeit sind nicht dasselbe (s.o. S. 703).

4) So ist BayVerfGH VGHE n.F. 2 II 1 (7); 4 II 212 (218) zu verstehen. Vgl. Zacher, Entschädigungslose Enteignung von Verkehrsflächen? S. 67.

5) Vg1. Martin Wolff, Reichsverfassung und Eigentum, 1923, S. 6. - Zur Deutung dieses Zitats im gegenwärtigen Grundrechtsbild s. aber Werner Weber, Eigentum und Enteignung, S. $357 \mathrm{f}$. 
gen, daß die Wegnahme eines Eigentumsrechts oder die Wegnahme des Eigentumsobjekts oder seine Zerstörung in keinem Falle als Eigentumsbindung privilegiert werden darf. 6) Aber nicht nur die radikalen, eindeutigen Entziehungsakte sind aus dem Kreis der Eigentumsbindungen auszuscheiden. Auch sonstwie ist es möglich, daß Beschränkungen des Eigentums kein Recht mehr übrig lassen, "das den Namen Eigentum verdient". Eine sozialisierende Fortführung des Mitbestimmungsrechts etwa 7) könnte diese Wendemarke erreichen. Dann kann nur mehr gefragt werden, ob die Beschränkung des Eigentums als Entziehung zulässig ist. Als Bindung ist sie es nicht mehr. ${ }^{8)}$ Die andere, relative

6) S. Zacher, a.a.O. S. 67 mit älteren Nachweisen (Fußn. 7 und 8); nachzutragen sind Scheuner, Die Abgrenzung der Enteignung, S. 587 ff; Schack, Generelle Eigentumsentziehung als Enteignungen NJW 7.Jhg. (1954) S. 577 ff (578 f); GieseSchunck, Art. 14 Anm. II 5; v. Mangoldt-Klein, Art. 14 Anm.V 2 b; BayVerf GH VGHE n. F. 9 II 14 (19), 158 (165). Zur Unrichtigkeit der Konstruktion einer entziehenden Sozialbindung von "Machteigentum" s. oben S.943 ff.S. dort auch zur Unrichtigkeit der These Knolls (Eingriffe in das Eigentum im Zuge der Umgestaltung gesellschaftlicher Verhältnisse, S.491), es sei "der Gesetzgebung überlassen, ... Inhalt und Schranken des Eigentums näher zu bestimmen" und dabei "eine Abgrenzung des grundgesetzlich anzuerkennenden Eigentums von solchem 'Eigentum' (vorzunehmen), dem der besondere Grundrechtsschutz zu versagen ist".

7) S. hierzu unten S. 950 und 4 f (S.982 ff).

8) Vgl. Scheuner, Verfassungsschutz des Eigentums, S. 111: "Die Wegnahme des Eigentums oder dessen, was seine eigentliche Substanz ausmacht, kann nicht in eine Änderung des Eigentumsinhalts umgedeutet werden". Übereinstimmend Wolff, Verwaltungsrecht I, S.328. - Für die Grenzziehung können und müssen die Argumente der Zumutbarkeits-, Schutzwürdigkeits-, Zweckentfremdungs- und Privatnützigkeitstheorie (zur Darstellung s. z.B. Weber, a.a.O. S. 372 ff; v. Mangoldt-Klein, Art. 14 Anm. VII 4; Forsthoff, Lehrbuch des Verwaltungsrechts, S.302; Nachweise s. dort) fruchtbar gemacht werden. Sie sollten nur nicht darauf angelegt werden, die gleichheitsorientierte Abgrenzung (s. das Folgende) zu erübrigen. Das können sie nicht. Werden sie aber unter dieser $Z$ weckrichtung konzipiert, so dringen sie $\mathrm{zu}$ weit in den Raum möglicher Eigentumsbindung ein. Da sie - wegen des nur unter der Gleichheitsmaxime aufgehenden, unaufgelösten Restes - nicht befriedigen können, kommt es 
Grenzziehung hat vom Gleichheits satz auszugehen. Im besonderen der Grundsatz der Lastengleichheit 9) muß als das tragende Regulativ der Inpflichtnahme des individuellen Vermögens durch die Gemeinschaft erkannt werden. 10) "Ungleiche" Bindung des Eigentums ist ohne Kompensation nicht zulässig. Sie ist entschädigungspflichtiger Eingriff, keine Bindung des Eigentums mehr. 11) In der Sphäre ungleicher Wegnahme bzw. eigentumsinstitutsverletzender Einschränkung des Eigentums treffen sich das gleichheitliche und das im engeren Sinne eigentumsgrundrechtliche Abgrenzungselement widerspruchsfrei.

Der Auftrag an den Gesetzgeber, die Eigentumsbindungen sozial ordnend und ausgleichend in das Eigentumsrecht hineinzutreiben, ist als solcher nur schwach sanktioniert. Viel stärker wird die soziale Gestalt des Eigentums in der Grenze dieses Auftrages, die zugleich die Grenze zulässiger Eigentumsbindung und als solche nachhaltig sanktioniert ist, sichtbar. Das gilt zunächst hinsichtlich der absoluten Grenze zulässiger Eigentumsbeschränkung. Obwohl gerade hier nicht einseitig geurteilt werden darf; denn der Sozialstaat, wie das geltende Verfassungsrecht ihn will, setzt die Funktion des Eigentums positiv ein 12 ) und duldet sie nicht nur. Es gilt auch hinsichtlich der gleichheitsorientierten Grenzziehung. Die Gleichheit hat immer auch eine sozial substantiierte Gleichheit zu sein. 13) Die soziale Gleichheitskonzeption und die gleichheitliche Eigentumsordnung erscheinen, ineinander gefügt, als sehr

$z u$ Überlagerungen und Verwirrung. Umgekehrt aber kann auch die Gleichheitslehre allein die ganze Lösung nicht bringen. Die gleichheitliche Wegnahme des Eigentums oder die gleichheitliche Aushöhlung des Eigentums kann nicht schon um deswillen gerechtfertigt sein, weil sie eben gleichheitlich ist. Hier muß das Eigentumsgrundrecht höchst eigenständig wirksam werden. Aber das liegt an der Peripherie der Figentumsgestaltung, am wesenhaften non plus ultra der Eigentumsbindung.

9) S.oben II 2 b, bb (S. 898 ff) und cc (S. 904 ff); s.a. oben Abschnitt 5 III 8 ( $S$. ff).

10) S. f.v.a. Scheuner, Die Abgrenzung der Enteignung.

11) Zur Abgrenzung für die Praxis zu Art.14 GG grundlegend: BGHZ 6, 270 (279 f); alles weitere s. bei Weber, a.a.O. S. $371 \mathrm{ff} ;$ v. Mangoldt-Klein, a.a.O.

12) S.o. S.934 f. Zur positiven, strukturbestimmenden Becieutung der Eigentumsgarantie s. ferner Reinhardt, Verfassungsschutz des Eigentums, S. 13 ff.

13) S. o. II 2 b, bb (S. 898 ff). 
wesentliche Flemente einer sozialen Eigentumsgestaltung.

Doch gilt las cum grano salis. Eine Nutzungsverschiebung oder - beschränkung etwa, die zwar sozialen Zwecken dient, jedoch nicht an der sozialen Position des Eigentums ausgerichtet ist, ist für denjenigen, den sie belastet, nicht schon deshalb eine "gleiche", zulässige Bindung, weil sie sozial wichtig oder notwendig ist. Soziale (sozial-staatliche) Hilfe ist eine Sache der Gemeinschaft, die auch ihre Lasten zu tragen hat. Da sie diese Lasten aber auf soziale Weise aufzuteilen hat, ist es denkbar, daß ein die Eigentumsherrschaft partiell verschiebender Vorgang auf der Aktiv- und Passivseite "sozial" ist. Nur eine Maßnahme, die auf diese Weise - nach Gegenstand (Eigentum), Verpflichtetem (Eigentümer), unmittelbar oder mittelbar Begünstigtem und Inhalt - der Bewegung von der sozialen Ungleichheit zur sozialen Gleichheit homogen ist, kann auch dann als Eigentumsbindung zulässig sein, wenn sie ohne die soziale Wertung als "ungleiche" Belastung des (sozial besser gestellten und deshalb in Anspruch genommenen) Eigentümers anzusehen wäre. ${ }^{15)}$ Dabei darf das komplexe und variierende Wesen der sozialen Differentialposition nicht übersehen werden. Sie besteht nicht von Natur aus zwischen den Inhabern und Nichtinhabern gewisser Eigentumsrechte. Die Herrschaft über gewisse Güter ist für die soziale Wohlstandsdifferenz von sehr verschiedener und wechselnder Bedeutung. Sie kann als soziales Spannungsmoment stärkstens hervortreten. Dann wird das Eigentum an diesem Gut in besonderem Maße gebunden werden dürfen. In bezug auf solches sozial kritische Eigentum wird übrigens nicht nur die gleichheitsorientierte sondern auch die absolute, im engeren Sinne eigentumsrechtliche Grenze zulässiger Eigentumsbindung maximal zurückverlegt werden müssen. Beides gilt umso deutlicher, wenn das gehäufte Eigentum an Gütern bestimmter Art als solches soziale Spannungen auslöst. Die soziale Bindung kann dann proportional zur quantitativen Zunahme des Eigentums qualitativ gesteigert werden. Aber grundsätzlich ist die soziale Position komplex. Das Eigentum an einer größeren Menge eines bestimmten Gutes ist an sich noch nicht sozial anstößig.

Welchen Inhalts die Figentumsbindungen im einzelnen sein können, hier darzustellen, ist weder möglich noch nötig. 16)

14) S.o. S.832ff. Zu diesem Dreier-Zusammenhang s. nochmals llerner, Sozialstaatliche Tendenzen in der Rechtsprechung, S. 100 .

15) S. zu Vorstehendem schon oben S.832 ff und die dortigen Nachweise. 


\section{b) Die sozialierende Bindung des Eigentums}

Ein besonderes Problem der Eigentumsbindung stellt sich im Rahmen des Art.15 GG. Die Überführung in Gemeineigentum ist zwar immer Eigentumsentziehung. Die Überführung in andere Formen der Gemeinwirtschaft kann dagegen auch bloße nicht entschädigungspflichtige - Eigentumsbindung sein. 1) Als solche ist sie nicht wesensmäßig unterschieden von einer Eigentumsbindung nach Art. 14 Abs. 1 Satz 2 GG. ${ }^{2}$ ) Im besonderen ist sie nicht auf den gegenständlichen Bereich des Art. 15 GG beschränkt. ${ }^{3)}$ Das Gegenteil wäre, vom vorrechtlichen Gesamtbild und der ganz unproblematisch gelebten Verfassungswirklichkeit her geurteilt, auch unerträglich. Die Formen der Gemeinwirtschaft sind außerordentlich vielfältig. ${ }^{4)}$ Im Raum der bloßen Eigentumsbindung verlaufen sie sich bis hin zur obrigkeitlichen Ingerenz in die private wirtschaftliche Eigentumsdisposition und -nutzung 5) auf der einen und zum Mitbestimmungsrecht auf der anderen Seite. 6) Eigentumsbindungen dieser Art können auch

16) Einige Beispiele s. schon oben Abschnitt 5 III (S. 762 ff) (insbes. 5 (S. $820 \mathrm{ff})$ und $8 \mathrm{~b}(\mathrm{~S} .832 \mathrm{ff}))$. Weitere Beispiele s. im folgenden Text. Abgrenzungsbeispiele zwischen Eigentumsbindung und enteignendem (enteignungsgleichem) Eingriff s. z.B. bei Weber, Eigentum und Enteignung, S. $376 \mathrm{ff}$; Maunz, Deutsches Staatsrecht, S. 135 f; Wolff, Verwaltungsrecht I, S. 329 f. - Eine Übersicht über die Bindungen des Eigentums s. insbes, bei Rudolph, Die Bindungen des Eigentums, 1960, S. $41 \mathrm{ff}$.

1) Vg1. Ipsen, Enteignung und Sozialisierung, S. 112 f; Huber, Wirtschaftsverwaltungsrecht, S. 175, $374 \mathrm{f}$; Scheuner, Verfassungsschutz des Eigentums, S. 141; v. Mangoldt-Klein, Art. $15 \mathrm{Anm}$. VII 2 und IX 2; Herbert Krüger, Sozialisierung, S. $318 \mathrm{ff}$.

2) Vg1. Krüger ebd.

3) Krüger, a.a.O. S. 319.

4) S. die Beispiele bei Huber, a.a.O. S. 171; v. Mangoldt-Klein, Art.15 Anm. VII 2. S. ferner die eigenwillige, im ganzen zu enge, aber sehr wichtige neue Aspekte eröffnende Interpretation bei Krüger, a.a.O. S.296 ff.

5) S. die Vorgenannten; Huber, a.a.O. S.220 ff.

6) Für die Mitbestimmung als wesensmäßig vergesellschaftende Erscheinung s. U. M. Wirtschaftliches Mitbestimmungsrecht und Enteignung, AöR Bd. 77 (1951/52), S.366 ff (369 f); Ipsen, Enteignung und Sozialisierung, S. 109, 116; Ridder, dass. S. 143; Huber, a.a.O. S. 143, 149 f, 158, 174, 574 f; Knoll, Eingriffe in das Eigentum im Zuge der Umgestaltung gesel1- 
außerhalb des sachlichen Geltungsbereichs des Art.15 GG nicht entbehrt werden.

Wo sich die Bindung zur Entziehung steigert, setzt dagegen die Beschränkung des Art.15 GG ein. Aber auch schon ein letzter Steigerungsgrad vergesellschaftender Eigentumsbindung ist nur in diesem Rahmen zu erreichen. Sonst wäre die Aufnahme auch der eigentumsbindenden Vergesellschaftung in Art.15 GG gegenstandslos. Doch unabhängig davon erschiene es nicht richtig anzunehmen, das Maß der nicht entschädigungspflichtigen, eigentumsbindenden, nichtentziehenden Vergesellschaftung dürfe für alle Güter - oder auch nur für alle Produktionsgüter - dasselbe sein. Das Sozialstaatsprinzip weist darauf hin, daß sich die zulässige Bindung mit der sozialen Bedeutung des Objekts steigern darf, sofern sie einen sozialen $Z$ weck adäquat verfolgt. Art. 15 GG setzt einen präziseren - aber nicht durchwegs auch spezielleren - Maßstab. Die dort a ufgeführten Produktionsgüter sind in besonderer Weise gemeinschaftsgebunden und gesteigerten Bindungen - im Sinne einer gemeinwirtschaftlichen Vergesellschaftung - zugängig. 7)

So wird von drei Zonen zu sprechen sein: derjenigen der allgemein zulässigen (vergesellschaftenden) Eigentumsbindung; derjenigen der nur im gegenständlichen Rahmen des Art.15 GG zulässigen gesteigerten Eigentumsbindung; und derjenigen der eigentumsentziehenden Vergesellschaftung, wie sie ebenfalls nur im Rahmen des Art.15 GG zulässig ist.

4. Die Entziehung des Eigentums

a) Übersicht

Die Verfassung hebt nur zwei Fälle der Eigentumsentziehung hervor: Die Enteignung (Art.14 Abs. 2 GG) und die Sozialisierung (Art. 15 GG). 1) Damit ist die Zahl der möglichen Entziehungsfälle jedoch nicht erschöpft. So gehört es zu den immanenten Schranken des Eigentums, daß es im Rahmen der Privatrechtsordnung infolge privatrechtlicher Verpflichtungen zwangsweise weggenommen werden kann. Ferner gehört es zu seiner Funktion, als Vermögensgegenstand des Berechtigten für dessen Verbindlichkeiten haftend, im Wege der. Zwangsvollstreckung zur Bef riedigung von Schulden herangezogen $z u$ werden. Zulässig ist - ohne verfassungs-

schaftlicher Verhältnisse, AöR Bd.79, S. 497; v. Mangoldt-Klein, Art. 15 Anm. VII 2; s.a. Ortlieb/Stavenhagen, Art. "Sozialisierung (II) Geschichte (1) Deutschland" im Handwörterbuch der Sozialwissenschaften. A.A. Krüger, a.a.O. S. 290 f, 298.

$\mathrm{S}$. hierzu noch unten $4 \mathrm{f}$ (S.982 ff).

7) S. Ipsen, a.a.O. S.95; Maunz, Deutsches Staatsrecht, S. 139;

Krüger, a.a.O. S.306.

1) Zur Abgrenzung zwischen bindender und entziehender Soziali- 
textliche Erwährung - die sog. Restitution ${ }^{2}$ ) und die kriminal- und ordnungsstrafrechtliche Einziehung. ${ }^{3)}$ In den Grenzen des Art. 18 GG kennt die geltende Verfassungsordnung auch eine der Konfiskation 4) nahekommende Eigentumsverwirkung. 5) 6) Schließlich ist der rechtlich eigentumsbindende, aber effektiv eigentumsentziehen de Ablieferungszwang als eine verwandte Erscheinung zu erwähnen. ${ }^{7)}$

Doch sind diese Typen der Eigentumsentziehung nicht von grundsätzlicher Bedeutung. Sie konzentriert sich vielmehr auf die Enteignung ${ }^{8)}$ und die Sozialisierung, 9) auf die Umlegung, 10) auf die - vom positiven Verfassungsrecht gegenüber Enteignung und Sozialisierung nicht verselbständigte - soziale Umschichtung 11) und auf die Abgabenerhebung. 12) Schließlich drängen sich Grenzerscheinungen ins Blickfeld, die das Eigentum zwar nur inhaltlich bestimmen, aber effektiv seiner Verkürzung nahe kommen. ${ }^{13)}$

\section{b) Die Enteignung}

\section{aa) Begriff und allgemeine soziale Bedeutung}

Unter der Enteignung (Art. 14 Abs. 3 GG) verbergen sich zwei verschiedene Erscheinungen: die klassische Enteignung, die der Güterbeschaffung für ein konkretes, dem öffentlichen Wohl dienendes "Unternehmen" dient; daneben die "Aufopferungsenteignung", in deren Rahmen "nicht Güter für ein bestimmtes Unternehmen des öfentlichen Wohles in Anspruch genommen und übertragen" werden, sondern "die vermögensrechtliche Rechtsstellung des Eigentümers oder sonst vermögensrechtlich Berechtigten in an-

sierung s. oben S.950f.

2) S. z.B. v. Mangoldt-Klein, Art. 14 Anm.VI 6; weit. Nachw.s.dc

3) ebd. Anm. VI 4.

4) S. hierzu ebd. Anm.VI 5.

5) Vg1. Huber, Wirtschaftsverwaltungsrecht, Bd. II, S. 43; v. Mangoldt-Klein, Art. 14 Anm. II 6 c und 12; Wolff, Verwaltungs recht I, S. 336 .

6) Als Folgeerscheinung tritt die Konfiskation auf beim Verbot politischer Parteien (Art.21 GG, $\$ 46$ Abs. 3 Satz 2 BTerfGG). Mittelbar berechtigten auch die Entnazifizierungsklauseln (Art. 139 GG) zu Konfiskationen.

7) S. hierzu Huber, a.a.O. S. 34 ff; v. Mangoldt-Klein, A.t. 14 Anm.VI 2; Wolff, a.a.O. S. 335.

8) S. unten b (S.952 ff).

9) S. unten d (S.963 ff). - S.a. nochmals oben S.951 zu Fußn. 1.

10) S. unten S.963f.

11) S. unten e (S.969 ff).

12) S. unten S. $987 \mathrm{ff}$.

13) S. unten h (S.991 ff). 
derer Weise beeinträchtigt" wird. 1) Beiden Arten der Enteignung ist gemeinsam, "laß sie auf eine voll anerkannte Vermögensposition" treffen, "daß sie die Eigentumsgarantie weder im Prinzip noch hinsichtlich der betroffenen konkreten Rechtsstellung in Frage $^{\prime \prime}$ stellen, sondern bestätigen "und lediglich durch zwingende Erfordernisse des öffentlichen Wohles sich genötigt" sehen, "die Eigentumsgarantie gegen eine Eigentumswertgarantie auszutauschen".2) 3)

Die Funktion der Enteignung ist keine spezifisch soziale, aber doch auch von größter sozialer Bedeutung. Das "Wohl der Allgemeinheit", zu dessen Diensten die Enteignung zulässig ist, 4) und $\mathrm{zu}$ dessen Gunsten die "Eigentumsgarantie gegen die Eigentumswertgarantie eingetauscht" werden darf, ist von der sozialstaatlichen Wertvorstellung bestimmt. Das öffentliche Unternehmen, dem Güter zugeführt werden sollen, kann ein soziales sein. Das öffentliche Interesse, dem das Eigentum weichen muß, kann das spezifisch soziale sein.

\section{bb) Die Entschädigungspflicht}

Die Enteignung ist nur gegen Entschädigung zulässig (Art. 14 Abs. 3 Satz 2 und 3 GG). Darin dokumentiert sich der soziale Immobilismus der Figentumsverteilung im Prinzip. Sein Ausmaß hängt jedoch vom Ausmaß der verfassungsrechtlich gebotenen Entschädigung ab.

\section{aaa) Die Höhe der Entschädigung}

1. Die Regelung des Grundgesetzes.

a) Meinungsstand und Rahmeninterpretation. Nach dem Grundgesetz ist "die Entschädigung unter gerechter Abwägung der Interessen der Allgemeinheit und der Beteiligten zu bestimmen" (Art. 14 Abs. 3 Satz 3). In der ersten Zeit nach Erlaß des Grundgesetzes wurde die Meinung vertreten, die Spanne zulässiger Entschädigung reiche von der vollen Schadloshaltung bis zur Nominalentschädigung. 1) Die herrschende Meinung glaubt jedoch in der

1) v. Mangoldt-Klein, Art.14 Anm.VII $3 \mathrm{~b}$.

2) Weber, Eigentum und Enteignung, S.351.

3) S. zu den beiden Begriffen f.v.a. die beiden Vorgenannten Anm. VII 2, 3, bzw. S. 339 ff, 343 ff, 349 ff. - Zur Abgrenzung von der Eigentumsbindung s. oben 3 (S.945 ff).

4) Art. 14 Abs. 3 Satz 1 GG.

1) v. Mangoldt, Bonner Grundgesetz (1.Auf1.) Art. 14 Anm. 5; ders., Grundrechte und Grundsatzfragen des Bonner Grund- 
Entschädigungsnorm des Art. 14 Abs. 3 Satz 3 GG der Sache nach nichts anderes als die Wiederholung des Gebotes der angemessenen Entschädigung in Art. 153 Abs. 2 Satz 2 RV 1919 sehen zu dürfen. ${ }^{2)}$ Die Folge ist, daß mit der herrschenden Praxis der Weimarer Zeit ein voller Ausgleich der auferlegten Vermögenseinbuße 3) verlangt wird. 4 )

Dabei wird übersehen, daß schon die Meinung zur Weimarer Verfassung (und den entsprechenden landesverfassungsrechtlichen und gesetzesrechtlichen Entschädigungsklauseln) geteilt war, 5) daß schon damals eine nicht unbedeutende Richtung für eine - unter Umständen von der vollen Entschädigung abweichende - gerechte Abwägung aller Belange, insbes. eben auch der Belange der Allgemeinheit eintrat 6$)$ und daß allenfalls im Sinne dieser Auslegungsrichtung gesagt werden kann, die Formulierung des Art. 14 Abs. 3 Satz 3 GG sei "überkommene Umschreibung des Begriffes 'angemessene Entschädigung" ". ") Dabei wird ferner über die Bemühungen des Parlamentarischen Rates, sich von der herrschenden Auslegung des Begriffes der "angemessenen Entschädigung" zu lösen, 8) so hinweggegangen, als ob diese subjektiven Momente keinen objektiven Niederschlag im Grundgesetz gefunden hätten, obwohl sie ihn doch gefunden haben.

gesetzes, AöR Bd. 75 (1949) S. 271 ff (289); Abraham, Bonner Kommentar, Art.14 Anm. II 9. Scholtissek (Die Eigentumsgarantie des Grundgesetzes, Betriebsberater, 7.Jhg. (1952) S. 981 ff (983)) wandte sich zwar gegen die Nominalentschädigung, wollte die zulässige Regelung aber immerhin "von einer geringfügigen Entschädigung bis zur vollen Gegenleistung" gehen lassen.

2) S. z.B. die Nachweise bei v. Mangoldt-Klein, Art.14 Anm. VII 9 b; Forsthoff, Lehrbuch des Verwaltungsrechts, S. 308; Wolff, Verwaltungsrecht I S. 332; ferner BGHZ 19, 139 (144 ff).

3) S. Schack, Das Maß der Enteignungsentschädigung, MDR Jhg. 7 (1953) S. 195 ff (195 f).

4) Weber, Enteignung und Entschädigung, S. $389 \mathrm{ff} \mathrm{m}$. eingeh. Nachw.; spätere Nachweise s. bei v. Mangoldt-Klein, a.a.O. (S. 451 u. - S.452 o.).

5) S. die Darstellung bei Knoll, Eingriffe in das Eigentum im Zuge der Umgestaltung gesellschaftlicher Verhältnisse, AöR Bd. 81 S. 342 ff, insbes. S. $364 \mathrm{ff}$.

6) S. Knoll, a.a.O.; s.a. Schack, a.a.O. S. 196 ff.

7) Zitat: Ipsen, Enteignung und Sozialisierung, S.98. - Zur Anlehnung an die Auslegungsrichtung s. v. Mangoldt-Klein, Art. $14 \mathrm{Anm}$. VII 9 b (S.452); s.a. Scheuner, Verfassungsschutz des Eigentums, S. 160 . 
Allerdings ist zuzugeben, daß die Beratungen des Parlamentarischen Rates keinen eindeutigen Weg für die Gestaltung der Entschädigung zeigen. ${ }^{9)}$ Sie führen nur weg von der "angemessenen Entschädigung" der fixen Weimarer Provenienz. Aber es ist auch nicht die Funktion des Art. 14 Abs. 3 Satz 3 GG, eine positive Lösung des Entschädigungsproblems zu geben. Die Junktim-Klausel (ebd. Satz 2) will die Entschädigungsregelung durch den Gesetzgeber an Stelle der Verfassung bzw. des die Verfassung unmittelbar anwendenden Richters. ${ }^{10)}$ Die Verfassung selbst will dem gesetzgeberischen Ermessen nur eine Grenze setzen. 11) Aber hinsichtlich dieser Grenze steht nach Wortlaut und Entstehungsgeschichte fest, daß sie auch - nicht durchwegs sondern für gewisse Fälle 12) - tiefer liegt als die der "angemessenen Entschädigung" im Sinne der herrschenden Weimarer Praxis. 13)

b) Die maßgebenden Elemente der Entschädigung. Für die Lösung des Problems, wo die Grenze verläuft, geben jedoch weder die Entstehungsgeschichte noch der Wortlaut des Art.14 GG eine definitive Hilfe. Sie muß in dem teleologisch-systematischen $\mathrm{Zu}-$ sammenhang gesucht werden, in dem die Entschädigungsnorm steht. Dieser ist entscheidend durch die - schon in bezug auf die Abgrenzung zwischen Eigentumsentziehung und Eigentumsbindung sichtbar gewordene ${ }^{14)}$ - doppelte Funktion der Entschädigung charakterisiert: sie ist Opferausgleich und alternative Realisation der Eigentumsgarantie. 15)

8) S. Doemmig-Matz-Füsslein, Die Entstehungsgeschichte der A rtikel des Grundgesetzes, S. 149 ff. Eine spezielle Darstellung s. bei Knoll, a.a.O. S.389.

9) S. z.B. Scheuner, a.a.O. S.129; Weber, Eigentum und Enteignung, S. 389 .

10) BVerfGE 4, 219 (234 ff); s.u. S.962.

11) BVerfGE 4, 236.

12) Zur Notwendigkeit der Differenzierung s. insbes. Knoll, a.a.O. S. 397 m.w. Nachw. (s.a. S. 395 und S.397 ff).

13) S. Scholtissek, Die Eigentumsgarantie des Grundgesetzes, S.983; Knoll, a.a.O. S. $389 \mathrm{ff}$, insbes. S. $391 \mathrm{f}, 396 \mathrm{ff}$.

Für einen gewissen Spielraum des Gesetzgebers wohl auch Scheuner, Diskussionsbeitrag zu "Enteignung und Sozialisierung", S.155; ders., Verfassungsschutz des Eigentums, S. 129; v. Mangoldt-Klein, Art. 14 Anm. VII 9 b; (widersprüchlich) Maunz, Deutsches Staatsrecht, S. 137.

14) S. o. S. $945 \mathrm{ff}$.

15) Zu dieser elementaren Grundlage der Entschädigungsdogmatik s. Scheuner, Verfassungsschutz des Eigentums, S. 125 und 129; Weber, a.a.O. S.389 f; s.a. v. Mangoldt-Klein, Art. 14 Anm. VII 9 b. 
Als Ausdruck der Eigentumsgarantie und Ausgleich ihrer Verletzung hat sie zu wirken, wenn die Enteignung sich ohne Rücksicht auf die Gleichheit oder Ungleichheit des Eingriffes - nur oder auch - wegen der eigentumsvernichtenden Intensität des Eingriffes als Enteignung qualifiziert; 16) als Opferausgleich - zugleich oder auch ohne einen Eingriff in die Substanz des Eigentums, also durch eine "ungleiche" Entziehung oder Bindung des Eigentums - wenn ein ungleiches Opfer auferlegt wird. 17) Die beiden Pri zipien konkurrieren also, wo eine ungleiche Vollentziehung des Eigentums ${ }^{18)}$ vorliegt. Das reine Eigentumsgarantieprinzip ist maßgeblich, wo eine gleichheitliche Vollentziehung 18) vorliegt. Diese darf nicht wegen fehlender Ungleichheit ohne Entschädigung bleiben, wenn die Eigentumsgarantie nicht vernachlässigt werden soll. Das Opferausgleichsprinzip allein ist maßgeblich, wenn eine bloße Eigentumsbindung infolge ihrer "Ungleichheit" nach einer Entschädigung verlangt, obwohl sie die Substanz des Eigentums nicht beeinträchtigt. Soweit eine ungleiche Vollentziehung in Frage steht, beide Prinzipien also konkurrieren, ist das für den Betroffenen günstigere anzuwenden, wenn anders weder das Eigentumsgrundrecht noch der Gleichheitssatz verletzt werden soll.

Soweit die Entschädigung dazu dient, die Eigentumsgarantie zu salvieren, hat sie ein veritables Äquivalent für das entzogene Gut zu sein - nicht mehr und nicht weniger. Eine bloße Nominalentschädigung - oder wie sie auch genannt wird: formale Entschädigung - 19) erfüllt diese Funktion nicht. Sie steht nicht für das Eigentum. Sie ist nicht der Schutz des Eigentums gegenüber dem Zugriff der Allgemeinheit, der die Entschädigung zu sein hat. ${ }^{20)}$ Der reine Eigentumsschutz verlangt aber keinen Ausgleich der Folgen der Entziehung. Weder auf die Wiederbeschaffungskosten - die freilich mit dem objektiven Wert des entzogenen Gutes übereinstimmen können - noch auf mittelbare Schäden kann es ankommen. Desgleichen zählt das Affektionsinteresse des Eigentümers, ebenfalls eine subjektive "Zutat" zum Wert des Gutes, nicht. 21)

16) S. o. S.945ff, insbes. S. 947 zu Fußn. 6 und 8.

17) S. oben S.947f zu Fußn. 8, 10 und 11.

18) S. oben S. 947 zu Fußn. 6 und 8 und den Text hierzu sowie den Text nach Fußn. 11.

19) S. oben S. 953 zu Fußn.1.

20) S. z.B. Scheuner, Verfassungsschutz des Eigentums, S. 126: "Das Ausmaß der Entschädigung bestimmt im Grunde das Maß wirklichen Schutzes der Eigentumssubstanz, das die Verfassung gewährt".

21) S. z.B. Knoll, a.a.O. S. 162 ff. 
Es muß etwas gegeben werden, was gerechterweise als Ausdruck des objektiven Wertes des entzogenen Gutes verstanden werden darf. Die Möglichkeiten liegen zwischen dem Marktwert und dem Ertragswert.22) Ganz anders der Opferausgleich: Er hat nicht mehr und nicht weniger zu beinhalten als die Differenz zwischen dem vollen Opfer des Betroffenen, das ihm aus der Bindung oder Entziehung des Eigentums erwachsen ist, und dem Opfer, das ihm nach den Merkmalen, die den Kreis der Betroffenen auszeichnen und von den Nichtbetroffenen abgrenzen, als ein gleichheitsgerechtes auferlegt hätte werden dürfen (welch letzteres auch gleich Null sein kann). Als Opferausgleich kann die Entschädigung von einem geringfügigen Betrag - der eine "Nominalentschädigung" aber auch in diesem Zusammenhang nicht sein darf als Ausgleich einer seichten Belastungsdifferenz ansteigen bis zum vollen Ausgleich aller objektiv bewertbaren 23) Nachteile, die ein exzeptionell Betroffener durch die Eigentumsentziehung erleidet.24)

22) S. Knoll, a.a.O. S. 190 ff. - Dafür, daß eine rein rechnerische Größe wie der Einheitswert in seiner gegenwärtigen Beschaffenheit, oder eine künstliche Preisgröße wie der StopPreis kein adäquater Wertausgleich sein können, s. ebenfalls Knoll, a.a.O. S. 179 ff und seine Nachweise.

23) Auch hier scheidet also das Affektionsinteresse vollkommen aus (s.o. S. 956 zu Fußn.21).

24) Für fiktive Werte, wie den Einheitswert, ist auch in diesem Zusammenhang kein Raum; genau so wie der Stop-Preis auch hier nur berücksichtigt werden darf, wenn er die Vermögenseinbuße ausdrückt (s.o. Fußn.22). Andererseits kann, ja muß auch das rein persönliche (objektiv feststellbare) Interesse (z.B. Gefährdung der Existenzbasis (Scheuner, Verfassungsschutz des Eigentums, S.136; Knoll, a.a.O. S. $408 \mathrm{ff}$; s. auch schon oben S. $832 \mathrm{ff}$, insbes. S. $834 \mathrm{zu}$ Fußn. 10)) berücksichtigt werden. - Sehr wichtig sind gerade unter dem Gesichtspunkt des Gleichheitsprinzips die beherzigenswerten Ausführungen Knolls (a.a.O. S. 400 ff) über die ungerechtfertigte Absetzung von "Überpreisen" gegenüber den Enteignungsbetroffenen (S.402 ff), soweit diese Preise, wo es an entsprechenden Preisvorschriften fehlt, den nicht Enteigneten doch verbleiben (!), über die ungerechtfertigte Abschöpfung sog. unverdienten Mehrzuwachses bei den Enteigneten ( $\mathrm{S} .403 \mathrm{ff}$ ), soweit dieser Mehrwert, weil es an einer entsprechenden Besteuerung fehlt, den Nichtenteignungsbetroffenen verbleibt (!), und über die - so sehr beliebte - Vorteilsausgleichung, die so ganz ohne Rücksicht darauf in An- 
In diesen Bahnen hat sich die Abwägung der Interessen der Al1gemeinheit und der Beteiligten 25 ) zu vollziehen: sub specie des Opferausgleichs verwirkiicht durch eine von Willkür und sachfremder Motivierung freie - im Sinne des Art. 14 Abs. 3 Satz 3 GG: "gerechte" - Verteilung und Bemessung der Lasten je nach ihrer Eigenart; sub specie der Eigentumsgarantie - allein als solcher - verwirklicht durch die sachgerechte Auswahl des Eigentumsäquivalents; beim Vollentzug des Eigentums nach unten durch das mindeste denkbare Eigentumsäquivalent absolut begrenzt, relativ immer - bei der entschädigungspflichtigen Eigentumsbindung: nur - durch das Maß des auszugleichenden Sonderopfers.

c) Die effektive Norm. Für die Masse der Fälle bedeutet das den vollen Ausgleich der erwachsenden Vermögenseinbuße, und zwar grundsätzlich schon unter dem Gesichtspunkt des Opferausgleichs; ${ }^{26)}$ denn in der Masse aller Enteignungsfälle wird die A uferlegung der Sonderopfer allein von dem Zusammenhang zwischen dem Vorhandensein eines Gutes und dem Bedürfnis, "zum Wohle der Allgemeinheit" die Nutzung- oder (und) Verfügungsberechtigung daran zu verschieben oder sonstwie zu beeinträchtigen, gesteuert - von einem Prinzip also, das seiner Natur nach grundsätzlich nicht dazu dienen kann, die aus seiner Verfolgung unmittelbar entspringende Lastenverteilung als gleichheitlich zu rechtfertigen. Aus diesem $\mathrm{G}$ runde hat die herrschende Meinung, die eine "angemessene Entschädigung" und somit grundsätzlich eine vollständige Entschädigung 27 ) verlangt, 28) für das Gros der Fälle recht. 29 ) Kein noch so triftiger Grund der Enteignung kann davon eine Ausnahme schaffen. "Hohe Bewertung" des "Zieles der Enteignung ist kein Grund, den Betroffenen Sonderopfer für die Durchführung aufzuerlegen, die von der Gesamtheit zu tragen sind". 30) Das gilt auch für Enteignungen, die sozialen Zwecken dienen. 31)

schlag gebracht wird, daß von dem enteignungsbegünstigten Unternehmen auch andere, nicht Enteignungsbetroffene profitieren könnten (S.406 f).

25) Die bisher eingehendste Analyse s. bei Knoll, a.a.O. S. 393 ff. S.a. Scheuner, a.a.O. S. $129 \mathrm{ff}$.

26) S. z.B. BGHZ 26, 248 (255).

27) Knoll, a.a.O. S. 342 ff.

28) S. oben S. 954 zu Fußn. 4.

29) Für den vollen Ausgleich in diesem Rahmen s.a. Knoll, a.a.O. S. $400 \mathrm{ff}$.

30) Scheuner, a.a.O. S.136; s.a. Knoll, a.a.O. S.410 ff.

31) S. oben S. 832 ff, insbes. S. 834 zu Fußn. 8. 
Von diesem "Grundsatz" gibt es im wesentlichen nur zwei (scheinbare) "Ausnahmen". Die eine besteht darin, daß für allgemeine Notzeiten (insbes. Kriegszeiten) eine Minderentschädigung zugelassen wird. ${ }^{32)}$ Sie ist gerechtfertigt durch die allgemeine breite, nicht voll faßbare und beherrschbare Streuung der Opfer und Lasten, 33) die eine nach "normalen" Maßstäben vollständige Entschädigung der evident Enteigneten als eine Bevorzugung gegenüber den "still" Belasteten erscheinen ließe - eine Pauschalierung der Lastenverteilung, die ihre engen Grenzen hat.

Die andere "Ausnahme" liegt dann vor, wenn die Enteignung und die Enteignungsentschädigung in ein als solches legitimes Lastenverteilungssystem einbezogen sind, insbes. in ein System des sozialen Ausgleichs. ${ }^{34)}$ Das zu entschädigende "Sonderopfer" wird dabei auf die Weise ermittelt, daß von der erlittenen Vermögenseinbuße substrahiert wird, was im Rahmen des allgemeinen Lastenverteilungssystems zu leisten wäre. Sind dieses und das Enteignungssystem homogen, so bleibt kein Rest. Im übrigen ergibt sich eine der Differenz entsprechende Minderentschädigung. Dabei darf die andere Komponente der Entschädigung nicht übergangen werden: Soweit Vollenteignung ${ }^{35}$ ) vorliegt, darf die Entschädigung nicht unter dem Eigentumswert bleiben. ${ }^{36)}$ Die legitime Dringlichkeit des $Z$ weckes wird aber ein Heruntergehen auf den mindestmöglichen Wertersatz rechtfertigen. ${ }^{37)}$

2. Zur funktionalen Bedeutung dieser Regelung. A uf diese Weise ist das Eigentum einbezogen in die Dynamik des Gemeinschaftlichen und bleibt es doch statisch, wie es seinem Wesen entspricht. Solchermaßen gehemmt, kann die Enteignung "kein Nebeninstitut des öffentlichen Abgabewesens" sein. ${ }^{38)}$ So widersteht die Eigentumsgarantie der Veränderung der Eigen-

32) S. Scheuner, a.a.O. S.136; Knoll, a.a.O. S. 407 f; s.a. BVerfGE 4, 219 (234 f).

33) S. hierzu auch oben II 2 b cc (S. 904 ff).

34) S. oben $\mathrm{S} .832 \mathrm{ff}$ und oben $\mathrm{S.945} \mathrm{ff}$.

35) S. oben S. 956 zu Fußn. 18.

36) Das gilt auch für den vorerwähnten Fall der Enteignung in Kriegs- und sonstigen Notzeiten. Doch bliebe insoweit zu prüfen, inwieweit ein Risikoabschlag aus der besonderen Situation heraus zulässig ist.

37) S. hierzu Knoll, a.a.O. S. 160 ff, 400, 415 f, 416 ff, dem damit jedoch hinsicht1ich der Voraussetzungen zulässiger Minderentschädigung nicht unbedingt beigetreten werden soll.

38) Weber, Eigentum und Enteignung, S.392. 
tums- und Besitzverhältnisse, um, in den Randzonen elastisch, dem Bedürfnis nach Neu- und Umverteilung doch nachzugeben. Es ist nur die halbe Wahrheit, wenn "die Enteignung... als ein Institut der unangefochtenen Ruhelage der Eigentümerposition, als ein Moment der Bewährung und Bestätigung der Eigentumsgarantie erkannt" wird. 39) Die Enteignung ist sicher "nicht das Einfallstor für Unterwanderungen der überlieferten Eigentums-
und Sozialverfassung", aber auch nicht "das Gegenteil davon". Sie ist "weder geeignetes noch legales Mittel zur Ausschaltung des Eigentümers aus sozialen Machtpositionen", 41) wenn darunter eine radikale Umwälzung verstanden werden soll. Sie widersetzt sich aber nicht einem schrittweisen Ausgleich. Das Interdikt einer entschädigungslosen Eigentumswegnahme auch zu sozialen Zwecken darf nicht über das Verbot einer sich außerhalb der Bahnen der verfassungsmäßigen Eigentumsgarantie bewegenden "sozialen Umschichtung" 42) hinaus aufgebauscht werden zu einem Verbot jeder sozialen Belastung des Eigentums und jeder sozialen Umverteilung außerhalb des Abgabewesens. ${ }^{43)}$ Hier muß sich die sozialstaatliche Interpretation der Grundrechte bewähren. 44) Das Eigentumsgrundrecht würde aus dem sozialstaatlichen Rahmen fallen, wenn es die Enteignung lediglich als ein "Institut der unangefochtenen Ruhelage der Eigentümerposition" 45 )

39) Für die ganze Wahrheit gehalten aber bei Weber, a.a.O. S. 389; s.a. Forsthoff, Eigentumsschutz öffentlichrechtlicher Rechtssteliungen, S. 1250; ders., Diskussionsbeitrag zu "Die Finanzverfassung im Rahmen der Staatsverfassung", S. $84 \mathrm{f}$ (ähnlich schon: Begriff und Wesen des sozialen Rechtsstaats, S.31 ff); Geiger, Grundrechte und Rechtsprechung, S.47. Vg1. ferner unten e (S. 969 ff).

40) So aber Weber ebd. S. $389 \mathrm{f}$.

41) Ipsen, Enteignung und Sozialisierung, S. 121, 87, $90 \mathrm{f}$. S. hierzu auch unten e (S. 969 ff).

42) S. hierzu unten e (S. 969 ff).

43) S. a. unten S.987 ff.

44) So geht Scheuner (Verfassungsschutz des Eigentums, S. 129) für die Auslegung der grundgesetzlichen Entschädigungsklausel von vorneherein davon aus, daß neben der Eigentumsgarantie und dem Gleichheitssatz auch das Prinzip des sozialen Rechtsstaates inhaltsbestimmend herangezogen werden muß. Zum Zusammenhang zwischen Sozialstaatsprinzip und Minderentschädigung s.a. Friesenhahn, Die politischen Grundlagen des Bonner Grundgesetzes, S. 179; v. Mangoldt, Diskussionsbeitrag zu "Enteignung und Sozialisierung", S.152; BVerfGE 4, 219 (235). 
kennen würde. Die sozialen Belange können nicht allein auf die Binclung des Eigentums verwiesen werden. 46) Die sozialen Belange können auch nicht auf die Sozialisierung im Sinne des Art. 15 GG verwiesen werden; 47 ) betrifft diese doch nur ganz bestimmte Güter und ganz bestimmte Veränderungen der Eigentumsherrschaft, in denen allein sich der Sozialstaat nicht hinreichend verwirklichen kann.

In Zeiten wachsender Volkswirtschaft verbreitet sich leicht die Neigung, die Möglichkeiten der sozialstaatlichen Hilfe und "Neuund Andersgestaltung der Eigentumsherrschaft" 48) auf dem Abgabenwege zu überschätzen. In Krisenzeiten dagegen nimmt die Kapazität dieses Mediums rasch ab und die - als Folge des Ausweichens in die Enteignung und einer unrichtigen Konzeption der Enteignungsentschädigung auft retenden - übersteigerten Entschädigungs-" Umsätze" führen zu inflationären Erscheinungen, die schließlich das vermeintlich zu treulich gehütete Enteignungsäquivalent, die Entschädigung, entwerten. Die aufgezeigte Wertausgleichsgrenze der grundgesetzlichen Eigentumsgarantie ist in diesen Situationen "hart" genug. Darüber hinaus an einem verabsolutierten Opferausgleich im Sinne des vollständigen Ausgleiches der Vermögenseinbuße festzuhalten, kann von Schaden sein. Je mehr es sub specie des Opferausgleichs gelingt, die Entschädigung in die allgemeine Lastenverteilung einzuschmelzen, desto besser wird es für das Eigentum selbst sein.

\section{bbb) Zur Art und Weise der Entschädigung}

Nicht nur das Ausmaß der Enteignungsentschädigung sondern auch die Art und Weise der Entschädigung hat gerade im sozialen Bereich immer wieder Bedeutung erlangt. Kann sich der Staat soziale "Anschaffungen" nicht leisten, muß oder will er sie aber doch machen, so versucht er gerne, die nominell korrekt bemessene Entschädigungslast dadurch zu verringern, daß er sie zulasten des Verpflichteten stundet, in Renten oder in Schuldverschreibungen gewährt. Modalitäten dieser Art sind nicht schlechthin unzulässig. Sie müssen aber so gehalten sein, daß der gebotene Wert- und Opferausgleich dadurch nicht beeinträchtigt wird. Von diesem Gedanken her ergeben sich enge Grenzen. ${ }^{1)}$

45) S. o. S.960 zu Fußn. 39.

46) Anders offenbar Weber, Eigentum und Enteignung, S. 389.

47) Anders Weber, a.a.O. S.357, 365, 389; Forsthoff, Lehrbuch des Verwaltungsrechts, S. 294.

48) Ipsen, Enteignung und Sozialisierung, S. 75.

1) Zu den Einzelheiten s. Scheuner, Verfassungsschutz des Eigentums, S. 148 ff; Weber, Eigentum und Enteignung, S.393 f. 
cсc) Der Gestaltungsspielraum des Gesetzgeber's

Wichtig ist, im Auge zu behalten, daß das Grundgesetz in Art. 14 Abs. 3 Satz 3 GG keine unmittelbar vollziehbare Entschädigungsnorm geschaffen hat. Der Gesetzgeber muß die Entschädigung anordnen bzw. zulassen und die Entschädigung im Rahmen des durch die Verfassung belassenen Ermessens regeln (Art. 14 Abs. 3 Satz 2 GG). 1)

Das ist von zentraler Bedeutung für die Struktur des Art. 14 GG. Während die Anordnung einer "angemessenen Ent schädigung" (Art.153 RV 1919) glauben macht, die Verfassung habe die Entschädigungsfrage unmittelbar geregelt, in Wirklichkeit aber zur. richterrechtlichen Entwicklung des Entschädigungsrechts führt, gibt das Grundgesetz Herrschaft und Verantwortung über den Gesamtkomplex der entschädigungspflichtigen Enteignung an den Gesetzgeber zurück. (Es bestätigt sich auch hier, daß "das Wesentliche zur Verwirklichung des Sozialstaates... nur der Gesetzgeber tun" kann. 2) Daß der Gesetzgeber sich seiner Verantwortung hinsichtlich der Entschädigungsfrage durch laxe Generalklauseln zu entschlagen sucht, steht auf einem anderen Blatte.

A uf den Gerichten lastet aber immer noch erhebliche Verantwortung für die Gestaltung und Anwendung des Entschädigungsrechts. Sie haben über die Einhaltung der verfassungsrechtlichen Grenzen durch den Gesetzgeber zu wachen. ${ }^{3)}$ Sie haben vor allem auch die den Art. 14 Abs. 3 Satz 3 GG erfüllenden Entschädigungsklauseln zu konkretisieren (Art. 14 Abs. 3 Satz 4 GG) - eine Aufgabe, deren Tragweite dort am deutlichsten sichtbar wird, wo, sei es auf Grund ausdrücklicher Vorschriften, sei es auf Grund altrechtlicher Ergänzung 4), noch mit dem Begriff der "angemessenen Entschädigung" gearbeitet werden muß.

\section{c) Die Umlegung}

Von der Enteignung wird die Eigentumsumlegung ${ }^{1)}$ unterschieden.

1) Vg1. BVerfGE 4, 219, 234 ff. - Alles Nähere zur Auslegung der Vorschrift s. bei v. Mangoldt-Klein, Art. 14 Anm. VII 8 und den dort Genannten.

2) BVerfGE 1, 97 (105).

3) BVerfGE 4, 219 (236).

4) S. hierzu BVerfGE ebd. S.236 f. - Für das bayerische Enteignungsrecht s.a. Zacher, Entschädigungslose Enteignung von Verkehrsflächen? S. 68.

1) Vgl. E.R. Huber, Wirtschaftsverwaltungsrecht, Bd.II S.46 ff; v. Mangoldt-Klein, Art.14 Anm. VI 7; Forsthoff, Lehrbuch 
Sie spielt in mehreren, durch ihre Tendenz, die Lebensbedingungen der Bevölkerung zu verbessern, auch sozial interessanten Regelungen - insbes. in der städtischen Bodenreform ${ }^{2}$ ) und in der Flurbereinigung - eine Rolle.

Die Frage, inwieweit es nutzbringend ist, sie vom Rechtsinstitut der Enteignung zu lösen, ist hier nicht zu beantworten. Fest steht, daß sie dann, wenn die Umlegung den Betroffenen keinen wertadäquaten Ausgleich in Grund und Boden verschafft, den für die Enteignung geltenden Regeln folgen muß. ${ }^{3)}$ Daher sind hinsichtlich der Umlegung hier wesentliche Besonderheiten nicht $\mathrm{zu}$ verzeichnen.

\section{d) Die Sozialisierung}

\section{aa) Zur allgemeinen Bedeutung}

Die soziale Bedeutung des Privateigentums an den Produktionsmitteln ist evident. Quelle wirtschaftlicher Macht und sozialer Überhebung, ist es auch Stimulanz der wirtschaftlichen Entfaltung und so Wohltat für alle. Wirtschaftlicher Ordnungsfaktor ersten Ranges, ist es das Substrat aller Störungsanfälligkeit der autonomen Wirtschaftsgesellschaft. Von Anfang an war es als Grundlage arbeitsloser Einkommen und Medium der Ausbeutung der arbeitenden Menschen durch den Unternehmer ein Hauptproblem der sozialen Bewegung.

Der entscheidende Ansatz einer Lösung jenseits der bloß korrigierenden Einflußnahme in die private Eigentumsdisposition und -nutzung ist mit dem Begriff der Sozialisierung, der Vergesellschaftung, der Überführung der Wirtschaftsmittel "in Gemeineigentum oder in andere Formen der Gemeinwirtschaft" (Art.15 Satz 1 GG), verbunden. Die Entscheidung über die Sozialisierung ist eine der wichtigsten sozial- und wirtschaftspolitischen Entscheidungen, die eine Verfassung zu treffen hat. Sie ist aber auch eine zentrale Entscheidung über die "Eigentumsverfassung"; denn "Sozialisierung" ist, trotz aller möglichen Übergänge, im Wesen eine Negation des individuellen und privaten Eigentums an den

des Verwaltungsrechts, S.296; Wolff, Verwaltungsrecht I, S. 335; weitere Nachweise s. dort. Für den weiteren Meinungsstand s. BayVerfGH VGHE n.F. 13 II 63 (67 f). -

$\mathrm{S}$. diese und ihre Nachweise auch zum Folgenden.

2) S. den Vierten Teil, Erster Abschnitt des Bundesbaugesetzes.

3) S. die Nachweise S. 962 zu Fußn.1. 
Wirtschaftsmitteln. 1)

bb) Inhalt und Grenzen der Sozialisierungsermächtigung

Das Grundgesetz sozialisiert nicht. Es ermächtigt aber den Gesetzgeber - den Bundes- wie den Landesgesetzgeber ${ }^{1)}$ - zu sozialisieren (Art.15 GG). Es verpflichtet ihn nicht hierzu. 2) Auch das Sozialstaatsprinzip schreibt die Sozialisierung nicht schlechthin vor. ${ }^{3)}$ Aber das Grundgesetz öffnet ihr, lenkend und begrenzend, den Weg in das Eigentum als Institution und als Rechtsstellung. Es erlaubt dem Gesetzgeber, gewisse Wirtschaftsmittel "zum Zwecke der Vergesellschaftung... in Gemeineigentum oder in andere Formen der Gemeinwirtschaft" zu überführen (Art. 15 Satz 1 GG).

Darin steckt das Doppelte, das die Sozialisierung - in dem hier

1) Zum Sozialisierungsproblem s. die Literaturzusammenstellung nach Art. "Sozialisierung" im Handwörterbuch der Sozialwissenschaften, Bd.9, 1956, S. 482. Zum Verzicht auf jeden Versuch einer näheren Darstellung der wirtschaftlichen, sozialen und allgemein rechtlichen Problematik darf v. Zwiedineck-Südenhorst in seinem Bericht "Zur Sozialisierungsliteratur" (Zeitschrift für die gesamte Staatswissenschaft, Bd. 109 (1953) S. 360 ff (368))zitiert werden: "Es sei zunächst hier nochmals an Leopold v. Wieses zutreffende Beobachtung erinnert: welch ein kompliziertes aus seiner Vielfalt von Teilproblemen zusammengesetztes Etwas ist in den drei Jahrzehnten seit dem Aufkommen der Bewegung für Sozialisierung diese anfänglich so einfache und glatt lösbar d.h. verwirklichbar scheinende Idee schon geworden! Labilität und Relativität, Beziehungs- und Abhängigkeitsvielfalt in jedem solchen Teilproblem, wo immer man es anpackt, und daher interessant, aber mit dieser Interessantheit doch wieder zerfließend, weil man immer noch mehr zupacken muß". Zur rechtlichen Problematik s. statt aller anderen: Enteignung und Sozialisierung", VVDStRL. H.10, 1952, S. 74 ff, mit den Referaten von Ipsen (S. $74 \mathrm{ff}, 169 \mathrm{ff}$ ) und Ridder (S.124 ff, $174 \mathrm{ff}$ ); Huber, Wirtschaftsverwaltungsrecht, Bd. II, S. 141 ff; Scheuner, Verfassungsschutz des Eigentums, S. 138 ff; v. Mangoldt-Klein, Erl. zu Art. 15 GG; Krüger, Sozialisierung. S. dort die weiteren Nachweise, ferner die Erläuterungen zu Art.15 GG, soweit die Probleme hier nicht besonders angesprochen werden.

1) Vg1. Art. $74 \mathrm{Nr} .15 \mathrm{GG}$.

2) S. Krüger, a.a.O. S. $308 \mathrm{~m} . \mathrm{w}$. Nachw.

3) S. o. S.813 ff. 
in Frage stehenden engeren Sinn - kennzeichnet: Vernichtung oder Abschwächung des individuellen Eigentums bei Unterwerfung der Wirtschaftsmittel unter die Verfügungsmacht überindividueller Willenssubjekte; und dienende Unterstellung unter das Interesse der Gesamtgesellschaft. ${ }^{4)}$ Gerade das letztere Element darf bei der institutionellen Ausformung des sozialisierten Eigentums nicht übergangen werden. Nicht jede Kollektivierung oder sonstige "Anonymisierung" des Eigentums ist schon eine "Vergesellschaftung" durch Überführung "in Gemeineigentum oder in andere Formen der Gemeinwirtschaft", genau so wenig, wie schon jede Überführung in Staatseigentum eine legitime Sozialisierung ist. 5)

Das Grundgesetz beschränkt die Sozialisierung auf "Grund und Boden, Naturschätze und Produktionsmittel". Der letztere Begriff ist nicht im weiteren volkswirtschaftlichen Sinn gemeint sondern im engeren von Gütern, die der Güterproduktion dienen. Das bedeutet vor allem, daß Wirtschaftsgüter des Handels, des Verkehrs und des Banken- und Versicherungswesens der Soziali-

4) Rittig, Art. "Sozialisierung (I) Theorie" im Handwörterbuch der Sozialwissenschaften, S.455: "... die Verfügung über Wirtschaftsmittel (insbes. Produktionsmittel) durch überindividuelle Instanzen, sei es durch Aufhebung des Sondereigentums an diesen, sei es durch Verfügungsbeschränkungen, die dem Eigentümer auferlegt werden, wobei beide Formen als im Interesse der Gesamtgesellschaft eingerichtet bzw. als nach der Errichtung diesem Interesse dauernd dienend unterstellt werden".

5) In diesem Sinne vor allem Krüger, a.a.O. S.286 ff, $291 \mathrm{ff}$, dessen Feststellungen im einzelnen, so treffend sie die Fragwürdigkeit einer institutionalisierten Gemeinwohlbindung zwischen Staat und prästabilierter Harmonie des Zusammenwirkens freier Individuen herausstellen, deshalb interpretatorisch bedenklich sind, weil sie verkennen, daß der Verfassunggeber selbst zweifellos "politischer", weniger gründlich - um nicht zu sagen: naiver - dachte. Damit stimmt auch das allgemeine Sachverständnis überein. Es geht nicht an, den Normgehalt so sehr vom Willen des Normsubjekts (im doppelten Sinne von verfassunggebenden Organen und von Staatsvolk) zu entfernen. Die Kataloge möglicher Sozialisierungsmaßnahmen - auf die im übrigen verwiesen werden darf - (vgl. Huber, Wirtschaftsverwaltungsrecht, Bd. II S. $168 \mathrm{ff}$; v. Mangoldt-Klein, Art. 15 Anm. VII) sind von der von Krüger pointierten und im Text aufgegriffenen Sicht her aber korrekturbedürftig. - Zum sozialwissenschaftlichen 
sierung nicht unterliegen. ${ }^{6)}$ Hinsichtlich der in Art. 15 GG aufgezählten Güterarten 1äßt die Verfassung die Sozialisierung unmittelbar zu. Einer besonderen "Sozialisierungsreife" bedarf es nicht. ${ }^{7)}$

Die Sozialisierung kann nur "durch Gesetz", nicht auch auf Grund Gesetzes vorgenommen werden (Art. 15 Satz 1 GG). 8) Selbst wenn man darunter nicht verstehen will, der Gesetzgeber müsse alle Dispositionen selbst und unmittelbar treffen, 9) so bindet dieser Vorbehalt die Sozialisierungsanordnung doch engstens an das Gesetz. 10) Das zieht die Sozialisierung in die unmittelbare politische Verantwortung der Legislative. Es bedeutet ferner, daß die Sozialisierung nur eine allgemeine, eine "Gruppensoziaj.isierung", sein kann. 11) Der Gesetzgeber muß "Gleiches" unmittelbar "gleich" behandeln. 12) Das heißt aber auch, daß ein außerordentliches Objekt, dem kein "gleiches" zur Seite steht, auch einzeln in Anspruch genommen werden kann. 13) Das muß jedoch sub specie des Vergesellschaftungszweckes zu rechtfertigen sein. Weder die Person des Inhabers noch etwa gar ein Güterbeschaffungsinteresse an einem bestimmten Objekt darf zu einer Sonderbehandlung führen.

cc) Insbes. die Sozialisierungsentschädigung

Die Sozialisierung kann Eigentumsbindung und Eigentumsentziehung sein. 1) Als die letztere ist sie entschädigungspflichtig wie die Enteignung (Art.15 Satz 2 GG). 2) Auf das oben ${ }^{3)}$ hierzu Aus-

Sozialisierungsbegriff s. entsprechend Rittig, a.a.O. S.455 f.

6) Zum Gegenstand der Sozialisierung vg1. Huber, a.a.O. S.161 ff; v. Mangoldt-Klein, Art. 15 Anm.VII; Krüger, a.a.O. S. 302 ff.

7) Krüger, a.a.O. S.302, 306; Maunz, Deutsches Staatsrecht, S. 139; a.A. Huber, a.a.O. S. 152 ff; v. Mangoldt-Klein, Art. 15 Anm.VI.

8) Diese Einschränkung ist voll zu respektieren. Vgl. v. Mangoldt-Klein, Art. 15 Anm. VIII $1 \mathrm{~m}$.w. Nachw.

9) Zur Bedeutung der Klausel s. v. Mangoldt-Klein ebd. 2 und 3; Krüger, a.a.O. S. 312 f; w. Nachw. s. dort.

10) S. hierzu Lerche, Grundrechtsbegrenzungen "durch Gesetz" im Wandel des Verfassungsbildes.

11) S.Krüger, a.a.O. S. 312 und 315 mit weiteren Nachweisen.

12) Dafür, daß der Gleichheitssatz das Regulativ des "allgemeinen" Gesetzes abgibt,s. nunmehr Zeidler, Bundesverfassungsgericht und "Maßnahmegesetz".

13) S. Krüger, a.a.O. S.315 f. 
geführte kann daher bezug genommen werden. 4)

\section{aаa) Zur Höhe}

Das bedeutet in erster Linie: auch dem im Wege der Sozialisierung Expropriierten ist ein Äquivalent für sein Eigentum zu leisten. 1) Es bedeutet ferner: auch dem Sozialisierungsbetroffenen ist der volle Ausgleich seines Sonderopfers zu gewähren. Grundsätzlich hat also der im Wege der Sozialisierung seines Eigentums verlustig Gehende einen Anspruch auf vollen Ausgleich seiner Vermögenseinbuße.

Wenn demgegenüber behauptet wird, die Entschädigung für die Sozialisierung werde häufig geringer sein, "als sie sein würde, wenn dieselben Rechte durch eine Enteignung aufgehoben worden wären", 2) so ist das trotzdem nicht unrichtig. Sozialisierungsmaßnahmen sind wesensmäßig häufiger - voll oder approximativ homogene Elemente eines sozialen Integrationsprozesses als Enteignungen. In dem Maße, in dem das den Sozialisierungsbetroffenen auferlegte Vermögensopfer einer gleichheitsgerecht bemessenen sozialen "Schuld" entspricht, kann die Entschädigung hinter der erlittenen Vermögenseinbuße zurückbleiben. Allerdings darf sie die Untergrenze eines Eigentumsäquivalents nicht unterschreiten. ${ }^{1)}$ Von einer Billigkeitsentschädigung ${ }^{3)}$ kann jedoch nicht die Rede sein.

Im übrigen darf nicht verkannt werden, daß Sozialisierungen nach dem Kreis der Betroffenen und dem Ausmaß ihrer Belastung,

1) S. hierzu schon oben S.950 f und die Nachweise.

2) S. oben S. $950 \mathrm{f}$.

3) S. oben b, bb (S.953 ff).

4) S. die lapidare Bemerkung bei Krüger, a.a.O. S. 319 Fußn. 222. - Zur Übereinstimmung der Enteignungs- und der Sozialisierungsentschädigung $\mathrm{s}$. den bei v. Mangoldt-Klein, Art. 15 Anm. IX 3, angegebenen Meinungsstand. Ipsen (Enteignung und Sozialisierung, S. 115 f) kann - entgegen v. MangoldtKlein - aber nicht für die andere Meinung in Anspruch genommen werden.

1) A.A. Ridder, Enteignung und Sozialisierung, S. 145, 149; ähnlich Weber, Zur Problematik der Enteignung und der Sozialisierung nach neuem deutschem Verfassungsrecht, S.403; ders., Diskussionsbeitrag zu "Enteignung und Sozialisierung", S.165. - S. hierzu auch noch unten e (S. 969 ff).

2) Ridder, a.a.O. S. 145.

3) Ridder, a.a.O. S. 141, 144 f, 149 (s. aber auch S. 174). 
nicht weniger aber auch nach ihrem Zweck ${ }^{4}$ ), keineswegs immer und notwendig rein und unmittelbar der sozialen Integration dienen. 5) Es ist nicht richtig, der Sozialisierung schlechthin zu unterstellen, sie sei als "Sozialentwährung" dadurch ausgezeichnet, daß sie "im Dienste der sozialen Gerechtigkeit und des sozialen gerechten Ausgleichs" stehe, 6) daß sie zwischen dem Eigentum auf der einen und dem "Nichts auf der anderen Seite" ausgleiche ${ }^{7)}$ und daraus $z u$ folgern, sie müsse also - trotz Art. 15 Satz 2 GG! - einem prinzipiell anderen Entschädigungsrecht unterliegen als die Enteignung. ${ }^{8)}$ Es kommt immer auf die konkrete Motivation und Gestaltung eines Sozialisierungsaktes an. ${ }^{9}$ )

4) S. Huber, Wirtschaftsverwaltungsrecht, Bd. II S. 157 f; Krüger, Sozialisierung, S.280 ff mit weit. Nachw.

5) Daß die Sozialisierung notwendig eine gleichheitliche Gruppensozialisierung $z u$ sein hat (s.o. S. 955 zu Fußn.11-13), ändert nichts daran, daß sich sub specie der Entschädigung das Gleichheitsproblem gesondert stellt. Es ist eine Sache $z u$ fragen, ob eine Sozialisierung, würde sie nicht entschädigt, ungleiche Opfer auferlegen würde, und eine ande re Sache, zu fragen, ob eine Sozialisierung nach objektiver und subjektiver Erstreckung "gleich" ist. - Unter diesem Gesichtspunkt sind übrigens auch Vorbehalte gegen Krüger (a.a.O. S. 320) anzubringen, der ausführt: "Da beide Arten der Vergesellschaftung" - gemeint sind die eigentumsentziehende Überführung in Gemeineigentum und die eigentumsbindende Überführung in andere Formen der Gemeinwirtschaft "notwendig allgemein sind, kann hier die Unterscheidung" zwischen Eigentumsbindung und Eigentumsentziehung "nur auf das Kriterium der Tiefenwirkung der Umgestaltung in dem Sinne abgestellt werden, daß es unmittelbar auf die Substanzminderung (nicht Substanzidentität) ankommt". Gewiß verlagert sich bei der Sozialisierung nach Art. 15 GG das Gewicht der Abgrenzung auf die Frage der Substanzintegrität. Aber das Abgrenzungskriterium der Ungleichheit scheidet deshalb nicht aus. Auch eine Gruppensozialisierung kann - ohne deshalb als solche "ungleich" und unzulässig zu sein - einer Gruppe oder einzelnen ihrer Mitglieder Sonderopfer auferlegen, die sie nur gegen Entschädigung hinzunehmen hat bzw. haben.

6) S. Ridder, a.a.O. S. 139

7) ebd. S. 145 .

8) S. о. S.967 zu Fußn.3.

9) Zahlreiche Einzelfragen aus dem Recht der Sozialisierungsentschädigung finden sich erörtert bei Scheuner, Verfassungsschutz des Eigentums, S. 143 ff. 


\section{bbb) Zur funktionalen Bedeutung}

Eine Sozialisierung, die in jedem Falle das - wirklich - "ungleiche" Opfer der Betroffenen auszugleichen und einen - wenngleich vielleicht auch den denkbar niedrigsten - Wertausgleich für das entzogene Gut zu leisten hat, ist von vorneherein kein taugliches Instrument einer sozialen Revolution. Nicht nur können die Mittel für eine größere Sozialisierungsaktion - ohne unlautere inflationäre Machenschaften - kaum je aufgebracht werden. Auch können Vermögensdifferenzen maximal nur in dem Maße eingeebnet werden, in dem nicht die als Wertausgleich zu gewährende Entschädigung dem Expropriierten gestattet, "die gleiche Position mit anderen Mitteln zu behaupten". 1) Aber die Abstellung von Mißbräuchen, die Abhilfe gegenüber engeren Krisensituationen usw. bleibt möglich, und auf lange Sicht auch eine soziale Evolution. ${ }^{2)}$ Die zentrale Bedeutung gerade dieser Entscheidung für das Gesamtbild des sozialen Rechtsstaates bedarf keiner Hervorhebung.

\section{e) Exkurs I: Die soziale Umschichtung \\ a) Zum Begriff}

Der Begriff der sozialen Umschichtung 1) im weitesten Sinn ist ein soziologischer und rechtspolitischer. 2) Als solcher bezeichnet er einen Vorgang, der die verschiedensten Formen der Eigentumsentziehung - Sozialisierung, Enteignung, Konfiskation, "so-

1) Ipsen, Enteignung und Sozialisierung, S. 87 (s. diesen auch zum Vorigen).

2) Dürig (Besprèchung von: Christian Friedrich Menger, Der Begriff des sozialen Rechtsstaats nach dem Bonner Grundgesetz, S.257) charakterisiert das Grundgesetz als eine Verfassung, "die, wie Art. 15 zeigt, eine nur durch einfaches Gesetz aufschiebend bedingte Sozialevolution (rechtsstaatlich gehemmte Sozialrevolution) durchaus in Rechnung stellt". S.a. Huber, Wirtschaftsverwaltungsrecht, Bd. II, S. $50 \mathrm{ff}$.

1) s. Werner Weber, Zur Problematik von Enteignung und Sozialisierung nach neuem Verfassungsrecht, S. $402 \mathrm{f}$; ders., Die Entschädigurg in der westdeutschen Bodenreform, DÖV 6. Jhg. (1953) S. 352 ff (354 f); ders., Eigentum und Enteignung, S. $348 \mathrm{f} \mathrm{u}$. passim; Huber, Wirtschaftsverwaltungsrecht, Bd. II, S. 48 f; Scheuner, Verfassungsschutz des Eigentums, S. $114 \mathrm{f}$ und passim; v. Mangoldt-Klein, Art. 14 Anm. VI 8; Forsthoff, Lehrbuch des Verwaltungsrechts, S. 294; Wolff, Verwaltungsrecht I, S.334 f; unter dem Begriff der "Sozial- 
ziale Umschichtung" als besonderen rechtlichen Typ der Eigentumsentziehung usw. - instrumental einbezieht. Enger gefaßt tritt er auch als Rechtsbegriff auf. Als solcher umschreibt er einen besonderen rechtlichen Typ der Eigentumsentziehung, der selbständig neben dem der Enteignung, der Sozialisierung, der Konfiskation usw. steht oder (und) mehrere Rechtstypen der Eigentumsentziehung zusammenfaßt. ${ }^{3)}$

Wesentlich ist der sozialen Umschichtung, die Eigentumsverteilung $z u$ ändern. Sie wendet sich - bei unterschiedlicher Schärfe des Akzents - gegen die subjektive Vermögenshäufung an sich, gegen das Vermögen einer bestimmten Eigentümergruppe (Klasse, Schicht), 4 ) oder gegen die Massierung bestimmter Vermögenswerte in der Hand weniger Eigentümer. ${ }^{5)}$ Sie führt die abgebauten Vermögenswerte entweder der Allgemeinheit $\mathrm{zu}$, indem sie verstaatlicht oder in anderes Gemeineigentum überführt, 6) oder verteilt sie an eine größere Zahl von Eigentümern. ${ }^{\text {) }}$ 8) Ihr Schwerpunkt kann bei der Depossedierung der bisherigen Eigentümer liegen, 9) aber auch bei der Neuverteilung bzw. der gemeinnützigen Verwendung der betroffenen Güter. ${ }^{10)}$

entwährung" zu demselben Phänomen: Ridder, Enteignung und Sozialisierung, S.138 ff; zum Problem ferner Knoll, Eingriffe in das Eigentum im Zuge der Umgestaltung gesellschaftlicher Verhältnisse.

2) S. Scheuner, a.a.O. S.114.

3) Die begriffliche Unklarheit belastet die Diskussion über die "soziale Umschichtung" als rechtliche Erscheinung und Gegenstand verfassungsrechtlicher Normierung unverhältnismäßig.

4) Ganz vom Depossedierungszweck beherrscht ist der Begriff der sozialen Umschichtung bei Werner Weber (Die Entschädigung in der westdeutschen Bodenreform, S. 354 f; Eigentum und Enteignung, S. 348 f, 351; s.a. Zur Problematik der Enteignung und Sozialisierung nach neuem Verfassungsrecht, $\mathrm{S} .402 \mathrm{f}$ ). Als Belastung einer bestimmten Schicht versteht ferner Forsthoff (a.a.O.) die soziale Umschichtung. Vgl. auch Knoll, a.a.O. AöR Bd. 79 S. 475 ff.

5) S. insbes. Huber, a.a.O.; v. Mangoldt-Klein, a.a.O.; Wolff, a.a.O.; s.a. Knoll, a.a.O.

6) S. Ridder, a.a.O., insbes. S. 140 (s.a. S. 142 Fußn.67).

7) S. Huber, v. Mangoldt-Klein und Wolff je a.a.O.

8) Beides hineinnehmend Weber, Eigentum und Enteignung, $S$. $348 \mathrm{f}$; Knoll, a.a.O. (durchgehend); s.a.Ridder, a.a.O. S. $143 \mathrm{f}$.

9) S. o. Fußn. 4.

10) S. o. Fußn. 5-7. 
bb) Soziale Umschichtung und Gleichheitssatz

Die soziale Umschichtung hat in der verfassungsrechtlichen Ordnung, insbes. auch in der Eigentumsordnung, nur Raum, soweit sie nicht den Gleichheitssatz verletzt. Je mehr sie aber auf subjektiv gezielter, depossedierender Aggressivität beruht, desto mehr neigt sie gerade dazu, wesenhaft "ungleich" zu sein.

Eigentumsentziehungen, die sich gegen eine Gruppe von Eigentümern, deren Gemeinsamkeit nach Art. 3 Abs. 3 GG nicht zum Anlaß einer Differenzierung genommen werden darf, als solche richten, sind schon aus diesem Grunde unzulässig. Das ist insbes. für Eigentümergruppen von Bedeutung, die durch ihre Herkunft verbunden sind. 1) Eine Eigentümerschicht etwa wegen ihrer historischen Funktion - genauer: wegen der historischen Funktion derjenigen, von denen sie abstammt, "her kommt" - zu expropriieren, wäre exemplarisch verfassungswidrig.

Aber auch außerhalb des strengen Art. 3 Abs. 3 GG kann es mit dem Gleichheitssatz grundsätzlich nicht vereinbart werden, daß sich eine Umschichtungsmaßnahme gegen eine Klasse, einen Stand oder eine Schicht in einer irgendwie personalen Abgrenzung richtet. Die bloße Depossedierung einer Gruppe wird in aller Regel ein willkürlicher, feindseliger Akt und ihr Motiv im Verhältnis zur Entziehung des Eigentums sachfremd sein. In der Regel wird sie selbst dann als gleichheitswidrig erscheinen, wenn eine Entschädigung in Betracht gezogen wird. 2)

Andererseits ist nicht jede an die "persönliche soziale Stellung des Eigentümers" und an seinen "Wohlstand" anknüpfende Eigentumsentziehung unzulässig ${ }^{3)}$ und nicht nur die Anknüpfung an die "besondere Funktion der betreffenden Sache innerhalb des Ganzen" gleichheitsgemäß.4) Die aktuelle, im Vermögen bzw. im Einkommen objektivierte soziale Potenz eines Menschen ist ein

1) S.o. S.914 ff und S.931 ff; ferner Scheuner, Verfassungsschutz des Eigentums, S. 73, 111 f, 137.

2) S. nochmals Scheuner, a.a.O. - Deshalb hat von seinem Standpunkt auch Werner Weber, der die soziale Umschichtung als einseitige Depossedierungsmaßnahme kennzeichnet (s.o. S. 965 zu Fußn.4), grundsätzlich recht, wenn er die soziale Umschichtung für unzulässig hält. (Die Entschädigung in der westdeutschen Bodenreform, S. 354 f; Eigentum und Enteignung, S. 348 f, 352, 357 ff, 361, 365, 388 ff; s.a. Huber, Wirt schaft sverwaltungsrecht, Bd. II, S.48).

3) So aber Scheuner, a.a.O. S.112, 137.

4) So aber Scheuner, a.a.O. S.111, s.a. S.73. 
zulässiges, ja notwendiges Unterscheidungsmoment für seine Beteiligung am sozialen Ausgleich. ${ }^{5)}$ Das Gegenteil hieße die Sozialstaatlichkeit ignorieren. Gleichheit ist immer auch sozial wertende Gleichheit. ${ }^{6}$ ) Soziale Umschichtung darf zwar nicht ein von Neid, Habgier oder Rachsucht diktierter sozialer Rollentausch sein. 7) Sie darf auch nicht eine mechanisch-formale sondern nur eine relative, "gerechte" Gleichheit anstreben. Sie darf das sozial-gerecht notwendige Maß staatlicher Korrektur der sozialen Verhältnisse nicht überschreiten. In diesen Grenzen ist sie aber nicht Widerspruch zum Gleichheitssatz sondern Ausdruck von Sozialstaatlichkeit und Gleichheit.

c) Soziale Umschichtung und Verfassungsgarantie des Eigentums

aaa) Soziale Umschichtung im Rahmen der allgemeinen Eigentumsentziehungstypen der Verfassung

1. Übersicht. Die positiv-verfassungsrechtliche Eigentumsgarantie läßt - abgesehen von der Abgabenerhebung, auf die gesondert zurückzukommen ist, 1) - drei grundsätzlich einschlägige Fälle der Eigentumsentziehung zu: die Enteignung, ${ }^{2)}$ die Sozialisierung und die Konfiskation.

Der Konfiskation 3) ist die soziale Umschichtung durch die ihr nicht selten beigelegte Entschädigungsfeindlichkeit und ihre subjektive Aggressivität verbunden. ${ }^{4}$ ) Die Verfassung steckt der Konfiskation jedoch Grenzen, ${ }^{5)}$ die sie als direktes Instrument sozialer Umschichtung ausschalten.6) Verbleiben also Enteignung und Sozialisierung.

5) Insbes. ist sie nicht "Herkunft" i.S. des Art. 3 Abs. 3 GG (s.o. S.931 ff).

6) S.o. II $2 \mathrm{~b} \mathrm{bb}(\mathrm{S} .898 \mathrm{ff})$, insbes. S.898ff.

7) S.o. S.832 ff.

1) S.u. S.987ff.

2) Der Umlegung kommt eine eigene, nicht schon durch die Enteignung umschlossene Problematik in diesem Zusammenhang nicht zu (s.o. S.962 f).

3) S.o. S.952 zu Fußn. 4.

4) S. hierzu Ridder, Enteignung und Sozialisierung, S. $140 \mathrm{f}$.

5) S.o.S.952 zu Fußn. 5 und 6. S.a. nochmals vorstehend S.971.

6) S.a. Weber, Die Entschädigung in der westdeutschen Bodenreform, S. $353 \mathrm{f}$. 
2. Soziale Umschichtung im Rahmen von Enteignung und Sozialisierung. Die Sozialisierung ist der sozialen Umschichtung in besonderer Weise gemäß. 7) Zwar darf sie nicht nur als ein Institut der sozialen Umschichtung betrachtet werden. Sie kann auch anderen wirtschafts- oder sozialpolitischen $Z$ wecken dienstbar sein. ${ }^{8}$ ) Aber sie erlaubt eine Neuverfassung des Eigentums, die sich gegen das Privateigentum an gewissen Gütern - somit also auch im Sinne der sozialen Umschichtung gegen die Anhäufung gewisser Güter in privater Hand 9) - richten kann, und deren vergesellschaftende Zuführung an die Allgemeinheit, d.h. mittelbar also auch an die bisher Ausgeschlossenen.

Aber die Sozialisierung ist gegenständlich beschränkt. 10) Die Sozialisierung ist ferner kein geeignetes Mittel, um die abzubauenden Vermögensmassen nicht nur kollektiven Gemeineigentumsträgern sondern auch individuellen Eigentumsträgern zuzuführen. 11)

7) Sie wird sogar als das in der Verfassung (allein) zugelassene Institut der Eigentumsumschichtung bezeichnet: vg1. Weber, Eigentum und Enteignung, S. 357, 365, 389; Forsthoff, Lehrbuch des Verwaltungsrechts, S.294; für die "Sozialentwährung" auch Ridder, a.a.O. S. 138 ff. Diese Charakterisierung beruht aber nicht zuletzt auf einer unrichtigen Interpretation insbes. der Entschädigungsklausel des Art. 15 Satz 2 i.V.m. Art. 14 Abs. 3 Satz 3 GG bei Weber und Ridder (s.o. d cc (S. 966 ff)) und darauf, daß Ridder glaubt, Art. 15 GG unter Nichtachtung seiner ausdrücklichen Begrenzungen als verfassungsmäßige Generalermächtigung zu sozial umschichtenden Eingriffen in das Eigentum deuten zu dürfen (s.u. S. 977 ). - Weber unterscheidet an anderer Stelle (Die Problematik der Enteignung und Sozialisierung nach neuem Verfassungsrecht, S. 402 f; Die Entschädigung in der westdeutschen Bodenreform, S.354 f) selbst zwischen der Sozialisierung im allgemeinen, die er als eine (mögliche) Einrichtung sozialer Umschichtung bezeichnet und der Sozialisierung nach Art.15 GG, deren Entschädigungspflichtigkeit er als eine Absage an die soziale Umschichtung wertet.

8) S.o. S.813 ff; S.966ff, S.967 zu Fußn. 4.

9) Zu den Möglichkeiten der Differenzierung s. Krüger, Sozialisierung, S. $315 \mathrm{f}$.

10) S.o. S. $964 \mathrm{ff}$.

11) Vg1. Huber, Wirtschaftsverwaltungsrecht, Bd.II, S.49; v. Mangoldt-Klein, Art. 14 Anm. VI 8; Wolff, Verwaltungsrecht I, 
Sozialisierung ist vor allem aber immer entschädigungspflichtig. Soziale Umschichtung nach Maßgabe der Sozialisierungsbestimmungen ist radikal gebremste Umschichtung. 12)

Dieselbe Einschränkung gilt für die Enteignung. Zwischen der Enteignungs - und der Sozialisierungsentschädi gung besteht kein grundsätzlicher Unterschied. Nicht nur die Sozialisierungs- sondern auch die Enteignungsentschädigung darf einerseits dem sozialen Zweck und Zusammenhang der Eigentumsentziehung angepaßt werden. 13) Aber andererseits geht die Anpassung weder hier noch dort bis zum Entschädigungsentzug wie ihn Art. 153 Abs.2 Satz 2 RV 1919 zur reichsgesetzlichen Disposition stellte - und nicht bis zu einer Nominal- oder Billigkeitsentschädigung unter der Wert- und Opferausgleichsgrenze. 14)

Abgesehen von der Entschädigungspflicht ist die Enteignung als Instrument der sozialen Umschichtung vor allem dadurch beschränkt, daß sie nicht unmittelbar und ausschließlich in den Dienst des Abbaues gegebenen Eigentums und seiner Neuverfassung genommen werden darf. 15) Sie "darf nicht dazu dienen, bloß jemandes Vermögensposition zu vernichten und ihn zu entrechten oder bloß Vermögensrechte von dem bisherigen Träger auf einen anderen umzuschichten". 16) Die Enteignung muß vom Wohl der Allgemeinheit erfordert sein; ${ }^{17)}$ d. h. die zu brechende Eigen-

S. 334; Krüger, a.a.O. S. 286 ff (passim). S.ferner Ridder, Enteignung und Sozialisierung, S. 143 f, 149, der nach der Möglichkeit einer analogen Anwendung des Art.15 GG sucht (s.u. S. 977 ); Knoll, Eingriffe in das Eigentum im Zuge der Umgestaltung gesellschaftlicher Verhältnisse, AöR Bd.79 S. 482, der für die "Sozialisierung" von Grund und Boden zu einer extensiven Auslegung kommen will.

12) S.o. d cc (S.966 ff), insbes. S.969.

13) Vgl. Knoll, a.a.O. AöR Bd. 79 S. 495 f, Bd. 81 S. 394 f, 416 ff.

14) S. zu Vorstehendem nochmals oben b, bb, aaa ( $\mathrm{S}, 953 \mathrm{ff})$ und d, cc (S. $966 \mathrm{ff})$.

15). S. Krüger, Sozialisierung, S.318. - Ohne Einschränkung auf die bedarfsseitig orientierte Umschichtung wird die Enteignung als Instrument der nicht kollektivierenden Eigentumsumschichtung zugelassen von Wolff, Verwaltungsrecht I, S.334 f. Analog wird sie zugelassen von Huber, Wirtschaftsverwaltungsrecht Bd.II, S. 48 f. S. hierzu auch Knoll, Eingriffe in das Eigentum im Zuge der Umgestaltung gesellschaftlicher Verhältnisse, AöR Bd.81 S.394 f, 416 ff.

16) Weber, Eigentum und Enteignung, S. 383.

17) S. о. S. 953 zu Fußn. 4. 
tumsherrschaft muß deshalb stören, weil sie einer dem öffentlichen Wohl dienenden $\mathrm{Zweckbestimmung} \mathrm{in} \mathrm{bezug} \mathrm{auf} \mathrm{das} \mathrm{inne} \mathrm{ge-}$ haltene, zu enteignende Gut im Wege steht. 18) Die Enteignung muß als soziale Umschichtung daher von der Bedarfsseite erfordert und gesteuert sein.

Das entfremdet die Enteignung der sozialen Umschichtung nicht völlig. 19) Der Sozialstaat ist immer in der Zwangslage, helfen und geben zu müssen. Befriedigt der Staat mit einer Umschichtungsaktion sein Bedürfnis, im Interesse des öffentlichen Wohles verteilen zu können, so stellt sich die entsprechende Eigentumsentziehung als Enteignung dar. Dem steht die eventuelle Unmittelbarkeit der Umschichtung nicht entgegen. Wenigstens eine "logische Sekunde" lang ist der umschichtende, enteignende Staat Herr des entzogenen Eigentumsobjekts, das er alsdann weitergibt. Wenigstens in dieser "logischen Sekunde" vollzieht sich eine Zweckänderung des Eigentumsobjektes, wie sie verschiedentlich für eine Essentiale der Enteignung gehalten wird; 20 ) denn es dient in diesem Durchgangsstadium dem Staat, der sich seiner bemächtigt hat, jenen Aufgaben nachzukommen, deretwegen er es an sich gezogen hat.

Die Enteignung ist aber nicht etwa in der Weise ein Gegenstück der Sozialisierung, daß diese die Neuverfassung des Eigentums durch Vergemeinschaftung, jene dagegen die Neuverfassung des Eigentums durch Begründung neuen individuellen Eigentums er-

18) S. die oben S. 970 zu Fußn.5 Zitierten.

19) A.A. wohl Ridder, Enteignung und Sozialisierung, S. 139: "Der Eingriff der Sozialentwährung... dient nicht einzelnen konkreten positiven Verwaltungsvorhaben, sondern steht nach dem Willen des sich hier vor allem sozialstaatlich gebarenden Staats im Dienste der sozialen Gerechtigkeit und des sozialen gerechten Ausgleichs. Nur deswegen und nur unter dem Bezugspunkt der sozialen Gerechtigkeit wird dem 'Wohl der Allgemeinheit' gedient, während bei der Enteignung die Erwägungen materieller Nützlichkeit ohne diese Bezugnahme tragend sind". Wie denn, wenn nichts anderes zum "einzelnen konkreten positiven Verwaltungsvorhaben" wird als die Erfüllung "sozialer Gerechtigkeit" und der "soziale gerechte Ausgleich"? Heißt es nicht den Sozialstaat eher apostrophieren als erkennen, wenn gerade diese Möglichkeit außer acht gelassen wird? - Für den Text darf in etwa auch Wolff (s.o. S. 974 zu Fußn.15) in Anspruch genommen werden.

20) S. Huber und v. Mangoldt-Klein, a.o. (S. 973 zu Fußn. 11) a. O. 
möglicht. 21) Das isolierte Bedürfnis nach einer Neuverfassung des Eigentums kann nur über die Sozialisierung befriedigt werden, nur für die ihr unterliegenden Güter und nur in Richtung auf das Gemeineigentum. 22) Gerade das ist auch sachgemäß, wenn das Eigentum nicht von vorneherein wegen individueller, in die Verantwortung der Gemeinschaft fallender Mangellagen sondern nur wegen anderer, direkt auf das bestehende Eigentum bezogener Interessen der Gemeinschaft entzogen wird. Die Verfassung vermutet durch Art.15 GG unwiderleglich, daß eine Entziehung des Eigentums lediglich um seiner eigenen Ordnung willen nur hinsichtlich der dort genannten Gegenstände notwendig werden kann. 23) In dieser Beschränkung erweist sich die Enteignung dem sozialstaatlichen Verfassungsbild in besonderer Weise homogen. Der Sozialstaat ist ein Staat des Ausgleiches von der Notwendigkeit der sozialen Hilfe, der Beseitigung sozialer Mangellagen her. Er ist nicht an sich ein Staat der Nivellierung. Er nimmt von "oben" und enthält "oben" nur vor, um "unten" geben zu können.

\section{bbb) Weitere Wege sozialer Umschichtung?}

1. Der Anla $B$ der Frage. Die verfassungsmäßigen Typen der Eigentumsentziehung befriedigen die an sich denkbaren Bedürfnisse einer sozialen Umschichtung 1) unter zwei Aspekten nicht: einmal insofern, als sie keine entschädigungslose oder minderentschädigte Eigentumswegnahme erlauben; ferner insofern, als sie eine von der unmittelbaren Notwendigkeit der Entziehung und Neugestaltung der Eigentumsherrschaft (und nicht von dem Bedarf an den entzogenen Gütern) bestimmte Entziehung außerhalb der verfassungsrechtlich geregelten Sozialisierung nicht zulassen. ${ }^{2}$ Um den danach unberücksichtigten Interessen

21) Zur sozialen Umschichtung durch Abbau und Neubegründung individuellen Eigentums s. 0. S.970 zu Fußn. 7 und 8. Zum Ausschluß der Sozialisierung von dieser Bewegung s.o. S. 973 zu Fußn. 11.

22) S.a. Ipsen, Enteignung und Sozialisierung, S. 104. S. ferner nochmals S.973 zu Fußn. 11.

23) Krüger, Sozialisierung, S. 318: "eine eigentumsentziehende Vergesellschaftung der in Art. 15 nicht genannten Gegenstände auf dem Umwege über Art. 14 III" ist "nicht möglich".

i) S. nochmals oben S.969f.

2) Daneben bleibt das Bedürfnis nach einer diskriminierenden Umschichtung unbefriedigt. Diesem Bedürfnis stellt sich jedoch schon der Gleichheitssatz entgegen (s.o. S.971f). Deshalb erübrigt es sich, im eigentumsrechtlichen Zusammen- 
entgegenkommen zu können, hat sich das Schrifttum bemüht, gewissermaßen iuxta constitutionem, besondere Eigentumsentziehungstypen der sozialen Umschichtung zu rechtfertigen.

2. Soziale Umschichtung als Inhaltsbestimmung des Eigentums? Der Versuch, die entschädigungslose Entziehung von "sozial mißbilligtem" Eigentum als Inhaltsbestimmung des Eigentums zu rechtfertigen, muß constitutione lata erfolglos bleiben. 3 )

3. Die "Sozialentwährung"? Getragen von der Überzeugung, die Verfassung könne den Weg einer minderentschädigten sozialen Umschichtung nicht schlechthin verschlossen haben, glaubte man, die Sozialisierung (Art.15 GG) als - nur äußerlich unvollkommenen - Ausdruck des entsprechenden konstitutionellen Wollens verstehen zu müssen. Als minder zu entschädigen wurde sie der voll entschädigungspflichtigen Enteignung gegenübergestellt. 4) Als "Sozialentwährung" (Ridder) auch (sprachlich) verallgemeinert sollte sie nicht nur die Vergemeinschaftung sondern auch die minderentschädigte Entziehung von Eigentum zum $Z$ wecke der Neubegründung individuellen Eigentums ermöglichen. ${ }^{5)}$ Das alles widerspricht aber der eindeutigen Aussage des Art.15 GG. Die Kongruenz der Enteignungs- und Sozialisierungsentschädigung ist in der Verfassung klar angeordnet (Art.15 Satz 2 i.V.m. Art. 14 Abs. 3 Satz 3 GG).6) Art.15 GG ist auch zu sehr positive und negative Entscheidung über die Grenzen der Sozialisierung, als daß die analoge Erstreckung seiner Eigentumsentziehungsermächtigung auf sachlich außerhalb Liegendes zulässig wäre. 7)

4. Die "soziale Umschichtung" als besonderer Eigentumsentziehungstyp. Das Bedürfnis, eine soziale

hang näher darauf einzugehen. - Zu den Grenzen der Konfiskation s. nochmals oben S.972.

3) S. o. S. $943 \mathrm{ff}$.

4) S. Ridder und - der Sache nach auch - Werner Weber, o. S. 967 zu Fußn. 1 ff. - Weber ist dabei allerdings nicht ganz konsequent, soweit er die Sozialisierung zwar nach geltendem Recht als Absage an die soziale Umschichtung ansieht (s.o. S. 973 zu Fußn. 7 a.E.), sie aber doch minderentschädigen will.

5) S. Ridder, Enteignung und Sozialisierung, S. $138 \mathrm{ff}$, insbes. S. 143 f, 149 .

6) S. o. d cc (S. 966 ff) und oben S. 974 zu Fußn. 13 und 14.

7) S. o. S.964 ff und oben S.973ff, insbes. die Nachw. S. $973 \mathrm{zu}$ Fußn. 11, S. 976 zu Fußn. 22 und 23. 
Umschichtung mit dem Ziele einer individuellen Neuverteilung des Eigentums zu rechtfertigen, hat schließlich zu der Annahme eines ungeschriebenen, verfassungsimmanenten Eigentumsentziehungstyps der "sozialen Umschichtung" geführt: "Eigentumsumschichtung ist ein staatlicher Eingriff, durch den bestimmte Vermögenswerte, die in der Hand von Wenigen konzentriert oder bestimmten Schichten oder Gruppen der Bevölkerung vorenthalten sind, zerlegt und auf eine größere Zah1 von Vermögensträgern aufgeteilt werden, um auf diese Weise die wirtschaftlichen Grundlagen der Gesellschaftsstruktur zu ändern". 8) Diese Eigentumsumschichtung unterscheide sich von der Enteignung dadurch, daß sie die Zweckbestimmung des entzogenen Gutes nicht ändere. ${ }^{9)}$ Der Sozialisierung gegenüber hebe sie sich durch die Individualverteilung anstelle der Kollektivierung ab. 10) Ein Rechtsinstitut dieser Art müsse zulässig sein; denn Bodenreform, Industrieentflechtung und Lastenausgleich gehörten zum Verfassungsbild, seien aber weder Sozialisierung noch Enteignung. Dem Grundgesetz müsse daher "eine ungeschriebene Ermächtigung zu solchen Maßnahmen der Eigentumsreform" unterstellt werden. 11) Für Entschädigung, Rechtsweg usw. seien die Vorschriften über die Enteignung entsprechend anzuwenden. 12)

Ein besonderer Typ einer Eigentumsentziehung dieses Inhalts neben Enteignung und Sozialisierung kann jedoch nicht anerkannt werden. Die Enteignung selbst kann die ihm zu unterstellenden Fälle aufnehmen, soweit sie vom Bedürfnis, zum Wohle der Allgemeinheit individuelles Eigentum neu zuzuteilen, bestimmt werden. 13) Ein Anhaltspunkt dafür, daß auch darüber hinaus noch eine "Ermächtigung zu solchen Maßnahmen der Eigentumsreform" in die Verfassung hineingelesen werden dürfte, besteht nicht.

Unter allen interpretatorisch legitimen Mitteln gibt von vorneherein nur das vorrechtliche Gesamtbild Anlaß zu näherer Prüfung. Aber findet sich darin Überzeugendes?

8) Huber, Wirtschaftsverwaltungsrecht, Bd.II, S.48; entsprechend v. Mangoldt-Klein, Art. 14 Anm. VI 8.

9) S. Huber, a.a.O. S. 48 f; v. Mangoldt-Klein, a.a.O. - S. hierzu schon oben S.975 zu Fußn. 20.

10) S. Huber, a.a.O. S. 48 f; v. Mangoldt-Klein, a.a.O.

11) Huber, a.a.O. S.49. Offen bei v. Mangoldt-Klein, a.a.O.

12) Huber, a.a.O. S. 49. Der Sache nach übereinstimmend Wolff, Verwaltungsrecht I, S. $334 \mathrm{ff}$, der diese soziale Umschichtung der Enteignung inkorporiert.

13) S. oben S. $973 \mathrm{ff}$. 
a) Zum Argument des Lastenausgleichs. Es wird auf den Lastenausgleich hingewiesen. 14) So, wie er gestaltet wurde, gehört er nicht hierher, ist er vielmehr abgabenrechtlicher Natur. 15) Doch selbst wenn er als Sachausgleich geståltet worden wäre, 16) könnte - ja müßte - er doch von der Bedürfnisseite her gedeutet werden. Nicht weil den einen etwas verblieben ist, muß es ihnen genommen werden; sondern weil die anderen etwas verloren haben, muß ihnen gegeben werden. 17) Ein unmittelbar sachneuverteilender Lastenausgleich könnte - wenngleich wegen des notwendigen Minimum an entschädigendem Wertausgleich unter Verlust an Zügigkeit - so gestaltet werden, daß er unter den verfassungsrechtlichen Entziehungstyp der Enteignung subsumiert werden kann.

b) Zum Argument der Entflechtung. Auch die Entflechtung 18) ist ein schlechtes Beispiel. 19) Zwar paßt die Entflechtung nicht in das Eigentumsentziehungsschema des Grundgesetzes. Sie ist weder Enteignung noch Sozialisierung. Richtig ist auch, daß es die Entflechtung bei Erlaß und auch noch unter der Herrschaft des Grundgesetzes gegeben hat. Aber heißt das, daß das Grundgesetz sie als selbstverständlich zulässig angesehen und "verschwiegen" hat? Die Entflechtung war eine besatzungsrechtliche Maßnahme. Das deutsche Recht hatte nicht die Möglichkeit, sich mit der Entflechtung auseinanderzusetzen. Die Entflechtung war von Anfang an heftig umstritten. Sie gehört mitnichten zum unproblematischen Bestand verfassungsrechtlich zulässiger Eigentumsentziehung.

14) S. Huber, a.a.O. S.49; v. Mangoldt-Klein, a.a.O.

15) Das erwähnt auch Huber (a.a.O.) selbst. Deshalb wohl nimmt Wolff (a.a.O. S.335) den Lastenausgleich von der "sozialen Umschichtung" aus.

16) S.a. Knoll, Eingriffe in das Eigentum im Zuge der Umgestaltung gesellschaftlicher Verhältnisse, AöR Bd.79, S.472 f.

17) Vgl. schon die Systematik des Soforthilfegesetzes, insbes. seinen $₫ 1$. S. nunmehr die Präambel des Lastenausgleichsgesetzes und dessen $\$ \$ 1 \mathrm{ff}$.

18) Zur eigentumsrechtlich sehr wichtigen (bei Knoll, a.a.O. $\mathrm{S} .461 \mathrm{f} \mathrm{z}$. B. nicht hervortretenden) Unterscheidung zwischen Entflechtung und Dekartellierung s. Huber, Wirtschaftsverwaltungsrecht Bd.I, S.342 f. Zur Darstellung der Entflechtung s. ebd. S. $335 \mathrm{ff}, 436 \mathrm{ff}, 794 \mathrm{ff}$.

19) Angeführt bei Huber, Wirtschaftsverwaltungsrecht, Bd. II, S. 49; v. Mangoldt-Klein, Art.14 Anm. VI 8. Als Beispiel für einen Fall der "Sozialentwährung" iuxta legem (Art.15 GG) angeführt bei Ridder, Enteignung und Sozialisierung, S. $143 \mathrm{f}$. S.a. Knoll, a.a.O. 
c) Zum Argument der Bodenreform. Bleibt die Bodenreform.20) Der Begriff deckt eine stark variierende Erscheinung. ${ }^{21)}$ Sie kann unproblematische Enteignung sein, wenn sie "Verwaltungszwecke" 22) wie die Siedlung, die Stützung des landwirtschaftlichen Kleinbesitzes oder ähnlichen sozial- und agrarpolitischen Inhalts verfolgt. 23) Sie kann unproblematisch Sozialisierung sein, wenn sie "Grund und Boden... in Gemeineigentum oder in andere Formen der Gemeinwirtschaft" überführt. 24) Aber sie kann auch einseitig den Abbau des landwirtschaftlichen Großgrundbesitzes bezwecken. Sie kann die Schicht der Großgrundbesitzer diskriminieren und "entmachten" wollen. Dann fällt sie aus dem Rahmen der Enteignung heraus. 25)

Konnte und wollte die Verfassung aber darauf wirklich nicht verzichten? Ja, war ihr eine Eigentumsentziehung dieser Zwecksetzung und dieses Inhalts so selbstverständlich, daß der Verfassunggeber glauben durfte, eine Regelung sei nicht nötig? Die Frage verneint sich wohl von selbst. Z war haben sich die Bodenreformgesetze der Nachkriegszeit - teils von den Besatzungsmächten erlassen, teils von diesen urgiert, teils vor den Verfassungen ergangen, teils sonstwie kein glaubwürdiger Ausdruck einer bewußten Verfassungspraxis 26 ) - nicht immer in den der Enteignung gesteckten Zweckgrenzen gehalten 27 ) (während sie an-

20) Als Beispiel der sozialen Umschichtung in dem hier in Frage stehenden Sinn angeführt bei Huber und v. Mangoldt-Klein, a.a.O. In verwandtem Sinne als möglicher Analogiefall zur Sozialisierung erwähnt bei Ridder, a.a.O. S. 143 .

2.1) S. v. Frauendorfer, Art. "Bodenreform" im Handwörterbuch der Sozialwissenschaften, Bd.2, 1959, S.336 ff (insbes. S. $336 \mathrm{ff}, 341 \mathrm{ff})$.

22) S. Ridder, a.a.O. S. 143 (und S.139).

23) Vg1. Ridder, a.a.O. S. 143; Knoll, Eingriffe in das Eigentum im Zuge der Umgestaltung gesellschaftlicher Verhältnisse, AöR Bd. 79 S. 462 ff und passim. S.ferner die Nachweise unten S. 981 zu Fußn. 29.

24) S. dazu auch den Versuch Knolls einer ausdehnenden Auslegung des Art. 15 (s.Knoll, a.a.O. S.482).

$25)$ S. insbes. Knoll, a.a.O. AöR Bd. 79 S. 462 ff, 475 ff (insbes. S. $481 \mathrm{ff}, 490 \mathrm{ff}$ ); Werner Weber, Die Entschädigung in der westdeutschen Bodenreform, insbes. S. $354 \mathrm{ff}$; ders., Die Rechtsbeständigkeit der Bodenreformgesetze in Hessen, 1954, insbes. S. $6 \mathrm{ff}$.

26) S. die Zusammenstellung der Gesetze bei Huber, Wirtschaftsverwaltungsrecht, Bd. II, S. 72 f; ferner Ehrenforth, Das Recht der Siedlung und Bodenreform. 
dererseits von der Möglichkeit der Überführung in Gemeineigentum keinen Gebrauch machten). 28) A ber die Abweichungen können als solche des Grades, des Akzentes gewertet werden. 29) Die Prätention einer exzeptionellen verfassungsrechtlichen $\mathrm{Zu}-$ lassung muß ihnen nicht beigelegt werden; genau so wie umgekehrt keine Anhaltspunkte dafür vorliegen, der Verfassunggeber sei sich der Divergenz zwischen Enteignungsrecht und Bodenreform recht bewußt gewesen und habe sie billigend hingenommen. Die herrschende Meinung nimmt denn auch an, die Bodenreform müsse, um zulässig zu sein, als Enteignung gerechtfertigt werden können. ${ }^{30)}$

27) S. die S.980 zu Fußn.25 Zitierten; ferner Huber, Wirtschaftsverwaltungsrecht, Bd. II, S. 73 .

28) S. Ehrenforth, a.a.O. "Einführung" (Bd. I) S. 83 a./84 m. w. Nachw.

29) Für die Charakterisierung der Bodenreform als Enteignung s. Kirchhoff, Die Enteignungsentschädigung in der Bodenreform, Recht der Landwirtschaft, 3.Jhg. (1951) S. 315 ff (316); Weber, Die Entschädigung in der westdeutschen Bodenreform, insbes. S. 354, 357; Diester, Enteignung und Entschädigung, 1953, S. $125 \mathrm{ff}$; Knoll, a.a.O. für die Bodenreform in der amerikanischen Zone; Reinhardt, Verfassungsschutz des Eigentums, 1954, S. 38 f; Scheuner ebd. S. 114 f; Hans J. Wolff, Verwaltungsrecht I, S.334 f; Ehrenforth, a.a.O. S. 79 ff; Hamann, Das Grundgesetz, Art. 14 Anm.C 8; Seufert, Bayerisches Enteignungsrecht, S.338; Möhring, Bodenreform und Verfassungsrecht, Recht der Landwirtschaft, 9. Jhg. (1957) S. 1 ff; BVerwGE 1, 140 (142 f); Württ. -Bad.VGH ESVGH 2, 205 (214).

30) S. die Fußn. 29 Zitierten; ferner Weber, Die Rechtsbeständigkeit der Bodenreformgesetze in Hessen, S. 3 ff. A. A. Huber, Wirtschaftsverwaltungsrecht, Bd. II S. 48 f (wegen des besonderen Rechtsinstituts der "sozialen Umschichtung' '); unentschieden insofern v. Mangoldt-Klein, Art. 14 Anm.VI 8. - Abweichend ferner unter Berufung auf die "soziale Umschichtung" als Bestimmung des Eigentumsinhalts: Sellschopp, Die Frage der Entschädigung in der Bodenreform; ders., Enteignung und Entschädigung in der Bodenreform; Knoll, a.a.O., insbes. Bd. 79 S. $481 \mathrm{ff}, 490 \mathrm{ff}$ - A. A. mit Rücksicht auf eine unrichtige, extreme Einzelaktlehre, welche in der Bodenreform wegen ihrer "Allgemeinheit" keine Enteignung sieht: Schulte, Die Rechtsgültigkeit der Bodenreformgesetzgebung in der britischen Zone, MDR 6. Jhg. (1952) S. 321 ff (322 f); Sellschopp, Die Frage der Entschädigung in der Bodenreform, S.244; ders., Enteignung und Ent- 
Der für die "soziale Umschichtung" beanspruchte Spielraum neben Enteignung und Sozialisierung läßt sich demnach nicht nachweisen.

\section{dd) Schlußbemerkung}

Zusammenfassend ist festzustellen: Die Eigentumsgarantie läßt eine soziale Umschichtung - außerhalb des Abgabenrechts - nur im Rahmen der Sozialisierung und der Enteignung zu. Es gibt keine soziale Umschichtung ohne entsprechende Entschädigung. 1) Es gibt - außerhalb der Sozialisierung - keine Enteignung, die nicht in der für die Enteignung spezifischen Weise unter dem Gebot des "Wohles der Allgemeinheit" stünde. Einen anderen Weg, das Eigentum sozial umschichtend zu entziehen, gibt es nicht. Ein eigenes (zusätzliches) Rechtsinstitut der "sozialen Umschichtung" ist dem geltenden Verfassungsrecht unbekannt.

Wer unter einer sozialen Umschichtung im soziologisch-rechtspolitischen Sinn eine entschädigungslose oder doch minderentschädigte Eigentumswegnahme versteht, kann mit Recht sagen, sie sei nicht zulässig. 2) Wer dagegen auch einen evolutionären, Eigentum und Besitzstand prinzipiell bejahenden und nur unter dem Vorbehalt des Wert- und Opferausgleiches umschichtenden Vorgang darunter begreift, muß ihre verfassungsrechtliche $\mathrm{Zu}$ lässigkeit anerkennen.

f) Exkurs II: Das Mitbestimmungsrecht im Schnittpunkt der Probleme

a) Allgemeines

Betriebliche Mitwirkung und Mitbestimmung sind nicht, wie gerne angenommen wird, 1) wesensmäßig Einrichtungen der Sozialisierung. ${ }^{2}$ Sozialisierung ist nicht nur Eigentümerwechsel, nicht nur Überführung des Eigentums auf ein Kollektiv und nicht nur Bindung des Eigentums an die mitverwaltende Einflußnahme eines Kollektivs. Sozialisierung ist notwendig Indienstnahme des Eigentums für die Gesamtgesellschaft. ${ }^{3)}$ Diese wird durch die Mitherrschaft des Betriebskollektivs über das Unternehmenseigentum al-

schädigung in der Bodenreform, S. 47.

1) S. Scheuner, Verfassungsschutz des Eigentums, S. 114 f; s. aber auch Huber, Wirtschaftsverwaltungsrecht, Bd. II, S. 49. Vgl. ferner die oben S. 981 zu Fußn.29 Zitierten.

2) S.a. Ipsen, Enteignung und Sozialisierung, S.90.

1) S.o. S. 950 zu Fußn.6.

2) S.Krüger, Sozialisierung, S.290 f, 298. 
lein nicht hinreichend sichergestellt. Vielmehr müssen zusätzliche Sicherungen zugunsten der Gesamtgesellschaft getroffen werden. Betriebliche Mitwirkung und Mitbestimmung kann als Sozialisierung darüber hinaus nur dort gewertet werden, wo sie sich im sachlichen Anwendungsbereich des Art.15 GG bewegt.

Die Unterscheidung zwischen sozialisierender und nicht sozialisierender betrieblicher Kollektivierung wird in jenem Grenzbereich $z$ wischen Eigentumsbindung und Eigentumsentziehung erheblich, in dem allenfalls noch eine sozialisierende Eigentumsbindung zulässig ist, während eine gleich intensive nicht sozialisierende Beschränkung der Eigentümerstellung schon als ein enteignender Substanzeingriff qualifiziert werden muß. 4) Dabei ist nicht zu übersehen, daß für den Eigentümer die Mitbestimmung ausschließlich durch das Betriebskollektiv möglicherweise weniger belastend wirkt als die Mitbestimmung von außen, die mit der Sozialisierung verbunden ist. Aber die gesteigerte Sozialbindung der in Art.15 GG bezeichneten Produktionsgüter kann nur im Wege der Sozialisierung in Anspruch genommen werden.

Die eigentumsentziehende Steigerung des Mitbestimmungsrechts ist ferner als Sozialisierung auch zum (bloßen) Zweck der Neuverfassung des Eigentums zulässig. Ist sie nicht als Sozialisierung ausgestaltet, so ist sie nur als Enteignung, d.h. also nur dann zulässig, wenn die Entziehung des Eigentums und seine Übertragung auf das Betriebskollektiv - in der für die Enteignung spezifischen Weise - zum Wohle der Allgemeinheit geboten ist. 5) Die theoretische Möglichkeit ist praktisch geringfügig. In jedem Fall ist die Eigentumsentziehung zu entschädigen. 6 )

\section{bb) Zur konkreten Grenzziehung}

Allgemein kann festgestellt werden, daß sich das gegenwärtige positive Betriebsverfassungs- und Mitbestimmungsrecht noch im Rahmen der Eigentumsbindung bewegt; 1 ) dies freilich teils hart an der Grenze zur Entziehung. 2)

3) S.o. S. 965 zu Fußn. 4 und 5.

4) S.o. S. $950 \mathrm{f}$.

5) S.hierzu nochmals oben S.973 ff.

6) S.hierzu auch nochmals oben e (S.969 ff).

1) U.M., Wirtschaftliches Mitbestimmungsrecht und Enteignung, S. 369 f; Küchenhoff, Mitbestimmungsrecht und Grundrechte, DÖV 5.Jhg. (1952) S.453 ff (454); Ipsen, Enteignung und Sozialisierung, S.115 f; Ridder, dass. S. 142 f; Huber, Wirtschaftsverwaltungsrecht, Bd. II, S. 149 f, 571 ff; ders., Der Streit um das Wirtschaftsverfassungsrecht, S.173; 
aaa) Zum Betriebsverfassungsrecht

Zugunsten der Qualifikation der Mitwirkung und Mitbestimmung der Arbeitnehmer nach dem geltenden Betriebsverfassungsgesetz als Eigentumsbindung fällt vor allem die gegenständliche Beschränkung ( $\$ 72$ BetrVG) und die bedingte, das Verfügungsrecht des Eigentümers im Kern erhaltende Sanktion ( $\$ \$ 73,74$ BetrVG) des sog. wirtschaftlichen Mitbestimmungsrechts ins Gewicht; denn dieses tritt dem Eigentümerrecht am nächsten. Allerdings kann das Eigentum auch von der sozialen und personellen Mitbestimmung her arg bedrängt werden, so daß immer das Gesamtbild zu entscheiden hat.

Die Grenzen, die einer eventuellen Erweiterung der Kollektivrechte gezogen sind, sind vor allem mil Rücksicht auf zwei Umstände zu bestimmen.

Der eine ist der soziale Zweck des Betriebsverfassungsrechts. $\left.{ }^{1}\right)$ Er erlaubt ein relativ weitgehendes Eindringen in das (sozialstaatlich zu bestimmende) Eigentum. 2)

Der andere Umstand wirkt gegenläufig: Die Betriebsverfassung in ihrer gegenwärtigen Gestalt ist keine Vergesellschaftung. Sehr zweifelhaft ist schon, ob sie institutionell als solche bezeichnet werden kann. Was kann an "gemeinwirtschaftlichen" Elementen gefunden werden? Die "konstitutionelle" Beschränkung der Unternehmerdisposition durch die Belegschaft, welche die Gemeinwirtschaftlichkeit zwar nicht konstituiert, wohl aber der Tendenz nach fördert; 3 ) der gesetzliche Anruf an Arbeitgeber und Betriebsrat, "unter Berücksichtigung des Gemeinwohls" zu verfahren ( $\$ 49$ Abs. 1 BetrVG), der, was seine Erfüllung durch den Betriebsrat betrifft, durch die arbeitsgerichtliche Kompetenz, auf Antrag eines Viertels der Arbeitnehmer, des Arbeitgebers, einer

Olbersdorf, Sozialer Rechtsstaat und Arbeitsrecht, S. 910 (im besonderen unter Berufung auf das Sozialstaatsprinzip); Nipperdev, Lehrbuch des Arbeitsrechts, Bd. II, S. 910 (ebenfalls unter Berufung auf das Sozialstaatsprinzip); Ballerstedt, Wirtschaftsverfassungsrecht, S. 80 .

2) S. insbes. U.M. und Huber, je a.a.O.; s.a. Weber, Eigentum und Enteignung, S. 359; Ridder, a.a.O. S. 142 f.

1) Zur sozialstaatlichen Notwendigkeit einer betriebsverfassungsrechtlichen Beschränkung der Unternehmerposition s. oben S. $788 \mathrm{f}$.

2) S. Olbersdorf und Nipperdey a.o. (S. 983 zu Fußn.1) a.O.

3) S. die oben S. 950 Fußn.6 Zitierten. Insofern zu weitgehend ablehnend Krüger, Sozialisierung, S. 290 f, 298; s. dazu schon oben S. 965 zu Fußn. 5 . 
im Betrieb vertretenen Gewerkschaft, und, soweit er sich gegen ein Betriebsratsmitglied wendet, auch des Betriebsrats, den Betriebsrat wegen "grober Vernachlässigung seiner gesetzlichen Pflichten" aufzulösen bzw. ein Betriebsratsmitglied aus entsprechendem Grund zu entlassen ( $\$ 23$ Abs. 1 BetrVG), eine zweifelhafte Sanktion erfährt; die Ingerenz der Gewerkschaften ( $\$ \$ 23$ Abs. 1, 31, 34 Abs. 1, 45 Satz 1 BetrVG) und die wesentlich geringere der Arbeitgebervereinigungen ( $\$ 45$ Satz 2 BetrVG), die auch ganz ungeachtet ihrer Geringfügigkeit unmittelbar und allein ebensowenig die "Gemeinwirtschaftlichkeit" begründet wie die betriebliche Kollektivierung, aber tendenziell doch in ihrer Richtung liegt; ${ }^{4}$ ) schließlich die hilfsweise statliche Ernennung des Vorsitzenden der Einigungsstelle ( $\$ 50$ Abs. 1 Satz 3 BetrVG) für die soziale Mitbestimmung sowie die behördliche Schlichtung und die hilfsweise Ernennung des Vorsitzenden der Vermittlungsstelle im Rahmen der wirtschaftlichen Mitbestimmung ( $\$ 72$ Abs. 2 BetrVG). Ob das ausreicht, die betriebliche Mitwirkung und Mitbestimmung als Vergesellschaftung zu klassifizieren, braucht aber letztlich nicht entschieden zu werden; denn es fehlt an einer Art.15 GG entsprechenden gegenständlichen Beschränkung des Betriebsverfassungsrechts. Das liegt in ihrem Wesen. Sie zielt auf die Hebung der sozialen Lage der Arbeitnehmer ab, wo immer sie in einem Unternehmen stehen.

\section{bbb) Zum engeren Mitbestimmungsrecht}

Das Maß für die zulässige Ausdehnung des allgemeinen betrieblichen Mitbestimmungsrechts darf keinesfalls von dem engeren Mitbestimmungsrecht der Arbeitnehmer in den Aufsichtsräten und Vorständen der Unternehmen des Bergbaues und der Eisen und Stahl erzeugenden Industrie genommen werden. Wenn gesagt wird, die Parität dieses Mitbestimmungsrechts - in Wahrheit eine Herrschaft des "elften Mannes" bzw. des "fünfzehnten Mannes" - dürfe nicht überschritten werden, 1) wenn die Mitbestimmung nicht die Substanz des Eigentums angreifen und somit nur mehr als entschädigungspflichtige Sozialisierung (bzw. Enteignung) zulässig sein soll, 2) so gilt das nur für die besonderen Ver-

4) Kritisch (aber auch z u kritisch) gegenüber der Meinung, die Gemeinbindung des Eigentums könne durch die Herrschaft der Sozialverbände, insbes. der Gewerkschaften, gewährleistet werden: Krüger, a.a.O. S.286 ff, $291 \mathrm{ff}$ (passim).

1) Vg1. Ridder, Enteignung und Sozialisierung, S. 369 f; Huber, Der Streit um das Wirtschaftsverfassungsrecht, S. 173.

2) S.a. U.M., Wirtschaftliches Mitbestimmungsrecht und Enteignung, S.369 f; Weber, Eigentum und Enteignung, S.359; 
hältnisse, die das Mitbestimmungsrecht auszeichnen, nicht für das allgemeine Betriebsverfassungsrecht. Eine entsprechend umfassende "Diktatur" der Vorsitzenden der Einigungs- und Vermittlungsausschüsse etwa, wie sie das allgemeine Betriebsverfassungsrecht nur in sehr zurückhaltenden Ansätzen kennt, hätte außerhalb der für das engere Mitbestimmungsrecht kennzeichnenden Grenzen das Eigentum bereits in seiner Substanz verletzt.

Das Mitbestimmungsrecht (im engeren Sinne) zeichnet sich durch vier Eigenschaften aus, die es erlauben, die Eigentümerherrschaft so weitgehend zu beschränken, ohne daß schon der Tatbestand einer Eigentumsentziehung gegeben wäre. Eine teilt es mit dem allgemeinen Betriebsverfassungsrecht: den sozialen Zweck. 3) Die übrigen unterscheiden beide Einrichtungen.

Erstens kann sich das Mitbestimmungsrecht auf die gesteigerte Sozialbindung der nach Art. 15 GG potentiell sozialisierungspflichtigen Güter berufen. Es beschränkt sich auf Unternehmen dieser Art. ${ }^{4}$ )

Zweitens kann es sich auf diese gesteigerte Sozialbindung insofern berufen, als es die Bindung der fraglichen Unternehmen, deren Betriebe schon durch das allgemeine Betriebsverfassungsrecht in der aufgezeigten Weise annähernd "vergesellschaftet" sind, 5) an die Gesamtgesellschaft intensiviert: durch die verstärkte Einschaltung der Gewerkschaften 6) und durch die Mitwirkung des Bundesministers für Arbeit. 7) Bezeichnend ist, daß die Spitzenorganisationen die Möglichkeit haben, einen Kandidaten des Betriebsrates mit der Begründung zu beanstanden, er biete nicht die Gewähr, "zum Wohle des Unternehmens und der gesamten Volkswirtschaft verantwortlich im Aufsichtsrat mitzuarbeiten" ${ }^{\prime \prime}$ ) und daß über die Berechtigung dieser Rüge der Bundesminister für A rbeit endgültig entscheidet.9)

Huber, Wirtschaftsverwaltungsrecht, Bd.II, S. 573 ff.

3) S. o. S. 984 zu Fußn. 1 und 2.

4) $₫ 1$ Abs. 1 des Mitbestimmungsgesetzes, $₫ 1$ Abs. 1 des Mitbestimmungsergänzungsgesetzes.

5) Das Betriebsverfassungsrecht gilt, abgesehen von der Mitwirkung im Aufsichtsrat, auch für die Unternehmen, auf die sich das Mitbestimmungsrecht erstreckt ( $\$ 2$ des Mitbestimmungsgesetzes).

6) $\$ \$ 6 \mathrm{f}$ des Mitbestimmungsgesetzes, $\$ \$ 6 \mathrm{f}$ des Mitbestimmungsergänzungsgesetzes.

7) das.

8) S. $\$ 6$ Abs. 2 Satz 3 des Mitbestimmungsgesetzes.

9) $₫ 6$ Abs. 2 Satz 2 des Mitbestimmungsgesetzes. In dem - 
Drittens aber ist noch hervorzuheben, daß das Mitbestimmungsrecht nur für Gesellschaften mit eigener Rechtspersönlichkeit gilt. 10) Es hat sich nicht das Eigentum dieser Rechtspersönlichkeit am Unternehmen verändert sondern die Struktur dieser Rechtspersönlichkeit. Entscheidend geschmälert wurde das "Eigentum" der Anteilseigner. Und dieses ist, eben weil es eine anteilige Berechtigung an einer fremden Rechtspersönlichkeit ist, an sich stärkeren Veränderungen ausgesetzt als etwa das unmittelbare Sacheigentum natürlicher Personen. 11) Pläne für eine Ausweitung des Mitbestimmungs- und des allgemeinen Betriebsverfassungsrechts werden sorgfältig darauf zu prüfen sein, inwieweit ihnen diese oder entsprechende Besonderheiten zugute kommen und inwieweit sie den allgemeinen Grenzen einer Eigentumsbindung zu unterwerfen sind.

\section{g) Der Eingriff in das Geldvermögen}

Die Erhebung öffentlicher Abgaben folgt grundsätzlich nicht den für die Enteignung geltenden Regeln. 1) Sie kann und muß für den einseitigen Zugriff des Staates auf das Vermögen des einzelnen offenbleiben. Sie entzieht zwar Eigentum, jedoch das "vertretbarste" und teilbarste aller Güter. Sie schont daher die persönlichen Beziehungen zwischen dem einzelnen und seinem Vermögen am meisten. Sie kann maximal "gleich" gestaltet werden, so daß der entschädigungsrechtliche Ausgleich besonderer Opfer grundsätzlich gegenstandslos ist. Geld ist der allgemeinste Nenner materiellen Werts, so daß der Gedanke eines Wertausgleiches für die Hergabe von Geld von vorneherein eine andere Interessenlage voraussetzt als der Austausch eines spezielleren Vermögenswertes gegen eine Geldentschädigung. 2)

späteren - Mitbestimmungsergänzungsgesetz fehlt bezeichnenderweise eine entsprechende Klausel.

10) $₫ 1$ Abs.2 des Mitbestimmungsgesetzes; $₫ 1$ des Mitbestimmungsergänzungsgesetzes.

11) Darauf stellen insbes. Korsch (Mitbestimmung und Eigentum, 1951) und Küchenhoff (Mitbestimmungsrecht und Grundrechte, S. 454) ab.

1) S.f.v.a. BVerfGE 4, 7 (17); 10, 89 (116), 354 (371). - Eine international vergleichende Betrachtung s. bei Mann, Zur Geschichte des Enteignungsrechts, in "Hundert Jahre Deutsches Rechtsleben", Festschrift Deutscher Juristentag, Bd. II 1960, S. $291 \mathrm{ff}$ (316 ff).

2) So rechtfertigt sich, daß der Staat sich mittels der Abgaben einseitig "bereichert"; nicht nimmt die "Bereicherungsabsicht" die Steuer vom Eigentumsschutz aus, wie Haas 
Vor allem die Freiheit der Abgabenerhebung von den Beschränkungen, denen andere Eigentumsentziehungen unterliegen, verschafft ihr die elementare Rolle, die ihr im Rahmen des sozialen Ausgleiches zukommt. ${ }^{3)}$ Die Erhebung von Geldabgaben ist das beweglichste, reibungsärmste und radikalste Mittel der sozialen Umverteilung, das der soziale Rechtsstaat anwenden kann.

Damit soll nicht gesagt sein, die Abgabenerhebung sei von eigentumsrechtlichen Beschränkungen überhaupt frei, und das Eigentumsgrundrecht berühre die Steuergesetzgebung nicht. Das Geld ist ein Bestandteil des Vermögens und das Vermögen ist das wesentliche Schutzobjekt des Eigentumsgrundrechts. ${ }^{4}$ ) Sobald eine Steuer generell so bemessen ist, daß sie nicht mehr aus dem Einkommen bezahlt werden kann sondern aus der Substanz bezahlt werden muß, tritt sie in Konkurrenz mit Konfiskation, Enteignung und Sozialisierung. 5) Es widerspräche der Negation einer entschädigungslosen Entziehung von Eigentum zum Wohle der Allgemeinheit und der Negation einer entschädigungslosen Neu- und Andersverteilung des Eigentums durch die Verfassung, wenn die Abgabenerhebung unbeschränkt in die Substanz eindringen dürfte. 6) Nicht nur das Privateigentum als solches muß erhalten bleiben (Art. 14 Abs. 1 Satz 1 GG). Der Gedanke des Wertausgleichs, der das übrige Recht der Eigentumsentziehung beherrscht, verlangt auch, daß der Besitzstand im Prinzip geschont wird. Andererseits dürfen die Grenzen nicht zu eng gezogen werden. Es wäre falsch, allgemein zu sagen, ein Umverteilungseffekt, der mit Enteignung und Sozialisierung nicht legitim verwirklicht werden könne, dürfte auch im Wege der Abgabenerhebung nicht verwirklicht werden. Damit würde die Sonderstellung der Abga-

(System öffentlichrechtlicher Entschädigungspflichten, S. $23 \mathrm{f}$ ) das anzunehmen scheint.

3) S. schon oben S. 14 zu Fußn. 46.

4) S. oben S. $935 \mathrm{ff}$.

5) Vgl. Knoll, Eingriffe in das Eigentum im Zuge der Umgesta1tung gesellschaftlicher Verhältnisse, AöR Bd.79, S.472; Lerche, Grundrechtsbegrenzungen "durch Gesetz" im Wandel des Verfassungsbildes, S. 527 Fußn. 14.

6) Vgl. Flume, Steuerwesen und Rechtsordnung, S. 61 f; Paulick, Die verfassungsrechtlichen Bindungen des Gesetzgebers beim Erlaß von Steuergesetzen, S.492; ders., Der Grundsatz der Gleichmäßigkeit der Besteuerung, S. 152; Scheuner, Verfassungsschutz des Eigentums, S.212; Weber, Eigentum und Enteignung, S. 359 ff; ders., Diskussionsbeitrag zu "Die Finanzverfassung im Rahmen der Staatsverfassung", S. 81 ff; Huber, Der Streit um das Wirtschaftsverfassungsrecht, 
benerhebung, ihre Herausnahme aus dem System der übrigen Eigentumsentziehungstypen, nach Sinn, Voraussetzungen und Rechtfertigung verkannt. Nicht zuletzt widerspräche es der Verfassungsentscheidung für den Sozialstaat, jeder sozialevolutionären Umverteilung auf dem Abgabenwege die Eigentumsgarantie entgegenzuhalten. "Die Finanzgewalt allein ermöglicht es, das Bekenntnis der Verfassung zum Sozialstaat zu verwirklichen". 7) Der Lastenausgleich ist das eindrucksvollste Beispiel für den notwendigen Spielraum der Steuergesetzgebung. ${ }^{8)}$

Vorausgesetzt ist immer, daß der Grundsatz der Lastengleichheit gewahrt ist. Dieser kann ausnahmsweise, z.B. durch Rückerstattung und Verzinsung einer $Z$ wangsanleihe, auch im Rahmen der Inanspruchnahme von Geldvermögen durch die Leistung einer Entschädigung für eine primär "ungleich" auferlegte Geldleistungspflicht salviert werden. Der Fall ist dem der Enteignung gleichzustellen. ${ }^{9)}$ Es entspricht dem Wesen des Geldes, die Geldabgabe vom Wertausgleich freizustellen. Es entspricht ferner der maximalen Teilbarkeit und Anschmiegsamkeit der Geldabgabe, daß sie, im allgemeinen "gleich" gestaltbar, auch sub specie des Opferausgleichs grundsätzlich zu keiner Entschädigung verpflichtet. Wo aber durch den staatlichen Zugriff auf das Geldvermögen besondere Opfer auferlegt werden, entfällt diese Voraussetzung und somit auch der Grund, die Geldhergabe aus dem Enteignungsbegriff auszuklammern.

Was für die Steuern und sonstigen Abgaben im allgemeinen gilt, gilt auch für den Sozialversicherungsbeitrag. ${ }^{10)}$ Hierbei kann sich insbesondere die Frage stellen, unter welchen Voraussetzungen die staatliche Fremdvorsorge unter Inanspruchnahme und Bindung von Mitteln der Beteiligten das Eigentum als Rechtsinstitut verletzt. Daß es eine Grenze, jenseits deren die Beschränkung der Verfügungsmacht des einzelnen über sein Vermögen unzuläs-

S. 172; Grimm, Besteuerung und Grundgesetz, S. 22 .

7) Hettlage, Die Finanzverfassung im Rahmen der Staatsverfassung, S.5. - Forsthoff (s. die Nachweise oben S. 960 zu Fußn. 39) hat die "A rbeitsteilung" $z$ wischen Abgabenrecht und Eigentumsgarantie - hier Statik und Konservierung der Vermögensverteilung, dort Dynamik und Umverteilung - mehr als gerechtfertigt zum Prinzip erhoben.

8) S. oben S. 979.

9) Hierzu eingehend Ipsen, Rechtsfragen der Investitionshilfe, AöR Bd. 78 (1952/53), S.284 ff (317 ff); Huber, Wirtschaftsverwaltungsrecht Bd. II, S. $21 \mathrm{f}, 240 \mathrm{ff}$. 
sig wird, gibt; wird grundsätzlich anerkannt werden müssen. 11) Doch wird sie vom gegenwärtigen Sozialversicherungsrecht wohl an keiner Stelle berührt. 12) 139

Abschließend noch ein Wort zum Währungswe sen. Von ihm hängt der Wert des Geldvermögens ab. Währungsrechtliche Regelungen betreffen aber nicht das Eigentum am Geld sondern das Geld selbst. 14) Abwertungen sind daher kein Eingriff in das Eigentum und verpflichten nicht zum Ausgleich einer eventuellen Wertdifferenz. Nur wo Geldentwertungen im Interesse der Allgemein-

10) Vgl. BVerfGE 10, 354 (371).

11) Das Bundesverfassungsgericht stellt (a.a.O. S.370) unter dem Gesichtspunkt des Art. 2 Abs. 1 GG die Frage, ob die Höhe der Beiträge zur bayerischen Ärzteversorgung etwa "die wirtschaftliche Bewegungsfreiheit der Ärzte unerträglich einschränke". Dieser Gedanke kann unmittelbar auch auf das Eigentumsrecht angewandt werden; denn auch das Eigentumsgrundrecht ist ein Freiheitsgrundrecht.

12) Für die umstrittene bayerische Ärzteversorgung s. BVerfGE a.a.O. S. 371: "Auch der (mittelbare und nur wirtschaftlich fühlbare) Zwang zur Aufgabe anderer Formen der Versorgung läßt sich nicht als Eigentumsverletzung ansehen". S. hierzu ferner (die Verfassungsmäßigkeit bejahend): Peters, Die verfassungsrechtliche Zulässigkeit berufsständischer Pflichtversorgungseinrichtungen für Ärzte, S. 34 ff; Maunz, Rechtsgutachten über die Verfassungsmäßigkeit der bayerischen Ärzteversorgung nach dem Grundgesetz, S. 39 ff.

13) Ipsen (Rechtsfragen berufsständischer Zwangsversorgung, S. $57 \mathrm{ff}$ ) erwägt die Möglichkeit, daß "die Einführung der Zwangsversorgung angesichts der Altersstruktur der Verbandsangehörigen zu einer Abbürdung der 'Altlast' auf einen Kreis von jüngeren Berufsgenossen führen würde, die ihrerseits durch ihre Beitragsleistungen in ungleicher Weise zur Finanzierung der Versorgung beitrügen oder im eigenen späteren Versorgungsfall eine ungleich geringere Versorgung erhielten, als die Angehörigen der 'Altlast' sie empfangen haben" (S.58). Er sieht darin einen enteignungsgleichen Aufopferungsfall. Die Frage ist aber die, ob es für diese - unterstelltermaßen - ungleiche Belastung eine veritable Entschädigung gibt, welche die Ungleichheit kompensiert. Ist das zu verneinen, so verstößt die Regelung unheilbar gegen den Gleichheitssatz und die Eigentumsproblematik tritt gar nicht ans Licht.

14) S. Huber, Wirtschaftsverwaltungsrecht Bd.II, S. 21. 
heit ungleich vorgenommen werden, verpflichten sie zum Opferausgleich. Daß auch im übrigen ein Bedürfnis besteht, eigentumszerstörenden und -verändernden Währungsmanipulationen vom Eigentumsrecht her zu begegnen, ist nicht zu leugnen. 15) Aber wie? Das ist in Anbetracht der Schwierigkeiten der Materie eine offene Frage. ${ }^{16)}$

h) Exkurs III: Die eigentumsinhaltsbestimmende Rechtsverkürzung

aa) Allgemeines

Die Ordnung des Inhalts und der Schranken des Eigentums umschließt in ihrem weitesten Sinn auch die - an die Wesensgehaltsgarantie und die ausdrückliche Regelung gewisser Entziehungstypen durch die Verfassung gebundene - Ordnung der Entziehung des Eigentums. 1) Vorhandenes Eigentum im Wege der Bestimmung von "Inhalt und Schranken" des Eigentums kurzweg des Eigentumscharakters $z u$ berauben und auf diese Weise dem ungebundenen - insbes. nicht durch die Entschädigungspflicht der Enteignung und Sozialisierung gehemmten - entziehenden Zugriff des Staates auszusetzen, ist jedoch nicht zulässig. 2) Inhaltsbestimmung im engeren Sinne ist Gegensatz zur Entziehung. ${ }^{3)}$ Inhaltsbestimmung im engeren Sinne ist aber nicht denkbar ohne Entscheidung über Wertelemente des Eigentums - über seinen Gesamtgehalt, seine objektive und subjektive Reichweite und gewisse Einzelausflüsse. Auch Verminderung der Wertigkeit des Eigentums ist demnach eine legitime Funktion der Inhaltsbestimmung, obgleich sie ihr Effekt in die Nähe der Entziehung rückt. Die Grenze zwischen Inhaltsbestimmung und Entziehung wird eigentumsspezifisch durch die wesensmäßige Substanz des fraglichen Eigentumsrechts bestimmt. ${ }^{4}$ )

Das Maß der zulässigen inhaltsbestimmenden Disposition wächst regelmäßig mit der Kompliziertheit ("Künstlichkeit") und der Verwobenheit eines Rechts mit anderweit staatlicherseits gesetzten Prämissen. 5) Einerseits, je weniger zwingende eigene Sach-

15) Vgl. Weber, Diskussionsbeitrag zu "Die Finanzverfassung im Rahmen der Staatsverfassung", S. 83.

16) S. hierzu schon oben S. $840 \mathrm{f}$.

1) S. o. S. 946 zu Fußn. 4 ff. - Zu den verfassungsimmanenten Figentumsentziehungsfällen s.o. S. $951 \mathrm{f}$.

2) S. o. S.943 ff.

3) S. O. S.945 ff, insbes. S. 946 zu Fußn. 4 ff.

4) S. o. 3 (S.945 ff).

5) Als Beispiel s. oben S.985ff die inhaltsbestimmende Berech- 
gesetzlichkeit ein Recht in die allgemeine verfassungsrechtliche Wesensgehaltsgarantie einbringt und je mehr es ein Produkt rechtspolitischer Willkür ist, andererseits, je mehr ein Recht in das sich ständig wandelnde und fortentwickelnde Gesamtgefüge des staatlichen Rechts wesensmäßig verstrickt ist, desto weniger Stabilität kann ihm die allgemeine verfassungsrechtliche Wesensgehaltsgarantie verschaffen. Auf diese Weise sind inhaltsbestimmende Eingriffe in das Eigentum denkbar, die den Rechtsinhaber effektiv mehr belasten als die Entziehung mancher "selbständigerer", "primitiverer" Eigentumsrechte, welche die Verfassung unter den eindeutigen Vorbehalt des öffentlichen Wohls und der Entschädigungspflicht stellt.

bb) Insbes. zur Verschlechterung sozialversicherungsrechtlicher Anwartschaften und Leistungen

Mit spezifisch sozialem Akzent zeigt sich diese Problematik im Sozialversicherungsrecht. Sozialversicherungsrechtliche Leistungsansprüche sind in der Regel Eigentum. 1) Ihre Vollentziehung ist demnach in der Regel Enteignung. Die wesensgerechte Änderung ihrer Voraussetzungen, der Leistungsmodalitäten usw. ist dementsprechend grundsätzlich Inhaltsbestimmung des Rentenanspruches bzw. der Rentenanwartschaft. ${ }^{2)}$

Wie ist im besonderen eine Leistungskürzung zu beurteilen? An sich ist davon auszugehen, daß sie keine Inhaltsbestimmung darstellt. Jeder Kürzungsbetrag kann als selbständige Einheit gedacht werden. Ihn wegzunehmen, ist grundsätzlich nichts anderes als die Wegnahme eines Randstreifens von einem größeren Grundstück. Auch sie ist immer Enteignung und nicht Bestimmung des Inhalts des größeren Grundstücks. Bei Geldeinheiten wird eine Abweichung zwar insofern zulässig sein, als der Rechnungs(Nominal-)betrag immer Wertausdruck ist. Nur wenn der Kürzung des Nominalbetrages auch eine Wertverminderung entspricht, entzieht sie wirklich etwas. Aber wann sollte das in einem Wirtschafts- und Währungssystem der permanenten Inflation jemals

tigung der Gesellschafterrechte durch das Mitbestimmungsrecht. - Nicht mehr zur engeren eigentumsgestaltenden Ordnung gehört dagegen die Währungspolitik (s. oben S. $987 \mathrm{ff}$ a.E.), obwohl ihr Zusammenhang mit dem Geldvermögen dem Gemeinten wenigstens analog ist.

1) S. oben S. 938 ff,insbes. S. 940 zu Fußn. 8.

2) S. hierzu BVerfGE 11, 221 (226 ff); Rohwer-Kahlmann, Die Krise des Eigentums, S. 310 f; Dürig, Der Staat und die vermögenswerten öffentlichrechtlichen Berechtigungen seiner Bürger, S. 55 . 
nicht der Fall sein; es sei denn bei der Anpassung des Nominalbetrages an eine allgemeine Währungsreform. Soll im übrigen nur eine entschädigungspflichtige Enteignung möglich sein? Was immer bedeuten würde, daß alles irgendwie beim Alten bleibt, da doch Wertausgleich geleistet werden muß. ${ }^{3)}$

Das kann nicht der Fall sein - jedenfalls nicht, soweit es sich um Renten handelt, die nicht reine, von jedem spezifisch "sozialen" oder (und) versorgungsmäßigen Einschlag freie Versicherungsrenten und nicht reine Schadensausgleichsrenten sind. Man darf "nicht an der Tatsache vorübergehen, daß der Versicherte mit solchen Beiträgen immer nur Anwartschaften innerhalb des vom Staat bereitgestellten, dem sozialen Ausgleich unterworfenen Fürsorgesystems öffentlich-rechtlicher Natur erwirbt". 4) Zwar ist es nicht zulässig, die Rente in "Eigentum" und "Nichteigentum" je nach der Beitrags-bzw. der Opferleistung und den öffentlichen Zuschüssen aufzuspalten. ${ }^{5)}$ Das würde ihrem Zweck und Wesen nicht gerecht. Wer angehalten wird, Beiträge zur Sozialversicherung zu leisten, wird das deshalb, damit er die Rente "erwirbt", die sich aus der Natur der fraglichen Sozialversicherung ergibt, und nicht etwa eine Rente, die sich aus den eingehobenen Beiträgen usw. errechnen würde, wenn die Versicherung bei einem privaten Versicherungsunternehmen nach reinen Versicherungsgrundsätzen eingegangen wäre. Aber er erwirbt andererseits auch eben nicht eine Anwartschaft, wie sie sich aus der besagten Privatversicherung ergeben würde, sondern die Anwartschaft auf eine öfentliche Sozialleistung, die ihrer Natur nach in das System der öfentlichen Sozialleistungen eingewoben ist. Diese Natur wohnt dem Eigentum an der Rente inne. Die Rente gibt daher, soweit sie auch "Versorgungs" - Rente ist, den Veränderungen der staatlichen Leistungsfähigkeit und der sozialen Leistungsnotwendigkeit gegenüber nach. ${ }^{6}$ ) Die aktuelle Anpassung der Rente an die sich aus ihrer Verflochtenheit mit dem Gesamtsystem der staatlichen Sozialleistungen ergebenden Notwendigkeiten ist Ausgestaltung ihres Inhalts. So kann eine "sozialbedingte

3) Dürig (a.a.O. S.55) meint, die "gerechte Abwägung der Interessen der Allgemeinheit und der Beteiligten" erlaube eine entschädigungslose Kürzung (= Reritenteilenteignung). Dem kann nach der hier vertretenen Auslegung des Art. 14 Abs. 3 Satz 3 GG nicht zugestimmt werden.

4) Altrock, Der Standort der Sozialversicherung im Rechtsgefüge, S. 33; s.a. BVerfGE 11, 221 (226 f).

5) S.o. S. 940 zu Fußn. 8 und die dortigen Nachweise.

6) BVerfGE 11, 221 (226 ff, insbes. S.226 f, 229, 231). Zu weitgehend v.Altrock (a.a.O.), wenn er die Angleichbarkeit 
ausgleichslose" Leistungskürzung zwar gerade nicht als enteignende "Rechtsverkürzung" 7) aber doch als Inhaltsbestimmung zulässig sein. ${ }^{8)}$ Die Grenzen müssen freilich eng gezogen werden. Das was als Eigentum "erworben" wurde, muß seinem Wesen nach erhalten bleiben. Nur eine sorgfältige Abwägung aller Umstände, wie sie für die Fülle der einschlägigen Erscheinungen hier nicht getroffen werden kann, kann dem Problem gerecht werden. ${ }^{9)}$

\section{Die Gewährleistung des Erbrechts}

Art.14 Abs.1 GG gewährleistet das Erbrecht.1) Über die elementare Bedeutung dieser Garantie für das soziale Leben braucht kaum ein Wort verloren zu werden. Das Erbrecht steigert den Fleiß, den Erwerbs- und Sparsinn und damit die Selbstbehauptung und den Lebenswillen des einzelnen. Es erhöht die Verantwortung des einzelnen gegenüber seiner Familie und stärkt, indem es eine familiäre Vorsorge langer Hand ermöglicht, auch die soziale Eigenwirksamkeit der Familie. $Z$ wischen dem verfassungsrechtlichen Schutz des Erbrechts und dem verfassungsrechtlichen Schutz der Familie besteht ein natürlicher, höchst beacht1icher Zusammenhang. 2) Das Erbrecht sichert dem einzelnen aber auch die Möglichkeit, über seinen Tod hinaus nach außen noch sozial zu wirken. Legate, Vermächtnisse, Stiftungen von Tode wegen haben schon unendlichen

an die "jeweilige fürsorgerische Tendenz" postuliert.

7) Dürig, a.a.O. spricht von "sozialbedingten ausgleichslosen Rechtsverkürzungen".

8) BVerfGE a.o. (S.993 Fußn.6) a.O. Im Ergebnis übereinstimmende, jedoch das Problem über die entschädigungslose Enteignung 1ösend, Dürig, a.a.O.; für eine gewisse Nachgiebigkeit auch Thieme, Umfang und Grenzen des verfassungsrechtlich gesicherten Bestandsschutzes der saarländischen Kriegsopferversorgung, S. 163; der Sache nach annähernd übereinstimmend, wenngleich den eigentumsrechtlichen Charakter der Rentenansprüche leugnend auch v.A1trock, a.a.O. S.33. - A.A. Rohwer-Kahlmann, Die Krise des Eigentums, S. 310 f. - S. zum Thema auch Weidner, Zur Rechtsprechung des Bundessozialgerichts, S. 761 .

9) Zu den Umwandlungsfällen s. BSGE 3, 77;9, 127; BSG SozR Berl. SVAG $\$ 56$ Aa 1; v.Altrock, a.a.O.; Weidner, a.a.O.

1) Zur Auslegung s. insbes. Boehmer, Erbrecht, in: NeumannNipperdey-Scheuner, Die Grundrechte, Bd.II, 1954, S. $401 \mathrm{ff}$.

2) Zum entsprechenden Inhalt der Erbrechtsgarantie s. Boehmer, a.a.O. S. $413 \mathrm{ff}$. 
Segen gestiftet - wie ihn eine die private Initiative tötende staatliche Allwirksamkeit nicht in gleicher Weise hätte spenden können.

Andererseits ist das Erbrecht die Ursache wirtschaftlicher Machtballungen in den Händen weniger. "Erbe" $\mathrm{zu}$ sein oder nicht, ist die Alternative zwischen wirtschaftlicher Chance und wirtschaftlichem Handikap. "Erbe" sein, ist in der Regel ein persönlich unverdienter, schicksalhaft zuteil gewordener wirtschaftlicher Vorsprung. Nicht "Erbe" sein heißt von vorne anfangen und allein für sich selbst zu sorgen. Die Gesetzmäßigkeiten des Lebens, die diese Ungleichheiten wieder ausgleichen, sind bekannt. Aber sie wirken auf lange Sicht. Jede Generation muß sich mit den Ungleichheiten, mit den Erscheinungen der reichen Erben und der Masse der "Habenichtse" neu auseinandersetzen.

Das Mittel, diese Ungleichheiten "künstlich" auszugleichen, ist die Beteiligung des Staates am Erbgut. Die Erbrechtsgarantie selbst schließt sie nicht ein, aber auch nicht aus. ${ }^{3)}$ Kann der Gesetzgeber die Schranken des Erbrechts bestimmen (Art. 14 Abs. 1 Satz 2 GG), so kann er auch eine Abgabe vom Nachlaß einführen. Es erscheint zumindest als eine Frage, ob nicht wenigstens das Sozialstaatsprinzip eine Beseitigung der Erbschaftssteuer ausschließt. Andererseits verbietet Art.14 Abs.1 GG eine Ausgestaltung der Erbschaftssteuer, die das Erbrecht aushöh1t. 4)

IV. Die verfassungsrechtliche Grundordnung der Ehe, der Familie, der Kindschaft und der Jugenderziehung und -förderung

1. Das Recht der Ehe und der Familie

a) Allgemeines

Die industriekapitalistische Ökonomisierung, die (primär wirtschaftlich und politisch bedingte) Mobilisierung, die Kollektivierung, die Egalisierung und schließlich der religiöse Substanzverlust der modernen Gesellschaft haben Fhe und Familie harter Bedrängnis ausgesetzt und einschneidenden Wandlungen unterworfen. 1) Die herrschaftsverbandliche Funktion der Familie ist auf

3) S. Boehmer, a.a.O. S.412; Giese-Schunck, Art. 3 Anm.2.

4) S. Giese-Schunck, Art. 3 Anm.2.

1) Jüngste Zusammenstellungen des Schrifttums s, bei Scheffler, Ehe und Familie, S.259 Fußn.67; Münke, Art. "Familie und Ehe" im Handwörterbuch der Sozialwissenschaften, 33. Lieferung, 1960, S.470 ff (477 f); nachzutragen etwa Neundörfer, 
das durch das Erziehungsverhältnis der Eltern zum Kind umschriebene Minimum geschrumpft. Von zufälligen Kongruenzen zwischen ökonomisch tragbaren Betriebs- und gegebenen Familiengrößen abgesehen, ist die Familie keine Produktionsgemeinschaft mehr sondern primär Konsumgemeinschaft und potentiell - wenn eine Familie mehrere Erwerbsträger umschließt - Erwerbsgemeinschaft. Ihre wirtschaftlich-soziale Garantiefunktion ist auf den schmalen - infolge der Opferwilligkeit und intimen, wechselseitigen Einfügsamkeit der Familienmitglieder und der damit verbundenen optimalen Ausnutzung der vorhandenen Hilfsquellen freilich elastisch begrenzten - Raum reduziert, den das eiserne wirtschaftliche Gesetz der (Primär-)Verteilung des Sozialprodukts je Arbeitskraft und Produktionsmittelanteil läßt. Das subsidiäre Eintreten größerer Leistungsgemeinschaften ist notwendig; und dessen Erfahrung und Erwartung schwächt die schicksalsbewußte Familienverbundenheit und weckt individualistisch-egalitär orientierte Leitvorstellungen, die der familiären Bindung negativ oder wenigstens fremd gegenüberstehen.

Dennoch ist die Familie die elementare Lebensgemeinschaft des Menschen geblieben - optimales Medium seiner Aufzucht und wesentlicher Entfaltungsraum persönlichkeitsintegrierender Selbstverwirklichung in der Du-Dimension. Sie hat sich jedenfalls als Kleinfamilie (Eltern-Kinder-Familie) den Tendenzen zum Abbau aller nicht-massengesellschaftlichen Gemeinschaftsinstitutionen gegenüber als ungleich widerstandsfähiger erwiesen als andere kleine und mittlere Gruppen.

Die soziale Intervention des Staates kann deshalb mit der Familie als gemeinbewußter lebendiger gesellschaftlicher Realität rechnen. Ein auf den Menschen abstellendes soziales System $\mathrm{m} u ß$ aber auch die Familie einbeziehen und den Menschen in der Familie sehen. Es darf nicht unbedingt durch die Schicht der familiären Gemeinschaft auf die Einzelperson durchgreifen, nicht nur an ihre individuelle soziale Position anknüpfen und sie nicht ohne konkrete Notwendigkeit aus der Familie herauslösen. Es würde aber weder seinem sozialen $Z$ weck noch dem Wesen der Familie gerecht, wenn es eine Leistungsfähigkeit der Familie fingieren würde, die ihr nicht zukommt. Vielmehr muß sich die Hilfe für die Familie, für den einzelnen in der Familie, für den einzelnen außerhalb der Familie und möglicherweise sogar gegen die Familie die Waage halten.

Dadurch, daß sich die Verfassung zu Ehe und Familie bekennt und sie "unter den besonderen Schutz" des Staates stellt (Art. 6 Abs. 1

Bilanz der Familie, Soziale Welt 10.Jhg. (1959/60), S. $310 \mathrm{ff}$. 
GG) 2), weist sie dem Sozialstaat verbindlich den Weg einer familiengerechten Sozialpolitik. ${ }^{3)}$ Die grundrechtliche, 4$)$ institutionelle 5) Sicherung von Ehe und Familie verhindert, daß der Staat diese Rechtseinrichtungen abbaut oder verfälscht, 6 ) und so Ehe und Familie als Elemente des sozialen Lebens ausschaltet oder auch nur wesentlich schwächt. Sie verbietet dem Staat, das familiäre und eheliche Leben übermäßig zu reglementieren ${ }^{7)}$ und auf diese Weise die freiheitliche Funktion 8 ) der Autonomie der ehelichen und familiären Gemeinschaft für das in ihr geborgene Individuum auszuhöhlen. Sie weist dem Staat eine - auch im engeren sozialen Bereich - subsidiäre Rolle "hinter" der Familie zu. 9) Sie gebietet ihm, die Integrität der Ehe und der Familie auch dann maximal zu schonen, wenn er zum sozial helfenden Eingriff genötigt ist. 10) Die Verfassungsgarantie wird durch die Proklamation des besonderen staatlichen Schutzes für Ehe und Familie zu dem Verbot verdeutlicht und ausgeweitet, Ehen und Familien genauer: die einer Ehe oder einer Familie Angehörenden - zu benachteiligen. 11) Positiv gewendet bedeutet das Versprechen des besonderen staatlichen Schutzes die Pflicht des Staates, Ehe und Familie zu fördern 12) - ein Programm, das sanktionär nur

2) Zur Auslegung des Art. 6 Abs. 1 GG s. im allgemeinen Scheffler, Ehe und Familie; weit. Nachw. s. dort.

3) Zum Zusammenhang zwischen Sozialstaatsprinzip und Art. 6 Abs. 1 GG s. BVerfGE 6, 55 (72); Scheffler, a.a.O. S. 310.

4) S. hierzu Scheffler, a.a.O. S. $272 \mathrm{f} \mathrm{m}$.w. Nachw. (S. 272 Fußn. 116), ferner S.254 ff, $279 \mathrm{f}$.

5) Zu Art. 6 Abs. 1 GG als Einrichtungsgarantie s. z.B. v. Mangoldt-Klein, Art. 6 Anm. III 3 und Scheffler, a.a.O. S. 257 ff je m.w. Nachw.

6) Zu den Wesenszügen s. insbes. Scheffler, a.a.O. S.257 ff, 281 ff u. ihre Nachw.

7) S. Scheffler, a.a.O. S. 256 m.w. Nachw. (Fußn. 55).

8) Vg1. Scheffler, a.a.O. S.254 ff.

9) S. Scheffler, a.a.O. S.256.

10) Vgl. Süsterhenn, Die kirchliche Liebestätigkeit im sozialen Rechtsstaat der Gegenwart, S. 115.

11) Vg1. BVerfGE 6, 55 (76 f; S. 72 ff passim); 9, 237 (247 f); Maunz, Die verfassungsrechtliche Gewähr von Ehe und Familie, Ehe und Familie im privaten und offentlichen Recht, 3.Jhg. (1956) S. 1 ff (1 f); Giese-Schunck, Grundgesetz, Art. 6 Anm. 1; Scheffler, a.a.O. S. $270 \mathrm{ff}, 317 \mathrm{ff} \mathrm{m}$. eingeh. Nachw.

12) S. zu Art.6 Abs. 1 GG: BVerfGE 6, 55 (76); Maunz, a.a.O. S. 2; Hamann, Das Grundgesetz, Art. 6 Anm.C 1 (S.110 f); Scheffler, a.a.O. S. $270 \mathrm{ff}, 310 \mathrm{ff} \mathrm{m}$. eingeh. Nachw. 
dort durchgesetzt werden kann, wo es exzeptionell "ungleich" nur für gewisse Gruppen unerfüllt zu bleiben droht ${ }^{13)}$ oder im Rahmen eines tendenziösen, ehe- und familienfeindlichen Abbaues vorhandener wesentlicher Förderungseinrichtungen und - maßnahmen nicht durch Unterlassen sondern durch positives Tun verletzt wird. 14) 15)

\section{b) Einzelfragen}

\section{aa) Benachteiligungsverbot, Förderungsgebot und verwandte Fragen}

Benachteiligungsverbot und Förderungsgebot sind in enger Beziehung zum Willkürverbot des Gleichheitssatzes zu sehen. 1) Die benachteiligende Anknüpfung allein an die Kriterien der Ehe und der Familie ist im Hinblick auf Art. 6 Abs. 1 GG unzulässige, willkürliche Diskriminierung. Die bevorzugende Anknüpfung an die Kriterien der Ehe und Familie ist dagegen durch das verfassungsrechtliche Förderungsgebot gedeckt und daher nicht an sich schon willkürlich i.S. des Art. 3 Abs. 1 GG. Freilich darf auch sie nicht sachfremd sein. Sie muß eine den besonderen Belastungen der Verehelichten und Familienmitglieder adäquate Förderung darstellen. Andererseits bedeutet das Benachteiligungsverbot nicht, Ehe und Familie seien schlechthin zu ignorieren. ${ }^{2)}$ Aber

13) Zur "relativen Unterlassung" des Gesetzgebers s. oben S.557ff. - Scheffler (a.a.O. S. $270 \mathrm{f}(271))$ meint etwas anderes, wenn sie ausführt: "Durch das Heranziehen eines Vergleichstatbestandes kann auch eine Verletzung des - positiven - Gebotes, Ehe und Familie zu fördern, rechtlich faßbar werden, wenn nämlich Leistungen der öffentlichen Hand für den in Ehe und Familie Eingeordneten bei sonst gleichem Sachverhalt niedriger bemessen werden als für andere". Das ist die Kehrseite des positiven Förderungsgebotes: das Benachteiligungsverbot.

14) S.a. Scheffler, a.a.O. S.271, die darauf abstellt, ob "Leistungen verkürzt würden, die durch ihre Bedeutung und die Dauer ihrer Gewährung im allgemeinen Rechtsgefühl mit dem Begriff des Familienschutzes untrennbar verbunden wären".

15) Zur inhaltlichen Unbestimmtheit des positiven Förderungsprogramms s. nochmals die S. 997 zu Fußn. 12 Zitierten, insbes. Scheffler S. $270 \mathrm{ff}$.

1) Vg1. Scheffler, a.a.O. S. $270 \mathrm{f}$ und passim. S.a. die kaum zu lösende Verknüpfung zwischen der Normenkontrolle auf Grund Art. 3 Abs. 1 GG und auf Grund Art. 6 Abs. 1 GG in der einschlägigen Rechtsprechung des Bundesverfassungsgerichts 
die Eigenarten und die Vorteile der ehelichen und familiären Gemeinschaft dürfen nicht in einer Weise in Anrechnung gebracht werden, die den in Ehe und (oder) Familie Eingeordneten als solchen schlechter stellt als den ehe- und familienfrei Lebenden. ${ }^{3)}$

Benachteiligungsverbot und Förderungsgebot wirken sich vor allem im Bereich der - allgemeinen oder spezifisch sozialen öffentlichen Belastungen und Leistungen aus. ${ }^{4}$ Steuer- und sonstiges Abgabenrecht, 5) Sozialversicherung, Lastenausgleich, Kriegsopferversorgung, Beamtenbesoldung und -versorgung, aber auch die staatliche Wohnungsbauförderung sind die problemreichsten Materien der "familiengerechten" Belastungs- und Leistungsgestaltung. Sie entfaltet sich von der bloßen - eine Benachteiligung vermeidenden aber keine Förderung bezweckenden - Anpassung der Belastungen und Leistungen an die Besonderheiten und Bedürfnisse der ehelichen und familiären Gemeinschaft bis zur fördernden Präferenz im Abgabenrecht und zur zusätzlichen Leistung für Familien(angehörige) im Leistungsrecht. 6)

In diesen fördernden Maßnahmen drückt sich der Gedanke des finanziellen Familienlastenausgleiches 7 ) aus, der am unmittelbarsten in den Kindergeldleistungen ${ }^{8)}$ - sowoh1 in den zusätzlichen des Beamtenbesoldungs-, des Versorgungsrechts usw. als auch in den isolierten des Kindergeldrechts - angesprochen

(BVerfGE 6, 55 (72 ff); 9, 237 (247 ff)).

2) S. z.B. BVerfGE 11, 50 (57 ff).

3) Vgl. Scheffler, a.a.O. S.270 ff, $317 \mathrm{ff} \mathrm{m.eingeh.Nachw.}$

4) S. die Problemübersicht bei Scheffler, a.a.O. S.270 ff, 309 ff, 317 ff und deren Nachw.

5) Zu den Auswirkungen des Art. 6 Abs. 1 GG auf das Abgabenrecht s. die Darstellungen und Nachweise bei Klein, Der Beschluß des Bundesverfassungsgerichts zur Ehegattenbesteuerung in verfassungsrecht1icher Sicht, DÖV 10.Jhg. (1957) S. 567 ff (573 ff); Scheffler, a.a.O. S.212 ff, 319 ff. Zur Rechtsprechung des Bundesfinanzhofes s. Grimm, Besteuerung und Grundgesetz, S.14 ff.

6) Auf klassische Weise finden sich beide Elemente der Förderung in der familiengünstigen Beitrags- und Leistungsgestaltung der Sozialversicherung vereinigt.

7) S. hierzu etwa Oeter, Der Ausgleich der Familienlasten, Schmollers Jahrbuch für Gesetzgebung, Verwaltung und Volkswirtschaft, 78. Jhg. (1958) S. $71 \mathrm{ff}$.

8) S. hierzu etwa Nahnsen, Kindergeld als Mittel der Familienpolitik, in "Sozialreform und Sozialrecht", Festschrift für Walter Bogs, 1959, S. 253 ff. 
wird. Ohne den finanziellen Ausgleich der Familienlasten über die öfentliche Hand kann die Differenz zwischen der "Kopfquote" des marktwirtschaftlichen Einkommens des (der) Familienernährer(s) und dem Bedarf der mitzuernährenden, absolut oder relativ erwerbsunfähigen Familienmitglieder - unter denen die Kinder eine besondere Rolle deshalb einnehmen, weil in bezug auf sie, anders als etwa in bezug auf die in der Familie mitlebenden Erwachsenen (Großeltern u. ä.) unmittelbare soziale Sicherungen regelmäßig nicht Platz greifen 9) - nicht ausgeglichen werden. Der "Familienlohn" 10) 1äßt sich der Wettbewerbswirtschaft auch in Zeiten der Vollbeschäftigung - von "schlechteren" Zeiten ganz abgesehen - nur sehr begrenzt oktroyieren, weil er mit dem Zwang zur Kostensenkung kollidiert. 11) Der "Familienlohn" des staatlichen Dienstrechts wird dagegen öffentlichen Mitteln entnommen und ist im Grunde auch Familienlastenausgleich.

Der Familienlastenausgleich verwirklicht ebenso Art. 6 Abs. 1 GG ${ }^{12)}$ wie das Sozialstaatsprinzip. 13) Wie er im einzelnen zu verwirklichen ist, läßt die Verfassung aber offen. 14) Sie garantiert auch nicht gewisse Einrichtungen, Präferenzen oder Leistungen. Einem tendenziellen Abbau wesentlicher Elemente des erreichten Standards müßte jedoch von Verfassungs wegen entgegengetreten werden.15)

Noch mehr als Programm und noch weniger als sanktionierte verfassungsrechtliche Sicherung wirkt die verfassungsrechtliche Schutzpflicht in bezug auf die nicht finanzielle, konkretsachliche

9) Das Kind, das seinen Ernährer dadurch entlastet, daß es Waisengeld erhält, ist - außerhalb der Hinterbliebenenversorgung für eine Restfamilie - eine Anomalie.

10) Vgl. Stein, Der Familienlohn, 1956.

11) S. hierzu etwa Nahnsen, a.a.O. und ihre Nachw.

12) Zum Zusammenhang des Familienlastenausgleiches mit Art. 6 GG s. Scheffler, a.a.O. S. $310 \mathrm{ff}$ und ihre Nachw. Zum Kindergeld (i.S. der Kindergeldgesetzgebung des Bundes) als Erfüllung der Förderungspflicht des Art . 6 Abs. 1 GG s. Schaefer, Kindergeldgesetzgebung und Grundgesetz, S. 354; Hamann, Grundgesetz, Art. 6 Anm. C 1 (S.110 f).

13) Zum Kindergeld als Ausfluß der Sozialstaatlichkeit s. Ipsen Anm. zu BVerfG Urt.v. 19. Dezember 1951, S.216; Berger, Bedeutung und Tragweite des Grundsatzes vom sozialen Rechtsstaat, S.6; Hamann, a.a.O.; s.a. BVerfGE 11, 105 (113).

14) BVerfGE 11, 105 (126).

15) S.o. S. 998 zu Fußn. 14. 
und persönliche Familienhilfe. 16) Engstens dem Konkreten verflochten ist sie noch kaum zu bestimmten Institutionen erstarkt. Der Verfassung können hierzu kaum andere Aussagen entnommen werden als die deklamatorische Legitimation der weiteren Entwicklung.

Familienlastenausgleich ist in erster Linie Ausgleich der durch die Kinder bedingten Lasten. Er muß umso wirksamer gestaltet sein, je mehr Kinder in einer Familie zu versorgen sind. A uf diese Weise ist der verfassungsrechtlich gebotene Schutz der Familie wesensmäßig immer auch der gesteigerte Schutz der kin derreichen Familie. Das Grundgesetz, welches die Notwendigkeit der besonderen staatlichen Fürsorge für die kinderreiche Familie nicht besonders herausstellt, entgeht damit dem Verdacht, den Kinderreichtum aus bevölkerungspolitischen - insbes. nationalen und machtpolitischen - Motiven prämieren $\mathrm{zu}$ wollen. 17)

Dem Schutz der Familie zuzuordnen ist schließlich auch die soziale Sicherung der Restfamilie, welche den (die) Garanten ihres Unterhalts verloren hat. Zwar ist es auch und in erster Linie ein allgemeines sozialstaatliches Anliegen, dem Erwerbsunfähigen zu helfen, dessen Unterhalt von keiner anderen Seite aufgebracht wird. Daß der Kreis der Unterhaltsgaranten der familiäre ist, ist ferner Ausdruck der institutionellen Garantie der Ehe und der Familie und nicht der Pflicht des Staates, Ehe und Familie zu fördern. Aber in den Voraussetzungen und im Inhalt der sozialen Sicherung der ehelichen und familiären $\mathrm{H}$ interbli ebenen zeigt sich gerade auch der Schutz der Familie. Dabei muß mehr als bisher beachtet werden, daß die Familie nicht nur durch den Ausfall des Trägers des marktwirtschaftlichen Einkommens - der typischen Vaterrolle - sondern auch durch den Ausfall des Trägers der Haushaltsführung - der typischen Mutterrolle - sozial bedrängt wird. Das Recht der Witwerrente und der Waisenrente nach der Mutter hat unter diesem Aspekt von Art. 6 Abs. 1 GG einen entscheidenden Impuls zu beziehen. 18)

Die staatliche Schutzpflicht gegenüber Ehe und Familie ist aber nicht nur durch soziale Leistungen und nicht nur durch die Verschonung mit Abgaben zu erfüllen. Alles statiche $\mathrm{Han}-$ de $1 \mathrm{n}$, das - daseinsvorsorgend oder auch Störungen der öffent-

16) Vgl. Scheffler, a.a.O. S. $311 \mathrm{f}$.

17) Vgl. Scheffler, a.a.O. S. 272.

18) Vgl. Scheffler, a.a.O. S. $315 \mathrm{f}$. S. ferner oben S.919 ff u.d. dort. Nachw.. Art. 3 Abs. 2 und 3 GG und Art. 6 Abs. 1 GG müssen hier - wie auch sonst so oft - zusammen gesehen werden. 
lichen Sicherheit und Ordnung abwehrend - die Lebensbasis und - sphäre der Familie und Ehe zu beeinflussen bestimmt ist oder sonstwie vermag, ist daran zu orientieren. Die Wohnraumbewirtschaftung, die Vertriebenenhilfe und die Ausländerpolizei haben Beispiele der vielfältigen Ausstrahlung der verfassungsrechtlichen Schutzpflicht geboten. 19)

bb) Der Schutz von Ehe und Familie im familien- und eheinternen und im sonstigen zwischenbürgerlichen Bereich

Die soziale Aktualität der subsidiären Wechselbeziehung zwischen Familie (Ehe) und Staat rückt die weniger durch die Einrichtungsgarantie als augenfälliger durch die Förderungspflicht und das Benachteiligungsverbot gekennzeichnete Position der Familie und der Ehe im Staat-Bürger-Verhältnis in den Vordergrund. Aber Ehe und Familie sind in erster Linie Lebenserscheinungen der zwischenmenschlichen Beziehungen und Rechtseinrichtungen des privaten Rechts. Diese sind der Ansatz der verfassungsrechtlichen Einrichtungsgarantie. 1) Der "besondere Schutz" des Staates für Ehe und Familie hat sich dementsprechend gerade auch gegen außerstaatliche Kräfte zu wenden, die Ehe und Familie zu verletzen und $z u$ schädigen drohen. $\left.{ }^{2}\right)$

Von besonderer sozialer Bedeutung ist, daß Ehe und Familie in sich funktionsgerecht wirken. Erste rechtliche Voraussetzung ist ein sachgerechtes Ehe- und Familienrecht, das der Staat in Entfaltung und unter Respektierung des Wesensgehalts der Einrichtungsgarantie zu entwickeln hat. ${ }^{3)} \mathrm{Zu}$ den vornehmsten Pflichten, die Ehe und Familie umschließen, gehört die Unterhaltspflicht. Daß es weder dem Wesen von Ehe und Familie noch ihrer verfassungsrechtlichen Garantie nach dem Sinn des auf den Menschen abstellenden Sozialstaatsprinzips entspricht, den Erwerbsunfähigen über das Maß der Leistungsfähigkeit von Ehe und Familie hinaus auf die Unterhaltspflicht ehelicher und familiärer Garanten zu verweisen, wurde bereits klargestellt. ${ }^{4)}$ Umgekehrt aber würde die Subsidiaritätsnorm, die das Verhältnis zwischen dem Sozialstaat und der verfassungsgarantierten Ehe und Familie $z u$ beherrschen hat, verfehlt, wenn Familie und Ehe nicht dazu angehalten würden, zu leisten, was sie den Umständen nach zu

\footnotetext{
19) S. hierzu Wolff, Verwaltungsrecht I, S.155; Scheffler, a.a.O. S. 317; je m.w. Nachw.

1) S. nochmals Scheffler, a.a.O. S.281 ff.

2) Vgl. BVerfGE 6, 55 (76 f); Scheffler, a.a.O. S. $270 \mathrm{ff}, 302 \mathrm{ff}$ (m.w.Nachw.).

3) S. nochmals Scheffler, a.a.O. S.281 ff.
} 
leisten vermögen. Deshalb ist die Befugnis und Aufgabe des Staates, die Unterhaltspflichten präzis aufzurichten und zur Geltung zu bringen, 5) von hervorragender sozialpolitischer und familien- und ehepolitischer Bedeutung.

Der sozialen Funktionsfähigkeit der Ehe und der Familie dient grundsätzlich auch, was der Staat vorsorgt, um Störungen abzuhalten, die von Dritten an die Familie und an die Ehe herangetragen werden. ${ }^{6)}$ Schadensersatzpflichten für den Ausfall von Unterhaltsträgern sind sozial bedeutsame Funktionssurrogate.

Außerordentlich schwierige Wertungsfragen stellen sich der staatlichen Rechtsordnung, wo weder unmittelbare exogene Störungen noch endogene Störungen von der Familie bzw. der Ehe abzuhalten sind sondern Interessen- und Pflichtenkol1isionen in ein- und derselben sowohl ehelich-familiär als auch nach a u $\beta$ en gebundenen Person auftreten. Es würde Ehe und Familie weder nützlich sein noch ihrem Wesen entsprechen, wenn der ehelichen bzw. familiären Pflichtstellung schlechthin der Vorrang gegeben würde. Es würde ferner dem Prinzip widersprechen, daß im allgemeinen Verkehr jeder die Umstände selbst zu vertreten hat, die in seiner Person liegen; denn um solche handelt es sich auch bei dem ehelichen bzw. familiären Pflichtstand. Eine schicksalhafte Verbindung zwischen den Außenbeziehungen der einzelnen, insbes. der verantwortlichen, unterhaltsgarantierenden Mitglieder und dem Ergebnis der Ehe bzw. Familie entspricht schließlich dem überkommenen Verständnis von Ehe und Familie. Aber die staatliche Rechtsordnung muß auch den "besonderen Schutz" bieten, den sie Ehe und Familie schuldet. Sie muß ihr ein Mindestmaß an Sicherheit und Lebensraum sowohl gegenüber der Vernachlässigung durch ihre verantwortlichen Glieder als auch gegenüber den objektiven Verhältnissen und den Eigeninteressen Dritter gewähren. Das Recht der Sicherung der Unterhaltsansprüche gegen den Zugriff Dritter auf

4) S.o. S.995 ff.

5) Der Durchsetzung dient in erster Linie das bürgerliche Verfahrensrecht (einschließlich der Hilfsmittel, die das Recht der elterlichen Gewalt, Vormundschaft und Pflegschaft und der freiwilligen Gerichtsbarkeit bieten). Daneben steht der strafrechtliche Schutz der Unterhaltspflicht (s. hierzu in diesem Zusammenhang Scheffler, a.a.O. S.302 ff, insbes. S. 303). Nicht zuletzt kommt die Befugnis der Verwaltung in Betracht, den Verpflichteten unmittelbar oder mittelbar zur tätigen Erfüllung anzuhalten ( $\mathrm{s}$. hierzu oben Abschnitt 5 III $3 \mathrm{c}$ bb (S. 801 ff) und d. dort. Nachw.).

6) Vgl. Scheffler, a.a.O. S.302 ff. 
die ihrer Erfüllung dienenden Mittel des Verpflichteten und haftende Objekte ${ }^{7)}$ ist Ausdruck des Bemühens, vermögensmäßige Kollisionen auszugleichen. Das Recht des Hausarbeitstags 8) um ein weiteres Beispiel zu nennen - ist die Frucht des Versuchs, der ehelich-familiären Haushaltsführungspflicht gegenüber der arbeits-(dienst-) rechtlichen Inanspruchnahme der Arbeitskraft Raum zu schaffen. 9 )

Nicht alle Interessen- und Pflichtenkollisionen dieser Art kann der Gesetzgeber sehen und aufgreifen. Der Schutz der Ehe und Familie hat jedoch umfassend zu sein. Es ist die Aufgabe der Gesetzesauslegung und insbes. der Handhabung der wertbegrifflichen Generalklauseln, die ausdrücklichen Bestimmungen des gesetzten Rechts entsprechend zu ergänzen. Hierin liegt die Drittwirkung des Art. 6 Abs. 1 GG. Die interpretatorischrechtsanwendende Entfaltung des Art. 6 Abs. 1 GG im Privatrecht darf aber nicht verkennen, daß dem verfassungsrechtlichen Schutz von Ehe und Familie immer auch Grundrechtspositionen des gegeninteressierten Dritten und individuelle Grundrechtspositionen des familien-(ehe-)gebundenen Beteiligten gegenüberstehen. Privater Rechtsgebrauch und private Autonomie sind mit A rt. 6 Abs. 1 GG in Einklang zu bringen, nicht aber schlechthin dem Schutz der Ehe und der Familie nachzuordnen. ${ }^{10)}$

\section{cc) Zum Zölibatsproblem}

Art. 6 Abs. 1 GG präzisiert Art. 2 Abs. 1 GG dahin, daß es zu dem der gesetzlichen Disposition unzugänglichen Kerngehalt der freien Entfaltung der Persönlichkeit 1) gehört, eine Ehe eingehen und eine Familie gründen zu können. ${ }^{2)}$ Das steht für die allgemeine

7) Zu den Einzelheiten s. Scheffler, a.a.O. S.307 f.

8) S. hierzu oben S. $923 \mathrm{ff}$.

9) Vgl. des Näheren Scheffler, a.a.O. S. $308 \mathrm{f} \mathrm{m.w.Nachw.}$

10) Zur Drittwirkung des Art. 6 Abs. 1 GG s. Scheffler, a.a.O. S. $273 \mathrm{f} \mathrm{m}$. w. Nachw. - Zu den entsprechenden allgemeinen Grundsätzen s. oben I 4 d aa (S.876 ff).

1) Vgl. BVerfGE 6, 32 (41).

2) Gelegent1ich wird auch auf Art.1 Abs.1 GG verwiesen. Doch dürfte das so allgemein, wie Art. 2 Abs. 1 und 6 Abs. 1 GG die Freiheit der Eheschließung und der Familiengründung garantieren, nicht zutreffen.- Positiv ist das Recht auf Eingehung einer Ehe in Art. 12 der Menschenrechtskonvention gesichert.S. hierzu außer den unten S.1006 zu Fußn. 7 Zitierten Wolff, Verwaltungsrecht I, S. 155. 
Ordnung des Eheschließungsrechts außer Zweifel. Insbes. auch soziale Hemmnisse der Familiengründung - wie der Nachweis der wirtschaftlichen Selbständigkeit und eines ausreichenden Einkommens (Vermögens) - sind ausgeschlossen. 3 )

Nur über die freiwillig übernommene Pflicht zur Ehelosigkeit bestehen Meinungsverschiedenheiten. Das Verfassungsbekenntnis $\mathrm{zu}$ Ehe und Familie stellt kein Unwerturteil über Ehelosigkeit und Familienlosigkeit dar. Dem Recht, eine Ehe einzugehen und eine Familie zu gründen, entspricht keine Pflicht hierzu. Es ist auch - wenigstens der Ausübung nach - nicht schlechthin unverzichtbar. 4) Aber die Zulässigkeit einer rechtlich sanktionierten Verpflichtung, die Eingehung einer Ehe und die Begründung einer Familie - für immer oder auf Zeit, ausnahmslos oder unter gewissen Voraussetzungen - zu unterlassen, unterliegt im Hinblick auf Art. 2 Abs. 1, 6 Abs. 1 GG 5) engen Grenzen. 6)

Von besonderer sozialer Bedeutung sind die dienstrecht 1 i chen "Zölibatsklauseln". 7) Daß Art.2 Abs.1, 6 Abs. 1 GG 5)

3) Vgl. Scheffler, a.a.O. S.256. - Eine andere Frage ist, ob der Staat die Eingehung der Ehe dadurch erschweren darf, daß er soziale Leistungen, die er einem Ledigen gewährt, nach dessen Verheiratung einstellt, wie das für die verschiedenen Waisenversorgungen und - renten die Regel ist. Mit dem Hinweis allein auf die Unterhaltspflicht des Ehegatten ist das Problem nicht zu lösen; denn der Ehegatte kann zur Unterhaltsleistung außerstande sein (was in BSGE 12, 27 (30) ausdrücklich für unerheblich erklärt wird!). Möglich ist freilich, daß durch die Eheschließung der Zweck einer Versorgungsleistung (z.B. Ausbildungsbeihilfe) ausscheidet. Möglich ist ferner, daß der Ehegatte mit Rücksicht auf die Waisenversorgung weniger Unterhalt leisten würde als er zu leisten imstande wäre. Darauf wird das Recht entsprechend zu reagieren haben. Aber die Waisenversorgung schlechthin mit der Eheschließung des Waisen enden zu lassen, ist mit Art.6 Abs. 1 GG nicht vereinbar.

4) Deshalb ist das Recht auf Ehe und Familie auch kein "für alle geltendes Gesetz" i.S. des Art. 137 Abs. 3 Satz 1 RV 1919 i. V.m. Art. 140 GG und das kirchliche Zölibatsrecht somit zulässig (Scheffler, a.a.O. S.317 f).

5) S. nochmals oben S.1004 zu Fußn.2.

6) Maunz (Die verfassungsrechtliche Gewähr von Ehe und Familie, S. 1) hält einen Vertrag auf Nichteingehung einer Ehe und Nichtgründung einer Familie für ungültig (sittenwidrig). Es wird jedoch auf die Umstände ankommen. S. das Folgende. 
die unfreiwillige Verpflichtung zur Ehe- und Familienlosigkeit in einem unfreiwillig eingegangenen Dienstverhältnis verbietet, steht außer Frage. Das gilt auch dort, wo der freie Wille nicht durch staatlich-rechtlichen Zwang sondern durch tatsächliche Abhängigkeit und Machtüberlegenheit aufgehoben ist. ${ }^{8)}$ Aber die freiwillig übernommene - bzw. bei freiwilliger Begründung eines Dienstverhältnisses bewußt mit übernommene - Verpflichtung zur Ehe- und Familienlosigkeit unterliegt nicht demselben ausnahmslosen Interdikt. Art. 2 Abs. 1 GG beinhaltet auch die persönliche Entscheidungsfreiheit gegen Ehe und Familie. Die Ehe- und Familienlosigkeit muß aber nicht nur freiwillig übernommen, sie muß nach Inhalt und $Z$ weck des Dienstverhältnisses auch sachlich notwendig und gerechtfertigt sein. Das gilt in erster Linie dort, wo der Staat den Zugang zu einem Beruf regelt. Im Hinblick auf Art.12 Abs. 1 GG darf die subjektive Zulassungsvoraussetzung der Ehe- und Familienlosigkeit und der Bereitschaft, diesen Zustand beizubehalten, 9) nur dann gefordert werden, wenn

7) Vg1. Molitor, Die Unzulässigkeit von Zölibatsklauseln in Einzelarbeitsverträgen, A rbeit und Recht, 1.Jhg. (1953) S.335 ff (nicht verfassungsrechtlich sondern rein privatrechtlich - über $\$ \$ 134,138$ BGB - argumentierend; in Anbetracht der Verwirklichung des Art. 6 Abs. 1 GG im Privatrecht über eben die Generalklauseln des Privatrechts - s.o. S. $1002 \mathrm{ff}-$ deshalb nicht ohne Interesse. - Dort insbes. weitere Nachweise aus der älteren Rechtsprechung und Lit.); Hildegard Krüger, Völkerrechts- und Verfassungswidrigkeit der Zölibatsklausel für Polizeivollzugsbeamte, Zeitschrift für Beamtenrecht, 3.Jhg. (1955) S. 289 ff; dies., Zölibatsklause1 im öffentlichen Dienst, DÖV 11.Jhg. (1958) S. 761 ff; Wilhelm Henrichs, Die dienstrechtliche Heiratserlaubnis im Lichte des Art. 12 der Menschenrechtskonvention von Rom, Ehe und Familie im privaten und öfentlichen Recht, 3.Jhg. (1956) S. 175 ff; Schneeberger, Zur Frage der Rechtswidrigkeit der Zölibatsklausel für Polizeivollzugsbeamte, Zeitschrift für Beamtenrecht, 4.Jhg. (1956) S. 33 ff; Schnupp, Zölibatsklausel für Polizeivollzugsbeamte, 4.Jhg. (1956) S. 343 ff; Dürig, in Maunz-Dürig, Art. 2 Abs. 1 Randn. 57; Scheffler, a.a.O. S. 256 f, 274, 317 ff. Weitere Nachw. insbes. aus der Rechtsprechung s. bei den Genannten.

8) Vg1. Dürig, a.a.O.; Scheffler, a.a.O. S.274, 318. - Zu den allgemeinen Grundsätzen s. oben I 4 a (S. $861 \mathrm{ff}$ ).

9) BVerfGE 7, 377 (406 f) hatte zwar unter subjektiven Zulassungsvoraussetzungen unmittelbar nur solche der Ausbildung im Auge. Doch erlauben die Kriterien der persönlichen Eigen- 
sie sich "aus der Sache heraus legitimiert" 10) und dem Berufswerber nur etwas zugemutet wird, "was er grundsätzlich der Sache nach ohnehin auf sich nehmen müßte, wenn er den Beruf ordnungsgemäß ausüben will".11) Daran werden mit Rücksicht auf A rt. 6 Abs. 1 GG die strengsten Anforderungen zu stellen sein. 12) Das gleiche gilt für den Zugang zum öffentlichen Dienst, der sich nicht in Art.12 Abs. 1 GG sondern in Art. 33 GG geregelt findet.13) Art. 6 Abs. 1 GG gebietet, die Verehelichung eines Bewerbers als Kriterium der Nichteignung und Nichtbefähigung zum öffentlichen Dienst (Art.33 Abs.2 GG) auf das unerläßliche Mindestmaß zu beschränken. ${ }^{14)}$ Die Privatautonomie genießt dem-

schaft (Qualifikation) (BVerfGE 7, $406 \mathrm{f}$ ) und der persönlichen Verfügungsmacht über die Voraussetzungen dieser Qualifikation (BVerfGE 7, 407) eine entsprechende Verallgemeinerung des Begriffs der subjektiven Zulassungsvoraussetzung (s. zur Abgrenzung auch Bachof, Freiheit des Berufs, S.217).

10) BVerfGE 7, 406.

11) BVerfGE 7, 407. - Das Bundesverfassungsgericht fährt dort fort: "Diese Freiheitsbeschränkung erweist sich so als das adäquate Mittel zur Verhütung möglicher Nachteile und Gefahren... Hier gilt das Prinzip der Verhältnismäßigkeit in dem Sinne, daß die vorgeschriebenen subjektiven Voraussetzungen zu dem angestrebten Zweck der ordnungsmäßigen Erfüllung der Berufstätigkeit nicht außer Verhältnis stehen dürfen".

12) Zu den Momenten der Güterabwägung s. allgemein BVerf GE 7, $405 \mathrm{ff}$. Im besonderen s. Scheffler, a.a.O. S. $318 \mathrm{f}$.

13) BVerfGE 7, 377 (397 f); 11, 30 (39 f).

14) Für die Zulässigkeit beamtenrechtlicher Zölibatsklauseln Schneeberger, a.a.O. (s.o. S.1006 zu Fußn.7); gegen die Zulässigkeit Krüger und Schnupp je a.a.O. (s.ebd.); für bedingte Zulässigkeit Henrichs und Scheffler - diese insbes. i.S. des Textes - je a.a.O. (s.ebd.), und wohl auch Maunz, Die verfassungsrechtliche Gewähr von Ehe und Familie, S.2. Dabei geht es vor allem um das Problem des kasernierten Polizeibeamten (gegen den Widerruf des Beamtenverhältnisses bei nicht genehmigter Eheschließung s.a. OVG Koblenz, Urt.v. 19. April 1955, Zeitschrift für Beamtenrecht, 3.Jhg. (1955) S.314). Hier wird von Verfassungs wegen die Zulässigkeit einer - zeitlich begrenzten - Zölibatsklausel nicht ausgeschlossen werden können (a.A. Krüger, Schnupp, Scheffler je a.a.O.; wie hier Henrichs und Schneeberger je a.a.O.). - Dagegen ist es - abgesehen von dem Verstoß gegen Art. 3 Abs. 2 und 3 GG - nicht zulässig, die Beamtin im 
gegenüber einen größeren Spielraum. Aber Art. 6 Abs. 1 und Art. 12 Abs. 1 GG verlangen auch hier ein Mindestmaß an Durchsetzung und dies umso dringlicher,je mehr die Überlegenheit des A rbeitgebers über den Arbeitnehmer dessen Grundrechtsposition einseitig bedrängt. 15) Die Unbedenklichkeit einer arbeitsrechtlichen Zölibatsklausel wird demnach mit ihrer Freiwilligkeit und ihrer sachlichen Adäquanz wachsen und mit ihrer Unfreiwilligkeit und ihrer sachlichen Willkürlichkeit abnehmen. 16) 17)

2. Elternrecht - Kinder- und Jugendschutz Schule

a) Elternrecht

Mit besonderer Intensität sichert die Verfassung die Integrität der Familie und präzisiert sie die subsidiäre Funktion des Staates gegenüber der Familie in bezug auf das Eltern-Kind-Verhältnis: 1) "Pflege und Erziehung der Kinder sind das natürliche Recht der Eltern und die zuvörderst ihnen obliegende Pflicht" (Art.6 Abs. 2 Satz 1 GG). 2) Hinter den Eltern steht der Staat als

Falle ihrer sie wirtschaftlich versorgenden Verehelichung allgemein mit der Entlassung zu bedrohen (s. z. B. Scheffler, a.a.O. S. 318 m.w. Nachw.).

15) S. o. S. 1006 zu Fußn. 8.

16) Für die bedingte Zulässigkeit: Dürig und Scheffler je a.a.O. (s. o. S. 1006 zu Fußn. 7); gegen die Zulässigkeit Krüger, a.a.O.; BAGE 4, 274; ferner (ohne verfassungsrecht1iche Argumentation) Molitor a.a.O. (S.o. S.1006 zu Fußn. 7).

17) Für die anzustellende Abwägung der Interessen- und Rechtspositionen ist immer auch zu berücksichtigen, unter welchen Umständen die berufliche Entscheidung zugunsten der Freiheit der Eheschließung revidiert werden kann. Eine lebenslängliche Bindung kommt schon unter dienstrechtlichen Aspekten nicht in Betracht (Art.2 Abs.1, 1 Abs.1 GG; vgl. $\$ 624$ $B G B)$. Jedoch können Kündigungsfristen und Entlassungsfristen differieren. Ferner kann die Beendigung des Dienstverhältnisses mit Vertragsstrafe o. ä. Sanktionen belastet sein. Vor allem aber kann die spezielle Berufsausbildung, das Dienstalter usw. einen Wechsel erschweren. Das alles wird in Anschlag zu bringen sein.

1) Zum Zusammenhang zwischen der verfassungsrechtlichen Garantie des Elternrechts mit der der Familie s.a. Scheffler, a.a.O. S. 252 .

2) Zur Auslegung s. im allgemeinen Peters, Elternrecht, Erziehung, Bildung und Schule, S. $371 \mathrm{ff}$, insbes. S. $373 \mathrm{ff}$. W. Nachw. s. dort. 
Wächter (Art.6 Abs.2 Satz 2 GG) ${ }^{3}$ ) und Helfer. 4) Grundsätzlich ist er darauf beschränkt, die Eltern kooperativ zu unterstützen. Nur wenn diese ihrer Pflicht 5) nicht nachkommen (können) und der Anspruch des Kindes auf Erziehung zu leiblicher, seelischer und gesellschaftlicher Tüchtigkeit 6 ) von der Familie nicht erfüllt wird, 7) kann der Staat sich über den Willen der Eltern hinwegsetzen und korrigierend eingreifen. Dabei hat er zunächst zu versuchen, die Eltern zur Erfüllung ihrer Pflicht anzuhalten und soweit nötig - instandzusetzen. Nur für den Fall, daß die Erziehungsberechtigten ${ }^{8)}$ versagen ${ }^{9}$ ) oder die Kinder aus anderen Gründen zu verwahrlosen drohen, 10) darf das Gesetz ${ }^{11)}$ die Trennung der Kinder von der Familie auch gegen den Willen der Erziehungsberechtigten zulassen (Art.6 Abs.3 GG). 12) 13)

3) S. hierzu Peters, a.a.O. S.390 f u. passim.

4) Das Grundgesetz hebt die kooperative Helferrolle des Staates gegenüber den Eltern nicht hervor. Doch ergibt sie sich abgesehen vom allgemeinen sozialstaatlichen Auftrag - daraus, daß den Eltern die Pflege und Erziehung der Kinder als Pflicht zwar "zuvörderst" aber doch nicht ausschließlich zugewiesen ist. (S. hierzu auch Peters, a.a.O. S. 379 f, $389 \mathrm{f}$ (insbes. S. 390)).

5) Zur Pflicht der Eltern nach Art. 6 Abs. 2 Satz 1 GG s. Peters, a.a.O. S.388 ff.

6) Zu diesem "Anspruch" s. $\ 1$ Abs. 1 und 3 des Jugendwoh1fahrtsgesetzes; s. ferner BVerfGE 7, 320 (323).

7) Vg1. $\$ 1$ Abs. 3 des Jugendwohlfahrtsgesetzes.

8) Zum Verhältnis des Begriffs "Erziehungsberechtigte" i.S. des Art. 6 Abs. 3 GG zu dem Begriff "Eltern" i.S. des Art. 6 Abs. 2 GG s. v. Mangoldt-Klein, Art.6 Anm. IV 2 b; Peters, a.a.O. S. $375 \mathrm{ff}, 387$.

9) Zum Tatbestand s. Peters, a.a.O. S. 387.

10) Zum Tatbestand s. v. Mangoldt-Klein, Art. 6 Anm. IV 5 c; Denecke, Mutterschutz und Jugendschutz, S.489; Peters, a.a.O. S. $387 \mathrm{f}$.

11) Art. 6 Abs. 3 GG darf nicht zu der Ansicht verleiten, nur die Trennung stehe unter dem Vorbehalt des Gesetzes. Auch jeder sonstige Eingriff unterliegt dem Allgemeinvorbehalt des Gesetzes (vgl. $\$ 1$ Abs. 2 Satz 2 des Jugendwohlfahrtsgesetzes; zumindest mißverständlich Peters, a.a.O. S.390).

12) Im wesentlichen geht es dabei um die Anordnung der Fürsorgeerziehung (vgl. Peters, a.a.O. S. 388; $\$ \mathbb{\$} 62$ ff des Jugendwohlfahrtsgesetzes).

13) Nicht unbedenklich ist, daß Art. 6 Abs. 3 GG den Eltern (Erziehungsberechtigten) die Befugnis, den Aufenthalt des Kindes 
Damit ist einer familienfeindlichen, etatistischen Jugendpolitik der Riegel vorgeschoben. Auch und gerade die soziale Kinderund Jugendhilfe des Staates hat sich in diese subsidiäre Rolle zu schicken. Sie hat in erster Linie Hilfe für die Eltern zu sein, ihre Pflicht der Erziehung und Pflege ihrer Kinder zu erfüllen. Die daraus zwangsläufig erwachsene Streuung in der Ausnutzung der vorhandenen Hilfs- und Förderungsmöglichkeiten ist um des Elternrechts und letztlich um des Menschen willen hinzunehmen. 14) Insbes. ist "eine zwangsweise Trennung der Kinder von den Eltern, lediglich um sie objektiv in materiell und ideell bessere Lebensverhältnisse zu bringen", nicht zulässig. 15)

Andererseits muß der Sozialstaat seine subsidiäre Rolle voll ausfüllen. Es geht nicht nur darum, die unmittelbare Not des Kindes abzuwenden. Vielleicht sozial noch bedeutsamer ist, daß das Kind durch Pflege und Erziehung instand gesetzt wird, sein Leben, herangewachsen, in sozial optimaler Weise zu meistern.

Wenn der Staat in diese Aufgabe die Träger der freien Jugendpflege einbezieht, so wird das nicht nur die Effektivität der Jugendhilfe erhöhen. Es wird den Eltern auch den Entschluß erleichtern, Hilfe von außen anzunehmen; denn sie haben dadurch regelmäßig die Möglichkeit, Hilfe von weltanschaulich oder sonstwie gleichgesinnter Seite zu erlangen, die der "neutrale" Staat (und die "neutrale" Gemeinde) nicht gewähren kann. 16) Aber einen grundrechtlichen Anspruch auf freie Jugendpflege und auf die Subsidiarität der staatlichen Jugendhilfe gegenüber der freien Jugendpflege gewährt Art.6 GG nicht. 17)

einschließlich seiner geschlossenen Unterbringung zu bestimmen - in den allgemeinen Grenzen des Art. 6 Abs. 2 GG -, voll beläßt. Das Elternrecht gerät hier in Kollision mit dem Freiheitsrecht des Kindes (zum Kollisionsproblem s. Peters, a.a.O. S. $391 \mathrm{ff}$ ). Das Problem sollte im Anschluß an BVerfGE 10, 302 neu überdacht werden (s. hierzu z. B. Erdsiek, Freiheitsentziehung und richterliche Kontrolle, NJW 13. Jhg. (1960) S. 1385 ff).

14) Vgl. Peters, a.a.O. S. 389.

15) Peters, a.a.O. S.388. - S. zu Vorstehendem auch Süsterhenn, Die kirchliche Liebestätigkeit im sozialen Rechtsstaat der Gegenwart, S. 115.

16) S. z.B. Peters, a.a.O. S. 390, 391.

17) S. Köttgen, Das umstrittene Mandat zur Jugendpflege, S. 5 f; s.a. Peters, a.a.O. - Im übrigen s. hierzu schon oben Abschnitt 2 I (S.219 ff) und III (S.242 ff). 
b) Kinder- und Jugendschutz

Das Grundgesetz spricht ausdrücklich nur die Beziehung StaatEltern-Kind an. Diese involviert den Schutz der Kinder durch die Eltern (Art. 6 Abs. 2 Satz 1 GG), 1) den Schutz der Kinder durch den an die Stelle der Eltern getretenen Staat bzw. die von ihm mit der Erziehung Beauftragten (Art. 6 Abs. 2 Satz 2 und Abs. 3 GG) und den Schutz der Kinder durch den Staat gegen die Eltern (ebd.). Der Schutz der Kinder und Jugendlichen gegen Gefährdungen und Schädigungen, die weder von den Eltern ausgehen noch von den Eltern hinreichend beherrscht werden können, wird von diesem Regulativ nicht erfaßt. Den Schutz von Kindern und Jugendlichen, die keine Eltern mehr haben, berührt es, indem es die Subsidiärfunktion des Staates klarstellt, allenfalls am Rande.

Den Kinder- und Jugendschutz in diesem weiteren Sinn 2) verschweigt das Grundgesetz. Trotzdem steht außer Frage, daß der auf Menschenwürde (Art. 1 Abs. 1 GG) und freie Entfaltung der Persönlichkeit (Art.2 Abs. 1 GG) abzielende Sozialstaat des Grundgesetzes den Kinder- und Jugendschutz umfassend zu entwickeln hat. Einzelheiten lassen sich - von dem Ausgeführten abgesehen aus der Verfassung jedoch nicht entnehmen. 3 )

\section{c) Schule und Bildung}

Unter den Elementen der Jugenderziehung hebt das Grundgesetz die Schule besonders hervor (Art. 7 GG).1) Die grundgesetzliche Sachordnung legt ihr Hauptgewicht auf das Verhältnis Staatsschule - konfessionelle (Weltanschauungs-)Schule - Privatschule. ${ }^{2}$ ) Soziale Bildungsfragen berührt sie nur am Rande (Art. 7 Abs. 4 Satz 3 und Abs.6 GG). ${ }^{3}$ ) Das Sozialstaatsprinzip und der sozial erfüllte Gleichheitssatz garantieren im wesentlichen jedoch auch sub specie des Grundgesetzes ein sozial zureichend gestaltetes schulwesen. 4) 5)

1) Vg1. Denecke, Mutterschutz und Jugendschutz, S. 489.

2) Zum gegenständlichen Bereich s.Denecke, a.a.O. S.488 ff.

3) Zum Stand der Entwicklung s. z.B. Denecke, a.a.O. S. $488 \mathrm{ff}$.

1) Zum Verhältnis Elternrecht und Schule s. Peters, Elternrecht, Erziehung, Bildung und Schule, S. $379 \mathrm{f}, 385 \mathrm{fm}$. w. Nachw.

2) Zur Darstellung des danach geltenden Rechts s. Peters, a.a.O. S. $401 \mathrm{ff}$.

3) S. hierzu oben S. 821.

4) S. ebd.

5) S. zu Vorstehendem auch Art. 2 Abs. 1 des Zusatzprotokolls 


\section{Der Mutterschutz}

"Jede Mutter hat Anspruch auf den Schutz und die Fürsorge der Gemeinschaft" (Art.6 Abs.4GG). Damit wird kein subjektives Recht gewährt sondern ein Programm aufgestellt. 1) Der Staat hat der Mutter 2) über ihre durch Schwangerschaft, Niederkunft, Stillzeit usw. bedingten Notsituationen hinwegzuhelfen. 3)

Das Programm der Verfassung zu verwirklichen, ist im wesentlichen Sache des Gesetzgebers. 4) Der gegenwärtige Stand des Mutterschutzes 5) erfüllt das verfassungsrechtliche Mindestmaß bereits. 6) Jedoch läge eine weitere Entwicklung im Sinne der Verfassung. 7) Einem wesentlichen Abbau würde sich Art. 6 Abs. 4 GG widersetzen. ${ }^{8)}$ Als verbindliches Programm hat Art. 6 Abs. 4 GG - kraft der Vermutung, daß der Gesetzgeber den Auftrag der Verfassung zu erfüllen trachtet - auch Richtlinie der

zur Konvention zum Schutze der Menschenrechte und Grundfreiheiten: "Das Recht auf Bildung darf niemandem verwehrt werden".

1) S. zu Art. 6 Abs. 4 GG v. Mangoldt-Klein, Art. 6 Anm. V 1 und Denecke, Mutterschutz und Jugendschutz, S.478 je m.w. Nachw.; ferner Giese-Schunck, Grundgesetz, Art. 6 Anm. 4; a.A. OVG Münster OVGE 5, 119; Hamann, Das Grundgesetz, Art. 6 Anm. C 7 (unter Berufung auf das Sozialstaatsprinzip!).

2) Mutter ist die eheliche und die uneheliche, sowie die werdende und die "gewordene" Mutter (vgl. v. Mangoldt-Klein, Art. 6 Anm.V 2 m.w. Nachw.).

3) Es geht nur um die "Notzeiten" der Mutter. Nicht etwa soll jede Frau, die einmal Mutter geworden ist, bis an ihr Lebensende privilegiert sein (vgl. Wernicke, Bonner Kommentar, Art. 6 Erl. II 4 b; v. Mangoldt-Klein, Art. 6 Anm.V 2). Zum Zusammenhang zwischen Mutterschutz und Sozialstaatsprinzip s.o. S. 778 zu Fußn. 3 und S. 785 zu Fußn. 6.

4) S. die Nachw. oben Fußn.1.

5) Vg1. z.B. Denecke, Mutterschutz und Jugendschutz, S. 482 ff.

6) Zuzugeben war dagegen dem Oberverwaltungsgericht Münster (OVGE 5, 119), daß der Mutterschutz in verfassungswidriger Weise unvollkommen war, solange er nicht auch die Beamtin erfaßte.

7) Vorschläge für die Erweiterung des Mutterschutzes für die uneheliche Mutter stützt Hildegard Krüger (Uneheliche Kinder, in: Bettermann-Nipperdey-Scheuner, Die Grundrechte, Bd. IV, 1. Halbbd. 1960, S. $325 \mathrm{ff}$ (328 ff)) insbes. auf Art. 6 Abs. 5 GG.

8) Vgl. Laufke, Vertragsfreiheit und Grundgesetz, S. 159. 
Rechtsanwendung, insbes. der Gesetzesauslegung zu sein. 9) Über die Auslegung der Normen, insbes. der Generalklauseln des Privatrechts entfaltet die Vorschrift so auch "Drittwirkung". 10)

\section{Zur Stellung des unehelichen Kindes}

Die typische Notlage des unehelichen Kindes liegt - von gesel1schaftspsychischen Vorurteilen abgesehen - darin, daß es keinen mit der Mutter in legitimer ehelicher Gemeinschaft lebenden Vater - keine Elternfamilie sondern nur eine Mutterfamilie hat, und des weiteren in der häufigen Schwierigkeit, auch nur den natürlichen Vater zu ermitteln. Der Auftrag, "den unehelichen Kindern... die gleichen Bedingungen für ihre leibliche und seelische Entwicklung und ihre Stellung in der Gesellschaft zu schaffen wie den ehelichen Kindern" (Art.6 Abs.5 GG), weist daher vor allem in vier Richtungen möglicher Abhilfe. 1) Erstens: Was kann getan werden, um dem unehelichen Kind zur Feststellung seines natürlichen Vaters zu verhelfen? 2) Zweitens: Was kann getan werden, um dem Kind in dem natürlichen Vater so gut als möglich einen "wirklichen" Vater zu geben, ohne sein Nicht-verheiratet-Sein mit der Mutter zu ignorieren? ${ }^{3)}$ Drittens: Inwieweit soll die Gemeinschaft in die "Vaterfunktion" eintreten, wenn der natürliche Vater nicht festgestellt werden kann 4) und - darüber hinaus - soweit der natürliche Vater nicht für die vo1le Vaterfunktion in Anspruch genommen werden kann. 5) Viertens: Wie kann das Mutter-Kind-Verhältnis gestaltet werden, um

9) S. die Nachw. o. S. 1012 zu Fußn. 1.

10) Vg1. Bundesarbeitsgericht, Urt.v.28. November 1958 - 1 AZR 199/58 - AP Art. 6 GG Nr.3 (B1.2 Rücks.).

1) Zum gesamten Problemstand s. Krüger, Uneheliche Kinder; w. Nachw. s. dort.

2) Vgl. Krüger, a.a.O. S. $347 \mathrm{ff} \mathrm{m.w.Nachw.}$

3) Vgl. Krüger, a.a.O. S. $347 \mathrm{ff} \mathrm{m.w.Nachw.} \mathrm{-} \mathrm{Zum} \mathrm{Verhältnis}$ der Garantie von Ehe und Familie (Art. 6 Abs. 1 GG) zu Art. 6 Abs. 5 GG s. Scheffler, Ehe und Familie, S. 297 f; Krüger, a.a.O. S. $339 \mathrm{ff}$; je m.w. Nachw.

4) S. z.B. die Vorschläge eines besonderen Kindergeldes für die uneheliche Mutter (Krüger, a.a.O. S.331) und einer kollektiven Zahlungspflicht potentieller Erzeuger für uneheliche Kinder (ebd. S. 352 f).

5) Das ist vor allem auch eine Frage der Ergänzung und Korrektur des Mutter-Kind-Verhältnisses durch die staatliche Mitsorge (s. hierzu Krüger, a.a.O. S. 342 ff m.w. Nachw.). 
dem unehelichen Kind durch die Mutterfamilie so weit als möglich die Elternfamilie zu ersetzen? ${ }^{6}$ )

Damit sind Problem - und Lösungsrichtungen angegeben, die sich aus der Natur der Sache ergeben. Die konkret zu wählende Lösung kann jedoch durch die kurze Formel des Art. 6 Abs. 5 GG nicht präjudiziert sein. "Die tatsächliche und die rechtliche Lage des unehelichen Kindes im Familienverband unterscheidet sich durch das Fehlen des ehelichen Vaters grundlegend und un a bänderlich 7) von der des ehelichen Kindes. ... Die Aufgabe, 'gleiche Bedingungen' zu schaffen, kann also im Familienrecht nur bedeuten, daß die rechtliche Situation des unehelichen Kindes, soweit sie für seine leibliche und seelische Entwicklung und seine Stellung in der Gesellschaft von Belang ist, der Situation des ehelichen möglichst gleichwertig7) gestaltet werden soll". 8) Das gilt im Prinzip über das Familienrecht hinaus. Was "gleichwertig", ist, kann im wesentlichen nur im Rahmen positiver Gesamtkonzeptionen vom Recht des ehelichen und des unehelichen Kindes gesagt werden - Gesamtkonzeptionen, die je nach den Teilentscheidungen, die sie umschließen, unterschiedlich sein können, ohne doch die Maxime der gleichen (gleichwertigen) Bedingungen zu verlassen. ${ }^{9}$ )

Mit Recht hat das Grundgesetz seinen Auftrag daher ausdrücklich an den Gesetzgeber gerichtet (Art.6 Abs. 5 GG). 10) Aber das Grundgesetz wollte den Gesetzgeber auch verpflichten. 11) "Das $\mathrm{Ob}$ und Wann der Erfüllung des Gesetzgebungsauftrages liegt ... nicht im freien Belieben des Gesetzgebers... er verletzt die Verfassung, wenn er es unterläßt, den Verfassungsauftrag in angemessener Frist auszuführen". 12) Diese Frist ist mittlerweile wohl abgelaufen. ${ }^{13)}$ Trotzdem hat der Gesetzgeber den Auftrag

6) Vgl. Krüger, a.a.O. S.342 ff m.w.Nachw.

7) Sperrung nicht im Original.

8) BVerfGE 8, 210 (215).

9) Wenn Hildegard Krüger (a.a.O. S. 327 und $327 \mathrm{ff}$ ) glaubt, aus Art. 6 Abs. 5 GG einen ganzen Codex des Rechts des unehelichen Kindes herauslesen zu können, so macht sie sich nicht klar, wie viel Rechtspolitik sie für Interpretation aus;ribt.

10) Zum Meinungsstand über den Programmcharakter s. z. B. v. Mangoldt-Klein, Art. 6 Anm. VI 1; Hildegard Krüger, Ist Art. 6 Abs. 5 GG ein Programmsatz? DÖV 10.Jhg. (1957) S. 256 ff (356 ff).

11) Vg1. Krüger, a.a.O. m.w.Nachw.; dies., Unehelich€ Kinder, S.325 ff.

12) BVerfGE 8, 210 (216). 
nur in sehr bescheidenen Grenzen erfüllt. Mit am weitesten vorgedrungen ist das Reeht der sozialen Sicherheit und der verwandten sozialen öffentlichen Leistungen, indem es die "gleichen Bedingungen" dadurch herzustellen sucht, daß es den unehelichen Vater weitgehend dem ehelichen bzw. das uneheliche Kind im Verhältnis $z u$ seinem Vater weitgehend dem ehelichen Kind im Verhältnis zum ehelichen Vater gleichstellt. 14) Sehr im argen liegt dagegen die Neuordnung der zentralen familienrechtlichen Problematik. 15) Die Möglichkeit eines Eintretens der Gemeinschaft für den nicht ermittelten Vater wurde noch nicht spezifisch aufgegriffen. Die Unterstützung der Mutter schließlich in der Ausübung der elterlichen Gewalt durch den Staat ist mit Beschränkungen verbunden, von denen zweifelhaft ist, ob sie der Herstellung gleicher Bedingungen dienlich sind. 16)

Damit erhebt sich die Frage nach der Sanktion der gesetzgeberischen Pflicht. Am wirksamsten wäre Art. 6 Abs. 5 GG nunmehr derogatorische Kraft beizulegen und Rechtsprechung und Verwaltung für ermächtigt zu halten, auf Grund dieser Verfassungsnorm als "einer Generalklausel für das gesamte Unehelichenrecht" 17) die gebotenen gleichen Bedingungen für eheliche und uneheliche Kinder zu schaffen. ${ }^{18)}$ Dabei könnte es sich für die Verwaltung, die in ihrem Funktionsbereich und innerhalb der Schranken aller sonst geltenden Verfassungs- und Gesetzesnormen rein leistend (nicht eingreifend) Art.6 Abs. 5 GG auch schon bisher verwirklichen konnte, nur darum handeln, daß sie darin nicht mehr an die

13) Zur Frist s. Krüger, Ist Art. 6 Abs. 5 GG ein Programmsatz? S. 358 f; dies., Uneheliche Kinder, S.326 f. (Krügers präzise Zeitbestimmung - Herbst 1954 - ist allerdings naiv und nicht überzeugend).

14) Vgl. die Zusammenstellung bei Krüger, Uneheliche Kinder, S.336; dies., Die Rechtsstellung des unehelichen Kindes nach dern Grundgesetz, 1960, S. 114 ff, 121 ff; s.a. Scheffler, Ehe und Familie, S.297.

15) Vgl. Krüger, Uneheliche Kinder.

16) Vgl. Krüger, a.a.O. S. 342 ff.

17) BVerfGE 8, 210 (216 f): ". . bedarf es keiner endgültigen Entscheidung, ob und in welchen Grenzen das Ausbleiben des Anpassungsgesetzes zu Art. 6 Abs. 5 GG einen solchen Funktionswechsel der Norm vom Gesetzgebungsauftrag zur aktuellen Rechtsnorm mit derogatorischer Kraft und der Bedeutung einer Generalklausel für das gesamte Unehelichenrecht zur Folge haben kann".

18) So insbes. Krüger, Ist Art. 6 Abs. 5 GG ein Programmsatz? S. 359 f; dies., Uneheliche Kinder, S.325 ff. 
Art. 6 Abs. 5 GG zuwiderlaufenden Gesetze gebunden wäre. A1s Rechtsgrundlage $z u$ belastenden Verwaltungsakten könnte Art. 6 Abs. 5 GG mangels Bestimmtheit sicher nicht dienen. Die Hauptlast der Erfüllung des Art. 6 Abs. 5 GG läge bei der Rechtsprechung - eine Aufgabe, die jener ähnlich wäre, die Art. 3 Abs. 2 und 3, Art. 117 GG der Rechtsprechung bis zum Nachziehen des Gesetzgebers auferlegten. 19) Gerade der Vergleich mit diesen Verfassungsbestimmungen macht aber deutlich, daß Art. 6 Abs. 5 GG nicht einen zweiten Auftrag zu richterlicher Rechtsschöpfung dieses Ausmaßes erteilen wollte 20): In Art. 3 Abs. 2 und 3 GG die präzise, strenge Gleichheitsanordnung - in Art. 6 Abs. 5 GG die Anordnung, tatsächlich Ungleiches durch gleichwertige Regelungen möglichst gleich zu stellen, also ein Auftrag, dessen Erfüllung noch mehr positiver Wertentscheidung bedarf als der der Art. 3 Abs. 2 und 3, Art. 117 GG; in Art. 117 GG der bindende Termin, der in Art. 6 Abs. 5 GG fehlt; in Art. 3 Abs. 2 und 3, Art. 117 GG der absolute Verfassungsbefeh1 - in Art. 6 Abs. 5 GG die betonte Beschränkung auf "die Gesetzgebung".

Somit bleibt als Sanktion die Verfassungsbeschwerde, zu der uneheliche Kinder legitimiert sind, wenn sie dartun können, daß eine Art. 6 Abs. 5 GG entsprechende Neuordnung sie besser stellen müßte als die gegenwärtige Regelung; und die auf diese Weise behaupten, durch die Unterlassung des Gesetzgebers in ihrem Recht aus Art. 6 Abs. 5 GG verletzt zu sein (Art. 19 Abs. 4 GG, $\S 90$ Abs. 1 BVerfGG). 21)

Die Negation des unmittelbaren Vollzugs des Art. 6 Abs. 5 GG durch Rechtsprechung und Verwaltung bedingt nicht auch die Negation der interpretatorischen Bedeutung des Art. 6 Abs. 5 GG für den Gesetzesvollzug. ${ }^{22)}$ Die interpretatorische Bedeutung von Programmsätzen beruht immer auf der Vermutung, der Gesetzgeber habe sich nach ihnen richten wollen. Für diese Vermutung ist auch und gerade dann Raum, wenn sich ein Programm nur an

19) Zur Verfassungsadäquanz dieses Auftrages s. BVerfGE 3 , 225 (237 ff).

20) Gegen diese Sanktion des Art. 6 Abs. 5 GG auch Maunz, Deutsches Staatsrecht, S. 82 f.

21) Für die Zulässigkeit einer Verfassungsbeschwerde Krüger, Ist Art. 6 Abs. 5 GG ein Programmsatz? S. 360 f; s.a. Dürig in Maunz-Dürig, Art. 1 Abs. III Randn.95 Fußn. 5. Zur Verfassungsbeschwerde gegen die gesetzgeberische Unterlassung s. ferner oben S. $557 \mathrm{ff}$.

22) Vgl. Krüger, Ist Art. 6 Abs. 5 GG ein Programmsatz? S. $\$ 56$ ff; BVerfGE 8, 210 (217) und passim. 
den Gesetzgeber richtet. 23) Die inhaltiche Unbestimmtheit des Art. 6 Abs. 5 GG weist freilich auch dessen interpretatorische Funktion in enge Schranken.

\section{Die (sonstigen) Freiheitsgrundrechte}

\section{Vorbemerkung}

Nicht alle Grund- und Freiheitsrechte sind von gleich entschiedener und weittragender sozialer Bedeutung. ${ }^{1)}$

Die Versammlungsfreiheit (Art. 8 GG) etwa ist von kaum einem nennenswerten sozialen Belang als dem, daß sie auch den verschiedenen sozialen Interessengruppen erlaubt, sich zu versammeln; wodurch das Gewicht der Masseninteressen eine nachdrückliche Stärkung erfährt.2)

Das Petitionsrecht (Art.17 GG) hat vielleicht gerade für die ärmeren Schichten - wenigstens psychologisch wägbare - Bedeutung. Der Vermögendere findet kraft seiner gesellschaftlichen Kontakte und der Möglichkeit, sich fachlich qualifizierter Hilfe zu bedienen, leichter den richtigen Weg, um seine Interessen durchzusetzen. Der "kleine Mann" ist eher darauf angewiesen, unbefangen direkt an die für zuständig gehaltene Behörde herantreten zu können.

Das Brief - und Postgeheimnis (Art.10GG) - bis zur Wesensgehaltssperre (Art.19 Abs.2 GG) zur Disposition des Gesetzgebers gestellt - hat soziale Bedeutung am ehesten wohl über seine "drittwirkende" A usstrahlung in das Privatrecht. Das Rechtsgut dieses Schutzrechts der persönlichen Intimssphäre ist nicht nur gegenüber dem Staat sondern auch gegenüber dem mäch-

23) Weil sich Art. 6 Abs. 5 GG an den Gesetzgeber richtet, hat das Bundesarbeitsgericht (BAGE 3, 313) im Ergebnis recht, wenn es eine interpretatorische Wirkung auf einen Tarifvertrag ablehnt. Die tarifliche Rechtsetzung ist nicht "die Gesetzgebung" i.S. des Art. 6 Abs. 5 GG; das ist nur die staatliche Rechtsetzung. Weil das Bundesarbeitsgericht aber den Unterschied zwischen tariflicher und staatlicher Rechtsetzung zu leugnen bestrebt ist, argumentiert es über die Negation jeder interpretatorischen Wirkung, um zum richtigen Ziel zu gelangen.

1) Zur sozialen Bedeutung der ausgrenzenden (Freiheits-) Grundrechte im allgemeinen s. oben I 3 (S. $848 \mathrm{ff}$ ).

2) S. hierzu auch nochmals oben Abschnitt 3 (S.315 ff), insbes. I 1 (S. $315 \mathrm{ff})$. 
tigeren Privatrechtsgenossen, insbes. dem Arbeitgeber, zu verteidigen. ${ }^{3)}$

Mehr zu diesen Grundrechten zu bemerken, ist hier nicht veranlaßt.

2. Das Recht auf Unverletzlichkeit der Wohnung

Das Grundgesetz statuiert ein Grundrecht auf Wohnung im rein ausgrenzenden Sinn (Art.13 GG). 1) Als Abwehrrecht steht es der auch aus sozialen Gründen bisweilen unerläßlichen öffentlichen Inanspruchnahme von Wohnraum 2) grundsätzlich entgegen. Der Vorbehalt zugunsten von "Eingriffen und Beschränkungen... auf Grund eines Gesetzes... zur Verhütung dringender Gefahren für die öffentliche Sicherheit und Ordnung, insbes. zur Behebung der Raumnot" (Art.13 Abs.3 GG) erlaubt jedoch dem Gesetzgeber, auch das sozial Notwendige vorzukehren. ${ }^{3 \text { ) }}$

\section{G1aubens-, Gewissens- und Bekenntnisfrei- he it}

Die Freiheit des Gewissens, des Glaubens und des Bekenntnisses (Art.4 GG) strahlt in den sozialen Bereich schon dadurch aus, daß sie - in Parallele zur Garantie der kirchlichen Liebestätigkeit und der Verkündung sozialethischer Lehren im Rahmen des kirchlichen Selbstbestimmungsrechts 1) - das Recht zum (auch) tätigen Bekenntnis religiöser Liebeshingabe und Hilfsverpflichtung und gewissens-, glaubens- oder bekenntnisbedingter sozialethischer Normen verbürgt. 2)

Bedeutung für die soziale Intervention des Staates erlangt das Grundrecht insbes. auch im Rahmen der sozial fürsorgenden Anstalts- oder Familienunterbringung. Art. 4 GG verlangt die größtmögliche Rücksichtnahme auf Glauben und Bekenntnis des Unterzubringenden. ${ }^{3)}$ Innerhalb der Anstalt muß sich die freie Aus-

3) S. hierzu oben I 4 d aa (S. $876 \mathrm{ff})$.

1) Dazu, daß Art.13 GG kein Teilhaberecht gewährt, s.Kern, Schutz des Lebens, der Freiheit und des Heims, in: Neumann-Nipperdey-Scheuner, Die Grundrechte, Bd. II, 1954, S. $51 \mathrm{ff}(102)$.

2) S. hierzu auch oben S.818f.

3) Zur Vereinbarkeit der Wohnraumbewirtschaftung mit Art.13 GG s. z. B. v. Mangoldt-Klein, Art. 13 A.nm. IV 5 c.

1) S. o. Abschnitt 2 IV 1 (S. 252 ff).

2) Vgl. Hamel, a.a.O. S.61 m.w.Nachw.

3) S. o. S.260 ff, insbes. S. 263 zu Fußn. 10 und S. 266 ff, insbes. 
übung zwar gewisse Beschränkungen gefallen lassen. 4) Zum Ausgleich ist die Anstaltsseelsorge verfassungsrechtlich und konkordatär verbürgt. ${ }^{5)}$

Daß im übrigen die aktive und passive Beteiligung des einzelnen an der sozialen Hilfe und Umverteilung des Staates vom Bekenntnis unabhängig $z u$ sein hat (Art. 3 Abs. 3, 33 Abs. 3, 140 GG, Art. 136 Abs. 1 und 2 RV 1919), wurde bereits hervorgehoben. 6)

Schließlich ist auf den Schutz der Gewissens-, Glaubens- und Bekenntnisfreiheit im öffentlichen und privaten Dienstrecht hinzuweisen. Für das öffentliche Dienstrecht, dessen unmittelbare Betroffenheit durch das Grundrecht des Art. 4 GG außer Frage steht, wird dies durch Art. 33 Abs. 3, 140 GG, Art.136 Abs.2 RV 1919 unterstrichen. Das Arbeitsrecht ist - entsprechend der potentiellen Bedrängnis der Gewissens-, Glaubens- und Bekenntnisfreiheit durch den präsumtiv überlegenen Arbeitgeber oder das Kollektiv der sozialen Selbstverwaltung - das zentrale Feld der Drittwirkung der Gewissens-, Glaubens- und Bekenntnisfreiheit. 7) Gewiß unterliegt die Ausübung Abstrichen, die sich aus dem Zweck und der zweckgerechten Gestaltung des Dienstverhältnisses ergeben und hier gerechten Gestaltung des Dienstverhältnisses ergeben und hier durch die Privatautonomie, ${ }^{8}$ ) dort durch die Einfügung in das besondere Gewaltverhältnis $\left.{ }^{9}\right)$ gedeckt sind. Aber das Wesentliche der Gewissens-, Glaubens- und Bekenntnisfreiheit ist zugunsten des Dienstnehmers geschützt. Für die Masse der religiös interes-

S. 269 zu Fußn. 4. - Die Frage, ob auch die Kirchen Bekenntnisfreiheit genießen und die Freiheit ihrer Diakonie usw. deshalb auch auf Art.4 GG gestützt werden könnte (in diesem Sinne etwa Hamel, a.a.O. S.67 f), ist in Anbetracht der Verfassungsgarantie des kirchlichen Selbstbestimmungsrechts ohne weitere Bedeutung. - Zum Verhältnis der kirchlichen Werke und Einrichtungen zu Art. 4 GG s.o. S. $282 \mathrm{ff}$, insbes. S. 283 zu Fußn. 4 und 5.

4) S. hierzu oben S. $871 \mathrm{ff}$.

5) S. hierzu oben S. 872 zu Fußn.6.

6) S. o. II 3 a (S. $914 \mathrm{ff})$ und 4 (S.933).

7) S. hierzu Bosch-Habscheid, Vertragspfiicht und Gewissenskonflikt, JZ 9.Jhg. (1954) S.213 ff; Blomeyer, Gewissensprivilegien im Vertragsrecht? ebd., S. 309 ff; Wieacker, Vertragsbruch aus Gewissensnot, ebd., S. 466 ff; Dürig, Grundrechte und Zivilrechtsprechung, S.161; Hame1, Glaubensund Gewissensfreiheit, S. $66 \mathrm{f}, 74 \mathrm{ff} \mathrm{m}$. w. Nachw.

8) Zu Einzelheiten s. die Vorgenannten.

9) S. hierzu oben I 4 c (S. 865 ff), insbes. S. $874 \mathrm{f}$. 
sierten Dienstnehmer ist übrigens ein Minimum an Kultausübung durch den verfassungsrechtlich angeordneten Schutz der Sonnund Feiertage (Art.140 GG, Art.139 RV 1919) gesichert. 10)

\section{Die Meinungsfreiheit}

Die allgemeinste, überaus bedeutsame soziale Funktion der Informations-, Meinungsäußerungs-, Presse-, Funk-, Film-, Forschungs- und Lehrfreiheit (Art.5 GG) liegt darin, daß sie die Bildung und Verbreitung sozialer Erkenntnisse und Meinungen ermöglicht. Die Durchsetzung ist freilich in erster Linie eine Frage der Herrschaftsordnung, wobei gerade in der demokratischen der Meinungsfreiheit die breiteste und tiefste Wirksamkeit zukommt. Die spezifischen Zusammenhänge zwischen Demokratie und sozialer Intervention ${ }^{1)}$ werden wesentlich durch die Meinungsfreiheit vermittelt.

Besonderem Druck ist die Meinungsfreiheit im Rahmen privater Macht- und Abhängigkeitsverhältnisse ausgesetzt. Vor allem das A rbeitsverhältnis ist permanent davon bedroht, über das durch die ökonomischen Prämissen und die betriebliche Einordnung unumgängliche Maß hinaus gerade durch Beschränkungen der Meinungsfreiheit sozial unerträglich unfreiheitlich gestaltet zu werden.2) Schon die Weimarer Verfassung ordnete deshalb in bezug auf die Meinungsfreiheit an: "An diesem Rechte darf ihn ${ }^{3)}$ kein A rbeits- oder Anstellungsverhältnis hindern und niemand darf ihn ${ }^{3)}$ benachteiligen, wenn er ${ }^{3}$ ) von diesem Rechte Gebrauch macht" (Art. 118 Abs. 1 Satz 2 RV 1919). Das Grundgesetz enthält gleiches dagegen nicht. Doch besteht im Ergebnis kein Unterschied. Genauso wie die Verabsolutierungsklausel des Art.118 Abs. 1 Satz 2 RV 1919 nicht so unbedingt zu verstehen ist, wie sie sich liest, genauso wenig darf das Schweigen des Grundgesetzes als eine Negation der "Drittwirkung" der Meinungsfreiheit des Art. 5 GG verstanden werden. Vielmehr sind die allgemeinen Grundsätze über die "Drittwirkung" 4) der gemeinsame Nenner, auf dem sich die Auslegung des Art. 118 Abs. 1 Satz 2 RV 1919 und die

10) Zur Problematik des Feiertagsschutzes für die Minderheitsgruppen s. Hamel, a.a.O. S.90 f.

1) S. O. Abschnitt 3 (S. 315 ff).

2) Zur sozialstaatlichen Notwendigkeit, die Meinungsf reiheit im Betrieb zu schützen, s. Olbersdorf, Sozialer Rechtsstaat und Arbeitsrecht, S. 139.

3) Gemeint ist "jeder Deutsche", den das Recht zusteht (Art. 118 Abs. 1 Satz 1 RV 1919).

4) S. o. S. $876 \mathrm{ff}$. 
Auslegung des Art. 5 GG zu treffen haben. 5)

A uf der anderen Seite besteht im Rahmen von Dienst- und Arbeitsverhältnissen ein legitimes Bedürfnis, die Meinungsfreiheit - im besonderen die Meinungsäußerungsfreiheit - zu beschränken. Die übermäßige Geltendmachung gegensätzlicher Meinungen innerhalb eines Betriebes würde die Zusammenarbeit $z$ wischen Arbeitgeber und Arbeitnehmer und vor allem zwischen den Arbeitnehmern untereinander gefährien. Gesetzliche Vorschriften, die dazu dienen, die Zusammenarbeit zumutbar zu erhalten und den Betriebsfrieden zu wahren, sind "allgemeine Gesetze" i. S. des Art. 5 Abs. 2 GG. 6) Beispielhaft ist das Verbot der politischen Betätigung von A rbeitgeber und Betriebsrat im Betrieb ( $\$ 51$ Satz 2 BetrVG ${ }^{7)}$ ). Das Privatrecht hat demnach auch keinen verfassungsrechtlichen Anlaß, vertragliche Abmachungen zu unterbinden, die Arbeitgeber und A rbeitnehmer im notwendigen Umfang beschränken. Dabei wird sich der Arbeitnehmer im sog. Tendenzbetrieb - soweit dieser seiner Tendenz nach legitim ist - einer gesteigerten Zurückhaltung zu unterziehen haben. ${ }^{8)}$ Das gilt insbes. für den - privat - oder öffentlichrechtlichen - öffentlichen Dienst, bei dem es nicht nur um den Betriebsfrieden sondern auch um das Ansehen der Behörde (vor allem ihre Qualifikation als unparteiisch) und um die Sicherung der öffentlichen Ordnung geht. Entsprechende Verhaltenspflichten der öffentlichrechtlich Bediensteten, insbes. der Beamten, sind gegenüber Art. 5 Abs. 1 GG vom Vorbehalt des "allgemeinen Gesetzes" (Art. 5 Abs.2 GG) abgesehen, durch die verfassungsrechtliche Institutionalisierung dieser Dienstverhältnisse gedeckt. 9) Im Bereich des privatrecht1ich konstituierten öffentlichen Dienstes öffnet sich der entsprechende Gestaltungsraum von der Privatautonomie her (Art. 2 Abs. 1 GG). 10)

5) Zur Drittwirkung des Art.5 GG s. ferner Laufke, Vertragsfreiheit und Grundgesetz, S. $184 \mathrm{~m}$. w. Nachw.

6) BAGE 1, 185 (191 ff).

7) S.a. $\$ 56$ Abs. 1 Satz 2 des Bundespersonalvertretungsgesetzes.

8) Genauer: Er hat die rechtliche Möglichkeit, sich entsprechenden Kontraktforderungen des Arbeitgebers binclend zu unterwerfen und die Unterwerfung kann, soweit sie nicht ausdrücklich vereinbart ist, dem Vertrag im Wege sinngerechter Auslegung $(\$ S 157,242 \mathrm{BGB})$ unterstellt werden.

9) Einzelheiten s.o. I 4 c (S. $865 \mathrm{ff}$ ), insbes. S. $874 \mathrm{f}$.

10) Vgl. BAGE 2, 266 (275); 7, 256 (260 ff). S.a. nochmals oben Fußn. 7) . 


\section{Die Freizügigkeit}

Das Grundrecht der Freizügigkeit (Art.11 GG) ist die verfassungsrechtliche Basis der gesellschaftlichen Mobilität, die das soziale Bild der Gegenwart so entscheidend kennzeichnet. 1) Die Freizügigkeit erlaubt die individuelle Anpassung an die wirtschaftlichen Standortgegebenheiten und die sonstigen territorialen Umweltbedingungen und damit deren optimale Ausnützung. Sie öffnet aber auch die Türe für Massenwanderungen, welche die bisherigen Siedlungsräume über das Maß des Notwendigen hinaus entleeren und die Aufnahmegebiete über das Maß des Zuträglichen hinaus füllen. Soziale Erosion auf der einen und ungesunde Ballung auf der anderen Seite sind die sozialen Schattenseiten der Freizügigkeit. Die Aushöhlung aller territorialen Gemeinschaftsordnungen - m.a. W.: die Abwertung und individuelle Verzichtbarkeit ("Verkäuflichkeit") der Zugehörigkeit zur angeborenen oder zugewachsenen territorialen Gemeinschaft - und ihre Entfunktionalisierung zugunsten der jeweils größeren, maximal zugunsten der größten Gebietsgemeinschaft, ist desgleichen eines ihrer schwerwiegendsten Passiven. 2) Andererseits ist die individuelle Beweglichkeit in der maximal verkehrserschlossenen, großräumigen, Raumbedingungen optimal nutzenden Wirtschaftswelt der Gegenwart für eine Bevölkerung, die politisch bedingte Wanderungen ohnedies weitgehend entwurzelt haben, eine der entscheidenden aber auch als selbstverständlich empfundenen sozialen Chancen, deren bevormundende Verkürzung zugunsten staatlicher Lenkung besonders tief und schmerzlich in die persönliche Entfaltungsfreiheit einschneiden würde.

Ein Mindestmaß an Kontrolle ist jedoch vor allem auch im sozialen Interesse unerläßlich. Das Grundgesetz hat deshalb die gesetzliche Einschränkung gerade auch für die Fälle zugelassen, "in denen eine ausreichende Lebensgrundlage nicht vorhanden ist und der Allgemeinheit daraus besondere Lasten entstehen würden ${ }^{3)}$ und in denen es zum Schutze des. Jugend vor Verwahrlosung 4 ) ... erforderlich ist" (Art.11 Abs.2 GG). 5) In einer Über-

1) S. oben A I (S. $1 \mathrm{ff})$ und B Abschnitı 1 (S. $45 \mathrm{ff})$, insbes.

S. $210 \mathrm{ff}$.

2) S. oben Abschnitt 1 (S. $45 \mathrm{ff})$, insbes. IV (S. $210 \mathrm{ff})$, und $2(\mathrm{~S} .219 \mathrm{ff})$, insbes. I 1 (S. $219 \mathrm{ff})$ und II 1 b aa (S. 228 if) und $2 \mathrm{~b}$ (S. $240 \mathrm{ff}$ ).

3) Zur Auslegung und gesetzlichen Ausfüllung s. insbes. Dürig, Freizügigkeit, $S .527 \mathrm{ff}$.

4) Zur Auslegung und gesetzlichen Ausfüllung s. insbes. Dürig, a.a.O. S. 529 . 
gangsvorschrift ist ferner die vorläufige Fortgeltung von Gesetzen angeordnet, "die das Recht der Freizügigkeit mit Rücksicht auf die gegenwärtige Raumnot einschränken" (Art.117 Abs.2 GG).6)

Weitergehende Beschränkungen der Freizügigkeit können im Rahmen gewisser Dienst- und geschlossener Anstaltsverhältnisse notwendig und zulässig sein. 7)

Wie die Sicherung der Freizügigkeit gegenüber der öffentlichen Gewalt von sozialer Bedeutung ist, so ist es auch deren Schutz gegenüber der Bedrohung durch private Macht- und Abhängigkeitsverhältnisse. Die Drittwirkung des Grundrechts auf Freizügigkeit steht in dieser Funktion. ${ }^{8)}$

Die A uswanderungsfreiheit - freiheitsgrundrechtliche Entsprechung eines alten Sozialproblems - ist in Art.11 GG nicht mitgarantiert. 9) Ihr Schutz obliegt dem allgemeinen Freiheitsgrundrecht des Art. 2 Abs. 1 GG. 10)

Das Grundgesetz kennt keine allgemeine Einwanderungsf reiheit. Die Freizügigkeit aller Deutschen im Bundesgebiet (Art.11 GG) umschließt aber auch die Einwanderungsfreiheit aller Deutschen, die, da sie sich nicht auf Deutsche beschränkt, die in Deutschland vordem ansässig oder wenigstens geboren waren, als Rückwanderungstreiheit zu eng bezeichnet wäre. 11) Diese Einwanderungsfreiheit hat besondere Bedeutung für die

5) Die Beschränkung "zur Bekämpfung von Seuchengefahr" (Art. 11 Abs. 2 GG) ist von mittelbarer sozialer Bedeutung. Die Beschränkungen, "um strafbaren Handlungen vorzubeugen" (ebd.), kann auch von sozialer Bedeutung sein.

6) Die Einseitigkeit der Klausel, die den Gesetzgeber gegenüber einer neu auftretenden Wohnraumnot hilflos läßt, ist ein typisches Zeugnis für die nicht seltene Unbeholfenheit des Grundgesetzgebers gegenüber den Notwendigkeiten der Zeit.

7) S.hierzu oben I $4 \mathrm{c}(\mathrm{S} .865 \mathrm{ff})$, insbes. S. $871 \mathrm{ff}$ und S. $874 \mathrm{ff}$.

8) Zur Drittwirkung des Art. 11 GG s. Dürig, Freizügigkeit, S. 525; s.a. v. Mangoldt-Klein, Art. 11 Anm. II 5. Zum vertraglichen "Rückkehrverbot" s. BGHZ 16, $71 \mathrm{~m}$. eingeh. Nachw.

9) BVerf GE 6, 32 (34 ff). - Zur gegenteiligen Ansicht s. etwa Dürig, a.a.O. S. 519; v. Mangoldt-Klein, Art. 11 Anm. III 2 (S.348); je m.w. Nachw.

10) BVerfGE 6, 32 (36).

11) S. hierzu insbes. Dürig, Freizügigkeit, S. 516 ff; BVerfGE 2, 266 (273 f). 
Bewohner der sowjetisch besetzten Zone Deutschlands (DDR) erlangt, deren Bewohner als Deutsche (Art.116 GG) Träger des Grundrechts der Freizügigkeit (Art.11 GG) sind. 12) Das Gesetz über die Notaufnahme von Deutschen in das Bundesgebiet v. 22 . August $1950^{13)}$ versucht, den damit verbundenen Schwierigkeiten im Rahmen des Art. 11 Abs.2 GG Rechnung zu tragen. 14)

\section{Die Berufsfreiheit}

a) Freiheit des Berufs, des Arbeitsplatzes und der Ausbildungsstätte - negativer und positiver Status

Das Grundgesetz gewährleistet die Freiheit, Beruf, Arbeitsplatz und Ausbildungsstätte frei zu wählen und den gewählten Beruf im Rahmen der Gesetze auszuüben (Art.12 Abs.1 GG). 1) Art.12 GG ist reines Ausgrenzungsrecht, ${ }^{2}$ ) das "Teilhabe" nur auf jene indirekte, individualitätsbezogene Weise gewährt, auf die Freiheitsrechte "Teilhabe" $z u$ verschaffen imstande sind: als Chance eines jeden, aus eigener Kraft aufzusteigen und sich sozial zu sichern. ${ }^{3)}$

\section{b) Zur Freiheit der Berufswahl und - ausübung}

aa) Freiheit und Schranken - Zum System

Der Wortlaut des Art. 12 Abs. 1 GG könnte "darauf hindeuten, daß Eingriffe nur bei der Berufs a u übung zulässig sein sollten, während die Berufs w a h1 der gesetzlichen Regelung entzogen wäre. Das kann indessen nicht der Sinn der Bestimmung sein. Denn die Begriffe 'Wahl' und 'A usübung' des Berufes lassen sich nicht so trennen, daß jeder von ihnen nur eine bestimmte zeitliche Phase des Berufslebens bezeichnete, die sich mit der anderen nicht überschnitte". 1) Vielmehr "ist A rt. 12 Abs. 1 ein einheitliches Grundrecht (der 'Berufsfreiheit') jedenfalls in dem Sinn,

12) BVerfGE 2, 266(272 f).

13) BGB1 S. 367; i.d.F. v.27.Juli 1957 (BGBl.I S. 1207).

14) Zur Verfassungsmäßigkeit des Gesetzes s. insbes. BVerf GE 2, 266; Dürig, a.a.O. S. 530 ff m.w. Nachw.

1) Zu allen Auslegungsfragen, die im Nachfolgenden nicht besonders berührt werden s. die Darstellung bei Bachof, Freiheit des Berufs.

2) Vgl. v. Mangoldt-Klein, Art. 12 Anm. VI 8 m.w.Nachw. (auch zur gegenteiligen Ansicht).

3) S.o. S. $848 \mathrm{ff}$, insbes. S. 850 zu Fußn. 6.

1) BVerfGE 7, 377 (401). 
daß der Regelungsvorbehalt des Satz 2 sich 'dem Grunde nach' sowohl auf die Berufsausübung wie auf die Berufswahl erstreckt. Das heißt jedoch nicht, daß die Befugnisse des Gesetzgebers hinsichtlich jeder dieser 'Phasen' der Berufstätigkeit inhaltlich gleich weit gehen. Denn es bleibt stets der im Wortlaut des Art. 12 Abs. 1 deutlich zum Ausdruck kommende Wille der Verfassung zu beachten, daß die Berufswahl 'frei' sein soll, die Berufsausübung geregelt werden darf". 2) "Der Freiheitsanspruch des einzelnen wirkt... umso stärker, je mehr sein Recht auf freie Berufswahl in Frage steht; der Gemeinschaftsschutz wird umso dringlicher, je größer die Nachteile und Gefahren sind, die aus gänzlich freier Berufsausübung der Gemeinschaft erwachsen könnten. Sucht man beiden - im sozialen Rechtsstaat gleichermaßen legitimen - Forderungen in möglichst wirksamer Weise so gerecht zu werden, so kann die Lösung nur jeweils in sorgfältiger A bwägung der Bedeutung der einander gegenüberstehenden und möglicherweise einander geradezu widerstreitenden Interessen gefunden werden. ... Für das Eingreifen des Gesetzgebers besteht danach von Verfassungs wegen ein Gebot der Differenzierung, deren Prinzipien zusammenfassend etwa wie folgt umschrieben werden können: Die Freiheit der Berufsausübung kann im Wege der 'Regelung' beschränkt werden, soweit vernünftige Erwägungen des Gemeinwohls es zweckmäßig erscheinen lassen. Die Freiheit der Berufs wah 1 darf dagegen nur eingeschränkt werden, soweit der Schutz besonders wichtiger ('überragender') Gemeinschaftsgüter es zwingend erfordert, d. h. soweit der Schutz von Gütern in Frage steht, denen bei sorgfältiger Abwägung der Vorrang vor dem Freiheitsanspruch des einzelnen eingeräumt werden muß und soweit dieser Schutz nicht auf andere Weise, nämlich mit Mitteln, die die Berufswahl nicht oder weniger einschränken, gesichert werden kann". 3)

Dabei ergibt sich für eine Regelung, "die schon die Aufnahme der Berufstätigkeit von der Erfüllung bestimmter Voraussetzungen abhängig macht und die damit die Freiheit der Berufswahl berührt, ... ein bedeutsamer Unterschied je nachdem, ob es sich um 'subjektive' Voraussetzungen, vor allem solche der Vor- und $\Lambda$ usbildung handelt oder um objektive Bedingungen der Zulassung, die mit der persönlichen Qualifikation des Berufsanwärters nichts $z u$ tun haben und auf die er keinen Einfluß nehmen kann. Die Regelung subjektiver Voraussetzungen der Berufsaufnahme... legitimiert sich aus der Sache heraus; sie beruht darauf, daß viele Berufe bestimmte, nur durch theoretische und praktische Schulung
2) ebd., S. 402 .
3) ebd., S.404f. 
erwerbbare technische Kenntnisse und Fertigkeiten (im weiteren Sinn) erfordern und daß die Ausübung dieser Berufe ohne solche Kenntnisse entweder unmöglich oder unsachgemäß wäre oder aber Schäden, ja Gefahren für die Allgemeinheit mit sich bringen würde. Der Gesetzgeber konkretisiert und 'formalisiert' nur dieses sich aus einem vorgegebenen Lebensverhältnis ergebende Erfordernis; dem einzelnen wird in Gestalt einer vorgeschriebenen formalen Ausbildung nur etwas zugemutet, was er grundsätzlich der Sache nach ohnehin auf sich nehmen müßte, wenn er den Beruf ordnungsgemäß ausüben will". 4)

"Anders liegt es bei der Aufstellung objektiver Bedingungen für die Berufszulassung. Ihre Erfüllung ist dem Einfluß des einzelnen schlechthin entzogen. Dem Sinn des Grundrechts wirken sie strikt entgegen". 5) An den Nachweis der Notwendigkeit einer solchen Freiheitsbeschränkung sind "besonders strenge Anforderungen zu stellen...; im allgemeinen wird nur die Abwehr nachweisbarer und höchstwahrscheinlicher schwerer Gefahren für ein überragend wichtiges Gemeinschaftsgut diesen Eingriff in die freie Berufswahl legitimieren können" ${ }^{\prime \prime}$ )

"Der Gesetzgeber muß Regelungen nach Art. 12 Abs. 1 Satz 2 jeweils auf der 'Stufe' vornehmen, die den geringsten Eingriff in die Freiheit der Berufswahl mit sich bringt". 7) Dabei darf die Möglichkeit der "stufen" - weisen Klassifikation der Eingriffe nicht überschätzt und diese nicht zum Selbstzweck erhoben werden. Die Übergänge sind unscharf. Darf ein bestimmter Beruf, wenn bestimmte - subjektive oder objektive - Voraussetzungen fehlen, nur unter bestimmten Beschränkungen ausgeübt werden, so betrifft diese Regelung nicht nur die Berufsausübung sondern auch die Berufswahl. ${ }^{8}$ ) Je tiefer sie in die freie Berufsausübung einschneidet, desto weniger kann sie wie eine reine Ausübungsregelung durch "vernünftige Gründe des Gemeinwohls" 9) allein schon gerechtfertigt werden und desto näher rücken die Voraussetzungen, unter denen die Beschränkung entfällt, dem Charakter einer - subjektiven oder objektiven - Zulassungsvoraussetzung. Sie sind schließlich, wie Zulassungsvoraussetzungen, "nur gerechtfertigt, wenn sie durch besonders wichtige Inter'essen der Allgemeinheit gefordert" werden. 10) Zwischen den subjektiven und objektiven
4) ebd., S. $406 \mathrm{f}$.
5) ebd., S. 407.
6) ebd., S. 408 .
7) ebd., S. 408.
8) Vg1. hierzu (m. Beispielen) Bachof, Freiheit des Berufs, S. 193 f, 216. 
Zulassungsvoraussetzungen 11) stehen andererseits jene Zulassungsvoraussetzungen, die zwar auf die Person des Berufsbewerbers abstellen, aber trotzdem seinem Einfluß entzogen sind. 12) Je weniger sie nur einer evidenten, absoluten Nichteignung Rechnung tragen, je mehr sie dagegen aus Gründen des Gemeinwohls in einen der Sache nach vorhandenen Spielraum der Berufswahl eingreifen, desto schärfer müssen sie den maximalen Anforderungen an objektive Zulassungsvoraussetzungen unterworfen werden. 13) Maßstab hat immer zu sein, daß Art. 12 Abs. 1 GG ein "einheitliches Grundrecht" ist, 14) das gegenüber Beschränkungen der Berufswahl fest, gegenüber Beschränkungen der Berufsausübung nachgiebig ist. "Der Gesetzgeber ist inhaltlich umso freier, je mehr er nur die Berufsausübung trifft, umso stärker gebunden, je mehr zugleich die Berufswahl berührt ist". 15) 16)

9) BVerfGE 10, 185 (197).

10) BVerfGE 11, 30 (42 f, $44 \mathrm{f}$ - zum Kassenarztproblem-); Bachof, a.a.O. S.216.

11) Beide Begriffe im Sinne von BVerfGE 7, 377 (405 ff).

12) Bachof, a.a.O. S.217, 228 mit Fußn.266, $233 \mathrm{ff}$.

13) S.a. Bachof, a.a.O. - A.A. BVerfGE 9, 338 (345): "Solche Regelungen sind nicht etwa deshalb objektive Voraussetzungen für die weitere Zulassung zum Beruf, weil sie eine absolute Sperrwirkung für alle von ihnen Betroffenen haben, so daß sie ihrem Einfluß schlechthin entzogen sind. Dies ist für die Frage, ob es sich um eine subjektive oder um eine objektive Zulassungsvoraussetzung handelt, nicht entscheidend; vielmehr kommt es auf die rechtliche Zurechnung der Erfüllung jener Voraussetzungen an: Wenn es um den Besitz persönlicher Eigenschaften, Fähigkeiten geht, liegt immer eine subjektive Zulassungsvoraussetzung vor".

14) BVerfGE 7, 377 (402).

15) BVerfGE 11, 30 (42) im Anschluß an BVerfGE 7, 377 (402 und $402 \mathrm{ff}$ ).

16) $\mathrm{Zu}$ der vorstehend in Umrissen wiedergegebenen Rechtslage a uf der Basis der Auslegung, die das "Apothekenurteil" des Bundesverfassungsgerichts Art. 12 Abs. 1 GG gegeben hat s. zusammenfassend Bachof, a.a.O., insbes. S.212 ff. Weitere Würdigungen des "A pothekenurteils" s. etwa bei Bachof, Zum A pothekenurteil des Bundesverfassungsgerichts, JZ 13. Jhg. (1958) S. 468 ff; Lerche, Zum A pothekenurteil des Bundesverfassungsgerichts, Bayerische Verwaltungsblätter n. F. 4. Jhg. (1958) S.231 ff. - Zur Fortentwicklung der Rechtsprechung des Bundesverfassungsgerichts s. BVerfGE 9, 39 (48 ff), 63 (71 f), 73 (76 ff), $213(221 \mathrm{f}) ; 10,185$ (192 ff), 354 
Neben diesen - im Text der Verfassurig "allerdings nicht zu voller sachlicher und begrifflicher Klärung" gelangten 17) - Vorbehaltsschranken des Grundrechts stehen die Gewährleistung s$\mathrm{sch} r a n k e n$, die der Berufsfreiheit teils ihrer Funktion und ihrem Gegenstand nach, teils kraft des vom Grundgesetz unkritisch übernommenen vorrechtlichen Gesamtbildes immanent sind oder (und) auf der Notwendigkeit beruhen, Art.12 GG in seinen einzelnen Teilen und mit den übrigen Bestimmungen der Verfassung zu harmonisieren. ${ }^{18)}$

Hierzu zählt, daß niemand das Recht hat, einen die Menschenwürde verletztenden, sittenwidrigen oder die Rechte Dritter angreifenden Beruf zu ergreifen und auszuüben (Art. 1 Abs. 1, 2 Abs. 1 GG). 19)

Hervorzuheben ist ferner, daß niemand das Recht hat, "Tätigkeiten..., welche nach heutigen Vorstellungen der organisierten Gemeinschaft, in erster Linie dem State, vorbeha 1 t e n bleiben müssen", 20) zur freien beruflichen Wahrnehmung in Anspruch zu nehmen. Das insofern "mögliche Maß an Freiheit der Berufswahl für den einzelnen wird durch den gleichen Zugang aller zu allen öffentlichen Ämtern bei gleicher Eignung (Art.33 Abs. 2 GG) gewährleistet". 21) Parallel hierzu beschränkt die Sozia 1 is ie rung (Art.15 GG) die Freiheit, den Betrieb eines in Gemeinwirtschaft überführten Produktionszweiges aufzunehmen und a uszuüben. 22)

Schließlich sind noch die Beschränkungen zu erwähnen, die sich aus besonderen Gewaltverhältnissen ergeben. ${ }^{23)}$

$(362 \mathrm{f}) ; 11,30$ (39 ff), 168 (183 ff).

17) BVerfGE 7, 377 (402).

18) Eine Übersicht s. bei v. Mangoldt-Klein, Art.12 GG Anm.V.

19) Vgl. Bachof, Freiheit des Berufs, S. 189 ff, 220 m.w. Nachw.$\mathrm{Zu}$ den allgemeinen Hintergrundprinzipien s. Dürig in MaunzDürig, Art. 2 Abs. I Randn. 72 ff.

20) BVerfGE 7, 377 (397). Sperrung nicht im Original.

21) ebd., S.398. - Im einzelnen s. hierzu außer BVerf GE 7, 377 (397f); 11, 30 (39 f): Rings, Verwaltungsmonopole und Art. 12 Abs. 1 Grundgesetz, NJW 10.Jhg. (1957) S. 657 f; Bachof, a.a.O. S. 200 ff, 220; w. Nachw. s. dort. - S. ferner unten S. $1035 \mathrm{ff}$.

22) S. z.B. Bachof, a.a.O.; ferner v. Mangoldt-Klein, Art. 12 Anm. V 2 b.

23) Vgl. Bachof, a.a.O. S. 175 f. - S. ferner oben I 4 c (S. 865 ff) (Einzelheiten S.871ff und S.874f). 
bb) Zur sozialen Problematik der Berufsfreiheit und ihrer Schranken

\section{aaa) Allgemeines}

Die Freiheit des Berufs ist die Freiheit, die Chancen des Erwerbs von marktwirtschaftlichem Einkommen nach eigener Wahrnehmung, eigenem Urteil und eigenen Kräften zu nutzen. Sie sichert, indem sie den Zugang zu den verschiedenen Berufen offen und auch die Berufsausübung im Kern frei hält, 1) ein Mindestmaß an freiem Spiel der Kräfte um dieses marktwirtschaftliche Einkommen - m.a.W.: um den individuellen Anteil am Sozialprodukt - und um die Position des einzelnen im Gefüge der arbeitsteiligen Erwerbsgesellschaft und in ihren Teilrelationen. Freiheit des Berufs bedeutet aber auch prinzipielle Freiheit zu und in den Berufen, die ihrem Wesen oder jedenfalls ihrer gemeinschaftsgewollten Bestimmung nach in - mehr oder weniger gesteigerter, unmittelbarer oder mittelbarer - sozialer Verantwortung stehen, und damit verfassungsbedingte Spannung zwischen Freiheit und bindender Verantwortung.

Damit ist die außerordentliche soziale Problemträchtigkeit der Berufsfreiheit - ihre sozial desintegrierende Wirksamkeitsrichtung, ihre elementare, freiheitlich-soziale Funktion als Ansporn zu maximaler Entfaltung der Eigenkräfte und zur Aktivierung von Mitarbeitern und Wettbewerbern und ihre stimulierende aber auch lähmende und lockernde Auswirkung auf wesentliche soziale Berufsfunktionen - angedeutet. Die sozialstaatliche Gebundenheit aller Grundrechte 2 ) muß sich auf das Grundrecht der Berufsfreiheit konzentrieren. ${ }^{3)}$ In erster Linie sozialstaatliche Erwägungen sind "vernünftige Gründe des Gemeinwohls", 4) die Regelungen der Berufsausübung legitimieren. In erster Linie Gemein-

1) Zur entsprechenden Begrenzung des Regelungsvorbehalts s. nochmals etwa Bachof, Freiheit des Berufs, S. $207 \mathrm{ff}$.

2) S. oben S.719ff und S.744ff.

3) S. vor allem Gerber, Die Sozialstaatsklausel des Grundgesetzes, S. $44 \mathrm{ff}$; ferner etwa Nipperdey, Diskussionsbeitrag $\mathrm{zu}$ "Begriff und Wesen des sozialen Rechtsstaats", S. $94 \mathrm{f}$; Stamm, Zur Verwirklichung des sozialstaatlichen Prinzips, S. 149 ff; Hamann, Das Grundgesetz, Art. 12 Anm. C 5 b; Schlochauer, Öffentliches Recht, S. 14. Zur notwendigen Korrektur der teilweise zu weitgehenden Thesen einer Nachgiebigkeit des Grundrechts gegenüber dem Sozialstaatsprinzip s. v. Mangoldt-Klein, Art. 12 Anm. VI 8.

4) BVerfGE 10, 185 (197). 
schaftsgüter sozialen Gehalts und sozialer Relevanz können "be sonders wichtige ('überragende') Gemeinschaftsgüter" 5) sein, die, soweit ihnen anders nicht Rechnung getragen werden kann, auch Beschränkungen des freien Berufszugangs rechtfertigen. Aber die Verfassung hat den Sozialstaat freiheitlich gewollt und die Berufsfreiheit ebenso scharf und speziell ausgebildet, wie sie die Sozialstaatlichkeit allgemein und unpräzis proklamiert hat. Der Sozialstaat muß die Berufsfreiheit respektieren. ${ }^{6}$ ) Er muß alle Mittel ausschöpfen, um mit ihr auszukommen. Ja die Funktion der Berufsfreiheit, die Chance eines nicht durch die rechtliche Protektion des gegebenen beruflichen "Besitzstandes" behinclerten sozial€n Aufstiegs aus eigener Kraft zu gewährleisten, muß als ihre primäre sozialstaatliche gesehen werden. ${ }^{7)}$ Dementsprechend liegt ein entscheidendes Gewicht schließlich auch darauf, daß die Beschränkungen der Berufsfreiheit in einem positiven, gerade auf die Aufstiegschance der Schwächeren Bedacht nehmenden Sinn sozial orientiert gleichheitlich gestaltet sind.

\section{bbb) Beschränkungen zum Schutz des Berufswilligen}

Der durch die Berufsfreiheit eingeräumten Chance eines nicht durch obrigkeitliche Absicherung des jeweils gegebenen sozialen Besitzstandes behinderten sozialen Aufstieges aus eigener Kraft entspricht das Risiko, aus persönlichen oder sachlichen Gründen den Beruf nicht erfolgreich ausüben zu können, "auf der Strecke zu bleiben", sozial abzusteigen oder wenigstens bei einem unbefriedigenden Stand zu stagnieren. Von hierher liegt als soziales Motiv einer Beschränkung der Berufsfreiheit der bevormundende Schutz des Berufswerbers vor den Risiken seiner Entscheidung nahe.

Sub specie des Art. 12 GG unproblematisch sind dabei Einrichtungen und Maßnahmen, die den Berufswerber gegen die Verminderung oder den Verlust seiner Fähigkeit, den gewählten (oder einen anderen) Beruf auszuüben, sozial absichern. Sie sind "nicht eigent-

5) BVerfGE 7, 377 (405).

6) S. v. Mangoldt-Klein, a.a.O. - Zu den allgemeinen Grundsätzen s. nochmals oben S. $719 \mathrm{ff}$, insbes. die Nachw. S. $720 \mathrm{f} \mathrm{zu}$ Fußn. 3 und 4.

7) S. nochmals Werner, Anm.zu OVG Berlin, Urt.v. 2. Juni 1954, S. 564; ders., Sozialstaatliche Tendenzen in der Rechtsprechung, S.99; Hamann, Deutsches Wirtschaftsverfassungsrecht, S. $114 \mathrm{f}$. 
lich berufspolitischer Art, sondern" stehen "in umfassenderen sozial - und gesellschaftspolitischen Zusammenhängen. Thre Verbindung mit der Berufsausübung... ist nur locker und mittelbar; die besondere Freiheitsverbürgung des Art. 12 Abs. 1 GG, der besondere Freiheitsraum, den gerade dieses Grundrecht sichern will, ist nicht berührt". 1) Art. 12 Abs.1 GG gibt kein Recht darauf, einen Beruf - auch nicht einen traditionell "freien Beruf" 2) - zu ergreifen, der von Sicherungen dieser Art frei ist. ${ }^{3)}$

Unbedenklich erscheint es ferner, den Berufsinteressenten zu beraten und vor dem Ergreifen eines persönlich unpassenden oder aus allgemeinen sachlichen Gründen riskanten Berufes zu warnen.

Dagegen läuft es dem Wesen der Berufsfreiheit zuwider, sie allein zu dem $Z$ weck zu beschränken, ihren Träger vor Nachteilen zu schützen, die ihm aus dem Gebrauch der Freiheit erwachsen könnten; denn die verfassungsrechtliche Gewähr der Freiheit geht von der Freiheitsmündigkeit des Menschen aus.

Am ehesten ließe sich daran denken, daß reine Ausübungsregelungen in eine Schutzfunktion zugunsten des Freiheitsträgers eintreten. Der berufliche Irrweg eines einzelnen kann die Gemeinschaft belasten - letztlich indem jener ihrer sozialen Hilfsverantwortung anheimfällt. "Vernünftige Gründe des Gemeinwoh1s" 4) können so zu Beschränkungen führen, die unmittelbar als bevormundender Schutz des Berufsträgers selbst wirken. Doch eignen sich Ausübungsregeln der Sache nach gerade hierzu nur sehr begrenzt.

Sachlich besonders nahe liegt der Einsatz subjektiver Zulassungsvoraussetzungen, die dem einzelnen nur zumuten, "was er grundsätzlich der Sache nach ohnehin auf sich nehmen müßte, wenn er den Beruf ordnungsgemäß ausüben will". 5) Aber ihr "Zweck der ordnungsgemäßen Erfüllung der Berufstätigkeit" 6)

1) BVerfGE 10, 354 (362 f - Zitat S. 363).

2) Zur verfassungsrechtlichen Tragweite des Begriffes des "freien Berufs" s. BVerfGE 10, 354 (362 ff, insbes. $364 \mathrm{ff}$ ).

3) Vg1. BVerfGE, a.a.O.; Peters, Die verfassungsrechtliche Zulässigkeit berufsständischer Pflichtversorgungseinrichtungen für Ärzte, S. 33 f; Maunz, Rechtsgutachten über die Verfassungsmäßigkeit der Bayerischen Ärzteversorgung nach dem Grundgesetz, S. 32 ff m.w. Nachw.; Schneider, Die öffentlich-rechtliche Alterssicherung freier Berufe und das Grundgesetz, S. 32 f m.w. Nachw. A.A. insbes. Scheuner, Berufsständische Versorgungseinrichtungen.

4) BVerfGE 10, 185 (197).

5) BVerfGE 7, 377 (407). 
ist nicht um des "Berufstätigen" sondern um der Gemeinwohlfunktion und -beziehung seiner "Berufstätigkeit" willen legitim. Sie müssen "adäquate Mittel zur Verhütung möglicher Nachteile und Gefahren für die Allgemeinheit" sein. 7) Subjektive Zulassungsvoraussetzungen, die an diesem Gemeinwohlzweck orientiert sind, werden sich in der Regel gleichwohl auch als Schutz des Berufswerbers vor der folgenschweren A ufnahme eines Berufes, dem er subjektiv nicht gewachsen ist, auswirken. ${ }^{8)} \mathrm{Be}-$ dingende causa einer subjektiven Zulassungsvoraussetzung darf dieser Schutz jedoch nicht sein.9)

Ein "besonders wichtiges ('überragendes') Gemeinschaftsgut", dessen notwendiger Schutz allein objektive Zulassungsbeschränkungen rechtfertigen könnte, ist die beruflich-wirtschaftliche Situation und Entwicklung eines einzelnen grundsätzlich nicht. Zwar ist die Menschenwürde jedes einzelnen ein überragend wichtiger Wert der ganzen Gemeinschaft (Art.1 Abs. 1 GG). Die staatliche Ordnung kann daher nicht nur eine Berufsausübung sondern auch eine Berufswahl, die - eventuell in spezifisch "sozialem" Zusammenhang - die Menschenwürde beeinträchtigt, verhindern. Regelungen, die verbieten, "menschenunwürdige" Berufe zu ergreifen, machen immanente Grenzen der Berufsfreiheit selbst sichtbar. 11) Der Fall, daß ein Beruf seinem Wesen nach nicht die Menschenwürde verletzt oder wenigstens gefährdet, sie aber zu verletzen droht, wenn der Zugang zu ihm nicht objektiv beschränkt wird umgekehrt ausgedrückt: wenn der Zugang nicht nur einem durch gewisse objektive Umstände begünstigten Personenkreis offen gehalten wird -, und daß diese Gefahr auf keine andere Weise als durch objektive Zulassungsvoraussetzungen abgewehrt werden kann, ist jedoch kaum denkbar. Die praktisch allein berechtigte, sozial gezielte Frage nach der Zulässigkeit objektiver Zulassungsvoraussetzungen zum Schutze der Berufswerber selbst kann vielmehr nur von der Befürchtung her gestellt werden, daß die Übersetzung eines Berufs zu sozialer Verelendung des Berufsstandes führen würde, die durch die sozialen Hilfseinrichtungen nicht mehr in einem für die engeren Beteiligten oder (und) die weitere staatliche Gemeinschaft zumutbaren Rahmen aufgefangen werden könnte. Doch dient eine objektive Zulassungsbeschränkung dieses Zwecks gerade nicht speziell dem Schutz des Berufsanwärters,

6) ebd.

7) Bachof, Freiheit des Berufs, S.228.

8) Beispiele s. bei Bachof, a.a.O. S.224 ff.

9) ebd., S.234.

10) BVerfGE 7, 377 (405).

11) S. o. S. 1028 zu Fußn. 19. 
de $r$ Erfüllung seiner Berufsfreiheit heischt; denn nichts gewährleistet generell, daß der ausgeschlossene Neubewerber zum Opfer der Übersetzung des Berufszweiges würde und sich gegenüber den altsässigen Berufsangehörigen nicht durchsetzen könnte. Im Gegenteil entspricht es der Natur der Sache, daß objektive $\mathrm{Zu}$ lassungsbeschränkungen dieser Art sich in erster Linie als Schutz derjenigen auswirken, die in dem Beruf bereits tätig sind.

\section{ccc) Der Schutz des Berufsstandes}

Die Sicherung des freien Zugangs zu den Berufen gegen die - interessenpolitisch so außerordentlich wirkungsvoll geltend gemachten 1) - Schutzforderungen der Berufsstände - d.h. in der Regel: der ihnen jeweils schon Angehörenden, der beruflich Installierten und nicht selten auch Saturierten - ist auch und gerade unter sozialen Aspekten die aktuelle Frontstellung des Grundrechts der Berufsfreiheit. Darüber darf nicht vergessen werden, da $\beta$ die staatliche Gemeinschaft ein legitimes Interesse an der Prosperität grundsätzlich aller Berufszweige hat; daß sie sich in eine spezifisch sozialstaatliche Pflicht zur wirtschaftlichen Hebung sozial bedrängter Berufsgruppen gestellt sehen kann; 2) und da $\beta$ endlich gewissen Berufsgruppen eine integrierende Gemeinwohlfunktion zufällt, die ein gesteigertes Interesse der Allgemeinheit an ihrer Leistungsfähigkeit und, um deretwillen, an ihrer wirtschaftlichen Gesichertheit rechtfertigt. Aber allen diesen Belangen ist grundsätzlich unter Aufrechterhaltung des freien $\mathrm{Zu}$ gangs zu dem Beruf Rechnung zu tragen.

$\mathrm{Zu}$ denken ist auch hier in erster Linie wieder an Hilfen, die weder Berufswahl noch Berufsausübung berühren: steuerliche Erleichterungen, Subventionen, Kreditmaßnahmen, Beratungs- und Schulungseinrichtungen, Maßnahmen der sozialen Sicherung ${ }^{3)}$ usw.

Im weitesten Umfang stehen ferner ausübungsregelnde Beschrän-

1) Zum Allgemeinen s. oben Abschnitt 3 III 5 b (S. 373 ff). Das Gefälle der Interessenvertretung ist evident. Der Berufsstand, auch sonst durch zahlreiche gemeinsame Interessen verbunden, organisiert sein Interesse auf Abwehr von Neuzugängen verhäitnismäßig leicht. Der "Außenseiter" steht zunächst jedoch allein. Erst wenn der Überdruck zu groß wird, setzt die Organisation auch der Außenseiter ein. A ber dann sind sie immer noch die wirtschaftlich Schwächeren; denn die "Inseiter" sitzen schon an den wirtschaftlichen Quellen, an denen die "Außenseiter" erst noch partizipieren wollen.

2) S.o. S. $838 \mathrm{f}$.

3) S.o. S. $1031 \mathrm{zu} \mathrm{Fußn.} 1$ ff. 
kungen zur. Verfügung. ${ }^{4)}$

Subjektive Zulassungsvoraussetzungen haben, indem sie die ordnungsgemäße Berufsausübung durch den einzelnen sicherstellen, die natürliche Funktion, auch die Leistungsfähigkeit des ganzen Berufsstandes zu fördern und zu bestärken. Indem sie ungeeignete Elemente von der Berufstätigkeit fernhalten, ersparen sie dem Berufsstand ferner die wirtschaftlichen Störungen, die mit dem Auftreten schwindlerischer, leichtfertiger oder arglos-unfähiger Konkurrenten verbunden sein können.

Aber weder subjektive noch objektive Zulassungsvoraussetzungen dürfen zu dem $Z$ weck eingeführt oder verschärft werden, die altsässigen Berufsträger vor den wirtschaftlichen Nachteilen des Wettbewerbs neuer Berufswerber zu schützen. Der "Konkurrenzschutz der bereits im Beruf Tätigen" kann "nach allgemeiner Meinung niemals einen Eingriff in das Recht der freien Berufswahl rechtfertigen". 5) Das gilt auch dann, wenn eine drohende oder schon vorhandene Übersetzung des Berufs ein soziales Absinken befürchten läßt oder andererseits durch Absperrmaßnahmen eine generelle Anhebung des sozialen Niveaus des Berufsstandes bewirkt werden könnte. 6) Art. 12 Abs. 1 GG überantwortet die "richtige" Berufswahl dem einzelnen und die Deckung des beruflichen Bedarfs sowie den Ausgleich beruflicher Überkapazitäten dem freien Spiel der Kräfte. Der Staat kann warnen, beraten, aneifern, fördern. Aber sein planender $Z$ wang ist grundsätzlich eliminiert. Steigert sich die Bedrohung eines Berufsstandes zur Gefahr sozialstaatlich unerträglicher Verelendung, so wird zwar anerkannt werden müssen, daß ein überragend wichtiges Gemeinschaftsgut in Frage gestellt ist (Art. 1 Abs. 1, 20 Abs. 1, 28 Abs. 1 Satz 1 GG). Aber nur dann, wenn dessen Schutz auf keine "andere Weise, nämlich mit Mitteln, die die Berufswahl nicht oder weniger einschränken, gesichert werden kann", 7) darf die Berufszulassung

4) S. hierzu auch BVerfGE 7, 377 (406): "Auch der Gedanke der Förderung eines Berufs und damit der Erzielung einer höheren sozialen Gesamtleistung seiner Angehörigen kann schon gewisse die Freiheit der Berufsausübung einengende Vorschriften rechtfertigen".

5) BVerfGE 7, 377 (408); 11, 168 (188 f); Bachof, Freiheit des Berufs, S.218, $234 \mathrm{f}, 236 \mathrm{f} \mathrm{u}$. passim.

6) BVerfGE 7, 377 (408): "Die Sorge für das soziale Prestige eines Berufs durch Beschränkung der Zahl seiner Angehör:gen reicht nicht aus (scil. eine objektive Zulassungsbeschränkung zu legitimieren), auch wenn solche Ziele im ükrigen gesetzgeberische Maßnahmen rechtfertigen würden". 
beschränkt werden. Objektive Zulassungsbeschränkungen zur sozialen Rettung eines Berufsstandes werden danach nur höchst selten und wohl immer nur vorübergehend zulässig sein. ${ }^{8)}$ Lediglich wenn die Übersetzung die Leistungsfähigkeit eines Berufsstandes, dessen Funktion ein 'besonders wichtiges ('überragendes') Gemeinschaftsgut" 9) darstellt oder integriert, gefährdet, wird an eine dauernde Kontrolle des Zuganges gedacht werden dürfen. 10)

\section{ddd) Die Sicherung sozialer Berufsfunktionen}

Das Ausgeführte gilt im besonderen auch für die wirtschaftliche Sicherung jener Berufe, die unmittelbar sozial bedeutsame Funktionen ausüben. Ihr sozialstaatlicher Wert erleichtert den Nachweis ihrer Gemeinwohlbedeutung und eventuell des an ihrer Funktionsfähigkeit bestehenden überragenden Gemeininteresses. Beispielhaft sind vor allem die verschiedenen Gesundheitsberufe. Die Gesundheitsversorgung ist nach dem gegenwärtigen System grundsätzlich freien Berufen überlassen. Deren Leistungsfähigkeit ist aber nicht nur von unmittelbarer Bedeutung für das überragend wichtige Gemeinschaftsgut der Volksgesundheit. 1) Sie dient im besonderen auch der sozialen Gesundheitspflege und Medizinalhilfe. Was notwendig ist, sie zu sichern, muß und darf geschehen. Die Anwendung des aufgezeigten strengen Verhältnismäßigkeitsmaßstabes hat jedoch ergeben, daß objektive Zulassungsvoraussetzungen zum $Z$ wecke der wirtschaftlichen Konsolidierung jedenfalls gegenwärtig kaum je gerechtfertigt werden können. 2) 3)

7) BVerfGE 7, 377 (406).

8) Für grundsätzliche Zulässigkeit Hamann, Das Grundgesetz, Art. 12 Anm. C 5 b. Für sozialen Schutz durch Zulassungsvoraussetzungen - wenn auch außerhalb der Kategorien der bundesverfassungsgerichtlichen Rechtsprechung zu Art. 12 Abs. 1 GG operierend - auch Gerber, Die Sozialstaatsklausel des Grundgesetzes, insbes. S. $44 \mathrm{ff}$.

9) BVerfGE 7, 377 (405).

10) Vgl. BVerfGE 11, 168 (188 ff); s.a. die Erwägungen in BVerf GE 7, 377 (413 ff). Weitere Beispiele finden sich erörtert bei Bachof, Freiheit des Berufs, S. 220 ff, insbes. S.220 ff, $233 \mathrm{ff}, 236 \mathrm{ff} ; \mathrm{w}$. Nachw.s. dort.

1) BVerfGE 7, 377 (414): "Unbestritten ist, daß die Volksgesundheit ein wichtiges Gemeinschaftsgut ist, dessen Schutz Einschränkungen der Freiheit des einzelnen zu rechtfertigen vermag".

2) Zur Bedürfnisprüfung für das Apothekenwesen s. BVerfGE 7, 377 (insbes. S. 413 ff); w. Nachw. s. oben S. 1027 zu Fußn. 16. Zur Quotenbeschränkung der Kassenarztzulassung s. 
Die unmittelbare Sicherung der sozialen Berufsfunktionen ist in erster Linie eine Sache der Ausübungsiegelungen. ${ }^{4)}$

In besonderem Maße geeignet, die Beruísfunktionen zu gewährleisten, sind ferner subjektive Zulassungsvoraussetzungen. 5)

Objektive Zulassungsvoraussetzungen 6) spielen dagegen - abgesehen von den Berufen, die in notwendiger Koordination und Kooperation mit der staatlichen Verwaltung stehen 7) - grundsätzlich keine Rolle. ${ }^{8)}$

Soll die Wahrnehmung einer bestimmten Aufgabe stärker an das Gemeinwohl gebunden werden, als das unter der Herrschaft des Art. 12 GG möglich ist, so bleibt die Möglichkeit, sie in - unmittelbare oder mittelbare - sta a t1 iche Velwaltung zu nehmen.9) Aber nicht jede öfentlich-rechtliche Berechtigung und (oder) Verpflichtung eines Berufs genügt, um ihn der Anwendung des Art. 12 Abs. 1 GG zu entziehen. "Staatlich gebundene Berufe" 10) fallen

BVerfGE 11, 30 (insbes. S. 41 ff); zum Problem- und Meinungsstand s. im übrigen etwa Rohwer-Kahlmann, Die Kassenarztzulassung und das Grundgesetz, Zeitschrift für Sozialreform, 4.Jhg. (1958) S. 594 ff, 670 ff; Küchenhoff, Die Freiheit der Zulassung zur kassenärztlichen Tätigkeit, Recht der Arbeit, 13.Jhg. (1960), S.202 ff, 242 ff. - Weiterhin problematisch die Zulassungsregelung des $\$ 10$ des Hebammengesetzes; s. hierzu Bachof, Freiheit des Berufs, S. $184 \mathrm{f} \mathrm{(m}$. Fußn. 124) und S. 203 f u. d. dort. Nachw.

3) Stamm (Zur Verwirklichung des sozialstaatlichen Prinzips, S. 150) glaubte eine sozialstaatliche Notwendigkeit für das Pfandleihgewerbe in Anspruch nehmen zu können, dessen Schutz vor dem freien Wettbewerb durch objektive Zulassungsvoraussetzungen gewährleistet werden müsse. Dagegen BVerwGE 5, 286 (290).

4) Ein Beispiel aus der Rechtsprechung: Die Rechtfertigung der Versicherungsaufsicht gegenüber Art.12 GG aus dem Sozialstaatsprinzip (BVerwGE, 3, 303).

5) Beispiele s. bei Bachof, a.a.O. \$. $225 \mathrm{ff}$.

6) $\mathrm{Zu}$ den verwandten Ausübungsregelungen und subjektiven $Z: 1-$ lassungsvoraussetzungen - m.a. W. zum wirkungsgleichen Umfeld der objektiven Zulassungsvoraussetzungen i.e.S. s.o. S.1026f zu Fußn. 8-13.

7) S. den nachfolgenden Text.

8) Zu objektiven Beschränkungen zum Zwecke der wirtschaftl:chen Sicherung s.o. S. 1035 zu Fußn. 2 und 3 .

9) S.o. S. 1028 zu Fußn. 19 und 20.

10) S. hierzu Bachof, a.a.O. S. 183 ff u. s. Nachw. 
unter Art.12 Abs.1 GG. 11) Je näher sie "durch öffentlich-rechtliche Bindungen und Auflagen an den 'öffentlichen Dienst' herangeführt" werden, "umso stärker können Sonderregelungen in Anlehnung an Art. 33 GG die Wirkung des Grundrechts aus Art.12 Abs. 1 tatsächlich zurückdrängen". 12) A ber "wenn und solange der Staat hoheitliche Befugnisse nicht seinem eigenen Verwaltungsapparat vorbehält, sondern ein öffentliches 'Amt' durch Inhaber selbständiger Berufe versehen läßt, muß er auch die sich daraus im Hinblick auf die Berufsfreiheit ergebenden Folgerungen in Kauf nehmen". 13) Eine andere Frage ist, wie weit der Staat bisher freiberuflich wahrgenommene Aufgaben zugunsten seiner Verwaltung in Anspruch nehmen darf. Abgesehen von den organisationsrechtlichen Begrenzungen sind dem vor allem von den Grundrechten her Grenzen gesteckt. 14) Insbes. muß Art. 12 GG als Grundsatznorm beachtet werden: die frei gewählte Berufstätigkeit und Berufsausübung $m u ß$ in einem wesentlichen Raum möglich bleiben. 15) Die Übernahme einzelner sozialstaatlicher Aufgaben in die direkte Verantwortung der - unmittelbaren oder mittelbaren - staatlichen Verwaltung berührt diese Grenze aber grundsätzlich nicht. ${ }^{16)}$

Im Rahmen der verfassungsrechtlichen Sozialisierungsermächtigung 17) ist eine stärkere Gemeinwohlbindung der beruf-

11) BVerfGE 7, 377 (398).

12) BVerfGE, ebd.

13) Bachof, a.a.O. S.186. S. im einzelnen hierzu Bachof, a.a.O. S. 183 ff, 200 ff, 204 f, 205 f, 220 u. s. Nachw. - Aus der Rechtsprechung s.insbes. die Ausführungen des Bundesverfassungsgerichts zum bayerischen Apothekenwesen (BVerfGE 7, 377 (397 f)) und zum Kassenarztwesen (BVerf GE 11, 30 (39 f)). Entgegen dem Bundesverfassungsgericht glaubte das Bundessozialgericht (BSGE 4, 54 (56); 5, $246(248$ f)), die beschränkte Kassenarztzulassung damit rechtfertigen zu können, daß es der Kassenarztstellung den Charakter eines öffentlichen Amtes beimaß (ebenso Bogs, Verfassungsrechtliche Entscheidungen des Bundessozialgerichts, S.358); s. hierzu auch Bachof, a.a.O., insbes. S. $184 \mathrm{ff}$; Weidner, Zur Rechtsprechung des Bundessozialgerichts, S. 758 f; ferner die Hinweise bei den oben S.1035 zu Fußn.2 Zitierten. - Zum Hebammenberuf s. Werner, Anmerkung zu OVG Berlin, Urt.v.2.Juni 1954, S. 564; Bachof, a.a.O., insbes. S. 184 ff; s.a. BVerf GE 9, 338 (insbes. S. 346 ff).

14) S. hierzu die Nachweise S. 34 ff, insbes. S. 36 zu Fußn. 5 und 6 .

15) Vgl. Bachof, a.a.O. S. 165 f, 200 ff, 220 und seine Nachw. 
lichen Tätigkeit auch durch die Überführung der Produktionsmittel in Gemeineigentum oder andere Formen der Gemeinwirtschaft möglich. 18)

\section{eee) Die Abwehr sozialer Gefährdungen}

Die Berufsfreiheit ist nicht nur $z u$ beschränken, um die berufliche Betätigung direkt auf eine ihr gemäße soziale Funktion festzulegen. Sie ist auch zu regulieren, um soziale Gefährdungen auszuschließen oder wenigstens einzuschränken, die von - gewollt oder ungewollt - unsozialen beruflichen Verhaltensweisen ausgehen. Vordringlich ist dabei der Schutz der abhängig Erwerbstätigen gegenüber der Berufstätigkeit des Arbeitgebers und des sonstwie wirtschaftlich Unterlegenen gegenüber dem wirtschaftlich Mächtigeren, letzteres insbes. auch in der Produzenten-Verbraucher-Relation (im weitesten Sinn). Das A rbeitsrecht, insbes. das A rbeitsschutzrecht, das Wettbewerbsrecht, das Recht der öfentlichen Kontrolle der Banken und Versicherungen, der - spezielle, exklusive oder in komplexen Gesamtregelungen eingeschlossene - Wettbewerbs- und Kunden-(Verbraucher-)Schutz in den verschiedenen $Z$ weigen des Gewerberechts, das Lebensmittelrecht, aber auch das Bewirtschaftungs- und Preisrecht usw. stehen in dieser Funktion.

Das berufene Mittel, diese Aufgabe zu bewältigen, ist die Ausübungsregelung. In gewissen Grenzen ist eine verläßliche, sachgerechte Kontrolle nur über subjektive Voraussetzungen möglich. Jedoch muß der Versuchung widerstanden werden, damit eine billige Prophylaxe zu treiben, die nicht nur die Berufsfreiheit inadäquat beschneidet sondern auch die laufende Ausübungskontrolle in Wahrheit nicht ersetzen kann. Nur in seltensten Fällen wird schließlich unerläßlicher sozialer Schutz Dritter (der Allgemeinheit) nur über die durch objektive Zugangsbeschränkungen bewirkte wirtschaftliche Sicherung des Berufsstandes gewahrt werden können. Eine überstarke Interessenvertretung will freilich gerne nackten Konkurrenzschutz als Verbraucher- und Kundenschutz verkleiden. Videant iudices! 1 )

fff) Die soziale Gestaltung der Beschränkungen

Die Beschränkungen der Berufsfreiheit, welchen Zweck sie auch

16) Vg1. Über, Freiheit des Berufs, 1952, S. 156.

17) Art.15 GG.

18) S. oben S.1028 zu Fußn. 22.

1) Beispiele, Einzelerörterungen und Nachweise zu Vorstehendem s. bei Bachof, Freiheit des Berufs, S.219 ff. 
haben mögen, sind so zu gestalten, daß sie die in der Berufsfreiheit liegende Chance einer sozial nützlichen, eigenbestimmten, optimalen Ausnutzung der individuellen Kräfte nicht ersticken. Dabei geht es einerseits darum, daß die Berufswerber unter sich möglichst - sozial gewertet - gleichheitlich behandelt werden. Es geht andererseits auch darum, die sozialen Interessen der betroffenen Berufswerber nicht hinter den Interessen Dritter unangemessen zurückzustellen.

Letzteres ist insbes. für die Ausübungsregelungen zu beachten. Zulassungsvoraussetzungen - insbes. objektive - können nur durch ihren bedingenden Zusammenhang mit dem Schutz überragend wichtiger Gemeinschaftsgüter gerechtfertigt werden. Ausübungsregelungen können dagegen jedem beliebigen Gemeininteresse Rechnung tragen. Der einseitig bedrängenden Belastung bestimmter Berufe sind daher von der Berufsfreiheit her die Tore weit geöfnet. Hier hat das Korrektiv einer - gerade auch unter sozial(staatlich)en Aspekten - wohlverstandenen Gleichheit einzugreifen.

Von äußerster sozialer Sensibilität ist die Berufsfreiheit in bezug auf die individuellen Zulassungsvoraussetzungen. Mögen subjektive Zulassungsvoraussetzungen abstrakt auch dem Einfluß des Berufswerbers unterliegen, so kann er sie im Konkreten doch nicht selten nur unter bestimmten sozialen Voraussetzungen erfüllen. Voraussetzungen der Aus- und Vorbildung, 1) des Erfordernisses eines bestimmten Betriebskapitals, des Nachweises der wirtschaftlichen Leistungsfähigkeit u. dgl. ${ }^{2)}$ belasten den sozial Schwächeren unverhältnismäßig hart, weil sie sein wirtschaftliches Unvermögen über dessen unmittelbaren Mangeleffekt hinaus zum Hemmnis des beruflichen Aufstieges werden lassen. Gerade unter dem sozialen Aspekt werden fast alle "subjektiven Zulassungsvoraussetzungen", indem sie durch die subjektive Beherrschbarkeit gekennzeichnet sein sollen, als solche fragwürdig. ${ }^{3)}$ Nicht weniger schwer treffen jene individuellen Voraussetzungen den Berufswerber, die seinem Einfluß auch abstrakt entzogen sind, wie etwa die gesundheitlichen und die eines bestimmten Alters: 4) Persönliche Behinderungen, die auch sonst sozial belasten, blockieren kraft solcher Zulassungsvoraussetzungen auch von Rechts wegen die berufliche Laufbahn.

1) Zur sozialen Tragweite s.a. Bachof, Freiheit des Berufs, S. 217 .

2) S. hierzu auch Bachof, a.a.O. S.233 f.

3) S. nochmals oben S.1024ff,insbes. S. $1027 \mathrm{zu} \mathrm{Fußn.} 12$ und 13, insbes. auch Bachof, a.a.O. S.217.

4) S. die Hinweise in Fußn. 3. 
Das legt den Gedanken nahe, Zulassungsvoraussetzungen sozial abzustufen. Wenn die für die verfassungsrechtliche Zulässigkeit der subjektiven Zulassungsvoraussetzungen entwickelten Maßstäbe ${ }^{5)}$ richtig - m.a.W.: streng - gehandhabt werden, ist jedoch ein Ausweichen zugunsten sozialer Momente unmöglich. Die überragend wichtigen Gemeinschaftsgüter, deren unerläßlicher Schutz Zweck aller - nicht nur der (rein) objektiven - Zulassungsvoraussetzungen $z u$ sein hat, ${ }^{6}$ ) würden durch soziale Ausnahmen gefährdet. Nur wo man es mit dem bedingenden Vérhältnis zwischen Zulassungsvoraussetzungen und Schutz der Gemeinschaftsgüter zu leicht genommen hat, kann der Gedanke des sozial motivierten Dispenses Wurzel schlagen. ${ }^{7)}$ Im übrigen beleuchtet die berufspolitische Notwendigkeit subjektiver Zulassungsvoraussetzungen nur die Wichtigkeit der sozialstaatlichen Programmpunkte des allgemeinen sozialen Ausgleiches, der besonderen sozialen Ausbildungs- und Existenzaufbauhilfen und der gesundheitlichen Habilitation und Rehabilitation. Ferner tritt die soziale Bedeutung der Berufsfreiheit und der äußeren Beschränkung von Zulassungsvoraussetzungen einmal mehr zutage.

Objektive Zulassungsvoraussetzungen treffen schließlich allgemein jeden sozial schlechter Gestellten deshalb schwer, weil er, der (präsumtiv) allein auf die Ausnutzung seiner beruflichen Leistungsfähigkeit angewiesen ist, durch sie gerade darin gehemmt wird. Sie belasten darüber hinaus gerade den besonders, "der durch Erfüllung aller von ihm geforderten Voraussetzungen die Wahl des Berufes bereits real vollzogen hat und hat vollziehen dürfen,... . Diese Freiheitsentziehung ist um so gewichtiger und wird demgemäß auch um so schwerer empfunden, je länger und je fachlich spezialisierter die Vor- und Ausbildung war". 8) Je größer die sozialen Hemmnisse waren, die dem Erwerb der subjektiven Qualifikation entgegenstanden, desto schwerer wiegt der Fehlschlag dieser Bemühungen. Auch für die objektiven Zulassungsvoraussetzungen gilt daher, daß sie um der sozialen Funktion der Berufsfreiheit willen im Prinzip möglichst eng zu halten sind.

5) S.o. S.1024 ff.

6) BVerfGE 7, $377(405 / 406)$.

7) Mit Recht weist Bachof (a.a.O. S.231 f mit Fußn.281) in anderem Zusammenhang darauf hin, daß die Möglichkeit von Ausnahmen die Notwendigkeit einer Zulassungsvoraussetzung zum Schutz des angeblichen Schutzgutes in $Z$ weifel zu setzen geeignet ist.

8) BVerfGE 7, 377 (407). 
c) Zur Freiheit der Wahl des Arbeitsplatzes

Der effektive Schwerpunkt der freien Wahl des Arbeitsplatzes (Art.12 Abs. 1GG) 1) liegt bei den unselbständigen Berufen. 2) Ihr wesentliches Bestimmungsobjekt ist die Ordnung des Arbeitsmarktes, die sie lenkungsfeindlich prägt.

Sie unterliegt freilich denselben Beschränkungen, denen auch die Freiheit des Berufs unterworfen ist. 4) Unter besonderen Umständen wird daher der Schutz überragend wichtiger Gemeinschaftsgüter auch Beschränkungen der freien Arbeitsplatzwahl - etwa durch Erlaubnisvorbehalte - rechtfertigen. ${ }^{5)}$

Es widerspricht nicht dem Grundrecht der freien Wahl des Arbeitsplatzes sondern entspricht vielmehr seinem freiheitlichen Charakter, wenn der Staat das Risiko seiner freien Wahl dem einzelnen überläßt. Wer durch leichtfertige oder gar dolose Ausübung seines Wahlrechts den Versicherungsfall der Arbeitslosigkeit herbeigeführt hat, kann z. B. ohne Verstoß gegen Art. 12 Abs. 1 GG von der Arbeitslosenversicherung ausgesperrt werden. 6) Art.12 Abs. 1 GG würde dagegen dann verletzt, wenn der Ausschluß von der A rbeitslosenversicherung die Sanktion dafür wäre, daß anstelle einer behördlich "zugewiesenen" 7) eine andere Arbeit angenommen wurde.

Das Grundrecht gibt die Freiheit der positiven Entscheidung. Sein Träger darf an der Wahl eines Arbeitsplatzes nicht gehindert werden. Wählt er keinen A rbeitsplatz sondern die Untätigkeit, so schützt ihn Art.12 Abs. 1 GG nicht gegen belastende Folgerungen, die der Sozialstaat, dessen Hilfe er, da ihm das Erwerbseinkommen fehlt, schließlich in Anspruch nehmen muß, daran knüpft und knüpfen muß. ${ }^{8)}$

1) Zur Auslegung s. im allgemeinen Bachof, Freiheit des Berufs, S. 250 ff u.s. Nachw.

2) Zum Geltungsbereich s. Bachof, a.a.O. S. 250 f; w. Nachw. s. dort.

3) Vgl. Bachof, a.a.O. $\$ .251 \mathrm{f} \mathrm{m.w.Nachw.}$

4) S. Bachof, a.a.O. S. 250.

5) S. Bachof, a.a.O. S.251 f.

6) $₫ 80$ AVAVG. S. hierzu BSGE 3, 298; Weidner, Zur Rechtsprechung des Bundessozialgerichts, S. 759 f (der Art. 12 Abs. 1 GG zu einseitig sieht und die soziale Bindung vernachlässigt).

7) oder vermittelten.

8) Näheres s. oben Abschnitt 5 III 3 c (S. 800 ff), insbes. S. $805 \mathrm{ff}$. 
Das Recht, die Ausbildungsstätte frei zu wählen (Art.12 Abs. 1 Satz 1 GG), 1) verlängert das Recht der freien Berufswahl gewissermaßen nach vorne, hebt sich aber doch eigenständig von ihm $\mathrm{ab}$ - dies nicht zuletzt hinsichtlich der sozialen Funktion. Der rein ausgrenzende Charakter des Art.12 Abs. 1 GG wird im Recht der freien Wahl der Ausbildungsstätte besonders spürbar. Es setzt nicht nur das Vorhandensein der Ausbildungsstätte voraus, ohne auf deren Einrichtung initiativen Einfluß zu nehmen. Es ist dem einzelnen auch nur nach Maßgabe seiner wirtschaftlichen, körperlichen und geistigen Fähigkeit, sich der Ausbildung an der gewählten Ausbildungsstätte zu unterziehen, von Nutzen. Der (un)soziale Effekt wird typischerweise dadurch verschärft, daß die wirtschaftliche Potenz der meist jugendlichen Ausbildungssuchenden regelmäßig nicht von ihrer eigenen Leistung sondern von der wirtschaftlichen Situation ihrer Unterhaltsträger abhängt. So ändert das Grundrecht der freien Wahl der Ausbildungsstätte grundsätzlich auch nichts daran, daß Berufsvoraussetzungen der Aus- und Vorbildung wesensmäßig dazu neigen, die sozialen Unterschiede in der individuellen wirtschaftlichen Möglichkeit der Aus- und Vorbildung relevant $z u$ machen. In Richtung auf die Negation von klassen- und standesmäßigen (Aus-)Bildungsmonopolen leistet Art. 12 Abs. 1 Satz 1 GG kaum etwas, was über die Wirksamkeit des Gleichheitssatzes hinausgeht. Erst von der sozialstaatlichen Programmatik der Ausbildungshilfen 2) wird das Ausbildungswesen kraft Verfassung sozial geprägt, nicht von Art. 12 GG. Art. 12 Abs. 1 Satz 1 GG sorgt vielmehr umgekehrt dafür, die Freiheit auch gegenüber den sozialen Ausbildungshilfen zu sichern. Der Sozialstaat ist zwar nicht verpflichtet, eine Vor- und Ausbildung zu gewähren, die nur dem Wunsch des Auszubildenden, nicht aber seiner körperlichen und geistigen Leistungsfärigkeit entspricht. Darüber hinaus aber würde jede lenkende Einflußnahme gegen Art. 12 GG verstoßen.

\section{e) Arbeitszwang und Zwangsarbeit}

Obrigkeitlichen $Z$ wang "zu einer bestimmten Arbeit" schließt das Grundgesetz im Prinzip ebenso aus wie (nicht gegenständlich keschränkte) Zwangsarbeit (Art. 12 Abs.2 Satz 1, Abs.4 GG).1) Es .

\footnotetext{
1) Alles Nähere s, bei Bachof, Freiheit des Berufs, S. 252 f: u. s. Nachw.

2) S.o. S. 821 .

1) Näheres s. bei Bachof, Freiheit des Berufs, S.256 ff u.s. Nachw.
} 
rundet damit das Recht der freien Wahl des Berufs, des Arbeitsplatzes und der Ausbildungsstätte ab und vertieft den lenkungsfeindlichen Charakter der grundgesetzlichen Arbeitsmarktkonzeption wie - im allgemeinen - der grundgesetzlichen Wirtschaftsverfassung. Der Staat wird sowohl in den Möglichkeiten wohltätiger Planung als auch in der persönlichkeits- und familienfeindlichen, totalitären Herrschaft über die menschliche Arbeitskraft beschnitten. Im Extrem eliminiert das Verbot der Zwangsarbeit eine im sozial verpflichteten, auf die Menschenwürde, die freie Entfaltung der Persönlichkeit, die körperliche Integrität des Menschen und das Eigenrecht der Familie eingeschworenen Staat nur als engst begrenzte Ausnahme tragbare Erscheinung.

Von dem grundsätzlichen Verbot von Arbeitszwang und Zwangsarbeit nimmt die Verfassung drei Fälle ausdrücklich aus: 2) die herkömmliche, allgemeine, für alle gleiche öffentliche Dienstleistungspflicht (Art. 12 Abs. 2 Satz 1 GG), den Wehrersatzdienst (ebd. Satz 2 und 3) und die Zwangsarbeit im Rahmen gerichtlich angeordneter Freiheitsentziehung (Art.12 Abs.4 GG). 1) Eine ihnen wesentliche positiv-soziale Tendenz fehlt diesen Ausnahmen. Soweit sie herkömmlich, allgemein und gleich ist, kann eine öffentliche Dienstpflicht aber auch unmittelbar zu sozialen Zwekken begründet werden; ${ }^{3)}$ ja das Sozialstaatsprinzip wird ihr zusätzliche legitimative Stütze sein. 4) Zwangsarbeit kann zwar nicht einfach $z u$ dem $Z$ weck angeordnet werden, die Arbeitskraft sozialen $Z$ wecken dienstbar zu machen. Indem das Grundgesetz der Zwangsarbeit Gesetz und Richterspruch vorschaltet (Art. 12 Abs. 4, 104 GG), hebt es nur die formalen Voraussetzungen ihrer Zulässigkeit hervor. Ihre sachliche Zulässigkeit muß sich aus der übrigen Grundrechtsordnung ergeben. 5) Insbes. darf das Gesetz nicht den Wesensgehalt des Art.12 (Abs.1-3) GG verletzen (Art.19 Abs.2 GG). Zwangsarbeit darf keine Umgehungsform der durch Art. 12 Abs. 2 und 3 GG eng beschränkten Dienstpflicht sein. Wenn aber die Verletzung sozialer Pflichten den Freiheitsentzug nötig macht, kann der damit verbundene Arbeitszwang auch dem Grunde nach sozial gezielt sein. ${ }^{6}$ ) Im übrigen kann sowohl die im

2) Verfassungsimmanente Vorbehalte und verwandte Grenzerscheinungen s. bei Bachof, a.a.O. S.258f.

3) Abgesehen von dem Grenzfall der Pflicht zur existenzerha1tenden A rbeit (s. den nächsten Absatz und oben S.805ff) sind typische Fälle jedoch nicht ersichtlich.

4) S. zum Problem auch oben S.835.

5) S. hierzu auch Bachof, a.a.O. S. 262.

6) S. den nächsten Absatz und oben S.805 ff. 
Rahmen einer allgemeinen öffentlichen Dienstpflicht, insbes, auch der Wehrersatzdienstpflicht ${ }^{7)}$ geleistete Arbeit als auch Zwangsarbeit sozialen $Z$ wecken zugewandt werden.

Art. 12 GG negiert nicht die sozialstaatliche Elementarlast jedes einzelnen, den eigenen Unterhalt und den Unterhalt (der ihrn gegenüber unterhaltsberechtigten Mitglieder) seiner Familie so weit möglich und nötig durch Arbeit zu erwerben, ehe öffentliche Hilfe in Anspruch genommen wird. Die Anweisung einer entsprechenden A rbeit und - im Falle gesteigerter Pflichtverletzung die $Z$ wangsarbeit im Rahmen gerichtlich angeordneter Freiheitsentziehung, die dazu dient, die Unterhaltslast, die der Arbeitsunwillige auf die sozialstaatliche Gemeinschaft abwälzen will, auf jenen zurückzuverlagern, verstößt nicht gegen Art.12 GG. ${ }^{8)}$

\section{f) Das Problem der Drittwirkung}

Die freie Wahl von Beruf und Arbeitsplatz verlangt Schutz nicht nur gegenüber dem Staat sondern auch gegenüber außerstaatlichen sozialen Gewalten. Andererseits ist die private Verfügungsmacht über die Freiheit des Berufs und die freie Wahl des A rbeitsplatzes tragendes Strukturelement der freiheitlichen Wirtschafts- und A rbeitsordnung. Daher kann es der Drittwirkung des Art. 12 GG nur darum gehen, das Grundrecht dagegen zu schützen, daß es in seinem Wesensgehalt verleugnet oder (und) kraft wirtschaftlicher Machtüberlegenheit beeinträchtigt wird. 1)

In diesem Sinne gibt Art.12 Abs. 1 GG der Wertung vereinbarter Wettbewerbsbeschränkungen im Rahmen der allgemeinen privatrechtlichen Generalklauseln ( $\$ \$ 138,157,242$ BGB) und der einschlägigen Sondernormen ( $\$ \$ 74 \mathrm{ff} H G B, \$ \$ 133 \mathrm{f}$ GewO) sowie der legislativen Gestaltung dieser Regelungen selbst letztverbindliche Maßstäbe an die Hand. Je härter der wirtschaftliche Druck ist, dem der sich Bindende weicht, und je einschneidender seine berufliche Selbstbestimmung beschränkt wird, desto mehr ist die ihm auferlegte Bindung von Art.12 GG her abzulehnen. Von einem grundsätzlichen Verbot vertraglicher Wettbewerbsbeschränkungen kann jedoch nicht die Rede sein. ${ }^{2}$ )

7) S. $\ 1$ des Gesetzes über den zivilen Ersatzdienst.

8) Näheres und Nachweise s. oben S.805ff.

1) Vgl. Bachof, Freiheit des Berufs, S. 172 ff; w. Nachw.s. dort. - Zu den allgemeinen Grundsätzen s. o. I 4 d (S. 876

2) In diesem Sinne BAGE 3, 296 (301); 6, 291 (293). Für die Durchsetzung des Art. 12 GG gegenüber Wettbewerbsverboten insbes. - im einzelnen allerdings differenzierend - 
Als verfassungsrechtliches Wertmaß ist Art.12 GG auch heranzuziehen, um die Grenzen des innerbetrieblichen Weisungsrechts, kraft dessen der Wechsel des Berufs oder der A rbeitsstätte innerhalb desselben A rbeit gebenden Unternehmens verlangt wird, auszumitteln, 3) desgleichen für die Begrenzung des Kündigungsrechts des Arbeitgebers. ${ }^{4)}$ Hier wie dort ist jedoch größte $\mathrm{Zu}$ rückhaltung am Platze. Dem Recht des Arbeitnehmers auf den frei gewählten Beruf und Arbeitsplatz steht das Recht des Arbeitgebers auf die freie Entfaltung seiner (unternehmerischen) Persönlichkeit, auf die freie Ausübung seines Berufs und auf die freie Nutzung seines Eigentums gegenüber, womit die Wahl der Mitarbeiter eng zusammenhängt. 5) Zudem ist Art. 12 Abs. 1 GG nicht Teilhabe- sondern Ausgrenzungsrecht. Die Verfassung beabsichtigt mit diesem Grundrecht nicht die t a t s ächliche Möglichkeit, einen bestimmten Beruf auszuüben und einen bestimmten Arbeitsplatz inne zu haben, zu gewährleisten.

Verträge, die den Arbeitnehmer lebenslänglich oder sonstwie überlang auf ein bestimmtes Arbeitsverhältnis festlegen, machen die getroffene Wahl von Beruf und Arbeitsplatz zugunsten eines anderen, des A rbeitgebers, unwiderruflich. Sie berühren die Freiheit der Wahl von Beruf und Arbeitsplatz in ihrem Kern. Die rechtspolitische Tendenz des $\$ 624$ BGB - nicht die Vorschrift im Detail - erhält durch Art.12 GG verfassungsrechtliche Verbindlichkeit.

Als Ausdruck unangemessen gebrauchter sozialer Macht sind ferner allgemeine Organisations- und Absperrklauseln, soweit sie - wie in der Regel - die freie Wahl des Berufs und des Arbeitsplatzes des Außenseiters empfindlich behindern, grundsätzlich zu mißbilligen.

Dás Recht der freien Wahl der A usbildungsstät te ist in den Möglichkeiten der Drittwirkung äußerst beschränkt. ${ }^{6)}$ Der

Spitzbarth, Wettbewerbsverbote bei den freien Berufen, NJW 7. Jhg. (1954) S.453 ff; ders., Gesetzliche Schranken für vertragliche Wettbewerbsverbote, ebd. S. 1026 f. Gegen die Anwendung des Art.12 GG auf private Wettbewerbsbeschränkungen: Stree, Gesetzliche Schranken für vertragliche Wettbewerbsverbote, NJW 7.Jhg. (1954) S. 1025 f.

3) S. LAG Berlin, Urt. v.27. August 1958 - 5 Sa 310/57 - AP $\$ 615$ BGB Nr.4, m.zust.Anm. von Hueck.

4) Sehr zurückhaltend - eher ablehnend - Bachof, Freiheit des Berufs, S. 251 m.Fußn. 364 u. S.252. W. Hinw. s. dort.

5) Vgl. Bachof, a.a.O. S.252.

6) S.a. Bachof, a.a.O. S.253 f. 
Inhaber einer privaten Ausbildungsstätte ist grundsätzlich frei in der Entscheidung über die Aufnahme eines Ausbildungswilligen. ${ }^{7)}$ Soweit ihm jedoch ein Ausbildungsmonopol zukommt, wird in erster Linie der Gesetzgeber, ${ }^{8)}$ soweit dieser nicht tätig wird, die richterliche Anwendung der für das Rechtsverhältnis des Auszubildenden zum Ausbildenden maßgeblichen Normen für "drittwirkenden" Schutz des Rechts auf freie Wahl der Ausbildungsstätte Sorge zu tragen haben.

7. Vereins- und Koalitionsfreiheit

a) Vorbemerkung

Die Vereins- und Koalitionsfreiheit (A rt.9 GG) ist das tragende verfassungsrechtliche Regulativ der staatsfreien gesellschaftlichen Selbstorganisation. Diese konkurriert, soweit sie im Bereich des Öffentlichen belegen ist oder ihn auch nur berührt, fruchtbar und konfliktsträchtig mit der verbandlichen Untergliederung der organisierten staatlichen Gemeinschaft. Das Grundrecht der Vereins- und Koalitionsfreiheit ist so auch Element der Verfassungsentscheidung über Abgrenzung und funktionelle Verbindung von staatlicher Organisation und gesellschaftlicher Selbstorganisation.

Daraus ergab sich die Notwendigkeit, die grundsätzliche Bedeutung der Vereins- und Koalitionsfreiheit für die verbandlichen Elemente des Soziallebens und die Struktur und Wirkungsweise der öffentlichen Sozialgestaltung bereits im Zusammenhang mit der verbandlichen Gliederung des Staatsganzen zu erörtern. 1) Darauf ist bezug zu nehmen. Jedoch sind einige zusammenfassende und ergänzende Bemerkungen veranlaßt.

b) Zur Vereinsfreiheit 1 )

aa) Ihre positive soziale Funktion

Die soziale Bedeutung der positiven Vereinsfreiheit liegt vor allem darin, daß sie kollektive Selbst- und Fremdhilfe außerhalb

7) Bachof, a.a.O. S.254.

8) S.a. den Hinweis Bachofs, a.a.O. S.254 Fußn. 375.

1) S. o. Abschnitt 2 (S.219 ff), insbes. I (S.219 ff), III (S. 242 ff) und IV 2 (S. 287 ff); s.a. Abschnitt 3 III $5 \mathrm{~b}$ $(\mathrm{S} .373 \mathrm{ff})$ und IV (S.390 ff).

1) Zur Vereinsfreiheit, Art.9 Abs. 1 und $2 \mathrm{GG}$, im besonde:en s. vor allem oben S.223 ff und S. $244 \mathrm{ff}$. 
der staatlichen Organisation ermöglicht. Dennoch hebt das Grundgesetz sozial zweckhafte Vereinigungen in keiner Weise hervor. Jedoch rechtfertigen, ja gebieten das Sozialstaatsprinzip, die allgemeine grundrechtliche Tendenz, dem Bürger einen staatsfreien Lebensbereich zu sichern, und zum Teil auch die Nachbarschaft zur privilegierten kirchlichen Sozialarbeit eine gewisse Förderung. 2)

Speziell als individuelles Recht ist die Vereinsfreiheit nicht von so betont sozialer Ausstrahlung wie die Koalitionsfreiheit. Im öffentlichen und privaten Dienstverhältnis entfaltet sie - einerseits kraft ihrer Widerstandsfähigkeit gegen besondere Gewaltverhältnisse, ${ }^{3)}$ andererseits kraft ihrer Drittwirkung 4$)$ - jene befreiende Wirkung, die allen Grundrechten zukommt, sofern sie sich der Neigung aller und insbes. der dienstrechtlichen Abhängigkeitsverhältnisse entgegenstellen, Macht hier und Unterwerfung dort zu vervollkommnen.

\section{bb) Die Grenze der Vereinsfreiheit}

Die Vereinigungsfreiheit ist nach Art.9 Abs.2 GG auf Vereinigungen beschränkt, deren $Z$ wecke und Tätigkeit nicht den Strafgesetzen zuwiderlaufen, und die sich nicht gegen die verfassungsmäßige Ordnung und nicht gegen den Gedanken der Völkerverständigung richten. 1) Anders als die Vorschriften der Art. 18 und 21 Abs. 2 Satz 1 GG impliziert Art.9 Abs.2 GG eine unmittelbare Verpflichtung auf die Sozialstaatlichkeit, deren Zugehörigkeit zur "verfassungsmäßigen Ordnung" 2) außer Zweifel steht.

\section{cc) Vereinsfreiheit und Vereinigungszwang}

Das Grundgesetz gewährt in Art. 9 Abs. 1 GG auch die negative

2) S. o. S.244ff, insbes. S. 248 zu Fußn.22 ff; s.a. ebd. S. $242 \mathrm{ff}$.

3) S.o. I 4 c (S.865 ff).

4) Zum Unterschied zur Koalitionsfreiheit ist die allgemeine Vereinigungsfreiheit nicht mit einer Verabsolutierungsklausel (Art. 9 Abs. 3 Satz 2 GG) ausgestattet. Die allgemeine, ungeschriebene Drittwirkung füllt diese "Lücke" jedoch ohne erhebliche Differenz.

1) Zur Auslegung s. im allgemeinen etwa Füsslein, Vereinsund Versammlungsfreiheit, S. $435 \mathrm{ff}$; v. Mangoldt-Klein, Art. 9 Anm.IV $2 \mathrm{ff}$.

2) Zum Begriff s. etwa v. Mangoldt-Klein, Art. 9 Anm. IV 4. S. hierzu auch noch unten S.1053 ff. 
Vereinigungsfreiheit. ${ }^{1)}$ Diese ist nicht gegen öffentlichrechtliche Zwangsorganisationen gewandt. ${ }^{2}$ ) Nur darf die staatliche Organisation nicht so weit gehen, die Gesellschaft erschöpfend durchzuorganisieren und die Wahrung privater Interessen bei öfentlichrechtlichen $Z$ wangsorganisationen $z u$ monopolisieren. Sie würde damit die positive Vereinigungsfreiheit verletzen. 3 )

Die negative Vereinigungsfreiheit wendet sich im wesentlichen gegen den Zwang, privatrechtlichen Vereinigungen beizutreten. Dahin gehender Zwang wird kaum je unmittelbar ausgeübt. ${ }^{4}$ ) Die öffentliche Gewalt droht die negative Vereinigungsfreiheit vielmehr durch mittelbaren Druck zu tangieren: indem sie private, rechtlich freiwillige Vereinigungen und ihre Mitglieder in einer. Weise begünstigt, daß der Vereinsfreie sich genötigt sieht, beizutreten. 5) Die gerade im sozialen Bereich weit verbreitete, im einzelnen auf recht verschiedene Weise institutionalisierte Teilnahme privater Vereinigungen an der Wahrnehmung öffentlicher Aufgaben 6 ) kann, wenn sie nicht die negative Vereinigungsfreiheit verletzen soll, nicht beliebig gesteigert werden. ${ }^{7)}$ Aber auch ohne die Stütze staatsgewährter Vorteile bedrängen private Vereinigun-

1) Vgl. Füsslein, Vereins- und Versammlungsfreiheit, S. 435; v. Mangoldt-Klein, Art. 9 Anm. III 8; Hamann, Das Grundgesetz, Art. 9 Anm.B 3; w. Nachw. s.dort.

2) S.o. S.244ff,insbes. S. 244 zu Fußn. 2 und S. 251 zu Fußn. 38 u.d. dort. Nachw.

3) S. ebd. S. 250 zu Fußn. 37 u.d.dort. Nachw.

4) Füßlein (Vereins- und Versammlungsfreiheit, S.431 f, 435) will Zwangsvereinigungen jeder Art von Art.9 Abs. 1 GG ausnehmen. Trotzdem erkennt er die negative Vereinsfreiheit an: "Die öffentliche Gewalt darf in dieser Richtung keine Schranke auferlegen und keinen Zwang ausüben" (a.a.O. S.435). Das leuchtet nicht ganz ein. Die negative Vereinigungsfreiheit muß in erster Linie die Zwangsmitgliedschaft unmöglich machen. Wird die negative Vereinigungsfreiheit im Prinzip anerkannt, so können $Z$ wangsvereinigung und Zwangsmitgliedschaft nur noch aus wesensmäßigen, immanenten Schranken des Grundrechts der Vereinigungsfreiheit legitimiert werden. So rechtfertigen sich insbes. die öfentlichrechtlichen Zwangsorganisationen daraus, daß Art.9 GG an sich nur private Vereinigungen betrifft. Aber der $Z$ wang zum Beitritt zu privaten Vereinigungen ist im Prinzip ebenso denkbar wie unzulässig.

5) Vgl. v. Mangoldt-Klein, Art. 9 Anm. III 8 (S.322).

6) S.o. Abschnitt 2 III (S. $242 \mathrm{ff})$ und IV $2(\mathrm{~S} .287 \mathrm{ff})$ und Abschnitt 3 III 5 b (S. 373 ff) und IV 2 (S. 392 ff).

7) Einen Problemfall s, bei Weidner, Ist der Ausschluß der 
gen auf Grund ihrer sozialen Mächtigkeit das Recht des einzelnen, ihnen fern zu bleiben. Art. 9 Abs. 1 GG umfassend realisieren, heißt deshalb wesentlich auch, die negative Vereinigungsfreiheit in die privatrechtliche Dimension übersetzen.

\section{c) Zur Koalitionsfreiheit 1)}

\section{aa) Allgemeines}

Zur positiven, kollektiven ${ }^{2)}$ Funktion der Koalitionsfreiheit ist dem oben 1) Ausgeführten nichts hinzuzufügen.

Der individualrechtliche Schutz der positiven Koalitionsfreiheit sowohl gegenüber der öffentlichen Gewalt 3 ) als auch gegen soziale (wirtschaftliche) Mächte ist heute grundsätzlich unproblematisch, zumal die Verabsolutierungsklausel des Art. 9 Abs. 3 Satz 2 GG den $Z$ weifeln über die Drittwirkung von vorneherein entgegenwirkt.

Die Grenzen der Koalitionsfreiheit richten sich nach Art. 9 Abs. 2 GG. ${ }^{4)}$

bb) Besondere Aspekte der individualrechtlichen Abwehrfunktion

D i e aktuelle, individualrechtliche Problematik ist mit der Freiheit verknüpft, keiner Koalition beizutreten und, für den Fall des Beitritts, einer freigewählten Koalition beitreten zu können. Dies ist eine Auswirkung der positiven Koalitionsfreiheit, jenes der Inbegriff der negativen Koalitionsfreiheit. ${ }^{1)}$ In beiden Richtungen ist die Koalitionsf reiheit weniger unmittelbar durch die öffentliche Gewalt gefährdet, der die Grenzen klar gesteckt sind, und

Armenanwaltsbeiordnung in den unteren Instanzen der Sozialgerichtsbarkeit verfassungsmäßig? S.625. - S. ferner zur freiheitlichen Notwendigkeit, den Außenseiter zu schützen, insbes. oben S. 221 zu Fußn. 9 und S. 303 zu Fußn. 7-9.

1) Zur Koalitionsfreiheit (Art.9 Abs. 3 GG) s. oben Abschnitt 2 IV 2 a (S. $287 \mathrm{ff})$.

2) Gerade für die Koalitionsfreiheit trifft Werner Webers (Die Verfassung der Bundesrepublik in der Bewährung, S. $11 \mathrm{f}$ ) Beobachtung zu, Art. 9 GG sei in positiver Richtung in erster Linie Kollektivgrundrecht.

3) Zur Koalitionsfreiheit im dienstrechtlichen Gewaltverhältnis s.o. S. 874 zu Fußn. 5. - S. ferner $₫ 91$ des Bundesbeamtengesetzes, $₫ 57$ des Beamtenrechtsrahmengesetzes.

4) S. hierzu oben S. 311 zu Fußn. 4.

1) S. hierzu die Nachweise oben S. 288 zu Fußn. 7. 
die allenfalls versucht ist, die Koalitionsfreiheit dadurch zu vernachlässigen, daß sie sich um den sozialen Schutz des Außenseiters zu wenig annimmt, und diesen vollends auf die sonach unentbehrliche Hilfe der Koalitionen, wenn nicht gar einer bestimmten Koalition zu verweisen. 2) Die aktuell bedeutsamere Gefahr geht von den sozialen und wirtschaftlichen Gewalten, insbes. von der Koalitionen - in der Regel meist: von den Gewerkschaften und (sekundär) deren Tarifpartnern auf der Arbeitgeberseite - aus.

Diese Gewalten in die Schranken der individuellen Koalitionsfreiheit $z u$ weisen, erfordert sorgfältige Abwägung. Wie im $\mathrm{Be}-$ reich der Drittwirkung auch sonst ${ }^{3)}$ steht Recht gegen Recht. 4) Versucht die Koalition, ihre Effektivität zu steigern und sich auszudehnen, so entfaltet sie grundsätzlich legitim die ihr durch Art. 9 Abs. 3 GG eingeräumte Rechtsposition. Das gilt auch für den Drang der Koalitionen, ihren subjektiven Einzugsbereich zu maximieren. Dabei fällt ins Gewicht, daß die kollektive Gestaltung der Wirtschafts- und Arbeitsbedingungen häufig von einer zwangsläufigen Allgemeinheit ist, die den Außenseiter an dem von den Koalitionen Erreichten teilhaben 1äßt, ohne daß er sich den Bindungen und Opfern unterzieht, die den Mitgliedern der Koalitionen auferlegt werden. Aber auf der anderen Seite steht das Recht des einzelnen auf negative und positive Koalitionsfreiheit und letztlich auch das Recht des einzelnen auf Entfaltung seiner Persönlichkeit (Art.2 Abs.1 GG). Wenn auch weder das Recht auf Freiheit von kollektiven Bindungen noch das Recht auf freie Wahl der Koalition irgend einen Anspruch des einzelnen legitimiert, ohne Teilnahme an der Koalition an ihrem Wirken nutznießend Teil zu haben, so erschöpfen sich beide Freiheitsgarantien doch mitnichten darin. ${ }^{5)}$ Sie dürfen durch die positive, kollektive Koalitionsfreiheit nicht aufgehoben werden. Zudem steht auf Seiten des einzelnen das durch den Expansionskampf der Koalitionen geradezu typisch bedrängte Recht auf freie berufliche Betätigung

2) S. hierzu oben S.303 f zu Fußn. 7-9 und S. $789 \mathrm{ff}$.

3) Die Drittwirkungsklausel des Art. 9 Abs. 3 Satz 2 GG hat im wesentlichen nur klarstellende Funktion, schafft aber nicht eine grundsätzlich andere als die allgemeine, ungeschriebene Drittwirkung. S. hierzu auch nochmals oben S. 880 .

4) $\mathrm{Zu}$ den allgemeinen Erwägungen $\mathrm{s}$. oben $\mathrm{I} 4 \mathrm{~d}(\mathrm{~S} .876 \mathrm{ff})$ insbes. S. $867 \mathrm{ff}$ und S. $883 \mathrm{ff}$.

5) S. hierzu auch Galperin, Organisationszwang und Koalitionsfreiheit, S. 99 m.w. Nachw. 
und freie Wahl des Arbeitsplatzes (Art.12 GG).6) Je mächtiger die soziale Gewalt ist, die in diese Rechtsposition des Individuums einzudringen sucht, und je tiefer der einzelne durch sie in seinen Rechten betroffen wird, desto entschiedener muß sie abgewehrt werden. ${ }^{7)}$ Dazu kommt, daß die Koalitionen durch Art. 9 Abs. 2 GG an die verfassungsmäßige Ordnung und somit in besonderem Maße auch an die Verfassungsnorm der Sozialstaatlichkeit gebunden sind. Der Staat darf nicht dulden, daß sie ihren Vorteil - auch den sozialen Vorteil ihrer Mitglieder - in einer Weise suchen, die andere in eine sozialstaatlich unerträgliche Notlage stürzen würde. Im besonderen ist, nachdem die Vorenthaltung eines Arbeitsplatzes und die Verdrängung aus einem Arbeitsplatz zu den bevorzugten Mitteln im Kampf um die gewerkschaftliche Expansion gehören, der sozialstaatlich notwendige Schutz des Arbeitsplatzes zu berücksichtigen. ${ }^{8)}$

Demnach ist eine pauschale Wertung der verschiedenen Organisations- und Tarifausschlußklauseln 9) nicht angebracht. Immer kommt es darauf an, wie weit im Einzelfall die Macht der Tarifparteien reicht - und insbes. die Macht des gewerkschaftlichen Teiles, der die Aufnahme der Klausel zu erzwingen pflegt -, und wie schwer der Ausgeschlossene in seiner sozialen Stellung und in seiner persönlichen, insbes. seiner beruflichen und erwerbswirtschaftlichen Entfaltung getroffen wird. 10) Aber sowoh1 die allgemeine Organisations- und Absperrklausel, die sich der Beschäftigung jedes Nichtorganisierten entgegenstellt, als auch die tarifliche Organisations- und Absperrklausel, die nur die Beschäftigung von Angehörigen der tarifvertragschließenden Koalition(en) zuläßt, kann von der individuellen Rechtssphäre des Betroffenen und vom Sozialstaatsprinzip her als rechtswidrig zu qualifizieren sein. 11) Bei der tariflichen Absperrklausel kommt

6) S. hierzu Nipperdey, Lehrbuch des Arbeitsrechts, Bd.II, S. $120 \mathrm{ff}$ (insbes. S. 120, $122 \mathrm{f}, 275 \mathrm{~F} u ß n .10$ ); s. ferner oben S. 887 zu Fußn. 16.

7) S. ähnliche Erwägungen auch bei Galperin, a.a.O. S.99 u. 104.

8) S. o. S. 785 zu Fußn.9 und S. $797 \mathrm{ff}$.

9) Zur Übersicht s. etwa Nipperdey, Lehrbuch des Arbeitsrechts, Bd.II, S. 121 ff; Galperin, a.a.O.

10) S. nochmals wie Fußn.7.

11) Zur Realisierung dieser Verfassungssätze in der Sphäre des Tarifvertrags- und A rbeitsrechts s. nochmals oben S. $735 \mathrm{f}$ und S. 793 zu Fußn. 20 und 21, sowie oben S. 876 ff und $\mathrm{S} .883 \mathrm{ff}$. Die Diskussion um die Wertung der besagten Klauseln unter dem Gesichtspunkt der Koalitionsfreiheit sieht die tariflichen Absperrklauseln im Vordergrund, die un- 
hinzu, daß sie auch die positive Koalitionsfreiheit beeinträchtigt. Die Gegenrechtsposition, die sich der Entfaltung der positiven, kollektiven Koalitionsfreiheit entgegenstellt, verstärkt sich also. Nicht nur ist die positive Koalitionsfreiheit in der Verfassung stärker betont als die nur implizierte negative Koalitionsfreiheit; der positiven kollektiven Koalitionsfreiheit der zum Monopol drängenden Koalition tritt vielmehr neben der individuellen Koalitionsfreiheit der Betroffenen auch die positive kollektive Koalitionsfreiheit der Koalition entgegen, deren Mitglieder durch diesen Druck "abgeworben" werden sollen. ${ }^{12)}$ Entsprechendes gilt grundsätzlich für die Druckkündigung, die entweder den Nichtorganisierten schlechthin bekämpft oder den Arbeitnehmer, der einer anderen als der auf die Kündigung drängenden Koalition angehört. 13)

Dagegen ist nichts gegen Tarifausschlußklauseln zu erinnern, die nur verhindern, daß ein tarifgebundener A rbeitgeber seine nicht-

mittelbar (auch) die positive Koalitionsfreiheit (a1s Gegenrecht) tangieren und deren Ablehnung deshalb nicht allein auf die - umstrittene und vor allem im arbeitsrechtlichen Schrifttum weithin auf Ablehnung stoßende - negative Koalitionsfreiheit gestützt werden muß. Zur Unzulässigkeit s. z. B. Nipperdey, Lehrbuch des Arbeitsrechts, Bd. II, S. $274 \mathrm{f}$; Dietz, Die Koalitionsfreiheit, S.449, Fußn.114; Galperin, a.a.O. S.90 f, 104; je m.w.Nachw.; s.a. Kaskel-Dersch, Lehrbuch des A rbeitsrechts, S.281. - Dagegen wird die allgemeine Organisations- und Absperrklausel mehr vom Gegenrecht der Berufsfreiheit und anderen individuellen Abwehrrechten her abgelehnt als von der - wie gesagt umstrittenen - negativen Koalitionsfreiheit. Zur Ablehnung unter dem Gesichtspunkt des Art.12 GG s. die Nachw. oben S. 887 zu Fußn.16. Zur allgemeinen Organisations- und Absperrklausel s. ferner Galperin, a.a.O. S.92 und 104, der zur grundsätzlichen Zulässigkeit neigt; desgl. Kaskel-Dersch, a.a.O.

12) S. die vorstehenden Nachw. und oben S. 288 zu Fußn. 7.

13) Im allgemeinen wird dabei der - verfassungsrechtlich weniger in Art.12 GG als im Sozialstaatsprinzip wurzelnde (s.o. S. 1051 zu Fußn. 8) - Schutz des Arbeitsplatzes im Vordergrund gesehen; s. insbes. Nipperdey, a.a.O. S.123; KaskelDersch, a.a.O. S.281; Galperin, a.a.O. S.102. - Unzulässig ist die Kündigung des organisierten Arbeitnehmers, der sich nicht dem Tarifvertrag einer anderen Gewerkschaft unterwerfen will: BAGE 4, 22; s.a. Kaskel-Dersch, a.a.O. S. 281 . 
organisierten oder einer anderen als der tarifschließenden Koalition angehörenden A rbeitnehmer "automatisch" nach dem Tarifvertrag behandelt. 14) Der Tarifvertrag ist die Frucht der Koalition. Der Außenseiter hat kein Recht darauf, sie zu ernten. Vielmehr muß er das Risiko, das, wie mit jeder Freiheit, auch mit der individualrechtlichen, positiven und negativen Koalitionsfreiheit verbunden ist, selbst tragen. ${ }^{15)}$

\section{d) Zum Kartellproblem}

Ein Problem der Vereinigungsfreiheit bilden auch die wirtschaftlichen Unternehmenszusammenschlüsse, insonderheit die Kartel1e. 1) Das Recht der Unternehmer, sich zu vereinigen - einschließlich der Organisation zur Beschränkung des Wettbewerbs ${ }^{2)}$ - ist durch Art. 9 Abs. 1 GG mit verbürgt. ${ }^{3)}$ Die Wirt-

14) Zur Zulässigkeit s. Nipperdey, a.a.O. S.123, 275; Galperin, a.a.O. S.92, $99 \mathrm{f}$.

15) S.a. Galperin, a.a.O. S. 101.

1) Zum Problem- und Meinungsstand hinsichtlich des Verhältnisses des Art.9 GG zum Kartell und ähnlichen Unternehmenszusammenschlüssen s. zusammenfassend: Dürig, Art. 9 Grundgesetz in der Kartellproblematik; Biedenkopf, Die Verfassungsproblematik eines Kartellverbotes, Betriebsberater, 11.Jhg. (1956) S. $473 \mathrm{ff}(475 \mathrm{ff})$; Hamann, Deutsches Wirtschaftsverfassungsrecht, S. 106 ff; alle älteren Nachw. s. dort. Nachzutragen insbes. Zweigert, Das neue Kartellgesetz, DVB1. 73.Jhg. (1958) S. 733 ff (735 f); Ballerstedt, Wirtschaftsverfassungsrecht, S. 71 f;. Maunz, Deutsches Staatsrecht, S.127. - Einen weiteren Problem- und Schrifttumsüberblick s. bei Fikentscher, Wettbewerb und gewerblicher Rechtsschutz, S. 48 ff und (insbes. zur verfassungsrechtlichen Diskussion) S. $198 \mathrm{ff}$.

2) Zur notwendigen Unterscheidung $z$ wischen dem Kartell als Zusammenschluß und der Wettbewerbsbehinderung als Handlung oder Zustand s. Fikentscher, a.a.O. S. $51 \mathrm{f}$.

3) Kartelle sind keine Koalitionen i.S. des Art.9 Abs. 3 GG, da sie nur Wirtschaftsbedingungen, jedoch nicht Wirtschafisund A rbeitsbedingungen zu wahren und zu fördern bestimmt sind (s. hierzu oben S. 287 zu Fußn. 2; zum Meinungsstand s. außer den dort Genannten z.B. Dürig, a.a.O. S. 729 f (der selbst die Gegenmeinung vertritt) und Biedenkopf, a.a.O. S. 475). Der Streitfrage, ob Art. 9 Abs. 1 oder Abs. 3 anzuwenden ist, kommt keine Bedeutung $z u$, wenn wie hier angenommen wird, daß die Schranken des Art.9 Abs. 2 GG auch für Art. 9 Abs. 3 GG gelten (s. z.B. Zweigert, a.a.O. S.735; 
schaftsordnung hat somit auf der Prämisse der grundsätzlichen Zulässigkeit der Unternehmenszusammenschlüsse aufzubauen. Aber Art. 9 Abs. 2 GG steckt auch hierfür Grenzen.

Entscheidendes Regulativ ist die Bindung an die verfassungsmäBige Ordnung. 4) Zu ihren wesentlichen Elementen gehört die wirtschaftliche Entfaltungsfreiheit des einzelnen (Art.2 Abs.1, 12 Abs.1, 14 Abs. 1 GG), deren Verwirklichung im Kollektiv Art. 9 GG zwar mit verbürgt, jedoch nur sekundär, während die Verfassung sie primär individualistisch konzipiert und die immanente Kehrseite des Art.9 GG, die negative Vereinigungsfreiheit, ebenfalls für das Recht des einzelnen streitet, seine wirtschaftliche Entwicklung vereinigungsfrei $\mathrm{zu}$ suchen. $\left.{ }^{5}\right)$ Die verfassungs-

s. hierzu auch Dürig, a.a.O. S. 731).

4) S. insbes. Biedenkopf, a.a.O. S.475; Hamann, a.a.O. S. 107;

Ballerstedt, a.a.O. S.71. - Art.9 Abs. 2 GG verweist zwar außer auf die verfassungsmäßige Ordnung auch auf die Strafge setze. So bedeutungsvoll diese aber für die Kartellbildung und ihre Schranken sein können, so wenig eignen sie sich - soweit sie nicht wiederum nur dazu dienen, die verfassungsmäßige Ordnung zu entfalten, sondern unabhängig davon, wie im Text des Art. 9 Abs. 2 GG wohl vorausgesetzt, einen selbständigen $Z$ weck verfolgen - als unmittelbares Instrument der staatlichen Kartellpolitik. "Strafgesetzwidrige Zwecke oder Tätigkeiten im Sinne des Abs. 2 sind nur solche, die auch dann, wenn sie nicht von Vereinigungen verfolgt werden, als strafwürdig erscheinen und die deswegen sowohl für Kollektiv- als auch für Individualpersönlichkeiten verpönt werden" (v. Mangoldt-Klein, Art. 9 Anm. IV 3). - Art. 9 Abs. 2 GG verbietet schließlich auch Vereinigungen, die sich gegen den Gedanken der Völkerverständigung richten. Dem kommt keine allgemeine Bedeutung zu. "Die Auffassung, daß Kartelle ihrer Natur nach kriegslüstern seien, (darf) als Produkt der Kriegspropaganda außer Betracht bleiben" (Krüger, Grundgesetz und Kartellgesetzgebung, S.25).

5) Für den, der die Kartelle Art.9 Abs. 3 GG unterstellt und die Koalitionen nicht den Schranken nach Art. 9 Abs. 2 GG unterwirft, ergibt sich Entsprechendes daraus, daß alle Grundrechte immanent dahin beschränkt sind, daß sie nicht dazı: dienen dürfen, die Rechte anderer zu verletzen (Art. 2 Abs. 1 GG. - s. hierzu allgemein Dürig, in Maunz-Dürig, Art.2 Abs. 1 Randn. 73; im besonderen Zusammenhang s. insbes. Dürig, Art. 9 Grundgesetz in der Kartellproblematik, S. $730 \mathrm{ff} ; \mathrm{w}$. Nachw. s. dort). 
mäßige Ordnung verurteilt also den wirtschaftlichen Zusammenschluß, der - primär oder sekundär - dazu dient, die individuelle erwerbswirtschaftliche Autonomie prinzipiell aufzuheben. Desgleichen gehört zur verfassungsmäßigen Ordnung das Sozialstaatsprinzip, 6) das je nach den konkreten Umständen den Schutz der Wettbewerber, die sich zusammenschließen, um einer unerträglichen sozialen Gefährdung abzuhelfen, oder den Schutz der durch den Zusammenschluß sozial bedrängten Außenseiter oder schließlich der durch ihn sozial überspielten Verbraucher fordern kann. 7) Ist also das Kartell zwar grundsätzlich zu dulden, so ist doch dem Mißbrauch der aus dem Unternehmenszusammenschluß erwachsenden wirtschaftlichen Macht entgegenzutreten, 8) welcher das Kartell in einen Gegensatz zur verfassungsmäßigen Ordnung führen kann.9) 10)

6) S. insbes. Hamann, Deutsches Wirtschaftsverfassungsrecht, S. 108 ff. - Für den, der die Kartelle Art. 9 Abs. 3 GG unterstellt und die Koalitionen nicht den Schranken nach Art. 9 Abs. 2 GG unterwirft, ergibt sich Entsprechendes daraus, daß alle Grundrechte immanent zugunsten der kardinalen öffentlichen Ordnungsnormen beschränkt sind (s. allgemein Dürig, in Maunz-Dürig, Art. 2 Abs. 1 Randn. 75; im besonderen Dürig, Art. 9 Grundgesetz in der Kartellproblematik, S.730. Für die Hereinnahme der Sozialstaatsbindung in das Recht auf Kartellvereinigung aus Art.9 GG über Art. 2 Abs. 1 GG auch noch Hamann, Das Grundgesetz, Art. 9 Anm. B 4).

7) Zu Einzelheiten s. insbes. Hamann, Deutsches Wirtschaftsverfassungsrecht, S. 108 ff. S. ferner oben S. 839 u.d.dort. Nachw. - In der sozialstaatlichen Forderung nach sozialem Ausgleich liegt auch der verfassungsrechtlich richtige Kern der von ihm selbst nicht überzeugend begründeten und hinsichtlich der Konsequenzen eindeutig überbeanspruchten Forderung Biedenkopfs (Die Verfassungsproblematik eines Kartellverbots, S. $477 \mathrm{f}$; clers., Grundgesetz und Kartellverbot, Betriebsberater, 11. Jhg. (1956) S.974 f; kritisch hierzu z. B. Helmut Müller, Grundgesetz und Kartellverbot, Betriebsberater, 11.Jhg. (1956) S.972 ff), das Privatrecht müsse annähernde materielle Gleichheit herstellen (s.a. Hamann, Deutsches Wirtschaftsverfassungsrecht, S.108).

8) S.a. Art. 74 Nr.16 GG (vgl. zur interpretatorischen Bedeutung dieser Vorschrift für Art.9 GG z. B. Maunz, Deutsches Staatsrecht, S. 127).

๖) Zu den spezifischen Einschränkungen des Monopolisten s.a. oben S.618 ff und S. $621 \mathrm{ff}$.

16) Im Konkreten obliegt es dem Gesetzgeber, die Grenzen zu 
8. Die allgemeine Handlungsfreireit

a) Grundsätzliches

aa) Zur Auslegung des Art. 2 Abs. 1 GG

Art. 2 Abs. 1 GG gewährt jedermann ein Recht "auf die freie Entfaltung seiner Persönlichkeit, soweit er nicht die Rechte anderer verletzt und nicht gegen die verfassungsmäßige Ordnung oder gegen das Sittengesetz verstößt". Die Verfassung meint damit nichts anderes als einen umfassenden grundrechtlichen 1) Schutz der allgemeinen Handlungsfreiheit 2) - ein "Auffangrecht für unbenannte Freiheiten", 3) das auch jenen Entfaltungsrichtungen der persönlichen Freiheit ein Mindestmaß verfassungsrechtlicher Sicherung geben soll, die durch die besonderen Grund- und Freiheitsrechte nicht geschützt sind und vielleicht auch nicht erfaßt werden können.

Ein Freiheitsgrundrecht von solcher gegenständlichen Universalität kann nicht schlechterdings gesetzesfest sein. Art. 2 Abs. 1 GG verweist auf die "verfassungsmäßige Ordnung" als legitimen Rahmen der Freiheitsbeschränkung. "Verfassungsmäßige Ordnung" in diesem Sinne ist nichts anderes als "die allgemeine Rechtsordnung..., die die materiellen und formellen Normen der Verfassung $\mathrm{zu}$ beachten hat, also eine verfassungsmäßige Rechtsordnung sein muß".4) Mit anderen Worten: "Der Bürger... wird in seiner allgemeinen Handlungsfreiheit legitim einge-

ziehen. Art.9 Abs.2 GG spricht ein unmittelbares Verbot aus. Aber dieses Verbot ist zugunsten des Gesetzes mediatisiert. Hinsichtlich des Tatbestandes des Verstoßes gegen die Strafgesetze ergibt sich das aus dem Wortlaut des Art. 9 Abs. 2 GG direkt. Hinsichtlich des Schutzes der verfassungsmäßigen Ordnung ergibt es sich daraus, daß diese weitgehend erst realisiert und präzisiert werden muß. Das gilt vor allem für das Sozialstaatsprinzip. Es gilt z.B. ferner für das Ineinanderfügen der verschiedenen Grundrechtspositionen der Bürger im Privatrecht.

1) Dazu, daß Art.2 Abs. 1 GG Grundrecht im Sinne eines subjektiven öffentlichen Rechts ist, s. Dürig in Maunz-Dürig, Art.2 Abs. I Randn. 5 u.s. Nachw. Die später erneut von Wertenbruch (Der Grundrechtsbegriff nach Art.2 Abs.1 GG, DVB1. 73. Jhg. (1958) S. $480 \mathrm{ff}$ ) vorgetragene Ansicht, die in Art.2 Abs. 1 GG kein Grundrecht sondern nur eine Grundsatznorm sehen will, kann nicht überzeugen.

2) Vgl. BVerfGE 6, 32 (36 f); alles weitere s. bei Dürig, a.a. C. Randn. 6 ff. 
schränkt nicht nur durch die Verfassung oder gar nur durch 'elementare Verfassungsgrundsätze', sondern durch jede formell und materiell verfassungsmäßige Rechtsnorm". 5) Einer positiven materiellen Rechtfertigung des beschränkenden Eingriffes aus der Verfassung bedarf es nicht. 6) Aber jeder Eingriff in die allgemeine Handlungsfreiheit, der wegen Widerspruchs zu materiellen oder formellen Normen der Verfassung oder einer anderen dem Eingriffsakt übergeordneten Norm oder mangels der erforderlichen Grundlage in der Verfassung oder einem verfassungsmäßigen Gesetz der verfassungsmäßigen Ordnung nicht zugerechnet werden kann, verstößt gegen Art. 2 Abs. 1 GG.

Die Bindung der Handlungsfreiheit zugunsten der "Rechte anderer" enthält keine weitergehende Beschränkung. Geschützt sind nur die Rechte, welche die verfassungsmäßige Ordnung gewährt. 7)

Schließlich weicht auch der Vorbehalt zugunsten des "Sittenge setzes" nicht entscheidend von dieser Linie ab. "Sittengesetz" im Sinne des Art. 2 Abs. 1 GG ist nicht die subjektive moralische Auffassung eines beliebigen einzelnen. "Sittengesetz" ist vielmehr die tragende ethische Haltung der Rechtsgemeinschaft. Dieser "ethischen Normallinie" (Dürig) gibt die verfas-

3) Dürig, a.a.O., Randn. 6.

4) BVerfGE 6, 32 (38).

5) ebd. - Zu der sehr weitgespannten Diskussion um den Begriff der "verfassungsmäßigen Ordnung" i.S. des Art. 2 Abs. 1 GG s. z.B. v. Mangoldt-Klein, Art. 2 Anm. IV 2; Hamann, Die "verfassungsmäßige Ordnung", Betriebsberater, 12. Jhg. (1957) S. 229 ff; dens. nochmals: Die "verfassungsmäßige Ordnung", ebd. S.343 f. Zur Kritik an der Rechtsprechung des Bundesverfassungsgerichts s. ferner insbes. Dürig, Anm. zu dem Urteil des Bundesverfassungsgerichts v. 16. Januar 1957 - 1 BvR 253/56 -; dens., in Maunz-Dürig, Art.2 Abs. I, Randn. 17 ff (insbes. Randn. 18); Maunz, Deutsches Staatsrecht, S.96. Alle weiteren Nachw. S. bei den Zitierten.

6) Unrichtig ist auch das vor allem von Dürig aus dem Sozialstaatsprinzip ertwickelte Erfordernis der Ableitbarkeit (wenigstens) aus d $\in \mathrm{m}$ staatlichen Sozialgestaltungsauftrag (s. hierzu oben S.691 ff, S. 717 zu F'ußn.6).

7) Zur unmittelbaren und mittelbaren Bedeutung des Vorbehalts der "Rechte ancerer" s. Dürig, in Maunz-Dürig, Art. 2 Abs. I Randn. 13 ff, 73. W. Nachw. dort. 
sungsmäßige Rechtsordnung grundsätzlich hinlänglichen Ausdruck. ${ }^{8)}$

Der grundrechtliche Schutz des Art.2 Abs. 1 GG läuft demnach grundsätzlich auf einen umfassenden Vorbehalt des verfassungsmäßigen Gesetzes für Eingriffe in die allgemeine Handlungsfreiheit hinaus. Jedoch dürfen die Gesetze "die geistige, politische und wirtschaftliche Freiheit des Menschen nicht so einschränken, daß sie in ihrem Wesensgehalt angetastet würde (Art. 19 Abs.2, Art. 1 Abs. 3, Art. 2 Abs. 1 GG). Hieraus ergibt sich, daß dem einzelnen Bürger eine Sphäre privater Lebensgestaltung verfassungskräftig vorbehalten ist, also ein letzter unantastbarer Bereich ${ }^{9}$ ) menschlicher Freiheit besteht, der der Einwirkung der gesamten öffentlichen Gewalt entzogen ist. Ein Gesetz, das in ihn eingreifen würde, könnte nie Bestandteil der 'verfassungsmäßigen Ordnung' sein. 10)

\section{bb) Zusammenfassende Würdigung}

In einem System prinzipiell gesetzesfester Grundrechte (Art.1 Abs. 3 GG) erscheint der unantastbare Kernbereich der freien Entfaltung der Persönlichkeit als die eigentliche grundrechtliche Bastion der individuellen Freiheit. Diese Wesensgehaltsgarantie trägt die universelle und somit - da ihr Gegenstandsbereich durch die Summe der besonderen Freiheitsrechte nicht annähernd erschöpft wird - letzte, zentrale Verantwortung dafür, daß die Verfassungsordnung, indem sie die Würde des Menschen achtet und schützt (Art. 1 Abs. 1 GG), dem Leitbild eines wahren, nämlich eines freien Menschentums folgt.

Aber auch die Wirkung des zur Disposition der "verfassungsmäBigen Ordnung" gestellten Grundrechtshofes der allgemeinen Handlungsfreiheit darf nicht gering geschätzt werden. Das objektive

8) Zur unmittelbaren und mittelbaren Bedeutung des Vorbehalts des "Sittengesetzes" s. Dürig, a.a.O. Randn.16, 74. S.a. BVerfGE 6, 389 (434). Zur grundsätzlichen sachlichen Übereinstimmung von verfassungsmäßiger Ordnung und Sittengesetz s. die verwandten Ausführungen zum Verhältnis der verfassungsmäßigen Ordnung zurr Gerechtigkeit o. S. 663 ff.

9) Sperrung nicht im Original.

10) BVerfGE 6, 32 (41), s.a. ebd. S.36 f. Ein Versuch, diese "Kernzone" des Grundrechts näher auszumessen,findet sich bei Roemer, Zum Grundrecht der freien Entfaltung der Persönlichkeit, in: "Hundert Jahre Deutsches Rechtsleben", Festschrift Deutscher Juristentag, Bd. I, 1960, S. $545 \mathrm{ff}$ (572 ff). W. Nachw. s. dort. 
Recht, insbes. die objektive Verfassungsordnung, wird in den individuellen Rechtskreis projiziert - in subjektives Recht "umgeschaltet": Der Eingriff in die Handlungsfreiheit, der gegen objektives (formelles oder materielles) Verfassungsrecht oder sonstiges, verfassungsmäßiges Recht verstößt oder auf einen Verstoß gegen objektives Recht zurückgeht, verletzt das Grundrecht aus Art. 2 Abs. 1 GG, somit also ein subjektives Recht. 1) Während so in der einen Richtung der nicht gesetzesfeste Grundrechtshof der allgemeinen Handlungsf reiheit die objektive Verfassungssubstanz individuumsbezogen effektuiert, materialisiert diese zugleich in der Gegenrichtung die allgemeine Handlungsf reiheit. Das objektive Verfassungsrecht, soweit es selbst dem Telos der Freiheit folgt, verbindet sich mit dem - für sich gesehen und auf die Gesetzesfestigkeit bezogen - "leerlaufenden" 2) Grundrecht zu einer substantiellen Summe subjektiver Berechtigung, die ihrer-

1) "Verfahrensrechtlich bedeutet das: Jedermann kann im Wege der Verfassungsbeschwerde geltend machen, ein seine Handlungsfreiheit beschränkendes Gesetz gehöre nicht zur verfassungsmäßigen Ordnung, weil es (formell oder inhaltlich) gegen einzelne Verfassungsbestimmungen oder allgemeine Verfassungsgrundsätze verstoße; deshalb werde sein Grundrecht aus Art.2 Abs. 1 GG verletzt" (BVerfGE 6, 32 (41); s. ferner BVerfGE 7, 111 (115); 9, 3 (11); BayVerfGH VGHE n.F. 2 II 9 (13); 8 II 1 (7); 10 II 1 (4)). Da schließlich nicht nur der auf nichtigem (weil verfassungswidrigem) Gesetz beruhende Eingriff sondern auch der sonstwie nicht gesetzesbegründete Eingriff das Grundrecht verletzt, bringt die "Umschaltnorm" des Art. 2 Abs. 1 GG die Verfassungsgerichte in die Gefahr, umfassend die Gesetzmäßigkeit aller Freiheitsbeschränkungen zu prüfen. Das kann ihre Aufgabe nicht sein. Die Verfassungsgerichte haben die richtige Grenze zwischen ihrer legitimen Funktion des Grundrechtsschutzes ( $\$ 90$ Abs. 1 BVerf GG) und dem an Gesetzmäßigkeitskontrolle, was sie den Nichtverfassungsgerichten endgültig zu überlassen haben (Art. 19 Abs. 4 GG, $\$ 90$ Abs. 2 BVerfGG), noch nicht eindeutig gefunden. Hier kommt dieser Frage jedoch keine wesentliche Bedeutung zu. Entscheidend ist, daß das objektive Recht subjektiviert wird, soweit es dem Eingriff in die individuelle Handlungsfreiheit vorgelagert ist. Soweit diese "Umschaltung" nicht durch die Verfassungsgerichtsbarkeit sanktioniert ist, ist sie es durch den Rechtsschutz vor den Nichtverfassungsgerichten (Art. 19 Abs. 4 GG).

2) Kritisch zur Annahme, Art.2 Abs.1 GG laufe leer, mit Recht Dürig, Maunz-Dürig, Art.2 Abs.I Randn.28 (ff) (w. Nachw. s. dort). 
seits einem gesetzesfesten Freiheitsgrundrecht gleichkommt. Besonders erweist sich das hinsichtlich der objektivrechtlichen Verfassungsnormen freiheitlicher Rechtsstaatlichkeit: ${ }^{3)}$ vor allem etwa der Gewaltenteilung, 4) der Gesetzmäßigkeit der Verwaltung, 5) der Verhältnismäßigkeit von Zweck und Mittel 6) und der aus dem rechtsstaatlichen Verfassungsgebot der Rechtssicherheit 7) abzuleitenden Grundsätze wie des bedingten Verbots rückwirkender Gesetze ${ }^{8)}$ und der Bestandskraft der Verwaltungsakte. 9)

3) Dürig, a.a.O., Randn. 47: "Überhaupt erhalten die allgemein rechtsstaatlichen Anforderungen an staatliche Interventionen im Bereiche der Wirtschaft... ihre materielle Wertbegründung vorwiegend durch Art. 19 II. ... Art. 2 I bewirkt in diesem Normenzusammenhang, daß das 'Ob' und das 'Wie' staatlicher Wirtschaftsintervention auch auf grundrechtlich unbenannten Lebensbereichen des Wirtschaftens dennoch stets auch grundrechtlich gerechtfertigt werden muß und folglich stets auch gerichtlicher Grundrechtsprüfung unterliegt". (Zur Kritik s. schon oben S. 638 zu Fußn. 1).

4) Nawiasky (Allgemeine Staatslehre, Teil 3, S.124) weist auf die freiheitliche Funktion der Gewaltenteilung hin. Er sieht ihrem Freiheitszweck in der Schweiz dadurch Rechnung getragen, daß ein entsprechendes subjektives Recht anerkannt wird (Nachw.s. dort). Über Art. 2 Abs. 1 GG ist die Rechtsliage in der Bundesrepublik im Ergebnis die gleiche.

5) S. hierzu oben S. 425 zu Fußn. 12 (2); s.a. vorstehend S. 1059 zu Fußn. 1 .

6) S. hierzu oben S.633 ff, insbes. S. 634 zu Fußn. 6.

7) Vgl. oben Abschnitt 4 III 2 (S. $637 \mathrm{ff})$.

8) Vgl. oben Abschnitt 4 III 2 b (S.638 ff) (zum Verhältnis zu Art. 2 Abs. 1 GG s. insbes. dort S.638 zu Fußn.1).

9) Zu den allgemeinen Grundsätzen s.o. Abschnitt 4 III 2 c (S. 647 ff). - Besonderer Beliebtheit erfreut sich Art.2 Abs. 1 GG in der Diskussion um den sog. "alte-Rentner-Fall" (s. hierzu schon oben S.658 zu Fußn. 10). Der unerwartete Entzug der ungerechtfertigt gewährten Rente soll gegen die freie Entfaltung der Persönlichkeit dessen verstoßen, dem die Rente zunächst gewährt, dann aber entzogen wird: Landessozialgericht Bremen, Urt. v.20.Febr. 1957 - LV 161/55 - Betriebsberater, 12. Jhg. (1957) S. 543 (543); Bernhardt, Der Rentner und seine Menschenwürde; Rohwer-Kahlmann, Sozialrecht und Grundgesetz, S.360 f; ders., Die Einwirkung verfassungsrechtlicher Normen auf das Recht der sozialen Sicherheit. S. 1641 f; w. Nachw. s. bei den Zitierten; a.A. insbes. BSGE 9, 199 (206); 11, 209 (211 f). Zur Kritik s.a. oben 
Nicht zuletzt aber schafft Art.2 Abs. 1 GG der Freiheit wenigstens einen Vorsprung vor der Bindung. Die Freiheit ist zuerst da. Die Bindung muß erst durch die verfassungsmäßige Rechtsordnung aufgerichtet werden. Wo immer die Bindung keine Gestalt findet, der Impuls zur Bindung ausbleibt, der positive Wille hierfür sich nicht bildet oder ihm unüberwindliche Schwierigkeiten entgegentreten, verbleibt das Feld der grundrechtlich gesicherten Freiheit.

\section{b) Freiheit und soziale Ordnung}

\section{aa) Freiheit und Teilhabe}

Art. 2 Abs. 1 GG gewährt kein Teilhaberecht. ${ }^{1)}$ Die programmatische Substanz des Grundrechts darf zwar nicht rein negativ mißverstanden werden. Die freie Entfaltung der Persönlichkeit ist positives Verfassungsziel. 2) Daß aber die staatliche Gemeinschaft helfend und leistend hinzuzutreten hat, wenn die Persönlichkeitsentfaltung nicht allein aus der materiellen Kraft des einzelnen verwirklicht werden kann, wird rechtsnormativ durch das Sozialstaatsprinzip, nicht durch das Grundrecht der allgemeinen Handlungsfreiheit gewährleistet. Aber mittelbar wirkt dieses doch auch im Sinne seiner positiven Programmatik. Indem es dem Staat den Weg der Unfreiheit abschneidet, zwingt es ihn auf die Bahn der freiheitlichen Sozialgestaltung - läßt es ihm nur die Wahl, die freie Entfaltung der Persönlichkeit zu fördern.

Wie alle Freiheitsgrundrechte so sichert auch das Hauptfreiheitsgrundrecht in erster Linie die "Freiheit von der Teilhabe": die Chance der individuellen sozialen Sicherung und des sozialen Aufstiegs aus eigener Kraft und der Freiheit von dem AngewiesenSein auf die Teilhabe am staatlich erfaßten Allgemeinen. 3) Die "Freiheit in der Teilhabe" 4) sichert es - vor allem deren objektivrechtliche rechtsstaatliche Sicherungen ${ }^{5)}$ subjektivierend,aber

S. 658 zu Fußn. 10 ff).

1) S. z.B. v. Mangoldt-Klein, Art. 2 Anm. III 4; Dürig, in Maunz-Dürig, Art. 2 Abs. I Anm. IV 1 (vor Randn. 26) (m. S. 25 Fußn. 1); je m.w. Nachw.

2) S. Peters, Die freie Entfaltung der Persönlichkeit als Verfassungsziel, in "Gegenwartsprobleme des internationalen Rechts und der Rechtsphilosophie", Festschrift für Rudolf Laun, 1953, S. $669 \mathrm{ff}$.

3) S.o. S.848ff.

4) S.o. S.431 ff.

5) S.o. Abschnitt 4 II (S. 406 ff) und III (S. 632 ff) passim; s.a. vorstehend S.1060 zu Fußn.3-9. 
auch durch das Sozialstaatsprinzip materialisiert - jedenfalls, soweit im Rahmen öfentlicher Teilhabegewährung die Handlungsfreiheit beengt wird. Doch erscheint es nicht ausgeschlossen, daß Teilhabepositionen so eng mit der Handlungsfreiheit verknüpft sind, daß ihre Vorenthaltung die Handlungsfreiheit selbst trifft und durch Art. 2 Abs. 1 GG negiert wird. Soweit aber die Teilhabeposition auf keine speziellere und präzisere Basis als das Sozialstaatsprinzip zurückgeführt und die Vorenthaltung allein durch die Differenz zur sozialstaatlichen Verfassungsnorm konstituiert wird, wird aus Art.2 Abs. 1 GG kaum jemals ein Anspruch auf Abwehr der Vorenthaltung - direkt: ein Anspruch auf Gewährung des Vorenthaltenen - hergeleitet werden können. Das Sozialstaatsprinzip ist - abgesehen von der Gewährung des absoluten Existenzminimums, dessen Versagung aber Art.2 Abs.2 GG und nicht Art. 2 Abs. 1 GG betrifft 6 ) - hinsichtlich dessen, was einem einzelnen zu leisten ist, in aller Regel zu unbestimmt, als daß aus ihm eindeutig abgelesen werden könnte, inwieweit der Staat zur freien Entfaltung der Persönlichkeit beitragen müßte.

\section{bb) Die soziale Bindung der Freiheit}

Sozialer Ausgleich und soziale Hilfe durch den Staat ist ohne Bindung der individuellen Freiheit nicht möglich - ja ist zu einem guten Teil identisch mit kollektiver Ordnung des Freiheitsgebrauchs. Die Vorbehalte, unter die das Freiheitsgrundrecht gestellt ist, lassen diesen Zusammenhang nicht unmittelbar aufscheinen. Der Vorbehalt der "verfassungsmäßigen Ordnung" stellt die individuelle Freiheit jedoch unter Vollmacht und Auftrag des sozialen Rechtsstaats, auf die ihm gemäße Weise den einzelnen in soziale Pflicht zu nehmen.

Entscheidendes Medium der sozialen Bindung der individuellen Freiheit ist das (verfassungsmäßige) Gesetz. 1) Das Sozialstaatsprinzip bindet die Freiheit nicht unmittelbar. 2) Unmittelbar verpflichtende Einzelregelungen fehlen im Grundgesetz. 3) Das Gesetz ist auch nicht auf eine konstitutive Legitimation aus der sozial-

6) S. hierzu unten S.1083 ff. - Zur Spezialität des Art.2 Abs.2 GG gegenüber Art. 2 Abs. 1 GG s. f.v.a. Dürig, a.a.O. Art. 2 Abs. II Randn. 2.

1) S.o. Abschnitt 4 II (S.406 ff) und Abschnitt 5 II 2 (S. 706 ff); s.a. o. I 2 (S. $845 \mathrm{ff})$.

2) S. insbes. oben Abschnitt 5 II 2 e (S. 729 ff) und die dort. Verweisungen.

3) S.o. S. 673 ff und oben I $2(\mathrm{~S} .845 \mathrm{ff})$ und $3 \mathrm{~b}$ (S. 859 ff). 
staatlichen Verfassungsnorm oder aus einem - daraus gefolgerten - allgemeineren Sozialgestaltungsauftrag des Staates angewiesen. 4 )

'Trotzdem ist das Sozialstaatsprinzip (zwar mittelbares aber doch) tragendes Regulativ der sozialen Bindung der Freiheit. Indem es den Staat zu sozialer Wirksamkeit anhält, 5) treibt es ihn auch, die soziale Bindung der individuellen Freiheit $\mathrm{zu}$ intensivieren. Indem es ferner die Möglichkeiten sozial relevanten verfassungsmäßigen staatlichen Handelns auf soziales Verhalten einengt und unsoziales Verhalten ausschließt, ${ }^{6}$ ) konzentriert es die entsprechenden verfassungsmäßigen Bindungen der Handlungsfreiheit in Richtung der Sozialstaatlichkeit. Schließlich aber wirkt vor allem die - auf der interpretatorischen Notwendigkeit, der sozialstaatlichen Aktion verfassungsmäßigen Entfaltungsraum zu schaffen, beruhende - affirmativ legitimierende Funktion der sozialstaatlichen Verfassungsnorm 7 ) im Sinne der sozialen Bindung der Freiheit. 8) Soziale (sozialstaatsgemäße) Gesetze und Vollziehungsakte haben die - freilich nur interpretatorisch wirksame, bedingte - Vermutung für sich, zur "verfassungsmäßigen Ordnung" im Sinne des Art.2 Abs. 1 GG zu gehören. 9)

Die soziale Verfassungsnorm kann schließlich auch bei der Abgrenzung des unantastbaren Wesensgehalts der persönlichen Freiheit nicht unbeachtet bleiben. 10) Der Vorbehalt der - wesentlich sozialstaatlichen - "verfassungsmäßigen Ordnung" und die Wesensgehaltsgarantie der freien persönlichen Entfaltung schließen sich nur dann nicht aus, 11) wenn sich dieser Kerngehalt der Handlungsfreiheit der sozialen Gemeinschaftsverpflichtung gegenüber nachgiebig zeigt. Aber die Wesensgehaltsgarantie darf nicht zugunsten des sozialen Verfassungselements aufgehoben werden.

4) S.o. S.716 ff ; s.a. vorstehend S.1057 zu Fußn.6.

5) S.o. Abschnitt 5 II 1 (S. 676 ff) und 2 (S. 706 ff), insbes. a (S. $706 \mathrm{ff}$ ).

6) S.o. Abschnitt 5 II 2 (S.706 ff), insbes. S. $709 \mathrm{ff}$.

7) S.o. S. $719 \mathrm{ff}$.

8) S. die Verweisung in Fußn. 7 und die dort. Nachw.; s. ferner oben S. 862 .

9) S. die Nachw. oben S. 722 zu Fußn. 8.

10) S. nochmals wie Fußn. 7-9.

11) Vg1. BVerfGE 6, 32 (36): ". . es wäre nicht verständlich, wie die Entfaltung innerhalb dieses Kernbereichs gegen das Sittengesetz, die Rechte anderer oder sogar gegen die verfassungsmäßige Ordnung einer freiheitlichen Demokratie sollte verstoßen können". 
Der Sozialstaat kann dieses absolute Minimum an Freiheitlichkeit nicht preisgeben, ohne seinen Dienst an der Menschenwürde zu verleugnen. 12)

\section{c) Einzelfragen}

\section{aаa) Vorbemerkung}

Die konkrete soziale Tragweite einer Freiheitsgarantie von der Universalität des Art. 2 Abs. 1 GG erschöpfend aufzuzeigen, ist kaum denkbar. Im folgenden sei deshalb nur auf einige Punkte von besonderer Wichtigkeit hingewiesen. 1) Dabei steht die Bedeutung der Wesensgehaltsgarantie der persönlichen Freiheit im Vordergrund. Bei ihr liegt die voll eigenständige Wirkung des Grundrechts. Die "Subjektivierung" des objektiven Verfassungsrechts durch den nicht gesetzesfesten Grundrechtshof 2 ) intensiviert und "individualisiert" dagegen vor allem die Wirkung eben jenes objektiven Verfassungsrechts. Zu dieser wurde das Wesentliche bereits oben 3 ) gesagt.

\section{$\mathrm{bbb})$ Freiheit und soziale Sicherheit}

In der Wesensgehaltsgarantie der freien Entfaltung der Persönlichkeit liegt der berechtigte verfassungsrechtliche Kern der Absage an einen "Versorgungsstaat", 1) der ohne Rücksicht auf die persönliche Freiheit oder gar in Feindschaft gegen sie, die soziale Sicherung und damit notwendigerweise auch deren Lasten und Bindungen maximal ausdehnt, die Eigenvorsorge - auch wo sie weder dem objektiv wohlverstandenen Eigeninteresse des Betroffenen noch dem Bedürfnis nach sozialer Sicherung hilfsbedürftiger Schichten entgegenstünde - ausschaltet und möglichst alle in Abhängigkeit von den öffentlichen Trägern der sozialen Sicherung versetzt. Das heißt jedoch mitnichten, jede Ausdehnung der sozialen Sicherung über den traditionellen subjektiven Einzugsbereich hinaus, wäre unzulässig. Vor allem ist die - von Interessenten nicht ungeschickt lancierte, wortspielerische - Behauptung unrichtig, der Staat könne die "freien Berufe" nicht in die soziale Sicherung einbeziehen, ohne das Grundrecht der freien

12) S. hierzu oben S. 862 u.d. dort. Verweisungen.

1) Im übrigen darf auf die umfassende Problemübersicht hingewiesen werden, die Dürig (in Maunz-Dürig) in seinen Erläuterungen zu Art. 2 Abs. 1 bietet.

2) S.o. a (S. $1056 \mathrm{ff}$ ), insbes. S.1058 ff.

3) S.o. Abschnitt 1-5 (S. 45 bis S. 841 ).

1) Vg1. oben S. 753 zu Fußn. 29. 
Entfaltung der Persönlichkeit zu verletzen. ${ }^{2)}$ Wo die soziale Sicherung ein Übermaß3) erreichen würde, das die freie Entfaltung der Persönlichkeit im Prinzip bedrohen würde, braucht hier nicht konkretisiert zu werden. Sollte die Expansion der sozialen Sicherung je an diese Grenze stoßen, so müßte ihr jedenfalls vom Freiheitsgrundrecht Einhalt geboten werden, auch wenn damit der Verzicht auf eine sozialstaatlich vielleicht wünschenswert erscheinende weitere Steigerung der Effektivität der sozialen Sicherheit verbunden wäre.

Zum freiheitszerstörenden Übermaß neigt die soziale Sicherung nicht nur hinsichtlich ihrer äußeren Erstreckung. Auch ihre innere, sachliche Perfektion gefährdet die Freiheit. Das Grundrecht verlangt auch insofern Schonung des Kernbereichs der individuellen Autonomie. Die Belastungen, die dem einzelnen im Rahmen der sozialen Sicherung auferlegt werden, dürfen dessen Eigenverantwortung und Eigenvorsorge nicht unnötig und übermäßig vermindern oder aufheben. Vor allem aber müssen die Leistungen auf die freie persönliche Entscheidung des Empfängers Rücksicht nehmen. Gewiß trifft gerade den, der auf die öffentliche Hilfe angewiesen ist, eine gesteigerte Pflicht, sich in die Notwendigkeiten einer öffentlichen Hilfe einzuordnen. Aber diese Pflicht hebt die Freiheit seiner Person nicht auf. Wo sich die öffentliche Hilfe in

2) BVerfGE 10, 354 (363 ff); Peters, Die verfassungsrechtliche Zulässigkeit berufsständischer Pflichtversorgungseinrichtungen für Ärzte, S.16 ff; Schmitt-Lermann, Die Verfassungsmäßigkeit der Pflichtmitgliedschaft bei der Bayerischen Ärzteversorgung, S.90 ff; Maunz, Rechtsgutachten über die Verfassungsmäßigkeit der Bayerischen Ärzteversorgung nach dem Grundgesetz, S. 15 ff; Bogs, Diskussionsbeitrag zu "Die verfassungsrechtliche Problematik der $Z$ wangsversorgung freier Berufe" in "Aktuelle Probleme der Versicherungswirtschaft vom Standpunkt der Versicherungswissenschaft betrachtet", hrsg. von Walter Rohrbeck, 1954, S.26 ff (29); Schneider, Die öfentlichrechtliche Alterssicherung freier Berufe und das Grundgesetz, S. 17 ff; w. Nachw.s. bei diesen. Für die Gegenmeinung s. insbes. Weber, Die verfassungsrecht1iche Problematik der $Z$ wangsversorgung der freien Berufe, S. 18 ff.

3) Der Gesichtspunkt des Übermaßverbotes greift sowohl aus der Interpretation der Wesensgehaltsgarantie heraus Platz a1s auch aus der "Subjektivierung" des allgemeinen rechtsstaatlichen Übermaßverbotes durch den nicht gesetzesfesten Grundrechtshof des Art.2 Abs.1 GG (s.o. S.1060 zu Fußn.6). Die Übergänge sind schwer zu fassen. 
zumutbarer Weise an die persönliche Entscheidung anpassen kann oder wo es um letzte persönliche Vorbehaltsbereiche geht, ist der Freiheit der Vorzug zu geben. Vor allem Dienst- und Sachleistungen tendieren - im Gegensatz zu den Geldleistungen danach, in den Raum der individuellen Persönlichkeitsentfaltung einzubrechen. ${ }^{4)}$ Hervorgehoben sei die Problematik der anstaltlichen Unterbringung, 5) der freien Arztwahl ${ }^{6)}$ und des Behandlungs- insbes. des Operationszwangs. 7)

\section{cсc) Freiheit und soziale Wirtschaftsordnung}

Art. 2 Abs. 1 GG schützt auch die Freiheit des wirtschaftlichen Handelns. 1) Neben Art. 12 und Art. 14 GG ist Art. 2 Abs. 1 GG das Herzstück der freiheitlichen Wirtschaftsordnungskonzeption des Grundgesetzes, die eine perfekte Planwirtschaft - jedenfalls als normale und dauernde Wirtschaftsverfassung - negiert. 2) Dagegen widersetzt sich Art. 2 Abs. 1 GG nicht dem gemäßigten, die wirtschaftliche Freiheit des einzelnen nicht im Kern berührenden korrigierenden Eingriff des Sozialstaates ${ }^{3)}$ in die Wirtschaft.2) Einen bestimmten Weg freiheitlicher Wirtschaftsordnung weist jedoch Art. 2 Abs. 1 GG auch in Verbindung mit dem Sozialstaatsprinzip nicht. Vor allem ist die Annahme, u.a. durch das Grundrecht der freien Entfaltung der Persönlichkeit und dessen Unterstellung unter eine sozial- und rechtsstaatliche "verfassungsmäBige Ordnung" sei das wirtschaftspolitische Programm der "sozialen Marktwirtschaft" verfassungskräftig rezipiert worden, nicht gerechtfertigt. 2)

Die individuelle Freiheit der wirtschaftlichen Betätigung wird von außerstaatlichen - insbes. kollektiven - sozialen Gewalten

4) S. zu diesen Problemen in anderem Zusammenhang schon oben S. $463 \mathrm{ff}$.

5) Das Problem hat seinen eigentlichen grundrechtlichen Sitz in Art. 2 Abs. 2 GG (s.u. 9 a (S. 1069 ff)). Die Wesensgehaltsbestimmung des Art. 2 Abs. 2 GG (Art. 19 Abs. 2 GG) kann aber nicht ohne die durch Art. 2 Abs. 1 GG vorgegebenen zentralen Wertaspekte erfolgen.

6) Zum Zusammenhang des Problems der freien Arztwahl mit Art. 2 Abs. 1 GG s. z.B. Weidner, Zur Rechtsprechung des Bundessozialgerichts, S. 759 .

7) S. hierzu noch unten $9 \mathrm{~b}$, bb, aaa (S. $1073 \mathrm{ff}$ ).

1) Näheres und Nachweise s, bei Dürig, in Maunz-Dürig, Art.2 Abs. I, Randn. 11, $43 \mathrm{ff}$.

2) Näheres und Nachweise s.o. S.34ff.

3) S. hierzu auch oben Abschnitt 5 III 9 (S. 835 ff). 
nicht selten annähernd oder ebenso mächtig bedrängt wie vom Staat. Art. 2 Abs. 1 GG fordert den Schutz der wirtschaftlichen A utonomie des einzelnen auch in dieser Dritt-Richtung, freilich nicht absolut wie in der Staats-Richtung. Recht steht wieder gegen Recht. 4) Der Freiheit individueller wirtschaftlicher Betätigung (Art.2 Abs.1, 12 Abs.1 GG) steht die Freiheit gegenüber, sich - auch darin - vertraglich zu binden und zu beschränken (Art.2 Abs.1 GG). 5) Der Freiheit, als einzelner zu wirtschaften (Art.2 Abs.1, 12 Abs. 1 GG) ${ }^{6}$ ), steht die Freiheit gegenüber, sich zum Zwecke wirtschaftlicher Betätigung zusammenzuschlieBen (Art.9 GG, Art.114). 7) Die Rechtsordnung darf keine dieser Freiheiten im Kern verletzen, aber auch keine so wuchern lassen, daß sie die andere erstickt. Sie hat abzuwägen und dem Zwang zu wehren, dem die wirtschaftliche Autonomie des einzelnen nicht in adäquater Entfaltung der Privatautonomie und nicht in freiem Gebrauch der Vereinigungsfreiheit sondern aus Not weicht. Weder das individuell vereinbarte Wettbewerbsverbot noch die kollektive Wettbewerbsbeschränkung ist demnach schlechthin unzulässig. Die Entartungserscheinung, die das Recht der freien Entfaltung der Persönlichkeit an der Wurzel zu treffen droht, muß jedoch hintangehalten werden. ${ }^{8)}$

ddd) Die Freiheit in der Privatautonomie

Die Privatautonomie, insbes. die Vertragsfreiheit, ist unentbehrliches rechtliches Mittel der freien Entfaltung der Persönlichkeit. Sie ist nicht nur in Art.2 Abs. 1 GG grundrechtlich beheimatet sondern vor allem auch in Art. 14 Abs. 1 GG und in Art. 12 Abs. 1 GG. Doch ist Art. 2 Abs. 1 GG mangels gegenständlicher Beschränkung als allgemeinstes Garantieprinzip von besonderer Bedeutung. 1)

4) Zu den allgemeinen Grundsätzen s. oben I 4 d (S. 876 ff), insbes. S. $876 \mathrm{ff}$.

5) Zur Privatautonomie s.a. unten S.1067ff; zu den entsprechenden Erwägungen in bezug auf Art.12 GG s.o. S. $1044 \mathrm{ff}$.

6) Ergänzend ist die negative Vereinigungs- und Koalitionsfreiheit heranzuziehen (s.o. S.1047ff, S. $1049 \mathrm{ff}$ und S. $1053 \mathrm{ff}$ ).

7) S.o. S. $1053 \mathrm{ff}$.

8) S. f.v.a. Dürig in Maunz-Dürig, Art. 2 Abs. I Randn. 48 ff, 53 ff (insbes. Randn. 50 f) u. d. dort. Nachw.; s. zu Vorstehendem ferner oben S. $1044 \mathrm{ff}$ und S. $1053 \mathrm{ff}$ u. d. dort. Nachw.

1) S. zu Vorstehendem f.v.a. Laufke, Vertragsfreiheit und Grundgesetz, S. 155 ff (zu Art.2 Abs. 1 GG insbes. S. 156 ff); Raiser, Vertragsfreiheit heute, S. 4 ff; Dürig, in MaunzDürig, Art.2 Abs. I Randn. 53; w. Nachw. s. dort. 
Art. 2 Abs. 1 GG setzt die Privatautonomie grundsätzlich dem ordnenden und begrenzenden Zugriff der "verfassungsmäßigen Ordnung" aus. In deren Spielraum sind die sozialstaatlich in gewissem Maße notwendigen 2) Einschränkungen der Vertragsfreiheit möglich, die vor allem für das A rbeitsrecht, das Wirtschaftsrecht (z.B. das Wettbewerbs-, Bewirtschaftungs- und Preisrecht) und das Miet- und Pachtrecht kennzeichnend geworden sind. Aber ein Minimum an Vertragsfreiheit und freier Verfügungsmacht ${ }^{3}$ ) ist der Entfaltung der menschlichen Persönlichkeit wesentlich und gehört zum unantastbaren Kern der allgemeinen Handlungsfreiheit. Die Grenze dieses Kernbereichs ist schwer zu fixieren. Nicht nur die staatliche Gewalt, auch wirtschaftliche und soziale Über- und Unterlegenheiten sowie tatsächliche Entwicklungen, die ohne - jedenfalls ohne die Vertragsfreiheit direkt betreffendes - staatliches Zutun zu einem partiellen oder totalen Funktionsausfall der individualistisch-privatautonomen Ordnung führen, können die Privatautonomie aufheben. Es wäre widersinnig, eine Vertragsfreiheit als zum Kernbereich der persönlichen Entfaltungsfreiheit gehörend der staatlichen Beschränkung zu entziehen, die ohne diese Ordnung durch die Macht der Tatsachen vollends aufgehoben würde, durch den regulierenden, staatlichen Eingriff aber wenigstens noch so gut als möglich gewahrt werden kann. Desgleichen verdient die Privatautonomie keinen unbedingten Schutz, die dazu gebraucht wird, die Privatautonomie anderer - wirtschaftlich Schwächerer, Abhängiger - effektiv auszulöschen. Schließlich wäre es abwegig, die Privatautonomie einem Individuum erhalten $\mathrm{zu}$ wollen, das durch den Funktionsausfall der privatautonomen Ordnung in seiner Existenz bedroht ist. ${ }^{4}$ ) "Der Rechts- und Sozialstaat des Bonner Grundgesetzes ... steht hier vor einem nicht mit glatten Formeln zu lösenden Problem" .5)

Damit ist auch noch einmal die Problematik der "Drittwirkung" der grundrechtlich gesicherten Privatautonomie angesprochen. Nicht nur steht individuelle Autonomie gegen individuelle Autono-

2) S. o. S. 826 f und S. 828 u.d.dort. Nachw.

3) Für alle vermögenswirksamen Verfügungsgeschäfte dürfte allerdings Art. 14 Abs. 1 GG Art. 2 Abs. 1 GG als grundrechtlichen Schutz verdecken (s. Laufke, a.a.O. S. $155 \mathrm{f}$; Dürig, a.a.O.).

4) S.a. Flume, Rechtsgeschäft und Privatautonomie, S.139 f: Vertragsfreiheit ist dem suum cuique nicht vorgeordnet und darf diese Maxime nicht verletzen.

5) Raiser, Vertragsfunktion und Vertragsfreiheit, in "Hundert Jahre deutsches Rechtsleben", Festschrift Deutscher Juristentag, Bd.I, 1960, S.101 ff (128). 
mie. Die Privatautonomie begründet wesentlich auch die Relativität der übrigen Grundrechtspositionen in der Dritt-Richtung mit: Die Grundrechtspositionen der privaten Verfügungsmacht zu entziehen, wäre um der freien Entfaltung der Persönlichkeit willen unerträglich. So stehen sich in der Dritt-Richtung nicht nur Grundrecht und Grundrecht sondern auch verfügbare Grundrechtsstellung und verfügbare $\mathrm{Grundrechtsstellung} \mathrm{gegenüber.}$ Jenes kann Verfügungsmacht und Rechtsposition eines Stärkeren, dieses Verfügungsmacht und Rechtsposition eines Schwächeren sein. Diese soziale Spannung ist im Prinzip hinzunehmen. Sie liegt im Wesen des freiheitlichen Sozialstaates. Die Freiheit ist die des Stärkeren ebensogut wie die des Schwächeren. Den Schwächeren könnte zudem ein aus vermeintlich sozialen Gründen getroffenes Verbot, sich seiner Freiheiten auch nur begrenzt und bedingt $z u$ begeben, härter in seinen Chancen der Existenzerhaltung und des sozialen Aufstiegs treffen als ihn die Einbuße an grundrechtlich gesicherter Freiheit belasten würde. Wenn jedoch die Macht des Stärkeren zur Zwangsgewalt anschwillt oder (und) die Freiheit des Schwächeren durch den ihm abgenötigten Verzicht in ihrem Kern bedroht wird, hat der auf die Menschenwürde verpflichtete, Grundrechte gewährende Sozialstaat die Grundrechtsposition des Schwächeren gegenüber der Macht des Stïrkeren abzuriegeln. Er beschränkt dann den Schwächeren auch nicht in der freien Verfügungsmacht über seine grundrechtliche Stellung sondern verbietet nur dem Stärkeren, den Grundrechtsverzicht zu erzwingen oder den erzwungenen Verzicht anzunehmen. So kann im Rahmen der - nicht zuletzt durch Art. 2 Abs. 1 GG - relativierten Grundrechtsdrittwirkung den sozialen Belangen adäquat Rechnung getragen werden. ${ }^{6)}$

9. Das Recht auf körperliche Freiheit, körperliche Unversehrtheit und Leben

a) Die körperliche Freiheit

aa) Allgemeines

"Die Freiheit der Person ist unverletzlich" (Art.2 Abs. 2 Satz 2 GG). Dieser euphemistische Ausruf des Grundge setzes bedeutet primär, daß in die körperlich-räumliche Bewegungsfreiheit

6) Zu den allgemeinen Grundsätzen s.o. I 4 d (S. 876 ff), insbes. S.876 ff.Zu den einzelnen Grundrechten s.o. I-IV (S. 842 ff - S. 1017) passim. Zu Art.2 Abs.1 s.oben S.1066f a.E. und das Vorstehende. Die Nachw.s. je a.a.O. Vgl. ferner Dürig, in Maunz-Dürig, Art. 2 Abs. I Randn. 53 ff u.d.dort. Nachw. 
des Menschen ${ }^{1)}$ nur nach Maßgabe des förmlichen Gesetzes und auf Grund Richterspruchs eingegriffen werden darf (Art.2 Abs. 2 Satz 3, 12 Abs. 4, 104 GG). 2) In seinem Wesenskern gibt das Grundrecht aber auch dem Gesetz nicht nach (Art.19 Abs.2 GG). ${ }^{3}$ ) Entziehung und Beschränkung der Freiheit bedürfen einer im Hinblick auf die gesamte Verfassungsordnung legitimen und adäquaten causa. 4) Verhältnismäßigkeitsprinzip und Übermaßverbot regieren die Grenzziehung. ${ }^{5)}$ Ist eine Freiheitsentziehung schließlich an sich zulässig, so ist doch immer die Personwürde des Festgehaltenen zu respektieren (Art. 1 Abs.1, 104 Abs. 1 Satz 2 GG).6)

\section{bb) Zur sozialen Problematik}

Soziale Intervention und grundrechtliche Sicherung der körperlichräumlichen Bewegungsfreiheit 1 ) treffen sich nicht frontal. Die allgemeinste Beziehung liegt darin, daß auch das sozial zweckhafte oder sonstwie relevante Recht nicht der polizeilichen oder strafrechtlichen Sanktion entraten kann und diese nicht ohne Entzug und Beschränkung der Freiheit auskommt.

Eines der die körperliche Freiheit am schärfsten bedrängenden Mittel der sozialen Intervention - keineswegs freilich nur ein Instrument derselben - ist die $Z$ wangsarbeit. Art.12 GG negiert sie grundsätzlich. 2) Der Frage, ob und inwieweit sie auch dem Wesensgehalt des Art.2 Abs.2 Satz 2 GG (Art. 19 Abs. 2 GG)

1) Zur "Freiheit der Person" als körperlich-räumliche Bewegungsfreiheit des Menschen s. insbes. Dürig in Maunz-Dürig, Art. 2 Abs. II Randn. 49 f, Art. 104 Randn. 5.

2) Zu den Einzelheiten s. Dürig, a.a.O. Art.2 Abs. II Randn. 52 ff, Art. 104 Randn. 1 ff; w. Nachw.s.dort.

3) S. z.B. v. Mangoldt-Klein, Art.2 Anm. VII 2; Hamann, Das Grundgesetz, Art. 2 Anm.C 11; Dürig, a.a.O. Art. 2 Abs. II Randn. 52 (ff), Art. 104 Randn. 1 a.E.

4) Zum herkömmlichen Bestand an Freiheitsentziehung s. die (kritische) Zusammenstellung bei Kern, Schutz des Lebens, der Freiheit und des Heims, S. $74 \mathrm{ff}$; s.a. Dürig, a.a.O. Art. 104 Randn. 16 ff.

5) Beispiele entsprechender Würdigung s. bei Dürig, a.a.O. S. 53 f.

6) S. hierzu Dürig, a.a.O. Art. 104 Randn.20-22.

1) Es ist gerade in diesem Zusammenhang wichtig, sie von de: Freizügigkeit (Art.11 GG) zu unterscheiden.

2) S.o. S.1042ff; s. ferner oben S. $805 \mathrm{ff}$. 
zuwiderläuft, ${ }^{3)}$ kommt daneben keine eigene Bedeutung zu.

Von spezifisch sozialer Problematik ist das Grundrecht der körperlichen Freiheit in bezug auf die $Z$ wangsunterbringung Kranker und sozial hilfsbedürftiger Personen. 4) Jedenfalls insoweit, als sie notwendig ist, um gemeinen Schaden, der von diesen Personen - subjektiv zu verantworten oder nur objektiv zurechenbar - droht, zu verhüten, verletzt sie den Wesensgehalt der Freiheit der Person nicht. Im Eigeninteresse des Betroffenen kann die Unterbringung dann angeordnet werden, wenn sie eine psychische oder (und) physische Behandlung ermöglichen soll, der sich der Betroffene nicht unterzieht, weil ihm - seiner Jugend oder geistiger Störungen wegen - die Einsicht in ihre Notwendigkeit fehlt. Im übrigen ist daran zu denken, Personen zwangsweise unterzubringen, die der Allgemeinheit deshalb zur Last fallen, weil sie ihre Arbeitskraft nicht in zumutbarer Weise ausnützen oder die ihnen zur Wiederherstellung ihrer Gesundheit zuzumutenden Maßnahmen nicht ergreifen. Die materielle Zulässigkeit der Unterbringung ist hier jedoch primär ein Problem der Legitimität des mittels der Freiheitsbeschränkung bezweckten Eindringens in die körperliche Integrität, ${ }^{5)}$ dort primär ein Problem der Freiheit von Arbeitszwang und Zwangsarbeit.6) Vom Grundrecht der körperlichen Bewegungsfreiheit her dürfte sie nicht schlechtweg abzulehnen sein. In jedem Fall hat die Unterbringung den förmlichen Voraussetzungen des Freiheitsentzugs zu genügen (Art.2 Abs. 2 Satz 3, 12 Abs. 4, 104 GG). 7)

Die richterliche Anordnung ist dabei auch dann erforderlich, wenn der Wille des Betroffenen nach Maßgabe des bürgerlichen Rechts durch den eines Vormundes ersetzt wird. Der Vormund leitet seine Gewalt vom Staat ab. Er ist ein Hilfsorgan der staatlichen Gemeinschaft, die sich durch ihn ihrer Obsorgepflicht für den außerhalb der elterlichen Gewalt stehenden Geschäftsunfähigen oder beschränkt Geschäftsfähigen entledigt. Es wäre nicht gerechtfertigt, seine "Einweisungsanordnung" von der richterli-

3) S. hierzu Kern, Schutz des Lebens, der Freiheit und des Heims, S. 67 u. S. 70; v. Mangoldt-Klein, Art. 2 Anm. VI 2 a (S. 189).

4) S. die Zusammenstellung bei Dürig in Maunz-Dürig, Art. 104 Randn. 17 f. Vg1. hierzu auch schon oben S. 448 zu Fußn. 87 ff.

5) S. hierzu unten b bb aaa (S. $1073 \mathrm{ff}$ ).

6) S. hierzu oben Abschnitt 5 III $3 \mathrm{c}$ bb (S. $801 \mathrm{ff}$ ), sowie oben S. $1042 \mathrm{ff}$.

7) Zu Unrecht einschränkend Nawiasky-Lechner, Erl.zu Art. 102 Abs.II. - Soweit die Festnahme außerhalb der Strafver- 
chen Kontrolle zu entbinden, der selbst alle öfentlichen Organe unterworfen sind, obwohl ihre Rechtsgebundenheit prinzipiell stärker und ihre Sachkunde nicht selten größer ist als die eines Vormundes. ${ }^{8)}$

Grundsätzlich anders zu würdigen ist die Befugnis der Eltern, den Aufenthalt ihrer Kinder zu bestimmen und dabei die körperlich-räumliche Bewegungsfreiheit $z u$ beschränken oder zu entziehen. Sie entströmt dem "natürlichen" Elternrecht (Art.6 Abs. 2 GG) und unterliegt, wie dessen Ausübung auch im übrigen, der staatlichen Mißbrauchskontrolle (Art.6 Abs. 2 Satz 2 und Abs. 3 GG). Trotzdem sollte überlegt werden, ob die sich aus Art.2 Abs.2 Satz 2 und 3, 12 Abs.4, 104 GG grundsätzlich auch für das Kind ergebende Freiheitsposition zugunsten des Elternrechts so weitgehend eingeschränkt werden darf, daß auf die notwendige und vorgängige richterliche Kontrolle elterlicherseits angeordneter (oder vorgenommener) Freiheitsbeschränkung schlechtweg verzichtet wird.9) 10)

folgung erfolgt, entfällt die Anwendung des Art.104 Abs. 3 GG.

8) Grundlegend BVerfGE 10,302. Zum danach geltenden Unt $\in \mathrm{r}-$ bringungsrecht s. z.B. Dunz, Grundrecht und Bevormundung, JZ 15.Jhg. (1960) S. 475 ff; Franke, Grundlagen der Anstaltsunterbringung Psychischkranker in verfassungs-, privat- und verwaltungsrechtlicher Sicht, NJW, 13.Jhg. (1960) S. 1369 ff; Böning, Zwangsunterbringung volljähriger Mündel, ebd., S. 1374 ff; Erdsieck, Freiheitsentziehung und richterliche Kontrolle, ebd. S. 1385 ff.

9) S. o. S. 1009 zu Fußn. 13. - Das Jugendwohlfahrtsgesetz läßt die Fürsorgeerziehung nur auf Grund richterlicher Anordnung $z u$, ohne Rücksicht darauf, ob die Eltern einwilligen oder nicht ( $\$ \$ 63 \mathrm{ff} J W G)$. Das ist zumindest rechtspolitisch erfueulich. Im Hinblick auf Art.104 GG erscheint es aber auch verfassungsrechtlich notwendig, obwohl nach Art. 6 Abs. 3 GG die gesetzliche Grundlage selbst dann zu genügen scheint, wenn die Unterbringung gegen den Willen der Eltern angeordnet wird (s.o. S. 1009 zu Fußn. 11). Art. 6 Abs. 3 GG betrifft den Schutz des Elternrechts, nicht den Schutz der Freiheit des Kindes.

10) Im übrigen ist die Drittwirkung sproblematik des Grundrechts der körperlich-räumlichen Bewegungsfreiheit nicht aktuell. $\mathrm{Zu}$ denken wäre etwa an das verfassungsrechtliche Unwerturteil, das vom Grundrecht auf eine arbeitsrechtliche Vertrags-Freiheits-Strafe ausginge (s. $\$ \$ 342$ ff, 138, 242 BGB). Dagegen sind Freiheitsbeschränkungen, die im Interes- 
Art. 2 Abs. 2 GG ist nicht betroffen, wenn einem Bedürftigen aus sonst legitimem Grund - öffentliche Hilfe nur in Anstaltspflege gewährt wird. 11) Zum Konflikt mit dem Grundrecht käme es nur dann, wenn der Bedürftige die Einsperrung in einer Anstalt aut sich nehmen soll, um die öffentliche Hilfe zu erlangen.

\section{b) Die körperliche Unversehrtheit}

\section{aa) Allgemeines}

Das Grundgesetz gewährt ein besonderes Grundrecht der körperlichen Unversehrtheit (Art.2 Abs.2 Satz 1 GG). 1) Es ist nicht gesetzesfest (ebd. Satz 3). Seinen Wesensgehalt darf jedoch der Gesetzgeber nicht antasten (Art.19 Abs.2 GG). Niemand darf mißhandelt ${ }^{2}$ ) und in menschenunwürdiger Weise zum bloßen Objekt körperlicher Behandlung herabgewürdigt werden. ${ }^{3)}$ Niemandes körperliche Unversehrtheit darf aus unzulänglichem Grund angetastet werden.

\section{bb) Zur sozialen Problematik}

\section{aail) Gesundheitspflegerische und Heileingriffe}

1. Vorbemerkung. Die körperliche Gesundheit ist die physische Grundlage der Arbeitskraft und diese eine der individuellen Voraussetzungen des Erwerbseinkommens. Krankheit und Körperschaden beeinträchtigen die Erwerbsfähigkeit oder heben sie auf. Darüber hinaus verursachen sie zusätzliche Bedürfnisse der Pflege, der Heilbehandlung und der prothetischen Wiederherstellung. Krankheit, Körperschaden und dadurch bedingter Tod bedeuten Schmerz und seelisches Leid. Der Volksanteil einerseits der Gesunden und Arbeitsfähigen, andererseits der Kranken und Hilfsbedüı.ftigen entscheidet über die Leistungsfähigkeit der Volkswirt-

se der Tätigkeit, die ein Arbeitnehmer übernimmt, notwendig sind - soweit sie sonst im Rahmen des Vertrages liegen - , zulässig (Geheimhaltungsmaßnahmen, hygienische Sicherungen usw.).

11) Vg1. $\$ 13$ Abs. 2 der Reichsgrundsätze über Voraussetzung, Art und Maß der öffentlichen Fürsorge.

1) Näheres und Nachweis hierzu s. bei Dürig, in Maunz-Dürig, Art. 2 Abs. II Randn. $29 \mathrm{ff}$.

2) S.a. Art. 104 Abs. 1 Satz 2 GG.

3) Dürig, a.a.O. Randn. 34: "Das Grundrecht auf Gesundheit i. S. des Art.2 II Satz 1 ... in seinem Wesensgehalt (Art. 19 II) = Menschenwürdegehalt (Art. 1 I) ..."; s.a. Dürig, a.a.O. Art.1 Abs. I Randn. 28, 30, 34 . 
schaft, über die soziale Leistungsfähigkeit des Staates und - was hier zurücktritt - über die Verteidigungskraft der Nation.

Gesundheitsschutz ist darum an sich schon eine elementare Aufgabe des Staates. In besonderem Maße aber ist der Sozialstaat aufgerufen, für den Schutz der Gesundheit und die Pflege, Heilung und Wiederherstellung im Falle von Krankheit und Beschädigung zu sorgen. 1) Gesundheitsschutz und Krankheitsheilung sind ohne Eingriffe in die körperliche Integrität nicht denkbar. Die staatliche Verantwortung verlangt nach einer staatlichen Ordnung der Eingriffe und schließt die absolute individuelle Willkür der Verfügungsmacht über den eigenen Körper aus. Der Staat muß die Entscheidung des einzelnen binden. Daß er dabei dem rechtsstaatlich freilich selbstverständlichen - Vorbehalt des Gesetzes (Art. 2 Abs. 2 Satz 3 GG) und der gesetzesfesten Wesensgehaltsgarantie der körperlichen Integrität (Art. 2 Abs. 2 Satz 1, 19 Abs.2 GG) begegnet, ist eines der konstituierenden Elemente des freiheitlichen sozialen Rechtsstaats.

2. Der Schutz vor Gemeingefahren. Zwangsweise Heileingriffe,2) Impfungen ${ }^{3)}$ und Gesundheitskontrollen, die notwendig sind, um die Ausbreitung übertragbarer Krankheiten zu verhindern und somit die sog. Volksgesundheit und die körperliche Integrität unübersehbar vieler anderer Träger des Grundrechts aus Art. 2 Abs. 2 Satz 1 GG zu schützen, verstoßen grundsätzlich nicht gegen die Wesensgehaltsgarantie dieses Grundrechts. ${ }^{4)}$ Dabei muß jedoch die Verhältnismäßigkeit zwischen dem Opfer des Betroffenen einerseits und der Gefahr, die von ihm ausgeht, sowie den Schwierigkeiten, sie auf andere Weise einzudämmen, andererseits gewahrt sein. ${ }^{5)}$ Zulässig erscheint

1) S. hierzu oben Abschnitt 5 III 1 (S. 762 ff), 2 (S. 764 ff), 3 b (S. $797 \mathrm{ff})$ und $5 \mathrm{c}(\mathrm{S} .821 \mathrm{f})$.

2) Vgl. $\$ \$ 11,23$ der Verordnung zur Bekämpfung übertragbarer Krankheiten; $\$ \$ 3,17,18$ des Gesetzes zur Bekämpfung der Geschlechtskrankheiten; $\$ 17$ Abs. 4 Satz 3 des Soldatengesetzes (s.a. die Ausweitung durch $₫ 24$ des Gesetzes über den zivilen Ersatzdienst).

3) S. $\$ \$ 1,12,13,14,15$ des Impfgesetzes v. 9.April 1874 (RGB1. S. 31).

4) Vgl. (auch zu den vorstehenden Beispielen) Kern, Schutz des Lebens, der Freiheit und des Heims, S. 62 f; v. MangoldtKlein, Art. 2 Anm.V 3 und VII 2; Hamann, Das Grundgesetz, Art. 2 Anm. C 12; Dürig, in Maunz-Dürig, Art. 2 Abs. II Randn. 39; w. Nachw. s. dort.

5) In diesem Zusammenhang ist auch das Problem des "medizi- 
auch die Zwangsheilung gemeingefährlicher Geisteskranker und Trinker. ${ }^{6)}$

Die Zwangsheilung kann die geschlossene Unterbringung nötig machen. Diese hat dann den Erfordernissen des Art.104 GG zu genügen. Andererseits rechtfertigt eine geschlossene Unterbringung keineswegs immer auch die $Z$ wangsheilung (über die bloße Pflege hinaus).7) Impliziert die Anordnung der Unterbringung die Anordnung der $Z$ wangsheilung, so muß sich diese der Sache nach unmittelbar gegenüber dem Grundrecht der körperlichen Integrität als legitim erweisen. ${ }^{8)}$

3. Der "soziale Heilzwang". Der erkrankte oder körperbeschädigte Versorgungs-, Sozialversicherungs- oder Fürsorgeempfänger, der sich weigert, einen möglichen Heileingriff, der seine Gesundheit und A rbeitskraft mehr oder weniger wieder herstellen und gegebenenfalls seine Pflegebedürftigkeit herabsetzen oder aufheben würde, zu dulden, schadet mit seiner Weigerung nicht nur - objektiv betrachtet - sich selbst; er überbürdet zudem der Allgemeinheit eine vermeidbare Last. Der Sozialstaat sieht sich deshalb - nicht nur aus Obsorge für den Betroffenen selbst sondern auch und zwar vor allem aus seiner Verantwortung für eine gerechte Verteilung der Opfer und Lasten und für die Erhaltung seiner sozialen Funktionsfähigkeit - veranlaßt, die Sozialpflichtigkeit gerade des Sozialleistungsempfängers zu aktivieren. Er stellt ihn vor die Alternative, den Heileingriff zu dulden oder die im Falle des Heileingriffes vermeidbaren Leistungen zu verlieren. ${ }^{9)}$

nischen Vorbehalts" (s.Dürig, a.a.O. Randn. 39 a.E.) zu sehen (s. z.B. $\$ 17$ Abs. 2 des Gesetzes zur Bekämpfung der Geschlechtskrankheiten; $₫ 2$ des Impfgesetzes).

6) Zu den Grundlagen s. Franke, Grundlagen der Anstaltsunterbringung Psychischkranker in verfassungs-, privat- und verwaltungsrechtlicher Sicht (s.o. S. 1072 zu Fußn. 8). Beispiele $\mathrm{s}$. ferner bei Barella, Behandlungszwang bei untergebrachten Personen? NJW 12.Jhg. (1959) S. 2291 f; BayVerfGH VGHE n. F. 10 II 101.

7) Vgl. Dürig, a.a.O. Randn. 51 .

8) Barella (a.a.O.) schematisiert zu sehr.

9) Aus dem Versorgungsrecht vg1. $\$ 137$ Abs. 2 Satz 2 und 3, Abs. 3, \$149 Abs. 2 des Bundesbeamtengesetzes; Art. 150 Abs. 2, 163 Abs. 2 des Bayerischen Beamtengesetzes; $\$ 17$ Abs. 4 des Soldatengesetzes; $\$ \$ 16,63$ des Bundesversorgungsgesetzes. Aus dem Recht der gehobenen Fürsorge s. $\$ 15$ des Körperbehindertengesetzes (nunmehr $₫ 42$ des Entwurfs eines 
Diese Heilungs last des Betroffenen greift nicht unmittelbar in seine körperliche Integrität ein. ${ }^{10)}$ Sie unterliegt dem Vorbehalt des Gesetzes (Art. 2 Abs. 2 Satz 3 GG) daher nur, soweit die Leistung selbst gesetzlich geregelt ist (bzw. geregelt werden muß) und somit auch nur nach Maßgabe des Gesetzes vorenthalten werden kann. 11) Aber sachlich muß sie dennoch an der Garantie der körperlichen Unversehrtheit orientiert sein. Auch der mittelbare Heilzwang, die bloße Heilungslast, würde deren Wesensgehalt verletzen, wenn Schwere und Risiko des Eingriffes außerhalb eines angemessenen Verhältnisses zu dem sozialstaatlichen Interesse an seiner (positiven) Auswirkung stünden. Welche Heilungslast unzumutbar ist, ist je nach dem in Frage stehenden Sachzusammenhang - von den konkreten physiologischen Verhältnissen abgesehen, insbes. nach dem Grund der Sozialleistung, ihrem Inhalt und nach der im Falle der Weigerung drohenden Einbuße - verschieden zu beurteilen. 12) Der lebensgefährliche oder das Risiko einer Verschlechterung einschließende Eingriff wird immer ausscheiden. ${ }^{13)}$

Bundessozialhilfegesetzes, Deutscher Bundestag, 3. Wahlperiode, Drucksache 1799); $₫ 29$ des Tuberkulosehilfegesetzes (nunmehr $₫ 63$ des Entwurfs eines Bundessozialhilfegesetzes). Aus der Sozialversicherung s. zur Krankenversicherung $₫ 184$ RVO; zur Unfallversicherung $₫ 606$ RVO. Die Weigerung, sich im Krankenhaus behandeln zu lassen ( $\$ 184 \mathrm{RVO}$ ), die, soweit sie unberechtigt ist, zum Ruhen der Krankenversicherungsleistung führt (vgl. z.B. Lehmann, Handbuch des Krankenversicherungsrechts, 6.Aufl., $1931 \mathrm{zu} \$ 184 \mathrm{RVO})$, spielt heute jedoch keine praktische Rolle mehr. Wenn heute Streit entsteht, dann über die Pflicht der Krankenkasse, die Krankenhausbehandlung (die der Erkrankte wünscht) zu decken (s. z.B. die Nachweise zu $₫ 184$ in "Sozialrecht"). - Anzumerken ist schließlich, daß die Rehabilitierungsmaßnahmen der Rentenversicherung ( $\$ \$ 1236$ f RVO n.F.; $\$ \$ 13$ f AnVG) einem absoluten Zustimmungsvorbehalt unterliegen ( $\$ 1237$ Abs. 4 RVO, $₫ 14$ Abs. 4 AnVG); s. hierzu z.B. Scharmann, Die Mitwirkung des Behinderten bei der Durchführung von Rehabilitierungsmaßnahmen, in "Sozialreform und Sozialrecht", Festschrift für Walter Bogs, 1959, S. 317.

10) Vgl. Dürig, Art.2 Abs. II, Randn. 38 (S. 100).

11) Das Schrifttum ist hinsichtlich des Gesetzesvorbehalts insofern nicht eindeutig (s. z.B. Wernicke, Bonner Kommentar, Art.2, Erl. II 2 c; v. Mangoldt-Klein, Art. 2 Anm.V 3; Hamann, Das Grundgesetz, Art. 2 Anm. C 9; Giese-Schunck, Das Grundgesetz, Art. 2 Anm. II 5).

12) S. die Beispiele oben S.1075 zu Fußn.9. 
A uf weniger als ein absolutes Minimum an sozialer Existenzhilfe kann jedoch der, der sich weigert, einen Eingriff zu dulden, nicht gesetzt werden. Der Sozialstaat kann ihn nicht ausstoßen und verelenden lassen. 14) Im Rahmen der Fürsorge ist die Minimalisierung der öffentlichen Leistungen deshalb von vorneherein die einzige Alternative. ${ }^{15)}$

Der direkte Zwangseingriff dürfte - im Gegensatz zur Duldungslast - weder aus dem Interesse der sozialstaatlichen Gemeinschaft

13) Die positiven gesetzlichen Vorbehalte greifen nicht auf das verfassungsrechtliche Minimum zurück und sparen insbes. auch den erheblichen operativen Eingriff aus, obwohl er nicht immer unangemessen sein muß ( $z u$ den Einzelheiten s. die Hinweise oben S.1075 zu Fußn.9, s.a. nochmals oben S.1074 zu Fußn. 5; aus der Rechtsprechung s. BSGE 4, 116 (118)).

14) S. hierzu die Ausführungen oben (S. $801 \mathrm{ff}) \mathrm{zu}$ der parallelen Frage, ob der Sozialstaat den Arbeitsunwilligen verelenden lassen darf.

15) Vg1. $\ 29$ des Tuberkulosehilfegesetzes ( $\$ 63$ des Entwurfs eines Bundessozialhilfegesetzes). Anders liegen die Verhältnisse hinsichtlich der - sonst weitgehend vergleichbaren besonderen Körperbehindertenfürsorge. Wenn $₫ 15$ des Körperbehindertengesetzes ( $\$ 42$ des Entwurfs eines Bundessozialhilfegesetzes) vorsieht, daß dem Pflegling, der durch sein Verhalten die Durchführung der fürsorgerischen Maßnahmen gefährdet, die Leistungen ganz oder teilweise versagt werden können, so ist dabei zu bedenken, daß nur die zusätzlichen Leistungen der Körperbehindertenfürsorge in Frage stehen. In der allgemeinen Fürsorge wird dem im Text aufgestellten Prinzip durch Anwendung der Bestimmungen über unwirtschaftliches Verhalten Rechnung zu tragen sein $(\$ 13$ der Reichsgrundsätze über Voraussetzungen, Art und Maß der öffentlichen Fürsorge; $₫ 23$ des Entwurfs eines Bundessozialhilfegesetzes). $₫ 13$ Abs. 2 der Reichsgrundsätze sieht zulässigerweise auch die Übernahme in Anstaltspflege vor. Dabei wird zu beachten sein, daß die Anstaltspflege nicht an sich schon zu Eingriffen in die körperliche Integrität berechtigt. - Dagegen ist es eine im Hinblick auf die Pflichtstellung des Sozialstaates untaugliche Fiktion, den kranken Fürsorgeempfänger, der sich der seitens der öffentlichen Fürsorge angebotenen Heilungsmaßnahme nicht unterzieht, als "insoweit nicht 'bedürftig" " zu erklären (so aber Dürig, a.a.O. Randn. 38 (S. 100); s. hierzu die parallelen Erwägungen oben Abschnitt 5 III $3 \mathrm{c} \mathrm{bb}$ (S. $801 \mathrm{ff}$ ), insbes. S.801ff). 
noch aus dem bevormundend wahrgenommenen, objektiven Interesse des Betroffenen selbst jemals gerechtfertigt werden können.

Abschließend sei darauf hingewiesen, daß auch die Heilungslast im Rahmen des sozialen Leistungswesens der Abwehr von Gemeingefahren dienstbar gemacht werden kann. Typisch ist die Heilungslast im Rahmen der Tuberkulosehilfe. 17) Ein anderes Beispiel bietet die Last der geschlossenen Unterbringung im Falle einer ansteckenden Krankheit. 18)

4. Das $Z$ wangsexperiment. Gegen Art.2 Abs. 2 Satz 1, 19 Abs. 2 GG würde der zwangsweise experimentelle Eingriff in den menschlichen Körper verstoßen, auch wenn er dazu dienen sollte, den sozialen Fortschritt mit medizinischen und physiologischen Mitteln zu fördern. ${ }^{19)}$

16) Vgl. Dürig, a.a.O. (S.99). Nicht eindeutig Maunz, Deutsches Staatsrecht, S.98. - Das gilt auch im Hinblick darauf, daß die soziale Hilfe dem sich Weigernden zwar gekürzt, aber nicht bis zur Existenzvernichtung entzogen werden kann. Die Verhältnisse hinsichtlich der Pflicht zur existenzerhaltenden A rbeit (s.o. Abschnitt 5 III $3 \mathrm{c}$ bb (S. $801 \mathrm{ff}$ ), und hinsichtlich der Last der Duldung von existenzerhaltenden Heileingriffen liegen verfassungsrechtlich verschieden. Das Grundrecht der körperlichen Integrität hat insofern gegenüber dem Grundrecht der freien Wahl des Berufs und des Arbeitsplatzes schon vom vorrechtlichen Gesamtbild her die stärkere Stellung. Eine Parallele zu den verschiedenen direkten Formen des Arbeitszwangs gegen den Arbeitsscheuen hat es auf dem Gebiet der Heilung kranker und körperbeschädigter Fürsorgeempfänger nie gegeben. Dazu kommt folgender Gesichtspunkt: der Arbeitsscheue gebraucht nicht so sehr das Recht der freien Wahl von Beruf und Arbeitsplatz als das Recht des Nichtstuns; derjenige, der sich einem Heileingriff entzieht, gebraucht dagegen unmittelbar das Recht, das die Verfassung ihm gewährt, nämlich das seiner freien Verfügung über seine körperliche Integrität. Diesen Erwägungen gegenüber kann sich auch die gesteigerte Sozialpflicht des Fürsorgeempfängers nicht durchsetzen.

17) Vgl. $\$ 29$ des Tuberkulosehilfegesetzes ( $\$ 63$ des Entwurfs eines Bundessozialhilfegesetzes).

18) Vgl. $₫ 184$ Abs. 3 Nr.2 RVO; $₫ 16$ Abs. 2 Nr. 2 des Bundesversorgungsgesetzes.

19) Vgl. v. Mangoldt-Klein, Art.2 Anm.IV 3; Dürig in MaunzDürig, Art.2 Abs.II Randn. 34; Maunz, Deutsches Staatsrecht, S.98; BVerfGE 1, 97 (105). 
bbb) Geburtenkont rolle

Übervölkerung und Degeneration bereiten soziale Schwierigkeiten. Quantitative oder (und) qualitative Geburtenbeschränkung kann daher zur sozialpolitischen Forderung erhoben werden. Eines der Mittel, sie zu verwirklichen, ist die Unfruchtbarmachung. Als $Z$ wangsunf ruchtbarmachung greift sie in das Grundrecht der körperlichen Unversehrtheit ein. 1) Zwangsweise Unfruchtbarmachung aus sozialpolitischen Gründen würde das Grundrecht in seinem Wesensgehalt verletzen. ${ }^{2)}$

Fine andere Frage ist, inwieweit der Staat mit Mitteln der Aufklärung und Überredung, durch sachliche Hilfeleistung u. ä., die Geburtenbeschränkung fördern darf. Eine Grenze wird er jedenfalls im Grundsatz der Achtung vor der Menschenwürde und ihres Schutzes (Art. 1 Abs. 1 GG) finden, der einerseits menschenunwürdige Modalitäten, andererseits - zusammen mit dem Gleichheitssatz (Art.3 GG) - die menschenunwürdige Diskriminierung z.B. der Träger einer "erbkranken" Erbmasse inhibiert. Eine andere Grenze ergibt sich aus Art. 6 Abs.1 GG. Der Staat darf die Familie - zu der wesentlich das Kind gehört - nicht als Institution angreifen und auch nicht mittelbar belasten. ${ }^{3)}$ Ob das Grundgesetz darüber hinaus - ungeschriebenen Rechts - ethische Postulate positiviert, ${ }^{4}$ ) die einer freiwilligen Geburtenbeschränkung entgegenstehen, soll hier nicht untersucht werden. Das Grundrecht des Art. 2 Abs. 2 Satz 1 GG würde sich jedenfalls dem Druck widersetzen, der die Freiwilligkeit aufheben würde.

I)agegen ist die bloße staatliche Duldung der freiwilligen Unfruchtbarmachung kein Problem der grundrechtlichen Abwehr eines Eingriffs in die körperliche Unversehrtheit.5) Der Staat hat insoweit lediglich dafür zu sorgen, daß die Menschenwürde von keiner Seite verletzt wird (Art.1 Abs.1 GG). Das bedeutet jedoch nicht die Notwendigkeit eines allgemeinen Verbots der freiwilli-

1) S. f.a. Dürig, a.a.O. Randn. $31 \mathrm{ff}$.

2) S. z.B. v.Mangoldt-Klein, a.a.O.; Dürig, a.a.O. Randn. 32; je m.w. Nachw.; s. ferner Maunz, Deutsches Staatsrecht, S. 98 .

3) S. hierzu oben S.998ff und S.1004 ff; im besonderen Zusammenhang s. hierzu auch Dürig, a.a.O. Randn. 31 Fußn.1 (S.95).

4) Zu den methodischen Fragen der Positivierung überpositiver Grundsätze durch das Grundgesetz s. die Ausführungen zur Positivierung der "Gerechtigkeit" oben S. 665 zu Fußn. $7 \mathrm{f}$ u. d. dort. Nachw.

5) Das verwischt Dürig, a.a.O. Randn.33. 
gen Unfruchtbarmachung. ${ }^{6)}$

\section{ccc) Pflichten zum Einsatz der Gesundheit}

Wie schon hinsichtlich des Heilungszwanges zur Abwehr von Gemeingefahren ${ }^{1)}$ angenommen wurde, hindert Art. 2 Abs. 2 GG den Staat nicht, dem einzelnen Opfer an körperlicher Integrität aufzuerlegen, um damit Leben und Gesundheit anderer oder sonstige vergleichbar hochwertige Güter - insbes. die fundamentale öffentliche Ordnung und die Existenz der staatlichen Gemeinschaft - zu erhalten. Pflichten dieser Art würden Art. 2 Abs. 2 GG jedoch in seinem Wesensgehalt verletzen, wenn sie außer Verhältnis zum Notwendigen stünden. Sie bedürfen ferner der sorgfältigsten Prüfung unter dem Gesichtspunkt des Gleichheitssatzes und zwar sowohl hinsichtlich des Verhältnisses zwischen Pflichtigen und Nichtpflichtigen als auch hinsichtlich des Verhältnisses zwischen den Belasteten (Gefährdeten) und den Begünstigten. In Betracht kommen als Pflichtige in erster Linie Personen, die als Störer oder auch als nur objektive Träger einer Störung selbst Zurechnungsobjekt der abzuwehrenden Gefährdung sind. ${ }^{2}$ ) Ferner kommen Personen in Betracht, die sich freiwillig in besondere Pflichtverhältnisse begeben haben, die den Einsatz der körperlichen Unversehrtheit einschließen (z.B. Polizeibeamte, Sanitätspersonal, Feuerwehrpersonal). ${ }^{3)}$ Aber auch wer zwangsweise in besondere

6) Andererseits wäre einem solchen Verbot gegenüber bereits zu fragen, inwieweit es mit Art. 2 Abs. 1 und Art. 2 Abs. 2 Satz 1 GG vereinbart werden kann.

1) S.o. S. $1074 \mathrm{f}$.

2) S. hierzu Dürig, a.a.O. Randn. 14 f, 17 u.s. Nachw.; s.a. rochmals oben S. $1074 \mathrm{f}$.

3) Vg1. Kern, Der Schutz des Lebens, der Freiheit und des Heims, S.60; v. Mangoldt-Klein, Art.2 Anm.V 2; Dürig, a.a.O. Randn. 17 (S.84). - Nur hinsichtlich der freiwillig eingegangenen Pflichtverhältnisse könnte an eine Ausnahme vom Gesetzesvorbehalt (Art.2 Abs. 2 Satz 3 GG) gedacht werden (abgesehen von dem ohnedies aus dem Gesetzesvorbehalt herausfallenden freiwilligen Einsatz des Lebens ad hoc). Soweit es sich um öffentlichrechtliche Dienstverhältnisse handelt, sind sie jedoch als solche der gesetzlichen Regelung bedürftig (s. hierzu o. S. 445 ff, insbes. S. 451 zu Fußn. 102). Daß diese die Einsatzpflicht besonders aussprechen müßte und nicht auch implizieren dürfte (so Hamann, Das Grundgesetz, Art.2 Anm.C 12), ist durch Art.2 Abs. 2 Satz 3 GG nicht gefordert (s. Dürig, a.a.O. Randn. 17 mit Fußn. 3 (S. 84 f)). Desgleichen bedarf es keiner besonderen Regelung der 
Pflicht genommen wurde (insbes. als wehrpflichtiger Soldat oder als Ersatzdienstverpflichteter), kann - wenn nur allen Abwägungselementen der Verhältnismäßigkeit und der Gleichheit Rechnung getragen ist - zum Einsatz der körperlichen Unversehrtheit angehalten werden. ${ }^{4)}$

Soziale Bedeutung kommt diesen Einsatz- und Opferpflichten primär insofern zu, als die sonach möglichen Maßnahmen auch soziale Notlagen beseitigen oder vermeiden helfen können. Sekundär wirft der Einsatz der körperlichen Unversehrtheit aber das soziale Folgeproblem des Opferausgleichs auf. 5)

\section{ddd) Zur Drittwirkung}

A us dem Problemkreis der Drittwirkung des Grundrechts der körperlichen Integrität ist die Frage der verfassungsrechtlichen

Einsatzpflicht im privatrechtlichen Dienstverhältnis.

4) S. die Vorgenannten. Dabei wird der Gesichtspunkt des besonderen Gewaltverhältnisses allerdings häufig überbetont. Die legitimierende Wirkung des unfreiwillig eingegangenen besonderen Gewaltverhältnisses ist keine selbständige, konstitutive. Seine überkommene oder (und) im Grundgesetz institutionalisierte Existenz ist ein Argument für die Annahme, daß die damit verbundene Einsatzpflicht sich mit dem Wesensgehalt des Grundrechts der körperlichen Integrität vereinbaren läßt. Aber es ist nicht so, als ob das besondere Gewaltverhältnis zunächst als solches (ohne wesentlichen Einschluß der Einsatzpflicht) begründet werden könnte und dann das "ureigene Wesen dieser Gewaltverhältnisse" (v. MangoldtKlein, Art.2 Anm.V 2) die Verpflichtung zum Einsatz rechtfertigen würde. Die Begründung eines die Einsatzpflicht einschließenden Gewaltverhältnisses muß selbst auch im Hinblick a uf diese Einsatzpflicht gerechtfertigt sein. Die Begründung erfolgt aber aus dem allgemeinen Gewaltverhältnis heraus. Die Rechtfertigung muß somit sachlich gegenüber dem allgemeinen Gewaltverhältnis Bestand haben. - Übrigens gibt es auch Einsatzpflichten, die unmittelbar im allgemeinen Gewaltverhältnis belegen sind (s.a. Dürig, a.a.O. Randn.16). Von der allgemeinen Nothilfepflicht nach $\$ 330$ c StGB dispensiert nur die "erhebliche eigene Gefahr", nicht also auch eine "unerhebliche" (aber doch vorhandene) Gefahr für die körperliche Integrität des Einsatzpflichtigen.

5) S. hierzu oben S. $771 \mathrm{ff}$; in diesem Abschnitt oben II $2 \mathrm{~b} \mathrm{cc}$ (S. $904 \mathrm{ff}$ ). 
Wertung von Leibesvisitationen im Arbeitsverhäitnis zu erwähnen. Sie sind, soweit sachlich gerechtfertigt, zulässig, 1) dürfen jedoch nicht willkürlich, unter Ausnutzung der sozialen Überlegenheit des Arbeitgebers, angeordnet werden.

Das Züchtigungsrecht des Arbeitgebers spielt im gegenwärtigen sozialen Leben keine Rolle mehr. Seine staatliche Zulassung könnte mit Art. 1 Abs.1, 2 Abs. 2 Satz 1, 19 Abs. 2 GG wohl in keinem denkbaren Fall in Einklang gebracht werden. $\left.{ }^{2}\right)$

\section{c) Das Recht auf Leben}

Das Grundrecht auf Leben (Art.2 Abs.2 Satz 1 GG) 1) wirkt in seiner rein ausgrenzenden Funktion in den sozialen Bereich etwa über das Verbot der Euthanasie ${ }^{2)}$ oder über das Verbot der sozial indizierten Schwangerschaftsunterbrechung 3 ) hinein.

Dagegen verpflichtet Art. 2 Abs. 2 Satz 1 GG den Staat nicht nur nicht, der freiwilligen Selbstaufopferung eines Menschen zur Rettung fremden Lebens entgegenzutreten. 4) Das Grundrecht erlaubt ihm auch, den Einsatz menschlichen Lebens zu verlangen, wenn dies zur Rettung anderen menschlichen Lebens oder zur Abwehr von Angriffen auf die äußere Existenz oder die fundamentale innere Ordnung der staatlichen Gemeinschaft notwendig erscheint. ${ }^{\text {) }}$ Die Grundsätze der Verhältnismäßigkeit und der Gleichheit sind dabei, dem Vorrang des Lebens vor der bloßen körperlichen Inte-

1) Vg1. LAG Mainz, Urt. v. 13.Januar 1953 - 1 Sa 255/52 - AP $\S 71$ HGB Nr.1 Bl.2.

2) Zum Gesamtproblem des Züchtigungsrechts sub specie des Art. 2 Abs. 2 GG s. Darstellung und Nachweise bei Dürig, a.a.O. Randn. $42 \mathrm{ff}$.

1) Näheres und Nachweise s. bei Dürig, in Maunz-Dürig, Art.2 Abs. II Randn. 8 ff. - Als Ergänzung des Art. 2 Abs. 2 GG ist insoweit Art. $102 \mathrm{GG}$ von besonderer, jedoch nicht von spezifisch sozialer Bedeutung.

2) Vgl. Kern, Der Schutz des Lebens, der Freiheit und des Heims, S. 59; v. Mangoldt-Klein, Art. 2 Anm.V 2; Hamann, Das Grundgesetz, Art.2 Anm.c 8; Dürig, a.a.O. Randn. $10 \mathrm{f}$; Maunz, Deutsches Staatsrecht, S.98 f.

3) Zu dem umstrittenen Problemkreis s. z.B. v. MangoldtKlein, Art.2 Anm.V 2; Dürig, a.a.O. Randn. 21 ff; w. Nachw. s. dort. Insbes. zur sozialen Indikation s. Dürig, a.a.O. Randn. 24.

4) S. Dürig, a.a.O. Randn. 13.

5) Einzelheiten und Nachweise s. bei Dürig, a.a.O. Randn. $13 \mathrm{ff}$. 
grität entsprechend, noch mehr anzuspannen als hinsichtlich der Pflicht zum Einsatz (nur) der körperlichen Integrität. ${ }^{6)}$ Wie diese kann auch der Einsatz menschlichen Lebens dazu dienen, soziale Schäden zu vermeiden oder zu beseitigen. Gegenüber den Hinterbliebenen derer, denen das Opfer ihres Lebens abverlangt wird, erwächst daraus aber die soziale Opferausgleichspflicht. 7)

d) Das Recht auf Leben und körperliche Unversehrtheit als indirektes Teilhaberecht

Das Recht auf Leben und körperliche Unversehrtheit ist negatives A bwehrrecht. 1) Das bedeutet jedoch weder, das Grundrecht wehre nur den unmittelbar physisch vorgetragenen Angriff auf Leben und körperliche Integrität ab; noch bedeutet es, das Grundrecht wende sich nur gegen den handelnden Eingriff. Das Grundgesetz formuliert das Recht auf Leben und körperliche Integrität umfassend und ohne Einschränkung. Dem wird die Auslegung nur gerecht, wenn sie die Abwehr des mittelbaren Eingriffes - die Aussperrung von dem, was zur Erhaltung der (integralen) Existenz notwendig ist 2 ) - und die Abwehr des Eingriffes durch pflichtwidriges Unterlassen ${ }^{3)}$ in die Schutzfunktion des Grundrechts ein-

6) Mit dieser Maßgabe gilt das oben S.1080f Ausgeführte entsprechend; s.a. die dort. Nachw.

7) S. auch hierzu oben S.771 ff und in diesem Abschnitt II $2 \mathrm{~b} \mathrm{cc}$ (S. $904 \mathrm{ff}$ ).

1) S. statt anderer v. Mangoldt-Klein, Art. 2 Anm.V 4; BVerfGE $1,97(104 \mathrm{f})$.

2) Das einfachste Beispiel: Das staatliche Verbot, einen Geächteten, dessen Vermögen ihm entzogen ist, zu nähren, zu bekleiden und $z u$ beherbergen, ihn $z u$ beschäftigen und zu entlohnen. - Verschiedentlich wird die Frage aufgeworfen, ob Art. 2 Abs. 2 GG auch die "wirtschaftliche Existenz" schützt (zweifelnd v. Mangoldt-Klein, a.a.O.). Einerseits kann aber kein Zweifel daran bestehen, daß Art. 2 Abs. 2 GG auch verbietet, die unmittelbaren und unerläßlichen Voraussetzungen der menschlichen Existenz vorzuenthalten oder zu entziehen. Andererseits ist nicht daran zu denken, Art. 2 Abs. 2 GG schütze auch das, was man "berufliche Existenz", "geschäftliche Existenz" oder auch "bürgerliche Existenz" nennt, nämlich eine bestimmte Einkommensbasis, Art. 2 Abs. 2 GG spricht von "Leben" und "körperlicher Unversehrtheit", nicht von "Existenz".

3) Das einfachste Beispiel: Dem Gefangenen wird die notwendige Nahrung nicht gereicht. Niemand wird bezweifeln, daß der Staat, der den Gefangenen nicht töten darf (Art.2 Abs.2, 102 
bezieht. Unterlassen staatliche Organe pflichtwidrig, dem einzelnen das Lebensnotwendige (das er nur von der öfentlichen Hand oder durch ihre Vermittlung erlangen kann) zu gewähren, und verursachen sie so den Tod eines Menschen oder einen Schaden an seinem Körper oder seiner Gesundheit, so verletzen sie dadurch dessen Recht aus Art. 2 Abs. 2 GG.

Woraus aber ergibt sich die Pflicht zum Handeln, die das Unterlassen erst rechtlich meßbar und dem Staat als Verpflichtetem zurechenbar macht? ${ }^{4)}$

Unterlassen staatliche Organe, was ihnen durch Gesetz zum Schutz von Leib und Leben aufgetragen ist, und verursachen sie dadurch den Tod eines Menschen oder Schaden an seinem Körper oder an seiner Gesundheit, so verletzen sie das Grundrecht schon deshalb, weil sie sich außerhalb des Gesetzes bewegen (Art.2 Abs. 2 Satz 3 GG). Aber der Gesetzgeber kann insofern grundsätzlich über die Zulässigkeit der unterlassenden Beeinträchtigung des einzelnen durch staatliche Organe verfügen. Nur dort, wo die Verfassung selbst ein gewisses Mindestma $\beta$ an staatlicher Handlungspflicht vorsieht, ist das Grundrecht gegenüber dem unterlassenden Eingriff gesetzesfest.

Die elementare Verfassungspflicht des Staates, zum Schutz des menschlichen Lebens und der körperlichen Unversehrtheit tätig zu werden, ergibt sich aus Art.20 Abs. 1, 28 Abs. 1 Satz 1 GG i.V. m.Art. 1 Abs. 1 GG: Der Sozialstaat ist verpflichtet, dem, der seiner Hilfe bedarf, wenigstens das zur menschenwürdigen Existenz Unerläßliche zu gewähren. 5) Kommt er dieser Pflicht nicht nach und verursacht er dadurch Schaden an Leib und Leben, so verletzt er das Grundrecht aus Art. 2 Abs. 2 GG. 6)

GG) auch nicht untätig zusehen darf, wie er verhungert. (Abgesehen von Art. 2 Abs. 2 GG ist dem auch durch Art. 104 Abs. 1 Satz 2 GG vorgebeugt.)

4) S.a. die zutreffende Fragestellung bei Dürig, in MaunzDürig, Art.2 Abs. II Randn. 26 (insbes, unter Anm. III 1 b).

5) S. hierzu oben S.679 f zu Fußn. 4, 5 und 7, S.730 ff, insbes. S. 731 zu Fußn. 5-8, S.766 ff ; s. ferner in diesem Abschnitt oben S.857 ff; w. Nachw. s. dort.

6) S. wie Fußn.5. Insbes. vgl. Dürig, Verfassung und Verwaltung im Wohlfahrtsstaat, S. 198 (allerdings noch zu sehr der unmittelbaren Umdeutung des Art. 2 Abs. 2 GG in ein selbständiges Teilhaberecht zuneigềnd, was auch für die meisten der Nachgenannten gilt); ders., in Maunz-Dürig, Art. 2 Abs. II Randn. 26 (wohl dem Standpunkt des Textes im einzelnen am nächsten stehend); Bachof, Begriff und Wesen des sozialen 
Aber nur die Vorenthaltung, die wirklich die menschliche Existenz und die körperliche Integrität - nicht etwa ein "standesgemäßes" oder sonstwie gehobenes Auskommen - bedroht, verstößt gegen Art. 2 Abs. 2 GG. Darum wird auch kaum eine Leistung gehobener sozialer Sicherung (Sozialversicherung, Versorgung) als durch Art. 2 Abs. 2 GG grundrechtlich subjektiviert angesehen werden können. 7) Wird die gehobene soziale Versicherung versagt, so bleibt immer noch das Auffangnetz der allgemeinen Fürsorge, welches das erforderliche Existenzminimum verbürgt. ${ }^{8}$ ) Der Anspruch auf Fürsorge ergibt sich - als subjektives Recht aus Art. 2 Abs. 2 GG aber jedenfalls insoweit, als die Versagung der Fürsorge zum Tode oder zu einer Beschädigung von Körper und Gesundheit führen würde. 9 )

Im allgemeinen ergibt sich die grundrechtliche Sicherung des sozialen Teilhabestatus schon aus dem Gleichheitssatz. 10) Was der Staat allgemein gewährt, darf er einem einzelnen (einer Gruppe) nicht willkürlich vorenthalten. Tragende Bedeutung gewinnt der Grundrechtsschutz aus Art.2 Abs. 2 GG dann, wenn die Differenzierung, die der Staat, indem er von der Erfüllung seiner sozialstaatlichen Fürsorgepflicht absieht, trifft, nicht unsachlich und willkürlich erscheint und sumit dem Gleichheitssatz nicht widerspricht. Im Ergebnis besteht eine gewisse Parallele dazu, daß

Rechtsstaats, S. 42 f; ders., Die Rechtsprechung des Bundesverwaltungsgerichts, JZ 12.Jhg. (1957) S. 334 ff (338 Ziff. 16); A bendroth, Diskussionsbeitrag zu "Begriff und Wesen des sozialen Rechtsstaats", S.87; Hamann, Das Grundgesetz, Art. 2 Anm. C 8; OVG Hamburg, Urt.v.22. Januar 1951 - Bf. II 366/50 - DVB1. 66.Jhg. (1951) S.311 (312); OVG Lüneburg - OVGE 4, 224 (225 f); s.a. BVerwGE 1, 159 (162); einige weitere Nachw. s. bei Hamann und Dürig, a.a.O. A.A. insbes. Paulick, Die verfassungsrechtlichen Bindungen des Gesetzgebers beim Erlaß von Steuergesetzen, S. 493; v. Mangoldt-Klein, Art. 2 Anm.V 4.

7) Vgl. Dürig, in Maunz-Dürig, Art.2 Abs. II Randn.27 (Anm. III 2 b); im Ergebnis übereinstimmend BVerfGE 1, 97 (105): "Aus Art. 2 GG kann ... ein Recht auf Zuteilung bestimmter, das allgemeine Maß öffentlicher Fürsorge übersteigender Renten nicht hergeleitet werden".

8) S.o. S.766 ff u. S.778 ff dort. Nachw.

9) S.o. S. 731 zu Fußn.5-8, S.766ff und w. Nachw. und Hinweise zu Einzelfragen s, bei Hamann, Das Grundgesetz, Art.2 Anm.C 8; Dürig, a.a.O. Randn. 27.

10) Zur Funktionsverwandt;chaft des Gleichheitssatzes und des Rechts auf Leben in der Teilhabesicherung s.a. S.857ff. 
der Staat einen Verbrecher auch dann nicht mit dem Tode bestrafen darf (Art.102 GG), 11) wenn sachliche Gründe dies gegenüber dem Gleichheitssatz rechtfertigen, und dazu, daß er seinen Bürger auch dann nicht aus der personalen staatlichen Gemeinschaft ausstoßen darf (Art.16 Abs. 1 und Abs.2 Satz 1 GG), 12) wenn er sich ihrer unwürdig erwiesen hat. Jedoch ist die Vorschrift des Art. 2 Abs. 2 GG entsprechend absolut nur insofern, als sie die an sich bestehende staatliche Handlungspflicht - ihre Nichterfüllung abwehrend - grundrechtlich subjektiviert. Materiell entscheidend ist, daß die sozialstaatliche Fürsorgepflicht kein völliges Fallenlassen eines Bedürftigen zuläßt. 13)

Die allgemeinen Lehren vom handlungsgleichen Unterlassen knüpfen die Zurechnung des einen verbotenen Erfolg bewirkenden Nichthandelns nicht nur an gesetzlich ausdrücklich angeordnete Handlungspflichten sondern auch an ungeschriebene Handlungspflichten - etwa aus voraufgegangenem Tun, übernommener Verpflichtung oder besonderem Gemeinschaftsverhältnis. 14) Diese sind nicht weniger Rechtspflichten als die gesetzlich ausdrücklich angeordneten. 15) Entweder sind sie von der rechtlichen Regelung des Lebensverhältnisses, aus dem sich die Garantiestellung ergibt, mit umschlossen; oder der rechtliche Tatbestand, an den die Sanktion des verbotenen Tuns geknüpft ist, impliziert sie. Was

11) Zum Verhältnis der Todesstrafe zu Art.2 Abs.2 GG s. Dürig, a.a.O. Randn. 14.

12) S. hierzu noch unten S.1090 ff.

13) Das ergibt sich schon aus der teleologischen Bindung der Sozialstaatlichkeit an die unverzichtbare und unverlierbare Menschenwürde (Art. 1 Abs. 1 GG). S. hierzu die einschlägigen (spezielleren) Ausführungen oben Abschnitt 5 III 3 c bb S. $801 \mathrm{ff}$ und oben S. $1077 \mathrm{zu} \mathrm{Fußn.14-16.}$

14) Entwickelt wurden diese allgemeinen Lehren vor allem im Strafrecht (zur älteren Lehre und Rechtsprechung s. etwa Nagler-Mezger, in "Strafgesetzbuch" (Leipziger Kommentar), 8.Auf1. 1956, S. 33 ff; zum jüngsten Stand s. z. B. SchönkeSchröder, Strafgesetzbuch, 10.Auf1. 1961, S. 28 ff). Auch das Privatrecht bedient sich ihrer, wenngleich elastischer ( $\mathrm{s}$. z. B. Enneccerus-Nipperdey, Allgemeiner Teil des Bürgerlichen Rechts, 14.Auf1. S. 572 f, 916 f, 932; Enneccerus-Lehmann, Recht der Schuldverhältnisse, 15. Bearbeitung, 1958, S. $74 \mathrm{ff}$ ). Als Gegenstand der allgemeinen Rechtslehre wurde das Problem der handlungsgleichen Unterlassung, soweit $z u$ sehen, noch zu wenig gesehen (einen Aufsatz s. z.B. bei Lehmann, Artikel "Unterlassung und Unterlassungspflicht" in Stier-Somlo und Elster, Handwörterbuch der Rechtswissen- 
der Staat dem Menschen und Bürger gegenüber an Pflichten übernommen hat, welche staatlichen Handlungspflichten sich aus dem staatlichen Gemeinschaftsverhältnis ergeben und welche Garantiestellung des Staates aus dem Staat-Bürger-Verhältnis erwächst, ist, soweit das soziale Interesse berührt ist, im Sozialstaatsprinzip sowie in den verschiedenen Schichten des unterverfassungsmäßigen Rechts erschöpfend geregelt. Zusätzliche verfassungsrechtliche soziale Handlungspflichten des Staates aus dem staatlichen Gemeinschaftsverhältnis und dem Staat-Bürger-Verhältnis zu postulieren, ist nicht veranlaßt; sie anzuerkennen, wäre nicht gerechtfertigt. Das präjudiziert jedoch nicht die Frage, ob das Abwehrrecht des Art.2 Abs. 2 GG seinerseits Handlungspflichten impliziert, deren unterlassende Verletzung es der handelnden Verursachung von Schäden an Leib und Leben gleichstellt.

In Betracht kommt lediglich die Handlungspflicht aus voraufgegangenem Tun. 16) Dabei wäre nicht nur an die Pflicht des Staates zu denken, für die Verpflegung, Bekleidung und Beherbergung der Personen zu sorgen, die er ihrer Freiheit und somit der Möglichkeit, sich selbst zu unterhalten, beraubt hat; oder an die Pflicht des Staates, für die Heilung der Personen zu sorgen, die er Zwangseingriffen unterworfen hat. Zu denken wäre vielmehr auch an die rechtliche Positivierung der Verantwortung des Staates für Personen, die im Rahmen des staatlichen Gesamtschicksals in ihrer Gesundheit, im Leben ihrer Unterhaltsgaranten oder in ihrem Vermögen geschädigt wurden und infolgedessen außerstande sind, sich ohne staatliche Hilfe zu erhalten. Ferner könnte in diesem Rahmen erwogen werden, die Verantwortung rechtlich zu positivieren, die dem Staat daraus erwächst, daß er die Verteilung lebenswichtiger Güter und Leistungen bei sich monopolisiert oder sonstwie kontrolliert, so daß der einzelne sie nur mehr von ihm oder über ihn erlangen kann. Ja selbst dann wäre der Gedanke einer Handlungspflicht aus voraufgegangenem Tun nicht von der Hand zu weisen, wenn der Staat in die Funktionszusammenhänge der Selbsterhaltung und der Fremderhaltung durch außerstaatliche, gesellschaftliche Hilfen nicht anders eingegriffen hat, als dadurch, daß er soziale Hilfen eingerichtet hat; desgleichen wenn er Daseinsvorsorgeveranstaltungen.nicht an Stelle einer mehr

schaft, Bd.6, 1929, S.240 ff).

15) Die Dogmatik vermittelt freilich nicht selten den Eindruck eines Gegensatzes zwischen den gesetzlichen ("rechtlichen") und den "sonstigen" Handlungspflichten.

16) S. hierzu nochmals die Nachw. oben S.1086 zu Fußn. 14. 
oder weniger leistungsfähigen Wirtschaft übernommen hat sondern in eine Lücke getreten ist. Wo läßt sich vorstellen und beweisen, wie sich die Funktion der autonomen Gesellschaft - und zwar einerseits ihre ökonomische Versorgungs- und Verteilungsfunktion, andererseits ihre (altruistisch-caritativ oder egoistisch motivierte) Hilfsfunktion - entwickelt hätte, wenn der Staat nicht in sie (mit) eingetreten wäre?

Die Handlungspflicht aus voraufgegangenem Tun hat ihre ursprüngliche Heimstatt im Strafrecht. Dieses rechnet die Tat demjenigen $z u$, der einen gewissen Erfolg verursacht und verschuldet hat. Wer den Erfolg unverschuldet verursacht, ist nicht verantwortlich. Das verlangt nach einer Korrektur, wenn derjenige, der den zum mißbilligten Erfolg führenden Kausalablauf in Gang gesetzt hat, - soweit er nicht schon vorher von seiner Urheberschaft erfährt und - die Möglichkeit erlangt, den Kausalablauf zu unterbrechen und den Erfolg abzuwenden. Diese Korrektur wird dogmatisch durch die aus dem "voraufgegangenen Tun" abgeleitete Pflicht, den Erfolg zu verhindern, vermittelt. Entsprechendes gilt für das Privatrecht, soweit es sich der doppelten Zurechnung über Kausalität und Verschulden bedient. Inwieweit auch die Zurechnung von Grundrechtsverletzungen zum Staat von einer entsprechenden Finalität der staatlichen Handlung und dem Verschulden der staatlichen Organe abhängt, ist eine überaus schwierige, hier nicht zu klärende Frage. ${ }^{17)}$ Soweit dies der Fall ist, kann auf die Handlungspflicht aus voraufgegangenem Tun auch im Rahmen des Grundrechtsschutzes nicht verzichtet werden. Staatliche Organe können davon, einen voraussehbar zum Tod oder zur Beschädigung eines Menschen führenden Kausalablauf, den sie handelnd in Gang gebracht haben und den zu unterbrechen nicht nur in ihrer Macht steht sondern auch nicht in der Möglichkeit und Funktion Dritter, zu unterbrechen, nur in dem Maße entbunden werden, in dem ihnen der verursachte Eingriff in Leib und Leben gestattet werden könnte. In diesem Sinn ist die Handlungspflicht aus voraufgegangenem Tun in Art. 2 Abs. 2 GG mit enthalten, ist sie nur eine ergänzende Präzisierung des Eingriffsbegriffs.

17) Eine Dogmatik der grundrechtsverletzenden Handlung steht noch aus. Sie verlangt nicht nur im vorstehenden Zusammenhang nach einer Lösung. Vor allem für die Unterscheidung zwischen Enteignung und enteignungsgleichem Eingriff und ihr Verhältnis zur Junktimklausel - die nur gegenüber dem finalen Eigentumseingriff sinnvoll ist - müßte aus ihr viel zu gewinnen sein. Desgleichen begegnet das Problem hinsichtlich des gleichheitsgrundrechtlichen Opferausgleiches (s.o. II 2 b cc (S. 904 ff)). 
Nicht selten aber wird die Handlungspflicht aus voraufgegangenem Tun weiter angesetzt denn als bloße Aushilfe der subjektiven Zurechnung zum Verursacher. Sie dient dann dazu, das Problem der Kausalität der Handlung (des "voraufgegangenen Tuns") für den schließlichen Erfolg zu überspringen. Wer eine Gefahrenlage geschaffen hat, aus der eine schädigende Kausalreihe ihren Anfang nehmen konnte, oder wer eine Schlüsselposition erlangt hat, von der aus er den Erfolg verhindern kann, dem wird die Pflicht, den mißbilligten Erfolg abzuwenden, als billig angelastet. Es kann hier dahinstehen, inwieweit die Handlungspflicht aus voraufgegangenem Tun in diesem weiteren Sinn im Straf- und Zivilrecht anzuerkennen ist. Im Rahmen des Grundrechtsschutzes und insbes. im Rahmen des Art. 2 Abs. 2 GG ist dafür kein Raum. Was der Staat zu tun hat, um Existenz und körperliche Unversehrtheit des einzelnen zu sichern, ergibt sich aus dem Sozialstaatsprinzip und - ergänzend - aus dem des Schutzes und der Achtung vor der Menschenwürde sowie dem Gleichheitssatz. Das gilt auch dann, wenn die Gefährdung von Leib und Leben, die es abzuwenden gilt, in die gesteigerte Verantwortung der staatlichen Gemeinschaft fällt. Daneben besteht nicht nur kein Anlaß, eine besondere verfassungsrechtliche Pflicht des Staates, aus voraufgegangenem Tun zur Erhaltung des menschlichen Lebens und der körperlichen Unversehrtheit tätig zu werden, zu postulieren. Es würde auch dem System der Verfassung widersprechen, die für geboten e rachtete Handlungspflicht des Staates als Implikation in einem Grundrecht $z u$ suchen, das jeden verbalen, systematischen und subjektiv-historischen 18) Anhaltspunkt dafür vermissen läßt, während andere Bestimmungen das staatliche Handeln eindeutig in die geforderte Richtung lenken.

Art. 2 Abs. 2 GG ist somit kein selbständiges Teilhaberecht. Aber in Verbindung mit den anderweit gegebenen staatlichen Handlungspflichten bewährt es seine umfassende Schutzfunktion als unselbständiges, indirektes Teilhaberecht. Das widerspricht nicht nur nicht seinem systematischen Standort und seiner Entstehungsgeschichte. ${ }^{19)}$ Es ist im Hinblick darauf, daß eine sozialstaatli-

18) Zur Entstehungsgeschichte s. Doemming-Matz-Füßlein, Die Entstehungsgeschichte der Artikel des Grundgesetzes, S. $58 \mathrm{ff}$.

19) Die ursprünglich vorgesehene Bestimmung, wonach jedem das Mindestmaß der zum Leben notwendigen Nahrung, Kleidung und Wohnung gewährleistet sein sollte, wurde nicht gestrichen, weil man diese Mindestsicherung nicht wollte, sondern weil man sie für selbstverständlich, auch ohne besondere Hervorhebung gegeben, erachtete und aus der ausdrücklichen Festlegung im Verfassungstext Mißbrauch befürchtete (s. Doemming-Matz-Füßlein, a.a.O. S.61). 
che Verfassung dieses Grundrecht gewährt und ein Sozialstaat daran gebunden sein soll, unerläßlich. ${ }^{20)}$

\section{Einige weitere Rechte}

1. Garantie der Staatsangehörigkeit, Deutschenstatus und Auslieferungsverbot

Art. 16 Abs. 1 GG gewährt ein Recht auf Verbleiben im Staatsverband. 1) Diese Garantie impliziert eine Gewährleistung auch des sozialstaatlichen Teilhabestatus. Während der Nichtdeutsche vom A sylberechtigten abgesehen 2) - aus dem Staatsgebiet verwiesen 3) und somit auch aus dem territorialen Sorgebereich des Sozialstaates entfernt werden kann, kann der Deutsche nicht nur nicht ausgeliefert (Art.16 Abs. 2 Satz 1 GG) 4) sondern auch sonst nicht aus dem Bundesgebiet verwiesen werden. ${ }^{5)}$ Dem Deutschen

20) S. nochmals wie oben S.1084 zu Fußn.6. - Im Streit um die teilhabeverschaffende Funktion des Art. 2 Abs. 2 GG wurde die entscheidende Differenz zwischen der Leib und Leben schützenden Subjektivierung an sich bestehender staatlicher Handlungspflichten und der unmittelbaren und eigenständigen subjektiven Berechtigung zu dem, was für Leib und Leben unerläßlich ist, nicht immer gesehen. Weder die direkte Anerkennung eines selbständigen Teilhaberechts aus Art. 2 Abs. 2 GG noch die pauschale Ablehnung jeder teilhabeverschaffenden Wirkung des Grundrechts wird der Verfassung gerecht.

1) Im allgemeinen s. hierzu z. B. Schätzel, Staatsangehörigkeit, in: Neumann-Nipperdey-Scheuner, Die Grundrechte, Bd. II, 1954, S. $535 \mathrm{ff}$; v. Mangoldt-Klein, Art. 16 Anm. II, III und VI; w. Nachw. s. dort.

2) S. u. S. $1093 \mathrm{f}$.

3) Vg1. hierzu etwa Walter Jellinek, Die Bundesverweisung, in: Festschrift für Carl Bilfinger, 1954, S. $109 \mathrm{ff}$.

4) $\mathrm{Zu}$ diesem sozial nicht weiter bedeutsamen Grundrecht des A uslieferungsverbots s. z.B. Grützner, Auslieferungsverbot und A sylrecht, in: Neumann-Nipperdey-Scheuner, Die Grundrechte, Bd.II 1954, S. 582 ff; v. Mangoldt-Klein, Art. 16 Anm. IV; w. Nachw. s. dort.

5) Im Ergebnis übereinstimmend Wernicke, Bonner Kommentar, Art. 11 Anm. II $1 \mathrm{c}$, Art. 16 Anm. II 4 b; Jellinek, a.a.O. S. 111; Dürig, Freizügigkeit, S. 516; v. Mangoldt-Klein, Art. 16 Anm. IV 2 f. Das Recht, im Bundesgebiet zu verbleiben, ist der unantastbare Mindestgehalt des Grundrechts der Freizügigkeit (Art.11, 19 Abs.2 GG). 
kann ferner die Ein- und Rückwanderung nur unter den Voraussetzungen des Art. 11 Abs. 2 GG, dem Nichtdeutschen dagegen grundsätzlich unbeschränkt versagt werden. Den Deutschen im Ausland zu schützen, hat der Staat in gewissen Grenzen sowohl die Pflicht als auch die Möglichkeit. ${ }^{6)}$ Dem Nichtdeutschen gegenüber ist er hierzu regelmäßig weder verpflichtet noch imstande.

Allerdings berechtigt das Grundgesetz außerhalb des Art. 16 Abs. 1 GG immer nur den "Deutschen", nicht den deutschen Staatsangehörigen als solchen. 7) "Deutscher" in diesem Sinne "ist vorbehaltlich anderweitiger gesetzlicher Regelung, wer die deutsche Staatsangehörigkeit besitzt oder als Flüchtling oder Vertriebener deutscher Volkszugehörigkeit oder als dessen Ehegatte oder Abkömmling in dem Gebiet des Deutschen Reiches nach dem Stande vom 31. Dezember 1937 Aufnahme gefunden hat" (Art.116 Abs.1 GG).8) Diese Bestimmung ist die Basis einer umfassenden Gleichstellung der volksdeutschen Flüchtlinge und Vertriebenen mit den deutschen Staatsangehörigen und somit ein höchst bedeutsamer verfassungsrechtlicher Ansatz und Beitrag zur Lösung des sozialen Flüchtlings- und Vertriebenenproblems. Aber sie stellt deutsche Staatsangehörige und nicht-staatsangehörige Deutsche nicht absolut gleich.9) Insbes. gewährt sie diesen nicht die deutsche Staatsangehörigkeit. 10) Verfassungsrechtlich verbindlich ist die spezi-

6) Einige Hinweise s, bei Dürig, Freizügigkeit, S. 519 f.

7) Zu den sog. "Deutschenrechten" des Grundgesetzes s. z. B. v. Mangoldt-Klein, I. Die Grundrechte, Vorbem. B V 7 (S. 100).

8) Zum allgemeinen Inhalt der Vorschrift s. z.B. Menzel im Bonner Kommentar, Erl. zu Art.116; w. Nachw.s.dort (S.50 f).

9) Zur Rechtslage s. etwa Menzel, a.a.O. Anm. II A 7; Maunz, Deutsches Staatsrecht, S. 32 ff. Zu einem besonderen Aspekt s. Ferid, Hat die Gleichstellung der Vertriebenen mit Inländern in Art. 116 I GG kollisionsrechtlichen Gehalt? in "Vom Bonner Grundgesetz zur gesamtdeutschen Verfassung", Festschrift für Hans Nawiasky, 1956, S.395 ff. W. Nachw.s. bei den Genannten.

10) Auch nicht eine "erweiterte Staatsangehörigkeit" (Grabendorff, Die Einflußnahme des Art. 116 des Bonner Grundgesetzes auf (las deutsche Staatsangehörigkeitsrecht, DÖV 4. Jhg. (1951) S.268 f (269)) oder eine "'innere' deutsche Staatsangehörigkeit" (Hansjörg Jellinek, Der automatische Erwerb und Verlust der Staatsangehörigkeit durch völkerrechtliche Vorgänge, 1951, S.92). Eindeutig i.S. des Textes: Der Zweite Abschnitt des Gesetzes zur Regelung von Fragen der Staatsangehörigkeit v.22. Februar 1955 (BGB1. I S.65; i.d.F. des 3. Gesetzes zur 
fische Gleichstellung der "Deutschen" nur im Rahmen der sog. "Deutschenrechte" (Art. 8, 9, 11, 12, 33 Abs.1 und 2 GG). 11) Im übrigen ist - im Rahmen des sonstigen Verfassungsrechts, insbes. des Art. 3 Abs. 1 und 3 GG ${ }^{12}$ ) - Raum für Unterscheidungen. 13) Darüber hinaus steht die Gleichstellungsnorm des Art.116 Abs. 1 GG an sich unter dem Vorbehalt "anderweitiger gesetzlicher Regelung". Der Spielraum, den dieser Vorbehalt gewährt, 14) ist hinsichtlich des deutschen Staatsangehörigen durch Art. 16 Abs. 1 GG eingeengt, zugunsten des nicht-staatsangehörigen Deutschen dagegen nicht. 15) Die Zugehörigkeit des deutschen Staatsangehörigen zum personellen Staatsverband ist also wesentlich stärker gesichert als die des "Deutschen", der nicht die deutsche Staatsangehörigkeit besitzt.

Der Gleichstellungsnorm des Art.116 Abs.1 GG ist durch den gemeinsamen Zweck, Folgen der nationalsozialistischen Herr-

Regelung von Fragen der Staatsangehörigkeit vom 19. August 1957, BGB1. I S. 1251). Zur Differenz zwischen Staatsangehörigkeit und bloßem Deutschen-Status s. ferner Schätzel, Staatsangehörigkeit, S.536; Menzel, a.a.O. Anm. II A 7 a; Maunz, a.a.O.

11) S. o. S. 1091 zu Fußn. 8.

12) Zu denken ist insbes. auch an das Verbot der Differenzierung nach der Heimat (Art. 3 Abs. 3 GG). S. oben S.914 ff und S.931 ff.

13) S. o. S.1091 zu Fußn. 10. - Mit Recht betont aber Menze1 (a.a.O. Anm. II A $7 \mathrm{~g}$ (S.33)): "Auch wenn in der Gesetzgebung bei der Gewährung von Berechtigungen nicht ausdrücklich ... auf Art. 116 Abs. 1 hingewiesen wird, bleibt stets zu prüfen, inwieweit hier beide Gruppen der 'Deutschen' im Sinne des Art. 116 gleich zu behandeln sind. Die Vermutung spricht für eine derartige Gleichstellung, und es müssen schon gewichtige Gründe vorliegen, um eine differenzierende Handhabung zu rechtfertigen".

14) S. zu diesem Spielraum z.B. Hamann, Das Grundgesetz, Art. 116 Anm. C 2.

15) BVerwGE 8, 340 (343); Schätzel, Staatsangehörigkeit, S. 576 f; Hamann, a.a.O. S. auch $\$ \$ 6,7$ des Gesetzes zur Regelung von Fragen der Staatsangehörigkeit. Zum Verlust der Stellung eines "Deutschen" s. zusammenfassend Menzel, a.a.O. Anm. II A 10. A.A. Grabendorff, Die Einflußnahme des Art. 116 des Bonner Grundgesetzes auf die deutsche Staatsangehörigkeit, S. 268 f; Wernicke, Bonner Kommentar, Art. 16 Anm. II 1 a (2); v. Mangoldt-Klein, Art. 16 Anm. III $1 \mathrm{~b}$. 
schaft zu liquidieren, die Bestimmung des Art.116 Abs.2 GG 16) verwandt. Diese dient der Wiedergutmachung willkürlicher Ausbürgerungen. Der soziale Wert der Wiederherstellung der entzogenen Staatsangehörigkeit ergibt sich aus dem Vorstehenden. Hinzu tritt die wohltätige immaterielle Funktion, die der Wiedergutmachung angetanen Unrechts immer zukommt.

Den Schutz, den Art. 16 Abs. 1 Satz 1 GG dem deutschen Staatsbürger bietet, relativiert Art. 16 Abs. 1 Satz 2 GG. 17) Die Staatsangehörigkeit kann danach auf Grund Gesetzes auch gegen den Willen des Betroffenen aberkannt werden, wenn dieser dadurch nicht staatenlos wird. Das gilt auch dann, wenn die Staatsbürgerschaft, auf die der Betroffene durch den Entzug der deutschen Staatsangehörigkeit verwiesen wird, mit einem geringeren (tatsächlichen und/oder rechtlichen) sozialen Status verbunden ist als die deutsche. Doch scheint äußerstenfalls eine Korrektur vom sozialstaatlichen Verbot unsozialen Handelns her möglich.

\section{Das Asylrecht}

Das Asylrecht (Art. 16 Abs. 2 Satz 2 GG) besteht in dem Anspruch des politisch Verfolgten ${ }^{1)}$ auf Schutz durch die Bundesrepublik Deutschland vor seiner weiteren Verfolgung durch den ihn verfolgenden Staat. 2) Dieser Schutz kann sich nicht in der "Nicht-Abweisung, Nicht-Abschiebung, Nicht-Auslieferung, Nicht-Ausweisung" 3) erschöpfen. Der auf die - jedermann zukommende - Menschenwürde verpflichtete Sozialstaat kann den Asylberechtigten nicht von seiner Hilfe ausnehmen. 4) Er hat ihm, soweit er sich das nicht selbst verschaffen kann, das zur Erhaltung seiner Existenz Notwendige zu gewähren. 5)

16) Im allgemeinen s. zur Bedeutung der Vorschrift z.B. Menzel, a.a.O. Anm. II B m.w. Nachw.

17) S. hierzuz.B. Schätzel, a.a.O. S. 574 ff; v. Mangoldt-Klein, Art. 16 Anm. III 2 c.

1) Zu diesem Begriff des Art. 16 Abs. 2 Satz 2 GG s. z.B. Grützner, Auslieferungsverbot und Asylrecht (s.o. S.1090 zu Fußn. 4), S. 596 ff; v. Mangoldt-Klein, Art. 16 Anm.V i; w. Nachw.s. dort; ergänzend vgl. insbes. BVerf GE 9, 174.

2) Zur Auslegung der Vorschrift des Art. 16 Abs. 2 Satz 2 GG im allgemeinen s. z.B. Grützner, a.a.O. S. 593 ff; v. MangoldtKlein, a.a.O. Anm.V; w. Nachw. s.dort.

3) v. Mangoldt-Klein, a.a.O. Anm.V 2 b.

4) S. Klein, Christ und Kirche in der sozialen Welt, S. 126 und S. 233 Fußn. 300 .

5) Wernicke (Bonner Kommentar, Art. 16 Anm. II 4 c) und Na- 
Vom Zentralwert der Menschenwürde her gesehen stellt das Asylrecht eine positive und bedeutsame Ergänzung des sozialstaatlichen Aufgabenkreises dar. Andererseits kann der von ihr nicht beherrschbare Zustrom von politischen Flüchtlingen die sozialstaatliche Gemeinschaft schwer und inadäquat belasten. Eine gerade auch unter diesem Gesichtspunkt nicht unwichtige Modifikation der sozialstaatlichen Hilfspflicht kann sich jedoch daraus ergeben, daß der Asylnehmer, soweit er nicht Deutscher ist, 6) sich gegenüber dem ordnenden und lenkenden Zugriff des Sozialstaates nur auf die Menschenrechte, nicht auch auf die Deutschenrechte unter den Grundrechten ${ }^{7)}$ berufen kann. ${ }^{8)}$

\section{Das rechtliche Gehör}

Die spezifisch soziale Problematik des Rechts auf rechtliches Gehör (Art. 103 Abs. 1 GG) 1) liegt im Bereich des Anwaltszwanges. Dem verfassungsmäßigen Recht auf rechtliches Gehör kann mit einer bloß abstrakten Gewährung des rechtlichen Gehörs nicht genügt werden. Wer nur durch den Mund eines Anwalts Gehör erlangen und sich diesen Anwalt nicht leisten kann, dem wird in Wahrheit das rechtliche Gehör nicht gewährt, auch wenn er formal die Gelegenheit, sich zu äußern, erhält. Deshalb ist im Bereich des Anwaltszwangs das Institut des Armenrechts nicht nur im Hinblick auf das Sozialstaatsprinzip ${ }^{2}$ ) und den Gleichheitssatz ${ }^{3)}$ sondern auch im Hinblick auf Art. 103 Abs. 1 GG unentbehrlich. 4) 5)

wiasky-Lechner (Erl.zu Art.105) weisen übereinstimmend darauf hin, das Asylrecht könne "die Verpflichtung zur Versorgung zur Folge" haben. v. Mangoldt-Klein (Art.16 Anm.V 2 b; s.a. Anm. II 5 (S. 478)) führt aus: " $Z$ u dieser Schutzgewährung gehören alle dazu notwendigen Maßnahmen wie Aufnahme, Hilfeleistung, Unterbringung, Unterstützung und Versorgung...".

6) Art. 16 Abs. 2 Satz 2 GG begünstigt den Deutschen wie den Nichtdeutschen (s. v. Mangoldt-Klein, Art. 16 Anm.V i f m.w. Nachw.). Für den Deutschen, insbes. den deutschen Staatsangehörigen, ist das Recht jedoch von geringerer Bedeutung als für den Nichtdeutschen (s.Art.11, 16 Abs. 1 und Abs. 2 Satz 1 GG; vgl. oben S. $1090 \mathrm{ff}$ ).

7) S.o. S.1091 zu Fußn. 8 und S. 1092 zu Fußn. 12.

8) S. z.B. Grützner, Auslieferungsverbot und A sylrecht, S. 595; v. Mangoldt-Klein, Art. 16 Anm.V 2 d.

1) Zum allgemeinen Gehalt des Rechts s. statt anderer Dürig, in Maunz-Dürig, Erl. zu Art.103 Abs. 1; w. Nachw.s. dort.

2) S.o. S. $823 \mathrm{f}$. 


\section{Der Grundrechtssatz von der Menschenwürde}

\section{Vorbemerkung}

Art. 151 der Weimarer Verfassung hatte die Ordnung des Wirtschaftslebens auf die "Gewährleistung eines menschenwürdigen Daseins" verpflichtet. Aus den ökonomischen Spannungen und Entwicklungen sah der Verfassunggeber des Jahres 1919 die Gefahr für die Würde des Menschen aufsteigen. Ihr glaubte er, wehren zu müssen. Dann kam die nationalsozialistische Herrschaft. Die Machtmittel des Staates wurden mißbraucht, um die Würde des Menschen mit Füßen zu treten, und nicht gebraucht, wo sie die Würde des Menschen hätten schützen können. Der staatliche Neuaufbau nach dem Kriege vollzog sich im Zeichen dieser Erfahrung. Das Grundgesetz - ergangen in "Verantwortung vor Gott und den Menschen" 1) - stellte allen anderen Bestimmungen das allgemeine Gebot voran: "Die Würde des Menschen ist unantastbar. Sie zu achten und zu schätzen ist Verpflichtung aller staatlichen Gewalt". Die Würde des Menschen war als zentraler Wert der verfassungsmäßigen Ordnung anerkannt worden.

Der systematische Ort, an den das Grundgesetz den Verfassungssatz von der Menschenwürde stellt, weist ihn unmittelbar als Bekenntnis zentralen verfassunggeberischen Wollens, als oberstes Konstitutionsprinzip, ${ }^{2)}$ aus. Gerade dadurch läßt der Text des Grundgesetzes aber Zweifel zu, ob zugleich ein Grundrecht im

3) S. o. S. $900 \mathrm{ff}$.

4) Vgl. Dürig, a.a.O. Randn. 75 f u.s. Nachw.; nachzutragen Pfeiffer, Bewilligung des Armenrechts im Klageerzwingungsverfahren nach $₫ 172$ StPO, S. 571. S. ferner wie S. $1094 \mathrm{f} \mathrm{zu}$ Fußn. 2 u. 3 u. d. dort. Nachw.

5) Das geltende Gesetzesrecht bietet, soweit zu sehen, nur ein Konfliktproblem: der Vorbehalt der Gegenseitigkeit in bezug auf das Armenrecht für Ausländer ( $\$ 114$ Abs. 2 Satz 1 ZPO). S. hierzu Dürig, a.a.O. Randn. 77; Echterhölter, Die Europäische Menschenrechtskonvention in der juristischen Praxis, JZ 11.Jhg. (1956) S. 142 ff (145). Dazu, daß das Armenrecht Staatenlosen nicht nur gewährt werden kann ( $\$ 114$ Abs. 2 Satz 2 ZPO) sondern gewährt werden muß,s. Dürig, ebd.

1) Präambel des Grundgesetzes.

2) S. statt aller anderen v. Mangoldt-Klein, Art. 1 Anm. III 1 und 9; Dürig, in Maunz-Dürig, Art. 1 Abs.I Randn. $4 \mathrm{f}, 14 \mathrm{f}$; Wertenbruch, Grundgesetz und Menschenwürde, S. $31 \mathrm{ff}$; w. Nachw. s. dort. 
Sinne eines subjektiven Rechts gemeint ist. ${ }^{3)}$

Der Herrenchiemseer Entwurf wollte das deutlicher gesagt wissen. Einer Vorschrift vom Inhalt des jetzigen Art. 1 Abs. 1 GG 4) stellte er den Satz voran: "Der Staat ist um des Menschen willen da, nicht der Mensch um des Staates willen". 5) Dieser Satz ist in das Grundgesetz nicht eingegangen. 6) Aber daß die Grundrechte an der Spitze des Grundgesetzes stehen und an der Spitze der Grundrechte das Bekenntnis zur Würde des Menschen, besagt auch ohnedies, daß der Mensch die teleologische Mitte der verfassungsmäßigen Ordnung ist. ${ }^{2}$ ) Die soziale Bedeutung dessen ist - wenn "sozial" nicht primär im Sinne der Gemeinschaftsbezogenheit und -verpflichtung des einzelnen sondern im Sinne der Hilfe für den Menschen und des Spannungsausgleichs unter den Menschen verstanden wird ${ }^{8)}$ - offensichtlich.

2. Grundsätz1iches zur Deutung und Tragweite 1)

a) Achtung und Schutz der Würde des Menschen

Wenn die Verfassung dem Staat die Würde des Menschen als unantastbar vorgibt, so meint sie damit den sozialen Wert- und Achtungsanspruch, der dem Menschen als Träger höchster gei-

3) Für eine subjektive Berechtigung aus Art.1 Abs.1 GG s. statt aller anderen Nipperdey, Die Würde des Menschen, S. $11 \mathrm{ff}$; Löw, Ist die Würde des Menschen im Grundgesetz eine Anspruchsgrundlage? Dagegen u.a. v. Mangoldt-Klein, Art. 1 Anm. III 2; Dürig, a.a.O. Randn. 4 f u.passim; Wertenbruch, a.a.O. S. 30 ff. Näheres zum Streitstand s.dort. S. hierzu auch noch unten S.1103.

4) Art.1 Abs.2 des Herrenchiemseer Entwurfs.

5) Art. 1 Abs. 1 des Herrenchiemseer Entwurfs.

6) Zur Entstehungsgeschichte des Art.1 Abs.1 GG s. DoemmingMatz-Füßlein, Die Entstehungsgeschichte des Grundgesetzes, S. $48 \mathrm{ff}$.

7) S. hierzu etwa Nipperdey, Die Würde des Menschen, S. 8 ff.

8) S. hierzu oben S. $18 \mathrm{ff}$ und B Abschnitt 5 II 1 (S.676 ff).

1) Zusammenfassend s. die Darstellung bei Nipperdey, Die Würde des Menschen; v. Mangoldt-Klein, Art. 1 Anm. III; Dürig, Der Grundrechtssatz von der Menschenwürde; ders., in Maunz-Dürig, Erl. zu Art. 1 Abs.I; Wintrich, Zur Problematik der Grundrechte, 1957, S. 1 ff; ders., Die Bedeutung der "Menschenwürde" für die Anwendung des Rechts; Wertenbruch, Grundgesetz und Menschenwürde; alle anderen Nachweise s. dort. 
stig-sittlicher Werte - "kraft seines Geistes, der ihn abhebt von der unpersönlichen Natur und ihn aus eigener Entscheidung dazu befähigt, seiner selbst bewußt zu werden, sich selbst zu bestimmen und sich und die Umwelt zu gestalten" 2) - zukommt. ${ }^{3)}$ Der Mensch darf nicht zum Objekt fremder Herrschaft und Machtausübung herabgewürdigt werden. ${ }^{4)}$

Ke in Mensch darf das. Die durch die Menschenwürde umschriebene Wertsubjektivität kommt allem zu, was Menschenantlitz trägt. 5)

Der Staat hat die Menschenwürde zu achten. "Achtung bedeutet Entzug der staatlichen Verfügungsgewalt über die Menschenwürde".6) "Die Menschenwürde muß respektiert, auf sie muß Rücksicht genommen werden. Alles, was sie zerstören, schädigen oder sonstwie beeinträchtigen könnte, ist zu unterlassen". 7) 8)

Die Verfassungspflicht, die Würde des Menschen zu schützen, gebietet dem Staat demgegenüber positives Tun. 9) Sie kann freilich nicht gebieten, einem Menschen Würde zu verschaffen. ${ }^{10)}$ Das widerspräche der aprioristischen Natur der Menschenwürde. Die Schutzpflicht kann sich auch nicht darin erschöpfen, daß der

2) Dürig, a.a.O. Randn. 18.

3) S. hierzu etwa v. Mangoldt-Klein, Art. 1 Anm. III 3; Dürig, a.a.O. Randn. 17 f; Wertenbruch, Grundgesetz und Menschenwürde; w. Nachw. s. dort.

4) Zum Kriterium der "Objektstellung" s. vor allem Wintrich, Zur Problematik der Grundrechte, S. $17 \mathrm{f}$; ders., Die Bedeutung der "Menschenwürde" für die Anwendung des Rechts, S. 139; Dürig, a.a.O. Randn. 28.

5) Zum Begriff "Mensch" s. z.B. Nipperdey, Die Würde des Menschen, S. 3 f; v. Mangoldt-Klein, Art. 1 Anm. III 3 c; Dürig, a.a.O. Randn. $19 \mathrm{ff}$; w. Nachw. s. dort.

6) Maunz, Deutsches Staatsrecht, S.94.

7) Wernicke, Bonner Kommentar, Art. 1 Anm. II 2 b.

8) Zur Achtungspflicht s. ferner etwa Nipperdey, Die Würde des Menschen, S. 26 ff; v. Mangoldt-Klein, Art. 1 Anm. III 4 und 5 a; Hamann, Das Grundgesetz, Art. 1 Anm. C 4; Dürig, in Maunz-Dürig, Art. 1 Abs. 1 Randn. 2 und 2 ff (passim). Mit Recht kritisch hierzu Nipperdey, a.a.O. S. 3;

Wintrich, Zur Auslegung und Anwendung des Art. 2 Abs. 1 GG, S. 2 Fußn. 2; Dürig, a.a.O. Randn. 4 Fußn. 3.

Randn. 4 Fußn. 3.

9) Einhellige Meinung. S. statt aller anderen BVerf GE 1, 97 (104).

10) V'g1. Dürig, a.a.O. Randn. 2 f und Randn. 13 Fußn. 1. 
Staat dem die Menschenwürde verletzenden Mißbrauch seiner eigenen Gewalt kontrollierend und hemmend entgegenwirkt. 11) Sonst wäre sie nur eine Umschreibung der Achtungspflicht. Die Schutzpflicht verlangt vom Staat vielmehr in erster Linie die Abwehr der Gefahren, die der Menschenwürde von anderer Seite als vom Staat - vom anderen Menschen oder auch von objektiven, sachlichen Entwicklungen oder Verhältnissen - her drohen. 12)

b) Das Verhältnis des Verfassungssatzes von der Menschenwürde zur gesamten Verfassungsordnung

Die Verfassung ist als ganzes von dem Bemühen getragen, die Würde des Menschen zur Entfaltung zu bringen und gegen Gefährdungen sowohl seitens des staatlichen Machtapparates als auch seitens außerstaatlicher Kräfte ${ }^{1)}$ abzusichern. ${ }^{2)}$ Demzufolge drücken sich in der Verfassung die wesentlichen Züge des Menschenbildes 3 ) aus, das dem Verfassunggeber vor Augen stand, als er den Wert- und Achtungsanspruch des Menschen in Art. 1 Abs. 1 GG positivierte. ${ }^{4)}$ Aber mag auch die Verfassung in ihrer Gesamtheit auf die Auslegung des Verfassungssatzes von der Menschenwürde zurückwirken - dieser ist seinerseits als die Seele des Verfassungswerks oberstes materiales Auslegungsprinzip der ganzen verfassungsmäßigen Ordnung. 5) 6)

\section{1) Mißverständlich Maunz, Deutsches Staatsrecht, S.95 (im Gegensatz zu S.94).}

12) Zur Schutzpflicht s. etwa Wernicke, Bonner Kommentar, Art. 1 Anm. Il 2 c; Nipperdey, a.a.O. S. 28; v. MangoldtKlein, Art. 1 Anm. III 5 c; Hamann, a.a.O. Art. 1 Anm.C 5; Dürig, a.a.O. Randn. 2 f und 4 ff (passim).

1) Zu dieser elementaren Doppelposition s. z.B. Dürig, a.a.O. Randn. 15 f.

2) S.a. den Vorspruch der Verfassung für Rheinland-Pfalz: "... von dem Willen beseelt, die Freiheit und Würde des Menschen zu sichern,..."

3) Vg1. Dürig, Die Menschenauffassung des Grundgesetzes; dens. in Maunz-Dürig, Art. 1 Abs. I Randn. 46; besonders eigenwillig und eingehend Wertenbruch, Grundgesetz und Menschenwürde; gegen die Annahme eines objektiv fixierten Menschenbildes der Verfassung Hamann, Das Grundgesetz, Art. 1 Anm. C 1.

4) Zum Positivierungszweck des Art. 1 Abs.1 GG s. Nipperdey, Die Würde des Menschen, S. $7 \mathrm{f}$.

5) Zu Art. 1 Abs. 1 GG als oberstes Konstitutionsprinzip s.o. S.1095 zu Fußn. 2; zur interpretatorischen Bedeutung s. insbes. etwa Nipperdey, a.a.O. S.23 f; Wintrich, Zur Proble- 
"Darum", weil die Würde des Menschen unantastbar und vor aller staatlichen Gewalt $\mathrm{zu}$ achten und zu schützen ist, bekennt sich "das Deutsche Volk... zu unverletzlichen und unveräußerlichen Menschenrechten als Grundlage jeder menschlichen Gemeinschaft" (Art.1 Abs.2 GG). ${ }^{7)}$ Aber nicht nur die Menschenrechte im engeren Sinn sind Ausdruck des Verfassungsbekenntnisses zur Würde des Menschen. Die ganze Grundrechtsordnung dient der Entfaltung und dem Schutz der menschlichen Persönlichkeit und Würde. ${ }^{8)}$ Weil diese allem Lebendigen zukommt, das Menschenantlitz trägt, 9) setzt die Verfassung durch den Gleichheitssatz alle Menschen gleich. 10) Weil der Mensch der Freiheit bedarf, um eigenverantwortlich handeln und sich darin selbst verwirklichen zu können, gewährt ihm die Verfassung Freiheitsrechte. 11) Einzelne unter ihnen dienen im besonderen auch der das geistig-sittlich menschenwürdige Dasein integrierenden Notwendigkeit einer

matik der Grundrechte, S. 13; ders., Zur Bedeutung der "Menschenwürde" für die Anwendung des Rechts, S. 138.

6) Zu den danach wesentlichen Elementen des Mensch-Seins s. außer den vorstehend S.1098 zu Fußn. 3 Genannten insbes. Wintrich, a.o. (S.1096 Fußn.1 vor oben a) a.O.; s. ferner die sonstigen oben S.1096 Fußn. 1 vor a Zitierten und deren Nachweise.

7) Zur grundsätzlichen Bedeutung dieses Verfassungssatzes s. z.B. v. Mangoldt-Klein, Art. 1 Anm.IV; Dürig, in MaunzDürig, Erl. zu Art. 1 Abs. II, insbes. Randn. 73 ff; Wertenbruch, a.a.O. S. $140 \mathrm{ff}$ u. passim.

8) Zum Verhältnis zwischen Menschenwürde und Grundrechtsordnung s. Dürig, der Grundrechtssatz von der Menschenwürde; ders., in Maunz-Dürig, Art. 1 Abs. I Randn. $4 \mathrm{ff}$ und zu Abs. II Randn. 73 ff; Wertenbruch, a.a.O. S. $29 \mathrm{ff}, 61 \mathrm{ff}$, $105 \mathrm{ff}, 119 \mathrm{ff}$; w. Nachw.s.dort. Zu Art. 1 Abs. 1 als "materiellem Haupt-Grundrecht" s. ferner Nipperdey, Die Würde des Menschen, S. $11 \mathrm{ff}$.

9) S. nochmals oben S.1097 zu Fußn. 5.

10) Zum Verhältnis zwischen Gleichheitssatz und Menschenwürde s. etwa Dürig, a.a.O. zu Abs. I Randn. 12; Wertenbruch, a.a.O. S. 120 ff u. passim.

11) S. hierzu etwa Wintrich, Zur Problematik der Grundrechte, S. 14 ff; ders., Die Bedeutung der "Menschenwürde" für die Anwendung des Rechts, S. 138; ders., Zur Auslegung und Anwendung des Art. 2 Abs.1 GG, S. 1 ff; s. ferner Dürig und Wertenbruch, a.o. (Fußn.8) a.O. 
geschützten individuellen Intimsphäre. ${ }^{12)}$

Unantastbarkeit der Menschenwürde bedingt jedoch nicht einseitigen Schutz ungebundener Freiheit. Im Gegenteil. Mensch-Sein heißt wesentlich auch Mitmensch-Sein, In-Gemeinschaft-Sein bedeutet gegenseitige Rücksichtnahme und Verantwortung. Die von der Verfassung "verfaßte" staatliche Gemeinschaft - der die Verfassung selbst Schutz und Achtung vor der Menschenwürde aufträgt 13) - ist daher ebenso Medium der menschlichen Selbstverwirklichung, wie es die von der Verfassung institutionalisierten oder sonstwie zugelassenen und gesteuerten menschlichen Gemeinschaften sind. 14) Das Mitmensch-Sein und In-GemeinschaftSein des Menschen bedeutet - in welchem Raum es sich auch vollzieht - Beschränkung der individuellen Freiheit. Somit entspricht auch die in der Verfassung angelegte Beschränkung der grundrechtlich konstituierten Freiheit und ihre in ihrer Beschränktheit und Beschränkbarkeit ${ }^{15)}$ und in der sozialstaatlichen Pflichtigkeit des einzelnen 16) sich äußernde Bindung dem obersten Konstitutionsprinzip der menschlichen Würde. 17) Nur darf diese Bindung nicht so weit gehen, daß sie den Wesensgehalt der Grundrechte einschränkt, der durch das im Hinblick auf die Würde des Menschen Notwendige an Freiheit und Intimsphäre gekennzeichnet ist. ${ }^{18)}$

12) Vg1. insbes. Wintrich, Zur Problematik der Grundrechte, S. 15 ff; ders., Zur Bedeutung der "Menschenwürde" für die Anwendung des Rechts, S.138; Dürig, a.a.O. zu Abs. I Randn. 37; w. Nachw. s.insbes. bei Dürig.

13) S. zu der Bedeutung des Art. 1 Abs. 1 Satz 2 GG als Argument für die Mit-Positivierung der apriorischen Sozialbindung des Menschen durch Art. 1 Abs. 1 GG Dürig, in Maunz-Dürig, Art. 1 Abs. I Randn. 48; s.a. Wertenbruch, a.a.O. S. $148 \mathrm{ff}$.

14) S. insbes. Dürig, a.a.O. Randn. 53; s.a. Wertenbruch, a.a.O. S. $54 \mathrm{f}$.

15) S. I 2 (S. 845 ff). Zur Bedeutung des Fehlens von Grundpflichten im Grundgesetz für die Auslegung des Art. 1 Abs. 1 GG s. Wertenbruch, a.a.O. S.62 ff.

16) S. o. S.676 ff und S.701, S. 719 ff. Für den besonderen Zusammenhang s. Dürig, a.a.O. Randn. 52.

17) Vg1. Dürig, Die Menschenauffassung des Grundgesetzes; ders., in Maunz-Dürig, Art. 1 Abs. I Randn. 46 ff; Wintrich, Zur Problematik der Grundrechte, insbes. S. 6 ff; Wertenbruch, a.a.O. S. $61 \mathrm{ff}$, insbes. S. $74 \mathrm{ff}, 84 \mathrm{ff}$; w. Nachw.s. dort, insbes. bei Dürig, a.a.O.

18) S. hierzu oben S.863 f u. die dort. Nachw. 
Dem Bemühen des Verfassunggebers um den Schutz und die Entfaltung der menschlichen Würde entspricht ferner die de mokratische Staatsordnung. 19) Weil es dem Menschen wesentlich ist, sein Geschick eigenverantwortlich zu bestimmen und gemeinsames Geschick mitverantwortlich zu tragen, ist die kollektiv-autonome, demokratische Ordnung ein ideales Medium seiner Selbstverwirklichung.

Die individuelle Autonomie verwirklicht sich über die kollektive umso dichter, je enger der Kreis des Kollektivs gezogen ist. Mit der persönlichen Gebundenheit des Menschen in der engeren Gemeinschaft wächst ferner die wechselseitige Mitverantwortung. Schließlich ermöglicht die sachgerechte Ausgrenzung engerer Gemeinschaften $z$ wischen Individuum und oberster staatlicher Einheit die gesteigerte Entfaltung individueller und gemeinschaftlicher menschlicher Eigenart. Um der Selbstverwirklichung des Menschen auch insofern Raum zu geben, hat das Grundgesetz eine bundesstat 1 iche Ordnung geschaffen, 20$)$ und haben Bundes- und Landesverfassung die verschiedenen Formen der Selbstverwaltung garantiert, angeregt oder wenigstens ermöglicht. 21)

Die menschliche Freiheit kann jedoch nicht nachhaltig gesichert werden ohne jene organisatorischen Vorkehrungen, die für den $\mathrm{R}$ e chts sta at kennzeichnend sind. Die rechtsstaatliche Ordnung gibt dem Recht auch jene Sicherheit und Verläßlichkeit, deren es bedarf, wenn der Mensch in der staatlichen Rechtsgemeinschaft eine einigermaßen vollkommene Heimstatt finden soll. Die rechtsstaatliche Verpflichtung des staatlichen Gemeinwesens schließlich auf die Gerechtigkeit entspricht unmittelbar der verfassungsmäßigen Grundgegebenheit, daß der Mensch in die staatliche Gemeinschaft eingesponnen ist und in ihr seine menschliche Würde und Persönlichkeit verwirklicht werden soll. Letzteres wäre in einem ungerechten Gemeinwesen nicht zu denken. 22)

19) Zum Ver'hältnis von Menschenwürde und Demokratie s. Wertenbruch, a.a.O. S.40 ff und passim.

20) S. zu diesem Zusammenhang Wertenbruch, a.a.O. S.54 f.

21) S.a. oben S.1100 zu Fußn. 14.

22) Zum Verhältnis zwischen (formeller und materieller) Rechtsstaatlichkeit und Verfassungsbekenntnis zur Menschenwürde s. vor allem Wertenbruch, a.a.O. passim (s. die Zusammenstellung der Hinweise S. 227 rechts unten); s.a. Wintrich, Zur Problematik der Grundrechte, S. $17 \mathrm{f}$ (insbes. S. 18); ders., Die Bedeutung der "Menschenwürde" für die Anwendung des Rechts, S. 139. 
In hervorragender Weise endlich ist die Sozialsta t snorm dem Verfassungsgrundwert der Menschenwürde zugeordnet: ${ }^{23}$ ) "Würde des Menschen, nichts mehr davon, ich bitt euch. Zu essen gebt ihm, zu wohnen; habt ihr die Blöße bedeckt, gibt sich die Würde von selbst" (Schiller). "Ohne ein Minimum an äußeren materiellen Leibes- und Lebensbedingungen hat der Mensch als solcher nicht das, was seine Würde ausmacht, nämlich die Fähigkeit, sich in freier Entscheidung über die unpersönliche Umwelt zu erheben. Er lebt nicht, er vegetiert". 24) So trifft sich die Pflicht des Staates, die Menschenwürde zu schützen, nicht nur mit dem sozialstaatlichen Minimalprogramm der Existenzerhaltung 25) sondern auch mit dem sozialstaatlichen Auftrag der weitergehenden, über die primitive Existenzerhaltung hinausführenden Hilfe. ${ }^{26}$ ) Der gemeinsame teleologische Kern des Verfassungssatzes von der Menschenwürde und des Sozialstaatsprinzips wird aber auch unter einem anderen Aspekt deutlich. Dem Gedanken der Würde eines jeden Menschen wohnt ein unerbittlicher egalitärer Zug inne, dem ökonomische Differenzen, soweit sie wie das grundsätzlich nur auf der "Unterseite" der Fall sein kann - in die Grundbedingungen der menschenwürdigen Existenz eingreifen, widersprechen. Der soziale Ausgleich ist um des Menschen willen $\mathrm{zu}$ fordern.

23) S. o. S.679 zu Fußn.4. S. ferner Wintrich, Zur Problematik der Grundrechte, S. 18 f; ders., Die Bedeutung der "Menschenwürde" für die Anwendung des Rechts, S.139; Wertenbruch, a.a.O. S. $51 \mathrm{ff}$.

24) Dürig, in Maunz-Dürig, Art. 1 Abs. I Randn.43; eingeh. Nachw. s. dort (Fußn. 1); nachzutragen: Winkelvoss, Das Recht auf ausreichende Wohnung, NJW 11.Jhg. (1958) S.2000 ff.

25) S. hierzu schon oben S.679 f zu Fußn. 4-6. Im besonderen s. Nipperdey, Die Würde des Menschen, S. 5 ff; Bachof, Begriff und Wesen des sozialen Rechtsstaats, S. 42 f; Dürig, Der Grundrechtssatz von der Menschenwürde, S. $132 \mathrm{f}$; ders., in Maunz-Dürig, Art. 1 Abs.I Randn. 43 f; Wintrich, Zur Problematik der Grundrechte, S.19; ders., Die Bedeutung der "Menschenwürde" für die Anwendung des Rechts, S. 139; Krause, Der verteilende Staat, S. 18 f; Winkelvoss, a.a.O.; Löw, Ist die Würde des Menschen im Grundgesetz eine Anspruchsgrundlage? S. 520; Maunz, Deutsches Staatsrecht, S.95. - Gegen das positive, Existenzerhaltung fordernde Angreifen des Art. 1 Abs. 1 GG: BVerfGE 1, 97 (104); Paulick, Die verfassungsrechtlichen Bindungen des Gesetzgebers beim Erlaß von Steuergesetzen, S.493; Giese-Schunck, Grundgesetz, Art.1 Anm.II 1.

26) Vg1. Wertenbruch, a.a.O. S.178 f. 
c) Der Grundrechtssatz von der Menschenwürde als subjektives Recht

Das Grundgesetz realisiert - wenn es vom Telos der Menschenwürde her verstanden und ausgelegt wird - das Gebot des Schutzes und der Achtung vor der Menschenwürde umfassend. 1) Der subjektive Schutz der Menschenwürde wird durch die (sonstige) Grundrechtsordnung, die weitgehend auch das objektive Verfassungsrecht "subjektiviert", gewährleistet. 1) Demnach kommt der Frage, ob Art. 1 Abs. 1 GG ein subjektives Recht gewährt, ${ }^{2}$ ) keine Bedeutung zu.

\section{Einzelfragen}

a) Schutz der Menschenwürde im Rahmen der sozialen Intervention

Die Geschichte der Menschheit ist voll von Beispielen, wie der Mensch - Volk gegen Volk, Rasse gegen Rasse, Klasse gegen Klasse, Stand gegen Stand, Jugend gegen Alter, Erwachsene gegen Kinder, Gesunde gegen Kranke, Starke gegen Schwache - versucht, seinen Vorteil darin zu finden, daß er andere von den Glücksgütern einer menschenwürdigen Existenz ausschließt, sie als A rbeitssklaven oder Handelsobjekt ausbeutet, entrechtet oder vernichtet. Der Effekt kann ein vermeintlich oder vorgeblich "sozialpolitischer", das Wohlergehen der jeweils Herrschenden sein. Die strenge Egalität der Würde a 11 e r Menschen enthält dieser sozialen Machtpolitik den Anschein der Legitimität vor. Versklavung, 1) Vernichtung "lebensunwerten Lebens", 2) "Menschenversuche" an "Minderwertigen"3) und dgl.4) sind keine zulässigen Mittel des verfassungsmäßigen Sozialstaates. Dieser hat alle

1) Vg1. Dürig, in Maunz-Dürig, Art. 1 Abs. I Randn. 13 und Art. 1 Abs. II Randn. 84 ff. S. ferner die Beispiele unten S. $1103 \mathrm{ff}$.

2) S.o. S.1096 zu Fußn.3.

1) Zum Verstoß gegen die Menschenwürde s. z.B. Nipperdey, Die Würde des Menschen, S.29; Dürig in Maunz-Dürig, Art. 1 Abs. I Randn. 30 .

2) Zum Verstoß gegen die Menschenwürde s. z.B. Nipperdey, a.a.O.; Dürig, a.a.O. Randn. $19 \mathrm{ff}, 25$.

3) Zum Verstoß gegen die Menschenwürde s. z.B. Nipperdey, a.a.O.; Dürig, a.a.O. Randn. 30, s.a. Randn. 40.

4) Weitere Beispiele s. bei den Vorgenannten, a.a.O. Eine eingehende Exemplifikation der Verstöße gegen die Menschenwürde s. bei Münch, Die Menschenwürde als Grundforderung unserer Verfassung, 1952. 
Menschen in seine Hilfe und seinen Wohlstandsausgleich einzubeziehen. Zur grundrechtlichen Abwehr dieser menschenunwürdigen Methoden bedarf es jedoch nicht des Rückgriffes auf ein subjektives Recht aus Art.1 Abs. 1 GG. So evident sie die Menschenwürde verletzen, so offenkundig ist, daß sie gegen die Gleichheit aller vor dem Gesetz, gegen den Wesensgehalt des Rechts auf Leben, 5) auf körperliche Integrität, 6) auf körperliche Freiheit 7) auf Freiheit von Arbeitszwang und $Z$ wangsarbeit verstoßen. ${ }^{8)}$

Menschenunwürdig ist immer auch die Entziehung des Existenzminimums - sei es durch die Wegnahme oder Zerstörung des die Existenz tragenden Vermögens (z.B. im Wege der Enteignung, der Besteuerung, sonstiger Inanspruchnahme des Eigentums im öffentlichen Interesse, ferner auch im Wege der Vollstreckung zivilrechtlicher Titel usw.), sei es dadurch, daß dem Menschen die Möglichkeit benommen wird, sich selbst das Notwendige zu beschaffen. 9) Doch ist auch insofern der unmittelbare Rückgriff auf einen subjektivrechtlichen Schutz des einzelnen Betroffenen aus Art. 1 Abs. 1 GG nicht nötig. Einerseits das Grundrecht des Eigentums, 10) andererseits die Freiheitsgrundrechte, insbes. das Grundrecht der Freiheit von Beruf und Arbeitsplatz, 11) das Grundrecht der körperlich-räumlichen Bewegungsfreiheit 12) und das Grundrecht der allgemeinen Handlungsfreiheit, 13) bieten wenn sie nur hinreichend als Grundrechte einer auf die Menschenwürde ausgerichteten sozialstaatlichen 14) Verfassung erkannt und ausgelegt werden - hinreichende Abwehrmöglichkeiten. Soweit an sich existenzbedrohende Einbußen auferlegt werden müssen, schließt das gleichheitsgrundrechtliche Opferausgleichsgebot den Kreis. 15)

5) S.o. S. $1082 \mathrm{f}$.

6) S.o. V 9 b (S.1073 ff).

7) S.o. V 9 a (S.1069 ff).

8) S.o. S. $1042 \mathrm{ff}$.

9) S. die Nachw. oben S. 1102 zu Fußn. 24 und 25.

10) Zum Menschenwürdegehalt des Eigentumsrechts s. z. B. Dürig, Der Staat und die vermögenswerten Berechtigungen seiner Bürger, S. 24 f. Zum Schutz der Existenz im Rahmen der Eigentumsentziehung s. oben S. 957 zu Fußn.24; s.a. die Hinweise unten S.1105 zu Fußn. 15.

11) S.o. V 6 (S.1024 ff).

12) S. o. V 9 a (S.1069 ff).

13) S. o. V 8 (S.1056 ff).

14) Zur Existenzerhaltung als sozialstaatlichem Minimalprogramm s. o. S. $679 \mathrm{f} \mathrm{zu} \mathrm{Fußn.} 5$ und 6, S. $824 \mathrm{f}$, S. $828 \mathrm{ff}$ a.E. und S. $823 \mathrm{ff}$ a. E. 
Die Pflicht des Staates, dem Menschen eine menschenwürdige Existenz zu erhalten und zu sichern, ist nicht auf die Fälle beschränkt, in denen er die Existenznot verursacht hat. Er muß auch dem Bedürftigen helfen, dessen menschenwürdige Existenz von dritter Seite oder durch tatsächliche Verhältnisse bedrängt ist. 16) Grundrechtlich geschützt ist der Bedürftige insofern, als der Staat nicht dadurch, daß er seiner sozialstaatlichen Hilfspflicht nicht genügt, - unterlassend - die körperliche Integrität und das Leben des Betroffenen verletzen darf. 17)

Schließlich ist hervorzuheben, daß der Mensch im Sozialstaat nicht zum Objekt der staatlichen Hilfe entwürdigt werden darf. Der Sozialstaat darf nicht zum menschenunwürdig über den einzelnen disponierenden und in seine Lebensverhältnisse ungehemmt eindringenden Versorgungsstaat ${ }^{18)}$ werden. Wird aber erkannt, was die Grundrechte, das Rechtsstaatsprinzip in seinen verschiedenen Ausprägungen und auch das auf die Menschenwürde hin orientierte Sozialstaatsprinzip für die Sicherung der menschlichen Würde im System der staatlichen Hilfen und Ausgleichsmaßnahmen - insbes. für die Freiheit von der Teilhabe und die Freiheit in der Teilhabe - leisten, 19) erübrigt sich auch insofern die direkte und selbständige Befassung des Verfassungssatzes von der Würde des Menschen. 20)

15) S. o. II 2 b cc (S. $904 \mathrm{ff})$.

16) S. o. S.1102 zu Fußn.25.

17) Zur entsprechenden Auslegung des Sozialstaatsprinzips s.o. Abschnitt 5 (S. 673 ff), insbes. S. 731 zu Fußn. 5-8 und S.766 ff. Zur Subjektivierung der sozialstaatlichen Hilfspflicht über Art. 2 Abs. 2 GG s.o. S.1083ffu. die dort. Nachw.

18) S. hierzu oben S. 753 zu Fußn. 29.

19) S. hierzu oben Abschnitt 4 (S. 396 ff) und 5 (S. 673 ff)) insbes. etwa Abschnitt 5 II 3 c (S. 744 ff)) und vorstehenden Abschnitt S. $842 \mathrm{ff}$ (insbes. etwa I 3 (S. $848 \mathrm{ff}$ )).

20) Im Hinblick auf die rechtsstaatlichen Sicherungen der individuellen Position war es auch unnötig, im sog. "alten-RentnerFall" (Abbruch unberechtigter Rentenzahlungen an Rentner, die in hohem Alter stehen) die "Menschenwürde des Rentners" (s. Bernhardt, Der Rentner und seine Menschenwürde) zu bemühen (s. hierzu schon oben S. 658 zu Fußn. 10 und oben S.1060 zu Fußn.9. - Für die Annahme eines Verstoßes außer Bernhardt, a.a.O. insbes. LSG Bremen, Urt.v. 20. Februar 1957 - LV 161/55 - Betriebsberater 12. Jhg. (1957) S. 543 (543); Rohwer-Kahlmann, Sozialrecht und Grundgesetz, S. 360 f; ders., Die Einwirkung verfassungsrechtlicher Normen 
b) Zur "Drittwirkung" des Grundrechtssatzes von der Menschenwürde

Die Unantastbarkeit der Menschenwürde ist absolut. Art. 1 Abs. 1 Satz 1 GG wendet sich an jedermanns Verhalten. ${ }^{1)}$ Die staatliche Pflicht, die menschliche Würde zu schützen, 2) richtet sich ferner nicht so sehr auf den Schutz vor dem die Menschenwürde verletzenden Mißbrauch der staatlichen Gewalt, dem schon die staatliche Achtungspflicht entgegentritt, als auf die Abwehr der von außerstaatlichen Kräften gegen die Menschenwürde vorgetragenen Angriffe. ${ }^{3)}$ Das bedeutet, daß der Grundrechtssatz von der Menschenwürde auch im primären Medium der zwischenbürgerlichen Rechtsbeziehungen, im Privatrecht, zu verwirklichen ist. 4)

Das Privatrecht als ein Recht zurückgedrängter Staatseinwirkung und privater Autonomie ist seinerseits nicht zuletzt um der Menschenwürde - insbes. um des Freiheitsraumes, dessen der Mensch zu seiner persönlichen Entfaltung bedarf - willen nicht aus der Rechtsordnung wegzudenken. ${ }^{5)}$ Aber der Staat darf die zwischenbürgerlichen Beziehungen der privaten Willkür und der Spannung von Macht und Ohnmacht nicht in einer Weise freigeben, die zur Verletzung der menschlichen Würde führen würde. 6)

Das Wesentliche, um die Menschenwürde zu schützen, geschieht schon, indem das Privatrecht sozialstaatsgerecht 7 ) und den grundrechtlichen Ausgangspositionen der bürgerlichen Rechtsstellung gemäß ${ }^{8)}$ gestaltet und - soweit es an unmittelbar entsprechenden

auf das Recht der sozialen Sicherheit, S. 1641 f; w. Nachw.s. dort. Gegen einen Verstoß gegen die Menschenwürde, BSGE 9, 199 (204); 11, 209 (211)).

1) S. insbes. Wintrich, Zur Problematik der Grundrechte, S. 12 f; dens., Die Bedeutung der "Menschenwürde" für die Anwendung des Rechts, S. 137.

2) S. o. S.1098 zu Fußn. 12.

3) S. wie Fußn. 2; ferner Hamel, Die Bedeutung der Grundrechte im sozialen Rechtsstaat, S. 21.

4) S. hierzu Wintrich, a.a.O. (S.1096 zu Fußn. 1); Nipperdey, Die Würde des Menschen, S. 18 ff, $21 \mathrm{f}, 35 \mathrm{ff}$; Dürig, in Maunz-Dürig, Art. 1 Abs. I Randn. 16, 38; w. Nachw. s. dort.

5) S.o. Abschnitt 4 II 5 (S.614 ff), insbes. S.629, ferner oben I 4 d (S.876 ff);s.a. die Ausführungen zur Drittwirkung oben II-VI (S.890 ff) passim.

6) S. o. Fußn. 4; ferner Laufke, Vertragsfreiheit und Grundgesetz, S. 167 .

7) S. oben Abschnitt 5 III 7 (S. 825 ff).

8) S. o. I 4 d (S.876 ff) und oben II-VI (S. 890 ff) passim. 
Regelungen fehlt: über eine verfassungsmäßige Auslegung und Handhabung der wertausfüllungsbedürftigen Generalklauseln des Privatrechts 9) - vollzogen wird. Aber wie der Grundrechtssatz von der Menschenwürde das ganze Verfassungsrecht beherrscht, so hat er letztlich die ganze Rechtsordnung und insbes. auch das Privatrecht $z u$ durchdringen. Die Schlüsse, die aus dem Verfassungsrecht auf die notwendige Gestaltung des Privatrechts gezogen werden, sind im Hinblick auf das oberste Konstitutionsprinzip der menschlichen Würde zu rechtfertigen; und die Determination, die von diesem Verfassungssatz auf die Gestaltung des Privatrechts unmittelbar ausgeht, kann stärker sein als die der übrigen, mehr auf das Staat-Bürger-Verhältnis eingerichteten und nicht ohne Schwierigkeit auf die privatrechtlichen Beziehungen übertragbaren Verfassungssätze. Der wertausfüllenden Heranziehung des Verfassungsbekenntnisses zur Menschenwürde für die Anwendung des Privatrechts stehen deshalb keine Bedenken entgegen. 10) Eine unmittelbare privatrechtliche Geltung des Art. $1 \mathrm{Abs} .1 \mathrm{GG}$ dürfte dagegen nicht anzunehmen sein. 11)

Über die für das Privatrecht im einzelnen zu ziehenden Folgerungen braucht dem, was über die Auswirkungen des Verfassungsrechts auf das Privatrecht bereits bisher gesagt wurde, nichts hinzugefügt $\mathrm{zu}$ werden. Jedoch ist auf eine besondere privatrechtliche Frucht der verfassungsrechtlich bedingten Konzentration der ganzen Rechtsordnung auf die menschliche Persönlichkeit und IIürde hinzuweisen: das allgemeine Persönlichkeitsrecht des Menschen, 12) das gerade auch für die sozial kritischen Rechtsverhältnisse von weittragender Bedeutung ist.

\section{c) Grundrechtsordnung und Subsidiaritätsprinzip}

Das Grundverhältnis zwischen Staat und Individuum, das die unantastbare Würde des Menschen mit dessen Eingebundenheit in die staatliche Gemeinschaft versöhnt und dem Staat erlaubt, die Menschenwürde zugleich zu achten und zu schützen, ist das der subsidiarität. 1) Den Komponenten der absoluten Position des ein-
9) S. o. S.735 f und oben I $4 \mathrm{~d}(\mathrm{~S} .876 \mathrm{ff})$.
10) S.o. S. 1106 zu Fußn. 4.
11) Vgl. Dürig, a.a.O. Randn.16; a.A. Nipperdey, a.a.O. (s.o. S.1106 zu Fußn. 4); w. Nachw.s. dort.

12) S. hierzu z.B. Nipperdey, a.a.O. S. 40 ff; Dürig, a.a.O. Randn. 38; Siebert, Zur allgemeinen Problematik des Persönlichkeitsrechts, NJW, 11.Jhg. (1958), S. 1369 ff (insbes. S. 1373); w. Nachw. s. dort.

1) S. zum Subsidiaritätsprinzip oben Abschnitt 2 I (S. 219 ff) u. 
zelnen Menschen, wie sie im Kern wesentlich durch Art. 1 Abs. 1 GG umschrieben ist, und des von der Verfassung bejahten umfassenden staatlichen Sozialgestaltungsauftrags 2) entspricht verfassungsrechtlich die Resultante einer subsidiären Ordnung und eines "Generalgrundrechts" auf deren Beachtung. ${ }^{\text {) }}$ Aber die Subsidiarität ist ein abstraktes gedankliches Prinzip, das in unmittelbarer Anwendung auf die konkreten Situationen allzuwenig zu leisten vermag und der vermittelnden Konkretisierung bedarf. ${ }^{4)}$

Das Grundgesetz bemüht sich um diese Konkretisierung. 5) Das Gesamtstaatswesen ist föderativ gegliedert. Zwischen Staat und Bürger sind autonome Verbände teils verpflichtend institutionalisiert, teils angeregt oder wenigstens zugelassen. Die freie Vergemeinschaftung der Bürger ist grundrechtlich gesichert. Dasselbe sind die intimen Urgemeinschaften der Ehe und der Familie. Vor allem aber determiniert die Grundrechtsordnung den Eigenraum des Individuums und schirmt ihn gegen das Eindringen des Staates und seiner Unterverbände ab. Die Grundrechtsordnung ist darin Ausdruck des Subsidiaritätsgedankens. ${ }^{6)}$ Ein darüber hinausgehendes, selbständiges, positivrechtliches Prinzip der Subsidiarität und ein selbständiges Grundrecht auf deren Beachtung wäre weder zu rechtfertigen noch wohl von Nutzen.

d. dort. Nachw. und S.755 ff. Im besonderen zur Verknüpfung des verfassungsimmanenten Subsidiaritätsgedankens mit Art. 1 Abs. 1 GG s. Dürig, Verfassung und Verwaltung im Wohlfahrtsstaat, S. 198; ders., in Maunz-Dürig, Art. 1 Abs. I Randn. 54. Zur Ableitung eines verfassungsimmanenten Subsidiaritätsgedankens aus der "Menschenauffassung" des Grundgesetzes s. v. Münch, Staatliche Wirtschaftshilfe und Subsidiaritätsprinzip, S. $305 \mathrm{~m}$. w. Nachw.

2) S. oben Abschnitt 5 II 1 a (S. 676 ff), b $(S .684$ f) und $c$ aa (S. $699 \mathrm{f}$ ).

3) S. hierzu Stern (Rechtsfragen der öffentlichen Subventionierung Privater, S. 523 Fußn.40), der im Subsidiaritätsprinzip "das notwendige Korrelat eines mit universaler Kompetenz ausgestatteten Sozialstaates" sieht.

4) S. oben S.223 ff.

5) S. oben S.223ff und S. $755 \mathrm{ff}$ und die dortigen weiteren Hinweise und Verweisungen.

6) S. die Nachweise oben S. 223 zu Fußn. 1 und S. 224 zu Fußn. 10 ; s. ferner Geiger, Grundgesetzliche Schranken für eine Kartellgesetzgebung, S. 21. 


\section{C) ABSCHLIESSENDE BEMERKUNGEN}

Die rechtsstaatliche Verfassung scheidet aus dem von der Summe aller innerhalb der staatlichen Gemeinschaft denkbaren selbst - und fremdbestimmenden, personal- und sachverfügenden, kollektiven und individuellen Entscheidungen erfüllten imaginären Raum, normativ ordnend das nach Objekt und/oder Subjekt Zulässige von dem nach Objekt und/oder Subjekt Unzulässigen trennend, individuelle und kollektive Freiheits - und Zuständigkeitsbereiche aus. Sie bewährt diese Verteilung in der, grundsätzlich von der Abwehrstellung der bedrohten oder verletzten Freiheitsräume und der konkurrierenden Zuständigkeitsbereiche her kontrollierten, Negation inkompetenter Dispositionen. Die Spielräume autonomer und heteronomer Entscheidungsmacht aufsaugen und, die möglichen Entscheidungen vorwegnehmend, vollends ausfüllen, kann sie nicht. Das überschritte nicht nur die Möglichkeiten des Rechts an sich sondern vor allem die einer Verfassung. Die Kompetenz der staatlichen Gemeinschaft kann um deren - von der Verfassung "verfaßten" - Existenz willen nicht einseitig preisgegeben werden. Den gesicherten Freiheitsraum des einzelnen kann die Verfassung schließlich nicht aufheben, ohne ihren freiheitlich-rechtsstaatlichen Auftrag zu verleugnen.

Die negativen Begrenzungen wirken in Anbetracht der vorhandenen, zur Aktivität drängenden Energien und im Hinblick auf die tatsächliche Beschränktheit der Wahlmöglichkeiten des konkreten Fintscheidungsträgers zwar auch positiv führend in die Freiheitsund Zuständigkeitsräume hinein. Aber eine Vorwegnahme positiver Entschlüsse und ihrer Verwirklichung ist der Verfassung grundsätzlich versagt. Entscheidungen, die sie nicht sachlich antizipieren kann, beherrscht die Verfassung nur insofern, als sie abst rakt bestimmen kann, welche Freiheits- und Zuständigkeitsräume welchen Subjekten zugewiesen werden.

Die vorstehende Untersuchung sollte zeigen, wie viel und wie wenig, auf welche $\Lambda \mathrm{rt}$ und Weise und in welcher Richtung das Grundgesetz auf die soziale Intervention des Staates Einfluß nimmt. Dabei wurde deutlich, wie schwach die Verfassung in dem Bemühen ist, den Trägernn der öffentlichen Gewalt die positive Gestaltung sozialer Verhältnisse und das Erbringen sozialer Leistungen abzufordern. Der Freiheitsraum des einzelnen seinerseits negiert die in ihn eingreifende heteronome Vorwegnahme der individuellen sozialen Verhaltensweisen wesensmäßig. Somit hängt Entscheidendes davon ab, wer welche sozial relevarten Zuständigkeiten und Freiheiten hat. Zwar sind auf sozialpschische Gesetzmäßigkeiten gestützte Verhaltenserwartun- 
gen nur von bedingter Gültigkeit. Doch bleibt die Relevanz etwa der sozialen Rollenverteilung zwischen der massendemokratischen Legislative und Exekutivspitze auf der einen und dem von der massendemokratischen Dynamik distanzierteren Richtertum und (weniger selbständigen) Berufsbeamtentum auf der anderen Seite, zwischen Bund und Ländern, zwischen Staat und unterstaatlichen Verbänden, zwischen Gebietskörperschaften und Personalverbänden, $z$ wischen $Z$ wangs- und freiwilligen Verbänden und - von der größten Bedeutung - $z$ wischen Kollektiv und Individuum evident.

Die Menschen, die sie ausfüllen und sich ihrer bedienen, bestimmen den Wert der Institutionen. Das Wesen der Subjekte, welchen die Verfassung - sie schaffend oder an Vorgefundenes (modifizierend oder nicht) anknüpfend - Kompetenz- und Freiheitsräume zuweist, bestimmt deren Erfüllung und letztlich die soziale Wirklichkeit. Die Tragweite der negativen Abgrenzungen erscheint in diesem Zusammenhang als relativ. Die Erfüllung der positiven Verfassungsprogrammatik hängt von den kompetenten Entscheidungssubjekten ab. Das darf, da die vordergründigen materiell sozialen Regelungen der Verfassung den Blick dessen, der nach dem Verfassungsrecht der sozialen Intervention sucht, zuerst fangen, nicht übersehen werden. 


\section{SCHRIFTTUMSVERZEICHNIS}

Gelegentlich herangezogene Literatur, die weder für die Arbeit von grundsätzlicher Bedeutung noch in ihr wiederholt zitiert ist, ist in das nachfolgende Verzeichnis nicht aufgenommen. Nähere Angaben über Veröffentlichungen, die in diesem Verzeichnis aufgeführt sind, finden sich innerhalb der A rbeit im allgemeinen nur bei der jeweils ersten Erwähnung.

A bendroth Wolfgang, Diskussionsbeitrag zu "Gegenwartsfragen sozialer Versicherung" in: "Gegenwartsfragen sozialer Versicherung", hrsg. v. Walter Bogs, Heidelberg 1950, S. $201 \mathrm{ff}$

- Diskussionsbeitrag zu "Begriff und Wesen des sozialen Rechtsstaates", VVDStRL Heft 12, 1954, S. 85 ff

- Zum Begriff des demokratischen und sozialen Rechtsstaats im Grundgesetz der Bundesrepublik Deutschland, in: "Aus Geschichte und Politik" Festschrift für Ludwig Bergstraesser, Düsseldorf 1954, S. 279 ff; desgl. in: Herbert Sultan und Wolfgang Abendroth, Bürokratischer Verwaltungsstaat und soziale Demokratie, Hannover/Frankfurt 1955, S. $81 \mathrm{ff}$

- Sultan Herbert und ---, Bürokratischer Verwaltungsstaat und soziale Demokratie, Hannover/Frankfurt 1955

- Die deutschen Gewerkschaften, 2.Aufl., Heidelberg 1955

A c hinger Hans, Soziale Sicherheit, Stuttgart 1953

- Zur Neuordnung der sozialen Hilfe, Stuttgart 1954

-, Höffner Joseph, Muthesius Hans, Neundörfer Ludwig, Neuordnung der sozialen Leistungen - Denkschrift auf Anregung des Herrn Bundeskanzlers erstattet von ..., Köln 1955

- Die Neuordnung der sozialen Leistungen, Hessische Hochschulwochen für staatswissenschaftliche Fortbildung, Band 13, Bad Homburg v. d. Höhe/Berlin/Zürich 1957, S.93 ff

Adle r Max, Politische oder soziale Demokratie, Berlin 1926

A dle $r$ Waldemar, Zulässigkeit von Alterszwangsversorgungseinrichtungen freier Berufe nach dem Grundgesetz, Deutsche Versicherungszeitschrift, VII.Jhg. (1953) S.200 ff 
A 1 be rs Willi, A ufgabe und Stellung der Gemeinde im Finanzsystem der öffentlichen Hand, Finanzarchiv n. F. Bd. 19 (1959) S. $399 \mathrm{ff}$

A $1 \mathrm{brecht}$ Gerhard, Sozialpolitik, Göttingen 1955

v. A 1 trock Albrecht, Der Standort der Sozialversicherung im Rechtsgefüge, in: "Sozialreform und Sozialrecht", Festschrift für Walter Bogs, Berlin 1959, S. 15 ff

A nkenbrand Kurt, Miesbach Hermann und ---., Sozialgerichtsgesetz, Frankfurt a. M. 1954 ff, Loseblatt Sammlung

Anschütz Gerhard, Die Verfassung des Deutschen Reiches, 14. Auf1., Berlin 1933

A pelt Willibalt, Betrachtungen zum Bonner Grundgesetz, NJW 2.Jhg. (1949) S.481 ff

- Verfassung und richterliches Prüfungsrecht, JZ 9. Jhg. (1954) S. $401 \mathrm{ff}$

- Diskussionsbeitrag zu "Begriff und Wesen des sozialen Rechtsstaates", VVDStRL Heft 12, 1954, S.107 f

A rndt Adolf, Das Problem der Wirtschaftsdemokratie, SJZ 1. Jhg. (1946) S. $137 \mathrm{ff}$

- Die Nichtigkeit verfassungswidriger Gesetze, DÖV 12.Jhg. (1959) S. $81 \mathrm{ff}$

- Vollstreckbarkeit verfassungswidriger (Steuer-)gesetze, Betriebsberater 14.Jhg. (1959) S. $533 \mathrm{ff}$

A rndt Claus, Die Bundesrepublik Deutschland als sozialer Rechtsstaat, Neue Gesellschaft, 3.Jhg. (1956) S.326 ff

- Die Gültigkeit rückwirkender Gesetze, DVB1. 73.Jhg. (1958) S. $120 \mathrm{ff}$

A rndt Erich, Artikel "Lohn (II) Politik", Handwörterbuch der Sozialwissenschaften, 27. Lieferung 1959, S. 17 ff

A rndt Herbert, Die ungeteilte Rechtsprechung, Deutsche Richterzeitung, 28.Jhg. (1950) S. $229 \mathrm{ff}$

- Empfiehlt es sich, die verschiedenen Zweige der Rechtsprechung ganz oder teilweise zusammenzufassen? Verhandlungen des 42. Deutschen Juristentages, Tübingen 1958, S. E $43 \mathrm{ff}$

A uffahrt, Anfechtbarkeit und Rechtsnatur der Allgemeinverbindlicherklärung von Tarifverträgen, Bundesarbeitsblatt 1957, S. $756 \mathrm{ff}$ 
A ugust in Karl, Zur Frage der verbundenen Steuerwirtschaft zwischen Bund, Ländern und Gemeinden, DÖV 6.Jhg. (1953) S. $709 \mathrm{ff}$

A ye Hans Adolf, Die Bedeutung der Selbstverwaltung für die Weiterentwicklung der gesetzlichen Krankenversicherung, in: "Beiträge zur Sozialversicherung", Festschrift für Johannes Krohn, Berlin 1954, S. 21 ff

Ba chof Otto, Verfassungswidrige Verfassungsnormen? Tübingen 1951

- Verwaltungsakt und innerdienstliche Weisung, in: "Verfassung und Verwaltung", Festschrift für Wilhelm Laforet, München 1952, S.285 ff

- Der Rechtsschutz im öffentlichen Recht: Gelöste und ungelöste Probleme, DÖV 6.Jhg. (1953) S. $417 \mathrm{ff}$

- Besprechung zu: Fechner, Freiheit und Zwang im sozialen Rechtsstaat, DVB1. 69.Jhg. (1954) S. $378 \mathrm{f}$

- Begriff und Wesen des sozialen Rechtsstaates, VVDStRL Heft 12, 1954, S. 37 ff, $121 \mathrm{ff}$

- Reflexwirkungen und subjektive Rechte im öffentlichen Recht, in: "Forschungen und Berichte aus dem öffentlichen Recht", Gedächtnisschrift für Walter Jellinek, München 1955, S.287ff

- Diskussionsbeitrag zu "Verwaltung und Verwaltungsrechtsprechung", VVDStRL Heft 14, 1956, S.176 ff

- Anmerkung zu BVerwG Urt. v.27. Juni 1955 - III C 25.54 JZ 11.Jhg. (1956) S. $35 \mathrm{f}$

-, Jesch Dietrich, Die Rechtsprechung der Landesverfassungsgerichte in der Bundesrepublik Deutschland, Jahrbuch des öffentlichen Rechts n.F., Bd.6, 1957, S. 47 ff

- Diskussionsbeitrag zu "Die besonderen Gewaltverhältnisse", VVDStRL Heft 15, 1957, S.203 ff

- Anmerkung zu BVerwG Urt. v.11. Oktober 1956 - I C 179/54DVB1. 72.Jhg. (1957) S. $788 \mathrm{ff}$

- Diskussionsbeitrag zu "Die Organisationsgewalt", VVDStRL Heft 16, 1958, S.264 ff

- Freiheit des Berufs, in: Bettermann-Nipperdey-Scheuner, Die Grundrechte, Bd. III 1. Halbbd., Berlin 1958, S. 155 ff 
Bärmann Johannes, Typisierte Zivilrechtsordnung der Daseinsvorsorge, Karlsruhe 1948

Balle rstedt Kurt, Rechtsstaat und Wirtschaftslenkung, AöR Bd. 74 (1948) S. $130 \mathrm{ff}$

- Unternehmen und Wirtschaftsverfassung, JZ 6. Jhg. (1951) S. $486 \mathrm{ff}$

- Diskussionsbeitrag zu "Grundgesetz und Energiewirtschaft", Elektrizitätswirtschaft, 56.Jhg. (1957) Heft 1, S.21 f

- Über wirtschaftliche Maßnahmegesetze, in: Festschrift für Walter Schmidt-Rimpler, Karlsruhe 1957, S.369 ff

- Wirtschaftsverfassungsrecht, in: Bettermann-NipperdeyScheuner, Die Grundrechte, Bd. III 1. Halbbd., Berlin 1958, S. $1 \mathrm{ff}$

Ba ring Martin, Die politische Selbstverwaltung und die Verwaltungsgerichtsbarkeit, DVB1. 70.Jhg. (1955) S.684 ff, $721 \mathrm{ff}$

Ba rocka Egon, Die Berücksichtigung sozialer Gesichtspunkte bei der Erhebung von Gebühren und Beiträgen für kommunale Abwasseranlagen, ihre Möglichkeiten, Problematik und Grenzen, DVB1. 75.Jhg. (1960) S. $825 \mathrm{ff}$

$\mathrm{B}$ a u e $\mathrm{r}$ Wilhelm, Aktuelle Kernfragen der Verwaltungsrechtspflege, DÖV 1.Jhg. (1948) S.28 ff

Ba ue $r$ Fritz, Lehrbuch der freiwilligen Gerichtsbarkeit, 1. Buch A T, Tübingen 1955

- Ist der Bundesgesetzgeber befugt, eine Vorschrift darüber $\mathrm{zu}$ treffen, daß Landesgerichte einem bestimmten Landesminister unterstellt werden? Deutsche Richterzeitung, 34 . Jhg. (1956) S.119 ff

- Sozialer Ausgleich durch Richterspruch, JZ 12.Jhg. (1957) S. $193 \mathrm{ff}$

B e cke r Erich, Die gemeindeverfassungsrechtliche Entwicklung im Bundesgebiet, Bad Godesberg 1953

- Die Selbstverwaltung als verfassungsmäßige Grundlage der kommunalen Ordnung in Bund und Ländern, in: Handbuch der kommunalen Wissenschaft und Praxis, hrsg. von Hans Peters, Bd.I, Berlin/Göttingen/Heidelberg 1956, S.113 ff

- Artikel "Anstalten des öffentlichen Rechts", Handwörterbuch der Sozialwissenschaften, Bd. 1, 1956, S.208 ff

- Verwaltung und Verwaltungsrechtsprechung, VVDStRL Heft 14,1956, S. $96 \mathrm{ff}$ 
Beit zke Günther, Die Gleichberechtigung von Mann und Frau im Arbeitsrecht, Recht der Arbeit, 6.Jhg. (1953) S.281 ff

- Gleichheit von Mann und Frau, in: Neumann-NipperdeyScheuner, Die Grundrechte, Bd.II, Berlin 1954, S. 199 ff

- Anmerkung zu BAG Urt. v.15.Januar 1955 - 1 AZR 305/54 AP Art. 3 GG $\mathrm{Nr} .4$

B e rg Christian, Das Diakonat als Lebensfunktion der Kirche, in: "Das diakonische Amt der Kirche", hrsg. v. Krimm, Stuttgart 1953, S. $477 \mathrm{ff}$

B e rger Hugo, Bedeutung und Tragweite des Grundsatzes vom sozialen Rechtsstaat, insbesondere für das Arbeitsrecht, Die Betriebsverfassung, 2.Jhg. (1955) Nr. 8, S. 4 ff

- Die Allgemeinverbindlicherklärung, DVB1. 71.Jhg. (1956) S. $858 \mathrm{f}$

- Die Rechtsnatur der Allgemeinverbindlicherklärung, Betriebsberater, 11.Jhg. (1956) S.533 ff

Berggrav Eivind, Der Staat und der Mensch, Hamburg 1946 Bernhardt Siegfried, Der Rentner und seine Menschenwürde, Zeitschrift für Sozialreform, 5.Jhg. (1959) S.540 ff

B e rnsdorf, Wilhelm, Bülow Friedrich, Wörterbuch der Soziologie, Stuttgart 1955

B e tte rmann Karl August, Grundfragen des Preisrechts für Mieten und Pachten, Tübingen 1952

- Verwaltungsakt und Richterspruch, in: "Forschungen und Berichte aus dem öffentlichen Recht", Gedächtnisschrift für Walter Jellinek, München 1955, S.361 ff

- Kompetenzfragen um den Kündigungsschutz im Kleingartenrecht, NJW 10.Jhg. (1957) S. 1497 ff

- Die freiwillige Gerichtsbarkeit im Spannungsfeld zwischen Verwaltung und Rechtsprechung, in: Festschrift für Friedrich Lent, München/Berlin 1957, S. 17 ff

- $\quad$ Bundeskompetenz für Jugendschutz, AöR Bd. 83 (1958) S.91 ff

- Der Schutz der Grundrechte in der ordentlichen Gerichtsbarkeit, in: Bettermann-Nipperdey-Scheuner, Die Grundrechte, Bd. III 2. Halbbd., Berlin 1959, S. 779 ff

- Die Unabhängigkeit der Gerichte und der gesetzliche Richter, in: Bettermann-Nipperdey-Scheuner, Die Grundrechte, Bd. III 2. Halbbd., Berlin 1959, S. 523 ff 
B ettermann Karl August, Anmerkung zu BGH Urt. v.4.Juni 1958 - V ZR 279/56 - NJW 12.Jhg. (1959) S. 43 f

- Das Verwaltungsverfahren, VVDStRL Heft 17, 1959, S.118 ff

- Die Allgemeinverbindlicherklärung eines Tarifvertrags: Rechtsschutz, Rechtskontrolle und Rechtsnatur, Recht der A rbeit, 12.Jhg. (1959) S.245 ff

B e ut le r Wilhelm, Stein Gustav, Wagner Hellmuth (Herausgeber), Der Staat und die Verbände, Heidelberg 1957

Beveridge, Lord, Freies Helfen - Nöte, die auch der Sozialstaat noch kennt, Zeitschrift für Sozialreform, 5.Jhg. (1959) S. 306 ff (= Übersetzung der Kapitel 7-12 von "Voluntary Action", 1948)

Bie denkopf Kurt H., Die Verfassungsproblematik eines Kartellverbots, Betriebsberater, 11.Jhg. (1956) S. $473 \mathrm{ff}$

Bisch off Hans-Albrecht, Staatsaufsicht und Selbstverwaltung in der Sozialversicherung, in: "Sozialpolitik, Arbeits- und Sozialrecht", Festschrift für Friedrich Sitzler, Stuttgart 1956, S. $113 \mathrm{ff}$

Blank Theodor, Die Freiheit im Wohlfahrtsstaat, Schriften der Gesellschaft für Sozialen Fortschritt e.V., Band 9, Berlin 1959 , S. $41 \mathrm{ff}$

Bleibtreu Otto, Demokratie, soziales Prinzip und Rechtsstaat, in: "Verantwortung für den Menschen", Festgabe für Heinrich Held, Stuttgart 1957, S. 100 ff

Boeckenfoerde Ernst-Wolfgang, Gesetz und gesetzgebende Gewalt, Berlin 1958

Boe ckenfoerde Werner, Der allgemeine Gleichheitssatz und die Aufgabe des Richters, Berlin 1957

Böhm Franz, Die Ordnung der Wirtschaft als geschichtliche Aufgabe und rechtsschöpferische Leistung, Stuttgart/Berlin 1937

- Die Bedeutung der Wirtschaftsordnung für die politische Verfassung, SJZ 1.Jhg. (1946) S. $141 \mathrm{ff}$

- Wirtschaftsordnung und Staatsverfassung, Tübingen 1950

- Das wirtschaftliche Mitbestimmungsrecht der Arbeitnehmer, ORDO Bd.IV (1951) S.21 ff

Boehme $r$ Gustav, Erbrecht, in: Neumann-Nipperdey-Scheuner, Die Grundrechte, Bd. II, Berlin 1954, S.401 ff 
B öhmert Viktor, Diskussionsbeitrag zu "Begriff und Wesen des sozialen Rechtsstaates", VVDStRL Heft 12, 1954, S. $116 \mathrm{f}$

Bötticher Eduard, Regelungsstreitigkeiten, in: Festschrift für Friedrich Lent, München/Berlin 1957, S. $89 \mathrm{ff}$

- Gesetzgebungskompetenz der Länder auf dem Gebiet des Arbeitsvertragsrechts? Recht der Arbeit, 11.Jhg. (1958) S. $361 \mathrm{ff}$

- Die Zuständigkeit der Einigungsstelle des $₫ 76$ Abs. 2 BetrVG in rechtsstaatlicher Sicht, in: "Beiträge zum Arbeits-, Handels- und Wirtschaftsrecht", Festschrift für Alfred Hueck, München/Berlin 1959, S. 149 ff

Bogs Walter, Entwicklung und Rechtsformen der Selbstverwaltung in der Sozialversicherung, in: "Gegenwartsfragen sozialer Versicherung", hrsg. von Walter Bogs, Heidelberg 1950 , S. $137 \mathrm{ff}$

- Zur Entwicklung der Rechtsform des Tarifvertrags, in: Festschrift für Julius Gierke, Berlin 1950, S. 39 ff

- Diskussionsbeitrag zu "Die verfassungsrechtliche Problematik der Zwangsversorgungseinrichtungen der freien Berufe", in: Aktuelle Probleme der Versicherungswirtschaft vom Standpunkt der Versicherungswissenschaft betrachtet, Berlin 1954 , S. $26 \mathrm{ff}$

- Zur Rechtsnatur der Versorgungseinrichtungen freier Berufe, in: "Beiträge zur Sozialversicherung", Festschrift für Johannes Krohn, Berlin 1954, S. 35 ff

- Zum Stand der Sozialreform, Recht der Arbeit, 8. Jhg. (1955) S. $331 \mathrm{ff}$

- Grundfragen des Rechts der sozialen Sicherheit und seiner Reform, Berlin 1955

- Probleme der Sozialreform, DÖV 8.Jhg. 1955, S.621 ff

- Artikel "Arbeitslosigkeit (II) A rbeitslosenfürsorge und Arbeitslosenversicherung", Handwörterbuch der Sozialwissenschaften, Bd.1 (1956) S. 312 ff

- Autonomie und verbandliche Selbstverwaltung im modernen A rbeits- und Sozialrecht, Recht der Arbeit, 9. Jhg. (1956) $\mathrm{S} .1 \mathrm{ff}=$ Hessische Hochschulwochen für staatswissenschaftliche Fortbildung, Band 9, Bad Homburg v.d. Höhe/Berlin 1956, S. $334 \mathrm{ff}$ 
Bogs Walter, Verfassungsrechtliche Entscheidungen des Bundessozialgerichts, in: "Sozialpolitik, Arbeits- und Sozialrecht", Festschrift für Friedrich Sitzier, Stuttgart 1956, S. $341 \mathrm{ff}$

- Zur Konstituierung des Sozialbeirates, Die Sozialgerichtsbarkeit, 5. Jhg. (1958) S. $141 \mathrm{ff}$

B ohley Erich, Die Behandlung der Gemeinden im Grundgesetz und in der Bayerischen Verfassung, Der Bayerische Bürgermeister, 2.Jhg. (1949) S.265 f; 3.Jhg. (1950) S. 5 f

de Boor Hans Otto, Die Auflockerung des Zivilprozesses, Tübingen 1939

Borris Maria, Staat und Verbände, Hessische Hochschulwochen für staatswissenschaftliche Fortbildung, Bd.20, Bad Homburg v. d. Höhe/Berlin/Zürich 1958, S. 134 ff

B rackmann Kurt, Gedanken zur Neuordnung des Verfahrens in der Sozialversicherung, in: "Gegenwartsfragen sozialer Versicherung", hrsg. von Walter Bogs, Heidelberg 1950, S. $115 \mathrm{ff}$

- Handbuch der Sozialversicherung, 1.-6.Auf1., Bad Godesberg 1959

Braun Heinrich, Motive sozialer Hilfeleistung, Frankfurt a. M. 1955

B ra u w ile r Heinz, Sozialverwaltung, Hamburg 1936

B reitling Rupert, Die Verbände in der Bundesrepublik, Meisenheim 1955

Brenner Günter, Zum Mitwirkungsrecht der Verbände und Vereinigungen bei der Gesetzgebung des Bundes und beim Erlaß von Verordnungen, Betriebsberater, 15. Jhg. (1960) S.373 ff

B riefs Goetz, Gewerkschaft und Freiheit, in: Erziehung zur Freiheit, Erlenbach-Zürich/Stuttgart 1959, S.111 ff

- Die Verbände - eine Gefahr für die Demokratie, Zeitwende, XXX. Jhg. (1959) S. 505 ff

Brill L., Gewaltenteilung im modernen Staat, Gewerkschaftliche Monatshefte, 7.Jhg. (1956) S.385 ff

B rill Hermann, Die soziale Bedeutung der Menschenrechte, Hessische Hochschulwochen für staatswissenschaftliche Fortbildung, Band 9, Bad Homburg v.d. Höhe/Berlin 1956, S. $128 \mathrm{ff}$

B rine $r$ Robert, Rechtsstaat und Sozialstaat, in: Arbeitgeberpolitik gestern und heute, Zürich 1958, S. 83 ff 
B r üge 1 m ann Hermann, Kommunale Versorgungswirtschaft, in: Handbuch der kommunalen Wissenschaft und Praxis, hrsg. von Hans Peters, Bd. III, Berlin/Göttingen/Heidelberg 1958, S. 655 ff

von Brünneck W., Die Verwaltungsgerichtsbarkeit im Verhältnis zur A rbeitsverwaltung und Sozialversicherung, Betriebsberater, 4.Jhg. (1949) S.619 f

Brunner Emil, Gerechtigkeit, Zürich 1943

Buchrucker A.E., Der Wohlfahrtsstaat als kirchliches Problem, Evangelisch-lutherische Kirchenzeitung, 1954, S. $36 \mathrm{ff}$

Bühler Ottmar, Gleichheit in der Lastenverteilung, in: Nipperdey, Die Grundrechte und Grundpflichten der Reichsverfassung, Bd.2, Berlin/Mannheim 1930, S.313 ff

- Diskussionsbeitrag zu "Begriff und Wesen des sozialen Rechtsstaates", VVDStRL Heft 12, 1954, S.98 f

B ü low Friedrich, Bernsdorf Wilhelm, -.-, Wörterbuch der Soziologie, Stuttgart 1955

Bul1a , Anmerkung zu BAG Urteile v. 14.Juli 1954 - 1 AZR 105, 89, 138/54 - (nach) AP Art. 3 GG Nr. 1-3

Bundesminister des Innern (Herausgeber), Die freie Wohlfahrtspflege, Beiträge zu einem Sozialatlas, Köln 1956

- Rechtliche Ordnung des Parteiwesens, 2.Aufl., Frankfurt a. M. / Berlin 1958

von Ca e m m e re r Ernst, Zur Gleichberechtigung der Geschlechter im Beamtenrecht, AöR Bd.76 (1950/51) S.144 ff

C1 1 a us en Wilhelm, Die Kosten des sozialen Fortschritts, Bundesarbeitsblatt, 11.Jhg. (1960) S. 52 ff

Coing Helmut, Grundsätzliches zur Rückwirkung von Gesetzen, Betriebsberater, 9.Jhg. (1954) S. $137 \mathrm{ff}$

Cornelssen Edmund, Über das Recht zur Schlichtung von Gesamtstreitigkeiten, Arbeit und Recht, 3.Jhg. (1955) S.41 ff

Dahrendorf Ralf, Reflektionen über Freiheit und Gleichheit, in: "Zur Ordnung von Wirtschaft und Gesellschaft", Hamburger Jahrbuch für Wirtschafts- und Gesellschaftspolitik, 4. Jhg. (Festausgabe für Eduard Heimann), Tübingen 1959, S. $56 \mathrm{ff}$ 
Dapprich Gerhard, Die Bindungswirkung von Bescheiden, Die Sozialgerichtsbarkeit, 7.Jhg. (1960) S.6 ff

Darmstaedter Friedrich, Die Grenzen der Wirksamkeit des Rechtsstaats, Heidelberg 1930

Decker Georg, Zum Begriff der Wirtschaftsdemokratie, Die Arbeit, 4. Jhg. (1927) S. $825 \mathrm{ff}$

Dehler Thomas, Gewerkschaften, Wirtschaftsdemokratie und Mitbestimmung, Arbeit und Sozialpolitik, 1954, S. $265 \mathrm{f}$

Deiting Gerhard, Freie Entfaltung der Persönlichkeit, Rechtssicherheit und Rückwirkung von Steuergesetzen, Steuer und Wirtschaft, XXXII. Jhg. (1955) Sp. $21 \mathrm{ff}$

De necke Johannes, Mutterschutz und Jugendschutz, in: Bettermann-Nipperdey-Scheuner, Die Grundrechte, Bd. III, 1. Halbbd., Berlin 1958, S. 475 ff

De rsch Hermann, Wechselwirkungen zwischen Sozialversicherung und A rbeitsrecht in der neueren Entwicklung, in: "Gegenwartsfragen sozialer Versicherung", hrsg. von Walter Bogs, Heidelberg 1950, S.33 ff

-, Kaskel Walter, ---, A rbeitsrecht, 5.Auf1., Berlin/Stuttgart/ Heidelberg 1957

- Die Sozialversicherung, in: Bettermann-Nipperdey-Scheuner, Die Grundrechte, Bd. III 1. Halbbd., Berlin 1958, S. $503 \mathrm{ff}$

- Der Verfassungsgrundsatz der Sozialstaatlichkeit und Rechtsstaatlichkeit in der Praxis der Sozialversicherung, in: "Sozialreform und Sozialrecht", Festschrift für Walter Bogs, Berlin 1959, S. $59 \mathrm{ff}$

Dersch-Volkmar, Dersch Hermann, Fitting Karl, Müller Gerhard, Schelp Günter, A rbeitsgerichtsgesetz, 6. Aufl., Berlin/Frankfurt a. M. 1955

D ibeli us Otto, Grenzen des Staates, Tübingen 1949

D i e ste $r$ Hans, Enteignung und Entschädigung nach altem und neuem Recht, o.O. 1953

Dietz Rolf, Keine Beschränkung der Tariffähigkeit auf Fachverbände, Betrieb 1951, S.325 ff

-, Nikisch Arthur, Arbeitsgerichtsgesetz, München/Berlin 1954 Die Betriebsverfassung in der Sozialordnung, Zeitschrift für die gesamte Staatswissenschaft, Bd. 110 (1954) S.651 ff 
Diet z Rolf, Betriebsverfassungsgesetz, 3.Auf1., München/Berlin 1955

- Das Monopol der Sozialpartner und die Betriebsvereinbarung, Recht der Arbeit, 8.Jhg. (1955) S.241 ff

- Personalvertretungsgesetz, München/Berlin 1956

- Rechtsgutachtliche Äußerung zu der Frage, ob Art. 3 Abs.2 und 3 des Grundgesetzes für die Bundesrepublik Deutschland der Berücksichtigung einer geringeren Wertigkeit von Frauenarbeit gegenüber der Männerarbeit sowie einer typisch geringeren sozialen Belastung der Frau gegenüber dem Mann bei der Aufstellung einer Norm für den Lohn entgegensteht, Köln 1957

- Freiheit und Bindung im kollektiven Arbeitsrecht - Historische und arbeitsrechtliche Betrachtung, Schriften der Gesellschaft für Sozialen Fortschritt e.V., Band 6, Berlin 1957, S. 13 ff

- Die Beteiligung der Arbeitnehmer an der Leitung und am Gewinn des Unternehmens, Deutsche Landesreferate zum V.Internationalen Kongreß für Rechtsvergleichung in Brüssel 1958, 1958, S. $113 \mathrm{ff}$

- Die Koalitionsfreiheit, in: Bettermann-Nipperdey-Scheuner, Die Grundrechte, Bd. III 1. Halbbd., Berlin 1958, S. $417 \mathrm{ff}$

Di11e r Georg, zur Rechtsprechung des Bayerischen Verfassungsgerichtshofes,

JZ 9.Jhg. (1954) S. $740 \mathrm{ff}$

JZ 10. Jhg. (1955) S. $15 \mathrm{ff}, 238 \mathrm{ff}, 270 \mathrm{ff}$

JZ 11.Jhg. (1956) S. $718 \mathrm{ff}, 756 \mathrm{ff}$

JZ 12. Jhg. (1957) S. $18 \mathrm{ff}, 53 \mathrm{ff}$

JZ 14.Jhg. (1959) S. 475 ff, $525 \mathrm{ff}, 568 \mathrm{ff}$

Dobbernack Wilhelm, Die Bedeutung des Grundgesetzes und (les Besatzungsstatuts für die Sozialversicherung und die Kriegsopferversorgung, Die Sozialversicherung, 4.Jhg. (1949) S. $146 \mathrm{ff}$

- Die grundsätzlichen Probleme der zwischenstaatlichen Abkommen über soziale Sicherheit, Bundesarbeitsblatt 1955, S. 12 ff

v. Doemming Klaus-Berto, Füßlein Rudolf Werner, Matz Werner, Entstehungsgeschichte der Artikel des Grundgesetzes, Jahrbuch des öffentlichen Rechts n.F., Bd.1 (1951) 
Draht Martin, Die Gewaltenteilung im heutigen deutschen Staatsrecht, in: "Faktoren der Machtbildung", Schriften des Instituts für politische Wissenschaften, Berlin 1952, S.99 ff

Drews Günter, Die Gewerkschaften in der Verwaltungsordnung, Heidelberg 1958

Dürig Günter, Die Menschenaufassung des Grundgesetzes, JR 1952, S. 259 ff

- Art.2 des Grundgesetzes und die Generalermächtigung zu allgemeinpolizeilichen Maßnahmen, AöR Bd. 79 (1953) S. 57 ff

- Verfassung und Verwaltung im Wohlfahrtsstaat, JZ 8. Jhg. (1953) S. $193 \mathrm{ff}$

- Besprechung zu: Menger, Der Begriff des sozialen Rechtsstaats im Bonner Grundgesetz, AöR Bd.79 (1953) S. 254 ff

- Das Eigentum als Menschenrecht, Zeitschrift für die gesamte Staatswissenschaft, Bd. 109 (1953) S. 326 ff

- Zurück zum klassischen Enteignungsbegriff! JZ 9. Jhg. (1954) S. $4 \mathrm{ff}$

- Freizügigkeit, in: Neumann-Nipperdey-Scheuner, Die Grundrechte, Bd. II, Berlin 1954, S. $507 \mathrm{ff}$

- Art.9 Grundgesetz in cler Kartellproblematik, NJW 8. Jhg. (1955) S. $729 \mathrm{ff}$

- Grundfragen des öffentlich-rechtlichen Entschädigungssystems, JZ 10.Jhg. (1955) S. $521 \mathrm{ff}$

- Der Grundrechtssatz von der Menschenwürde, AöR Bd. 81 (1956) S. $117 \mathrm{ff}$

- Grundrechte und Privatrechtsprechung, in: "Vom Bonner Grundgesetz zur gesamtdeutschen Verfassung"', Festschrift für Hans Nawiasky, München 1956, S. 157 ff

- Artikel "Staatsformen", Handwörterbuch der Sozialwissenschaften, Bd.9, 1956, S. $742 \mathrm{ff}$

- Anmerkung zu BVerfG Urt. v. 16.Januar 1957 - 1 BvR 253/ 56 - JZ 12.Jhg. (1957) S. $169 \mathrm{ff}$

- Anmerkung zu BSG Urt. v. 19. Mäız 1957 - $6 \mathrm{RKa} \mathrm{5/55,} \mathrm{JZ}$ 13.Jhg. (1958) S.22 ff

Der Staat und die vermögenswerten öfentlich-rechtlichen Berechtigungen seiner Bürger, in: "Staat und Bürger", Festschrift für Willibalt Apelt, München/Berlin 1958, S. 13 ff 
D ürig Günter, Maunz Theodor, ---, Grundgesetz, München/ Berlin 1958 ff (abgekürzt zit. mit: Maunz-Dürig)

Ebbinghaus J.E., Sozialismus der Wohlfahrt und Sozialismus des Rechts, SJZ 2. Jhg. (1947) S. 137 ff

Eckert-Schraft, hrsg. von Maunz Theodor und Schraft H., Das Selbstverwaltungsrecht der Sozialversicherung, Berlin o.J. (Loseblattausg.)

Ehard Hans, Das Verhältnis zwischen Bund und Ländern und der Bundesrat, Bayerische Verwaltungsblätter n.F., 7.Jhg. (1961) S. $1 \mathrm{ff}$

Ehle rmann Claus-Dieter, Wirtschaftslenkung und Entschädigung, Heidelberg 1957

Ehle rs Hans, Zur Verfassungswidrigkeit des Kindergeldgesetzes, Der Betrieb, 10.Jhg. (1957) S.308 ff

Ehrenforth Werner, Das Recht des Wohnungswesens, der Siedlung, Landwirtschaft und Bodenreform, München/Berlin o. J. (Loseblattausg.)

Ehrensberger Otto, Verfassungsrechtliche Fragen im Grenzgebiet $z$ wischen kommunaler Selbstverwaltung und freier Wirtschaft, DÖV 9.Jhg. (1956) S. 129 ff

Engis ch Karl, Die Idee der Konkretisierung in Recht und Rechtswissenschaft unserer Zeit, Heidelberg 1953

Erdmann Ernst-Gerhard, Das Recht der Arbeitnehmer auf Beteiligung an der Verwaltung der Betriebe in der gewerblichen Wirtschaft, Schriftenreihe der Bundesvereinigung der A rbeitgeberverbände, Heft 5, Düsseldorf 1952

- Die soziale Selbstverwaltung in ihrer rechts- und staatspolitischen Bedeutung, in: "Sozialpolitik, Arbeits- und Sozialrecht", Festschrift für Friedrich Sitzler, Stuttgart 1956, S. $43 \mathrm{ff}$

Erdsiek, Freiheitsentziehung und richterliche Kontrolle, NJW 13.Jhg. (1960) S. 1385 ff

Frmacora Felix, Die Organisationsgewalt, VVDStRL Heft 16, 1958, S. $191 \mathrm{ff}$

Erning Adolf, Der Grundsatz der Rechtsstaatlichkeit und die Widerrufbarkeit des begünstigenden, mangelhaften Verwaltungsaktes, DVB1. 75.Jhg. (1960) S. $188 \mathrm{ff}$

- Der Widerruf begünstigender mangelhafter Verwaltungsakte mit Doppelwirkung, DVBl. 75.Jhg. (1960) S. $467 \mathrm{ff}$ 
Eschenburg Theodor, Herrschaft der Verbände? (2. Aufl. von

"Staatsautorität und Gruppenegoismus"), Stuttgart 1955

Evers Hans-Ulrich, Der Richter und das unsittliche Gesetz, Berlin 1956

Eyermann Erich, Die Rechtsstaatlichkeit in der Rechtsprechung des Bayerischen Verwaltungsgerichtshofs, Bayerische Verwaltungsblätter n.F., 5.Jhg. (1959) S. 310 ff

v. Eynern Gert, Der Finanzausgleich zwischen Bund, Ländern und Gemeinden, in "Bund und Länder", hrsg. von Ossip K. Flechtheim, Berlin 1959, S. $124 \mathrm{ff}$

- Über den Einfluß des Bundes auf seine Unternehmen, in:

"Zur Ordnung von Wirtschaft und Gesellschaft", Hamburger Jahrbuch für Wirtschafts- und Gesellschaftspolitik, 4.Jhg. (Festausgabe für Eduard Heimann), Tübingen 1959, S.113 ff

Fechner Erich, Freiheit und Zwang im sozialen Rechtsstaat, Tübingen 1953

- Die soziologische Grenze der Grundrechte, Tübingen 1954

- Sozialer Rechtsstaat und Arbeitsrecht, Recht der Arbeit, 8. Jhg. (1955) S. $161 \mathrm{ff}$

- Artikel "A rbeitspflicht und A rbeitszwang", Handwörterbuch der Sozialwissenschaften, Bd.1, 1956, S.337

-, Maier Hedwig, Die Rechtswirksamkeit der arbeitsrechtlichen Bestimmungen des sog. Truppenvertrages, Recht der A rbeit, 9.Jhg. (1956) S. $87 \mathrm{ff}$

Fe de re $r$ Julius, Die Rechtsprechung des Bundesverfassungsgerichts zum Grundgesetz für die Bundesrepublik Deutschland, Jahrbuch des öffentlichen Rechts n.F., Bd. 3 (1954) S. $15 \mathrm{ff}$

Fehrs Detlef, Die wirtschaftlichen Verhältnisse der Sozialleistungsempfänger in der Bundesrepublik Deutschland und Berlin (West), Bundesarbeitsblatt 1956, S. $810 \mathrm{ff}$

- Die öffentlichen Sozialleistungen in der Bundesrepublik Deutschland einschließlich Berlin (West) von 1949 bis 1958, Bundesarbeitsblatt, 10.Jhg. (1959), S. 762 ff

Fikentscher Wolfgang, Wettbewerb und gewerblicher Rechtsschutz, München/Berlin 1958 
Fischbach Oscar Georg, Inwieweit läßt Art. 33 Abs. 5 GG eine Reform des Beamtenrechts zu? Verhandlungen des 39. Deutschen Juristentages, 'Tübingen 1951, S.D 33 ff

Fischerhof Hans, Öffentliche Versorgung mit Wasser, Gas, Elektrizität und öffentliche Verwaltung, DÖV 10.Jhg. (1957) S. $305 \mathrm{ff}$

- "Daseinsvorsorge" und wirtschaftliche Betätigung der Gemeinden, DÖV 13.Jhg. (1960) S.41 ff

Fischer-Menshausen Herbert, Die Abgrenzung der Finanzverantwortung zwischen Bund und Ländern, DÖV 5.Jhg. (1952) S. $673 \mathrm{ff}$

- Bemerkungen, DÖV 6.Jhg. (1953) S.229 f

- Die staatswirtschaftliche Bedeutung des neuen Finanzausgleichs, DÖV 8.Jhg. (1955) S.261 ff

- Das Finanzverfassungsgesetz, DÖV 9.Jhg. (1956) S. 161 ff

Fless a Richard, Schuldverhältnisse des Staates auf Grund Verwaltungsaktes, DVB1. 72.Jhg. (1957) S. $118 \mathrm{ff}$

Flume Werner, Steuerwesen und Rechtsordnung, in: "Rechtsprobleme in Staat und Kirche", Festschrift für Rudolf Smend, Göttingen 1952, S. 59 ff

- Diskussionsbeitrag zu "Enteignung und Sozialisierung", VVDStRL Heft 10, 1952, S. 156 ff

- Rechtsgeschäft und Privatautonomie, in: "Hundert Jahre Deutsches Rechtsleben", Festschrift Deutscher Juristentag, Bd.I, Karlsruhe 1960, S. 135 ff

F'ödisch Rolf A., Freiheit und Zwang im geltenden Koalitionsrecht, Recht der Arbeit, 8. Jhg. (1955) S. 88 ff

Föh 1 Carl, Das Steuerparadoxon, Finanzarchiv n.F., Bd.17 (1956/57) S. 1 ff

Foohs Ludwig, Kommunalgesetzgebung und Finanzausgleich in Bayern, in: "Verfassung und Verwaltung", Festschrift für Wilhelm Laforet, München 1952, S.351 ff

Forschbach Edmund, Grundsätzliche Erwägungen zum Flüchtlingsnotleistungsgesetz, DVB1. 68. Jhg. (1953) S. $331 \mathrm{f}$

Forsthoff Ernst, Die Verwaltung als Leistungsträger, Stuttgart/Berlin 1938 
Forsthoff Ernst, Die Wirtschaftsverfassung im Rahmen der Gesamtverfassung, in: "Ratgeber von Parlament und Regierung", hrsg. vom Institut zur Förderung öffentlicher Angelegenheiten e.V., Frankfurt a.M. 1951, S. $127 \mathrm{ff}$

- Verfassungsrechtliche Prolegomena zu Art.33 Abs.5 GG, DÖV 4.Jhg. (1951) S.460 ff

- Zur Problematik des Bundeswirtschaftsrates, DÖV 5. Jhg. (1952) S. $714 \mathrm{ff}$

- Verfassungsprobleme des Sozialstaats, Münster 1954

- Begriff und Wesen des sozialen Rechtsstaates, VVDStRL Heft 12, 1954, S. 8 ff, 126 ff

- Eigentumsschutz öffentlich-rechtlicher Rechtsstellungen, NJW 8.Jhg. (1955) S. $1249 \mathrm{ff}$

- Über Maßnahme-Gesetze, in: "Forschungen und Berichte aus dem öffentlichen Recht", Gedächtnisschrift für Walter Jellinek, München 1955, S.221 ff

- Diskussionsbeitrag zu "Verwaltung und Verwaltungsrechtsprechung", VVDStRL Heft 14, 1956, S. $187 \mathrm{f}$

- Anmerkung zu BVerwG Urt. v.24. Oktober 1956 - V C 236/ 54 - DVB1. 72.Jhg. (1957) S. $724 \mathrm{ff}$

- Die Daseinsvorsorge der Kommunen, Köln-Marienburg 1958

- Lehrbuch des Verwaltungsrechts, I. Band: Allgemeiner Teil (zitiert: Lehrbuch des Verwaltungsrechts), 7.Aufl., München/Berlin 1958

- Die Umbildung des Verfassungsgesetzes, Festschrift für Carl Schmitt, Berlin 1959, S.35 ff

- Die Bindung an Gesetz und Recht (Artikel 20 Abs. 3 GG), DÖV 12. Jhg. (1959) S. $41 \mathrm{ff}$

- Rechtsfragen der leistenden Verwaltung, Stuttgart 1959

Franke Wolfgang, Grundlagen der Anstaltsunterbringung Psychischkranker in verfassungs-, privat- und verwaltungsrechtlicher Sicht, NJW 13.Jhg. (1960) S. 1369 ff

Fraenkel Ernst, Die repräsentative und die plebiszitäre Komponente im demokratischen Verfassungsstaat, Tübingen 1958

v. Frauendorfer Sigmund, Artikel "Bodenreform", Handwörterbuch der Sozialwissenschaften, Bd.2, 1959, S.336 ff 
Freese Heinrich, Das konstitutionelle System im Fabrikbetrieb, Die Verhandlungen des 10. Evangelisch-sozialen Kongresses, abgehalten in Kiel am 25. u. 26. Mai 1899, Göttingen 1899 , S. 56 ff

- Die konstitutionelle Fabrik, Jena 1909

Freudenberger Georg, Beiträge zur Lehre vom besonderen Gewaltverhältnis im öffentlichen Recht, Annalen des Deutschen Reichs, 64.Jhg. (1931) S. 163 ff

Frey Erich, Der Grundsatz der Gleichbehandlung im Arbeitsrecht, München/Düsseldorf 1954

- Gleichheitserwägungen im Privatrecht und Sozialversicherungsrecht, Arbeit und Recht, 7.Jhg. (1959) S. 362 ff

- Der Begriffsinhalt des Grundsatzes der Gleichbehandlung im A rbeitsrecht, Arbeit und Recht, 8.Jhg. (1960) S. $37 \mathrm{ff}$

- Argumente gegen die Gleichbehandlung im Arbeitsrecht als Rechtsprinzip, Arbeit und Recht, 8. Jhg. (1960) S.97 ff

- Allgemeine Regeln bei der Anwendung des Grundsatzes der Gleichbehandlung im Arbeitsrecht, Arbeit und Recht, 8.Jhg. (1960) S. $168 \mathrm{ff}$

- Zivilrechtliche Institute und Fürsorgedenken als versuchte Dogmatisierung des Gleichbehandlungsgrundsatzes im Arbeitsrecht, A rbeit und Recht, 8.Jhg. (1960) S.231 ff

- Die konkrete Ordnung im Betrieb und die Übung im Betrieb als versuchte Dogmatisierung des Gleichbehandlungsgrundsatzes im Arbeitsrecht, A rbeit und Recht, 8.Jhg. (1960) S. $302 \mathrm{ff}$

F rey Helmut, Die Rechtsnatur der Belegschaft und des Betriebsrates, Recht der A rbeit, 13.Jhg. (1960) S. $89 \mathrm{ff}$

Freyer Hans, Theorie des gegenwärtigen Zeitalters, Stuttgart 1956,1958

Friederichs Helmut, Zwei Jahre Sozialgerichtsbarkeit, Betriebsberater 11.Jhg. (1956) S. $276 \mathrm{ff}$

- Zwei Jahre Sozialgerichtsbarkeit - Gegenstellungnahme, Betriebsberater 11.Jhg. (1956) S.662 f

- Ressortvereinheitlichurg - allzuständiges Gericht, NJW 10. Jhg. (1957) S. $1344 \mathrm{ff}$

- Zur Verfassungsmäßigkeit der Kindergeldgesetzgebung, Betriebsberater 13.Jhg. (1958) S. 1024 ff 
Friedrich Carl Joachim, Der Verfassungsstaat der Neuzeit, Berlin/Göttingen/Heidelberg 1953

- Artikel "Demokratie", Handwörterbuch der Sozialwissenschaften, Bd.2, 1959, S. $560 \mathrm{ff}$

Friedrich Otto A., Recht und Grenzen der Interessenvertretung, in: "Legitime Interessenvertretung", hrsg. v. der Evangelischen Akademie Loccum, Loccum 1956, S. 19 ff

Friesenhahn Ernst, Über Begriff und Arten der Rechtsprechung, in: Festschrift für Richard Thoma, Tübingen 1950, S. $21 \mathrm{ff}$

- Die politischen Grundlagen des Bonner Grundgesetzes, Recht Staat Wirtschaft, Bd.2, 1950, S. $164 \mathrm{ff}$

- Die rechtsstaatlichen Grundlagen des Verwaltungsrechts, Recht Staat Wirtschaft, Bd.2, 1950, S.239 ff

- Schmidt-Rimpler Walter, Gieseke Paul, --- und Knur Alexander, Die Lohngleichheit von Männern und Frauen, AöR Bd. $76(1950 / 51)$ S. $165 \mathrm{ff}$

- Staatsrechtslehrer und Verfassung, Krefeld 1950 - Recht Staat Wirtschaft, Bd. 3, 1951, S. $51 \mathrm{ff}$

- Grundgesetz und Energiewirtschaft, Elektrizitätswirtschaft, Bd. 56 (1957) Heft 1, S. 12 ff

- Parlament und Regierung im modernen Staat, VVDStRL Heft 16,1958 , S. 9 ff

Frisch Alfred, Wohlfahrts- und Interessenstaat, Dokumente, 14.Jhg. (1958) S. $439 \mathrm{ff}$

Fröhle r Ludwig, Landesgesetzliche Beschränkungen der wirtschaftlichen Betätigung der öffentlichen Hand? Bayerische Verwaltungsblätter n.F., 2.Jhg. (1956) S. 135 ff

$F \ddot{~ u ̈ ~} 1$ e in Rudolf Werner, v. Doemming Klaus Berto, --., Matz Werner, Entstehungsgeschichte der Artikel des Grundgesetzes, Jahrbuch des öffentlichen Rechts n.F., Bd. 1 (1951)

- Der überregionale Verwaltungsakt, DVB1. 66. Jhg. (1951) S. $33 \mathrm{ff}$

- Vereins- und Versammlungsfreiheit, in: Neumann-Nipperdey-Scheuner, Die Grundrechte, Bd.II, Berlin 1954, S. 425 ff

- Mischverwaltung oder Mitverwaltung, DVBl. 71.Jhg. (1956) S. $1 \mathrm{ff}$ 
Fuss Ernst-Werner, Grundrechtsgeltung für Hoheitsträger? DVB1. 73.Jhg. (1958) S. $739 \mathrm{ff}$

- Gleichheitssatz und Richtermacht, JZ 14. Jhg. (1959)S. 329 ff

Gablentz Otto-Heinrich, Die politischen Parteien als Ausdruck gesellschaftlicher Kräfte, Berlin 1952

- Die Chancen des Föderalismus in der gegenwärtigen Gesellschaft, in: "Bund und Länder", hrsg. v. Ossip K. Flechtheim, Berlin 1959, S. 142 ff

Ga 1 pe rin Hans, Anmerkung zu BAG Urt. v.14.Juli 1954 AZR 105/54 - JZ 9.Jhg. (1954) S. 571 ff

- Gleicher Lohn für Männer und Frauen, JZ 11.Jhg. (1956) S. $105 \mathrm{ff}$

- Die Arbeitsgerichtsbarkeit als besondere Gerichtsbarkeit, Die Betriebsverfassung, 4.Jhg. (1957) S. $81 \mathrm{ff}$

- Die Vereinheitlichung der Gerichtsbarkeit und die Gerichte für A rbeitssachen, Zeitschrift für Sozialreform, 3.Jhg. (1957) S. $133 \mathrm{ff}$

- Organisationszwang und Koalitionsfreiheit, in: "Sozialreform und Sozialrecht", Festschrift für Walter Bogs, Berlin 1959 , S. $87 \mathrm{ff}$

Gass Berthold, Zur verfassungsrechtlichen Problematik der saarländischen A rbeitskammer und der bremischen Arbeitnehmerkammern, DÖV 13.Jhg. (1960) S. 778 ff

Ga a 1 Dieter, Die Bedeutung der Frauenlohnurteile des Bundesarbeitsgerichts für die Tarifpraxis und das ILO-Übereinkommen 100, Recht der Arbeit, 8.Jhg. (1955) S.361 ff

- Der Frauenlohn in den 'Tarifverträgen, Recht der Arbeit, 9. Jhg. (1956) S. $254 \mathrm{ff}$

Gawronsky Vital, Staatsgewalt und Volkswohlfahrt, 2.Aufl., München 1950

Gebauer Werner, Eigentumspolitische Probleme unserer Wirtschaftsverfassung, in: "Vom Bonner Grundgesetz zur gesamtdeutschen Verfassung", Festschrift für Hans Nawiasky, München 1956, S. $317 \mathrm{ff}$

$\mathrm{G} \epsilon \cdot \mathrm{k}$ Adolf, Erkenntnis und Heilung des Soziallebens, Soziale Welt, 1.Jhg. (1949/50) S. 3 ff

- Die soziale Problematik und das Recht, Soziale Welt, 6. Jhg. (1955) S. $117 \mathrm{ff}$ 
Gehlen Arnold, Zur Problematik des Sozialstaates, Hessische Hochschulwochen für staatswissenschaftliche Fortbildung, Bd. 11, Berlin/Zürich 1956, S. 51 ff

- Bürokratisierung und Daseinssicherung, Universitas, 12. Jhg. (1957) S. 43 ff

Geige $r$ Willi, Die Bundesverfassungsgerichtsbarkeit in ihrem Verhältnis zur Landesverfassungsgerichtsbarkeit und ihre Einwirking auf die Verfassungsordnung der Länder, in: "Verfassung und Verwaltung", Festschrift für Wilhelm Laforet, München 1952, S.251 ff

- Grundgesetzliche Schranken für eine Kartellgesetzgebung, Köln/Berlin 1955

- Der Gleichheitssatz und der Gesetzgeber, in: "Staats- und verwaltungswissenschaftliche Beiträge", Stuttgart 1957, S. $167 \mathrm{ff}$

- Grundrechte und Rechtsprechung, München 1959

- Artikel "Gerechtigkeit", Staatslexikon Bd.III, 6.Aufl., 1959, S. $779 \mathrm{ff}$

Ge $r$ be $r$ Hans, Die grundsätzliche Bedeutung der beamtenrechtlichen Regelungen des Bonner Grundgesetzes, DVB1. 66. Jhg. (1951) S. 489 ff

- Die Sozialstaatsklausel des Grundgesetzes, AöR Bd.81 (1956) S. 1 ff

Gerne $r$ Erich, Zur Frage der Mischverwaltung im Verhältnis zwischen Bund und Ländern, Bayerische Verwaltungsblätter n.F., 1.Jhg. (1955) S. $193 \mathrm{ff}$

Gerstenmaier Eugen, "Wichern zwei" - Zum Verhältnis von Diakonie und Sozialpolitik, in: "Das diakonische Amt der Kirche", Stuttgart 1953, S. 499 ff

Gi e rke Otto, Die Genossenschaftstheorie und die deutsche Rechtsprechung, Berlin 1887

- Die soziale Aufgabe des Privatrechts, Berlin 1889

- Deutsches Privatrecht, Band I, Leipzig 1895

Giese Friedrich, Staatsrechtliche Gedanken zur Verwaltungsreform, DÖV 9.Jhg. (1956) S. $357 \mathrm{ff}$

-, Schunck Egon, Grundgesetz für die Bundesrepublik Deutschland, 5.Auf1., Frankfurt a. M. 1960 (abgekürzt zitiert mit: Giese-Schunck) 
Gie seke Paul, Schmidt-Rimpler Walter, ---, Friesenhahn Ernst und Knur Alexander, Die Lohngleichheit von Männern und Frauen, AöR Bd. 76 (1950/51) S. 165 ff

Gönnenwein Otto, Anmerkung zu OVG Lüneburg Urt. v. 14. März 1951 - II OVG - A 602/50 - JZ 6.Jhg. (1951) S. 525

Görg Hubert, Kommunales Dienstrecht, in: Handbuch der kommunalen Wissenschaft und Praxis, hrsg. von Hans Peters, Bd. II, Berlin/Göttingen/Heidelberg 1957, S. 44 ff

- Probleme der Bundesfinanzverfassung, in: "Staats- und verwaltungswissenschaftliche Beiträge", Stuttgart 1957, S.205 ff

- Bundesauftragsangelegenheiten der Gemeinden und Gemeindeverbände und ihre Pflichtaufgaben nach Weisung, DÖV 14.Jhg. (1961) S. $41 \mathrm{ff}$

Götz Volkmar, Wirtschaftsverwaltungsrechtliche Ausgleichsabgaben, AöR Bd. 85 (1960) S.200 ff

Grabowsky Adolf, Staatsverfestigung oder Staatsabbau? Zeitschrift für Politik n. F., 5.Jhg. (1958) S.97 ff

Grafe Walter, Gemeindliche Personalhoheit unter Selbstverwaltungsgarantie, DÖV 8.Jhg. (1955) S. $650 \mathrm{ff}$

Greiner Gottfried, Wiederbelebung des klassischen Enteignungsbegriffes, DÖV 7. Jhg. (1954) S. 583 ff

Grewe Wilhelm, Das bundesstaatliche System des Grundgesetzes, DRZ 4.Jhg. (1949) S. 349 ff

- Die Bundesrepublik als Rechtsstaat, DRZ 4.Jhg. (1949) S. 392 ff

- Der Begriff des "sozialen Staates" in der deutschen Verfassungsentwicklung, Der A rbeitgeber 1950/51, Nr. 24/1, S. $39 \mathrm{ff}$

- Zur Gleichberechtigung der Geschlechter im Beamtenrecht, Ä̈le Bd. $76(1950 / 51)$ S. $161 \mathrm{ff}$

- Inwiefern 1äßt Art.33 Abs.5 GG eine Reform des Beamtenrechts zu? Verhandlungen des 39. Deutschen Juristentages, Tübingen 1951, S.D 3 ff

Grim m Claus, Besteuerung und Grundgesetz, Stuttgart 1959

G1.ob Rudolf, Staatliche Sozialfürsorge oder christliche Liebestätigkeit? Kirche in der Zeit, 8.Jhg. (1953) S. 173 ff 
v.d. Gröben, Mitwirkung von Ausschüssen in der staatlichen Verwaltung - Möglichkeit, Bewährung, Grenzen - A) Der norddeutsche Raum, Verwaltungsarchiv, Bd.49 (1958)

S. $231 \mathrm{ff}$

Gröm ig Hans, Die Zulässigkeit der Klage nach $₫ 54$ SGG, NJW 7. Jhg. (1954) S. $1183 \mathrm{ff}$

- Die sittliche Rechtfertigung für eine Schadensersatzrente nach dem Bundesversorgungsgesetz, Zeitschrift für Sozialreform, 5.Jhg. (1959) S. $188 \mathrm{ff}, 265 \mathrm{ff}$

Grossmann Ruprecht, Änderung der vorkonstitutionellen Urlaubsgesetze durch die Länder, Betriebsberater, 15. Jhg. (1960) S. $867 \mathrm{ff}$

Gruner Erich, Die Wirtschaftsverbände in der Demokratie, Erlenbach-Zürich/Stuttgart 1956

Gygi Fritz, Verwaltungsrecht und Privatrecht, Bern 1956

- Interventionsrecht und Interventionsverwaltung, Bern 1958

Ha a s Diether, System der öffentlichrechtlichen Entschädigungspflichten, Karlsruhe 1955

- Bundesgesetze über Organisation und Verfahren der Landesbehörden, AöR Bd.80 (1955/56) S.81 ff

- Ausschüsse in der Verwaltung, Verwaltungsarchiv, Bd.49 (1958) S. $14 \mathrm{ff}$

- Das Verwaltungsprivatrecht im System der Verwaltungshandlungen und der fiskalische Bereich, DVBl. 75.Jhg. (1960) S. $303 \mathrm{ff}$

Habscheid Walther J., Die Zivilrechtspflege im Spannungsfeld verfassungsrechtlicher Grundsätze, JR 1958 S.321 ff

$\mathrm{H}$ a cke $r$ Horst, Finanzausgleich, in: Handbuch der kommunalen Wissenschaft und Praxis, hrsg. von Hans Peters, Bd. III, Berlin/Göttingen/Heidelberg 1958, S.395 ff

Halls te in Walter, Von der Sozialisierung des Privatrechts, Zeitschrift für die gesamte Staatswissenschaft, Bd.102 (1942) S. $530 \mathrm{ff}$

- Wiederherstellung des Privatrechts, SJZ 1. Jhg. (1946) S. $1 \mathrm{ff}$

H a mann Andreas, Wirtschaftslenkung durch Steuern, Betriebsberater, 7. Jhg. (1952) S.956 ff

- Rechtsstaat und Wirtschaftslenkung, Heidelberg 1953 
Hamann Andreas, Die Ermessensfreiheit der Gesetzgebung, NJW 8. Jhg. (1955) S. 969 ff

- Vereinheitlichung der Gerichtsbarkeiten? DVB1. 70.Jhg. (1955) S.205 ff

- Das Grundgesetz, Berlin/Neuwied/Darmstadt 1956

- Die Bindung der staatlichen Organisationsgewalt an die Gesetzgebung, NJW 9.Jhg. (1956) S. 1 ff

- Die Rechtsprechung des Bundesverfassungsgerichts über den Gleichheitsgrundsatz, NJW 10.Jhg. (1957) S. 2 ff

- Die "verfassungsmäßige Ordnung", Betriebsberater, 12.Jhg. (1957) S. $229 \mathrm{ff}$

- Nochma1s: Die "verfassungsmäßige Ordnung", Betriebsberater, 12.Jhg. (1957) S. $343 \mathrm{f}$

- Deutsches Wirtschaftsverfassungsrecht, Neuwied/Berlin/ Darmstadt 1958

- Autonome Satzungen und Verfassungsrecht, Heidelberg 1958

- Aussetzung der Vollziehung von Steuerbescheiden bei verfassungsrechtlich zweifelhaften Steuergesetzen, NJW 12.Jhg. (1959) S. $1465 \mathrm{ff}$

Ha mel Walter, Die Bedeutung der Grundrechte im sozialen Rechtsstaat, Berlin 1957

- Glaubens- und Gewissensfreiheit, in: Bettermann-NipperdeyScheuner, Die Grundrechte, Bd. IV 1. Halbbd., Berlin 1960, S. $37 \mathrm{ff}$

Hansmeyer Karl-Heinrich, Der Weg zum Wohlfahrtsstaat, Frankfurt a. M. 1957

Hartz Wilhelm, Sittlichkeit, Rechtssicherheit und Gewaltenteilung als Elemente des Rechtsstaats, Steuerberaterjahrbuch $1958 / 59$, S. $31 \mathrm{ff}$

Hastler Hanns, Rohwer-Kahlmann Harry, Aufbau und Verfahren der Sozialgerichtsbarkeit, Bad Godesberg 1953 ff

$\mathrm{H}$ a ueisen, Zur rechtlichen Qualifikation des Rentenbescheids, N.JW 11.Jhg. (1958) S. 441 ff

- Verwaltungsakte mit Dauerwirkung, NJW 11.Jhg. (1958) s. $1065 \mathrm{ff}$

- Betrachtungen über die Rücknahme fehlerhafter Verwaltungsat.te, DVB1. 74.Jhg. (1959) S. $229 \mathrm{ff}$ 
v. Ha u sen Heinz, v.d. Heide Hans Jürgen, Die rechtliche und funktionelle Bedeutung der Art. 84 und 85 GG, DÖV 11.Jhg. (1958) S. $753 \mathrm{ff}$

- Nochmals: Die Zuständigkeit des Bundesgesetzgebers aus A rt. 84 und 85 GG, DÖV 13. Jhg. (1960) S. 1 ff

- Zur Diskussion über die Bundeszuständigkeit aus Art. 84 und 85 GG, DÖV 13.Jhg. (1960) S. $441 \mathrm{ff}$

$\mathrm{H}$ a $\mathrm{u} \beta \mathrm{l}$ e it e $\mathrm{r}$ Otto, Die Wirtschaftspolitik in den Maschen des Bonner Grundgesetzes, DÖV 4.Jhg. (1951) S. 157 ff

- Maßnahmerecht und Dauerrecht auf dem Gebiet der wirtschaftspolitischen Verordnungs- und Gesetzgebung, DÖV 9. Jhg. (1956) S. $143 \mathrm{ff}$

Hayek Friedrich A., Was ist und was heißt "sozial"? in: "Masse und Demokratie", Erlenbach-Zürich/Stuttgart 1957, S. $71 \mathrm{ff}$

He ckel Johannes, Kirchliche Autonomie und staatliches Stiftungsrecht, o.O. (Nördlingen) 1932

- Das staatskirchenrechtliche Schrifttum 1930 und 1931, Verwalt ungsarchiv Bd. 37 (1932) S. $280 \mathrm{ff}$

- Melanchthon und das heutige deutsche Staatskirchenrecht, in: "Um Recht und Gerechtigkeit", Festgabe für Erich Kaufmann, Stuttgart/Köln 1950, S. 83 ff

- Kirchengut und Staatsgewalt, in: "Rechtsprobleme in Staat und Kirche", Festschrift für Rudolf Smend, Göttingen 1952, S. $103 \mathrm{ff}$

$\mathrm{Heckt}$ Wilhelm, Die gemeindliche Selbstverwaltung und die Finanzreform, DÖV 8.Jhg. (1955) S. 265 ff

- Die Neuordnung der verfassungsrechtlichen Grundlagen der gemeindlichen Selbstverwaltung, DÖV 10.Jhg. (1957) S. $164 \mathrm{ff}$

He de mann Justus Wilhelm, Die Flucht in die Generalklauseln, Tübingen 1933

- Was ist sozial? Der A rbeitgeber, 1956, S. $198 \mathrm{ff}$

v.d. Heide Hans-Jürgen, Zur Abgrenzung zwischen den Bundes-, den Ländern- und den Kommunalfinanzen, DVB1. 68. Jhg. (1953) S. $289 \mathrm{ff}$

-, v.Hausen Heinz, Die rechtliche und funktionelle Bedeutung der Art. 84 und 85 GG, DÖV 11.Jhg. (1958) S. 753 ff 
Heimann Eduard, Die rechtliche Möglichkeit eines staatlichen Eingriffes in die Tarifautonomie der Sozialpartner, Recht der Arbeit, 9. Jhg. (1956) S. $409 \mathrm{f}$

He imerich Hermann, Das überlebte Armenrecht, Betriebsberater, 15. Jhg. (1960) S. $1071 \mathrm{ff}$

Held Hermann, Fürsorgepflicht und Fürsorgeanspruch nach geltendem Verfassungs- und Verwaltungsrecht, DÖV 4.Jhg. (1951) S. 8 ff

H e $1 \mathrm{~d}$ Kurt, Der autonome Verwaltungsstil der Länder und das Bundesratsveto nach Art. 84 Abs. 1 GG, AöR Bd. $80(1955 / 56)$ S. $50 \mathrm{ff}$

He 11 e r Hermann, Rechtsstaat oder Diktatur, Tübingen 1930 Staatslehre, Leiden 1934

He $1 \mathrm{~m}$ re i ch Karl, Widtmann Julius, Bayerische Gemeindeordnung, 2.Aufl., München 1959

Hengstenberg H.E., Philosophische Begründung des Subsidiaritätsprinzips, in: "Das Subsidiaritätsprinzip", hrsg. v. Fridolin Utz, Heidelberg 1953, S. 19 ff

Henke W., Die Staatsverwaltung unter der Verwaltungsgerichtsordnung, DVB1. 76.Jhg. (1961) S.109 ff

Henrich Gustav, Das österreichische Sozialrecht in der Kritik seiner Anwendung, Österreichische Juristenzeitung, 11.Jhg. (1956) S. 4 ff, $29 \mathrm{ff}$

Hen richs Wilhelm, Die Rechtsprechung zur Verfassungsgarantie der kommunalen Selbstverwaltung in Deutschland, DVB1. 69. Jhg. (1954) S. $728 \mathrm{ff}$

- Die dienstrechtliche Heiratserlaubnis im Lichte des Art.12 der Menschenrechte-Konvention von Rom, Ehe und Familie im privaten und öffentlichen Recht, 3.Jhg. (1956) S. 175 ff

- Art.113 des Grundgesetzes, Bonn 1958

Herder-Dorneich Philipp, Theorie der Bestimmungsfaktoren finanzwirtschaftlicher Staatstätigkeit, o.O. (Freiburg i. Br.) 1957

Herkner Heinrich, Sozialrevolutionäre Bewegungen in der Demokratie, Schmollers Jahrbuch für Gesetzgebung, Verwa1tung und Volkswirtschaft, Bd.XXXIII (1909) Heft 2, S.669 ff

- Die Arbeiterfrage, 8. Aufl., Berlin/Leipzig 1923 (aus technischen Gründen zitiert nach 7.Auf1. 1921) 
H e r schel Wilhelm, Gleichberechtigung der Frau und Lohngleichheit, Betriebsberater, 10.Jhg. (1955) S.290 ff

- Arbeitsschutz im sozialen Rechtsstaat, Bundesarbeitsblatt 1955, S. $571 \mathrm{ff}$

- Rationalisierung des Rechts, insbesondere des Arbeitsrechts, in: "Sozialpolitik, A rbeits- und Sozialrecht", Festschrift für Friedrich Sitzler, Stuttgart 1956, S.287 ff

- Das Arbeitsrecht, in: Bettermann-Nipperdey-Scheuner, Die Grundrechte, Bd. III 1. Halbbd., Berlin 1958, S. 325 ff

- Zur Rechtsnatur der Allgemeinverbindlicherklärung von Tarifverträgen, in: "Sozialreform und Sozialrecht", Festschrift für Walter Bogs, Berlin 1959, S. $125 \mathrm{ff}$

- Vom Arbeiterschutz zum Arbeitsrecht, in: "Hundert Jahre Deutsches Rechtsleben", Festschrift Deutscher Juristentag, Bd. I, Karlsruhe 1960, S. 135 ff

He rze r Joachim, Die Anfechtbarkeit behördlicher Kündigungszustimmungen, DVB1. 72.Jhg. (1957) S.410 ff

Hesse Konrad, Der Gleichheitsgrundsatz im Staatsrecht, AöR Bd. 77 (1951/52) S. 167 ff

- Der Rechtsschutz durch staatliche Gerichte im kirchlichen Bereich, Göttingen 1956

- Die normative Kraft der Verfassung, Tübingen 1959

- Die verfassungsrechtliche Stellung der politischen Parteien im modernen Staat, VVDStRL Heft 17, 1959, S. 10 ff

Hes se 1 Philipp, Staatliche Zwangsschlichtung? A rbeits- und Sozialrecht, 1953 , S. $268 \mathrm{f}$

- Weltanschauung des Arbeitgebers und Kündigungsschutz im A rbeitsverhältnis, Betriebsberater 11.Jhg. (1956) S. $406 \mathrm{ff}=$ Arbeits- und Sozialrecht, 5.Jhg. (1956) S. 125 ff

Hettlage Karl-Maria, Die Neuordnung der deutschen Finanzverfassung, Finanzarchiv n.F. Bd. 14 (1953/54) S. 405 ff

- Finanzpolitik und Finanzrecht - Grundsätzliche Überlegungen zur Neuordnung des Bundesfinanzrechts, DÖV 8.Jhg. (1955) S. $1 \mathrm{ff}, 33 \mathrm{ff}$

- Die Finanzverfassung im Rahmen der Staatsverfassung, VVDStRL Heft 14, 1956, S. 2 ff

Heyde Ludwig, Artikel "Sozialpolitik (II) Allgemeines", Handwörterbuch der Sozialwissenschaften, Bd.9, 1956, S. $539 \mathrm{ff}$ 
Freiherr v.d. Heydte Friedrich August, Diskussionsbeitrag zu "Die Tragweite der Generalklausel in Art. 19 Abs. 4 des Bonner Grundgesetzes", VVDStRL Heft 8, 1950, S.162 ff

- Freiheit der Parteien, in: Neumann-Nipperdey-Scheuner, Die Grundrechte, Bd. II, Berlin 1954, S. $457 \mathrm{ff}$

- Diskussionsbeitrag zu "Begriff und Wesen des sozialen Rechtsstaates", VVDStRL Heft 12, 1954, S. $108 \mathrm{f}$

- Richterfunktion und "Richtergesetz", in: "Forschungen und Berichte aus dem öfentlichen Recht", Gedächtnisschrift für Walter Jellinek, München 1955, S.493 ff

-, Sacherl Karl, Soziologie der deutschen Parteien, München 1955

He yland Carl, Das Berufsbeamtentum im neuen demokratischen deutschen Staat, Berlin 1949

H e yn Walther, Die soziale Sicherung der Selbständigen, in: "Beiträge zur Sozialversicherung", Festschrift für Johannes Krohn, Berlin 1954, S. 127 ff

Hicks Ursula, Steuerpolitik im Wohlfahrtsstaat, Berlin 1953

v. Hippe 1 Ernst, Die Krise des Staatsgedankens und die Grenzen der Staatsgewalt, Stuttgart 1950

Höffner Joseph, A chinger Hans, ---, Muthesius Hans, Neundörfer Ludwig, Neuordnung der sozialen Leistungen - Denkschrift auf Anregung des Herrn Bundeskanzlers erstattet von ..., Köln 1955

- Die soziale Gerechtigkeit und die überlieferte abendländische Gerechtigkeitslehre, in: Festschrift für Karl Arnold, Köln/Opladen 1955, S. 35 ff

- Die Entwicklungen im Schicksal und Lebensgefühl der Arbeiterschaft und der Wandel der sozialpolitischen Leitbilder, in: "Sozialreform und Sozialrecht", Festschrift für Walter Bogs, Berlin 1959, S. 139 ff

Hoegner Wilhelm, Lehrbuch des Bayerischen Verfassungsrechts, München 1949 (abgekürzt zitiert mit: Hoegner)

$\mathrm{H}$ ö $1 \mathrm{z} 1$ Josef, Gemeindeordnung für den Freistaat Bayern, 3 . A uf1. von Hölzl-Rollwagen, Gemeindeordnung für den Freistaat Bayern, München 1960

Höpker-A schoff Hermann, Das Finanz- und Steuerwesen des Bonner Grundgesetzes, AöR Bd.75 (1949) S. 306 ff 
Höpker-A sch off Hermann, Das Finanzwesen der Bundesrepublik, Finanzarchiv n.F. Bd. $12(1950 / 51)$ S. $725 \mathrm{ff}$

Hof mann Kurt, Schroeter Kurt, Sozialgerichtsgesetz, 2. Aufl., Berlin/Frankfurt a. M. 1957

$\mathrm{Hube} r$ Ernst Rudolf, Rechtsformen der wirtschaftlichen Selbstverwaltung, Verwaltungsarchiv, Bd.37 (1932) S. $301 \mathrm{ff}$

- Wirtschaftsverwaltungsrecht, Bd.I: 1953; Bd.II: 1954 Tübingen

- Der Streit um das Wirtschaftsverfassungsrecht, DÖV 9. Jhg. (1956) S. $97 \mathrm{ff}, 135 \mathrm{ff}, 172 \mathrm{ff}, 200 \mathrm{ff}$

- Beliehene Verbände, DVB1. 67.Jhg. (1956) S.456 ff

- Selbstverwaltung der Wirtschaft, Stuttgart 1958

Huber Hans, Soziale Verfassungsrechte? in: "Die Freiheit des Bürgers in der Schweiz", Festgabe zur Hundertjahrfeier der Bundesverfassung, hrsg. v. den Juristischen Fakultäten der schweizerischen Universitäten, Zürich 1948, S. 149 ff

- Das Staatsrecht des Interventionismus, Zeitschrift für schweizerisches Recht n.F., Bd. 70 (1951) S. 173 ff

- Niedergang des Rechts und Krise des Rechtsstaats, in: "Demokratie und Rechtsstaat", Festschrift für Zaccharia Giacometti, Zürich 1953, S. 59 ff

- Die Umwälzungen im Staatsgefüge durch die Verbände, ORDO Bd. VII (1955) S. $189 \mathrm{ff}$

- Probleme des ungeschriebenen Verfassungsrechts, in:

"Rechtsquellenprobleme im schweizerischen Recht", Festgabe der rechts- und wirtschaftswissenschaftlichen Fakultät für. den Schweizerischen Juristenverein (= Band 91 bis 96 der Zeitschrift des Bernischen Juristenvereins) Bern 1955, S.95 ff

- $\quad$ Staat und Verbände, Tübingen 1958

H ue ck Alfred, Normenverträge, Jherings Jahrbücher für die Dogmatik des bürgerlichen Rechts, Bd. 73 (der zweiten Folge 37. Bd.) (1923) S.33 ff

- Freiheit und $Z$ wang im deutschen Arbeitsrecht, in: "Staat und Wirtschaft", Festschrift für Hans Nawiasky, Einsiedeln/ Zürich/Köln 1950, S. 187 ff

- Die Bedeutung des Art. 3 des Bonner Grundgesetzes für die Lohn- und Arbeitsbedingungen der Frauen, Köln 1951

- Probleme des Mitbestimmungsrechts, Karlsruhe 1953 
H u e ck Alfred, Nipperdey Hans Carl, Tophoven Ernst, Tarifvertragsgesetz, 3.Auf1., München/Berlin 1955

Von der sozialen Fürsorge zur sozialen Gerechtigkeit, in:

"Probleme des modernen Sozialstaates in christlicher Sicht", hrsg. von Th. Heckel, München 1955, S. 5 ff

- Der Sozialstaatsgedanke in der Rechtsprechung des Bundesarbeitsgerichts, in: "Staat und Bürger", Festschrift für Willibalt Apelt, München/Berlin 1958, S. $57 \mathrm{ff}$

Nipperdey Hans Carl, Lehrbuch des A rbeitsrechts, 6.Aufl., Berlin/Frankfurt a. M. Bd.I 1959, Bd.II 1957, Bd. I zitiert a1s "Hueck, Lehrbuch des A rbeitsrechts, Bd. I"

H u e ck Götz, Die Betriebsvereinbarung, Münster/Köln 1952

Der Grundsatz der gleichmäßigen Behandlung im Privatrecht, München/Berlin 1958

Hüttl Adolf, Kommunale Versorgungswirtschaft - Teil der Daseinsvorsorge im modernen Staat, Der bayerische Bürgermeister, 8.Jhg. (1955) S.122 ff

- Verfassungswidrige Beschränkungen der Gemeinden auf dem Gebiete der Daseinsvorsorge, Baye rische Verwaltungsblätter n.F., 2.Jhg. (1956) S. $324 \mathrm{ff}$

Sind die gemeindlichen Versorgungsbetriebe den "wirtschaftlichen Unternehmen" in $\$ 67$ DGO zuzuordnen? DÖV 11. Jhg. (1958) S. $198 \mathrm{ff}$

v. Humboldt Wilhelm, Ideen zu einem Versuch, die Grenzen der Wirksamkeit des Staates zu bestimmen, 1792 (zitiert nach: Deutsche Bibliothek Band 106, Berlin 1923)

I m boden Max, Das Gesetz als Garantie rechtsstaatlicher Verwaltung, Basel/Stuttgart 1954

- Der verwaltungsrechtliche Vertrag, Zeitschrift für schweizerisches Recht n. F., Bd. 77 (1958) S. 1 a ff

I psen Hans Peter, Gesetzliche Indienstnahme Privater für Verwaltungsaufgaben, in: "Um Recht und Gerechtigkeit", Festgabe für Erich Kaufmann, Stuttgart/Köln 1950, S. 141 ff

- Über das Grundgesetz, Hamburg 1950 = Das Grundgesetz in seiner Vorläufigkeit, Recht Staat Wirtschaft Bd.2 (1950) S. $182 \mathrm{ff}$

Anmerkung zu BVerfG Urt. v.19. Dezember 1951 - 1 BvR 220/51 - DÖV 5.Jhg. (1952) S.217 f 
Ipsen Hans Peter, Staatliche Wirtschaftsintervention, Staatsverfassung und Wirtschaftsordnung, JZ 7.Jhg. (1952) S. $759 \mathrm{ff}$

- Enteignung und Sozialisierung, VVDStRL Heft 10, 1952, S. $75 \mathrm{ff}, 169 \mathrm{ff}$

- Rechtsfragen der Investitionshilfe, AöR, Bd. 78 (1952/53) S. $284 \mathrm{ff}$

- Die hessische Bodenreform vor dem Bundesverfassungsgericht, DVB1. 68. Jhg. (1953) S.617 ff

- Empfiehlt es sich, die vollständige Selbstverwaltung aller Gerichte im Rahmen des Grundgesetzes gesetzlich einzuführen? Verhandlungen des 40. Deutschen Juristentages, Band 2 , Tübingen 1953, S.C 5 ff

- Diskussionsbeitrag zu "Die staatliche Intervention im Bereich der Wirtschaft, VVDStRL Heft 11, 1954, S.129 ff

- Diskussionsbeitrag zu "Begriff und Wesen des sozialen Rechtsstaates", VVDStRL Heft 12, 1954, S. 119 ff

- Gleichheit, in: Neumann-Nipperdey-Scheuner, Die Grundrechte, Bd. II, Berlin 1954, S. 111 ff

- Rechtsfragen berufsständischer Zwangsversorgung, in: "Aktuelle Probleme der Versicherungswirtschaft vom Standpunkt der Versicherungswissenschaft betrachtet", hrsg. v. Walter Rohrbeck, Berlin 1954, S. $31 \mathrm{ff}$

- Gemeindliche Personalhoheit unter Selbstverwaltungsgarantie, DÖV 8.Jhg. (1955) S. $225 \mathrm{ff}$

- Öffentliche Subventionierung Privater, DVB1. 71.Jhg. (1956) S.461 ff, $489 \mathrm{ff}, 602 \mathrm{ff}$; als selbständige Veröffentlichung: Berlin-Köln 1956

- Diskussionsbeitrag zu "Das besondere Gewaltverhältnis", VVDStRL Heft 15, 1957, S. 200 ff

- Diskussionsbeitrag zu "Die Organisationsgewalt", VVDStRL Heft 16 (1958) S. 257 ff

J a c obi Erwin, Grundlehren des Arbeitsrechts, Leipzig 1927

Jahrrei $\beta$ Hermann, Die Rechtspflege im Bonner Grundgesetz Verhandlungen des 37. Deutschen Juristentages, Berlin 1950, S. $26 \mathrm{ff}$ 
Jahrrei $\beta$ Hermann, Demokratischer Rechts-Staat und Rechtsprechung (Der Rechtsweg-Staat des Bonner Grundgesetzes), Recht Staat Wirtschaft Bd.2 (1950) S. $203 \mathrm{ff}$

- Mensch und Staat, Köln/Berlin 1957

- Freiheit und Sozialstaat, Kölner Universitätsreden Nr. 17, Krefeld 1957 = "Mensch und Staat", Köln/Berlin 1957, S.69 ff

Jans Karl Wilhelm, Jugendhilfe, in: Handbuch der kommunalen Wissenschaft und Praxis, hrsg. von Hans Peters, Bd. II, Berlin/Göttingen/Heidelberg 1957, S.315 ff

Jans sen Karl, Probleme des Wohlfahrtsstaates, in: "Verantwortung für den Menschen", Festgabe für Heinrich Held, Stuttgart 1957, S. 125 ff

J e cht Horst, Staatliche Wirtschaftspolitik und Einkommensverteilung, Schriften des Vereins für Sozialpolitik n.F., Bd. 13 (1957) S. $126 \mathrm{ff}$

J e 11 in ek Walter, Zur Gleichberechtigung der Geschlechter im Beamtenrecht, AöR, Bd. 76 (1950/51) S. 137 ff

- Diskussionsbeitrag zu "Begriff und Wesen des sozialen Rechtsstaates", VVDStRL Heft 12, 1954, S. $117 \mathrm{ff}$

Jerosch Werner, Die rechtsstaatliche Funktion der Rechtsprechung im Sozialrecht, Die Sozialgerichtsbarkeit, 5.Jhg. (1958) S. $73 \mathrm{ff}$

- Zur Frage, worin sich Verwaltung und Rechtsprechung im Sozialrecht unterscheiden, Die Sozialgerichtsbarkeit, 5. Jhg. (1958) S. $212 \mathrm{ff}$

J e s ch Dietrich, Unbestimmter Rechtsbegriff und Ermessen in rechtstheoretischer und verfassungsrechtlicher Sicht, AöR, Bd. 82 (1957) S. $163 \mathrm{ff}$

-, Bachof Otto, ---, Die Rechtsprechung der Landesverfassungsgerichte in der Bundesrepublik Deutschland, Jahrbuch des öffentlichen Rechts n.F., Bd.6, 1957, S. $47 \mathrm{ff}$

- Zulässigkeit gesetzesvertretender Verwaltungsverordnungen, AöR Bd. 84 (1959) S. 74 ff

Käg i Werner, Die Verfassung als rechtliche Grundordnung des Staates, Zürich 1945

- Rechtsstaat - Sozialstaat - sozialer Rechtsstaat, Die Schweiz - ein nationales Jahrbuch, Aarau 1945, S. 129 ff 
Kägi Werner, Persönliche Freiheit, Demokratie und Föderalismus, in: "Die Freiheit des Bürgers im schweizerischen Recht", Festgabe zur Hundertjahrfeier der Bundesverfassung, hrsg. von den Juristischen Fakultäten der schweizerischen Universitäten, Zürich 1948, S. 53 ff

- Die Entwicklung des schweizerischen Rechtsstaats seit 1848, Zeitschrift für schweizerisches Recht n.F., Bd. 71 (1952) S. $173 \mathrm{ff}$

- Falsche und wahre Gleichheit im Staat der Gegenwart, Universitas 8. Jhg. (1953) S. $735 \mathrm{ff}$

- Rechtsstaat und Demokratie, in: "Demokratie und Rechtsstaat", Festschrift für Zaccharia Giacometti, Zürich 1953, S. $107 \mathrm{ff}$

- Föderalismus und Freiheit, in: "Erziehung zur Freiheit", Erlenbach-Zürich/Stuttgart 1959, S.171 ff

Kafka Gustav E., Die verfassungsrechtliche Stellung der politischen Parteien im modernen Staat, VVDStRL Heft 17 (1959) S. $53 \mathrm{ff}$

Ka i s e $r$ Joseph H., Die Repräsentation organisierter Interessen, Berlin 1956

$\mathrm{Ka} 1$ is ch Werner, Kirchengesetzlich angeordnete Kürzungen von Dienst- und Versorgungsbezügen, Zeitschrift für evangelisches Kirchenrecht, Bd.1 (1951) S.280 ff

- Grund- und Einzelfragen des kirchlichen Dienstrechts, Zeitschrift für evangelisches Kirchenrecht, Bd.2 (1952/53) S.24 ff

Ka ske1 Walter, Dersch Hermann, Arbeitsrecht, 5. Aufl., Berlin/Stuttgart/Heidelberg 1957

Katzenstein Dietrich, Rechtliche Erscheinungsformen der Machtverschiebung zwischen Bund und Ländern seit 1949, DÖV 11.Jhg. (1958) S. 593 ff

Ka ufmann Erich, Artikel "Verwaltung, Verwaltungsrecht", Wörterbuch des Deutschen Staats- und Verwaltungsrechts, begründet v. Frh.v. Stengel, hrsg. von Fleischmann, Bd. III, 2.Auf1. 1914, S. $688 \mathrm{ff}$

- Die Gleichheit vor dem Gesetz im Sinne des Art.109 der Reichsverfassung, VVDStRL Heft 3, 1927, S.2 ff

- Grundrechte und Wohlfahrtsstaat, Recht Staat Wirtschaft, Bd. 4 (1953) S. 77 ff

Kel sen Hans, Sozialismus und Staat, Leipzig 1920 
Kelsen Hans, Hauptprobleme der Staatsrechtslehre, 2.Auf1., Tübingen 1923

- Allgemeine Staatslehre, Berlin 1925

- Wesen und Wert der Demokratie, 2.Auf1., Tübingen 1929

v. Ke mpski Jürgen, Artikel "Sozialwissenschaft", Handwörterbuch der Sozialwissenschaften, Bd.9, 1956, S. $617 \mathrm{ff}$

Ke rn Ernst, Die Verfassungsfunktion des Berufsbeamtentums, DÖV, 4.Jhg. (1951) S. $432 \mathrm{f}$

Ke rn Eduard, Schutz des Lebens, der Freiheit und des Heims, in: Neumann-Nipperdey-Scheuner, Die Grundrechte, Bd.II, Berlin 1954, S. $51 \mathrm{ff}$

Ke rn Ernst, Aspekte des Verwaltungsrechts im Industriezeitalter, Festschrift für Carl Schmitt, Berlin 1959, S. 81 ff

- Die Verfassungsaufgabe des Berufsbeamtentums in internationaler Sicht, Verwaltungsarchiv, Bd.52 (1961) S.24 ff

Kessle r, Der Bund und die Kommunalpolitik, DVB1. 68. Jhg. (1953) S. 1 ff

Kipp H., Staatslehre: Mensch, Recht und Staat, 2.Auf1., Köln 1950

Kirchne $r$ K., Verfassungsrechtliche Probleme der Rückwirkung der Neuregelungsgesetze, Die Sozialgerichtsbarkeit, 6. Jhg. (1959) S. $251 \mathrm{ff}$

Kisch Wilhelm, Die soziale Bedeutung des Zivilprozesses, Judicium, 1. Jhg. (1928/29) S. 1 ff

K1e in Franz, Christ und Kirche in der sozialen Welt, Freiburg i. Breisgau o.J. (1956)

- Das Recht des sozial-caritativen Arbeitsbereichs, Freiburg i. Breisgau 1959

K 1 e in Friedrich, Bonner Grundgesetz und Rechtsstaat, Zeitschrift für die gesamte Staatswissenschaft, Bd. 106 (1950) S. $390 \mathrm{ff}$

- Verordnungsermächtigungen nach deutschem Verfassungsrecht und

Die Übertragung rechtsetzender Gewalt nach deutschem Verfassungsrecht, in: "Die Übertragung rechtsetzender Gewalt im Rechtsstaat", Schriftenreihe des Instituts zur Förderung öffentlicher Angelegenheiten e.V., Bd.12, S. $7 \mathrm{ff}$ bzw. S. $79 \mathrm{ff}$, Frankfurt a. M. 1952 
Kle in Friedrich, Von der föderativen zur stärker unitarischen Gestaltung des Finanzwesens in der Bundesrepublik Deutschland, in: Festschrift für Friedrich Giese, Frankfurt a. M. 1953 , S. $61 \mathrm{ff}$

- Von der Zulässigkeit zur Unzulässigkeit rückwirkender Steuergesetze, Steuer und Wirtschaft, XXXI.Jhg. (1954) Sp. $1 \mathrm{ff}$

- Rechtsgutachten über verfassungsrechtliche Fragen des Urteils des Bundesarbeitsgerichts vom 2. März 1955 - betreffend Lohngleichheit von Mann und Frau, Düsseldorf 1955

- v. Mangoldt Hermann, -..., Das Bonner Grundgesetz, 2.Auf1., Berlin/Frankfurt a. M. 1955 ff (abgekürzt zitiert mit: v. Mangoldt-Klein)

- Der Beschluß des Bundesverfassungsgerichts zur Ehegattenbesteuerung in verfassungsrechtlicher Sicht, DÖV 10. Jhg. (1957) S. $587 \mathrm{ff}$

- Diskussionsbeitrag zu "Das Gesetz als Norm und Maßnahme", VVDStRL Heft 15, 1957, S. 66 ff

- Kammerbeitrag und Finanzverfassung, DVB1. 74.Jhg. (1959) S. $315 \mathrm{ff}$

K1 e in Karl Heinz, Vorschriften über die Fürsorgeunterbringung zur A rbeit, DÖV 9.Jhg. (1956) S.488 f

Kloten Norbert, Finanzpolitik, Einkommensgestaltung und Vermögensschichtung, ORDO Bd.IX (1957) S. $199 \mathrm{ff}$

Kno 11 Ernst, Eingriffe in das Eigentum im Zuge der Umgesta1tung gesellschaftlicher Verhältnisse, AöR Bd. 79 (1953/54) S. 455 ff; Bd. 81 (1956) S. 157 ff, 343 ff

- Die sozialethischen und rechtlichen Wandlungen in der Beurteilung des Armenwesens, Zeitschrift für die gesamte Staatswissenschaft, Bd.111 (1955) S.418 ff

- Eigentum, Enteignung und Entschädigung, JR 1958 S.325 ff

Knoll Joachim H., Licht- und Schattenseiten des Wohlfahrtsstaates, Politische Studien, 11.Jhg. (1960) S. $353 \mathrm{ff}$

Kn olle H., Arbeitsbedingungen der Frau und Grundrechte, Betriebsberater, 4.Jhg. (1949) S. $451 \mathrm{f}$

Knur Alexander, Schmidt-Rimpler Walter, Gieseke Paul, Friesenhahn Ernst und ---, Die Lohngleichheit von Männern und Frauen, AöR Bd. 76 (1950/51) S.165 ff 
$\mathrm{K}$ ölble Josef, Verwaltungsabkommen zwischen Bund und Ländern, DÖV 13.Jhg. (1960) S. $650 \mathrm{ff}$

Koel1reutte r Otto, Deutsches Staatsrecht, Stuttgart/Köln 1953

- Grundfragen des Verwaltungsrechts, Köln/Berlin 1955

König Hans-Günther, Die Einschränkung von Grundrechten der Bayerischen Verfassung, Bayerische Verwaltungsblätter n. F., 6. Jhg. (1960) S. $329 \mathrm{ff}$

Köttgen Arnold, Kommunale Auftragsverwaltung und Grundgesetz, Die Selbstverwaltung, 5.Jhg. (1951) S.346 ff

- Innere Struktur und Zuständigkeit der Gemeindevertretung, DVB1. 67. Jhg. (1952) S. $421 \mathrm{ff}$

- Kirche im Spiegel deutscher Staatsverfassung der Nachkriegszeit, DVB1. 67.Jhg. (1952) S. 485 ff

- Sachverantwortung als verfassungsrechtlicher Maßstab des Finanzausgleichs, DÖV 6. Jhg. (1953) S. $398 \mathrm{ff}$

- Subventionen als Mittel der Verwaltung, DVB1. 68.Jhg. (1953) S. $485 \mathrm{ff}$

- Der Einfluß des Bundes auf die deutsche Verwaltung und die Organisation der bundeseigenen Verwaltung (abgekürzt zitiert a1s: Der Einfluß des Bundes auf die deutsche Verwaltung), Jahrbuch des öffentlichen Rechts n.F., Bd. 3 (1954) S. $67 \mathrm{ff}$

- Der Einwand der Mischverwaltung und das Grundgesetz, DÖV 8. Jhg. (1955) S. $485 \mathrm{ff}$

- Gemeindliches Satzungsrecht und Grundgesetz, DVB1. 70. Jhg. (1955) S. $445 \mathrm{ff}$

- Artikel "Staatsaufsicht", Handwörterbuch der Sozialwissenschaften, Bd.9, 1956, S. $738 \mathrm{ff}$

- Artikel "Selbstverwaltung", Handwörterbuch der Sozialwissenschaften, Bd.9, 1956, S.220 ff

- Kodifikation des Privatrechts und arbeitsrechtliche Zuständigkeiten der Landesgesetzgebung, Betriebsberater, 11.Jhg. (1956) S. $441 \mathrm{ff}$

- Wesen und Rechtsform der Gemeinden und Gemeindeverbände, in: Handbuch der kommunalen Wissenschaft und Praxis, hrsg. von Hans Peters, Bd.I, Berlin/Göttingen/Heidelberg 1956, S. $185 \mathrm{ff}$ 
Köttgen Arnold, Die gegenwärtige Lage der deutschen Verwaltung, DVBl. 72.Jhg. (1957) S. $441 \mathrm{ff}$

- Die Organisationsgewalt, VVDStRL Heft 16, 1958, S.154 ff

- Die wirtschaftliche Betätigung der Gemeinden, in: "Hundert Jahre Deutsches Rechtsleben", Festschrift Deutscher Juristentag, Bd.I, Karlsruhe 1960, S. $577 \mathrm{ff}$

- Das umstrittene Mandat zur Jugendpflege, DÖV 14. Jhg. (1961) S. $1 \mathrm{ff}$

Kofle $\mathrm{r}$ Leo, Liberalismus und Demokratie, Zeitschrift für Politik n.F., 6. Jhg. (1959) S. $113 \mathrm{ff}$

Kolm s Heinz, Der Einfluß der nicht-staatlichen Instanzen auf die Einkommensverteilung, Schriften des Vereins für Sozialpolitik n.F., Bd. 13 (1957) S. 166 ff

Korsch Hans, Mitbestimmung und Arbeitsrecht, Köln 1951

Koulis Johannes, Soziale Gestaltung der Besteuerung oder volkswirtschaftliche Steuerpolitik, Tübingen 1949

Kraege 1 oh Walter, Begriff und Gegenstand der Sozialgerichtsbarkeit, Der Betrieb, 5.Jhg. (1952) S. 534 ff

Kratze r Jakob, Artikel 142 des Grundgesetzes und die Grundrechte in der Bayerischen Verfassung, in: "Verfassung und Verwaltung", Festschrift für Wilhelm Laforet, München 1952 , S. $107 \mathrm{ff}$

- Ist das Gesetz zur Beschaffung von Siedlungsland und zur Bodenreform Bundes- oder Landesrecht? Recht der Landwirtschaft, 5. Jhg. (1953) S. 32 ff

K raus Otto, Wirtschaftsdemokratie und Wirtschaftsaufbau, München 1947

Krause Hermann, Allgemeine Geschäftsbedingungen und das Prinzip des sozialen Rechtsstaates, Betriebsberater, 10.Jhg. (1955) S.265 ff

- Der verteilende Staat, in: "Beiträge zum Recht der Wasserwirtschaft und zum Energierecht", Karlsruhe 1958, S. 1 ff

- Wirtschaftslenkung und Ermächtigungsstil, in: "Beiträge zum A rbeits-, Handels- und Wirtschaftsrecht", Festschrift für Alfred Hueck, München/Berlin 1959, S.413 ff

Kreutzer Heinz, Bund und Länder in der Bundesrepublik Deutschland, in: "Bund und Länder", hrsg. von Ossip K. Flechtheim, Berlin 1949, S. 1 ff 
K rohn Johannes, Zur Rechtsnatur der Sozialversicherung, in: "Beiträge zur Versicherungswissenschaft", Festgabe für Walter Rohrbeck, Berlin 1955, S. 175 ff

Krohe W., Bibliographie zur Mitbestimmung, in: "Wege zum sozialen Frieden", hrsg. von Ortlieb und Schelsky, Stuttgart/ Düsseldorf 1954, S. $277 \mathrm{ff}$

K r üge $r$ Herbert, Grundgesetz und Kartellgesetzgebung, Göttingen 1950

- "Der Staat sind wir", Der Beamtenbund, 1. Jhg. (1950) S. 4 ff

- Staatsverfassung und Wirtschaftsverfassung, DVB1. 66. Jhg. (1951) S. $361 \mathrm{ff}$

- Der Bundeswirtschaftsrat in verfassungspolitischer Sicht, DÖV 5.Jhg. (1952) S. $545 \mathrm{ff}$

- Wirtschaftsverfassung, Wirtschaftsverwaltung, Rechtsstaat, Betriebsberater, 8.Jhg. (1953) S. 565 ff

- Diskussionsbeitrag zu "Die staatliche Intervention im Bereich der Wirtschaft", VVDStRL Heft 11, 1954, S. 139 ff

- Diskussionsbeitrag zu "Begriff und Wesen des sozialen Rechtsstaates", VVDStRL Heft 12, 1954, S. 109 ff

- Neues zur Freiheit der Persönlichkeitsentfaltung und deren Schranken, NJW 8.Jhg. (1955) S.201 ff

- Die Auflage als Instrument der Wirtschaftsverwaltung, DVB1. 70.Jhg. (1955) S. $380 \mathrm{ff}, 450 \mathrm{ff}, 518 \mathrm{ff}$

- Rechtsstaatliche Gesetzgebungstechnik, DÖV, 9.Jhg. (1956) S. $550 \mathrm{ff}$

- Die Verbände in der westdeutschen Politik, in: "Legitime Interessenvertretung", hrsg. von der Evangelischen Akademie Loccum, Loccum 1956, S. 12 ff

- Die Stellung der Interessenverbände in der Verfassungswirklichkeit, NJW 9.Jhg. (1956) S. $1217 \mathrm{ff}$

- Staatliche Gesetzgebung und nichtstaatliche Rechtsetzung, Recht der Arbeit, 10. Jhg. (1957) S.201 ff

- Das besondere Gewaltverhältnis, VVDStRL Heft 15, 1957, S. $109 \mathrm{ff}$

- Diskussionsbeitrag zu "Die Organisationsgewalt", VVDStRL Heft 16, 1958, S.253 ff

- Sozialisierung, in: Bettermann-Nipperdey-Scheuner, Die Grundrechte, Bd. III 1. Halbbd., Berlin 1958, S.267 ff 
Kr üge $r$ Herbert, Artikel "Verfassung", Handwörterbuch der Sozialwissenschaften, 29. Lieferung 1960, S. $72 \mathrm{ff}$

$\mathrm{K} r$ üg e $r$ Hildegard, Die Rechtsprechung des Bundesarbeitsgerichts zum Kündigungsschutzgesetz, NJW 8.Jhg. (1955) S. $1049 \mathrm{ff}$

- Ein Jahr Bundesarbeitsgericht, Recht der Arbeit, 8. Jhg. (1955) S. $244 \mathrm{ff}$

- Der Gleichbehandlungsgrundsatz als Rechtsgrundlage öffentlich-rechtlicher Gruppenrechte, DVB1. 70.Jhg. (1955) S. $178 \mathrm{ff}, 208 \mathrm{ff}$

- Völkerrechts- und Verfassungswidrigkeit der Zölibatsklausel für Polizeivollzugsbeamte, Zeitschrift für Beamtenrecht, 3.Jhg. (1955) S. $289 \mathrm{ff}$

- Die Grundrechte im besonderen Gewaltverhältnis, Zeitschrift für Beamtenrecht, 4.Jhg. (1956) S. $308 \mathrm{ff}$

- Witwerrente und Waisengeld nach dem Tod der sozialversicherten (versorgungsberechtigten) Ehefrau und Mutter, MDR 11.Jhg. (1957) S.68 ff

- Art.6 Abs.5 GG ein Programmsatz? DÖV 10.Jhg. (1957) S. $356 \mathrm{ff}$

- Die Rechtsnatur der Allgemeinverbindlicherklärung, Recht der A rbeit, 10. Jhg. (1957) S. 46 ff

- Die Rechtsprechung des Bundessozialgerichts zu den Witwerrenten, NJW 10.Jhg. (1957) S. $1209 \mathrm{ff}$

- Zölibatsklausel im öffentlichen Dienst, DÖV 11.Jhg. (1958) S. $761 \mathrm{ff}$

- Uneheliche Kinder, in: Bettermann-Nipperdey-Scheuner, Die Grundrechte, Bd.IV 1. Halbbd., Berlin 1960, S.325 ff

K ü chenhoff Erich, Küchenhoff Günther, ---, Allgemeine Staatslehre, 4.Aufl., Stuttgart 1960

$\mathrm{K} \ddot{\mathrm{u}} \mathrm{c}$ he nhof $\mathrm{G}$ ünther, Mitbestimmungsrecht und Grundrechte, DÖV 5.Jhg. (1952) S.453 ff

- Staatsverfassung und Subsidiarität, in: "Das Subsidiaritätsprinzip", hrsg. von Fridolin Utz, Heidelberg 1953, S. 67 ff

- Bund und Gemeinde, Bayerische Verwaltungsblätter n. F., 4. Jhg. (1958) S. $65 \mathrm{ff}, 101 \mathrm{ff}$

- Das Prinzip der staatlichen Subsidiarität im Arbeitsrecht, Recht der Arbeit, 12.Jhg. (1959) S.201 ff 
Küchenhoff Günther, Gleichheit und Ungleichheit im Verfassungsrecht, JR 1959 S. $281 \mathrm{ff}$

- Die Freiheit der Zulassung zur kassenärztlichen Tätigkeit, Recht der Arbeit, 13.Jhg. (1960) S.202 ff, 242 ff

-, Küchenhoff Erich, Allgemeine Staatslehre, 4.Aufl., Stuttgart 1960

Kümme 1 Wilhelm, Die Problematik des kirchlichen Dienstes im Beamten-, Besoldungs- und Tarifrecht des Staates, Das Recht im Amt, 3.Jhg., 1956

Küng Emil, Artikel "Interventionismus", Handwörterbuch der Sozialwissenschaften, Bd. 5, 1956, S.321 ff

K üste r Otto, Das Gewaltenproblem im modernen Staat, AöR Bd. 75 (1949) S. $397 \mathrm{ff}$

K unze Otto, Verfassungswidriger Zwang zur Schlichtung, Sozialer Fortschritt, 9. Jhg. (1960) S.98 ff

L a f o ret Wilhelm, Verwaltung und Ausführung von Gesetzen nach dem Bonner Grundgesetz, DÖV 2.Jhg. (1949) S.221 ff

Landshut Siegfried, Mitbestimmung und Wirtschaftsdemokratie, in: "Wege zum sozialen Frieden", hrsg. von Ortlieb und Sche1sky, Stuttgart/Düsseldorf 1954, S. 36 ff

- Wandlungen der parlamentarischen Demokratie, in: "Zur Ordnung von Wirtschaft und Gesellschaft", Hamburger Jahrbuch für Wirtschafts- und Gesellschaftspolitik, 4.Jhg. (Festausgabe für Eduard Heimann) S.151 ff, Tübingen 1959

L a ube Horst, Die Vereinheitlichung der Gerichtsbarkeit und die Gerichte der Sozialgerichtsbarkeit, Zeitschrift für Sozialreform, 3.Jhg. (1957) S.161 f

La ufke Franz, Vertragsfreiheit und Grundgesetz, in: "Das deutsche Privatrecht in der Mitte des 20. Jahrhunderts", Festschrift für Heinrich Lehmann, I. Band, Berlin/Tübingen/ Frankfurt a. M., 1956, S. $145 \mathrm{ff}$

Le chner Hans, Nawiasky Hans, -- -, Die Verfassung des Freistaates Bayern - Ergänzungsband - München 1953 (abgekürzt zitiert als: Nawiasky-Lechner)

- Zur Zulässigkeit der Verfassungsbeschwerden gegen Unterlassungen des Gesetzgebers, NJW 8.Jhg. (1955) S. $1817 \mathrm{ff}$

L e ibholz Gerhard, Der Parteienstaat des Bonner Grundgesetzes, Recht Staat Wirtschaft Bd. 3 (1951) S. 99 ff 
Leibholz Gerhard, Der Parteienstaat des Bonner Grundgesetzes und das Beamtentum, Der Beamtenbund 1951, Sonderheft zu Delegiertentag, S. 6 ff

- Die kritischen Punkte des Grundgesetzes, Deutsche Universitätszeitung, 12.Jhg. (1957) Heft 13/14, S. 18 ff

- Strukturprobleme der modernen Demokratie, Karlsruhe 1958

- Die Gleichheit vor dem Gesetz, 2.Auf1., München/Berlin 1959

Leisne $r$ Walter, Die schutzwürdigen Rechte im besonderen Gewaltsverhältnis, DVB1. 75. Jhg. (1960) S. $617 \mathrm{ff}$

L e mke Bernhard, Pensionskassen und sozialer Rechtsstaat, Recht der Arbeit, 10.Jhg. (1957) S.256 ff

Le rche Peter, Verbot des Übermaßes und Gerichtsschutz, Bayerische Verwaltungsblätter n.F., 3.Jhg. (1957) S.321 f

- Grundrechtsbegrenzungen "durch Gesetz" im Wandel des Verfassungsbildes, DVB1. 73.Jhg. (1958) S. 524 ff

- Zum Apotheken-Urteil des Bundesverfassungsgerichts, Bayerische Verwaltungsblätter n.F., 4.Jhg. (1958) S.231 ff

- Grundrechte der Soldaten, in: Bettermann-Nipperdey-Scheuner, Die Grundrechte, Bd. IV 1. Halbbd., Berlin 1960, S. $447 \mathrm{ff}$

Le us ser Claus, Nawiasky Hans, -.-, Die Verfassung des Freistaates Bayern, München/Berlin 1948 (abgekürzt zitiert als: Nawiasky-Leusser)

Ritter von Lex Hans, Die Entwicklung des Verhältnisses von Bund und Ländern in der Bundesrepublik, in: "Verfassung und Verwaltung", Festschrift für Wilhelm Laforet, München 1952 , S. $51 \mathrm{ff}$

- Zehn Jahre Grundgesetz, Bayerische Verwaltungsblätter n. F., 5. Jhg. (1959) S. 133 ff

L i e b Manfred, Rechtsnatur und Mängel der Allgemeinverbindlicherklärung eines Tarifvertrages, Recht der A rbeit, 10.Jhg. (1957) S. $260 \mathrm{ff}$

Liefmann-Keil Elisabeth, Zur Entwicklung der Theorie der Bewilligung öfentlicher Einnahmen und Ausgaben, Finanzarchiv n.F., Bd. 19 (1959) S.218 ff 
Lincke $1 \mathrm{mann}$ Karl, Zum staats rechtlichen Lehrbegriff der mittelbaren Staatsverwaltung und Nochmals: Zum staatsrechtlichen Lehrbegriff der mittelbaren Staatsverwaltung, DÖV 12.Jhg. (1959) S. $561 \mathrm{ff}$ bzw. $813 \mathrm{ff}$

Littmann Konrad, Bestimmungsgründe der Einkommensverteilung in der modernen Wirtschaft, Zeitschrift für die gesamte Staatswissenschaft, Bd. 113 (1957) S. 678 ff

- Raumwirtschaftliche Auswirkungen der Finanzpolitik, Finanzarchiv n.F., Bd. 19 (1959) S. 367 ff

Loening Hellmuth, Der ministerialfreie Raum in der Staatsverwaltung, DVB1. 69.Jhg. (1954) S. $173 \mathrm{ff}$

L öw Konrad, Fiskalgeltung der Grundrechte? DÖV 10. Jhg. (1957) S. $879 \mathrm{ff}$

- Ist die Würde des Menschen im Grundgesetz eine Anspruchsgrundlage, DÖV 11.Jhg. (1958) S. 516 ff

L o e we nste in Karl, Verfassungsrecht und Verfassungsrealität, AöR, Bd. $77(1951 / 52) \mathrm{S} .387 \mathrm{ff}$

- Über das Verhältnis von politischen Ideologien zu politischen Institutionen, Zeitschrift für Politik n.F., 2.Jhg. (1955) S. 191 ff

- Verfassungslehre, Tübingen 1959

Ma e r cks, Symbolische Urteilsvollstreckung, NJW 8.Jhg. (1955) S. $820 \mathrm{ff}$

M a i e r Hedwig, Fechner Erich, -.-., Die Rechtswirksamkeit der arbeitsrechtlichen Bestimmungen des sog. Truppenvertrages, Recht der Arbeit, 9.Jhg. (1956) S. $87 \mathrm{ff}$

U. M. (Mallmann Ulrich?), Wirtschaftliches Mitbestimmungsrecht und Enteignung, AöR Bd.77 (1951/52) S.366 ff

Mang Johann (Herausgeber), Verwaltungsrecht in Bayern Bd. I/ 1951; Bd. II/ 1952; München

v. Mangoldt Hermann, Ist die Zwangsmitgliedschaft bei Berufs- und Wirtschaftsverbänden mit dem Grundgesetz vereinbar? Betriebsberater, 6. Jhg. (1951) S. $621 \mathrm{ff}$

- Diskussionsbeitrag zu "Enteignung und Sozialisierung", VVDStRL Heft 10, 1952, S. 150 ff, $161 \mathrm{f}$ 
v. Mangoldt Hermann, Das Bonner Grundgesetz, 1.Auf1., Berlin/Frankfurt a. M. 1953 - 2.Auf1. (bearbeitet von Friedrich Klein) Berlin/Frankfurt a. M. 1955 ff (abgekürzt mit: v. Mangoldt-Klein)

Mann Frederick A., Zur Geschichte des Enteignungsrechts, in: "Hundert Jahre deutsches Rechtsleben", Festschrift Deutscher Juristentag, Bd.2, S.291, Karlsruhe 1960

Marbach, Zur Frage der wirtschaftlichen Staatsintervention, Bern 1950

Ma r cic René, Vom Gesetzesstaat zum Richterstaat, Wien 1957

Ma s son Christoph, Beschränken die Art. 75 ff BayGO überhaupt die gemeindliche Daseinsvorsorge? Bayerische Verwaltungsblätter n.F., 2.Jhg. (1956) S. $327 \mathrm{ff}$

- Gemeindeaufgaben im Schutz der Verfassung, Bayerische Verwaltungsblätter n. F., 4.Jhg. (1958) S. $161 \mathrm{ff}, 197 \mathrm{ff}$

Matz Werner, v. Doemmig Klaus-Berto, Füßlein Rudolf Werner, -.- Entstehungsgeschichte der Artikel des Grundgesetzes, Jahrbuch des öffentlichen Rechts n.F., Bd. 1 (1951)

- Grundgesetz für die Bundesrepublik Deutschland, 2. Aufl., Stuttgart/Köln 1954

Ma unz Theodor, Die oberste sozialrechtliche Gerichtsbarkeit nach dem Bonner Grundgesetz, Versicherungswissenschaft/ Versicherungspraxis/Versicherungsmedizin, 4.Jhg. (1950) S. $113 \mathrm{ff}$

- Die Bedeutung des Bundesverfassungsgerichts für das Arbeits- und Sozialrecht, Recht der A rbeit, 4.Jhg. (1951) S. $161 \mathrm{ff}$

- Der deutsche Standpunkt zu den Empfehlungen des Europarates zur Schaffung einer Europäischen Sozialversicherungsordnung, Deutsche Versicherungszeitschrift, 5.Jhg. (1951) S. $272 \mathrm{ff}$

- Wirtschaftsrecht, Die Verwaltung, Heft 27, Braunschweig 1955

- Rechtsgutachten über die Verfassungsmäßigkeit der Bayerischen Ärzteversorgung nach dem Grundgesetz, München 1955 (ungedruckt)

- Das Verhältnis der Baulandentschädigung zum Grundgesetz, Düsseldorf 1955 
M a unz Theodor, Die verfassungsrechtliche Gewähr von Ehe und Familie, Ehe und Familie im privaten und öfentlichen Recht, 3.Jhg. (1956) S. 1 ff

- Rechtsgutachten zur Frage, ob Tarifverträge dem Grundsatz der Lohngleichheit von Mann und Frau unterworfen sind, München 1956 (ungedruckt)

- Die Finanzverfassung im Rahmen der Staatsverfassung, VVDStRL Heft 14, 1956, S. 37 ff

- Sind Staat und Kirche auf dem rechten Weg? in: "Die Katholiken vor der Politik", hrsg. v. Gustav E. Kafka, Freiburg 1958 , S. $67 \mathrm{ff}$

- Die kulturelle Sicherheit des Bürgers, in: "Staat und Bürger", Festschrift für Willibalt A pelt, München/Berlin 1958, S. $113 \mathrm{ff}$

-, Dürig Günther, Grundgesetz, München/Berlin 1958 ff (abgekürzt zitiert mit: Maunz-Dürig)

- Deutsches Staatsrecht, 9.Auf1., München/Berlin 1959

- Grundfragen des Energiewirtschaftsrechts, Verwaltungsa rchiv, Bd.50 (1959) S. $315 \mathrm{ff}$

- Die verfassungsrechtliche Stellung der politischen Parteien in Bayern, Bayerische Verwaltungsblätter n.F., 6. Jhg. (1960) S. $1 \mathrm{ff}$

M a u Wilhelm, Beteiligung von Ausschüssen an Verwaltung und Normsetzung im A rbeitsrecht, in: "Sozialreform und Sozialrecht", Festschrift für Walter Bogs, Berlin 1959, S. 169 ff

Meier-Hayoz Arthur, Der Richter als Gesetzgeber, Zürich 1951

Me is singe $r$ Hermann, Tarifhoheit in der sozialen Selbstverwaltung, Recht der Arbeit, 4.Jhg. (1951) S.46 ff

- Reliefbild des Arbeitsrechts, München/Düsseldorf 1952

- Koalitionsrecht ein Mittel zum Zweck der sozialen Selbstverwaltung, A rbeit und Recht, 2.Jhg. (1954) S. 65 ff

- Soziale Selbstverwaltung im Fachprinzip, Arbeit und Recht, 3. Jhg. (1955) S. $1 \mathrm{ff}$

- Die Gewerkschaften im staatsfreien Raum der sozialen Selbstverwaltung, A rbeit und Recht, 3.Jhg. (1955) S. 339 ff

- Grundlagen und Grenzen der gewerkschaftlichen Machtmittel, Recht der Arbeit, 9.Jhg. (1956) S.401 ff 
Mel1witz Artur, Die Interpretation der Sozialstaatserklärung in der höchstrichterlichen Rechtsprechung, Die Sozialgerichtsbarkeit, 6. Jhg. (1959) S. $248 \mathrm{ff}$

M e nge $r$ Anton, Die soziale Aufgabe der Rechtswissenschaft, 2.Aufl., Wien 1905

- Das bürgerliche Recht und die besitzlosen Volksklassen, 5. Aufl., 1927

M enge $r$ Christian-Friedrich, Der Begriff des sozialen Rechtsstaates im Bonner Grundgesetz, Tübingen 1953

- System des verwaltungsgerichtlichen Rechtsschutzes, Tübingen 1954

- Rechtssatz, Verwaltung und Verwaltungsgerichtsbarkeit, DÖV 8.Jhg. (1955) S. 587 ff

- Das Gesetz als Norm und Maßnahme, VVDStRL Heft 15, 1957 , S. 3 ff, $105 \mathrm{ff}$

- Der Schutz der Grundrechte in der Verwaltungsgerichtsbarkeit, in: Bettermann-Nipperdey-Scheuner, Die Grundrechte, Bd. III 2. Halbband, Berlin 1959, S. 717 ff

- Höchstrichterliche Rechtsprechung zum Verwaltungsrecht, Verwaltungsarchiv, Bd. 50 (1959) S. 193 ff; Bd. 51 (1960) S. $64 \mathrm{ff}, 149 \mathrm{ff}$

- Anmerkung zu BGH Urt. v.21. April 1959 - 1 StR 504/58 JZ 15. Jhg. (1960) S. $168 \mathrm{ff}$

- Die Bestimmung der öffentlichen Verwaltung nach den Zwekken, Mitteln und Formen des Verwaltungshandelns, DVB1. 75. Jhg. (1960) S. $297 \mathrm{ff}$

Me rk Wilhelm, Diskussionsbeitrag zu "Begriff und Wesen des sozialen Rechtsstaates", VVDStRL Heft 12, 1954, S.99 ff

- Diskussionsbeitrag zu "Das Gesetz als Norm und Maßnahme", VVDStRL Heft 15, 1957, S. 76 ff

- Diskussionsbeitrag zu "Das besondere Gewaltverhältnis", VVDStRL Heft 15, 1957, S. 192 ff

- Diskussionsbeitrag zu "Die Organisationsgewalt", VVDStRL Heft 16 (1958) S. $251 \mathrm{ff}$

Messne r Johannes, Die soziale Frage, 6.Aufl., Innsbruck/ Wien/München 1956

Meyer-Cording Ulrich, Die Rückwirkung von Gesetzen, JZ 7. Jhg. (1952) S. $161 \mathrm{ff}$ 
M ey rich Carl, Rohrbeck Walter, Roehrbein Erich, ---, Zum Problem der Realisierbarkeit der Vorschläge der Rothenfelser Denkschrift über "Die Neuordnung der sozialen Leistungen", Berlin 1955

Michel Helmut, Normenkontrolle durch die vollziehende Gewalt, NJW 13.Jhg. (1960) S. $841 \mathrm{ff}$

Michels Robert, Soziologie des Parteiwesens, 2. Aufl., Stuttgart 1925 (Neudruck, veranstaltet von Conze, o.J.)

Mi esbach Hermann, Gestaltung der Gerichtsbarkeit für Arbeitsrecht, Sozialversicherung und Kriegsopferversorgung, Deutsche Versicherungszeitschrift, 5.Jhg. (1951) S.228 ff

-, Ankenbrank Kurt, Sozialgerichtsgesetz, Frankfurt a. M. $1954 \mathrm{ff}$

- Das Bundessozialgericht, Bayerische Verwaltungsblätter n.F., 5.Jhg. (1959) S. 233 ff, $272 \mathrm{ff}$

Mikat Paul, Kirchen und Religionsgemeinschaften, in: Bettermann-Nipperdey-Scheuner, Die Grundrechte, Bd.IV 1. Halbbd., Berlin 1960, S.111 ff

Mö11e r Hans, Die Abgrenzung zwischen Sozial- und Privatversicherung, in: "Gegenwartsfragen sozialer Versicherung" hrsg. von Walter Bogs, Heidelberg 1950, S. 74 ff

Molitor Bruno, Sozialpolitik im sozialen Rechtsstaat, Hessische Hochschulwochen für staatswissenschaftliche Fortbildung, Bd.21, Bad Homburg v.d. Höhe/Berlin/Zürich 1959, S. $98 \mathrm{ff}$

- Artikel "Eigentum (I) Soziologie des Eigentums", Handwörterbuch der Sozialwissenschaften, 28. Lieferung, 1960, S.33 ff

Mo1itor Erich, Über öffentliches Recht und Privatrecht, Karlsruhe 1949

- Die Vereinheitlichung des Arbeitsrechts, NJW 2.Jhg. (1949) S. $699 \mathrm{ff}$

- Die arbeitsrechtliche Bedeutung des Art. 3 des Bonner Grundgesetzes, Archiv für civilistische Praxis, Bd. 151 (1950/51) S. $385 \mathrm{ff}$

- Die Unzulässigkeit von Zölibatsklauseln in Einzelarbeitsverträgen, Arbeit und Recht, 1.Jhg. (1953) S.335 ff

- Anmerkung zu BAG Urt. v.21. Oktober 1954 - 2 AZR 40/53 A rbRBlattei, MuSch Entscheidung 4 
- Anmerkung zu BAG Urt. v. 15. Januar 1955 - AZR 305/54 A rbRBlattei, Gleichbehandlung im A rbeitsverhältnis, Entscheidung 6

- Arbeitsrecht und Gerichtszuständigkeit, in: "Sozialpolitik, A rbeits- und Sozialrecht", Stuttgart 1956, S.303 ff

- Beamtentum und Personalvertretung, in: "Staat und Bürger", Festschrift für Willibalt Apelt, München/Berlin 1958, S. $219 \mathrm{ff}$

Mü11e r Gerhard, Zur Rechtsprechung des Bundesarbeitsgerichts, Betriebsberater, 10.Jhg. (1955) S. $577 \mathrm{ff}$

- Die Selbständigkeit der einzelnen Gerichtszweige, insbesondere der Arbeits- und Sozialgerichtsbarkeit, Die Betriebsverfassung, 3.Jhg. (1956) S. $199 \mathrm{f}$

- Der Gedanke des sozialen Staats in der bisherigen Rechtsprechung des Bundesarbeitsgerichts, Der Betrieb, 9. Jhg. (1956) S. $524 \mathrm{ff}, 549 \mathrm{ff}$

- Kritische Gedanken zur Forderung nach der Einheit der Rechtspflege, Recht der Arbeit, 10.Jhg. (1957) S. $313 \mathrm{ff}$

M ülle r Hans, Zur Problematik des Finanzausgleichs zwischen Oberstaat und Gliedstaaten im Bundesstaat, AöR Bd. 83 (1958) S. $25 \mathrm{ff}$

Mülle r-A rma ck Alfred, Artikel "Soziale Marktwirtschaft", Handwörterbuch der Sozialwissenschaften, Bd.9, 1956, S. $390 \mathrm{ff}$

Münch Fritz, Die Menschenwürde als Grundforderung unserer Verfassung, Bocholt 1951

- Diskussionsbeitrag zu "Das Gesetz als Norm und Maßnahme" VVDStRL Heft 15, 1957, S. 87 ff

v. Münch Ingo, Staatliche Wirtschaftshilfe und Subsidiaritätsprinzip, JZ 15. Jhg. (1960) S. 303 ff

Muthesius Hans, A chinger Hans, Höffner Joseph, --- , Neundörfer Ludwig, Neuordnung der sozialen Leistungen - Denkschrift auf Anregung des Herrn Bundeskanzlers erstattet von ..., Köln 1955

Naphtali Fritz, Wirtschaftsdemokratie, 4.Aufl., Berlin 1929

$\mathrm{Na}$ umann Richard, Anmerkung zu BayVGH Urt. v. 8. März 1949 - Nr.308 I 48 - DV 2. Jhg. (1949) S. $442 \mathrm{f}$ 
Naumann Richard, Diskussionsbeitrag zu "Begriff und Wesen des sozialen Rechtsstaates", VVDStRL Heft 12, 1954, S. $114 \mathrm{ff}$

Nawiasky Hans, Forderungs- und Gewaltverhä1tnis, in: Festschrift für Ernst Zitelmann, München/Leipzig 1913

- Die Gleichheit vor dem Gesetz im Sinne des Art.109 der Reichsverfassung, VVDStRL Heft 3, 1927, S.25 ff

- Staatstypen der Gegenwart, St.Gallen 1934

- Rechtsfragen des wirtschaftlichen Neuaufbaues, Zürich 1935

- Allgemeine Rechtslehre, 2.Aufl., Einsiedeln/Zürich/Köln 1948

- Die Grundgedanken des Grundgesetzes für die Bundesrepublik Deutschland, Stuttgart/Köln 1950

- Positives und überpositives Recht, JZ 9. Jhg. (1954) S. $717 \mathrm{ff}$

- Allgemeine Staatslehre

1. Teil: Grundlegung 1945

2. Teil: Staatsgesellschaftslehre

Bd. I 1952

Bd. II 1955

3. Teil: Staatsrechtslehre 1956

4. Teil: Staatsideenlehre 1958

sämtliche Einsiedeln/Zürich/Köln

-, Lechner Hans, Die Verfassung des Freistaates Bayern - Ergänzungsband - München 1953 (abgekürzt zitiert als:

Nawiasky-Lechner)

-, Leusser Claus, Die Verfassung des Freistaates Bayern, München/Berlin 1948 (abgekürzt zitiert als: NawiaskyLeusser)

Nef Ilans, Gleichheit und Gerechtigkeit, Zürich 1941

Ne 1 l- Hile uning Oskar v., Freiheit und Bindung im kollektiven Arbeitsrecht - Philosophische und gesellschaftskritische Betrachtung, Schriften der Gesellschaft für Sozialen Fortschritt e.V., Bd.6, Berlin 1957, S.27 ff

v. Nell-Breuning Oswald, Sacher Hermann, Zur christlichen Staatslehre, 2.Auf1., Freiburg i. Breisgau 1957

- Artikel "Ständischer Gesellschaftsaufbau", Handwörterbuch (ier Sozialwissenschaften, Bd. 10, 1959, S.6 ff

Neuhoff Robert, Kommunale Selbstverwaltung und Bonner (irundgesetz, DÖV 5.Jhg. (1952) S.259 ff 
Neumann Franz L., Zum Begriff der politischen Freiheit, Zeitschrift für die gesamte Staatswissenschaft, Bd. 109 (1953) S. $25 \mathrm{ff}$

Neumann-Duesberg Horst, Das Mitbestimmungsrecht, in: Bettermann-Nipperdey-Scheuner, Die Grundrechte, Bd. III 1. Halbbd., Berlin 1958, S. 373 ff

- Rechtsprobleme der betrieblichen Einigung, in: "Sozialreform und Sozialrecht", Festschrift für Walter Bogs, Berlin 1959 , S. $275 \mathrm{ff}$

Ne undörfe $r$ Ludwig, A chinger Hans, Höfner Joseph, Muthesius Hans, ---, Neuordnung der sozialen Leistungen - Denkschrift auf Anregung des Herrn Bundeskanzlers erstattet von ... Köln 1955

Nikisch Arthur, Dietz Rolf, ---, A rbeitsgerichtsgesetz, München/Berlin 1954

- Kündigungsschutz bei sog. Kettenverträgen und bei befristeten A rbeitsverträgen, Betriebsberater, 10.Jhg. (1955)

S. $197 \mathrm{ff}$

- Anmerkung zu BVerfG Urt. v. 18. November 1954 - 1 BvR 629/ 52 - JZ 10.Jhg. (1955) S.205 ff

- Arbeitsrecht, 2.Auf1., Bd.I Tübingen 1955; Bd.II Tübingen 1959

- Die Schlichtung von Arbeitsstreitigkeiten, in: "Hundert Jahre Deutsches Rechtsleben", Festschrift Deutscher Juristentag Bd. I, Karlsruhe 1960, S. $317 \mathrm{ff}$

$\mathrm{N}$ i p pe rdey Hans Carl, Die Grundprinzipien des Wirtschaftsverfassungsrechts, DRZ 5. Jhg. (1950) S. $193 \mathrm{ff}$

- Gleicher Lohn für gleiche Leistung, Betriebsberater, 6. Jhg. (1951) S.282 ff

- Die Grundprinzipien des Wirtschaftsverfassungsrechts, Recht Staat Wirtschaft Bd. 3 (1951) S.223 ff

- Diskussionsbeitrag zu "Begriff und Wesen des sozialen Rechtsstaates", VVDStRL Heft 12, 1954, S.92 ff

- Die soziale Marktwirtschaft in der Verfassung der Bundesrepublik, Karlsruhe 1954 = Wirtschaft und Wettbewerb, 4. Jhg. (1954) S.211 ff

- Die Würde des Menschen, in: Neumann-Nipperdey-Scheuner, Die Grundrechte, Bd. II, Berlin 1954, S. 1 ff 
Nipperdey Hans Carl, Hueck Alfred, ---, Tophoven Ernst, Tarifvertragsgesetz, 3. Aufl., München/Berlin 1955

- Der A rbeitskampf als unerlaubte Handlung, in: "Sozialpolitik, Arbeits- und Sozialrecht", Festschrift für Friedrich Sitzler, Stuttgart 1956, S. 79 ff

-, Hueck Alfred, -.-, Lehrbuch des Arbeitsrechts, 6.Aufl., Berlin/Frankfurt a. M. Bd. I 1959; Bd. II 1957. Bd. II zitiert als "Nipperdey, Lehrbuch des Arbeitsrechts, Bd. II"

- Boykott und freie Meinungsäußerung, DVBl. 73.Jhg. (1958) S. $445 \mathrm{ff}$

- Die Rolle des Staates bei der Regelung des Arbeitsverhältnisses - ein internationaler Rechtsvergleich - Recht der A rbeit, 11.Jhg. (1958) S. $321 \mathrm{ff}$

- Artikel "Stiftungen (I) Recht der Stiftungen", Handwörterbuch der Sozialwissenschaften, Bd. 10, 1959, S.201 ff

O be $r$ ma ye $r$ Klaus, Rechtsverordnung im formellen Sinn, DÖV 8. Jhg. (1955) S. $364 \mathrm{ff}$

- Verwaltungsakt und innerdienstlicher Rechtsakt, Stuttgart/ München/Hannover 1956

- Das Bundesverfassungsgericht und der Vorbehalt des Gesetzes, DVB1. 74.Jhg. (1959) S. $354 \mathrm{ff}$

Obe rwinste $r$ Gustav, Paritätische Selbstverwaltung in der Sozialversicherung, in: "Beiträge zur Sozialversicherung", Festschrift für Johannes Krohn, Berlin 1954, S. 185 ff

O1bersdorf Gert, Sozialer Rechtsstaat und Arbeitsrecht, Arbeit und Recht, 3.Jhg. (1955) S. $129 \mathrm{ff}$

Ortlieb Heinz-Dietrich, Der Kampf um Wirtschaftsdemokratie und Mitbestimmung, in: "Wege zum sozialen Frieden", hrsg. von Ortlieb und Schelsky, Stuttgart/Düsseldorf 1954, S. 9 ff

-, Stavenhagen Gerhard, Artikel "Sozialisierung (II) Geschichte (1) Deutschland", Handwörterbuch der Sozialwissenschaften, Bil. 9, 1956, S. $464 \mathrm{ff}$

- Unsere Konsumgesellschaft, in: "Zur Ordnung von Wirtschaft und Gesellschaft", Hamburger Jahrbuch für Wirtschafts- und Gesellschaftspolitik 4.Jhg. (Festausgabe für Eduard Heimann) Tübingen 1959, S. $225 \mathrm{ff}$ 
Osterkorn Willy, Angemessene oder gerechte Entschädigung im Enteignungsrecht, Bayerische Verwaltungsblätter n. F., 1. Jhg. (1955) S. $132 \mathrm{ff}$

Partsch Karl Josef, Angelegenheiten der örtlichen Gemeinschaft, in: Festschrift für Carl Bilfinger, Köln/Berlin 1954, S. $301 \mathrm{ff}$

- Die verfassungsmäßige Sicherung der Wirtschaftsprinzipien, ORDO Bd. VI (1954) S. 19 ff

- Verfassungsprinzipien und Verwaltungsinstitutionen, Tübingen 1958

- Parlament und Regierung im modernen Staat, VVDStRL Heft 16 (1958) S. $74 \mathrm{ff}$

du Pasquie $r$ Claude, La notion de justice sociale et son influence sur le droit suisse, Zeitschrift für schweizerisches Recht n.F., Bd. 71 (1952) S. 69 ff

Pathe Karl, Die Ausführung der Bundesgesetze, DVB1. 66. Jhg. (1951) S.681 ff

Patschke Hellmuth, Die Bedeutung rechtsstaatlichen Denkens für die Wirtschaft, Betriebsberater, 9.Jhg. (1954) S. $1 \mathrm{f}$

Patzig Werner, Klagbarer Rechtsanspruch der öffentlichen Fürsorge, NJW 4.Jhg. (1951) S. $62 \mathrm{f}$

- Der kommunale Finanzausgleich im Zeichen des Steuerverbundes, DVB1. 74.Jhg. (1959) S. 1 ff

Pa uli ck Heinz, Die verfassungsrechtlichen Bindungen des Gesetzgebers beim Erlaß von Steuergesetzen, Zeitschrift für die gesamte Staatswissenschaft, Bd. 109 (1953) S. $483 \mathrm{ff}$

- Der Grundsatz der Gleichmäßigkeit der Besteuerung - sein Inhalt und seine Grenzen, in: "Probleme des Finanz- und Steuerrechts", Festschrift für Ottmar Bühler, Köln 1954, S. $121 \mathrm{ff}$

- Grundgesetz und Besteuerung, Steuerberaterjahrbuch 1957/ 58 , S. $85 \mathrm{ff}$

Pechan Hermann, Artikel "Arbeiterschutz (I) Geschichte", Handwörterbuch der Sozialwissenschaften, Bd. 1, 1956, S. $245 \mathrm{ff}$

Peters Hans, Über gerechte Verteilung des Einkommens und Eigentums, Zeitschrift für die gesamte Staatswissenschaft, Bd. 112 (1956) S. 218 ff 
P eters Hans, Lehrbuch der Verwaltung, Berlin/Göttingen/Heidelberg 1949

- Rechtsstaat und Rechtssicherheit, Recht Staat Wirtschaft Bd. 3 (1951) S. 66 ff

- Nichtwirtschaftliche Organisationen im Bundeswirtschaftsrat, DÖV 5.Jhg. (1952) S.556 ff

- Der Kampf um den Verwaltungsstaat, in: "Verfassung und Verwaltung", Festschrift für Wilhelm Laforet, München 1952 , S. $19 \mathrm{ff}$

- Die freie Entfaltung der Persönlichkeit als Verfassungsziel, in: "Gegenwartsprobleme des internationalen Rechts und der Rechtsphilosophie", Festschrift für Rudolf Laun, Hamburg 1953, S. $669 \mathrm{ff}$

- Entwicklungstendenzen der Demokratie in Deutschland seit 1949, in: "Demokratie und Rechtsstaat", Festschrift für Zaccharia Giacometti, Zürich 1953, S.229 ff

- Verfassungsrechtliche Fragen des Entwurfs eines Gesetzes über die Beziehungen zwischen Ärzten, Zahnärzten und Krankenkassen (Kassenarztrecht), Köln $1953=$ Deutscher Bundestag, 1. Wahlperiode, Drucksache Nr.3904

- Die Gewaltentrennung in moderner Sicht, Köln/Opladen 1954

- Die Gegenwartslage des Staatskirchenrechts, VVDStRL Heft 11, 1954, S. $177 \mathrm{ff}, 251 \mathrm{ff}$

- Die verfassungsrechtliche Zulässigkeit berufsständischer Pflichtversorgungseinrichtungen für Ärzte, Köln 1954

- Die Wandlungen der öffentlichen Verwaltung in der neuesten Zeit, Krefeld 1954

- Ist es verfassungsmäßig zulässig, daß der Staat durch bestimmte Arbeitsschutzvorschriften auch Personen erfaßt, die keine oder nur solche Arbeitnehmer beschäftigen, welche infolge der Art oder Organisation des Betriebes insoweit nicht schutzbedürftig sind? Bundesarbeitsblatt 1954, S.205 ff, $241 \mathrm{ff}$ (auch als Sonderdruck)

- Kombination verschiedener Verfassungsgrundsätze als Mittel der Verfassungsauslegung, in: Festschrift für Karl Arnold, Köln/Opladen 1955, S. 117 ff

- (Herausgeber), Handbuch der kommunalen Wissenschaft und Praxis Bd.I 1956; Bd.II 1957; Bd. III 1958; Berlin/Göttingen/Heidelberg 
Peters Hans, Diskussionsbeitrag zu "Die Organisationsgewalt", VVDStRL Heft 16 (1958) S. $247 \mathrm{ff}$

- Artikel "Demokratie", Staatslexikon Bd. II, 6.Aufl., 1958, Sp. $560 \mathrm{ff}$

- Elternrecht, Erziehung, Bildung und Schule, in: BettermannNipperdey-Scheuner, Die Grundrechte, Bd.IV 1.Halbbd., Berlin 1960, S. $369 \mathrm{ff}$

Peters Horst, Sautter Theodor, Wolff Richard, Kommentar zur Sozialgerichtsbarkeit, 2.Auf1., Stuttgart 1958

Pfeifer Helfried, Diskussionsbeitrag zu "Begriff und Wesen des sozialen Rechtsstaates", VVDStRL Heft 12, 1954, S. $111 \mathrm{ff}$

- Diskussionsbeitrag zu "Die Organisationsgewalt", VVDStRL Heft 16 (1958) S.259 ff

$P$ fe if fe $r$ Gerd, Bewilligung des Armenrechts im Klageerzwingungsverfahren nach $₫ 172$ StPO, NJW 6.Jhg. (1953) S.571 f

Pfister Bernhard, Der Wandel der Sozialstruktur in Westdeutschland und die Probleme der sozialen Sicherung, Deutsche Versicherungszeitschrift, 5.Jhg. (1951) S. $266 \mathrm{ff}$

Pinz enöller, Verfassungsmäßigkeit des Kindergeldgesetzes, Die Sozialgerichtsbarkeit, 7.Jhg. (1960) S. $70 \mathrm{f}$

Plat z Hermann, Die gerichtliche Kontrolle der Leistungsverwaltung, DÖV 12.Jhg. (1959) S. 340 ff (= Rechtsprechung zur Wiedergutmachung, 10.Jhg. (1959) S. $351 \mathrm{ff}$ )

P ohle Rudolf, Der Bürger vor der Vielzahl der Gerichte, in:

"Staat und Bürger", Festschrift für Willibalt Apelt, München/Berlin 1958, S. 171 ff

Preiser Erich, Artikel "Distribution(I) Theorie", Handwörterbuch der Sozialwissenschaften, Bd.2, 1959, S.620 ff

Prelle r Ludwig, Vorsorge als Grundanspruch eines modernen Sozialrechts, in: "Sozialpolitik, A rbeits- und Sozialrecht", Festschrift für Friedrich Sitzler, Stuttgart 1956, S. 165 ff

Quante Peter, Artikel "Invaliden-, Alters- und Hinterbliebenenversicherung", Handwörterbuch der Sozialwissenschaften, Bd. 5, 1956, S. 329 ff

$R$ a i s e $r$ Ludwig, Wirtschaftsverfassung als Rechtsproblem, in: Festschrift für Julius Gierke, Berlin 1950, S. 181 ff 
Raiser Ludwig, Diskussionsbeitrag zu "Enteignung und Sozialisierung", VVDStRL Heft 10, 1952, S. 158 f, 167

- Zur Eigentumsgarantie des Grundgesetzes, AöR Bd.78 (1952/53) S. 118

- Vertragsfreiheit heute, JZ 13.Jhg. (1958) S. $1 \mathrm{ff}$

R a u W., Wirtschaftslenkende Verwaltung, DVB1. 75.Jhg. (1960) S. $339 \mathrm{ff}$

Ra ue cker Bruno, Wirtschaftsdemokratie, Berlin 1929

Re deker K., Kammerbegriff und Grundgesetz, DVB1. 67.Jhg. (1952) S. $201 \mathrm{ff}, 239 \mathrm{ff}$

Re if Hans, Das Parlament im demokratischen Staat, Zeitschrift für Politik n. F., 6.Jhg. (1959) S.204 ff

Reigrotzki Erich, Artikel "Sozialstruktur (I) Soziale Schichtung", Handwörterbuch der Sozialwissenschaften, Bd.9, 1956, S. $578 \mathrm{ff}$

Reinhardt Rudolf - Scheuner Ulrich, Verfassungsschutz des Eigentums, Tübingen 1954, Reinhardt zitiert als: Reinhardt, Verfassungsschutz des Eigentums

- Empfiehlt es sich, die verschiedenen Pflichten des Staates zur Entschädigungsleistung aus der Wahrnehmung von Hoheitsrechten nach Grund, Inhalt und Geltendmachung gesetzlich neu zu regeln? Verhandlungen des 41. Deutschen Juristentages, Bd.I 1.Halbbd., Tübingen 1955, S.237 ff

Reinhold Johannes, Innere und äußere Freiheit im Wohlfahrtsstaat, Zeitschrift für Sozialreform, 5. Jhg. (1959) S. $529 \mathrm{ff}$

R onner Karl, Wege der Verwirklichung - Betrachtungen über politische Demokratie, Wirtschaftsdemokratie und Sozialismus, Berlin 1929

Reu $\beta$ Hermann, Die dritte Gewalt - Einheit oder Differenzierung in der Organisation der Rechtspflege, JR 1957 S. $321 \mathrm{ff}$

- Grundfragen des Wirtschaftsverwaltungsrechts, DVB1. 73. Jhg. (1958) S. 683 ff

- Die Wirkungseinheit von Verwaltungs- und Verfassungsrecht, DÖV 12.Jhg. (1959) S. $321 \mathrm{ff}$

- Freiheit und Bindung der Verwaltung im Rechtsstaat, DVB1. 74.Jhg. (1959) S. 533 ff 
R e u $\beta$ Wilhelm, Zwei Jahre Sozialgerichtsbarkeit, Betriebsberater, 11.Jhg. (1956) S. $660 \mathrm{ff}$

- Die Organisation der Wirtschaft, in: Bettermann-NipperdeyScheuner, Die Grundrechte, Band III 1. Halbbd., Berlin 1958, S. $91 \mathrm{ff}$

- Gleicher Lohn für gleiche Arbeit? Arbeit und Recht, 8. Jhg. (1960) S. $33 \mathrm{ff}$

Re wolle Hans-Dietrich, Rohlfing Theodor, -.-, Arbeitsgerichtsgesetz, Frankfurta.M. 1959 ff

Rhode Heinz, Arbeitsrecht, Sozialrecht, Gemeinschaftsrecht, Berlin 1944

Richter Ernst Günter, Neue Rechtsformen für das Leistungsverwaltungsrecht, NJW 11.Jhg. (1958) S.1518 ff

R ichter Lutz, Die Organisationsgewalt, Jena 1926

- Sozialversicherungsrecht, Berlin 1931

Ridde $r$ Helmut K.J., Enteignung und Sozialisierung, VVDStRL Heft 10, 1952, S. $124 \mathrm{ff}, 174 \mathrm{ff}$

- Finanzausgleich und Grundgesetz, AöR Bd.78(1952/53)

$\mathrm{S} .237 \mathrm{ff}$

- Empfiehlt es sich, die vollständige Selbstverwaltung aller Gerichte im Rahmen des Grundgesetzes gesetzlich einzuführen? Verhandlungen des 40. Deutschen Juristentages, Bd. 1, Tübingen 1953, S.91 ff

- Meinungsfreiheit, in: Neumann-Nipperdey-Scheuner, Die Grundrechte, Bd.II, Berlin 1954, S.243 ff

Rietdorf Fritz, Die Finanzverantwortung des Bundes gegenüber den Gemeinden, DÖV 6.Jhg. (1953) S. $225 \mathrm{ff}$

- Zum staatsrechtlichen Lehrbegriff der "mittelbaren Staatsverwaltung", DÖV 12.Jhg. (1959) S.671 ff

Ritsch 1 Hans, Eine Neuregelung des Finanzausgleichs, Finanzarchiv n.F., Bd. 13 (1951/52) S.369 ff

- Wirtschaftsordnung und Rechtsstaat, in: "Zur Ordnung von Wirtschaft und Gesellschaft", Hamburger Jahrbuch für Wirtschafts- und Gesellschaftspolitik, 4.Jhg. (Festausgabe für Eduard Heimann) Tübingen 1959, S.256 ff

Rittig Gisbert, Artikel "Sozialisierung (I) Theorie", Handwörterbuch der Sozialwissenschaften, Bd.9 (1956) S. 455 ff 
Roehrbein Erich, Rohrbeck Walter, ---, Meyrich Carl, Zum Problem der Realisierbarkeit der Vorschläge der Rothenfelser Denkschrift über "Die Neuordnung der sozialen Leistungen", Berlin 1955

R o e me $r$ Walter, Zur Rechtsprechung des Bayerischen Verfassungsgerichtshofs, SJZ 4.Jhg. (1949) Sp. 24 ff, 184 ff; 5.Jhg. (1950) Sp. 569 ff

- Zum Grundrecht der freien Entfaltung der Persönlichkeit, in: "Hundert Jahre Deutsches Rechtsleben", Festschrift Deutscher Juristentag, Bd. I, Karlsruhe 1960, S. 545 ff

Rönitz Dieter, Nochmals: Die Aussetzung der Vollziehung von Steuerbescheiden bei verfassungsrechtlich zweifelhaften

Steuergesetzen, NJW 13.Jhg. (1960) S.226 ff

Röpke Wilhelm, Die Gesellschaftskrisis der Gegenwart, 5.Aufl., Erlenbach-Zürich 1948

Roesler Hermann, Das soziale Verwaltungsrecht, Bd.I 1872; Bd. II 1873, Erlangen

Rogge Heinrich, Das Flüchtlingsproblem als internationale Rechtsfrage, Internationales Recht und Diplomatie 1958, S. $28 \mathrm{ff}, 109 \mathrm{ff}$

- Flüchtlingsverwaltung, Flüchtlingsrecht und Sozialstaat, DVB1. 71.Jhg. (1956) S. $37 \mathrm{ff}$

Rohlfing Theodor, Rewolle Hans-Dietrich, Arbeitsgerichtsgesetz, Frankfurt a. M. 1959 ff

Rohrbeck Walter, Der Begriff der Sozialversicherung und ihre A bgrenzung zur Versorgung und Fürsorge, in: "Gegenwartsfragen sozialer Versicherung", hrsg. von Walter Bogs, Heidelberg 1950, S. $17 \mathrm{ff}$

- Die freiwillige Altersversorgung als Bestandteil der sozialen Sicherheit, Deutsche Versicherungszeitschrift, 8. Jhg. (1954) S. 4 ff

-, Roehrbein Erich, Meyrich Carl, Zum Problem der Realisierbarkeit der Vorschläge der Rothenfelser Denkschrift über

"Die Neuordnung der sozialen Leistungen", Berlin 1955

Rohwe r-Kahlmann Harry, Hastler Hanns, -.-, A ufbau und Verfahren der Sozialgerichtsbarkeit, Bad Godesberg 1953 ff

- Verfassungsrechtliche Schranken der Zustimmungsgesetze, Ä̈R Bd. 79 (1953/54) S.208 ff 
Rohwer-Kahlmann Harry, Die Krise des Eigentums, Zeitschrift für Sozialreform, 2.Jhg. (1956) S. $239 \mathrm{ff}, 308 \mathrm{ff}$

- Die neuen Rentengesetze und der soziale Rechtsstaat, Zeitschrift für Sozialreform, 3.Jhg. (1957) S. $114 \mathrm{ff}, 136 \mathrm{ff}$

- Einheit der rechtsprechenden Gewalt oder eigenständige Sozialgerichtsbarkeit? Zeitschrift für Sozialreform, 3.Jhg. (1957) S. $163 \mathrm{ff}$

- Sozialrecht und Grundgesetz, Soziale Sicherheit, 6.Jhg. (1957) S. $358 \mathrm{ff}$

- Renten und Anwartschaften unter Eigentumsschutz, Die Sozialgerichtsbarkeit, 5.Jhg. (1958) S. $144 \mathrm{ff}, 172 \mathrm{ff}$

- Die Kassenarztzulassung und das Grundgesetz, Zeitschrift für Sozialreform, 4.Jhg. (1958) S. $594 \mathrm{ff}, 670 \mathrm{ff}$

- Die soziale Fürsorge nach dem Bundesversorgungsgesetz eine Versorgungsleistung, Die Sozialgerichtsbarkeit, 6.Jhg. (1959) S. $341 \mathrm{ff}$

- Die Rechtsnatur des Versorgungsanspruchs nach dem Bundesversorgungsgesetz, in: "Sozialreform und Sozialrecht", Festschrift für Walter Bogs, Berlin 1959, S.303 ff

- Die verkannte Selbstversicherung, Die Sozialgerichtsbarkeit, 6. Jhg. (1959) S. $245 \mathrm{ff}$

- Die Einwirkung verfassungsrechtlicher Normen auf das Recht der sozialen Sicherheit, NJW 13.Jhg. (1960) S. 1641 ff

Romberg W., Allgemeinverbindlicherklärung von Tarifverträgen und Grundgesetz, AöR Bd. 77 (1951/52) S. 110 f

Roos Gottfried, Der Grundsatz der gesetzmäßigen Verwaltung und seine Bedeutung für die Anwendung des Verwaltungsrechts, in: "Rechtsquellenprobleme im schweizerischen Recht", Festgabe der rechts- und wirtschaftswissenschaftlichen Fakultät der Universität Bern für den Schweizerischen Juristenverein ( $=$ Bd.91 bis 96 der Zeitschrift des Bernischen Juristenvereins) Bern 1955, S. $117 \mathrm{ff}$

Rosenberg Arthur, Demokratie und Sozialismus, Amsterdam 1938

Rothländer Albrecht, Zum Begriff des Sozialstaates, Der deutsche Beamte, V.Jhg. (1955) S.92 
Rothländer Albrecht, Zur Entwicklungsgeschichte des Sozialstaates, Der deutsche Beamte, V.Jhg. (1955) S. 139

- Zur Praxis des Sozialstaates, Der Deutsche Beamte, VI. Jhg. (1956) S. 21

Ruck Erwin, Freiheit und Rechtsstaat, in: "Die Freiheit des Bürgers im schweizerischen Recht", Festgabe zur Hundertjahrfeier der Bundesverfassung, hrsg. von den juristischen Fakultäten der schweizerischen Universitäten, Zürich 1948, S. $75 \mathrm{ff}$

R ü st ow Alexander, Ortsbestimmung der Gegenwart, Bd. I 1950; Bd.II 1952; Bd.III 1957; Erlenbach-Zürich

$\mathrm{R} u \mathrm{mpf}$ Helmut, Verwaltung und Verwaltungsrechtsprechung, VVDStRL Heft 14, 1956, S. 136 ff

- Der ideologische Gehalt des Bonner Grundgesetzes, Karlsruhe 1958

R upp Hans Heinrich, Die Beseitigungs- und Unterlassungsklage gegen Träger hoheitlicher Gewalt, DVB1. 73.Jhg. (1958) S. 113 ff

S a che r Hermann, v. Nell-Breuning Oswald, ---, Zur christlichen Staatslehre, 2.Auf1., Freiburg i. Breisgau 1957

Sacher 1 Karl, Freiherr v.d. Heydte Friedrich August, ---, Soziologie der deutschen Parteien, München 1955

Saitzew Manuel, Der Interventionismus, in: Festgabe für Fritz Fleiner, Zürich 1937, S. 321 ff

Sattle $r$ Herbert, Gemeindliche Finanzverfassung. Bedeutung gemeindlicher Finanzhoheit für die Selbstverwaltung, in: Handbuch der kommunalen Wissenschaft und Praxis, hrsg. von Hans Peters, Bd. III, Berlin/Göttingen/Heidelberg 1958, S. $l$ ff

Sa u e r born Maximilian, Soziale Strukturwandlungen, in: "Beiträge zur Versicherungswissenschaft", Festgabe für Walter Rohrbeck, Berlin 1955, S. $347 \mathrm{ff}$

Savelsberg Gertrud, Artikel "Sozialpolitik (V) Internationale Sozialpolitik", Handwörterbuch der Sozialwissenschaften, Bd. 9 (1956) S. 564 ff

- Artikel "Sozialversicherung (II) Entwicklung und heutiger Stand", Handwörterbuch der Sozialwissenschaften, Bd. 9 (1956) S.604 ff 
Scupin Hans Ulrich, Diskussionsbeitrag zu "Die Organisationsgewalt", VVDStRL Heft 16, 1958, S.261 ff

Se i d el Bruno, Artikel "Sozialpolitik (I) Geschichte", Handwörterbuch der Sozialwissenschaften, Bd.9 (1956) S. 532 ff

Seidel Hanns, Wirtschaftspolitik und soziale Ethik, in: Festschrift für Hans Ehard, München 1957, S. 14 ff

- Die deutsche Bundesrepublik und der Föderalismus, Bayerische Verwaltungsblätter n.F., 4.Jhg. (1958) S. 193 ff

Se $11 \mathrm{mann}$, Zur Zuständigkeitsabgrenzung zwischen den allgemeinen Verwaltungsgerichten und den Sozialgerichten, DVB1. 71. Jhg. (1956) S. $118 \mathrm{ff}, 154 \mathrm{ff}$

- Verwaltungsgerichtsbarkeit und Sozialgerichtsbarkeit, NJW 10. Jhg. (1957) S. $1091 \mathrm{ff}$

Sel1s chopp Hermann, Zur Frage der Entschädigung in der Bodenreform, DÖV, 5. Jhg. (1952) S. $242 \mathrm{ff}=$ Zeitschrift für das gesamte Siedlungswesen, 1.Jhg. (1952) S.46 ff

S e uf e rt Günther, Bayerisches Enteignungsrecht, Berlin 1957

Si e bert Wolfgang, Privatrecht im Bereich öfentlicher Verwaltung, in: Festschrift für Hans Niedermeyer, Göttingen 1953, S. $215 \mathrm{ff}$

- Einige Grundgedanken des gegenwärtigen Arbeitsrechts, Recht der Arbeit, 9.Jhg. (1956) S. 12 ff

- Diskussionsbeitrag zu "Freiheit und Bindung im kollektiven Arbeitsrecht", Schriften der Gesellschaft für Sozialen Fortschritt e.V., Band 6, Berlin 1957, S. $47 \mathrm{ff}$

- Faktische Vertragsverhältnisse, Karlsruhe 1958

- Einige Entwicklungslinien im neueren Individualarbeitsrecht, Recht der Arbeit, 11.Jhg. (1958) S.366 ff

- Einige Fragen zur Wirkung der Verwaltungsakte im Arbeitsverhältnis, in: Festschrift für Karl Gottfried Hugelmann, Bd. II, Aalen 1959, S. 605 ff

Si e vers Ernst R., Kindergeldgesetzgebung und Grundgesetz, NJW 10.Jhg. (1957) S. $441 \mathrm{ff}$

Simitis Spiros, Die faktischen Vertragsverhältnisse, Frankfurt a. M. 1957

Sitzler Friedrich, Soziale Selbstverwaltung im demokratischen Staat, Sozialer Fortschritt, 1.Jhg. (1952) S. 73 ff 
Smend Rudolf, Verfassung und Verfassungsrecht, München und Leipzig 1928 (abgedruckt auch in "Staatsrechtliche Abhandlungen", Berlin 1955, S. $119 \mathrm{ff}$ )

- Staatsrechtliche Abhandlungen, Berlin 1955

Sombart Werner, Der proletarische Sozialismus (10. Auf1. von

"Sozialismus und soziale Bewegung"), 2 Bände, Jena 1924

Spanne r Hans, Die Rolle der Verfassung im gegenwärtigen politischen und sozialen Leben, Österreichische Zeitschrift für öffentliches Recht, Bd.VII (1955) S. 9 ff

- Organisationsgewalt und Organisationsrecht, DÖV 10.Jhg. (1957) S.640 ff

- Bundesverfassungsgericht und freies Ermessen, Bayerische Verwaltungsblätter n.F., 4.Jhg. (1958) S. 1 ff

- Diskussionsbeitrag zu "Die Organisationsgewalt", VVDStRL Heft 16, 1958, S.255 ff

Spiegelhalter Franz, Die Struktur der betrieblichen Sozialaufwendungen, Der Arbeitgeber, 12.Jhg. (1960) S. $459 \mathrm{ff}$, $499 \mathrm{ff}, 565 \mathrm{ff}$

Süste $\mathrm{rhenn}$ Adolf, Einheitliches Gerichtsministerium? DVB1. 71.Jhg. (1956) S. $737 \mathrm{ff}$

- Das Subsidiaritätsprinzip als Grundlage der vertikalen Gewaltenteilung, in: "Vom Bonner Grundgesetz zur gesamtdeutschen Verfassung", Festschrift für Hans Nawiasky, München 1956, S. $141 \mathrm{ff}$

- Die kirchliche Liebestätigkeit im sozialen Rechtsstaat der Gegenwart, in: "Die Katholiken vor der Politik", hrsg. von Gustav E.Kafka, Freiburg i.Breisgau 1958, S. 105 ff

Sult an Herbert, A bendroth Wolfgang, Bürokratischer Verwaltungsstaat und soziale Demokratie, Hannover/Frankfurt 1955

Syrup Friedrich, Hundert Jahre staatliche Sozialpolitik (aus dem Nachlaß von Friedrich Syrup, bearbeitet von Otto Nëuloh, hrsg. von Julius Scheible) Stuttgart 1957

Schaar G., Jie Aussetzung der Vollziehung von Steuerbescheiden bei verfassungsrechtlich zweifelhaften Steuergesetzen, NJW 13.Jhg. (1960) S. $852 \mathrm{f}$

Schack Friedrich, Das $M a ß$ der Enteignungsentschädigung, MDR 7.Jhg. (1953) S. 195 ff 
Schack Friedrich, Generelle Eigentumsentziehungen als Enteignungen, NJW 7.Jhg. (1954) S. $577 \mathrm{ff}$

- Empfiehlt es sich, die verschiedenen Pflichten des Staates zur Entschädigungsleistung aus der Wahrnehmung von Hoheitsrechten nach Grund, Inhalt und Geltendmachung gesetzlich neu zu regeln? Verhandlungen des 41 . Deutschen Juristentages, Bd.I 1. Halbbd. Tübingen 1955, S. 5 ff

- Rechtsverordnungen im formellen Sinn? DÖV 11. Jhg. (1958) S. $273 \mathrm{ff}$

Schäfer Hans, Bundesaufsicht und Bundeszwang, AöR Bd. 78 (1952/53) S. 1 ff

- Die bundeseigene Verwaltung, DÖV 11.Jhg. (1958) S.241 ff

- Zehn Jahre Grundgesetz, DVB1. 74.Jhg. (1959) S.341 ff

- Die Bundesauftragsverwaltung, DÖV 13.Jhg. (1960) S.641 ff

$\mathrm{Sch}$ a e f e $\mathrm{r}$ Rolf, Kindergeldgesetzgebung und Grundgesetz, Ehe und Familie im privaten und öffentlichen Recht, 4. Jhg.

(1957) S. $353 \mathrm{ff}$

Scharmann Theodor, Die Mitwirkung des Behinderten bei der Durchführung von Rehabilitationsmaßnahmen, in: "Sozialreform und Sozialrecht", Festschrift für Walter Bogs, Berlin 1959 , S. $317 \mathrm{ff}$

Scheffler Erna, Ehe und Familie, in: Bettermann-NipperdeyScheuner, Die Grundrechte, Bd. IV 1. Halbbd., Berlin 1960, S. $245 \mathrm{ff}$

Scheune $r$ U1rich, Grundfragen des modernen Staates, Recht Staat Wirtschaft Bd.3 (1951) S. 126 ff

- Der Bereich der Regierung, in: "Rechtsprobleme in Staat und Kirche", Festschrift für Rudolf Smend, Göttingen 1952, S. $253 \mathrm{ff}$

- Probleme und Verantwortungen der Verfassungsgerichtsbarkeit in der Bundesrepublik, DVB1. 67.Jhg. (1952) S.293 ff

- Diskussionsbeitrag zu "Enteignung und Sozialisierung", VVDStRL Heft 10, 1952, S. 153 ff, 168 f

- Die Selbständigkeit und Einheit der Rechtspflege, DÖV 6.Jhg. (1953) S. $517 \mathrm{ff}$

- Die institutionellen Garantien des Grundgesetzes, Recht Staat Wirtschaft, Bd.4 (1953) S. 88 ff 
Scheuner U1rich, Berufsständische Versorgungseinrichtungen und Grundgesetz, in: "Aktuelle Probleme der Versicherungswirtschaft vom Standpunkt der Versicherungswissenschaft betrachtet", hrsg. v. Walter Rohrbeck, Berlin 1954, S. 71 ff

- Die staatliche Intervention im Bereich der Wirtschaft, VVDStRL Heft 11, 1954, S. 1 ff, $147 \mathrm{ff}$

- Die Abgrenzung der Enteignung, DÖV 7.Jhg. (1954) S. 587 ff

-, Reinhardt Rudolf, Verfassungsschutz des Eigentums, Tübingen 1954" Scheuner zitiert als: Scheuner, Verfassungsschutz des Eigentums

- Diskussionsbeitrag zu "Verwaltung und Verwaltungsrechtsprechung", VVDStRL Heft 14, 1956, S.181 ff

- Moderne Strukturfragen des demokratischen Staats, in: "Legitime Interessenvertretung", hrsg. von der Evangelischen Akademie Loccum, Loccum 1956, S. 3 ff

- Stellung und Einfluß der Verbände im heutigen Staat, Der Güterverkehr, 5.Jhg. (1956) S.289 ff

- Grundrechtsinterpretation und Wirtschaftsordnung (zur Auslegung des Art.12 GG), DÖV 9.Jhg. (1956) S.65 ff

- Begriff und Entwicklung des Rechtsstaates in: "Macht und Recht", hrsg. von Hans Dombois und Erwin Wilkens, Berlin 1956 , S. $76 \mathrm{ff}$

- Ausländische Erfahrungen zum Problem der Übertragung rechtsetzender Gewalt, in: "Die Übertragung rechtsetzender Gewalt im Rechtsstaat", Schriftenreihe des Instituts zur Förderung öffentlicher Angelegenheiten e.V., Bd.12, Frankfurt a. M. 1956, S. $118 \mathrm{ff}$

- Diskussionsbeitrag zu "Das Gesetz als Norm und Maßnahme", VVIStRI, Heft 15, 1957, S. 69 ff

- Kirche und Staat in der neueren deutschen Entwicklung, Zeitschrift für evangelisches Kirchenrecht, Bd. 7 (1960) S.225 ff

- Die Aufgabe der Gesetzgebung in unserer Zeit, DÖV 13.Jhg. $(1960)$ s.601 ff

- Die neuere Entwicklung des Rechtsstaats in Deutschland, in: "Hundert Jahre Deutsches Rechtsleben", Festschrift Deutscher Juristentag, Bd. II, Karlsruhe 1960, S.229 ff

Schewe Dieter, Zur Verfassungsmäßigkeit der Wertfestsetzung von Sachbezügen nach $₫ 160$ Abs. 2 RVO, Die Sozialversicherung, 9.Jhig. (1954) S.2 ff 
Schewe Dieter, Zur Abgrenzung von Verwaltungs- und Sozialgerichtsbarkeit - eine verschiedene Lesart des "Sozialen" in Art.96 GG und $₫ 51$ SGG, Die Sozialgerichtsbarkeit, 1.Jhg. (1954) S. $133 \mathrm{ff}$

- Ist eine Vereinheitlichung der Gerichtsbarkeiten verfassungsrechtlich zulässig? Zeitschrift für Sozialreform, 3.Jhg. (1957) S. $241 \mathrm{f}$

- Über den sozialen Ausgleich in der Rentenversicherung, in: "Sozialreform und Sozialrecht", Festschrift für Walter Bogs, Berlin 1959, S.333 ff

- Körperschaften ohne Selbstverwaltung? Die Sozialgerichtsbarkeit, 7.Jhg. (1960) S.97 ff

$\mathrm{S}$ chindle r Dietrich, Recht und Staat, Verhandlungen des Schweizerischen Juristentages, Basel 1931, S. 83 ff

- Verfassungsrecht und soziale Struktur, 2.Aufl., Zürich 1944

- Recht, Staat, Völkergemeinschaft (ausgewählte Schriften und Fragmente aus dem Nachlaß) Zürich 1948

Schlocha ue r Hans-Jürgen, Öffentliches Recht, Karlsruhe 1957

Schmidt Friedrich, Das Grundgesetz und das Sozialrecht, Deutsche Richterzeitung, 38.Jhg. (1960) S.282 ff

$\mathrm{Schmidt}$ Kurt, Zur ordnungspolitischen Problematik der Progressivbesteuerung, ORDO Bd. IX (1957) S.217 ff

- Möglichkeiten und Grenzen einer Finanzpolitik des sozialen A usgleiches, ORDO Bd.X (1958) S. 315 ff

- Zum Problem der Zweckkollision im modernen Steuerrecht, Finanzarchiv n.F., Bd. 19 (1959) S.204 ff

Schmidt-Rimple r Walter, Gieseke Paul, Friesenhahn Ernst und Knur Alexander, Die Lohngleichheit von Männern und Frauen, AöR Bd.76 (1950/51) S. 165 ff

Schmitt Carl, Verfassungslehre, Berlin 1928 (unverändert neu gedruckt 1954 und 1957)

- Inhalt und Bedeutung des zweiten Hauptteils der Reichsverfassung, in Anschütz-Thoma, Handbuch des Deutschen Staatsrechts, Bd. II, Tübingen 1932, S. 572 ff

- Nehmen/Teilen/Weiden, Gemeinschaft und Politik, 1. Jhg. (1953) S. $18 \mathrm{ff}$

- Verfassungsrechtliche Aufsätze, Berlin 1958 
Schmitt-Lermann Hans, Die Verfassungsmäßigkeit der Pflichtmitgliedschaft bei der Bayerischen Ärzteversorgung, München 1954 (ungedruckt)

Schmölders Günter, Finanzpolitik, Berlin/Göttingen/Heidelberg 1955

Schneeberger, Zur Frage der Rechtswidrigkeit der Zölibatsklausel für Polizeivollzugsbeamte, Zeitschrift für Beamtenrecht, 4.Jhg. (1956) S.33 ff

Schneider Hans, Das soziale Jahrhundert, Frankfurt a. M., Bonn 1950

- $\quad$ Fünf Jahre Grundgesetz, NJW 7.Jhg. (1954) S.937 ff

- Diskussionsbeitrag zu "Das Gesetz als Norm und Maßnahme", VVDStRL Heft 15, 1957, S. 89 ff

- Staatsverträge und Verwaltungsabkommen zwischen deutschen Bundesländern, DÖV 10.Jhg. (1957) S. 644 ff

- Körperschaftliche Verbundverwaltung, AöR Bd. 83 (1958) S. $1 \mathrm{ff}$

- Über Einzelfallgesetze, in: Festschrift für Carl Schmitt, Berlin 1959, S. 159 ff

- Die öffentlich-rechtliche Alterssicherung freier Berufe und das Grundgesetz, Stuttgart 1959

Schneider Hellmuth, Gewissensfreiheit und Kündigungsschutz, A rbeit und Recht, 4.Jhg. (1956) S.97 ff

Schneider Joseph, Die Entwicklung des Rechtsschutzes in der Sozialversicherung, in: "Sozialpolitik, Arbeits- und Sozialrecht", Festschrift für Friedrich Sitzler, Stuttgart 1956, S. 329 ff

Schneider Peter, Zur Problematik der Gewaltenteilung im Rechtsstaat der Gegenwart, AöR Bd.82 (1957) S. 1 ff

Schnitzler, Zur Verfassungsmäßigkeit der Kindergeldgesetzgebung, MDR 10.Jhg. (1956) S. $712 \mathrm{ff}$

$\mathrm{Schnor}$ Gerhard, Bundesverfassungsgericht und kollektives Arbeitsrecht, Recht der Arbeit, 8.Jhg. (1955) S. 3 ff

- Die Rechtsidee im Grundgesetz, AöR Bd.85 (1960) S.121 ff

Schrorr von Carolsfeld Ludwig, Arbeitsrecht, 2. Auf1., Göttingen 1954 
S chnupp G., Zölibatsklausel für Polizeivollzugsbeamte, Zeitschrift für Beamtenrecht, 4.Jhg. (1956) S.343 ff

S choeck Helmut, Das Problem des Neides in der Massendemokratie, in "Masse und Demokratie", Erlenbach-Zürich/Stuttgart 1957

S choen Xaver, Das Sozialgericht, ein besonderes Verwaltungsgericht, DÖV 7.Jhg. (1954) S. $597 \mathrm{ff}$

S choltissek Herbert, Die Eigentumsgarantie des Grundgesetzes, Betriebsberater, 7.Jhg. (1952) S.981 ff

$\mathrm{Schrader,} \mathrm{Die} \mathrm{Neutralität} \mathrm{des} \mathrm{Staates} \mathrm{bei} \mathrm{Arbeitskämpfen} \mathrm{und}$

A rbeitslosigkeit, Zeitschrift für Sozialreform, 2. Jhg. (1956)

S. $345 \mathrm{ff}$

$\mathrm{S} c h \mathrm{r}$ äde $\mathrm{r}$ Hildegard, Die sozialen Aufgaben der Städte, DÖV 9.Jhg. (1956) S.492 ff

- Kommunale Sozialpolitik, in: Handbuch der kommunalen Wissenschaft und Praxis, hrsg. von Hans Peters, Bd. II, Berlin/Göttingen/Heidelberg 1957, S.265 ff

S chraeple r Ernst, Quellen zur Geschichte der sozialen Frage, Bd.I 1955; Bd.II 1957; Göttingen/Berlin/Frankfurt a. M.

Schroeter Kurt, Hofmann Kurt, ---, Sozialgerichtsgesetz, 2.Auf1., Berlin/Frankfurt a. M. 1957

S ch üle Adolf, Verfassung und Wirtschaft, 1948

- Demokratie als politische Form und als Lebensform, in: "Rechtsprobleme in Staat und Kirche", Festgabe für Rudolf Smend, Göttingen 1952, S. $321 \mathrm{ff}$

- Die staatliche Intervention im Bereich der Wirtschaft, VVDStRL Heft 11, 1954, S. 75 ff, 143 ff

- Diskussionsbeitrag zu "Begriff und Wesen des sozialen Rechtsstaates", VVDStRL Heft 12, 1954, S. 106 f

S chütz Erwin, Der Widerruf gesetzwidriger begünstigender Verwaltungsakte, DÖV 11.Jhg. (1958) S.449 ff

Schulte, Zur Rechtsgültigkeit der Bodenreformgesetzgebung in der britischen Zone, MDR 6.Jhg. (1952) S.321

Schumpeter Joseph A., Kapitalismus, Sozialismus und Demokratie, 2.Aufl., München 1950

Schunck Egon, Die Rechtsstellung der Gemeinden und Gemeindeverbände nach dem Grundgesetz, Recht im Amt, 3.Jhg. (1956) S. 369 ff 
Schunck Egon, Giese Friedrich, ---, Grundgesetz für die Bundesrepublik Deutschland, 5.Aufl., Frankfurt a. M. 1960 (abgekürzt zitiert mit: Giese-Schunck)

Schur Heinz, Zur Bindung an fehlerhafte begünstigende Verwaltungsakte im Sozialversicherungs- und Versorgungsrecht, Zentralblatt für Sozialversicherung und Versorgung, 14. Jhg. (1960) S.113 ff

$\mathrm{Schwankhart} \mathrm{Franz,} \mathrm{Besonderheiten} \mathrm{der} \mathrm{Sozialverwaltung} \mathrm{im}$ Verhältnis zur allgemeinen Verwaltung, Bayerische Verwaltungsblätter n.F., 3.Jhg. (1957) S. $111 \mathrm{ff}, 149 \mathrm{ff}$

- Zweifelsfragen aus dem Sozialversicherungsrecht, Bayerische Verwaltungsblätter n.F., 3.Jhg. (1957) S.237 ff

S chwe ig e $r$ Karl, Rechtsverordnung im formellen Sinn? DÖV 8.Jhg. (1955) S. $360 \mathrm{ff}, 366$

v. Schwenk Ernst, Demokratie und Mitbestimmung, Gewerkschaftliche Monatshefte, 2.Jhg. (1951) S. $541 \mathrm{ff}$

St a $m$ m Albert, Zur Verwirklichung des sozialstaatlichen Prinzips, JZ 10.Jhg. (1955) S. $149 \mathrm{ff}$

St a ve nhagen Gerhard, Ortlieb Heinz-Dietrich, ---, Artikel "Sozialisierung (II) Geschichte (1) Deutschland", Handwörterbuch der Sozialwissenschaften, Bd.9 (1956) S. 464 ff

Ste ding Erich, Verwirrung über das Wesen der Kriegsopferversorgung, Zeitschrift für Sozialreform, 5.Jhg. (1959) S. $89 \mathrm{ff}$

v. Stein Lorenz, Die Geschichte der sozialen Bewegung in Frankreich von 1789 bis auf unsere Tage. Band III: Das Königtum, die Republik und die Souveränität der französischen Gesellschaft seit der Februarrevolution 1848, 2. Auf1., Leipzig 1855 (zitiert nach Neuauflage, München 1921)

$S t \in r n$ Klaus, Zur Grundlegung einer Lehre des öffentlich-rechtlichen Vertrages, Verwaltungsarchiv, Bd.49 (1958) S.106 ff

- Zur Problematik des energiewirtschaftlichen Konzessionsvertrages, AöR Bd.84 (1959) S. 138 ff, 273 ff

- Rechtsfragen der öffentlichen Subventionierung Privater, JZ 15.Jhg. (1960) S. 518 ff, 575 ff

St ötzner Hermann, Der fehlerhafte begünstigende Verwaltungsakt in den gesetzlichen Rentenversicherungen, Die Sozialversicherung, 15.Jhg. (1960) S.96 ff 
Strauß Walter, Wirtschaftsverfassung und Staatsverfassung, Tübingen 1952

Strickrodt Georg, Die Finanzverfassung des Bundes als politisches Problem, Tübingen 1951

- Verfassungsgarantierte Währung, Zeitschrift für das gesamte Kreditwesen, 5. Jhg. (1952) S. 533 ff

- Finanzverfassungsrecht - Idee und Gestaltungsmöglichkeit, Betriebsberater, 8. Jhg. (1953) S. $805 \mathrm{ff}$

- Finanzverfassung als selbständiges Normensystem, JZ 10. Jhg. (1955) S. 129 ff

- Finanzverfassung - Verwirklichungsmöglichkeiten im System, JZ 10.Jhg. (1955) S. $469 \mathrm{ff}$

- Finanzverfassung als Real- und Rechtsstruktur der Wirtschafts- und Sozialordnung, Karlsruhe o.J. (1956)

- Die Idee der Wirtschaftsverfassung als Gestaltungs- und Interpretationsprinzip, JZ 12. Jhg. (1957) S. $361 \mathrm{ff}$

Tatarin-Tarnheyden Edgar, Berufsverbände und Wirtschaftsdemokratie, Berlin 1930

- Recht der Berufsverbände und Wirtschaftsdemokratie, in: Nipperdey, Die Grundrechte und Grundpflichten der Reichsverfassung, Bd.III, Berlin 1930, S. $519 \mathrm{ff}$

Te ut sch A ugust, Die Sozialgerichtsbarkeit und die allgemeine Verwaltungsgerichtsbarkeit, DÖV 3.Jhg. (1950) S. $159 \mathrm{ff}$

- Das künftige obere Bundesgericht für die Sozialgerichtsbarkeit, Recht der A rbeit, 3.Jhg. (1950) S. $254 \mathrm{ff}$

Thielicke Helmut, Probleme des Wohlfahrtsstaates, Zeitschrift für evangelische Ethik, 1958, S. $193 \mathrm{ff}$

Thieme Werner, Die besonderen Gewaltverhältnisse, DÖV 9. Jhg. (1956) S. $521 \mathrm{ff}$

- Liberalismus und Grundgesetz, Zeitschrift für die gesamte Staatswissenschaft, Bd. 113 (1957) S. 285 ff

- Umfang und Grenzen des verfassungsrechtlich gewährleisteten Bestandsschutzes der saarländischen Kriegsopferrenten, Zeitschrift für Sozialreform, 5.Jhg. (1959) S. 149 ff, 243 ff

- Der Beamte im sozialen Rechtsstaat, Zeitschrift für Beamtenrecht, 8. Jhg. (1960) S. $169 \mathrm{ff}$ 
Thierfelder Hermann, Mitwirkung von Ausschüssen in der staatlichen Verwaltung - Möglichkeiten, Bewährung und Grenzen - B) Der süddeutsche Raum, Verwaltungsarchiv, Bd. 49 (1958) S. $249 \mathrm{ff}$

Thoma Max, Die öffentliche Fürsorge, in: Handbuch der kommunalen Wissenschaft und Praxis, hrsg. von Hans Peters, Bd. II, Berlin/Göttingen/Heidelberg 1957, S.283 ff

Thoma Richard, Die juristische Bedeutung der grundrechtlichen Sätze der Deutschen Reichsverfassung im allgemeinen, in: Nipperdey, Die Grundrechte und Grundpflichten der Reichsverfassung, Bd.I, Berlin 1929, S. 1 ff

- Cber Wesen und Erscheinungsformen der modernen Demokratie, Bonn 1948

- Die Grundrechte im Grundgesetz der Bundesrepublik Deutschland, Recht Staat Wirtschaft, Bd. 3 (1951) S. 9 ff

$T$ ödt Jürgen, Möglichkeiten und Probleme einer Änderung der Einkommensverteilung, Bundesarbeitsblatt, 10.Jhg. (1959) S. 773 ff

Topitsch Frnst, Sozialtheorie und Gesellschaftsgestaltung, Archiv für Rechts- und Sozialphilosophie, Bd.XLII (1956) S. $171 \mathrm{ff}$

Tophoven Frnst, Hueck Alfred, Nipperdey Hans Carl, --Tarifvertragsgesetz, 3.Aufl., München/Berlin 1955

Torz Robert, Die privatwirtschaftliche Betätigung der öffentlichen Hand und das Grundgesetz, DÖV 11.Jhg. (1958) S. $205 \mathrm{ff}$

Trieschmann Günther, Zur Zulässigkeit von Kettenverträgen im Arbeitsrecht, Der Betrieb, 5. Jhg. (1955) S. 336 ff

- Soziale Menschenrechte - internationale Normen und deutsches Arbeitsrecht, Bundesarbeitsblatt 1956, S. $452 \mathrm{ff}$

Tschischgal e M., Das Armenrecht im Verfahren der Sozialgerichtsbarkeit, NJW 10.Jhg. (1957) S.164 ff

Ule Carl Hesmann, Anmerkung zu OVG Hamburg Urt. v. 1. November 1950 - OVG Bf I 327/50 - DVB1.66.Jhg. (1951) S. 52 ff

Zur Anwendung unbestimmter Rechtsbegriffe im Verwaltungsrecht, in: "Forschungen und Berichte aus dem öffentlichen Recht", Gedächtnisschrift für Walter Jellinek, München 1955, S. $309 \mathrm{ff}$ 
U1 e Carl Hermann, Rentenkürzungen als Enteignung? Zeitschrift für Sozialreform, 2.Jhg. (1956) S. 138 ff, $180 \mathrm{ff}$

- Anmerkung zu OVG Lüneburg, Urt. v.22. Juni 1955 - V OVG A 40/54 - DVB1. 71.Jhg. (1956) S. $25 \mathrm{ff}$

- Über das Verhältnis von Verwaltungsstaat und Rechtsstaat, in: "Staats- und verwaltungswissenschaftliche Beiträge", Stuttgart 1957, S. $127 \mathrm{ff}$

- Das besondere Gewaltverhältnis, VVDStRL Heft 15, 1957, S. $133 \mathrm{ff}$

- Anmerkung zu BVerwG Urt. v. 19. Februar 1957 - II C 72. 57 - JZ 13.Jhg. (1958) S. $628 \mathrm{ff}$

- Empfiehlt es sich, die verschiedenen Zweige der Rechtsprechung ganz oder teilweise zusammenzufassen? Verhandlungen des 42. Deutschen Juristentages, 1958, S.E 3 ff

Utz A rthur Fridolin, Die geistesgeschichtlichen Grundlagen des Subsidiaritätsprinzips

und

Die Subsidiarität als Aufbauprinzip der drei Ordnungen:

Wirtschaft, Gesellschaft und Staat, in: "Das Subsidiaritätsprinzip", hrsg. von Arthur Fridolin Utz, Heidelberg 1953, S. $7 \mathrm{ff}, 101 \mathrm{ff}$

- Formen und Grenzen des Subsidiaritätsprinzips, Heidelberg 1956

del Vecchio Giorgio, Die Gerechtigkeit, Basel 1950

van der Ven J.J.M., Rechtswege zur sozialen Sicherheit, Zeitschrift für die gesamte Staatswissenschaft, Bd. 113 (1957) S. $520 \mathrm{ff}$

Via 1 on Friedrich Karl, Das Haushaltsrecht der Bundesrepublik Deutschland, AöR Bd.77 (1951/52) S. 19 ff

Vogel A., Zur Frage der Rückwirkung von Steuergesetzen, NJW 13. Jhg. (1960) S. $1182 \mathrm{ff}$

V o g e 1 Klaus, Kammerbeitrag und Finanzverfassung, DVB1. 73. Jhg. (1958) S. $491 \mathrm{ff}$

- Das Bundesverfassungsgericht zum Bremer Personalvertretungsgesetz, MDR 13.Jhg. (1959) S. $894 \mathrm{ff}$

Voigt Fritz, Wirtschaftsverfassung und Wirtschaftsentwicklung der Bundesrepublik Deutschland, in: "Staat und Bürger", Festschrift für Willibalt A pelt, München/Berlin 1958, S. 73 ff 
Volkmann Jürgen, Ausnahmen von der bindenden Wirkung der Verwaltungsakte nach $₫ 77$ SGG, Die Sozialgerichtsbarkeit, 7. Jhg. (1960) S. $100 \mathrm{ff}$

W a cke Gerhard, Das Finanzwesen cler Bundesrepublik, Tübingen 1950

- Das Gesetz über die Finanzverwaltung, Finanzarchiv n.F., Bd. $12(1950 / 51)$ S. $713 \mathrm{ff}$

- Die Finanzverfassung, DÖV, 8.Jhg. (1955) S. 577 ff

Wa ckernage 1 Jacob, Gesetzmäßigkeit der Verwaltung und persönliche Freiheit, in: "Die Freiheit des Bürgers in der Schweiz", Festgabe zur Hundertjahrfeier der Bundesverfassung, hrsg. von den Juristischen Fakultäten der schweizerischen Universitäten, Zürich 1948, S.243 ff

W a s s e Günter, Die Werke und Einrichtungen der evangelischen Kirche, Göttingen 1954

Wa s s e rab Karl, Sozialwissenschaft und soziale Frage, Leipzig 1900

We be r Karl-Friedrich, Innere Mission und Wohlfahrtsstaat, in: "Macht und Recht", hrsg. von Hans Dombois und Erwin Wilkens, Berlin 1956, S. $174 \mathrm{ff}$

W e be $r$ Werner, Zur Problematik von Enteignung und Sozialisierung nach neuem Verfassungsrecht, NJW 3.Jhg. (1950) S. $401 \mathrm{ff}$

- Diskussionsbeitrag zu "Enteignung und Sozialisierung", VVDStRL Heft 10, 1952, S. 164 ff

- Das Richtertum in der deutschen Verfassungsordnung, in: Festschrift für Hans Niedermeyer, Göttingen 1953, S.261 ff

- Die Entschädigung in der westdeutschen Bodenreform, DÖV 6. Jhg. (1953) S. $353 \mathrm{ff}$

- Staats- und Selbstverwaltung in der Gegenwart, Stuttgart 1953

- Die Gegenwartslage des Staatskirchenrechts, VVDStRL Heft 11, 1954, S. 153 ff, $253 \mathrm{ff}$

- Eigentum und Enteignung, in: Neumann-Nipperdey-Scheuner, Die Grundrechte, Bd. II, Berlin 1954, S. $331 \mathrm{ff}$

- Die Rechtsbeständigkeit der Bodenreformgesetze in Hessen, Kassel 1954 
We be $r$ Werner, Die verfassungsrechtliche Problematik der Zwangsversorgungseinrichtungen der freien Berufe, in: "Aktuelle Probleme der Versicherungswirtschaft vom Standpunkt der Versicherungswissenschaft betrachtet", Berlin 1954, S. 7 ff

- Diskussionsbeitrag zu "Die Finanzverfassung im Rahmen der Staatsverfassung", VVDStRL Heft 14, 1956, S. 81 ff

- Diskussionsbeitrag zu "Verwaltung und Verwaltungsrechtsprechung", VVDStRL Heft 14, 1956, S. 188 ff

- Artikel "Juristische Person(II) Juristische Personen des öffentlichen Rechts", Handwörterbuch der Sozialwissenschaften, Bd. 5, 1956, S.449 ff

- Artikel "Staatskirchenrecht", Handwörterbuch der Sozialwissenschaften, Bd.9, 1956, S. 753 ff

- Die Einheit der rechtsprechenden Gewalt, Zeitschrift für Sozialreform, 3.Jhg. (1957) S. $109 \mathrm{ff}$

- Diskussionsbeitrag zu "Das besondere Gewaltverhältnis", VVDStRL Heft 15, 1957, S. 186 ff

- Die Verfassung der Bundesrepublik in der Bewährung, Göttingen/Berlin/Frankfurt a. M. 1957

- Zur Problematik des Rechtsprechungsministeriums, DVB1. 72. Jhg. (1957) S. $737 \mathrm{ff}$

- Diskussionsbeitrag zu "Die Organisationsgewalt", VVDStRL Heft 16, 1958, S. 240 ff

- Mittelbare und unmittelbare Demokratie, in: Festschrift für Karl Gottfried Hugelmann, Bd. II, Aalen 1959, S. 765 ff

- Artikel "Körperschaften des öffentlichen Rechts", Handwörterbuch der Sozialwissenschaften, Bd.6, 1959, S.38 ff

- Spannungen und Kräfte im westdeutschen Verfassungssystem, 2. Aufl., Stuttgart 1959

- Die Teilung der Gewalten als Gegenwartsproblem, in: Festschrift für Carl Schmitt, Berlin 1959, S.253 ff

We ddigen Walter, Artikel "Sozialpolitik (IV) Träger und Methoden", Handwörterbuch der Sozialwissenschaften, Bd.9, 1956, S. $554 \mathrm{ff}$

- Artikel "Sozialversicherung (I) Theorie", Handwörterbuch der Sozialwissenschaften, Bd.9, 1956, S. $594 \mathrm{ff}$ 
Wehrhahn Herbert, Das Gesetz als Norm und Maßnahme, VVDStRL Heft 15, 1957, S. 35 ff

W e i dne r Viktor, Ist der Ausschluß der Armenanwaltsbeiordnung in den unteren Instanzen der Sozialgerichtsbarkeit verfassungsmäßig? JZ 14.Jhg. (1959) S. 622 ff

- Zur Rechtsprechung des Bundessozialgerichts, JZ 14.Jhg. (1959) S. $698 \mathrm{ff}, 758 \mathrm{ff}$

Weisser Gerhard, Artikel "Soziale Sicherheit", Handwörterbuch der Sozialwissenschaften, Bd.9, 1956, S.396 ff

- Artikel "Distribution (II) Politik", Handwörterbuch der Sozialwissenschaften, Bd.2, 1959, S.635 ff

W e ndt Siegfried, Bemerkungen über das Verhältnis von Wirtschaftspolitik und Sozialpolitik, in: "Sozialreform und Sozialrecht", Festschrift für Walter Bogs, Berlin 1959, S. 365 $\mathrm{ff}$

We rne r Fritz, Die Zuständigkeit des Bundes für ein Bundesbaugesetz, DVB1. 69.Jhg. (1954) S. $481 \mathrm{ff}$

- Allgemeine Verwaltungsgerichtsbarkeit und Sozialgerichtsbarkeit, NJW 7.Jhg. (1954) S. 1625 ff

- Anmerkung zu OVG Berlin Urt. v.2.Juni 1954 - OVG I B 159/53 - DVB1. 70.Jhg. (1955) S. $652 \mathrm{ff}$

- Sozialstaatliche Tendenzen in der Rechtsprechung, AöR Bd.81 (1956) S. 84 ff

- Verwaltungsrecht als konkretisiertes Verfassungsrecht, DV131. 74. Jhg. (1959) S. $527 \mathrm{ff}$

Wertenbruch Wilhelm, Grundgesetz und Menschenwürde, Köln/Berlin 1958

Wessel Franz, Die Verwaltung, DV 2.Jhg. (1949) S. 327 ff

Widtinann Julius, Helmreich Karl, ---, Bayerische Gemeindeordnung, 2.Auf1., München 1959

W i e a cker Franz, Das Sozialmodell der klassischen Privatrechtsgesetzbücher und die Entwicklung der modernen Gesellschaft, Karlsruhe 1953

- Die faktischen Vertragsverhältnisse als Ausdruck der gewancielten sozialen Funktion der Rechtsinstitute des Privatrechts, JZ 14.Jhg. (1959) S. 382 f 
Wi ea cker Franz, Das Bürgerliche Recht im Wandel der Gesellschaftsordnungen, in: "Hundert Jahre Deutsches Rechtsleben", Festschrift Deutscher Juristentag, Bd. II, Karlsruhe 1960, S. 1 ff

Wi edemann Herbert, Zeitliche Grenzen kollektiver Gestaltungsmacht, Recht der Arbeit, 12.Jhg. (1959) S. $454 \mathrm{ff}$

v. Wi e se Leopold, Soziale Sicherheit und sozialer Aufstieg als Probleme unserer Zeit, Soziale Welt, 1.Jhg. $(1949 / 50)$ Heft 3, S. 3 ff

- Über die Armut, Kölner Zeitschrift für Soziologie und Sozialpsychologie, 6.Jhg. (1953/54) S. 42 ff

- Artikel "Sozialpolitik (III) Sozialpolitik als Wissenschaft", Handwörterbuch der Sozialwissenschaften, Bd.9, 1956, S. $547 \mathrm{ff}$

Wild Hans Walter, Reform oder Berichtigung des Art. 75 GO? Der Bayerische Bürgermeister, 8.Jhg. (1955) S. $145 \mathrm{ff}$

- Der Versorgungsbetrieb eine wesenseigene Funktion der Gemeinde, Der Bayerische Bürgermeister, 9. Jhg. (1956) S. $196 \mathrm{ff}$

Wilkens Erwin, Probleme des Wohlfahrtsstaates, in: "Macht und Recht", hrsg. von Hans Dombois und Erwin Wilkens, Berlin 1956, S. 149 ff

Wi 11 igmann Klaus, Koppelung mehrerer Verwaltungsobliegenheiten, DVB1. 75.Jhg. (1960) S. $753 \mathrm{ff}$

Winkle $r$ Günther, Zum Verwaltungsbegriff, Österreichische Zeitschrift für öffentliches Recht n.F., Bd. IX (1958/59) S. $66 \mathrm{ff}$

Wintrich Josef Marquard, Über Eigenart und Methode verfassungsgerichtlicher Rechtsprechung, in: "Verfassung und Verwaltung", Festschrift für Wilhelm Laforet, München 1952 , S. $227 \mathrm{ff}$

- Die Verfassungsgerichtsbarkeit im Gesamtgefüge der Verfassung, Bayerische Verwaltungsblätter n.F., 2. Jhg. (1956) S. $97 \mathrm{ff}, 132 \mathrm{ff}$

- Aufgaben, Wesen und Grenzen der Verfassungsgerichtsbarkeit, in: "Vom Bonner Grundgesetz zur gesamtdeutschen Verfassung", Festschrift für Hans Nawiasky, München 1956, S. $191 \mathrm{ff}$ 
Wintrich Josef Marquard, Die Bedeutung der Menschenwürde für die Anwendung des Rechts, Bayerische Verwaltungsblätter n.F., 3.Jhg. (1957) S. $137 \mathrm{ff}$

- Grundfragen des Verfassungsrechts in der Rechtsprechung des Bayerischen Verfassungsgerichtshofs, Bayerische Verwaltungsblätter n.F., 4.Jhg. (1958) S.97 ff, $132 \mathrm{ff}$

- Zur Auslegung und Anwendung des Art. 2 Abs. 1 GG in: "Staat und Bürger", Festschrift für Willibalt Apelt, München/Berlin 1958, S. $1 \mathrm{ff}$

W itten Egmont, Subventionen in der Rechtsprechung, DVB1. 73. Jhg. (1958) S. $699 \mathrm{ff}$

Wolany, Vom Sozialstaat und sozialen Recht, in: "Forum der Rechtsphilosophie", hrsg. von Ernst Sauer, o.O. 1950, S. $141 \mathrm{ff}$

W olff Bernhard, Die Ermächtigung zum Erlaß von Rechtsverordnungen nach dem Grundgesetz, AöR Bd. 78 (1952/53) S. 194 ff

- Die Rechtsprechung des Bundesverfassungsgerichts von 1954 bis 1957, Jahrbuch des öffentlichen Rechts n.F., Bd. 7 (1958) S. $108 \mathrm{ff}$

Wolff Hans J., Der Abwendungsanspruch aus öffentlichen Reflexrechten insbes. im Fürsorgerecht, in: "Verwaltung und Wirtschaft", Festschrift zur Feier des 25jährigen Bestehens der Westfälischen Verwaltungsakademie Münster und der Verwaltungs- und Wirtschaftsakademie Industriebezirk Sitz Bochum, Münster/Berlin/Bad Godesberg 1950, S. $119 \mathrm{ff}$

- Der Unterschied $z$ wischen öfentlichem und privatem Recht, AöR Bd. 76 (1950/51) S. 205 ff

- Rechtsgrundsätze und verfassungsgestaltende Grundentscheidungen als Rechtsquellen, in: "Forschungen und Berichte aus dem ïfentlichen Recht", Gedächtnisschrift für Walter Jellinek, München 1955, S.33 ff

- Verwaltungsrecht I, 3.Aufl., München/Berlin 1959

Wolff Walter, Zur Frage eines eigenständigen Sozialrechts, Gewerkschaftliche Monatshefte, 1.Jhg. (1950) S. 566 ff 
$\mathrm{Z}$ a che r Hans F., Entschädigungslose Enteignung von Verkehrsflächen, Bayerische Verwaltungsblätter n.F., 2.Jhg. (1956) S. $66 \mathrm{ff}, 109 \mathrm{ff}$

- Struktur und Stellung des Bayerischen Senats, Bayerische Verwaltungsblätter, n. F. 3.Jhg. (1957) S. 369 ff; 4.Jhg. (1958) S. $10 \mathrm{ff}$

Z e idle r Karl, Über die Technisierung der Verwaltung, Karlsruhe 1959

- Bundesverfassungsgericht und "Maßnahmegesetz", JZ 15. Jhg. (1960) S.391 ff

$Z$ ei $B$ Friedrich, Kommunales Wirtschaftsrecht und Wirtschaftspolitik, in: Handbuch der kommunalen Wissenschaft und Praxis, hrsg. von Hans Peters, Bd.III, Berlin/Göttingen/Heidelberg 1958, S. $611 \mathrm{ff}$

- Die Versorgungs- und Verkehrsbetriebe als wirtschaftliche Unternehmen, DÖV 11.Jhg. (1958) S.201 ff

Z imme rmann Waldemar, Das "Soziale" im geschichtlichen Sinn- und Begriffswandel, in: Festgabe für Leopold v. Wiese, Mainz 1948, S. $173 \mathrm{ff}$

- Die Arbeiterfrage heute, Schmollers Jahrbuch für Gesetzgebung, Verwaltung und Volkswirtschaft, 74.Jhg. (1954) S.1 ff

$\mathrm{Z}$ inn Georg August, Der Bund und die Länder, AöR, Bd. 75 (1949) S. $291 \mathrm{ff}$

- Die Rechtspflege im Bonner Grundgesetz, Verhandlungen des 37. Deutschen Juristentages, 1950, S. 46 ff

Zippelius Reinhold, Verordnungen der Landesregierungen auf Grund bundesgesetzlicher Ermächtigung, NJW 11. Jhg. (1958) S. $445 \mathrm{ff}$

$Z$ öllne r Detlev, Entwicklungsphasen der Sozialpolitik, in: "Sozialreform und Sozialrecht", Festschrift für Walter Bogs, Berlin 1959, S. 397 ff

$\mathrm{Z}$ öllne $\mathrm{r}$ Wolfgang, Zur Publikation von Tarifvertrag und Betriebsvereinbarung, DVB1. 73. Jhg. (1958) S. $124 \mathrm{ff}$

$Z$ we ige rt Kurt, Das neue Kartellgesetz, DVB1. 73.Jhg. (1958) S. $733 \mathrm{ff}$ 


\section{SACHREGISTER}

Abgabenrecht

s. auch Eigentumsentziehung, soziale Umschichtung

$828 \mathrm{ff}$

allgemeine Handlungsf reiheit

s. Handlungsf reiheit

Allgemeinverbindlicherklärung von Tarifverträgen

s. Kollektives Arbeitsrecht, Selbsteintritt

Amtshaftungsrecht

$635 \mathrm{ff}$

Anstalten

- Anstaltsfürsorge 450

- Grundrechte im geschlossenen Anstaltsverhältnis $871 \mathrm{ff}$

Anwartschaftsrecht

s. Eigentum

Arbeiterversicherung

770

Arbeitgeberverbände

s. auch soziale Selbstverwaltung

128

Arbeitnehmererfindung

786

arbeitsgerichtliches Beschlußverfahren

514,525

Arbeitsgerichtsbarkeit

s. auch Sozialgerichtsbarkeit

- Arbeitsgerichte $361 \mathrm{f}$

- Verhällnis zur ordentlichen Gerichtsbarkeit 582 ff

- Verhältnis zur Sozialgerichtsbarkeit $587 \mathrm{ff}$

533

Arbeitsgesetzbuch

$\mathrm{XCI}$

Arbeitsgesetzbuchkommission

s. Kommission

Arbeitskampf

s. auch soriale Selbstverwaltung

$299 \mathrm{ff}$ 
Arbeitslosenquote

LXXV, LXXXVI, XCVIII

Arbeitslosenversicherung

- s. auch Beruf sf reiheit

799

Arbeitspflicht

$801 \mathrm{ff}$

Arbeitsrecht

s. auch Berufsfreiheit, Gleichberechtigung, Handlungsf reiheit sozialer Rechtsstaat

- Arbeitsschutzrecht 784

- Arbeitsvertragsrecht 784

- Frauenarbeitsschutz 923 ff

- Gleichheit von Mann und Frau 923 ff

- kirchliches Dienstrecht $274 \mathrm{ff}$

- sozialstaatliches Arbeitsrecht 782

- Vollzug 121

$67 \mathrm{ff}, 911 \mathrm{ff}, \mathrm{LXXV}$

Arbeitsschutzrecht

s. Arbeitsrecht

Arbeitsvertragsrecht

s. Arbeitsrecht

A rbeitsverwaltung

s. bundesunmittelbare Selbstverwaltung

Arbeitszwang

s. Berufsfreiheit

Armenrecht

s. auch Gleichheitsgrundrecht, rechtliches Gehör

823

Armutsdiskussion

LXXXIX

Asylrecht

1093

Aufopf erungsenteignung

s. Enteignung

Ausbildungsförderung

559

Ausgleich

s. sozialer Ausgleich 
Ausländerbeschäftigung

LII, LXXXIII, XCV

Auslief erungsverbot

$1090 \mathrm{ff}$

Ausschüsse

- Beschwerdeausschuß für das Schwerbeschädigtengesetz 131

- Landesjugendwohlf ahrtsausschuß 132

$125,130 \mathrm{ff}, 392 \mathrm{ff}$

Beamtenrecht

- Abfindung 922

- Berufsbeamtentum $365 \mathrm{ff}$

- Kirchliches Beamtenrecht 281

$794 \mathrm{ff}$

Beitragsrecht

$185 \mathrm{ff}, 832$

Beruf sbeamtentum

s. Beamtenrecht

Berufsfreiheit

- Arbeitslosenversicherung 1041

- Arbeitsplatzwahl $1041 \mathrm{ff}$

- Arbeitsrecht 1045

- Arbeitszwang 1042

- Ausbilclungsstätte 1042

- Drittwirkung 1044

- Grundrechtsschranken 1029

$1024 \mathrm{ff}$

Berufsrichter

s. Gerichtsbarkeit

berufsständische Körperschaften

$251 \mathrm{f}$

Beschäftigungspolitik

$\mathrm{XCVIII}$

besonderes Gewaltverhältnis

s. auch Grundrechte, körperliche Unversehrtheit

- dienstrechtliches Gewaltverhältnis $874 \mathrm{ff}$

- Krankenanstalt 449

- Rechtssetzungsbefugnis 496

- im Sozialbereich 448

- und Sozialversicherungsverhältnis 450

- Versicherungsanstalt 447

$445 \mathrm{ff}$ 
Bestandsgarantie

s. Sozialstaatsprinzip

Bestimmtheitsgebot

- in der Sozialversicherung $467 \mathrm{ff}$

463

betriebliche Sozialpolitik

184

Betriebsvereinbarung

s. Grundrecht sgeltung,

soziale Selbstverwaltung

Betriebsverfassungsrecht

s. Eigentumsbindung, soziale Selbstverwaltung

Bildungspolitik

$\mathrm{XC}$

Bildungswesen

s. auch Gleichheitsgrundrecht

821

Bodenreform

s. auch soziale Umschichtung

$72 \mathrm{ff}, 816$

Briefgeheimnis

s. Freiheitsgrundrechte

bürgerliches Recht

s. Sozialstaatsprinzip

Bürokratie

$365 \mathrm{ff}$

Bundesanstalt für Arbeitsvermittlung und Arbeitslosenversicherung 246,494

Bundesauftragsverwaltung

$112 \mathrm{ff}$

Bundesbank

s. Bundesunmittelbare Selbstverwaltung

Bundeseigenverwaltung

- Bundesversicherungsamt $85 \mathrm{ff}$

- Finanzverwaltung $82 \mathrm{ff}$

- Versorgung 82

Bundesentschädigungsgesetz

s. Entschädigungsrecht 
Bundesministerialverwaltung

- Fondsverwaltung $108 \mathrm{f}$

- nichtakzessorische Verwaltung $106 \mathrm{f}$

$91 \mathrm{ff}$

Bundespräsident

$349 \mathrm{f}$

Bundesrat

$208 \mathrm{ff}, 210,350 \mathrm{ff}$

Bundessozialhilfegesetz (Entwurf)

$140,148,242,273,1075,1077,1085$

Bundesstaat

- gesetzesfreie Verwaltung 422

- Gesetzgebungskompetenz $45 \mathrm{ff}$

- öffentliches Dienstrecht 774

- rechtsprechende Gewalt 352 ff

- Rechtsprechungskompetenz $170 \mathrm{ff}$

- Verwaltungskompetenz $81 \mathrm{ff}$

$45 \mathrm{ff}, 223$

Bundesstaatliche Finanzverfassung

s. Finanzverfassung

Bundesunmittelbare Selbstverwaltung

- Arbeitsverwaltung 89

- Bundesbank 91

- Sozialversicherungsträger 89 ff

Bundesverfassungsgericht

- sozialpolitische Entscheidungen LXXIX

$360 \mathrm{ff}$, LXXII

Bundeswehr

- Beschädigtenversorgung der Bundeswehr 115

Bundeswirtschaftsrat

386

Bundeszwang

738

Daseinsvorsorge

s. auch Staat

$37 \mathrm{ff}, 232 \mathrm{ff}$ 
Demokratie

s. auch soziale Demokratie

- formale Demokratie $334 \mathrm{ff}, 338$

- reale Demokratie $392 \mathrm{ff}$

- unmittelbare Demokratie $351 \mathrm{f}$

$340 \mathrm{ff}, 688 \mathrm{f}$

Demokratieverständnis

LXXXVI,

LXXXVII

Dienstrechtliches Gewaltverhältnis

- s. besonders Gewaltverhältnis und Grundrechte

Drittwirkung

s. Beruf sfreiheit, Grundrechte, Körperliche Unversehrtheit, Menschenwürde

Eherecht

- Mutterschutz 778, 1012

- Zölibatsklausel 1004

$995 \mathrm{ff}$

Eigentum

- Anwartschaftsrechte 940, 992 ff

- Eigentumsbindung 832 ff, 945, $950 \mathrm{ff}$

- Eigentumsschutz 938

- Gleichheitssatz 948

- Inhaltsbestimmung $991 \mathrm{ff}$

- Lastenausgleich 941

- Monopoleigentum 943

- Privateigentum 944

- Sozialversicherungsansprüche 940, $992 \mathrm{ff}$

$934 \mathrm{ff}$

Eigentumsbindung

s. auch Eigentum, Sozialstaat

- Betriebsverfassungsrecht $954 \mathrm{ff}$

$832 \mathrm{ff}, 945,950 \mathrm{ff}$

Eigentumsentziehung

- Abgabenrecht 952

- Aufopferungsenteignung 952

- Enteignung $952 \mathrm{ff}$

- Sozialisierung $963 \mathrm{ff}$

- Umlegung 952, $962 \mathrm{ff}$

- Umschichtung $951 \mathrm{ff}, 969 \mathrm{ff}$

$951 \mathrm{ff}$ 
Eigentumsgarantie

s. Entschädigung, soziale Umschichtung

Eigenvorsorge

765

Eingriffsverwaltung

421

Einheitsgerichtsbarkeit

$575 \mathrm{f}, 581 \mathrm{ff}$

Einkommensverteilung

764

Elternfamilie

s. Familienrecht

E1ternrecht

1072

Enteignung

s. auch Eigentumsentziehung

- Aufopferungsenteignung 952

- Entschädigung 953

- soziale Umschichtung 960

$71,832 \mathrm{ff}$

Entflechtung

s. soziale Umschichtung

Entschädigung

s. auch Enteignung

- Affektionsinteresse 956

- Bundesentschädigungsgesetz $635 \mathrm{ff}$

- Eigentumsgarantie 955 ff

- Opferausgleich 955 ff

$973 \mathrm{ff}$

Entscheidungsträger

$534 \mathrm{ff}$

Entwicklungspolitik

LIII, LXXXIII, XCIV

Erbrecht

$994 \mathrm{ff}$

Ermessensentscheidung

551

Europäische Menschenrechtskonvention

s. Menschenrechtskonvention 
Familienlastenausgleich

s. Familienrecht, Lastenausgleichsrecht

Familienrecht

- Elternfamilie 1013

- Familienlastenausgleich 999

- Hausarbeitstag 925 ff, 1004

- Hinterbliebenensicherung 1002 ff

- Kindergeldrecht 999

- Kinderreiche 1001

- Kinderschutz 1011

- Mutterfamilie 1013

- Mutterschutz 1012

- uneheliches Kind 1013 ff

- Unterhaltspflicht 1002

Finanzaufkommen

$180 \mathrm{ff}$

Finanzausgleich

s. auch soziale Intervention

$205 \mathrm{ff}$.

Finanzmacht des Bundes

$199 \mathrm{ff}$

Finanzreform

s. Verfassungsänderungen

Finanzverfassung

s. auch soziale Intervention

- Beiträge $185 \mathrm{ff}$

- bundesstaatliche Finanzverfassung 175 ff

- Erwerbseinkünfte $181 \mathrm{ff}$

- Gebühren $187 \mathrm{ff}$

- Kredit 180 ff

- Mittelverteilung 176 ff

- Steuern 189 ff

- Steuerverfassung LXXII

- Zentralisation des Finanzwesens $205 \mathrm{ff}$

$175 \mathrm{ff}$, LXXI

Finanzverwaltung

s. Verwaltung

Fiskalgeltung

- s. Grundrechte

Flüchtlingsrecht

64,119 
Föderalismus

$212 \mathrm{ff}$

Fondsverwaltung

s. Bundesministerialverwaltung

Formale Demokratie

s. Demokratie

Formeller Rechtsstaat

s. auch Rechtsstaat

$398 \mathrm{ff}$

Freie Berufe

s. auch Handlungsf reiheit, soziale Sicherheit

59

Freiheitsgrundrechte

s. auch Grundrechte

- Briefgeheimnis 1017

- Freizügigkeit 1022 ff

- Glaubensfreiheit 1018

- Meinungsfreiheit $1020 \mathrm{ff}$

- Petitionsfreiheit 1017

- Unverletzlichkeit der Wohnung 1018

- Versammlungsf reiheit 1017

$1017 \mathrm{ff}$

Freiwillige Gerichtsbarkeit

514

Freizügigkeit

s. Freihe it sgrundrecht

Fürsorge

- Fürsorgeanspruch 767

- Fürsorgerechtliche Kompetenz 60 ff

- Vollzug 120, 121, 148

$120,469,766$ ff

Fürsorgeverbände

s. Verbände

Gebühren

s. auch Finanzverfassung

$187 \mathrm{ff}, 832$

Geburtenkontrolle

s. körperliche Unversehrtheit

$\mathrm{G} \cdot \mathrm{meindeautonomie}$

231 
Gemeinden

s. auch Interventionsträger

- Organisationskompetenz des Bundes $153 \mathrm{ff}$

$225 \mathrm{ff}$

Gemeindesteuern

$236 \mathrm{ff}$

Gemeindeverbände

s. Verbände

gemeindliche Finanzautonomie

$236 \mathrm{ff}$

gemeindliche Selbstverwaltung

s. Selbstverwaltung

gemeindliche Sozialarbeit

s. Sozialarbeit

Gemeinwohlstaat

703

Generalklauseln

523

Genossenschaftsprinzip

128

Gerechtigkeitspostulat

678

Gerechtigkeitsprinzip

663

Gerechtigkeitsstaat

$702 \mathrm{f}$

Gerichtsbarkeit

- Berufsrichter $360 \mathrm{ff}$

- Laienrichter $360 \mathrm{ff}$

Gerichtsorganisation

$592 \mathrm{ff}$

Gesetze

s. Sozialpolitik

Gesetzesauslegung

s. Sozialstaatsprinzip

gesetzesfreie Verwaltung

s. Bundesstaat 
Gesetzesvollzug

s. Sozialstaatsprinzip

Gesetzesvorbehalt

s. auch Grundrechte

$420 \mathrm{ff}$

Gesetzgebung

s. Sozialstaatsprinzip

Gesetzgebungskompetenz

s. auch Bundesstaat

- öffentlicher Dienst $49 \mathrm{ff}$

- Sozialversicherungsrecht $52 \mathrm{ff}$

- Versorgung 49

$45 \mathrm{ff}$

Gesetzesstaat

- und soziale Intervention $492 \mathrm{ff}$

Gesundheitsschutz

s. körperliche Unversehrtheit

Gesundheitswesen

$821 \mathrm{f}$

Gewaltenteilung

$406 \mathrm{ff}, 595$

Gewerkschaften

s. auch soziale Selbstverwaltung

$128,333,744,789$, LXIX

Glaubensf reiheit

s. auch Freiheitsgrundrechte

- und öffentliches und privates Dienstrecht 1019

$1018 \mathrm{ff}$

G]eichberechtigung

s. auch Gleichheitsgrundrecht

- Arbeitsrec:ht 923

- Lohngleichheit 926

- soziale sicherung 919

XCVI 
Gleichheitsgrundrecht

s. auch Grundrechte, Eigentum

- Armenrecht 901

- Bildungswesen 902

- Gleichberechtigung (s. auch dort) $917 \mathrm{ff}$

- Lastenausgleichsrecht $910 \mathrm{ff}$

- Leistungsanspruch $900 \mathrm{ff}$

- soziale Gerechtigkeit 891

- sozialer Rechtsstaat 890 ff

- Sozialversicherungsrecht 898

- Willkürverbot $893 \mathrm{ff}$

$890 \mathrm{ff}$

Gleichheitssatz

s. auch soziale Umschichtung, Verwaltung

$418 \mathrm{ff}, 561,776,890 \mathrm{ff}, 1085$

Grundgesetz

XL, LXXI

Grundpflichten

s. Sozialstaatserklärung

Grundrechte

s. auch Sozialstaatserklärung, Sozialstaatsprinzip

- ausgrenzende Grundrechte 848 ff, 859 ff

- Betriebsvereinbarung 889

- besonderes Gewaltverhältnis 865

- dienstrechtliches Gewaltverhältnis $874 \mathrm{ff}$

- Drittwirkung 876 ff, LXXIV

- Fiskalgeltung $880 \mathrm{ff}$

- Funktionen 848

- Gewährleistungsschranken 1028

- Gesetzesvorbehalt 862

- Gleichheitsgrundrecht 848

- Grundrechtsgeltung $861 \mathrm{ff}$

- soziale Grundrechte $848 \mathrm{ff}, 859 \mathrm{ff}$

- Sozialrecht - Teilhaberecht: Verhältnis $848 \mathrm{ff}$

- unechte Grundrechte 854

- Vorbehaltsschranke 1026

- einzelne Grundrechte:

- Asylrecht 1093

- Bekenntnisf reiheit 1018

- Berufsfreiheit 1024

- Gewissensfreiheit 1018

- Glaubensfreiheit 1018

- Gleichheit 890 ff 
Grundrechte (Fortsetzung)

- Eigentum $934 \mathrm{ff}$

- Ehe $995 \mathrm{ff}$

- Elternrecht $1008 \mathrm{ff}$

- Familie 995 ff

- Freizügigkeit $1022 \mathrm{ff}$

- Handlungsfreiheit 1056 ff

- Kinderschutz 1011 ff

- Koalitionsfreiheit $1049 \mathrm{ff}$

- Körperliche Freiheit 1069 ff

- Körperliche Unversehrtheit 1073 ff

- Leben 1082

- Meinungsf reiheit 1020

- Menschenwürde 1095 ff

- rechtliches Gehör 1094

- Staatsangehörigkeitsrecht 1090 ff

- Unverletzlichkeit der Wohnung 1018

- Vereinsf reiheit 1046 ff

Grundrechtsauslegung

s. Grundrechte

Grundrechtsgeltung

s. auch Grundrechte

- Tarifvertragsrecht $883 \mathrm{ff}$

- Betriebsvereinbarung 889 ff

Günstigkeitsklausel

725

Güterversorgung

s. Staatsleistungen

Handlungsf reiheit

- Arbeitsrecht 1068

- freie Berufe 1064

- Privatautonomie 1067

- soziale Sicherheit $1064 \mathrm{ff}$

- Sozialstaatsprinzip 1063

- Teilhaberechte 1061

- und soziale Ordnung 1061

- und soziale Wirtschaftsordnung 1066 ff

- verfassungsmäßige Ordnung 1051, 1068

- Versorgungsstaat 1064

$1056 \mathrm{ff}$

$\mathrm{Hausarbeitstag}$

s. Familienrecht 
Hausgerichtsbarkeit

$577 \mathrm{ff}$

Heimarbeitsgesetz

s. Selbsteintritt

Heimkehrergesetz

773

Hinterbliebenensicherung

s. Familienrecht

Individualversicherung

$58 \mathrm{ff}$

Interessenverbände

s. Verbände

internationale Organisationen

(Europarat, ILO, UN, UNICEF, Westeuropäische Union,

Wirtschafts- und Sozialrat)

$25 \mathrm{ff}$

internationale Sozialpolitik

s. Sozialpolitik

Intervention

s. soziale Intervention, wirtschaftliche Intervention

Interventionsträger

- Bund und Länder 22 ff

- Gemeinden 30 ff, 225 ff

- Gemeindeverbände $240 \mathrm{ff}$

- internationale Organisationen $25 \mathrm{ff}$

- Kirchen 31

- Sozialversicherungsträger 30, 89 ff

- supranationale Organisationen 26 ff

Investitionshilfegesetz

477

Junktim-Klausel

955

Justizstaat

- und soziale Intervention $508 \mathrm{ff}$

$508 \mathrm{ff}$

Kartelle

s. Vereinigungsfreiheit 
Kindergeldrecht

s. Familienrecht, körperschaftliche Verbundverwaltung

Kinderreiche

s. Familienrecht

Kinderschutz

s. Familienrecht

Kirchen

- Caritas 260 ff

- Sammlungsrecht 266 ff

- Selbstbestimmungsrecht 259

- Verhältnis zum Staat 252

- Wirkungskreis $259 \mathrm{ff}$

$252 \mathrm{ff}$

kirchliche Liebestätigkeit

- und staatliche soziale Intervention $261 \mathrm{f}$

kirchliches Dienstrecht

$274 \mathrm{ff}$

kirchliches Selbstbestimmungsrecht

s. Kirche

Klassenstaat

741

Koalitionsf reiheit

s. auch soziale Selbstverwaltung

$287 \mathrm{ff}, 790,1049 \mathrm{ff}$

Körperliche Freiheit

- Zwangsarbeit $1070 \mathrm{ff}$

- Zwangsunterbringung $1071 \mathrm{ff}$

$1069 \mathrm{ff}$

Körperliche Unversehrtheit

- besonderes Gewaltverhältnis 1081

- Drittwirkung 1081

- Geburtenkontrolle 1079

- Gesundheitsschutz 1073

- Teilhaberc.cht 1048

- Zwangsexperiment 1078

- Zwangsheilung 1074

- Zwangsunterbringung 1075

$1073 \mathrm{ff}$ 
Körperschaftliche Verbundverwaltung

- Kindergeldrecht 161

- Krankenversicherung 161

- landwirtschaftliche Berufsgenossenschaft 161

$160 \mathrm{ff}$

kollektives Arbeitsrecht

s. auch soziale Selbstverwaltung

- Allgemeinverbindlicherklärung 92 ff

- Tarifvertrag 289, 503, 931

- Tarifvertragsgesetz LXIX

- Tarifvertragsrecht 69, $294 \mathrm{ff}$

Kommission

- Arbeitsgesetzbuchkommission LVI

- Sozialgesetzbuchkommission LVI

- über Gleichstellung von Mann und Frau in der gesetzlichen Rentenversicherung LVI

- über wirtschaftlichen und sozialen Wandel in der BRD LVI, LVIII

Konfiskation

s. soziale Umschichtung

Konsumgüterverteilung

817

Koordinationskompetenz

$110 \mathrm{ff}$

Krankenversicherung

s. körperschaftliche Verbundverwaltung

Kriegsfolgelasten

s. auch Verfassungsänderungen

- Aufwendungen durch den Bund 196 ff

LXXVII

Kriegsopf erversorgung

771

Kriegsschäden

65

Kündigungsschutz

523

Laienrichter

s. Gerichtsbarkeit

Landeseigenverwaltung

$115 \mathrm{ff}$ 
Landesgerichtsbarkeit

$171 \mathrm{ff}$

Landesjugendwohlfahrtsausschuß

s. Ausschüsse

Landesverwaltung

$164 \mathrm{ff}$

Landwirtschaftliche Berufsgenossenschaft

s. körperschaftliche Verbundverwaltung

Lastenausgleichsrecht

s. auch Eigentum, Gleichheitsgrundrecht, soziale Umschichtung, Verfassungsände rungen

- Familienlastenausgleich 999 ff

- Lastenausgleichsabgabe 113

$642,651 \mathrm{ff}, 772,979,989$

LXIX, LXXI

Lastenausgleichsverwaltung

s. auch Verwaltung

- Ausschüsse $132 \mathrm{f}$

Legitimationswirkung

s. Sozialstaat sprinzip

Leistungsanspruch

s. Gleichheitsgrundrecht

Le'istungsver'sorgl:ng

s. Staatsleistungen

Le.istungsverwiliung

s. auch sonialgerichtsbarkeit

- gesetzosfreie Leistungsverwaltung $431 \mathrm{ff}$

- subjektives Recht auf Leistung 544

$622 \mathrm{ff}$

Lohngleichheit

$926 \mathrm{ff}$

Marshallplan

LXX

Maßnahmegeset $z$

477

Mehrheitswahl recht

s. Wahlsystem

Mr:inungsfreiheit

s. Freiheitsgrundrecht 
Menschenrechtskonvention

$842 \mathrm{ff}$

Menschenwürde

- Drittwirkung 1106

- Existenzminimum 1104

- und Privatrecht 1107

- Rechtsstaat 1101

- Sozialstaatsnorm 1102

- subjektives Recht 1103

- und Verfassungsordnung 1098

$1095 \mathrm{ff}$

Mindestarbeitsbedingungen

s. Selbsteintritt

Mitbestimmung

s. auch Sozialisierung

$302,332,788,982 \mathrm{ff}, 985 \mathrm{ff}, \mathrm{XCVIf}$

Mittelverteilung

s. auch Finanzverfassung

$175 \mathrm{ff}$

Mittlerfunktion der Verfassungsgerichtsbarkeit

s. Verfassungsgerichtsbarkeit

Monopoleigentum

s. Eigentum

Mutterfamilie

s. Familienrecht

Mutterschutz

s. Eherecht

Nachkriegszeit

LXVIII

Nichtstaatliche Entscheidungsträger

s. Entscheidungsträger

Notstandsverfassung

s. Verfassungsände rungen

Öffentlich-rechtliche Schiedsgerichtsbarkeit

537

Öffentliches Dienstrecht

s. Bundesstaat 
Öffentliches Recht

- Verhältnis zum Privatrecht $614 \mathrm{ff}$

- und Rechtsstaatlichkeit 618,621

Opferausgleich

s. Entschädigung

Opfergleichtheit

905

Organisationskompetenz

125

Parlament

- Wahl recht 342

- und Regierung 344 ff

$342 \mathrm{ff}$

Parteien

- Parteienfinanzierung $371 \mathrm{ff}$

- Parteienstaat 370

- parteipolitische Kräfte XLX

$370 \mathrm{ff}$

Parteienfinanzierung

s. Parteien

Parteienstaat

s. Parteien

Personalverbände:

- und berufsst ändische Körperschaften 250

- Sozialstaalsiprinzip 248

- Sozialversicherungsträger $245 \mathrm{ff}$

$244 \mathrm{ff}$

Petitionsfreineit

s. Freiheitsfrundrecht

Politische Parteien

s. Parteien

Privatautonomis

s. auch Handilungsf reiheit

630

Privateigentum

- s. Figentum

Privatrecht

s. Verwaltung, öffentliches Recht 
Reale Demokratie

s. Demokratie

rechtliches Gehör

- Armenrecht 1094

Rechtsfähige Verwaltungseinheiten

- Fürsorgeverbände 140

- Sozialversicherungsträger 140, $145 \mathrm{ff}$

Rechtsprechende Gewalt

s. Bundesstaat

Rechtsprechung

s. auch Sozialstaatsprinzip

- gerichtliche Nachprüfung von Gesetzen 553 ff

- Gesetzgebung 527

- richterliche Sozialgestaltung $521 \mathrm{ff}$

- und soziale Intervention $566 \mathrm{ff}, 597 \mathrm{ff}$

- Trennung von der Exekutive 595

- verfassungsrechtliche Fünftgliederung 567

- und Verwaltung 526

$512 \mathrm{ff}$

Rechtsschutz

- gegenüber leistendem Staat 543

- gegen untätigen Gesetzgeber $557 \mathrm{ff}$

- im besonderen Gewaltverhältnis 549

Rechtssicherheit

s. auch sozialer Rechtsstaat

$637 \mathrm{ff}, 658,661$

Rechtsstaat

s. auch Menschenwürde, sozialer Rechtsstaat

- und Gesetze 420 ff

- rechtsstaatliche Hemmung 748 ff

- Verhältnis zur Sozialgestaltung 690

$218,396 \mathrm{ff}, 663 \mathrm{ff}$

Rechtsstaatlichkeit

s. auch öffentliches Recht

- materielle Rechtsstaatlichkeit 633

Rechtsstaatslehren

$398 \mathrm{ff}$

Rechtsstaatsprinzip

$626,632 \mathrm{ff}$ 
Rechtsverordnungen

- funktionelles Verhältnis zu Satzungen $501 \mathrm{ff}$ $489 \mathrm{ff}$

Regierung

$342 \mathrm{ff}, 344 \mathrm{ff}$

Rehabilitation

799

Reichsversicherungsamt

569,596

Renten

s. Eigentum

Rentenanpassungsgeset $z$

479

Rentenbewilligung

$658 \mathrm{ff}$

Rezession

LXXXI, LXXXVI

richterliche Sozialgestaltung

s. Rechtsprechung

Rückwirkungsverbot

$638 \mathrm{ff}$

Satzungsrecht

- verbandliches Satzungsrecht 494 ff

Schadensersatzrecht

s. Sozialstaatsprinzip

Scheidungs rechtsreform

XCIV

Schiedsämter der kassenärztlichen Versorgung 535,538

Schiedsgerichtsbarkeit

$535 \mathrm{ff}$

Schiedsgerichtsbarkeit in Arbeitssachen

536

Schlichtungswesen

s. auch soziale Selbstverwaltung

$299 \mathrm{ff}$ 
Schwerbeschädigtengesetz

s. Ausschüsse

Selbständige

$58 \mathrm{ff}$

Selbsteintritt

- Allgemeinverbindlicherklärung $92 \mathrm{ff}, 307$

- Heimarbeitsgesetz $306 \mathrm{f}$

- Mindestarbeitsbedingungen $305 \mathrm{f}$

- Zwangsschlichtung $309 \mathrm{f}$

$305 \mathrm{ff}$

Selbstverwaltung

s. auch soziale Selbstverwaltung, verbandliche Selbstverwaltung

- gemeindliche Selbstverwaltung 225

- politische Selbstverwaltung 126

- und rechtsprechende Gewalt 363

$245 \mathrm{f}, 347 \mathrm{ff}, 390 \mathrm{ff}, 780$

Siedlungswesen

471

Solidargemeinschaft

54

Sonderversorgung

s. Versorgung

Soziabilitätspflicht

$694 \mathrm{f}$

"sozial"

- demokratisch $688 \mathrm{ff}$

- unsozial 710

$18 \mathrm{ff}, 676 \mathrm{ff}, 685 \mathrm{ff}$

Sozialabgaben

644

Sozialarbeit

- gemeindliche Sozialarbeit 229 ff

LXIII $f$

Sozialauftrag

s. Sozialstaatsprinzip

Sozialbegriff

historisch-konkreter 687

Sozialbeirat

385, LVII 
Sozialbeitrag

186

Sozialberichte

LVII, XC

Sozialbudget

LVII, XC

soziale Demokratie

$741 \mathrm{ff}$

soziale Gerechtigkeit

s. auch Gleichheitsgrundrecht

571, $702 \mathrm{f}$

soziale Grundrechte

s. Grundrechte

soziale Herausforderung

XLI ff, LIV

soziale Indikatoren

$\mathrm{XCI}$

soziale Intervention

s. auch Finanzverfassung, Gesetzesstaat, Justizstaat, Rechtsprechung, Verwaltungsstaat

- bundeseinheitliche Regelungen $213 \mathrm{ff}$

- Daseinsvorsorge $37 \mathrm{ff}$

- Finanzausgleich 205 ff

- Grundrechtsordnung $842 \mathrm{ff}$

- kirchliche Liebestätigkeit $261 \mathrm{ff}$

- der Länder XL

- Rechtsprechung 358, 606

- Verfassungsrecht $41 \mathrm{ff}$

- Verhältnis: Wirtschaftspolitik - Sozialpolitik $217 \mathrm{ff}$

- wirtschaftliche Intervention $31 \mathrm{ff}$

- Zentralisation des Finanzwesens $205 \mathrm{ff}$

$315 \mathrm{ff}, 396 \mathrm{ff}$

soziale Marktwirtschaft

$34 \mathrm{ff}, 837$

Sozial-Enquete

LXI, LXXXII

Sozialentscheidung

s. Sozialstaatsprinzip

Soziale Ordnung

s. Handlungsfreiheit 
Soziale Selbstverwaltung

- Arbeitgeberverbände 1050

- Arbeitskampf $299 \mathrm{ff}$

- Betriebsvereinbarung $313 \mathrm{ff}$

- Betriebsverfassungsrecht 69, 788, $954 \mathrm{ff}$

- Gewerkschaften 128, 333, 744, 789, 1050

- Koalitionsf reiheit 287 ff, 790, 1049

- nichtstaatliche Rechtsetzung $291 \mathrm{ff}$

- Schlichtungswesen 299 ff

- Sozialversicherungsträger 140, $244 \mathrm{ff}$

- Tarifautonomie 503

- 'Tarifmacht 289 ff

- Tarifvertragspartner $287 \mathrm{ff}$

- Tarifvertragsrecht 69, 289, 294 ff, 503, 931

- Verbandsautonomie $295 \mathrm{ff}$

- Verfassungsgarantie $289 \mathrm{ff}$

$287 \mathrm{ff}, 791$

Soziale Sicherheit

s. auch Handlungsf reiheit

- freie Berufe 1064

$637,645,764 \mathrm{ff}$, LXI

Soziale Situation

XLI ff

Soziale Umschichtung

s. auch Enteignung

- Abgabenrecht $987 \mathrm{ff}$

- Bodenreform 980

- Enteignung $973 \mathrm{ff}$

- Entflechtung 979

- Gleichheitssatz 971

- Konfiskation 972

- Lastenausgleich 979, 989

- Sozialisierung $973 \mathrm{ff}$

- Sozialversicherungsbeitrag 989

- verfassungsrechtliche Eigentumsgarantie $972 \mathrm{ff}$

- Währungswesen 990

Soziale Wirtschaftsordnung

s. Handlungsfreiheit

Sozialer Ausgleich

$54 \mathrm{ff}, 606,762 \mathrm{ff}$

Sozialer Bundesstaat

- Begriff $686 \mathrm{ff}$

$737 \mathrm{ff}$ 
Sozialer Rechtsstaat

s. auch Gleichheitsgrundrecht, Rechtsstaat, Rechtsstaatslehren

- Rechtssicherheit 760 ff

- Rechtsstaatslehren 689

- rechtsstaatliche Hemmung 748 ff

- Subsidiaritätsbegriff $755 \mathrm{ff}$

- Verhältnis zum Sozialstaat $744 \mathrm{ff}$

$473 \mathrm{ff}$

Sozialgerichtsbarkeit

- Abgrenzungsprinzipien $571 \mathrm{ff}$

- Arbeitsgerichtsbarkeit $587 \mathrm{ff}$

- Fürsorgerecht 574

- Gewaltenteilung 596

- Richterbesetzung 584

- Sozialgerichte $361 \mathrm{f}$

- Spruchkörper 589 ff

567, 577, LX

Sozialgerichtsgesetz

$573 \mathrm{ff}$

Sozialgerichtsv e rband

LXXXII

Sozialgesetzbuch

LXII, XCI

Sozialgesetzbuchkommission

s. Kommission

Sozialgesetzgebung

XLVIII

Sozialgestaltun:s

s. auch richterliche Sozialgestaltung 685

Snzialgestaltungrauftrag $699 \mathrm{ff}$

Sozialgestaltungssompetenz

685

Sozialhilfegesetz

s. Bundessozialhilfegesetz 
Sozialisie rung

s. auch Eigentumsentziehung, soziale Umisichichtung

- Entschädigung $966 \mathrm{ff}$

- Mitbestimmung $982 \mathrm{ff}, 985 \mathrm{ff}$

- Sozialentwährung 968,970, 977

813

Sozialleistungen

$467 \mathrm{ff}$

Sozialleistungssystem

LXII

Sozialpolitik

s. auch soziale Intervention

- internationale Entwicklung LXXVIII, LXXXXIII, XCIT, CI

- internationale Sozialpolitik $24 \mathrm{ff}$, L ff

- Literatur zur Sozialpolitik LIV ff, LXXX, XCIII

- sozialpolitische Gesetze (Übersicht) LXXVII f, LXXXIf, XCII f, XCIX ff

- und Soziologie XCI

Sozialpolitikgeschichte XLIX

Sozialpolitische Aktion

183

Sozialrecht

$615 \mathrm{ff}$, LVIII ff

Sozialreform

LXXVI

Sozialstaat

s. auch sozialer Rechtsstaat

- und Bundesstaat 218

- Eigentumsbindung $950 \mathrm{ff}$

- Sachordnung $762 \mathrm{ff}$

$673 \mathrm{ff}, 690$

Sozialstaatlichkeit

LXXI

Sozialstaatlichkeit der Länder $208,862 \mathrm{ff}$

Sozialstaatsdeutung 687 
Sozialstiatse rklärrung

- Gemeinschiaftsgebundenheit des Individuums 691

- unci Grundpsfichten 693

- uni Grundrechte $691 \mathrm{f}$

- Sozialverpfflichtung des Staates 691

676 it

Sozialsiatsnorm

s. Venschen!würde

Sozialstactsprinziip

s. auch Handilungsf reiheit, Personalverbände

- Bestandsgarrantie 524, $645 \mathrm{ff}, 711 \mathrm{ff}$

- bürgerliches Recht 825

- Drittwirkumg $735 \mathrm{ff}, 787$

- Ergänzung der Grundrechtsordnung 692

- Geltungsweise 706 ff

- Gesetzesauislegung $724 \mathrm{ff}$

- Gesetzesvollizug 723 ff

- Gesetzgebung 714

- Grundrechte 720, 735

- ideologischie Interpretation $704 \mathrm{ff}$

- Legit!naticonswirkung 716 ff

- Rechtiprechung 728 ff

- Schadenser'satzrecht 827

- Sozialauftr:ag 718

- Sozialentsc:heidung 718

- subjektive Rechte $730 \mathrm{ff}$

- Unterhaltspflicht 828

- Veriahrens;recht 822

- Vertragsf reiheit 826

- Verwaltung; 726 ff

- Vollstreckungsschutz 824 ff

- Wirtschaftsiverfassung 835 ff

645, LXXIII f:, LXXXV

Sirzialverfassisungssecht

LXXI

Sozialversicherun:g

s. auch l'ersonalverbände

- Bundesversicherungsamt 86

- Bundeszusc:hüsse 196 ff

- Finanzen L.XXII, LXXXI, LXXXVI

- Geldleistunigen $467 \mathrm{ff}$

- Mittel der Suzialpolitik 53 ff

- personalverrbandliche Organisation 245 ff

- Sozialversicherungsträger 89 ff 
Sozialversicherung (Fortsetzung)

- Verwaltungsakt 650, 652,654

- Vollzug 122

$52 \mathrm{ff}, 69 \mathrm{f}, 769 \mathrm{ff}$

Sozialversicherungsansprüche

- s. Eigentum

Sozialversicherungsbeitrag

s. auch soziale Umschichtung

832

Sozialversicherungsrecht

s. auch Gleichheitsgrundsatz

- Gesetzgebungskompetenz 52 ff

- kirchliches Dienstrecht 274

- Solidarität 780

Sozialversicherungsträger

s. auch Personalverbände, soziale Selbstverwaltung, Sozial versicherung

$30,89 \mathrm{ff}, 140,144 \mathrm{ff}$

Sozialversicherungsverhältnis

s. besonderes Gewaltverhältnis

Sozialverwaltung

- Ausschüsse $130 \mathrm{ff}$

- und Gesetzgebung 477

$123 \mathrm{ff}, 166 \mathrm{ff}, 607 \mathrm{ff}$

Soziologie

s. Sozialpolitik

Spezialisierung der Gerichtszweige (Vorteile - Nachteile)

- Verhältnis zueinander $581 \mathrm{ff}$

$575 \mathrm{ff}, 591$

Staat

- Daseinsvorsorgestaat $703 \mathrm{ff}$

- Verteilerstaat 703

Staatsangehörigkeitsgarantie

$1090 \mathrm{ff}$

Staatsbürgerversorgung

$780 \mathrm{ff}$

Staatsleistungen

- Güterversorgung 820

- Leistungsversorgung 820 
Ssit aatsverständnis

685

sstatus positivus socialis

752

SSt euern

s. auch Finanzverfassung

189 if

SSt euerprogression

830

Sst euerverfassung

s. Finanzverfassung

St reitentscheidender Verwaltungsakt

517

Ssubjektive Rechte

s. auch Sozialstaatsprinzip, Menschenwürde

547

s.jubsidiaritätsprinzip

s. auch sozialer Rechtsstaat

- und Verbände $757 \mathrm{ff}$

$219 \mathrm{ff}, 223 \mathrm{ff}, 1107$

SSupranationale Organisationen (EGKS, EWG, EURATOM)

$s$. Interventionsträger

'Tarifausschlußklauseln

1052

'Tarifautonomie

s. soziale Selbstverwaltung

'Tarifmacht

s. soziale Selbstverwaltung

"Tarifvertrag

s. kollektives Arbeitsrecht

"I'arifvertragsgesetz

s. kollektives Arbeitsrecht

"l'arifvertragspartner

s. soziale Selbstverwaltung

"Teilhaberechte

s. Grundrechte, körperliche Unversehrtheit, Handlungsfreiheit

LXXVI 


\section{Umlegung}

s. Eigentumsentziehung

Umschichtung

s. soziale Umschichtung

Umverteilung

$748,765,810 \mathrm{ff}, 830$, LXXII

uneheliches Kind

s. Familienrecht

unmittelbare Demokratie

s. Demokratie

Unterbringung

s. Zwangsunterbringung

Unterhaltspflicht

s. Familienrecht, Sozialstaatsprinzip

Unterlassung des Gesetzgebers (relative-absolutie)

561

Verbindliches Satzungsrecht

s. Satzungsrecht

Verbandliche Selbstverwaltung 489

Verbandsautonomie

s. auch soziale Selbstverwaltung

$219 \mathrm{ff}$

Verbände

s. auch Arbeitgeberverbände, Fürsorgeverkände, Gemeindeverbände, Personalverbände, Subsidiaritäts prinzip

- Fürsorgeverbände 140

- Gemeindeverbände $239 \mathrm{ff}$

- und 'Grundgesetz $383 \mathrm{ff}$

- Mitspracherecht der Verbände 377 ff

- Verbändedemokratie 383 ff

- Verbändestaat 373

- Institutionalisierung des Verbandseinflusses $384 \mathrm{ff}$

- organisierte soziale Interessen $381 \mathrm{ff}$

- Wesen 370

- Wohlfahrtsverbände $247 \mathrm{f}$

373 ff, 577

Verbändestaat

s. Verbände 
Verbrnaverwaltung

$s$. körperschaftliche Verbundverwaltung

Vereinigungsingeihceit

- Kartle 10!53 ff

- ncrative Ve:reinigungsfreiheit 1047

1046

Verfahrentecht

s. Sozialstaat:sprinzip

Verfassung

XL, XLVI ff

Verfassungsände rungen

- Finanzreform LXXXIV

- Lastenausgileich LXXI

- Kriegsfolge:lasten LXXVIII

- Notstandsveerfassung LXXXIV

- Finanzreform LXXXIV

Verfassungsgerichtsbarkeit

- Mitilerfunktion der Verfassungsgerichtsbarkeit 565

$170,564 \mathrm{ff}$

Verfassungsmäßig;e Ordnung

s. Handlungsf reiheit

Vorfassungsordnuing

s. Menschenwürrde

Vuriassungsirecht

s. soriale Intervention

Vorfassungsrechtisprechung

556

Vurfassungswidlige Verfassungsnorm

669

Verge:sellichaftun,g

951,984

$\mathrm{V} \supseteq$ rhältnismäßigk eit sgrundsatz

$634 \mathrm{ff}$

V ərhältniswahlrec:ht

s. Wahlsysterm

$\mathrm{V} \geq \mathrm{r}$ mögensbildungr

811

V $\supseteq$ rnehmlassungsiverfahren

384,386 
Versammlungsf reiheit

s. Freiheitsgrundrechte

Versicherungsprinzip

$56 \mathrm{ff}$

Versorgung

s. auch Handlungsf reiheit

- Kompetenzordnung 49 ff

- Sonderversorgung 556, $771 \mathrm{ff}$

- Versorgungsgerichtsbarkeit 570

- Versorgungsstaat 753

- Vollzug $121 \mathrm{f}$

Versorgungsausgleich

XCIV, XCVII

Versorgungsgerichtsbarkeit

s. Versorgung

Versorgungsstaat

s. Versorgung

Verteilerstaat

s. Staat

Vertikale Gewaltenteilung

219

Vertragsfreiheit

s. Sozialstaatsprinzip

Vertragshilfeverfahren

524

Vertriebenenrecht

64

Verwaltung

s. auch Bundesministerialverwaltung, Bundesstaat, Sozialstaatsprinzip

- Begriff 604

- Bestimmtheitsgebot 463

- Bundesverwaltung 82 ff

- Ermessensentscheidung 551

- Finanzverwaltung $112 \mathrm{ff}$

- Gesetzesbindung 457

- Gleichheitsgrundsatz 461, 476

- Kontrollierende Rechtsprechung 550 ff

- Landeseigenverwaltung $115 \mathrm{ff}$

- Lastenausgleichsverwaltung $114 \mathrm{ff}$ 
V'erwaltung (Fortsetzung)

- und Privatrecht $621 \mathrm{ff}$

- Rechtsetzungsbefugnis 480 ff

- unbestimmte Rechtsbegriffe 551

Ve rwaltungsakt

- Bestandskraft 647 ff

- Rücknahme 647 ff

V e rwaltungsgerichtsbarkeit

$584 \mathrm{ff}$

Verwaltungsrechtsprechung

$540 \mathrm{ff}$

Verwaltungsstaat

- und soziale Intervention $603 \mathrm{ff}$

$418 \mathrm{f}$

V e rwaltungsstruktur

$613 \mathrm{ff}$

V olksversicherung

$55 \mathrm{ff}$

Vollstreckungsschutz

s. Sozialstaatsprinzip

Vollzugsauftrag

$152 \mathrm{ff}$

Währungspolitik

840

Währungsreform

LXX

Währungswesen

s. soziale Umschichtung

II ahl system

- Mehrheitswahlrecht 342

- Verhältniswahlrecht 342

Wehrrecht

LXXI

Weisungsgebundenheit

343

Wiedergut machungsrecht

- Vollzug 120 
IIillkürverbot

s. Gleichheitsgrundrecht

wirtschaftliche Intervention

$31 \mathrm{ff}$

Mirtschaftsclemokratie

s. auch Sozialstaatsdemokratie

$329 \mathrm{ff}$

Wirtschaftspolitik

s. soziale Intervention

IIirtschaftspolitische Neutralität des Grundgesetrzes

35,36

Nir.tschaftsrecht

- Vollzug 121

Nirtschaftsverfassung

s. Sozialstaatsprinzip

Wirtschaftsverfassungsrecht

$34 \mathrm{ff}$

II ir.tschaftswuncler

LXXIV f

Witwen (Witwer-)-rente

919

II ohlfahrtspflege

62

IIohlfahrtsstaat

748,753

II ohlfahrtsverbände

s. Verbäncle

II ohnungsbauför clerung

471

II ohnungsiecht

- Unverletzlichkeit der llohnung s. Freiheitsgrundrechte

IIohnungswesen

72, $111 \mathrm{ff}, 122,818 \mathrm{ff}, \mathrm{LXXV}$

Zent ralverwaltungswirtschaft

35 
Zölibatsklausel

s. Fherecht

Zwangsart

s. Bensfreineit, körperliche Freiheit

Zwang ses: imernt

s. kir.rerliche Unversehrtheit

Zwangsheilung

s. körperliche Unversehrtheit

Zwangsschilichtunig

s. Selbsteint:ritt

Zwangsunterbrinģung

s. körperlichı Freiheit, körperliche Unversehrtheit 



\section{J. Schweitzer Verlag • Berlin}

\section{Vierteljahresschrift für Sozialrecht (VSSR)}

Herausgeber Ministerialdirektor a. D. Otto Fichtner, Beigeordneter für Soziales, Jugend und Gesundheit der Stadt Duisburg; Professor Dr. Wolfgang Gitter, Universität Bayreuth; Professor Dr. Hermann Heußner, Richter des Bundesverfassungsgerichts, Karlsruhe, Justus-Liebig-Universität, Gießen; Professor Dr. Theo Mayer-Maly, Universität Salzburg; Professor Dr. Dr. Detlef Merten, Hochschule für Verwaltungswissenschaften, Speyer (Geschäftsführender Herausgeber); Professor Dr. Dieter Schäfer, Universität Bamberg; Präsident Dr. h. c. Josef Stingl, Bundesanstalt für Arbeit, Nürnberg; Professor Dr. Hans F. Zacher, Universität München.

Seit 1973 hat sich die VSSR zum Forum einer lebhaften sozialrechtlichen Debatte entwickelt. Hoher wissenschaftlicher Standard wird durch weitgehenden Praxisbezug ergänzt. Dieses bewährte Konzept einer erfolgreichen Zeitschrift führen Herausgeber und Verlag fort. Sie freuen sich, jetzt zwei weitere bedeutende Herausgeber gewonnen zu haben: Josef Stingl, Präsident der Bundesanstalt für Arbeit, Nürnberg, und Dietrich Schäfer, Professor für Volkswirtschaftslehre an der Universität Trier.

Josef Stingl, erfahrener Sozialpolitiker und langjähriger Präsident der Bundesanstalt, wird insbesondere der Darstellung aus dem bedeutsamen Themenkreis "Arbeitsmarktpolitik" seine Aufmerksamkeit schenken. Der „Sozialpolitik" wird sich der neue Mitherausgeber Dietrich Schäfer annehmen.

Unter Wahrung der Kontinuität wird die VSSR folgende Akzente setzen:

- Umfassende wissenschaftliche Pflege des Sozialrechts,

- Einordnung des Sozialrechts in die gesamte Rechtswissenschaft, zugleich aber interdisziplinäre Zuordnung zu anderen Wissenschaftsbereichen wie Wirtschaftswissenschaften und Soziologie, aber auch Medizin und Erziehungswissenschaften,

- Arbeitsmarkt- und Sozialpolitik,

- Informationen über supra- und internationale sozialrechtliche Entwicklungen,

- fortlaufende Berichterstattung und Kommentierung wichtiger sozialgerichtlicher Entscheidungen.

Erscheinungsweise und Bezugsbedingungen: Die Zeitschrift erscheint bandweise, ein Band besteht aus 4 Heften zu je 96 Seiten. Format 16,2 $\times 24,2 \mathrm{~cm}$. Im Bedarfsfall werden zwei Hefte zu einem Doppelheft zusammengefaßt. Jährlich soll ein Band erscheinen. Abonnementspreis pro Band in Heften DM 178,-; Vorzugspreis für Studenten und Referendare (gegen Vorlage einer Ausbildungsbestätigung) in Heften DM 136,-; Einzelheft DM 52,-, Doppelheft DM 104,-; Einbanddecke DM 9,80. 


\section{Sozialrecht J. Schweitzer Verlag • Berlin}

IGL / SCHULTE / SIMONS

\section{Einführung in das Recht der sozialen Sicherheit von Frankreich, Großbritannien und Italien}

Von Dr. Gerhard Igl, Dr. Bernd Schulte und Thomas Simons, Mitarbeiter der Projektgruppe für Internationales und Vergleichendes Sozialrecht der Max-Planck-Gesellschaft in München. Groß-Oktav. VIII, 478 Seiten. 1978. Kartoniert DM 68,- ISBN 3805905017

(Vierteljahresschrift für Sozialrecht, Beiheft 1)

Der Band enthält drei Beiträge als Einführung in das Recht der sozialen Sicherheit der drei wichtigsten EG-Länder. Sie vermitteln einen Überblick über das bestehende Sozialleistungssystem. Die jeweils besonderen Gegebenheiten in diesen Ländern bedingten eine unterschiedliche Betonung juristischer, sozialpolitischer, historischer und institutioneller Aspekte. 